PNNL-18741

WTP-RPT-193, Rev 0

U.S. DEPARTMENT OF ENERGY

Prepared for the U.S. Department of Energy

under Contract DE-AC05-76RL01830

\title{
PEP Integrated Test D Run Report- Caustic and Oxidative Leaching in UFP-VSL-T02A
}

$\begin{array}{ll}\text { GJ Sevigny } & \text { JGH Geeting } \\ \text { OP Bredt } & \text { EC Golovich } \\ \text { CA Burns } & \text { CE Guzman-Leong } \\ \text { DE Kurath } & \text { GB Josephson }\end{array}$

December 2009

\section{Pacific Northwest}

NATIONAL LABORATORY

Proudly Operated by Battelle Since 1965 


\title{
PEP Integrated Test D Run Report- Caustic and Oxidative Leaching in UFP-VSL-T02A
}

\author{
GJ Sevigny \\ OP Bredt \\ JGH Geeting \\ CA Burns \\ CE Guzman-Leong \\ DE Kurath \\ GB Josephson \\ EC Golovich
}

December 2009

Test Specification: 24590-PTF-TSP-RT-07-001 Rev 2

Work Authorization: WA\# 2007-024

Test Plan: TP-RPP-WTP-506, Rev. 0.3; TP-WTP-PEP-044, Rev 0.1

Test Exceptions: 24590-PTF-TEF-RT-08-00002

24590-WTP-TEF-RT-09-00003

24590-PTF-TEF-RT-09-00001

24590-WTP-TEF-RT-09-00002 Rev 0

24590-PTF-TEF-RT-09-00001 Rev 1

R\&T focus area: Pretreatment

Test Scoping Statement(s): NA

Prepared for

the U.S. Department of Energy

under Contract DE-AC05-76RL01830

Pacific Northwest National Laboratory

Richland, Washington 99352 


\section{Completeness of Testing}

This report describes the results of work and testing specified by Test Specification 24590-PTF-TSP-RT-07-001 Rev 2 "Pretreatment Engineering Platform (PEP) Testing (Phase 1)" and Test Plans TP-RPP-WTP-506 Rev 0.4 "Pretreatment Engineering Platform (PEP) Testing (Phase 1) and TP-WTP-PEP-044 Rev 0.2" Test Plan for the PEP Parallel Laboratory Testing." The work and any associated testing followed the quality assurance requirements outlined in the Test Specification/Plan. The descriptions provided in this test report are an accurate account of both the conduct of the work and the data collected. Test plan results are reported. Also reported are any unusual or anomalous occurrences that are different from expected results. The test results and this report have been reviewed and verified.

\section{Approved:}

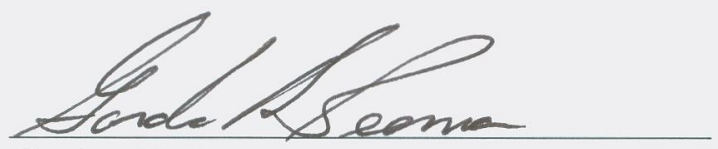

Gordon H. Beeman, Manager WTP R\&T Support Project

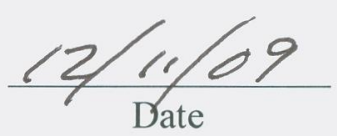




\section{Contents}

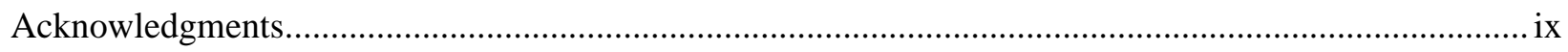

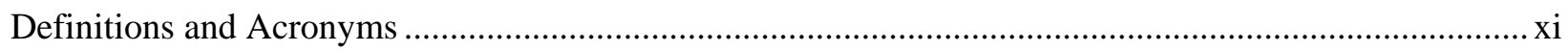

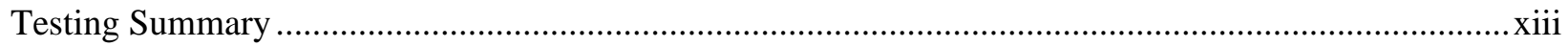

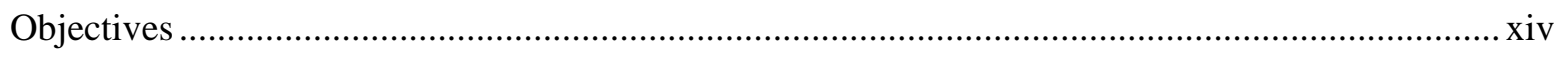

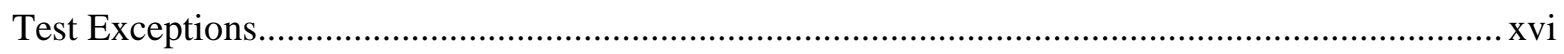

Results and Performance Against Success Criteria .................................................................... xix

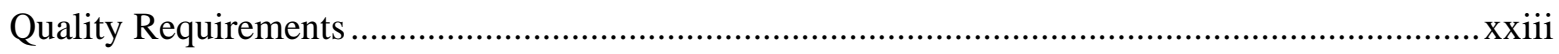

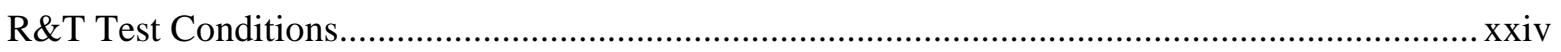

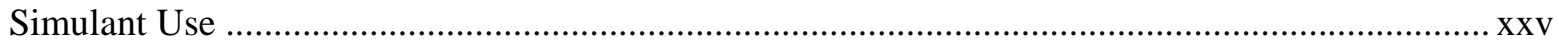

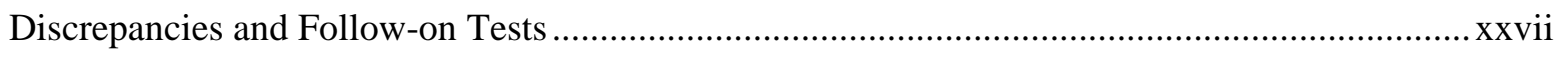

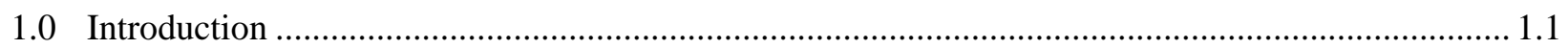

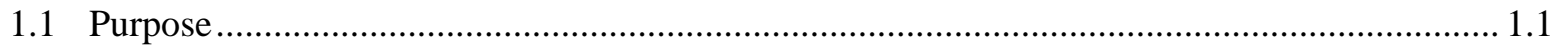

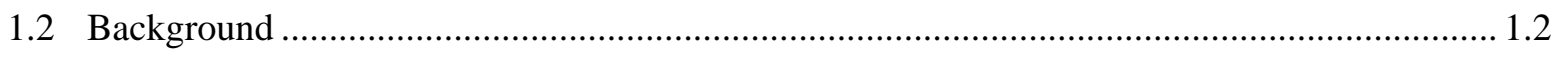

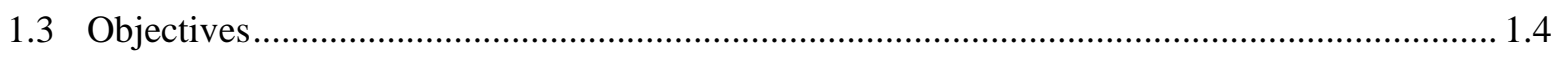

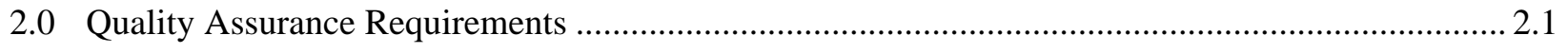

3.0 Experimental Methods and Analysis .......................................................................................... 3.1

3.1 Pretreatment Engineering Platform Overview ….......................................................... 3.1

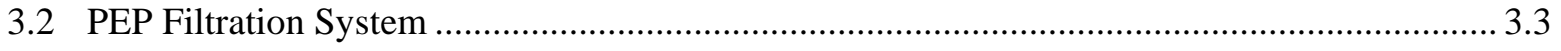

3.2.1 Ultrafiltration Feed Tank........................................................................................... 3.3

3.2.2 Slurry Filtration Circulation Loop........................................................................... 3.3

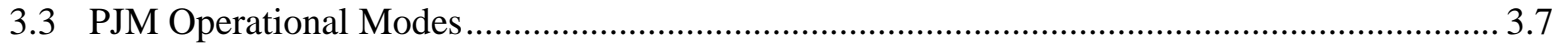

3.3.1 Standard Mode (Regular) Description ........................................................................ 3.7

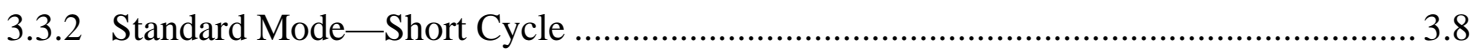

3.3.3 Standard Mode-Star Pattern........................................................................................ 3.9

3.3.4 Simple PJM Mode Description ................................................................................ 3.9

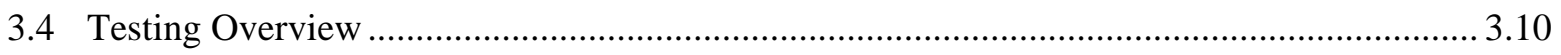

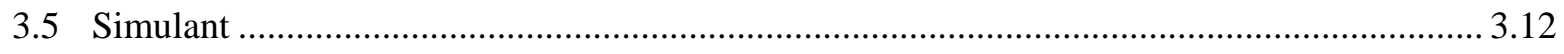

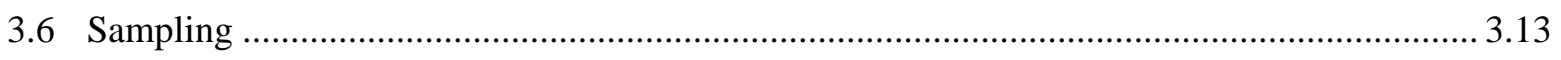

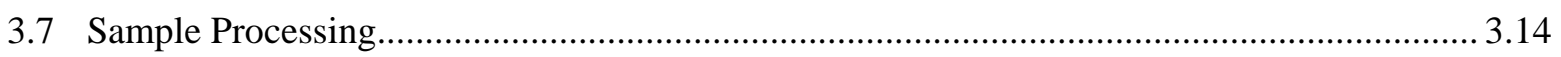

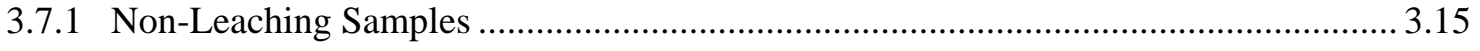

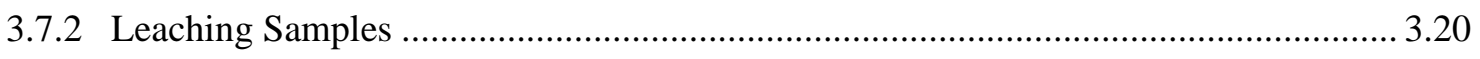

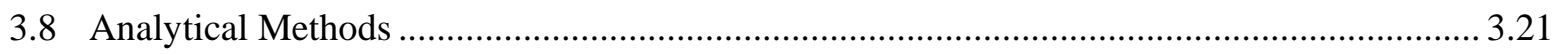

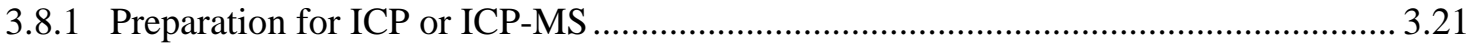

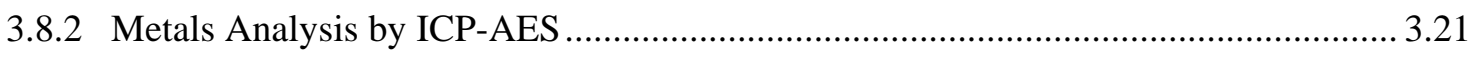

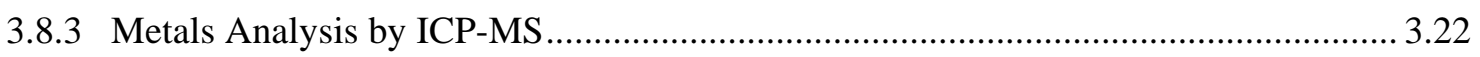

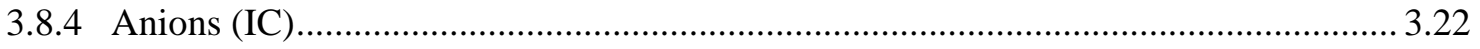




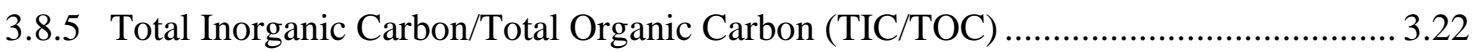

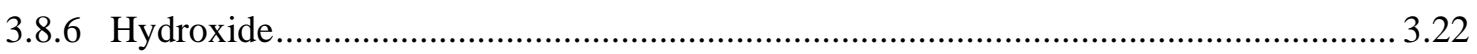

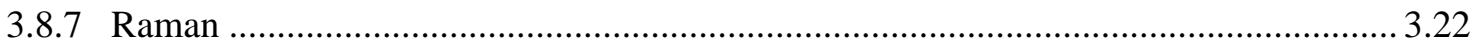

3.8.8 Preparation for Gel Permeation Chromatography (AFA components) .......................... 3.23

3.8.9 Gel Permeation Chromatography (AFA components) .............................................. 3.23

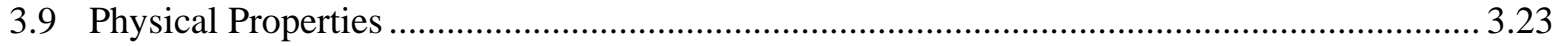

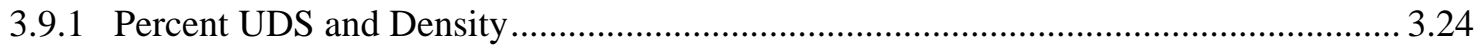

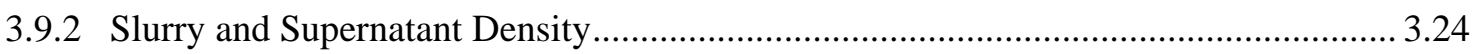

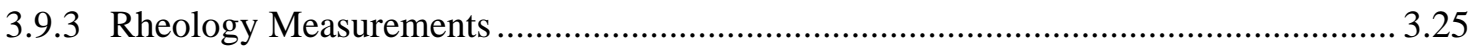

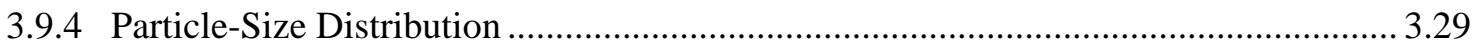

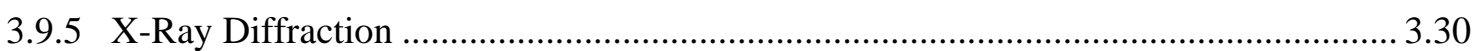

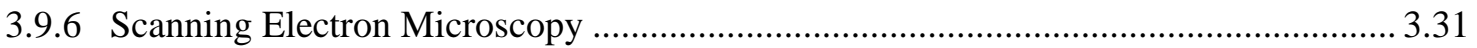

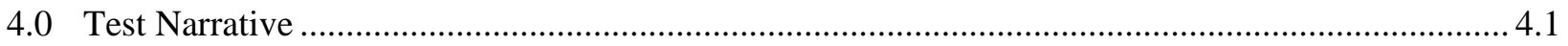

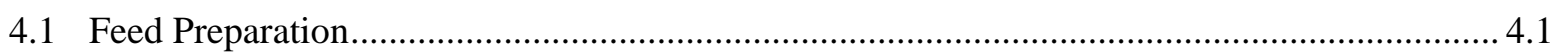

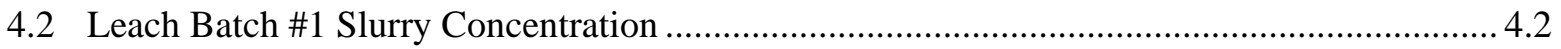

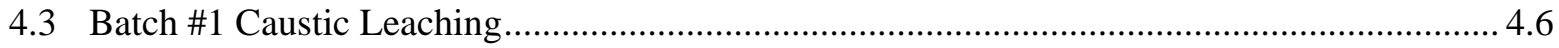

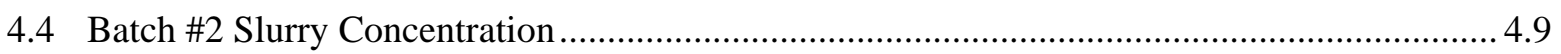

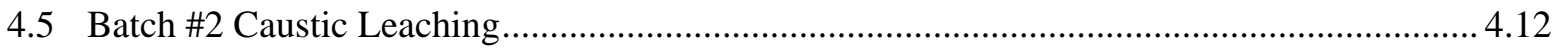

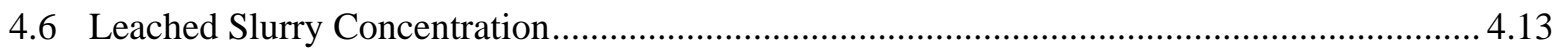

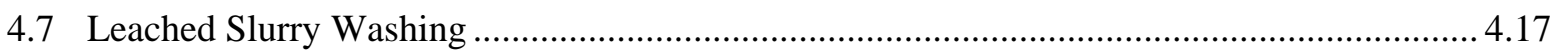

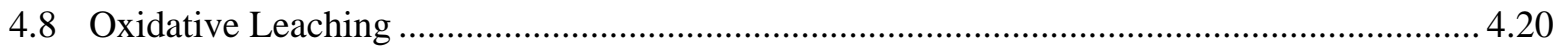

4.9 Oxidative-Leach Washing .................................................................................................... 4.21

4.10 Nitric Acid Filter Cleaning After Integrated Test D ........................................................ 4.26

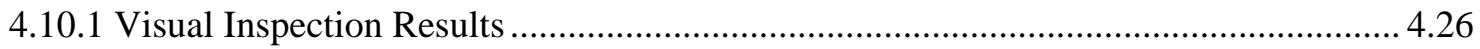

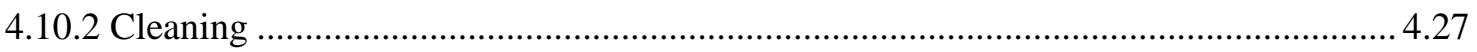

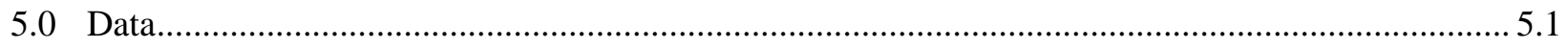

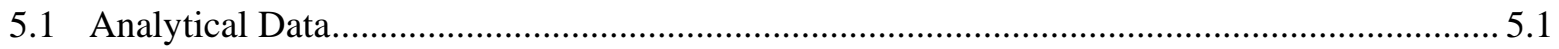

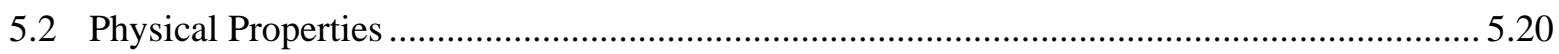

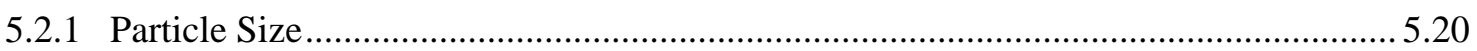

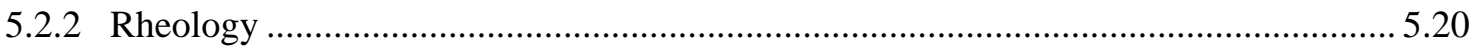

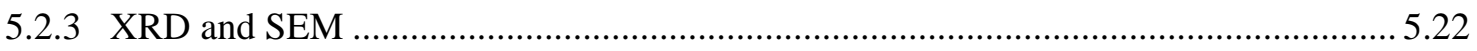

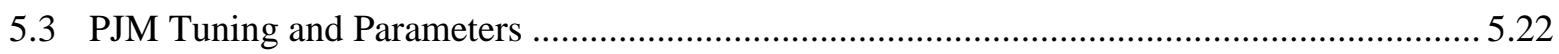

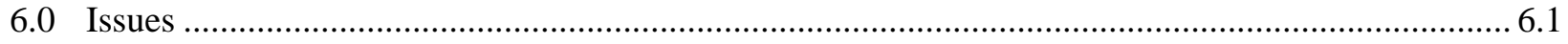

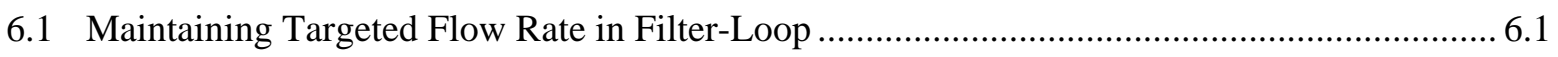

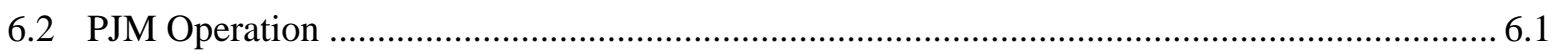

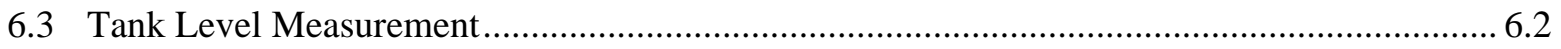

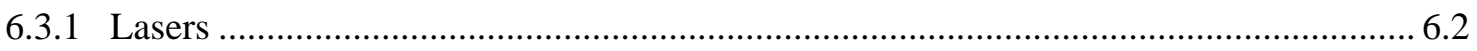

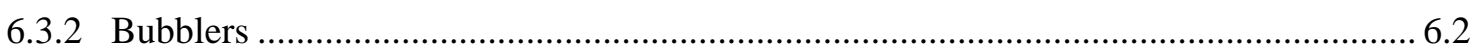

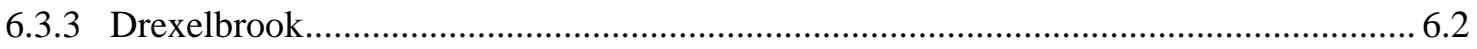




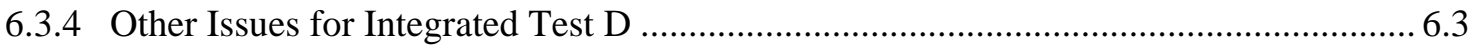

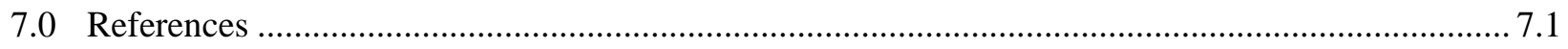

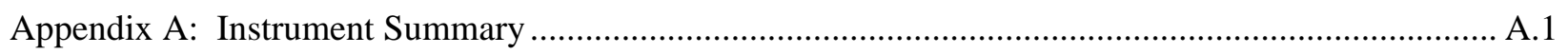

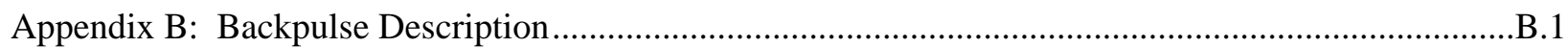

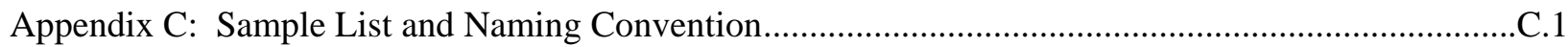

Appendix D: Coriolis Sampler Elevations .......................................................................................... D.1

Appendix E: PEP Data Acquisition System ………..............................................................................

Appendix F: Evaluation of PJM Peak Average Velocity .........................................................................1

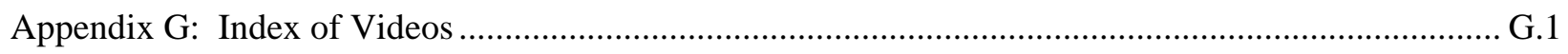

Appendix H: Pump Operating Guidance ..................................................................................... H.1

Appendix I: T02A Systems Operations Guidance for Integrated Test D ...............................................1

Appendix J: Integrated Test D Data Plots..............................................................................................

Appendix K: Integrated Test D Summary .................................................................................................. K.1

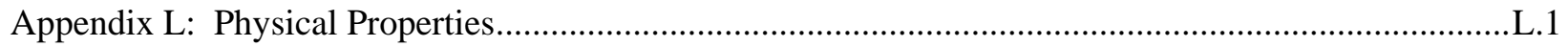

Appendix M: Integrated Test D Run Sheet............................................................................................

Appendix N: Reagent Analysis................................................................................................... N.1 


\section{Figures}

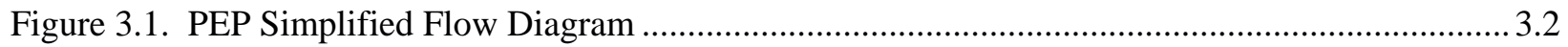

Figure 3.2. Schematic of Filtration Loop.............................................................................................. 3.4

Figure 3.3. Integrated Test D Timeline .............................................................................................. 3.11

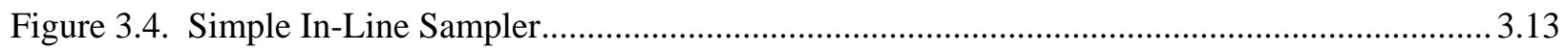

Figure 3.5. In-Tank Sampling Showing the Three Radial Positions at Three Heights and Sampling

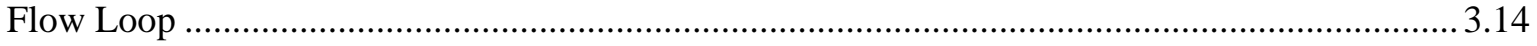

Figure 3.6. Sample Processing for Decantate Handling ................................................................... 3.16

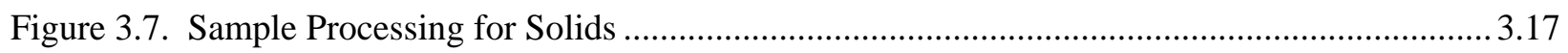

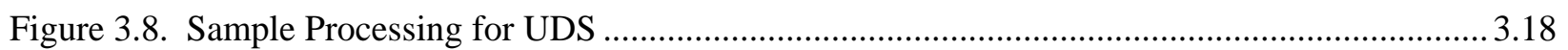

Figure 4.1. TMP for Pre-Caustic-Leach Concentration, Simulant Batch \#1 ......................................... 4.3

Figure 4.2. Axial Velocity Based on Flow Measurements at the Suction to T42A and the

Discharge to T43A for Pre-Caustic-Leach Concentration, Simulant Batch \#1

Figure 4.3. Tank T02A Temperature (TK-0619) for Pre-Caustic-Leach Concentration, Simulant Batch \#1

Figure 4.4. Permeate Production Rate for Pre-Caustic-Leach Concentration, Simulant Batch \#1

Figure 4.5. Filter-Loop Flow Rate, Level in Tank T02A, and Axial Pressure Drop During Batch \#1 Concentration

Figure 4.6. Surface of Slurry Sample in Carboy Drained from Tank T02A.......................................... 4.7

Figure 4.7. Tank T02A Level and Batch 1 Leach Temperatures........................................................... 4.8

Figure 4.8. TMP for Pre-Caustic-Leach Concentration, Simulant Batch \#2 ......................................... 4.10

Figure 4.9. Axial Velocity Based on Flow Measurements at the Suction to T42A and the Discharge to T43A for Pre-Caustic-Leach Concentration, Simulant Batch \#2 ............................. 4.10

Figure 4.10. Tank T02A Prototypic Temperature for Pre-Caustic-Leach Concentration, Simulant

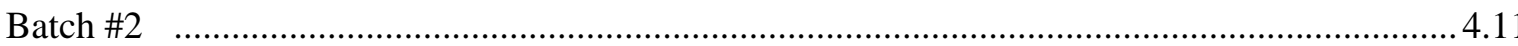

Figure 4.11. Permeate Production Rate for Pre-Caustic-Leach Concentration, Simulant Batch \#2 ....... 4.11

Figure 4.12. Filter-Loop Flow Rate, Level in Tank T02A, and Axial Pressure Drop During

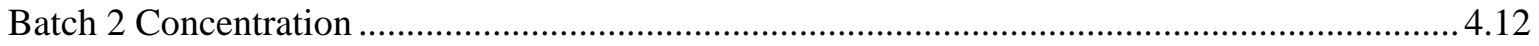

Figure 4.13. Batch \#2 Leach: Tank T02A Level and Leach Batch \#2 Temperatures.............................4.13

Figure 4.14. TMP for Post-Caustic-Leach Concentration .................................................................... 4.14

Figure 4.15. Axial Velocity Based on Flow Measurements at the Suction to T42A and the Discharge to T43A for Post-Caustic-Leach Concentration ........................................................... 4.15

Figure 4.16. Tank T02A Temperature for Post-Caustic-Leach Concentration...................................... 4.15

Figure 4.17. Permeate Production Rate for Post-Caustic-Leach Concentration .................................... 4.16

Figure 4.18. Integrated Test D Post-Leach Concentration Filter-Loop Flow Rate, Tank T02A Level, Axial Pressure Drop ......................................................................................................... 4.17 
Figure 4.19. Axial Velocity Based on Flow Measurements at the Suction to T42A and the Discharge to T43A for Post-Caustic-Leach Wash..................................................................... 4.18

Figure 4.20. TMP for Post-Caustic-Leach Wash ............................................................................ 4.18

Figure 4.21. Tank T02A Temperature for Post-Caustic-Leach Wash ............................................... 4.19

Figure 4.22. Permeate Production Rate for Post-Caustic-Leach Wash............................................... 4.19

Figure 4.23. Filter Axial Velocity During Oxidative-Leach Operations, Integrated Test D ................ 4.20

Figure 4.24. Tank T02A Temperature (TTK-0619) During Oxidative-Leach, Integrated Test D......... 4.21

Figure 4.25. TMP for Post-Oxidative-Leach Wash ...........................................................................22

Figure 4.26. Axial Velocity Based on Flow Measurements at the Suction to T42A and the Discharge to T43A for Post-Oxidative-Leach Wash .................................................................... 4.22

Figure 4.27. Tank T02A Temperature for Post-Oxidative-Leach Wash.............................................. 4.23

Figure 4.28. Permeate Production Rate for Post-Oxidative-Leach Wash.......................................... 4.23

Figure 4.29. TMP for Post-Oxidative-Leach Concentration............................................................. 4.24

Figure 4.30. Axial Velocity Based on Flow Measurements at the Suction to T42A and the Discharge to T43A for Post-Oxidative-Leach Concentration ................................................... 4.24

Figure 4.31. Tank T02A Temperature for Post-Oxidative-Leach Concentration ................................. 4.25

Figure 4.32. Permeate Production Rate for Post-Oxidative-Leach Concentration ............................... 4.25

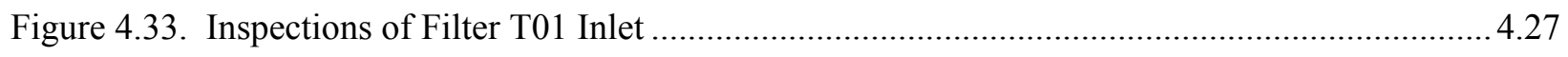

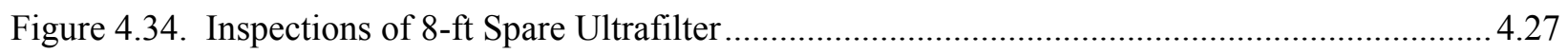

Figure 4.35. Picture of Filter Shellside After Settling ........................................................................29

Figure 4.36. Elemental Concentrations During Filter Cleaning ….................................................... 4.30

Figure 4.37. Trace Element Concentrations During Filter Cleaning ................................................. 4.31

Figure 4.38. Temperature and TMP-Corrected Filter Flux ............................................................ 4.32 


\section{Tables}

Table S.1. Summary of Test Objectives and Results .........................................................................

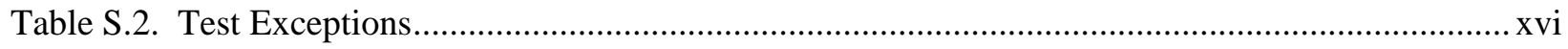

Table S.3. Deviations from Test Specification ..................................................................................

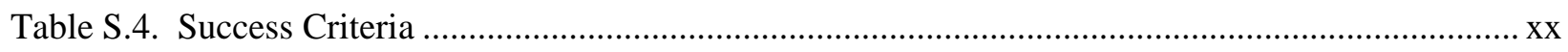

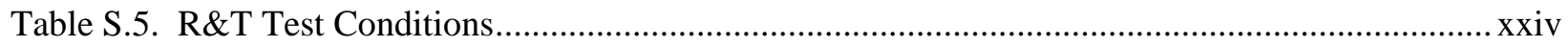

Table 2.1. Description of NCRs Active During Integrated Test D .....................................................2.2

Table 3.1. Specifications of the Five PEP Cross-Flow Filtration Bundles .............................................. 3.6

Table 3.2. Permeate Metering and Pulse-Pot Configurations for PEP.................................................. 3.6

Table 3.3. Vane Immersion Depth and Container Geometry Constraints for Shear-Strength Tests

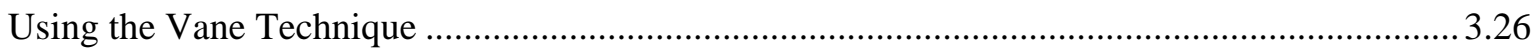

Table 3.4. Vane and Cup and Rotor Measuring System Dimensions .................................................... 3.28

Table 3.5. Properties Applied to Group 8 Test Materials ......................................................................... 3.30

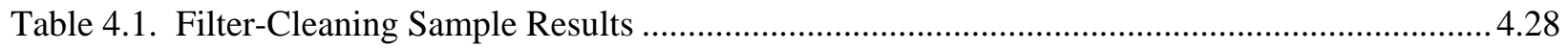

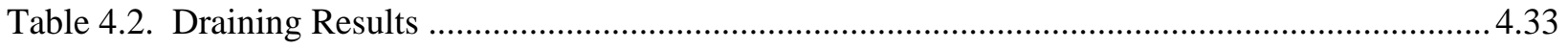

Table 5.1. Caustic-Leach Batch 1: Initial Solids Concentration to 20-wt\% .......................................... 5.2

Table 5.2. Caustic-Leach Batch 2: Initial Solids Concentration to 20-wt\% ......................................... 5.3

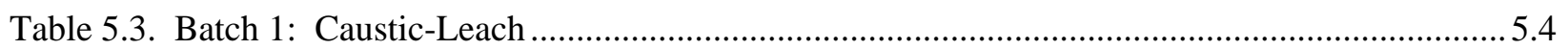

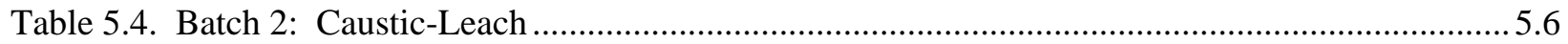

Table 5.5. Batch 1: Caustic-Leach—Raman Results ............................................................................ 5.8

Table 5.6. Batch 2: Caustic-Leach—Raman Results ............................................................................... 5.8

Table 5.7. Post-Caustic-Leach Concentration of Solids ....................................................................... 5.9

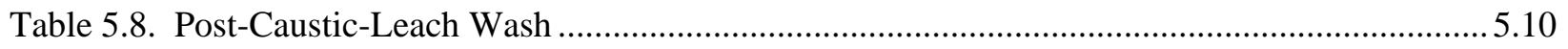

Table 5.9. Post-Caustic-Leach Wash—Wet Centrifuged Solids ....................................................... 5.11

Table 5.10. Post-Caustic-Leach Wash—Raman Analysis ................................................................. 5.11

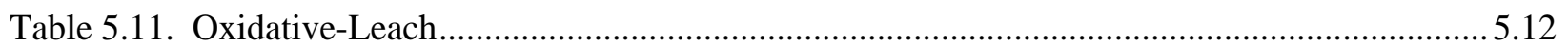

Table 5.12. Oxidative-Leach—Raman Results....................................................................................14

Table 5.13. Post-Oxidative-Leach Wash .............................................................................................. 5.15

Table 5.14. Post-Oxidative-Leach Wash—Raman Results ................................................................... 5.16

Table 5.15. Analysis of Key Process Steps......................................................................................... 5.17

Table 5.16. Final Slurry Composition Before Transfer to Waste Tank ................................................. 5.19

Table 5.17. Analysis of Material in Filter-Loop ................................................................................19

Table 5.18. Slurry Particle-Size Distribution....................................................................................... 5.20

Table 5.19. Integrated Test D Rheology Data Summary ….................................................................. 5.21

Table 5.20. Integrated Test D Rheology Data Summary ….................................................................... 5.22

Table 5.21. PJM Parameters for Integrated Test D (TI-082) ................................................................ 5.23 


\section{Acknowledgments}

This report was supported by many dedicated staff involved in laboratory experiments, sampling, data acquisition, and technical reviews. Individuals on the operations and sampling crew are especially recognized for supporting the Pretreatment Engineering Platform Project by working unpredictable, long, and off-hour shifts for the 10 months of PEP operations. The tests and reports could not have gotten this far without their extraordinary effort. The authors gratefully acknowledge the help and support of the following staff:

$\begin{array}{lll}\text { JM Alzheimer } & \text { MS Fountain } & \text { JH Sachs } \\ \text { EJ Antonio } & \text { K Groves } & \text { RC Shannon } \\ \text { EBK Baer } & \text { AD Guzman } & \text { SV Shoemaker } \\ \text { R Bang } & \text { SD Halstead } & \text { DS Sklarew } \\ \text { NN Bauman } & \text { GL Harvey } & \text { CT Smith } \\ \text { JD Bohlke } & \text { RE Hohimer } & \text { DM Smith } \\ \text { JR Bontha } & \text { DE Hurley } & \text { SA Smith } \\ \text { CF Brown } & \text { SD Lehrman } & \text { JJ Soelberg } \\ \text { WC Buchmiller } & \text { ML Kimura } & \text { BA Stiver } \\ \text { KJ Cantrell } & \text { SN Kundu } & \text { Y Su } \\ \text { CC Chapman } & \text { JB Lang } & \text { JC Tucker } \\ \text { J Chun } & \text { JS Loveland } & \text { PLJ Valdez } \\ \text { DA Clark } & \text { JR Markillie } & \text { D Vonghalath } \\ \text { E Cordova } & \text { ES Mast } & \text { BE Wells } \\ \text { BP Crume } & \text { K Miller } & \text { AD Woodstock } \\ \text { JM Cuta } & \text { DP Mendoza } & \text { S Wright } \\ \text { RL Daubert } & \text { KE Parker } & \text { ST Yokuda } \\ \text { CS Dreyer } & \text { RP Pires } & \text { JK Young } \\ \text { EP Dresel } & \text { KD Quigley } & \text { L Zhong } \\ \text { BW Dunn } & \text { BJ Riley } & \text { MR Zumhoff } \\ \text { A Edmondson } & \text { CP Rodriguez } & \end{array}$

The authors also thank Wayne Cosby for valuable editorial support, Dave MacPherson and Kirsten Meier for Quality Assurance support throughout the project, Chrissy Charron, Andrea Boehler, and Mona Champion for their administrative support through the months of PEP testing, and Wesley Lawrence, Dean Kurath, James Huckaby, Steve Barnes, John Truax, Donald Bachand, Robert Burk, and Gordon Beeman for their leadership and technical guidance during PEP operations. We also thank Brady Hanson and Michael Minette for the management and coordination of data analysis activities. 



\section{Definitions and Acronyms}

\begin{tabular}{|c|c|}
\hline AFA & antifoam agent \\
\hline APEL & Advanced Process Engineering Laboratory \\
\hline ASO & Analytical Support Operations \\
\hline ASR & Analytical Services Request \\
\hline ASME & American Society of Mechanical Engineers \\
\hline $\mathrm{BNI}$ & Bechtel National Inc. \\
\hline BS & blank spike \\
\hline $\mathrm{CD}$ & Coriolis densitometer \\
\hline CFD & computational fluid dynamics \\
\hline CFR & Code of Federal Regulations \\
\hline CUF & Cell Unit Filter \\
\hline CXP & cesium ion exchange process system \\
\hline DAS & Data Acquisition System \\
\hline DIW & deionized water \\
\hline DOE & U.S. Department of Energy \\
\hline EFRT & External Flowsheet Review Team \\
\hline FEP & Feed Evaporator Process (vessel) \\
\hline FRP & Feed Receipt Process (vessel) \\
\hline GPC & gel permeation chromatography \\
\hline HDI & "How Do I...?" \\
\hline HLP & HLW lag storage and feed blending process system \\
\hline HLW & high-level waste \\
\hline HMI & human-machine interface \\
\hline IC & ion chromatography \\
\hline $\mathrm{ICP}$ & inductively coupled plasma \\
\hline ICP-AES & inductively coupled plasma-atomic emission spectrometry \\
\hline ICP-MS & inductively coupled plasma-mass spectroscopy \\
\hline IW & inhibited water (0.01-M NaOH) \\
\hline JTG & Joint Test Group \\
\hline LCS & laboratory control sample \\
\hline LTE & lead test engineer \\
\hline LRB & laboratory record book \\
\hline M\&TE & measuring and test equipment \\
\hline MS & matrix spike \\
\hline NCR & nonconformance report \\
\hline
\end{tabular}




\begin{tabular}{|c|c|}
\hline PDMS & polydimethylsiloxane \\
\hline PB & preparation blank \\
\hline PDL-W & Process Development Laboratory-West \\
\hline PEP & Pretreatment Engineering Platform \\
\hline P\&ID & piping and instrumentation diagram \\
\hline PJM & pulse-jet mixer \\
\hline PLM & polarized light microscopy \\
\hline PNNL & Pacific Northwest National Laboratory \\
\hline PPG & polypropylene glycol \\
\hline PSD & particle-size distribution \\
\hline PTF & Pretreatment Facility \\
\hline QA & quality assurance \\
\hline QAM & Quality Assurance Manual \\
\hline QAP & Quality Assurance Plan \\
\hline QARD & Quality Assurance Requirements and Descriptions \\
\hline QC & Quality Control \\
\hline $\operatorname{Re}$ & Reynolds number \\
\hline R\&T & research and technology \\
\hline RPP & River Protection Project \\
\hline RTD & resistance temperature detector \\
\hline SBMS & Standards Based Management System \\
\hline SEM & scanning electron microscopy \\
\hline SLM & stable level measurement \\
\hline SwRI & Southwest Research Institute \\
\hline SPG & specific gravity \\
\hline TAT & turn around time \\
\hline TDS & total dissolved solids \\
\hline TIC & total inorganic carbon \\
\hline TOC & total organic carbon \\
\hline THF & tetrahydrofuran \\
\hline TMP & transmembrane pressure \\
\hline UDS & undissolved solids \\
\hline UFP & ultrafiltration process \\
\hline VFD & variable frequency drive \\
\hline VSL & vessel \\
\hline $\mathrm{wt} \%$ & weight percent \\
\hline WTP & Hanford Tank Waste Treatment and Immobilization Plant \\
\hline XRD & X-ray diffraction \\
\hline
\end{tabular}




\section{Testing Summary}

Pacific Northwest National Laboratory (PNNL) has been tasked by Bechtel National Inc. (BNI) on the River Protection Project-Hanford Tank Waste Treatment and Immobilization Plant (RPP-WTP) project to perform research and development activities to resolve technical issues identified for the Pretreatment Facility (PTF). The Pretreatment Engineering Platform (PEP) was designed, constructed and operated as part of a plan to respond to issue M12, "Undemonstrated Leaching Processes" of the External Flowsheet Review Team (EFRT) issue response plan. ${ }^{\text {(a) }}$ The PEP is a $1 / 4.5$-scale test platform designed to simulate the WTP pretreatment caustic leaching, oxidative leaching, ultrafiltration solids concentration, and slurry washing processes. ${ }^{(b)}$ The PEP replicates the WTP leaching processes using prototypic equipment and control strategies. The PEP also includes nonprototypic ancillary equipment to support the core processing.

Two process flowsheets are currently being evaluated for the ultrafiltration process (UFP) and leaching operations. The baseline flowsheet (Integrated Test A) has caustic leaching conducted in the UFP-1 ultrafiltration feed preparation vessels (i.e., vessels UFP-VSL-T01A and B in the PEP; vessels UFP-VSL-00001A and B [UFP-1] in the WTP PTF). The alternative scenario (Integrated Tests B and D) has caustic leaching performed in the UFP-2 ultrafiltration feed vessels (i.e., vessel UFP-VSL-T02A ${ }^{(\mathrm{c})}$ in the PEP and vessels UFP-VSL-00002A and B [UFP-2] in the WTP PTF).

In Integrated Test $\mathrm{D}, 19-\mathrm{M}$ sodium hydroxide $(\mathrm{NaOH}$, caustic) was added to the waste slurry in the UFP-VSL-T02A vessel after the solids were concentrated to $\sim 20 \%$ undissolved solids (UDS). The $\mathrm{NaOH}$ was added to leach solid aluminum compounds (e.g., gibbsite, boehmite). Caustic addition was followed by heating to $85^{\circ} \mathrm{C}$ using direct injection of steam to accelerate the leach process. The main difference of Integrated Test $\mathrm{D}$ compared to Integrated Test $\mathrm{B}$ is that the leach temperature was $85^{\circ} \mathrm{C}$ for $24 \mathrm{hrs}$ as compared to $100^{\circ} \mathrm{C}$ for 12 hours. The other difference is the Integrated Test D simulant had $\mathrm{Cr}$ in the simulant from the start of processing and Integrated Test $\mathrm{B}$ had $\mathrm{Cr}$ added to adjust the simulant composition after aluminum leaching. Following the caustic leach, the UFP-VSL-T02A vessel contents were cooled using the vessel cooling jacket. The slurry was then concentrated to $17-w t \%$ UDS and washed with inhibited water to remove $\mathrm{NaOH}$ and other soluble salts. Next, the slurry was oxidatively leached using sodium permanganate to solubilize chromium. The slurry was then washed to remove the dissolved chromium and concentrated.

This is one in a series of reports that summarize Phase 1 results from testing in the PEP located in the Process Development Laboratory-West (PDL-W) located in Richland, Washington. Separate run reports have been prepared for each Phase 1 test (i.e., Functional Testing [WTP-RPT-190], Integrated Tests A

(a) SM Barnes, and R Voke. 2006. "Issue Response Plan for Implementation of External Flowsheet Review Team (EFRT) Recommendations - M12: Undemonstrated Leaching Process." 24590-WTP-PL-ENG-06-0024 Rev. 0.

(b) The scale of $1 / 4.5$ was chosen because this scale enables the ultrafiltration loop to be configured to meet two important criteria: 1) using one filter bundle, the ratio of solids in the feed tank to filter surface area will be the same as in the plant, and 2) using five filter bundles, the type and extent of mixing in the feed vessel will be approximately prototypic during the solids washing processes.

(c) In this report, the UFP vessels are generally denoted as Tank T01A/B and Tank T02A. In some cases alternative designations are used to maintain continuity with previous documentation (e.g., test specification/plan). 
[WTP-RPT-191], Integrated Test B [WTP-RPT-192], and Integrated Test D [WTP-RPT-193]). In addition, reports have been written that specifically address:

1. Filtration scale-up (WTP-RPT-185)

2. Caustic leaching scale-up (WTP-RPT-186)

3. Solids washing (WTP-RPT-187)

4. Oxidative leaching scale-up (WTP-RPT-188).

This report focuses on Integrated Test D and summarizes test conduct and results. It includes only very limited data analysis. Integrated Test D was conducted under Test Plan TP-RPP-WTP-506 ${ }^{(\mathrm{a})}$ and in accordance with Test Instruction TI-WTP-PEP-082. Supporting data files and analytical reports have been supplied on transportable hard drives because of the large amount of data.

\section{Objectives}

Table S.1 summarizes the objectives for the entire PEP testing program along with a discussion of contributions made by the results of Integrated Test D to meeting these objectives.

(a) GB Josephson, OP Bredt, JK Young, and DE Kurath. 2009. Test Plan for Pretreatment Engineering Platform (PEP) Testing (Phase I). TP-RPP-WTP-506, Rev. 0.4, Pacific Northwest National Laboratory, Richland, Washington. 
Table S.1. Summary of Test Objectives and Results

\begin{tabular}{|c|c|c|}
\hline Test Objective & \begin{tabular}{|c|} 
Objective \\
Met?
\end{tabular} & Discussion \\
\hline $\begin{array}{l}\text { Caustic-leach process: Compare } \\
\text { engineering- and laboratory-scale results to } \\
\text { determine impact of scale-up. }\end{array}$ & Yes & $\begin{array}{l}\text { Data from Integrated Test D were analyzed and compared } \\
\text { with laboratory-scale data, with results presented in report } \\
\text { WTP-RPT-197. }\end{array}$ \\
\hline $\begin{array}{l}\text { Oxidative-leach process: Compare } \\
\text { engineering- and laboratory-scale results to } \\
\text { determine impact of scale-up. }\end{array}$ & Yes & $\begin{array}{l}\text { Data from Integrated Test D were analyzed and compared } \\
\text { with laboratory-scale data, with results presented in report } \\
\text { WTP-RPT-197. }\end{array}$ \\
\hline $\begin{array}{l}\text { Cross-flow Ultrafiltration: Monitor } \\
\text { cross-flow filter performance at } \\
\text { engineering- and laboratory-scale to } \\
\text { determine scale-up. }\end{array}$ & NA & $\begin{array}{l}\text { Data from Integrated Test D were analyzed and compared } \\
\text { with laboratory-scale data, with results presented in report } \\
\text { WTP-RPT-197. }\end{array}$ \\
\hline $\begin{array}{l}\text { Slurry wash process: Determine the } \\
\text { post-caustic and oxidative leaching slurry } \\
\text { wash efficiencies. }\end{array}$ & Yes & $\begin{array}{l}\text { Data from Integrated Test D were used to determine } \\
\text { washing efficiencies for several components after caustic } \\
\text { and oxidative leaches, and the results are presented in } \\
\text { WTP-RPT-197. }\end{array}$ \\
\hline $\begin{array}{l}\text { Process Integration: Evaluate the chemical } \\
\text { addition, filter operation cycle } \\
\text { performance, and pressure pot operations. } \\
\text { Also perform mass balances for aluminum, } \\
\text { chromium, manganese, sodium, hydroxide, } \\
\text { oxalate, phosphate, sulfate, and water and } \\
\text { monitor permeates for post-filtration } \\
\text { precipitation. }\end{array}$ & Yes & $\begin{array}{l}\text { Supporting data from Integrated Test D are presented in this } \\
\text { report, and results to meet this objective are discussed in } \\
\text { WTP-RPT-197. }\end{array}$ \\
\hline $\begin{array}{l}\text { Monitor the performance of the } \\
\text { recirculation system pumps, filters, and } \\
\text { heat exchanger to support Engineering } \\
\text { fabrication decisions for these components. }\end{array}$ & Yes & $\begin{array}{l}\text { The data required to meet this objective were provided on } \\
\text { Compact Discs transmitted in the letter from GH Beeman to } \\
\text { H Hazen, "Subcontract No. 24590-QL-HC9-WA49-00001, } \\
\text { Project No. } 53569 \text { (WA-024) Engineering Ties Data } \\
\text { Transmittal: The Electronic File Enclosed With This letter } \\
\text { has been reviewed for technical accuracy per the QA } \\
\text { Program," WTP/RPP-MOA-PNNL-00392, dated 4/10/09. }\end{array}$ \\
\hline
\end{tabular}




\section{Test Exceptions}

A summary description of the Test Exceptions applied to these tests is shown in Table S.2.

Table S.2 Test Exceptions

\begin{tabular}{|c|c|}
\hline Test Exceptions & Description of Test Exceptions \\
\hline $\begin{array}{l}\text { 1) 24590-PTF-TEF-RT-08- } \\
\text { 00002, incorporated into ICN-1 } \\
\text { to Test Plan TP-RPP-WTP-506. }\end{array}$ & $\begin{array}{l}\text { This test exception: } \\
\text { 1. Added a stage during the filter conditioning section of the } \\
\text { Shakedown/functional Test where the simulant slurry was concentrated from } \\
\text { approximately } 5 \text {-wt } \% \text { solids to } 20 \text {-wt } \% \text { solids in one operation. This is in } \\
\text { addition to the previously specified low-solids filter and high-solids filter } \\
\text { testing. } \\
\text { 2. Documented the Joint Test Group (JTG) decision regarding the number of } \\
\text { replicate samples to be collected at various processing times. } \\
\text { 3. Revised the terminology specifying the Coriolis densitometer (CD) sample } \\
\text { locations changed to be consistent with PEP operating procedures. Renamed } \\
\text { the "center" array to "inner." } \\
\text { 4. The sampling specified in the low-solids filtration test over-specifies the } \\
\text { sample collection timing required. The technical requirement is to get } 30 \\
\text { unique samples. The sampling schedule specified is not required to achieve } \\
\text { this test objective. }\end{array}$ \\
\hline $\begin{array}{l}\text { 2) 24590-PTF-TEF-RT-09- } \\
\text { 00001 incorporated into ICN-2 } \\
\text { and ICN-3 to Test Plan } \\
\text { TP-RPP-WTP-506. }\end{array}$ & $\begin{array}{l}\text { 1. In several steps, the sampling location was changed from the filer-loop } \\
\text { in-line location to a middle-low CD sample loop location in the UFP-T02A } \\
\text { vessel. This change impacted sampling in the Shakedown/Functional and all } \\
\text { Integrated tests (ref CCN 187749). } \\
\text { 2. Added a step to the Shakedown/Functional Test (step A.1.31) to add sodium } \\
\text { permanganate to UFP-VSL-T02A to assess possible foaming issue (ref CCN } \\
\text { 187749). } \\
\text { 3. Changed location of second sample for laboratory-scale Cells Unit Filter } \\
\text { (CUF) testing from the in-line filter loop to the middle-low CD port in the } \\
\text { UFP-VSL-T02A (step A.1.10; Shakedown/Functional Test) (ref CCN } \\
\text { 187749). } \\
\text { 4. Collected samples for laboratory-scale laboratory leaching test before and } \\
\text { after caustic addition in UFP-VSL-T01A (A.1.20; Shakedown/Functional } \\
\text { Test) and UFP-VSL-T02A (step A.1.15; Shakedown/Functional Test) and in } \\
\text { the Integrated Test steps (B1.2; Integrated Test A, B2.6; Integrated Tests } \\
\text { B/D) (ref CCN 192734). } \\
\text { 5. Deleted reconfiguration of the filter-loop to bypass UFP-VSL-T02A and } \\
\text { circulate flush water with UFP-PMP-T02A and/or UFP-PMP-43A to allow a } \\
\text { representative in-line sample to be collected. This step (step A.1.17; } \\
\text { Shakedown/Functional Test) could not be done under the operating } \\
\text { restrictions in place on the operation of the filter loop (ref CCN 192734). } \\
\text { 6. Eliminated step A.1.25 (filter-loop bypass test with tracer) from the } \\
\text { Shakedown/Functional Test. This test was conducted after Integrated Test B } \\
\text { was completed (ref CCN 187753). } \\
\text { 7. Modified step A.1.29 (Shakedown/Functional Test) to eliminate the removal } \\
\text { of solids from UFP-VSL-T02A before the High-Solids Filter Test. This step } \\
\text { was not needed as the amount of solids was less than anticipated (ref CCN } \\
\text { 187752). } \\
\text { 8. Modified step A.1.30 (Shakedown/Functional Test) to include five filter } \\
\text { backpulses before starting the High-Solids Filter Test (ref CCN 187752). } \\
\text { 9. Modified step B.1.8 (Integrated Test A) to allow } 80 \% \text { of caustic to be added }\end{array}$ \\
\hline
\end{tabular}


Table S.2 Test Exceptions

\begin{tabular}{|c|c|}
\hline Test Exceptions & Description of Test Exceptions \\
\hline & 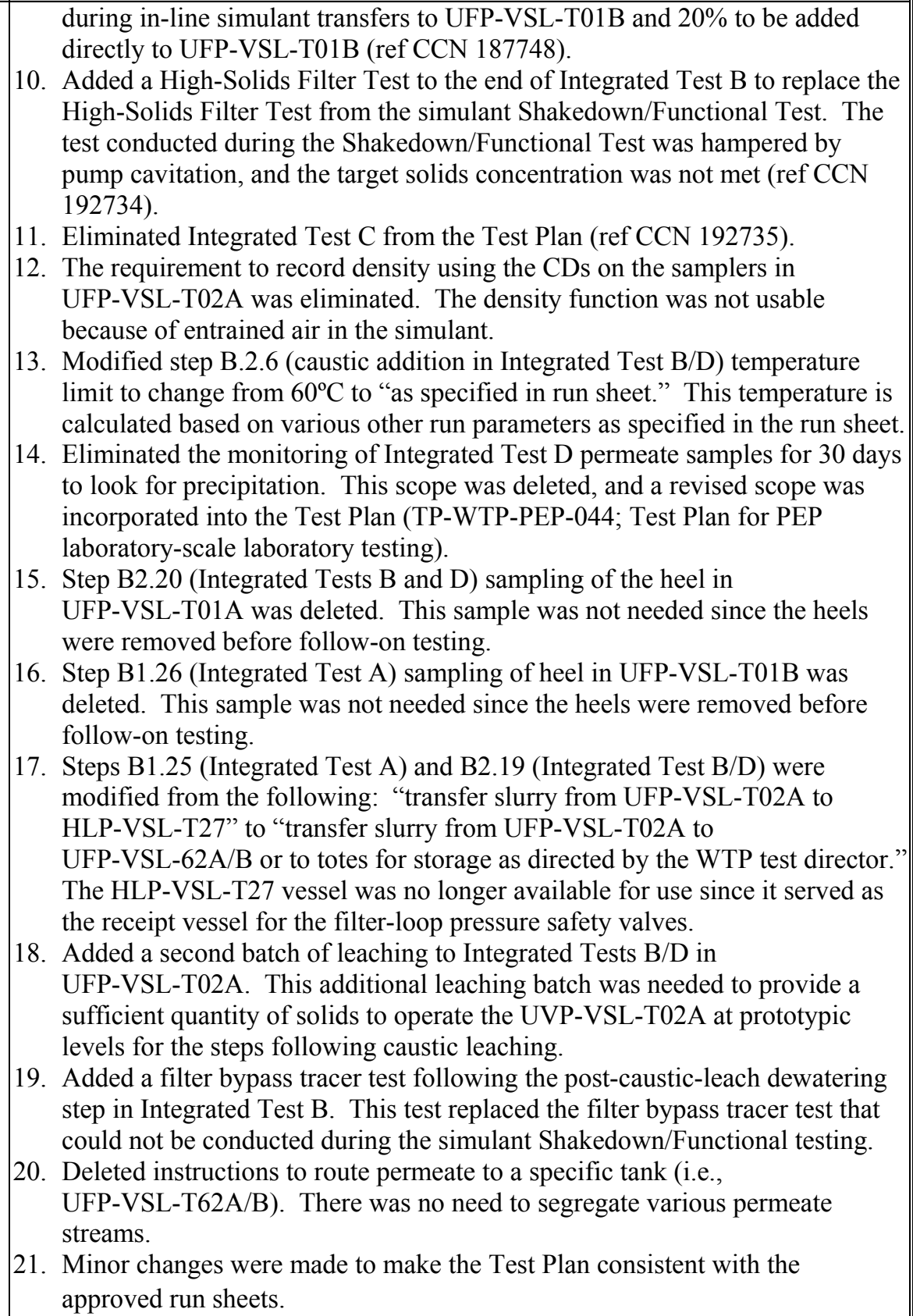 \\
\hline $\begin{array}{l}\text { 3) } 24590 \text {-WTP-TEF-RT-09- } \\
\text { 00003 incorporated into ICN-1 } \\
\text { to Test Plan TP-WTP-PEP-044. }\end{array}$ & $\begin{array}{l}\text { This Test Exception specified activities to be performed with permeate samples } \\
\text { obtained from Integrated Test D. The Integrated Test D permeate samples were } \\
\text { originally stored in a temperature-controlled environment and then moved to a } \\
\text { location with a reduced temperature where precipitation was likely to occur. The } \\
\text { Test Exception requested that the approximate size distribution of the solids be } \\
\text { measured in several (three or four) selected PEP samples from Integrated Test D } \\
\text { using polarized light microscopy (PLM). Size-calibrated photographs should be } \\
\text { provided along with the analysis. If possible, record the mineral identification of } \\
\text { the solids phase(s) along with the particle-size distribution. WTP personnel will }\end{array}$ \\
\hline
\end{tabular}


Table S.2 Test Exceptions

\begin{tabular}{|c|c|}
\hline Test Exceptions & Description of Test Exceptions \\
\hline & $\begin{array}{l}\text { select the samples in consultation with the subcontractor, and this will be based in } \\
\text { part on observing which samples contain the most solids or appear to contain } \\
\text { different types of solids. Repeat the size-distribution analysis approximately } \\
1 \text { week after the initial measurements to determine whether there was a significant } \\
\text { change in crystal size, habit, or composition. } \\
\text { Perform each size-distribution analysis by measuring the diameter (or length and } \\
\text { width for elongated crystals) of approximately } 100 \text { individual particles in each } \\
\text { sample. The size may be measured either on the microscope slide, using a } \\
\text { calibrated ocular scale, or on the size-calibrated photographs. The program } \\
\text { recognizes the limitations of the statistical significance of a size-distribution } \\
\text { measurement based on such a small population. This Test Exception did not } \\
\text { affect any of the existing Test Plan objectives. }\end{array}$ \\
\hline $\begin{array}{l}\text { 4) 24590-WTP-TEF-RT-09- } \\
\text { 00002 Rev 0, incorporated into } \\
\text { ICN-4 to Test Plan } \\
\text { TP-RPP-WTP-506. }\end{array}$ & $\begin{array}{l}\text { This Test Exception: } \\
\text { 1. Requests a report summarizing the lessons learned during scale-up, } \\
\text { manufacture, and transport of the PEP simulant. } \\
\text { 2. Specifies the sampling and analysis scope to be performed to complete the } \\
\text { prototypic nitric acid PEP filter cleaning process. } \\
\text { 3. Deletes the Engineering Ties report scope. } \\
\text { 4. Specifies additional experimental and analytical work required to estimate the } \\
\text { amount of excess caustic in caustic-leachate samples and post-caustic-leach } \\
\text { wash solutions containing } \approx 3.5-\mathrm{M} \mathrm{Na} \text {. }\end{array}$ \\
\hline $\begin{array}{l}\text { 5) 24590-WTP-TEF-RT-09- } \\
\text { 00001 Rev } 1 \text { incorporated into } \\
\text { ICN-2 to Test Plan } \\
\text { TP-WTP-PEP-044. }\end{array}$ & $\begin{array}{l}\text { This Test Exception specifies additional work to be conducted with caustic-leach } \\
\text { solutions and post-caustic-leach washing permeate samples obtained from PEP } \\
\text { Integrated Tests A, B, and D. It contains the following tasks: } \\
\text { 1. Determine precipitate mineralogy, precipitate phase compositions, and } \\
\text { solution saturation composition. } \\
\text { 2. Determine rate of approach to saturation concentrations. } \\
\text { 3. Identify and characterize precipitates formed in post-caustic-leach filtrate. } \\
\text { 4. Determine the dilution required to redissolve the precipitate. } \\
\text { 5. Determine super-saturation in post-caustic-leach filtrates from Integrated Test } \\
\text { 6. Din the PEP. } \\
\text { and wash cycle. }\end{array}$ \\
\hline
\end{tabular}


As documented in the PEP Test Plan, the deviations from the Test Specification are provided in Table S.3.

Table S.3. Deviations from Test Specification

\begin{tabular}{|c|c|}
\hline Test Specification Reference & Exception Taken \\
\hline $\begin{array}{l}\text { Section 6.4.4 "Analytical measurements will } \\
\text { be made in conformance to the Guidelines for } \\
\text { Performing Chemical Physical, and } \\
\text { Rheological Properties Measurements (BNI } \\
\text { 2002-3) }{ }^{(a)} \text { as applicable." }\end{array}$ & $\begin{array}{l}\text { Three method exceptions are required under this Test Plan: } \\
\text { 1. Caustic-leach and oxidative-leach samples taken during this } \\
\text { testing must be separated more quickly than the standard } \\
\text { method using syringes. This testing will use a modified } \\
\text { method with a shorter centrifuge time and will apply higher } g \\
\text { forces (e.g., } 4000 \mathrm{~g} \text { vs. } 1000 \mathrm{~g} \text { ). } \\
\text { Impact on results: If the standard method were used, the } \\
\text { longer time could very well lead to greater precipitation and } \\
\text { inaccurate results. Laboratory testing will be conducted with } \\
\text { simulants to confirm that this method of sample handling is } \\
\text { adequate. } \\
\text { 2he densities of samples smaller than } 10 \text {-mL can only be } \\
\text { established within two significant figures of accuracy. Density } \\
\text { measurements for this Test Plan require greater accuracy. } \\
\text { Therefore, a more accurate method employing a pycnometer } \\
\text { will be used. } \\
\text { Impact on results: The change to a pycnometer will generate } \\
\text { more precise results than the standard method. The main } \\
\text { impact is expected to be on analysis time. The pycnometer } \\
\text { method will be slower. } \\
\text { The process for determining the wt\% UDS content of the } \\
\text { slurries will in some cases be determined with a moisture } \\
\text { analyzer. In addition, the method of drying samples will be } \\
\text { modified to allow glass fiber filters to be used in drying the } \\
\text { samples. } \\
\text { Impact on results: Both modifications are intended to decrease } \\
\text { the time required to obtain results. }\end{array}$ \\
\hline
\end{tabular}

\section{Results and Performance Against Success Criteria}

The PEP system tests were designed to generate the data necessary to:

- Provide engineering-scale system performance data. This information is used to support the WTP computer process models projections of the waste processing campaign.

- Confirm the operability and functionality of UFP system components.

The Research and Technology (R\&T) success criteria for achieving these objectives are discussed in Table S.4. The success criteria for the entire PEP testing program are provided with discussion limited to

(a) GL Smith and K Prindiville. 2002. Guidelines for Performing Chemical, Physical, and Rheological Properties Measurements. 24590-WTP-GPG-RTD-001, Rev 0, Bechtel National, Inc., Richland, Washington. 
the success criteria covered by the scope of this report. The success criteria not addressed in this report are shaded in gray.

Table S.4. Success Criteria

\begin{tabular}{|c|c|}
\hline Success Criteria & How Testing Did or Did Not Meet Success Criteria \\
\hline \multicolumn{2}{|l|}{ UFP System Process Performance } \\
\hline $\begin{array}{l}\text { Measure the aluminum leaching performance } \\
\text { of the PEP and laboratory systems as a } \\
\text { function of time under WTP UFP-2 projected } \\
\text { leaching conditions at low process } \\
\text { temperatures of nominally } 100 \text { and } 80^{\circ} \mathrm{C} \text { ). } \\
\end{array}$ & $\begin{array}{l}\text { Aluminum leaching at } 85^{\circ} \mathrm{C} \text { was measured as a function of time } \\
\text { under WTP UFP-2 projected leaching conditions during Integrated } \\
\text { Test D. Results are presented in this report and in report } \\
\text { WTP-RPT-197. }\end{array}$ \\
\hline $\begin{array}{l}\text { Compare aluminum leach performance in } \\
\text { UFP- } 1 \text { where all of the } \mathrm{NaOH} \text { is added in-line } \\
\text { to the case where a fraction of the total } \mathrm{NaOH} \\
\text { is added directly to the tank. }\end{array}$ & $\begin{array}{l}\text { Results to meet this success criterion are discussed in report } \\
\text { WTP-RPT-197. }\end{array}$ \\
\hline $\begin{array}{l}\text { Measure chromium leaching performance in } \\
\text { the PEP and laboratory systems as a function } \\
\text { of time at the WTP projected conditions in } \\
\text { UFP-2. }\end{array}$ & $\begin{array}{l}\text { Chromium leaching was measured as a function of time under WTP } \\
\text { UFP-2 projected leaching conditions during Integrated Test D. } \\
\text { Results are presented in report WTP-RPT-197. }\end{array}$ \\
\hline $\begin{array}{l}\text { Evaluate the process control strategy for } \\
\text { specifying required reagent additions, } \\
\text { including } \mathrm{NaOH}, \mathrm{NaMnO}_{4} \text {, and wash } \\
\text { solutions provided in the PEP Phase } 1 \text { Testing } \\
\text { Process Description. }\end{array}$ & $\begin{array}{l}\text { The process control strategy for specifying the amount of reagent } \\
\text { was to analyze a sample of the simulant feed for aluminum and } \\
\text { chromium content and specify the amount of } \mathrm{NaOH} \text { and } \mathrm{NaMnO}_{4} \\
\text { based on the result. The amount of reagent added was correct } \\
\text { within the analytical error of the analysis method. Results are } \\
\text { presented in report WTP-RPT-197. A comparison of targeted and } \\
\text { delivered reagent additions is provided in report WTP-RPT-188 for } \\
\text { Integrated Tests A and B. Additional discussion and results for } \\
\text { Integrated Test D are provided in report WTP-RPT-197. }\end{array}$ \\
\hline $\begin{array}{l}\text { Measure the filter system performance at the } \\
\text { nominal flow velocity and transmembrane } \\
\text { pressures for the solids concentration and } \\
\text { washing stages for the UFP-1 and UFP-2 } \\
\text { aluminum leaching flowsheets. }\end{array}$ & $\begin{array}{l}\text { Filter performance was measured at a nominal axial flow velocity of } \\
15 \mathrm{ft} / \mathrm{sec} \text { and a transmembrane pressure (TMP) of } 40 \text { psid during } \\
\text { solids concentration and washing during Integrated Test D. Actual } \\
\text { permeate flux and filtration conditions are provided in this report. A } \\
\text { summary of filter system performance is provided in } \\
\text { WTP-RPT-197. }\end{array}$ \\
\hline $\begin{array}{l}\text { Evaluate the control strategy for make-up } \\
\text { additions from UFP-VSL-00001A/B to } \\
\text { UFP-VSL-00002A/B during initial dewatering } \\
\text { process. }\end{array}$ & $\begin{array}{l}\text { The control strategy for make-up additions between } \\
\text { UFP-VSL-T01A and UFP-VSL-T02A during the initial dewatering } \\
\text { process was demonstrated during initial dewatering during } \\
\text { Integrated Test D. The control strategy was determined to be } \\
\text { adequate, although maintaining a high operating level in } \\
\text { UFP-VSL-T02A until the end of processing should reduce the } \\
\text { possibility of entraining air into the recirculation pumps. Results are } \\
\text { presented in report WTP-RPT-197. }\end{array}$ \\
\hline $\begin{array}{l}\text { Measure the wash water volumes required to } \\
\text { remove or reduce the free hydroxide following } \\
\text { the aluminum leaching stage and dissolved } \\
\text { chromium after the oxidative leaching process } \\
\text { to the specified concentrations. }\end{array}$ & $\begin{array}{l}\text { Washing performance during Integrated Test } \mathrm{D} \text { is presented in } \\
\text { report WTP-RPT- } 197 \text {. }\end{array}$ \\
\hline
\end{tabular}


Table S.4. Success Criteria

\begin{tabular}{|c|c|}
\hline Success Criteria & How Testing Did or Did Not Meet Success Criteria \\
\hline $\begin{array}{l}\text { Perform mass balances for selected } \\
\text { constituents, including aluminum, chromium, } \\
\text { manganese, sodium, hydroxide, oxalate, } \\
\text { phosphate, sulfate, and water to evaluate } \\
\text { leaching and washing process performance. }\end{array}$ & $\begin{array}{l}\text { Results necessary for performing mass balances for selected } \\
\text { constituents for Integrated Test D are presented in this report. } \\
\text { Results to meet this success criterion are discussed for Cr in the } \\
\text { oxidative leaching process for Integrated Tests A and B in report } \\
\text { WTP-RPT-188 and are fully discussed for all tests and constituents } \\
\text { in report WTP-RPT-197. }\end{array}$ \\
\hline $\begin{array}{l}\text { Measure solids distribution under scaled } \\
\text { mixing conditions before and after caustic } \\
\text { leaching evolutions. }\end{array}$ & $\begin{array}{l}\text { Solids distribution before and after caustic leaching is presented in } \\
\text { reports WTP-RPT-190 and WTP-RPT-197. }\end{array}$ \\
\hline $\begin{array}{l}\text { Measure the rheology of the slurry simulant } \\
\text { and shear strength of the settled solids before } \\
\text { and after each leaching and washing unit } \\
\text { operation and following final concentration. }\end{array}$ & $\begin{array}{l}\text { The rheology of the slurry simulant was measured for Integrated } \\
\text { Test D and is provided in this report. }\end{array}$ \\
\hline $\begin{array}{l}\text { Estimate the quantity of excess hydroxide } \\
\text { added in the process that may not be needed to } \\
\text { keep aluminate in solution following filtration. }\end{array}$ & $\begin{array}{l}\text { Results to meet this success criterion are expected to be discussed in } \\
\text { report WTP-RPT-197. }\end{array}$ \\
\hline $\begin{array}{l}\text { Collect and retain permeate samples for } \\
\text { extended precipitation studies (including } \\
\text { permeate/simulated supernatant blended cases) } \\
\text { from each concentration cycle. }\end{array}$ & $\begin{array}{l}\text { Permeate samples were collected during Integrated Test D for } \\
\text { precipitation studies. The results of the precipitation studies are } \\
\text { discussed in WTP-RPT-197, WTP-RPT-200 and WTP-RPT-205. }\end{array}$ \\
\hline \multicolumn{2}{|l|}{ UFP System Operability and Functionality } \\
\hline $\begin{array}{l}\text { Verify that the dual, in-series pump } \\
\text { configuration is controllable and maintains the } \\
\text { required slurry velocity and pressures for } \\
\text { ultrafilter operation. }\end{array}$ & $\begin{array}{l}\text { Pumps were operated in-series and were controllable. There were } \\
\text { some air entrainment issues associated with the PEP system design } \\
\text { that need to be evaluated for the WTP. } \\
\text { The data required to meet this success criterion were provided on } \\
\text { compact disks transmitted in the following reference: Letter from } \\
\text { GH Beeman to H Hazen, "Subcontract No. 24590-QL-HC9-WA49- } \\
\text { 00001, Project No. 53569 (WA-024) Engineering Ties Data } \\
\text { Transmittal: The Electronic File Enclosed with this letter Has Been } \\
\text { Reviewed for Technical Accuracy Per the QA Program," } \\
\text { WTP/RPP-MOA-PNNL-00392, dated 4/10/09. }\end{array}$ \\
\hline $\begin{array}{l}\text { Measure the operating characteristics for the } \\
\text { cooling heat exchanger for the } \\
\text { UFP-VSL-00002 filter recirculation loop } \\
\text { (temperature changes as a function of flow to } \\
\text { determine how to achieve the desired } \\
\text { performance in the PTF analog). }\end{array}$ & $\begin{array}{l}\text { The data required to meet this success criterion were provided on } \\
\text { compact disks transmitted in the following reference: Letter from } \\
\text { GH Beeman to H Hazen, "Subcontract No. 24590-QL-HC9-WA49- } \\
\text { 00001, Project No. 53569 (WA-024) Engineering Ties Data } \\
\text { Transmittal: The Electronic File Enclosed with this Letter Has Been } \\
\text { Reviewed for Technical Accuracy Per the QA Program," } \\
\text { WTP/RPP-MOA-PNNL-00392, dated 4/10/09. }\end{array}$ \\
\hline $\begin{array}{l}\text { Confirm whether the WTP process control } \\
\text { strategies for ultrafilter system filling, } \\
\text { operating, backpulsing, draining, flushing, and } \\
\text { cleaning are adequate for stable operation. } \\
\text { Provide to WTP data to determine whether } \\
\text { backpulsing is a required and effective means }\end{array}$ & $\begin{array}{l}\text { Results to meet this success criterion are expected to be discussed in } \\
\text { report WTP-RPT-197. }\end{array}$ \\
\hline
\end{tabular}


Table S.4. Success Criteria

\begin{tabular}{|c|c|}
\hline Success Criteria & How Testing Did or Did Not Meet Success Criteria \\
\hline \multicolumn{2}{|l|}{$\begin{array}{l}\text { of restoring the filter permeate rates to ensure } \\
\text { production throughput is maintained and } \\
\text { whether operation of the backpulse system } \\
\text { induces any process or equipment operations } \\
\text { issues. }\end{array}$} \\
\hline $\begin{array}{l}\text { Use only the process information and data } \\
\text { available to the WTP PTF operating staff } \\
\text { during WTP operations (e.g., caustic and } \\
\text { permanganate addition volumes, permeate } \\
\text { mass balances for solids concentration, etc.) to } \\
\text { operate the PEP. }\end{array}$ & $\begin{array}{l}\text { This success criterion was met by developing a run sheet of all the } \\
\text { operating parameters (e.g., transfer volumes, reagent addition } \\
\text { volumes, control levels, etc.) based on prototypic characterization } \\
\text { data before the start of Integrated Test D. Changes to the run sheet } \\
\text { made during the test itself were based only on data that would be } \\
\text { available to the plant, and were not, for example, based on } \\
\text { information from non-prototypic samples. This success criterion is } \\
\text { fully discussed in WTP-RPT-197. }\end{array}$ \\
\hline $\begin{array}{l}\text { Confirm whether the elevated temperature } \\
\text { PJM operating strategy is adequate for stable } \\
\text { PEP and WTP operation. }\end{array}$ & $\begin{array}{l}\text { Results to meet this success criterion are discussed in report } \\
\text { WTP-RPT-197. }\end{array}$ \\
\hline $\begin{array}{l}\text { Measure the heat-up rate and controllability of } \\
\text { the PEP UFP-VSL-00001 and } \\
\text { UFP-VSL-00002 vessels and the cooling } \\
\text { performance for UFP vessels. }\end{array}$ & $\begin{array}{l}\text { The heat up, thermal control at } 85^{\circ} \mathrm{C} \text {, and cool-down performance of } \\
\text { UFP-VSL-T02A was measured during Integrated Test D. Thermal } \\
\text { profiles are provided in this report. This information for the other } \\
\text { tests is discussed in the other run reports and summarized in } \\
\text { WTP-RPT-197. }\end{array}$ \\
\hline $\begin{array}{l}\text { Measure the performance of the in-line } \\
\text { addition of process chemicals into the } \\
\text { simulated wastes and determine the extent of } \\
\text { blending in the process vessels. }\end{array}$ & $\begin{array}{l}\text { The blending of process chemicals added in-line is presented in } \\
\text { report WTP-RPT-190 and WTP-RPT- } 197 .\end{array}$ \\
\hline $\begin{array}{l}\text { Monitor ultrafilter performance (to include } \\
\text { visual inspection of the filter tubes, tube } \\
\text { sheets, and heads from an ultrafilter for any } \\
\text { evidence of flow mal-distribution and/or } \\
\text { solids buildup at least once during Phase 1). }\end{array}$ & $\begin{array}{l}\text { Ultrafilter performance was measured and the tubes were inspected } \\
\text { after the completion of Integrated Test D. The inspections showed } \\
\text { no evidence of flow mal-distribution, solids build-up, or corrosion. }\end{array}$ \\
\hline $\begin{array}{l}\text { Measure, record, and control ultrafiltration } \\
\text { temperature, transmembrane pressure, and } \\
\text { slurry flow during filter-loop operations. }\end{array}$ & $\begin{array}{l}\text { Slurry flow rate, temperature, and TMP were recorded and } \\
\text { controlled during Integrated Test D. Results are provided in this } \\
\text { report. }\end{array}$ \\
\hline $\begin{array}{l}\text { Record any solids accumulations observed } \\
\text { during any operating stage or maintenance } \\
\text { evolution. }\end{array}$ & $\begin{array}{l}\text { Results to meet this success criterion are discussed in report } \\
\text { WTP-RPT-197. }\end{array}$ \\
\hline $\begin{array}{l}\text { Monitor the permeate production rate of each } \\
\text { ultrafilter assembly in operation. }\end{array}$ & $\begin{array}{l}\text { Permeate production rate of each ultrafilter was recorded during } \\
\text { Integrated Test D. Results are provided in this report. }\end{array}$ \\
\hline $\begin{array}{l}\text { Record operating time of each ultrafilter } \\
\text { assembly. }\end{array}$ & $\begin{array}{l}\text { The operating time of each ultrafilter assembly was recorded during } \\
\text { Integrated Test D. Results are provided in this report. The } \\
\text { operating time of each filter assembly for each test is discussed in } \\
\text { the relevant run report and summarized in WTP-RPT-197. }\end{array}$ \\
\hline $\begin{array}{l}\text { Record each ultrafilter assembly cleaning } \\
\text { event (backpulse, flush, chemical cleaning, } \\
\text { etc.). }\end{array}$ & $\begin{array}{l}\text { At the completion of Integrated Test D the ultrafilters were cleaned } \\
\text { with nitric acid and the results are provided in this report. }\end{array}$ \\
\hline
\end{tabular}


Table S.4. Success Criteria

\begin{tabular}{|l|l||}
\hline \multicolumn{1}{|c|}{ Success Criteria } & \multicolumn{1}{c||}{ How Testing Did or Did Not Meet Success Criteria } \\
\hline $\begin{array}{l}\text { Evaluation of the pulse-pot operation and } \\
\text { backpulse operation strategies contained in } \\
\begin{array}{l}\text { Pretreatment Engineering Platform (PEP) } \\
\text { Phase 1 Testing Process Description. }\end{array}\end{array}$ & $\begin{array}{l}\text { Significant backpulsing was not performed in Integrated Test D. } \\
\text { Evaluation of backpulse operations is discussed in report } \\
\text { WTP-RPT-197. }\end{array}$ \\
\hline $\begin{array}{l}\text { Evaluate permeate and permeate blends for } \\
\text { precipitation of solids, particularly aluminum } \\
\text { and oxalate solids. }\end{array}$ & $\begin{array}{l}\text { Permeate samples were collected during Integrated Test D for } \\
\text { precipitation studies. Results to meet this success criterion are } \\
\text { discussed in reports WTP-RPT-197, WTP-RPT-200 and } \\
\text { WTP-RPT-205. }\end{array}$ \\
\hline
\end{tabular}

\section{Quality Requirements}

The PNNL Quality Assurance Program is based upon the requirements as defined in the U.S. Department of Energy (DOE) Order 414.1C, Quality Assurance and 10 CFR 830, Energy/Nuclear Safety Management, Subpart A-Quality Assurance Requirements (a.k.a. the Quality Rule). PNNL has chosen to implement the following consensus standards in a graded approach:

- ASME NQA-1-2000, Quality Assurance Requirements for Nuclear Facility Applications, Part 1, Requirements for Quality Assurance Programs for Nuclear Facilities

- ASME NQA-1-2000, Part II, Subpart 2.7, Quality Assurance Requirements for Computer Software for Nuclear Facility Applications

- ASME NQA-1-2000, Part IV, Subpart 4.2, Graded Approach Application of Quality Assurance Requirements for Research and Development.

The procedures necessary to implement the requirements are documented in PNNL's "How Do I...? (HDI). ${ }^{(a)}$

The RPP-WTP quality requirements are implemented by performing work in accordance with the River Protection Project-Waste Treatment Plant Support Program (RPP-WTP) Quality Assurance Plan (RPP-WTP-QA-001, QAP). Work was performed to the quality requirements of NQA-1-1989, Part I, Basic and Supplementary Requirements, NQA-2a-1990, Part 2.7, and DOE/RW-0333P, Rev 13, Quality Assurance Requirements and Descriptions (QARD), as applicable. These quality requirements are implemented through the River Protection Project-Waste Treatment Plant Support Program (RPP-WTP) Quality Assurance Manual (RPP-WTP-QA-003, QAM). The requirements of DOE/RW-0333P Rev 13, Quality Assurance Requirements and Descriptions (QARD), and 10 CFR 830 Subpart A were not required for this work.

RPP-WTP addresses internal verification and validation activities by conducting an Independent Technical Review of the final data report in accordance with RPP-WTP's procedure QA-RPP-WTP-604. This review procedure is part of PNNL's RPP-WTP Quality Assurance Manual (RPP-WTP-QA-003).

(a) PNNL's system for managing the delivery of laboratory-level policies, requirements, and procedures. 
Following this procedure, a technical review verified that the reported results are traceable, that inferences and conclusions are soundly based, and the reported work satisfies the objectives.

\section{R\&T Test Conditions}

The R\&T test conditions as defined in the Test Specification are summarized in Table S.5. The R\&T test conditions for the entire PEP testing program are provided with discussion limited to the R\&T test conditions covered by the scope of this report. R\&T test conditions not addressed in this report are shaded in gray.

Table S.5. R\&T Test Conditions

\begin{tabular}{|c|c|}
\hline List R\&T Test Conditions & Were Test Conditions Followed? \\
\hline \multicolumn{2}{|l|}{ General Requirements } \\
\hline $\begin{array}{l}\text { Perform mass balances for selected constituents, } \\
\text { including aluminum, chromium, manganese, sodium, } \\
\text { hydroxide, oxalate, phosphate, sulfate, and water, to } \\
\text { evaluate leaching and washing process performance. }\end{array}$ & $\begin{array}{l}\text { Necessary samples were taken to conduct a mass } \\
\text { balance for Integrated Test B. Mass balance results } \\
\text { are provided in WTP-RPT-197. }\end{array}$ \\
\hline $\begin{array}{l}\text { Evaluate ultrafilter performance (to include visual } \\
\text { inspection of the filter tubes, tube sheets, and heads } \\
\text { from an ultrafilter for any evidence of flow } \\
\text { mal-distribution and/or solids buildup or evidence of } \\
\text { potential failure). }\end{array}$ & $\begin{array}{l}\text { Ultrafilter performance was measured, and the } \\
\text { tubes were inspected after completing Integrated } \\
\text { Test D. The inspections showed no evidence of } \\
\text { flow mal-distribution, solids build-up, or corrosion. } \\
\text { This R\&T test condition is also discussed in report } \\
\text { WTP-RPT-197. }\end{array}$ \\
\hline $\begin{array}{l}\text { Assess the blending achieved during in-line additions } \\
\text { of leaching and washing solutions. }\end{array}$ & $\begin{array}{l}\text { In-line addition of wash water during Integrated } \\
\text { Tests D and B is discussed in WTP-RPT-187 and is } \\
\text { fully discussed in report WTP-RPT-197. }\end{array}$ \\
\hline $\begin{array}{l}\text { Record any solids accumulations observed during } \\
\text { any operating stage or maintenance evolution (e.g., } \\
\text { photography, particle-size distribution). }\end{array}$ & $\begin{array}{l}\text { This R\&T test condition is discussed in report } \\
\text { WTP-RPT-197. }\end{array}$ \\
\hline \multicolumn{2}{|l|}{ Leaching Operations } \\
\hline $\begin{array}{l}\text { Maintain the caustic leaching temperature at the } \\
\text { required setpoint and record the steam usage to } \\
\text { remain in the temperature range. }\end{array}$ & $\begin{array}{l}\text { The temperature during caustic leaching was } \\
\text { maintained at setpoint with steam usage measured } \\
\text { during Integrated Test D. Additional discussion of } \\
\text { this condition is provided in WTP-RPT-197. }\end{array}$ \\
\hline $\begin{array}{l}\text { Maintain oxidative leaching temperature at the } \\
\text { required setpoint. }\end{array}$ & $\begin{array}{l}\text { The temperature during oxidative leaching was } \\
\text { maintained at setpoint during Integrated Test D. } \\
\text { Additional discussion of this condition is provided } \\
\text { in WTP-RPT-197. }\end{array}$ \\
\hline $\begin{array}{l}\text { Obtain periodic samples during the leaching } \\
\text { operations to monitor the amount of aluminum or } \\
\text { chromium that has dissolved and concentrations of } \\
\text { the reactants and products in the liquid fraction in the } \\
\text { vessel. }\end{array}$ & $\begin{array}{l}\text { This R\&T condition was met for the caustic } \\
\text { leaching tests discussed in this report. Additional } \\
\text { discussion of this R\&T condition is provided in } \\
\text { WTP-RPT-188 and WTP-RPT- } 197 \text {. }\end{array}$ \\
\hline $\begin{array}{l}\text { Provide data to demonstrate the WTP process control } \\
\text { strategy for the caustic and permanganate addition. }\end{array}$ & $\begin{array}{l}\text { This R\&T test condition is discussed in report } \\
\text { WTP-RPT- } 197 .\end{array}$ \\
\hline $\begin{array}{l}\text { Measure the rheology of the slurry simulant and } \\
\text { shear strength of the settled solids before and } \\
\text { following each leaching unit operation. }\end{array}$ & $\begin{array}{l}\text { This R\&T test condition is discussed in report } \\
\text { WTP-RPT-197. }\end{array}$ \\
\hline
\end{tabular}


Table S.5. R\&T Test Conditions

\begin{tabular}{|c|c|}
\hline List R\&T Test Conditions & Were Test Conditions Followed? \\
\hline \multicolumn{2}{|l|}{ Concentration Operations } \\
\hline $\begin{array}{l}\text { Monitor the permeate production rate of each } \\
\text { ultrafilter assembly in operation. }\end{array}$ & $\begin{array}{l}\text { The slurry rheology was measured with samples } \\
\text { taken before and after each leaching unit operation. } \\
\text { Results are provided in this report. Rheology } \\
\text { results for the other tests are included in the } \\
\text { relevant run reports. }\end{array}$ \\
\hline Record operating time of each ultrafilter assembly. & $\begin{array}{l}\text { The operating time of each ultrafilter was recorded } \\
\text { during Integrated Test B, with results discussed in } \\
\text { report WTP-RPT-197. }\end{array}$ \\
\hline $\begin{array}{l}\text { Record each ultrafilter assembly “cleaning” event } \\
\text { (backpulse, flush, chemical cleaning, etc.). }\end{array}$ & $\begin{array}{l}\text { Ultrafilter cleaning events were recorded with } \\
\text { results of the cleaning after Integrated Test D } \\
\text { provided in this report. A summary of the filter } \\
\text { cleaning events is provided in WTP-RPT- } 197 \text {. }\end{array}$ \\
\hline $\begin{array}{l}\text { Confirm pulse-pot operation and backpulse operation } \\
\text { strategies. }\end{array}$ & $\begin{array}{l}\text { This R\&T test condition is discussed in report } \\
\text { WTP-RPT-197. }\end{array}$ \\
\hline $\begin{array}{l}\text { Control ultrafiltration temperature, transmembrane } \\
\text { pressure, and slurry flow as specified in test-specific } \\
\text { run sheets. }\end{array}$ & $\begin{array}{l}\text { Ultrafilter temperature, transmembrane pressure, } \\
\text { and slurry flow rate were controlled. This R\&T } \\
\text { test condition is discussed in the run reports for the } \\
\text { individual tests and WTP-RPT-197. }\end{array}$ \\
\hline $\begin{array}{l}\text { Collect and retain permeate samples for extended } \\
\text { precipitation studies (including permeate/simulated } \\
\text { supernatant blended cases) from each concentration } \\
\text { cycle. }\end{array}$ & $\begin{array}{l}\text { Samples were collected and retained for extended } \\
\text { precipitation studies. The results of the } \\
\text { precipitation studies are discussed in } \\
\text { WTP-RPT-197, WTP-RPT-200, and } \\
\text { WTP-RPT-205. }\end{array}$ \\
\hline $\begin{array}{l}\text { Demonstrate WTP ultrafiltration system control } \\
\text { scheme in normal operating modes (e.g., fill and } \\
\text { startup, operation, backpulsing, flush and drain, } \\
\text { cleaning and return to service). }\end{array}$ & $\begin{array}{l}\text { This R\&T test condition is discussed in report } \\
\text { WTP-RPT-197. }\end{array}$ \\
\hline \multicolumn{2}{|l|}{ Washing Operations } \\
\hline $\begin{array}{l}\text { Wash slurries using a washing protocol to be } \\
\text { specified in test-specific run sheets. }\end{array}$ & $\begin{array}{l}\text { Slurries were washed as specified in the Integrated } \\
\text { Test B run sheet. Washing results are discussed in } \\
\text { reports WTP-RPT-187 and WTP-RPT- } 197 \text {. }\end{array}$ \\
\hline $\begin{array}{l}\text { Sample permeate immediately before each wash } \\
\text { solution addition to monitor washing } \\
\text { performance/efficiency. }\end{array}$ & $\begin{array}{l}\text { Permeate was sampled and monitored during } \\
\text { washing with results provided in report } \\
\text { WTP-RPT-197. }\end{array}$ \\
\hline Measure rheology of the washed solids. & $\begin{array}{l}\text { The rheology of the washed solids was measured } \\
\text { with results provided in this report. Rheology } \\
\text { results for the other tests are included in the } \\
\text { relevant run reports with selected results also in } \\
\text { WTP-RPT-197. }\end{array}$ \\
\hline
\end{tabular}

\section{Simulant Use}

The PEP testing program was conducted using a nonradioactive aqueous slurry of simulant waste chemicals and solids. The simulant composition and make-up recipe were provided by WTP as documented in Simulant Recommendation for Phase 1 Testing in the Pretreatment Engineering 
Platform. ${ }^{(a)}$ Aqueous chemical concentrations were within the ranges expected for waste feeds to the PTF. The hydroxide concentration was marginally one standard deviation lower than the average concentration expected in the feeds to the plant. The oxalate and phosphate components were at the lower end of the expected ranges, but the oxalate component was at the solubility limit, and the phosphate component was at or near the solubility limit. The solids components and blend were selected to obtain targeted solids mass loss (aluminum and chromium leaching and oxalate washing) and treatment time. The simulant was not selected to represent any particular Hanford tank waste type.

The simulant was blended from the components listed below. The basis for selecting the individual components and the comparison to actual waste behavior is provided where applicable in the indicated references

- Boehmite (for Al) (Russell et al. 2009a)

- Gibbsite (for Al) (Russell et al. 2009b)

- Chromium oxyhydroxide (CrOOH) slurry (Rapko et al. 2007)

- Sodium oxalate

- Filtration simulant (Russell et al. 2009c)

- Supernate (Russell et al. 2009c).

A separate chromium solids slurry simulant was prepared and added to the PEP process after post-caustic-leach washing (a nonprototypic addition) during the Shakedown/Functional Tests and Integrated Tests A and B. This approach was taken because laboratory-scale tests had shown that the high-temperature caustic leaching step dissolved significant amounts of the $\mathrm{CrOOH}$ solids (Russell et al. 2009a). In Integrated Test D, the chromium solids component of the simulant was added during the simulant make-up process to demonstrate the PTF permanganate addition strategy.

Simulant was procured from NOAH Technologies Corporation (San Antonio, TX). Samples of each simulant batch were characterized to make certain that chemical and physical properties requirements were met. Batches of the simulant were procured as follows:

- A 15-gallon trial batch of the blended simulant for laboratory testing to demonstrate the efficacy of the simulant fabrication procedure.

- A 250-gallon scale-up batch of the blended simulant to demonstrate scale-up of the simulant fabrication procedure to an intermediate scale.

- Batches 0,1 , and 2, each nominally 3500 gallons, of blended simulant for the Shakedown/Functional Tests and Integrated Tests A and B. These batches did not contain the $\mathrm{CrOOH}$ component.

- The CrOOH solids slurry for the Shakedown/Functional Test and Integrated Tests A and B was obtained in two separate batches, containing nominally 18 and $36 \mathrm{~kg}$ of $\mathrm{Cr}$ as $\mathrm{CrOOH}$.

(a) P Sundar. 2008. Simulant Recommendation for Phase 1 Testing in the Pretreatment Engineering Platform, 24590-PTF-RPT-RT-08-006 Rev 0, Bechtel National, Inc., Richland, WA. 


\section{Discrepancies and Follow-on Tests}

No discrepancies or follow-on tests were identified. 



\subsection{Introduction}

This is one in a series of reports that summarize Phase 1 testing results from the Pretreatment Engineering Platform (PEP) located in the Process Development Laboratory-West (PDL-W) located in Richland, Washington. Separate run reports have been prepared for each Phase 1 test (i.e., Shakedown/Functional Testing [Josephson et al. 2009], Integrated Test A [Guzman-Leong et al. 2009], Integrated Test B [Geeting et al. 2009], and Integrated Test D [Sevigny et al. 2009]). In addition, reports have been written that specifically address the following:

1. Filtration (Daniel et al. 2009)

2. Caustic Leaching (Mahoney et al. 2009)

3. Washing (Baldwin et al. 2009)

4. Oxidative Leaching (Rapko et al. 2009).

This report focuses on Integrated Test D and summarizes test conduct and results. It includes only very limited data analysis. Data files have been supplied in an electronic format because of the large amount of data. The test reported here was conducted according to TI-WTP-PEP-082, which was written in accordance with Test Plan TP-RPP-WTP-506, Rev. 0.4, which was written in response to Test Specification 24590-PTF-TSP-RT-07-001, Rev 2.

\subsection{Purpose}

The purpose of the M-12 testing program is to provide WTP with data to "...confirm the ultrafiltration process (UFP) system design and sludge treatment process flowsheet."(a) The WTP system design and treatment process flowsheet will be confirmed by evaluating the following operations on an engineering-scale integrated platform (the PEP):

- Solids concentration

- Aluminum leaching

- Washing

- Chromium leaching.

Tests will be used to collect data needed for design input and to improve the prediction of full-scale plant performance:

- Demonstration of component operation and determination of operating characteristics

- Integrated simulations of leaching scenarios.

The PEP data will be used by WTP along with laboratory-scale data and appropriate application of scaling to improve the WTP plant models used to predict plant operating performance.

(a) S Barnes and R Voke. 2006. "Issue Response Plan for Implementation of External Flowsheet Review Team (EFRT) Recommendations - M12, Undemonstrated Leaching Processes.” 24590-WTP-PL-ENG-06-0024 Rev. 0. 


\subsection{Background}

In October 2005, an External Flowsheet Review Team (EFRT) was assembled to provide a critical review of the design of the Hanford Tank Waste Treatment and Immobilization Plant (WTP). The review $^{(a)}$ identified a number of issues and potential issues that if not addressed could impact the operation of the plant. One of the issues that must be addressed in the Pretreatment Facility (PTF) is "Undemonstrated Leaching Processes." The EFRT reported that neither the caustic leaching nor oxidative leaching process has been demonstrated at greater than bench-scale. Without a scale-up study, the EFRT indicated that the ability to predict the effectiveness of these processes is limited.

The WTP project under Bechtel National Inc. (BNI) and the U.S. Department of Energy (DOE) developed the "Issue Response Plan for Implementation of External Flowsheet Review Team (EFRT) Recommendations-M12, Undemonstrated Leaching Processes" to resolve the "Undemonstrated Leaching Processes" issue. ${ }^{(b)}$ The plan addresses related topics that are not specifically in response to EFRT concerns. These include caustic addition and leaching concerns that were better understood after the EFRT report was issued, information to support revision of the contract design basis for the PTF, including system capacities, and earlier initiatives on enhancing plant throughput capacity. The solution for closing this issue includes conducting engineering-scale testing of all leaching (caustic and oxidative), washing processes, and filtration scenarios.

The flowsheet and equipment design demonstration will be performed in the following two phases:

- Phase 1 - Confirm the UFP system design and sludge treatment process flowsheet (Barnes and Voke 2006, p. 5).

- Phase 2-Confirm the UFP system performance over a range of anticipated plant process conditions, including the principle types of WTP feeds.

The data provided by the Phase 1 engineering-scale testing will be used to confirm the performance of the selected process flowsheet design and equipment based on post-Phase 1 test modeling.

On 10/23/06 and 10/24/06, a WTP Project ultrafiltration leaching process technical review meeting was held to review the Issue Response Plan for M12. ${ }^{(\mathrm{g})}$ Participants included members of the DOE, EFRT, the WTP project, and Pacific Northwest National Laboratory (PNNL). At the meeting, PNNL made recommendations on the methodology and scale for the leaching processes.

Members of the EFRT also presented their assessment (Integrated Test Platform, M12 - Test Review) with specific recommendations. The general system requirements recommended by EFRT and PNNL staff members included the following:

(a) JP Henschel. 2006. Contract No. DE-AC27-01RV14136 - Report of External Flowsheet Review Team for the Hanford Tank Waste Treatment and Immobilization Plant: "Comprehensive Review of the Waste Treatment Plant Flowsheet and Throughput.” Letter to RJ Schepens. CCN: 132846, Bechtel National, Inc., Richland, Washington.

(b) SM Barnes, and R Voke. 2006. "Issue Response Plan for Implementation of External Flowsheet Review Team (EFRT) Recommendations - M12: Undemonstrated Leaching Process.” 24590-WTP-PL-ENG-06-0024 Rev. 0. 
- Principal processing equipment elements of the UFP system need to be included in the demonstration (including UFP-VSL-00001A/B, UFP-VSL-00002, the ultrafiltration loop recirculation pumps, and the ultrafilters with supporting equipment).

- The demonstration system needs to be flexible to accommodate testing of the baseline processes and process options for a range of operating conditions and processing times.

- Geometric similarity (prototypic) is needed in the key pieces of processing equipment (including UFP-VSL-00001A/B and UFP-VSL-00002).

- Ultrafilter elements must be prototypic length and diameter to obtain expected filter performance data. The test equipment should be scaled down by using fewer filter elements in each assembly.

The following system parameters were developed and approved by the EFRT consultants:

- The engineering-scale test facility should be a factor of 4.5 smaller than the full-scale Pretreatment Facility.

- Each ultrafilter assembly should contain 12 full-scale elements.

- Five ultrafilter assemblies should be provided (based on M13 recommendations).

Additional bases for the engineering-scale test system factor of 4.5 are provided in Scaling Relationships for the Pretreatment Engineering Platform. (Kuhn et al. 2008). Some of the scaling factors are listed below.

- Selected processes within the PEP will be operated at both scale-time (4.5 times shorter than plant time) and plant time in separate test runs to address scaling issues.

- Prototypic tanks will be dimensionally scaled with a radius $1 / 4.5$ times their full-scale radius, and the operating height $1 / 4.5$ that of full-scale. The tank volume will be ${ }^{1} /(4.5)^{3}$ or $\sim^{1} / 90^{\text {th }}$ of the plant.

- Filtration design is scaled by filter area. The total filtration area is $1 /(4.5)^{2}$ or $\sim 1 / 20^{\text {th }}$ that of the plant.

- Fluid velocities in pipes are kept approximately the same (using commercially available pipe diameters) to mimic solids settling that may occur in plant piping.

- Chemical reaction times are not scaled.

- The pulse-jet mixer (PJM) nozzle velocity in the PEP will be scaled to provide the same mixing power per volume of tank contents. The plant targets a nozzle discharge velocity of $8 \mathrm{~m} / \mathrm{s}$ in UFP-VSL-00001A/B and $12 \mathrm{~m} / \mathrm{s}$ in UFP-VSL-00002A/B. For non-Newtonian fluids, the nozzle velocity will be the same in the PEP and WTP. For Newtonian fluids, the velocity is scaled by $1 /(4.5)^{0.333}$. The total PJM cycle time will be scaled to maintain the fraction of the cycle in active drive mode. It is recognized that there is not a sharp distinction from Newtonian to non-Newtonian behavior. For the purposes of Phase 1 testing, we will scale the PJM velocities to maintain equal power per volume for the initial concentration and caustic leach. After the slurry is concentrated following the caustic leach, the PJMs will be adjusted to have the same PJM nozzle velocities as the plant (non-Newtonian scaling) and kept in that regime for the remainder of the process (post-caustic-leach wash, slurry wash, oxidative leaching, final slurry washing, and final concentration). 
Section 6.4 of the Pretreatment Engineering Platform (PEP) Testing (Phase 1) Test Specification ${ }^{\text {(a) }}$ identifies the requirements for engineering-scale tests. The PEP data will be used by WTP along with laboratory-scale data and appropriate application of scaling to improve the WTP plant models used to predict plant operating performance.

\subsection{Objectives}

The objective of this report is to present the results of Integrated Test D with only very limited data analysis. This includes a test narrative, sample analyses, summaries of PEP monitoring data, evaluations or summaries of problems encountered, and deviations from the test protocols. Specific test objectives and summary results are provided in the summary section of this report.

(a) JL Huckaby and JR Markillie. 2008. Pretreatment Engineering Platform (PEP) Testing (Phase I). 24590-PTF-TSP-RT-07-001, Rev 2, Bechtel National, Inc., Richland, Washington. 


\subsection{Quality Assurance Requirements}

The PNNL quality assurance (QA) program is based upon the requirements as defined in DOE Order 414.1C, Quality Assurance and 10 CFR 830, Energy/Nuclear Safety Management, Subpart A-Quality Assurance Requirements (a.k.a. the Quality Rule). PNNL has chosen to implement the following consensus standards in a graded approach:

- ASME NQA-1-2000, Quality Assurance Requirements for Nuclear Facility Applications, Part 1, Requirements for Quality Assurance Programs for Nuclear Facilities.

- ASME NQA-1-2000, Part II, Subpart 2.7, Quality Assurance Requirements for Computer Software for Nuclear Facility Applications.

- ASME NQA-1-2000, Part IV, Subpart 4.2, Graded Approach Application of Quality Assurance Requirements for Research and Development.

The procedures necessary to implement the requirements are documented through PNNL's "How Do I...?" (HDI). ${ }^{\text {(a) }}$ PNNL implements the RPP-WTP quality requirements by performing work in accordance with the River Protection Project-Waste Treatment Plant Support Program (RPP-WTP) Quality Assurance Plan (RPP-WTP-QA-001, QAP). Work was performed to the quality requirements of NQA-1-1989, Part I, Basic and Supplementary Requirements, NQA-2a-1990, Part 2.7, and DOE/RW-0333P, Rev 13, Quality Assurance Requirements and Descriptions (QARD) as applicable. These quality requirements are implemented through the River Protection Project-Waste Treatment Plant Support Program (RPP-WTP) Quality Assurance Manual (RPP-WTP-QA-003, QAM). The requirements of DOE/RW-0333P, Rev 13, Quality Assurance Requirements and Descriptions (QARD) and 10 CFR 830 Subpart A were not required for this work.

RPP-WTP addresses internal verification and validation activities by conducting an Independent Technical Review of the final data report in accordance with RPP-WTP's procedure QA-RPP-WTP-604. This review procedure is part of PNNL's RPP-WTP Quality Assurance Manual (RPP-WTP-QA-003). Following this procedure, a technical review would verify that the reported results are traceable, that inferences and conclusions are soundly based, and the reported work satisfies the objectives.

Key analytes in the laboratory control sample (LCS) and PEP control sample were plotted over time to look for anomalies. The PEP control sample is a project-provided material generated from material very similar to the initial simulant feed. In general, the plots constructed to date associated with the inductively coupled plasma (ICP) and ion chromatography (IC) analysis of solutions shows recovery within limits of $80 \%$ to $120 \%$.

Table 2.1 shows list of nonconformance reports (NCRs) active during Integrated Test D.

(a) PNNL's system for managing the delivery of laboratory-level policies, requirements, and procedures. 
Table 2.1. Description of NCRs Active During Integrated Test D

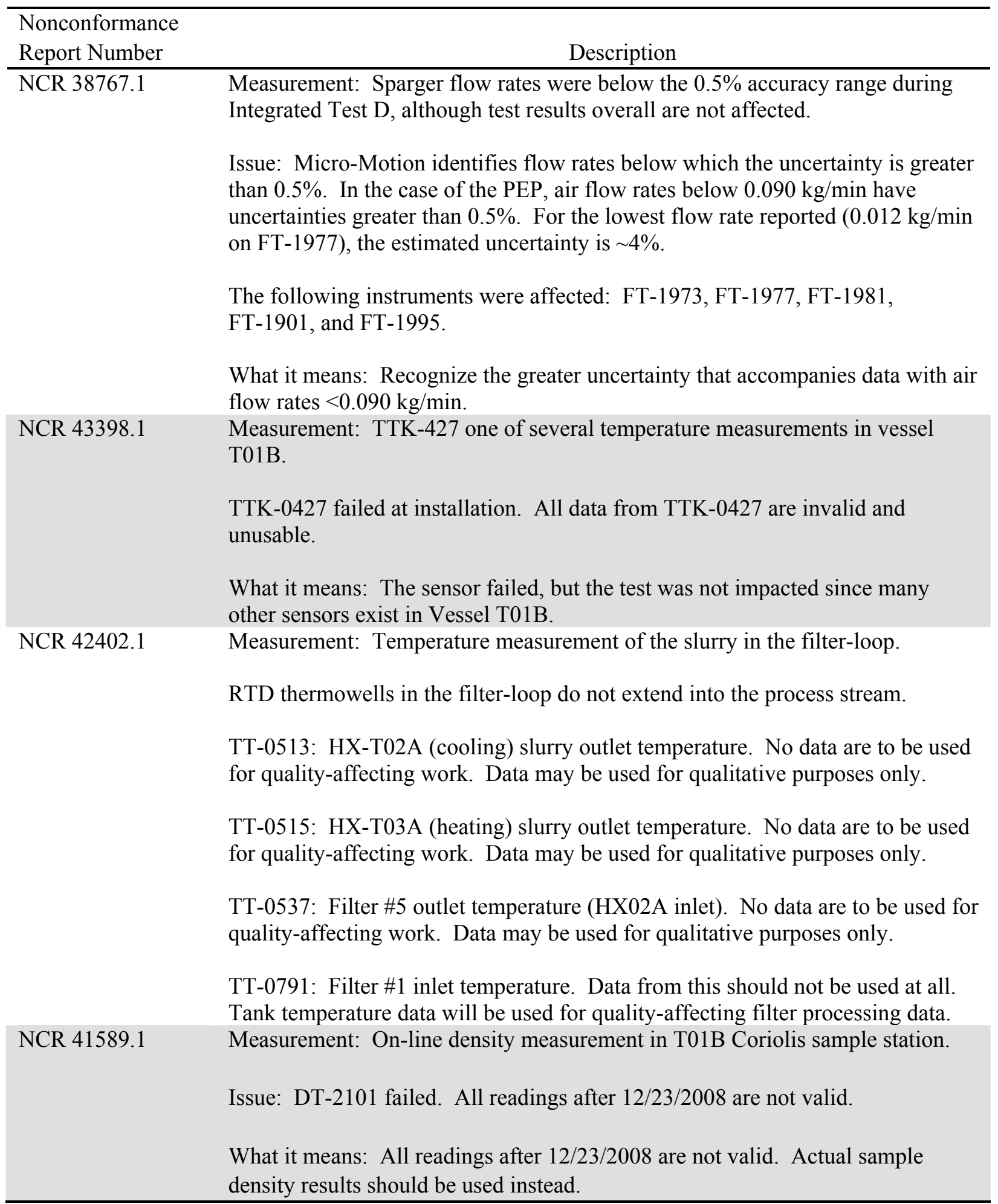




\subsection{Experimental Methods and Analysis}

\subsection{Pretreatment Engineering Platform Overview}

The following section provides an overview of the PEP to orient the reader. This section does not provide details on PEP equipment or instrumentation. The interested reader is referred to the following documents for more details on the PEP:

- P\&IDs and mechanical data books.

- Pretreatment Engineering Platform (PEP) Phase I Testing Process Description, 24590-WTP-RPT-PET-07-002, Rev 1.

- Functional Requirements for Pretreatment Engineering Platform (PEP), 24590-PTF-3YD-UFP-00002, Rev 1.

The PEP test system is designed to perform engineering-scale demonstrations of most WTP pretreatment processes. These include (but are not limited to) vessel-to-vessel transfers, waste pumping, cross-flow filtration, filter cleaning, solids washing, chemical reagent addition and mixing, waste slurry heating and cooling, and waste chemical leaching. Figure 3.1 presents a simplified process diagram showing the vessels, pumps, heat exchangers, and filter systems associated with the PEP. Equipment that has been considered critical for evaluating the integrated system performance has been scaled to be prototypic. Specifically, the ultrafiltration feed preparation and feed vessels have been scaled to be geometrically similar to WTP with a $1 / 4.5$ scale; the working height and diameter are scaled to $1 / 4.5$. Pipe sizes are scaled to have approximately $1 / 4.5$ the diameter, but the fluid velocity is to be approximately the same as the full-scale plant.

Waste simulant feed can be provided from three primary sources: High Level Waste (HLW) Feed Receipt Vessel (HLP-VSL-T22), Feed Receipt Process (FRP) Vessels (FRP-VSL-T01), or Feed Evaporator Process (FEP) Vessel (FEP-VSL-T01). Feed is received into the Ultrafiltration Feed Preparation Vessels UFP-VSL-T01A/B (henceforth Tank T01A and Tank T01B). In Integrated Test D, feed from Tanks T01A/B was used to provide simulant feed to UFP-VSL-T02A (henceforth Tank T02A) during simulant concentration. Simulant concentration, caustic leaching, oxidative leaching, and washing were conducted in Tank T02A and the associated filter-loop. The concentrated solids were transferred into totes while the liquid fraction (permeate) was stored in permeate collection vessels (UFP-VSL-T62A/B). Wash and leach solutions were sent to UFP-VSL-T62A/B. 


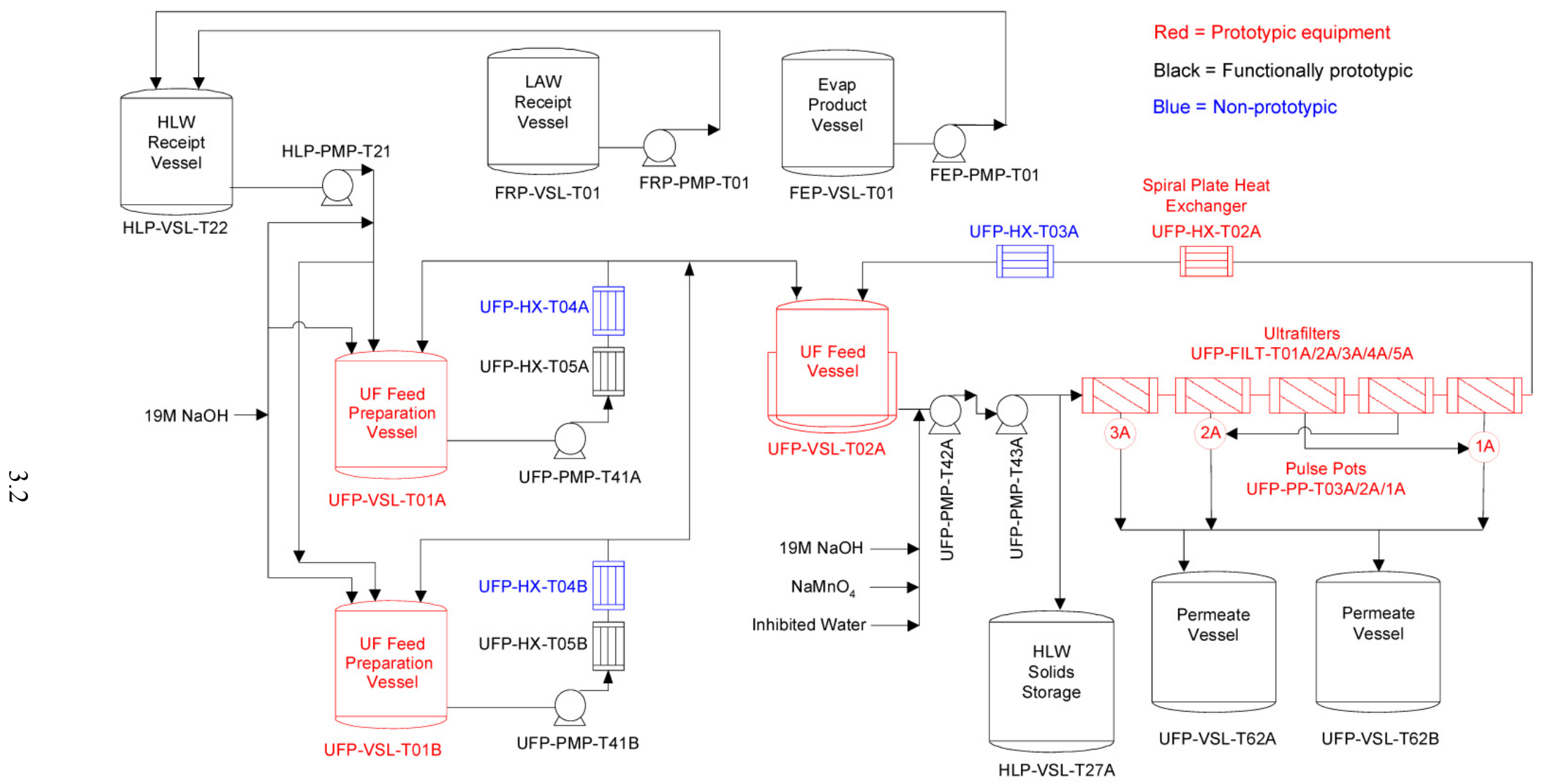

Figure 3.1. PEP Simplified Flow Diagram 


\subsection{PEP Filtration System}

The PEP filtration system is composed of an ultrafiltration feed tank, Tank T02A, a slurry circulation and filtration loop, a permeate metering and collection system, and a filter backpulse and cleaning system. A simplified schematic of the filtration system is shown in Figure 3.2. The PEP filtration system was configured to measure the feed flow rate, temperatures, and axial and transmembrane pressure (TMP) for each filter. In addition, the system is configurable such that filters 1 through 5 may be connected in series to the slurry circulation loop or bypassed such that flow is directed through filter bundle 1 or through filters 2 through 5. A summary of process instrumentation is provided in Appendix A. In the following paragraphs, key process equipment for slurry filtration operations are identified and discussed. Interested readers are referred to the documents listed in Section 3.1 if more information is needed.

\subsubsection{Ultrafiltration Feed Tank}

Tank T02A serves as a primary supply and mixing reservoir for slurry being circulated through the filtration loop. The contents of this tank are mixed using an array of six PJMs and the filter-loop return jet. Ancillary systems for Tank T02A include 1) air spargers, which aid in mixing and also limit inflammable gas hold-up in the actual waste treatment system, 2) bubblers to measure slurry density and level, 3) laser level sensors, and 4) an array of resistance temperature detectors (RTDs) to measure the tank temperature profile. Specific locations of the RTD arrays for Tanks T02A and T01A are available in laboratory record book (LRB) 59944, pages 12-17. Tank T02A is equipped with a water jacket to cool and a steam ring to heat the contained slurry.

\subsubsection{Slurry Filtration Circulation Loop}

The filtration loop contains process equipment key to slurry dewatering and washing operations. Two centrifugal slurry pumps, UFP-PMP-T42A and UFP-PMP-T43A (hereafter referred to as Pump T42A and Pump T43A, respectively), are operated in-series to provide the required slurry flow rate and pressure for the cross-flow filters. The suction to Pump T42A is fed from Tank T02A. In addition, the feed to Pump T42A is connected to process inhibited water ${ }^{(a)}$ supplies used for slurry washing and dilution operations. The discharge from Pump T42A feeds Pump T43A. Slurry discharge from Pump T43A can be fed through, or bypassed around, the cross-flow filters. Pumps T42A and T43A are identical pumps rated at $150 \mathrm{gpm}$ and $243 \mathrm{psi}$.

The cross-flow filter system is the core of slurry liquid-solid separations. It is composed of five filters connected in-series. These filters are designated as UFP-FILT-T01A to -T05A (hereafter referred to as Filters 1 through 5). The filter-loop is equipped with slurry bypass valves to allow slurry flow through Filter 1 and/or Filters 2 through 5.

(a) Inhibited water is $0.01-\mathrm{M} \mathrm{NaOH}$. 


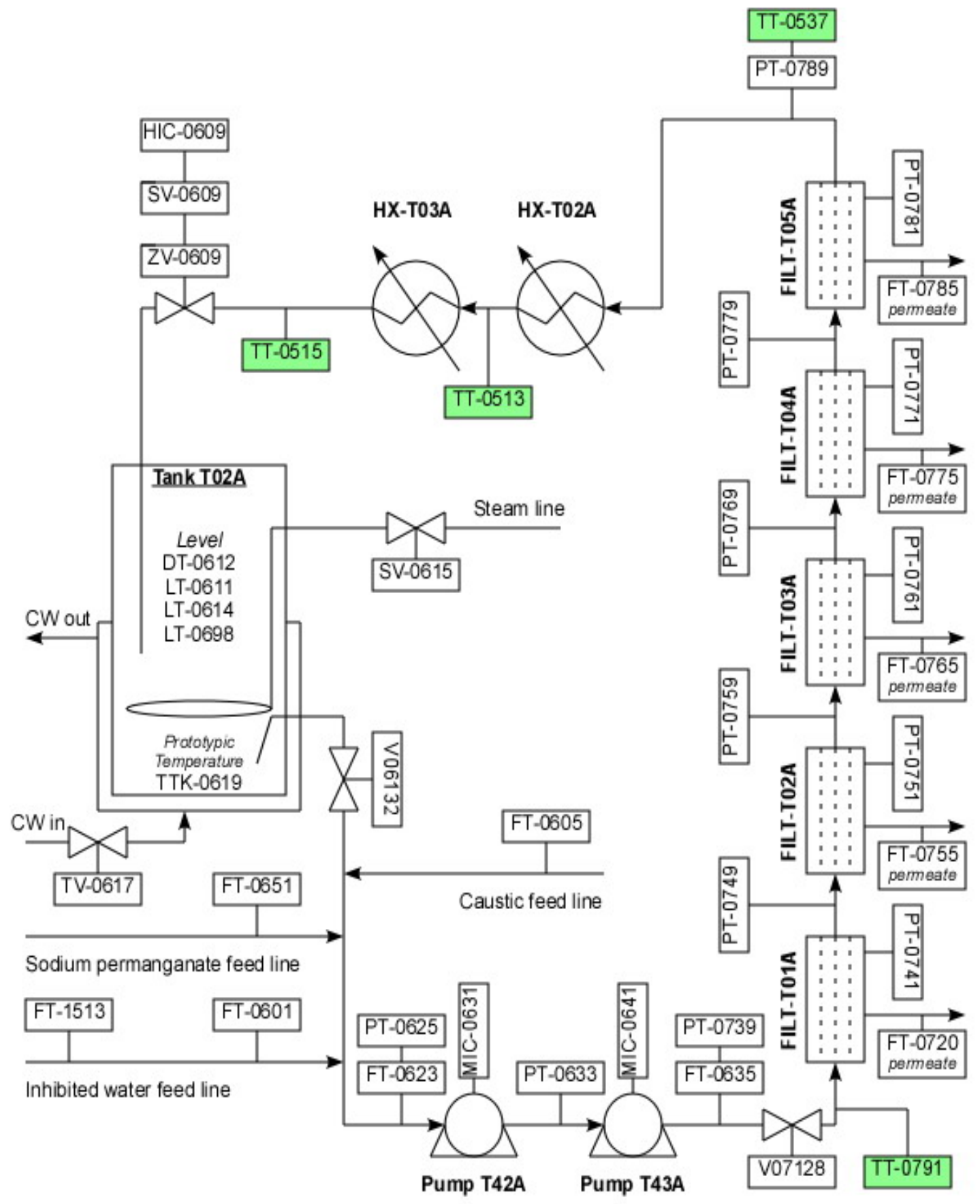

Figure 3.2. Schematic of Filtration Loop

The filters purchased for the PEP were obtained from the Mott Corporation (Farmington, CT) using the same specifications for the filters being purchased for the PTF. The filters are constructed of porous sintered 316 stainless steel with an effective filtration rating of $0.1-\mu \mathrm{m}$. The PEP test system employs a combination of 8-ft-long and 10-ft-long filter elements (which were formed by welding either four or five 2-ft filter elements together). As such, the PEP elements have the same radial dimensions and filtration 
ratings as the 2-ft elements, but have a longer filtration length of either 96 or 120 inches. A summary of the geometries of the five filters is provided in Table 3.1.

The tubeside slurry flow rate and pressure are monitored by a series of flow meters and pressure transducers. As shown in Figure 3.2, slurry flow to Pump T42A is measured by magnetic flow meter FT-0623. Slurry discharge flow from Pump T43A is measured by a second magnetic flow meter (FT-0635). Circulation loop pressure is monitored by a series of pressure transducers located at the entrance to each slurry pump, filter bundle, and heat exchanger.

The temperature in both Tank T02A and the slurry filtration loop is controlled with two in-line heat exchangers. The first heat exchanger, UFP-HX-T02A, is a (prototypic) spiral plate heat exchanger that uses chilled water to cool the circulating slurry. The second heat exchanger, UFP-HX-T03A, is a (nonprototypic) steam exchanger used to heat the circulating slurry, if needed. Both heat exchangers are equipped with a bypass loop so that they can be isolated from slurry flow. RTDs installed in thermowells monitor the performance of the heat exchanger. ${ }^{(a)}$ For the current testing, UFP-HX-T03A was not used and was bypassed. The final process element in the slurry circulation loop is a pressure control valve (ZV-0609) that can be adjusted in combination with the slurry pumps to provide adequate backpressure for permeate production. The filter-loop in-line sampler is located immediately downstream of ZV-0609. After passing through ZV-0609 and past the in-line sampler, the circulating slurry is recycled back into Tank T02A.

(a) The RTD measuring the slurry outlet temperature (TT-0513) did not extend into the process stream, and data were to be used for qualitative purposes only. See discussion in Section 2 for a description of this nonconformance (NCR 42402.1). The impact for testing was that during Integrated Test B, the temperature control for the cooling heat exchanger in the filter-loop, UFP-HX-T02A, was with a hybrid control method: The cooling water control valve (TV-0513) being adjusted (in automatic) to control the outlet slurry temperature TT-0513 to a targeted setpoint. However, the temperature setpoint was changed manually by an operator to try to maintain the temperature setting in Tank T02A.. 
Table 3.1. Specifications of the Five PEP Cross-Flow Filtration Bundles

\begin{tabular}{cccccc}
\hline Filter \# & Filter ID & $\begin{array}{c}\text { Number of } \\
\text { Elements in } \\
\text { Bundle }\end{array}$ & $\begin{array}{c}\text { Element } \\
\text { Inside } \\
\text { Diameter } \\
\text { (inches) }\end{array}$ & $\begin{array}{c}\text { Element } \\
\text { Length }(\mathrm{ft})\end{array}$ & $\begin{array}{c}\text { Bundle } \\
\text { Surface Area } \\
\left(\mathrm{ft}^{2}\right)\end{array}$ \\
\hline 1 & UFP-FILT-T01A & 12 & 0.5 & 10 & 15.7 \\
2 & UFP-FILT-T02A & 12 & 0.5 & 10 & 15.7 \\
3 & UFP-FILT-T03A & 12 & 0.5 & 10 & 15.7 \\
4 & UFP-FILT-T04A & 12 & 0.5 & 8 & 12.6 \\
5 & UFP-FILT-T05A & 12 & 0.5 & 8 & 12.6 \\
\hline Total & -- & -- & -- & -- & 72.3 \\
\hline
\end{tabular}

\subsubsection{Permeate Metering and Collection Systems/Filtration Backpulse Systems}

The permeate metering and collection systems consist of Coriolis mass flow meters for monitoring permeate production rates, three pulse-pots connected to high-pressure air supplies for backpulsing the filters, and permeate collection tanks.

Permeate (shellside) mass production rates from Filters 1 through 5 are monitored by Coriolis flow meters. Permeate flow from each of the filters is directed to three pulse-pots (designated as UFP-PP-T01A to UFP-PP-T03A). Pulse-pot UFP-PP-T03A serves Filter 1, pulse-pot UFP-PP-T02A serves Filters 2 and 4, and pulse-pot UFP-PP-T01A serves Filters 3 and 5. The pulse-pots are filled with a sufficient volume of collected permeate to backpulse the filters. Overflow from the pulse-pots may be directed to 1) permeate or process slurry collection tanks (UFP-VSL-T62A/B during slurry dewatering operations, or 2) a return line to Tank T02A during continuous recycle filtration operations. Table 3.2 summarizes the permeate metering and pulse-pot systems.

Table 3.2. Permeate Metering and Pulse-Pot Configurations for PEP

\begin{tabular}{lll}
\hline Filter Bundle No. / ID & $\begin{array}{c}\text { Permeate } \\
\text { Coriolis Meter }\end{array}$ & $\begin{array}{c}\text { Associated Pulse } \\
\text { Pot }\end{array}$ \\
\hline 1-UFP-FILT-T01A & FT-0720 & UFP-PP-T03A \\
2-UFP-FILT-T02A & FT-0755 & UFP-PP-T02A \\
3- UFP-FILT-T03A & FT-0765 & UFP-PP-T01A \\
4- UFP-FILT-T04A & FT-0775 & UFP-PP-T02A \\
5- UFP-FILT-T05A & FT-0785 & UFP-PP-T01A \\
\hline
\end{tabular}

During backpulsing, one of the pulse-pots is isolated, drained to a specific level, and charged with high-pressure air until the pulse-pot pressure exceeds the slurry pressure at the filter inlet by a given amount (typically 40 psid). After the target pulse-pot pressure is reached, a large, fast-acting valve isolating the pulse-pot from the filter is opened, and a fraction of the liquid in the pulse-pot (typically less than 1 gal) flows back to the filter bundle, forcing permeate from the shellside to the tubeside of the filter 
tubes. The backflow of permeate forces loosens any particles that are weakly entrained in the filter pores or that have caked on the filter surface. A description of the backpulsing process, as it was implemented in the PEP, is provided in Appendix B.

\subsection{PJM Operational Modes}

The leaching vessels UFP-VSL-T02A and UFP-VSL-T01A and B were equipped with PJMs and several different operating programs to allow plant prototypic mixing, low-level operation, and additional data collection.

PJM operating modes have the same basic cycle: Drive Phase, Vent Phase, and Vacuum Phase, followed by a Hold (or Vent) Phase. PJM mixing technology involves a pulse tube coupled with a jet nozzle. One end of the tube is immersed in the tank while periodic pressure, vacuum, and venting are supplied to the opposite end. Changing the applied pressure creates four operating phases for the pulse tube: 1) the Drive Phase, when pressure is applied to discharge the contents of the PJM tube through the nozzle, 2) the Vent Phase, when the pressure is vented to the atmosphere, 3) the Refill Phase, when vacuum is applied to refill the pulse tube (at temperatures above $60^{\circ} \mathrm{C}$, the vacuum is disabled, and the pulse tubes refill by gravity.), and 4) the Hold Phase, when all valves to the PJMs are closed, causing the fluid level in each PJM to remain constant until the next Drive Phase. The PJM system uses these operating phases to produce a sequence of drive cycles that provide mixing in the vessel.

A timer set to the overall Cycle Time starts at the beginning of each Drive Phase. A new Drive Phase begins when either the cycle timer runs out, or the cycle enters the final Hold/Vent Phase, whichever is later. This condition exists to make sure the Vacuum Phase has completed before moving on to the next cycle.

PJM operations at PEP consisted of one of several control modes: standard mode (regular), standard mode (star pattern - Tank T02A only), standard mode (short cycle), and simple mode. However, PJM controls at PEP were not prototypic. During Integrated Test B, the standard mode (regular) was used whenever possible and the standard mode (star pattern) was used when the level was low, typically $<23$ inches. If the standard mode was nonfunctional (e.g., during caustic leaching, the PJM Drexelbrook level probes ceased functioning), the PJMs were operated in simple mode. For all tanks, if the PJMs were operating in standard mode, the short cycle function would automatically activate when the tank level dropped to 12 inches and would remain active until the tank level rose above 22 inches for Tank T01A and Tank T01B. The short cycle activation occurred automatically in Tank T02A when the level dropped to 11.5 inches and remained until the level returned to 16 inches.

\subsubsection{Standard Mode (Regular) Description}

Standard mode operations in PEP controls each PJM individually based on that PJM level instrument. The PJMs have one overall cycle time, which keeps all PJMs in synch at the beginning of each cycle. Each cycle is controlled by five main variables: Cycle Time, Drive Time Set Point, Vent Time Set Point, L1 Level, and L2 Level. L1 and L2 Levels are user-definable upper and lower level set points used by the control software to indicate an overblow. Additionally, each PJM could be enabled or disabled individually. 
The entered Cycle Time controls the peak-to-peak distance between cycles. However, if the value of the Cycle Time set point is shorter than the combined entered times for the PJM phases, the Cycle Time set point would be overridden, and the actual PJM Cycle Time would be the time it took the PJMs to complete the first three phases (Drive, Vent, and Vacuum). The fourth phase would be skipped.

The Drive Phase is controlled by the time entered as the Drive Time Set Point (corrected for temperature if enabled). Each PJM begins the Drive Phase at the same instant, but can have different lengths of time specified for driving each PJM. If any PJM does not finish within 30 seconds of the PJM with the shortest drive time, that PJM is disabled, and the cycle continues to the next phase.

The Vent Phase is controlled by the Vent Time Set Point, which has no correction factors. Each PJM begins the Vent Phase at the same instant and can have different lengths of time specified for each PJM. If any PJM does not finish within 30 seconds of the PJM with the shortest vent time, that PJM will be disabled, and the cycle will continue to the next phase. Generally, each Vent Time Set Point was set to a small number, such as 500 milliseconds, to smooth out the transition between the Drive and Vacuum Phases.

The Vacuum Phase is controlled by the L1 Level, which is set at the top of the desired PJM stroke. All PJMs begin the Vacuum Phase at the same instant, but each PJM L1 Level is set separately. If any PJM does not reach the L1 Level within 30 seconds of the first PJM to reach its L1 Level, that PJM is disabled, and the cycle continues to the next phase. During high temperature $\left(>60^{\circ} \mathrm{C}\right)$ operations, the vacuum was disabled, and each PJM tube was gravity filled up to its L1 Level. If the tank level was less than 44 inches (T01A/B) or 46 inches (T02A), then the PJM would switch operation to Standard Mode--Short Cycle until either the temperature dropped below the $60^{\circ} \mathrm{C}$ threshold, or the level rose above the 44/46-in. threshold.

The final phase in standard mode is a Hold Phase. All valves to the PJM are closed, causing the fluid level in each PJM to remain constant at the L1 Level.

The standard mode operation also contains a temperature linearization variable that reduces the drive time to prevent overblows due to the difference in slurry properties as the temperature increases. The variable is expressed as a slope, the percent of drive time decrease per degree Celsius increase from zero degrees Celsius. This function was largely untested. A modest $0.25 \%$ linearization factor was used in early testing and adopted for the remainder of testing simply because it seemed to work, and further optimization was not conducted.

\subsubsection{Standard Mode-Short Cycle}

A Short Cycle consists of a Drive Phase in which each enabled PJM drives for $20 \%$ of the Drive Time Set Point followed by a 10-sec Vent Phase. The Short Cycle function would automatically activate when the tank level dropped to 12 inches and would remain active until the tank level rose above 22 inches for Tank T01A and Tank T01B. The Short Cycle activation occurred automatically in Tank T02A when the level dropped to 11.5 inches and remained until the level returned to 16 inches. Additionally, the Short Cycle would activate during high-temperature operations $\left(>60^{\circ} \mathrm{C}\right)$ if the tank level fell below 44 inches (T01A/B) or 46 inches (T02A) to confirm that there was enough fluid to gravity fill above the L1 Level for each PJM because the vacuum was disabled at high temperatures. 


\subsubsection{Standard Mode-Star Pattern}

Tank T02A additionally can operate in standard mode - star pattern. The star pattern option follows the same rules as the regular standard PJM mode. The difference is that only two PJMs are enabled at a given time. When the operator sets the star pattern button on the human machine interface (HMI), the center PJM and one other PJM will be enabled for five cycles. Then the outer PJM will be disabled, and a different outer PJM will be enabled for another five cycles. The pattern of enabling and disabling the five outer PJMs forms a five point star. The disabled PJMs are vented.

The star pattern was developed by PEP test engineers in an effort to reduce the level fluctuations in Tank T02A and operate the PJMs in a manner that could be implemented in the PTF. During Integrated Test B, the star pattern was enabled when the level in Tank T02A was approximately 23 inches or when the filter-loop recirculation target could not be achieved. Enabling the star pattern increased the achievable filter-loop recirculation rate because the star pattern reduced the tank level fluctuations because fewer PJMs were filling and discharging in this mode.

\subsubsection{Simple PJM Mode Description}

As mentioned above, the simple mode operates substantially the same as the standard mode. Each cycle consists of Drive, Vent, Vacuum, and Hold/Vent phases. There are two main differences. The first difference is that all PJMs operate together as one unit. There are no individual levels used or individual enabling or disabling of PJMs. The second difference is that each phase is controlled by a time (instead of level). An operator sets the Cycle Time, Drive Time Set Point (uncorrected), Vent Time Set Point, and Vacuum Time Set Point (uncorrected). Additionally, the operator can choose whether the last phase holds the PJM level or vents (returning PJM level to the same as the tank level).

During Integrated Test B, the simple mode was used when the standard mode was not working. The standard mode did not work during leaching operations because the PJM level probe ceased to function at elevated temperatures in high-caustic solutions.

The Drive Time had additional correction factors for temperature (same as in standard mode) and tank level. The tank level correction (if enabled) reduced the drive time according to the user-entered slope (\% drive time/inch) for every inch below the top of the PJM head (46 inches by default). For example, if the Drive Time Set Point was 10,000 milliseconds, the Drive Slope was 1\%/inch, and the tank level was at 36 inches, then the corrected drive time would be $(10,000$ milliseconds $) *\{1.00-[0.01 /$ inch $*(46-36$ inches $)]\}=9000$ milliseconds. The operator determines the tank level used in the calculation using either the tank bubbler, laser, or Drexelbrook probe.

The Vacuum Time also contained a correction factor for tank level, but not for temperature. As the tank level decreased, the PJM fill level would decrease during the Vacuum Phase; therefore, a vacuum correction was implemented. The vacuum correction (if enabled) increased the VacuumTtime according to a user-entered vacuum slope (\% vacuum time/inch) for every inch the tank level was below 46 inches. For example, if the Vacuum Time Set Point was 10,000 milliseconds, the vacuum slope was 1\%/inch, and the tank level was at 36 inches, then the corrected drive time would be $(10000$ milliseconds $) *\{1.00+[0.01 /$ inch $*(46-36$ inches $)]\}=11000$ milliseconds. 
The operator selectable Hold Phase was created to give the option to more closely resemble PJM standard mode operation. The Hold Phase prevented the PJM level from dropping after completing the Vacuum Phase. However, since the PJM phase set points were time based, and there was no level checking in the PJMs in simple mode, the PJM fill level could increase over successive cycles when using the Hold Phase - whether or not the Drive or the Vacuum Time Set Points were decreased or increased, respectively. The successive increase in PJM level over time could result in fluid to travel all the way up into the hoses on top of the tank. Similarly, if the Vacuum Time was too low, the PJM fill level could decrease over successive cycles, eventually resulting in an overblow. If the Hold Phase was disabled, each PJM just vented to the tank level during the remainder of the PJM cycle.

\subsection{Testing Overview}

Nitric acid cleaning of the filters was performed before Integrated Test B but was not repeated before Integrated Test $\mathrm{D}$. The filters were cleaned using nitric acid after Integrated Test D was complete. The LRBs used during testing to record testing activities were BNW-60272 and BNW-60280.

The following is a summary level overview of testing reported herein. Figure 3.3 shows a graphical schedule of events. Refer to the test narrative (Section 4), Test Instruction TI-WTP-PEP-082, and the LRBs listed above for additional details.

1. Transfer simulant from HLP-VSL-T22 to UFP-VSL-T01B.

2. Transfer simulant from UFP-VSL-T01B to UFP-VSL-T02A and concentrate solids to 20 -wt $\%$ using one filter, UFP-FILT-T01A.

3. Maintain caustic-leach concentrated simulant at $85^{\circ} \mathrm{C}$ for 24 hours (Batch 1).

4. Transfer Batch 1 leached simulant to UFP-VSL-T01A for temporary storage.

5. Transfer simulant from HLP-VSL-T22 to UFP-VSL-T01B.

6. Transfer simulant from UFP-VSL-T01B to UFP-VSL-T02A and concentrate solids to 20 -wt $\%$ using all five filters.

7. Maintain caustic-leach concentrated simulant at $85^{\circ} \mathrm{C}$ for 24 hours (Batch 2).

8. Concentrate leached solids (Batch 1 and 2) using all five filters.

9. Wash leached slurry with IW and remove permeate using all five filters.

10. Add permanganate and conduct oxidative-leach on slurry for 6 hours at $25^{\circ} \mathrm{C}$.

11. Wash oxidative leached slurry using IW and all five filters and then concentrate.

12. Flush filter-loop with IW.

13. Drain system and clean filters with $2 \mathrm{M}$ nitric acid. 


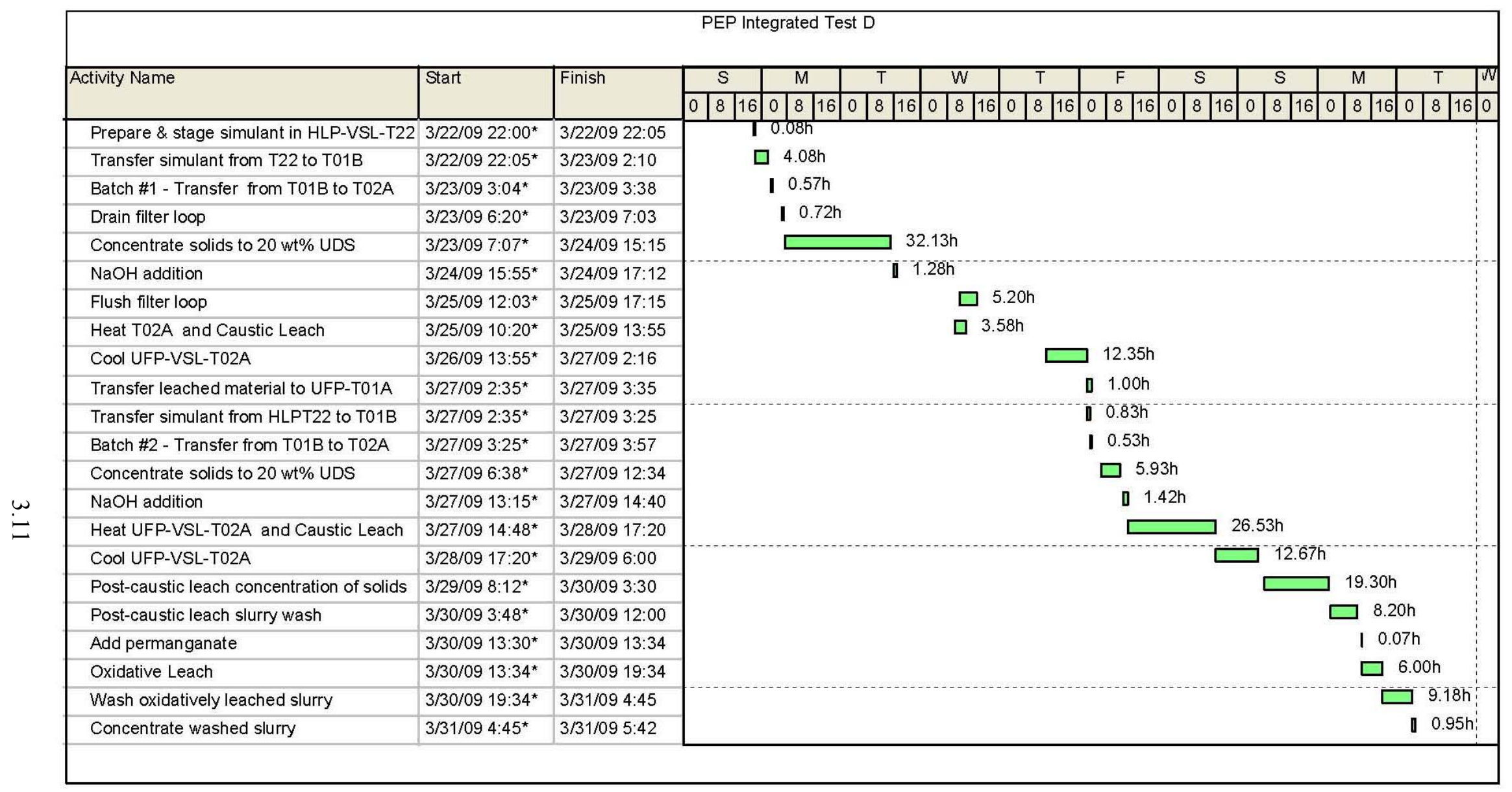

Figure 3.3. Integrated Test D Timeline 


\subsection{Simulant}

The PEP process testing was performed with nonradioactive aqueous slurry of simulant waste solids and liquids. The simulant composition and make-up recipe were provided by WTP as documented in Simulant Recommendation for Phase 1 Testing in the Pretreatment Engineering Platform. ${ }^{\text {(a) }}$ Aqueous chemical concentrations were within the ranges expected for waste feeds to the PTF. The hydroxide concentration was marginally one standard deviation lower than the average concentration expected in the feeds to the plant. The oxalate and phosphate components were at the lower end of the expected ranges, but the oxalate component was at the solubility limit, and the phosphate component was at or near the solubility limit. The solids components and blend were selected to obtain targeted solids mass loss (aluminum and chromium leaching and oxalate washing) and treatment time. The simulant was not selected to represent any particular Hanford tank waste type.

The simulant was blended from the components listed below. The basis for selecting the individual components and comparison to actual waste behavior is provided where applicable in the indicated references:

- Boehmite (for Al) (Russell et al., 2009a)

- Gibbsite (for Al) (Russell et al, 2009b)

- Chromium oxyhydroxide (CrOOH) slurry (Rapko, 2008)

- Sodium oxalate

- Filtration simulant ((Russell et al. 2009c)

- Supernate.

A separate chromium solids slurry simulant was prepared and added to the PEP process after post-caustic-leach washing (a nonprototypic addition) during the Shakedown/Functional Tests and Integrated Tests A and B. This approach was taken because laboratory-scale tests had shown that the high-temperature caustic leaching step dissolved significant amounts of the $\mathrm{CrOOH}$ solids (Russell et al. 2009a). In Integrated Test D, the chromium solids component of the simulant was added during the simulant make-up process to demonstrate the PTF permanganate addition strategy. Simulant was procured from NOAH Technologies Corporation (San Antonio, TX). Samples of each simulant batch were characterized to make certain that chemical and physical property requirements were met. Batches of the simulant were procured as follows:

- A 15-gallon trial batch of the blended simulant for laboratory testing to demonstrate the efficacy of the simulant fabrication procedure.

- A 250-gallon scale-up batch of the blended simulant to demonstrate scale-up of the simulant fabrication procedure to an intermediate scale.

- Batches 0, 1, and 2, each nominally 3500 gal, of blended simulant for the Shakedown/Functional Tests and Integrated Tests A and B. These batches did not contain the $\mathrm{CrOOH}$ component.

(a) P Sundar. 2008. Simulant Recommendation for Phase 1 Testing in the Pretreatment Engineering Platform, 24590-PTF-RPT-RT-08-006 Rev 0, Bechtel National, Inc., Richland, Washington. 
- Batch 3, nominally 1200 gal, for Integrated Test D. This batch contained the CrOOH solids component.

- The CrOOH solids slurry for the Shakedown/Functional Test and Integrated Tests A and B was obtained in two separate batches containing nominally 18 and $36 \mathrm{~kg}$ of $\mathrm{Cr}$ as $\mathrm{CrOOH}$.

\subsection{Sampling}

A list of samples taken and their purpose is provided in Appendix C. Actual sample times were recorded in the Test Instruction.

In general, slurry samples were collected using either an in-tank sampler or an in-line sampler. In-line samples were obtained from the slurry recirculation loop or transfer piping by drawing a side stream from the process flow as shown in Figure 3.4. To obtain a sample, the downstream valve was fully opened, and then the upstream valve was opened sufficiently to allow samples to be safely obtained. The sample line and valves were purged with at least three line volumes before a sample was collected. The vent and the pressure gauge shown are for a different sampling method that would allow samples to be collected from the volume between the two main processing valves while being isolated from the process flow. This method was not implemented in Phase 1 testing.

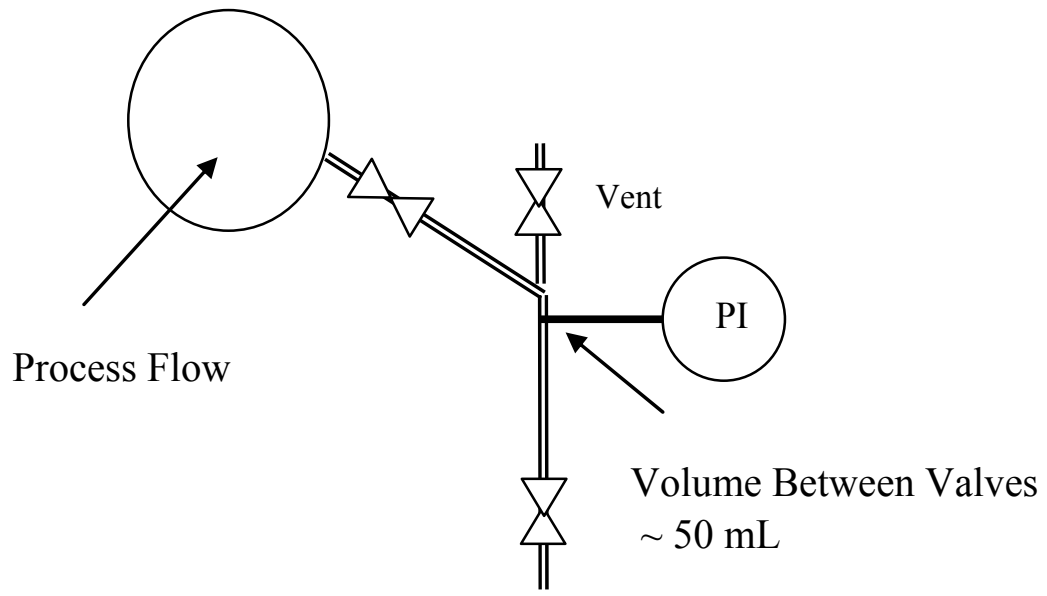

Figure 3.4. Simple In-Line Sampler

Figure 3.5 is a schematic of the in-tank sampling system for UFP-VSL-T01A/B and UFP-VSL-T02A. Samples were obtained with the sample loop in recirculation mode with slurry returned to the vessel. To obtain a sample, a valve was used to divert the entire flow to the sample bottle. The sampling valve and line were purged before each sample to minimize cross-contamination with previous sampling events. Sample line inlet heights are provided in Appendix D.

Permeate (liquid) samples were taken from the permeate piping between the filter and the pulse-pot. The sample line and valves were purged with at least three line volumes before each sampling event. 


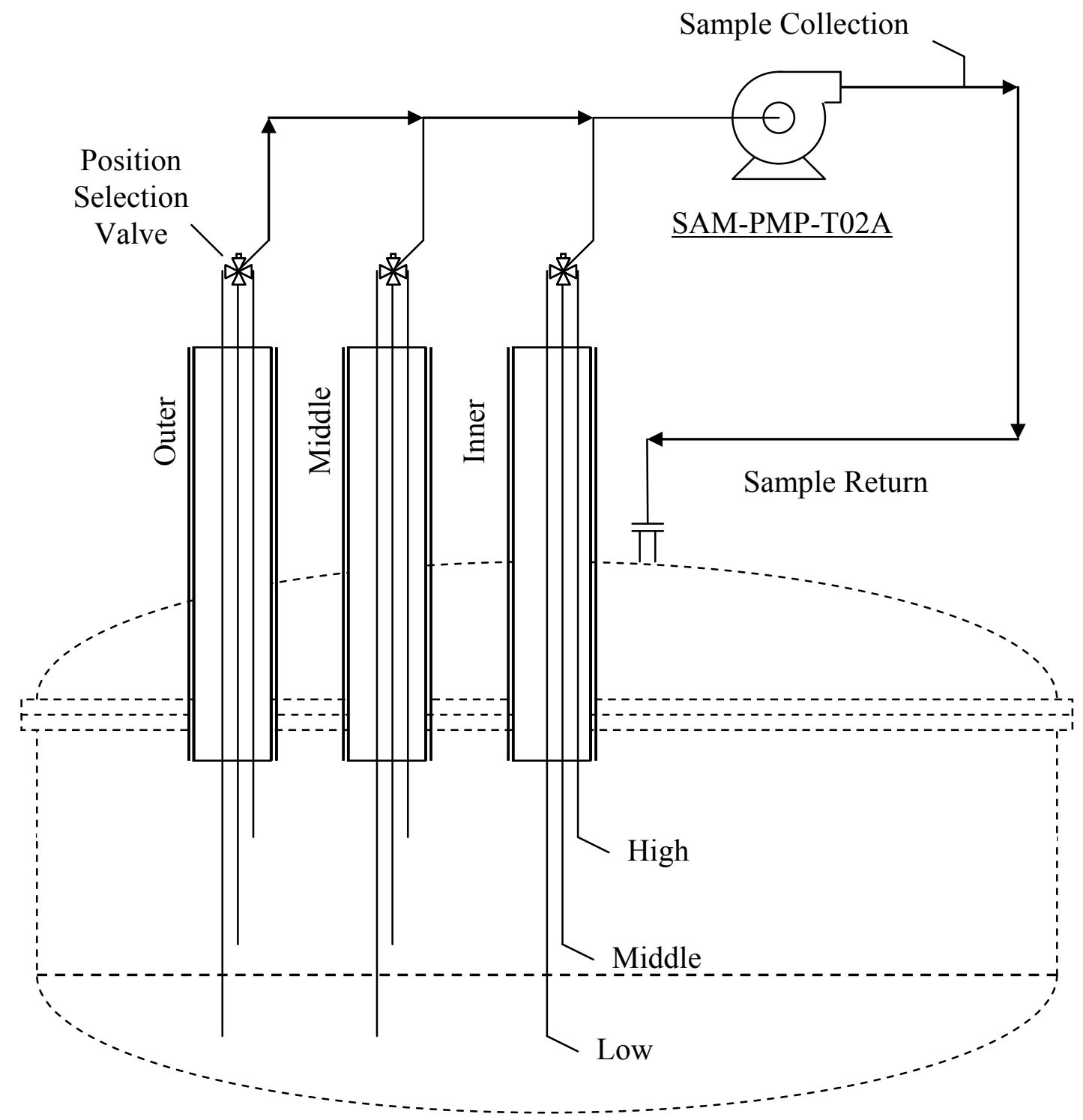

Figure 3.5. In-Tank Sampling Showing the Three Radial Positions at Three Heights and Sampling Flow Loop

\subsection{Sample Processing}

The samples were collected in pre-labeled sample containers that were prepared and staged within PDL-W, based upon the Sample Collection and Analysis table in the governing Test Instruction. The required analysis determined the sample volume and sample collection container. Sample handling flow diagrams are given in Figure 3.6 through Figure 3.8 for samples collected and processed in PDL-W. The letters "D," "B," "R," and "S" which are shown in the figures, were included in the sample names for phase-separated processed samples. The letter " $D$ " was included in the decanted supernatant sample names. The letter " $B$ " was included in the wet centrifuged solids sample names. The letter " $R$ " was included in the sample name of the combined rinse solution. The letter " $S$ " was included in the sample 
names of the wet rinsed centrifuged solids. These figures represent two basic sample processing methods. One approach was used during non-leaching test steps, and another was used during leaching.

\subsubsection{Non-Leaching Samples}

During non-leaching steps, sample processing was not time sensitive, and several samples were shipped as collected. Non-leach samples used for the analyses listed below were shipped as collected in the container size specified, and with the exception of the archive samples, tare and full sample weights were not required.

- weight percent undissolved solids (UDS) (50-mL)

- density $(50-\mathrm{mL})$

- heat capacity $(50-\mathrm{mL})$

- shear strength $(2 \times 1-\mathrm{L})$

- shear stress vs. shear rate on original intact slurry $(100-\mathrm{mL})$

- shear stress vs. shear rate on supernatant (100-mL)

- total organic carbon on the slurry $(50-\mathrm{mL})$

- inductively coupled plasma - Silicon (50-mL)

- $\operatorname{archive}(50-\mathrm{mL})$.

During a sampling event, if an intact slurry sample was collected for density analysis and another intact slurry sample was collected for wt $\%$ UDS, then density measurements were performed on the supernatant in addition to the intact slurry submitted for density analysis. These density measurements were higher accuracy than density measurements obtained following the wt $\%$ UDS method described in Bechtel procedure, Guidelines for Performing Chemical, Physical, and Rheological Properties Measurements (24590-WTP-GPG-RTD-001 Rev 0.) ${ }^{(\mathrm{a})}$

(a) GL Smith and K Prindiville. 2002. Guidelines for Performing Chemical, Physical, and Rheological Properties Measurements. 24590-WTP-GPG-RTD-001, Rev 0, Bechtel National, Inc., Richland, Washington. 


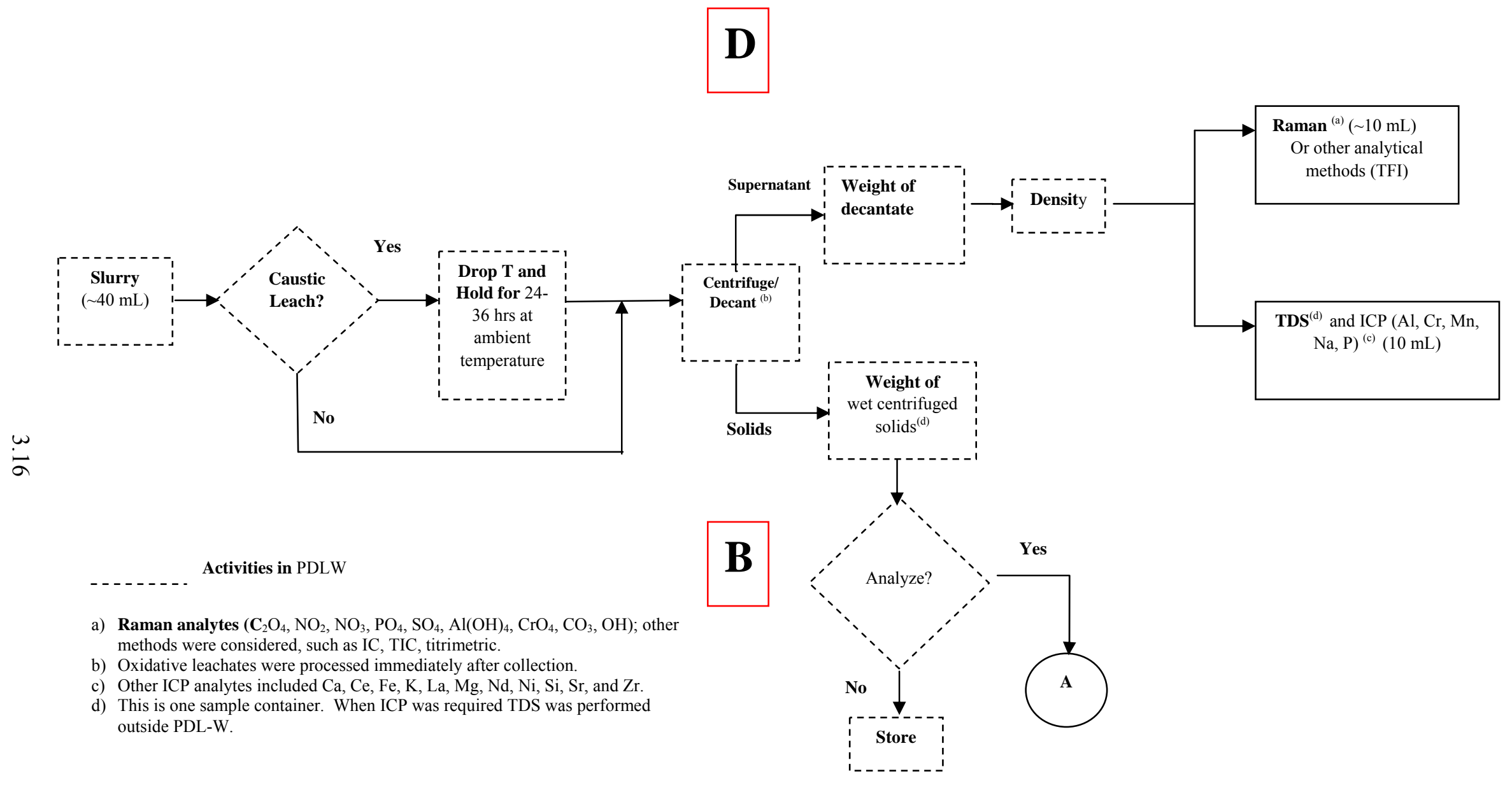

Figure 3.6. Sample Processing for Decantate Handling 


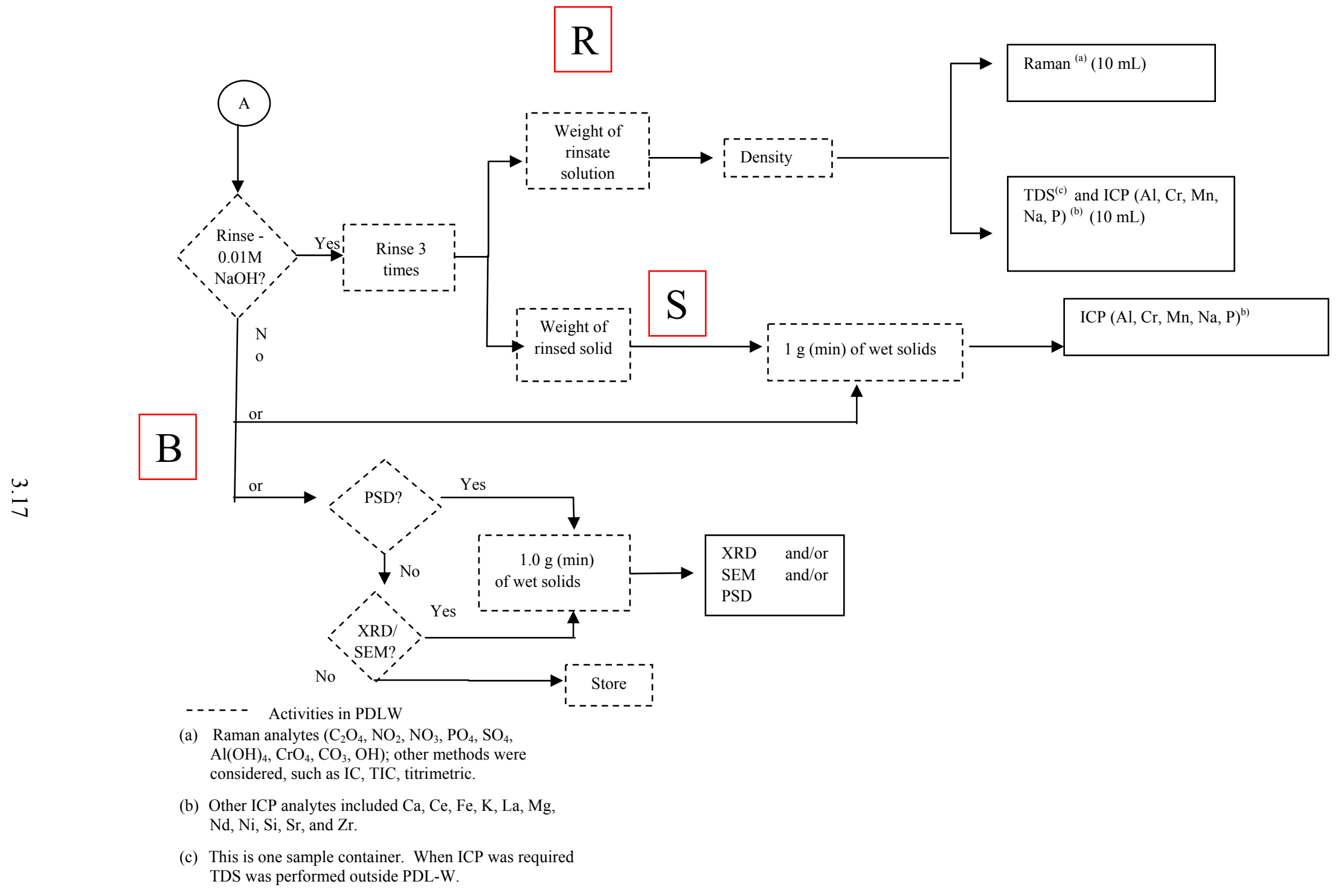

Figure 3.7. Sample Processing for Solids 


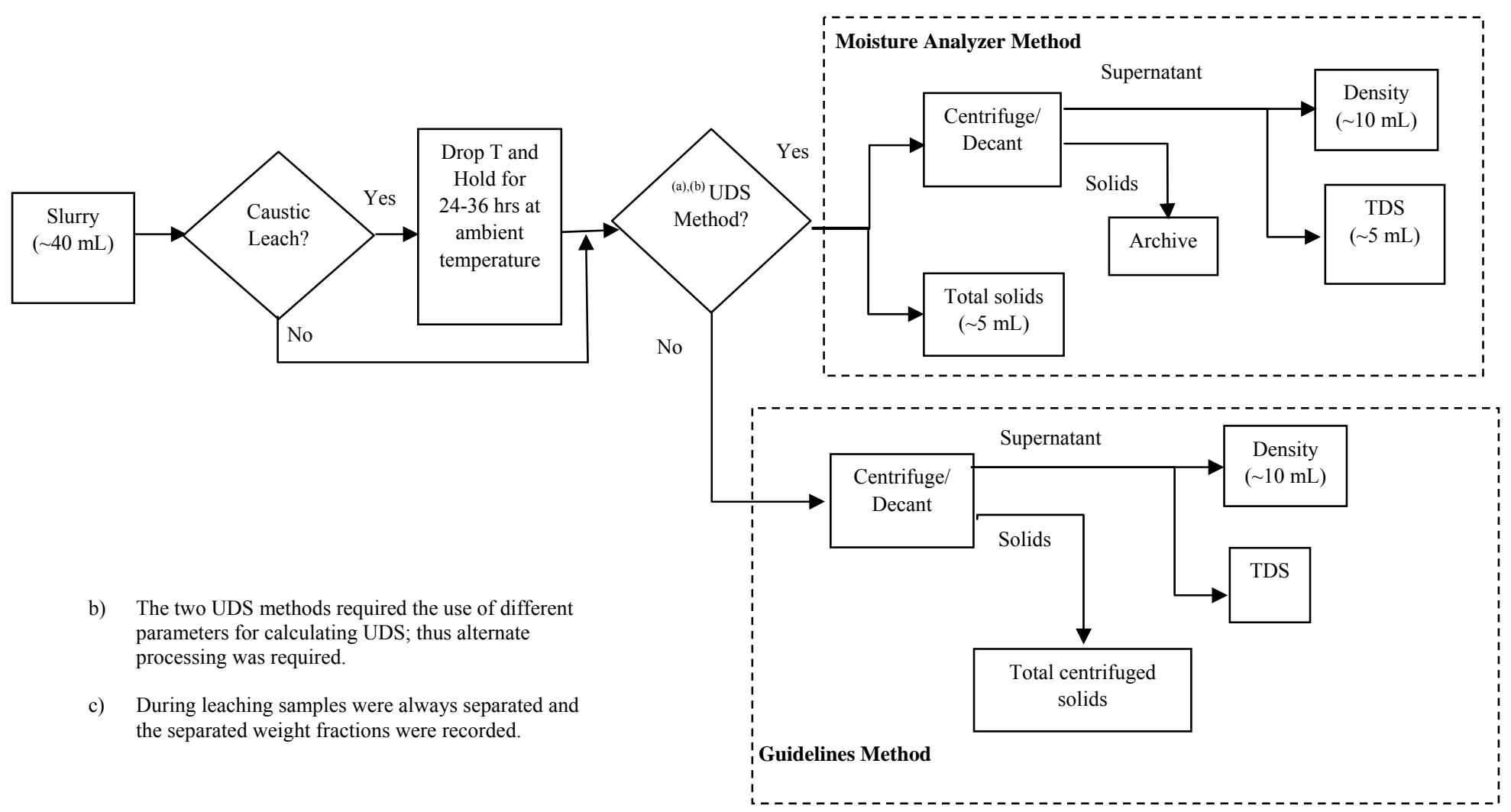

Figure 3.8. Sample Processing for UDS 
A single 50-mL sample was centrifuged and the supernatant decanted to allow multiple laboratories to perform several analyses simultaneously on the supernatant. To perform this phase separation, the original sample was centrifuged at $\sim 4500 \mathrm{G}$ with a swinging bucket rotor in PDL-W. The centrifuging time was initially set for 10 minutes. This centrifuging time was sufficient to cause phase separation during Shakedown, Integrated Test A, and oxidative leaching. However, during some of the Integrated Test B and Integrated Test D process steps, phase separation was not achieved after 10 minutes, so the samples were centrifuged for an hour. The actual centrifuging time is recorded on the sample bench sheets. After centrifuging, the supernatant was decanted and submitted for some or all of the analyses listed below.

- inductively coupled plasma (ICP)

- total dissolved solids

- density

- ion chromatography (IC)

- total organic carbon (TOC)

- Raman

- free hydroxide.

Not all of these analyses were necessarily performed on every decanted supernatant. The specific analysis was identified in the Sample Collection and Analysis table in the governing Test Instruction. Density was determined on the decanted supernatant at PDL-W for all samples being analyzed by Raman spectroscopy before the samples were transported for analysis. In addition, at times, the density was determined by SwRI before ICP analysis. The wet centrifuged solids from this same container were either submitted for ICP analysis, if it was required, or stored in the original sample collection container as excess. A tare weight (before filling) and gross weight (after filling) of the sample container were documented on sample bench sheets.

For DOW Corning to quantify the antifoam agent (AFA) compounds by GPC in the solid and supernatant fractions of the slurry, two 50-mL slurry samples were collected and centrifuged at $4500 \mathrm{G}$ for 10 minutes, and the supernatant was decanted into two additional properly labeled $50-\mathrm{mL}$ containers before shipping. Weighing empty and filled containers was not required.

For SwRI to quantify silicon by ICP in the AFA, a 50-mL slurry sample was collected and shipped as collected during non-leaching process steps. Once at SwRI, the slurry was centrifuged at $2200 \mathrm{G}$ for an hour, the supernatant was separated from the wet centrifuged solids, and then each phase was analyzed separately. During leaching, the phase separation occurred in PDL-W following the standard practice of centrifuging at $\sim 4500 \mathrm{G}$ for 10 minutes.

A single 50-mL container was filled for particle-size distribution (PSD), XRD, and SEM. Initially, these samples were centrifuged. The supernatant was decanted and stored while the wet solids were submitted for analysis. Intact slurry samples were submitted after shakedown. If a phase-separated sample was submitted, then descriptor 7 was included in the sample name. If descriptor 7 was not in the name, then an intact sample was submitted for analysis. Weighing empty and filled containers was not required. 
For parallel CUF and bench-scale testing, varying amounts of either permeate or slurry samples were collected. A tare weight (before filling) and gross weight (after filling) of the sample container was recorded on the sample container. These samples were delivered to the Advanced Process Engineering Laboratory (APEL) by the next business day after sample collection.

\subsubsection{Leaching Samples}

The core critical analyses for leached samples were wt\% UDS, slurry density, inductively coupled plasma, ion chromatography, Raman, and free-hydroxide analyses. Two 50-mL samples were collected for the UDS and density analyses. Another 50-mL sample was collected for the remaining core analyses.

- During caustic leaching, the original samples were immediately placed in a thermostatically controlled water bath at $20^{\circ} \pm 2^{\circ} \mathrm{C}$ to decrease the sample temperature to $25 \pm 5^{\circ} \mathrm{C}$ after collection. Once the desired temperature was reached, which typically took less than 10 minutes for $50-\mathrm{mL}$ containers, the samples were allowed to sit for 24 hours in PDL-W. The density sample was shipped as collected. The two other samples to be used for analysis were centrifuged following the sample process described for non-leached samples.

- During oxidative leaching, sample processing began immediately after sample collection. The oxidative-leach density sample was shipped as collected while the other two samples were phase-separated immediately after collection by centrifuging and decanting the supernatant as described above for non-leached samples. To allow for consistency in comparing analytical results, the samples for ICP analysis collected immediately before adding $\mathrm{NaMnO}_{4}$ were phase-separated immediately after collection. The oxidatively leached centrifuged solids from samples collected immediately before adding $\mathrm{NaMnO}_{4}$ and at the end of oxidative leaching for analysis were weighed and rinsed three times with $0.01-\mathrm{M} \mathrm{NaOH}$ solution. The actual quantity of rinse is recorded on sample bench sheets. The wet solids were vortexed three times to suspend and rinse the solids after each addition of $\mathrm{NaOH}$ solution. The rinsate was collected and weighed. The density of the rinsate was measured at PDL-W, and then it was split into sub-samples for ICP and Raman analysis.

During leaching, additional 50-mL samples were collected for archiving. Caustic-leached archived samples were also cooled and phase-separated as described above before storage. The oxidatively leached archived samples were also immediately phase-separated after collection as described above. The centrifuged oxidatively leached solids that went to storage were not rinsed.

\subsubsection{Undissolved Solids}

The sample processing for UDS is given in Figure 3.8. The UDS was measured at PNNL only when results were needed the same day the sample was collected. A halogen moisture analyzer (HG63, Mettler Toledo) was used to determine the wt\% UDS under procedure TPR-RPP-WTP-648. If results for multiple samples were required, then a modified version of the oven method outlined in Guidelines for Performing Chemical, Physical, and Rheological Properties Measurements (24590-WTP-GPG-RTD-001 Rev. 0) was used. (a)

(a) L Smith and K Prindiville. 2002. Guidelines for Performing Chemical, Physical, and Rheological Properties Measurements. 24590-WTP-GPG-RTD-001 Rev. 0, Bechtel National, Inc., Richland, Washington. 


\subsubsection{Supernatant Density}

Density measurements were performed at PDL-W on samples that were analyzed by Raman. Density was measured in accordance with TPR-WTP-PEP-054, Determination of Density using Pycnometer or Graduated Cylinder. All other density values were analyzed externally by SwRI.

Slurry samples requiring a higher accuracy supernatant density than provided by the UDS analysis were sub-sampled and centrifuged for 1 hour at $1000 \mathrm{G}$, and the phase-separated supernatant was analyzed as described in the paragraph above.

\subsection{Analytical Methods}

This section describes the analytical methods used to determine the chemical composition of the PEP simulant samples collected during testing. Analytical results are provided in Section 5.

\subsubsection{Preparation for ICP or ICP-MS}

For the solutions, aliquots were diluted with hydrochloric acid and then analyzed. For the dilutions, a representative sample aliquot of approximately 2 grams was combined with $5-\mathrm{mL}$ of $50 \%$ hydrochloric acid and then diluted to a final volume of $50-\mathrm{mL}$ with deionized water (DIW).

For solids, two preparative techniques were used. The first preparative technique was lithium metaborate/tetraborate fusion, referred to as prep method "80/20 Fusion." Aluminum, barium, cerium, chromium, iron, lanthanum, manganese, neodymium, silicon, and strontium were reported from the fusion. The second preparative method used concentrated nitric, perchloric, hydrofluoric, and hydrochloric acids in an open vessel and was referred to as the "Teflon" prep method. If residue remained from the "Teflon" method, then the residue was separated, dried, and fused using the lithium metaborate/tetraborate fusion technique. Both the "Teflon" and residue preparations were analyzed. The remaining metals were reported from either the "Teflon" digestion only or the combination of the two. If an analyte was detected in both the Teflon digestate and the residue fusions, then the reported result was the sum of the results obtained from the two preparations. These results were identified as "combined" on Sample Analysis Data Sheets while analytes reported from only the fusion were identified as " $80 / 20$ Fusion," and analytes reported solely from the acid digestions were identified as "Teflon" on the Sample Analysis Data Sheets. The preparative QC samples included a sample duplicate, preparation blank (PB), solid laboratory control samples (LCS) consisting of obsidian rock and basalt rock, and an aqueous laboratory control sample (LCS) and a matrix spike (MS) for "Teflon." The results are reported on an "as received" or wet weight basis. The percent solids were determined at $105^{\circ} \mathrm{C}$ and reported on the Sample Analysis Data Sheets for all solids.

\subsubsection{Metals Analysis by ICP-AES}

All metals were determined by ICP-AES using SwRI procedure TAP01-0406-130 with the exception of cerium, cesium, lanthanum, and neodymium. The preparative QC samples (duplicate, PB, LCS, MS) were processed along with analytical workstation QC (initial and continuing calibration verifications, initial and continuing blanks, interference check samples, and post-digestion spikes). 


\subsubsection{Metals Analysis by ICP-MS}

Cerium, cesium, lanthanum, and neodymium were determined by ICP-MS in accordance with SwRI procedure TAP01-0406-046. The preparative QC samples (duplicate, PB, LCS, MS) were processed along with analytical workstation QC (initial and continuing calibration verifications, initial and continuing blanks, interference check samples, and post-digestion spikes).

\subsubsection{Anions (IC)}

Decanted supernatant and rinsants were analyzed by IC for chloride, nitrate, nitrite phosphate, sulfate, and oxalate at SwRI in accordance with procedure SwRI TAP 01-0406-042. Approximately $0.25 \mathrm{~g}$ of the sample was diluted to $50-\mathrm{mL}$ using DIW. Since the dilution was performed by weight, the sample results are reported on a weight basis. The standard reporting by the laboratory is nitrate as N, nitrite as N, and phosphate as P. Shortly after PEP testing began, PNNL requested that results be reported as nitrate, nitrite, and phosphate and not as nitrogen or phosphorus. The IC analytical report narrative identifies conversion factors used to report as anions. QC samples generated at the analytical workstation included a sample replicate determination, process blank, LCS, and matrix spike (MS).

\subsubsection{Total Inorganic Carbon/Total Organic Carbon (TIC/TOC)}

The samples were analyzed for total carbon (TC) using a Dohrman DC-80 Carbon Analyzer in accordance with SwRI procedure TAP 01-0406-001. The liquids were directly injected, and the slurry was analyzed using the soil/sludge sampler. Another aliquot of the sample was acidified with sulfuric acid and sparged to remove inorganic carbon and then analyzed for TOC. The TIC is calculated from the difference in the TC and TOC results. All samples were analyzed in duplicate, and average results were reported when the relative percent differences (RPDs) were less than 20\%. If the RPD was greater than $20 \%$, then the sample was analyzed twice more, and the average of the quadruplicate analysis was reported. The liquids were corrected for density, and all sample results were reported on a weight basis. QC samples were generated at the analytical workstation and included a sample replicate determination, process blank, LCS, and MS.

\subsubsection{Hydroxide}

The free-hydroxide concentration was determined by potentiometric titration with standardized $\mathrm{HCl}$ according to procedure RPG-CMC-228, "Determination of Hydroxyl (OH-) and Alkalinity of Aqueous Solutions, Leachates, and Supernates and Operation of Brinkman 636 Auto-Titrator." The free hydroxide was defined as the first inflection point on the titration curve. QC samples were generated at the analytical workstation and included a sample replicate determination, process blank, and blank spike (BS).

\subsubsection{Raman}

Raman was used to quantify aluminate, carbonate, chromate, hydroxide, nitrate, nitrite, oxalate, phosphate, and sulfate following procedure RPG-CMC-240. If precipitate formed in the solution samples submitted for Raman before the analysis, then the samples were centrifuged, and aliquots of the liquid were pipetted and analyzed. Two sets of Raman results were reported for Shakedown, Integrated Test A, 
and some of the Integrated Test B samples. The first set of results was generated using calibrations that were periodically adjusted to optimize performance of QC check samples. The second set of results was recalculated based on the original calibration parameters. The generation of these two sets of results and the discovery of the calibration adjustments are documented as RPP-WTP CAR, number 42708.1. Only Raman results from the recalculation are provided. As a result of using the original calibration parameters, an occasional QC sample falls outside of established performance limits. QC samples were generated at the analytical workstation and included a sample replicate determination, process blank, BS, and MS.

\subsubsection{Preparation for Gel Permeation Chromatography (AFA components)}

Duplicate samples were collected to support this analysis. Both samples were centrifuged and phase-separated at PDL-W before shipping. Once at the analytical laboratory, one of the two liquid fractions was mixed with toluene while the other was mixed with tetrahydrofuran (THF). Both were shaken for an hour and allowed to settle overnight. The upper organic layer was removed and allowed to concentrate. The toluene extract was dried at room temperature to completeness, and then 3.0-mL toluene was added. The THF extracts were concentrated to approximately $2-\mathrm{mL}$ at room temperature and then placed in an $80^{\circ} \mathrm{C}$ oven to dry to completeness and brought up to 3.0-mL THF. One of the two solids fractions was extracted with $10-\mathrm{mL}$ of toluene while the other was extracted with $10.0-\mathrm{mL}$ of THF. In both cases, the solvent was added directly into the receipt vessel, and the initial sample and solvent were shaken for 2 hours. All solutions were filtered through $0.45-\mu \mathrm{m}$ PTFE syringe filters. Calibration verification was performed before sample analysis and after every 15 samples.

\subsubsection{Gel Permeation Chromatography (AFA components)}

The toluene extract allowed polydimethylsiloxane (PDMS) to be analyzed by gel permeation chromatography (GPC) while the THF extract allowed polypropylene glycol (PPG) to be analyzed by GPC. The toluene extract was analyzed by a Waters 717 autosampler and a Waters 2410 differential refractometer. Two columns, a PLgel 5- $\mu \mathrm{m}$ guard column and a PLgel 5- $\mu \mathrm{m}$ Mixed-C column, were used for separation, and an HPLC-grade toluene at a flow of $1.0-\mathrm{mL} /$ minute was used as the eluent. Both the columns and detector were heated to $45^{\circ} \mathrm{C}$. The THF extract was analyzed by a Waters 2695 Separation Module equipped with a vacuum degasser and a Waters 2410 differential refractometer. Two columns, a PLgel 5- $\mu \mathrm{m}$ guard column and a PLgel 5- $\mu \mathrm{m}$ Mixed-C column, were used for separation, and a certified grade THF at a flow of $1.0-\mathrm{mL} / \mathrm{minute}$ was used as the eluent. Both the columns and detector were heated to $35^{\circ} \mathrm{C}$. The quantity of PDMS and PPG was used to determine the amount of AFA, Dow Corning Q2-3183A Antifoam, in the samples. Since the AFA is a proprietary composition belonging to Dow Corning, they performed the analytical work. Calibration verification was performed before sample analysis and after every 15 samples.

\subsection{Physical Properties}

This section describes the methods used to determine the physical properties of the PEP simulant samples, the crystal form, and the solids environment, density, wt $\%$ UDS, rheology, particle-size attributes, and heat capacity. A more detailed outline of the methods used in this section is given, where applicable, in the appropriate Test Data Package supplied with the sample results for each characterization. 


\subsubsection{Percent UDS and Density}

Weight percent UDS, wt\% dissolved solids, bulk slurry density, and supernatant density were determined following Bechtel procedure 24590-WTP-GPG-RTD-001, Rev 0. ${ }^{\text {(a) }}$ Some Bechtel 24590-WTP-GPG-RTD-001, Rev 0 steps were not performed because the results generated from these steps were not needed, or steps were slightly modified to reduce analysis time. These modifications are not believed to impact the final results.

Slurry sample UDS analysis was performed with the following modifications:

- Steps 4, 6, and 7 were omitted because the settling data were not required.

- Steps 8 and 9. Centrifuge the cones at $\sim 1000 \mathrm{G}$ for 1 hour. Record the volume of the total sample and the volume of centrifuged solids on the physical properties data sheet. After this, the WTP procedures required that the supernatant be decanted into a pre-weighed graduated cylinder to obtain the supernatant mass and volume. Rather than use a graduated cylinder, the volume of supernatant was calculated as the difference between the volume of the total sample and the volume of centrifuged solids.

- Step 11 requires decanting the centrifuged supernatant liquid to a pre-weighed graduated cylinder. Because of the high concentration of $\mathrm{NaOH}$ in some of the samples, some of the liquid was left in the cylinder. Rather than decant, the centrifuged supernatant liquid was pipetted to a pre-weighed glass Petri dish or vial, and the mass of the supernatant liquid was recorded.

- Step 12 was omitted because air-drying was not necessary.

Separated slurry samples UDS analysis was performed with the following modifications:

- Step 8 requires centrifuging at $\sim 1000$ gravities for 1 hour. Samples were centrifuged at $\sim 4500$ gravities for either 10 minutes or 1 hour. The centrifuge time is documented on the sample handling benchsheets in TDP-WTP-349.

- Wet solids (designated as "B") and decanted supernatants (designated as "D") were sent to SwRI along with empty vial and separated sample weights. These weights are also documented on the sample handing bench sheets in TDP-WTP-349.

- The wet solids were transferred to a tared container using DIW to completely remove the solids. The solids and DIW rinses were then oven dried to constant weight.

- The total weight of the supernatant was calculated from the sample-handling bench sheets. Since it was not feasible for the entire volume of supernatant to be oven dried, approximately 5-mL was transferred to a Petri dish for drying.

- Density was determined on the supernatant liquid using a 5-mL volumetric flask.

\subsubsection{Slurry and Supernatant Density}

Three preweighed 5-mL Class A volumetric flasks were filled to the specified line with the liquid sample and reweighed. The density was calculated as the mass of the sample divided by the certified volume of the volumetric flask.

(a) GL Smith and K Prindiville. May 20, 2002. Guidelines for Performing Chemical, Physical, and Rheological Properties Measurements. 24590-WTP-GPG-RTD-001, Rev 0, Bechtel National, Inc., Richland, Washington. 
Slurry samples requiring a higher accuracy supernatant density than provided by the UDS analysis were sub-sampled and centrifuged for 1 hour at $1000 \mathrm{G}$, and the phase-separated supernatant was analyzed as described in the paragraph above.

\subsubsection{Rheology Measurements}

Rheological testing was conducted on the solids in contact with the supernatant generated as part of the homogenization process. Testing was conducted according to RPL-COLLIOD-02, Measurement of Physical and Rheological Properties of Solutions, Slurries and Sludges. For the current study, two regions of tank waste flow behavior are considered: 1) incipient motion in settled tank waste solids (shear strength) and 2) non-elastic flow of tank waste slurries and supernates (flow curve).

\subsubsection{Shear-Strength Testing}

For tank waste slurries, a finite stress must be applied before the material will begin to flow. The stress required to transition the material from elastic deformation to viscous flow is referred to as the shear strength, and its origin can be attributed to static and kinetic friction between individual particles and/or aggregates, the strength of the matrix supporting the coarse fraction (i.e., the interstitial fluid), and sludge cohesion arising from interparticle adhesive forces such as van der Waals forces.

The shear strength was measured using the vane method with operating constraints shown in Table 3.3. For the vane technique, the stress required to begin motion is determined by slowly rotating a vane immersed in the test sample's settled solids while continuously monitoring the resisting torque as a function of time. A material's static shear strength is then associated with the maximum torque measured during the transition from initial to steady-state vane rotation.

The maximum torque required for incipient motion is dependent on vane geometry. To account for vane-geometry effects, the shear strength is expressed in terms of the uniform and isotropic stress acting over the surface area of the cylinder of rotation swept out by the vane. The shear strength is related to the maximal torque during incipient motion according to Equation 3.1 (Barnes and Dzuy 2001):

$$
\tau_{S S}=\frac{M_{\max }}{4 \pi R^{3}\left(\frac{H}{2 R}+\frac{1}{3}\right)}
$$

Here, $\tau_{s s}$ is the shear strength $\left(\mathrm{N} / \mathrm{m}^{2}\right), M_{\max }$ is the maximum torque $(\mathrm{N} \cdot \mathrm{m})$, and $R$ and $H$ are the radius and height of the cylinder of rotation swept out by the vane $(\mathrm{m})$. Because the shear band observed upon slow rotation of the vane does not extend appreciably beyond the vane paddles, $R$ and $H$ are taken to be the dimensions of the vane itself.

The proximity of the vane to the sample container inner surfaces as well as the free surface of the settled solids can impact shear-strength results. As such, certain geometric constraints must be satisfied for the test to be considered independent of container geometry. 
Table 3.3. Vane Immersion Depth and Container Geometry Constraints for Shear-Strength Tests Using the Vane Technique

\begin{tabular}{lll}
\hline Constraint & Criterion & For $8 \times 16 \mathrm{~mm}(\mathrm{R} \times \mathrm{H})$ Vane \\
\hline Vane height to radius & $\mathrm{H}<7 \mathrm{R}$ & $\mathrm{H}<56 \mathrm{~mm}$ (Satisfied) \\
Container radius to vane radius & $\mathrm{R}_{\text {cont }}>2 \mathrm{R}$ & $\mathrm{R}_{\text {cont }}>16 \mathrm{~mm}$ \\
Immersion depth to vane height & $\mathrm{h}>\mathrm{H}$ & $\mathrm{h}>16 \mathrm{~mm}$ \\
$\begin{array}{l}\text { Separation between bottom of vane and } \\
\text { container floor }\left(\mathrm{h}_{\text {floor }}\right)\end{array}$ & $\mathrm{h}_{\text {floor }}>0.5 \mathrm{H}$ & $\mathrm{h}_{\text {floor }}>8 \mathrm{~mm}$ \\
\hline $\mathrm{R}=$ radius & & \\
$\mathrm{H}=$ height & & \\
\hline
\end{tabular}

\subsubsection{Flow-Curve Testing}

The non-elastic flow of tank waste slurries and supernates is characterized with rotational viscometry. The typical result of such testing is a set of flow-curve data, which shows the stress response of a material to a range of applied rates-of-deformation. Specifically, flow-curve testing allows characterization of a material's shear stress, $\tau$, which is the response as a function of applied shear rate, $\dot{\gamma}$. Once measured, the flow-curve data can be interpreted with several constitutive equations for the viscous stress/rate-of-strain relationship. Such analysis allows the flow behavior over a broad range of conditions to be described with just a few rheological descriptors, such as viscosity, yield stress, consistency, and flow index.

A concentric cylinder rotational viscometer operated in controlled-rate mode was used for flow-curve testing of tank waste slurries and supernates. Rotational viscometers operate by placing a given volume of test sample into a measurement cup of known geometry. A cylindrical rotor attached to a torque sensor is then lowered into the sample until the slurry is even with, but does not cover, the top of the rotor. A single-point determination of a fluid's flow properties is made by spinning a rotor at a known rotational speed, $\Omega$, and measuring the resisting torque, $M$, acting on the rotor. The torque acting on the rotor can be directly related to the shear stress at the rotor using the equation,

$$
\tau=\frac{M}{2 \pi H R_{I}^{2}}
$$

The shear stress has units of force per area $\left(\mathrm{N} / \mathrm{m}^{2}\right)$. The rotational rate is related to the shear rate. However, calculating the fluid shear rate at the rotor is complicated by the fact that shear rate depends on both the measurement-system geometry and the fluid rheological properties. For the simplest fluids (i.e., Newtonian fluids), the shear rate of the fluid at the rotor can be calculated given the geometry of the cup rotor shear by using the equation,

$$
\dot{\gamma}=\left(\frac{2 R_{O}^{2}}{R_{O}^{2}-R_{I}^{2}}\right) \Omega
$$

Here, the shear rate has units of inverse seconds $\left(\mathrm{s}^{-1}\right)$. Calculating the shear rate for materials showing more complex shear-stress versus shear-rate behavior (i.e., non-Newtonian fluids) requires 
estimates of yield stress and a degree of shear-thinning or shear-thickening. As the goal of rheological testing is to determine and quantify such behavior, these values are typically not known. This requirement can be circumvented by using a cup-and-rotor system with a small gap $(\sim 1 \mathrm{~mm})$ for fluid shear. For fluid flow in small-gap cup and rotor systems, shear-rate effects introduced by fluid properties are minimized such that Equation B.3 provides an accurate determination of shear rate for non-Newtonian materials.

The resistance of a fluid to flow is often described in terms of the fluid's apparent viscosity, $\eta_{a p p}$, which is defined as the ratio of the shear stress to the shear rate:

$$
\eta_{a p p}=\frac{\tau}{\dot{\gamma}}
$$

For Newtonian fluids, the apparent viscosity is independent of the shear rate. For non-Newtonian fluids, the apparent viscosity will vary as a function of the shear rate. The unit of apparent viscosity is $\mathrm{Pa} \cdot \mathrm{s}$, although it is typically reported in the unit of centipoise $(\mathrm{cP}$; where $1 \mathrm{cP}=1 \mathrm{mPa} \cdot \mathrm{s})$.

Flow-curve data are usually combined plots of $\tau$ and $\eta_{\text {app }}$ as a function of $\dot{\gamma}$. As stated above, flow-curve data can be interpreted with several constitutive equations (i.e., flow curves), allowing characterization of those data with just a few rheological descriptors. The behavior of tank waste sludges, slurries, and supernates can be described by four common flow-curve equations:

Newtonian-Newtonian fluids flow as a result of any applied stress and show constant viscosity over all shear conditions. The flow curve for Newtonian fluids is

$$
\tau=\eta \dot{\gamma}
$$

where $\eta$ is the Newtonian viscosity.

Ostwald (Power Law) - Power-law fluids flow as a result of any applied stress and have viscosities that either increase or decrease with increasing shear rate. They are described by,

$$
\tau=m \dot{\gamma}^{n}
$$

where $m$ is the power-law consistency index, and $n$ is the power-law index. Power-law fluids with $n<1$ are referred to as pseudoplastic (shear-thinning), whereas power-law fluids with $n>1$ are referred to as dilatant (shear-thickening).

Bingham Plastic - Bingham plastics are fluids that show finite yield points. A finite stress (i.e., the yield stress) must be exceeded before these types of materials flow. Once flow is initiated, the stress response of the material is Newtonian over the rest of the shear-rate range. Bingham plastics are described by

$$
\tau=\tau_{O}^{B}+k_{B} \dot{\gamma}
$$


where $\tau_{O}^{B}$ is the Bingham yield index, and $k_{B}$ is the Bingham consistency index.

Casson-Fluids that behave in accordance with a Casson model show a finite yield followed by pseudoplastic behavior. They are described by,

$$
(\tau)^{0.5}=\left(\tau_{o}^{C}\right)^{0.5}+\left(k_{C} \dot{\gamma}\right)^{0.5}
$$

where $\tau_{o}^{C}$ is the Casson yield index, and $k_{C}$ is the Casson consistency index. Although more limited in the types of flow behavior that it can describe relative to the Herschel-Bulkley equation, the Casson model is popular because it is capable of accurately describing many shear-thinning fluids and because units on the parameters are more physically meaningful (e.g., the consistency is in Pa.s versus $\mathrm{Pa} \cdot \mathrm{s}^{\mathrm{n}}$ for the Herschel-Bulkley model).

Power-law fluids, Bingham plastics, and Casson fluids are referred to as non-Newtonian fluids. Generally, liquids without internal and/or interconnected structures (such as tank waste supernatants) are Newtonian. Sludges and slurries are typically non-Newtonian, but their exact behavior depends on the concentration of solids and suspending phase chemistry. Sufficiently dilute slurries may show Newtonian behavior.

\subsubsection{Rheology Instrumentation}

Rheological characterization was accomplished with an Anton Parr Rheometer (MCR 301) for shear-rate measurements, and shear strength was determined on a HAAKE RS-600 Measuring System equipped with an M5 measuring head and RC20 controller sold by HAAKE Mess-Technik GmbH u Co. (now the Thermo Electron Corporation). The M5 measuring head is a "Searle" type viscometer capable of producing rotational speeds up to $500 \mathrm{rpm}$ and measuring torques up to $0.049 \mathrm{~N} \cdot \mathrm{m}$. The minimum rotational speed and torque resolution achievable by this measuring head are $0.05 \mathrm{rpm}$ and $0.49 \mathrm{mN} \cdot \mathrm{m}$, respectively.

Calibration and analysis were performed according to TPR-WTP-PEP-049.

Specific measurement tools, such as cup-and-rotor assemblies and shear vanes, are attached to measure selected rheological properties. Shear-strength measurements employ an $8 \mathrm{~mm} \times 16 \mathrm{~mm}(\mathrm{R} \times \mathrm{H})$ shear vane tool. Flow-curve measurements employed an MV1 stainless steel measuring cup and rotor. The dimensions of the MV1 and vane measuring systems are listed in Table 3.4.

Table 3.4. Vane and Cup and Rotor Measuring System Dimensions

\begin{tabular}{lcccc}
\hline Measuring System & $\begin{array}{c}\text { Vane/Rotor Radius } \\
(\mathrm{mm})\end{array}$ & $\begin{array}{c}\text { Vane/Rotor Height } \\
(\mathrm{mm})\end{array}$ & $\begin{array}{c}\text { Container Radius } \\
(\mathrm{mm})\end{array}$ & $\begin{array}{c}\text { Gap Width } \\
(\mathrm{mm})\end{array}$ \\
\hline Vane Tool & 8 & 16 & $>16$ & $>8$ \\
MV1 & 20.04 & 60 & 21 & 0.96 \\
\hline
\end{tabular}

The temperature is controlled with a combination of the standard measuring-system temperature jacket and a temperature-controlled recirculator. The jacket temperature is monitored using a Type-K thermocouple calibrated over 0 to $100^{\circ} \mathrm{C}$ and connected to a calibrated multichannel temperature display. 
The temperature control is employed only for flow-curve measurements. Shear-strength measurements are carried out at ambient temperatures.

The rheometer was controlled, and data were acquired with a remote computer connection using the RheoWin Pro Job Manager Software, Version 2.96. During measurement, the software automatically collects and converts rotor torque readings into shear stresses based on Equation 3.1 (for vane testing) or Equation 3.2 (for flow-curve testing). Likewise, the software also automatically converts the rotational rate readings into shear rates based on Equation 3.3.

\subsubsection{Rheology Materials and Methods}

No sample treatment was performed before analysis with the exception of the mechanical agitation required to mix and sub-sample selected sample containers.

\subsubsection{Shear-Strength Testing}

Before testing, the simulant slurries that were provided for shear-strength testing were mixed thoroughly and subsequently allowed to settle for at least 48 to 72 hours. When possible, the shear strength was measured by immersing the $8 \times 16 \mathrm{~mm}$ ( $\mathrm{R}$ to $\mathrm{H}$ ) vane tool to a depth of $15 \mathrm{~mm}$ into the settled solids. The vane was slowly rotated at $0.3 \mathrm{rpm}$ for 180 seconds. For the entire duration of rotation, the time, rotational rate, and vane torque were continuously monitored and recorded. At the end of the measurement, shear stress versus time data were parsed, and the maximum measured shear stress (i.e., the material's shear strength) was determined.

\subsubsection{Flow-Curve Testing}

Each flow curve was measured over an 11-min period and split into three intervals. Over the first 5 minutes, the shear rate was smoothly increased from zero to $1000 \mathrm{~s}^{-1}$. For the next minute, the shear rate was held constant at $1000 \mathrm{~s}^{-1}$. For the final 5 minutes, the shear rate was smoothly reduced back to zero. During this time, the resisting torque and rotational rate were continuously monitored and recorded.

Results are provided in the Test Data Packages listed below, with summary results provided in Appendix L.

\subsubsection{Particle-Size Distribution}

Particle sizes were characterized according to procedure RPL-COLLOID-01, Rev. 1, Particle Size Analysis Using Malvern MS2000. This procedure uses a Mastersizer 2000 (Malvern Instruments, Inc., Southborough, MA 01772 USA) with a Hydro S wet dispersion accessory. Malvern lists the Mastersizer particle-size measurement range as nominally 0.02 to $2000-\mu \mathrm{m}$. The actual PSD measurement range is dependent on the accessory used as well as the properties of the solids being analyzed. The Malvern 2000 uses laser diffraction technology to define PSD.

The Hydro S wet-dispersion accessory consisted of a 150-mL dispersion unit coupled with a sample flow cell with a continuous variable and independent pump and stirrer and ultrasound. Flow, stirring rate, and sonication can be controlled and altered during measurement. PSD measurements can be made 
before, during, and after sonication, allowing the influence of each on the sample PSD to be determined. The primary measurement functions of the Malvern analyzer were controlled through Mastersizer 2000 software (Malvern Instruments, Ltd. Copyright 1998-2002). The properties applied to the test samples are summarized in Table 3.5.

The PSD measurements were conducted in either DIW or in a $0.01-\mathrm{M} \mathrm{NaOH}$ dispersion solution matrix, depending on the sample being analyzed. The sample dispersion was added drop-wise to the dispersion unit (while the pump and stirrer were active) until an obscuration in the range of 10 to $20 \%$ was reached.

Table 3.5. Properties Applied to Group 8 Test Materials

\begin{tabular}{cc}
\hline Property & \\
\hline Material Selected for Optical Properties & Ferric Oxide Hydroxide \\
\hline Refractive Index (RI) & 2.94 \\
Absorption & 0 \\
Analysis mode & General Purpose \\
Sensitivity & Normal \\
Suspending Phase & Water/0.01-M NaOH \\
\hline
\end{tabular}

The size distributions of particles were measured under varying flow conditions before and after sonication. For each condition, multiple measurements of PSD were taken. The analyzer software then generated an average of these measurements. Both the individual measurement and average were saved to the analyzer data file.

\subsubsection{X-Ray Diffraction}

The sample mounts for XRD examination were prepared by first cleaning the solids. This procedure included centrifuging the solids into a pellet and decanting the solute. Fresh washing solution was added to the pellet, and it was resuspended. The pellets in solution were vortexed to reconstitute them into the solution, and the centrifuging procedure was repeated three times. Following the final centrifuging and decant, the remaining pellet was left to dry in a $105^{\circ} \mathrm{C}$ oven overnight. The pellet was then pulverized to a powder with a tungsten carbide milling chamber for 1 minute in the Angstrom shaker mill, mixed with an internal standard (rutile, $\mathrm{TiO}_{2}$, or alumina, $\mathrm{Al}_{2} \mathrm{O}_{3}$ ), milled for another 2 minutes to make sure that the two powders were a homogenous mixture, and then mounted into an off-axis, zero background, quartz sample holder. The XRD examination was conducted according to procedure APEL-PAD-V, Operation of Scintag Pad-V X-Ray Diffractometer. The XRD instrument used for these samples was the PNNL Scintag PAD V XRD (property number WD33356), located in Laboratory 102 in the APEL building. The data range for the sample was $5^{\circ}$ to $80^{\circ} 2 \theta$, with a step size of $0.02^{\circ} 2 \theta$ and count time of 2.0 seconds per step. Copper $\mathrm{K} \alpha \mathrm{X}$-rays were used. The X-ray tube operating conditions were $45 \mathrm{kV}$ and $40 \mathrm{~mA}$. Phase identification was done by use of the JADE search match routines (Version 6.0, Materials Data Inc.) with comparison to the International Centre for Diffraction Data (ICDD) database PDF-2, release 1999, which includes the Inorganic Crystal Structure Database (ICSD) maintained by Fachinformationszentrum (FIZ), Karlsruhe, Germany. The chemistry provided for Group 7, in order of decreasing concentration, was $\mathrm{Fe}, \mathrm{Na}, \mathrm{U}, \mathrm{P}, \mathrm{Ca}, \mathrm{Al}, \mathrm{Si}, \mathrm{Bi}, \mathrm{Sr}$, and $\mathrm{Mg}$. Phase identifications were first done without chemistry restrictions. Searches were restricted to the PDF and ICSD inorganic sections. 
The pattern was also examined using RIQAS (release 4.0.0.26, 6/10/2002, Materials Data Inc.) Rietveld analysis software. The phases identified above were input into the analysis along with a polynomial background and an amorphous hump at $\sim 35^{\circ} 2 \theta$.

Details of the XRD analysis and results are provided in Appendix L.

\subsubsection{Scanning Electron Microscopy}

The specimen was vortexed, and a small volume of slurry was drawn up using a pipette and placed on an aluminum stub. This was done within the same sample processing as above for the XRD sample preparation, the final step just before the supernatant was decanted. The slurry was placed in an oven at $105^{\circ} \mathrm{C}$ to dry overnight. The sample was then coated with gold-palladium using a Polaron Range plasma sputter coater and analyzed with a JEOL SEM (property number WD30596) according to APEL-102-SEM, Scanning Electron Microscope Examination. Selected sample areas were evaluated by X-ray energy dispersive spectroscopy (EDS) for qualitative elemental composition. Results are provided in Appendix L as part of the Test Data Package, TDP-WTP-356. 



\subsection{Test Narrative}

This section describes the execution of Integrated Test $D$ that was run from 03/22/09 to 03/31/09. Testing was conducted in accordance with Test Instruction TI-WTP-PEP-082. Observations were written in this Test Instruction and in LRBs BNW-60272 and BNW-60280.

Integrated Test D started with loading the simulant that had chromium oxyhydroxide $(\mathrm{CrOOH})$ already in the simulant, unlike previous tests. The slurry was kept at temperatures below $45^{\circ} \mathrm{C}$ until use to make sure that the $\mathrm{Cr}$ did not oxidize during transportation and storage.

The Operational Process Sheet section of the Test Instruction provided the Lead Test Engineer (LTE) with target or setpoint values for key process operations. A reproduction of the Operational Process Sheet, with actual values from the LTE or other data source, is provided in Appendix M.

Most of the data reported in the text of this section of the report are NOT NQA-1 because they were taken from the HMI during the conduct of the test. NQA-1 data are available in the graphs in Appendix J, selected values in the Operational Process Sheets, and the DAS files recorded as described in Section 3.6.

Caustic leaching in vessel UFP-VSL-T02A was demonstrated in Integrated Test D using nonradioactive simulant. To view the summary for sampling events, please refer to Appendix C. The subsequent paragraphs summarize the process steps executed for Integrated Test D. However, refer to Appendix K for start and stop times of process steps during Integrated Test D efforts.

Before starting Integrated Test B, all five filters were cleaned with 2-M nitric acid. No cleaning was performed between Integrated Tests B and D. At the conclusion of Integrated Test D, the filters were cleaned in a prototypic manner with 2-M nitric acid. The results are included in this report.

\subsection{Feed Preparation}

The slurry was delivered as simulant Batch 3 to PEP on 3/16/09, in a heated trailer. The delivery included three totes of slurry at a concentration of $~ 7.4-\mathrm{wt} \%$ undissolved solids (UDS) and two totes of supernate. The solids contained $1.6-\mathrm{wt} \% \mathrm{Cr}$ as $\mathrm{CrOOH}$. The slurry batch was mixed with previous Batch 2 slurry in the FRP vessel to produce slurry with $\sim 5.0$-wt \% UDS. The FRP vessel held approximately 1009 gallons of Batch 2 slurry before adding Batch 3. All 720 gallons of Batch 3 slurry and 410 gallons of supernate were added on 3/16/09. The FRP was allowed to agitate for approximately 8 hours, and then 29 samples were taken. Twenty three of the samples were taken in the 50-mL containers for analysis to verify the UDS and Cr content. In addition, a larger 1-L sample was taken for a laboratory caustic-leaching test to determine how much $\mathrm{Cr}$ would be oxidized during the caustic-leaching process. ${ }^{\text {(a) }}$ This value was used to determine the quantity of $\mathrm{NaMnO}_{4}$ to be added during the PEP oxidative-leach process.

(a) RD Scheele, GN Brown, and DE Kurath. 2009. Scale-Up, Production, and Procurement of PEP Simulants. WTP-RPT-204, Pacific Northwest National Laboratory, Richland Washington. 
The HLP-VSL-T22 vessel received 2160 gallons of $\sim 5$-wt $\%$ solids from the FRP-VSL-T01 starting on 3/22/09 at 22:00 hours. For Integrated Test D, 1600 gallons of slurry were needed to make two batches of leached solids in Tank T02A.

From the HLP-T22 vessel, 593 gallons of slurry were transferred on 3/23 at 02:10 hours to UFP-VSL-T01B at a rate of $7.4 \mathrm{gpm}$ for the start of Batch 1. UFP-VSL-T01B was used as directed by the Test Instruction, although it was different than the Test Plan because one PJM in UFP-VSL-T01A was inoperable. During the transfer, samples were taken after 3, 200, and 400 gallons of slurry were transferred. The PJMs were started when the level in Tank T01B was 16 inches, and the pressure was adjusted later to obtain the correct nozzle velocity and stroke length. The final level in Tank T01B was 65.8 inches, based on the laser level monitor. The PJMs were tuned to obtain a 29-in. (80\%) stroke and an average maximum velocity of $5.1 \mathrm{~m} / \mathrm{sec}$. The PJMs were operated with a $35-\mathrm{sec}$ cycle time in the standard mode. One thousand $\mathrm{mL}$ of Dow Corning Q2-3183A Antifoam Agent (AFA) diluted with 3 parts water to 1 part AFA was added (target concentration of $\approx 350 \mathrm{ppm}$ ) to minimize foaming.

From UFP-VSL-T01B, 218 gallons of slurry were transferred to UFP-VSL-T02A on 3/23/09 at 03:04 hours with the filter-loop inlet valve from Tank T02A closed. After filling the vessel to 50 inches, the PJMs in Tank T02A were operated with $7.7 \mathrm{~m} / \mathrm{sec}$ nozzle velocity, a 32-in. (80 \%) stroke and a 33-sec cycle time. The filter-loop was drained of inhibited water, and Filter T02A was backpulsed as a simple way to vent the system and increase the draining rate. After the filter-loop was drained, the filter-loop inlet valve V06132 was opened, and the filter-loop was filled with slurry. The automatic transfers from Tank T01B were set-up for 11-gallon batch transfers that occurred when the Tank T02A level was below 27 inches. Additional slurry was transferred to Tank T01B for the rest of leach Batch 1 and Batch 2 when the level was low. The laser level sensors in Tank T02A and T01B were the most reliable level sensors and were used most of the time.

\subsection{Leach Batch \#1 Slurry Concentration}

The objective of the slurry concentration was to concentrate the $\sim 5$-wt $\%$ UDS slurry to 20 -wt $\%$ by adding forty-six 11-gallon batches to Tank T02A from Tank T01B and concentrate Tank T02A down to 19 inches. The recirculation pumps were started for the first leach batch by setting Pump 42A to 25\%, and then Pump 43A was ramped up to $65 \%$ to obtain a flowrate of 96 gpm at 07:50 hours. Pump 43A was then adjusted slowly to achieve the desired flow rate of $109 \mathrm{gpm}$. The lower air spargers and steam ring purge were set at $0.01 \mathrm{~kg} / \mathrm{min}$, and the upper spargers were off. Later the steam ring air purge was increased to $0.14 \mathrm{~kg} / \mathrm{min}$. The PJMs had a 33-sec cycle time, a nozzle velocity of $7.7 \mathrm{~m} / \mathrm{s}$, and stroke length of 32 inches. The filter permeate valves were opened, the slurry solids concentration was started on 3/23/09 at 07:17 hours, and the permeate was directed to UFP-VSL-T62A. Initially, all of the filters' permeate valves were opened for a short time to remove air from the system and allow stable filter-loop flow rates. Only Filter \#1 was used to concentrate Tank T02A Batch \#1. The filtration rate after Tank T01B transfer \#9 ( $\sim 3$ hours) was $1.5 \mathrm{~kg} / \mathrm{min}$, and the automatic fill level was set at 27 inches based on the laser level probe. There was not enough slurry in Tank T01B to complete additions to Tank T02A to obtain the target 20 -wt $\%$ solids for caustic-leach batch, so additional slurry was added to Tank T01B. The first refill of Tank T01B from HLP-T22 occurred on 3/23 when Tank T01B reached the 29.7-inch level. The transfer was 362 gallons at $7.4 \mathrm{gpm}$, and 612-mL of AFA was added to Tank T01B after the transfer. Figure 4.1 through Figure 4.4 illustrate TMP, axial velocity, temperature, permeate production, and Tank T02A tank level during the concentration of Batch 1. 
After adding the 46 batches, the solids concentration continued, dropping the level in the Tank T02A vessel to 18.3 inches on 3/24/09 at 15:15 hours. When the level was below 25 inches, the PJM star mode was used. The concentration was performed with a slurry flow rate of $109 \mathrm{gpm}$, although the flow rate rose and fell a couple percent near the end because of tank level decreases, slurry rheology changes, and manual adjustments of the pump settings. When the level was low ( $<23$ inches), the system had difficulty maintaining a flow rate of $109 \mathrm{gpm}$ because of entrained air. The operations personnel adjusted the pumps to try and maintain the flow, but ultimately, the flow decreased to values less than $100 \mathrm{gpm}$. The TMP of 40 psid was maintained. The permeate rates were not significantly affected by the lower flow rates and the stable level measurements had larger temporary effects on the permeate flow rate. Stopping the pumps and restarting the pumps for stable level measurements caused some of the filter-loop flow fluctuations and flow disruptions. The final slurry UDS concentration for caustic leach Batch \#1 in T02A was $23.4-w t \%$ with the target being 20 -wt $\%$. Figure 4.5 provides the filter-loop flow rate level in Tank T02A and the axial pressure drop during Batch 1 concentration.

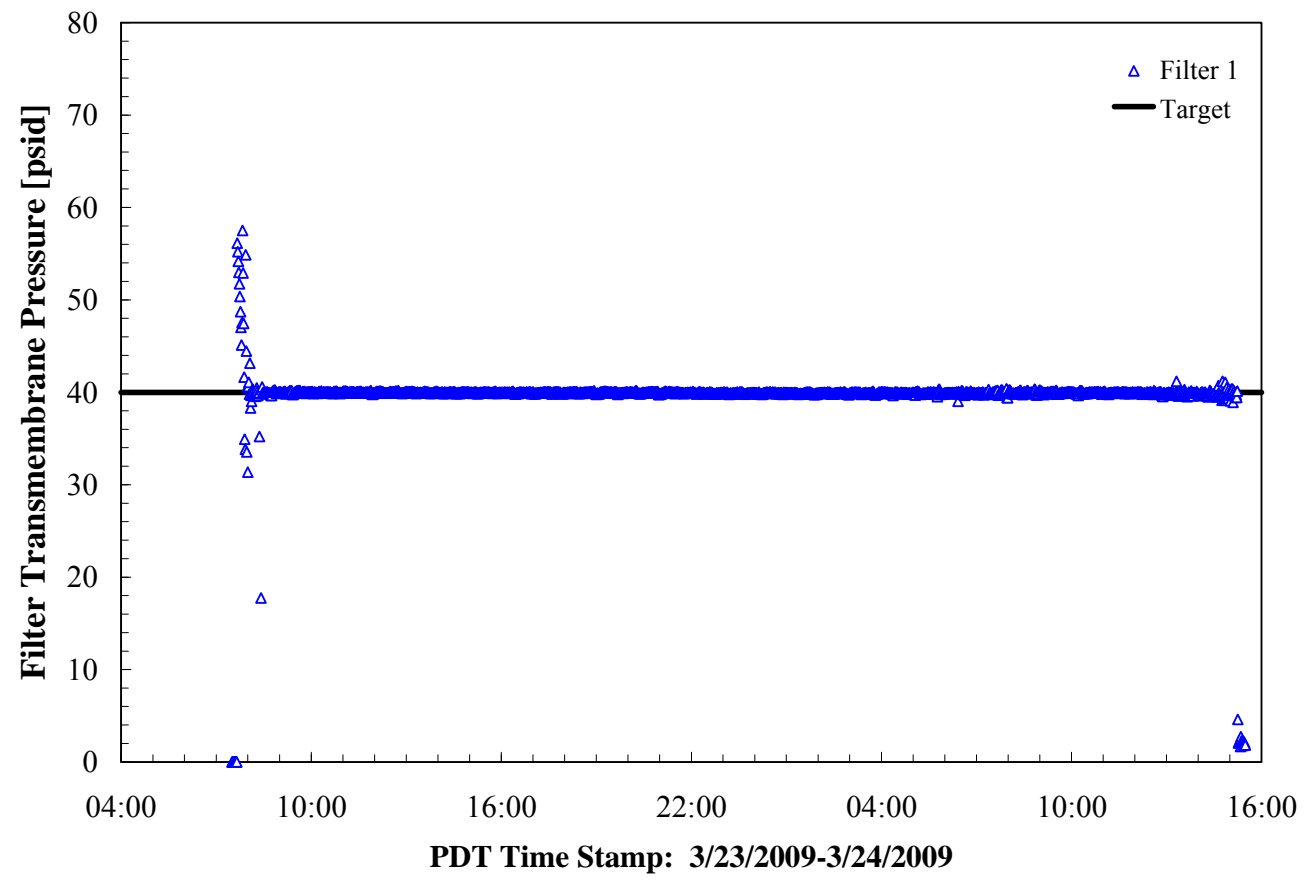

Figure 4.1. TMP for Pre-Caustic-Leach Concentration, Simulant Batch \#1 


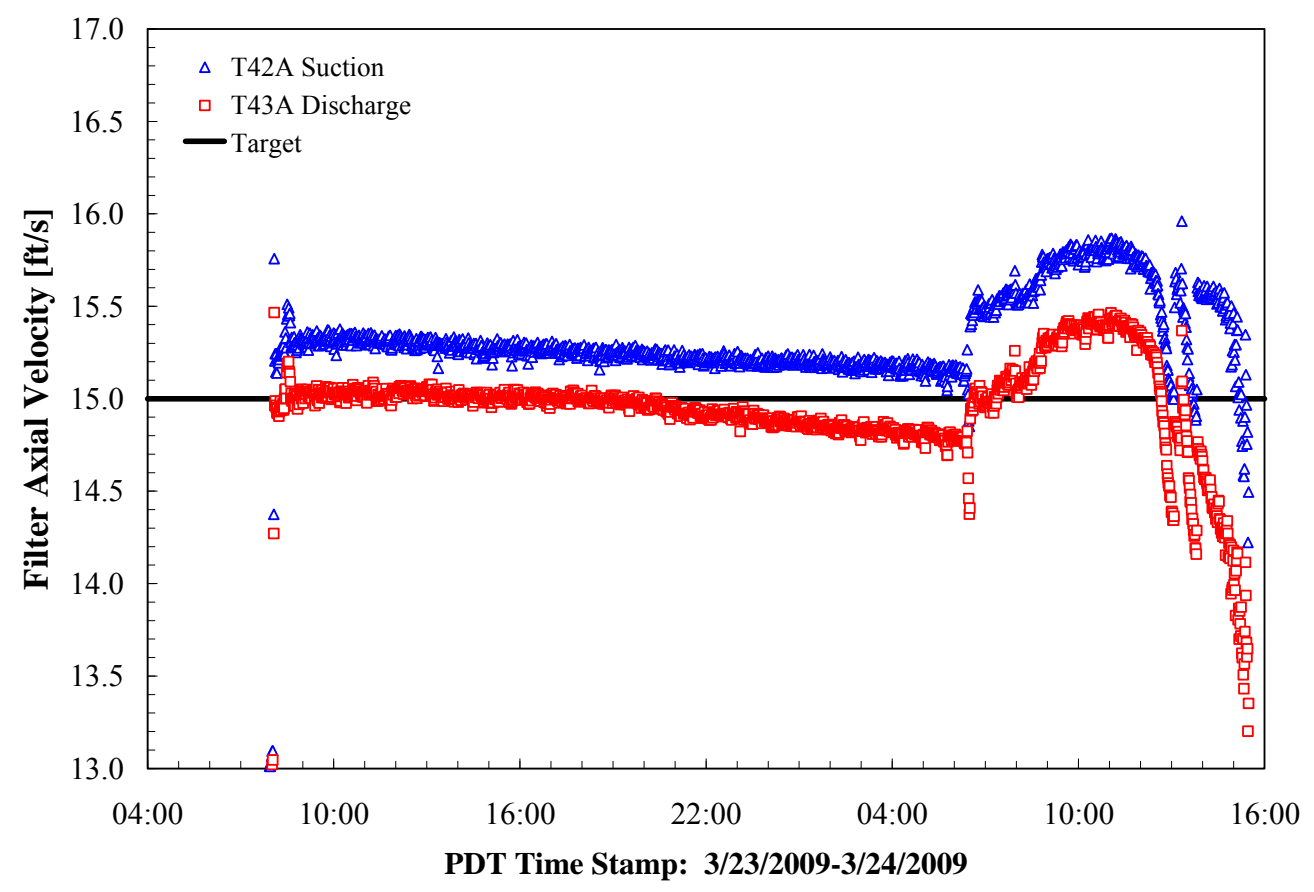

Figure 4.2. Axial Velocity Based on Flow Measurements at the Suction to T42A and the Discharge to T43A for Pre-Caustic-Leach Concentration, Simulant Batch \#1

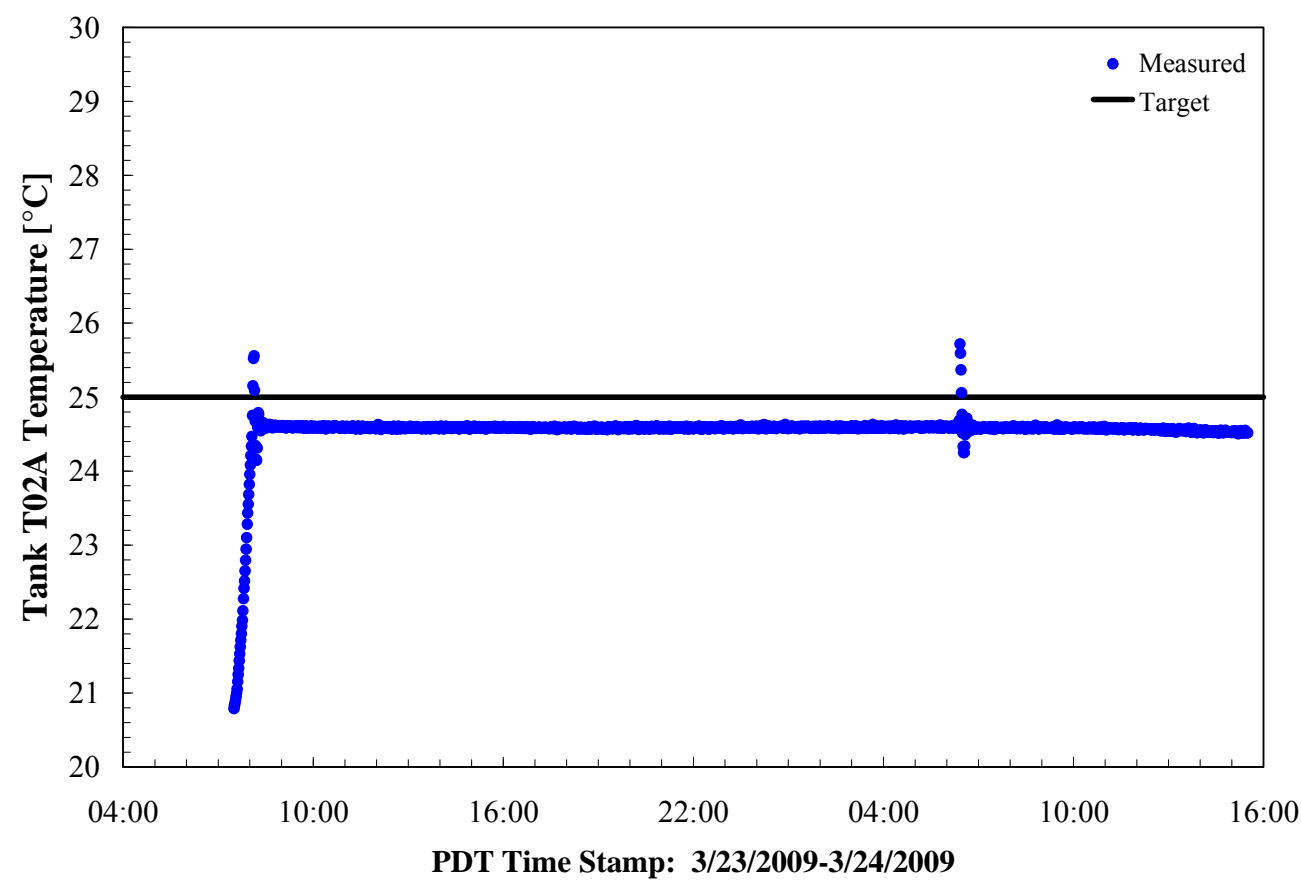

Figure 4.3. Tank T02A Temperature (TK-0619) for Pre-Caustic-Leach Concentration, Simulant Batch \#1 


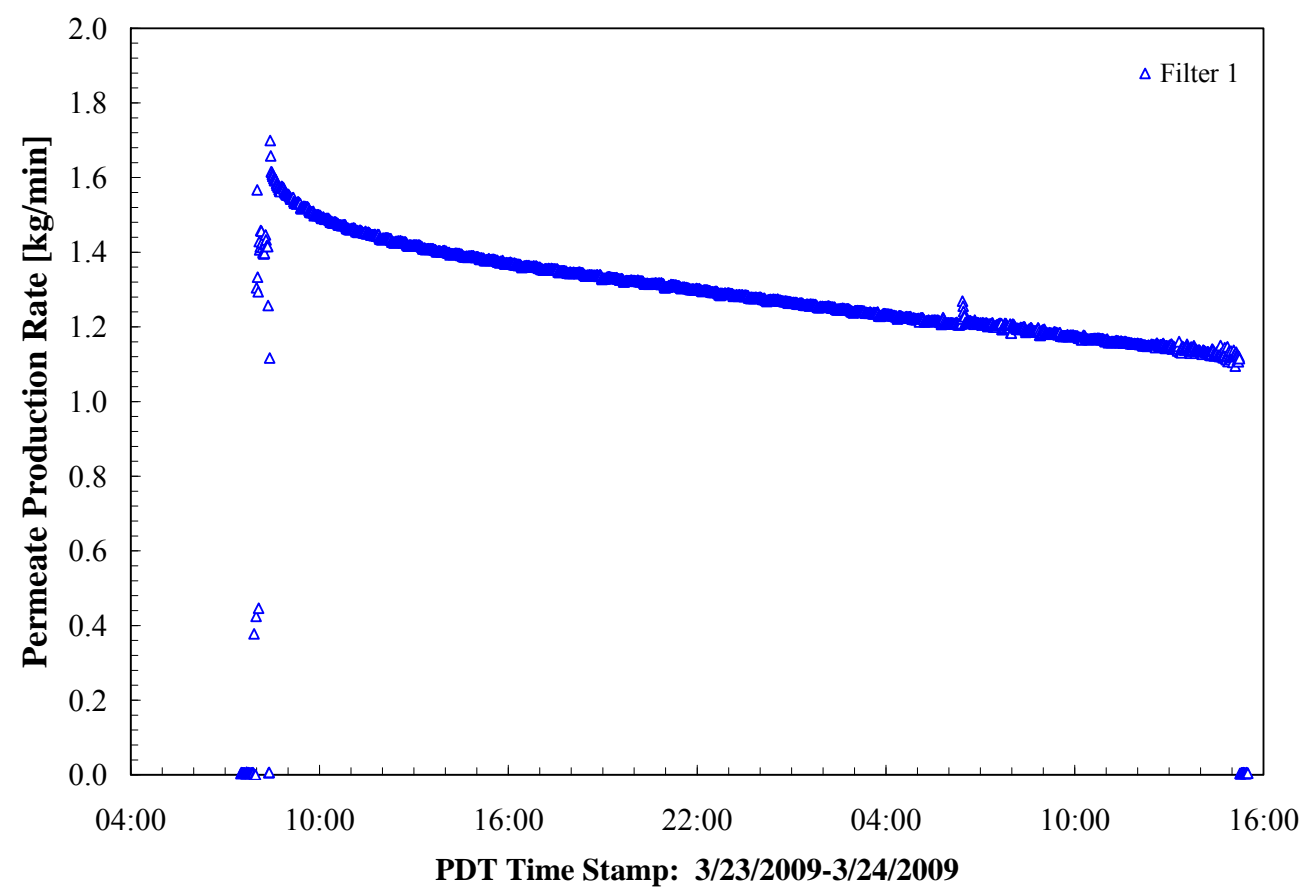

Figure 4.4. Permeate Production Rate for Pre-Caustic-Leach Concentration, Simulant Batch \#1

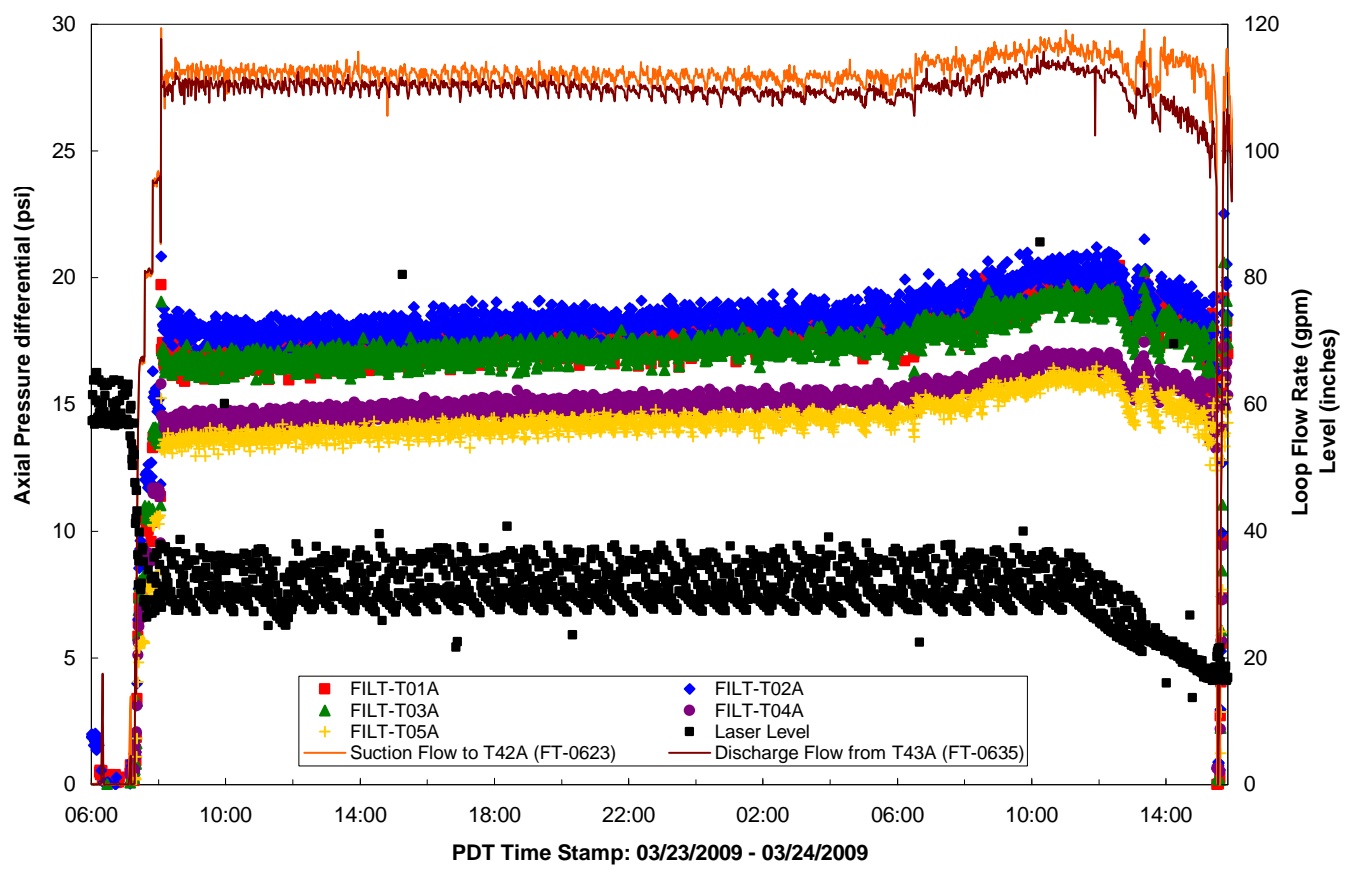

Figure 4.5. Filter-Loop Flow Rate, Level in Tank T02A, and Axial Pressure Drop During Batch \#1 Concentration 


\subsection{Batch \#1 Caustic Leaching}

After concentration, $939 \mathrm{~kg}$ of $19-\mathrm{M} \mathrm{NaOH}$ was added on 3/24/09 at 15:49 hours to the inlet of the recirculation pumps at a rate of $11.5 \mathrm{~kg} / \mathrm{min}$. The $\mathrm{NaOH}$ flow control valve was manually set at $12.3 \%$ open, and the $\mathrm{NaOH}$ manual recirculation valve that could be adjusted to control the $\mathrm{NaOH}$ header pressure was $100 \%$ open. The filter-loop flow rate was $\sim 109 \mathrm{gpm}$ with the lower air spargers set at $0.01 \mathrm{~kg} / \mathrm{min}$, and the upper air spargers and steam purge were off. The PJMs were changed from star mode to standard mode at 16:07 hours with the same settings. The steam ring air purge was restored to $0.14 \mathrm{~kg} / \mathrm{min}$ at $16: 20$ hours. The controller for the heat exchanger used to cool the filter-loop (UFP-HX-T02A) was adjusted to allow the temperature to increase to $65^{\circ} \mathrm{C}$. After the $\mathrm{NaOH}$ was added over $\sim 1.4$ hours, the temperature of the slurry was $\sim 65^{\circ} \mathrm{C}$. The upper spargers were turned on at a rate of $0.1 \mathrm{~kg} / \mathrm{min}$ at 17:09 hours when the Tank T02A level was $\sim 50$ inches with the pumps on. The Tank T02A level was 62.4 inches with SpG of 1.42 at the end of the caustic addition with the pumps on. The tank level was higher than expected, mainly because of air entrainment and/or foaming in the slurry. After caustic addition was complete, all air into the tank was turned off at 17:17 hours to perform an standard level measurement (SLM) and to reduce air entrainment. The PJMs were operated in simple mode with a 7.25 -sec drive time.

After the cause of the high tank level was investigated and before filter-loop flushing, $\sim 137 \mathrm{~kg}$ (25 gal) (LRB 60272, pg. 35-36) of slurry was removed from Tank T02A via the recirculation loop sampling port to lower the level and prevent overfilling the tank during leaching. The slurry was weighed in five batches to determine the amount removed. In addition, 2 liters of 4:1 diluted AFA was added on 3/25/09 at 00:08 hours to attempt to reduce the foaming in the tank. The slurry removed had a significant amount of bubbles as shown in the carboy sample in Figure 4.6. Additional 2 liter mixtures of AFA were added at 00:57 hours and 01:32 hours. 


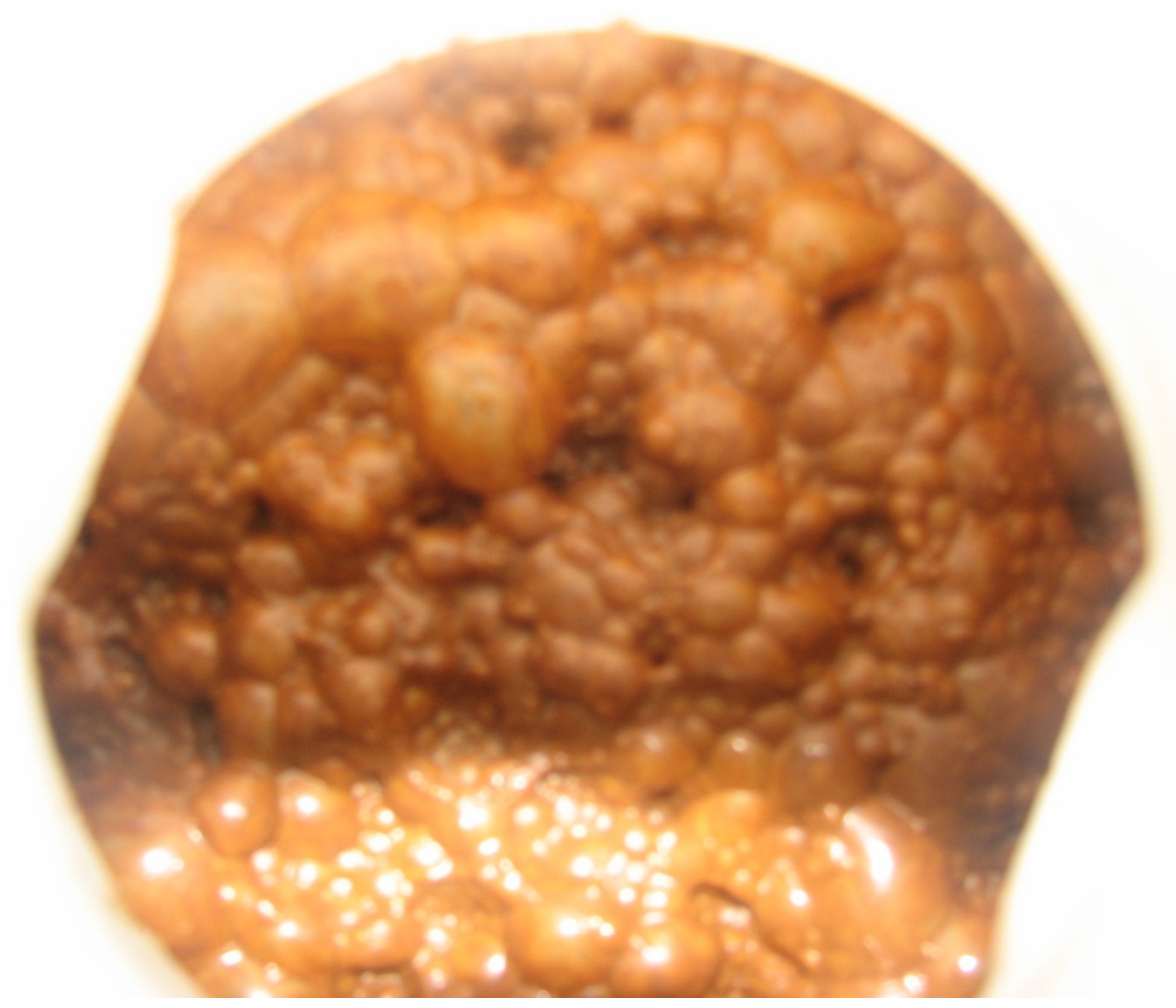

Figure 4.6. Surface of Slurry Sample in Carboy Drained from Tank T02A

After the tank level had been adjusted by removing slurry, a stable level measurement was performed, and various sparger rate settings and de-aeration hold times were performed to reduce entrained air and to obtain an accurate level measurement. A camera was also used to look in the tank to assess conditions. The camera view showed that the level appeared to match the laser sensor values, there was some foam, and that the laser level was aimed appropriately.

The filter loop had $74 \mathrm{~kg}$ of IW added to the loop at a rate of $75 \mathrm{~kg} / \mathrm{min}$ on 3/25/09 at 12:03 hours, which caused $\sim 74 \mathrm{~kg}$ of slurry to transfer back to Tank T02A. This purge was only a small portion of the $\sim 400 \mathrm{~kg}$ in the filter-loop, but additional water was not used to prevent too much slurry in the tank. The TI instructions had not planned to transfer more of the filter-loop slurry back to the tank to make sure Tank T02A was not diluted if the flush did not occur as plug flow. After the initial IW addition, the rest of the filter-loop was isolated, recirculated, sampled, and transferred separately to T62A using portable diaphragm pumps.

The tank investigation and level adjustment took approximately 18 hours, and the slurry with caustic was held at temperatures between 50 and $65^{\circ} \mathrm{C}$ for that time. This time was not included in the leach time since the temperature was below $65^{\circ} \mathrm{C}$. 
After the IW addition to the filter-loop was complete and the Tank T02A isolated, steam was used to heat and hold the vessel contents at $85^{\circ} \mathrm{C}$. The final SLM level before steam heating was 57.6 inches. The automatically controlled heating started on $3 / 25 / 2009$ at $12: 18$ hours and reached $85^{\circ} \mathrm{C}$ at $13: 52$ about 1.6 hours later as specified in the Test Instruction. The Tank T02A temperature showing the heat-up rate while the $\mathrm{NaOH}$ was added and during steam heating is shown in Figure 4.7. The batch was leached for 24 hours before cooling started. The control system worked well, controlling the temperature between 83 and $87^{\circ} \mathrm{C}$, except right at the start where an overshoot caused temperatures of $\sim 89^{\circ} \mathrm{C}$ as was observed in previous test and may be attributed to the SLM performed just before. The SLM entails stopping the PJMs and reducing mixing for a short period of time. The tank level started at 57.6 inches after the $\mathrm{NaOH}$ was added, and flushing was completed. The level increased to 70.1 inches by the end of the leaching period shown in Figure 4.7. While holding the vessel temperature at $85^{\circ} \mathrm{C}$, the condensate from direct steam injection increased the Tank T02A level approximately $<0.3 \mathrm{in} / \mathrm{hr}$. Many samples were taken to assess leaching progress. During heating, the PJM condensate drain valves were open when the Tank T02A temperature was above $65^{\circ} \mathrm{C}$, and condensate from the PJM air lines was collected in a separate carboy.

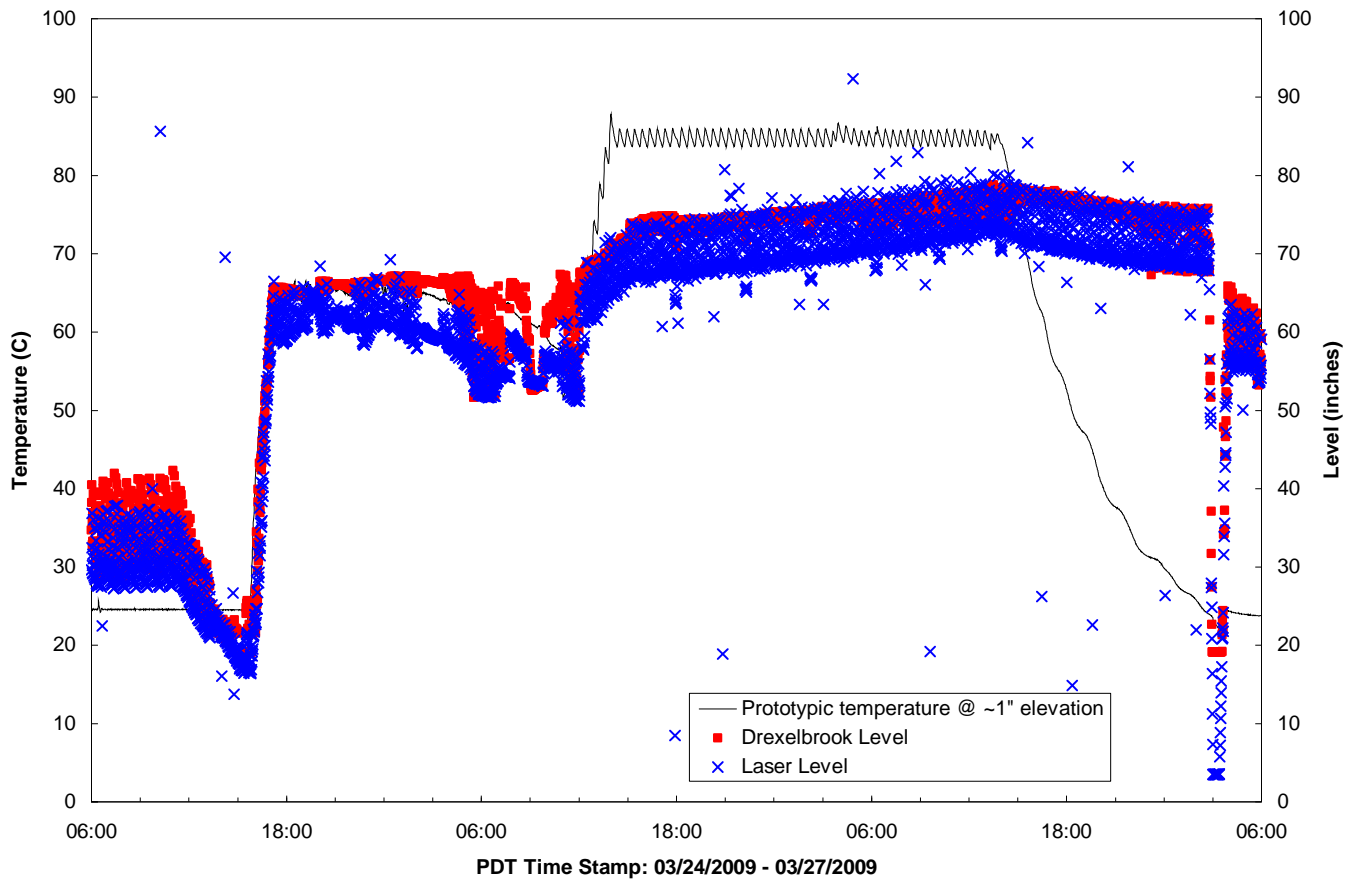

Figure 4.7. Tank T02A Level and Batch 1 Leach Temperatures

After the leaching process was complete, the Tank T02A vessel was cooled to $25^{\circ} \mathrm{C}$ over a period of $12.5 \mathrm{hrs}$ as specified in the Test Instruction. The cooling process was fairly smooth as shown in Figure 4.7, and only the cooling jacket was used. The cooling control valve was slowly opened manually by the operator in 5\% increments to control the tank cooling. A typical value at lower temperatures was $20 \%$ open.

During the leaching process on $3 / 26$, the second refill of Tank T01B was performed by adding an additional 362 gallons of slurry, which was transferred from HLP-T22 to Tank T01B at a rate of 7.4 gpm. 
AFA was also added in the amount of $612-\mathrm{mL}$ undiluted. The AFA was always added in a 3 parts water to 1 part AFA mixture.

The first batch of leach solids was transferred to Tank T01A for storage until Batch 2 could be completed, and then the two batches were concentrated together. The UDS of the first leach batch was 5.02-wt\%. The heel left in Tank T02A is about 5 gal.

\subsection{Batch \#2 Slurry Concentration}

The second batch started by filling Tank T02A with 218 gallons of simulant from Tank T01B. The second batch concentration started on 3/27 0700 using five filters, and was almost the same as the first batch. The final tank level was 17 inches with the recirculation pumps operating. When the tank level is below 20 inches, part of the filter-loop drains back into the tank when the pumps are off, so the stable level measurement was about 19 inches. The lower air spargers were set at $0.01 \mathrm{~kg} / \mathrm{min}$ and the steam ring purge was $0.14 \mathrm{~kg} / \mathrm{min}$. The upper air spargers were off and the PJMs were set the same as Batch \#1 with a $33 \mathrm{sec}$ drive time, a $7.7 \mathrm{~m} / \mathrm{s}$ nozzle velocity, and a $31.5 \mathrm{inch}$ stroke. The filtering conditions were the same as Batch \#1 with a 109 gpm flow rate and a 40 psid TMP. The permeate rates were slightly lower than Batch \#1. The filtration time was 5.5 hours, including the pause to refill Tank T01B between 08:45 and 10:00. The final UDS concentration was $23.8-\mathrm{wt} \%$ and the target was 20 -wt $\%$. Figure 4.8 through Figure 4.11 illustrate TMP, axial velocity, temperature, and permeate production during the concentration of Batch 2. Figure 4.12 provides the filter-loop flow rate, level in Tank T02A, and axial pressure drop during Batch 2 concentration.

During the concentration in Tank T02A, the UFP-VSL-T01B was refilled the third time with 361 gallons at $10 \mathrm{gpm}$. Filtration was stopped while Tank T01B was being filled as noted in Figure 4.8. The target fill rate was $7.4 \mathrm{gpm}$, but the pump did not operate well at that rate. After the slurry addition, 612-mL of AFA was added to Tank T01B. 


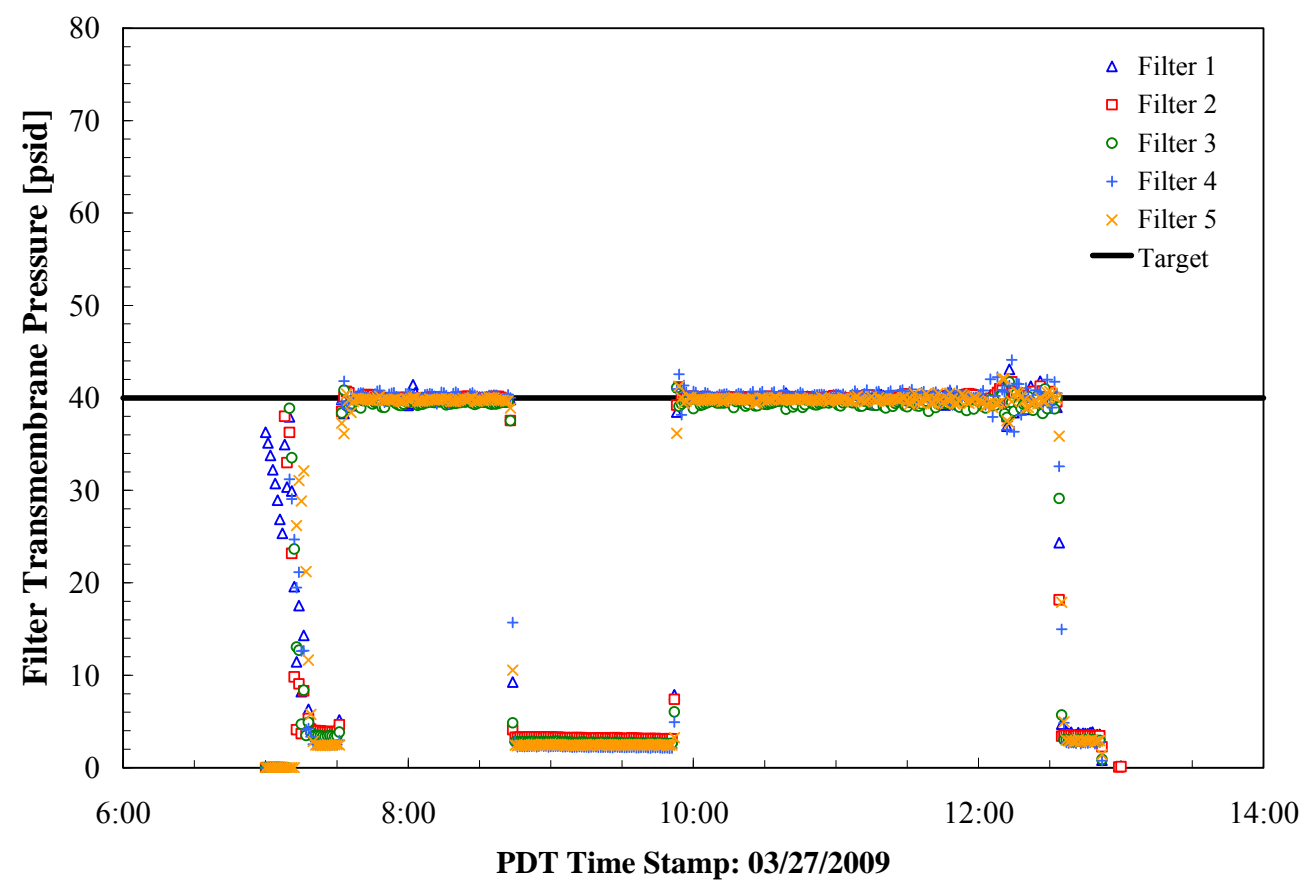

Figure 4.8. TMP for Pre-Caustic-Leach Concentration, Simulant Batch \#2

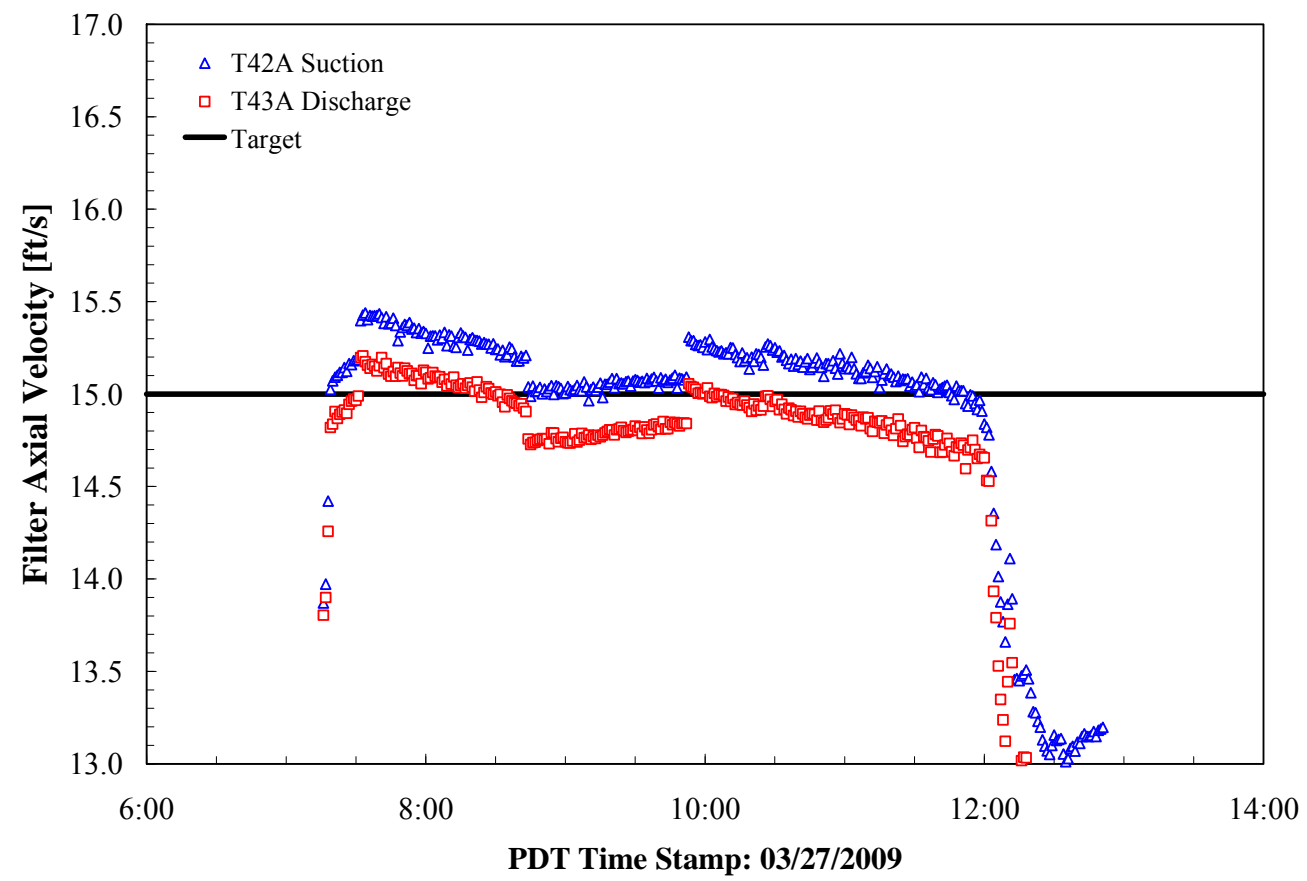

Figure 4.9. Axial Velocity Based on Flow Measurements at the Suction to T42A and the Discharge to T43A for Pre-Caustic-Leach Concentration, Simulant Batch \#2 


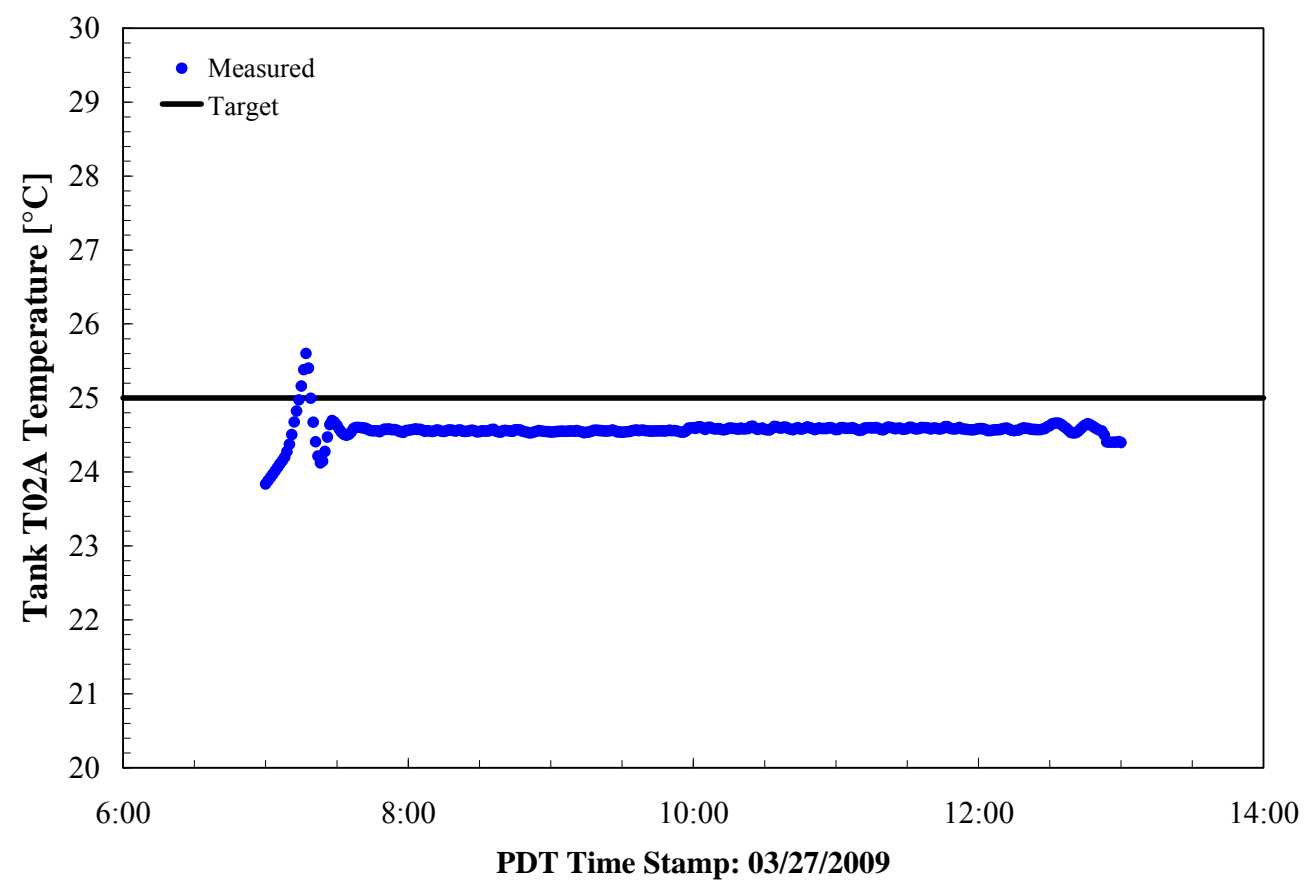

Figure 4.10. Tank T02A Prototypic Temperature for Pre-Caustic-Leach Concentration, Simulant Batch \#2

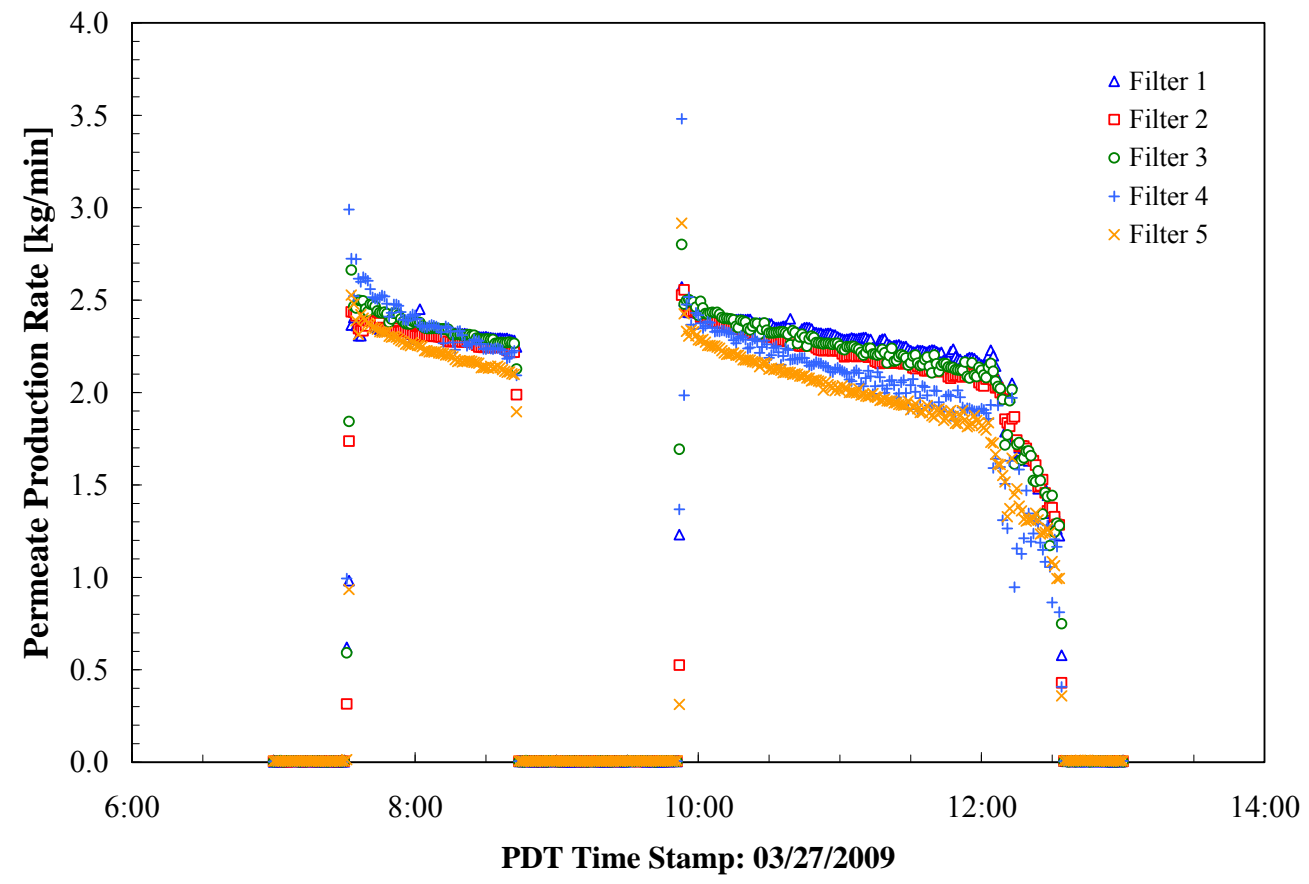

Figure 4.11. Permeate Production Rate for Pre-Caustic-Leach Concentration, Simulant Batch \#2 


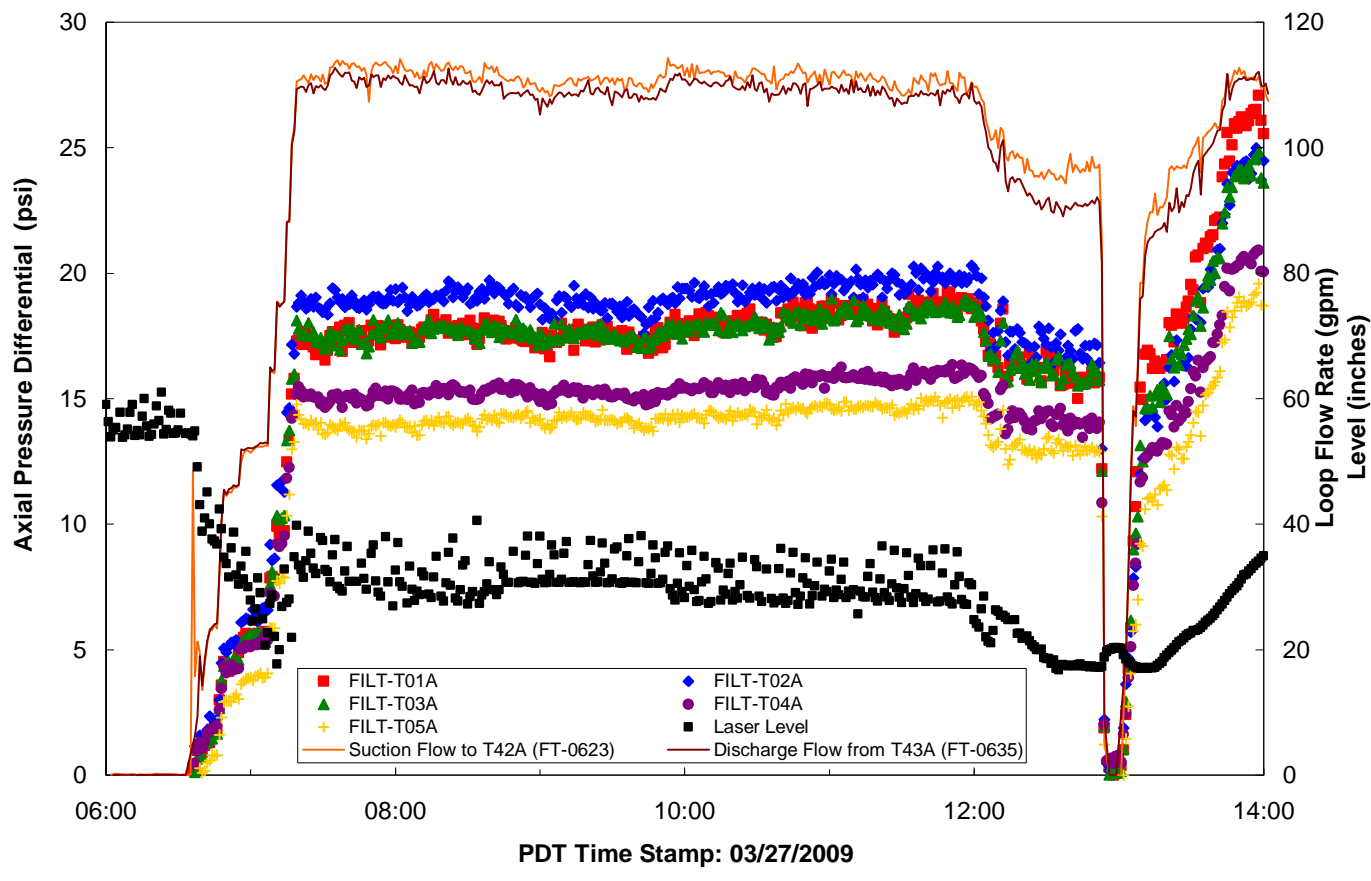

Figure 4.12. Filter-Loop Flow Rate, Level in Tank T02A, and Axial Pressure Drop During Batch 2 Concentration

\subsection{Batch \#2 Caustic Leaching}

After concentration in Tank T02A, $928 \mathrm{~kg}$ of $19-\mathrm{M} \mathrm{NaOH}$ was added on 3/27 at 13:15 hours to the inlet of the recirculation pumps at a rate of $10.2 \mathrm{~kg} / \mathrm{min}$. The $\mathrm{NaOH}$ addition and initial heat-up rate of $0.47^{\circ} \mathrm{C} / \mathrm{min}$ are shown in Figure 4.13. The heat from the $\mathrm{NaOH}$ reaction and the heat from pump were used to initially heat the slurry to $70^{\circ} \mathrm{C}$. At the same time, the controller for heat exchanger used to cool the filter-loop (HX-02A) was adjusted to allow the temperature to increase to but not exceed $70^{\circ} \mathrm{C}$. Also an additional $400-\mathrm{mL}$ of diluted AFA was added to Tank T02A. The tank level after caustic addition was 57 inches. The target was 55 inches \pm 2 . The level was within the target range, and the test proceeded. The filter-loop was not flushed back to Tank T02A because the test director was concerned the level would be too high at the end of the caustic-leach process. The PJMs were operated in simple mode with a 7.25 -sec drive time after several adjustments. The slurry was heated with direct steam heating to raise the temperature of Tank $\mathrm{T} 02 \mathrm{~A}$ to $85^{\circ} \mathrm{C}$ in $\sim 1.2$ hours as shown in Figure 4.13. The heating time target from 70 to $85^{\circ} \mathrm{C}$ was $1.2 \mathrm{hrs}$.

The PJM stroke and high laser level readings caused the steam to turn off during the leaching process several times (3/28/2009 at 09:44, 16:50, and 17:05 hours), allowing the tank contents to cool slightly for part of the leach. The bubblers were flushed with hot water to try and obtain good level readings using the bubblers, but specific gravity was not stable enough to obtain good readings. The Drexelbrook level probe was used for tank level alarms and operator controls for awhile to avoid the high alarms that were possibly caused by foam. Eventually, an additional 2-L of diluted AFA was added on 3/27 at 20:30 hours and the level monitor control was switched back to the laser. Additional AFA appears to have alleviated some of the foam problems. A stable level measurement of 65.7 inches was made on 3/28 at 05:30 hours 
with all air, steam, and PJMs off. The projected level increase from steam condensation was $\sim 0.3 \mathrm{in} . / \mathrm{hr}$ (1.2 gal/hr). On 3/28 at 19:45 and 19:49, it appeared some of the bottom spargers were plugging based on drops in the flow rate although the total flow was still $0.4 \mathrm{~kg} / \mathrm{min}$. No corrective actions were taken to clear the partially plugged sparger. Heating continued until 3/28 at 17:20 hrs, and the steam was turned off and cooling started. Cooling was similar to leach Batch 1, except cooling water was colder, and the initial temperature decrease was higher than planned. Intermittent opening and closing of the cooling water control valve was used for much of the remaining cooling period $(22 \%$ to $0 \%)$ to control the cooling rate. The cooling took $\sim 12.5 \mathrm{hrs}$ as planned to reach $25^{\circ} \mathrm{C}$. Samples were taken, and the stable level measurement was 66.5 inches from the laser and 70.2 inches from the bubblers. The final UDS concentration of leach Batch 2 was 5.4-wt $\%$.

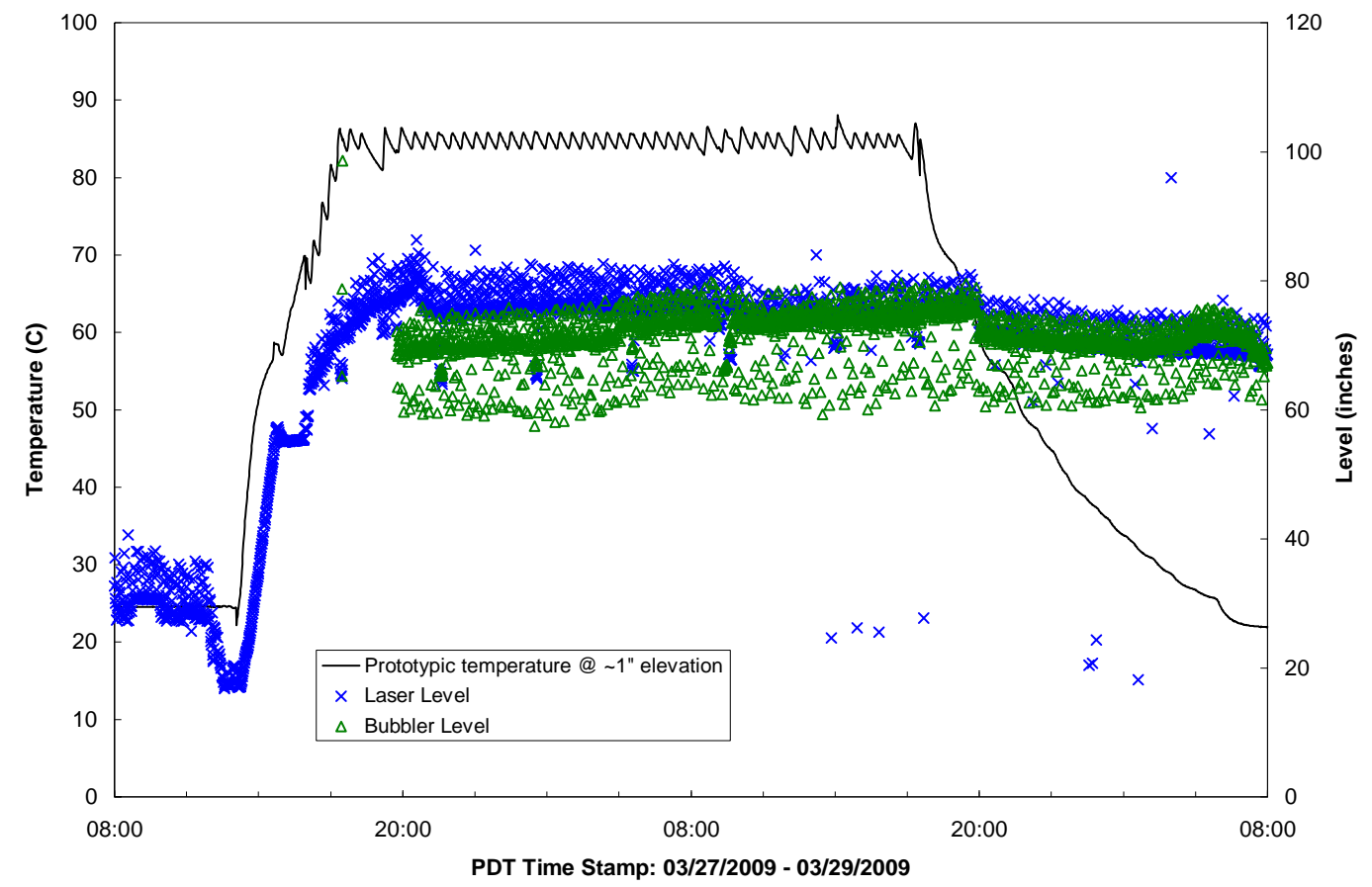

Figure 4.13. Batch \#2 Leach: Tank T02A Level and Leach Batch \#2 Temperatures

\subsection{Leached Slurry Concentration}

After the second batch was cooled, the leached solids were concentrated starting on 3/29/09 at 08:10 hours. When the Tank T02A tank level reached 53 inches, automatic transfers of the previous leached batch from Tank T01A were made. The upper and lower spargers in Tank T02A were set to $0.01 \mathrm{~kg} / \mathrm{min}$. The last couple of batches of slurry from Tank T01A were made with a portable pump so the tank could be drained completely. The filter-loop recirculation pumps were stopped during the portable pump transfers. The first transfer from the Tank T01A bottom drain to Tank T02A was started on 3/29/09 at 12:54 and completed at 13:40 hours. The second transfer was made on 3/29/09 at 15:24 hours as seen by disruptions in Figure 4.14 through Figure 4.17, including filter-loop temperatures. Turning off the filter-loop pumps caused small oscillations in the tank temperature as the controller tried to respond, and there were many PJM adjustment toward the end of the concentration to prevent aspiration or overblows. The leached solids were concentrated using five filters at an initial flow rate of 
109 gpm and a TMP of 40 psid. Filter-loop flow rate changes occurred shortly after the first portable pump addition because of adjustments by the operations crew to obtain stable flow. The flow rate was also reduced near the end of the concentration as the tank level decreased, and the slurry became more concentrated. The pumps were turned off at $\sim 22: 10$ hours to switch the Tank T02A PJMs to star mode. The pumps were turned off just in case of a PJM overblow, and the tank level was 22.5 inches. Towards the end of the concentration, the level in Tank T02A dropped below 20 inches, and the flow rate had to be reduced to $77.6 \mathrm{gpm}$ because of air entrainment problems in the pumping system. The pumps were adjusted manually several times during the final concentration to try and maintain the filter-loop flow rate. The total permeate rate through all five filters started out at $\sim 3.5 \mathrm{~kg} / \mathrm{min}$ and slowed to $<1.5 \mathrm{~kg} / \mathrm{min}$ as the slurry became more concentrated. The UDS at the end of concentration was 18.8 -wt $\%$. Figure 4.14 through Figure 4.17 illustrate TMP, axial velocity, temperature, and permeate production during the concentration of the leached slurry.

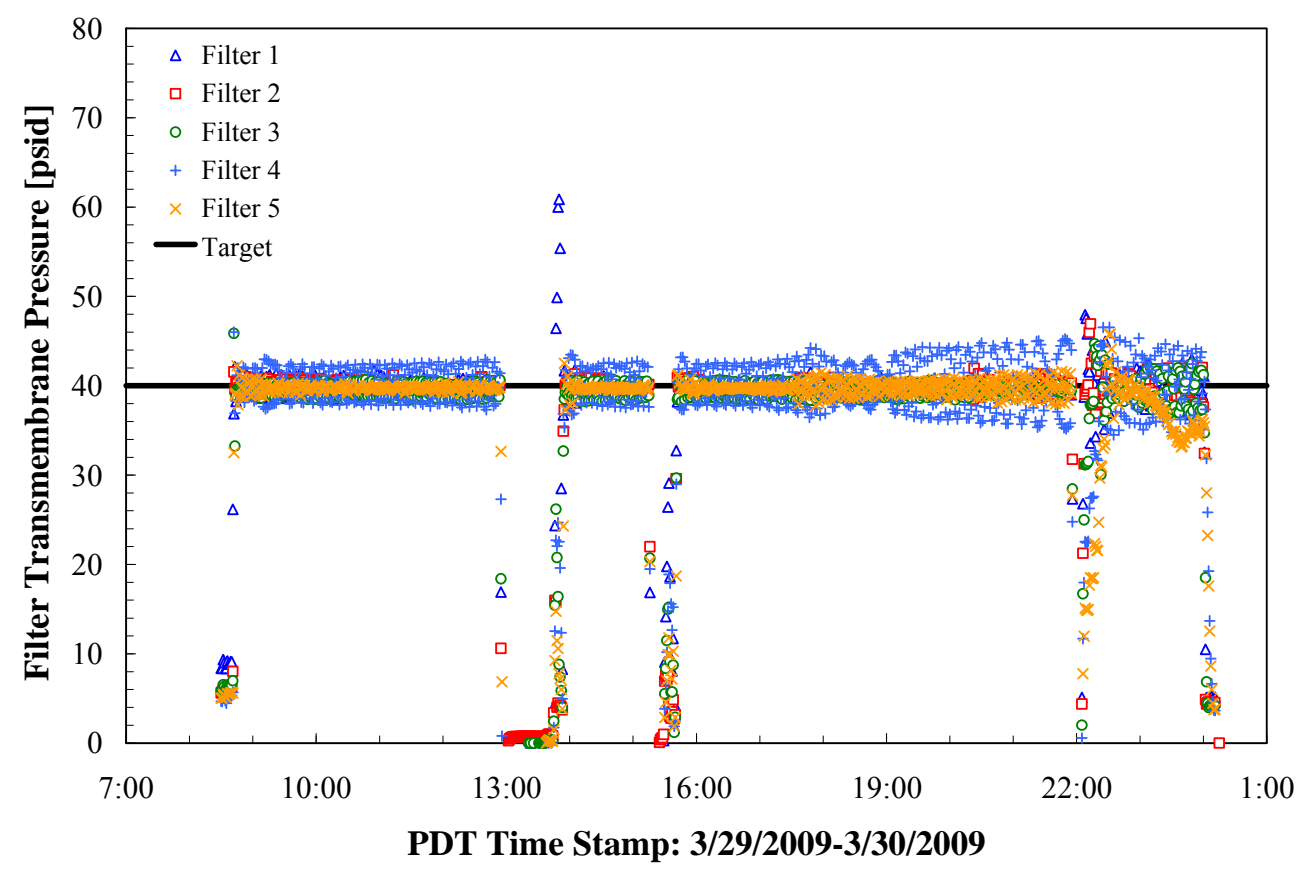

Figure 4.14. TMP for Post-Caustic-Leach Concentration 


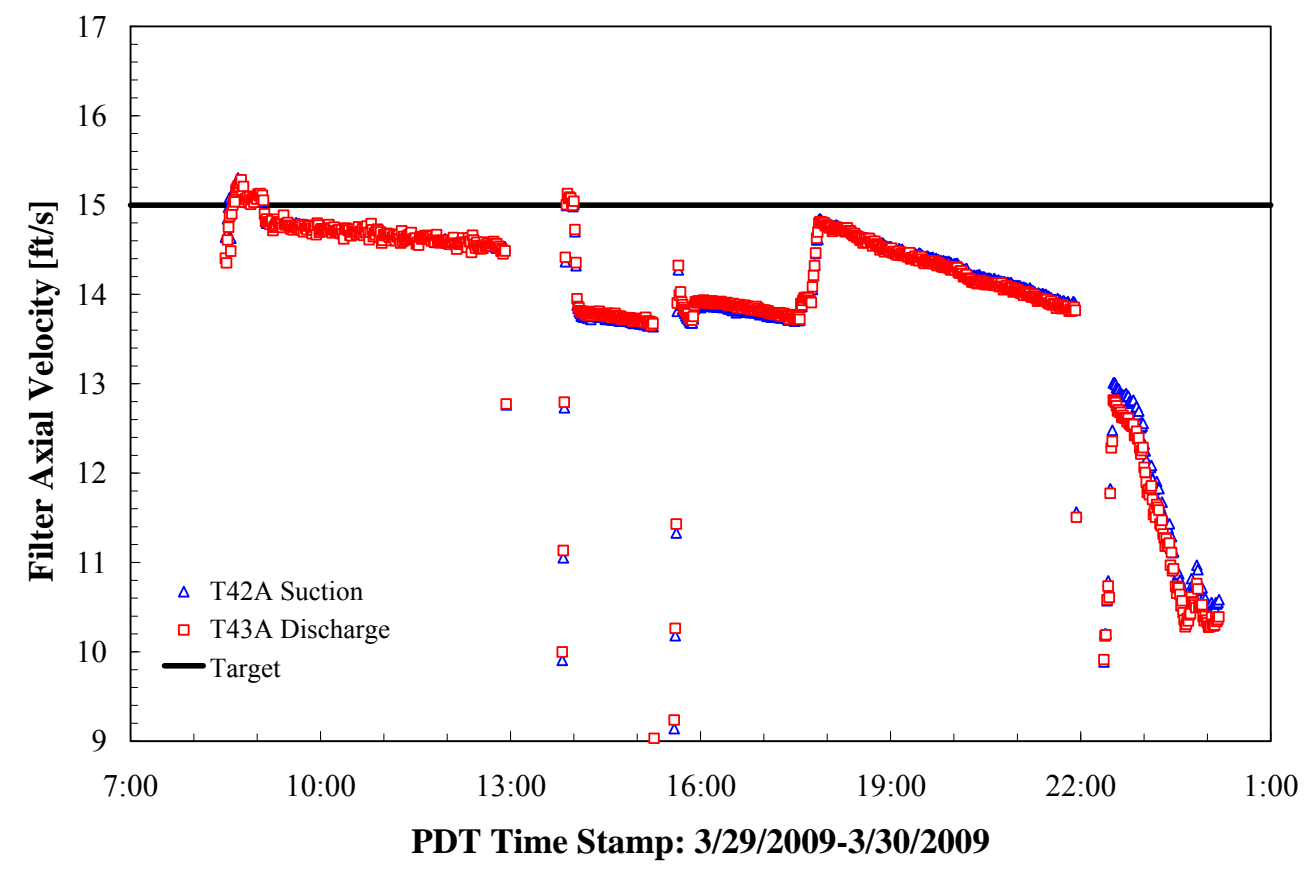

Figure 4.15. Axial Velocity Based on Flow Measurements at the Suction to T42A and the Discharge to T43A for Post-Caustic-Leach Concentration

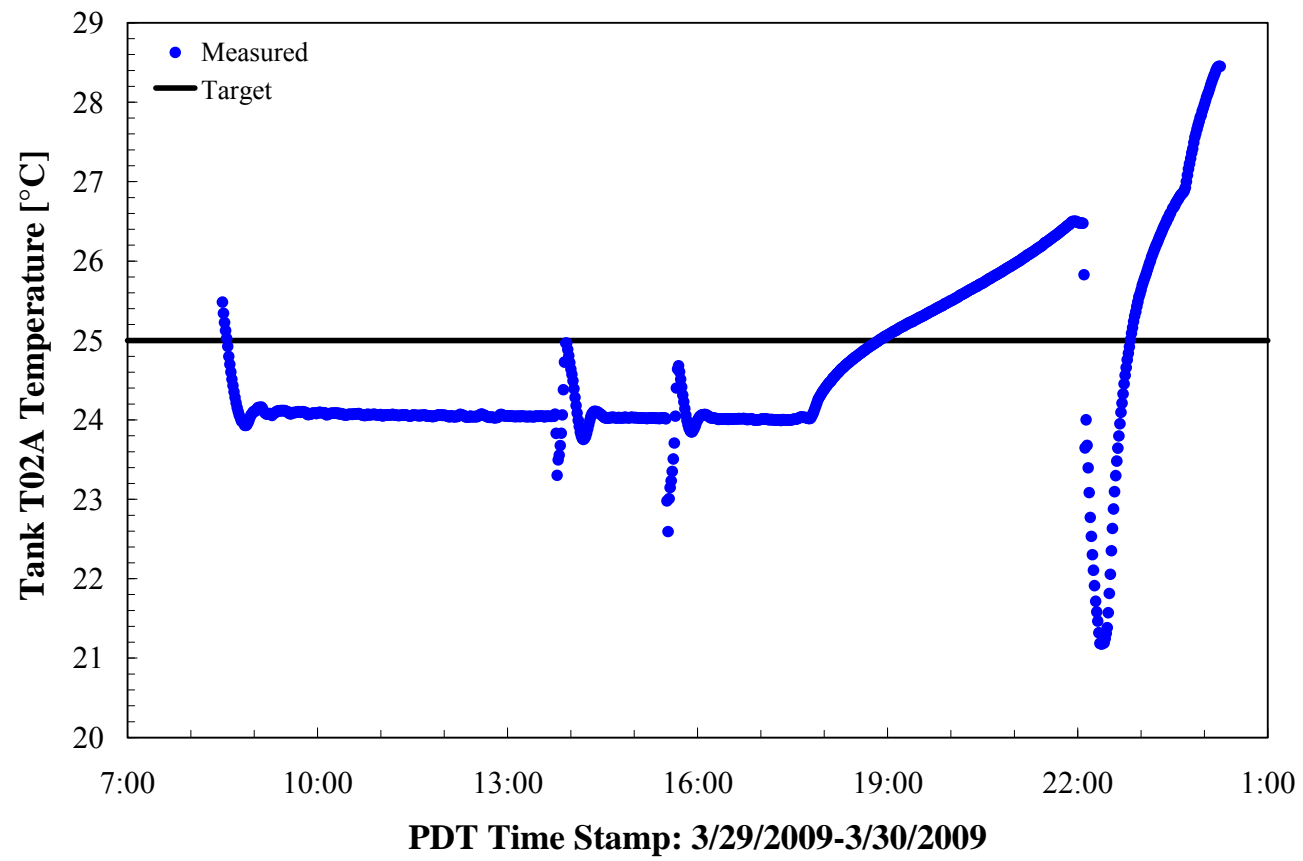

Figure 4.16. Tank T02A Temperature for Post-Caustic-Leach Concentration 


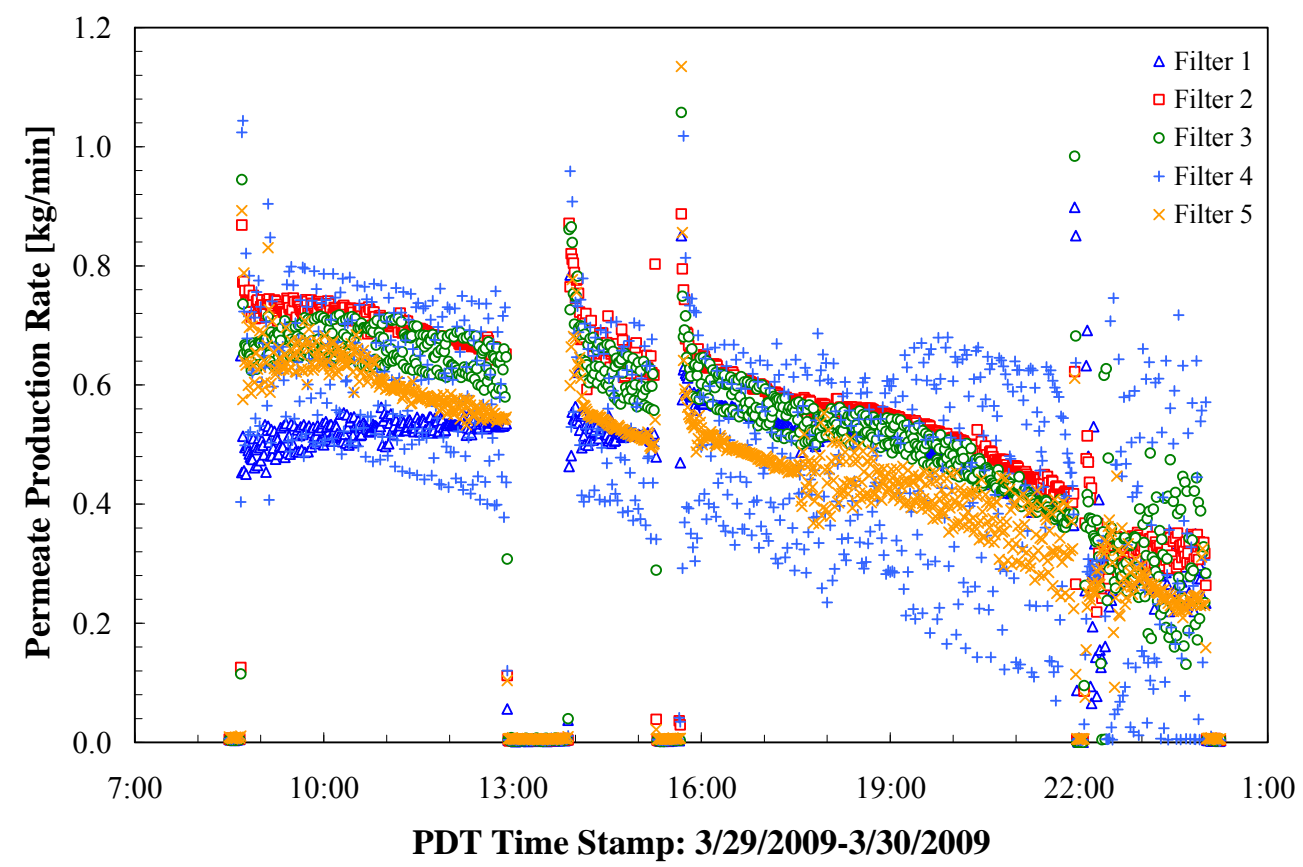

Figure 4.17. Permeate Production Rate for Post-Caustic-Leach Concentration

The final level in Tank T02A was 18.2 inches (17.2 inches with pumps on) with the pumps off or a total volume of $\sim 168$ gallons in the tank and the filter-loop. Figure 4.18 provides the filter-loop flow rate, Tank T02A tank level, and axial pressure drop during concentration. The post-caustic-leach concentration was completed on 3/30/09 at 00:15. 


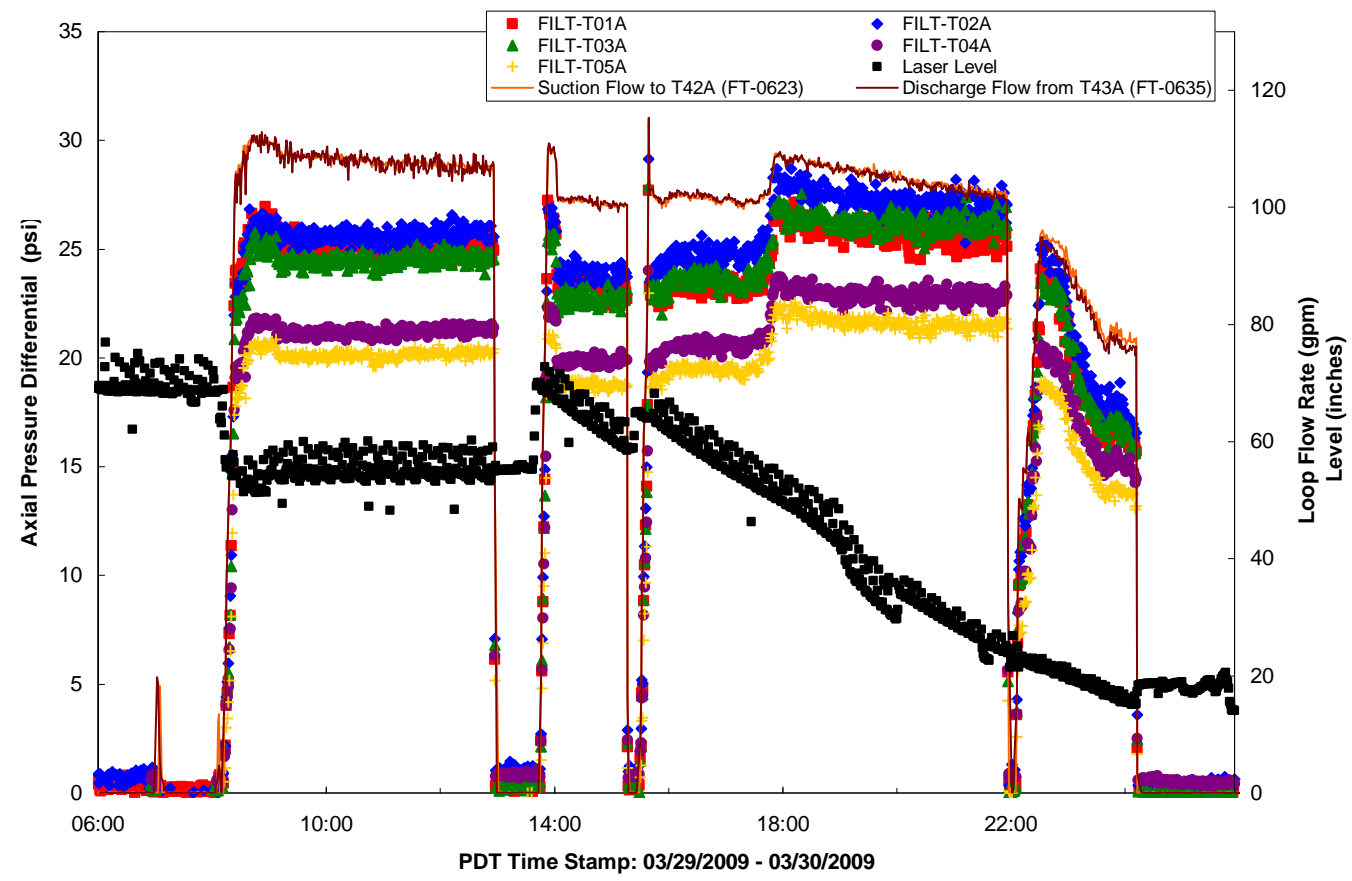

Figure 4.18. Integrated Test D Post-Leach Concentration Filter-Loop Flow Rate, Tank T02A Level, Axial Pressure Drop

\subsection{Leached Slurry Washing}

The leached and reconcentrated solids were washed with $2207 \mathrm{~kg}$ of IW using 53 batches starting on 3/30/09 at 03:48 hours. The batch size was $41.6 \mathrm{~kg}$ and was added when the tank level reached 17.4 inches. The IW used for washing was added at $28 \mathrm{~kg} / \mathrm{min}$, and the concurrent filtration was performed with five filters with a filter axial velocity of $\sim 15 \mathrm{ft} / \mathrm{sec}$ as shown in Figure 4.19 and a TMP of 40 psid shown in Figure 4.20. The axial velocity slowly increased initially since the pumps were manually controlled, and the flow was reduced to $\sim 13 \mathrm{ft} / \mathrm{sec}$ near the end of washing at the direction of Test Director Steve Barnes to head off pumping problems. Initially, the cooling water was having trouble maintaining the Tank T02A temperature and on 3/30/09 at 04:30 hours, the cooling water temperature was reduced from 42 to $40^{\circ} \mathrm{C}$. Forty-four $\mathrm{mL}$ of AFA was added to every third batch to maintain the target AFA concentration on $350 \mathrm{ppm}$. As the washing progressed, the filtering rate improved significantly as expected as the dissolved solids decreased and the UDS increased. At the end of slurry washing with 50 batches of IW, the free hydroxide content was $0.16 \mathrm{M}$ and the UDS content was 22.0-wt\% Figure 4.20 through Figure 4.22 provide the temperature, and permeate production rates during the washing of the leached slurry.

The initial permeate rate per filter was 0.4 , the maximum was 1.8 , and the final was $\sim 1.5 \mathrm{~kg} / \mathrm{min}$. The final tank level after washing was 17 inches with the pumps on. 


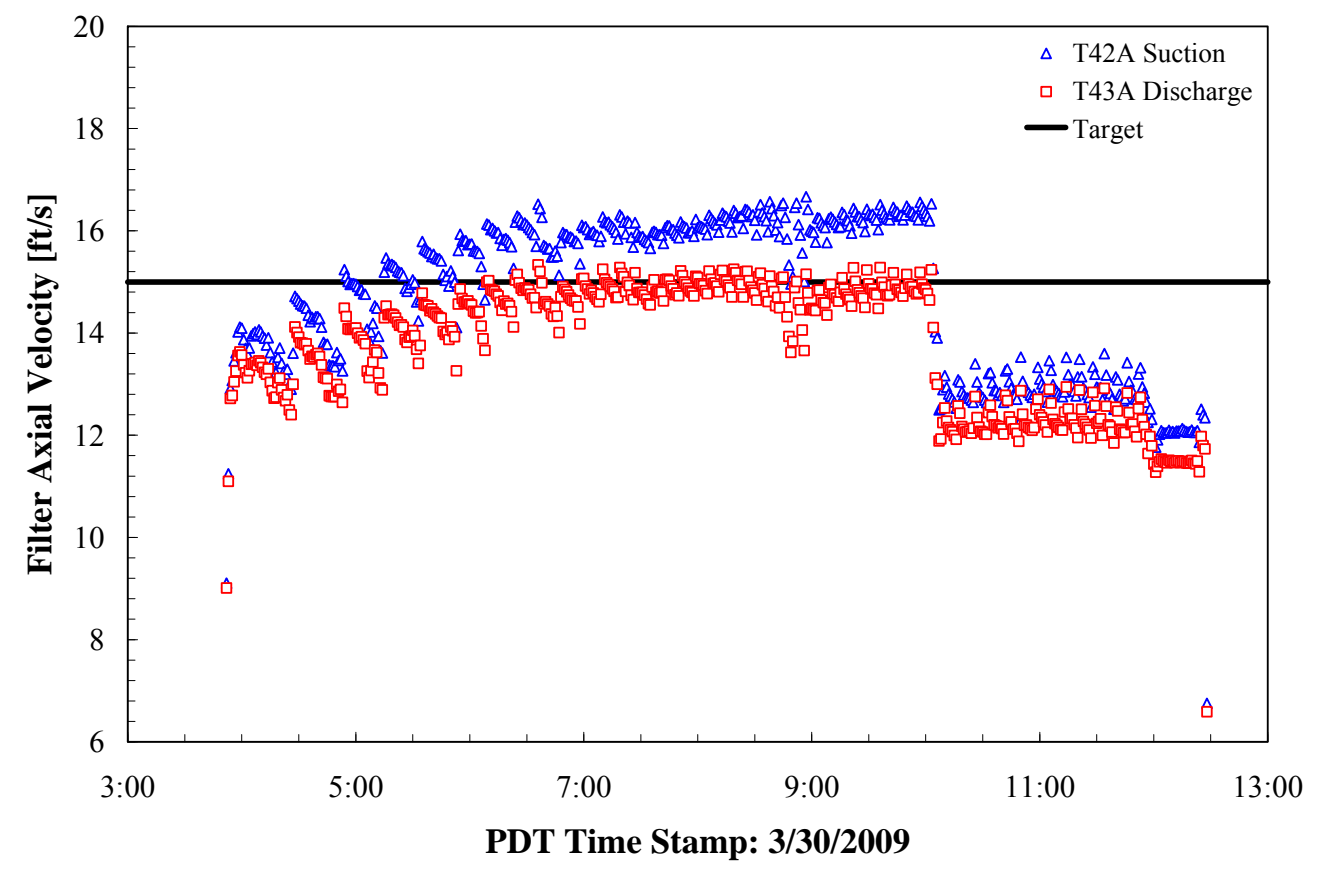

Figure 4.19. Axial Velocity Based on Flow Measurements at the Suction to T42A and the Discharge to T43A for Post-Caustic-Leach Wash

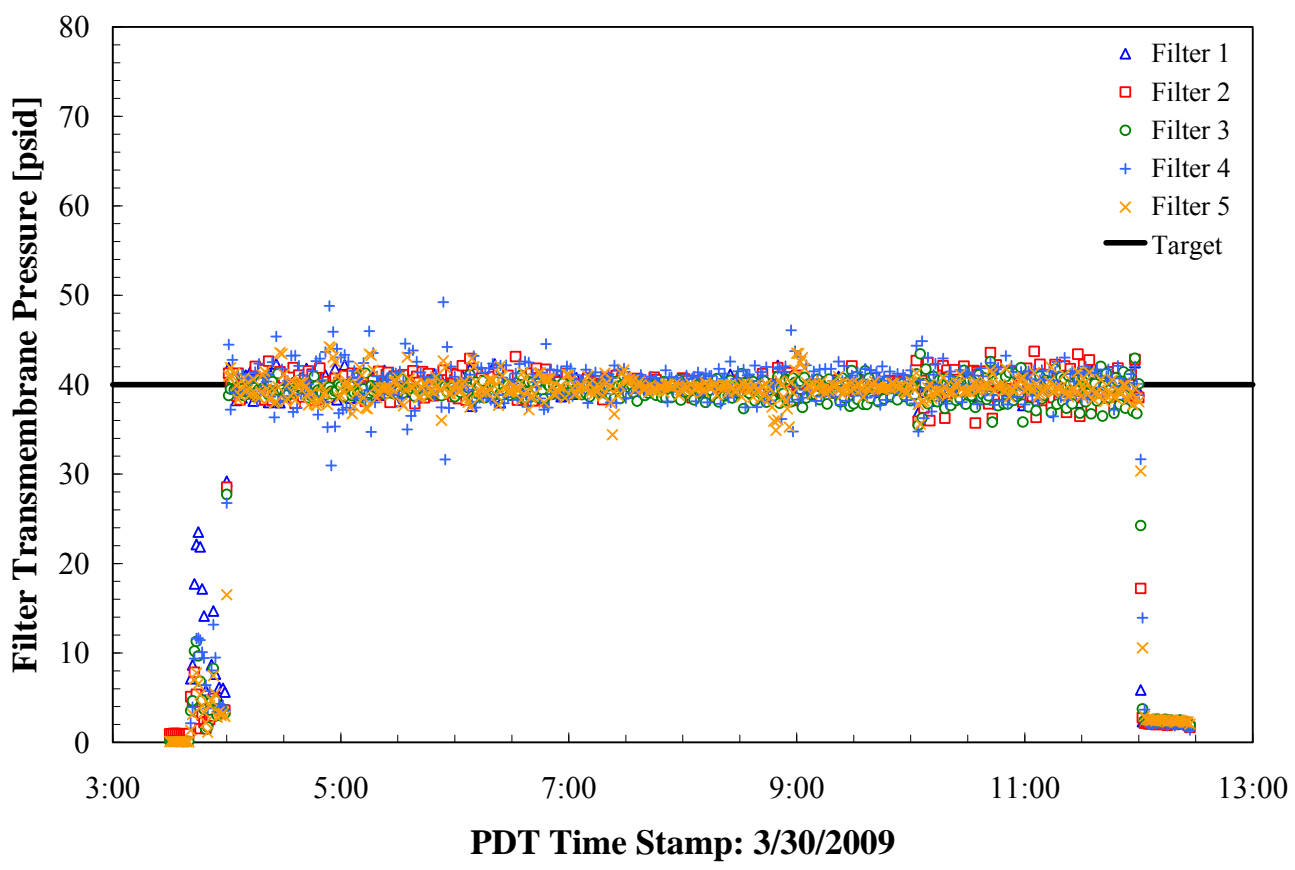

Figure 4.20. TMP for Post-Caustic-Leach Wash 


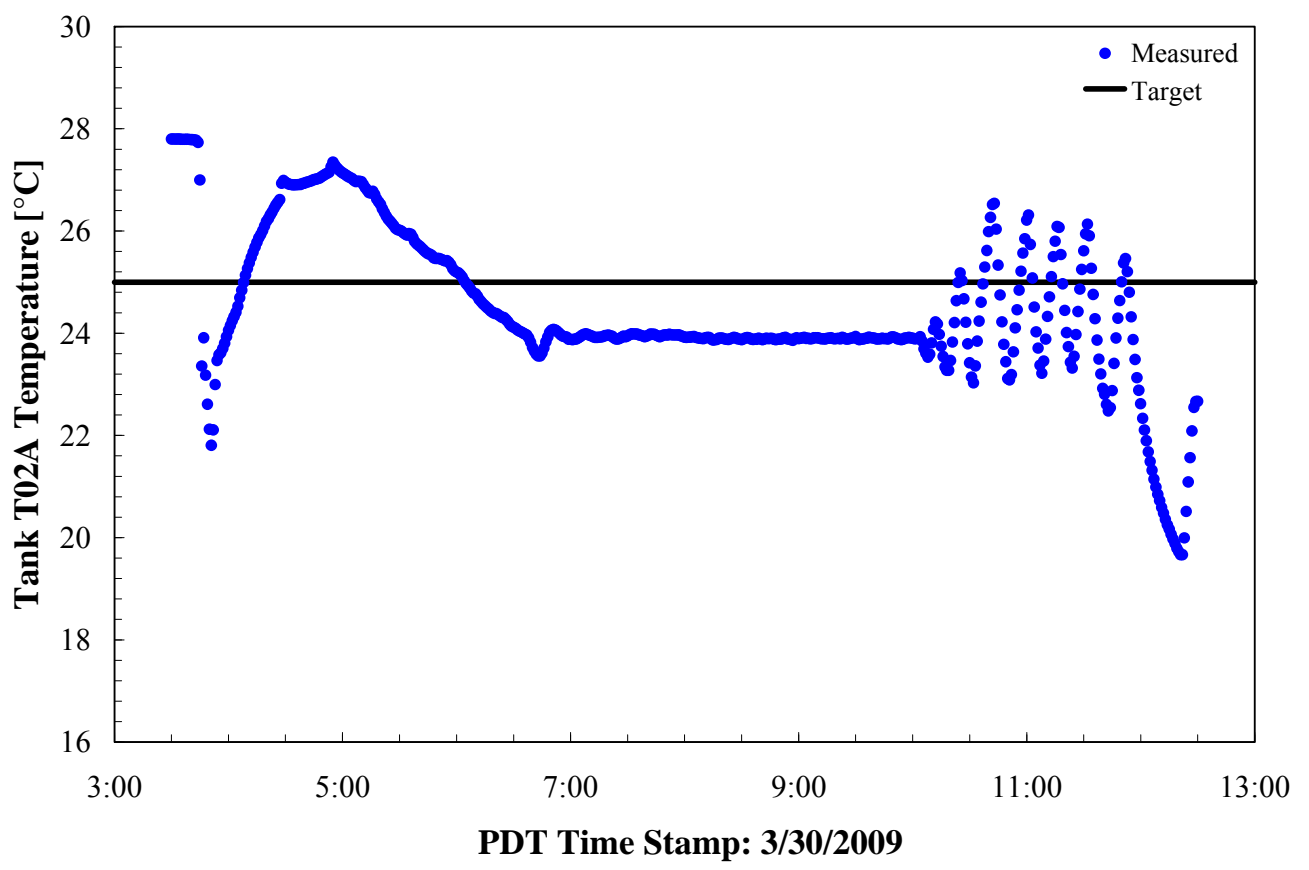

Figure 4.21. Tank T02A Temperature for Post-Caustic-Leach Wash

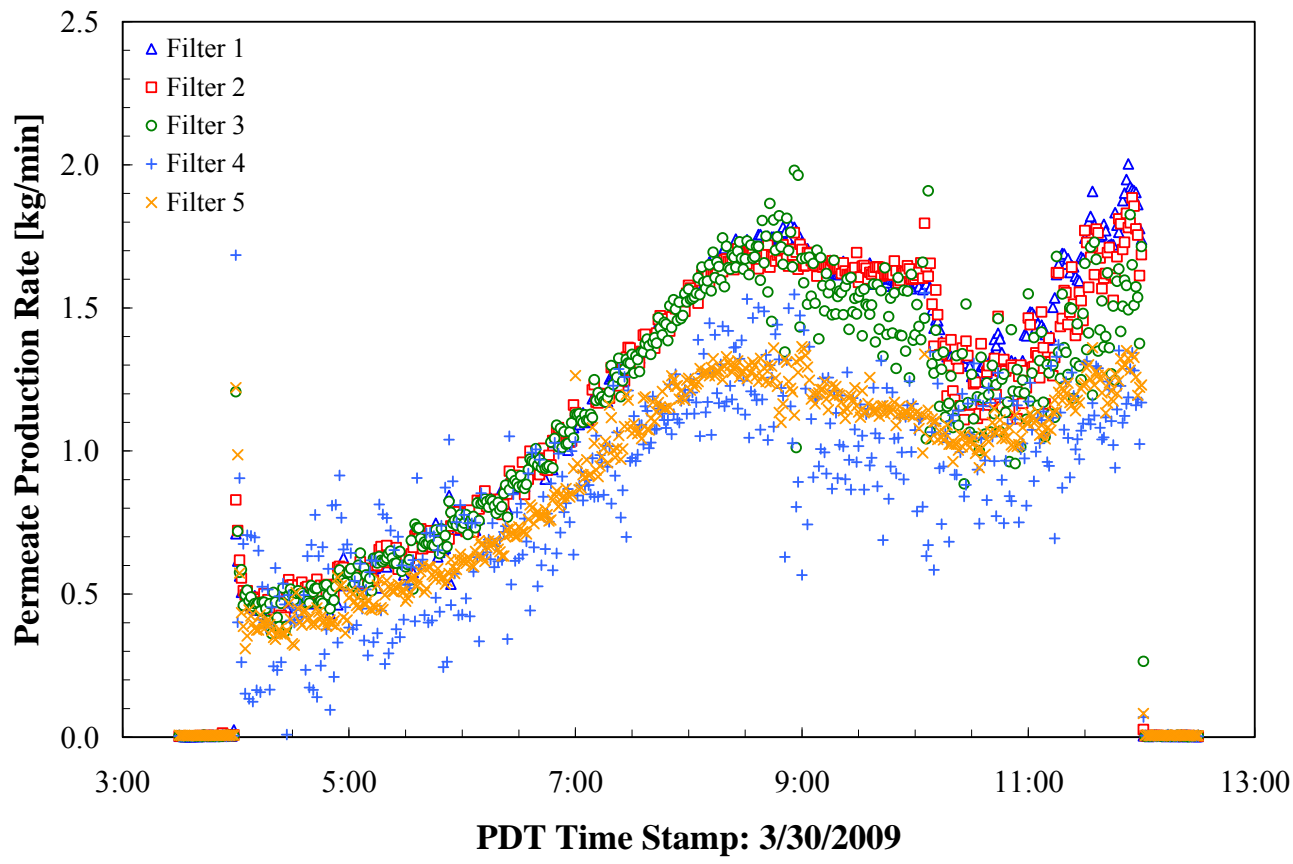

Figure 4.22. Permeate Production Rate for Post-Caustic-Leach Wash 


\subsection{Oxidative Leaching}

The slurry was oxidatively leached after post-caustic-leach washing to remove chromium by adding 9.6 gal of $1 \mathrm{M} \mathrm{NaMnO}_{4}$ at $5 \mathrm{gpm}$ to the filter-loop at $25^{\circ} \mathrm{C}$. This volume was confirmed by the level change in the $\mathrm{NaMnO}_{4}$ addition tank as well as the flow meter. The level in UFP-VSL-T02A increased more than it should have from adding 9.6 gal, and this is attributed to foaming. All air spargers and the steam ring purge were off. The PJMs were set in the star mode on 3/30/09 at 13:03 hours with a 20-sec cycle time, an $11.9 \mathrm{~m} / \mathrm{s}$ nozzle velocity, and a 29.5 inch stroke length. The UFP-VSL-T02A temperature was controlled automatically using HX-T02A and the outlet RTD, but was manually adjusted to obtain a Tank T02A temperature of $23^{\circ} \mathrm{C}$ during the oxidative-leach process. The temperature fluctuated early in the test because pumps were turned off, and the tank level was low, which caused controller fluctuations during restart. During the leach, the filter axial velocity was $\sim 13 \mathrm{ft} \mathrm{sec} \mathrm{(} \sim 90 \mathrm{gpm}$ filter flow rate), and the air spargers and the steam air purge were turned to off avoid pumping problems. The pumps were adjusted frequently between 13:55 and 14:23 hours and several times after that to try and maintain the filter-loop flow rate. The two flow meters on the filter-loop differed significantly, indicating that there was entrained air in the slurry. The filter-loop flow rate also dropped and rose (burped) for no apparent reason during the leach. The slurry was recirculated for 6 hours after the permanganate was added, and then the slurry was washed and dewatered. At the end of the oxidative-leach, the slurry UDS content was 21.2-wt\%. The axial velocity in the filter-loop and the Tank T02A level is shown in Figure 4.23 and Figure 4.24.

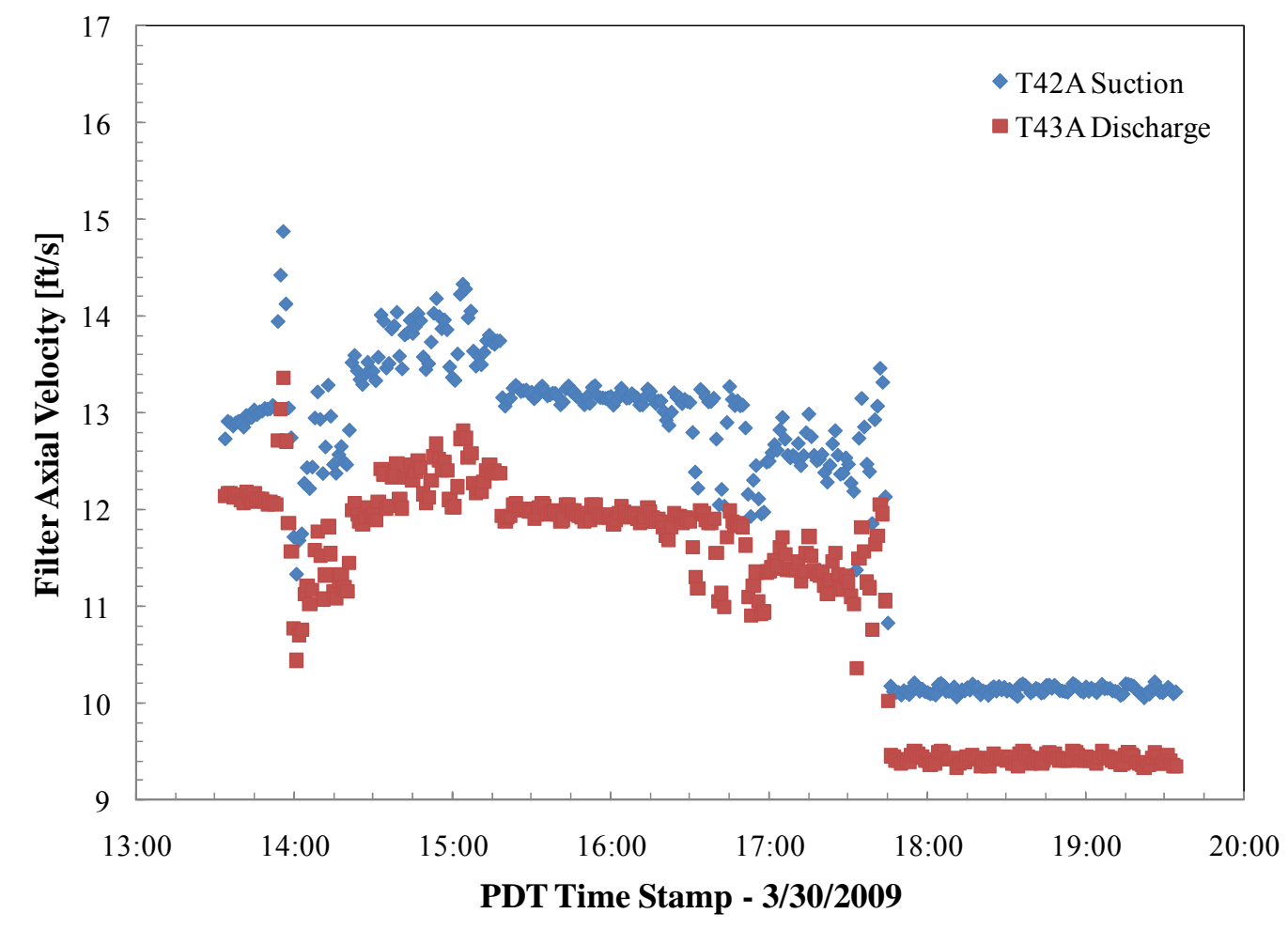

Figure 4.23. Filter Axial Velocity During Oxidative-Leach Operations, Integrated Test D 


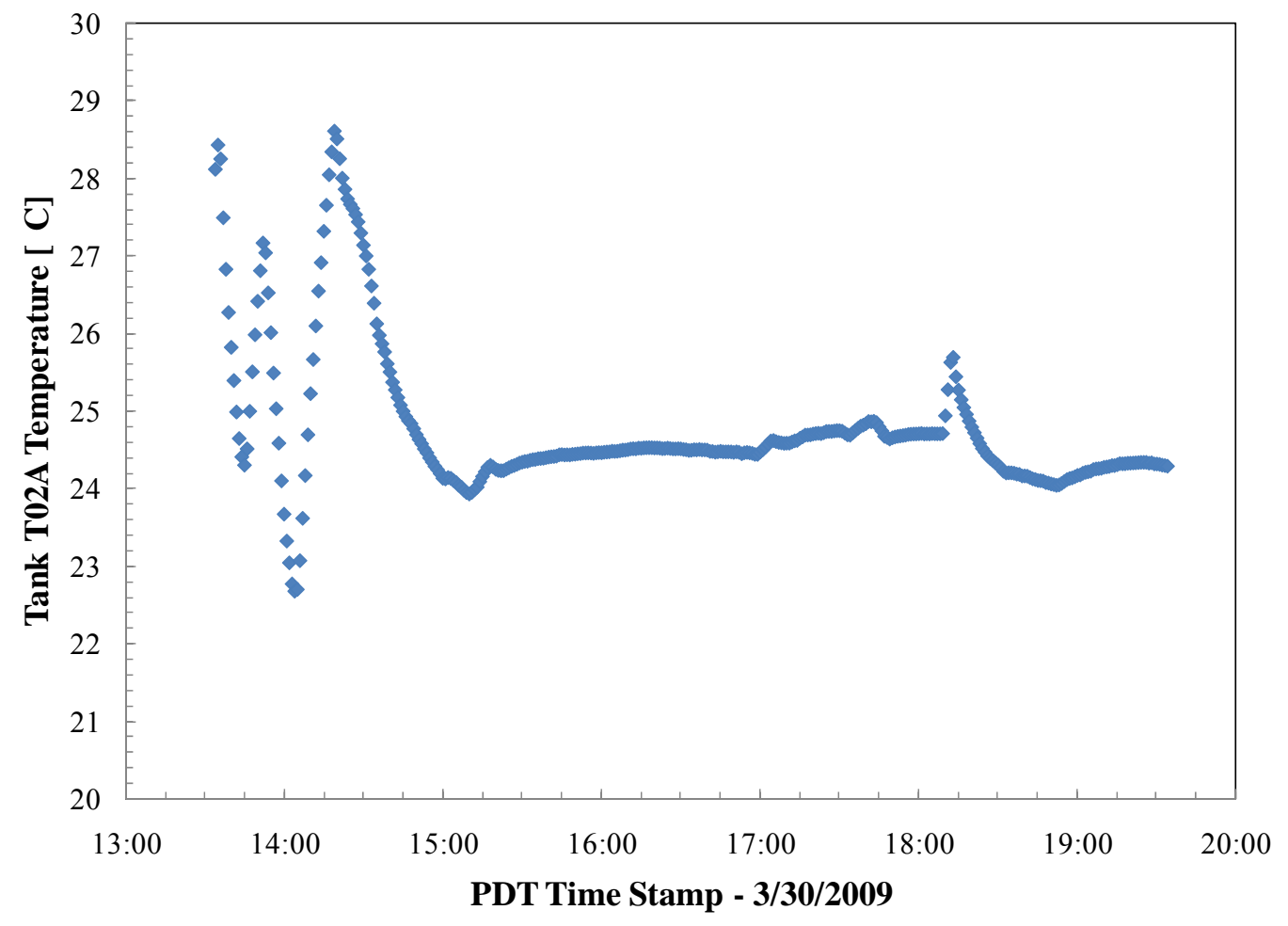

Figure 4.24. Tank T02A Temperature (TTK-0619) During Oxidative-Leach, Integrated Test D

\subsection{Oxidative-Leach Washing}

The washing and dewatering was started on 3/30/09 at 19:54 hours with five filters with automatic wash addition at a tank level of 19.4 inches. The wash water was added at a rate of $28 \mathrm{~kg} / \mathrm{min}$. The filtering temperature was $25^{\circ} \mathrm{C}$ in Tank T02A. A total of $1874 \mathrm{~kg}$ in forty-five $42 \mathrm{~kg}$ batches of IW were used to wash the slurry. An AFA mixture (1 part AFA in 3 parts IW) was added at a rate of 44-mL AFA every third wash batch to maintain the target AFA concentration of $350 \mathrm{ppm}$. The air spargers and steam ring purge were off during the washing and the PJMs were set to star mode at 19:56 hours.

Figure 4.25 through Figure 4.28 provide the TMP, axial velocity, temperature, and permeate production during the washing of the slurry. The instantaneous permeate rates during washing were erratic, so data in Figure 4.28 show 10-min averaged data. The suspected cause of the erratic operation was low permeate flow rates and relatively low loop pressures as indicated by the low TMP pressure for Filter T05A at the end of washing.

The final slurry concentration was completed on 3/31/09 05:42 hours with a final level of 15.6 inches according to the laser level probe. The slurry UDS content was 20.6-wt\%. Figure 4.29 through Figure 4.32 provide the TMP, axial velocity, temperature, and permeate production during the final concentration of the slurry. 
Finally, the filters were flushed back to Tank T02A with $340 \mathrm{~kg}$ of IW. UFP-VSL-T02A was drained to a tote, and Tank T02A was refilled with $400 \mathrm{~kg}$ of IW. The tank and filter-loop were recirculated, sampled, and drained to another tote. The filter-loop was filled with IW, and the test was complete on $3 / 31 / 09$ at $10: 28$ hours.

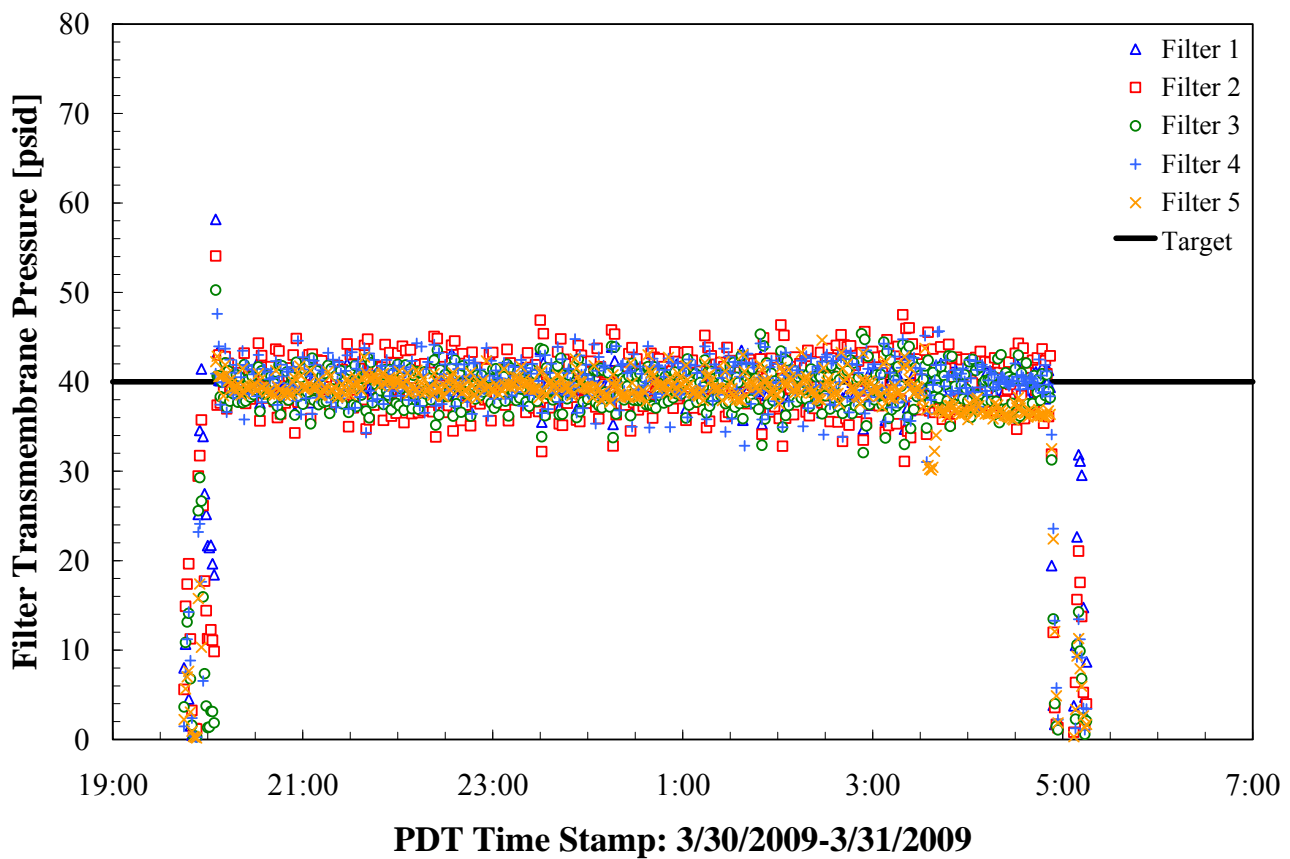

Figure 4.25. TMP for Post-Oxidative-Leach Wash

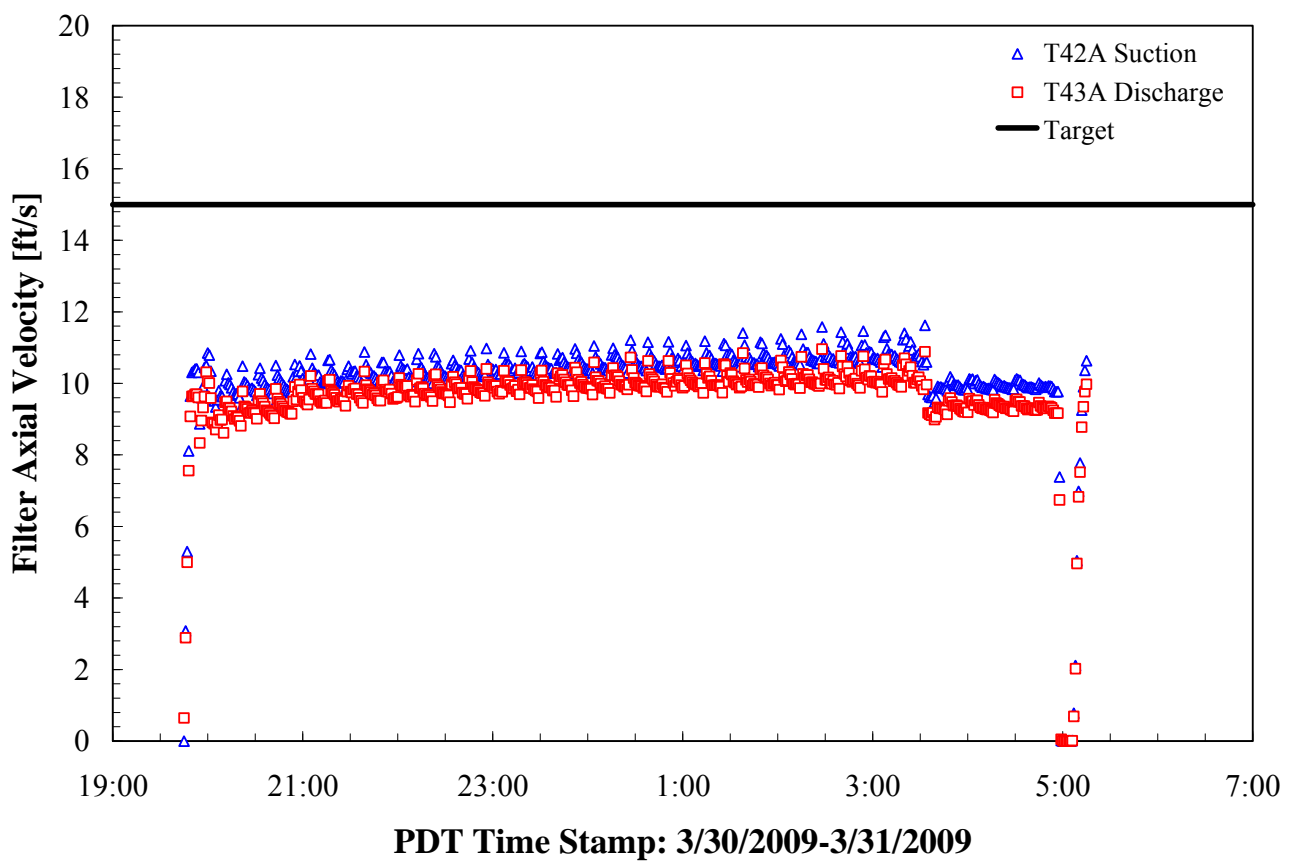

Figure 4.26. Axial Velocity Based on Flow Measurements at the Suction to T42A and the Discharge to T43A for Post-Oxidative-Leach Wash 


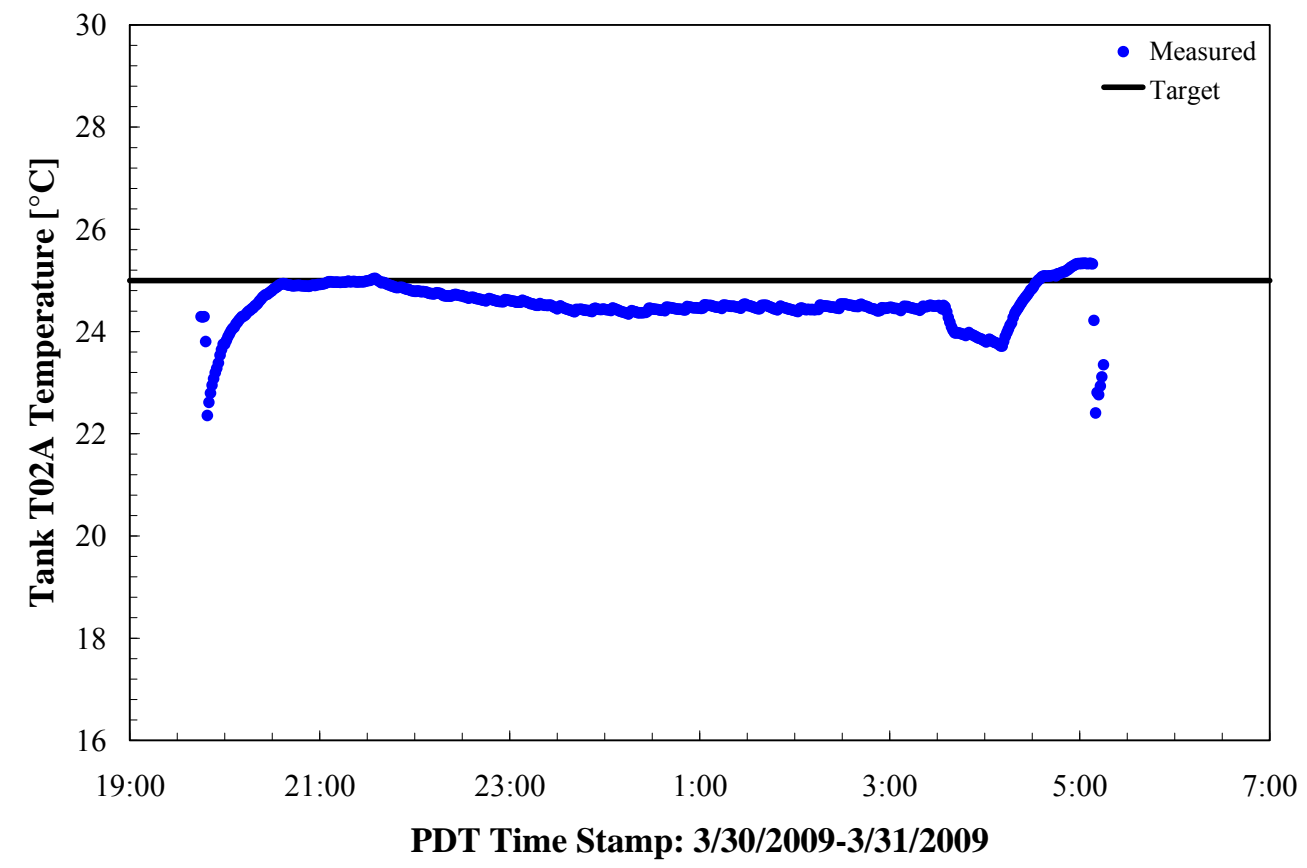

Figure 4.27. Tank T02A Temperature for Post-Oxidative-Leach Wash

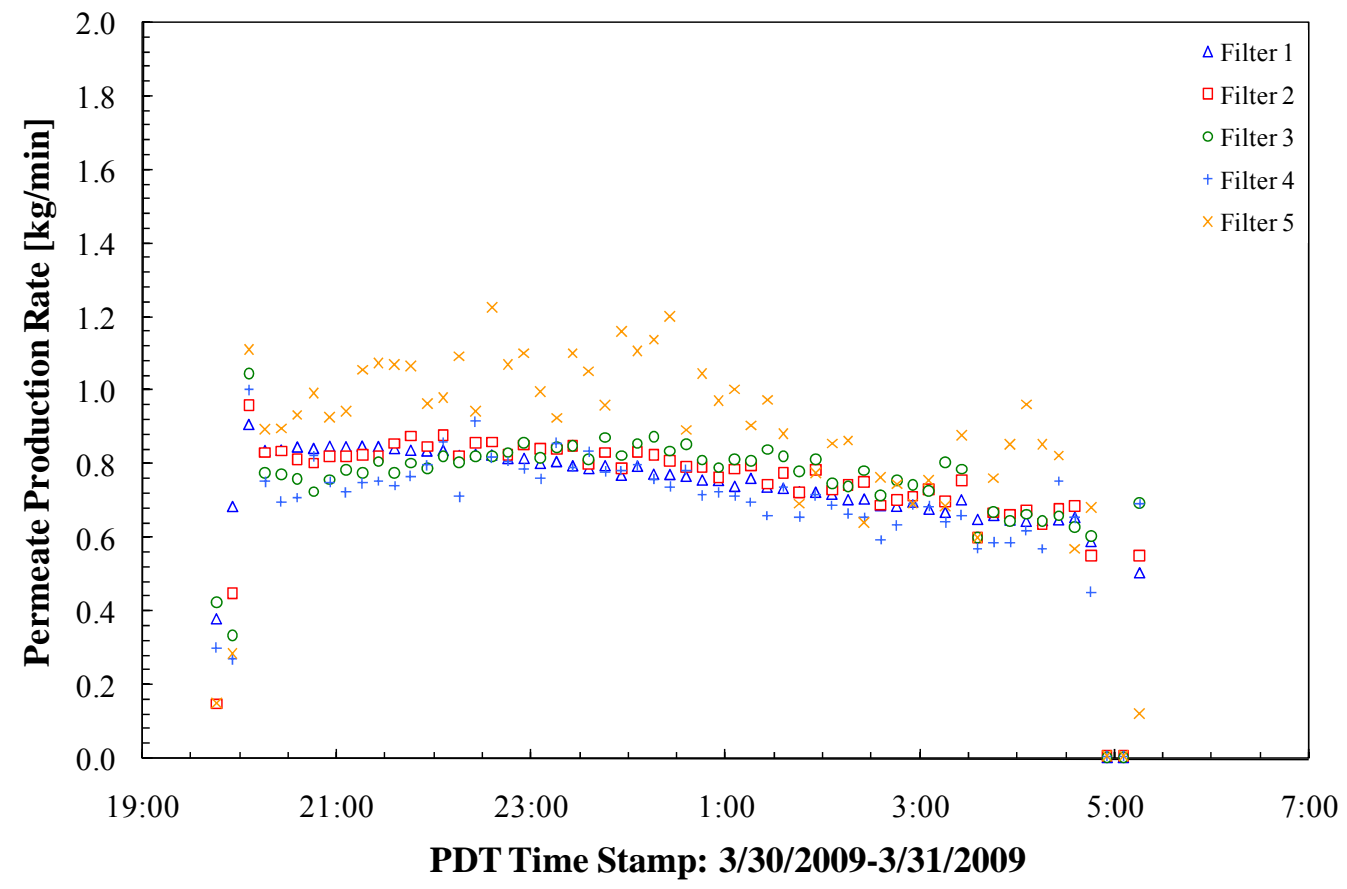

Figure 4.28. Permeate Production Rate for Post-Oxidative-Leach Wash 


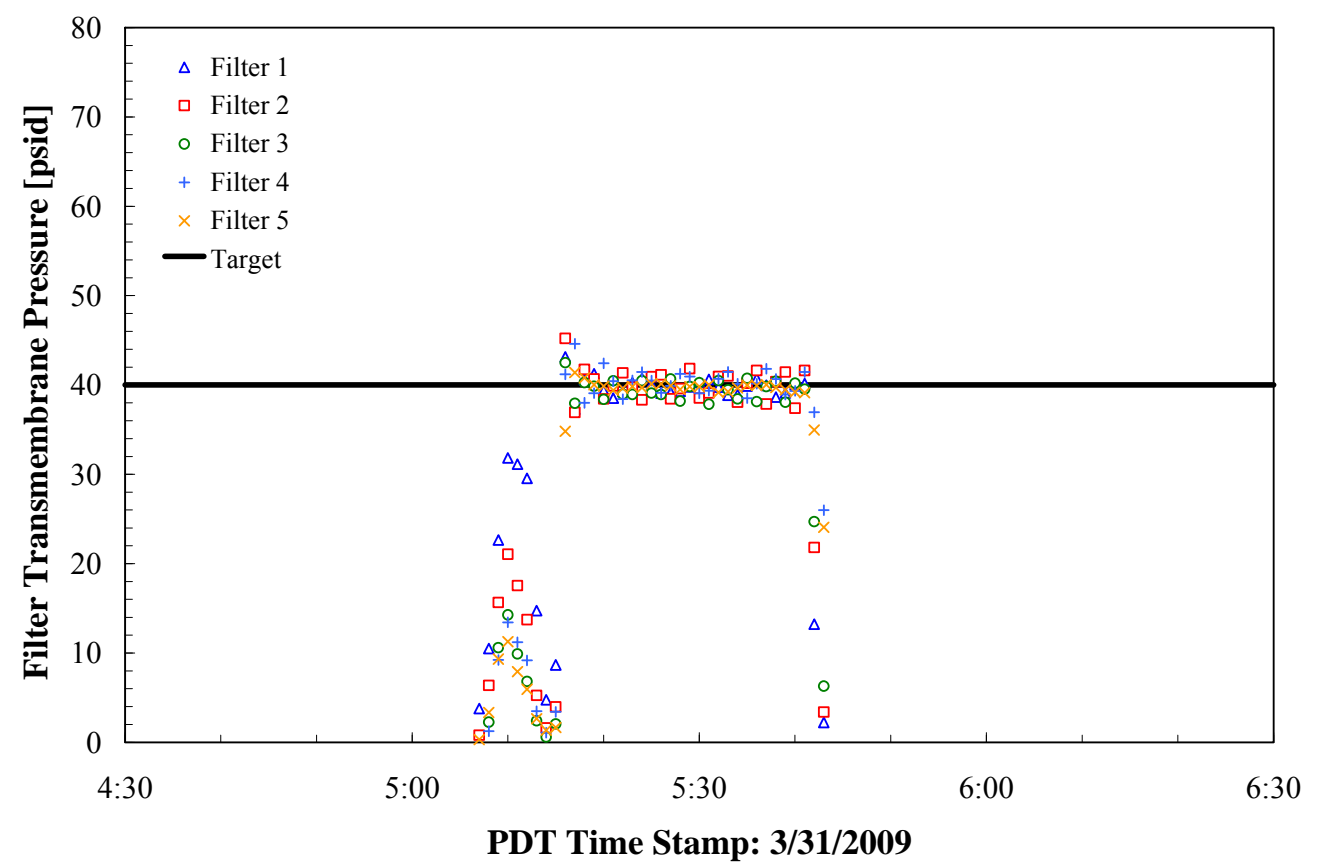

Figure 4.29. TMP for Post-Oxidative-Leach Concentration

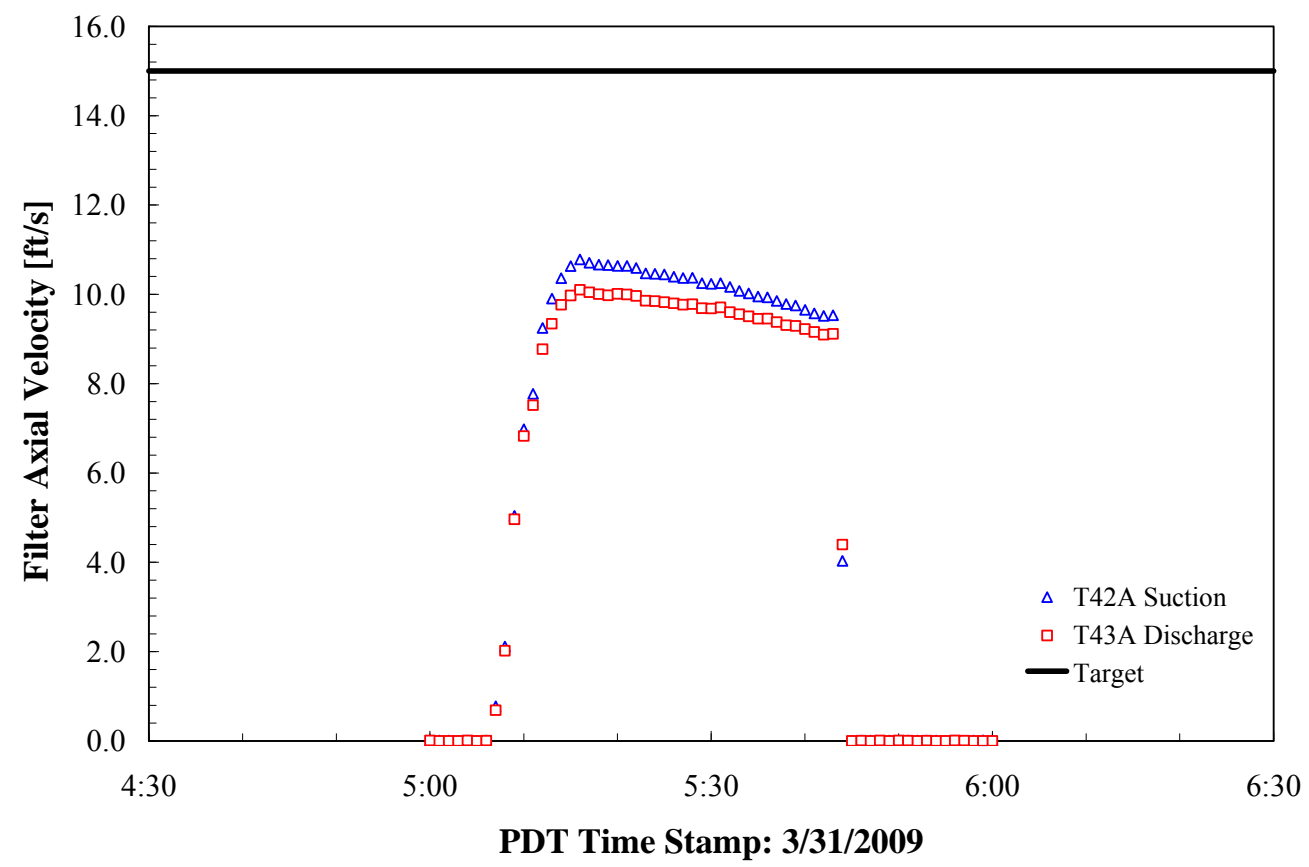

Figure 4.30. Axial Velocity Based on Flow Measurements at the Suction to T42A and the Discharge to T43A for Post-Oxidative-Leach Concentration 


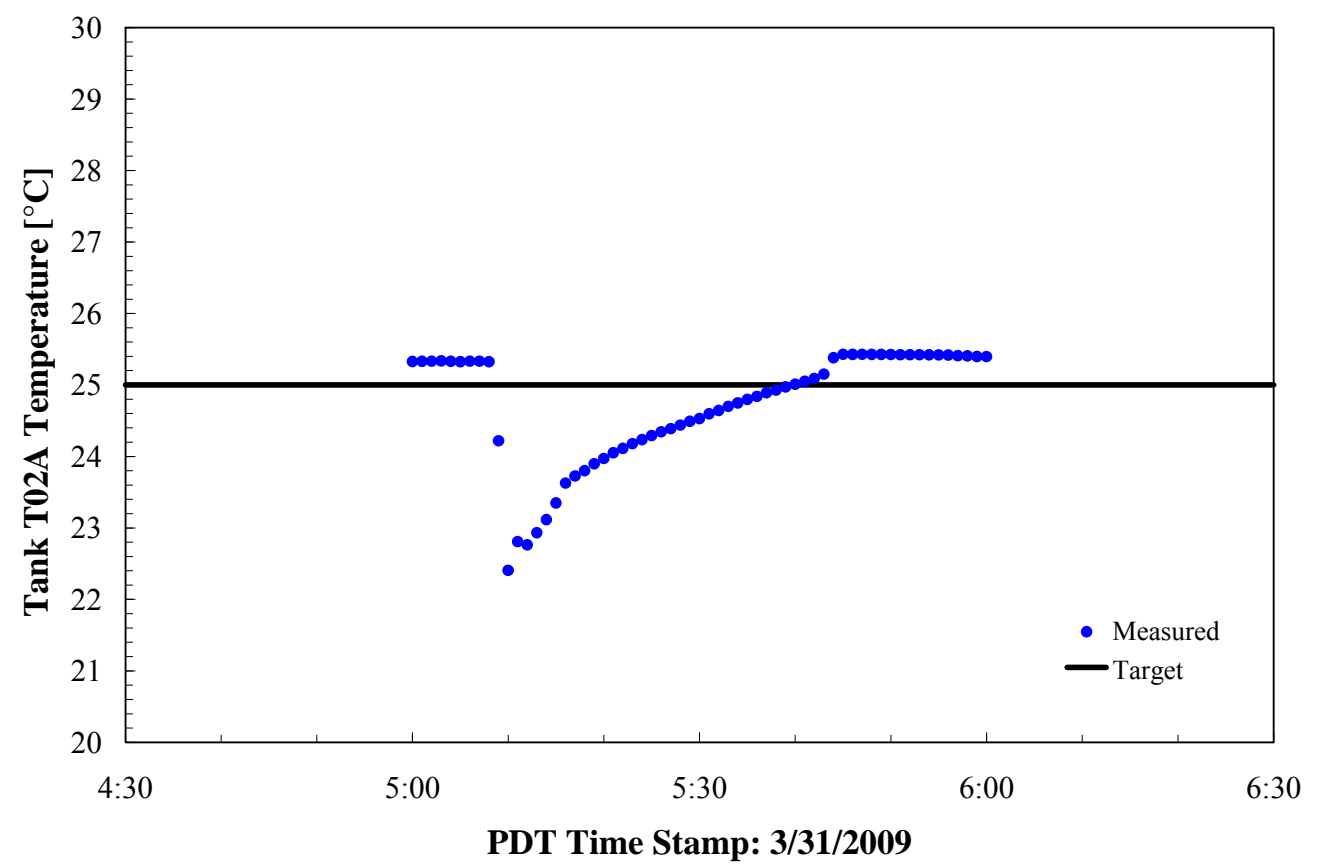

Figure 4.31. Tank T02A Temperature for Post-Oxidative-Leach Concentration

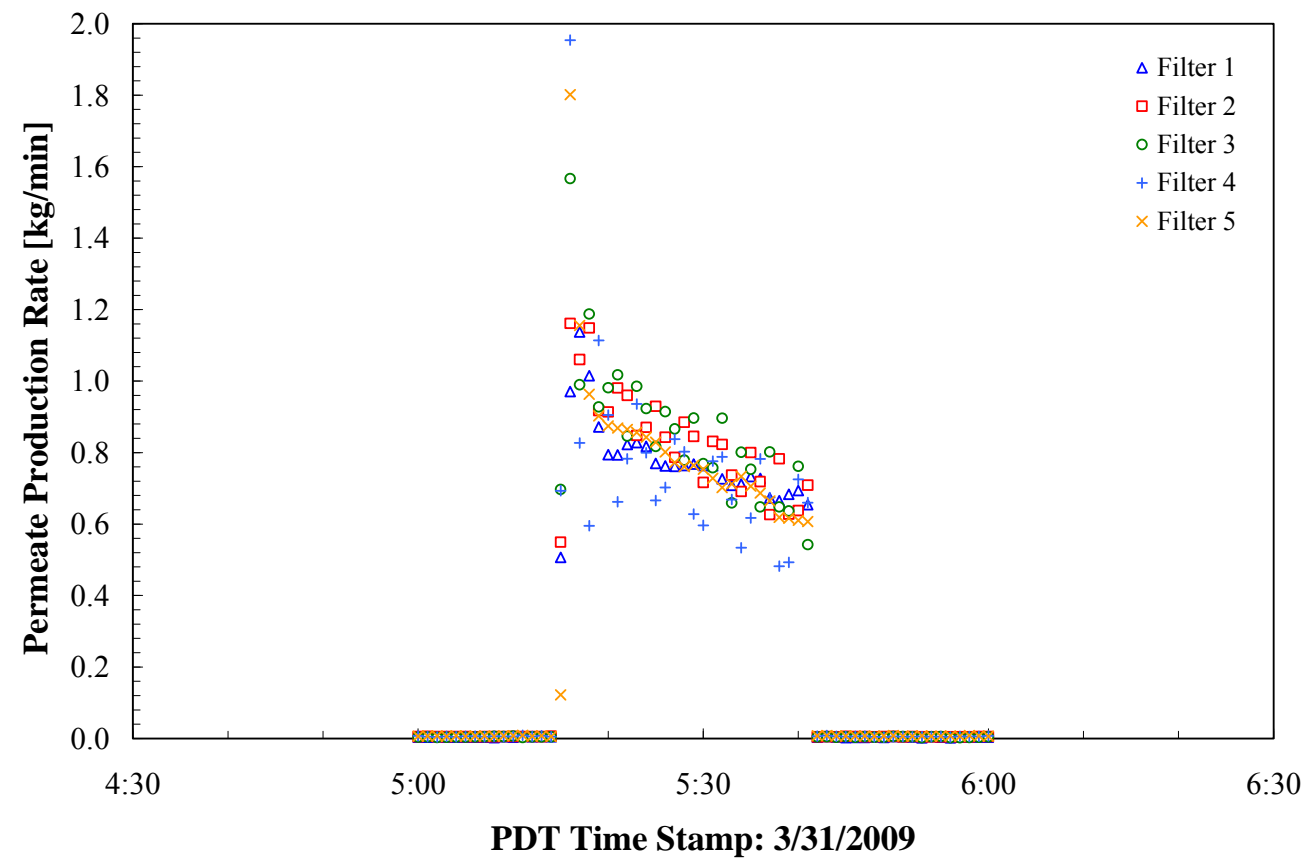

Figure 4.32. Permeate Production Rate for Post-Oxidative-Leach Concentration 


\subsection{Nitric Acid Filter Cleaning After Integrated Test D}

At the conclusion of Integrated Test D, the tank, pumps, and filters were flushed out with IW twice to prepare for cleaning with nitric acid. The Tank T02A vessel was inspected before introducing the IW with a small video camera inserted through a flange in the top of the vessel (DVD titled "UFP-02A tank inspection" on 4/23/09). The video included inner tank walls, bottom head, upper vessel head, steam pipe and ring (top and bottom), and other internals (look for bathtub ring and donuts on internals, especially near upper simulant levels).

\subsubsection{Visual Inspection Results}

A visual inspection was performed at the inlet to ultrafilter UFP-FILT-T01A. The inspection was performed on 4/23/09, after Phase I, Integrated Test D. Valve V07128 was removed from the filter-loop to provide access to the inlet of Filter T01A.

The conditions of the filter-loop before the video were as follows:

- Simulant slurry remaining in the filter-loop at the end of Integrated Test D was drained to totes $(3 / 31 / 09)$.

- A single 0.01-M IW flush of the filter-loop and Tank T02A was performed.

- The filters were laid up in 0.01-M IW after the flush.

- Filter T01A was drained just before the video.

The visual inspection consisted of two parts. The first part was performed using a Mirion C911 Series inspection camera. The camera was connected to a Dell flat-panel monitor and Panasonic DMR-EZ48V DVD recorder. This part of the inspection was recorded to a DVD. The camera was inserted into the filter inlet and positioned by hand to observe features of the filter head.

The second part of the inspection was performed using an Olympus 1F8S2-20 fiberscope and ILK-4 cold light supply. This part of the inspection was not recorded. The fiberscope was also inserted into the filter inlet and positioned by hand to observe features of the filter head. No unique observations were noted during the inspection with the fiberscope.

The inlet to Filter T01A (piping and filter head) had a light brown discoloration as shown in Figure 4.33 that was due to residual simulant film on the metal surfaces. Darker areas of heavier simulant deposition were also observed on the filter head. No significant solids buildup was observed at the filter inlet. The unused spare filter is pictured in Figure 4.34. 


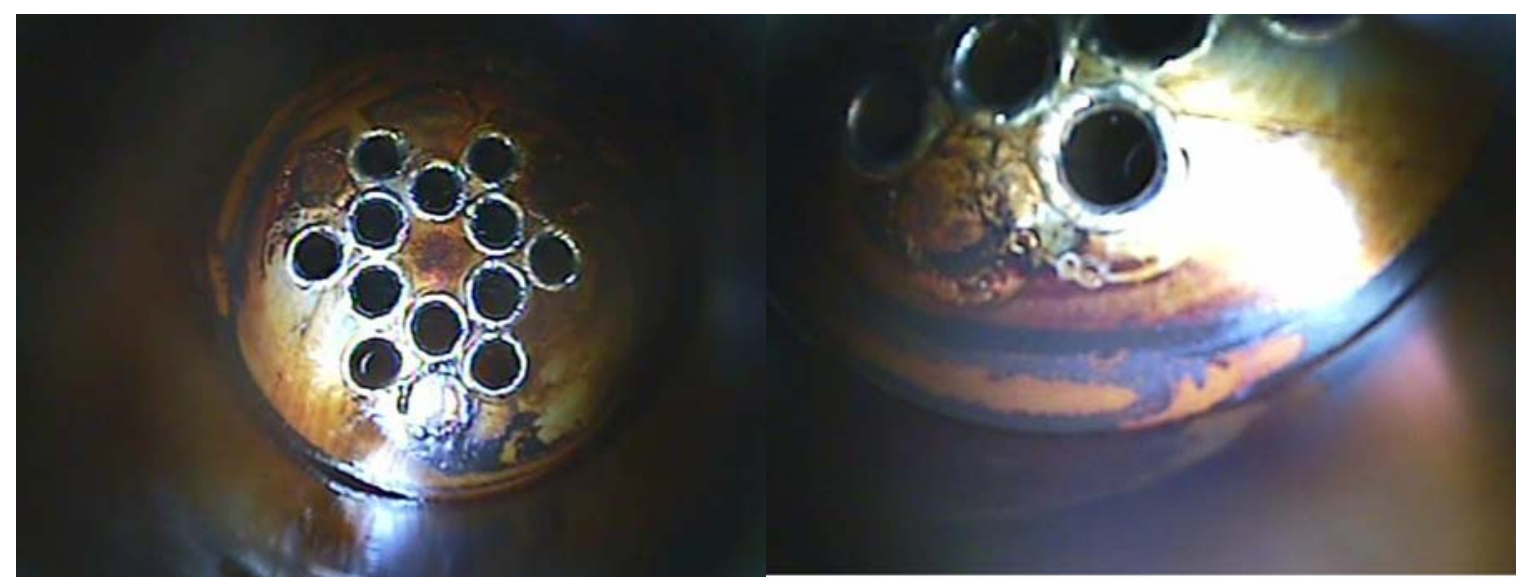

Figure 4.33. Inspections of Filter T01 Inlet

Several small (approximately $1 / 2$ to $1 \mathrm{~mm}$ ) reflective beads were observed near the inlet of the individual ultrafilter tubes. The beads observed near the inlet to the individual ultrafilter tubes appear to be stray weld material from the fabrication process and do not appear to be large enough to affect filter performance. The 8-ft spare ultrafilter shown in Figure 4.34 was inspected for comparison and also found to have reflective beads near the ultrafilter tube inlet.

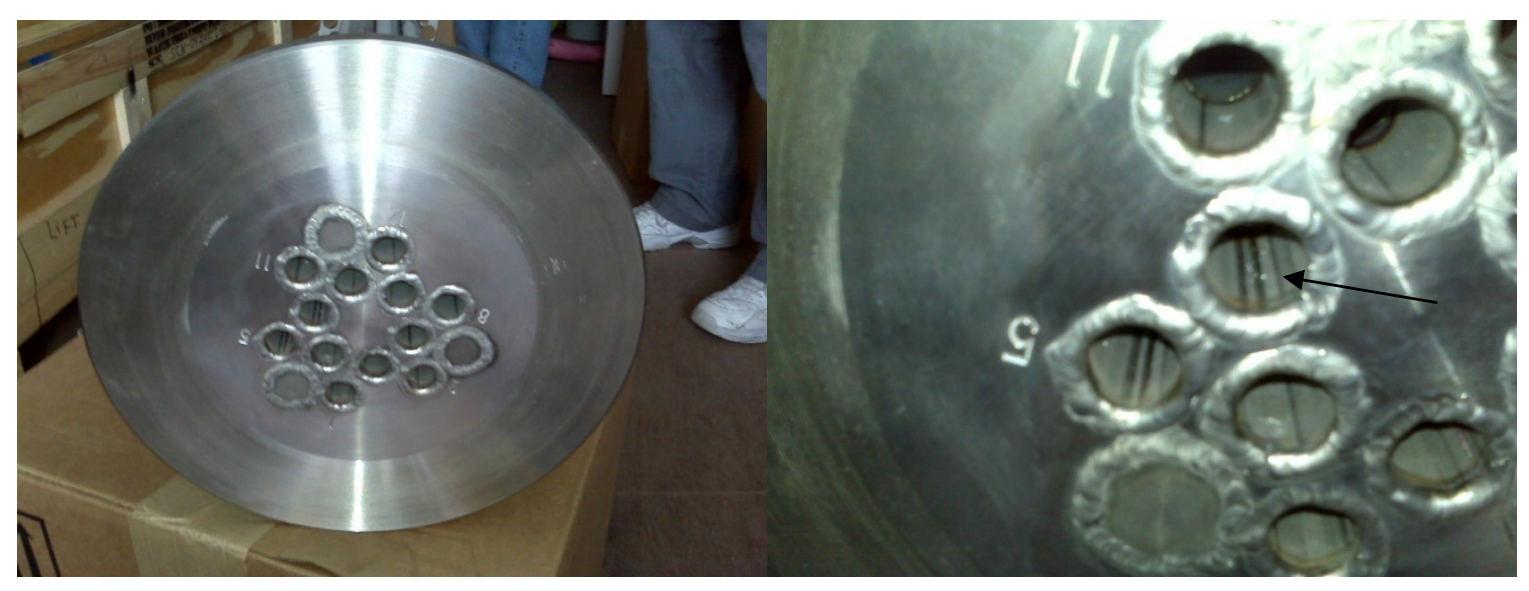

Figure 4.34. Inspections of 8-ft Spare Ultrafilter

In conclusion, no significant solids were observed at the inlet to UFP-FILT-T01A during the 4/23/09 inspection and the visual inspection did not identify any indications of flow mal-distribution or evidence of potential filter failure.

\subsubsection{Cleaning}

After the inspection, the tank was filled with 300 gallons of IW to obtain baseline filtration rates.

After the IW rinses, the IW drained from the loop appeared to be dirty, and samples were taken for analyses. The UDS analyses showed $0.25-\mathrm{wt} \%$ solids. The solution was dark brown when shaken, and when settled, there was a $\sim 2 \%$ layer of solids on the bottom. The oven-dried solids were 10.8 -wt $\%$ of the centrifuged solids. The permeate sample from Filter T01A was yellow with little visible solids, but the 
sample from the shellsides of the other filters was brown and contained visible solids. After the shellside samples were allowed to settle, the supernatant was yellow, and there was a thin layer of solids on the bottom of a 1-L container as shown in Figure 4.36.

The nitric acid cleaning started with approximately 200 gallons is Tank T02A, and this proceeded as described in the_Steps for PEP Prototypic Filter Cleaning instructions below. Samples were taken from the filter-loop during each cleaning evolution and analyzed. The third cleaning solution turned brown because of particulate precipitation when neutralized with IW and $2 \mathrm{M} \mathrm{NaOH}$. The first two cleaning solutions had visible solids while the third one had very little solids. The UDS, $\mathrm{pH}$, and total solids results are provided in Table 4.1. The slurry samples were also analyzed by ICP, and the results are shown in Figure 4.37 and Figure 4.38.

Table 4.1. Filter-Cleaning Sample Results

\begin{tabular}{|c|c|c|c|c|}
\hline Sample Description & $\begin{array}{l}\text { UDS } \\
\text { wt } \%\end{array}$ & $\begin{array}{l}\text { Ave } \\
\mathrm{pH}\end{array}$ & $\begin{array}{c}\text { Total Solids } \\
\text { wt } \%\end{array}$ & Observations \\
\hline Dirty water filter-loop sample & 0.25 & 12.59 & 1.52 & $\begin{array}{l}\text { Significant layer of solids on } \\
\text { bottom of sample container }\end{array}$ \\
\hline Permeate sample dirty water & 0 & 12.57 & 1.45 & $\begin{array}{l}\text { Permeate yellow, no visible } \\
\text { solids }\end{array}$ \\
\hline $\begin{array}{l}\text { Permeate sample filter shell } \\
\text { sample after dirty-water flux }\end{array}$ & 0.01 & 12.56 & 1.61 & $\begin{array}{l}\text { Permeate yellow, thin layer } \\
\text { of settle solids on the bottom } \\
\text { of } 1 \text {-L container }\end{array}$ \\
\hline $\begin{array}{l}\text { 1st acid wash filter-loop } \\
\text { sample }\end{array}$ & 0.09 & 0.12 & 0.56 & $\begin{array}{l}\text { Settled solids visible in } \\
\text { sample carboy. Solution } \\
\text { dark brown when mixed. }\end{array}$ \\
\hline $\begin{array}{l}\text { 2nd acid wash filter-loop } \\
\text { sample }\end{array}$ & 0.02 & 0.06 & 0.13 & $\begin{array}{l}\text { Solids visible in sample } \\
\text { carboy. }\end{array}$ \\
\hline $\begin{array}{l}\text { 3rd acid wash filter-loop } \\
\text { sample }\end{array}$ & 0.00 & 0.05 & 0.10 & $\begin{array}{l}\text { Yellow supernatant with no } \\
\text { visible solids in large carboy. } \\
\text { Solids visible when } \\
\text { neutralized. }\end{array}$ \\
\hline $\begin{array}{l}\text { Before final } \mathrm{pH} \text { adjustment } \\
\text { filter-loop sample }\end{array}$ & 0.00 & 1.86 & 1.6 & \\
\hline $\begin{array}{l}\text { Before final } \mathrm{pH} \text { adjustment } \\
\text { permeate sample }\end{array}$ & 0.00 & 1.83 & 1.63 & \\
\hline $\mathrm{pH} \sim 13$ filter-loop sample & 0.04 & 12.07 & 2.03 & \\
\hline $\mathrm{pH} \sim 13$ permeate sample & 0 & 12.08 & 1.99 & \\
\hline
\end{tabular}




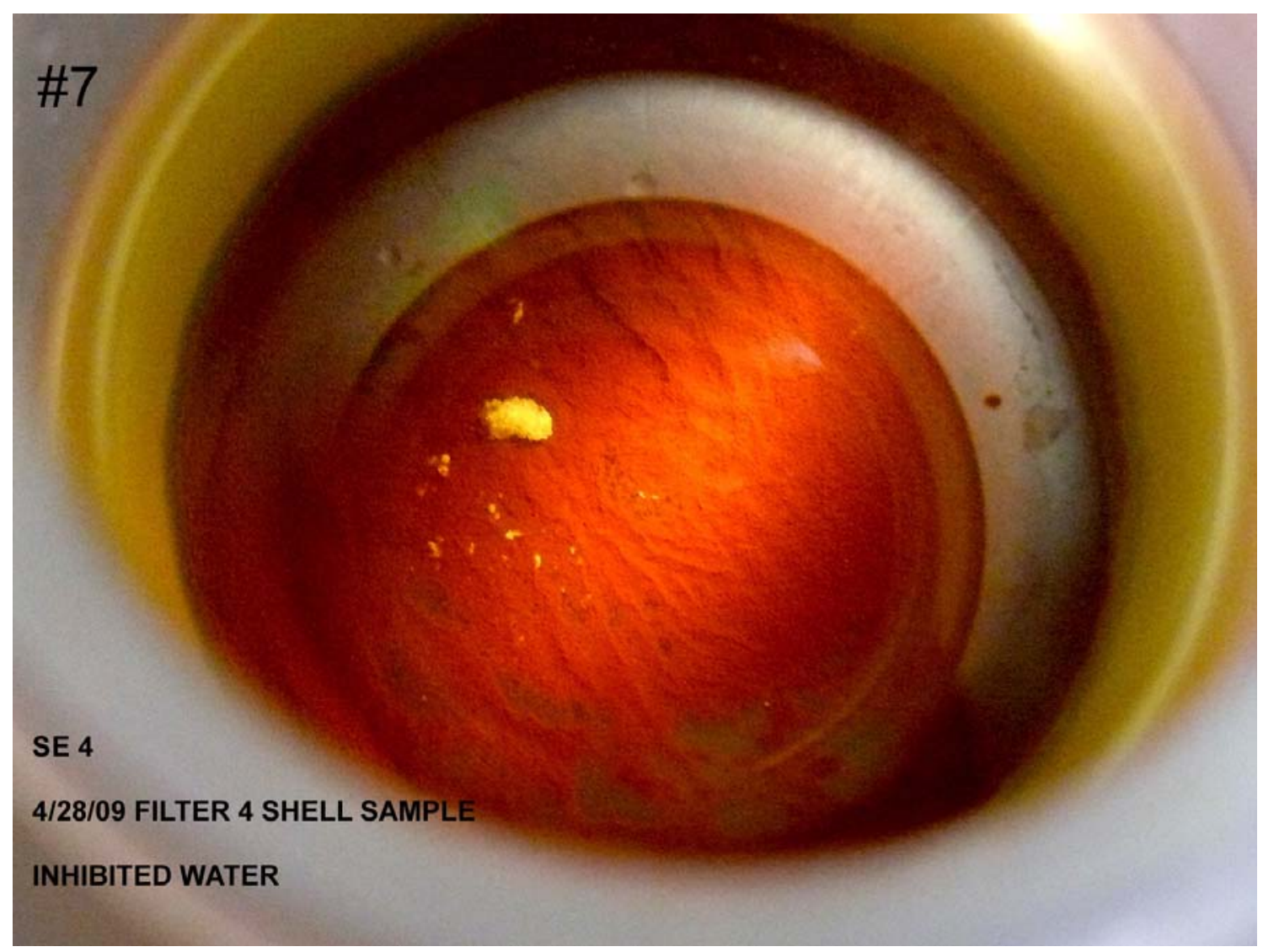

Figure 4.35. Picture of Filter Shellside After Settling 


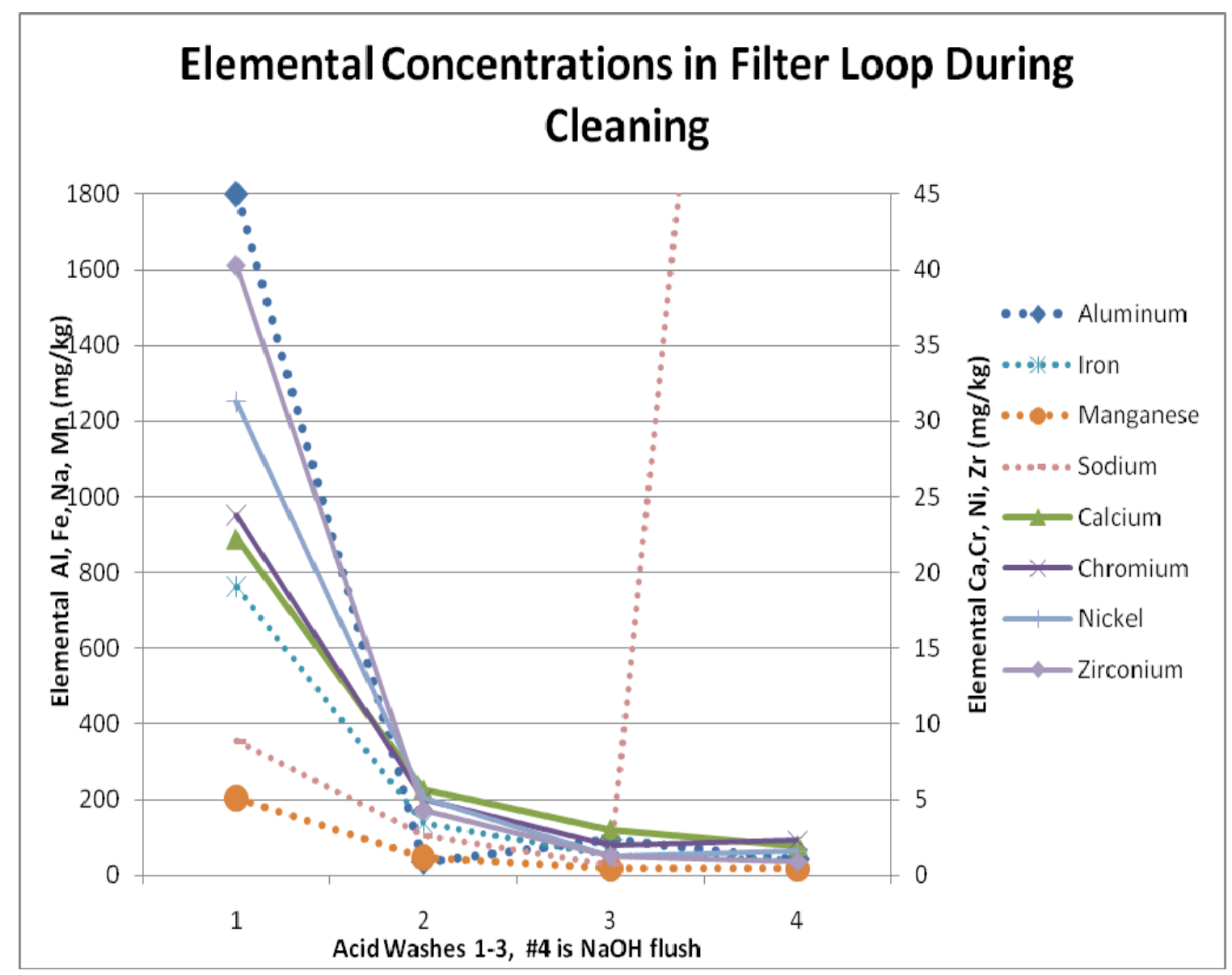

Figure 4.36. Elemental Concentrations During Filter Cleaning 


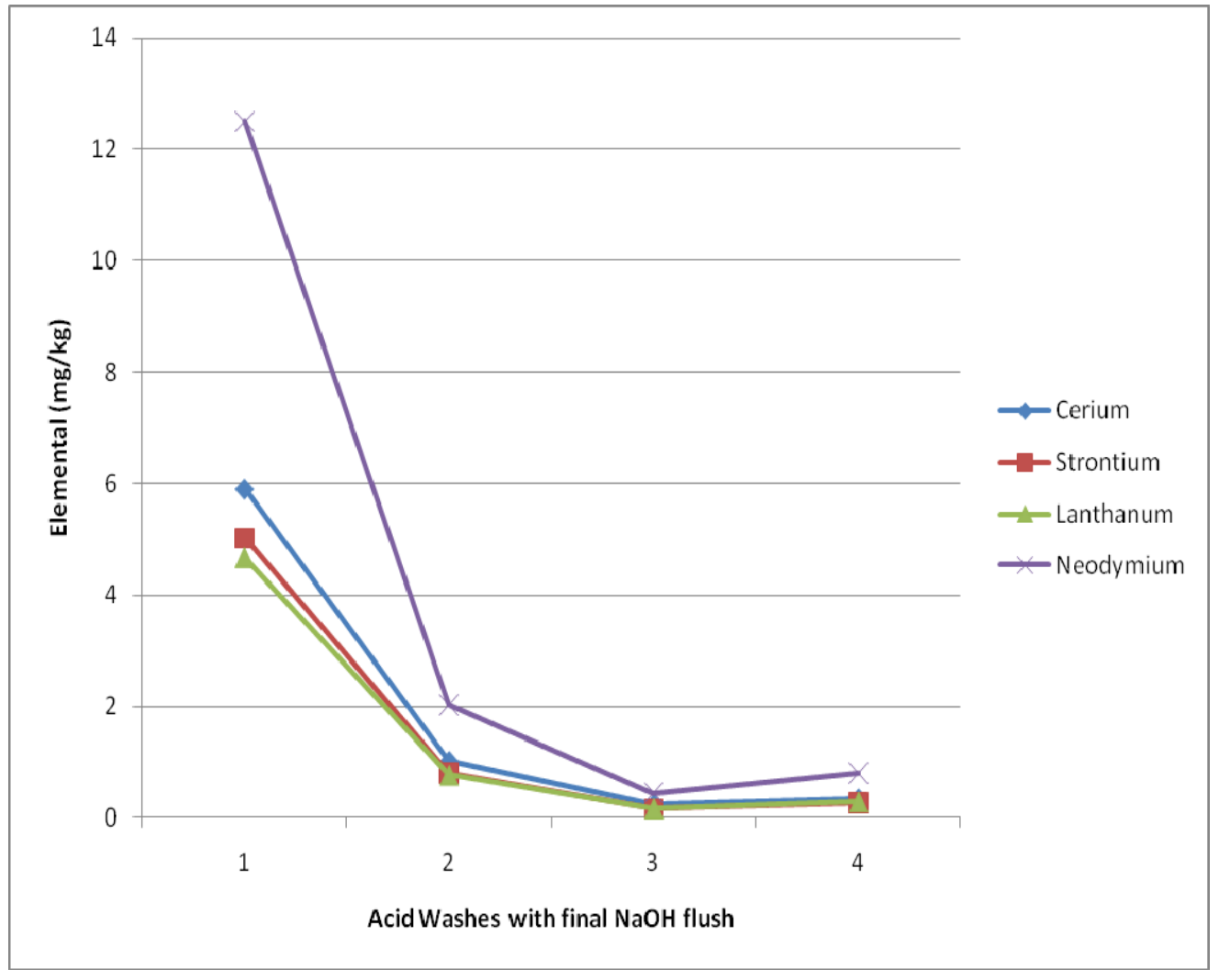

Figure 4.37. Trace Element Concentrations During Filter Cleaning 
Temperature corrected Filter flux

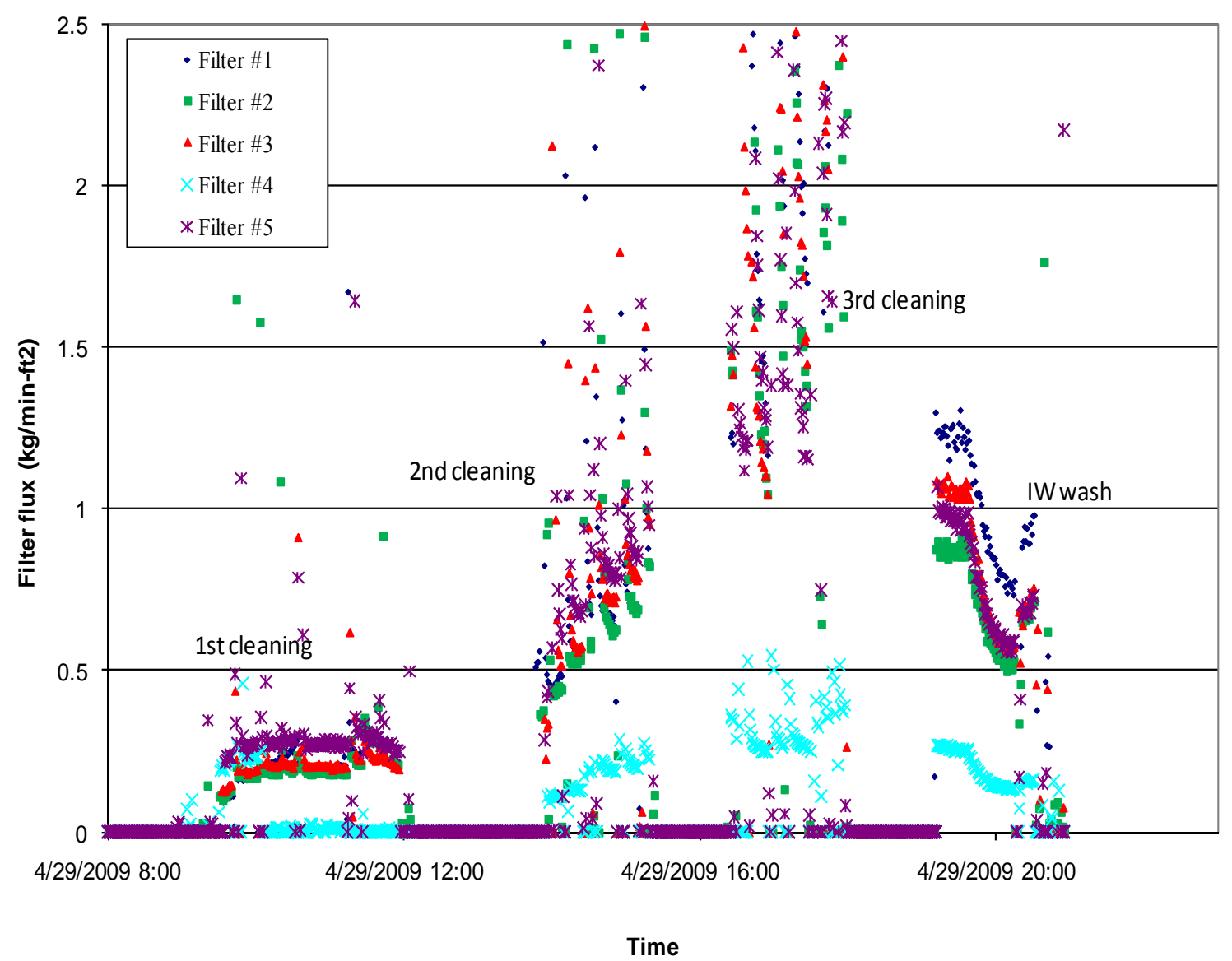

Figure 4.38. Temperature and TMP-Corrected Filter Flux 
Selected centrifuged solids collected from the first IW filter-loop sample (6501) and the filter shell sample (6524) were also analyzed. The solids material from the filter shellside was mainly manganese with quantities of zirconium, and zinc significantly above the solids concentration of material in the filter-loop as shown in Table 4.2. It is probable that these solids are oxalates that formed during washing activities and did not redissolve The solids may have deposited in dead legs. The particle size distribution for the solids collected from the permeate sample before cleaning started was significantly larger than the leached slurry and more comparable to the original slurry. The values are provided in Table 5.18.

The UDS content in the material collected from the filter-loop during the three washes decreased during each successive wash but overall composition did not change. The solids were mainly aluminates estimated as $>90 \%$ of the total solids weight. There were also small amounts of chromium, iron, silicon, and zirconium. The overall quantity of solids was small as indicated by the UDS measurements.

Table 4.2. Draining Results

\begin{tabular}{ll}
\hline Section of Filter-Loop Drained & Amount Drained \\
\hline Tubeside & $518 \mathrm{lbs}$ \\
Spiral Heat Exchanger & $559 \mathrm{lbs}$ cumulative \\
After $1^{\text {st }}$ and $2^{\text {nd }}$ shellside drain & $1226 \mathrm{lbs}$ cumulative \\
After $2^{\text {nd }}$ filter-loop side drain & 1288 (154 gal) cumulative \\
Spiral HX volume & 4.9 gallons drained \\
Pulse-pots and shell volume & 79.6 gallons drained \\
Tubeside volume & 69.2 gallons \\
$\begin{array}{l}\text { Filter-loop bypass drained ( not part of } \\
\text { cumulative total) }\end{array}$ & 5.4 gallons \\
\hline
\end{tabular}

The cleaning worked well with permeate rates increasing from the baseline IW rate of $0.1 \mathrm{~kg} / \mathrm{min}-\mathrm{ft}^{2}$ to values approaching $0.2,0.8$, and $1.5 \mathrm{~kg} / \mathrm{min}-\mathrm{ft}^{2}$, respectively, for each wash as shown in Figure 4.38 . The final IW water rate was approximately $0.8 \mathrm{~kg} / \mathrm{min}-\mathrm{ft}^{2}$. Filter $\# 4$ rates were low, but it appears that the backpulse valve was leaking or the flow meter was incorrect, creating low flows through the flow meter. The leak was indicated by the calculated permeate rates based on the pulse-pot filling rate after a backpulse and the similarity of filling rate compared to the other pulse pots.

During the cleaning, the PJMs were off (except when specified), the lower air spargers, and the steam ring air purge were off during all cleaning steps. Initially, the lower air spargers were on at idle flow, but filter-loop pumping difficulties caused them to be turned off. The cooling heat exchanger had a 45-degree outlet setpoint. After refilling the filter-loop and pulse-pots, the tank level was $\sim 16$ inches (WTP=72 inches). The TMP was set at 40 psi, but if 40 psi could not be met, a lesser TMP was acceptable. The backpulsing pressure set point was 40 psi above the tubeside. The filter-loop backpressure valve started at $50 \%$ open but was adjusted to $1 \%$ to obtain 110 psi pressure and 100 gpm. 


\section{Steps for PEP Prototypic Filter Cleaning}

1. Fill UFP-VSL-T02A with IW to the 300-gallon level. This step is not prototypic. In the WTP, the vessel would be filled with IW to rinse out the solids, but not after sitting for a long period of time. Completed.

2. Verify that all five filters and the cooling heat exchanger are aligned. Open V06132 and recirculate UFP-VSL-T02A contents at $70 \mathrm{gpm}$, with all five permeate valves open and aligned to UFP-VSL-T02A. Backpulse as soon as the pulse-pots are full. Recirculation should continue until the permeate rate through each filter has stabilized. This is the baseline flux. This step is not prototypic. Completed.

3. Close the permeate valves and turn off pumps. This step is prototypic.

4. Isolate UFP-VSL-T02A by closing V06132. This step is non-prototypic.

5. Drain the filter-loop into the empty tote to measure the effectiveness (volume) of the drain. The filter-loop drain should include the slurry (tubeside) of filters, the spiral heat exchanger via the sample port on the north end of the skid, pulse-pots, and shellsides of the filters. Record the tube side/spiral HX volume as one total volume and the filter shell and pulse-pot volume as another total. This step is prototypic.

6. The volume of the filter-loop, pulse-pots, and shells is 182 gallons. Subtract the volume in the tote from 182 gallons to obtain the volume remaining in the filter-loop. Subtract the volume remaining in the filter-loop from 33 gallons, and leave this volume in the tank after draining UFP-VSL-T02A. The sum of the volume in the tank and the volume in the filter-loop should equal $\sim 33$ gallons. This step will give prototypic nitric acid dilution, as expected, in the WTP. The actual calculated volume left in the filter-loop was 28 gallons.

7. Fill UFP-VSL-T02A with 207 gallons of 2-M nitric acid. This step is prototypic. Completed.

8. Take stable level measurement. This step is not prototypic. The stable tank level should be approximately 49 inches. The level measurement was $\mathbf{5 0 . 4}$ inches and $\mathbf{2 1 2}$ gallons. NAR vessel indicates 199 gallons transferred.

9. Run PJMs for 1 hour at $\sim 7.3 \mathrm{~m} / \mathrm{s}$, with a 33 -sec cycle time and an $80 \%$ stroke. Take a sample from UFP-VSL-T02A to determine nitric acid concentration and UDS. Samples taken.

10. Turn PJMs off, open V06132, and begin recirculating the nitric acid at 70 gpm, with all five permeate valves open and aligned to UFP-VSL-T02A, for 1.5 hours. This step is prototypic. During this step, the permeate rates should be monitored. Each filter should be backpulsed as soon as filtration begins (when pulse-pot level is $>10$ inches) and at $0.5,1$, and 1.5 hours. Take a 5-gallon sample near the end of 1.5 hours from the filter-loop to determine nitric acid concentration and UDS, and complete possible precipitation study. Nitric acid recirculated at $109 \mathbf{g p m}$.

11. Close the permeate valves and turn off the pumps. This step is prototypic.

12. Isolate UFP-VSL-T02A by closing V06132. This step is non-prototypic. Completed.

13. Take stable level measurement. This step is non-prototypic. The difference in stable level measurements between steps 12 and 17 should equal the volume drained during step 5. Completed.

14. Drain UFP-VSL-T02A (leaving the same volume in the tank as was left in Step 6), and drain the filter-loop. The pulse-pots and shellsides of the filters should be drained. This step is prototypic. Completed.

15. Fill UFP-VSL-T02A with 207 gallons of 2-M nitric acid. This step is prototypic. Filled with 229 gallons. 
16. Take stable level measurement. This step is not prototypic. The stable tank level should be approximately 49 inches. Level at $\mathbf{5 4 . 1}$ inches.

17. A second nitric acid wash will begin. Recirculate the nitric acid at $70 \mathrm{gpm}$, with all five permeate valves open and recycled to UFP-VSL-T02A for 1.5 hours. This step is prototypic. (Note: A third nitric acid step may be needed after looking at the permeate flow rates during the first two nitric acid steps.) During this step, the permeate rates should be monitored. Each filter should be backpulsed as soon as filtration begins (when the pulse-pot level is $>10$ inches) and at $0.5,1$, and 1.5 hours. Take a 5 -gallon sample near the end of 1.5 hours from the filter-loop to determine nitric acid concentration and UDS, and complete the possible precipitation study. The recirculation rate was 100 to $110 \mathrm{gpm}$, and a sample was obtained.

18. Close the permeate valves and turn off pumps. This step is prototypic.

19. Isolate UFP-VSL-T02A by closing V06132. This step is non-prototypic.

20. Take stable level measurement. This step is non-prototypic. The difference in stable level measurements between steps 20 and 24 should equal the volume drained during step 5. Level 18.4 inches (69 gallons).

21. Drain UFP-VSL-T02A (leaving the same volume in the tank as was left in Step 6) and drain the filter-loop. The pulse-pots and shellsides of the filters should be drained. The contents can be drained to UFP-VSL-T62A or B. This step is prototypic.

22. Fill UFP-VSL-T02A with 207 gallons of 2-M nitric acid. This step is prototypic. Added 219 gals--level was 52 inches.

23. Take stable level measurement. This step is not prototypic. The stable tank level should be approximately 49 inches.

24. A third nitric acid wash will begin. Recirculate the nitric acid at $70 \mathrm{gpm}$, with all five permeate valves open and recycled to UFP-VSL-T02A for 1.5 hours. This step is prototypic. During this step, the permeate rates should be monitored. Each filter should be backpulsed as soon as filtration begins (when the pulse-pot level is $>10$ inches) and at $0.5,1$, and 1.5 hours. Take a 5-gal sample near the end of 1.5 hours from the filter-loop to determine the nitric acid concentration and UDS, and complete the possible precipitation study. Recirculated solution at $\sim \mathbf{1 0 9} \mathbf{~ g p m}$, and samples were taken.

25. Close the permeate valves, and turn off the pumps. This step is prototypic.

26. Isolate UFP-VSL-T02A by closing V06132. This step is non-prototypic.

27. Take stable level measurement. This step is non-prototypic. Tank T02A level was 17.4 inches (64 gallons).

28. Drain UFP-VSL-T02A (leaving the same volume in the tank as was left in Step 6, and drain the filter-loop. The pulse-pots and shellsides of the filters should be drained. The contents can be drained to UFP-VSL-T62A or B. This step is prototypic. Completed.

29. Fill UFP-VSL-T02A with 173 gallons of IW and 34 gallons of 2-M sodium hydroxide. This step is prototypic. Completed-Tank T02A level was 51.4 inches (217 gallons).

30. Recirculate the contents at $70 \mathrm{gpm}$, with all five permeate valves open and aligned to UFP-VSL-T02A, for 1 hour. This step is prototypic. During this step, the permeate rates should be monitored. Do not backpulse. Sample the permeate every 10 minutes, test, and record the $\mathrm{pH}$ using $\mathrm{pH}$ paper. Take a sample from the filer-loop and each of the permeate sample ports at the end to determine the $\mathrm{pH}$ and the UDS. The $\mathrm{pH}$ target is to be greater than 12 . Recirculated solution at $\sim 109 \mathrm{gpm}$, and samples were taken. The pH started out at 13, but decreased to 2 in 40 minutes. 
An additional $50 \mathrm{~kg}$ of 2-M NaOH was added to the tank, and the $\mathrm{pH}$ was $>12$. The sample results of the filter cleaning are provided in Table 4.1.

31. Close the permeate valves, and turn off the pump. Leave the filter-loop full and wetted.

32. Isolate vessel UFP-VSL-T02A (close V06132), and drain the Tank T02A vessel to UFP-VSL-T62A or B. The SLM was 16.2 inches before draining.

33. Inspect the vessel, and take a video of the tank, steam ring, and all internals to determine the effectiveness of cleaning tank internals. Complete. 


\subsection{Data}

Selected data obtained from the DAS during Integrated Test D have been plotted in 12-hour intervals and are provided in Appendix $\mathrm{J}$ tables summarizing the results of sample measurements taken during testing. These data are provided in Section 5.1 (analytical results) and Section 5.2 (physical property results). The analysis of the analytical data is done in the final report Sections 9, 10, 11, and 12 of the PEP Phase 1 Final Test Report, WTP-RPT-197. The PJM peak average velocity and stroke length, tuned iteratively to target values during testing, are provided in Section 5.3.

\subsection{Analytical Data}

This section provides analytical summary tables for key processes. Reporting limits and uncertainties are in the final analytical reports submitted by each analytical laboratory. These reports are identified for each sample in Appendix C, which provides a list of all samples collected, the disposition of each sample, and references to final electronic analytical reports.

In many cases, such as during caustic and oxidative leaching, the slurry samples taken from PEP were analyzed after phase separation was performed. The wet centrifuged solids and the supernatant liquid from the samples were analyzed separately. In other cases, data are presented in a more raw form: the species concentration in the supernatant, the concentration in the wet centrifuged solids, and the masses of the tare sample vial, the vial plus total slurry, and the vial plus wet centrifuged solids or the calculated value of the $\mathrm{wt} \%$ centrifuged solids. The latter three masses can be used to calculate the mass fraction of wet centrifuged solids in the slurry, which in turn can be used in calculating the total species concentration in the slurries of the original samples. See Section A.5 in Appendix A of WTP-RPT-186, Rev. 0 for more information on calculating the species concentration in the slurry.

Table 5.1 and Table 5.2 provide the wt $\%$ UDS for slurry samples collected during the concentration of the first and second batch of slurry (respectively) before caustic leaching in Tank T02A. The wt $\%$ wet centrifuged solids in the slurry can be used in calculating the total species concentration in the slurries of the original samples. See Section A.5 in Appendix A of WTP-RPT-186, Rev. 0 for more information on calculating the species concentration in the slurry. An aliquot of the wet centrifuged solids was dried at $105^{\circ} \mathrm{C}$ to determine the percent solids that are reported with the reported analytes in the wet centrifuged solids.

Table 5.3, Batch 1: Leach, and Table 5.4, Batch 2: Leach, respectively, provide analytical results for samples collected during the Batch 1 and Batch 2 caustic leach in Tank T02A. The slurry density results were performed on intact slurry submitted to the analytical laboratory. The wt $\%$ UDS, aluminum, and strontium slurry concentrations were calculated from samples phase-separated at PDL-W. The liquid analysis results are analytical results obtained from the phase-separated supernatants. The wt $\%$ wet centrifuged solids in the slurry can be used in calculating the total species concentration in the slurries of the original samples. See Section A.5 in Appendix A of WTP-RPT-186, Rev. 0 for more information on calculating the species concentration in the slurry. An aliquot of the wet centrifuged solids was dried at $105^{\circ} \mathrm{C}$ to determine the percent solids that are reported with the reported analytes in the wet centrifuged solids. 
Raman results, shown in Table 5.5 and Table 5.6, are provided as part of the liquid analyses and presented in molar concentration (mole/liter).

Table 5.1. Caustic-Leach Batch 1: Initial Solids Concentration to $20-w t \%$

\begin{tabular}{|c|c|c|c|}
\hline $\begin{array}{l}\text { Sample Location: Filter-Loop Condition: } \\
\text { CD Pump Repair }\end{array}$ & wt $\%$ UDS (slurry) & Cr in liquid $(\mu \mathrm{g} / \mathrm{g})$ & $\begin{array}{c}\text { Cr in Wet } \\
\text { Centrifuged Solids } \\
(\mu \mathrm{g} / \mathrm{g})\end{array}$ \\
\hline Transfer to Tank T01B & 5.00 & - & $5493^{(b)}$ \\
\hline Prior to Concentration & 6.69 & - & - \\
\hline After Batch 3 & 6.41 & - & - \\
\hline After Batch 6 & 6.98 & - & - \\
\hline After Batch 9 & 7.78 & - & - \\
\hline After Batch 12 & 8.81 & - & - \\
\hline After Batch 15 & 9.23 & - & - \\
\hline After Batch 18 & 9.88 & - & - \\
\hline After Batch 21 & 10.7 & - & - \\
\hline After Batch 24 & 11.5 & - & - \\
\hline After Batch 27 & 12.2 & - & - \\
\hline After Batch 30 & 13.0 & - & - \\
\hline After Batch 33 & 13.7 & - & - \\
\hline After Batch 36 & 14.5 & - & - \\
\hline After Batch 39 & 15.2 & - & - \\
\hline After Batch 42 & 16.0 & - & - \\
\hline After Batch 45 & 16.7 & - & - \\
\hline After Concentration $^{(a)}$ & 23.4 & 43.6 & $8307^{(c)}$ \\
\hline After Caustic Addition and Filter Flush & 8.00 & 566 & $4770^{(d)}$ \\
\hline \multicolumn{4}{|c|}{$\begin{array}{l}\text { (a) Analytical results duplicated in Analysis at Key Process Steps table in column Post Concentration of } \\
\text { (b) The } w t \% \text { centrifuged solids value for this step is } 14.8 \% \text {. } \\
\text { (c) The } w t \% \text { centrifuged solids value for this step found in Analysis at Key Process Steps table in colum } \\
\text { Solid Batch \#1. } \\
\text { (d) The } w t \% \text { centrifuged solids value for this step found in Batch 1: Caustic Leach in row after NaOH. } \\
\text { - Analysis not required by Test Plan. } \\
\text { Bold numbers are calculated values. }\end{array}$} \\
\hline
\end{tabular}


Table 5.2. Caustic-Leach Batch 2: Initial Solids Concentration to $20-w t \%$

\begin{tabular}{|c|c|c|c|}
\hline $\begin{array}{l}\text { Sample Location: Filter-Loop } \\
\text { Condition: CD Pump Repair }\end{array}$ & wt $\%$ UDS (slurry) & $\mathrm{Cr}$ in liquid $(\mu \mathrm{g} / \mathrm{g})$ & $\begin{array}{c}\text { Cr in Wet Centrifuged } \\
\text { Solids }(\mu \mathrm{g} / \mathrm{g})\end{array}$ \\
\hline Transfer to Tank T01B & 5.21 & - & $5040^{(b)}$ \\
\hline Prior to Concentration & 6.35 & - & - \\
\hline After Batch 3 & 6.44 & - & - \\
\hline After Batch 6 & 7.44 & - & - \\
\hline After Batch 9 & 8.60 & - & - \\
\hline After Batch 12 & 8.58 & - & - \\
\hline After Batch 15 & 9.16 & - & - \\
\hline After Batch 18 & 9.99 & - & - \\
\hline After Batch 21 & 10.40 & - & - \\
\hline After Batch 24 & 11.40 & - & - \\
\hline After Batch 27 & 12.30 & - & - \\
\hline After Batch 30 & 13.00 & - & - \\
\hline After Batch 33 & 13.60 & - & - \\
\hline After Batch 36 & 14.70 & - & - \\
\hline After Batch 39 & 15.20 & - & - \\
\hline After Batch 42 & 15.40 & - & - \\
\hline After Batch 45 & 16.30 & - & - \\
\hline After Concentration $^{(a)}$ & 23.83 & 46.9 & $7240^{(\mathrm{c})}$ \\
\hline $\begin{array}{c}\text { After Caustic Addition and } \\
\text { Filter Flush } \\
\end{array}$ & 6.63 & 179 & $4320^{(d)}$ \\
\hline \multicolumn{4}{|c|}{$\begin{array}{l}\text { (a) Analytical results duplicated in Analysis at Key Process Steps table in column Post Concentration of Solid Batch \#2. } \\
\text { (b) The } w t \% \text { centrifuged solids value for this step is } 15.3 \% \text {. } \\
\text { (c) The } w t \% \text { centrifuged solids value for this step found in Analysis at Key Process Steps table in column Post Concentration of } \\
\text { Solid Batch } \# 2 \text {. } \\
\text { (d) The } w t \% \text { centrifuged solids value for this step found in Batch 2: Caustic Leach in row After NaOH. } \\
\text { - Analysis not required by Test Plan. } \\
\text { Bold numbers are calculated values. }\end{array}$} \\
\hline
\end{tabular}


Table 5.3. Batch 1: Caustic-Leach ${ }^{(a)}$

\begin{tabular}{|c|c|c|c|c|c|c|c|c|c|c|c|c|c|c|}
\hline \multirow{2}{*}{$\begin{array}{c}\text { Sample } \\
\text { Location: } \\
\text { Tank } \\
\text { T02A, } \\
\text { Condition: } \\
\end{array}$} & \multicolumn{5}{|c|}{ Slurry Analyses } & \multicolumn{9}{|c|}{ Liquid Analyses } \\
\hline & $\begin{array}{l}\text { UDS } \\
\text { wt } \% \\
\end{array}$ & $\begin{array}{c}\text { Slurry } \\
\text { Density } \\
\text { g/mL }\end{array}$ & $\begin{array}{cc}\mathrm{Al} & \mathrm{Fe} \\
\mu \mathrm{g} / \mathrm{g} & \mu \mathrm{g} / \mathrm{g} \\
\end{array}$ & $\begin{array}{c}\mathrm{Sr} \\
\mu \mathrm{g} / \mathrm{g} \\
\end{array}$ & $\begin{array}{c}\text { Wt-\% } \\
\text { Cent } \\
\text { Solids } \\
\text { wt } \% \\
\end{array}$ & \begin{tabular}{|c} 
Liquid \\
Density \\
$\mathrm{g} / \mathrm{mL}$
\end{tabular} & $\begin{array}{c}\mathrm{Al} \\
\mu \mathrm{g} / \mathrm{g}\end{array}$ & $\begin{array}{c}\mathrm{Cr} \\
\mu \mathrm{g} / \mathrm{g} \\
\end{array}$ & $\begin{array}{c}\text { Free } \\
\mathrm{OH}^{-} \\
\mathrm{M} \\
\end{array}$ & $\begin{array}{l}\mathrm{C}_{2} \mathrm{O}_{4} \\
\mu \mathrm{g} / \mathrm{g}\end{array}$ & $\begin{array}{c}\mathrm{Cl}^{-} \\
\mu \mathrm{g} / \mathrm{g}\end{array}$ & $\begin{array}{l}\mathrm{NO}_{3} \\
\mu \mathrm{g} / \mathrm{g}\end{array}$ & $\begin{array}{l}\mathrm{NO}_{2} \\
\mu \mathrm{g} / \mathrm{g}\end{array}$ & $\begin{array}{r}\mathrm{SO}_{4} \\
\mu \mathrm{g} / \mathrm{g}\end{array}$ \\
\hline $\begin{array}{c}\text { After } \\
\mathrm{NaOH}\end{array}$ & 8.00 & 1.468 & 319139485 & 91 & 23.83 & 1.383 & 13800 & 566 & 8.78 & $<19.0$ & 434 & 37200 & 8780 & 800 \\
\hline $75^{\circ} \mathrm{C}$ & 7.76 & 1.450 & - & - & 23.45 & 1.391 & 12500 & 557 & 8.37 & 21.8 & 422 & 35900 & 8450 & 1440 \\
\hline $\begin{array}{l}85^{\circ} \mathrm{C}- \\
\text { hour } 0\end{array}$ & 7.07 & 1.439 & 295998950 & 86 & 22.66 & 1.372 & 11933 & 617 & 8.03 & 30.2 & 403 & 34600 & 8113 & 2403 \\
\hline $\begin{array}{l}85^{\circ} \mathrm{C}- \\
\text { hour } 1\end{array}$ & 6.63 & 1.436 & - & - & 22.74 & 1.377 & 12300 & 742 & 7.83 & 27.4 & 403 & 34300 & 8110 & 2570 \\
\hline $\begin{array}{l}85^{\circ} \mathrm{C}- \\
\text { hour } 2\end{array}$ & 6.82 & 1.435 & - & - & 21.88 & 1.377 & 12500 & 825 & 7.81 & 28.6 & 394 & 34000 & 8030 & 2700 \\
\hline $\begin{array}{l}85^{\circ} \mathrm{C}- \\
\text { hour } 4\end{array}$ & 6.79 & 1.434 & 290258969 & 85 & 21.30 & 1.378 & 12600 & 976 & 7.48 & 30.5 & 403 & 33900 & 8060 & 3080 \\
\hline $\begin{array}{l}85^{\circ} \mathrm{C}- \\
\text { hour } 8\end{array}$ & 6.32 & 1.428 & 290648758 & 83 & 19.64 & 1.373 & 13100 & 1220 & 7.56 & 37.0 & 391 & 32600 & 7650 & 3680 \\
\hline $\begin{array}{l}85^{\circ} \mathrm{C}- \\
\text { hour } 10\end{array}$ & 6.06 & 1.422 & - & - & 18.79 & 360 & 13300 & 1300 & 7.38 & 29.5 & 389 & 32900 & 7710 & 4030 \\
\hline $\begin{array}{l}85^{\circ} \mathrm{C}- \\
\text { hour } 12\end{array}$ & 5.85 & .405 & 279478507 & 80 & 18.74 & 366 & 13800 & 1390 & 7.12 & 37.5 & 381 & 32300 & 7630 & 4430 \\
\hline $\begin{array}{l}85^{\circ} \mathrm{C}- \\
\text { hour } 14\end{array}$ & 5.54 & 1.402 & - & - & 17.61 & 1.364 & 12500 & 1270 & 6.81 & 30.5 & 372 & 31300 & 7420 & 5110 \\
\hline $\begin{array}{l}85^{\circ} \mathrm{C}- \\
\text { hour } 16\end{array}$ & 5.61 & 1.398 & 270578415 & 78 & 16.80 & 1.362 & 13200 & 1360 & 7.30 & 33.3 & 376 & 31500 & 7400 & 5460 \\
\hline $\begin{array}{l}85^{\circ} \mathrm{C}- \\
\text { hour } 18\end{array}$ & 5.18 & 1.406 & - & - & 16.95 & 1.355 & 13500 & 1350 & 7.04 & 34.2 & 363 & 31000 & 7320 & 5820 \\
\hline $\begin{array}{l}85^{\circ} \mathrm{C}- \\
\text { hour } 20\end{array}$ & 4.98 & 1.400 & - & - & 16.29 & 349 & 13800 & 1350 & 6.79 & 32.4 & 358 & 30500 & 7200 & 6200 \\
\hline $\begin{array}{l}85^{\circ} \mathrm{C}- \\
\text { hour } 22\end{array}$ & 5.09 & 1.404 & - & - & 16.50 & 359 & 13900 & 1340 & 6.75 & 33.3 & 363 & 30600 & 7200 & 6330 \\
\hline $\begin{array}{l}85^{\circ} \mathrm{C}- \\
\text { hour } 24\end{array}$ & 5.03 & 1.394 & 265058007 & 75 & 15.55 & 1.356 & 14067 & 1347 & 6.84 & 34.2 & 358 & 30267 & 7120 & 6253 \\
\hline $\begin{array}{c}\text { After cool } \\
\text { down } \\
\text { to } 25^{\circ} \\
\end{array}$ & 5.02 & 1.402 & 278058358 & 79 & 15.09 & 1.357 & 14800 & 1400 & 6.78 & 31.0 & 374 & 30900 & 7290 & 6040 \\
\hline ) $\mathrm{Ca}, \mathrm{Mg}$, & & ite & ded in this & & $00 t$ & 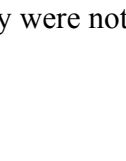 & cod in & & & & & 1 & & \\
\hline
\end{tabular}


Table 5.3 (contd)

\begin{tabular}{|c|c|c|c|c|c|c|}
\hline \multirow[b]{2}{*}{$\begin{array}{c}\text { Sample Location: } \\
\text { Tank T02A, } \\
\text { Condition: }\end{array}$} & \multicolumn{6}{|c|}{ Wet Centrifuged Solids Analyses } \\
\hline & $\begin{array}{c}\mathrm{Al} \\
\mu \mathrm{g} / \mathrm{g}\end{array}$ & $\begin{array}{c}\mathrm{Cr} \\
\mu \mathrm{g} / \mathrm{g}\end{array}$ & $\begin{array}{c}\mathrm{Fe} \\
\mu \mathrm{g} / \mathrm{g}\end{array}$ & $\begin{array}{c}\mathrm{Na} \\
\mu \mathrm{g} / \mathrm{g}\end{array}$ & $\begin{array}{c}\mathrm{Sr} \\
\mu \mathrm{g} / \mathrm{g}\end{array}$ & $\begin{array}{c}\text { Solids } \\
\text { Content } \\
\%\end{array}$ \\
\hline After $\mathrm{NaOH}$ & 89800 & 4770 & 39800 & 157000 & 380 & 62.79 \\
\hline $75^{\circ} \mathrm{C}$ & - & - & - & - & - & - \\
\hline $85^{\circ} \mathrm{C}-$ hour 0 & 89900 & 4283 & 39500 & 144333 & 377 & 63.64 \\
\hline $85^{\circ} \mathrm{C}-$ hour 1 & - & - & - & - & - & - \\
\hline $85^{\circ} \mathrm{C}-$ hour 2 & - & - & - & - & - & - \\
\hline $85^{\circ} \mathrm{C}-$ hour 4 & 89700 & 3210 & 42100 & 133000 & 398 & 64.94 \\
\hline $85^{\circ} \mathrm{C}-$ hour 8 & 94400 & 2210 & 44600 & 137000 & 422 & 60.73 \\
\hline $85^{\circ} \mathrm{C}-$ hour 10 & - & - & - & - & - & - \\
\hline $85^{\circ} \mathrm{C}-$ hour 12 & 89300 & 1460 & 45400 & 126000 & 427 & 61.92 \\
\hline $85^{\circ} \mathrm{C}$ - hour 14 & - & - & - & - & - & - \\
\hline $85^{\circ} \mathrm{C}-$ hour 16 & 95700 & 1170 & 50100 & 114000 & 465 & 60.82 \\
\hline $85^{\circ} \mathrm{C}-$ hour 18 & - & - & - & - & - & - \\
\hline $85^{\circ} \mathrm{C}-$ hour 20 & - & - & - & - & - & - \\
\hline $85^{\circ} \mathrm{C}-$ hour 22 & - & - & - & - & - & - \\
\hline $85^{\circ} \mathrm{C}-$ hour 24 & 94067 & 1087 & 51500 & 119667 & 485 & 57.92 \\
\hline $\begin{array}{l}\text { After cool down to } \\
25^{\circ}\end{array}$ & 101000 & 1120 & 55400 & 115000 & 524 & 59.26 \\
\hline
\end{tabular}

(a) $\mathrm{Ca}, \mathrm{Mg}$, and $\mathrm{Nd}$ are not provided in this table because they were not used in the caustic-leach data analysis.

- Analysis not required by Test Plan.

Bold numbers are calculated values.

M-Molarity. 
Table 5.4. Batch 2: Caustic-Leach ${ }^{(\mathrm{a})}$

\begin{tabular}{|c|c|c|c|c|c|c|c|c|c|c|c|c|c|c|c|}
\hline \multirow[b]{2}{*}{$\begin{array}{c}\text { Sample } \\
\text { Location: } \\
\text { Tank } \\
\text { T02A, } \\
\text { Condition: }\end{array}$} & \multicolumn{6}{|c|}{ Slurry Analyses } & \multicolumn{9}{|c|}{ Liquid Analyses } \\
\hline & $\begin{array}{l}\text { UDS } \\
\text { wt } \% \\
\end{array}$ & $\begin{array}{c}\text { Slurry } \\
\text { Density } \\
\mathrm{g} / \mathrm{mL}\end{array}$ & $\begin{array}{c}\mathrm{Al} \\
\mu \mathrm{g} / \mathrm{g}\end{array}$ & $\begin{array}{r}\mathrm{Fe} \\
\mu \mathrm{g} / \mathrm{g}\end{array}$ & $\begin{array}{r}\mathrm{Sr} \\
\mu \mathrm{g} / \mathrm{g} \\
\end{array}$ & $\begin{array}{c}\text { Wt-\% } \\
\text { Cent } \\
\text { Solids } \\
\text { wt } \% \\
\end{array}$ & $\begin{array}{c}\text { Liquid } \\
\text { Density } \\
\mathrm{g} / \mathrm{mL}\end{array}$ & $\begin{array}{c}\mathrm{Al} \\
\mu \mathrm{g} / \mathrm{g}\end{array}$ & $\begin{array}{c}\mathrm{Cr} \\
\mu \mathrm{g} / \mathrm{g}\end{array}$ & $\begin{array}{c}\text { Free } \\
\mathrm{OH}^{-} \\
\mathrm{M} \\
\end{array}$ & $\begin{array}{l}\mathrm{C}_{2} \mathrm{O}_{4} \\
\mu \mathrm{g} / \mathrm{g} \\
\end{array}$ & $\begin{array}{r}\mathrm{Cl}^{-} \\
\mu \mathrm{g} / \mathrm{g}\end{array}$ & $\begin{array}{l}\mathrm{NO}_{3} \\
\mu \mathrm{g} / \mathrm{g}\end{array}$ & $\begin{array}{l}\mathrm{NO}_{2} \\
\mu \mathrm{g} / \mathrm{g} \\
\end{array}$ & $\begin{array}{l}\mathrm{SO}_{4} \\
\mu \mathrm{g} / \mathrm{g} \\
\end{array}$ \\
\hline $\begin{array}{c}\text { After } \\
\mathrm{NaOH}\end{array}$ & 6.63 & 1.489 & 30289 & 8864 & 83 & 32.12 & 1.418 & 12400 & 179 & 9.64 & 26.6 & 366 & 31200 & 7340 & 1080 \\
\hline $75^{\circ} \mathrm{C}$ & 6.69 & 1.474 & - & - & - & 30.96 & 1.403 & 12900 & 229 & 9.06 & $<19.5$ & 364 & 32000 & 7550 & 1650 \\
\hline $\begin{array}{l}85^{\circ} \mathrm{C}- \\
\text { hour } 0\end{array}$ & 6.36 & 1.462 & 30816 & 8920 & 84 & 27.25 & 1.392 & 13367 & 381 & 8.83 & 34.4 & 374 & 31667 & 7430 & 1337 \\
\hline $\begin{array}{l}85^{\circ} \mathrm{C}- \\
\text { hour } 1\end{array}$ & 6.14 & 1.452 & - & - & - & 27.16 & 1.392 & 13600 & 541 & 6.72 & 45.6 & 374 & 31300 & 7330 & 1540 \\
\hline $\begin{array}{l}85^{\circ} \mathrm{C}- \\
\text { hour } 2\end{array}$ & 6.19 & 1.427 & - & - & - & 26.44 & 1.378 & 13600 & 663 & 8.64 & 27.6 & 369 & 31200 & 7340 & 1690 \\
\hline $\begin{array}{l}85^{\circ} \mathrm{C}- \\
\text { hour } 4\end{array}$ & 5.89 & 1.421 & 30888 & 9077 & 86 & 24.40 & 1.377 & 14100 & 957 & 8.45 & 31.6 & 367 & 31100 & 7300 & 1920 \\
\hline $\begin{array}{l}85^{\circ} \mathrm{C}- \\
\text { hour } 8\end{array}$ & 5.76 & .441 & 29001 & 8425 & 80 & 23.47 & 379 & 13300 & 180 & 8.25 & 27.4 & 351 & 30200 & 7140 & 2450 \\
\hline $\begin{array}{l}85^{\circ} \mathrm{C}- \\
\text { hour } 10\end{array}$ & 5.89 & 1.433 & - & - & - & 21.78 & 1.379 & 13600 & 300 & 7.91 & 27.0 & 328 & 28700 & 6790 & 2620 \\
\hline $\begin{array}{l}85^{\circ} \mathrm{C}- \\
\text { hour } 12\end{array}$ & 5.96 & 1.432 & 29083 & 8691 & 82 & 20.99 & 1.380 & 13800 & 1380 & 7.51 & 29.7 & 333 & 28800 & 6780 & 2900 \\
\hline $\begin{array}{l}85^{\circ} \mathrm{C}- \\
\text { hour } 14\end{array}$ & 5.69 & 1.425 & - & - & - & 20.44 & 1.373 & 13900 & 1390 & 7.46 & 26.7 & 327 & 28400 & 6620 & 3140 \\
\hline $\begin{array}{l}85^{\circ} \mathrm{C}- \\
\text { hour } 16\end{array}$ & 5.48 & 1.421 & 28356 & 8245 & 79 & 19.40 & 1.376 & 14000 & 1390 & 7.90 & 28.5 & 315 & 27400 & 6500 & 3460 \\
\hline $\begin{array}{l}85^{\circ} \mathrm{C}- \\
\text { hour } 18\end{array}$ & 5.23 & 1.415 & - & - & - & 19.29 & 1.371 & 14300 & 1400 & 7.56 & 24.4 & 322 & 28400 & 6690 & 3930 \\
\hline $\begin{array}{l}85^{\circ} \mathrm{C}- \\
\text { hour } 20\end{array}$ & 4.90 & .415 & - & - & - & 18.65 & 1.365 & 14200 & 1360 & 7.26 & 33.5 & 308 & 27100 & 6390 & 4120 \\
\hline $\begin{array}{l}85^{\circ} \mathrm{C}- \\
\text { hour } 22\end{array}$ & 4.42 & 1.407 & - & - & - & 18.62 & 1.365 & 14300 & 1350 & 7.31 & 30.2 & 307 & 27100 & 6380 & 4540 \\
\hline $\begin{array}{c}85^{\circ} \mathrm{C}- \\
\text { hour } 24\end{array}$ & 4.74 & 1.399 & 27398 & 8190 & 77 & 17.13 & 1.365 & 14433 & 1337 & 7.64 & 32.1 & 310 & 26733 & 6323 & 5013 \\
\hline $\begin{array}{l}\text { After cool } \\
\text { down } \\
\text { to } 25^{\circ} \\
\end{array}$ & 5.40 & 1.411 & 27947 & 8487 & 79 & 17.04 & 1.360 & 14500 & 1340 & 6.90 & 25.4 & 314 & 27200 & 6340 & 4350 \\
\hline $\begin{array}{l}\text { Id } n \\
-M\end{array}$ & & atec & $\begin{array}{l}\text { ded ir } \\
\text { Plan. } \\
\text { es. }\end{array}$ & & & 0 & & 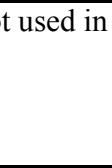 & & & & & 7 & & \\
\hline
\end{tabular}


Table 5.4 (contd)

\begin{tabular}{|c|c|c|c|c|c|c|}
\hline \multirow[b]{2}{*}{$\begin{array}{c}\text { Sample Location: } \\
\text { Tank T02A, } \\
\text { Condition: }\end{array}$} & \multicolumn{6}{|c|}{ Wet Centrifuged Solids Analyses } \\
\hline & $\begin{array}{c}\mathrm{Al} \\
\mu \mathrm{g} / \mathrm{g}\end{array}$ & $\begin{array}{c}\mathrm{Cr} \\
\mu \mathrm{g} / \mathrm{g}\end{array}$ & $\begin{array}{c}\mathrm{Fe} \\
\mu \mathrm{g} / \mathrm{g}\end{array}$ & $\begin{array}{c}\mathrm{Na} \\
\mu \mathrm{g} / \mathrm{g}\end{array}$ & $\begin{array}{c}\mathrm{Sr} \\
\mu \mathrm{g} / \mathrm{g}\end{array}$ & $\begin{array}{c}\text { Solids } \\
\text { Content } \\
\%\end{array}$ \\
\hline After $\mathrm{NaOH}$ & 68100 & 4320 & 27600 & 162000 & 258 & 57.82 \\
\hline $75^{\circ} \mathrm{C}$ & - & - & - & - & - & - \\
\hline $85^{\circ} \mathrm{C}-$ hour 0 & 77400 & 4640 & 32733 & 148667 & 308 & 59.38 \\
\hline $85^{\circ} \mathrm{C}-$ hour 1 & - & - & - & - & - & - \\
\hline $85^{\circ} \mathrm{C}-$ hour 2 & - & - & - & - & - & - \\
\hline $85^{\circ} \mathrm{C}-$ hour 4 & 82900 & 3420 & 37200 & 142000 & 353 & 58.51 \\
\hline $85^{\circ} \mathrm{C}-$ hour 8 & 80200 & 2090 & 35900 & 141000 & 340 & 61.56 \\
\hline $85^{\circ} \mathrm{C}-$ hour 10 & - & - & - & - & - & - \\
\hline $85^{\circ} \mathrm{C}-$ hour 12 & 86600 & 1450 & 41400 & 136000 & 389 & 61.25 \\
\hline $85^{\circ} \mathrm{C}-$ hour 14 & - & - & - & - & - & - \\
\hline $85^{\circ} \mathrm{C}-$ hour 16 & 88000 & 1210 & 42500 & 131000 & 409 & 63.47 \\
\hline $85^{\circ} \mathrm{C}-$ hour 18 & - & - & - & - & - & - \\
\hline $85^{\circ} \mathrm{C}-$ hour 20 & - & - & 一 & - & - & - \\
\hline $85^{\circ} \mathrm{C}-$ hour 22 & - & - & - & - & - & - \\
\hline $85^{\circ} \mathrm{C}-$ hour 24 & 90100 & 1177 & 47800 & 122333 & 450 & 56.83 \\
\hline $\begin{array}{l}\text { After cool down to } \\
25^{\circ}\end{array}$ & 93400 & 1180 & 49800 & 127000 & 462 & 57.77 \\
\hline
\end{tabular}

(a) $\mathrm{Ca}, \mathrm{Mg}$, and $\mathrm{Nd}$ are not provided in this table because they were not used in the caustic-leach data analysis.

- Analysis not required by Test Plan.

Bold numbers are calculated values.

M-Molarity. 
Table 5.5. Batch 1: Caustic Leach—Raman Results

\begin{tabular}{|c|c|c|c|c|c|c|c|c|}
\hline $\begin{array}{c}\text { Sample Location: } \\
\text { Tank T02A, } \\
\text { Condition: }\end{array}$ & $\begin{array}{c}\mathrm{Al}(\mathrm{OH})_{4}{ }^{-} \\
{[\mathrm{M}]}\end{array}$ & $\begin{array}{c}\text { Free OH- } \\
{[\mathrm{M}]} \\
\end{array}$ & $\begin{array}{c}\mathrm{CrO}_{4}^{-2} \\
{[\mathrm{M}]} \\
\end{array}$ & $\begin{array}{c}\mathrm{C}_{2} \mathrm{O}_{4} \\
{[\mathrm{M}]} \\
\end{array}$ & $\begin{array}{l}\mathrm{NO}_{3} \\
{[\mathrm{M}]} \\
\end{array}$ & $\begin{array}{l}\mathrm{NO}_{2} \\
{[\mathrm{M}]} \\
\end{array}$ & $\begin{array}{l}\mathrm{SO}_{4} \\
{[\mathrm{M}]}\end{array}$ & $\begin{array}{l}\mathrm{PO}_{4} \\
{[\mathrm{M}]}\end{array}$ \\
\hline \multirow{3}{*}{$85^{\circ} \mathrm{C}$ - hour 0} & 0.471 & 8.238 & 0.018 & $<0.01$ & 0.774 & 0.273 & 0.033 & $0.036^{(a)}$ \\
\hline & 0.478 & 8.282 & 0.018 & $<0.01$ & 0.782 & 0.270 & 0.033 & $0.034^{(a)}$ \\
\hline & 0.475 & 8.236 & 0.018 & $<0.01$ & 0.784 & 0.264 & 0.034 & $0.039^{(a)}$ \\
\hline $85^{\circ} \mathrm{C}-$ hour 12 & 0.536 & 7.385 & 0.041 & $<0.01$ & 0.724 & 0.239 & 0.062 & $0.031^{(\mathrm{a})}$ \\
\hline $85^{\circ} \mathrm{C}-$ hour 16 & 0.539 & 7.112 & 0.041 & $<0.01$ & 0.695 & 0.244 & 0.074 & $0.026^{(a)}$ \\
\hline \multirow{3}{*}{$85^{\circ} \mathrm{C}$-hour 24} & 0.561 & 6.686 & 0.040 & $<0.01$ & 0.668 & 0.220 & 0.086 & $0.028^{(\mathrm{a})}$ \\
\hline & 0.570 & 6.652 & 0.040 & $<0.01$ & 0.674 & 0.224 & 0.086 & $0.029^{(a)}$ \\
\hline & 0.569 & 6.740 & 0.040 & $<0.01$ & 0.677 & 0.230 & 0.086 & $0.018^{(a)}$ \\
\hline
\end{tabular}

(a) Detected, results are qualitative: results $>$ IDL but $<$ EQL (estimated quantitation limit) M-Molarity.

Table 5.6. Batch 2: Caustic-Leach-Raman Results

\begin{tabular}{|c|c|c|c|c|c|c|c|c|}
\hline $\begin{array}{l}\text { Sample Location: } \\
\text { Tank T02A, } \\
\text { Condition: }\end{array}$ & $\begin{array}{c}\mathrm{Al}(\mathrm{OH})_{4} \\
{[\mathrm{M}]}\end{array}$ & $\begin{array}{c}\text { Free OH- } \\
{[\mathrm{M}]}\end{array}$ & $\begin{array}{c}\mathrm{CrO}_{4}^{-2} \\
{[\mathrm{M}]}\end{array}$ & $\begin{array}{l}\mathrm{C}_{2} \mathrm{O}_{4} \\
{[\mathrm{M}]}\end{array}$ & $\begin{array}{l}\mathrm{NO}_{3} \\
{[\mathrm{M}]}\end{array}$ & $\begin{array}{l}\mathrm{NO}_{2} \\
{[\mathrm{M}]}\end{array}$ & $\begin{array}{l}\mathrm{SO}_{4} \\
{[\mathrm{M}]}\end{array}$ & $\begin{array}{l}\mathrm{PO}_{4} \\
{[\mathrm{M}]}\end{array}$ \\
\hline \multirow{3}{*}{$85^{\circ} \mathrm{C}$ - hour 0} & 0.528 & 9.002 & 0.011 & $<0.01$ & 0.710 & 0.248 & 0.018 & $0.036^{(\mathrm{a})}$ \\
\hline & 0.536 & 9.027 & 0.011 & $<0.01$ & 0.713 & 0.250 & 0.018 & $0.034^{(\mathrm{a})}$ \\
\hline & 0.527 & 9.069 & 0.011 & $<0.01$ & 0.706 & 0.246 & 0.018 & $0.036^{(a)}$ \\
\hline $85^{\circ} \mathrm{C}$-hour 12 & 0.581 & 8.022 & 0.047 & $<0.01$ & 0.661 & 0.220 & 0.041 & $0.033^{(a)}$ \\
\hline $85^{\circ} \mathrm{C}$-hour 16 & 0.595 & 7.694 & 0.047 & $<0.01$ & 0.642 & 0.217 & 0.050 & $0.028^{(\mathrm{a})}$ \\
\hline \multirow{3}{*}{$85^{\circ} \mathrm{C}$-hour 24} & 0.611 & 7.226 & 0.044 & $<0.01$ & 0.608 & 0.203 & 0.070 & $0.028^{(a)}$ \\
\hline & 0.608 & 7.238 & 0.044 & $<0.01$ & 0.604 & 0.197 & 0.070 & $0.029^{(a)}$ \\
\hline & 0.620 & 7.266 & 0.045 & $<0.01$ & 0.617 & 0.192 & 0.071 & $0.032^{(a)}$ \\
\hline
\end{tabular}

(a) Detected, results are qualitative: results $>$ IDL but $<$ EQL (estimated quantitation limit).

M-Molarity.

Table 5.7 provides analytical results for samples collected during solids concentration of the caustic-leached slurry in Tank T02A. This concentration combined the leached solids from Batch 1 and 2 as described in Section 4. The wt $\%$ UDS and densities were obtained following analytical methods described in Section 3 for slurry not phase-separated. The wt $\%$ wet centrifuged solids in the slurry can be used in calculating the total species concentration in the original samples slurry. See Section A.5 in Appendix A of WTP-RPT-186, Rev. 0 for more information on calculating the species concentration in the slurry. An aliquot of the wet centrifuged solids was dried at $105^{\circ} \mathrm{C}$ to determine the percent solids that are reported with the reported analytes in the wet centrifuged solids. 
Table 5.7. Post-Caustic-Leach Concentration of Solids

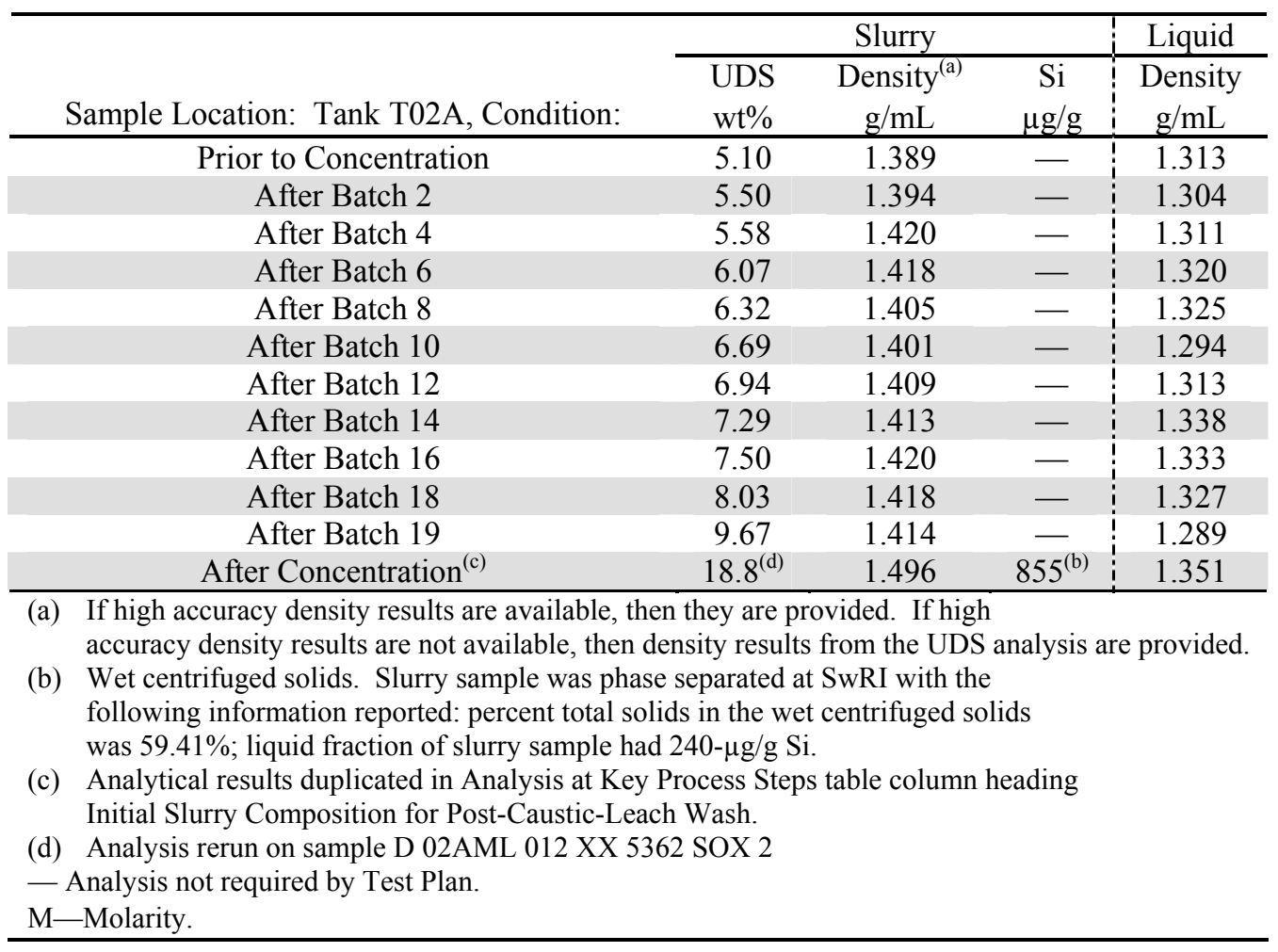

Table 5.8 through Table 5.10 provide analytical results for samples collected during the post-caustic-leach washing in Tank T02A. Two separate slurry samples were collected for the wt $\%$ UDS and slurry density analyses. The supernatant density is a higher accuracy density than can be provided by the UDS analysis. The silicon slurry concentrations were obtained by directed analysis of the slurry. The liquid analysis results are supernatant analytical results obtained from samples phase-separated in PDL-W. An aliquot of the wet centrifuged solids was dried at $105^{\circ} \mathrm{C}$ to determine the percent solids that are reported with the reported analytes in the wet centrifuged solids. Raman results, shown in Table 5.10, are provided as part of the liquid analyses and presented in molar concentration (mole/liter). 
Table 5.8. Post-Caustic-Leach Wash

\begin{tabular}{|c|c|c|c|c|c|c|c|c|c|c|c|c|c|}
\hline \multirow[b]{2}{*}{$\begin{array}{c}\text { Sample } \\
\text { Location: } \\
\text { Tank T02A } \\
\end{array}$} & \multicolumn{2}{|c|}{ Slurry Analyses } & \multicolumn{11}{|c|}{ Liquid Analyses } \\
\hline & $\begin{array}{l}\text { UDS } \\
\mathrm{wt} \%\end{array}$ & $\begin{array}{c}\text { Slurry } \\
\text { Density } \\
\text { (a) } \\
\mathrm{g} / \mathrm{mL}\end{array}$ & \begin{tabular}{|l} 
(a) \\
Density \\
$\mathrm{g} / \mathrm{mL}$
\end{tabular} & $\begin{array}{c}\mathrm{Al} \\
\mu \mathrm{g} / \mathrm{g}\end{array}$ & $\begin{array}{c}\mathrm{Cr} \\
\mu \mathrm{g} / \mathrm{g}\end{array}$ & $\begin{array}{c}\text { Free } \\
\mathrm{OH}^{-} \\
\mathrm{M}\end{array}$ & $\begin{array}{c}\mathrm{Na} \\
\mu \mathrm{g} / \mathrm{g}\end{array}$ & $\begin{array}{l}\mathrm{C}_{2} \mathrm{O}_{4} \\
\mu \mathrm{g} / \mathrm{g}\end{array}$ & $\begin{array}{l}\mathrm{NO}_{3} \\
\mu \mathrm{g} / \mathrm{g}\end{array}$ & $\begin{array}{l}\mathrm{NO}_{2} \\
\mu \mathrm{g} / \mathrm{g}\end{array}$ & $\begin{array}{l}\mathrm{SO}_{4} \\
\mu \mathrm{g} / \mathrm{g}\end{array}$ & $\begin{array}{l}\mathrm{PO}_{4} \\
\mu \mathrm{g} / \mathrm{g}\end{array}$ & $\begin{array}{c}\mathrm{TDS}^{(\mathrm{b})} \\
\mathrm{wt} \%\end{array}$ \\
\hline $\begin{array}{r}\text { After } \\
3\end{array}$ & - & - & 1.287 & 12300 & 1120 & 5.60 & 30000 & 88.1 & 23800 & 5650 & 540 & 1550 & 31.00 \\
\hline $\begin{array}{c}\text { After Wash } \\
6\end{array}$ & 18.3 & 1.390 & 1.239 & 9320 & 883 & .35 & 4000 & 253 & 19000 & 4550 & 280 & 030 & 26.30 \\
\hline $\begin{array}{c}\text { After Wash } \\
8\end{array}$ & - & - & 1.180 & 8950 & 807 & .71 & 93500 & 414 & 16700 & 4020 & 4690 & 2050 & 22.50 \\
\hline $\begin{array}{c}\text { After Wash } \\
11\end{array}$ & 20.5 & 1.309 & 1.176 & 6590 & 627 & 2.92 & 74300 & 805 & 16400 & 3440 & 3750 & 1700 & 19.10 \\
\hline $\begin{array}{c}\text { After Wash } \\
13\end{array}$ & - & - & 1.130 & 6310 & 571 & .51 & 66000 & 1070 & 12600 & 3010 & 3340 & 1510 & 16.20 \\
\hline $\begin{array}{c}\text { After Wash } \\
16\end{array}$ & 2.0 & 1.238 & .123 & 4670 & 450 & 92 & 2000 & 680 & 880 & 320 & 610 & 170 & 3.70 \\
\hline $\begin{array}{r}\text { After } \\
1 S\end{array}$ & - & - & 1.081 & 4170 & 378 & 58 & 43500 & 2320 & 7980 & 1860 & 2140 & 936 & 10.80 \\
\hline $\begin{array}{r}\text { After } \\
22\end{array}$ & 22.5 & 1.240 & 1.076 & 3000 & 293 & 1.22 & 34300 & 3410 & 6150 & 1440 & 1670 & 737 & 9.30 \\
\hline $\begin{array}{r}\text { After } \\
2\end{array}$ & - & - & 1.050 & 2840 & 265 & 04 & 31200 & 4070 & 5320 & 1250 & 1470 & 540 & 8.13 \\
\hline $\begin{array}{r}\text { After } \\
2\end{array}$ & 2.6 & 1.214 & 055 & 990 & 99 & 9 & $\$ 700$ & 440 & 3940 & 948 & 1100 & 461 & 7.00 \\
\hline $\begin{array}{r}\text { After } \\
2\end{array}$ & - & - & 1.033 & 2050 & 81 & 65 & 23000 & 6360 & 3470 & 836 & 077 & 416 & 6.24 \\
\hline $\begin{array}{r}\text { After } \\
3\end{array}$ & 21.8 & 1.199 & 1.042 & 1470 & 140 & .56 & 19100 & 8090 & 2590 & 63 & 747 & 312 & 5.42 \\
\hline $\begin{array}{r}\text { After } \\
3 .\end{array}$ & - & - & 1.020 & 1380 & 20 & 46 & 17700 & 910 & 2120 & 27 & 613 & 254 & 4.98 \\
\hline $\begin{array}{r}\text { After } \\
3\end{array}$ & 2.0 & 1.187 & .069 & 1060 & 5.5 & 36 & 5600 & 200 & 700 & 430 & 495 & 208 & 4.83 \\
\hline $\begin{array}{r}\text { After } \\
4\end{array}$ & - & - & 2 & 1020 & 6.0 & 6 & 00 & 100 & 1500 & 382 & 436 & 84 & 4.49 \\
\hline $\begin{array}{c}\text { After W } \\
43\end{array}$ & 21.3 & 1.165 & 1026 & 718 & 60.1 & 23 & 00 & 100 & 1010 & 27 & 0 & 132 & 4.16 \\
\hline $\begin{array}{c}\text { After Wc } \\
\quad 45\end{array}$ & - & - & 1.016 & 744 & 8.8 & 22 & 13400 & 4500 & 967 & 256 & 279 & 118 & 4.10 \\
\hline $\begin{array}{c}\text { After Wash } \\
48\end{array}$ & 20.5 & 1.176 & 1.017 & 534 & 1.8 & 17 & 9310 & 400 & 71 & 196 & 207 & 94.3 & 3.19 \\
\hline $\begin{array}{c}\text { After Wash } \\
50\end{array}$ & - & - & 1.009 & 格 & 0.9 & .16 & 8470 & 10300 & 0 & ti & 193 & 79.8 & 2.88 \\
\hline $\begin{array}{c}\text { After Final } \\
\text { Wash }^{(\mathrm{c})}\end{array}$ & 22.0 & 1.167 & 1.016 & 397 & 30.2 & 12 & 0 & 6970 & 523 & 11 & 142 & 65.4 & 2.19 \\
\hline $\begin{array}{l}\text { (b) TDS r } \\
\text { phase s } \\
\text { (c) Analyt } \\
\text { Wash } \\
\text { - Analysi }\end{array}$ & sults & duplica & Ana & t & 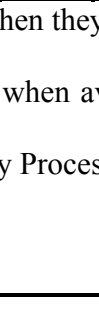 & Stans & le & 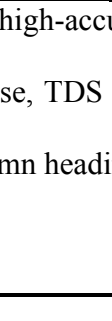 & 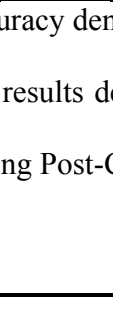 & & 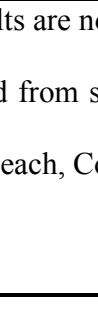 & 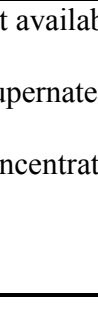 & les \\
\hline
\end{tabular}


Table 5.9. Post-Caustic-Leach Wash-Wet Centrifuged Solids

\begin{tabular}{|c|c|c|c|c|c|c|c|c|c|c|c|c|c|}
\hline \multirow[b]{2}{*}{$\begin{array}{c}\text { Sample } \\
\text { Location: } \\
\text { Tank T02A }\end{array}$} & \multicolumn{2}{|c|}{ Slurry Analyses } & \multicolumn{11}{|c|}{ Wet Centrifuged Solids Analyses } \\
\hline & $\begin{array}{l}\text { UDS } \\
\mathrm{wt} \%\end{array}$ & $\begin{array}{c}\text { Slurry } \\
\text { Density }^{(a)} \\
\text { g/mL }\end{array}$ & $\begin{array}{l}\text { PDMS } \\
\mathrm{mg} / \mathrm{g}\end{array}$ & $\begin{array}{l}\mathrm{PPG} \\
\mathrm{mg} / \mathrm{g}\end{array}$ & $\begin{array}{c}\mathrm{Al} \\
\mu \mathrm{g} / \mathrm{g}\end{array}$ & $\begin{array}{c}\mathrm{Cr} \\
\mu \mathrm{g} / \mathrm{g}\end{array}$ & $\begin{array}{c}\mathrm{Fe} \\
\mu \mathrm{g} / \mathrm{g}\end{array}$ & $\begin{array}{l}\mathrm{Na} \\
\mu \mathrm{g} / \mathrm{g}\end{array}$ & $\begin{array}{c}\mathrm{P} \\
\mu \mathrm{g} / \mathrm{g}\end{array}$ & $\begin{array}{c}\mathrm{S} \\
\mu \mathrm{g} / \mathrm{g}\end{array}$ & $\begin{array}{l}\mathrm{Si}^{(\mathrm{b})} \\
\mu \mathrm{g} / \mathrm{g}\end{array}$ & $\begin{array}{c}\mathrm{Sr} \\
\mu \mathrm{g} / \mathrm{g}\end{array}$ & $\begin{array}{c}\text { Solids } \\
\text { Content } \\
\%\end{array}$ \\
\hline $\begin{array}{l}\text { After Final } \\
\text { Wash }^{(\mathrm{c})}\end{array}$ & 22.0 & 1.167 & $8.8 \mathrm{E}-02$ & 3.0 & 157000 & 504 & 91500 & 11100 & 216 & 60.5 & $\begin{array}{c}\text { wet solid }^{(\mathrm{b})} 1170 ; 50.22 \% \text { solids } \\
\text { liquid }^{(\mathrm{b})} 17.7\end{array}$ & 865 & 56.27 \\
\hline
\end{tabular}

(a) If high-accuracy density results are available, then they are provided. If high-accuracy density results are not available, then density results from the UDS are provided.

(b) Original intact slurry submitted to analytical laboratory, so phase separation was performed at analytical laboratory.

(c) The wt \% centrifuged solids value for this step found in Analysis at Key Process Steps table in column Post-Caustic-Leach, Concentration, and Wash Sample.

Table 5.10. Post-Caustic-Leach Wash-Raman Analysis

\begin{tabular}{|c|c|c|c|c|c|c|c|c|}
\hline $\begin{array}{c}\text { Sample Location: Tank } \\
\text { T02A }\end{array}$ & $\begin{array}{c}\mathrm{Al}(\mathrm{OH})_{4}{ }^{-} \\
{[\mathrm{M}]}\end{array}$ & $\begin{array}{c}\text { Free OH- } \\
{[\mathrm{M}]}\end{array}$ & $\begin{array}{c}\mathrm{CrO}_{4}^{-2} \\
{[\mathrm{M}]} \\
\end{array}$ & $\begin{array}{l}\mathrm{C}_{2} \mathrm{O}_{4} \\
{[\mathrm{M}]} \\
\end{array}$ & $\begin{array}{l}\mathrm{NO}_{3} \\
{[\mathrm{M}]} \\
\end{array}$ & $\begin{array}{l}\mathrm{NO}_{2} \\
{[\mathrm{M}]}\end{array}$ & $\begin{array}{l}\mathrm{SO}_{4} \\
{[\mathrm{M}]}\end{array}$ & $\begin{array}{l}\mathrm{PO}_{4} \\
{[\mathrm{M}]}\end{array}$ \\
\hline After Wash 3 & 0.499 & 5.728 & 0.031 & $<0.01$ & 0.504 & 0.152 & 0.085 & $0.012^{\text {(a) }}$ \\
\hline After Wash 27 & 0.074 & 0.900 & $0.004^{(\mathrm{a})}$ & $0.052^{\text {(a) }}$ & 0.076 & $0.036^{(a)}$ & $0.013^{(\mathrm{a})}$ & $<0.01$ \\
\hline After Wash 50 & $0.016^{(\mathrm{a})}$ & $0.229^{(a)}$ & $<0.001$ & 0.104 & 0.021 & $<0.03$ & $0.003^{(a)}$ & $<0.01$ \\
\hline
\end{tabular}

Table 5.11 and Table 5.12 provide analytical results for samples collected during the oxidative leaching in Tank T02A. The slurry density results and silicon slurry concentrations were performed on intact slurry submitted to the analytical laboratory. The wt\% UDS were calculated from samples phase-separated at PDL-W. The liquid analyses results are supernatant analytical results obtained from samples phase-separated at PDL-W. The solids analyses results are analytical results of rinsed solids obtained from sample phase separation and rinsing at PDL-W. The wet centrifuged solids were immediately rinsed after phase separation to remove the remaining supernatant from the wet solids in an attempt to interrupt further reaction. The rinsate results are analytical results of composited rinse solutions used during the rinsing of phase-separated solids. An aliquot of the wet centrifuged solids was dried at $105^{\circ} \mathrm{C}$ to determine the percent solids that are reported with the reported analytes in the wet centrifuged solids. Raman results, shown in Table 5.12, are provided as part of the liquid analyses and presented in molar concentration (mole/liter). 
Table 5.11. Oxidative-Leach

\begin{tabular}{|c|c|c|c|c|c|c|c|c|c|c|c|c|c|c|c|c|}
\hline \multirow[b]{2}{*}{$\begin{array}{l}\text { Sample Location: Tank } \\
\text { T02A, Condition: }\end{array}$} & \multicolumn{2}{|c|}{ Slurry Analyses } & \multicolumn{14}{|c|}{ Liquid Analyses } \\
\hline & $\begin{array}{l}\text { UDS } \\
\mathrm{wt} \%\end{array}$ & $\begin{array}{c}\text { Slurry } \\
\text { Density }^{(a)} \\
\text { g/mL }\end{array}$ & \begin{tabular}{|c} 
Liquid \\
Density $^{(a)}$ \\
$\mathrm{g} / \mathrm{mL}$
\end{tabular} & $\begin{array}{c}\mathrm{Al} \\
\mu \mathrm{g} / \mathrm{g}\end{array}$ & $\begin{array}{c}\mathrm{Al} \\
\text { (rinsate) } \\
\mu \mathrm{g} / \mathrm{g}\end{array}$ & $\begin{array}{c}\text { Free } \\
\mathrm{OH}^{-} \\
\mathrm{M}\end{array}$ & $\begin{array}{c}\mathrm{Cr} \\
\mu \mathrm{g} / \mathrm{g}\end{array}$ & $\begin{array}{c}\mathrm{Cr} \\
\text { (rinsate) } \\
\mu \mathrm{g} / \mathrm{g}\end{array}$ & $\begin{array}{c}\mathrm{Si} \\
\mu \mathrm{g} / \mathrm{g}\end{array}$ & $\begin{array}{c}\mathrm{PDMS} \\
\mathrm{mg} / \mathrm{g}\end{array}$ & $\begin{array}{l}\mathrm{PPG} \\
\mathrm{mg} / \mathrm{g}\end{array}$ & $\begin{array}{l}\mathrm{C}_{2} \mathrm{O}_{4} \\
\mu \mathrm{g} / \mathrm{g}\end{array}$ & $\begin{array}{c}\mathrm{Cl}^{-} \\
\mu \mathrm{g} / \mathrm{g}\end{array}$ & $\begin{array}{l}\mathrm{NO}_{3} \\
\mu \mathrm{g} / \mathrm{g}\end{array}$ & $\begin{array}{l}\mathrm{NO}_{2} \\
\mu \mathrm{g} / \mathrm{g}\end{array}$ & $\begin{array}{l}\mathrm{SO}_{4} \\
\mu \mathrm{g} / \mathrm{g}\end{array}$ \\
\hline Before $\mathrm{MnO}_{4}$ Addition ${ }^{(\mathrm{e})}$ & 22.0 & 1.173 & 1.017 & 354 & 132 & 0.12 & 27.6 & 7.60 & 17.7 & $\mathrm{n} / \mathrm{d}^{(\mathrm{b})}$ & $\begin{array}{c}\text { SX } \\
\text { Failed }\end{array}$ & 7050 & $\mathbf{n} / \mathbf{d}$ & 514 & 150 & 142 \\
\hline After $\mathrm{MnO}_{4}$ Addition- $\mathrm{Hr} 0$ & 20.7 & 1.165 & 1.022 & 473 & - & 0.12 & 135 & - & - & - & - & 7830 & $<19.3$ & 809 & 116 & 258 \\
\hline After $\mathrm{MnO}_{4}$ Addition- $\mathrm{Hr} 1$ & 20.9 & 1.165 & 1.025 & 454 & - & 0.15 & 164 & - & - & - & - & 7820 & $<19.9$ & 748 & 197 & 254 \\
\hline After $\mathrm{MnO}_{4}$ Addition- $\mathrm{Hr} 2$ & 21.0 & 1.165 & 1.021 & 452 & - & 0.14 & 177 & - & - & - & - & 7940 & $<19.9$ & 782 & 205 & 269 \\
\hline After $\mathrm{MnO}_{4}$ Addition- $\mathrm{Hr} 3$ & 21.0 & 1.167 & 1.020 & 466 & - & 0.15 & 186 & - & - & - & - & 7850 & $<20.0$ & 813 & 212 & 267 \\
\hline After $\mathrm{MnO}_{4}$ Addition- $\mathrm{Hr} 4$ & 21.1 & 1.171 & 1.028 & 473 & - & 0.15 & 196 & - & - & - & - & 7870 & $<19.8$ & 807 & 211 & 268 \\
\hline After $\mathrm{MnO}_{4}$ Addition- $\mathrm{Hr} 5$ & 21.2 & 1.159 & 1.018 & 490 & - & 0.16 & 201 & - & - & - & - & 7900 & $<20.0$ & 830 & 218 & 272 \\
\hline $\begin{array}{c}\text { After } \mathrm{MnO}_{4} \text { Addition-Hr } 6 \\
\text { (Final after } \\
\text { Oxidative-Leach) })^{(\mathrm{f})}\end{array}$ & 21.2 & 1.159 & 1.022 & 506 & 119 & 0.17 & 207 & 40.6 & 12.1 & $\mathrm{n} / \mathrm{d}^{(\mathrm{b})}$ & $\begin{array}{l}\text { SX } \\
\text { Failed }\end{array}$ & 7960 & $<19.9$ & 842 & 222 & 276 \\
\hline
\end{tabular}

(a) If high-accuracy density results are available, then they are provided. If high-accuracy density results are not available, then density results from the UDS are provided.

(b) Single sample non-detect with analysis results below method reporting limit.

(c) Original intact slurry submitted to analytical laboratory, so phase-separation was performed at analytical laboratory.

ur (d) The wt\% centrifuged solids value for this step found in Analysis at Key Process Steps table in column Starting Slurry Composition Before Permanganate Addition.

$\vec{\sim}$ (e) The $w t \%$ centrifuged solids value for this step found in Analysis at Key Process Steps table in column Initial Slurry Composition for Post-Oxidative-Leach Wash

- Analysis not required by Test Plan.

Bold numbers are calculated values.

$\mathrm{n} / \mathrm{d}$ - Triplicate samples with analysis results below method reporting limit.

SX Failed-Analysis failed due to solvent extraction issue.

M-Molarity. 
Table 5.11 (contd)

\begin{tabular}{|c|c|c|c|c|c|c|c|c|}
\hline \multirow[b]{2}{*}{$\begin{array}{l}\text { Sample Location: Tank } \\
\text { T02A, Condition: }\end{array}$} & \multicolumn{8}{|c|}{ Rinsed Wet Centrifuged Solids Analyses } \\
\hline & $\begin{array}{c}\mathrm{Al} \\
\mu \mathrm{g} / \mathrm{g}\end{array}$ & $\begin{array}{c}\mathrm{Cr} \\
\mu \mathrm{g} / \mathrm{g}\end{array}$ & $\begin{array}{c}\mathrm{Fe} \\
\mu \mathrm{g} / \mathrm{g}\end{array}$ & $\begin{array}{c}\mathrm{Na} \\
\mu \mathrm{g} / \mathrm{g}\end{array}$ & $\begin{array}{l}\mathrm{Si} \\
\mu \mathrm{g} / \mathrm{g}\end{array}$ & $\begin{array}{c}\mathrm{Sr} \\
\mu \mathrm{g} / \mathrm{g}\end{array}$ & $\begin{array}{c}\text { PDMS } \\
\mathrm{mg} / \mathrm{g}\end{array}$ & $\begin{array}{l}\mathrm{PPG} \\
\mathrm{mg} / \mathrm{g}\end{array}$ \\
\hline Before $\mathrm{MnO}_{4}$ Addition ${ }^{(\mathrm{d})}$ & 152667 & 503 & 92667 & 8357 & $\begin{array}{l}\text { wet solid }^{(\mathrm{c})} \\
1210 \\
50.29 \% \text { solids } \\
\text { liquid }^{(\mathrm{c})} 17.7\end{array}$ & 859 & 0.13 & 2.4 \\
\hline After $\mathrm{MnO}_{4}$ Addition- $\mathrm{Hr} 0$ & - & - & - & - & - & - & - & - \\
\hline After $\mathrm{MnO}_{4}$ Addition- $\mathrm{Hr} 1$ & - & - & - & - & - & - & - & - \\
\hline After $\mathrm{MnO}_{4}$ Addition- $\mathrm{Hr} 2$ & - & - & - & - & - & - & - & - \\
\hline After $\mathrm{MnO}_{4}$ Addition- $\mathrm{Hr} 3$ & - & - & - & - & - & - & - & - \\
\hline After $\mathrm{MnO}_{4}$ Addition- $\mathrm{Hr} 4$ & - & - & - & - & - & - & - & - \\
\hline After $\mathrm{MnO}_{4}$ Addition- $\mathrm{Hr} 5$ & - & - & - & - & - & - & - & - \\
\hline $\begin{array}{c}\text { After } \mathrm{MnO}_{4} \text { Addition-Hr } 6 \\
\text { (Final after Oxidative- }^{\text {Leach) }}{ }^{(\mathrm{e})}\end{array}$ & 151000 & 297 & 89400 & 10100 & $\begin{array}{c}\text { wet solid } 1250 \\
53.89 \% \text { solids } \\
\text { liquid } 12.1 \\
\end{array}$ & 842 & 0.04 & 1.5 \\
\hline
\end{tabular}

(c) Original intact slurry submitted to analytical lab so phase separation was performed at analytical laboratory.

(d) The weight percent centrifuged solids value for this step found in Analysis at Key Process Steps table in column Starting Slurry Composition Before Permanganate Addition.

(e) The weight percent centrifuged solids value for this step found in Analysis at Key Process Steps table in column Initial Slurry Composition for Post-Oxidative-Leach Wash. - Analysis not required by Test Plan.

Bold numbers are calculated values. 
Table 5.12. Oxidative-Leach—Raman Results

\begin{tabular}{|c|c|c|c|c|c|c|c|c|c|c|}
\hline $\begin{array}{l}\text { Sample Location: Tank T02A, } \\
\text { Condition: }\end{array}$ & $\begin{array}{c}\mathrm{Al}(\mathrm{OH})_{4}{ }^{-} \\
{[\mathrm{M}]}\end{array}$ & $\begin{array}{l}\mathrm{Al}(\mathrm{OH})_{4}^{-} \\
\text {(rinsate) } \\
{[\mathrm{M}]}\end{array}$ & $\begin{array}{c}\text { Free } \mathrm{OH}^{-} \\
{[\mathrm{M}]}\end{array}$ & $\begin{array}{c}\mathrm{CrO}_{4}^{-2} \\
{[\mathrm{M}]}\end{array}$ & $\begin{array}{l}\mathrm{CrO}_{4}^{-2} \\
\text { (rinsate) } \\
{[\mathrm{M}]}\end{array}$ & $\begin{array}{c}\mathrm{C}_{2} \mathrm{O}_{4} \\
{[\mathrm{M}]}\end{array}$ & $\begin{array}{l}\mathrm{NO}_{3} \\
{[\mathrm{M}]}\end{array}$ & $\begin{array}{l}\mathrm{NO}_{2} \\
{[\mathrm{M}]}\end{array}$ & $\begin{array}{l}\mathrm{SO}_{4} \\
{[\mathrm{M}]}\end{array}$ & $\begin{array}{l}\mathrm{PO}_{4} \\
{[\mathrm{M}]}\end{array}$ \\
\hline \multirow{3}{*}{ Before $\mathrm{MnO}_{4}$ Addition } & $<0.01$ & $<0.01$ & $0.203^{(a)}$ & $<0.001$ & $<0.001$ & 0.078 & $0.019^{(\mathrm{a})}$ & $0.025^{(\mathrm{a})}$ & $0.002^{(\mathrm{a})}$ & $<0.01$ \\
\hline & $<0.01$ & $<0.01$ & $0.191^{(\mathrm{a})}$ & $<0.001$ & $<0.001$ & 0.076 & $0.019^{(a)}$ & $0.029^{(\mathrm{a})}$ & $0.003^{(\mathrm{a})}$ & $<0.01$ \\
\hline & $<0.01$ & $<0.01$ & $0.163^{(\mathrm{a})}$ & $<0.001$ & $<0.001$ & 0.074 & $0.019^{(\mathrm{a})}$ & $0.026^{(\mathrm{a})}$ & $0.003^{(\mathrm{a})}$ & $<0.01$ \\
\hline After $\mathrm{MnO}_{4}$ Addition- $\mathrm{Hr} 0$ & $<0.01$ & $\overline{-1}$ & $<0.04$ & $<0.001$ & & $0.016^{(\mathrm{a})}$ & 0.128 & $<0.03$ & $<0.001$ & $<0.01$ \\
\hline $\begin{array}{c}\text { After } \mathrm{MnO}_{4} \text { Addition-Hr } 6 \\
\text { (Final after Oxidative-Leach) }\end{array}$ & $0.012^{(\mathrm{a})}$ & $<0.01$ & $0.201^{(\mathrm{a})}$ & $0.002^{\text {(a) }}$ & $<0.001$ & 0.081 & 0.024 & $<0.03$ & $0.004^{(\mathrm{a})}$ & $<0.01$ \\
\hline \multicolumn{11}{|c|}{$\begin{array}{l}\text { (a) Detected, results are qualitative: results }>\text { IDL but }<\text { EQL (estimated quantitation limit). } \\
\text { - Analysis not required by Test Plan. } \\
\text { M-Molarity }\end{array}$} \\
\hline
\end{tabular}

Table 5.13 provides analytical results for samples collected during the post-oxidative-leach washing in Tank T02A. Two separate slurry samples were collected for the weight percent UDS and slurry density. The supernatant density is a higher accuracy density than can be provided by the UDS analysis. The liquid analyses results are supernatant analytical results obtained from samples phase-separated in PDL-W. Raman results, shown in Table 5.14, are provided as part of the liquid analyses and presented in molar concentration (mole/liter). 
Table 5.13. Post-Oxidative-Leach Wash

\begin{tabular}{|c|c|c|c|c|c|c|c|c|c|c|c|c|c|c|}
\hline \multirow[b]{2}{*}{$\begin{array}{c}\text { Sample Location: } \\
\text { Tank T02A, } \\
\text { Condition: }\end{array}$} & \multicolumn{2}{|c|}{ Slurry Analyses } & \multicolumn{12}{|c|}{ Liquid Analyses } \\
\hline & $\begin{array}{l}\text { UDS } \\
\mathrm{wt} \%\end{array}$ & $\begin{array}{c}\text { Slurry } \\
\text { Density }^{(a)} \\
\text { g/mL }\end{array}$ & $\begin{array}{c}\text { Liquid } \\
\text { Density }^{(a)} \\
\text { g/mL }\end{array}$ & $\begin{array}{c}\mathrm{Al} \\
\mu \mathrm{g} / \mathrm{g}\end{array}$ & $\begin{array}{c}\mathrm{Na} \\
\mu \mathrm{g} / \mathrm{g}\end{array}$ & $\begin{array}{c}\mathrm{Cr} \\
\mu \mathrm{g} / \mathrm{g}\end{array}$ & $\begin{array}{c}\mathrm{Sr} \\
\mu \mathrm{g} / \mathrm{g}\end{array}$ & $\begin{array}{c}\text { Free } \\
\mathrm{OH}^{-} \\
\mathrm{M}\end{array}$ & $\begin{array}{l}\mathrm{NO}_{3} \\
\mu \mathrm{g} / \mathrm{g}\end{array}$ & $\begin{array}{l}\mathrm{NO}_{2} \\
\mu \mathrm{g} / \mathrm{g}\end{array}$ & $\begin{array}{c}\mathrm{SO}_{4} \\
\mu \mathrm{g} / \mathrm{g}\end{array}$ & $\begin{array}{c}\mathrm{C}_{2} \mathrm{O}_{4} \\
\mu \mathrm{g} / \mathrm{g}\end{array}$ & $\begin{array}{c}\mathrm{Cl}^{-} \\
\mu \mathrm{g} / \mathrm{g}\end{array}$ & $\begin{array}{c}\mathrm{TDS}^{(\mathrm{b})} \\
\mathrm{wt}^{\mathrm{o}} \%\end{array}$ \\
\hline After Wash 3 & 19.5 & 1.198 & 1.008 & 413 & 7660 & 165 & $<0.124$ & 0.14 & 687 & 190 & 222 & 6120 & $<20.1$ & 2.30 \\
\hline After Wash 6 & - & - & 1.002 & 402 & 7140 & 151 & $<0.124$ & 0.13 & 645 & 181 & 203 & 5500 & $<20.1$ & 2.11 \\
\hline After Wash 9 & 19.5 & 1.171 & 1.031 & 273 & 5000 & 105 & $<0.125$ & 0.09 & 466 & 136 & 138 & 3860 & $<20.3$ & 1.70 \\
\hline After Wash 12 & - & - & 1.000 & 255 & 4590 & 94 & $<0.123$ & 0.09 & 425 & 127 & 123 & 3510 & $<20.6$ & 1.40 \\
\hline After Wash 15 & 19.5 & 1.211 & 1.001 & 193 & 3520 & 71 & $<0.124$ & 0.07 & 336 & 105 & 98.1 & 2610 & $<20.1$ & 1.22 \\
\hline After Wash 18 & - & - & 0.999 & 181 & 3170 & 62 & $<0.124$ & 0.06 & 301 & 98.2 & 92.6 & 2260 & $<20.2$ & 0.931 \\
\hline After Wash 21 & - & - & 0.996 & 130 & 2300 & 44 & $<0.117$ & 0.05 & 231 & 81.6 & 58.7 & 1570 & $<20.3$ & 0.672 \\
\hline After Wash 24 & - & - & 0.990 & 113 & 2020 & 37 & $<0.116$ & 0.05 & 208 & 75.0 & 50.5 & 1310 & $<20.2$ & 0.606 \\
\hline After Wash 27 & 19.3 & 1.181 & 1.001 & 98.0 & 1740 & 31 & $<0.125$ & 0.04 & 182 & 68.1 & 45.2 & 1070 & $<18.7$ & 0.631 \\
\hline After Wash 30 & - & - & 0.994 & 86.7 & 1540 & 26 & $<0.117$ & 0.04 & 174 & 66.5 & 37.2 & 908 & $<19.7$ & 0.503 \\
\hline After Wash 33 & 19.3 & 1.154 & 1.000 & 81.1 & 1460 & 24 & $<0.123$ & 0.04 & 168 & $<64.9$ & 34.9 & 851 & $<19.7$ & 0.426 \\
\hline After Wash 36 & - & - & 1.000 & 68.4 & 1220 & 19 & $<0.115$ & 0.03 & 142 & $<62.3$ & 23.3 & 625 & $<18.9$ & $<0.5$ \\
\hline After Wash 39 & 19.8 & 1.142 & 1.000 & 53.9 & 978 & 14 & $<0.122$ & 0.03 & 132 & $<66.3$ & 20.3 & 474 & $<20.1$ & 0.284 \\
\hline After Wash 42 & - & - & 1.001 & 45.8 & 852 & 11 & $<0.123$ & 0.02 & 121 & $<66.5$ & $<20.2$ & 365 & $<20.2$ & - \\
\hline After Wash 44 & 18.9 & 1.161 & 1.000 & 45.4 & 815 & 10 & $<0.119$ & 0.02 & 116 & $<62.8$ & $<19.1$ & 329 & $<19.1$ & 0.288 \\
\hline After Final Wash & 20.6 & 1.129 & 1.003 & 47.3 & 812 & 10 & $<0.120$ & 0.02 & 127 & $<66.6$ & $<20.2$ & 316 & $<20.2$ & 0.225 \\
\hline \multicolumn{15}{|c|}{$\begin{array}{l}\text { (a) If high-accuracy density results are available, then they are provided. If high-accuracy density results are not available, then density results from the UDS are } \\
\text { provided. }\end{array}$} \\
\hline
\end{tabular}


Table 5.14. Post-Oxidative-Leach Wash—Raman Results

\begin{tabular}{|c|c|c|c|c|c|c|c|c|}
\hline $\begin{array}{c}\text { Sample Location: Tank } \\
\text { T02A, Condition: }\end{array}$ & $\begin{array}{c}\mathrm{Al}(\mathrm{OH})_{4}{ }^{-} \\
{[\mathrm{M}]}\end{array}$ & $\begin{array}{c}\text { Free } \mathrm{OH}^{-} \\
{[\mathrm{M}]}\end{array}$ & $\begin{array}{c}\mathrm{CrO}_{4}{ }^{-2} \\
{[\mathrm{M}]}\end{array}$ & $\begin{array}{l}\mathrm{C}_{2} \mathrm{O}_{4} \\
{[\mathrm{M}]}\end{array}$ & $\begin{array}{l}\mathrm{NO}_{3} \\
{[\mathrm{M}]} \\
\end{array}$ & $\begin{array}{l}\mathrm{NO}_{2} \\
{[\mathrm{M}]} \\
\end{array}$ & $\begin{array}{l}\mathrm{SO}_{4} \\
{[\mathrm{M}]}\end{array}$ & $\begin{array}{l}\mathrm{PO}_{4} \\
{[\mathrm{M}]}\end{array}$ \\
\hline After Wash 3 & $0.011^{(\mathrm{a})}$ & $0.194^{(a)}$ & $0.003^{(\mathrm{a})}$ & $0.060^{(\mathrm{a})}$ & 0.022 & $<0.03$ & $0.004^{(\mathrm{a})}$ & $<0.01$ \\
\hline After Wash 21 & $<0.01$ & $0.096^{(\mathrm{a})}$ & $<0.001$ & $0.015^{(\mathrm{a})}$ & $0.013^{(a)}$ & $0.030^{(\mathrm{a})}$ & $0.002^{(\mathrm{a})}$ & $<0.01$ \\
\hline After Wash 44 & $<0.01$ & $0.07^{(\mathrm{a})}$ & $<0.001$ & $<0.01$ & $0.011^{(\mathrm{a})}$ & $0.033^{(\mathrm{a})}$ & $0.002^{(a)}$ & $<0.01$ \\
\hline
\end{tabular}

Table 5.15 provides the concentration of key metal analytes, anions, total inorganic carbon (TIC), wt $\%$ UDS, and density at key process steps. Two separate slurry samples were collected for the wt\% UDS and slurry density. The supernatant density is a higher accuracy density than can be provided by the UDS analysis. The concentrations of the metals and TIC in the slurry were calculated from samples phase-separated at PDL-W. The liquid analysis results are supernatant analytical results obtained from samples phase-separated in PDL-W. Table 5.16 provides the composition of the final slurry in T02A. The weight percent of wet centrifuged solids in the slurry can be used in calculating the total species concentration in the original samples slurry. See Section A.5 in Appendix A of WTP-RPT-186, Rev. 0 for more information on calculating the species concentration in the slurry. An aliquot of the wet centrifuged solids was dried at $105^{\circ} \mathrm{C}$ to determine the percent solids that are reported 
Table 5.15. Analysis of Key Process Steps

\begin{tabular}{|c|c|c|c|c|c|c|c|c|c|c|}
\hline \multirow[b]{2}{*}{ Analyte } & \multicolumn{2}{|c|}{ Simulant Feed Composition ${ }^{(\mathrm{e})}$} & \multicolumn{2}{|c|}{$\begin{array}{l}\text { Post Concentration of } \\
\text { Solid Batch \#1 }\end{array}$} & \multicolumn{2}{|c|}{$\begin{array}{l}\text { Post Concentration of } \\
\text { Solid Batch \#2 }\end{array}$} & \multicolumn{2}{|c|}{$\begin{array}{l}\text { Initial Slurry Composition for } \\
\text { Post-Caustic-Leach Wash }\end{array}$} & \multicolumn{2}{|c|}{$\begin{array}{l}\text { Post-Caustic-Leach, Concentration, } \\
\text { and Wash Sample }\end{array}$} \\
\hline & $\begin{array}{c}\text { Wet Centrifuged } \\
\text { Solids } \\
\mu \mathrm{g} / \mathrm{g}\end{array}$ & $\begin{array}{c}\text { Liquid Phase } \\
\mu \mathrm{g} / \mathrm{g}\end{array}$ & $\begin{array}{c}\text { Wet Centrifuged } \\
\text { Solids } \\
\mu \mathrm{g} / \mathrm{g}\end{array}$ & $\begin{array}{l}\text { Liquid Phase } \\
\mu \mathrm{g} / \mathrm{g}\end{array}$ & $\begin{array}{c}\text { Wet Centrifuged } \\
\text { Solids } \\
\mu \mathrm{g} / \mathrm{g}\end{array}$ & $\begin{array}{c}\text { Liquid Phase } \\
\mu \mathrm{g} / \mathrm{g}\end{array}$ & $\begin{array}{c}\text { Wet Centrifuged } \\
\text { Solids } \\
\mu \mathrm{g} / \mathrm{g}\end{array}$ & $\begin{array}{l}\text { Liquid Phase } \\
\mu \mathrm{g} / \mathrm{g}\end{array}$ & $\begin{array}{c}\text { Wet Centrifuged } \\
\text { Solids } \\
\mu \mathrm{g} / \mathrm{g}\end{array}$ & $\begin{array}{l}\text { Liquid Phase } \\
\mu \mathrm{g} / \mathrm{g}\end{array}$ \\
\hline$\overline{\mathrm{Al}}$ & $106000 \pm 2066^{(\mathrm{a})}$ & $3230 \pm 56$ & $146333 \pm 5699$ & $2957 \pm 103$ & $132000 \pm 5148$ & $3230 \pm 114$ & $110000 \pm 7430$ & $14900 \pm 895$ & $157000 \pm 10600$ & $397 \pm 24$ \\
\hline $\mathrm{Ca}$ & $881 \pm 17$ & $\mathrm{n} / \mathrm{d}$ & $1310 \pm 51$ & $\mathbf{n} / \mathbf{d}$ & $1407 \pm 57$ & $1.24 \pm 0.35$ & $1870 \pm 135$ & $1.4 \pm 0.6$ & $2910 \pm 221$ & $<1.23 \pm 0.62$ \\
\hline $\mathrm{Ce}$ & $328 \pm 6$ & $0.006 \pm 0.001$ & $562 \pm 22$ & $0.0327 \pm 0.0018$ & $522 \pm 20$ & $0.0977 \pm 0.0037$ & $708 \pm 48$ & $0.0973 \pm 0.0064$ & $1100 \pm 74$ & $0.0134 \pm 0.0026$ \\
\hline $\mathrm{Cr}$ & $5253 \pm 102$ & $30.30 \pm 0.53$ & $8307 \pm 162$ & $43.6 \pm 1.5$ & $7240 \pm 141$ & $46.9 \pm 1.8$ & $1130 \pm 76$ & $1380 \pm 83$ & $504 \pm 34$ & $30.2 \pm 1.8$ \\
\hline $\mathrm{Fe}$ & $29200 \pm 569$ & $\mathrm{n} / \mathrm{d}$ & $50900 \pm 1984$ & $4.60 \pm 0.72$ & $43100 \pm 1681$ & $12.6 \pm 0.8$ & $57500 \pm 3880$ & $31.5 \pm 2.3$ & $91500 \pm 6180$ & $<2.45 \pm 1.23$ \\
\hline $\mathrm{K}$ & $590 \pm 15$ & $1083 \pm 20$ & $483 \pm 28$ & $961 \pm 35$ & $546 \pm 27$ & $982 \pm 36$ & $175 \pm 32$ & $425 \pm 32$ & $35.2 \pm 14.2$ & $11.2 \pm 5.0$ \\
\hline $\mathrm{La}$ & $250 \pm 5$ & $0.006 \pm 0.001$ & $426 \pm 17$ & $0.029 \pm 0.002$ & $398 \pm 16$ & $0.0851 \pm 0.0033$ & $535 \pm 36$ & $0.0969 \pm 0.0063$ & $845 \pm 57$ & $0.0100 \pm 0.0025$ \\
\hline $\mathrm{Mg}$ & $532 \pm 11$ & $\mathrm{n} / \mathrm{d}$ & $959 \pm 44$ & $n / d$ & $993 \pm 41$ & $3.01 \pm 0.70$ & $1340 \pm 95$ & $<2.49 \pm 1.25$ & $1800 \pm 137$ & $<2.45 \pm 1.23$ \\
\hline $\mathrm{Mn}$ & $6550 \pm 128$ & $\mathrm{n} / \mathrm{d}$ & $10400 \pm 406$ & $0.171 \pm 0.035$ & $8743 \pm 341$ & $0.624 \pm 0.041$ & $13900 \pm 938$ & $2.83 \pm 0.18$ & $20900 \pm 1410$ & $0.288 \pm 0.064$ \\
\hline $\mathrm{Na}$ & $70967 \pm 1393$ & $99900 \pm 1733$ & $62033 \pm 2442$ & $88100 \pm 3054$ & $61267 \pm 2403$ & $95500 \pm 3311$ & $117000 \pm 7920$ & $160000 \pm 9600$ & $11100 \pm 751$ & $6800 \pm 408$ \\
\hline $\mathrm{Nd}$ & $680 \pm 13$ & $0.016 \pm 0.001$ & $1183 \pm 46$ & $0.079 \pm 0.003$ & $1097 \pm 43$ & $0.218 \pm 0.008$ & $1480 \pm 100$ & $0.222 \pm 0.014$ & $2190 \pm 148$ & $0.0289 \pm 0.0030$ \\
\hline $\mathrm{Ni}$ & $952 \pm 19$ & $\mathrm{n} / \mathrm{d}$ & $1683 \pm 66$ & $0.496 \pm 0.039$ & $1357 \pm 53$ & $2.04 \pm 0.08$ & $1790 \pm 121$ & $0.494 \pm 0.069$ & $2910 \pm 197$ & $<0.245 \pm 0.123$ \\
\hline $\mathrm{P}$ & $1270 \pm 30$ & $2057 \pm 36$ & $1103 \pm 46$ & $1740 \pm 60$ & $1290 \pm 51$ & $1773 \pm 62$ & $1440 \pm 101$ & $648 \pm 40$ & $216 \pm 15$ & $14.8 \pm 0.9$ \\
\hline $\mathrm{Si}^{(\mathrm{g})}$ & $511 \pm 15$ & $5.70 \pm 0.41$ & $1080 \pm 48$ & $22.7 \pm 0.9$ & $1133 \pm 50$ & $46.1 \pm 5.8$ & $864 \pm 68$ & $262 \pm 19$ & $1430 \pm 104$ & $7.99 \pm 0.69$ \\
\hline $\mathrm{Sr}$ & $282 \pm 6$ & $\mathrm{n} / \mathrm{d}$ & $462 \pm 18$ & $\mathbf{n} / \mathbf{d}$ & $471 \pm 19$ & $0.124 \pm 0.035$ & $590 \pm 40$ & $0.184 \pm 0.064$ & $865 \pm 59$ & $<0.123 \pm 0.062$ \\
\hline $\mathrm{Zr}$ & $872 \pm 17$ & $0.588 \pm 0.020$ & $1607 \pm 63$ & $0.786 \pm 0.044$ & $1533 \pm 60$ & $1.060 \pm 0.079$ & $1980 \pm 134$ & $5.47 \pm 0.82$ & $2630 \pm 178$ & $<0.123 \pm 0.062$ \\
\hline $\mathrm{Cl}$ & - & $1023 \pm 18$ & - & $1013 \pm 36$ & - & $1067 \pm 37$ & - & $350 \pm 23$ & - & $<19.7 \pm 9.9$ \\
\hline $\mathrm{NO}_{2}$ & - & $18200 \pm 363$ & - & $18233 \pm 728$ & - & $19400 \pm 692$ & - & $6920 \pm 438$ & - & $149 \pm 34$ \\
\hline $\mathrm{NO}_{3}$ & - & $75633 \pm 1332$ & - & $76200 \pm 2684$ & - & $82800 \pm 2877$ & - & $29400 \pm 1774$ & - & $523 \pm 54$ \\
\hline $\mathrm{PO}_{4}$ & - & $5023 \pm 87$ & - & $5100 \pm 177$ & - & $5250 \pm 182$ & - & $1790 \pm 111$ & - & $65.4 \pm 30.4$ \\
\hline $\mathrm{SO}_{4}$ & - & $14033 \pm 249$ & - & $14200 \pm 504$ & - & $14733 \pm 513$ & - & $4880 \pm 296$ & - & $142 \pm 13$ \\
\hline $\mathrm{C}_{2} \mathrm{O}_{4}$ & - & $619 \pm 11$ & - & $697 \pm 25$ & - & $679 \pm 24$ & - & $76.7 \pm 9.7$ & - & $6970 \pm 421$ \\
\hline$\%$ Solid & 52.83 & - & 65.69 & - & 59.68 & - & 68.67 & - & 56.27 & - \\
\hline Free $\mathrm{OH}(\mu \mathrm{g} / \mathrm{mL})$ & - & $13983 \pm 211^{(\mathrm{c})}$ & - & $1.70 \mathrm{E}+04$ & - & $1.65 E+04$ & - & $1.25 \mathrm{E}+05$ & - & $2.03 \mathrm{E}+03$ \\
\hline $\operatorname{TIC}^{(b)}$ & - & $5766 \pm 116$ & - & - & - & - & - & - & - & - \\
\hline PDMS (mg/g) & $\mathrm{n} / \mathrm{d}^{(\mathrm{d})}$ & $\mathrm{n} / \mathrm{d}^{(\mathrm{d})}$ & - & - & - & - & $\mathrm{n} / \mathrm{d}^{(\mathrm{d})}$ & $\mathrm{n} / \mathrm{d}^{(\mathrm{d})}$ & $8.8 \mathrm{E}-02$ & $\mathrm{n} / \mathrm{d}^{(\mathrm{d})}$ \\
\hline PPG (mg/g) & $9.0 \mathrm{E}-02$ & $1.0 \mathrm{E}-03$ & - & - & - & - & $1.4 \mathrm{E}-01$ & $9.8 \mathrm{E}-02$ & 3.0 & SX Failed \\
\hline Density $(\mathrm{g} / \mathrm{mL})$ & - & $1.236 \pm 0.005$ & - & $1.233 \pm 0.011$ & - & $1.249 \pm 0.011$ & - & $1.351 \pm 0.021$ & - & $1.016 \pm 0.016$ \\
\hline $\mathrm{Wt} \% \mathrm{H}_{2} \mathrm{O}$ & - & $73.1 \pm 0.12$ & - & - & - & - & - & - & - & - \\
\hline Slurry wt $\%$ UDS & $4.97 \pm 0.02$ & - & $23.5 \pm 0.2$ & - & $23.9 \pm 0.2$ & - & $18.8 \pm 0.3^{(\mathrm{h})}$ & - & $22.0 \pm 0.3$ & - \\
\hline $\begin{array}{l}\text { Slurry Density } \\
(\mathrm{g} / \mathrm{mL})\end{array}$ & $1.276 \pm 0.006$ & - & $1.419 \pm 0.013$ & - & $1.427 \pm 0.013$ & - & $1.496 \pm 0.023$ & - & $1.167 \pm 0.018$ & - \\
\hline $\begin{array}{l}\text { Weight Percent } \\
\text { Centrifuged } \\
\text { Solids (\%) }\end{array}$ & 14.7 & - & 45.4 & - & 52.4 & - & 46.9 & - & 40.6 & - \\
\hline $\begin{array}{l}\text { (a) Fraction of sol } \\
\text { (b) TIC = total in } \\
\text { (c) Free OH is ex } \\
\text { (d) Single sample } \\
\text { (e) Uncertainty va } \\
\text { values reported thr } \\
\text { SX Failed Analys }\end{array}$ & $\begin{array}{l}\text { lid-phase } \mathrm{Al} \text { that is } \\
\text { organic carbon. } \\
\text { pressed in } \mathrm{mg} / \mathrm{kg} \text {. } \\
\text { non-detect with an } \\
\text { alues reported for th } \\
\text { roughout the rest of } \\
\text { sis failed due to sol }\end{array}$ & $\begin{array}{l}\text { n gibbsite }=0.4 \\
\text { lysis results bel } \\
\text { Simulant Feed } \\
\text { the table. } \\
\text { ent extraction is }\end{array}$ & $\begin{array}{l}\text { Composition are } 1 \\
\text { sue. }\end{array}$ & $\begin{array}{l}\text { g limit. } \\
\sigma, \text { instead of the } 2\end{array}$ & $\begin{array}{l}\text { (f) Liq } \\
\text { includec } \\
\text { (g) Si r } \\
\text { (h) Ana } \\
\text { n/d Trip } \\
\text { - Anal } \\
\text { Bold nu }\end{array}$ & $\begin{array}{l}\text { uid phase data con } \\
\text { esults from sample } \\
\text { lysis rerun on sam } \\
\text { olicate samples wi } \\
\text { ysis not required } \\
\text { mbers are calculat }\end{array}$ & $\begin{array}{l}\text { tains only results } \mathrm{f} \\
\text { named "ICP" rath } \\
\text { ple D 02AML } 012 \\
\text { th analysis results } \\
\text { y Test Plan. } \\
\text { ed values. }\end{array}$ & $\begin{array}{l}\text { rom the decanted } \\
\text { XX } 5362 \text { SOX } 2 \\
\text { below method rep }\end{array}$ & $\begin{array}{l}\text { supernate. No rin } \\
\text { med "AFA". } \\
\text { orting limit. }\end{array}$ & \\
\hline
\end{tabular}


Table 5.15 (contd)

\begin{tabular}{|c|c|c|c|c|c|c|c|c|}
\hline \multirow[b]{2}{*}{ Analyte } & \multicolumn{2}{|c|}{$\begin{array}{l}\text { Starting Slurry Composition Before } \\
\text { Permanganate Addition }\end{array}$} & \multicolumn{2}{|c|}{$\begin{array}{l}\text { Initial Slurry Composition for } \\
\text { Post-Oxidative-Leach Wash }\end{array}$} & \multicolumn{2}{|c|}{$\begin{array}{c}\text { Post-Oxidative-Leach and } \\
\text { Wash Sample }\end{array}$} & \multicolumn{2}{|c|}{$\begin{array}{l}\text { Post-Oxidative-Leach, Wash, and } \\
\text { Concentration Sample }\end{array}$} \\
\hline & $\begin{array}{c}\text { Wet Centrifuged } \\
\text { Solids } \\
\mu \mathrm{g} / \mathrm{g}\end{array}$ & $\begin{array}{c}\text { Liquid Phase }^{(\mathrm{f})} \\
\mu \mathrm{g} / \mathrm{g}\end{array}$ & $\begin{array}{c}\text { Wet Centrifuged } \\
\text { Solids } \\
\mu \mathrm{g} / \mathrm{g}\end{array}$ & $\begin{array}{c}\text { Liquid Phase }^{(\mathrm{f})} \\
\mu \mathrm{g} / \mathrm{g}\end{array}$ & $\begin{array}{c}\text { Wet Centrifuged } \\
\text { Solids } \\
\mu \mathrm{g} / \mathrm{g} \\
\end{array}$ & $\begin{array}{c}\text { Liquid Phase } \\
\mu \mathrm{g} / \mathrm{g}\end{array}$ & $\begin{array}{c}\text { Wet Centrifuged } \\
\text { Solids } \\
\mu \mathrm{g} / \mathrm{g} \\
\end{array}$ & $\begin{array}{c}\text { Liquid Phase } \\
\mu \mathrm{g} / \mathrm{g}\end{array}$ \\
\hline$\overline{\mathrm{Al}}$ & $152667 \pm 5947$ & $354 \pm 12$ & $151000 \pm 10200$ & $506 \pm 30$ & - & $47.3 \pm 3.1$ & $142000 \pm 9590$ & $662 \pm 40$ \\
\hline $\mathrm{Ca}$ & $2833 \pm 121$ & $n / d$ & $2640 \pm 178$ & $<1.25 \pm 0.63$ & - & $<1.20 \pm 0.60$ & $2730 \pm 185$ & $<1.24 \pm 0.62$ \\
\hline $\mathrm{Ce}$ & $1080 \pm 42$ & $\mathbf{n} / \mathbf{d}$ & $1070 \pm 72$ & $<0.005 \pm 0.003$ & - & $<0.0048 \pm 0.0024$ & $1030 \pm 70$ & $<0.00497 \pm 0.00249$ \\
\hline $\mathrm{Cr}$ & $503 \pm 20$ & $27.6 \pm 1.0$ & $297 \pm 21$ & $207 \pm 12$ & - & $9.83 \pm 0.60$ & $472 \pm 32$ & $72.7 \pm 4.4$ \\
\hline $\mathrm{Fe}$ & $92667 \pm 3613$ & $\mathbf{n} / \mathbf{d}$ & $89400 \pm 6040$ & $<2.5 \pm 1.3$ & - & $<4.81 \pm 2.41$ & $87600 \pm 5910$ & $<4.97 \pm 2.49$ \\
\hline $\mathrm{K}$ & $41 \pm 8$ & $11.4 \pm 2.8$ & $105 \pm 16$ & $15.0 \pm 5.1$ & - & $<7.21 \pm 3.61$ & $150 \pm 36$ & $<7.46 \pm 3.75$ \\
\hline $\mathrm{La}$ & $828 \pm 32$ & $\mathbf{n} / \mathbf{d}$ & $827 \pm 56$ & $<0.005 \pm 0.003$ & - & $<0.0048 \pm 0.0024$ & $775 \pm 52$ & $<0.00497 \pm 0.00249$ \\
\hline $\mathrm{Mg}$ & $1760 \pm 75$ & $n / d$ & $1600 \pm 108$ & $<2.5 \pm 1.3$ & - & $<2.4 \pm 1.2$ & $1700 \pm 115$ & $<2.49 \pm 1.25$ \\
\hline $\mathrm{Mn}$ & $20867 \pm 812$ & $\mathbf{n} / \mathbf{d}$ & $27200 \pm 1840$ & $165 \pm 10$ & - & $<0.120 \pm 0.060$ & $25000 \pm 1690$ & $<0.124 \pm 0.062$ \\
\hline $\mathrm{Na}$ & $8357 \pm 327$ & $6563 \pm 227$ & $10100 \pm 683$ & $9120 \pm 547$ & - & $812 \pm 51$ & $13600 \pm 962$ & $8330 \pm 500$ \\
\hline $\mathrm{Nd}$ & $2180 \pm 85$ & $\mathbf{n} / \mathbf{d}$ & $2140 \pm 144$ & $0.00594 \pm 00253$ & - & $0.00946 \pm 0.00247$ & $2140 \pm 144$ & $<0.00497 \pm 0.00249$ \\
\hline $\mathrm{Ni}$ & $2857 \pm 112$ & $\mathbf{n} / \mathbf{d}$ & $2750 \pm 186$ & $<0.25 \pm 0.13$ & - & $<0.12 \pm 0.06$ & $2900 \pm 196$ & $<0.124 \pm 0.062$ \\
\hline $\mathrm{P}$ & $193 \pm 8$ & $15.8 \pm 0.6$ & $192 \pm 13$ & $35.6 \pm 2.2$ & - & $3.83 \pm 0.38$ & $246 \pm 17$ & $42.0 \pm 2.5$ \\
\hline $\mathrm{Si}^{(\mathrm{g})}$ & $1473 \pm 62$ & $6.84 \pm 0.37$ & $1450 \pm 106$ & $10.2 \pm 0.8$ & - & $3.38 \pm 0.52$ & $1740 \pm 121$ & $14.4 \pm 1.0$ \\
\hline $\mathrm{Sr}$ & $859 \pm 34$ & $\mathbf{n} / \mathbf{d}$ & $842 \pm 57$ & $<0.125 \pm 0.063$ & - & $<0.12 \pm 0.06$ & $831 \pm 56$ & $<0.124 \pm 0.062$ \\
\hline $\mathrm{Zr}$ & $2547 \pm 99$ & $n / d$ & $2470 \pm 167$ & $<0.125 \pm 0.063$ & - & $<0.24 \pm 0.12$ & $2590 \pm 175$ & $<0.249 \pm 0.125$ \\
\hline $\mathrm{Cl}$ & - & $\mathbf{n} / \mathbf{d}$ & - & $<19.9 \pm 10.0$ & - & $<20.2 \pm 10.1$ & - & $28.2 \pm 10.0$ \\
\hline $\mathrm{NO}_{2}$ & - & $150 \pm 20$ & - & $222 \pm 35$ & - & $<66.6 \pm 33.5$ & - & $366 \pm 39$ \\
\hline $\mathrm{NO}_{3}$ & - & $514 \pm 31$ & - & $842 \pm 67$ & - & $127 \pm 46$ & - & $1400 \pm 95$ \\
\hline $\mathrm{PO}_{4}$ & - & $69 \pm 18$ & - & $124 \pm 31$ & - & $<61.9 \pm 31.0$ & - & $153 \pm 32$ \\
\hline $\mathrm{SO}_{4}$ & - & $142 \pm 8$ & - & $276 \pm 19$ & - & $<20.2 \pm 10.2$ & - & $378 \pm 25$ \\
\hline $\mathrm{C}_{2} \mathrm{O}_{4}$ & - & $7050 \pm 246$ & - & $7960 \pm 480$ & - & $316 \pm 22$ & - & $1800 \pm 108$ \\
\hline$\%$ Solid & 57.26 & - & 55.99 & - & - & - & 58.43 & - \\
\hline Free $\mathrm{OH}(\mu \mathrm{g} / \mathrm{mL})$ & - & $1.99 \mathrm{E}+03$ & - & $2.88 \mathrm{E}+03$ & - & $4.18 \mathrm{E}+02$ & - & $5.02 \mathrm{E}+03$ \\
\hline $\mathrm{TIC}^{(\mathrm{b})}$ & - & - & - & - & - & - & - & - \\
\hline PDMS (mg/g) & $1.3 \mathrm{E}-01$ & $\mathrm{n} / \mathrm{d}^{(\mathrm{d})}$ & $4.0 \mathrm{E}-02$ & $\mathrm{n} / \mathrm{d}^{(\mathrm{d})}$ & - & - & 1 & $\mathrm{n} / \mathrm{d}^{(\mathrm{d})}$ \\
\hline PPG (mg/g) & 2.4 & SX Failed & 1.5 & SX Failed & - & - & 1.6 & SX Failed \\
\hline Density $(\mathrm{g} / \mathrm{mL})$ & - & $1.017 \pm 0.009$ & - & $1.022 \pm 0.016$ & - & $1.003 \pm 0.016$ & - & $1.055 \pm 0.016$ \\
\hline $\mathrm{Wt} \% \mathrm{H}_{2} \mathrm{O}$ & - & - & - & - & - & - & - & - \\
\hline Slurry wt $\%$ UDS & $22.0 \pm 0.2$ & - & $21.2 \pm 0.3$ & - & $20.6 \pm 0.3$ & - & $20.7 \pm 0.3$ & - \\
\hline $\begin{array}{l}\text { Slurry Density } \\
\quad(\mathrm{g} / \mathrm{mL})\end{array}$ & $1.173 \pm 0.010$ & - & $1.159 \pm 0.018$ & - & $1.125 \pm 0.017$ & - & $1.217 \pm 0.019$ & - \\
\hline $\begin{array}{c}\text { Weight Percent } \\
\text { Centrifuged Solids } \\
(\%)\end{array}$ & 39.2 & - & 37.6 & - & - & - & 40.6 & - \\
\hline \multicolumn{4}{|c|}{$\begin{array}{l}\text { (a) Fraction of solid-phase } \mathrm{Al} \text { that is in gibbsite }=0.435 \text {. } \\
\text { (b) TIC }=\text { total inorganic carbon. } \\
\text { (c) Free } \mathrm{OH} \text { is expressed in } \mathrm{mg} / \mathrm{kg} \text {. } \\
\text { (d) Single sample non-detect with analysis results below method reporting limit. } \\
\text { (e) Uncertainty values reported for the Simulant Feed Composition are } 1 \sigma \text {, instead of the } 2-\sigma \text { values } \\
\text { reported throughout the rest of the table. }\end{array}$} & \multicolumn{5}{|c|}{$\begin{array}{l}\text { (f) Liquid phase data contains only results from the decanted supernate. No rinsate results are } \\
\text { included. } \\
\text { (g) Si results from sample named "ICP" rather than sample named "AFA." } \\
\text { n/d-Triplicate samples with analysis results below method reporting limit. } \\
\text { - Analysis not required by test plan. } \\
\text { Bold numbers are calculated values. } \\
\text { SX Failed-Analysis failed due to solvent extraction issue. }\end{array}$} \\
\hline
\end{tabular}


Table 5.16. Final Slurry Composition Before Transfer to Waste Tank

\begin{tabular}{|c|c|c|c|c|c|c|c|c|c|c|c|c|c|}
\hline \multirow[b]{2}{*}{ Sample Location } & \multicolumn{2}{|c|}{ Slurry Analyses } & \multicolumn{11}{|c|}{ Liquid Analyses } \\
\hline & $\begin{array}{l}\text { UDS } \\
\mathrm{wt} \% \\
\end{array}$ & $\begin{array}{c}\text { Slurry Density } \\
\mathrm{g} / \mathrm{mL}\end{array}$ & $\begin{array}{r}\mathrm{Al} \\
\mu \mathrm{g} / \mathrm{g} \\
\end{array}$ & $\begin{array}{r}\mathrm{Na} \\
\mu \mathrm{g} / \mathrm{g} \\
\end{array}$ & $\begin{array}{r}\mathrm{Cr} \\
\mu \mathrm{g} / \mathrm{g} \\
\end{array}$ & $\begin{array}{r}\mathrm{Sr} \\
\mu \mathrm{g} / \mathrm{g} \\
\end{array}$ & $\begin{array}{c}\text { Free } \\
\mathrm{OH}^{-} \\
\mathrm{M} \\
\end{array}$ & $\begin{array}{l}\mathrm{NO}_{3} \\
\mu \mathrm{g} / \mathrm{g} \\
\end{array}$ & $\begin{array}{l}\mathrm{NO}_{2} \\
\mu \mathrm{g} / \mathrm{g} \\
\end{array}$ & $\begin{array}{r}\mathrm{SO}_{4} \\
\mu \mathrm{g} / \mathrm{g} \\
\end{array}$ & $\begin{array}{l}\mathrm{C}_{2} \mathrm{O}_{4} \\
\mu \mathrm{g} / \mathrm{g} \\
\end{array}$ & $\begin{array}{r}\mathrm{Cl}^{-} \\
\mu \mathrm{g} / \mathrm{g} \\
\end{array}$ & $\begin{array}{l}\text { TDS } \\
\mathrm{wt} \% \\
\end{array}$ \\
\hline $\begin{array}{l}\text { Prior to transfer of slurry from } \\
\text { Tank T02A to UFP-VSL-T62A/B }\end{array}$ & 20.5 & 1.163 & 68.3 & 1100 & 13 & $<0.121$ & 0.03 & 178 & $<66.5$ & 33.4 & 373 & $<20.2$ & 0.453 \\
\hline
\end{tabular}

M-Molarity.

Table 5.17 provides the composition of the flush of the filter-loop with Tank T02A bypassed after 5 minutes of recirculation.

Table 5.17. Analysis of Material in Filter-Loop

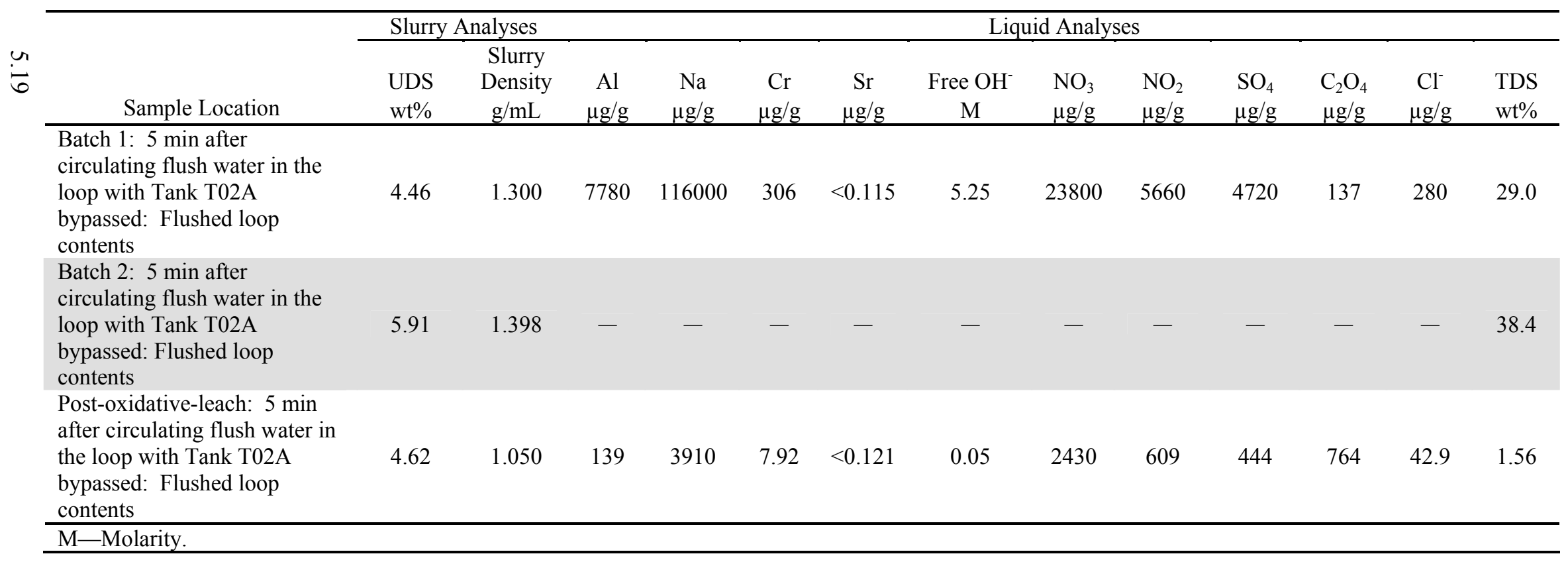




\subsection{Physical Properties}

This section summarizes the PSD, rheology, XRD, and SEM results. The interested reader is referred to Appendix L for additional information.

\subsubsection{Particle Size}

Table 5.18, Slurry Particle-Size Distribution, provides the PSD data at key process steps, before and after sonication. The average particle size, i.e., the average equivalent diameter, is defined as the diameter where 50 mass \% (of the particles) have a larger equivalent diameter, and the other 50 mass \% have a smaller equivalent diameter. Hence, the average particle size is denoted as equivalent $\mathrm{d}(0.500)$. The definition of $\mathrm{d}(0.100)$ is the equivalent diameter where 10 mass \% (of the particles) has a smaller diameter (and hence the remaining $90 \%$ is coarser). The definition of $\mathrm{d}(0.900)$ can be derived similarly. A summary of the run conditions, sample preparation, and sample analysis is given in Appendix L.

Table 5.18. Slurry Particle-Size Distribution

\begin{tabular}{|c|c|c|c|c|c|c|}
\hline \multirow[b]{2}{*}{ Process Step Description } & \multicolumn{3}{|c|}{$\begin{array}{l}\text { Pre-Sonication } \\
\text { (microns) }\end{array}$} & \multicolumn{3}{|c|}{$\begin{array}{l}\text { Sonicated } \\
\text { (microns) }\end{array}$} \\
\hline & $\mathrm{d}(0.100)$ & $\mathrm{d}(0.500)$ & $\mathrm{d}(0.900)$ & $\mathrm{d}(0.100)$ & $\mathrm{d}(0.500)$ & $\mathrm{d}(0.900)$ \\
\hline Initial simulant characterization from HLP-VSL-T22 & 1.636 & 7.485 & 27.558 & 1.572 & 6.704 & 19.661 \\
\hline $\begin{array}{l}\text { Initial simulant characterization at test start from } \\
\text { HLP-VSL-T22 }\end{array}$ & 1.819 & 8.585 & 31.923 & 1.685 & 7.49 & 22.199 \\
\hline \multirow{2}{*}{$\begin{array}{l}\text { Batch \#1-pre-leach concentration in Tank T02A—final } \\
\text { slurry }\end{array}$} & 0.872 & 4.186 & 14.68 & 1.008 & 4.512 & 14.943 \\
\hline & 0.822 & 4.419 & 14.097 & 0.95 & 4.642 & 13.967 \\
\hline $\begin{array}{l}\text { Batch \#1-pre-leach concentration in Tank T02A-final } \\
\text { slurry }\end{array}$ & 1.263 & 6.549 & 19.721 & 1.404 & 6.637 & 19.271 \\
\hline \multirow{2}{*}{ Post-leach concentration-initial unwashed slurry } & 1.066 & 3.81 & 15.996 & 1.034 & 3.645 & 14.015 \\
\hline & 1.075 & 3.722 & 13.03 & 1.046 & 3.491 & 11.262 \\
\hline \multirow{3}{*}{ Post-leach concentration - concentrated unwashed slurry } & 0.787 & 2.364 & 15.531 & 0.772 & 2.669 & 25.546 \\
\hline & 0.769 & 2.005 & 5.787 & 0.704 & 1.849 & 6.054 \\
\hline & 0.757 & 1.981 & 5.794 & 0.705 & 1.856 & 6.014 \\
\hline Post-leach concentration - final washed slurry & 0.697 & 1.761 & 4.245 & 0.592 & 1.349 & 3.644 \\
\hline Permeate sample before filter cleaning & 1.537 & 4.498 & 36.335 & 1.076 & 4.159 & 52.445 \\
\hline
\end{tabular}

\subsubsection{Rheology}

Table 5.19 provides a summary of rheology measurements performed at key points throughout Integrated Test D. For simplicity, only Bingham yield stress and consistency fits for the down ramps have been reported here. A more extensive analysis of the rheology measurements taken are provided in Appendix L with flow curve analysis using both the Bingham and Casson models for both the up and down ramps. Table 5.20 provides additional shear-strength results. 
Table 5.19. Integrated Test D Rheology Data Summary

\begin{tabular}{|c|c|c|c|c|c|}
\hline Process Test Step & Form & $\begin{array}{c}\text { Shear } \\
\text { Strength } \\
{[\mathrm{Pa}]^{(\mathrm{b})}} \\
\end{array}$ & $\begin{array}{c}\text { Bingham } \\
\text { Yield } \\
{[\mathrm{Pa}]^{(\mathrm{a})}} \\
\end{array}$ & $\begin{array}{l}\text { Bingham } \\
\text { Consistency } \\
{[\mathrm{mPa} \cdot \mathrm{s}]^{(\mathrm{a})}}\end{array}$ & $\begin{array}{l}\text { Supernate } \\
\text { Viscosity } \\
{[\mathrm{mPa} \cdot \mathrm{s}]^{(\mathrm{a})}}\end{array}$ \\
\hline Feed UFP-VSL-FRP & Slurry & 11.61 & - & - & - \\
\hline Feed UFP-VSL-FRP & Slurry & - & $0^{(\mathrm{c})}$ & 4.272 & - \\
\hline Feed UFP-VSL-FRP & Supernate & - & - & - & 2.689 \\
\hline Feed HLP-VSL-T22 & Slurry & - & $0^{(\mathrm{c})}$ & 4.264 & - \\
\hline $\begin{array}{l}\text { Batch \#1-Pre-leach concentration in Tank } \\
\text { T02A-initial slurry }\end{array}$ & Slurry & - & $0^{(\mathrm{c})}$ & 5.011 & - \\
\hline $\begin{array}{l}\text { Batch \#1-Pre-leach concentration in Tank } \\
\text { T02A-final slurry }\end{array}$ & Slurry & - & 2.831 & 11.18 & - \\
\hline $\begin{array}{l}\text { Batch \#2_-Pre-leach concentration in Tank } \\
\text { T02A-initial slurry }\end{array}$ & Slurry & - & $0^{(\mathrm{c})}$ & 5.503 & - \\
\hline $\begin{array}{l}\text { Batch \#2-Pre-leach concentration in Tank } \\
\text { T02A-final slurry }\end{array}$ & Slurry & - & 5.98 & 14.05 & - \\
\hline $\begin{array}{l}\text { Post-caustic-leach concentration in Tank T02A- } \\
\text { initial slurry }\end{array}$ & Slurry & - & $0^{(\mathrm{c})}$ & 19.84 & - \\
\hline $\begin{array}{l}\text { Post-caustic-leach concentration in Tank T02A- } \\
\text { initial slurry }\end{array}$ & Supernate & - & - & - & 11.85 \\
\hline $\begin{array}{l}\text { Post-caustic-leach concentration in Tank T02A- } \\
\text { final slurry }\end{array}$ & Slurry & - & 12.107 & 41.51 & - \\
\hline $\begin{array}{l}\text { Post-caustic-leach concentration in Tank T02A- } \\
\text { final slurry }\end{array}$ & Supernate & - & - & - & 10.75 \\
\hline Post-caustic-leach wash-intermediate slurry & Slurry & - & 16.966 & 9.702 & - \\
\hline Post-caustic-leach wash-intermediate slurry & Supernate & - & - & - & 1.245 \\
\hline Post-caustic-leach wash-final slurry & Slurry & - & 24.034 & 8.976 & - \\
\hline Post-caustic-leach wash-final slurry & Supernate & - & - & - & 1.027 \\
\hline Oxidative-leach - before permanganate addition & Slurry & - & 23.982 & 9.05 & - \\
\hline Oxidative-leach - before permanganate addition & Slurry & 34.73 & - & - & - \\
\hline Oxidative-leach — final slurry & Supernate & - & - & - & 1.064 \\
\hline Post-oxidative-leach wash - intermediate slurry & Slurry & - & 15.443 & 6.939 & - \\
\hline Post-oxidative-leach wash - intermediate slurry & Supernate & - & - & - & 0.9851 \\
\hline Post-oxidative-leach wash-final slurry & Slurry & - & 15.608 & 6.737 & - \\
\hline Post-oxidative-leach wash-final slurry & Supernate & - & - & - & 0.9847 \\
\hline Post-oxidative-leach concentration-final slurry & Slurry & - & 26.613 & 8.987 & - \\
\hline Post-oxidative-leach concentration-final slurry & Supernate & - & - & - & 0.9719 \\
\hline Post-oxidative-leach concentration-final slurry & Slurry & 37.96 & - & - & - \\
\hline \multicolumn{6}{|c|}{$\begin{array}{l}\text { - Analysis not required by Test Plan. } \\
\text { (a) All results derived from flow curve analysis correspond to the down-ramp. } \\
\text { (b) Shear strength measurements correspond to a 72-hr gel time. } \\
\text { (c) Newtonian slurry treated as a Bingham Plastic with a zero yield stress. }\end{array}$} \\
\hline
\end{tabular}


Table 5.20. Integrated Test D Rheology Data Summary

\begin{tabular}{cccc}
\hline $\begin{array}{c}\text { Settling } \\
\text { Time } \\
(\mathrm{hr})\end{array}$ & $\begin{array}{c}\text { Feed UFP-VSL-FRP } \\
\text { Maximum Shear } \\
\text { Stress (Pa) }\end{array}$ & $\begin{array}{l}\text { Oxidative leach-before } \\
\text { permanganate addition }\end{array}$ & $\begin{array}{l}\text { Post-oxidative-leach } \\
\text { concentration-final slurry }\end{array}$ \\
\hline 1 & 1.734 & Maximum Shear Stress (Pa) & Maximum Shear Stress (Pa) \\
\hline 2 & 1.785 & 17.830 & 16.400 \\
4 & 1.837 & 13.350 & 15.150 \\
8 & 2.899 & 17.390 & 16.370 \\
16 & 3.193 & 17.680 & 16.540 \\
32 & 5.369 & 22.000 & 21.530 \\
72 & 11.610 & 34.730 & 37.960 \\
\hline
\end{tabular}

\subsubsection{XRD and SEM}

Slurry samples for XRD and SEM analysis were taken before testing and after the oxidative-leach. Results are provided in Appendix L.

\subsection{PJM Tuning and Parameters}

In the PJM operation of the RPP-WTP PEP testing, air pressure was used to drive liquid inside the PJM tubes to mobilize and mix tank contents. The data obtained in the test runs included liquid surface levels in steady periodic vertical motion inside the PJM tubes and the PJM tank, and the steady periodic driving PJM tube pressures. The measured liquid levels in the PJM tubes and the PJM tank as well as the driving pressure in the PJM tubes were used to determine the PJM jet velocity (peak average velocity). The measured liquid levels in the PJM tubes and the PJM tank were used to determine the average PJM stroke length. In the PEP testing, the drive pressures and cycle times were iteratively adjusted to meet the target drive velocities and stroke lengths specified by the Test Instructions. Table 5.21 shows the PJM parameters for Integrated Test D, and Appendix F provides details on how the PJM peak average velocities were determined. 
Table 5.21. PJM Parameters for Integrated Test D (TI-082)

\begin{tabular}{|c|c|c|c|c|c|c|c|c|c|c|}
\hline $\begin{array}{c}\text { Data Set } \\
\text { Date:Time } \\
\text { (mm/dd/yr) } \\
\text { (hr:min) }\end{array}$ & $\begin{array}{c}\text { TI step \# (TI } \\
\mathrm{p \#})\end{array}$ & Vessel & $\begin{array}{l}\text { PJM } \\
\text { Operation } \\
\text { Mode }\end{array}$ & $\begin{array}{c}\text { Process Step } \\
\text { Description }\end{array}$ & $\begin{array}{l}\text { Target PJM } \\
\text { Nozzle } \\
\text { Velocity } \\
(\mathrm{m} / \mathrm{s})\end{array}$ & $\begin{array}{l}\text { Actual PJM } \\
\text { Nozzle } \\
\text { Velocity } \\
(\mathrm{m} / \mathrm{s})\end{array}$ & $\begin{array}{c}\text { Target } \\
\text { Stroke } \\
\text { Length } \\
\text { (in.) } \\
(\%)\end{array}$ & $\begin{array}{c}\text { Actual } \\
\text { Stroke } \\
\text { Length } \\
\text { (in.) } \\
(\%)\end{array}$ & $\begin{array}{l}\text { Target } \\
\text { PJM } \\
\text { Cycle } \\
\text { Time } \\
\text { (sec) }\end{array}$ & $\begin{array}{c}\text { Actual } \\
\text { PJM } \\
\text { Cycle } \\
\text { Time } \\
(\mathrm{sec}) \\
\end{array}$ \\
\hline $\begin{array}{c}3 / 23 / 09 \\
02: 25-02: 44\end{array}$ & $\begin{array}{l}7.2 .7 .1 \\
(\mathrm{p} 33)\end{array}$ & Tank T01B & Standard & $\begin{array}{c}\text { After transfer from } \\
\text { HLP-VSL-T22 to } \\
\text { Tank T01B for } \\
\text { Batch } 1\end{array}$ & $4.8 \pm 0.3$ & 4.3 & $\begin{array}{c}28.1 \pm 1.7 \% \\
80 \pm 5 \%\end{array}$ & $\begin{array}{l}28.3 \% \\
81 \%\end{array}$ & $35 \pm 1$ & 35.1 \\
\hline $\begin{array}{c}3 / 23 / 09 \\
05: 47-06: 05\end{array}$ & 7.3.5.1 (p 37) & Tank T02A & Standard & $\begin{array}{l}\text { After transfer from } \\
\text { Tank T01B to Tank } \\
\text { T02A for Batch } 1\end{array}$ & $7.3 \pm 0.4$ & 5.9 & $\begin{array}{c}30.3 \pm 1.8 \\
80 \pm 5 \%\end{array}$ & $\begin{array}{l}30.2 \% \\
80 \%\end{array}$ & $33 \pm 1$ & 33.2 \\
\hline $\begin{array}{l}3 / 25 / 09 \\
\sim 15: 50\end{array}$ & $7.6 .21(\mathrm{p} 59)$ & Tank T02A & Simple & $\begin{array}{c}\text { Caustic-leach } \\
\text { @ } 85^{\circ} \mathrm{C} \text { for Batch } 1\end{array}$ & $7.3 \pm 0.4$ & 7.1 & $\begin{array}{c}30.3 \pm 1.8 \% \\
80 \pm 5 \%\end{array}$ & $\begin{array}{l}29.3 \% \\
78 \%\end{array}$ & $33 \pm 1$ & 33.2 \\
\hline $\begin{array}{c}3 / 27 / 09 \\
05: 33-05: 44\end{array}$ & $\begin{array}{c}7.8 .4 .1 \\
(\operatorname{pp~} 75-76)\end{array}$ & Tank T01A & Simple & $\begin{array}{l}\text { After transfer from } \\
\text { Tank T02A to Tank } \\
\text { T01A for Batch } 1\end{array}$ & $4.8 \pm 0.3$ & 5.5 & $\begin{array}{c}28.1 \pm 1.7 \% \\
80 \pm 5 \%\end{array}$ & $\begin{array}{l}26.8 \% \\
76 \%\end{array}$ & $35 \pm 1$ & 33.2 \\
\hline $\begin{array}{c}3 / 26 / 09 \\
04: 04-04: 51\end{array}$ & $\begin{array}{c}7.9 .6 \\
(\text { pp } 78-79)\end{array}$ & Tank T01B & Standard & $\begin{array}{l}\text { After transfer from } \\
\text { HLP-VSL-T22 to } \\
\text { Tank T01B for } \\
\text { Batch } 2\end{array}$ & $4.8 \pm 0.3$ & 4.5 & $\begin{array}{c}28.1 \pm 1.7 \% \\
80 \pm 5 \%\end{array}$ & $\begin{array}{l}27.8 \% \\
79 \%\end{array}$ & $35 \pm 1$ & 35.1 \\
\hline $\begin{array}{c}3 / 27 / 09 \\
05: 33-05: 44\end{array}$ & $\begin{array}{l}7.10 .5 .1 \\
(\mathrm{p} 82)\end{array}$ & Tank T02A & Simple & $\begin{array}{l}\text { After transfer from } \\
\text { Tank T01B to Tank } \\
\text { T02A for Batch } 2\end{array}$ & $7.3 \pm 0.4$ & 6.3 & $\begin{array}{c}30.3 \pm 1.8 \\
80 \pm 5 \%\end{array}$ & $\begin{array}{l}28.7^{\prime} \\
76 \%\end{array}$ & $33 \pm 1$ & 33.2 \\
\hline $\begin{array}{l}3 / 27 / 09 \\
\sim 18: 20\end{array}$ & $\begin{array}{l}7.13 .21 \\
(\mathrm{p} 103)\end{array}$ & Tank T02A & Simple & $\begin{array}{c}\text { Caustic-leach } \\
\text { (a) } 85^{\circ} \mathrm{C} \text { for Batch } 2\end{array}$ & $7.3 \pm 0.4$ & 6.8 & $\begin{array}{c}30.3 \pm 1.8 \% \\
80 \pm 5 \%\end{array}$ & $\begin{array}{l}30.1 \% \\
80 \%\end{array}$ & $33 \pm 1$ & 33.2 \\
\hline $\begin{array}{c}3 / 30 / 09 \\
00: 19-03: 22\end{array}$ & $\begin{array}{l}7.15 .17 .1 \\
(\mathrm{p} \mathrm{127})\end{array}$ & Tank T02A & Standard & $\begin{array}{c}\text { Post-Caustic-Leach } \\
\text { Tank T02A }\end{array}$ & $12 \pm 0.6$ & 11.9 & $\begin{array}{c}30.3 \pm 1.8 \\
80 \pm 5 \%\end{array}$ & $\begin{array}{l}29.1 \% \\
77 \%\end{array}$ & $20 \pm 1$ & 20.2 \\
\hline
\end{tabular}





\subsection{Issues}

No improvements to the test system or operational changes were made between Integrated Test B and Integrated Test D. Issues for Integrated Test B also occurred in Integrated Test D and are repeated here.

\subsection{Maintaining Targeted Flow Rate in Filter-Loop}

The flow rate in the filter-loop was unable to meet the targeted rate of $109 \mathrm{gpm}$ when the level in the tank was below $\sim 22$ inches. This is the approximate level that the return leg of the slurry coming back into UFP-VSL-T02A is exposed to (i.e., the slurry in the tank is lower than the return leg). The result is air entrainment into the slurry, which causes apparent cavitation and decreased performance of the pumps. (Actual cavitation is the formation of gas bubbles due to low pressure at the pump impeller, resulting in decreased pump performance.) However, the degassing protocol applied in Integrated Test D did not result in lower levels or increased pumping rates. Additional AFA provided some benefit.

\subsection{PJM Operation}

Standard Mode-The Drexelbrook level instruments in the PJMs (which determined how long pressure and vacuum to the PJMs would be applied) did not work at elevated temperatures in caustic solution. As a result, while heating during the leach, the PJMs would have to be switched from standard mode to simple mode. (See Section 3.4 for PJM operational details.)

Simple Mode - In simple mode, pressure and vacuum are applied for predetermined time intervals. These time intervals are modified by tank level and temperature. These corrections generally worked, but operators would have to closely monitor the PJMs as these correction factors did not work perfectly. The PJMs would overblow (that is, pressurized air would be on too long, causing the air to come out the bottom of the PJM) and overdraw (that is, vacuum being applied too long and drawing slurry up into the vacuum delivery piping). Both issues caused operational problems.

In UFP-VSL-T02A, air from PJM overblows was drawn into the pump suction causing severe pumping problems. Overblows were heard for PJM-1801 during Integrated Test D, and drive pressures and times were reduced. Because the pump flow rate in UFP-VSL-T01A/B was much lower, PJM overblows in these tanks did not present an operational issue.

Overdraws did not cause immediate problems, but could eventually be observed if there were any leaks in the air delivery piping where the slurry was present. During Integrated Test B, simulant was observed leaking from the air line outside the tank. Also, it is expected that over long durations, the overdraws would cause plugging issues.

PJM-1605 was inoperative during Integrated Test D. During testing, it was observed that PJM-1605 did not fill as high as other PJMs, and as a result, it was prone to overblows during the Drive Phase. No

plug was found during Post-Phase 1 testing inspection. However, tanks were rinsed with water, and PJMs operated before they were inspected. 


\subsection{Tank Level Measurement}

\subsubsection{Lasers}

The issues with the laser reported in Integrated Test A were largely corrected for Integrated Tests B and D. Two software filters were used to remove spurious readings. The first was an out-of-range filter that ignored any high or low readings that were out of range. The second filter ignored readings when the rate of change was greater than 3 inches in 0.5 seconds.

The spurious readings may have been generated for a variety reasons including aerosol, condensation on the lens, and foam. The issue with aerosols was largely corrected by implementing two fixes initiated in Integrated Test A. The first was to open a tank vent, which allowed air to sweep through the tank head, effectively reducing the aerosol concentration and may have also changed the foam on the surface. The second was to remove the laser vent plugs, which allowed air to flow directly past the lens. Previously air flowed around the protective tube attached to the lens but not directly on the lens. It was also possible that some condensation on the lenses caused spurious readings.

\subsubsection{Bubblers}

Bubblers were susceptible to plugging on a regular basis. Blowing high pressure air through the bubbler piping, which was sometimes followed by water (steam condensate and inhibited water were used for bubbler cleaning), left bubblers operational-sometimes. When bubbler cleaning was successful, the duration of functionality was unpredictable.

Another issue with the bubbler is that the readings in Tank UFP-VSL-T02A were affected when the filter-loop pumps (UFP-PMP-T42A and/or UFP-PMP-T43A) were running. The flow from these pumps would cause pressure changes at the bubbler dip legs. Consequently, the bubbler level and density readings were wrong when the filter-loop pumps were on. The bubblers in Tanks UFP-VSL-T01A/B were not influenced by the recirculation pumps in these tanks because of lower flow or better placement within the tank.

The lesson learned on the bubblers is that they need to be equipped with cleaning capability, and the placement of the dip legs should be chosen so as not to be influenced by moving liquid within the tank.

\subsubsection{Drexelbrook}

The Drexelbrook level indicators did not function properly in the PJM s at elevated temperatures and elevated caustic solutions. This may have due to the narrow annulus in the air line and contact with the wall. The Drexelbrook probes used in the tanks worked much better. During the temperature ramp from ambient to $85^{\circ} \mathrm{C}$ in both batches, the PJMs quit functioning in standard mode (which relied on the Drexelbrook level sensors in the PJMs to signal when the slurry reach the Drive Level Set Points) and had to be switched to simple mode (which did not rely on the Drexelbrook level sensors). 


\subsubsection{Other Issues for Integrated Test D}

Other issues for Integrated Test $\mathrm{D}$ were the excessive oxidation of $\mathrm{Cr}$ during the caustic leaching step before the oxidative-leach step was started and foaming in T02A during caustic addition.

The oxidation of $\mathrm{Cr}$ was affected since the starting level was much lower than planned. In addition, the vessel T02A sampler pump failed during the tests, and samples were taken from the recirculation loop. However, this should not affect the sample results.

Foaming in Integrated Test $\mathrm{D}$ during the $\mathrm{NaOH}$ addition caused high-level readings in $\mathrm{T} 02 \mathrm{~A}$ and a concern that the level would be too high during the leaching process. The caustic addition was higher than in previous tests and could have contributed to the air entrainment/foaming issue. Slurry was removed from T02A during Batch 1, additional AFA was added, air sparging was reduced, and the loop was not flushed back to the tank to alleviate the level concern. In Batch 2, no slurry was removed, but additional AFA was added, and the tank-level high alarms had to be monitored closely during leaching to prevent the steam from automatically turning off. It is believed that these activities did not have a significant impact on the process. However, there was slightly less slurry leached than originally planned, and the mixing in the vessel was altered. 



\subsection{References}

10 CFR 830. 2009. "Energy/Nuclear Safety Management, Subpart A-Quality Assurance Requirements." Code of Federal Regulations, U.S. Department of Energy.

Baldwin DL, PP Schonewill, JJ Toth, JL Huckaby, PW Eslinger, BD Hanson, DE Kurath, and MJ Minette. 2009. EFRT M12 Issue Resolution: Solids Washing. WTP-RPT-187, PNNL-18499, Pacific Northwest National Laboratory, Richland, Washington.

Barnes HA and NQ Dzuy. 2001. "Rotating vane rheometry - a review." J. Non-Newtonian Fluid Mech. 98:1-14.

Daniel RC, JM Billing, JR Bontha, CF Brown, PW Eslinger, BD Hanson, JL Huckaby, NK Karri, ML Kimura, DE Kurath, and MJ Minette. 2009. EFRT M12 Issue Resolution: Comparison of Filter Performance at PEP and CUF Scale. WTP-RPT-185, PNNL-18498, Pacific Northwest National Laboratory, Richland, Washington.

Geeting JGH, OP Bredt, CA Burns, EC Golovich, CE Guzman-Leong, GB Josephson, DE Kurath, GJ Sevigny, and RL Aaberg. 2009. Pretreatment Engineering Platform (PEP) Integrated Test B Run Report - Caustic and Oxidative Leaching in UFP-VSL-T02A. WTP-RPT-192, PNNL-18723, Pacific Northwest National Laboratory, Richland, Washington.

Guzman-Leong CE, OP Bredt, CA Burns, RC Daniel, YF Su, JGH Geeting, EC Golovich, GB Josephson, DE Kurath, GJ Sevigny, DM Smith, PLJ Valdez, ST Yokuda, and JK Young. 2009. PEP Run Report for Integrated Test A; Caustic Leaching in UFP-VSL-T01A, Oxidative Leaching in UFP-VSL-T02A. WTP-RPT-191, PNNL-18755, Pacific Northwest National Laboratory, Richland, Washington.

Josephson GB, JGH Geeting, OP Bredt, CA Burns, EC Golovich, CE Guzman-Leong, DE Kurath, and GH Sevigny. 2009. PEP Run Report for Simulant Shakedown/Functional Testing. WTP-RPT-190, PNNL-18823, Pacific Northwest National Laboratory, Richland, Washington.

Kuhn WL, ST Arm, JL Huckaby, DE Kurath, SD Rassat. 2008. Technical Basis for Scaling Relationships for the Pretreatment Engineering Platform. WTP-RPT-160, PNNL-16948, Pacific Northwest National Laboratory, Richland, Washington.

Mahoney LA, SD Rassat, PW Eslinger, RL Aaberg, PM Aker, EC Golovich, BD Hanson, TS Hausmann, JL Huckaby, DE Kurath, MJ Minette, SK Sundaram, and ST Yokuda. 2009. EFRT Issue Resolution: Caustic Leach Rate Constants from PEP and Lab-Scale Tests. WTP-RPT-186, PNNL-18502, Pacific Northwest National Laboratory, Richland Washington.

Rapko BM, GJ Lumetta, JR Deschane, and RA Peterson. 2007. Process Development for Permanganate Addition During Oxidative Leaching of Hanford Tank Sludge Simulants. WTP-RPT-164, PNNL-16794, Pacific Northwest National Laboratory, Richland, Washington. 
Rapko BM, CF Brown, PW Eslinger, MS Fountain, TS Hausmann, JL Huckaby, BD Hanson, DE Kurath, and MJ Minette. 2009. EFRT M12 Issue Resolution: Comparison of PEP and Bench-Scale Oxidative Leaching Results. WTP-RPT-188, PNNL-18500, Pacific Northwest National Laboratory, Richland, Washington.

Russell RL, RA Peterson, HD Smith, DE Rinehart, PM Aker, and EC Buck. 2009a. Development and Characterization of Boehmite Component Simulant. WTP-RPT-184, PNNL-18176, Pacific Northwest National Laboratory, Richland, Washington.

Russell RL, Peterson RA, DE Rinehart, HD Smith. 2009b. Development and Characterization of Gibbsite Component Simulant. WTP-RPT-176, PNNL-18013, Pacific Northwest National Laboratory, Richland Washington.

Russell RL, JM Billing, RA Peterson, DE Rinehart, and HD Smith. 2009c. Development and Demonstration of Ultrafiltration Simulants. WTP-RPT-183, PNNL-18090, Pacific Northwest National Laboratory, Richland, Washington. 
Appendix A

Instrument Summary 



\section{Appendix A: Instrument Summary}

This table provides a partial list of instruments used in the PEP. The interested reader is referred to the P\&IDs and the M\&TE list for a complete list of instruments.

\begin{tabular}{|c|c|c|c|c|c|c|}
\hline & Instrument & & & & oleranc & \\
\hline Component & ID & Min & Max & Units & $( \pm)$ & Notes \\
\hline \multicolumn{7}{|l|}{ Vessel T02A } \\
\hline T02A level (bubbler) & LT-0611 & 0.00 & 200.00 & in $\mathrm{H}_{2} \mathrm{O}$ & 0.15 & \\
\hline T02A density (bubbler) & DT-0612 & 0.00 & 200.00 & in $\mathrm{H}_{2} \mathrm{O}$ & 0.15 & \\
\hline T02A level (laser) & LT-0614 & -3.95 & 96.00 & in & 0.25 & \\
\hline T02A prototypic temperature & TTK-0619 & 10.00 & 110.00 & $\mathrm{C}$ & 2 & \\
\hline \multicolumn{7}{|l|}{ T02A Temperature Array } \\
\hline $\mathrm{x}=\mathrm{A}, \mathrm{B}, \mathrm{D}, \mathrm{E}, \mathrm{F}, \mathrm{G}, \mathrm{H}, \mathrm{J}, \mathrm{K}, \mathrm{L}$ & TTx-0619 & 10.00 & 110.00 & $\mathrm{C}$ & 2 & \\
\hline $\mathrm{x}=\mathrm{A}, \mathrm{B}, \mathrm{D}, \mathrm{E}, \mathrm{F}, \mathrm{G}, \mathrm{H}, \mathrm{J}, \mathrm{K}, \mathrm{L}$ & TTx-0621 & 10.00 & 110.00 & $\mathrm{C}$ & 2 & \\
\hline$x=1-7$ & N39-x & 10.00 & 110.00 & $\mathrm{C}$ & 2 & \\
\hline$x=1-7$ & N41-X & 10.00 & 110.00 & $\mathrm{C}$ & 2 & \\
\hline$x=1-7$ & N42-x & 10.00 & 110.00 & $\mathrm{C}$ & 2 & \\
\hline$x=1-7$ & N52-X & 10.00 & 110.00 & $\mathrm{C}$ & 2 & \\
\hline \multicolumn{7}{|l|}{ HX-T02A } \\
\hline HX-T02A cooling water flow & FT-0541 & 0.00 & 70.00 & gpm & 0.88 & \\
\hline $\begin{array}{l}\text { HX-T02A cooling water inlet } \\
\text { temperature }\end{array}$ & TT-0539 & 0.00 & 110.00 & $\mathrm{C}$ & 1.8 & \\
\hline HX-T02A cooling water outlet & TT-0540 & 0.00 & 110.00 & $\mathrm{C}$ & 1.8 & \\
\hline $\begin{array}{l}\text { HX-T02A process fluid inlet } \\
\text { temperature }\end{array}$ & TT-0537 & 0.00 & 110.00 & $\mathrm{C}$ & 1.8 & $\begin{array}{l}\text { For Information Only } \\
\text { re: NCR } 42402.1\end{array}$ \\
\hline $\begin{array}{l}\text { HX-T02A process fluid outlet } \\
\text { temperature }\end{array}$ & TT-0513 & 0.00 & 110.00 & $\mathrm{C}$ & 1.8 & $\begin{array}{l}\text { For Information Only } \\
\text { re: NCR } 42402.1\end{array}$ \\
\hline \multicolumn{7}{|l|}{ Pumps T42A/T43A } \\
\hline $\begin{array}{l}\text { T42A pump discharge pressure } \\
\text { (T43A suction) }\end{array}$ & PT-0633 & 0.00 & 348.00 & psig & 0.26 & \\
\hline T42A pump inlet flow & FT-0623 & 0.00 & 220.00 & gpm & 1.6 & \\
\hline T42A pump speed & ST-0627 & 0.00 & 1785.00 & $\mathrm{rpm}$ & 4 & \\
\hline T42A pump suction pressure & PT-0625 & -260.00 & 260.00 & in $\mathrm{H} 2 \mathrm{O}$ & 0.4 & \\
\hline T42A pump motor HP & JT-0629 & 0.00 & 100.00 & HP & 1.5 & For Information Only \\
\hline T43A Outlet temperature & TT-0791 & 0.00 & 110.00 & $\mathrm{C}$ & 1.8 & $\begin{array}{l}\text { Should not be used as } \\
\text { an indicator of } \\
\text { temperature re: NCR } \\
42402.1\end{array}$ \\
\hline T43A pump discharge pressure & PT-0739 & 0.00 & 348.00 & psig & 0.26 & \\
\hline T43A pump outlet flow & FT-0635 & 0.00 & 220.00 & gpm & 1.6 & \\
\hline T43A pump speed & ST-0639 & 0.00 & 1785.00 & $\mathrm{rpm}$ & 4 & \\
\hline T43A pump motor HP & JT-0637 & 0.00 & 100.00 & HP & 1.5 & For Information Only \\
\hline \multicolumn{7}{|l|}{$\begin{array}{c}\text { Pumps Air Entrainment Trouble } \\
\text { Shoot }\end{array}$} \\
\hline $\begin{array}{l}\text { Air purge flow to steam sparger } \\
\text { FT-1995 }\end{array}$ & FT-1995 & 0.00 & 0.73 & $\mathrm{~kg} / \mathrm{min}$ & 0.02 & $\begin{array}{c}\text { Accuracy revised at } \\
\text { flow rates below } \\
0.090 \mathrm{~kg} / \mathrm{min} \text { re: } \mathrm{NCR} \\
38767.1 \\
(0.00045 \mathrm{~kg} / \mathrm{min} / \mathrm{flow} \\
\text { rate in } \mathrm{kg} / \mathrm{min} \times 100 \%)\end{array}$ \\
\hline
\end{tabular}




\begin{tabular}{|c|c|c|c|c|c|c|}
\hline & Instrument & & & & oleran & \\
\hline Component & ID & Min & Max & Units & $( \pm)$ & Notes \\
\hline Upper air sparger flow FT-1901 & FT-1901 & 0.00 & 0.73 & $\mathrm{~kg} / \mathrm{min}$ & 0.01 & $\begin{array}{c}\text { Accuracy revised at } \\
\text { flow rates below } \\
0.090 \mathrm{~kg} / \mathrm{min} \text { re: NCR } \\
38767.1 \\
(0.00045 \mathrm{~kg} / \mathrm{min} / \mathrm{flow} \\
\text { rate in } \mathrm{kg} / \mathrm{min} \times 100 \%)\end{array}$ \\
\hline Lower air sparger flow FT-1977 & FT-1977 & 0.00 & 0.73 & $\mathrm{~kg} / \mathrm{min}$ & 0.01 & $\begin{array}{c}\text { Accuracy revised at } \\
\text { flow rates below } \\
0.090 \mathrm{~kg} / \mathrm{min} \text { re: NCR } \\
38767.1 \\
(0.00045 \mathrm{~kg} / \mathrm{min} / \text { flow } \\
\text { rate in } \mathrm{kg} / \mathrm{min} \times 100 \%)\end{array}$ \\
\hline High pressure steam flow & FT-0645 & 0.00 & 33.43 & $\mathrm{cfm}$ & 0.41 & \\
\hline High pressure steam pressure & PT-0643 & 0.00 & 150.00 & psig & 0.11 & \\
\hline Inhibited water process water & FT-0601 & 0.00 & 189.27 & $\mathrm{~kg} / \mathrm{min}$ & 0.24 & \\
\hline 19M sodium hydroxide & FT-0605 & 0.00 & 75.71 & $\mathrm{~kg} / \mathrm{min}$ & 0.95 & \\
\hline $1 \mathrm{M}$ sodium pemanganate & FT-0651 & 0.00 & 15.00 & gpm & 0.11 & \\
\hline $2 \mathrm{M}$ caustic flow & FT-0655 & 0.00 & 57.10 & $\mathrm{~kg} / \mathrm{min}$ & 0.71 & \\
\hline $2 \mathrm{M}$ nitric acid flow & FT-0659 & 0.00 & 15.00 & gpm & 0.11 & \\
\hline \multicolumn{7}{|l|}{ Filter UFP-FILT-T01A } \\
\hline Tubeside inlet temp. & TT-0791 & 0.00 & 110.00 & $\mathrm{C}$ & 1.8 & $\begin{array}{l}\text { Should not be used as } \\
\text { an indicator of } \\
\text { temperature re: NCR } \\
42402.1\end{array}$ \\
\hline Tubeside inlet press. & PT-0739 & 0.00 & 348.00 & psig & 0.26 & \\
\hline Tubeside flow & FT-0635 & 0.00 & 220.00 & gpm & 1.6 & \\
\hline Shellside inlet press. & PT-0741 & 0.00 & 700.00 & psig & 0.53 & \\
\hline Shellside outlet flow & FT-0720 & 0.00 & 35.85 & $\mathrm{~kg} / \mathrm{min}$ & 0.45 & \\
\hline \multicolumn{7}{|l|}{ Filter UFP-FILT-T02A } \\
\hline Tubeside inlet temp. & TT-0791 & 0.00 & 110.00 & $\mathrm{C}$ & 1.8 & $\begin{array}{c}\text { Should not be used as } \\
\text { an indicator of } \\
\text { temperature re: NCR } \\
42402.1\end{array}$ \\
\hline Tubeside inlet press. & PT-0749 & 0.00 & 348.00 & psig & 0.26 & \\
\hline Shellside inlet press. & PT-0751 & 0.00 & 700.00 & psig & 0.53 & \\
\hline Shellside flow & FT-0755 & 0.00 & 37.85 & $\mathrm{~kg} / \mathrm{min}$ & 0.05 & \\
\hline \multicolumn{7}{|l|}{ Filter UFP-FILT-T03A } \\
\hline Tubeside inlet temp. & TT-0791 & 0.00 & 110.00 & $\mathrm{C}$ & 1.8 & $\begin{array}{c}\text { Should not be used as } \\
\text { an indicator of } \\
\text { temperature re: NCR } \\
42402.1\end{array}$ \\
\hline Tubeside inlet press. & PT-0759 & 0.00 & 348.00 & psig & 0.26 & \\
\hline Shellside inlet press. & PT-0761 & 0.00 & 700.00 & psig & 0.53 & \\
\hline Shellside flow & FT-0765 & 0.00 & 37.85 & $\mathrm{~kg} / \mathrm{min}$ & 0.05 & \\
\hline \multicolumn{7}{|l|}{ Filter UFP-FILT-T04A } \\
\hline Tubeside inlet temp. & TT-0791 & 0.00 & 110.00 & $\mathrm{C}$ & 1.8 & $\begin{array}{c}\text { Should not be used as } \\
\text { an indicator of } \\
\text { temperature re: NCR } \\
42402.1\end{array}$ \\
\hline Tubeside inlet press. & PT-0769 & 0.00 & 348.00 & psig & 0.26 & \\
\hline Shellside inlet press. & PT-0771 & 0.00 & 700.00 & psig & 0.53 & \\
\hline Shellside flow & FT-0775 & 0.00 & 37.85 & $\mathrm{~kg} / \mathrm{min}$ & 0.47 & \\
\hline
\end{tabular}




\begin{tabular}{|c|c|c|c|c|c|c|}
\hline \multirow[b]{2}{*}{ Component } & \multirow{2}{*}{$\begin{array}{l}\text { Instrument } \\
\text { ID }\end{array}$} & \multirow[b]{2}{*}{ Min } & \multicolumn{4}{|c|}{ Tolerance } \\
\hline & & & Max & Units & $( \pm)$ & Notes \\
\hline Tubeside inlet temp. & TT-0791 & 0.00 & 110.00 & $\mathrm{C}$ & 1.8 & $\begin{array}{c}\text { Should not be used as } \\
\text { an indicator of } \\
\text { temperature re: NCR } \\
42402.1\end{array}$ \\
\hline Tubeside inlet press. & PT-0779 & 0.00 & 348.00 & psig & 0.26 & \\
\hline Tubeside outlet press. & PT-0789 & 0.00 & 348.00 & psig & 0.26 & \\
\hline Shellside inlet press. & PT-0781 & 0.00 & 700.00 & psig & 0.53 & \\
\hline Shellside flow & FT-0785 & 0.00 & 37.85 & $\mathrm{~kg} / \mathrm{min}$ & 0.24 & \\
\hline \multicolumn{7}{|l|}{ Pulse-pot UFP-PP-T03A } \\
\hline Level & LT-0733 & 0.00 & 44.00 & inches & 0.1 & For Information Only \\
\hline Permeate flow from FILT T01A & FT-0720 & 0.00 & 35.85 & $\mathrm{~kg} / \mathrm{min}$ & 0.45 & \\
\hline Inlet pressure & PT-0731 & 0.00 & 700.00 & psig & 0.53 & \\
\hline Outlet pressure & PT-0741 & 0.00 & 700.00 & psig & 0.53 & \\
\hline \multicolumn{7}{|l|}{ Pulse-pot UFP-PP-T02A } \\
\hline Level & LT-0725 & 0.00 & 44.00 & inches & 0.1 & For Information Only \\
\hline Permeate flow from FILT T02A & FT-0755 & 0.00 & 37.85 & $\mathrm{~kg} / \mathrm{min}$ & 0.05 & \\
\hline Permeate flow from FILT T04A & FT-0775 & 0.00 & 37.85 & $\mathrm{~kg} / \mathrm{min}$ & 0.47 & \\
\hline inlet pressure & PT-0723 & 0.00 & 700.00 & psig & 0.53 & \\
\hline Outlet pressure to FILT T02A & PT-0751 & 0.00 & 700.00 & psig & 0.53 & \\
\hline Outlet pressure to FILT T04A & PT-0771 & 0.00 & 700.00 & psig & 0.53 & \\
\hline \multicolumn{7}{|l|}{ Pulse-pot UFP-PP-T01A } \\
\hline Level & LT-0717 & 0.00 & 44.00 & inches & 0.1 & For Information Only \\
\hline Permeate flow from FILT T03A & FT-0765 & 0.00 & 37.85 & $\mathrm{~kg} / \mathrm{min}$ & 0.05 & \\
\hline Permeate flow from FILT T05A & FT-0785 & 0.00 & 37.85 & $\mathrm{~kg} / \mathrm{min}$ & 0.24 & \\
\hline inlet pressure & PT-0715 & 0.00 & 700.00 & psig & 0.53 & \\
\hline Outlet pressure to FILT T03A & PT-0761 & 0.00 & 700.00 & psig & 0.53 & \\
\hline Outlet pressure to FILT T05A & PT-0781 & 0.00 & 700.00 & psig & 0.53 & \\
\hline
\end{tabular}



Appendix B

\section{Backpulse Description}





\section{Appendix B: Backpulse Description}

Backpulse Description:

The backpulsing function of the filter-loop can be operated only when actively filtering T02A contents. There are three variables that can be set by the operator: Level Drain Set Point, Backpulse Pressure Set Point, and Pressure Deadband for Completion.

The Level Drain Set Point is the height of fluid in the pulse-pot used for the backpulse.

The Backpulse Pressure Set Point is the amount above the filter inlet pressure that the pulse-pot should be charged to (i.e., if the inlet pressure is 100 psig and the Backpulse Pressure Set Point is set to $40 \mathrm{psig}$, the control system will charge the pulse-pot to $140 \mathrm{psig}$ ).

The Pressure Deadband for Completion is the amount above the filter inlet pressure that will cause the backpulse to be marked as finished (i.e., if the inlet pressure is 100 psig and the Deadband is set to $10 \mathrm{psig}$, the backpulse will complete when the pulse-pot pressure indicator gets down to $110 \mathrm{psig}$ ).

During filtering, the operator presses the "Start Backpulse" button in the HMI which initiates the backpulse cycle. The first step is to close all valves entering and leaving the pulse-pot. Next, the high pressure air line is opened and the pulse-pot is pressurized to $50 \mathrm{psig}$. The high pressure air valve is closed and the drain valve to T62A/B is opened. The pulse-pot fluid level falls until reaching the Level Drain Set Point when the drain valve is closed. The high pressure air valve is opened again and pressurizes the pulse-pot to the sum of the filter inlet pressure plus the Backpulse Pressure Set Point $(100 \mathrm{psig}+40 \mathrm{psig}=140 \mathrm{psig}$ in the above example). The air valve is closed and the backpulse cycle pauses for 15 seconds. The fast acting valve then opens and the pressure in the pulse-pot pushes fluid back through the filter until the pressure in the pulse-pot is equal to the filter inlet pressure plus the Deadband (100 psig $+10 \mathrm{psig}=110 \mathrm{psig}$ in the above example). The final step is to return to filtering conditions. The fast acting valve closes and the filter outlet valve and pulse-pot outlet valve to T62A/B (not the drain valve) are opened. 

Appendix C

Sample List and Naming Convention 



\section{Appendix C: Sample List and Naming Convention}

\section{C.1 Sample Naming Convention}

Every sample was given a unique sample name. The sample names were a composite of either six or seven separate descriptors. The descriptors are defined in Table C.1, and the acronyms for each descriptor are defined in Table C.2. The spacings between descriptors were separated by either an underscore symbol ( $\_$) or a space ( ). Sample naming examples are provided after Table C.1.

Table C.1. Sample Naming Nomenclature Definitions

\begin{tabular}{|c|c|c|}
\hline Descriptor & Identification & Explanation \\
\hline Descriptor 1 & Test Name & $\begin{array}{l}\text { Refers to the Shakedown Test, Functional Test, Integrated } \\
\text { Test A, Integrated Test B, or Integrated Test D. }\end{array}$ \\
\hline Descriptor 2 & Location & $\begin{array}{l}\text { Identifies the location that the sample is being collected from } \\
\text { based on Table } 3 \text {. For example, a sample collected from a } \\
\text { tank will include the acronym of the tank followed by the } \\
\text { location within the tank. }\end{array}$ \\
\hline Descriptor 3 & Test Process Step & $\begin{array}{l}\text { Refers to the process step as identified in the sample collection } \\
\text { and analysis table in the governing Test Instruction. The test } \\
\text { process step includes an identifier for processes that are } \\
\text { repeated during testing. }\end{array}$ \\
\hline Descriptor 4 & Sequential Number & $\begin{array}{l}\text { Unique number identifier that increments by } 1 \text { each time a } \\
\text { sample was collected. All sub-samples and separated samples } \\
\text { generated from the original sample had the same unique } \\
\text { number identifier. }\end{array}$ \\
\hline Descriptor 5 & Sample Routing & $\begin{array}{l}\text { Refers to the sample destination, type of analysis, storage, or } \\
\text { archive. }\end{array}$ \\
\hline Descriptor 6 & Store code & Final destination code. \\
\hline Descriptor 7 & $\begin{array}{l}\text { Separated-sample } \\
\text { identifier }\end{array}$ & $\begin{array}{l}\text { Refers to the type of sub-sample; e.g., decantate, solids, rinse } \\
\text { solution, etc. For a separated-sample, a descriptor of the } \\
\text { matrix was added after the sample routing identifier. }\end{array}$ \\
\hline
\end{tabular}


Table C.2. Sample Naming Acronyms

\begin{tabular}{|c|c|}
\hline Acronym & Definition \\
\hline \multicolumn{2}{|c|}{ Test Name (1 character) Descriptor 1} \\
\hline $\mathrm{S}$ & Shakedown testing \\
\hline $\mathrm{F}$ & Functional testing \\
\hline A & First integrated test to be performed \\
\hline B & Second integrated test to be performed \\
\hline $\mathrm{C}$ & Third integrated test to be performed \\
\hline $\mathrm{D}$ & Fourth integrated test to be performed \\
\hline \multirow{2}{*}{\multicolumn{2}{|c|}{$\begin{array}{l}\text { Location (maximum of } 5 \text { characters) Descriptor } 2 \\
\text { Vessels Name ( } 3 \text { characters) }\end{array}$}} \\
\hline & \\
\hline $\mathrm{T} 22$ & HLP-VSL-T22 \\
\hline FRP & FRP-VSL-T01 \\
\hline FEP & FEP-VSL-T01 \\
\hline $01 \mathrm{~A}$ & UFP-VSL-T01A \\
\hline 01B & UFP-VSL-T01B \\
\hline $02 \mathrm{~A}$ & UFP-VSL-T02A \\
\hline $\mathrm{T} 27$ & HLP-VSL-T27A \\
\hline $62 \mathrm{~A}$ & UFP-VSL-T62A \\
\hline $62 \mathrm{~B}$ & UFP-VSL-T62B \\
\hline \multicolumn{2}{|c|}{ Vessel Sampling Location (2 characters) } \\
\hline $\mathrm{IH}$ & Inner High \\
\hline IM & Inner Middle \\
\hline IL & Inner Low \\
\hline $\mathrm{MH}$ & Middle High \\
\hline MM & Middle Middle \\
\hline ML & Middle Low \\
\hline $\mathrm{OH}$ & Outer High \\
\hline $\mathrm{OM}$ & Outer Middle \\
\hline $\mathrm{OL}$ & Outer Low \\
\hline RL & Recirculation line \\
\hline GT & Grab sample at top of a tank \\
\hline GM & Grab sample at middle of a tank \\
\hline GB & Grab sample at bottom of a tank \\
\hline \multicolumn{2}{|c|}{ In-Line/Transfer Sampling Locations (5 characters) } \\
\hline $\mathrm{T} 221 \mathrm{~A}$ & In-line transfer from HLP-T22 to T01A \\
\hline 01A2A & In-line transfer from $\mathrm{T} 01 \mathrm{~A}$ to $\mathrm{T} 02 \mathrm{~A}$ \\
\hline 01B2A & In-line transfer from $\mathrm{T} 01 \mathrm{~B}$ to $\mathrm{T} 02 \mathrm{~A}$ \\
\hline $\mathrm{T} 221 \mathrm{~B}$ & In-line transfer from HLP-T22 to T01B \\
\hline 000FL & Filter-loop in-line sample \\
\hline 00PF1 & Permeate filter number 1 \\
\hline 00PF2 & Permeate filter number 2 \\
\hline 00PF3 & Permeate filter number 3 \\
\hline
\end{tabular}


Table C.2. Sample Naming Acronyms

\begin{tabular}{|c|c|}
\hline Acronym & Definition \\
\hline 00PF4 & Permeate filter number 4 \\
\hline 00PF5 & Permeate filter number 5 \\
\hline $00 \mathrm{C} 01$ & Downstream of CS-PMP-T01 \\
\hline $00 \mathrm{C} 02$ & Downstream of CS-PMP-T02 \\
\hline $00 \mathrm{C} 03$ & Downstream of CS-PMP-T03 \\
\hline \multicolumn{2}{|c|}{ Test Process Step $\left(3\right.$ characters ${ }^{(a)}$ plus 2 repetitive process characters $\left.{ }^{(b)}\right)$ Descriptor 3} \\
\hline (a) 001 through 032 (initial 3 characters). & As described in the guiding document such as \\
\hline $\begin{array}{l}\text { (b) A two-character field to identify any } \\
\text { repetitive process. }\end{array}$ & $\begin{array}{l}\text { Appendix A or B in TP-RPP-WTP-506 Rev.0 or } \\
\text { the governing Test Instruction. }\end{array}$ \\
\hline \multicolumn{2}{|l|}{ Repetitive Process (2 characters) } \\
\hline $\mathrm{XX}$ & No repeating process. \\
\hline bT & $10^{\circ} \mathrm{C}$ below set-point temperature \\
\hline 00 & $\begin{array}{l}\text { Time when set-point temperature reached (in } \\
\text { hours). }\end{array}$ \\
\hline 01 through 16 & $\begin{array}{l}\text { Time after set-point temperature reached (in } \\
\text { hours) or cycle number, depending on the process } \\
\text { step. }\end{array}$ \\
\hline
\end{tabular}

Sequence Number (4 characters) Descriptor 4 0001 through 9999

Sequential number incremented by 1 for replicate samples.

Sample Routing (3 characters) Descriptor 5

\begin{tabular}{ll}
\hline ARC & Archive \\
UDS & Undissolved solids \\
AFA & XRD, SEM, and/or PSD \\
SOX & Antifoaming agent analysis \\
HTC & Solid oxalate analysis \\
DEN & Heat capacity \\
ICP & Density \\
& Inductively coupled plasma optical emission \\
RAM & spectrometry (ICP) analysis \\
RHE & Raman analysis \\
TDS & Rheology (shear strength/shear stress) \\
CUF & Total dissolved solids \\
TFI & Cross-flow ultrafilter (CUF)/parallel testing \\
& Total inorganic carbon analysis (TIC)/Free \\
& hydroxide analysis (FOH)/Ion chromatography \\
ALK & (IC) analysis \\
\hline ADT & Total alkalinity \\
OST & Acidity titration \\
\hline
\end{tabular}


Table C.2. Sample Naming Acronyms

\begin{tabular}{ll}
\hline Acronym & Definition \\
\hline OTR & Other \\
SUP & Supernate, used when no Raman required \\
Separated-samples (1 character) Descriptor 6 & \\
\hdashline 0 & RTL-520 Store \\
1 & RTL-520 Archive \\
2 & SWRI \\
3 & RPL \\
4 & APEL \\
5 & Dow Corning \\
6 & Other \\
Separated-samples (1 character) Descriptor 7 & \\
\hline D & \\
B & Decanted supernatant (decantate) \\
R & Bulk solids not rinsed \\
S & Rinsate composite \\
\hline F & Rinsed solids \\
\hline
\end{tabular}

The sample names are constructed in the following manner:

\section{Descriptor1_Descriptor2_Descriptor3a_Descriptor3b_Descriptor4_Descriptor5_Descriptor6_} Descriptor7

The following description is an example of sample naming for samples collected from HLP-VSL-T22 during Shakedown/Functional testing.

- The sample name for the first Functional Test grab slurry sample collected from the top of HLP-VSL-T22 during process step 1 that was to be archived would have been:

F_T22GT_001_XX_0001_ARC_1.

- For the same sample location and type described above, analyzed for PSD on a bulk solid that was not rinsed and ICP on the decantate, the original sample vial would have been labeled:

F_T22GM_001_XX_0009_XSP_4_B for the solid.

- Since the solid phase always stayed in the original sample vial, and the liquid was decanted off into a new vial, then the new vial would have been labeled:

F_T22GM_001_XX_0009_DEN_0_D for the decantate.

- The decantate from the above sample container could have been sub-sampled for ICP and Raman; the ICP container would have been labeled as follows:

F_T22GM_001_XX_0009_ICP_2_D.

- The Raman container would have been labeled as follows:

F_T22GM_001_XX_0009_RAM_3_D. 


\section{C.2 Sample List}

This appendix contains a listing of all the samples collected during Integrated Test B. The sample listing in the table below includes:

- Sample name

- Test Instruction number

- Test Instruction step number

- Test Instruction step description

- Sample disposition.

The sample disposition was analysis, storage, or archive. If analysis was performed, it is identified. Archive samples are samples that were identified in the Pretreatment Engineering Platform (PEP) Testing (Phase I) Test Plan (TP-RPP-WTP-506) as samples to be collected and archived. Samples submitted for storage were excess sample material. In addition to the sample disposition, a reference is provided to an electronic folder and electronic analytical report containing sample results.

Analysis acronyms are used in the table, so brief acronym descriptions are provided.

- Density slurry - analysis performed on slurry

- Density supernate - analysis performed on supernate

- Free hydroxide $(\mathrm{OH})$

- Inductively coupled plasma supernate (ICP supernate) - analysis performed on the supernate

- Inductively coupled plasma wet solids (ICP wet solids) — analysis performed on wet solids

- Ion chromatography (IC)

- Particle size distribution (PSD)

- Rheology is a general term used to describe either shear strength or shear stress vs. shear rate analysis - the actual analytical report specifies the specific analysis

- Scanning electron microscope (SEM)

- Total dissolved solids (TDS)

- THF Wet Solids, THF Supernate, Toluene Wet Solids, and Toluene Supernate are the solvent extractions performed on either the supernate or wet solid before being analyzed by gel permeation chromatography (GPC)

- Total inorganic carbon and total organic carbon (TIC/TOC)

- Weight Percent Undissolved Solids (UDS)

- X-ray diffraction (XRD). 



\begin{tabular}{|c|c|c|c|c|c|c|}
\hline TI \# & TI Step \# & TI Step Description & Sample ID & Analysis & $\begin{array}{l}\text { Electronic Folder } \\
\text { (SWRI Task Order \#, ASR \#, TDP\#) }\end{array}$ & Final Electronic Report File Name \\
\hline TI-082 & N/A & Prepare and Stage Simulant & D FRPRL 001 XX 4903 UDS 2 & UDS & SWRI-090318-2 & 090318-2 UDS \\
\hline TI-082 & N/A & Prepare and Stage Simulant & D FRPRL 001 XX 4904 UDS 2 & UDS & SWRI-090318-2 & 090318-2 UDS \\
\hline TI-082 & N/A & Prepare and Stage Simulant & D FRPRL 001 XX 4905 UDS 2 & UDS & SWRI-090318-2 & 090318-2 UDS \\
\hline TI-082 & N/A & Prepare and Stage Simulant & D FRPRL 001 XX 4906 DEN 2 & Density Supernate & SWRI-090318-1 & $090318-1$ and $090319-3$ and $090320-9$ DEN slurry and liquid \\
\hline TI-082 & N/A & Prepare and Stage Simulant & D FRPRL 001 XX 4906 DEN 2 & Density Slurry & SWRI-090318-1 & 090318-1 and 090319-3 and 090320-9 DEN slurry and liquid \\
\hline TI-082 & N/A & Prepare and Stage Simulant & D FRPRL 001 XX 4907 DEN 2 & Density Supernate & SWRI-090318-1 & 090318-1 and 090319-3 and 090320-9 DEN slurry and liquid \\
\hline TI-082 & N/A & Prepare and Stage Simulant & D FRPRL 001 XX 4907 DEN 2 & Density Slurry & SWRI-090318-1 & 090318-1 and 090319-3 and 090320-9 DEN slurry and liquid \\
\hline TI-082 & N/A & Prepare and Stage Simulant & D FRPRL 001 XX 4908 DEN 2 & Density Supernate & SWRI-090318-1 & 090318-1 and 090319-3 and 090320-9 DEN slurry and liquid \\
\hline TI-082 & N/A & Prepare and Stage Simulant & D FRPRL 001 XX 4908 DEN 2 & Density Slurry & SWRI-090318-1 & 090318-1 and 090319-3 and 090320-9 DEN slurry and liquid \\
\hline TI-082 & N/A & Prepare and Stage Simulant & D FRPRL 001 XX 4909 RHE 4 & Rheology & TDP WTP 366 & TDP WTP 366 Int Test D RHE Data on PEP Slurry \\
\hline TI-082 & N/A & Prepare and Stage Simulant & D FRPRL 001 XX 4910 RHE 4 & Rheology & TDP WTP 366 & TDP WTP 366 Int Test D RHE Data on PEP Slurry \\
\hline TI-082 & N/A & Prepare and Stage Simulant & D FRPRL 001 XX 4911 RHE 4 & Rheology & TDP WTP 366 & TDP WTP 366 Int Test D RHE Data on PEP Slurry \\
\hline TI-082 & N/A & Prepare and Stage Simulant & D FRPRL 001 XX 4912 RHE 4 & Rheology & TDP WTP 366 & TDP WTP 366 Int Test D RHE Data on PEP Slurry \\
\hline TI-082 & N/A & Prepare and Stage Simulant & D FRPRL 001 XX 4913 ICP 2 B & ICP Wet Solids & SWRI-090318-4 & 090318-4 and 090319-6 ICP ICPMS \\
\hline TI-082 & N/A & Prepare and Stage Simulant & D FRPRL 001 XX 4913 ICP 2 D & ICP Supernate & SWRI-090318-3 & 090318-3 and 090319-5 ICP and ICPMS \\
\hline TI-082 & N/A & Prepare and Stage Simulant & D FRPRL 001 XX 4913 RAM 3 D & Raman & ASR8384 & ASR 8384 RAM \\
\hline TI-082 & N/A & Prepare and Stage Simulant & D FRPRL 001 XX 4913 TFI 2 D & IC & $\begin{array}{l}\text { SWRI-090318-1 SWRI-090318-9 } \\
\text { SWRI-090319-9 }\end{array}$ & $\begin{array}{l}090318-9 \text { and } 090319-9 \text { and } 090320-11 \text { and } 090324-20 \text { IC and TIC } \\
\text { TOC }\end{array}$ \\
\hline TI-082 & $\mathrm{N} / \mathrm{A}$ & Prepare and Stage Simulant & D FRPRL 001 XX 4913 TFI 2 D & TIC/TOC & $\begin{array}{l}\text { SWRI-090318-1 SWRI-090318-9 } \\
\text { SWRI-090319-9 }\end{array}$ & $\begin{array}{l}090318-9 \text { and } 090319-9 \text { and } 090320-11 \text { and } 090324-20 \text { IC and TIC } \\
\text { TOC }\end{array}$ \\
\hline TI-082 & N/A & Prepare and Stage Simulant & D FRPRL 001 XX 4913 TFI 3 D & $\mathrm{OH}$ & ASR8386 & ASR $8386 \mathrm{OH}$ \\
\hline TI-082 & N/A & Prepare and Stage Simulant & D FRPRL 001 XX 4914 ICP 2 B & ICP Wet Solids & SWRI-090318-4 & 090318-4 and 090319-6 ICP ICPMS \\
\hline TI-082 & N/A & Prepare and Stage Simulant & D FRPRL 001 XX 4914 ICP 2 D & ICP Supernate & SWRI-090318-3 & 090318-3 and 090319-5 ICP and ICPMS \\
\hline TI-082 & N/A & Prepare and Stage Simulant & D FRPRL 001 XX 4914 RAM 3 D & Raman & ASR8384 & ASR 8384 RAM \\
\hline TI-082 & N/A & Prepare and Stage Simulant & D FRPRL 001 XX 4914 TFI 2 D & IC & $\begin{array}{l}\text { SWRI-090318-1 SWRI-090318-9 } \\
\text { SWRI-090319-9 }\end{array}$ & $\begin{array}{l}090318-9 \text { and } 090319-9 \text { and } 090320-11 \text { and } 090324-20 \text { IC and TIC } \\
\text { TOC }\end{array}$ \\
\hline TI-082 & N/A & Prepare and Stage Simulant & D FRPRL 001 XX 4914 TFI 2 D & $\mathrm{TIC} / \mathrm{TOC}$ & $\begin{array}{l}\text { SWRI-090318-1 SWRI-090318-9 } \\
\text { SWRI-090319-9 }\end{array}$ & $\begin{array}{c}090318-9 \text { and } 090319-9 \text { and } 090320-11 \text { and } 090324-20 \text { IC and TIC } \\
\text { TOC }\end{array}$ \\
\hline TI-082 & N/A & Prepare and Stage Simulant & D FRPRL 001 XX 4914 TFI 3 D & $\mathrm{OH}$ & ASR8386 & ASR $8386 \mathrm{OH}$ \\
\hline TI-082 & N/A & Prepare and Stage Simulant & D FRPRL 001 XX 4915 ICP 2 B & ICP Wet Solids & SWRI-090318-4 & 090318-4 and 090319-6 ICP ICPMS \\
\hline TI-082 & N/A & Prepare and Stage Simulant & D FRPRL 001 XX 4915 ICP 2 D & ICP Supernate & SWRI-090318-3 & 090318-3 and 090319-5 ICP and ICPMS \\
\hline TI-082 & N/A & Prepare and Stage Simulant & D FRPRL 001 XX 4915 RAM 3 D & Raman & ASR8384 & ASR 8384 RAM \\
\hline
\end{tabular}


Integrated Test D Sample List

\begin{tabular}{|c|c|c|c|c|c|c|}
\hline TI\# & TI Step \# & TI Step Description & Sample ID & Analysis & $\begin{array}{c}\text { Electronic Folder } \\
\text { (SWRI Task Order \#, ASR \#, TDP\#) }\end{array}$ & Final Electronic Report File Name \\
\hline TI-082 & $\mathrm{N} / \mathrm{A}$ & Prepare and Stage Simulant & D FRPRL 001 XX 4915 TFI 2 D & IC & $\begin{array}{l}\text { SWRI-090318-1 SWRI-090318-9 } \\
\text { SWRI-090319-9 }\end{array}$ & $\begin{array}{l}\text { 090318-9 and 090319-9 and 090320-11 and 090324-20 IC and TIC } \\
\text { TOC }\end{array}$ \\
\hline TI-082 & $\mathrm{N} / \mathrm{A}$ & Prepare and Stage Simulant & D FRPRL 001 XX 4915 TFI 2 D & TIC/TOC & $\begin{array}{l}\text { SWRI-090318-1 SWRI-090318-9 } \\
\text { SWRI-090319-9 }\end{array}$ & $\begin{array}{l}\text { 090318-9 and 090319-9 and 090320-11 and 090324-20 IC and TIC } \\
\text { TOC }\end{array}$ \\
\hline TI-082 & N/A & Prepare and Stage Simulant & D FRPRL 001 XX 4915 TFI 3 D & $\mathrm{OH}$ & ASR8386 & ASR $8386 \mathrm{OH}$ \\
\hline TI-066 & N/A & Prepare and Stage Simulant & D FRPRL 001 XX 4916 XSP 4 & PSD & $\begin{array}{l}\text { TDP-WTP-360; } \\
\text { TDP-WTP-365; } \\
\text { TDP-WTP-364 }\end{array}$ & $\begin{array}{l}\text { TDP WTP } 365 \text { Int Test D PSD Data Analysis; } \\
\text { TDP WTP } 364 \text { PEP Integrated Test D XRD Data Analysis } \\
\text { TDP WTP } 360 \text { Int Test D SEM Data Analysis }\end{array}$ \\
\hline TI-082 & N/A & Prepare and Stage Simulant & D FRPRL 001 XX 4917 SOX 2 & TIC/TOC & $\begin{array}{l}\text { SWRI-090318-9, SWRI-090320-1, } \\
\text { SWRI-090324-20 }\end{array}$ & $\begin{array}{l}090318-9 \text { and } 090319-9 \text { and } 090320-11 \text { and } 090324-20 \text { IC and TIC } \\
\text { TOC }\end{array}$ \\
\hline TI-082 & N/A & Prepare and Stage Simulant & D FRPRL 001 XX 4918 AFA 2 & ICP Supernate & SWRI-090318-10 & $\begin{array}{l}\text { 090317-22 and 090317-42 and 090318-6 and 090318-10 and } \\
090320-10 \text { and } 090320-12 \text { ICP and ICPMS }\end{array}$ \\
\hline TI-082 & N/A & Prepare and Stage Simulant & D FRPRL 001 XX 4918 AFA 2 & ICP Wet Solids & SWRI-090318-10 & $\begin{array}{l}090317-23 \text { and } 090317-43 \text { and } 090318-10 \text { and } 090320-10 \text { and } \\
090320-13 \text { ICP ICPMS }\end{array}$ \\
\hline TI- 82 & $\mathrm{n} / \mathrm{a}$ & Prepare and Stage Simulant & D FRPRL 001 XX 4919 AFA 5 B & THF Wet Solids & 49437 & PNNL 49437 Report.pdf \\
\hline TI- 82 & $\mathrm{n} / \mathrm{a}$ & Prepare and Stage Simulant & D FRPRL 001 XX 4919 AFA 5 D & THF Supernate & 49437 & PNNL 49437 Report.pdf \\
\hline TI- 82 & $\mathrm{n} / \mathrm{a}$ & Prepare and Stage Simulant & D FRPRL 001 XX 4920 AFA 5 B & Toluene Wet Solids & 49437 & $\begin{array}{l}\text { PNNL } 49437 \text { Report.pdf - No detectable peak present for Toluene } \\
\text { Ext. }\end{array}$ \\
\hline TI-82 & $\mathrm{n} / \mathrm{a}$ & Prepare and Stage Simulant & D FRPRL 001 XX 4920 AFA 5 D & Toluene Supernate & 49437 & $\begin{array}{l}\text { PNNL } 49437 \text { Report.pdf - No detectable peak present for Toluene } \\
\text { Ext. }\end{array}$ \\
\hline TI-082 & N/A & Prepare and Stage Simulant & D FRPRL 001 XX 5611 UDS 3 & UDS & ASR8384 & ASR 8384 UDS \\
\hline TI-082 & N/A & Prepare and Stage Simulant & D FRPRL 001 XX 5612 UDS 3 & UDS & ASR8384 & ASR 8384 UDS \\
\hline TI-082 & N/A & Prepare and Stage Simulant & D FRPRL 001 XX 5613 UDS 3 & UDS & ASR8384 & ASR 8384 UDS \\
\hline TI-082 & N/A & Prepare and Stage Simulant & D FRPRL 001 XX 5614 DEN 3 & Density Slurry & ASR8384 & ASR 8384 Density \\
\hline TI-082 & N/A & Prepare and Stage Simulant & D FRPRL 001 XX 5615 DEN 3 & Density Slurry & ASR8384 & ASR 8384 Density \\
\hline TI-082 & N/A & Prepare and Stage Simulant & D FRPRL 001 XX 5616 DEN 3 & Density Slurry & ASR8384 & ASR 8384 Density \\
\hline TI-082 & N/A & Prepare and Stage Simulant & D FRPRL 001 XX 5617 ICP 3 B & ICP Wet Solids & ASR8384 & ASR 8384 ICP solids rev 1 \\
\hline TI-082 & $\mathrm{N} / \mathrm{A}$ & Prepare and Stage Simulant & D FRPRL 001 XX 5617 ICP 3 B & ICP Wet Solids & ASR8384 & ASR 8384 ICP solids acid leach rev 1 \\
\hline TI-082 & $\mathrm{N} / \mathrm{A}$ & Prepare and Stage Simulant & D FRPRL 001 XX 5617 ICP 3 B & ICP Wet Solids & ASR8384 & ASR 8384 ICP solids custom leach rev 1 \\
\hline TI-082 & N/A & Prepare and Stage Simulant & D FRPRL 001 XX 5617 ICP 3 D & ICP Supernate & ASR8384 & ASR 8384 ICP liquid \\
\hline TI-082 & N/A & Prepare and Stage Simulant & D FRPRL 001 XX 5617 TFI 3 D & $\mathrm{OH}$ & ASR8384 & ASR $8384 \mathrm{OH}$ \\
\hline TI-082 & N/A & Prepare and Stage Simulant & D FRPRL 001 XX 5618 ICP 3 B & ICP Wet Solids & ASR8384 & ASR 8384 ICP solids rev 1 \\
\hline TI-082 & N/A & Prepare and Stage Simulant & D FRPRL 001 XX 5618 ICP 3 B & ICP Wet Solids & ASR8384 & ASR 8384 ICP solids acid leach rev 1 \\
\hline TI-082 & N/A & Prepare and Stage Simulant & D FRPRL 001 XX 5618 ICP 3 B & ICP Wet Solids & ASR8384 & ASR 8384 ICP solids custom leach rev 1 \\
\hline
\end{tabular}


Integrated Test D Sample List

\begin{tabular}{|c|c|c|c|c|c|c|}
\hline TI \# & TI Step \# & TI Step Description & Sample ID & Analysis & $\begin{array}{c}\text { Electronic Folder } \\
\text { (SWRI Task Order \#, ASR \#, TDP\#) }\end{array}$ & Final Electronic Report File Name \\
\hline TI-082 & $\mathrm{N} / \mathrm{A}$ & Prepare and Stage Simulant & D FRPRL 001 XX 5618 ICP 3 D & ICP Supernate & ASR8384 & ASR 8384 ICP liquid \\
\hline TI-082 & $\mathrm{N} / \mathrm{A}$ & Prepare and Stage Simulant & D FRPRL 001 XX 5618 TFI 3 D & $\mathrm{OH}$ & ASR8384 & ASR $8384 \mathrm{OH}$ \\
\hline TI-082 & N/A & Prepare and Stage Simulant & D FRPRL 001 XX 5619 ICP 3 B & ICP Wet Solids & ASR8384 & ASR 8384 ICP solids rev 1 \\
\hline TI-082 & $\mathrm{N} / \mathrm{A}$ & Prepare and Stage Simulant & D FRPRL 001 XX 5619 ICP 3 B & ICP Wet Solids & ASR8384 & ASR 8384 ICP solids acid leach rev 1 \\
\hline TI-082 & N/A & Prepare and Stage Simulant & D FRPRL 001 XX 5619 ICP 3 B & ICP Wet Solids & ASR8384 & ASR 8384 ICP solids custom leach rev 1 \\
\hline TI-082 & N/A & Prepare and Stage Simulant & D FRPRL 001 XX 5619 ICP 3 D & ICP Supernate & ASR8384 & ASR 8384 ICP liquid \\
\hline TI-082 & N/A & Prepare and Stage Simulant & D FRPRL 001 XX 5619 TFI 3 D & $\mathrm{OH}$ & ASR 8384 & ASR $8384 \mathrm{OH}$ \\
\hline TI-082 & N/A & Prepare and Stage Simulant & D FRPRL 001 XX 5620 ICP 2 B & ICP Wet Solids & SWRI-090319-6 & 090318-4 and 090319-6 ICP ICPMS \\
\hline TI-082 & N/A & Prepare and Stage Simulant & D FRPRL 001 XX 5620 ICP 2 D & ICP Supernate & SWRI-090319-5 & 090318-3 and 090319-5 ICP and ICPMS \\
\hline TI-082 & N/A & Prepare and Stage Simulant & D FRPRL 001 XX 5620 RAM 3 D & Raman & ASR8387 & ASR 8387 RAM \\
\hline TI-082 & N/A & Prepare and Stage Simulant & D FRPRL 001 XX 5620 TFI 2 D & IC & $\begin{array}{l}\text { SWRI-090318-9 SWRI-090319-8 } \\
\text { SWRI-090319-9 }\end{array}$ & $\begin{array}{l}090318-9 \text { and } 090319-9 \text { and } 090320-11 \text { and } 090324-20 \text { IC and TIC } \\
\text { TOC }\end{array}$ \\
\hline TI-082 & N/A & Prepare and Stage Simulant & D FRPRL 001 XX 5620 TFI 2 D & TOC/TIC & $\begin{array}{l}\text { SWRI-090318-9 SWRI-090319-8 } \\
\text { SWRI-090319-9 }\end{array}$ & $\begin{array}{l}090318-9 \text { and } 090319-9 \text { and } 090320-11 \text { and } 090324-20 \text { IC and TIC } \\
\text { TOC }\end{array}$ \\
\hline TI-082 & N/A & Prepare and Stage Simulant & D FRPRL 001 XX 5620 TFI 3 D & $\mathrm{OH}$ & ASR8388 & ASR $8388 \mathrm{OH}$ \\
\hline TI-082 & $\mathrm{N} / \mathrm{A}$ & Prepare and Stage Simulant & D FRPRL 001 XX 5621 ICP 2 B & ICP Wet Solids & SWRI-090319-6 & 090318-4 and 090319-6 ICP ICPMS \\
\hline TI-082 & N/A & Prepare and Stage Simulant & D FRPRL 001 XX 5621 ICP 2 D & ICP Supernate & SWRI-090319-5 & 090318-3 and 090319-5 ICP and ICPMS \\
\hline TI-082 & N/A & Prepare and Stage Simulant & D FRPRL 001 XX 5621 RAM 3 D & Raman & ASR8387 & ASR 8387 RAM \\
\hline TI-082 & N/A & Prepare and Stage Simulant & D FRPRL 001 XX 5621 TFI 2 D & $\mathrm{IC}$ & $\begin{array}{l}\text { SWRI-090318-9 SWRI-090319-8 } \\
\text { SWRI-090319-9 }\end{array}$ & $\begin{array}{c}090318-9 \text { and } 090319-9 \text { and } 090320-11 \text { and } 090324-20 \text { IC and TIC } \\
\text { TOC }\end{array}$ \\
\hline TI-082 & N/A & Prepare and Stage Simulant & D FRPRL 001 XX 5621 TFI 2 D & TOC/TIC & $\begin{array}{l}\text { SWRI-090318-9 SWRI-090319-8 } \\
\text { SWRI-090319-9 }\end{array}$ & $\begin{array}{c}090318-9 \text { and } 090319-9 \text { and } 090320-11 \text { and } 090324-20 \text { IC and TIC } \\
\text { TOC }\end{array}$ \\
\hline TI-082 & N/A & Prepare and Stage Simulant & D FRPRL 001 XX 5621 TFI 3 D & $\mathrm{OH}$ & ASR8388 & ASR $8388 \mathrm{OH}$ \\
\hline TI-082 & N/A & Prepare and Stage Simulant & D FRPRL 001 XX 5622 ICP 2 B & ICP Wet Solids & SWRI-090319-6 & 090318-4 and 090319-6 ICP ICPMS \\
\hline TI-082 & N/A & Prepare and Stage Simulant & D FRPRL 001 XX 5622 ICP 2 D & ICP Supernate & SWRI-090319-5 & 090318-3 and 090319-5 ICP and ICPMS \\
\hline TI-082 & N/A & Prepare and Stage Simulant & D FRPRL 001 XX 5622 RAM 3 D & Raman & ASR8387 & ASR 8387 RAM \\
\hline TI-082 & N/A & Prepare and Stage Simulant & D FRPRL 001 XX 5622 TFI 2 D & $\mathrm{IC}$ & $\begin{array}{l}\text { SWRI-090318-9 SWRI-090319-8 } \\
\text { SWRI-090319-9 }\end{array}$ & $\begin{array}{l}\text { 090318-9 and 090319-9 and 090320-11 and 090324-20 IC and TIC } \\
\text { TOC }\end{array}$ \\
\hline TI-082 & N/A & Prepare and Stage Simulant & D FRPRL 001 XX 5622 TFI 2 D & TOC/TIC & $\begin{array}{l}\text { SWRI-090318-9 SWRI-090319-8 } \\
\text { SWRI-090319-9 }\end{array}$ & $\begin{array}{l}090318-9 \text { and } 090319-9 \text { and } 090320-11 \text { and } 090324-20 \text { IC and TIC } \\
\text { TOC }\end{array}$ \\
\hline TI-082 & $\mathrm{N} / \mathrm{A}$ & Prepare and Stage Simulant & D FRPRL 001 XX 5622 TFI 3 D & $\mathrm{OH}$ & ASR8388 & ASR $8388 \mathrm{OH}$ \\
\hline TI-082 & N/A & Prepare and Stage Simulant & D T22GM 002 XX 4926 XSP 4 & PSD & TDP-WTP-365 & TDP WTP 365 Int Test D PSD Data Analysis \\
\hline TI-082 & 7.2.1 & Transfer simulant from HLP-T22 to UFP-VSL-T01B & D T22GM 002 XX 4924 UDS 2 & UDS & SWRI-090324-30 & 090324-30UDS R1 \\
\hline
\end{tabular}


Integrated Test D Sample List

\begin{tabular}{|c|c|c|c|c|c|c|}
\hline TI\# & TI Step \# & TI Step Description & Sample ID & Analysis & $\begin{array}{c}\text { Electronic Folder } \\
\text { (SWRI Task Order \#, ASR \#, TDP\#) }\end{array}$ & Final Electronic Report File Name \\
\hline TI-082 & 7.2 .1 & Transfer simulant from HLP-T22 to UFP-VSL-T01B & D T22GM 002 XX 4925 RHE 4 & Rheology & TDP WTP 366 & TDP WTP 366 Int Test D RHE Data on PEP Slurry \\
\hline TI-082 & 7.2.1 & Transfer from HLP-T22 to UFP-VSL-T01B & D T22GM 002 XX 4926 XSP 4 & PSD & TDP-WTP-365 & TDP WTP 365 Int Test D PSD Data Analysis \\
\hline TI-082 & 7.2 .1 & Transfer from HLP-T22 to UFP-VSL-T01B & D T22GT 002 XX 4921 ARC 1 & Archive & & \\
\hline TI-082 & 7.2 .1 & Transfer from HLP-T22 to UFP-VSL-T01B & D T22GM 002 XX 4922 ARC 1 & Archive & & \\
\hline TI-082 & 7.2 .1 & Transfer from HLP-T22 to UFP-VSL-T01B & D T22GB 002 XX 4923 ARC 1 & Archive & & \\
\hline TI-082 & 7.2.2 & Transfer from HLP-T22 to UFP-VSL-T01B & D T221B 002 XX 4927 ARC 1 & Archive & & \\
\hline TI-082 & 7.2.2 & Transfer from HLP-T22 to UFP-VSL-T01B & D T221B 002 XX 4928 ARC 1 & Archive & & \\
\hline TI-082 & 7.2.2 & Transfer from HLP-T22 to UFP-VSL-T01B & D T221B 002 XX 4929 ARC 1 & Archive & & \\
\hline TI-082 & 7.2.2 & Transfer from HLP-T22 to UFP-VSL-T01B & D T221B 002 XX 4930 ARC 1 & Archive & & \\
\hline TI-082 & 7.2.8 & End of transfer into UFP-VSL-T01A from HLP-T22 & D 01BIH 002 XX 4931 UDS 2 & UDS & SWRI-090324-30 & 090324-30UDS R1 \\
\hline TI-082 & 7.2.8 & End of transfer into UFP-VSL-T01A from HLP-T22 & D 01BIH 002 XX 4934 ICP 2 B & ICP Wet Solids & SWRI-090324-1 & 090324-1 ICP and ICPMS \\
\hline TI-082 & 7.2.8 & End of transfer into UFP-VSL-T01A from HLP-T22 & D 01BIL 002 XX 4933 UDS 2 & UDS & SWRI-090324-30 & 090324-30UDS R1 \\
\hline TI-082 & 7.2.8 & End of transfer into UFP-VSL-T01A from HLP-T22 & D 01BIL 002 XX 4936 ICP 2 B & ICP Wet Solids & SWRI-090324-1 & 090324-1 ICP and ICPMS \\
\hline TI-082 & 7.2.8 & End of transfer into UFP-VSL-T01A from HLP-T22 & D 01BIM 002 XX 4932 UDS 2 & UDS & SWRI-090324-30 & 090324-30UDS R1 \\
\hline TI-082 & 7.2.8 & End of transfer into UFP-VSL-T01A from HLP-T22 & D 01BIM 002 XX 4935 ICP 2 B & ICP Wet Solids & SWRI-090324-1 & 090324-1 ICP and ICPMS \\
\hline TI-082 & 7.3.4 & Transfer of simulant from UFP-VSL-T01B to UFP-VSL-T02A & D 01B2A 003 XX 4937 ARC 1 & Archive & & \\
\hline TI-082 & 7.3.4 & Transfer of simulant from UFP-VSL-T01B to UFP-VSL-T02A & D 01B2A 003 XX 4938 ARC 1 & Archive & & \\
\hline TI-082 & 7.3.4 & Transfer of simulant from UFP-VSL-T01B to UFP-VSL-T02A & D 01B2A 003 XX 4939 ARC 1 & Archive & & \\
\hline TI-082 & 7.3.4 & Transfer of simulant from UFP-VSL-T01B to UFP-VSL-T02A & D 01B2A 003 XX 4940 ARC 1 & Archive & & \\
\hline TI-082 & 7.5.7 & $\begin{array}{c}\text { Concentration in UFP-VSL-T02A to } 20 \text {-wt } \% \text { UDS - immediately after } \\
\text { permeate valves are opened }\end{array}$ & D 02AML 005 XX 4949 UDS 2 & UDS & SWRI-090326-1 & 090326-1UDS R1 \\
\hline TI-082 & 7.5.7 & $\begin{array}{l}\text { Concentration in UFP-VSL-T02A to } 20 \text {-wt } \% \text { UDS - immediately after } \\
\text { permeate valves are opened }\end{array}$ & D 02AML 005 XX 4950 RHE 4 & Rheology & TDP WTP 366 & TDP WTP 366 Int Test D RHE Data on PEP Slurry \\
\hline TI-082 & 7.5.7 & Concentration in UFP-VSL-T02A to 20 -wt $\%$ UDS & D 02AML 005 XX 4951 UDS 2 & UDS & SWRI-090326-1 & 090326-1UDS R1 \\
\hline TI-082 & 7.5.7 & Concentration in UFP-VSL-T02A to 20 -wt\% UDS & D 02AML 005 XX 4952 UDS 2 & UDS & SWRI-090326-1 & 090326-1UDS R1 \\
\hline TI-082 & 7.5.7 & Concentration in UFP-VSL-T02A to 20 -wt $\%$ UDS & D 02AML 005 XX 4953 UDS 2 & UDS & SWRI-090326-1 & 090326-1UDS R1 \\
\hline TI-082 & 7.5.7 & Concentration in UFP-VSL-T02A to 20 -wt $\%$ UDS & D 02AML 005 XX 4954 UDS 2 & UDS & SWRI-090326-1 & 090326-1UDS R1 \\
\hline TI-082 & 7.5.7 & Concentration in UFP-VSL-T02A to 20-wt\% UDS & D 02AML 005 XX 4955 UDS 2 & UDS & SWRI-090326-1 & 090326-1UDS R1 \\
\hline TI-082 & 7.5.7 & Concentration in UFP-VSL-T02A to 20 -wt $\%$ UDS & D 02AML 005 XX 4956 UDS 2 & UDS & SWRI-090326-1 & 090326-1UDS R1 \\
\hline TI-082 & 7.5.7 & Concentration in UFP-VSL-T02A to 20 -wt $\%$ UDS & D 02AML 005 XX 4957 UDS 2 & UDS & SWRI-090326-1 & 090326-1UDS R1 \\
\hline TI-082 & 7.5.7 & Concentration in UFP-VSL-T02A to 20 -wt $\%$ UDS & D 02AML 005 XX 4958 UDS 2 & UDS & SWRI-090326-1 & 090326-1UDS R1 \\
\hline TI-082 & 7.5.7 & Concentration in UFP-VSL-T02A to 20 -wt $\%$ UDS & D 02AML 005 XX 4959 UDS 2 & UDS & SWRI-090326-1 & 090326-1UDS R1 \\
\hline
\end{tabular}


Integrated Test D Sample List

\begin{tabular}{|c|c|c|c|c|c|c|}
\hline TI\# & TI Step \# & TI Step Description & Sample ID & Analysis & $\begin{array}{c}\text { Electronic Folder } \\
\text { (SWRI Task Order \#, ASR \#, TDP\#) }\end{array}$ & Final Electronic Report File Name \\
\hline TI-082 & 7.5 .7 & Concentration in UFP-VSL-T02A to 20 -wt $\%$ UDS & D 02AML 005 XX 4960 UDS 2 & UDS & SWRI-090326-1 & 090326-1UDS R1 \\
\hline TI-082 & 7.5.7 & Concentration in UFP-VSL-T02A to 20 - $\mathrm{wt} \%$ UDS & D 02AML 005 XX 4961 UDS 2 & UDS & SWRI-090326-1 & 090326-1UDS R1 \\
\hline TI-082 & 7.5.7 & Concentration in UFP-VSL-T02A to 20 - wt $\%$ UDS & D 02AML 005 XX 4962 UDS 2 & UDS & SWRI-090326-1 & 090326-1UDS R1 \\
\hline TI-082 & 7.5.7 & Concentration in UFP-VSL-T02A to 20 - $\mathrm{wt} \%$ UDS & D 02AML 005 XX 4963 UDS 2 & UDS & SWRI-090326-1 & 090326-1UDS R1 \\
\hline TI-082 & 7.5.7 & Concentration in UFP-VSL-T02A to 20 -wt $\%$ UDS & D 02AML 005 XX 4964 UDS 2 & UDS & SWRI-090326-11 & 090326-11UDS R1 \\
\hline TI-082 & 7.5.7 & Concentration in UFP-VSL-T02A to 20 -wt\% UDS & D 02AML 005 XX 4965 UDS 2 & UDS & SWRI-090326-11 & 090326-11UDS R1 \\
\hline TI-082 & 7.5.7 & Concentration in UFP-VSL-T02A to 20 -wt $\%$ UDS & D 00PF1 005 XX 4946 ARC 1 & Archive & & \\
\hline TI-082 & 7.5.7 & Concentration in UFP-VSL-T02A to 20 -wt $\%$ UDS & D 01B2A 005 XX 4941 ARC 1 & Archive & & \\
\hline TI-082 & 7.5.7 & Concentration in UFP-VSL-T02A to 20 -wt $\%$ UDS & D 01B2A 005 XX 4942 ARC 1 & Archive & & \\
\hline TI-082 & 7.5.7 & Concentration in UFP-VSL-T02A to 20 -wt\% UDS & D 01B2A 005 XX 4943 ARC 1 & Archive & & \\
\hline TI-082 & 7.5.7 & Concentration in UFP-VSL-T02A to 20 -wt $\%$ UDS & D 01B2A 005 XX 4944 ARC 1 & Archive & & \\
\hline TI-082 & 7.5.7 & Concentration in UFP-VSL-T02A to 20 -wt $\%$ UDS & D 01B2A 005 XX 4945 ARC 1 & Archive & & \\
\hline TI-082 & 7.5.7 & Concentration in UFP-VSL-T02A to 20 -wt\% UDS & D 00PF1 005 XX 5597 ARC 1 & Archive & & \\
\hline TI-082 & 7.5 .9 & $\begin{array}{l}\text { Completion of dewatering solids in UFP-VSL-T02A to 20-wt } \% \text { UDS } \\
\text { using ONE ultrafilter }\end{array}$ & D 00PF1 005 XX 4982 ARC 4 & Permeate Study & & \\
\hline TI-082 & 7.5.9 & $\begin{array}{l}\text { Concentration in UFP-VSL-T02A to } 20 \text {-wt } \% \text { UDS - after solids } \\
\text { concentration is complete }\end{array}$ & D 02AML 005 XX 4970 UDS 2 & UDS & SWRI-090326-11 & 090326-11UDS R1 \\
\hline TI-082 & 7.5.9 & $\begin{array}{l}\text { Concentration in UFP-VSL-T02A to } 20 \text {-wt } \% \text { UDS - after solids } \\
\text { concentration is complete }\end{array}$ & D 02AML 005 XX 4971 UDS 2 & UDS & SWRI-090326-11 & 090326-11UDS R1 \\
\hline TI-082 & 7.5.9 & $\begin{array}{l}\text { Concentration in UFP-VSL-T02A to } 20 \text {-wt } \% \text { UDS - after solids } \\
\text { concentration is complete }\end{array}$ & D 02AML 005 XX 4972 UDS 2 & UDS & SWRI-090326-11 & 090326-11UDS R1 \\
\hline TI-082 & 7.5 .9 & $\begin{array}{l}\text { Concentration of solid in UFP-VSL-T02A to } 20 \text {-wt } \% \text { UDS - after } \\
\text { solids concentration is complete }\end{array}$ & D 02AML 005 XX 4973 DEN 2 & Density Supernate & SWRI-090326-10 & 090324-9 and $090324-10$ and $090326-10$ DEN slurry and liquid \\
\hline TI-082 & 7.5.9 & $\begin{array}{l}\text { Concentration of solid in UFP-VSL-T02A to } 20 \text {-wt } \% \text { UDS - after } \\
\text { solids concentration is complete }\end{array}$ & D 02AML 005 XX 4973 DEN 2 & Density Slurry & SWRI-090326-10 & 090324-9 and 090324-10 and 090326-10 DEN slurry and liquid \\
\hline TI-082 & 7.5 .9 & $\begin{array}{l}\text { Concentration of solid in UFP-VSL-T02A to } 20 \text {-wt } \% \text { UDS - after } \\
\text { solids concentration is complete }\end{array}$ & D 02AML 005 XX 4974 DEN 2 & Density Supernate & SWRI-090326-10 & 090324-9 and $090324-10$ and $090326-10$ DEN slurry and liquid \\
\hline TI-082 & 7.5 .9 & $\begin{array}{l}\text { Concentration of solid in UFP-VSL-T02A to } 20 \text {-wt } \% \text { UDS - after } \\
\text { solids concentration is complete }\end{array}$ & D 02AML 005 XX 4974 DEN 2 & Density Slurry & SWRI-090326-10 & 090324-9 and $090324-10$ and $090326-10 \mathrm{DEN}$ slurry and liquid \\
\hline TI-082 & 7.5 .9 & $\begin{array}{l}\text { Concentration of solid in UFP-VSL-T02A to } 20 \text {-wt } \% \text { UDS - after } \\
\text { solids concentration is complete }\end{array}$ & D 02AML 005 XX 4975 DEN 2 & Density Supernate & SWRI-090326-10 & 090324-9 and 090324-10 and 090326-10 DEN slurry and liquid \\
\hline TI-082 & 7.5 .9 & $\begin{array}{l}\text { Concentration of solid in UFP-VSL-T02A to } 20 \text {-wt } \% \text { UDS - after } \\
\text { solids concentration is complete }\end{array}$ & D 02 AML 005 XX 4975 DEN 2 & Density Slurry & SWRI-090326-10 & 090324-9 and 090324-10 and 090326-10 DEN slurry and liquid \\
\hline TI-082 & 7.5 .9 & $\begin{array}{l}\text { Concentration of solid in UFP-VSL-T02A to 20-wt\% UDS - after } \\
\text { solids concentration is complete }\end{array}$ & D 02AML 005 XX 4976 RHE 4 & Rheology & TDP WTP 366 & TDP WTP 366 Int Test D RHE Data on PEP Slurry \\
\hline
\end{tabular}


Integrated Test D Sample List

\begin{tabular}{|c|c|c|c|c|c|c|}
\hline TI \# & TI Step \# & TI Step Description & Sample ID & Analysis & $\begin{array}{c}\text { Electronic Folder } \\
\text { (SWRI Task Order \#, ASR \#, TDP\#) }\end{array}$ & Final Electronic Report File Name \\
\hline TI-082 & 7.5 .9 & $\begin{array}{l}\text { Concentration in UFP-VSL-T02A to 20-wt } \% \text { UDS - after solids } \\
\text { concentration is complete }\end{array}$ & D 02AML 005 XX 4977 ICP 2 B & ICP Wet Solids & SWRI-090326-12 & 090326-12 ICP and ICPMS \\
\hline TI-082 & 7.5 .9 & $\begin{array}{l}\text { Concentration in UFP-VSL-T02A to } 20 \text {-wt } \% \text { UDS - after solids } \\
\text { concentration is complete }\end{array}$ & D 02AML 005 XX 4977 ICP 2 D & ICP Supernatant & SWRI-090326-13 & 090324-31 and 090326-13 ICP and ICPMS \\
\hline TI-082 & 7.5.9 & $\begin{array}{l}\text { Concentration in UFP-VSL-T02A to } 20 \text {-wt } \% \text { UDS - after solids } \\
\text { concentration is complete }\end{array}$ & D 02AML 005 XX 4977 TFI 2 D & IC & SWRI-090326-14 & 090326-14 IC \\
\hline TI-082 & 7.5 .9 & $\begin{array}{l}\text { Concentration of solid in UFP-VSL-T02A to } 20 \text {-wt } \% \text { UDS - after } \\
\text { solids concentration is complete }\end{array}$ & D 02AML 005 XX 4977 TFI 3 D & $\mathrm{OH}$ & ASR8396 & ASR 8396 OH \\
\hline TI-082 & 7.5 .9 & $\begin{array}{c}\text { Concentration in UFP-VSL-T02A to } 20 \text {-wt } \% \text { UDS - after solids } \\
\text { concentration is complete }\end{array}$ & D 02AML 005 XX 4978 ICP 2 B & ICP Wet Solids & SWRI-090326-12 & 090326-12 ICP and ICPMS \\
\hline TI-082 & 7.5.9 & $\begin{array}{c}\text { Concentration in UFP-VSL-T02A to } 20 \text {-wt } \% \text { UDS - after solids } \\
\text { concentration is complete }\end{array}$ & D 02AML 005 XX 4978 ICP 2 D & ICP Supernatant & SWRI-090326-13 & 090324-31 and 090326-13 ICP and ICPMS \\
\hline TI-082 & 7.5 .9 & $\begin{array}{c}\text { Concentration in UFP-VSL-T02A to } 20 \text {-wt } \% \text { UDS - after solids } \\
\text { concentration is complete }\end{array}$ & D 02AML 005 XX 4978 TFI 2 D & IC & SWRI-090326-14 & 090326-14 IC \\
\hline TI-082 & 7.5 .9 & $\begin{array}{l}\text { Concentration of solid in UFP-VSL-T02A to 20-wt\% UDS - after } \\
\text { solids concentration is complete }\end{array}$ & D 02AML 005 XX 4978 TFI 3 D & $\mathrm{OH}$ & ASR8396 & ASR 8396 OH \\
\hline TI-082 & 7.5 .9 & $\begin{array}{c}\text { Concentration in UFP-VSL-T02A to } 20 \text {-wt } \% \text { UDS - after solids } \\
\text { concentration is complete }\end{array}$ & D 02AML 005 XX 4979 ICP 2 B & ICP Wet Solids & SWRI-090326-12 & 090326-12 ICP and ICPMS \\
\hline TI-082 & 7.5 .9 & $\begin{array}{c}\text { Concentration in UFP-VSL-T02A to } 20 \text {-wt } \% \text { UDS - after solids } \\
\text { concentration is complete }\end{array}$ & D 02AML 005 XX 4979 ICP 2 D & ICP Supernatant & SWRI-090326-13 & 090324-31 and 090326-13 ICP and ICPMS \\
\hline TI-082 & 7.5 .9 & $\begin{array}{c}\text { Concentration in UFP-VSL-T02A to } 20 \text {-wt } \% \text { UDS - after solids } \\
\text { concentration is complete }\end{array}$ & D 02AML 005 XX 4979 TFI 2 D & IC & SWRI-090326-14 & 090326-14 IC \\
\hline TI-082 & 7.5.9 & $\begin{array}{l}\text { Concentration of solid in UFP-VSL-T02A to } 20 \text {-wt } \% \text { UDS - after } \\
\text { solids concentration is complete }\end{array}$ & D 02AML 005 XX 4979 TFI 3 D & $\mathrm{OH}$ & ASR8396 & ASR 8396 OH \\
\hline TI-082 & 7.5.9 & $\begin{array}{l}\text { Concentration of solid in UFP-VSL-T02A to } 20 \text {-wt } \% \text { UDS - after } \\
\text { solids concentration is complete }\end{array}$ & D 02AML 005 XX 4980 XSP 4 & PSD & TDP-WTP-365 & TDP WTP 365 Int Test D PSD Data Analysis \\
\hline TI-082 & 7.5.9 & $\begin{array}{l}\text { Concentration of solid in UFP-VSL-T02A to } 20 \text {-wt } \% \text { UDS - after } \\
\text { solids concentration is complete }\end{array}$ & D 02AML 005 XX 4981 CUF 4 & Parallel Bench Test & & \\
\hline TI-082 & 7.6.13 & After caustic addition before UFP-VSL-T02A leach begins & D 02AML 007 XX 4985 UDS 2 B & UDS & SWRI-090331-10 & 090331-10UDS R1 \\
\hline TI-082 & 7.6.13 & After caustic addition before UFP-VSL-T02A leach begins & D 02AML 007 XX 4985 UDS 2 D & UDS & SWRI-090331-10 & 090331-10UDS R1 \\
\hline TI-082 & 7.6.13 & After caustic addition before UFP-VSL-T02A leach begins & D 02AML 007 XX 4986 DEN 2 & Density Slurry & SWRI-090331-11 & 090331-11DEN slurry and liquid \\
\hline TI-082 & 7.6.13 & After caustic addition before UFP-VSL-T02A leach begins & D 02AML 007 XX 4987 ICP 2 B & ICP Wet Solids & SWRI-090331-13 & 090331-13 and 090331-25 and 090331-24 ICP and ICPMS \\
\hline TI-082 & 7.6.13 & After caustic addition before UFP-VSL-T02A leach begins & D 02AML 007 XX 4987 ICP 2 D & ICP Supernate & SWRI-090331-12 & 090331-12 and 090331-22 and 090331-23 ICP and ICPMS \\
\hline TI-082 & 7.6.13 & After caustic addition, before UFP-VSL-T02A leach begins & D 02AML 007 XX 4987 RAM 3 D & Raman & ASR8398 & ASR 8398 RAM \\
\hline TI-082 & 7.6.13 & After caustic addition before UFP-VSL-T02A leach begins & D 02AML 007 XX 4987 TFI 2 D & IC & SWRI-090331-14 & 090331-14 IC \\
\hline TI-082 & 7.6.13 & After caustic addition, before UFP-VSL-T02A leach begins & D 02AML 007 XX 4987 TFI 3 D & $\mathrm{OH}$ & ASR8396 & ASR 8396 OH \\
\hline
\end{tabular}


Integrated Test D Sample List

\begin{tabular}{|c|c|c|c|c|c|c|}
\hline TI \# & TI Step \# & TI Step Description & Sample ID & Analysis & $\begin{array}{c}\text { Electronic Folder } \\
\text { (SWRI Task Order \#, ASR \#, TDP\#) }\end{array}$ & Final Electronic Report File Name \\
\hline TI-082 & 7.6 .13 & After caustic addition, before UFP-VSL-T02A leach begins & D 02AML 007 XX 4988 CUF 4 & Archive & & \\
\hline TI-082 & N/A & N/A & D 02ARL 008 XX 5627 ARC 1 & Archive & & \\
\hline TI-082 & 7.6.18 & Beginning of UFP-VSL-T02A caustic-leach & D 02AML 008 BT 4989 UDS 2 B & UDS & SWRI-090331-10 & 090331-10UDS R1 \\
\hline TI-082 & 7.6.18 & Beginning of UFP-VSL-T02A caustic-leach & D 02AML 008 BT 4989 UDS 2 D & UDS & SWRI-090331-10 & 090331-10UDS R1 \\
\hline TI-082 & 7.6.18 & Beginning of UFP-VSL-T02A caustic-leach & D 02AML 008 BT 4990 DEN 2 & Density Slurry & SWRI-090331-11 & 090331-11DEN slurry and liquid \\
\hline TI-082 & 7.6.18 & Beginning of UFP-VSL-T02A caustic-leach & D 02AML 008 BT 4991 ICP 2 D & ICP Supernate & SWRI-090331-12 & $090331-12$ and $090331-22$ and $090331-23$ ICP and ICPMS \\
\hline TI-082 & 7.6.18 & Beginning of UFP-VSL-T02A caustic-leach & D 02AML 008 BT 4991 TFI 2 D & IC & SWRI-090331-14 & 090331-14 IC \\
\hline TI-082 & 7.6.18 & Beginning of UFP-VSL-T02A caustic-leach & D 02AML 008 BT 4991 TFI 3 D & $\mathrm{OH}$ & ASR8396 & ASR 8396 OH \\
\hline TI-082 & 7.6.18 & Beginning of UFP-VSL-T02A caustic-leach & D 02AIL 008 BT 4992 ARC 1 B & Archive & & \\
\hline TI-082 & 7.6.18 & Beginning of UFP-VSL-T02A caustic-leach & D 02AIL 008 BT 4992 ARC 1 D & Archive & & \\
\hline TI-082 & 7.6.18 & Beginning of UFP-VSL-T02A caustic-leach & D 02AIM 008 BT 4993 ARC 1 B & Archive & & \\
\hline TI-082 & 7.6.18 & Beginning of UFP-VSL-T02A caustic-leach & D 02AMM 008 BT 4995 ARC 1 B & Archive & & \\
\hline TI-082 & 7.6.18 & Beginning of UFP-VSL-T02A caustic-leach & D 02AIM 008 BT 4993 ARC 1 D & Archive & & \\
\hline TI-082 & 7.6.18 & Beginning of UFP-VSL-T02A caustic-leach & D 02AMM 008 BT 4995 ARC 1 D & Archive & & \\
\hline TI-082 & 7.6.18 & Beginning of UFP-VSL-T02A caustic-leach & D 02AMH 008 BT 4996 ARC 1 B & Archive & & \\
\hline TI-082 & 7.6.18 & Beginning of UFP-VSL-T02A caustic-leach & D 02AMH 008 BT 4996 ARC 1 D & Archive & & \\
\hline TI-082 & 7.6.18 & Beginning of UFP-VSL-T02A caustic-leach & D 02AOL 008 BT 4997 ARC 1 B & Archive & & \\
\hline TI-082 & 7.6.18 & Beginning of UFP-VSL-T02A caustic-leach & D 02AOL 008 BT 4997 ARC 1 D & Archive & & \\
\hline TI-082 & 7.6.18 & Beginning of UFP-VSL-T02A caustic-leach & D 02AOM 008 BT 4998 ARC 1 B & Archive & & \\
\hline TI-082 & 7.6.18 & Beginning of UFP-VSL-T02A caustic-leach & D 02AOM 008 BT 4998 ARC 1 D & Archive & & \\
\hline TI-082 & 7.6.18 & Beginning of UFP-VSL-T02A caustic-leach & D 02AOH 008 BT 4999 ARC 1 B & Archive & & \\
\hline TI-082 & 7.6.18 & Beginning of UFP-VSL-T02A caustic-leach & D 02AOH 008 BT 4999 ARC 1 D & Archive & & \\
\hline TI-082 & 7.6 .20 & Caustic-leach UFP-VSL-T02A & D 02AML 008005000 UDS 2 B & UDS & SWRI-090331-10 & 090331-10UDS R1 \\
\hline TI-082 & 7.6 .20 & Caustic-leach UFP-VSL-T02A & D 02AML 008005000 UDS 2 D & UDS & SWRI-090331-10 & 090331-10UDS R1 \\
\hline TI-082 & 7.6.20 & Caustic-leach UFP-VSL-T02A & D 02AML 008005001 UDS 2 B & UDS & SWRI-090331-10 & 090331-10UDS R1 \\
\hline TI-082 & 7.6.20 & Caustic-leach UFP-VSL-T02A & D 02AML 008005001 UDS 2 D & UDS & SWRI-090331-10 & 090331-10UDS R1 \\
\hline TI-082 & 7.6.20 & Caustic-leach UFP-VSL-T02A & D 02AML 008005002 UDS 2 B & UDS & SWRI-090331-10 & 090331-10UDS R1 \\
\hline TI-082 & 7.6.20 & Caustic-leach UFP-VSL-T02A & D 02AML 008005002 UDS 2 D & UDS & SWRI-090331-10 & 090331-10UDS R1 \\
\hline TI-082 & 7.6 .20 & Caustic-leach UFP-VSL-T02A & D 02AML 008005003 DEN 2 & Density Slurry & SWRI-090331-11 & 090331-11DEN slurry and liquid \\
\hline TI-082 & 7.6 .20 & Caustic-leach UFP-VSL-T02A & D 02AML 008005004 DEN 2 & Density Slurry & SWRI-090331-11 & 090331-11DEN slurry and liquid \\
\hline TI-082 & 7.6.20 & Caustic-leach UFP-VSL-T02A & D 02AML 008005005 DEN 2 & Density Slurry & SWRI-090331-11 & 090331-11DEN slurry and liquid \\
\hline TI-082 & 7.6.20 & Caustic-leach UFP-VSL-T02A & D 02AML 008005006 ICP 2 B & ICP Wet Solids & SWRI-090331-13 & 090331-13 and 090331-25 and 090331-24 ICP and ICPMS \\
\hline
\end{tabular}


Integrated Test D Sample List

\begin{tabular}{|c|c|c|c|c|c|c|}
\hline TI \# & TI Step \# & TI Step Description & Sample ID & Analysis & $\begin{array}{c}\text { Electronic Folder } \\
\text { (SWRI Task Order \#, ASR \#, TDP\#) }\end{array}$ & Final Electronic Report File Name \\
\hline TI-082 & 7.6.20 & Caustic-leach UFP-VSL-T02A & D 02AML 008005006 ICP 2 D & ICP Supernate & SWRI-090331-12 & $090331-12$ and $090331-22$ and $090331-23$ ICP and ICPMS \\
\hline TI-082 & 7.6.20 & Caustic-leach UFP-VSL-T02A & D 02AML 008005006 RAM 3 D & Raman & ASR8398 & ASR 8398 RAM \\
\hline TI-082 & 7.6 .20 & Caustic-leach UFP-VSL-T02A & D 02 AML 008005006 TFI 2 D & IC & SWRI-090331-14 & 090331-14 IC \\
\hline TI-082 & 7.6 .20 & Caustic-leach UFP-VSL-T02A & D 02AML 008005006 TFI 3 D & $\mathrm{OH}$ & ASR8396 & ASR $8396 \mathrm{OH}$ \\
\hline TI-082 & 7.6 .20 & Caustic-leach UFP-VSL-T02A & D 02AML 008005007 ICP 2 B & ICP Wet Solids & SWRI-090331-13 & $090331-13$ and $090331-25$ and $090331-24$ ICP and ICPMS \\
\hline TI-082 & 7.6 .20 & Caustic-leach UFP-VSL-T02A & D 02AML 008005007 ICP 2 D & ICP Supernate & SWRI-090331-12 & $090331-12$ and $090331-22$ and $090331-23$ ICP and ICPMS \\
\hline TI-082 & 7.6 .20 & Caustic-leach UFP-VSL-T02A & D 02AML 008005007 RAM 3 D & Raman & ASR8398 & ASR 8398 RAM \\
\hline TI-082 & 7.6.20 & Caustic-leach UFP-VSL-T02A & D 02AML 008005007 TFI 2 D & IC & SWRI-090331-14 & 090331-14 IC \\
\hline TI-082 & 7.6 .20 & Caustic-leach UFP-VSL-T02A & D 02 AML 008005007 TFI 3 D & $\mathrm{OH}$ & ASR8396 & ASR $8396 \mathrm{OH}$ \\
\hline TI-082 & 7.6.20 & Caustic-leach UFP-VSL-T02A & D 02AML 008005008 ICP 2 B & ICP Wet Solids & SWRI-090331-13 & 090331-13 and 090331-25 and 090331-24 ICP and ICPMS \\
\hline TI-082 & 7.6 .20 & Caustic-leach UFP-VSL-T02A & D 02AML 008005008 ICP 2 D & ICP Supernate & SWRI-090331-12 & $090331-12$ and $090331-22$ and $090331-23$ ICP and ICPMS \\
\hline TI-082 & 7.6.20 & Caustic-leach UFP-VSL-T02A & D 02AML 008005008 RAM 3 D & Raman & ASR 8398 & ASR 8398 RAM \\
\hline TI-082 & 7.6.20 & Caustic-leach UFP-VSL-T02A & D 02AML 008005008 TFI 2 D & IC & SWRI-090331-14 & 090331-14 IC \\
\hline TI-082 & 7.6 .20 & Caustic-leach UFP-VSL-T02A & D 02AML 008005008 TFI 3 D & $\mathrm{OH}$ & ASR8396 & ASR $8396 \mathrm{OH}$ \\
\hline TI-082 & 7.6 .20 & Caustic-leach UFP-VSL-T02A & D 02AIM 008005010 ARC 1 B & Archive & & \\
\hline TI-082 & 7.6 .20 & Caustic-leach UFP-VSL-T02A & D 02AIM 008005010 ARC 1 D & Archive & & \\
\hline TI-082 & 7.6.20 & Caustic-leach UFP-VSL-T02A & D 02AMM 008005012 ARC 1 B & Archive & & \\
\hline TI-082 & 7.6.20 & Caustic-leach UFP-VSL-T02A & D 02AMM 008005012 ARC 1 D & Archive & & \\
\hline TI-082 & 7.6.20 & Caustic-leach UFP-VSL-T02A & D 02AMH 008005013 ARC 1 B & Archive & & \\
\hline TI-082 & 7.6 .20 & Caustic-leach UFP-VSL-T02A & D 02AMH 008005013 ARC 1 D & Archive & & \\
\hline TI-082 & 7.6.20 & Caustic-leach UFP-VSL-T02A & D 02AOL 008005014 ARC 1 B & Archive & & \\
\hline TI-082 & 7.6.20 & Caustic-leach UFP-VSL-T02A & D 02AOL 008005014 ARC 1 D & Archive & & \\
\hline TI-082 & 7.6.20 & Caustic-leach UFP-VSL-T02A & D 02AOM 008005015 ARC 1 B & Archive & & \\
\hline TI-082 & 7.6.20 & Caustic-leach UFP-VSL-T02A & D 02AOM 008005015 ARC 1 D & Archive & & \\
\hline TI-082 & 7.6 .20 & Caustic-leach UFP-VSL-T02A & D 02AOH 008005016 ARC 1 B & Archive & & \\
\hline TI-082 & 7.6 .20 & Caustic-leach UFP-VSL-T02A & D 02AOH 008005016 ARC 1 D & Archive & & \\
\hline TI-082 & 7.6.20 & Caustic-leach UFP-VSL-T02A & D 02AIL 008005009 ARC 1 B & Archive & & \\
\hline TI-082 & 7.6.20 & Caustic-leach UFP-VSL-T02A & D 02AIL 008005009 ARC 1 D & Archive & & \\
\hline TI-082 & 7.6.23.1 & After flushing T02A filter-loop & D 000FL 007 XX 4983 UDS 2 & UDS & SWRI-090331-10 & 090331-10UDS R1 \\
\hline TI-082 & 7.6.23.1 & After flushing T02A filter-loop & D 000FL 007 XX 4984 ICP 2 D & ICP Supernate & SWRI-090331-12 & 090331-12 and 090331-22 and 090331-23 ICP and ICPMS \\
\hline TI-082 & 7.6 .23 .1 & After flushing T02A filter-loop & D 000FL 007 XX 4984 ICP 0 B & Storage & & \\
\hline TI-082 & 7.6.23.1 & After flushing T02A filter-loop & D 000FL 007 XX 4984 TFI 2 D & IC & SWRI-090331-14 & 090331-14 IC \\
\hline
\end{tabular}


Integrated Test D Sample List

\begin{tabular}{|c|c|c|c|c|c|c|}
\hline TI \# & TI Step \# & TI Step Description & Sample ID & Analysis & $\begin{array}{c}\text { Electronic Folder } \\
\text { (SWRI Task Order \#, ASR \#, TDP\#) }\end{array}$ & Final Electronic Report File Name \\
\hline TI-082 & 7.6.23.1 & After flushing TO2A filter-loop & D 000FL 007 XX 4984 TFI 3 D & $\mathrm{OH}$ & ASR8396 & ASR $8396 \mathrm{OH}$ \\
\hline TI-082 & 7.6.23.1 & After flushing T02A filter-loop & D 02ARL 008 XX 5623 UDS 4 & UDS & CCP WTPSP 654 & CCP WTPSP 654 Int Test D UDS Data Analysis \\
\hline TI-082 & 7.6.23.1 & After flushing T02A filter-loop & D 02ARL 008 XX 5624 UDS 4 & UDS & CCP WTPSP 654 & CCP WTPSP 654 Int Test D UDS Data Analysis \\
\hline TI-082 & 7.6.23.1 & After flushing T02A filter-loop & D 02ARL 008 XX 5625 UDS 4 & UDS & CCP WTPSP 654 & CCP WTPSP 654 Int Test D UDS Data Analysis \\
\hline TI-082 & 7.6.24 & Caustic-leach UFP-VSL-T02A & D 02AML 008015017 UDS 2 B & UDS & SWRI-090331-10 & 090331-10UDS R1 \\
\hline TI-082 & 7.6.24 & Caustic-leach UFP-VSL-T02A & D 02AML 008015017 UDS 2 D & UDS & SWRI-090331-10 & 090331-10UDS R1 \\
\hline TI-082 & 7.6.24 & Caustic-leach UFP-VSL-T02A & D 02AML 008015018 DEN 2 & Density Slurry & SWRI-090331-11 & 090331-11DEN slurry and liquid \\
\hline TI-082 & 7.6.24 & Caustic-leach UFP-VSL-T02A & D 02AML 008015019 ICP 0 B & Storage & & \\
\hline TI-082 & 7.6.24 & Caustic-leach UFP-VSL-T02A & D 02AML 008015019 ICP 2 D & ICP Supernate & SWRI-090331-12 & $090331-12$ and $090331-22$ and $090331-23$ ICP and ICPMS \\
\hline TI-082 & 7.6.24 & Caustic-leach UFP-VSL-T02A & D 02AML 008015019 TFI 2 D & IC & SWRI-090331-14 & 090331-14 IC \\
\hline TI-082 & 7.6.24 & Caustic-leach UFP-VSL-T02A & D 02AML 008015019 TFI 3 D & $\mathrm{OH}$ & ASR8396 & ASR $8396 \mathrm{OH}$ \\
\hline TI-082 & 7.6.24 & Caustic-leach UFP-VSL-T02A & D 02AML 008025020 UDS 2 B & UDS & SWRI-090331-10 & 090331-10UDS R1 \\
\hline TI-082 & 7.6.24 & Caustic-leach UFP-VSL-T02A & D 02AML 008025020 UDS 2 D & UDS & SWRI-090331-10 & 090331-10UDS R1 \\
\hline TI-082 & 7.6.24 & Caustic-leach UFP-VSL-T02A & D 02AML 008025021 DEN 2 & Density Slurry & SWRI-090331-11 & 090331-11DEN slurry and liquid \\
\hline TI- 082 & 7.6.24 & Caustic-leach UFP-VSL-T02A & D 02AML 008025022 ICP 2 D & ICP Supernate & SWRI-090331-12 & 090331-12 and 090331-22 and 090331-23 ICP and ICPMS \\
\hline TI-082 & 7.6 .24 & Caustic-leach UFP-VSL-T02A & D 02AML 008025022 TFI 2 D & IC & SWRI-090331-14 & 090331-14 IC \\
\hline TI-082 & 7.6.24 & Caustic-leach UFP-VSL-T02A & D 02AML 008025022 TFI 3 D & $\mathrm{OH}$ & ASR8396 & ASR 8396 OH \\
\hline TI-082 & 7.6.24 & Caustic-leach UFP-VSL-T02A & D 02AML 008025022 ICP 0 B & Storage & & \\
\hline TI- 082 & 7.6.24 & Caustic-leach UFP-VSL-T02A & D 02AML 008035023 ARC 1 B & Archive & & \\
\hline TI-082 & 7.6.24 & Caustic-leach UFP-VSL-T02A & D 02AML 008035023 ARC 1 D & Archive & & \\
\hline TI-082 & 7.6.25 & Caustic-leach UFP-VSL-T02A & D 02AML 008045024 UDS 2 B & UDS & SWRI-090331-10 & 090331-10UDS R1 \\
\hline TI-082 & 7.6.25 & Caustic-leach UFP-VSL-T02A & D 02AML 008045024 UDS 2 D & UDS & SWRI-090331-10 & 090331-10UDS R1 \\
\hline TI-082 & 7.6.25 & Caustic-leach UFP-VSL-T02A & D 02AML 008045025 DEN 2 & Density Slurry & SWRI-090331-11 & 090331-11DEN slurry and liquid \\
\hline TI-082 & 7.6 .25 & Caustic-leach UFP-VSL-T02A & D 02 AML 008045026 ICP 2 B & ICP Wet Solids & SWRI-090331-13 & $090331-13$ and $090331-25$ and $090331-24$ ICP and ICPMS \\
\hline TI-082 & 7.6.25 & Caustic-leach UFP-VSL-T02A & D 02AML 008045026 ICP 2 D & ICP Supernate & SWRI-090331-12 & $090331-12$ and $090331-22$ and $090331-23$ ICP and ICPMS \\
\hline TI-082 & 7.6.25 & Caustic-leach UFP-VSL-T02A & D 02AML 008045026 TFI 2 D & IC & SWRI-090331-14 & 090331-14 IC \\
\hline TI-082 & 7.6 .25 & Caustic-leach UFP-VSL-T02A & D 02AML 008045026 TFI 3 D & $\mathrm{OH}$ & ASR8396 & ASR $8396 \mathrm{OH}$ \\
\hline TI-082 & 7.6.25 & Caustic-leach UFP-VSL-T02A & D 02AIL 008045027 ARC 1 B & Archive & & \\
\hline TI-082 & 7.6 .25 & Caustic-leach UFP-VSL-T02A & D 02AIL 008045027 ARC 1 D & Archive & & \\
\hline TI- 082 & 7.6.25 & Caustic-leach UFP-VSL-T02A & D 02 AIM 008045028 ARC 1 B & Archive & & \\
\hline TI-082 & 7.6 .25 & Caustic-leach UFP-VSL-T02A & D 02 AIM 008045028 ARC 1 D & Archive & & \\
\hline TI-082 & 7.6 .25 & Caustic-leach UFP-VSL-T02A & D 02AMM 008045030 ARC 1 B & Archive & & \\
\hline
\end{tabular}


Integrated Test D Sample List

\begin{tabular}{|c|c|c|c|c|c|c|}
\hline TI \# & TI Step \# & TI Step Description & Sample ID & Analysis & $\begin{array}{c}\text { Electronic Folder } \\
\text { (SWRI Task Order \#, ASR \#, TDP\#) }\end{array}$ & Final Electronic Report File Name \\
\hline TI-082 & 7.6.25 & Caustic-leach UFP-VSL-T02A & D 02AMM 008045030 ARC 1 D & Archive & & \\
\hline TI-082 & 7.6.25 & Caustic-leach UFP-VSL-T02A & D 02AMH 008045031 ARC 1 B & Archive & & \\
\hline TI-082 & 7.6 .25 & Caustic-leach UFP-VSL-T02A & D 02AMH 008045031 ARC 1 D & Archive & & \\
\hline TI-082 & 7.6.25 & Caustic-leach UFP-VSL-T02A & D 02AOL 008045032 ARC 1 B & Archive & & \\
\hline TI-082 & 7.6 .25 & Caustic-leach UFP-VSL-T02A & D 02AOL 008045032 ARC 1 D & Archive & & \\
\hline TI-082 & 7.6 .25 & Caustic-leach UFP-VSL-T02A & D 02AOM 008045033 ARC 1 B & Archive & & \\
\hline TI-082 & 7.6 .25 & Caustic-leach UFP-VSL-T02A & D 02AOM 008045033 ARC 1 D & Archive & & \\
\hline TI-082 & 7.6.25 & Caustic-leach UFP-VSL-T02A & D 02AOH 008045034 ARC 1 B & Archive & & \\
\hline TI-082 & 7.6 .25 & Caustic-leach UFP-VSL-T02A & D 02AOH 008045034 ARC 1 D & Archive & & \\
\hline TI-082 & 7.6.25 & Caustic-leach UFP-VSL-T02A & D 02AML 008055035 ARC 1 B & Archive & & \\
\hline TI-082 & 7.6 .25 & Caustic-leach UFP-VSL-T02A & D 02AML 008055035 ARC 1 D & Archive & & \\
\hline TI-082 & 7.6.25 & Caustic-leach UFP-VSL-T02A & D 02AML 008065036 ARC 1 B & Archive & & \\
\hline TI-082 & 7.6 .25 & Caustic-leach UFP-VSL-T02A & D 02AML 008065036 ARC 1 D & Archive & & \\
\hline TI-082 & 7.6 .25 & Caustic-leach UFP-VSL-T02A & D 02AML 008075037 ARC 1 B & Archive & & \\
\hline TI-082 & 7.6 .25 & Caustic-leach UFP-VSL-T02A & D 02AML 008075037 ARC 1 D & Archive & & \\
\hline TI-082 & 7.6 .25 & Caustic-leach UFP-VSL-T02A & D 02ARL 008 XX 5626 TFI 3 & $\mathrm{OH}$ & ASR8396 & ASR $8396 \mathrm{OH}$ \\
\hline TI-082 & 7.6.26 & Caustic-leach UFP-VSL-T02A & D 02AML 008085038 UDS 2 B & UDS & SWRI-090331-10 & 090331-10UDS R1 \\
\hline TI-082 & 7.6.26 & Caustic-leach UFP-VSL-T02A & D 02AML 008085038 UDS 2 D & UDS & SWRI-090331-10 & 090331-10UDS R1 \\
\hline TI-082 & 7.6.26 & Caustic-leach UFP-VSL-T02A & D 02AML 008085039 DEN 2 & Density Slurry & SWRI-090331-11 & 090331-11DEN slurry and liquid \\
\hline TI-082 & 7.6 .26 & Caustic-leach UFP-VSL-T02A & D 02AML 008085040 ICP 2 B & ICP Wet Solids & SWRI-090331-13 & 090331-13 and 090331-25 and 090331-24 ICP and ICPMS \\
\hline TI-082 & 7.6.26 & Caustic-leach UFP-VSL-T02A & D 02AML 008085040 ICP 2 D & ICP Supernate & SWRI-090331-12 & 090331-12 and 090331-22 and 090331-23 ICP and ICPMS \\
\hline TI-082 & 7.6.26 & Caustic-leach UFP-VSL-T02A & D 02AML 008085040 TFI 2 D & IC & SWRI-090331-14 & 090331-14 IC \\
\hline TI-082 & 7.6.26 & Caustic-leach UFP-VSL-T02A & D 02 AML 008085040 TFI 3 D & $\mathrm{OH}$ & ASR8396 & ASR 8396 OH \\
\hline TI-082 & 7.6.26 & Caustic-leach UFP-VSL-T02A & D 02AIL 008085041 ARC 1 B & Archive & & \\
\hline TI-082 & 7.6.26 & Caustic-leach UFP-VSL-T02A & D 02AIL 008085041 ARC 1 D & Archive & & \\
\hline TI-082 & 7.6.26 & Caustic-leach UFP-VSL-T02A & D 02 AIM 008085042 ARC 1 B & Archive & & \\
\hline TI-082 & 7.6.26 & Caustic-leach UFP-VSL-T02A & D 02 AIM 008085042 ARC 1 D & Archive & & \\
\hline TI-082 & 7.6.26 & Caustic-leach UFP-VSL-T02A & D 02AIH 008085043 ARC 1 B & Archive & & \\
\hline TI-082 & 7.6.26 & Caustic-leach UFP-VSL-T02A & D 02AIH 008085043 ARC 1 D & Archive & & \\
\hline TI-082 & 7.6.26 & Caustic-leach UFP-VSL-T02A & D 02AMM 008085044 ARC 1 B & Archive & & \\
\hline TI-082 & 7.6.26 & Caustic-leach UFP-VSL-T02A & D 02AMM 008085044 ARC 1 D & Archive & & \\
\hline TI-082 & 7.6.26 & Caustic-leach UFP-VSL-T02A & D 02AMH 008085045 ARC 1 B & Archive & & \\
\hline
\end{tabular}


Integrated Test D Sample List

\begin{tabular}{|c|c|c|c|c|c|c|}
\hline TI \# & TI Step \# & TI Step Description & Sample ID & Analysis & $\begin{array}{c}\text { Electronic Folder } \\
\text { (SWRI Task Order \#, ASR \#, TDP\#) }\end{array}$ & Final Electronic Report File Name \\
\hline TI-082 & 7.6 .26 & Caustic-leach UFP-VSL-T02A & D 02AMH 008085045 ARC 1 D & Archive & & \\
\hline TI-082 & 7.6.26 & Caustic-leach UFP-VSL-T02A & D 02AOL 008085046 ARC 1 B & Archive & & \\
\hline TI-082 & 7.6.26 & Caustic-leach UFP-VSL-T02A & D 02AOL 008085046 ARC 1 D & Archive & & \\
\hline TI-082 & 7.6.26 & Caustic-leach UFP-VSL-T02A & D 02AOM 008085047 ARC 1 B & Archive & & \\
\hline TI-082 & 7.6.26 & Caustic-leach UFP-VSL-T02A & D 02AOM 008085047 ARC 1 D & Archive & & \\
\hline TI-082 & 7.6 .26 & Caustic-leach UFP-VSL-T02A & D 02AOH 008085048 ARC 1 B & Archive & & \\
\hline TI-082 & 7.6 .26 & Caustic-leach UFP-VSL-T02A & D 02AOH 008085048 ARC 1 D & Archive & & \\
\hline TI-082 & 7.6.26 & Caustic-leach UFP-VSL-T02A & D 02AML 008095049 ARC 1 B & Archive & & \\
\hline TI-082 & 7.6.26 & Caustic-leach UFP-VSL-T02A & D 02AML 008095049 ARC 1 D & Archive & & \\
\hline TI-082 & 7.6.26 & Caustic-leach UFP-VSL-T02A & D 02AML 008105050 UDS 2 B & UDS & SWRI-090331-10 & 090331-10UDS R1 \\
\hline TI-082 & 7.6.26 & Caustic-leach UFP-VSL-T02A & D 02AML 008105050 UDS 2 D & UDS & SWRI-090331-10 & 090331-10UDS R1 \\
\hline TI-082 & 7.6 .26 & Caustic-leach UFP-VSL-T02A & D 02AML 008105051 DEN 2 & Density Slurry & SWRI-090331-11 & 090331-11DEN slurry and liquid \\
\hline TI-082 & 7.6 .26 & Caustic-leach UFP-VSL-T02A & D 02AML 008105052 ICP 2 D & ICP Supernate & SWRI-090331-12 & 090331-12 and 090331-22 and 090331-23 ICP and ICPMS \\
\hline TI-082 & 7.6.26 & Caustic-leach UFP-VSL-T02A & D 02AML 008105052 TFI 2 D & IC & SWRI-090331-14 & 090331-14 IC \\
\hline TI-082 & 7.6.26 & Caustic-leach UFP-VSL-T02A & D 02AML 008105052 TFI 3 D & $\mathrm{OH}$ & ASR8396 & ASR $8396 \mathrm{OH}$ \\
\hline TI-082 & 7.6 .26 & Caustic-leach UFP-VSL-T02A & D 02AML 008105052 ICP 0 B & Storage & & \\
\hline TI-082 & 7.6.26 & Caustic-leach UFP-VSL-T02A & D 02AML 008115053 ARC 1 B & Archive & & \\
\hline TI-082 & 7.6.26 & Caustic-leach UFP-VSL-T02A & D 02AML 008115053 ARC 1 D & Archive & & \\
\hline TI-082 & 7.6.27 & Caustic-leach UFP-VSL-T02A & D 02AML 008125054 UDS 2 B & UDS & SWRI-090331-10 & 090331-10UDS R1 \\
\hline TI-082 & 7.6.27 & Caustic-leach UFP-VSL-T02A & D 02AML 008125054 UDS 2 D & UDS & SWRI-090331-10 & 090331-10UDS R1 \\
\hline TI-082 & 7.6.27 & Caustic-leach UFP-VSL-T02A & D 02AML 008125055 DEN 2 & Density Slurry & SWRI-090331-11 & 090331-11DEN slurry and liquid \\
\hline TI-082 & 7.6.27 & Caustic-leach UFP-VSL-T02A & D 02AML 008125056 ICP 2 B & ICP Wet Solids & SWRI-090331-13 & $090331-13$ and $090331-25$ and $090331-24$ ICP and ICPMS \\
\hline TI-082 & 7.6.27 & Caustic-leach UFP-VSL-T02A & D 02AML 008125056 ICP 2 D & ICP Supernate & SWRI-090331-12 & 090331-12 and 090331-22 and 090331-23 ICP and ICPMS \\
\hline TI-082 & 7.6.27 & Caustic-leach UFP-VSL-T02A & D 02AML 008125056 RAM 3 D & Raman & ASR8398 & ASR 8398 RAM \\
\hline TI-082 & 7.6.27 & Caustic-leach UFP-VSL-T02A & D 02AML 008125056 TFI 2 D & IC & SWRI-090331-14 & 090331-14 IC \\
\hline TI-082 & 7.6.27 & Caustic-leach UFP-VSL-T02A & D 02AML 008125056 TFI 3 D & $\mathrm{OH}$ & ASR8396 & ASR $8396 \mathrm{OH}$ \\
\hline TI-082 & 7.6.27 & Caustic-leach UFP-VSL-T02A & D 02AIH 008125059 ARC 1 B & Archive & & \\
\hline TI-082 & 7.6.27 & Caustic-leach UFP-VSL-T02A & D 02AIH 008125059 ARC 1 D & Archive & & \\
\hline TI-082 & 7.6.27 & Caustic-leach UFP-VSL-T02A & D 02AMM 008125060 ARC 1 B & Archive & & \\
\hline TI-082 & 7.6.27 & Caustic-leach UFP-VSL-T02A & D 02AMM 008125060 ARC 1 D & Archive & & \\
\hline TI-082 & 7.6.27 & Caustic-leach UFP-VSL-T02A & D 02AMH 008125061 ARC 1 B & Archive & & \\
\hline TI-082 & 7.6.27 & Caustic-leach UFP-VSL-T02A & D 02AMH 008125061 ARC 1 D & Archive & & \\
\hline
\end{tabular}


Integrated Test D Sample List

\begin{tabular}{|c|c|c|c|c|c|c|}
\hline TI\# & TI Step \# & TI Step Description & Sample ID & Analysis & $\begin{array}{c}\text { Electronic Folder } \\
\text { (SWRI Task Order \#, ASR \#, TDP\#) }\end{array}$ & Final Electronic Report File Name \\
\hline TI-082 & 7.6.27 & Caustic-leach UFP-VSL-T02A & D 02AOL 008125062 ARC 1 B & Archive & & \\
\hline TI-082 & 7.6.27 & Caustic-leach UFP-VSL-T02A & D 02AOL 008125062 ARC 1 D & Archive & & \\
\hline TI-082 & 7.6.27 & Caustic-leach UFP-VSL-T02A & D 02AOM 008125063 ARC 1 B & Archive & & \\
\hline TI-082 & 7.6.27 & Caustic-leach UFP-VSL-T02A & D 02AOM 008125063 ARC 1 D & Archive & & \\
\hline TI-082 & 7.6.27 & Caustic-leach UFP-VSL-T02A & D 02AOH 008125064 ARC 1 B & Archive & & \\
\hline TI-082 & 7.6.27 & Caustic-leach UFP-VSL-T02A & D 02AOH 008125064 ARC 1 D & Archive & & \\
\hline TI-082 & 7.6.27 & Caustic-leach UFP-VSL-T02A & D 02AIL 008125057 ARC 1 B & Archive & & \\
\hline TI-082 & 7.6.27 & Caustic-leach UFP-VSL-T02A & D 02AIL 008125057 ARC 1 D & Archive & & \\
\hline TI-082 & 7.6.27 & Caustic-leach UFP-VSL-T02A & D 02AIM 008125058 ARC 1 B & Archive & & \\
\hline TI-082 & 7.6.27 & Caustic-leach UFP-VSL-T02A & D 02AIM 008125058 ARC 1 D & Archive & & \\
\hline TI-082 & 7.6.27 & Caustic-leach UFP-VSL-T02A & D 02AML 008135065 ARC 1 B & Archive & & \\
\hline TI-082 & 7.6.27 & Caustic-leach UFP-VSL-T02A & D 02AML 008135065 ARC 1 D & Archive & & \\
\hline TI-082 & 7.6.27 & Caustic-leach UFP-VSL-T02A & D 02AML 008145066 UDS 2 B & UDS & SWRI-090331-10 & 090331-10UDS R1 \\
\hline TI-082 & 7.6.27 & Caustic-leach UFP-VSL-T02A & D 02AML 008145066 UDS 2 D & UDS & SWRI-090331-10 & 090331-10UDS R1 \\
\hline TI-082 & 7.6.27 & Caustic-leach UFP-VSL-T02A & D 02AML 008145067 DEN 2 & Density Slurry & SWRI-090331-11 & 090331-11DEN slurry and liquid \\
\hline TI-082 & 7.6.27 & Caustic-leach UFP-VSL-T02A & D 02AML 008145068 ICP 2 D & ICP Supernate & SWRI-090331-12 & $090331-12$ and $090331-22$ and $090331-23$ ICP and ICPMS \\
\hline TI-082 & 7.6.27 & Caustic-leach UFP-VSL-T02A & D 02AML 008145068 TFI 2 D & $\mathrm{IC}$ & SWRI-090331-14 & 090331-14 IC \\
\hline TI-082 & 7.6.27 & Caustic-leach UFP-VSL-T02A & D 02AML 008145068 TFI 3 D & $\mathrm{OH}$ & ASR8396 & ASR $8396 \mathrm{OH}$ \\
\hline TI-082 & 7.6.27 & Caustic-leach UFP-VSL-T02A & D 02AML 008145068 ICP 0 B & Storage & & \\
\hline TI-082 & 7.6.27 & Caustic-leach UFP-VSL-T02A & D 02AML 008155069 ARC 1 B & Archive & & \\
\hline TI-082 & 7.6.27 & Caustic-leach UFP-VSL-T02A & D 02AML 008155069 ARC 1 D & Archive & & \\
\hline TI-082 & 7.6.28 & Caustic-leach UFP-VSL-T02A & D 02AML 008165070 UDS 2 B & UDS & SWRI-090331-20 & 090331-20UDS R1 \\
\hline TI-082 & 7.6.28 & Caustic-leach UFP-VSL-T02A & D 02AML 008165070 UDS 2 D & UDS & SWRI-090331-20 & 090331-20UDS R1 \\
\hline TI-082 & 7.6.28 & Caustic-leach UFP-VSL-T02A & D 02AML 008165071 DEN 2 & Density Slurry & SWRI-090331-11 & 090331-11DEN slurry and liquid \\
\hline TI-082 & 7.6.28 & Caustic-leach UFP-VSL-T02A & D 02AML 008165073 ICP 2 B & ICP Wet Solids & SWRI-090331-24 & 090331-13 and 090331-25 and 090331-24 ICP and ICPMS \\
\hline TI-082 & 7.6.28 & Caustic-leach UFP-VSL-T02A & D 02AML 008165073 ICP 2 D & ICP Supernatant & SWRI-090331-22 & 090331-12 and 090331-22 and 090331-23 ICP and ICPMS \\
\hline TI-082 & 7.6.28 & Caustic-leach UFP-VSL-T02A & D 02AML 008165073 RAM 3 D & Raman & ASR8398 & ASR 8398 RAM \\
\hline TI-082 & 7.6 .28 & Caustic-leach UFP-VSL-T02A & D 02AML 008165073 TFI 2 D & IC & SWRI-090331-26 & 090331-26 IC \\
\hline TI-082 & 7.6.28 & Caustic-leach UFP-VSL-T02A & D 02AML 008165073 TFI 3 D & $\mathrm{OH}$ & ASR8399 & ASR $8399 \mathrm{OH}$ \\
\hline TI-082 & 7.6.28 & Caustic-leach UFP-VSL-T02A & D 02AIL 008165074 ARC 1 B & Archive & & \\
\hline TI-082 & 7.6.28 & Caustic-leach UFP-VSL-T02A & D 02AIL 008165074 ARC 1 D & Archive & & \\
\hline TI-082 & 7.6.28 & Caustic-leach UFP-VSL-T02A & D 02AIM 008165075 ARC 1 B & Archive & & \\
\hline
\end{tabular}


Integrated Test D Sample List

\begin{tabular}{|c|c|c|c|c|c|c|}
\hline TI \# & TI Step \# & TI Step Description & Sample ID & Analysis & $\begin{array}{c}\text { Electronic Folder } \\
\text { (SWRI Task Order \#, ASR \#, TDP\#) }\end{array}$ & Final Electronic Report File Name \\
\hline TI-082 & 7.6.28 & Caustic-leach UFP-VSL-T02A & D 02AIM 008165075 ARC 1 D & Archive & & \\
\hline TI-082 & 7.6.28 & Caustic-leach UFP-VSL-T02A & D 02AIH 008165076 ARC 1 B & Archive & & \\
\hline TI-082 & 7.6.28 & Caustic-leach UFP-VSL-T02A & D 02AIH 008165076 ARC 1 D & Archive & & \\
\hline TI-082 & 7.6.28 & Caustic-leach UFP-VSL-T02A & D 02AMM 008165077 ARC 1 B & Archive & & \\
\hline TI-082 & 7.6.28 & Caustic-leach UFP-VSL-T02A & D 02AMM 008165077 ARC 1 D & Archive & & \\
\hline TI-082 & 7.6.28 & Caustic-leach UFP-VSL-T02A & D 02AMH 008165078 ARC 1 B & Archive & & \\
\hline TI-082 & 7.6.28 & Caustic-leach UFP-VSL-T02A & D 02AMH 008165078 ARC 1 D & Archive & & \\
\hline TI-082 & 7.6.28 & Caustic-leach UFP-VSL-T02A & D 02AOL 008165079 ARC 1 B & Archive & & \\
\hline TI-082 & 7.6.28 & Caustic-leach UFP-VSL-T02A & D 02AOL 008165079 ARC 1 D & Archive & & \\
\hline TI-082 & 7.6.28 & Caustic-leach UFP-VSL-T02A & D 02AOM 008165080 ARC 1 B & Archive & & \\
\hline TI-082 & 7.6.28 & Caustic-leach UFP-VSL-T02A & D 02AOM 008165080 ARC 1 D & Archive & & \\
\hline TI-082 & 7.6.28 & Caustic-leach UFP-VSL-T02A & D 02AOH 008165081 ARC 1 B & Archive & & \\
\hline TI-082 & 7.6.28 & Caustic-leach UFP-VSL-T02A & D 02AOH 008165081 ARC 1 D & Archive & & \\
\hline TI-082 & 7.6.28 & Caustic-leach UFP-VSL-T02A & D 02AML 008175082 ARC 1 B & Archive & & \\
\hline TI-082 & 7.6.28 & Caustic-leach UFP-VSL-T02A & D 02AML 008175082 ARC 1 D & Archive & & \\
\hline TI-082 & 7.6.28 & Caustic-leach UFP-VSL-T02A & D 02AML 008185083 UDS 2 B & UDS & SWRI-090331-20 & 090331-20UDS R1 \\
\hline TI-082 & 7.6.28 & Caustic-leach UFP-VSL-T02A & D 02AML 008185083 UDS 2 D & UDS & SWRI-090331-20 & 090331-20UDS R1 \\
\hline TI-082 & 7.6.28 & Caustic-leach UFP-VSL-T02A & D 02AML 008185084 DEN 2 & Density Slurry & SWRI-090331-11 & 090331-11DEN slurry and liquid \\
\hline TI-082 & 7.6.28 & Caustic-leach UFP-VSL-T02A & D 02AML 008185085 ICP 2 D & ICP Supernatant & SWRI-090331-22 & 090331-12 and 090331-22 and 090331-23 ICP and ICPMS \\
\hline TI-082 & 7.6.28 & Caustic-leach UFP-VSL-T02A & D 02AML 008185085 TFI 2 D & IC & SWRI-090331-26 & 090331-26 IC \\
\hline TI-082 & 7.6.28 & Caustic-leach UFP-VSL-T02A & D 02AML 008185085 TFI 3 D & $\mathrm{OH}$ & ASR8399 & ASR $8399 \mathrm{OH}$ \\
\hline TI-082 & 7.6.28 & Caustic-leach UFP-VSL-T02A & D 02AML 008195086 ARC 1 B & Archive & & \\
\hline TI-082 & 7.6.28 & Caustic-leach UFP-VSL-T02A & D 02AML 008195086 ARC 1 D & Archive & & \\
\hline TI-082 & 7.6.29 & Caustic-leach UFP-VSL-T02A & D 02AML 008205087 UDS 2 B & UDS & SWRI-090331-20 & 090331-20UDS R1 \\
\hline TI-082 & 7.6.29 & Caustic-leach UFP-VSL-T02A & D 02AML 008205087 UDS 2 D & UDS & SWRI-090331-20 & 090331-20UDS R1 \\
\hline TI-082 & 7.6.29 & Caustic-leach UFP-VSL-T02A & D 02AML 008205088 DEN 2 & Density Slurry & SWRI-090331-11 & 090331-11DEN slurry and liquid \\
\hline TI-082 & 7.6 .29 & Caustic-leach UFP-VSL-T02A & D 02AML 008205089 ICP 2 D & ICP Supernatant & SWRI-090331-22 & 090331-12 and 090331-22 and 090331-23 ICP and ICPMS \\
\hline TI-082 & 7.6 .29 & Caustic-leach UFP-VSL-T02A & D 02AML 008205089 TFI 2 D & IC & SWRI-090331-26 & 090331-26 IC \\
\hline TI-082 & 7.6.29 & Caustic-leach UFP-VSL-T02A & D 02AML 008205089 TFI 3 D & $\mathrm{OH}$ & ASR8399 & ASR $8399 \mathrm{OH}$ \\
\hline TI-082 & 7.6 .29 & Caustic-leach UFP-VSL-T02A & D 02AIL 008205090 ARC 1 B & Archive & & \\
\hline TI-082 & 7.6.29 & Caustic-leach UFP-VSL-T02A & D 02AIL 008205090 ARC 1 D & Archive & & \\
\hline TI-082 & 7.6.29 & Caustic-leach UFP-VSL-T02A & D 02AIM 008205091 ARC 1 B & Archive & & \\
\hline
\end{tabular}


Integrated Test D Sample List

\begin{tabular}{|c|c|c|c|c|c|c|}
\hline TI\# & TI Step \# & TI Step Description & Sample ID & Analysis & $\begin{array}{c}\text { Electronic Folder } \\
\text { (SWRI Task Order \#, ASR \#, TDP\#) }\end{array}$ & Final Electronic Report File Name \\
\hline TI-082 & 7.6 .29 & Caustic-leach UFP-VSL-T02A & D 02AIM 008205091 ARC 1 D & Archive & & \\
\hline TI-082 & 7.6.29 & Caustic-leach UFP-VSL-T02A & D 02AMM 008205093 ARC 1 B & Archive & & \\
\hline TI-082 & 7.6.29 & Caustic-leach UFP-VSL-T02A & D 02AMM 008205093 ARC 1 D & Archive & & \\
\hline TI-082 & 7.6 .29 & Caustic-leach UFP-VSL-T02A & D 02AMH 008205094 ARC 1 B & Archive & & \\
\hline TI-082 & 7.6 .29 & Caustic-leach UFP-VSL-T02A & D 02AMH 008205094 ARC 1 D & Archive & & \\
\hline TI-082 & 7.6 .29 & Caustic-leach UFP-VSL-T02A & D 02AOL 008205095 ARC 1 B & Archive & & \\
\hline TI-082 & 7.6.29 & Caustic-leach UFP-VSL-T02A & D 02AOL 008205095 ARC 1 D & Archive & & \\
\hline TI-082 & 7.6.29 & Caustic-leach UFP-VSL-T02A & D 02AOM 008205096 ARC 1 B & Archive & & \\
\hline TI-082 & 7.6.29 & Caustic-leach UFP-VSL-T02A & D 02AOM 008205096 ARC 1 D & Archive & & \\
\hline TI-082 & 7.6.29 & Caustic-leach UFP-VSL-T02A & D 02AOH 008205097 ARC 1 B & Archive & & \\
\hline TI-082 & 7.6.29 & Caustic-leach UFP-VSL-T02A & D 02AOH 008205097 ARC 1 D & Archive & & \\
\hline TI-082 & 7.6.29 & Caustic-leach UFP-VSL-T02A & D 02AML 008215098 ARC 1 B & Archive & & \\
\hline TI-082 & 7.6 .29 & Caustic-leach UFP-VSL-T02A & D 02AML 008215098 ARC 1 D & Archive & & \\
\hline TI-082 & 7.6.29 & Caustic-leach UFP-VSL-T02A & D 02AML 008225099 UDS 2 B & UDS & SWRI-090331-20 & 090331-20UDS R1 \\
\hline TI-082 & 7.6.29 & Caustic-leach UFP-VSL-T02A & D 02AML 008225099 UDS 2 D & UDS & SWRI-090331-20 & 090331-20UDS R1 \\
\hline TI-082 & 7.6 .29 & Caustic-leach UFP-VSL-T02A & D 02AML 008225100 DEN 2 & Density Slurry & SWRI-090331-11 & 090331-11DEN slurry and liquid \\
\hline TI-082 & 7.6.29 & Caustic-leach UFP-VSL-T02A & D 02AML 008225101 ICP 2 D & ICP Supernatant & SWRI-090331-22 & $090331-12$ and $090331-22$ and $090331-23$ ICP and ICPMS \\
\hline TI-082 & 7.6.29 & Caustic-leach UFP-VSL-T02A & D 02AML 008225101 TFI 2 D & IC & SWRI-090331-26 & 090331-26 IC \\
\hline TI-082 & 7.6 .29 & Caustic-leach UFP-VSL-T02A & D 02AML 008225101 TFI 3 D & $\mathrm{OH}$ & ASR 8399 & ASR 8399 OH \\
\hline TI-082 & 7.6.29 & Caustic-leach UFP-VSL-T02A & D 02AML 008225101 ICP 0 B & Storage & & \\
\hline TI-082 & 7.6.29 & Caustic-leach UFP-VSL-T02A & D 02AML 008235102 ARC 1 B & Archive & & \\
\hline TI-082 & 7.6 .29 & Caustic-leach UFP-VSL-T02A & D 02AML 008235102 ARC 1 D & Archive & & \\
\hline TI-082 & 7.6 .30 & Caustic-leach UFP-VSL-T02A & D 02AML 008245103 UDS 2 B & UDS & SWRI-090331-20 & 090331-20UDS R1 \\
\hline TI-082 & 7.6 .30 & Caustic-leach UFP-VSL-T02A & D 02AML 008245103 UDS 2 D & UDS & SWRI-090331-20 & 090331-20UDS R1 \\
\hline TI-082 & 7.6.30 & Caustic-leach UFP-VSL-T02A & D 02AML 008245104 UDS 2 B & UDS & SWRI-090331-20 & 090331-20UDS R1 \\
\hline TI-082 & 7.6 .30 & Caustic-leach UFP-VSL-T02A & D 02AML 008245104 UDS 2 D & UDS & SWRI-090331-20 & 090331-20UDS R1 \\
\hline TI-082 & 7.6 .30 & Caustic-leach UFP-VSL-T02A & D 02AML 008245105 UDS 2 B & UDS & SWRI-090331-20 & 090331-20UDS R1 \\
\hline TI-082 & 7.6 .30 & Caustic-leach UFP-VSL-T02A & D 02AML 008245105 UDS 2 D & UDS & SWRI-090331-20 & 090331-20UDS R1 \\
\hline TI-082 & 7.6 .30 & Caustic-leach UFP-VSL-T02A & D 02AML 008245106 DEN 2 & Density Slurry & SWRI-090331-11 & 090331-11DEN slurry and liquid \\
\hline TI-082 & 7.6 .30 & Caustic-leach UFP-VSL-T02A & D 02AML 008245107 DEN 2 & Density Slurry & SWRI-090331-11 & 090331-11DEN slurry and liquid \\
\hline TI-082 & 7.6.30 & Caustic-leach UFP-VSL-T02A & D 02AML 008245108 DEN 2 & Density Slurry & SWRI-090331-11 & 090331-11DEN slurry and liquid \\
\hline TI-082 & 7.6.30 & Caustic-leach UFP-VSL-T02A & D 02AML 008245109 ICP 2 B & ICP Wet Solids & SWRI-090331-24 & 090331-13 and 090331-25 and 090331-24 ICP and ICPMS \\
\hline
\end{tabular}


Integrated Test D Sample List

\begin{tabular}{|c|c|c|c|c|c|c|}
\hline TI \# & TI Step \# & TI Step Description & Sample ID & Analysis & $\begin{array}{c}\text { Electronic Folder } \\
\text { (SWRI Task Order \#, ASR \#, TDP\#) }\end{array}$ & Final Electronic Report File Name \\
\hline TI-082 & 7.6.30 & Caustic-leach UFP-VSL-T02A & D 02AML 008245109 ICP 2 D & ICP Supernatant & SWRI-090331-22 & $090331-12$ and $090331-22$ and $090331-23$ ICP and ICPMS \\
\hline TI-082 & 7.6 .30 & Caustic-leach UFP-VSL-T02A & D 02AML 008245109 RAM 3 D & Raman & ASR8398 & ASR 8398 RAM \\
\hline TI-082 & 7.6 .30 & Caustic-leach UFP-VSL-T02A & D 02AML 008245109 TFI 2 D & IC & SWRI-090331-26 & 090331-26 IC \\
\hline TI-082 & 7.6 .30 & Caustic-leach UFP-VSL-T02A & D 02AML 008245109 TFI 3 D & $\mathrm{OH}$ & ASR8399 & ASR $8399 \mathrm{OH}$ \\
\hline TI-082 & 7.6 .30 & Caustic-leach UFP-VSL-T02A & D 02AML 008245110 ICP 2 B & ICP Wet Solids & SWRI-090331-24 & $090331-13$ and $090331-25$ and $090331-24$ ICP and ICPMS \\
\hline TI-082 & 7.6 .30 & Caustic-leach UFP-VSL-T02A & D 02AML 008245110 ICP 2 D & ICP Supernatant & SWRI-090331-22 & $090331-12$ and $090331-22$ and $090331-23$ ICP and ICPMS \\
\hline TI-082 & 7.6 .30 & Caustic-leach UFP-VSL-T02A & D 02AML 008245110 RAM 3 D & Raman & ASR8398 & ASR 8398 RAM \\
\hline TI-082 & 7.6.30 & Caustic-leach UFP-VSL-T02A & D 02AML 008245110 TFI 2 D & IC & SWRI-090331-26 & 090331-26 IC \\
\hline TI-082 & 7.6 .30 & Caustic-leach UFP-VSL-T02A & D 02AML 008245110 TFI 3 D & $\mathrm{OH}$ & ASR8399 & ASR $8399 \mathrm{OH}$ \\
\hline TI-082 & 7.6.30 & Caustic-leach UFP-VSL-T02A & D 02AML 008245111 ICP 2 B & ICP Wet Solids & SWRI-090331-24 & 090331-13 and 090331-25 and 090331-24 ICP and ICPMS \\
\hline TI-082 & 7.6 .30 & Caustic-leach UFP-VSL-T02A & D 02AML 008245111 ICP 2 D & ICP Supernatant & SWRI-090331-22 & $090331-12$ and $090331-22$ and $090331-23$ ICP and ICPMS \\
\hline TI-082 & 7.6.30 & Caustic-leach UFP-VSL-T02A & D 02AML 008245111 RAM 3 D & Raman & ASR8398 & ASR 8398 RAM \\
\hline TI-082 & 7.6 .30 & Caustic-leach UFP-VSL-T02A & D 02AML 008245111 TFI 2 D & IC & SWRI-090331-26 & 090331-26 IC \\
\hline TI-082 & 7.6 .30 & Caustic-leach UFP-VSL-T02A & D 02AML 008245111 TFI 3 D & $\mathrm{OH}$ & ASR8399 & ASR $8399 \mathrm{OH}$ \\
\hline TI- 082 & 7.6.30 & Caustic-leach UFP-VSL-T02A & D 02AIL 008245112 ARC 1 B & Archive & & \\
\hline TI-082 & 7.6 .30 & Caustic-leach UFP-VSL-T02A & D 02AIL 008245112 ARC 1 D & Archive & & \\
\hline TI-082 & 7.6.30 & Caustic-leach UFP-VSL-T02A & D 02AIM 008245113 ARC 1 B & Archive & & \\
\hline TI-082 & 7.6.30 & Caustic-leach UFP-VSL-T02A & D 02AIM 008245113 ARC 1 D & Archive & & \\
\hline TI- 082 & 7.6.30 & Caustic-leach UFP-VSL-T02A & D 02AMM 008245115 ARC 1 B & Archive & & \\
\hline TI-082 & 7.6 .30 & Caustic-leach UFP-VSL-T02A & D 02AMM 008245115 ARC 1 D & Archive & & \\
\hline TI- 082 & 7.6 .30 & Caustic-leach UFP-VSL-T02A & D 02AMH 008245116 ARC 1 B & Archive & & \\
\hline TI-082 & 7.6 .30 & Caustic-leach UFP-VSL-T02A & D 02AMH 008245116 ARC 1 D & Archive & & \\
\hline TI-082 & 7.6.30 & Caustic-leach UFP-VSL-T02A & D 02AOL 008245117 ARC 1 B & Archive & & \\
\hline TI-082 & 7.6 .30 & Caustic-leach UFP-VSL-T02A & D 02AOL 008245117 ARC 1 D & Archive & & \\
\hline TI-082 & 7.6 .30 & Caustic-leach UFP-VSL-T02A & D 02AOM 008245118 ARC 1 B & Archive & & \\
\hline TI-082 & 7.6 .30 & Caustic-leach UFP-VSL-T02A & D 02AOM 008245118 ARC 1 D & Archive & & \\
\hline TI-082 & 7.6 .30 & Caustic-leach UFP-VSL-T02A & D 02AOH 008245119 ARC 1 B & Archive & & \\
\hline TI-082 & 7.6 .30 & Caustic-leach UFP-VSL-T02A & D 02AOH 008245119 ARC 1 D & Archive & & \\
\hline TI-082 & 7.7 .5 & Cool-down of UFP-VSL-T02A & D 02AML 009 XX 5128 UDS 2 & UDS & SWRI-090331-10 & 090331-10UDS R1 \\
\hline TI-082 & 7.7.5 & Cool-down of UFP-VSL-T02A & D 02AML 009 XX 5129 DEN 2 & Density Slurry & SWRI-090331-11 & 090331-11DEN slurry and liquid \\
\hline TI-082 & 7.7.5 & Cool-down of UFP-VSL-T02A & D 02AML 009 XX 5129 DEN 2 & Density Supernate & SWRI-090331-11 & 090331-11DEN slurry and liquid \\
\hline TI-082 & 7.7.5 & Cool-down of UFP-VSL-T02A & D 02AML 009 XX 5130 ICP 2 B & ICP Wet Solids & SWRI-090331-13 & $090331-13$ and $090331-25$ and $090331-24$ ICP and ICPMS \\
\hline
\end{tabular}


Integrated Test D Sample List

\begin{tabular}{|c|c|c|c|c|c|c|}
\hline TI \# & TI Step \# & TI Step Description & Sample ID & Analysis & $\begin{array}{l}\text { Electronic Folder } \\
\text { (SWRI Task Order \#, ASR \#, TDP\#) }\end{array}$ & Final Electronic Report File Name \\
\hline TI-082 & 7.7 .5 & Cool-down of UFP-VSL-T02A & D 02AML 009 XX 5130 ICP 2 D & ICP Supernate & SWRI-090331-12 & 090331-12 and 090331-22 and 090331-23 ICP and ICPMS \\
\hline TI-082 & 7.7.5 & Cool-down of UFP-VSL-T02A & D 02AML 009 XX 5130 TFI 2 D & $\mathrm{IC}$ & SWRI-090331-14 & 090331-14 IC \\
\hline TI-082 & 7.7.5 & Cool-down of UFP-VSL-TO2A using cooling jacket & D 02AML 009 XX 5130 TFI 3 D & $\mathrm{OH}$ & ASR8396 & ASR $8396 \mathrm{OH}$ \\
\hline TI-082 & 7.7.5 & Cool-down of UFP-VSL-TO2A using cooling jacket & D 02AIL 009 XX 5120 ARC 1 & Archive & & \\
\hline TI-082 & 7.7 .5 & Cool-down of UFP-VSL-TO2A using cooling jacket & D 02 AIM 009 XX 5121 ARC 1 & Archive & & \\
\hline TI-082 & 7.7.5 & Cool-down of UFP-VSL-TO2A using cooling jacket & D 02AIH 009 XX 5122 ARC 1 & Archive & & \\
\hline TI-082 & 7.7 .5 & Cool-down of UFP-VSL-TO2A using cooling jacket & D 02AMM 009 XX 5123 ARC 1 & Archive & & \\
\hline TI-082 & 7.7.5 & Cool-down of UFP-VSL-TO2A using cooling jacket & D 02AMH 009 XX 5124 ARC 1 & Archive & & \\
\hline TI-082 & 7.7.5 & Cool-down of UFP-VSL-TO2A using cooling jacket & D 02AOL 009 XX 5125 ARC 1 & Archive & & \\
\hline TI-082 & 7.7 .5 & Cool-down of UFP-VSL-TO2A using cooling jacket & D 02AOM 009 XX 5126 ARC 1 & Archive & & \\
\hline TI-082 & 7.7 .5 & Cool-down of UFP-VSL-TO2A using cooling jacket & D 02AOH 009 XX 5127 ARC 1 & Archive & & \\
\hline TI-082 & 7.9.1 & Transfer simulant from HLP-VSL-T22 to UFP-VSL-T01B & D T221B 02A XX 5131 ARC 1 & Archive & & \\
\hline TI-082 & 7.9 .1 & Transfer simulant from HLP-VSL-T22 to UFP-VSL-T01B & D T221B 02A XX 5132 ARC 1 & Archive & & \\
\hline TI-082 & 7.9.1 & Transfer simulant from HLP-VSL-T22 to UFP-VSL-T01B & D T221B 02A XX 5133 ARC 1 & Archive & & \\
\hline TI-082 & 7.9 .1 & Transfer simulant from HLP-VSL-T22 to UFP-VSL-T01B & D T221B 02A XX 5134 ARC 1 & Archive & & \\
\hline TI-082 & 7.9.7 & End of transfer into UFP-VSL-T01A from HLP-T22 & D 01BIH 02A XX 5135 UDS 2 & UDS & SWRI-090327-8 & 090327-8UDS R1 \\
\hline TI-082 & 7.9.7 & End of transfer into UFP-VSL-T01A from HLP-T22 & D 01BIH 02A XX 5136 ICP 2 B & ICP Wet Solids & SWRI-090327-9 & 090327-9 and 090331-30 and 090401-25 Density and ICP \\
\hline TI-082 & 7.9.7 & End of transfer into UFP-VSL-T01A from HLP-T22 & D 01BIL 02A XX 5139 UDS 2 & UDS & SWRI-090327-8 & 090327-8UDS R1 \\
\hline TI-082 & 7.9.7 & End of transfer into UFP-VSL-T01A from HLP-T22 & D 01BIL 02A XX 5140 ICP 2 B & ICP Wet Solids & SWRI-090327-9 & 090327-9 and $090331-30$ and $090401-25$ Density and ICP \\
\hline TI-082 & 7.9.7 & End of transfer into UFP-VSL-T01A from HLP-T22 & D 01BIM 02A XX 5137 UDS 2 & UDS & SWRI-090327-8 & 090327-8UDS R1 \\
\hline TI-082 & 7.9.7 & End of transfer into UFP-VSL-T01A from HLP-T22 & D 01BIM 02A XX 5138 ICP 2 B & ICP Wet Solids & SWRI-090327-9 & 090327-9 and 090331-30 and 090401-25 Density and ICP \\
\hline TI-082 & 7.10 .4 & Transfer simulant from HLP-VSL-T01B to UFP-VSL-T02A & D 01B2A 03A XX 5141 ARC 1 & Archive & & \\
\hline TI-082 & 7.10 .4 & Transfer simulant from HLP-VSL-T01B to UFP-VSL-T02A & D 01B2A 03A XX 5142 ARC 1 & Archive & & \\
\hline TI-082 & 7.10 .4 & Transfer simulant from HLP-VSL-T01B to UFP-VSL-T02A & D 01B2A 03A XX 5143 ARC 1 & Archive & & \\
\hline TI-082 & 7.10 .4 & Transfer simulant from HLP-VSL-T01B to UFP-VSL-T02A & D 01B2A 03A XX 5144 ARC 1 & Archive & & \\
\hline TI-082 & 7.12 .7 & $\begin{array}{l}\text { Concentration in UFP-VSL-T02A to } 20 \text {-wt } \% \text { UDS - immediately after } \\
\text { permeate valves are opened }\end{array}$ & D 02AML 05A XX 5153 UDS 2 & UDS & SWRI-090331-10 & 090331-10UDS R1 \\
\hline TI-082 & 7.12.7 & $\begin{array}{l}\text { Dewatering solids in UFP-VSL-T02A to 20-wt\% UDS using ONE } \\
\text { ultrafilter }\end{array}$ & D 02AML 05A XX 5154 RHE 4 & Rheology & TDP WTP 366 & TDP WTP 366 Int Test D RHE Data on PEP Slurry \\
\hline TI-082 & 7.12 .7 & Concentration in UFP-VSL-T02A to 20 -wt $\%$ UDS & D 02AML 05A XX 5155 UDS 2 & UDS & SWRI-090331-10 & 090331-10UDS R1 \\
\hline TI-082 & 7.12.7 & Concentration in UFP-VSL-T02A to $20-\mathrm{wt} \%$ UDS & D 02AML 05A XX 5156 UDS 2 & UDS & SWRI-090331-10 & 090331-10UDS R1 \\
\hline TI-082 & 7.12 .7 & Concentration in UFP-VSL-T02A to $20-\mathrm{wt} \%$ UDS & D 02AML 05A XX 5157 UDS 2 & UDS & SWRI-090331-18 & 090331-18UDS R1 \\
\hline
\end{tabular}


Integrated Test D Sample List

\begin{tabular}{|c|c|c|c|c|c|c|}
\hline TI \# & TI Step \# & TI Step Description & Sample ID & Analysis & $\begin{array}{c}\text { Electronic Folder } \\
\text { (SWRI Task Order \#, ASR \#, TDP\#) }\end{array}$ & Final Electronic Report File Name \\
\hline TI-082 & 7.12 .7 & Concentration in UFP-VSL-T02A to 20 -wt $\%$ UDS & D 02AML 05A XX 5158 UDS 2 & UDS & SWRI-090331-18 & 090331-18UDS R1 \\
\hline TI-082 & 7.12 .7 & Concentration in UFP-VSL-T02A to $20-\mathrm{wt} \%$ UDS & D 02AML 05A XX 5159 UDS 2 & UDS & SWRI-090331-18 & 090331-18UDS R1 \\
\hline TI-082 & 7.12 .7 & Concentration in UFP-VSL-T02A to 20 -wt $\%$ UDS & D 02AML 05A XX 5160 UDS 2 & UDS & SWRI-090331-18 & 090331-18UDS R1 \\
\hline TI-082 & 7.12 .7 & Concentration in UFP-VSL-T02A to $20-\mathrm{wt} \%$ UDS & D 02AML 05A XX 5161 UDS 2 & UDS & SWRI-090331-18 & 090331-18UDS R1 \\
\hline TI-082 & 7.12.7 & Concentration in UFP-VSL-T02A to 20 -wt $\%$ UDS & D 02AML 05A XX 5162 UDS 2 & UDS & SWRI-090331-18 & 090331-18UDS R1 \\
\hline TI-082 & 7.12 .7 & Concentration in UFP-VSL-T02A to 20 -wt $\%$ UDS & D 02AML 05A XX 5163 UDS 2 & UDS & SWRI-090331-18 & 090331-18UDS R1 \\
\hline TI-082 & 7.12.7 & Concentration in UFP-VSL-T02A to 20 -wt $\%$ UDS & D 02AML 05A XX 5164 UDS 2 & UDS & SWRI-090331-19 & 090331-19UDS R1 \\
\hline TI-082 & 7.12.7 & Concentration in UFP-VSL-T02A to 20 -wt\% UDS & D 02AML 05A XX 5165 UDS 2 & UDS & SWRI-090331-19 & 090331-19UDS R1 \\
\hline TI-082 & 7.12.7 & Concentration in UFP-VSL-T02A to 20 -wt $\%$ UDS & D 02AML 05A XX 5166 UDS 2 & UDS & SWRI-090331-19 & 090331-19UDS R1 \\
\hline TI-082 & 7.12 .7 & Concentration in UFP-VSL-T02A to 20 -wt $\%$ UDS & D 02AML 05A XX 5167 UDS 2 & UDS & SWRI-090331-19 & 090331-19UDS R1 \\
\hline TI-082 & 7.12 .7 & Concentration in UFP-VSL-T02A to $20-\mathrm{wt} \%$ UDS & D 02AML 05A XX 5168 UDS 2 & UDS & SWRI-090331-19 & 090331-19UDS R1 \\
\hline TI-082 & 7.12.7 & Concentration in UFP-VSL-T02A to 20 -wt $\%$ UDS & D 02AML 05A XX 5169 UDS 2 & UDS & SWRI-090331-19 & 090331-19UDS R1 \\
\hline TI-082 & 7.12 .7 & Concentration in UFP-VSL-T02A to 20 -wt $\%$ UDS & D 01B2A 05A XX 5145 ARC 1 & Archive & & \\
\hline TI-082 & 7.12 .7 & Concentration in UFP-VSL-T02A to 20 -wt $\%$ UDS & D 01B2A 05A XX 5146 ARC 1 & Archive & & \\
\hline TI-082 & 7.12 .7 & Concentration in UFP-VSL-T02A to 20 -wt $\%$ UDS & D 00PF1 05A XX 5150 ARC 1 & Archive & & \\
\hline TI-082 & 7.12.7 & Concentration in UFP-VSL-T02A to 20 -wt $\%$ UDS & D 00PF2 05A XX 5629 ARC 1 & Archive & & \\
\hline TI-082 & 7.12.7 & Concentration in UFP-VSL-T02A to 20 -wt $\%$ UDS & D 00PF3 05A XX 5630 ARC 1 & Archive & & \\
\hline TI-082 & 7.12.7 & Concentration in UFP-VSL-T02A to 20 -wt $\%$ UDS & D 00PF4 05A XX 5631 ARC 1 & Archive & & \\
\hline TI-082 & 7.12 .7 & Concentration in UFP-VSL-T02A to 20 -wt $\%$ UDS & D 00PF5 05A XX 5632 ARC 1 & Archive & & \\
\hline TI-082 & 7.12 .7 & Concentration in UFP-VSL-T02A to 20 -wt $\%$ UDS & D 00PF1 05A XX 5151 ARC 1 & Archive & & \\
\hline TI-082 & 7.12 .7 & Concentration in UFP-VSL-T02A to 20 -wt $\%$ UDS & D 00PF1 05A XX 5152 ARC 1 & Archive & & \\
\hline TI-082 & 7.12.7 & Concentration in UFP-VSL-T02A to 20 -wt $\%$ UDS & D 00PF2 05A XX 5633 ARC 1 & Archive & & \\
\hline TI-082 & 7.12 .7 & Concentration in UFP-VSL-T02A to 20 -wt $\%$ UDS & D 00PF3 05A XX 5634 ARC 1 & Archive & & \\
\hline TI-082 & 7.12.7 & Concentration in UFP-VSL-T02A to 20 -wt\% UDS & D 00PF4 05A XX 5635 ARC 1 & Archive & & \\
\hline TI-082 & 7.12 .7 & Concentration in UFP-VSL-T02A to 20 -wt $\%$ UDS & D 00PF5 05A XX 5636 ARC 1 & Archive & & \\
\hline TI-082 & 7.12 .7 & Concentration in UFP-VSL-T02A to 20 -wt $\%$ UDS & D 00PF2 05A XX 5637 ARC 1 & Archive & & \\
\hline TI-082 & 7.12 .7 & Concentration in UFP-VSL-T02A to 20 -wt $\%$ UDS & D 00PF3 05A XX 5638 ARC 1 & Archive & & \\
\hline TI-082 & 7.12 .7 & Concentration in UFP-VSL-T02A to 20 -wt $\%$ UDS & D 00PF4 05A XX 5639 ARC 1 & Archive & & \\
\hline TI-082 & 7.12 .7 & Concentration in UFP-VSL-T02A to 20 -wt $\%$ UDS & D 00PF5 05A XX 5640 ARC 1 & Archive & & \\
\hline TI-082 & 7.12.7 & Concentration in UFP-VSL-T02A to 20-wt\% UDS & D 01B2A 05A XX 5147 ARC 1 & Archive & & \\
\hline TI-082 & 7.12 .7 & Concentration in UFP-VSL-T02A to 20 -wt $\%$ UDS & D 01B2A 05A XX 5148 ARC 1 & Archive & & \\
\hline
\end{tabular}


Integrated Test D Sample List

\begin{tabular}{|c|c|c|c|c|c|c|}
\hline TI\# & TI Step \# & TI Step Description & Sample ID & Analysis & $\begin{array}{c}\text { Electronic Folder } \\
\text { (SWRI Task Order \#, ASR \#, TDP\#) }\end{array}$ & Final Electronic Report File Name \\
\hline TI-082 & 7.12 .9 & $\begin{array}{l}\text { Completion of dewatering solids in UFP-VSL-T02A to 20-wt\% UDS } \\
\text { using ONE ultrafilter }\end{array}$ & D 00PF1 05A XX 5186 ARC 4 & Precipitation Study & & \\
\hline TI-082 & 7.12 .9 & $\begin{array}{l}\text { Concentration in UFP-VSL-T02A to } 20 \text {-wt\% UDS - after solids } \\
\text { concentration is complete }\end{array}$ & D 02AML 05A XX 5174 UDS 2 & UDS & SWRI-090331-19 & 090331-19UDS R1 \\
\hline TI-082 & 7.12 .9 & $\begin{array}{l}\text { Concentration in UFP-VSL-T02A to } 20 \text {-wt } \% \text { UDS - after solids } \\
\text { concentration is complete }\end{array}$ & D 02AML 05A XX 5175 UDS 2 & UDS & SWRI-090331-19 & 090331-19UDS R1 \\
\hline TI-082 & 7.12 .9 & $\begin{array}{l}\text { Concentration in UFP-VSL-T02A to } 20 \text {-wt\% UDS - after solids } \\
\text { concentration is complete }\end{array}$ & D 02AML 05A XX 5176 UDS 2 & UDS & SWRI-090331-19 & 090331-19UDS R1 \\
\hline TI-082 & 7.12 .9 & $\begin{array}{l}\text { Concentration in UFP-VSL-T02A to 20-wt } \% \text { UDS - after solids } \\
\text { concentration is complete }\end{array}$ & D 02AML 05A XX 5177 DEN 2 & Density Slurry & SWRI-090331-28 & 090331-28DEN liquid and slurry \\
\hline TI-082 & 7.12 .9 & $\begin{array}{l}\text { Concentration in UFP-VSL-T02A to } 20 \text {-wt } \% \text { UDS - after solids } \\
\text { concentration is complete }\end{array}$ & D 02AML 05A XX 5177 DEN 2 & Density Supernate & SWRI-090331-28 & 090331-28DEN liquid and slurry \\
\hline TI-082 & 7.12 .9 & $\begin{array}{l}\text { Concentration in UFP-VSL-T02A to } 20 \text {-wt\% UDS - after solids } \\
\text { concentration is complete }\end{array}$ & D 02AML 05A XX 5178 DEN 2 & Density Slurry & SWRI-090331-28 & 090331-28DEN liquid and slurry \\
\hline TI-082 & 7.12 .9 & $\begin{array}{l}\text { Concentration in UFP-VSL-T02A to } 20 \text {-wt\% UDS - after solids } \\
\text { concentration is complete }\end{array}$ & D 02AML 05A XX 5178 DEN 2 & Density Supernate & SWRI-090331-28 & 090331-28DEN liquid and slurry \\
\hline TI-082 & 7.12 .9 & $\begin{array}{l}\text { Concentration in UFP-VSL-T02A to } 20 \text {-wt\% UDS - after solids } \\
\text { concentration is complete }\end{array}$ & D 02AML 05A XX 5179 DEN 2 & Density Slurry & SWRI-090331-28 & 090331-28DEN liquid and slurry \\
\hline TI-082 & 7.12 .9 & $\begin{array}{l}\text { Concentration in UFP-VSL-T02A to } 20 \text {-wt\% UDS - after solids } \\
\text { concentration is complete }\end{array}$ & D 02AML 05A XX 5179 DEN 2 & Density Supernate & SWRI-090331-28 & 090331-28DEN liquid and slurry \\
\hline TI-082 & 7.12 .9 & $\begin{array}{l}\text { Dewatering solids in UFP-VSL-T02A to 20-wt\% UDS using ONE } \\
\text { ultrafilter }\end{array}$ & D 02AML 05A XX 5180 RHE 4 & Rheology & TDP WTP 366 & TDP WTP 366 Int Test D RHE Data on PEP Slurry \\
\hline TI-082 & 7.12 .9 & $\begin{array}{l}\text { Concentration in UFP-VSL-T02A to } 20 \text {-wt } \% \text { UDS - after solids } \\
\text { concentration is complete }\end{array}$ & D 02AML 05A XX 5181 ICP 2 B & ICP Wet Solids & SWRI-090331-24 & 090331-13 and 090331-25 and 090331-24 ICP and ICPMS \\
\hline TI-082 & 7.12 .9 & $\begin{array}{l}\text { Concentration in UFP-VSL-T02A to } 20 \text {-wt } \% \text { UDS - after solids } \\
\text { concentration is complete }\end{array}$ & D 02AML 05A XX 5181 ICP 2 D & ICP Supernatant & 090331-22 & $090331-12$ and $090331-22$ and $090331-23$ ICP and ICPMS \\
\hline TI-082 & 7.12 .9 & $\begin{array}{l}\text { Concentration in UFP-VSL-T02A to } 20 \text {-wt } \% \text { UDS - after solids } \\
\text { concentration is complete }\end{array}$ & D 02AML 05A XX 5181 TFI 2 D & IC & SWRI-090331-26 & 090331-26 IC \\
\hline TI-082 & 7.12 .9 & $\begin{array}{l}\text { Dewatering solids in UFP-VSL-T02A to 20-wt\% UDS using ONE } \\
\text { ultrafilter }\end{array}$ & D 02AML 05A XX 5181 TFI 3 D & $\mathrm{OH}$ & ASR8399 & ASR 8399 OH \\
\hline TI-082 & 7.12 .9 & $\begin{array}{l}\text { Concentration in UFP-VSL-T02A to 20-wt\% UDS - after solids } \\
\text { concentration is complete }\end{array}$ & D 02AML 05A XX 5182 ICP 2 B & ICP Wet Solids & SWRI-090331-24 & 090331-13 and 090331-25 and 090331-24 ICP and ICPMS \\
\hline TI-082 & 7.12 .9 & $\begin{array}{l}\text { Concentration in UFP-VSL-T02A to 20-wt\% UDS - after solids } \\
\text { concentration is complete }\end{array}$ & D 02AML 05A XX 5182 ICP 2 D & ICP Supernatant & SWRI-090331-22 & 090331-12 and 090331-22 and 090331-23 ICP and ICPMS \\
\hline TI-082 & 7.12 .9 & $\begin{array}{l}\text { Concentration in UFP-VSL-T02A to } 20 \text {-wt\% UDS - after solids } \\
\text { concentration is complete }\end{array}$ & D 02AML 05A XX 5182 TFI 2 D & IC & SWRI-090331-26 & 090331-26 IC \\
\hline TI-082 & 7.12 .9 & $\begin{array}{l}\text { Dewatering solids in UFP-VSL-T02A to 20-wt\% UDS using ONE } \\
\text { ultrafilter }\end{array}$ & D 02AML 05A XX 5182 TFI 3 D & $\mathrm{OH}$ & ASR 8399 & ASR $8399 \mathrm{OH}$ \\
\hline
\end{tabular}


Integrated Test D Sample List

\begin{tabular}{|c|c|c|c|c|c|c|}
\hline TI \# & TI Step \# & TI Step Description & Sample ID & Analysis & $\begin{array}{c}\text { Electronic Folder } \\
\text { (SWRI Task Order \#, ASR \#, TDP\#) }\end{array}$ & Final Electronic Report File Name \\
\hline TI-082 & 7.12 .9 & $\begin{array}{l}\text { Concentration in UFP-VSL-T02A to } 20 \text {-wt\% UDS - after solids } \\
\text { concentration is complete }\end{array}$ & D 02AML 05A XX 5183 ICP 2 B & ICP Wet Solids & SWRI-090331-24 & $090331-13$ and $090331-25$ and $090331-24$ ICP and ICPMS \\
\hline TI-082 & 7.12 .9 & $\begin{array}{l}\text { Concentration in UFP-VSL-T02A to } 20 \text {-wt } \% \text { UDS - after solids } \\
\text { concentration is complete }\end{array}$ & D 02AML 05A XX 5183 ICP 2 D & ICP Supernatant & SWRI-090331-22 & $090331-12$ and $090331-22$ and $090331-23$ ICP and ICPMS \\
\hline TI-082 & 7.12 .9 & $\begin{array}{l}\text { Concentration in UFP-VSL-T02A to } 20 \text {-wt\% UDS - after solids } \\
\text { concentration is complete }\end{array}$ & D 02AML 05A XX 5183 TFI 2 D & IC & SWRI-090331-26 & 090331-26 IC \\
\hline TI-082 & 7.12 .9 & $\begin{array}{c}\text { Dewatering solids in UFP-VSL-T02A to 20-wt\% UDS using ONE } \\
\text { ultrafilter }\end{array}$ & D 02AML 05A XX 5183 TFI 3 D & $\mathrm{OH}$ & ASR8399 & ASR $8399 \mathrm{OH}$ \\
\hline TI-082 & 7.12 .9 & $\begin{array}{l}\text { Dewatering solids in UFP-VSL-T02A to 20-wt\% UDS using ONE } \\
\text { ultrafilter }\end{array}$ & D 02AML 05A XX 5184 XSP 4 & PSD & TDP WTP 365 & TDP WTP 365 Int Test D PSD Data Analysis \\
\hline TI-082 & 7.12 .9 & $\begin{array}{l}\text { Dewatering solids in UFP-VSL-T02A to 20-wt\% UDS using ONE } \\
\text { ultrafilter }\end{array}$ & D 02AML 05A XX 5185 CUF 4 & Parallel Bench Test & & \\
\hline TI-082 & 7.13.13 & After caustic addition before UFP-VSL-T02A leach begins & D 02AML 07A XX 5189 UDS 2 B & UDS & SWRI-090331-20 & 090331-20UDS R1 \\
\hline TI-082 & 7.13.13 & After caustic addition before UFP-VSL-T02A leach begins & D 02AML 07A XX 5189 UDS 2 D & UDS & SWRI-090331-20 & 090331-20UDS R1 \\
\hline TI-082 & 7.13.13 & After caustic addition before UFP-VSL-T02A leach begins & D 02AML 07A XX 5190 DEN 2 & Density Slurry & SWRI-090331-28 & 090331-28DEN liquid and slurry \\
\hline TI-082 & 7.13 .13 & After caustic addition before UFP-VSL-T02A leach begins & D 02AML 07A XX 5191 ICP 2 B & ICP Wet Solids & SWRI-090331-24 & $090331-13$ and $090331-25$ and $090331-24$ ICP and ICPMS \\
\hline TI-082 & 7.13 .13 & After caustic addition before UFP-VSL-T02A leach begins & D 02AML 07A XX 5191 ICP 2 D & ICP Supernatant & SWRI-090331-22 & $090331-12$ and $090331-22$ and $090331-23$ ICP and ICPMS \\
\hline TI-082 & 7.13.13 & After caustic addition, before UFP-VSL-T02A leach begins & D 02AML 07A XX 5191 RAM 3 D & Raman & ASR8398 & ASR 8398 RAM \\
\hline TI-082 & 7.13 .13 & After caustic addition before UFP-VSL-T02A leach begins & D 02AML 07A XX 5191 TFI 2 D & IC & SWRI-090331-26 & 090331-26 IC \\
\hline TI-082 & 7.13 .13 & After caustic addition, before UFP-VSL-T02A leach begins & D 02AML 07A XX 5191 TFI 3 D & $\mathrm{OH}$ & ASR8399 & ASR 8399 OH \\
\hline TI-082 & 7.13 .13 & After caustic addition, before UFP-VSL-T02A leach begins & D 02AML 07A XX 5198 CUF 4 & Parallel Bench Test & & \\
\hline TI-082 & 7.13 .18 & Beginning of UFP-VSL-T02A caustic-leach & D 02AML 08A BT 5199 UDS 2 B & UDS & SWRI-090331-21 & 090331-21UDS R1 \\
\hline TI-082 & 7.13.18 & Beginning of UFP-VSL-T02A caustic-leach & D 02AML 08A BT 5199 UDS 2 D & UDS & SWRI-090331-21 & 090331-21UDS R1 \\
\hline TI-082 & 7.13.18 & Beginning of UFP-VSL-T02A caustic-leach & D 02AML 08A BT 5200 DEN 2 & Density Slurry & SWRI-090331-29 & 090331-29DEN liquid and slurry \\
\hline TI-082 & 7.13.18 & Beginning of UFP-VSL-T02A caustic-leach & D 02AML 08A BT 5201 ICP 2 D & ICP Supernatant & SWRI-090331-23 & 090331-12 and $090331-22$ and $090331-23$ ICP and ICPMS \\
\hline TI-082 & 7.13.18 & Beginning of UFP-VSL-T02A caustic-leach & D 02AML 08A BT 5201 TFI 2 D & IC & SWRI-090331-27 & 090331-27 IC \\
\hline TI-082 & 7.13.18 & Beginning of UFP-VSL-T02A caustic-leach & D 02AML 08A BT 5201 TFI 3 D & $\mathrm{OH}$ & ASR8399 & ASR $8399 \mathrm{OH}$ \\
\hline TI-082 & 7.13 .18 & Beginning of UFP-VSL-T02A caustic-leach & D 02AML 08A BT 5201 ICP 0 B & Storage & & \\
\hline TI-082 & 7.13 .18 & Beginning of UFP-VSL-T02A caustic-leach & D 02AIL 08A BT 5202 ARC 1 B & Archive & & \\
\hline TI-082 & 7.13.18 & Beginning of UFP-VSL-T02A caustic-leach & D 02AIL 08A BT 5202 ARC 1 D & Archive & & \\
\hline TI-082 & 7.13.18 & Beginning of UFP-VSL-T02A caustic-leach & D 02AIM 08A BT 5203 ARC 1 B & Archive & & \\
\hline TI-082 & 7.13.18 & Beginning of UFP-VSL-T02A caustic-leach & D 02AIM 08A BT 5203 ARC 1 D & Archive & & \\
\hline TI-082 & 7.13.18 & Beginning of UFP-VSL-T02A caustic-leach & D 02AMM 08A BT 5205 ARC 1 B & Archive & & \\
\hline TI-082 & 7.13 .18 & Beginning of UFP-VSL-T02A caustic-leach & D 02AMM 08A BT 5205 ARC 1 D & Archive & & \\
\hline
\end{tabular}


Integrated Test D Sample List

\begin{tabular}{|c|c|c|c|c|c|c|}
\hline TI\# & TI Step \# & TI Step Description & Sample ID & Analysis & $\begin{array}{c}\text { Electronic Folder } \\
\text { (SWRI Task Order \#, ASR \#, TDP\#) }\end{array}$ & Final Electronic Report File Name \\
\hline TI-082 & 7.13 .18 & Beginning of UFP-VSL-T02A caustic-leach & D 02AMH 08A BT 5206 ARC 1 B & Archive & & \\
\hline TI-082 & 7.13 .18 & Beginning of UFP-VSL-T02A caustic-leach & D 02AMH 08A BT 5206 ARC 1 D & Archive & & \\
\hline TI-082 & 7.13 .18 & Beginning of UFP-VSL-T02A caustic-leach & D 02AOL 08A BT 5207 ARC 1 B & Archive & & \\
\hline TI-082 & 7.13 .18 & Beginning of UFP-VSL-T02A caustic-leach & D 02AOL 08A BT 5207 ARC 1 D & Archive & & \\
\hline TI-082 & 7.13 .18 & Beginning of UFP-VSL-T02A caustic-leach & D 02AOM 08A BT 5208 ARC 1 B & Archive & & \\
\hline TI-082 & 7.13 .18 & Beginning of UFP-VSL-T02A caustic-leach & D 02AOM 08A BT 5208 ARC 1 D & Archive & & \\
\hline TI-082 & 7.13 .18 & Beginning of UFP-VSL-T02A caustic-leach & D 02AOH 08A BT 5209 ARC 1 B & Archive & & \\
\hline TI-082 & 7.13 .18 & Beginning of UFP-VSL-T02A caustic-leach & D 02AOH 08A BT 5209 ARC 1 D & Archive & & \\
\hline TI-082 & 7.13 .20 & Caustic-leach UFP-VSL-T02A & D 02AML 08A 005210 UDS 2 B & UDS & SWRI-090331-20 & 090331-20UDS R1 \\
\hline TI-082 & 7.13 .20 & Caustic-leach UFP-VSL-T02A & D 02AML 08A 005210 UDS 2 D & UDS & SWRI-090331-20 & 090331-20UDS R1 \\
\hline TI-082 & 7.13 .20 & Caustic-leach UFP-VSL-T02A & D 02AML 08A 005211 UDS 2 B & UDS & SWRI-090331-20 & 090331-20UDS R1 \\
\hline TI-082 & 7.13 .20 & Caustic-leach UFP-VSL-T02A & D 02AML 08A 005211 UDS 2 D & UDS & SWRI-090331-20 & 090331-20UDS R1 \\
\hline TI-082 & 7.13 .20 & Caustic-leach UFP-VSL-T02A & D 02AML 08A 005212 UDS 2 B & UDS & SWRI-090331-20 & 090331-20UDS R1 \\
\hline TI-082 & 7.13 .20 & Caustic-leach UFP-VSL-T02A & D 02AML 08A 005212 UDS 2 D & UDS & SWRI-090331-20 & $\begin{array}{l}\text { 090331-20UDS R1 -SWRI analyst spilled sample during analysis - } \\
\text { sample lost not retrievable }\end{array}$ \\
\hline TI-082 & 7.13 .20 & Caustic-leach UFP-VSL-T02A & D 02AML 08A 005213 DEN 2 & Density Slurry & SWRI-090331-28 & 090331-28DEN liquid and slurry \\
\hline TI-082 & 7.13 .20 & Caustic-leach UFP-VSL-T02A & D 02AML 08A 005214 DEN 2 & Density Slurry & SWRI-090331-28 & 090331-28DEN liquid and slurry \\
\hline TI-082 & 7.13 .20 & Caustic-leach UFP-VSL-T02A & D 02AML 08A 005215 DEN 2 & Density Slurry & SWRI-090331-28 & 090331-28DEN liquid and slurry \\
\hline TI-082 & 7.13 .20 & Caustic-leach UFP-VSL-T02A & D 02AML 08A 005216 ICP 2 B & ICP Wet Solids & SWRI-090331-24 & $090331-13$ and $090331-25$ and $090331-24$ ICP and ICPMS \\
\hline TI-082 & 7.13 .20 & Caustic-leach UFP-VSL-T02A & D 02AML 08A 005216 ICP 2 D & ICP Supernatant & SWRI-090331-22 & 090331-12 and 090331-22 and 090331-23 ICP and ICPMS \\
\hline TI-082 & 7.13 .20 & Caustic-leach UFP-VSL-T02A & D 02AML 08A 00 5216 RAM 3 D & Raman & ASR8398 & ASR 8398 RAM \\
\hline TI-082 & 7.13 .20 & Caustic-leach UFP-VSL-T02A & D 02AML 08A 005216 TFI 2 D & IC & SWRI-090331-26 & 090331-26 IC \\
\hline TI-082 & 7.13 .20 & Caustic-leach UFP-VSL-T02A & D 02AML 08A 005216 TFI 3 D & $\mathrm{OH}$ & ASR8399 & ASR $8399 \mathrm{OH}$ \\
\hline TI-082 & 7.13 .20 & Caustic-leach UFP-VSL-T02A & D 02AML 08A 005217 ICP 2 B & ICP Wet Solids & SWRI-090331-24 & 090331-13 and 090331-25 and 090331-24 ICP and ICPMS \\
\hline TI-082 & 7.13 .20 & Caustic-leach UFP-VSL-T02A & D 02AML 08A 005217 ICP 2 D & ICP Supernatant & SWRI-090331-22 & 090331-12 and 090331-22 and 090331-23 ICP and ICPMS \\
\hline TI-082 & 7.13 .20 & Caustic-leach UFP-VSL-T02A & D 02AML 08A 005217 RAM 3 D & Raman & ASR8398 & ASR 8398 RAM \\
\hline TI-082 & 7.13 .20 & Caustic-leach UFP-VSL-T02A & D 02AML 08A 005217 TFI 2 D & IC & SWRI-090331-26 & 090331-26 IC \\
\hline TI-082 & 7.13 .20 & Caustic-leach UFP-VSL-T02A & D 02AML 08A 005217 TFI 3 D & $\mathrm{OH}$ & ASR8399 & ASR $8399 \mathrm{OH}$ \\
\hline TI-082 & 7.13 .20 & Caustic-leach UFP-VSL-T02A & D 02AML 08A 005218 ICP 2 B & ICP Wet Solids & SWRI-090331-24 & 090331-13 and 090331-25 and 090331-24 ICP and ICPMS \\
\hline TI-082 & 7.13 .20 & Caustic-leach UFP-VSL-T02A & D 02AML 08A 005218 ICP 2 D & ICP Supernatant & SWRI-090331-22 & 090331-12 and 090331-22 and 090331-23 ICP and ICPMS \\
\hline TI-082 & 7.13 .20 & Caustic-leach UFP-VSL-T02A & D 02AML 08A 005218 RAM 3 D & Raman & ASR8398 & ASR 8398 RAM \\
\hline TI-082 & 7.13 .20 & Caustic-leach UFP-VSL-T02A & D 02AML 08A 005218 TFI 2 D & IC & SWRI-090331-26 & 090331-26 IC \\
\hline
\end{tabular}


Integrated Test D Sample List

\begin{tabular}{|c|c|c|c|c|c|c|}
\hline TI \# & TI Step \# & TI Step Description & Sample ID & Analysis & $\begin{array}{c}\text { Electronic Folder } \\
\text { (SWRI Task Order \#, ASR \#, TDP\#) }\end{array}$ & Final Electronic Report File Name \\
\hline TI-082 & 7.13 .20 & Caustic-leach UFP-VSL-T02A & D 02AML 08A 005218 TFI 3 D & $\mathrm{OH}$ & ASR8399 & ASR $8399 \mathrm{OH}$ \\
\hline TI-082 & 7.13.20 & Caustic-leach UFP-VSL-T02A & D 02AIL 08A 005219 ARC 1 B & ICP Wet Solids & SWRI-090827 & $090827-7$ and $090827-8$ ICP and ICPMS \\
\hline TI-082 & 7.13.20 & Caustic-leach UFP-VSL-T02A & D 02AIL 08A 005219 ARC 1 D & IC & SWRI 090827 & 090827-5 and 0908027-6 IC and TDS ${ }^{(\mathrm{a})}$ \\
\hline TI-082 & 7.13 .20 & Caustic-leach UFP-VSL-T02A & D 02AIL 08A 005219 ARC 1 D & TDS & SWRI 090827 & $090827-5$ and $0908027-6 \mathrm{IC}^{2}$ and $\mathrm{TDS}^{(\mathrm{a})}$ \\
\hline TI-082 & 7.13.20 & Caustic-leach UFP-VSL-T02A & D 02AIM 08A 005220 ARC 1 B & ICP Wet Solids & SWRI-090827 & $090827-7$ and $090827-8$ ICP and ICPMS \\
\hline TI-082 & 7.13 .20 & Caustic-leach UFP-VSL-T02A & D 02AIM 08A 005220 ARC 1 D & IC & SWRI 090827 & $090827-5$ and $0908027-6$ IC and TDS ${ }^{(a)}$ \\
\hline TI-082 & 7.13 .20 & Caustic-leach UFP-VSL-T02A & D 02AIM 08A 005220 ARC 1 D & TDS & SWRI 090827 & 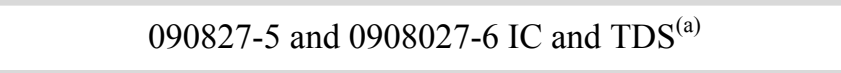 \\
\hline TI-082 & 7.13.20 & Caustic-leach UFP-VSL-T02A & D 02AMM 08A 005222 ARC 1 B & ICP Wet Solids & SWRI-090827 & $090827-7$ and $090827-8$ ICP and ICPMS \\
\hline TI-082 & 7.13 .20 & Caustic-leach UFP-VSL-T02A & D 02AMM 08A 005222 ARC 1 D & IC & SWRI 090827 & 090827-5 and 0908027-6 IC and TDS ${ }^{(a)}$ \\
\hline TI-082 & 7.13 .20 & Caustic-leach UFP-VSL-T02A & D 02AMM 08A 005222 ARC 1 D & TDS & SWRI 090827 & 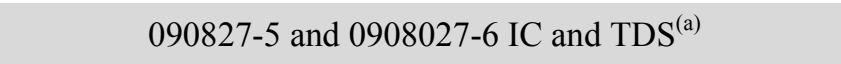 \\
\hline TI-082 & 7.13.20 & Caustic-leach UFP-VSL-T02A & D 02AMH 08A 005223 ARC 1 B & ICP Wet Solids & SWRI-090827 & 090827-7 and 090827-8 ICP and ICPMS \\
\hline TI-082 & 7.13 .20 & Caustic-leach UFP-VSL-T02A & D 02AMH 08A 005223 ARC 1 D & IC & SWRI 090827 & 090827-5 and 0908027-6 IC and TDS ${ }^{(a)}$ \\
\hline TI-082 & 7.13 .20 & Caustic-leach UFP-VSL-T02A & D 02AMH 08A 005223 ARC 1 D & TDS & SWRI 090827 & 090827-5 and 0908027-6 IC and TDS ${ }^{(a)}$ \\
\hline TI-082 & 7.13 .20 & Caustic-leach UFP-VSL-T02A & D 02AOL 08A 005224 ARC 1 B & ICP Wet Solids & SWRI-090827 & $090827-7$ and $090827-8$ ICP and ICPMS \\
\hline TI-082 & 7.13.20 & Caustic-leach UFP-VSL-T02A & D 02AOL 08A 005224 ARC 1 D & IC & SWRI 090827 & $090827-5$ and $0908027-6 \mathrm{IC}^{2}$ and $\mathrm{TDS}^{(\mathrm{a})}$ \\
\hline TI-082 & 7.13 .20 & Caustic-leach UFP-VSL-T02A & D 02AOL 08A 005224 ARC 1 D & TDS & SWRI 090827 & 090827-5 and 0908027-6 IC and TDS ${ }^{(a)}$ \\
\hline TI-082 & 7.13.20 & Caustic-leach UFP-VSL-T02A & D 02AOM 08A 005225 ARC 1 B & Archive & & \\
\hline TI-082 & 7.13.20 & Caustic-leach UFP-VSL-T02A & D 02AOM 08A 005225 ARC 1 D & Archive & & \\
\hline TI-082 & 7.13 .20 & Caustic-leach UFP-VSL-T02A & D 02AOH 08A 005226 ARC 1 B & ICP Wet Solids & SWRI-090827 & 090827-7 and 090827-8 ICP and ICPMS \\
\hline TI-082 & 7.13 .20 & Caustic-leach UFP-VSL-T02A & D 02AOH 08A 005226 ARC 1 D & IC & SWRI 090827 & 090827-5 and 0908027-6 IC and TDS ${ }^{(a)}$ \\
\hline TI-082 & 7.13 .20 & Caustic-leach UFP-VSL-T02A & D 02AOH 08A 005226 ARC 1 D & TDS & SWRI 090827 & 090827-5 and 0908027-6 IC and TDS ${ }^{(a)}$ \\
\hline TI-082 & 7.13.23.1 & Caustic-leach UFP-VSL-T02A & D 000FL 07A XX 5187 UDS 2 & UDS & SWRI-090331-18 & 090331-18UDS R1 \\
\hline TI-082 & 7.13.23.1 & Caustic-leach UFP-VSL-T02A & D 000FL 07A XX 5188 ICP 0 B & Storage & & \\
\hline TI-082 & 7.13.23.1 & Caustic-leach UFP-VSL-T02A & D 000FL 07A XX 5188 SUP 0 D & Storage & & \\
\hline TI-082 & 7.13 .24 & Caustic-leach UFP-VSL-T02A & D 02AML 08A 015227 UDS 2 B & UDS & SWRI-090331-20 & 090331-20UDS R1 \\
\hline TI-082 & 7.13 .24 & Caustic-leach UFP-VSL-T02A & D 02AML 08A 015227 UDS 2 D & UDS & SWRI-090331-20 & 090331-20UDS R1 \\
\hline TI-082 & 7.13 .24 & Caustic-leach UFP-VSL-T02A & D 02AML 08A 015228 DEN 2 & Density Slurry & SWRI-090331-28 & 090331-28DEN liquid and slurry \\
\hline TI-082 & 7.13 .24 & Caustic-leach UFP-VSL-T02A & D 02AML 08A 015229 ICP 2 D & ICP Supernatant & SWRI-090331-22 & 090331-12 and 090331-22 and 090331-23 ICP and ICPMS \\
\hline TI-082 & 7.13.24 & Caustic-leach UFP-VSL-T02A & D 02AML 08A 015229 TFI 2 D & $\mathrm{IC}$ & SWRI-090331-26 & 090331-26 IC \\
\hline TI-082 & 7.13.24 & Caustic-leach UFP-VSL-T02A & D 02AML 08A 015229 TFI 3 D & $\mathrm{OH}$ & ASR8399 & ASR $8399 \mathrm{OH}$ \\
\hline TI-082 & 7.13 .24 & Caustic-leach UFP-VSL-T02A & D 02AML 08A 015229 ICP 0 B & Storage & & \\
\hline TI-082 & 7.13 .24 & Caustic-leach UFP-VSL-T02A & D 02AML 08A 025230 UDS 2 B & UDS & SWRI-090331-20 & 090331-20UDS R1 \\
\hline
\end{tabular}


Integrated Test D Sample List

\begin{tabular}{|c|c|c|c|c|c|c|}
\hline TI \# & TI Step \# & TI Step Description & Sample ID & Analysis & $\begin{array}{c}\text { Electronic Folder } \\
\text { (SWRI Task Order \#, ASR \#, TDP\#) }\end{array}$ & Final Electronic Report File Name \\
\hline TI-082 & 7.13.24 & Caustic-leach UFP-VSL-T02A & D 02AML 08A 025230 UDS 2 D & UDS & SWRI-090331-20 & 090331-20UDS R1 \\
\hline TI-082 & 7.13.24 & Caustic-leach UFP-VSL-T02A & D 02AML 08A 025231 DEN 2 & Density Slurry & SWRI-090331-28 & 090331-28DEN liquid and slurry \\
\hline TI-082 & 7.13 .24 & Caustic-leach UFP-VSL-T02A & D 02AML 08A 025232 ICP 2 D & ICP Supernatant & SWRI-090331-22 & $090331-12$ and $090331-22$ and $090331-23$ ICP and ICPMS \\
\hline TI-082 & 7.13.24 & Caustic-leach UFP-VSL-T02A & D 02AML 08A 025232 TFI 2 D & IC & SWRI-090331-26 & 090331-26 IC \\
\hline TI-082 & 7.13 .24 & Caustic-leach UFP-VSL-T02A & D 02AML 08A 025232 TFI 3 D & $\mathrm{OH}$ & ASR8399 & ASR 8399 OH \\
\hline TI-082 & 7.13.24 & Caustic-leach UFP-VSL-T02A & D 02AML 08A 025232 ICP 0 B & Storage & & \\
\hline TI-082 & 7.13.24 & Caustic-leach UFP-VSL-T02A & D 02AML 08A 035233 ARC 1 B & Archive & & \\
\hline TI-082 & 7.13.24 & Caustic-leach UFP-VSL-T02A & D 02AML 08A 035233 ARC 1 D & Archive & & \\
\hline TI-082 & 7.13.25 & Caustic-leach UFP-VSL-T02A & D 02AML 08A 045234 UDS 2 B & UDS & SWRI-090331-20 & 090331-20UDS R1 \\
\hline TI-082 & 7.13.25 & Caustic-leach UFP-VSL-T02A & D 02AML 08A 045234 UDS 2 D & UDS & SWRI-090331-20 & 090331-20UDS R1 \\
\hline TI-082 & 7.13.25 & Caustic-leach UFP-VSL-T02A & D 02AML 08A 045235 DEN 2 & Density Slurry & SWRI-090331-28 & 090331-28DEN liquid and slurry \\
\hline TI-082 & 7.13 .25 & Caustic-leach UFP-VSL-T02A & D 02AML 08A 045236 ICP 2 B & ICP Wet Solids & SWRI-090331-24 & 090331-13 and 090331-25 and 090331-24 ICP and ICPMS \\
\hline TI-082 & 7.13.25 & Caustic-leach UFP-VSL-T02A & D 02AML 08A 045236 ICP 2 D & ICP Supernatant & SWRI-090331-22 & $090331-12$ and $090331-22$ and $090331-23$ ICP and ICPMS \\
\hline TI-082 & 7.13.25 & Caustic-leach UFP-VSL-T02A & D 02AML 08A 045236 TFI 2 D & IC & SWRI-090331-26 & 090331-26 IC \\
\hline TI-082 & 7.13 .25 & Caustic-leach UFP-VSL-T02A & D 02AML 08A 045236 TFI 3 D & $\mathrm{OH}$ & ASR8399 & ASR 8399 OH \\
\hline TI-082 & 7.13.25 & Caustic-leach UFP-VSL-T02A & D 02AIL 08A 045237 ARC 1 B & Archive & & \\
\hline TI-082 & 7.13.25 & Caustic-leach UFP-VSL-T02A & D 02AIL 08A 045237 ARC 1 D & Archive & & \\
\hline TI-082 & 7.13 .25 & Caustic-leach UFP-VSL-T02A & D 02AIM 08A 045238 ARC 1 B & Archive & & \\
\hline TI-082 & 7.13.25 & Caustic-leach UFP-VSL-T02A & D 02AIM 08A 045238 ARC 1 D & Archive & & \\
\hline TI-082 & 7.13.25 & Caustic-leach UFP-VSL-T02A & D 02AIH 08A 045239 ARC 1 B & Archive & & \\
\hline TI-082 & 7.13.25 & Caustic-leach UFP-VSL-T02A & D 02AIH 08A 045239 ARC 1 D & Archive & & \\
\hline TI-082 & 7.13 .25 & Caustic-leach UFP-VSL-T02A & D 02AMM 08A 045240 ARC 1 B & Archive & & \\
\hline TI-082 & 7.13 .25 & Caustic-leach UFP-VSL-T02A & D 02AMM 08A 045240 ARC 1 D & Archive & & \\
\hline TI-082 & 7.13.25 & Caustic-leach UFP-VSL-T02A & D 02AMH 08A 045241 ARC 1 B & Archive & & \\
\hline TI-082 & 7.13 .25 & Caustic-leach UFP-VSL-T02A & D 02AMH 08A 045241 ARC 1 D & Archive & & \\
\hline TI-082 & 7.13 .25 & Caustic-leach UFP-VSL-T02A & D 02AOL 08A 045242 ARC 1 B & Archive & & \\
\hline TI-082 & 7.13.25 & Caustic-leach UFP-VSL-T02A & D 02AOL 08A 045242 ARC 1 D & Archive & & \\
\hline TI-082 & 7.13 .25 & Caustic-leach UFP-VSL-T02A & D 02AOM 08A 045243 ARC 1 B & Archive & & \\
\hline TI-082 & 7.13 .25 & Caustic-leach UFP-VSL-T02A & D 02AOM 08A 045243 ARC 1 D & Archive & & \\
\hline TI-082 & 7.13.25 & Caustic-leach UFP-VSL-T02A & D 02AOH 08A 045244 ARC 1 B & Archive & & \\
\hline TI-082 & 7.13 .25 & Caustic-leach UFP-VSL-T02A & D 02AOH 08A 045244 ARC 1 D & Archive & & \\
\hline TI-082 & 7.13 .25 & Caustic-leach UFP-VSL-T02A & D 02AML 08A 055245 ARC 1 B & Archive & & \\
\hline
\end{tabular}


Integrated Test D Sample List

\begin{tabular}{|c|c|c|c|c|c|c|}
\hline TI \# & TI Step \# & TI Step Description & Sample ID & Analysis & $\begin{array}{c}\text { Electronic Folder } \\
\text { (SWRI Task Order \#, ASR \#, TDP\#) }\end{array}$ & Final Electronic Report File Name \\
\hline TI-082 & 7.13 .25 & Caustic-leach UFP-VSL-T02A & D 02AML 08A 055245 ARC 1 D & Archive & & \\
\hline TI-082 & 7.13 .25 & Caustic-leach UFP-VSL-T02A & D 02AML 08A 065246 ARC 1 B & Archive & & \\
\hline TI-082 & 7.13 .25 & Caustic-leach UFP-VSL-T02A & D 02AML 08A 065246 ARC 1 D & Archive & & \\
\hline TI-082 & 7.13 .25 & Caustic-leach UFP-VSL-T02A & D 02AML 08A 075247 ARC 1 B & Archive & & \\
\hline TI-082 & 7.13 .25 & Caustic-leach UFP-VSL-T02A & D 02AML 08A 075247 ARC 1 D & Archive & & \\
\hline TI-082 & 7.13 .26 & Caustic-leach UFP-VSL-T02A & D 02AML 08A 085248 UDS 2 B & UDS & SWRI-090331-20 & 090331-20UDS R1 \\
\hline TI-082 & 7.13 .26 & Caustic-leach UFP-VSL-T02A & D 02AML 08A 085248 UDS 2 D & UDS & SWRI-090331-20 & 090331-20UDS R1 \\
\hline TI-082 & 7.13 .26 & Caustic-leach UFP-VSL-T02A & D 02AML 08A 085249 DEN 2 & Density Slurry & SWRI-090331-28 & 090331-28DEN liquid and slurry \\
\hline TI-082 & 7.13 .26 & Caustic-leach UFP-VSL-T02A & D 02AML 08A 085250 ICP 2 B & ICP Wet Solids & SWRI-090331-24 & $090331-13$ and $090331-25$ and $090331-24$ ICP and ICPMS \\
\hline TI-082 & 7.13 .26 & Caustic-leach UFP-VSL-T02A & D 02AML 08A 085250 ICP 2 D & ICP Supernatant & SWRI-090331-23 & 090331-12 and $090331-22$ and $090331-23$ ICP and ICPMS \\
\hline TI-082 & 7.13.26 & Caustic-leach UFP-VSL-T02A & D 02AML 08A 085250 TFI 2 D & IC & SWRI-090331-26 & 090331-26 IC \\
\hline TI-082 & 7.13 .26 & Caustic-leach UFP-VSL-T02A & D 02AML 08A 085250 TFI 3 D & $\mathrm{OH}$ & ASR8399 & ASR $8399 \mathrm{OH}$ \\
\hline TI-082 & 7.13 .26 & Caustic-leach UFP-VSL-T02A & D 02AIL 08A 085251 ARC 1 B & Archive & & \\
\hline TI-082 & 7.13 .26 & Caustic-leach UFP-VSL-T02A & D 02AIL 08A 085251 ARC 1 D & Archive & & \\
\hline TI-082 & 7.13 .26 & Caustic-leach UFP-VSL-T02A & D 02AIM 08A 085252 ARC 1 B & Archive & & \\
\hline TI-082 & 7.13.26 & Caustic-leach UFP-VSL-T02A & D 02AIM 08A 085252 ARC 1 D & Archive & & \\
\hline TI-082 & 7.13 .26 & Caustic-leach UFP-VSL-T02A & D 02AIH 08A 085253 ARC 1 B & Archive & & \\
\hline TI-082 & 7.13 .26 & Caustic-leach UFP-VSL-T02A & D 02AIH 08A 085253 ARC 1 D & Archive & & \\
\hline TI-082 & 7.13 .26 & Caustic-leach UFP-VSL-T02A & D 02AMM 08A 085254 ARC 1 B & Archive & & \\
\hline TI-082 & 7.13 .26 & Caustic-leach UFP-VSL-T02A & D 02AMM 08A 085254 ARC 1 D & Archive & & \\
\hline TI-082 & 7.13 .26 & Caustic-leach UFP-VSL-T02A & D 02AMH 08A 085255 ARC 1 B & Archive & & \\
\hline TI-082 & 7.13.26 & Caustic-leach UFP-VSL-T02A & D 02AMH 08A 085255 ARC 1 D & Archive & & \\
\hline TI-082 & 7.13 .26 & Caustic-leach UFP-VSL-T02A & D 02AOL 08A 085256 ARC 1 B & Archive & & \\
\hline TI-082 & 7.13 .26 & Caustic-leach UFP-VSL-T02A & D 02AOL 08A 085256 ARC 1 D & Archive & & \\
\hline TI-082 & 7.13 .26 & Caustic-leach UFP-VSL-T02A & D 02AOM 08A 085257 ARC 1 B & Archive & & \\
\hline TI-082 & 7.13 .26 & Caustic-leach UFP-VSL-T02A & D 02AOH 08A 085258 ARC 1 B & Archive & & \\
\hline TI-082 & 7.13 .26 & Caustic-leach UFP-VSL-T02A & D 02AOM 08A 085257 ARC 1 D & Archive & & \\
\hline TI-082 & 7.13 .26 & Caustic-leach UFP-VSL-T02A & D 02AOH 08A 085258 ARC 1 D & Archive & & \\
\hline TI-082 & 7.13 .26 & Caustic-leach UFP-VSL-T02A & D 02AML 08A 095259 ARC 1 B & Archive & & \\
\hline TI-082 & 7.13 .26 & Caustic-leach UFP-VSL-T02A & D 02AML 08A 095259 ARC 1 D & Archive & & \\
\hline TI-082 & 7.13 .26 & Caustic-leach UFP-VSL-T02A & D 02AML 08A 105260 UDS 2 B & UDS & SWRI-090331-20 & 090331-20UDS R1 \\
\hline TI-082 & 7.13 .26 & Caustic-leach UFP-VSL-T02A & D 02AML 08A 105260 UDS 2 D & UDS & SWRI-090331-20 & 090331-20UDS R1 \\
\hline
\end{tabular}


Integrated Test D Sample List

\begin{tabular}{|c|c|c|c|c|c|c|}
\hline TI \# & TI Step \# & TI Step Description & Sample ID & Analysis & $\begin{array}{c}\text { Electronic Folder } \\
\text { (SWRI Task Order \#, ASR \#, TDP\#) }\end{array}$ & Final Electronic Report File Name \\
\hline TI-082 & 7.13 .26 & Caustic-leach UFP-VSL-T02A & D 02AML 08A 105261 DEN 2 & Density Slurry & SWRI-090331-28 & 090331-28DEN liquid and slurry \\
\hline TI-082 & 7.13.26 & Caustic-leach UFP-VSL-T02A & D 02AML 08A 105262 ICP 2 D & ICP Supernatant & SWRI-090331-23 & $090331-12$ and $090331-22$ and $090331-23$ ICP and ICPMS \\
\hline TI-082 & 7.13.26 & Caustic-leach UFP-VSL-T02A & D 02AML 08A 105262 TFI 2 D & IC & SWRI-090331-27 & 090331-27 IC \\
\hline TI-082 & 7.13.26 & Caustic-leach UFP-VSL-T02A & D 02AML 08A 105262 TFI 3 D & $\mathrm{OH}$ & ASR8399 & ASR 8399 OH \\
\hline TI-082 & 7.13.26 & Caustic-leach UFP-VSL-T02A & D 02AML 08A 105262 ICP 0 B & Storage & & \\
\hline TI-082 & 7.13.26 & Caustic-leach UFP-VSL-T02A & D 02AML 08A 115263 ARC 1 B & Archive & & \\
\hline TI-082 & 7.13.26 & Caustic-leach UFP-VSL-T02A & D 02AML 08A 115263 ARC 1 D & Archive & & \\
\hline TI-082 & 7.13.27 & Caustic-leach UFP-VSL-T02A & D 02AML 08A 125264 UDS 2 B & UDS & SWRI-090331-20 & 090331-20UDS R1 \\
\hline TI-082 & 7.13.27 & Caustic-leach UFP-VSL-T02A & D 02AML 08A 125264 UDS 2 D & UDS & SWRI-090331-20 & 090331-20UDS R1 \\
\hline TI-082 & 7.13.27 & Caustic-leach UFP-VSL-T02A & D 02AML 08A 125265 DEN 2 & Density Slurry & SWRI-090331-28 & 090331-28DEN liquid and slurry \\
\hline TI-082 & 7.13.27 & Caustic-leach UFP-VSL-T02A & D 02AML 08A 125266 ICP 2 B & ICP Wet Solids & SWRI-090331-24 & $090331-13$ and $090331-25$ and $090331-24$ ICP and ICPMS \\
\hline TI-082 & 7.13.27 & Caustic-leach UFP-VSL-T02A & D 02AML 08A 125266 ICP 2 D & ICP Supernatant & SWRI-090331-23 & 090331-12 and 090331-22 and 090331-23 ICP and ICPMS \\
\hline TI-082 & 7.13.27 & Caustic-leach UFP-VSL-T02A & D 02AML 08A 125266 RAM 3 D & Raman & ASR8398 & ASR 8398 RAM \\
\hline TI-082 & 7.13.27 & Caustic-leach UFP-VSL-T02A & D 02AML 08A 125266 TFI 2 D & IC & SWRI-090331-27 & 090331-27 IC \\
\hline TI-082 & 7.13.27 & Caustic-leach UFP-VSL-T02A & D 02AML 08A 125266 TFI 3 D & $\mathrm{OH}$ & ASR8399 & ASR 8399 OH \\
\hline TI-082 & 7.13.27 & Caustic-leach UFP-VSL-T02A & D 02AMM 08A 125270 ARC 1 B & Archive & & \\
\hline TI-082 & 7.13.27 & Caustic-leach UFP-VSL-T02A & D 02AMM 08A 125270 ARC 1 D & Archive & & \\
\hline TI-082 & 7.13.27 & Caustic-leach UFP-VSL-T02A & D 02AMH 08A 125271 ARC 1 B & Archive & & \\
\hline TI-082 & 7.13.27 & Caustic-leach UFP-VSL-T02A & D 02AMH 08A 125271 ARC 1 D & Archive & & \\
\hline TI-082 & 7.13.27 & Caustic-leach UFP-VSL-T02A & D 02AOL 08A 125272 ARC 1 B & Archive & & \\
\hline TI-082 & 7.13.27 & Caustic-leach UFP-VSL-T02A & D 02AOL 08A 125272 ARC 1 D & Archive & & \\
\hline TI-082 & 7.13.27 & Caustic-leach UFP-VSL-T02A & D 02AOM 08A 125273 ARC 1 B & Archive & & \\
\hline TI-082 & 7.13.27 & Caustic-leach UFP-VSL-T02A & D 02AOM 08A 125273 ARC 1 D & Archive & & \\
\hline TI-082 & 7.13.27 & Caustic-leach UFP-VSL-T02A & D 02AOH 08A 125274 ARC 1 B & Archive & & \\
\hline TI-082 & 7.13.27 & Caustic-leach UFP-VSL-T02A & D 02AOH 08A 125274 ARC 1 D & Archive & & \\
\hline TI-082 & 7.13.27 & Caustic-leach UFP-VSL-T02A & D 02AIH 08A 125269 ARC 1 B & Archive & & \\
\hline TI-082 & 7.13.27 & Caustic-leach UFP-VSL-T02A & D 02AIH 08A 125269 ARC 1 D & Archive & & \\
\hline TI-082 & 7.13.27 & Caustic-leach UFP-VSL-T02A & D 02AIM 08A 125268 ARC 1 B & Archive & & \\
\hline TI-082 & 7.13.27 & Caustic-leach UFP-VSL-T02A & D 02AIM 08A 125268 ARC 1 D & Archive & & \\
\hline TI-082 & 7.13.27 & Caustic-leach UFP-VSL-T02A & D 02AIL 08A 125267 ARC 1 B & Archive & & \\
\hline TI-082 & 7.13.27 & Caustic-leach UFP-VSL-T02A & D 02AIL 08A 125267 ARC 1 D & Archive & & \\
\hline TI-082 & 7.13.27 & Caustic-leach UFP-VSL-T02A & D 02AML 08A 135275 ARC 1 D & Archive & & \\
\hline
\end{tabular}


Integrated Test D Sample List

\begin{tabular}{|c|c|c|c|c|c|c|}
\hline TI \# & TI Step \# & TI Step Description & Sample ID & Analysis & $\begin{array}{c}\text { Electronic Folder } \\
\text { (SWRI Task Order \#, ASR \#, TDP\#) }\end{array}$ & Final Electronic Report File Name \\
\hline TI-082 & 7.13.27 & Caustic-leach UFP-VSL-T02A & D 02AML 08A 135275 ARC 1 B & Archive & & \\
\hline TI-082 & 7.13.27 & Caustic-leach UFP-VSL-T02A & D 02AML 08A 145276 UDS 2 B & UDS & SWRI-090331-20 & 090331-20UDS R1 \\
\hline TI-082 & 7.13.27 & Caustic-leach UFP-VSL-T02A & D 02AML 08A 145276 UDS 2 D & UDS & SWRI-090331-20 & 090331-20UDS R1 \\
\hline TI-082 & 7.13 .27 & Caustic-leach UFP-VSL-T02A & D 02AML 08A 145277 DEN 2 & Density Slurry & SWRI-090331-28 & 090331-28DEN liquid and slurry \\
\hline TI-082 & 7.13 .27 & Caustic-leach UFP-VSL-T02A & D 02AML 08A 145278 ICP 2 D & ICP Supernatant & SWRI-090331-23 & $090331-12$ and $090331-22$ and $090331-23$ ICP and ICPMS \\
\hline TI-082 & 7.13 .27 & Caustic-leach UFP-VSL-T02A & D 02AML 08A 145278 TFI 2 D & IC & SWRI-090331-27 & 090331-27 IC \\
\hline TI-082 & 7.13 .27 & Caustic-leach UFP-VSL-T02A & D 02AML 08A 145278 TFI 3 D & $\mathrm{OH}$ & ASR8399 & ASR $8399 \mathrm{OH}$ \\
\hline TI-082 & 7.13.27 & Caustic-leach UFP-VSL-T02A & D 02AML 08A 145278 ICP 0 B & Storage & & \\
\hline TI-082 & 7.13 .27 & Caustic-leach UFP-VSL-T02A & D 02AML 08A 155279 ARC 1 B & Archive & & \\
\hline TI-082 & 7.13.27 & Caustic-leach UFP-VSL-T02A & D 02AML 08A 155279 ARC 1 D & Archive & & \\
\hline TI-082 & 7.13 .28 & Caustic-leach UFP-VSL-T02A & D 02AML 08A 165280 UDS 2 B & UDS & SWRI-090331-20 & 090331-20UDS R1 \\
\hline TI-082 & 7.13 .28 & Caustic-leach UFP-VSL-T02A & D 02AML 08A 165280 UDS 2 D & UDS & SWRI-090331-20 & 090331-20UDS R1 \\
\hline TI-082 & 7.13 .28 & Caustic-leach UFP-VSL-T02A & D 02AML 08A 165281 DEN 2 & Density Slurry & SWRI-090331-28 & 090331-28DEN liquid and slurry \\
\hline TI-082 & 7.13 .28 & Caustic-leach UFP-VSL-T02A & D 02AML 08A 165282 ICP 2 B & ICP Wet Solids & SWRI-090331-24 & $090331-13$ and $090331-25$ and $090331-24$ ICP and ICPMS \\
\hline TI-082 & 7.13 .28 & Caustic-leach UFP-VSL-T02A & D 02AML 08A 165282 ICP 2 D & ICP Supernatant & SWRI-090331-23 & 090331-12 and 090331-22 and 090331-23 ICP and ICPMS \\
\hline TI-082 & 7.13 .28 & Caustic-leach UFP-VSL-T02A & D 02AML 08A 165282 RAM 3 D & Raman & ASR8398 & ASR 8398 RAM \\
\hline TI-082 & 7.13 .28 & Caustic-leach UFP-VSL-T02A & D 02AML 08A 165282 TFI 2 D & $\mathrm{IC}$ & SWRI-090331-27 & 090331-27 IC \\
\hline TI-082 & 7.13 .28 & Caustic-leach UFP-VSL-T02A & D 02AML 08A 165282 TFI 3 D & $\mathrm{OH}$ & ASR8399 & ASR 8399 OH \\
\hline TI-082 & 7.13.28 & Caustic-leach UFP-VSL-T02A & D 02AIM 08A 165284 ARC 1 B & Archive & & \\
\hline TI-082 & 7.13 .28 & Caustic-leach UFP-VSL-T02A & D 02AIM 08A 165284 ARC 1 D & Archive & & \\
\hline TI-082 & 7.13.28 & Caustic-leach UFP-VSL-T02A & D 02AIH 08A 165285 ARC 1 B & Archive & & \\
\hline TI-082 & 7.13 .28 & Caustic-leach UFP-VSL-T02A & D 02AIH 08A 165285 ARC 1 D & Archive & & \\
\hline TI-082 & 7.13 .28 & Caustic-leach UFP-VSL-T02A & D 02AMM 08A 165286 ARC 1 B & Archive & & \\
\hline TI-082 & 7.13 .28 & Caustic-leach UFP-VSL-T02A & D 02AMM 08A 165286 ARC 1 D & Archive & & \\
\hline TI-082 & 7.13 .28 & Caustic-leach UFP-VSL-T02A & D 02AMH 08A 165287 ARC 1 B & Archive & & \\
\hline TI-082 & 7.13 .28 & Caustic-leach UFP-VSL-T02A & D 02AMH 08A 165287 ARC 1 D & Archive & & \\
\hline TI-082 & 7.13 .28 & Caustic-leach UFP-VSL-T02A & D 02AOL 08A 165288 ARC 1 B & Archive & & \\
\hline TI-082 & 7.13 .28 & Caustic-leach UFP-VSL-T02A & D 02AOL 08A 165288 ARC 1 D & Archive & & \\
\hline TI-082 & 7.13 .28 & Caustic-leach UFP-VSL-T02A & D 02AOM 08A 165289 ARC 1 B & Archive & & \\
\hline TI-082 & 7.13 .28 & Caustic-leach UFP-VSL-T02A & D 02AOM 08A 165289 ARC 1 D & Archive & & \\
\hline TI-082 & 7.13 .28 & Caustic-leach UFP-VSL-T02A & D 02AOH 08A 165290 ARC 1 B & Archive & & \\
\hline TI-082 & 7.13 .28 & Caustic-leach UFP-VSL-T02A & D 02AOH 08A 165290 ARC 1 D & Archive & & \\
\hline
\end{tabular}


Integrated Test D Sample List

\begin{tabular}{|c|c|c|c|c|c|c|}
\hline TI \# & TI Step \# & TI Step Description & Sample ID & Analysis & $\begin{array}{c}\text { Electronic Folder } \\
\text { (SWRI Task Order \#, ASR \#, TDP\#) }\end{array}$ & Final Electronic Report File Name \\
\hline TI-082 & 7.13 .28 & Caustic-leach UFP-VSL-T02A & D 02AIL 08A 165283 ARC 1 B & Archive & & \\
\hline TI-082 & 7.13 .28 & Caustic-leach UFP-VSL-T02A & D 02AIL 08A 165283 ARC 1 D & Archive & & \\
\hline TI-082 & 7.13 .28 & Caustic-leach UFP-VSL-T02A & D 02AML 08A 175291 ARC 1 B & Archive & & \\
\hline TI-082 & 7.13 .28 & Caustic-leach UFP-VSL-T02A & D 02AML 08A 175291 ARC 1 D & Archive & & \\
\hline TI-082 & 7.13 .28 & Caustic-leach UFP-VSL-T02A & D 02AML 08A 185292 UDS 2 B & UDS & SWRI-090331-21 & 090331-21UDS R1 \\
\hline TI-082 & 7.13 .28 & Caustic-leach UFP-VSL-T02A & D 02AML 08A 185292 UDS 2 D & UDS & SWRI-090331-21 & 090331-21UDS R1 \\
\hline TI-082 & 7.13 .28 & Caustic-leach UFP-VSL-T02A & D 02AML 08A 185293 DEN 2 & Density Slurry & SWRI-090331-28 & 090331-28DEN liquid and slurry \\
\hline TI-082 & 7.13 .28 & Caustic-leach UFP-VSL-T02A & D 02AML 08A 185294 ICP 2 D & ICP Supernatant & SWRI-090331-23 & $090331-12$ and $090331-22$ and $090331-23$ ICP and ICPMS \\
\hline TI-082 & 7.13 .28 & Caustic-leach UFP-VSL-T02A & D 02AML 08A 185294 TFI 2 D & IC & SWRI-090331-27 & 090331-27 IC \\
\hline TI-082 & 7.13 .28 & Caustic-leach UFP-VSL-T02A & D 02AML 08A 185294 TFI 3 D & $\mathrm{OH}$ & ASR8399 & ASR $8399 \mathrm{OH}$ \\
\hline TI-082 & 7.13 .28 & Caustic-leach UFP-VSL-T02A & D 02AML 08A 185294 ICP 0 B & Storage & & \\
\hline TI-082 & 7.13 .28 & Caustic-leach UFP-VSL-T02A & D 02AML 08A 195295 ARC 1 B & Archive & & \\
\hline TI-082 & 7.13 .28 & Caustic-leach UFP-VSL-T02A & D 02AML 08A 195295 ARC 1 D & Archive & & \\
\hline TI-082 & 7.13 .29 & Caustic-leach UFP-VSL-T02A & D 02AML 08A 205296 UDS 2 B & UDS & SWRI-090331-21 & 090331-21UDS R1 \\
\hline TI-082 & 7.13 .29 & Caustic-leach UFP-VSL-T02A & D 02AML 08A 205296 UDS 2 D & UDS & SWRI-090331-21 & 090331-21UDS R1 \\
\hline TI-082 & 7.13 .29 & Caustic-leach UFP-VSL-T02A & D 02AML 08A 205297 DEN 2 & Density Slurry & SWRI-090331-28 & 090331-28DEN liquid and slurry \\
\hline TI-082 & 7.13 .29 & Caustic-leach UFP-VSL-T02A & D 02AML 08A 205298 ICP 2 D & ICP Supernatant & SWRI-090331-23 & $090331-12$ and $090331-22$ and $090331-23$ ICP and ICPMS \\
\hline TI-082 & 7.13 .29 & Caustic-leach UFP-VSL-T02A & D 02AML 08A 205298 TFI 2 D & IC & SWRI-090331-27 & 090331-27 IC \\
\hline TI-082 & 7.13 .29 & Caustic-leach UFP-VSL-T02A & D 02AML 08A 205298 TFI 3 D & $\mathrm{OH}$ & ASR8399 & ASR $8399 \mathrm{OH}$ \\
\hline TI-082 & 7.13 .29 & Caustic-leach UFP-VSL-T02A & D 02AML 08A 205298 ICP 0 B & Storage & & \\
\hline TI-082 & 7.13 .29 & Caustic-leach UFP-VSL-T02A & D 02AIL 08A 205299 ARC 1 B & Archive & & \\
\hline TI-082 & 7.13 .29 & Caustic-leach UFP-VSL-T02A & D 02AIL 08A 205299 ARC 1 D & Archive & & \\
\hline TI-082 & 7.13 .29 & Caustic-leach UFP-VSL-T02A & D 02AIM 08A 205300 ARC 1 B & Archive & & \\
\hline TI-082 & 7.13 .29 & Caustic-leach UFP-VSL-T02A & D 02AIM 08A 205300 ARC 1 D & Archive & & \\
\hline TI-082 & 7.13 .29 & Caustic-leach UFP-VSL-T02A & D 02AIH 08A 205301 ARC 1 B & Archive & & \\
\hline TI-082 & 7.13 .29 & Caustic-leach UFP-VSL-T02A & D 02AIH 08A 205301 ARC 1 D & Archive & & \\
\hline TI-082 & 7.13 .29 & Caustic-leach UFP-VSL-T02A & D 02AMM 08A 205302 ARC 1 D & Archive & & \\
\hline TI-082 & 7.13 .29 & Caustic-leach UFP-VSL-T02A & D 02AMM 08A 205302 ARC 1 B & Archive & & \\
\hline TI-082 & 7.13 .29 & Caustic-leach UFP-VSL-T02A & D 02AMH 08A 205303 ARC 1 B & Archive & & \\
\hline TI-082 & 7.13 .29 & Caustic-leach UFP-VSL-T02A & D 02AMH 08A 205303 ARC 1 D & Archive & & \\
\hline TI-082 & 7.13 .29 & Caustic-leach UFP-VSL-T02A & D 02AOL 08A 205304 ARC 1 B & Archive & & \\
\hline TI-082 & 7.13 .29 & Caustic-leach UFP-VSL-T02A & D 02AOL 08A 205304 ARC 1 D & Archive & & \\
\hline
\end{tabular}


Integrated Test D Sample List

\begin{tabular}{|c|c|c|c|c|c|c|}
\hline TI \# & TI Step \# & TI Step Description & Sample ID & Analysis & $\begin{array}{c}\text { Electronic Folder } \\
\text { (SWRI Task Order \#, ASR \#, TDP\#) }\end{array}$ & Final Electronic Report File Name \\
\hline TI-082 & 7.13 .29 & Caustic-leach UFP-VSL-T02A & D 02AOM 08A 205305 ARC 1 B & Archive & & \\
\hline TI-082 & 7.13 .29 & Caustic-leach UFP-VSL-T02A & D 02AOM 08A 205305 ARC 1 D & Archive & & \\
\hline TI-082 & 7.13 .29 & Caustic-leach UFP-VSL-T02A & D 02AOH 08A 205306 ARC 1 B & Archive & & \\
\hline TI-082 & 7.13 .29 & Caustic-leach UFP-VSL-T02A & D 02AOH 08A 205306 ARC 1 D & Archive & & \\
\hline TI-082 & 7.13 .29 & Caustic-leach UFP-VSL-T02A & D 02AML 08A 215307 ARC 1 B & Archive & & \\
\hline TI-082 & 7.13 .29 & Caustic-leach UFP-VSL-T02A & D 02AML 08A 215307 ARC 1 D & Archive & & \\
\hline TI-082 & 7.13 .29 & Caustic-leach UFP-VSL-T02A & D 02AML 08A 225308 UDS 2 B & UDS & SWRI-090331-21 & 090331-21UDS R1 \\
\hline TI-082 & 7.13 .29 & Caustic-leach UFP-VSL-T02A & D 02AML 08A 225308 UDS 2 D & UDS & SWRI-090331-21 & 090331-21UDS R1 \\
\hline TI-082 & 7.13 .29 & Caustic-leach UFP-VSL-T02A & D 02AML 08A 225309 DEN 2 & Density Slurry & SWRI-090331-28 & 090331-28DEN liquid and slurry \\
\hline TI-082 & 7.13 .29 & Caustic-leach UFP-VSL-T02A & D 02AML 08A 225310 ICP 2 D & ICP Supernatant & SWRI-090331-23 & 090331-12 and 090331-22 and 090331-23 ICP and ICPMS \\
\hline TI-082 & 7.13 .29 & Caustic-leach UFP-VSL-T02A & D 02AML 08A 225310 TFI 2 D & IC & SWRI-090331-27 & 090331-27 IC \\
\hline TI-082 & 7.13 .29 & Caustic-leach UFP-VSL-T02A & D 02AML 08A 225310 TFI 3 D & $\mathrm{OH}$ & ASR8399 & ASR $8399 \mathrm{OH}$ \\
\hline TI-082 & 7.13 .29 & Caustic-leach UFP-VSL-T02A & D 02AML 08A 225310 ICP 0 B & Storage & & \\
\hline TI-082 & 7.13 .29 & Caustic-leach UFP-VSL-T02A & D 02AML 08A 235311 ARC 1 B & Archive & & \\
\hline TI-082 & 7.13 .29 & Caustic-leach UFP-VSL-T02A & D 02AML 08A 235311 ARC 1 D & Archive & & \\
\hline TI-082 & 7.13 .30 & Caustic-leach UFP-VSL-T02A & D 02AML 08A 245312 UDS 2 B & UDS & SWRI-090331-21 & 090331-21UDS R1 \\
\hline TI-082 & 7.13 .30 & Caustic-leach UFP-VSL-T02A & D 02AML 08A 245312 UDS 2 D & UDS & SWRI-090331-21 & 090331-21UDS R1 \\
\hline TI-082 & 7.13 .30 & Caustic-leach UFP-VSL-T02A & D 02AML 08A 245313 UDS 2 B & UDS & SWRI-090331-21 & 090331-21UDS R1 \\
\hline TI-082 & 7.13 .30 & Caustic-leach UFP-VSL-T02A & D 02AML 08A 245313 UDS 2 D & UDS & SWRI-090331-21 & 090331-21UDS R1 \\
\hline TI-082 & 7.13 .30 & Caustic-leach UFP-VSL-T02A & D 02AML 08A 245314 UDS 2 B & UDS & SWRI-090331-21 & 090331-21UDS R1 \\
\hline TI-082 & 7.13 .30 & Caustic-leach UFP-VSL-T02A & D 02AML 08A 245314 UDS 2 D & UDS & SWRI-090331-21 & 090331-21UDS R1 \\
\hline TI-082 & 7.13 .30 & Caustic-leach UFP-VSL-T02A & D 02AML 08A 245315 DEN 2 & Density Slurry & SWRI-090331-28 & 090331-29DEN liquid and slurry \\
\hline TI-082 & 7.13 .30 & Caustic-leach UFP-VSL-T02A & D 02AML 08A 245316 DEN 2 & Density Slurry & SWRI-090331-29 & 090331-29DEN liquid and slurry \\
\hline TI-082 & 7.13 .30 & Caustic-leach UFP-VSL-T02A & D 02AML 08A 245317 DEN 2 & Density Slurry & SWRI-090331-29 & 090331-29DEN liquid and slurry \\
\hline TI-082 & 7.13 .30 & Caustic-leach UFP-VSL-T02A & D 02AML 08A 245318 ICP 2 B & ICP Wet Solids & SWRI-090331-24 & 090331-13 and 090331-25 and 090331-24 ICP and ICPMS \\
\hline TI-082 & 7.13 .30 & Caustic-leach UFP-VSL-T02A & D 02AML 08A 245318 ICP 2 D & ICP Supernatant & SWRI-090331-23 & 090331-12 and 090331-22 and 090331-23 ICP and ICPMS \\
\hline TI-082 & 7.13 .30 & Caustic-leach UFP-VSL-T02A & D 02AML 08A 245318 RAM 3 D & Raman & ASR8398 & ASR 8398 RAM \\
\hline TI-082 & 7.13 .30 & Caustic-leach UFP-VSL-T02A & D 02AML 08A 245318 TFI 2 D & IC & SWRI-090331-27 & 090331-27 IC \\
\hline TI-082 & 7.13 .30 & Caustic-leach UFP-VSL-T02A & D 02AML 08A 245318 TFI 3 D & $\mathrm{OH}$ & ASR8399 & ASR $8399 \mathrm{OH}$ \\
\hline TI-082 & 7.13 .30 & Caustic-leach UFP-VSL-T02A & D 02AML 08A 245319 ICP 2 B & ICP Wet Solids & SWRI-090331-13 & 090331-13 and 090331-25 and 090331-24 ICP and ICPMS \\
\hline TI-082 & 7.13 .30 & Caustic-leach UFP-VSL-T02A & D 02AML 08A 245319 ICP 2 D & ICP Supernatant & SWRI-090331-23 & $090331-12$ and $090331-22$ and $090331-23$ ICP and ICPMS \\
\hline TI-082 & 7.13 .30 & Caustic-leach UFP-VSL-T02A & D 02AML 08A 245319 RAM 3 D & Raman & ASR8398 & ASR 8398 RAM \\
\hline
\end{tabular}


Integrated Test D Sample List

\begin{tabular}{|c|c|c|c|c|c|c|}
\hline TI \# & TI Step \# & TI Step Description & Sample ID & Analysis & $\begin{array}{c}\text { Electronic Folder } \\
\text { (SWRI Task Order \#, ASR \#, TDP\#) }\end{array}$ & Final Electronic Report File Name \\
\hline TI-082 & 7.13 .30 & Caustic-leach UFP-VSL-T02A & D 02AML 08A 245319 TFI 2 D & IC & SWRI-090331-27 & 090331-27 IC \\
\hline TI-082 & 7.13 .30 & Caustic-leach UFP-VSL-T02A & D 02AML 08A 245319 TFI 3 D & $\mathrm{OH}$ & ASR8399 & ASR $8399 \mathrm{OH}$ \\
\hline TI-082 & 7.13 .30 & Caustic-leach UFP-VSL-T02A & D 02AML 08A 245320 ICP 2 B & ICP Wet Solids & SWRI-090331-25 & $090331-13$ and $090331-25$ and $090331-24$ ICP and ICPMS \\
\hline TI-082 & 7.13 .30 & Caustic-leach UFP-VSL-T02A & D 02AML 08A 245320 ICP 2 D & ICP Supernatant & SWRI-090331-23 & 090331-12 and 090331-22 and 090331-23 ICP and ICPMS \\
\hline TI-082 & 7.13 .30 & Caustic-leach UFP-VSL-T02A & D 02AML 08A 245320 RAM 3 D & Raman & ASR8398 & ASR 8398 RAM \\
\hline TI-082 & 7.13 .30 & Caustic-leach UFP-VSL-T02A & D 02AML 08A 245320 TFI 2 D & IC & SWRI-090331-27 & 090331-27 IC \\
\hline TI-082 & 7.13 .30 & Caustic-leach UFP-VSL-T02A & D 02AML 08A 245320 TFI 3 D & $\mathrm{OH}$ & ASR8399 & ASR $8399 \mathrm{OH}$ \\
\hline TI-082 & 7.13 .30 & Caustic-leach UFP-VSL-T02A & D 02AIL 08A 245321 ARC 1 B & Archive & & \\
\hline TI-082 & 7.13 .30 & Caustic-leach UFP-VSL-T02A & D 02AIL 08A 245321 ARC 1 D & Archive & & \\
\hline TI-082 & 7.13 .30 & Caustic-leach UFP-VSL-T02A & D 02AIM 08A 245322 ARC 1 B & Archive & & \\
\hline TI-082 & 7.13 .30 & Caustic-leach UFP-VSL-T02A & D 02AIM 08A 245322 ARC 1 D & Archive & & \\
\hline TI-082 & 7.13 .30 & Caustic-leach UFP-VSL-T02A & D 02AIH 08A 245323 ARC 1 B & Archive & & \\
\hline TI-082 & 7.13 .30 & Caustic-leach UFP-VSL-T02A & D 02AIH 08A 245323 ARC 1 D & Archive & & \\
\hline TI-082 & 7.13 .30 & Caustic-leach UFP-VSL-T02A & D 02AMM 08A 245324 ARC 1 B & Archive & & \\
\hline TI-082 & 7.13 .30 & Caustic-leach UFP-VSL-T02A & D 02AMM 08A 245324 ARC 1 D & Archive & & \\
\hline TI-082 & 7.13 .30 & Caustic-leach UFP-VSL-T02A & D 02AMH 08A 245325 ARC 1 B & Archive & & \\
\hline TI-082 & 7.13 .30 & Caustic-leach UFP-VSL-T02A & D 02AMH 08A 245325 ARC 1 D & Archive & & \\
\hline TI-082 & 7.13 .30 & Caustic-leach UFP-VSL-T02A & D 02AOL 08A 245326 ARC 1 B & Archive & & \\
\hline TI-082 & 7.13 .30 & Caustic-leach UFP-VSL-T02A & D 02AOL 08A 245326 ARC 1 D & Archive & & \\
\hline TI-082 & 7.13 .30 & Caustic-leach UFP-VSL-T02A & D 02AOM 08A 245327 ARC 1 B & Archive & & \\
\hline TI-082 & 7.13 .30 & Caustic-leach UFP-VSL-T02A & D 02AOM 08A 245327 ARC 1 D & Archive & & \\
\hline TI-082 & 7.13 .30 & Caustic-leach UFP-VSL-T02A & D 02AOH 08A 245328 ARC 1 B & Archive & & \\
\hline TI-082 & 7.13 .30 & Caustic-leach UFP-VSL-T02A & D 02AOH 08A 245328 ARC 1 D & Archive & & \\
\hline TI-082 & 7.14 .6 & Cool-down of UFP-VSL-T02A & D 02AML 09A 015642 ICP 2 D & Density-TDS & SWRI-090331-30, SWRI-090401-18 & 090327-9 and 090331-30 and 090401-25 Density and ICP \\
\hline TI-082 & 7.14.6 & Cool-down of UFP-VSL-T02A & D 02AML 09A 015642 ICP 2 D & ICP Supernate & SWRI-090331-30 & 090331-30 and 090401-25 ICP and ICPMS \\
\hline TI-082 & 7.14.6 & Cool-down of UFP-VSL-T02A & D 02AML 09A 015642 TFI 2 D & IC & SWRI-090331-27 & 090331-27 IC \\
\hline TI-082 & 7.14.6 & Cool-down of UFP-VSL-T02A & D 02AML 09A 015642 TFI 3 D & $\mathrm{OH}$ & ASR8399 & ASR 8399 OH \\
\hline TI-082 & 7.14.6 & Cool-down of UFP-VSL-T02A & D 02AML 09A 015642 ICP 0 B & Storage & & \\
\hline TI-082 & 7.14.6 & Cool-down of UFP-VSL-T02A & D 02AML 09A 165646 ICP 2 D & Density-TDS & SWRI-090331-30, SWRI-090401-18 & 090327-9 and 090331-30 and 090401-25 Density and ICP \\
\hline TI-082 & 7.14.6 & Cool-down of UFP-VSL-T02A & D 02AML 09A 165646 ICP 2 D & ICP Supernate & SWRI-090331-30 & 090331-30 and 090401-25 ICP and ICPMS \\
\hline TI-082 & 7.14.6 & Cool-down of UFP-VSL-T02A & D 02AML 09A 165646 TFI 2 D & IC & SWRI-090331-27 & 090331-27 IC \\
\hline TI-082 & 7.14.6 & Cool-down of UFP-VSL-T02A & D 02AML 09A 165646 TFI 3 D & $\mathrm{OH}$ & ASR8399 & ASR $8399 \mathrm{OH}$ \\
\hline
\end{tabular}


Integrated Test D Sample List

\begin{tabular}{|c|c|c|c|c|c|c|}
\hline TI\# & TI Step \# & TI Step Description & Sample ID & Analysis & $\begin{array}{c}\text { Electronic Folder } \\
\text { (SWRI Task Order \#, ASR \#, TDP\#) }\end{array}$ & Final Electronic Report File Name \\
\hline TI-082 & 7.14 .6 & Cool-down of UFP-VSL-T02A & D 02AML 09A 4D 5648 ICP 2 D & ICP Supernate & SWRI-090407-14 & 090402-26 and 090407-14 liquid ICP and IC and density and TDS \\
\hline TI-082 & 7.14 .6 & Cool-down of UFP-VSL-T02A & D 02AML 09A 4D 5648 ICP 2 D & Density-TDS & SWRI-090407-14 & 090402-26 and 090407-14 liquid ICP and IC and density and TDS \\
\hline TI-082 & 7.14 .6 & Cool-down of UFP-VSL-T02A & D 02AML 09A 4D 5648 TFI 2 D & IC & SWRI-090407-14 & 090402-26 and 090407-14 liquid ICP and IC and density and TDS \\
\hline TI-082 & 7.14 .6 & Cool-down of UFP-VSL-T02A & D 02AML 09A 4D 5648 TFI 3 D & $\mathrm{OH}$ & ASR8410 & ASR8410 OH \\
\hline TI-082 & 7.14 .6 & Cool-down of UFP-VSL-T02A & D 02AML 09A 4D 5648 ICP 0 B & Storage & & \\
\hline TI-082 & 7.14 .6 & Cool-down of UFP-VSL-T02A & D 02AML 09A XX 5337 UDS 2 & UDS & SWRI-090331-19 & 090331-19UDS R1 \\
\hline TI-082 & 7.14 .6 & Cool-down of UFP-VSL-T02A & D 02AML 09A XX 5338 DEN 2 & Density Slurry & SWRI-090331-29 & 090331-29DEN liquid and slurry \\
\hline TI-082 & 7.14 .6 & Cool-down of UFP-VSL-T02A & D 02AML 09A XX 5338 DEN 2 & Density Supernate & SWRI-090331-29 & 090331-29DEN liquid and slurry \\
\hline TI-082 & 7.14 .6 & Cool-down of UFP-VSL-T02A & D 02AML 09A XX 5339 ICP 2 B & ICP Wet Solids & SWRI-090331-25 & 090331-13 and 090331-25 and 090331-24 ICP and ICPMS \\
\hline TI-082 & 7.14 .6 & Cool-down of UFP-VSL-T02A & D 02AML 09A XX 5339 ICP 2 D & ICP Supernatant & SWRI-090331-23 & 090331-12 and 090331-22 and 090331-23 ICP and ICPMS \\
\hline TI-082 & 7.14 .6 & Cool-down of UFP-VSL-T02A & D 02AML 09A XX 5339 TFI 2 D & IC & SWRI-090331-27 & 090331-27 IC \\
\hline TI-082 & 7.14 .6 & Cool-down of UFP-VSL-T02A & D 02AML 09A XX 5339 TFI 3 D & $\mathrm{OH}$ & ASR8399 & ASR $8399 \mathrm{OH}$ \\
\hline TI-082 & 7.14 .6 & Cool-down of UFP-VSL-T02A & D 02AIL 09A XX 5329 ARC 1 & Archive & & \\
\hline TI-082 & 7.14 .6 & Cool-down of UFP-VSL-T02A & D 02AIM 09A XX 5330 ARC 1 & Archive & & \\
\hline TI-082 & 7.14 .6 & Cool-down of UFP-VSL-T02A & D 02AIH 09A XX 5331 ARC 1 & Archive & & \\
\hline TI-082 & 7.14 .6 & Cool-down of UFP-VSL-T02A & D 02AMM 09A XX 5332 ARC 1 & Archive & & \\
\hline TI-082 & 7.14 .6 & Cool-down of UFP-VSL-T02A & D 02AMH 09A XX 5333 ARC 1 & Archive & & \\
\hline TI-082 & 7.14 .6 & Cool-down of UFP-VSL-T02A & D 02AOL 09A XX 5334 ARC 1 & Archive & & \\
\hline TI-082 & 7.14 .6 & Cool-down of UFP-VSL-T02A & D 02AOM 09A XX 5335 ARC 1 & Archive & & \\
\hline TI-082 & 7.14 .6 & Cool-down of UFP-VSL-T02A & D 02AOH 09A XX 5336 ARC 1 & Archive & & \\
\hline TI-082 & 7.14 .6 & Cool-down of UFP-VSL-T02A & D 02AML 09A 005641 ARC 0 B & Archive & & \\
\hline TI-082 & 7.14 .6 & Cool-down of UFP-VSL-T02A & D 02AML 09A 025643 ARC 0 B & Archive & & \\
\hline TI-082 & 7.14 .6 & Cool-down of UFP-VSL-T02A & D 02AML 09A 045644 ARC 0 B & Archive & & \\
\hline TI-082 & 7.14.6 & Cool-down of UFP-VSL-T02A & D 02AML 09A 085645 ARC 0 B & Archive & & \\
\hline TI-082 & 7.14.6 & Cool-down of UFP-VSL-T02A & D 02AML 09A 485647 ARC 0 B & Archive & & \\
\hline TI-082 & 7.14.6 & Cool-down of UFP-VSL-T02A & D 02AML 09A 8D 5649 ARC 0 B & Archive & & \\
\hline TI-082 & 7.15 .6 & Post-caustic-leach concentration of solids to 17 -wt $\%$ UDS & D 00PF1 012 XX 5344 XSP 4 & PSD & TDP WTP 365 & TDP WTP 365 Int Test D PSD Data Analysis \\
\hline TI-082 & 7.15 .6 & Post-caustic-leach concentration of solids to 17 -wt $\%$ UDS & D 02AML 012 XX 5340 UDS 2 & UDS & SWRI-090331-18 & 090331-18UDS R1 \\
\hline TI-082 & 7.15 .6 & Post-caustic-leach concentration of solids to 17 -wt $\%$ UDS & D 02AML 012 XX 5341 RHE 4 & Rheology & TDP WTP 366 & TDP WTP 366 Int Test D RHE Data on PEP Slurry \\
\hline TI-082 & 7.15 .6 & Post-caustic-leach concentration of solids to 17 -wt $\%$ UDS & D 02AML 012 XX 5342 RHE 4 & Rheology & TDP WTP 366 & TDP WTP 366 Int Test D RHE Data on PEP Slurry \\
\hline TI-082 & 7.15 .6 & Post-caustic-leach concentration of solids to $17-\mathrm{wt} \%$ UDS & D 02AML 012 XX 5343 XSP 4 & PSD & TDP WTP 365 & TDP WTP 365 Int Test D PSD Data Analysis \\
\hline TI-082 & 7.15 .6 & Post-caustic-leach concentration of solids to $17-\mathrm{wt} \%$ UDS & D 00PF1 012015650 ARC 6 & Permeate Study & & \\
\hline
\end{tabular}


Integrated Test D Sample List

\begin{tabular}{|c|c|c|c|c|c|c|}
\hline TI \# & TI Step \# & TI Step Description & Sample ID & Analysis & $\begin{array}{c}\text { Electronic Folder } \\
\text { (SWRI Task Order \#, ASR \#, TDP\#) }\end{array}$ & Final Electronic Report File Name \\
\hline TI-082 & 7.15 .6 & Post-caustic-leach concentration of solids to 17 -wt $\%$ UDS & D 00PF1 012025651 ARC 6 & Permeate Study & & \\
\hline TI-082 & 7.15 .6 & Post-caustic-leach concentration of solids to 17 -wt $\%$ UDS & D 00PF1 012035652 ARC 6 & Permeate Study & & \\
\hline TI-082 & 7.15.6 & Post-caustic-leach concentration of solids to 17 -wt $\%$ UDS & D 00PF1 012045653 ARC 6 & Permeate Study & & \\
\hline TI-082 & 7.15.6 & Post-caustic-leach concentration of solids to 17 -wt $\%$ UDS & D 00PF1 012055654 ARC 6 & Permeate Study & & \\
\hline TI-082 & 7.15.6 & Post-caustic-leach concentration of solids to 17 -wt $\%$ UDS & D 00PF1 012065655 ARC 6 & Permeate Study & & \\
\hline TI-082 & 7.15.6 & Post-caustic-leach concentration of solids to 17 -wt $\%$ UDS & D 00PF1 012 XX 5353 ARC 1 & Archive & & \\
\hline TI-082 & 7.15.6 & Post-caustic-leach concentration of solids to 17 -wt $\%$ UDS & D 00PF1 012 XX 5354 ARC 1 & Archive & & \\
\hline TI-082 & 7.15 .12 & Dewatering solids to 20 -wt $\%$ UDS & D 02AML 012 XX 5345 UDS 2 & UDS & SWRI-090331-18 & 090331-18UDS R1 \\
\hline TI-082 & 7.15 .12 & Dewatering solids to $20-\mathrm{wt} \%$ UDS & D 02AML 012 XX 5346 UDS 2 & UDS & SWRI-090331-18 & 090331-18UDS R1 \\
\hline TI-082 & 7.15 .12 & Dewatering solids to 20 -wt $\%$ UDS & D 02AML 012 XX 5347 UDS 2 & UDS & SWRI-090331-18 & 090331-18UDS R1 \\
\hline TI-082 & 7.15 .12 & Dewatering solids to 20 -wt $\%$ UDS & D 02AML 012 XX 5348 UDS 2 & UDS & SWRI-090331-18 & 090331-18UDS R1 \\
\hline TI-082 & 7.15 .12 & Dewatering solids to 20 -wt $\%$ UDS & D 02AML 012 XX 5349 UDS 2 & UDS & SWRI-090331-18 & 090331-18UDS R1 \\
\hline TI-082 & 7.15 .12 & Dewatering solids to 20 -wt $\%$ UDS & D 02AML 012 XX 5350 UDS 2 & UDS & SWRI-090331-18 & 090331-18UDS R1 \\
\hline TI-082 & 7.15 .12 & Dewatering solids to 20 -wt $\%$ UDS & D 02AML 012 XX 5351 UDS 2 & UDS & SWRI-090331-18 & 090331-18UDS R1 \\
\hline TI-082 & 7.15 .12 & Dewatering solids to 20 -wt $\%$ UDS & D 02AML 012 XX 5352 UDS 2 & UDS & SWRI-090331-18 & 090331-18UDS R1 \\
\hline TI-082 & 7.15 .12 & Dewatering solids to 20 -wt $\%$ UDS & D 02AML 012 XX 5609 UDS 2 & UDS & SWRI-090331-18 & 090331-18UDS R1 \\
\hline TI-082 & 7.15 .14 & Post-caustic-leach concentration of solids to 17 -wt $\%$ UDS & D 00PF1 012 XX 5366 ARC 4 & Permeate Study & & \\
\hline TI-082 & 7.15 .14 & Post-caustic-leach concentration of solids to $17-w t \%$ UDS & D 00PF1 012 XX 5367 ARC 4 & Permeate Study & & \\
\hline TI-082 & 7.15 .14 & Post-caustic-leach concentration of solids to 17 -wt $\%$ UDS & D 00PF1 012 XX 5656 ARC 6 P & Permeate Study & & \\
\hline TI-082 & 7.15 .14 & Post-caustic-leach concentration of solids to $17-w t \%$ UDS & D 00PF1 012 XX 5657 ARC 6 P & Permeate Study & & \\
\hline TI-082 & 7.15 .14 & Dewatering solids to $20-\mathrm{wt} \%$ UDS & D 01A2A XXX XX 5691 ICP 2 B & ICP Wet Solids & SWRI-090331-24 & 090331-13 and 090331-25 and 090331-24 ICP and ICPMS \\
\hline TI-082 & 7.15 .14 & Dewatering solids to 20 -wt $\%$ UDS & D 01A2A XXX XX 5691 ICP 2 D & ICP Supernatant & SWRI-090331-22 & 090331-12 and 090331-22 and 090331-23 ICP and ICPMS \\
\hline TI-082 & 7.15 .14 & Dewatering solids to 20 -wt $\%$ UDS & D 02AML 012 XX 5356 UDS $2^{(b)}$ & UDS & SWRI-090331-18 & 090331-18UDS R1 \\
\hline TI-082 & 7.15 .14 & Dewatering solids to 20 -wt $\%$ UDS & D 02AML 012 XX 5357 DEN 2 & Density Slurry & SWRI-090331-28 & 090331-28DEN liquid and slurry \\
\hline TI-082 & 7.15 .14 & Dewatering solids to 20 -wt $\%$ UDS & D 02AML 012 XX 5357 DEN 2 & Density Supernate & SWRI-090331-28 & 090331-28DEN liquid and slurry \\
\hline TI-082 & 7.15 .14 & Dewatering solids to 20 -wt $\%$ UDS & D 02AML 012 XX 5358 RHE 4 & Rheology & TDP WTP 366 & TDP WTP 366 Int Test D RHE Data on PEP Slurry \\
\hline TI-082 & 7.15 .14 & Dewatering solids to 20 -wt $\%$ UDS & D 02AML 012 XX 5359 RHE 4 & Rheology & TDP WTP 366 & TDP WTP 366 Int Test D RHE Data on PEP Slurry \\
\hline TI-082 & 7.15 .14 & Dewatering solids to 20 -wt $\%$ UDS & D 02AML 012 XX 5360 ICP 2 B & ICP Wet Solids & SWRI-090331-24 & $090331-13$ and $090331-25$ and $090331-24$ ICP and ICPMS \\
\hline TI-082 & 7.15 .14 & Dewatering solids to $20-w t \%$ UDS & D 02AML 012 XX 5360 ICP 2 D & ICP Supernatant & SWRI-090331-22 & $090331-12$ and $090331-22$ and $090331-23$ ICP and ICPMS \\
\hline TI-082 & 7.15 .14 & Dewatering solids to 20 -wt $\%$ UDS & D 02AML 012 XX 5360 TFI 2 D & IC & SWRI-090331-26 & 090331-26 IC \\
\hline TI-082 & 7.15 .14 & Dewatering solids to 20 -wt $\%$ UDS & D 02AML 012 XX 5360 TFI 3 D & $\mathrm{OH}$ & ASR 8399 & ASR $8399 \mathrm{OH}$ \\
\hline TI-082 & 7.15 .14 & Dewatering solids to $20-\mathrm{wt} \%$ UDS & D 02AML 012 XX 5361 XSP 4 & PSD & TDP WTP 365 & TDP WTP 365 Int Test D PSD Data Analysis \\
\hline
\end{tabular}


Integrated Test D Sample List

\begin{tabular}{|c|c|c|c|c|c|c|}
\hline TI \# & TI Step \# & TI Step Description & Sample ID & Analysis & $\begin{array}{c}\text { Electronic Folder } \\
\text { (SWRI Task Order \#, ASR \#, TDP\#) }\end{array}$ & Final Electronic Report File Name \\
\hline TI-082 & 7.15 .14 & Dewatering solids to 20 -wt $\%$ UDS & D 02AML 012 XX 5362 SOX 2 & TIC/TOC & SWRI-090331-31 SWRI-090401-26 & 090331-31 and 090401-26 TIC TOC ${ }^{(a)}$ \\
\hline TI-082 & 7.15 .14 & Dewatering solids to 20 -wt $\%$ UDS & D 02AML 012 XX 5362 SOX $2^{(b)}$ & UDS & SWRI-090331-31 & 090331-31 UDS ${ }^{(a)}$ \\
\hline TI-082 & 7.15 .14 & Dewatering solids to 20 -wt $\%$ UDS & D 02AML 012 XX 5363 AFA 2 & ICP Supernatant & SWRI-090331-23 & 090331-12 and 090331-22 and 090331-23 ICP and ICPMS \\
\hline TI-082 & 7.15 .14 & Dewatering solids to 20 -wt $\%$ UDS & D 02AML 012 XX 5363 AFA 2 & ICP Wet Solids & SWRI-090331-30 & 090327-9 and 090331-30 and 090401-25 Density and ICP \\
\hline TI- 82 & 7.15 .14 & Dewatering solids to 20 -wt $\%$ UDS & D 02AML 012 XX 5364 AFA 5 B & THF Wet Solids & 49694 & PNNL 49694 Report.pdf \\
\hline TI-82 & 7.15 .14 & Dewatering solids to $20-\mathrm{wt} \%$ UDS & D 02AML 012 XX 5364 AFA 5 D & THF Supernate & 49694 & PNNL 49694 Report.pdf \\
\hline TI-82 & 7.15 .14 & Dewatering solids to $20-\mathrm{wt} \%$ UDS & D 02AML 012 XX 5365 AFA 5 B & Toluene Wet Solids & 49694 & $\begin{array}{l}\text { PNNL } 49694 \text { Report.pdf - No detectable peak present for Toluene } \\
\text { Ext. }\end{array}$ \\
\hline TI- 82 & 7.15 .14 & Dewatering solids to 20 -wt $\%$ UDS & D 02AML 012 XX 5365 AFA 5 D & Toluene Supernate & 49694 & $\begin{array}{l}\text { PNNL } 49694 \text { Report.pdf - No detectable peak present for Toluene } \\
\text { Ext. }\end{array}$ \\
\hline TI-082 & 7.15 .14 & Dewatering solids to $20-\mathrm{wt} \%$ UDS & D 02AML 012 XX 5610 UDS 2 & UDS & SWRI-090331-18 & 090331-18UDS R1 \\
\hline TI-082 & 7.16 .4 & Post-caustic slurry washing & D 00PF1 014 XX 5437 ARC 4 & Permeate Study & & \\
\hline TI-082 & 7.16 .4 & Post-caustic slurry washing & D 00PF1 014 XX 5438 ARC 4 & Permeate Study & & \\
\hline TI-082 & 7.16 .4 & Post-caustic slurry washing & D 00PF1 014 XX 5439 ARC 4 & Permeate Study & & \\
\hline TI-082 & 7.16 .4 & Post-caustic slurry washing & D 00PF1 014 XX 5660 ARC 6 & Permeate Study & & \\
\hline TI-082 & 7.16 .4 & Post-caustic slurry washing & D 00PF1 014 XX 5440 ARC 4 & Permeate Study & & \\
\hline TI-082 & 7.16 .4 & Post-caustic slurry washing & D 00PF1 014 XX 5441 ARC 4 & Permeate Study & & \\
\hline TI-082 & 7.16 .4 & Post-caustic slurry washing & D 00PF1 014 XX 5442 ARC 4 & Permeate Study & & \\
\hline TI-082 & 7.16 .4 & Post-caustic slurry washing & D 00PF1 014 XX 5443 ARC 4 & Permeate Study & & \\
\hline TI-082 & 7.16 .4 & Post-caustic slurry washing & D 00PF1 014 XX 5658 ARC 6 & Permeate Study & & \\
\hline TI-082 & 7.16 .4 & Post-caustic slurry washing & D 00PF1 014 XX 5659 ARC 6 & Permeate Study & & \\
\hline TI-082 & 7.16 .4 & Post-caustic slurry washing & D 00PF1 014 XX 5663 ARC 6 & Permeate Study & & \\
\hline TI-082 & 7.16 .4 & Post-caustic slurry washing & D 00PF1 014 XX 5664 ARC 6 & Permeate Study & & \\
\hline TI-082 & 7.16 .4 & Post-caustic slurry washing & D 00PF1 014 XX 5665 ARC 6 & Permeate Study & & \\
\hline TI-082 & 7.16 .4 & Post-caustic slurry washing & D 00PF1 014 XX 5667 ARC 6 & Permeate Study & & \\
\hline TI-082 & 7.16 .4 & Post-caustic slurry washing & D 00PF1 014 XX 5668 ARC 6 & Permeate Study & & \\
\hline TI-082 & 7.16 .4 & Post-caustic slurry washing & D 00PF1 014 XX 5669 ARC 6 & Permeate Study & & \\
\hline TI-082 & 7.16 .4 & Post-caustic slurry washing & D 00PF1 014 XX 5671 ARC 6 & Permeate Study & & \\
\hline TI-082 & 7.16 .4 & Post-caustic slurry washing & D 00PF1 014 XX 5672 ARC 6 & Permeate Study & & \\
\hline TI-082 & 7.16 .4 & Post-caustic slurry washing & D 00PF1 014 XX 5673 ARC 6 & Permeate Study & & \\
\hline TI-082 & 7.16 .4 & Post-caustic slurry washing & D 00PF1 014 XX 5675 ARC 6 & Permeate Study & & \\
\hline TI-082 & 7.16 .4 & Post-caustic slurry washing & D 00PF1 014 XX 5676 ARC 6 & Permeate Study & & \\
\hline
\end{tabular}


Integrated Test D Sample List

\begin{tabular}{|c|c|c|c|c|c|c|}
\hline TI\# & TI Step \# & TI Step Description & Sample ID & Analysis & $\begin{array}{c}\text { Electronic Folder } \\
\text { (SWRI Task Order \#, ASR \#, TDP\#) }\end{array}$ & Final Electronic Report File Name \\
\hline TI-082 & 7.16 .4 & Post-caustic slurry washing & D 00PF1 014 XX 5677 ARC 6 & Permeate Study & & \\
\hline TI-082 & 7.16 .4 & Post-caustic slurry washing & D 00PF1 014 XX 5679 ARC 6 & Permeate Study & & \\
\hline TI-082 & 7.16 .4 & Post-caustic slurry washing & D 00PF1 014 XX 5680 ARC 6 & Permeate Study & & \\
\hline TI-082 & 7.16 .4 & Post-caustic slurry washing & D 00PF1 014 XX 5681 ARC 6 & Permeate Study & & \\
\hline TI-082 & 7.16 .4 & Post-caustic slurry washing & D 00PF1 014 XX 5684 ARC 6 & Permeate Study & & \\
\hline TI-082 & 7.16 .4 & Post-caustic slurry washing & D 00PF1 014 XX 5685 ARC 6 & Permeate Study & & \\
\hline TI-082 & 7.16 .4 & Post-caustic slurry washing & D 00PF1 014 XX 5686 ARC 6 & Permeate Study & & \\
\hline TI-082 & 7.16 .4 & Post-caustic slurry washing & D 00PF1 014 XX 5687 ARC 6 & Permeate Study & & \\
\hline TI-082 & 7.16 .4 & Post-caustic slurry washing & D 00PF1 014 XX 5688 ARC 6 & Permeate Study & & \\
\hline TI-082 & 7.16 .4 & Post-caustic slurry washing & D 00PF1 014 XX 5689 ARC 6 & Permeate Study & & \\
\hline TI-082 & 7.16 .4 & Post-caustic slurry washing & D 00PF1 014 XX 5690 ARC 6 & Permeate Study & & \\
\hline TI-082 & 7.16 .4 & Post-caustic slurry washing & D 00PF1 014 XX 5444 ARC 4 & Permeate Study & & \\
\hline TI-082 & 7.16 .4 & Post-caustic slurry washing & D 00PF1 014 XX 5445 ARC 4 & Permeate Study & & \\
\hline TI-082 & 7.16 .4 & Post-caustic slurry washing & D 00PF1 014 XX 5446 ARC 4 & Permeate Study & & \\
\hline TI-082 & 7.16 .4 & Post-caustic slurry washing & D 00PF1 014 XX 5447 ARC 4 & Permeate Study & & \\
\hline TI-082 & 7.16 .4 & Post-caustic slurry washing & D 00PF1 014 XX 5448 ARC 4 & Permeate Study & & \\
\hline TI-082 & 7.16 .4 & Post-caustic slurry washing & D 00PF1 014 XX 5449 ARC 4 & Permeate Study & & \\
\hline TI-082 & 7.16 .4 & Post-caustic slurry washing & D 00PF1 014 XX 5450 ARC 4 & Permeate Study & & \\
\hline TI-082 & 7.16 .4 & Post-caustic slurry washing & D 00PF1 014 XX 5451 ARC 4 & Permeate Study & & \\
\hline TI-082 & 7.16 .4 & Post-caustic slurry washing & D 00PF1 014 XX 5452 ARC 4 & Permeate Study & & \\
\hline TI-082 & 7.16 .4 & Post-caustic slurry washing & D 00PF1 014 XX 5453 ARC 4 & Permeate Study & & \\
\hline TI-082 & 7.16 .4 & Post-caustic slurry washing & D 00PF1 014 XX 5454 ARC 4 & Permeate Study & & \\
\hline TI-082 & 7.16 .4 & Post-caustic slurry washing & D 00PF1 014 XX 5455 ARC 4 & Permeate Study & & \\
\hline TI-082 & 7.16 .4 & Post-caustic slurry washing & D 00PF1 014 XX 5456 ARC 4 & Permeate Study & & \\
\hline TI-082 & 7.16 .4 & Post-caustic slurry washing & D 00PF1 014 XX 5457 ARC 4 & Permeate Study & & \\
\hline TI-082 & 7.16 .4 & Post-caustic slurry washing & D 00PF1 014 XX 5458 ARC 4 & Permeate Study & & \\
\hline TI-082 & 7.16 .4 & Post-caustic slurry washing & D 00PF1 014 XX 5459 ARC 4 & Permeate Study & & \\
\hline TI-082 & 7.16 .4 & Post-caustic slurry washing & D 00PF1 014 XX 5460 ARC 4 & Permeate Study & & \\
\hline TI-082 & 7.16 .4 & Post-caustic slurry washing & D 00PF1 014 XX 5461 ARC 4 & Permeate Study & & \\
\hline TI-082 & 7.16 .4 & Post-caustic slurry washing & D 00PF1 014 XX 5462 ARC 4 & Permeate Study & & \\
\hline TI-082 & 7.16 .4 & Post-caustic slurry washing & D 00PF1 014 XX 5463 ARC 4 & Permeate Study & & \\
\hline TI-082 & 7.16 .4 & Post-caustic slurry washing & D 00PF1 014 XX 5464 ARC 4 & Permeate Study & & \\
\hline
\end{tabular}


Integrated Test D Sample List

\begin{tabular}{|c|c|c|c|c|c|c|}
\hline TI\# & TI Step \# & TI Step Description & Sample ID & Analysis & $\begin{array}{c}\text { Electronic Folder } \\
\text { (SWRI Task Order \#, ASR \#, TDP\#) }\end{array}$ & Final Electronic Report File Name \\
\hline TI-082 & 7.16 .4 & Post-caustic slurry washing & D 00PF1 014 XX 5465 ARC 4 & Permeate Study & & \\
\hline TI-082 & 7.16 .4 & Post-caustic slurry washing & D 00PF1 014 XX 5466 ARC 4 & Permeate Study & & \\
\hline TI-082 & 7.16 .4 & Post-caustic slurry washing & D 00PF1 014 XX 5467 ARC 4 & Permeate Study & & \\
\hline TI-082 & 7.16 .4 & Post-caustic slurry washing & D 00PF1 014 XX 5468 ARC 4 & Permeate Study & & \\
\hline TI-082 & 7.16 .4 & Post-caustic slurry washing & D 00PF1 014 XX 5469 ARC 4 & Permeate Study & & \\
\hline TI-082 & 7.16 .4 & Post-caustic slurry washing & D 00PF1 014 XX 5470 ARC 4 & Permeate Study & & \\
\hline TI-082 & 7.16 .4 & Post-caustic slurry washing & D 00PF1 014 XX 5471 ARC 4 & Permeate Study & & \\
\hline TI-082 & 7.16 .4 & Post-caustic slurry washing & D 00PF1 014 XX 5472 ARC 4 & Permeate Study & & \\
\hline TI-082 & 7.16 .4 & Post-caustic slurry washing & D 00PF1 014 XX 5473 ARC 4 & Permeate Study & & \\
\hline TI-082 & 7.16 .4 & Post-caustic slurry washing & D 00PF1 014 XX 5475 ARC 4 & Permeate Study & & \\
\hline TI-082 & 7.16 .4 & Post-caustic slurry washing & D 00PF1 014 XX 5474 ARC 4 & Permeate Study & & \\
\hline TI-082 & 7.16 .4 & Post-caustic slurry washing & D 00PF1 014 XX 5476 ARC 4 & Permeate Study & & \\
\hline TI-082 & 7.16 .4 & Post-caustic slurry washing & D 00PF1 014 XX 5477 ARC 4 & Permeate Study & & \\
\hline TI-082 & 7.16 .4 & Post-caustic slurry washing & D 00PF1 014 XX 5478 ARC 4 & Permeate Study & & \\
\hline TI-082 & 7.16 .4 & Post-caustic slurry washing & D 00PF1 014 XX 5479 ARC 4 & Permeate Study & & \\
\hline TI-082 & 7.16 .4 & Post-caustic slurry washing & D 00PF1 014 XX 5480 ARC 4 & Permeate Study & & \\
\hline TI-082 & 7.16 .4 & Post-caustic slurry washing & D 00PF1 014 XX 5481 ARC 4 & Permeate Study & & \\
\hline TI-082 & 7.16 .4 & Post-caustic slurry washing & D 00PF1 014 XX 5482 ARC 4 & Permeate Study & & \\
\hline TI-082 & 7.16 .4 & Post-caustic slurry washing & D 00PF1 014 XX 5483 ARC 4 & Permeate Study & & \\
\hline TI-082 & 7.16 .4 & Post-caustic slurry washing & D 00PF1 014 XX 5484 ARC 4 & Permeate Study & & \\
\hline TI-082 & 7.16 .4 & Post-caustic slurry washing & D 00PF1 014 XX 5485 ARC 4 & Permeate Study & & \\
\hline TI-082 & 7.16 .4 & Post-caustic slurry washing & D 00PF1 014 XX 5486 ARC 4 & Permeate Study & & \\
\hline TI-082 & 7.16 .4 & Post-caustic slurry washing & D 00PF1 014 XX 5487 ARC 4 & Permeate Study & & \\
\hline TI-082 & 7.16 .4 & Post-caustic slurry washing & D 00PF1 014 XX 5488 ARC 4 & Permeate Study & & \\
\hline TI-082 & 7.16 .4 & Post-caustic slurry washing & D 00PF1 014 XX 5489 ARC 4 & Permeate Study & & \\
\hline TI-082 & 7.16 .4 & Post-caustic slurry washing & D 00PF1 014 XX 5490 ARC 4 & Permeate Study & & \\
\hline TI-082 & 7.16 .4 & Post-caustic slurry washing & D 00PF1 014 XX 5661 ARC 6 P & Permeate Study & & \\
\hline TI-082 & 7.16 .4 & Post-caustic slurry washing & D 00PF1 014 XX 5666 ARC 6 P & Permeate Study & & \\
\hline TI-082 & 7.16 .4 & Post-caustic slurry washing & D 00PF1 014 XX 5670 ARC 6 P & Permeate Study & & \\
\hline TI-082 & 7.16 .4 & Post-caustic slurry washing & D 00PF1 014 XX 5674 ARC 6 P & Permeate Study & & \\
\hline TI-082 & 7.16 .4 & Post-caustic slurry washing & D 00PF1 014 XX 5678 ARC 6 P & Permeate Study & & \\
\hline TI-082 & 7.16 .4 & Post-caustic slurry washing & D 00PF1 014 XX 5682 ARC 6 P & Permeate Study & & \\
\hline
\end{tabular}


Integrated Test D Sample List

\begin{tabular}{|c|c|c|c|c|c|c|}
\hline TI \# & TI Step \# & TI Step Description & Sample ID & Analysis & $\begin{array}{c}\text { Electronic Folder } \\
\text { (SWRI Task Order \#, ASR \#, TDP\#) }\end{array}$ & Final Electronic Report File Name \\
\hline TI-082 & 7.16 .4 & Post-caustic slurry washing & D 00PF1 014 XX 5683 ARC 6 P & Permeate Study & & \\
\hline TI-082 & 7.16.4 & Post-caustic slurry washing & D 00PF1 014 XX 5693 CPB 6 F & Permeate Study & & \\
\hline TI-082 & 7.16 .4 & Post-caustic slurry washing & D 00PF1 014 XX 5692 CPA 6 F & Permeate Study & & \\
\hline TI-082 & 7.16 .5 & Post-caustic slurry washing & D 02AOL 014 XX 5431 RHE 4 & Rheology & TDP WTP 366 & TDP WTP 366 Int Test D RHE Data on PEP Slurry \\
\hline TI-082 & 7.16 .5 & Post-caustic slurry washing & D 02AOL 014 XX 5428 UDS 2 & UDS & SWRI-090401-19 & 090401-19UDS R1 \\
\hline TI-082 & 7.16 .5 & Post-caustic slurry washing & D 02AOL 014 XX 5429 DEN 2 & Density Supernate & SWRI-090401-21 & 090401-21DEN liquid and slurry \\
\hline TI-082 & 7.16 .5 & Post-caustic slurry washing & D 02AOL 014 XX 5429 DEN 2 & Density Slurry & SWRI-090401-21 & 090401-21DEN liquid and slurry \\
\hline TI-082 & 7.16 .5 & Post-caustic slurry washing & D 02AOL 014 XX 5430 RHE 4 & Rheology & TDP WTP 366 & TDP WTP 366 Int Test D RHE Data on PEP Slurry \\
\hline TI-082 & 7.16.5 & Post-caustic slurry washing & D 02AOL 014 XX 5432 ICP 2 B & ICP Wet Solids & SWRI-090401-25 & 090327-9 and $090331-30$ and $090401-25$ Density and ICP \\
\hline TI-082 & 7.16 .5 & Post-caustic slurry washing & D 02AOL 014 XX 5432 ICP 2 D & ICP Supernate & SWRI-090401-23 & 090401-23 and 090401-24 liquid ICP and density \\
\hline TI-082 & 7.16 .5 & Post-caustic slurry washing & D 02AOL 014 XX 5432 TFI 2 D & IC & SWRI-090401-28 & 090401-28 IC \\
\hline TI-082 & 7.16 .5 & Post-caustic slurry washing & D 02AOL 014 XX 5432 TFI 3 D & $\mathrm{OH}$ & ASR8401 & ASR8401 OH \\
\hline TI-082 & 7.16 .5 & Post-caustic slurry washing & D 02AOL 014 XX 5433 SOX 2 & TIC/TOC & SWRI-090331-31 SWRI-090401-26 & 090331-31 and 090401-26 TIC TOC ${ }^{(a)}$ \\
\hline TI-082 & 7.16 .5 & Post-caustic slurry washing & D 02AOL 014 XX 5434 AFA 2 & ICP Supernate & SWRI-090401-24 & 090401-23 and 090401-24 liquid ICP and density \\
\hline TI- 082 & 7.16 .5 & Post-caustic slurry washing & D 02AOL 014 XX 5434 AFA 2 & ICP Wet Solids & SWRI-090401-25 & 090327-9 and 090331-30 and 090401-25 Density and ICP \\
\hline TI-82 & 7.16 .5 & Post-caustic slurry washing & D 02AOL 014 XX 5435 AFA 5 B & THF Wet Solids & 49737 & PNNL 49737 Report.pdf \\
\hline TI- 82 & 7.16 .5 & Post-caustic slurry washing & D 02AOL 014 XX 5435 AFA 5 D & THF Supernate & 49737 & $\begin{array}{l}\text { PNNL } 49737 \text { Report.pdf - Not analyzed due to poor separation } \\
\text { during extraction process }\end{array}$ \\
\hline TI- 82 & 7.16 .5 & Post-caustic slurry washing & D 02AOL 014 XX 5436 AFA 5 B & Toluene Wet Solids & 49737 & PNNL 49737 Report.pdf \\
\hline TI-82 & 7.16 .5 & Post-caustic slurry washing & D 02AOL 014 XX 5436 AFA 5 D & Toluene Supernate & 49737 & PNNL 49737 Report.pdf \\
\hline TI-082 & 7.16 .14 & Post-caustic slurry washing & D 02AOL 014015389 ICP 2 D & Density-TDS & SWRI-090331-30, SWRI-090401-18 & 090401-18 TDS and density and ICP \\
\hline TI-082 & 7.16 .14 & Post-caustic slurry washing & D 02AOL 014015389 ICP 2 D & ICP Supernate & SWRI-090331-30, SWRI-090401-18 & 090401-18 TDS and density and ICP \\
\hline TI-082 & 7.16 .14 & Post-caustic slurry washing & D 02AOL 014015389 RAM 3 D & Raman & ASR 8400 & ASR 8400 RAM rev 1 \\
\hline TI-082 & 7.16 .14 & Post-caustic slurry washing & D 02AOL 014015389 TFI 2 D & IC & SWRI-090401-27 & 090401-27 IC \\
\hline TI-082 & 7.16 .14 & Post-caustic slurry washing & D 02AOL 014015389 TFI 3 D & $\mathrm{OH}$ & ASR8401 & ASR8401 OH \\
\hline TI-082 & 7.16 .14 & Post-caustic slurry washing & D 02AOL 014015389 DEN 0 B & Storage & & \\
\hline TI-082 & 7.16 .14 & Post-caustic slurry washing & D 02AOL 014025390 UDS 2 & UDS & SWRI-090401-19 & 090401-19UDS R1 \\
\hline TI-082 & 7.16 .14 & Post-caustic slurry washing & D 02AOL 014025391 DEN 2 & Density Supernate & SWRI-090401-21 & 090401-21DEN liquid and slurry \\
\hline TI-082 & 7.16 .14 & Post-caustic slurry washing & D 02AOL 014025391 DEN 2 & Density Slurry & SWRI-090401-21 & 090401-21DEN liquid and slurry \\
\hline TI-082 & 7.16 .14 & Post-caustic slurry washing & D 02AOL 014025392 ICP 2 D & ICP Supernate & SWRI-090401-23 & 090401-23 and 090401-24 liquid ICP and density \\
\hline TI-082 & 7.16 .14 & Post-caustic slurry washing & D 02AOL 014025392 TFI 2 D & IC & SWRI-090401-27 & 090401-27 IC \\
\hline TI-082 & 7.16 .14 & Post-caustic slurry washing & D 02AOL 014025392 TFI 3 D & $\mathrm{OH}$ & ASR8401 & ASR8401 OH \\
\hline
\end{tabular}


Integrated Test D Sample List

\begin{tabular}{|c|c|c|c|c|c|c|}
\hline TI \# & TI Step \# & TI Step Description & Sample ID & Analysis & $\begin{array}{c}\text { Electronic Folder } \\
\text { (SWRI Task Order \#, ASR \#, TDP\#) }\end{array}$ & Final Electronic Report File Name \\
\hline TI-082 & 7.16 .14 & Post-caustic-leach slurry wash & D 02AOL 014025392 ICP 0 B & Storage & & \\
\hline TI-082 & 7.16 .14 & Post-caustic-leach slurry wash & D 02AOL 014035393 ICP 2 D & Density-TDS & SWRI-090331-30, SWRI-090401-18 & 090401-18 TDS and density and ICP \\
\hline TI-082 & 7.16 .14 & Post-caustic-leach slurry wash & D 02AOL 014035393 ICP 2 D & ICP Supernate & SWRI-090331-30, SWRI-090401-18 & 090401-18 TDS and density and ICP \\
\hline TI-082 & 7.16 .14 & Post-caustic-leach slurry wash & D 02AOL 014035393 TFI 2 D & IC & SWRI-090401-27 & 090401-27 IC \\
\hline TI-082 & 7.16 .14 & Post-caustic-leach slurry wash & D 02AOL 014035393 TFI 3 D & $\mathrm{OH}$ & ASR8401 & ASR8401 OH \\
\hline TI-082 & 7.16 .14 & Post-caustic-leach slurry wash & D 02AOL 014035393 ICP 0 B & Storage & & \\
\hline TI-082 & 7.16 .14 & Post-caustic-leach slurry wash & D 02AOL 014045394 UDS 2 & UDS & SWRI-090401-19 & 090401-19UDS R1 \\
\hline TI-082 & 7.16 .14 & Post-caustic-leach slurry wash & D 02AOL 014045395 DEN 2 & Density Supernate & SWRI-090401-21 & 090401-21DEN liquid and slurry \\
\hline TI-082 & 7.16 .14 & Post-caustic-leach slurry wash & D 02AOL 014045395 DEN 2 & Density Slurry & SWRI-090401-21 & 090401-21DEN liquid and slurry \\
\hline TI-082 & 7.16 .14 & Post-caustic-leach slurry wash & D 02AOL 014045396 ICP 2 D & ICP Supernate & SWRI-090401-23 & 090401-23 and 090401-24 liquid ICP and density \\
\hline TI-082 & 7.16 .14 & Post-caustic-leach slurry wash & D 02AOL 014045396 TFI 2 D & IC & SWRI-090401-27 & 090401-27 IC \\
\hline TI-082 & 7.16 .14 & Post-caustic-leach slurry wash & D 02AOL 014045396 TFI 3 D & $\mathrm{OH}$ & ASR8401 & ASR8401 OH \\
\hline TI-082 & 7.16 .14 & Post-caustic-leach slurry wash & D 02AOL 014045396 ICP 0 B & Storage & & \\
\hline TI-082 & 7.16 .14 & Post-caustic-leach slurry wash & D 02 AOL 014055397 ICP 2 D & Density-TDS & SWRI-090331-30, SWRI-090401-18 & 090401-18 TDS and density and ICP \\
\hline TI-082 & 7.16 .14 & Post-caustic-leach slurry wash & D 02AOL 014055397 ICP 2 D & ICP Supernate & SWRI-090331-30, SWRI-090401-18 & 090401-18 TDS and density and ICP \\
\hline TI-082 & 7.16 .14 & Post-caustic-leach slurry wash & D 02AOL 014055397 TFI 2 D & IC & SWRI-090401-27 & 090401-27 IC \\
\hline TI-082 & 7.16 .14 & Post-caustic-leach slurry wash & D 02AOL 014055397 TFI 3 D & $\mathrm{OH}$ & ASR8401 & ASR8401 OH \\
\hline TI-082 & 7.16 .14 & Post-caustic-leach slurry wash & D 02AOL 014055397 ICP 0 B & Storage & & \\
\hline TI-082 & 7.16 .14 & Post-caustic-leach slurry wash & D 02AOL 014065398 UDS 2 & UDS & SWRI-090401-19 & 090401-19UDS R1 \\
\hline TI-082 & 7.16 .14 & Post-caustic-leach slurry wash & D 02AOL 014065399 DEN 2 & Density Supernate & SWRI-090401-21 & 090401-21DEN liquid and slurry \\
\hline TI-082 & 7.16 .14 & Post-caustic-leach slurry wash & D 02AOL 014065399 DEN 2 & Density Slurry & SWRI-090401-21 & 090401-21DEN liquid and slurry \\
\hline TI-082 & 7.16 .14 & Post-caustic-leach slurry wash & D 02AOL 014065400 ICP 2 D & ICP Supernate & SWRI-090401-23 & 090401-23 and 090401-24 liquid ICP and density \\
\hline TI-082 & 7.16 .14 & Post-caustic-leach slurry wash & D 02AOL 014065400 TFI 2 D & IC & SWRI-090401-27 & 090401-27 IC \\
\hline TI-082 & 7.16 .14 & Post-caustic-leach slurry wash & D 02AOL 014065400 TFI 3 D & $\mathrm{OH}$ & ASR8401 & ASR8401 OH \\
\hline TI-082 & 7.16 .14 & Post-caustic-leach slurry wash & D 02AOL 014065400 ICP 0 B & Storage & & \\
\hline TI-082 & 7.16 .14 & Post-caustic-leach slurry wash & D $02 \mathrm{AOL} 014075401$ ICP 2 D & Density-TDS & SWRI-090331-30, SWRI-090401-18 & 090401-18 TDS and density and ICP \\
\hline TI-082 & 7.16 .14 & Post-caustic-leach slurry wash & D 02 AOL 014075401 ICP 2 D & ICP Supernate & SWRI-090331-30, SWRI-090401-18 & 090401-18 TDS and density and ICP \\
\hline TI-082 & 7.16 .14 & Post-caustic-leach slurry wash & D 02AOL 014075401 TFI 2 D & IC & SWRI-090401-27 & 090401-27 IC \\
\hline TI-082 & 7.16 .14 & Post-caustic-leach slurry wash & D 02AOL 014075401 TFI 3 D & $\mathrm{OH}$ & ASR8401 & ASR8401 OH \\
\hline TI-082 & 7.16 .14 & Post-caustic-leach slurry wash & D 02AOL 014075401 ICP 0 B & Storage & & \\
\hline TI-082 & 7.16 .14 & Post-caustic-leach slurry wash & D 02AOL 014085402 UDS 2 & UDS & SWRI-090401-19 & 090401-19UDS R1 \\
\hline TI-082 & 7.16 .14 & Post-caustic-leach slurry wash & D 02AOL 014085403 DEN 2 & Density Supernate & SWRI-090401-21 & 090401-21DEN liquid and slurry \\
\hline
\end{tabular}


Integrated Test D Sample List

\begin{tabular}{|c|c|c|c|c|c|c|}
\hline TI \# & TI Step \# & TI Step Description & Sample ID & Analysis & $\begin{array}{c}\text { Electronic Folder } \\
\text { (SWRI Task Order \#, ASR \#, TDP\#) }\end{array}$ & Final Electronic Report File Name \\
\hline TI-082 & 7.16 .14 & Post-caustic-leach slurry wash & D 02AOL 014085403 DEN 2 & Density Slurry & SWRI-090401-21 & 090401-21DEN liquid and slurry \\
\hline TI-082 & 7.16 .14 & Post-caustic-leach slurry wash & D 02AOL 014085404 ICP 2 D & ICP Supernate & SWRI-090401-23 & 090401-23 and 090401-24 liquid ICP and density \\
\hline TI-082 & 7.16 .14 & Post-caustic-leach slurry wash & D 02AOL 014085404 TFI 2 D & IC & SWRI-090401-27 & 090401-27 IC \\
\hline TI-082 & 7.16 .14 & Post-caustic-leach slurry wash & D 02AOL 014085404 TFI 3 D & $\mathrm{OH}$ & ASR8401 & ASR8401 OH \\
\hline TI-082 & 7.16 .14 & Post-caustic-leach slurry wash & D 02AOL 014085404 ICP 0 & Storage & & \\
\hline TI-082 & 7.16 .14 & Post-caustic-leach slurry wash & D 02AOL 014095405 ICP 2 D & Density-TDS & SWRI-090331-30, SWRI-090401-18 & 090401-18 TDS and density and ICP \\
\hline TI-082 & 7.16 .14 & Post-caustic-leach slurry wash & D 02AOL 014095405 ICP 2 D & ICP Supernate & SWRI-090331-30, SWRI-090401-18 & 090401-18 TDS and density and ICP \\
\hline TI-082 & 7.16 .14 & Post-caustic-leach slurry wash & D 02AOL 014095405 TFI 2 D & IC & SWRI-090401-27 & 090401-27 IC \\
\hline TI-082 & 7.16 .14 & Post-caustic-leach slurry wash & D 02AOL 014095405 TFI 3 D & $\mathrm{OH}$ & ASR8401 & ASR8401 OH \\
\hline TI-082 & 7.16 .14 & Post-caustic-leach slurry wash & D 02AOL 014095405 ICP 0 B & Storage & & \\
\hline TI-082 & 7.16 .14 & Post-caustic-leach slurry wash & D 02AOL 014105406 UDS 2 & UDS & SWRI-090401-19 & 090401-19UDS R1 \\
\hline TI-082 & 7.16 .14 & Post-caustic-leach slurry wash & D 02AOL 014105407 DEN 2 & Density Supernate & SWRI-090401-21 & 090401-21DEN liquid and slurry \\
\hline TI-082 & 7.16 .14 & Post-caustic-leach slurry wash & D 02AOL 014105407 DEN 2 & Density Slurry & SWRI-090401-21 & 090401-21DEN liquid and slurry \\
\hline TI-082 & 7.16 .14 & Post-caustic-leach slurry wash & D 02AOL 014105408 RHE 4 & Rheology & TDP WTP 366 & TDP WTP 366 Int Test D RHE Data on PEP Slurry \\
\hline TI-082 & 7.16 .14 & Post-caustic-leach slurry wash & D 02AOL 014105409 RHE 4 & Rheology & TDP WTP 366 & TDP WTP 366 Int Test D RHE Data on PEP Slurry \\
\hline TI-082 & 7.16 .14 & Post-caustic-leach slurry wash & D 02AOL 014105410 ICP 2 D & ICP Supernate & SWRI-090401-23 & 090401-23 and 090401-24 liquid ICP and density \\
\hline TI-082 & 7.16 .14 & Post-caustic-leach slurry wash & D 02AOL 014105410 RAM 3 D & Raman & ASR 8400 & ASR 8400 RAM rev 1 \\
\hline TI-082 & 7.16 .14 & Post-caustic-leach slurry wash & D 02AOL 014105410 TFI 2 D & IC & SWRI-090401-27 & 090401-27 IC \\
\hline TI-082 & 7.16 .14 & Post-caustic-leach slurry wash & D 02AOL 014105410 TFI 3 D & $\mathrm{OH}$ & ASR8401 & ASR8401 OH \\
\hline TI-082 & 7.16 .14 & Post-caustic-leach slurry wash & D 02AOL 014105410 DEN 0 B & Storage & & \\
\hline TI-082 & 7.16 .14 & Post-caustic-leach slurry wash & D 02AOL 014115411 ICP 2 D & Density-TDS & SWRI-090331-30, SWRI-090401-18 & 090401-18 TDS and density and ICP \\
\hline TI-082 & 7.16 .14 & Post-caustic-leach slurry wash & D 02AOL 014115411 ICP 2 D & ICP Supernate & SWRI-090331-30, SWRI-090401-18 & 090401-18 TDS and density and ICP \\
\hline TI-082 & 7.16 .14 & Post-caustic-leach slurry wash & D 02AOL 014115411 TFI 2 D & IC & SWRI-090401-27 & 090401-27 IC \\
\hline TI-082 & 7.16 .14 & Post-caustic-leach slurry wash & D 02AOL 014115411 TFI 3 D & $\mathrm{OH}$ & ASR8401 & ASR8401 OH \\
\hline TI-082 & 7.16 .14 & Post-caustic-leach slurry wash & D 02AOL 014115411 ICP 0 B & Storage & & \\
\hline TI-082 & 7.16 .14 & Post-caustic-leach slurry wash & D 02AOL 014125412 UDS 2 & UDS & SWRI-090401-19 & 090401-19UDS R1 \\
\hline TI-082 & 7.16 .14 & Post-caustic-leach slurry wash & D 02AOL 014125413 DEN 2 & Density Supernate & SWRI-090401-21 & 090401-21DEN liquid and slurry \\
\hline TI-082 & 7.16 .14 & Post-caustic-leach slurry wash & D 02AOL 014125413 DEN 2 & Density Slurry & SWRI-090401-21 & 090401-21DEN liquid and slurry \\
\hline TI-082 & 7.16 .14 & Post-caustic-leach slurry wash & D 02AOL 014125414 ICP 2 D & ICP Supernate & SWRI-090401-23 & 090401-23 and 090401-24 liquid ICP and density \\
\hline TI-082 & 7.16 .14 & Post-caustic-leach slurry wash & D 02AOL 014125414 TFI 2 D & IC & SWRI-090401-27 & 090401-27 IC \\
\hline TI-082 & 7.16 .14 & Post-caustic-leach slurry wash & D 02AOL 014125414 TFI 3 D & $\mathrm{OH}$ & ASR8401 & ASR8401 OH \\
\hline TI-082 & 7.16 .14 & Post-caustic-leach slurry wash & D 02AOL 014125414 ICP 0 B & Storage & & \\
\hline
\end{tabular}


Integrated Test D Sample List

\begin{tabular}{|c|c|c|c|c|c|c|}
\hline TI \# & TI Step \# & TI Step Description & Sample ID & Analysis & $\begin{array}{c}\text { Electronic Folder } \\
\text { (SWRI Task Order \#, ASR \#, TDP\#) }\end{array}$ & Final Electronic Report File Name \\
\hline TI-082 & 7.16 .14 & Post-caustic-leach slurry wash & D 02AOL 014135415 ICP 2 D & Density-TDS & SWRI-090331-30, SWRI-090401-18 & 090401-18 TDS and density and ICP \\
\hline TI-082 & 7.16 .14 & Post-caustic-leach slurry wash & D 02AOL 014135415 ICP 2 D & ICP Supernate & SWRI-090331-30, SWRI-090401-18 & 090401-18 TDS and density and ICP \\
\hline TI-082 & 7.16 .14 & Post-caustic-leach slurry wash & D 02AOL 014135415 TFI 2 D & IC & SWRI-090401-27 & 090401-27 IC \\
\hline TI-082 & 7.16 .14 & Post-caustic-leach slurry wash & D 02AOL 014135415 TFI 3 D & $\mathrm{OH}$ & ASR8401 & ASR8401 OH \\
\hline TI-082 & 7.16 .14 & Post-caustic-leach slurry wash & D 02AOL 014135415 ICP 0 B & Storage & & \\
\hline TI-082 & 7.16 .14 & Post-caustic-leach slurry wash & D 02AOL 014145416 UDS 2 & UDS & SWRI-090401-19 & 090401-19UDS R1 \\
\hline TI-082 & 7.16 .14 & Post-caustic-leach slurry wash & D 02AOL 014145417 DEN 2 & Density Supernate & SWRI-090401-21 & 090401-21DEN liquid and slurry \\
\hline TI-082 & 7.16 .14 & Post-caustic-leach slurry wash & D 02AOL 014145417 DEN 2 & Density Slurry & SWRI-090401-21 & 090401-21DEN liquid and slurry \\
\hline TI-082 & 7.16 .14 & Post-caustic-leach slurry wash & D 02AOL 014145418 ICP 2 D & ICP Supernate & SWRI-090401-23 & 090401-23 and 090401-24 liquid ICP and density \\
\hline TI-082 & 7.16 .14 & Post-caustic-leach slurry wash & D 02AOL 014145418 TFI 2 D & IC & SWRI-090401-27 & 090401-27 IC \\
\hline TI-082 & 7.16 .14 & Post-caustic-leach slurry wash & D 02AOL 014145418 TFI 3 D & $\mathrm{OH}$ & ASR8401 & ASR8401 OH \\
\hline TI-082 & 7.16 .14 & Post-caustic-leach slurry wash & D 02AOL 014145418 ICP 0 B & Storage & & \\
\hline TI-082 & 7.16 .14 & Post-caustic-leach slurry wash & D 02AOL 014155419 ICP 2 D & Density-TDS & SWRI-090331-30, SWRI-090401-18 & 090401-18 TDS and density and ICP \\
\hline TI-082 & 7.16 .14 & Post-caustic-leach slurry wash & D 02AOL 014155419 ICP 2 D & ICP Supernate & SWRI-090331-30, SWRI-090401-18 & 090401-18 TDS and density and ICP \\
\hline TI-082 & 7.16 .14 & Post-caustic-leach slurry wash & D 02AOL 014155419 TFI 2 D & IC & SWRI-090401-27 & 090401-27 IC \\
\hline TI-082 & 7.16 .14 & Post-caustic-leach slurry wash & D 02AOL 014155419 TFI 3 D & $\mathrm{OH}$ & ASR 8401 & ASR8401 OH \\
\hline TI-082 & 7.16 .14 & Post-caustic-leach slurry wash & D 02AOL 014155419 ICP 0 B & Storage & & \\
\hline TI-082 & 7.16 .14 & Post-caustic-leach slurry wash & D 02AOL 014165420 UDS 2 & UDS & SWRI-090401-19 & 090401-19UDS R1 \\
\hline TI-082 & 7.16 .14 & Post-caustic-leach slurry wash & D 02AOL 014165421 DEN 2 & Density Supernate & SWRI-090401-21 & 090401-21DEN liquid and slurry \\
\hline TI-082 & 7.16 .14 & Post-caustic-leach slurry wash & D 02AOL 014165421 DEN 2 & Density Slurry & SWRI-090401-21 & 090401-21DEN liquid and slurry \\
\hline TI-082 & 7.16 .14 & Post-caustic-leach slurry wash & D 02AOL 014165422 ICP 2 D & ICP Supernate & SWRI-090401-23 & 090401-23 and 090401-24 liquid ICP and density \\
\hline TI-082 & 7.16 .14 & Post-caustic-leach slurry wash & D 02AOL 014165422 TFI 2 D & IC & SWRI-090401-27 & 090401-27 IC \\
\hline TI-082 & 7.16 .14 & Post-caustic-leach slurry wash & D 02AOL 014165422 TFI 3 D & $\mathrm{OH}$ & ASR8401 & ASR8401 OH \\
\hline TI-082 & 7.16 .14 & Post-caustic-leach slurry wash & D 02AOL 014165422 ICP 0 B & Storage & & \\
\hline TI-082 & 7.16 .14 & Post-caustic-leach slurry wash & D 02AOL 014175423 ICP 2 D & Density-TDS & SWRI-090331-30, SWRI-090401-18 & 090401-18 TDS and density and ICP \\
\hline TI-082 & 7.16 .14 & Post-caustic-leach slurry wash & D 02AOL 014175423 ICP 2 D & ICP Supernate & SWRI-090331-30, SWRI-090401-18 & 090401-18 TDS and density and ICP \\
\hline TI-082 & 7.16 .14 & Post-caustic-leach slurry wash & D 02AOL 014175423 TFI 2 D & IC & SWRI-090401-27 & 090401-27 IC \\
\hline TI-082 & 7.16 .14 & Post-caustic-leach slurry wash & D 02AOL 014175423 TFI 3 D & $\mathrm{OH}$ & ASR8401 & ASR8401 OH \\
\hline TI-082 & 7.16 .14 & Post-caustic-leach slurry wash & D 02AOL 014175423 ICP 0 B & Storage & & \\
\hline TI-082 & 7.16 .14 & Post-caustic-leach slurry wash & D 02AOL 014185424 UDS 2 & UDS & SWRI-090401-19 & 090401-19UDS R1 \\
\hline TI-082 & 7.16 .14 & Post-caustic-leach slurry wash & D 02AOL 014185425 DEN 2 & Density Supernate & SWRI-090401-21 & 090401-21DEN liquid and slurry \\
\hline TI-082 & 7.16 .14 & Post-caustic-leach slurry wash & D 02AOL 014185425 DEN 2 & Density Slurry & SWRI-090401-21 & 090401-21DEN liquid and slurry \\
\hline
\end{tabular}


Integrated Test D Sample List

\begin{tabular}{|c|c|c|c|c|c|c|}
\hline TI \# & TI Step \# & TI Step Description & Sample ID & Analysis & $\begin{array}{c}\text { Electronic Folder } \\
\text { (SWRI Task Order \#, ASR \#, TDP\#) }\end{array}$ & Final Electronic Report File Name \\
\hline TI-082 & 7.16 .14 & Post-caustic-leach slurry wash & D 02AOL 014185426 ICP 2 D & ICP Supernate & SWRI-090401-23 & 090401-23 and 090401-24 liquid ICP and density \\
\hline TI-082 & 7.16 .14 & Post-caustic-leach slurry wash & D 02AOL 014185426 TFI 2 D & IC & SWRI-090401-27 & 090401-27 IC \\
\hline TI-082 & 7.16 .14 & Post-caustic-leach slurry wash & D 02AOL 014185426 TFI 3 D & $\mathrm{OH}$ & ASR8401 & ASR8401 OH \\
\hline TI-082 & 7.16 .14 & Post-caustic-leach slurry wash & D 02AOL 014185426 ICP 0 B & Storage & & \\
\hline TI-082 & 7.16 .14 & Post-caustic-leach slurry wash & D 02AOL 014195427 ICP 2 D & Density-TDS & SWRI-090331-30, SWRI-090401-18 & 090401-18 TDS and density and ICP \\
\hline TI-082 & 7.16 .14 & Post-caustic-leach slurry wash & D 02AOL 014195427 ICP 2 D & ICP Supernate & SWRI-090331-30, SWRI-090401-18 & 090401-18 TDS and density and ICP \\
\hline TI-082 & 7.16 .14 & Post-caustic-leach slurry wash & D 02AOL 014195427 RAM 3 D & Raman & ASR 8400 & ASR 8400 RAM rev 1 \\
\hline TI-082 & 7.16 .14 & Post-caustic-leach slurry wash & D 02AOL 014195427 TFI 2 D & IC & SWRI-090401-27 & 090401-27 IC \\
\hline TI-082 & 7.16 .14 & Post-caustic-leach slurry wash & D 02AOL 014195427 TFI 3 D & $\mathrm{OH}$ & ASR8401 & ASR8401 OH \\
\hline TI-082 & 7.16 .14 & Post-caustic-leach slurry wash & D 02AOL 014195427 DEN 0 B & Storage & & \\
\hline TI-082 & 7.17.3 & Add permanganate & D 02AOL 017 XX 5502 UDS 2 & UDS & SWRI-090401-19 & 090401-19UDS R1 \\
\hline TI-082 & 7.17.3 & Add permanganate & D 02AOL 017 XX 5503 UDS 2 & UDS & SWRI-090401-19 & 090401-19UDS R1 \\
\hline TI-082 & 7.17.3 & Add permanganate & D 02AOL 017 XX 5504 UDS 2 & UDS & SWRI-090401-19 & 090401-19UDS R1 \\
\hline TI-082 & 7.17.3 & Add permanganate & D 02AOL 017 XX 5508 RHE 4 & Rheology & TDP WTP 366 & TDP WTP 366 Int Test D RHE Data on PEP Slurry \\
\hline TI-082 & 7.17.3 & Add permanganate & D 02AOL 017 XX 5509 RHE 4 & Rheology & TDP WTP 366 & TDP WTP 366 Int Test D RHE Data on PEP Slurry \\
\hline TI-082 & 7.17.3 & Add permanganate & D 02AOL 017 XX 5510 RHE 4 & Rheology & TDP WTP 366 & TDP WTP 366 Int Test D RHE Data on PEP Slurry \\
\hline TI-082 & 7.17.3 & Add permanganate & D 02AOL 017 XX 5511 ICP 2 D & ICP Supernate & SWRI-090401-23 & 090401-23 and 090401-24 liquid ICP and density \\
\hline TI-082 & 7.17.3 & Add permanganate & D 02AOL 017 XX 5511 ICP 2 R & ICP Rinsate & SWRI-090401-24 & 090401-23 and 090401-24 liquid ICP and density \\
\hline TI-082 & 7.17.3 & Add permanganate & D 02AOL 017 XX 5511 ICP 2 S & ICP Wet Solids & SWRI-090401-25 & 090331-30 and 090401-25 ICP and ICPMS \\
\hline TI-082 & 7.17.3 & Add permanganate & D 02AOL 017 XX 5511 RAM 3 D & Raman & ASR 8400 & ASR 8400 RAM rev 1 \\
\hline TI-082 & 7.17.3 & Add permanganate & D 02AOL 017 XX 5511 RAM 3 R & Raman & ASR 8400 & ASR 8400 RAM rev 1 \\
\hline TI-082 & 7.17.3 & Add permanganate & D 02AOL 017 XX 5511 TFI 2 D & IC & SWRI-090401-28 & 090401-28 IC \\
\hline TI-082 & 7.17.3 & Add permanganate & D 02AOL 017 XX 5511 TFI 3 D & $\mathrm{OH}$ & ASR8401 & ASR8401 OH \\
\hline TI-082 & 7.17.3 & Add permanganate & D 02AOL 017 XX 5512 ICP 2 D & ICP Supernate & SWRI-090401-23 & $090401-23$ and $090401-24$ liquid ICP and density \\
\hline TI-082 & 7.17.3 & Add permanganate & D 02AOL 017 XX 5512 ICP 2 R & ICP Rinsate & SWRI-090401-24 & 090401-23 and 090401-24 liquid ICP and density \\
\hline TI-082 & 7.17.3 & Add permanganate & D 02AOL 017 XX 5512 ICP 2 S & ICP Wet Solids & SWRI-090401-25 & 090331-30 and 090401-25 ICP and ICPMS \\
\hline TI-082 & 7.17.3 & Add permanganate & D 02AOL 017 XX 5512 RAM 3 D & Raman & ASR8400 & ASR 8400 RAM rev 1 \\
\hline TI-082 & 7.17.3 & Add permanganate & D 02AOL 017 XX 5512 RAM 3 R & Raman & ASR8400 & ASR 8400 RAM rev 1 \\
\hline TI-082 & 7.17.3 & Add permanganate & D 02AOL 017 XX 5512 TFI 2 D & IC & SWRI-090401-28 & 090401-28 IC \\
\hline TI-082 & 7.17.3 & Add permanganate & D 02AOL 017 XX 5512 TFI 3 D & $\mathrm{OH}$ & ASR8401 & ASR8401 OH \\
\hline TI-082 & 7.17.3 & Add permanganate & D 02AOL 017 XX 5513 ICP 2 D & ICP Supernate & SWRI-090401-23 & 090401-23 and 090401-24 liquid ICP and density \\
\hline TI-082 & 7.17.3 & Add permanganate & D 02AOL 017 XX 5513 ICP 2 R & ICP Rinsate & SWRI-090401-24 & 090401-23 and 090401-24 liquid ICP and density \\
\hline
\end{tabular}


Integrated Test D Sample List

\begin{tabular}{|c|c|c|c|c|c|c|}
\hline TI\# & TI Step \# & TI Step Description & Sample ID & Analysis & $\begin{array}{c}\text { Electronic Folder } \\
\text { (SWRI Task Order \#, ASR \#, TDP\#) }\end{array}$ & Final Electronic Report File Name \\
\hline TI-082 & 7.17 .3 & Add permanganate & D 02AOL 017 XX 5513 ICP $2 \mathrm{~S}$ & ICP Wet Solids & SWRI-090401-25 & 090331-30 and 090401-25 ICP and ICPMS \\
\hline TI-082 & 7.17 .3 & Add permanganate & D 02AOL 017 XX 5513 RAM 3 D & Raman & ASR 8400 & ASR 8400 RAM rev 1 \\
\hline TI-082 & 7.17.3 & Add permanganate & D 02AOL 017 XX 5513 RAM 3 R & Raman & ASR 8400 & ASR 8400 RAM rev 1 \\
\hline TI-082 & 7.17 .3 & Add permanganate & D 02AOL 017 XX 5513 TFI 2 D & IC & SWRI-090401-28 & 090401-28 IC \\
\hline TI-082 & 7.17 .3 & Add permanganate & D 02AOL 017 XX 5513 TFI 3 D & $\mathrm{OH}$ & ASR8401 & ASR8401 OH \\
\hline TI-082 & 7.17 .3 & Add permanganate & D 02AOL 017 XX 5514 AFA 2 & ICP Supernate & SWRI-090401-24 & 090401-23 and 090401-24 liquid ICP and density \\
\hline TI-082 & 7.17 .3 & Add permanganate & D 02AOL 017 XX 5514 AFA 2 & ICP Wet Solids & SWRI-090401-25 & 090327-9 and 090331-30 and 090401-25 Density and ICP \\
\hline TI-82 & 7.17 .3 & Add permanganate & D 02AOL 017 XX 5515 AFA 5 B & THF Wet Solids & 49737 & PNNL 49737 Report.pdf \\
\hline TI-82 & 7.17.3 & Add permanganate & D 02AOL 017 XX 5515 AFA 5 D & THF Supernate & 49737 & $\begin{array}{l}\text { PNNL } 49737 \text { Report.pdf - Not analyzed due to poor separation } \\
\text { during extraction process }\end{array}$ \\
\hline TI-82 & 7.17 .3 & Add permanganate & D 02AOL 017 XX 5516 AFA 5 B & Toluene Wet Solids & 49737 & PNNL 49737 Report.pdf \\
\hline TI-82 & 7.17 .3 & Add permanganate & D 02AOL 017 XX 5516 AFA 5 D & Toluene Supernate & 49737 & PNNL 49737 Report.pdf \\
\hline TI-082 & 7.17 .3 & Add permanganate & D 02AOL 017 XX 5517 CUF 4 & Parallel Bench Test & & \\
\hline TI-082 & 7.17 .6 & Add permanganate & D 02AOL 017 XX 5505 DEN 2 & Density Supernate & SWRI-090401-21 & 090401-21DEN liquid and slurry \\
\hline TI-082 & 7.17.6 & Add permanganate & D 02AOL 017 XX 5505 DEN 2 & Density Slurry & SWRI-090401-21 & 090401-21DEN liquid and slurry \\
\hline TI-082 & 7.17.6 & Add permanganate & D 02AOL 017 XX 5506 DEN 2 & Density Supernate & SWRI-090401-21 & 090401-21DEN liquid and slurry \\
\hline TI-082 & 7.17 .6 & Add permanganate & D 02AOL 017 XX 5506 DEN 2 & Density Slurry & SWRI-090401-21 & 090401-21DEN liquid and slurry \\
\hline TI-082 & 7.17.6 & Add permanganate & D 02AOL 017 XX 5507 DEN 2 & Density Supernate & SWRI-090401-21 & 090401-21DEN liquid and slurry \\
\hline TI-082 & 7.17.6 & Add permanganate & D 02AOL 017 XX 5507 DEN 2 & Density Slurry & SWRI-090401-21 & 090401-21DEN liquid and slurry \\
\hline TI-082 & 7.17.6 & Add permanganate & D 02AOL 017 XX 5518 UDS 2 B & UDS & SWRI-090401-20 & 090401-20 UDS separated R $1^{(a)}$ \\
\hline TI-082 & 7.17.6 & Add permanganate & D 02AOL 017 XX 5518 UDS 2 D & UDS & SWRI-090401-20 & 090401-20 UDS separated R1 ${ }^{(a)}$ \\
\hline TI-082 & 7.17 .6 & Add permanganate & D 02AOL 017 XX 5519 DEN 2 & Density Supernate & SWRI-090401-21 & 090401-21DEN liquid and slurry \\
\hline TI-082 & 7.17 .6 & Add permanganate & D 02AOL 017 XX 5519 DEN 2 & Density Slurry & SWRI-090401-21 & 090401-21DEN liquid and slurry \\
\hline TI-082 & 7.17 .6 & Add permanganate & D 02AOL 017 XX 5520 ICP 2 D & ICP Supernate & SWRI-090401-25 & 090331-30 and 090401-25 ICP and ICPMS \\
\hline TI-082 & 7.17.6 & Add permanganate & D 02AOL 017 XX 5520 RAM 3 D & Raman & ASR 8400 & ASR 8400 RAM rev 1 \\
\hline TI-082 & 7.17.6 & Add permanganate & D 02AOL 017 XX 5520 TFI 2 D & IC & SWRI-090401-28 & 090401-28 IC \\
\hline TI-082 & 7.17.6 & Add permanganate & D 02AOL 017 XX 5520 TFI 3 D & $\mathrm{OH}$ & ASR 8401 & ASR8401 OH \\
\hline TI-082 & 7.17.6 & Oxidative-leach & D 02AOL 018015522 UDS $2 \mathrm{~B}$ & UDS & SWRI-090401-20 & 090401-20 UDS separated R $1^{(a)}$ \\
\hline TI-082 & 7.17.6 & Oxidative-leach & D 02AOL 018015522 UDS 2 D & UDS & SWRI-090401-20 & 090401-20 UDS separated R ${ }^{(a)}$ \\
\hline TI-082 & 7.17.6 & Oxidative-leach & D 02AOL 018015523 DEN 2 & Density Slurry & SWRI-090401-21 & 090401-21DEN liquid and slurry \\
\hline TI-082 & 7.17.6 & Oxidative-leach & D 02AOL 018015524 ICP 2 D & ICP Supernate & SWRI-090401-23 & 090401-23 and 090401-24 liquid ICP and density \\
\hline TI-082 & 7.17.6 & Oxidative-leach & D 02AOL 018015524 TFI 2 D & IC & SWRI-090401-28 & 090401-28 IC \\
\hline
\end{tabular}


Integrated Test D Sample List

\begin{tabular}{|c|c|c|c|c|c|c|}
\hline TI \# & TI Step \# & TI Step Description & Sample ID & Analysis & $\begin{array}{c}\text { Electronic Folder } \\
\text { (SWRI Task Order \#, ASR \#, TDP\#) }\end{array}$ & Final Electronic Report File Name \\
\hline TI-082 & 7.17.6 & Oxidative-leach & D 02AOL 018015524 TFI 3 D & $\mathrm{OH}$ & ASR8401 & ASR8401 OH \\
\hline TI-082 & 7.17.6 & Oxidative-leach & D 02AOL 018015524 ICP 0 B & Storage & & \\
\hline TI-082 & 7.17 .6 & Oxidative-leach & D 02AOL 018025526 UDS $2 \mathrm{~B}$ & UDS & SWRI-090401-20 & 090401-20 UDS separated R ${ }^{(a)}$ \\
\hline TI-082 & 7.17.6 & Oxidative-leach & D 02AOL 018025526 UDS 2 D & UDS & SWRI-090401-20 & 090401-20 UDS separated R ${ }^{(a)}$ \\
\hline TI-082 & 7.17.6 & Oxidative-leach & D 02AOL 018025527 DEN 2 & Density Slurry & SWRI-090401-21 & 090401-21DEN liquid and slurry \\
\hline TI-082 & 7.17.6 & Oxidative-leach & D 02AOL 018025528 ICP 2 D & ICP Supernate & SWRI-090401-23 & 090401-23 and 090401-24 liquid ICP and density \\
\hline TI-082 & 7.17.6 & Oxidative-leach & D 02AOL 018025528 TFI 2 D & IC & SWRI-090401-28 & 090401-28 IC \\
\hline TI-082 & 7.17.6 & Oxidative-leach & D 02AOL 018025528 TFI 3 D & $\mathrm{OH}$ & ASR8401 & ASR8401 OH \\
\hline TI-082 & 7.17 .6 & Oxidative-leach & D 02AOL 018025528 ICP 0 B & Storage & & \\
\hline TI-082 & 7.17.6 & Oxidative-leach & D 02AOL 018035530 UDS $2 \mathrm{~B}$ & UDS & SWRI-090401-20 & 090401-20 UDS separated R1 ${ }^{(\mathrm{a})}$ \\
\hline TI-082 & 7.17.6 & Oxidative-leach & D 02AOL 018035530 UDS 2 D & UDS & SWRI-090401-20 & 090401-20 UDS separated R1 ${ }^{(a)}$ \\
\hline TI-082 & 7.17.6 & Oxidative-leach & D 02AOL 018035531 DEN 2 & Density Slurry & SWRI-090401-21 & 090401-21DEN liquid and slurry \\
\hline TI-082 & 7.17.6 & Oxidative-leach & D 02AOL 018035532 ICP 2 D & ICP Supernate & SWRI-090401-23 & 090401-23 and 090401-24 liquid ICP and density \\
\hline TI-082 & 7.17.6 & Oxidative-leach & D 02AOL 018035532 TFI 2 D & IC & SWRI-090401-28 & 090401-28 IC \\
\hline TI-082 & 7.17 .6 & Oxidative-leach & D 02AOL 018035532 TFI 3 D & $\mathrm{OH}$ & ASR8401 & ASR8401 OH \\
\hline TI-082 & 7.17.6 & Oxidative-leach & D 02AOL 018035532 ICP 0 B & Storage & & \\
\hline TI-082 & 7.17.6 & Oxidative-leach & D 02AOL 018045534 UDS 2 B & UDS & SWRI-090401-20 & 090401-20 UDS separated R ${ }^{(a)}$ \\
\hline TI-082 & 7.17.6 & Oxidative-leach & D 02AOL 018045534 UDS 2 D & UDS & SWRI-090401-20 & 090401-20 UDS separated R $1^{(\mathrm{a})}$ \\
\hline TI-082 & 7.17.6 & Oxidative-leach & D 02AOL 018045535 DEN 2 & Density Slurry & SWRI-090401-21 & 090401-21DEN liquid and slurry \\
\hline TI-082 & 7.17.6 & Oxidative-leach & D 02AOL 018045536 ICP 2 D & ICP Supernate & SWRI-090401-23 & 090401-23 and 090401-24 liquid ICP and density \\
\hline TI-082 & 7.17.6 & Oxidative-leach & D 02AOL 018045536 TFI 2 D & IC & SWRI-090401-28 & 090401-28 IC \\
\hline TI-082 & 7.17.6 & Oxidative-leach & D 02AOL 018045536 TFI 3 D & $\mathrm{OH}$ & ASR8401 & ASR8401 OH \\
\hline TI-082 & 7.17.6 & Oxidative-leach & D 02AOL 018045536 ICP 0 B & Storage & & \\
\hline TI-082 & 7.17.6 & Oxidative-leach & D 02AOL 018055538 UDS 2 B & UDS & SWRI-090401-20 & 090401-20 UDS separated R1 ${ }^{(a)}$ \\
\hline TI-082 & 7.17 .6 & Oxidative-leach & D 02AOL 018055538 UDS 2 D & UDS & SWRI-090401-20 & 090401-20 UDS separated R1 ${ }^{(a)}$ \\
\hline TI-082 & 7.17.6 & Oxidative-leach & D 02AOL 018055539 DEN 2 & Density Slurry & SWRI-090401-21 & 090401-21DEN liquid and slurry \\
\hline TI-082 & 7.17.6 & Oxidative-leach & D 02AOL 018055540 ICP 2 D & ICP Supernate & SWRI-090401-23 & 090401-23 and 090401-24 liquid ICP and density \\
\hline TI-082 & 7.17.6 & Oxidative-leach & D 02AOL 018055540 TFI 2 D & IC & SWRI-090401-28 & 090401-28 IC \\
\hline TI-082 & 7.17 .6 & Oxidative-leach & D 02AOL 018055540 TFI 3 D & $\mathrm{OH}$ & ASR8401 & ASR8401 OH \\
\hline TI-082 & 7.17.6 & Oxidative-leach & D 02AOL 018055540 ICP 0 B & Storage & & \\
\hline TI-082 & 7.17.6 & Oxidative-leach & D 02AOL 018065542 UDS 2 B & UDS & SWRI-090401-20 & 090401-20 UDS separated R $1^{(a)}$ \\
\hline TI-082 & 7.17.6 & Oxidative-leach & D 02AOL 018065542 UDS 2 D & UDS & SWRI-090401-20 & 090401-20 UDS separated R $1^{(a)}$ \\
\hline
\end{tabular}


Integrated Test D Sample List

\begin{tabular}{|c|c|c|c|c|c|c|}
\hline TI \# & TI Step \# & TI Step Description & Sample ID & Analysis & $\begin{array}{c}\text { Electronic Folder } \\
\text { (SWRI Task Order \#, ASR \#, TDP\#) }\end{array}$ & Final Electronic Report File Name \\
\hline TI-082 & 7.17 .6 & Oxidative-leach & D 02AOL 018065543 DEN 2 & Density Slurry & SWRI-090401-21 & 090401-21DEN liquid and slurry \\
\hline TI-082 & 7.17.6 & Oxidative-leach & D 02AOL 018065544 RHE 4 & Rheology & TDP WTP 366 & TDP WTP 366 Int Test D RHE Data on PEP Slurry \\
\hline TI-082 & 7.17.6 & Oxidative-leach & D 02AOL 018065545 ICP 2 D & ICP Supernate & SWRI-090401-23 & 090401-23 and 090401-24 liquid ICP and density \\
\hline TI-082 & 7.17.6 & Oxidative-leach & D 02AOL 018065545 ICP 2 R & ICP Rinsate & SWRI-090401-24 & 090401-23 and 090401-24 liquid ICP and density \\
\hline TI-082 & 7.17.6 & Oxidative-leach & D 02AOL 018065545 ICP $2 \mathrm{~S}$ & ICP Wet Solids & SWRI-090401-25 & 090331-30 and 090401-25 ICP and ICPMS \\
\hline TI-082 & 7.17.6 & Oxidative-leach & D 02AOL 018065545 RAM 3 D & Raman & ASR 8400 & ASR 8400 RAM rev 1 \\
\hline TI-082 & 7.17.6 & Oxidative-leach & D 02AOL 018065545 RAM 3 R & Raman & ASR 8400 & ASR 8400 RAM rev 1 \\
\hline TI-082 & 7.17.6 & Oxidative-leach & D 02AOL 018065545 TFI 2 D & IC & SWRI-090401-28 & 090401-28 IC \\
\hline TI-082 & 7.17.6 & Oxidative-leach & D 02AOL 018065545 TFI 3 D & $\mathrm{OH}$ & ASR8401 & ASR8401 OH \\
\hline TI-082 & 7.17.6 & Oxidative-leach & D 02AOL 018065547 AFA 2 B & ICP Wet Solids & SWRI-090401-25 & 090331-30 and 090401-25 ICP and ICPMS \\
\hline TI-082 & 7.17.6 & Oxidative-leach & D 02AOL 018065547 AFA 2 D & ICP Supernate & SWRI-090401-24 & 090401-23 and 090401-24 liquid ICP and density \\
\hline TI- 82 & 7.17.6 & Oxidative-leach & D 02AOL 018065548 AFA 5 D & THF Supernate & 49737 & $\begin{array}{l}\text { PNNL } 49737 \text { Report.pdf - Not analyzed due to poor separation } \\
\text { during extraction process }\end{array}$ \\
\hline TI- 82 & 7.17.6 & Oxidative-leach & D 02AOL 018065548 AFA 5 B & THF Wet Solids & 49737 & PNNL 49737 Report.pdf \\
\hline TI- 82 & 7.17.6 & Oxidative-leach & D 02AOL 018065549 AFA 5 D & Toluene Supernate & 49737 & PNNL 49737 Report.pdf \\
\hline TI- 82 & 7.17.6 & Oxidative-leach & D 02AOL 018065549 AFA 5 B & Toluene Wet Solids & 49737 & PNNL 49737 Report.pdf \\
\hline TI-082 & 7.18 .6 & Post-oxidative-leach wash & D 02AOL 019015550 UDS 2 & UDS & SWRI-090401-19 & 090401-19UDS R1 \\
\hline TI-082 & 7.18 .6 & Post-oxidative-leach wash & D 02AOL 019015551 ICP 2 D & Density Supernate & SWRI-090401-24 & 090401-23 and 090401-24 liquid ICP and density \\
\hline TI-082 & 7.18 .6 & Post-oxidative-leach wash & D 02AOL 019015551 ICP 2 D & ICP Supernate & SWRI-090401-24 & 090401-23 and 090401-24 liquid ICP and density \\
\hline TI-082 & 7.18 .6 & Post-oxidative-leach wash & D 02AOL 019015551 RAM 3 D & Raman & ASR 8400 & ASR 8400 RAM rev 1 \\
\hline TI-082 & 7.18.6 & Post-oxidative-leach wash & D 02AOL 019015551 TFI 2 D & IC & SWRI-090401-28 & 090401-28 IC \\
\hline TI-082 & 7.18 .6 & Post-oxidative-leach wash & D 02AOL 019015551 TFI 3 D & $\mathrm{OH}$ & ASR8401 & ASR8401 OH \\
\hline TI-082 & 7.18.6 & Post-oxidative-leach wash & D 02AOL 019015551 DEN 0 B & Storage & & \\
\hline TI-082 & 7.18 .6 & Post-oxidative-leach wash & D 02AOL 019025552 ICP 2 D & Density-TDS & SWRI-090331-30, SWRI-090401-18 & 090401-18 TDS and density and ICP \\
\hline TI-082 & 7.18 .6 & Post-oxidative-leach wash & D 02AOL 019025552 ICP 2 D & ICP Supernate & SWRI-090331-30, SWRI-090401-18 & 090401-18 TDS and density and ICP \\
\hline TI-082 & 7.18 .6 & Post-oxidative-leach wash & D 02AOL 019025552 TFI 2 D & IC & SWRI-090401-28 & 090401-28 IC \\
\hline TI-082 & 7.18.6 & Post-oxidative-leach wash & D 02AOL 019025552 TFI 3 D & $\mathrm{OH}$ & ASR8401 & ASR8401 OH \\
\hline TI-082 & 7.18 .6 & Post-oxidative-leach wash & D 02AOL 019025552 ICP 0 B & Storage & & \\
\hline TI-082 & 7.18 .6 & Post-oxidative-leach wash & D 02AOL 019035553 UDS 2 & UDS & SWRI-090401-19 & 090401-19UDS R1 \\
\hline TI-082 & 7.18 .6 & Post-oxidative-leach wash & D 02AOL 019035554 ICP 2 D & Density Supernate & SWRI-090401-24 & 090401-23 and 090401-24 liquid ICP and density \\
\hline TI-082 & 7.18 .6 & Post-oxidative-leach wash & D 02AOL 019035554 ICP 2 D & ICP Supernate & SWRI-090401-24 & 090401-23 and 090401-24 liquid ICP and density \\
\hline TI-082 & 7.18 .6 & Post-oxidative-leach wash & D 02AOL 019035554 TFI 2 D & IC & SWRI-090401-28 & 090401-28 IC \\
\hline
\end{tabular}


Integrated Test D Sample List

\begin{tabular}{|c|c|c|c|c|c|c|}
\hline TI \# & TI Step \# & TI Step Description & Sample ID & Analysis & $\begin{array}{c}\text { Electronic Folder } \\
\text { (SWRI Task Order \#, ASR \#, TDP\#) }\end{array}$ & Final Electronic Report File Name \\
\hline TI-082 & 7.18 .6 & Post-oxidative-leach wash & D 02AOL 019035554 TFI 3 D & $\mathrm{OH}$ & ASR8401 & ASR8401 OH \\
\hline TI-082 & 7.18 .6 & Post-oxidative-leach wash & D 02AOL 019035554 ICP 0 B & Storage & & \\
\hline TI-082 & 7.18 .6 & Post-oxidative-leach wash & D 02AOL 019045555 ICP 2 D & Density-TDS & SWRI-090401-18 & 090401-18 TDS and density and ICP \\
\hline TI-082 & 7.18 .6 & Post-oxidative-leach wash & D 02AOL 019045555 ICP 2 D & ICP Supernate & SWRI-090401-18 & 090401-18 TDS and density and ICP \\
\hline TI-082 & 7.18.6 & Post-oxidative-leach wash & D 02AOL 019045555 TFI 2 D & IC & SWRI-090401-28 & 090401-28 IC \\
\hline TI-082 & 7.18 .6 & Post-oxidative-leach wash & D 02AOL 019045555 TFI 3 D & $\mathrm{OH}$ & ASR8401 & ASR8401 OH \\
\hline TI-082 & 7.18.6 & Post-oxidative-leach wash & D 02AOL 019045555 ICP 0 B & Storage & & \\
\hline TI-082 & 7.18 .6 & Post-oxidative-leach wash & D 02AOL 019055556 UDS 2 & UDS & SWRI-090401-19 & 090401-19UDS R1 \\
\hline TI-082 & 7.18 .6 & Post-oxidative-leach wash & D 02AOL 019055557 ICP 2 D & Density Supernate & SWRI-090401-24 & 090401-23 and 090401-24 liquid ICP and density \\
\hline TI-082 & 7.18 .6 & Post-oxidative-leach wash & D 02AOL 019055557 ICP 2 D & ICP Supernate & SWRI-090401-24 & 090401-23 and 090401-24 liquid ICP and density \\
\hline TI-082 & 7.18 .6 & Post-oxidative-leach wash & D 02AOL 019055557 TFI 2 D & IC & SWRI-090401-28 & 090401-28 IC \\
\hline TI-082 & 7.18.6 & Post-oxidative-leach wash & D 02AOL 019055557 TFI 3 D & $\mathrm{OH}$ & ASR8401 & ASR8401 OH \\
\hline TI-082 & 7.18.6 & Post-oxidative-leach wash & D 02AOL 019055557 ICP 0 B & Storage & & \\
\hline TI-082 & 7.18 .6 & Post-oxidative-leach wash & D 02AOL 019065558 ICP 2 D & Density-TDS & SWRI-090331-30, SWRI-090401-18 & 090401-18 TDS and density and ICP \\
\hline TI-082 & 7.18 .6 & Post-oxidative-leach wash & D 02AOL 019065558 ICP 2 D & ICP Supernate & SWRI-090331-30, SWRI-090401-18 & 090401-18 TDS and density and ICP \\
\hline TI-082 & 7.18.6 & Post-oxidative-leach wash & D 02AOL 019065558 TFI 2 D & IC & SWRI-090401-28 & 090401-28 IC \\
\hline TI-082 & 7.18.6 & Post-oxidative-leach wash & D 02AOL 019065558 TFI 3 D & $\mathrm{OH}$ & ASR8401 & ASR8401 OH \\
\hline TI-082 & 7.18.6 & Post-oxidative-leach wash & D 02AOL 019065558 ICP 0 B & Storage & & \\
\hline TI-082 & 7.18 .6 & Post-oxidative-leach wash & D 02AOL 019075559 DEN 2 & Density Slurry & SWRI-090401-22 & 090401-22DEN liquid and slurry \\
\hline TI-082 & 7.18.6 & Post-oxidative-leach wash & D 02AOL 019075560 RHE 4 & Rheology & TDP WTP 366 & TDP WTP 366 Int Test D RHE Data on PEP Slurry \\
\hline TI-082 & 7.18 .6 & Post-oxidative-leach wash & D 02AOL 019075561 RHE 4 & Rheology & TDP WTP 366 & TDP WTP 366 Int Test D RHE Data on PEP Slurry \\
\hline TI-082 & 7.18.6 & Post-oxidative-leach wash & D 02AOL 019075562 ICP 2 D & Density-TDS & SWRI-090331-30, SWRI-090401-18 & 090401-18 TDS and density and ICP \\
\hline TI-082 & 7.18.6 & Post-oxidative-leach wash & D 02AOL 019075562 ICP 2 D & ICP Supernate & SWRI-090331-30, SWRI-090401-18 & 090401-18 TDS and density and ICP \\
\hline TI-082 & 7.18.6 & Post-oxidative-leach wash & D 02AOL 019075562 RAM 3 D & Raman & ASR 8400 & ASR 8400 RAM rev 1 \\
\hline TI-082 & 7.18 .6 & Post-oxidative-leach wash & D 02AOL 019075562 TFI 2 D & IC & SWRI-090401-28 & 090401-28 IC \\
\hline TI-082 & 7.18 .6 & Post-oxidative-leach wash & D 02AOL 019075562 TFI 3 D & $\mathrm{OH}$ & ASR8401 & ASR8401 OH \\
\hline TI-082 & 7.18.6 & Post-oxidative-leach wash & D 02AOL 019075562 DEN 0 B & Storage & & \\
\hline TI-082 & 7.18.6 & Post-oxidative-leach wash & D 02AOL 019085563 ICP 2 D & Density-TDS & SWRI-090331-30, SWRI-090401-18 & 090401-18 TDS and density and ICP \\
\hline TI-082 & 7.18 .6 & Post-oxidative-leach wash & D 02AOL 019085563 ICP 2 D & ICP Supernate & SWRI-090331-30, SWRI-090401-18 & 090401-18 TDS and density and ICP \\
\hline TI-082 & 7.18 .6 & Post-oxidative-leach wash & D 02AOL 019085563 TFI 2 D & IC & SWRI-090401-28 & 090401-28 IC \\
\hline TI-082 & 7.18 .6 & Post-oxidative-leach wash & D 02AOL 019085563 TFI 3 D & $\mathrm{OH}$ & ASR 8401 & ASR8401 OH \\
\hline TI-082 & 7.18 .6 & Post-oxidative-leach wash & D 02AOL 019085563 ICP 0 B & Storage & & \\
\hline
\end{tabular}


Integrated Test D Sample List

\begin{tabular}{|c|c|c|c|c|c|c|}
\hline TI \# & TI Step \# & TI Step Description & Sample ID & Analysis & $\begin{array}{c}\text { Electronic Folder } \\
\text { (SWRI Task Order \#, ASR \#, TDP\#) }\end{array}$ & Final Electronic Report File Name \\
\hline TI-082 & 7.18 .6 & Post-oxidative-leach wash & D 02AOL 019095564 UDS 2 & UDS & SWRI-090401-19 & 090401-19UDS R1 \\
\hline TI-082 & 7.18 .6 & Post-oxidative-leach wash & D 02AOL 019095565 ICP 2 D & Density Supernate & SWRI-090401-24 & 090401-23 and 090401-24 liquid ICP and density \\
\hline TI-082 & 7.18 .6 & Post-oxidative-leach wash & D 02AOL 019095565 ICP 2 D & ICP Supernate & SWRI-090401-24 & 090401-23 and 090401-24 liquid ICP and density \\
\hline TI-082 & 7.18 .6 & Post-oxidative-leach wash & D 02AOL 019095565 TFI 2 D & IC & SWRI-090401-29 & 090401-29 IC \\
\hline TI-082 & 7.18 .6 & Post-oxidative-leach wash & D 02AOL 019095565 TFI 3 D & $\mathrm{OH}$ & ASR8401 & ASR8401 OH \\
\hline TI-082 & 7.18 .6 & Post-oxidative-leach wash & D 02AOL 019095565 ICP 0 B & Storage & & \\
\hline TI-082 & 7.18 .6 & Post-oxidative-leach wash & D 02AOL 019105566 ICP 2 D & Density-TDS & SWRI-090331-30, SWRI-090401-18 & 090401-18 TDS and density and ICP \\
\hline TI-082 & 7.18 .6 & Post-oxidative-leach wash & D 02AOL 019105566 ICP 2 D & ICP Supernate & SWRI-090331-30, SWRI-090401-18 & 090401-18 TDS and density and ICP \\
\hline TI-082 & 7.18 .6 & Post-oxidative-leach wash & D 02AOL 019105566 TFI 2 D & IC & SWRI-090401-29 & 090401-29 IC \\
\hline TI-082 & 7.18 .6 & Post-oxidative-leach wash & D 02AOL 019105566 TFI 3 D & $\mathrm{OH}$ & ASR8401 & ASR8401 OH \\
\hline TI-082 & 7.18 .6 & Post-oxidative-leach wash & D 02AOL 019105566 ICP 0 B & Storage & & \\
\hline TI-082 & 7.18 .6 & Post-oxidative-leach wash & D 02AOL 019115567 UDS 2 & UDS & SWRI-090401-19 & 090401-19UDS R1 \\
\hline TI-082 & 7.18 .6 & Post-oxidative-leach wash & D 02AOL 019115568 ICP 2 D & Density Supernate & SWRI-090401-24 & 090401-23 and 090401-24 liquid ICP and density \\
\hline TI-082 & 7.18 .6 & Post-oxidative-leach wash & D 02AOL 019115568 ICP 2 D & ICP Supernate & SWRI-090401-24 & 090401-23 and 090401-24 liquid ICP and density \\
\hline TI-082 & 7.18 .6 & Post-oxidative-leach wash & D 02AOL 019115568 TFI 2 D & IC & SWRI-090401-29 & 090401-29 IC \\
\hline TI-082 & 7.18 .6 & Post-oxidative-leach wash & D 02AOL 019115568 TFI 3 D & $\mathrm{OH}$ & ASR8401 & ASR8401 OH \\
\hline TI-082 & 7.18 .6 & Post-oxidative-leach wash & D 02AOL 019115568 ICP 0 B & Storage & & \\
\hline TI-082 & 7.18 .6 & Post-oxidative-leach wash & D 02AOL 019125569 ICP 2 D & Density-TDS & SWRI-090331-30, SWRI-090401-18 & 090401-18 TDS and density and ICP \\
\hline TI-082 & 7.18 .6 & Post-oxidative-leach wash & D 02AOL 019125569 ICP 2 D & ICP Supernate & SWRI-090331-30, SWRI-090401-18 & 090401-18 TDS and density and ICP \\
\hline TI-082 & 7.18 .6 & Post-oxidative-leach wash & D 02AOL 019125569 TFI 2 D & IC & SWRI-090401-29 & 090401-29 IC \\
\hline TI-082 & 7.18 .6 & Post-oxidative-leach wash & D 02AOL 019125569 TFI 3 D & $\mathrm{OH}$ & ASR8401 & ASR8401 OH \\
\hline TI-082 & 7.18 .6 & Post-oxidative-leach wash & D 02AOL 019125569 ICP 0 B & Storage & & \\
\hline TI-082 & 7.18 .6 & Post-oxidative-leach wash & D 02AOL 019135570 UDS 2 & UDS & SWRI-090401-19 & 090401-19UDS R1 \\
\hline TI-082 & 7.18 .6 & Post-oxidative-leach wash & D 02AOL 019135571 ICP 2 D & Density Supernate & SWRI-090402-26 & 090402-26 and 090407-14 liquid ICP and IC and density and TDS \\
\hline TI-082 & 7.18 .6 & Post-oxidative-leach wash & D 02AOL 019135571 ICP 2 D & ICP Supernate & SWRI-090402-26 & 090402-26 and 090407-14 liquid ICP and IC and density and TDS \\
\hline TI-082 & 7.18 .6 & Post-oxidative-leach wash & D 02AOL 019135571 TFI 2 D & IC & SWRI-090402-27 & 090402-27 IC \\
\hline TI-082 & 7.18 .6 & Post-oxidative-leach wash & D 02AOL 019135571 TFI 3 D & $\mathrm{OH}$ & ASR8401 & ASR8401 OH \\
\hline TI-082 & 7.18 .6 & Post-oxidative-leach wash & D 02AOL 019135571 ICP 0 B & Storage & & \\
\hline TI-082 & 7.18 .6 & Post-oxidative-leach wash & D 02AOL 019145572 ICP 2 D & Density Supernate & SWRI-090402-26 & 090402-26 and 090407-14 liquid ICP and IC and density and TDS \\
\hline TI-082 & 7.18 .6 & Post-oxidative-leach wash & D 02AOL 019145572 ICP 2 D & ICP Supernate & SWRI-090402-26 & 090402-26 and 090407-14 liquid ICP and IC and density and TDS \\
\hline TI-082 & 7.18 .6 & Post-oxidative-leach wash & D 02AOL 019145572 TFI 2 D & IC & SWRI-090402-27 & 090402-27 IC \\
\hline TI-082 & 7.18 .6 & Post-oxidative-leach wash & D 02AOL 019145572 TFI 3 D & $\mathrm{OH}$ & ASR8401 & ASR8401 OH \\
\hline
\end{tabular}


Integrated Test D Sample List

\begin{tabular}{|c|c|c|c|c|c|c|}
\hline TI \# & TI Step \# & TI Step Description & Sample ID & Analysis & $\begin{array}{c}\text { Electronic Folder } \\
\text { (SWRI Task Order \#, ASR \#, TDP\#) }\end{array}$ & Final Electronic Report File Name \\
\hline TI-082 & 7.18 .6 & Post-oxidative-leach wash & D 02AOL 019145572 ICP 0 B & Storage & & \\
\hline TI-082 & 7.18 .6 & Post-oxidative-leach wash & D 02AOL 019155573 UDS 2 & UDS & SWRI-090401-19 & 090401-19UDS R1 \\
\hline TI-082 & 7.18 .6 & Post-oxidative-leach wash & D 02AOL 019155574 ICP 2 D & Density Supernate & SWRI-090402-26 & 090402-26 and 090407-14 liquid ICP and IC and density and TDS \\
\hline TI-082 & 7.18 .6 & Post-oxidative-leach wash & D 02AOL 019155574 ICP 2 D & ICP Supernate & SWRI-090402-26 & 090402-26 and 090407-14 liquid ICP and IC and density and TDS \\
\hline TI-082 & 7.18 .6 & Post-oxidative-leach wash & D 02AOL 019155574 RAM 3 D & Raman & ASR 8400 & ASR 8400 RAM rev 1 \\
\hline TI-082 & 7.18 .6 & Post-oxidative-leach wash & D 02AOL 019155574 TFI 2 D & $\mathrm{IC}$ & SWRI-090402-27 & 090402-27 IC \\
\hline TI-082 & 7.18 .6 & Post-oxidative-leach wash & D 02AOL 019155574 TFI 3 D & $\mathrm{OH}$ & ASR8401 & ASR8401 OH \\
\hline TI-082 & 7.18 .6 & Post-oxidative-leach wash & D 02AOL 019155574 DEN 0 B & Storage & & \\
\hline TI-082 & 7.18 .6 & Post-oxidative-leach wash & D 02AOL 019 XX 5579 ICP 2 D & Density Supernate & SWRI-090402-26 & 090402-26 and 090407-14 liquid ICP and IC and density and TDS \\
\hline TI-082 & 7.18 .6 & Post-oxidative-leach wash & D 02AOL 019 XX 5579 ICP 2 D & ICP Supernate & SWRI-090402-26 & 090402-26 and 090407-14 liquid ICP and IC and density and TDS \\
\hline TI-082 & 7.18 .7 & Post-oxidative-leach wash & D 02AOL 019 XX 5575 UDS 2 & UDS & SWRI-090401-20 & 090401-20 UDS separated R ${ }^{(a)}$ \\
\hline TI-082 & 7.18.7 & Post-oxidative-leach wash & D 02AOL 019 XX 5576 DEN 2 & Density Supernate & SWRI-090401-22 & 090401-22DEN liquid and slurry \\
\hline TI-082 & 7.18.7 & Post-oxidative-leach wash & D 02AOL 019 XX 5576 DEN 2 & Density Slurry & SWRI-090401-22 & 090401-22DEN liquid and slurry \\
\hline TI-082 & 7.18 .7 & Post-oxidative-leach wash & D 02AOL 019 XX 5577 RHE 4 & Rheology & TDP WTP 366 & TDP WTP 366 Int Test D RHE Data on PEP Slurry \\
\hline TI-082 & 7.18.7 & Post-oxidative-leach wash & D 02AOL 019 XX 5578 RHE 4 & Rheology & TDP WTP 366 & TDP WTP 366 Int Test D RHE Data on PEP Slurry \\
\hline TI-082 & 7.18 .7 & Post-oxidative-leach wash & D 02AOL 019 XX 5579 TFI 2 D & IC & SWRI-090402-27 & 090402-27 IC \\
\hline TI-082 & 7.18.7 & Post-oxidative-leach wash & D 02AOL 019 XX 5579 TFI 3 D & $\mathrm{OH}$ & ASR8401 & ASR8401 OH \\
\hline TI-082 & 7.18.7 & Post-oxidative-leach wash & D 02AOL 019 XX 5579 ICP 0 B & Storage & & \\
\hline TI-082 & 7.18 .10 & Post-oxidative-leach concentration & D 02AML 020 XX 5580 UDS 2 & UDS & SWRI-090401-20 & 090401-20 UDS separated R $1^{(a)}$ \\
\hline TI-082 & 7.18 .10 & Post-oxidative-leach concentration & D 02AML 020 XX 5581 DEN 2 & Density Supernate & SWRI-090401-22 & 090401-22DEN liquid and slurry \\
\hline TI-082 & 7.18 .10 & Post-oxidative-leach concentration & D 02AML 020 XX 5581 DEN 2 & Density Slurry & SWRI-090401-22 & 090401-22DEN liquid and slurry \\
\hline TI-082 & 7.18 .10 & Post-oxidative-leach concentration & D 02AML 020 XX 5582 RHE 4 & Rheology & TDP WTP 366 & TDP WTP 366 Int Test D RHE Data on PEP Slurry \\
\hline TI-082 & 7.18 .10 & Post-oxidative-leach concentration & D 02AML 020 XX 5583 RHE 4 & Rheology & TDP WTP 366 & TDP WTP 366 Int Test D RHE Data on PEP Slurry \\
\hline TI-082 & 7.18 .10 & Post-oxidative-leach concentration & D 02AML 020 XX 5583 UDS 2 & UDS & SWRI-090818-10 & 090818-10 UDS \\
\hline TI-082 & 7.18 .10 & Post-oxidative-leach concentration & D 02AML 020 XX 5584 RHE 4 & Rheology & TDP WTP 366 & TDP WTP 366 Int Test D RHE Data on PEP Slurry \\
\hline TI-082 & 7.18 .10 & Post-oxidative-leach concentration & D 02AML 020 XX 5585 RHE 4 & Rheology & TDP WTP 366 & TDP WTP 366 Int Test D RHE Data on PEP Slurry \\
\hline TI-082 & 7.18 .10 & Post-oxidative-leach concentration & D 02AML 020 XX 5586 ICP 2 B & ICP Wet Solids & SWRI-090402-28 & 090402-28 ICP and ICPMS \\
\hline TI-082 & 7.18 .10 & Post-oxidative-leach concentration & D 02AML 020 XX 5586 ICP 2 D & ICP Supernate & SWRI-090402-26 & 090402-26 and 090407-14 liquid ICP and IC and density and TDS \\
\hline TI-082 & 7.18 .10 & Post-oxidative-leach concentration & D 02AML 020 XX 5586 TFI 2 D & IC & SWRI-090402-27 & 090402-27 IC \\
\hline TI-082 & 7.18 .10 & Post-oxidative-leach concentration & D 02AML 020 XX 5586 TFI 3 D & $\mathrm{OH}$ & ASR8401 & ASR8401 OH \\
\hline TI-082 & 7.18 .10 & Post-oxidative-leach concentration & D 02AML 020 XX 5587 XSP 4 & PSD & TDP WTP 365 & TDP WTP 365 Int Test D PSD Data Analysis; \\
\hline TI-082 & 7.18 .10 & Post-oxidative-leach concentration & D 02AML 020 XX 5587 XSP 4 & XRD & TDP-WTP-364 & TDP WTP 364 PEP Integrated Test D XRD Data Analysis \\
\hline
\end{tabular}


Integrated Test D Sample List

\begin{tabular}{|c|c|c|c|c|c|c|}
\hline TI \# & TI Step \# & TI Step Description & Sample ID & Analysis & $\begin{array}{l}\text { Electronic Folder } \\
\text { (SWRI Task Order \#, ASR \#, TDP\#) }\end{array}$ & Final Electronic Report File Name \\
\hline TI-082 & 7.18 .10 & Post-oxidative-leach concentration & D 02AML 020 XX 5587 XSP 4 & SEM & TDP WTP 360 & TDP WTP 360 Int Test D SEM Data Analysis \\
\hline TI-082 & 7.18 .10 & Post-oxidative-leach concentration & D 02AML 020 XX 5588 AFA 2 & ICP Supernate & SWRI-090401-24 & 090401-23 and 090401-24 liquid ICP and density \\
\hline TI-082 & 7.18 .10 & Post-oxidative-leach concentration & D 02AML 020 XX 5588 AFA 2 & ICP Wet Solids & SWRI-090401-25 & 090327-9 and $090331-30$ and $090401-25$ Density and ICP \\
\hline TI-82 & 7.18 .10 & Post-oxidative-leach concentration & D 02AML 020 XX 5589 AFA 5 B & Toluene Wet Solids & 49772 & PNNL 49772 Report.pdf \\
\hline TI-82 & 7.18 .10 & Post-oxidative-leach concentration & D 02AML 020 XX 5589 AFA 5 D & Toluene Supernate & 49772 & $\begin{array}{l}\text { PNNL } 49772 \text { Report.pdf - Not analyzed due to poor separation } \\
\text { during extraction process }\end{array}$ \\
\hline TI-82 & 7.18 .10 & Post-oxidative-leach concentration & D 02AML 020 XX 5590 AFA 5 B & Toluene Wet Solids & 49772 & PNNL 49772 Report.pdf \\
\hline TI-82 & 7.18 .10 & Post-oxidative-leach concentration & D 02AML 020 XX 5590 AFA 5 D & Toluene Supernate & 49772 & PNNL 49772 Report.pdf \\
\hline TI-082 & 7.19 .2 & Prior to transfer of slurry from UFP-VSL-T02A to UFP-VSL-T62A/B & D 02AML 022 XX 5593 UDS 2 & UDS & SWRI-090401-20 & 090401-20 UDS separated R1 ${ }^{(a)}$ \\
\hline TI-082 & 7.19 .2 & Prior to transfer of slurry from UFP-VSL-T02A to UFP-VSL-T62A/B & D 02AML 022 XX 5594 ICP 2 D & ICP Supernate & SWRI-090402-26 & 090402-26 and 090407-14 liquid ICP and IC and density and TDS \\
\hline TI-082 & 7.19 .2 & Prior to transfer of slurry from UFP-VSL-T02A to UFP-VSL-T62A/B & D 02AML 022 XX 5594 TFI 2 D & IC & SWRI-090402-27 & 090402-27 IC \\
\hline TI-082 & 7.19 .2 & Prior to transfer of slurry from UFP-VSL-T02A to UFP-VSL-T62 & D 02AML 022 XX 5594 TFI 3 D & $\mathrm{OH}$ & ASR 8401 & ASR8401 OH \\
\hline TI-082 & 7.19 .2 & Prior to transfer of slurry from UFP-VSL-T02A to UFP-VSL-T62 & D 02AML 022 XX 5594 ICP 0 B & Storage & & \\
\hline TI-082 & 7.19 .3 & Flush filter-loop forward after all permeate samples are taken & D 000FL 021 XX 5591 UDS 2 & UDS & SWRI-090402-25 & 090402-25UDS R1 \\
\hline TI-082 & 7.19 .3 & Flush filter-loop forward after all permeate samples are taken & D 000FL 021 XX 5592 ICP 2 D & ICP Supernate & SWRI-090402-26 & 090402-26 and 090407-14 liquid ICP and IC and density and TDS \\
\hline TI-082 & 7.19 .3 & Flush filter-loop forward after all permeate samples are taken & D 000FL 021 XX 5592 TFI 2 D & IC & SWRI-090402-27 & 090402-27 IC \\
\hline TI-082 & 7.19 .3 & Flush filter-loop forward after all permeate samples are taken & D 000FL 021 XX 5592 TFI 3 D & $\mathrm{OH}$ & ASR8401 & ASR8401 OH \\
\hline
\end{tabular}

(b) Insufficient sample to rerun UDS so performed UDS on sample D 02AML 012 XX 5362 SOX 2

" and "Storage" indicate samples were sent to storage/archive in RTL or sent out of PDL-W for additional studies.

TI Step \# have been adjusted to allow samples collected in a single sampling event to listed together.

Density slurry—analysis performed on slurry.

Density supernate - analysis performed on supernate.

Free hydroxide (OH).

Inductively coupled plasma supernate (ICP Supernate) ICP performed on the supernate.

(1)

Inductively coupled plasm

Pon chromatography (IC)

(PSD)

Sheorog strength or Shear stress vs. shear rate analysis - actual analytical report specify specific analysis.

作

Weric

$\mathrm{X}$-ray diffraction $(\mathrm{XRD})$ 

Appendix D

Coriolis Sampler Elevations 



\section{Appendix D: Coriolis Sampler Elevations (Kurath 2008)}

$\begin{array}{llll}\text { Date: } & \mathbf{1 2 / 3 1 / 2 0 0 8} & \text { Project No.: } & <53032> \\ \text { To: } & \text { Dean Kurath } & \text { Internal } & \text { File/LB } \\ \text { From: } & \begin{array}{l}\text { Matt Fountain } \\ \text { Gary Josephson }\end{array} & \text { Distribution: } & \\ & & & \end{array}$

Subject: Coriolis Sampler Elevations

'As installed' elevations of the Coriolis samplers were estimated by bubbling air through each sampler leg and measuring the bubbler pressure on the tank's lower bubbler leg calibrated pressure transmitter.

Method: After recording the pressure of the lowest bubbler leg the bubbler tubing was disconnected from the air supply and the supply attached to the Coriolis sampler stand via the low point drain and connecting Teflon tubing with Swagelock fittings. Air was bubbled through the tubing to each sampler leg and the pressure recorded. In UFP-1A and UFP-1B the PJMs were operating and the "lowest" pressure was recorded, when the PJMs were filled. Levels in UFP-1A, UFP-1B, and UFP-2A were measured on LT-0323, LT-0423, and LT-0611, respectively.

The measured pressures were compared with the measured differences in tubing lengths between the bottom-middle and middle-upper to make the final estimate sample elevations. Measured tubing differences were considered absolute and measured elevations were adjusted as much as an inch so that the offsets matched measured lengths.

Below are listed the "expected" sampler elevations based upon initial design and the results of this study:

\begin{tabular}{|c|c|c|c|c|c|c|}
\hline \multirow{2}{*}{$\begin{array}{l}\text { Vessel } \\
\text { UFP-1A }\end{array}$} & \multicolumn{3}{|c|}{ Initial design elevation } & \multicolumn{3}{|c|}{ "as installed" sample tube elevatio } \\
\hline & Low & Middle & High & Low & Middle & High \\
\hline Inner & 2 & 33 & 64 & 11 & 33 & 64 \\
\hline Middle & 11 & 33 & 55 & 9 & 31 & 53 \\
\hline Outer & 11 & 33 & 55 & 9 & 31 & 53 \\
\hline \multicolumn{7}{|l|}{ UFP-1B } \\
\hline Inner & 2 & 33 & 64 & 10 & 32 & 63 \\
\hline Middle & 11 & 33 & 55 & 6 & 28 & 51 \\
\hline Outer & 11 & 33 & 55 & 6 & 51 & 29 \\
\hline \multicolumn{7}{|l|}{ UFP-2A } \\
\hline Inner & 50 & 57 & 64 & 51 & 58 & 65 \\
\hline Middle & 2" off bottom & 33 & 55 & 6 & 34 & 56 \\
\hline Outer & 11 & 33 & 55 & 11 & 33 & 56 \\
\hline
\end{tabular}


Conclusions: The 'as installed' sampler levels agree quite well with the design with the following exceptions:

- The UFP-1B outer/middle and outer/high sampling tubing has been switched. (An NCR is being written and the tubing needs to be corrected and the correction date recorded. Samples taken until then are incorrect.)

- The inner low sampler tubes were cut shorter than originally anticipated. Instead of sampling very close (2") from the bottom of the vessel the sample is 10"-11" off the bottom.

- The middle and outer samplers in UFP-1B were installed about 4"-5" lower than initially intended.

The design of the UFP-2A middle/low position was designed to be 2 inches off the vessel bottom at the middle radial location. With a 2:1 elliptical head the elevation rise for the middle sampling location is estimated to be $\sim 3.5$ " so the measured 6 " elevation from the center tank bottom is actually very close. 


\section{Appendix E}

\section{PEP Data Acquisition System}





\section{Appendix E: PEP Data Acquisition System}

The data acquisition system (DAS) for PEP is composed of four data acquisition servers and one graphical user interface (GUI) PC. They are networked together, along with the rest of the PEP equipment as depicted below.

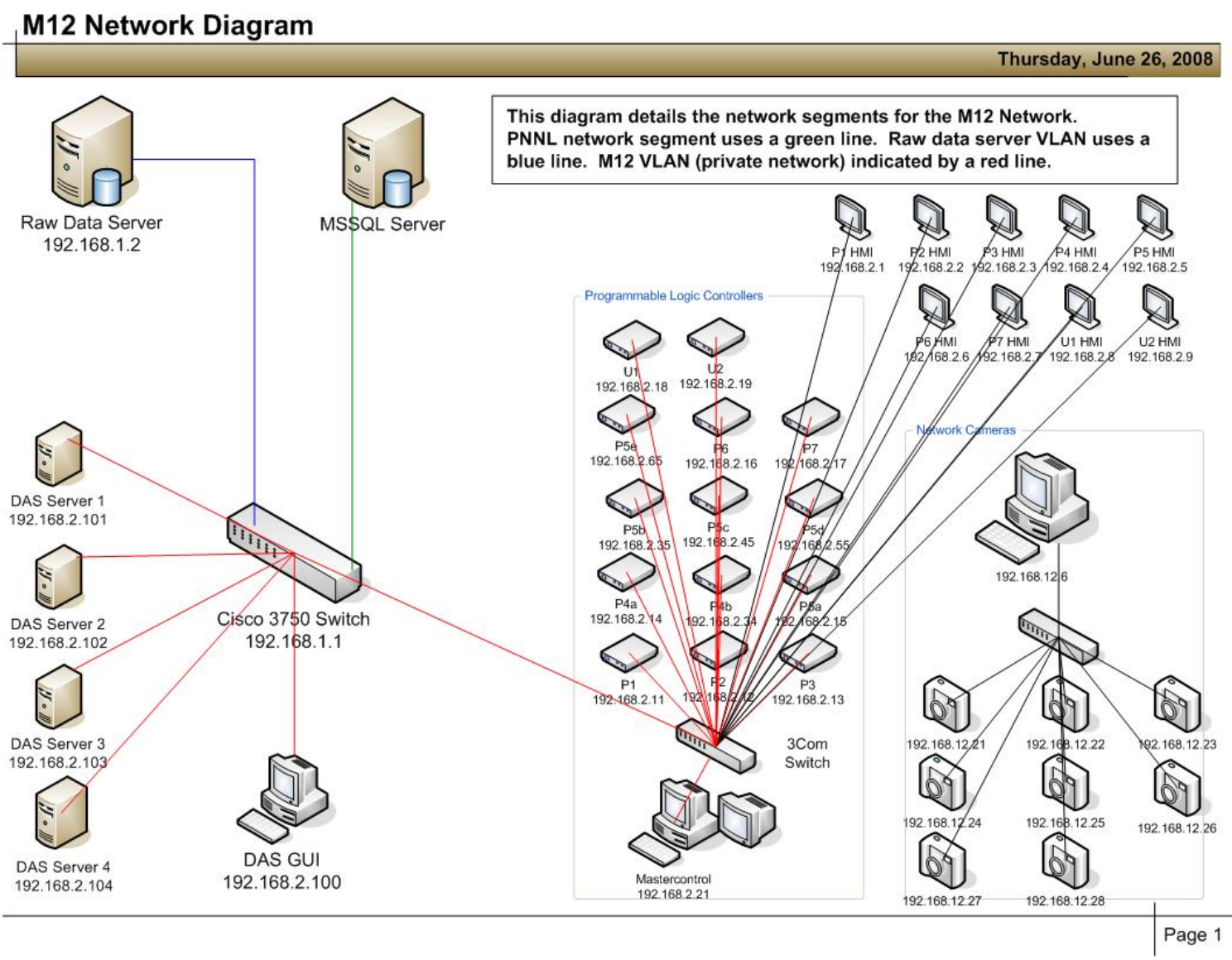

The GUI PC resides in the control room and is used to start and stop the data acquisition servers and set the recording rate. Each server that is located out in the high bay is independent of the others while collecting data. A global positioning system (GPS) receiver is used to provide a time stamp to each DAS server.

\section{E.1 Background}

The PEP data acquisition and control system was designed to be very robust and flexible in operation. While the same sensors are used for controlling the PEP and recording data, the sensor outputs are split into two loops to make certain that the data acquisition system is completely separate from the control system. This requirement was put into the system to allow changes to the control system of the PEP to be performed without the rigorous Verification and Validation process that is required of any quality-affecting software program. This allowed many changes to the control system to be made during operation of the PEP system without affecting the quality of the data. The data acquisition system and all 
related software did undergo PNNL software control procedures to make certain that the data meet quality standards.

From each signal splitter, one loop went to the control system and the other went to the data acquisition system. 4-20ma outputs from all sensors were selected to confirm the reliability of the system and prevent long cable runs from introducing error in the signals. The data acquisition servers are manufactured by Microstar Laboratories, located in Bellevue, WA. Each server is capable of storing a large number of channels at a high sampling rate. For PEP, they have been set to a maximum sampling rate of $100 \mathrm{~Hz}$. Each server stores its information in a file local to that server. After data was collected, it was transferred to the raw data server and to the database server for analysis.

\section{E.2 Data Retrieval}

During operations of the PEP during Shakedown and Phase 1 testing, over a terabyte of data was recorded by the four data acquisition servers. That data is stored in binary files that are not human readable. Software was developed to provide analysts with an easy tool to retrieve the data they required by specifying the date/time, instruments, and sampling rate. This tool is comprised of three main components. The data ingest server, the database itself, and the data retrieval tool. The data ingest server watches a specified directory on the database server and when new files are put there it uploads the data from that location into the database and transfers those data files into a directory where processed files are stored. The database itself utilizes Microsoft's SQL server as a basis for the large database that stores all data and sensor information for the PEP. Finally, the data retrieval tool is a web based application that allows staff to recover the data they need by specifying the time/date, instruments, and sampling rate necessary. The software produces a text file that can easily be imported into Excel or any other analysis package. This method provides a data file that meets quality standards for the PEP project.

Another method for retrieving data was commonly referred to the DAS widget. This tool is a simple application that allows a user with detailed knowledge of the system to retrieve data if they don't have access to the web based tool, or if they need access to the data before the data has been imported into the database. This tool did not go through the software control procedure and does not provide data that meets quality standards for PEP. It will read a file from one server and produce a file with all the raw (ma) values from every instrument on that server. With that data, and the information in the M\&TE (Measurement and Test Equipment) list, staff can retrieve the data from all sensors in engineering units. It is more time consuming to retrieve data in this manner, but it allows data to be read in near real-time. This method was commonly used to provide near real-time data for PJM tuning.

\section{E.3 Data Storage}

All data recorded during operation of the PEP was first copied to the raw data server in PDL-W and then copied to the database server in LSB. This procedure is detailed in the data management plan and provides redundant storage of all data to make certain that data are not lost. 
Appendix F Evaluation of PJM Peak Average Velocity 



\section{Appendix F: Evaluation of PJM Peak Average Velocity}

\section{F.1 Introduction}

A number of Microsoft Excel macros were developed in the Visual Basic language to evaluate the peak average velocity and average PJM stroke length. The definitions of the peak average velocity and stroke length and the background theory of evaluating these quantities are given in Section F.2. In Section F.3, the Excel macros developed to evaluate the peak average velocity and stroke length, and their implementation procedures are described. Finally, the loss coefficients used for the nozzle velocity evaluation from the PJM tube pressures are presented in Section F.4.

\section{F.2 Background Theory}

This section defines the peak average velocity and stroke length, and describes the methods used to evaluate these quantities.

\section{F.2.1 Definitions of Peak Average Velocity and Stroke Length}

In the PJM operation, steady periodic variation in PJM tube pressure drives flow through the PJM nozzle, which results in cyclic vertical motion of the liquid level in the PJM tube and the PJM tank. Typical nozzle velocity and PJM tube level profiles as a function of time for a complete operating cycle are shown in Figure F.1 and Figure F.2, respectively.

From Figure F.1, the peak average time $t_{\text {peak }}$ and the discharge time $t_{\text {disch arge }}$ are defined as:

$$
\begin{gathered}
t_{\text {peak }}=t_{\text {end }}-t_{\max } \\
t_{\text {discharge }}=t_{\text {end }}-t_{o}
\end{gathered}
$$

where $t_{o}$ is the start of pressurization (start of Drive Cycle), $t_{\text {end }}$ is the end of pressurization (nozzle velocity begins to decrease rapidly), and $t_{\max }$ is the time at maximum discharge.

The peak average velocity $\bar{U}_{\text {peak }}$ for the discharge process is defined as:

$$
\bar{U}_{\text {peak }}=\frac{1}{t_{\text {peak }}} \int_{t_{\max }}^{t_{\text {end }}} U(t) d t
$$

where $U(t)$ is the nozzle velocity. 


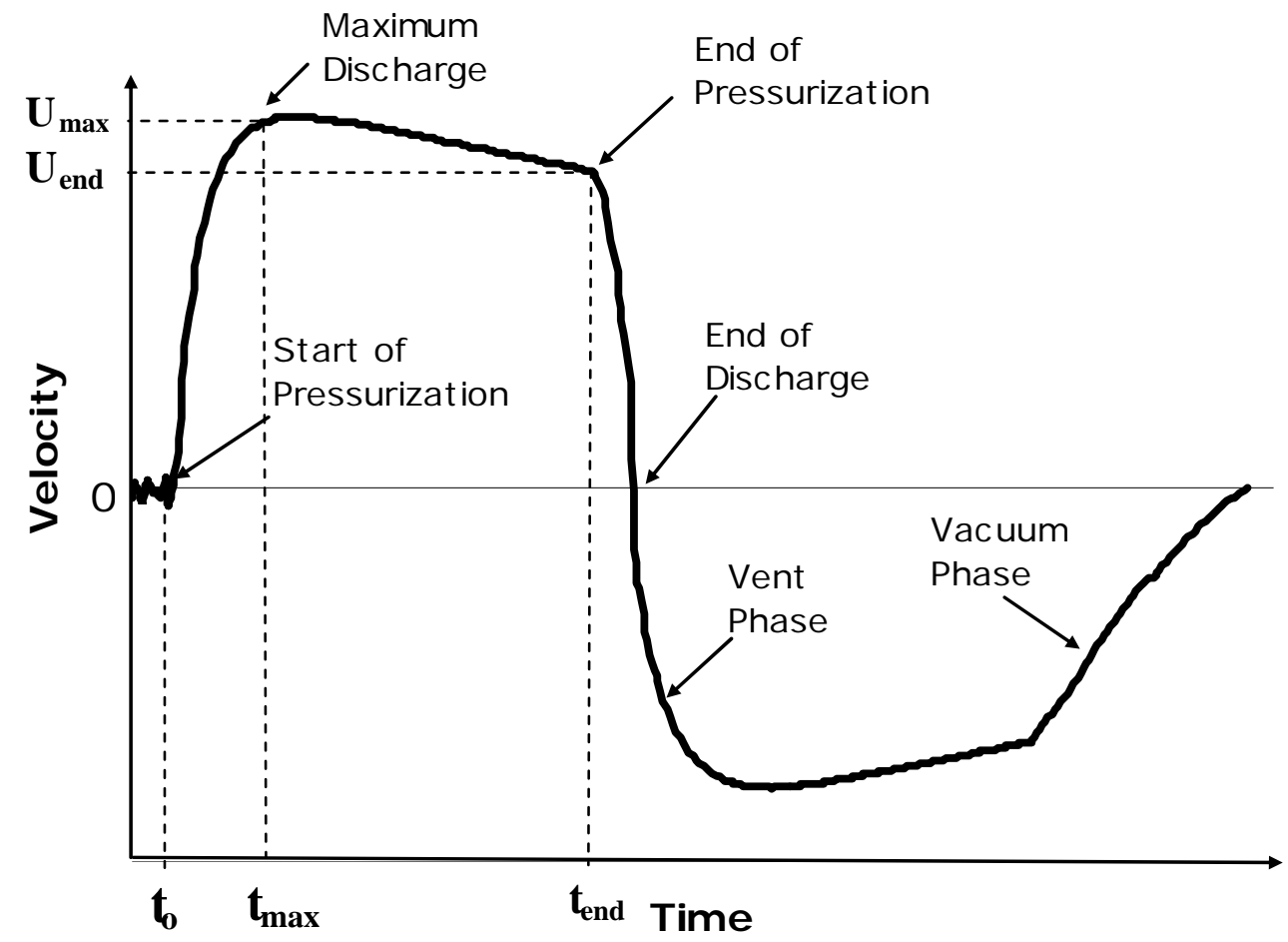

Figure F.1. Typical Nozzle Velocity Time Distribution

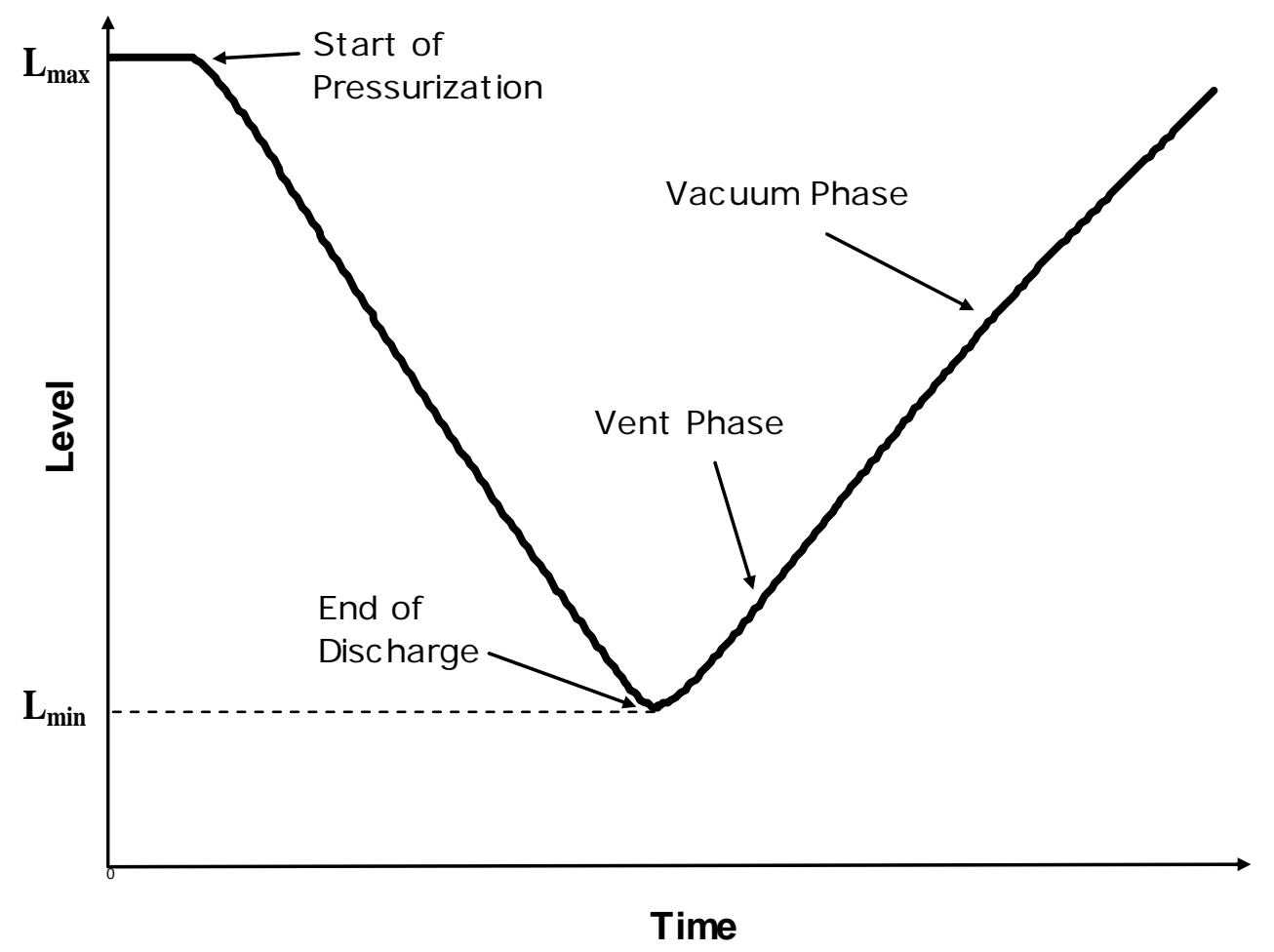

Figure F.2. Typical PJM Tube Level Time Distribution 
The nozzle velocity $U(t)$ is evaluated from the measured PJM tube liquid level and the PJM tank level, and the PJM tube pressure. Calculation of the nozzle velocity $U(t)$ is described in Section F.3 in detail. The Trapezoidal rule is used for the numerical integration of Equation (F.3).

From Figure F.2, the PJM tube stroke length $L_{S T R}$ is defined as:

$$
L_{S T R}=L_{\max }-L_{\min }
$$

where $L_{\max }$ is the PJM tube level at start of pressurization, and $L_{\min }$ is the PJM tube level at the end of discharge.

Along with Equation (F.4), the PJM tube stroke length percentage $L_{S T R P}$ is defined as:

$$
L_{\text {STRP }}=\frac{L_{S T R} \cdot A_{\text {tube }}}{V}
$$

where $A_{\text {tube }}$ is the PJM tube cross-sectional area, and $V$ is the PJM tube volume. Namely, the PJM tube

stroke length percentage $L_{\text {STRP }}$ is defined as the ratio of the volume of the PJM liquid displacement to the entire PJM tube volume.

\section{F.3 Methods}

The methods used to evaluate the nozzle velocity $U(t)$ from the level and pressure data are described in this section.

\section{F.3.1 Nozzle Velocity Evaluation from PJM Tube and Tank Liquid Level Data}

Significantly large fluctuations were contained in the level data measured for the PJM tubes and the PJM tanks, due to the hydrodynamics of the mixing operation. To smooth out these fluctuations and capture the effective level motion in an operating cycle, the level measurements were averaged. The measured level data was averaged over multiple sequential sampling cycles (typically 10 cycles) to obtain the average cyclic level distribution for each tube, or for the PJM tank. In addition, the averages for each PJM tube were combined to obtain the average cyclic level distribution for all of the PJM tubes. Prior to the data averaging, the PJM tank level data were filtered to remove the outliers.

For the case in which averaging was insufficient to remove fluctuations, the averaged liquid level distribution was further smoothed by applying the $6^{\text {th }}$ power binomial coefficients $(1,6,15,20,15,6,1) / 64$ for smoothing of the interior data points, the $3^{\text {rd }}$ power binomial coefficients $(1,4,6,4,1) / 16$ for smoothing at the $3^{\text {rd }}$ exterior data point, the $2^{\text {nd }}$ power binomial coefficients $(1,2,1) / 4$ for smoothing at the $2^{\text {nd }}$ exterior data point.

The averaged liquid surface levels with or without smoothing were used to evaluate the nozzle velocity $U$ as: 


$$
U=\left(\frac{A}{A_{n}}\right) \frac{d L}{d t}
$$

where

$$
\begin{aligned}
A A^{L} & =\text { averaged liquid level } \\
A_{n} & =\text { area ratio } \\
A & =\text { area of the PJM tube or the PJM tank liquid surface } \\
A_{n} & =\text { area of the PJM nozzle. }
\end{aligned}
$$

The finite central difference method is used to evaluate $\frac{d L}{d t}$.

\section{F.3.2 Nozzle Velocity Evaluation from Tube Pressure Data}

The average of the PJM tube pressure data was taken prior to the nozzle velocity evaluation, using the same approach as described above for averaging of the level measurements. The averaged cyclic distribution in pressure was used to evaluate the nozzle velocity by applying the Bernoulli equation with the pressure loss effect taken into account.

The Bernoulli's equation taking account of the pressure loss coefficient is given as:

$$
P_{t}+\rho g\left(L_{i n i}-x-H\right)-P_{H S P}=\frac{1}{2} \rho\left[\left(1+k_{f}\right)\left(\frac{R}{R_{n}}\right)^{4}-1\right] \dot{x}^{2}
$$

where $\quad \dot{x}=$ liquid velocity in the PJM tube

$x=$ length of the displaced liquid inside the PJM tube

$P_{t}=$ averaged PJM tube pressure

$P_{H S P}=$ headspace pressure of the PJM tank

$L_{\text {ini }}=$ initial liquid level height inside the PJM tube

$H=$ liquid level height inside the tank

$\rho=$ liquid density

$g=$ gravitational acceleration $9.81\left(\mathrm{~m} / \mathrm{s}^{2}\right)$

$k_{f}=$ empirically determined loss coefficient

$R=$ PJM tube radius

$R_{n}=$ nozzle radius.

The coefficient $\left(\frac{R}{R_{n}}\right)^{2}$ in Equation (F.7) is exactly equivalent to the area ratio defined in

Equation (F.6) for the ratio of the pulse tube area to the pulse tube nozzle area. The parameters $x, P_{t}$, $P_{H S P}, L_{i n i}$, and $H$ used for Equation (F.7) are illustrated in the schematic diagram of Figure F.3. 
Along with Equation (F.7), the nozzle velocity $U$, the length of the displaced liquid $x$, the liquid level height of the tank $H$ are evaluated as:

$$
\begin{gathered}
U=\left(\frac{R}{R_{n}}\right)^{2} \dot{x} \\
x=x_{\text {old }}+\Delta t \dot{x} \\
H=H_{\text {ini }}+\left(\frac{A_{P L}}{A_{T L}}\right) x
\end{gathered}
$$

where $\Delta t=$ sampling time

$x_{\text {old }}=$ length of the displaced liquid at the previous pressure measurement time

$H_{i n i}=$ initial tank liquid level height

$A_{P L}=$ total liquid surface area of all of the PJM tubes

$A_{T L} \quad$ tank liquid surface area.

In order to solve Equation (F.7) numerically, the initial liquid level height inside the PJM tube $L_{i n i}$ is needed as a starting point. This can be determined by imposing the zero initial velocity condition for the given initial tank liquid level height $H_{i n i}$ as:

$$
L_{i n i}=\left(\frac{P_{H S P}-P_{t i}}{\rho g}\right)+H_{i n i}
$$

where $P_{t i}$ is the averaged PJM tube pressure at the pressurization start point of the PJM pressure cycle process (see Figure F.1). 


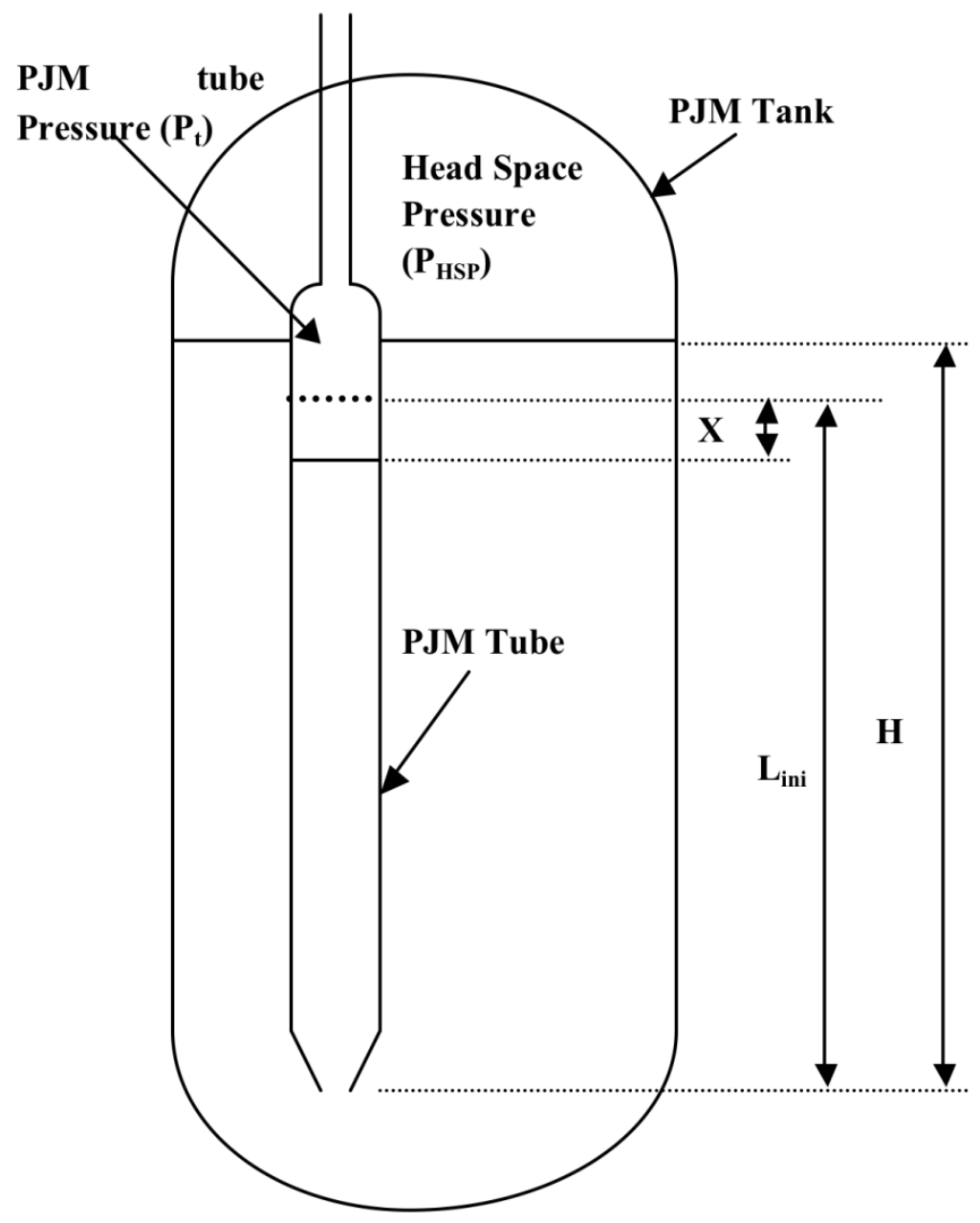

Figure F.3. Schematic of PJM Tank and Tube

The loss coefficients were obtained by iterating to a 'best fit' of the nozzle velocity distribution evaluated by applying Equation (F.7) through Equation (F.11), compared to the distribution determined from the tank level data measured by a laser anemometer.

\subsection{Loss Coefficient Evaluations}

In order to evaluate the nozzle velocity time distribution from the PJM pressure data with Equation (F.7) through Equation (F.11), the empirically determined loss coefficients were needed. The loss coefficients were obtained by iterating to a 'best fit' of the nozzle velocity distribution evaluated from the pressure data, compared to the distribution determined from the tank level data measured by a laser anemometer.

This section presents the loss coefficients evaluated in the RPP-WTP PEP testing in Table F.1. The plots used for the evaluations of the loss coefficients are given in Figure F.4 through Figure F.7. 
Table F.1. Loss Coefficients Evaluated

\begin{tabular}{cccc}
\hline Tank & $\begin{array}{c}\text { Loss Coefficient for } \\
\text { Forward Flow }\end{array}$ & $\begin{array}{c}\text { Loss Coefficient for } \\
\text { Backward Flow }\end{array}$ & $\begin{array}{c}\text { Target Velocity } \\
(\mathrm{m} / \mathrm{s})\end{array}$ \\
\hline UFP-VSL-T01A & 0.25 & 1.2 & 4.8 \\
UFP-VSL-T01B & 0.38 & 1.3 & 4.8 \\
UFP-VSL-T02A & 0.34 & 0.1 & 7.3 \\
UFP-VSL-T02A & 0.1 & 0.1 & 12 \\
\hline
\end{tabular}

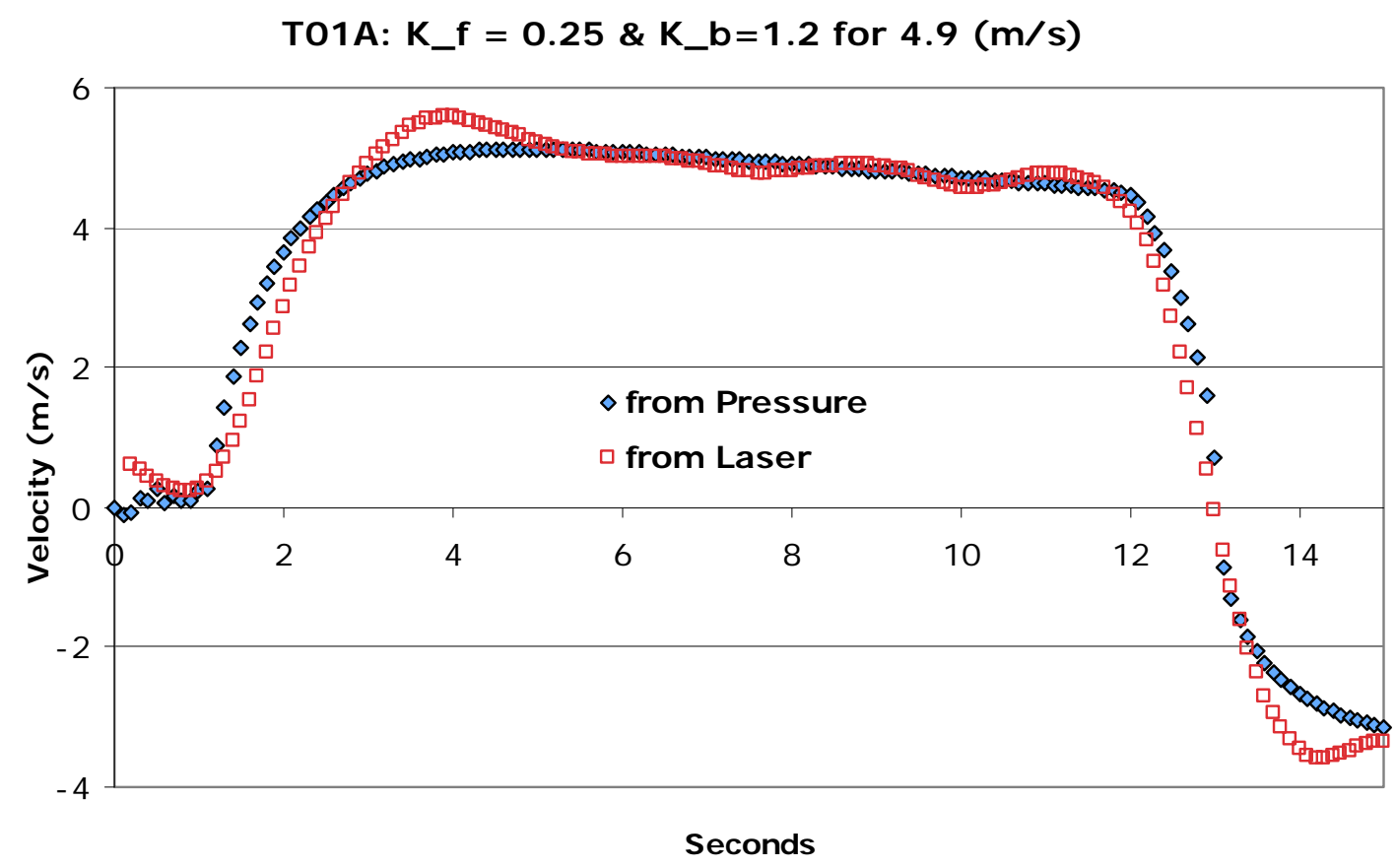

Figure F.4. Nozzle Velocity Distributions Used to Evaluate the Loss Coefficients for UFP-VSL-T01A Tank at the Peak Average Velocity of $4.9(\mathrm{~m} / \mathrm{s}) ; \mathrm{k}_{-} \mathrm{f}=0.25$ is the loss coefficient of the forward flow, and $\mathrm{k} \_\mathrm{b}=1.2$ is the loss coefficient of the backward flow. 
T01B: $K_{-} f=0.38$ and $K_{-} b=1.3$ for $4.9(\mathrm{~m} / \mathrm{s})$

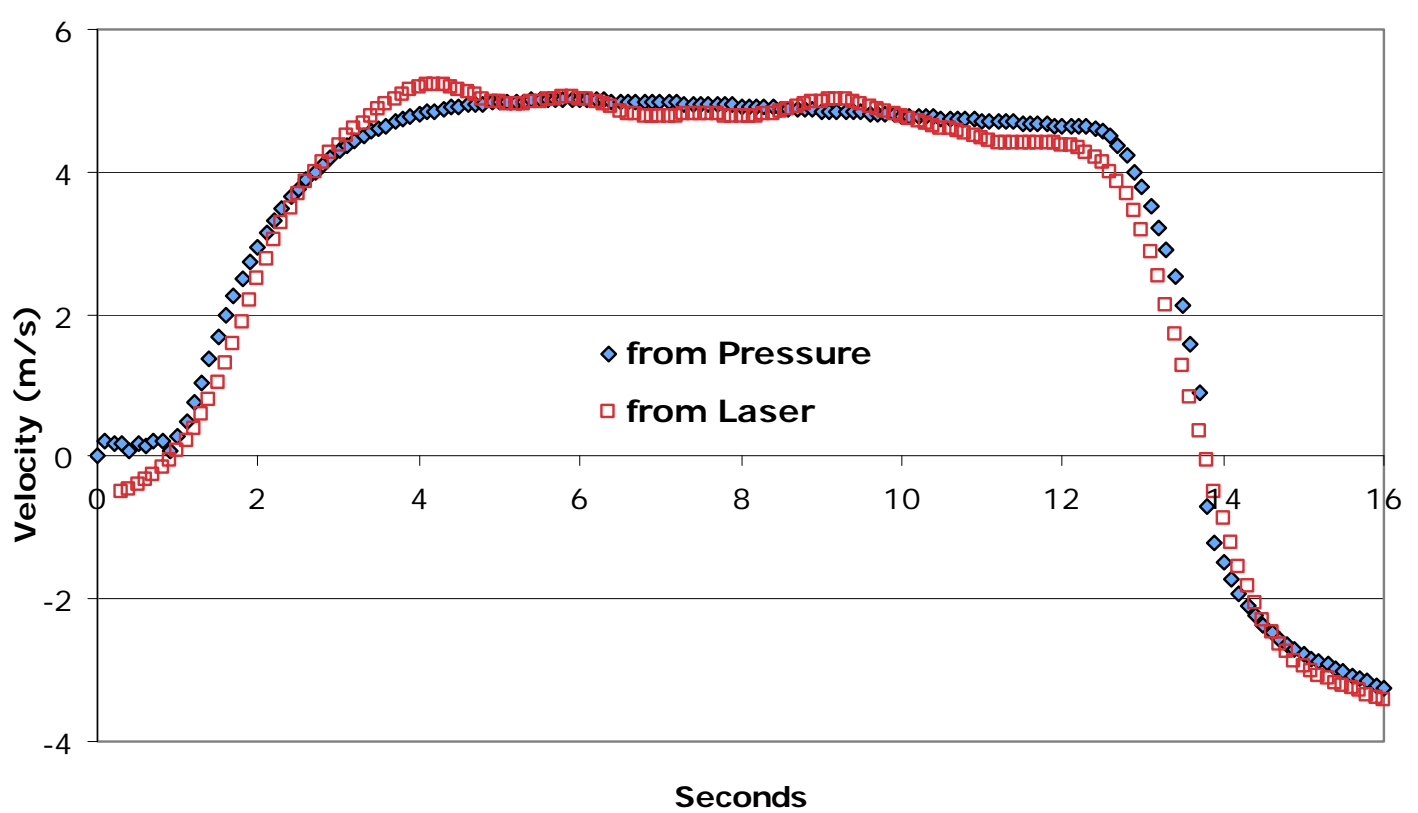

Figure F.5. Nozzle Velocity Distributions Used to Evaluate the Loss Coefficients for UFP-VSL-T01B Tank at the Peak Average Velocity of $4.9(\mathrm{~m} / \mathrm{s}) ; \mathrm{k} \_\mathrm{f}=0.38$ is the loss coefficient of the forward flow, and $\mathrm{k} \_\mathrm{b}=1.3$ is the loss coefficient of the backward flow. 


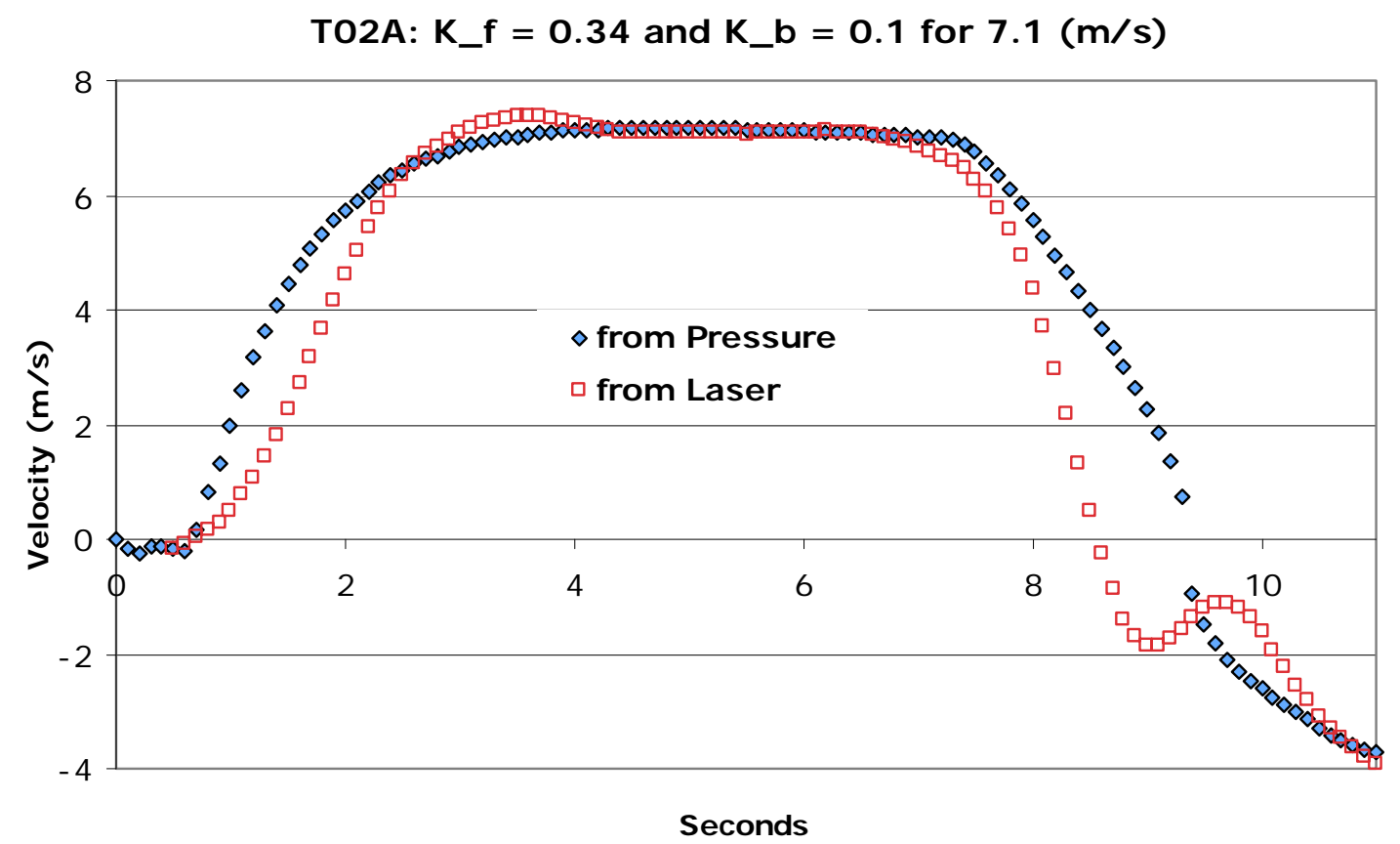

Figure F.6. Nozzle Velocity Distributions Used to Evaluate the Loss Coefficients for UFP-VSL-T02A Tank at the Peak Average Velocity of $7.1(\mathrm{~m} / \mathrm{s}) ; \mathrm{k}_{-} \mathrm{f}=0.34$ is the loss coefficient of the forward flow, and $\mathrm{k} \_\mathrm{b}=0.1$ is the loss coefficient of the backward flow.

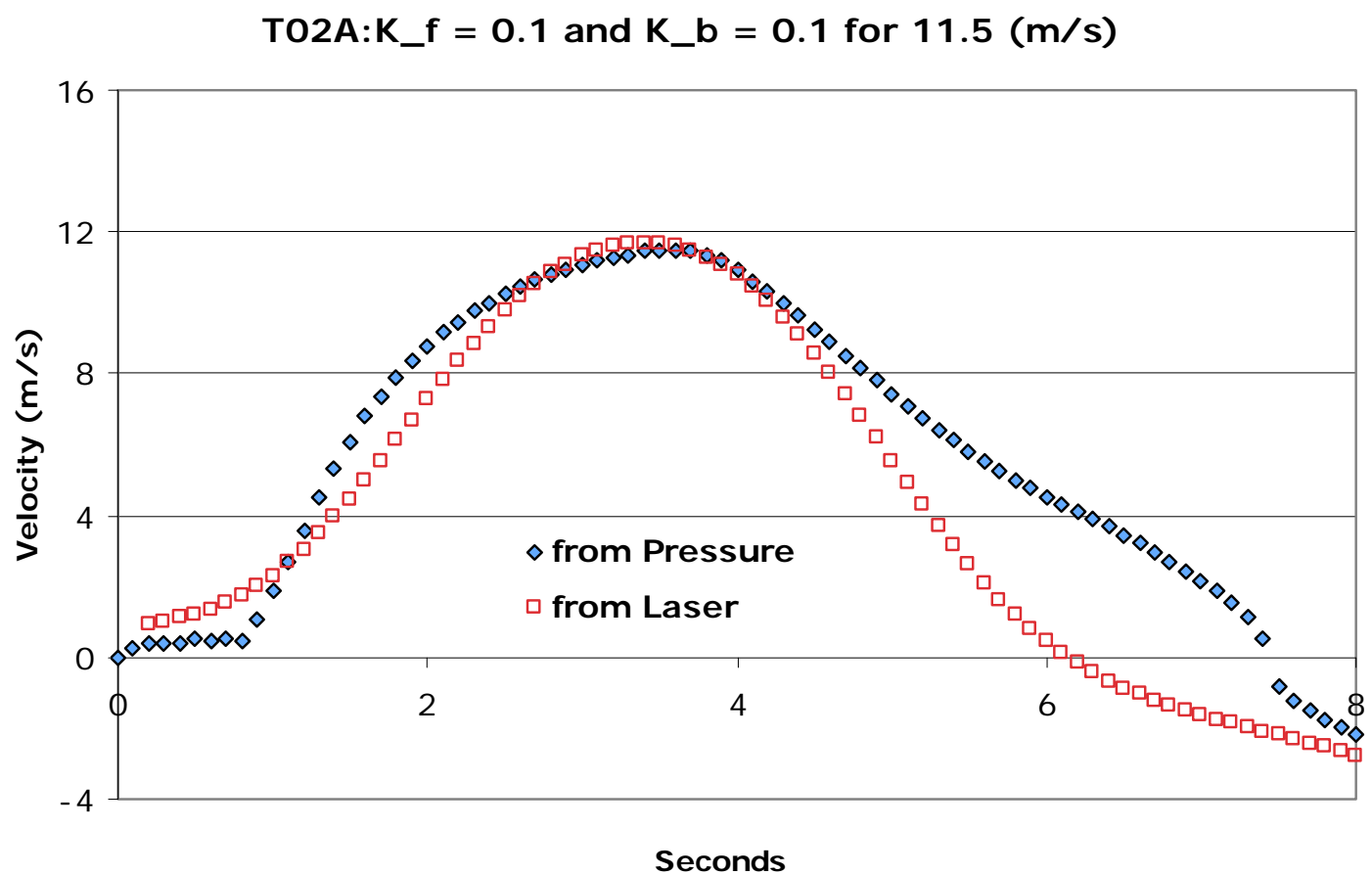

Figure F.7. Nozzle Velocity Distributions Used to Evaluate the Loss Coefficients for UFP-VSL-T02A Tank at the Peak Average Velocity of $11.5(\mathrm{~m} / \mathrm{s}) ; \mathrm{k}_{-} \mathrm{f}=0.1$ is the loss coefficient of the forward flow, and $k_{-} b=0.1$ is the loss coefficient of the backward flow. 

Appendix G

Index of Videos 



\section{Appendix G: Index of Videos}

\begin{tabular}{|c|c|c|c|c|c|}
\hline I.D. & Title & $\begin{array}{c}\text { Date } \\
\text { Recorded }\end{array}$ & Highlight & $\begin{array}{l}\text { Length } \\
\text { (h:mm) }\end{array}$ & Note \\
\hline 12 & Filter 1 Inlet Inspection & $4 / 15 / 2009$ & Filter 1 inlet & $0: 30$ & Ignore Titles $1 \& 2$ \\
\hline \multirow[t]{2}{*}{13} & T02A Tank Inspection & $4 / 23 / 2009$ & $\begin{array}{l}\text { PJMs, steam ring } \\
\text { nozzles, welding } \\
\text { spots, dome }\end{array}$ & $1: 13$ & Ignore Title 1 \\
\hline & T01A Tank Inspection & $4 / 23 / 2009$ & $\begin{array}{l}\text { PJMs, steam ring } \\
\text { nozzles, welding } \\
\text { spots, dome }\end{array}$ & $0: 16$ & $\begin{array}{l}\text { Recorded on DVD } \\
\text { Recorder }\end{array}$ \\
\hline 14 & $\begin{array}{l}\text { T02A Inspection after } \\
\text { Acid Leaching }\end{array}$ & $5 / 1 / 2009$ & $\begin{array}{l}\text { PJMs, steam ring } \\
\text { nozzles, welding } \\
\text { spots, dome }\end{array}$ & $0: 15$ & Ignore Title 1 \\
\hline 15 & $\begin{array}{l}\text { T01A Inspection after } \\
\text { Hot Water Flush }\end{array}$ & $5 / 18 / 2009$ & $\begin{array}{l}\text { PJMs, steam ring } \\
\text { nozzles, welding } \\
\text { spots, dome }\end{array}$ & $0: 22$ & $\begin{array}{l}\text { Recorded on DVD } \\
\text { Recorder }\end{array}$ \\
\hline 16 & T01A PJM Inspection & $5 / 19 / 2009$ & PJMs and others & $0: 20$ & $\begin{array}{l}\text { Recorded on DVD } \\
\text { Recorder }\end{array}$ \\
\hline 17 & $\begin{array}{l}\text { T02A Oxidative } \\
\text { Leaching per TI-032 }\end{array}$ & $1 / 9 / 2009$ & & & $\begin{array}{l}\text { Transferred from } \\
\text { VHS tape }\end{array}$ \\
\hline
\end{tabular}



Appendix $\mathrm{H}$

\section{Pump Operating Guidance}





\section{Appendix H: Pump Operating Guidance}

1) Initial Pump Startup.

a. Ensure that seal pot pressures are within spec.

b. START pump T42A in MANUAL at $25 \%$.

c. If not already positioned, POSITION flow control valve 0609 to $50 \%$ OPEN.

d. Allow system parameters to stabilize for one minute or when flow rates and pressures appear stable, whichever is longer.

e. START pump T43A in MANUAL at $25 \%$.

f. Increase pump T43A speed in $10 \%$ increments, waiting one minute before each increase, until the target flow rate is achieved.

g. MONITOR system pressures, ensure that PT-0625 is not lower than -200 inches water, PT-0633 is positive, and filter pressures are within spec.

h. If pump T43A speed is at $95 \%$ and desired flow rate has NOT been achieved, INCREASE pump T42A speed in 5\% increments and DECREASE pump T43A to obtain desired flow rate.

i. If desired flow rate is not achieved, OPEN flow control valve $06095 \%$, do not exceed $60 \%$ OPEN.

j. MONITOR system pressures, ensure that PT-0625 is not lower than -200 inches water, PT-0633 is positive, and filter pressures are within spec.

k. If desired flow rate is not achieved, repeat previous three steps.

2) MONITOR and MAINTAIN system flow rate during testing.

a. Monitor system flow rates and pressures for oscillations or erratic behavior. If unstable or erratic system performance is observed restore stable operation by performing the following in order of preference from most preferred to least preferred:

i. Reduce sources of air entrainment.

ii. Reduce flow rate by closing flow control valve and reducing pump speed in alternating 5\% increments until lowest acceptable flow rate is reached.

iii. Increase level in Tank T02A to highest acceptable level.

3) Pump SHUT DOWN.
a. Turn pump T43A OFF.
b. Adjust pump T42A to $25 \%$ speed.
c. CLOSE flow control valve 0609.
d. Turn pump T42A OFF. 



\section{Appendix I}

T02A Systems Operations Guidance for Integrated Test D 



\section{Appendix I: T02A Systems Operations Guidance for Integrated Test D}

\section{I.1 T02A Systems Operations Guidance}

In the event that filter-loop flow rates can not be maintained at the targeted $109 \pm 10$ gpm using the pump-control guidance and there is evidence that there is significant entrained air in the slurry, the following actions are to be taken.

\section{I.1.1 T02A Systems Guidance}

1. Turn level bubbler off.

2. Turn steam ring air purge off.

3. Allow 30 minutes to determine if the T02A recirculation system recovers the desired flow rate. If flow is recovered, proceed with testing.

4. If flow does not recover, implement the initial degassing protocol listed below.

5. If flow recovers, proceed with testing.

6. If flow does not recover, turn off lower air spargers.

7. Allow 30 minutes to see if the system recovers flow. If flow is recovered, proceed with testing.

8. If flow does not recover, implement initial degassing protocol.

9. If flow recovers, proceed with testing.

10. If flow does not recover contact the on-call Test Director.

11. Perform the extended degassing protocol listed below as needed to fully degas the system.

12. Reinitiate testing.

13. If flow rates can not be maintained at the targeted $109 \pm 10$ gpm perform the initial degassing protocol.

14. If flow does not recover, reduce the filter recirculation flow to $88 \pm 10 \mathrm{gpm}$ filter-loop flow rate (gives $\sim 12 \mathrm{ft} / \mathrm{s}$ axial velocity in the filter tubes).

15. If $88 \mathrm{gpm}$ can not be maintained perform the extended degassing protocol as needed to fully degas T02A.

16. Reinitiate testing with the filter recirculation loop flow rate reduced to $67 \pm 10$ gpm filter-loop flow rate (gives $\sim 9 \mathrm{ft} / \mathrm{s}$ axial velocity in the filter tubes and power/volume scaled mixing from the return nozzle jet).

17. If none of these actions are successful, begin raising the T02A level by diluting with IW. Raise the tank level in 2 inch increments, allowing at least 30 minutes between IW additions.

$\underline{\text { Initial degassing protocol }}$

1. Turn off filter-loop pumps.

2. Take a stable level measurement.

3. Adjust lower air sparge flow rate to normal full flow $(0.40 \mathrm{~kg} / \mathrm{min}, \sim 2.4 \mathrm{scfm} / \mathrm{tube})$ and turn on PJMs.

4. Allow this configuration to run for $50 \mathrm{~min}$.

5. Turn off spargers and PJMs.

6. Wait for $10 \mathrm{~min}$.

7. Take a stable level measurement. 
8. Turn pumps on and attempt to achieve target filter-loop flow rate.

9. Restore T02A mixing systems per the stage of the T02A systems operating guidance above where the initial degassing process was referenced.

\section{Extended degassing protocol}

1. Turn off filter-loop pumps and take a stable level measurement.

2. Adjust lower air sparge flow rate to normal full flow $(0.40 \mathrm{~kg} / \mathrm{min}, \sim 2.4 \mathrm{scfm} / \mathrm{tube})$ and turn on PJMs.

3. Allow this configuration to run for 4.5 hours.

4. Turn off spargers and PJMs.

5. Wait for 20 minutes.

6. Operate the filter loop pumps for 10 minutes.

7. Take a stable level measurement.

8. Repeat steps 2 through 7 as needed to degas T02A as determined by prior degassed level readings or by less than $5 \%$ gas volume holdup measured by centrifuging a slurry sample.

9. Turn pumps on and attempt to achieve target filter-loop flow rate.

10. Restore T02A mixing systems per the T02A systems operating guidance above.

\section{Pumps 042A and 043A Operating Guidance}

Operate both pumps in the manual mode. Pump T43A is to be the more heavily loaded of the two pumps. The overall objective is smooth operation and steady flow rates. A trend that provides the flow rates (FT-0623 and FT-0635), system pressures (PT-0625, PT-0633, and PT-0739) and horsepower of both pumps is recommended.

Some speed settings cause the system to vibrate or resonate. Adjust the manual pump speed of T42A or T43A as needed to find an improved operating point as supported by the data from the trend, but maintain the flow rate required by the test objectives.

\section{$\underline{\text { Filter-loop pump general guidance }}$}

1. As pumps are started and ramped up, the filter pressures (transmembrane and axial) need to be watched and maintained within specifications ( $<75$ psig TMP and $<25$ psig axial).

2. Keep T42A suction pressure (PT-0625) at an absolute pressure above -200 inches of water.

3. Pressure at PT-633 should always be greater than 0 psig.

4. OPENING the flow control valve 0609 will ALWAYS make the suction pressure (PT-0625) go down.

5. When system pressures are varying wildly while pump speeds appear stable, there is air in the system.

6. These pumps can handle 5-10\% entrained air--they will rumble, but the air won't hurt the pump--they will just make noise and system pressures may be unstable.

\section{$\underline{\text { Initial Pump Startup }}$}

1. Ensure that seal pot pressures are within specifications $(225+25 \mathrm{psig})$.

2. If not already positioned, POSITION flow control valve 0609 to $50 \%$ OPEN.

3. START pump T42A in MANUAL at $25 \%$. 
4. After any adjustment WAIT for system parameters to stabilize for at least one minute AND flow rates and pressures appear stable and TMP is $<60$ psi.

5. START pump T43A in MANUAL at $25 \%$.

6. INCREASE pump T43A speed in $10 \%$ increments, waiting at least one minute and assuring that TMP is $<60$ psi before each increase, until the target flow rate is achieved.

7. MONITOR system pressures:

a. PT-0633 should remain POSITIVE. Increase T42A in 5\% increments if PT-0633 drops below 0 .

b. PT-0789 should not be much higher than necessary to maintain the target TMP (e.g., usually $50-60$ psig is adequate). If PT-0789 is $>10$ psi higher than needed, gradually OPEN XV-0689.

8. If pump T43A speed is at $95 \%$ and desired flow rate has NOT been achieved, INCREASE pump T42A speed in 5\% increments.

9. If the final $5 \%$ change on T42A raises the flow above the target DECREASE T43A in 1\% increments to obtain desired flow rate. Wait at least 1 minute before making additional changes to judge the full affect of the current change.

10. Repeat steps 8) and 9) as necessary to obtain both flow and pressure targets. If any setting on T42A or T43A creates a noisy resonance move away from that condition and adjust the other pump accordingly.

\section{T02A PJM Operations Guidance at Low Tank Levels}

Should a PJM over blow be detected, or suspected, shut down the filter recirculation pumps until stable PJM operation is restored. Also, secure these pumps during any PJM 'tuning' operations. Note: collect a $10 \mathrm{~Hz}$ PJM data set for a period of at least 25 PJM cycles following any PJM adjustments to enable PJM parameter calculation.

\section{$\underline{\text { PJM Operations }}$}

1. Operate at nominally $80 \%$ stroke as listed in the Run Sheet at T02A levels above 20 inches.

2. When the operating level drops to the 20 inch slurry level in T02A (as measured when all PJMs are full) ENABLE the "Star" pattern on the Standard PJM control. When the "Star" switch is enabled only the center and one other PJM will be operated in a rotating pattern.

a. Operate the center (1811) and 1801 PJMs at 80\% stroke.

b. After 4-5 PJM strokes operate PJMs 1811 and 1803 at $80 \%$ stroke.

c. After 4-5 PJM strokes operate PJMs 1811 and 1805 at 80\% stroke.

d. After 4-5 PJM strokes operate PJMs 1811 and 1807 at 80\% stroke.

e. After 4-5 PJM strokes operate PJMs 1811 and 1809 at 80\% stroke.

3. Cease all PJM operation at levels at 13 " or below. 



\section{Appendix J}

\section{Integrated Test D Data Plots}





\title{
Appendix J: Integrated Test D Data Plots
}

\author{
03/22/09 00:00-03/22/09 12:00
}
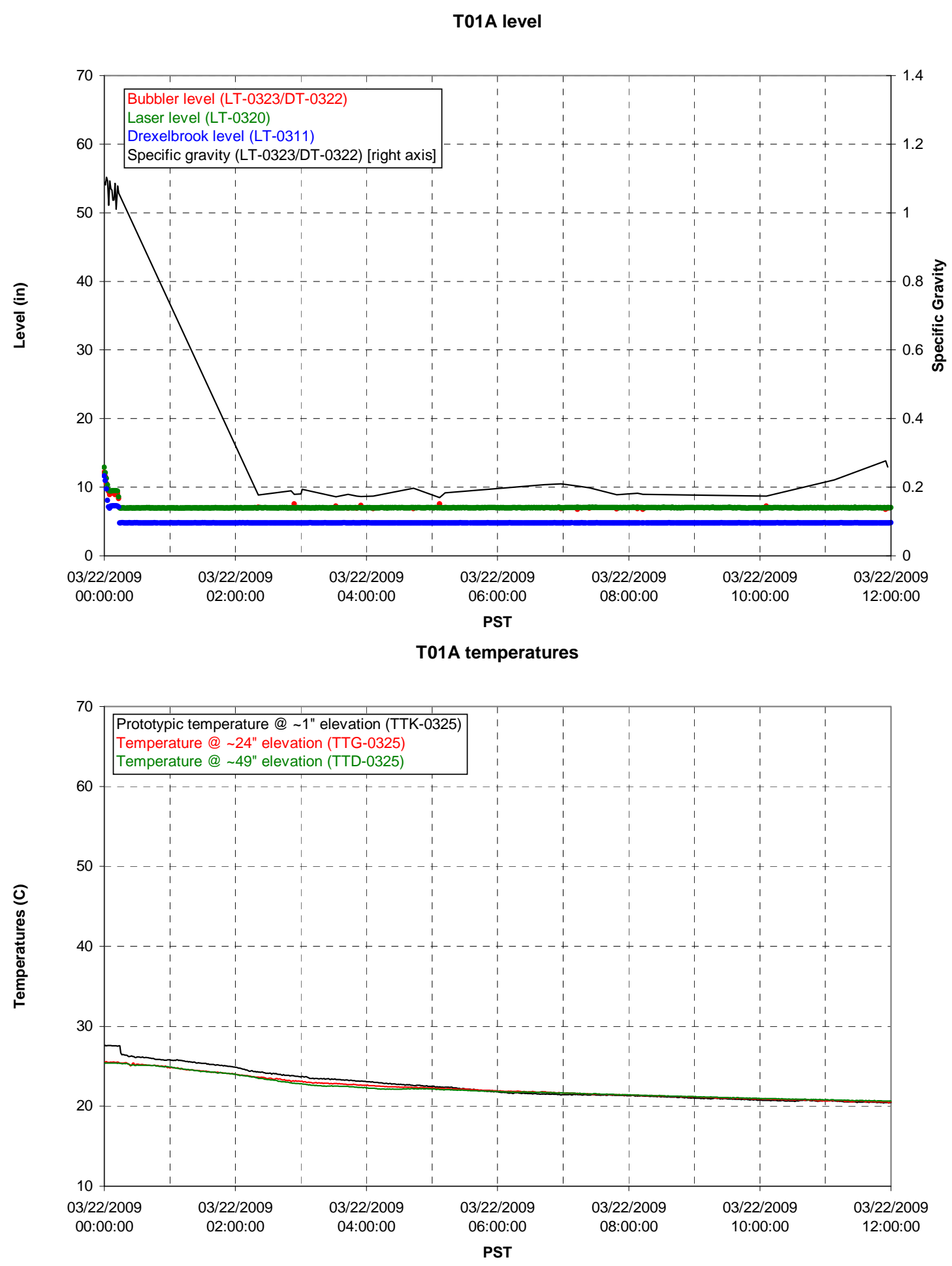
T01B level

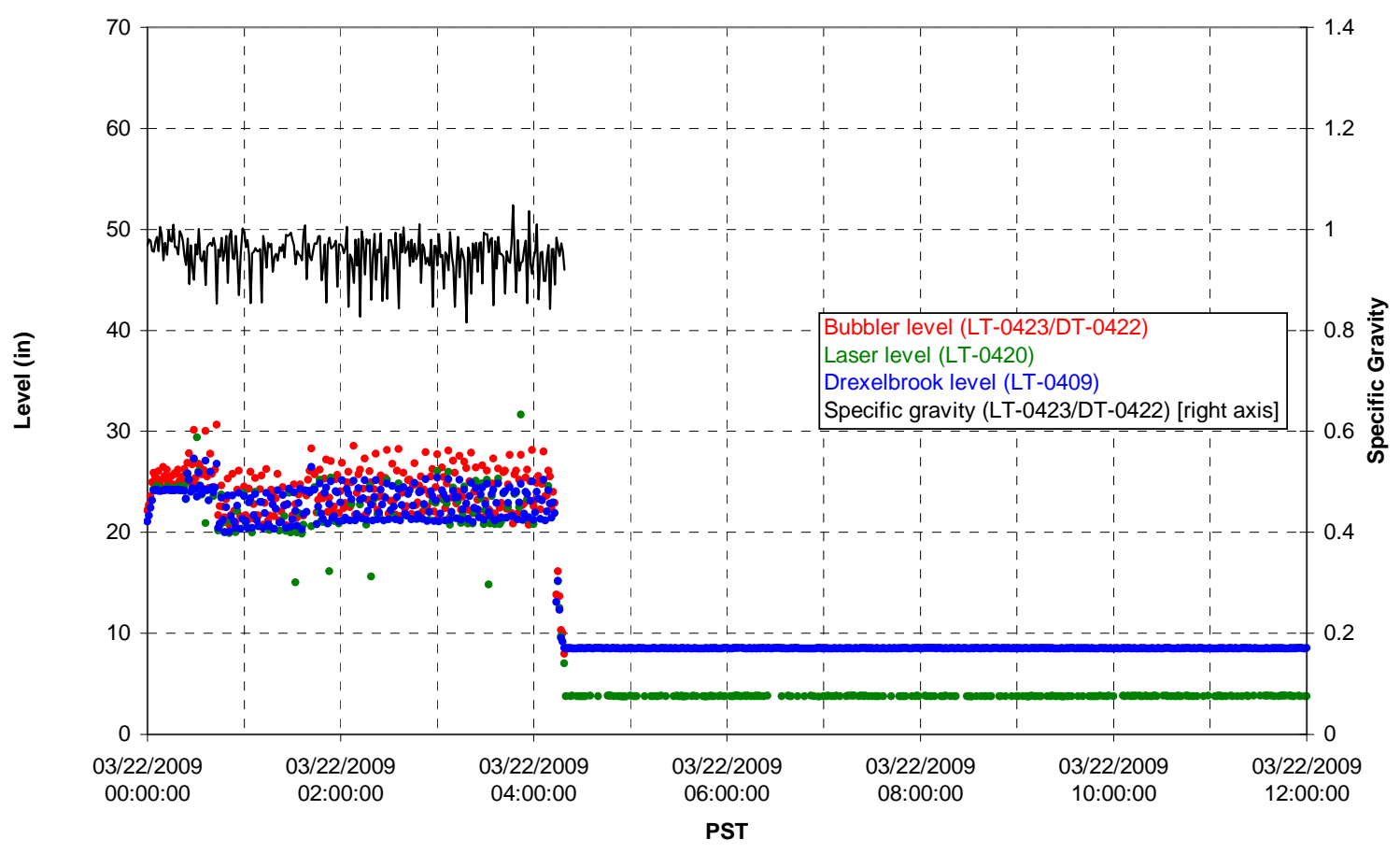

T01B temperatures

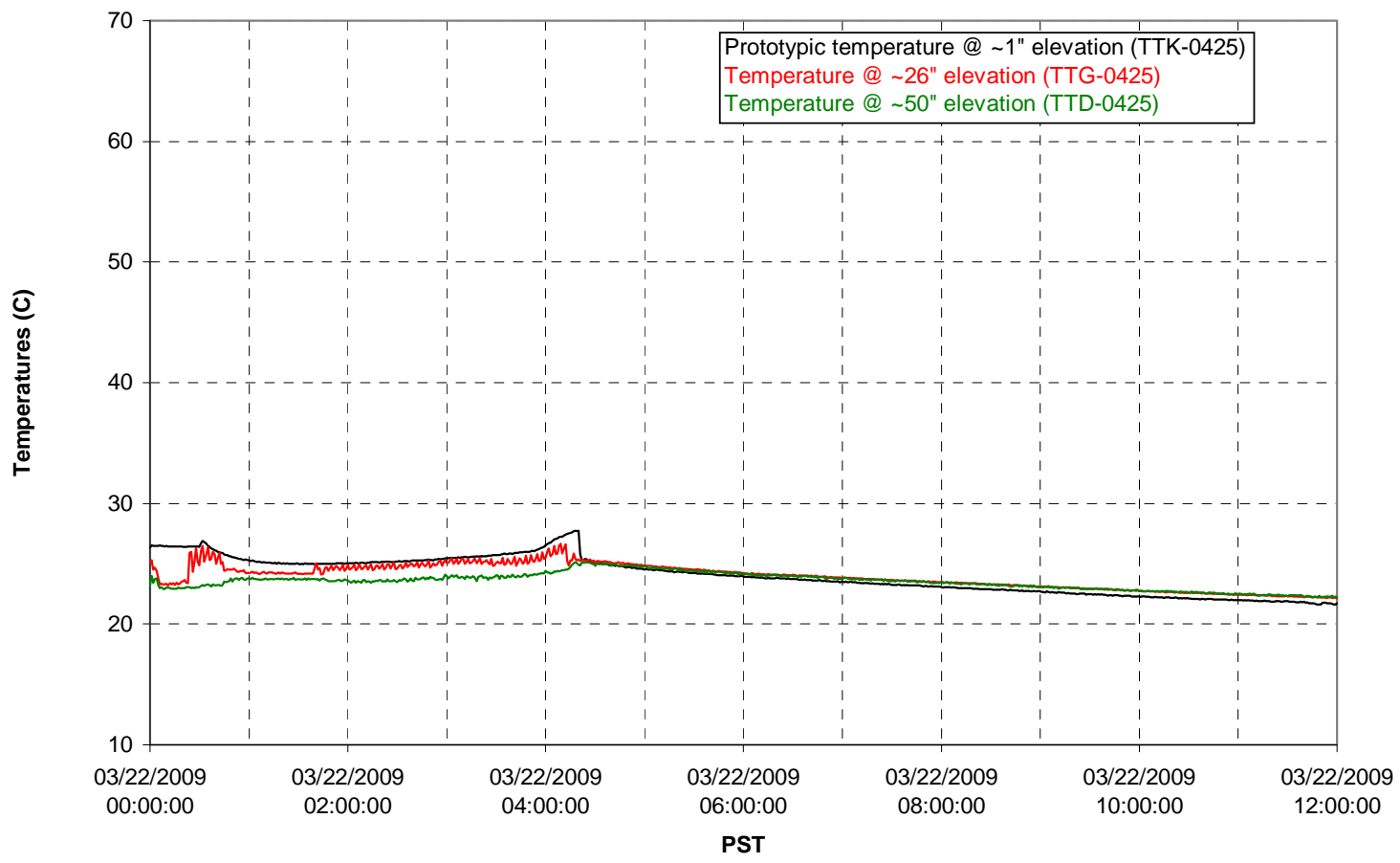


T02A level

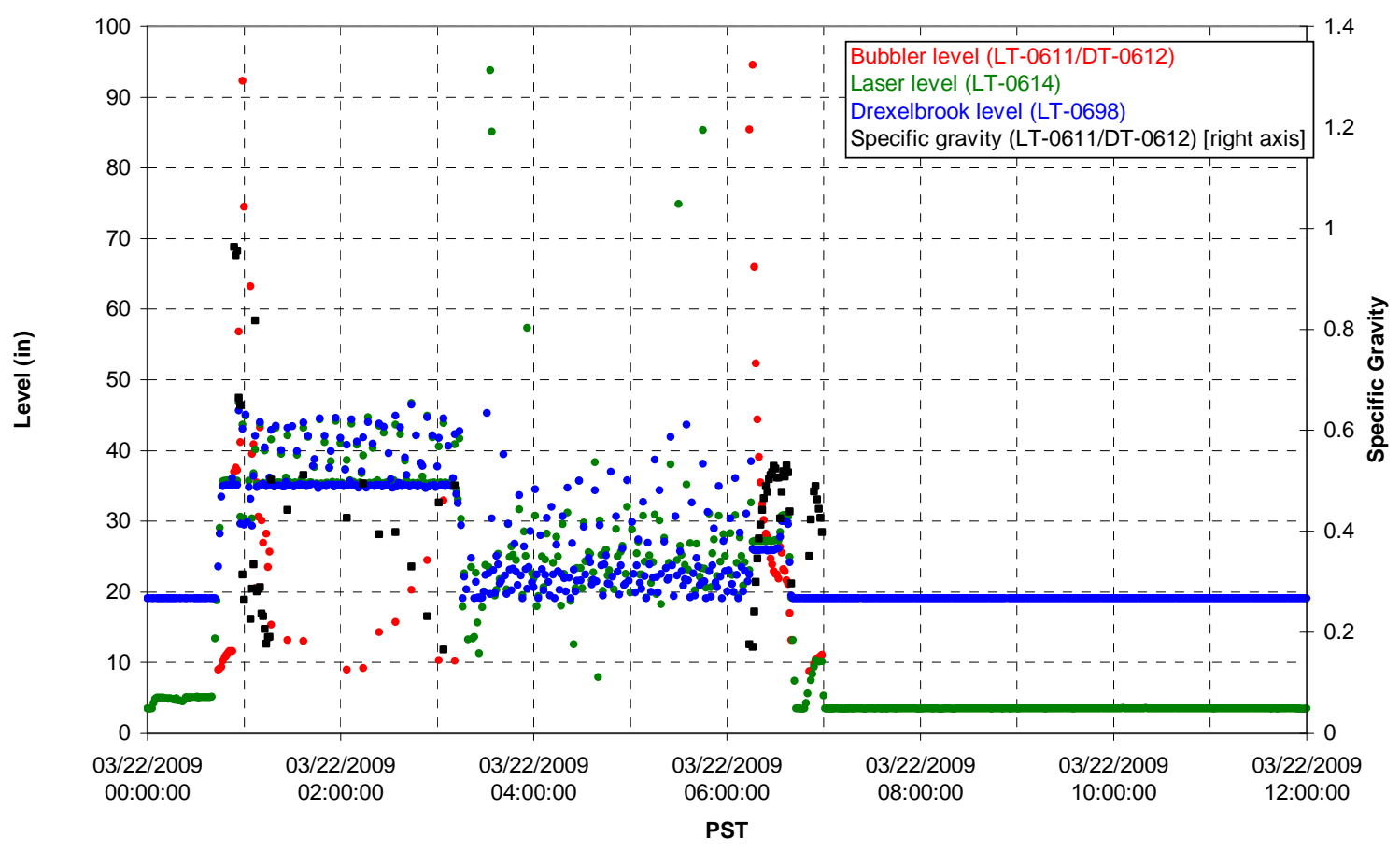

T02A temperatures

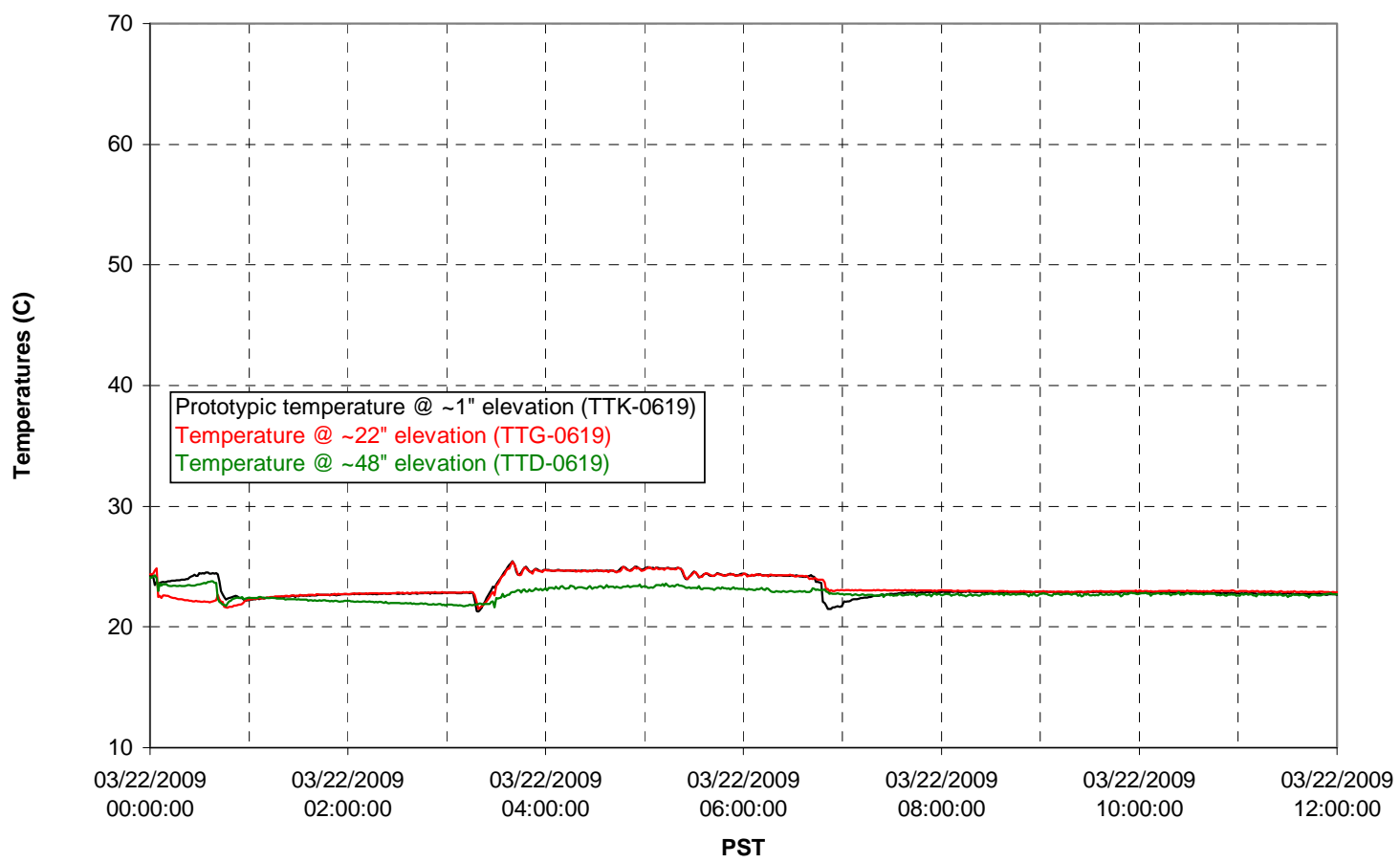


T02A and filter loop temperatures

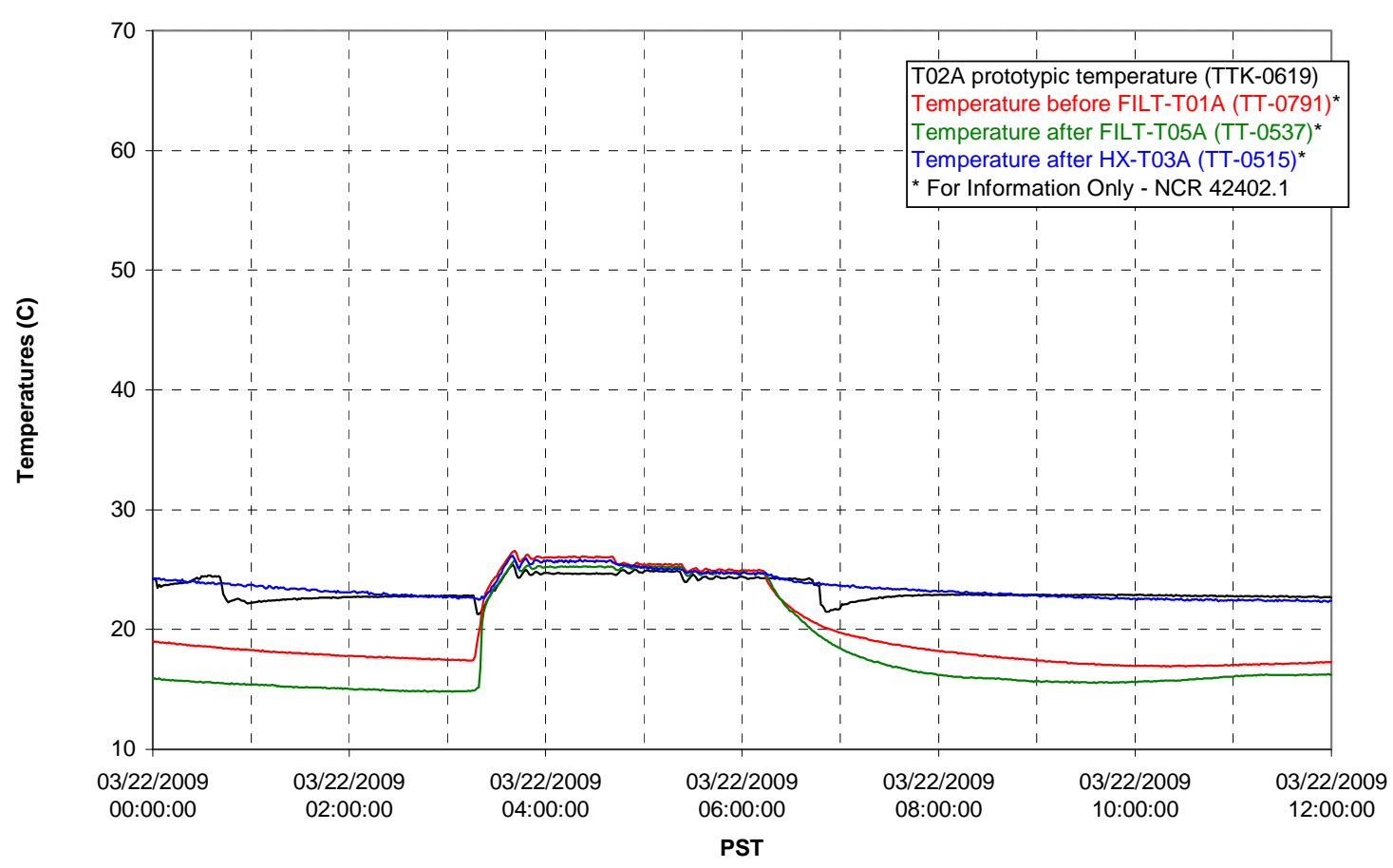

Pump Pressures and Flow

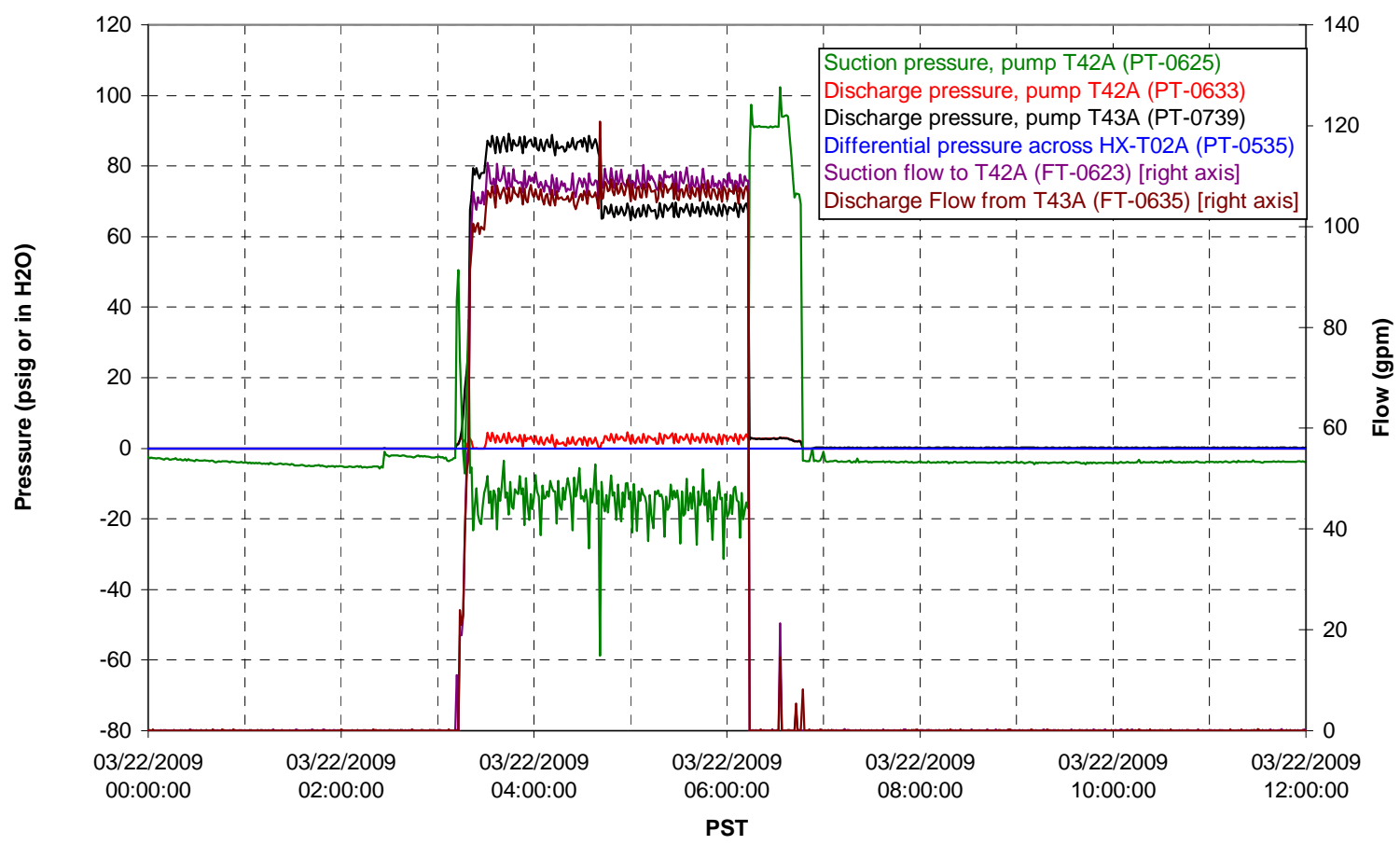




\section{Axial pressure drop}

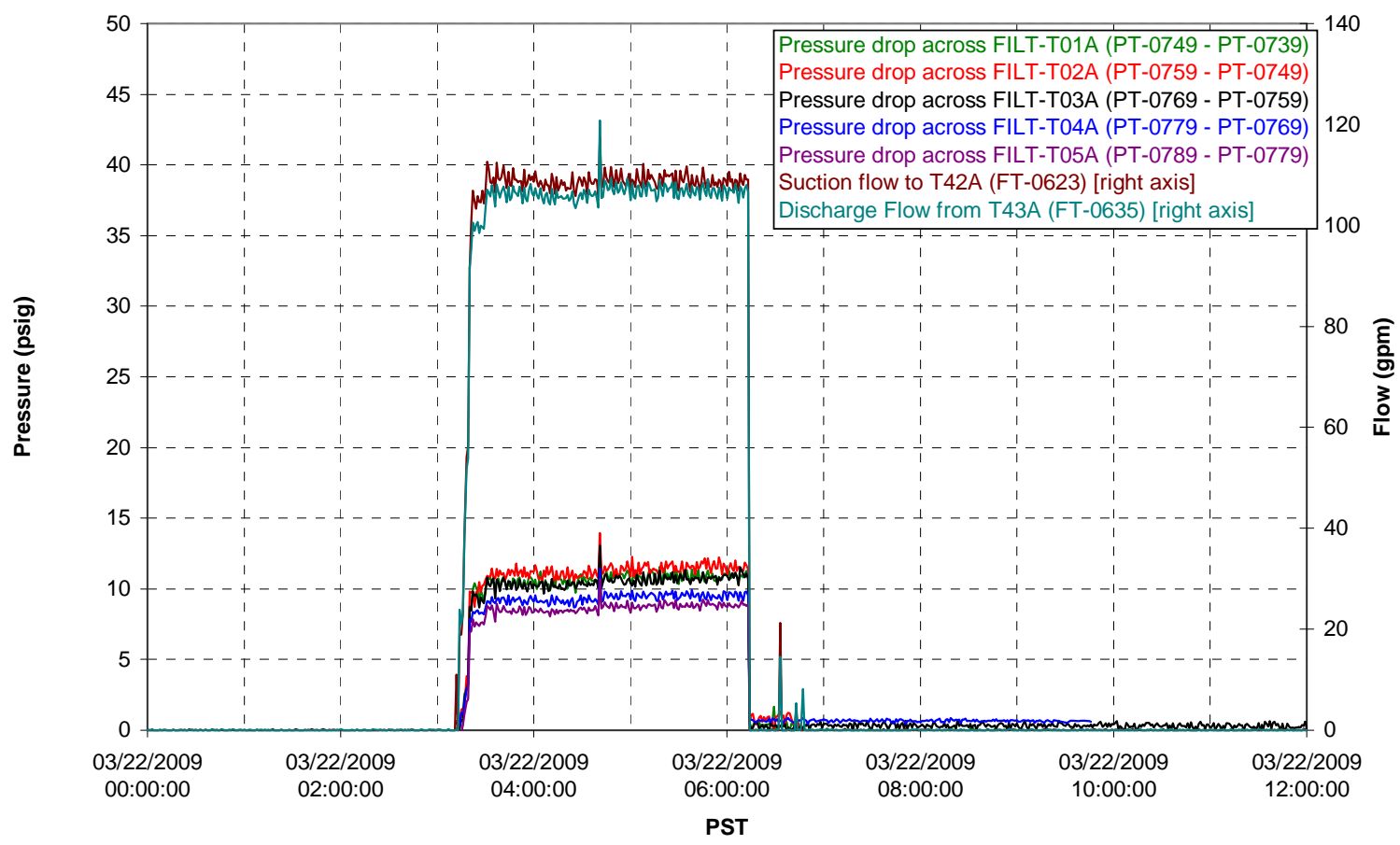

Permeate flow rates

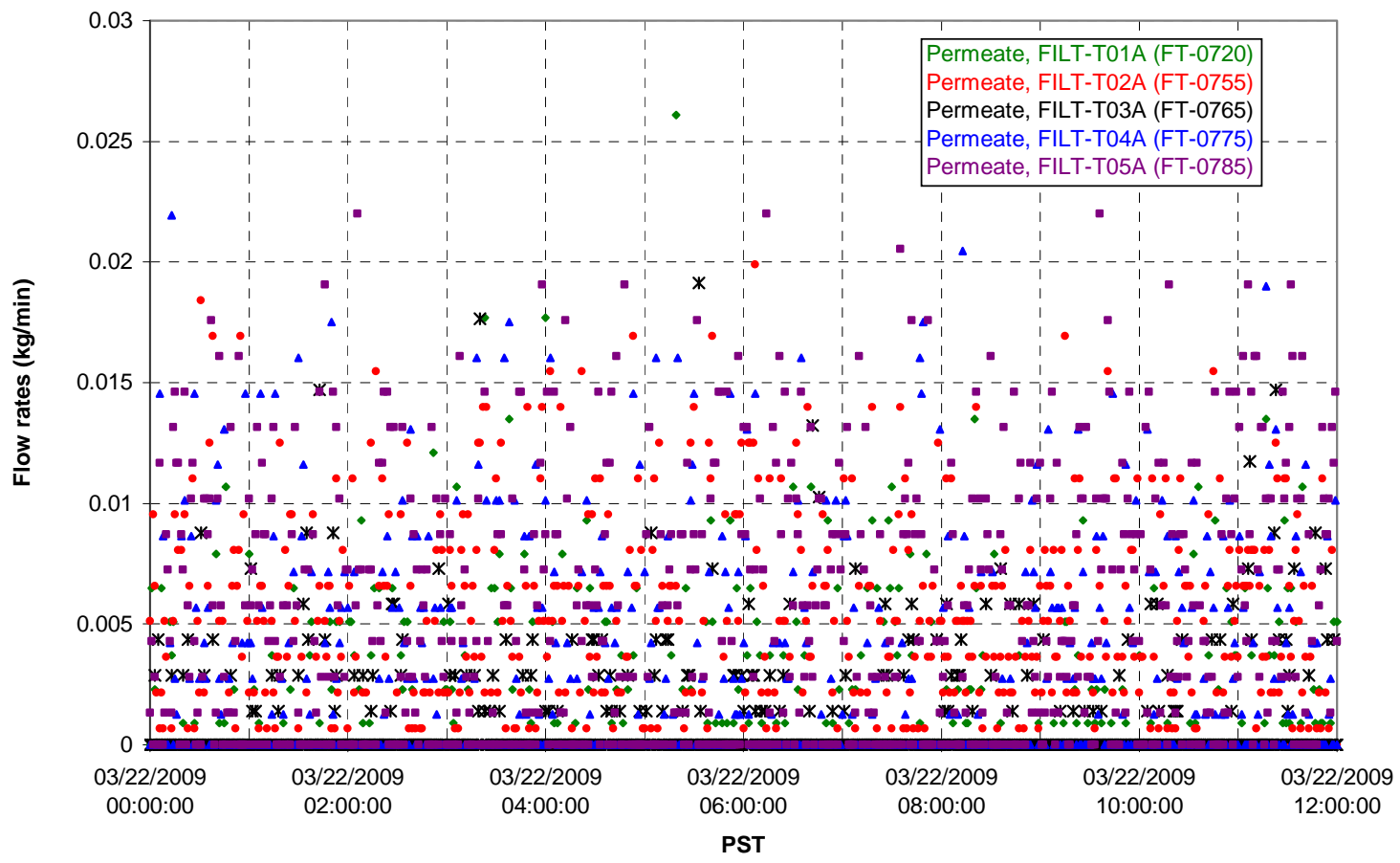


T02A Inner Temperature Tree

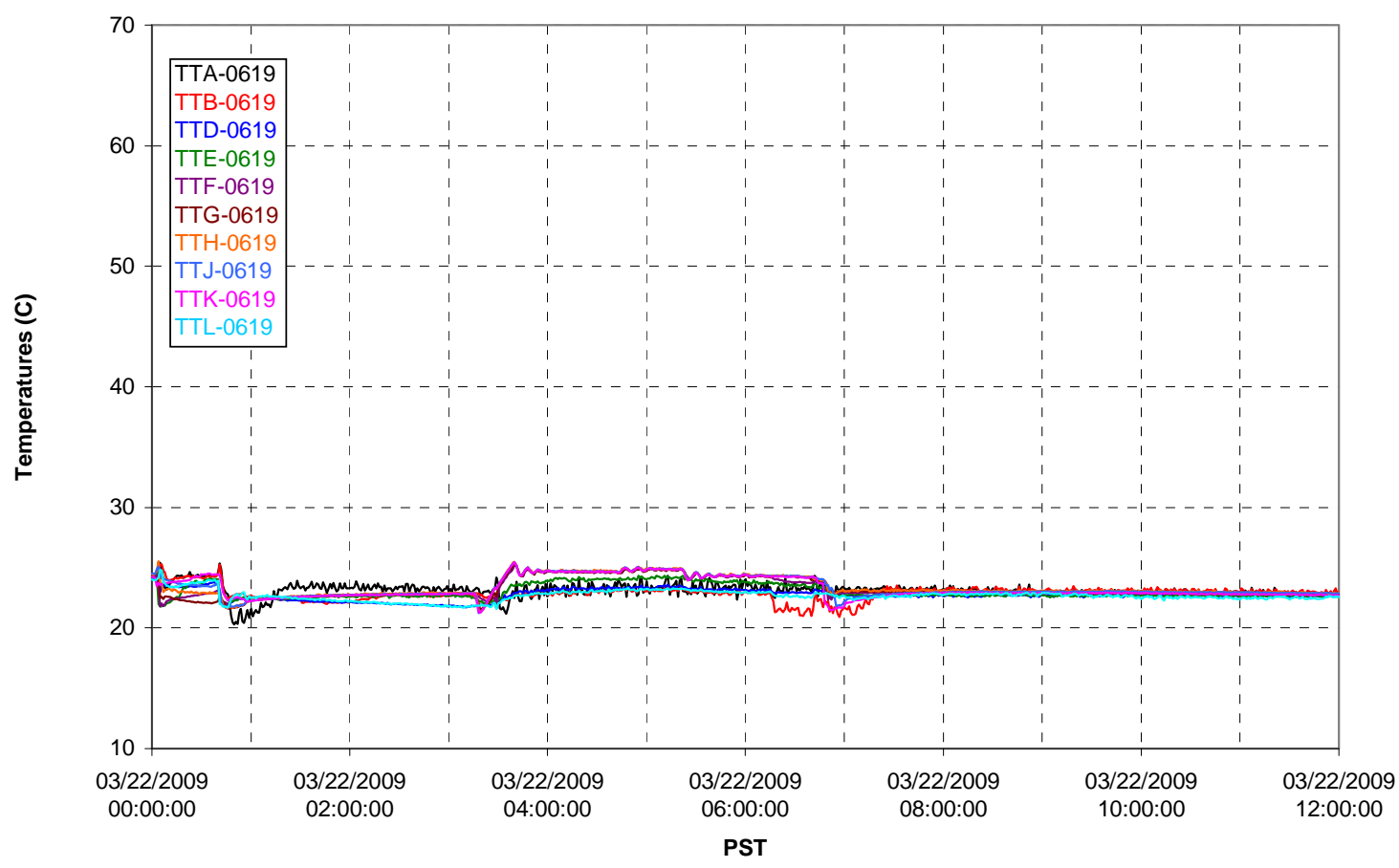

T02A Outer Temperature Tree

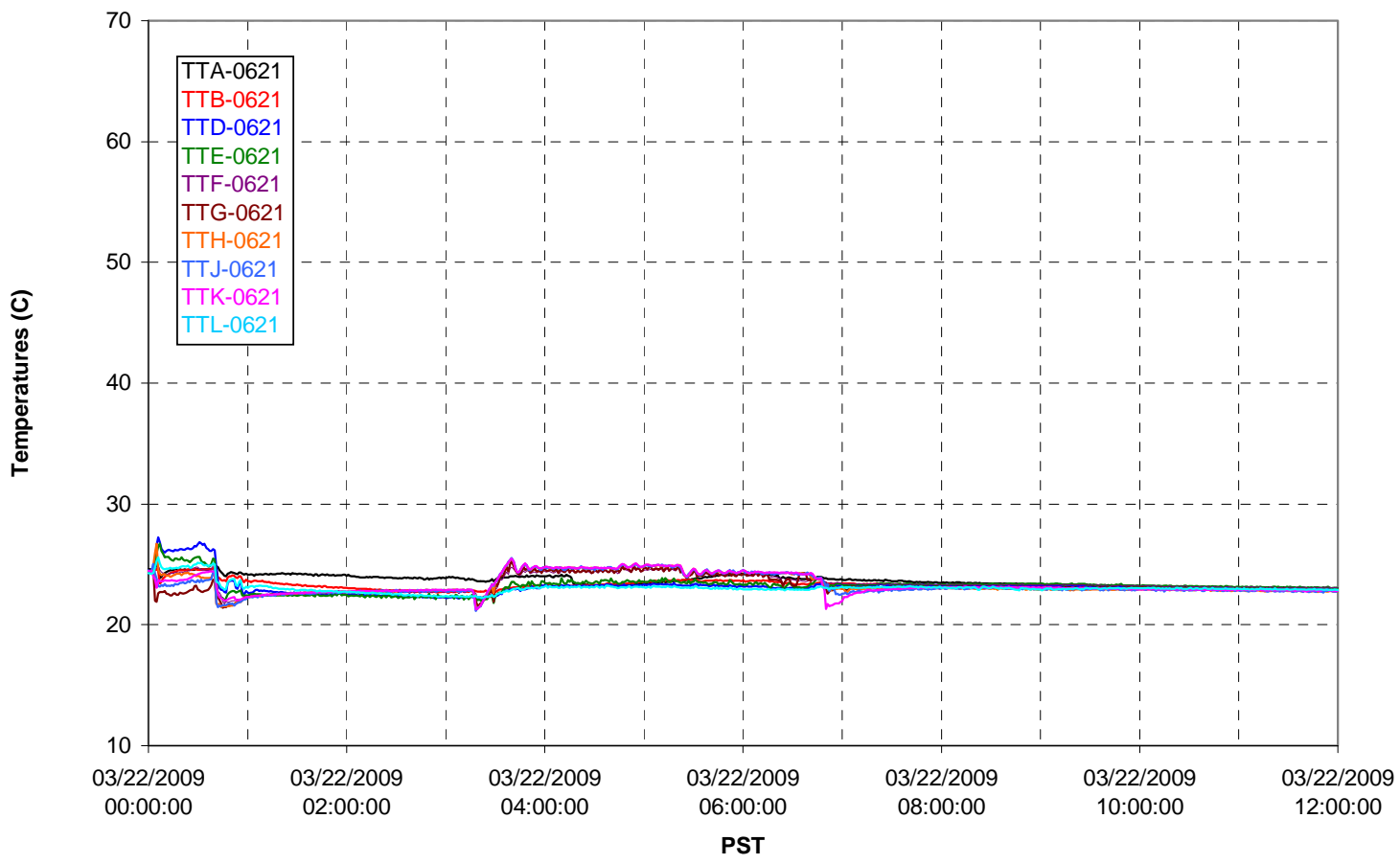


T02A temperatures

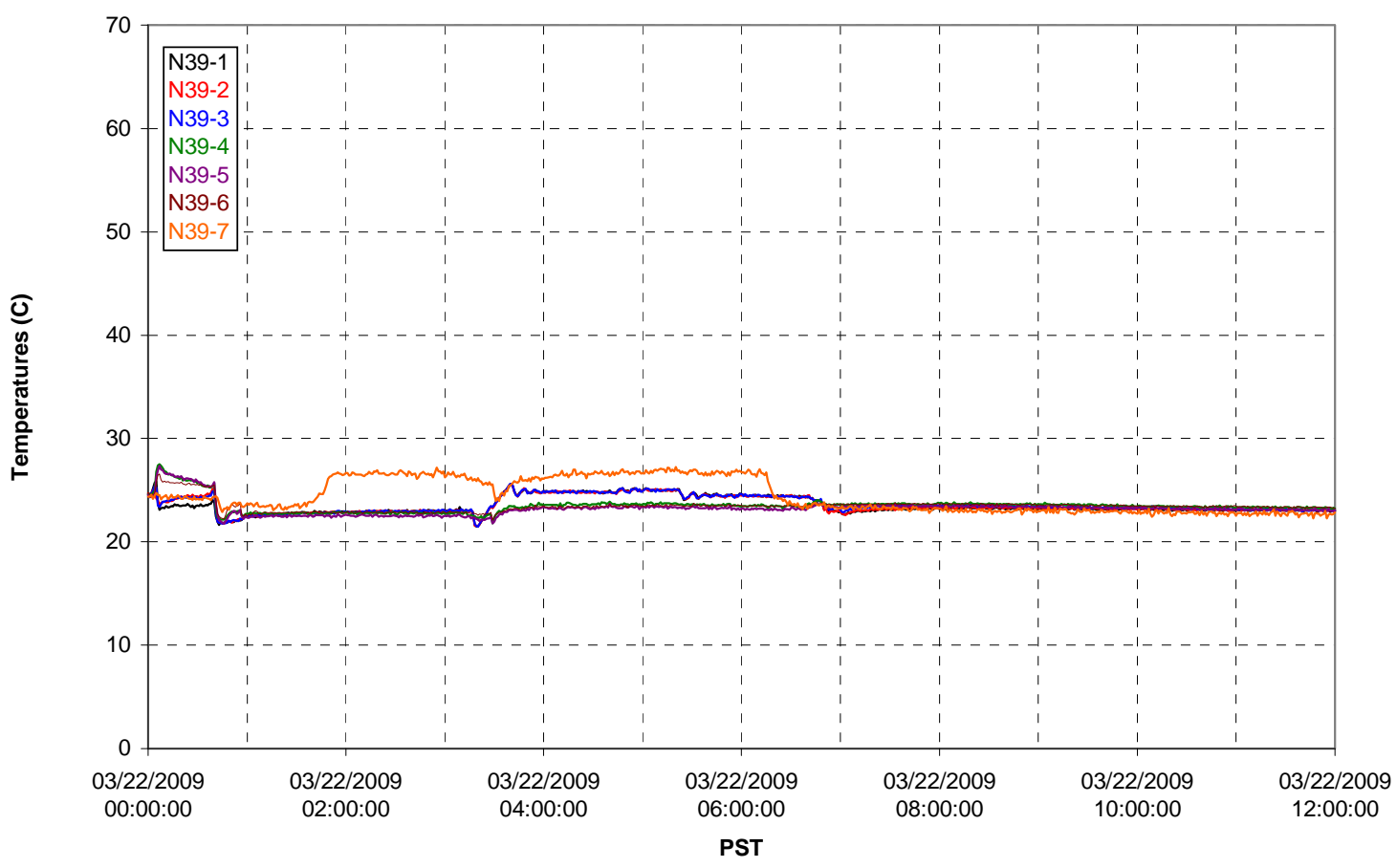

T02A temperatures

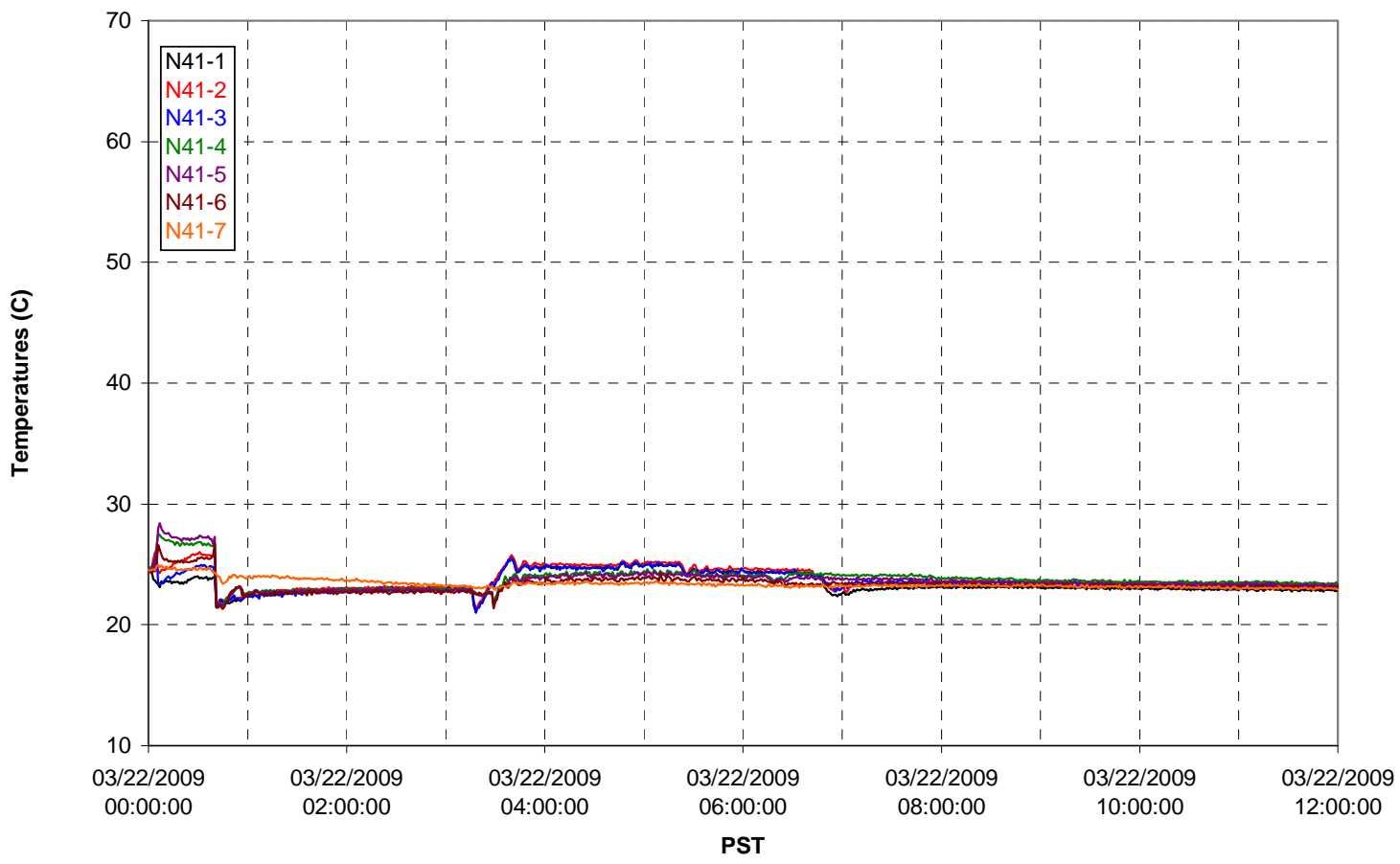


T02A temperatures

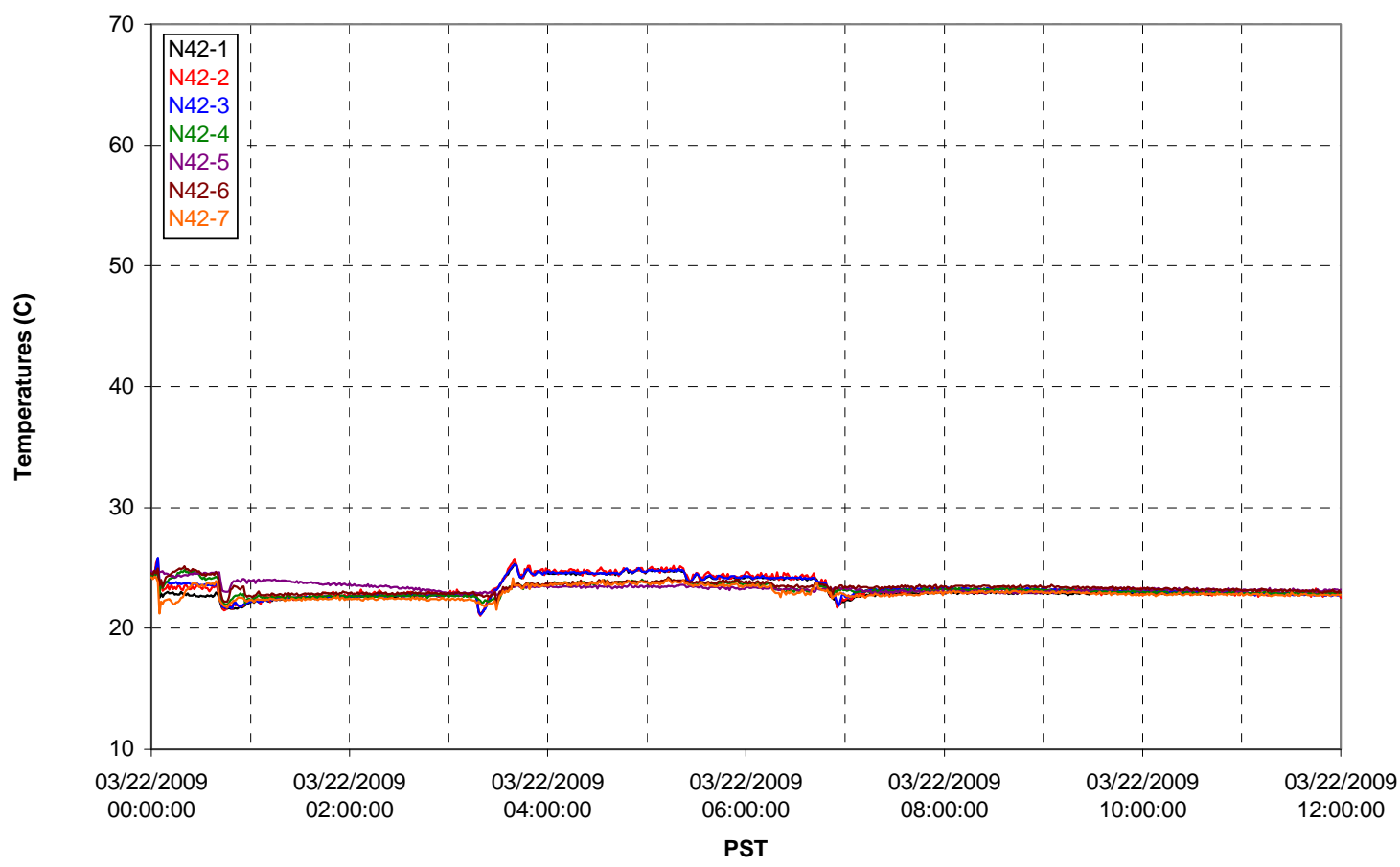

T02A temperatures

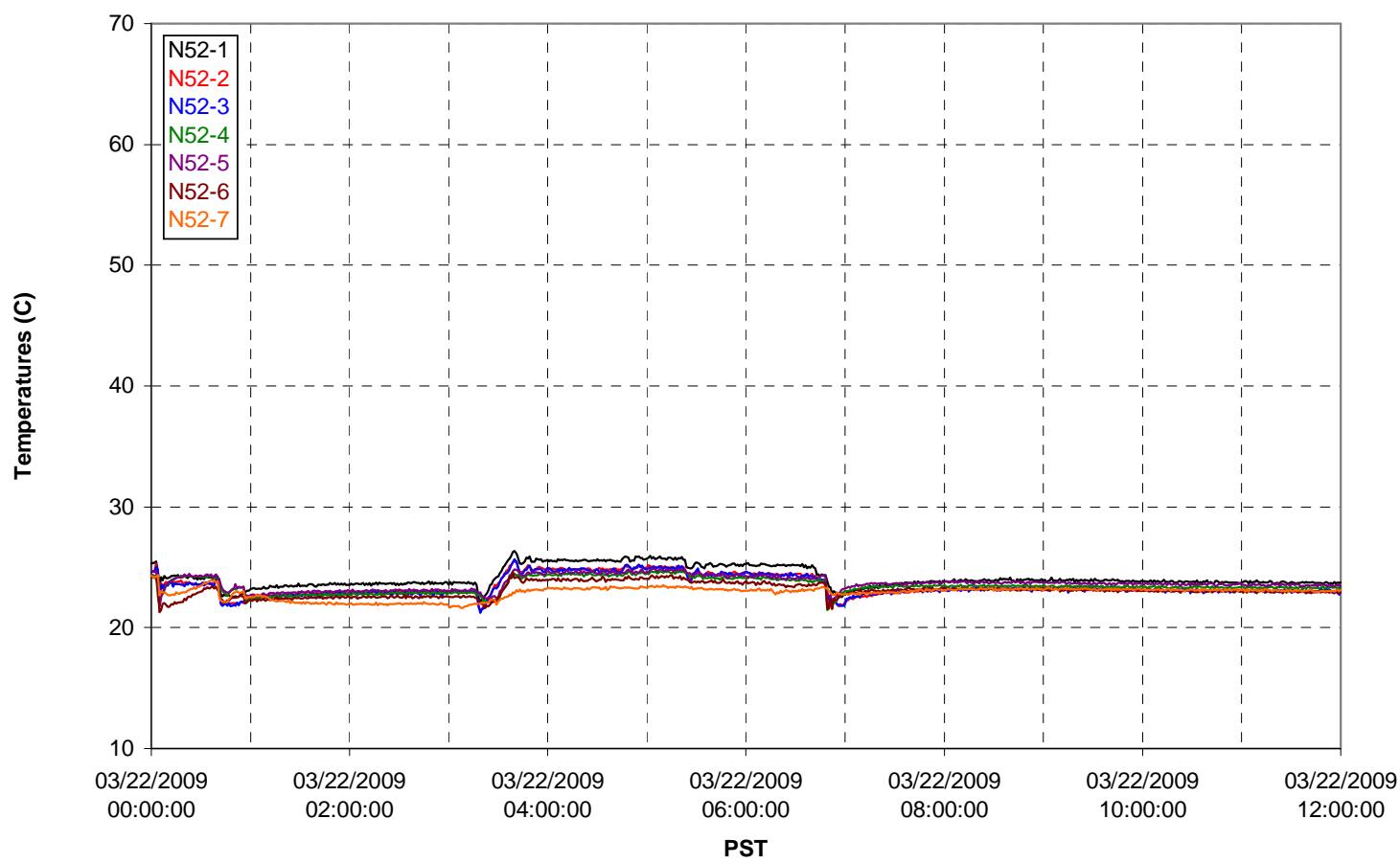


T02A Heating and Cooling

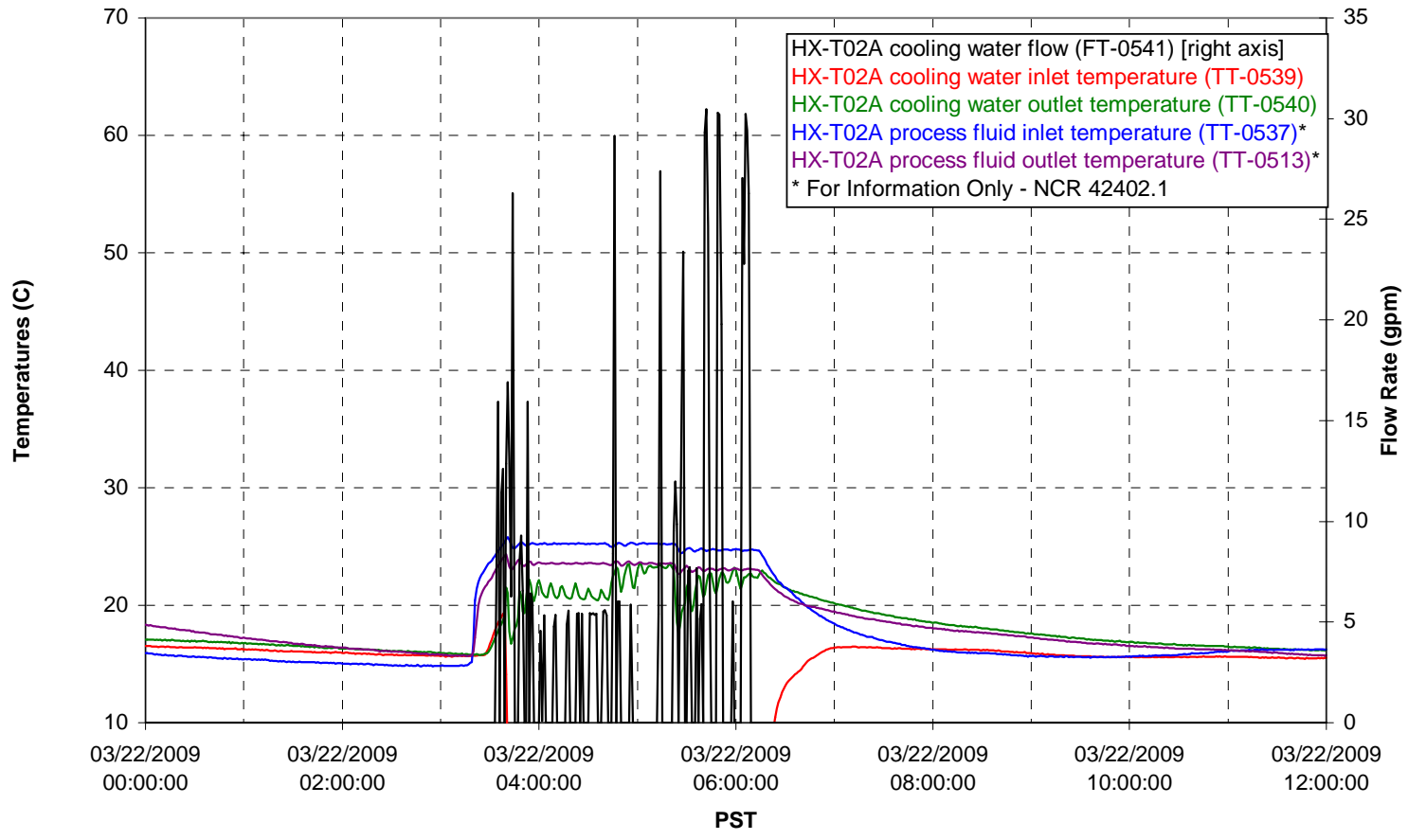

Pump Operation

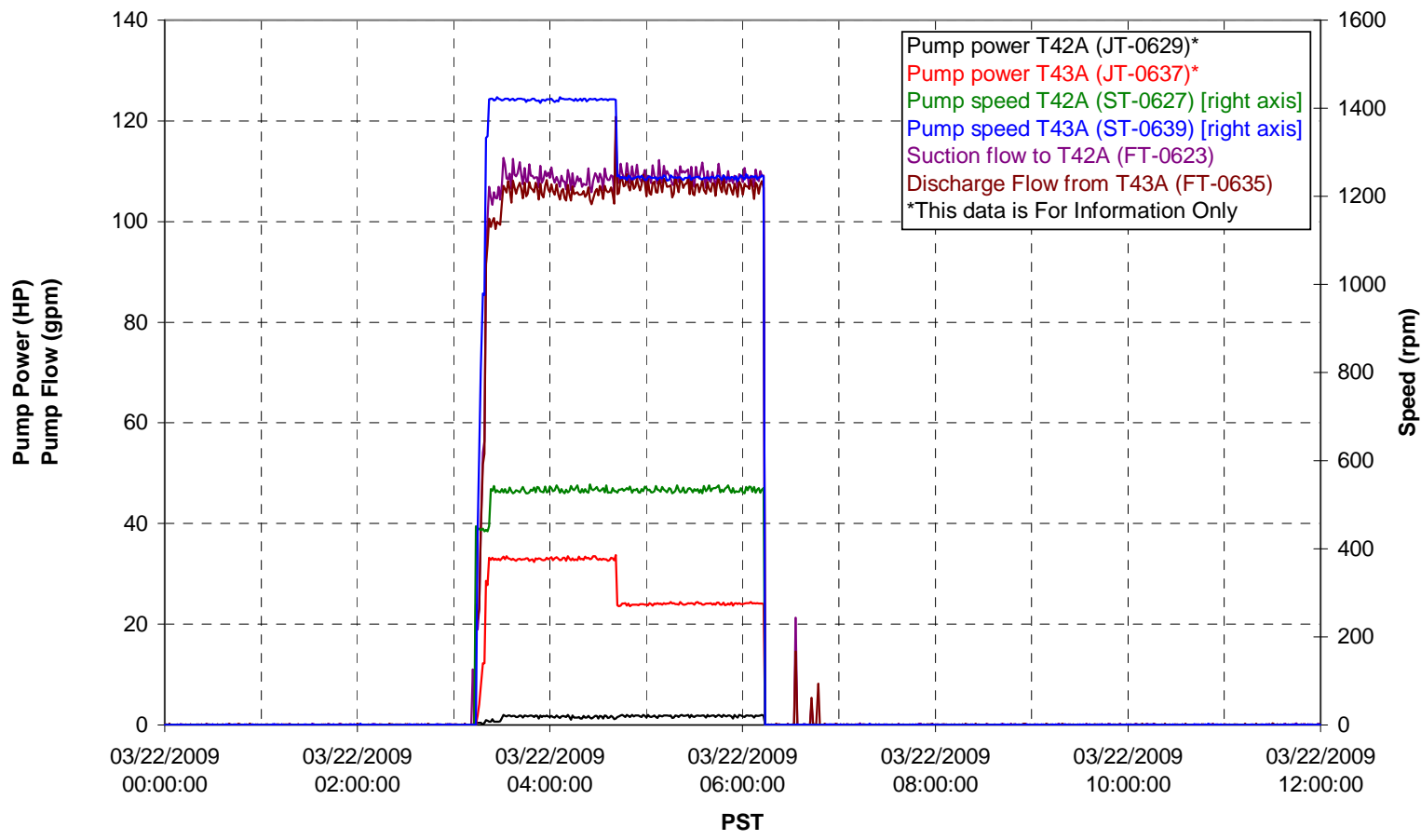


Pulsepot UFP-PP-T01A

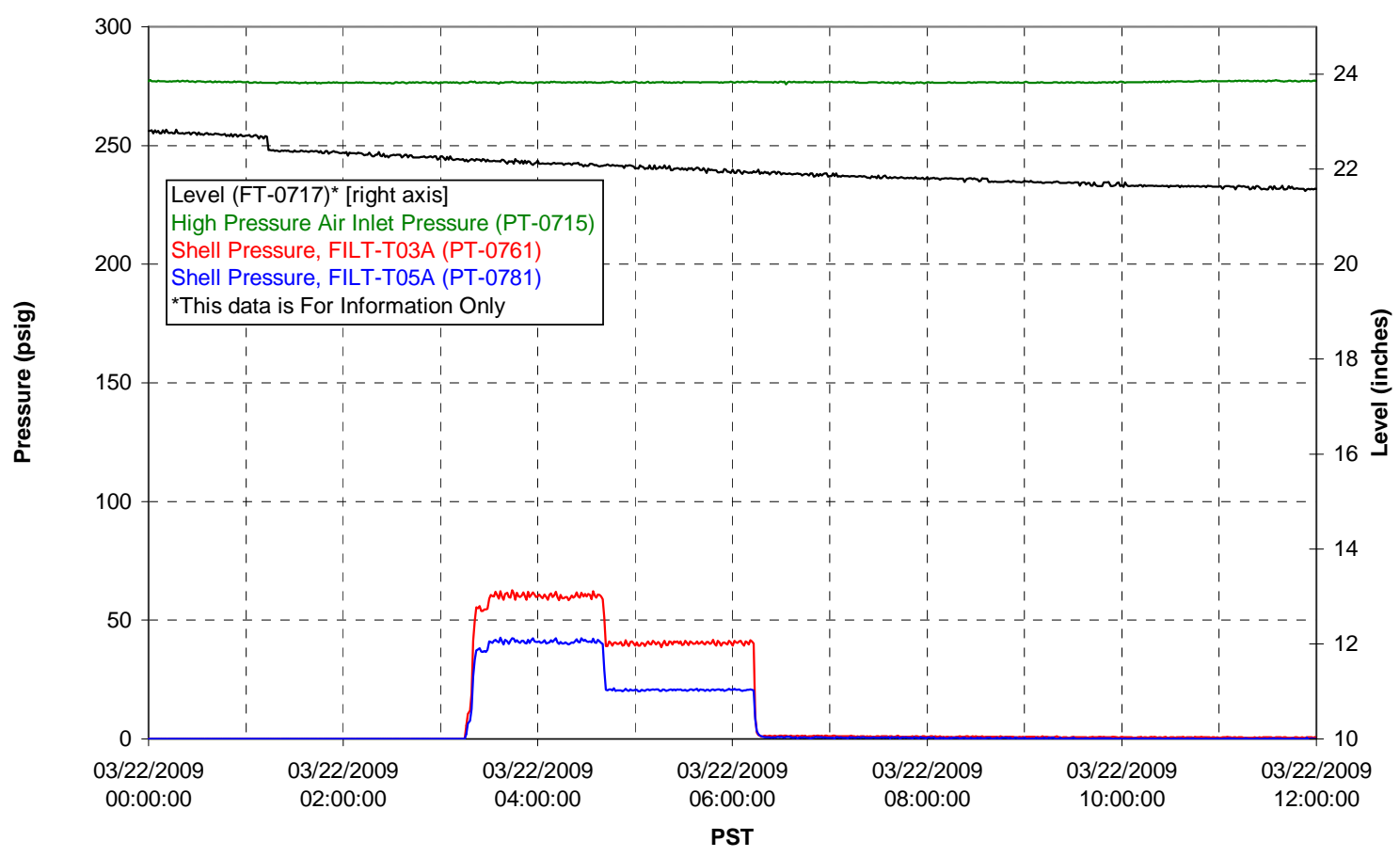

Pulsepot UFP-PP-T02A

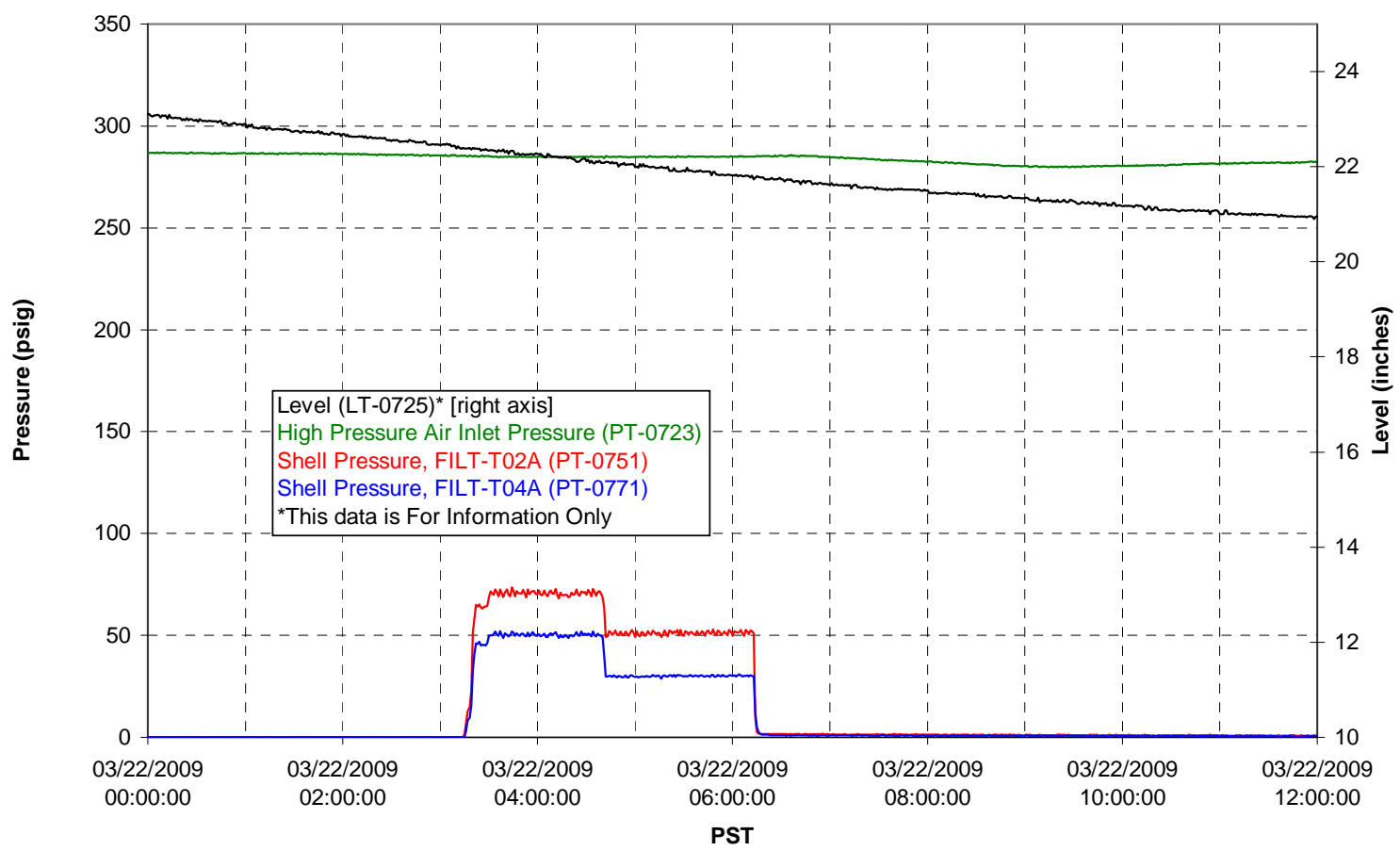


Pulsepot UFP-PP-T03A

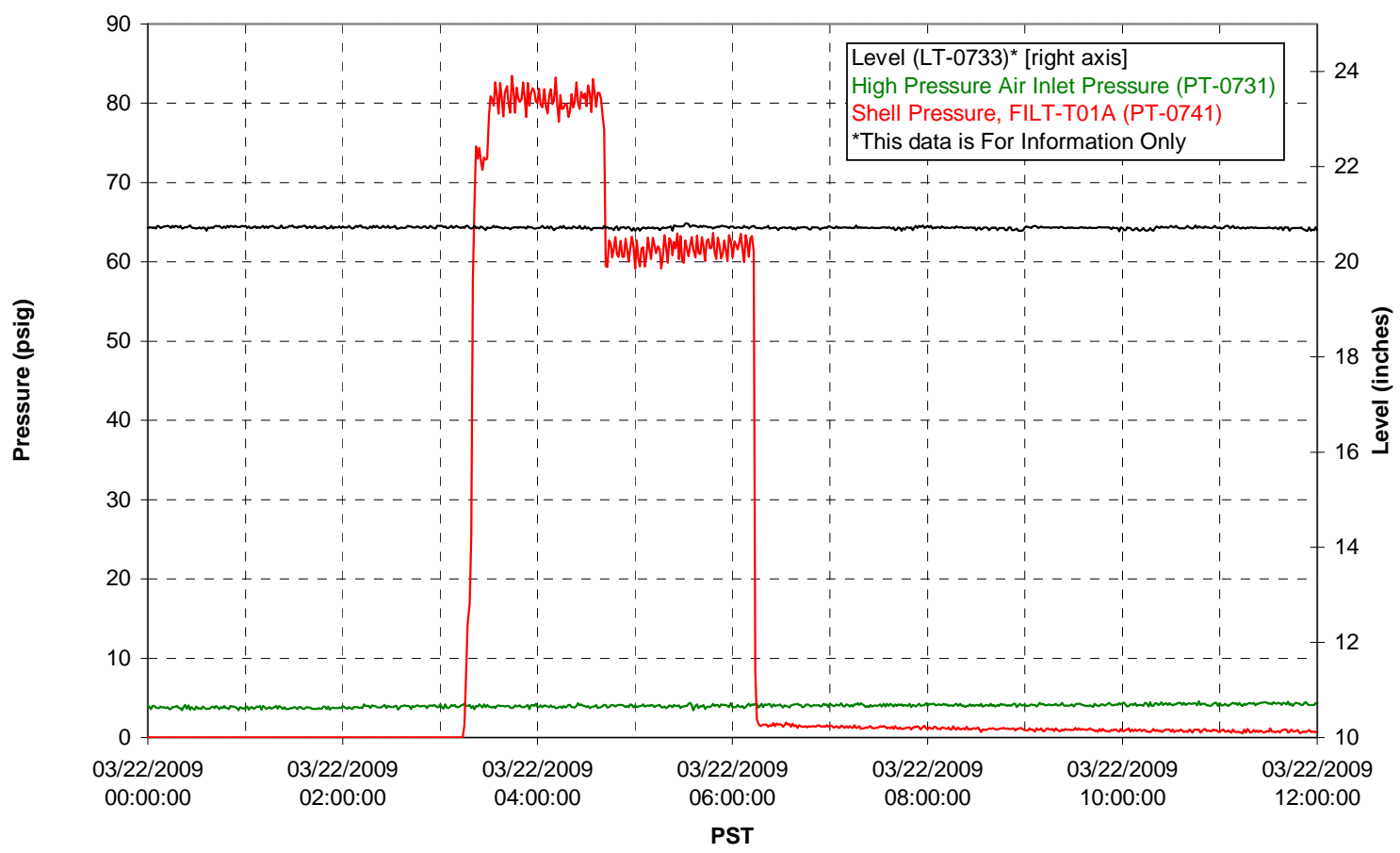

Pulsepot Levels

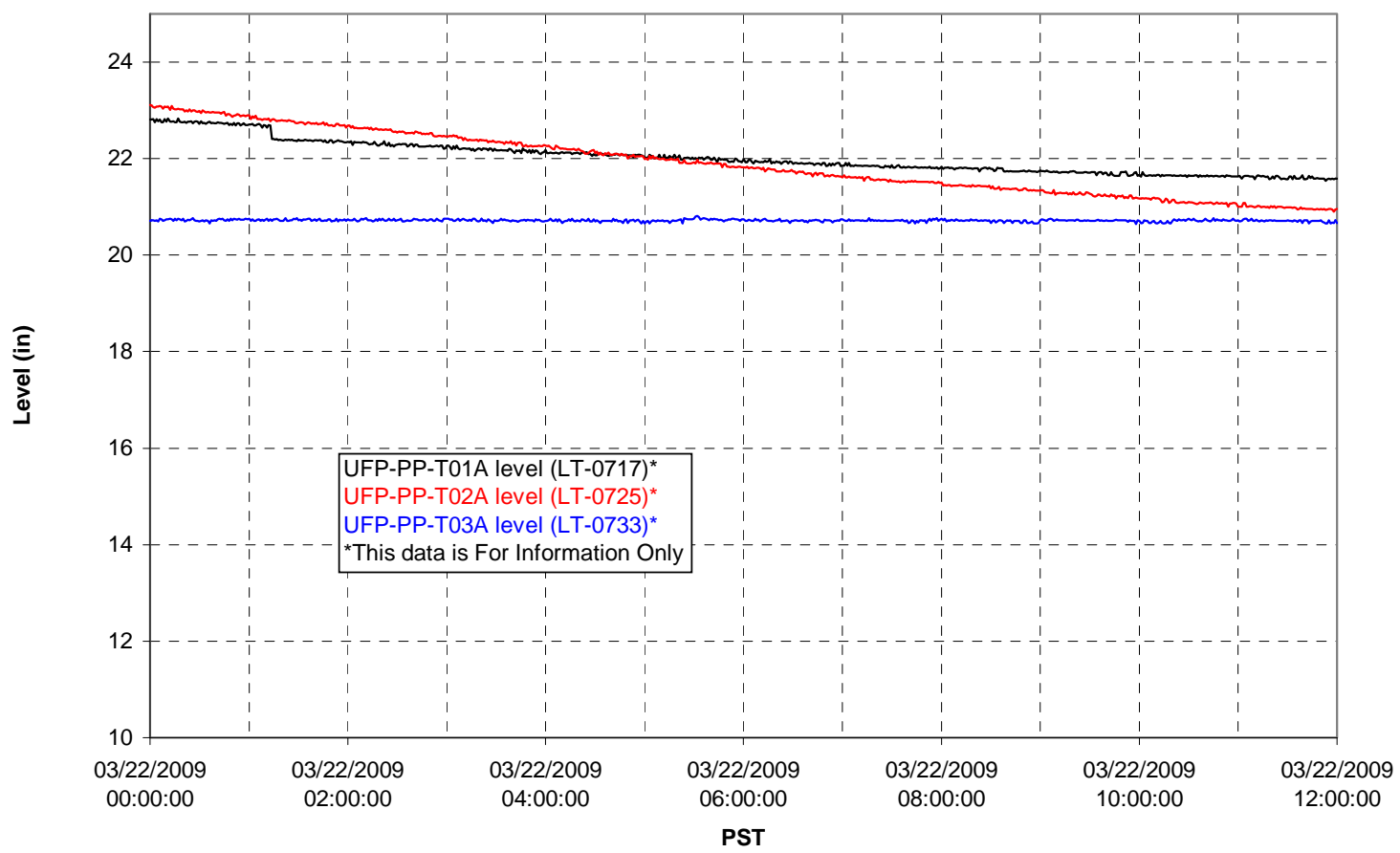


Filter UFP-FILT-T01A

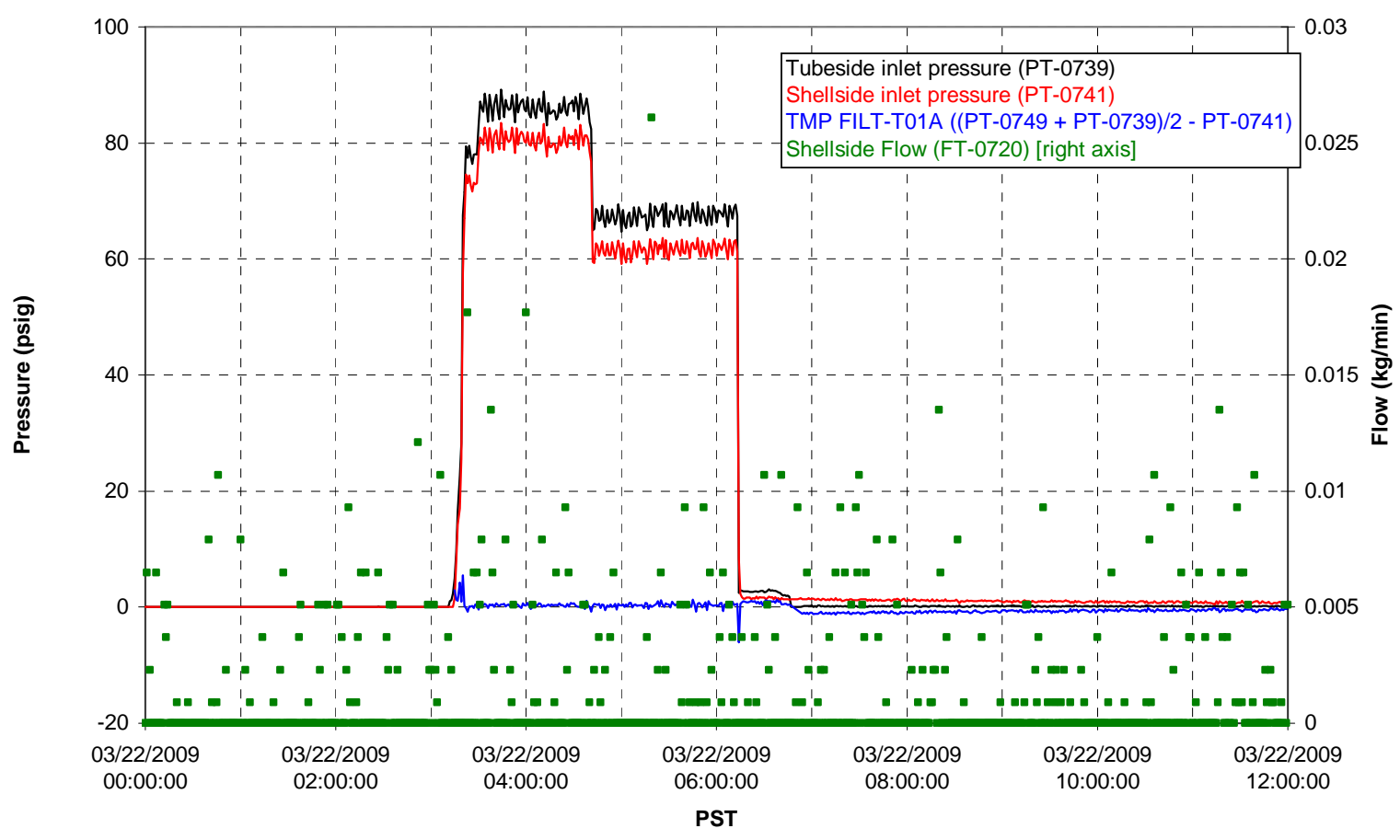

Filter UFP-FILT-T02A

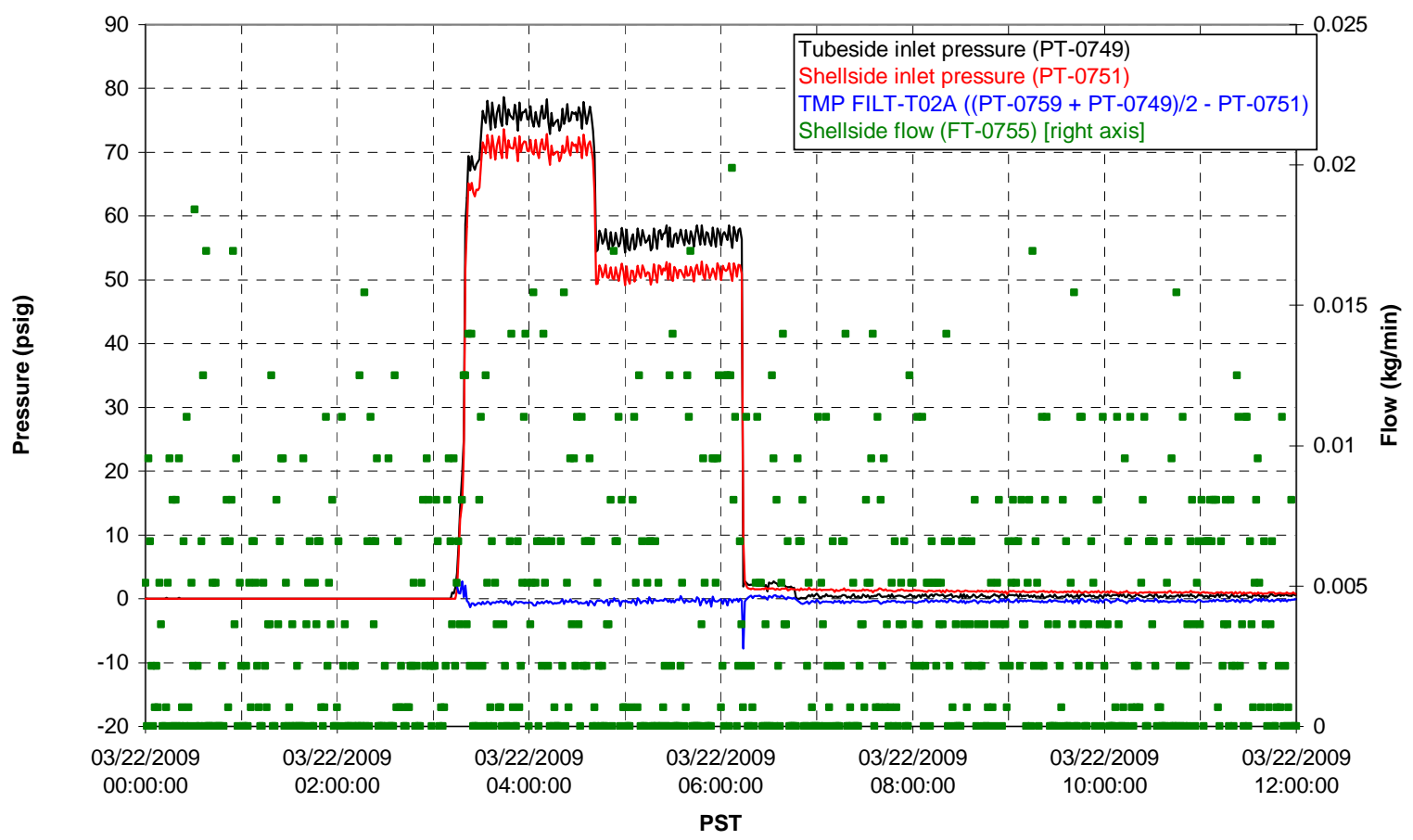


Filter UFP-FILT-T03A

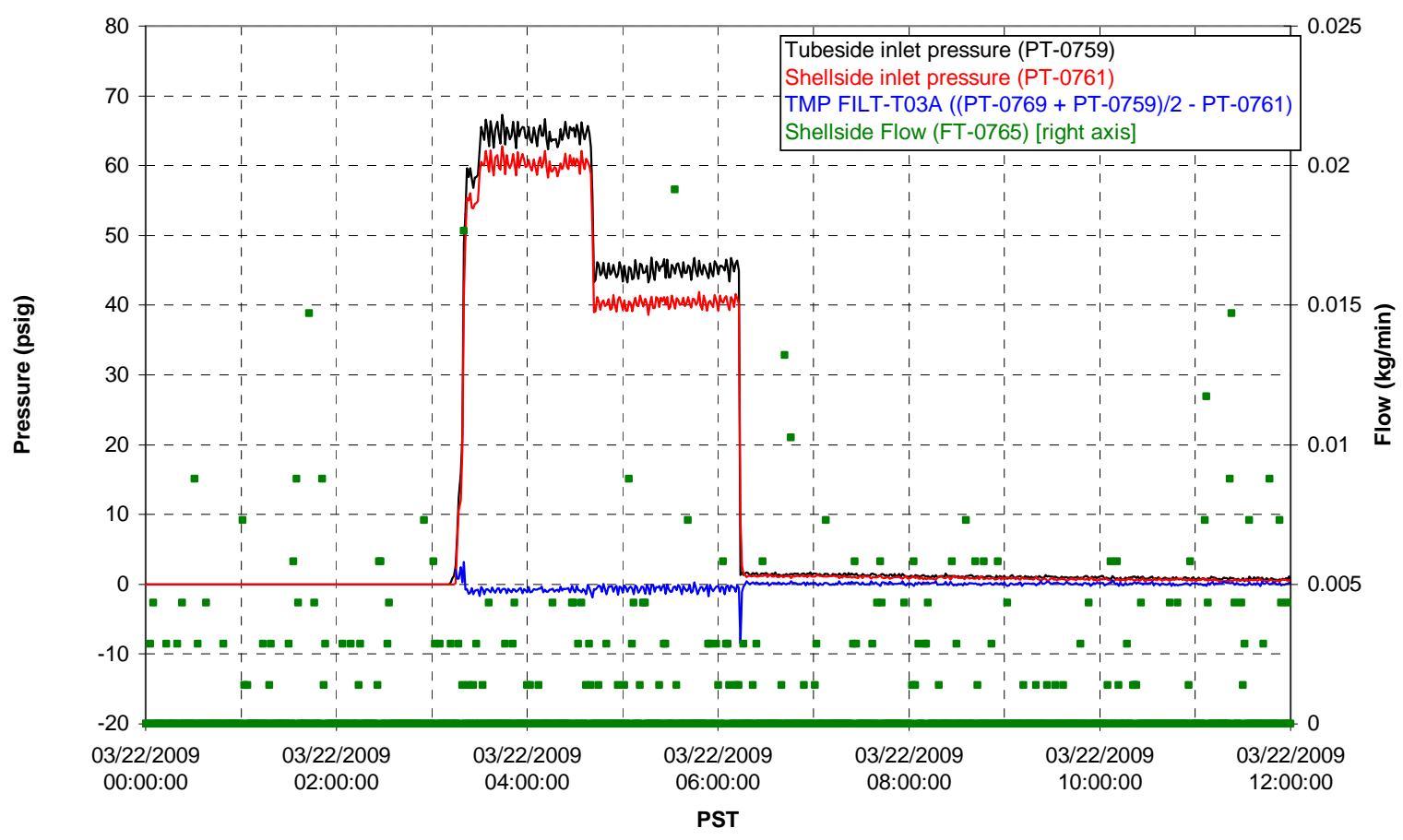

Filter UFP-FILT-T04A

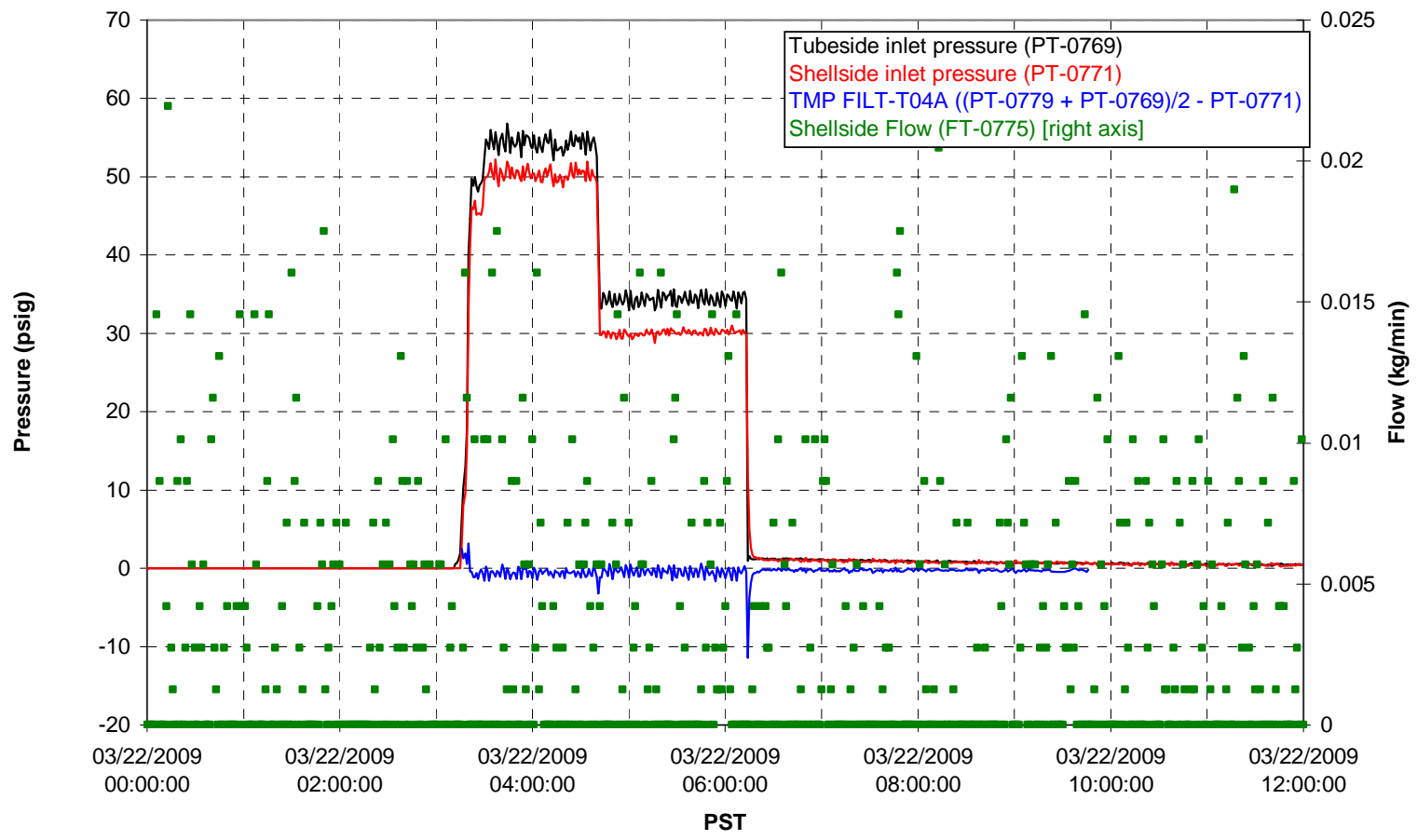


Filter UFP-FILT-T05A

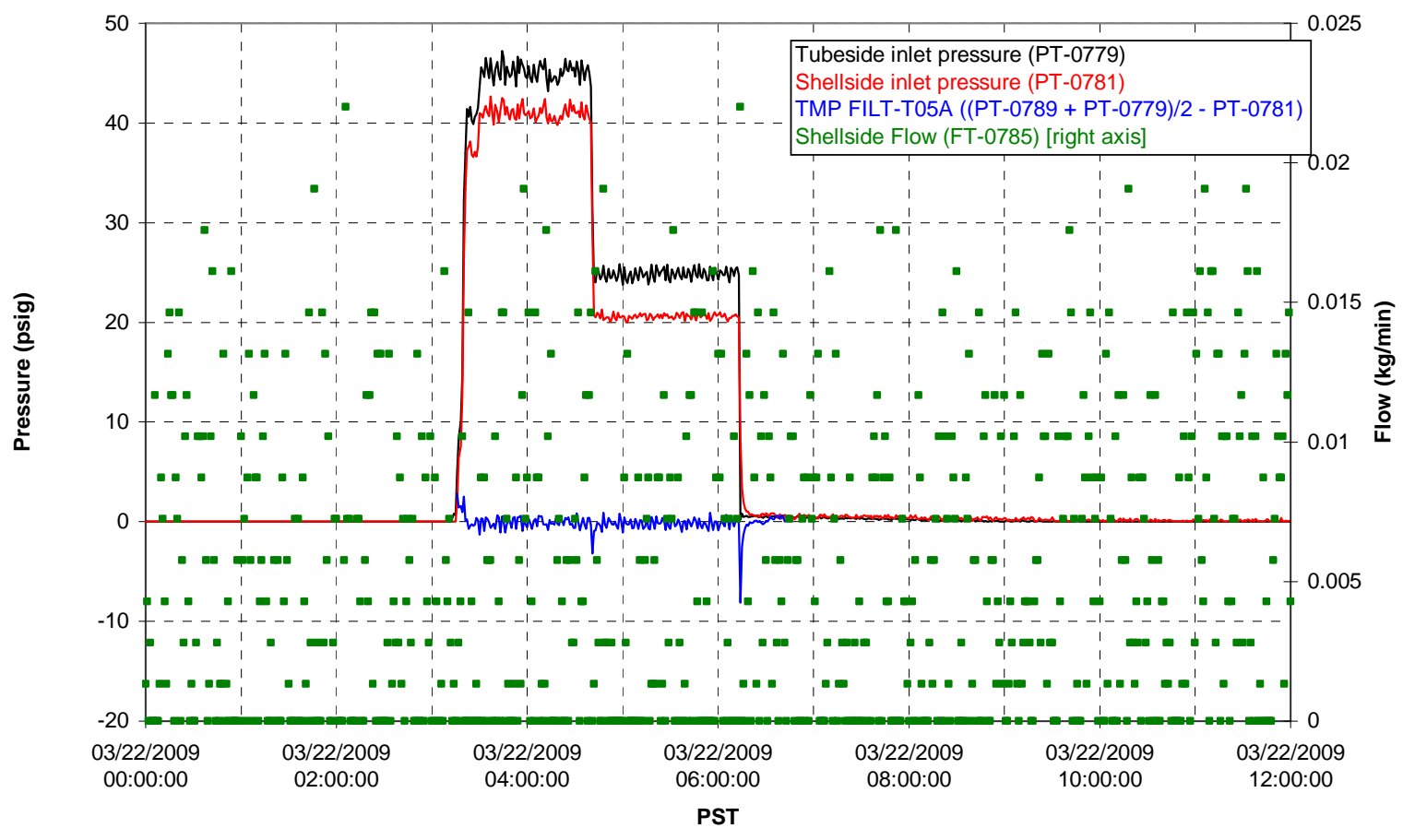

Chemical Flow

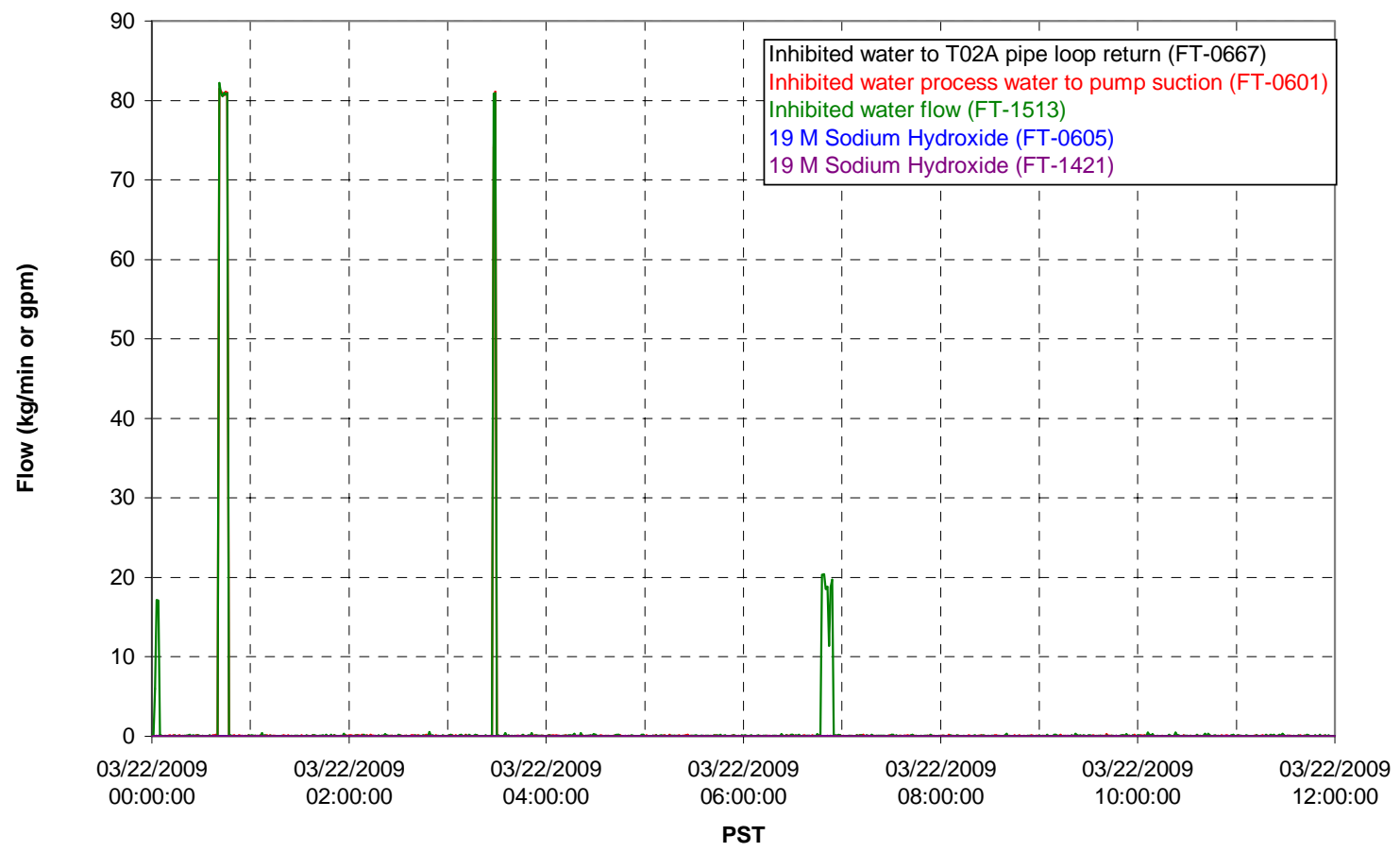




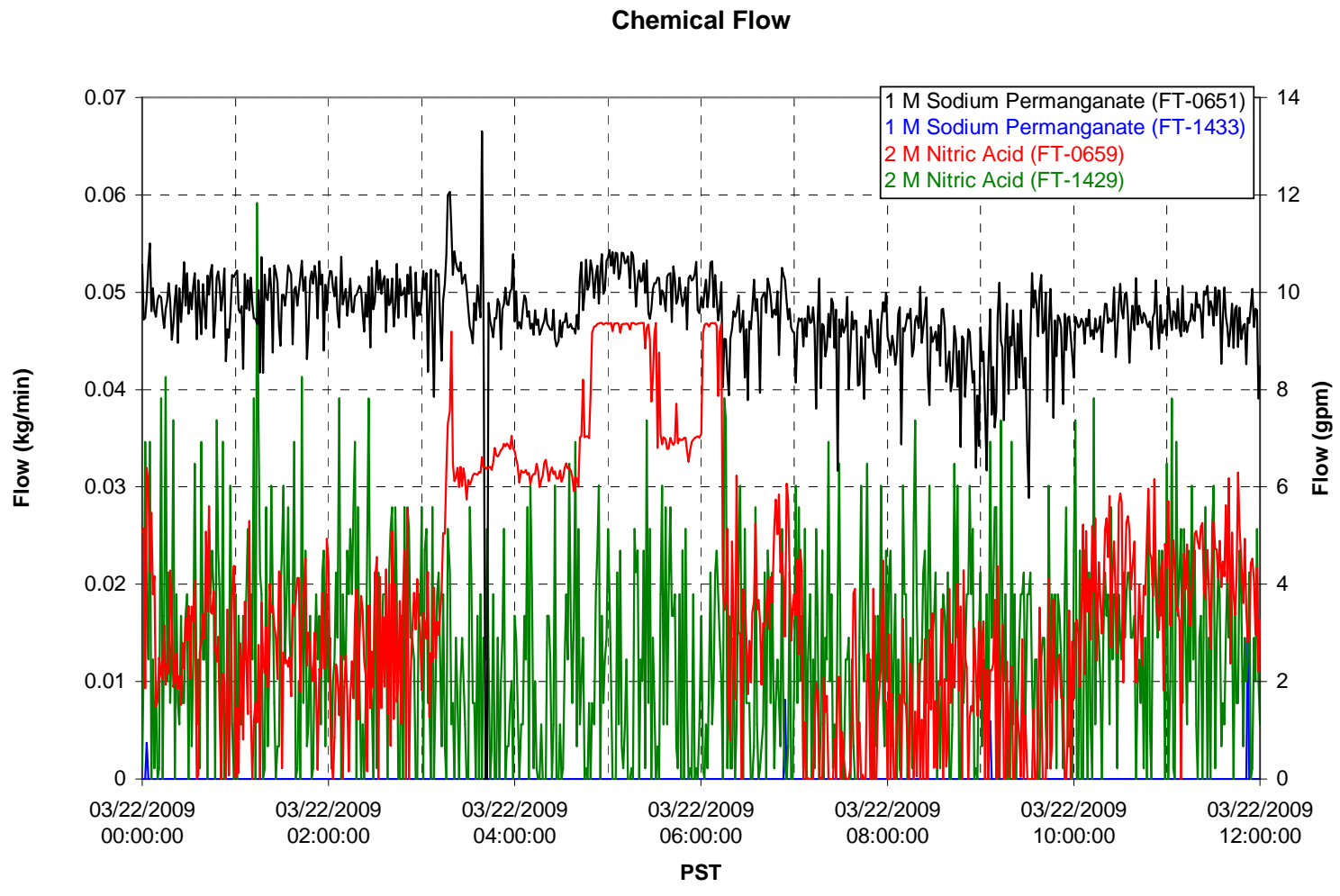

Air Flows

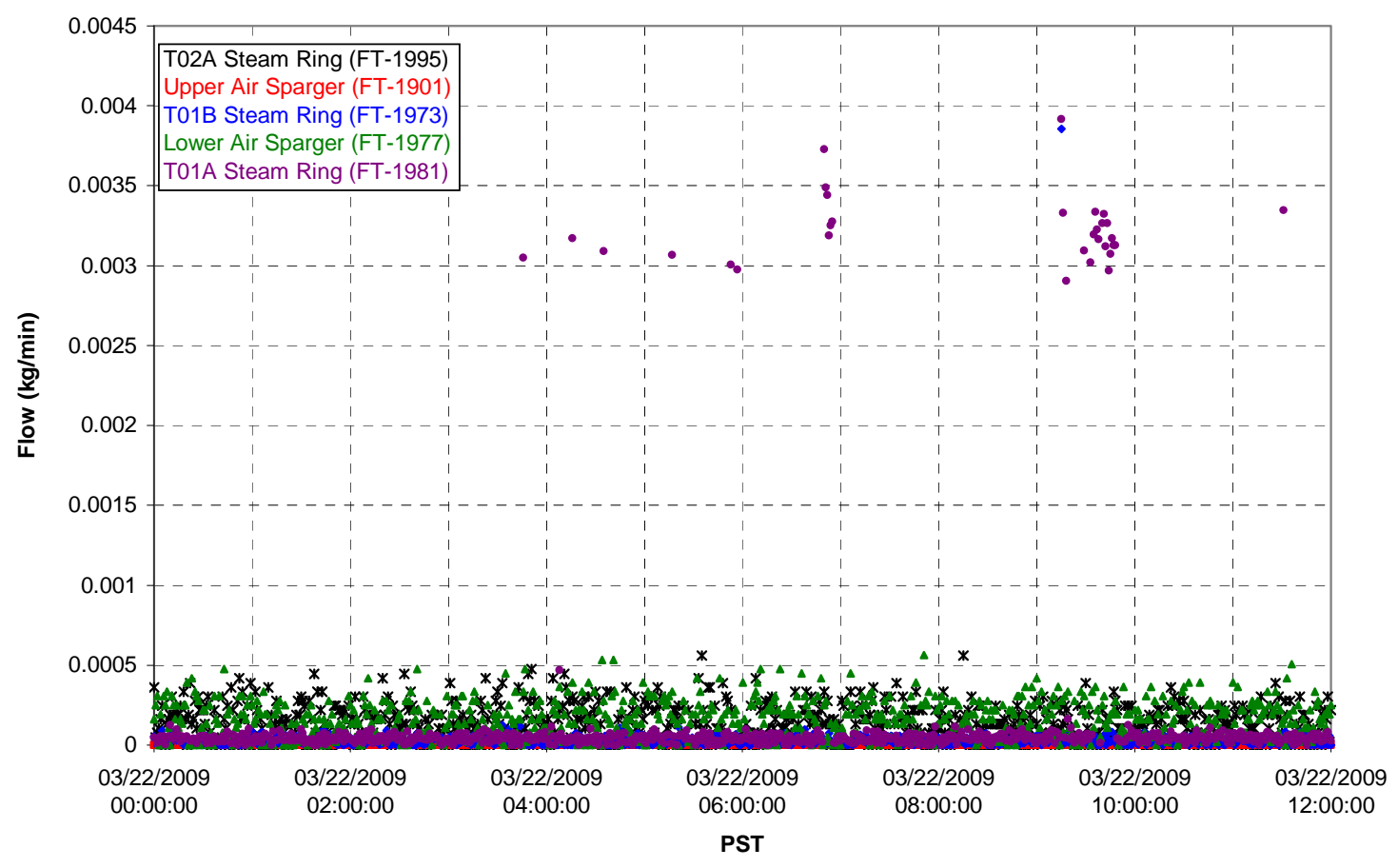


T02A Steam

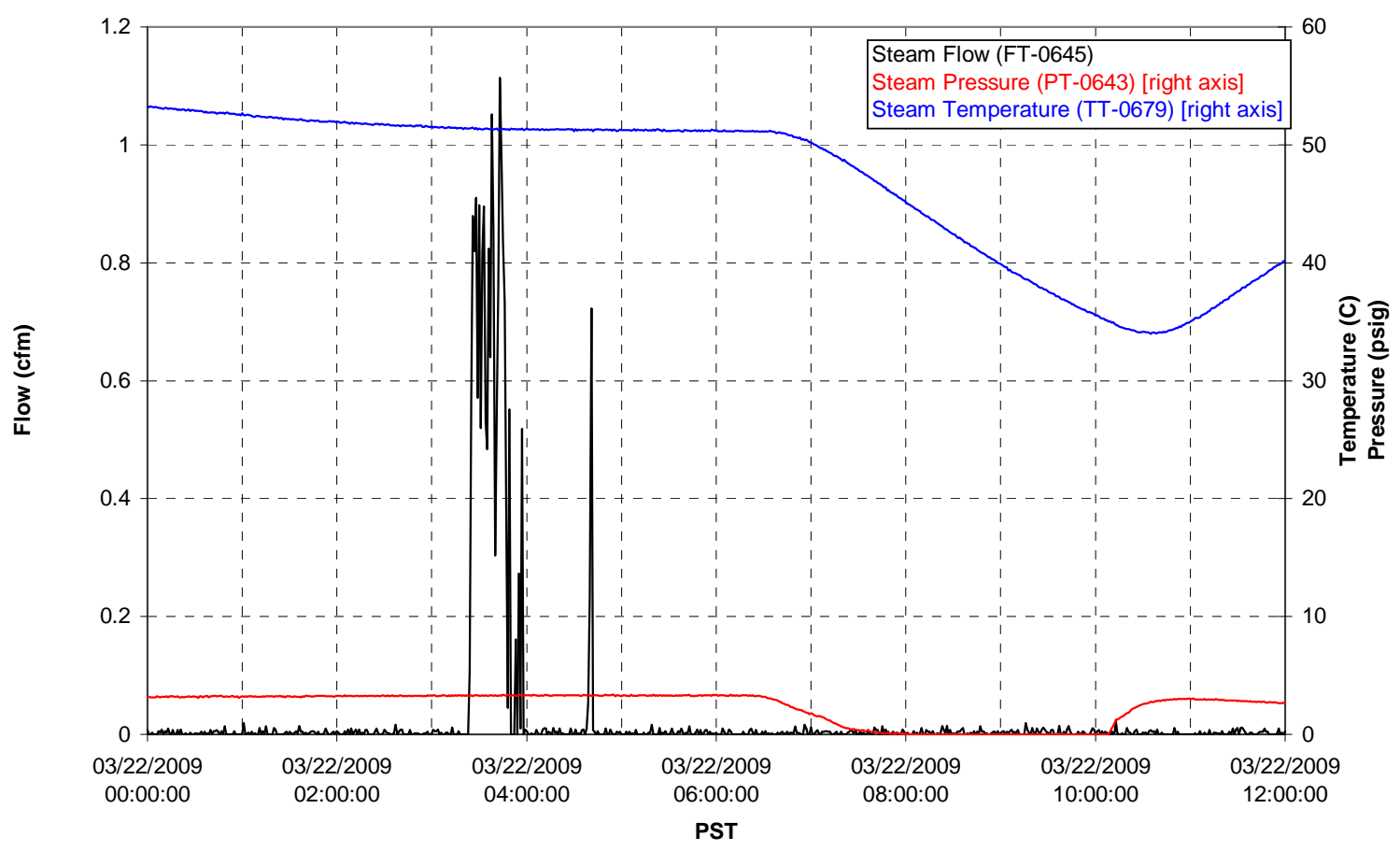

T01A Steam

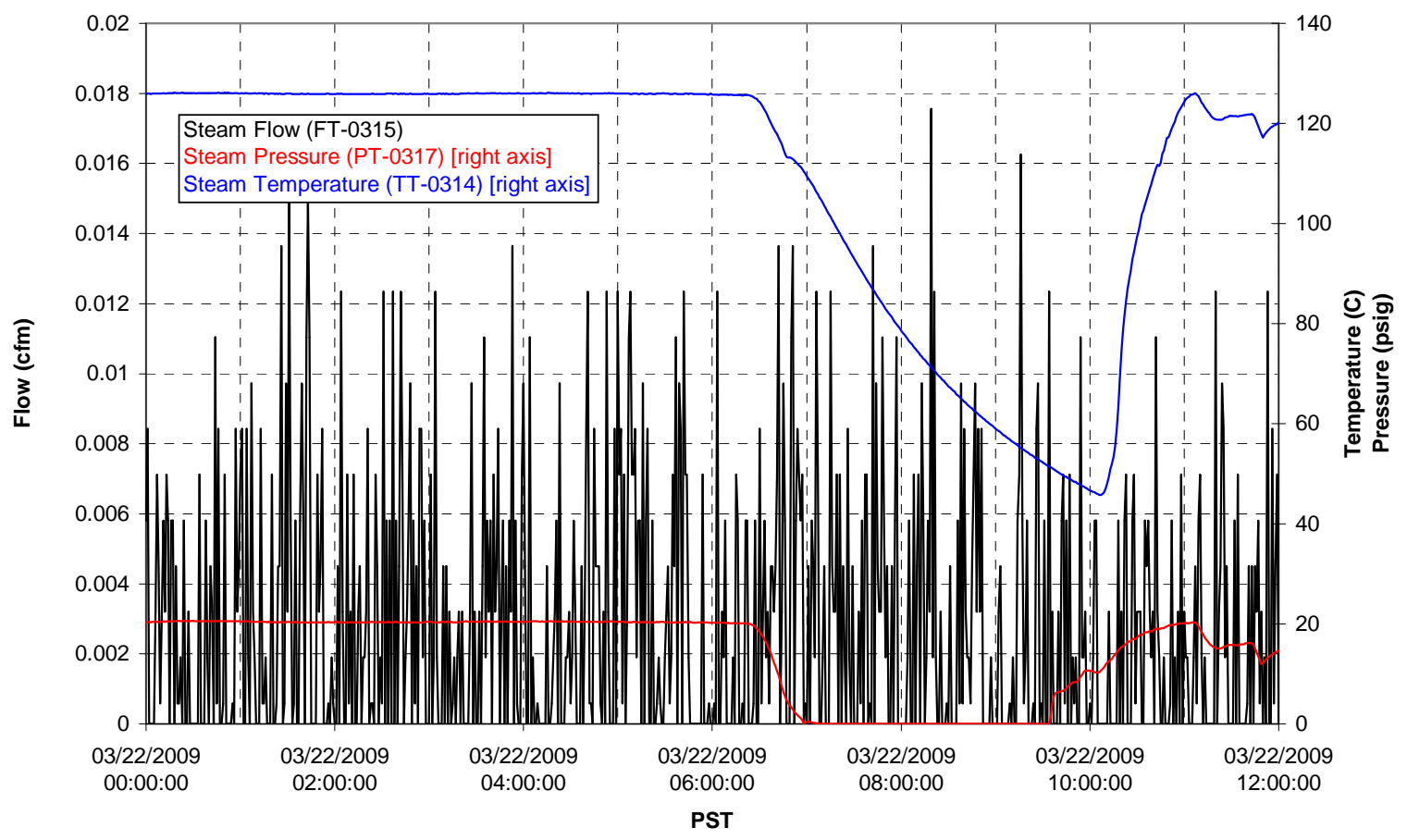


T01B Steam

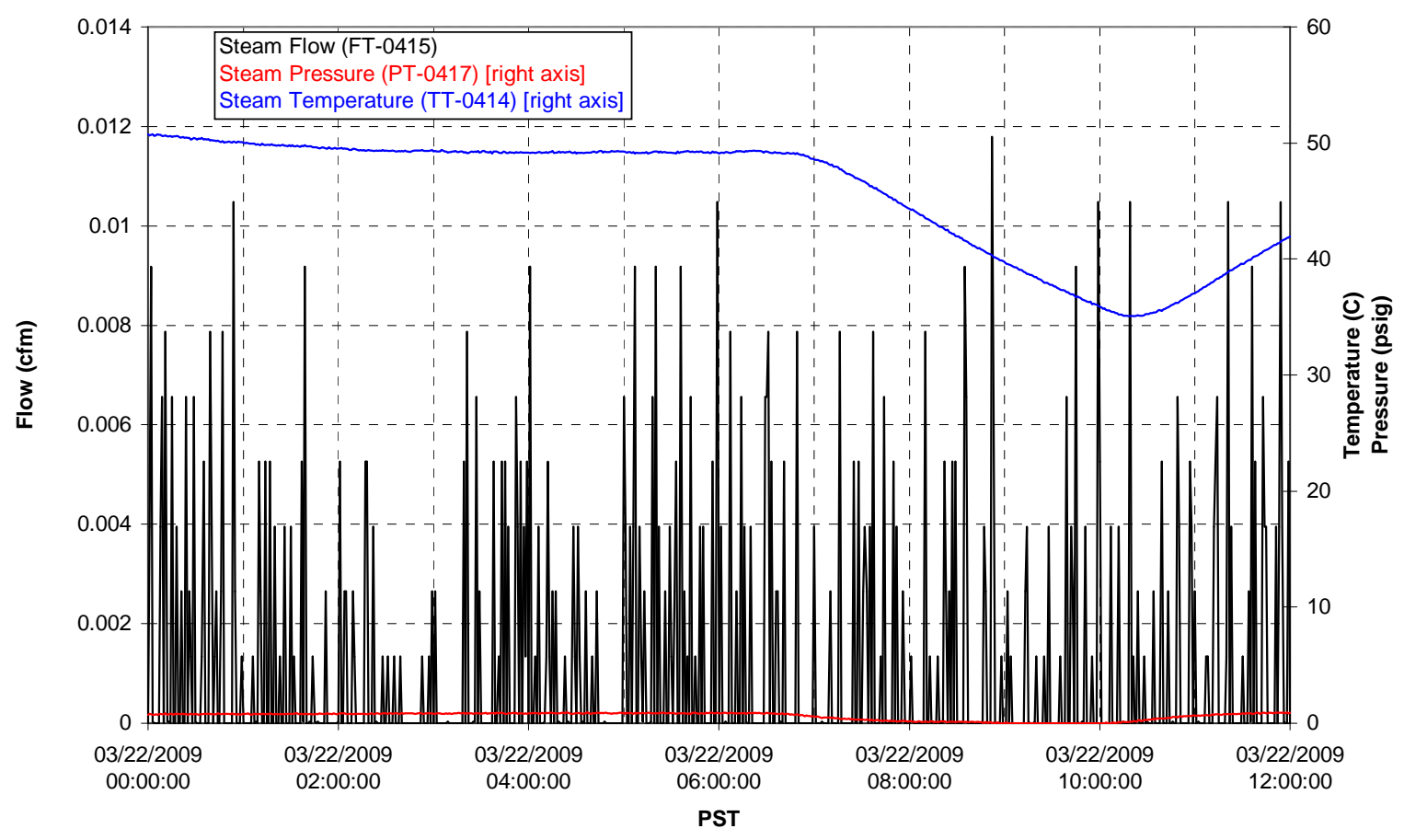




\section{Integrated Test D Data Plots 03/22/09 12:00 - 03/23/09 00:00}


T01A level

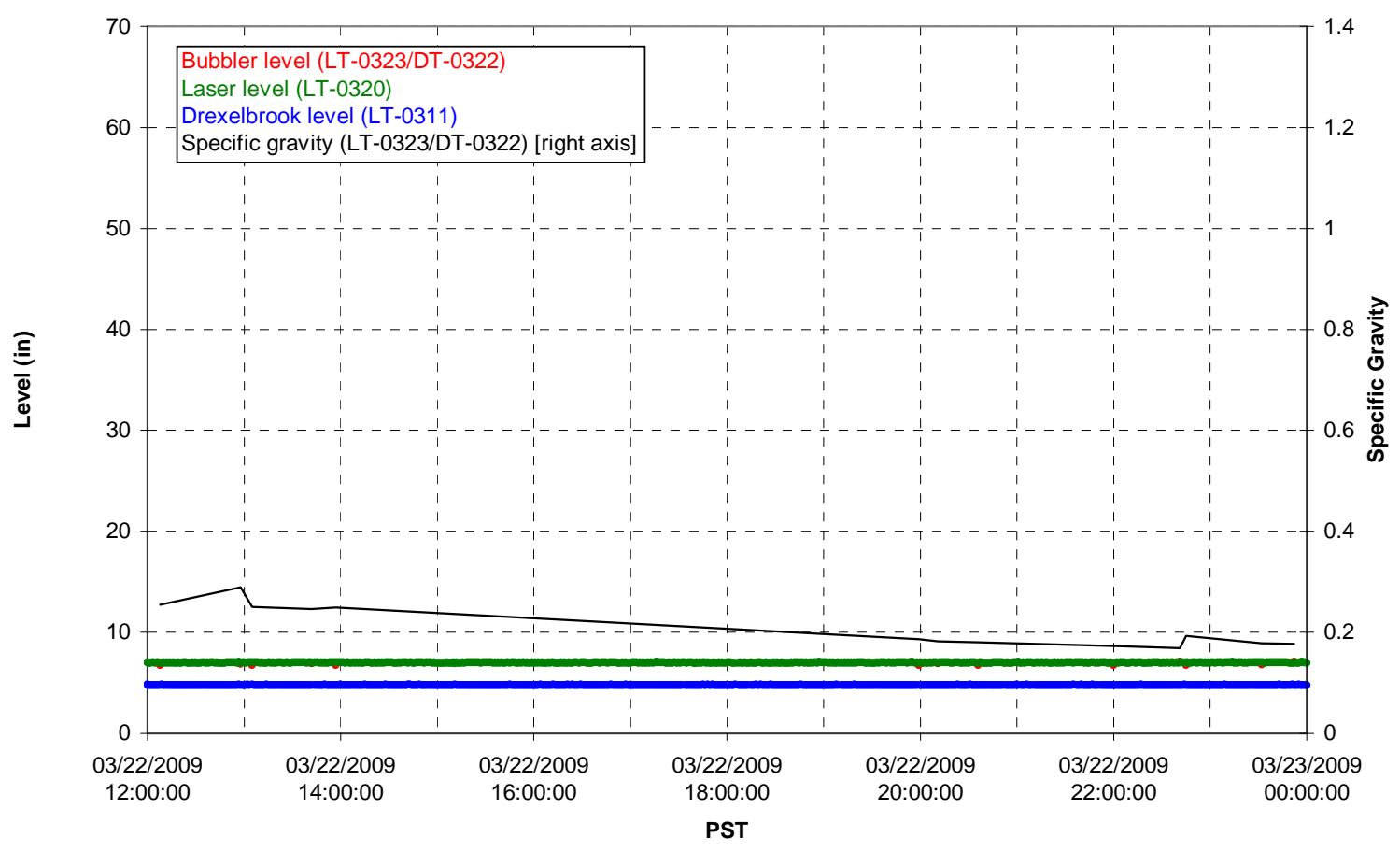

T01A temperatures

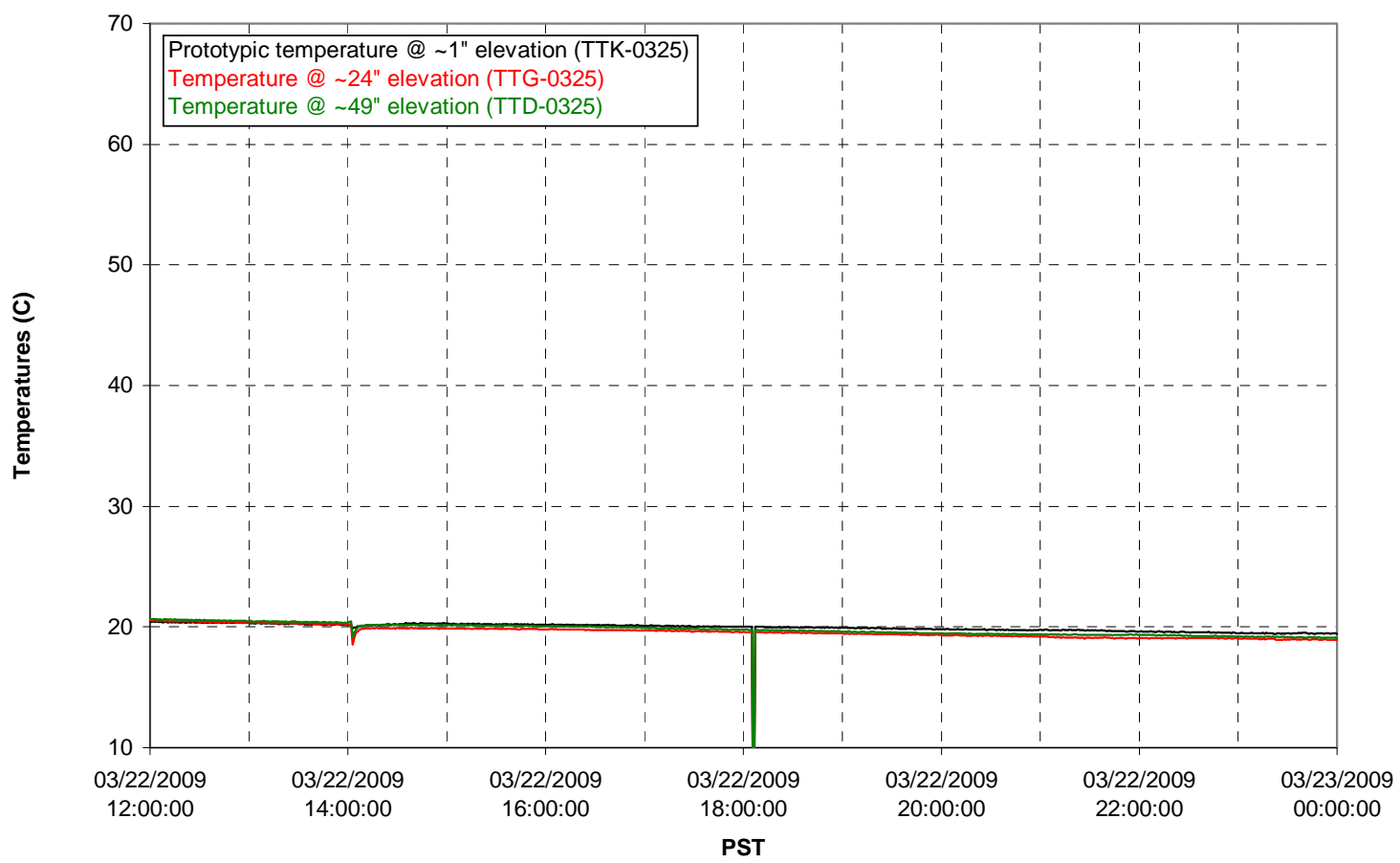


T01B level

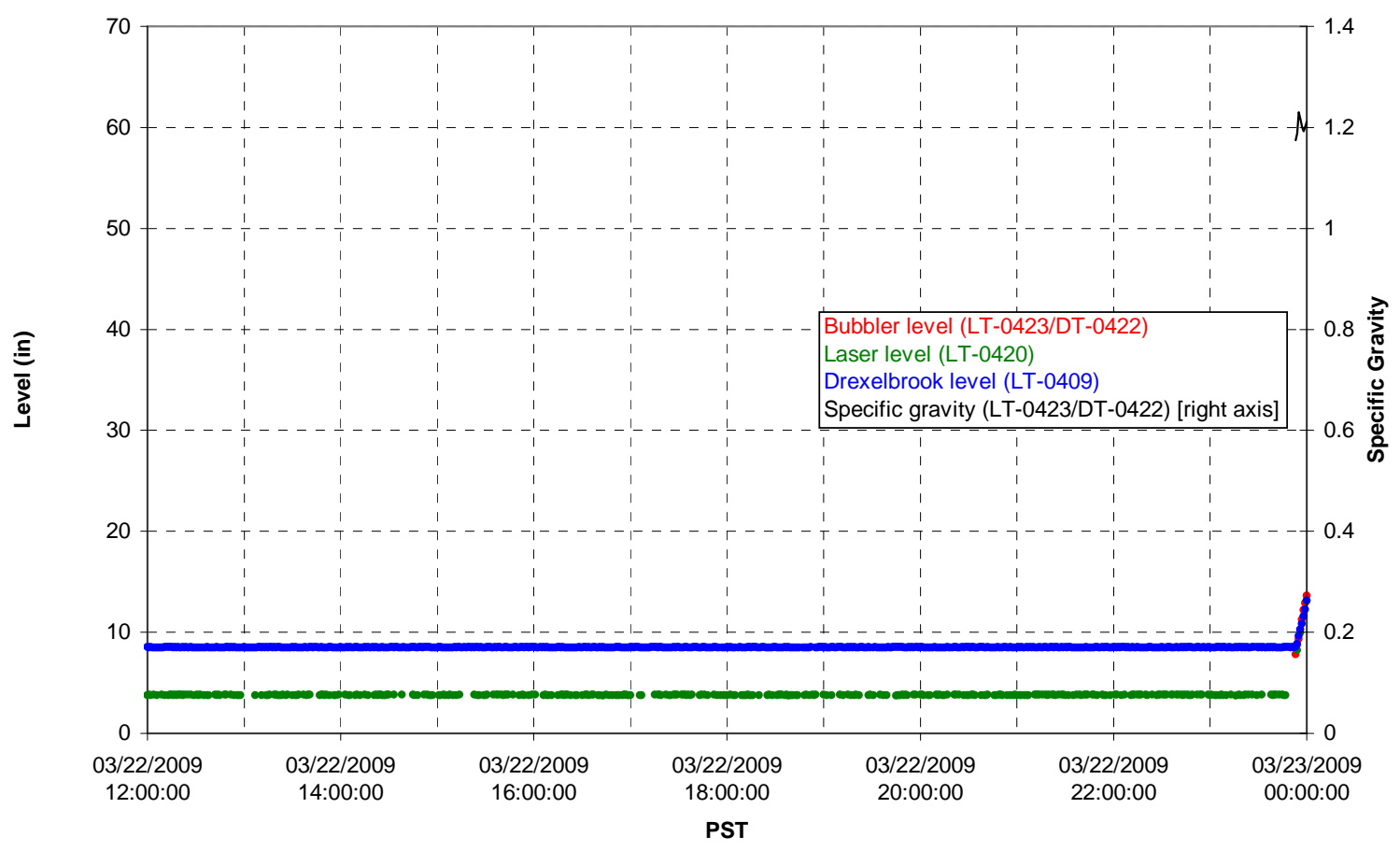

T01B temperatures

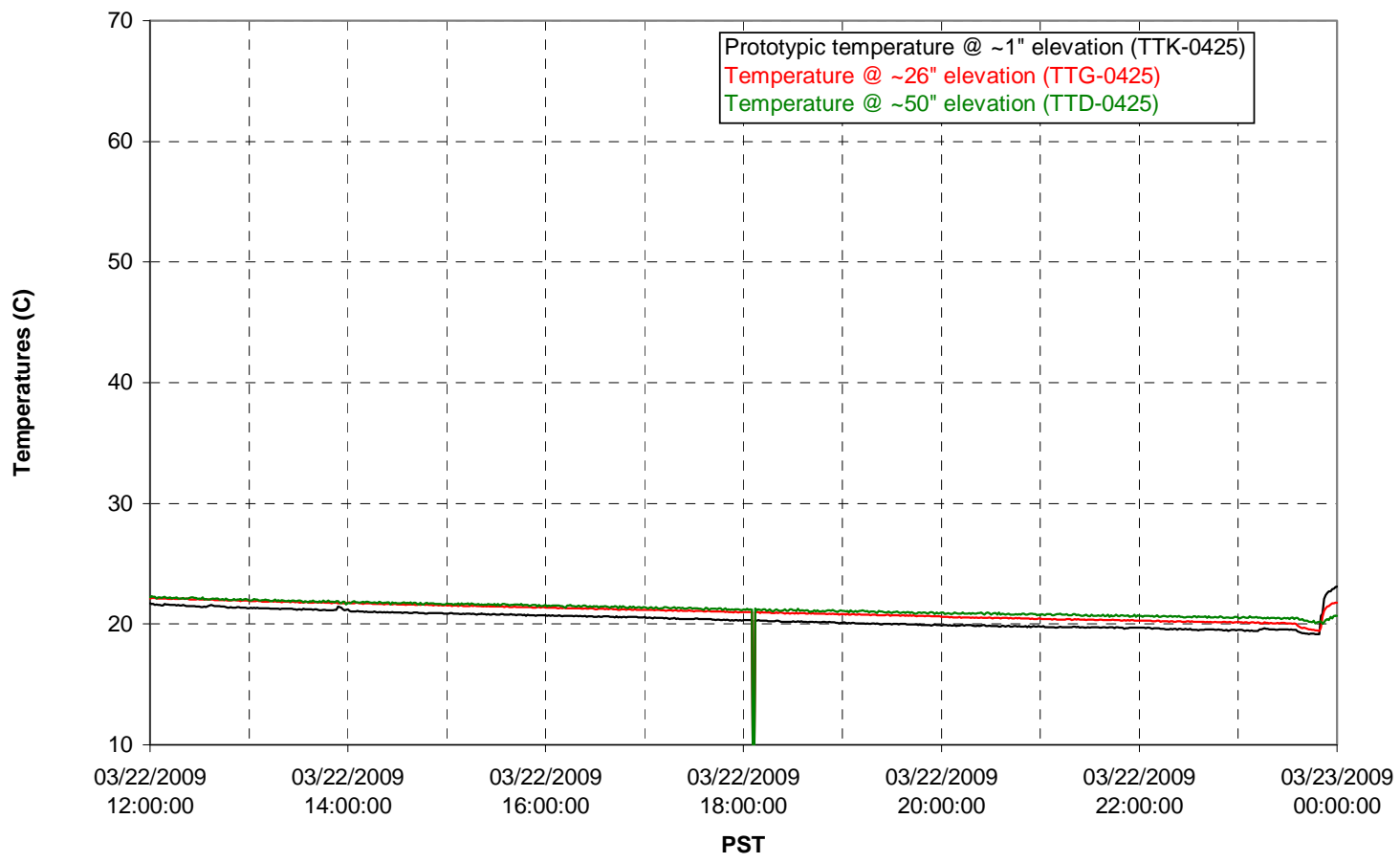


T02A level

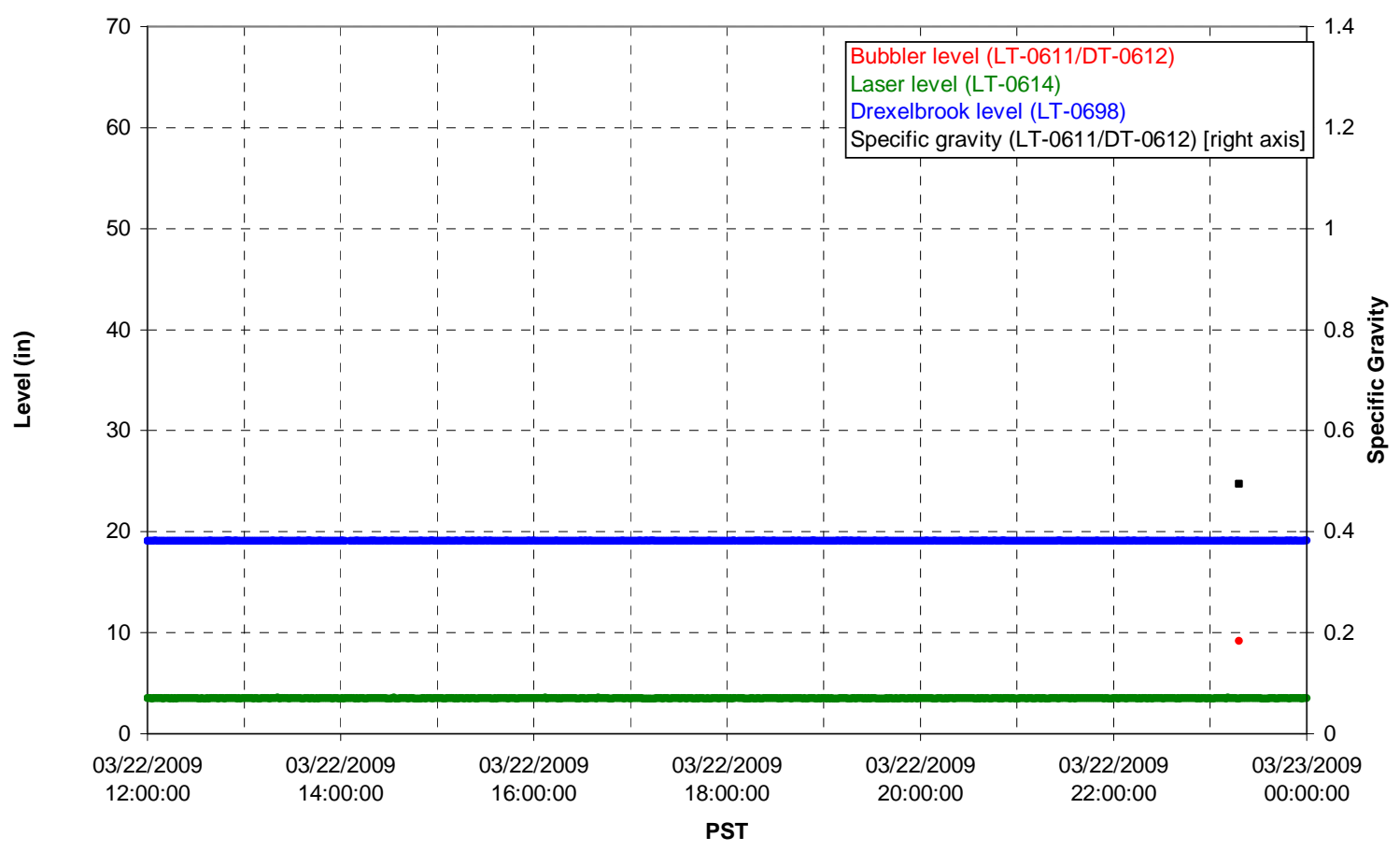

T02A temperatures

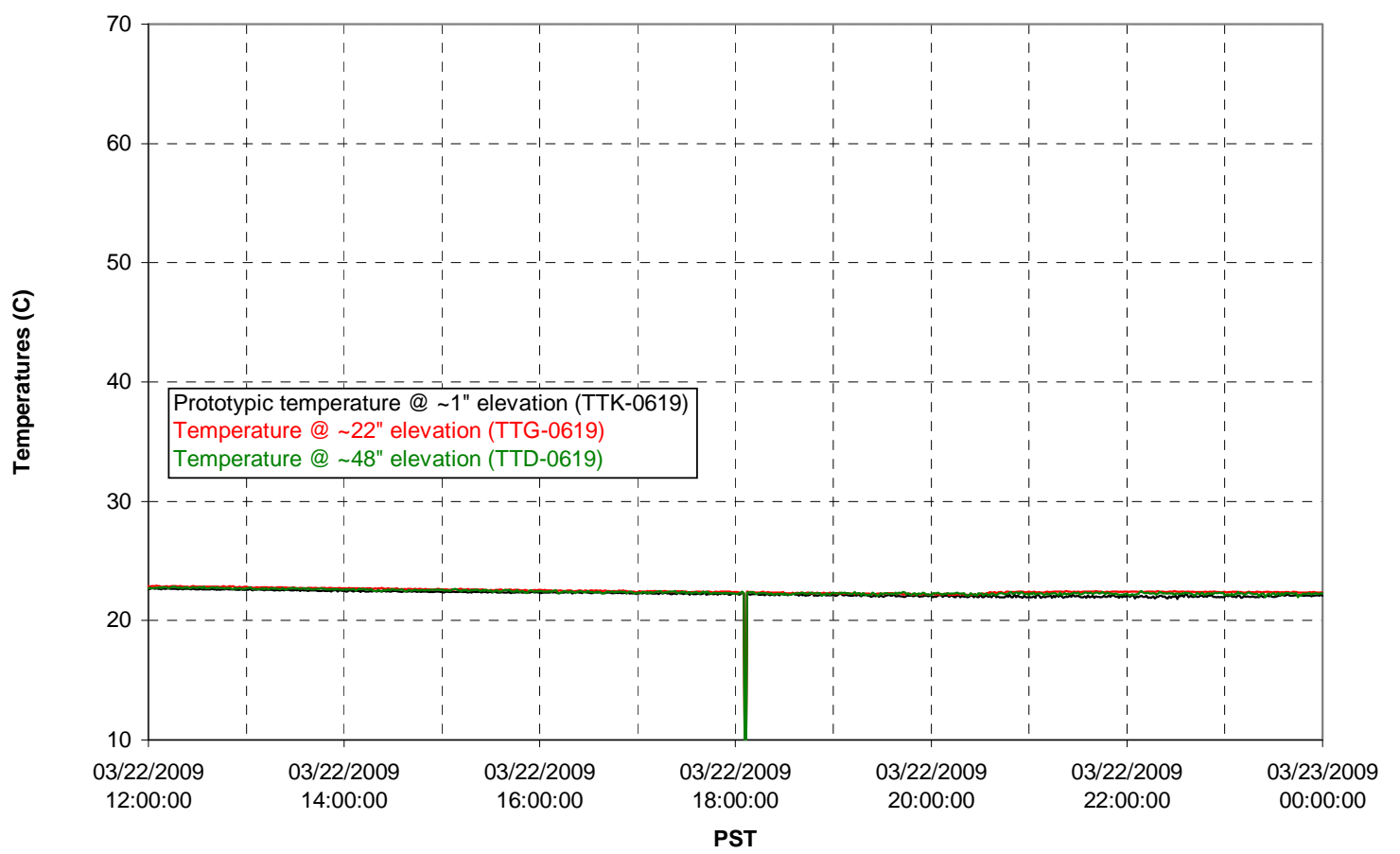


T02A and filter loop temperatures

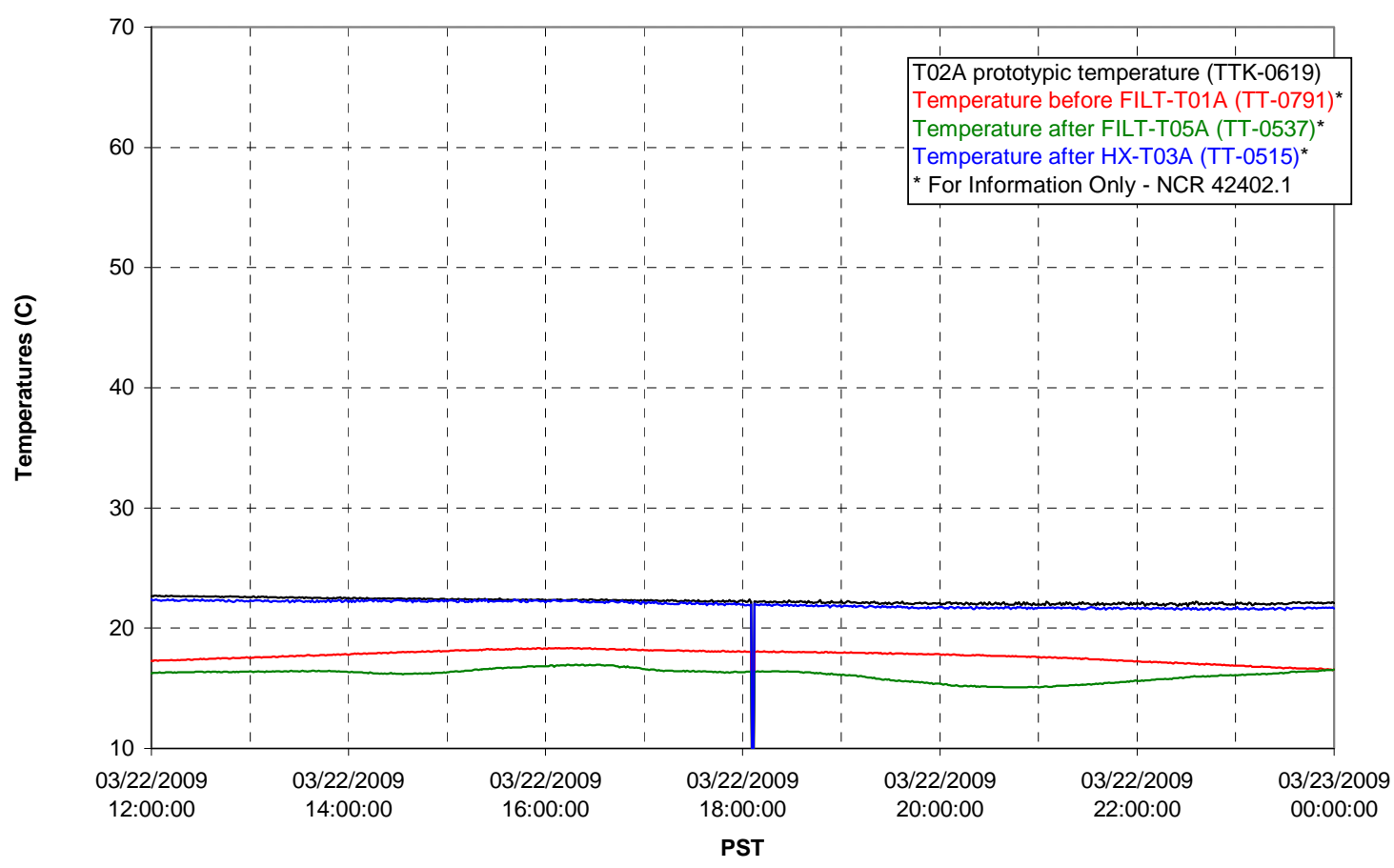

Pump Pressures and Flow

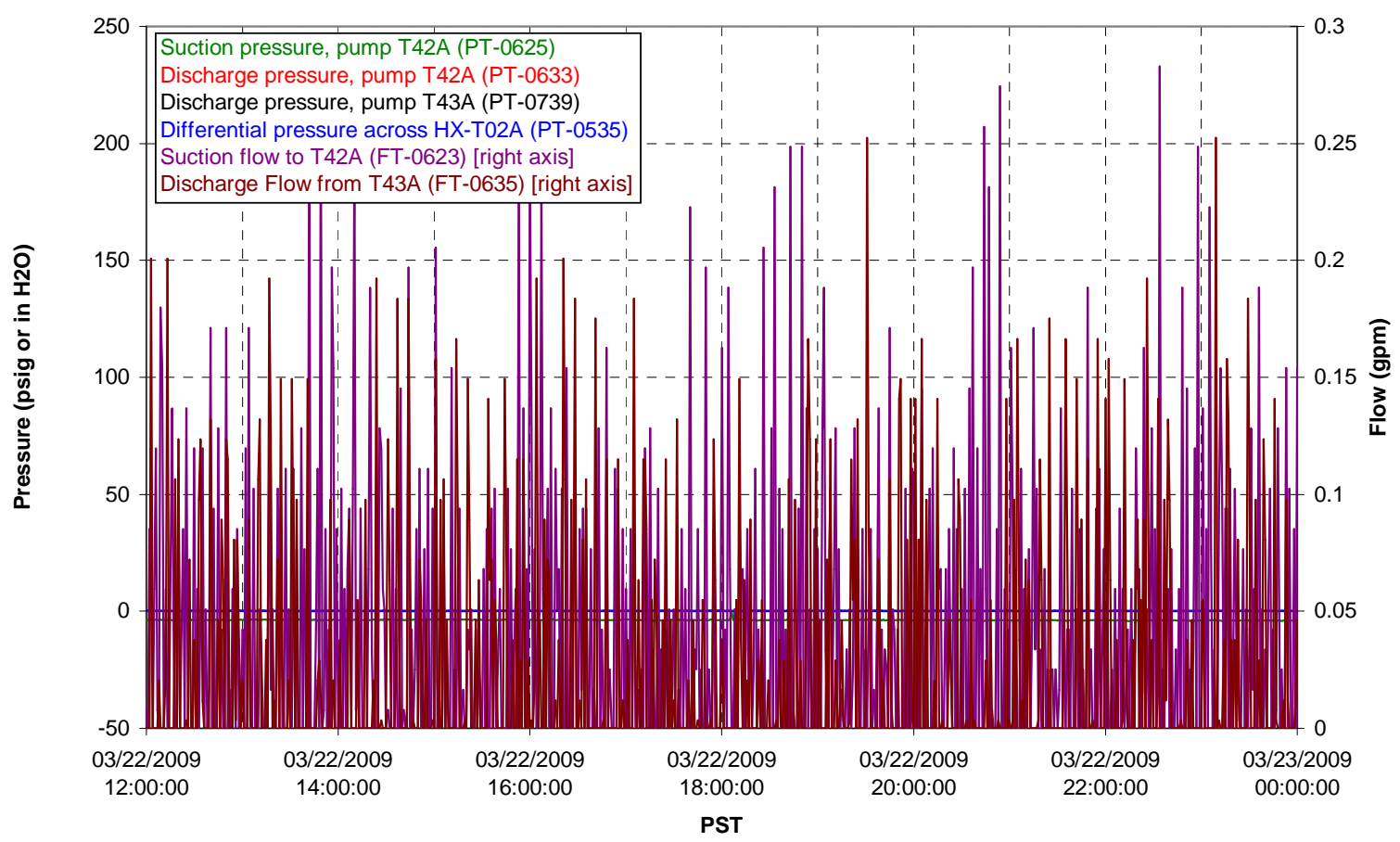




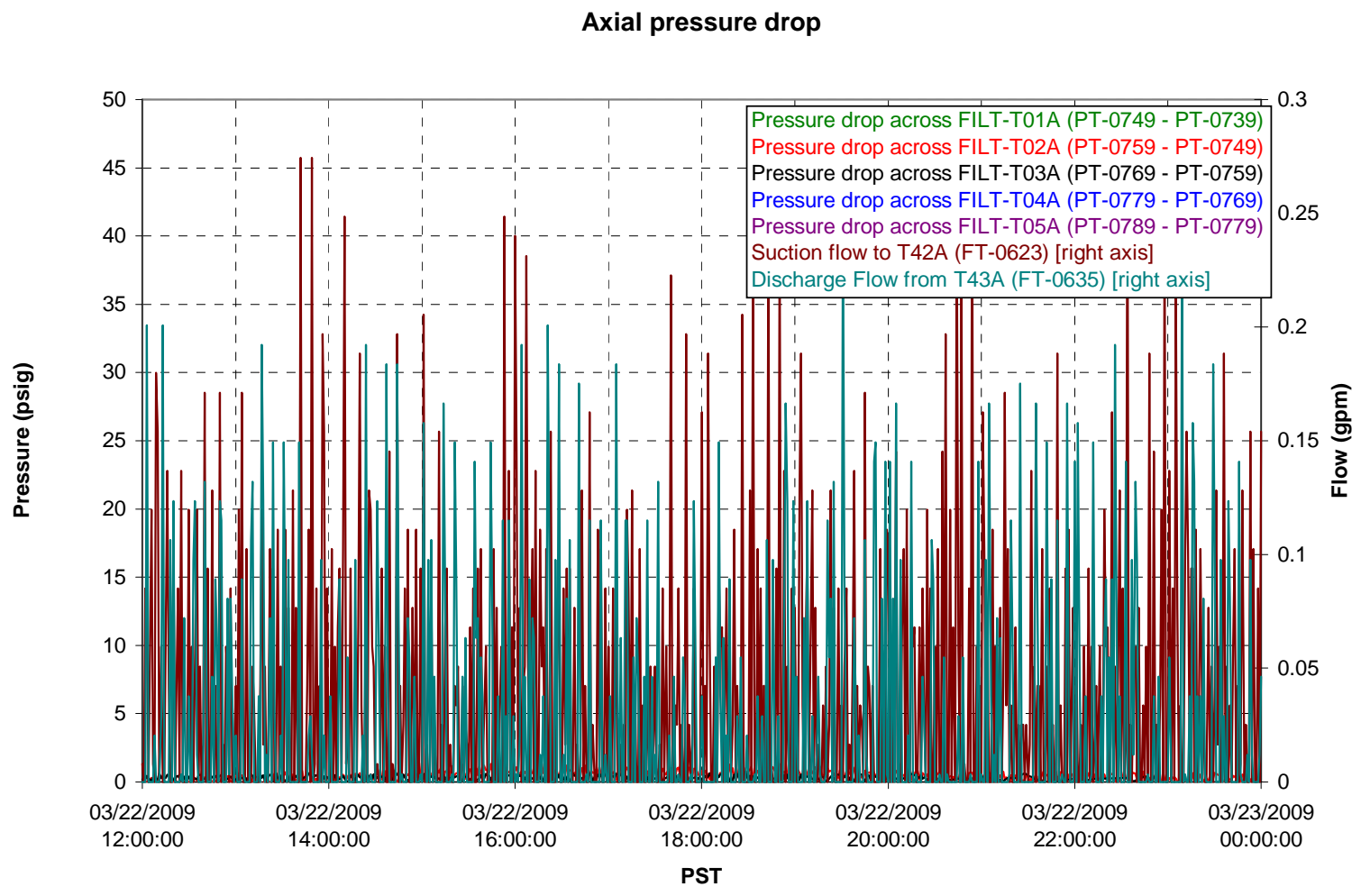

Permeate flow rates

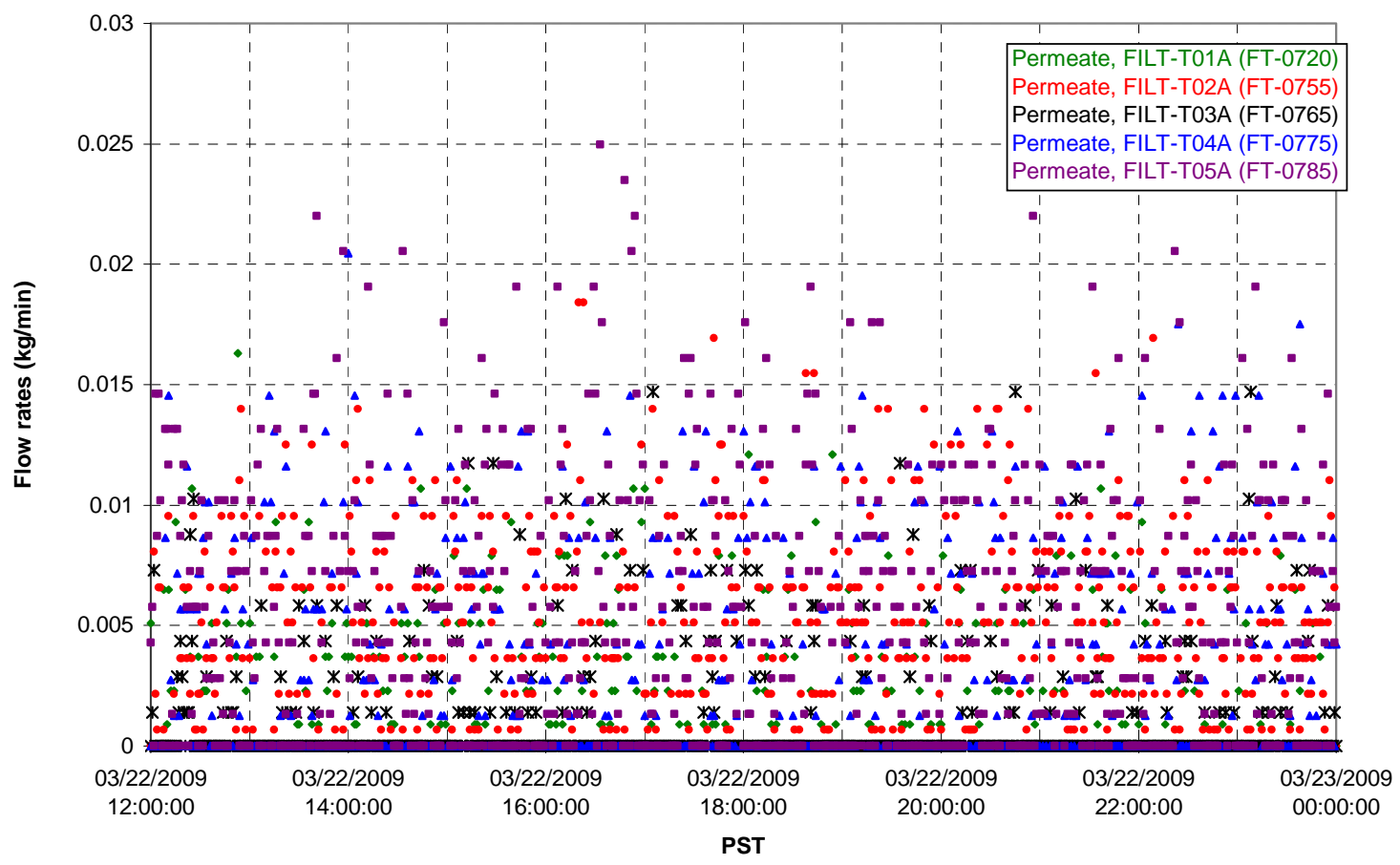


T02A Inner Temperature Tree

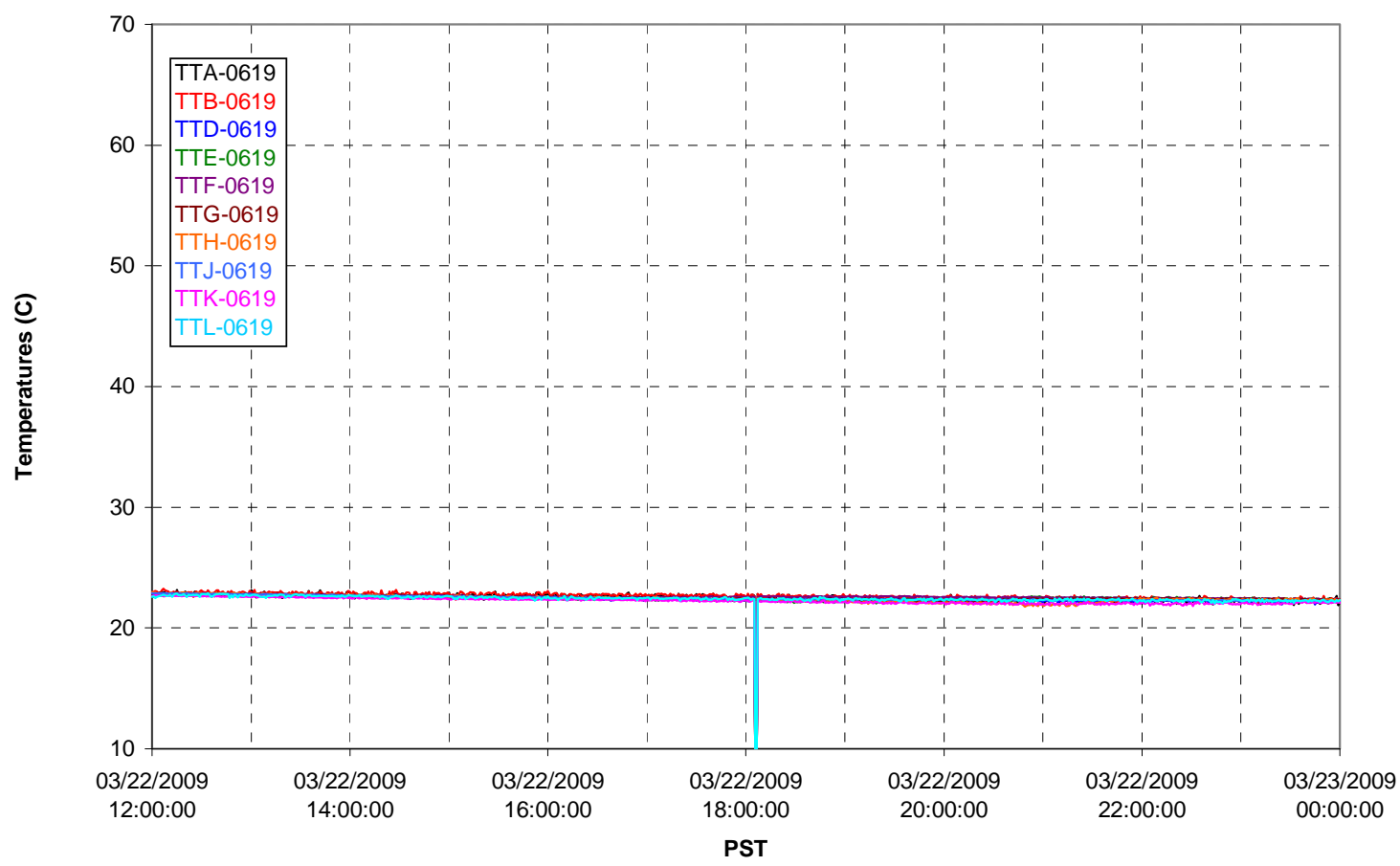

T02A Outer Temperature Tree

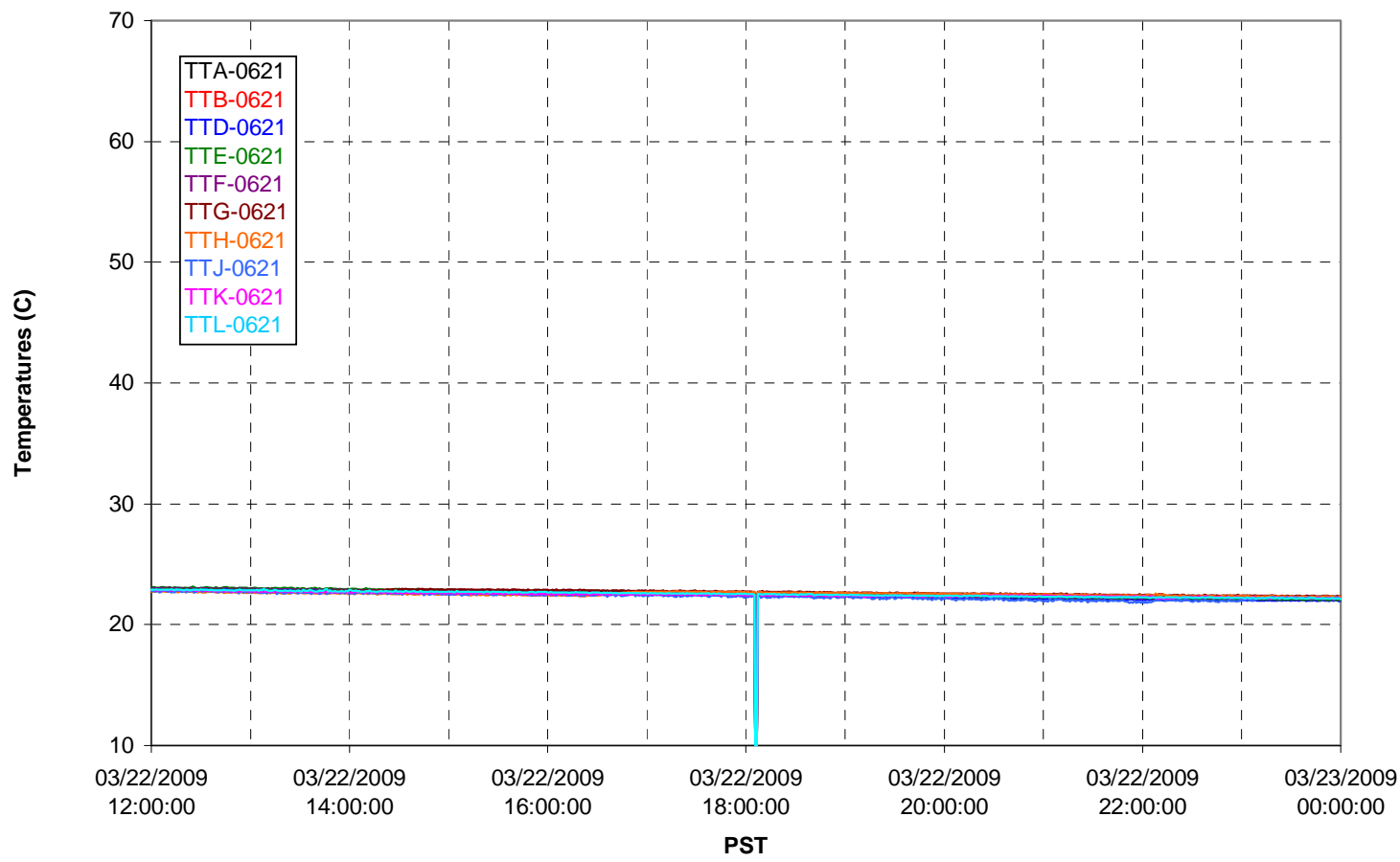


T02A temperatures

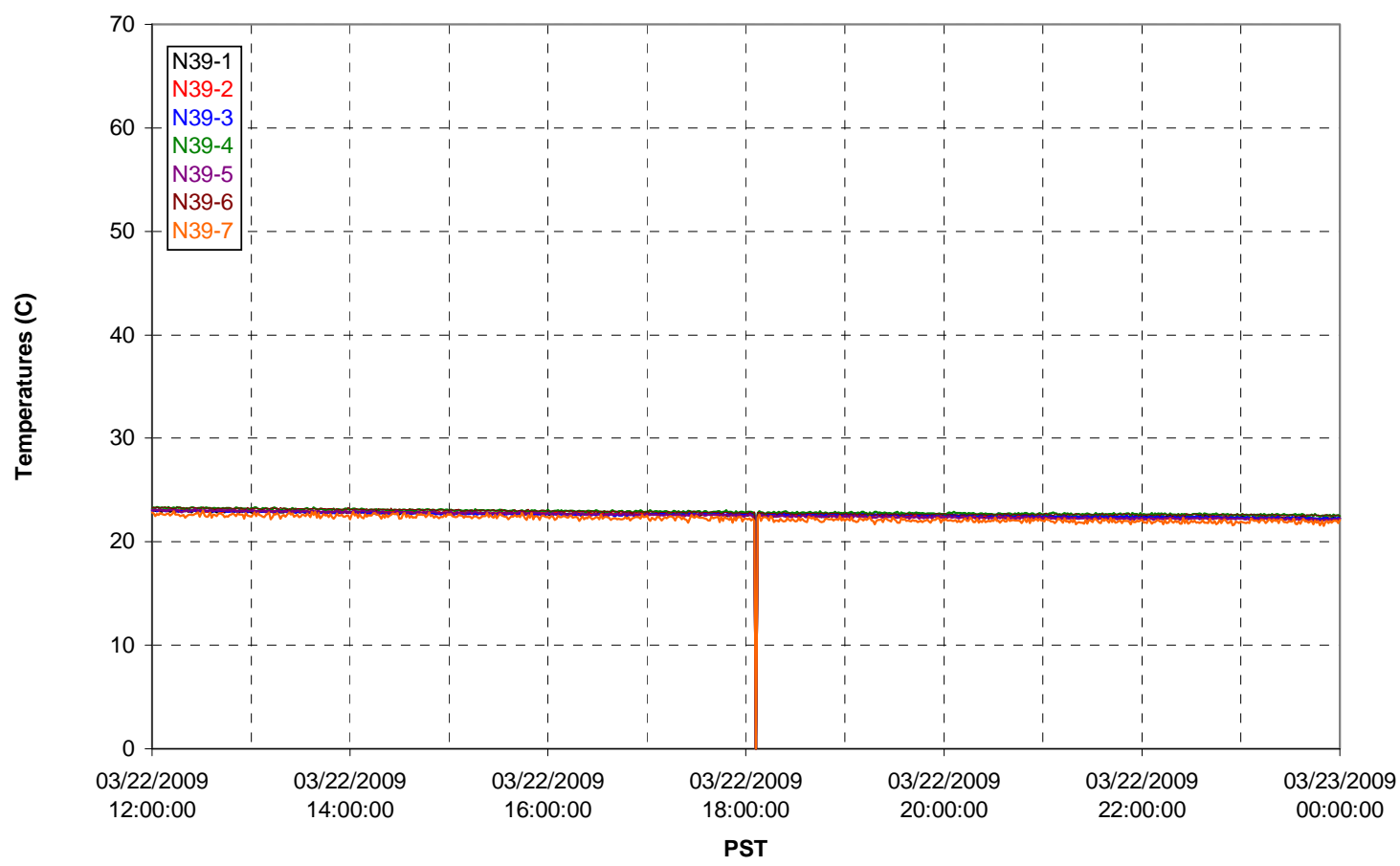

T02A temperatures

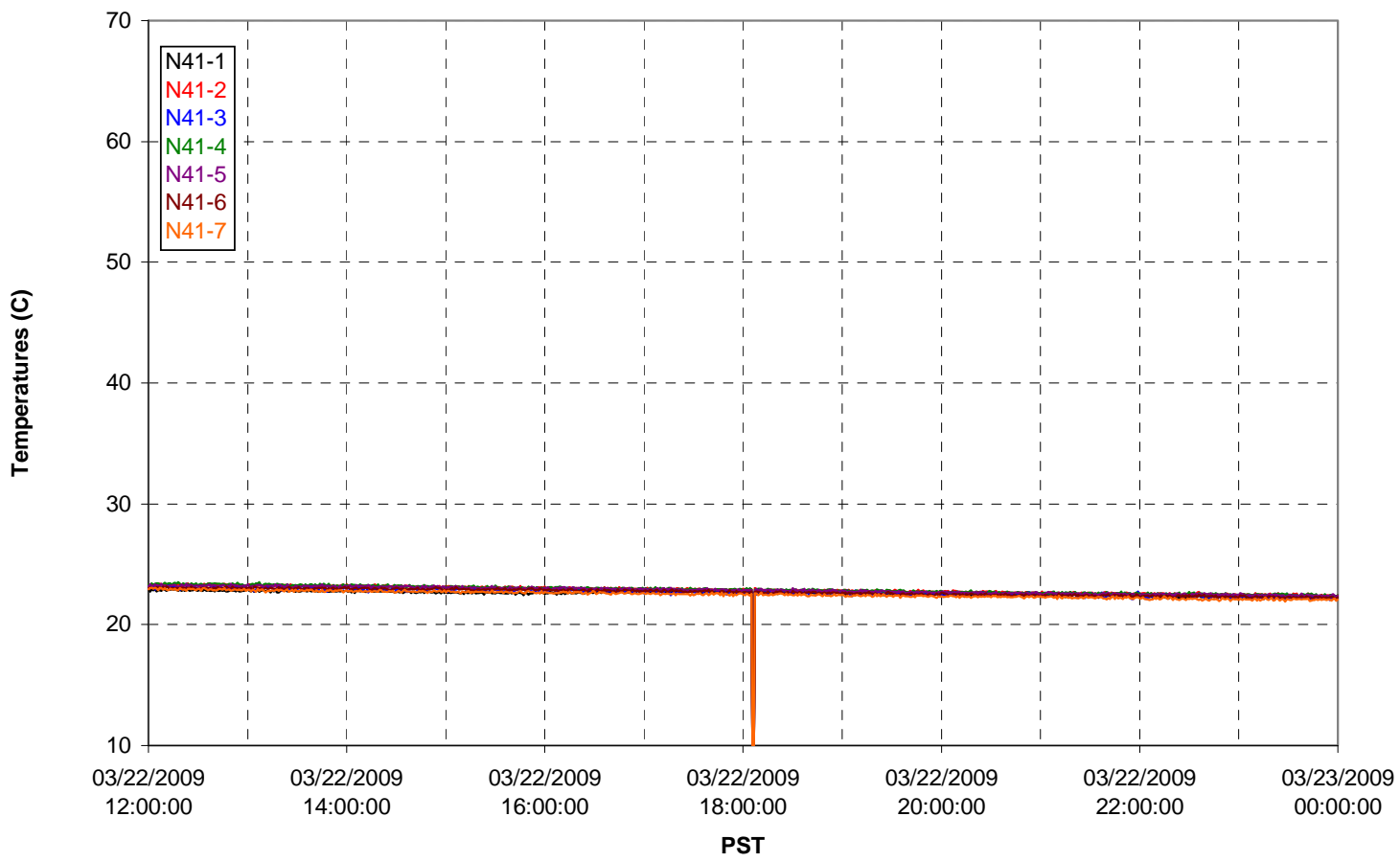


T02A temperatures

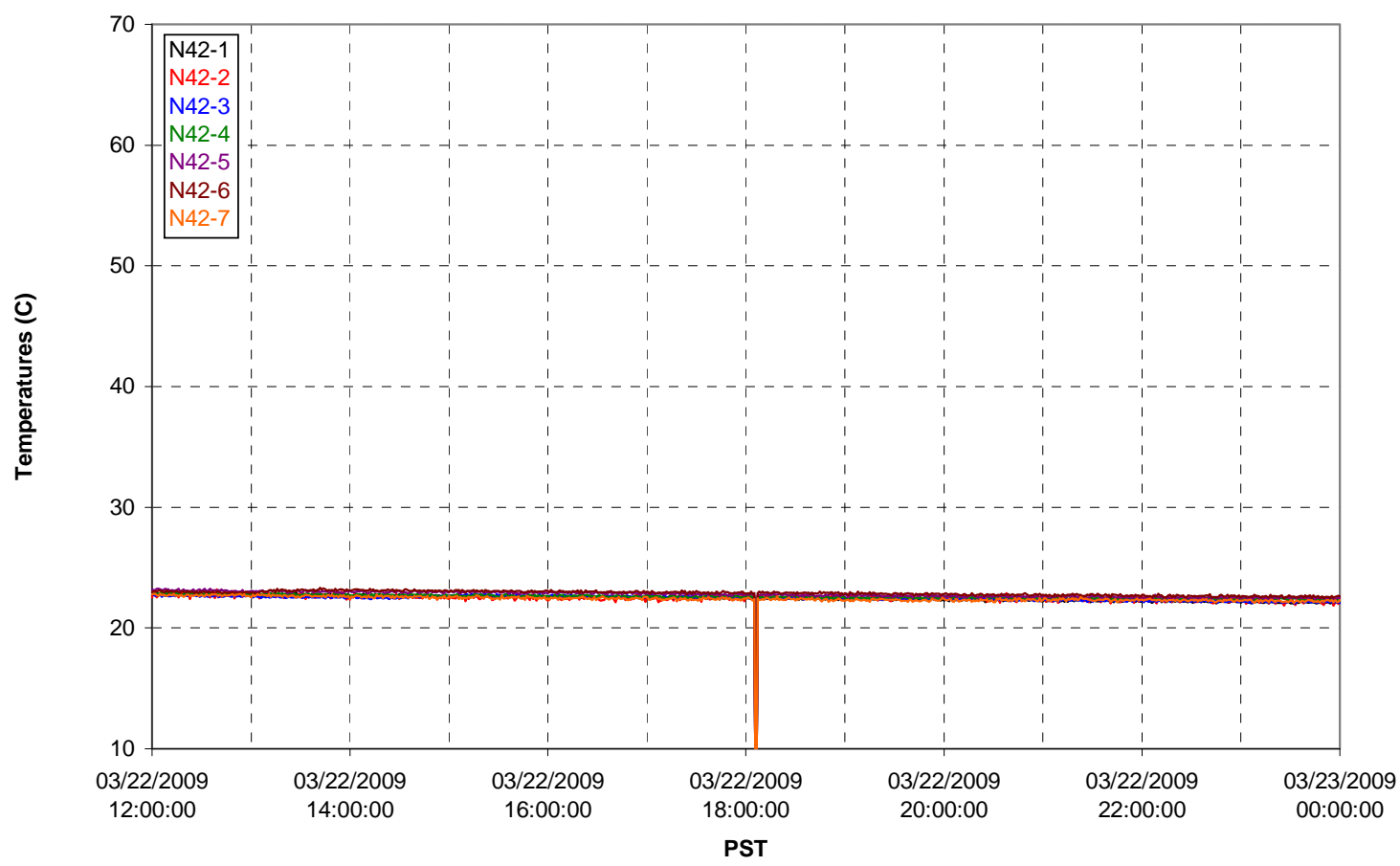

T02A temperatures

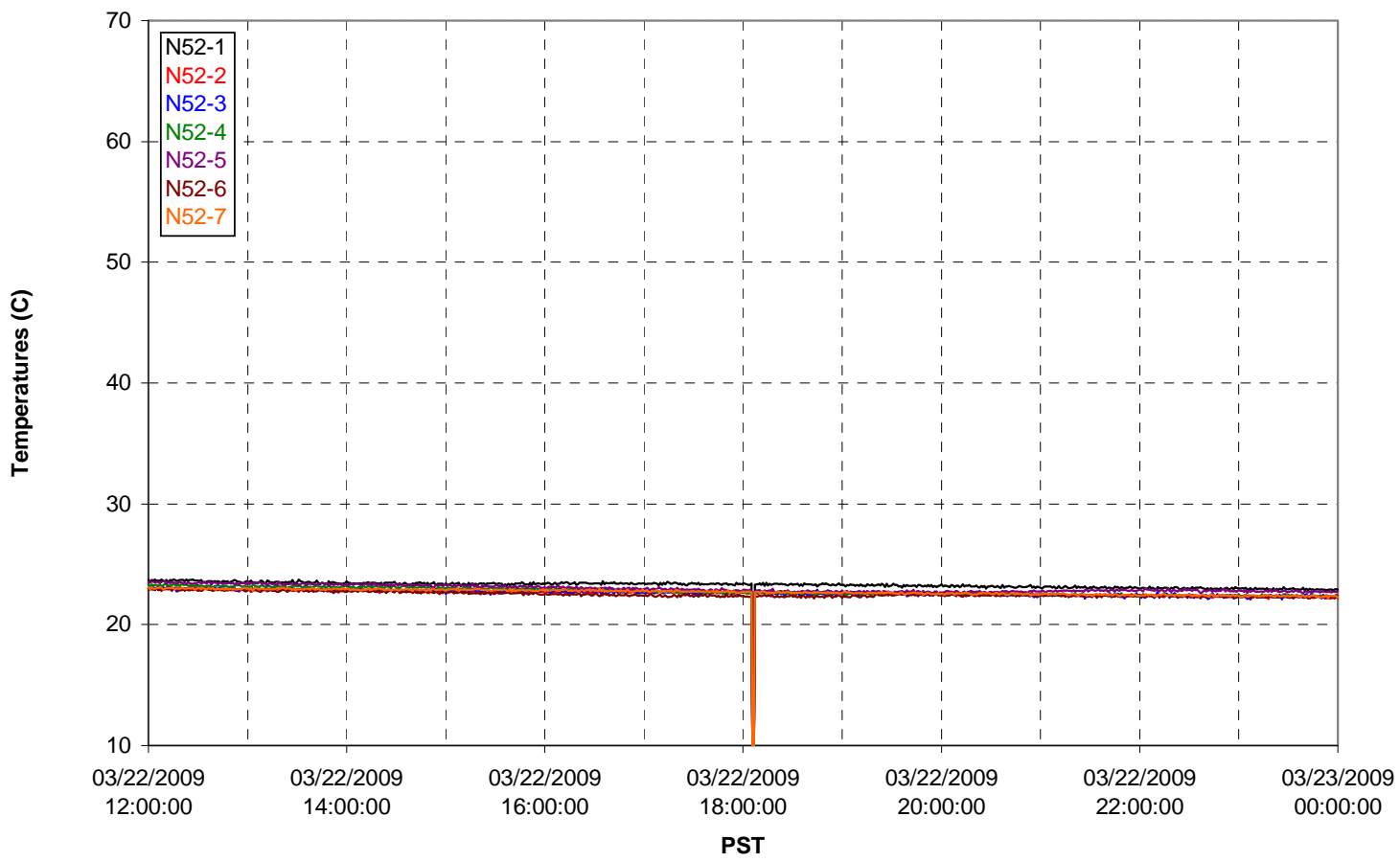


T02A Heating and Cooling

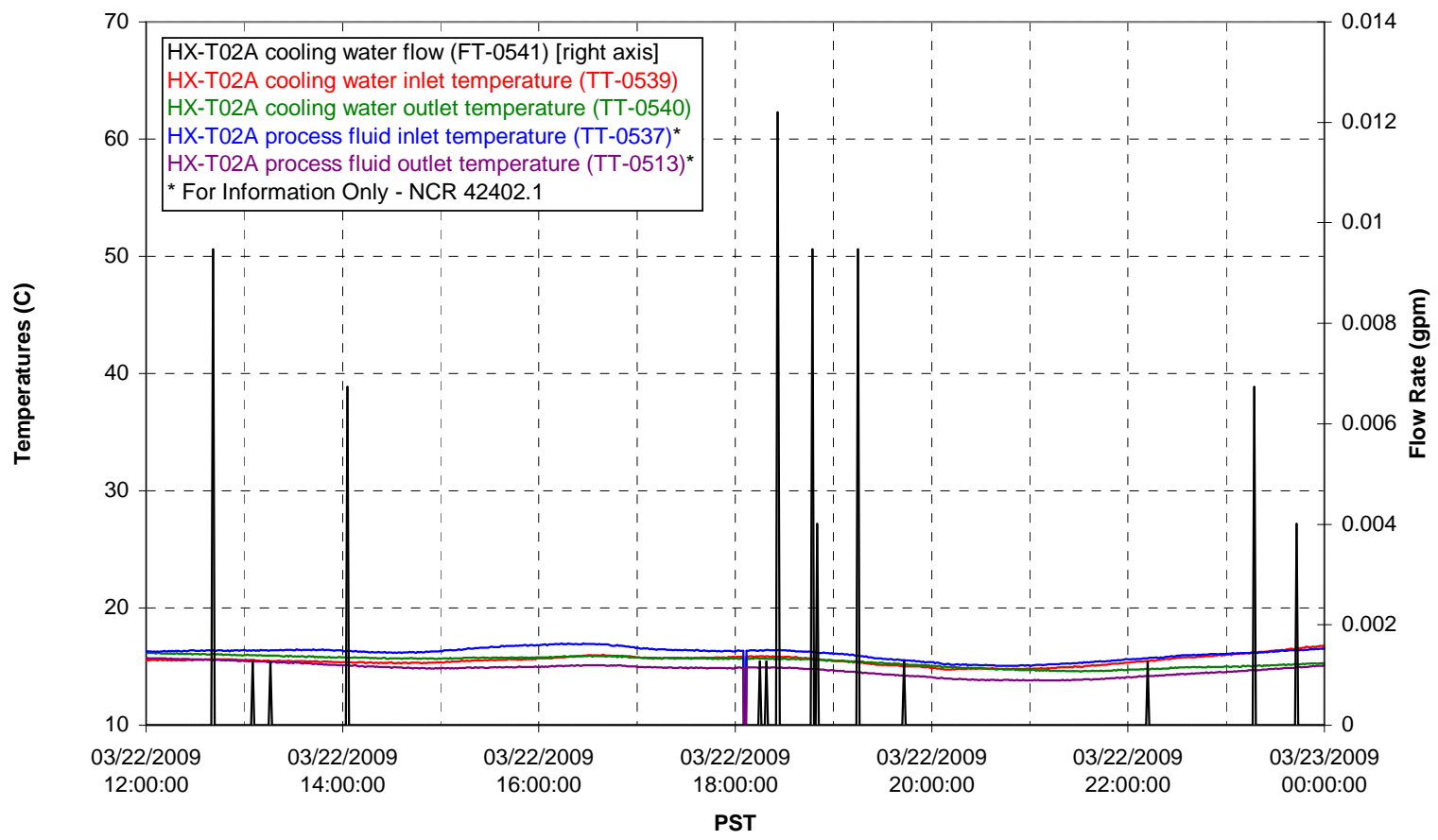

Pump Operation

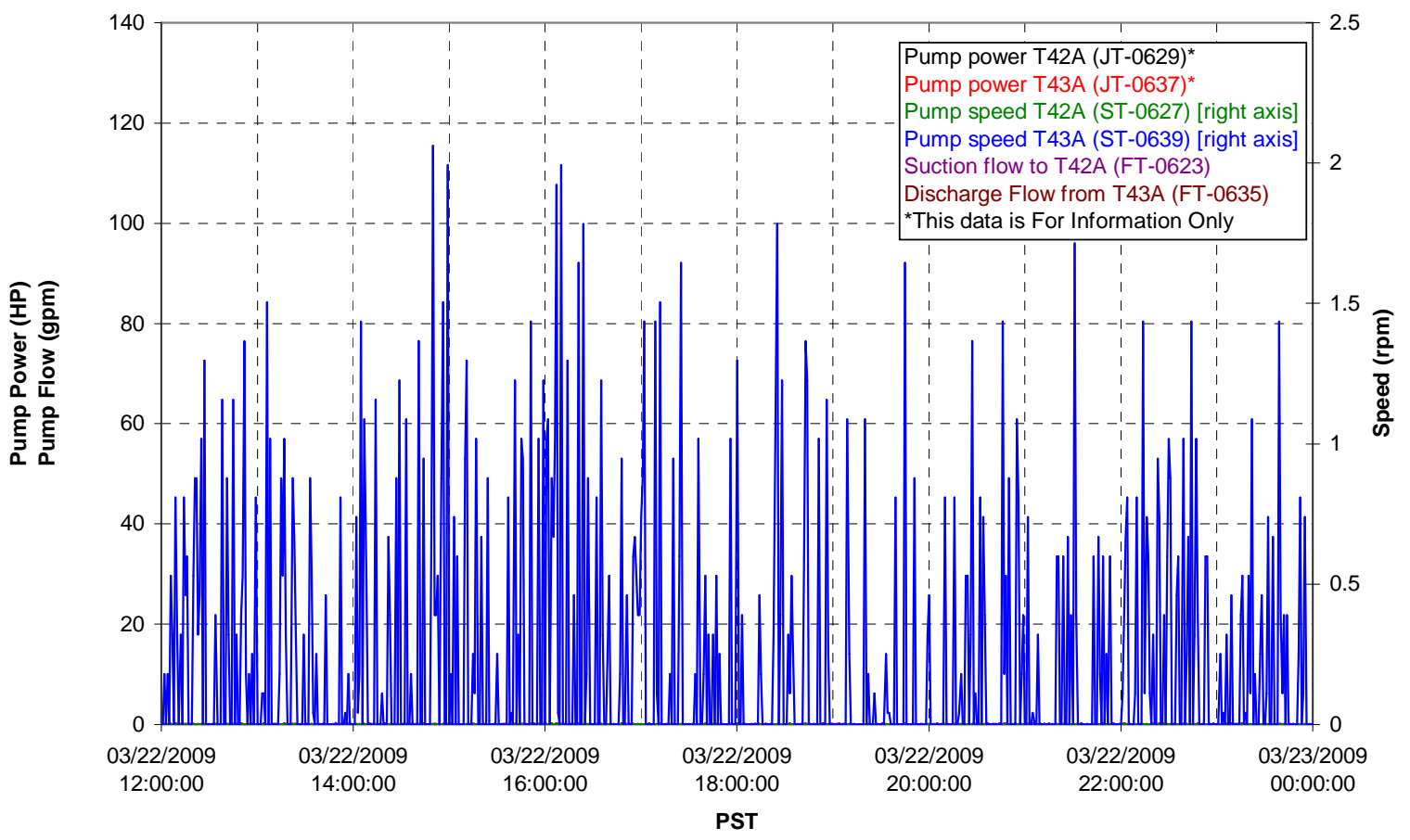


Pulsepot UFP-PP-T01A

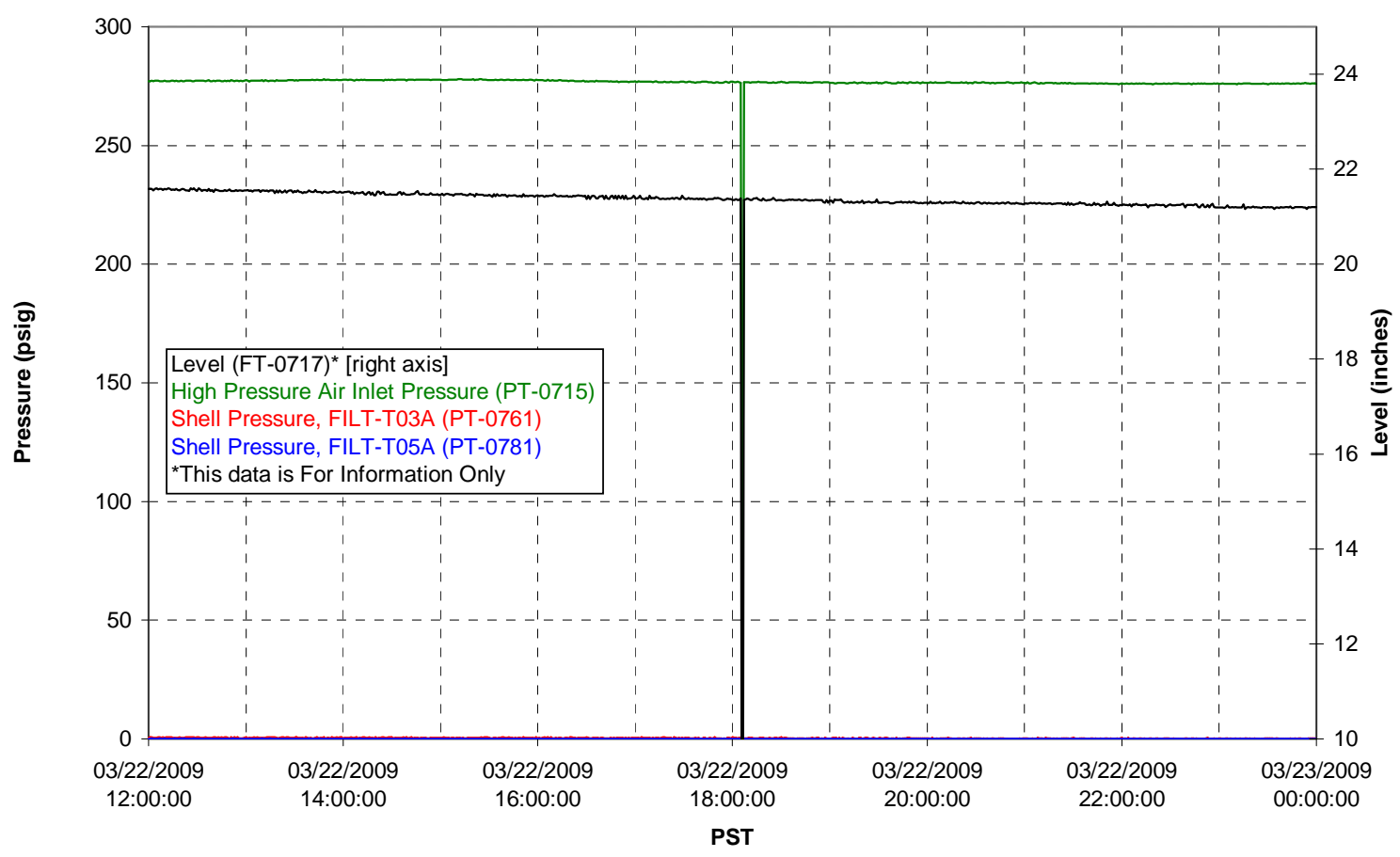

Pulsepot UFP-PP-T02A

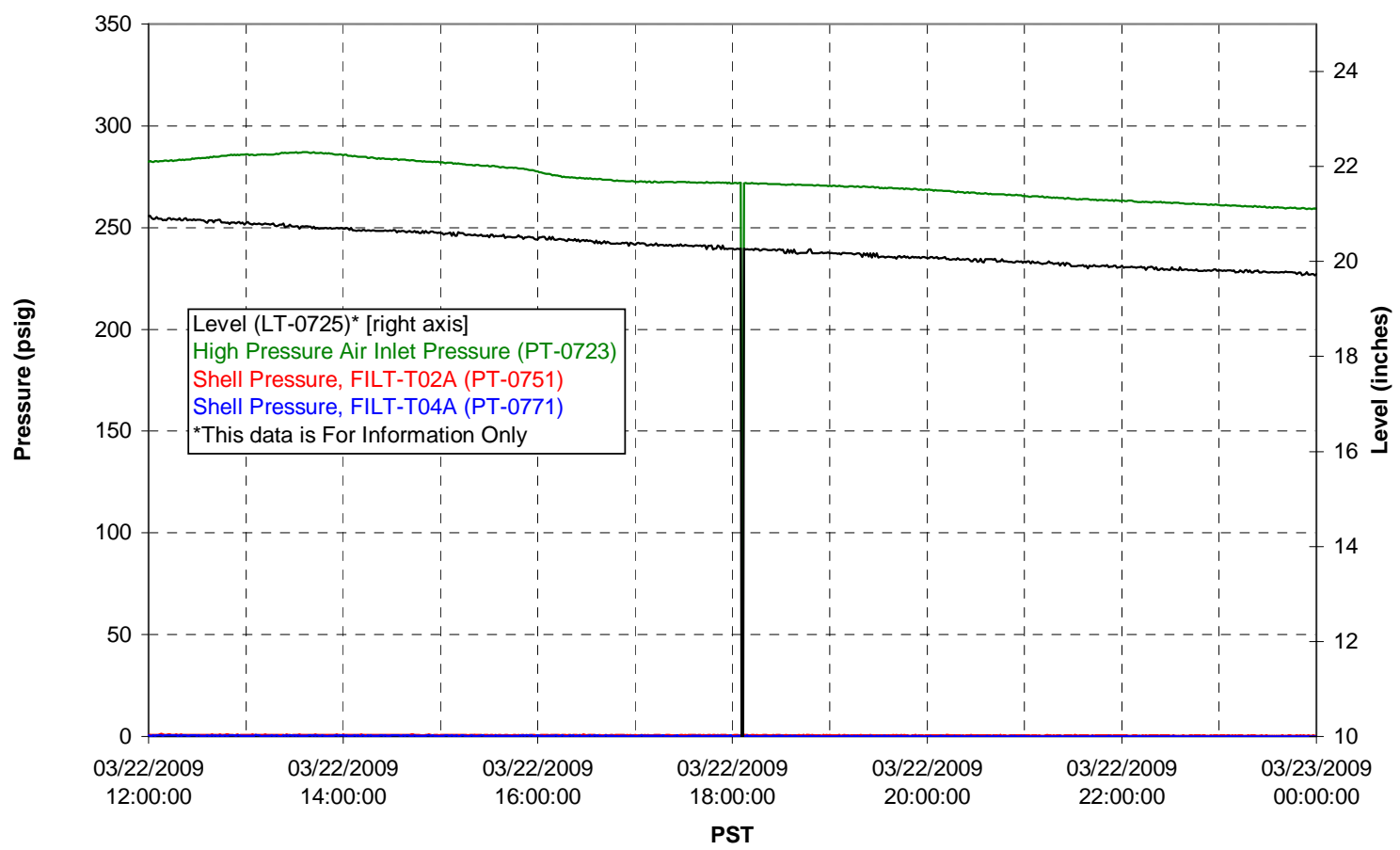


Pulsepot UFP-PP-T03A

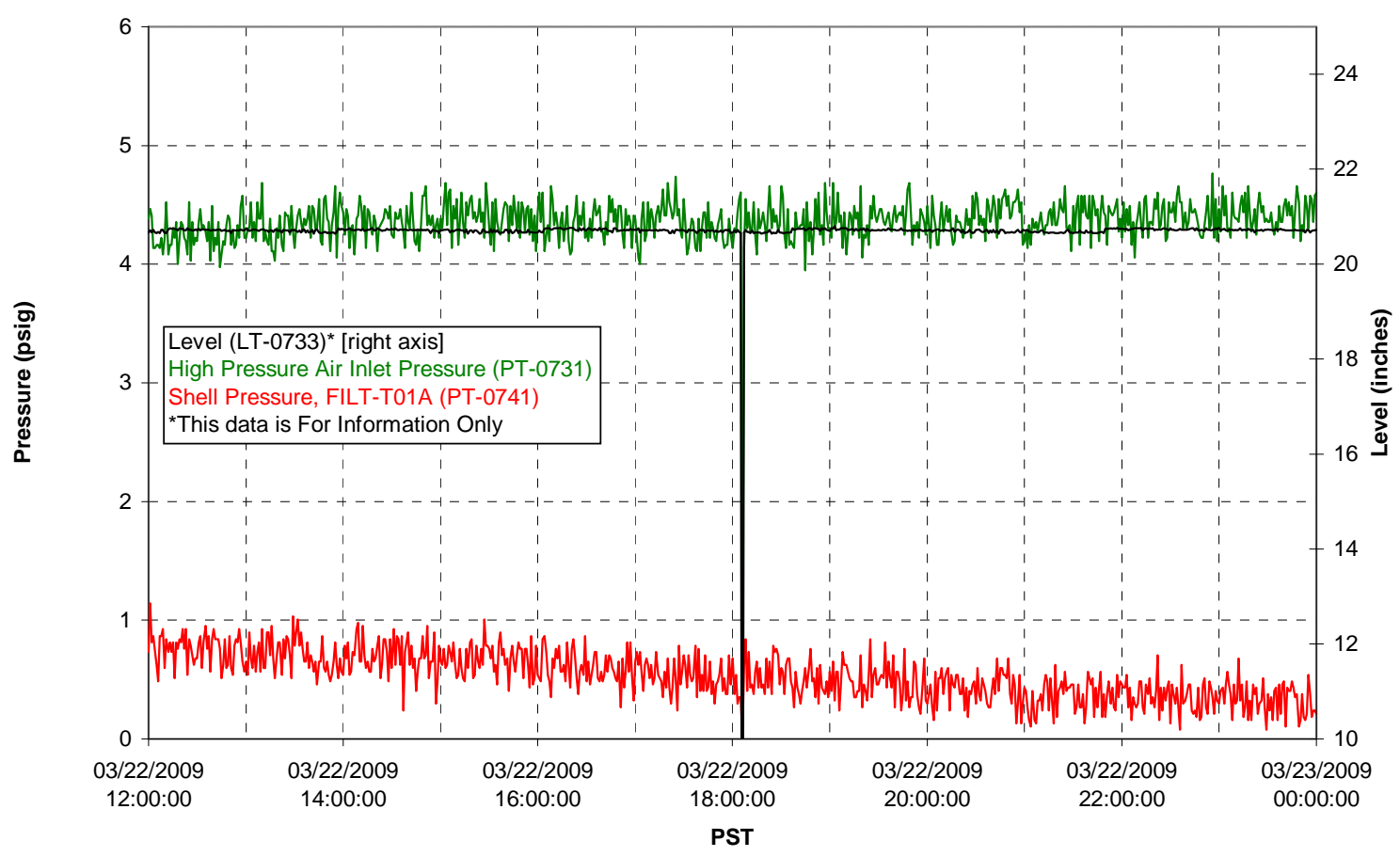

Pulsepot Levels

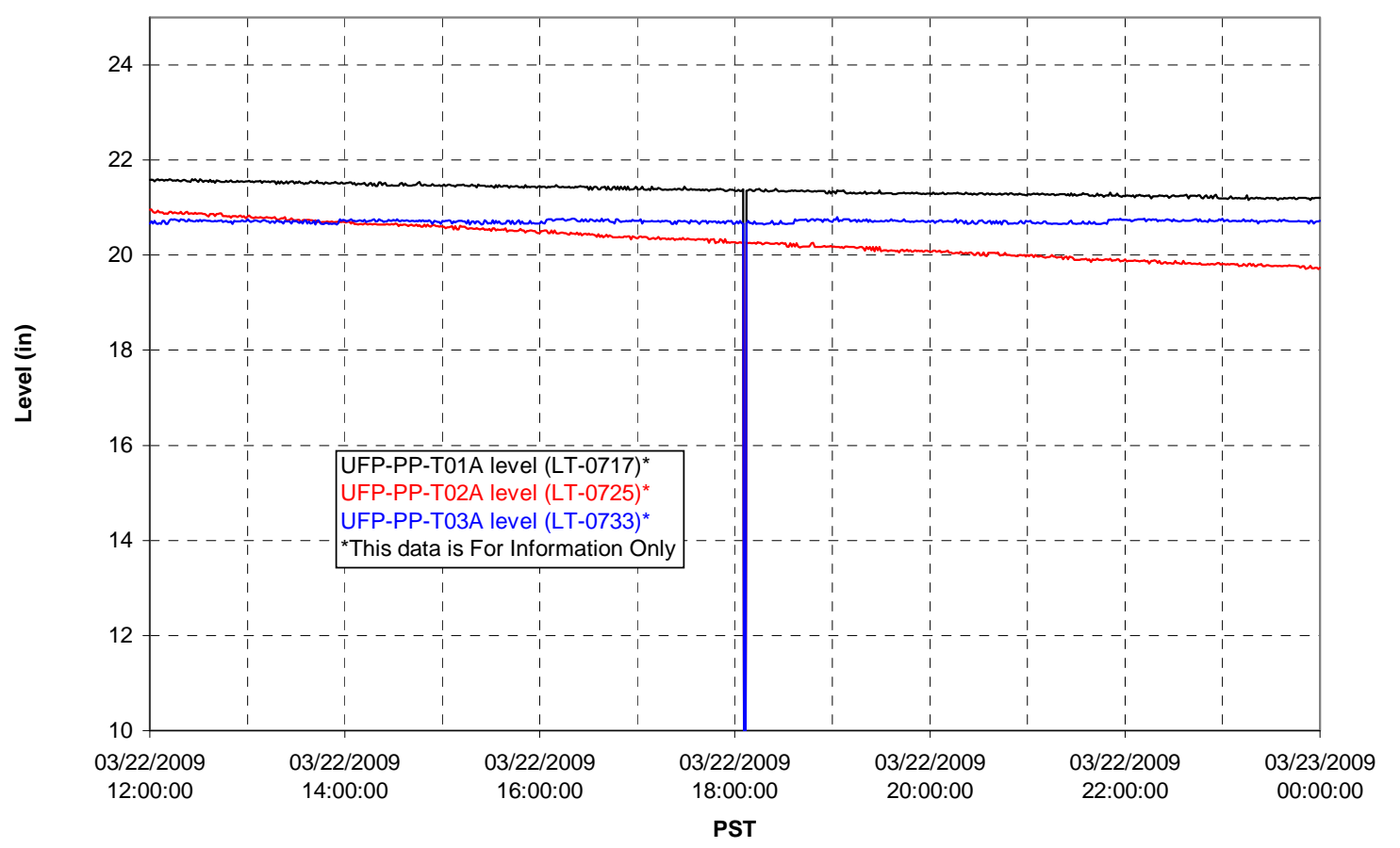


Filter UFP-FILT-T01A

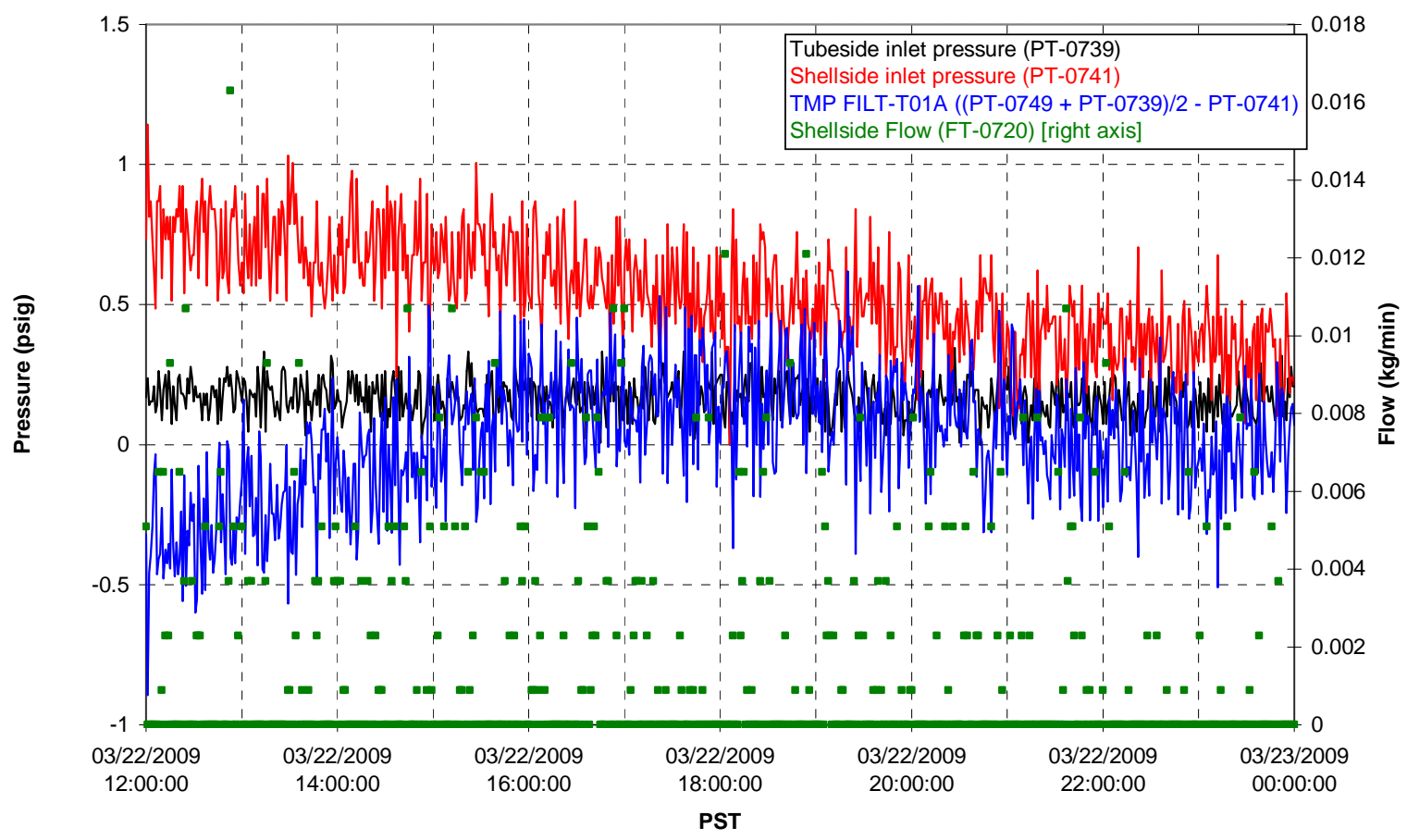

Filter UFP-FILT-T02A

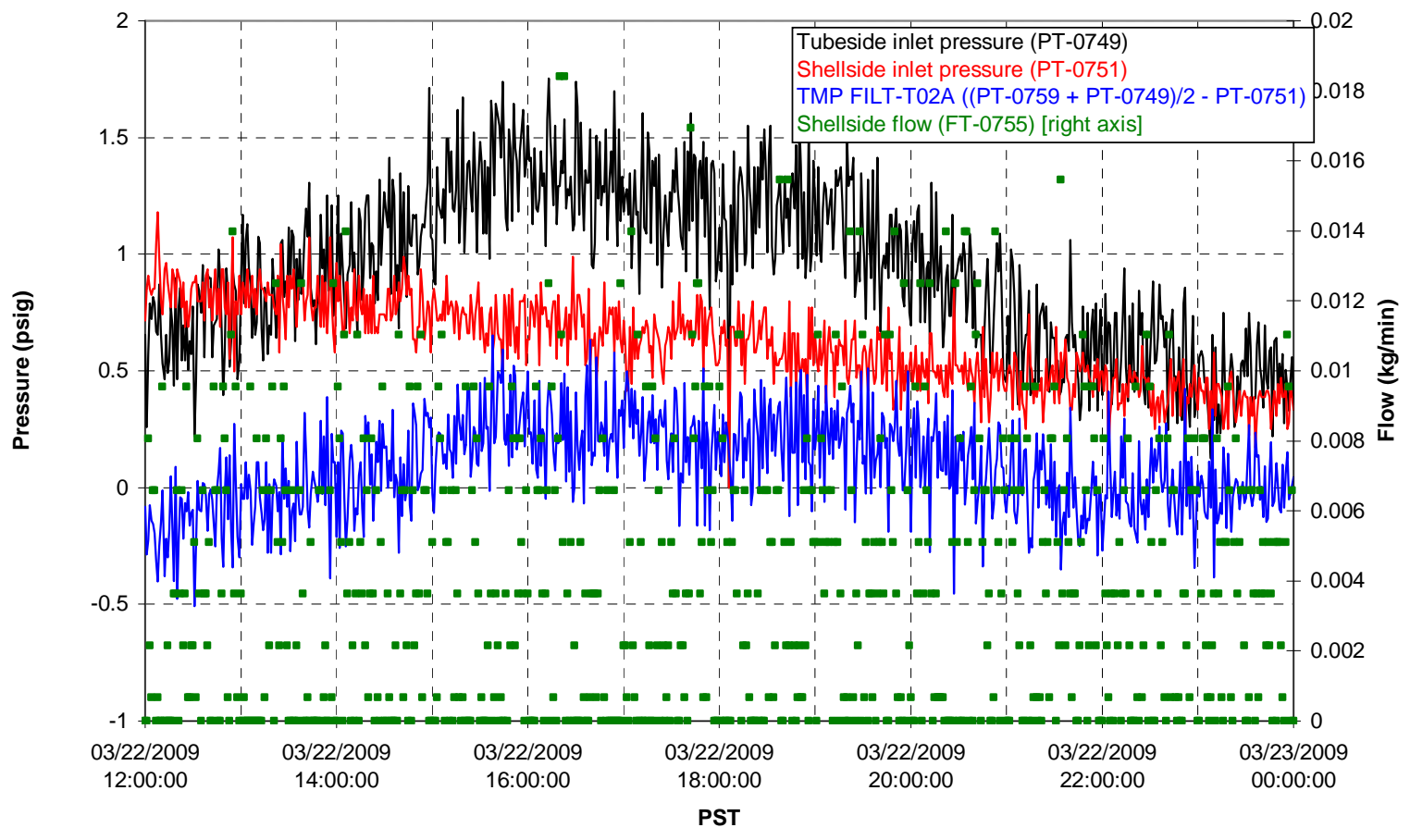


Filter UFP-FILT-T03A

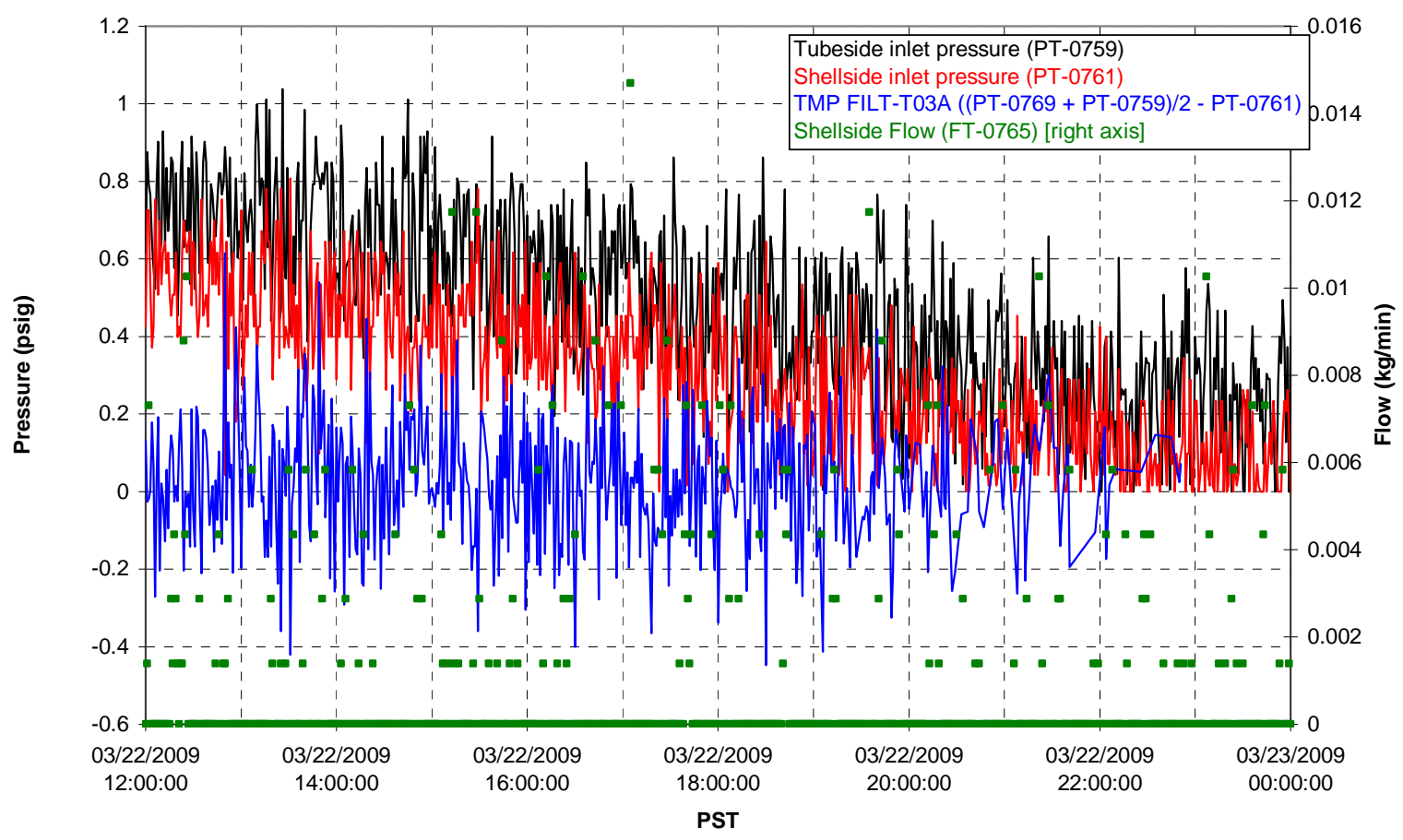

Filter UFP-FILT-T04A

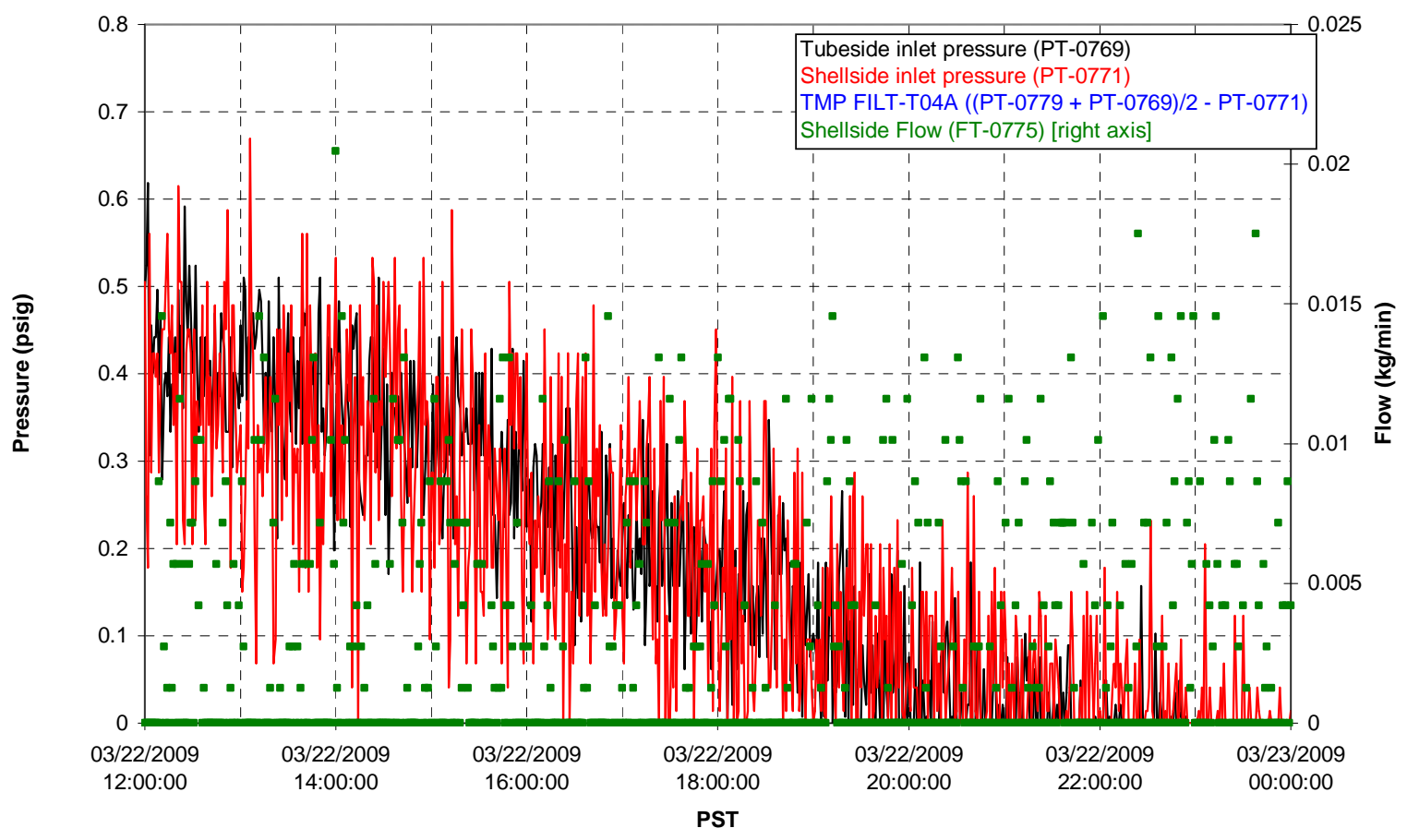


Filter UFP-FILT-T05A

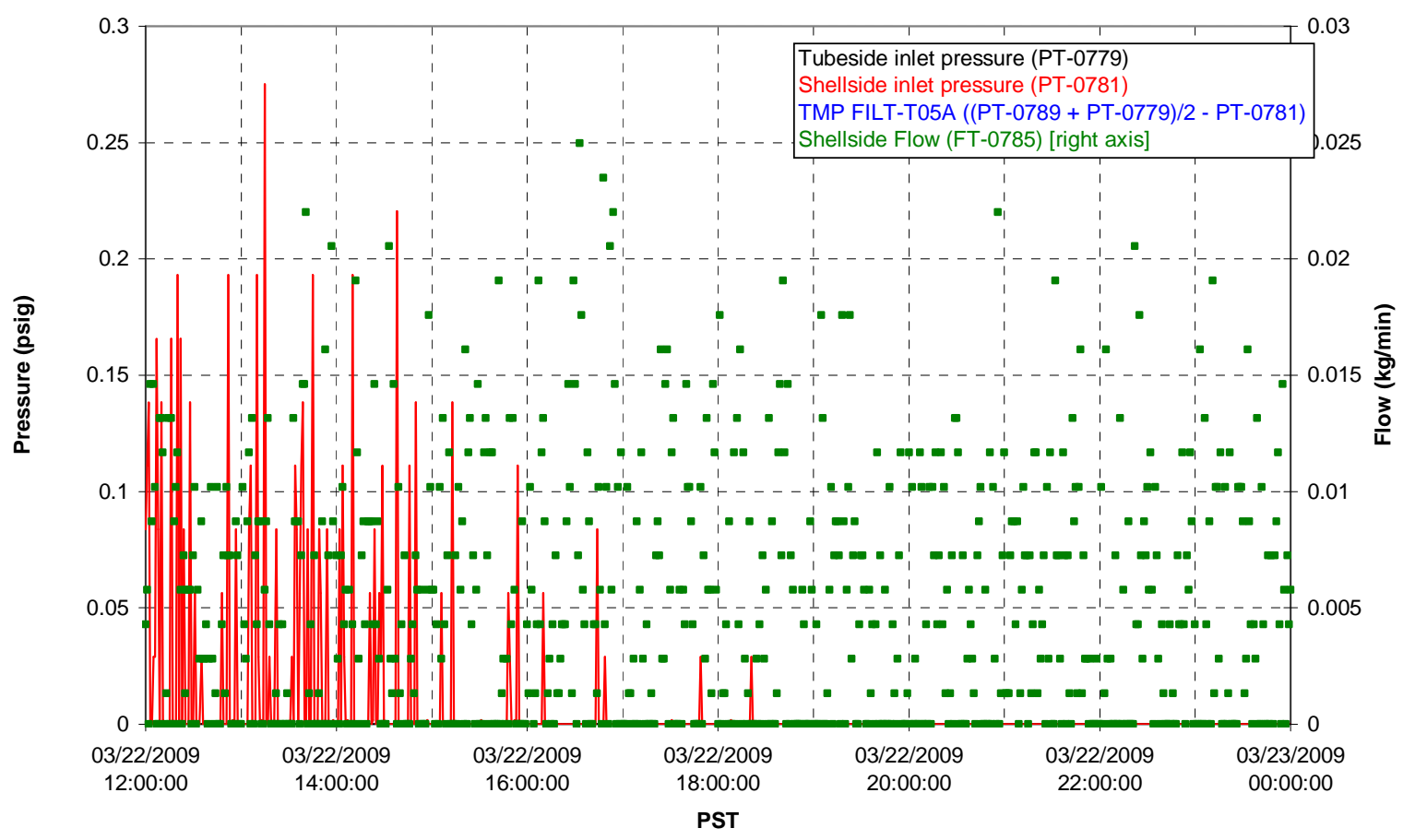

Chemical Flow

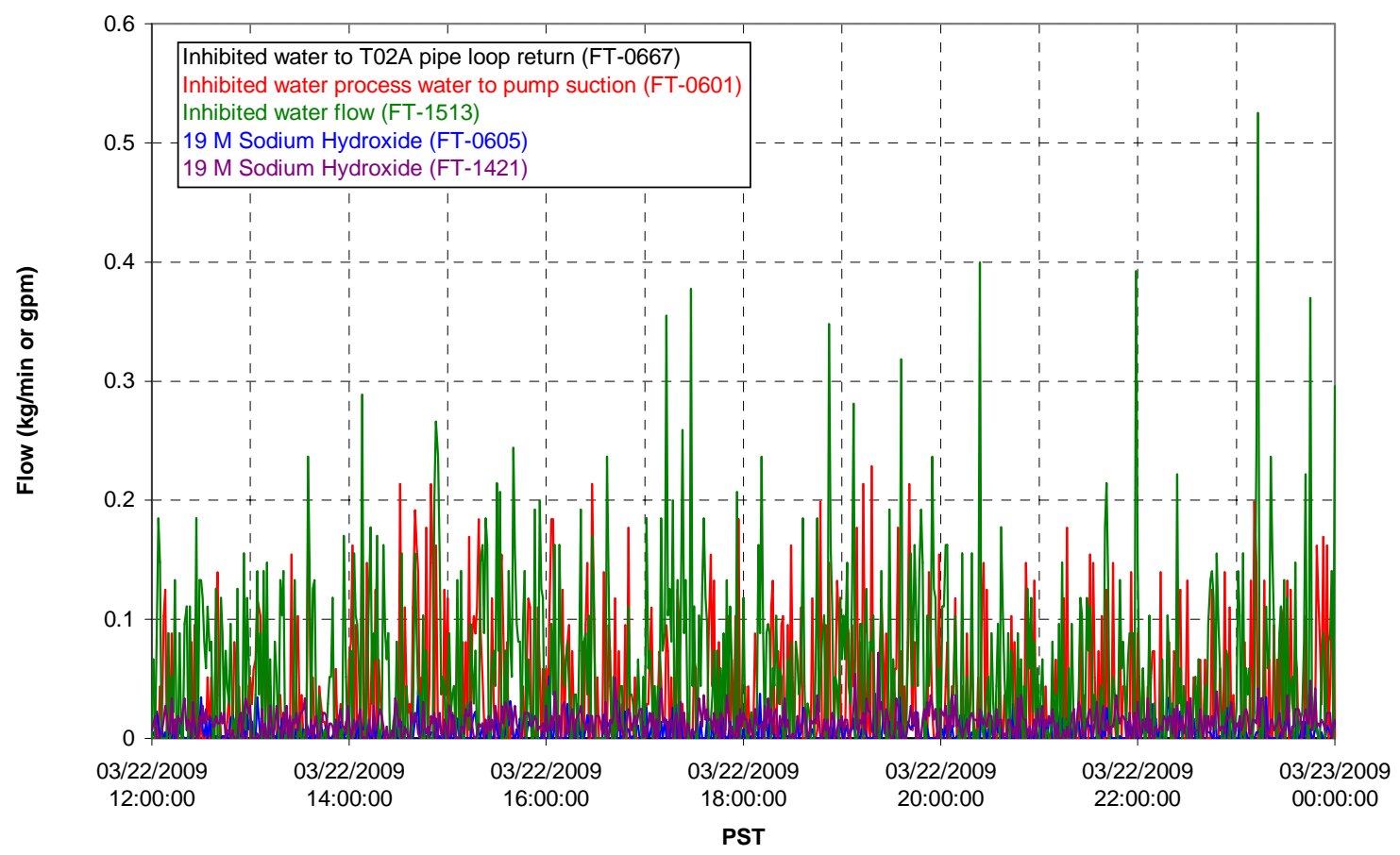




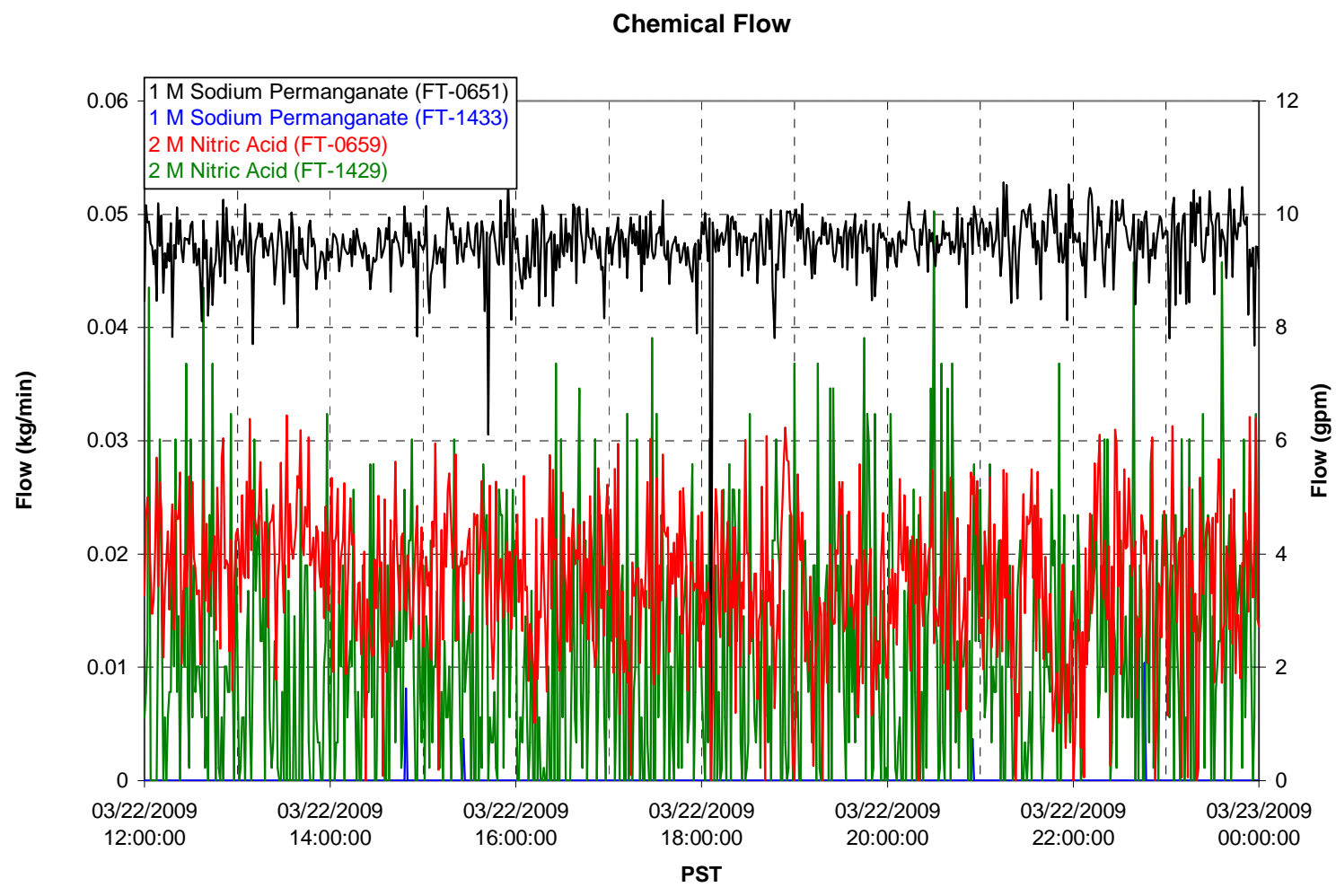

Air Flows

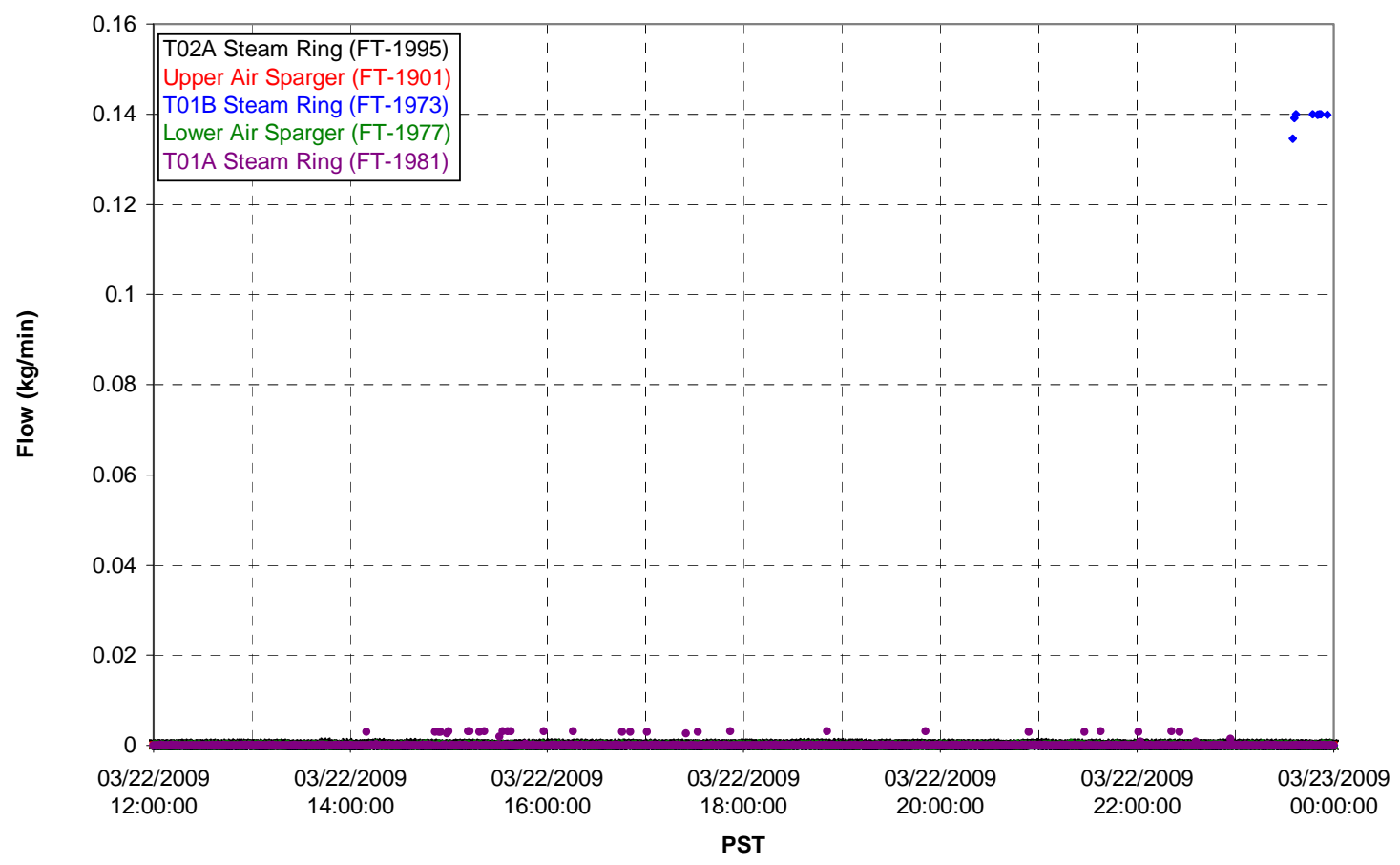


T02A Steam

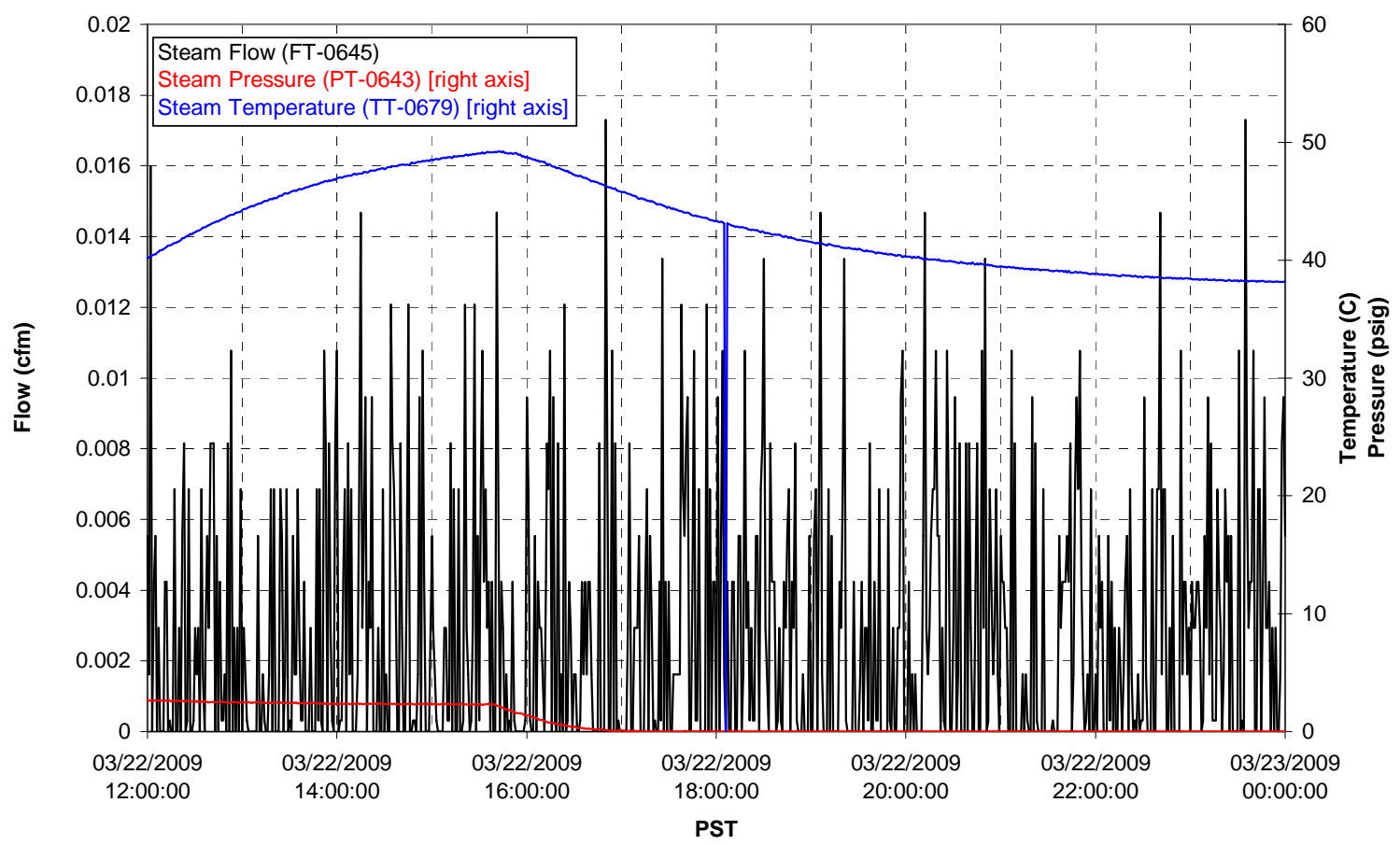

T01A Steam

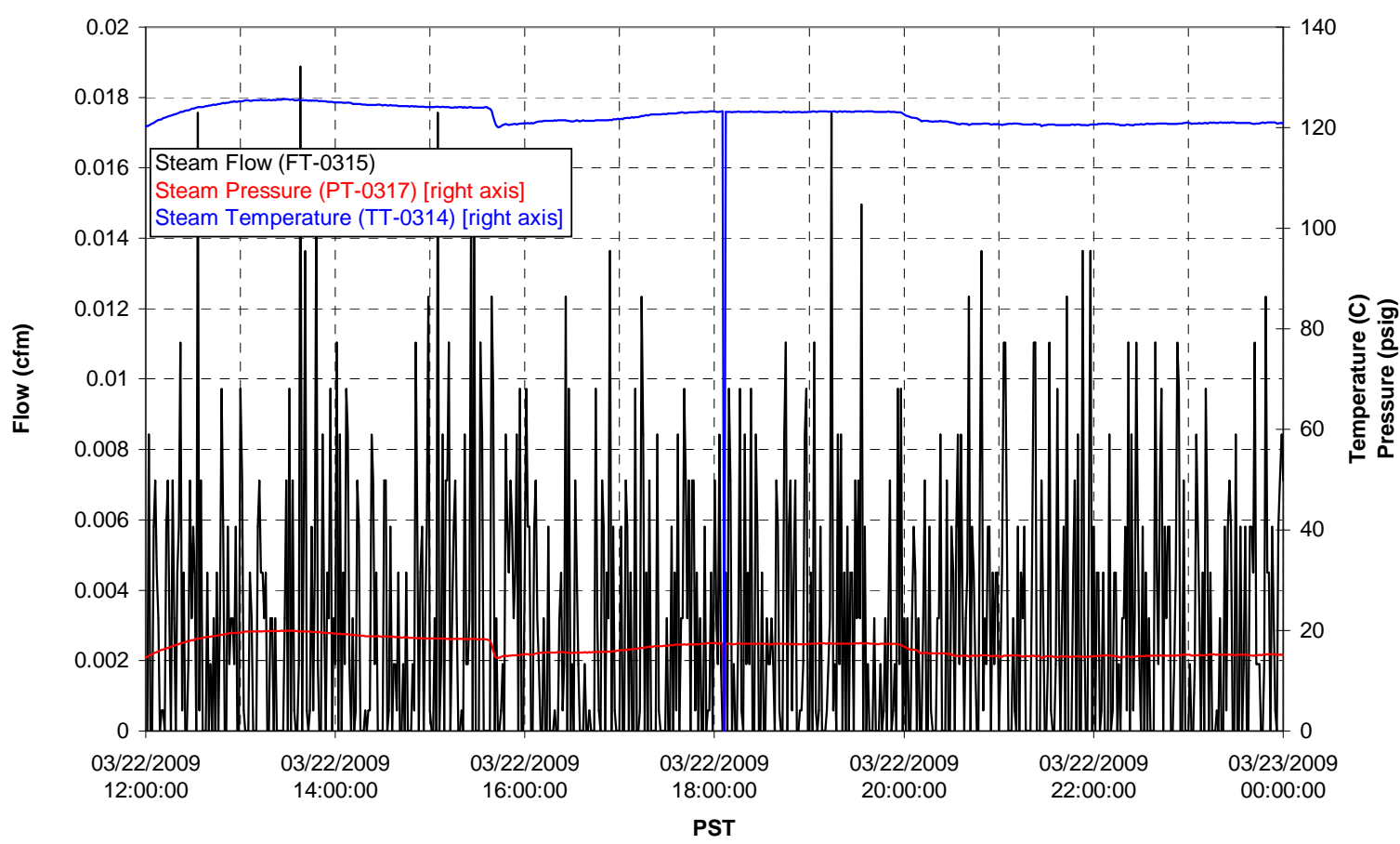


T01B Steam

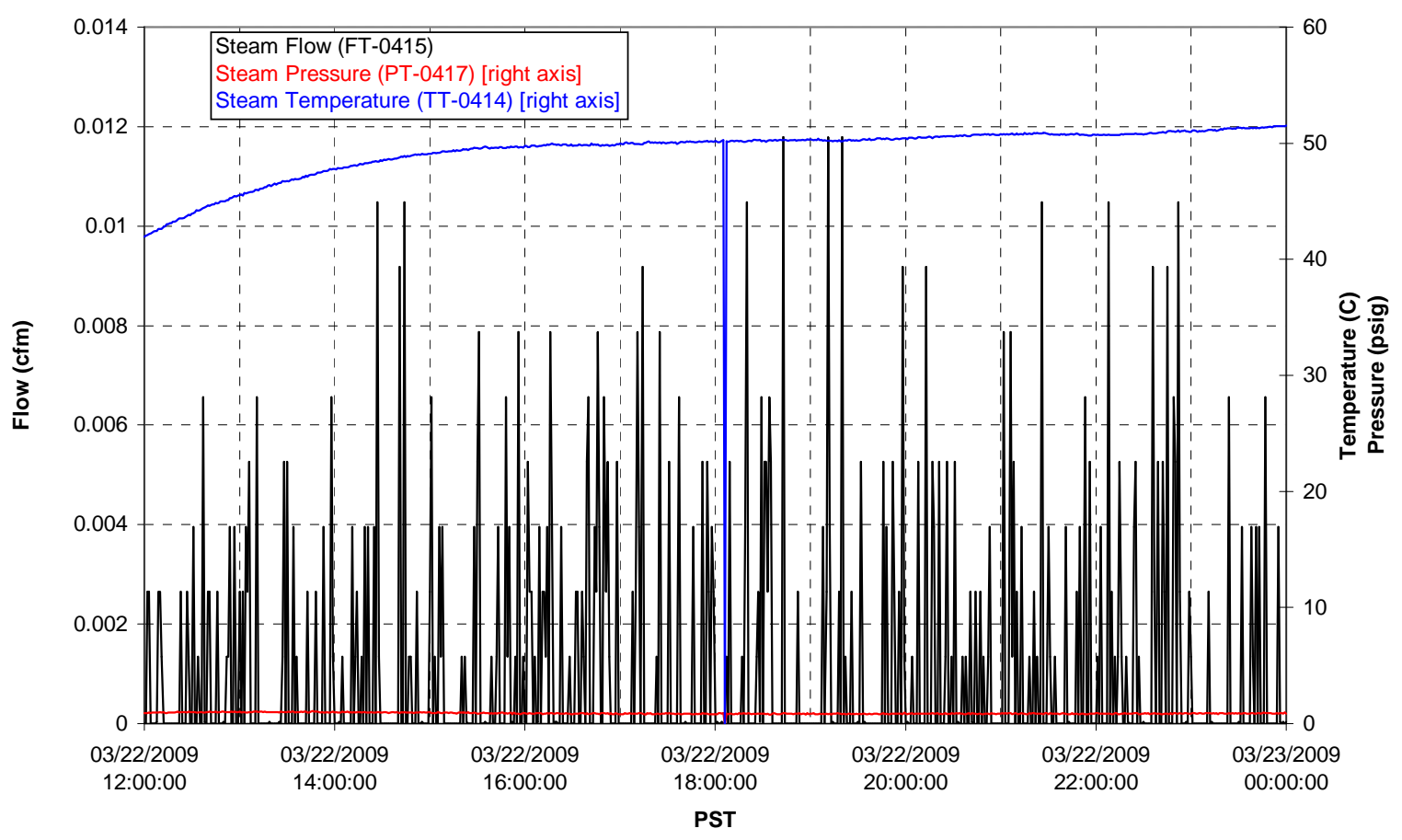




\section{Integrated Test D Data Plots 03/23/09 00:00 - 03/23/09 12:00}


T01A level

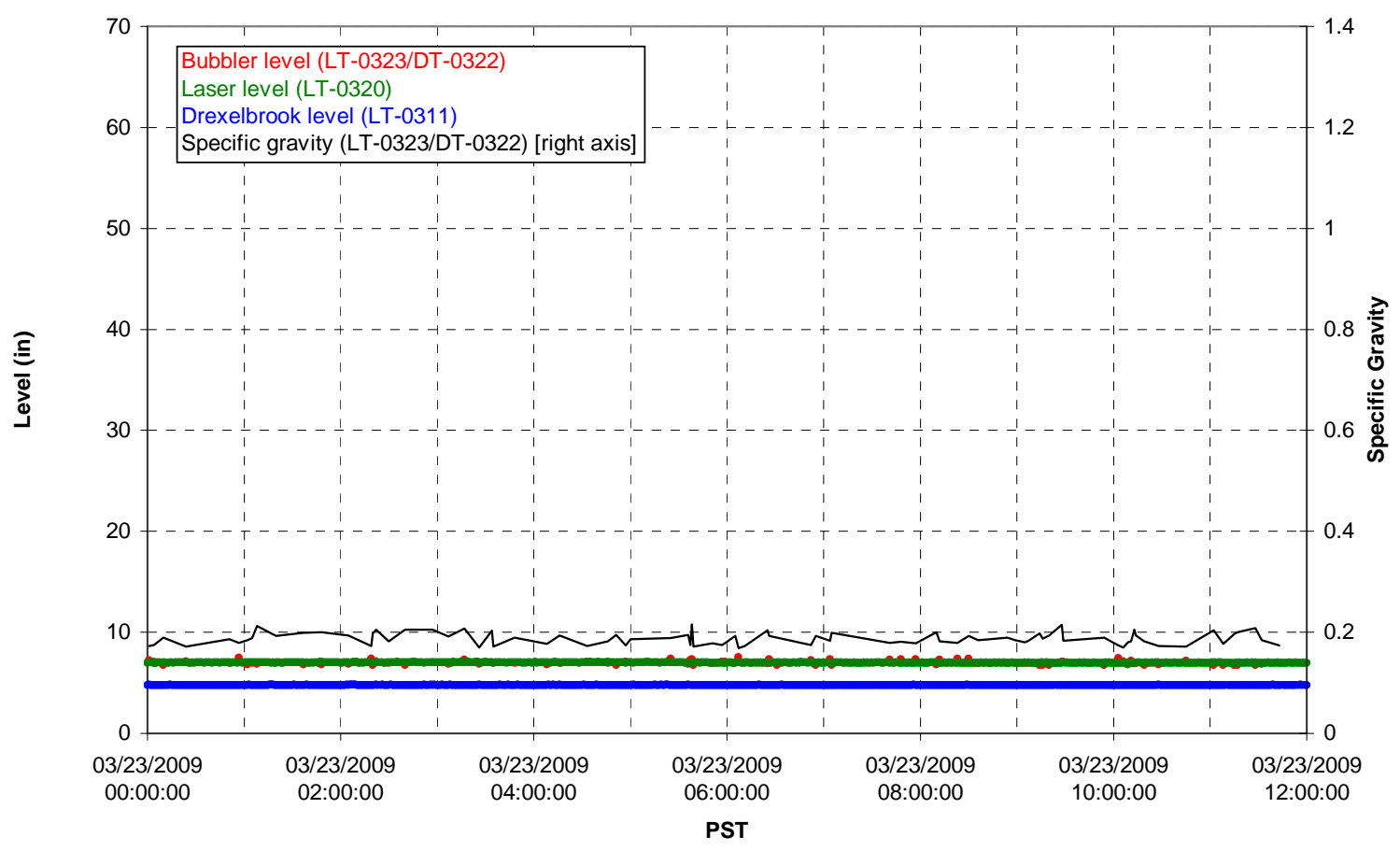

T01A temperatures

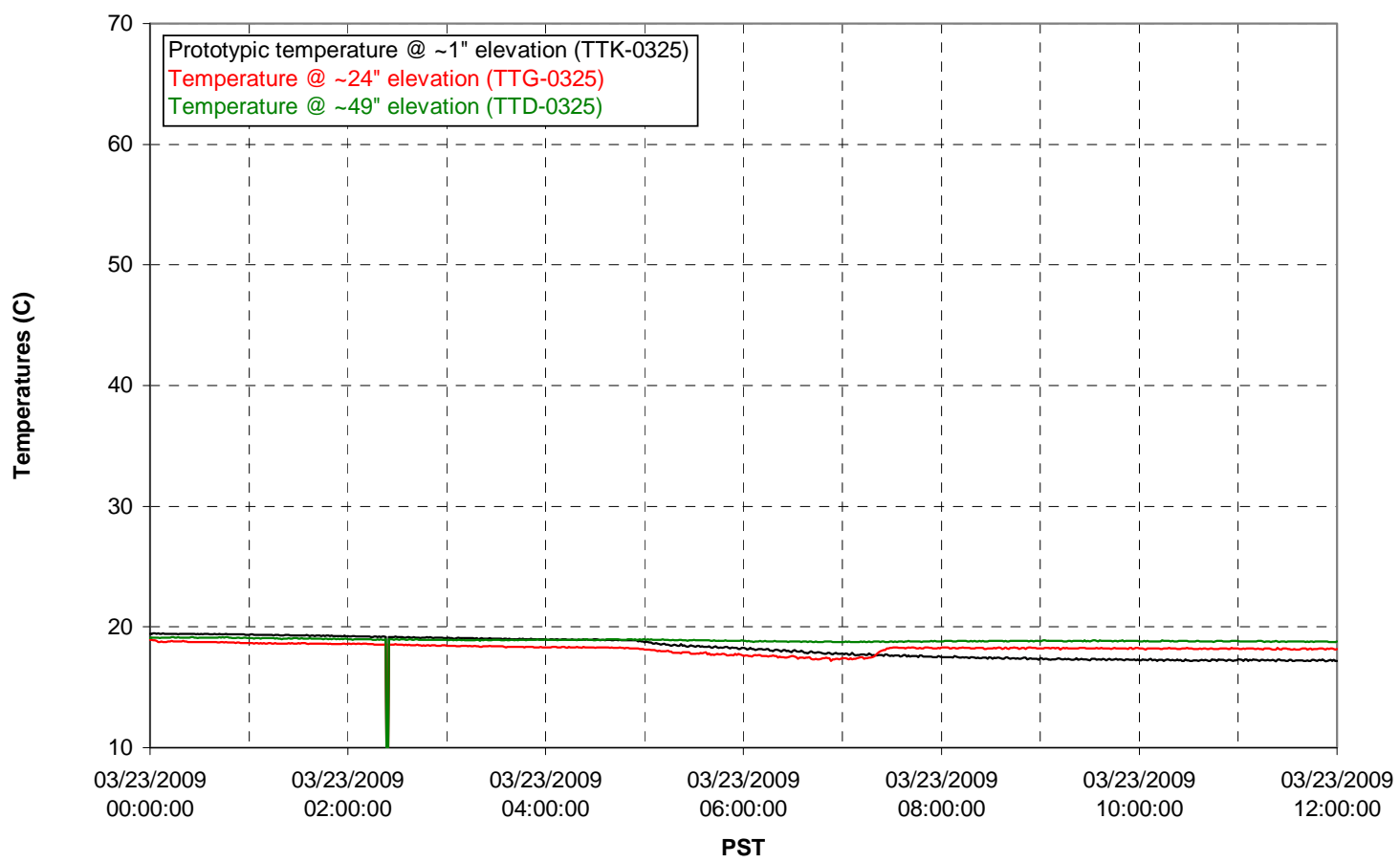


T01B level

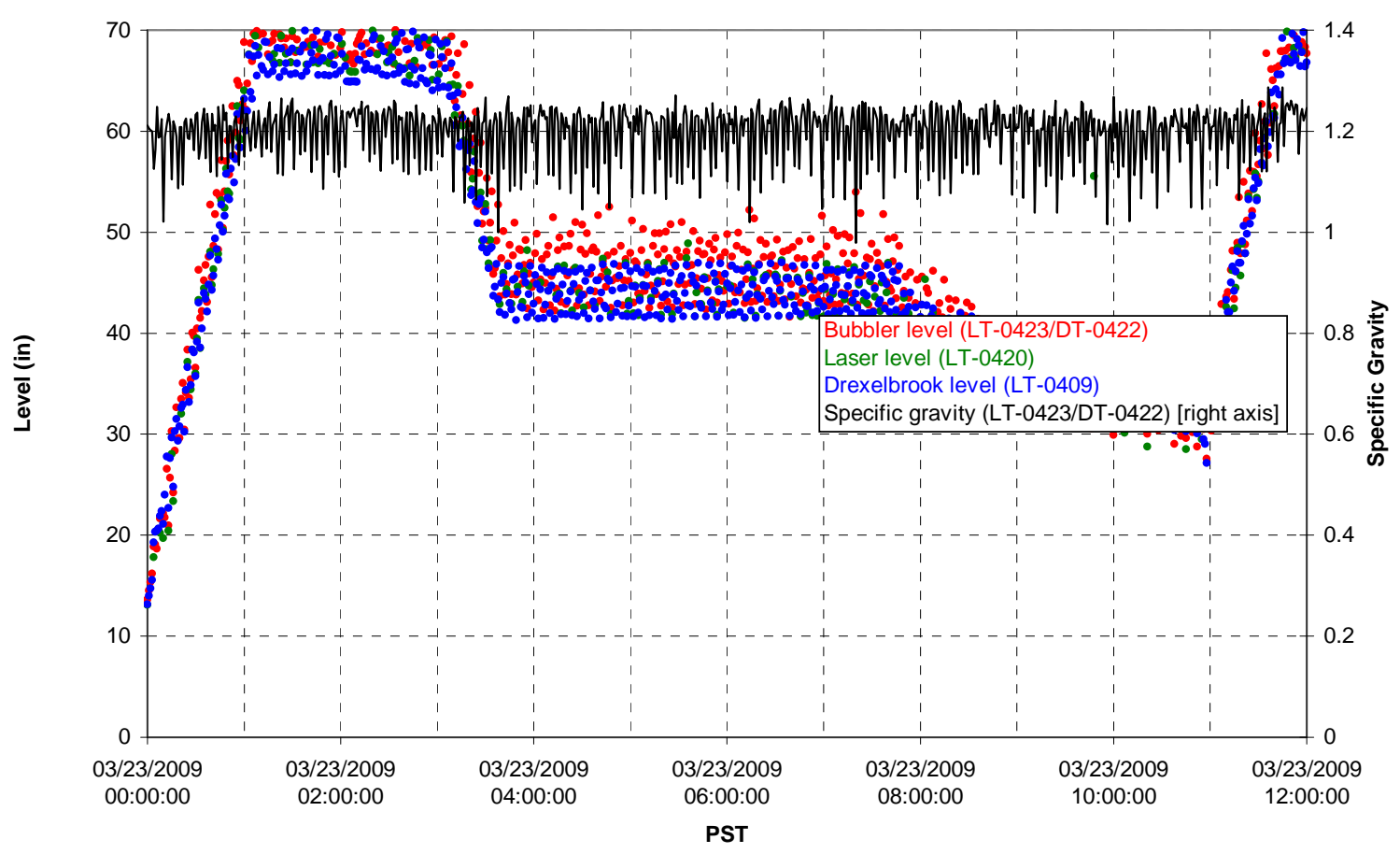

T01B temperatures

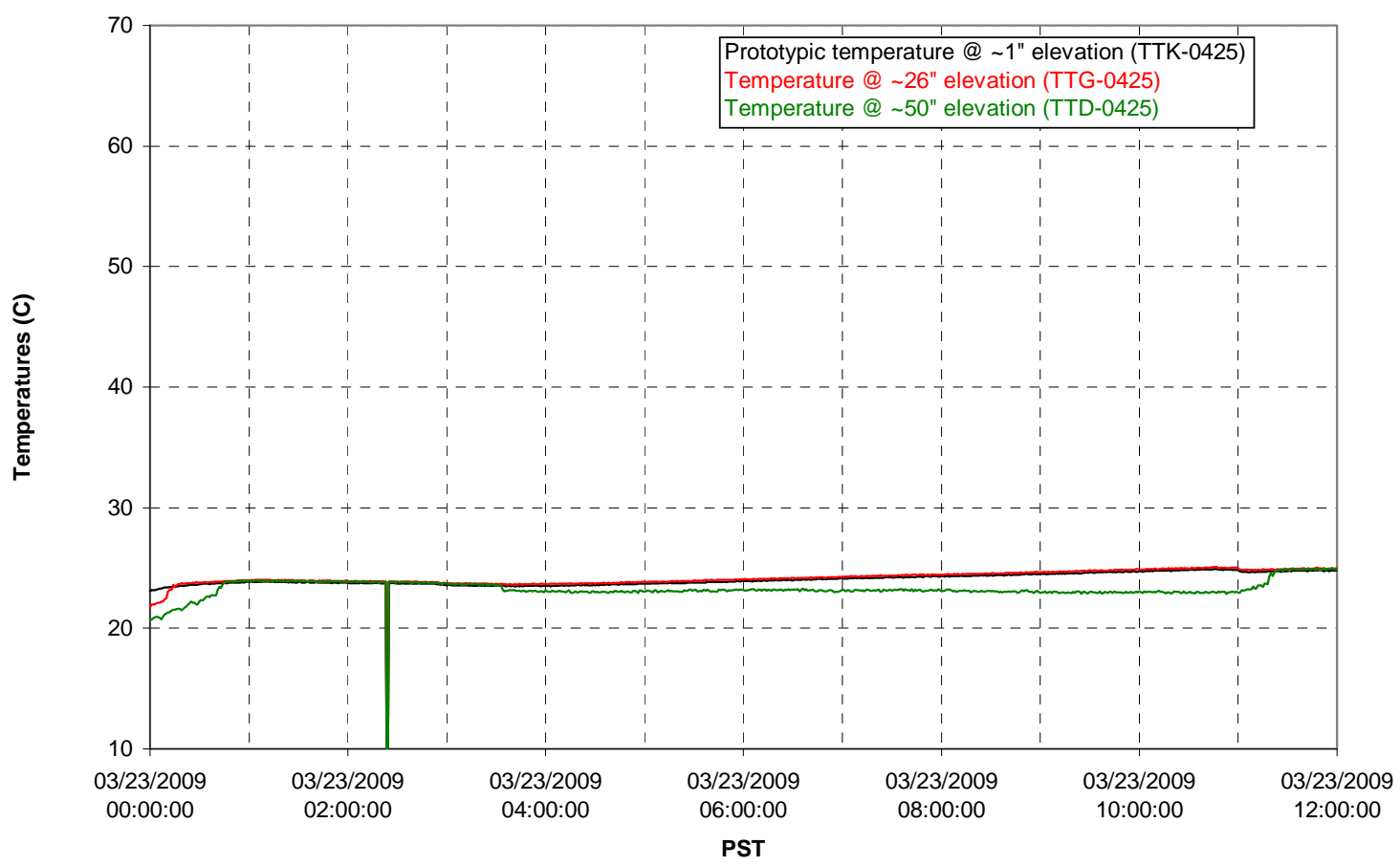


T02A level

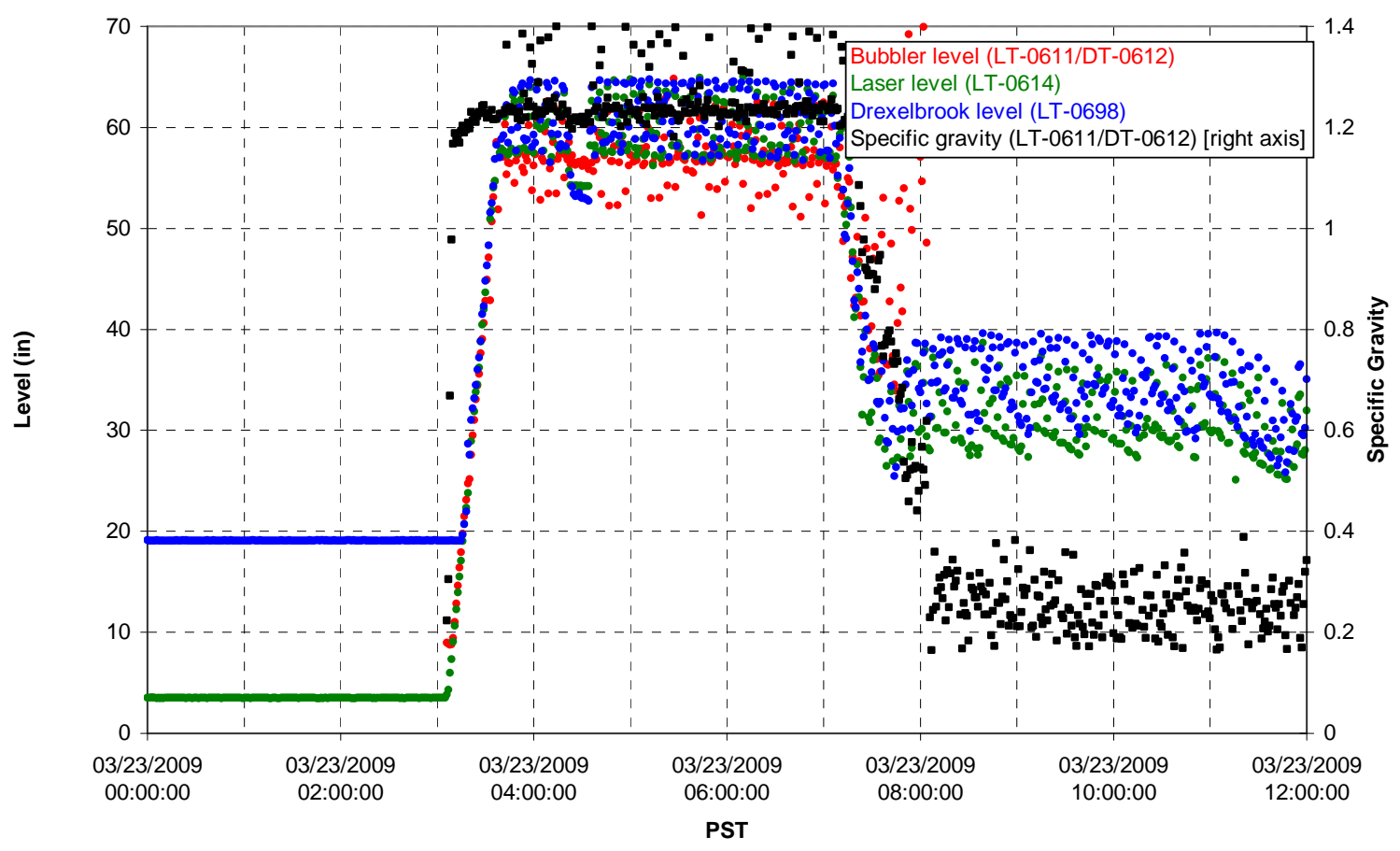

T02A temperatures

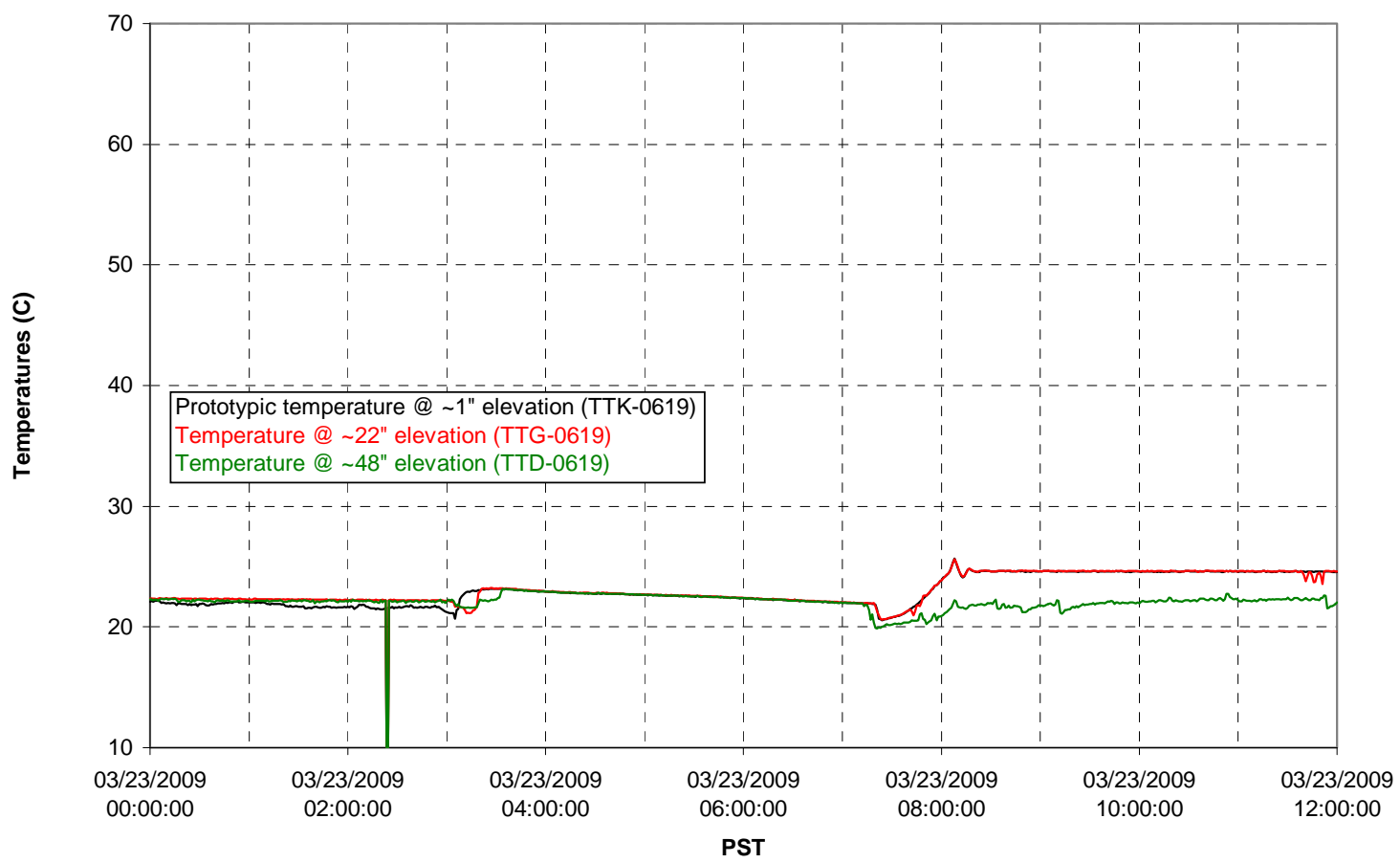


T02A and filter loop temperatures

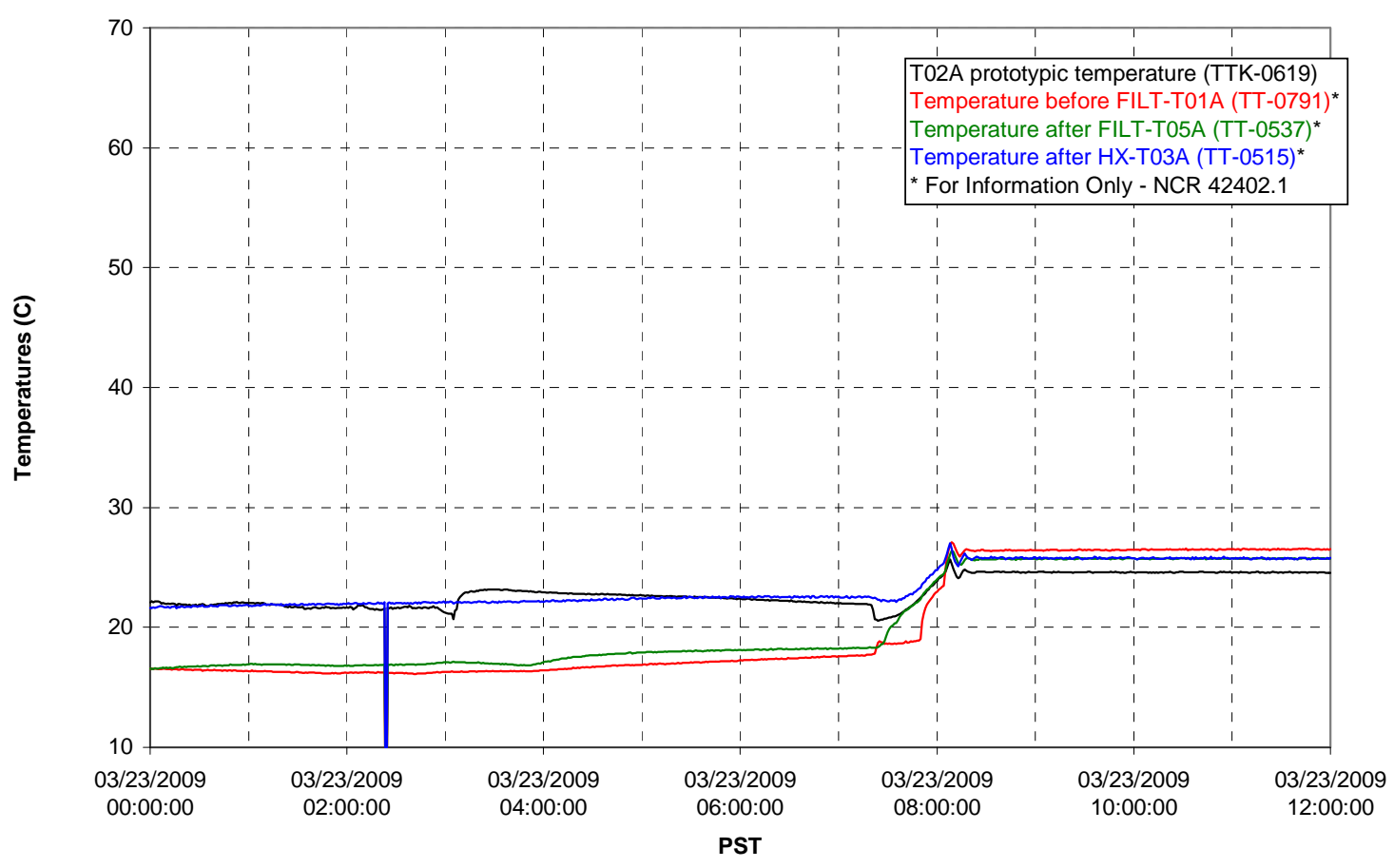

Pump Pressures and Flow

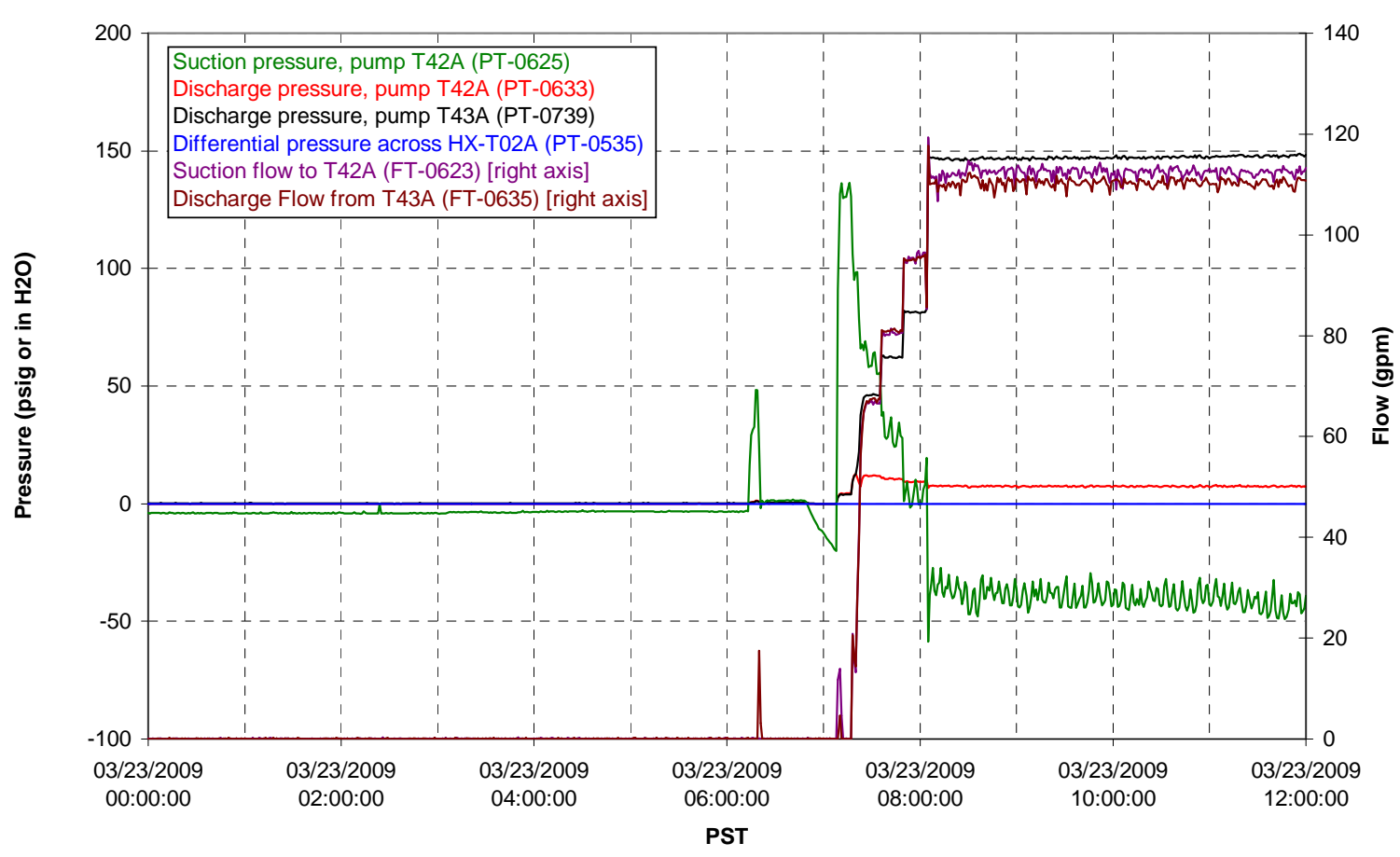




\section{Axial pressure drop}

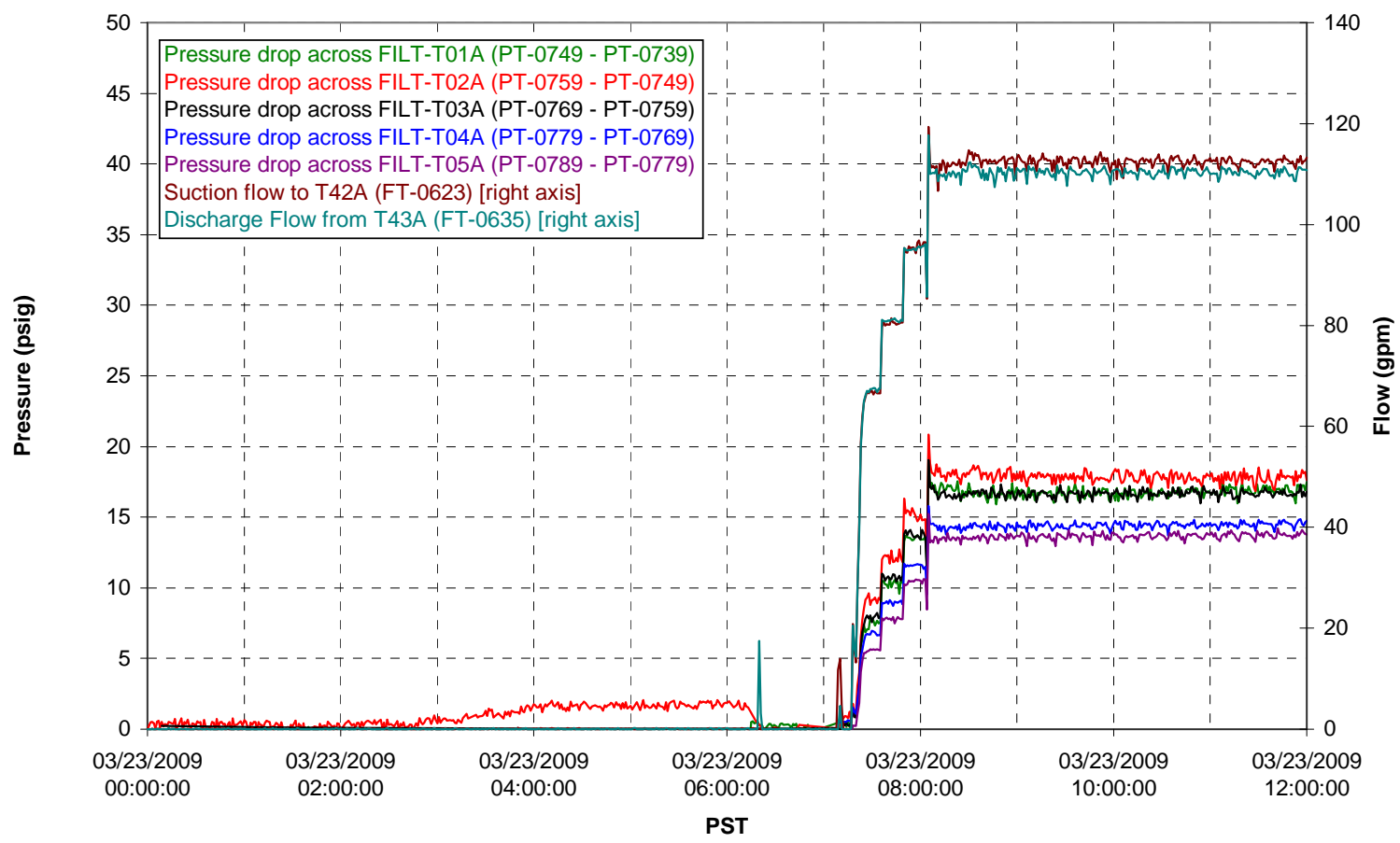

Permeate flow rates

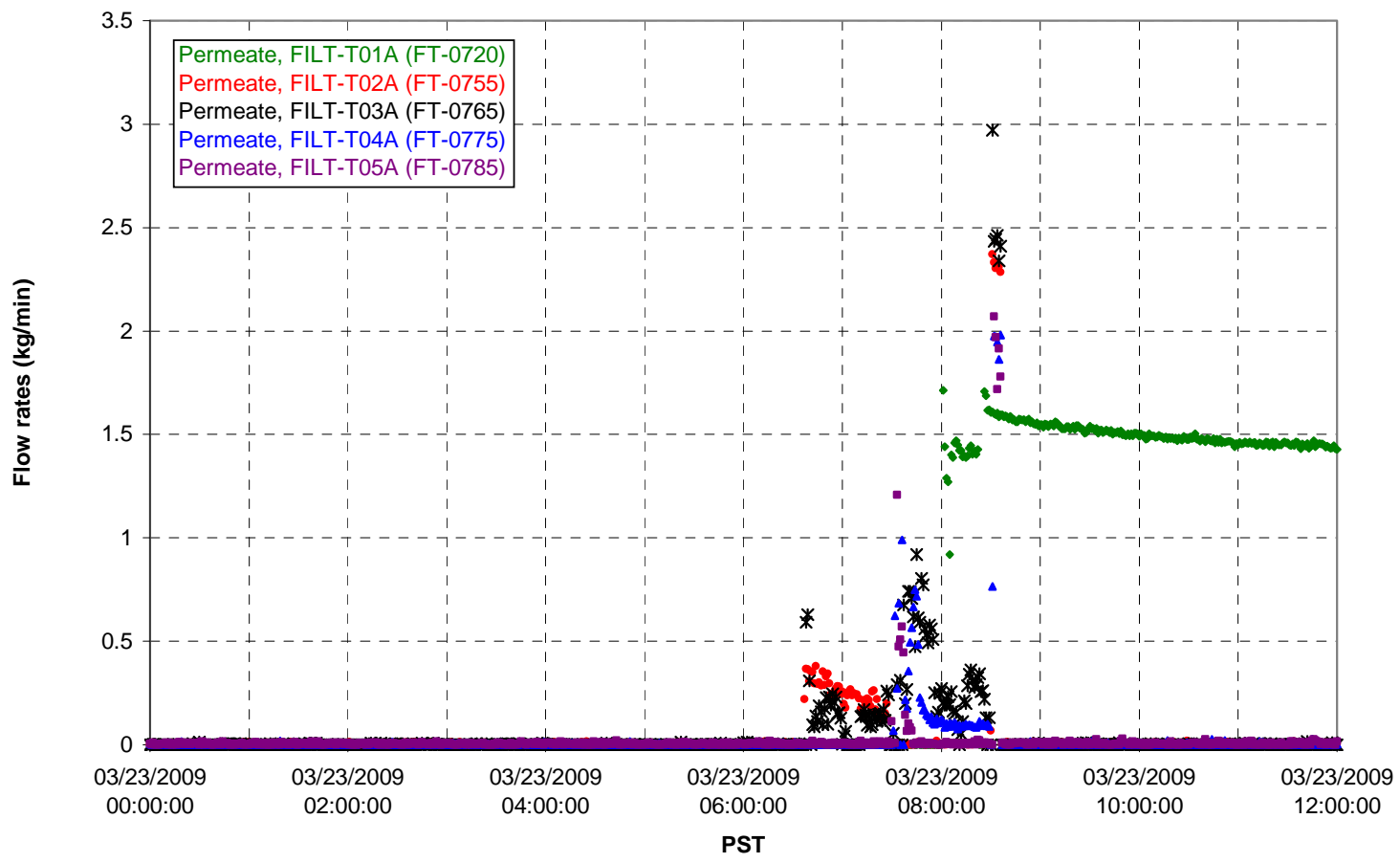


T02A Inner Temperature Tree

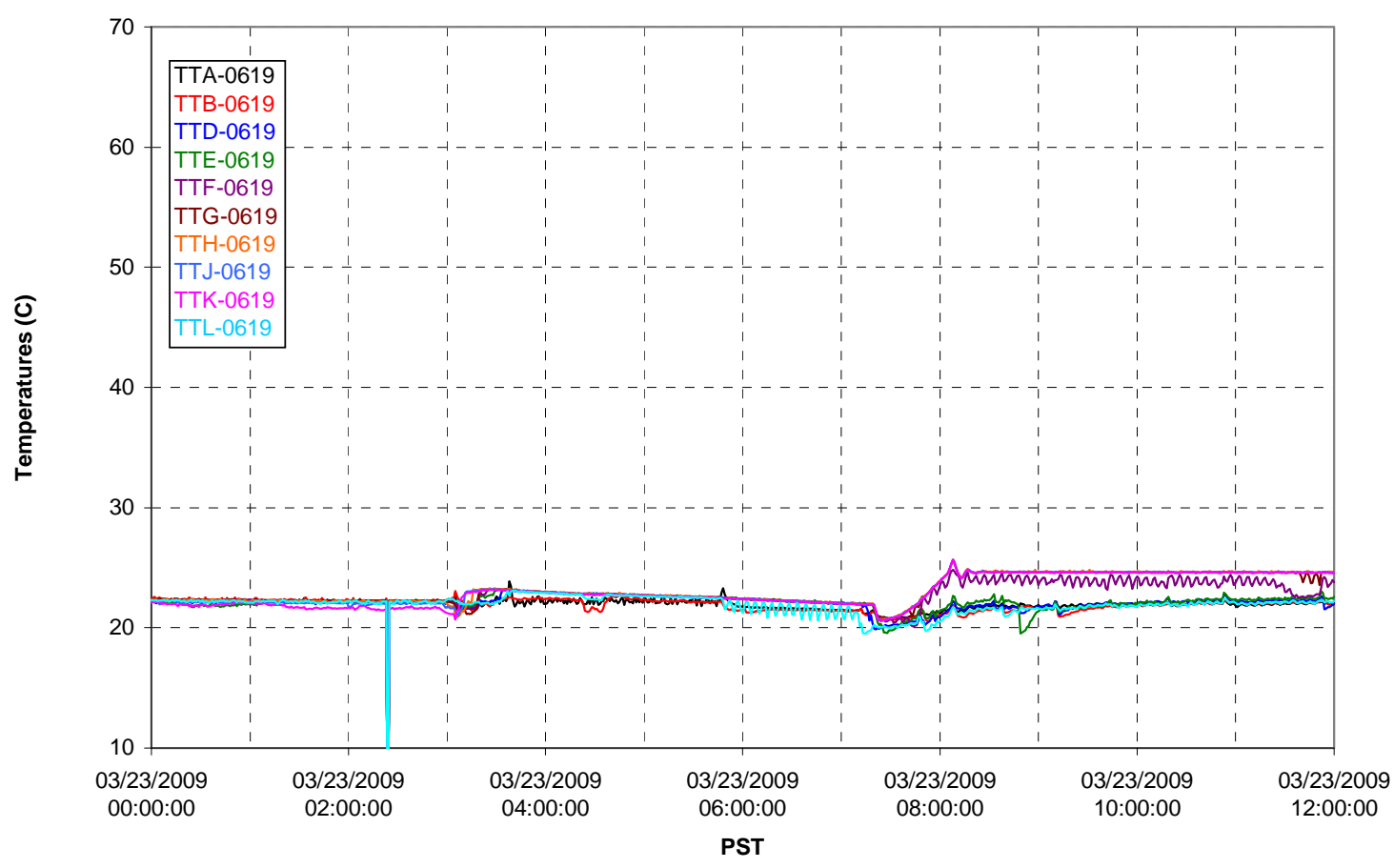

T02A Outer Temperature Tree

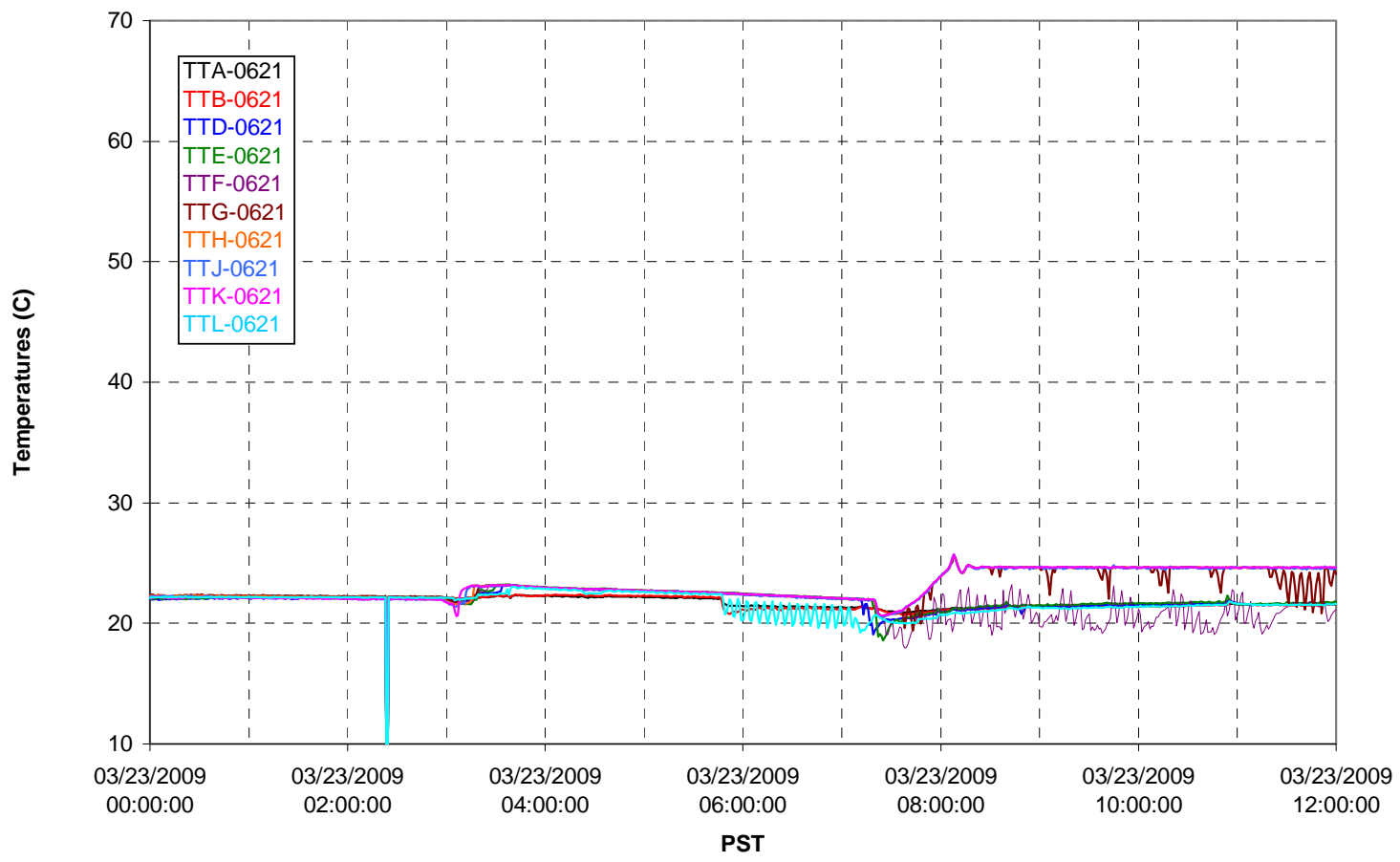


T02A temperatures

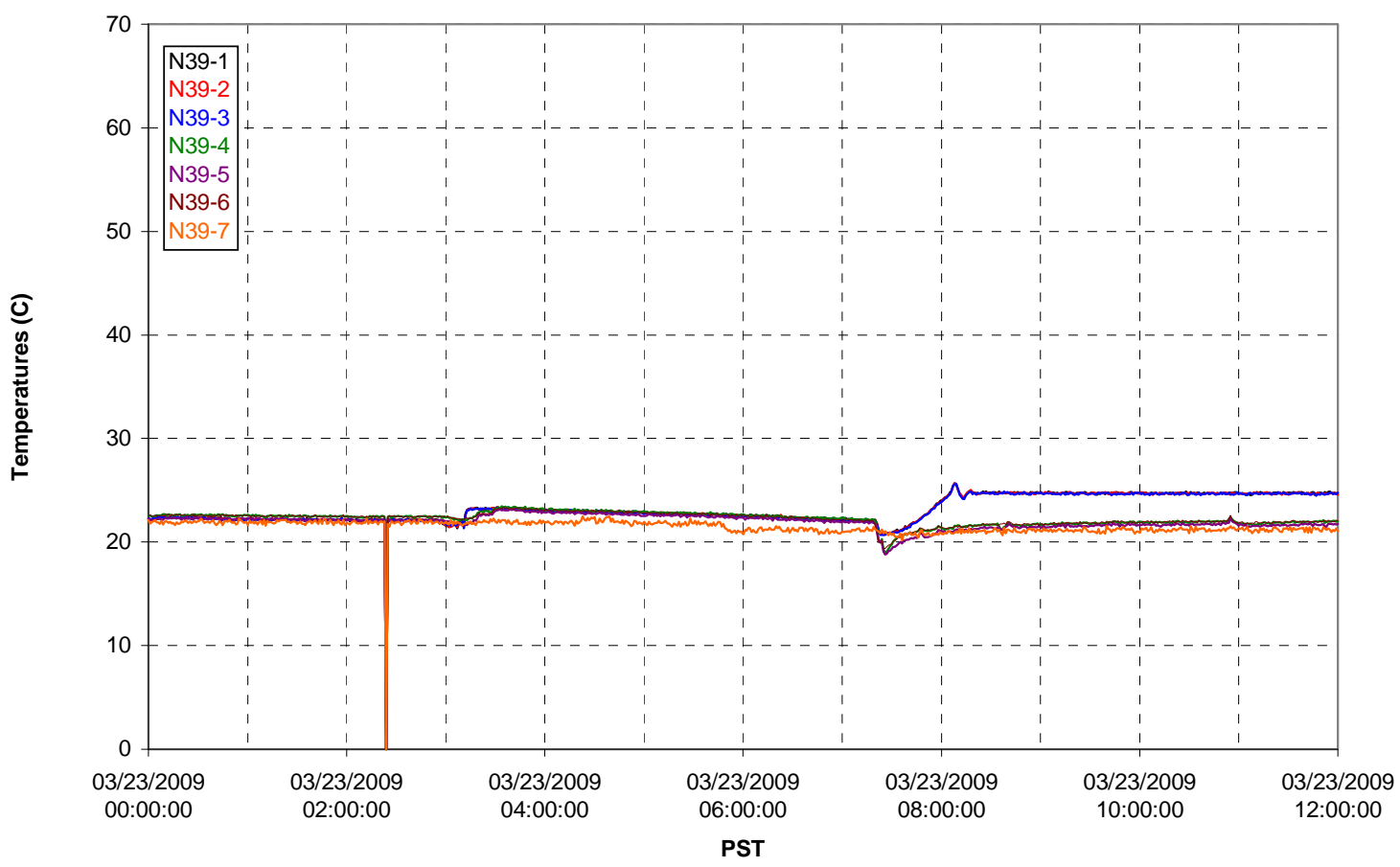

T02A temperatures

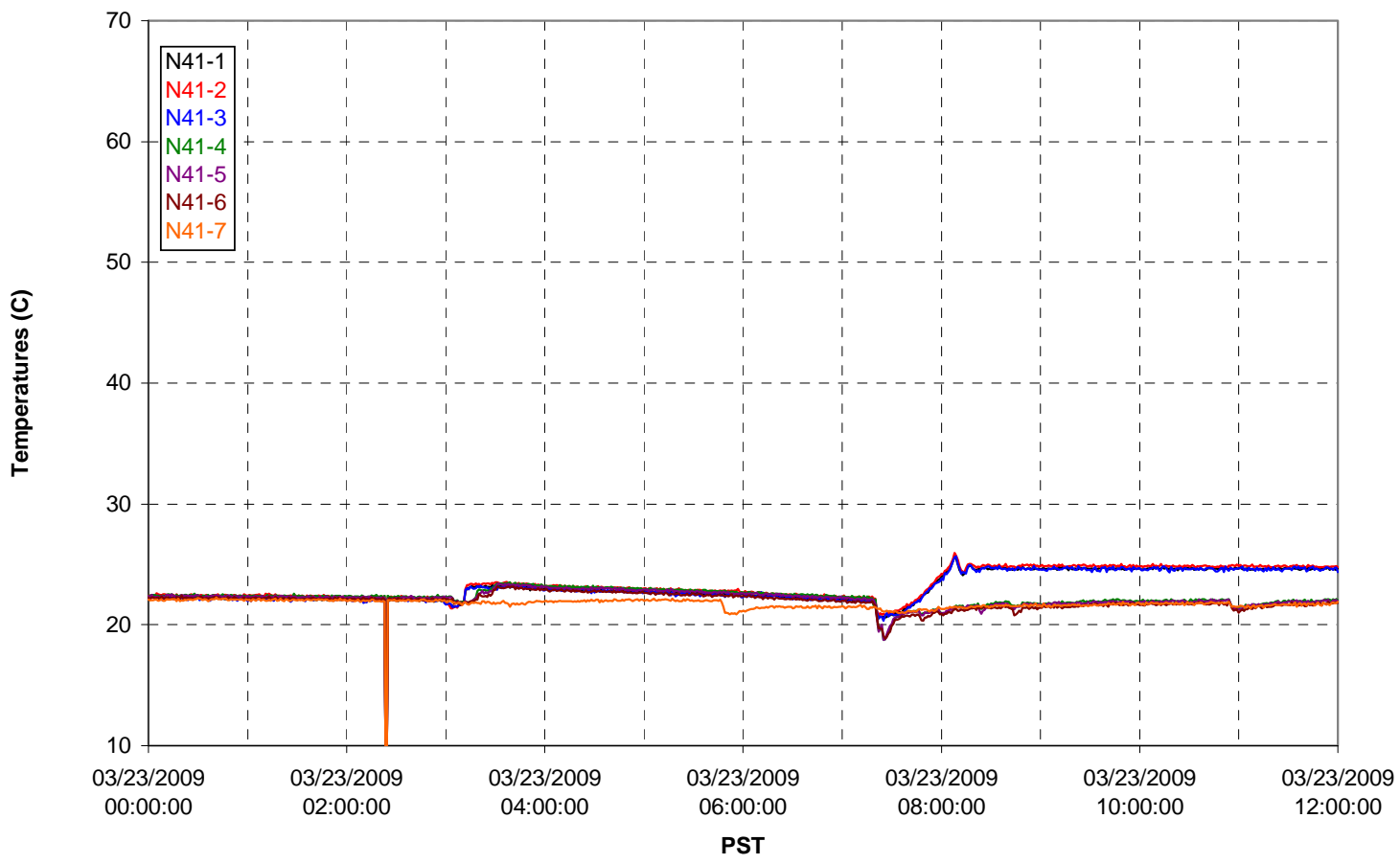


T02A temperatures

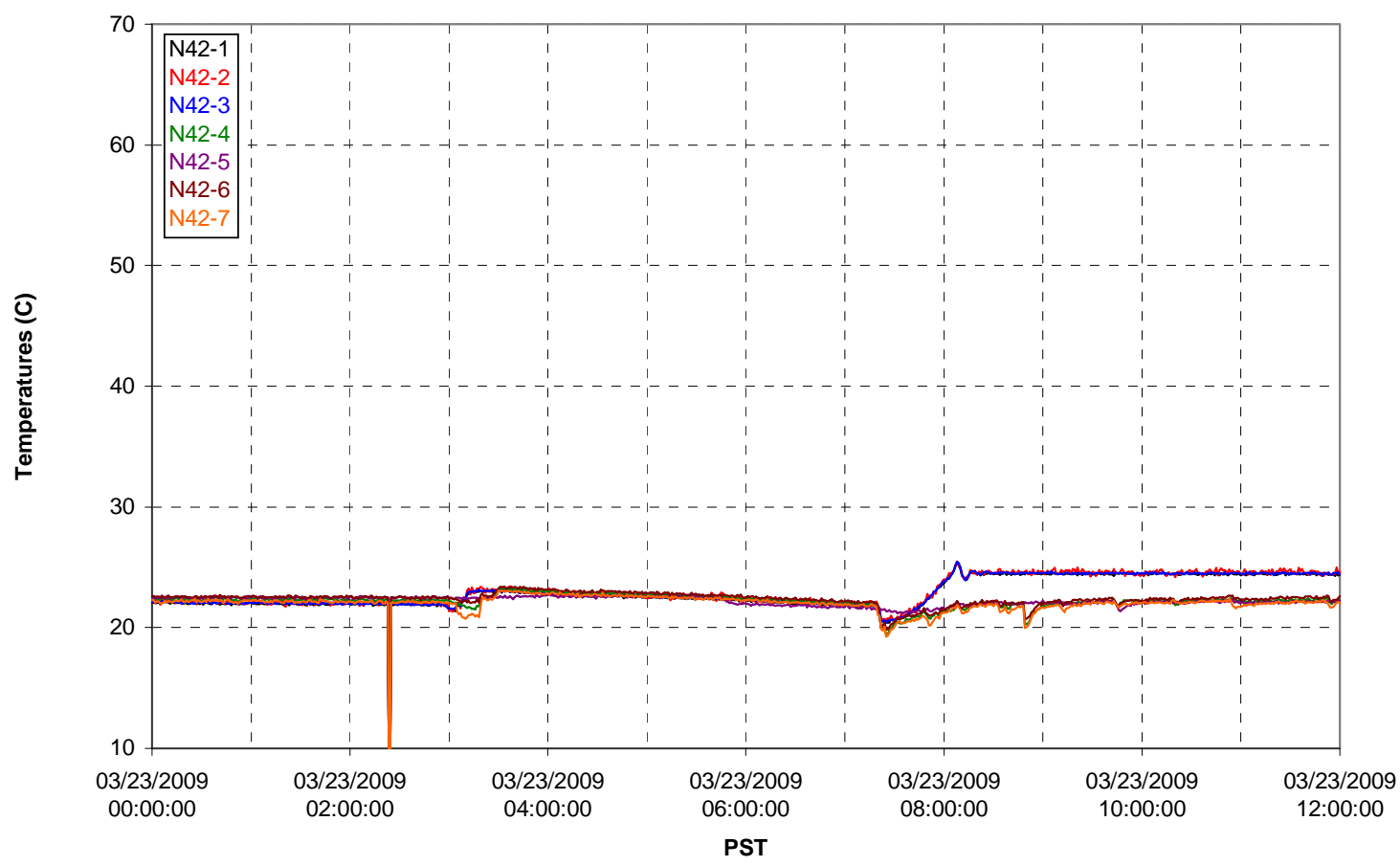

T02A temperatures

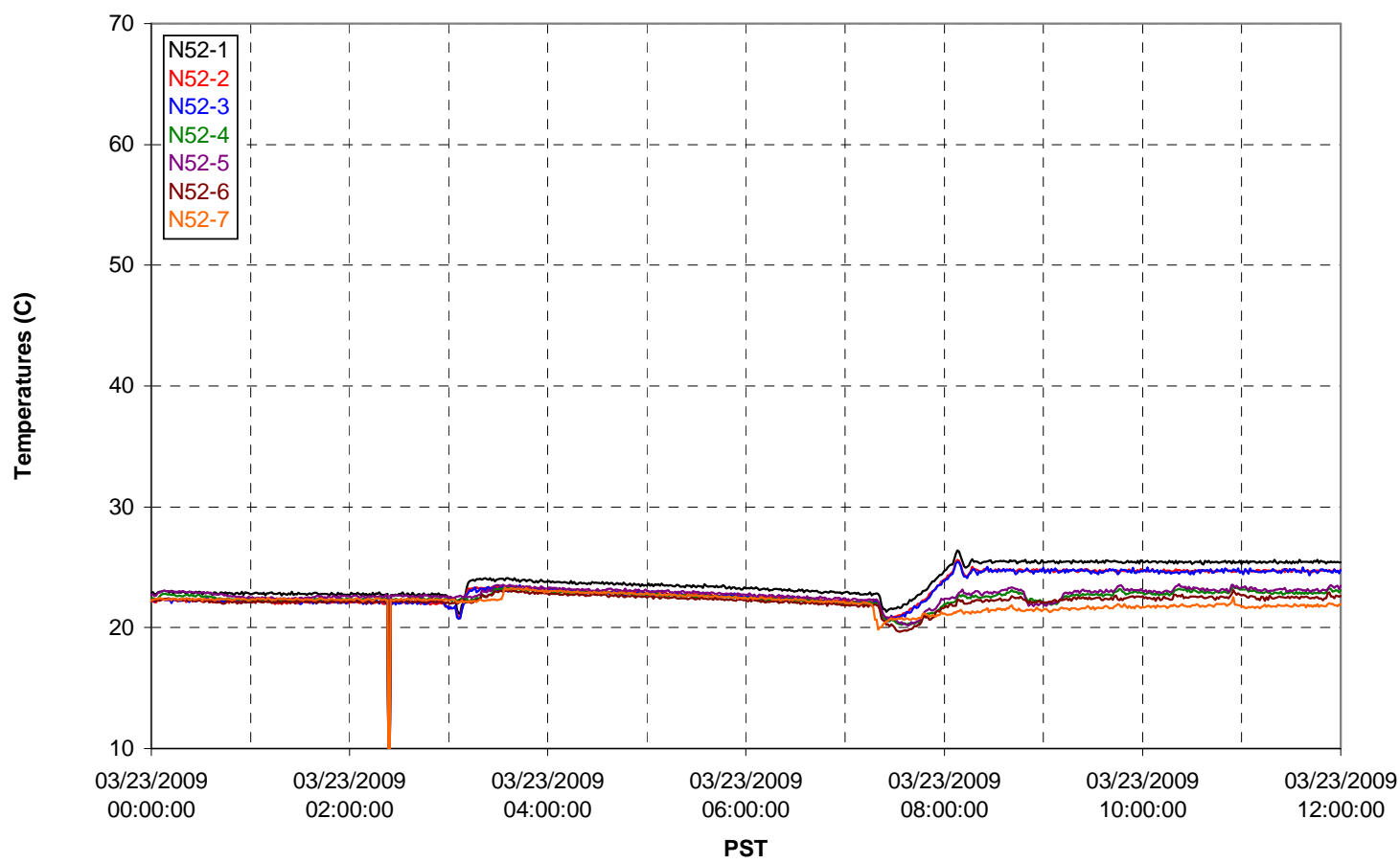


T02A Heating and Cooling

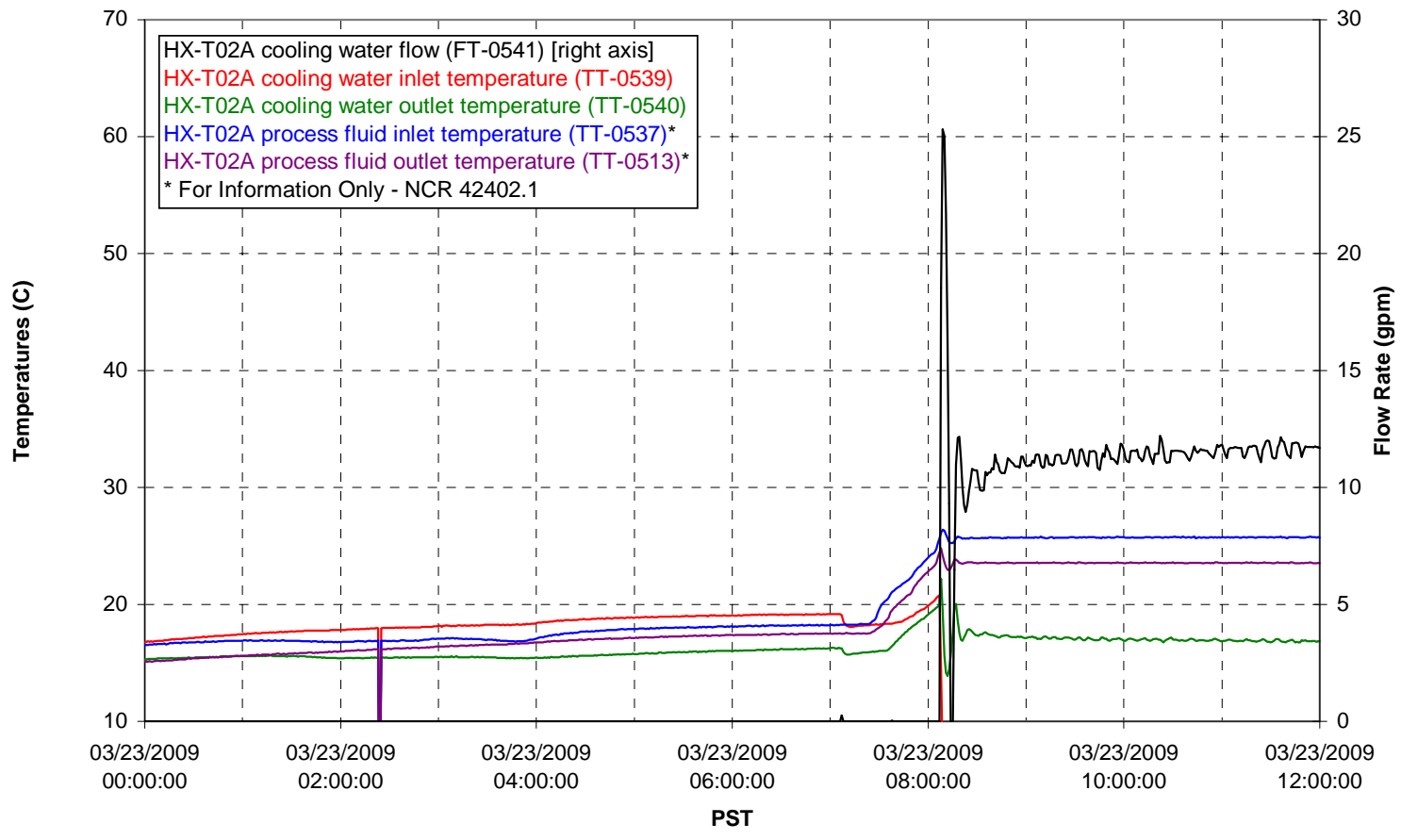

Pump Operation

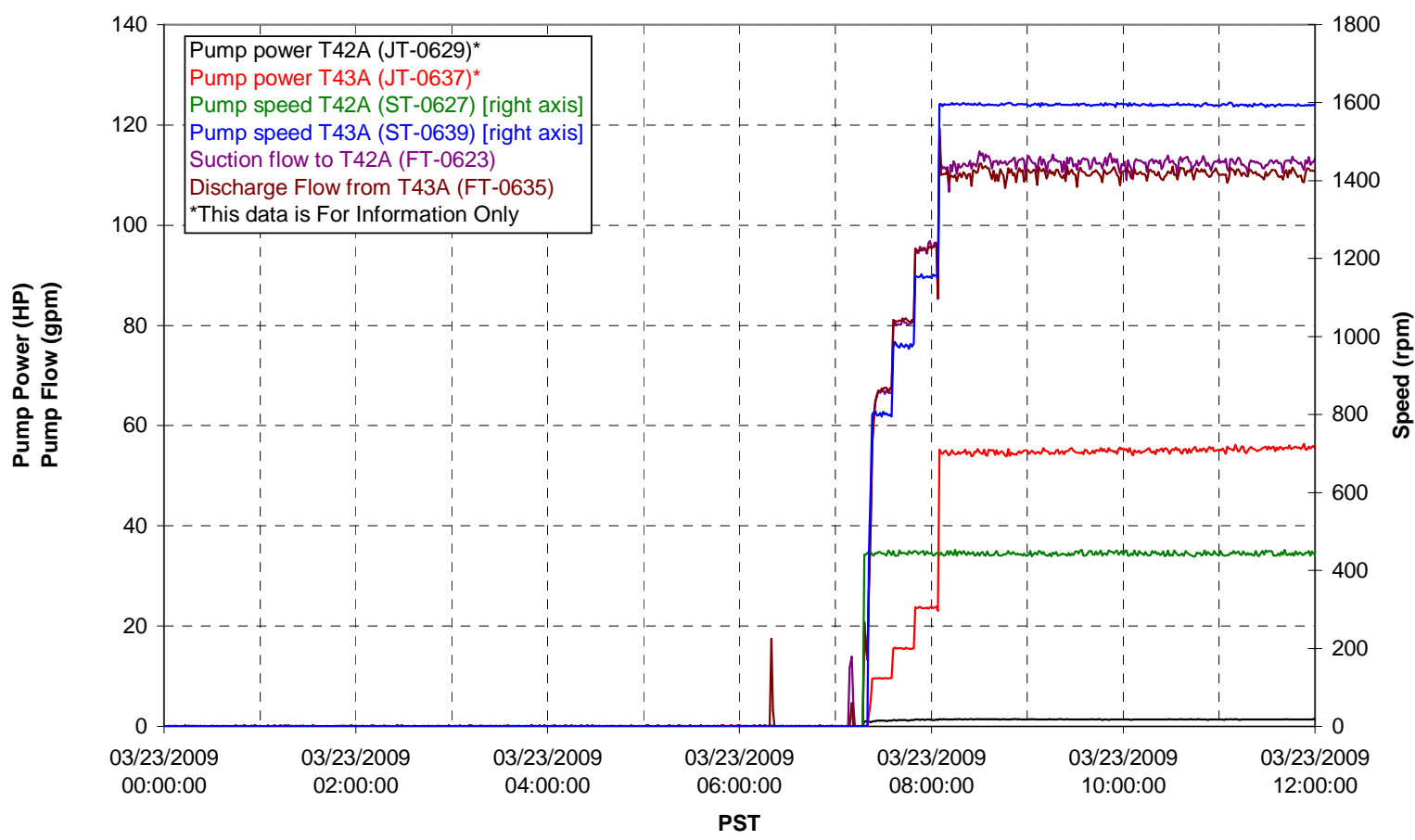


Pulsepot UFP-PP-T01A

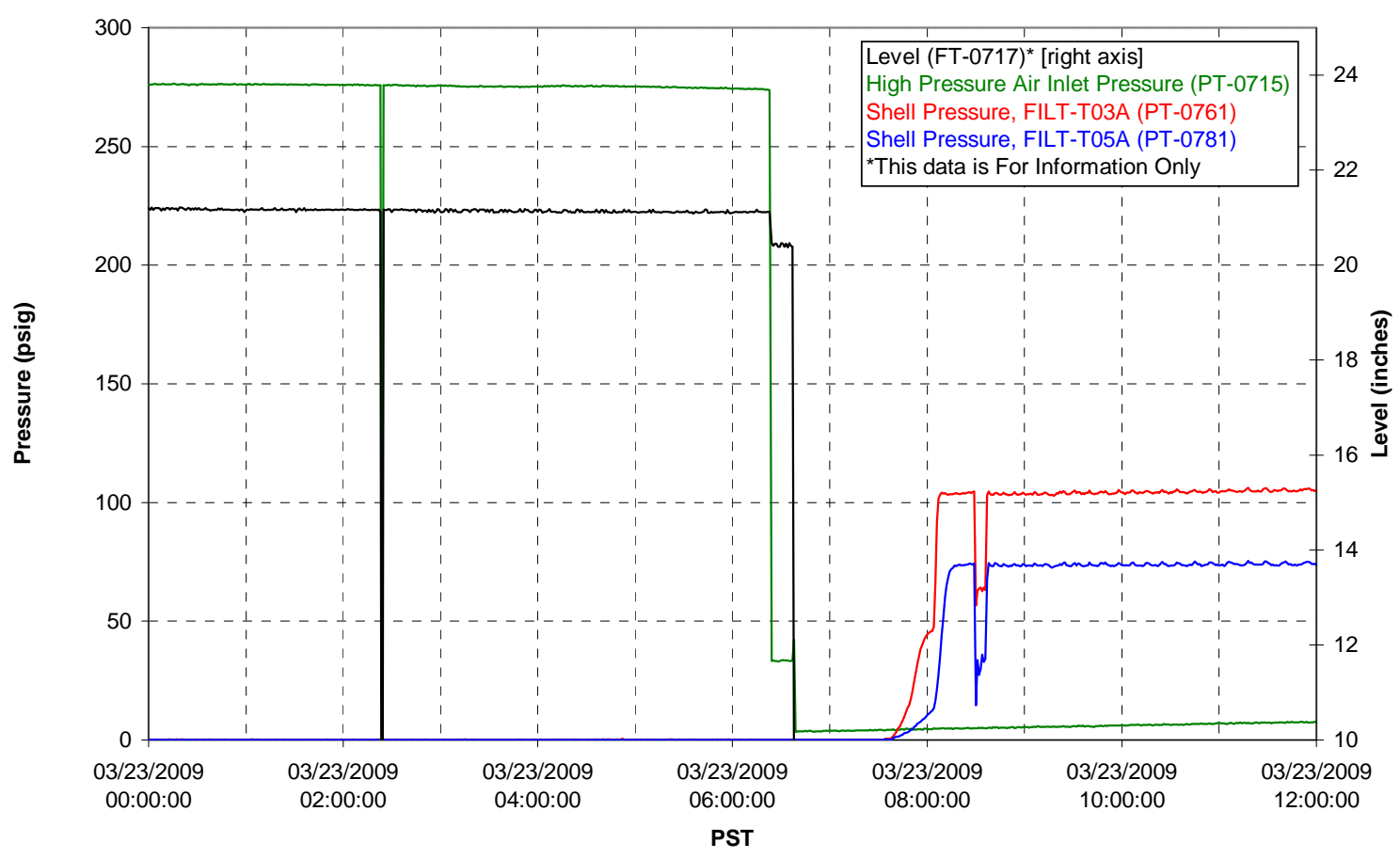

Pulsepot UFP-PP-T02A

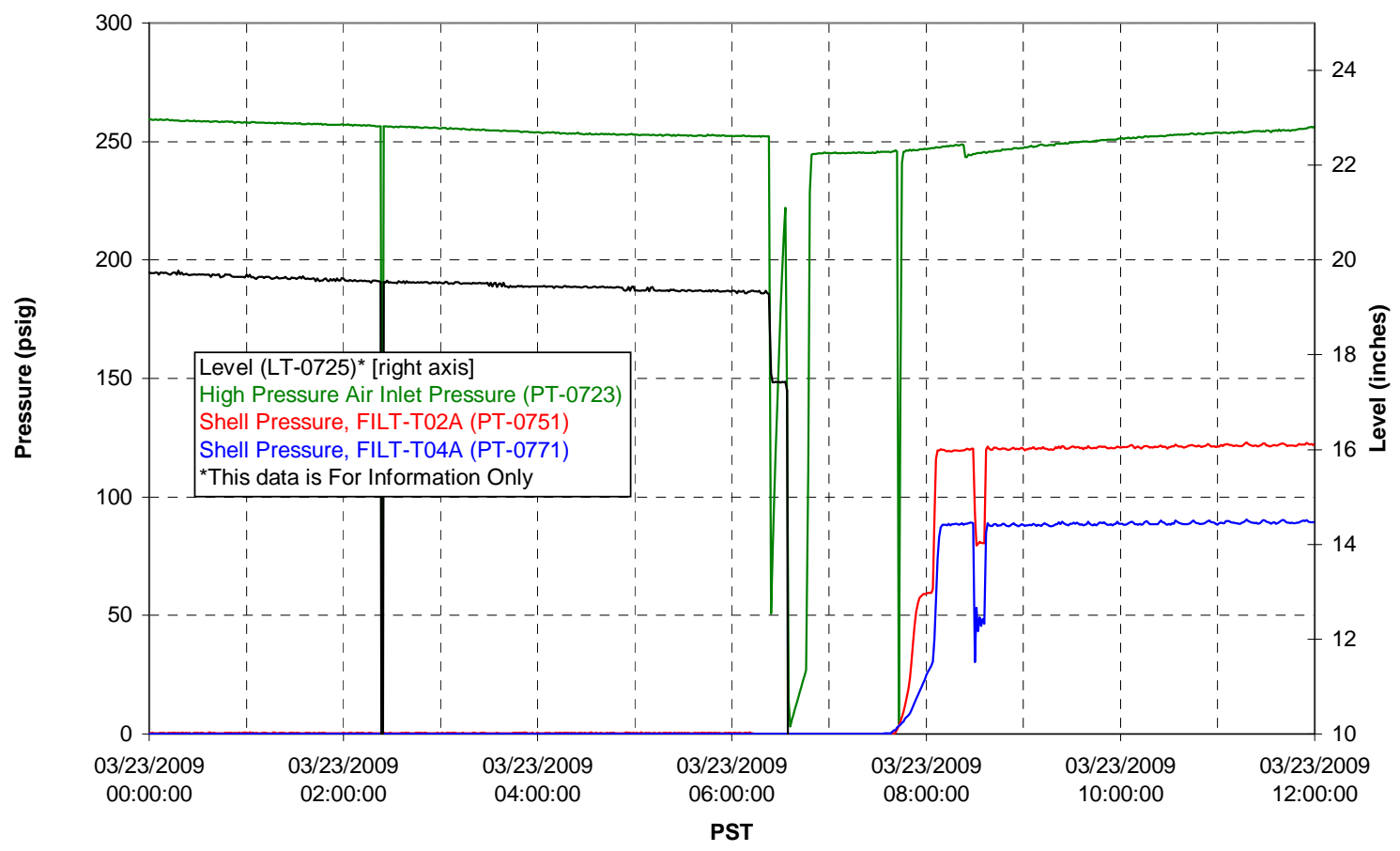


Pulsepot UFP-PP-T03A

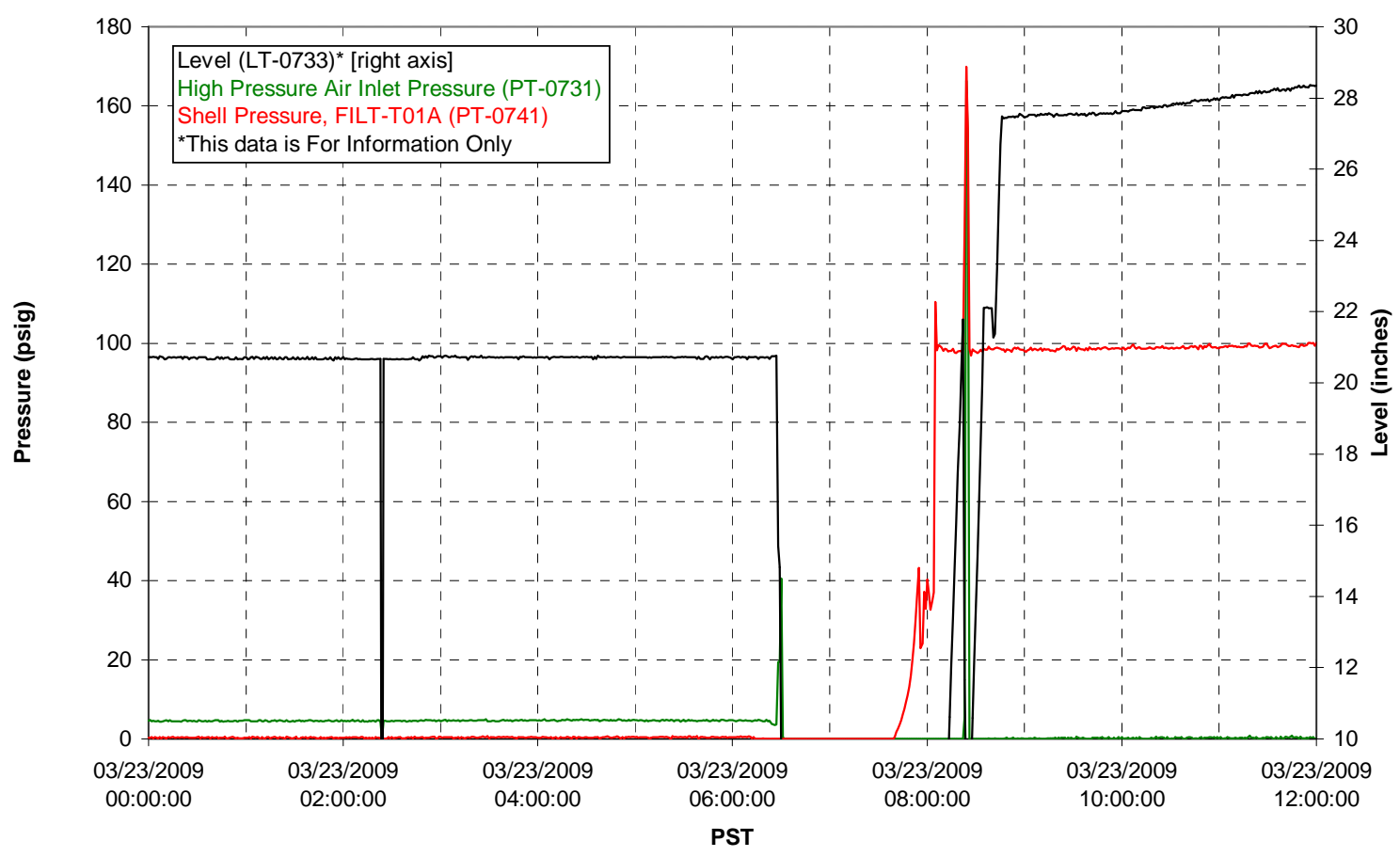

Pulsepot Levels

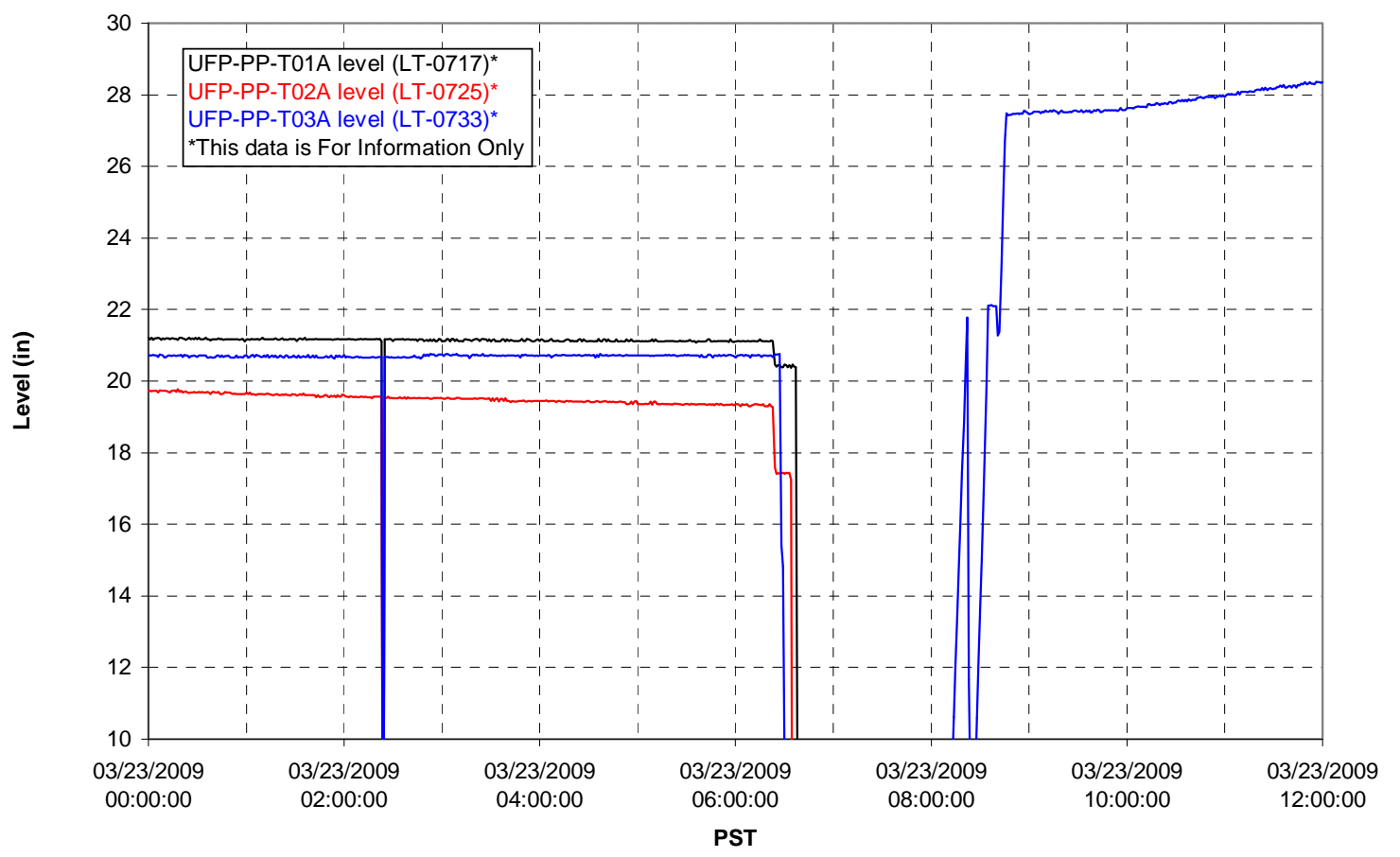


Filter UFP-FILT-T01A

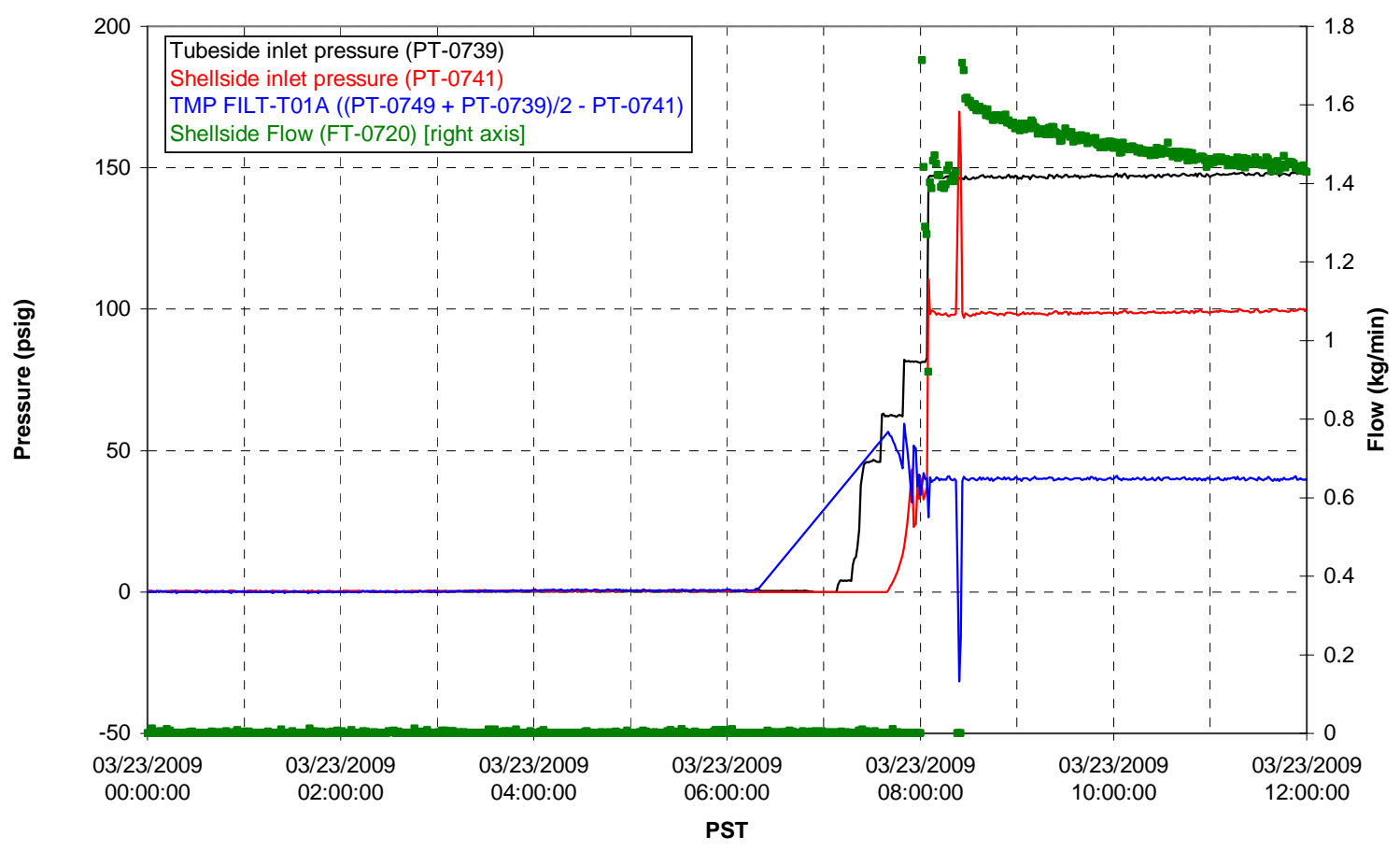

Filter UFP-FILT-T02A

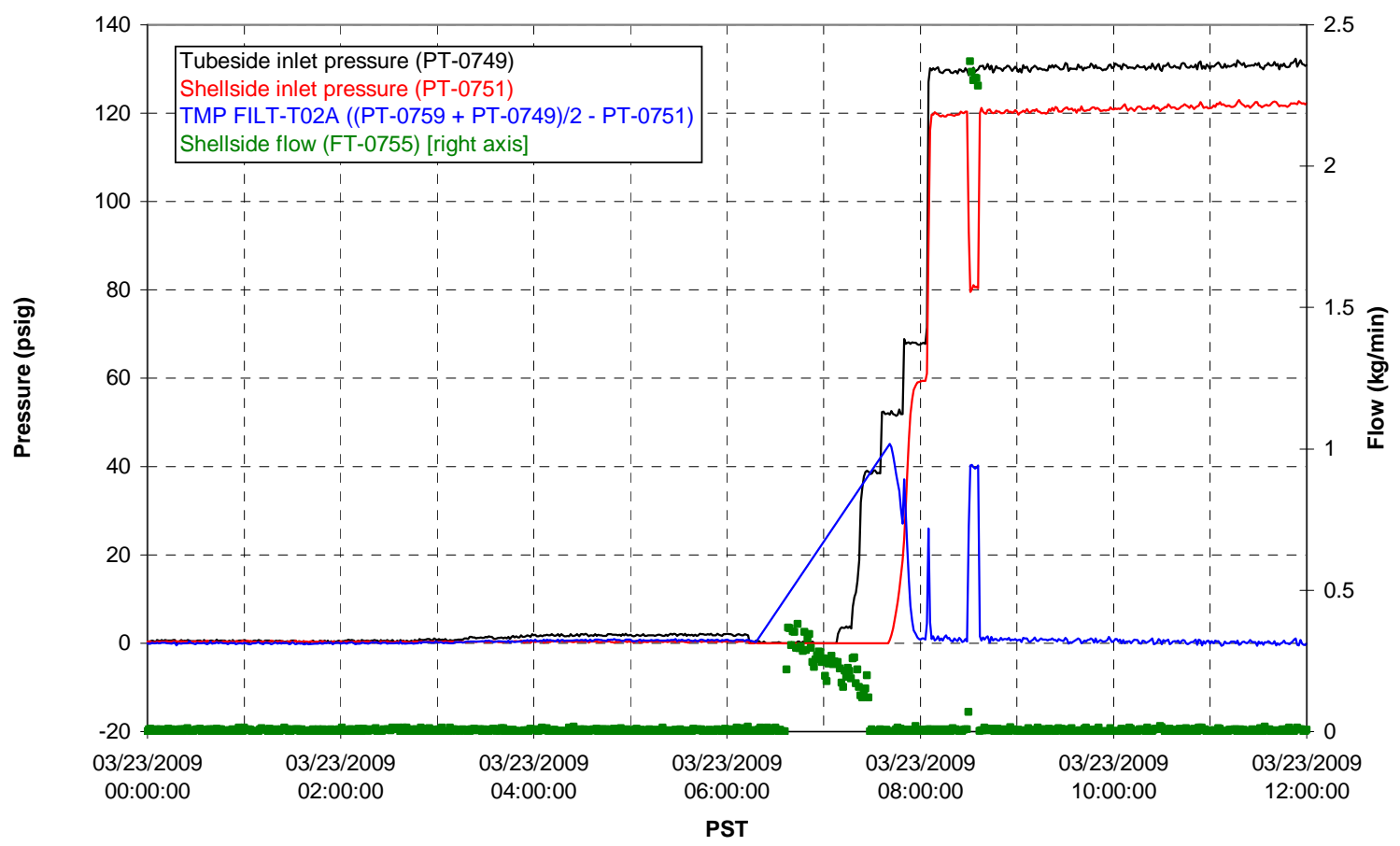


Filter UFP-FILT-T03A

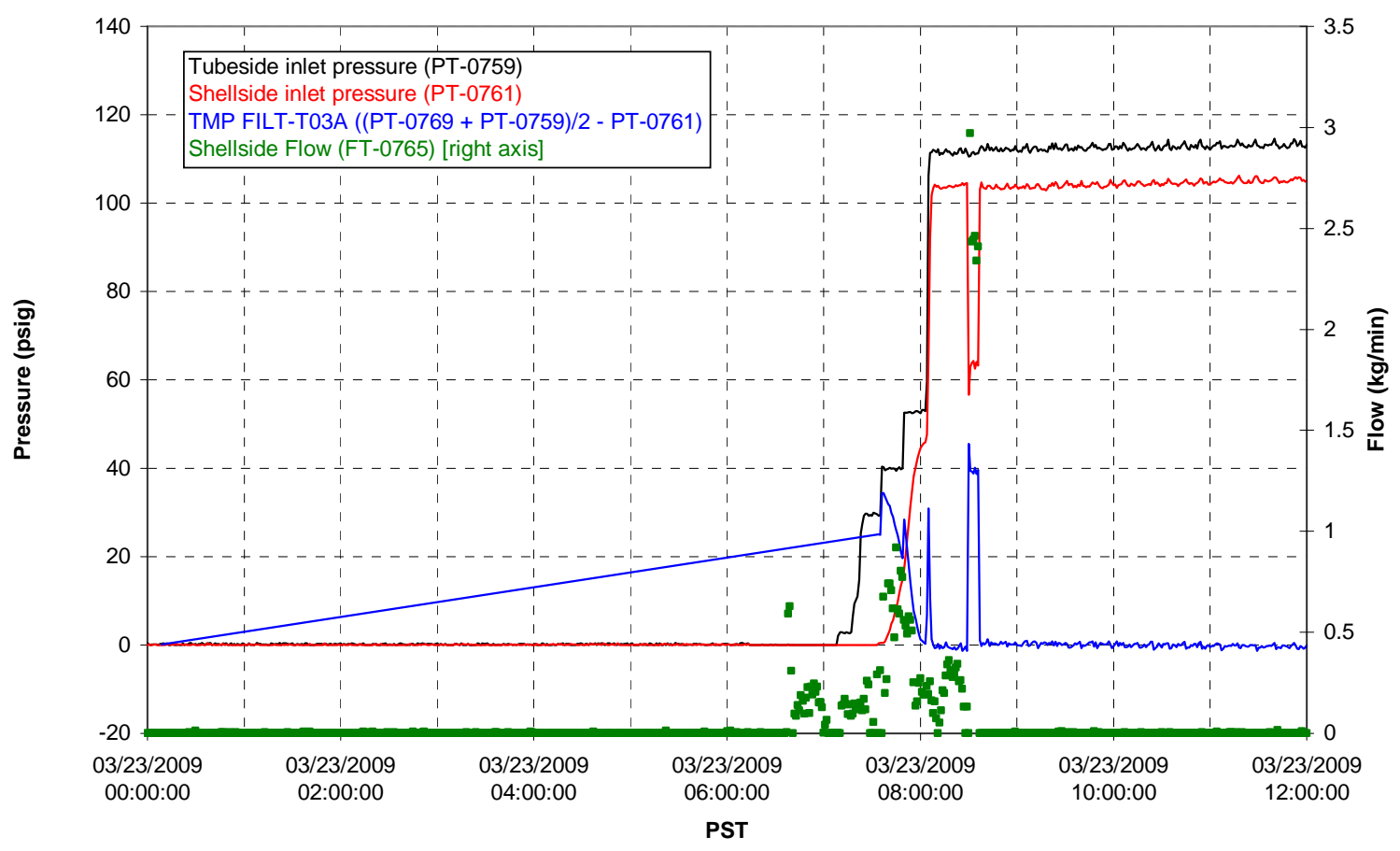

Filter UFP-FILT-T04A

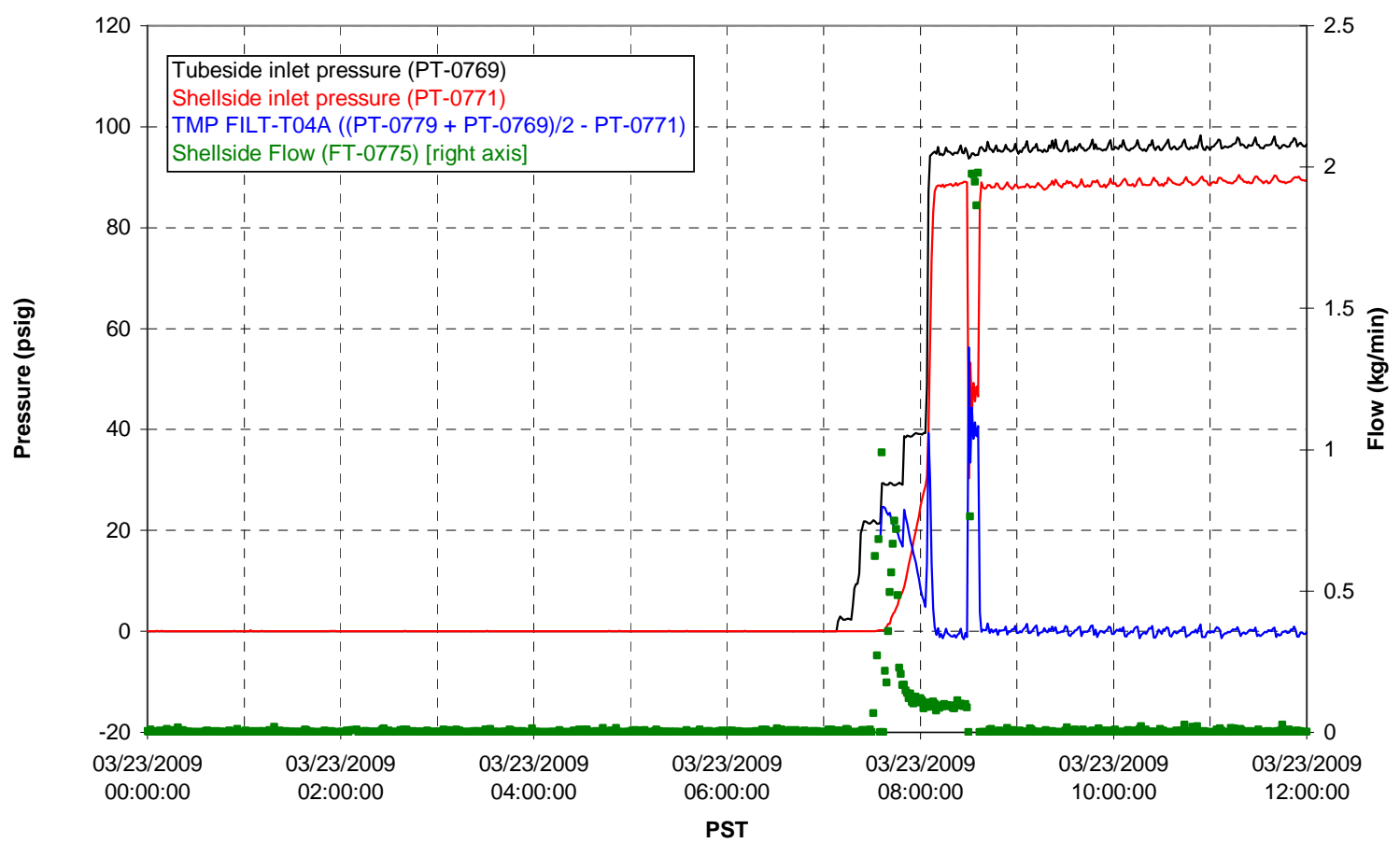


Filter UFP-FILT-T05A

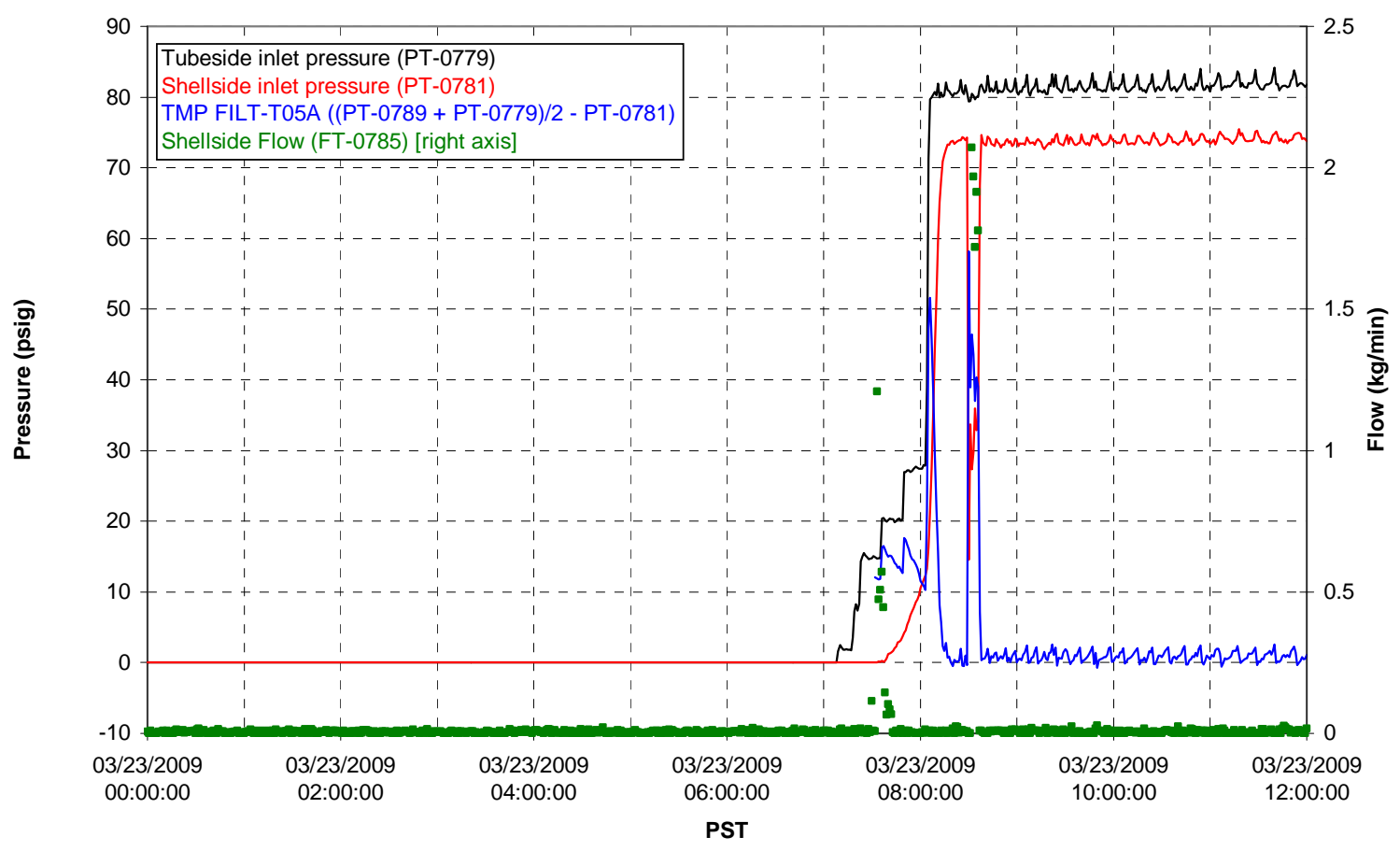

Chemical Flow

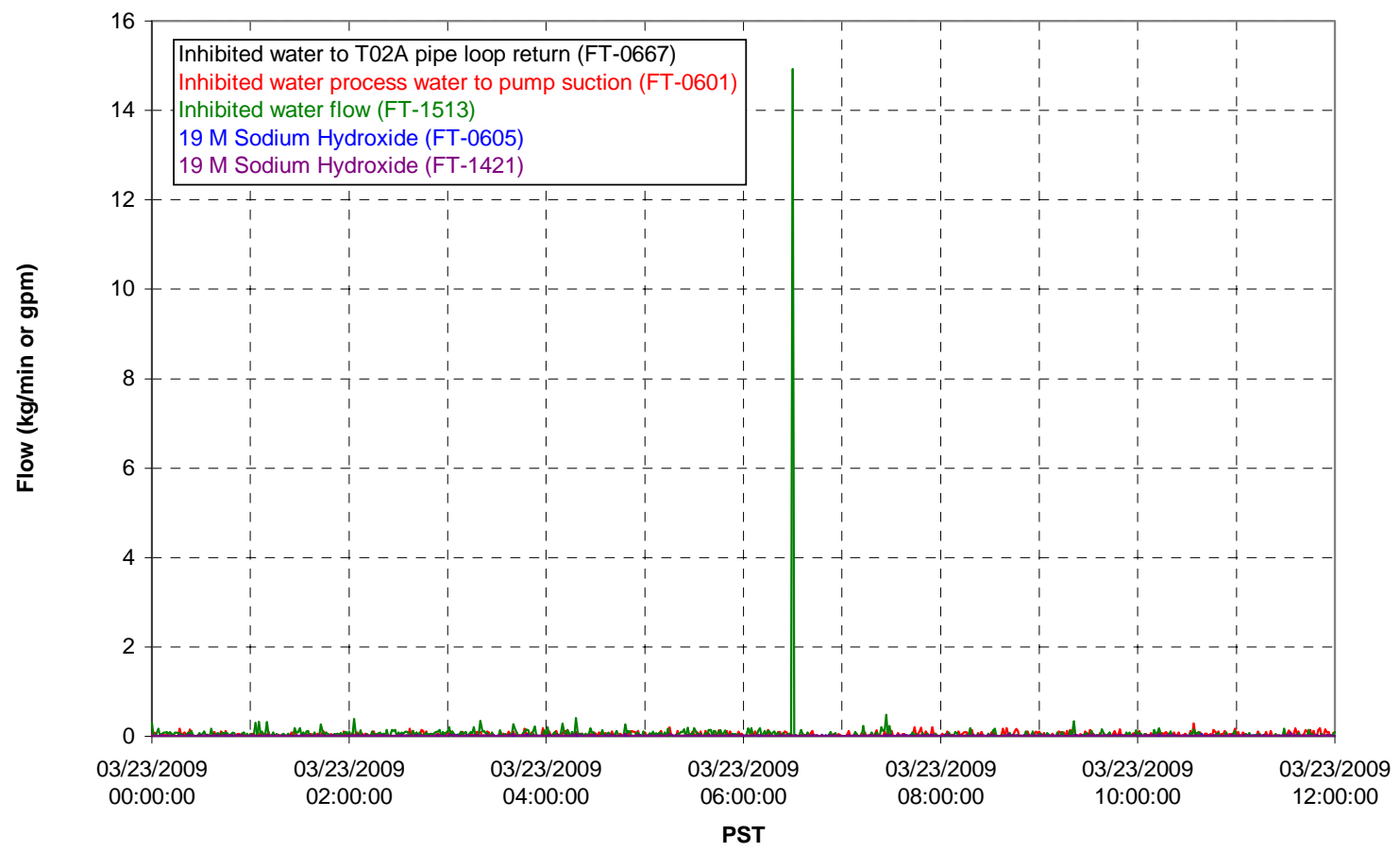




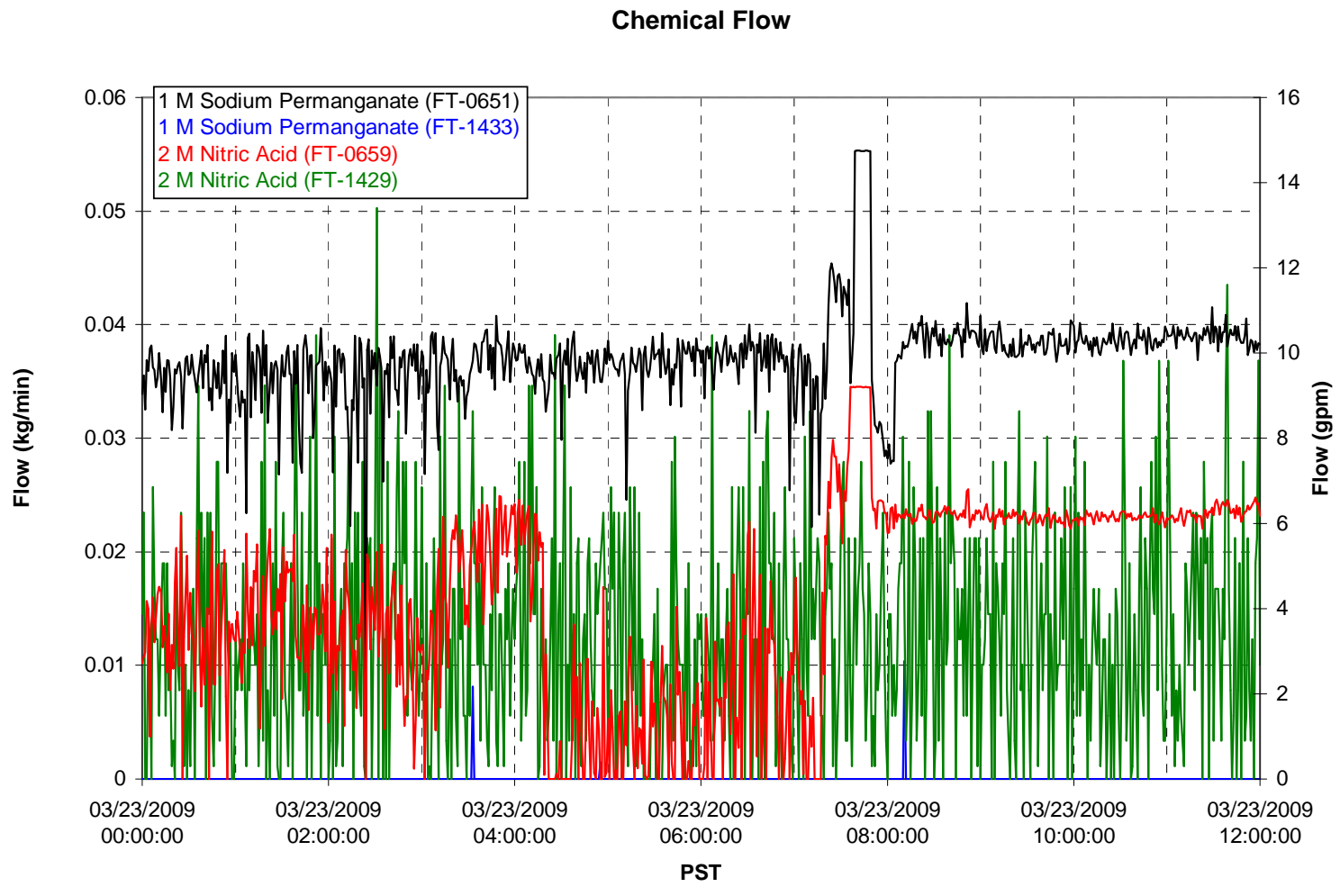

Air Flows

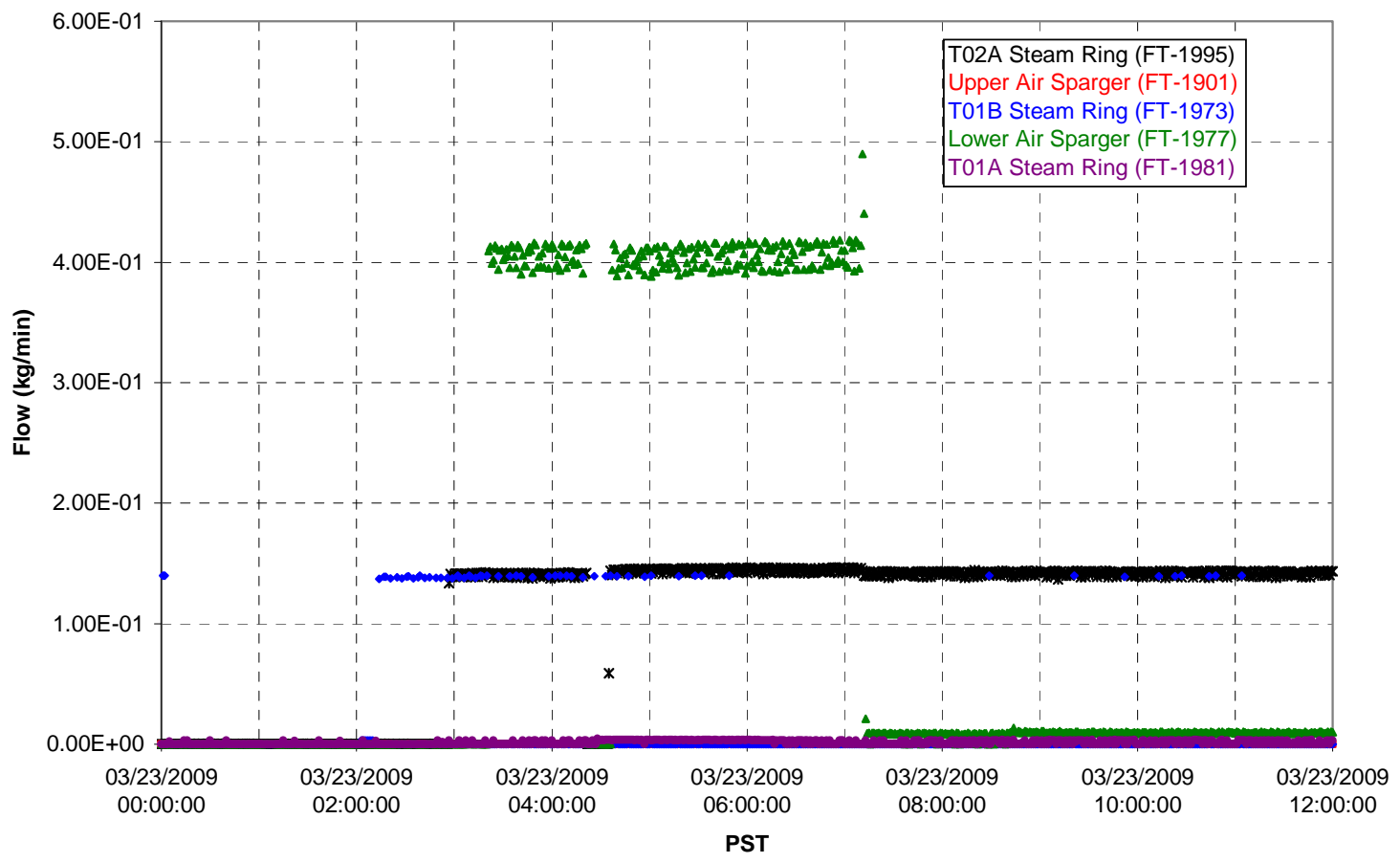


T02A Steam

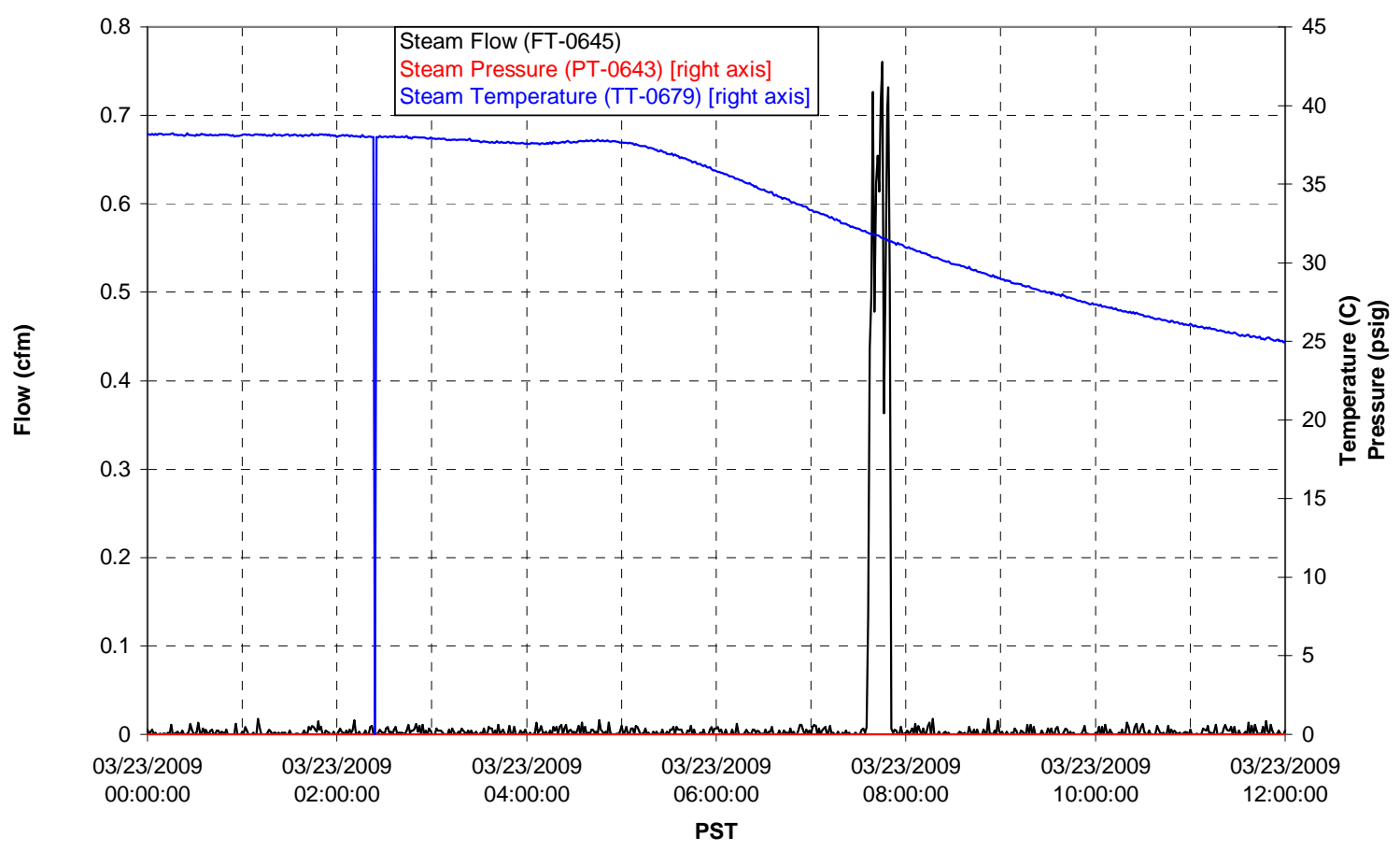

T01A Steam

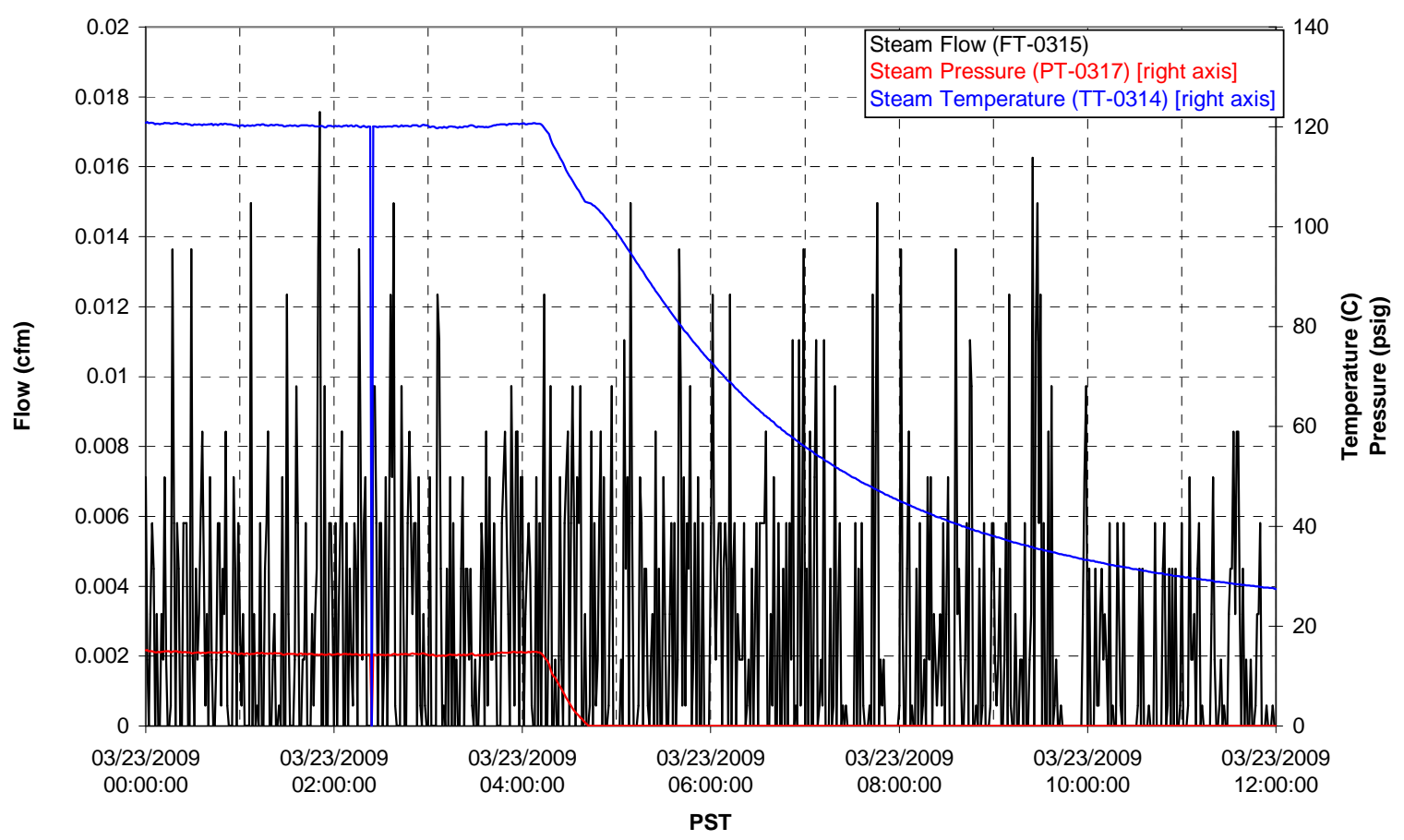


T01B Steam

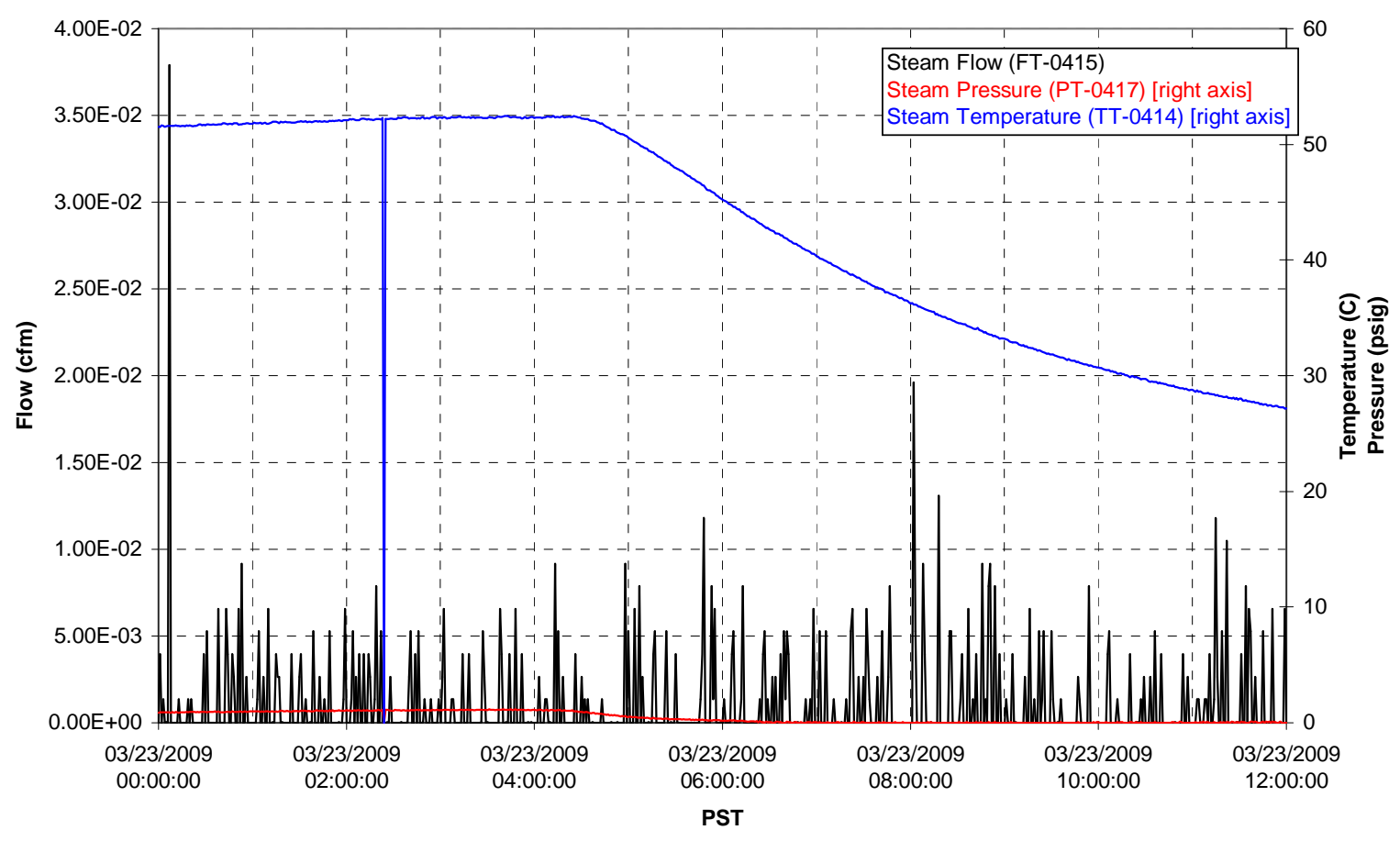




\section{Integrated Test D Data Plots 03/23/09 12:00 - 03/24/09 00:00}


T01A level

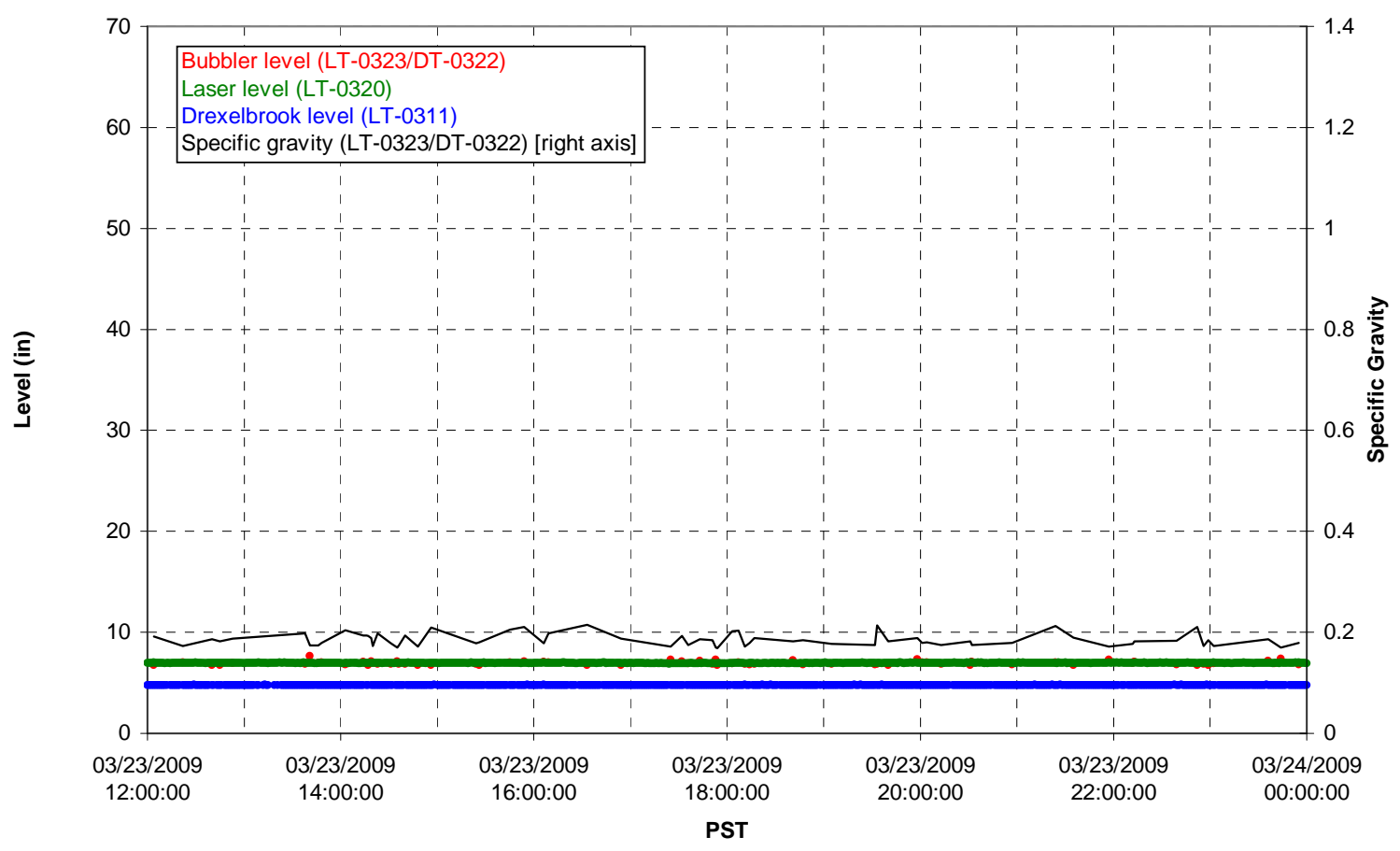

T01A temperatures

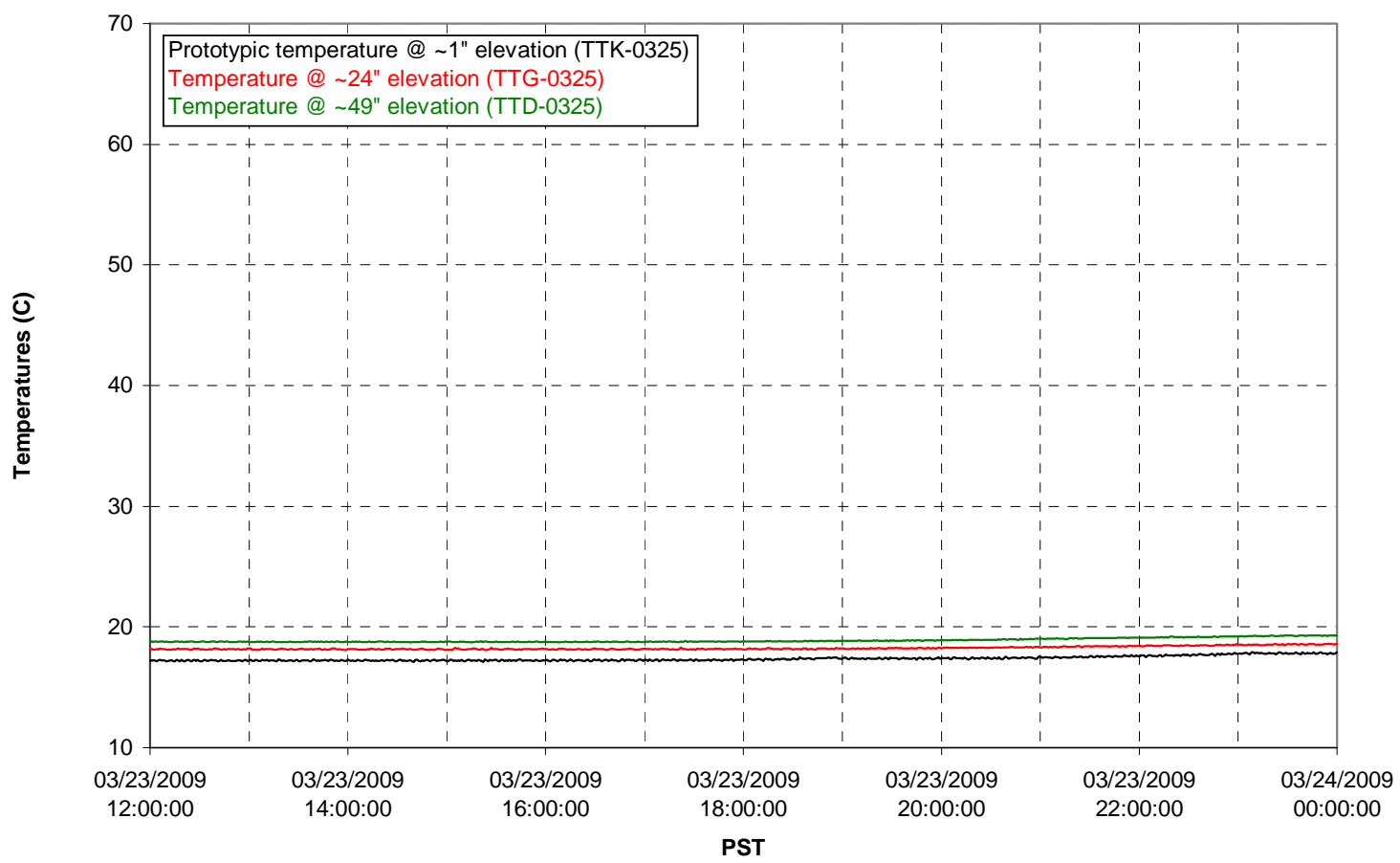


T01B level

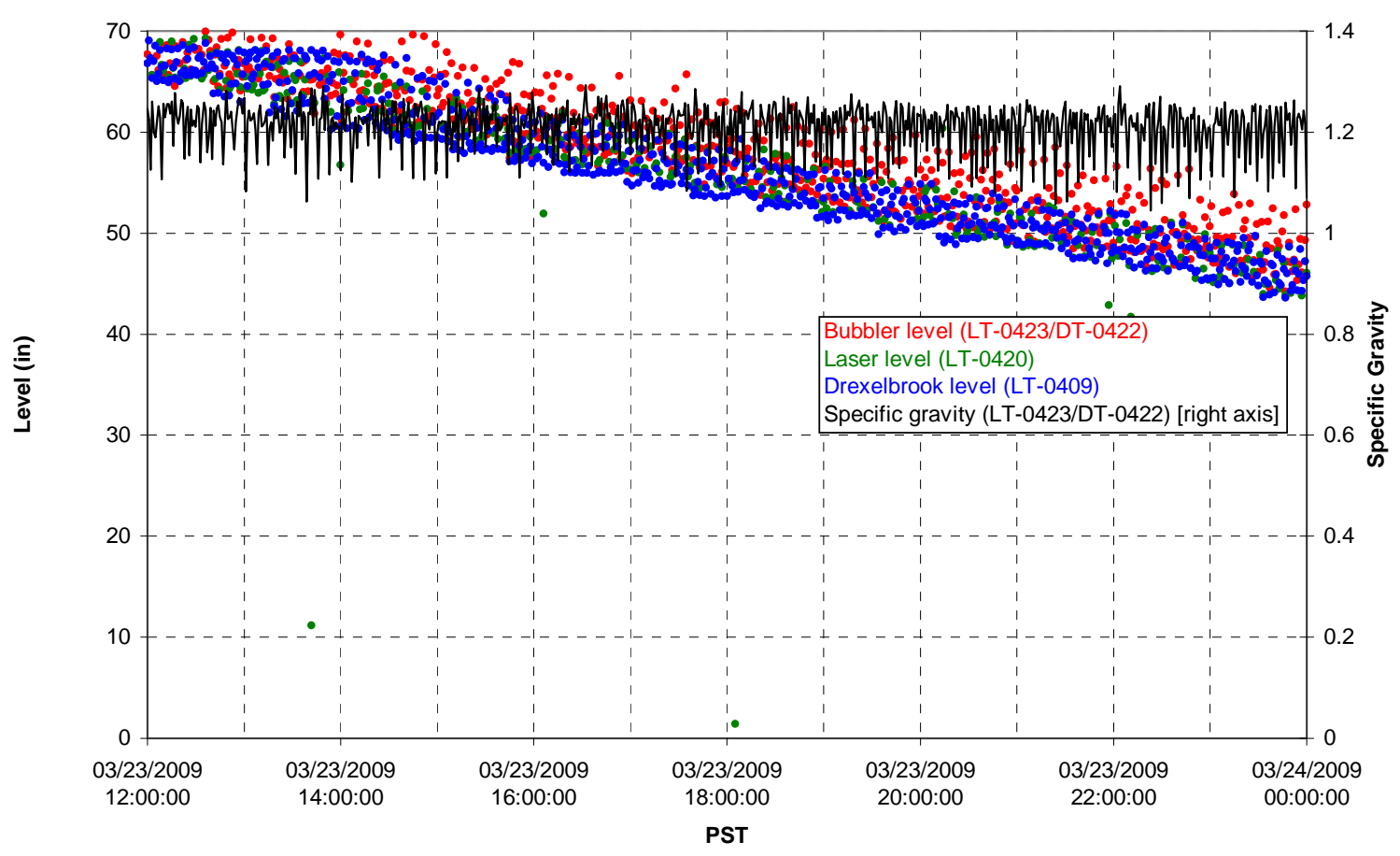

T01B temperatures

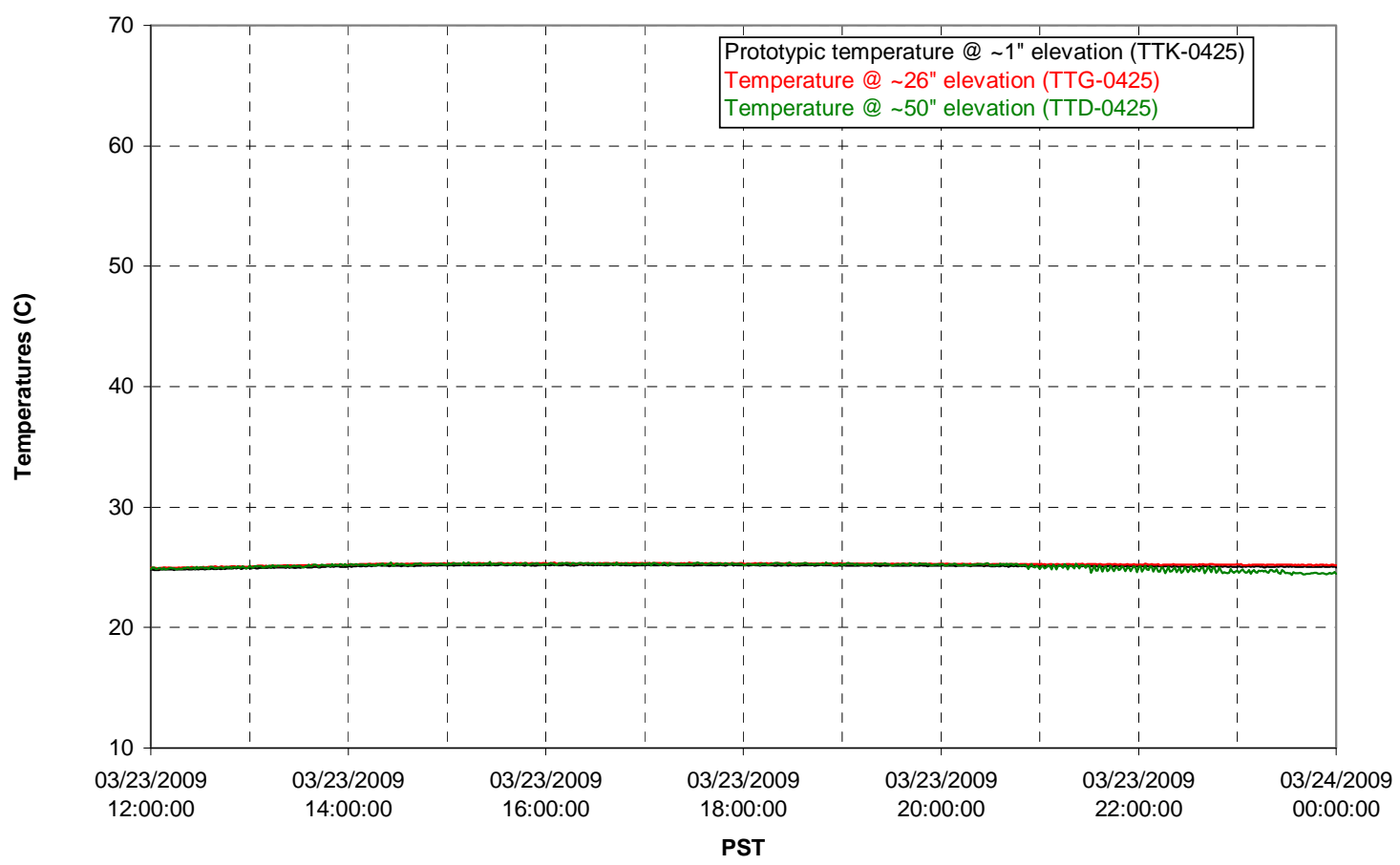


T02A level

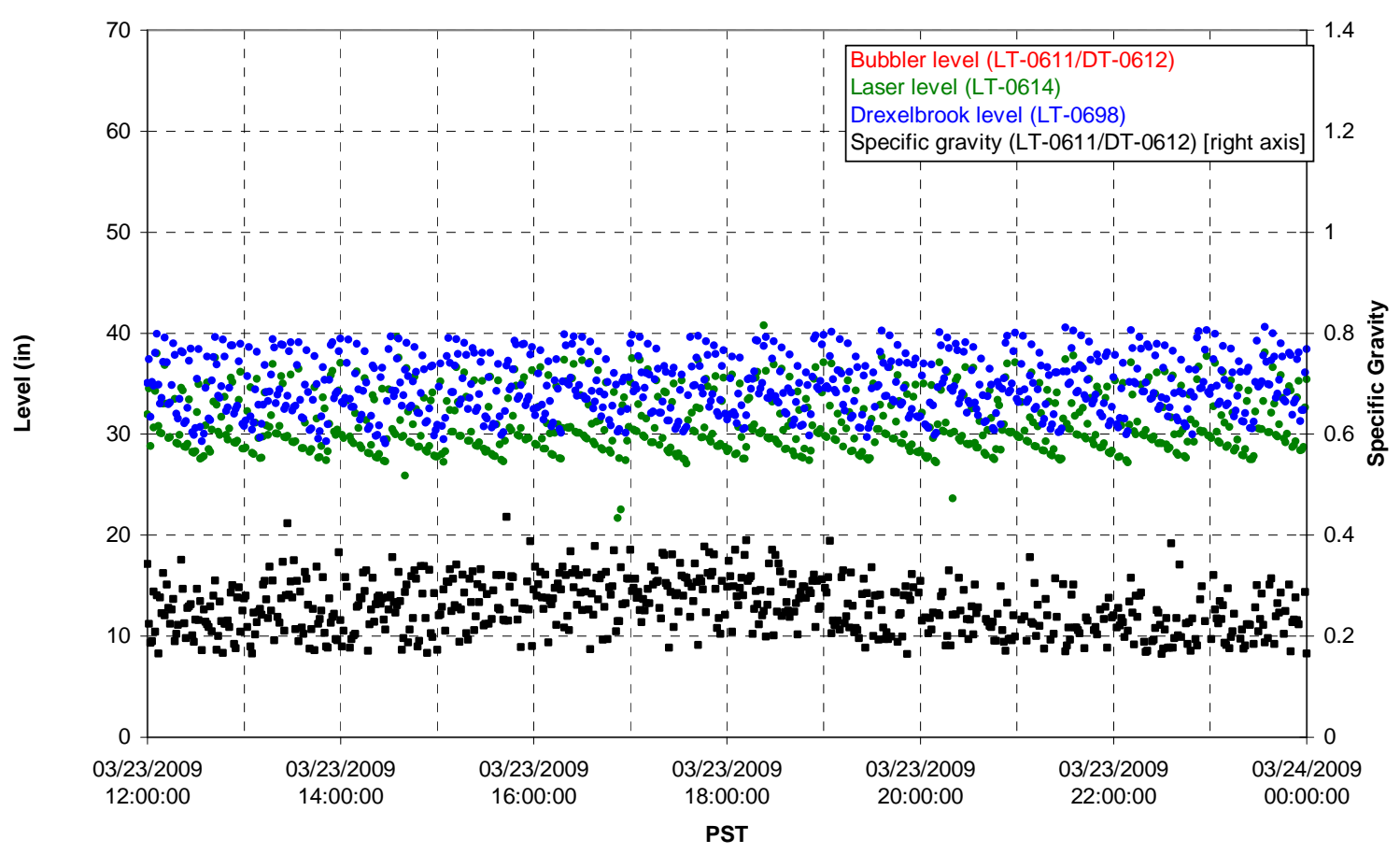

T02A temperatures

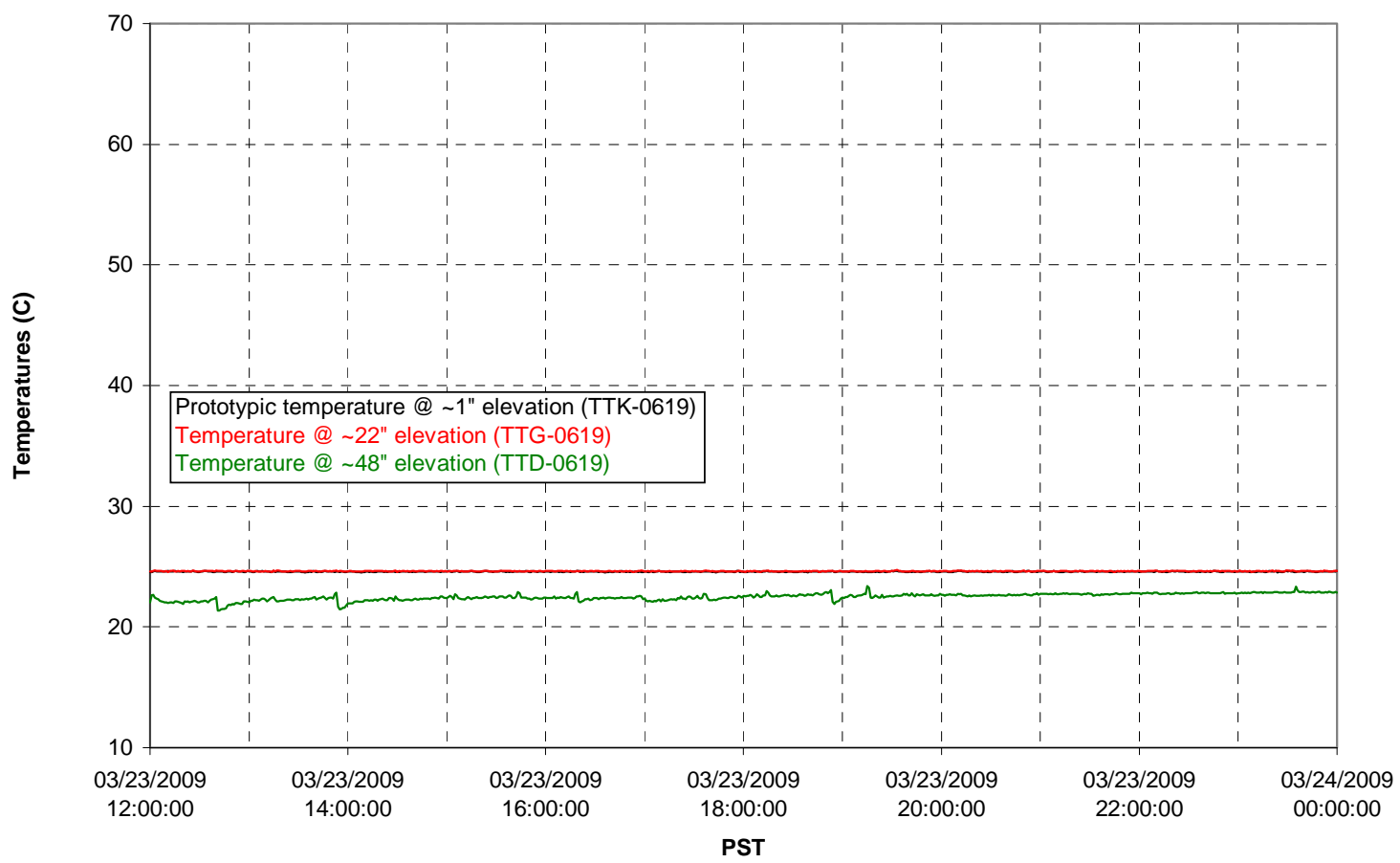


T02A and filter loop temperatures

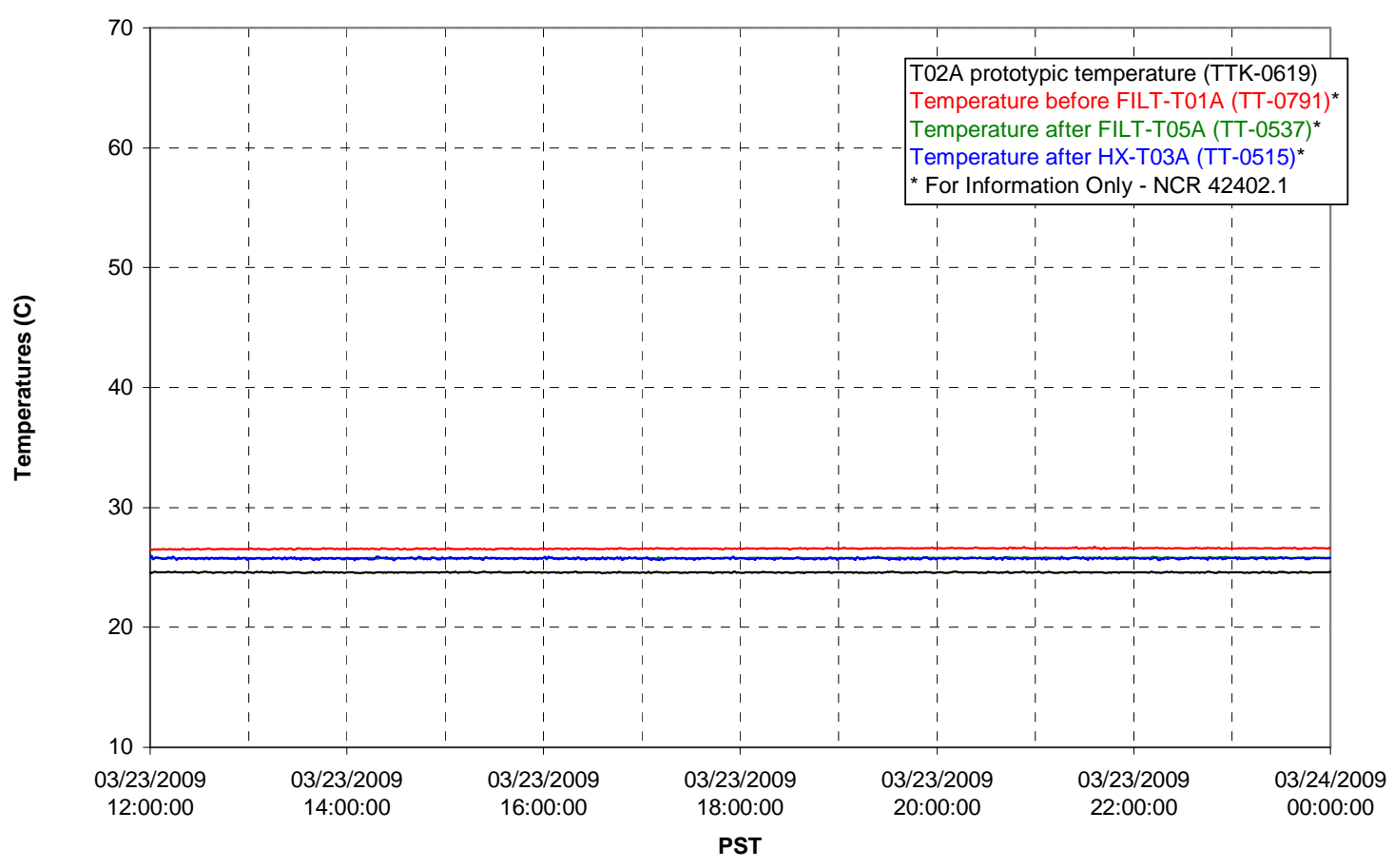

Pump Pressures and Flow

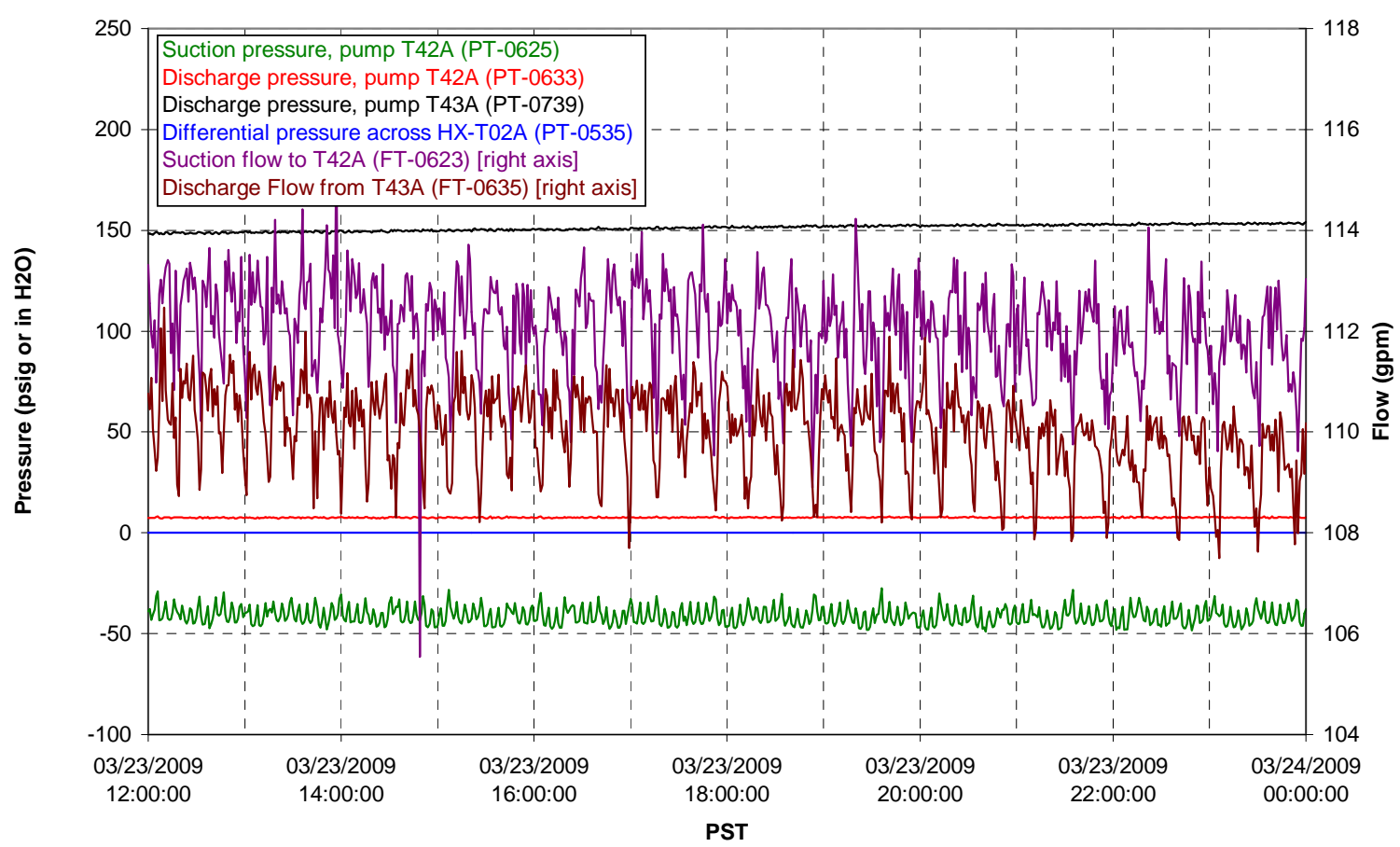




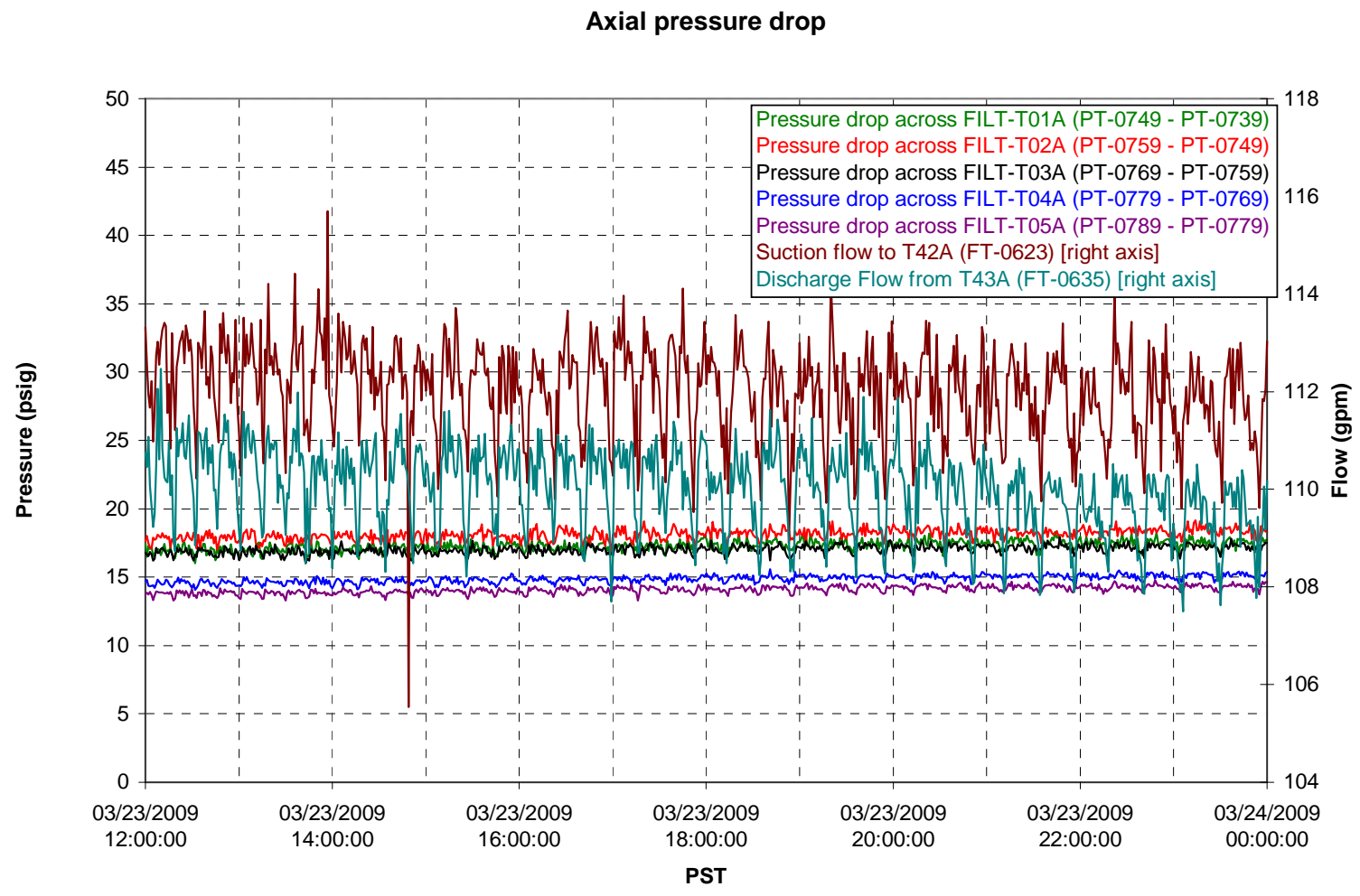

Permeate flow rates

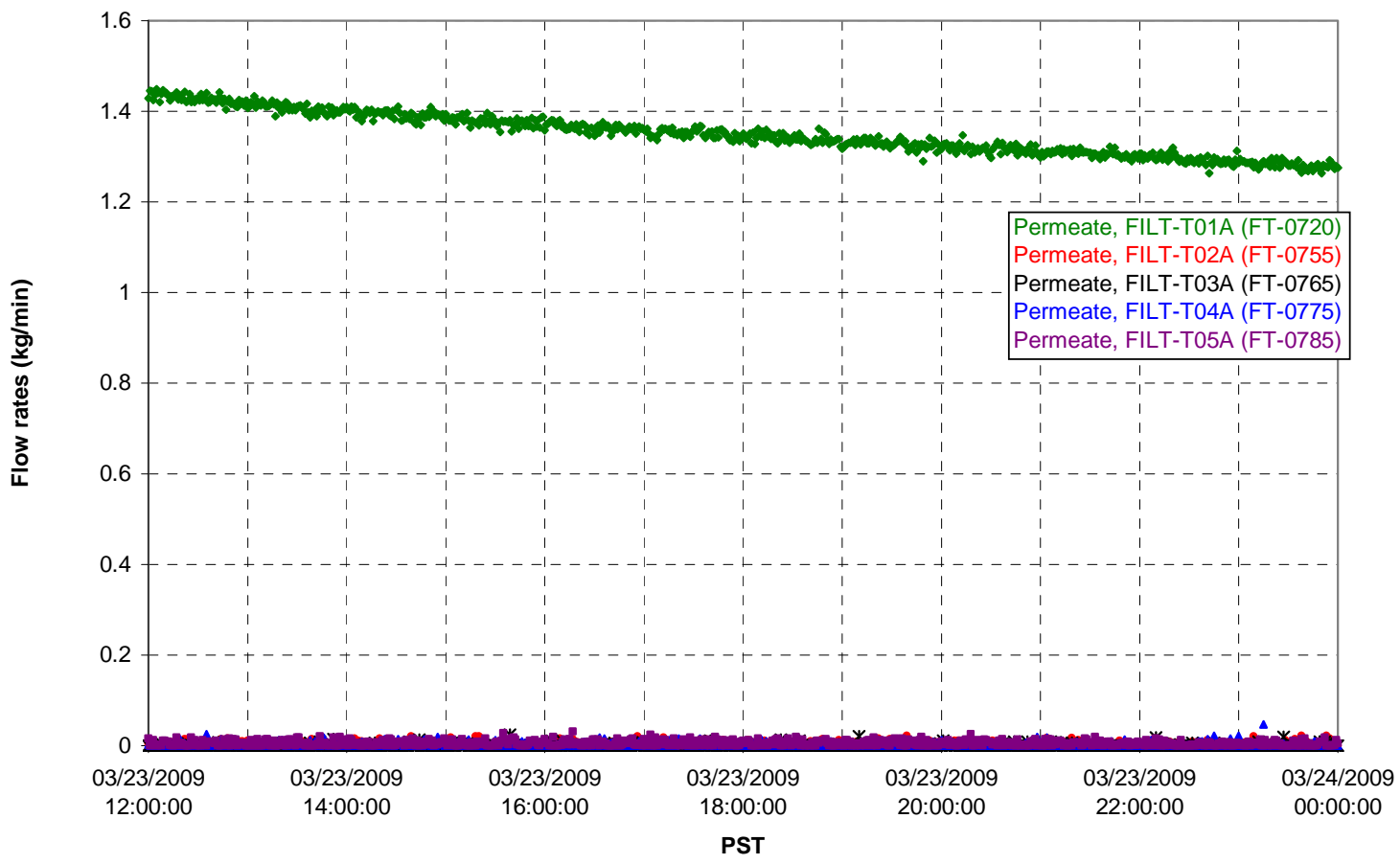


T02A Inner Temperature Tree

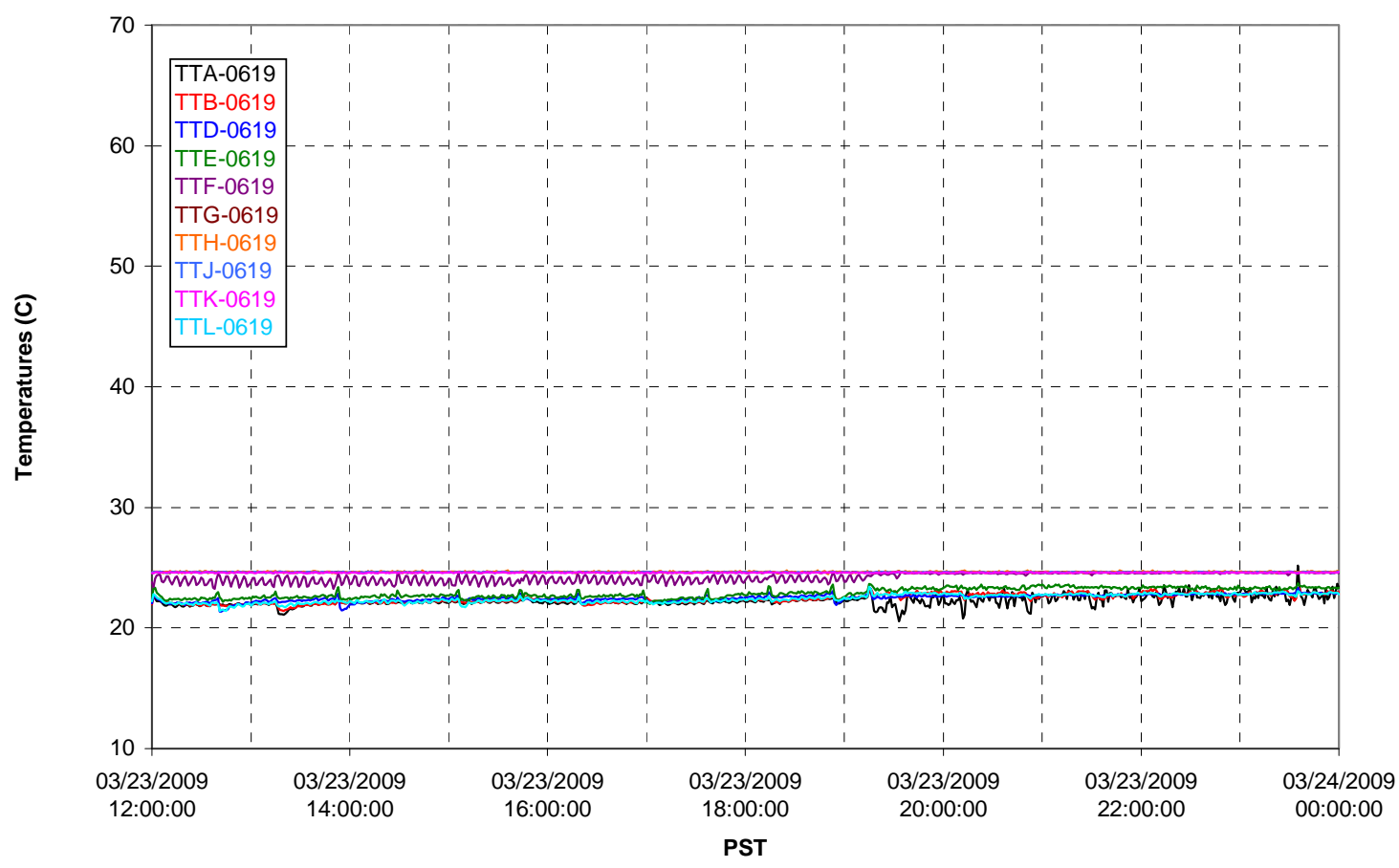

T02A Outer Temperature Tree

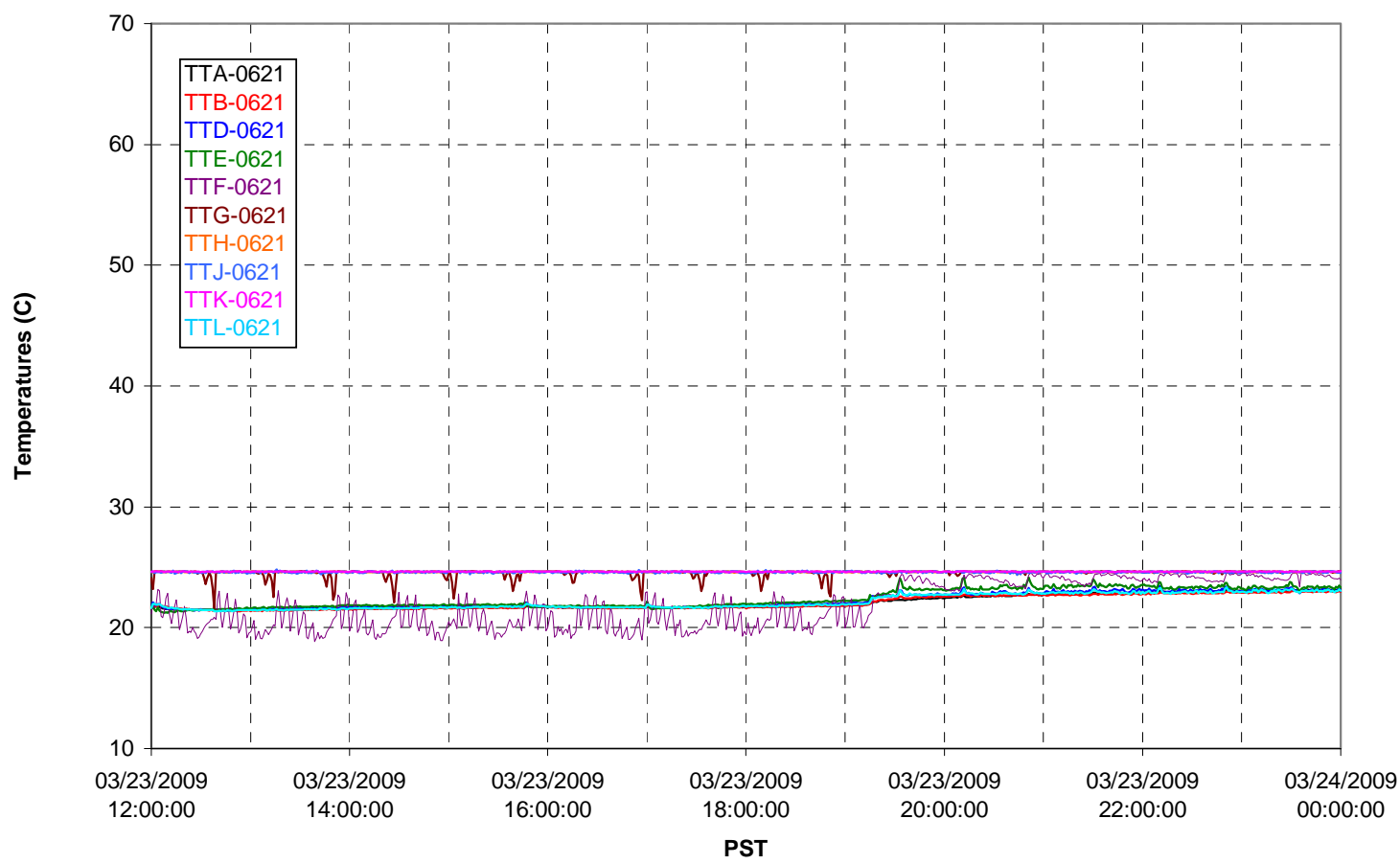


T02A temperatures

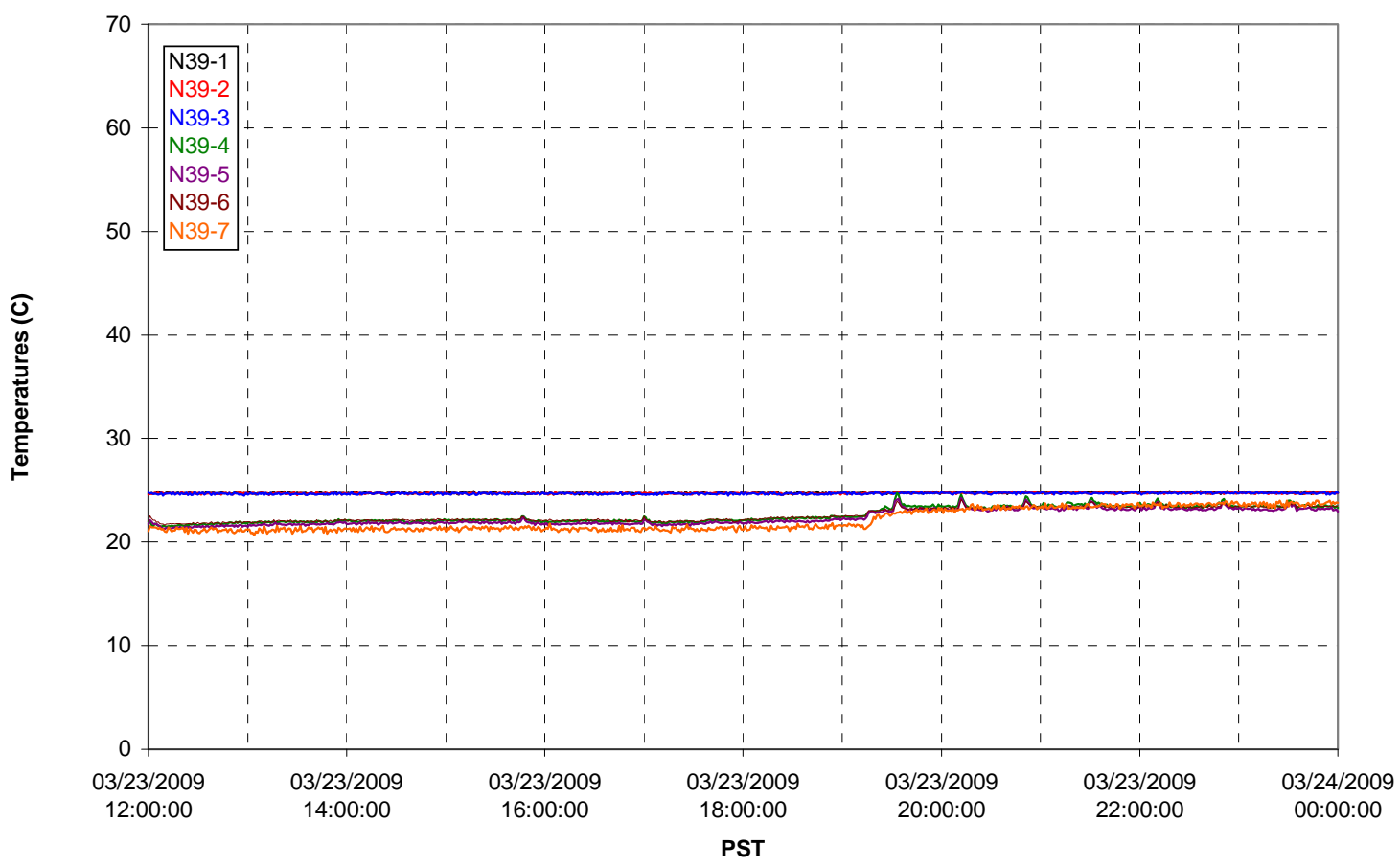

T02A temperatures

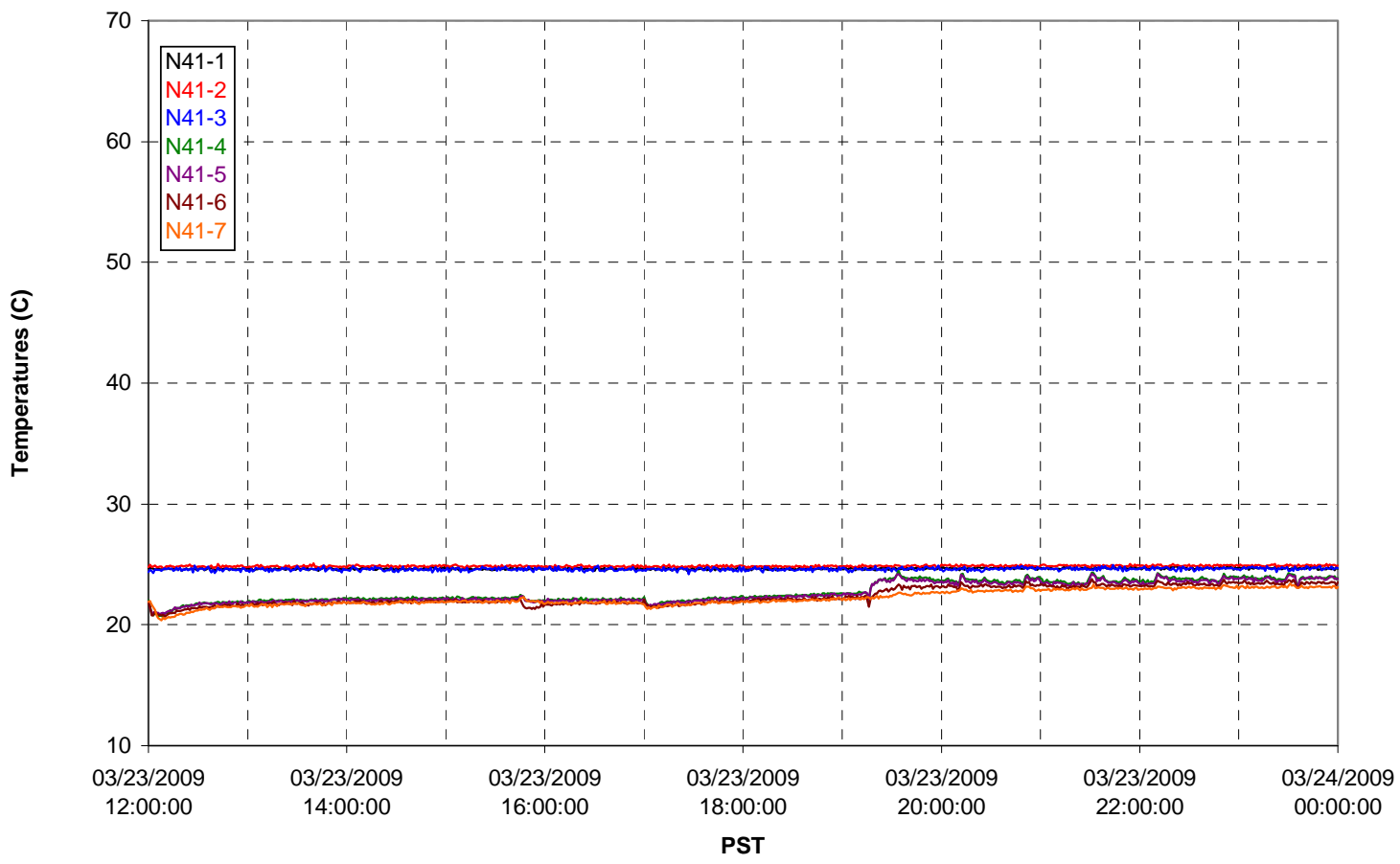


T02A temperatures

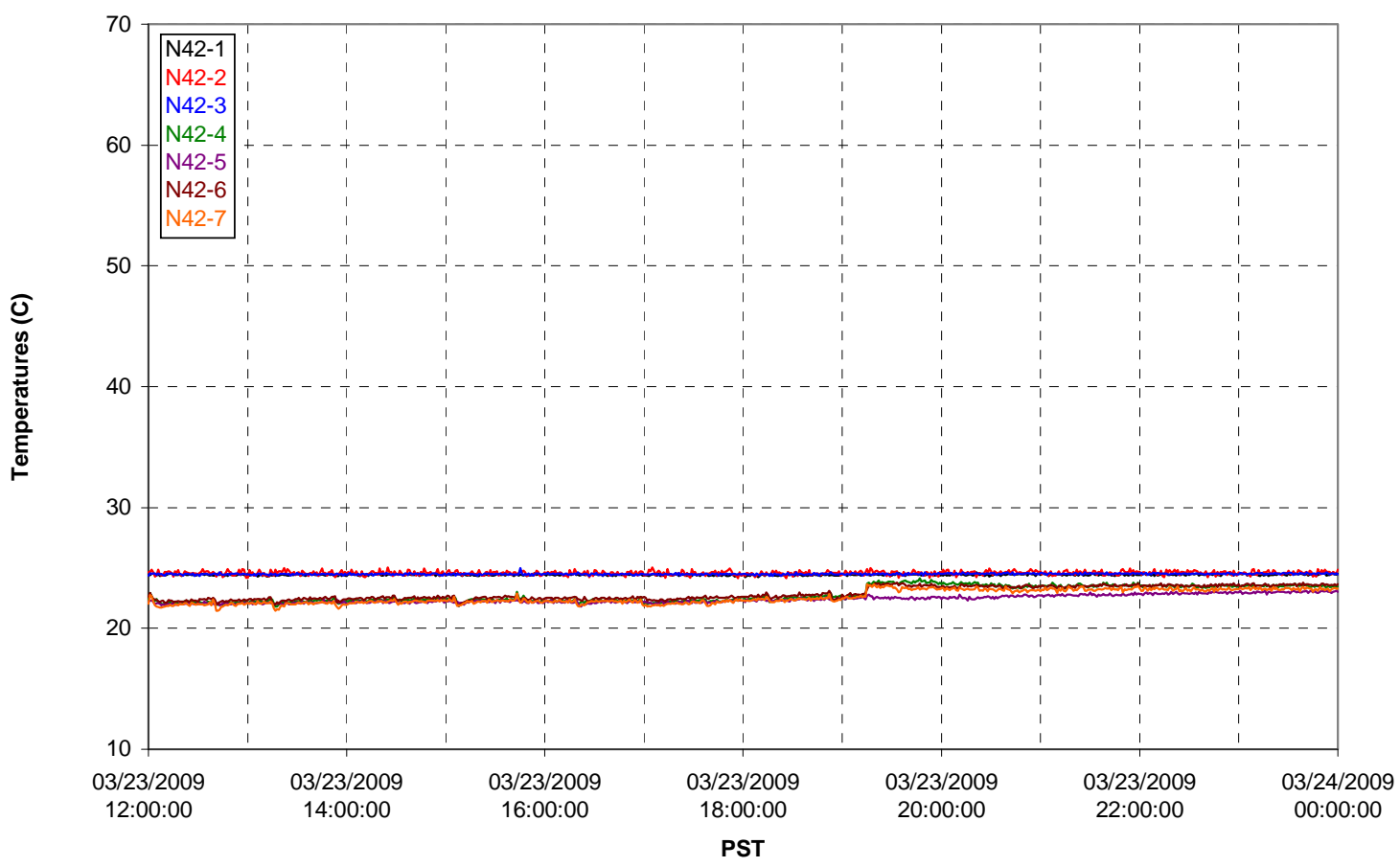

T02A temperatures

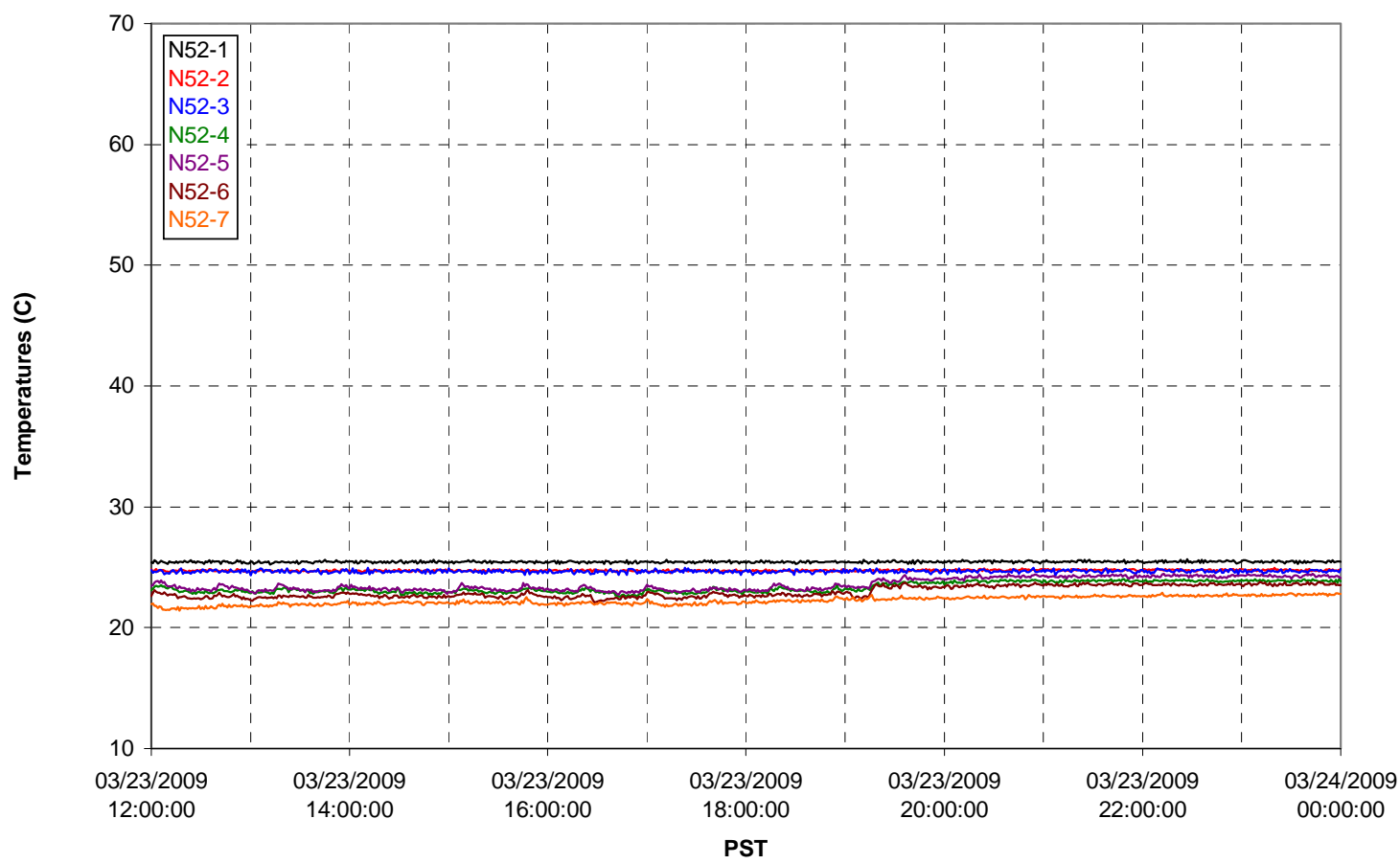


T02A Heating and Cooling

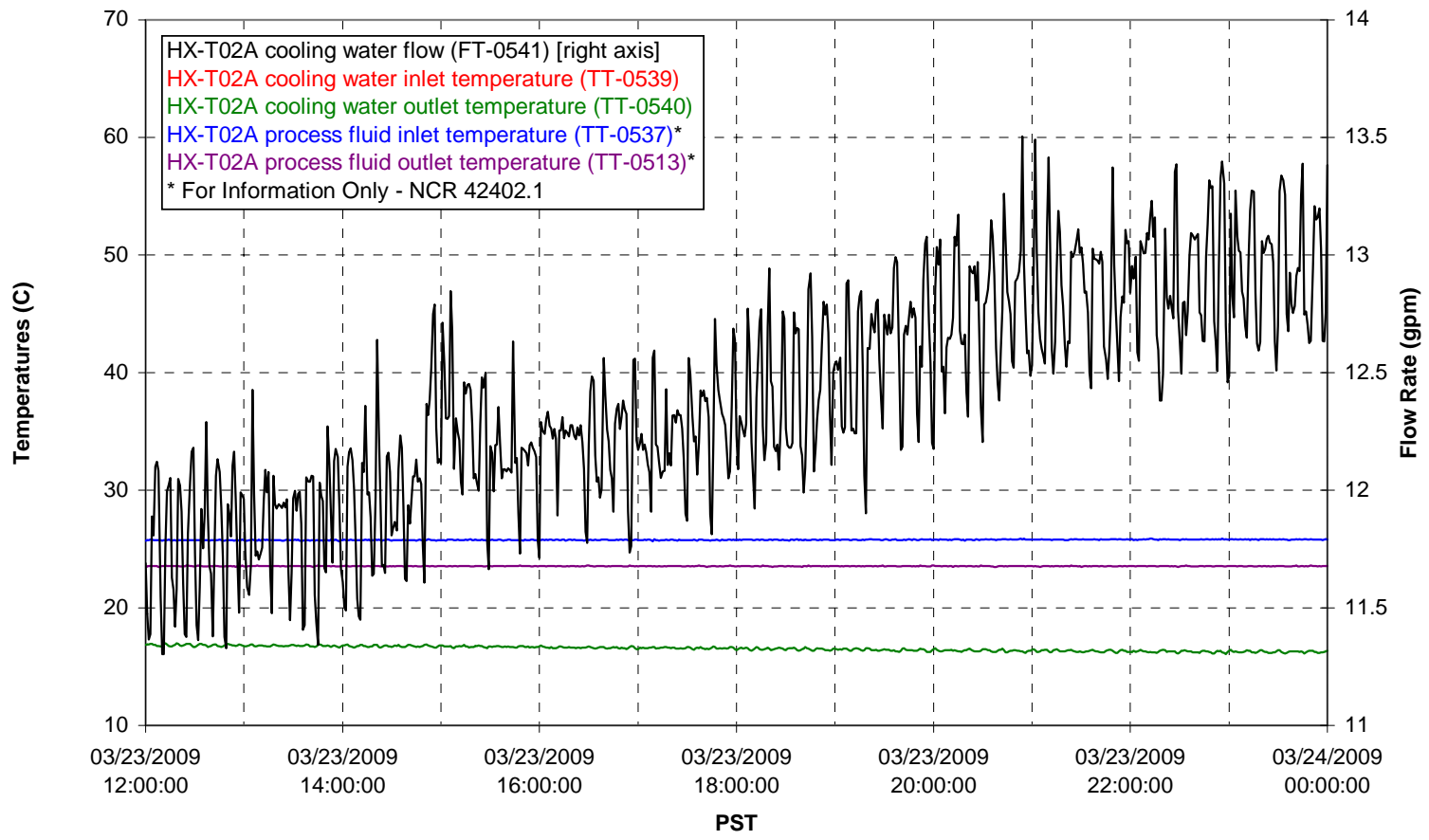

Pump Operation

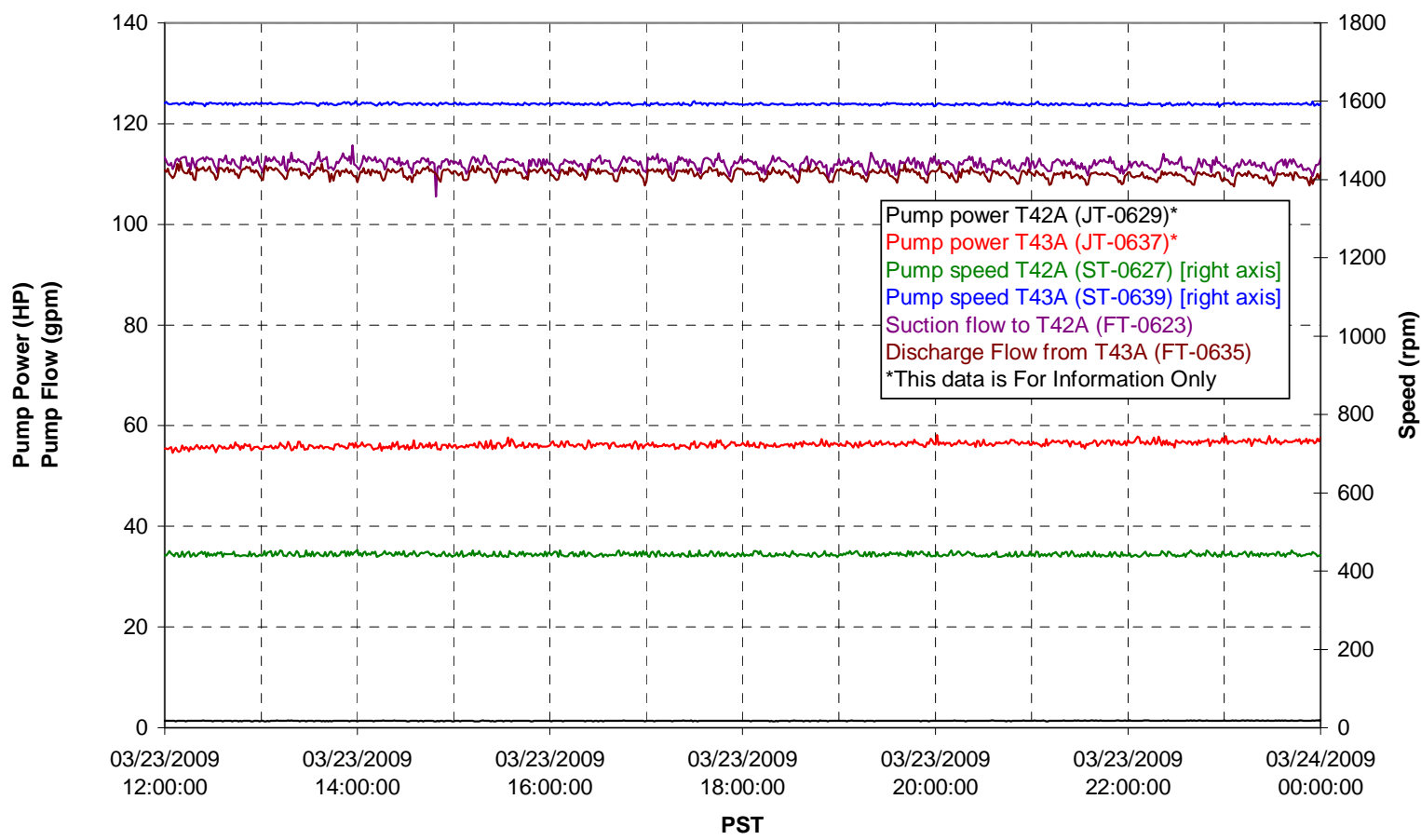


Pulsepot UFP-PP-T01A

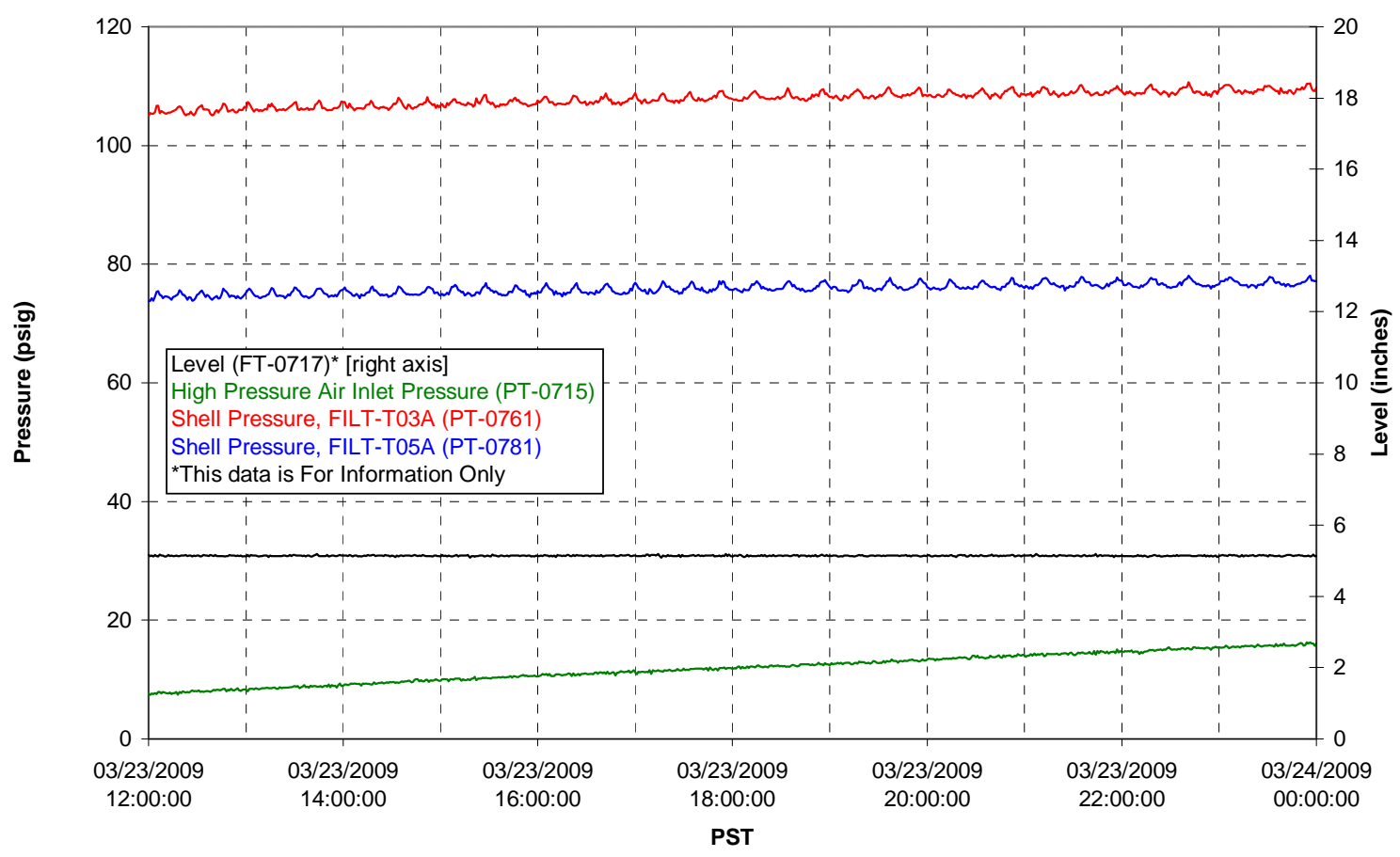

Pulsepot UFP-PP-T02A

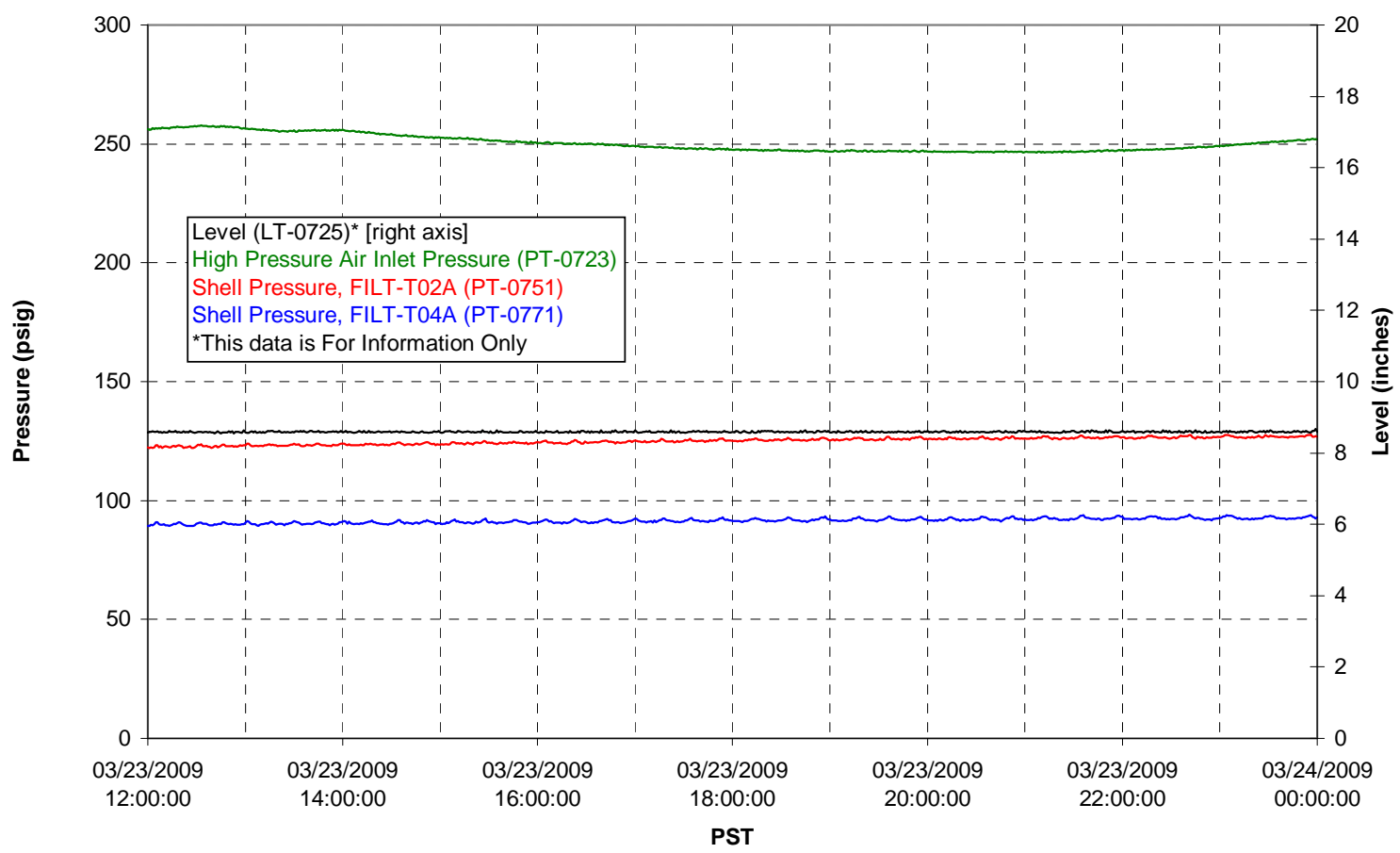


Pulsepot UFP-PP-T03A

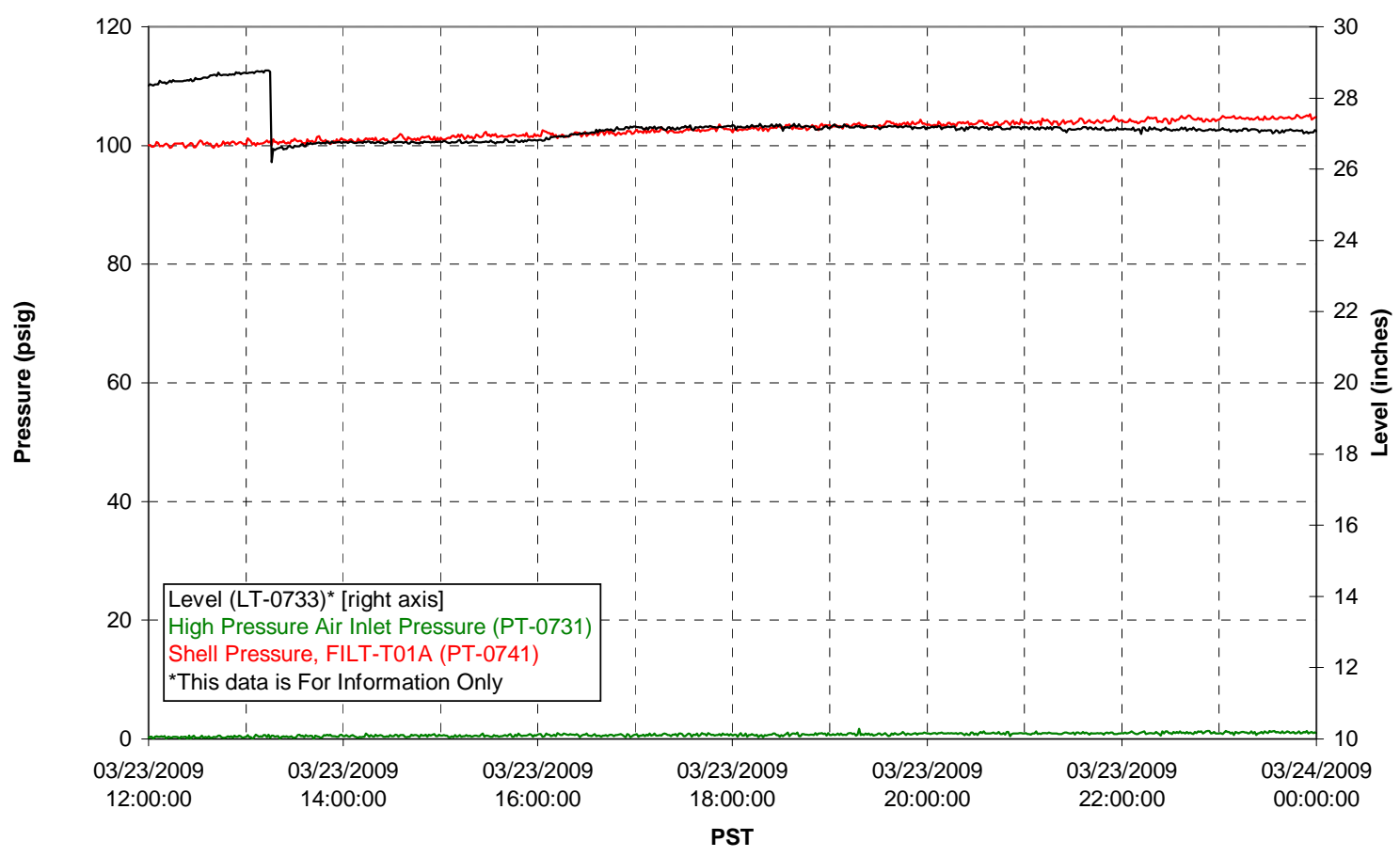

Pulsepot Levels

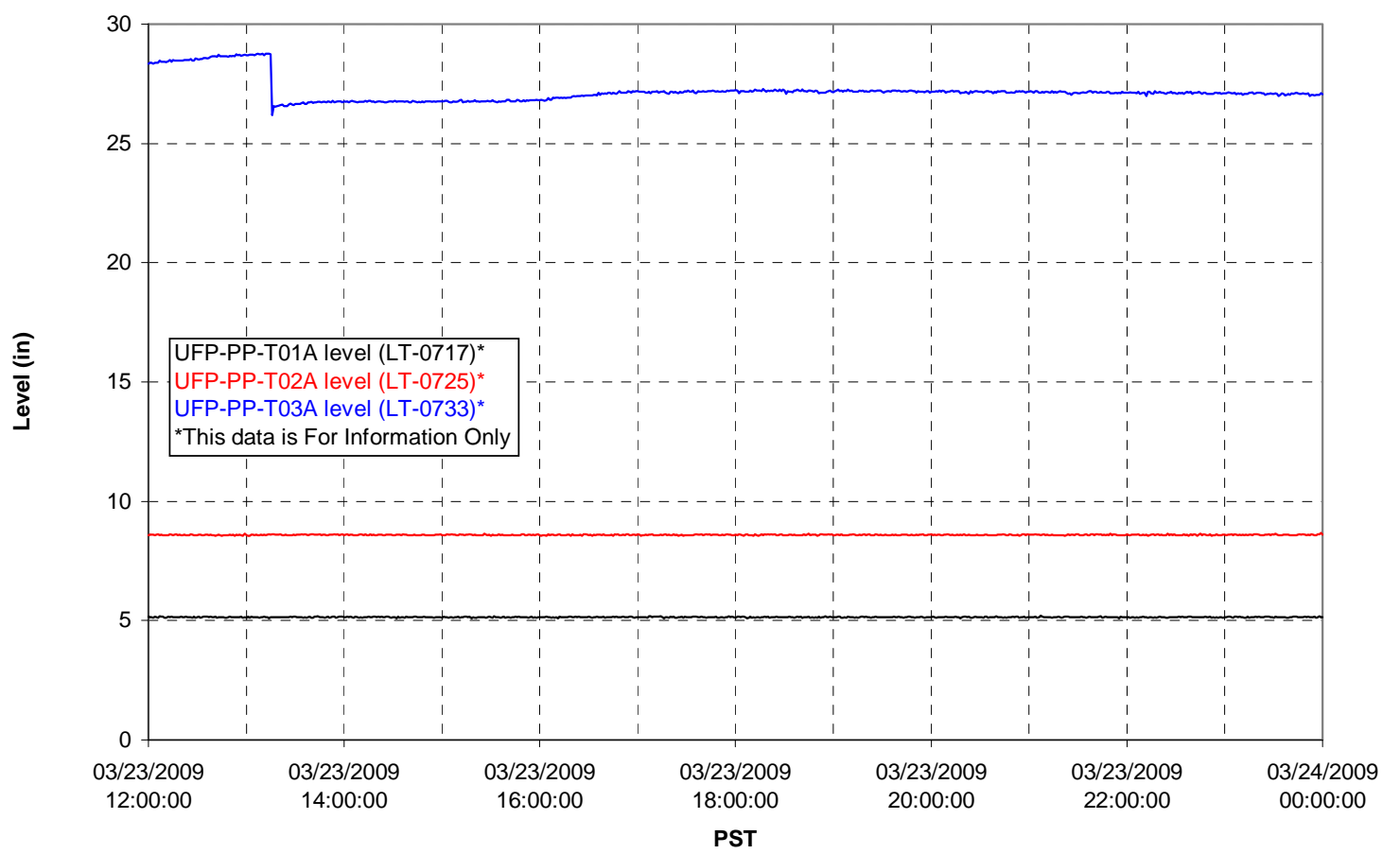


Filter UFP-FILT-T01A

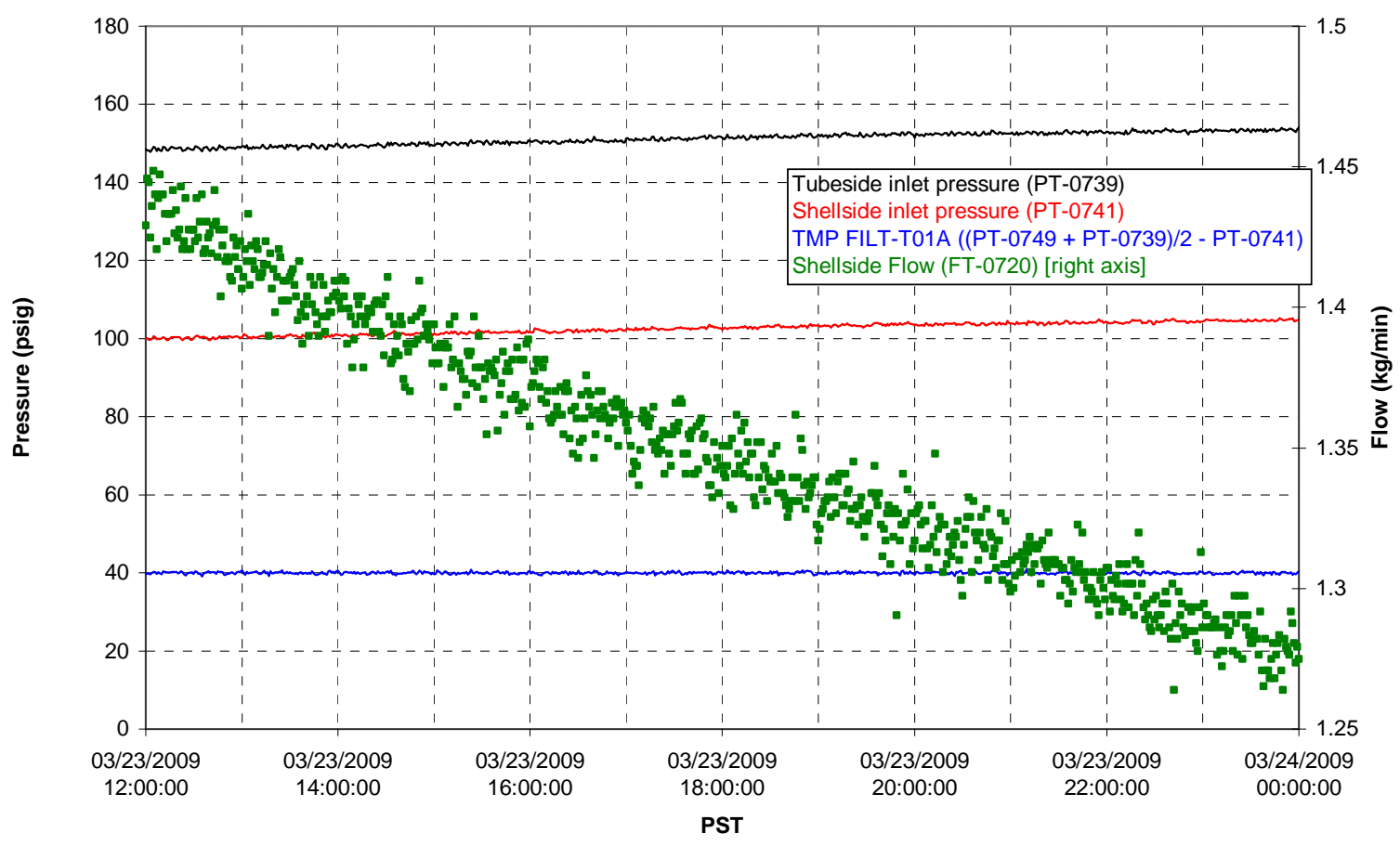

Filter UFP-FILT-T02A

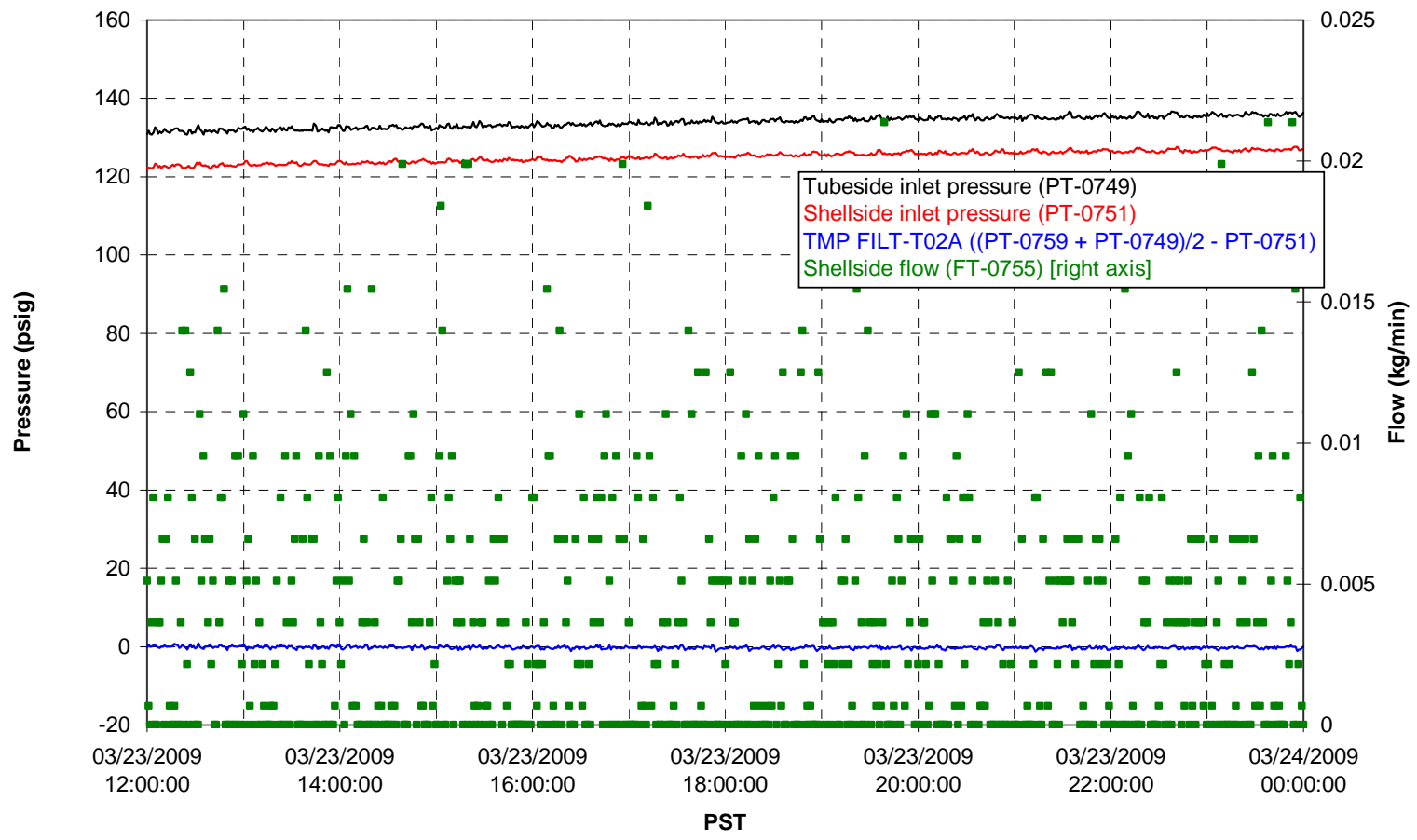


Filter UFP-FILT-T03A

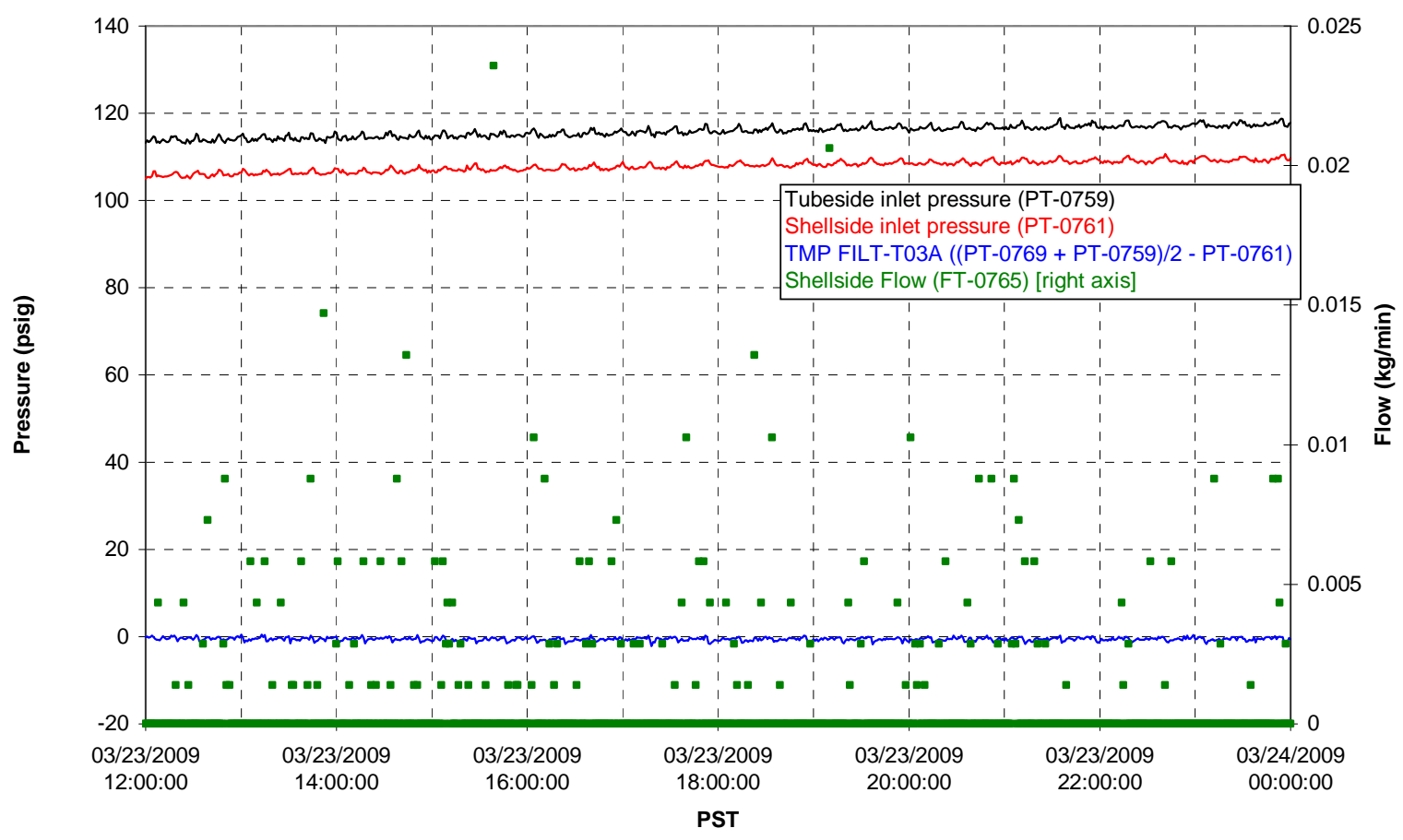

Filter UFP-FILT-T04A

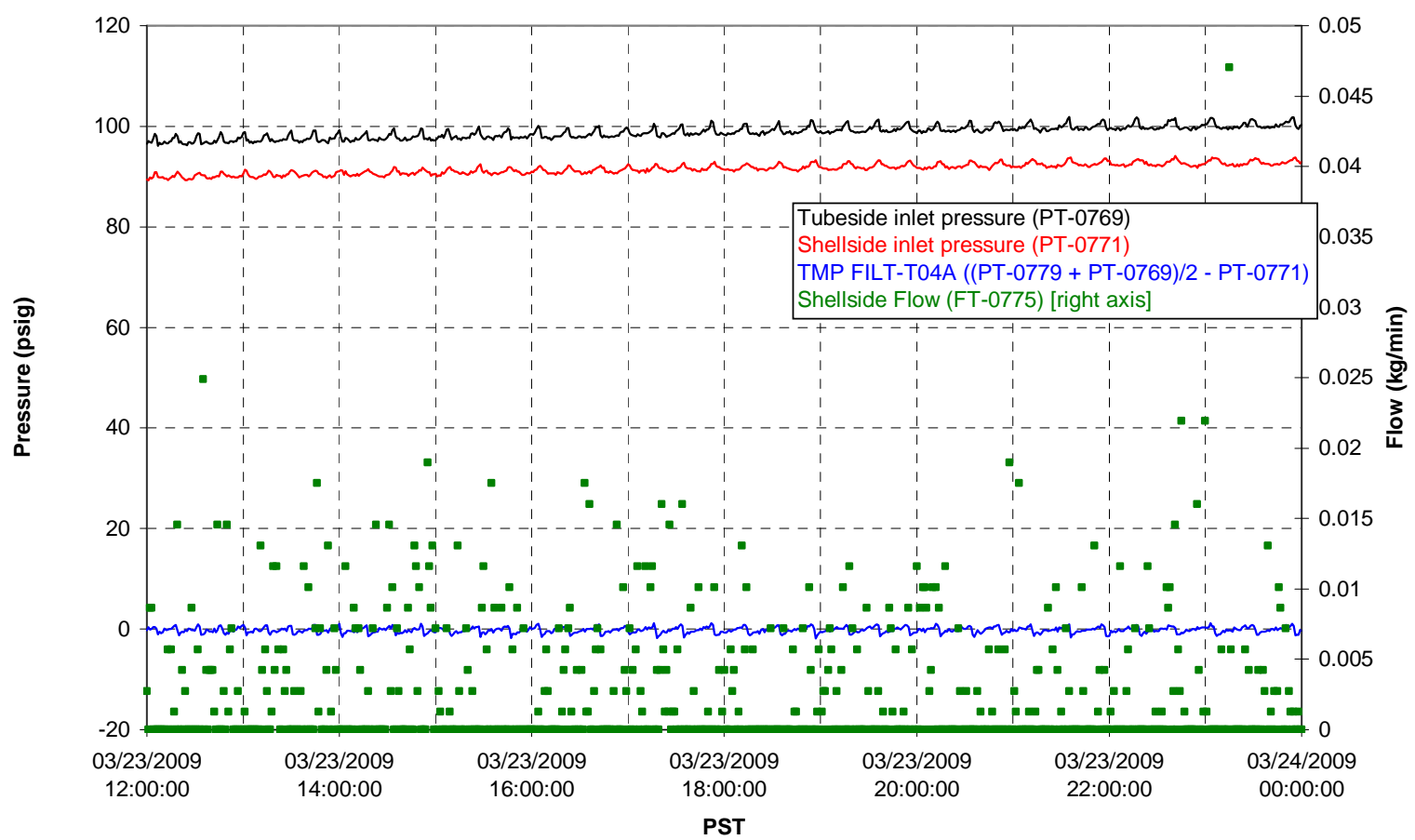


Filter UFP-FILT-T05A

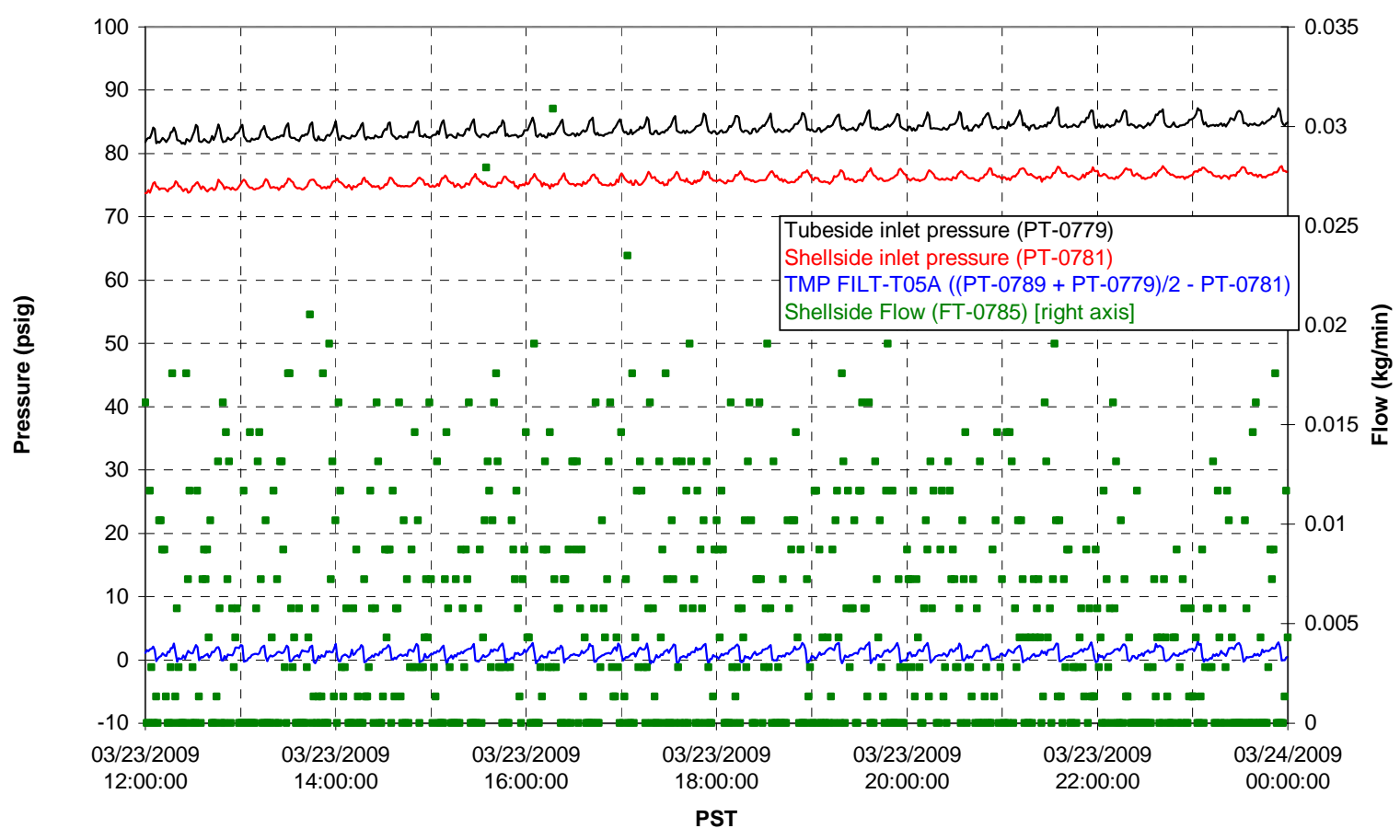

Chemical Flow

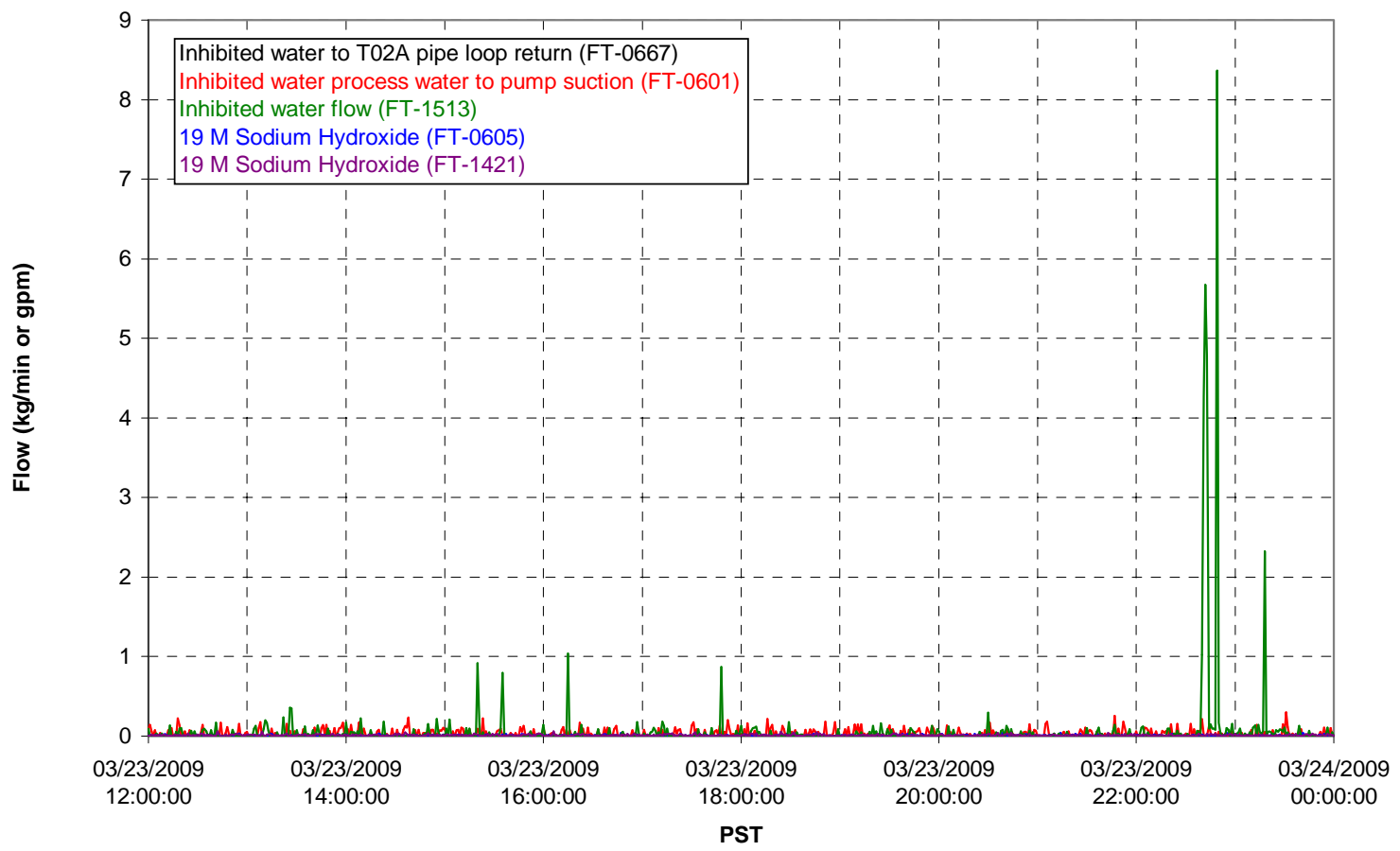




\section{Chemical Flow}

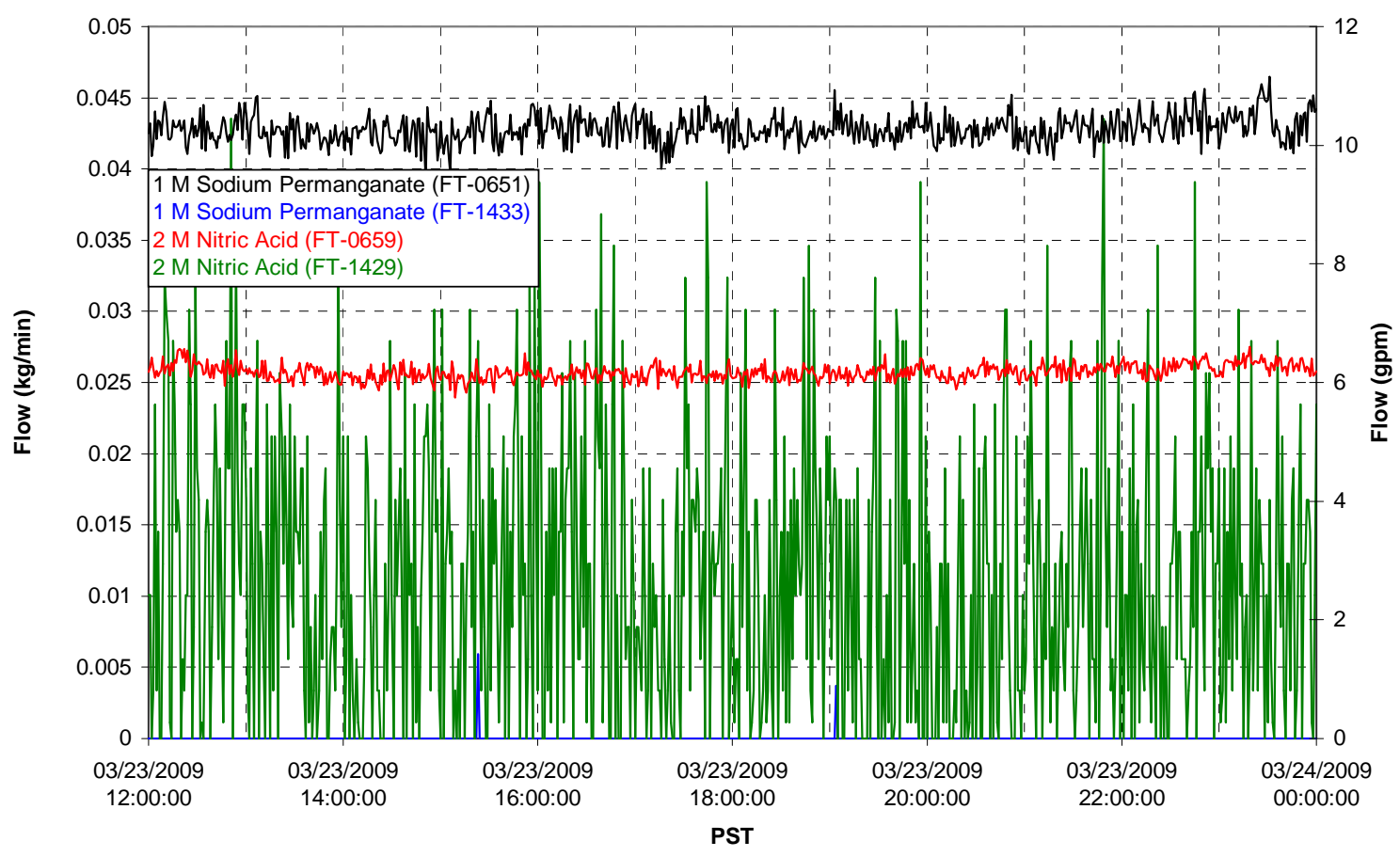

Air Flows

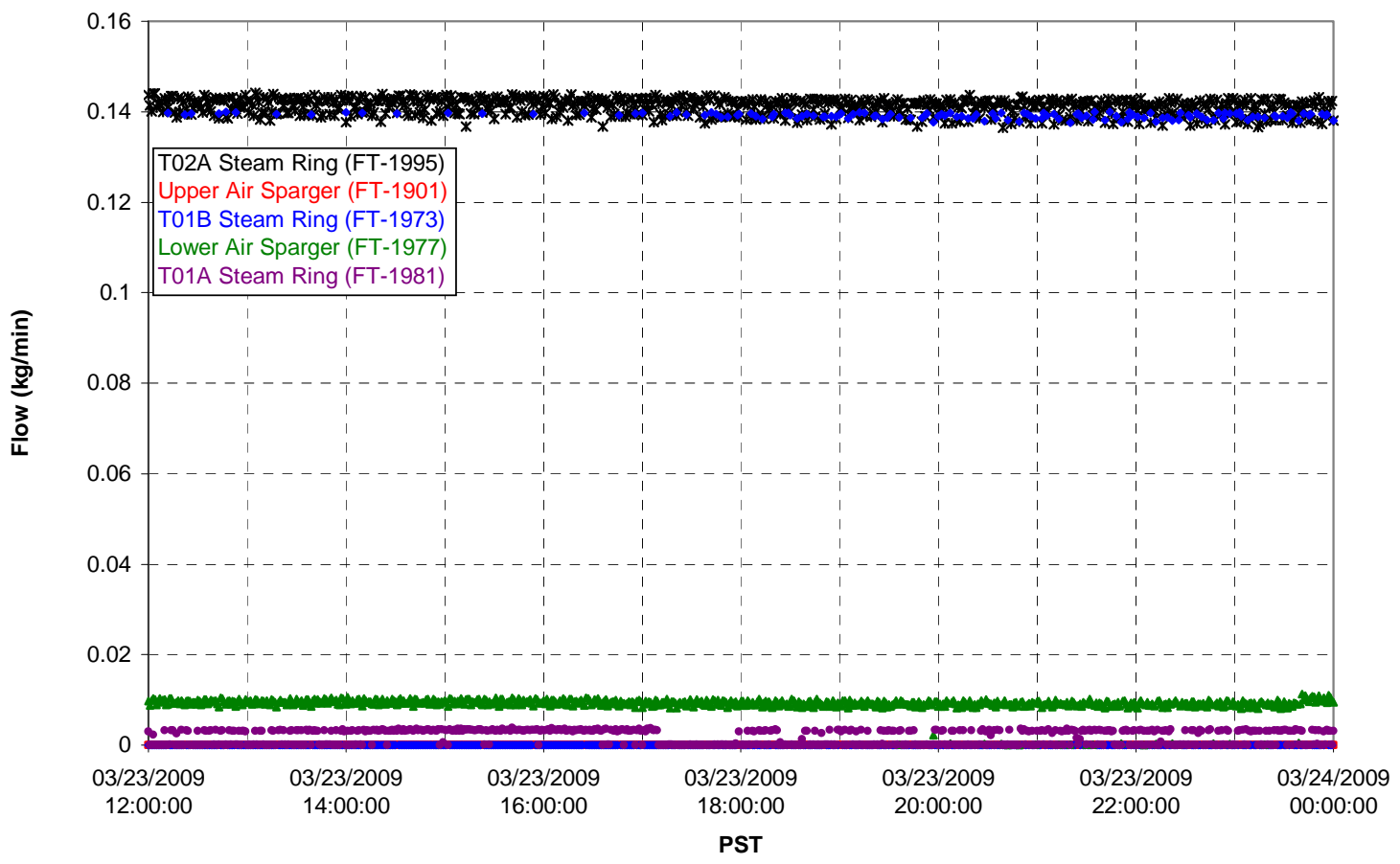


T02A Steam

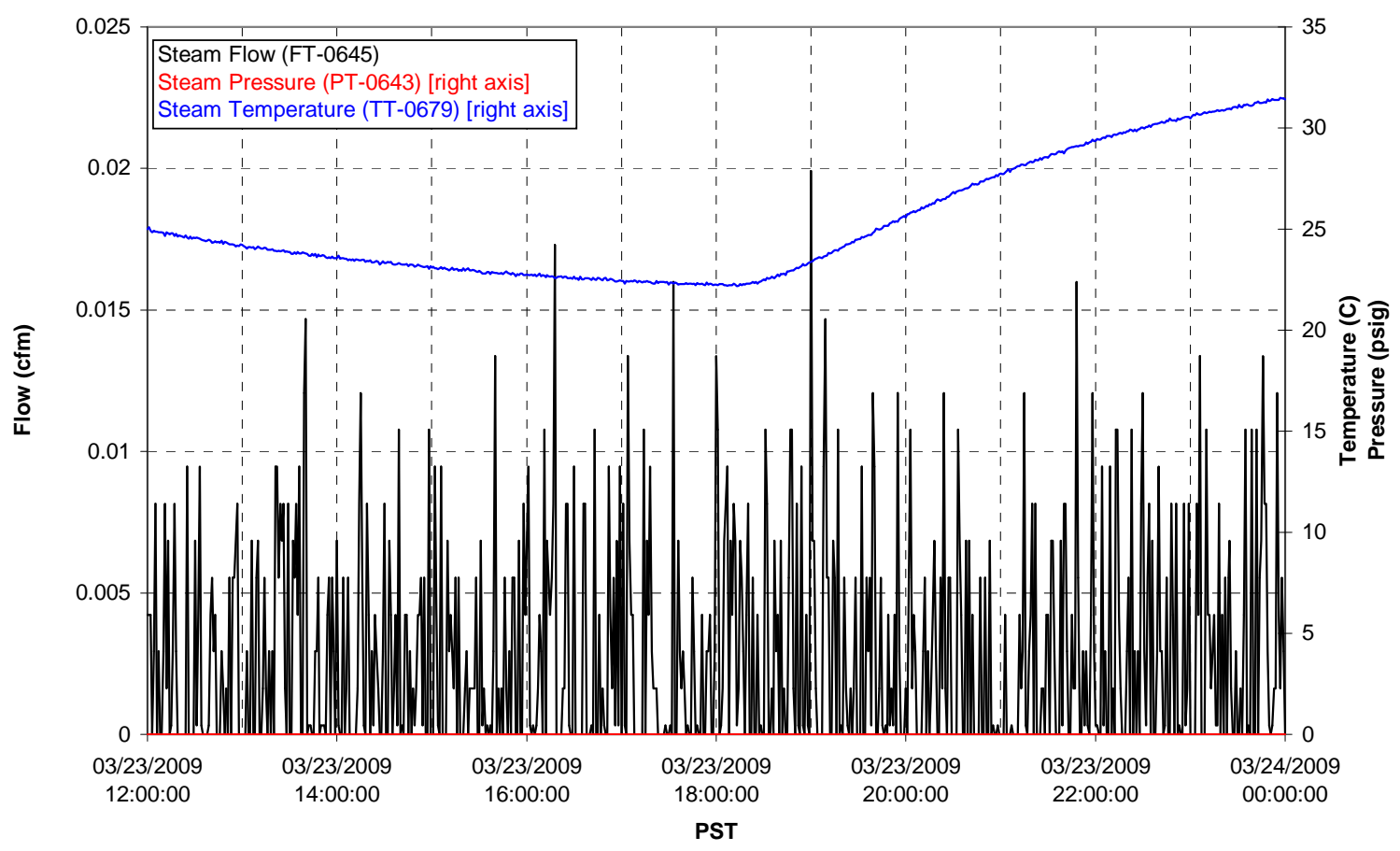

T01A Steam

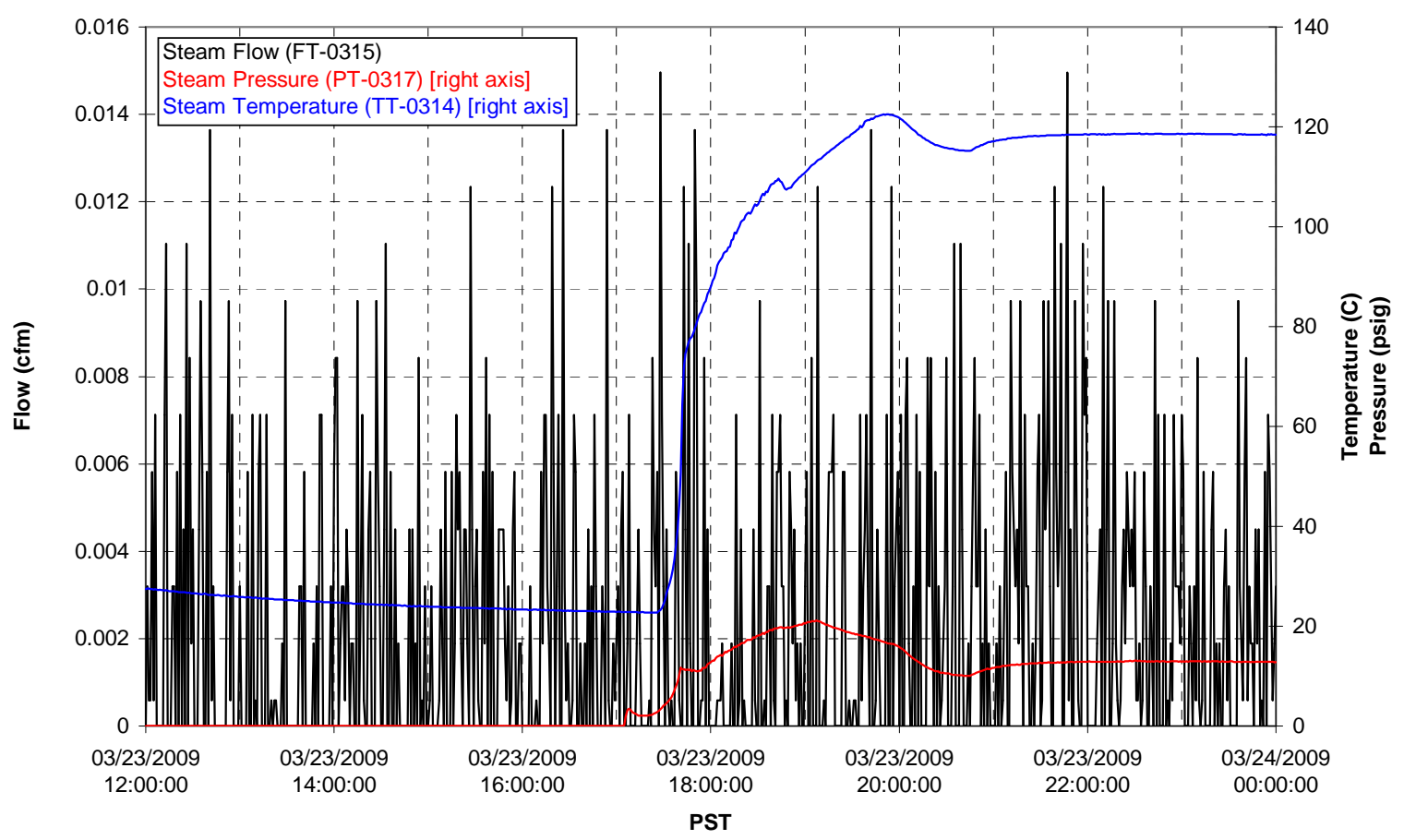


T01B Steam

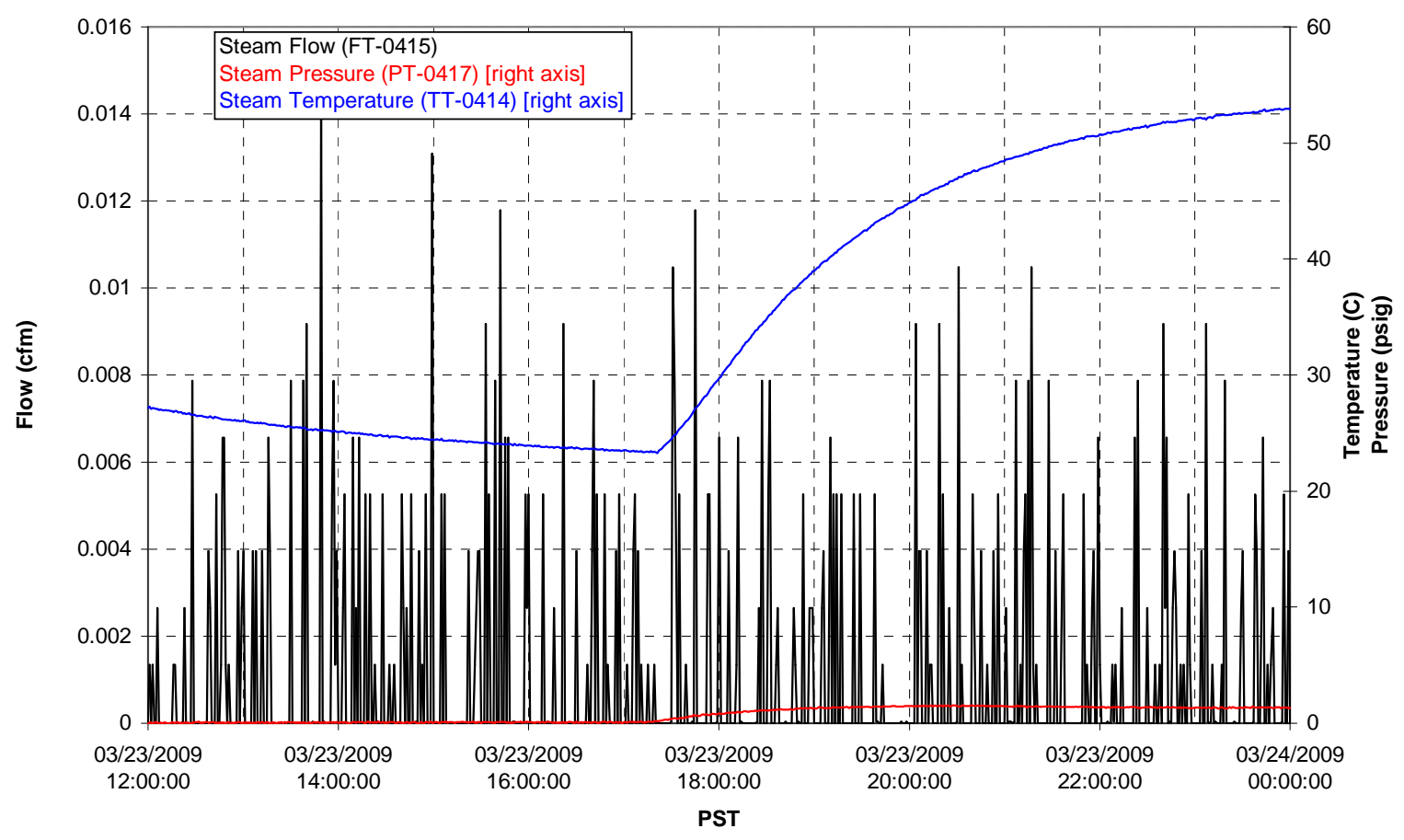




\section{Integrated Test D Data Plots 03/24/09 00:00 - 03/24/09 12:00}


T01A level

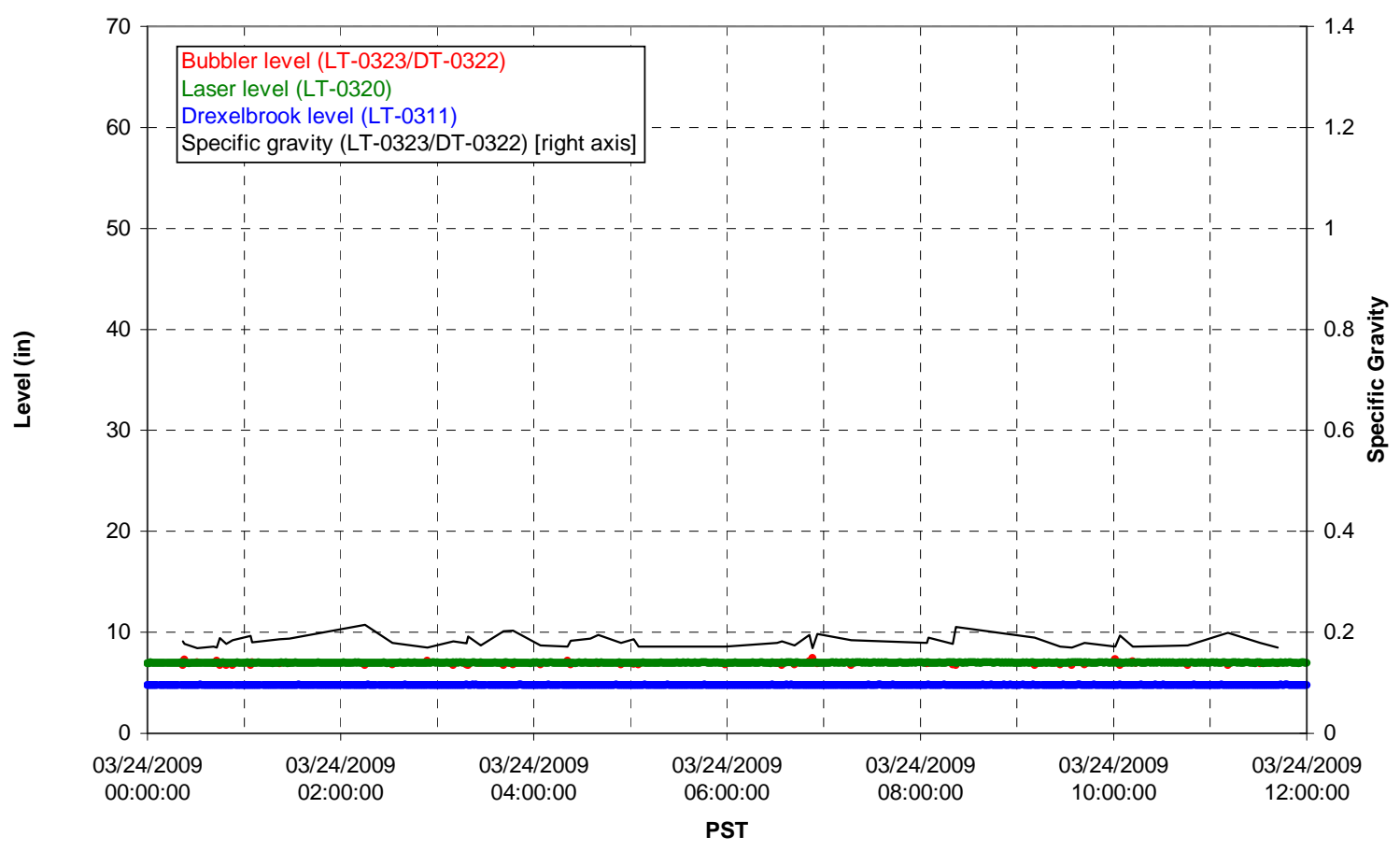

T01A temperatures

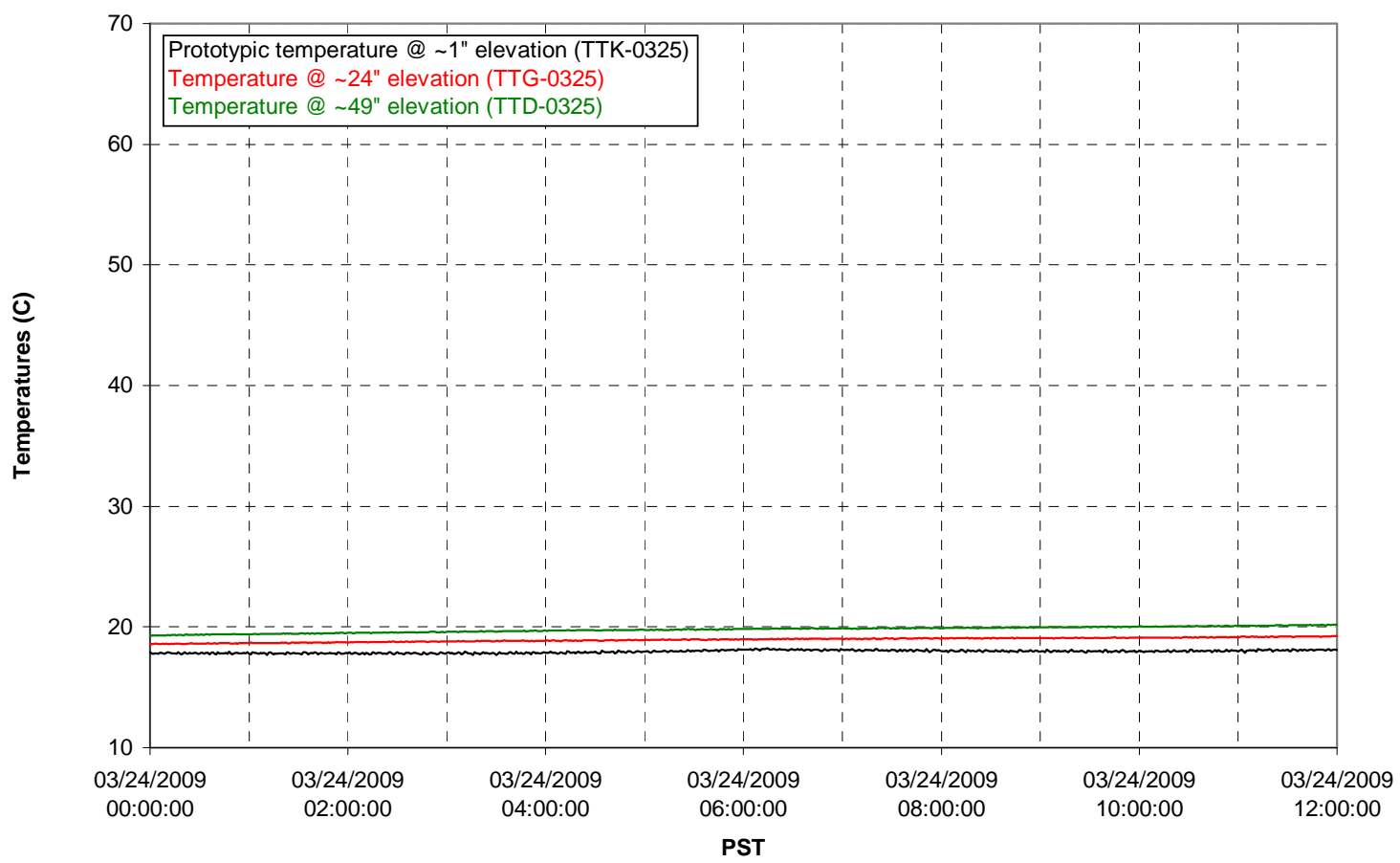


T01B level

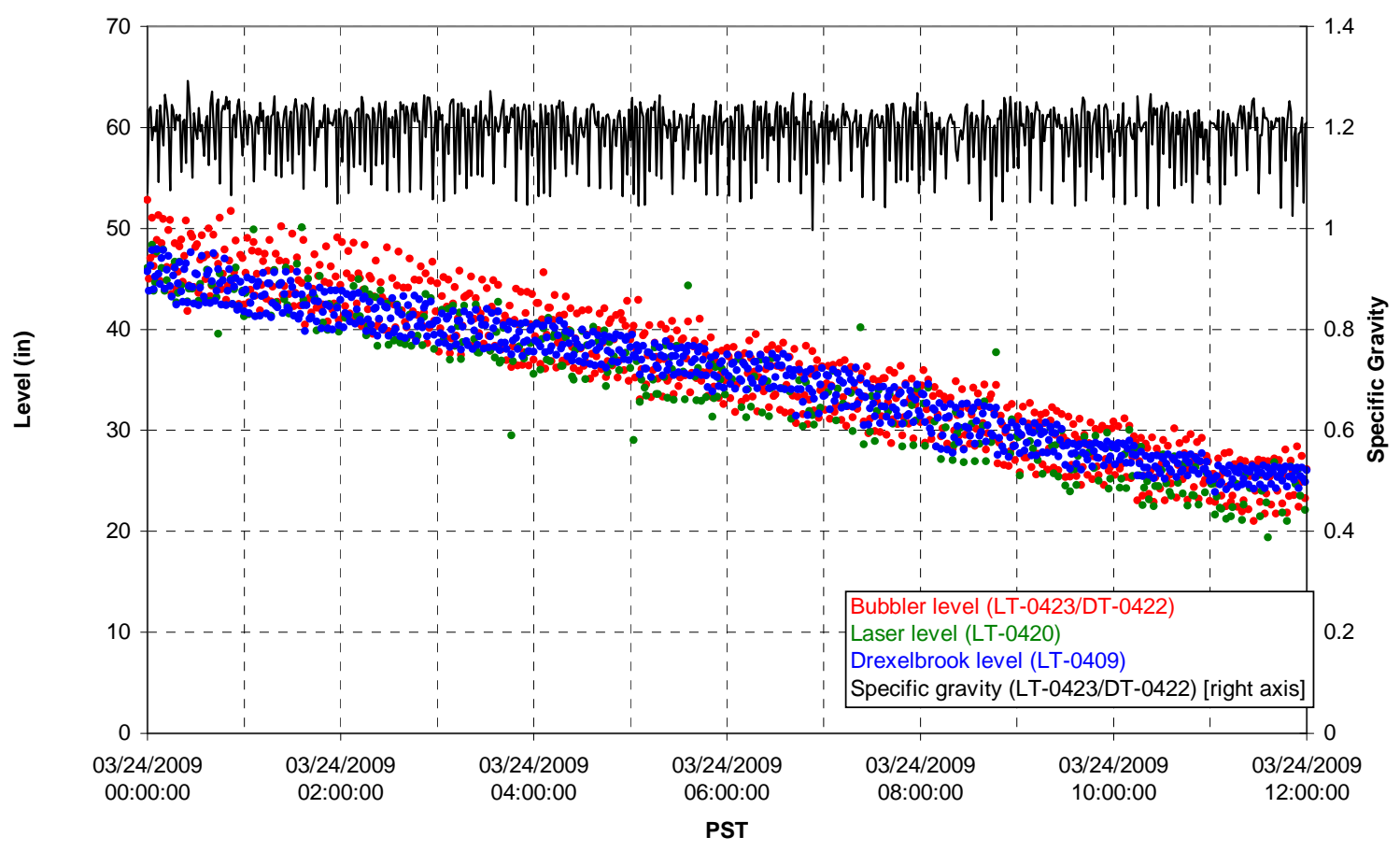

T01B temperatures

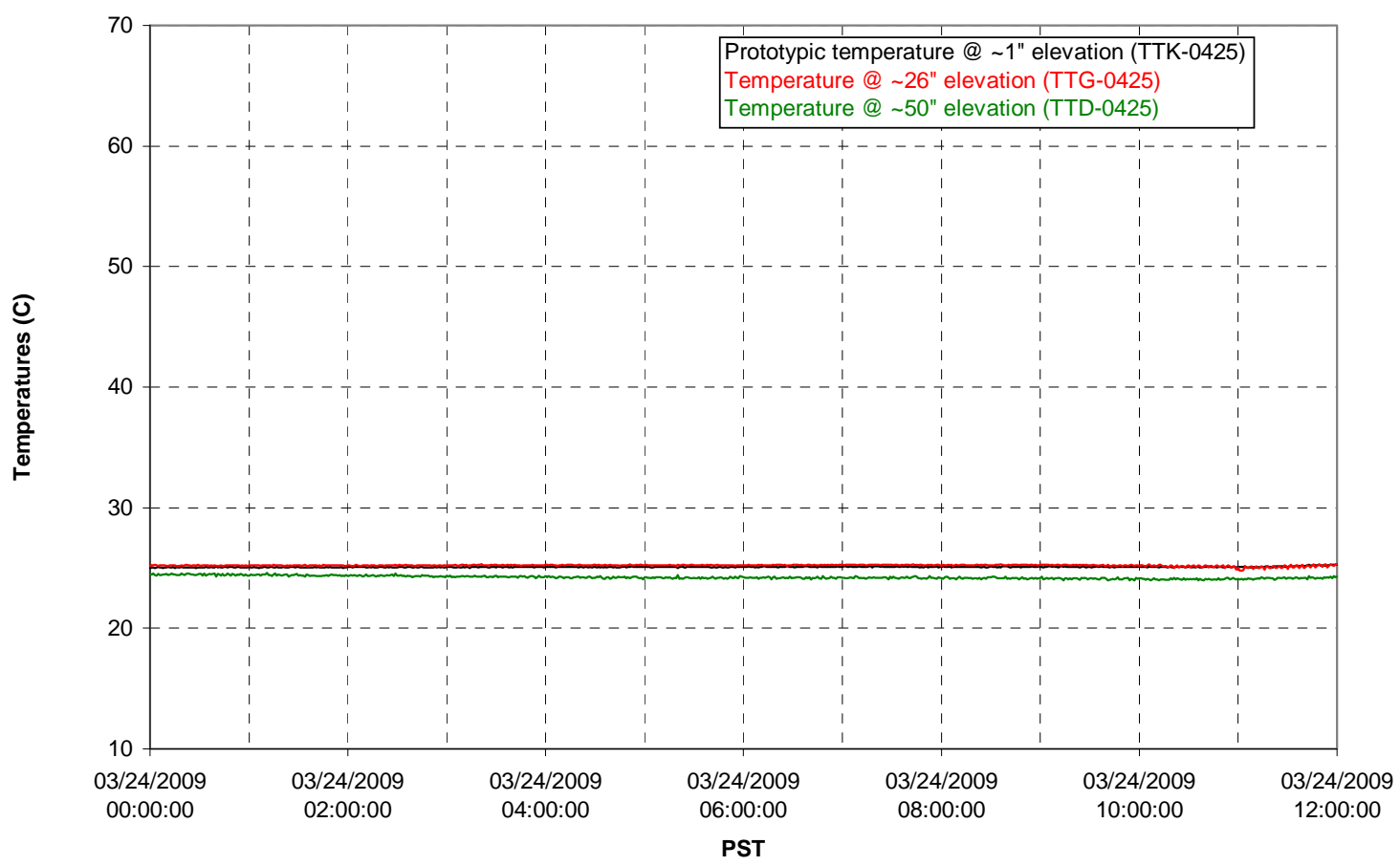


T02A level

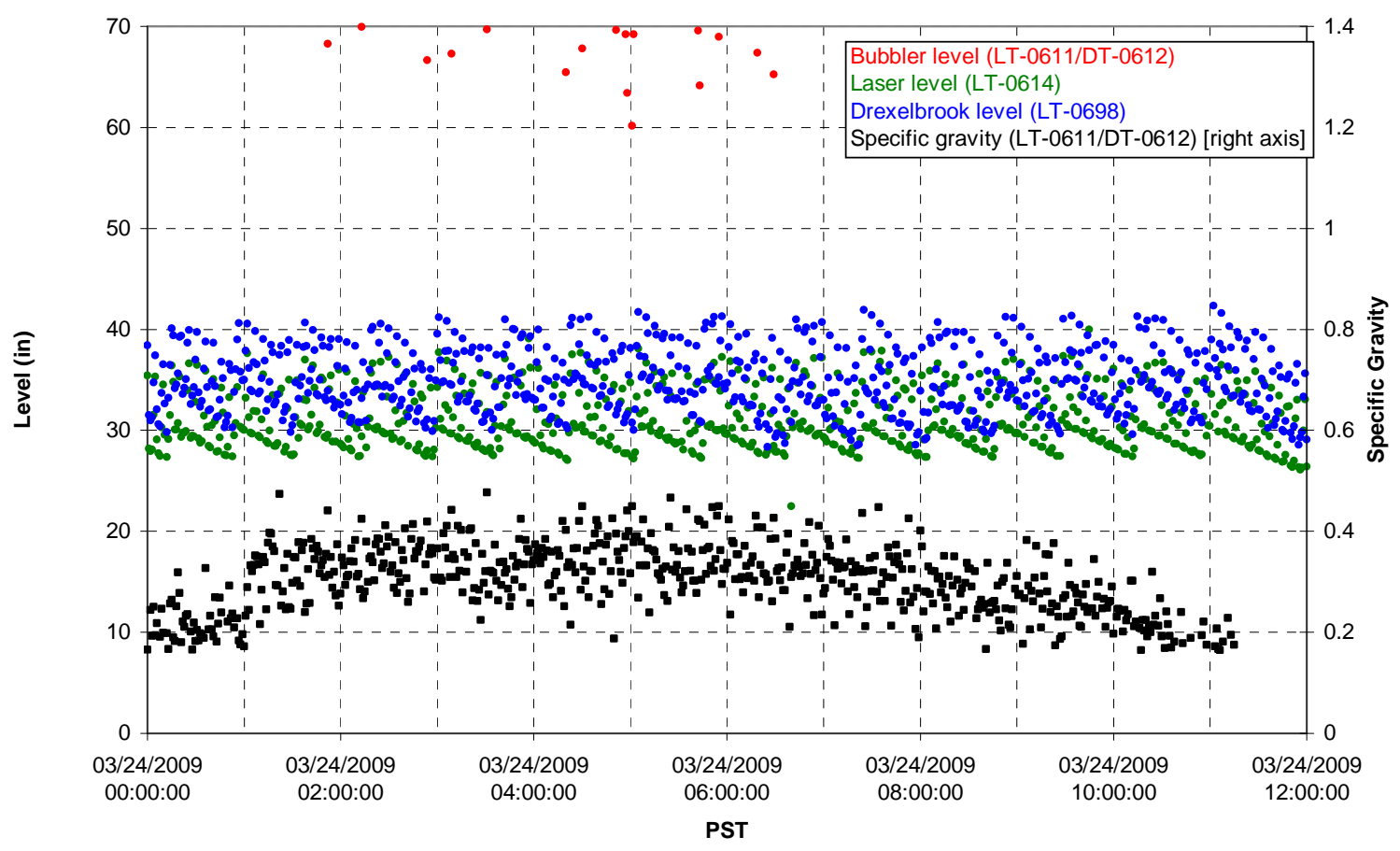

T02A temperatures

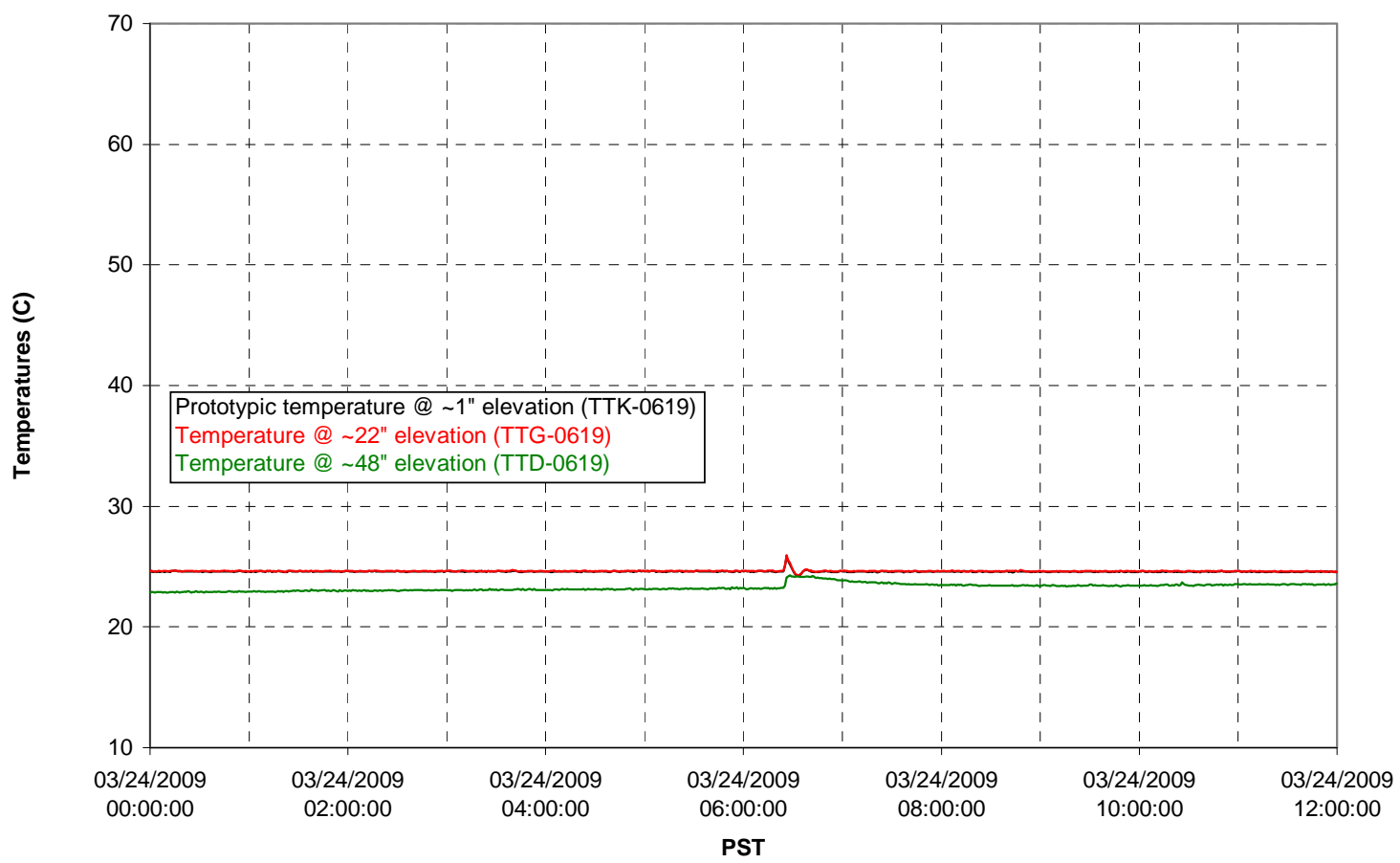


T02A and filter loop temperatures

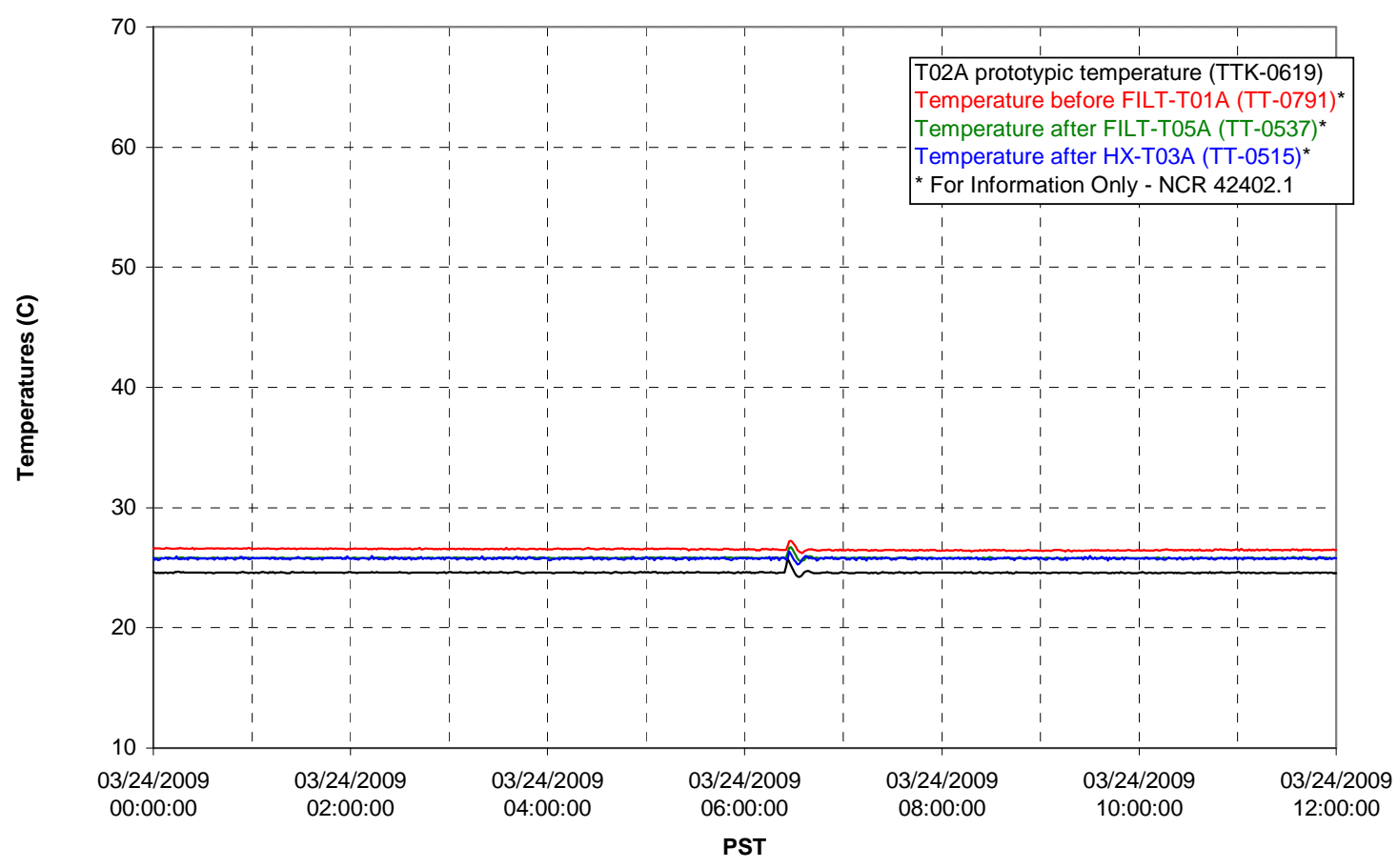

Pump Pressures and Flow

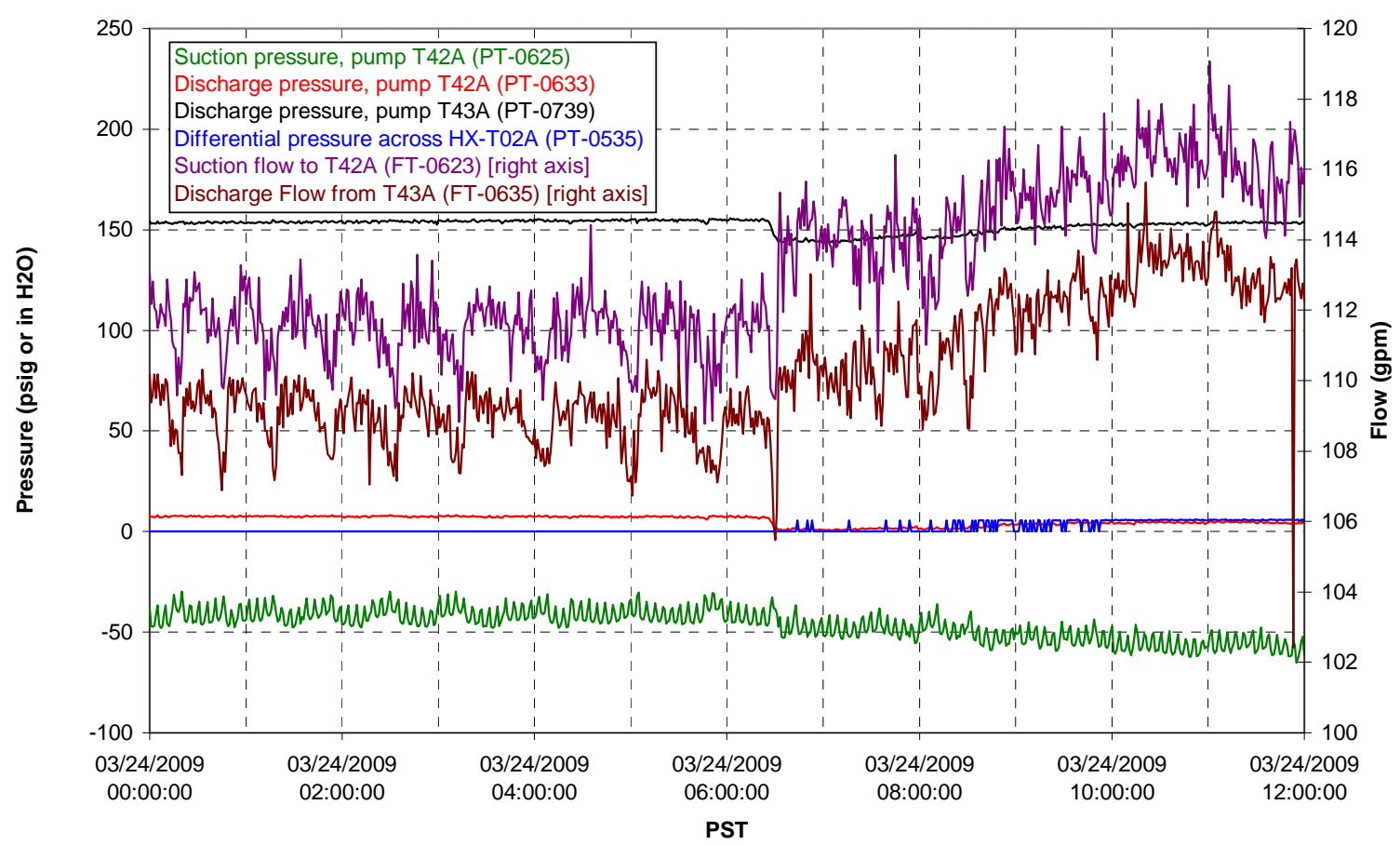


Axial pressure drop

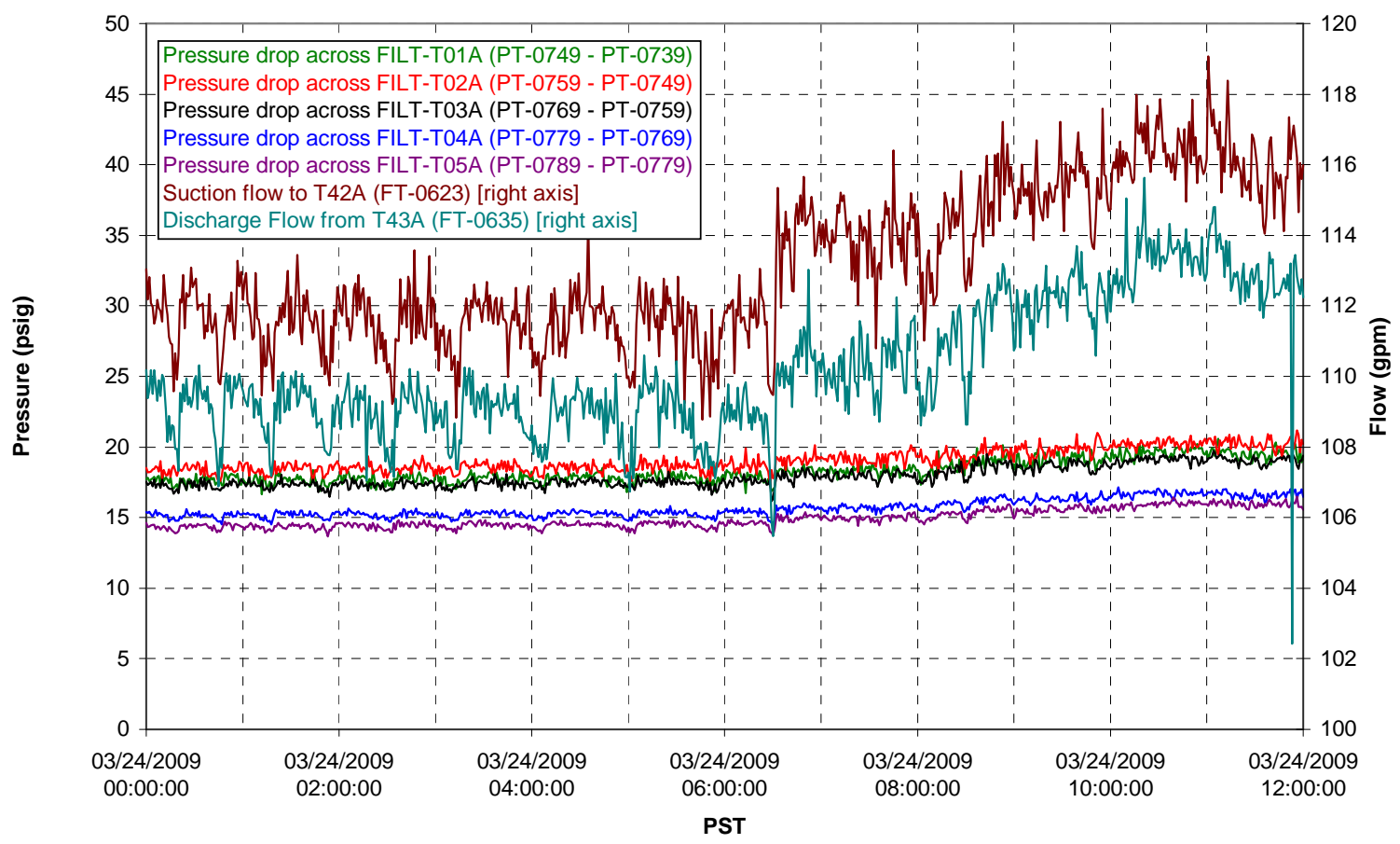

Permeate flow rates

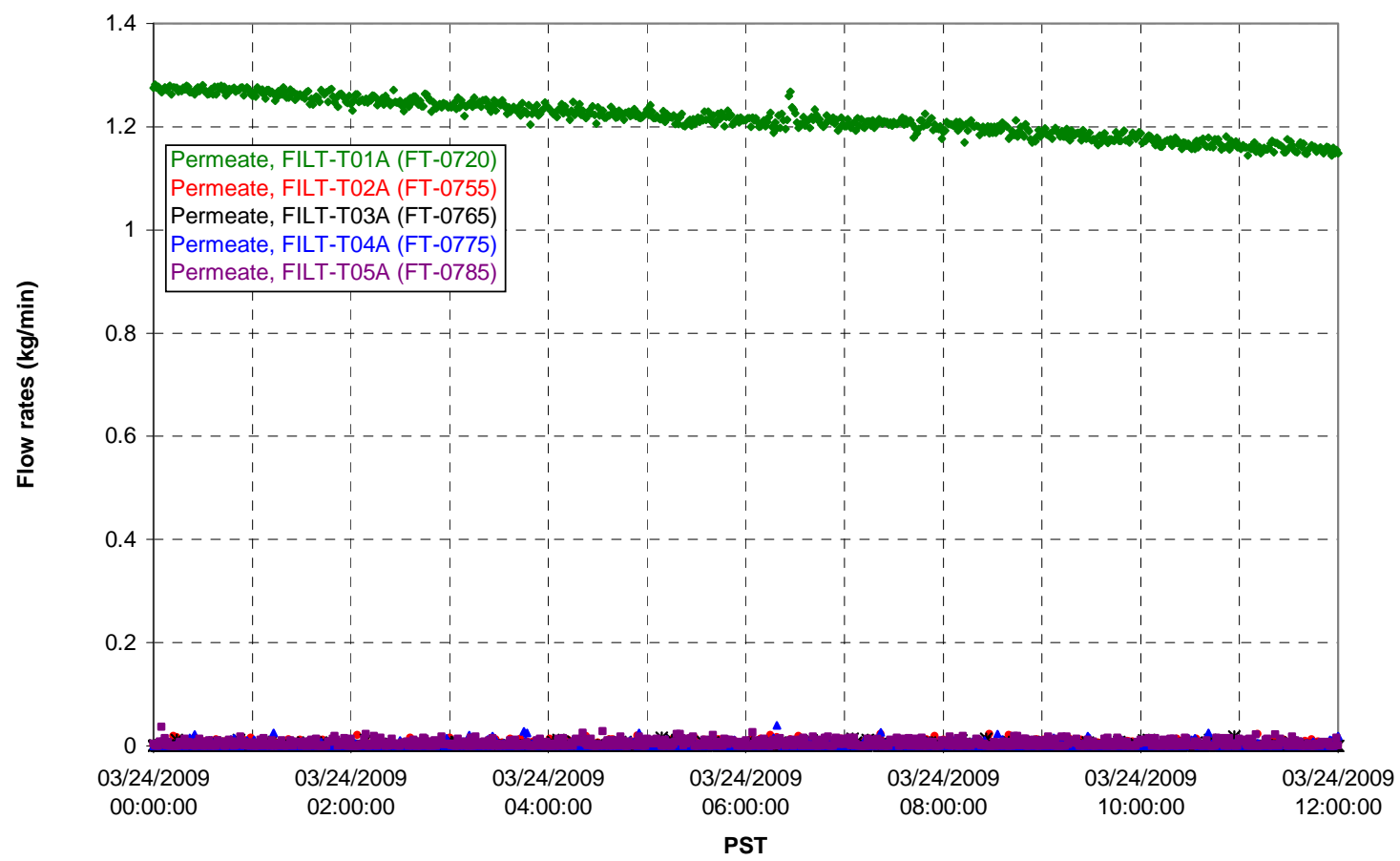


T02A Inner Temperature Tree

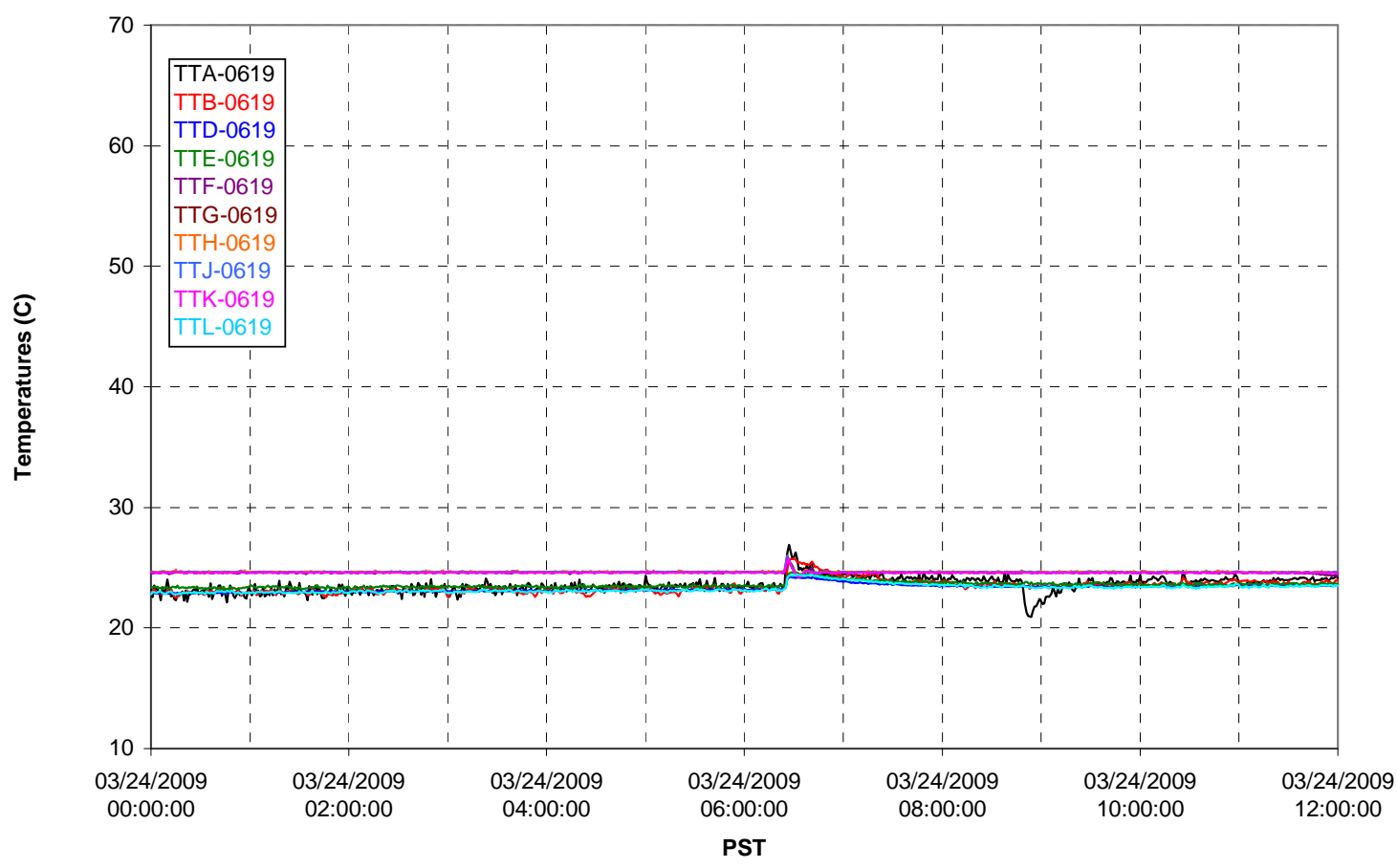

T02A Outer Temperature Tree

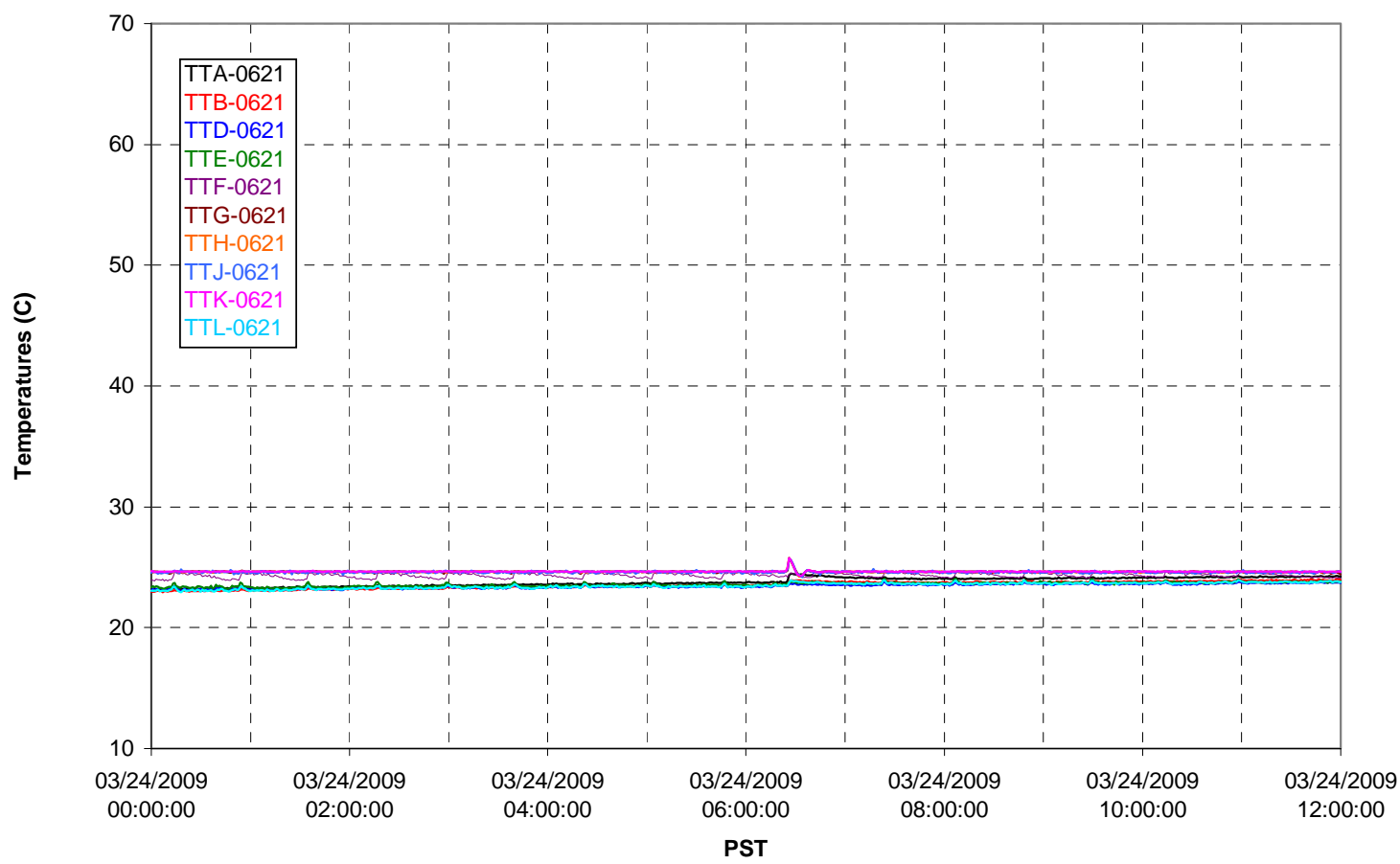


T02A temperatures

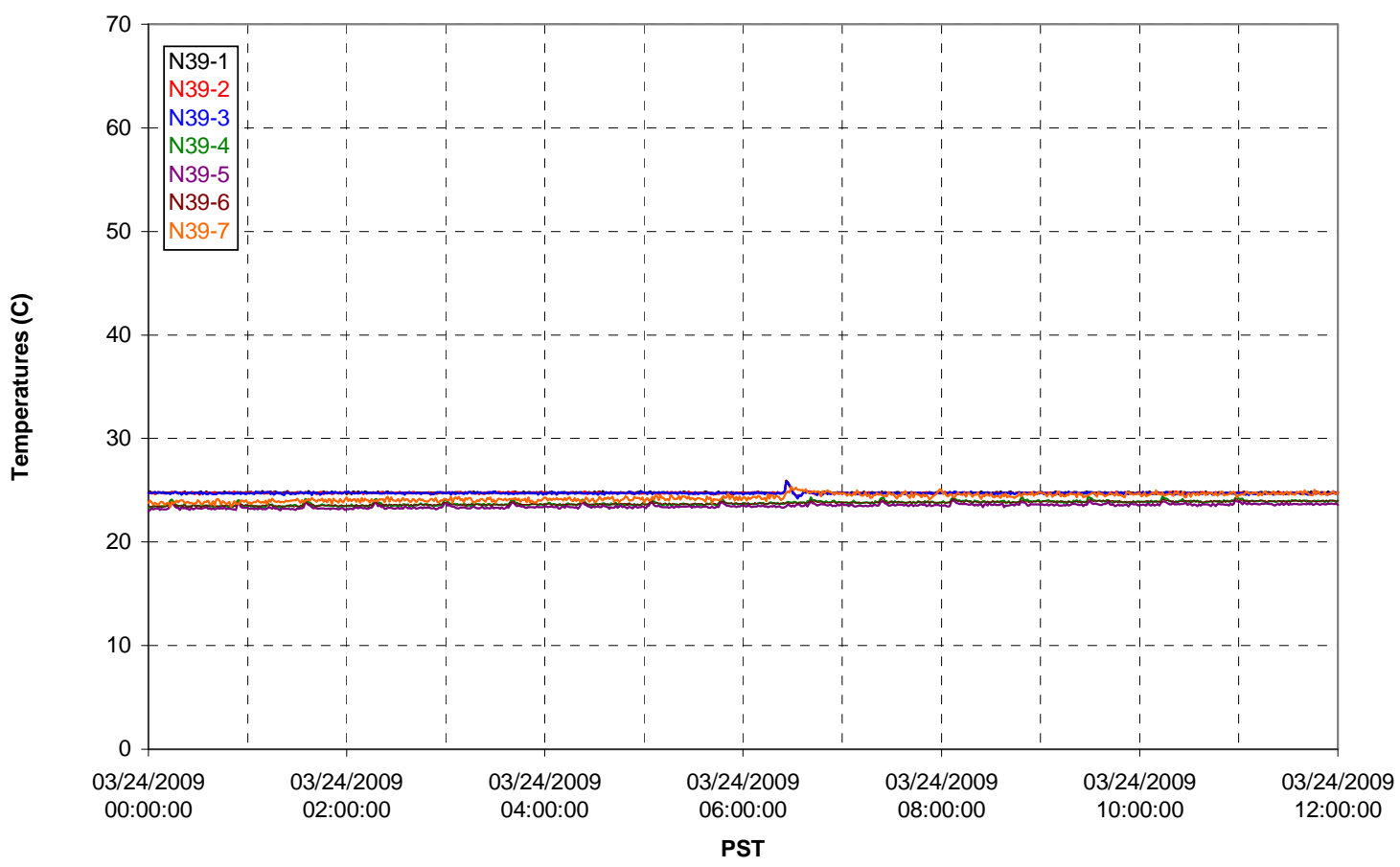

T02A temperatures

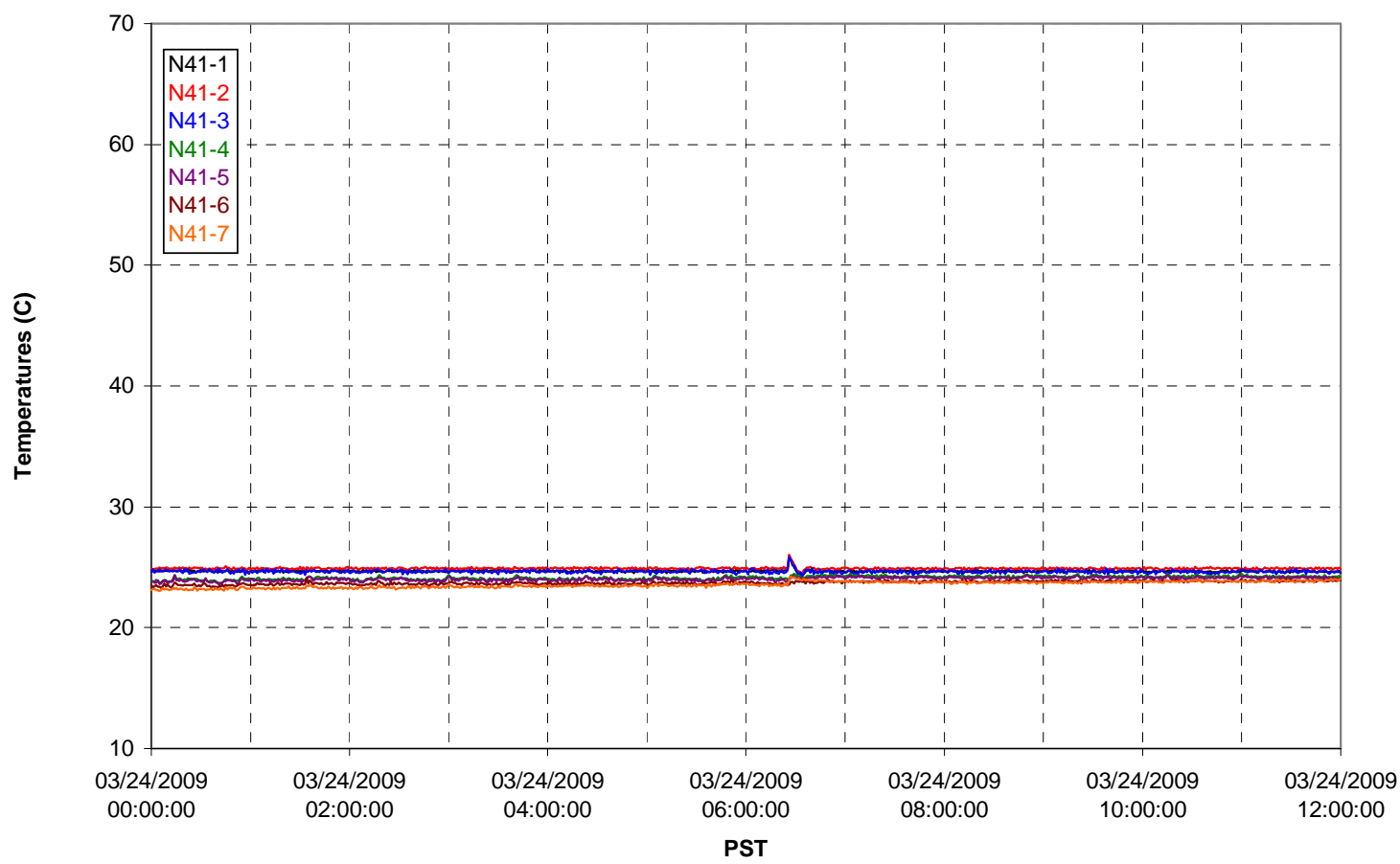


T02A temperatures

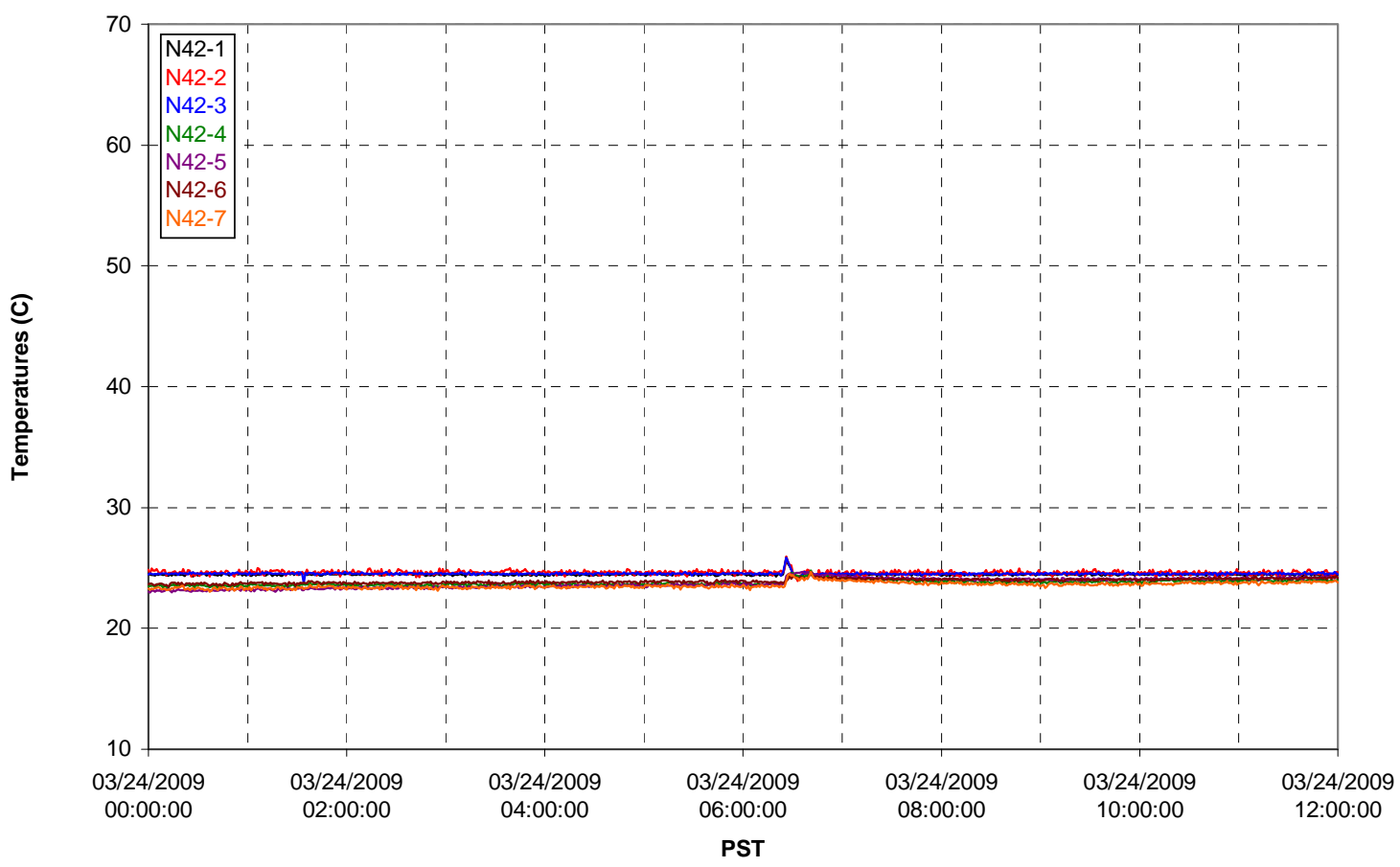

T02A temperatures

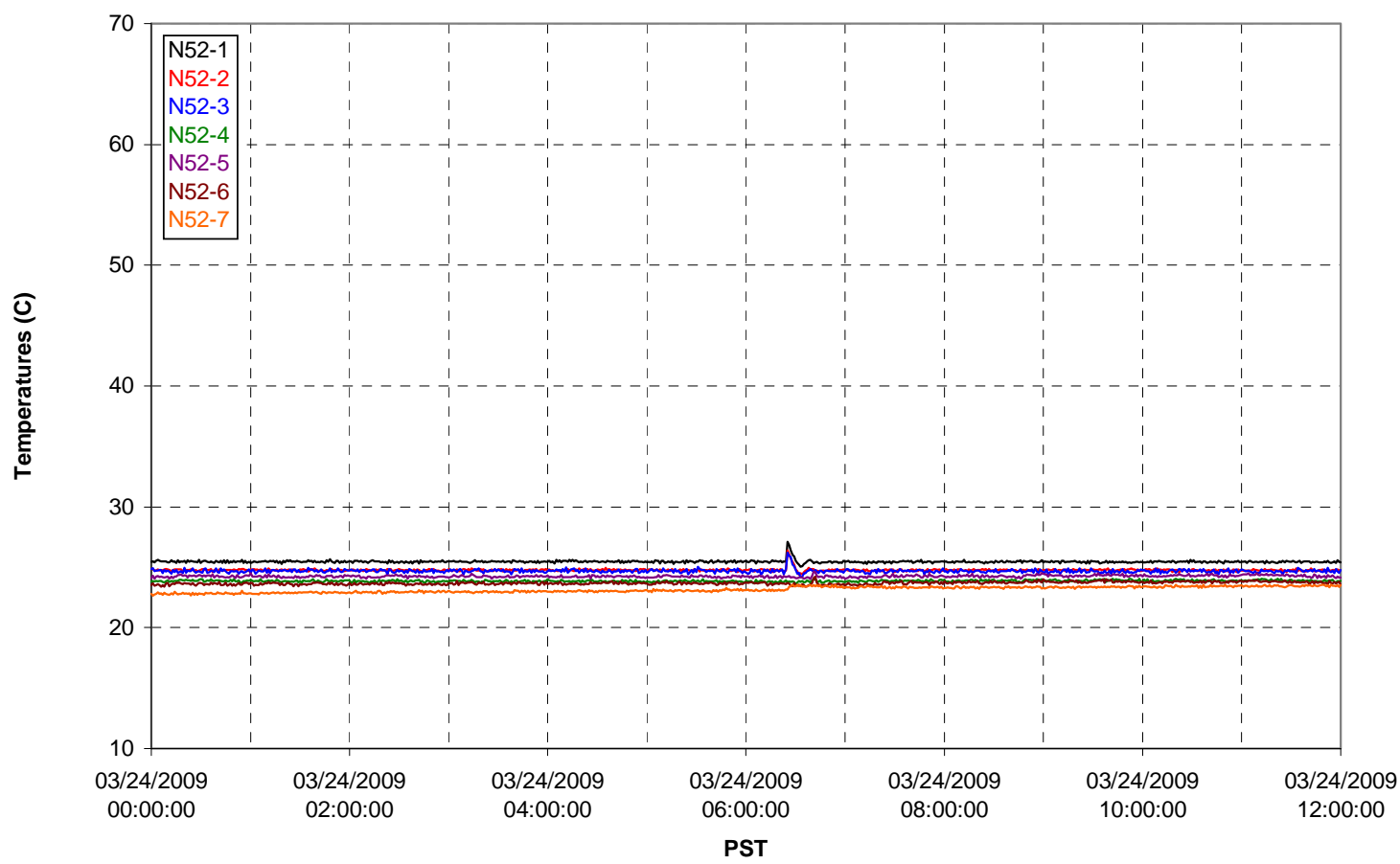


T02A Heating and Cooling

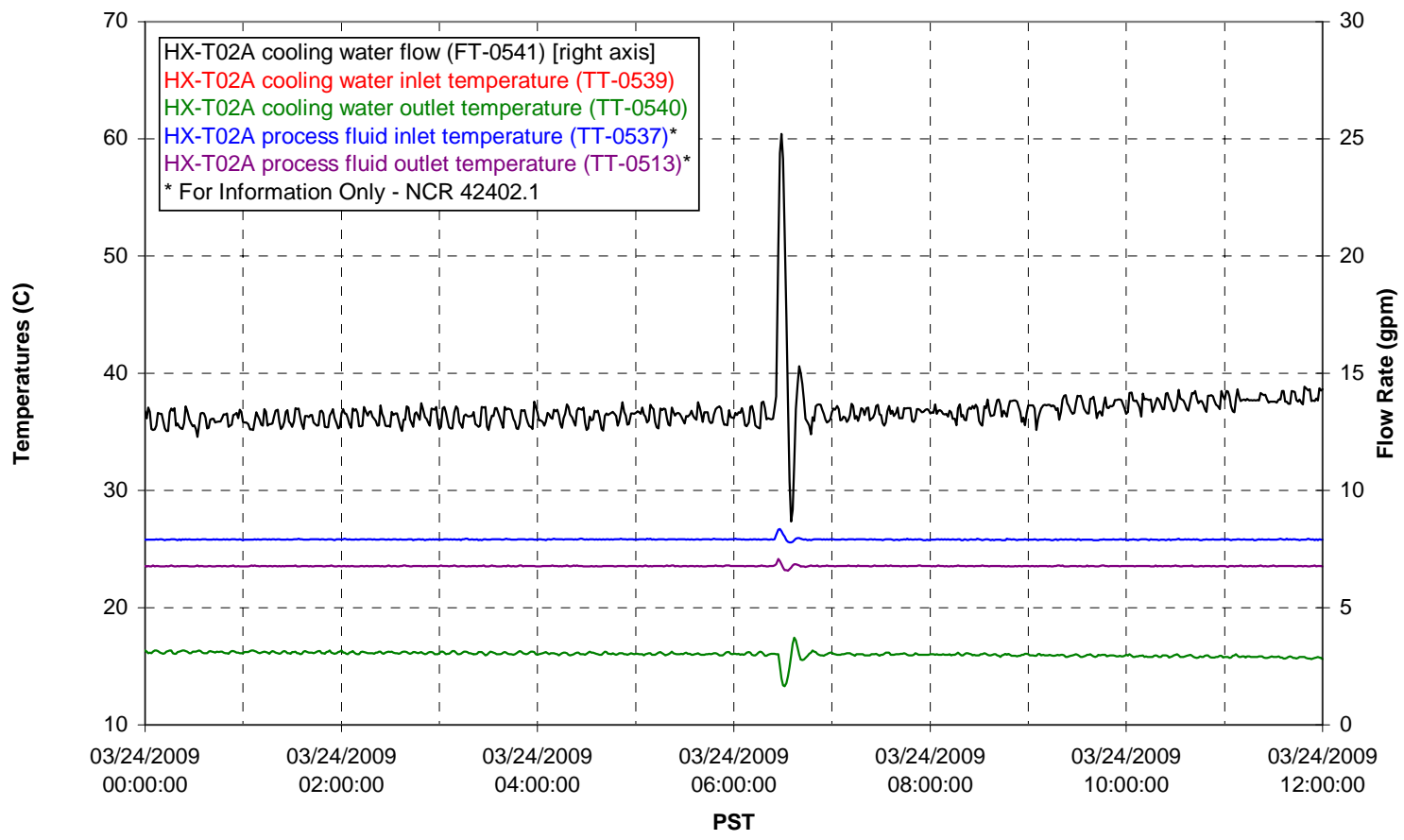

Pump Operation

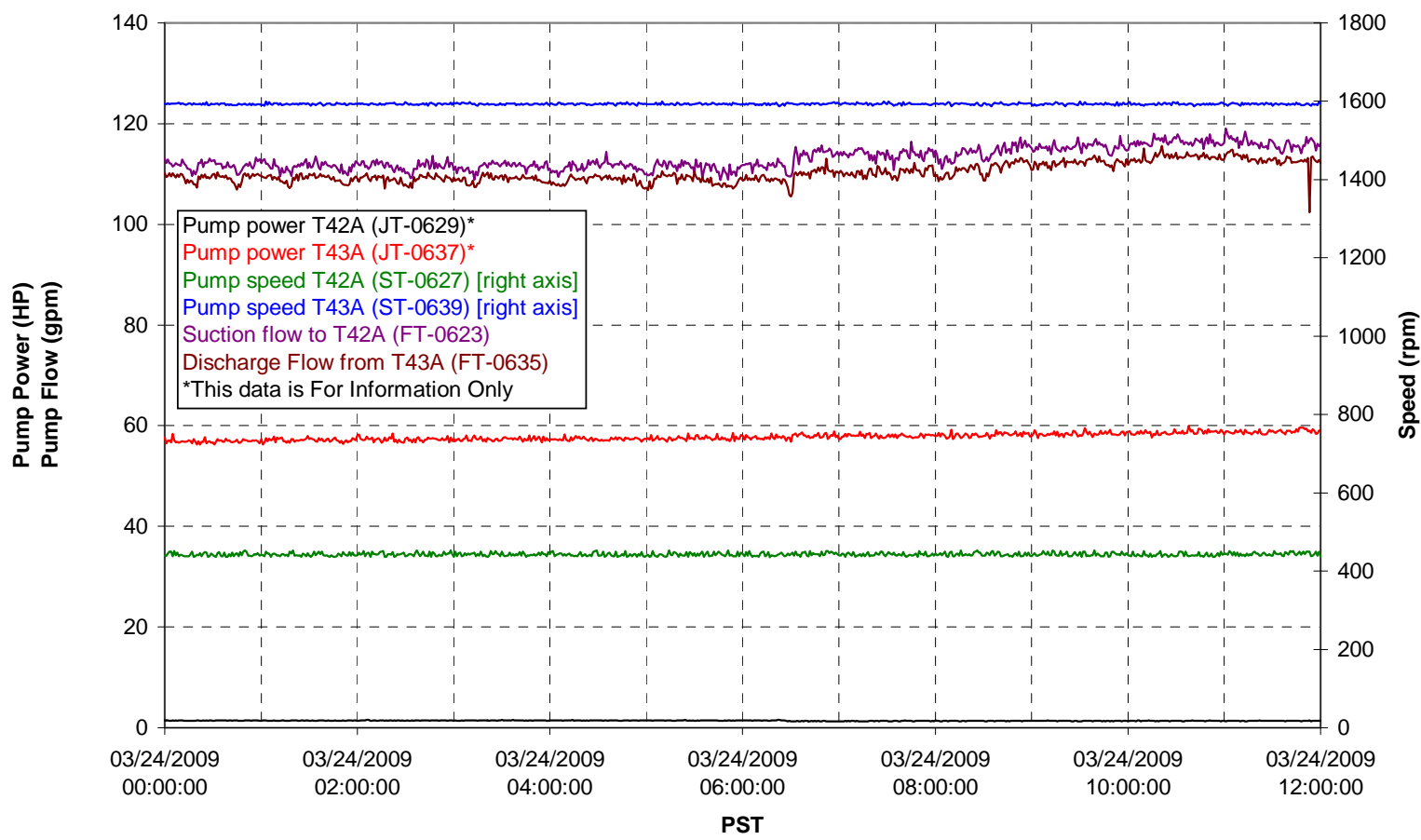


Pulsepot UFP-PP-T01A

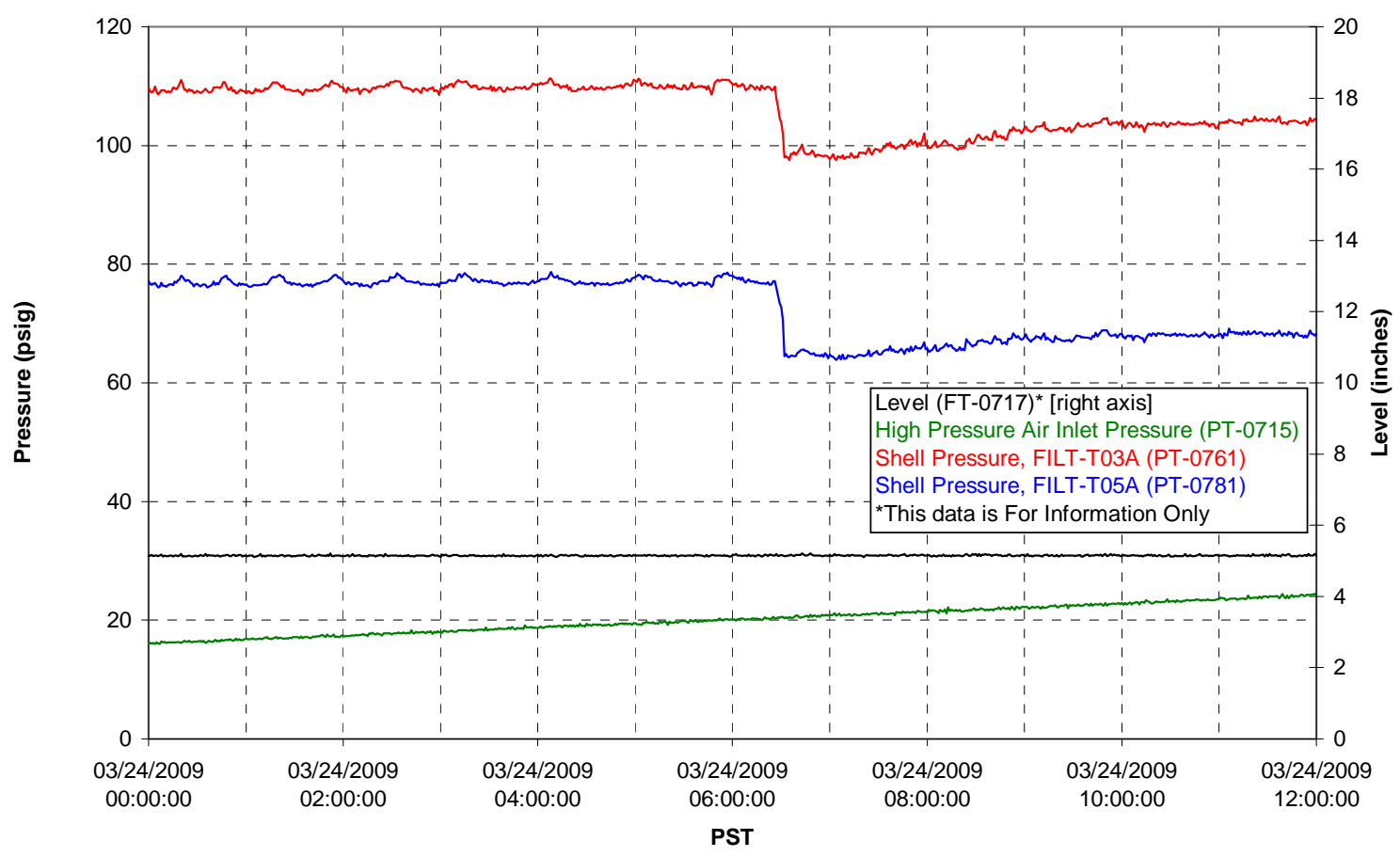

Pulsepot UFP-PP-T02A

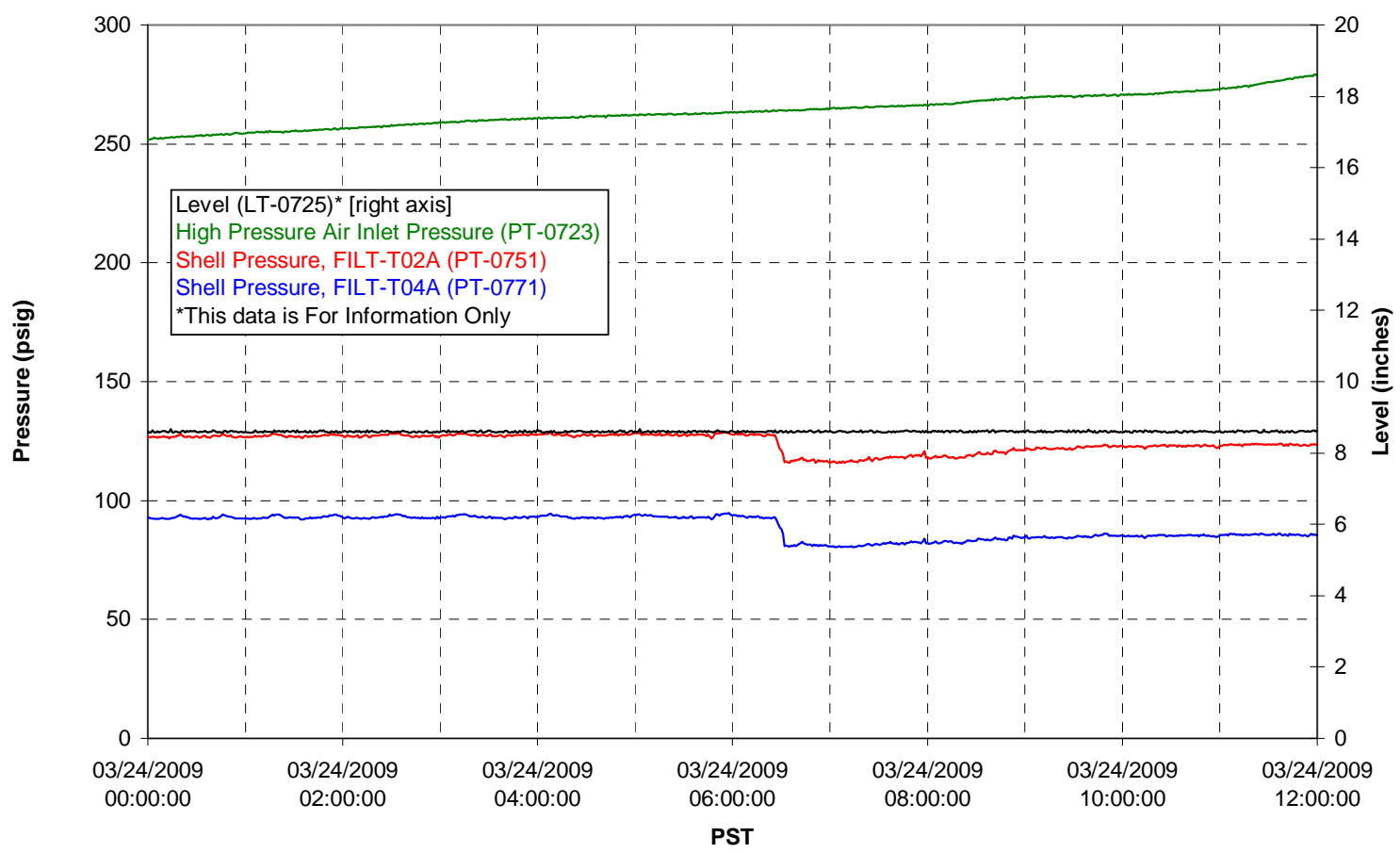


Pulsepot UFP-PP-T03A

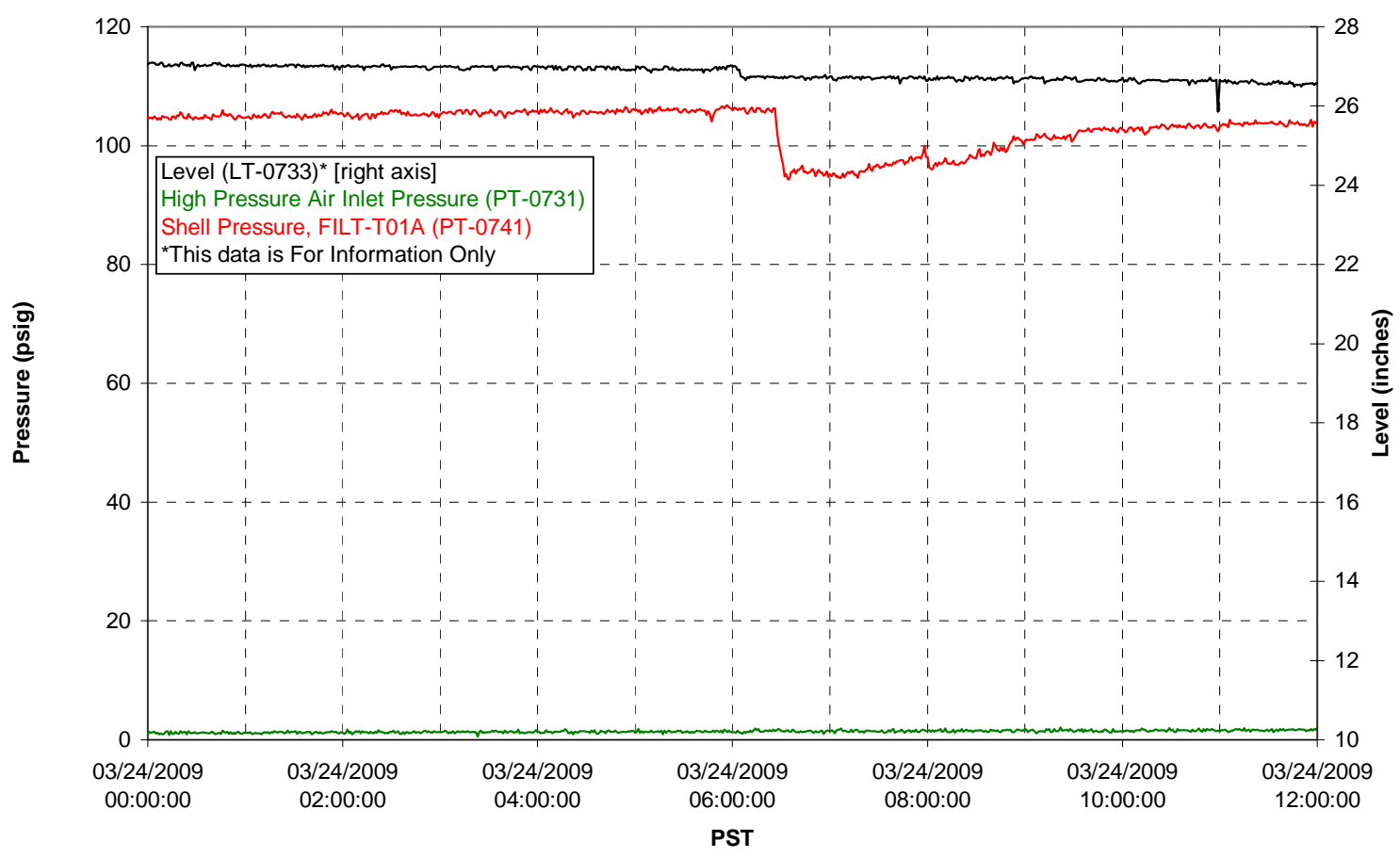

Pulsepot Levels

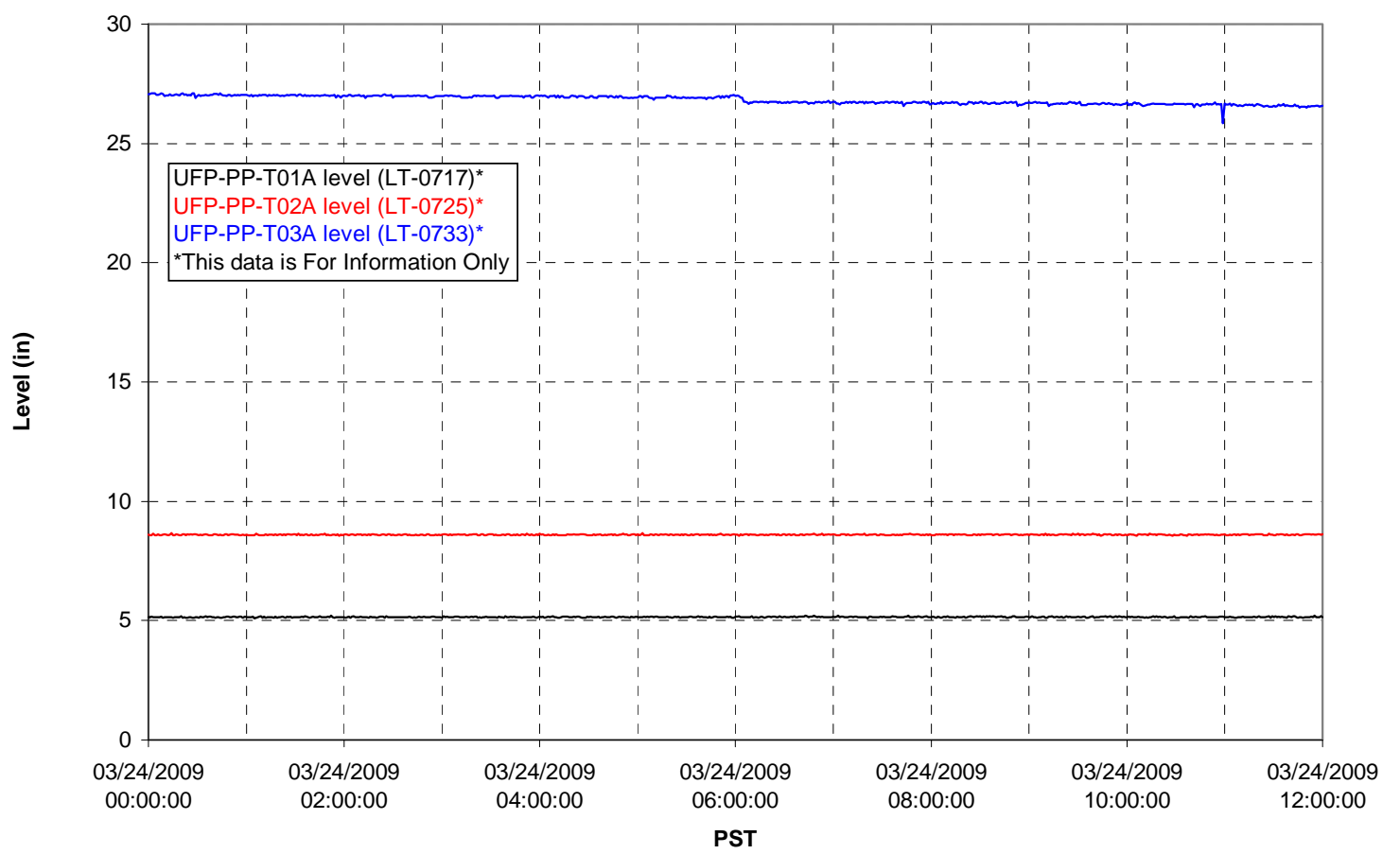


Filter UFP-FILT-T01A

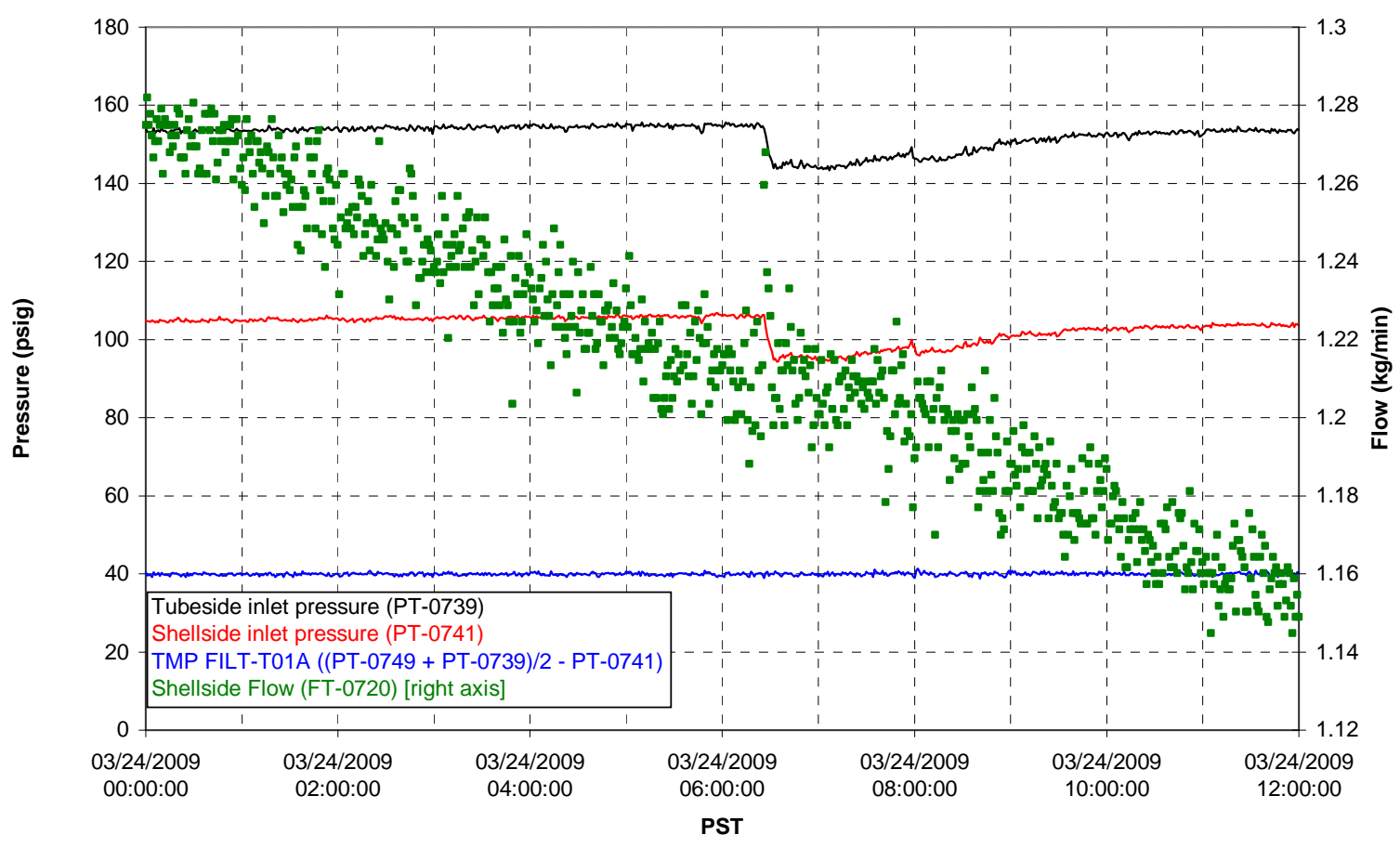

Filter UFP-FILT-T02A

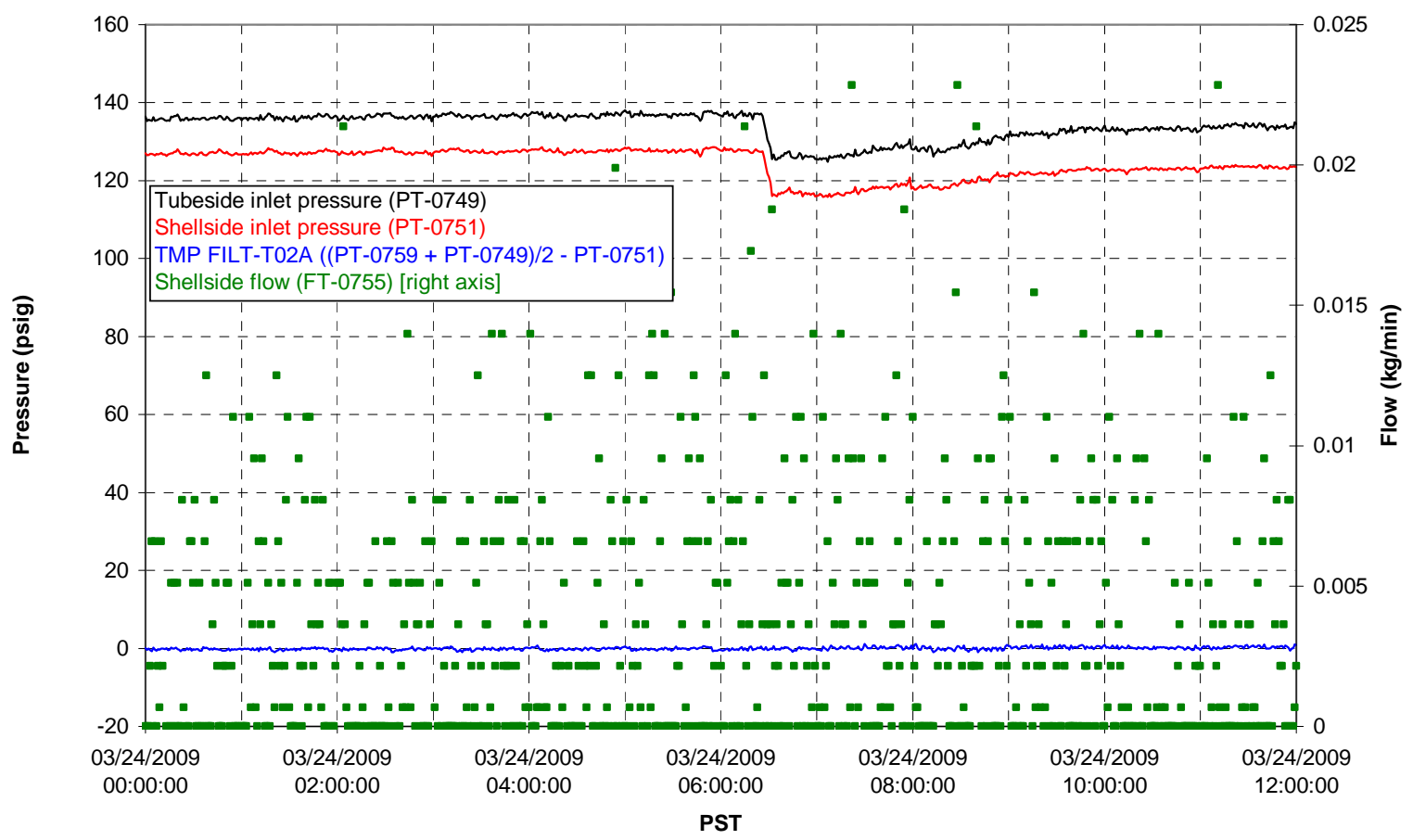


Filter UFP-FILT-T03A

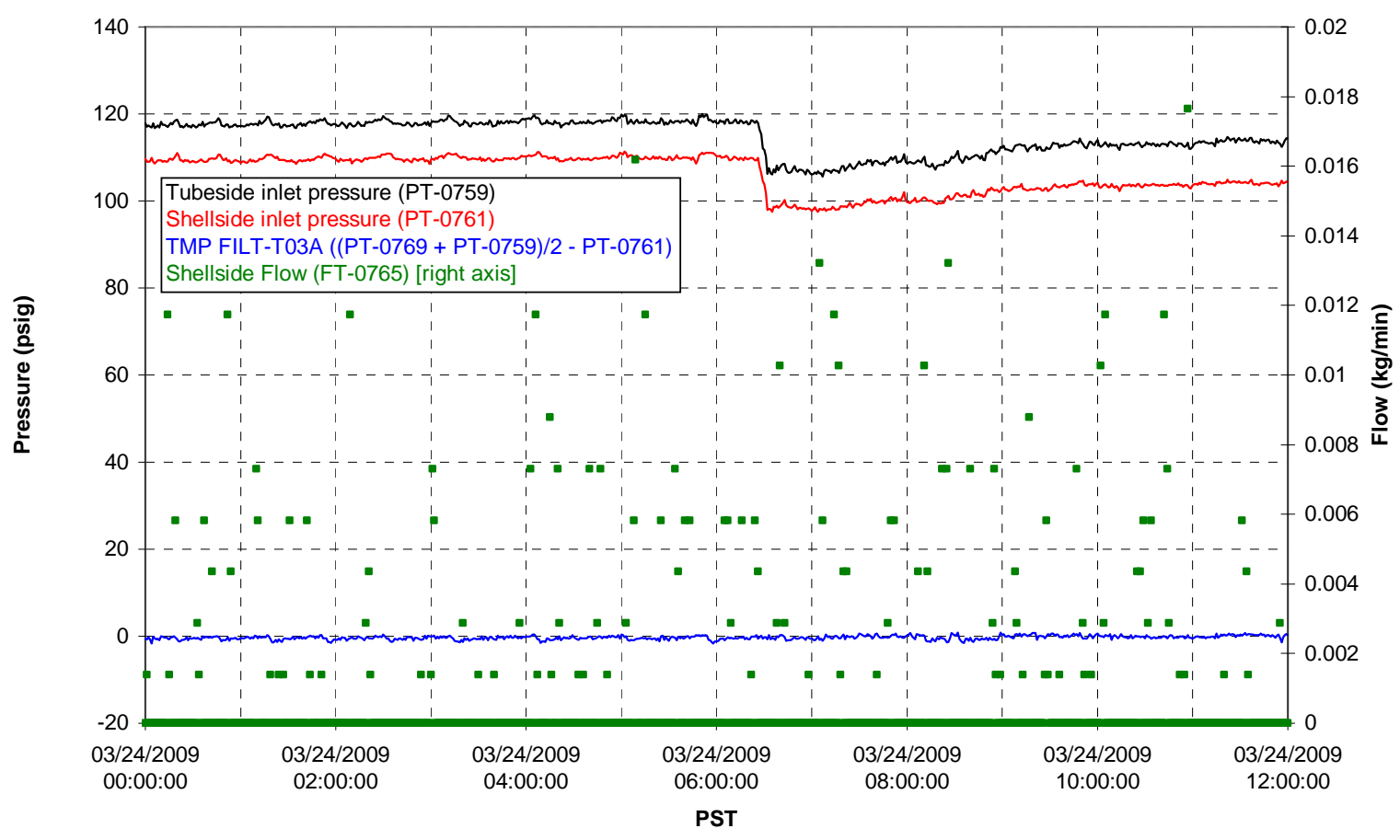

Filter UFP-FILT-T04A

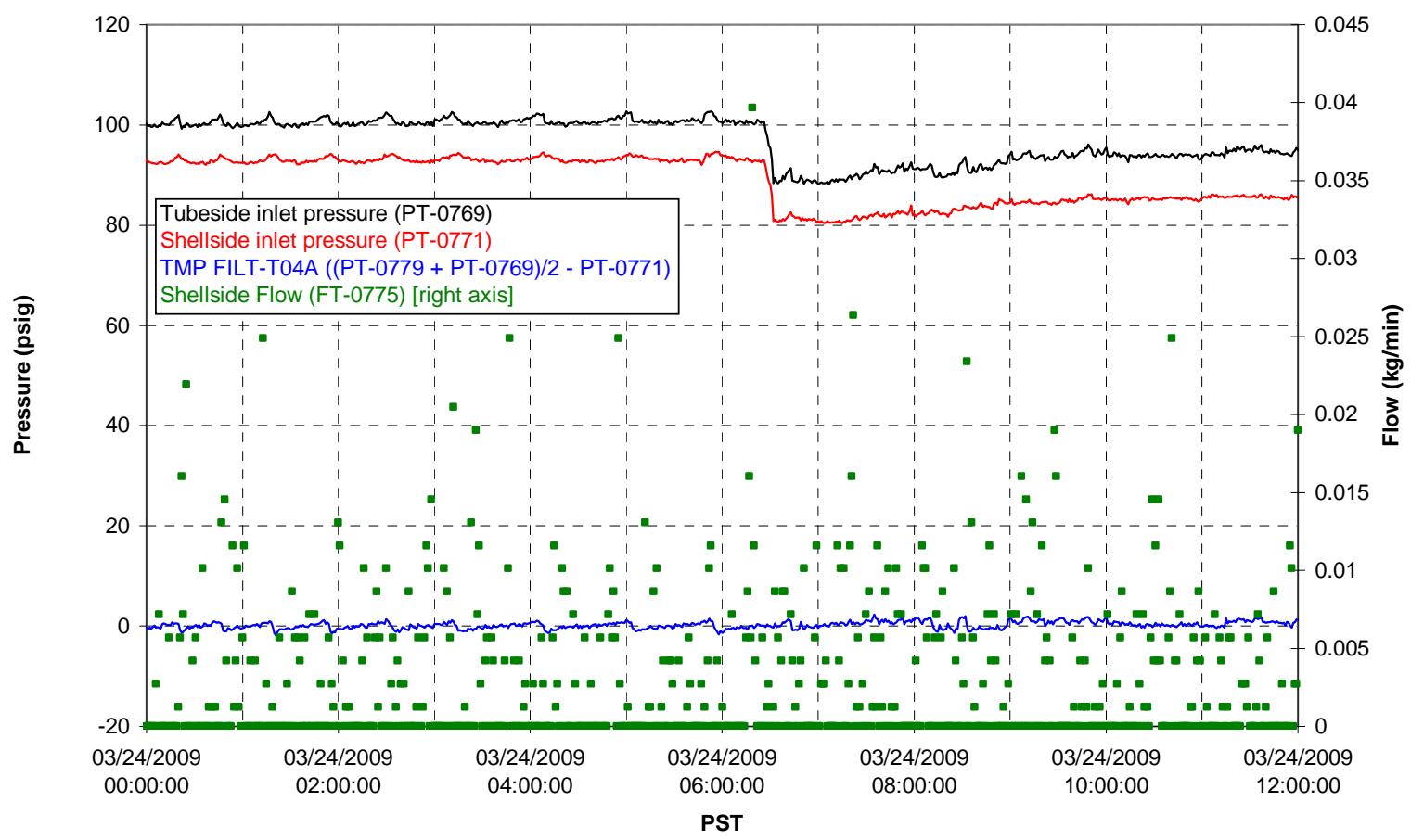


Filter UFP-FILT-T05A

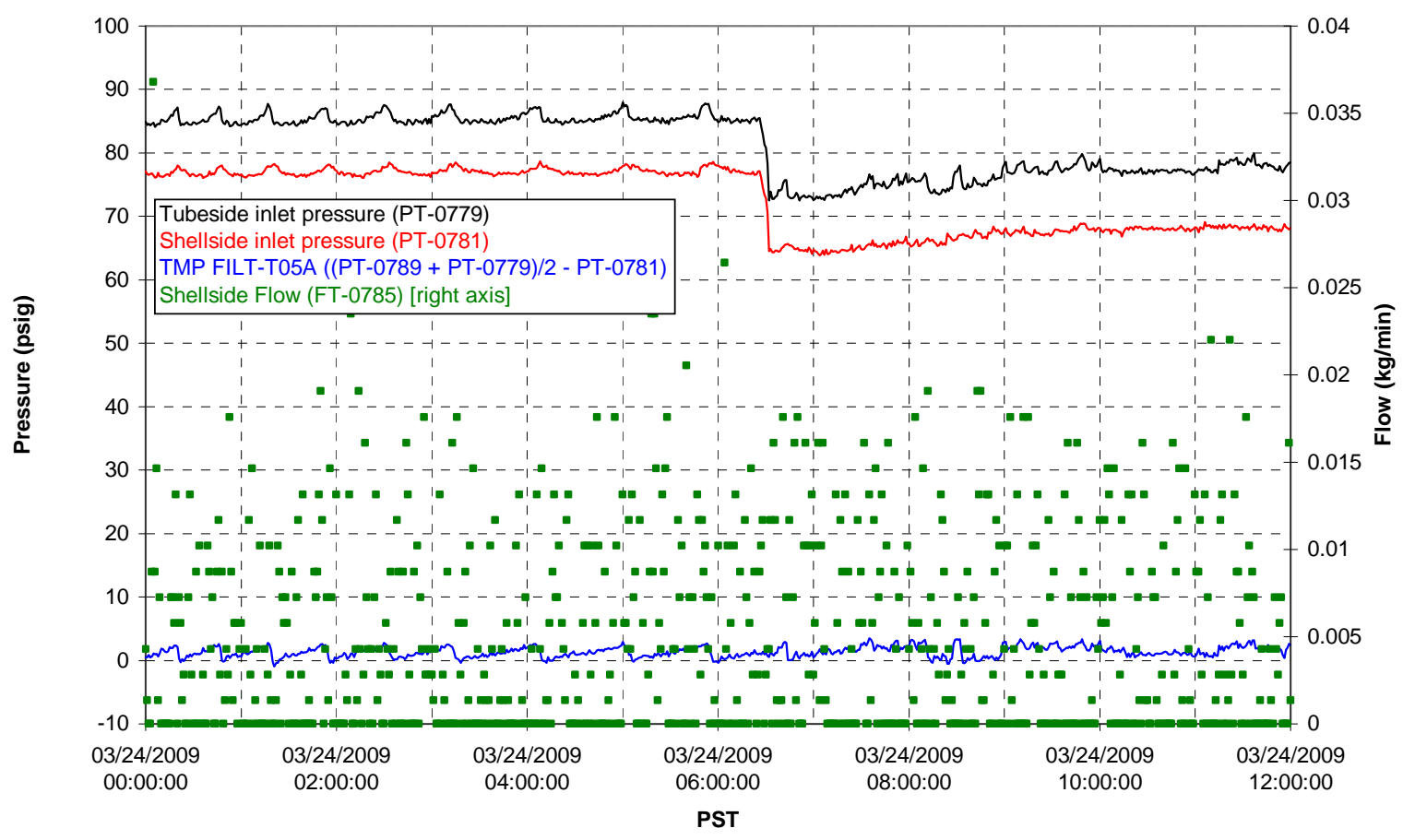

Chemical Flow

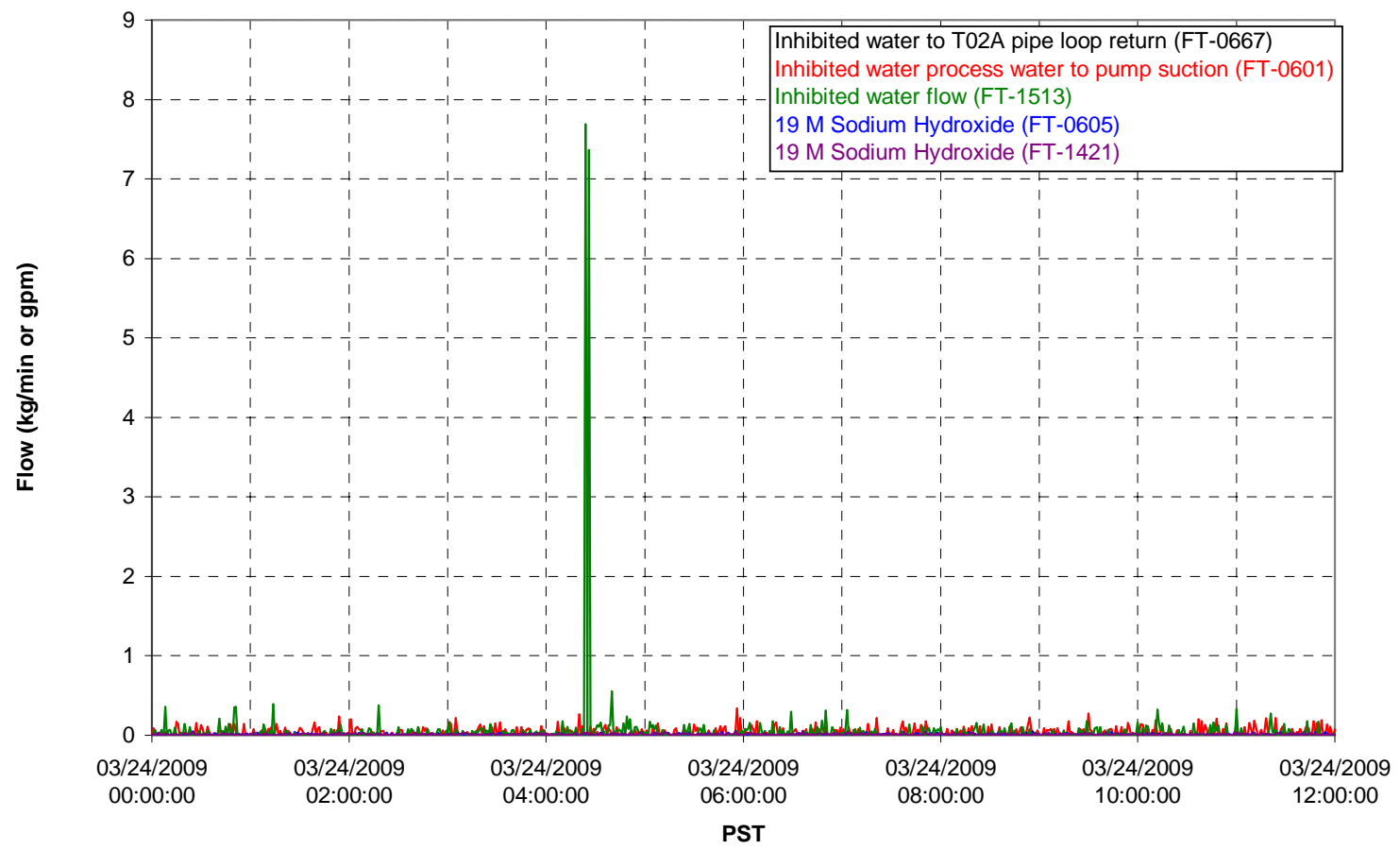




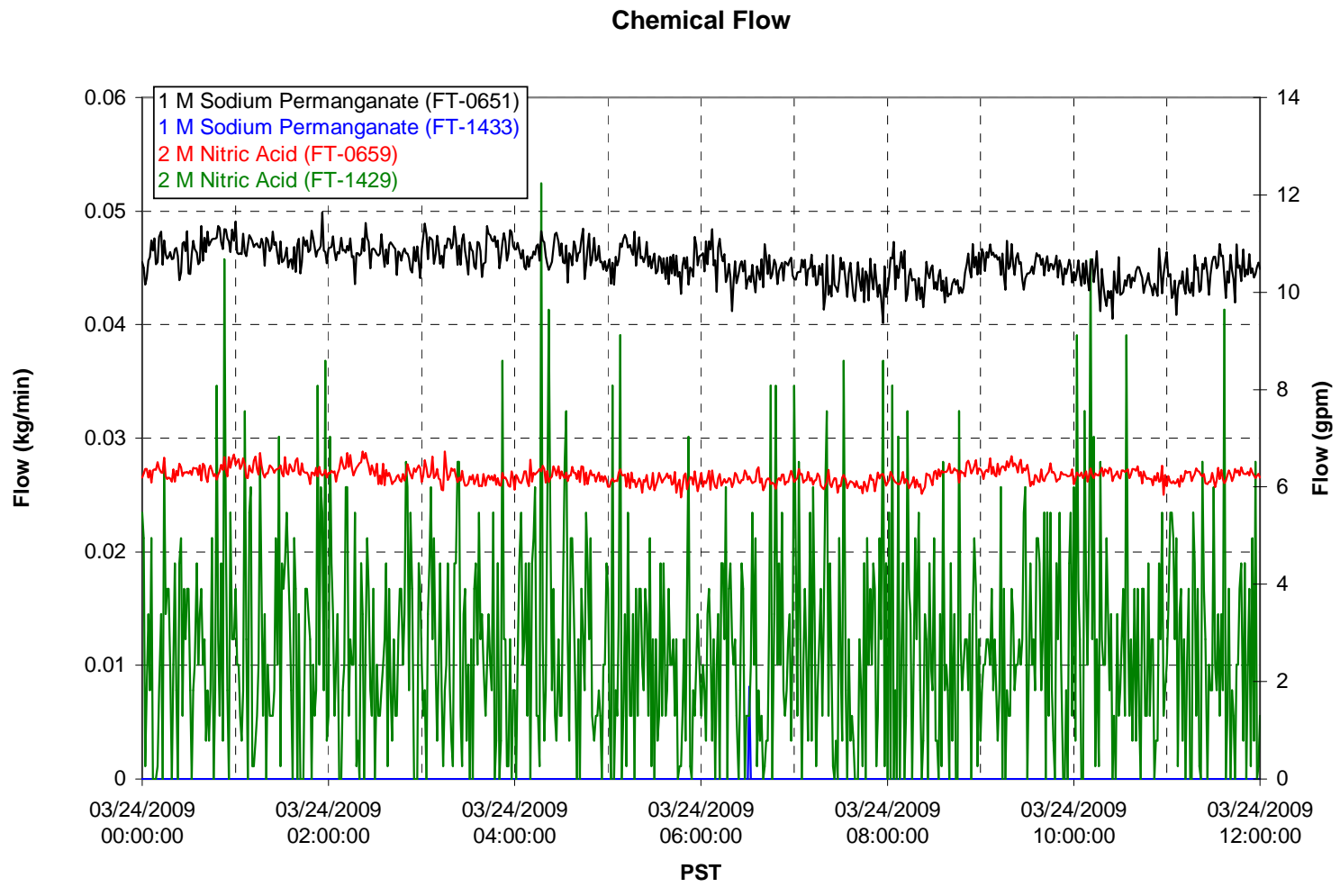

Air Flows

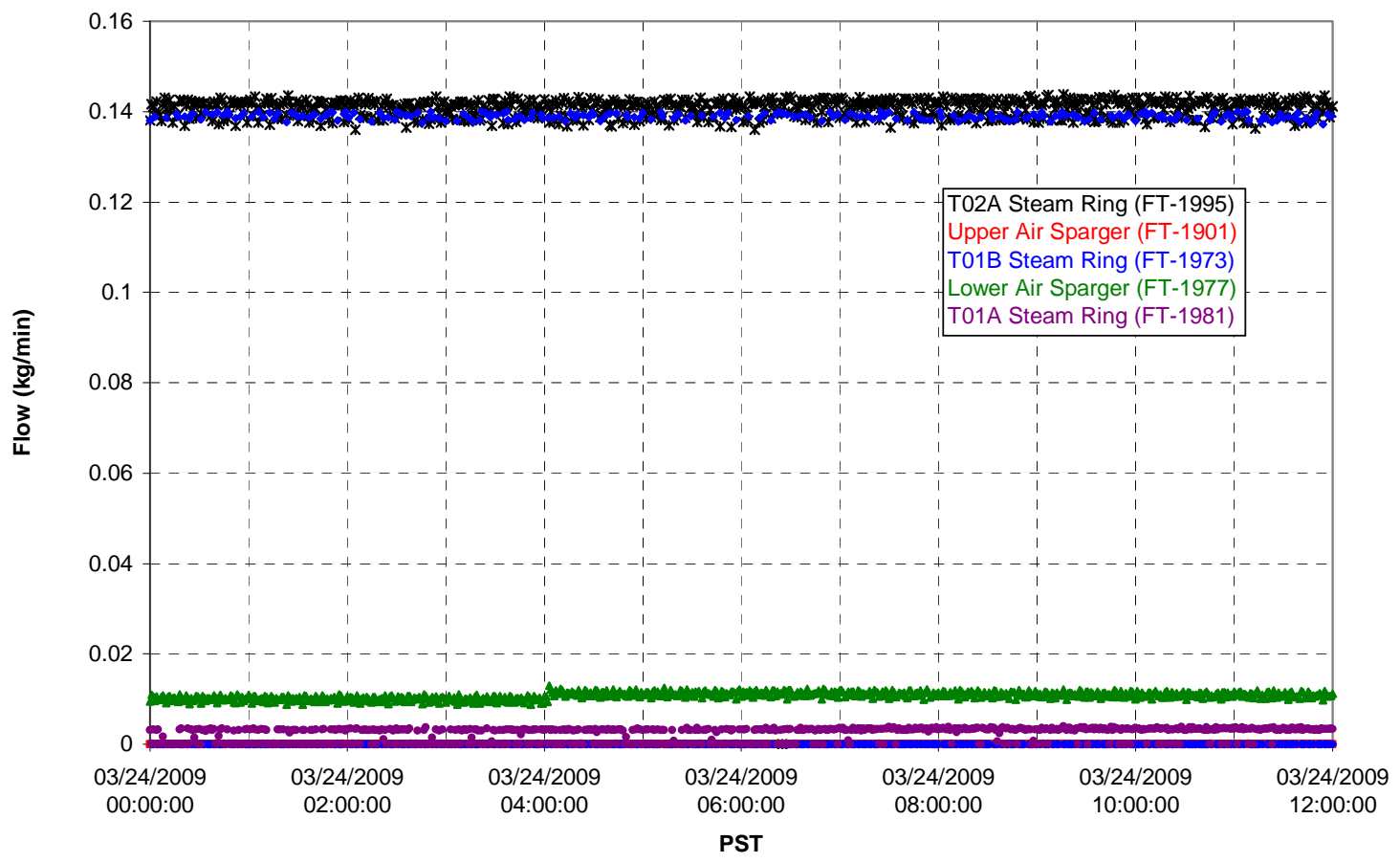


T02A Steam

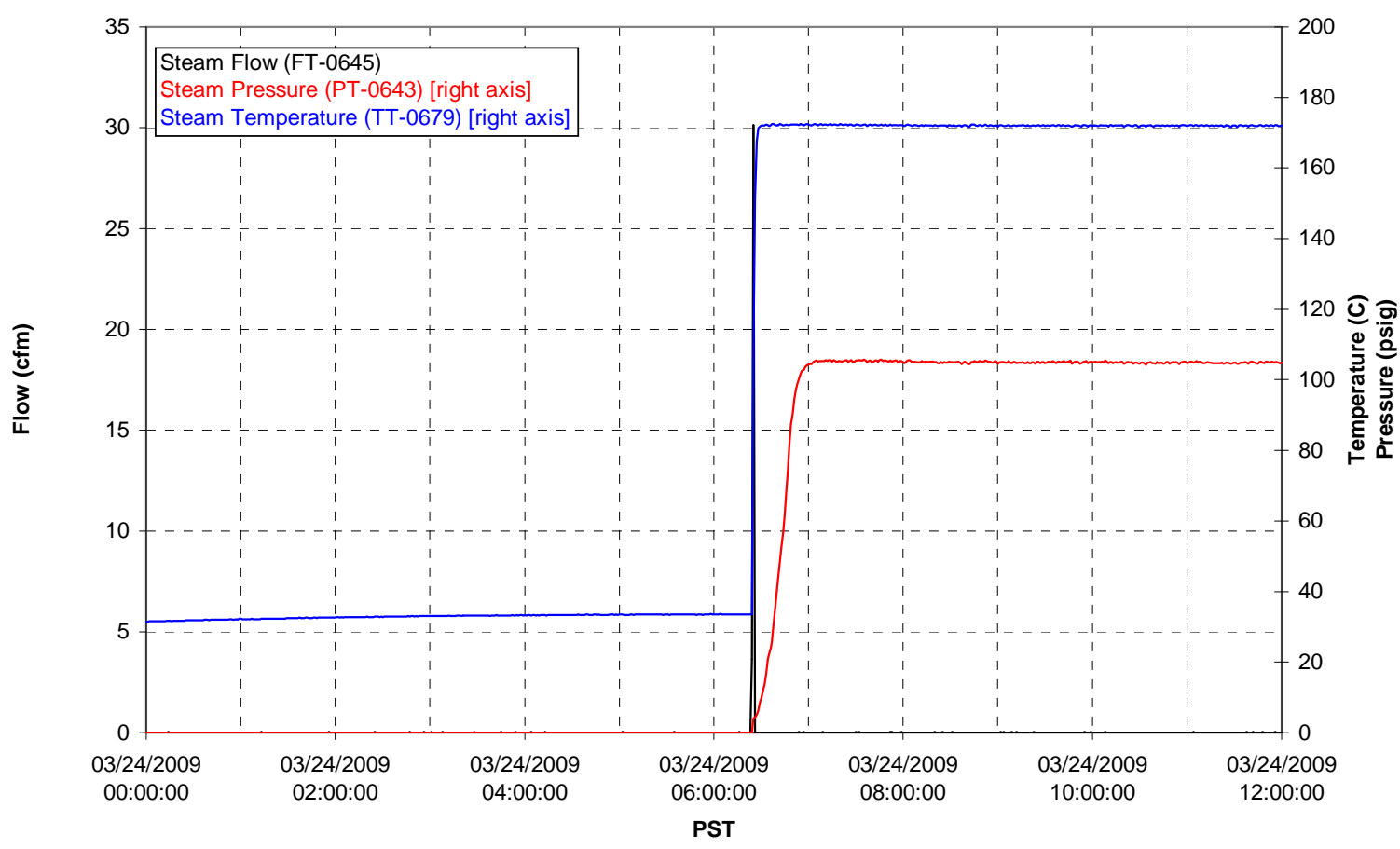

T01A Steam

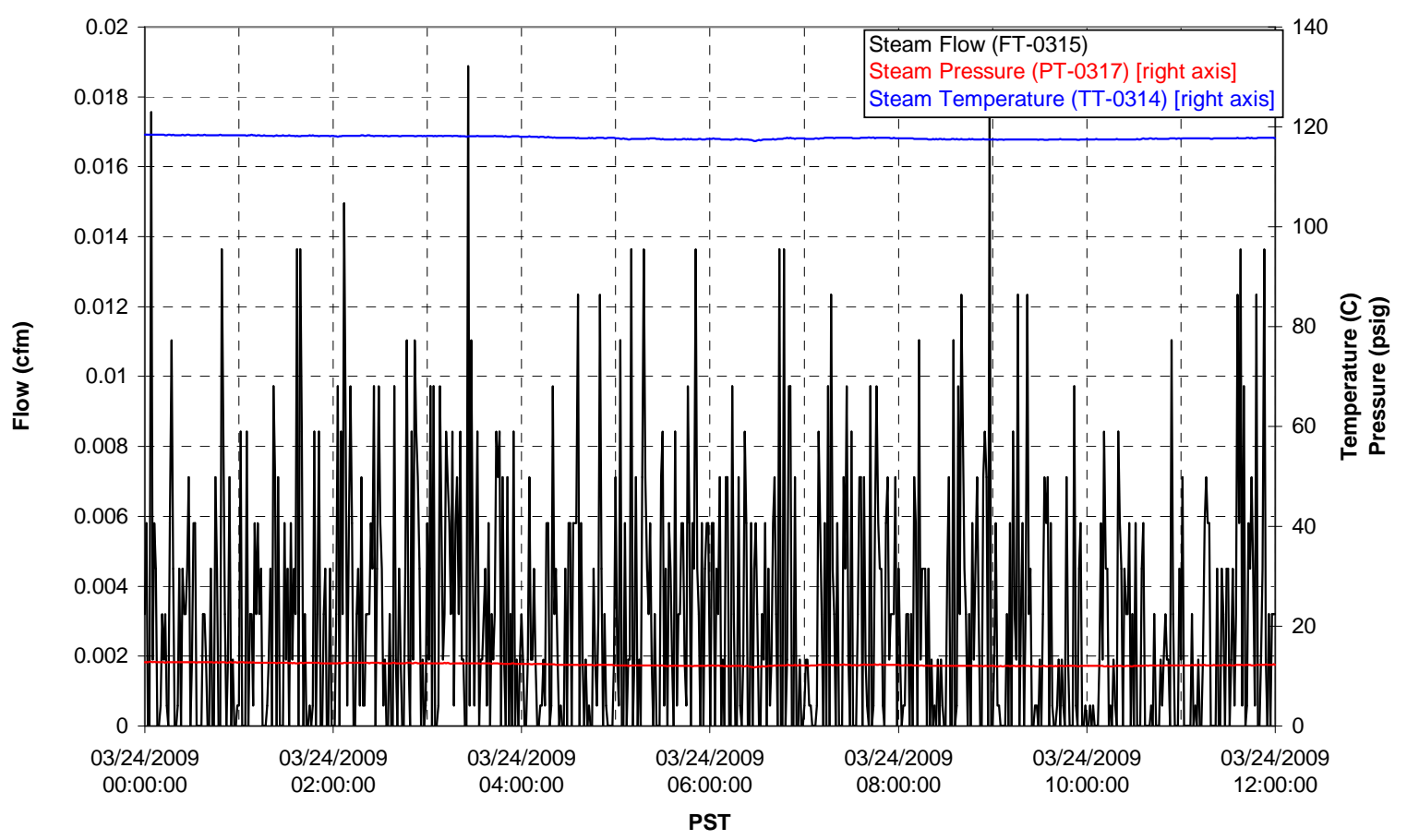




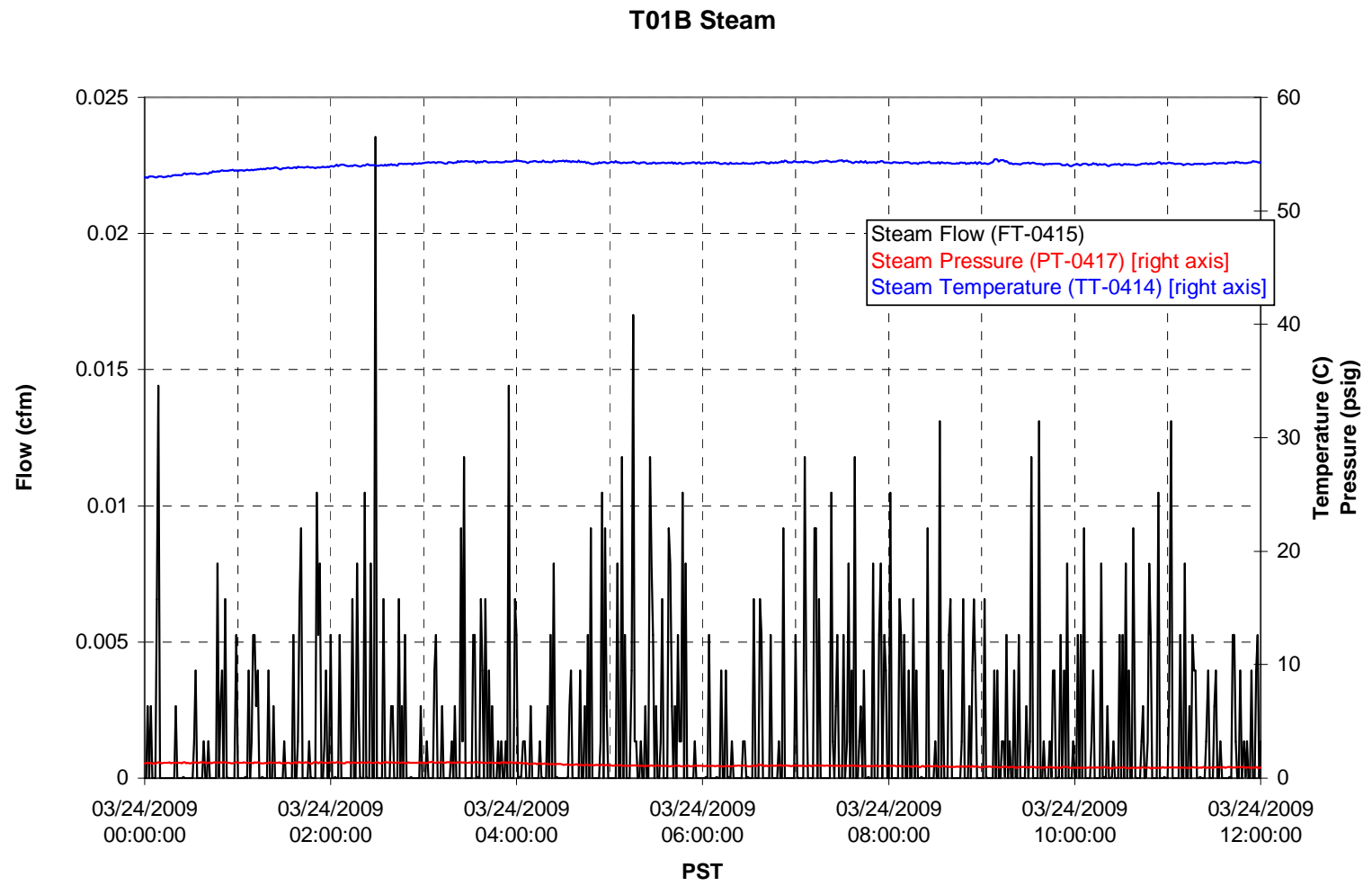




\section{Integrated Test D Data Plots 03/24/09 12:00 - 03/25/09 00:00}


T01A level

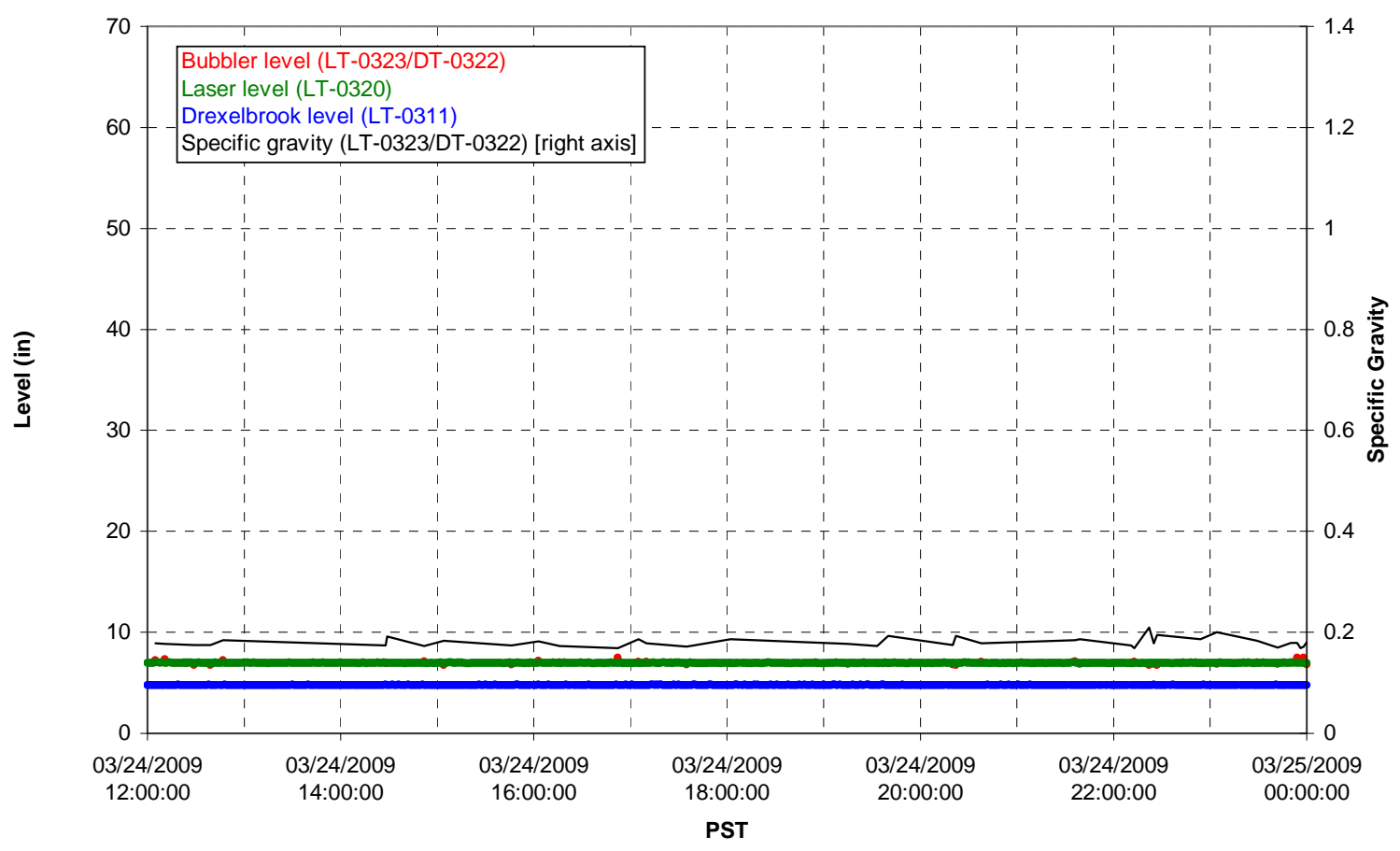

T01A temperatures

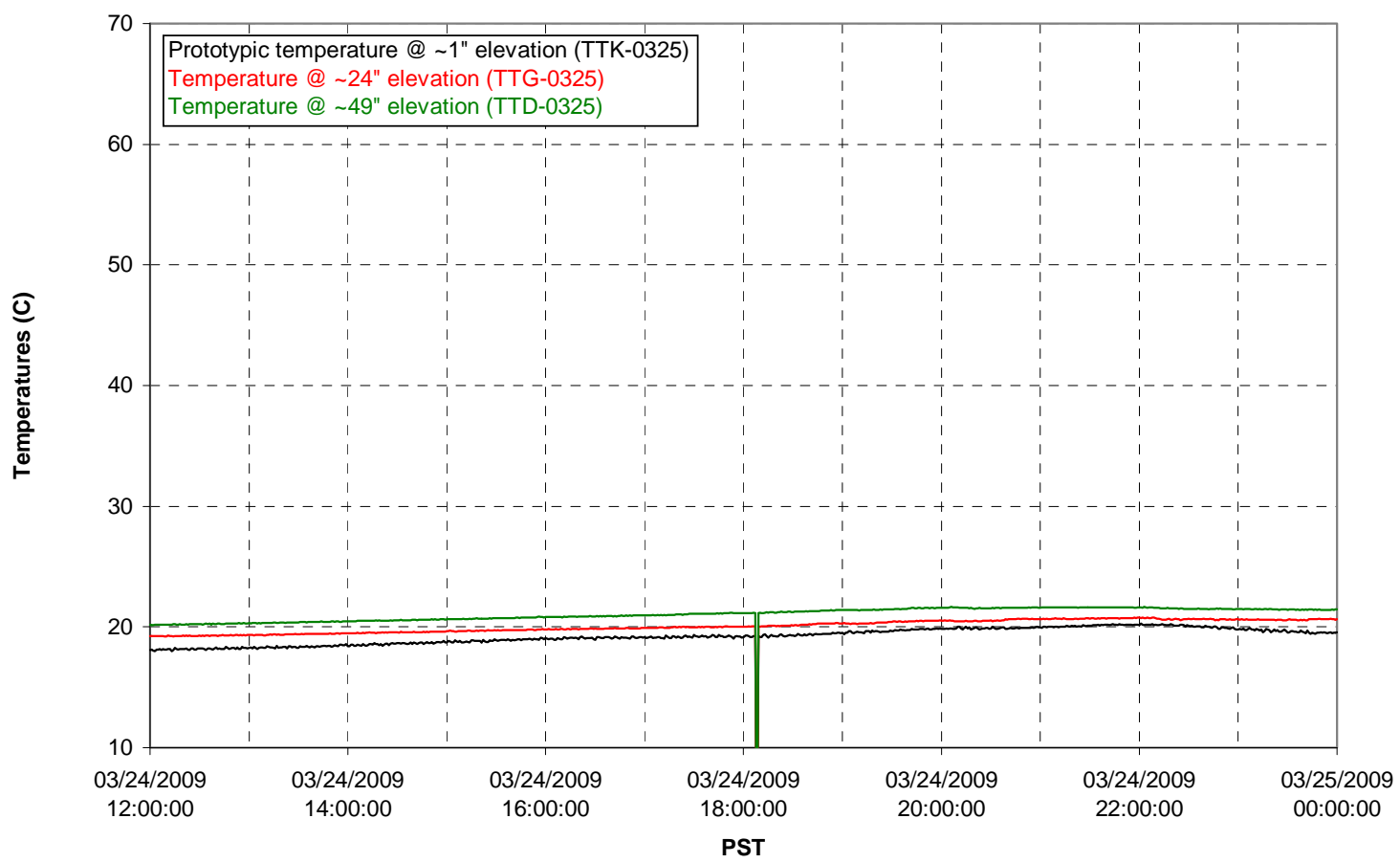


T01B level

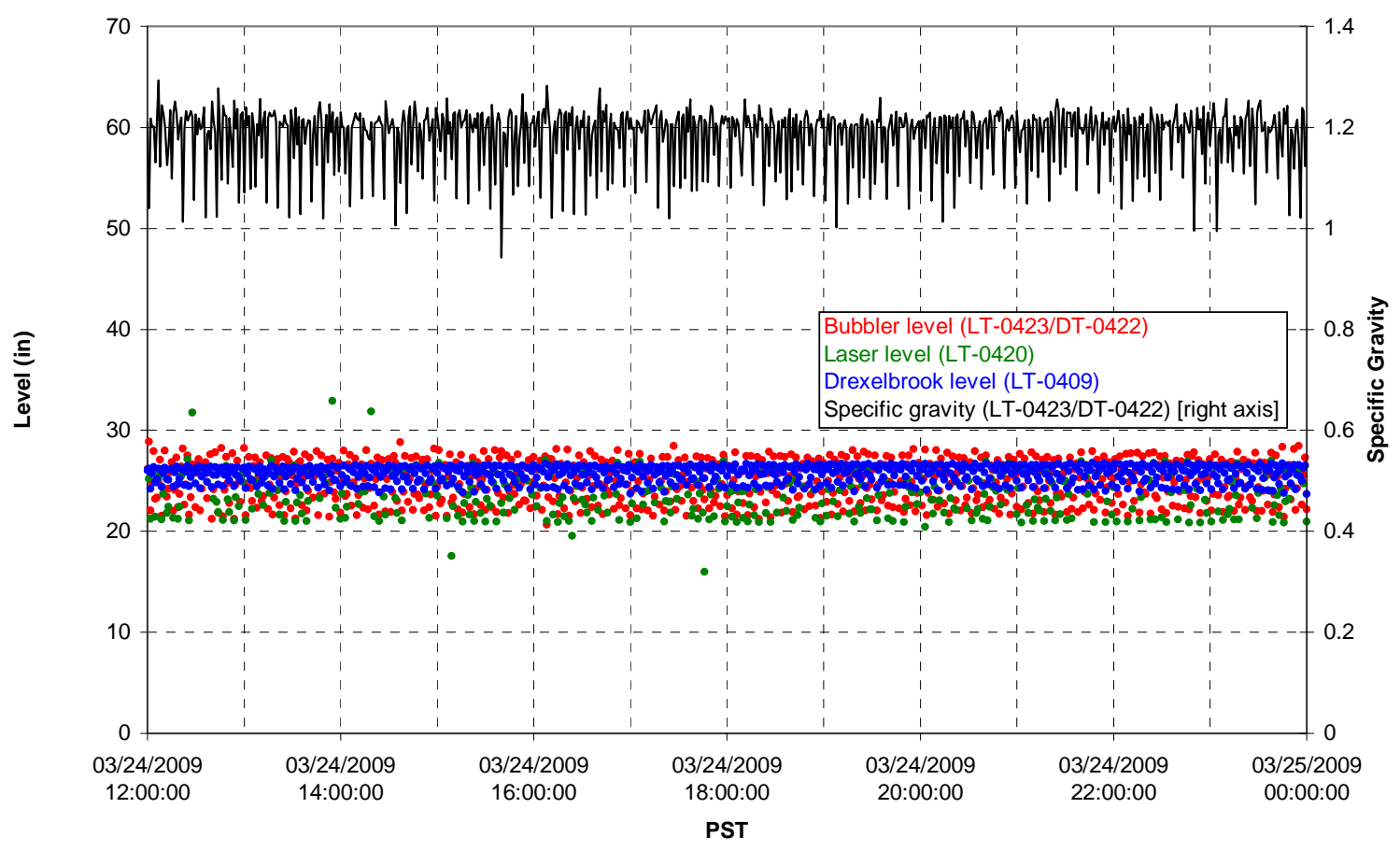

T01B temperatures

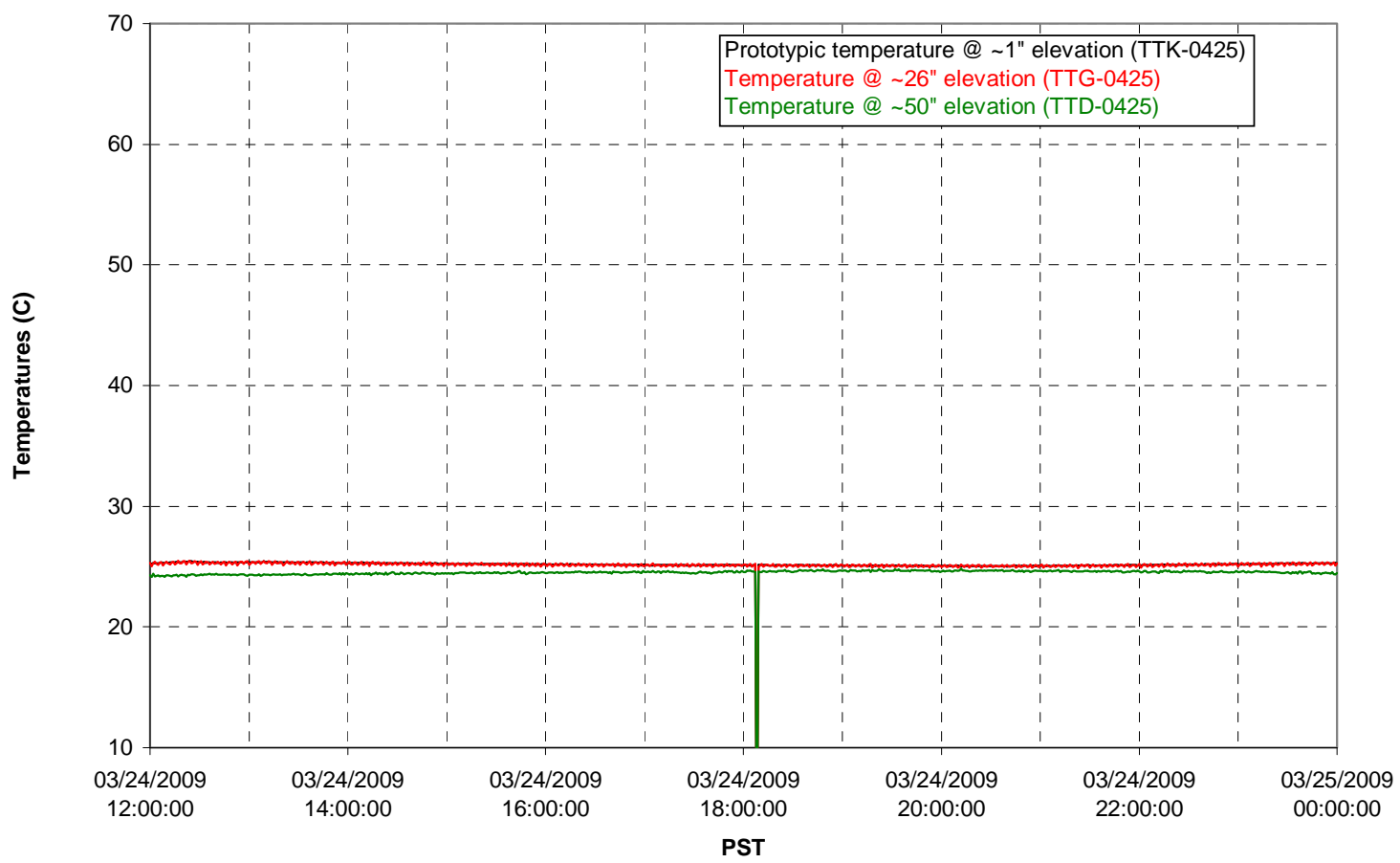


T02A level

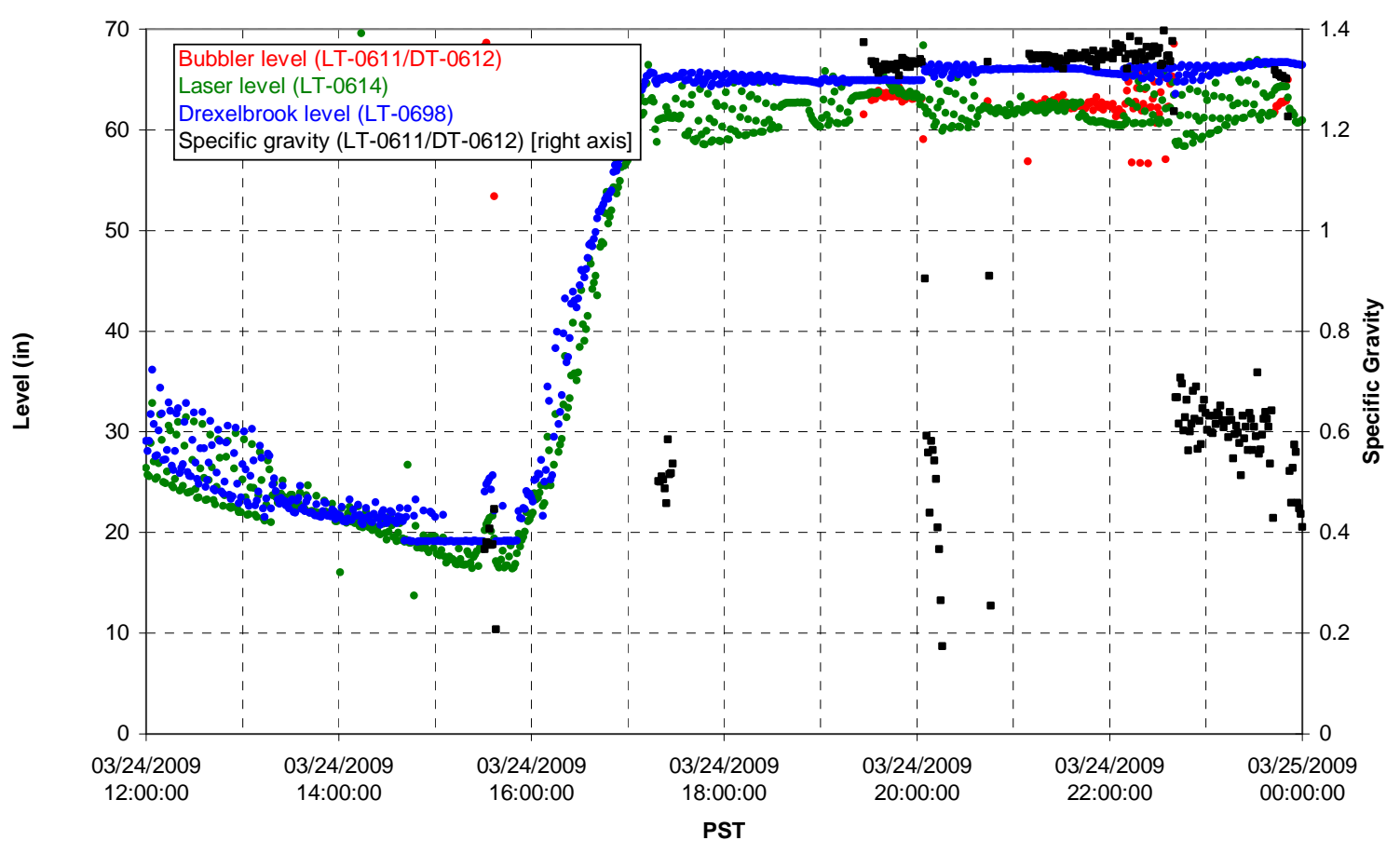

T02A temperatures

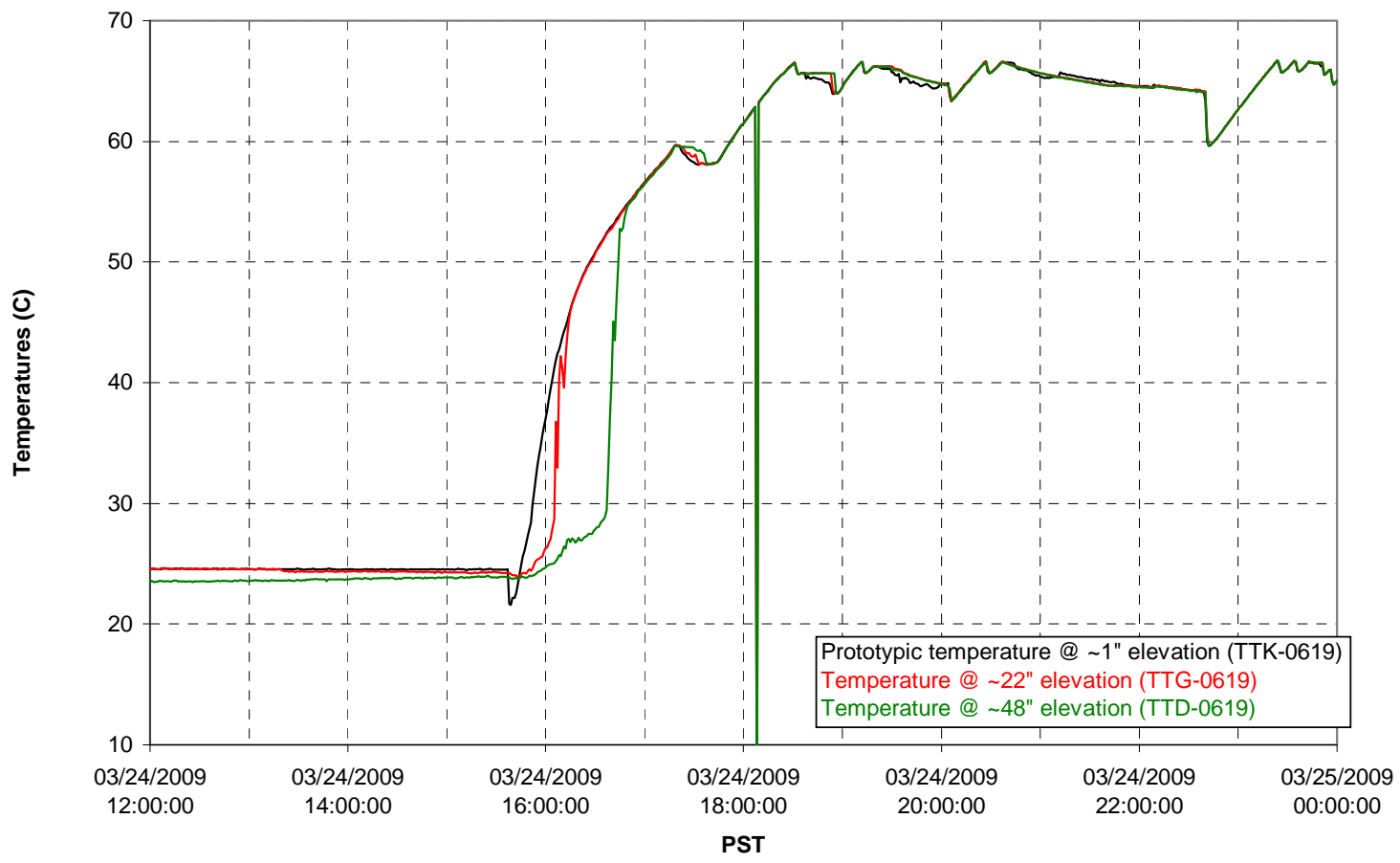


T02A and filter loop temperatures

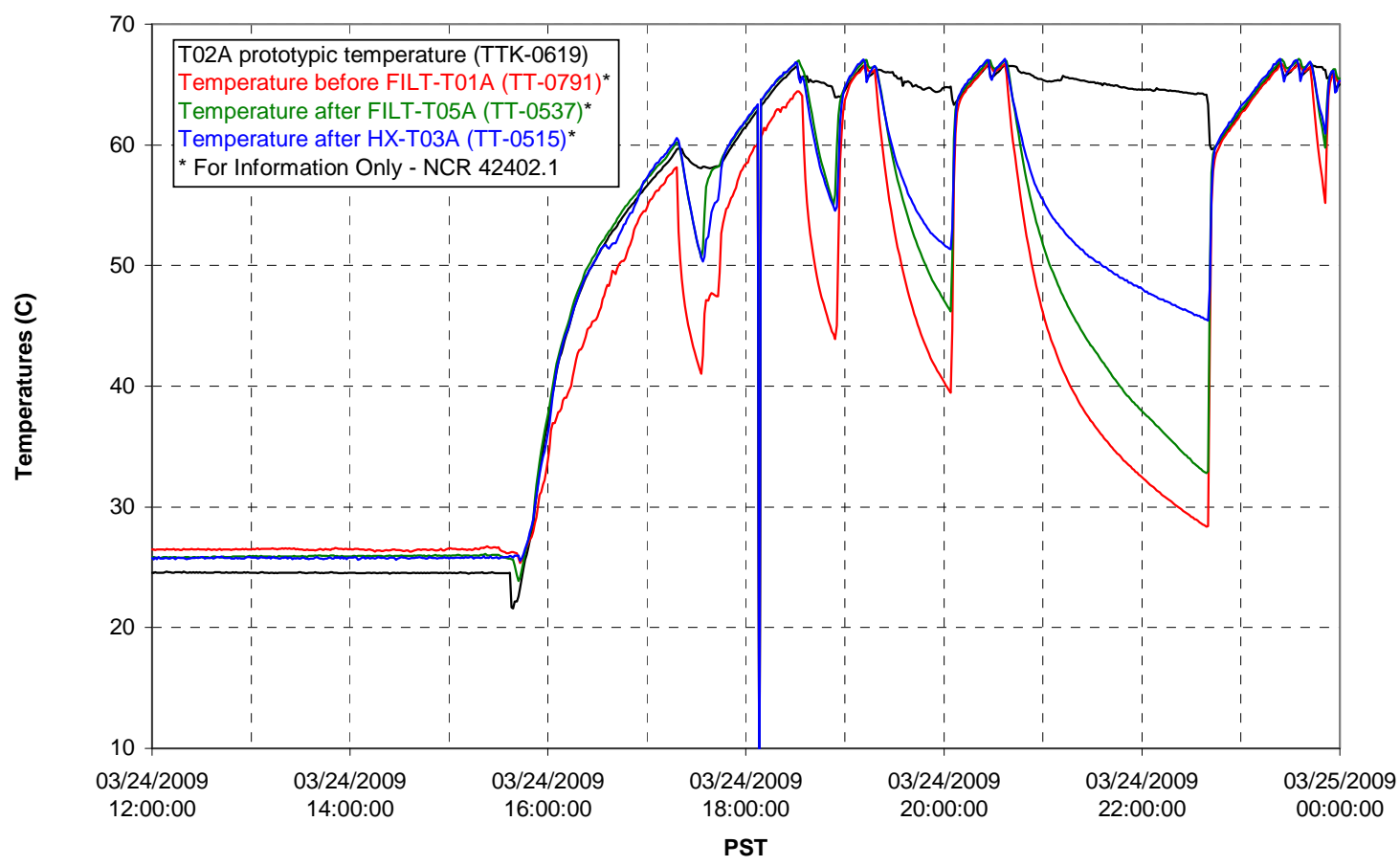

Pump Pressures and Flow

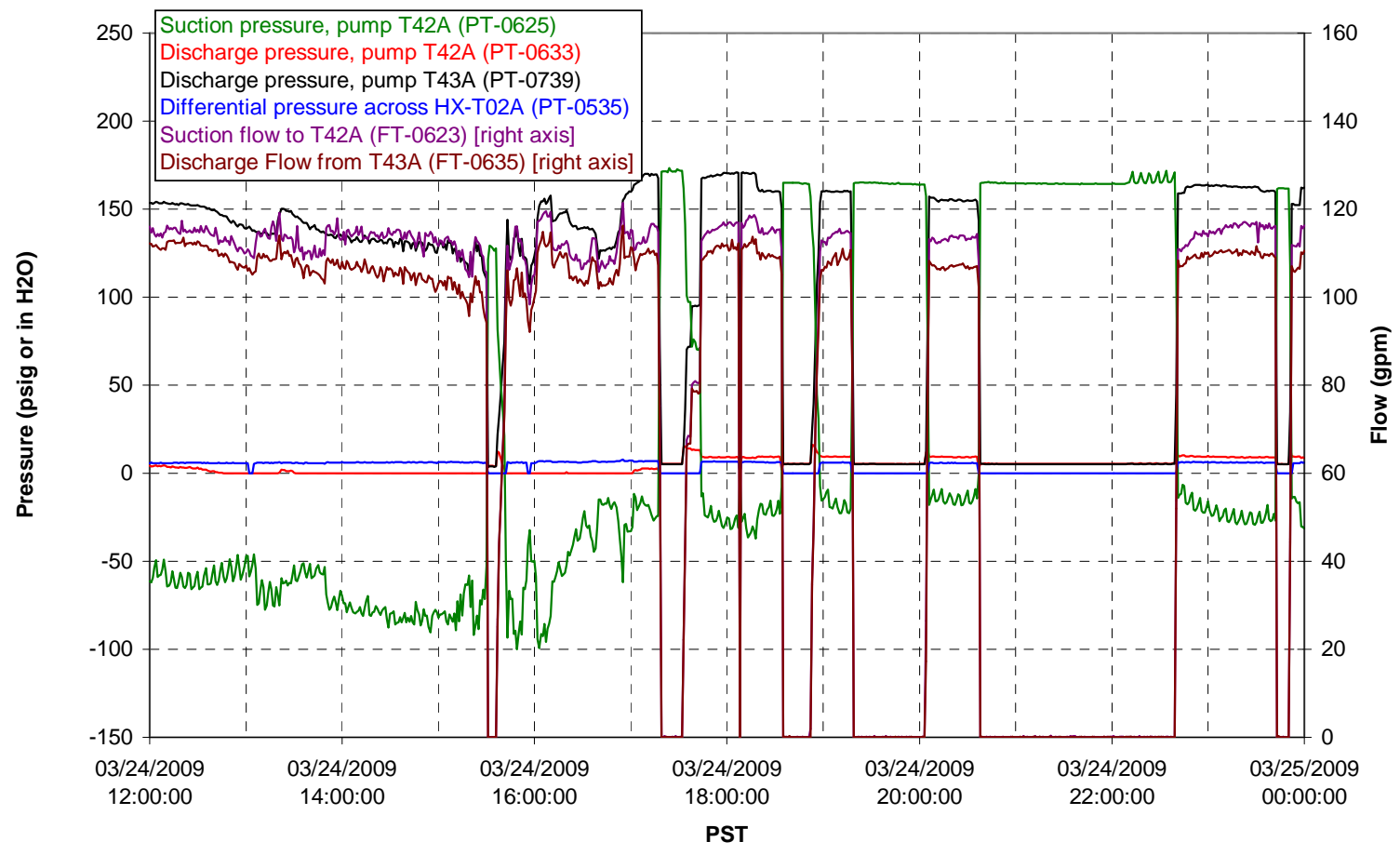




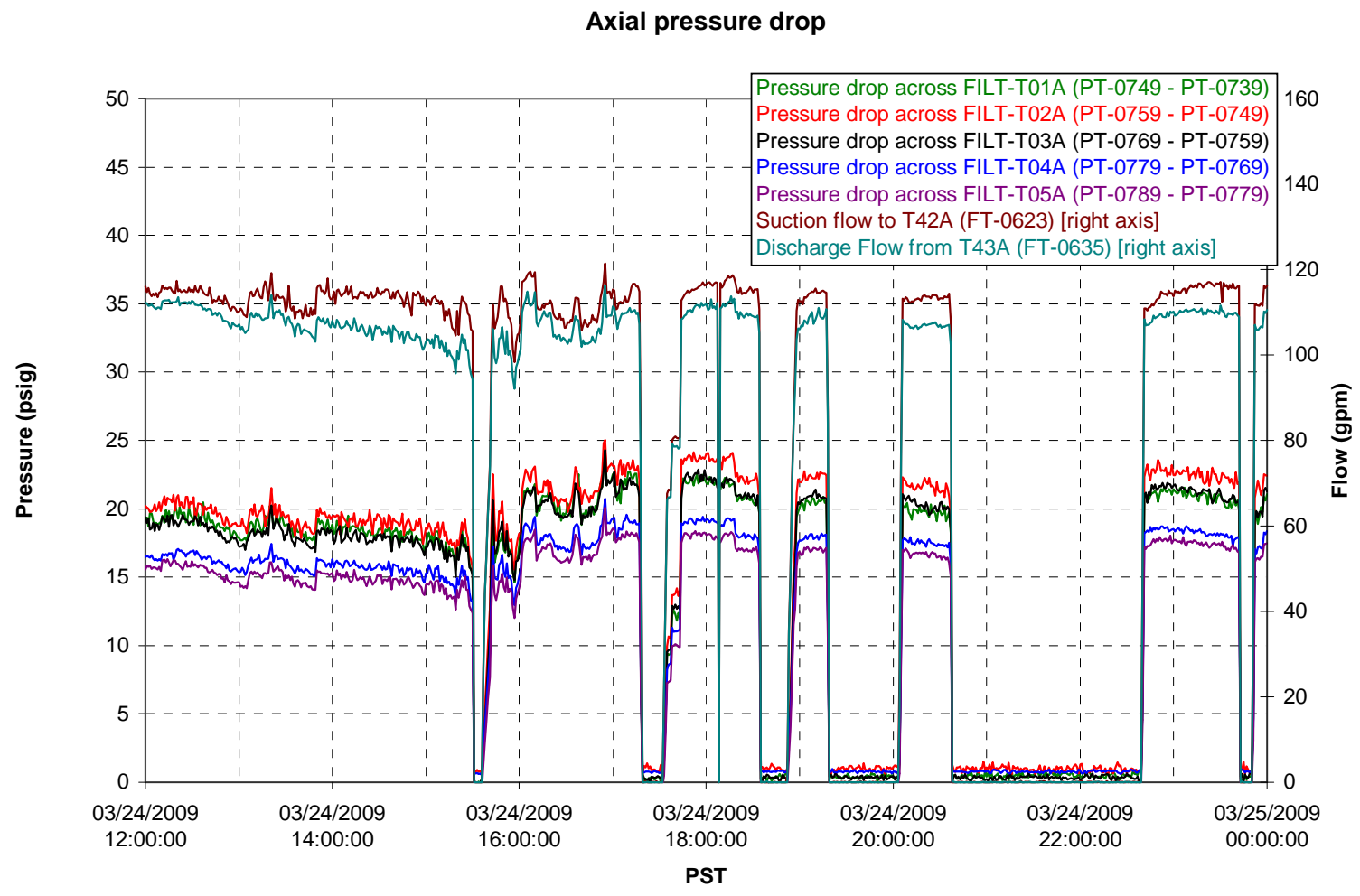

Permeate flow rates

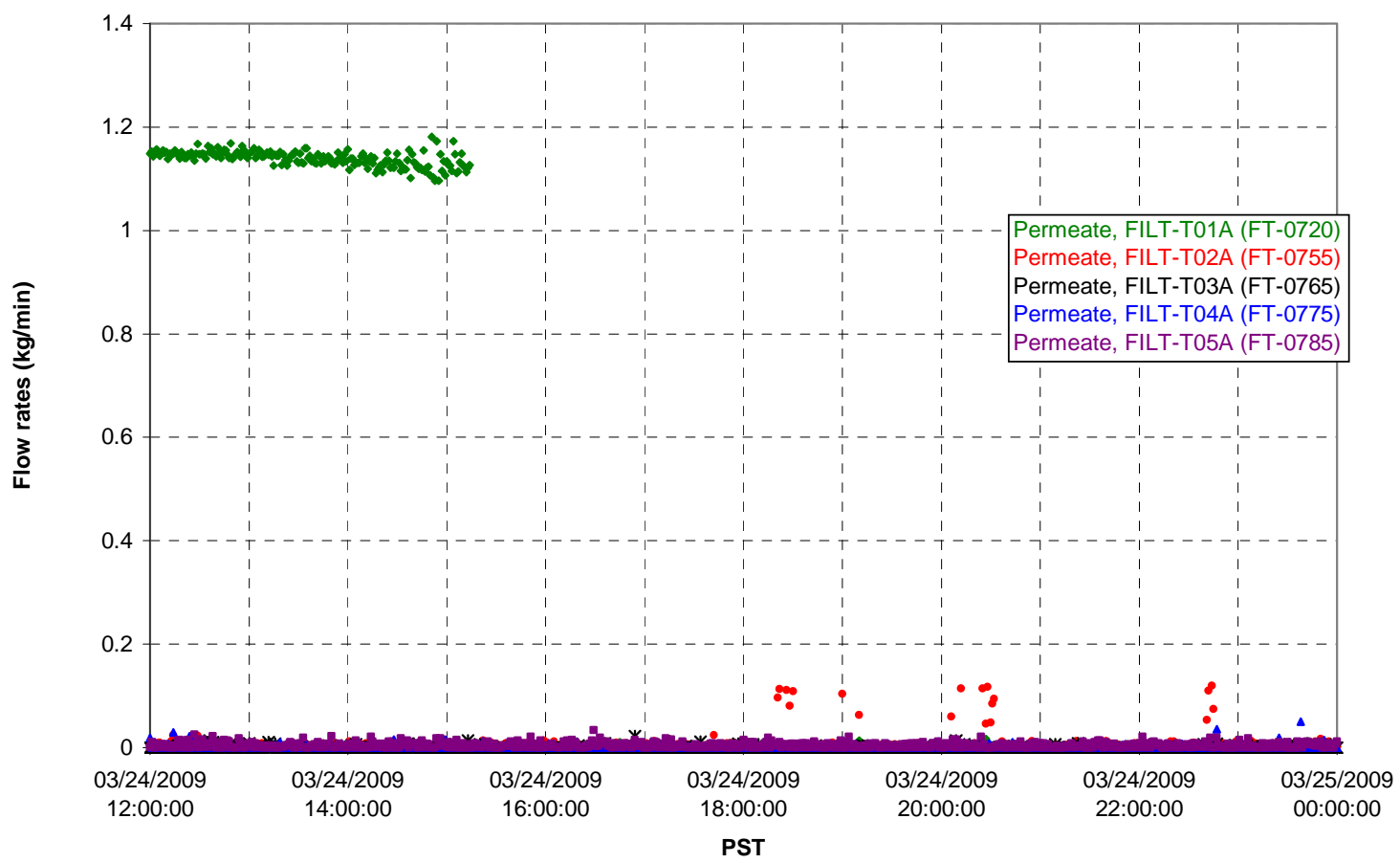


T02A Inner Temperature Tree

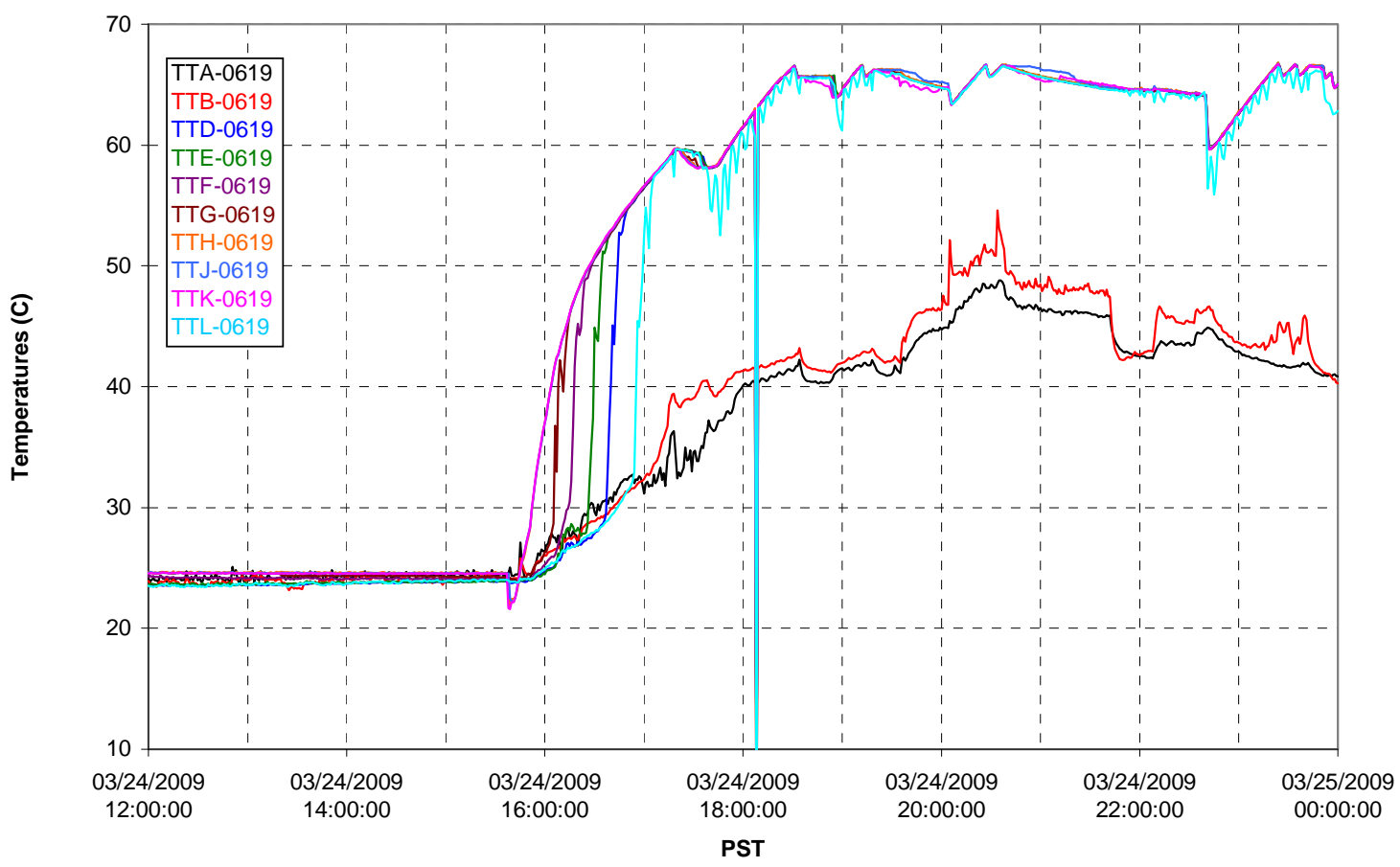

T02A Outer Temperature Tree

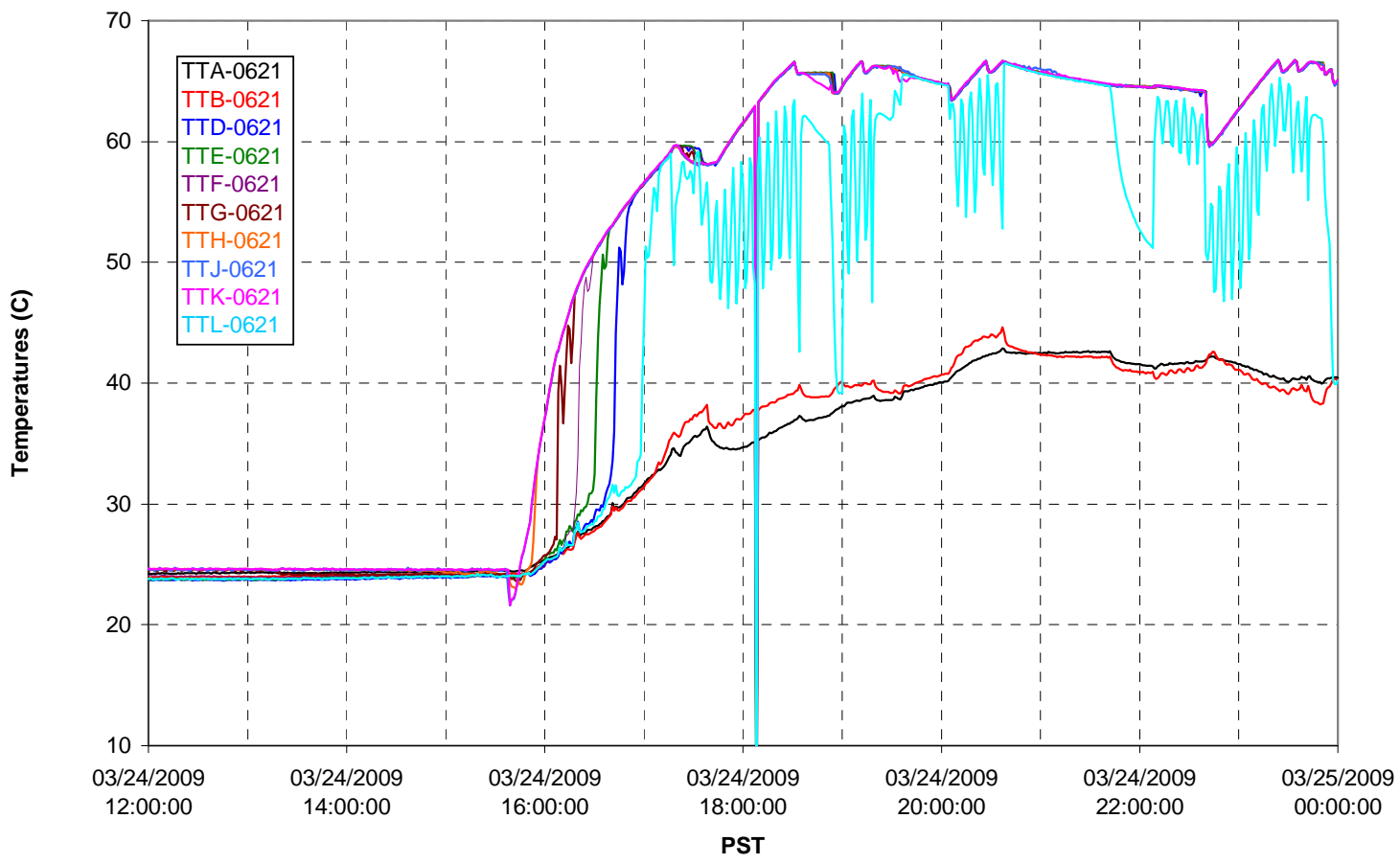


T02A temperatures

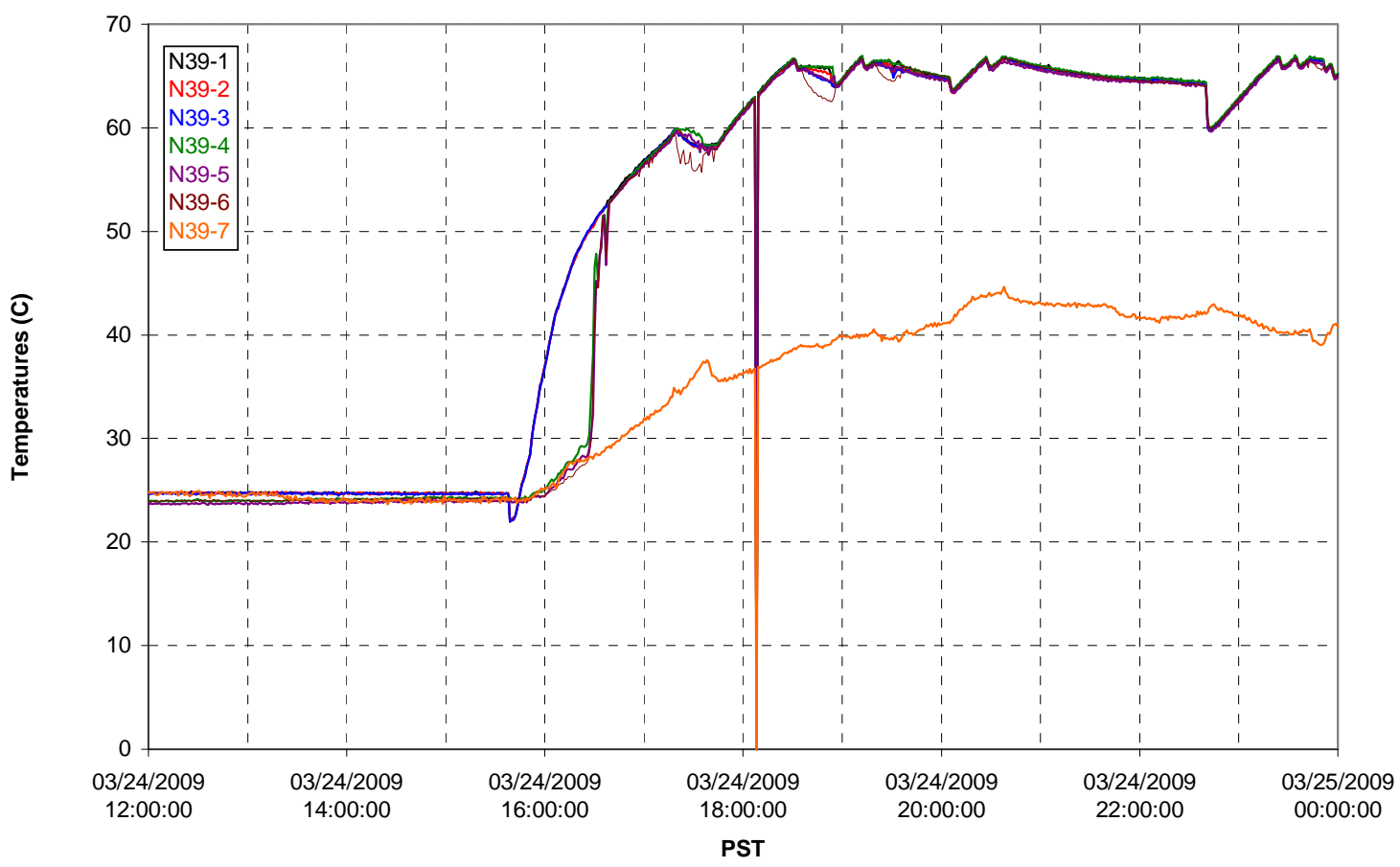

T02A temperatures

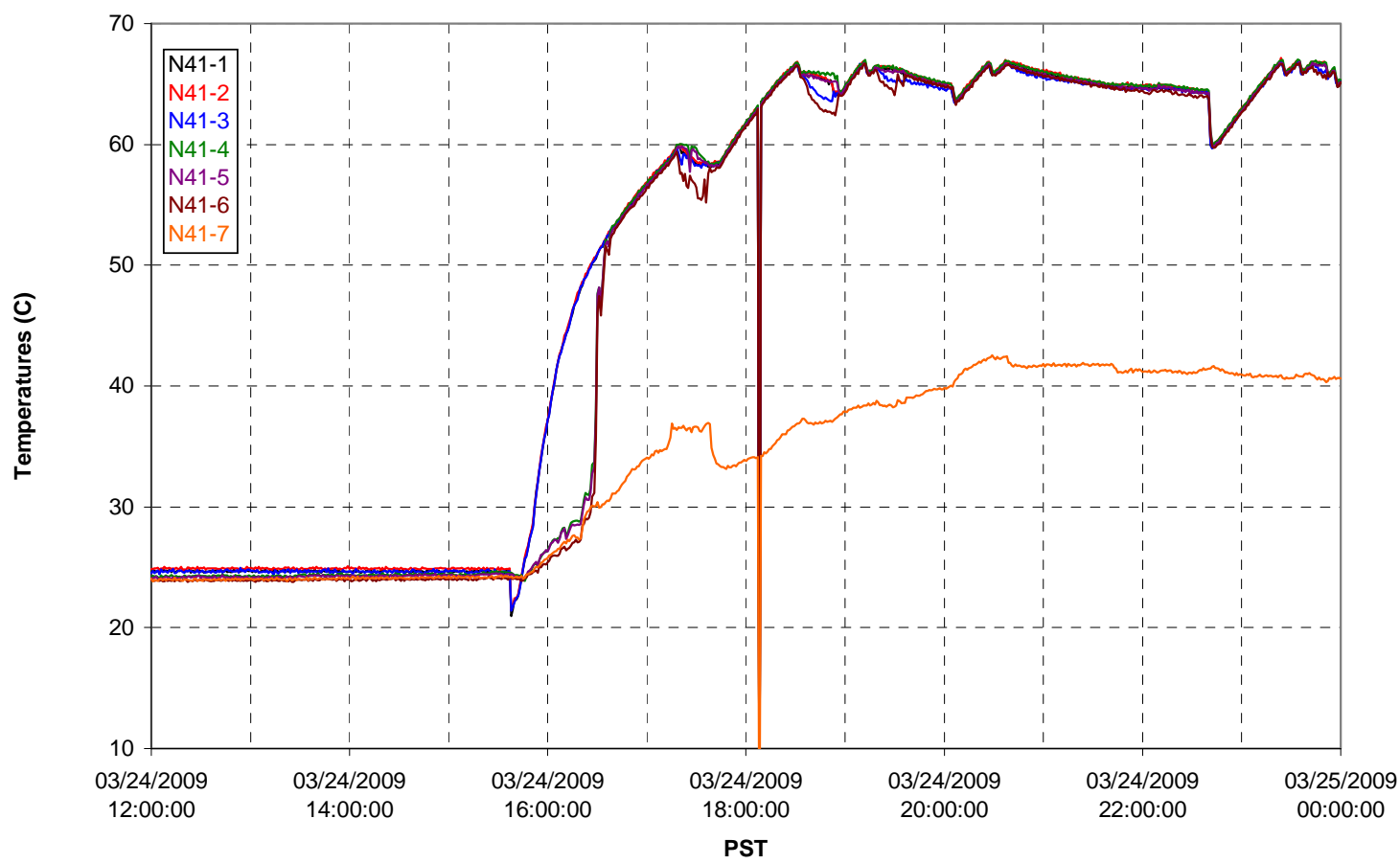


T02A temperatures

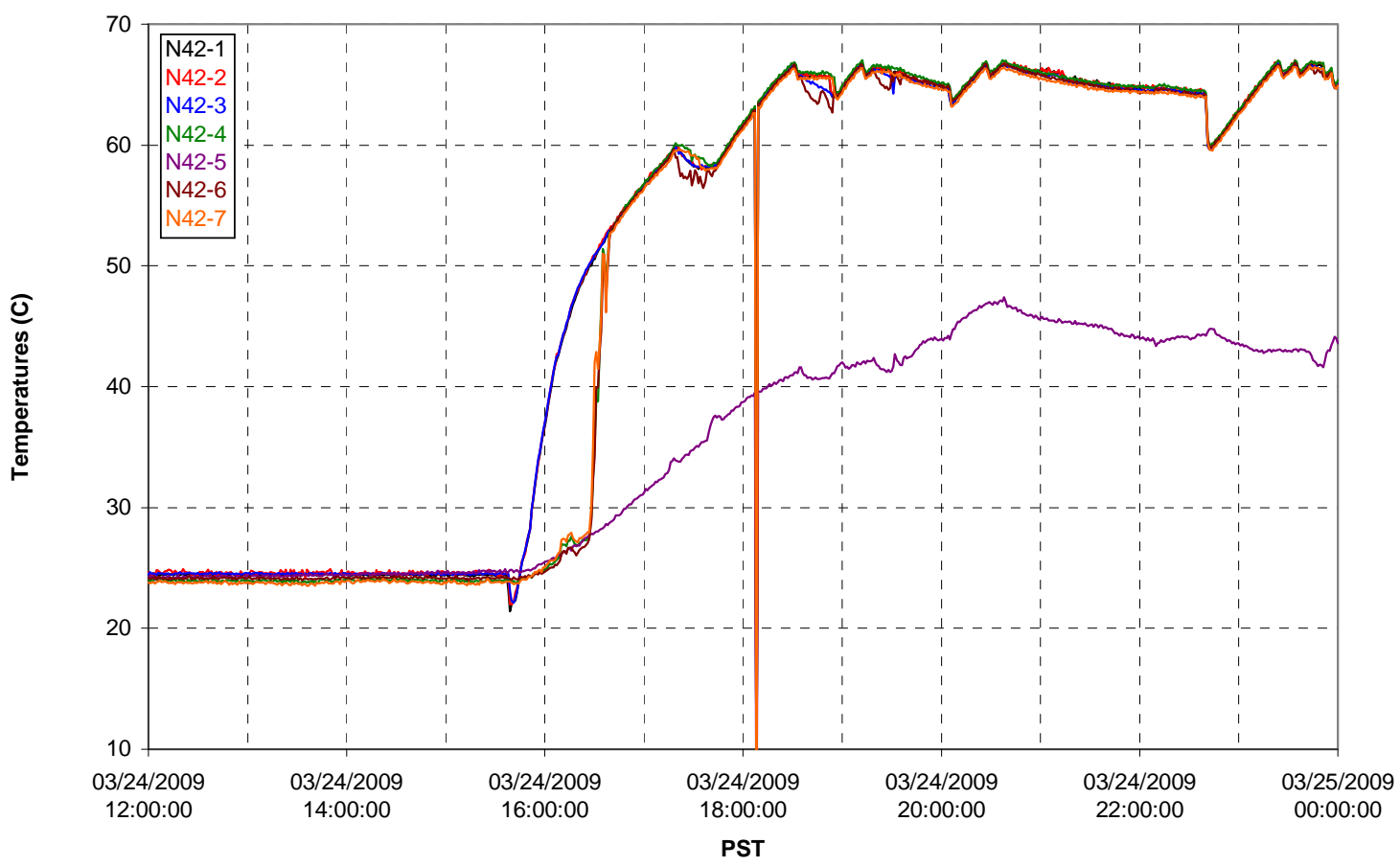

T02A temperatures

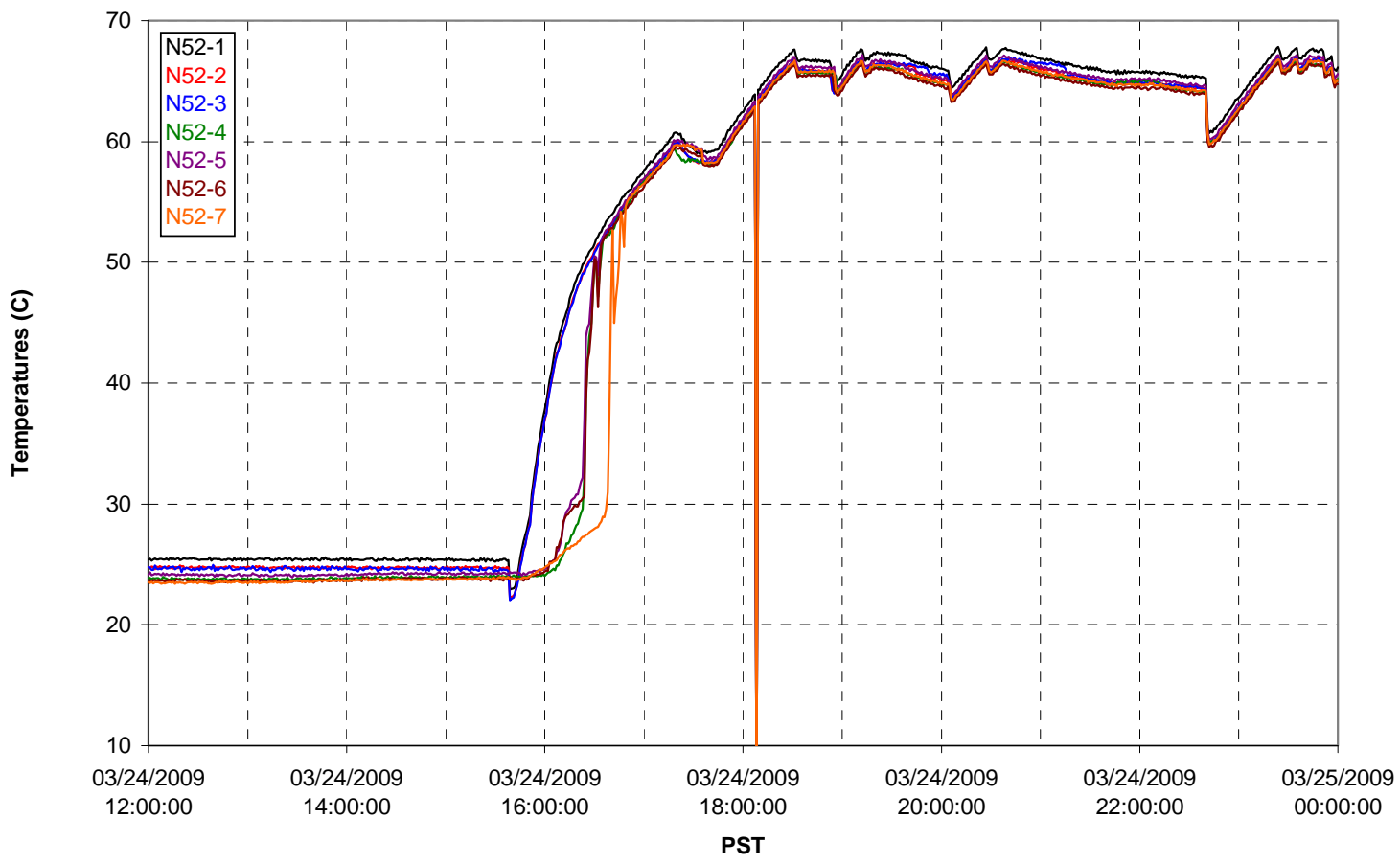


T02A Heating and Cooling
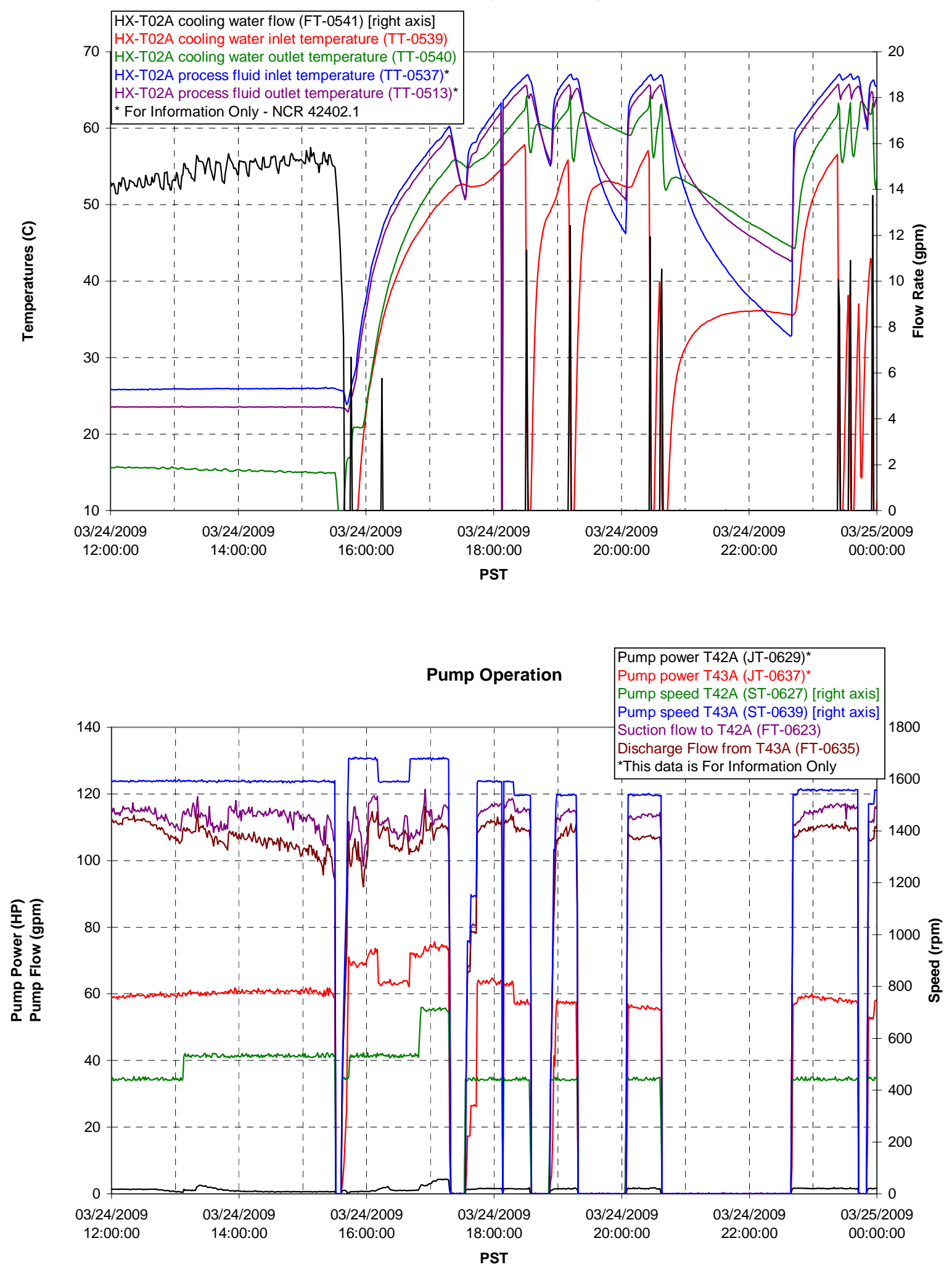
Pulsepot UFP-PP-T01A

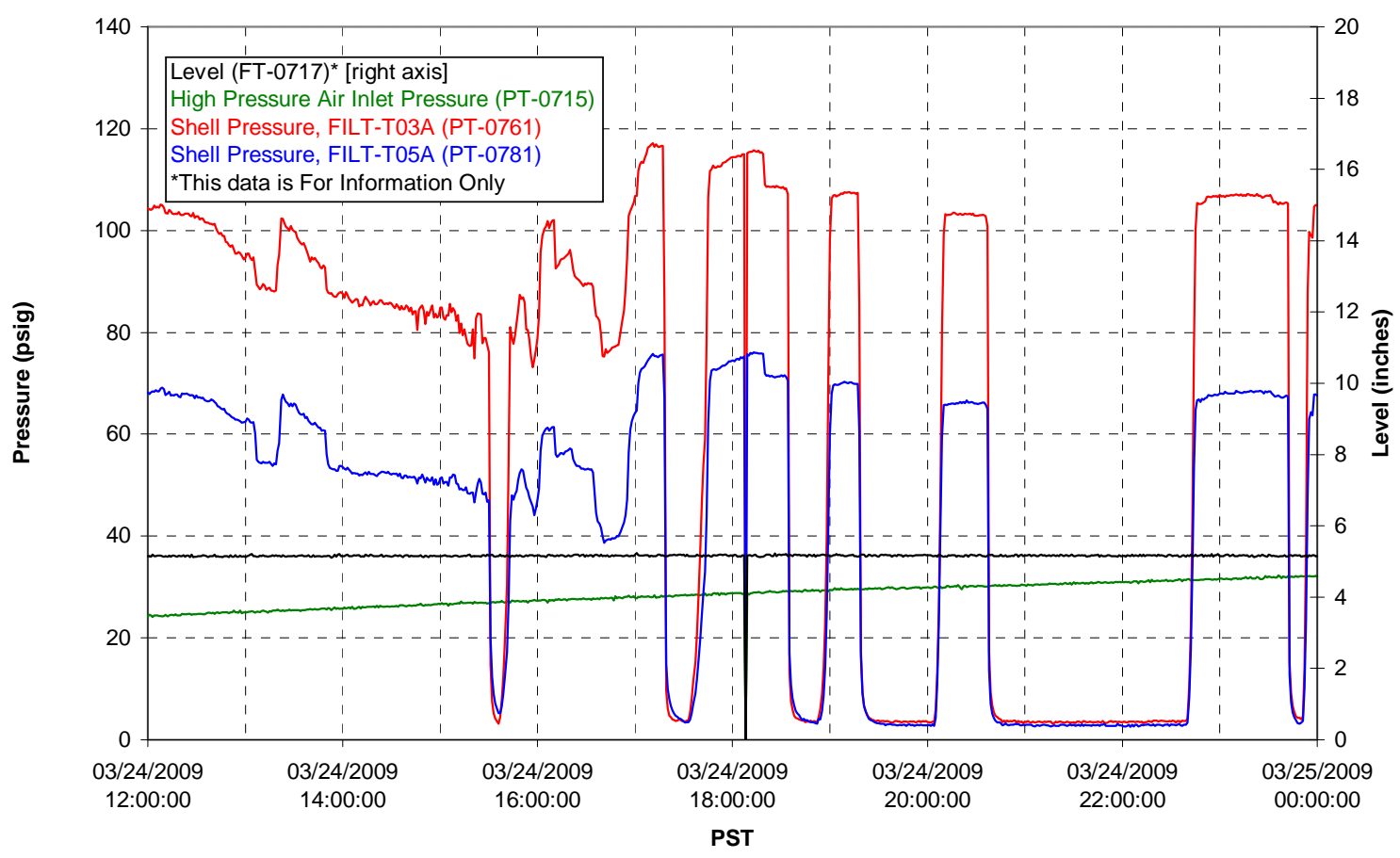

Pulsepot UFP-PP-T02A

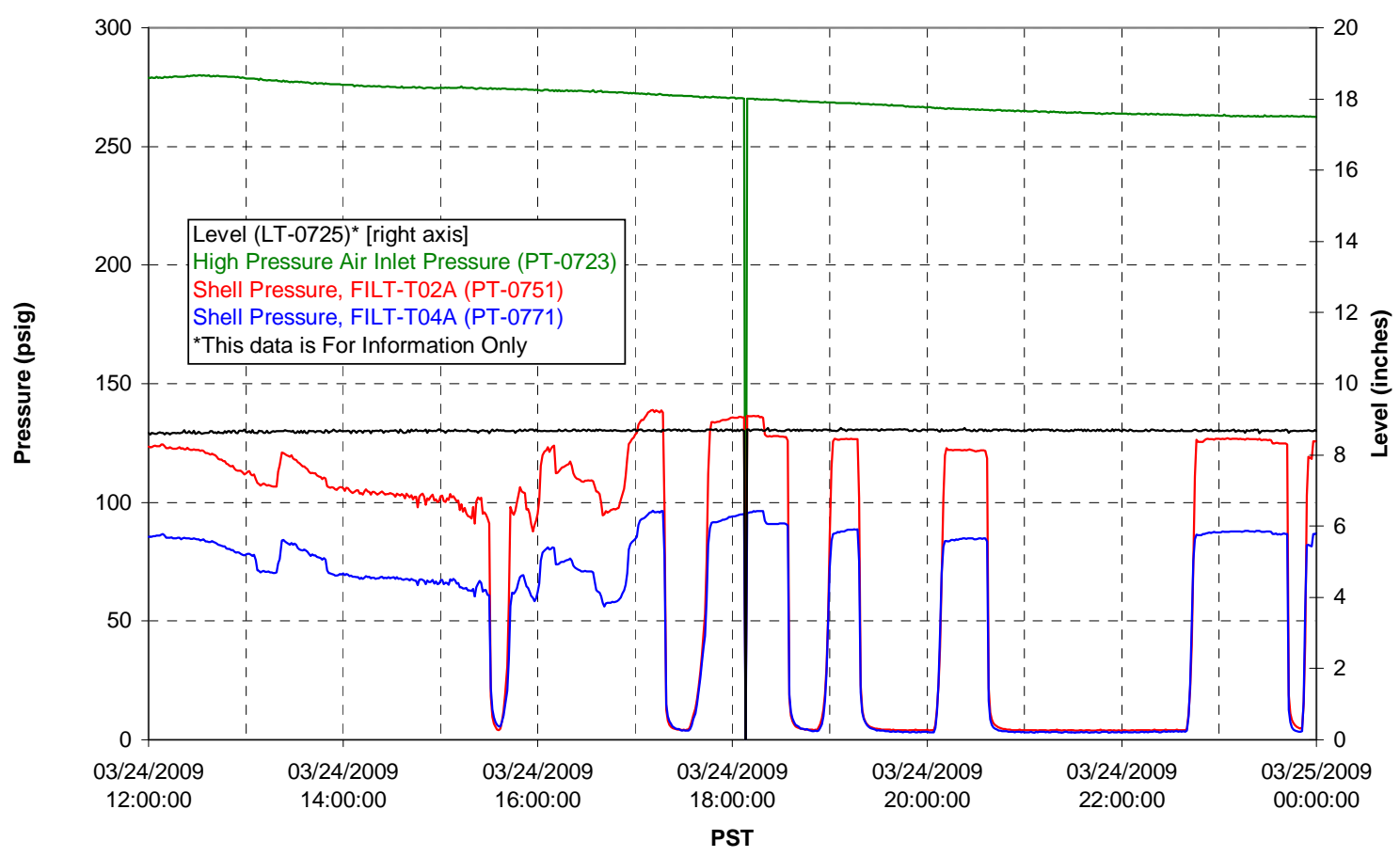


Pulsepot UFP-PP-T03A

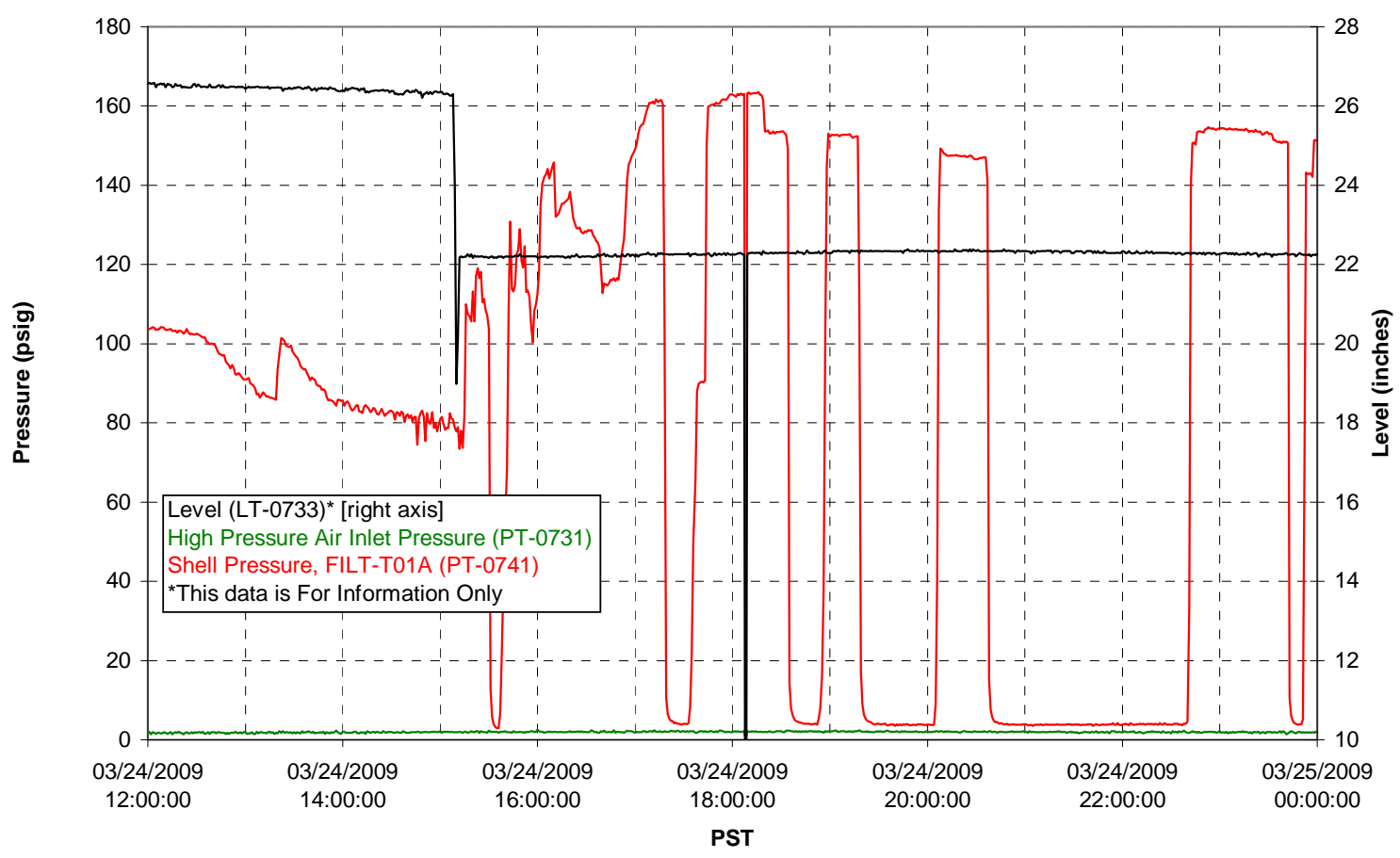

Pulsepot Levels

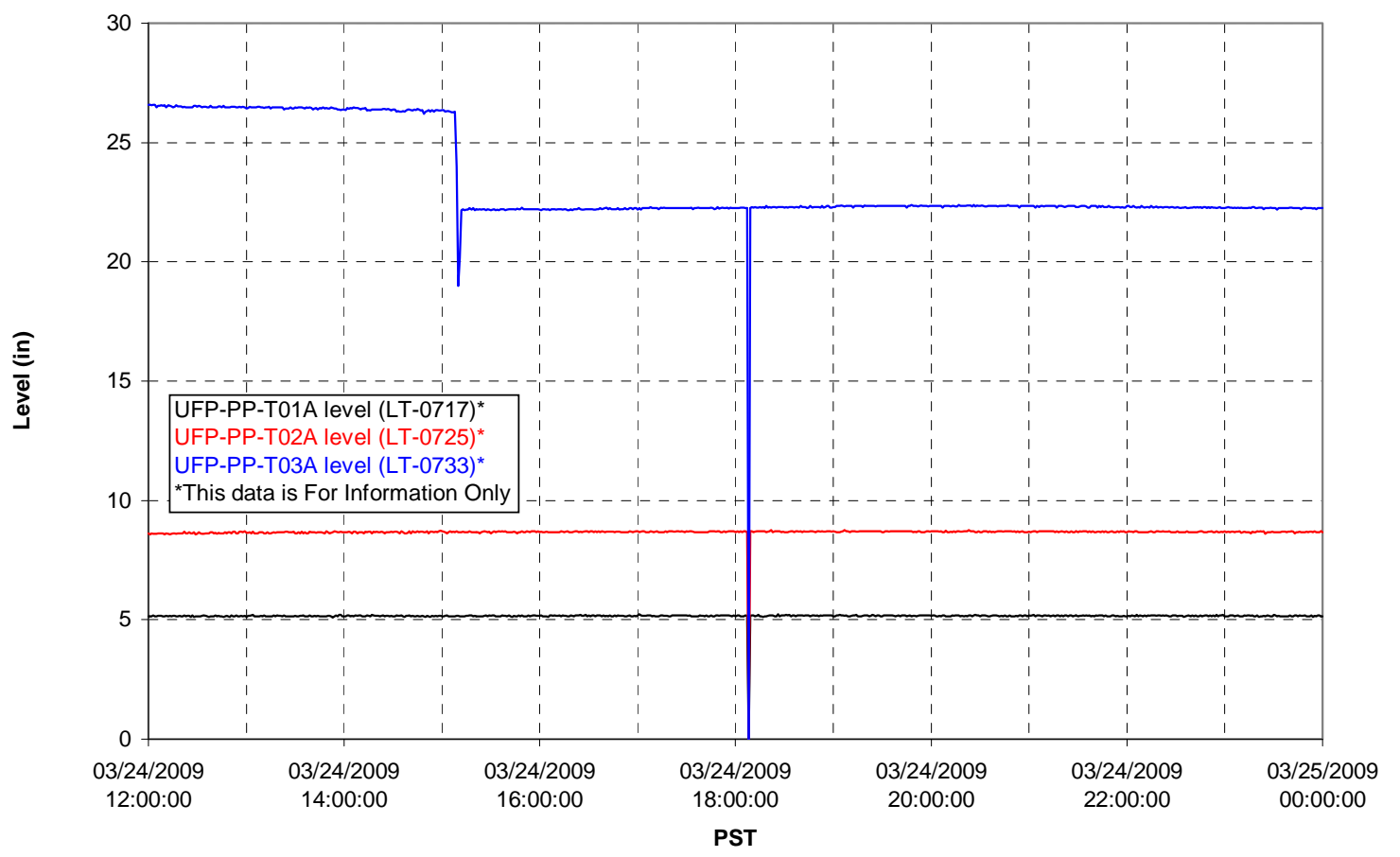


Filter UFP-FILT-T01A

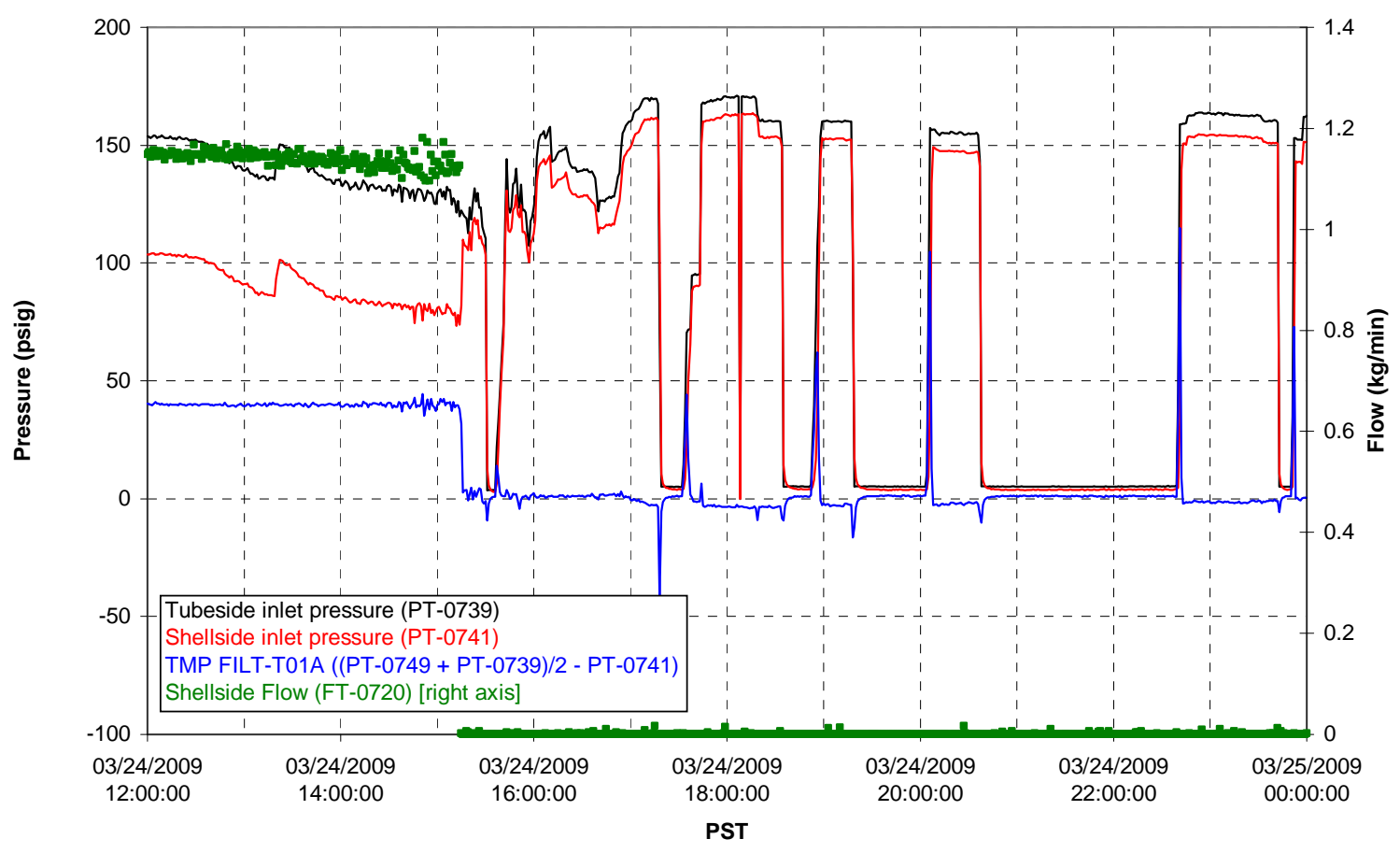

Filter UFP-FILT-T02A

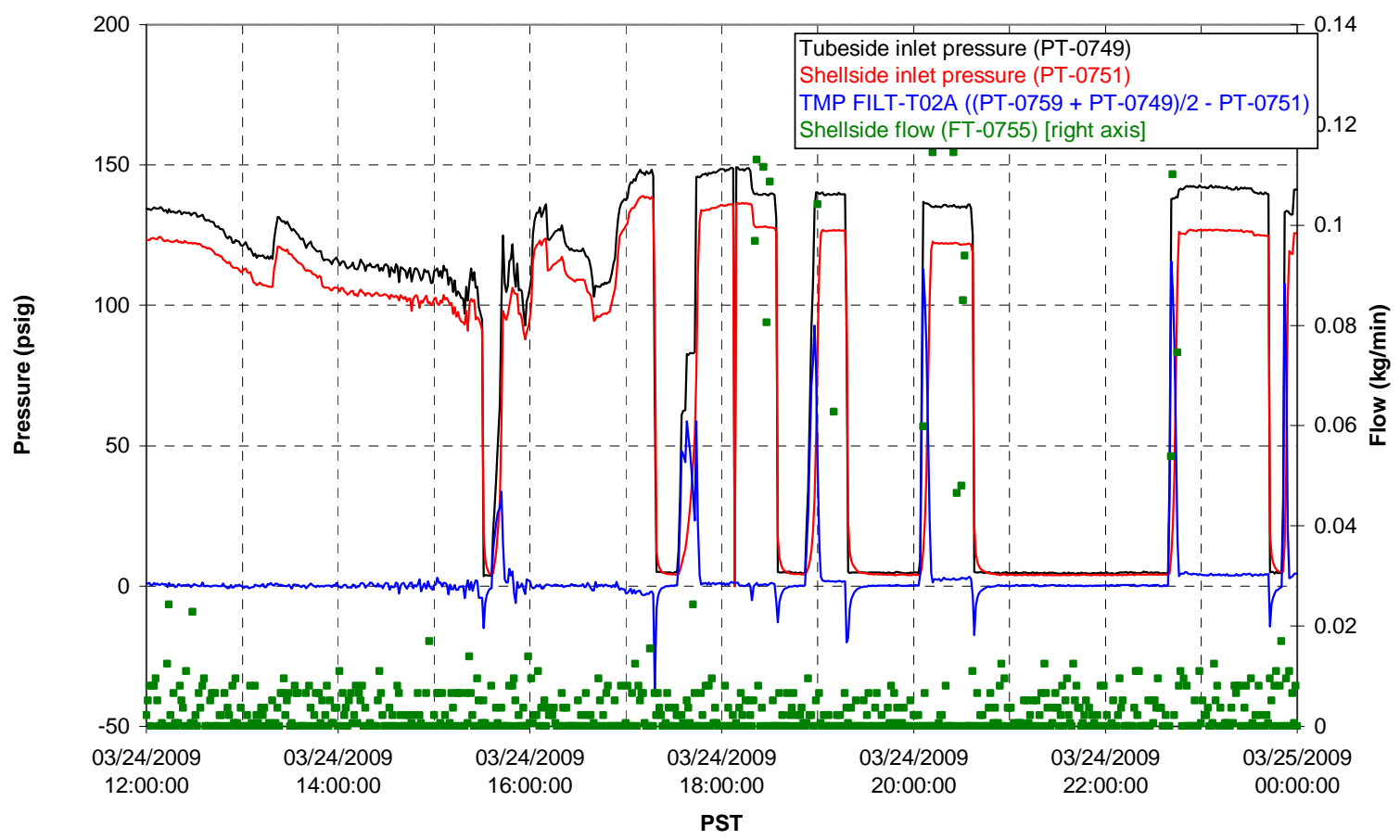


Filter UFP-FILT-T03A

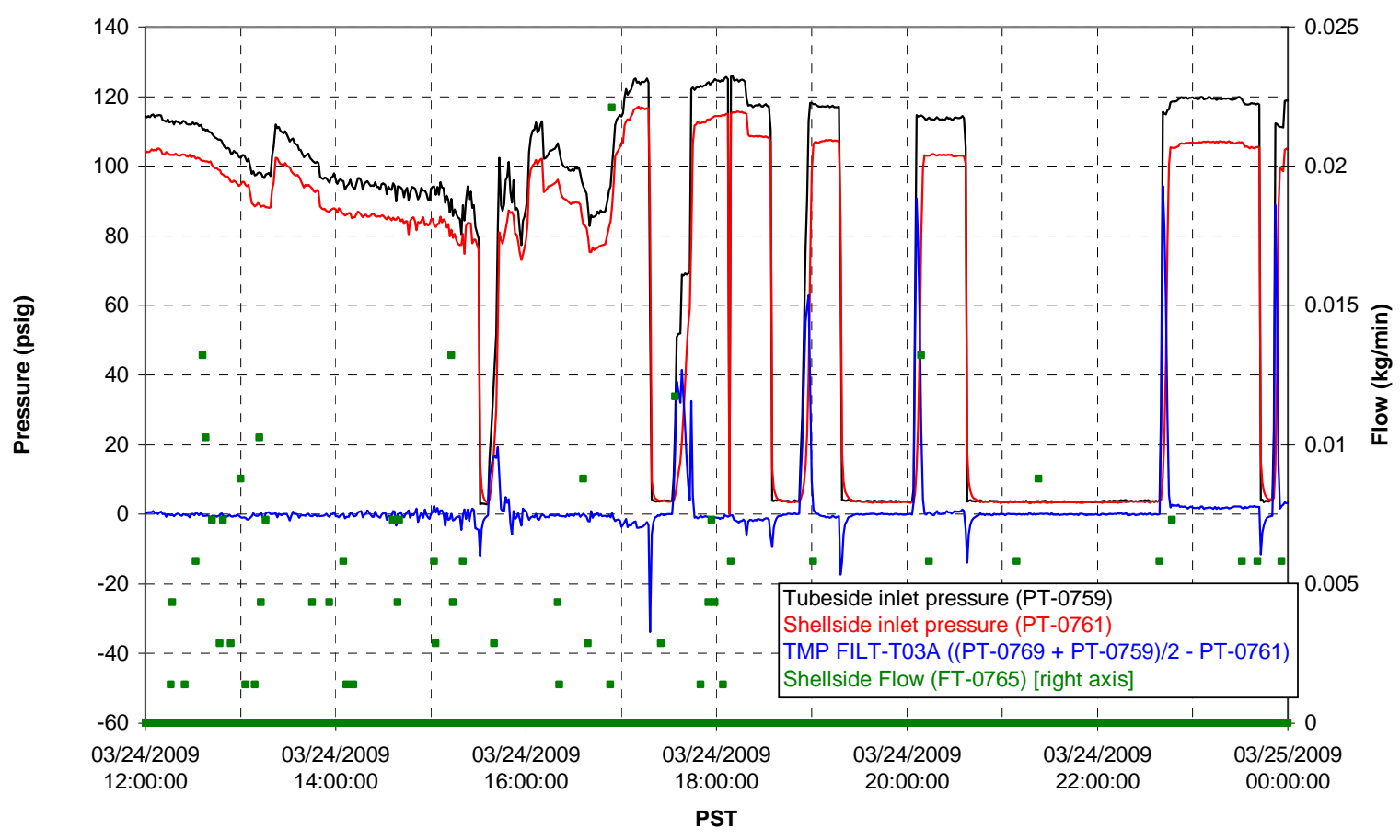

Filter UFP-FILT-T04A

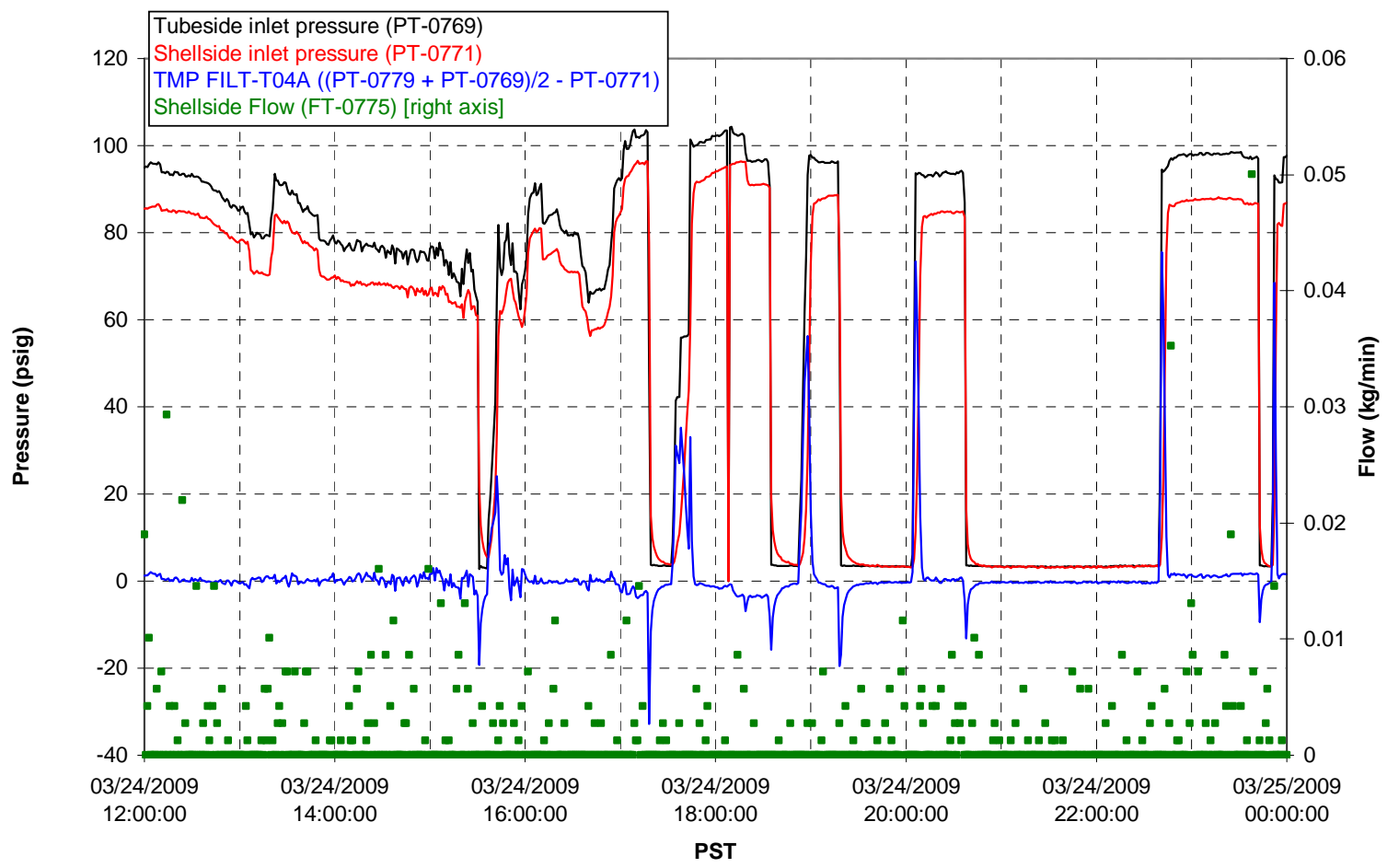


Filter UFP-FILT-T05A

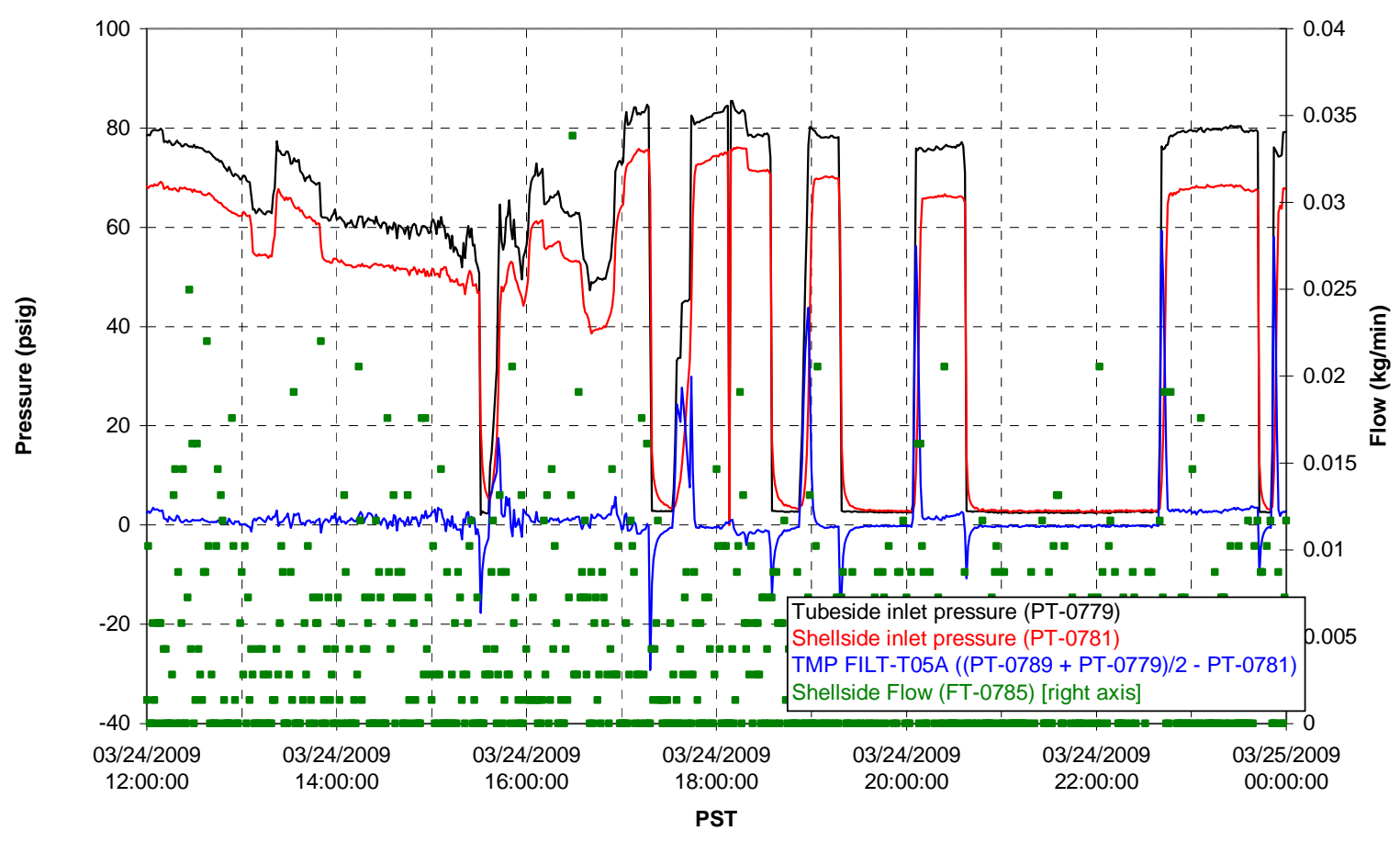

Chemical Flow

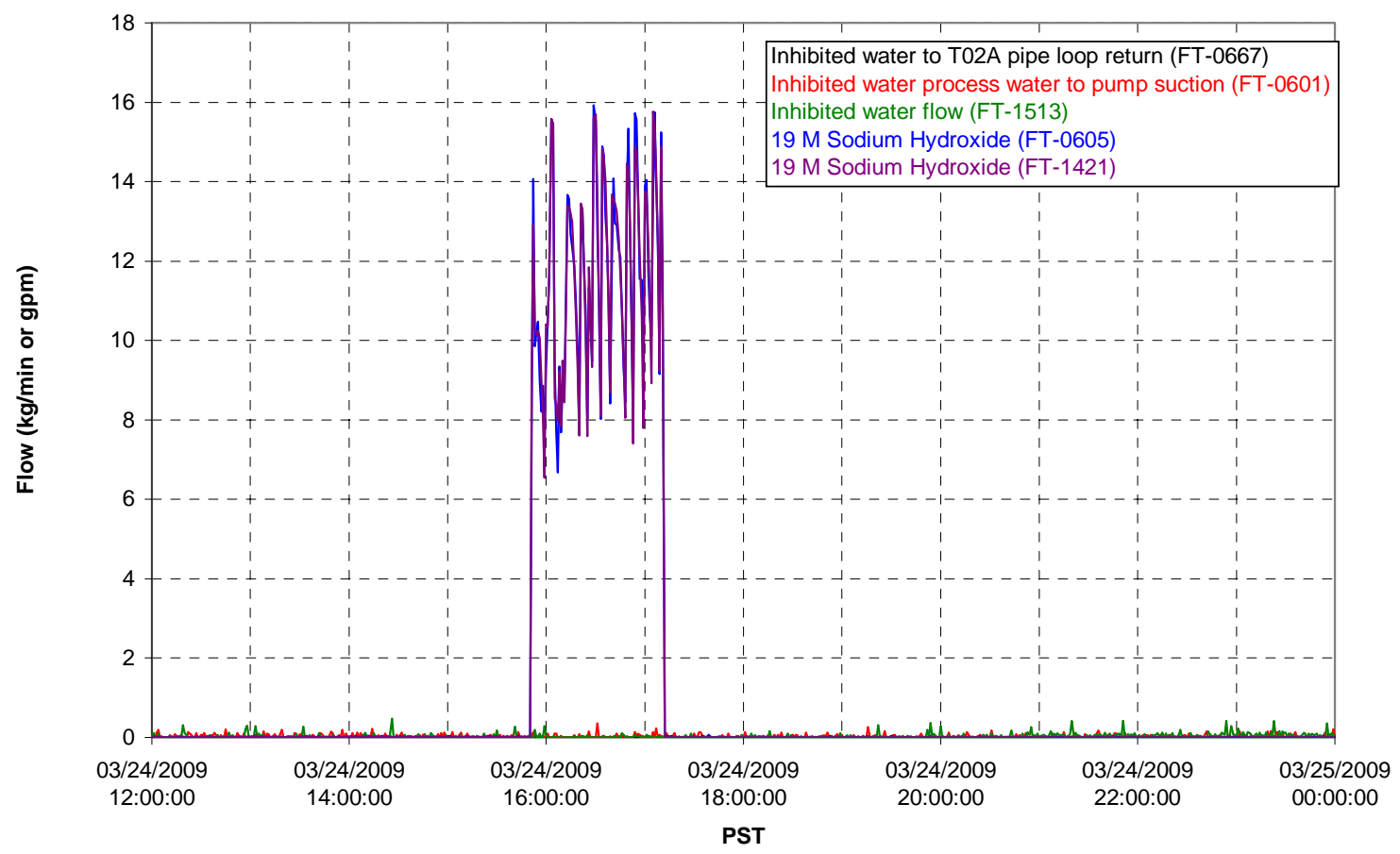




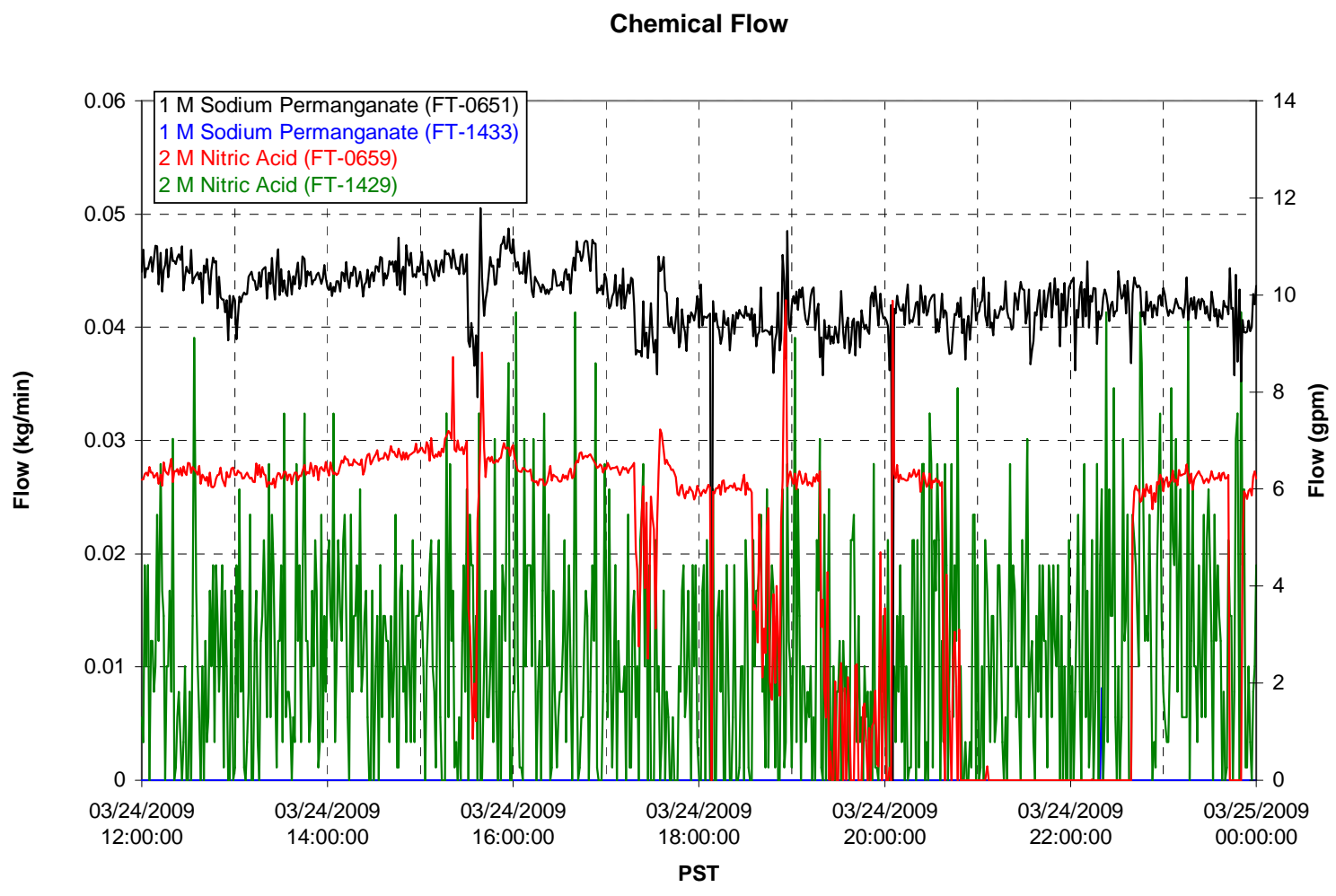

Air Flows

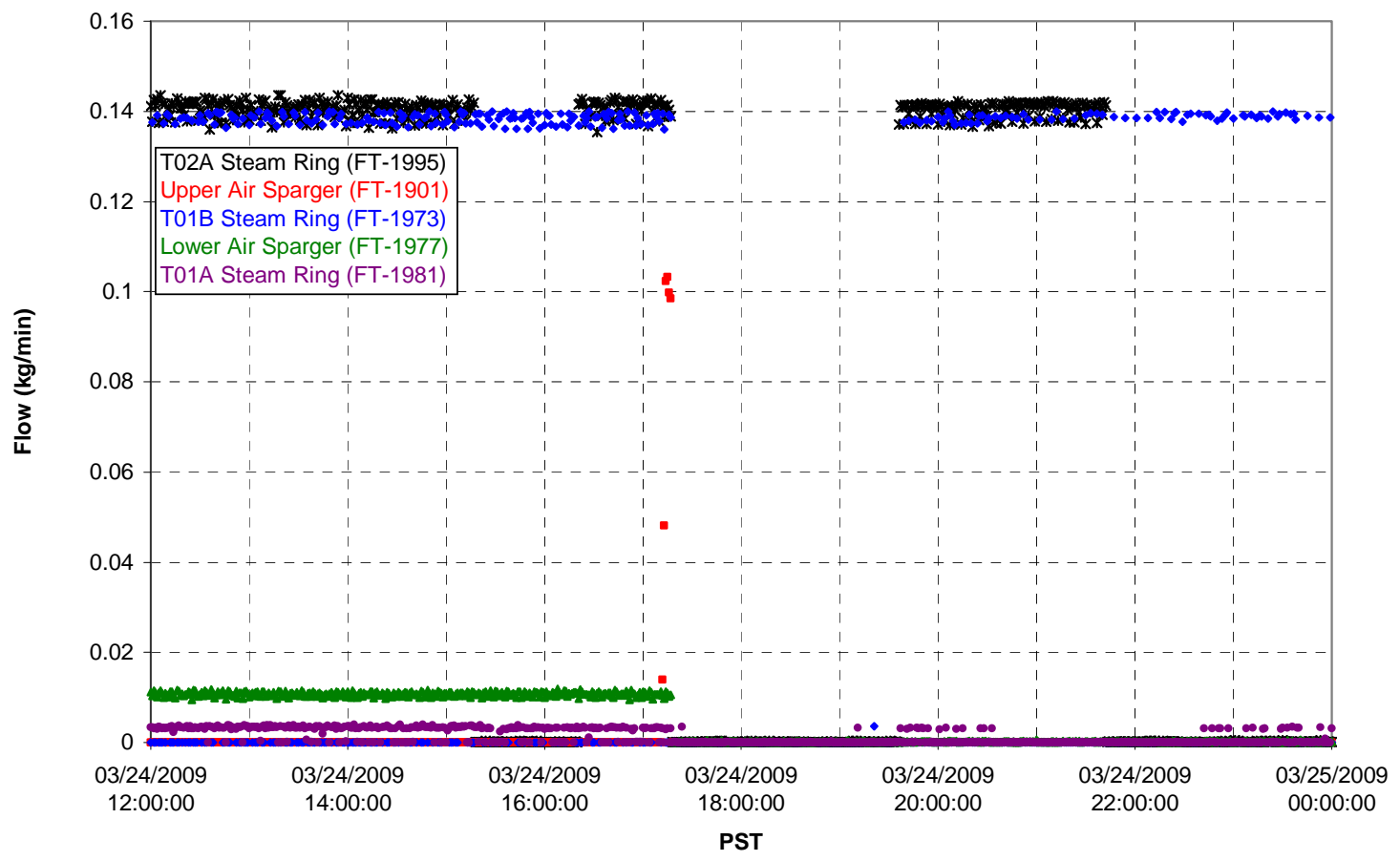


T02A Steam

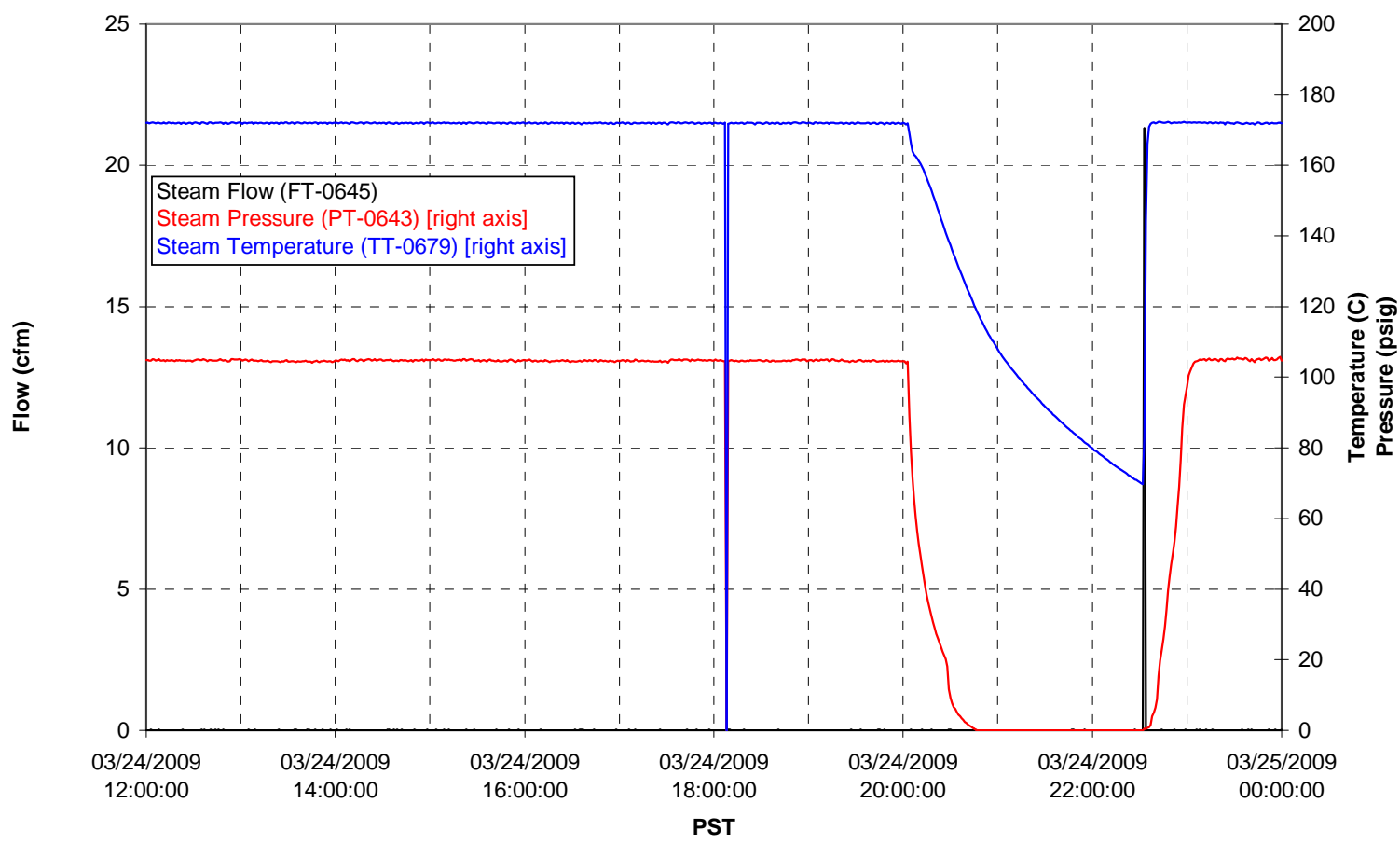

T01A Steam

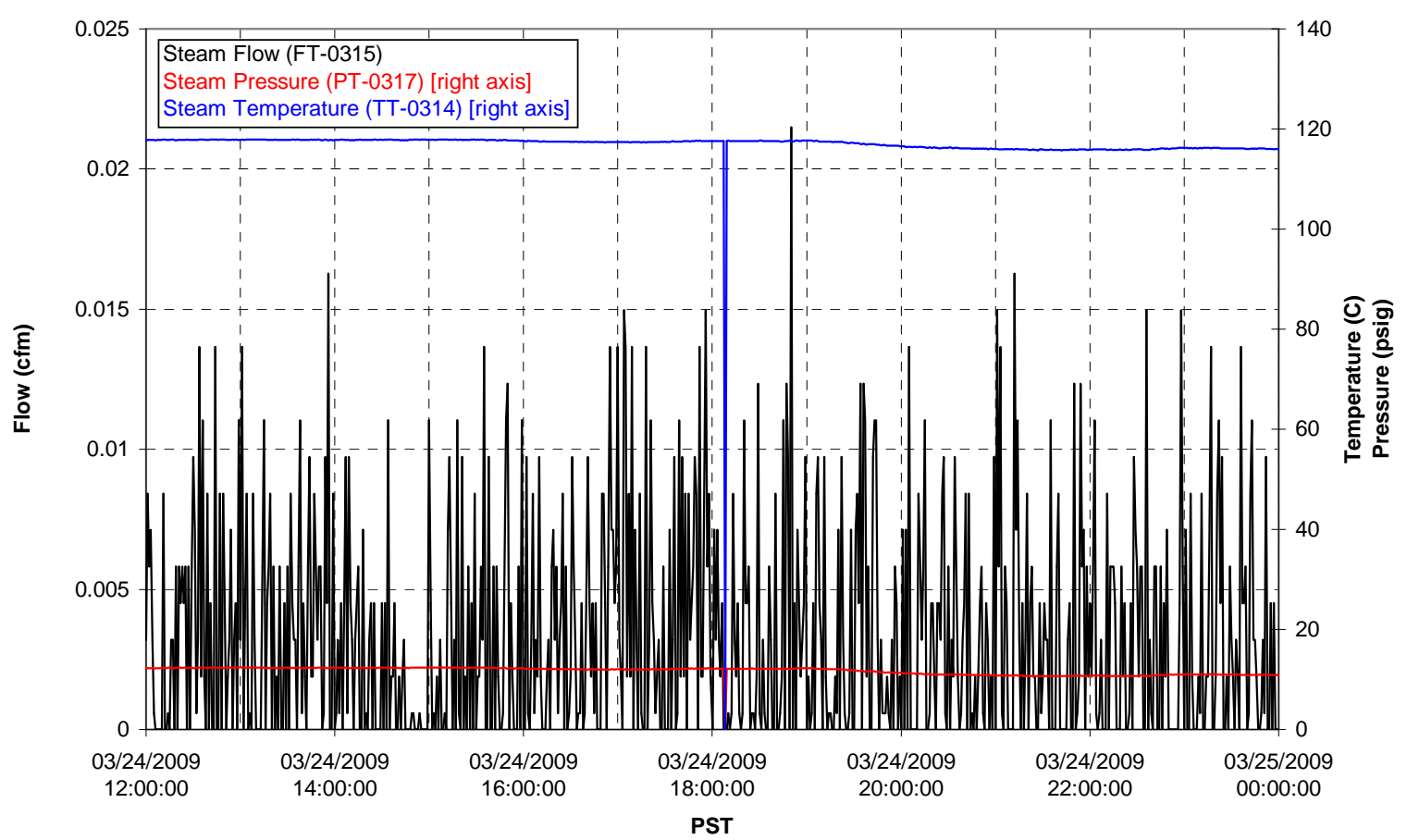


T01B Steam

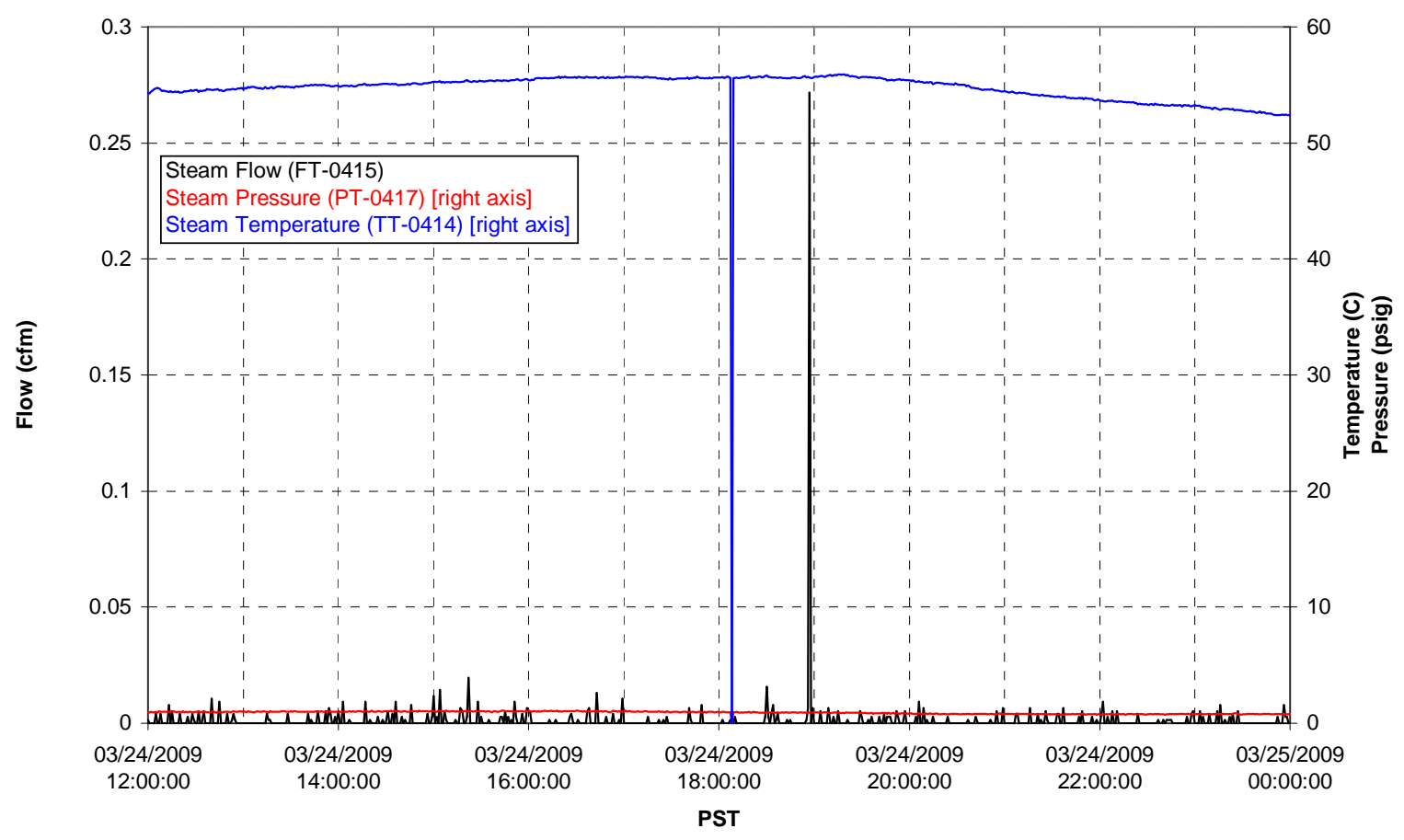




\section{Integrated Test D Data Plots 03/25/09 00:00 - 03/25/09 12:00}


T01A level

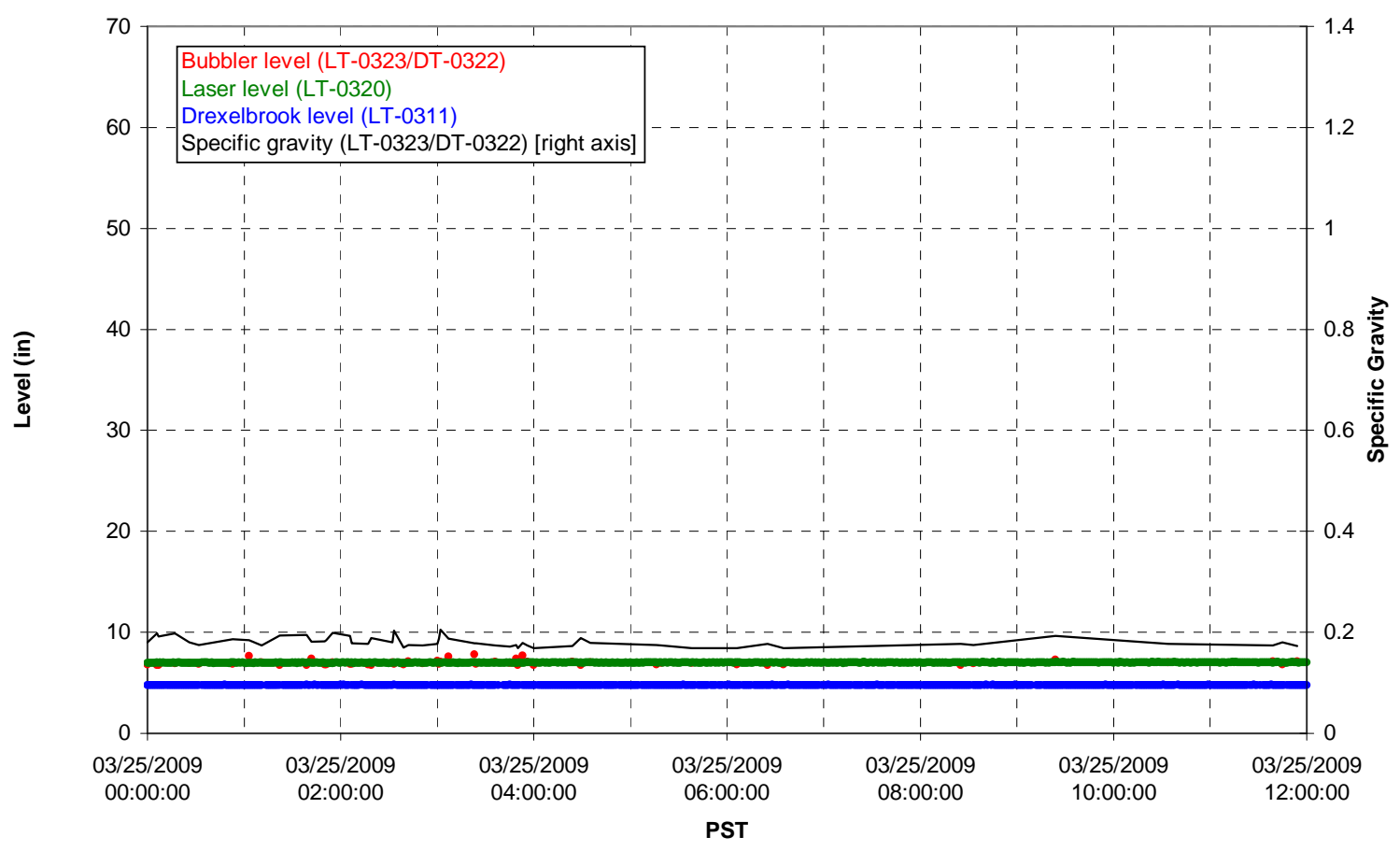

T01A temperatures

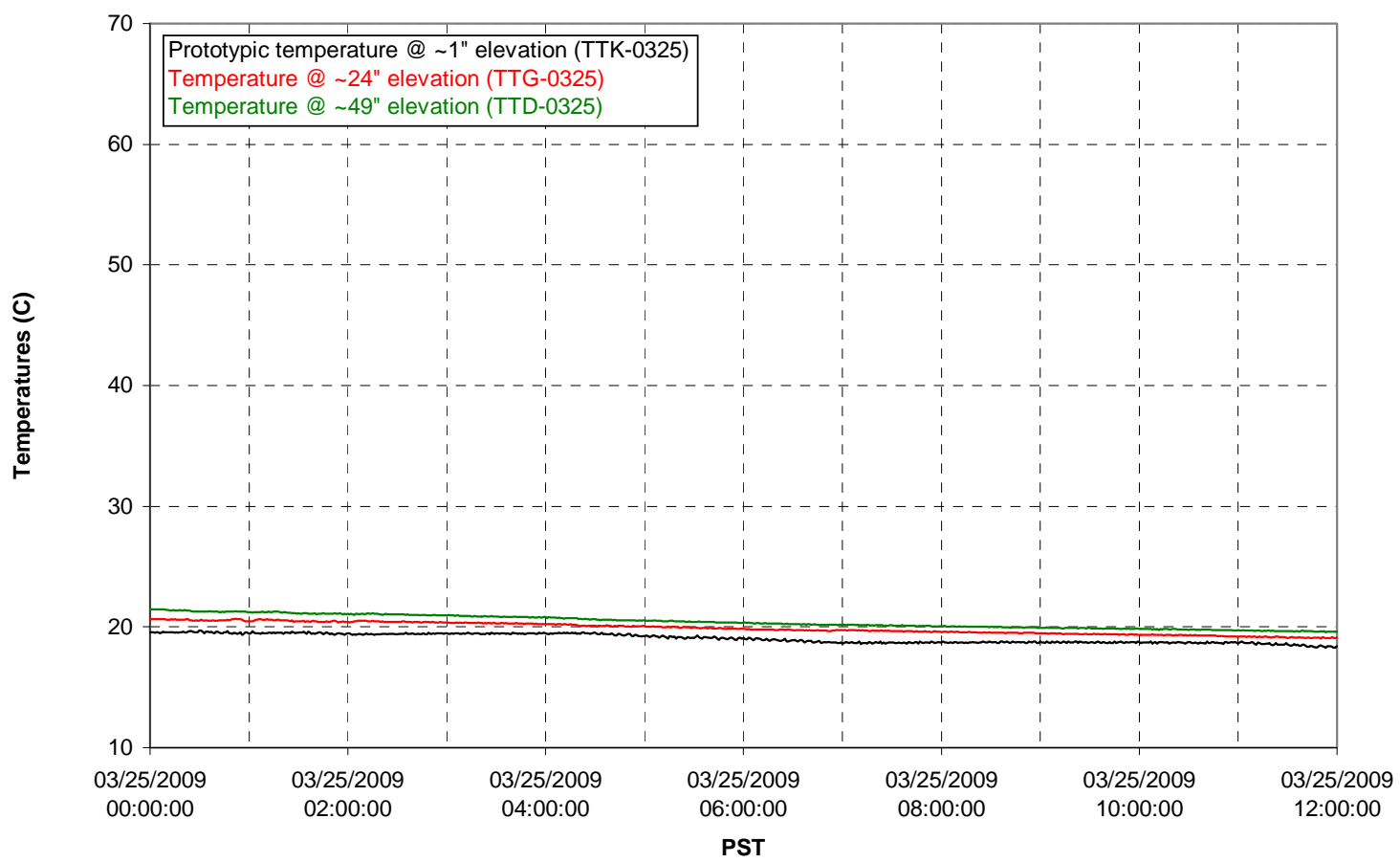


T01B level

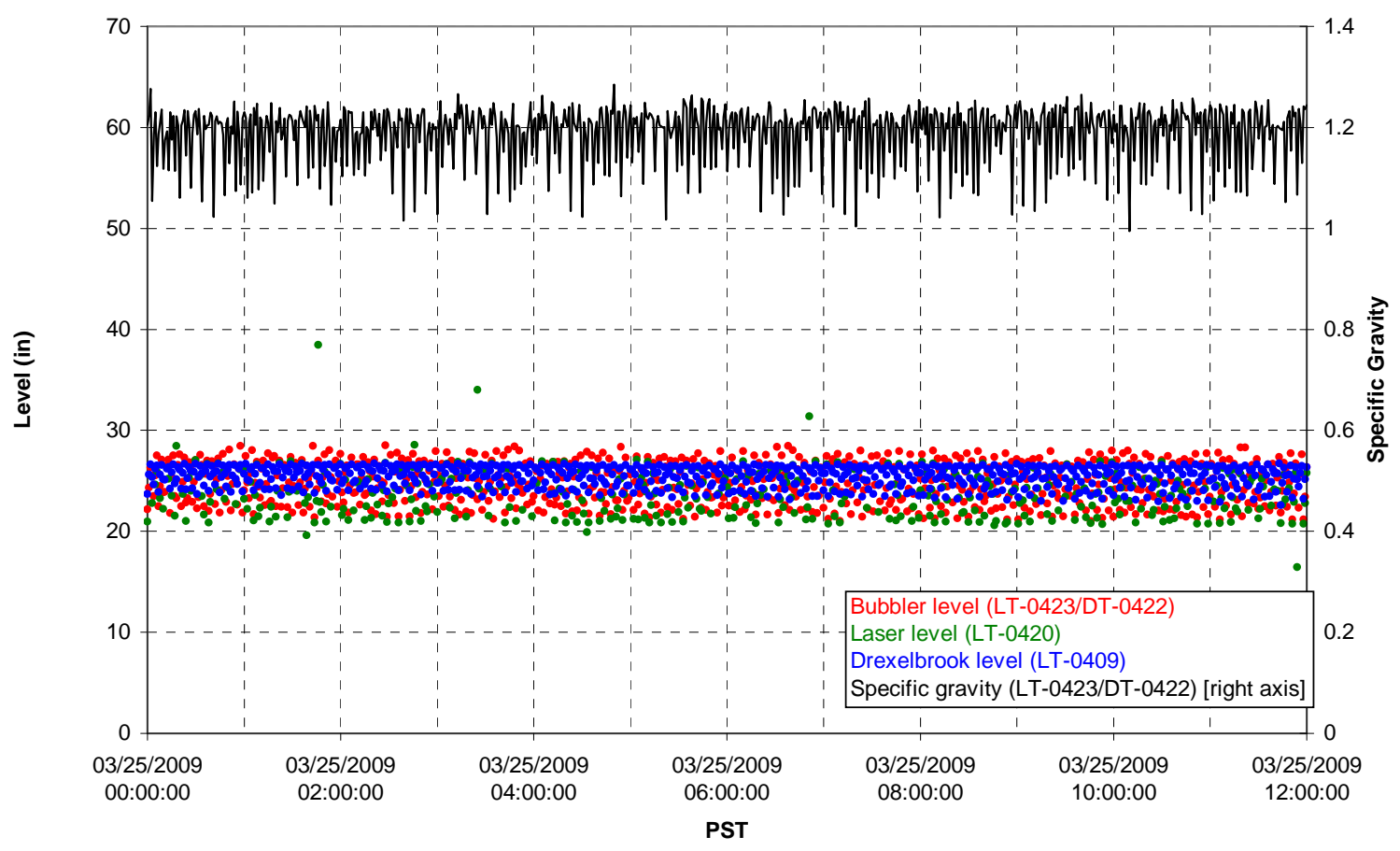

T01B temperatures

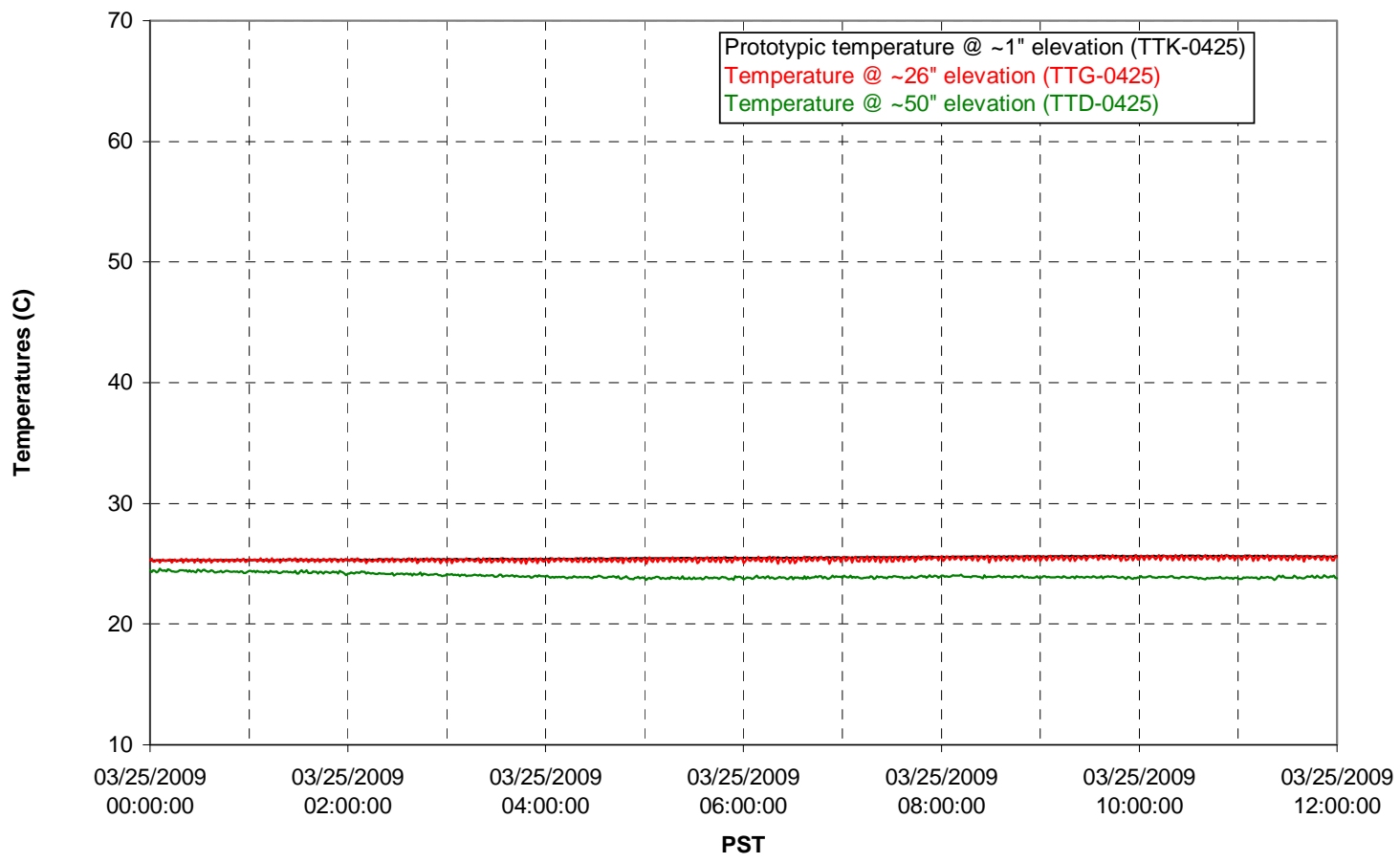


T02A level

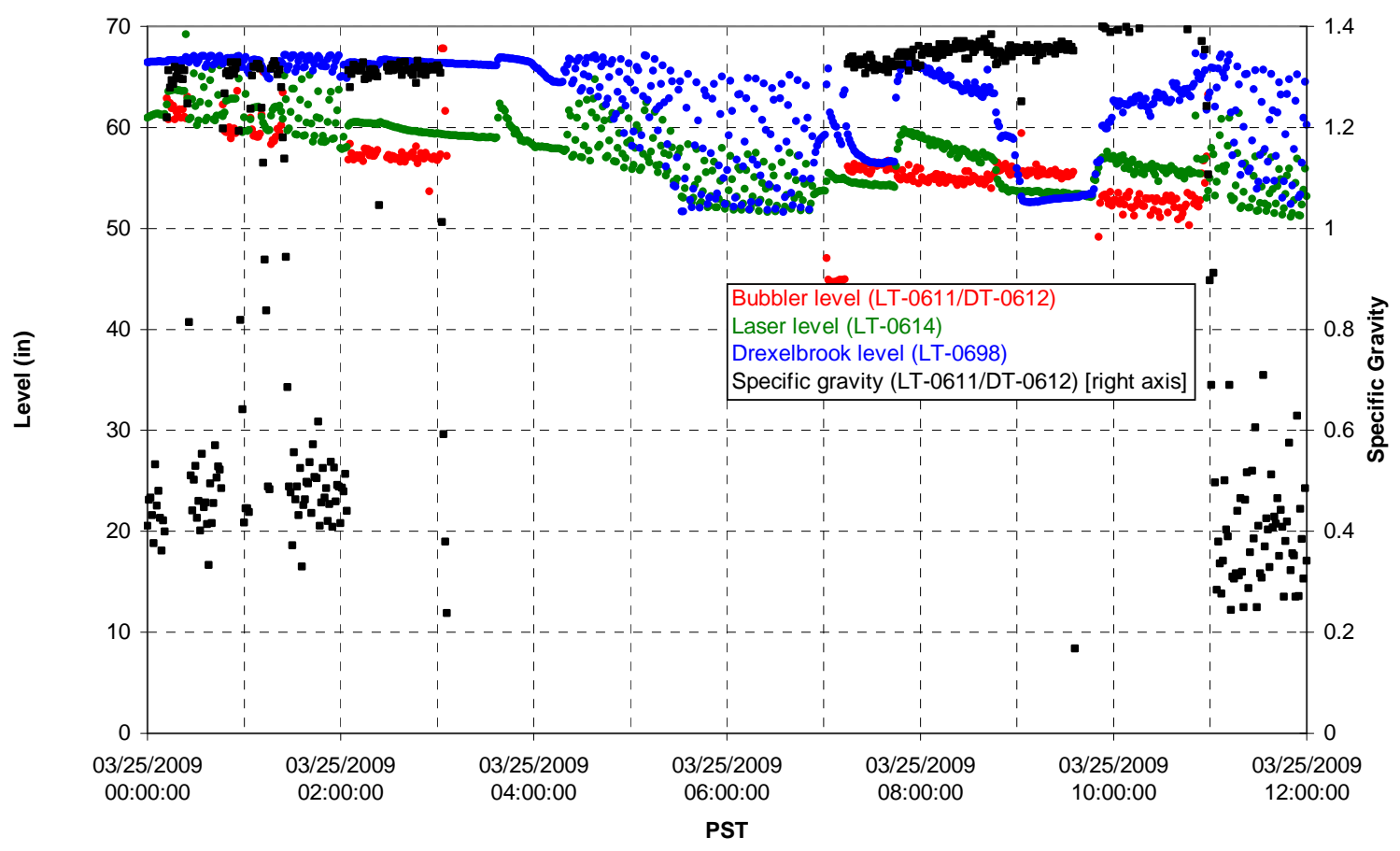

T02A temperatures

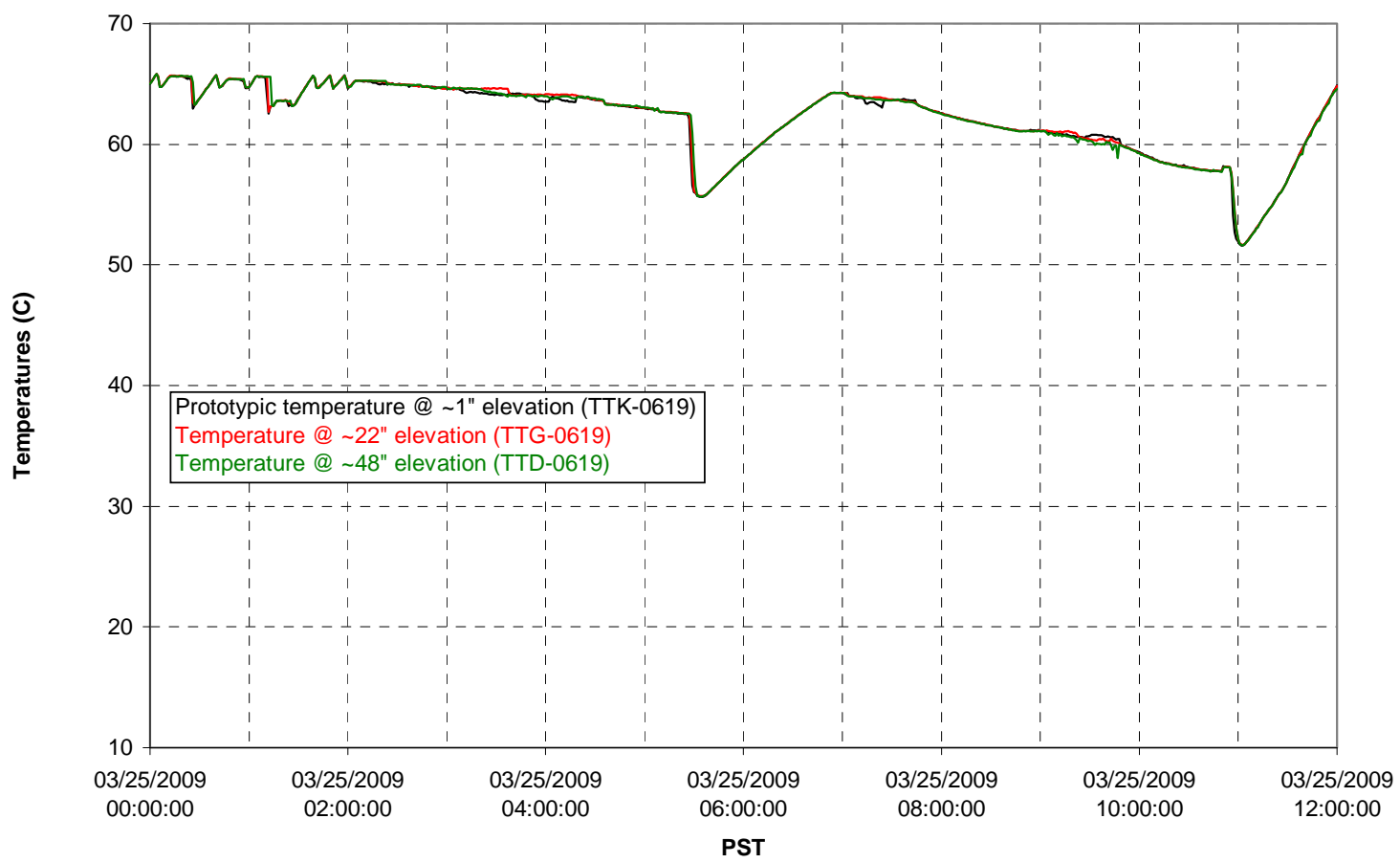


T02A and filter loop temperatures

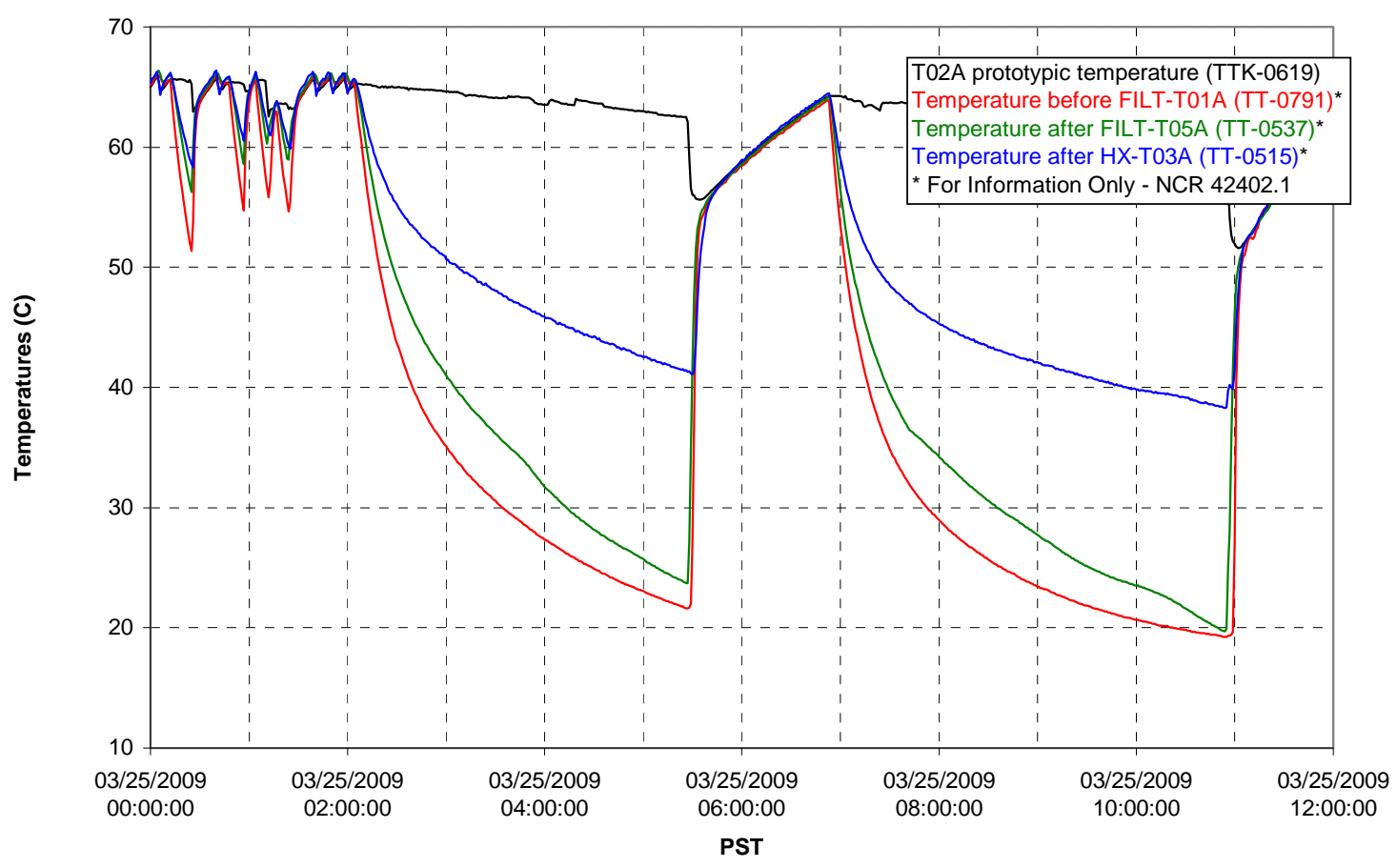

Pump Pressures and Flow

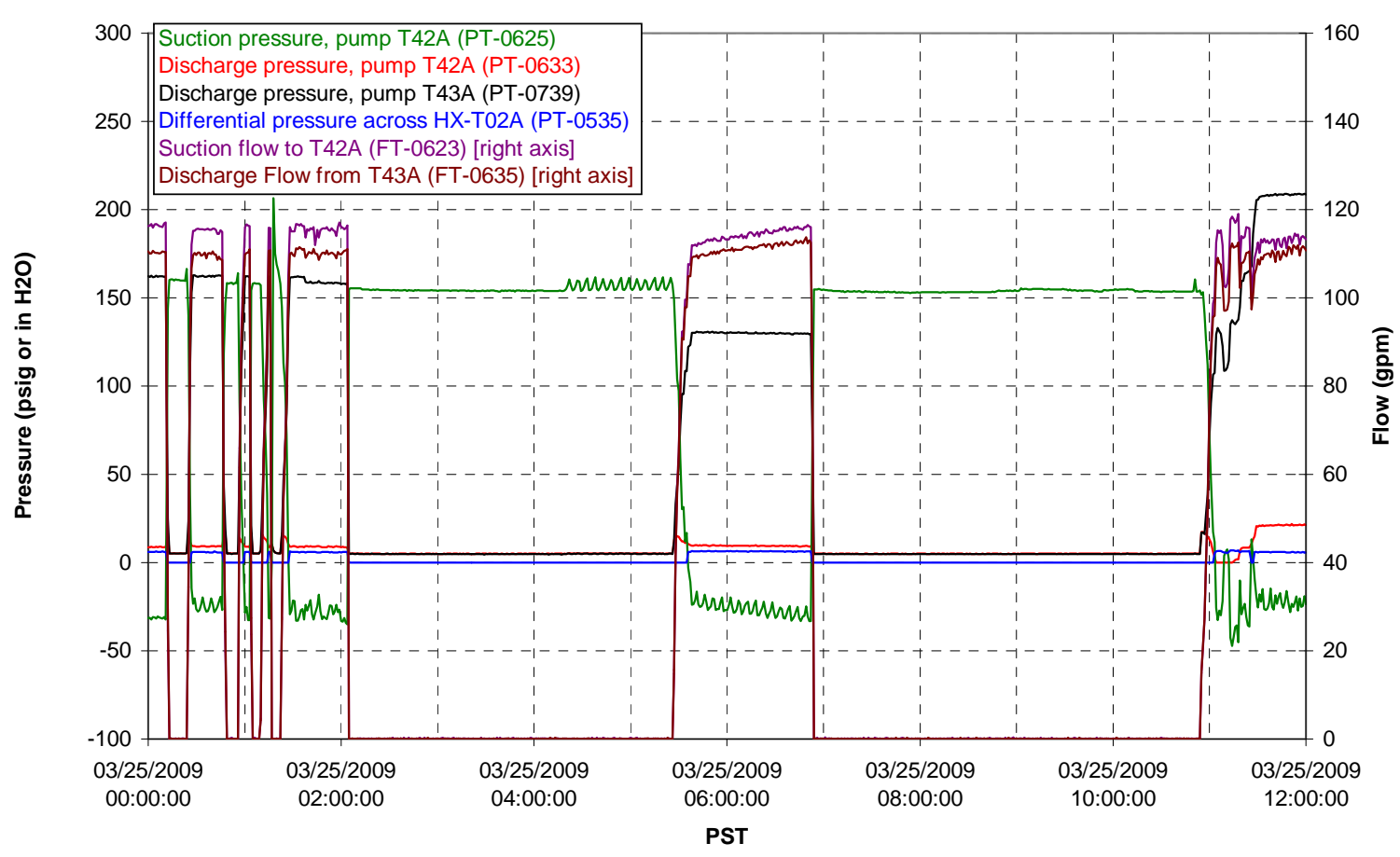




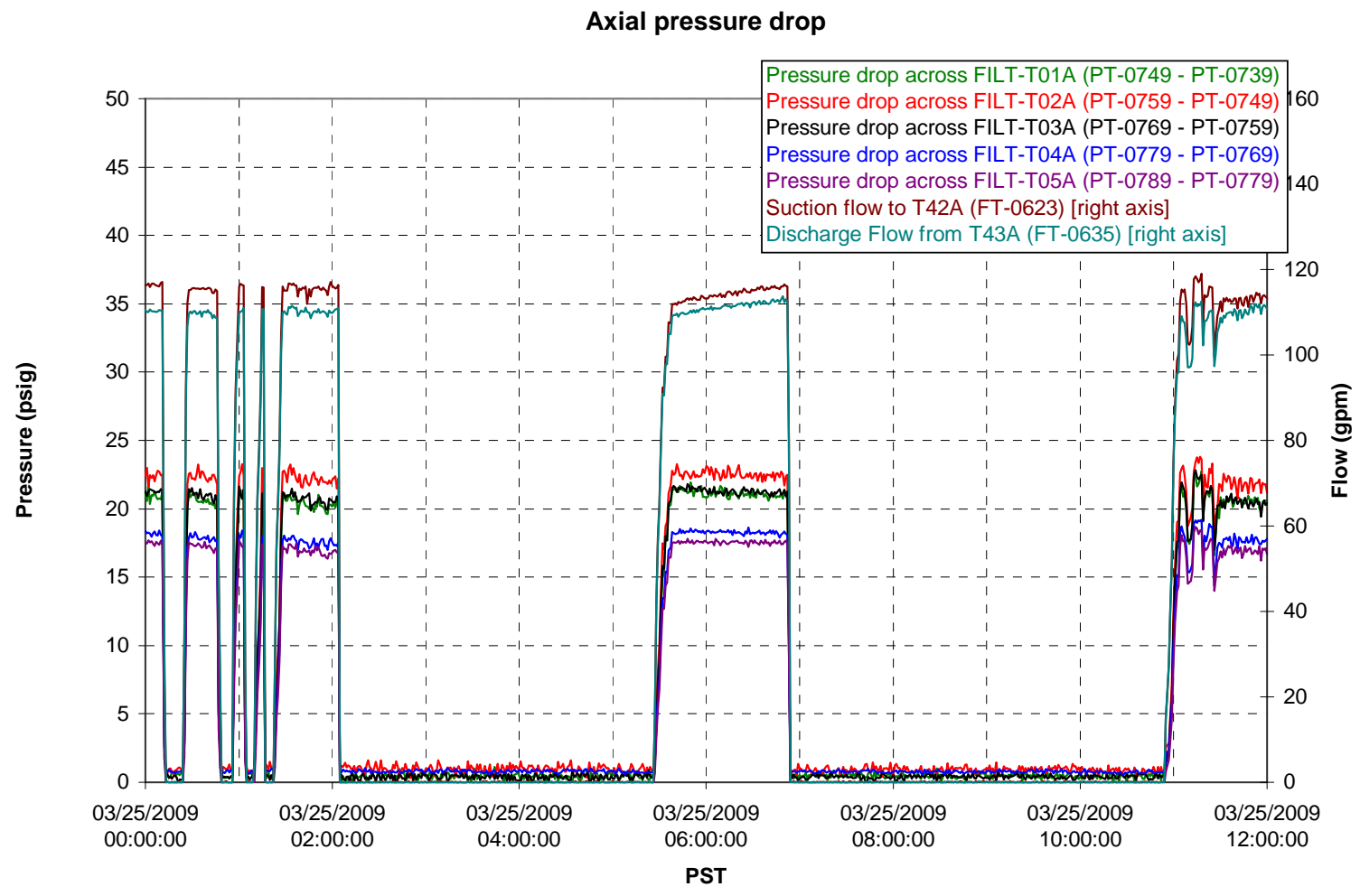

Permeate flow rates

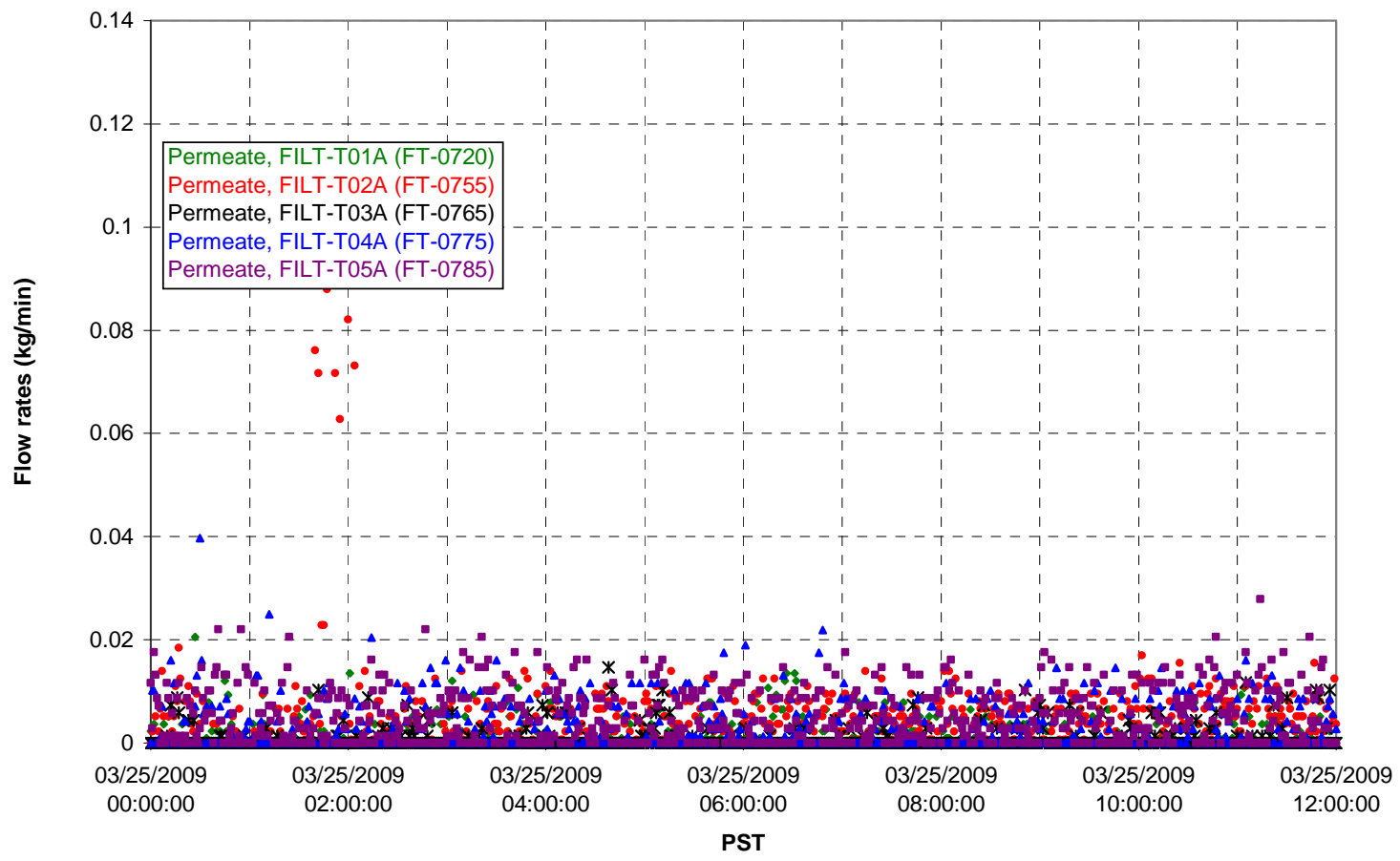


T02A Inner Temperature Tree

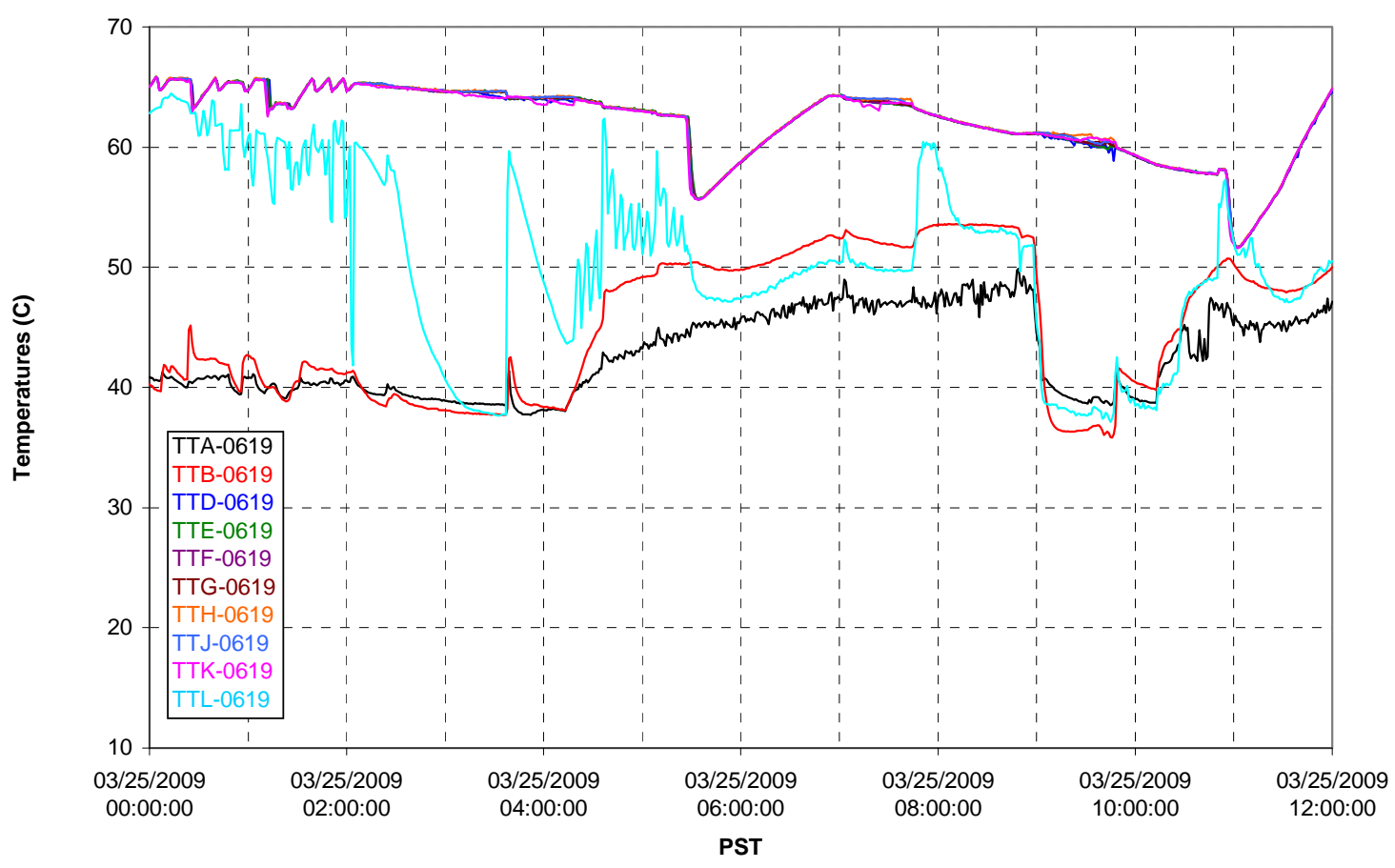

T02A Outer Temperature Tree

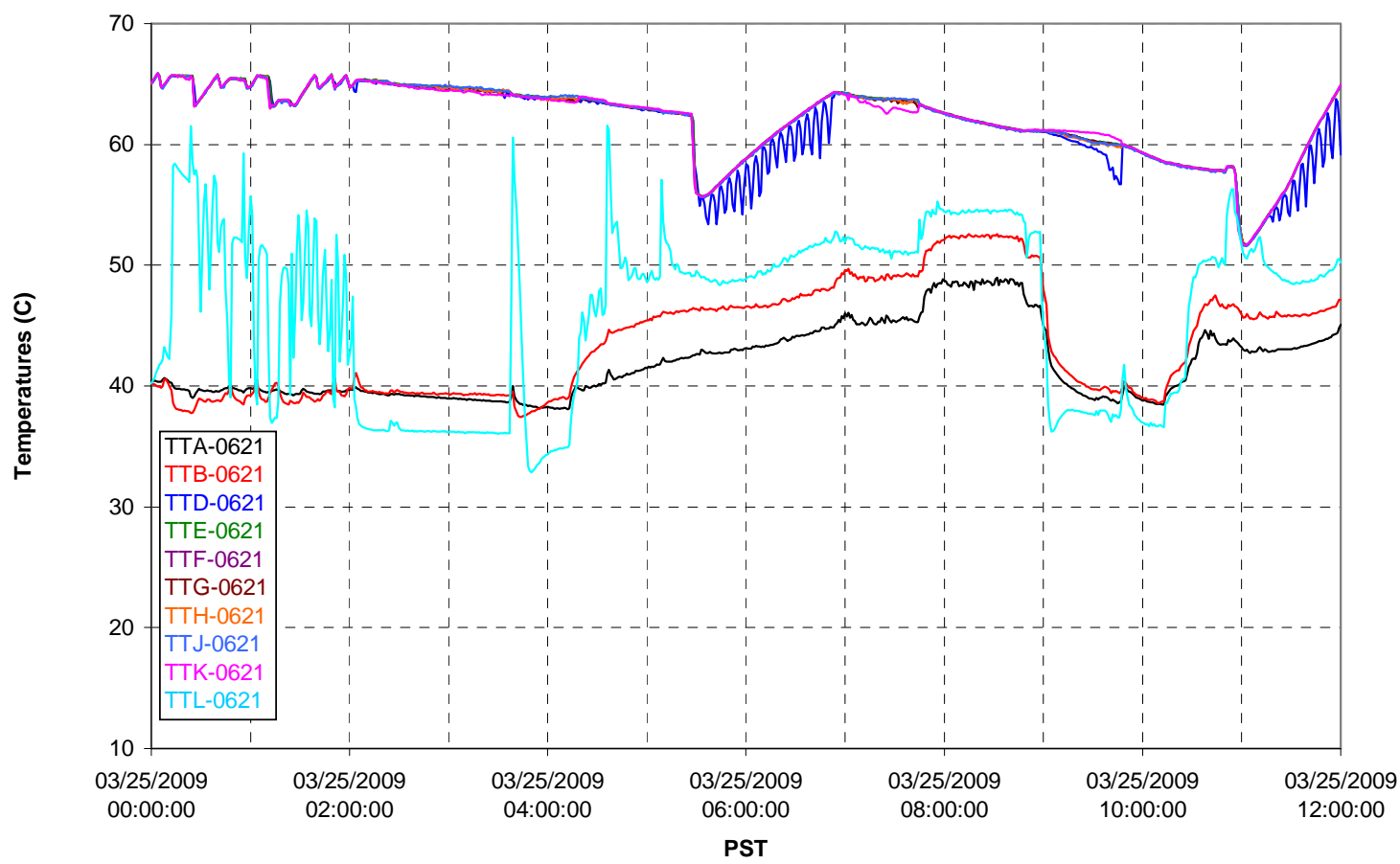


T02A temperatures

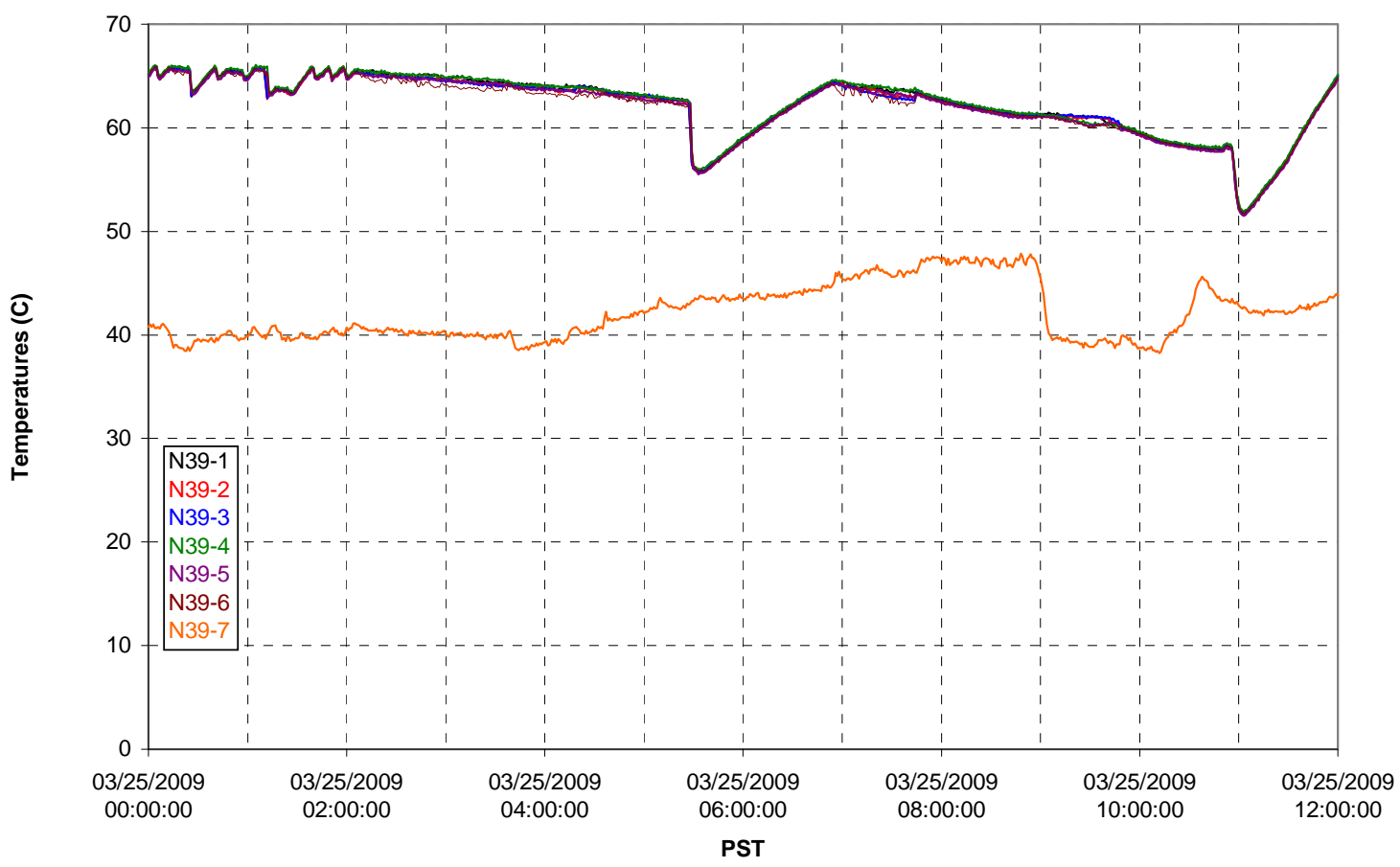

T02A temperatures

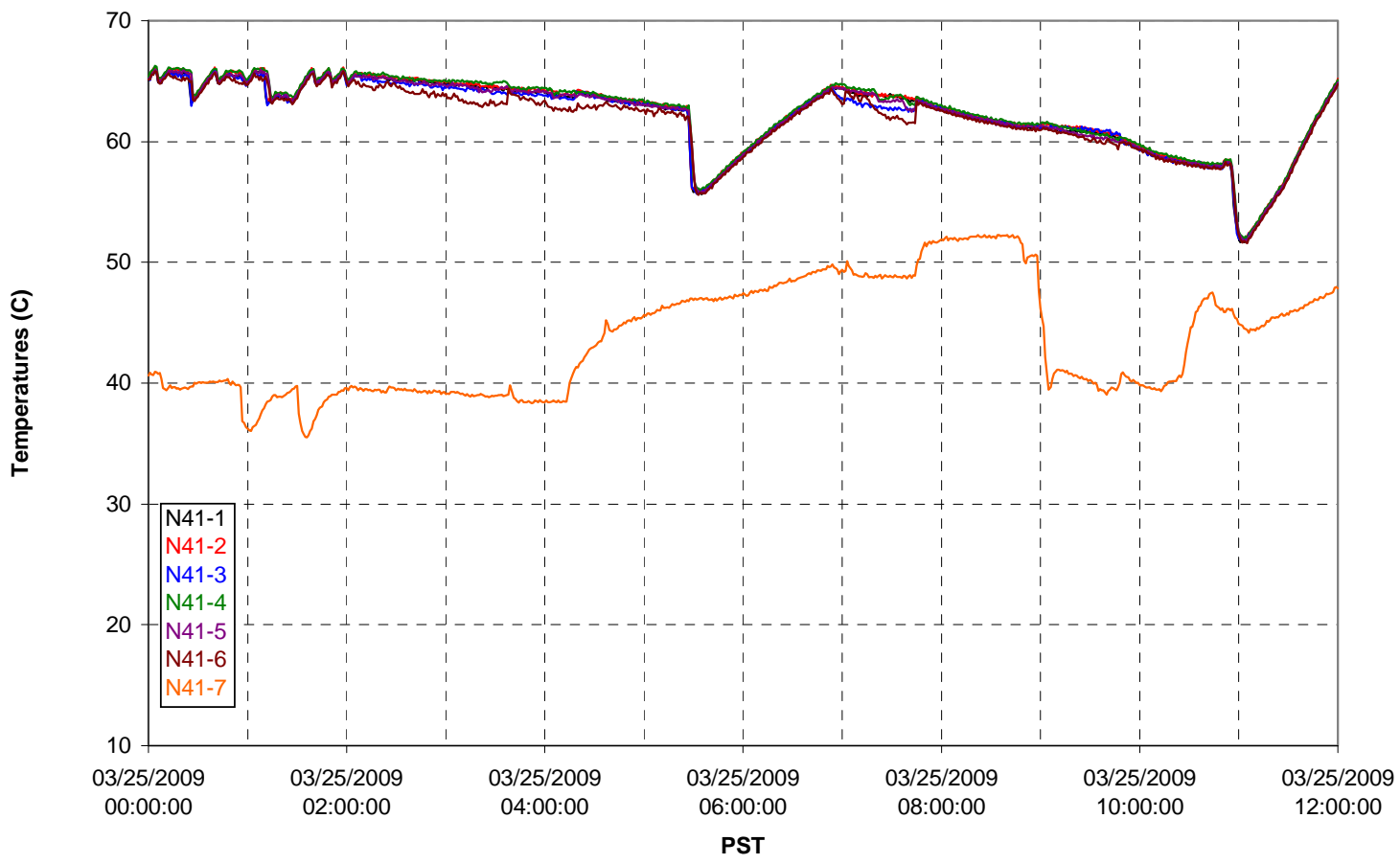


T02A temperatures

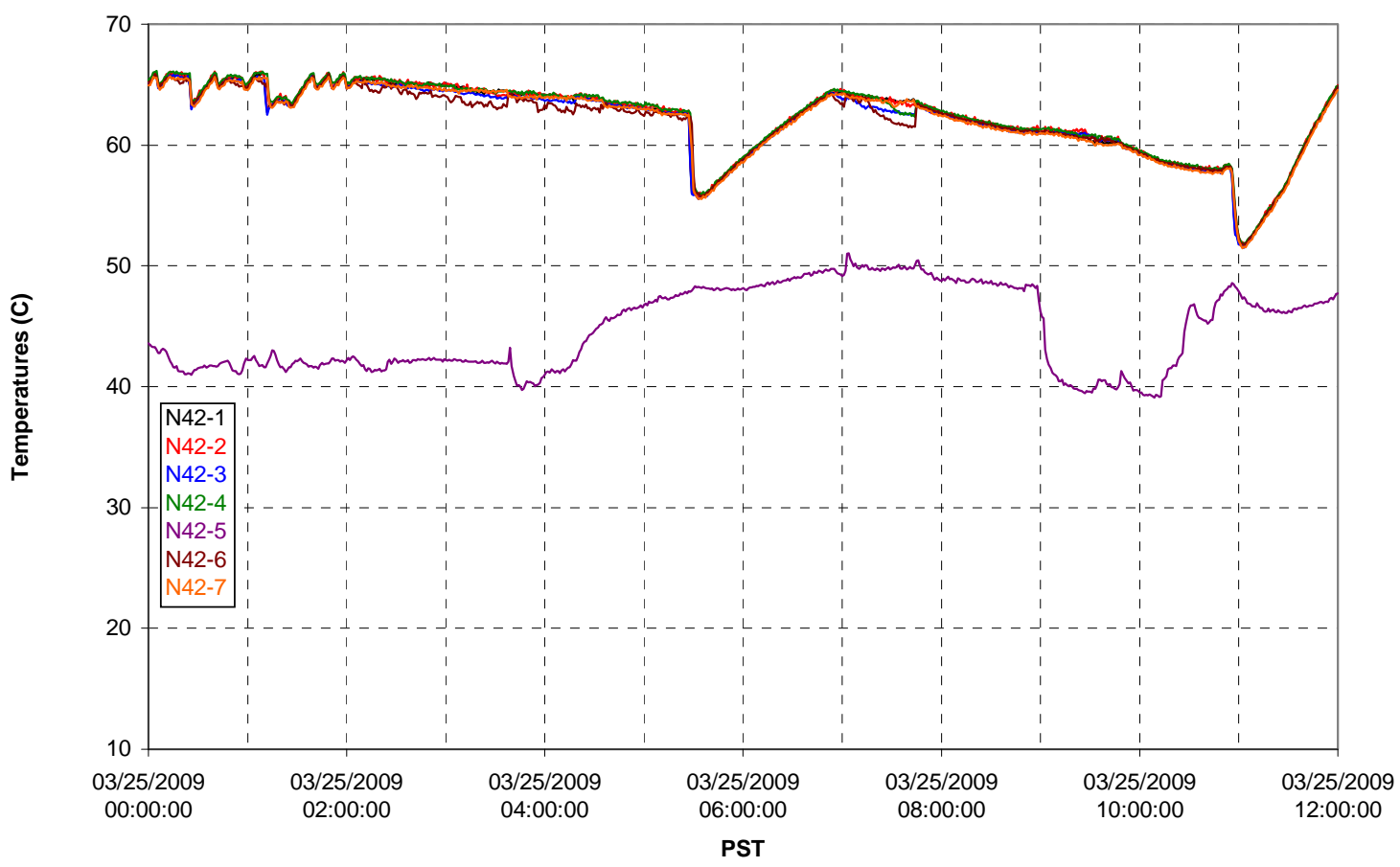

T02A temperatures

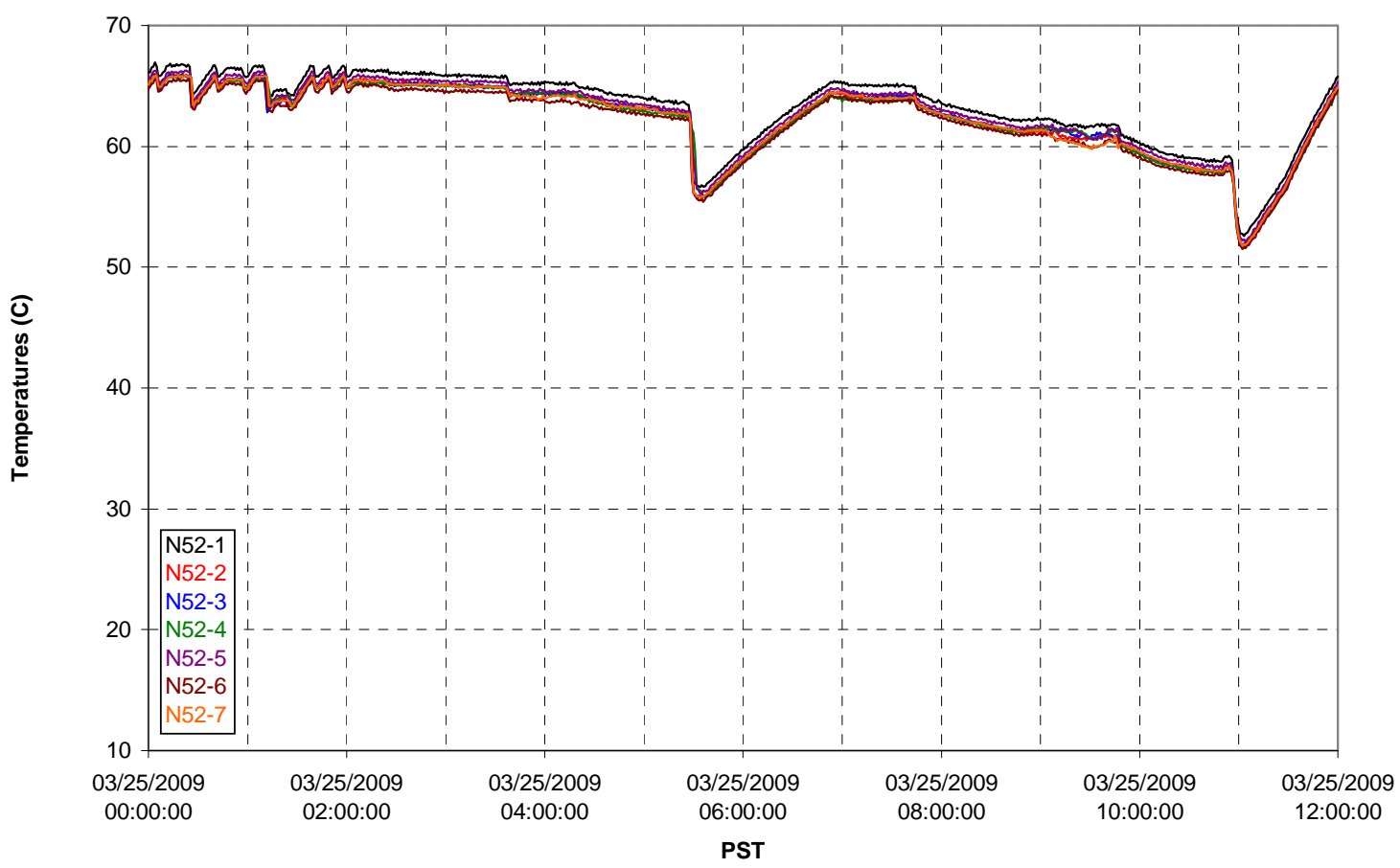


T02A Heating and Cooling

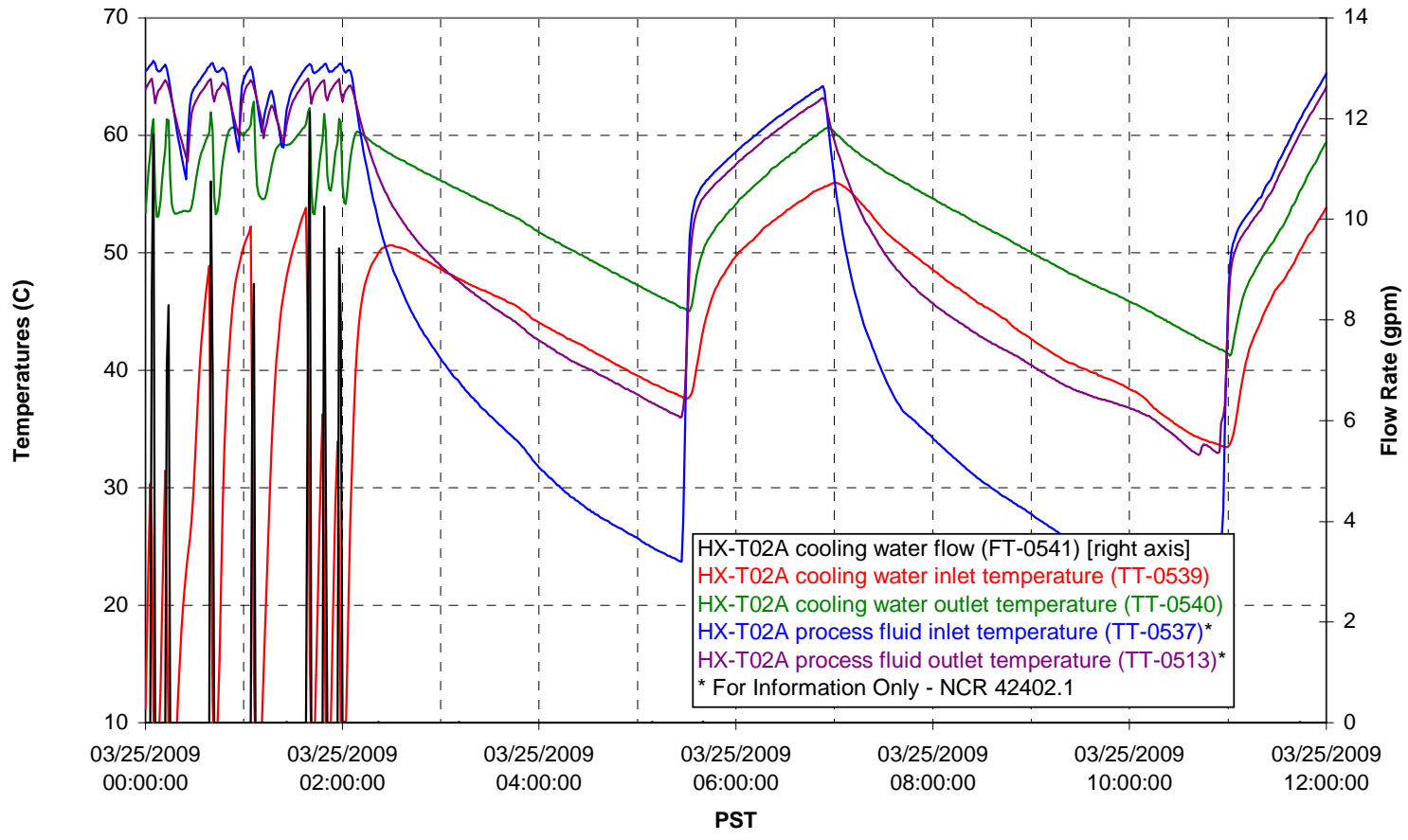

Pump Operation

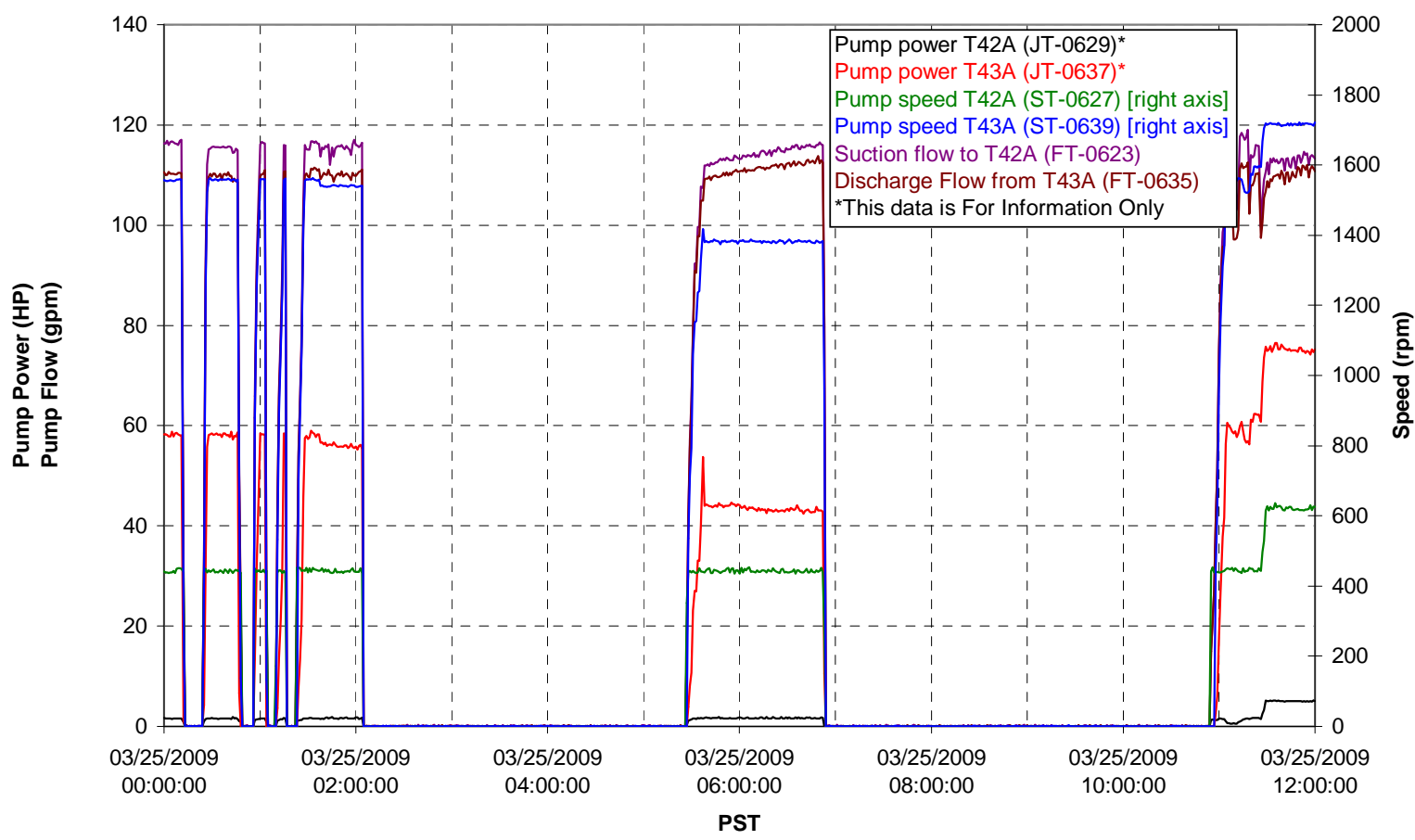


Pulsepot UFP-PP-T01A

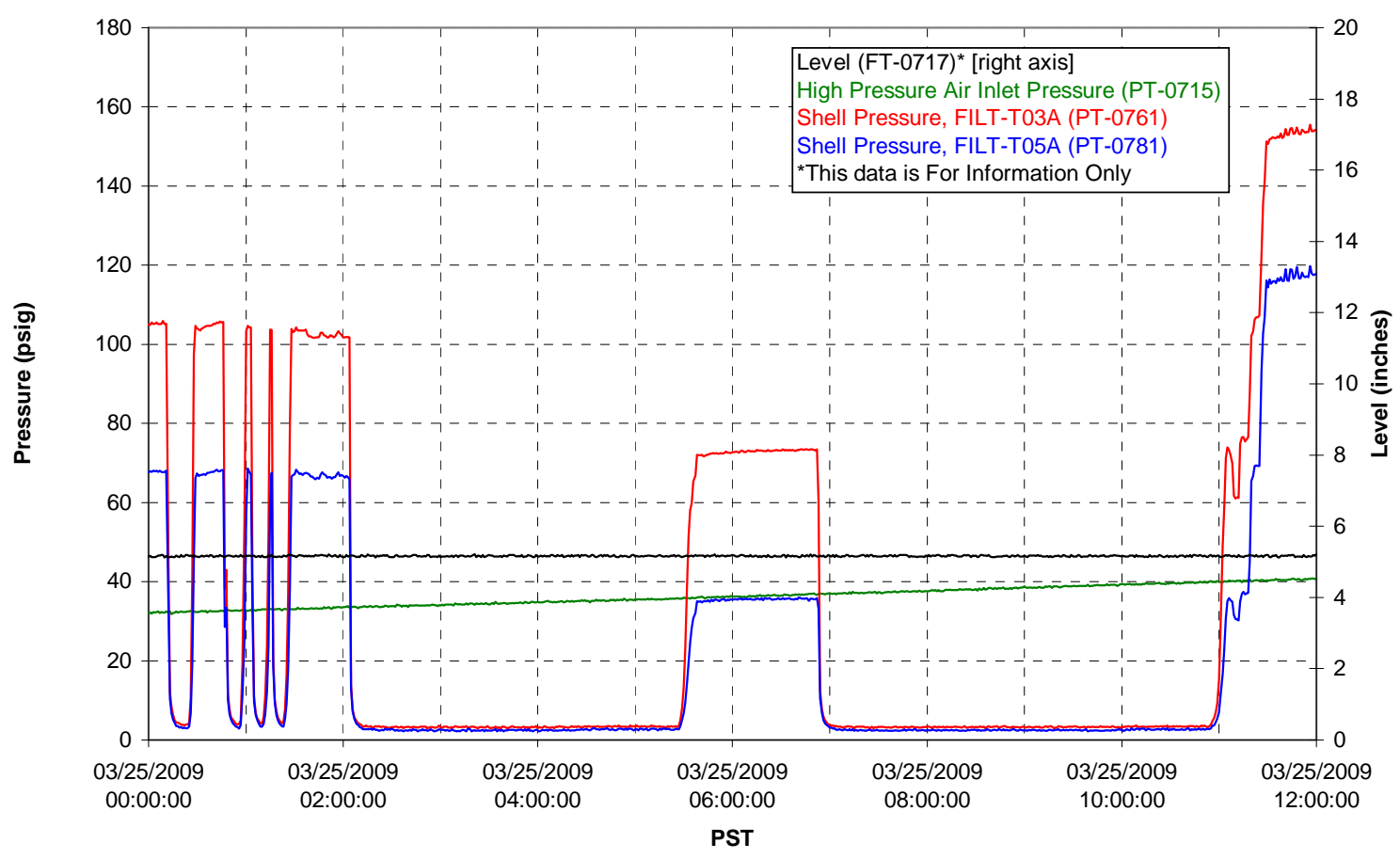

Pulsepot UFP-PP-T02A

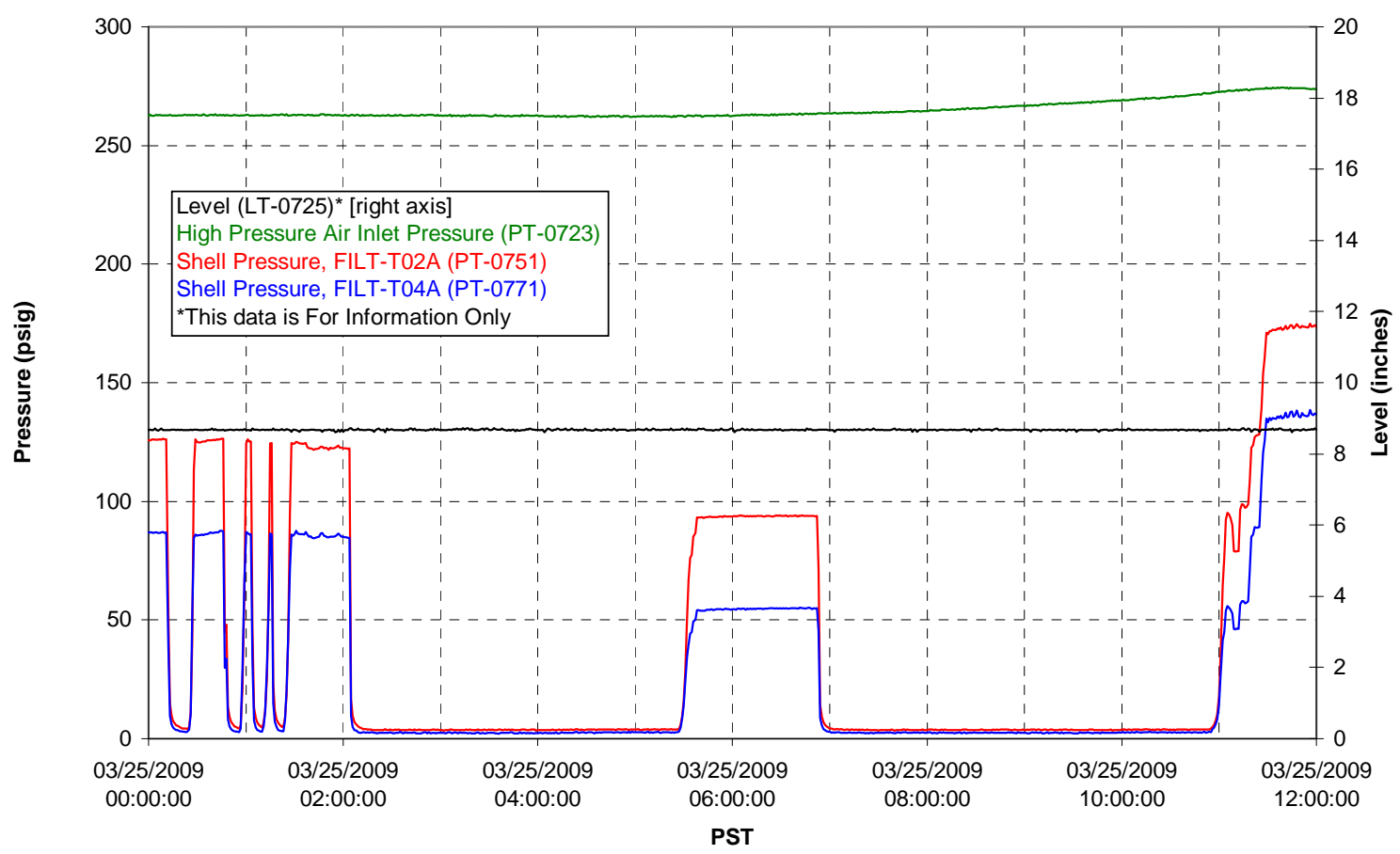


Pulsepot UFP-PP-T03A

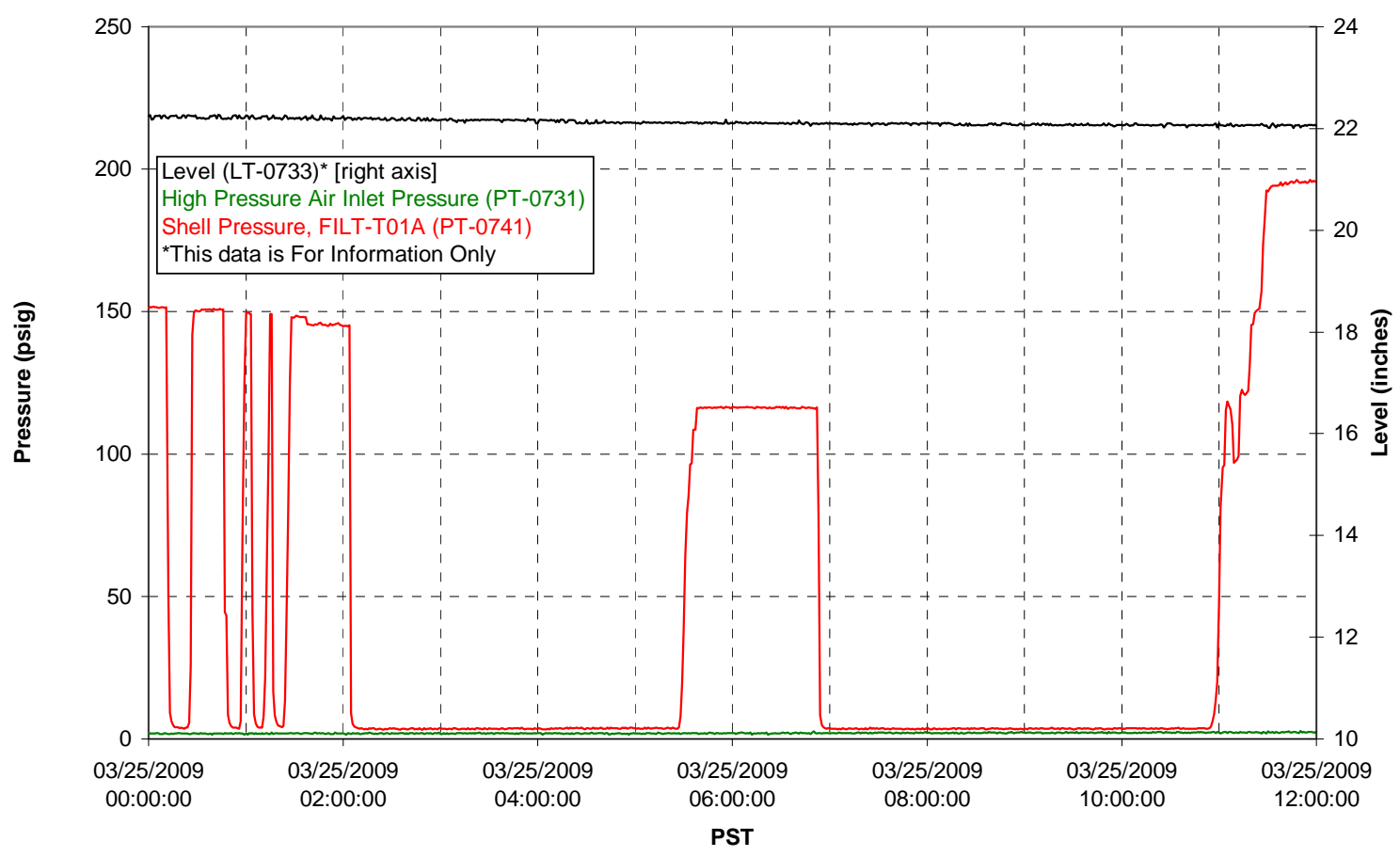

Pulsepot Levels

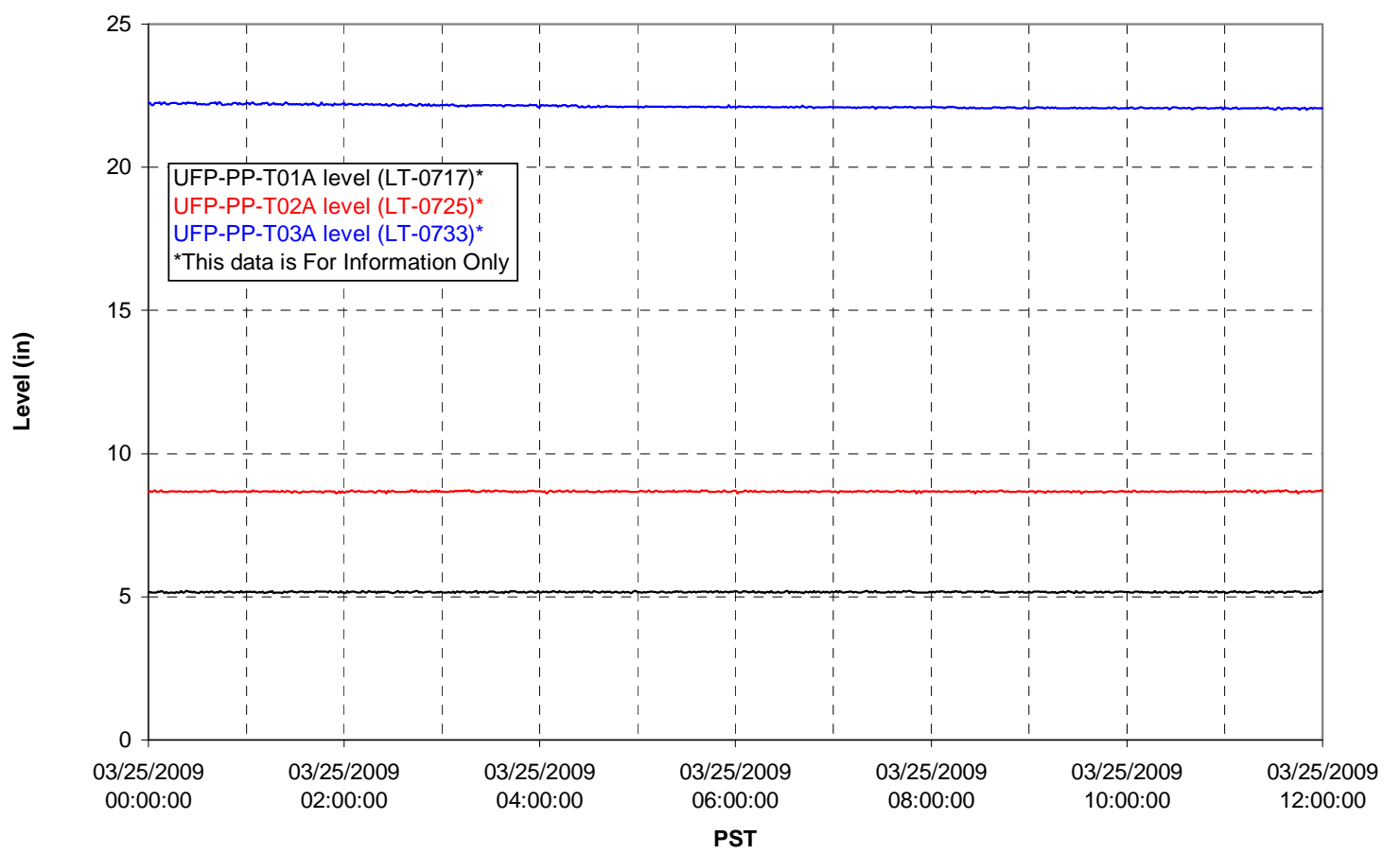


Filter UFP-FILT-T01A

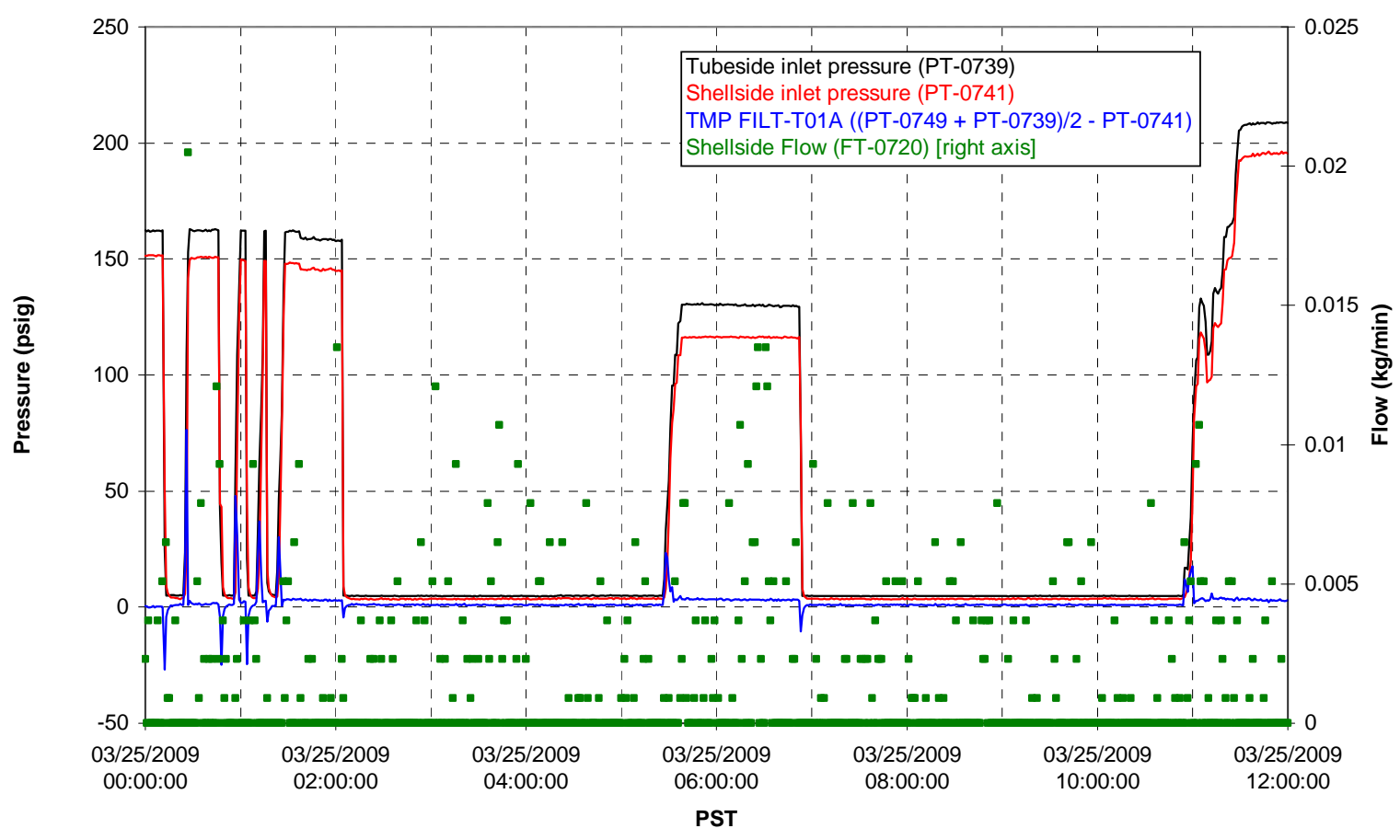

Filter UFP-FILT-T02A

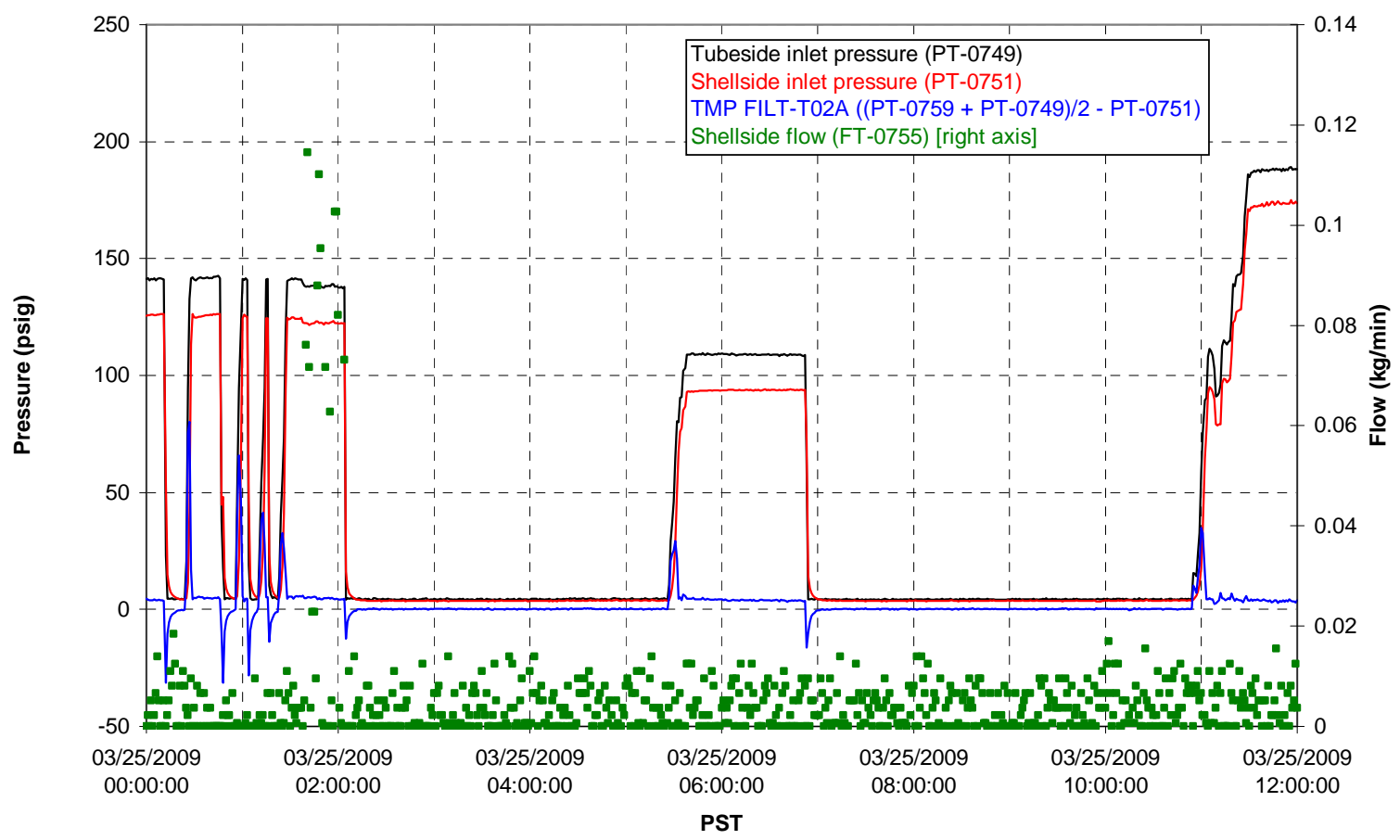


Filter UFP-FILT-T03A

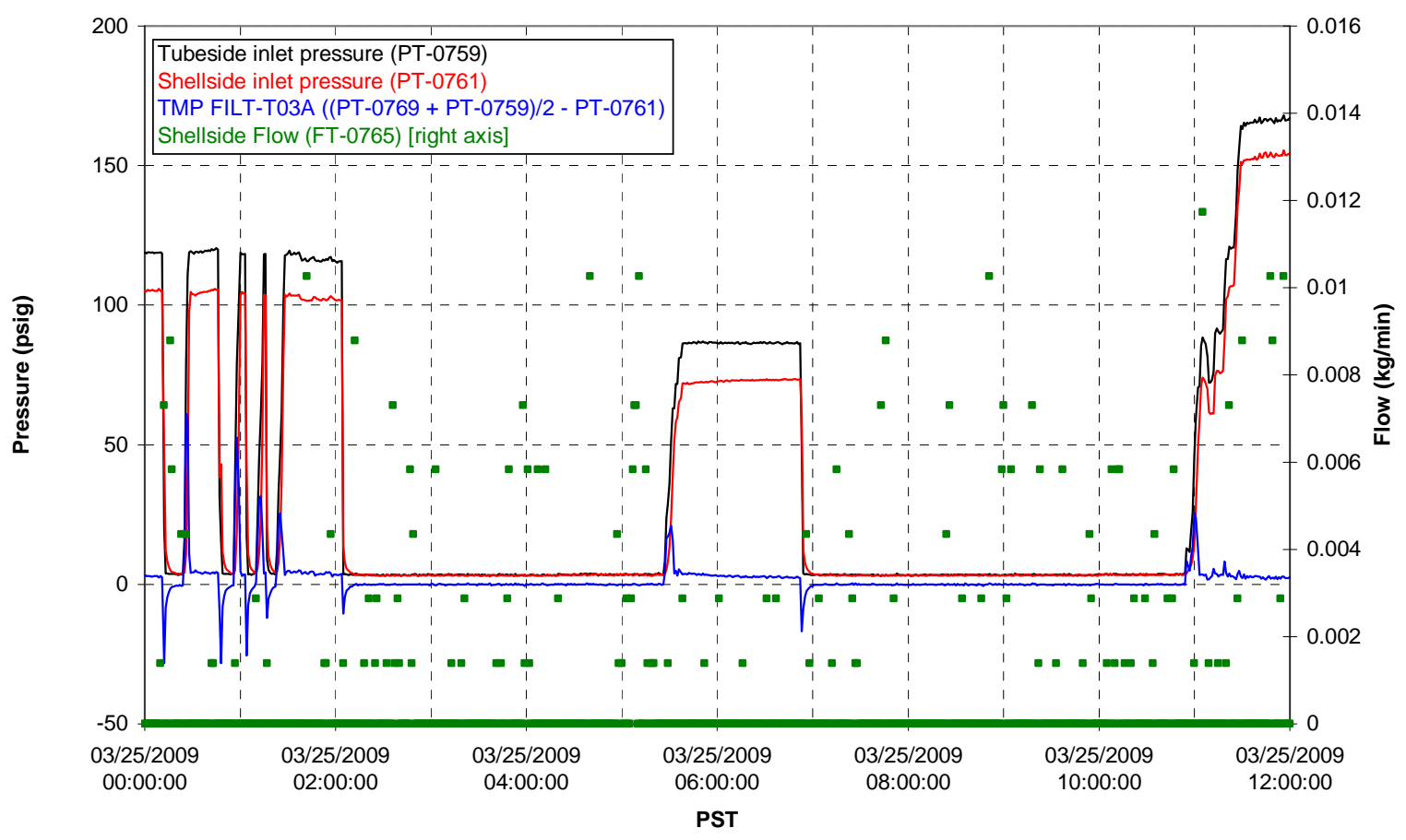

Filter UFP-FILT-T04A

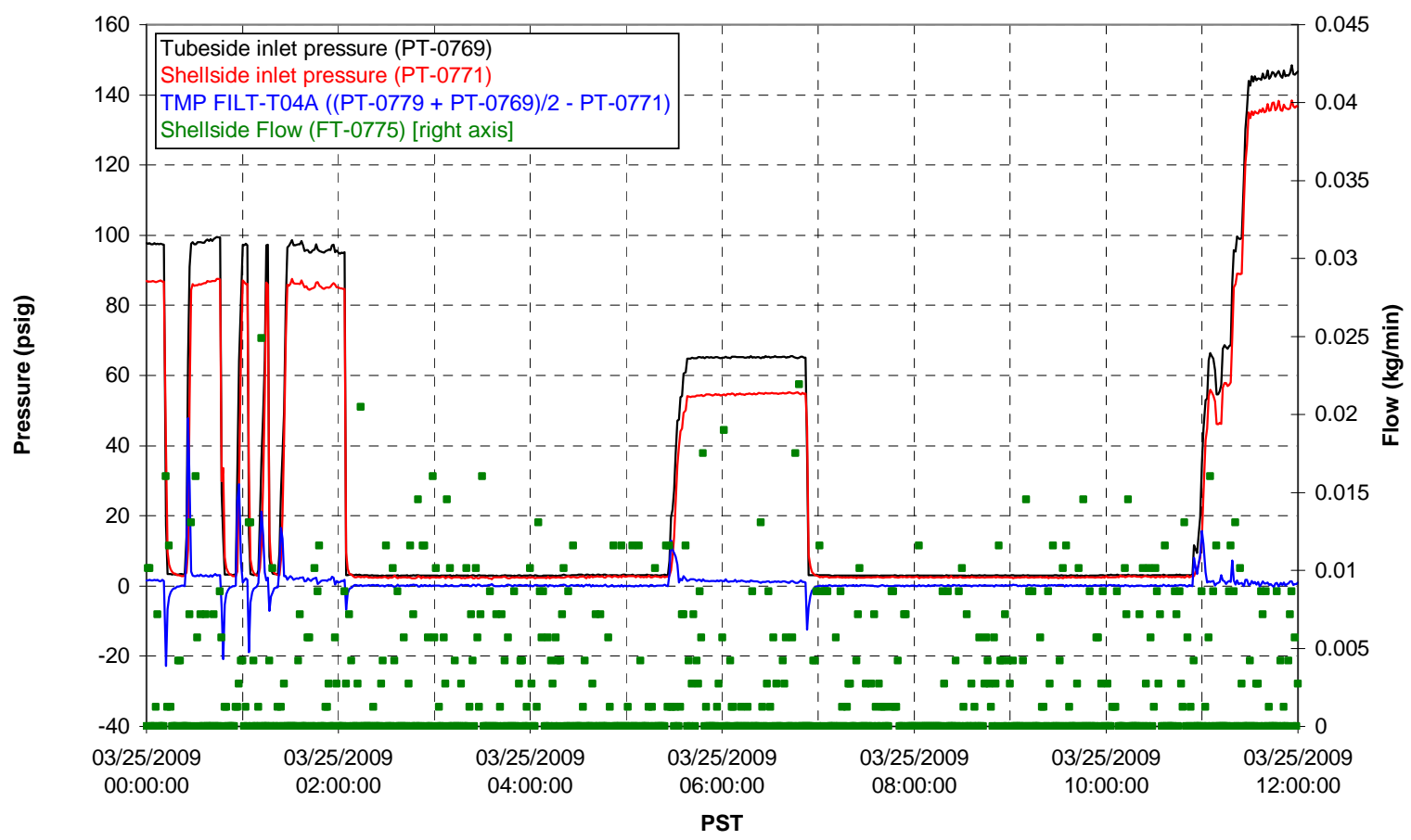


Filter UFP-FILT-T05A

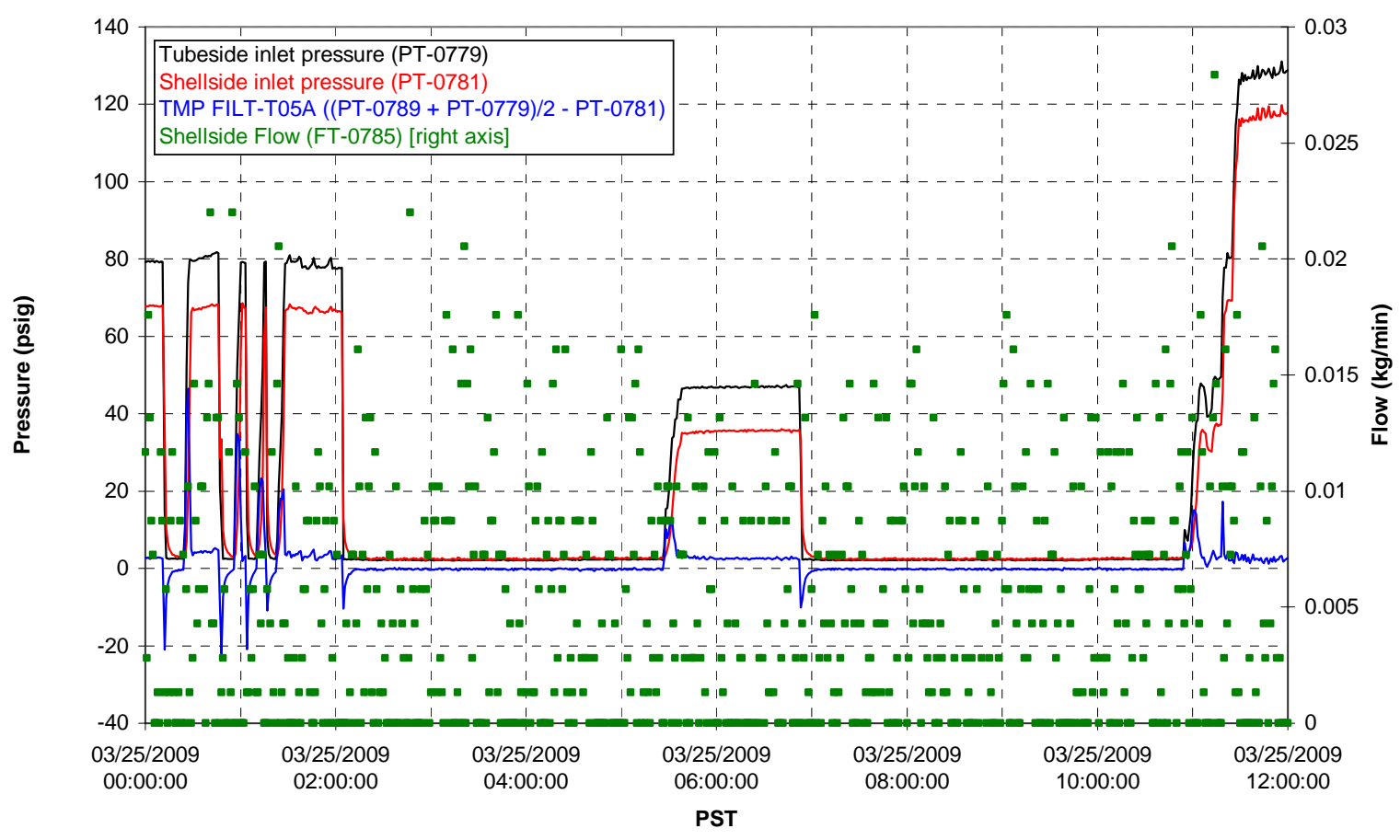

Chemical Flow

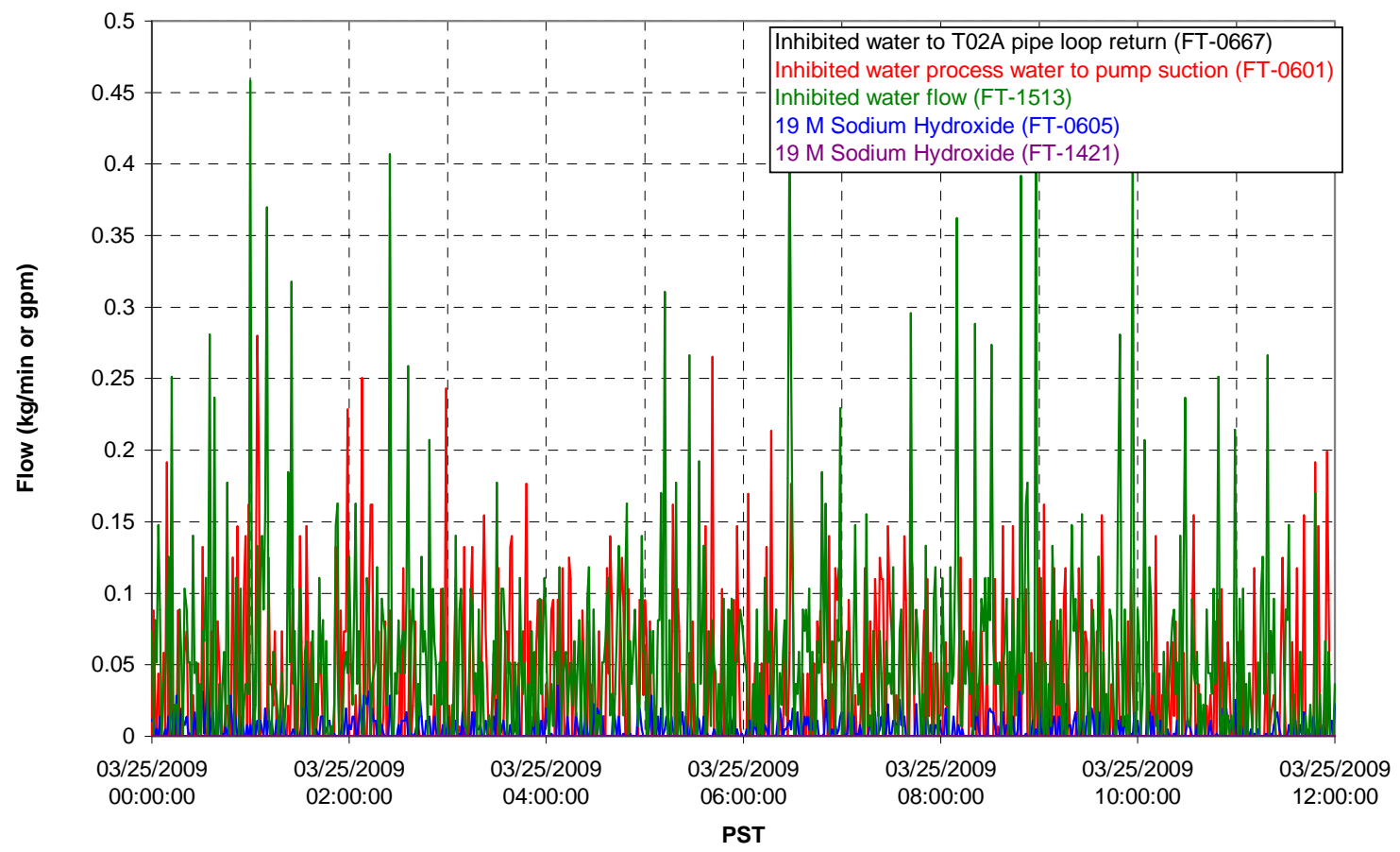




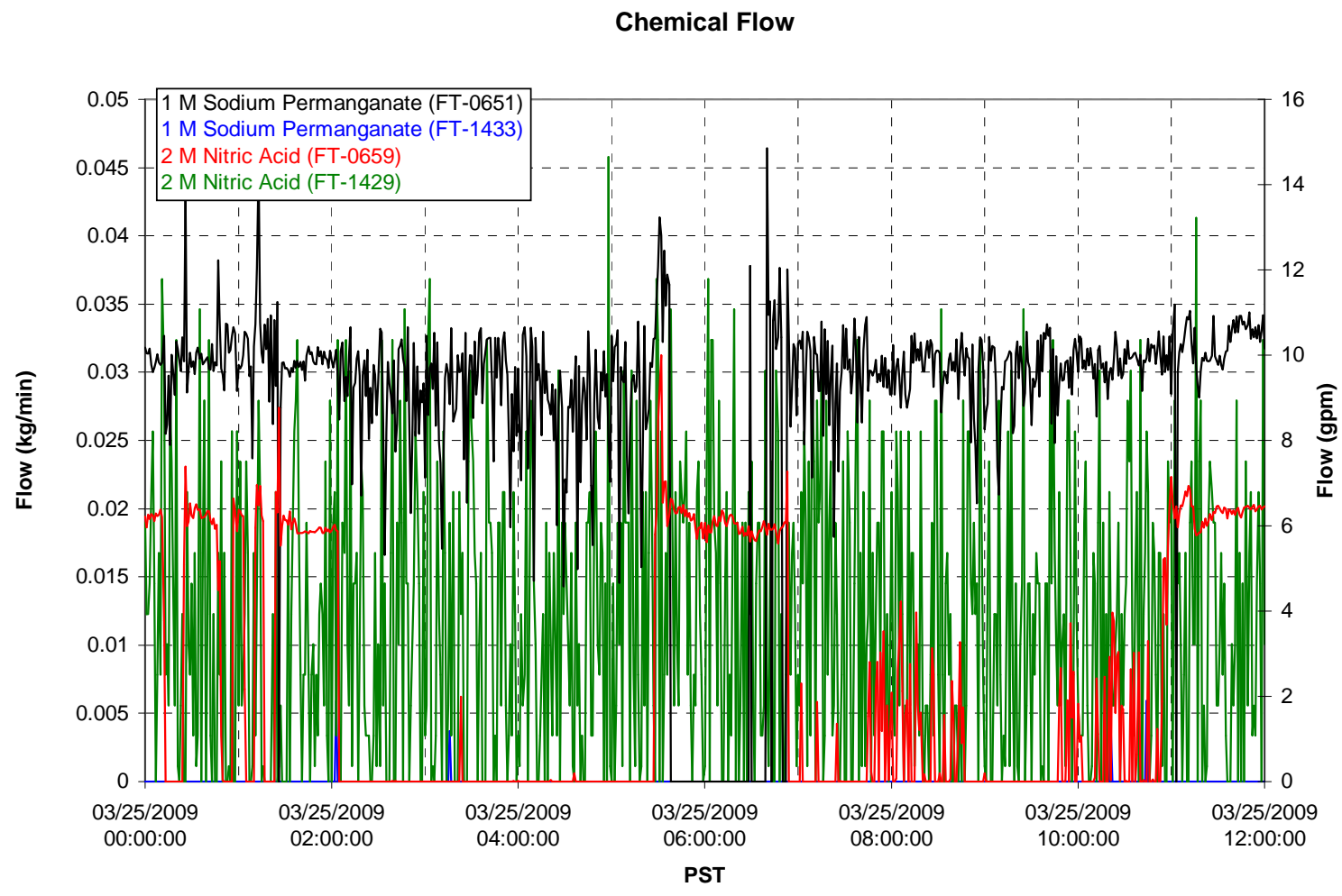

Air Flows

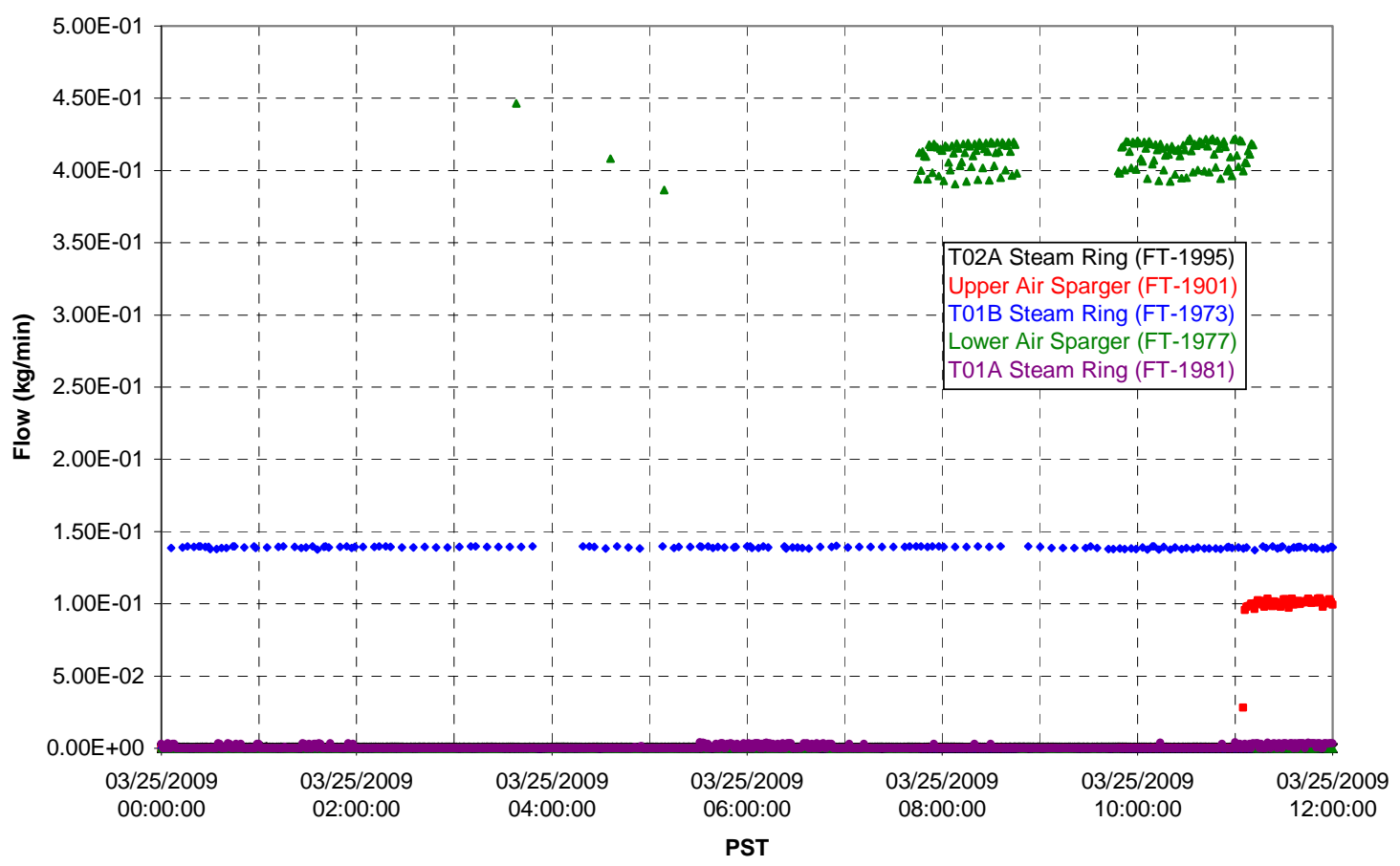


T02A Steam

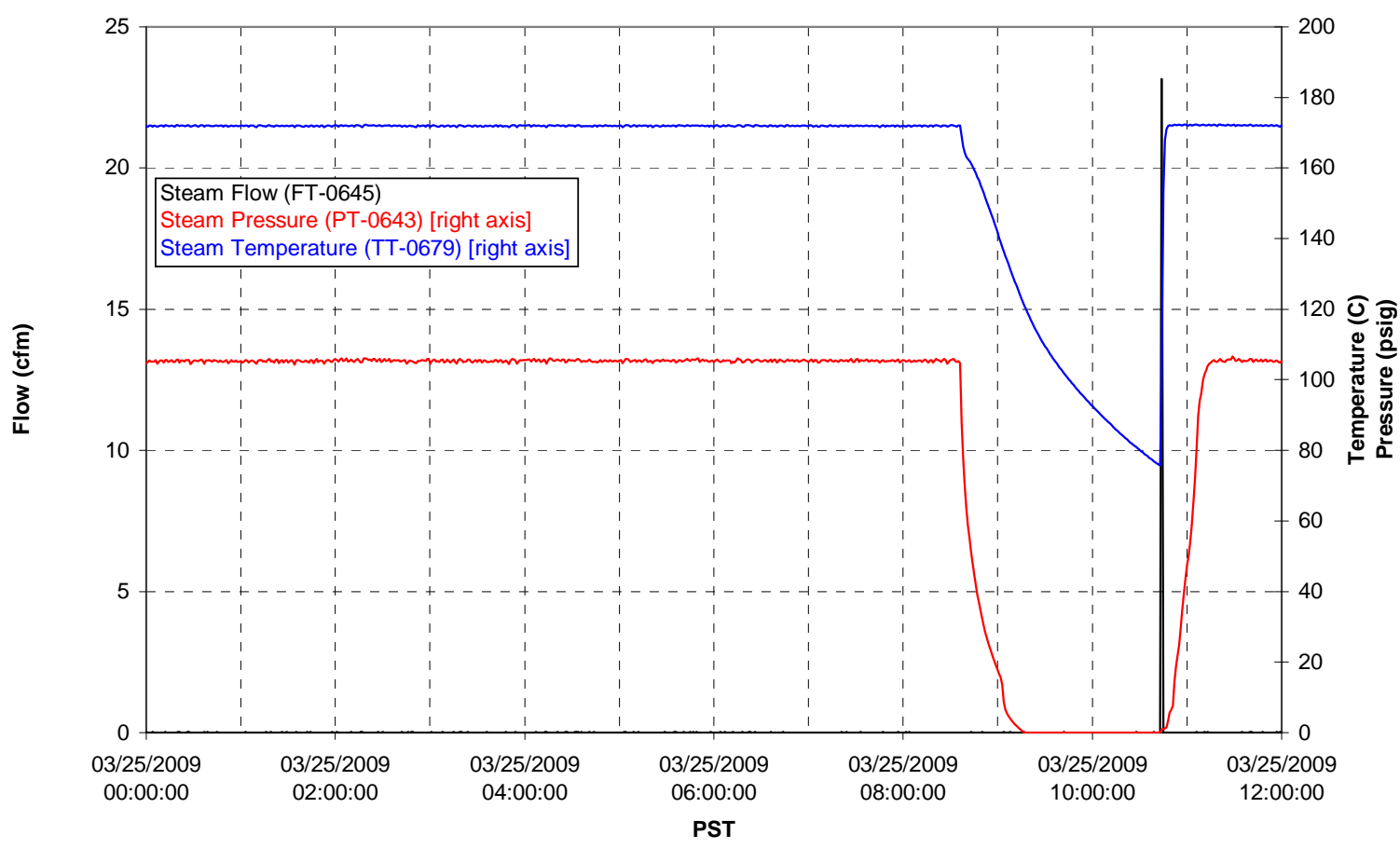

T01A Steam

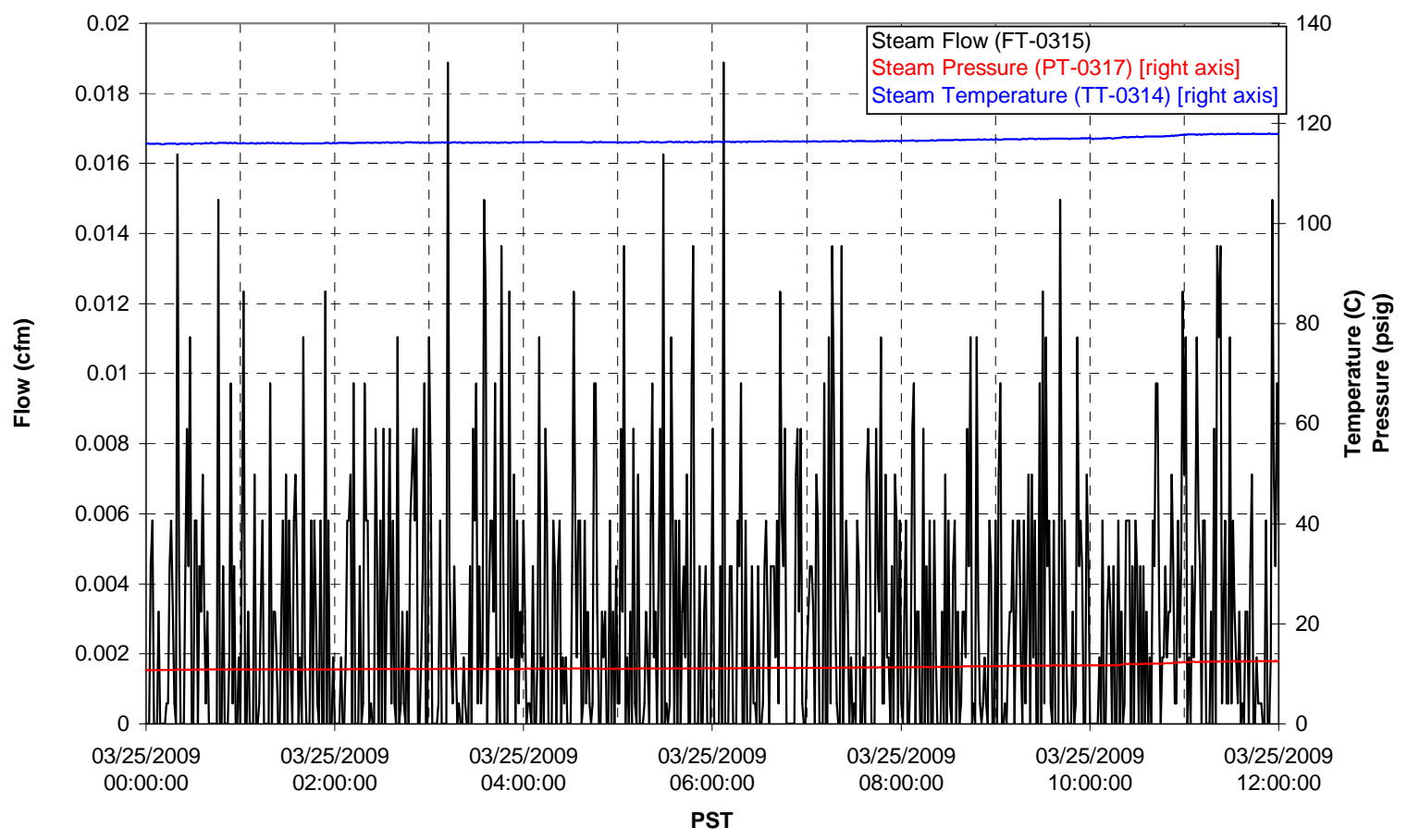


T01B Steam

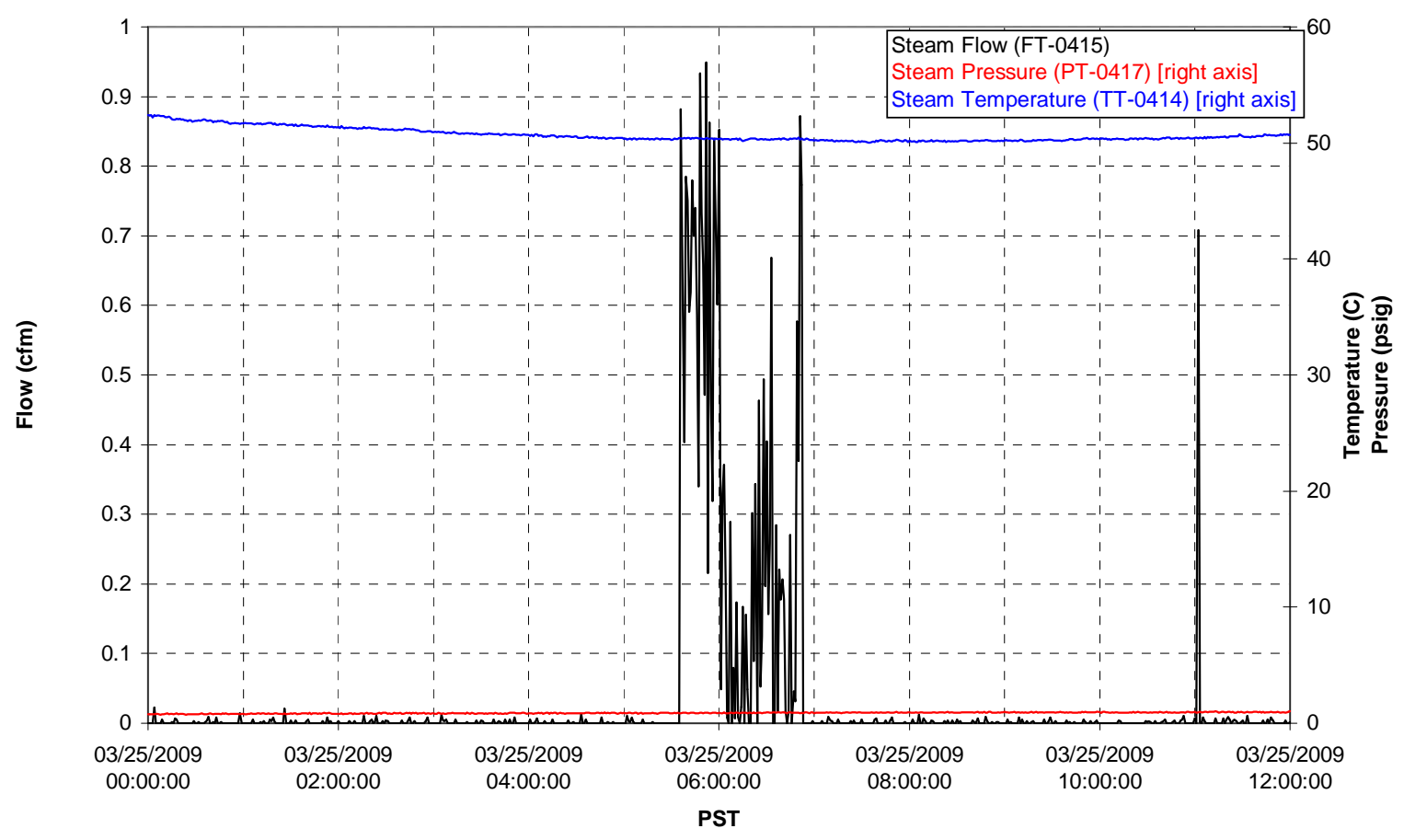




\section{Integrated Test D Data Plots 03/25/09 12:00 - 03/26/09 00:00}


T01A level

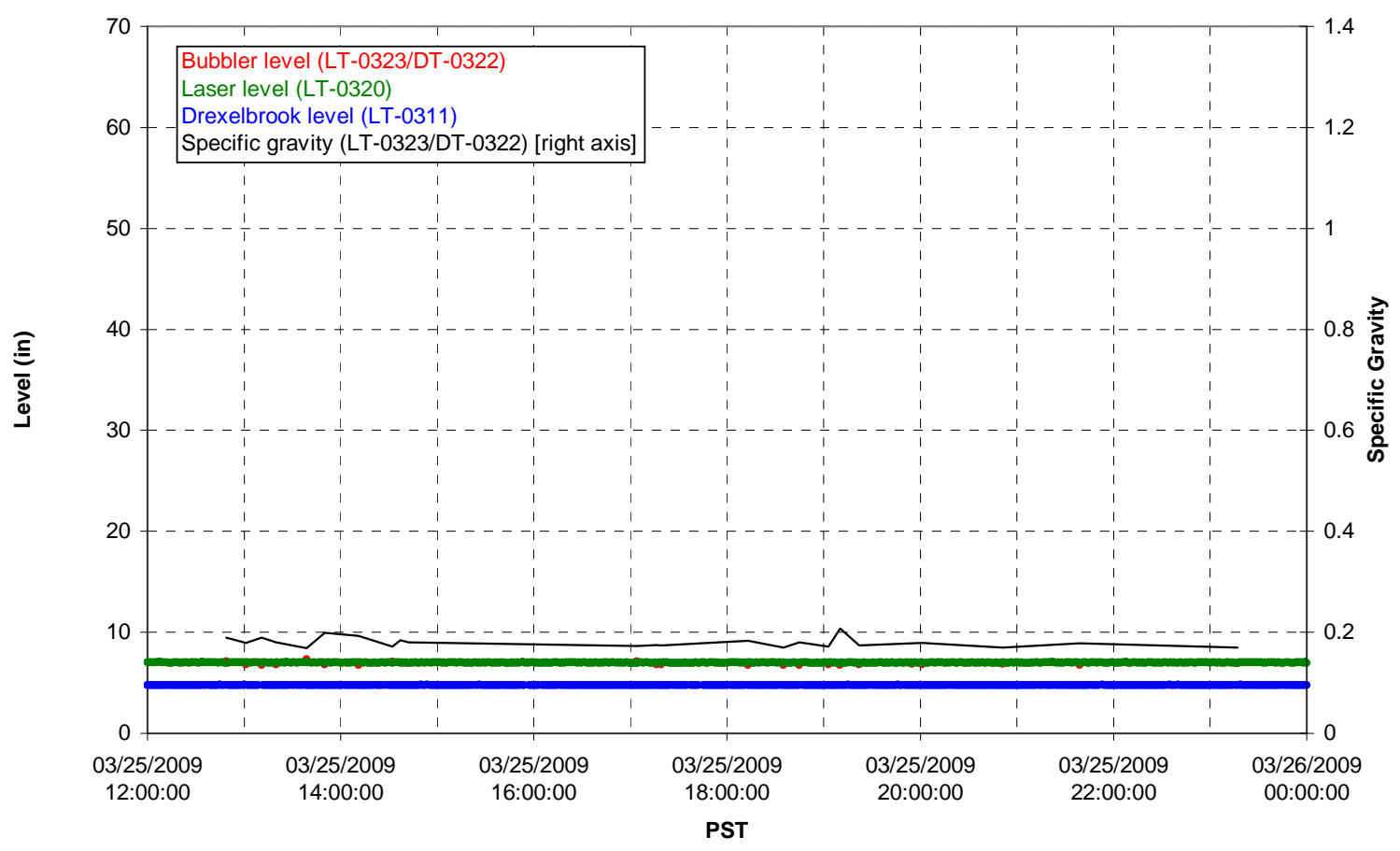

T01A temperatures

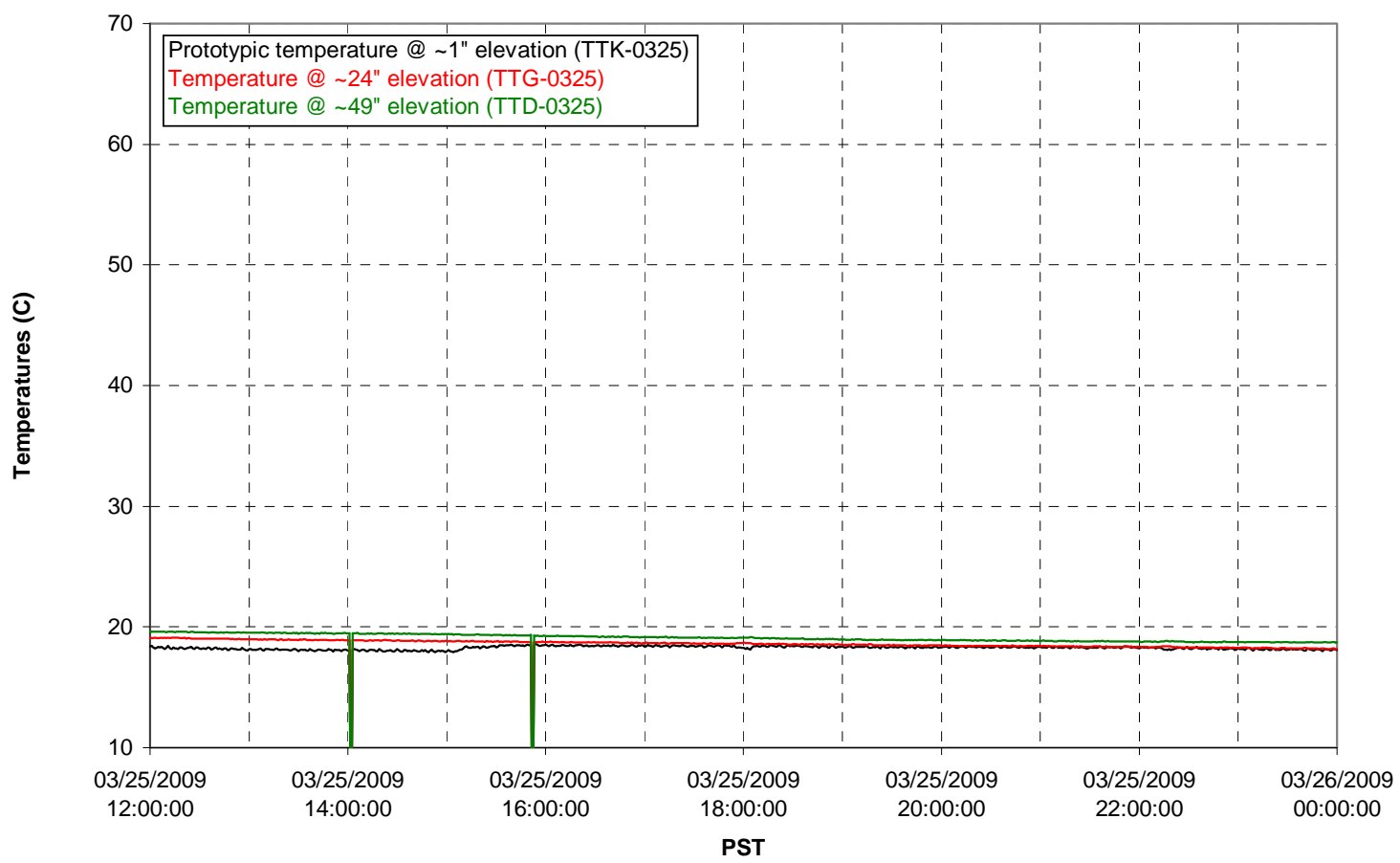


T01B level

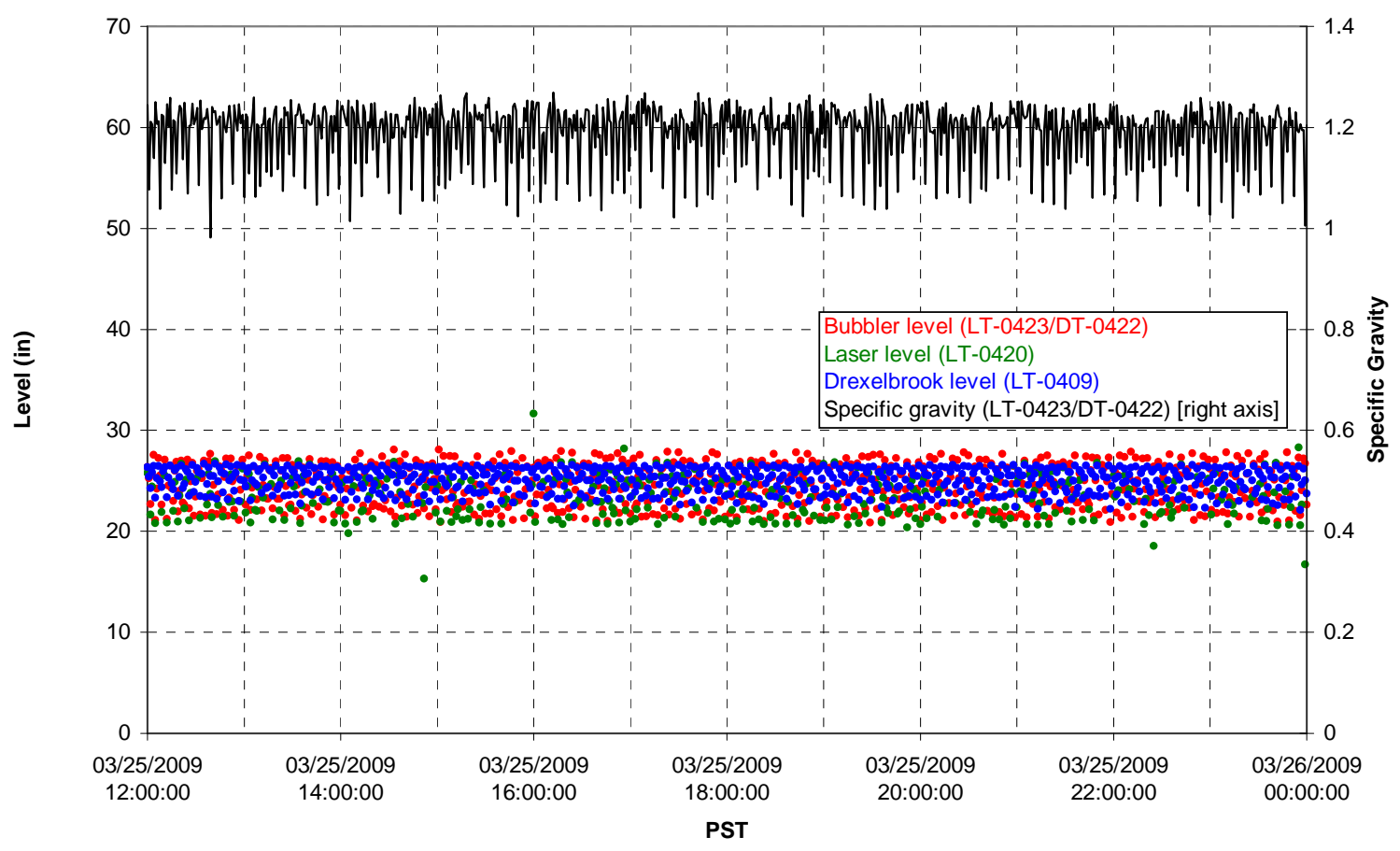

T01B temperatures

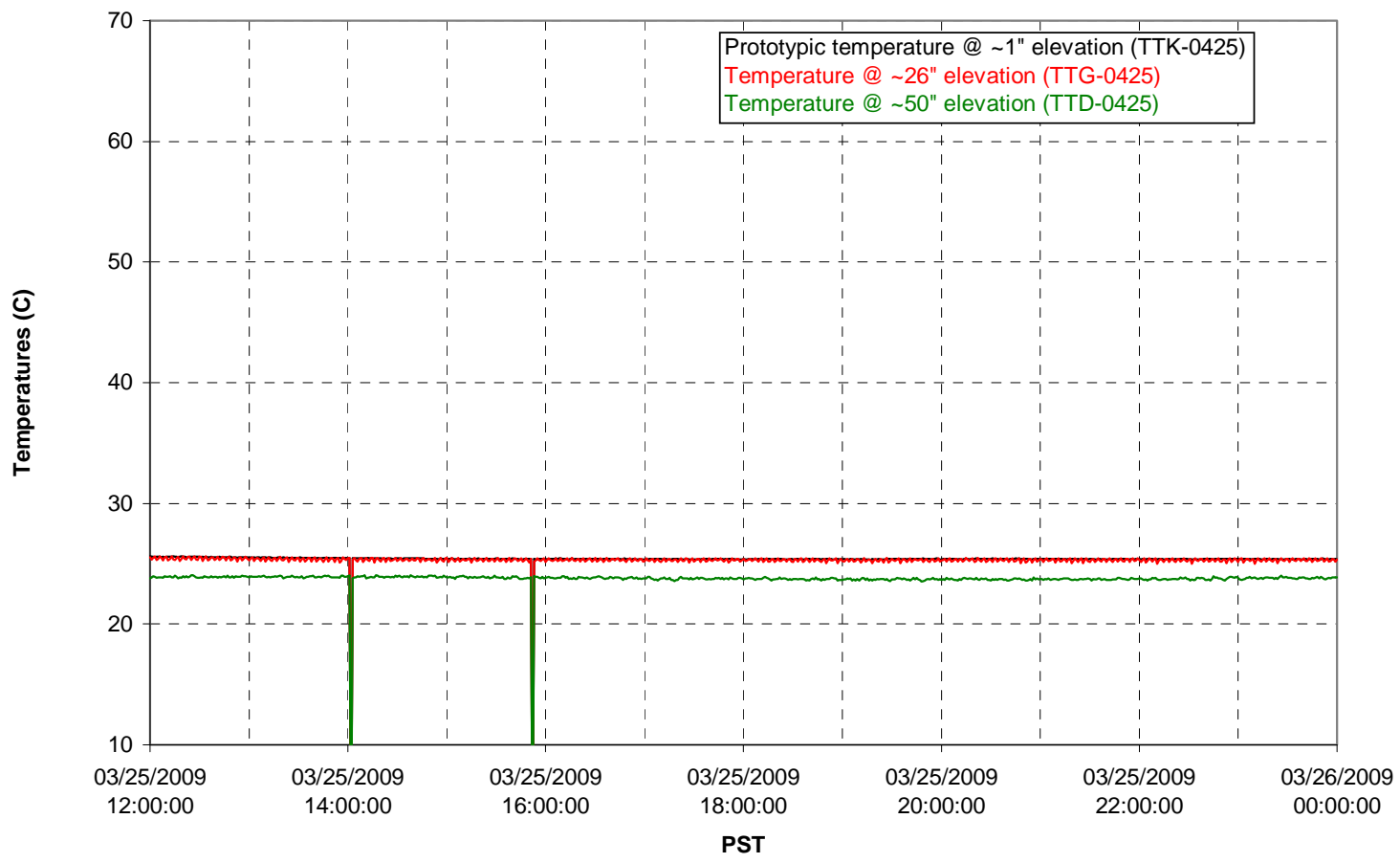


T02A level

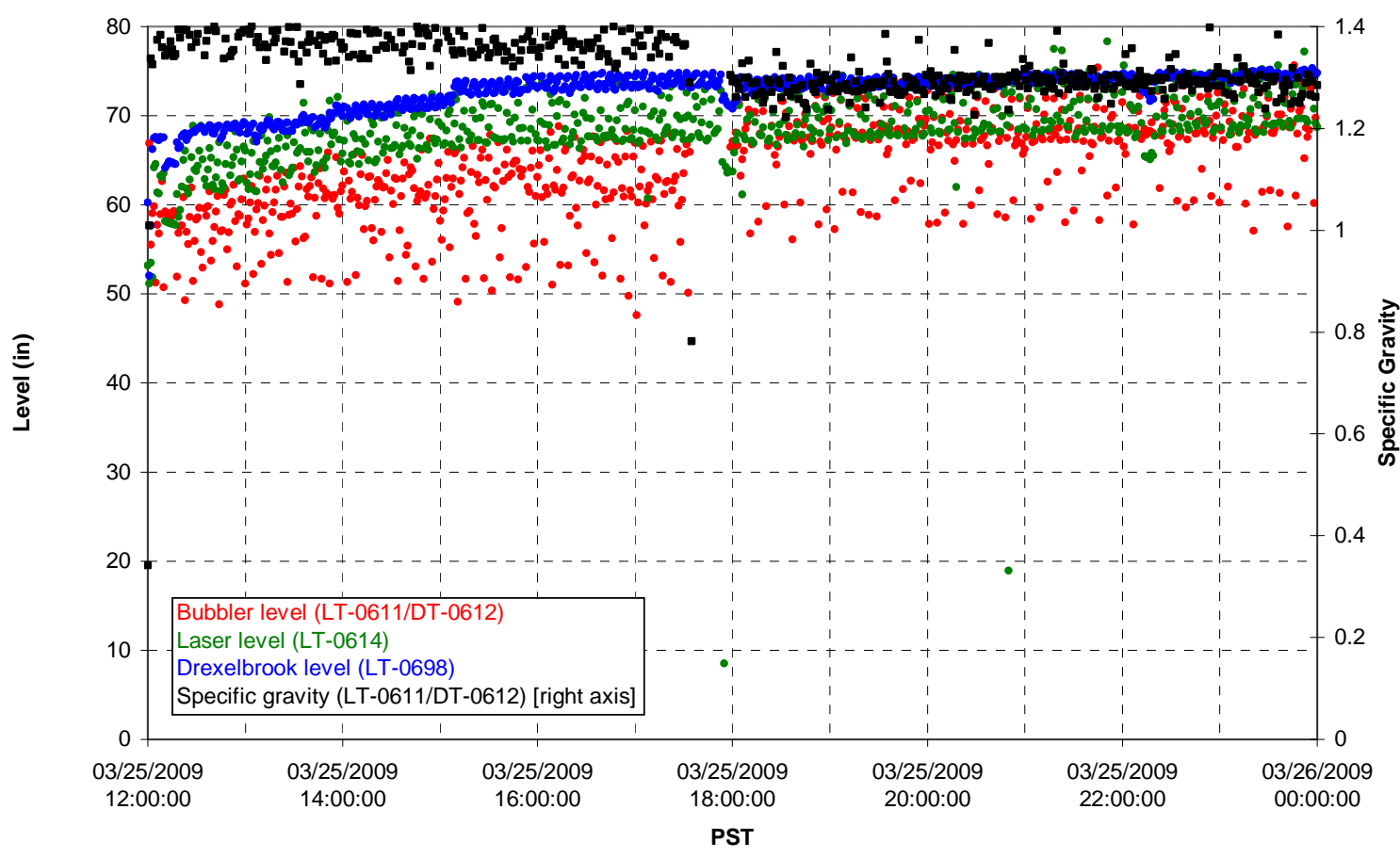

T02A temperatures

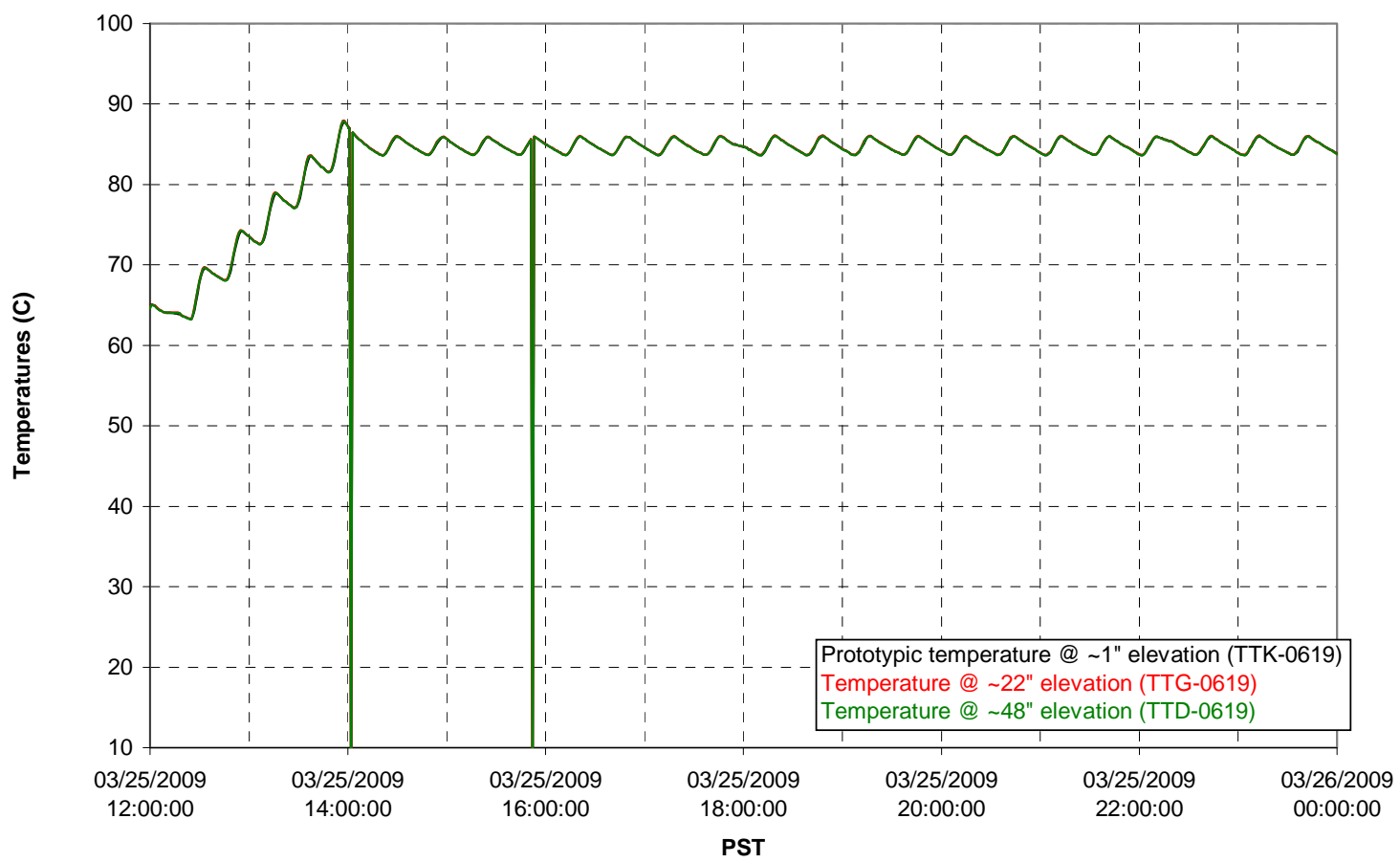


T02A and filter loop temperatures

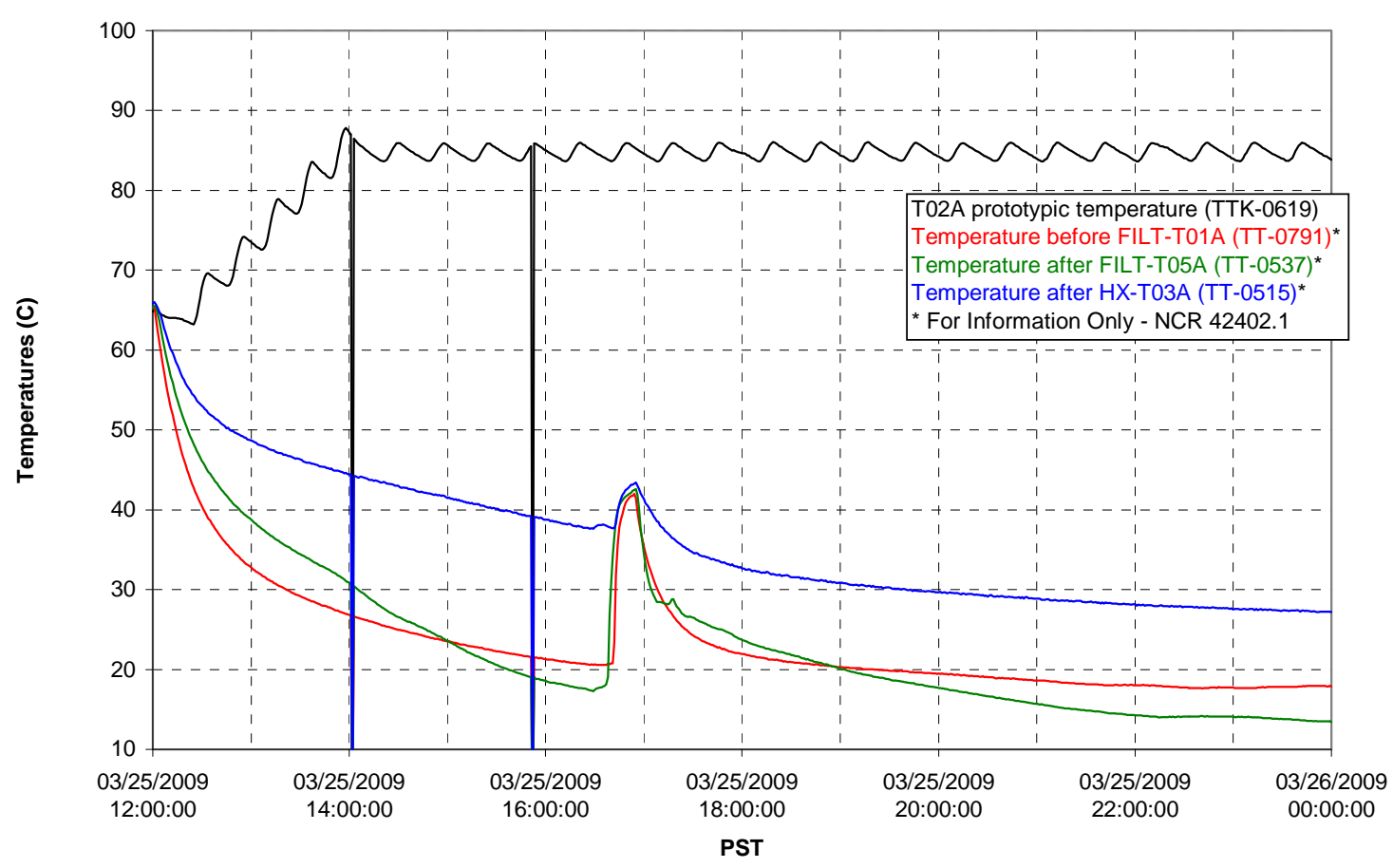

Pump Pressures and Flow

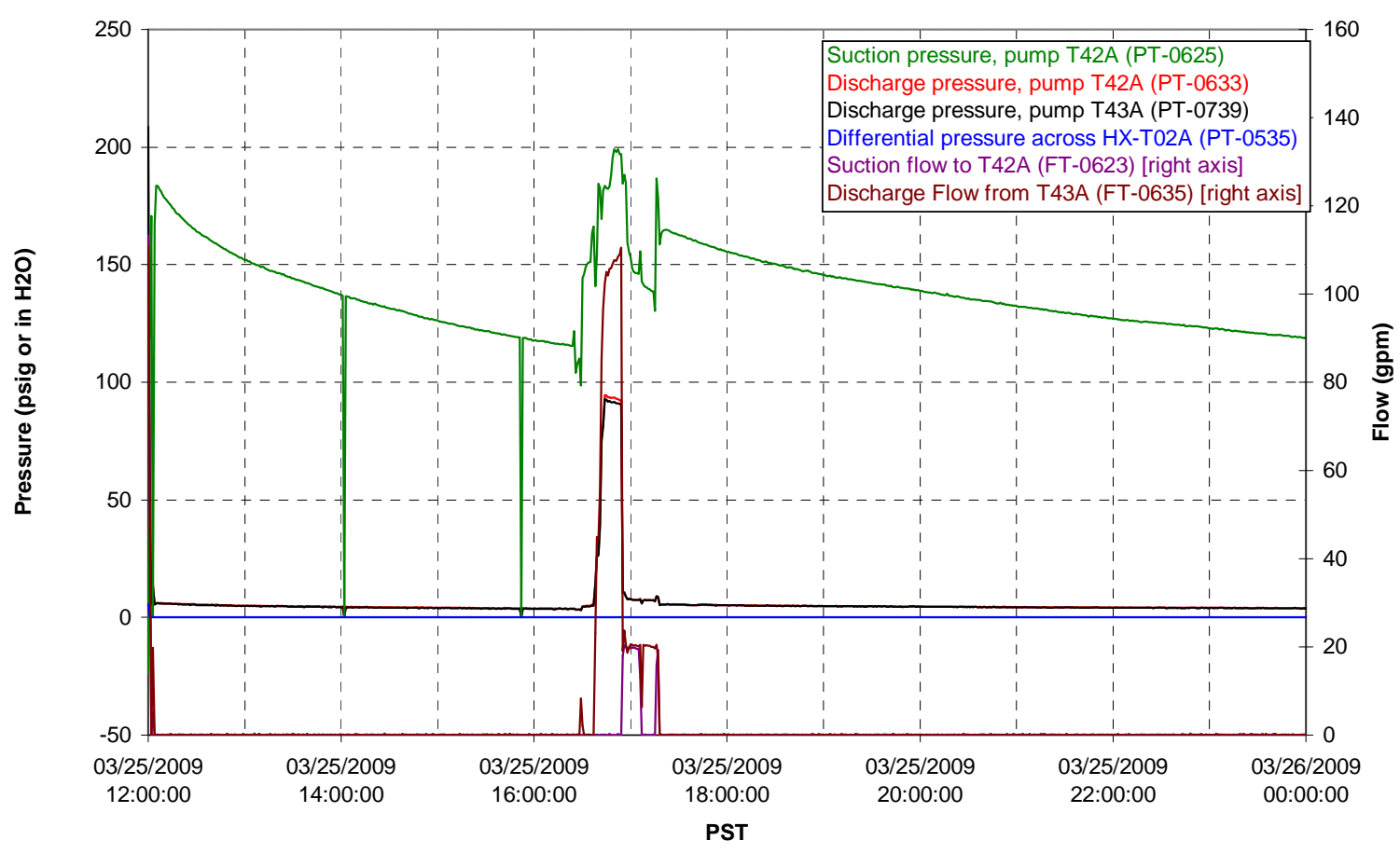


Axial pressure drop

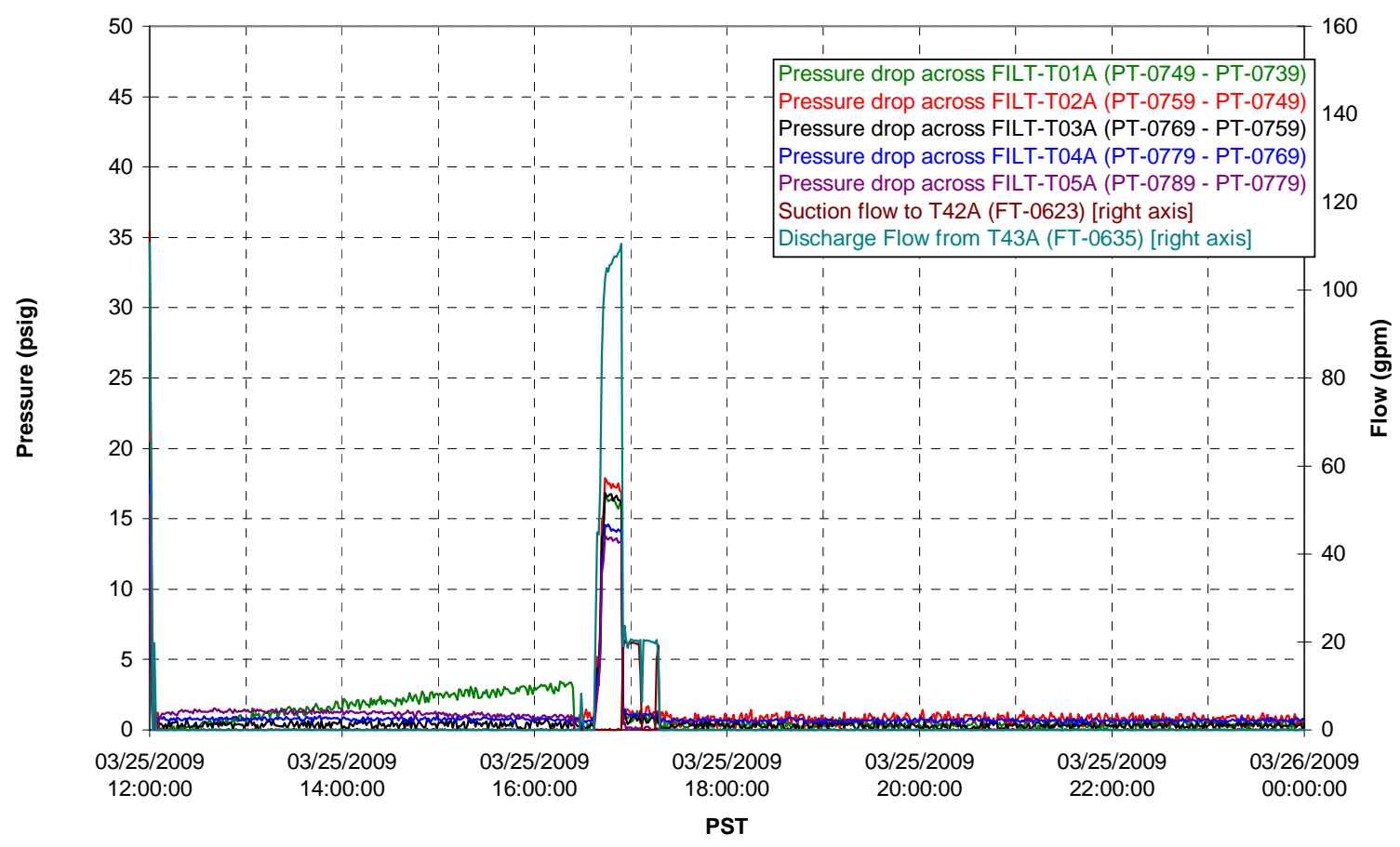

Permeate flow rates

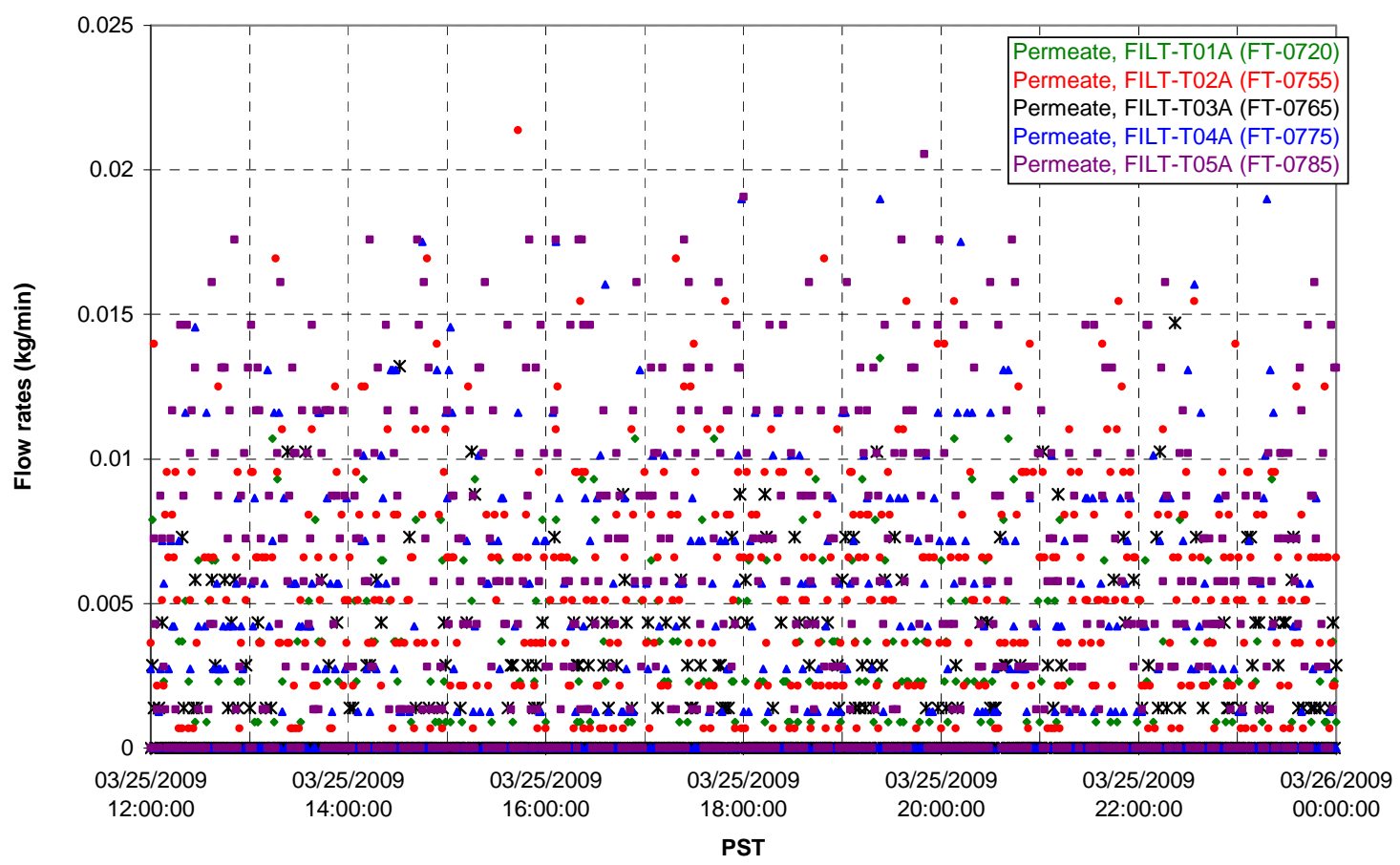


T02A Inner Temperature Tree

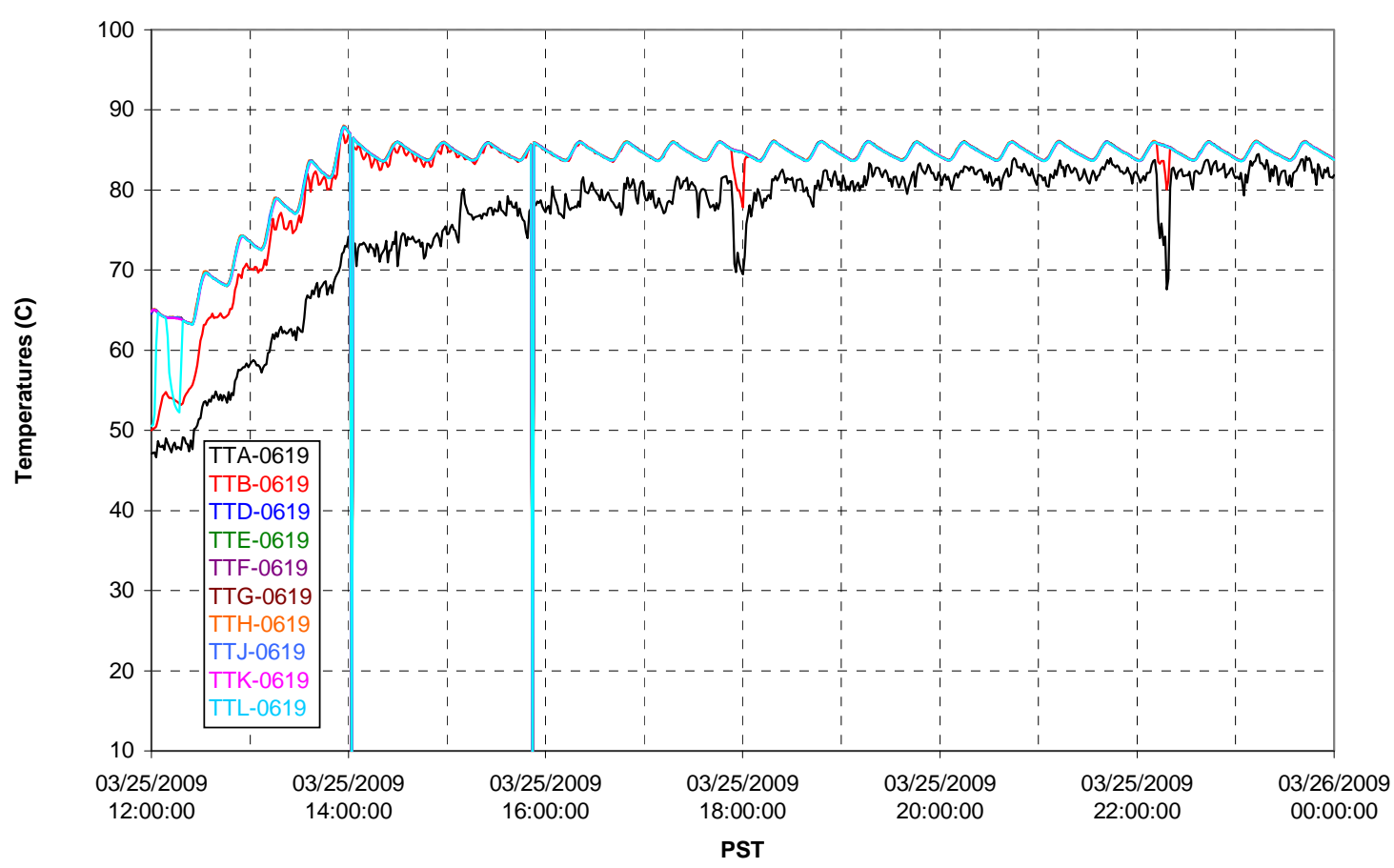

T02A Outer Temperature Tree

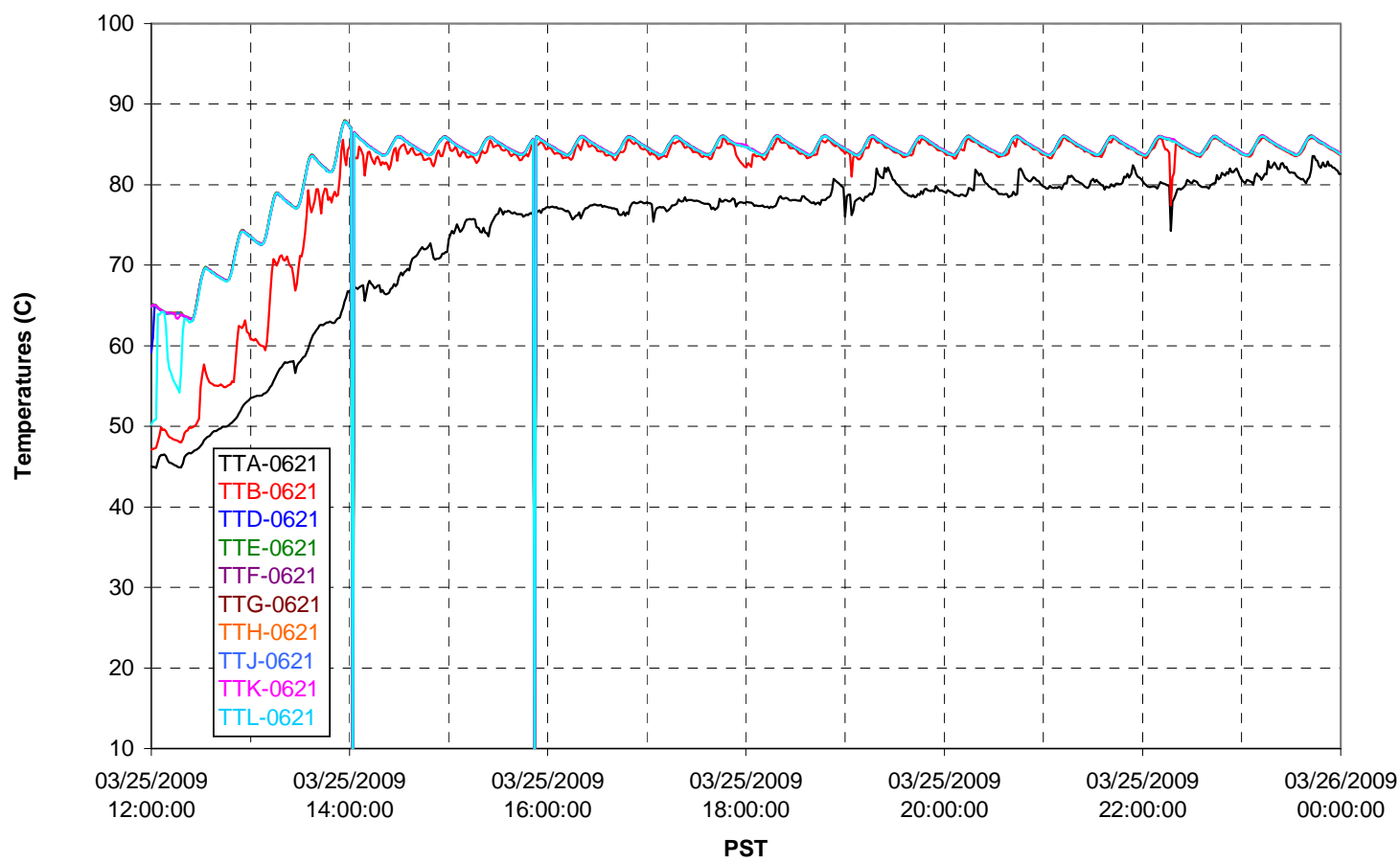


T02A temperatures

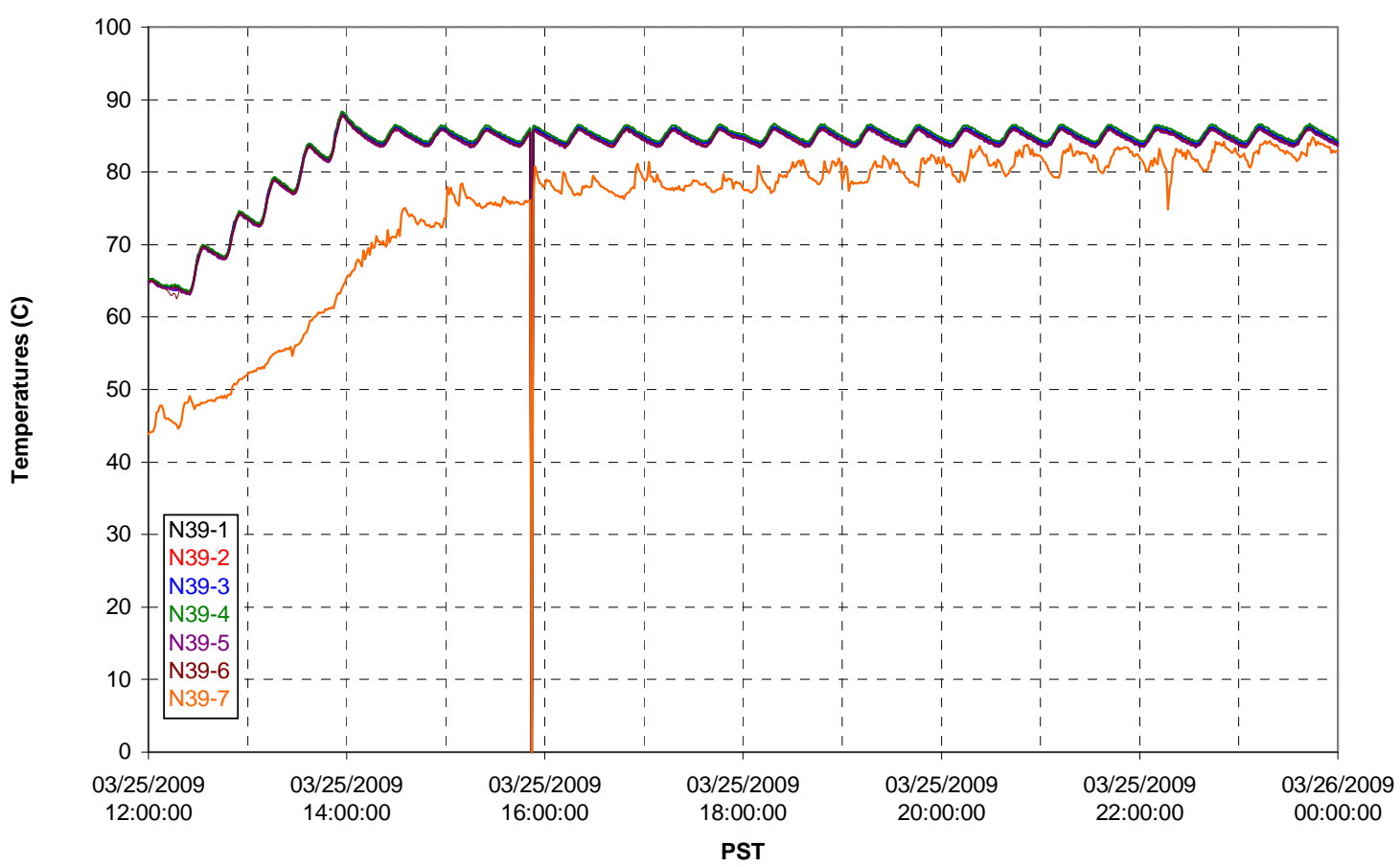

T02A temperatures

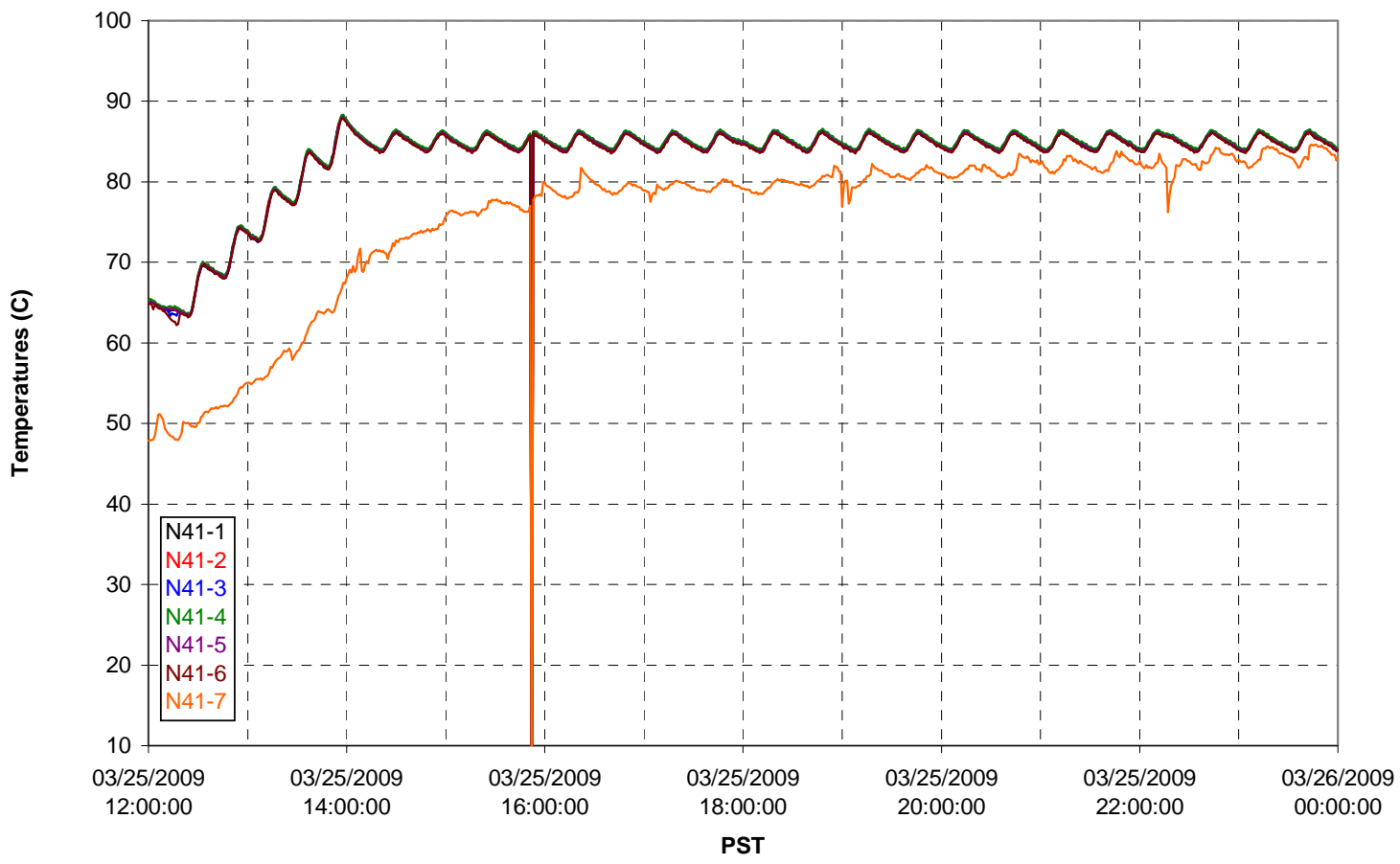


T02A temperatures

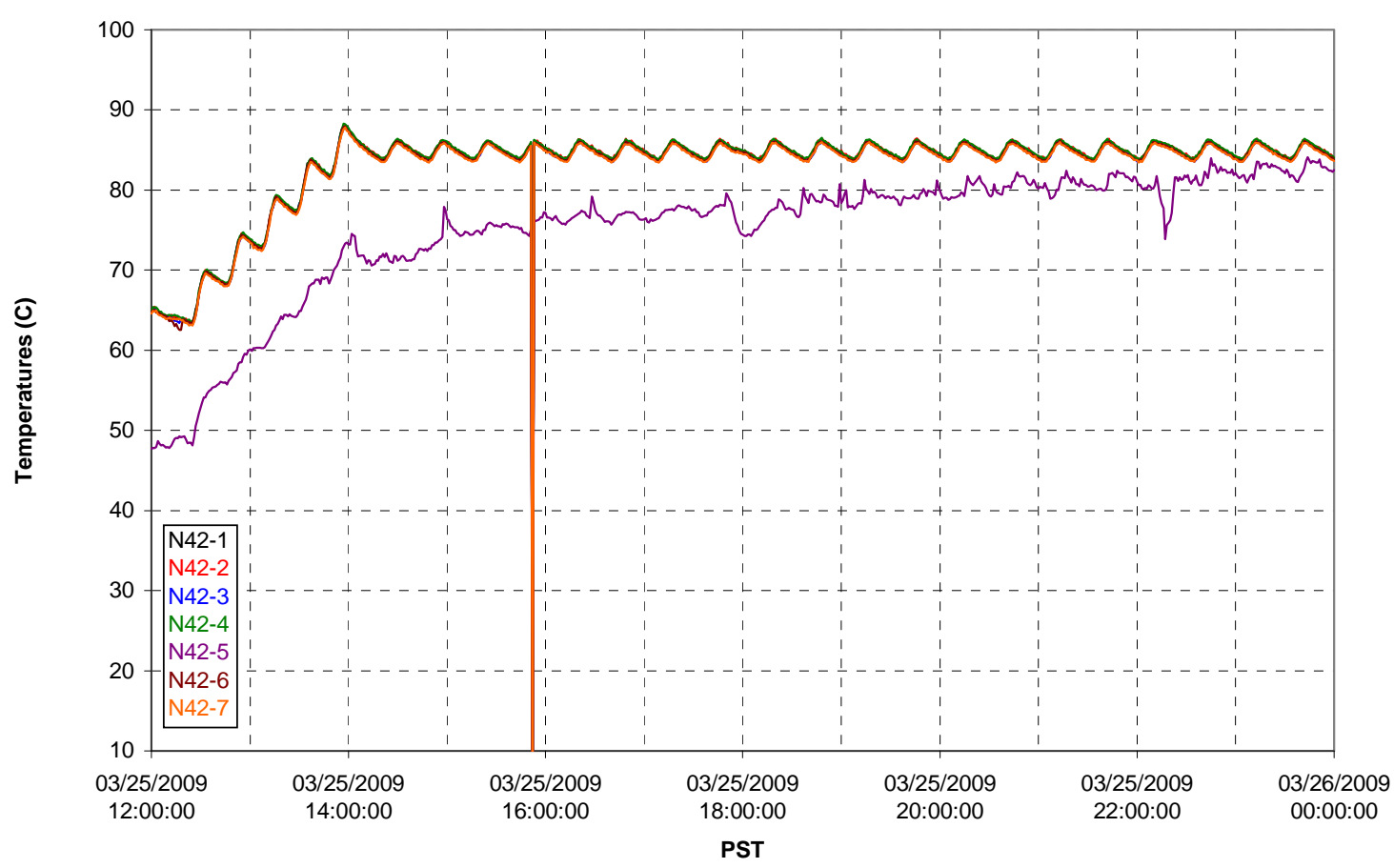

T02A temperatures

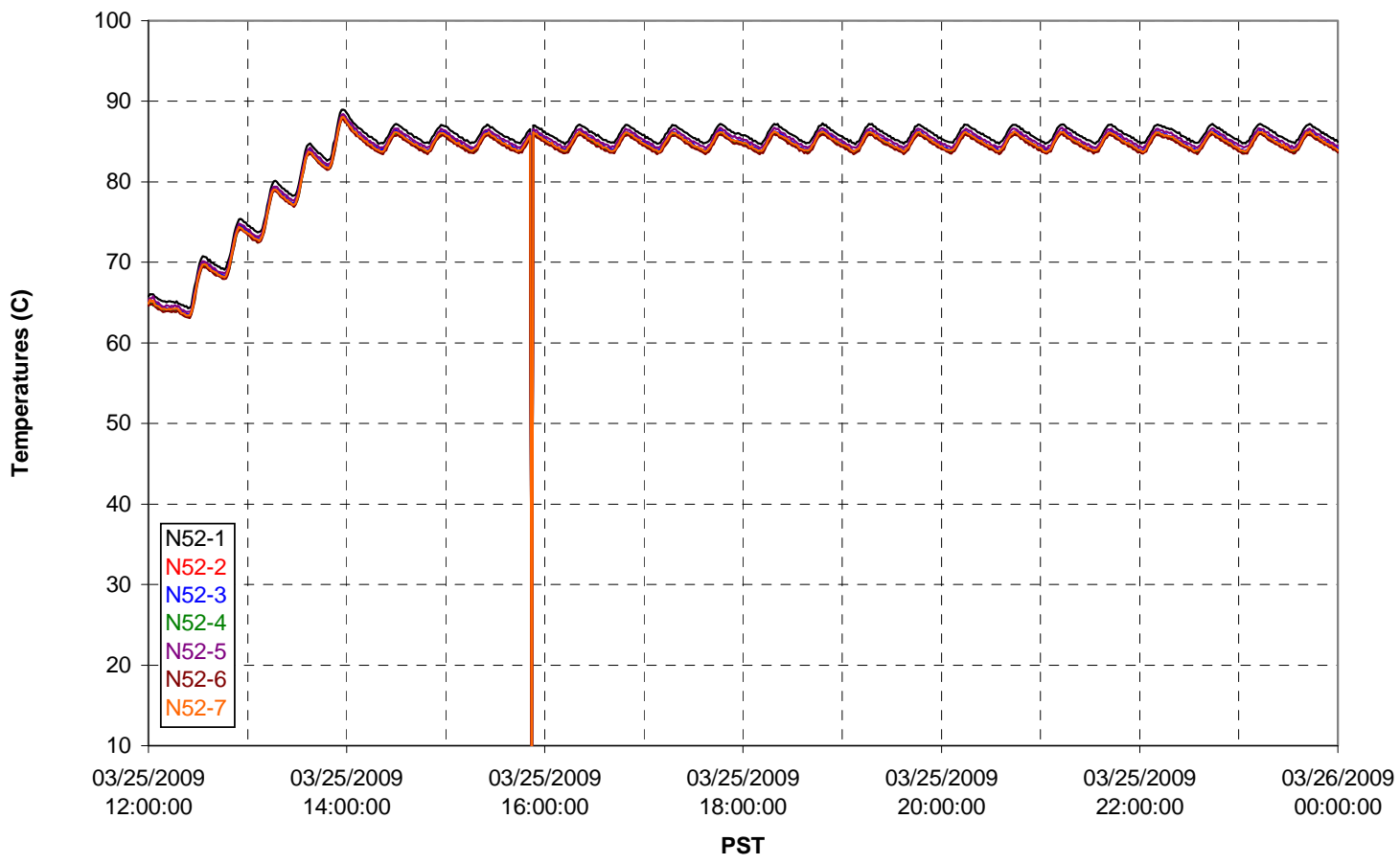


T02A Heating and Cooling

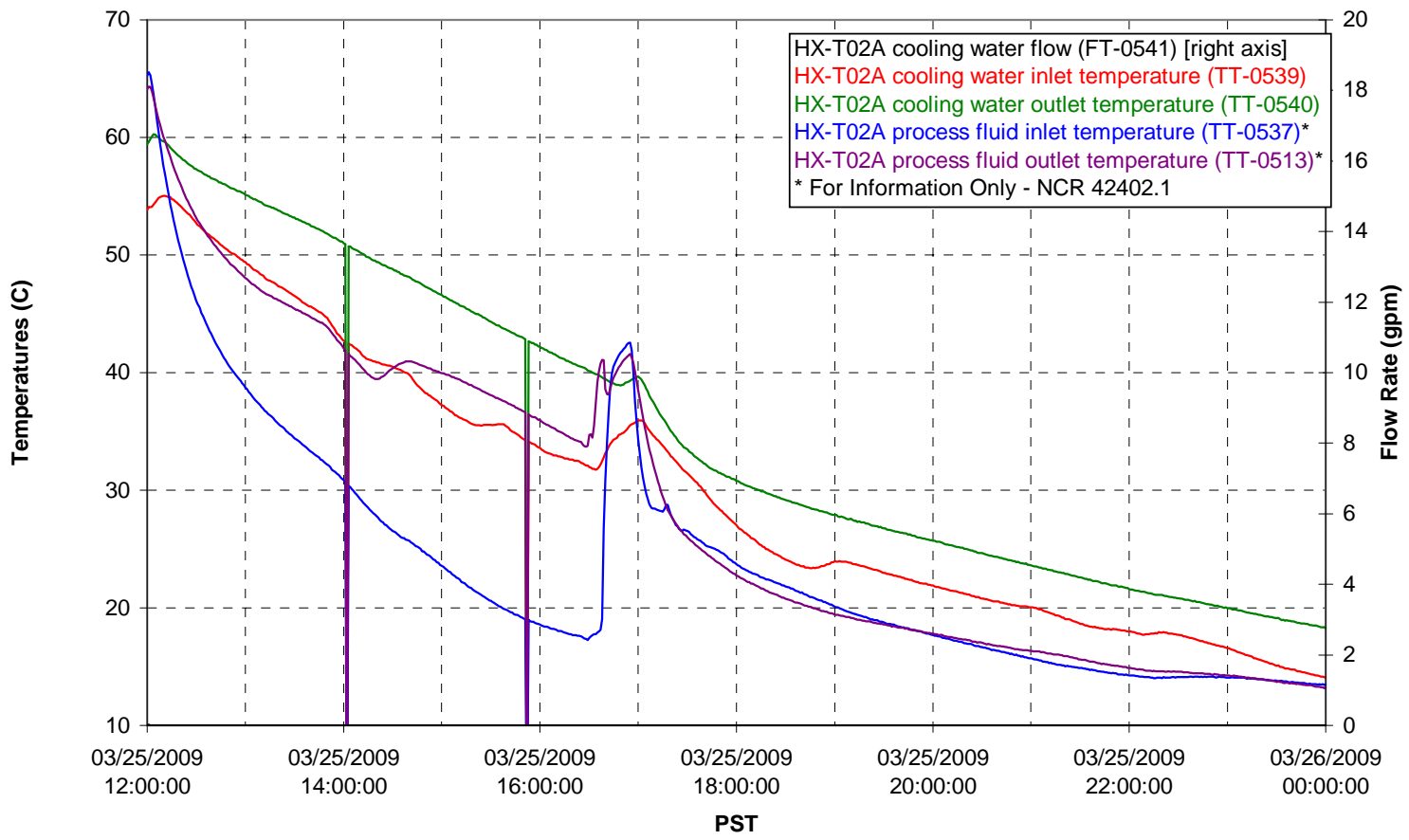

Pump Operation

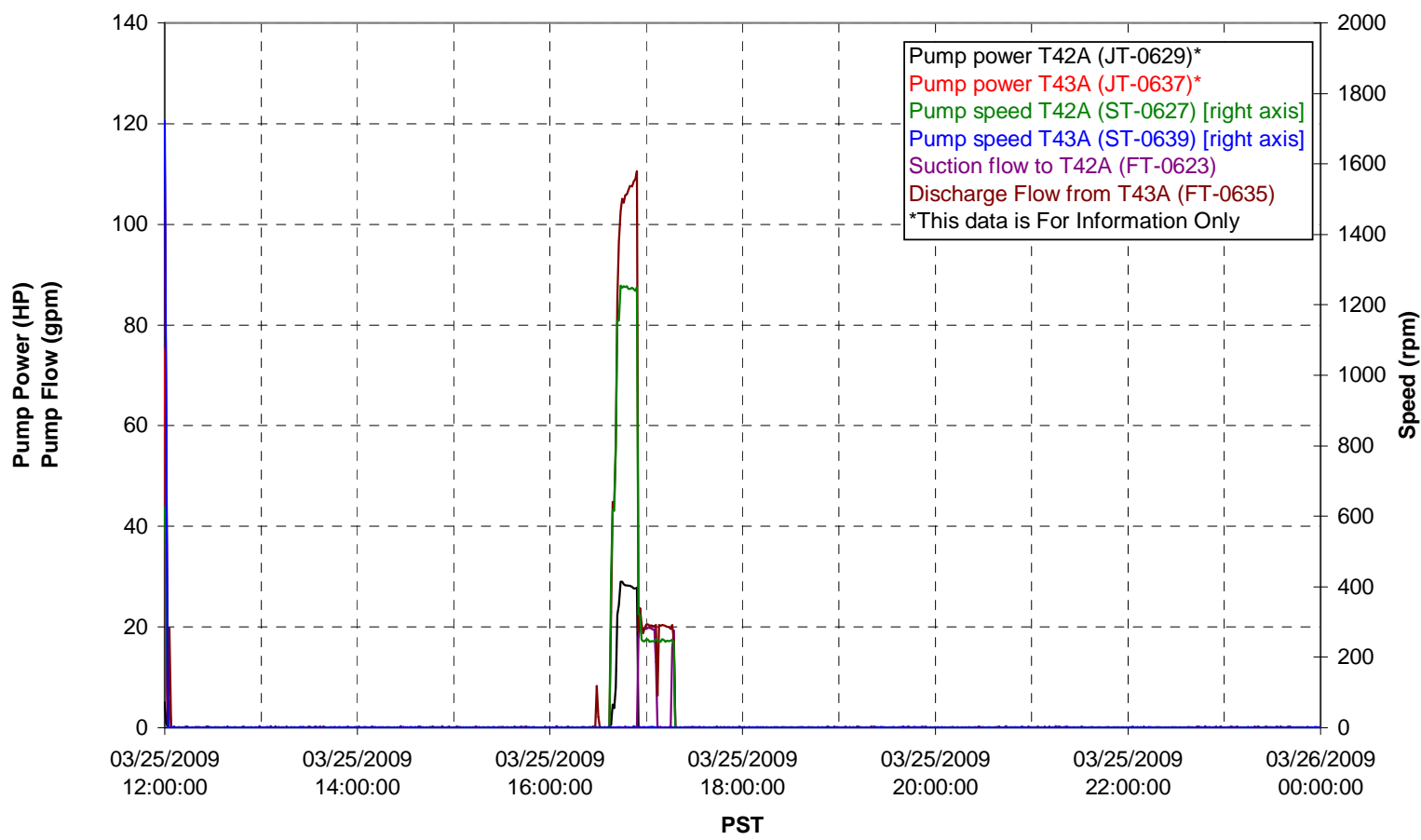


Pulsepot UFP-PP-T01A

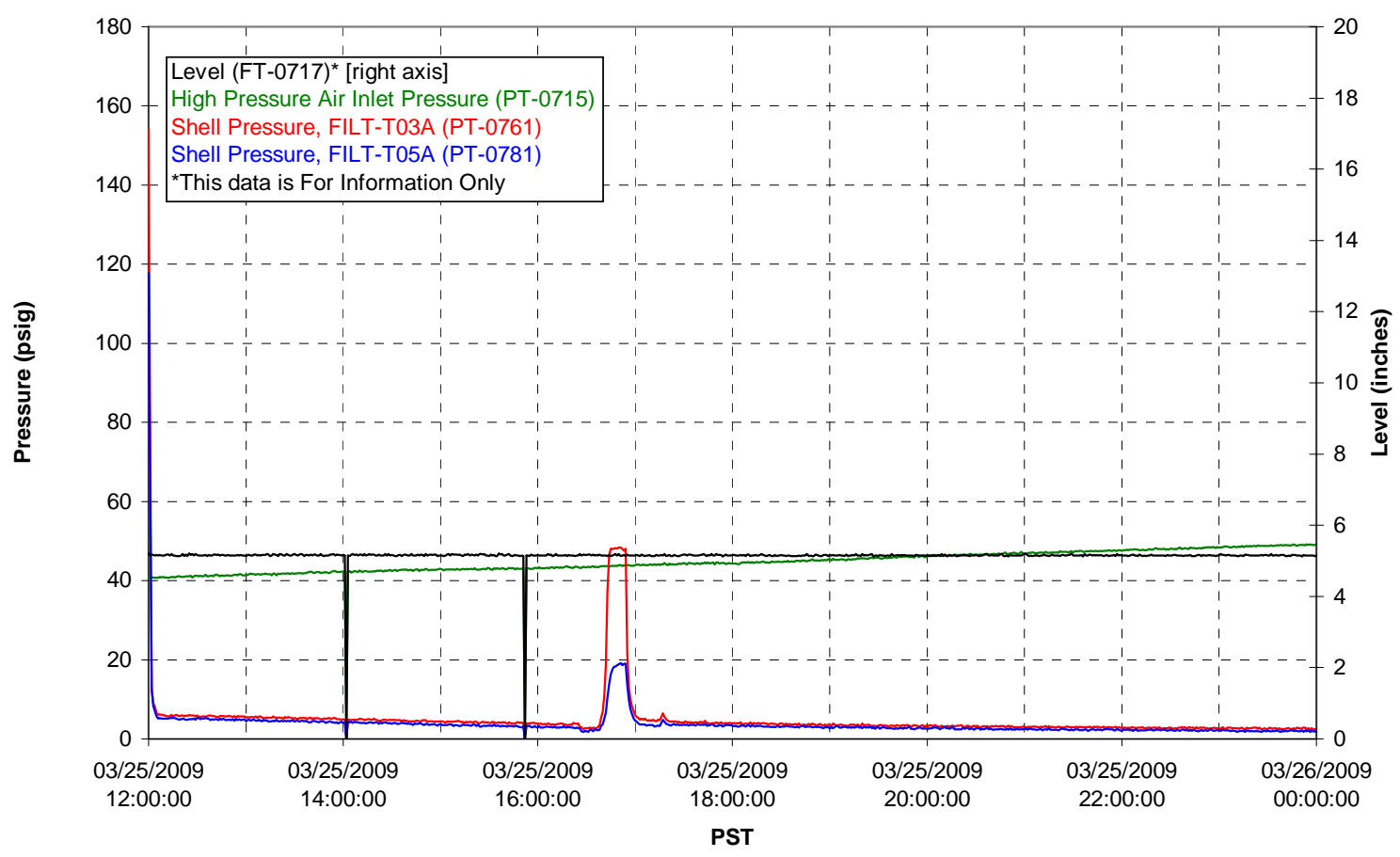

Pulsepot UFP-PP-T02A

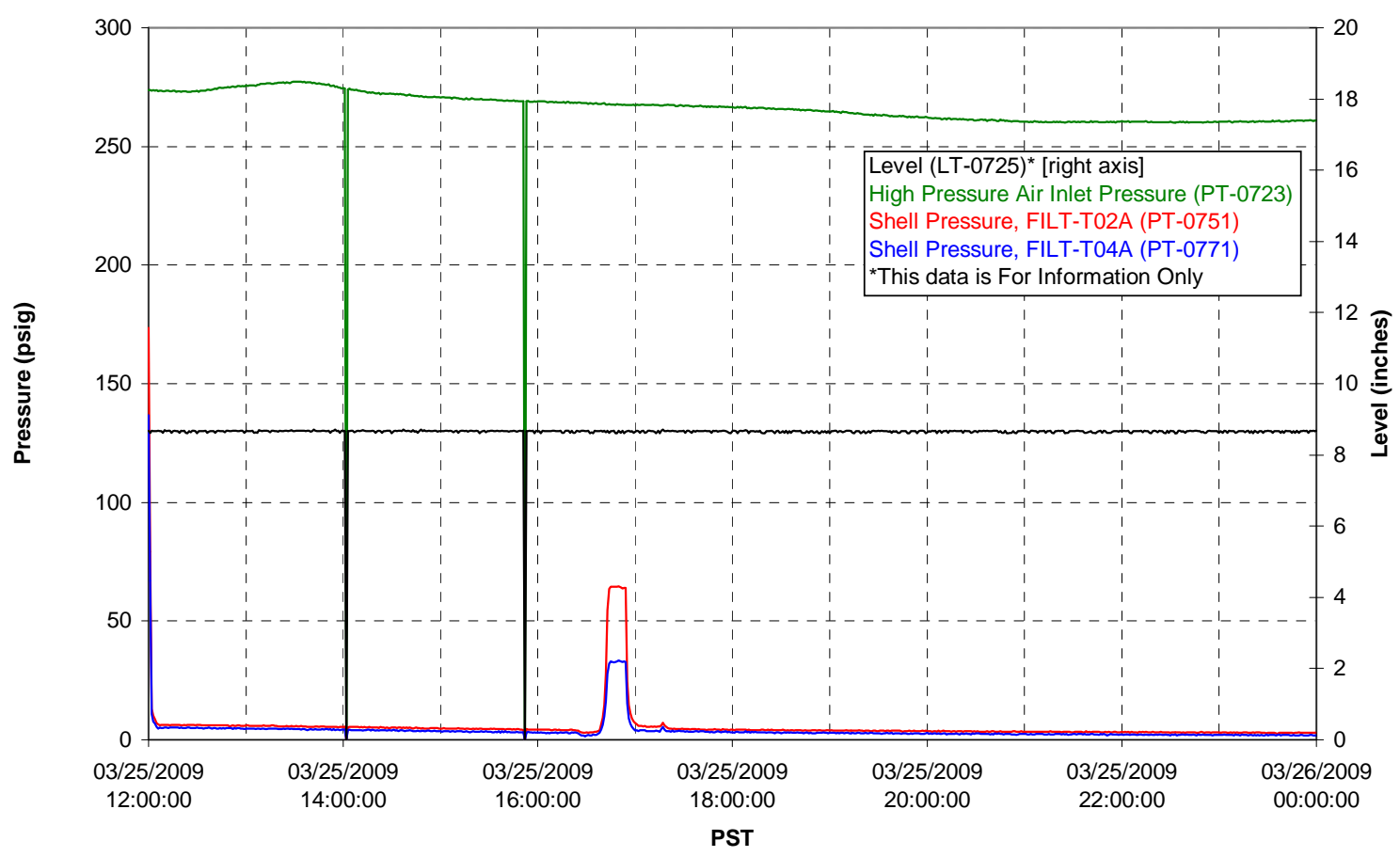


Pulsepot UFP-PP-T03A

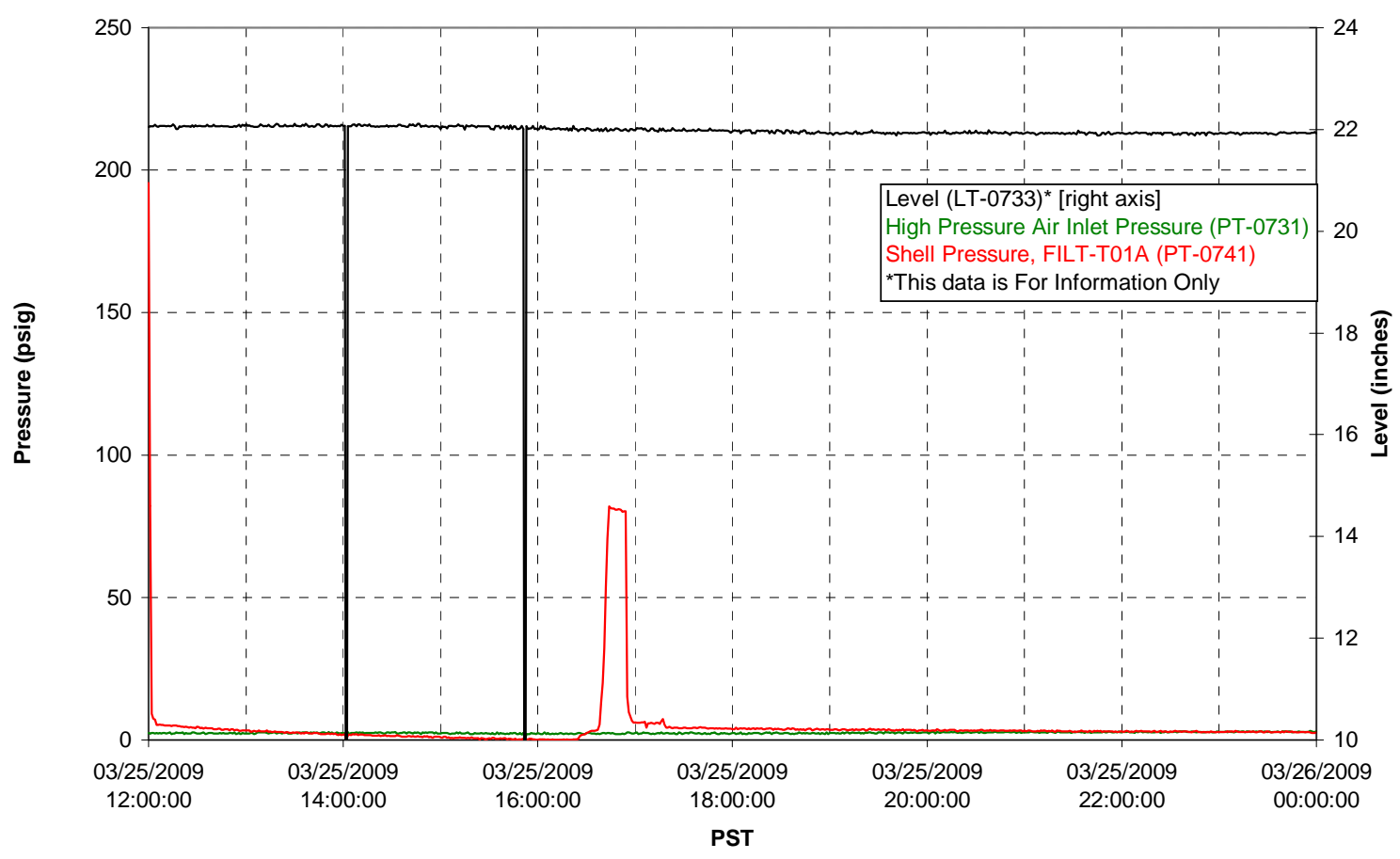

Pulsepot Levels

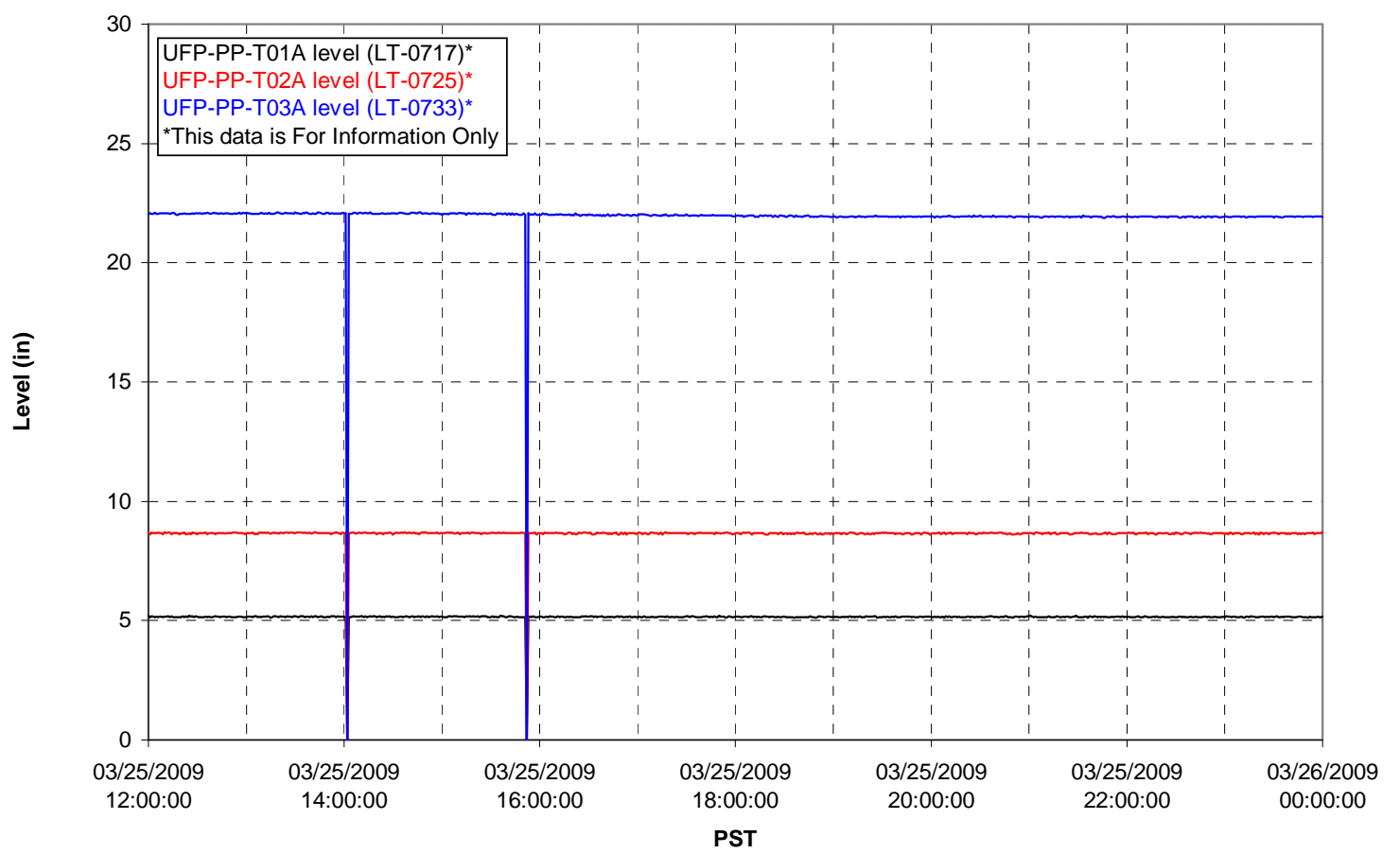


Filter UFP-FILT-T01A

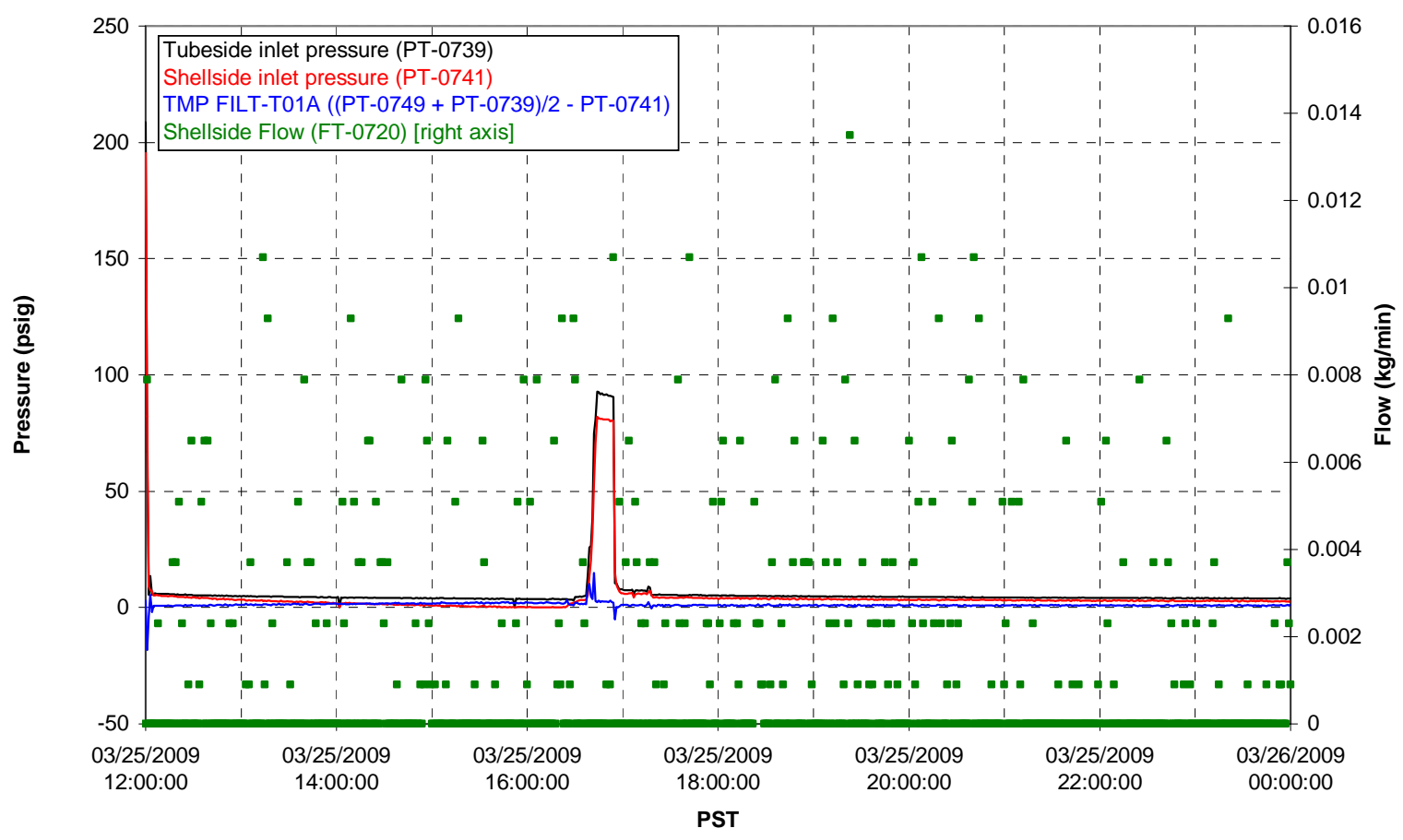

Filter UFP-FILT-T02A

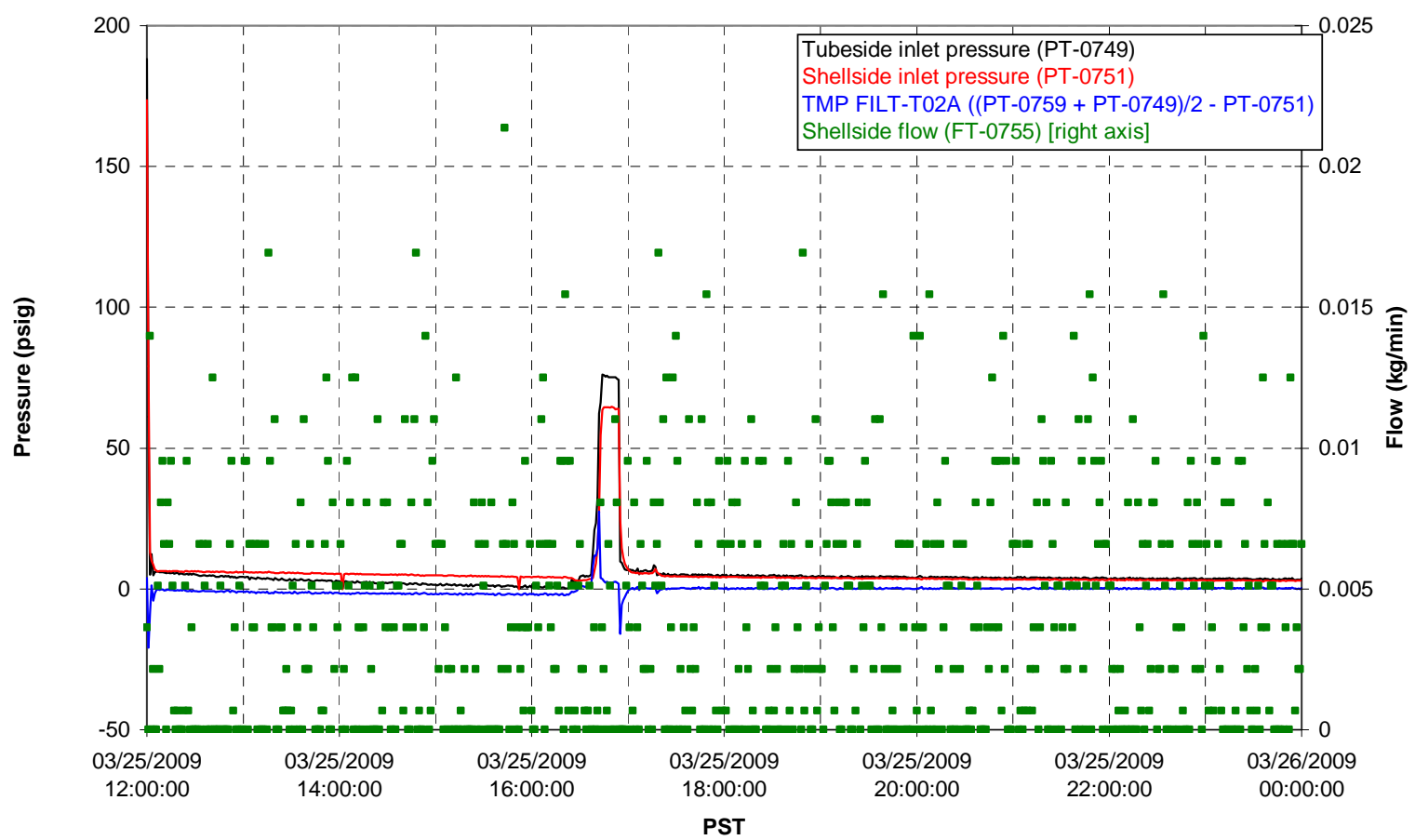


Filter UFP-FILT-T03A

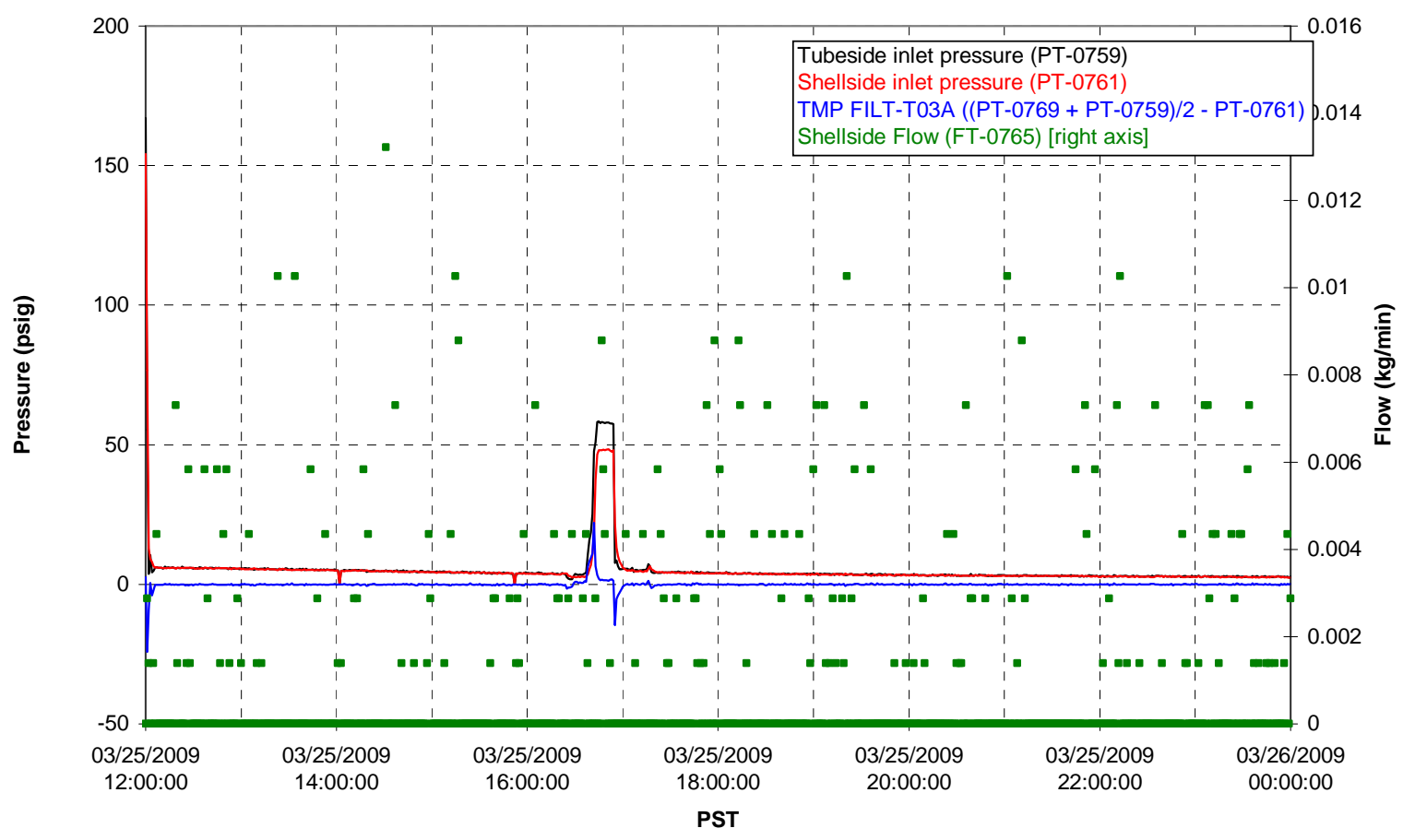

Filter UFP-FILT-T04A

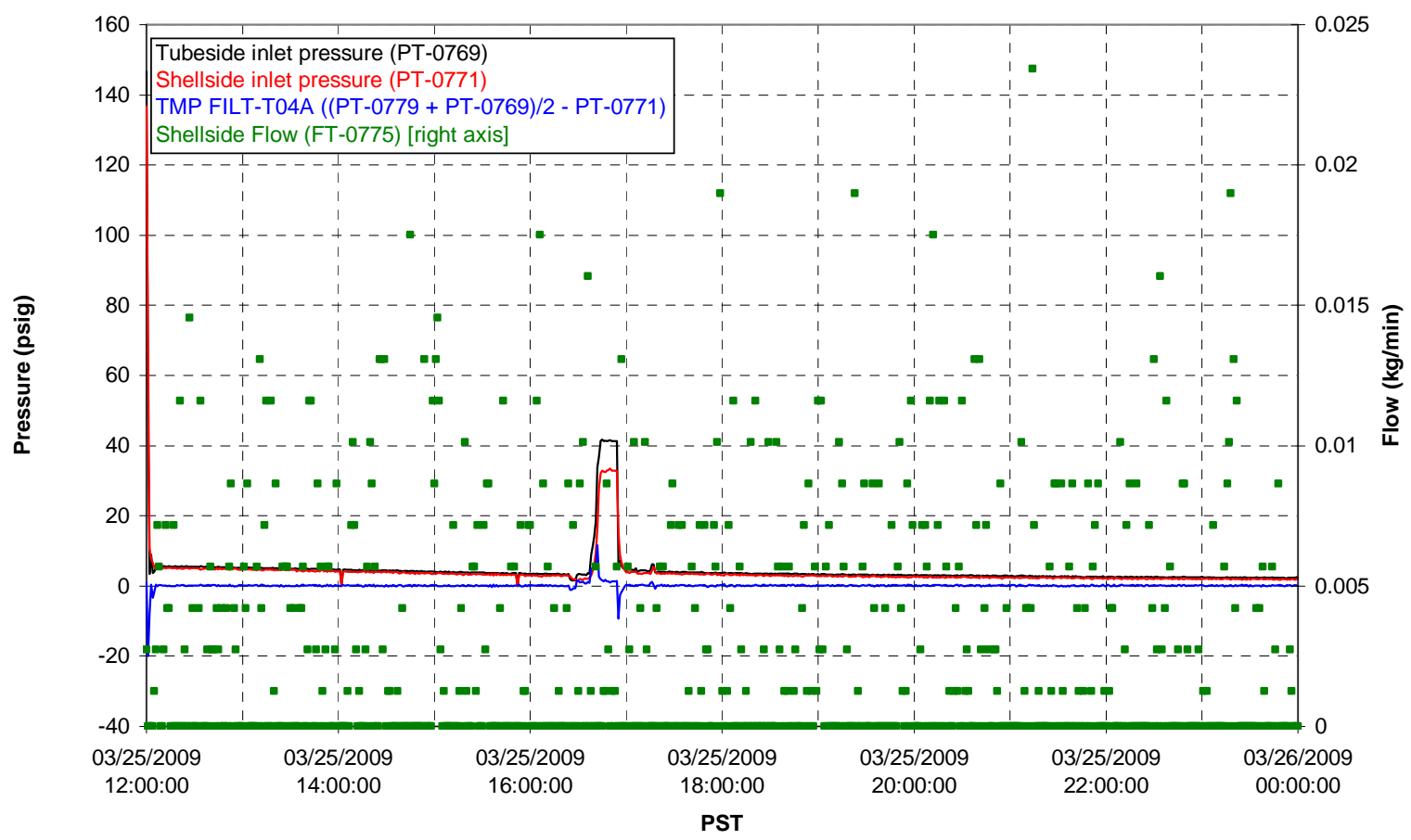


Filter UFP-FILT-T05A

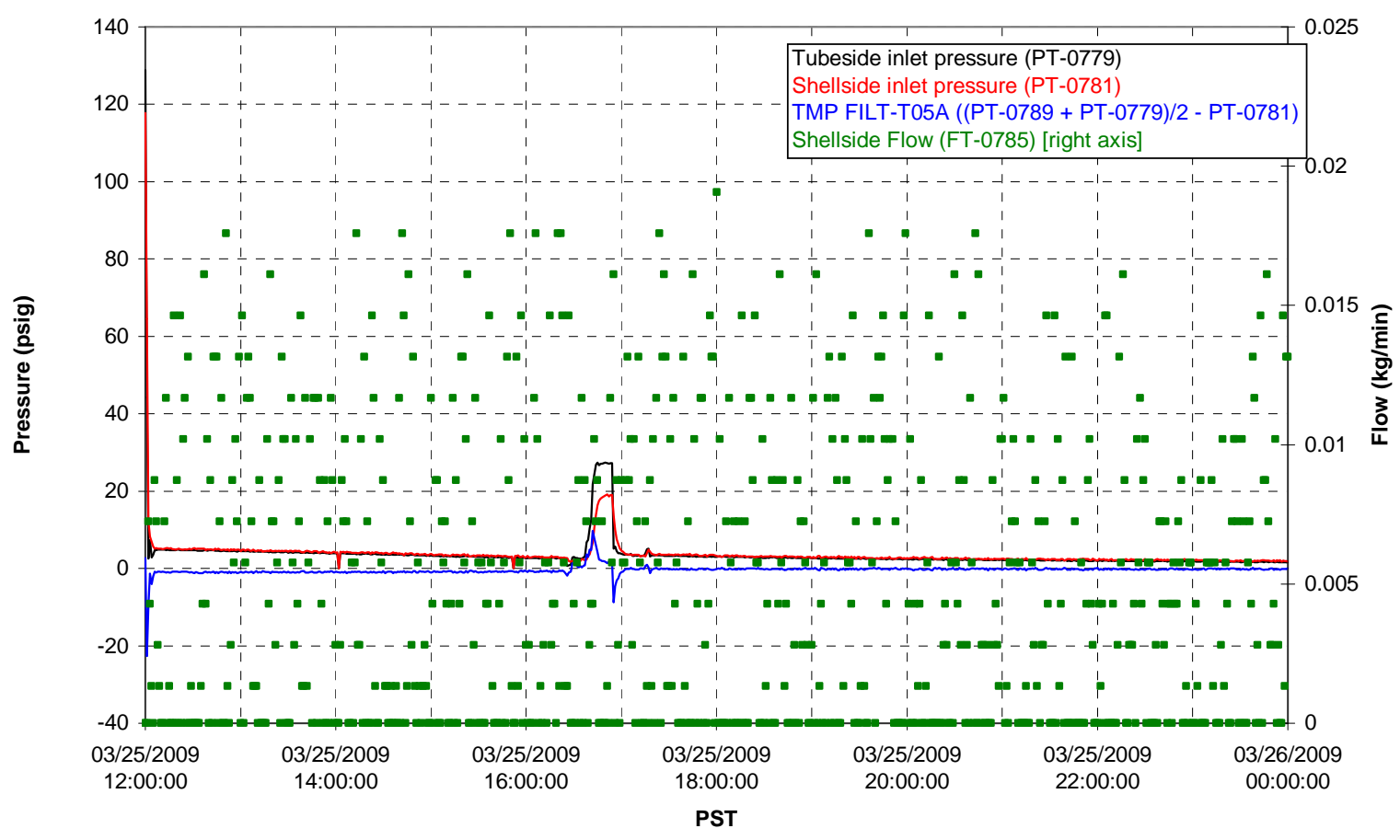

Chemical Flow

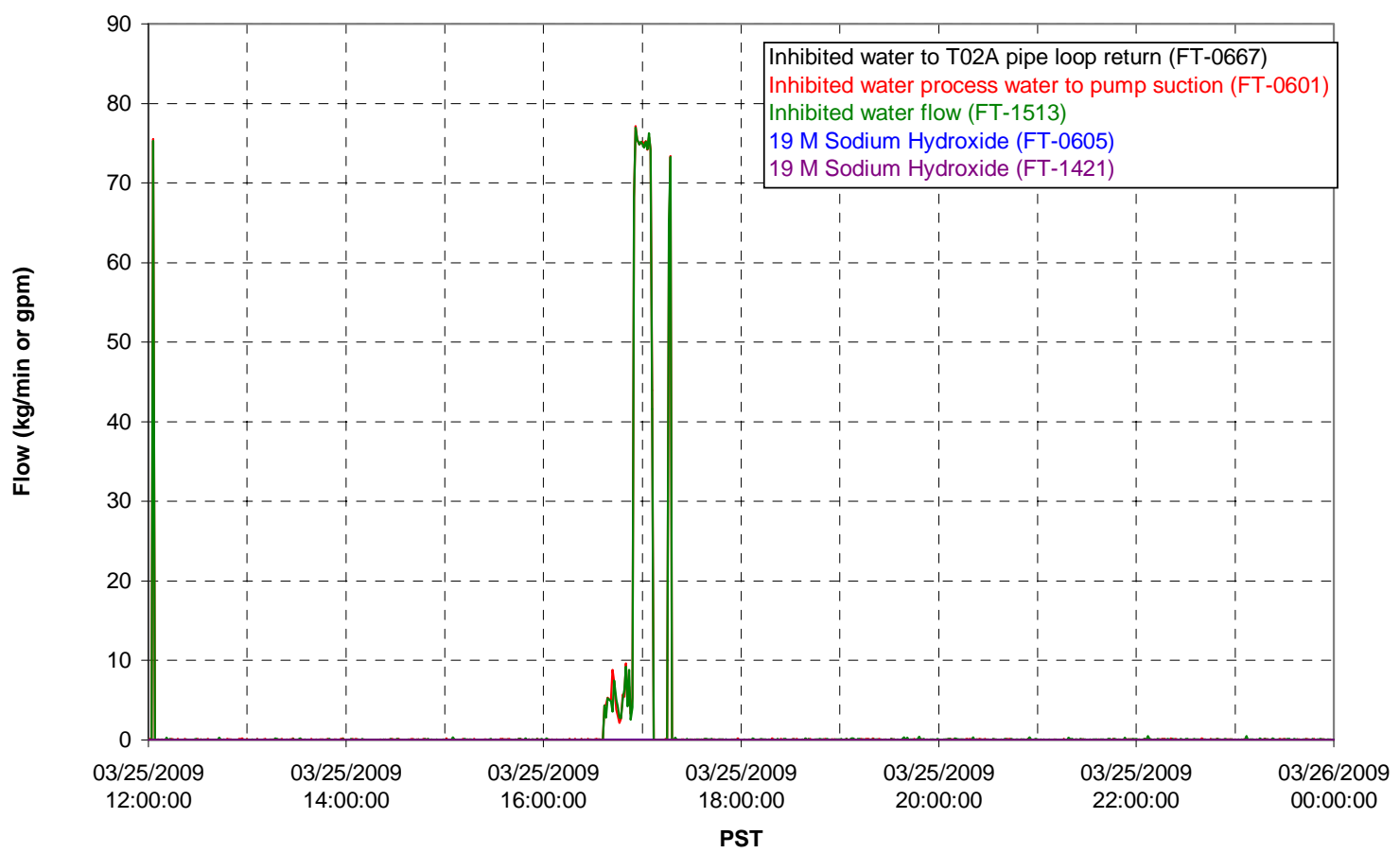




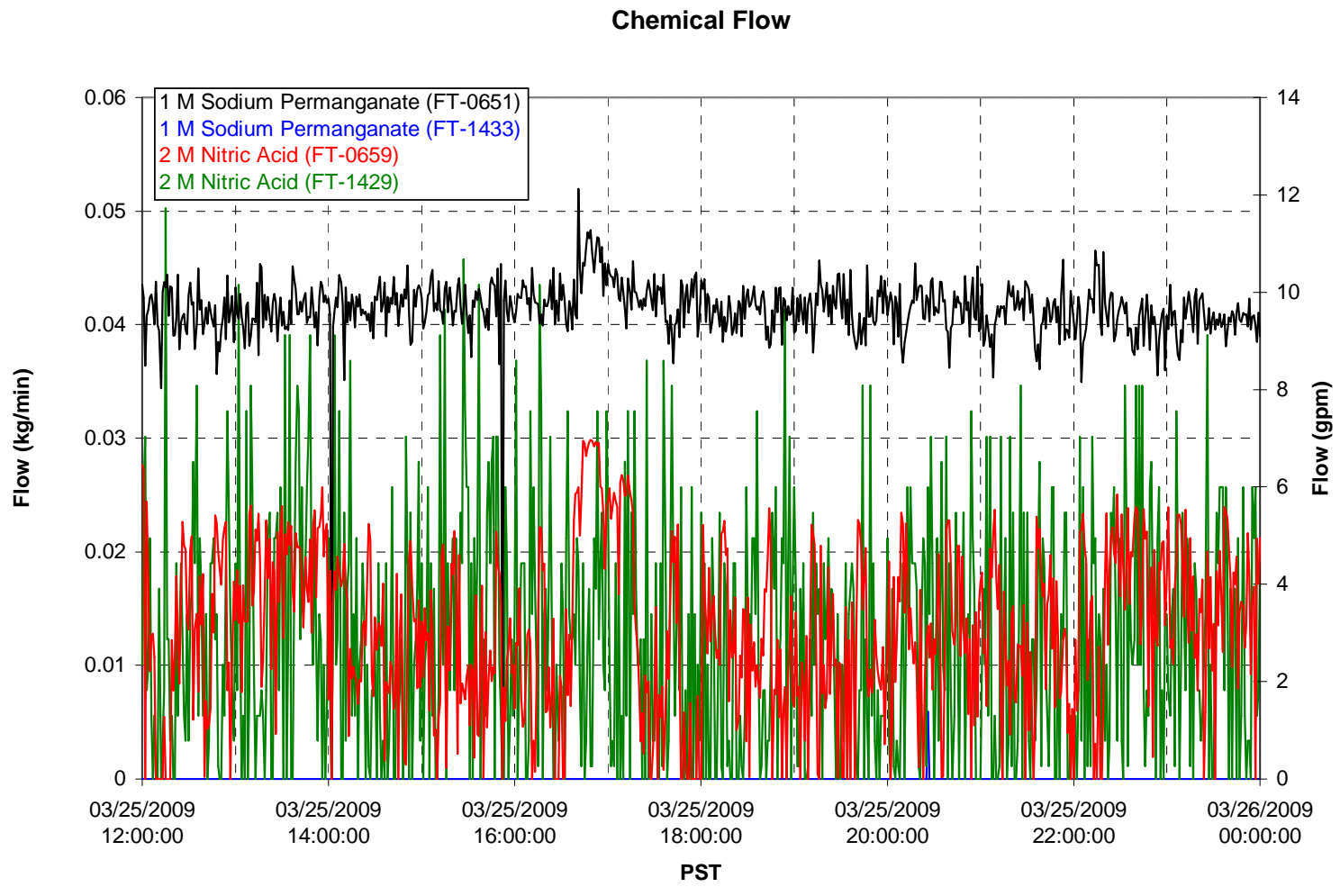

Air Flows

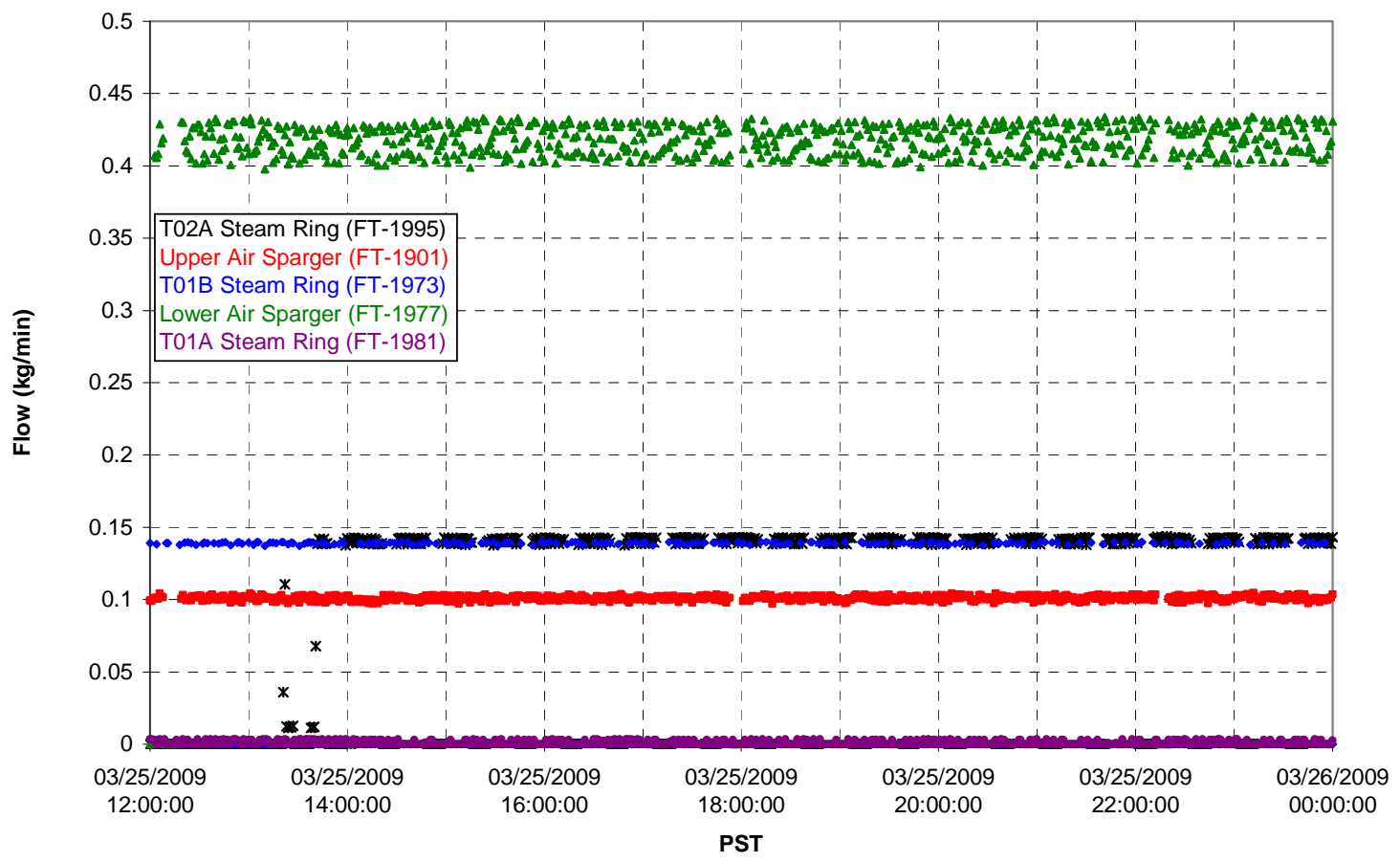


T02A Steam

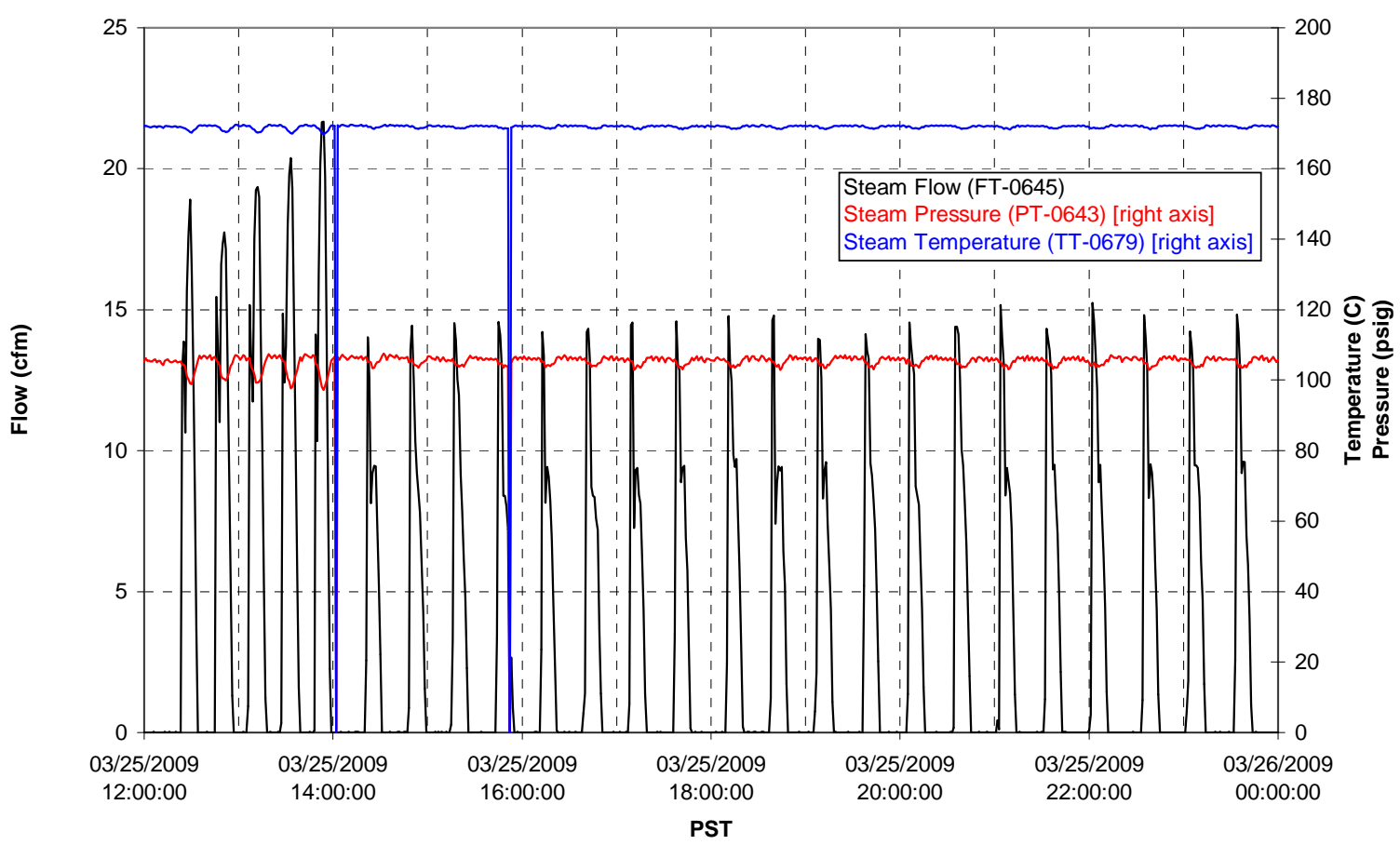

T01A Steam

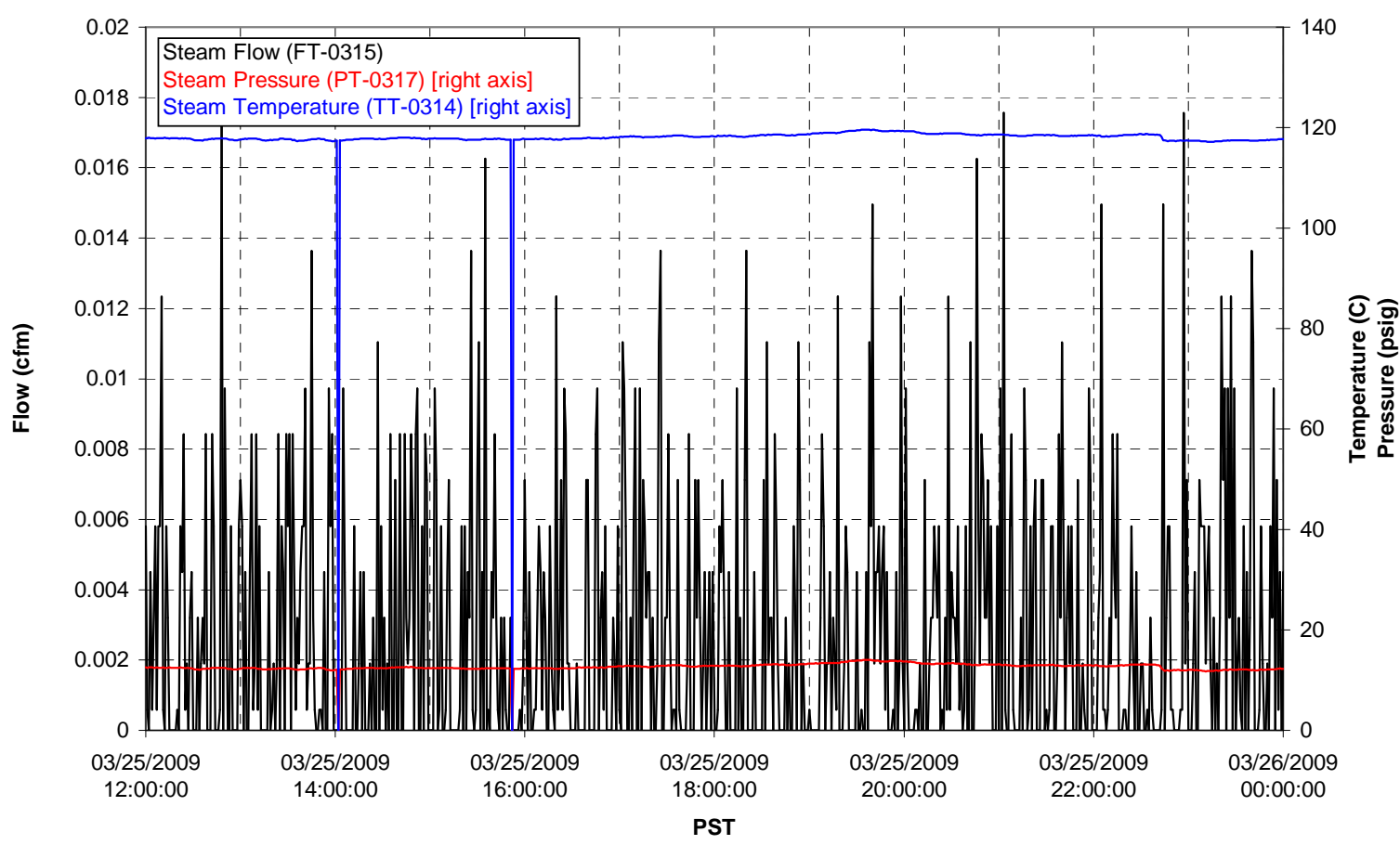


T01B Steam

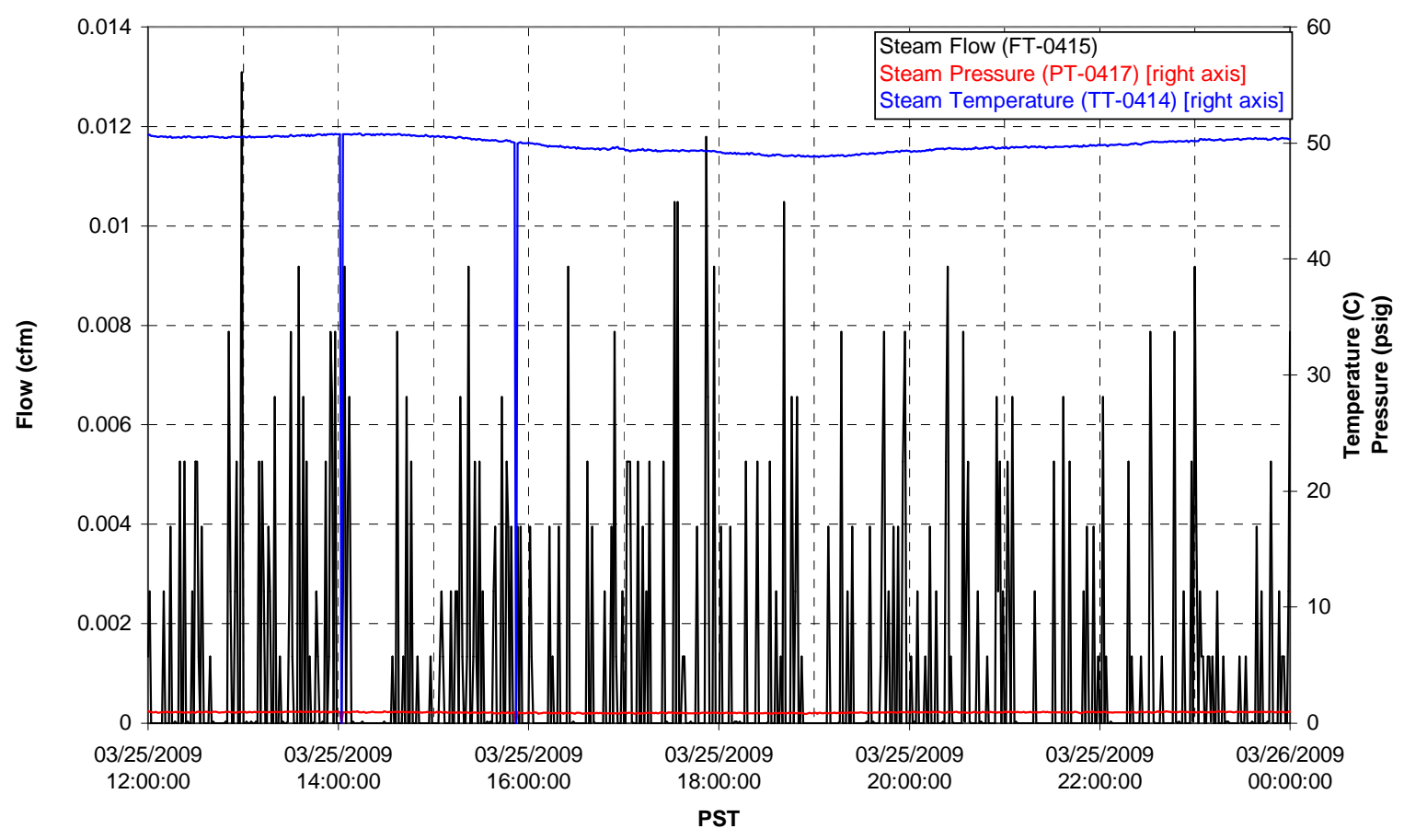




\section{Integrated Test D Data Plots 03/26/09 00:00 - 03/26/09 12:00}


T01A level

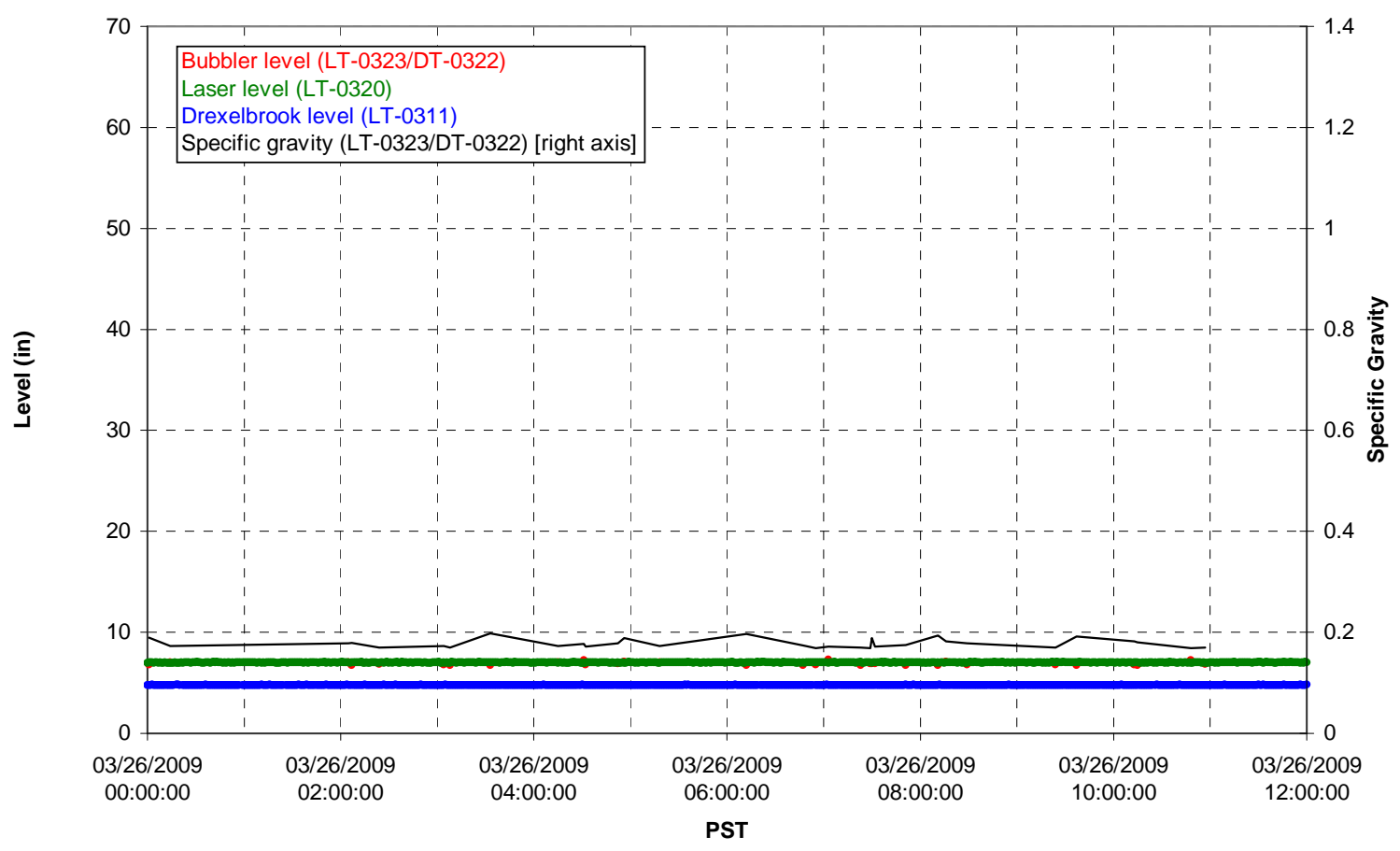

T01A temperatures

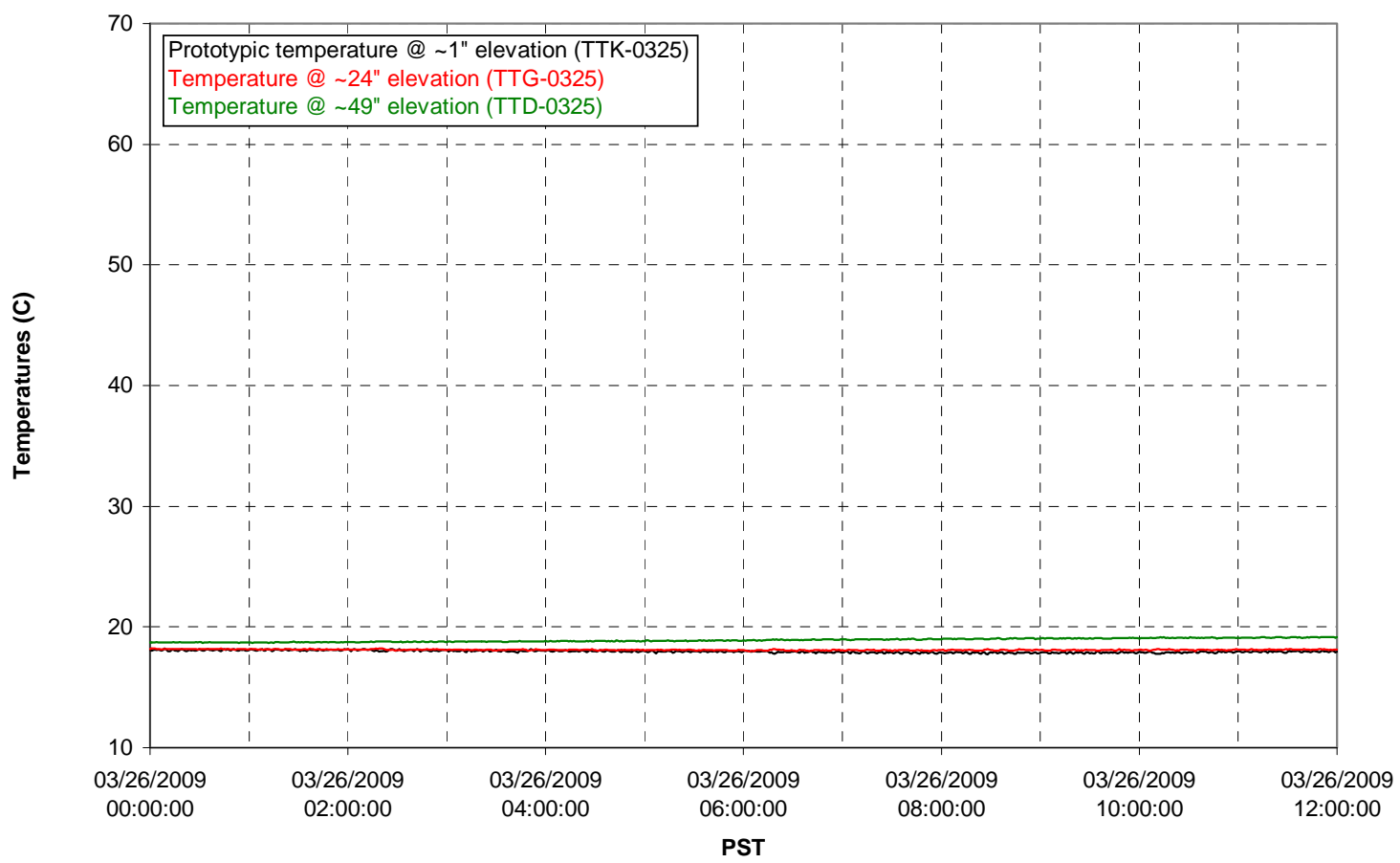


T01B level

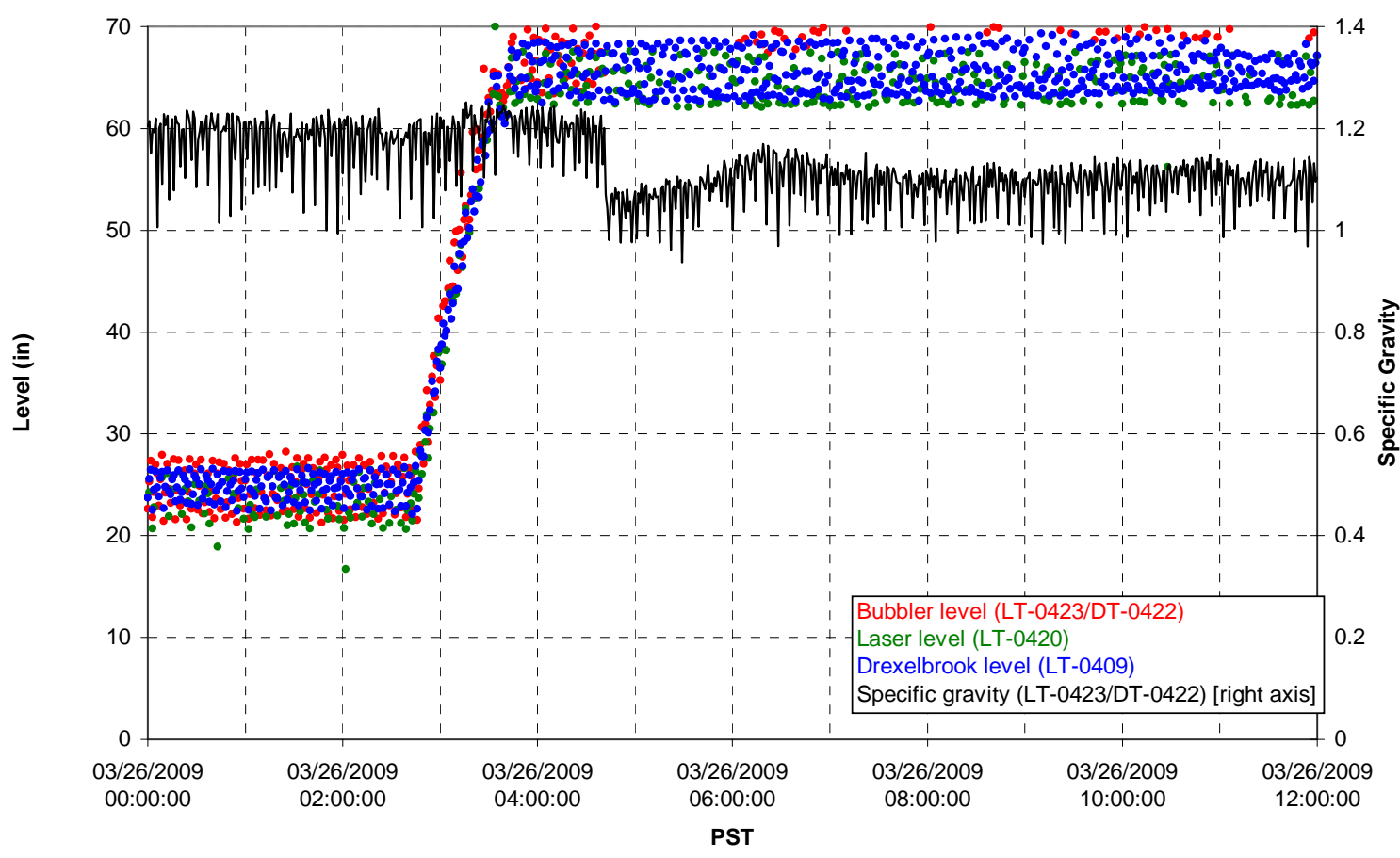

T01B temperatures

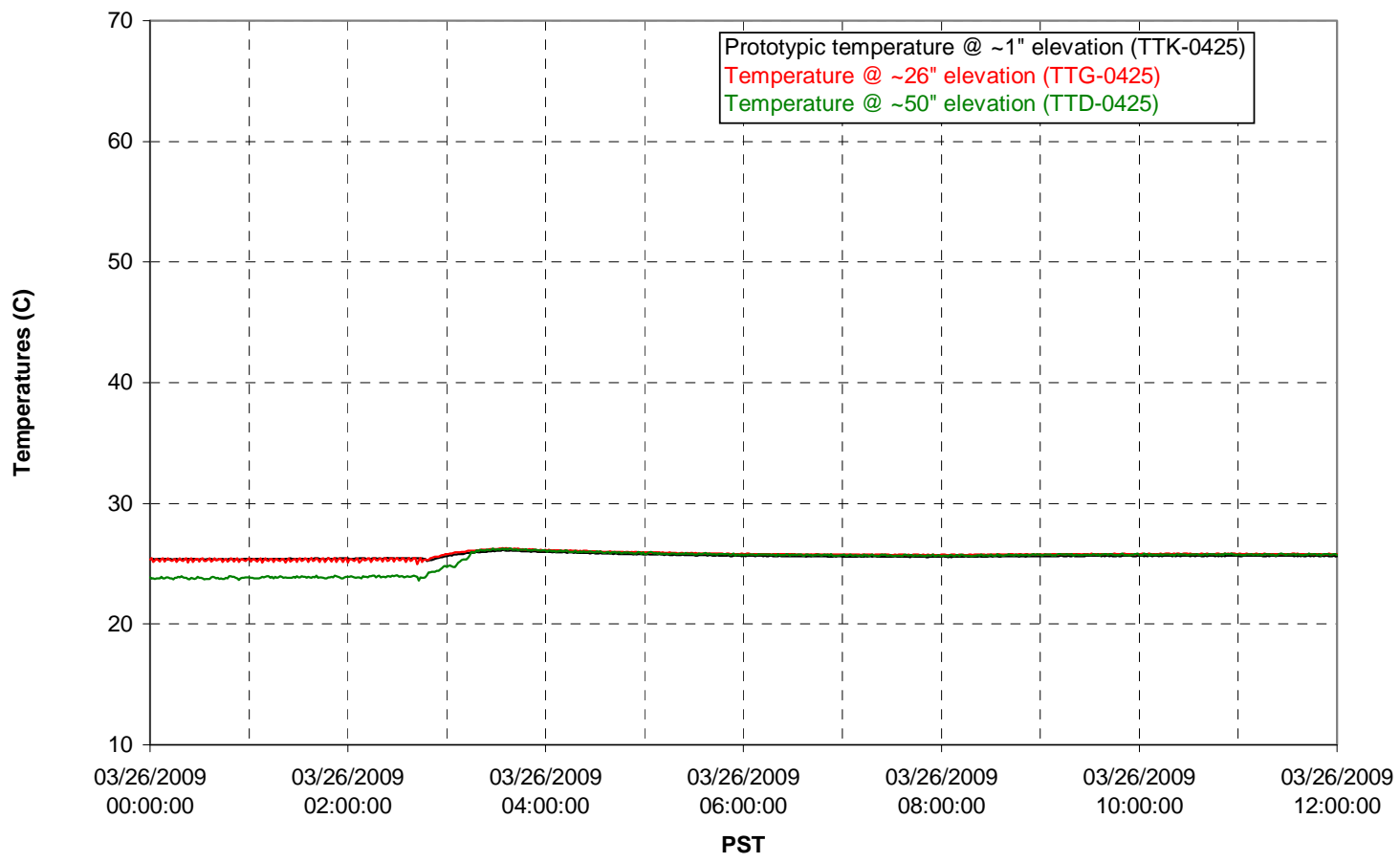


T02A level

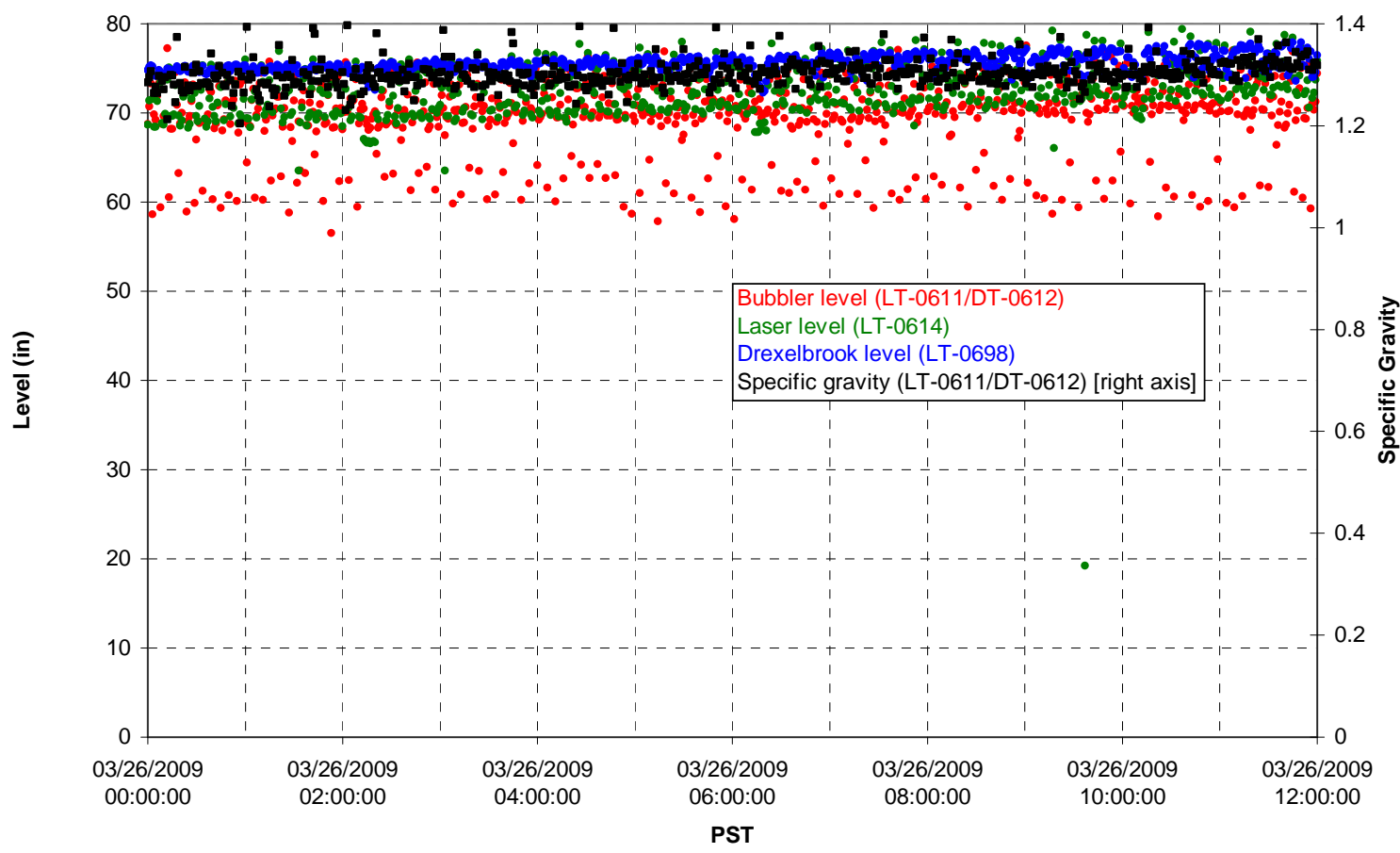

T02A temperatures

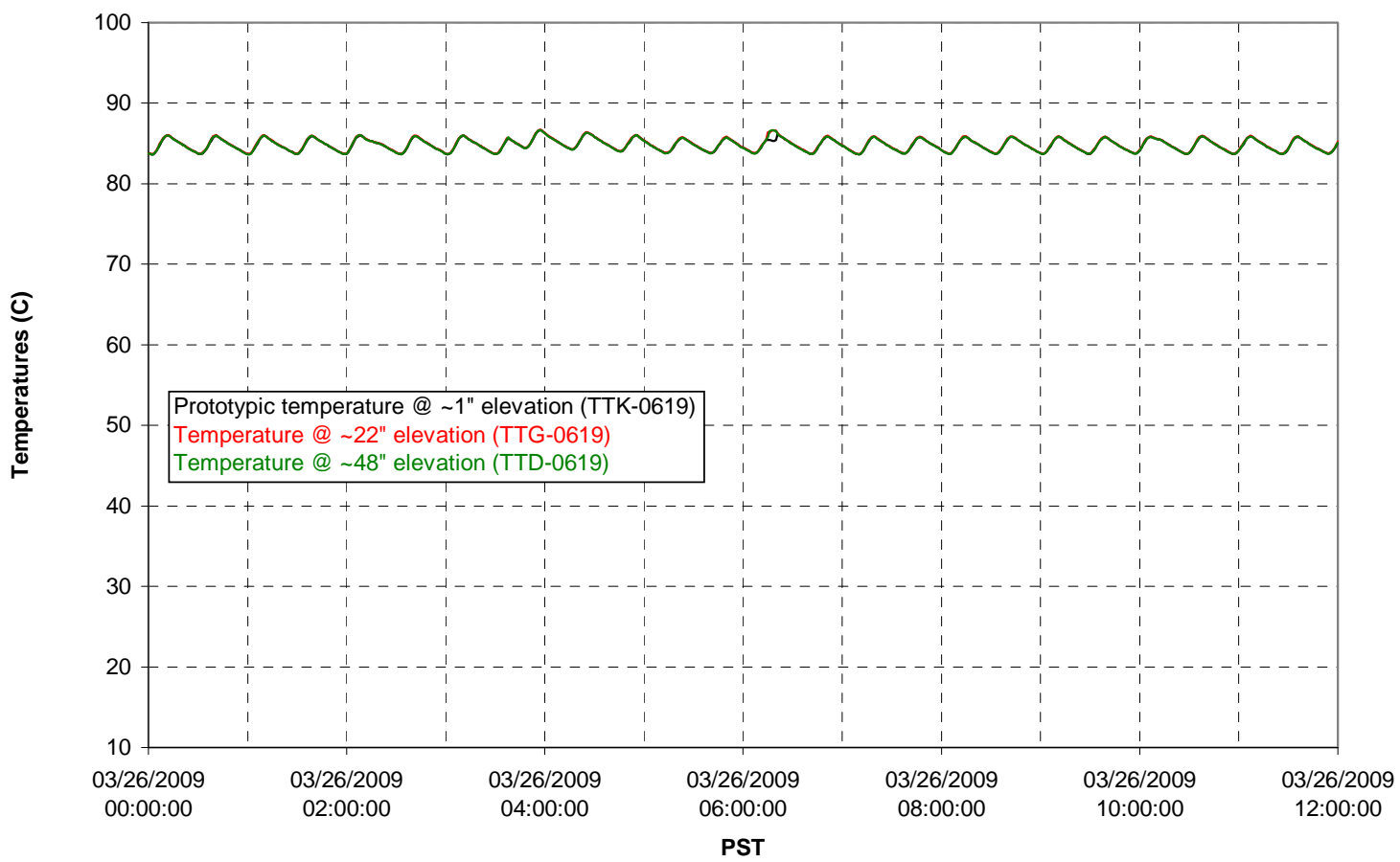


T02A and filter loop temperatures

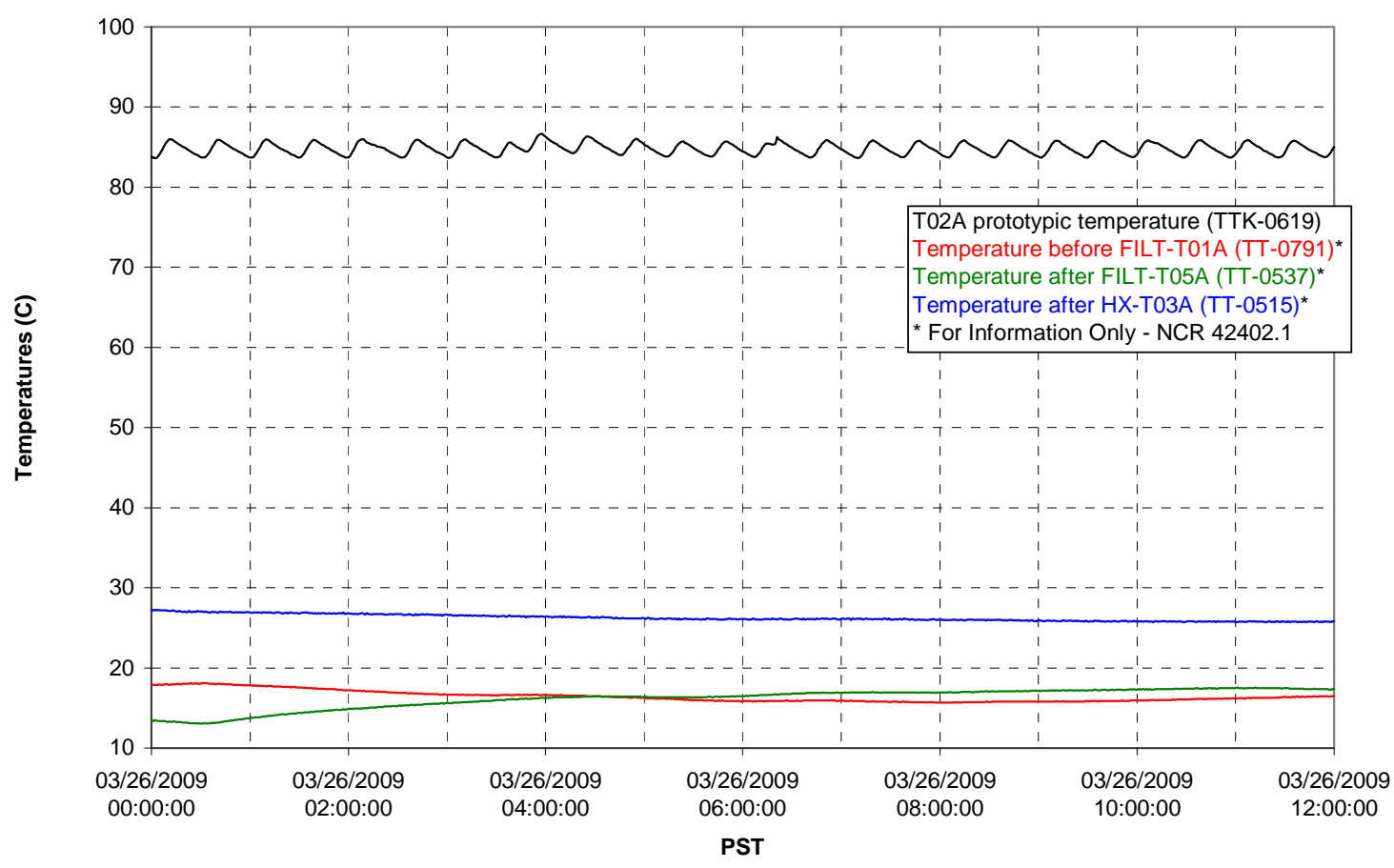

Pump Pressures and Flow

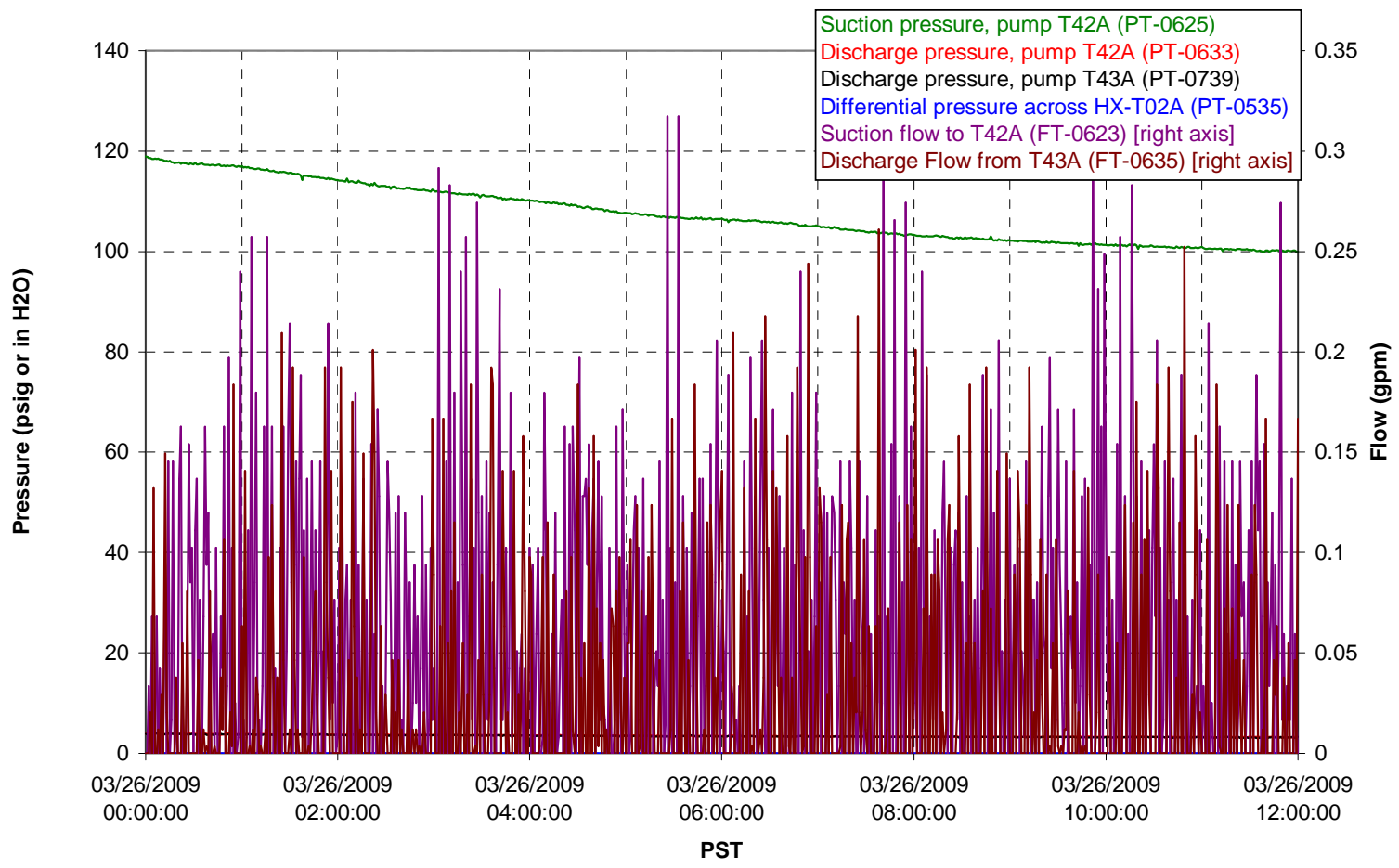


Axial pressure drop

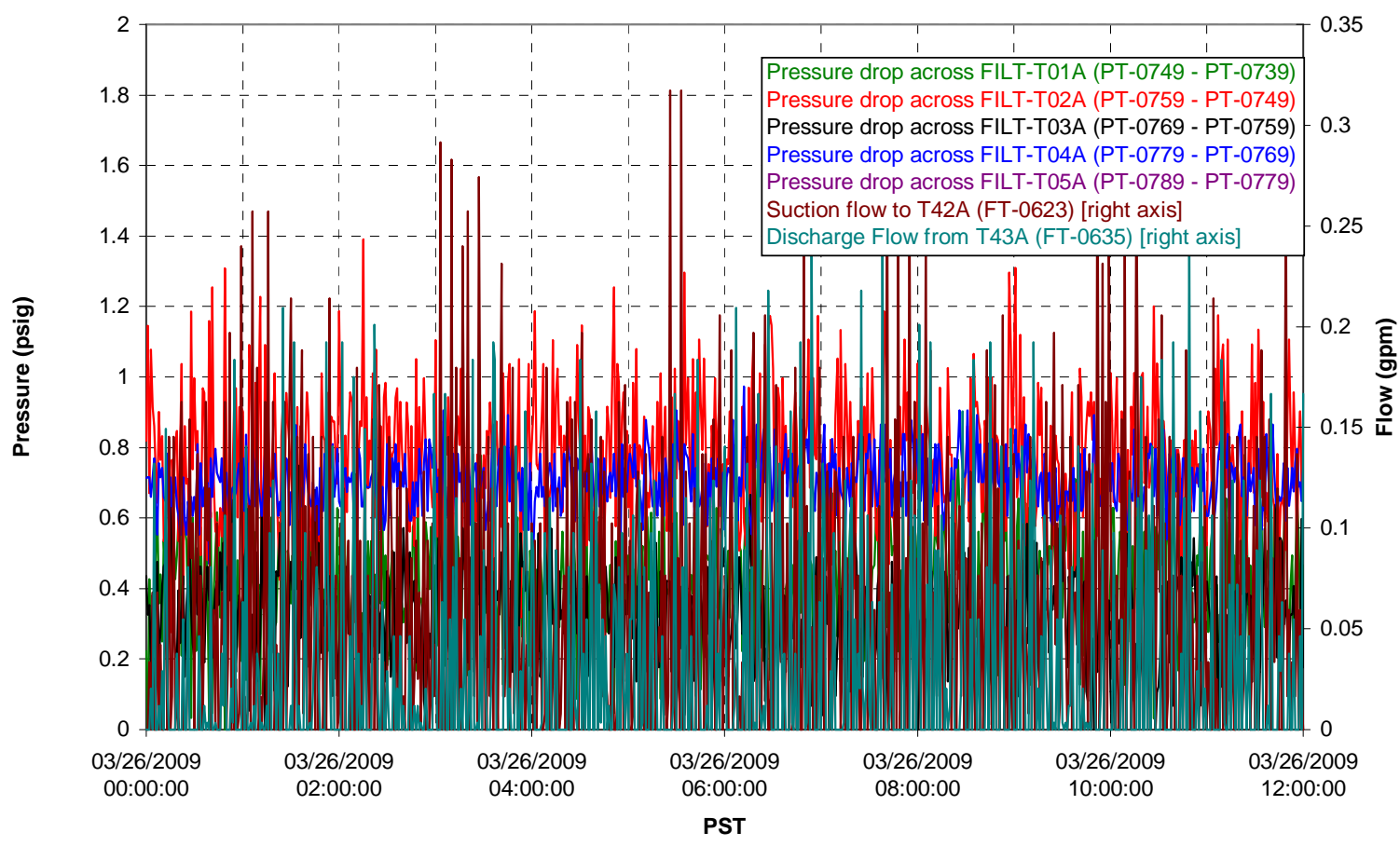

Permeate flow rates

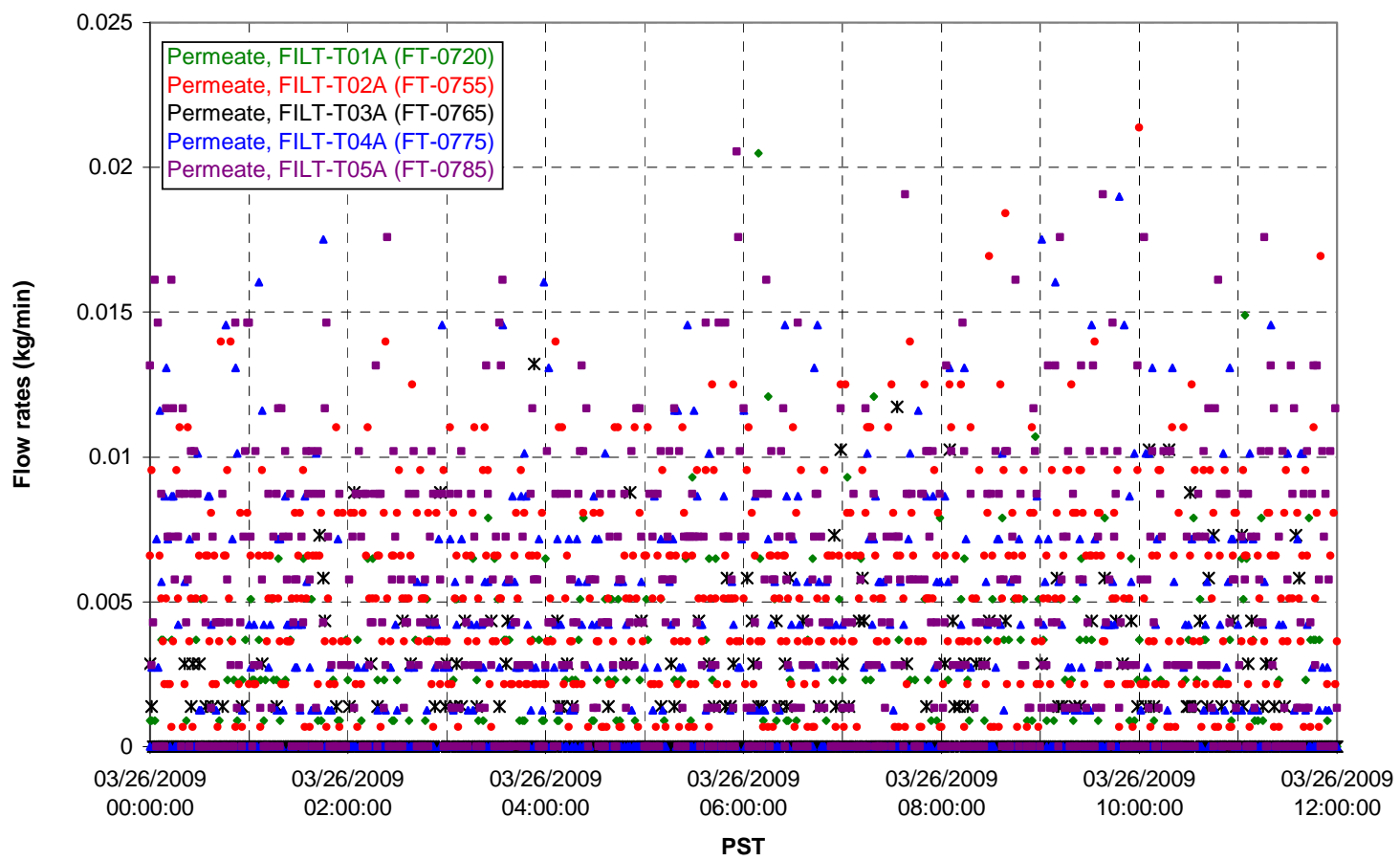


T02A Inner Temperature Tree

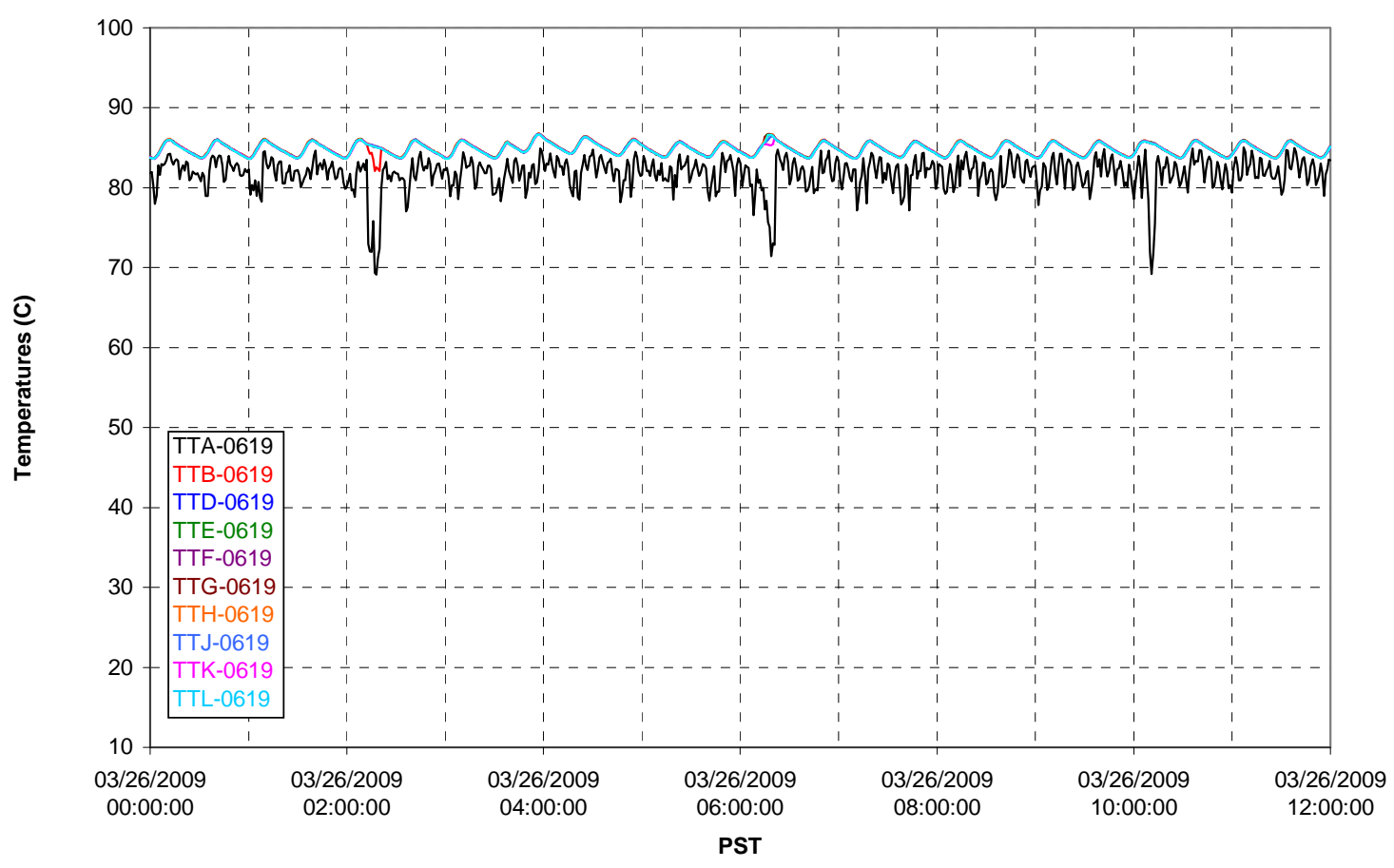

T02A Outer Temperature Tree

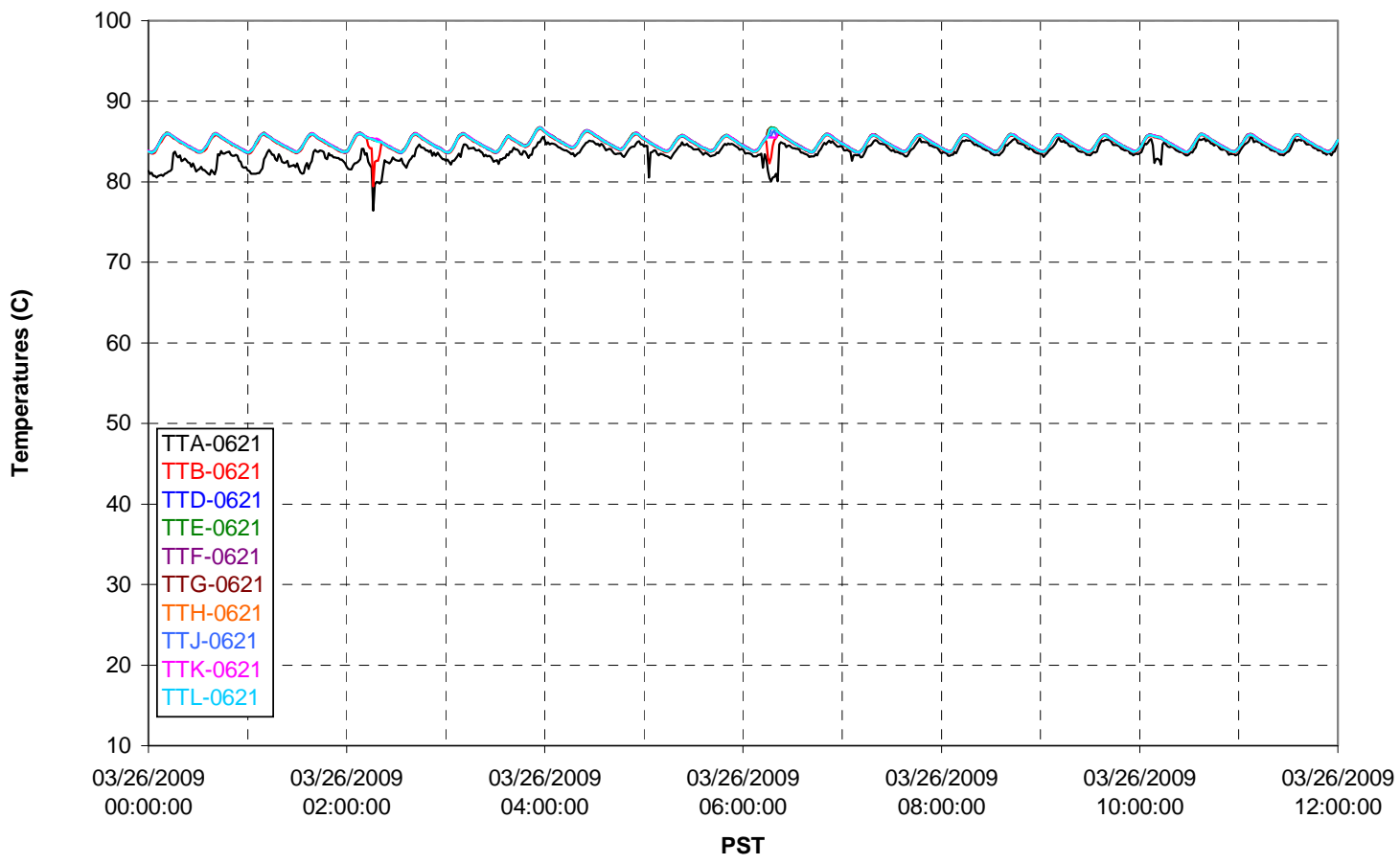


T02A temperatures

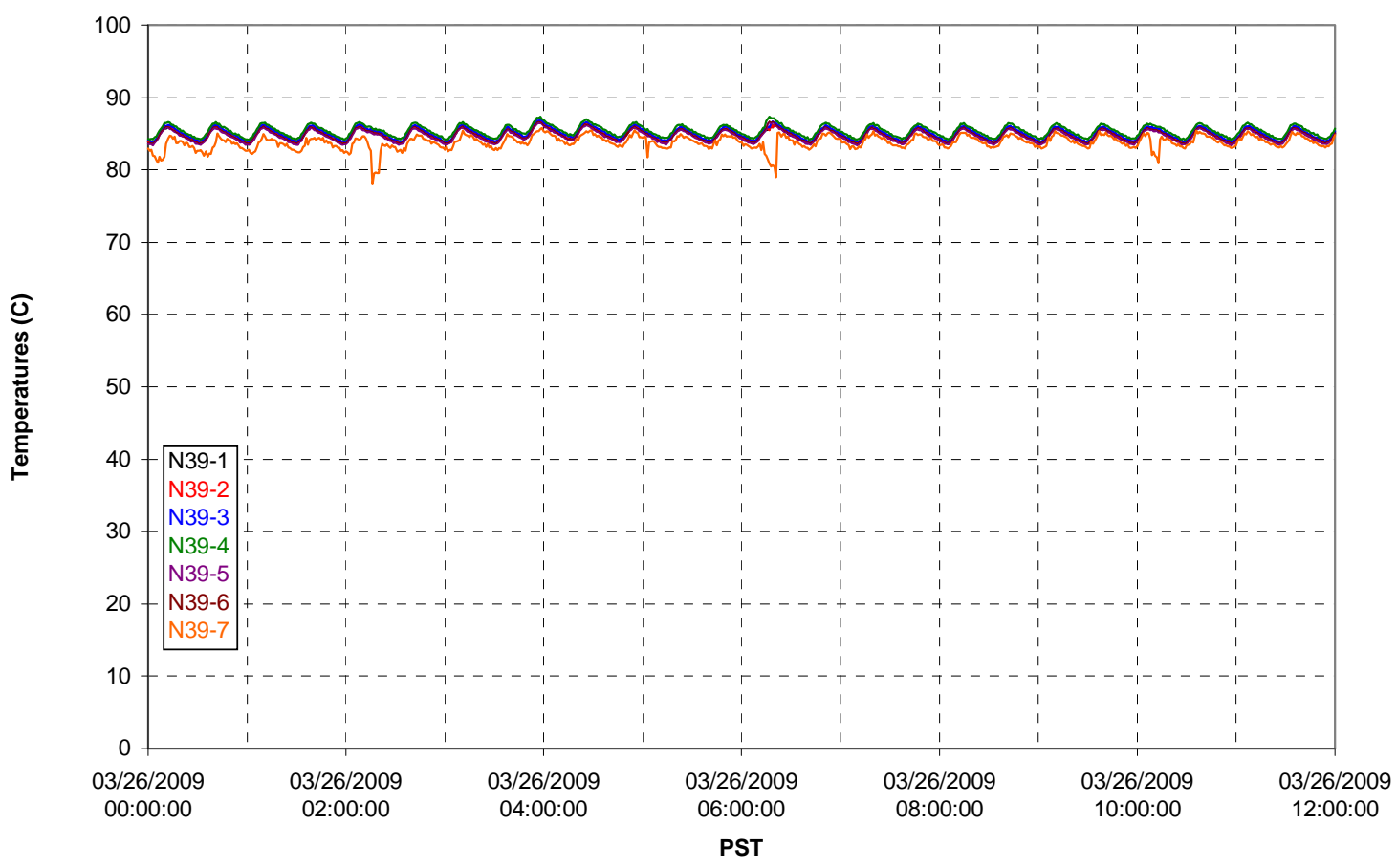

T02A temperatures

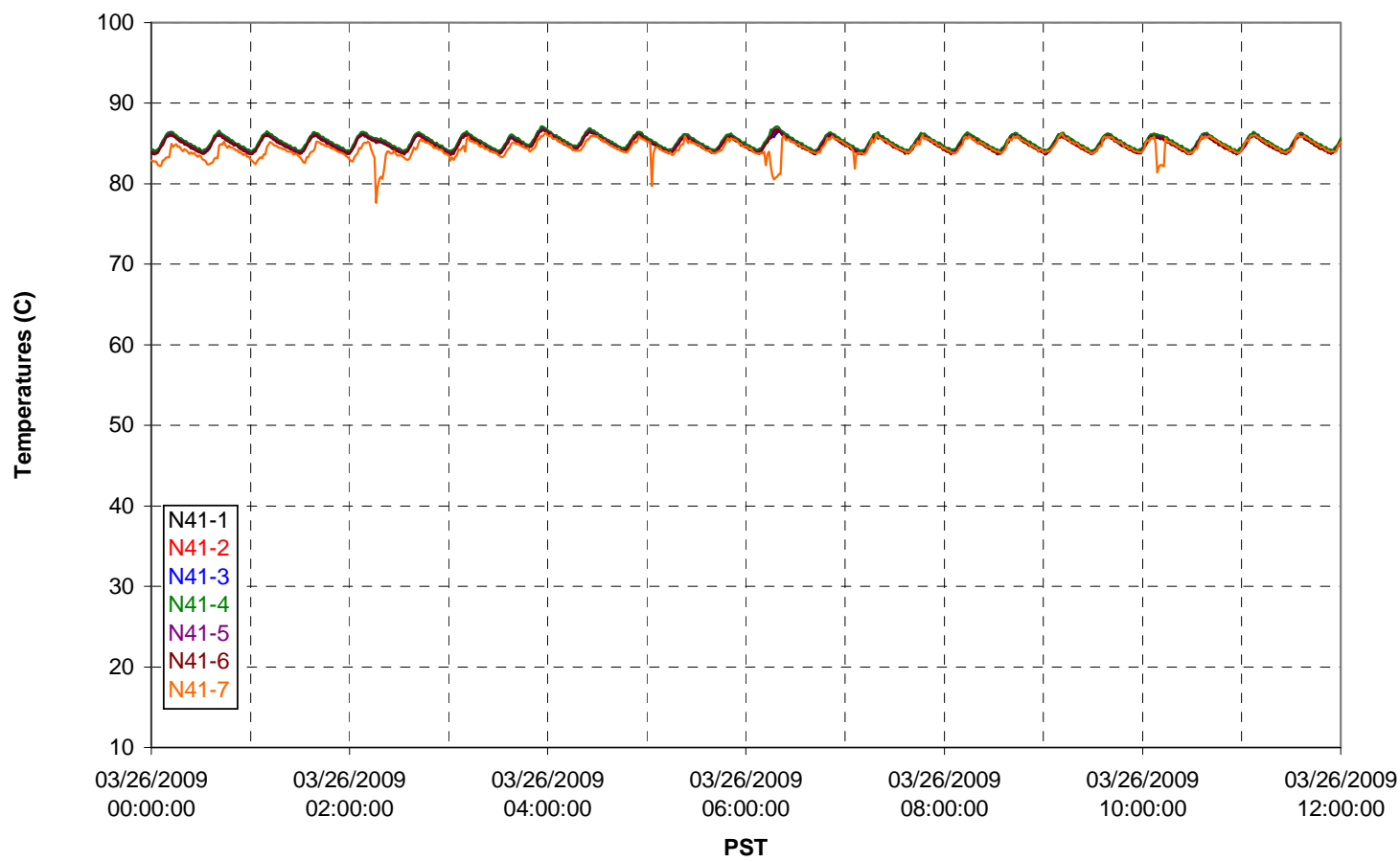


T02A temperatures

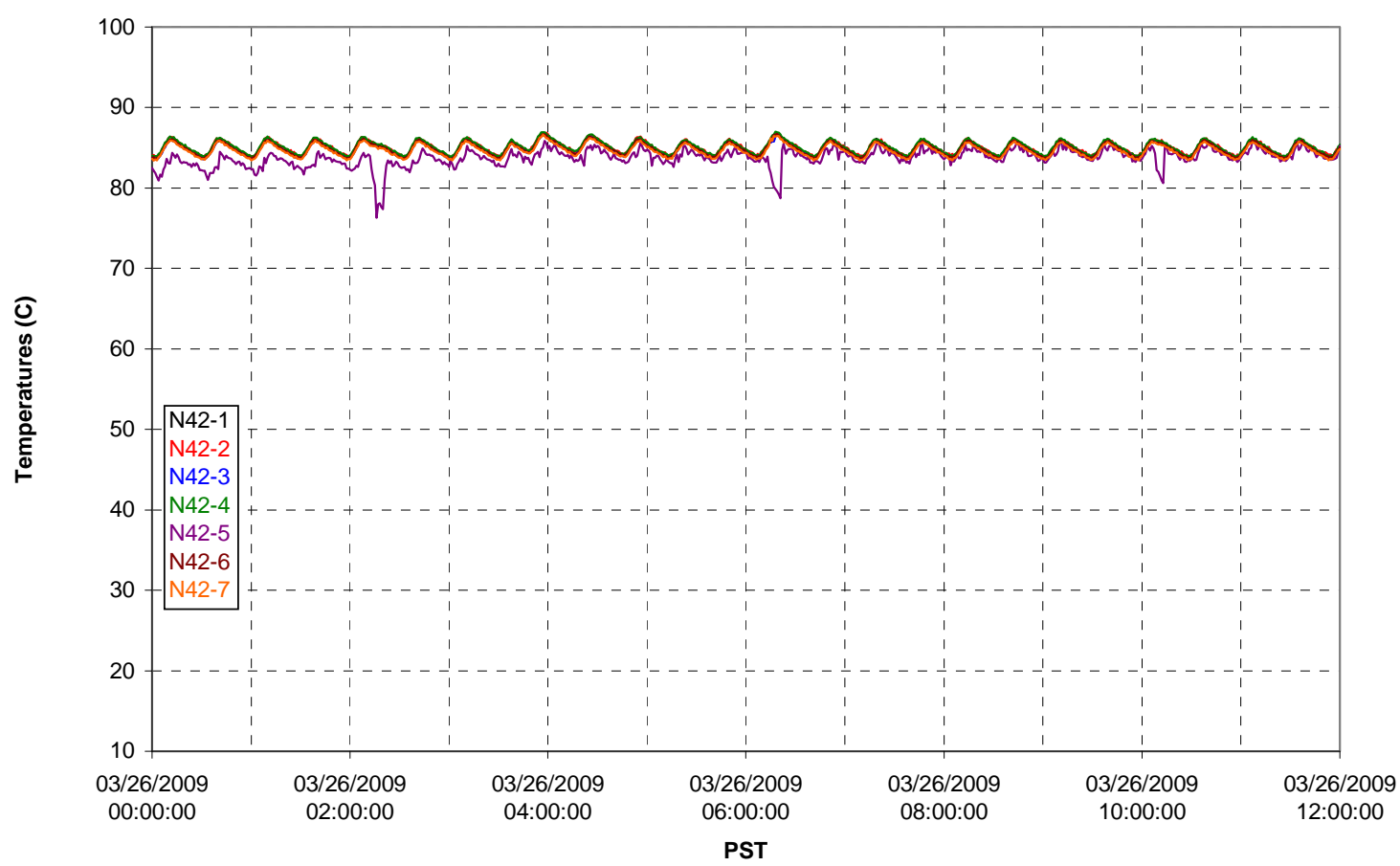

T02A temperatures

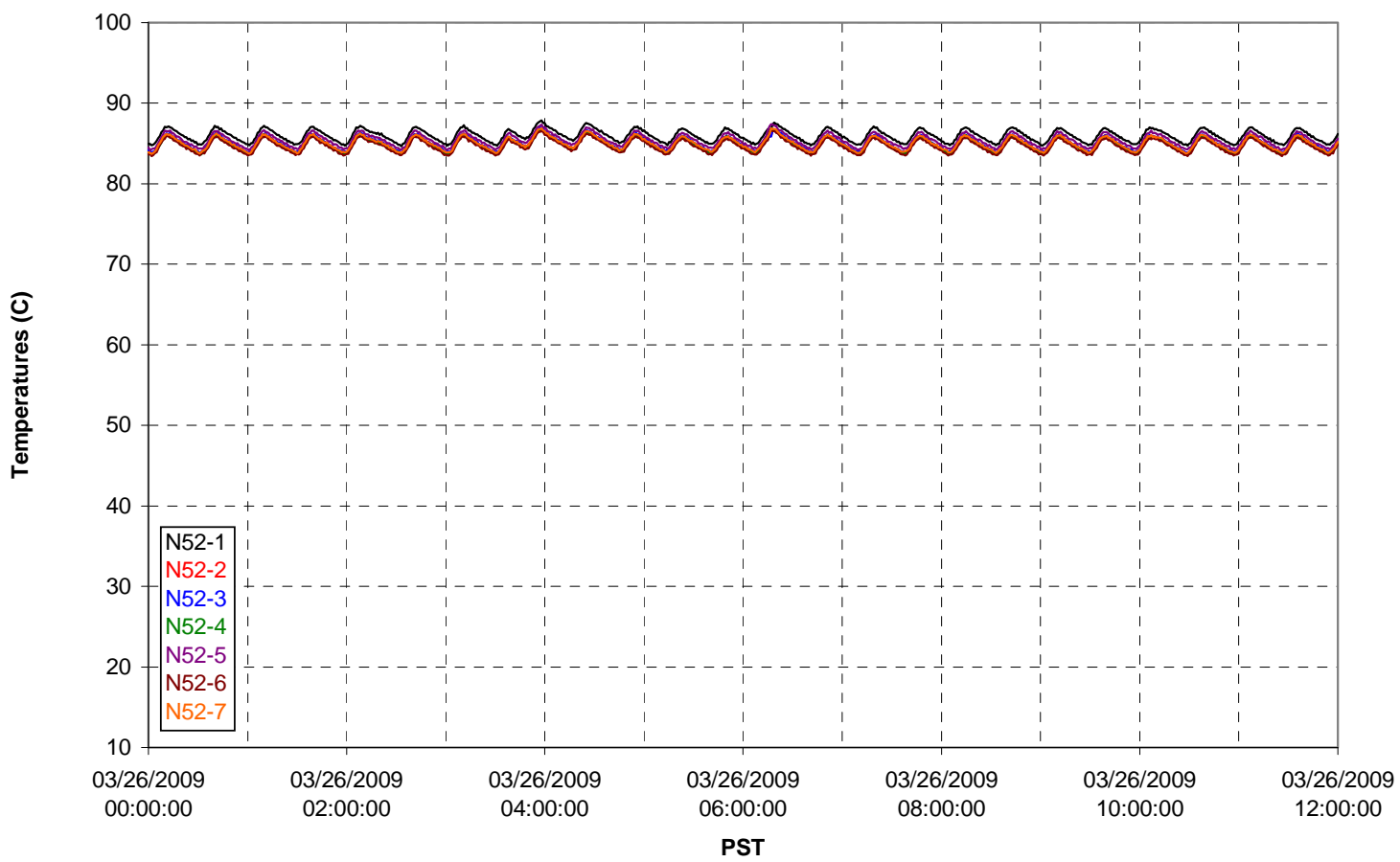


T02A Heating and Cooling

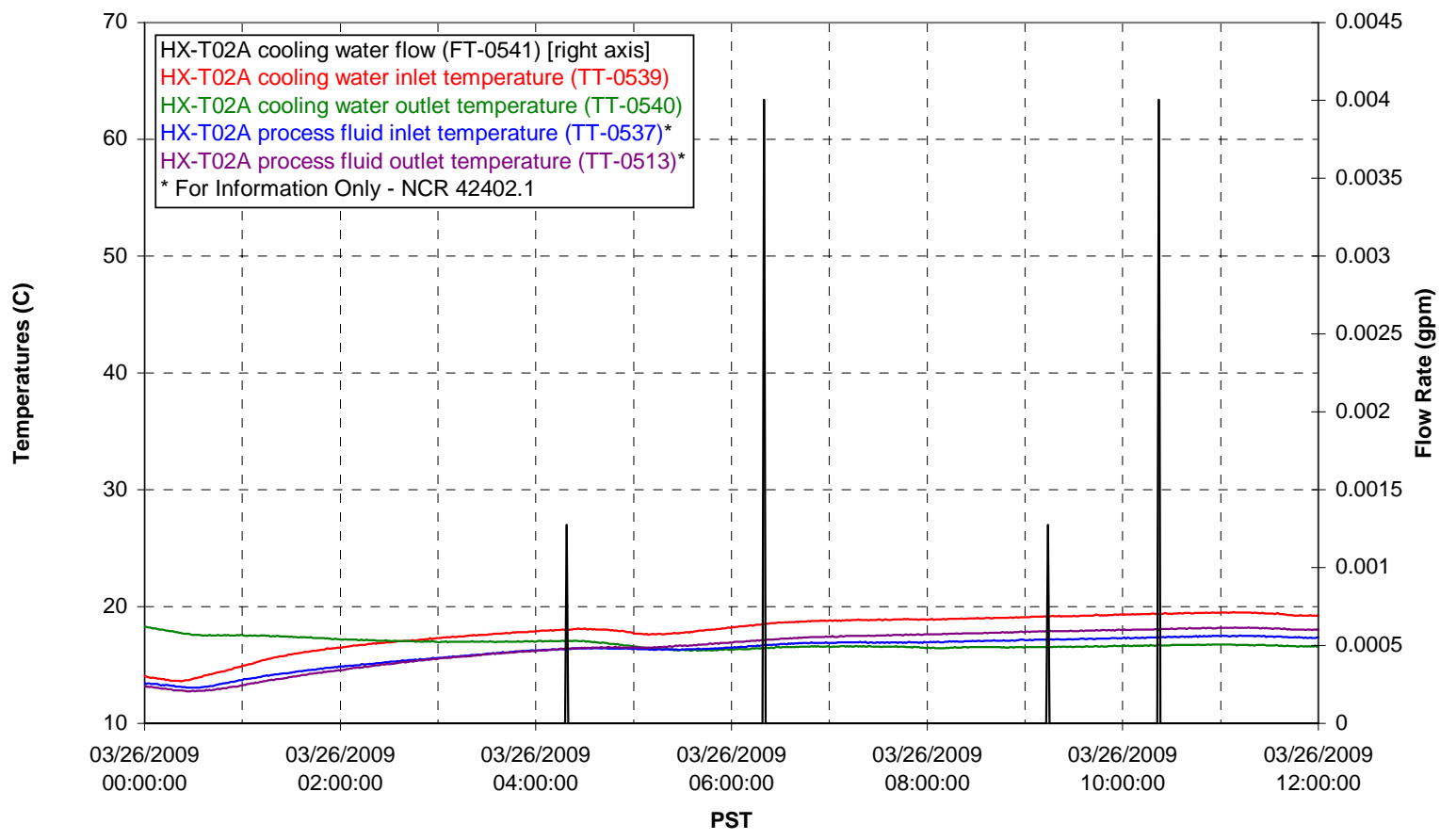

Pump Operation

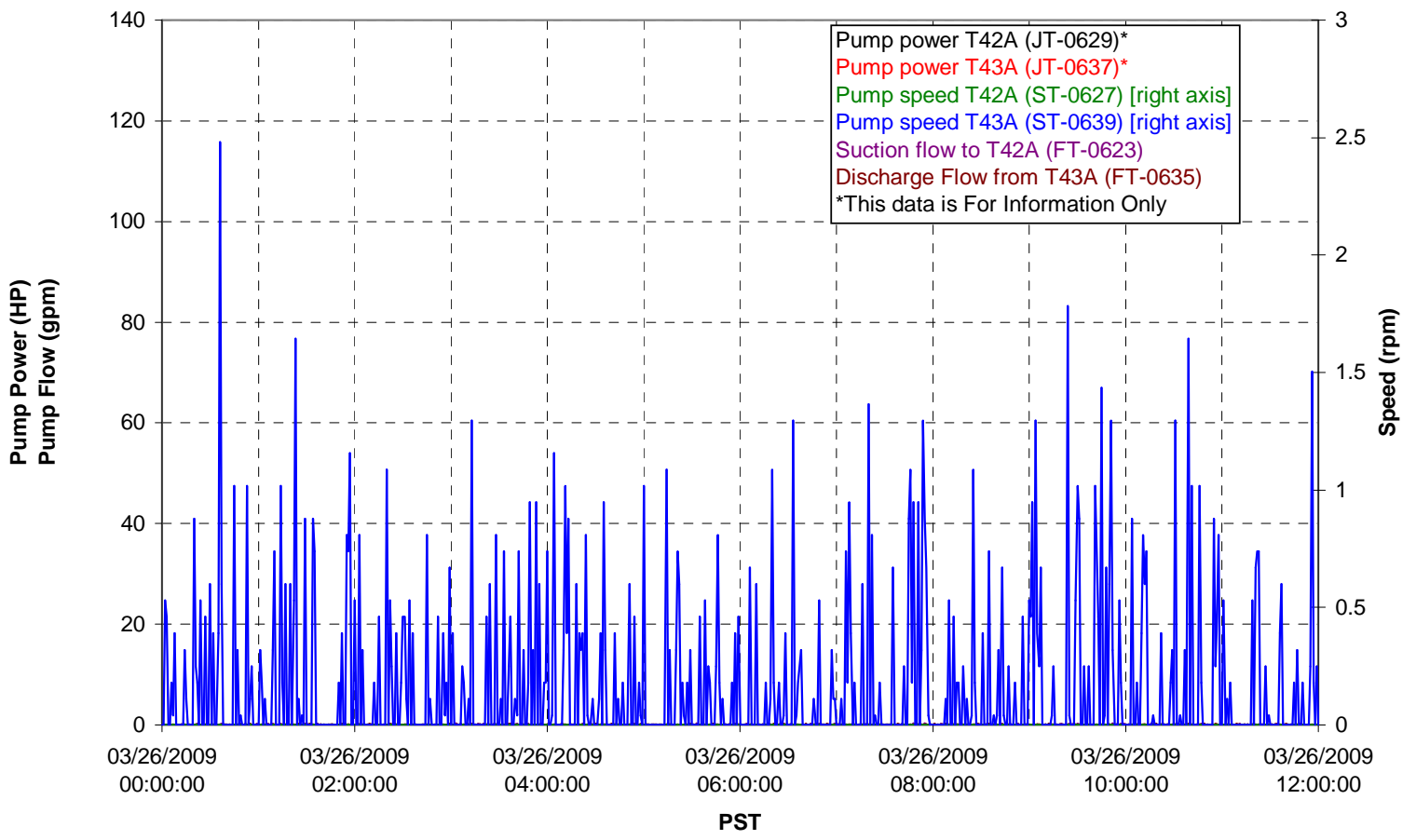


Pulsepot UFP-PP-T01A

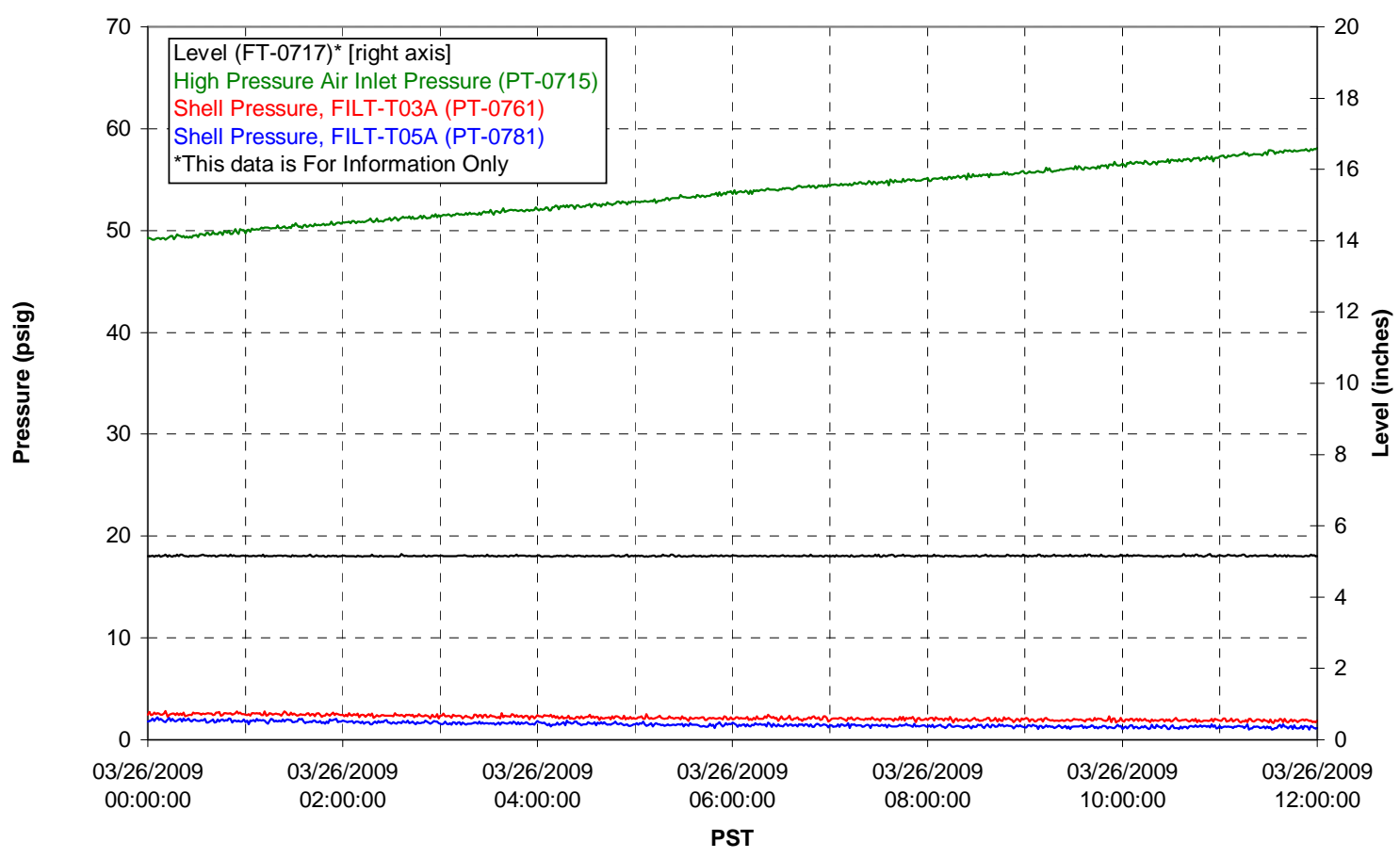

Pulsepot UFP-PP-T02A

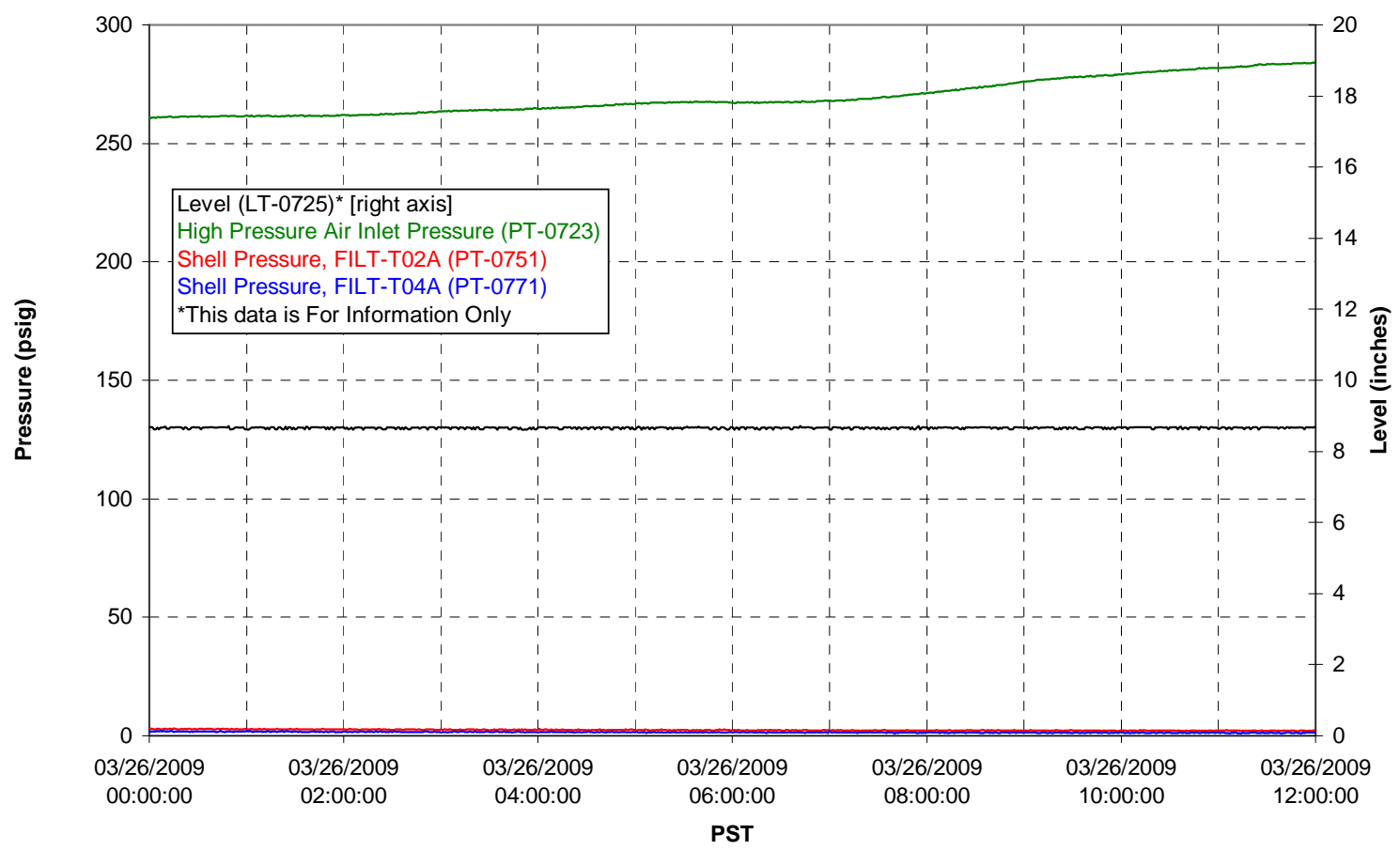


Pulsepot UFP-PP-T03A

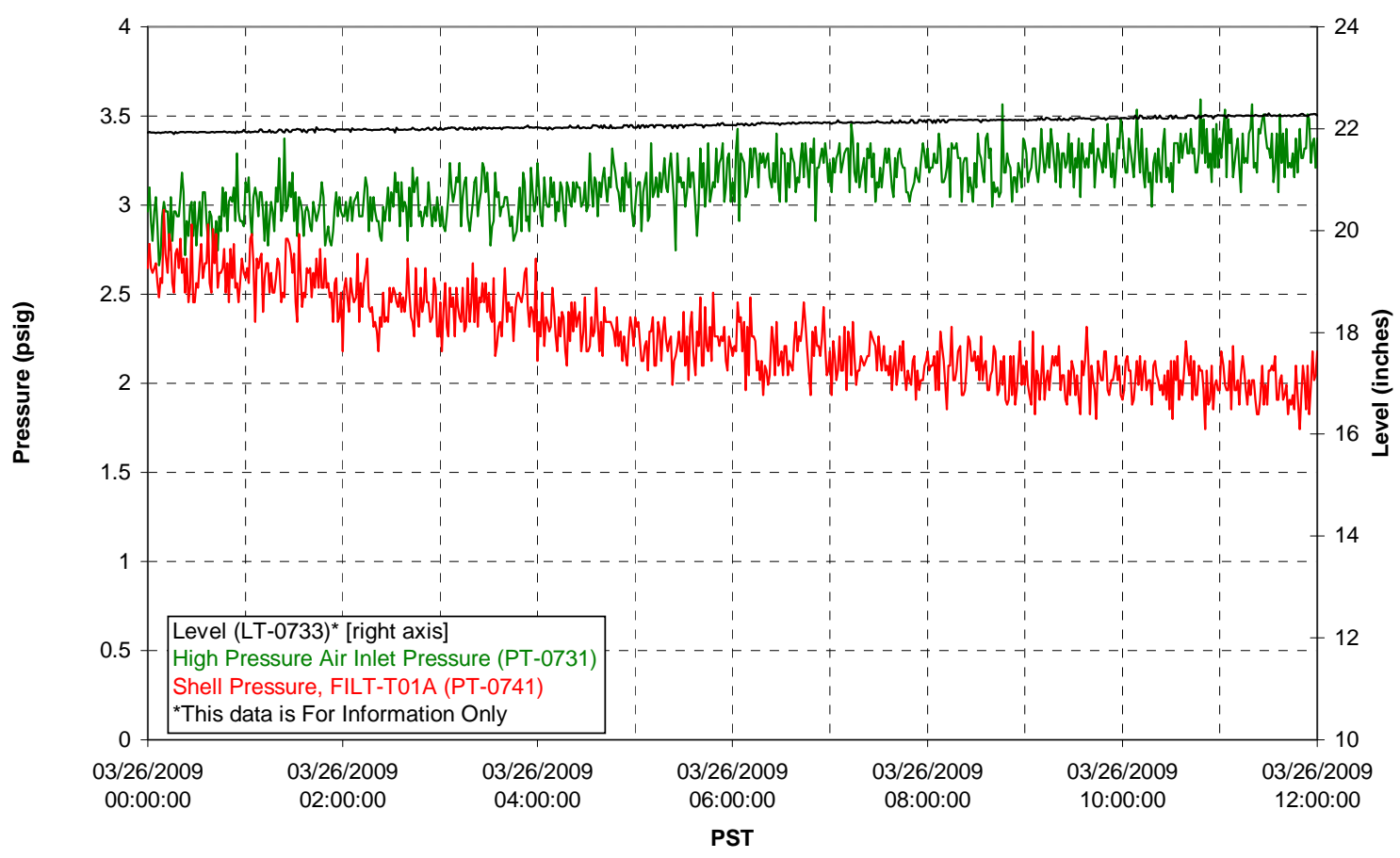

Pulsepot Levels

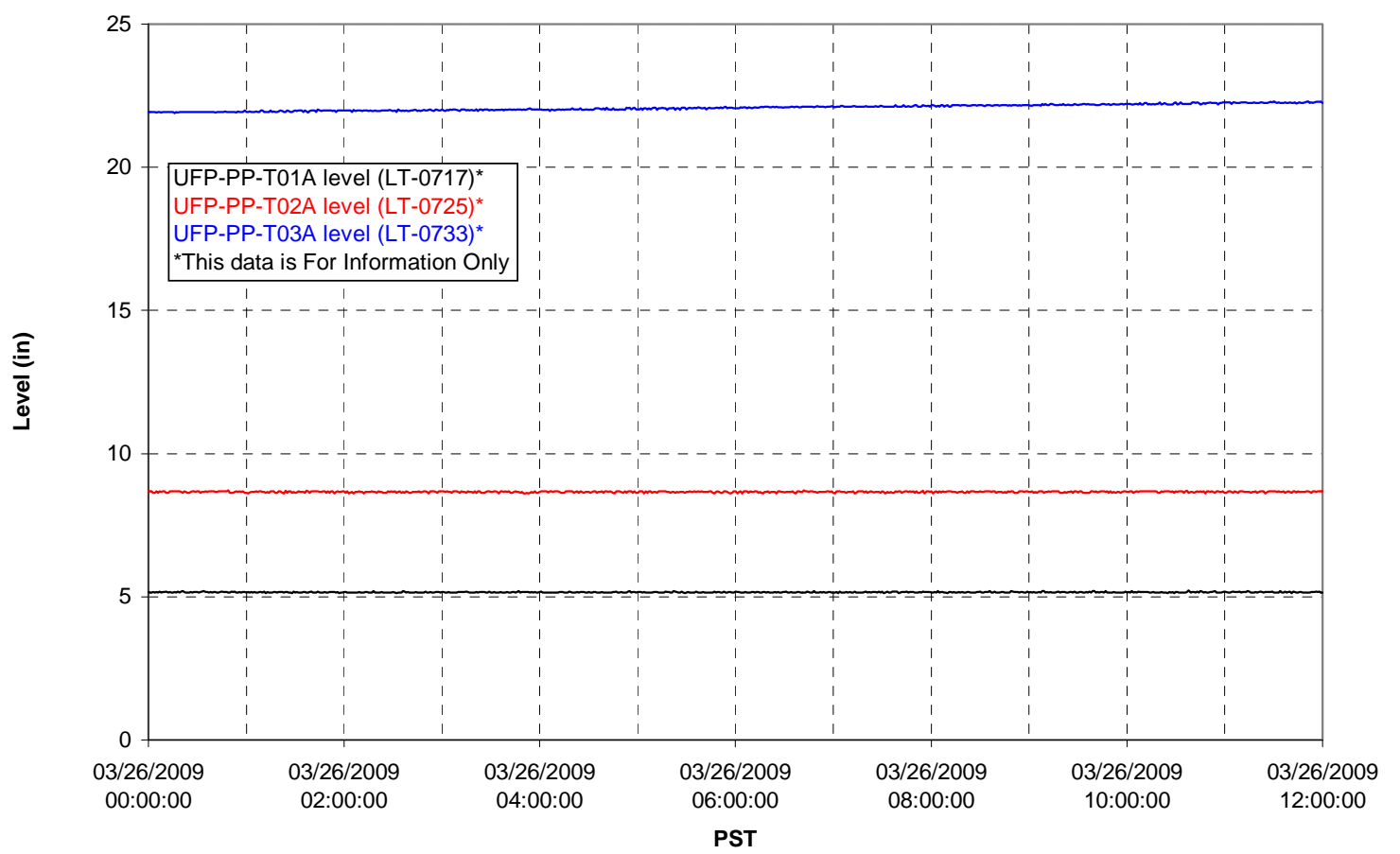


Filter UFP-FILT-T01A

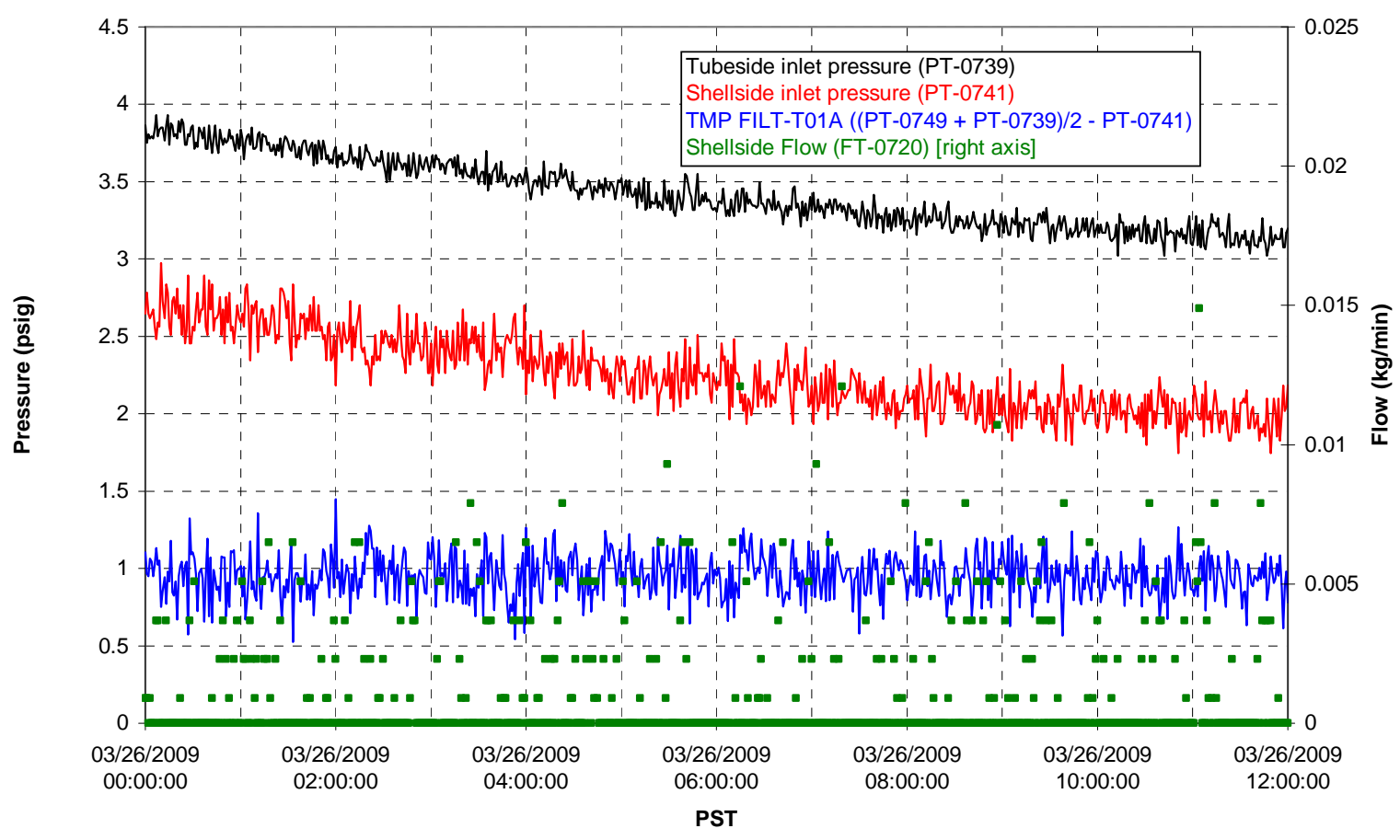

Filter UFP-FILT-T02A

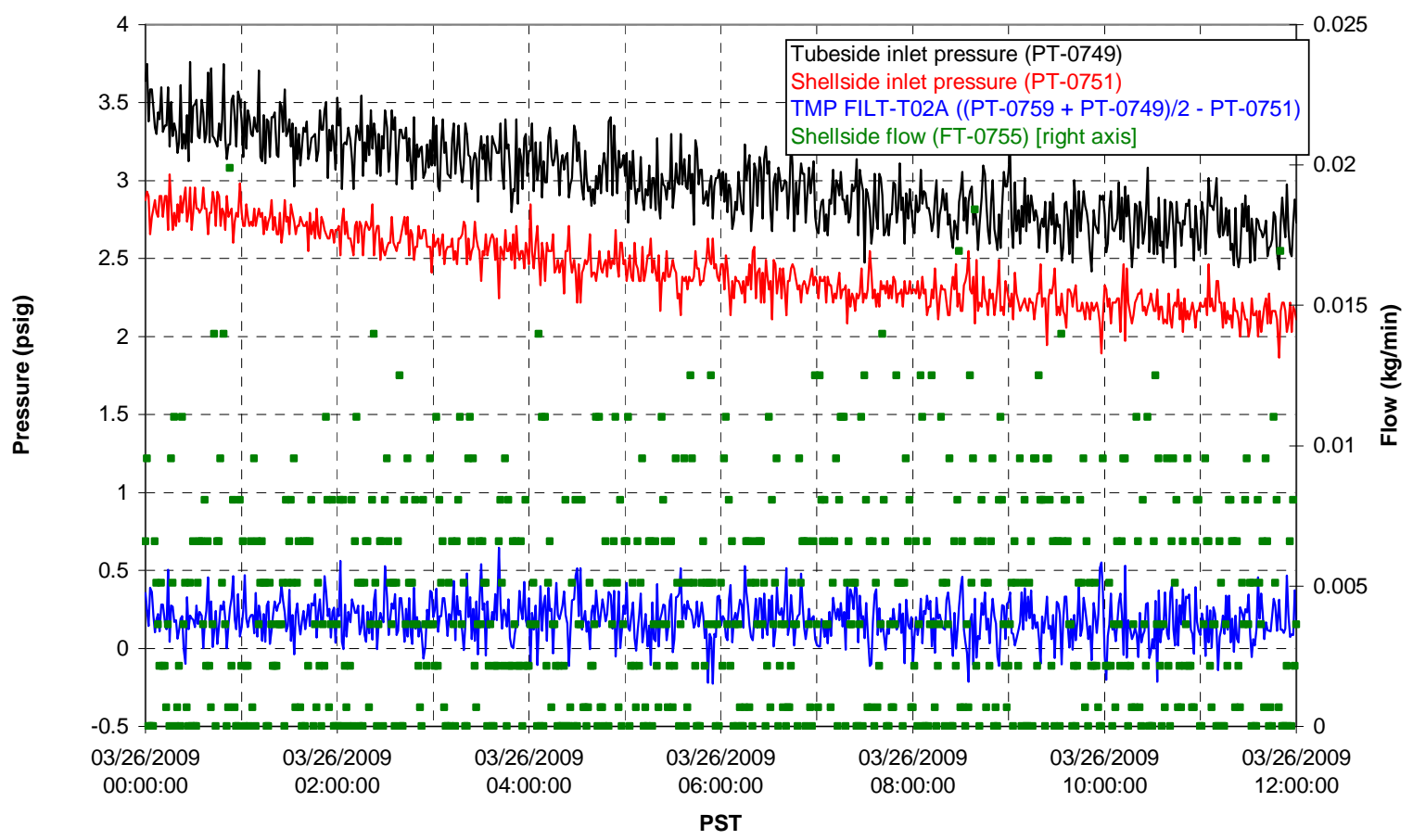


Filter UFP-FILT-T03A

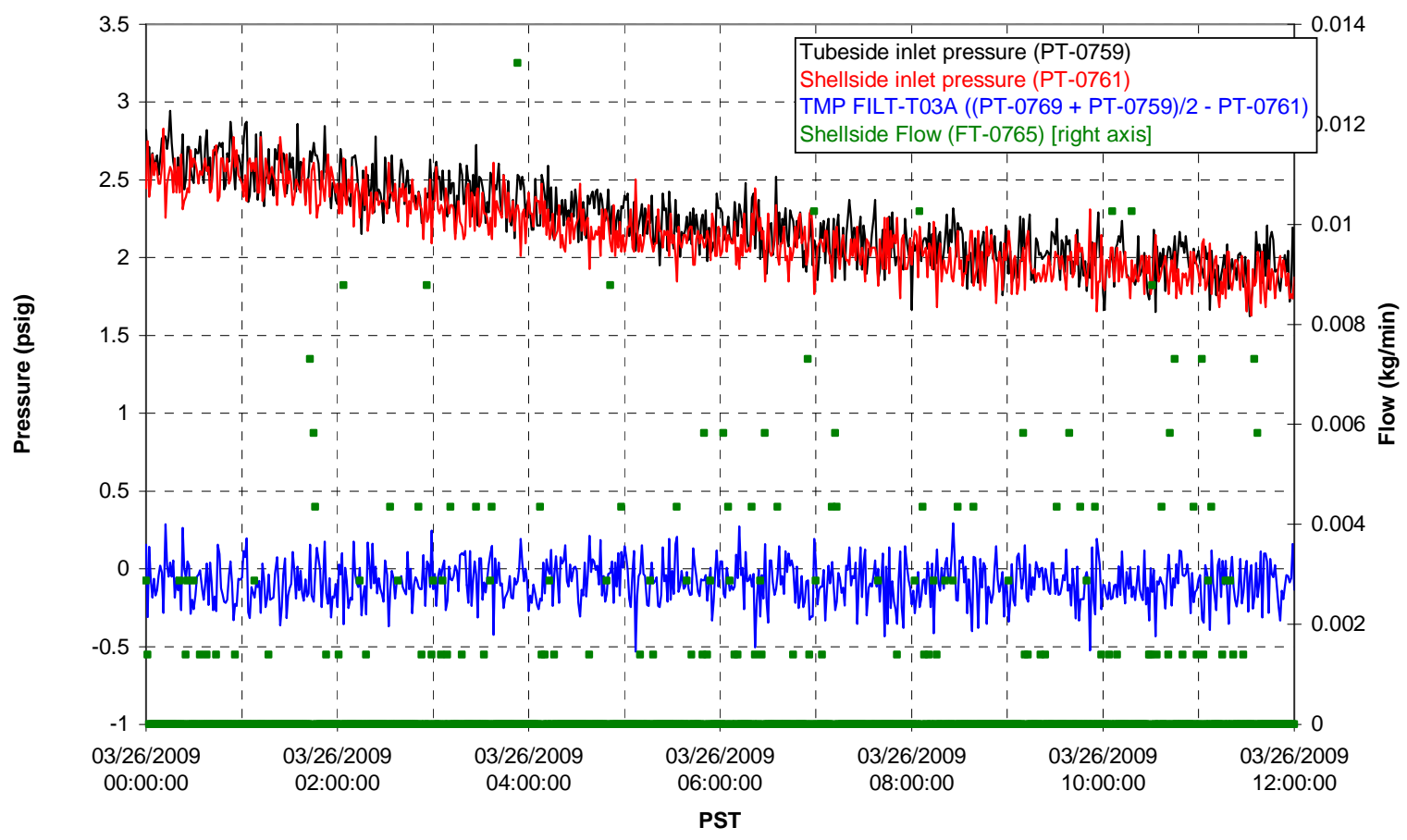

Filter UFP-FILT-T04A

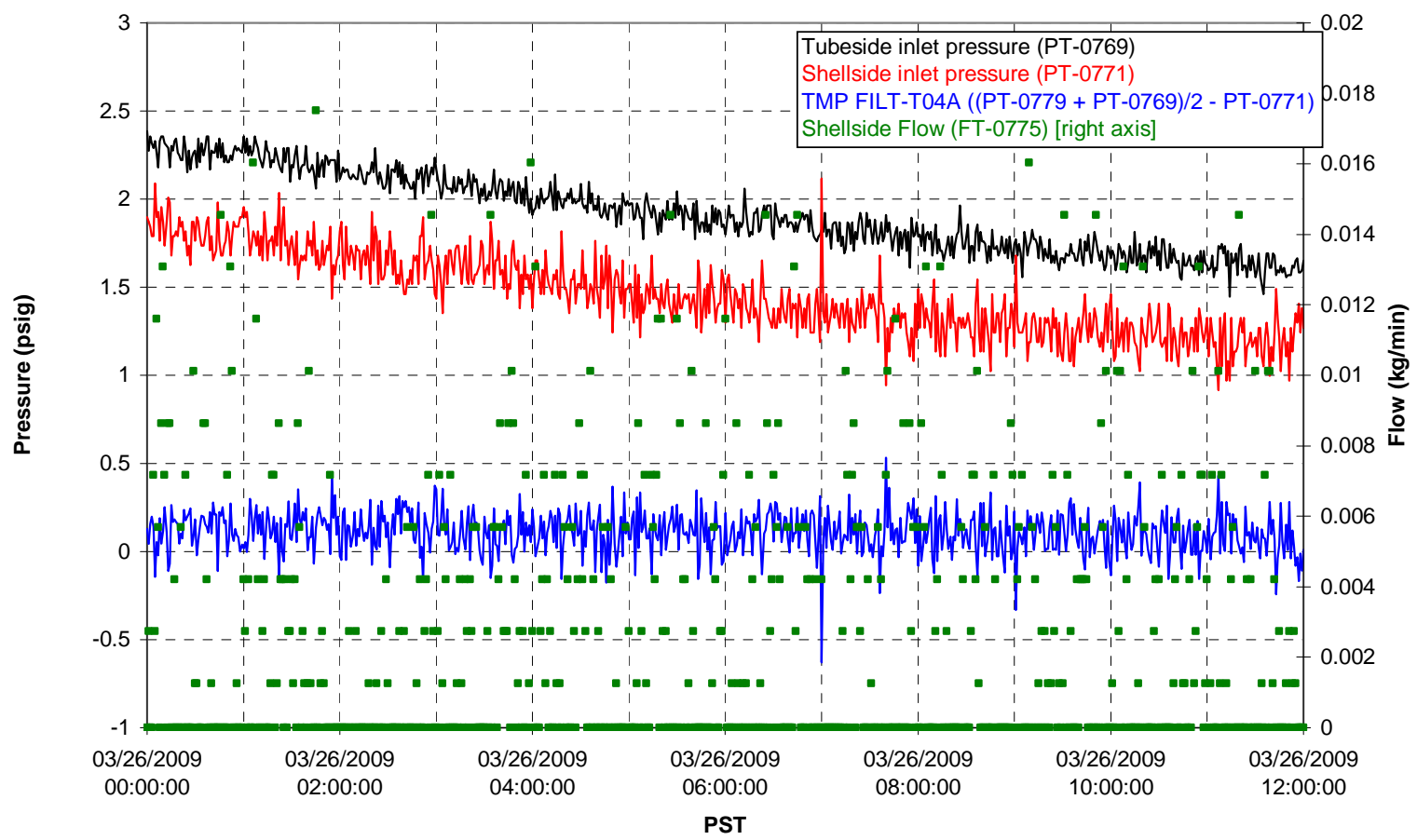


Filter UFP-FILT-T05A

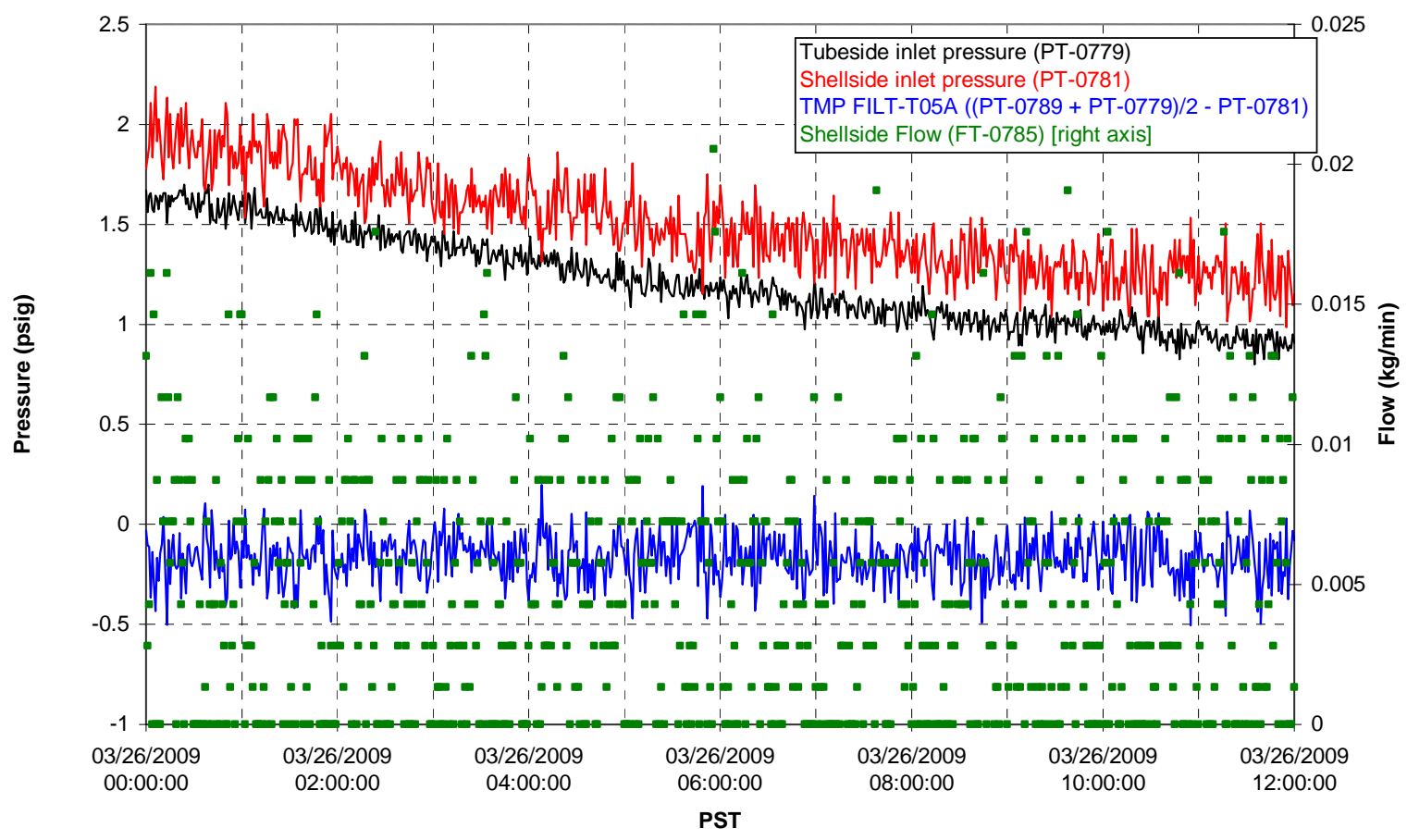

Chemical Flow

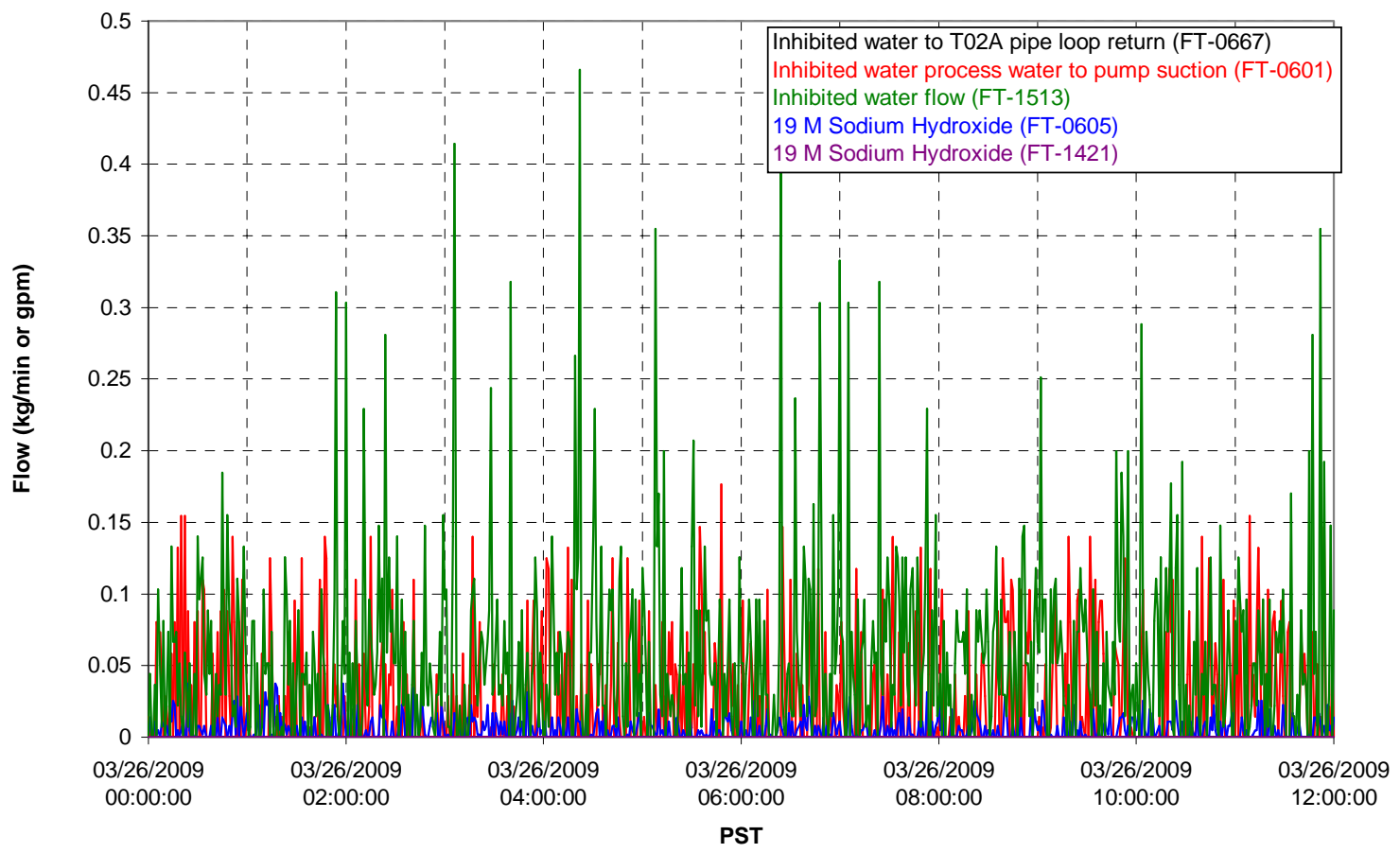




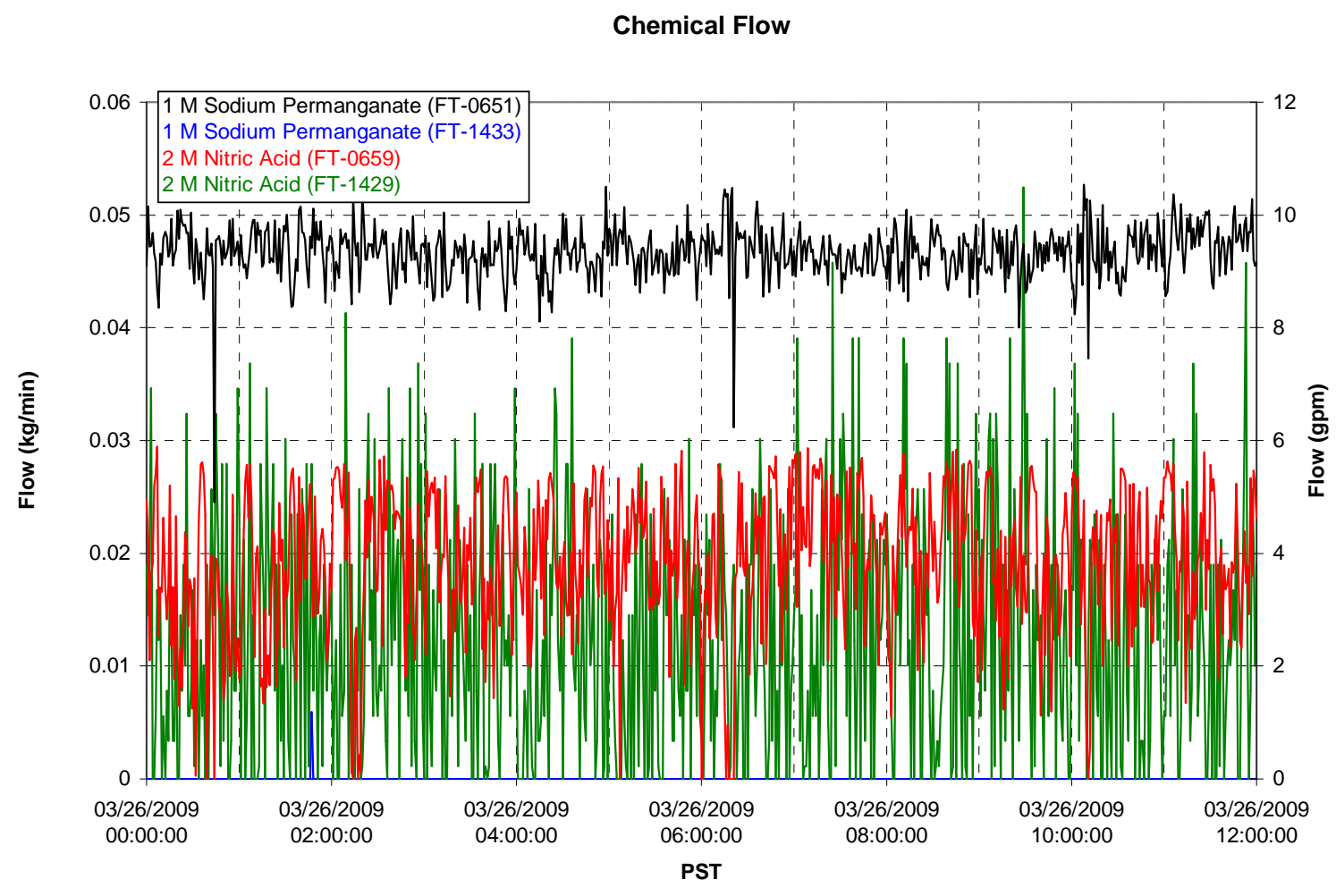

Air Flows

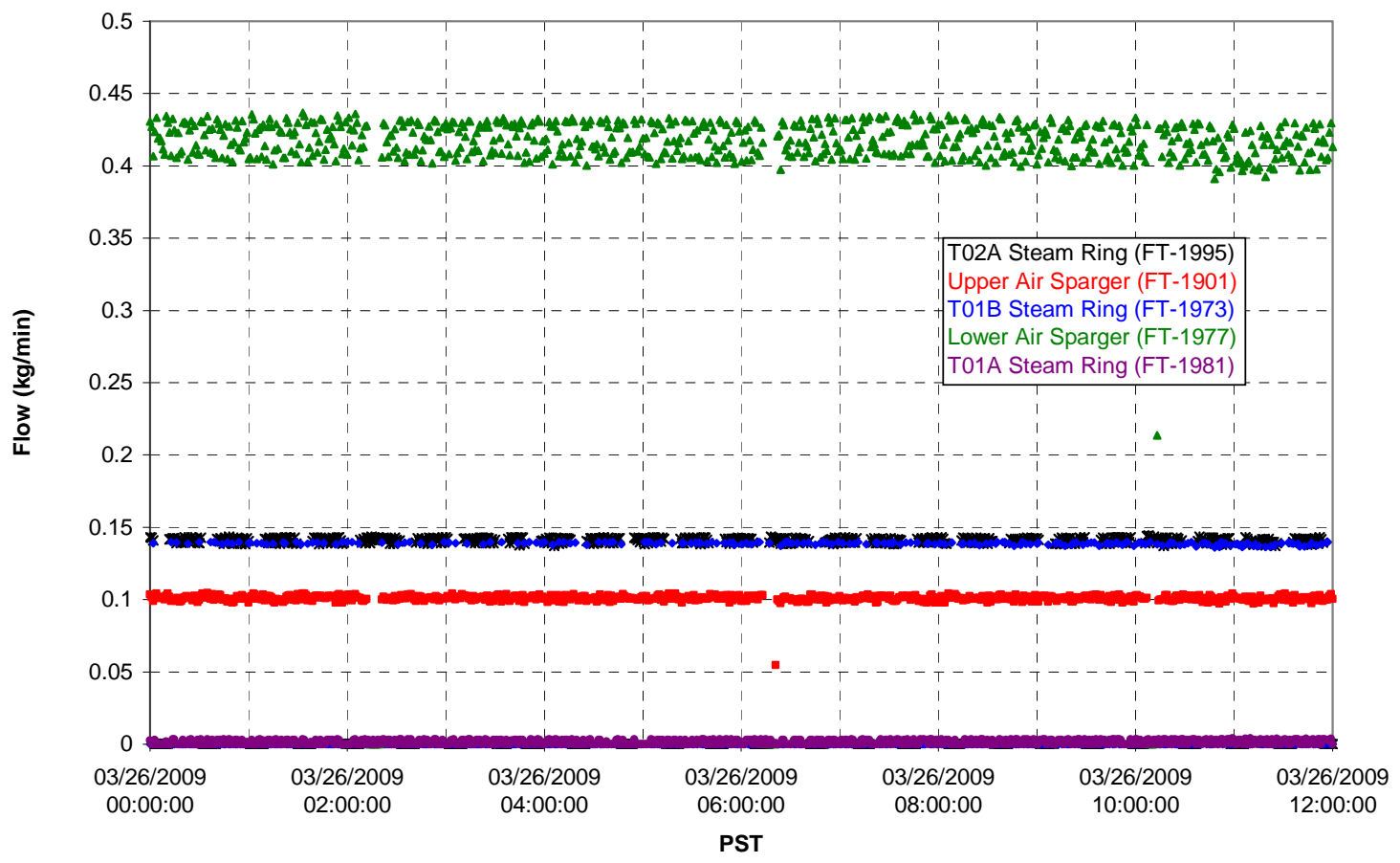


T02A Steam

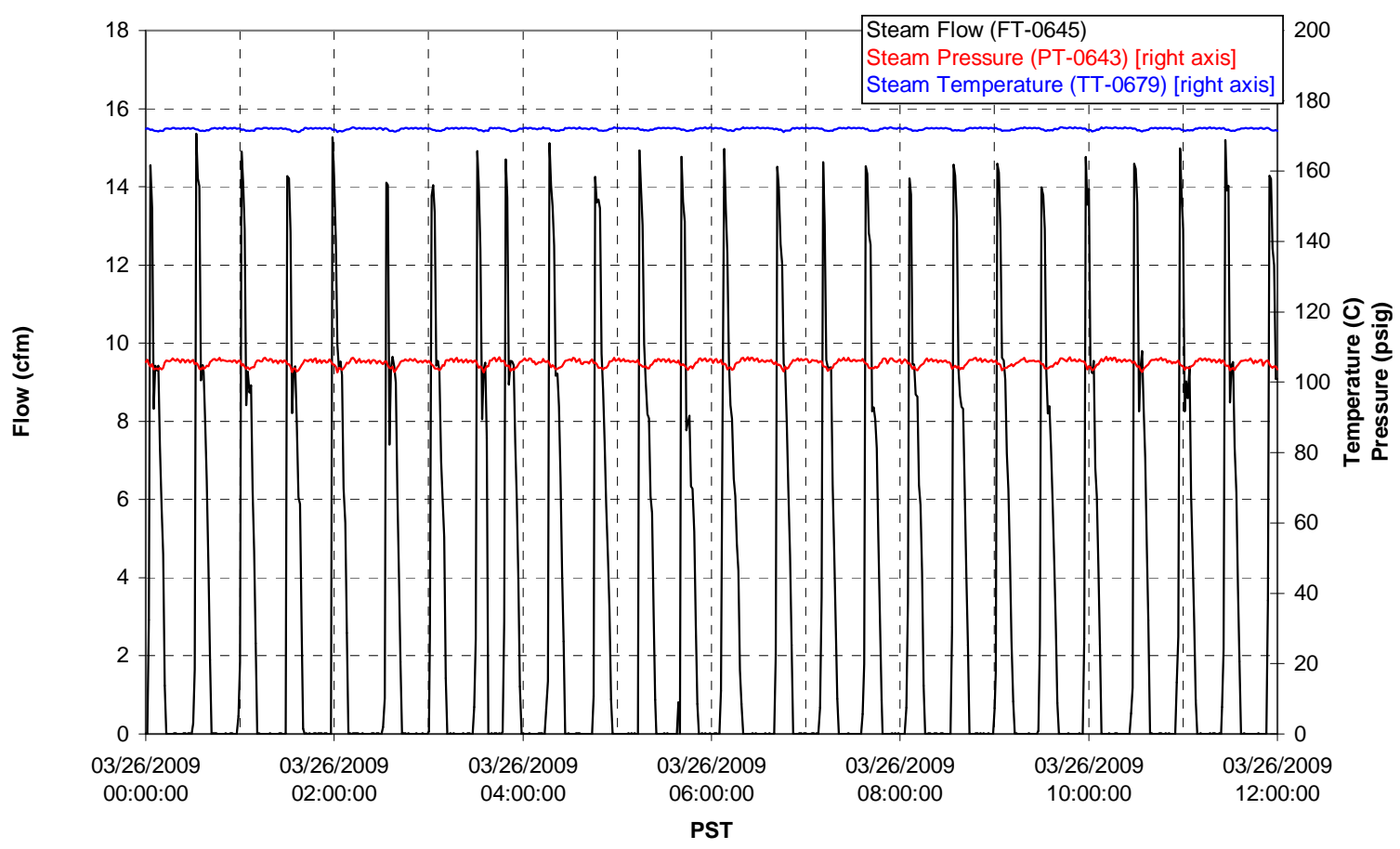

T01A Steam

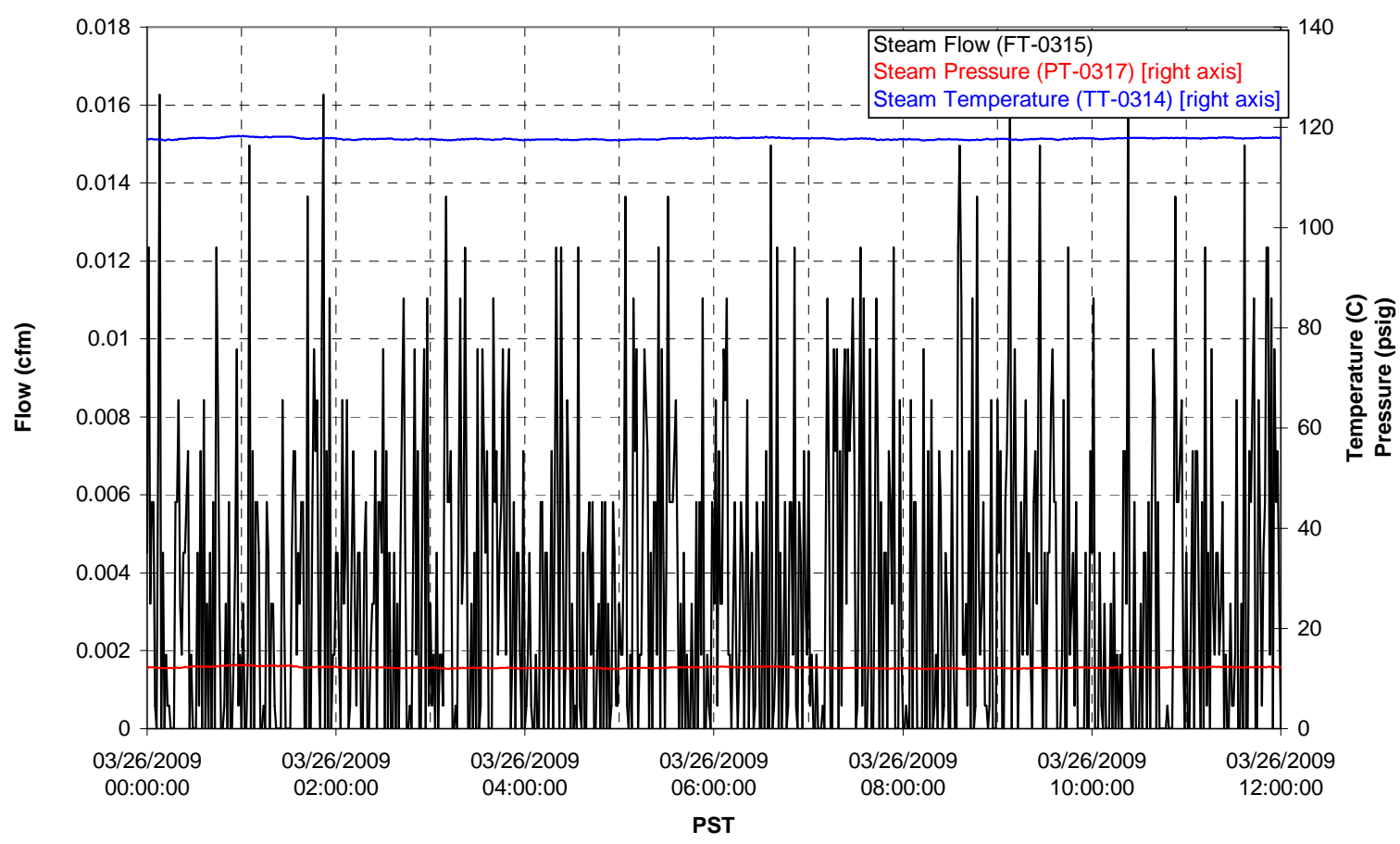




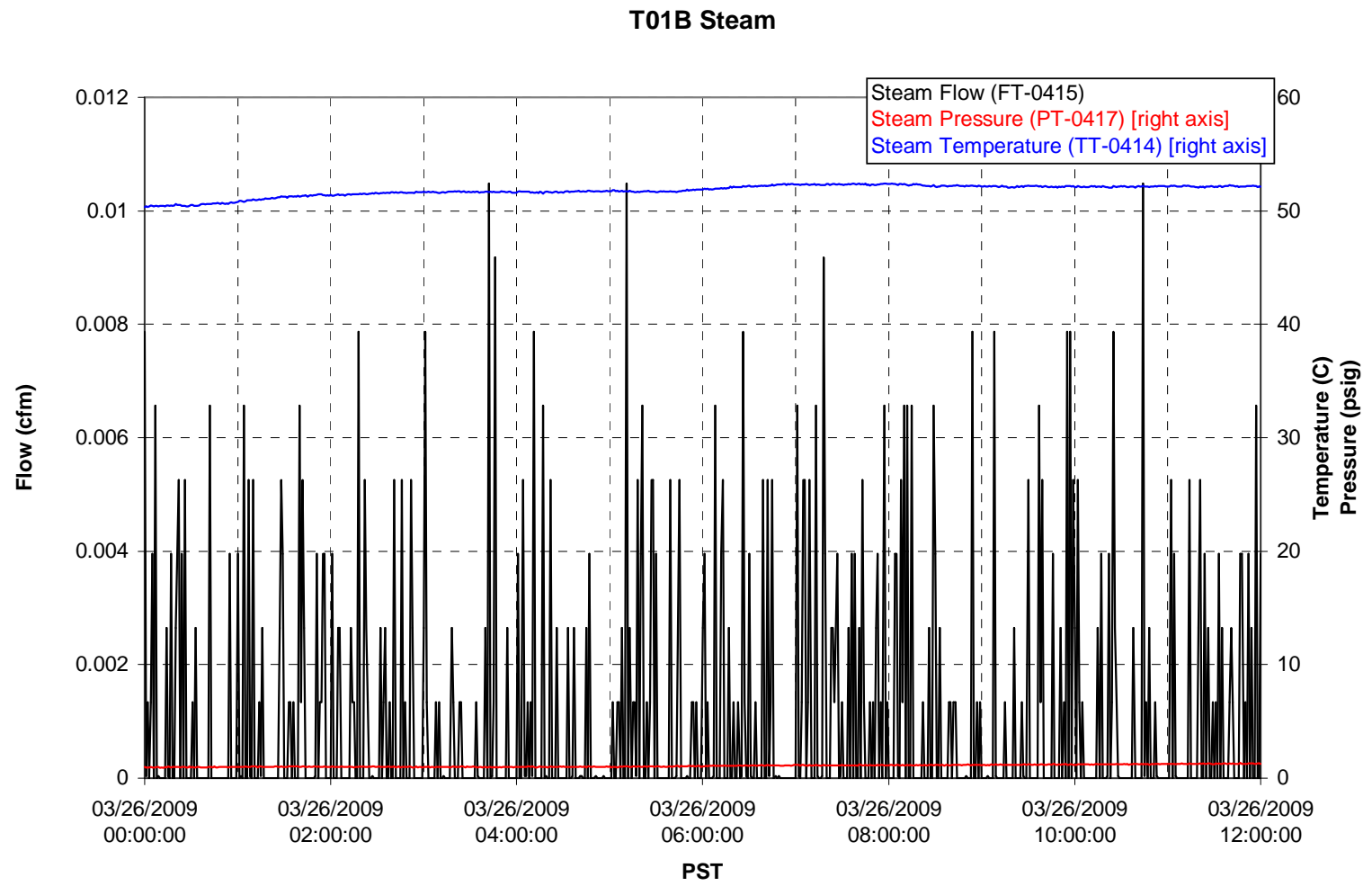




\section{Integrated Test D Data Plots 03/26/09 12:00 - 03/27/09 00:00}


T01A level

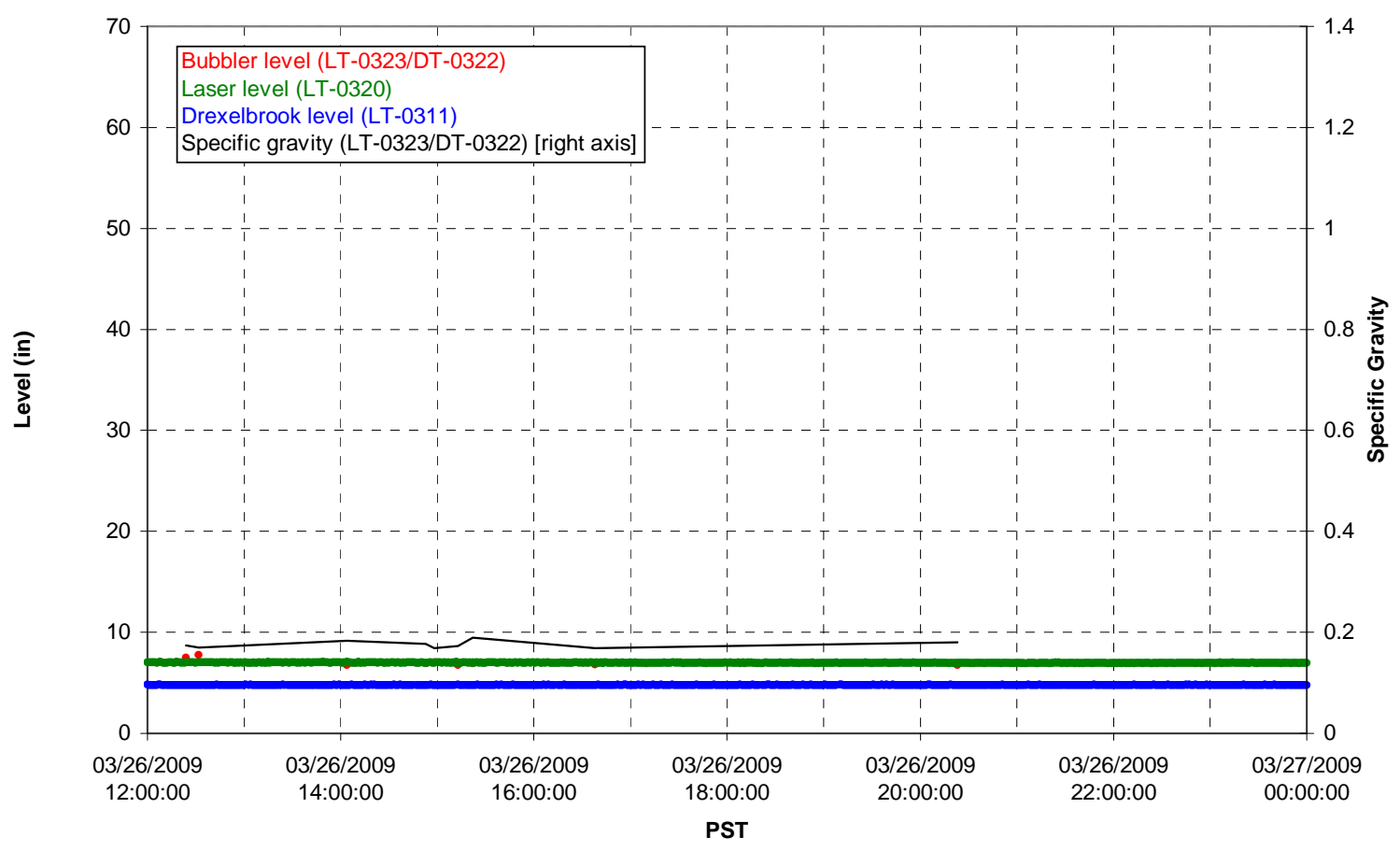

T01A temperatures

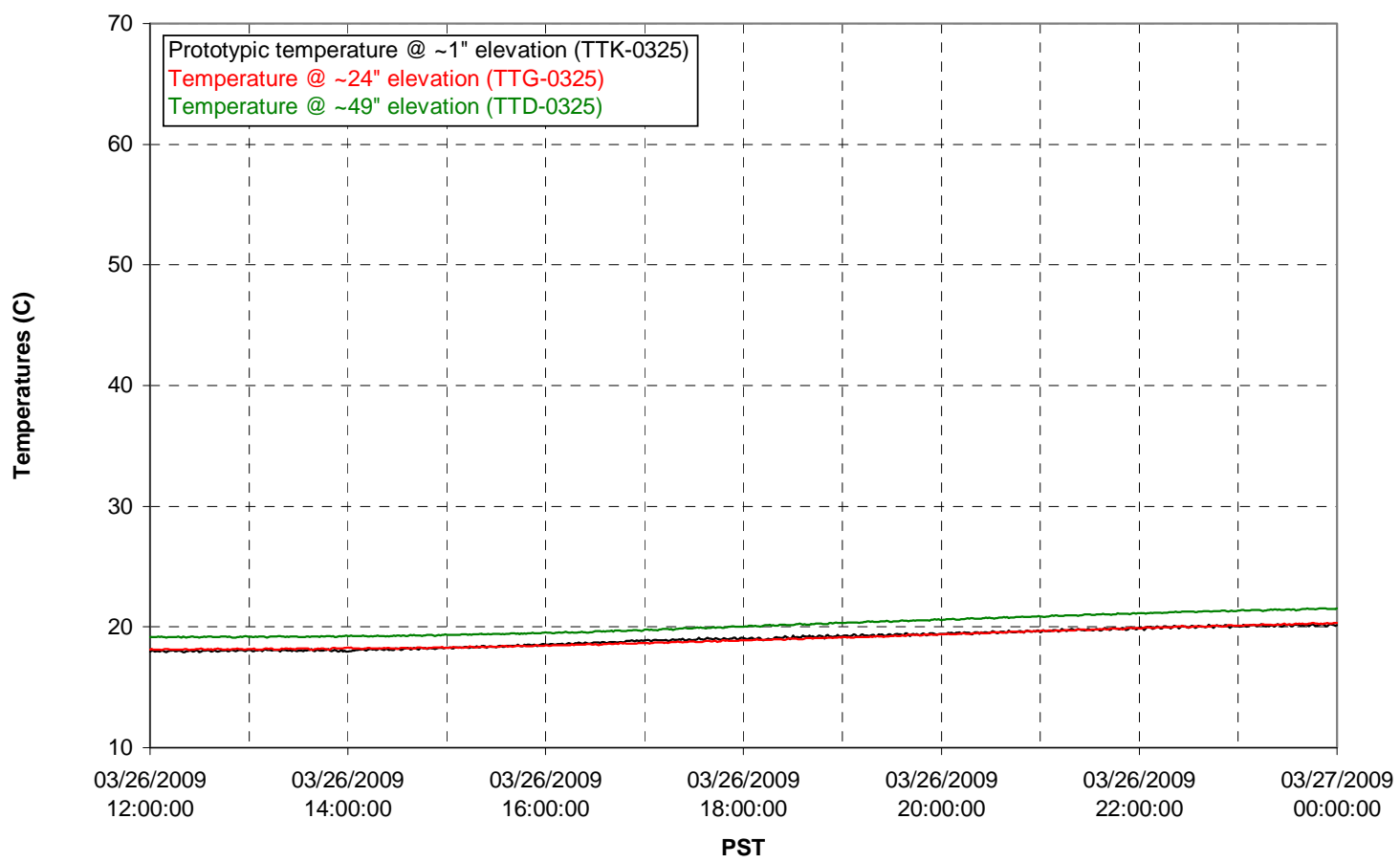


T01B level

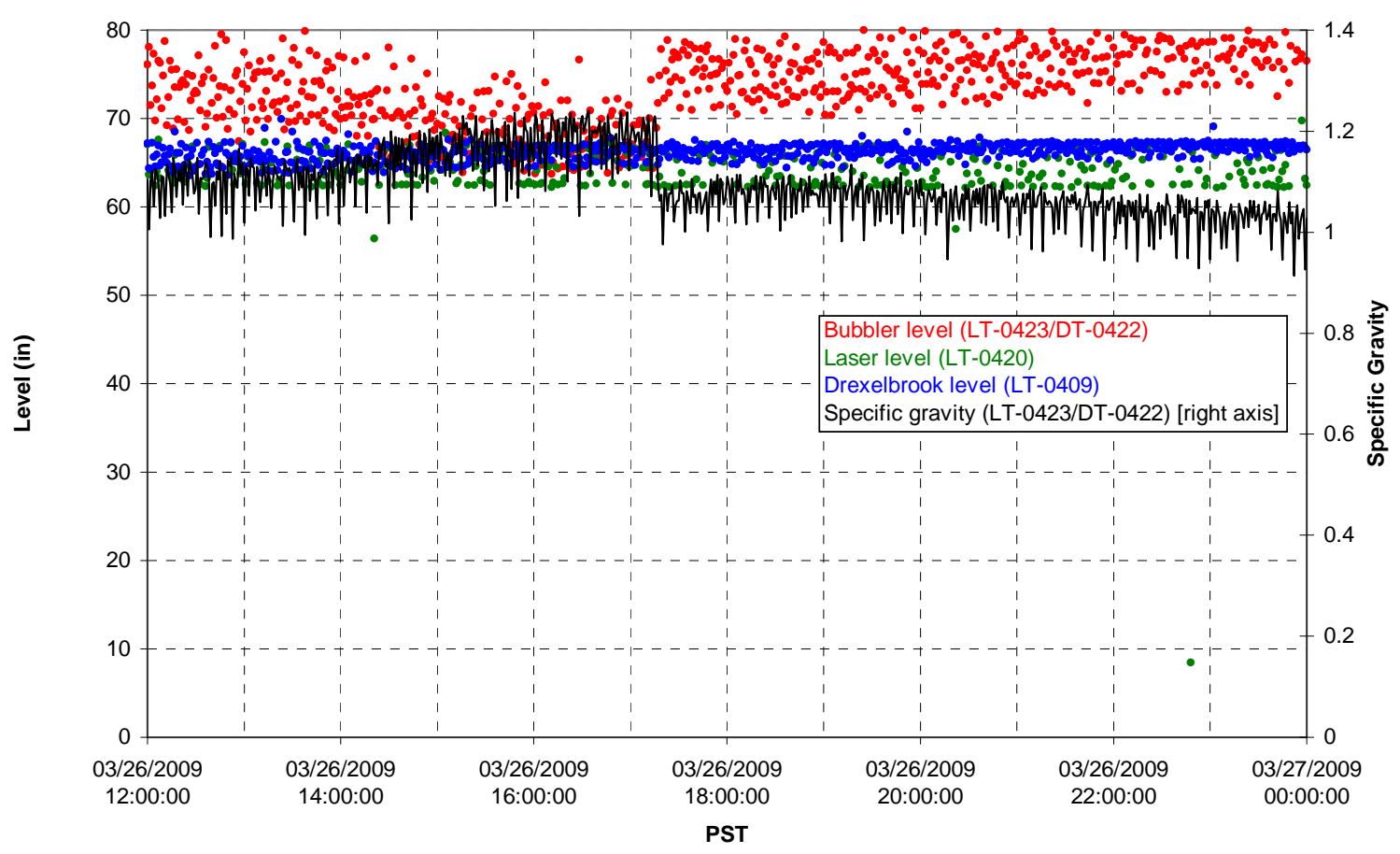

T01B temperatures

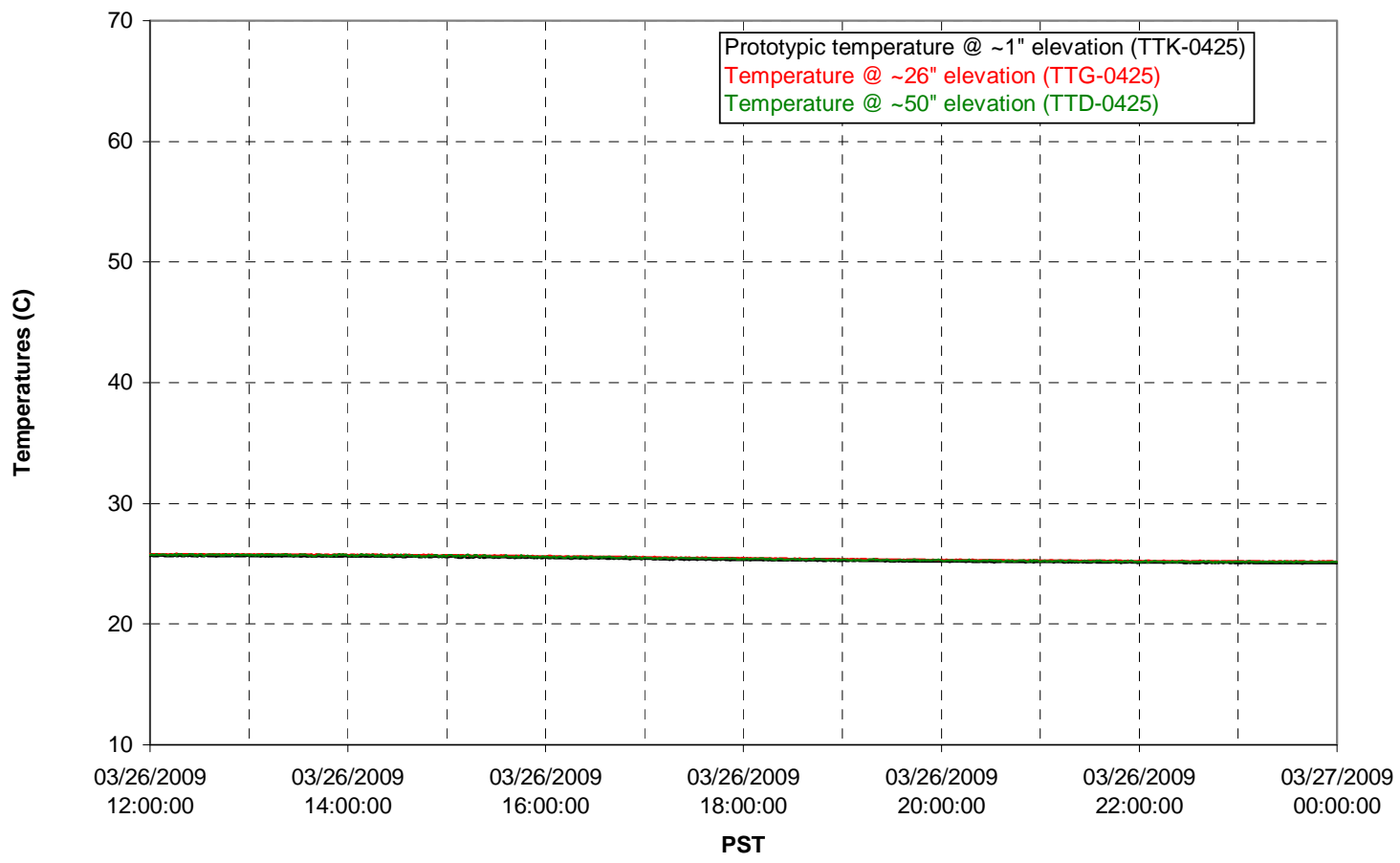


T02A level

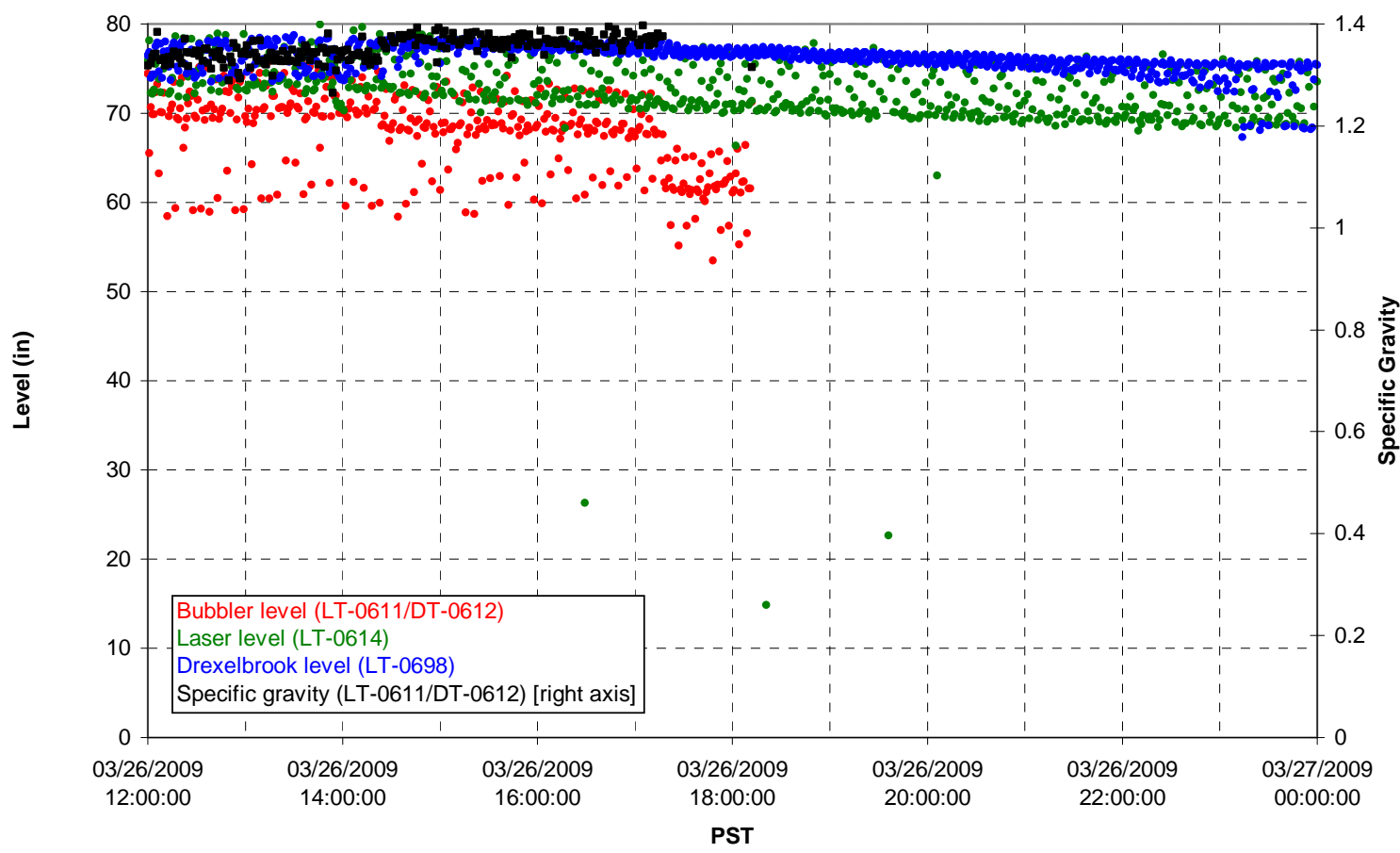

T02A temperatures

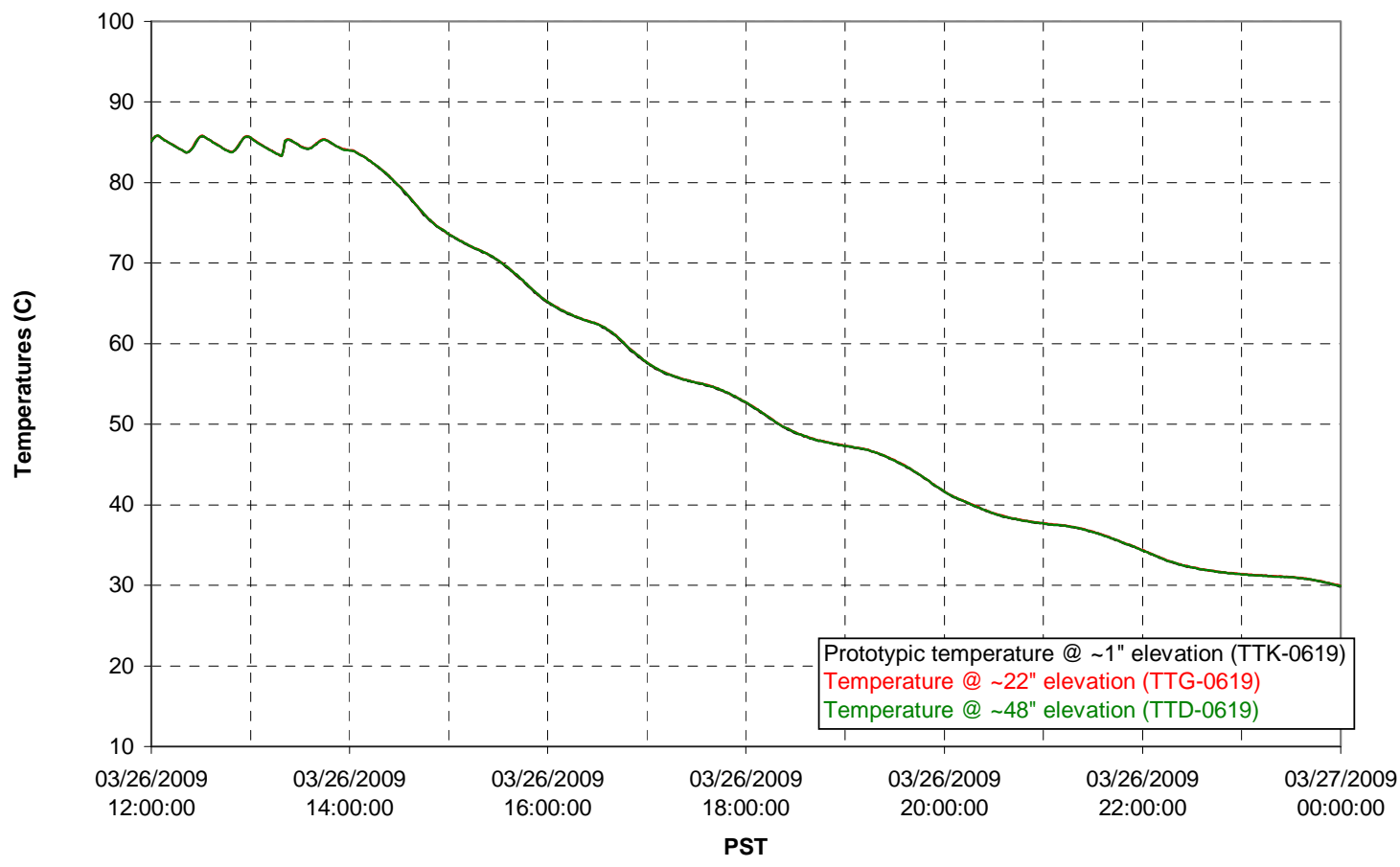


T02A and filter loop temperatures

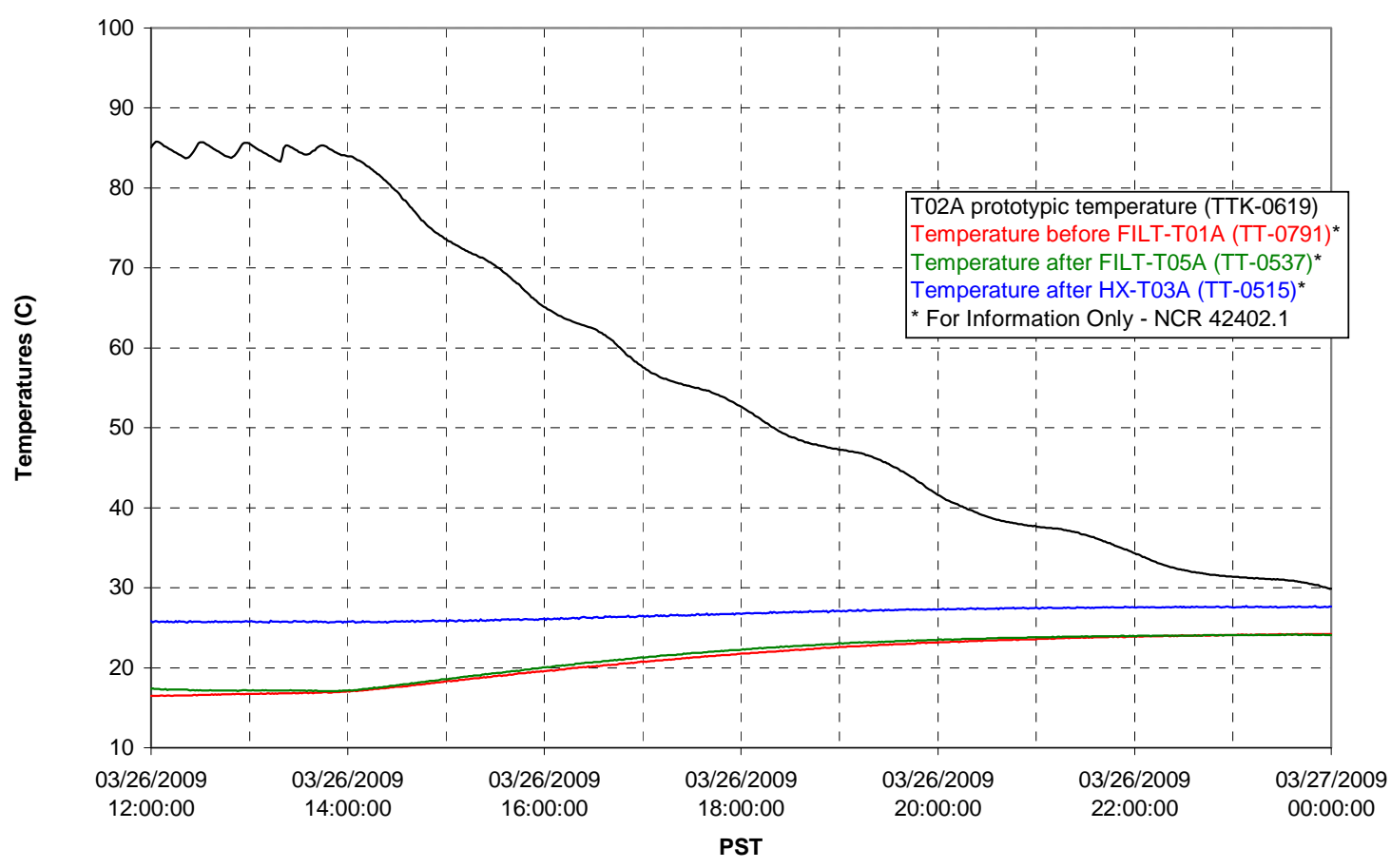

Pump Pressures and Flow

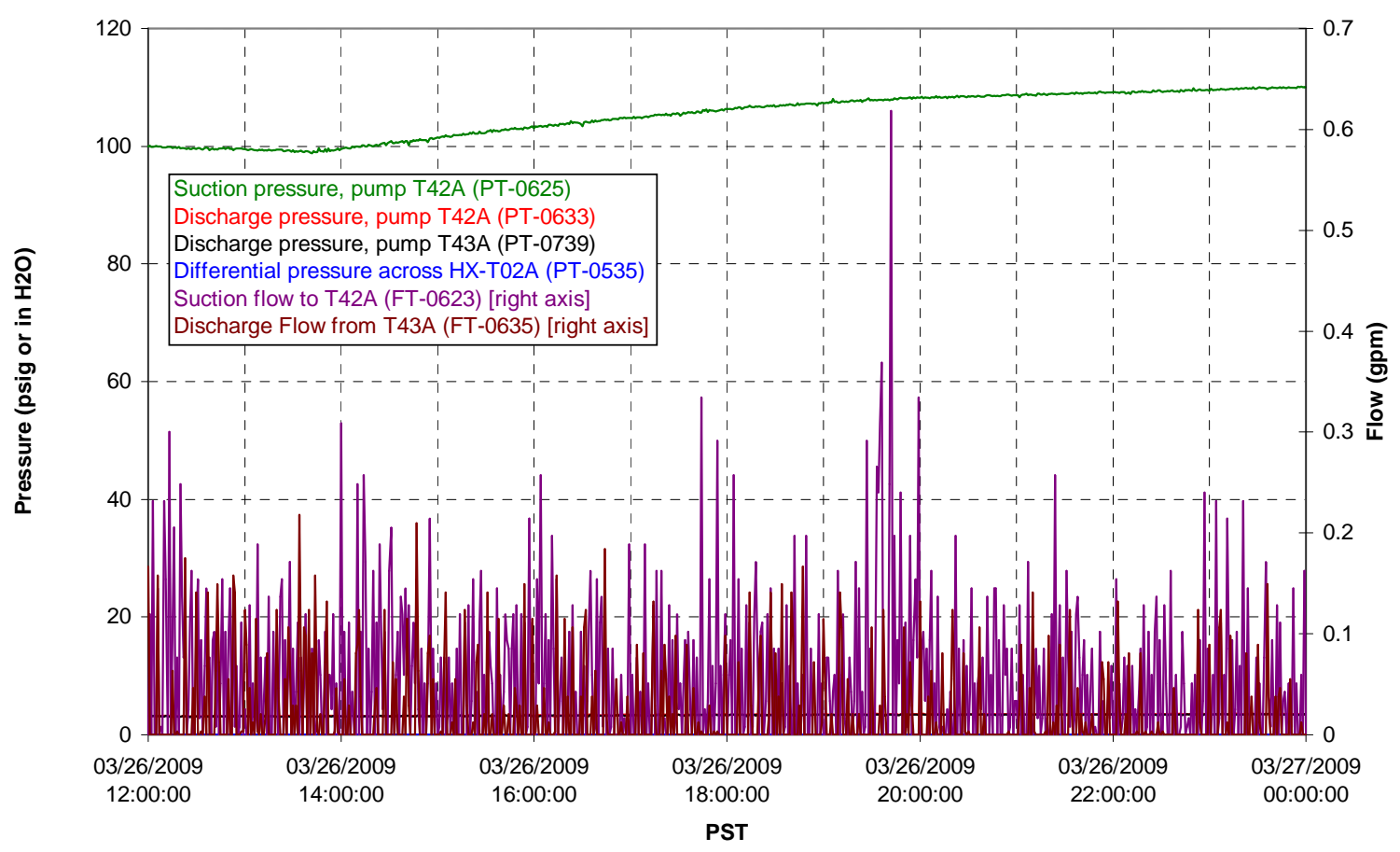


Axial pressure drop

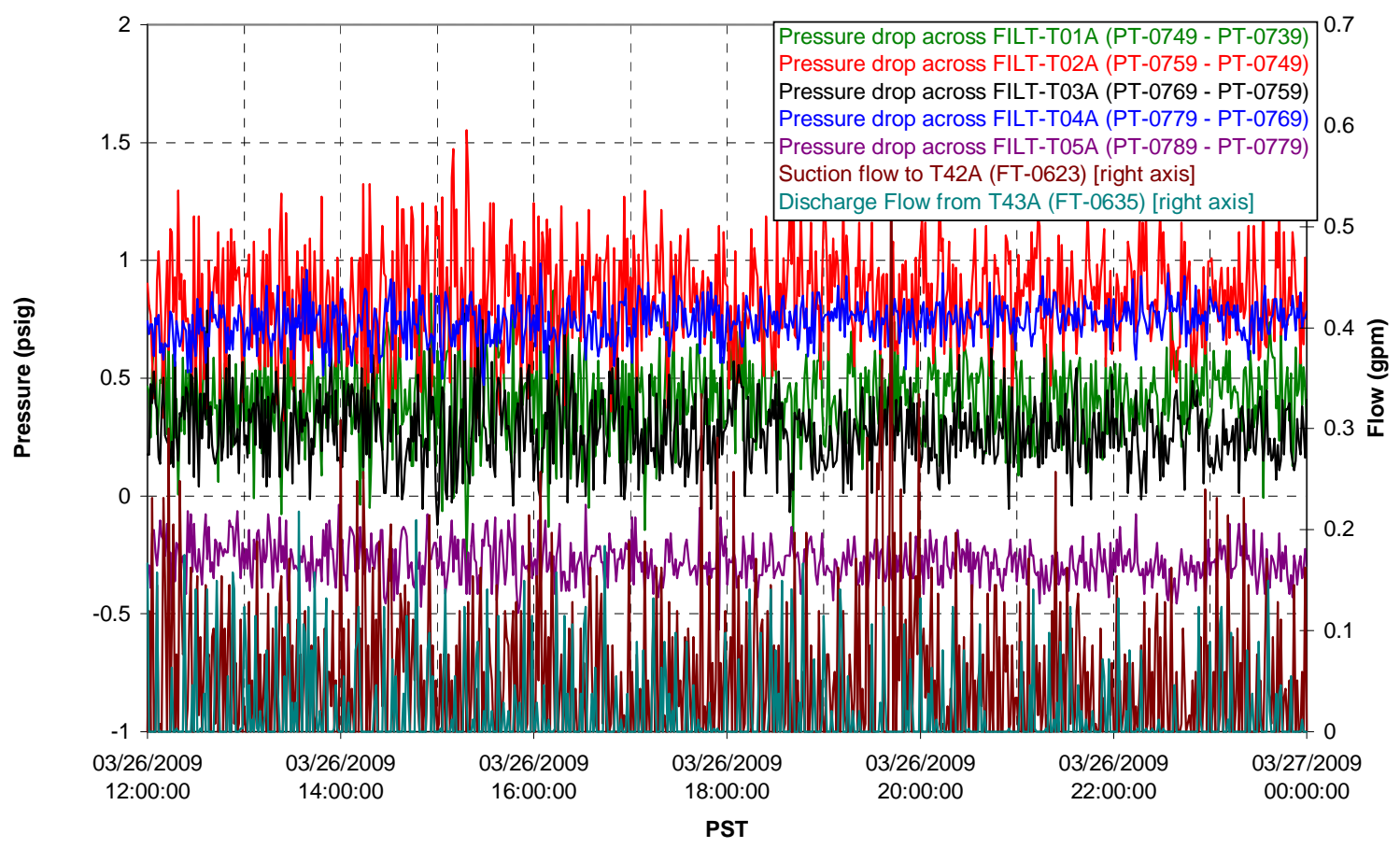

Permeate flow rates

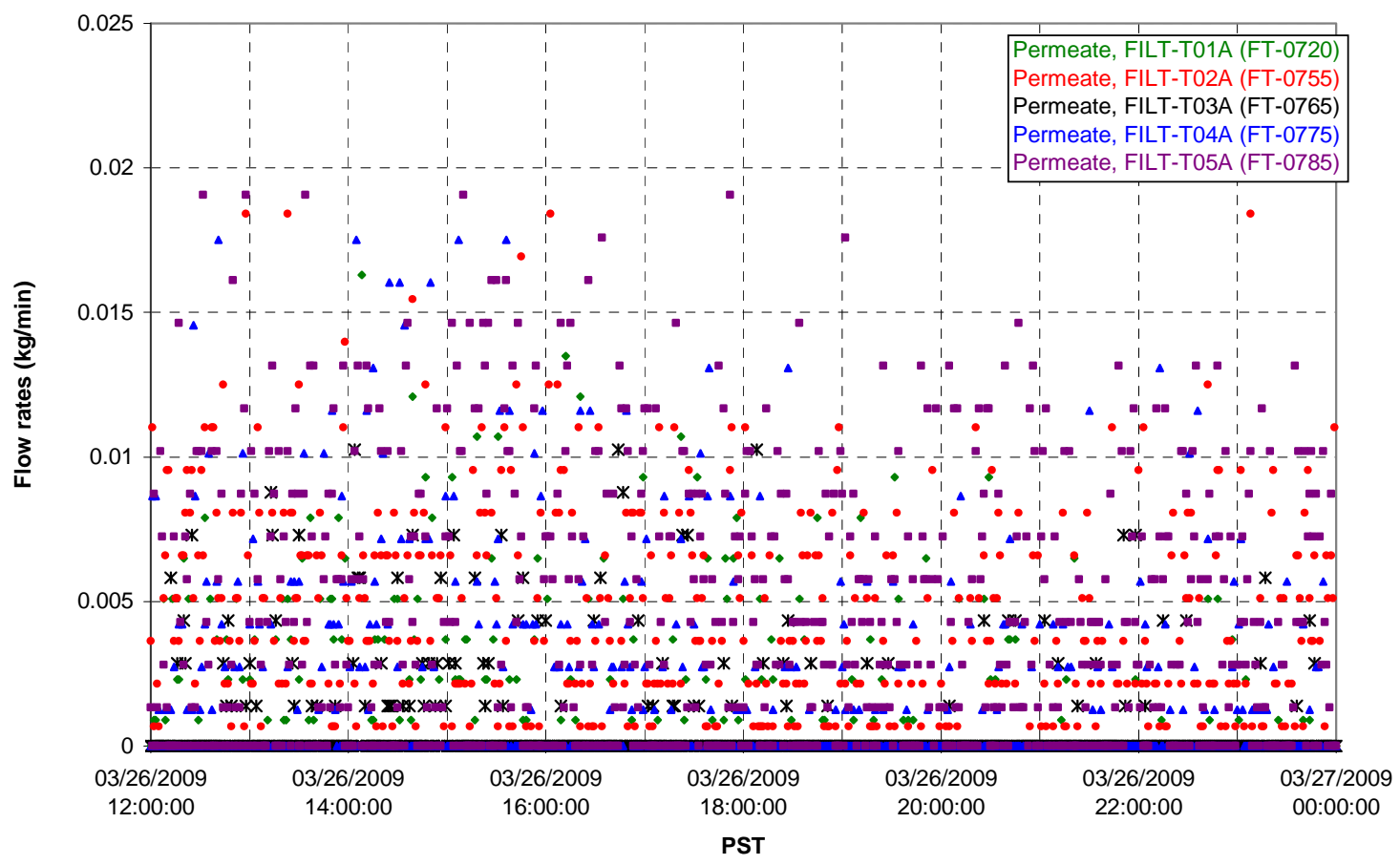


T02A Inner Temperature Tree

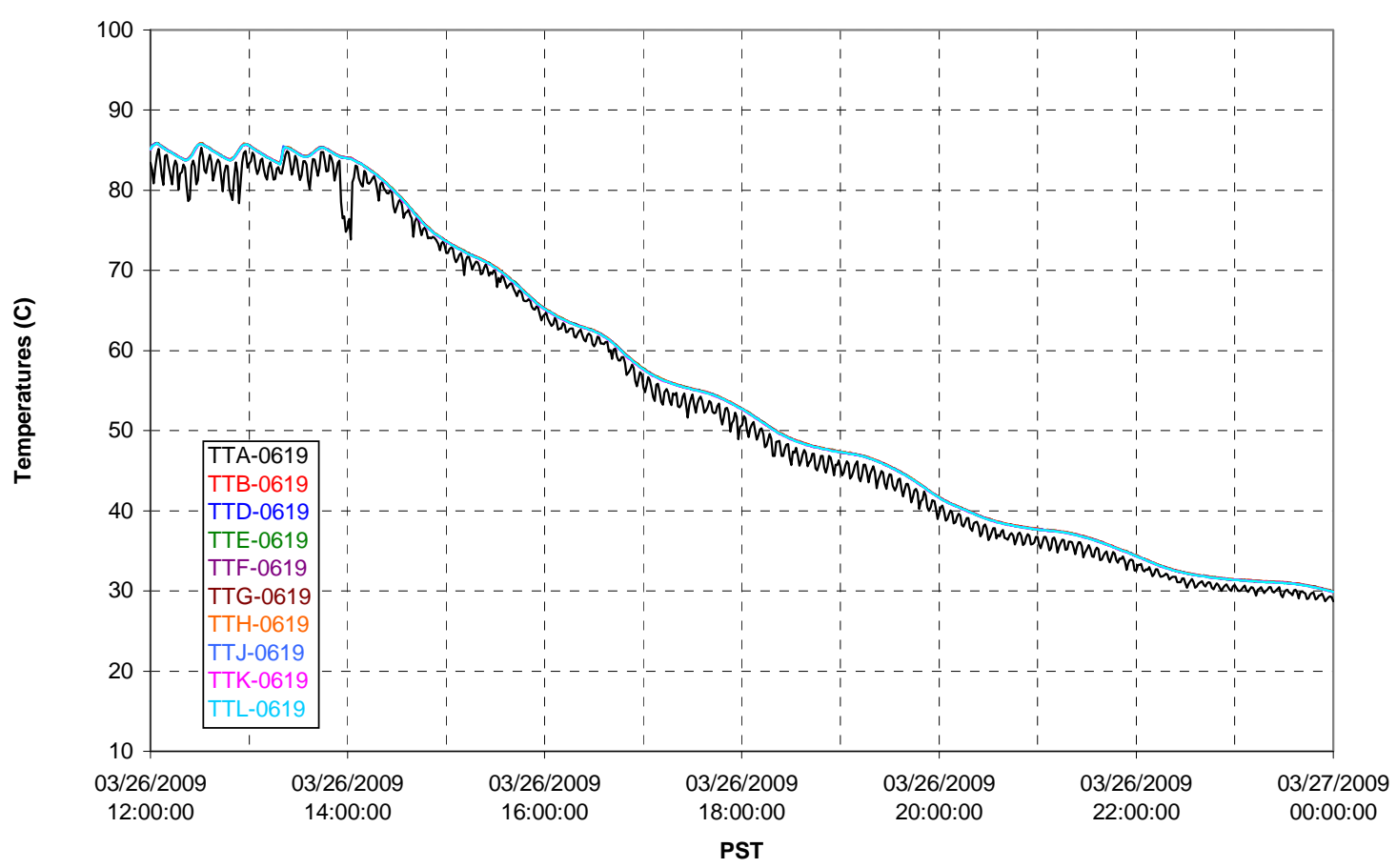

T02A Outer Temperature Tree

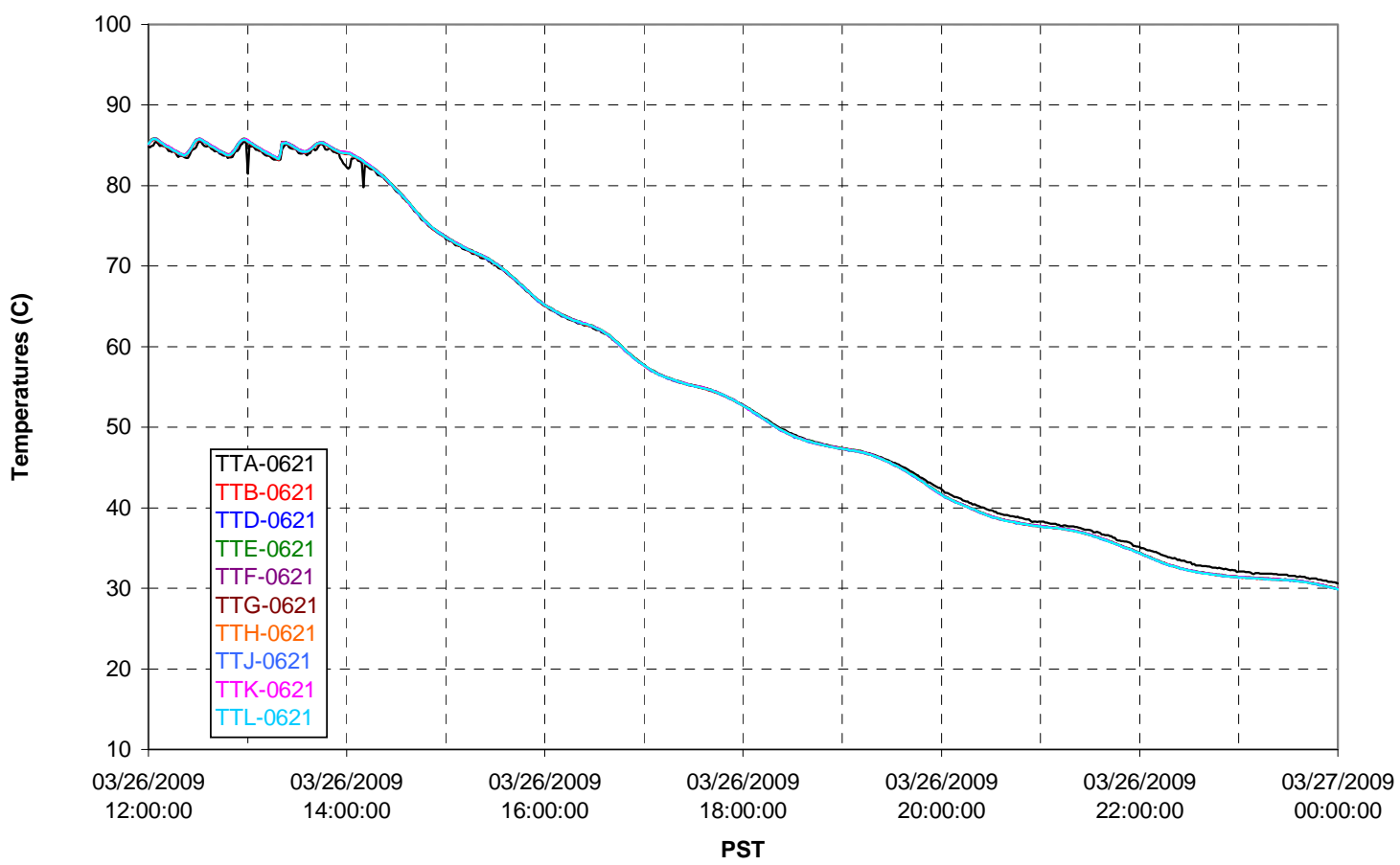


T02A temperatures

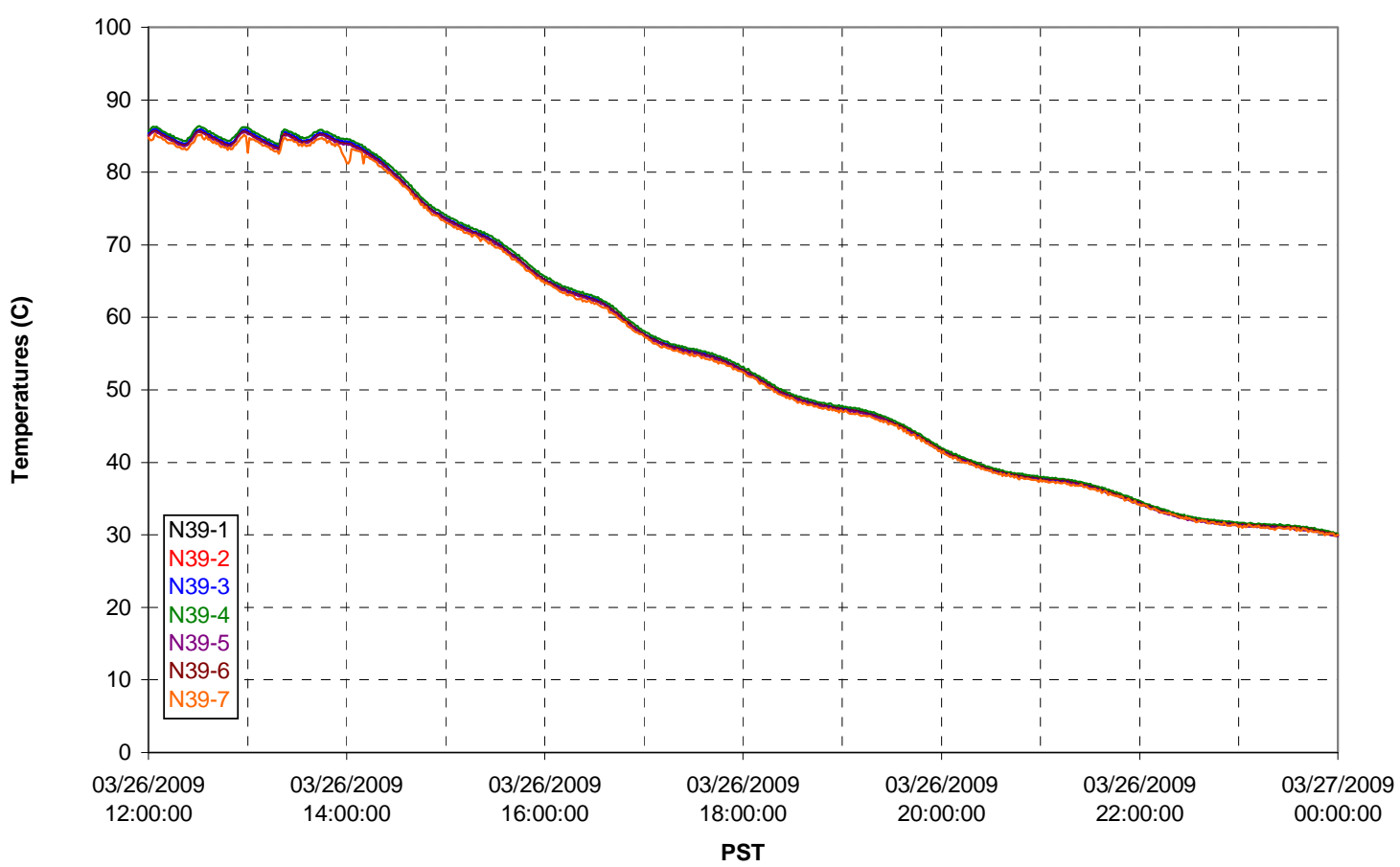

T02A temperatures

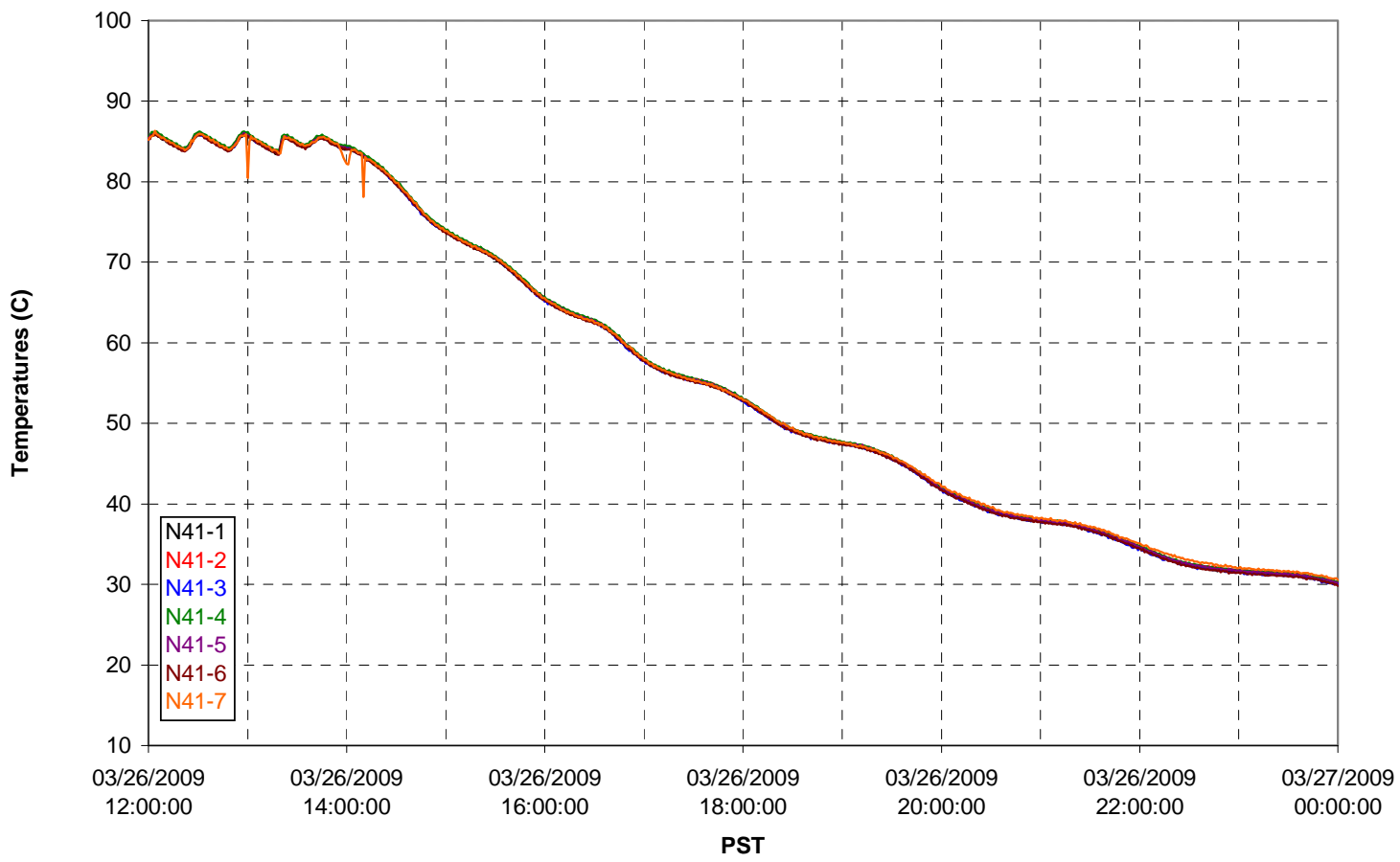


T02A temperatures

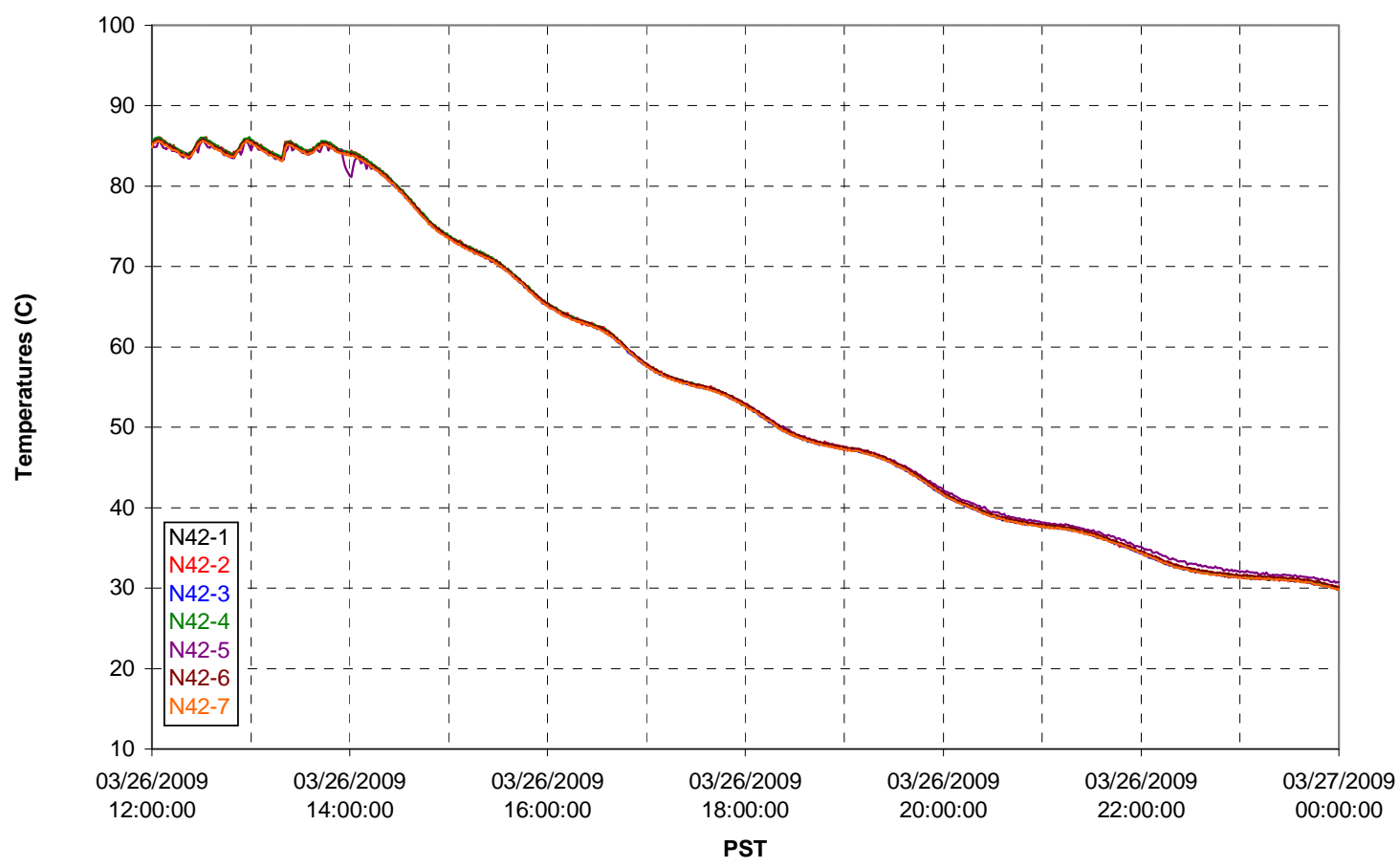

T02A temperatures

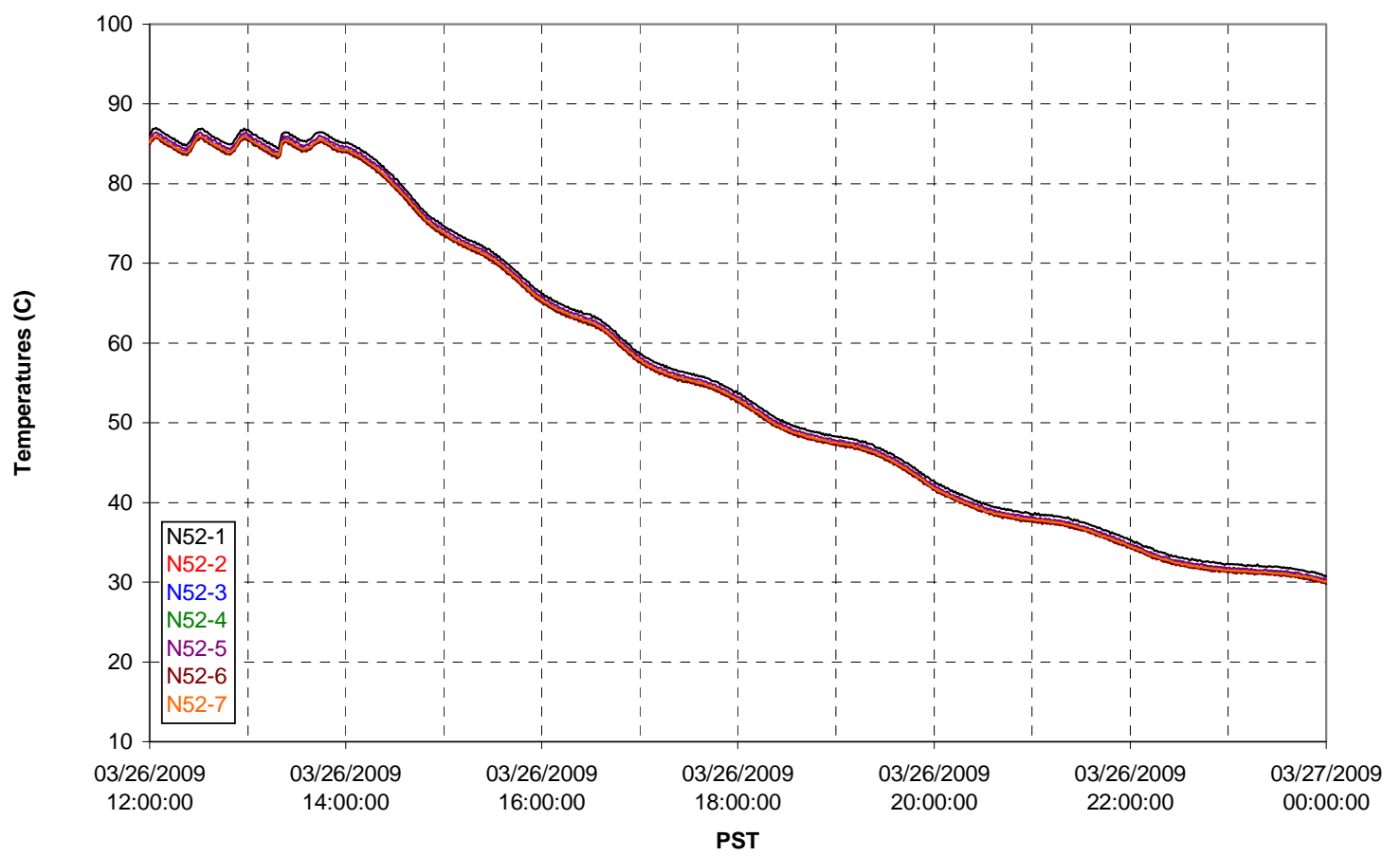


T02A Heating and Cooling

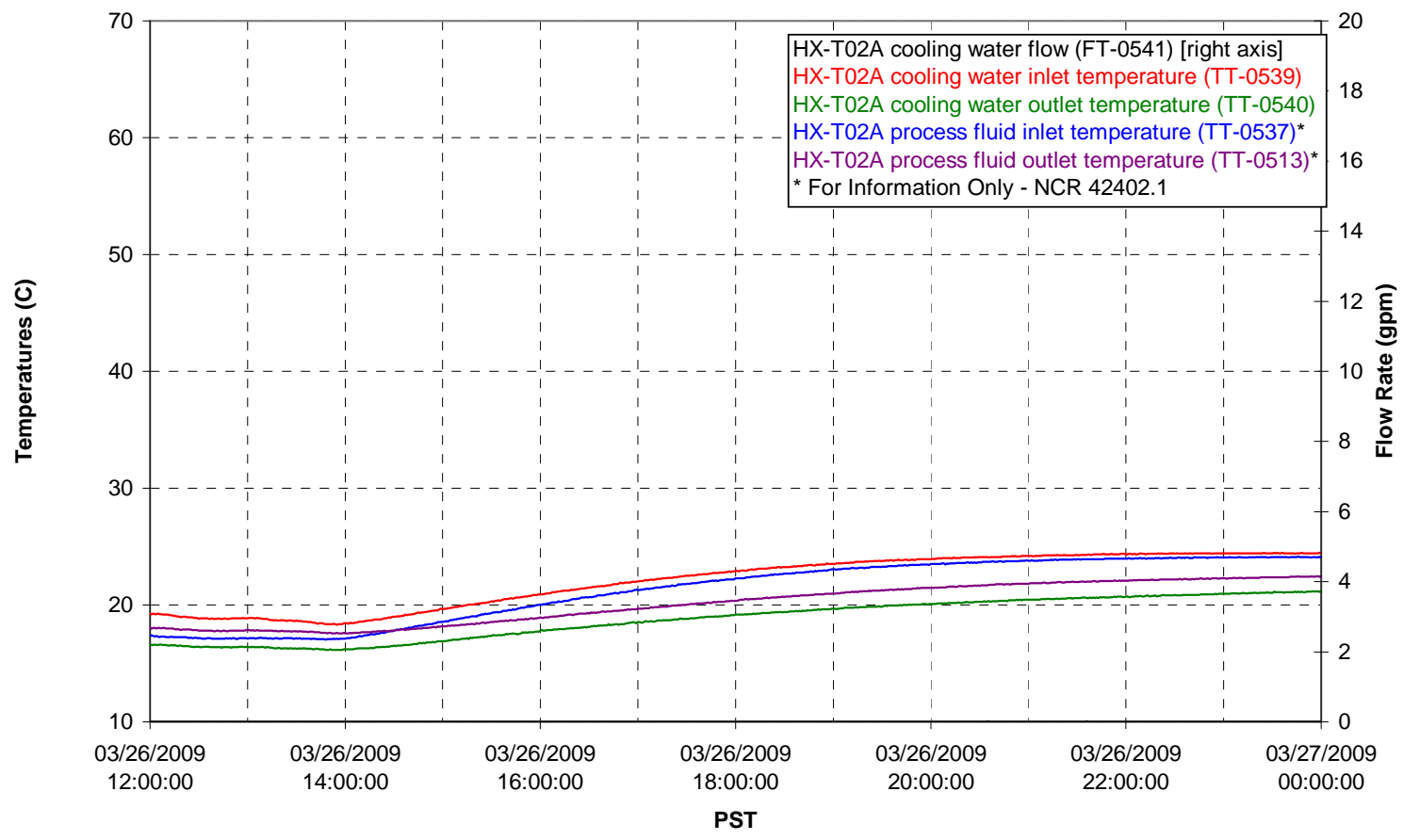

Pump Operation

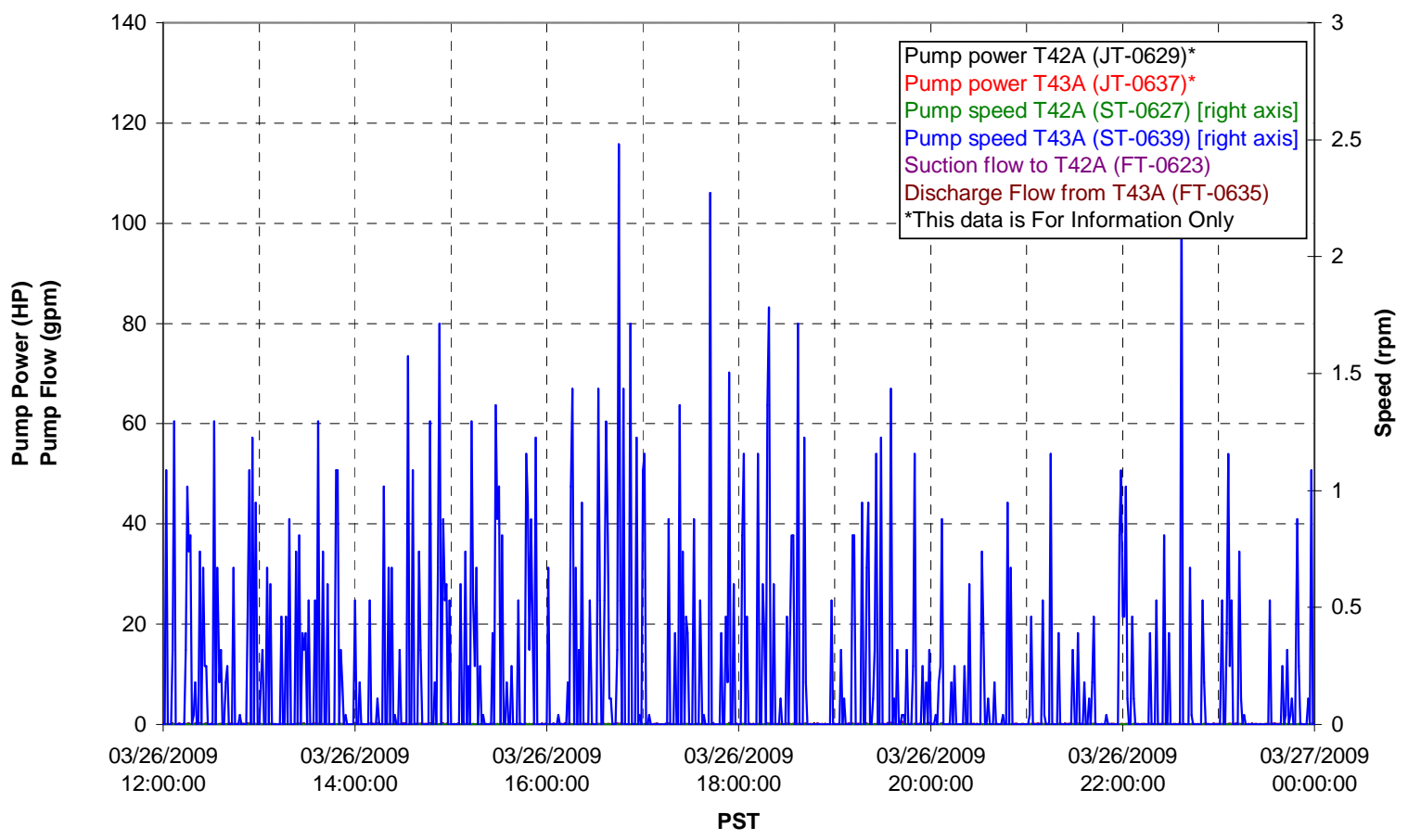


Pulsepot UFP-PP-T01A

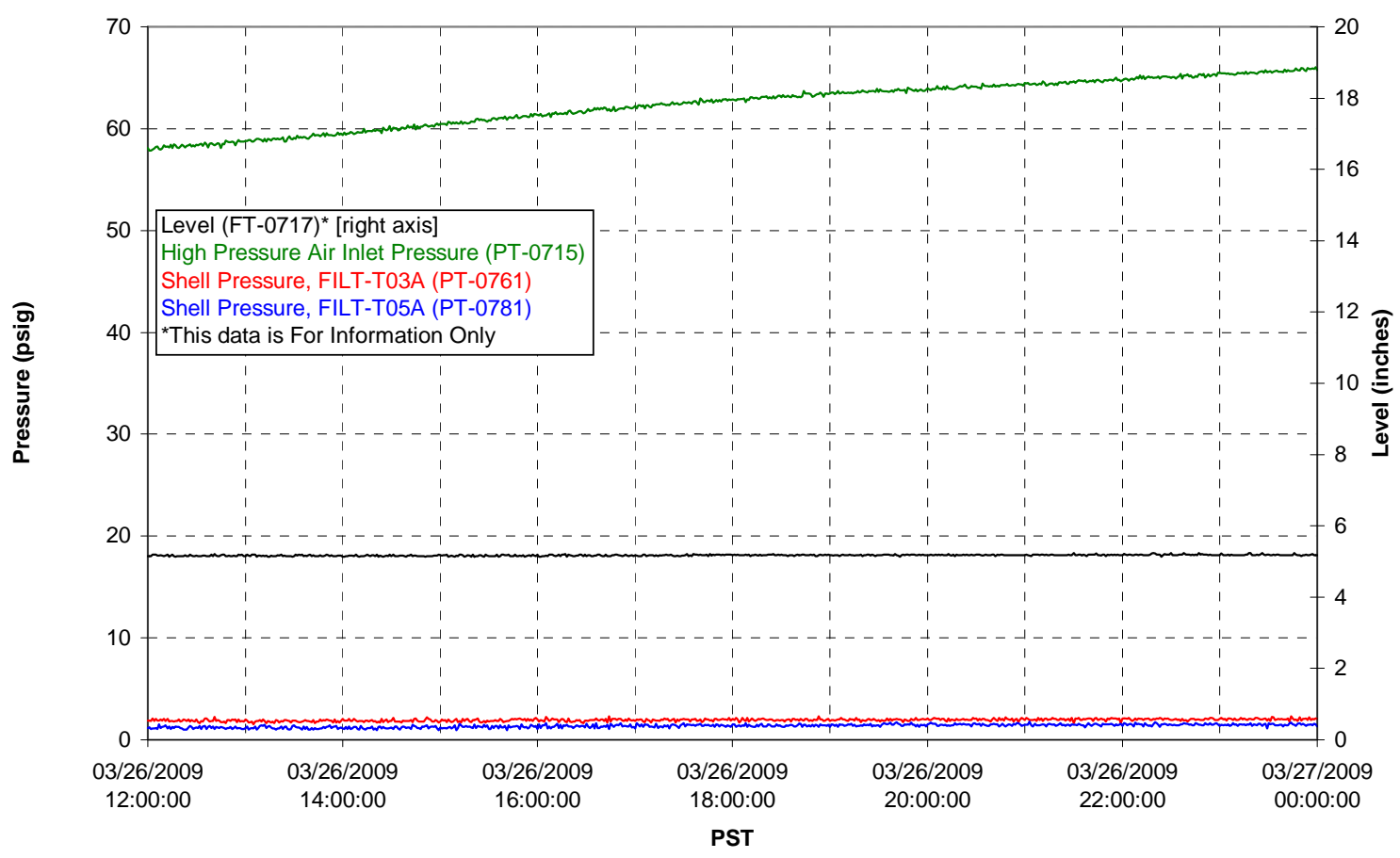

Pulsepot UFP-PP-T02A

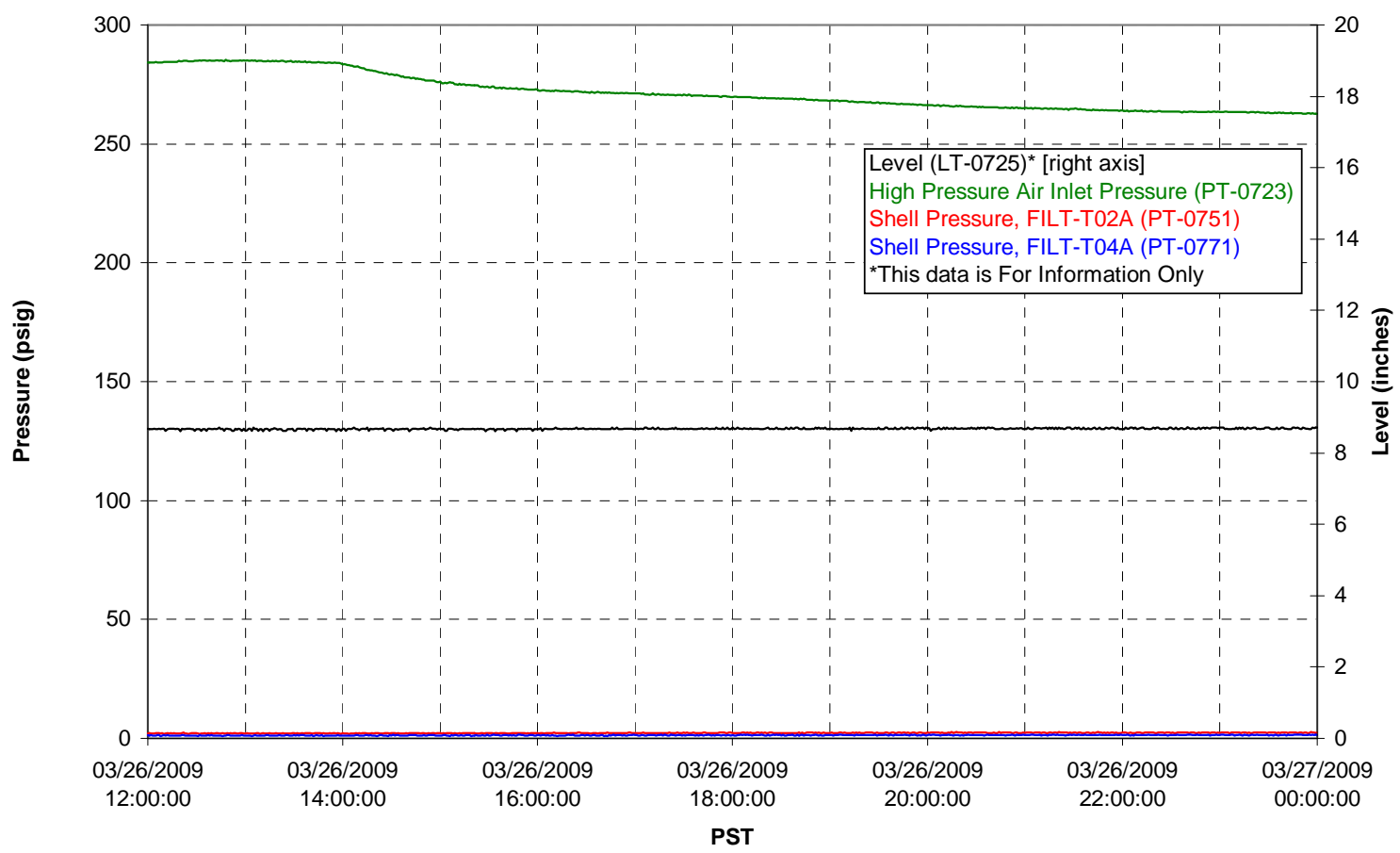


Pulsepot UFP-PP-T03A

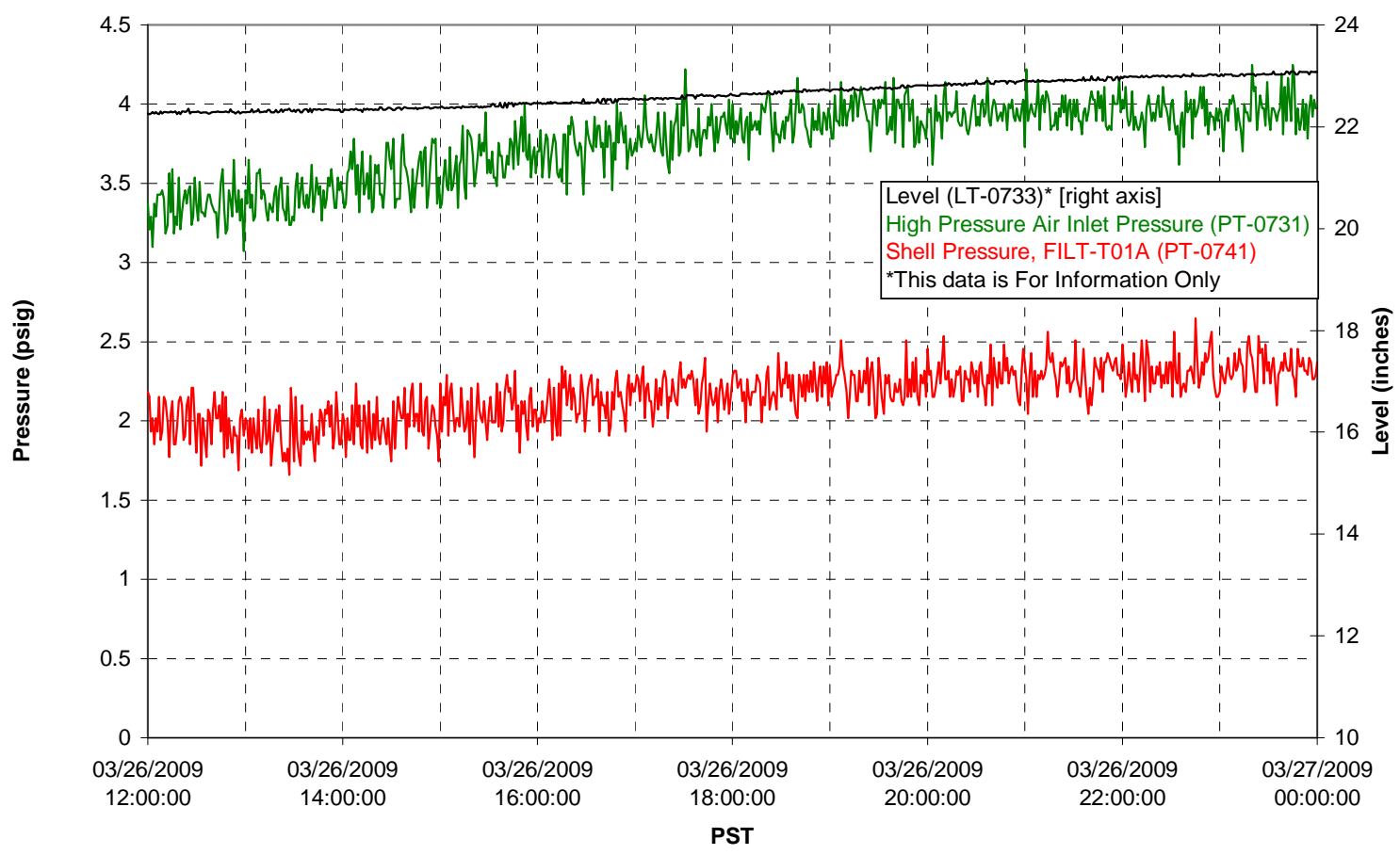

Pulsepot Levels

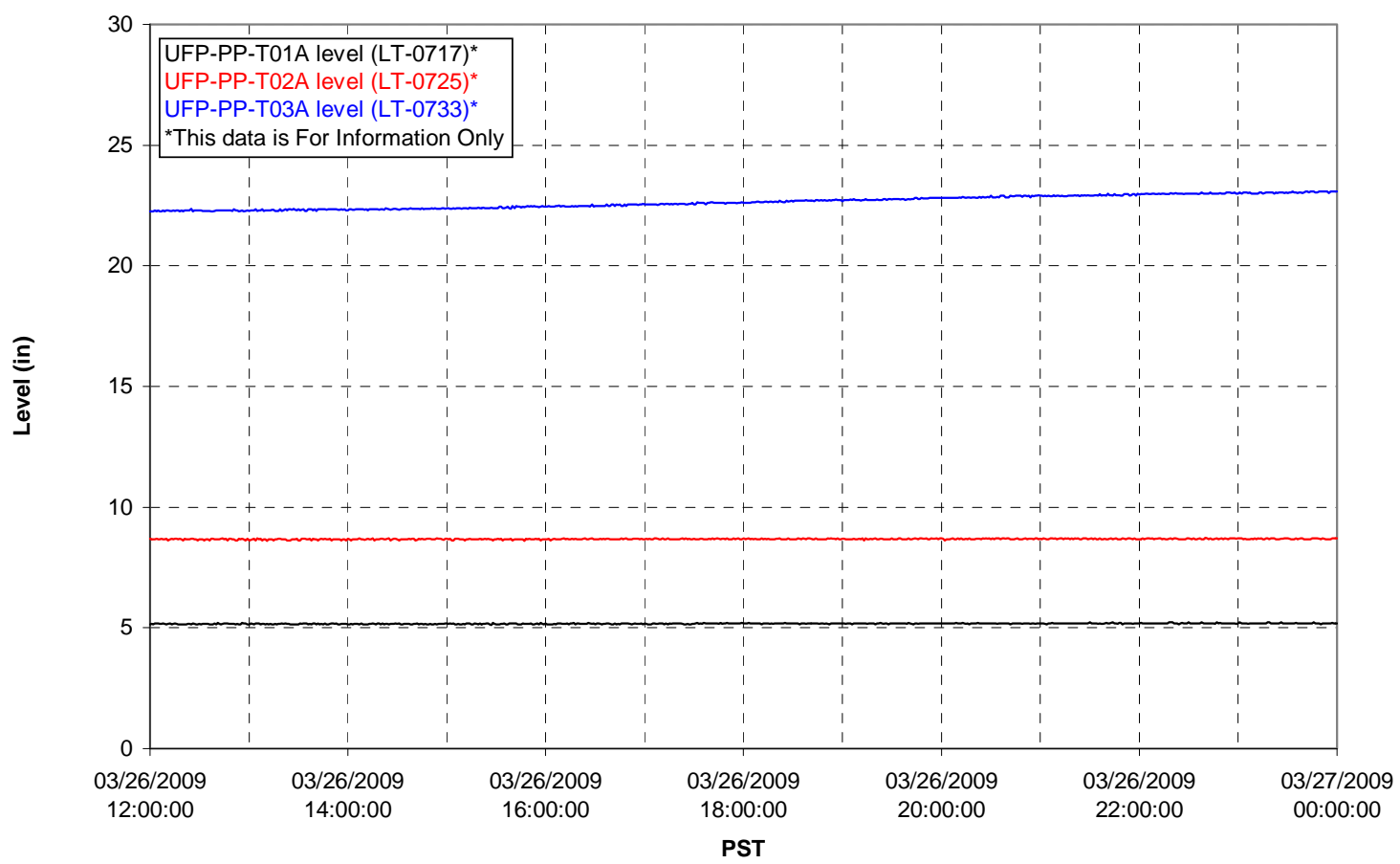


Filter UFP-FILT-T01A

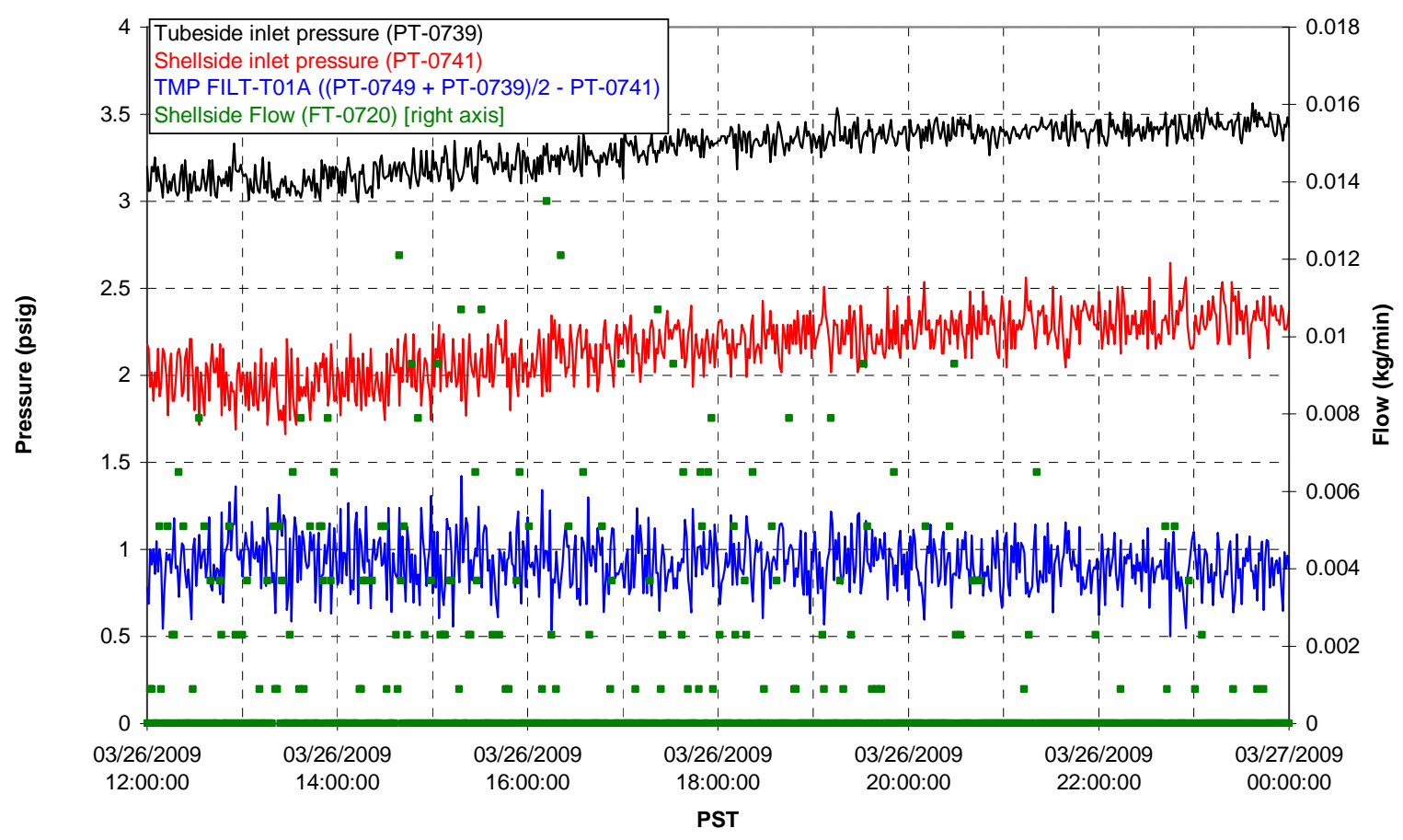

Filter UFP-FILT-T02A

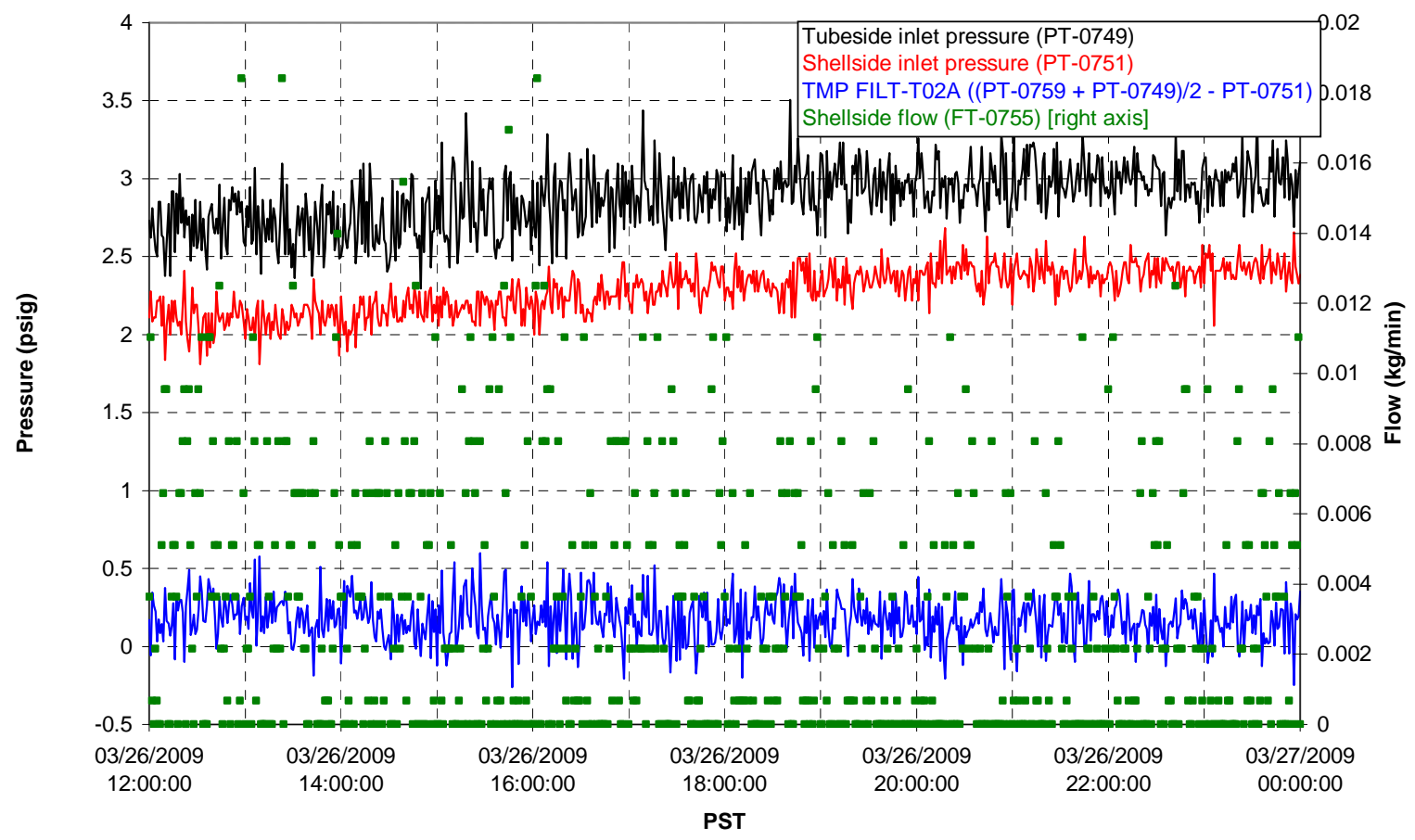


Filter UFP-FILT-T03A

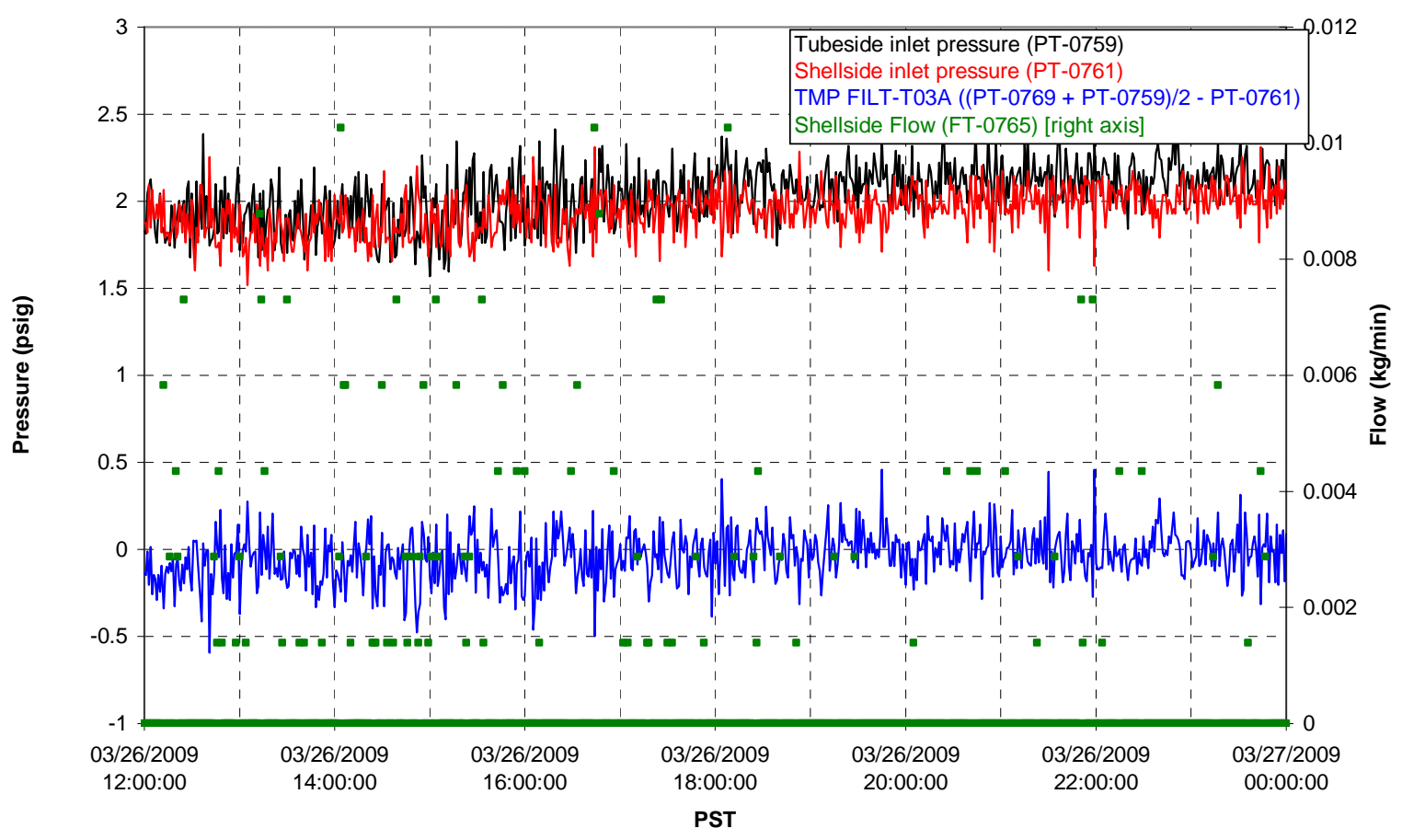

Filter UFP-FILT-T04A

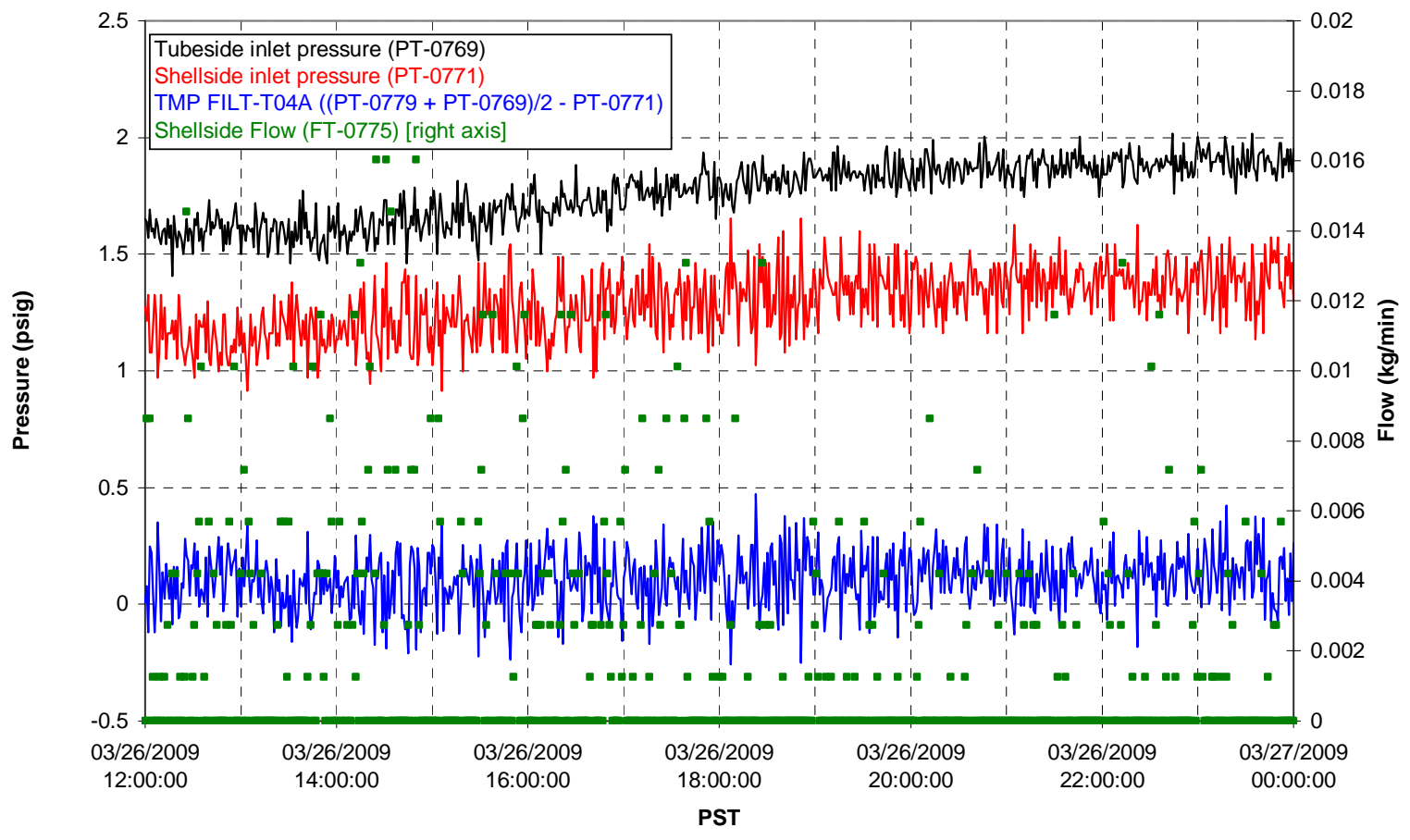


Filter UFP-FILT-T05A

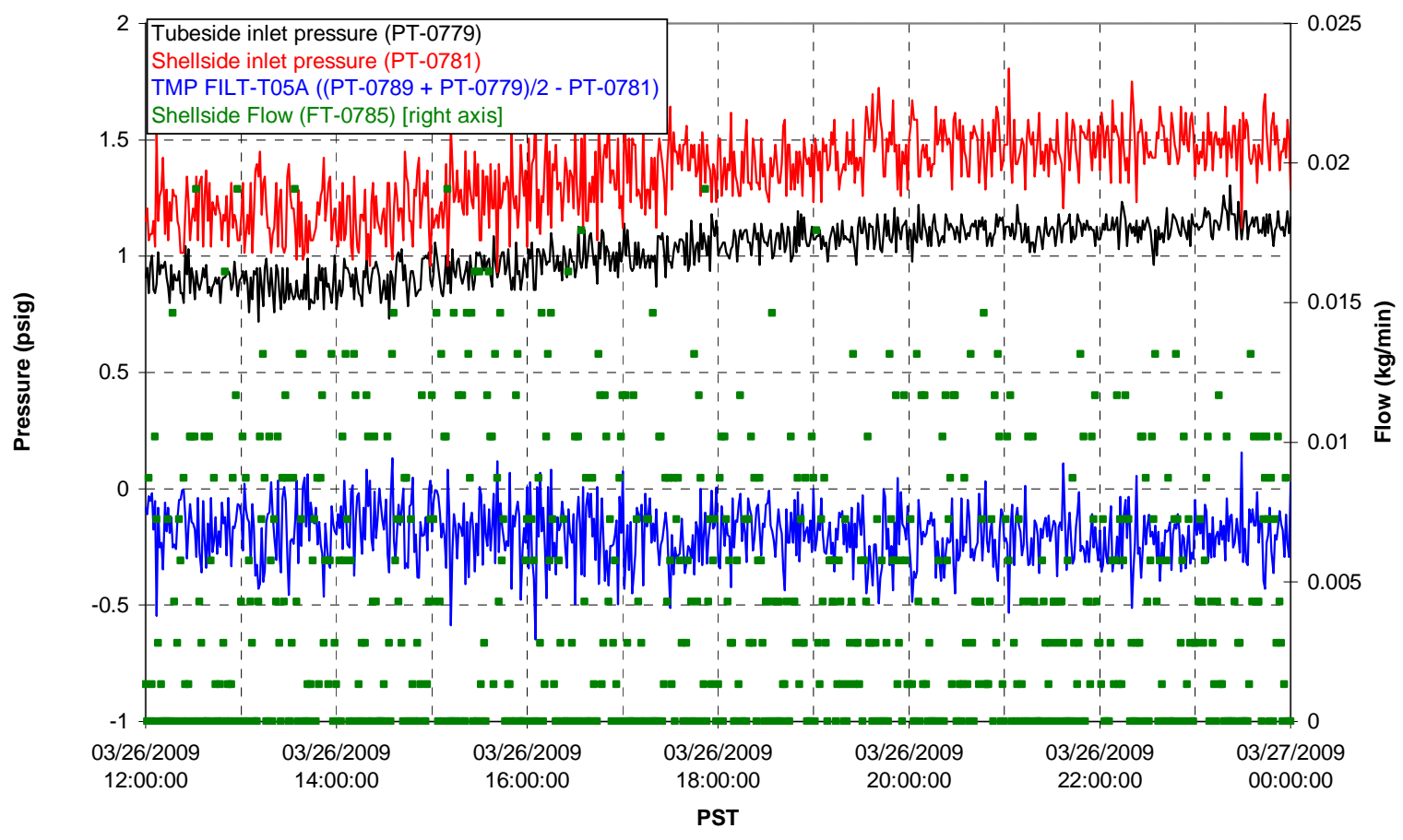

Chemical Flow

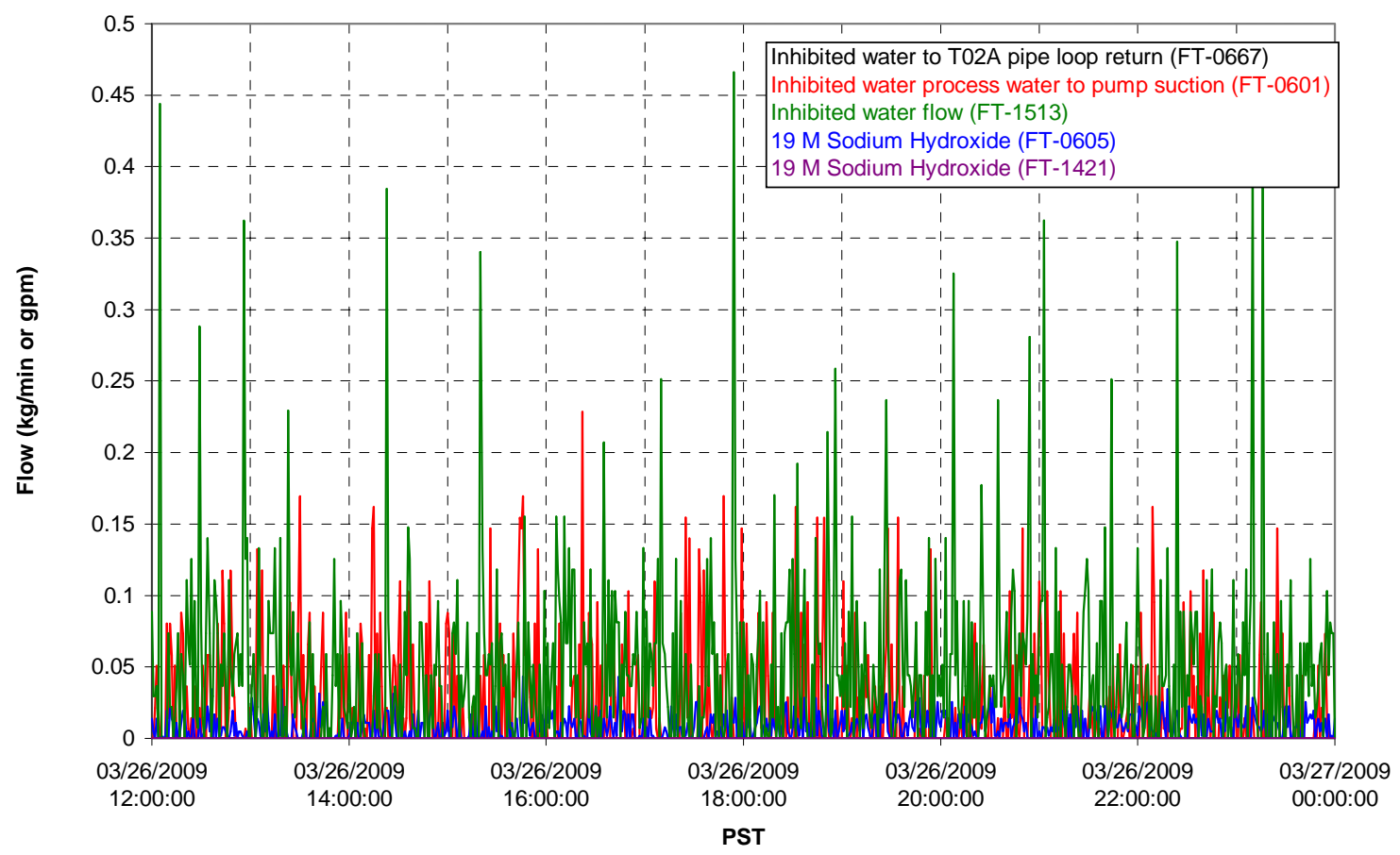




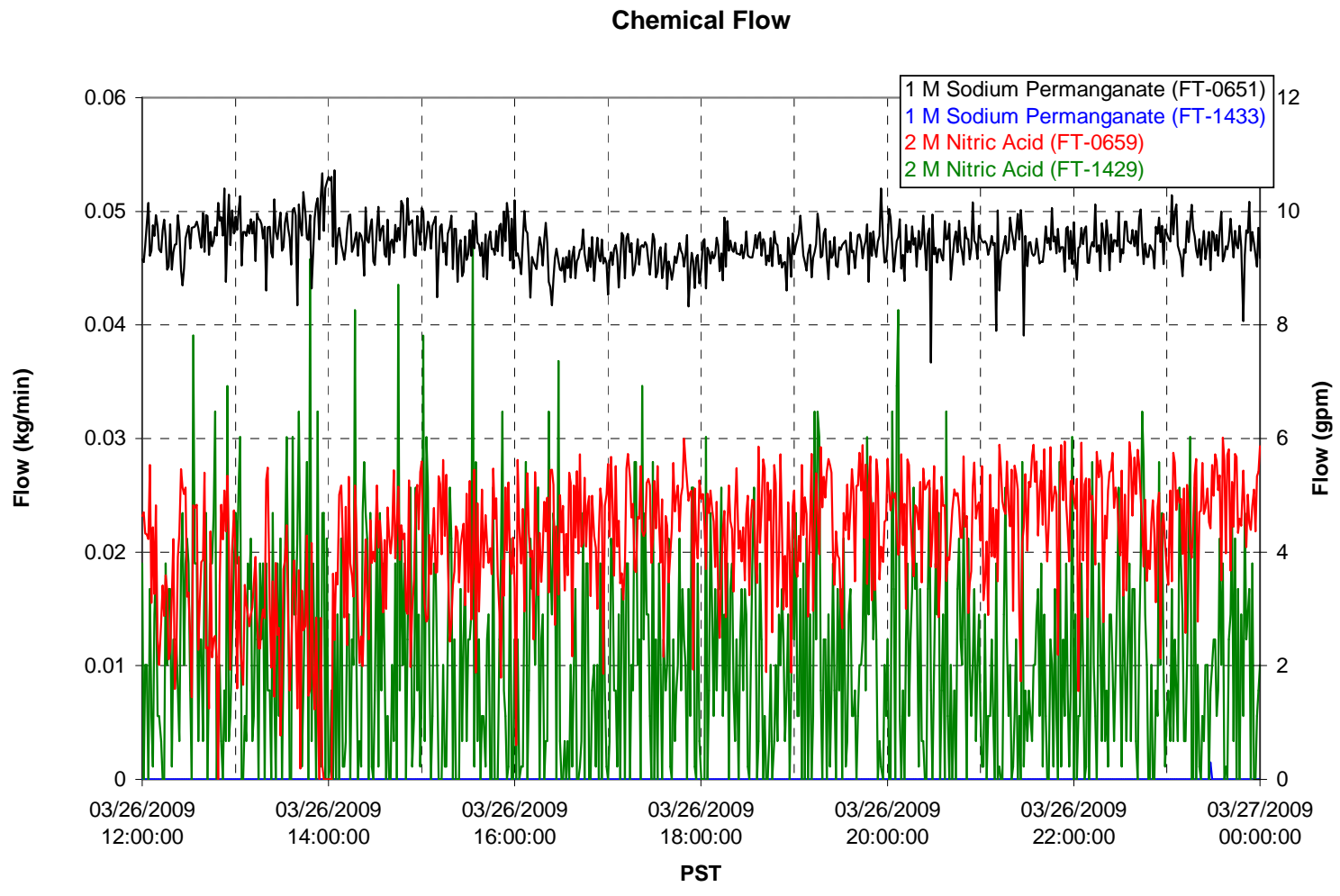

Air Flows

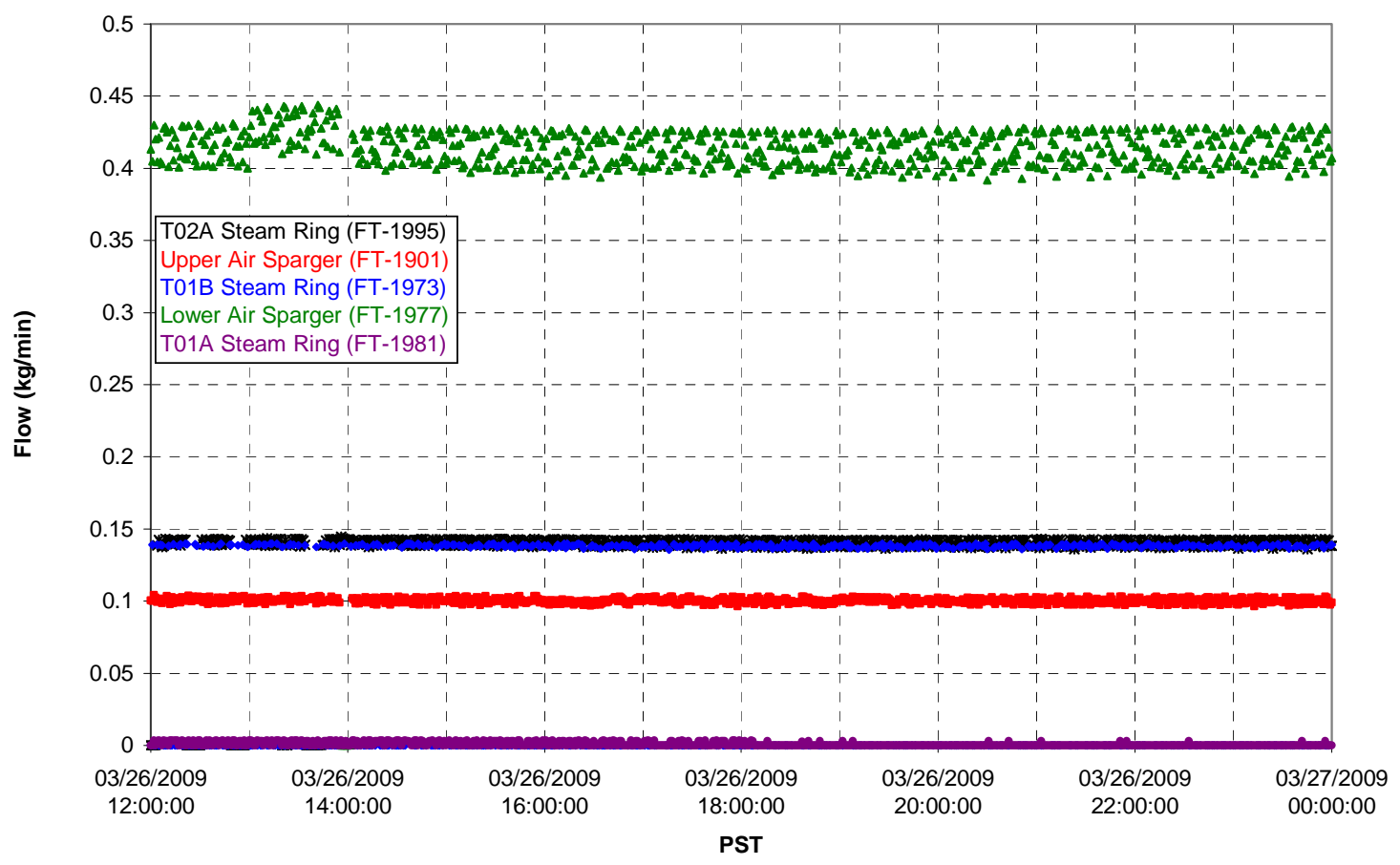


T02A Steam

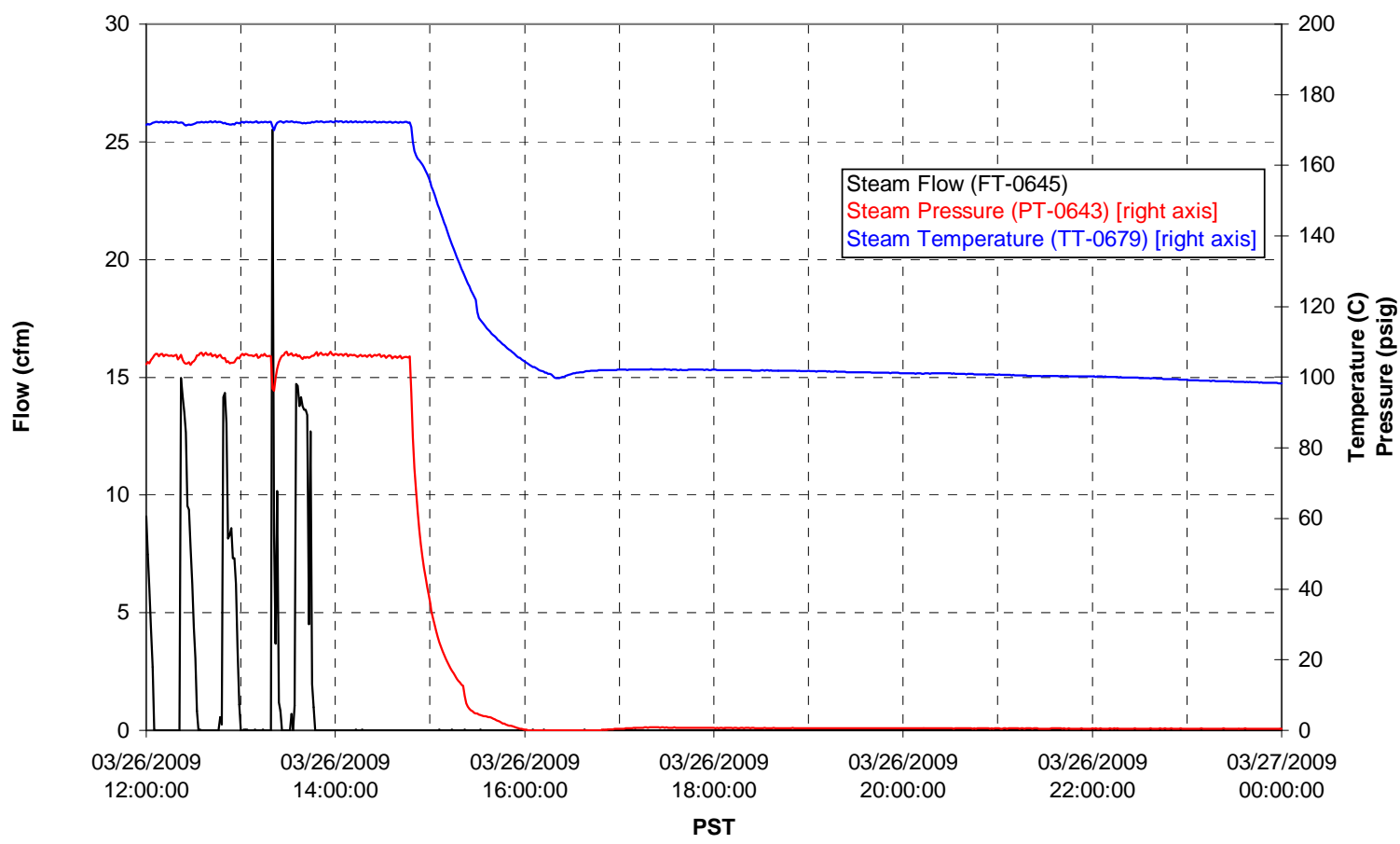

T01A Steam

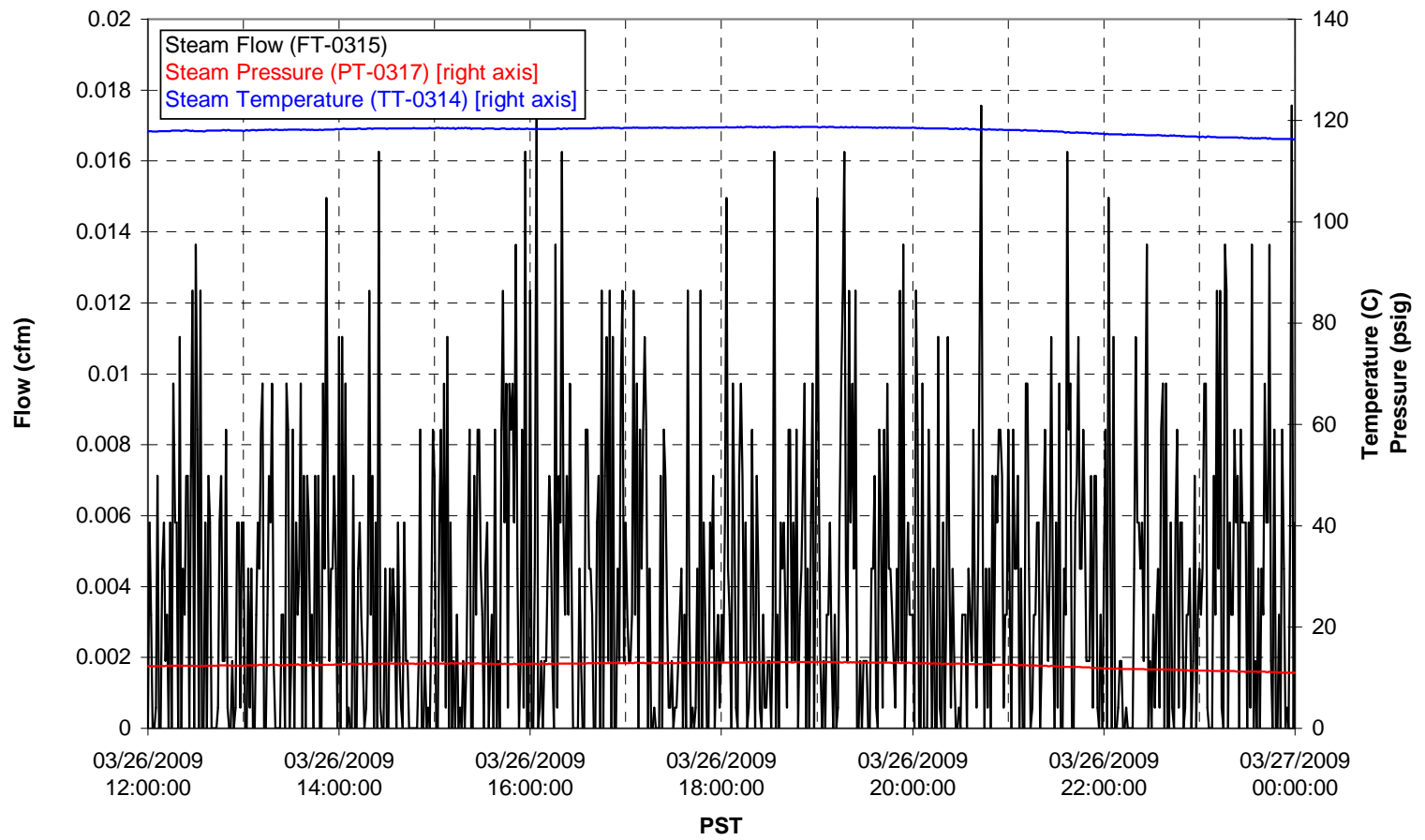


T01B Steam

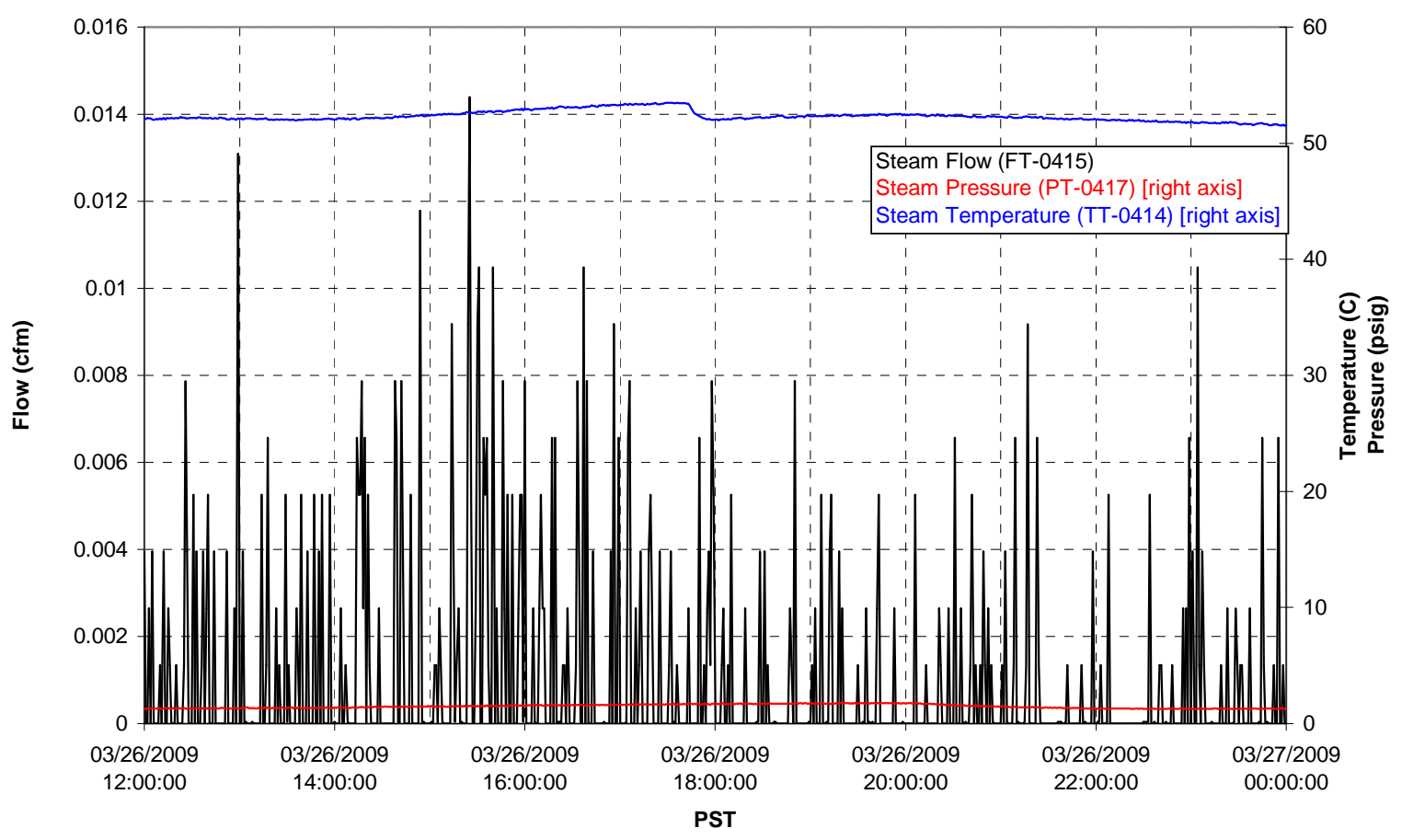




\section{Integrated Test D Data Plots 03/27/09 00:00 - 03/27/09 12:00}


T01A level

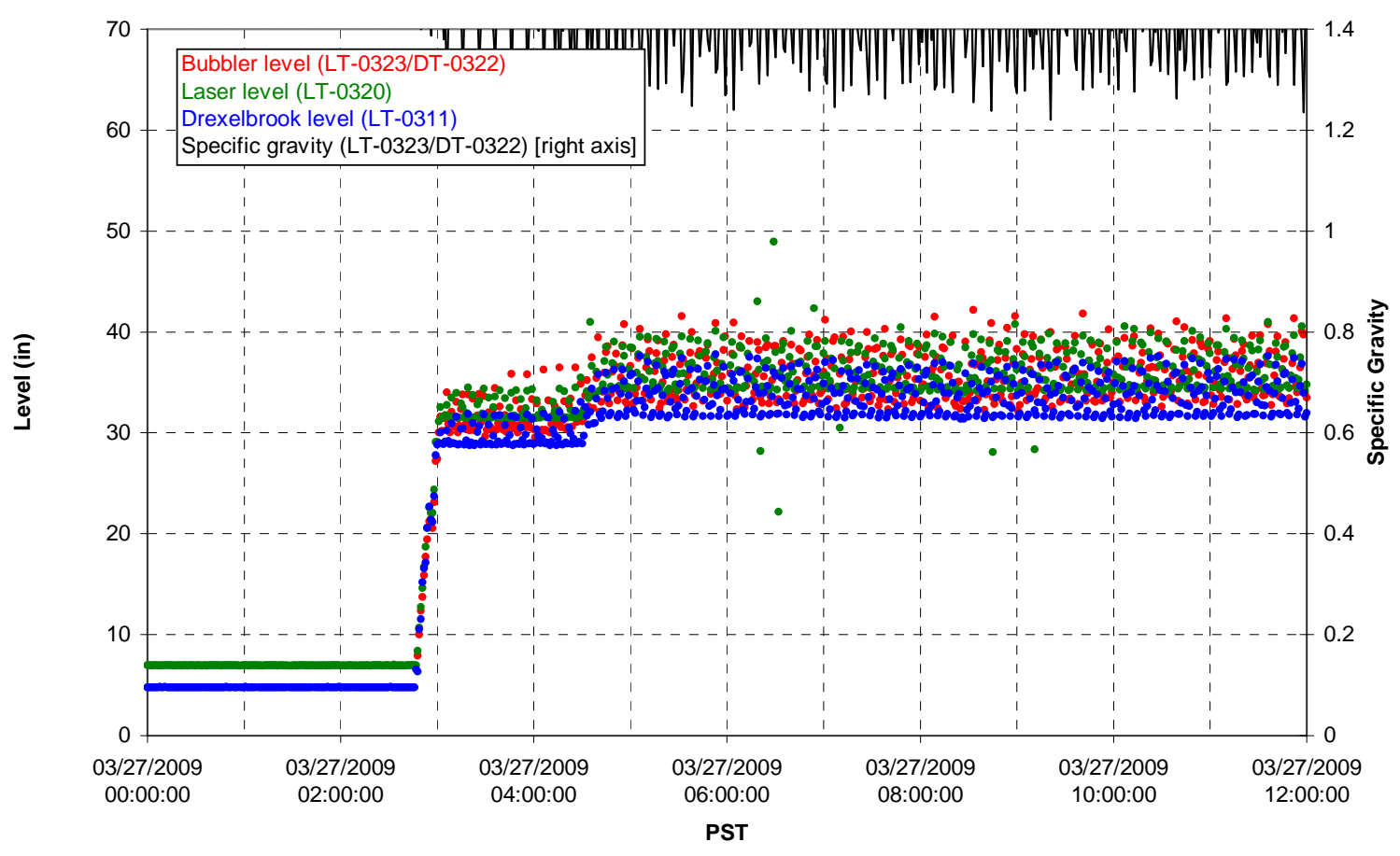

T01A temperatures

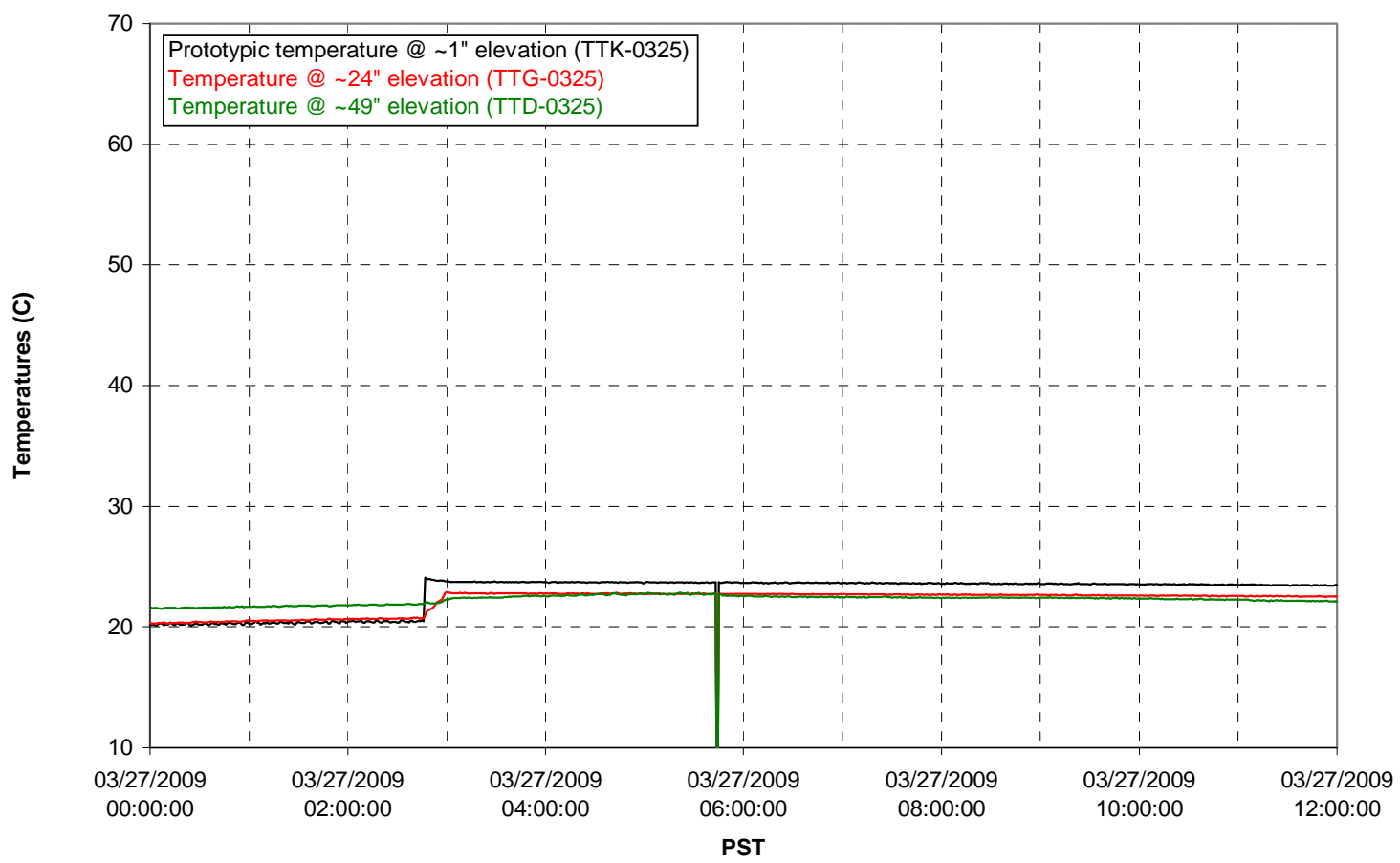


T01B level

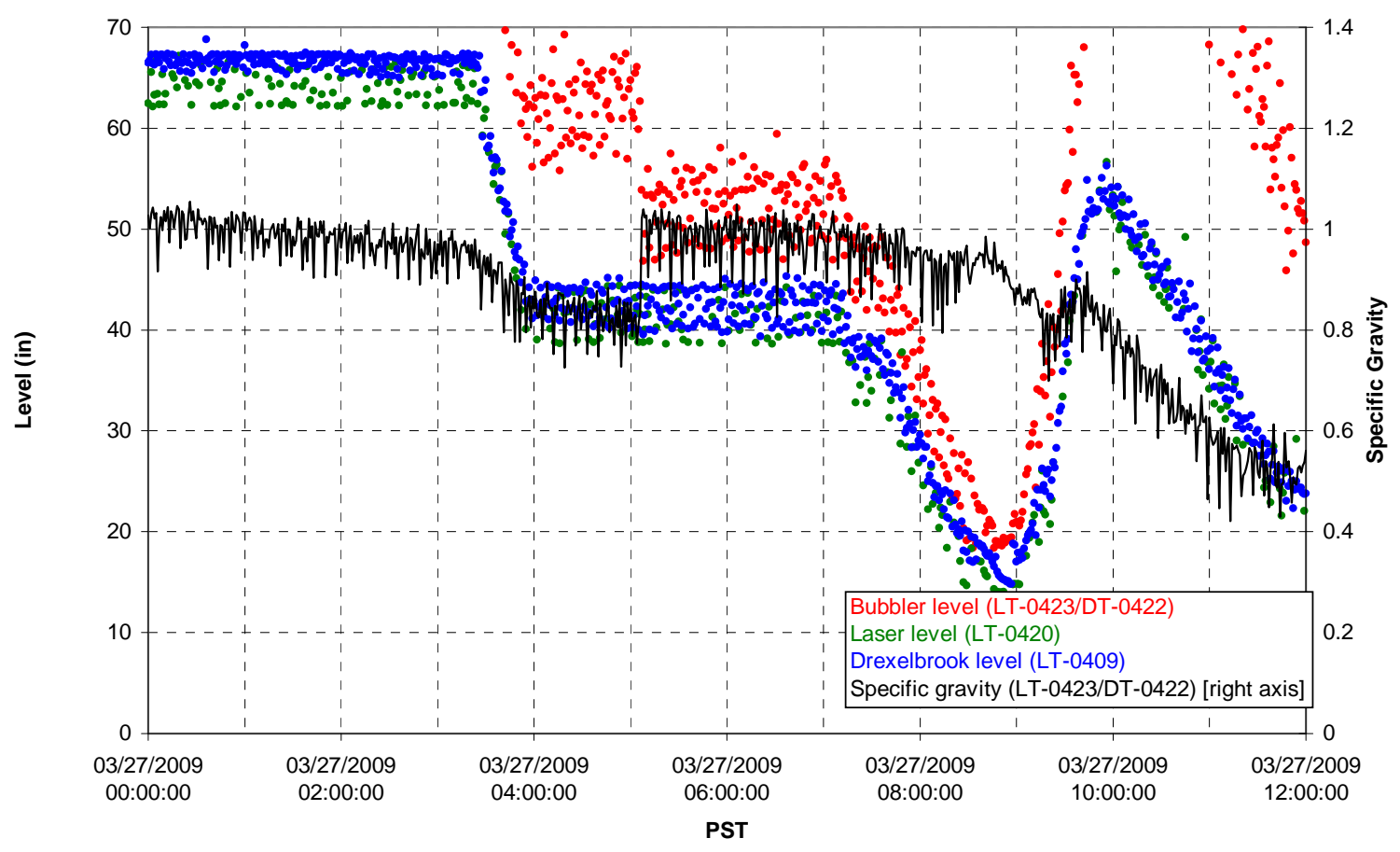

T01B temperatures

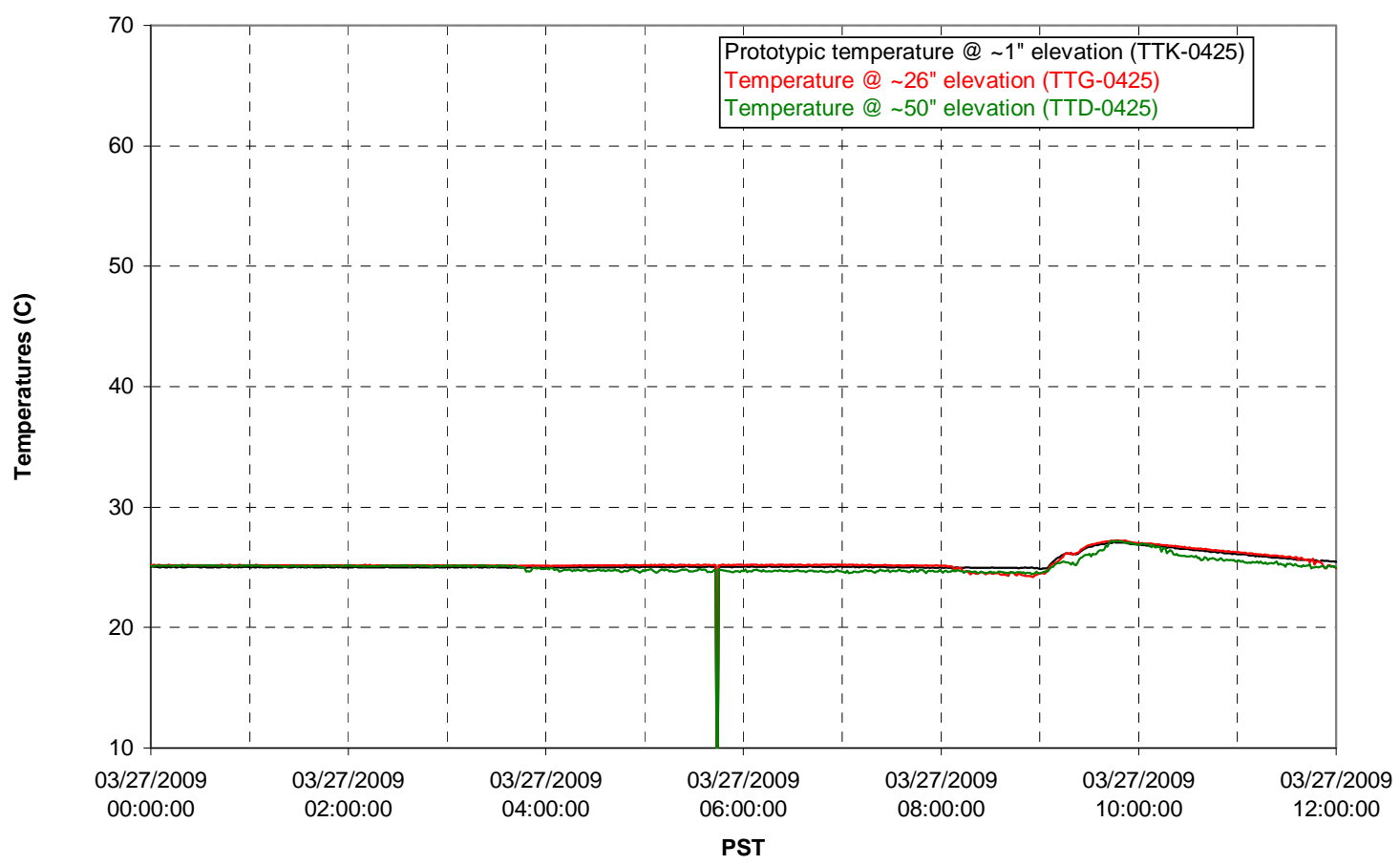


T02A level

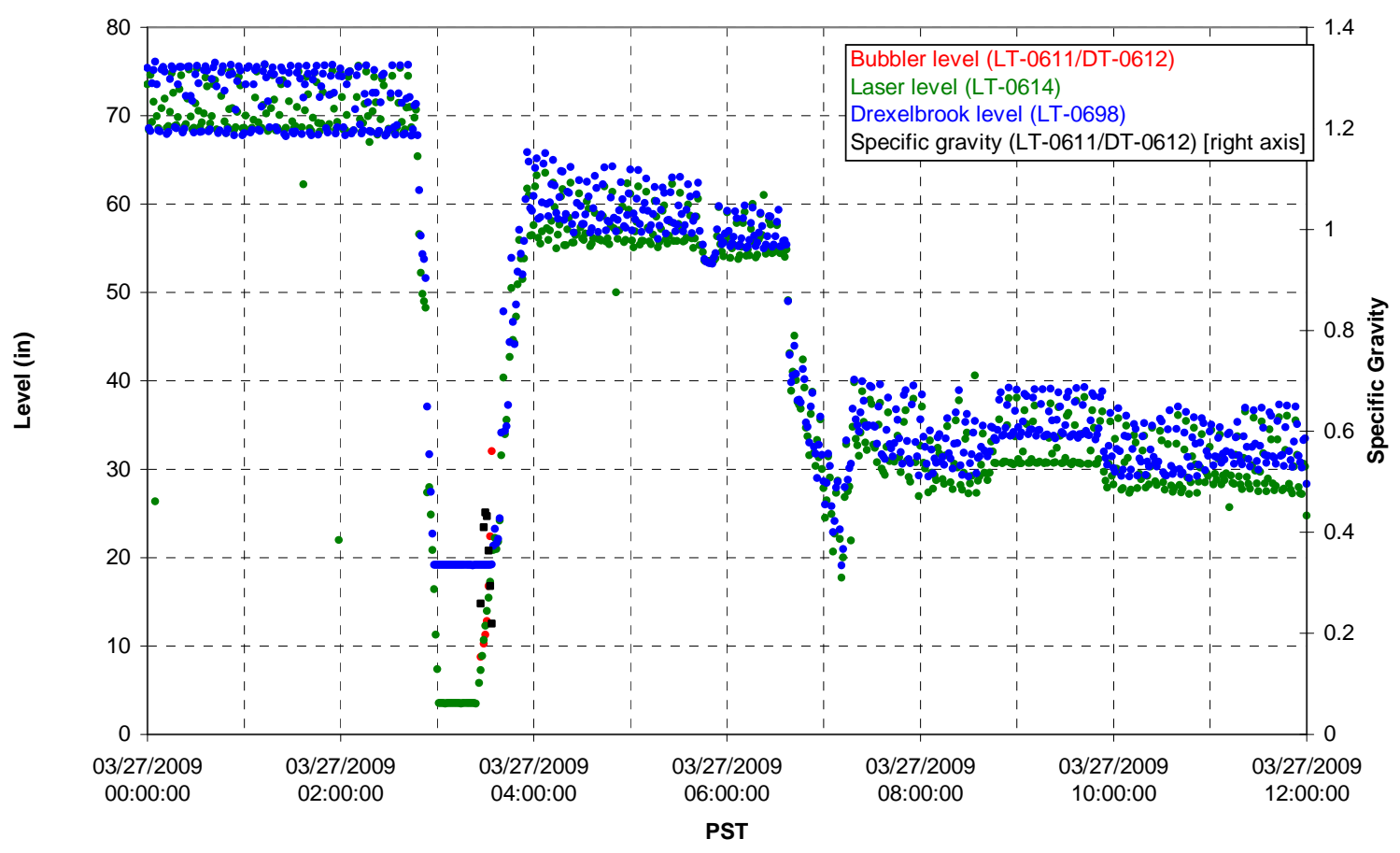

T02A temperatures

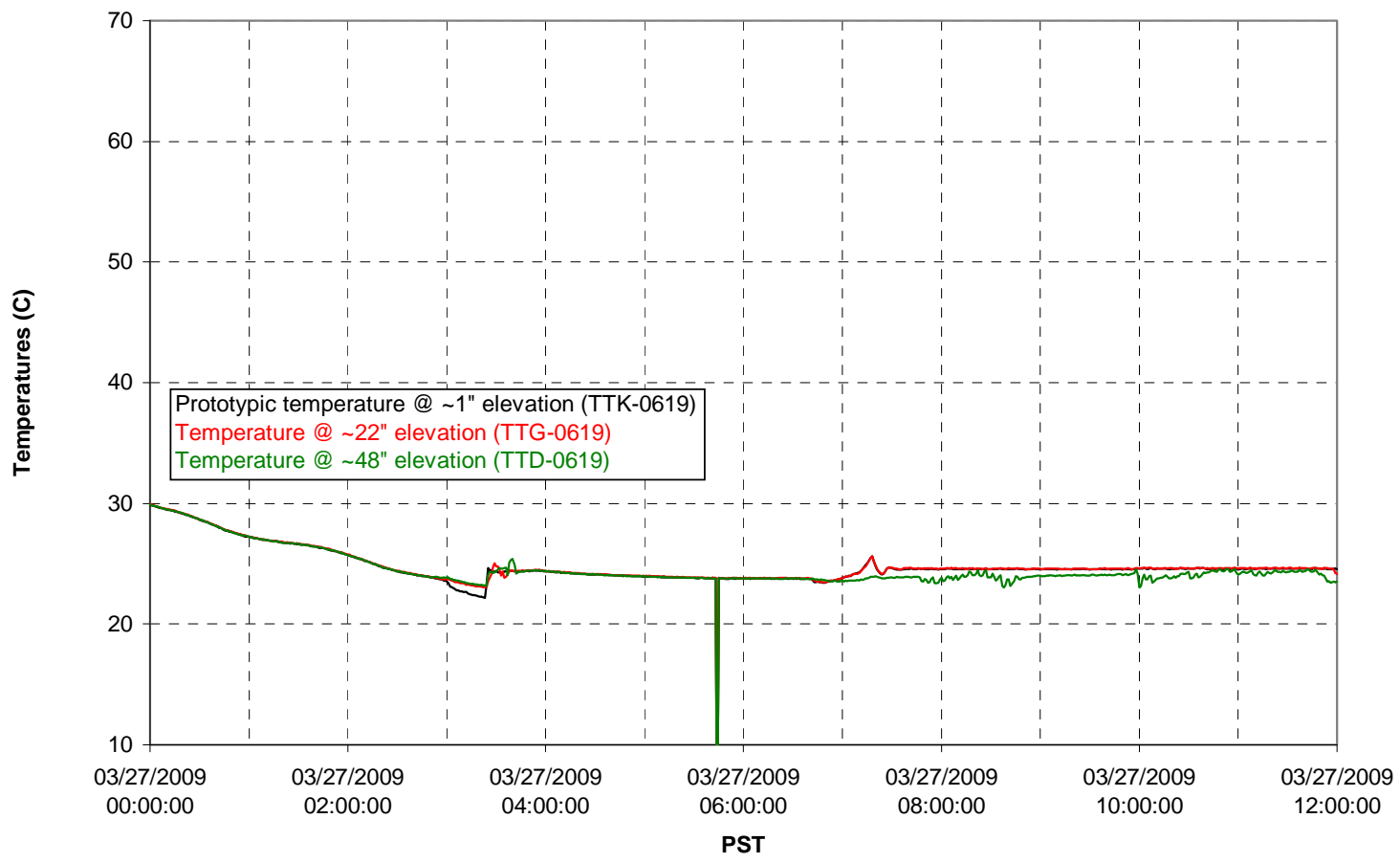


T02A and filter loop temperatures

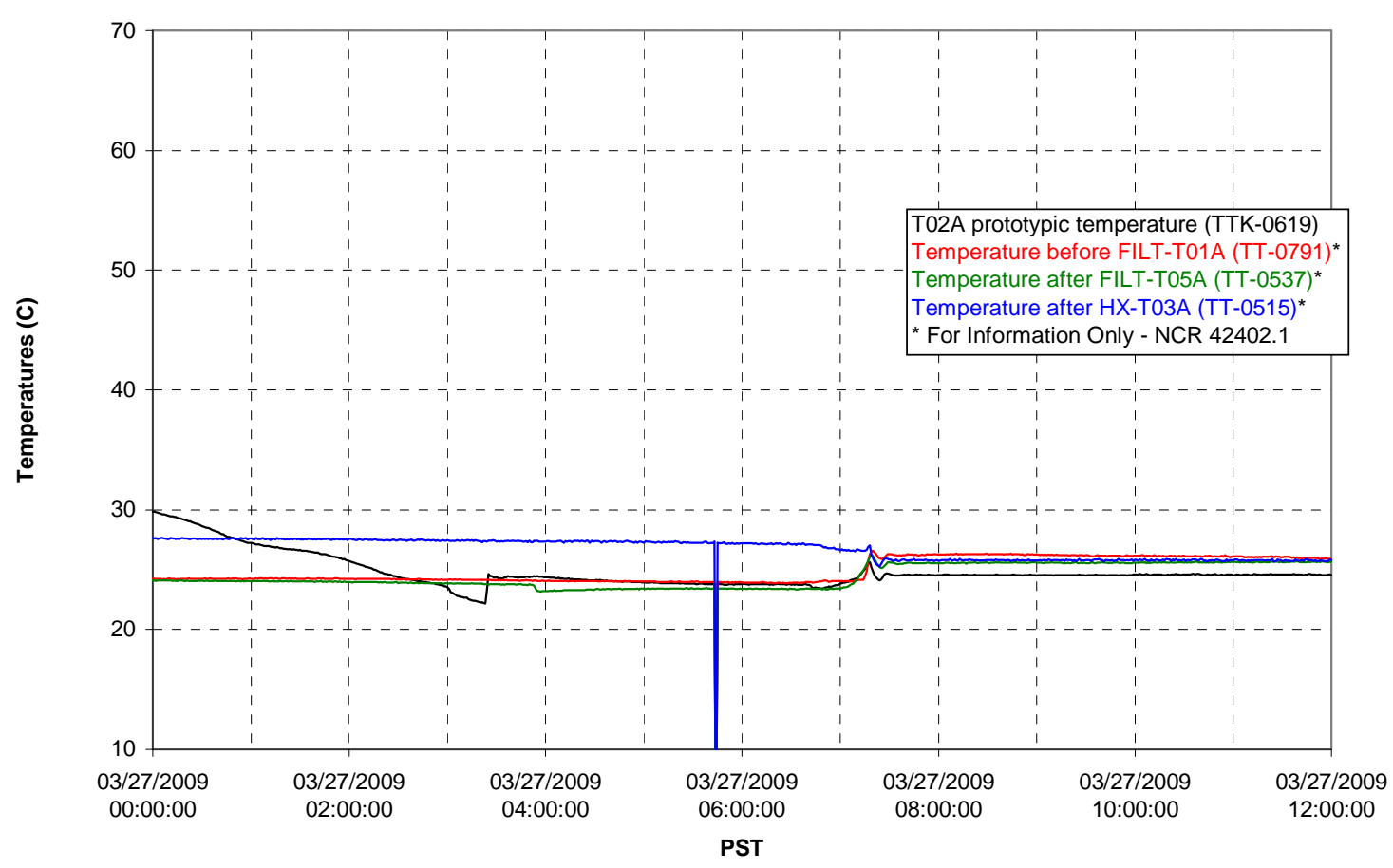

Pump Pressures and Flow

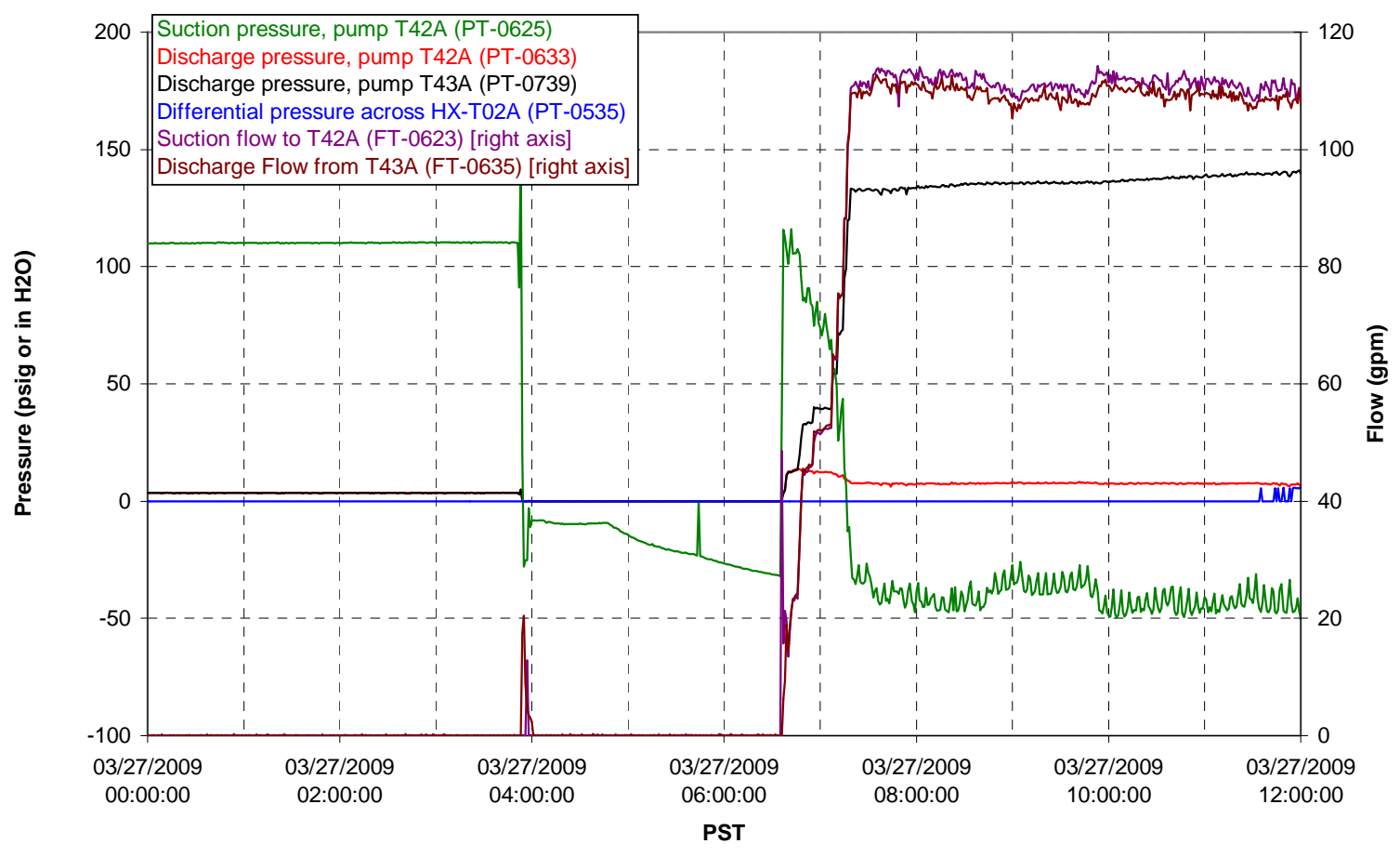




\section{Axial pressure drop}

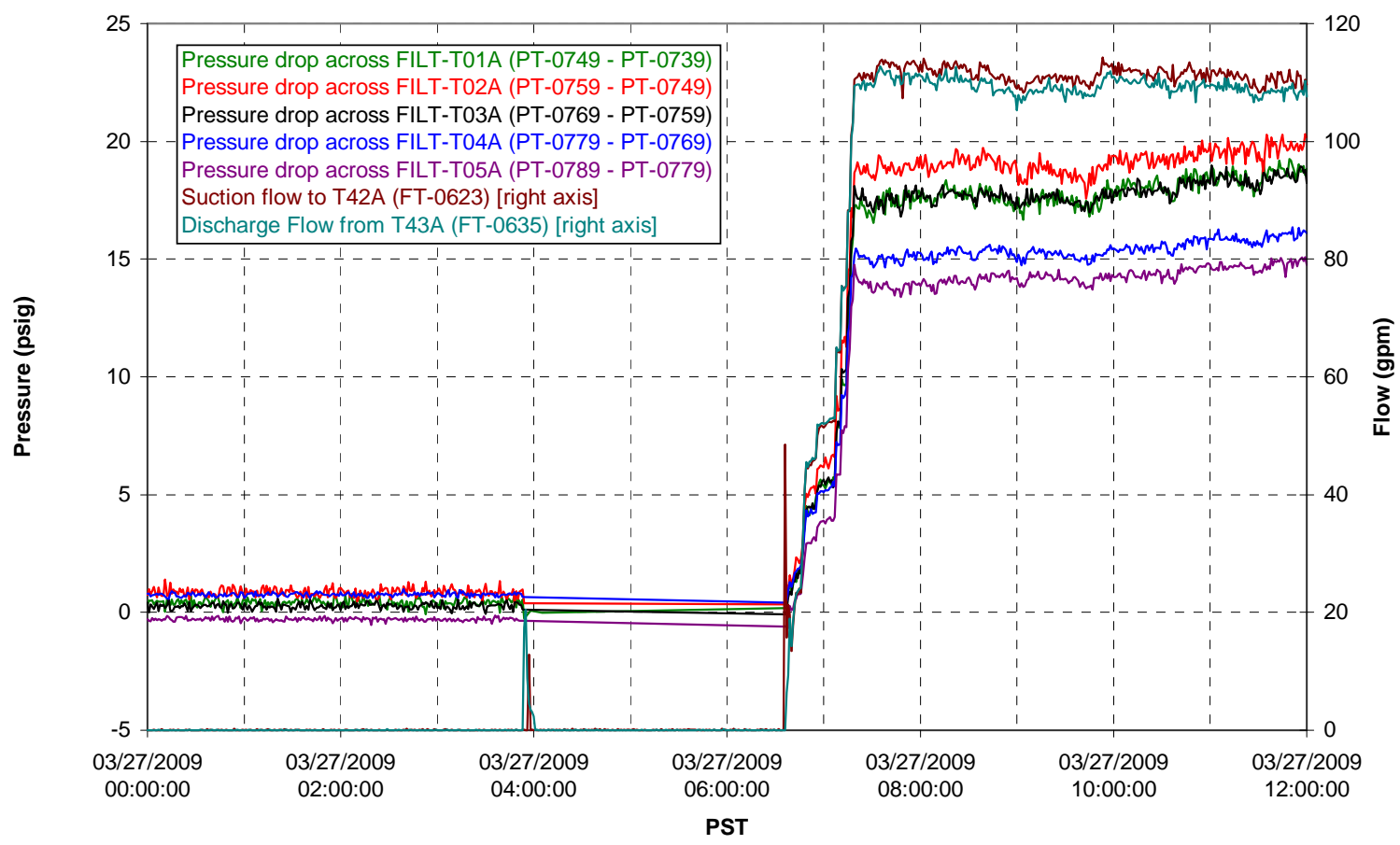

Permeate flow rates

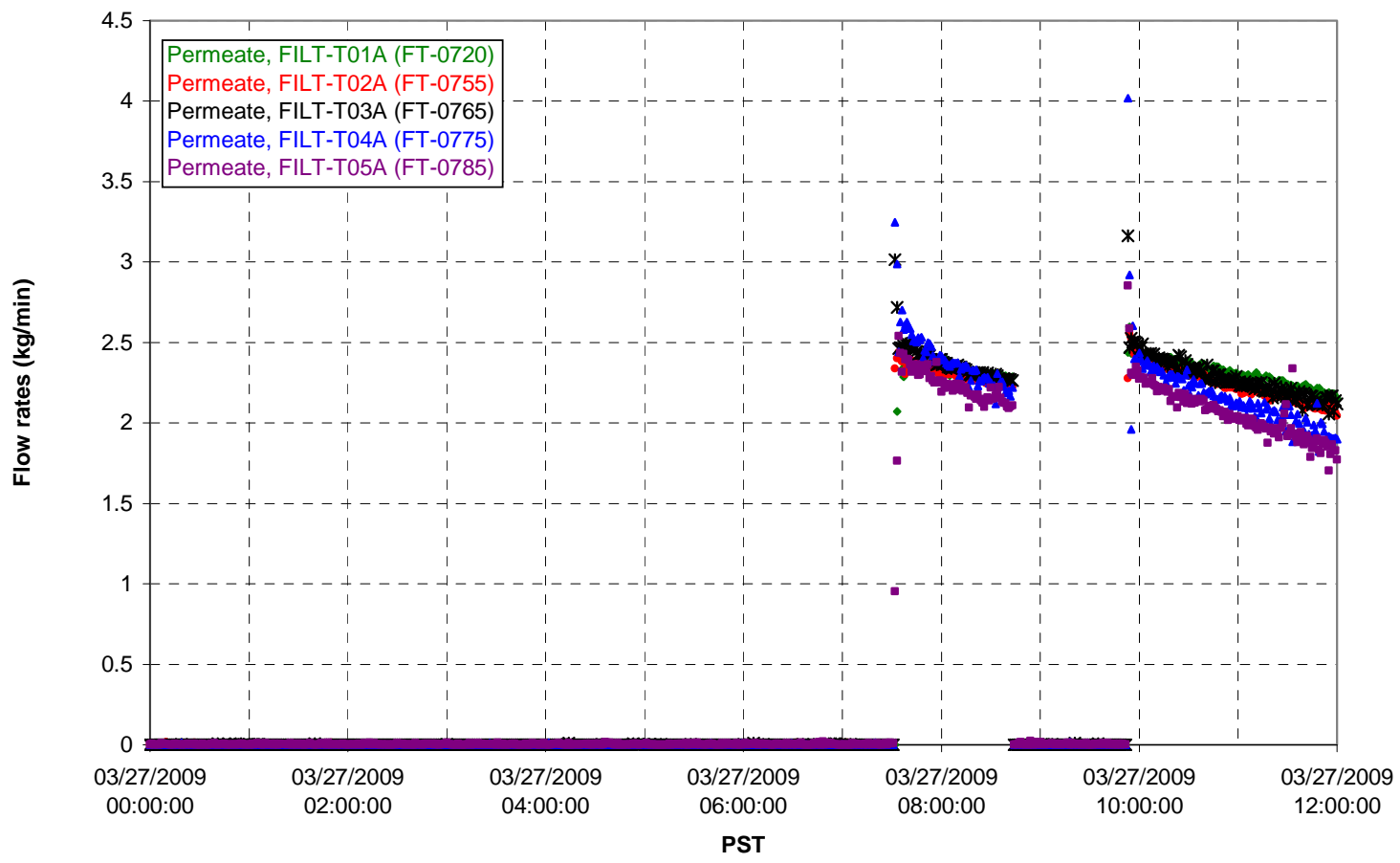


T02A Inner Temperature Tree

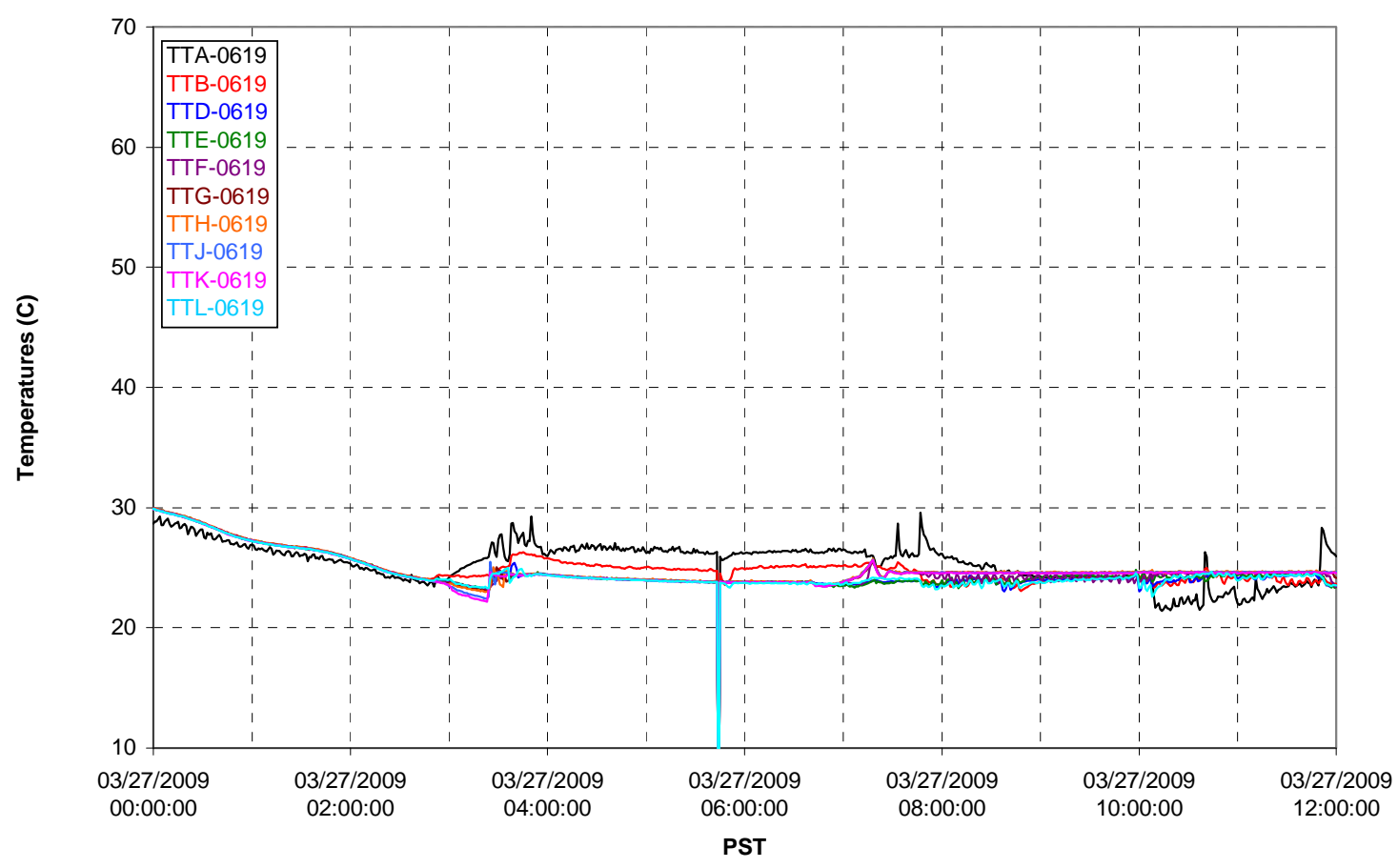

T02A Outer Temperature Tree

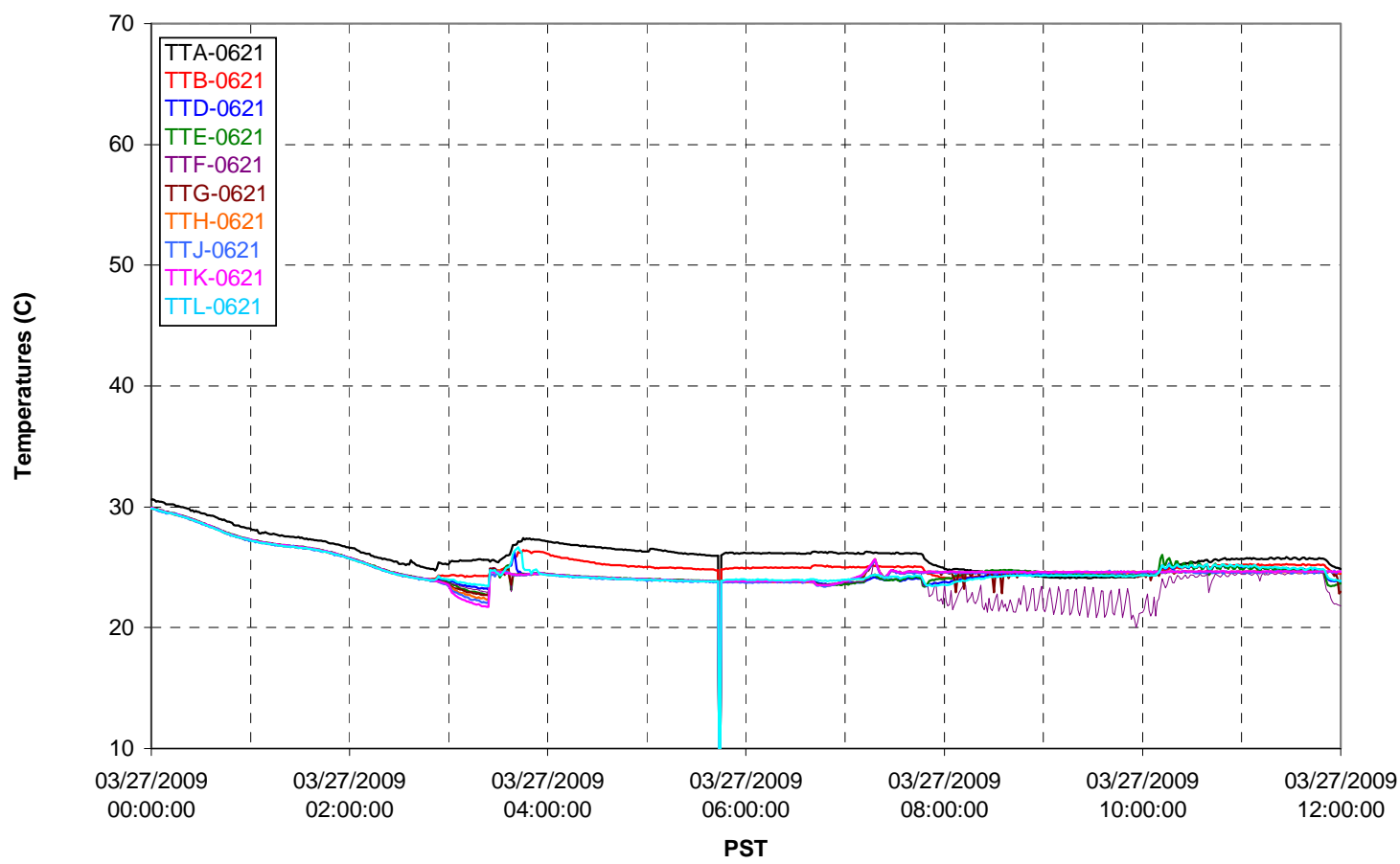


T02A temperatures

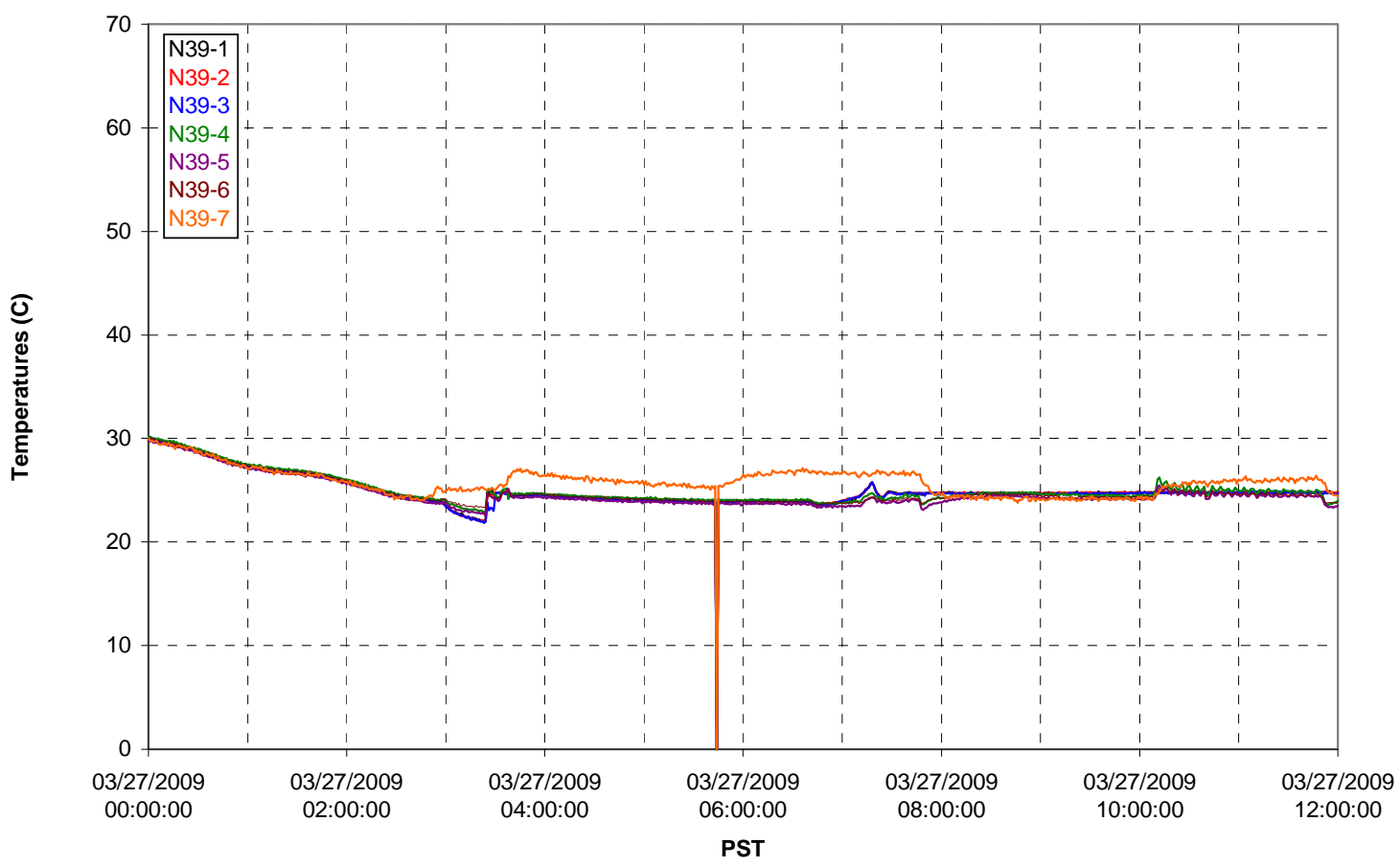

T02A temperatures

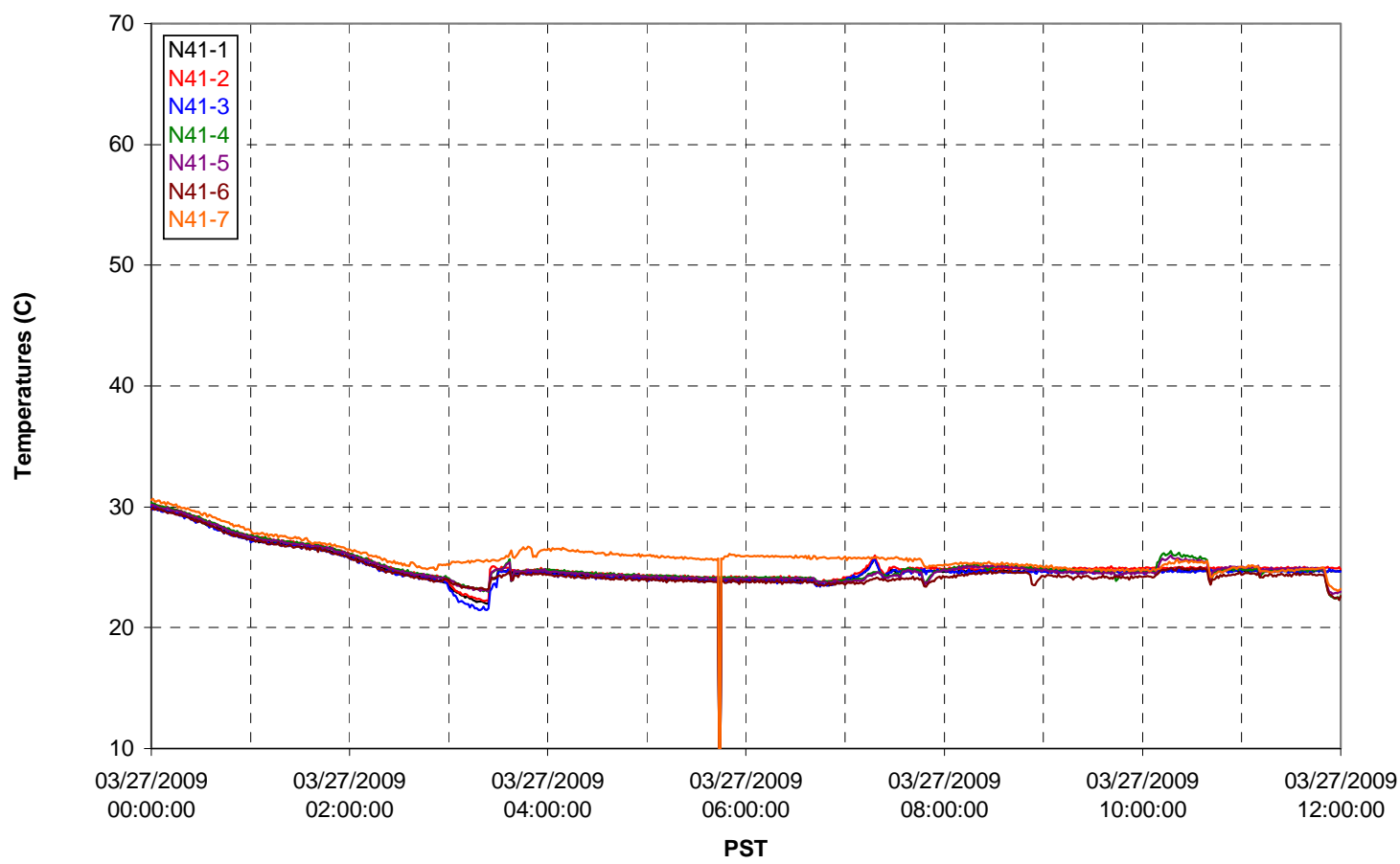


T02A temperatures

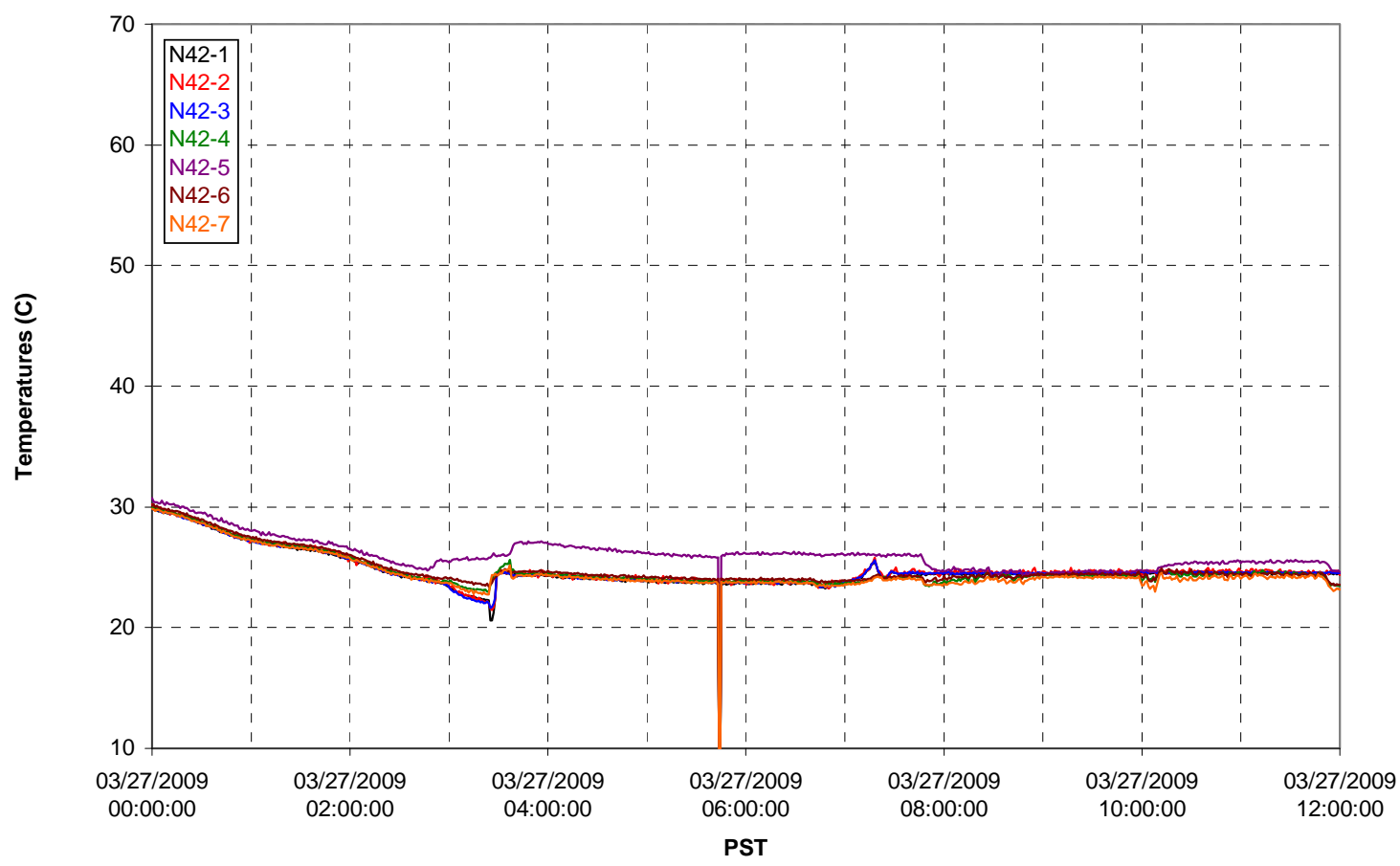

T02A temperatures

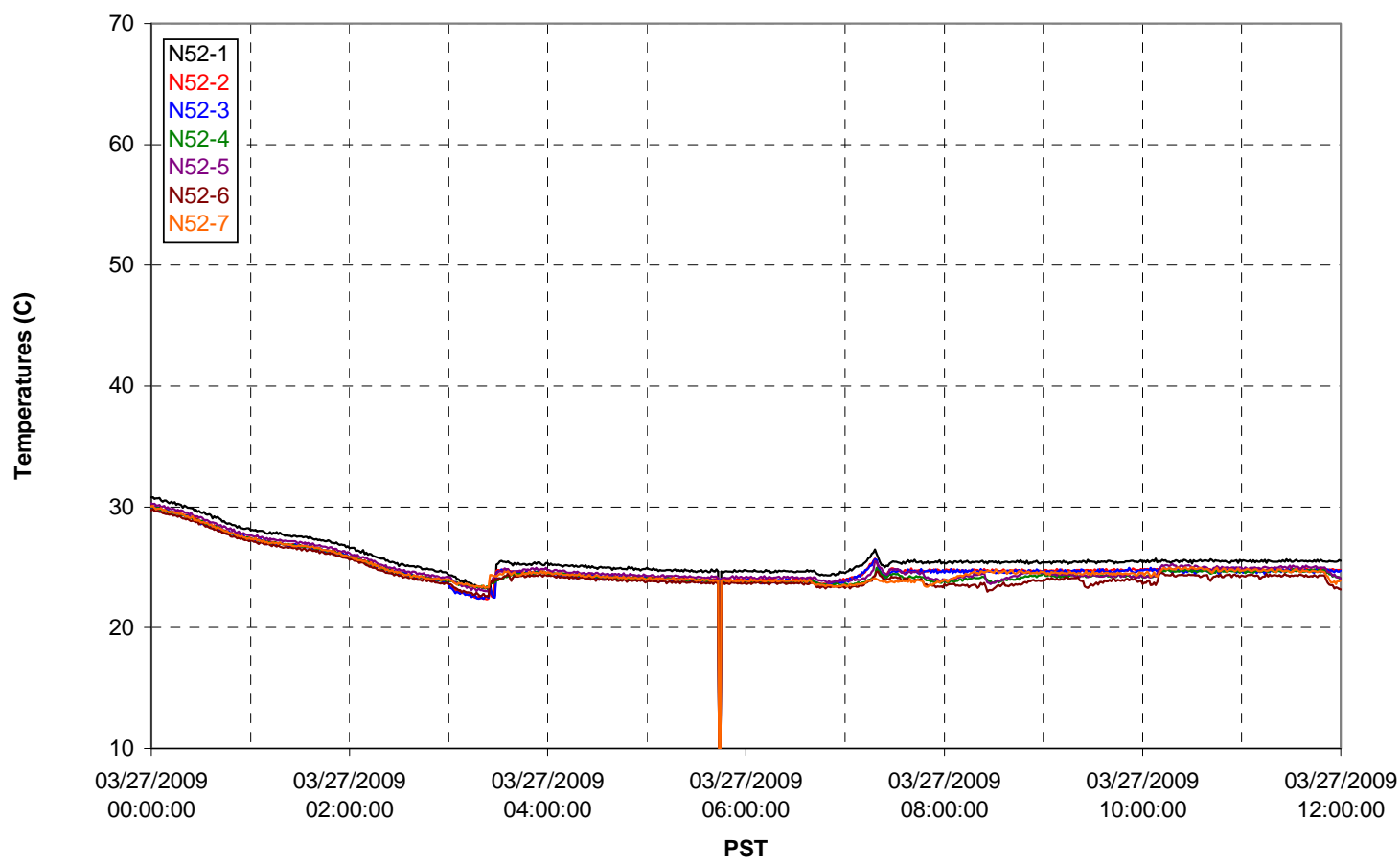


T02A Heating and Cooling

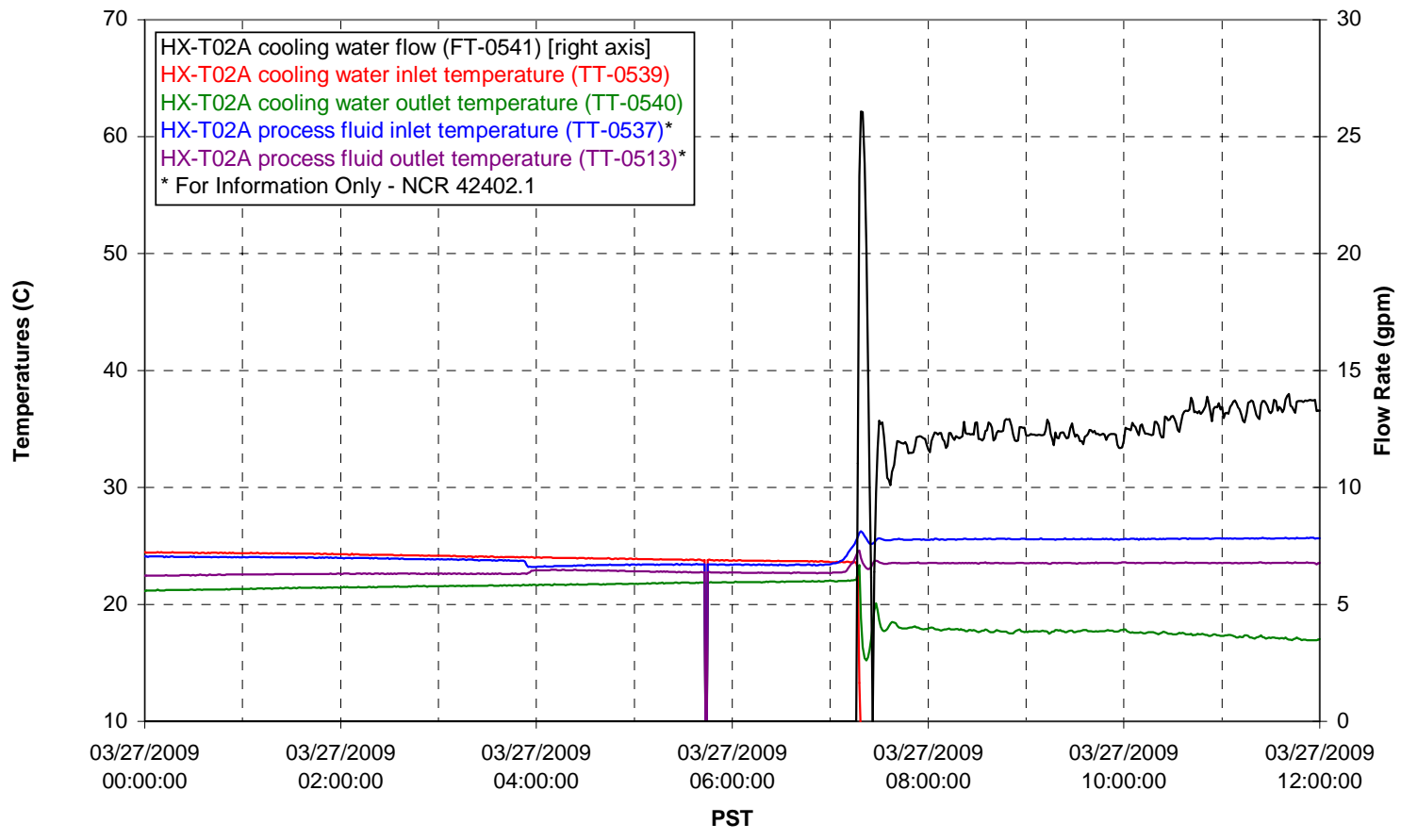

Pump Operation

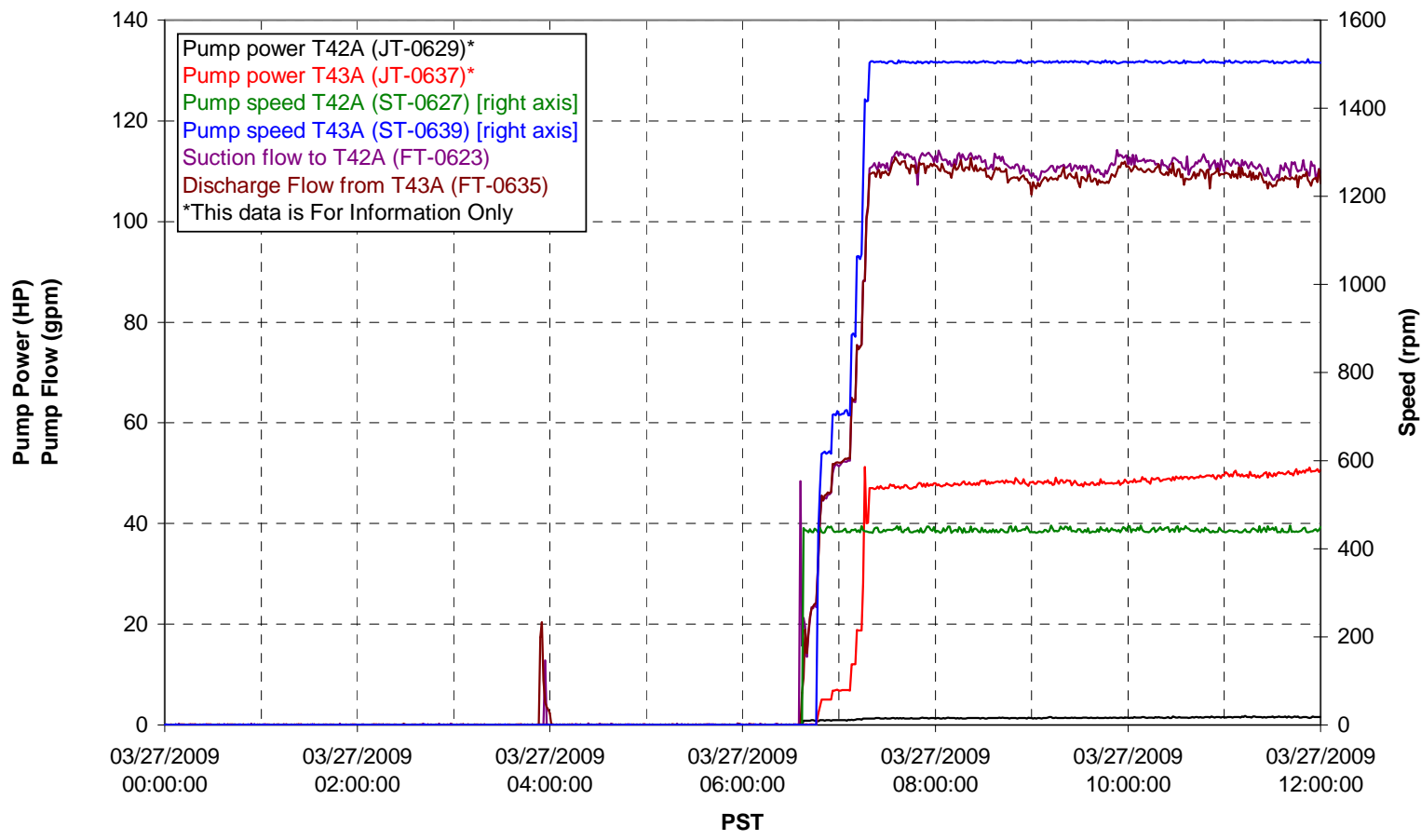


Pulsepot UFP-PP-T01A

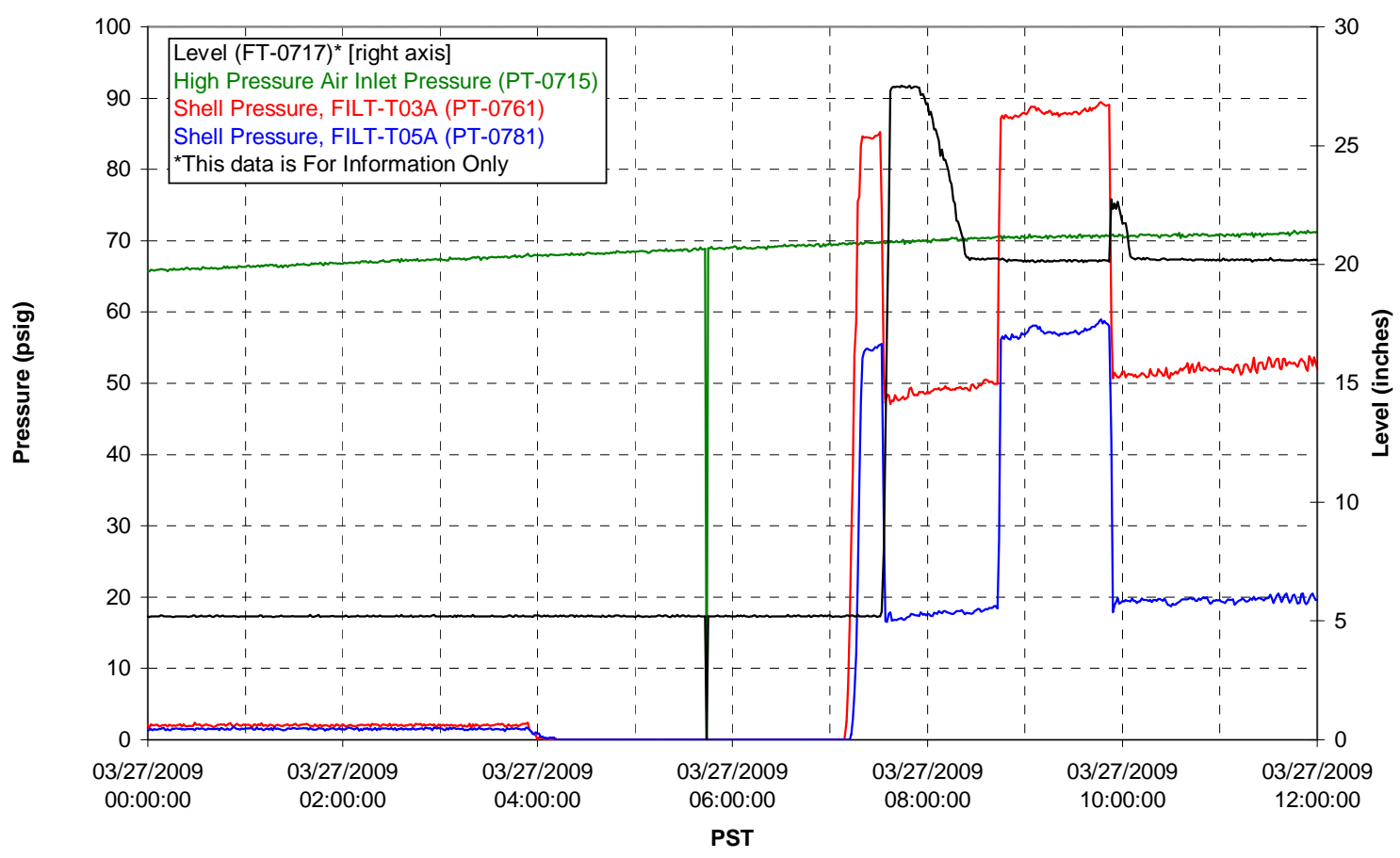

Pulsepot UFP-PP-T02A

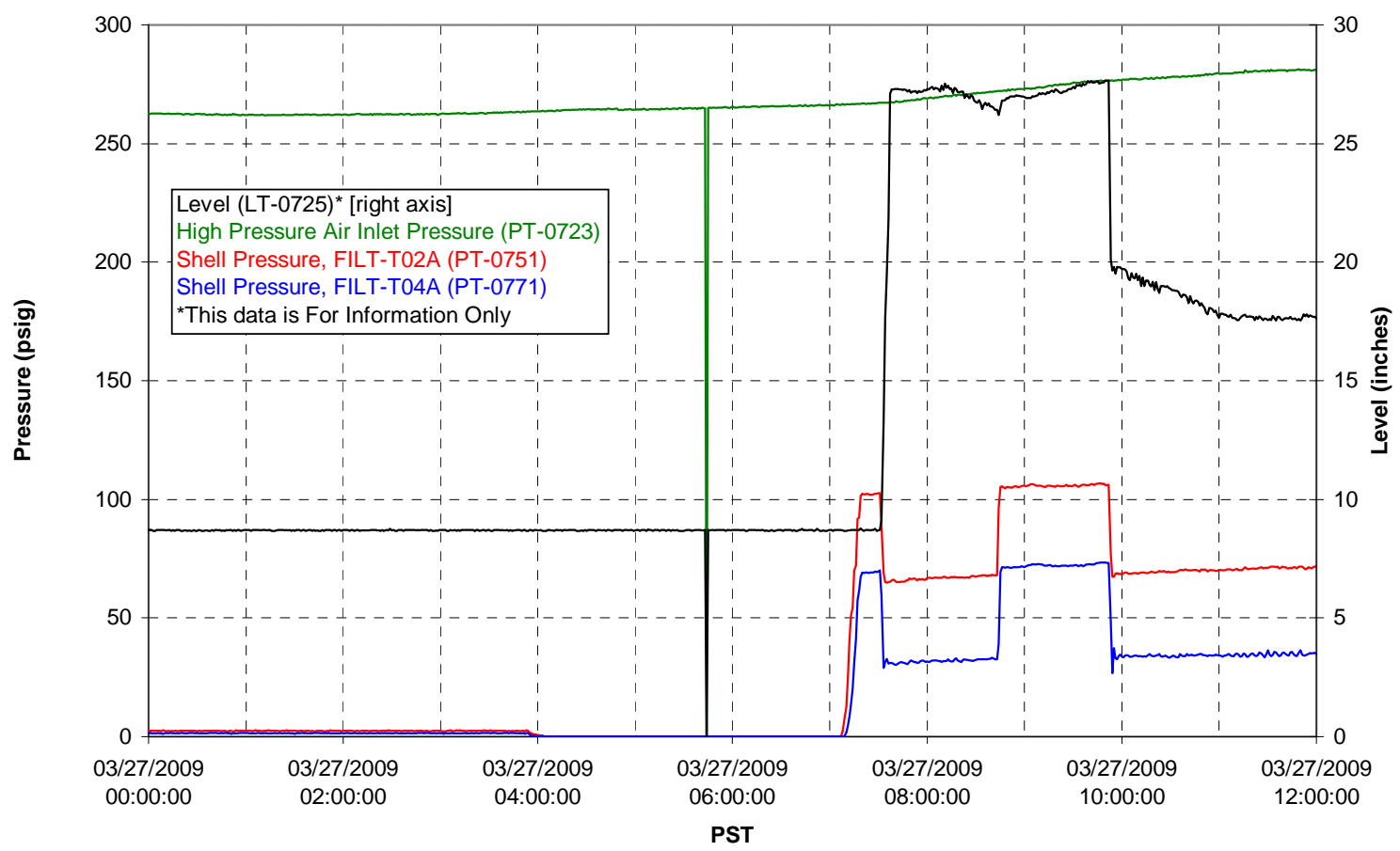


Pulsepot UFP-PP-T03A

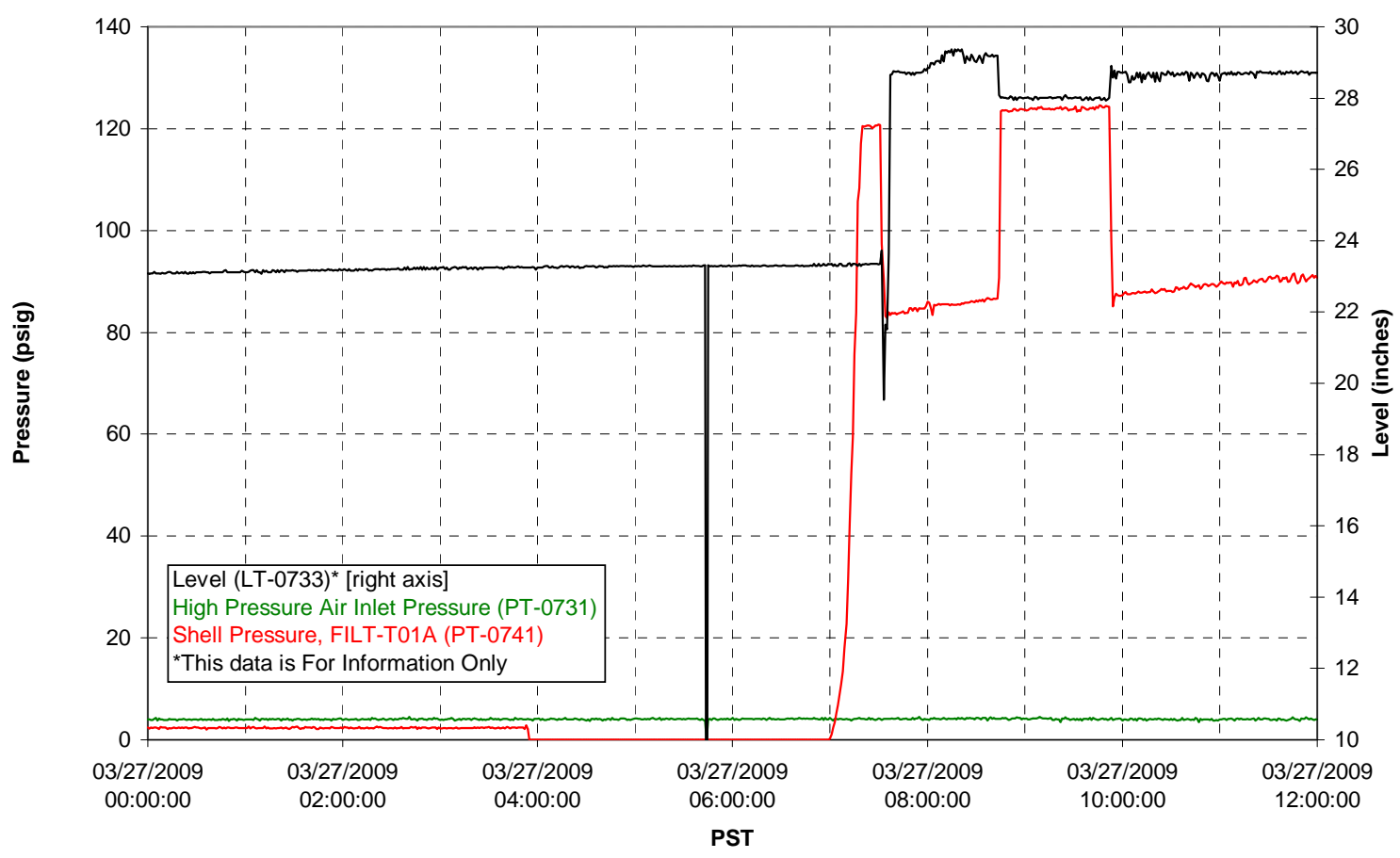

Pulsepot Levels

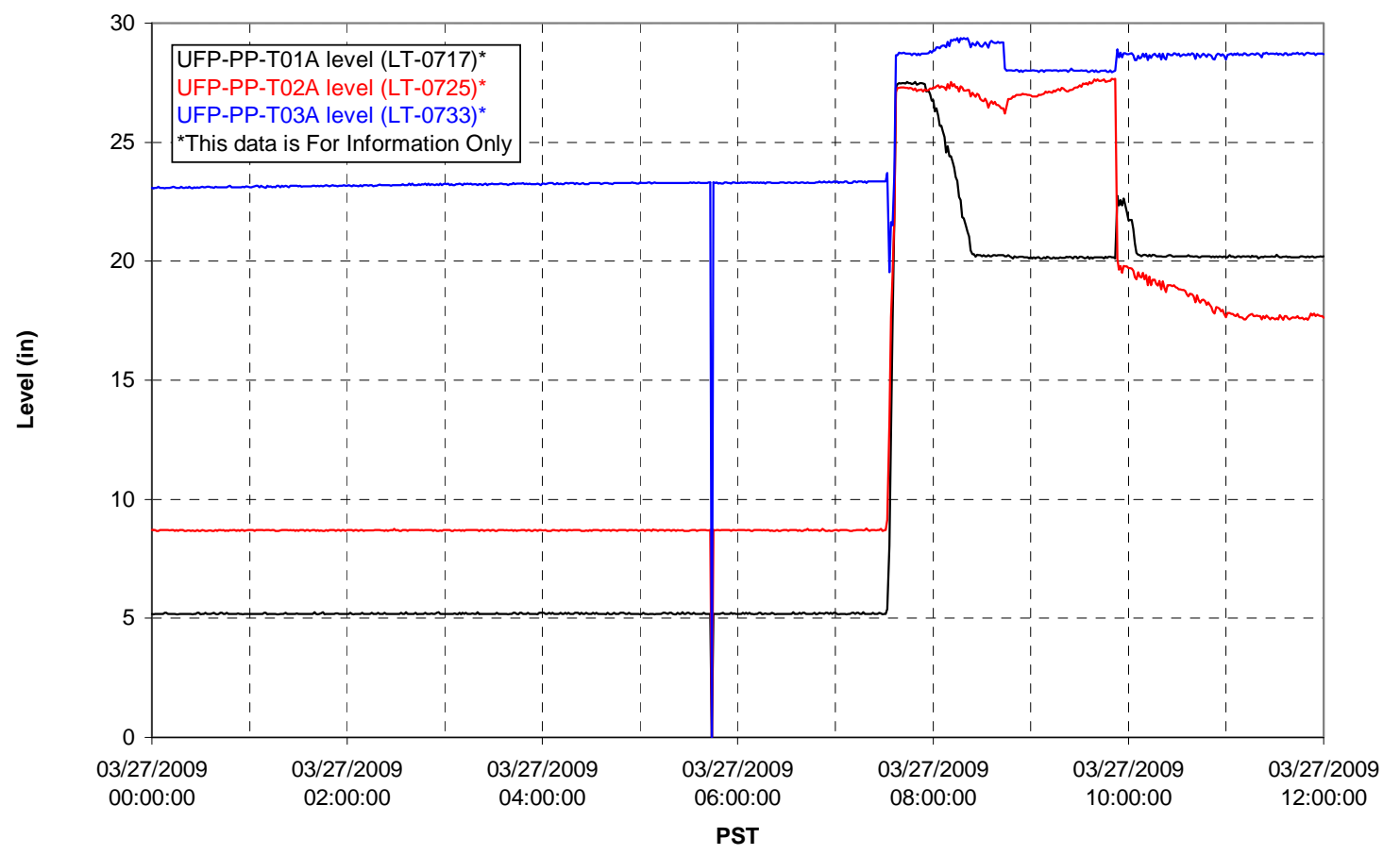


Filter UFP-FILT-T01A

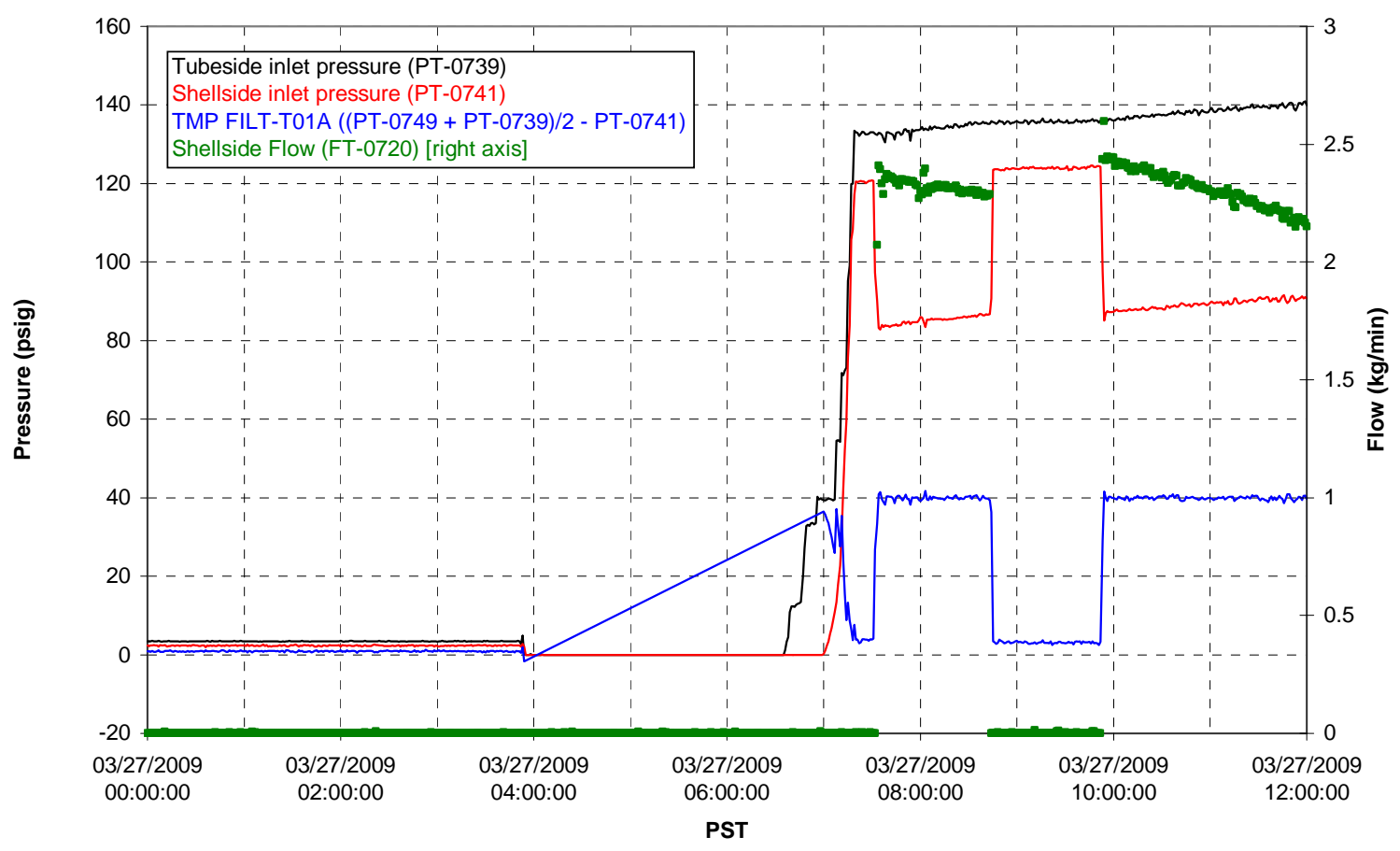

Filter UFP-FILT-T02A

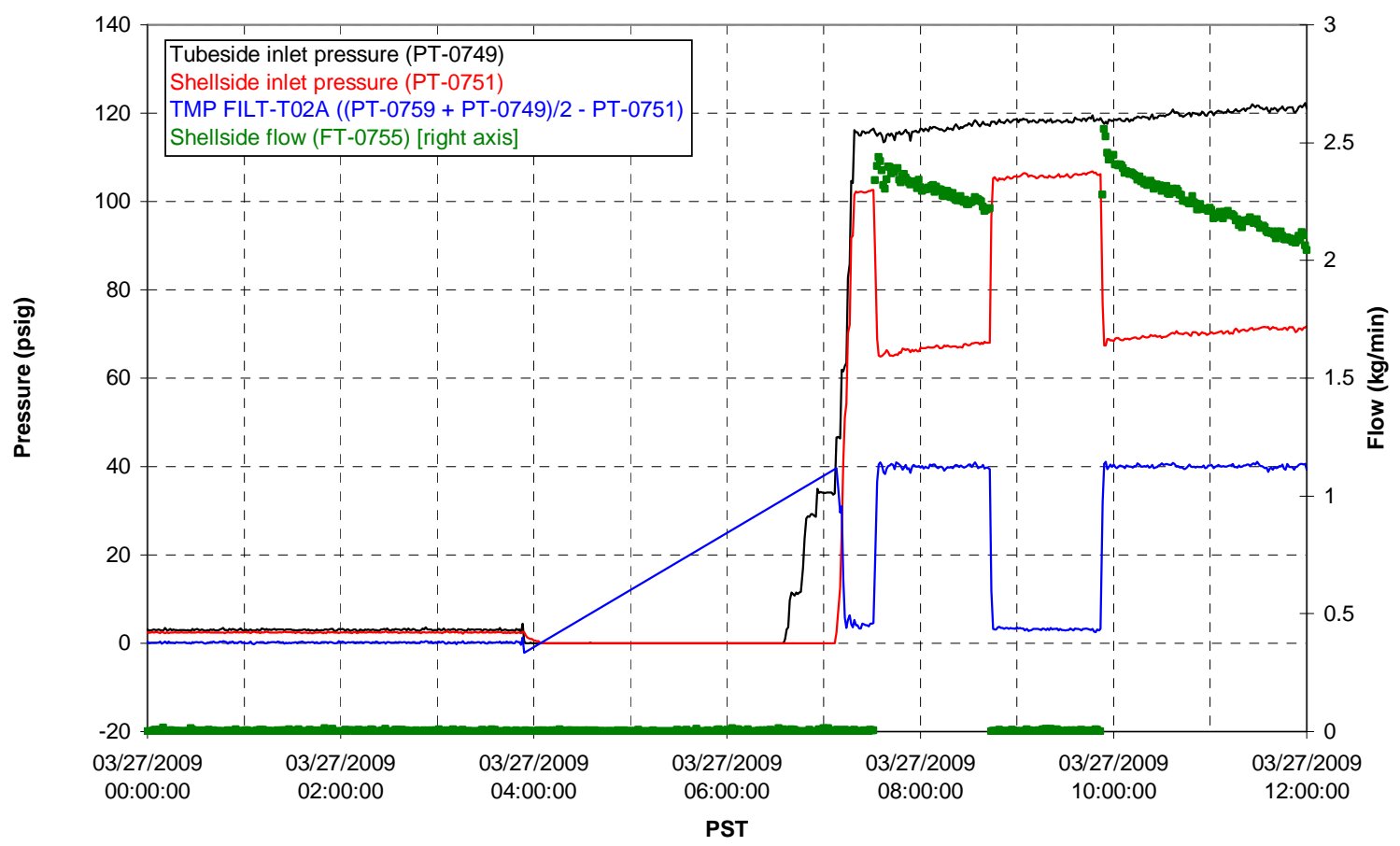


Filter UFP-FILT-T03A

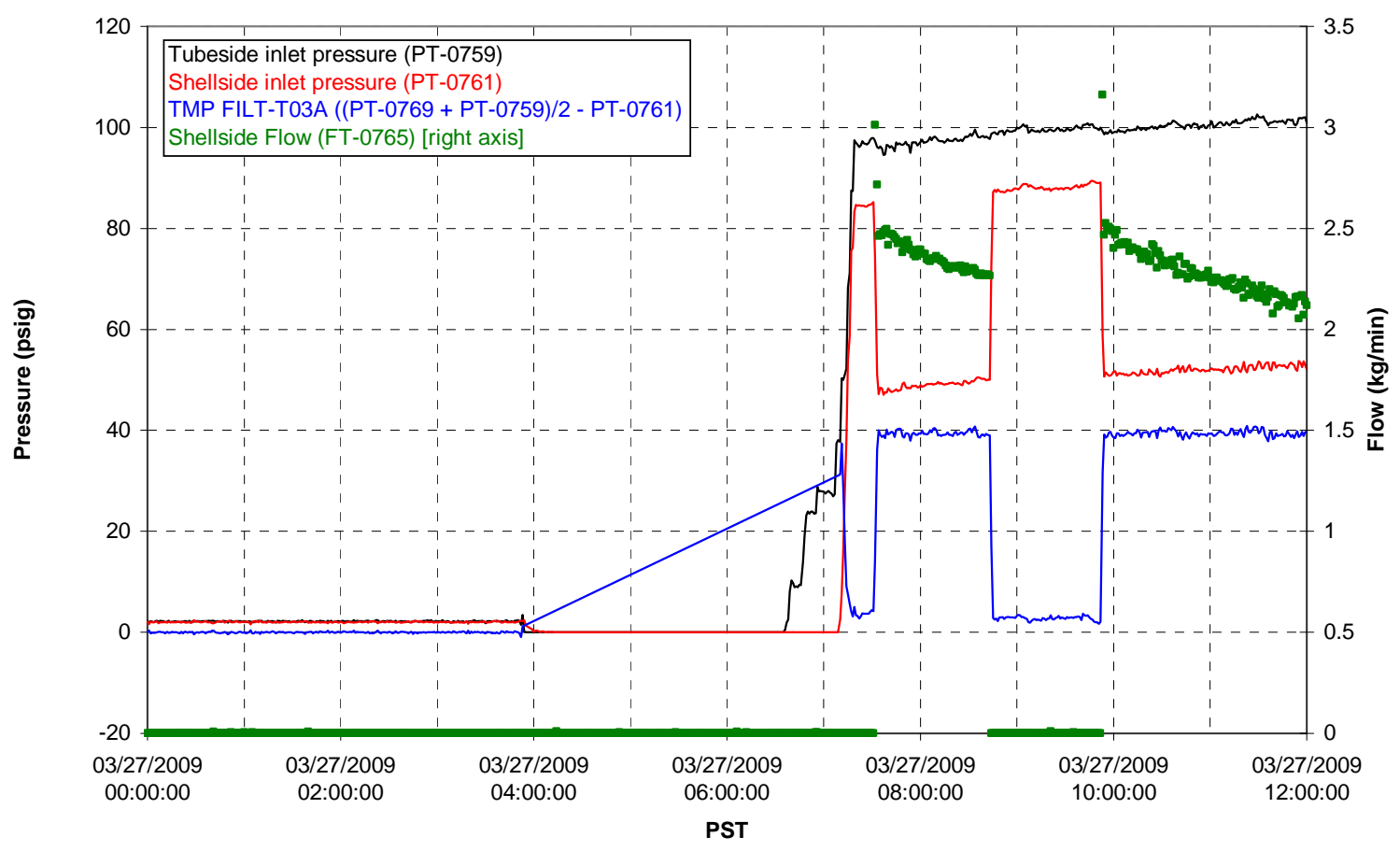

Filter UFP-FILT-T04A

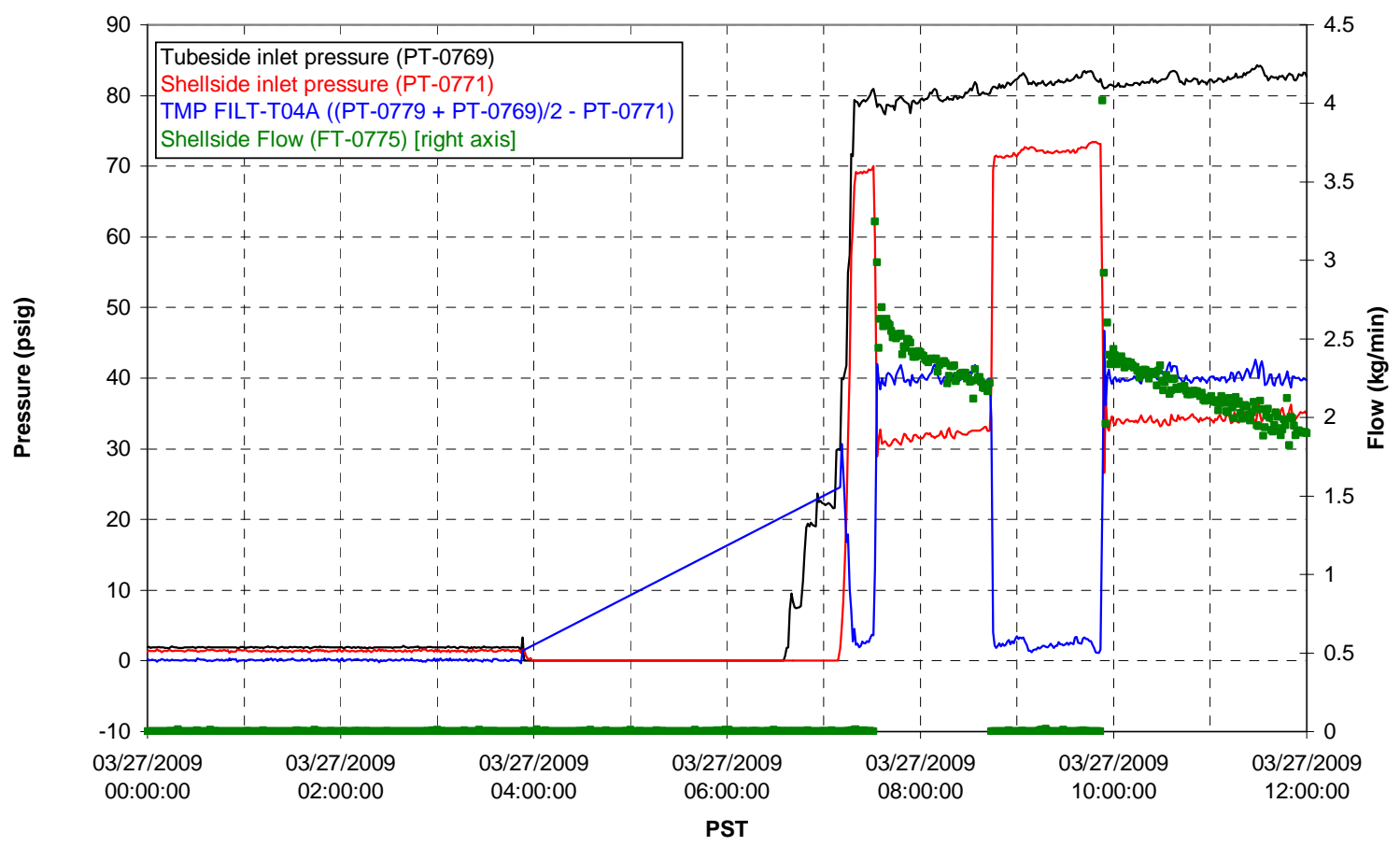


Filter UFP-FILT-T05A

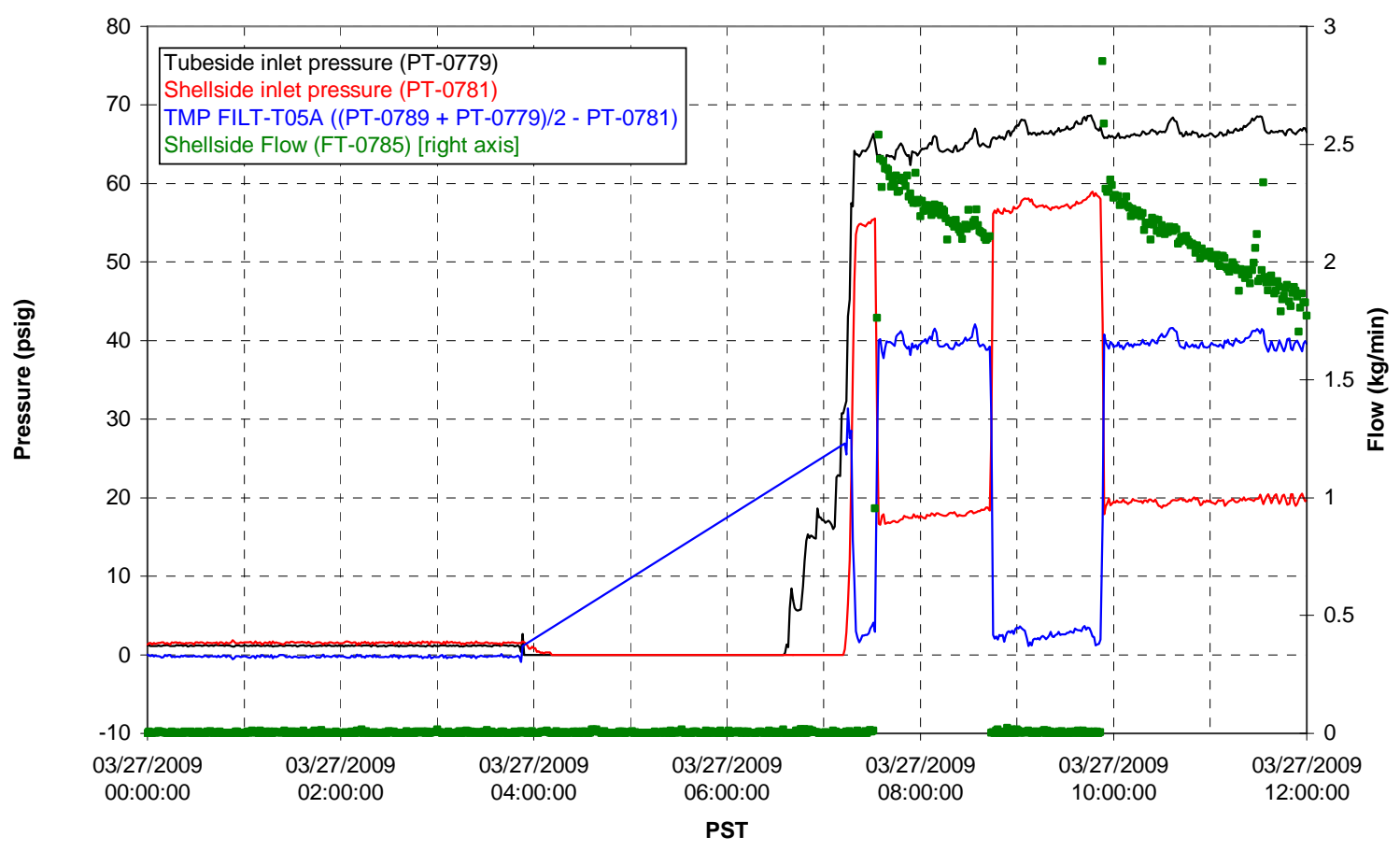

Chemical Flow

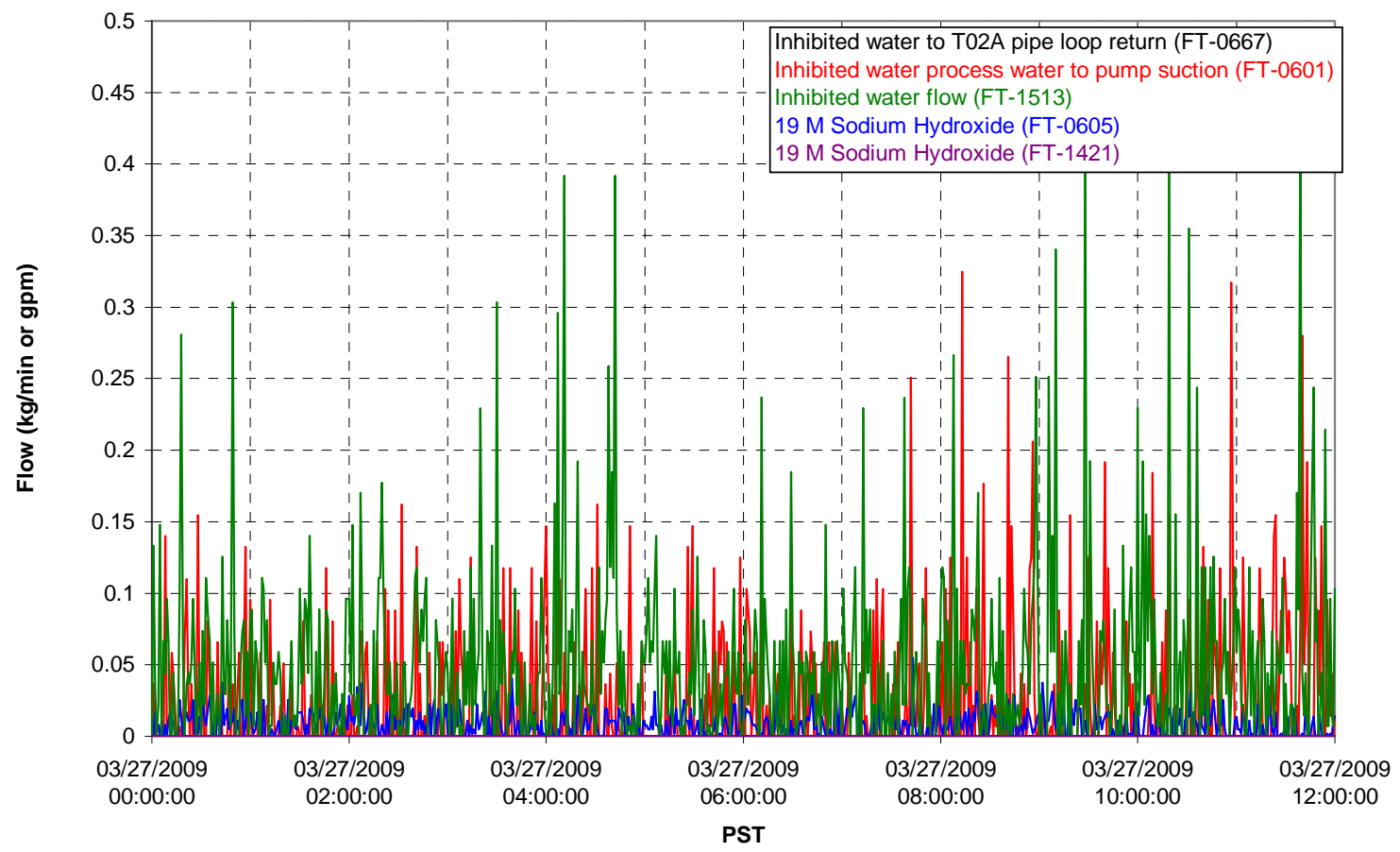




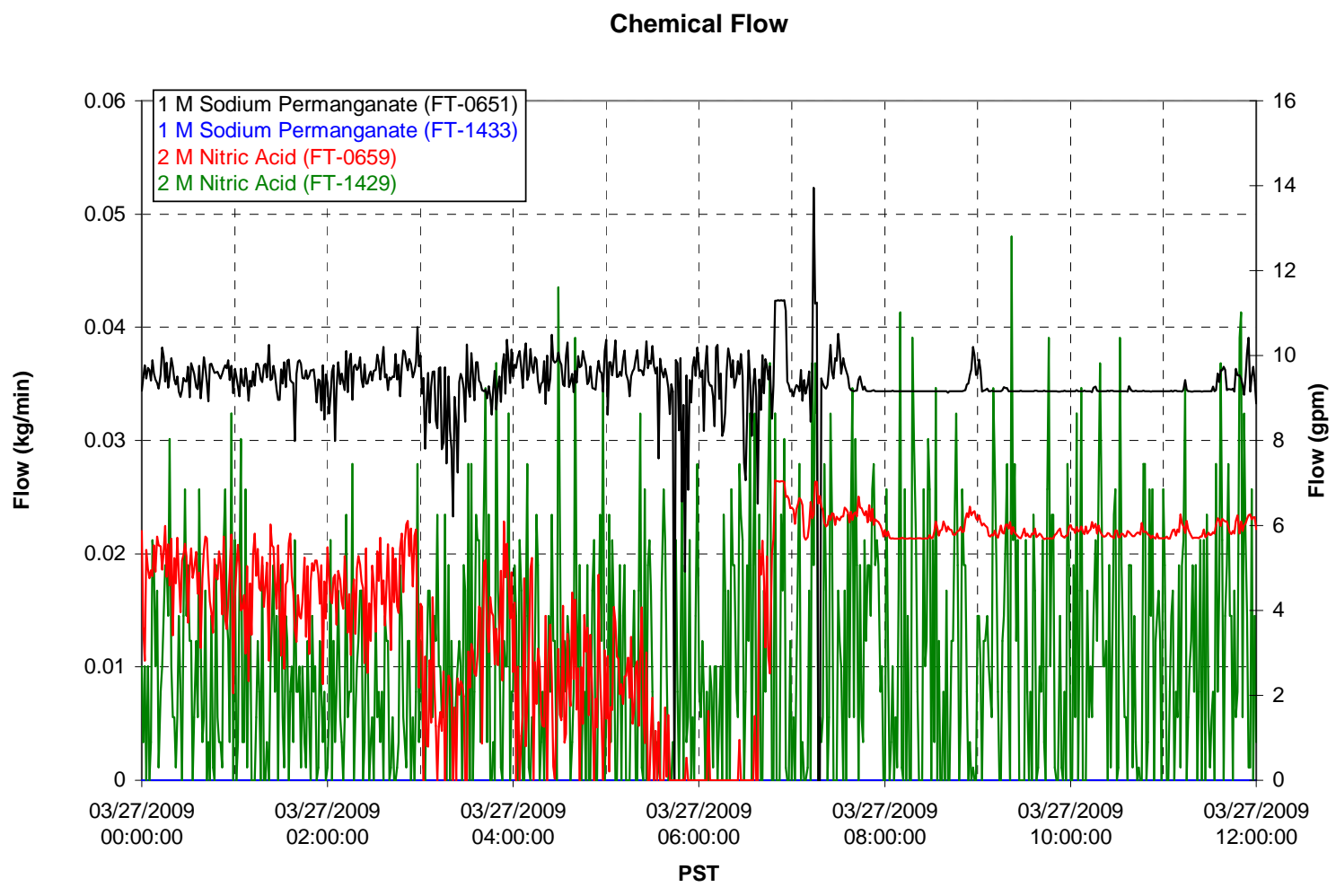

Air Flows

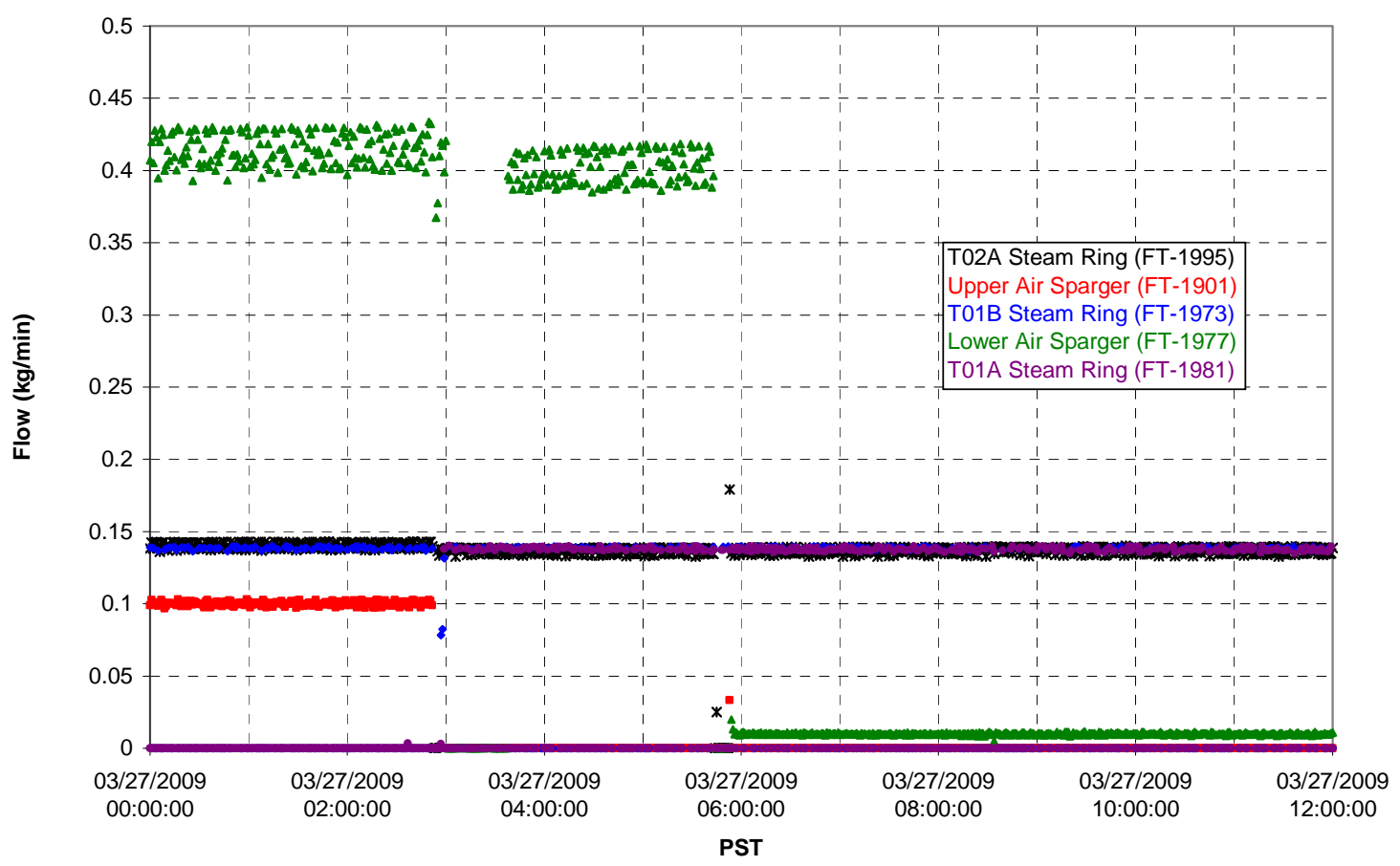


T02A Steam

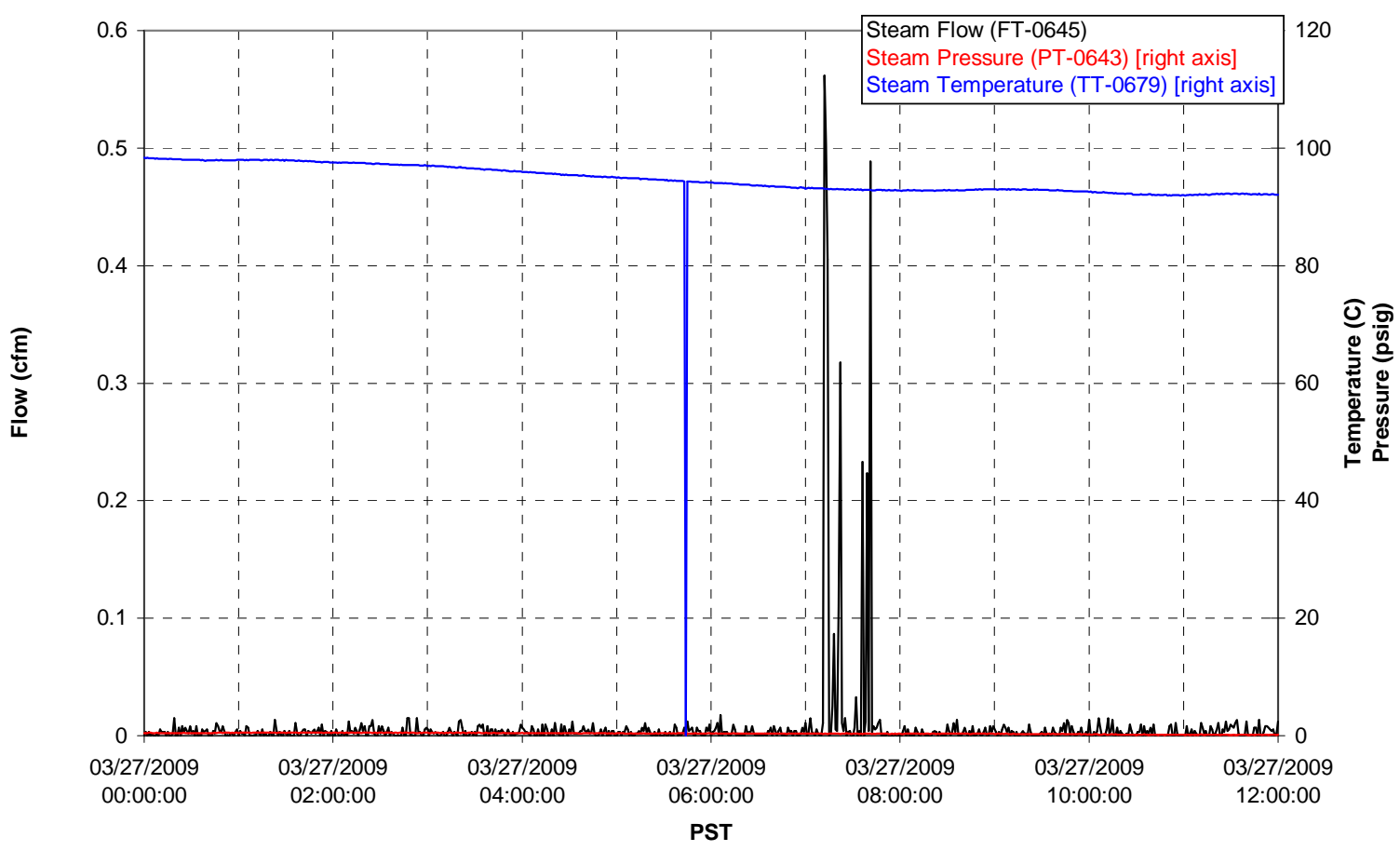

T01A Steam

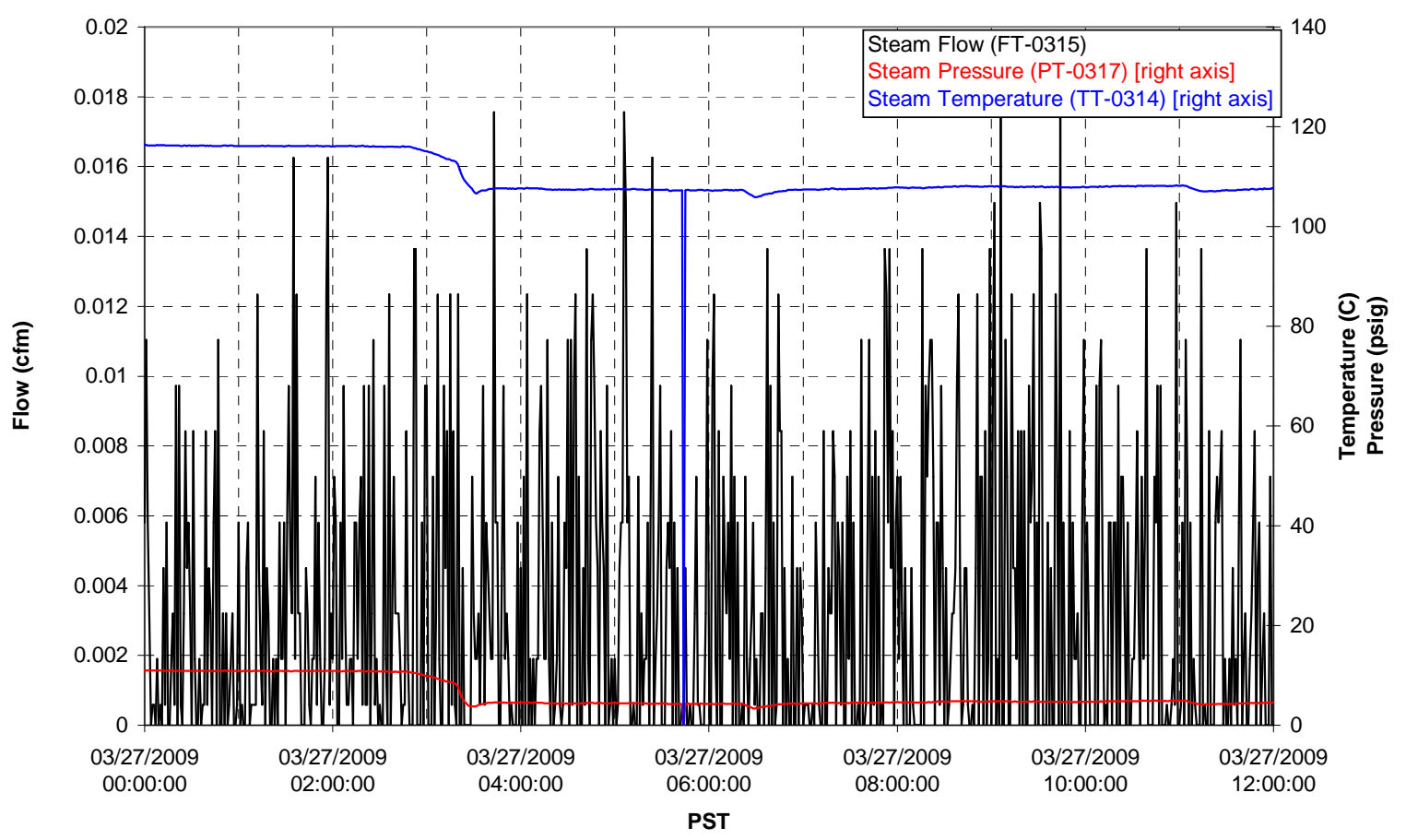




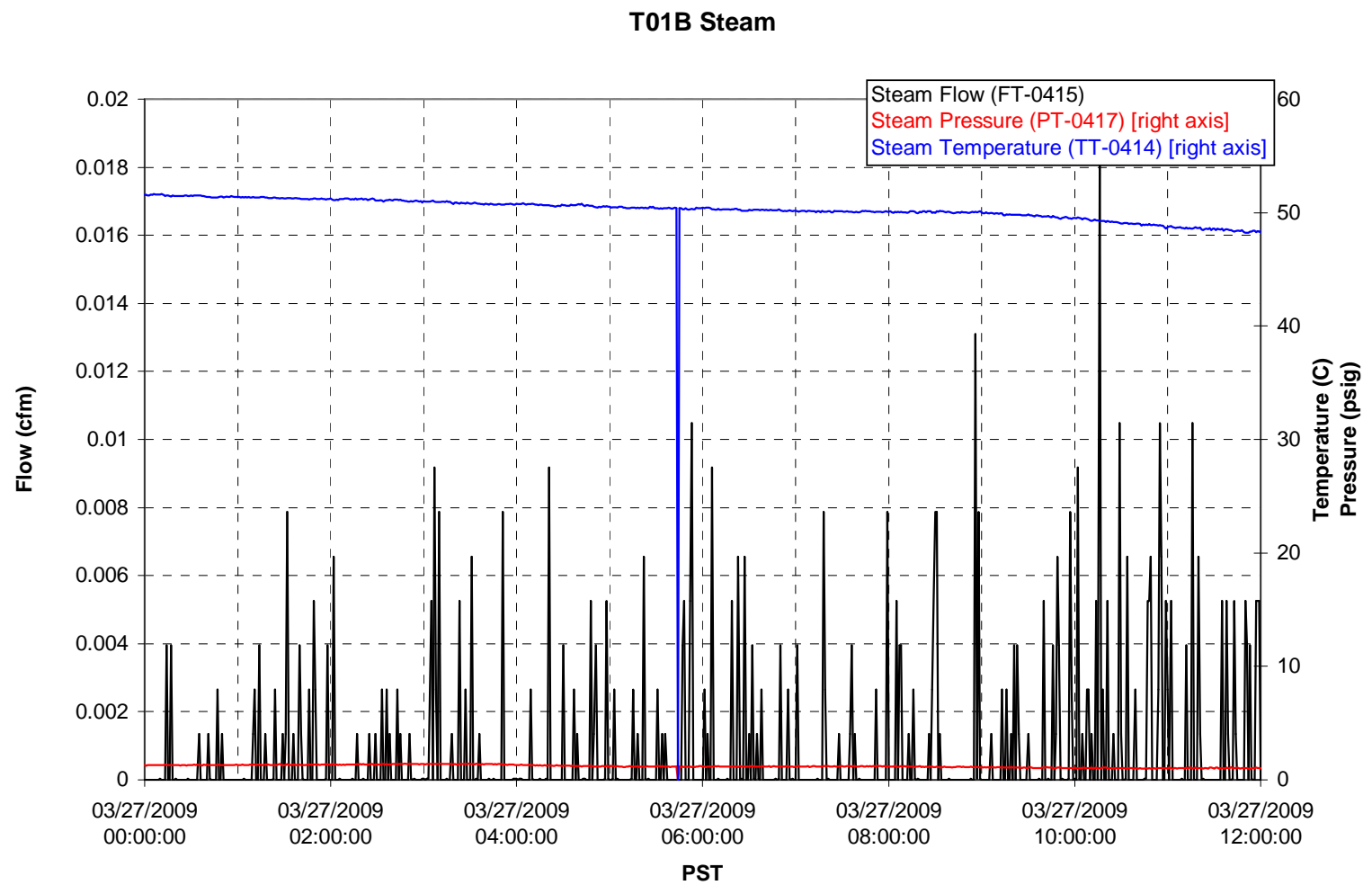




\section{Integrated Test D Data Plots 03/27/09 12:00 - 03/28/09 00:00}


T01A level

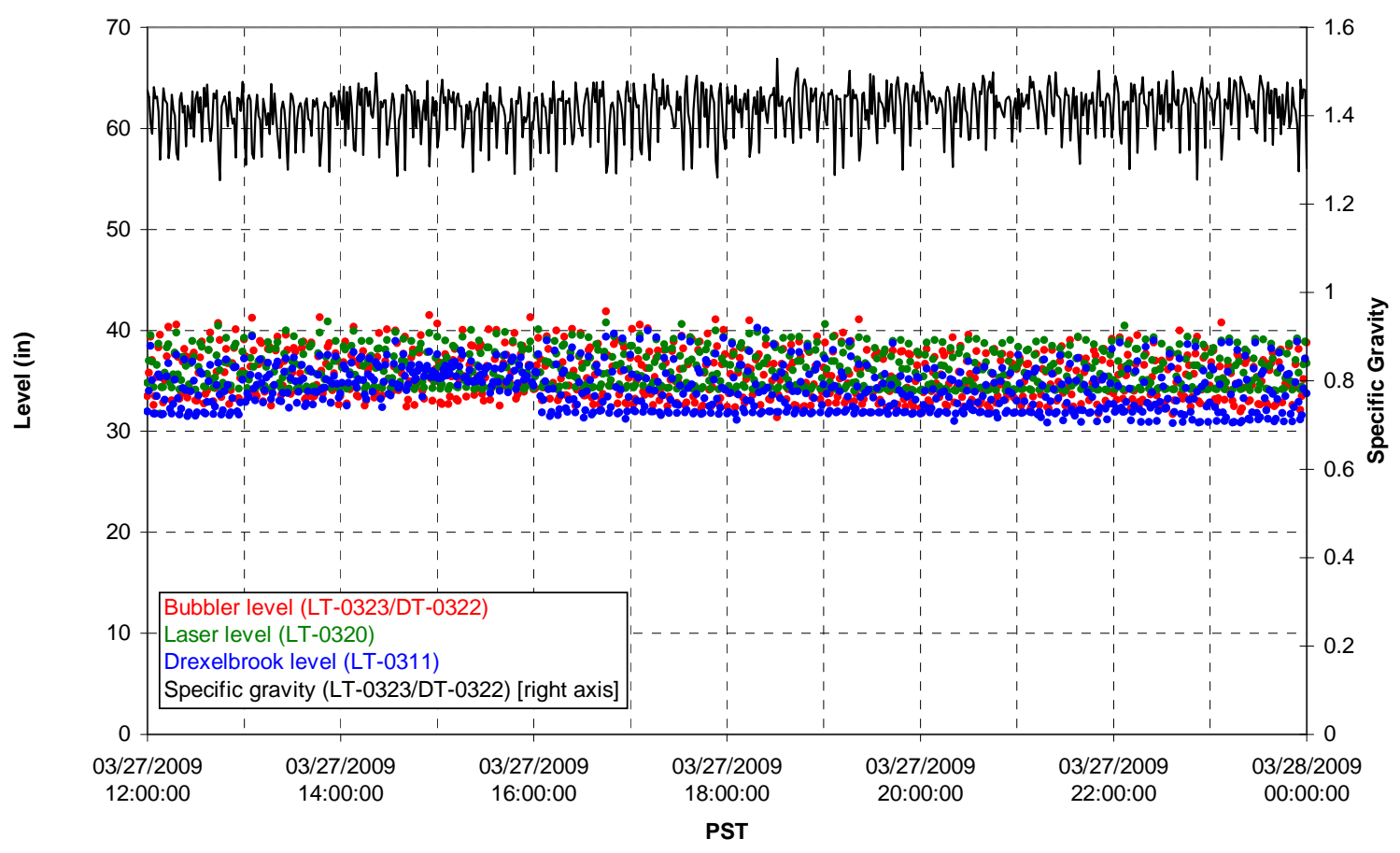

T01A temperatures

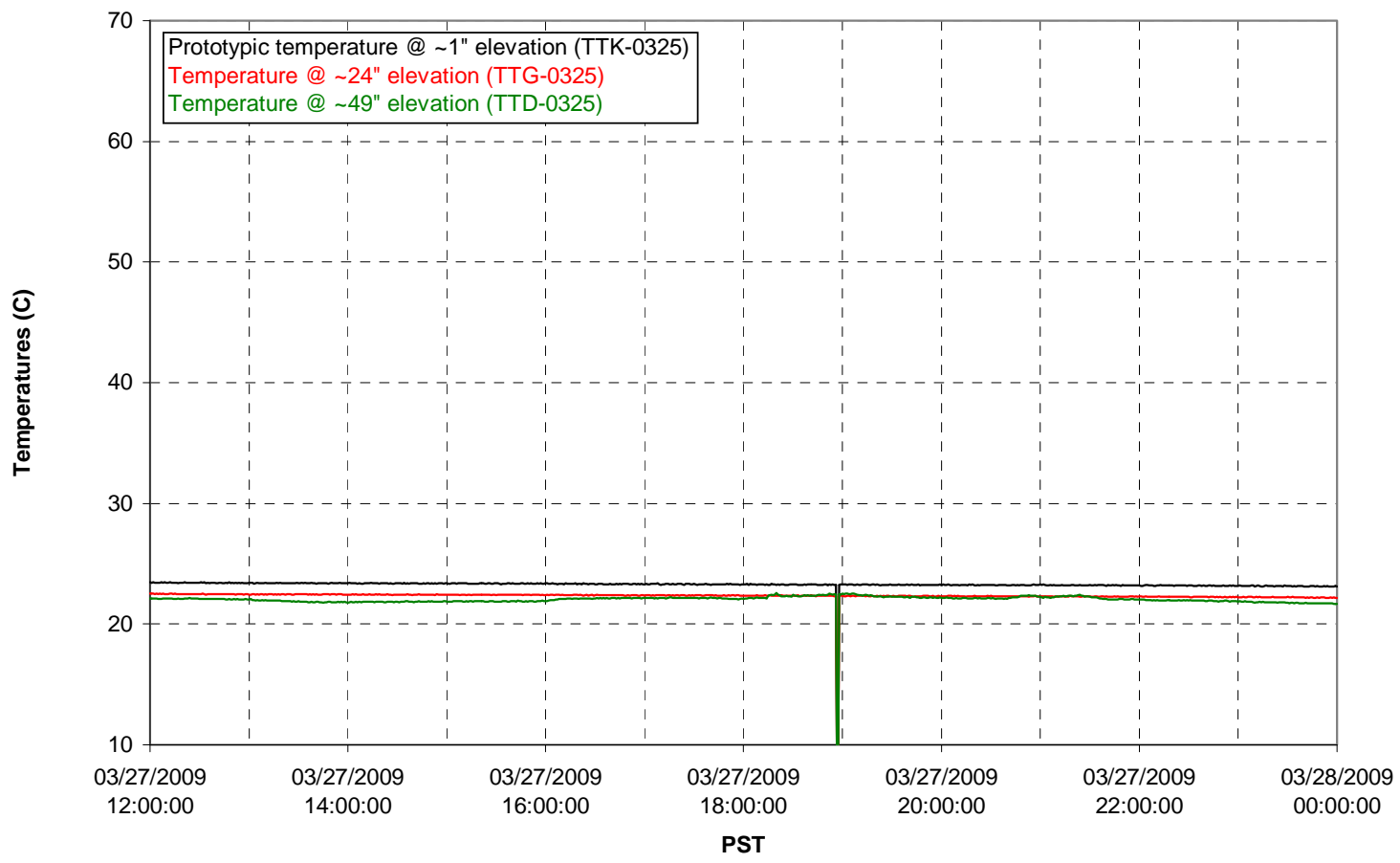


T01B level

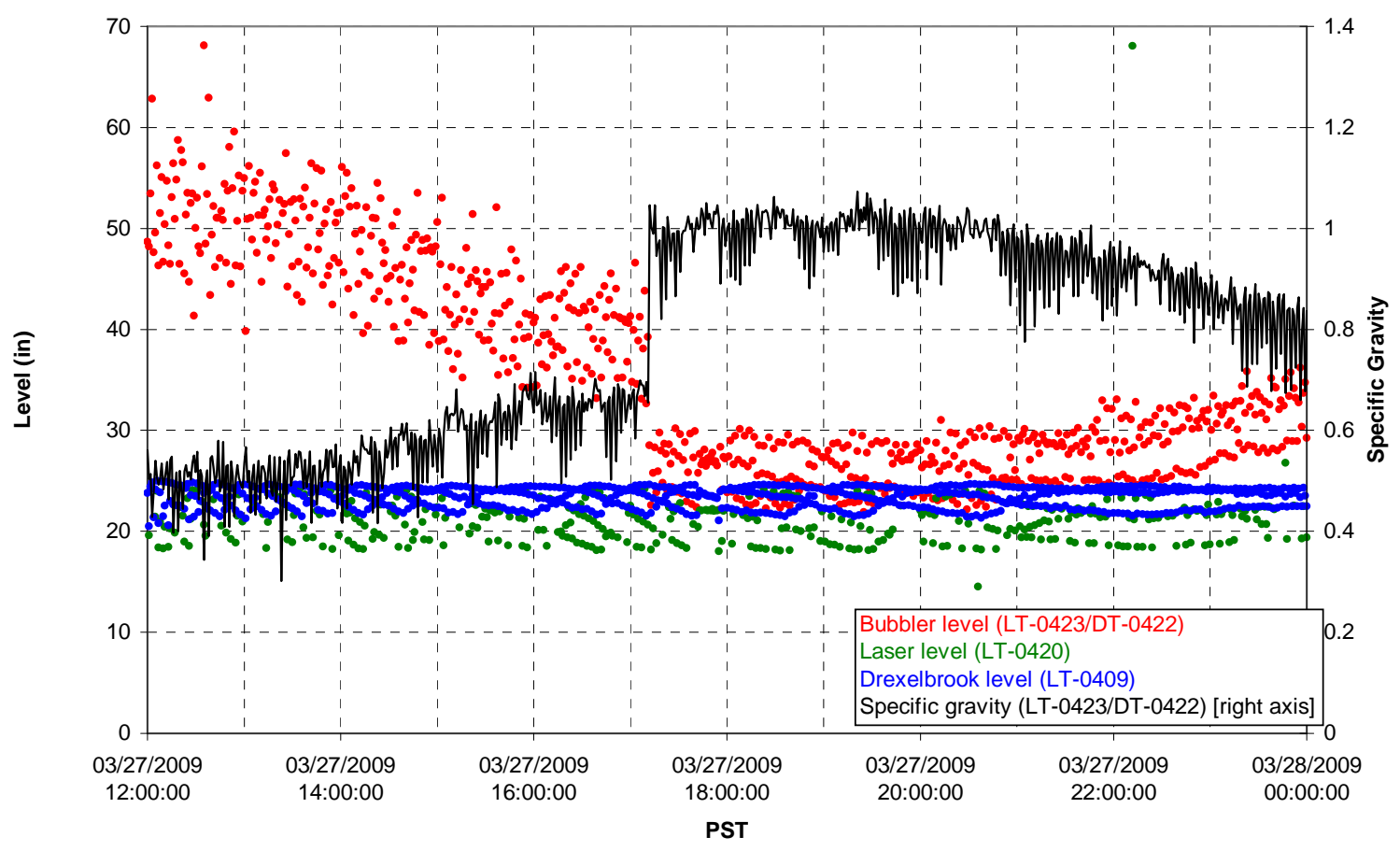

T01B temperatures

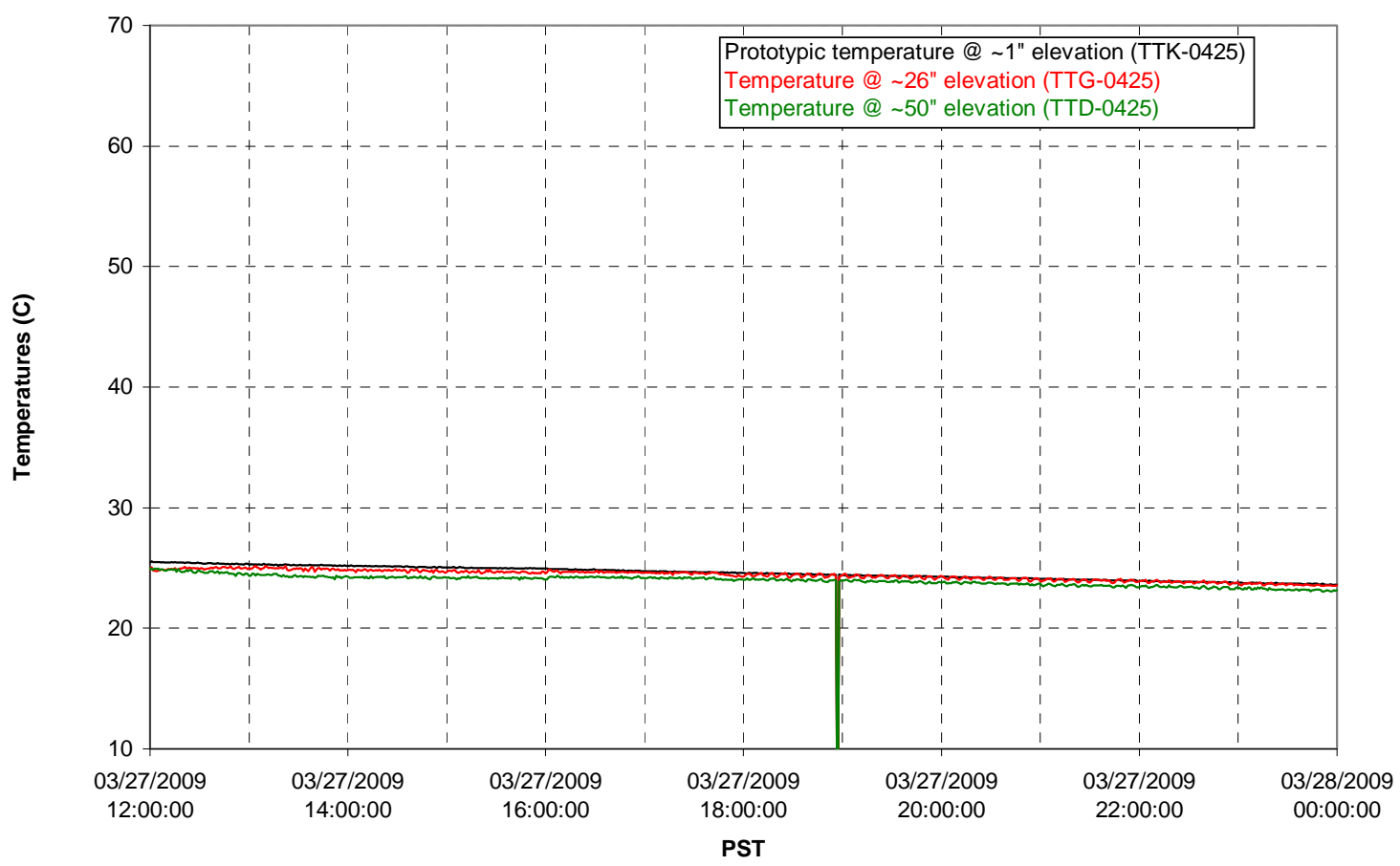


T02A level

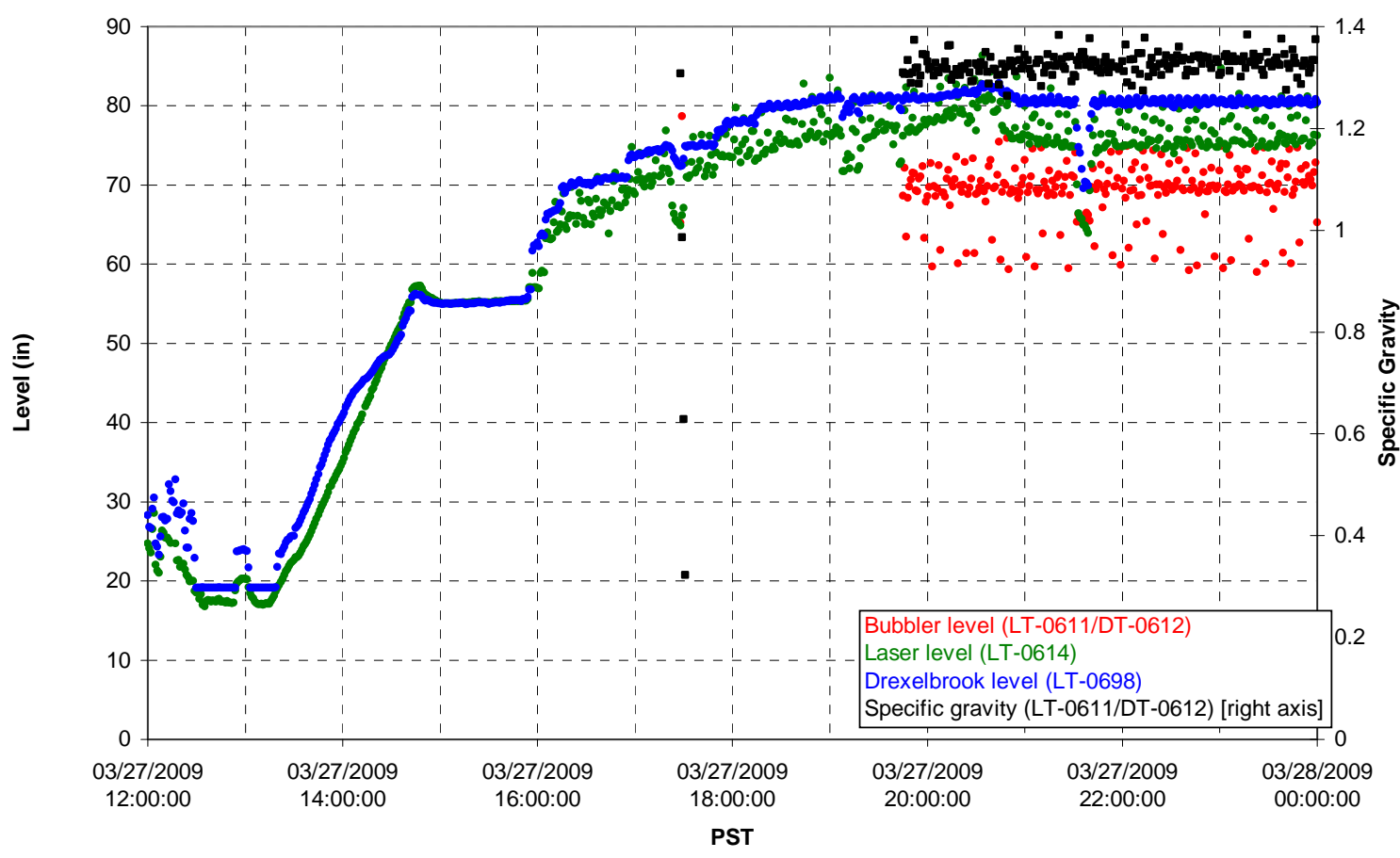

T02A temperatures

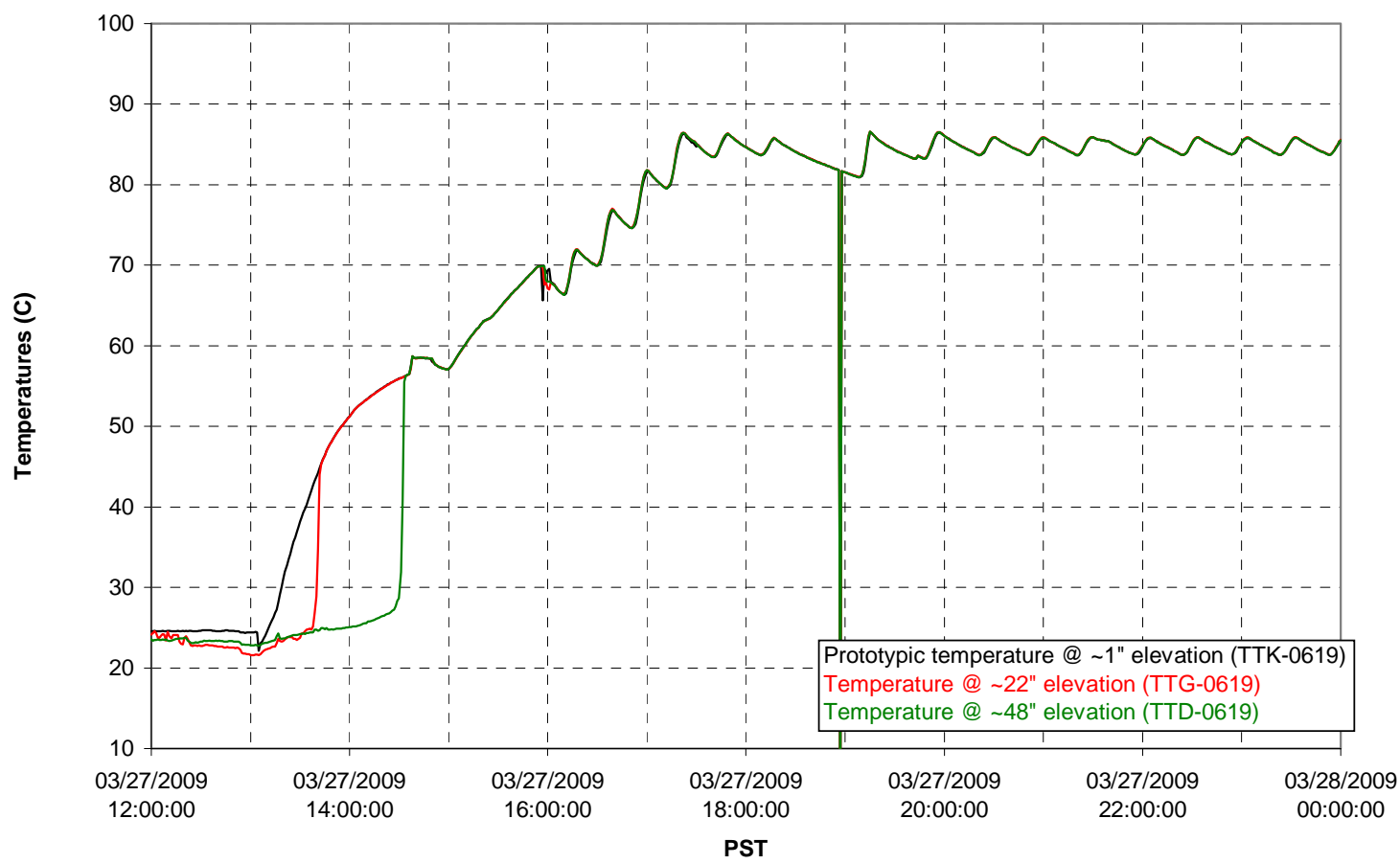


T02A and filter loop temperatures

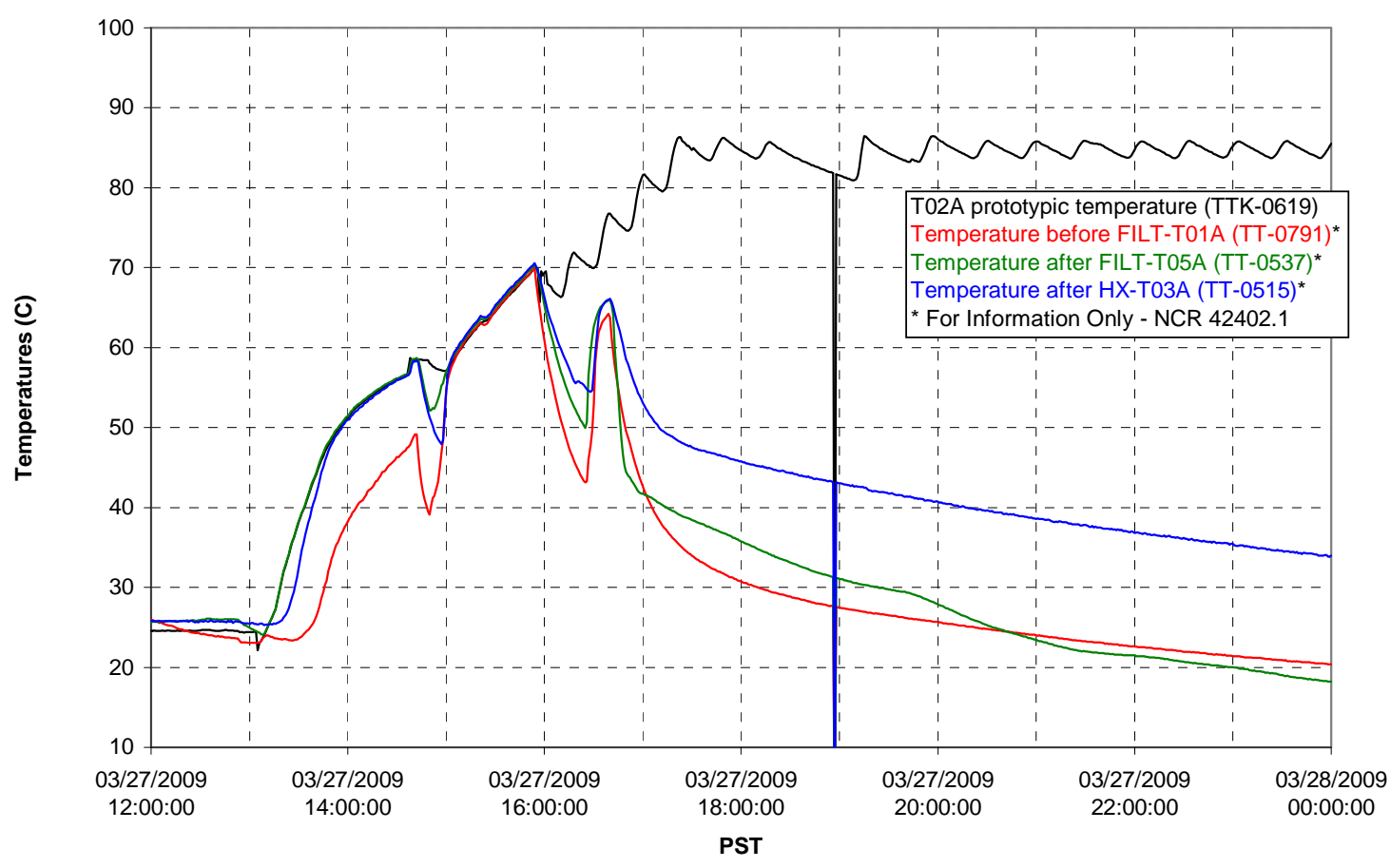

Pump Pressures and Flow

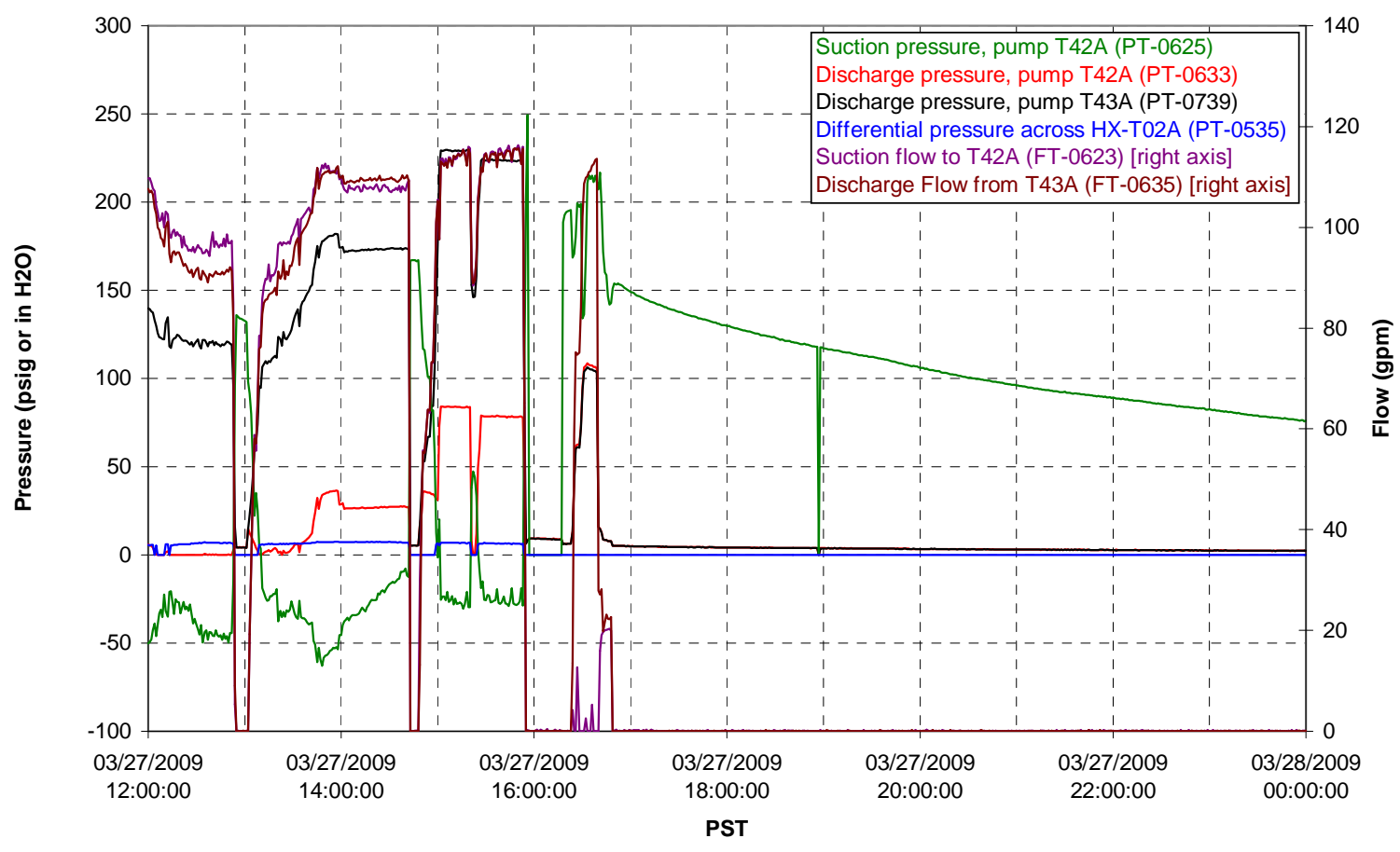




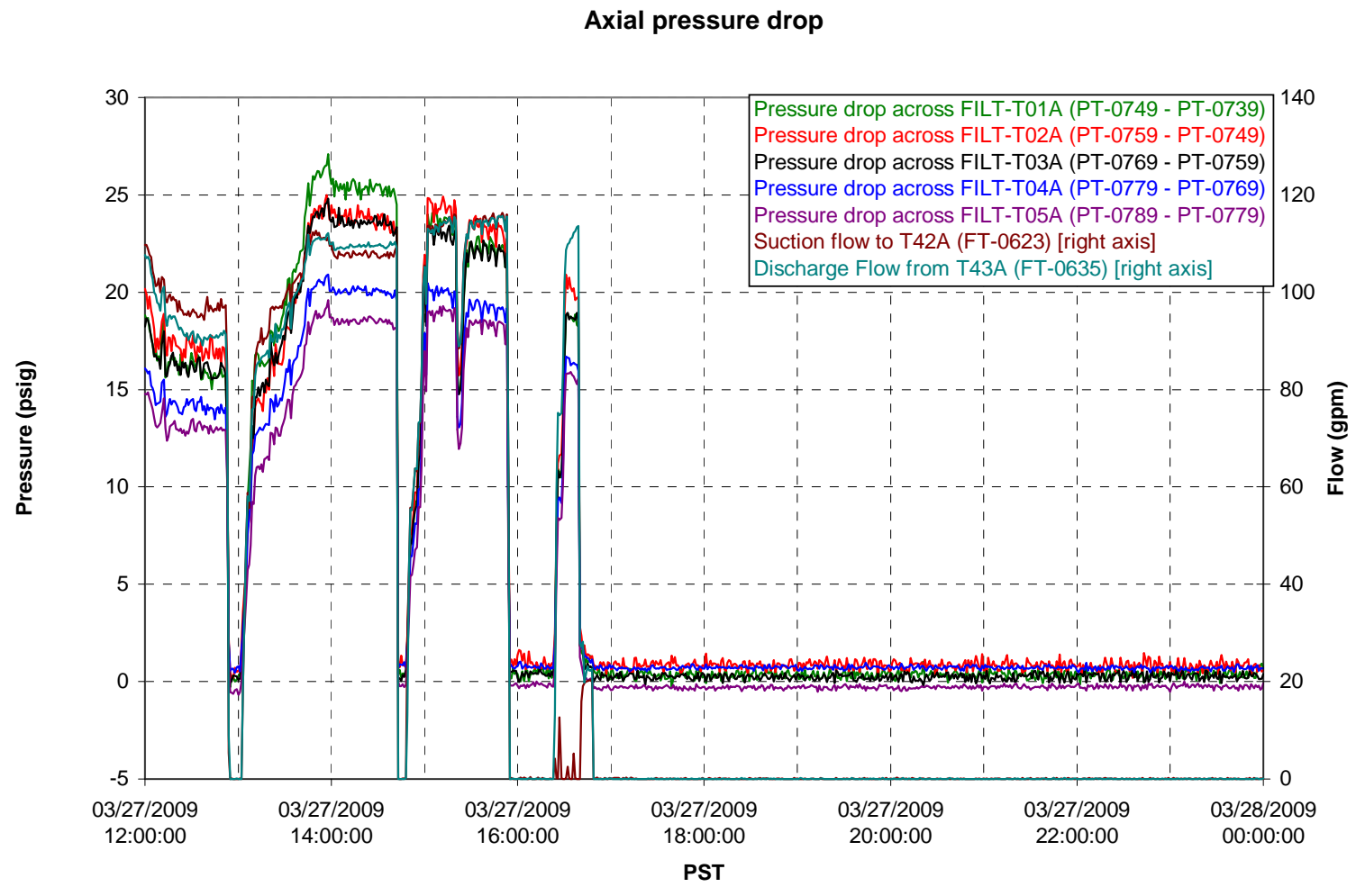

Permeate flow rates

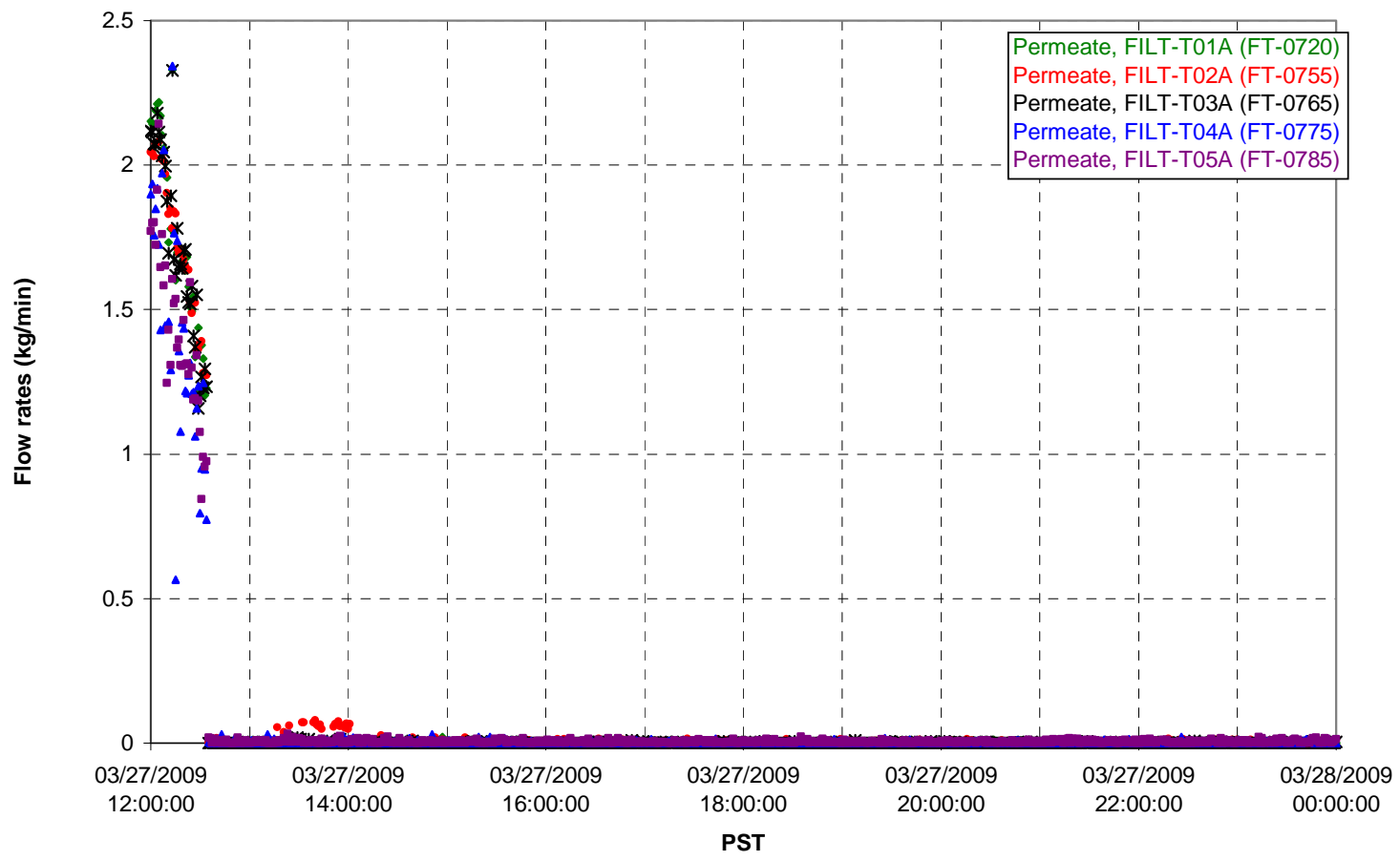


T02A Inner Temperature Tree

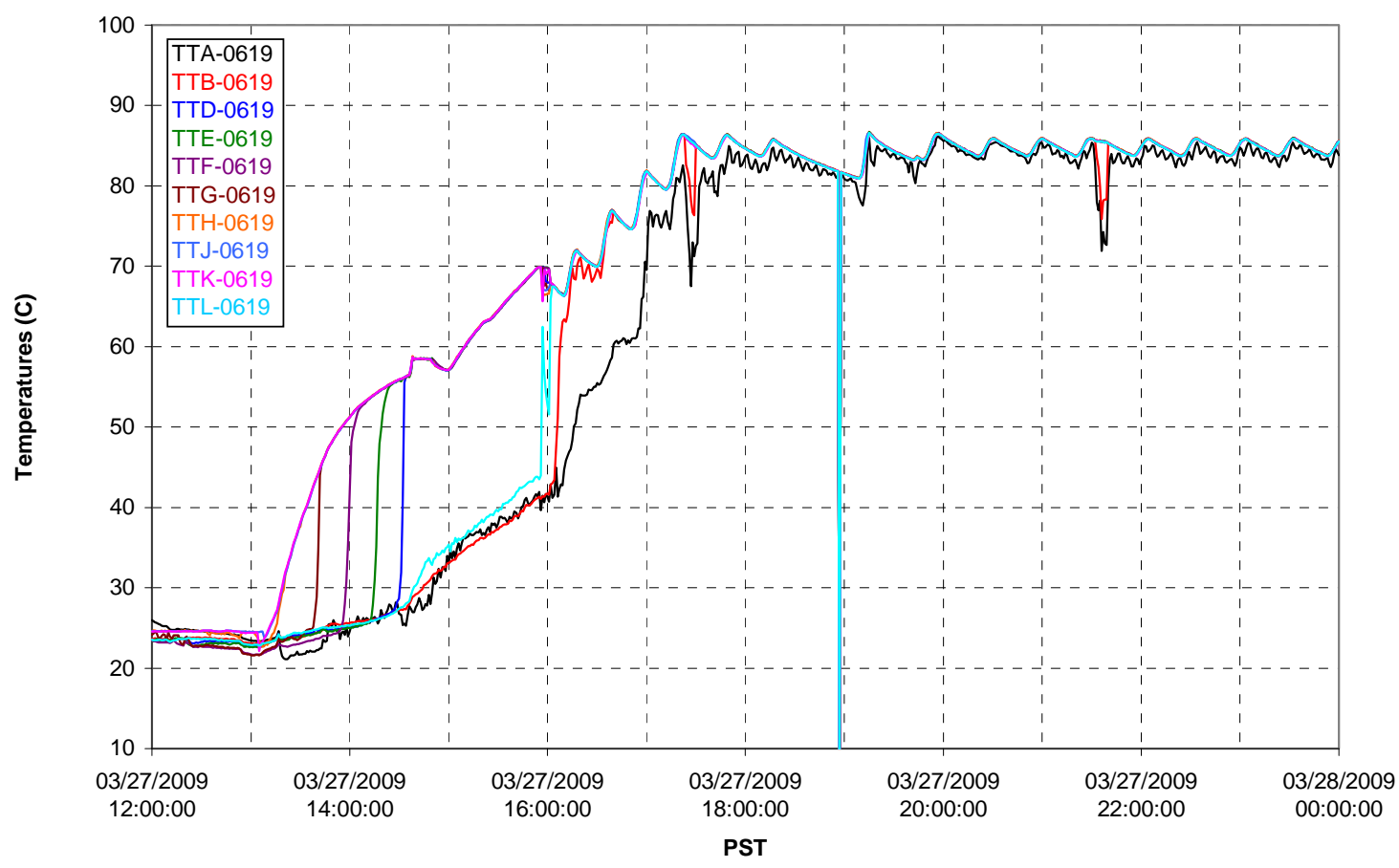

T02A Outer Temperature Tree

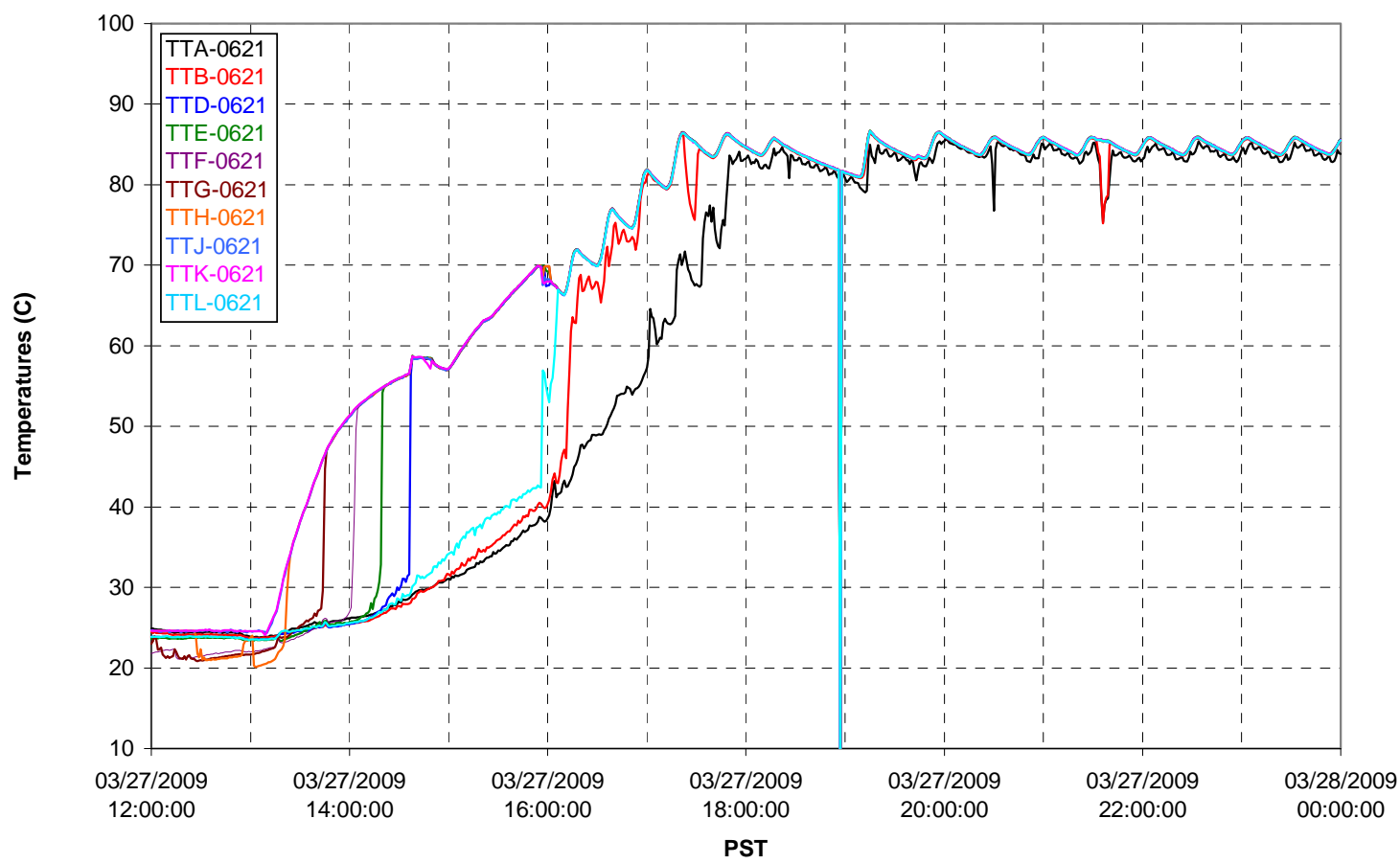


T02A temperatures

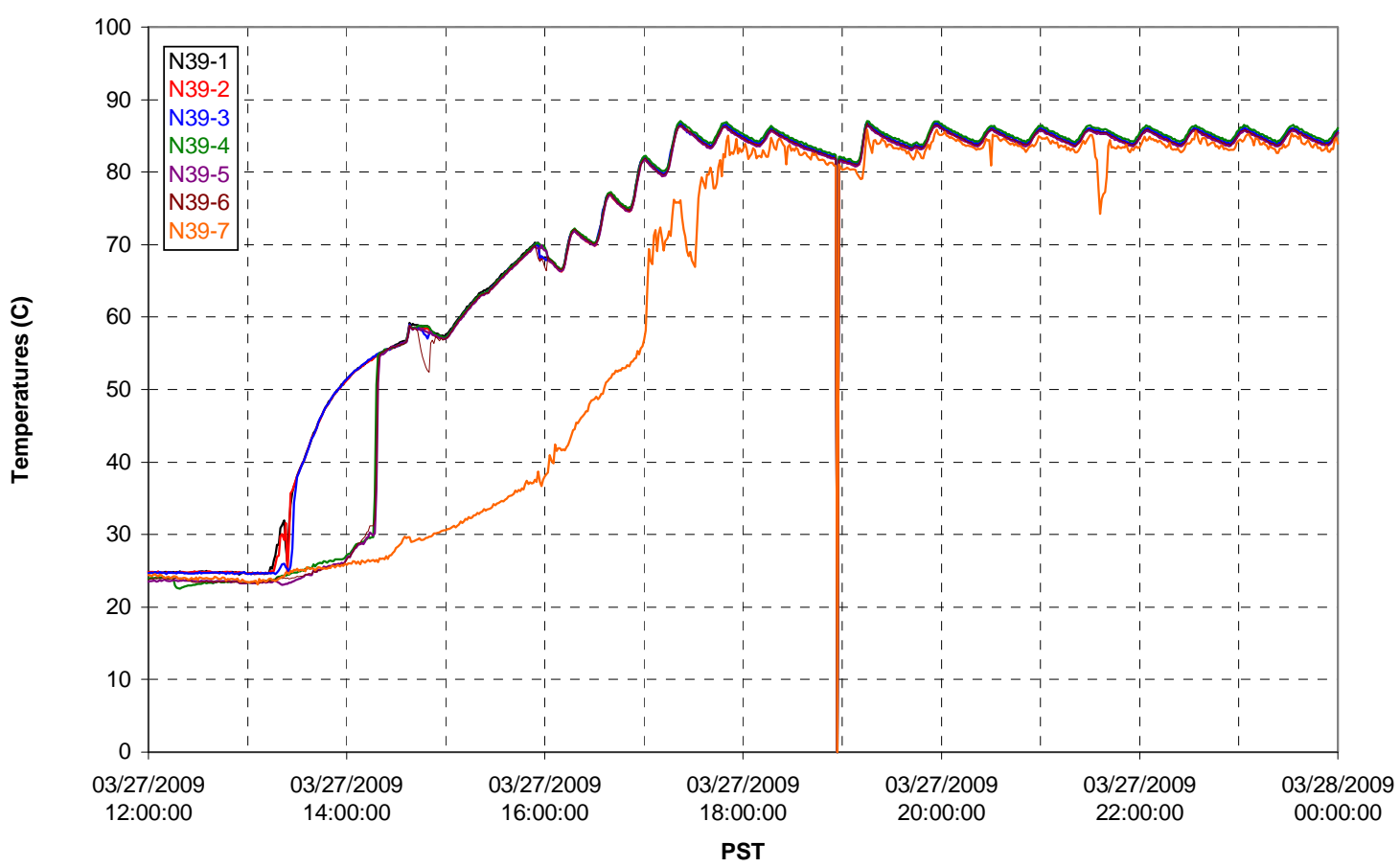

T02A temperatures

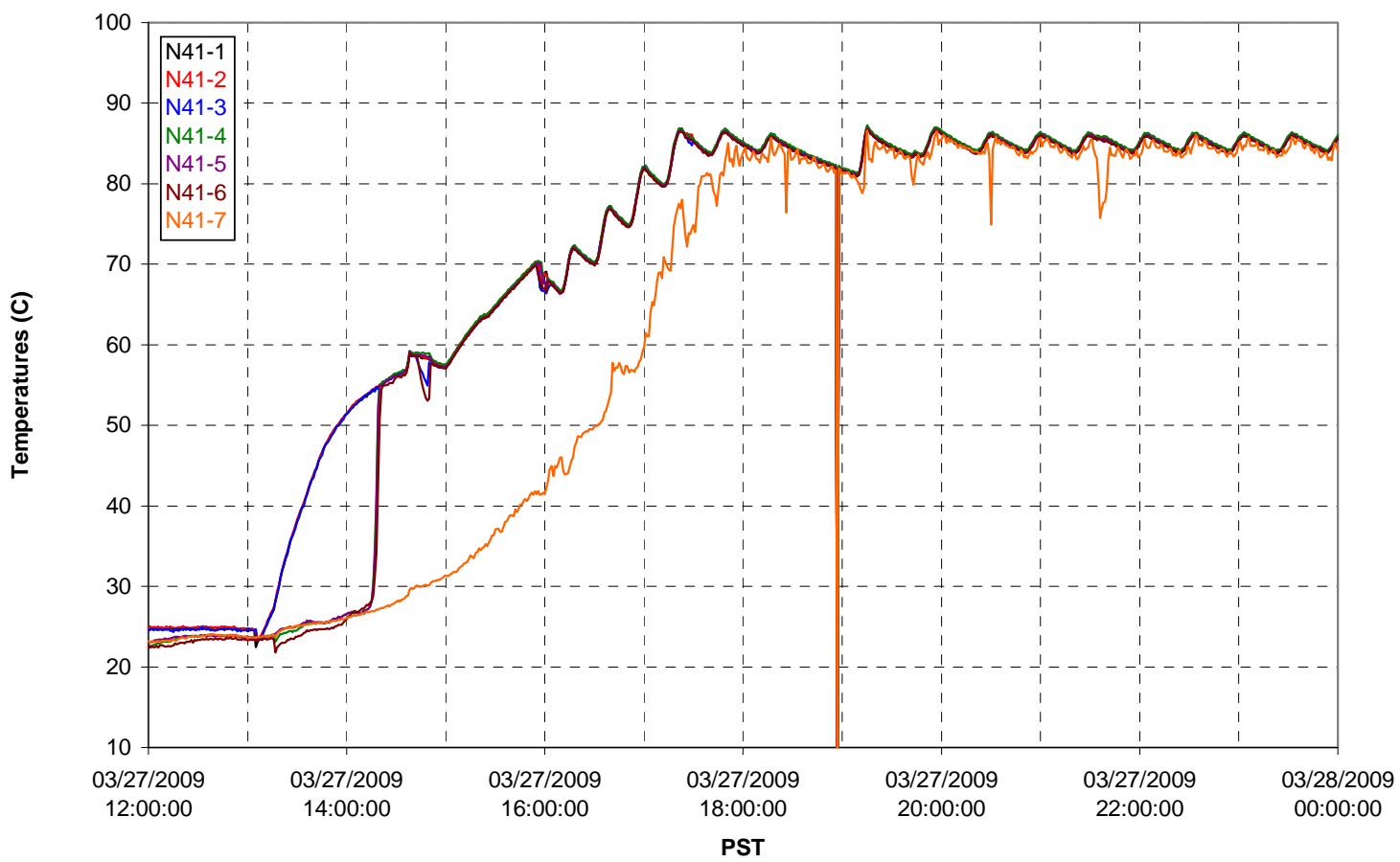


T02A temperatures

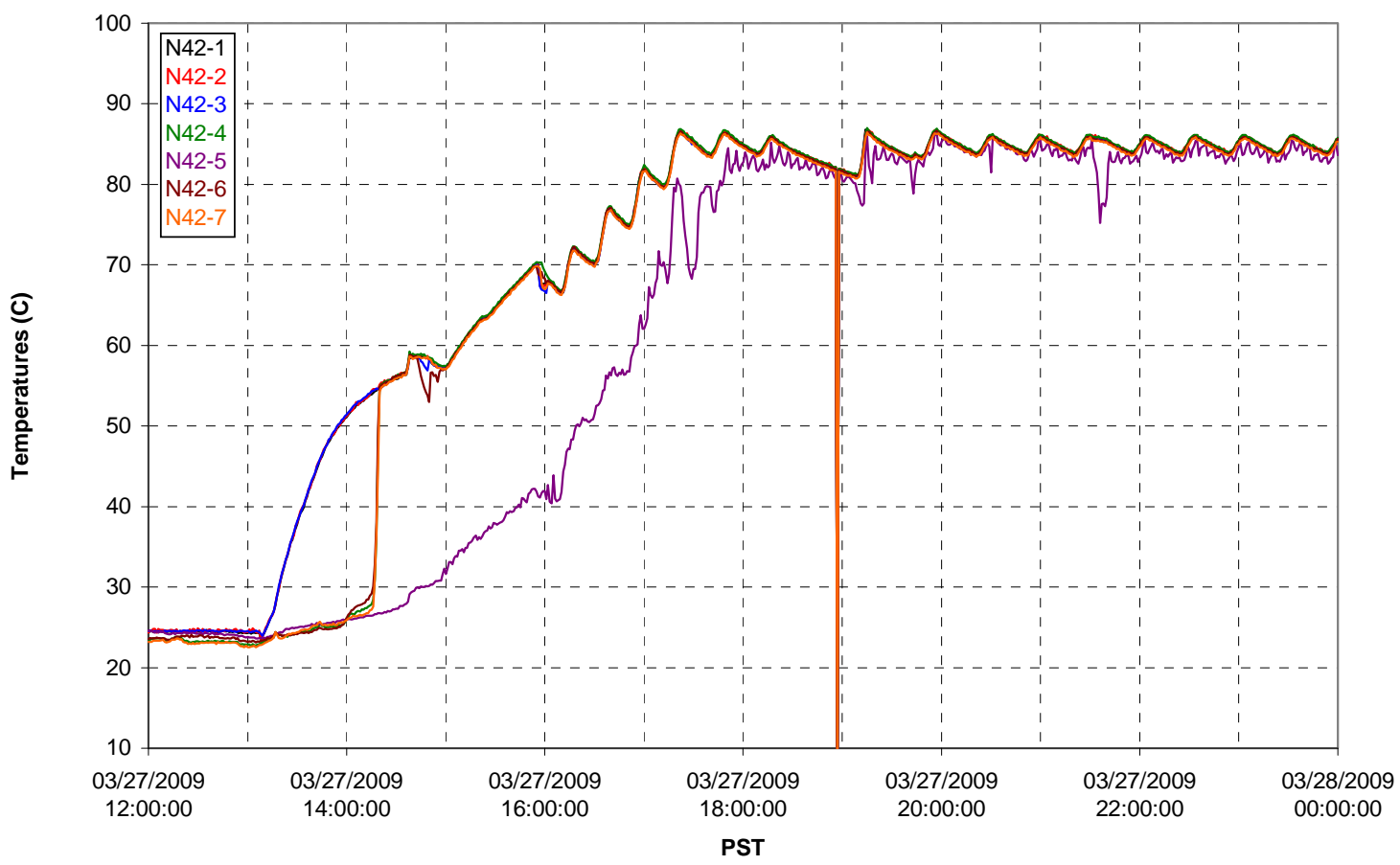

T02A temperatures

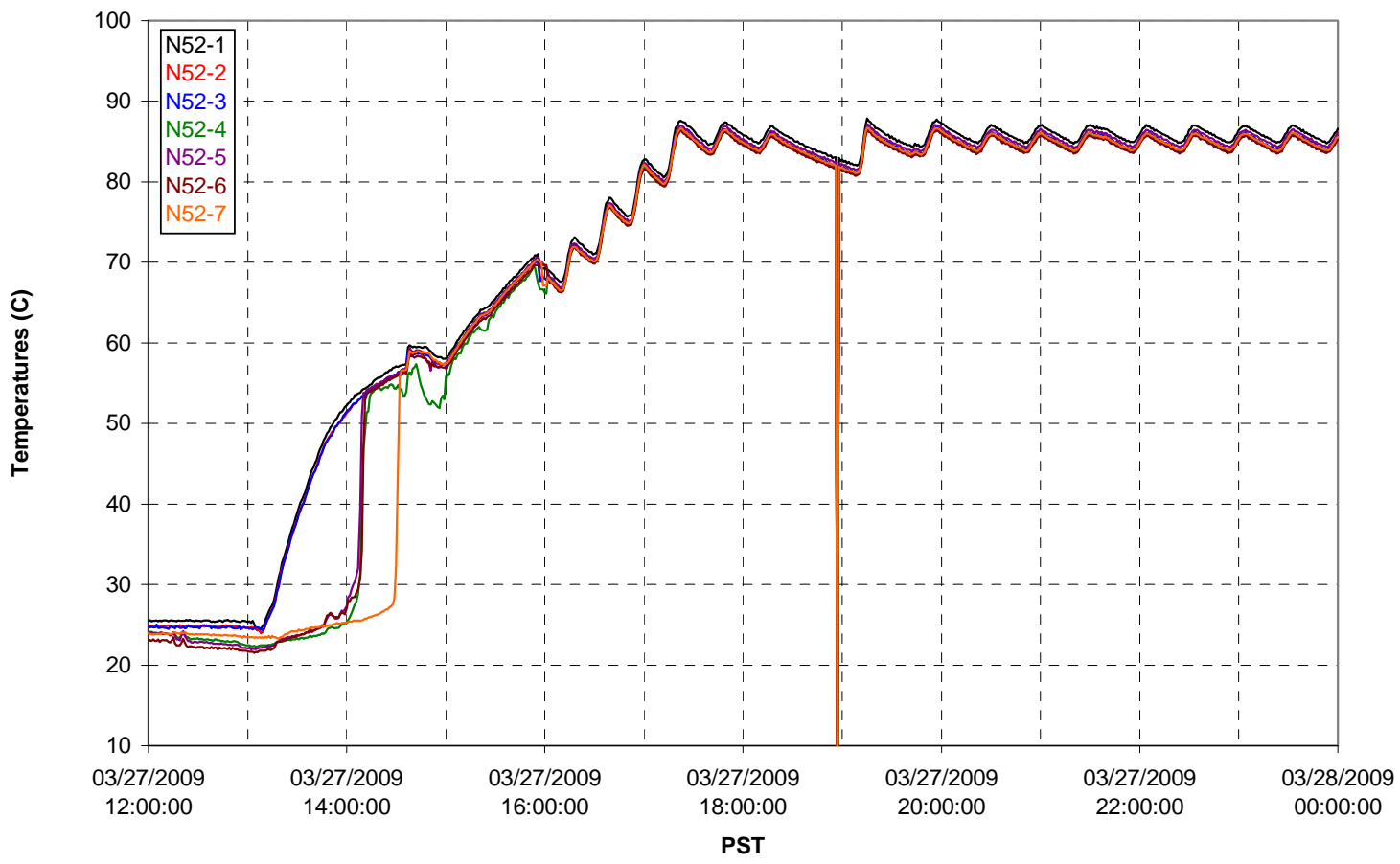


T02A Heating and Cooling

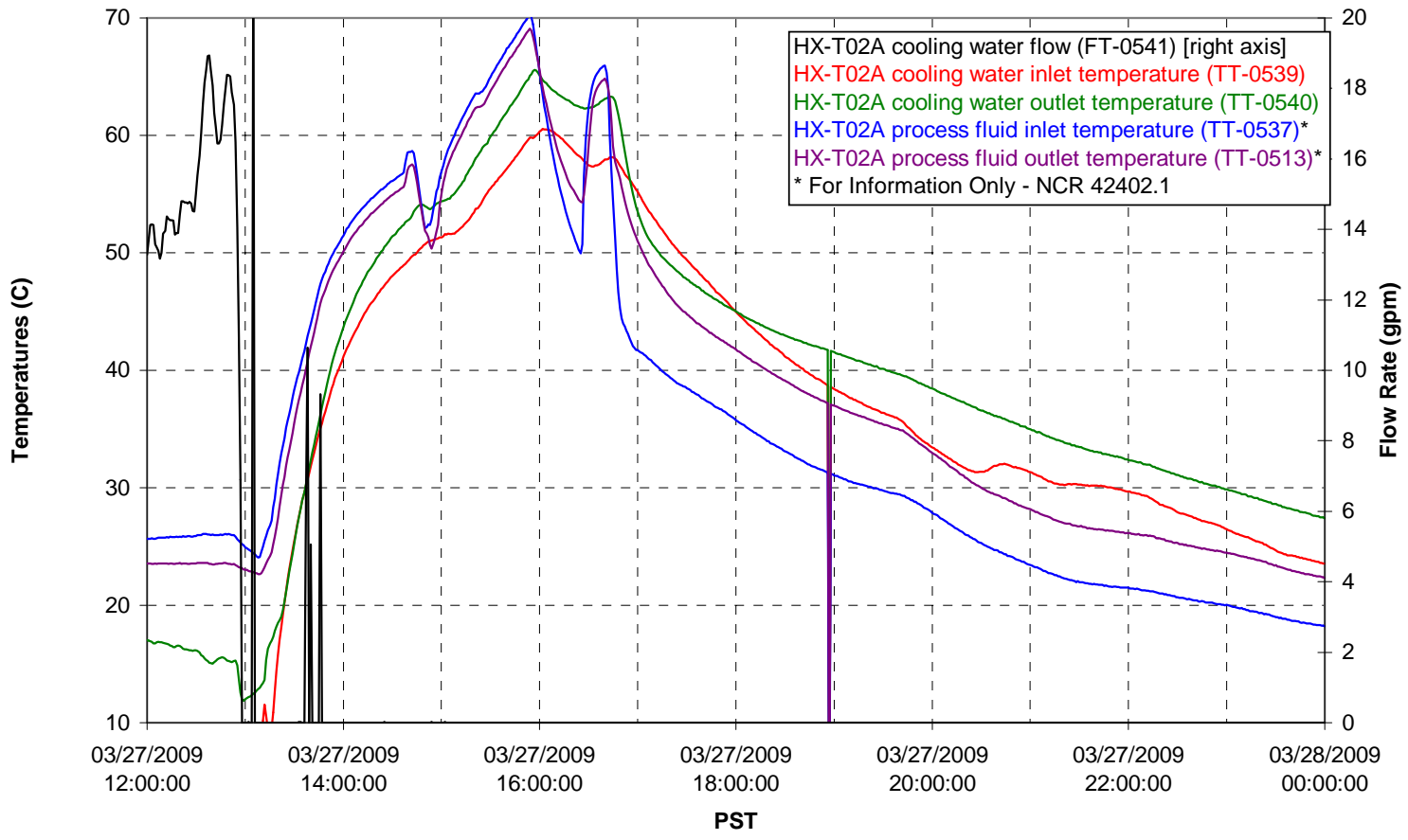

Pump Operation

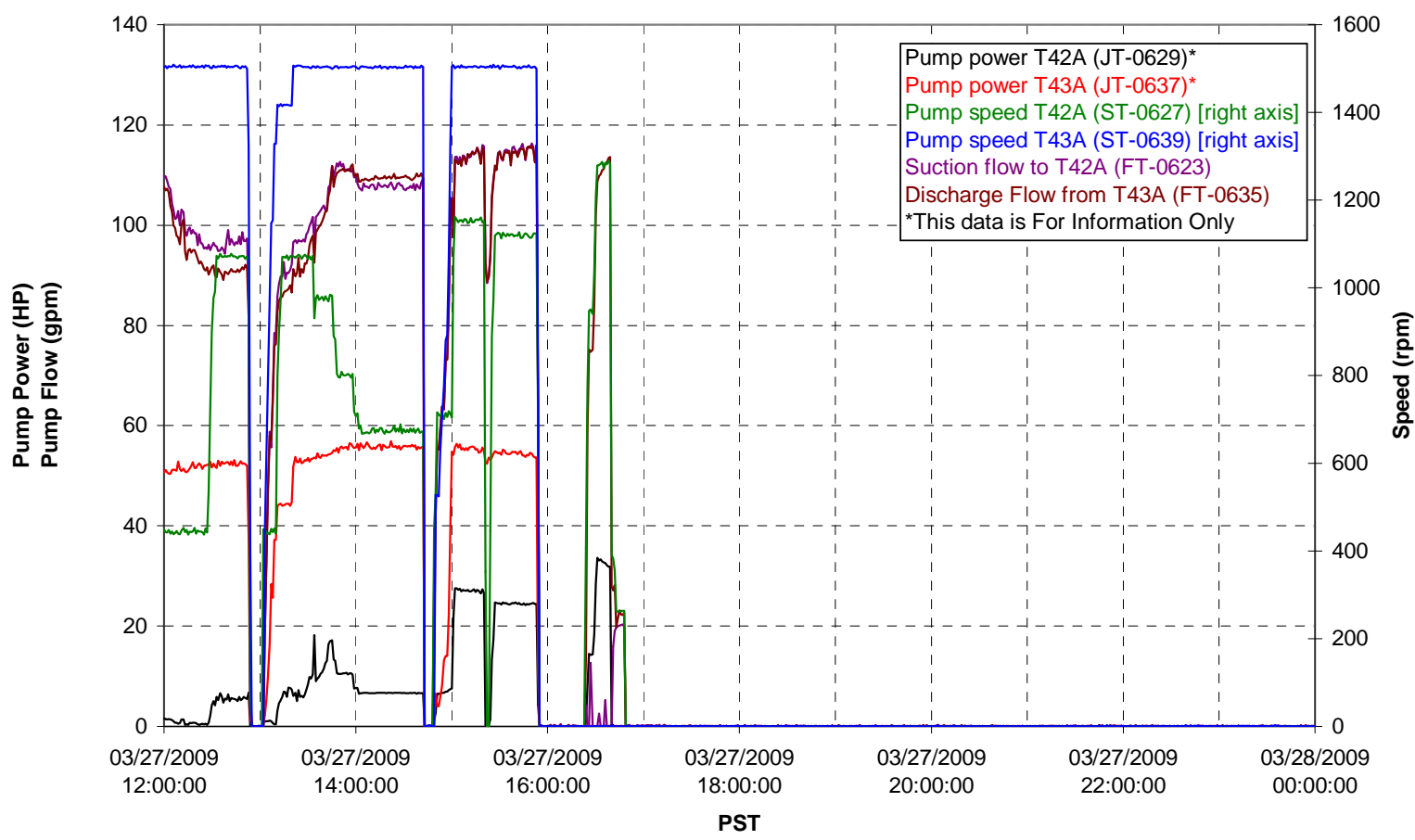


Pulsepot UFP-PP-T01A

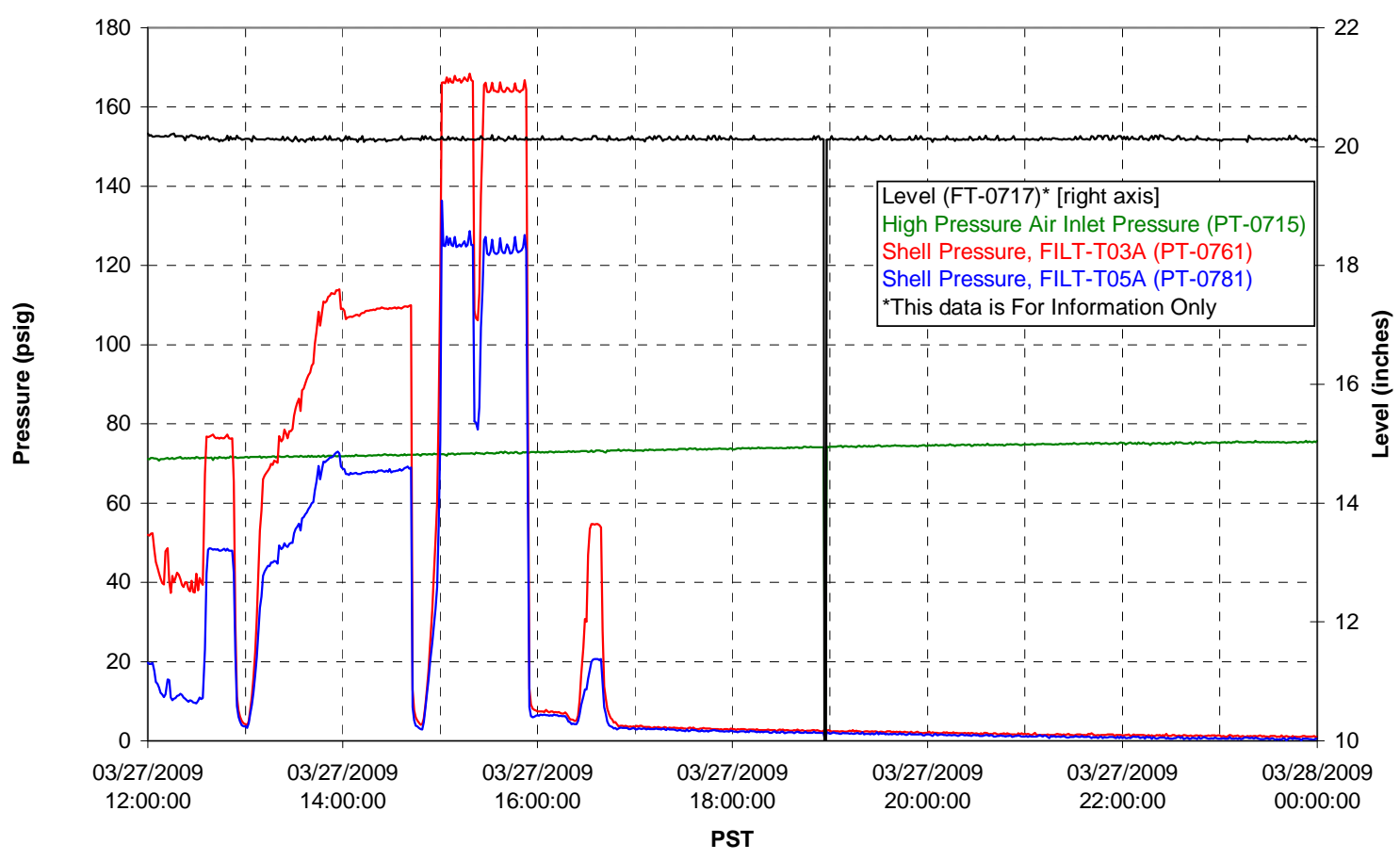

Pulsepot UFP-PP-T02A

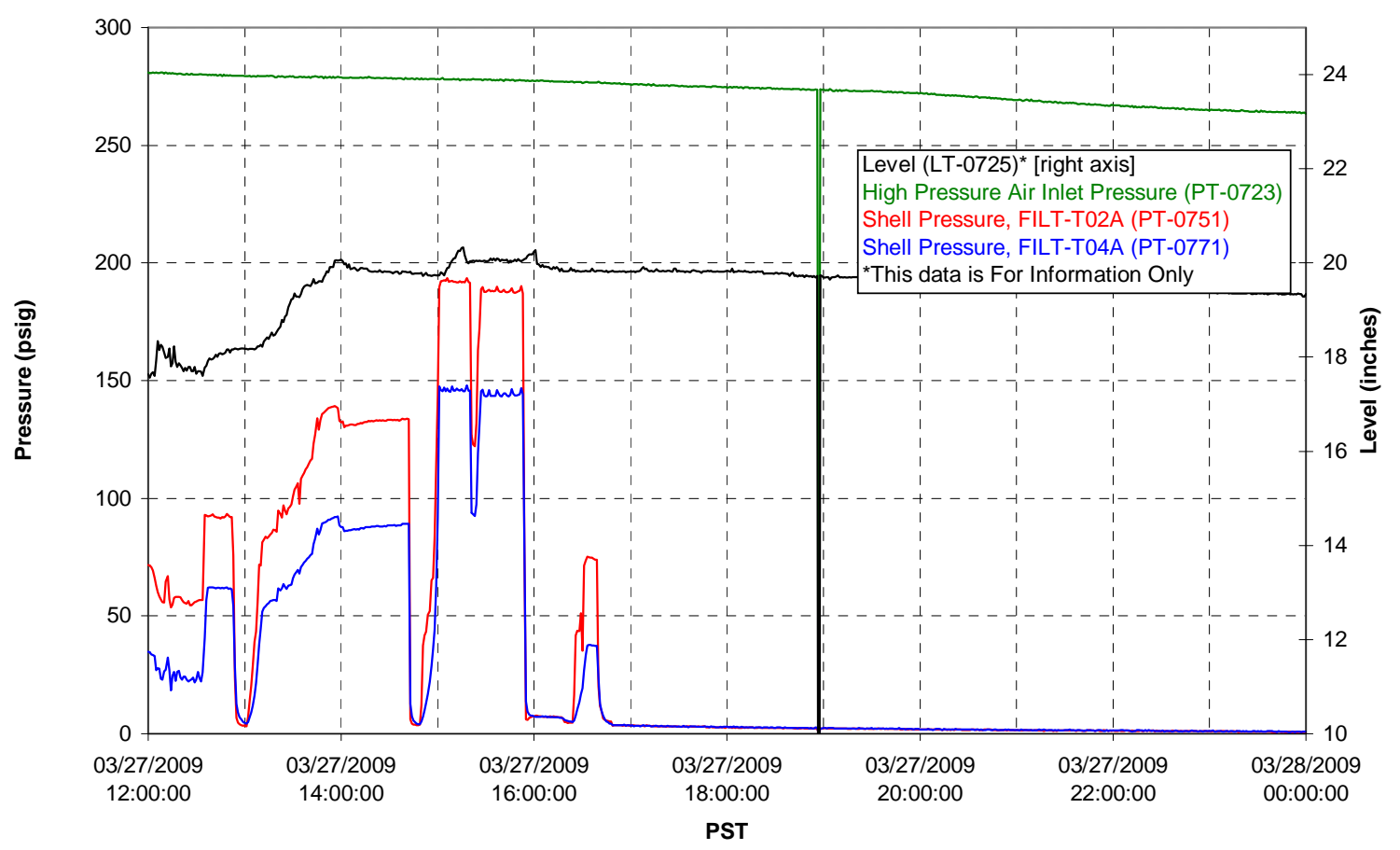


Pulsepot UFP-PP-T03A

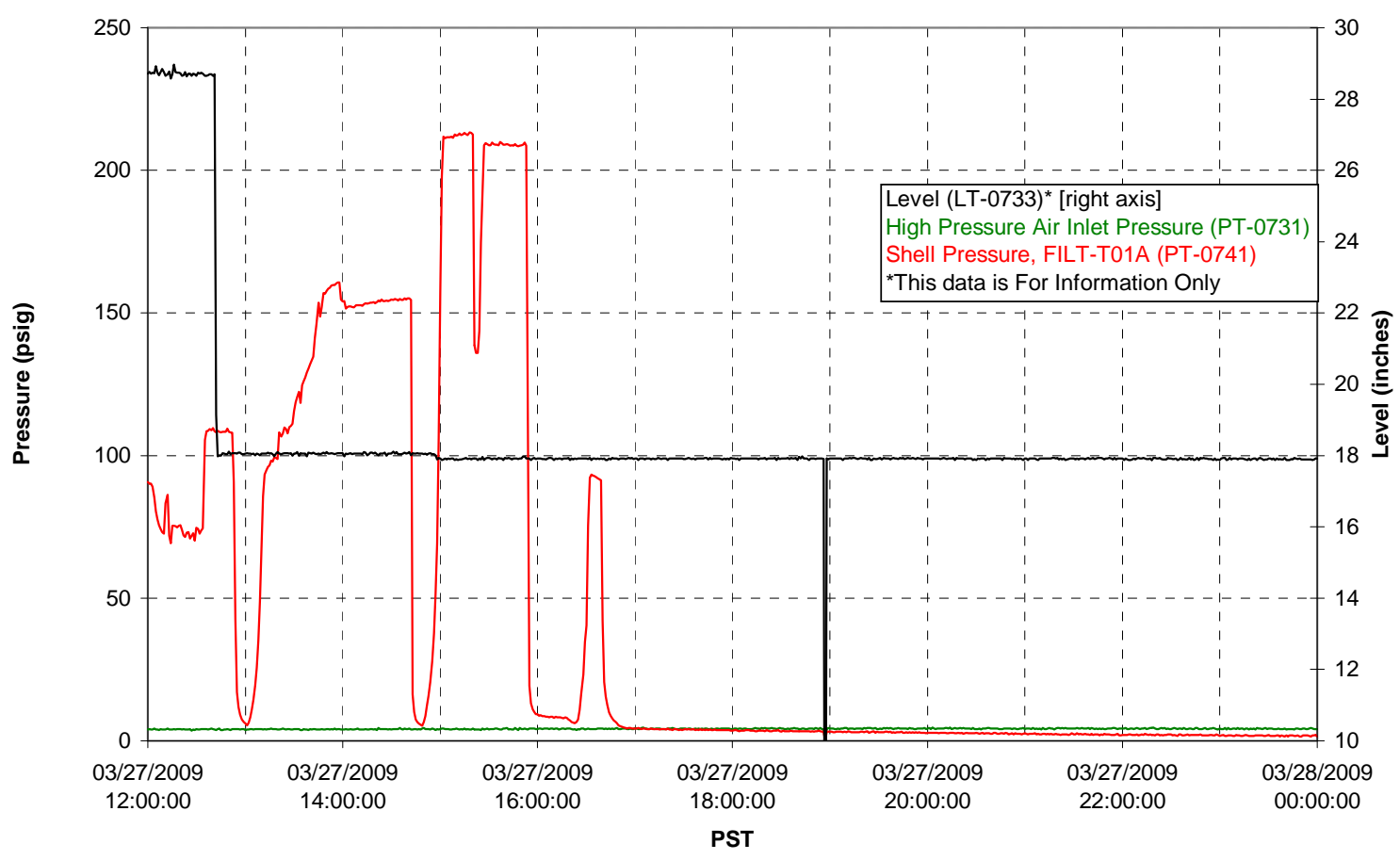

Pulsepot Levels

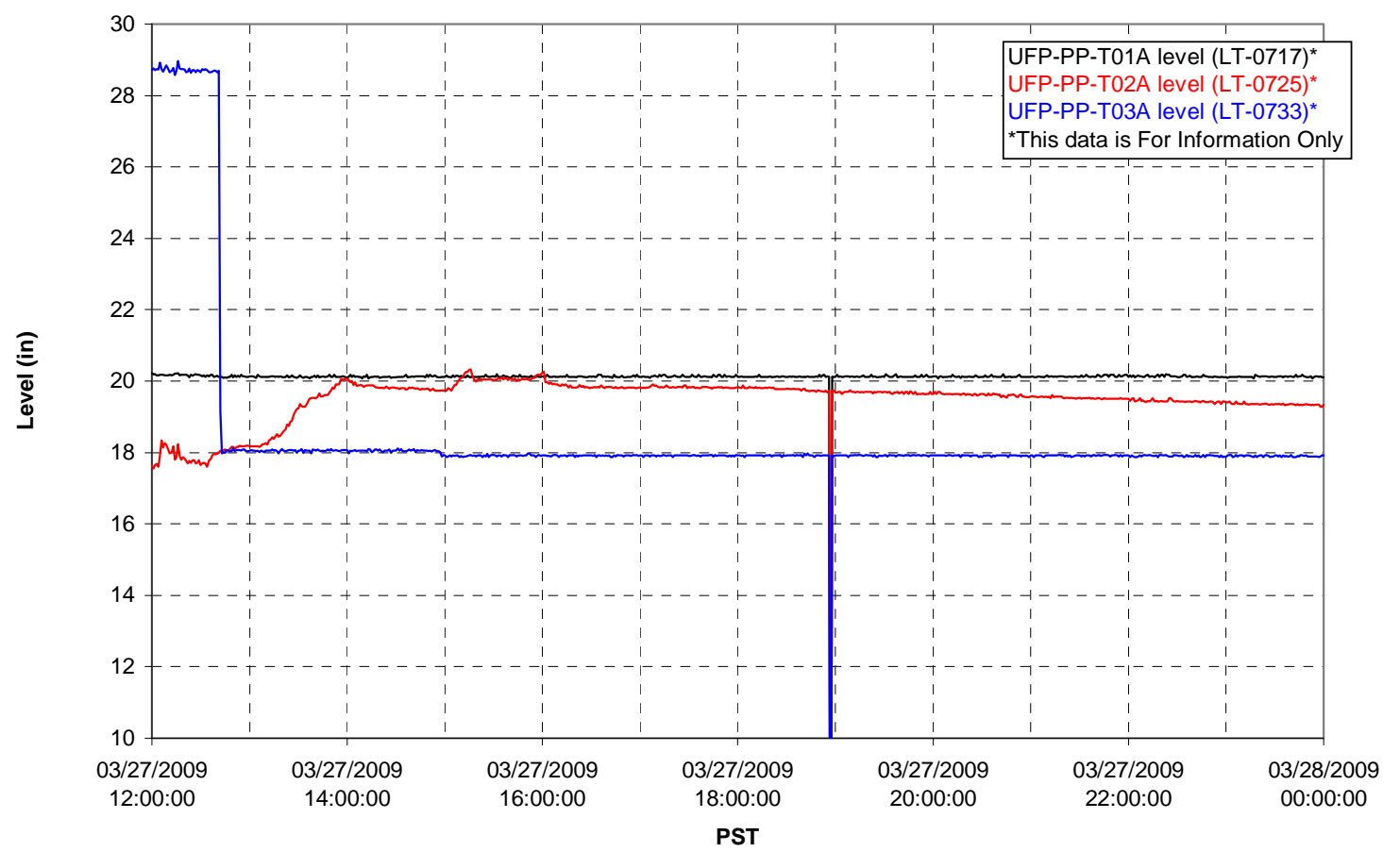


Filter UFP-FILT-T01A

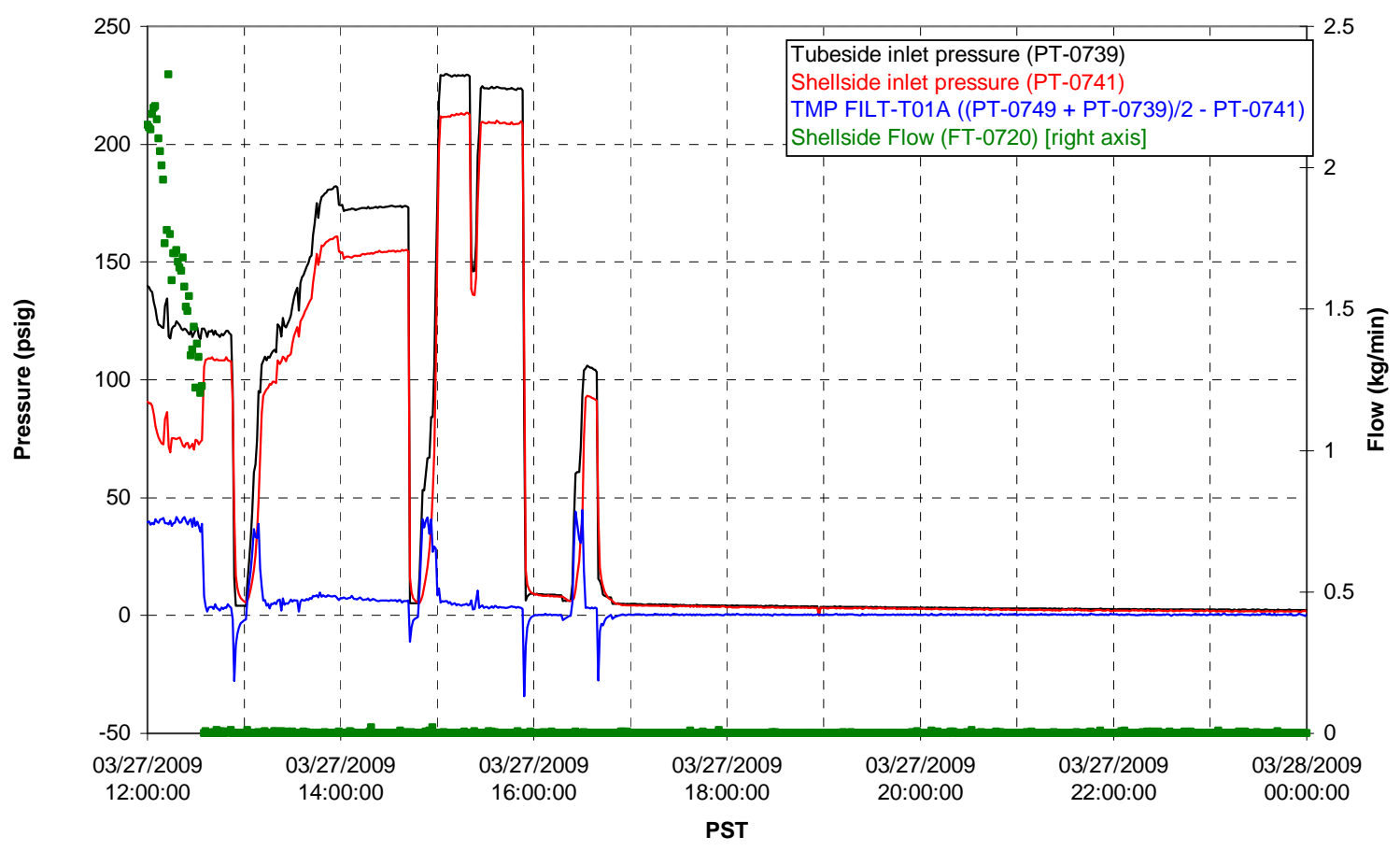

Filter UFP-FILT-T02A

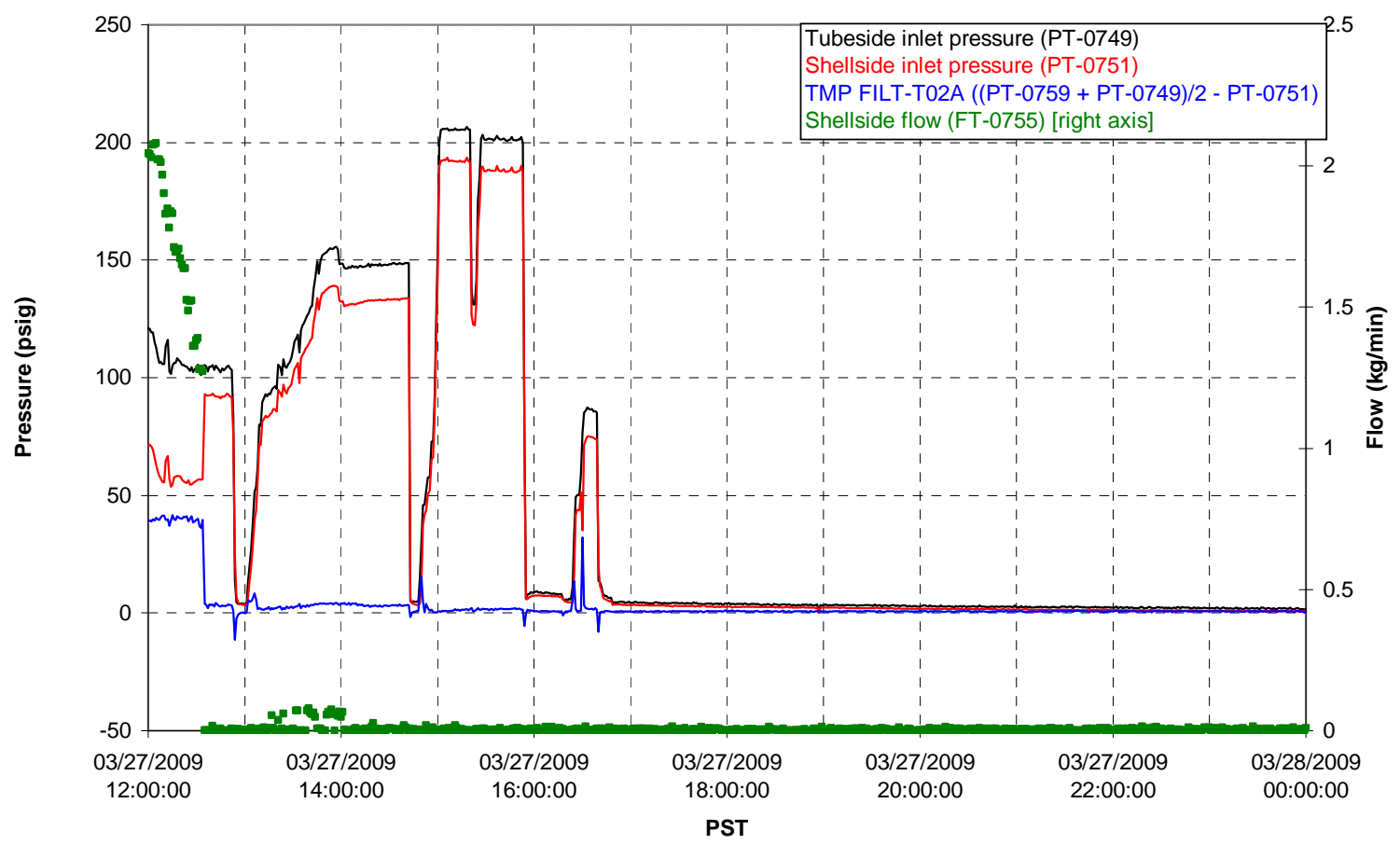


Filter UFP-FILT-T03A

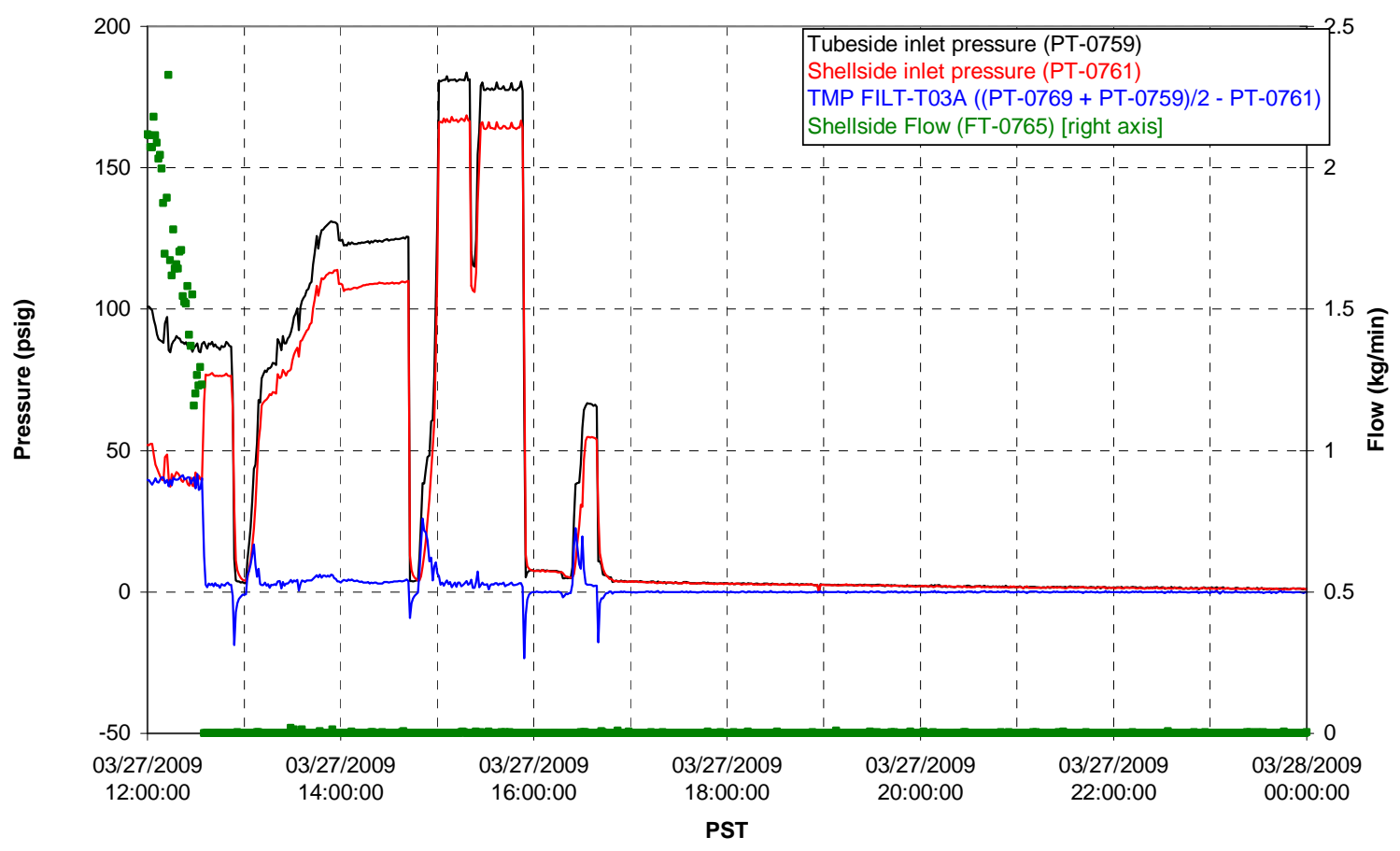

Filter UFP-FILT-T04A

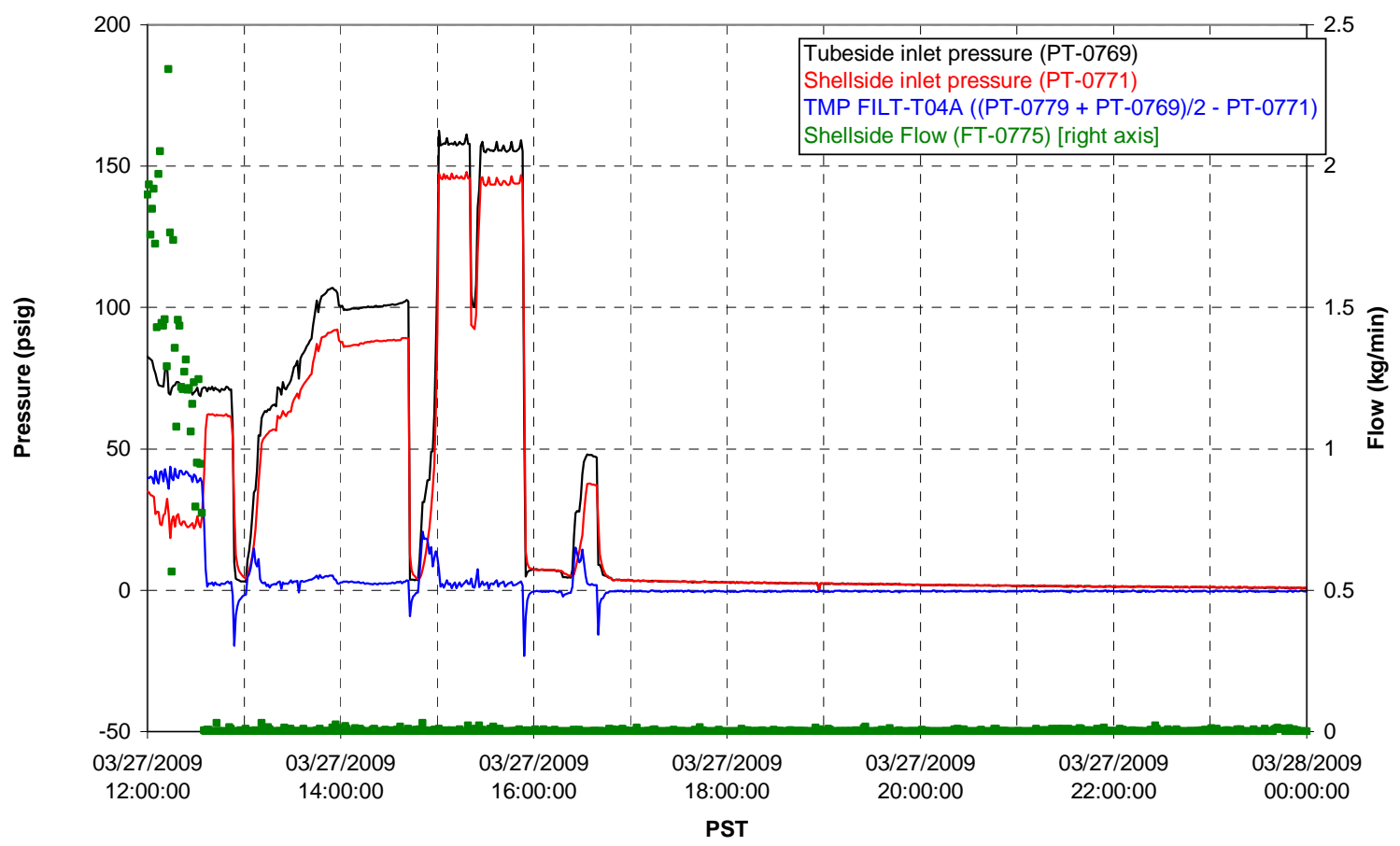


Filter UFP-FILT-T05A

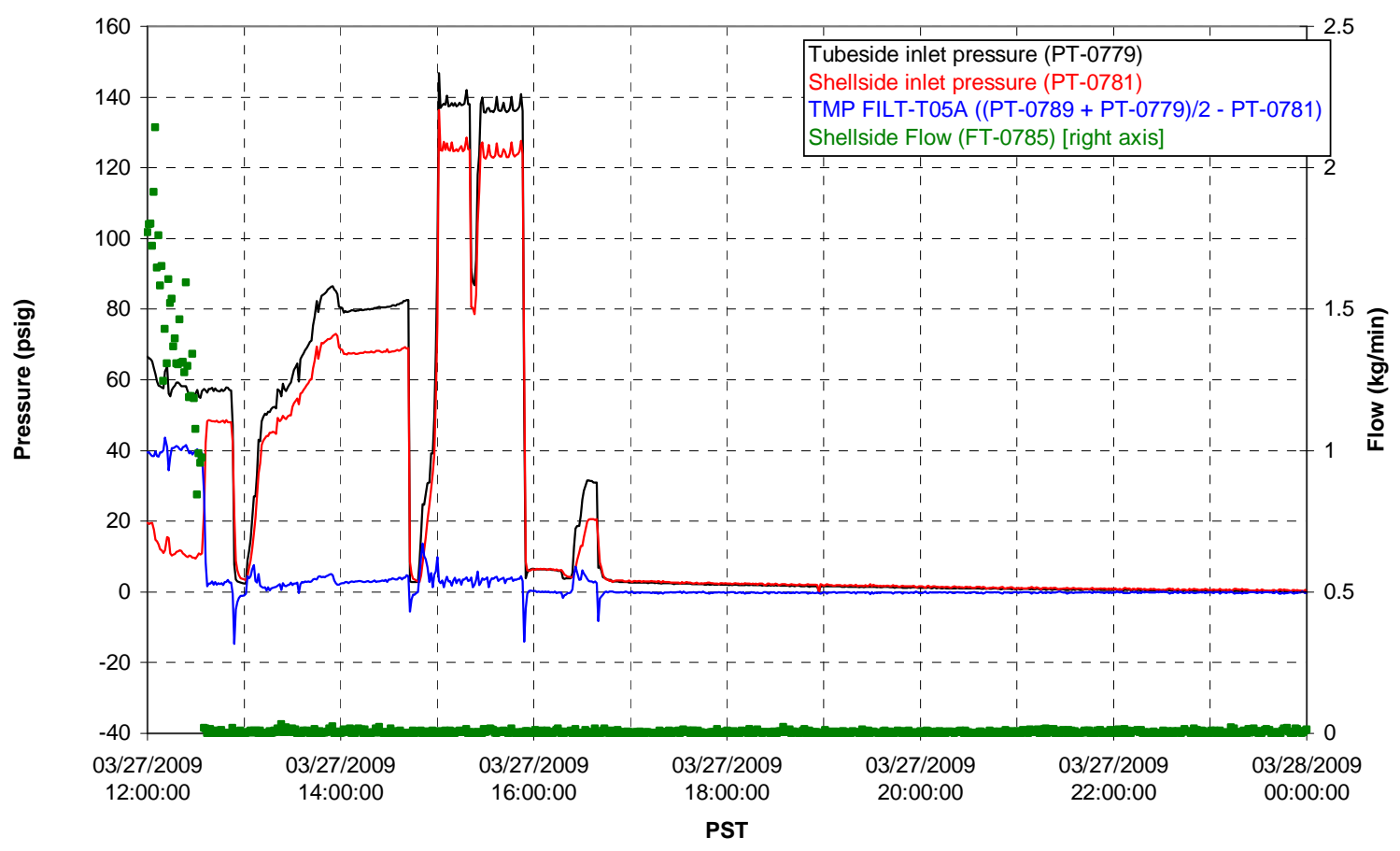

Chemical Flow

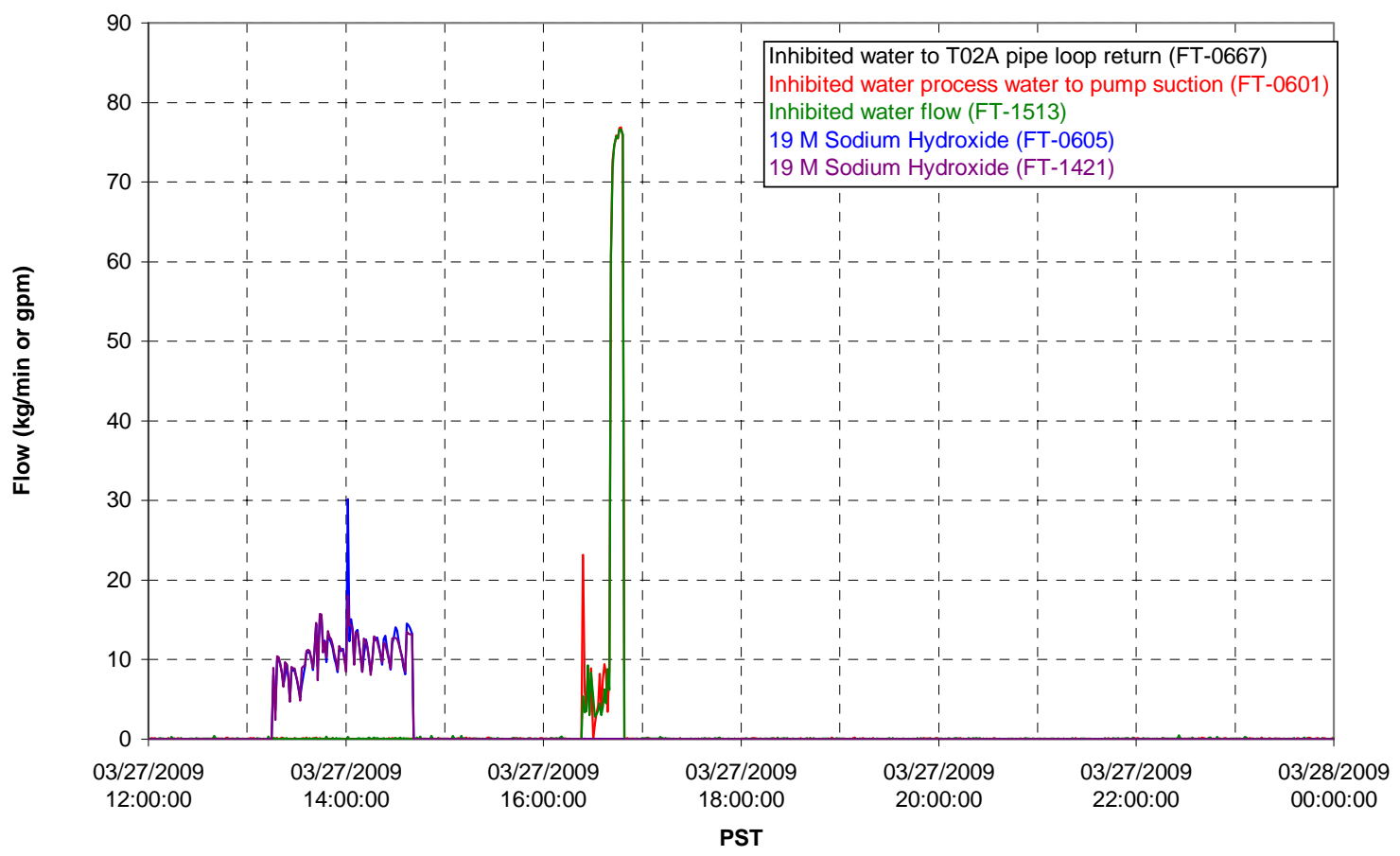




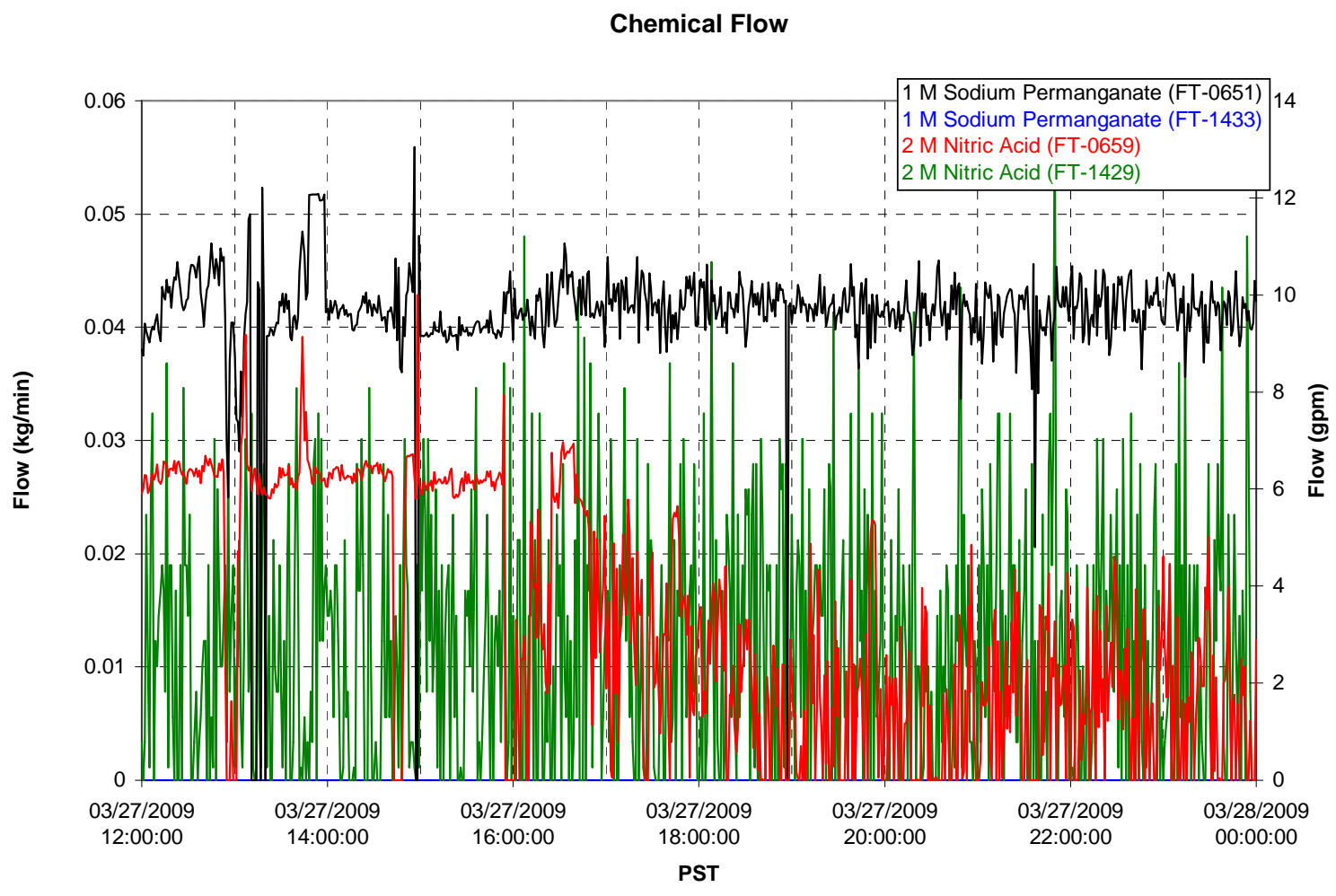

Air Flows

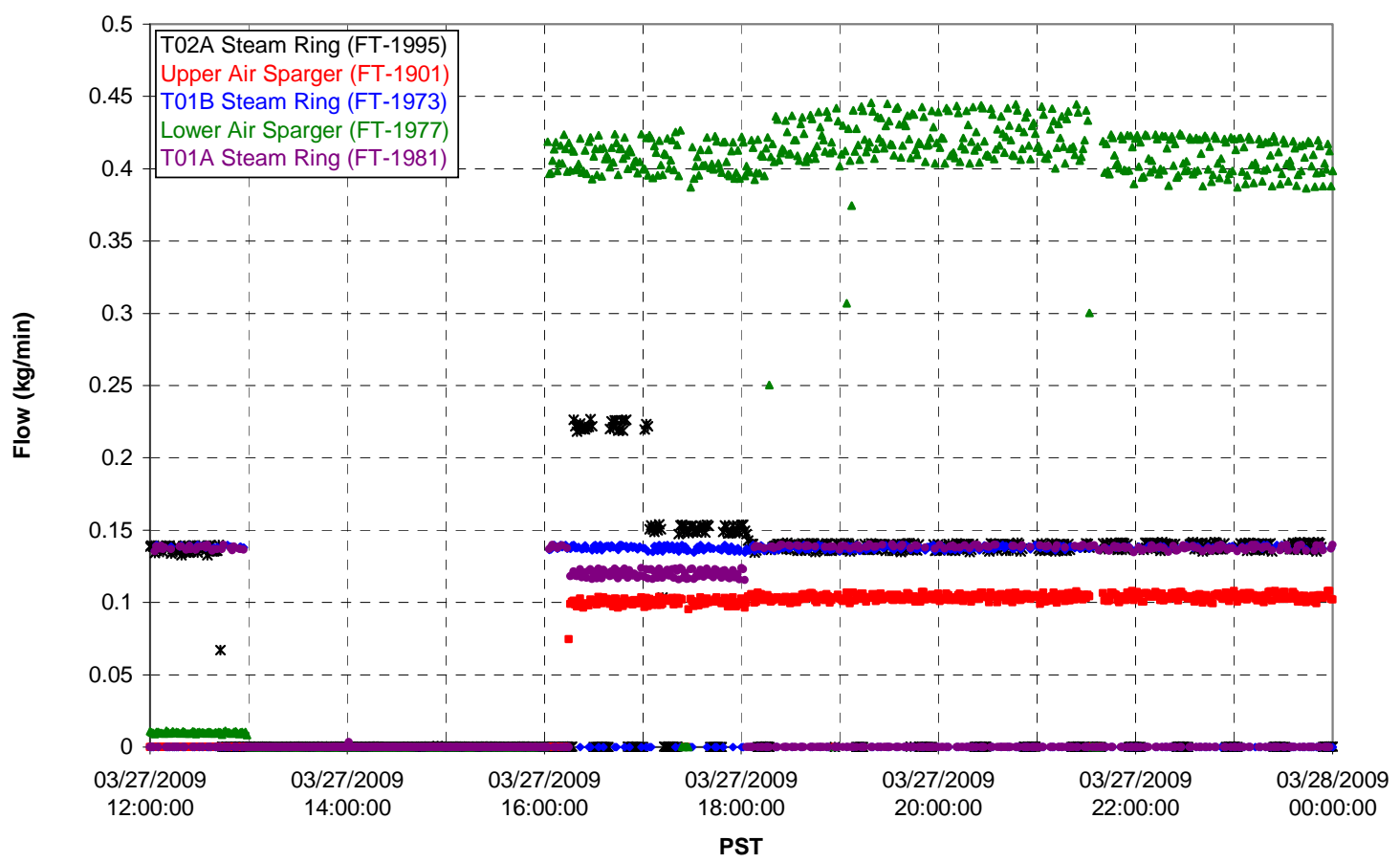


T02A Steam

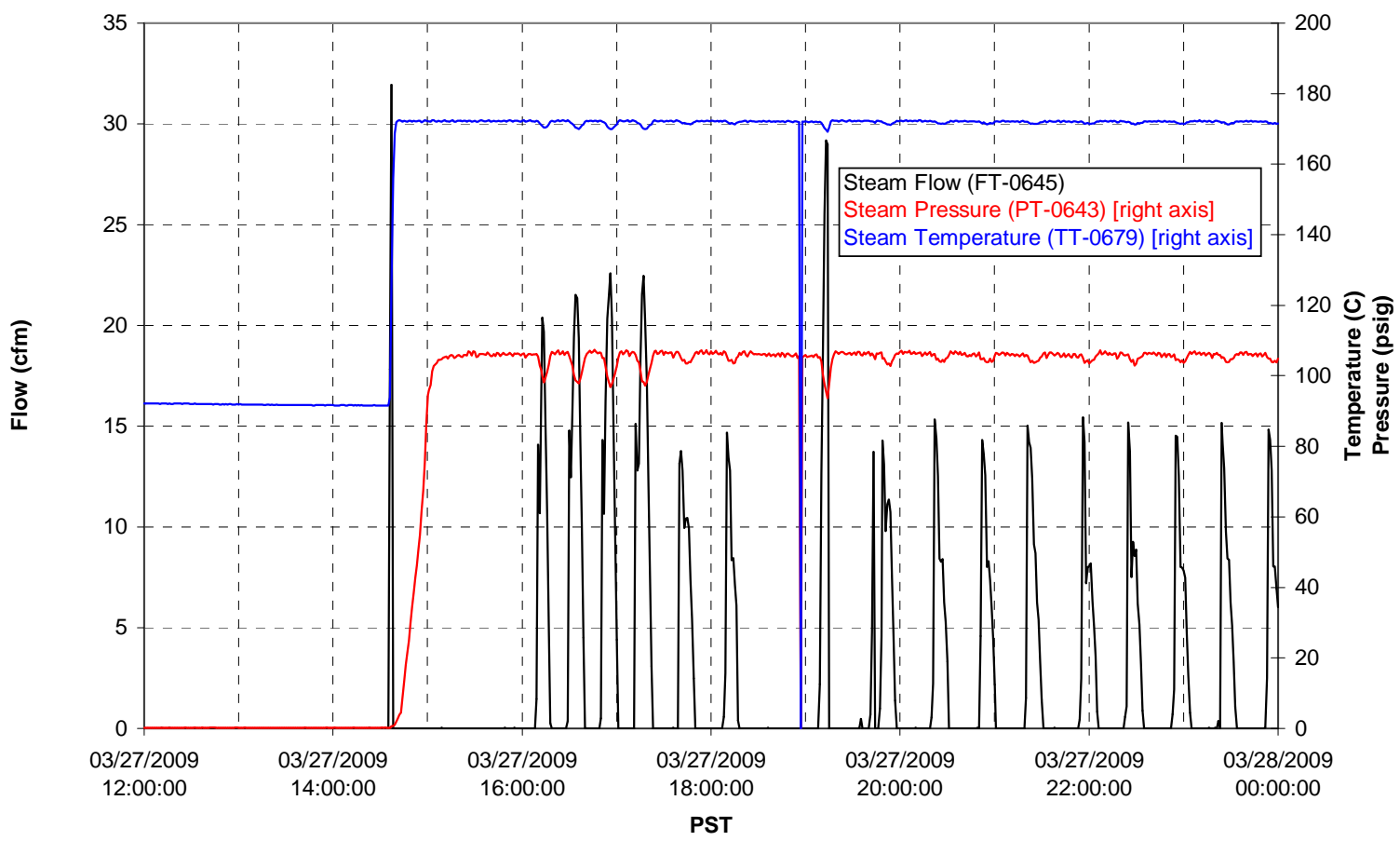

T01A Steam

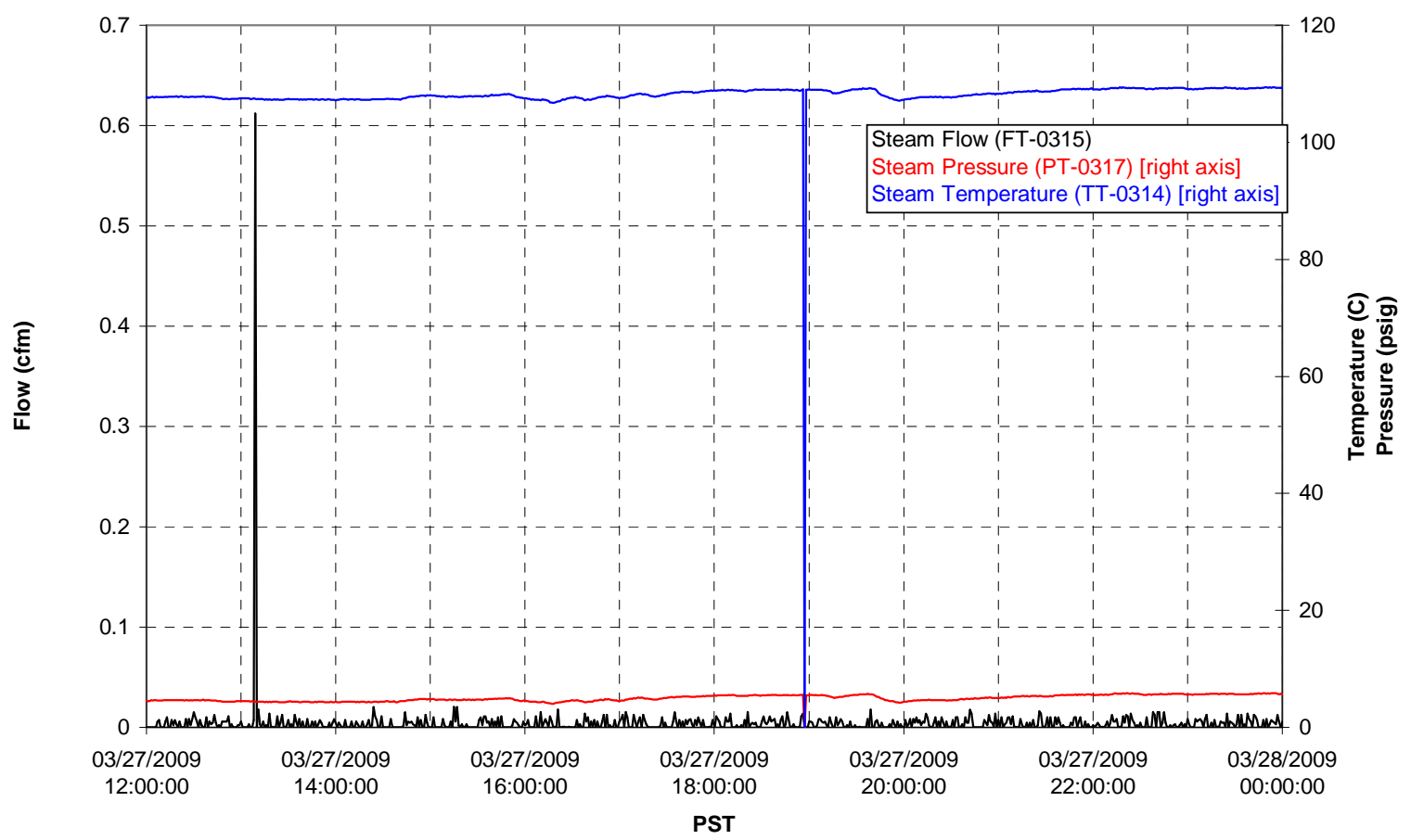


T01B Steam

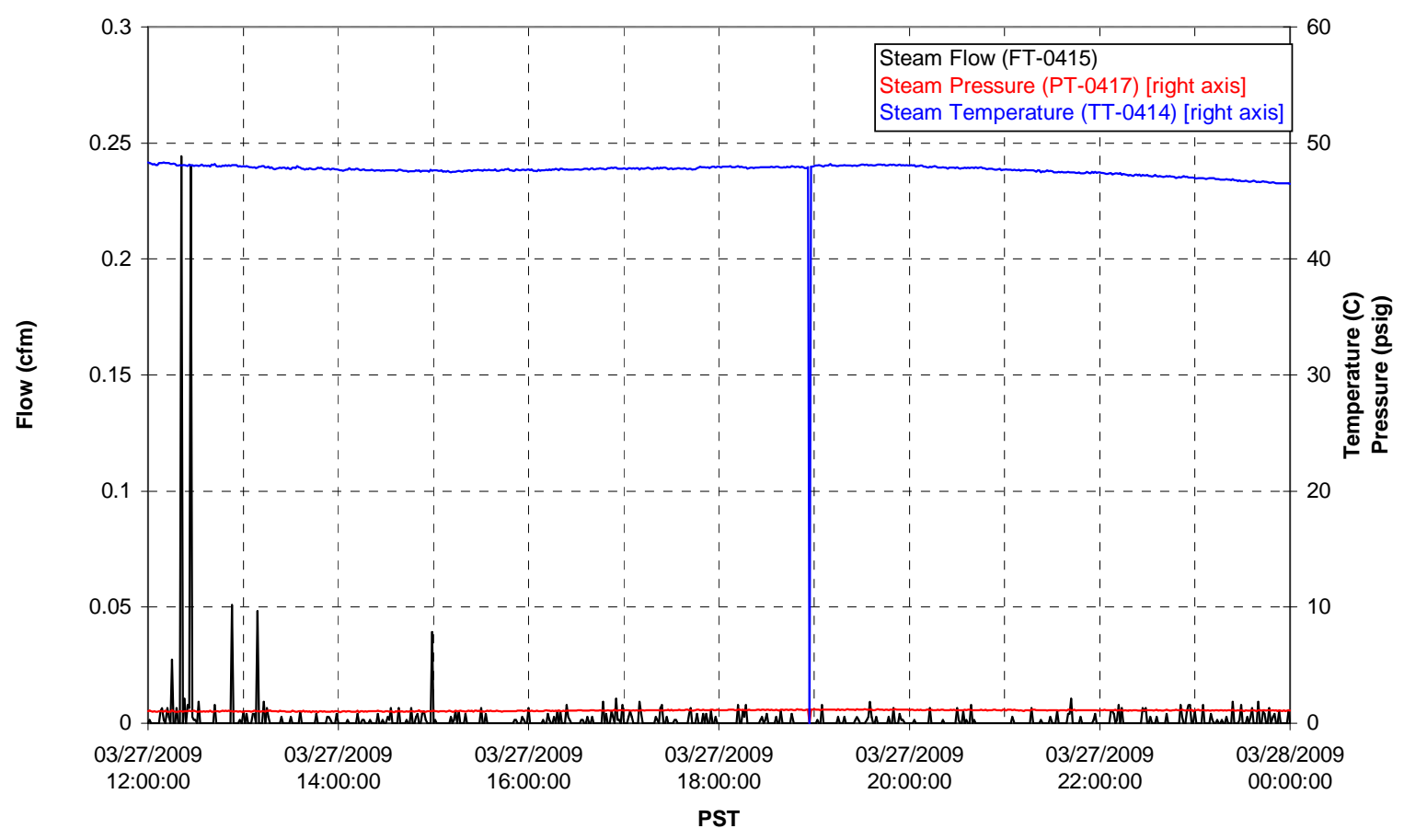




\section{Integrated Test D Data Plots 03/28/09 00:00 - 03/28/09 12:00}


T01A level

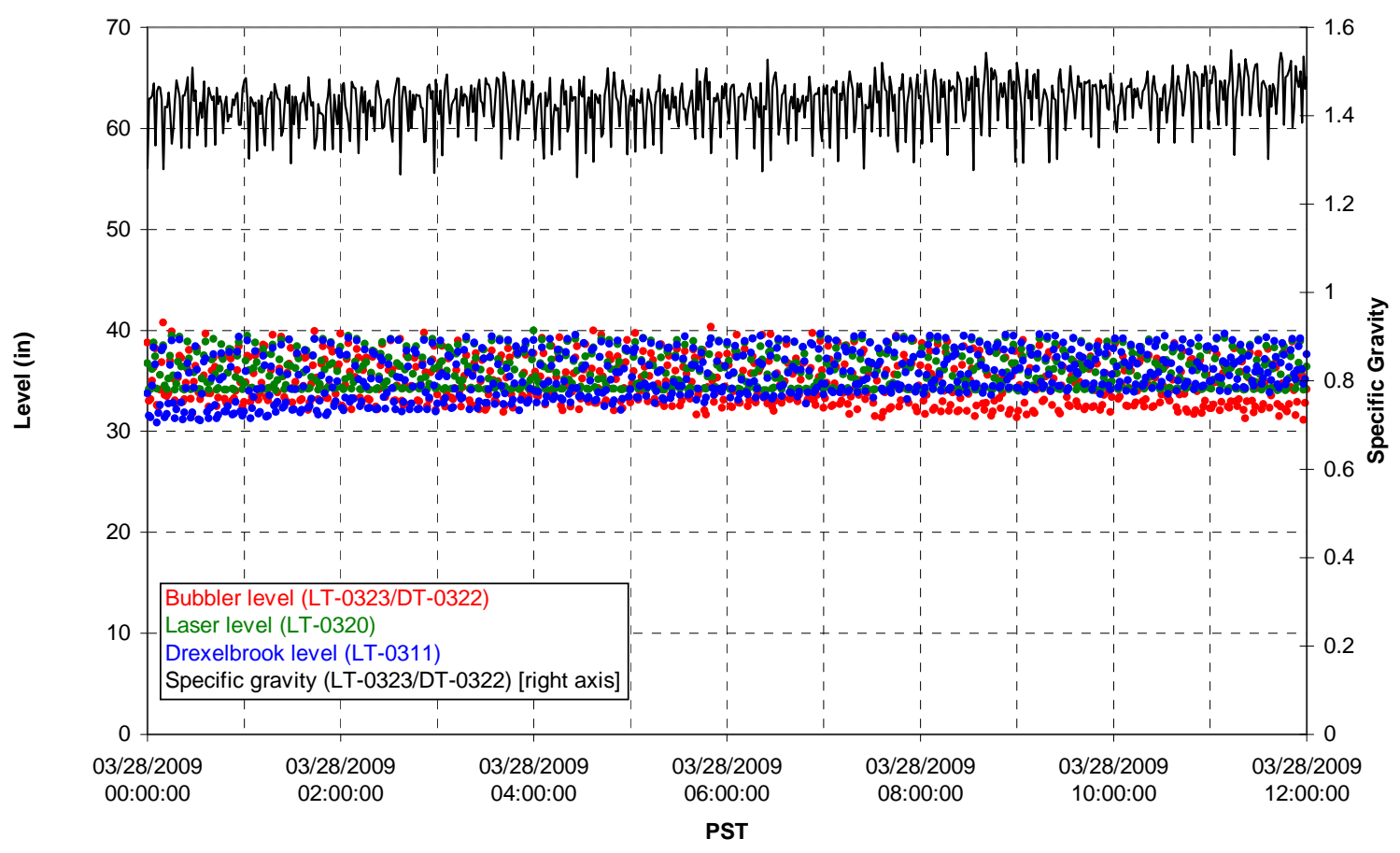

T01A temperatures

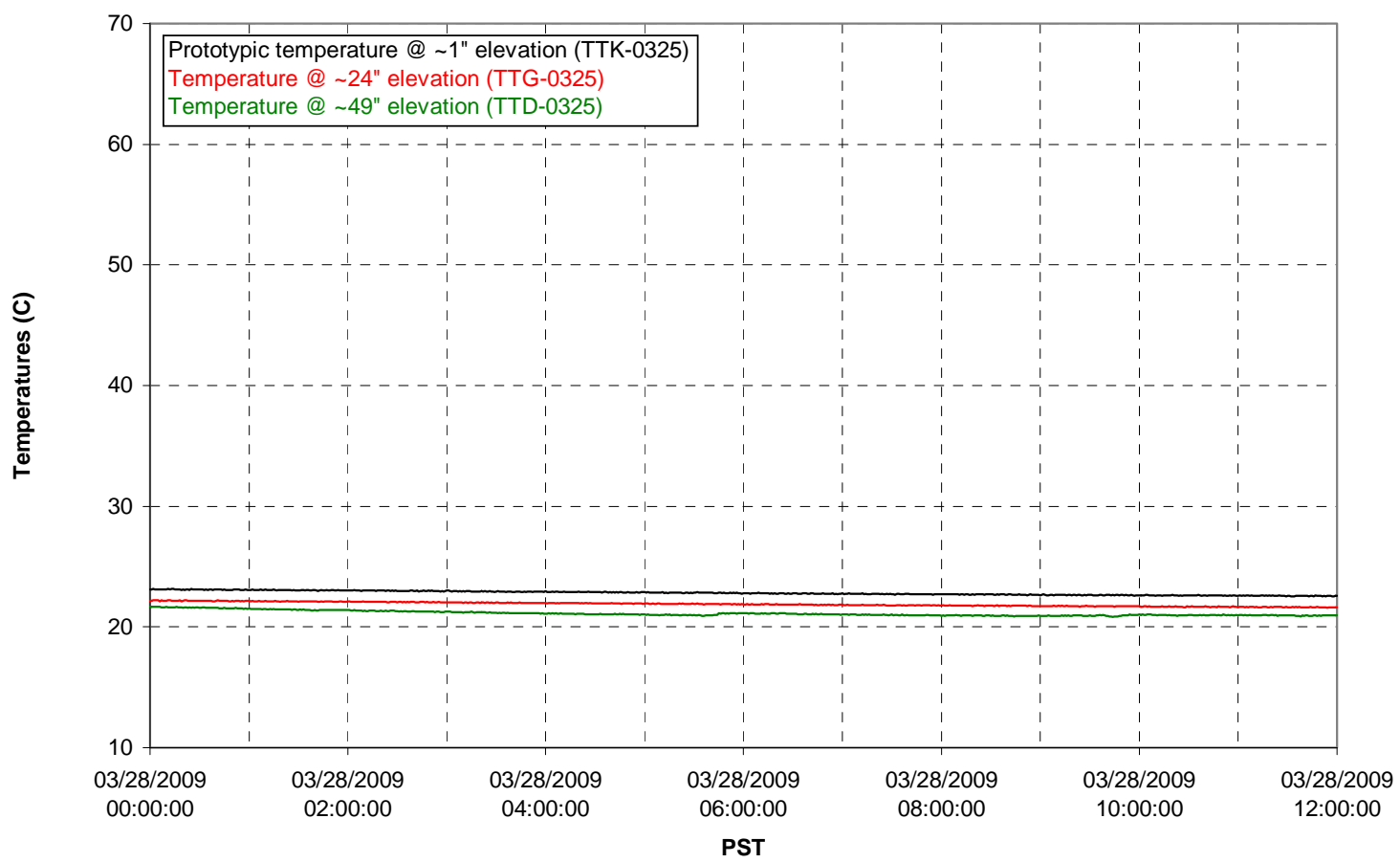


T01B level

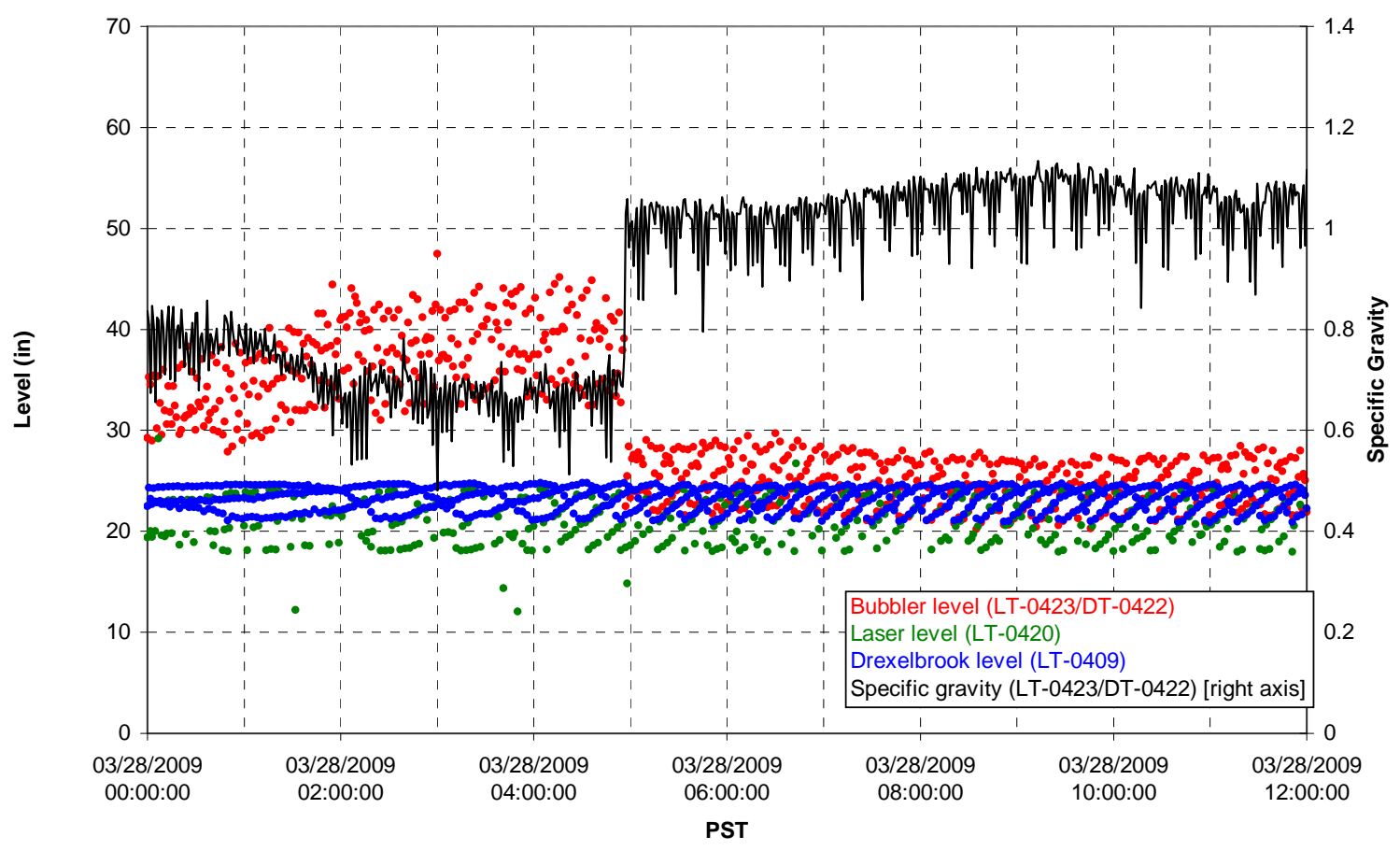

T01B temperatures

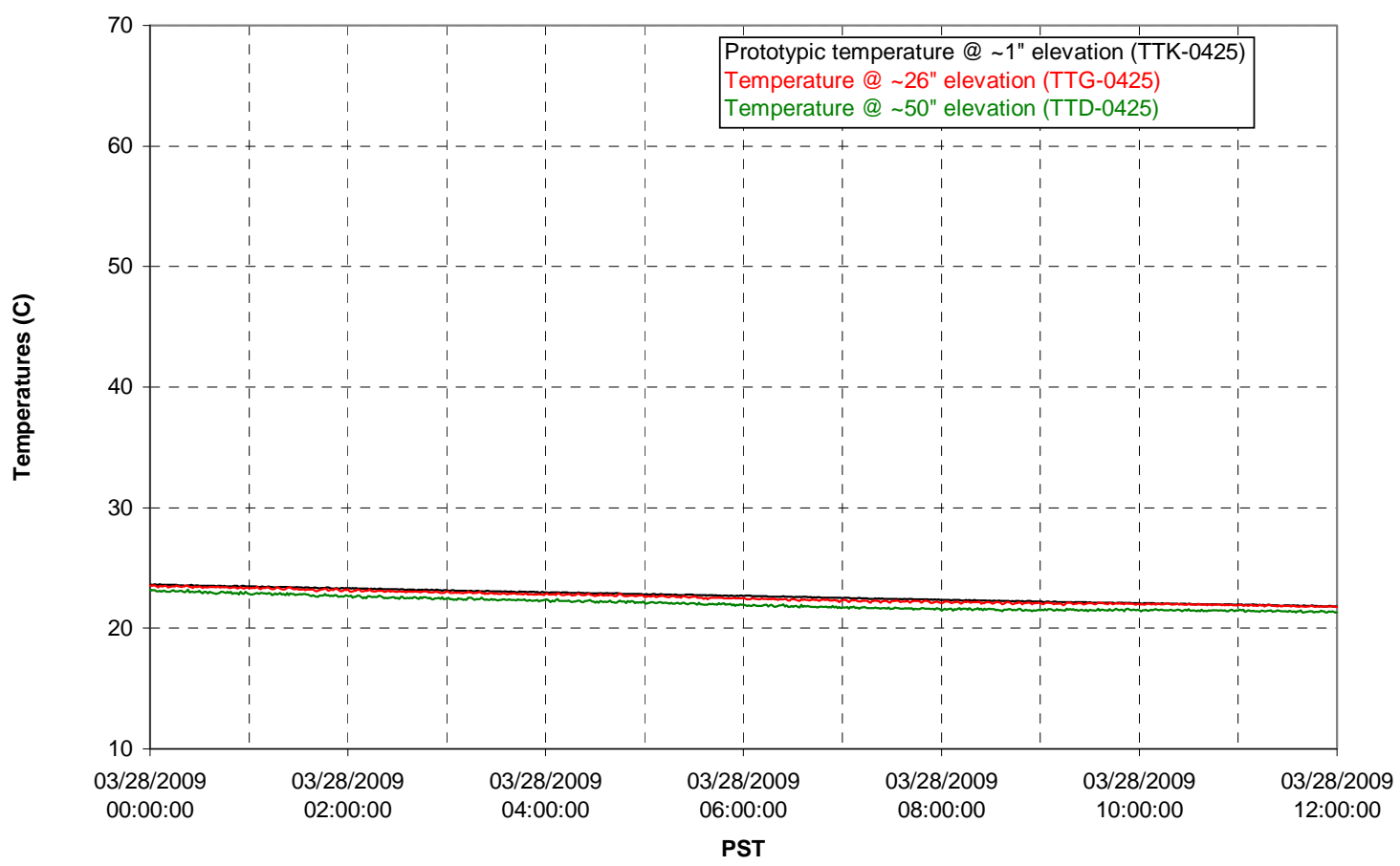


T02A level

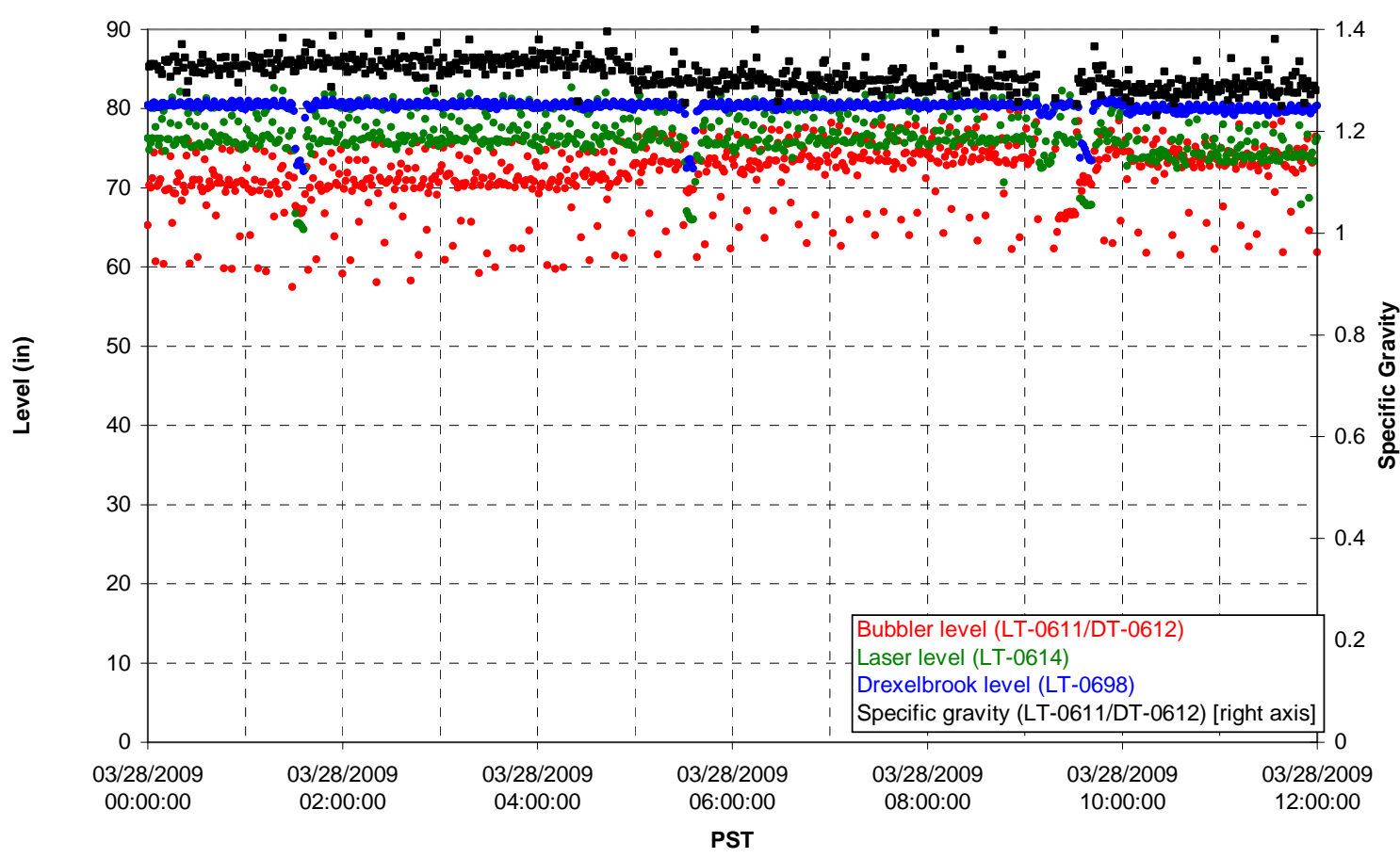

T02A temperatures

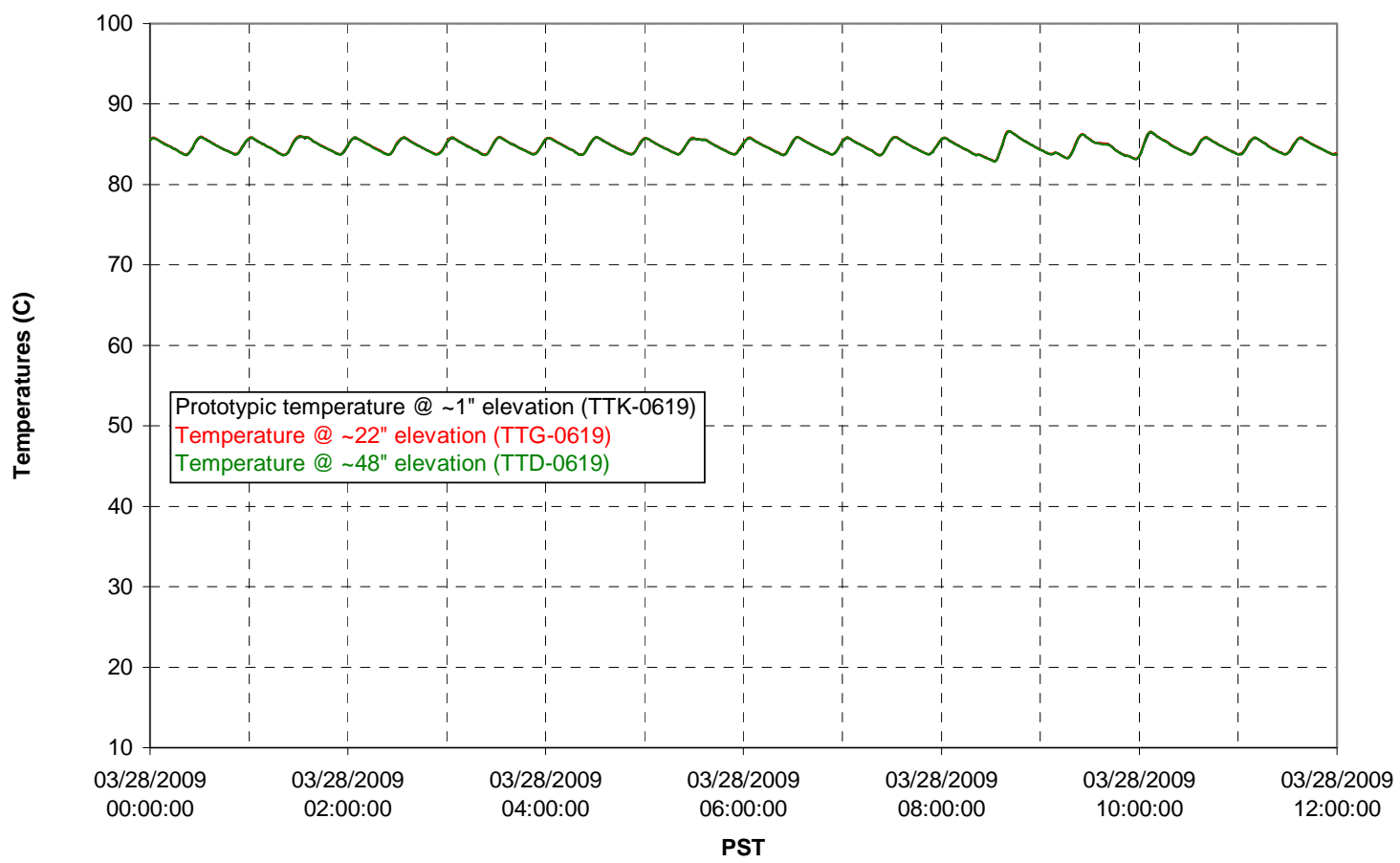


T02A and filter loop temperatures

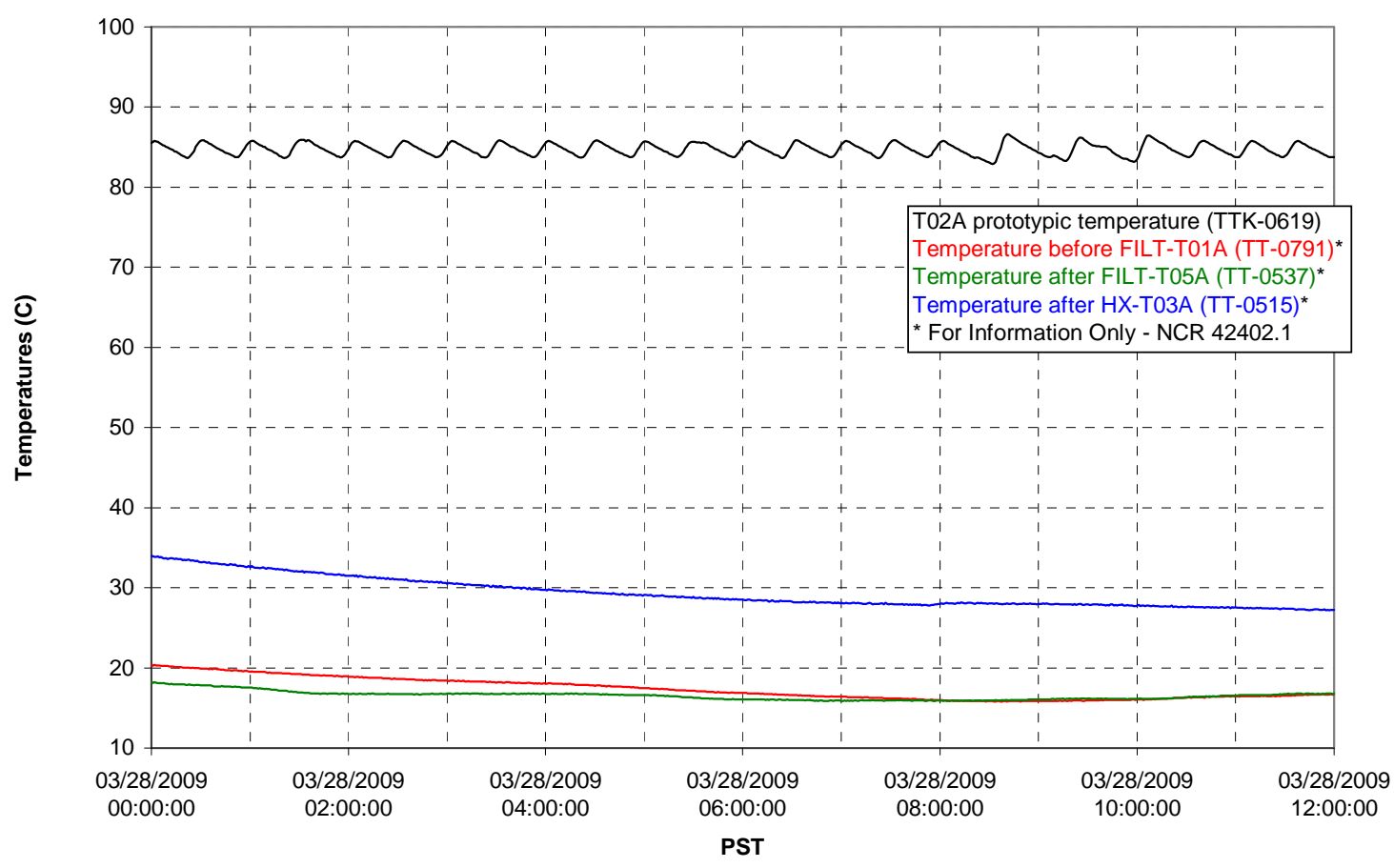

Pump Pressures and Flow

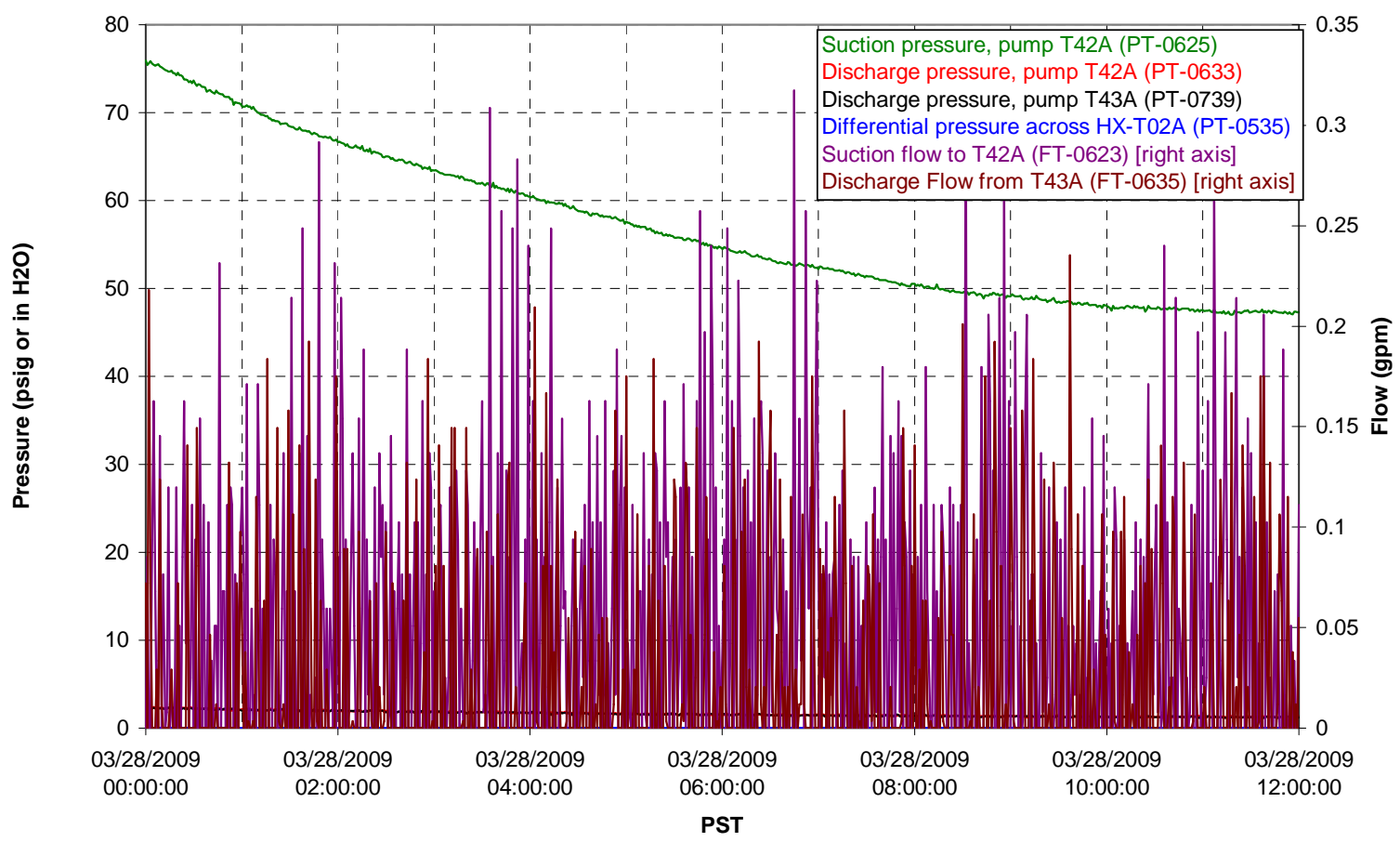


Axial pressure drop

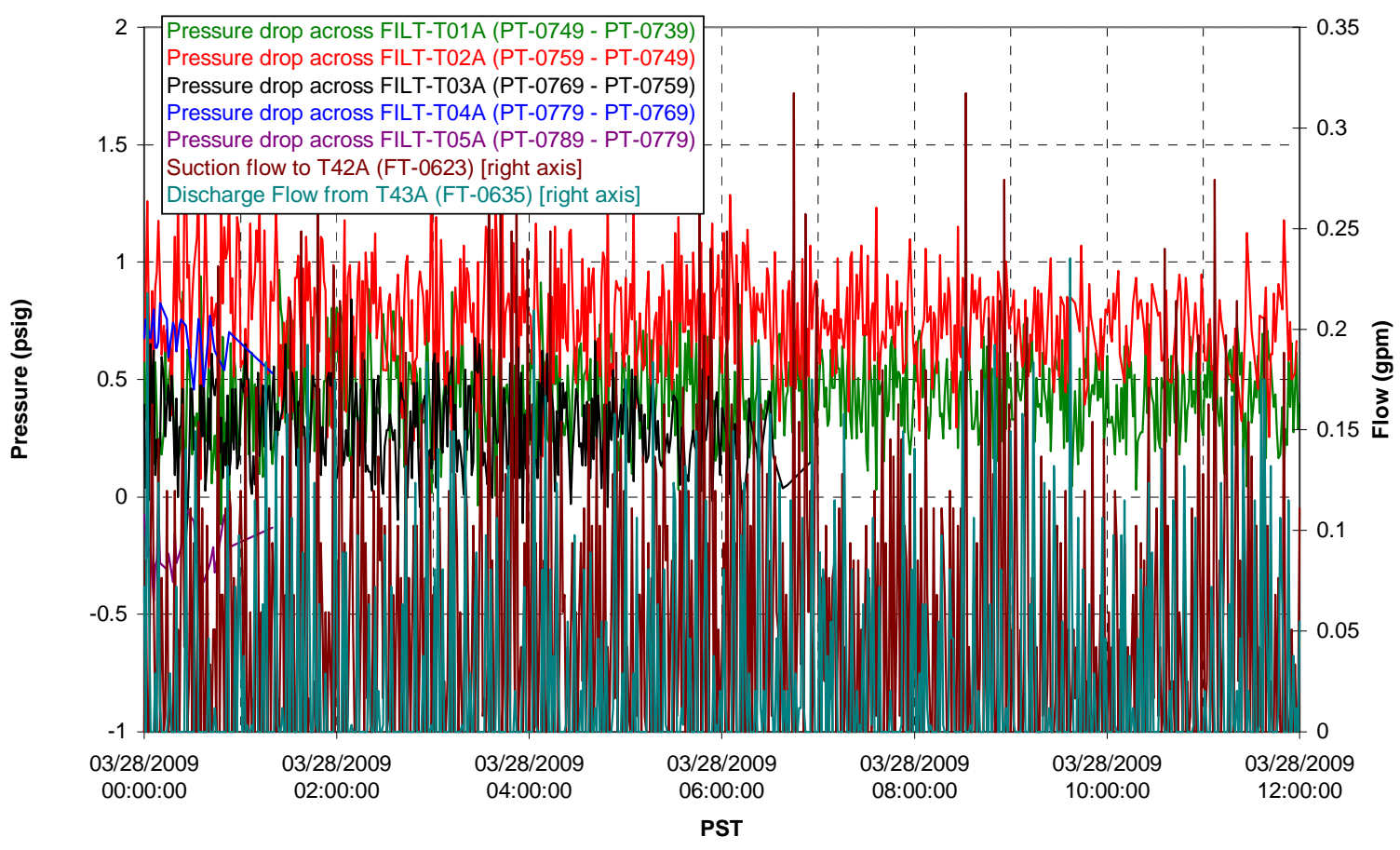

Permeate flow rates

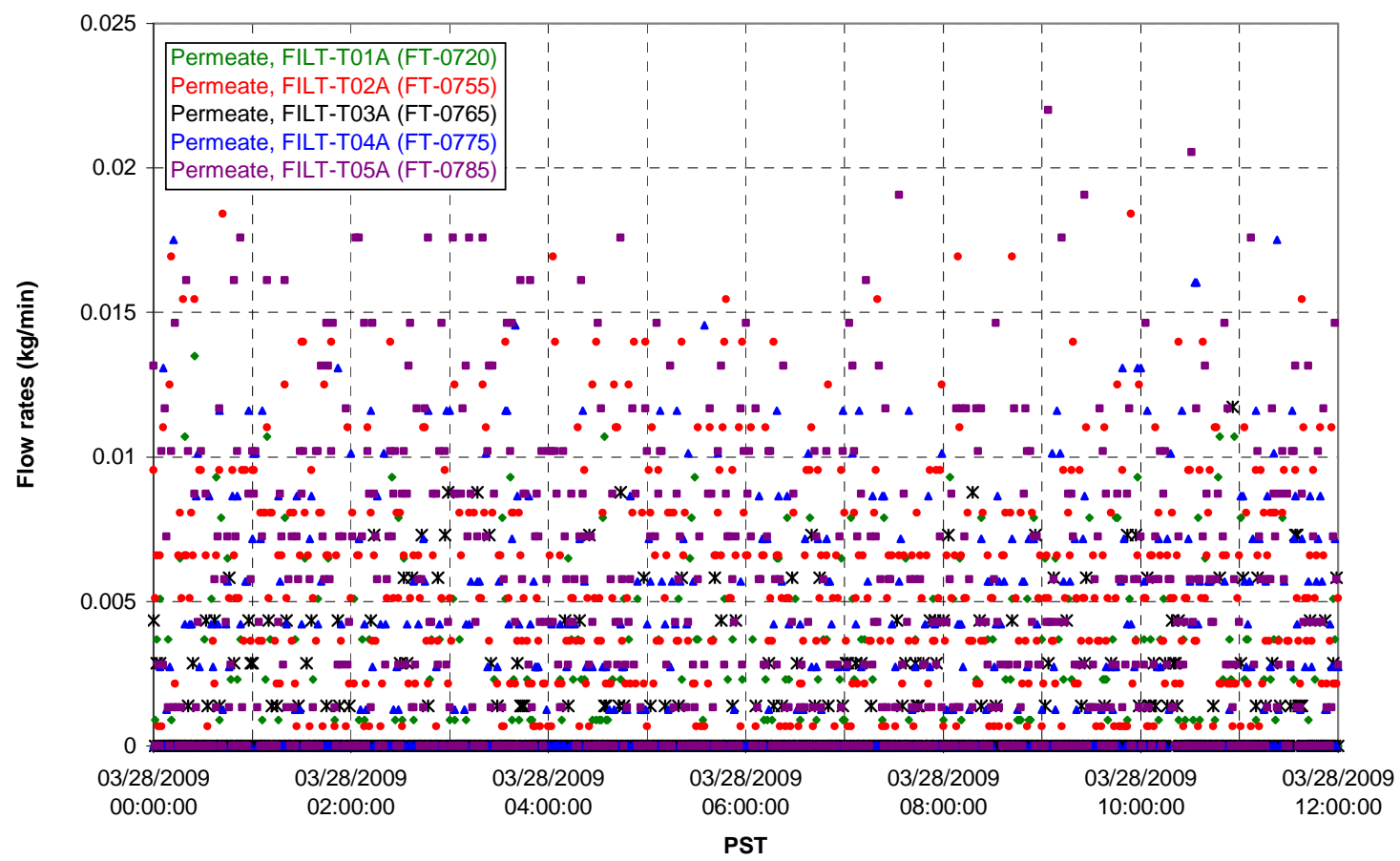


T02A Inner Temperature Tree

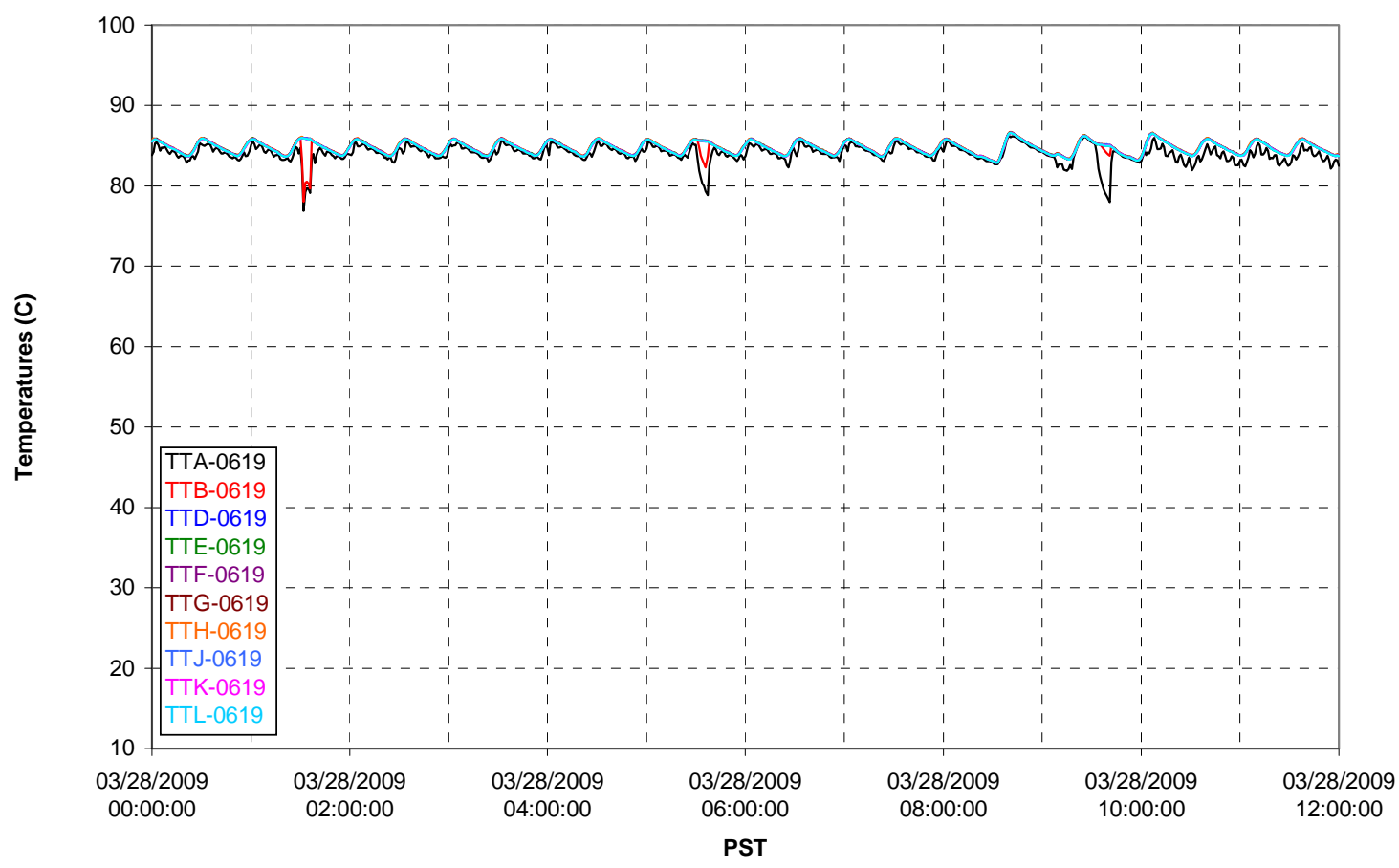

T02A Outer Temperature Tree

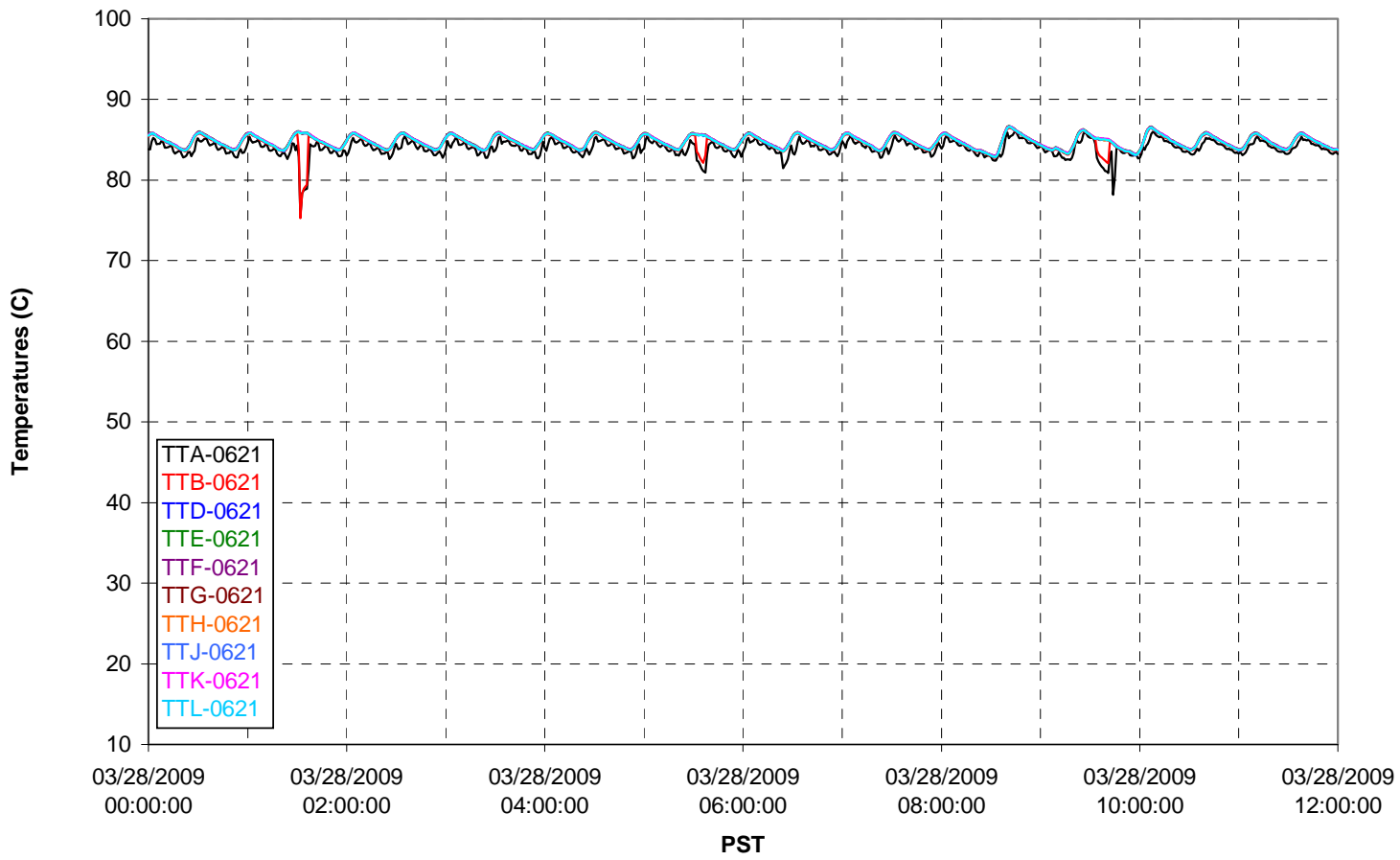


T02A temperatures

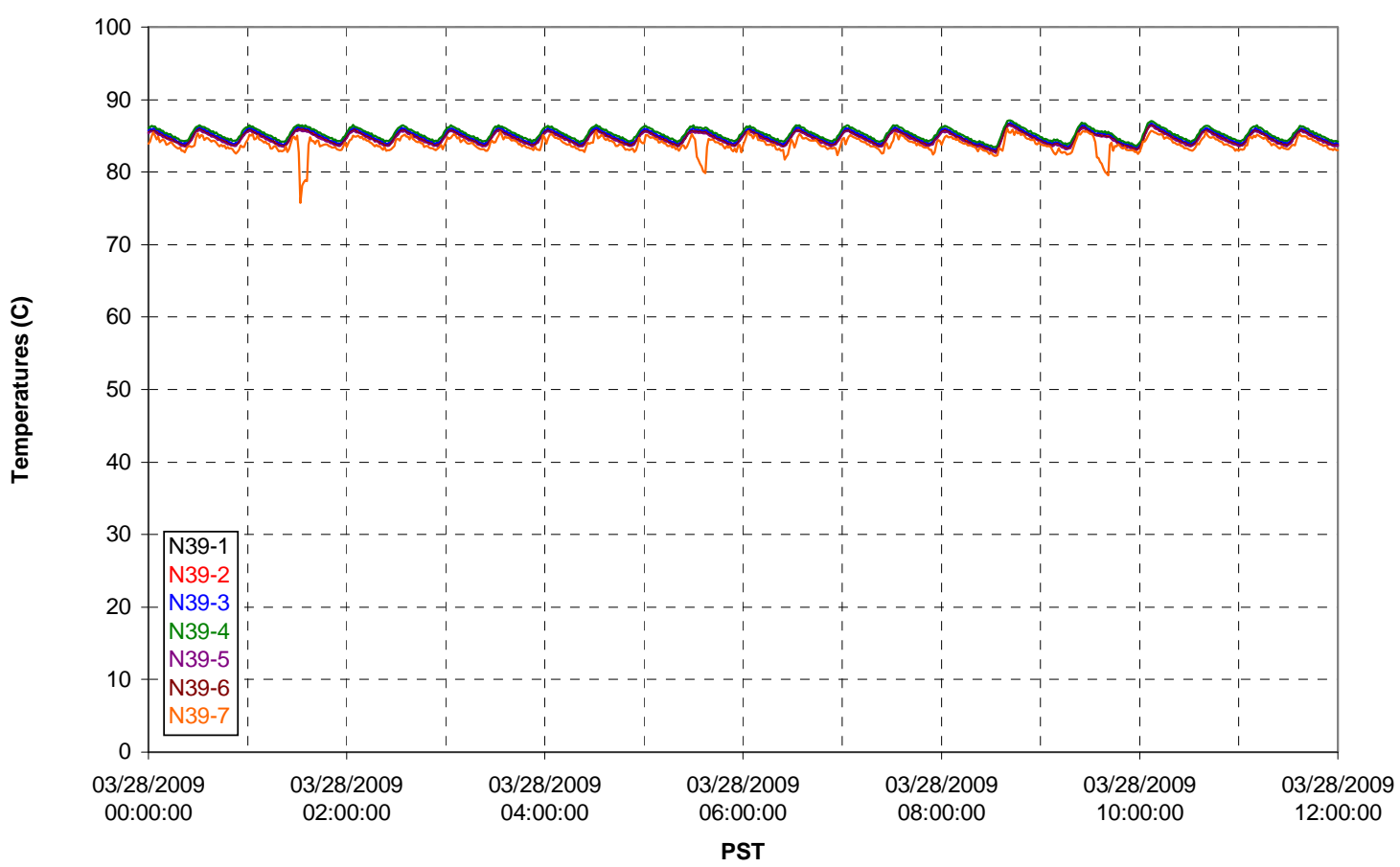

T02A temperatures

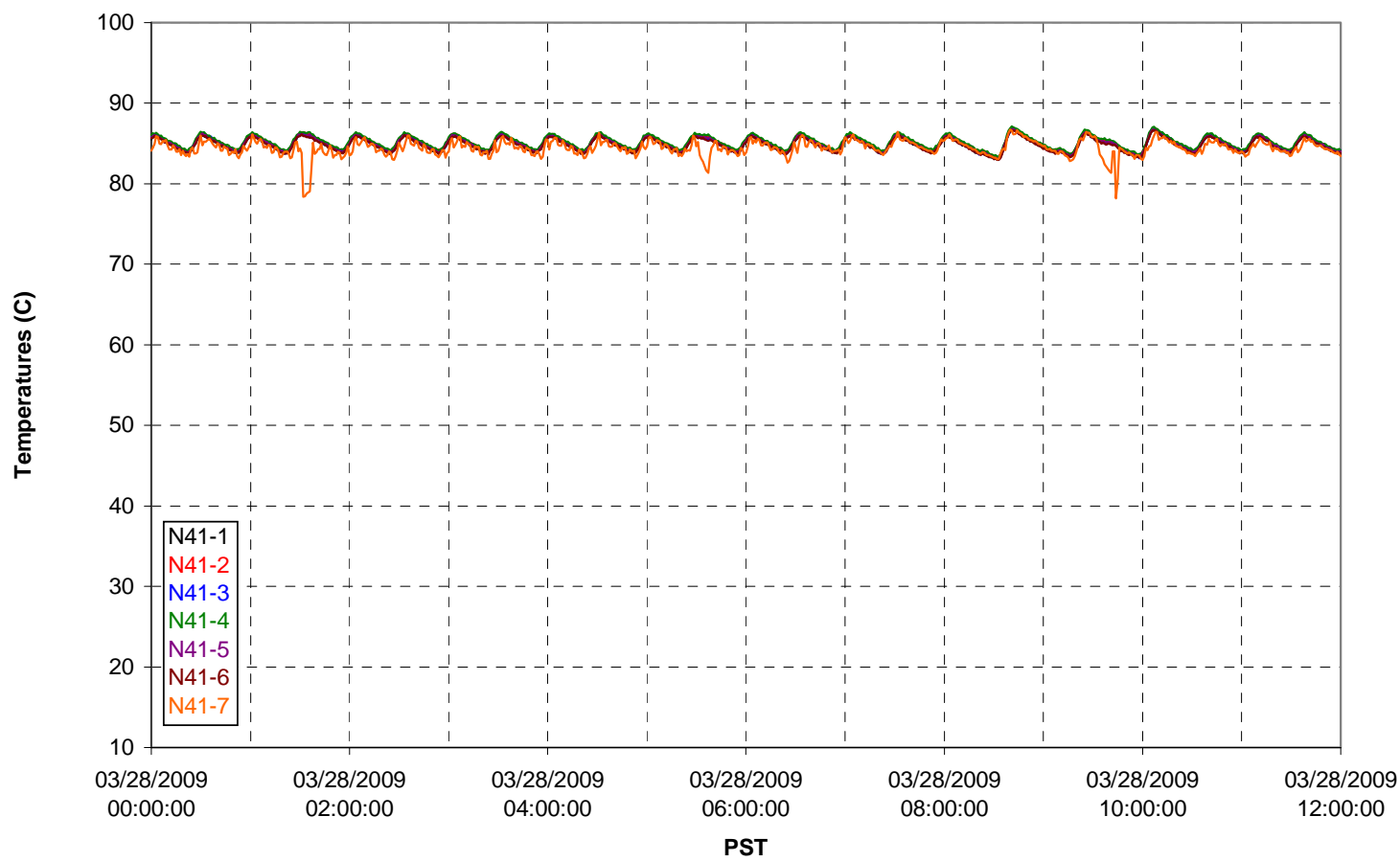


T02A temperatures

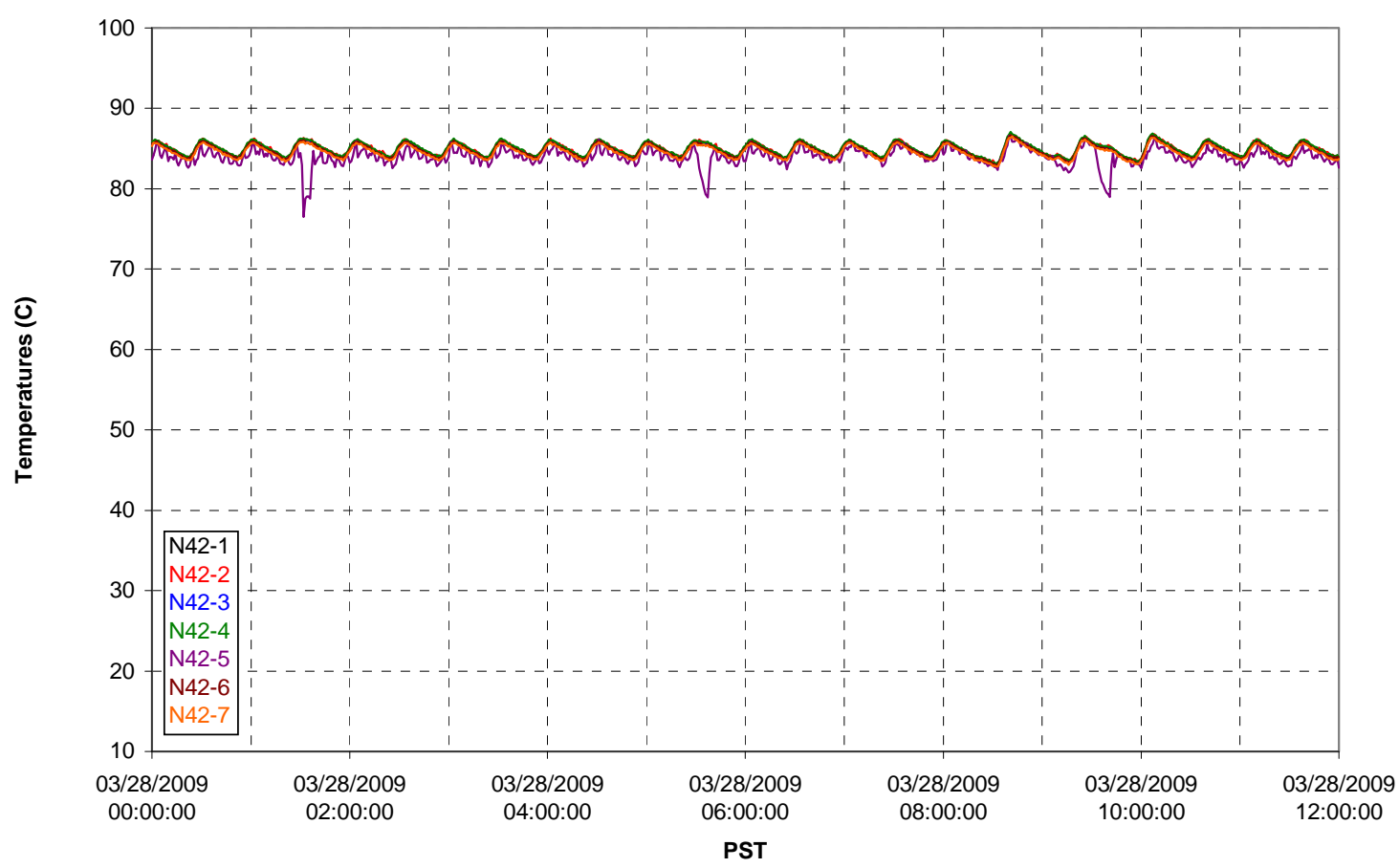

T02A temperatures

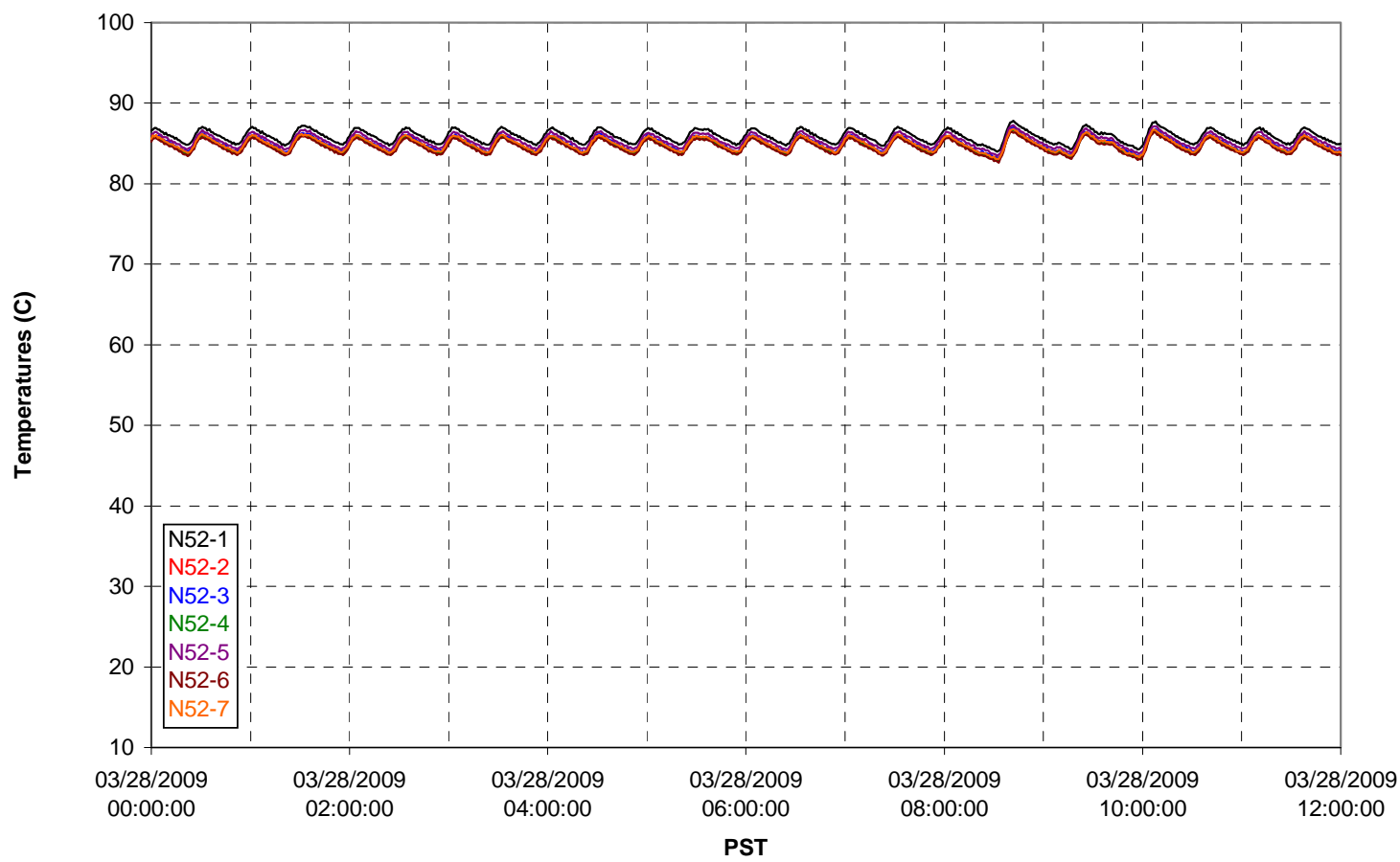


T02A Heating and Cooling

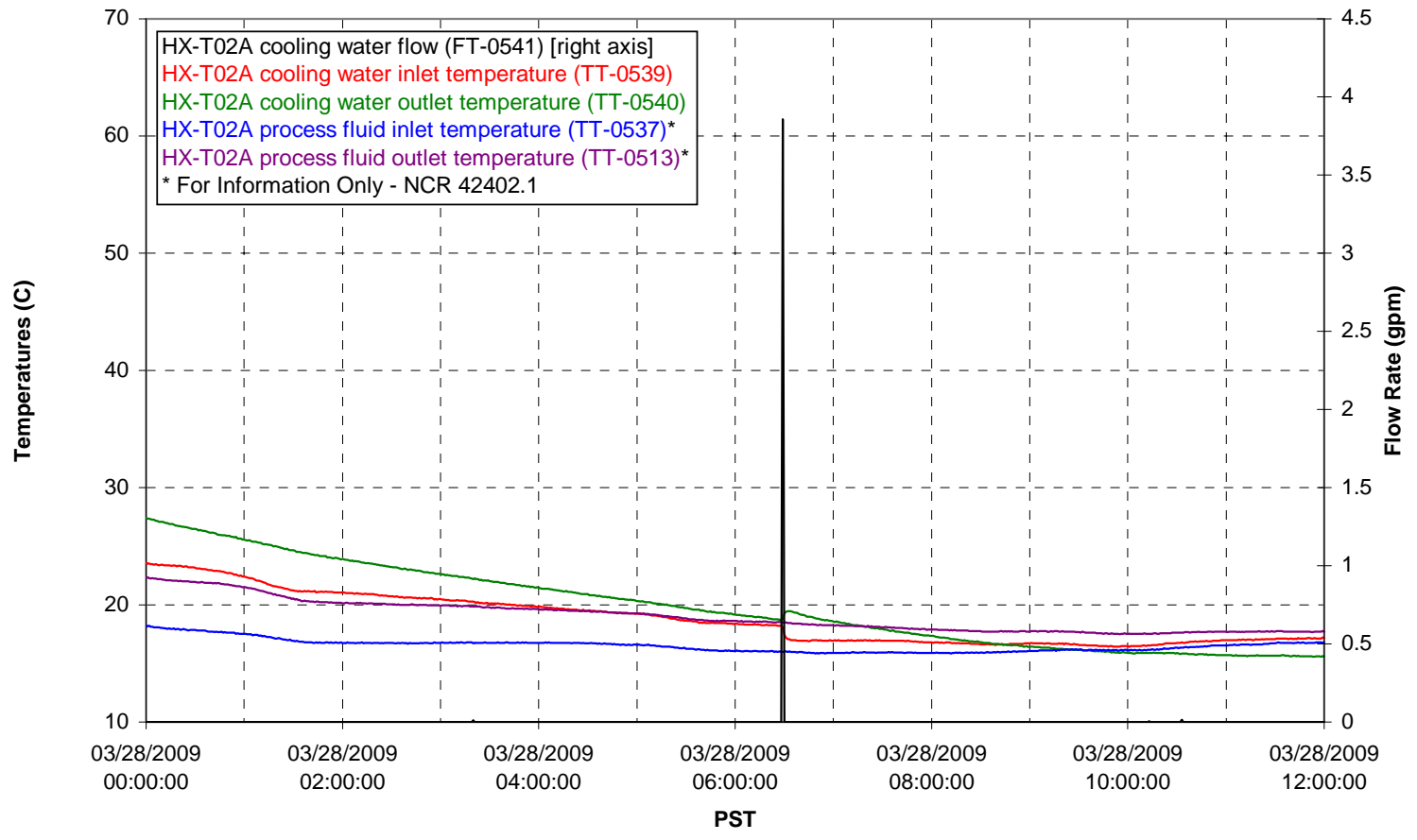

Pump Operation

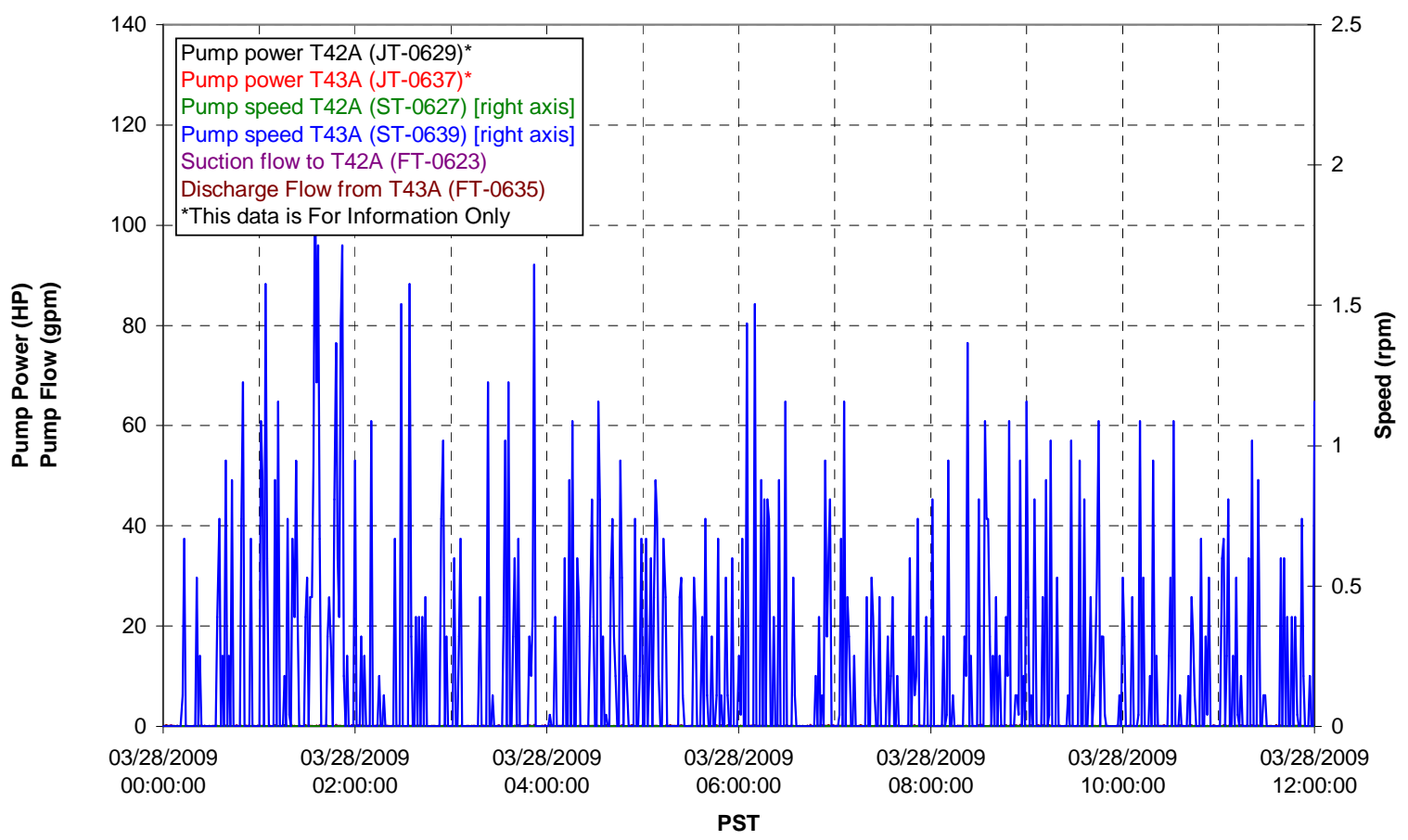


Pulsepot UFP-PP-T01A

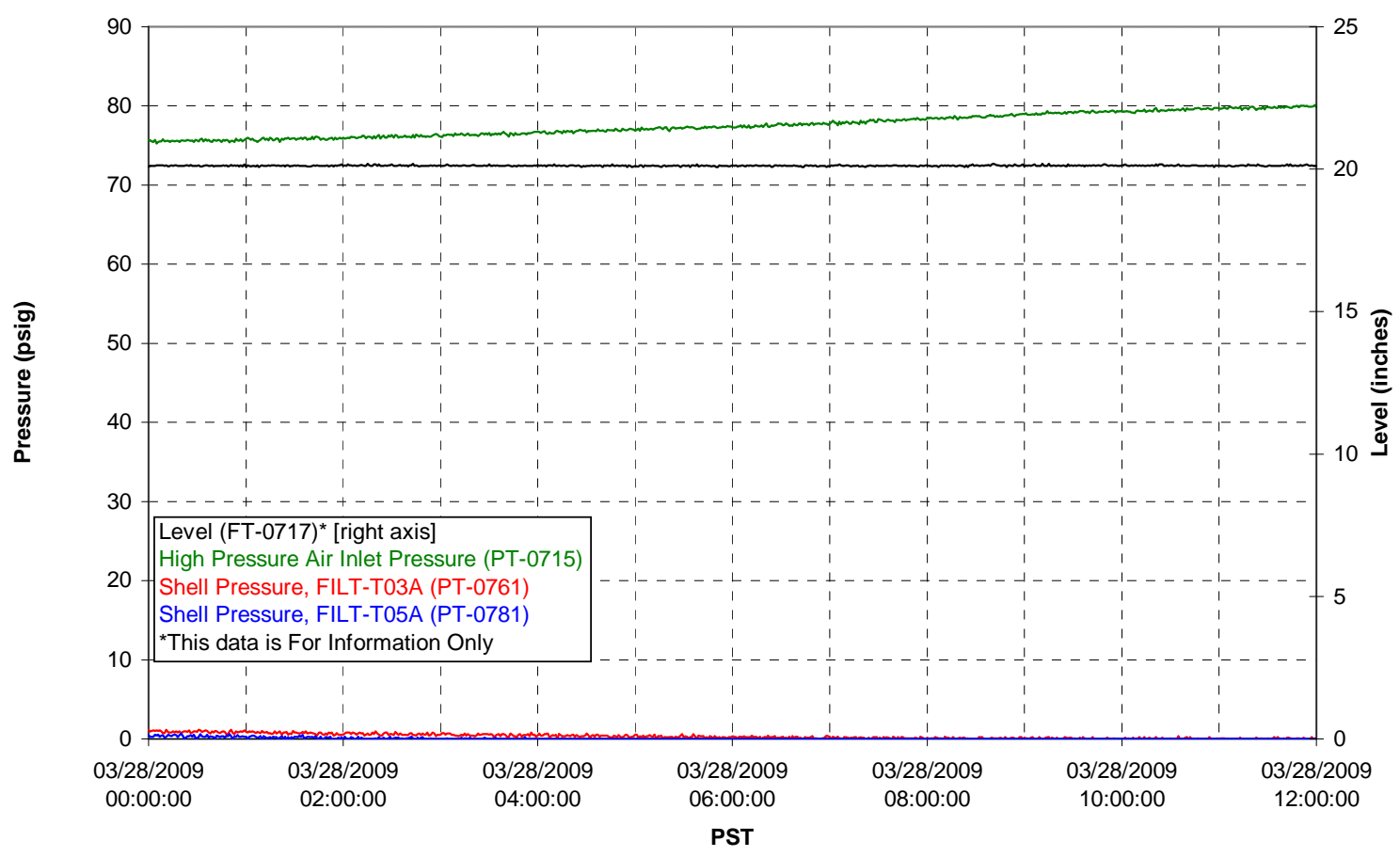

Pulsepot UFP-PP-T02A

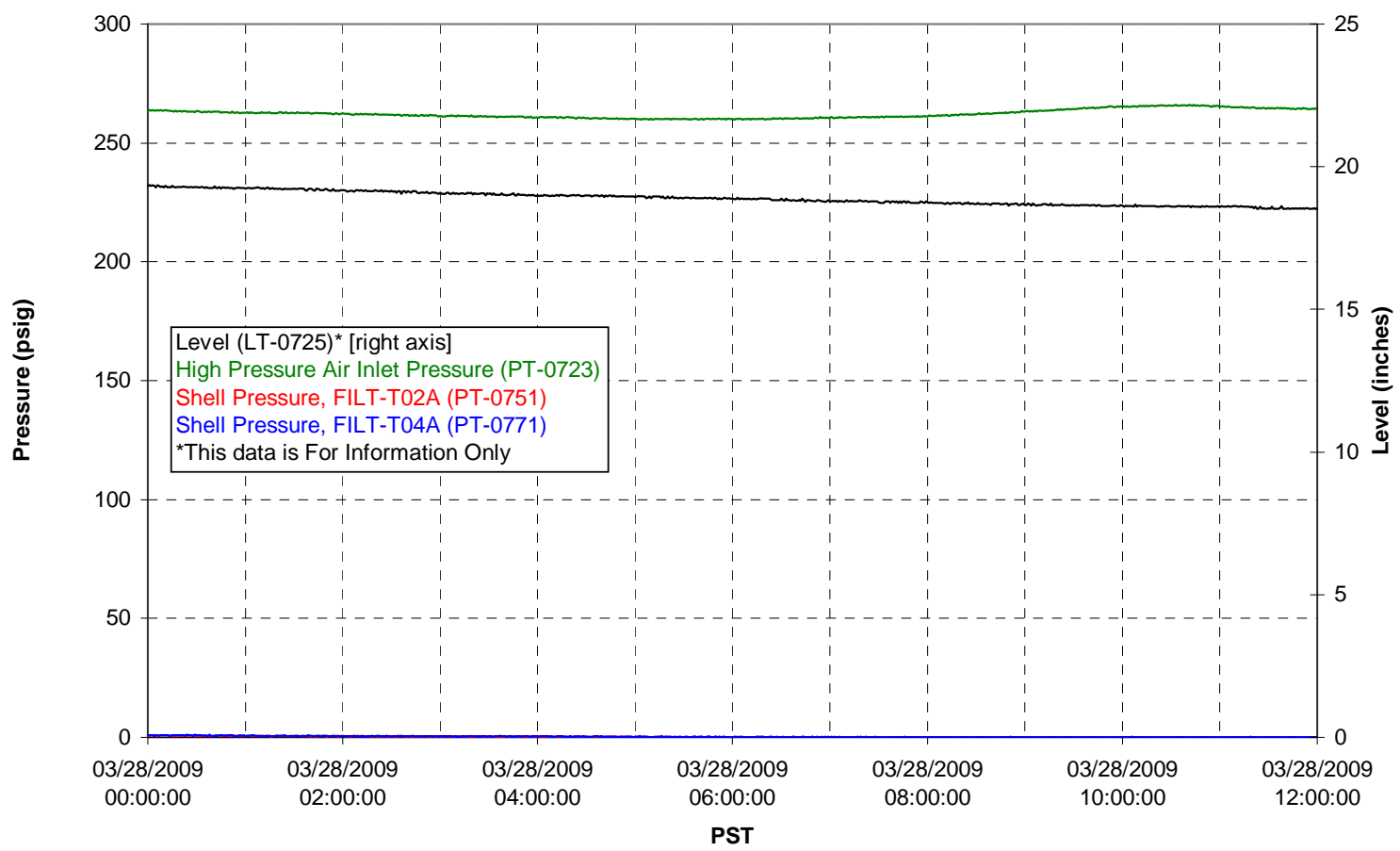


Pulsepot UFP-PP-T03A

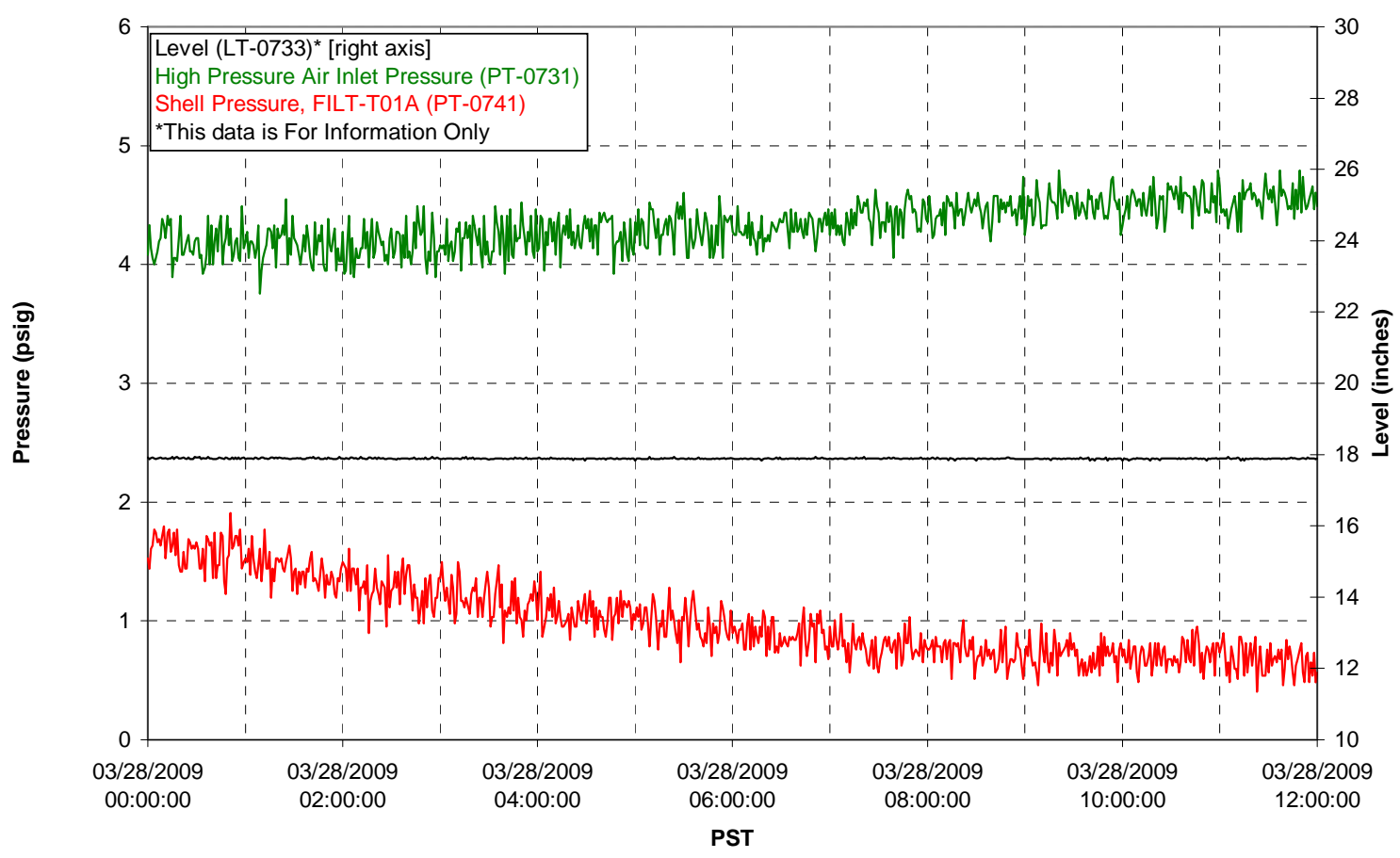

Pulsepot Levels

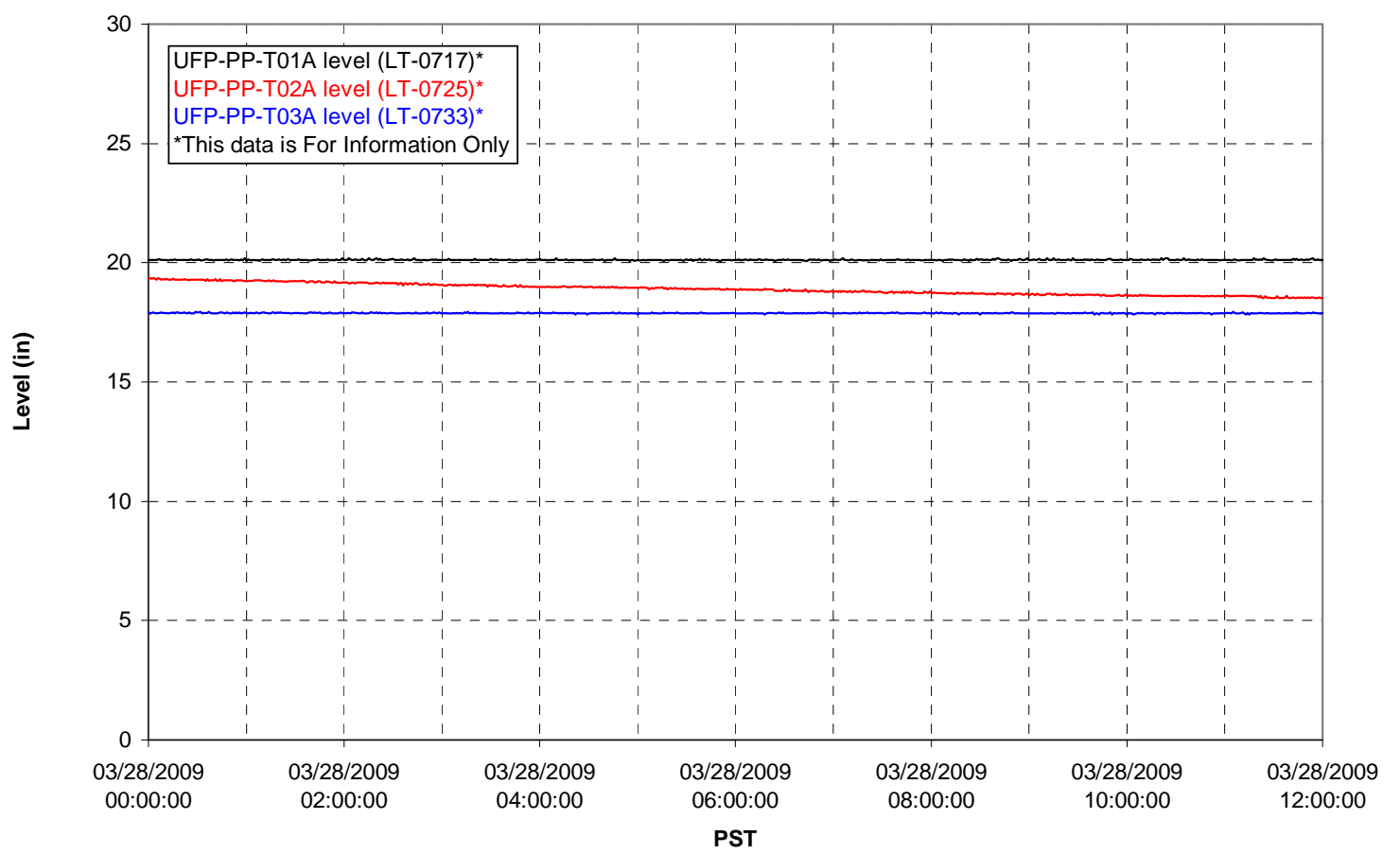


Filter UFP-FILT-T01A

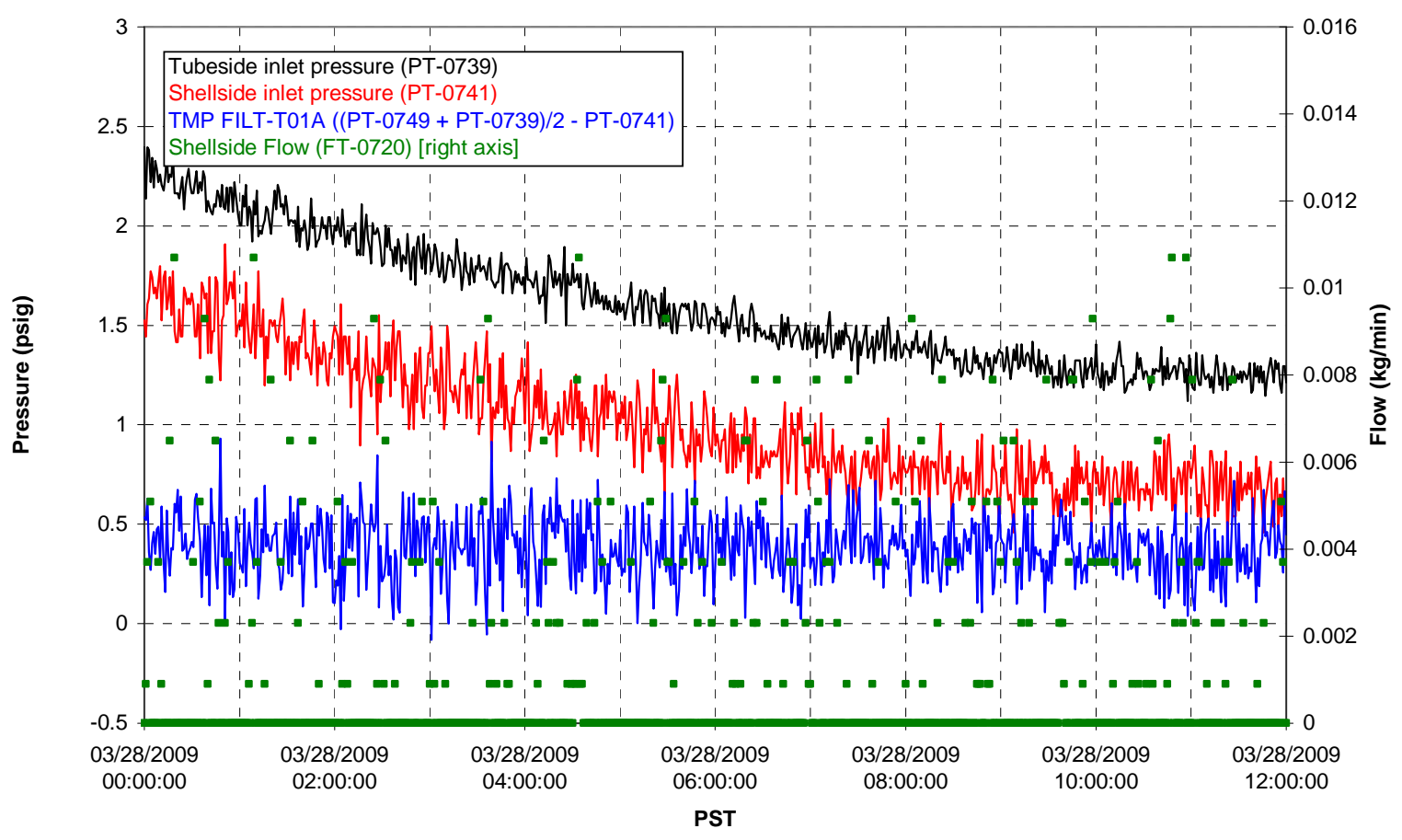

Filter UFP-FILT-T02A

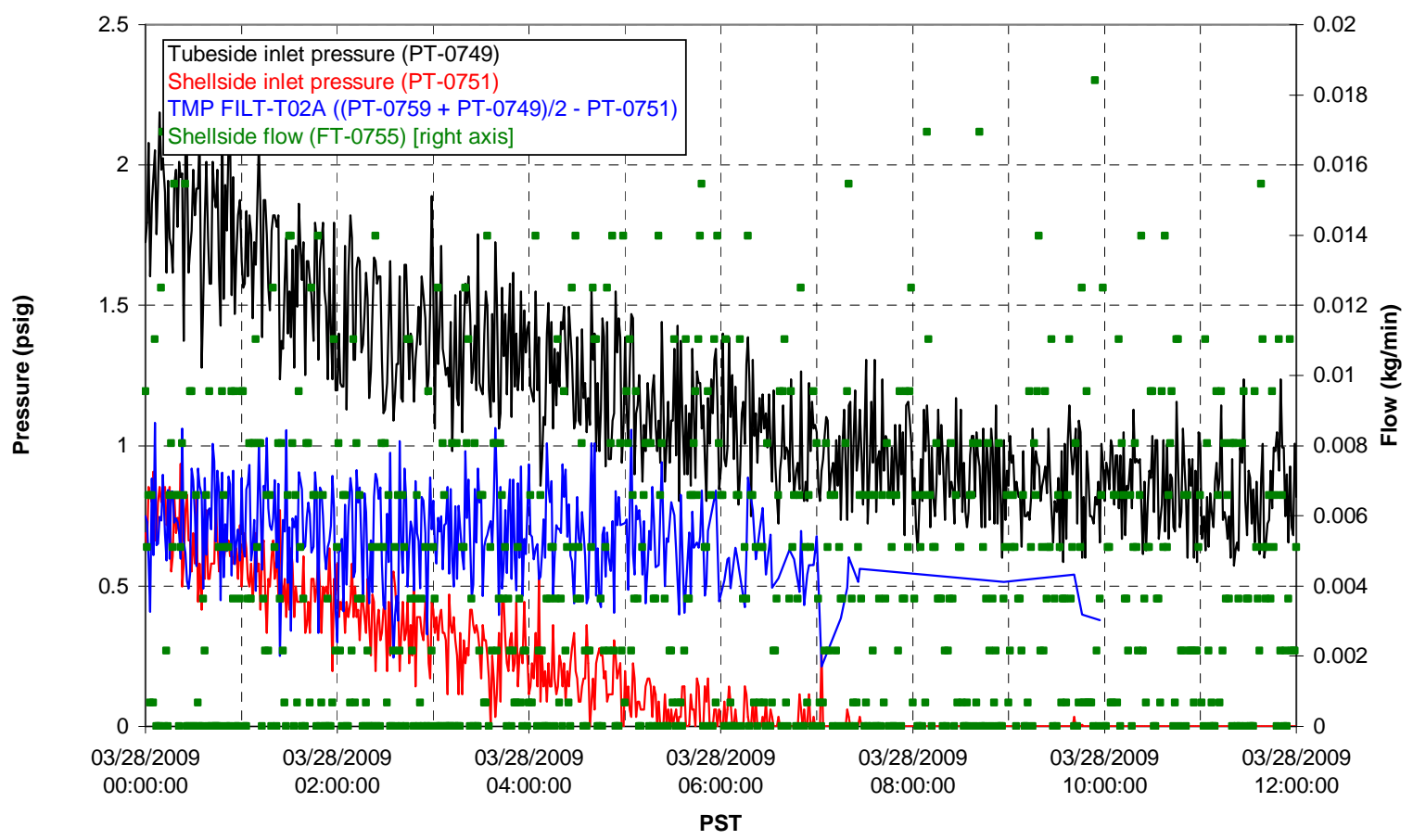


Filter UFP-FILT-T03A

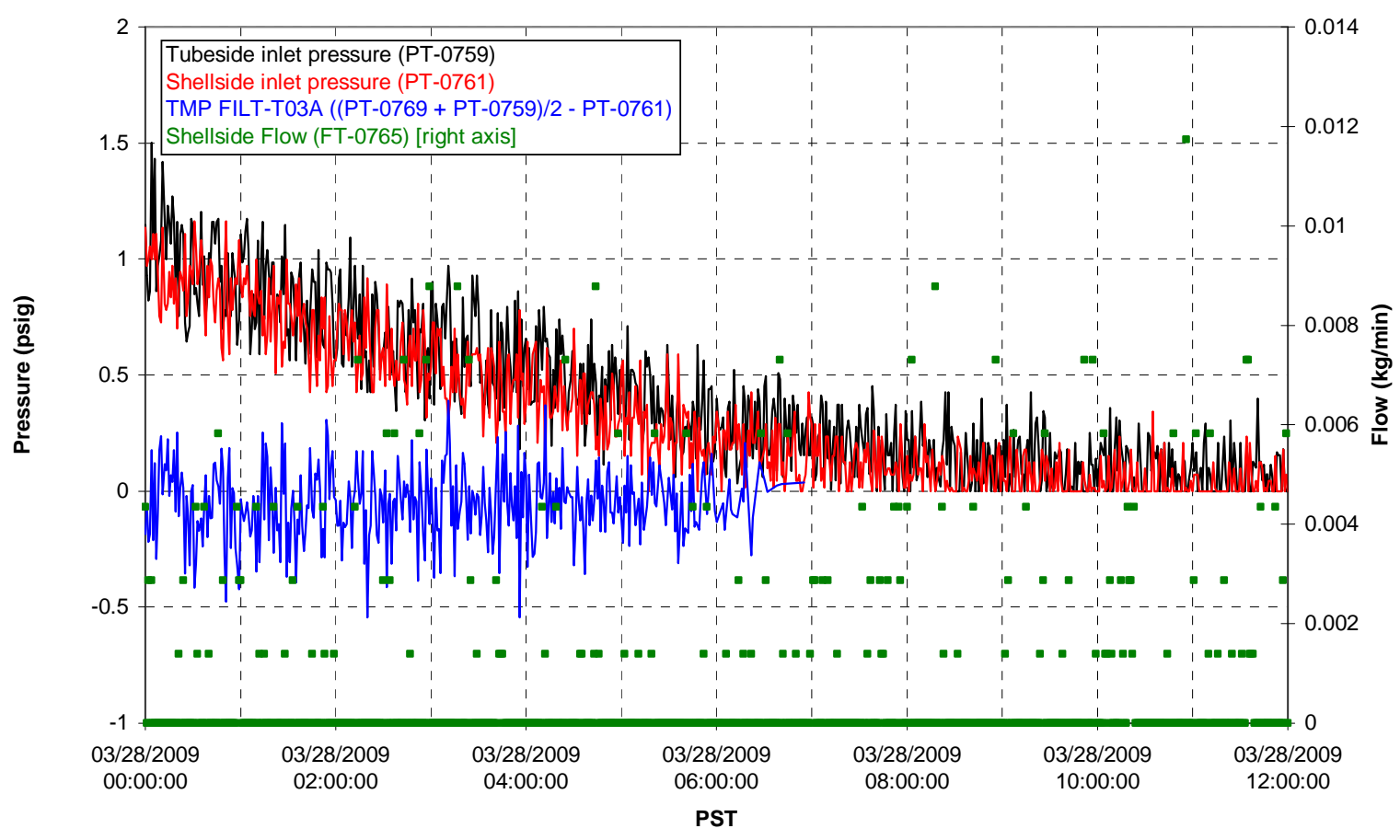

Filter UFP-FILT-T04A

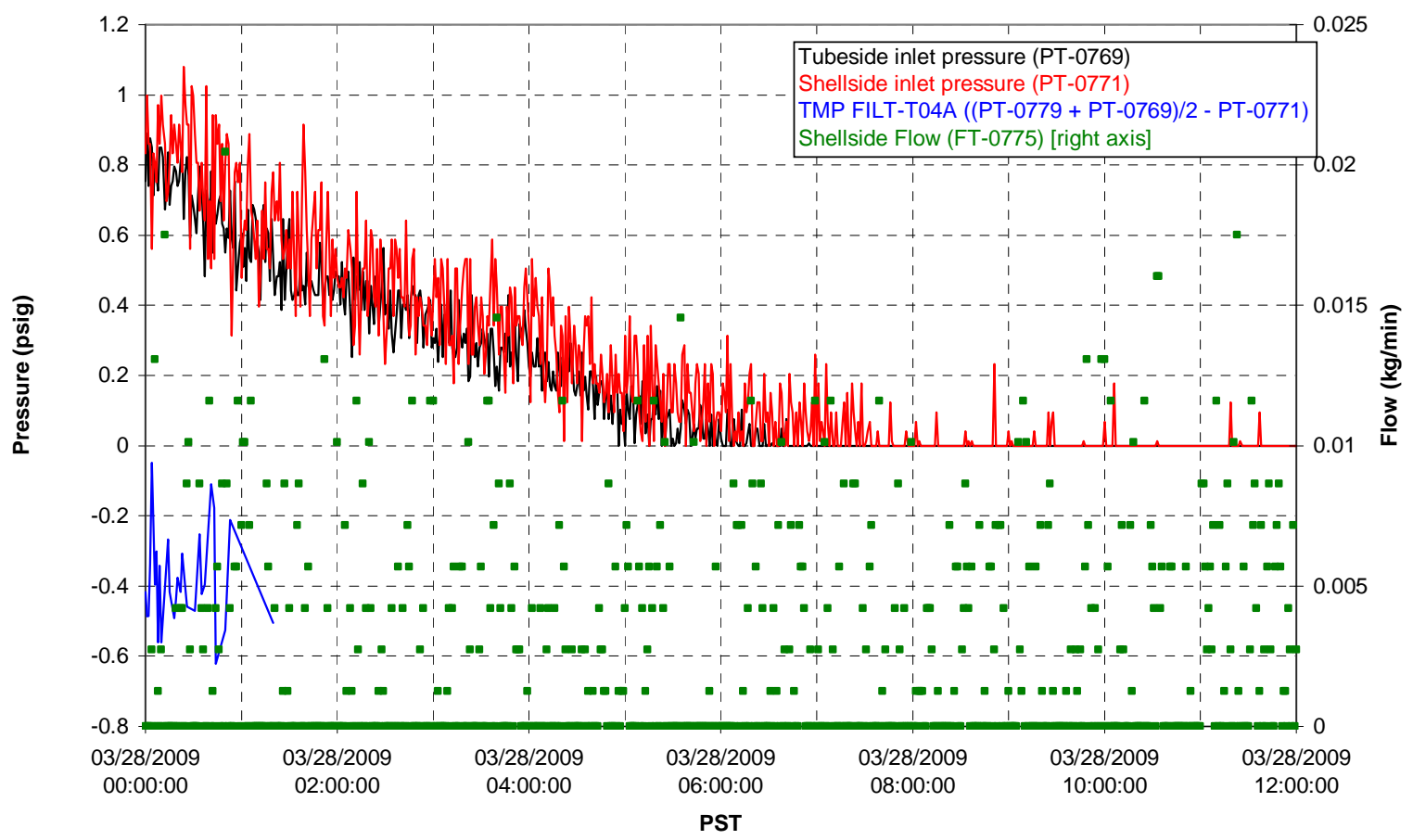


Filter UFP-FILT-T05A

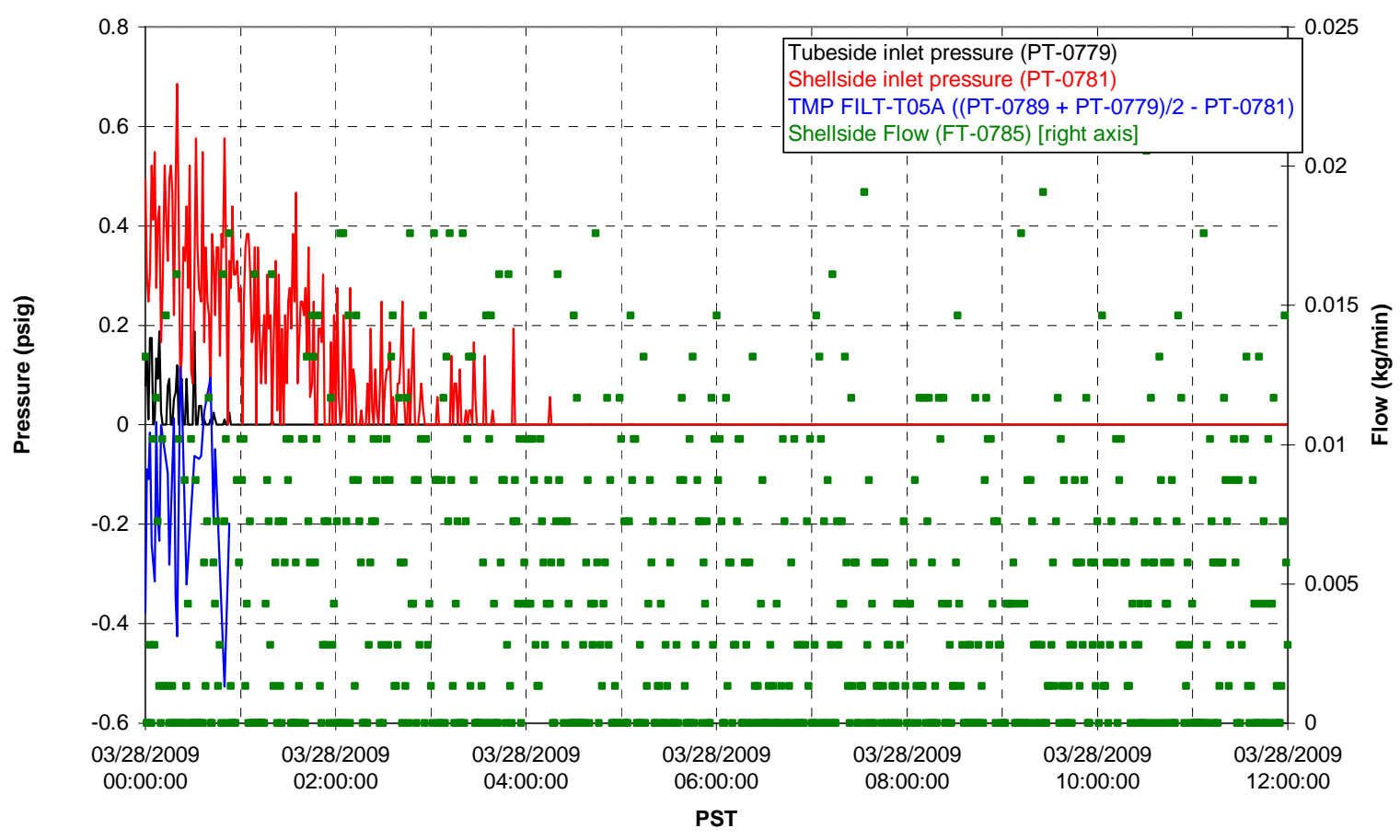

Chemical Flow

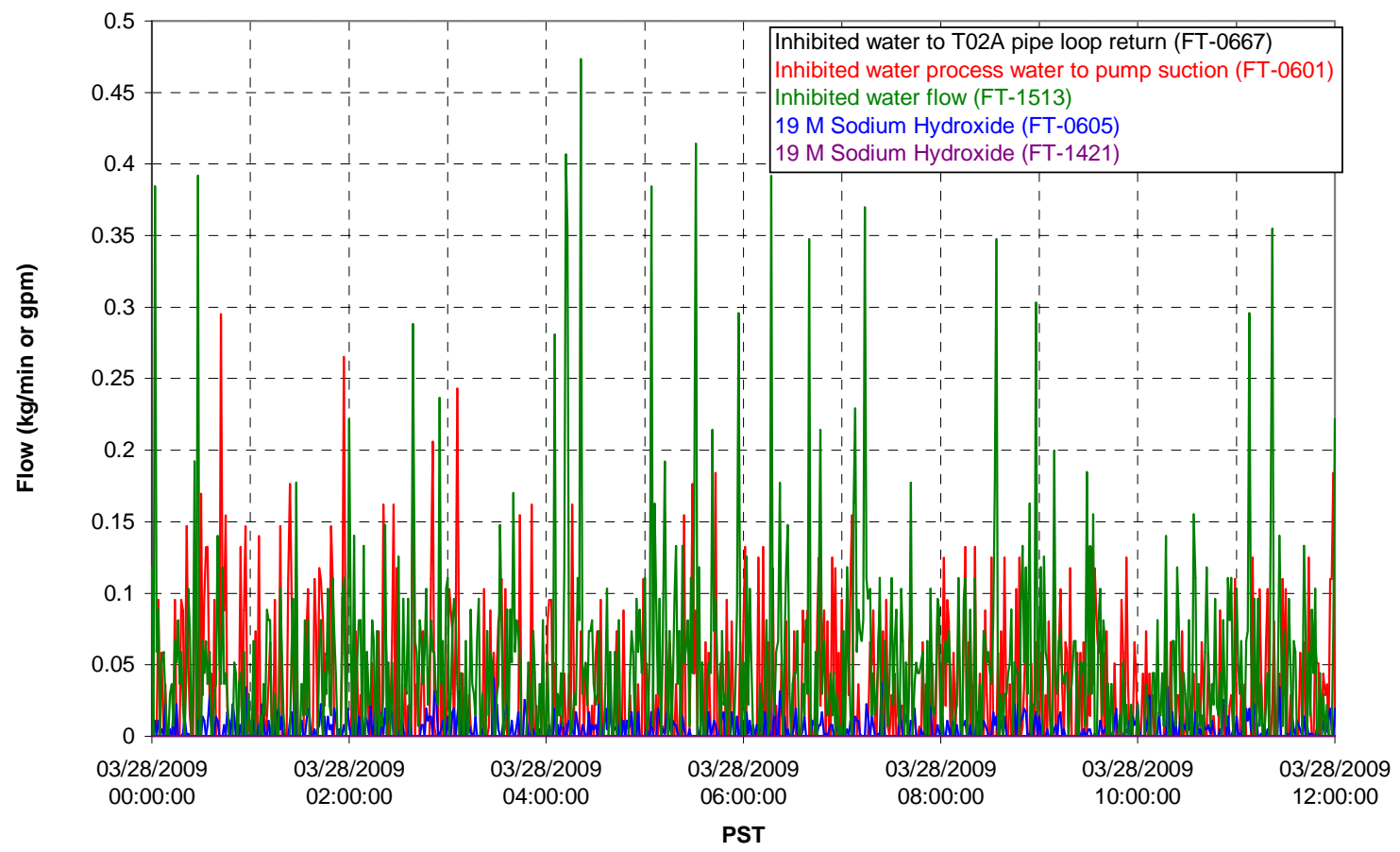




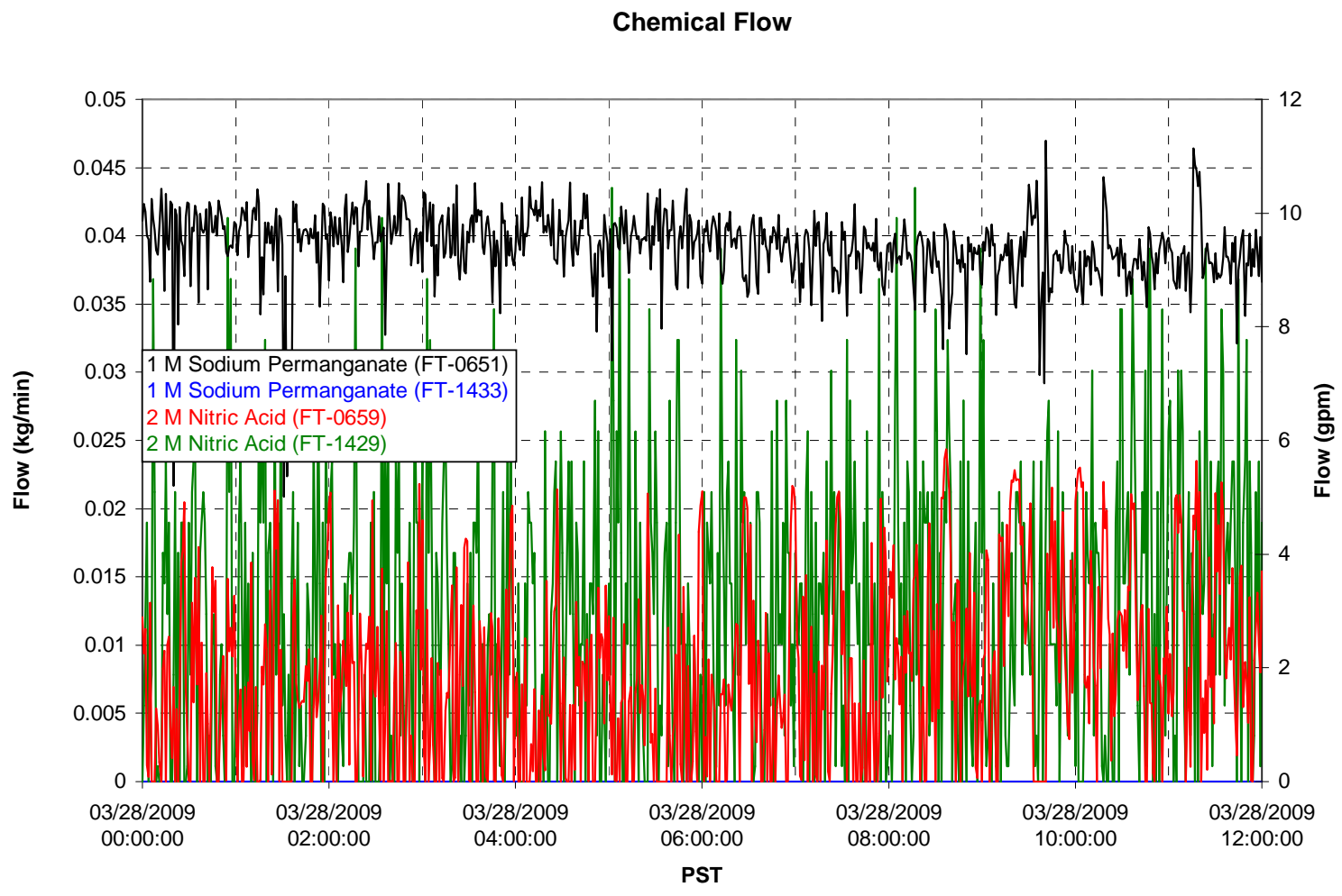

Air Flows

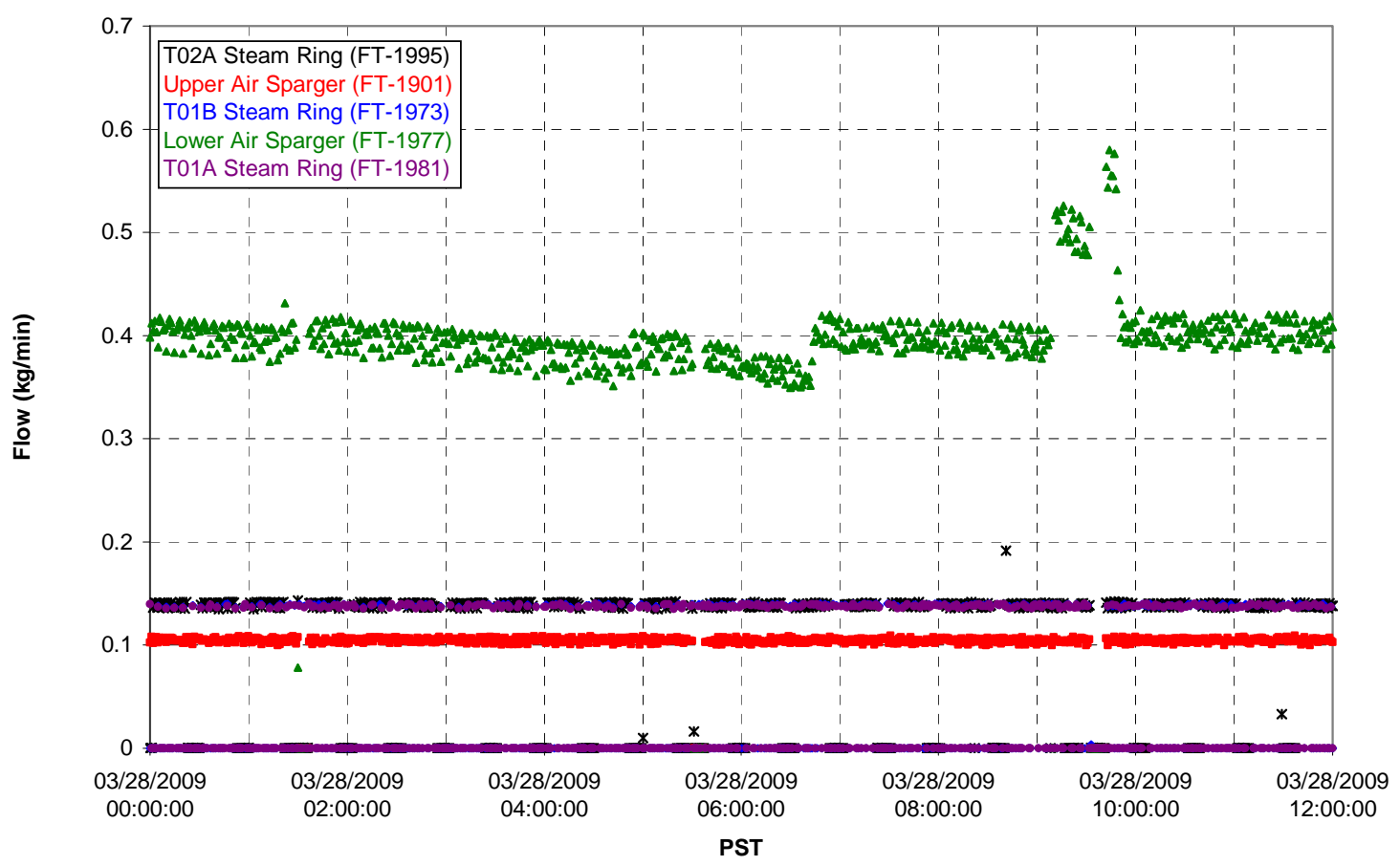


T02A Steam

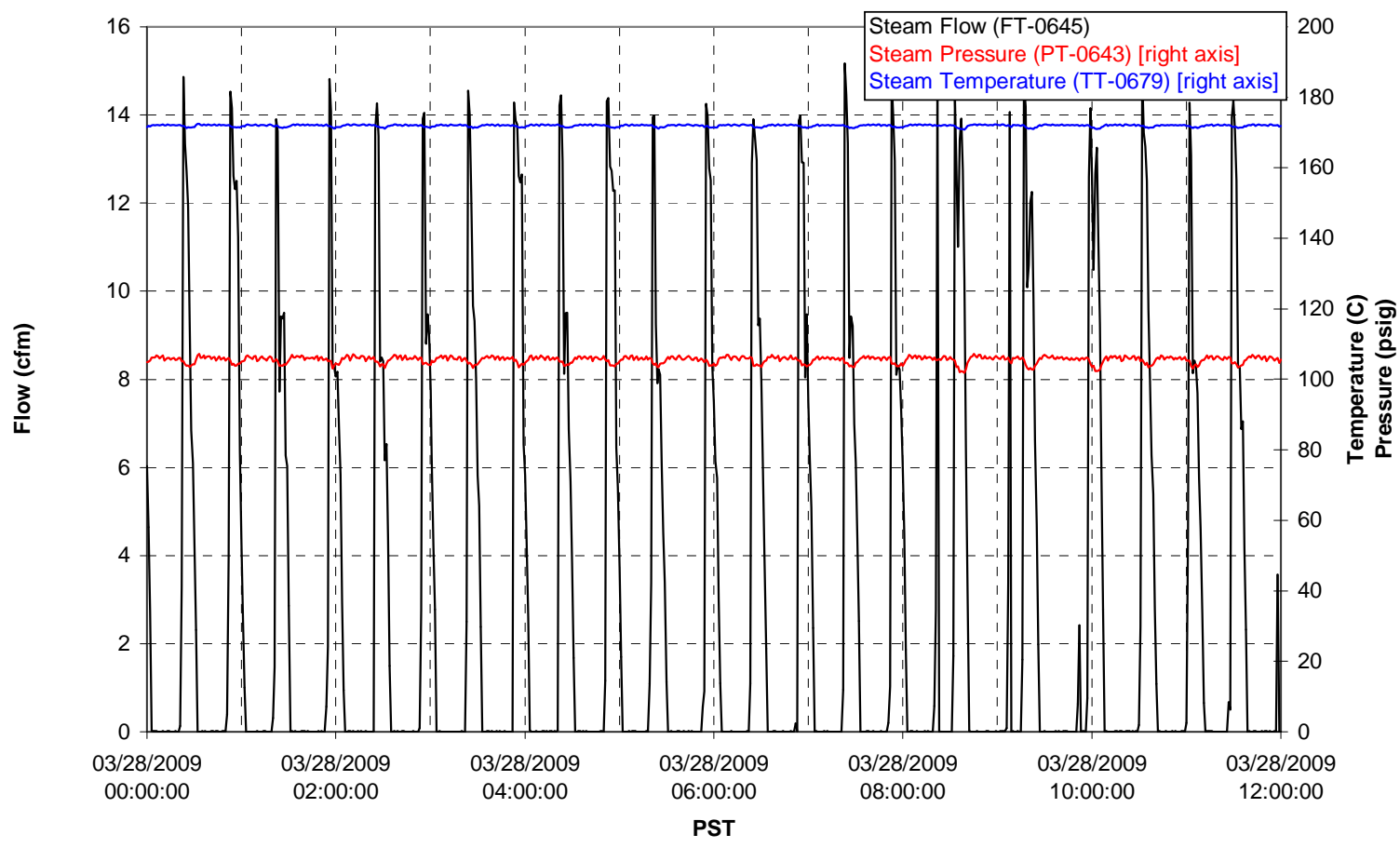

T01A Steam

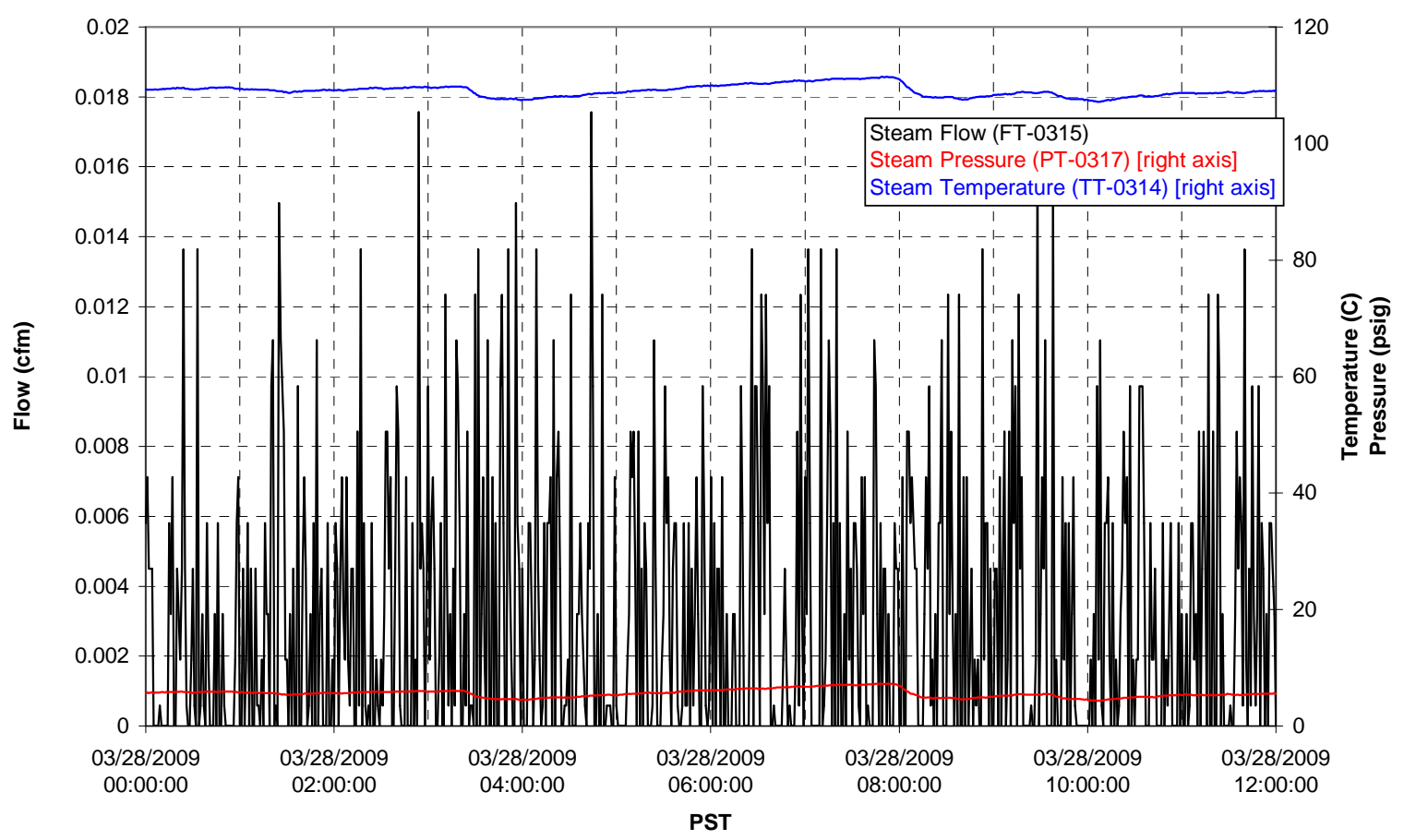


T01B Steam

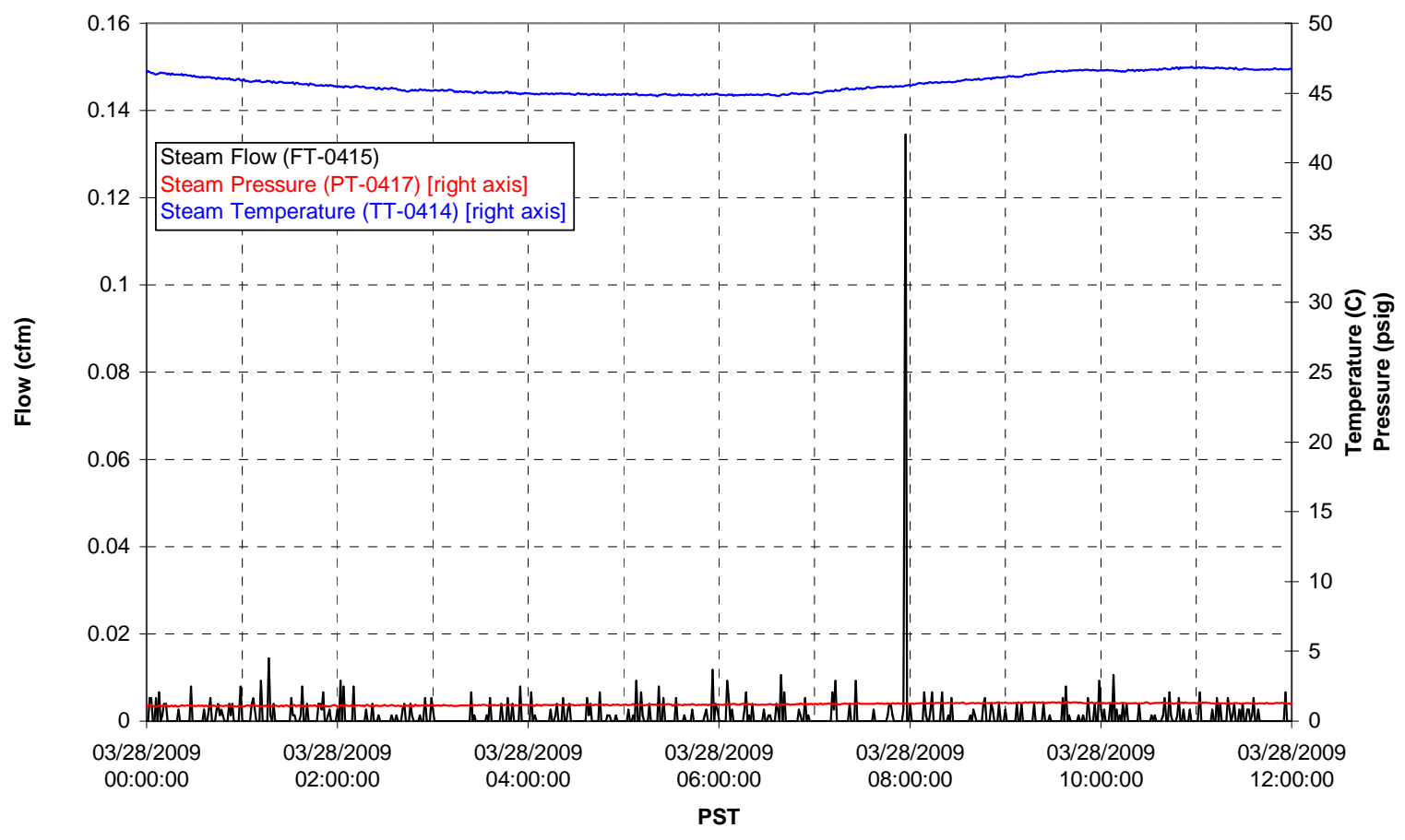




\section{Integrated Test D Data Plots 03/28/09 12:00 - 03/29/09 00:00}


T01A level

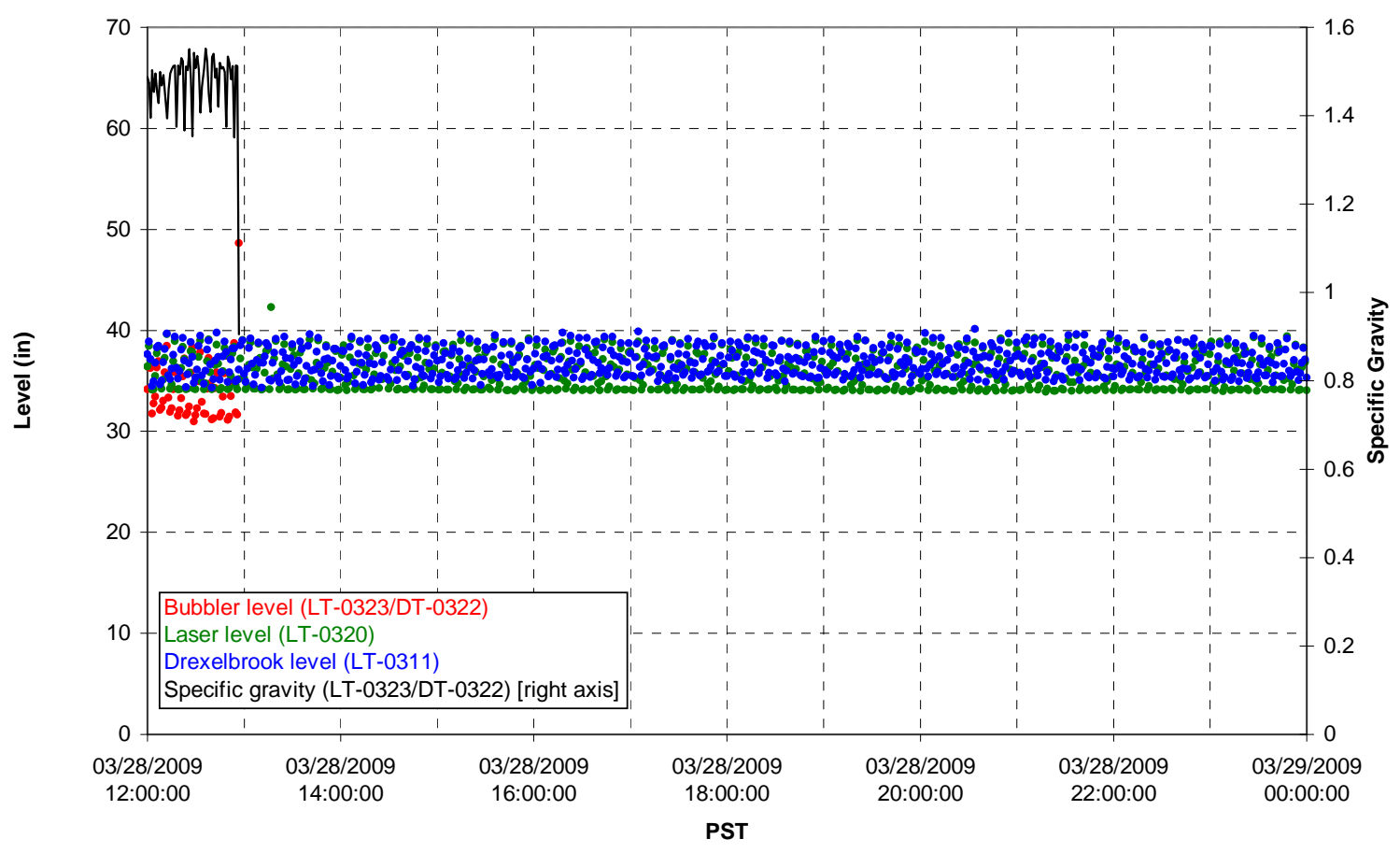

T01A temperatures

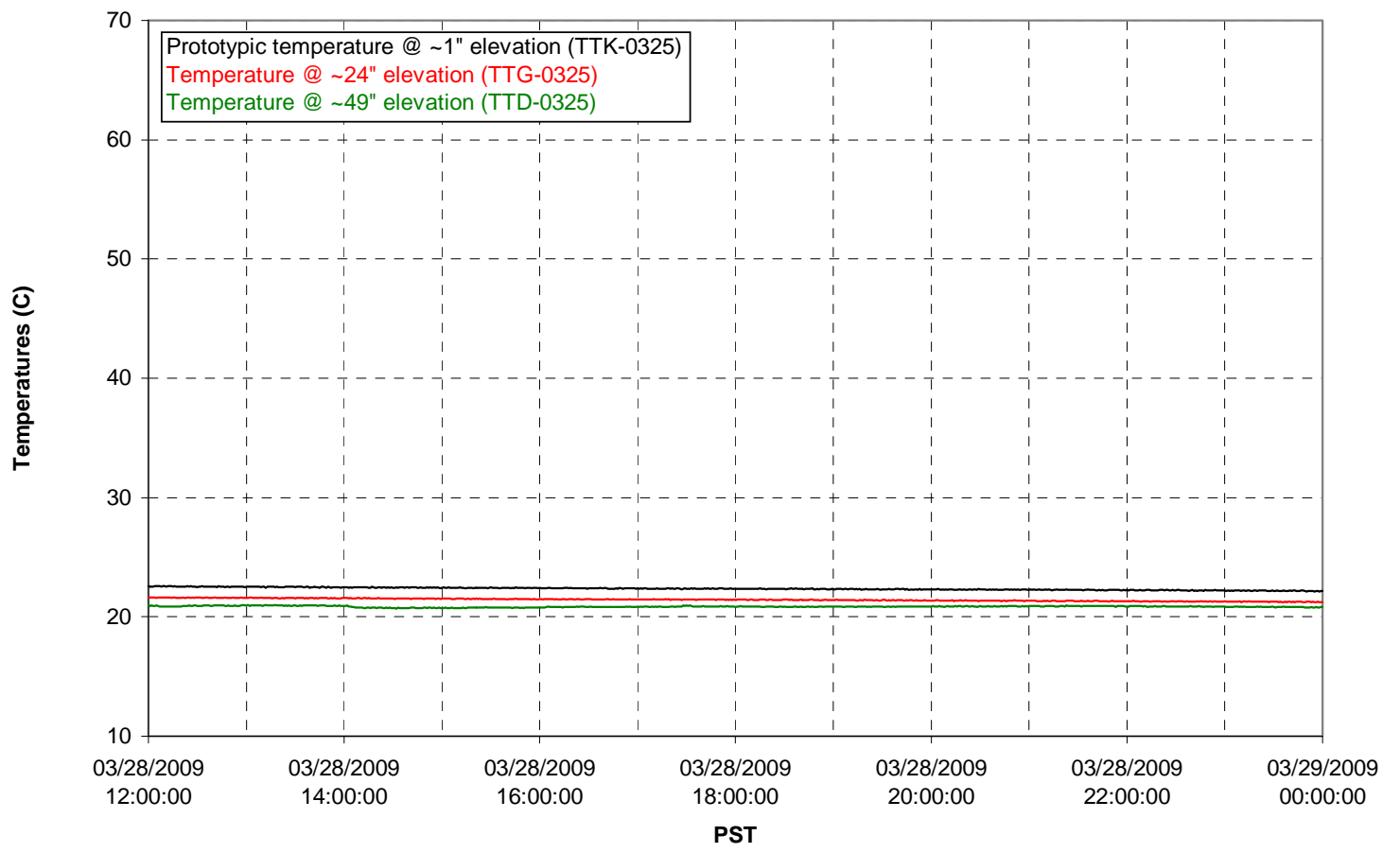


T01B level

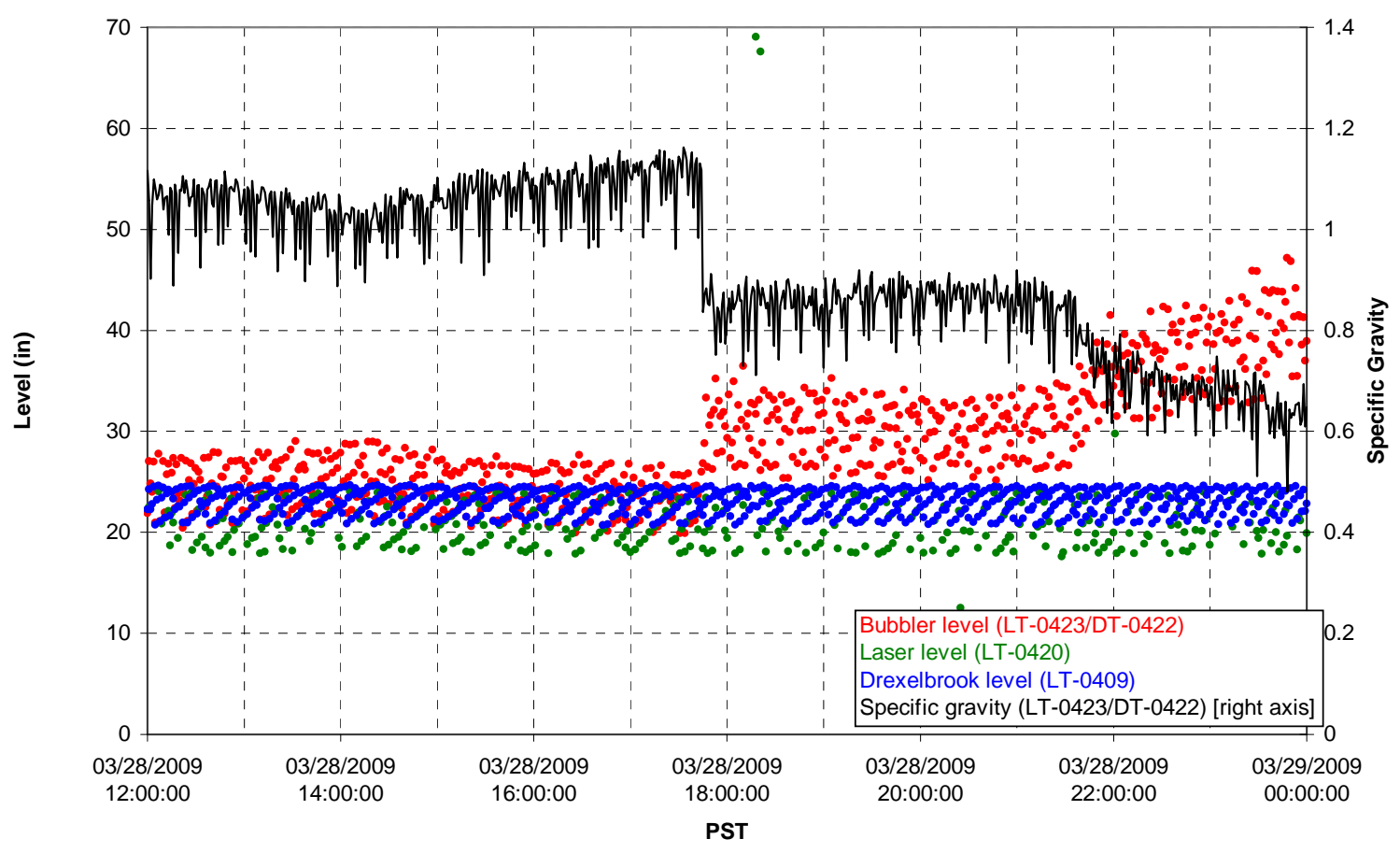

T01B temperatures

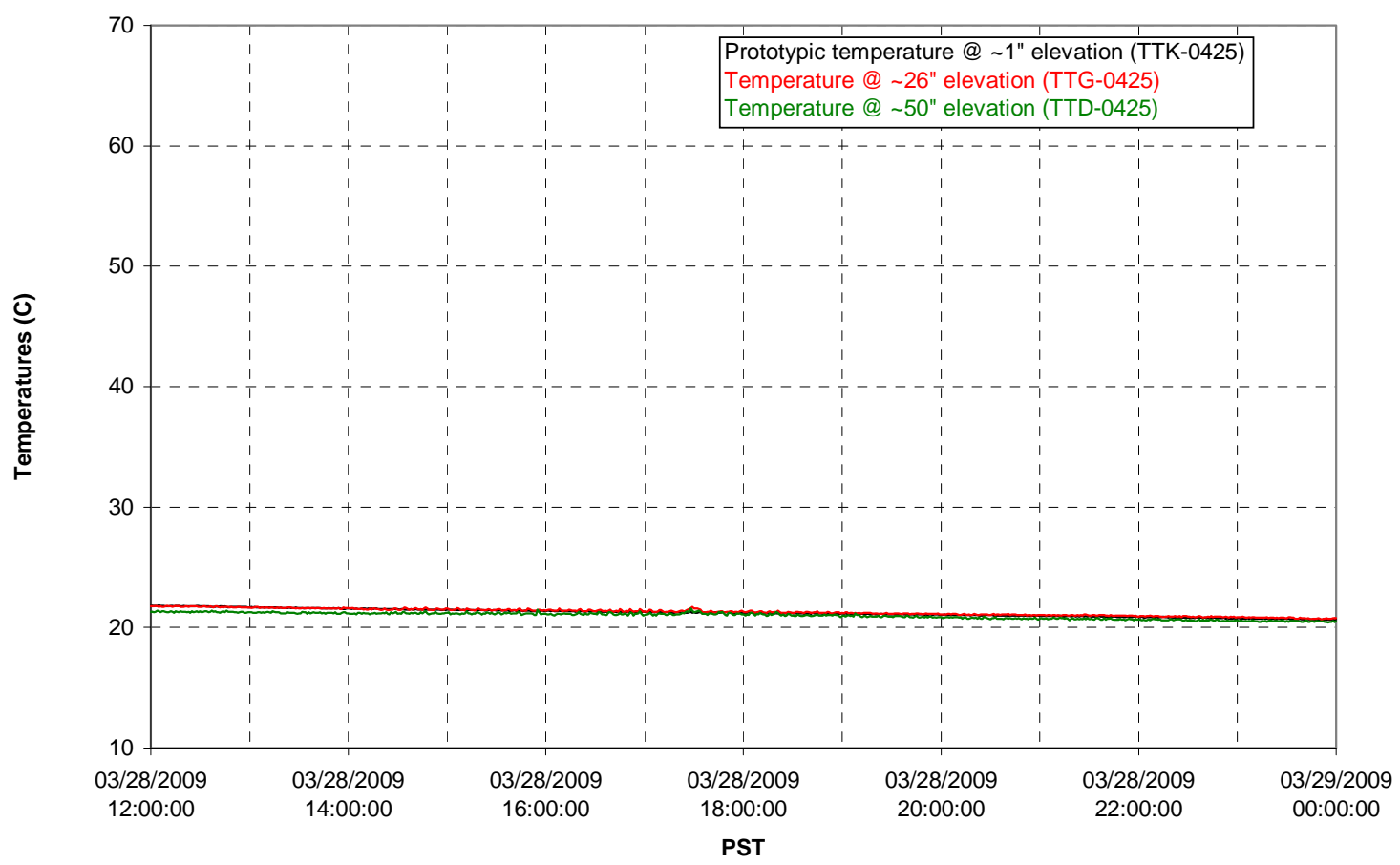


T02A level

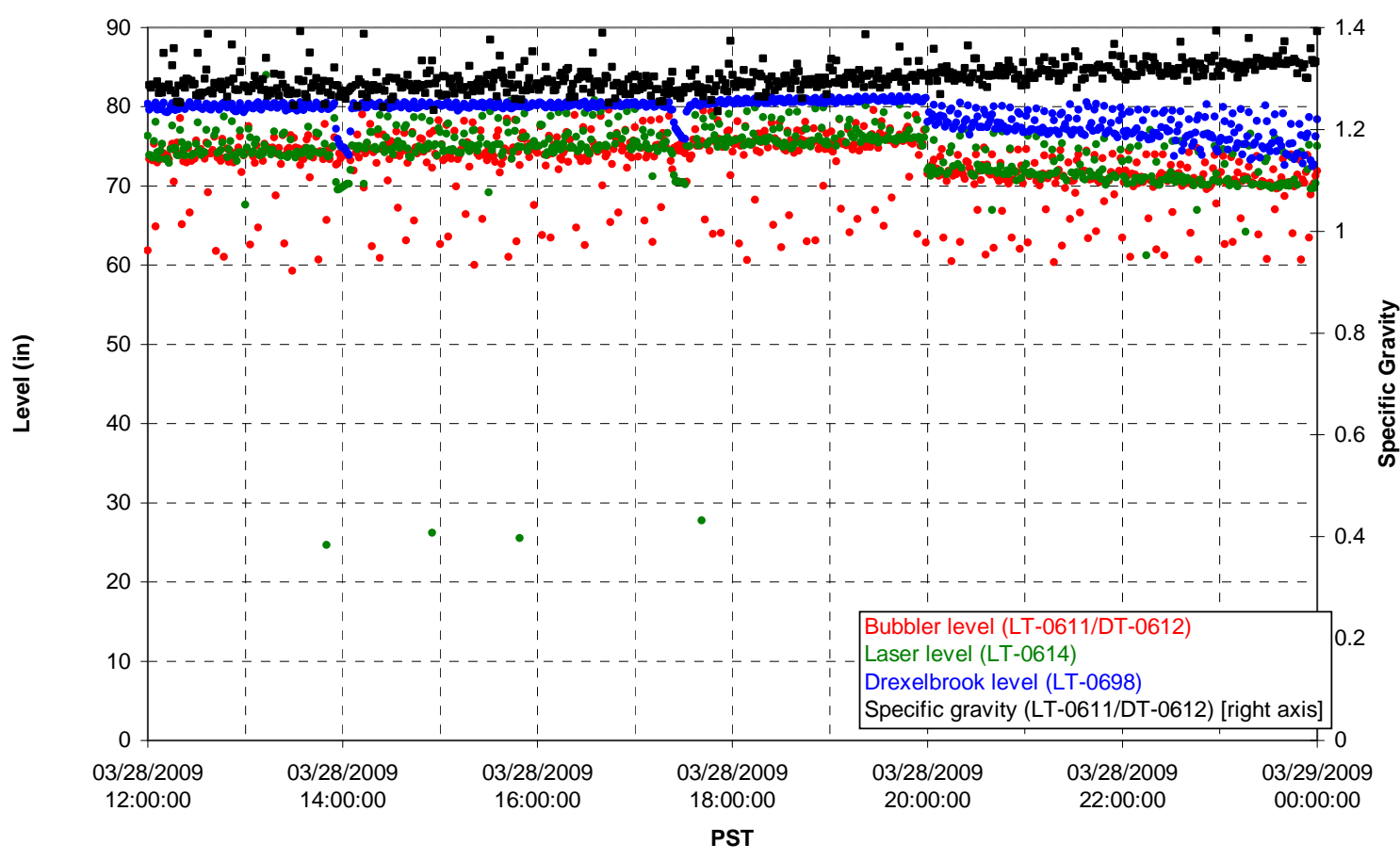

T02A temperatures

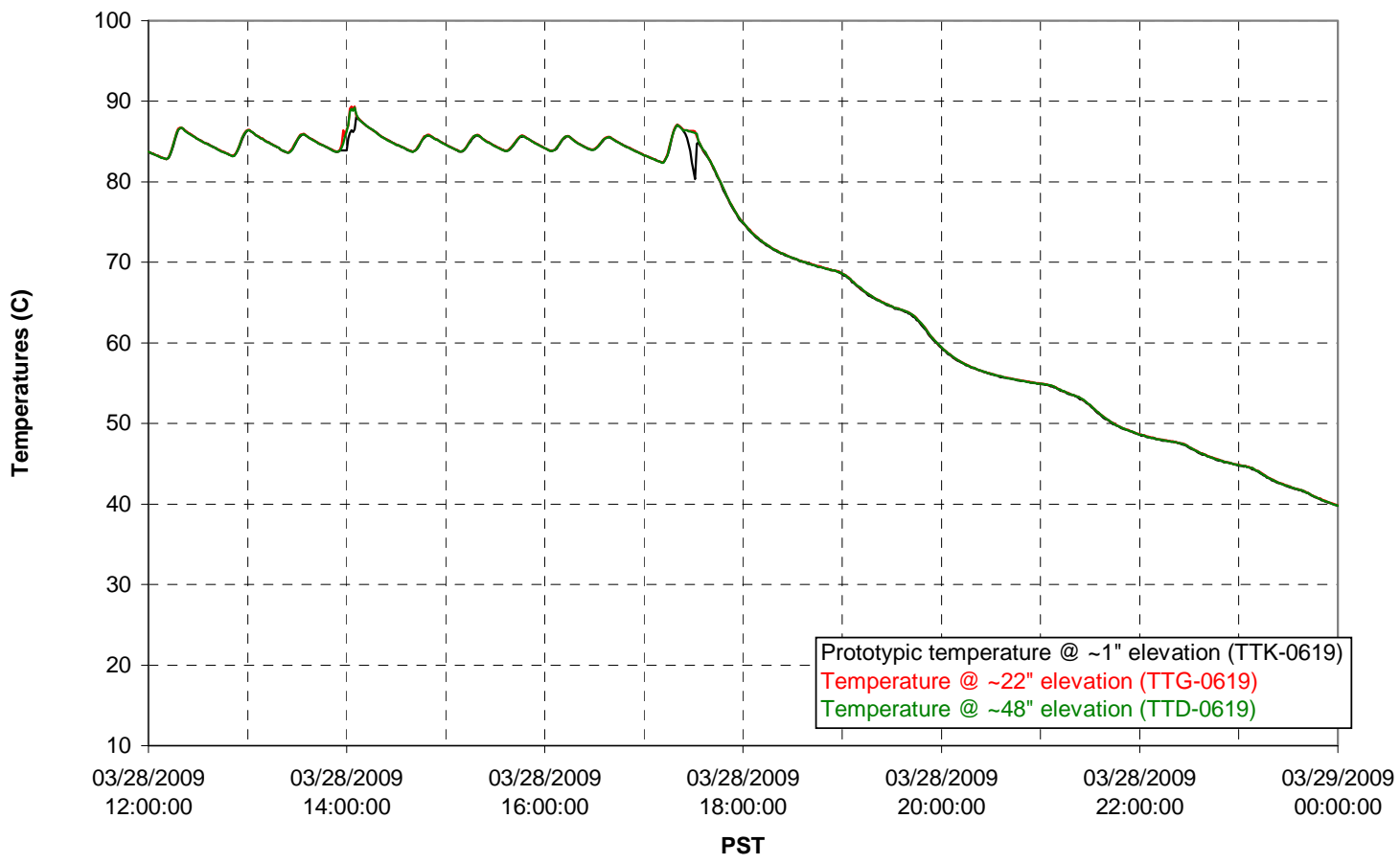


T02A and filter loop temperatures

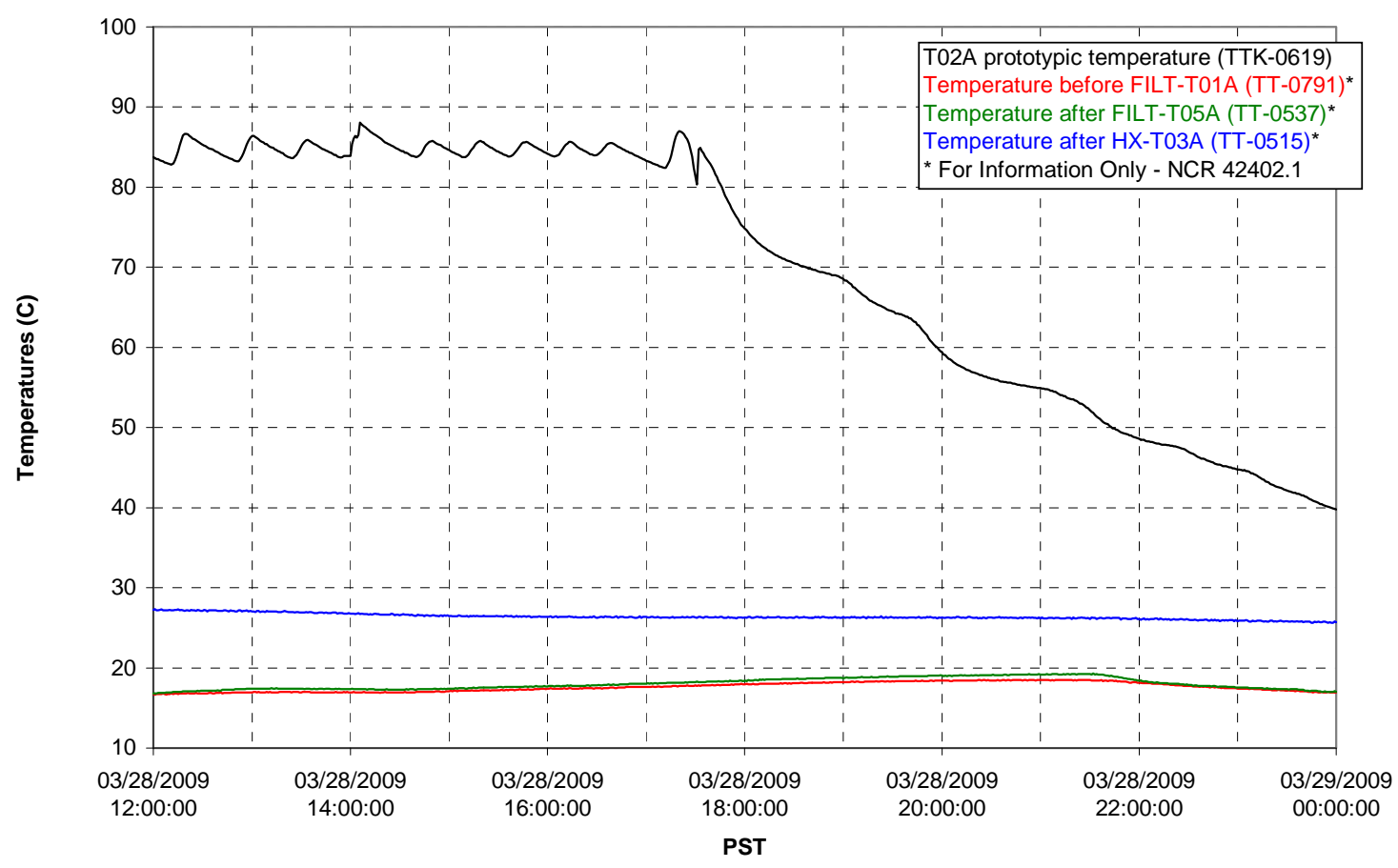

Pump Pressures and Flow

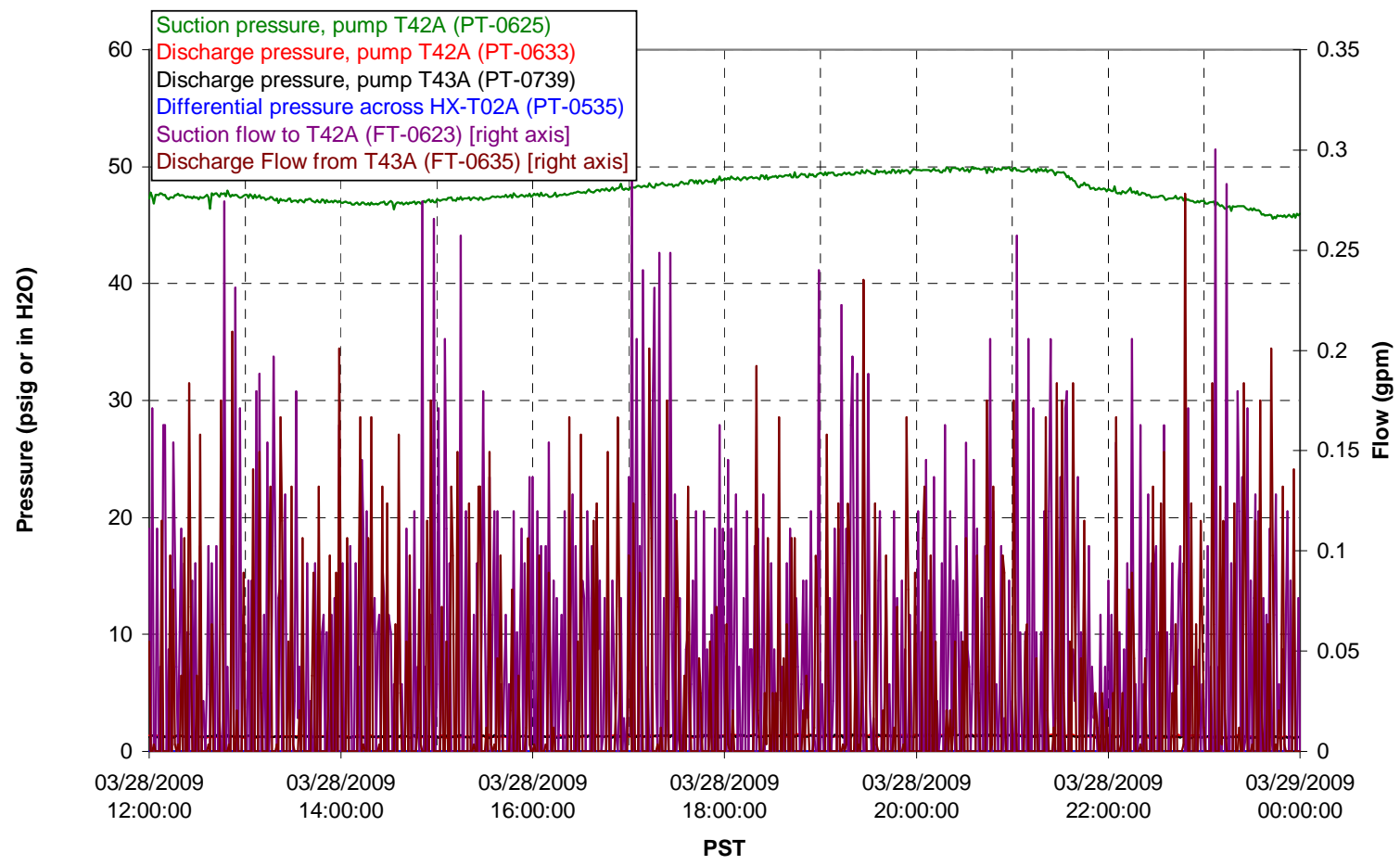


Axial pressure drop

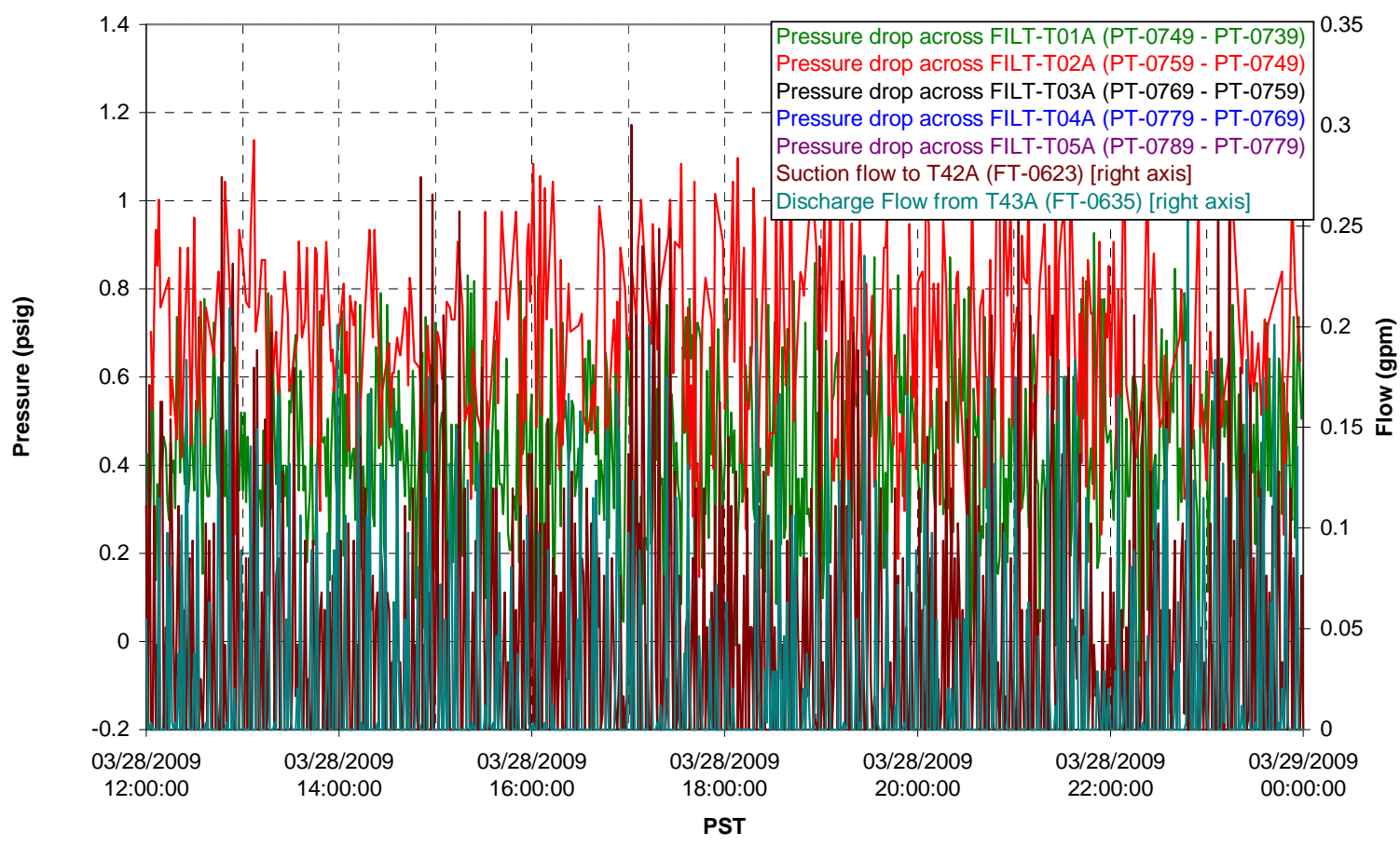

Permeate flow rates

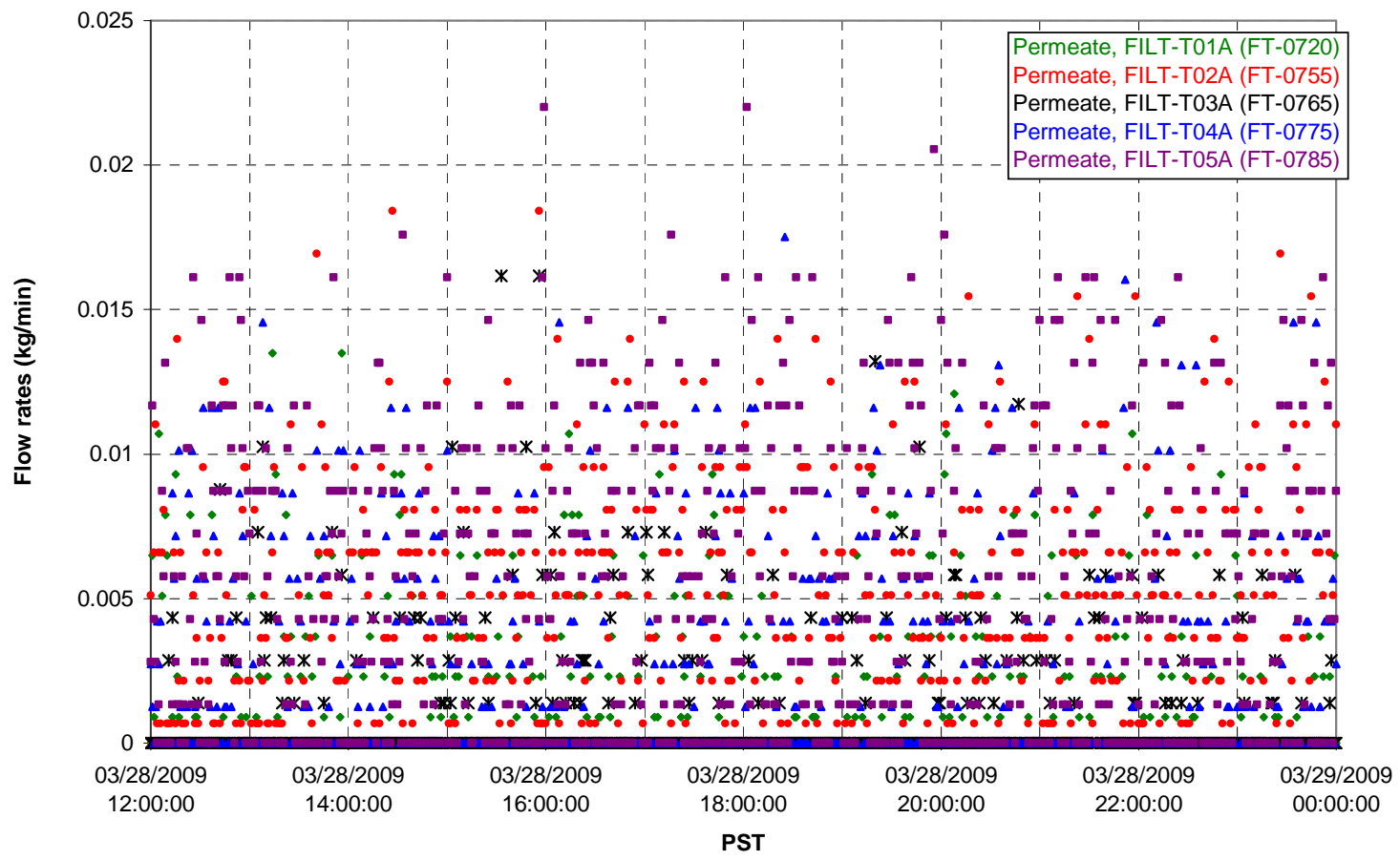


T02A Inner Temperature Tree

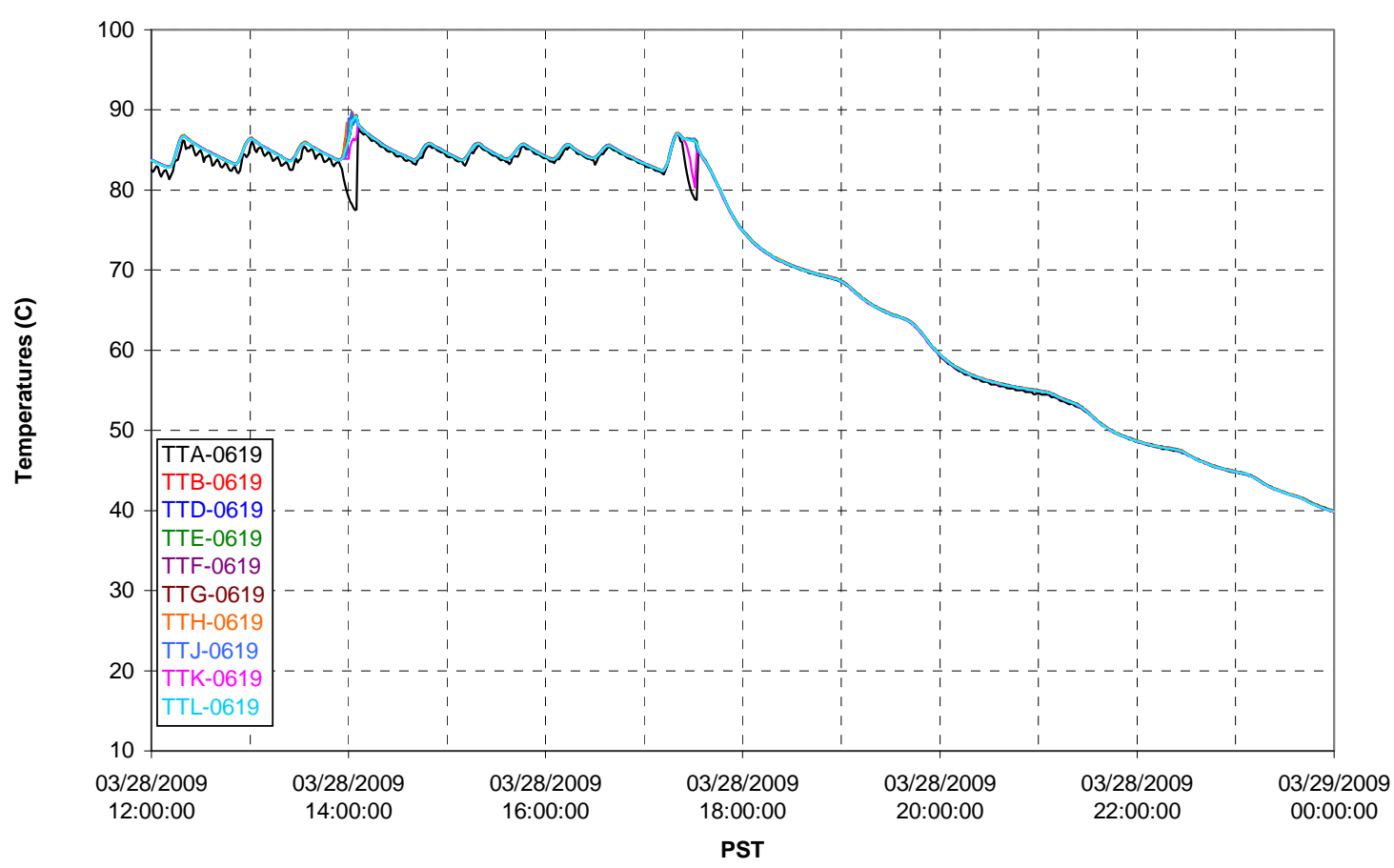

T02A Outer Temperature Tree

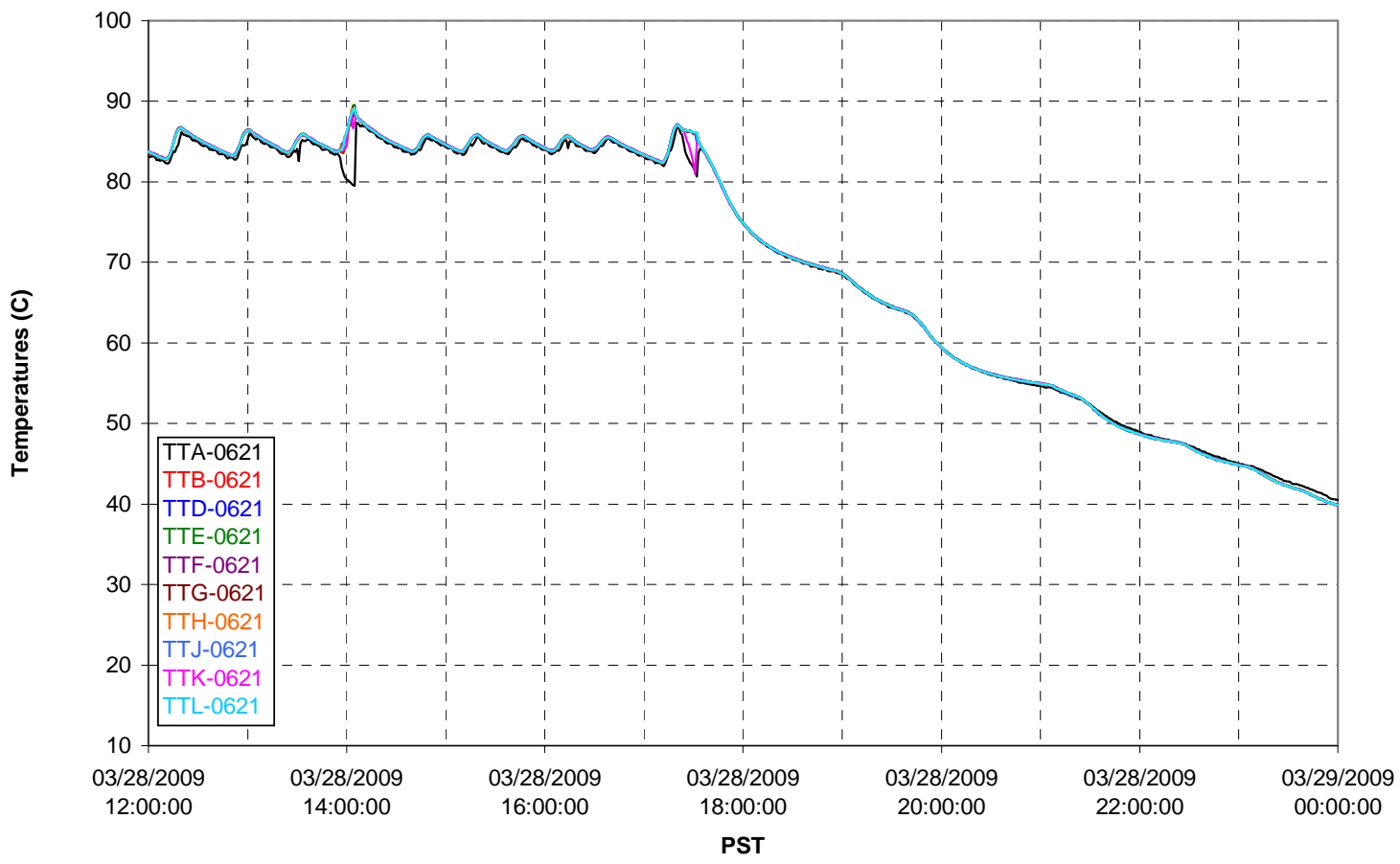


T02A temperatures

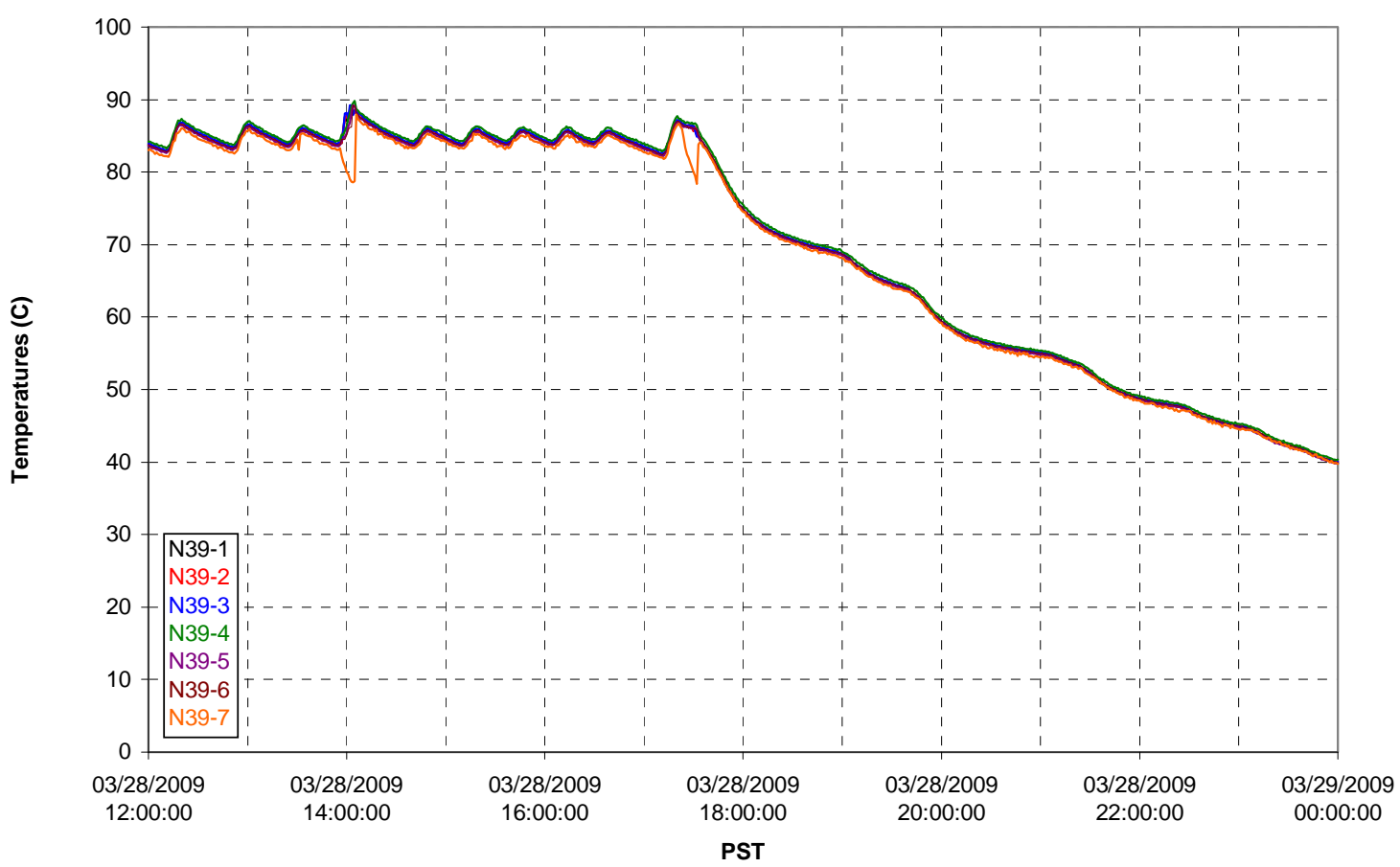

T02A temperatures

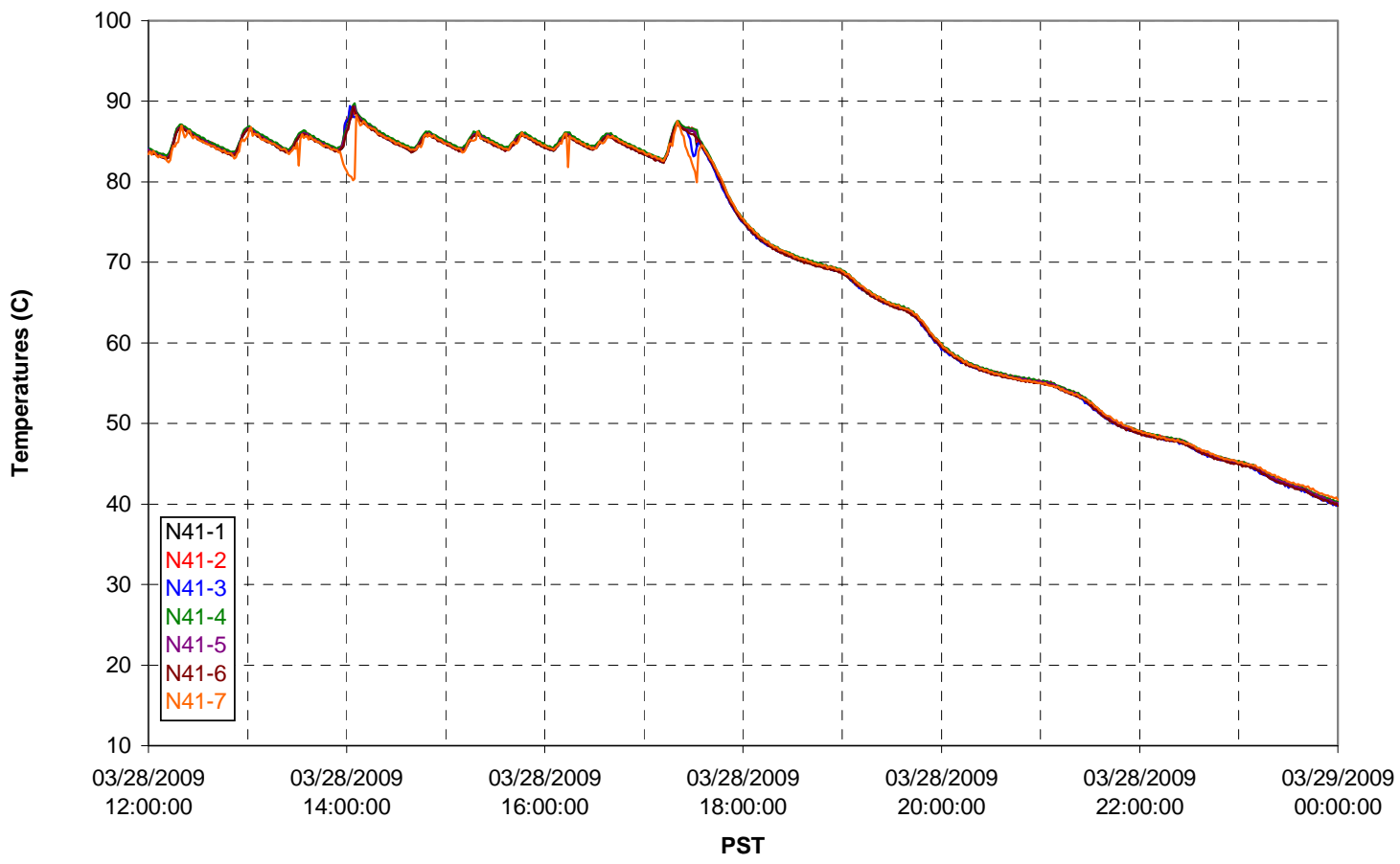


T02A temperatures

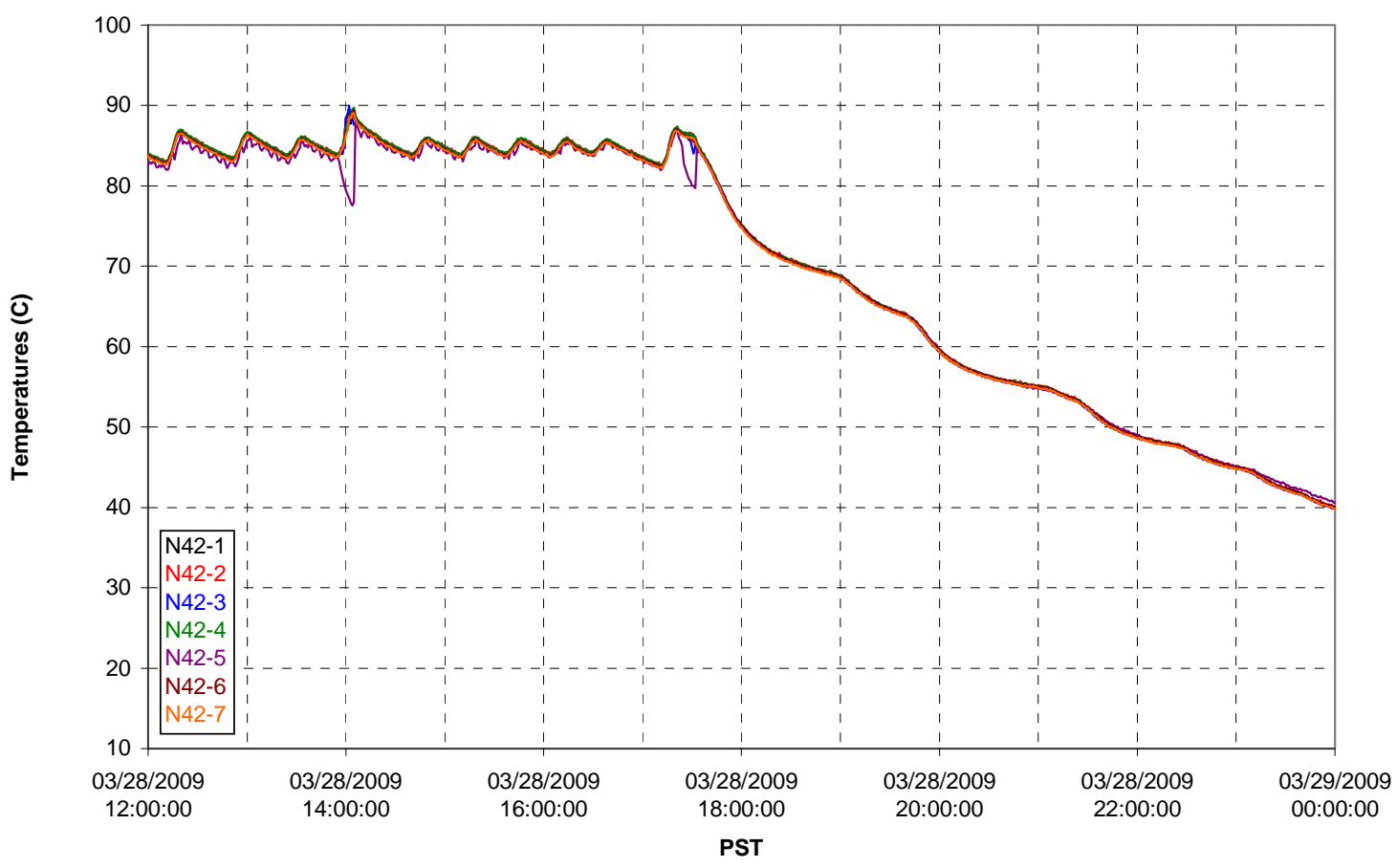

T02A temperatures

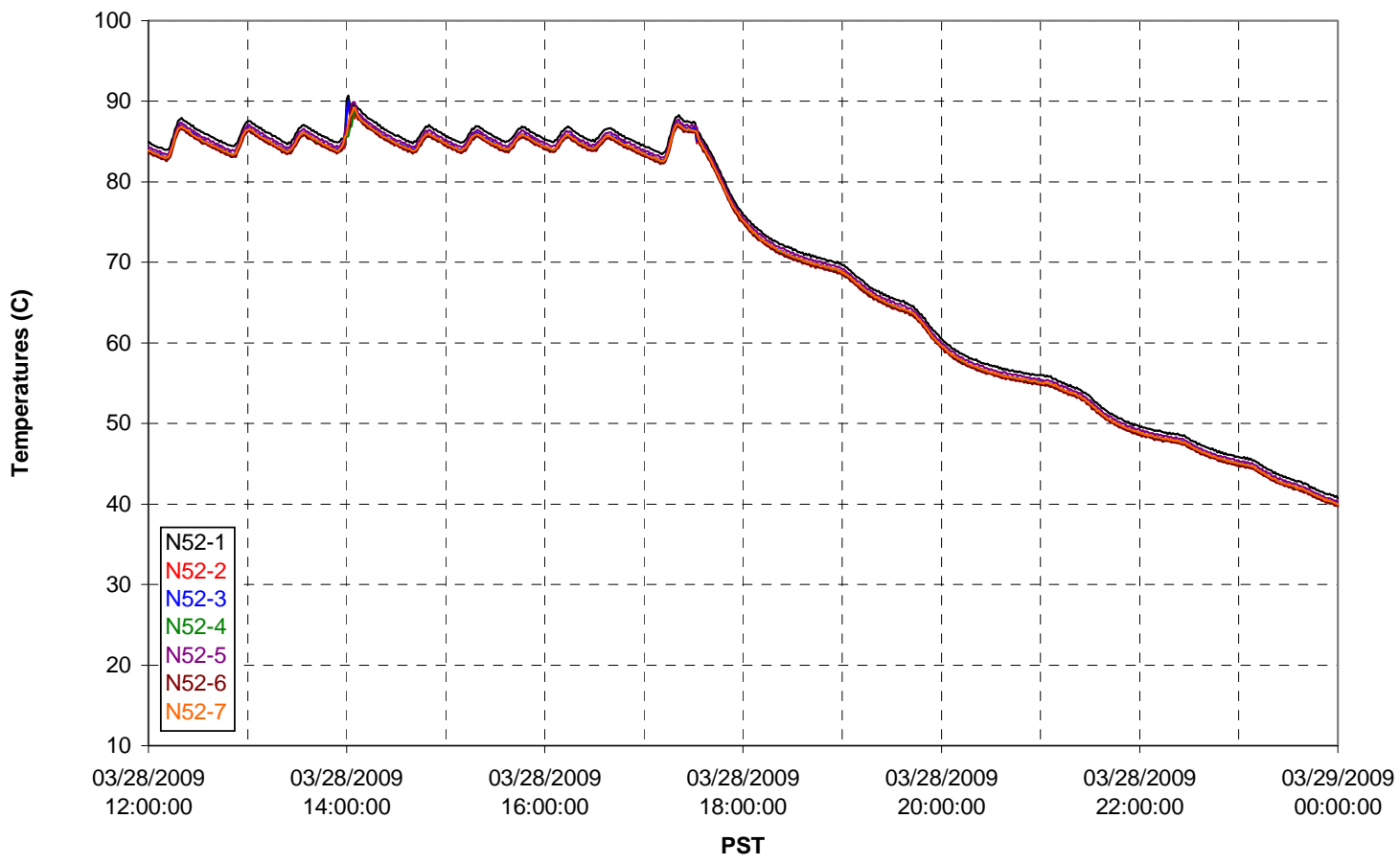


T02A Heating and Cooling

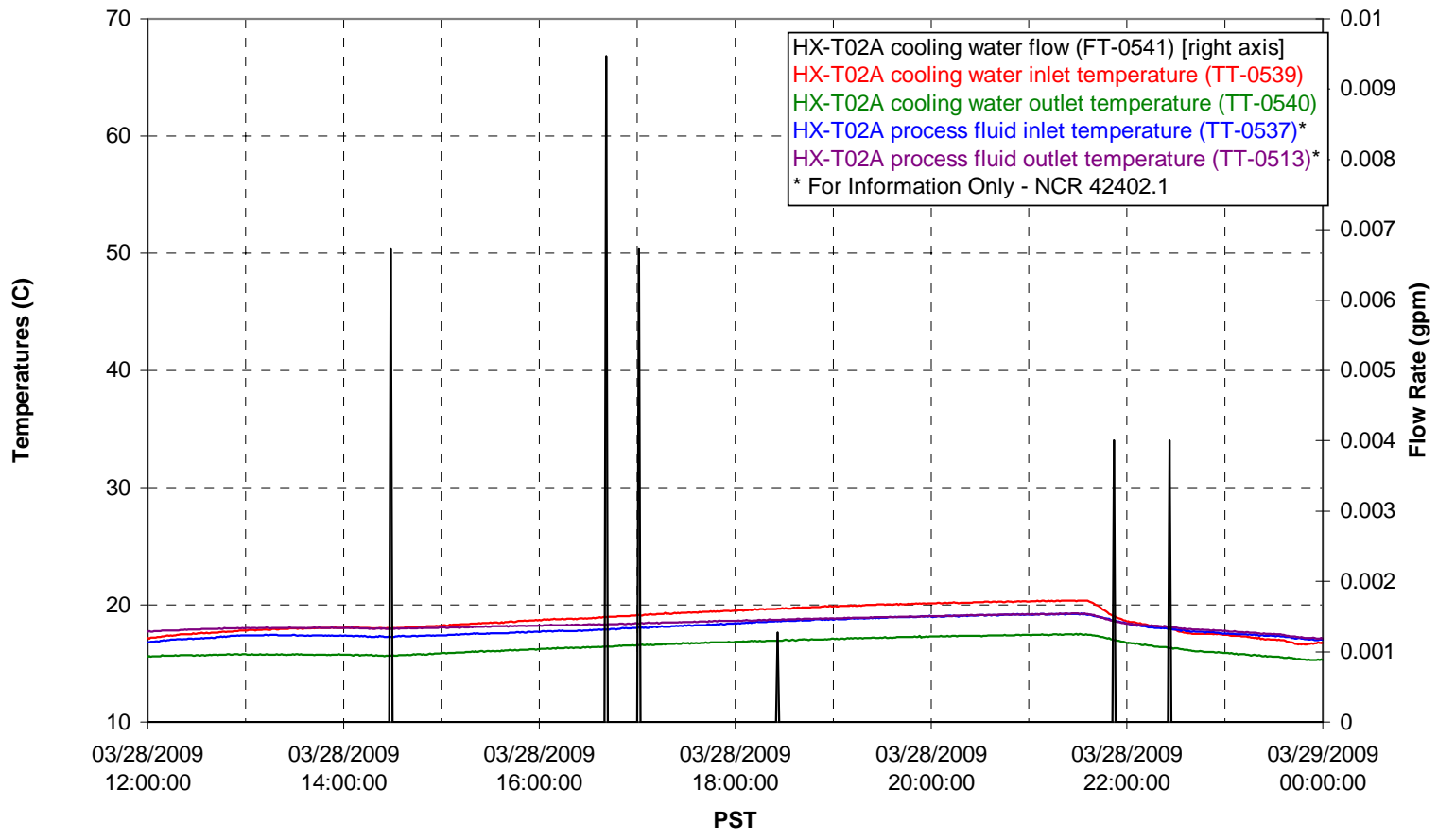

Pump Operation

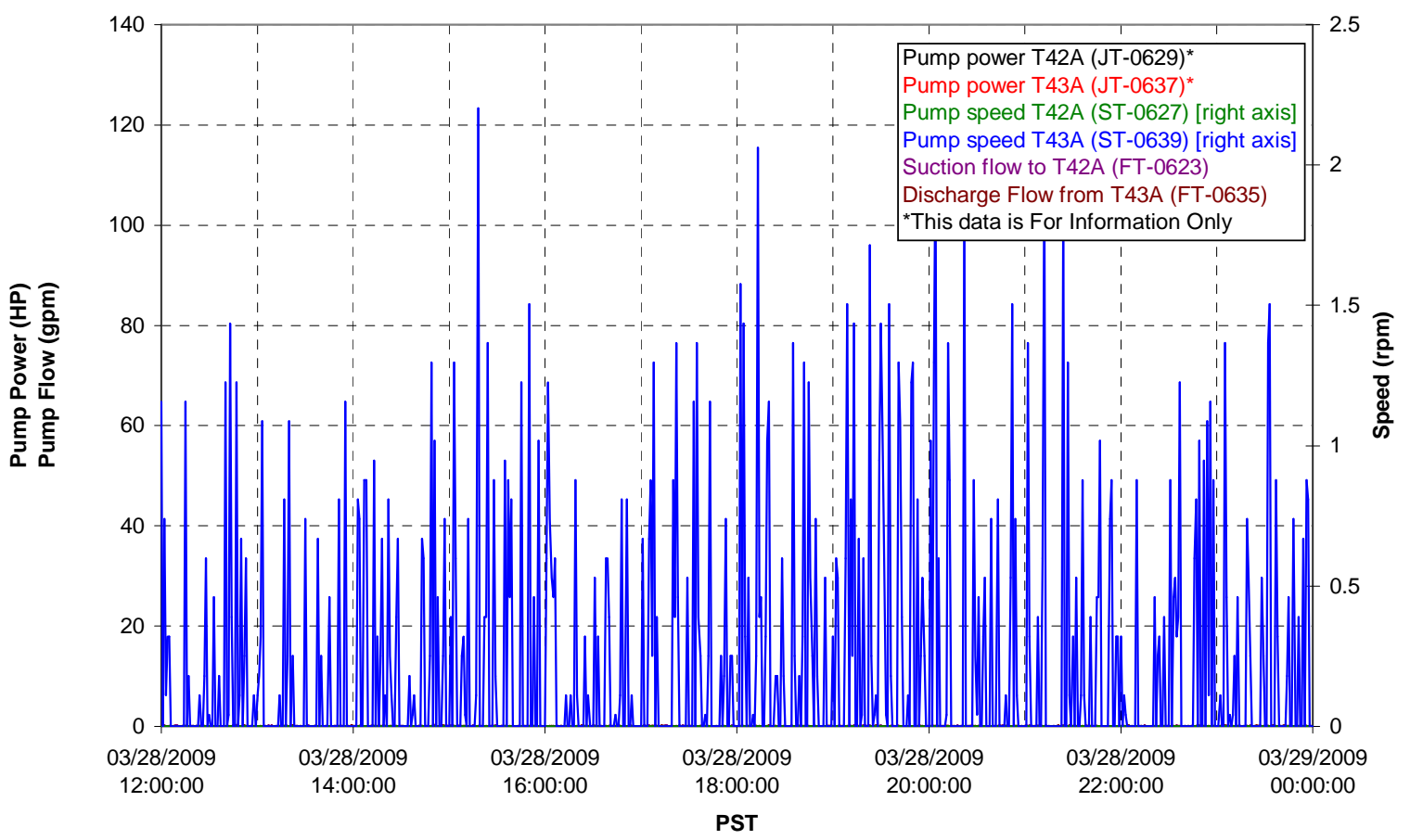


Pulsepot UFP-PP-T01A

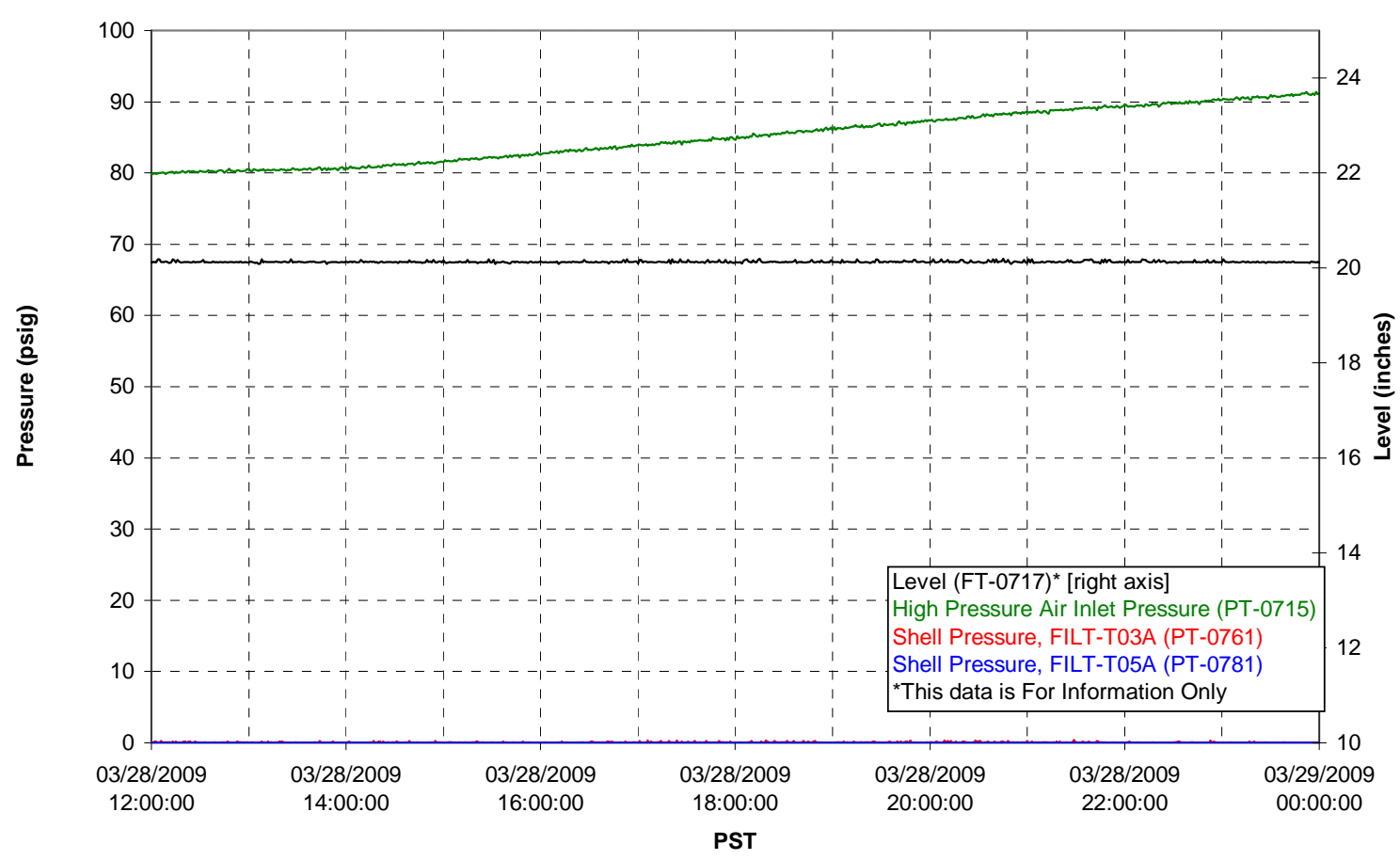

Pulsepot UFP-PP-T02A

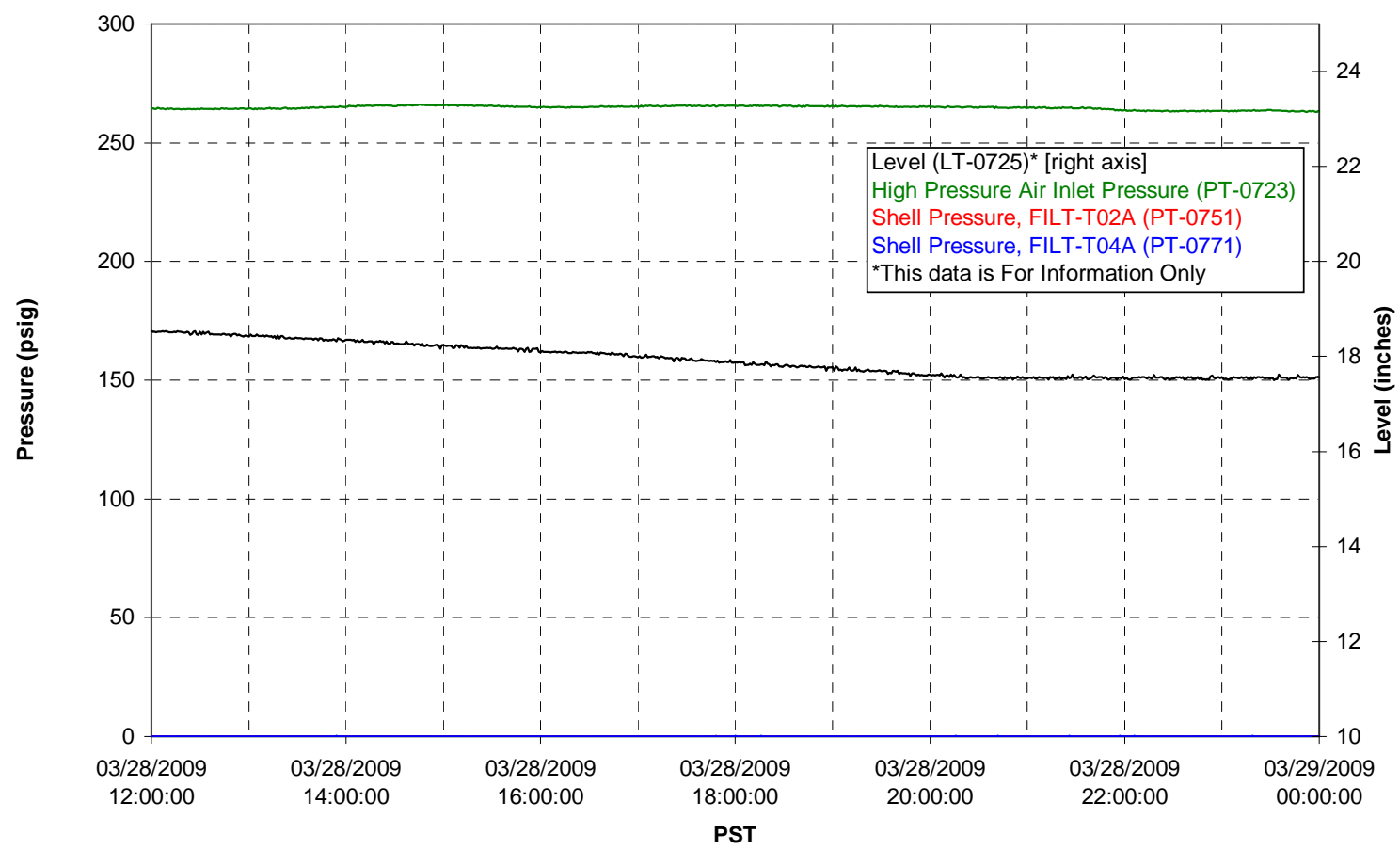


Pulsepot UFP-PP-T03A

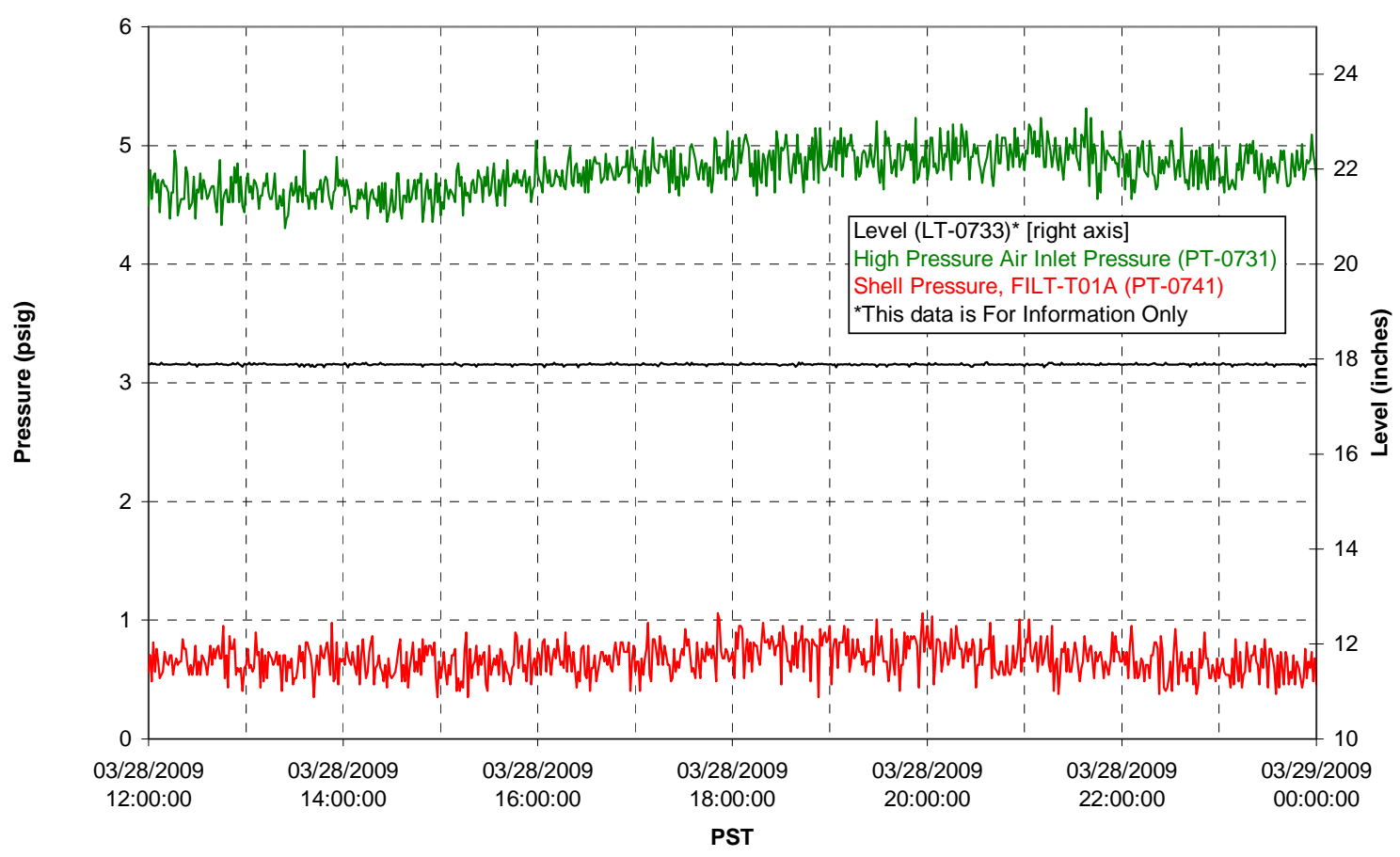

Pulsepot Levels

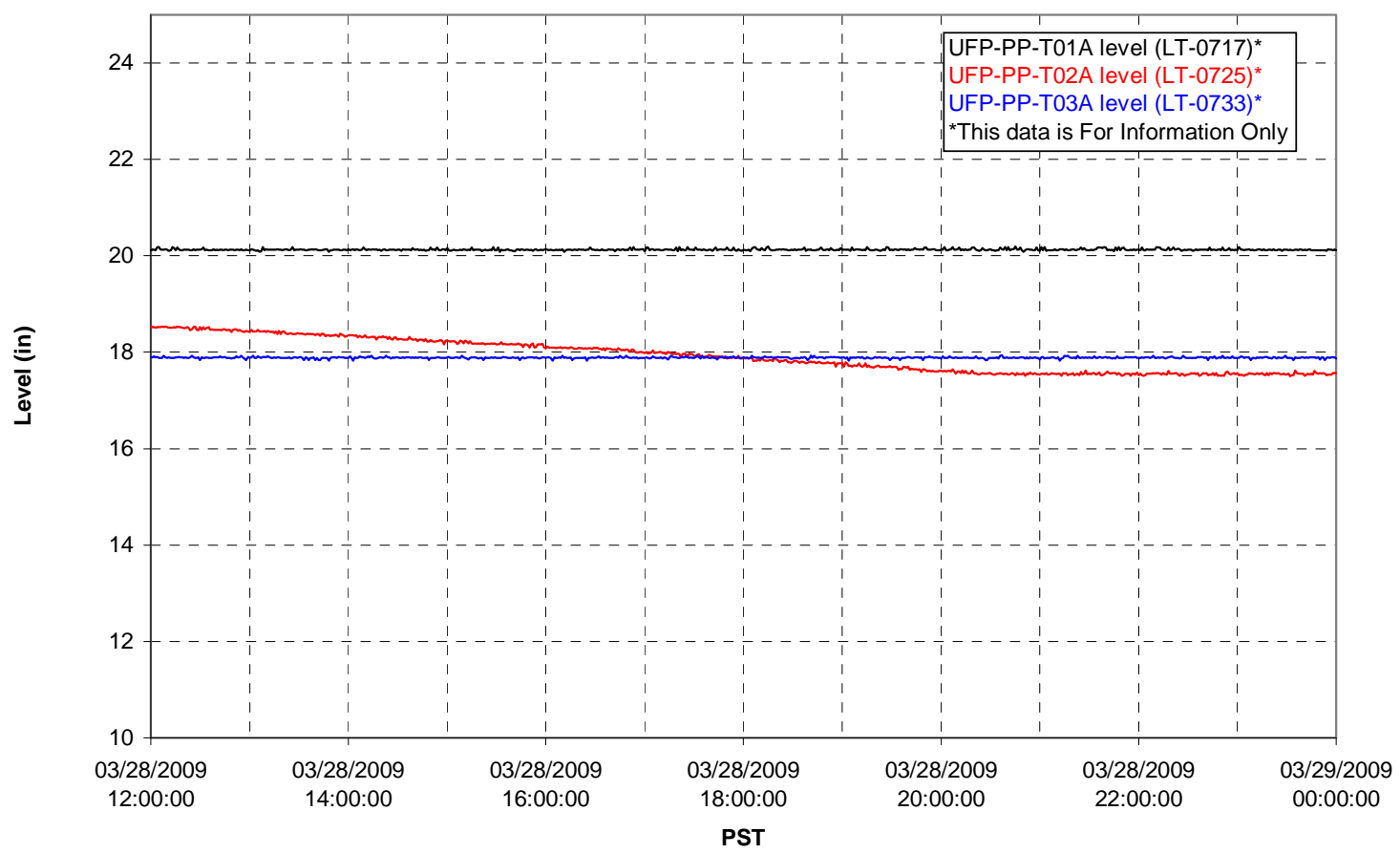


Filter UFP-FILT-T01A

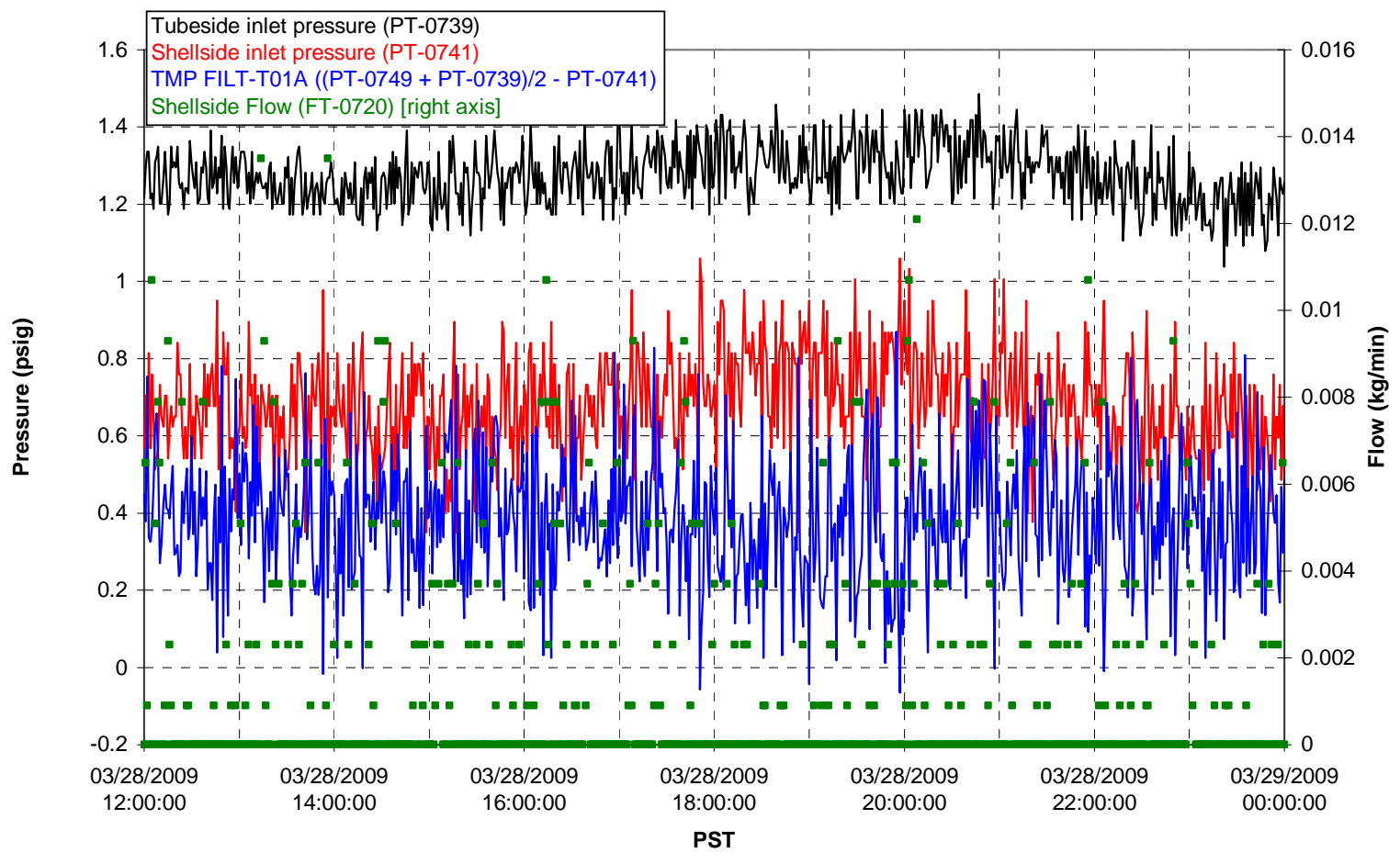

Filter UFP-FILT-T02A

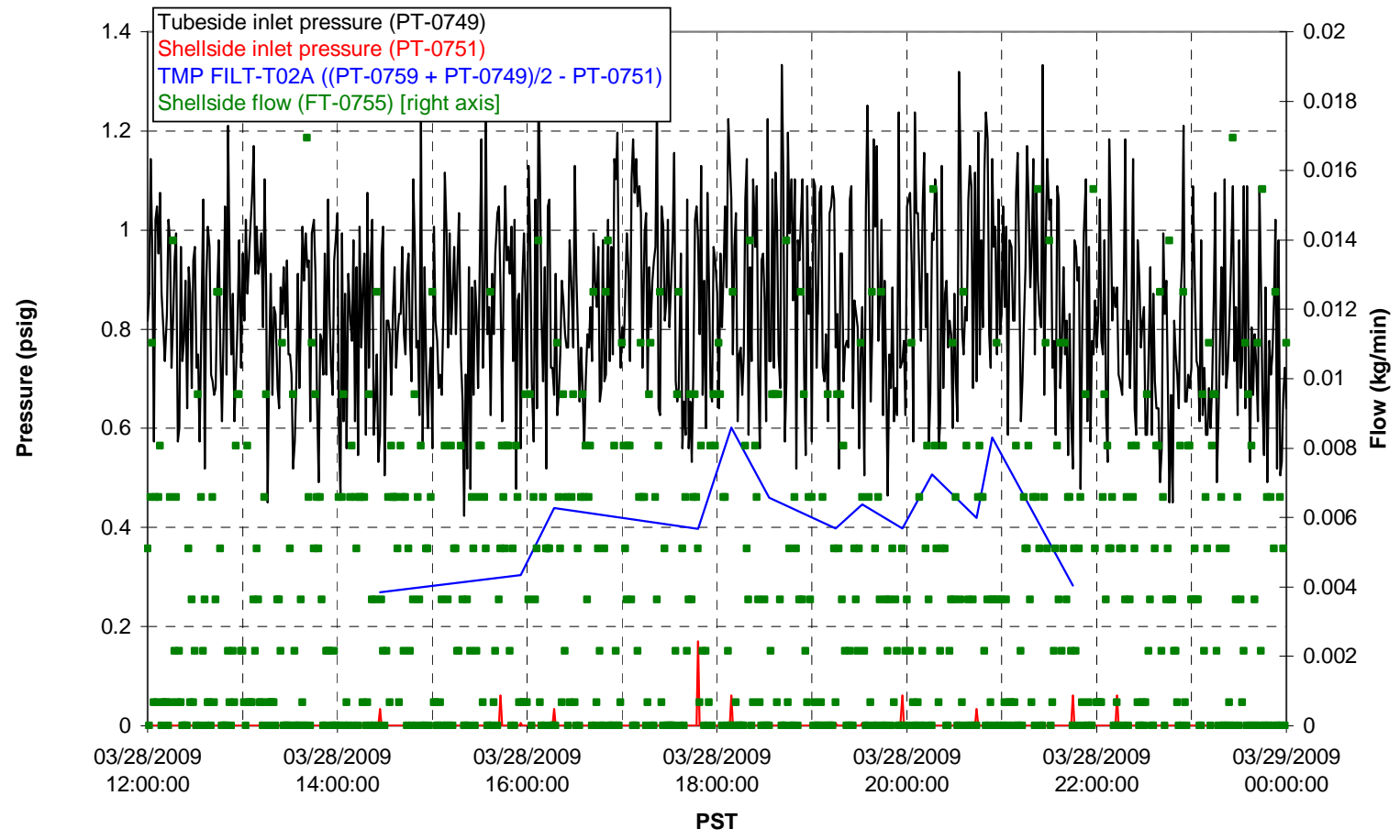


Filter UFP-FILT-T03A

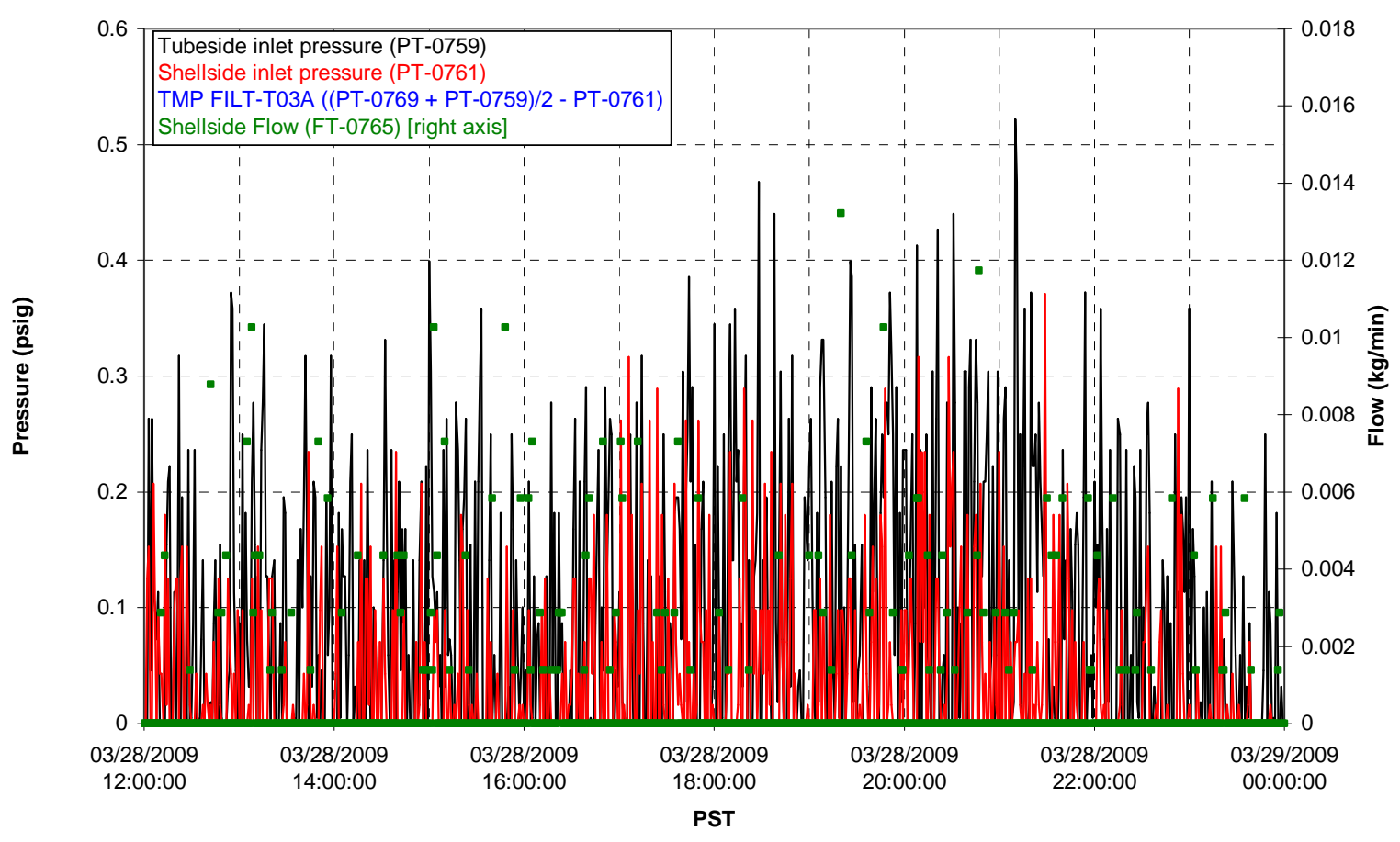

Filter UFP-FILT-T04A

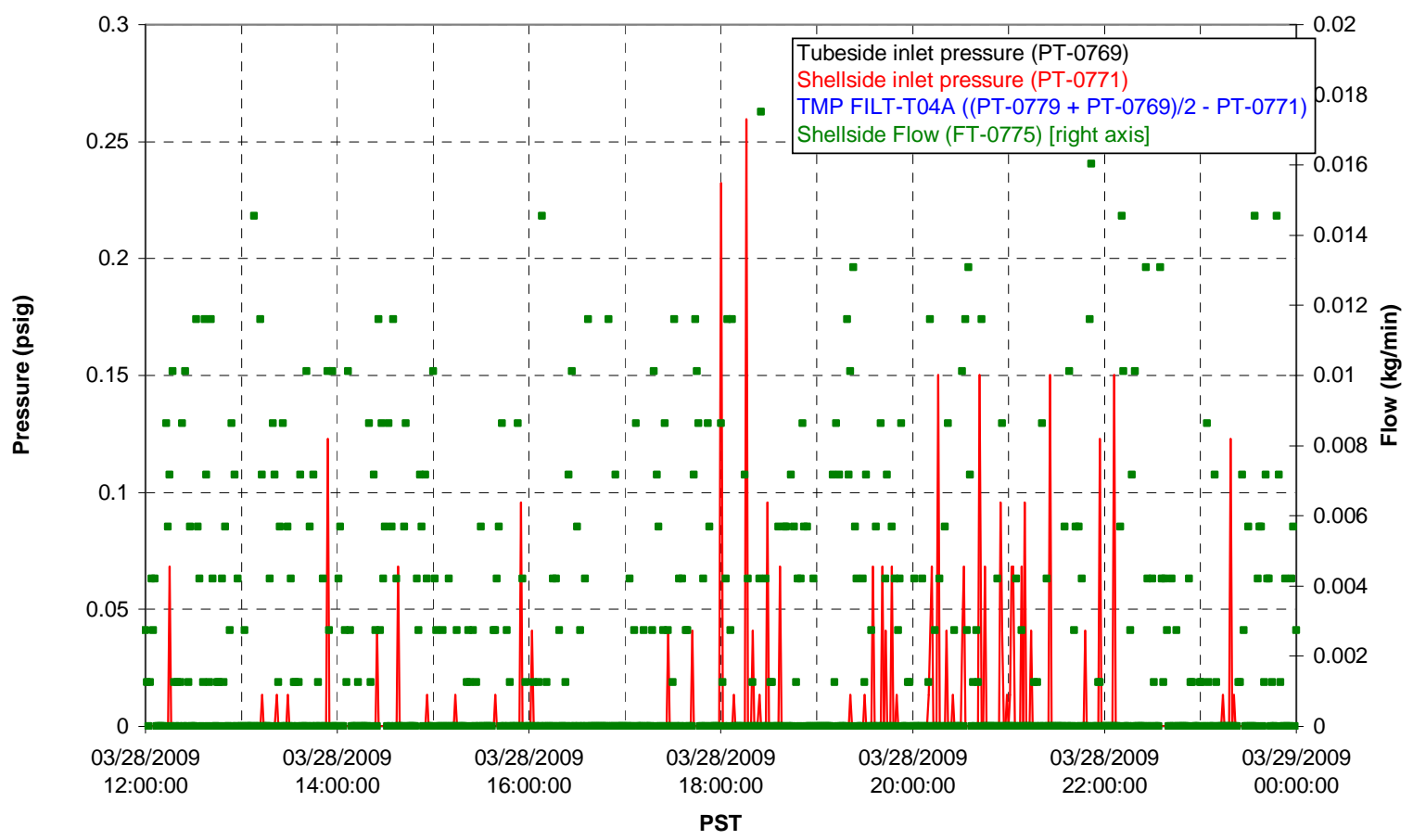


Filter UFP-FILT-T05A

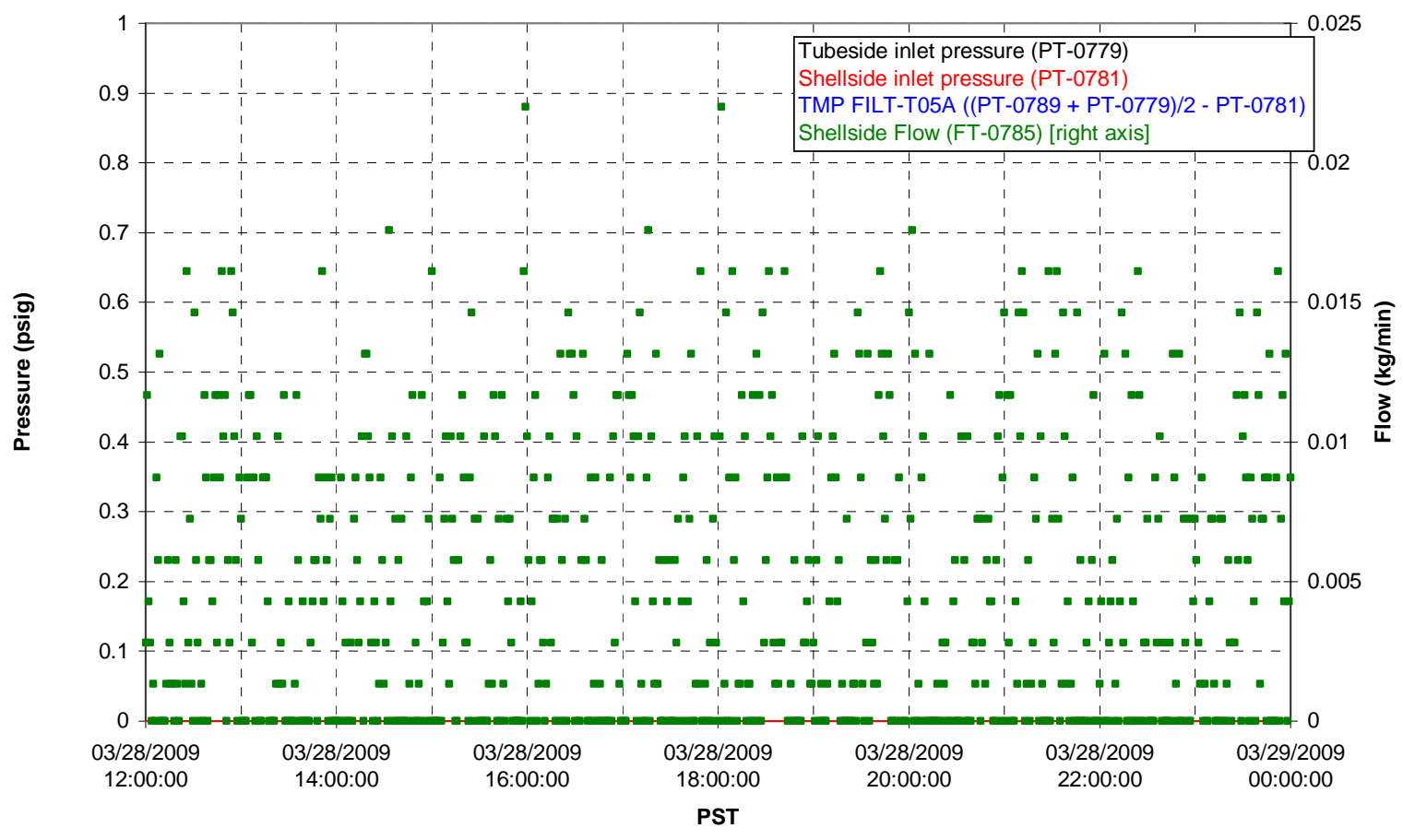

Chemical Flow

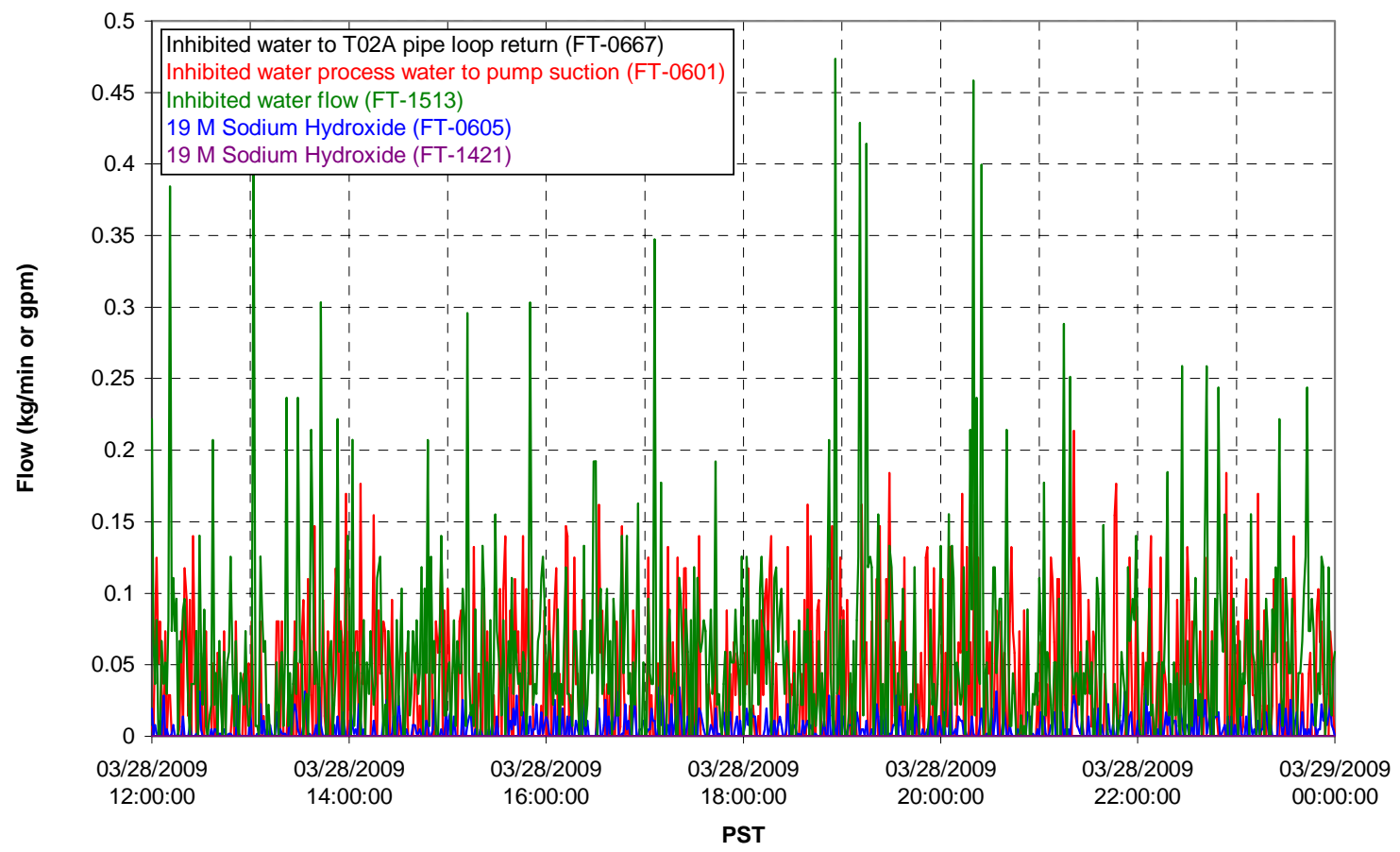




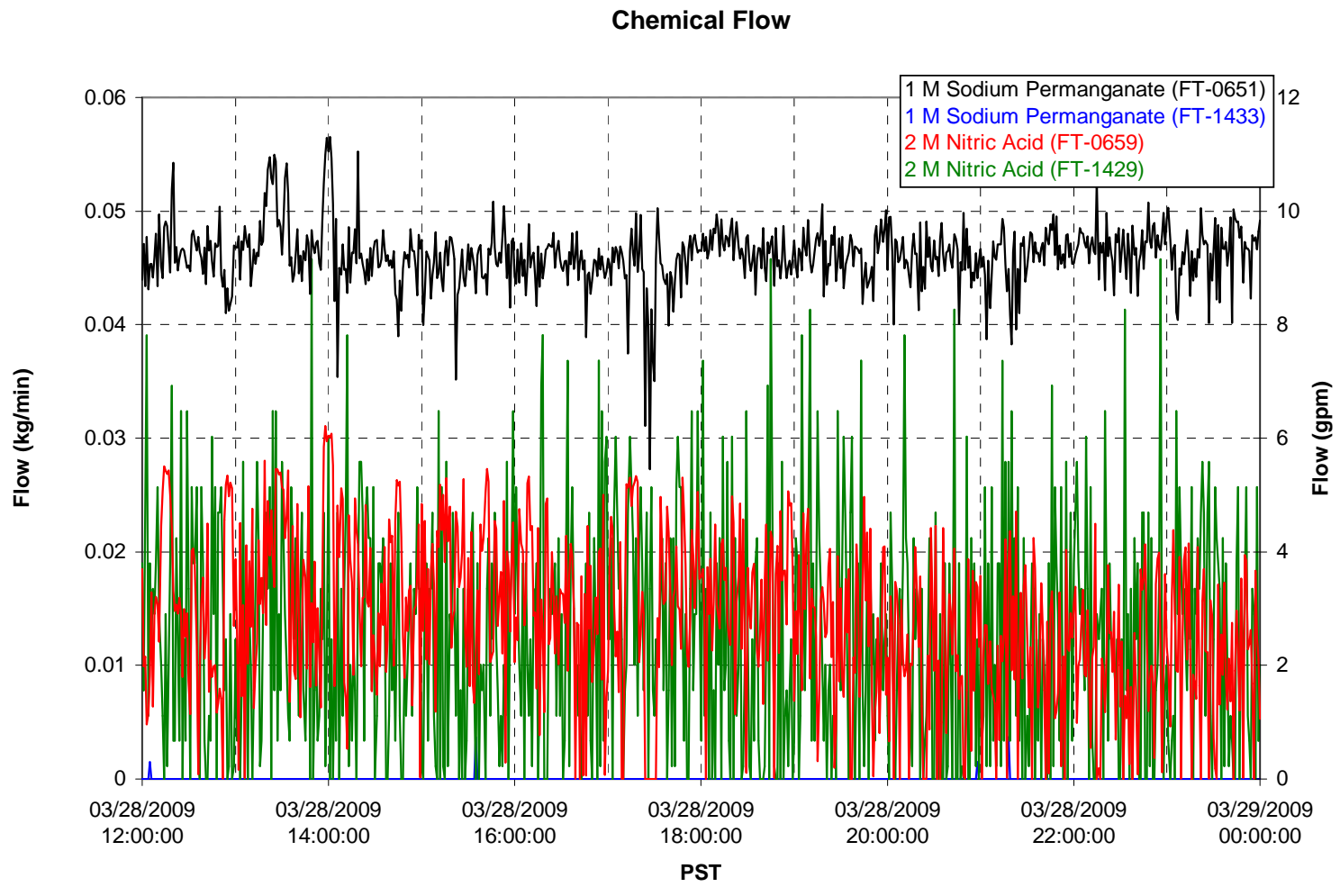

Air Flows

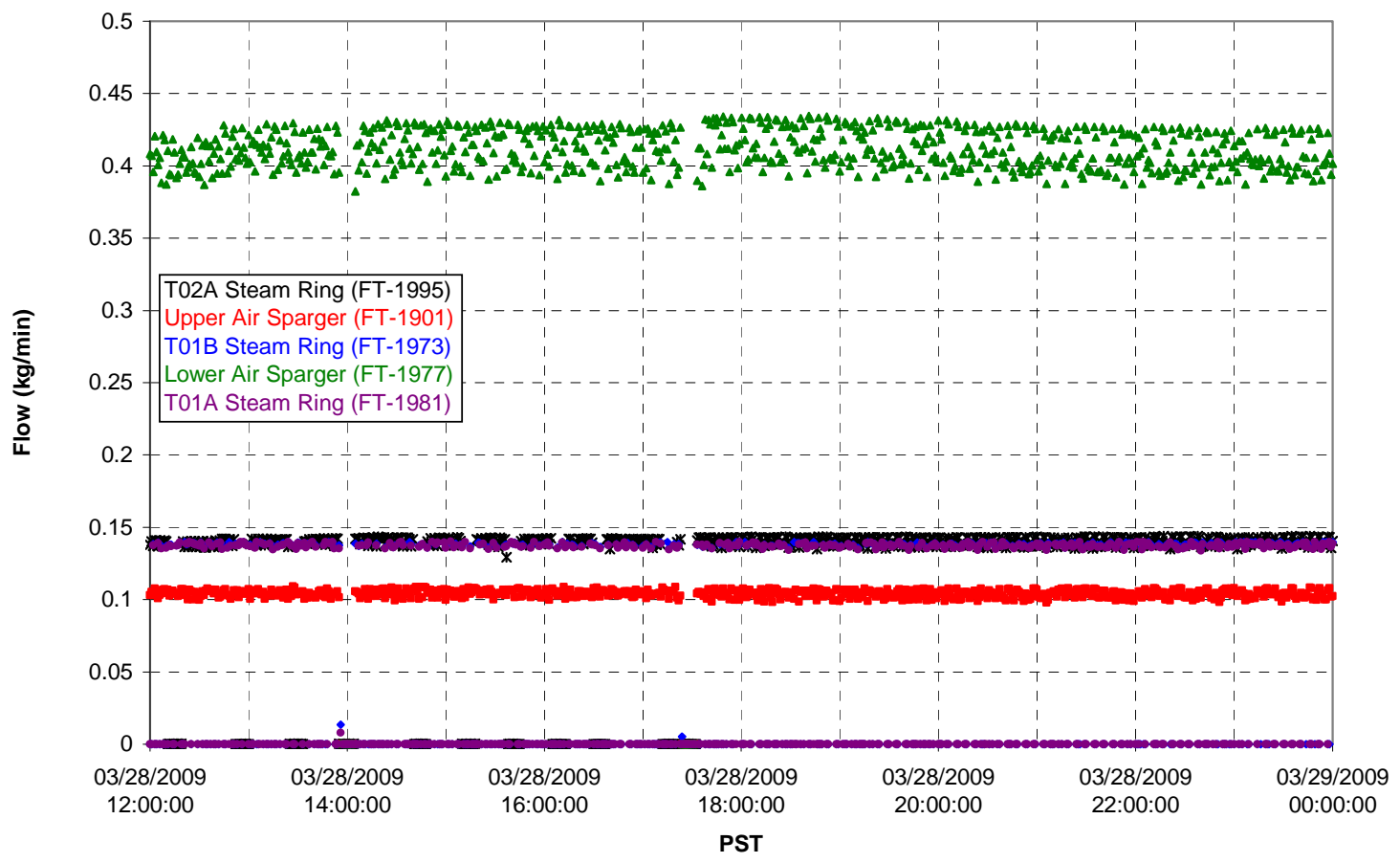


T02A Steam

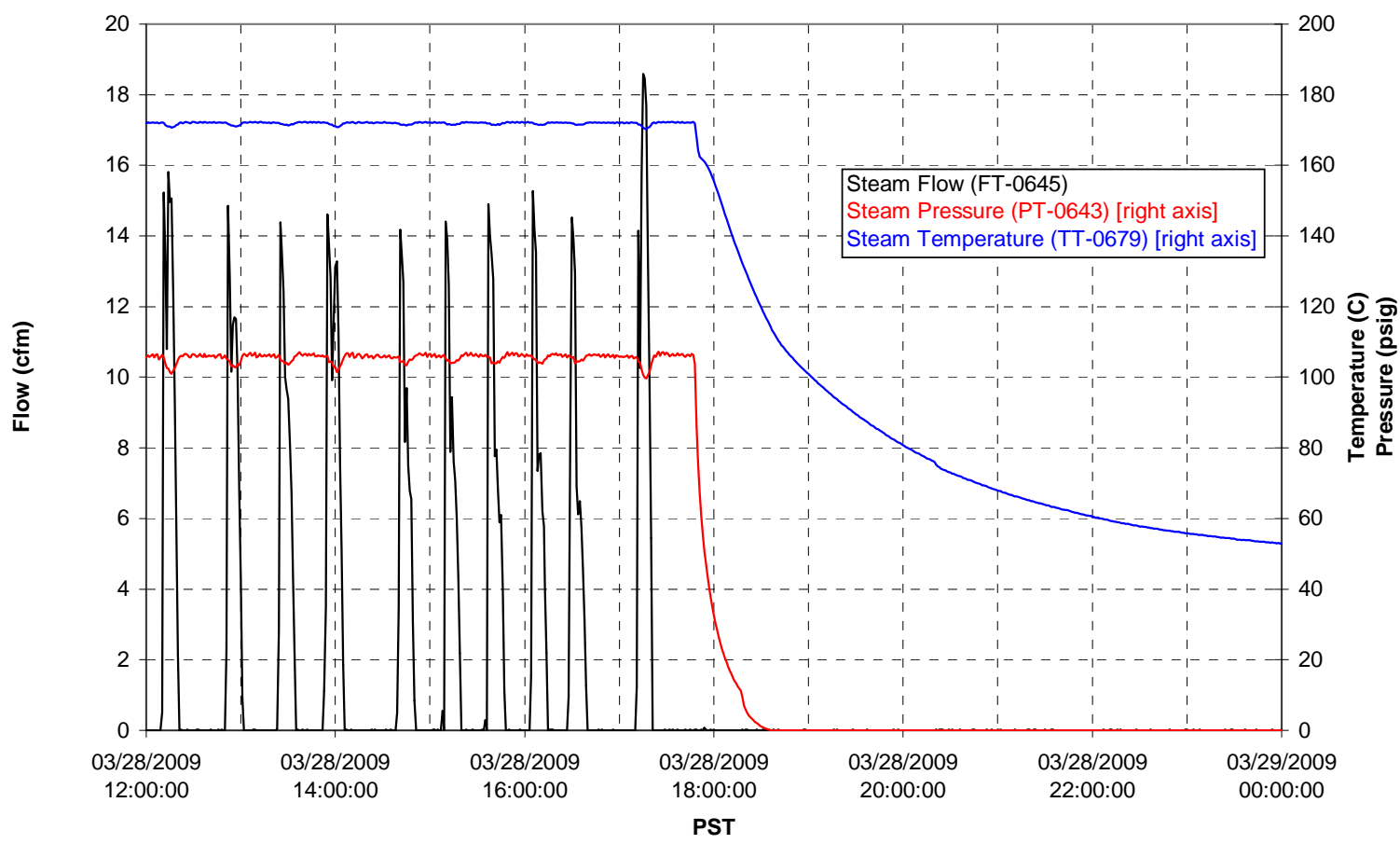

T01A Steam

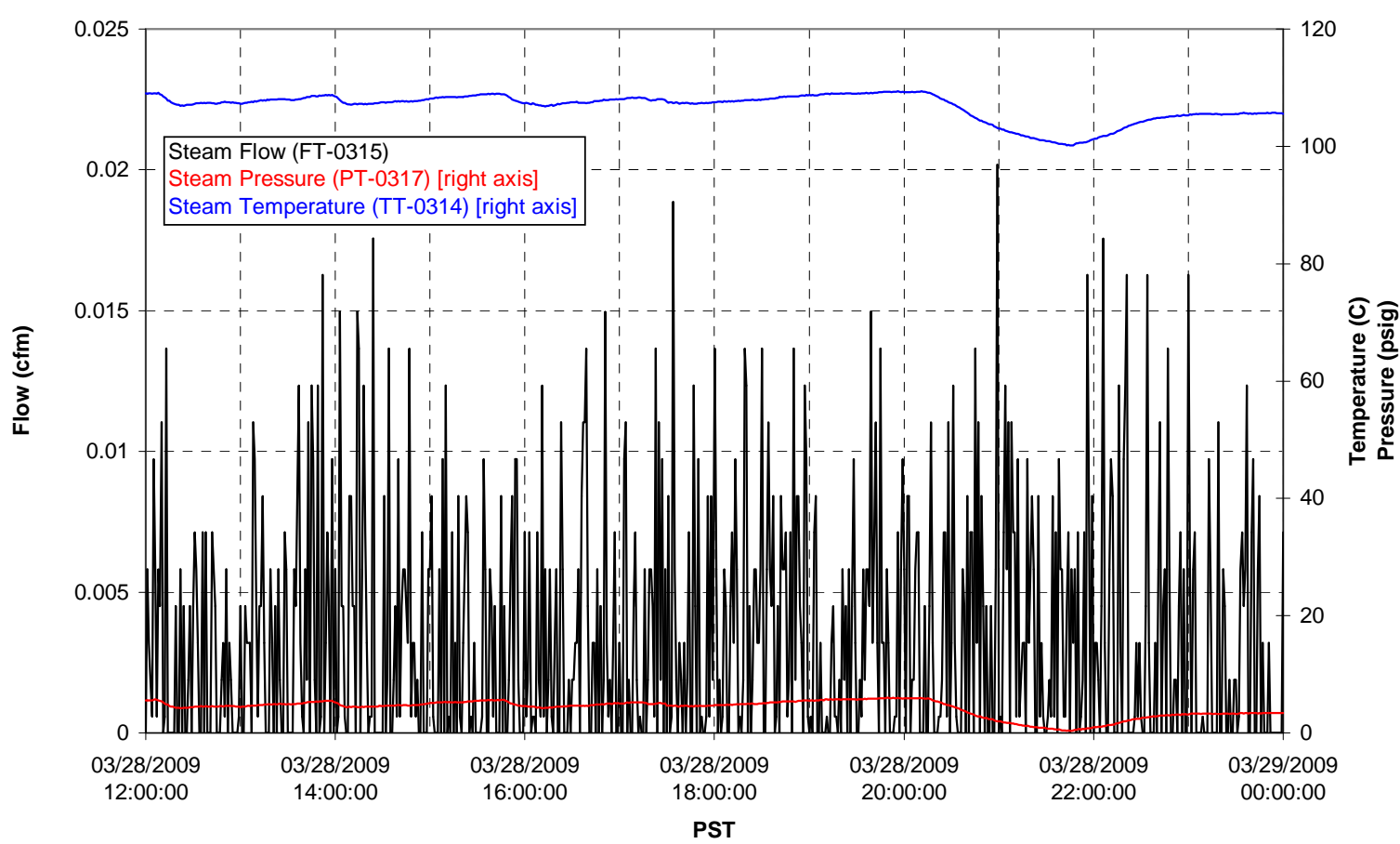


T01B Steam

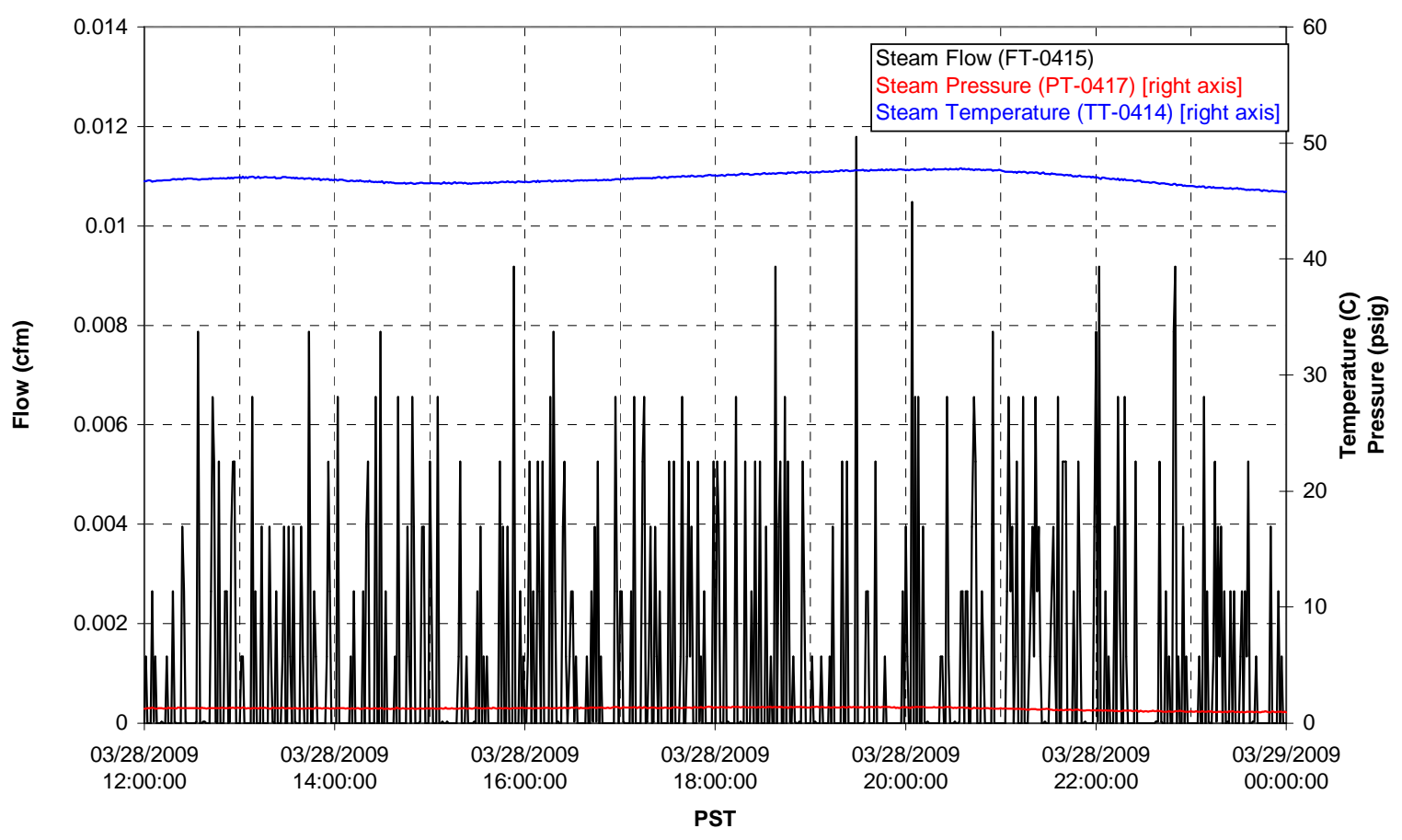




\section{Integrated Test D Data Plots 03/29/09 00:00 - 03/29/09 12:00}


T01A level

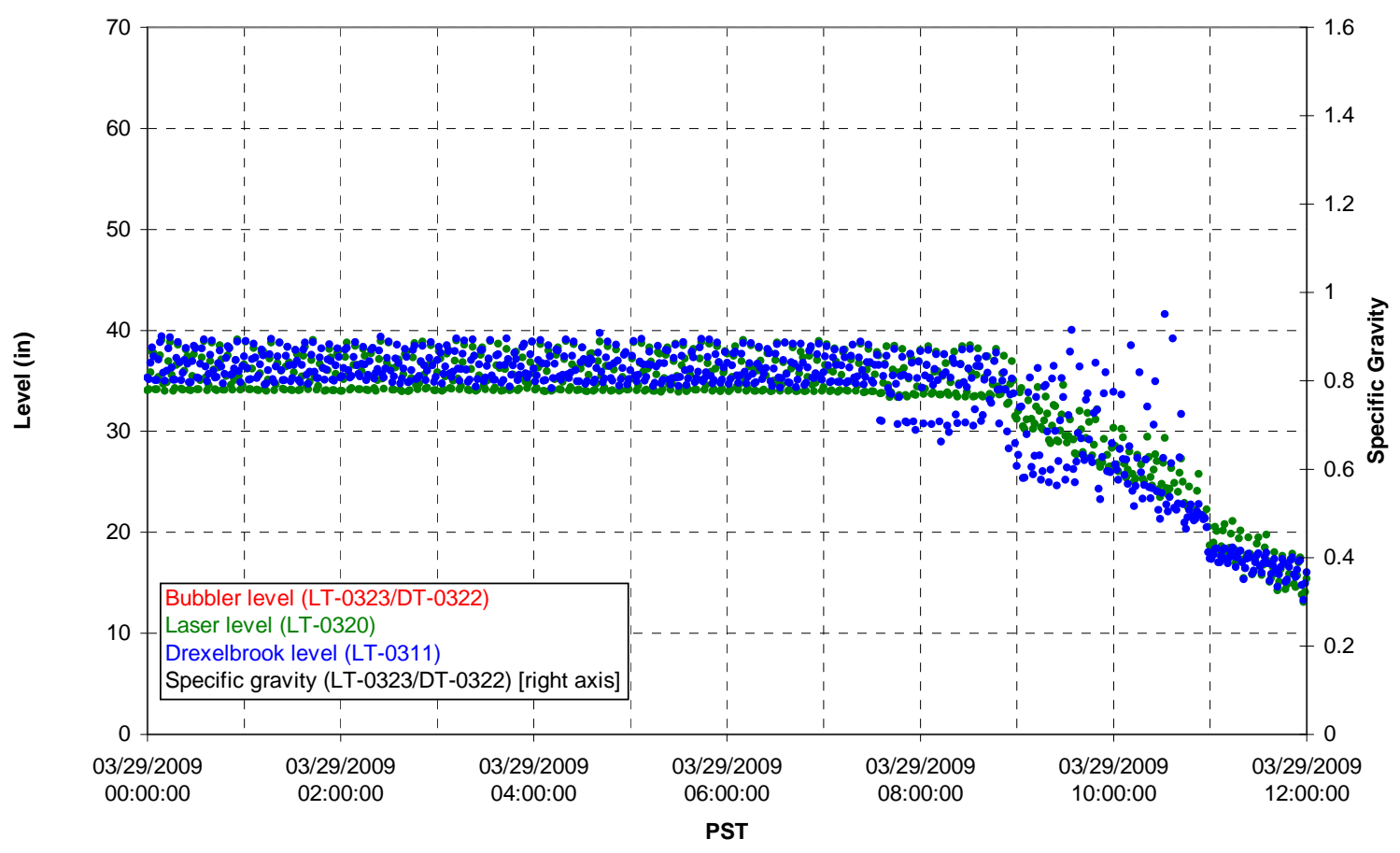

T01A temperatures

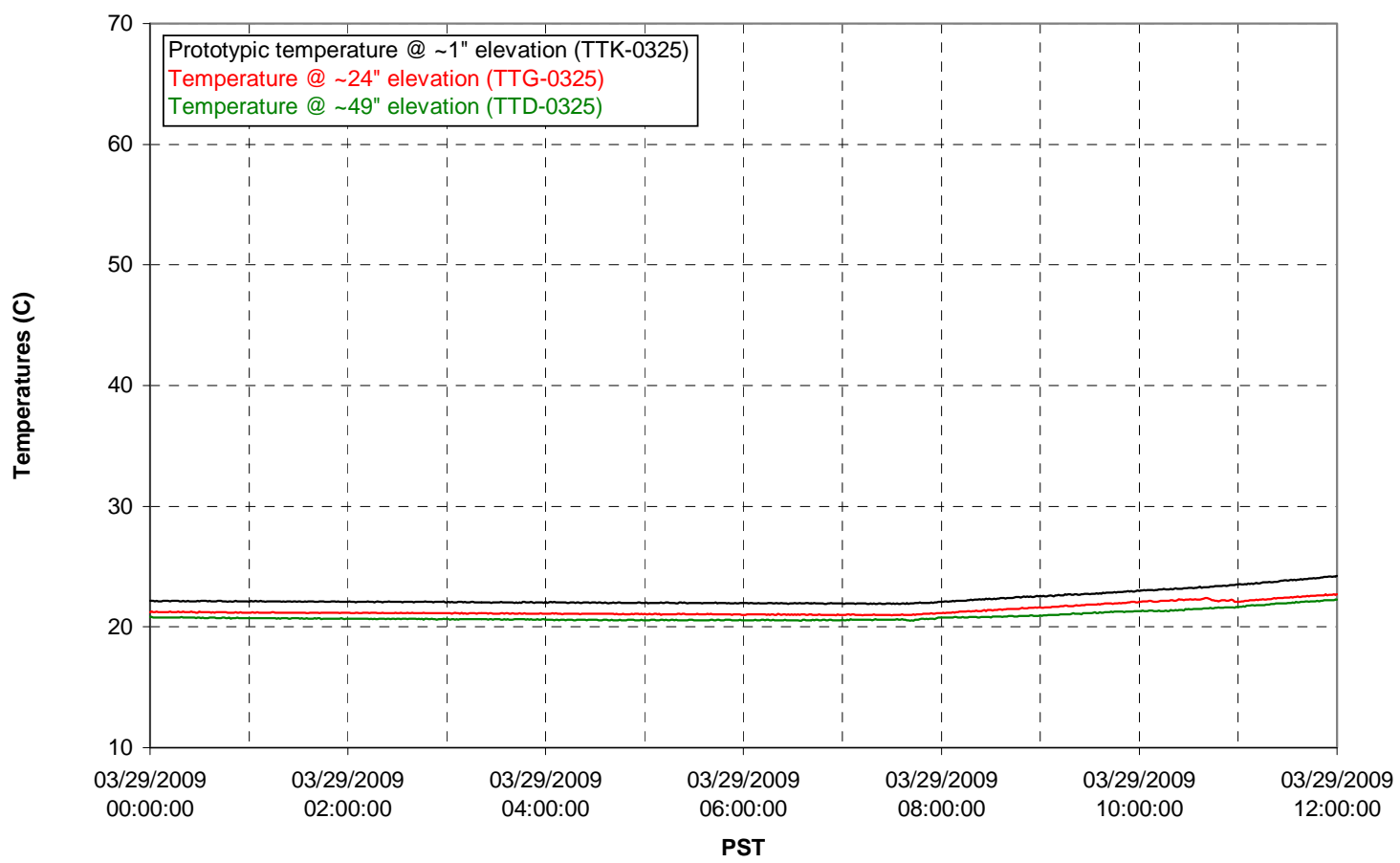


T01B level

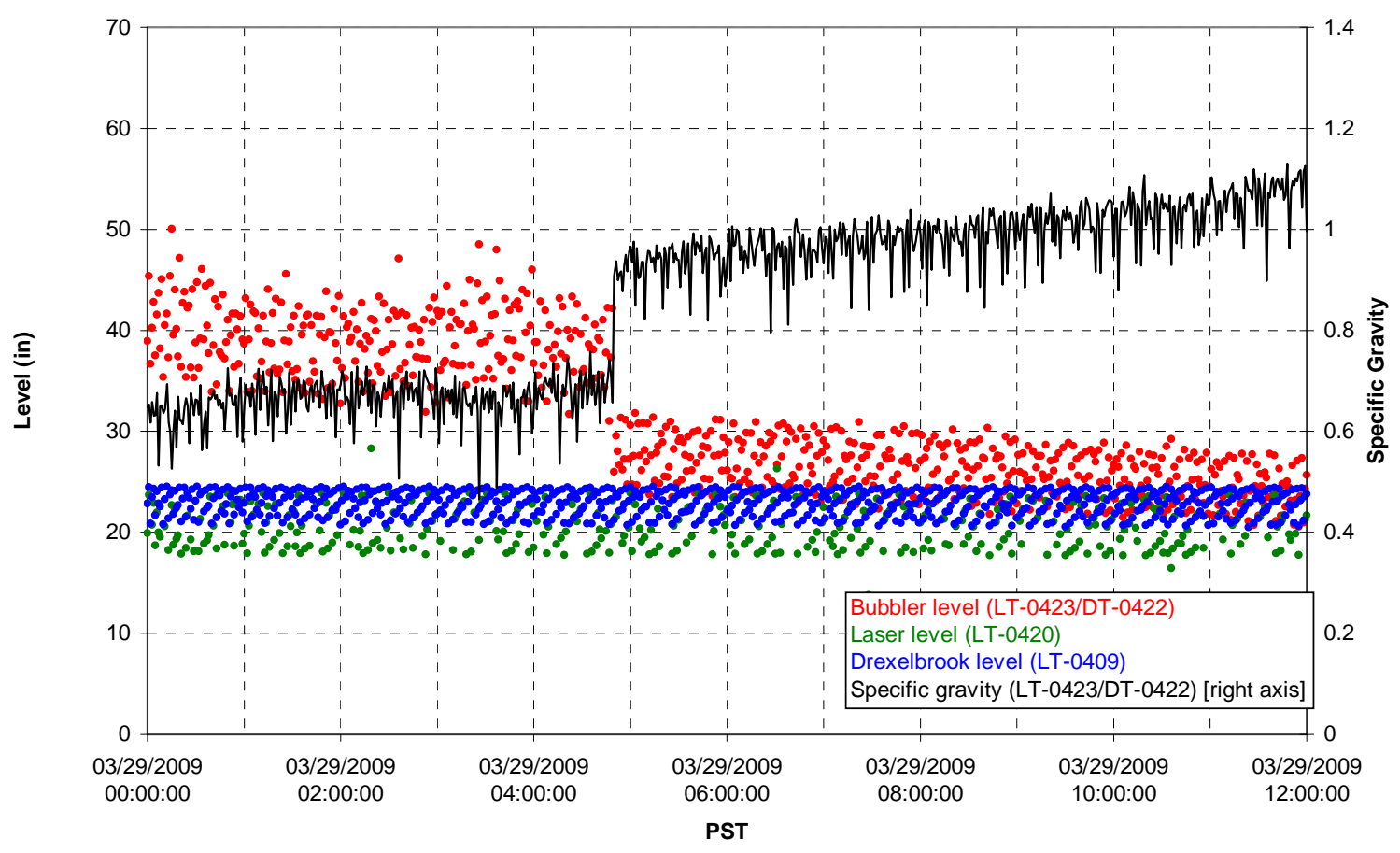

T01B temperatures

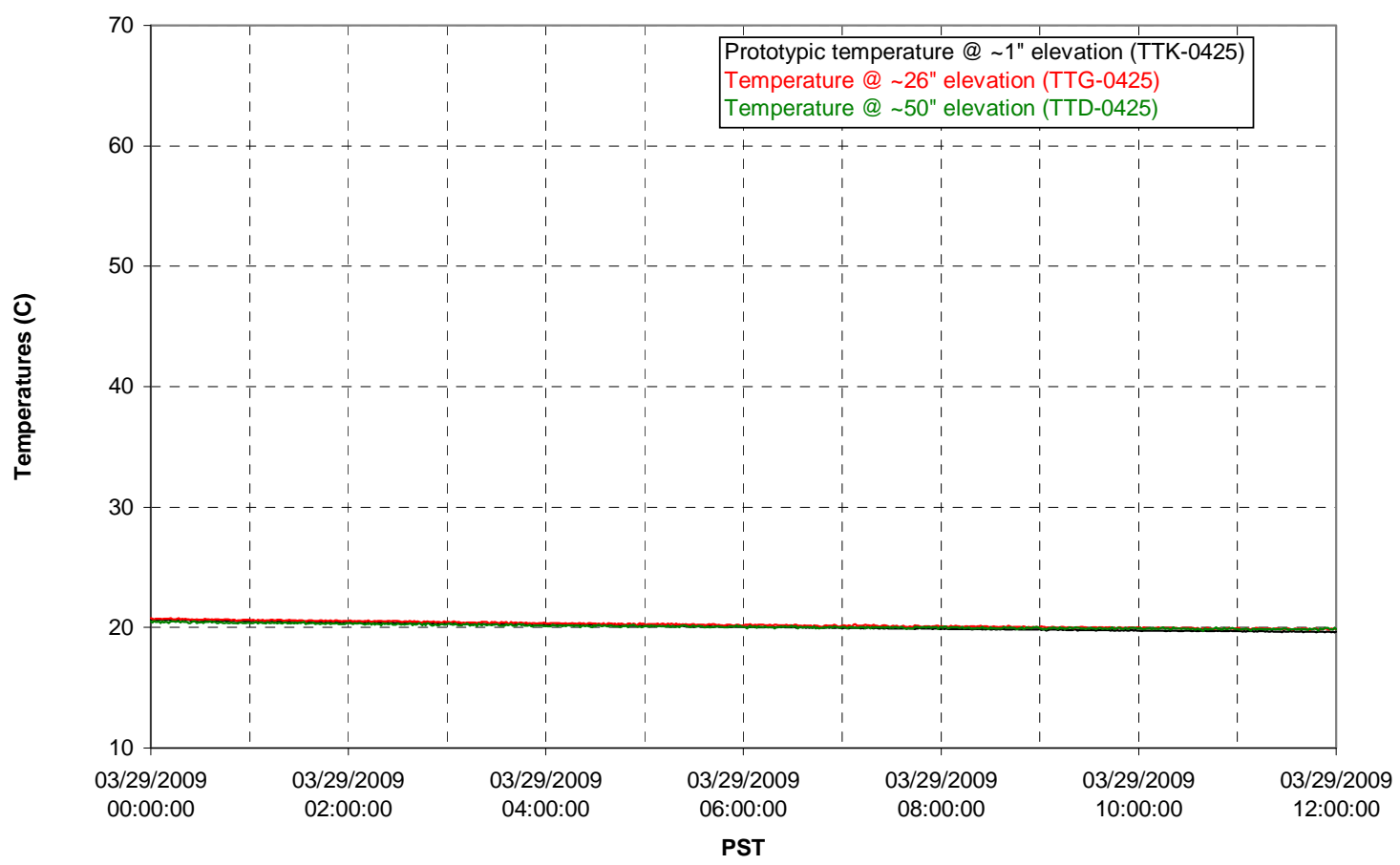


T02A level

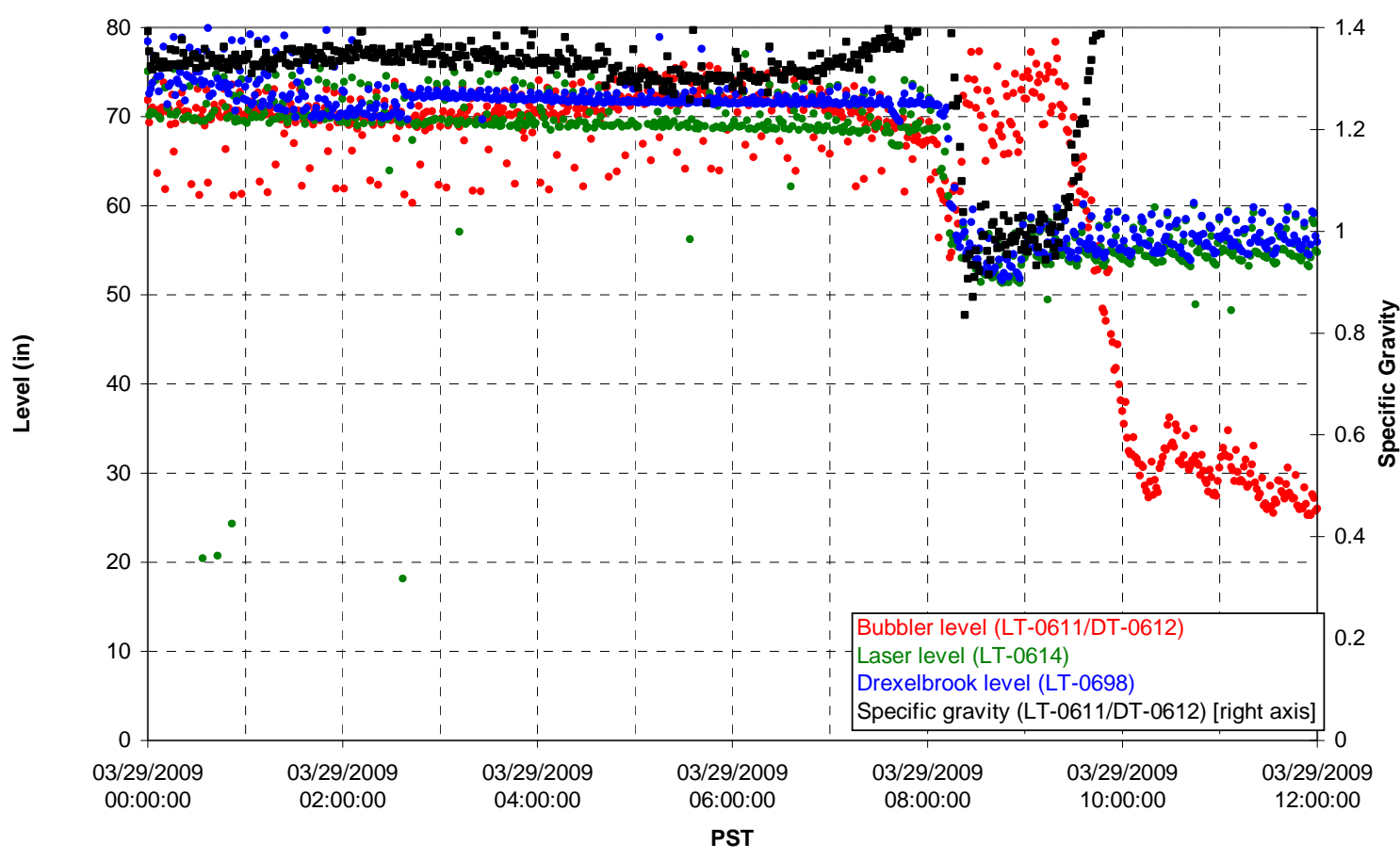

T02A temperatures

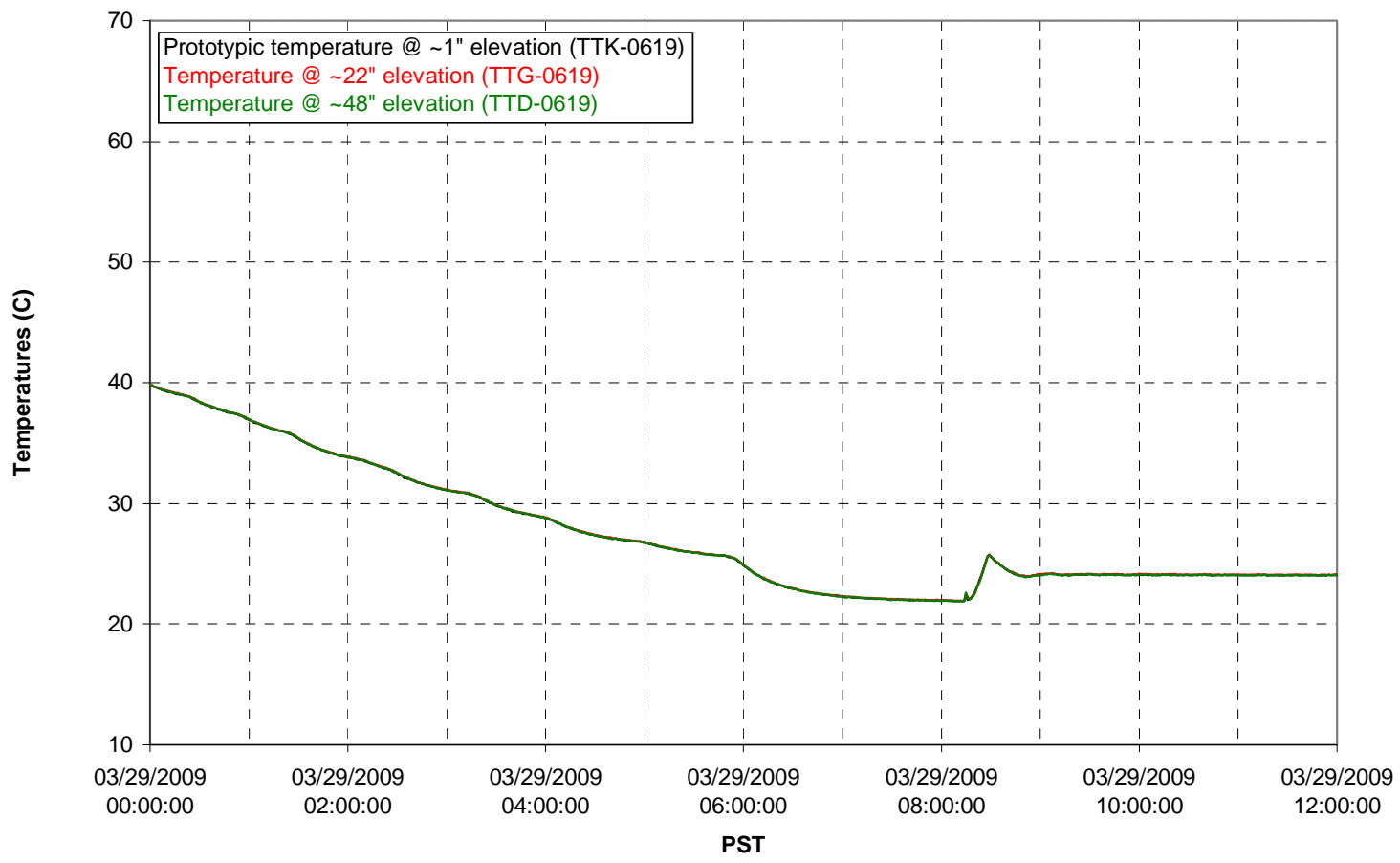


T02A and filter loop temperatures

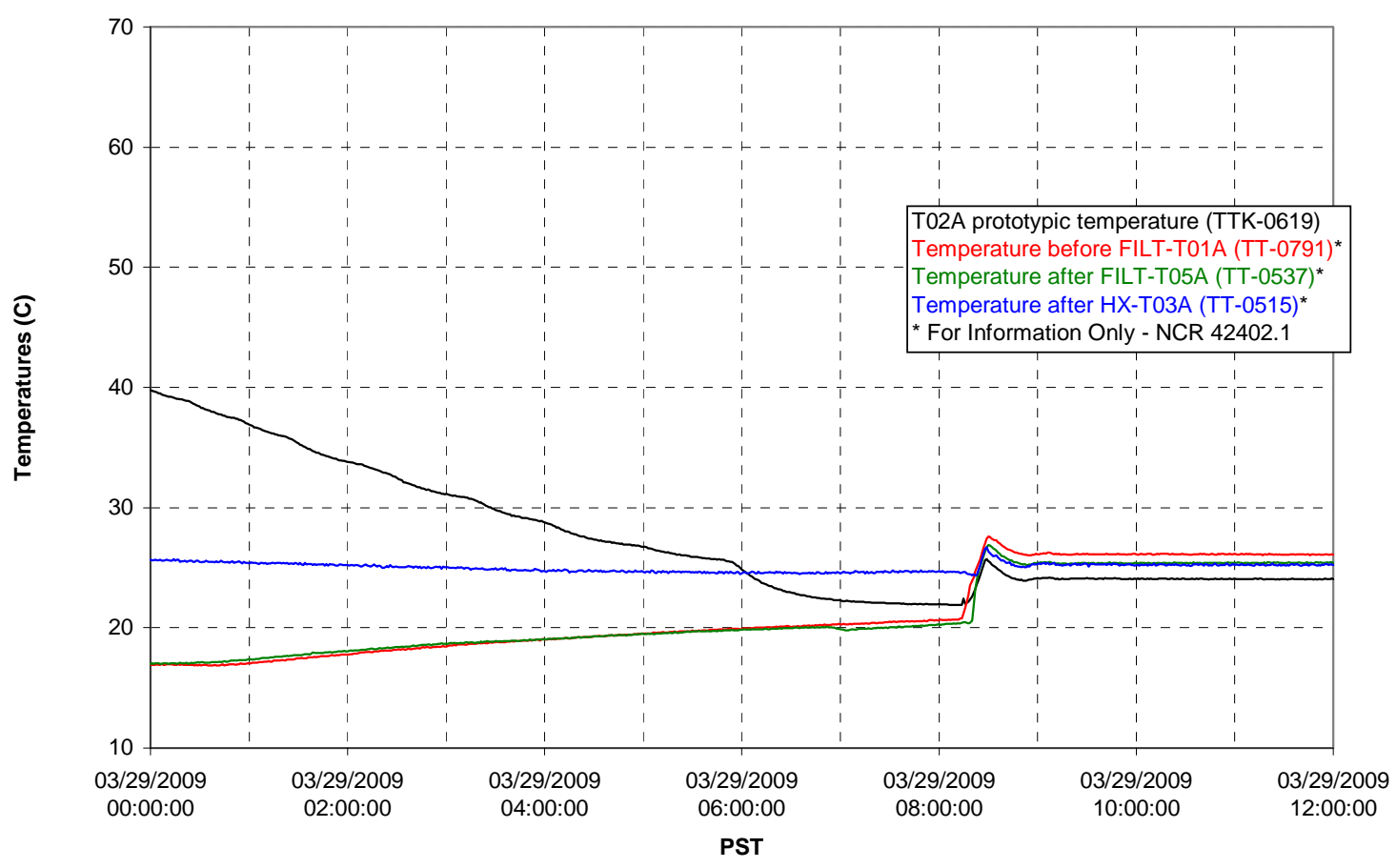

Pump Pressures and Flow

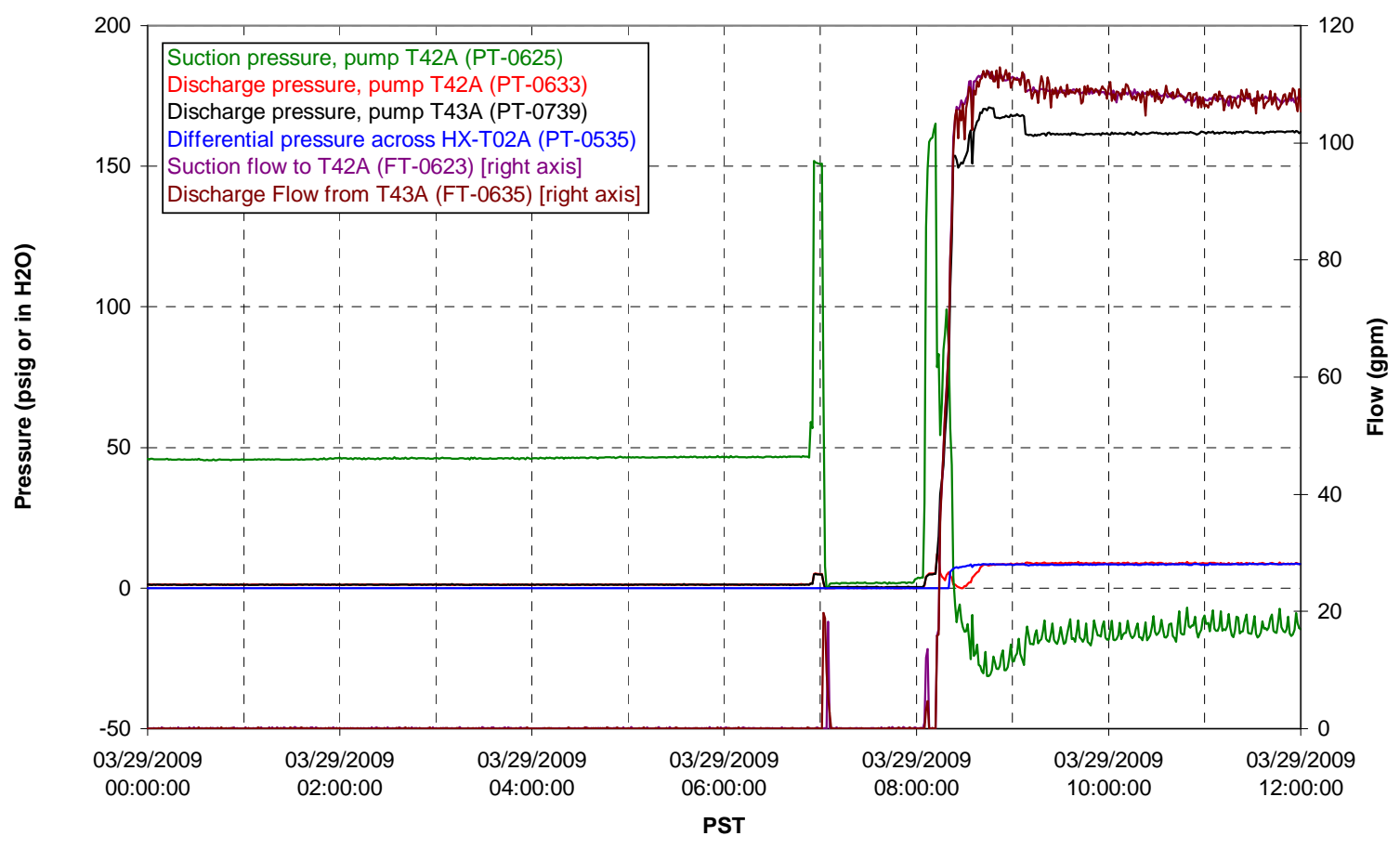




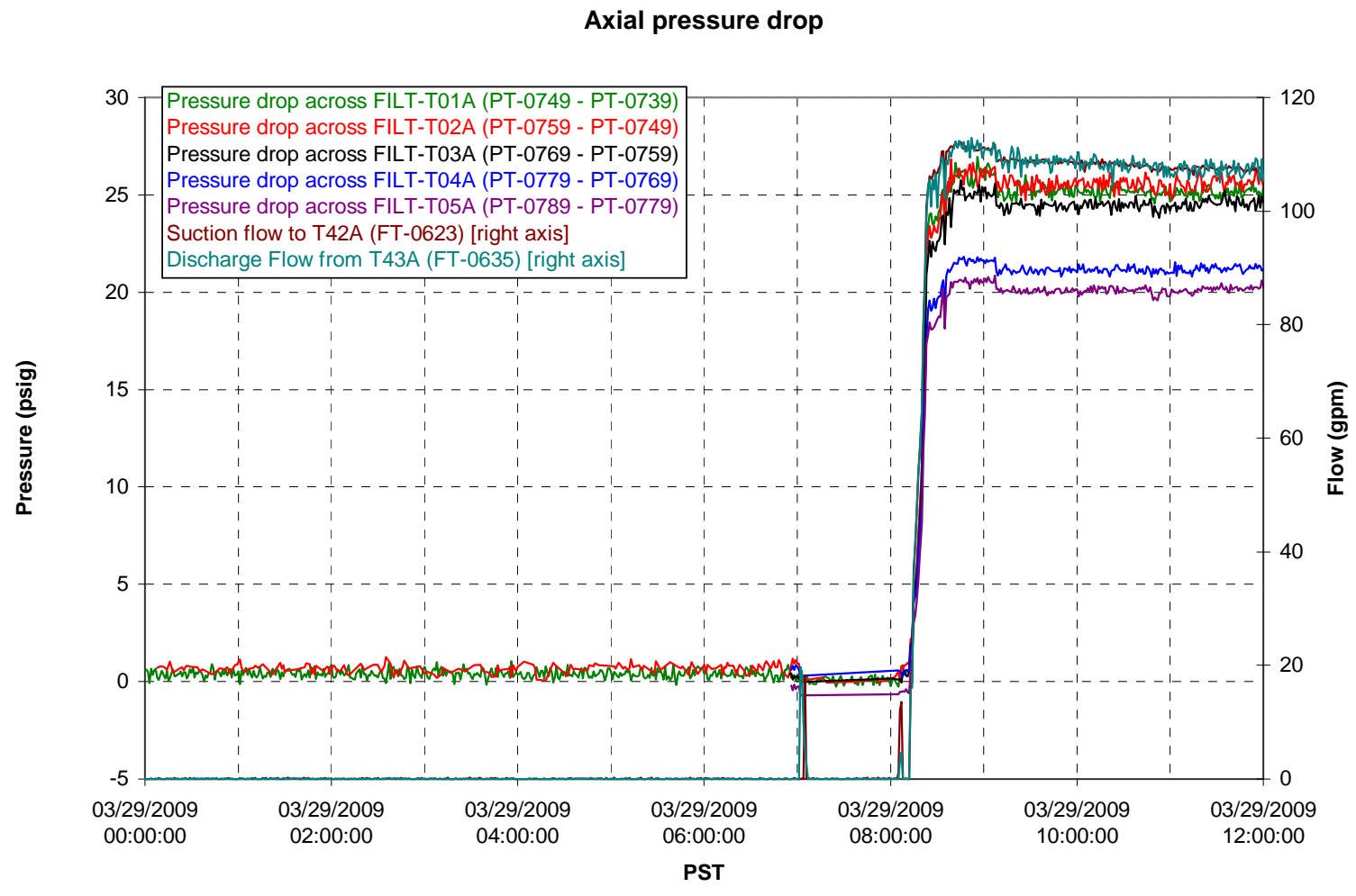

Permeate flow rates

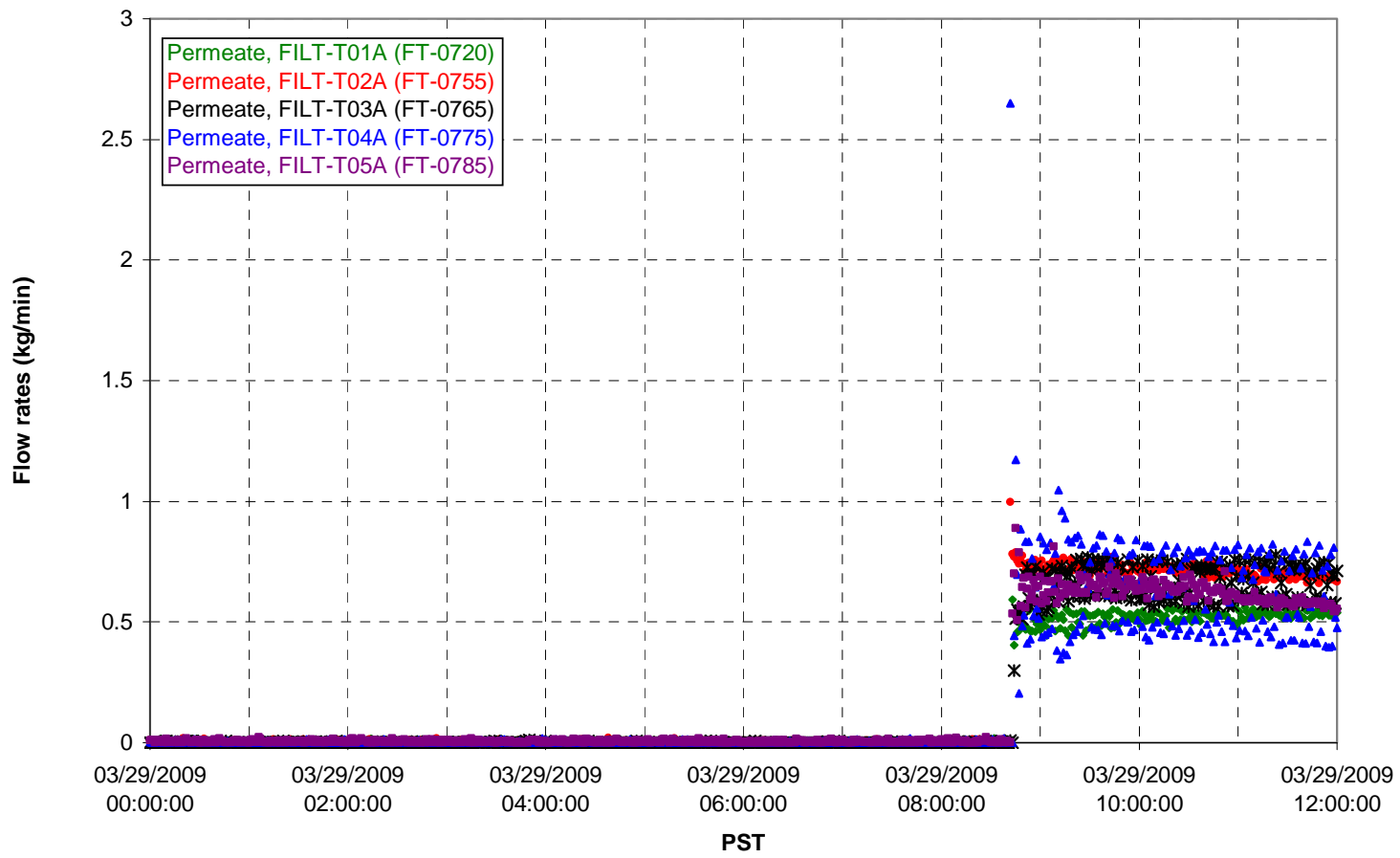


T02A Inner Temperature Tree

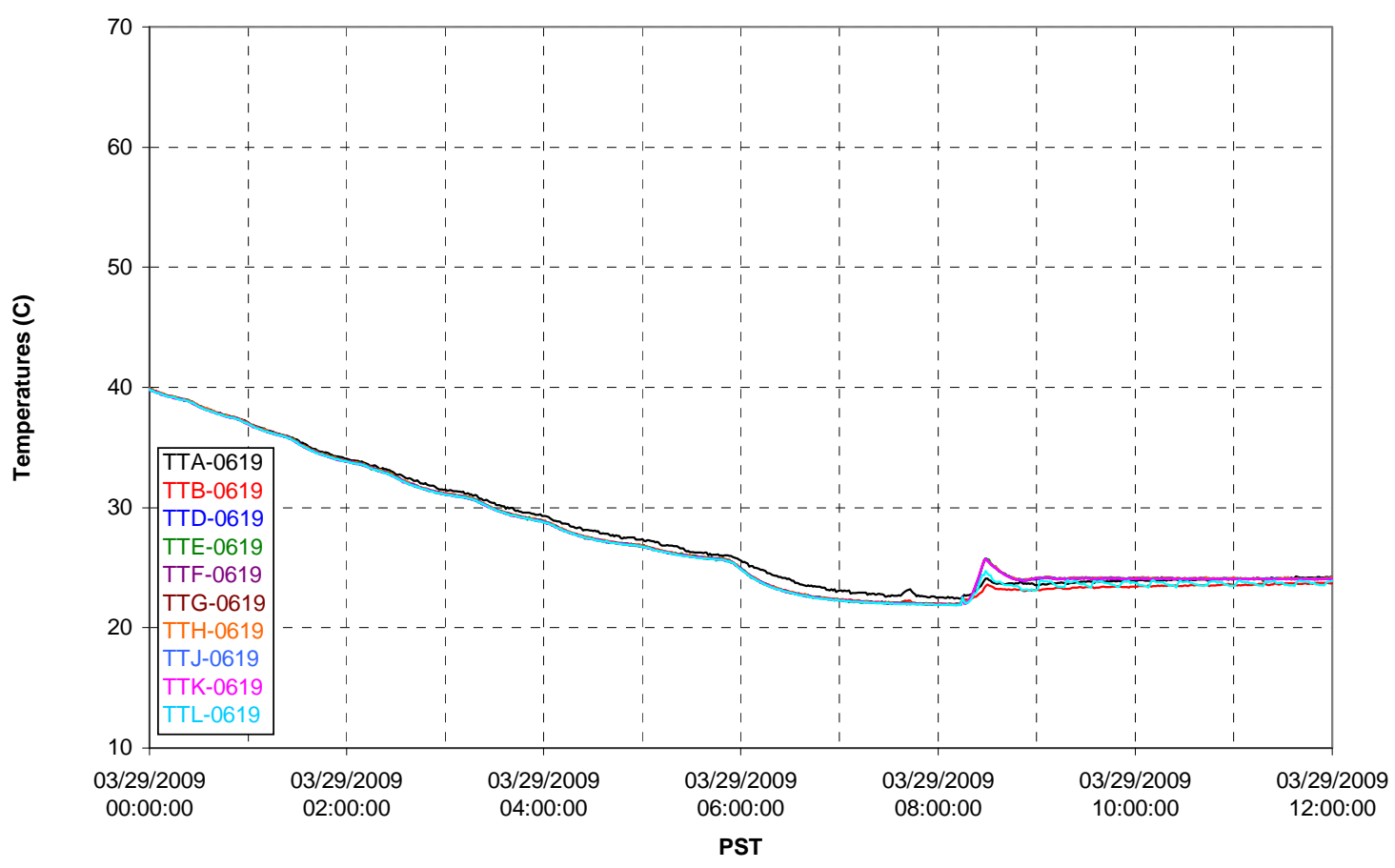

T02A Outer Temperature Tree

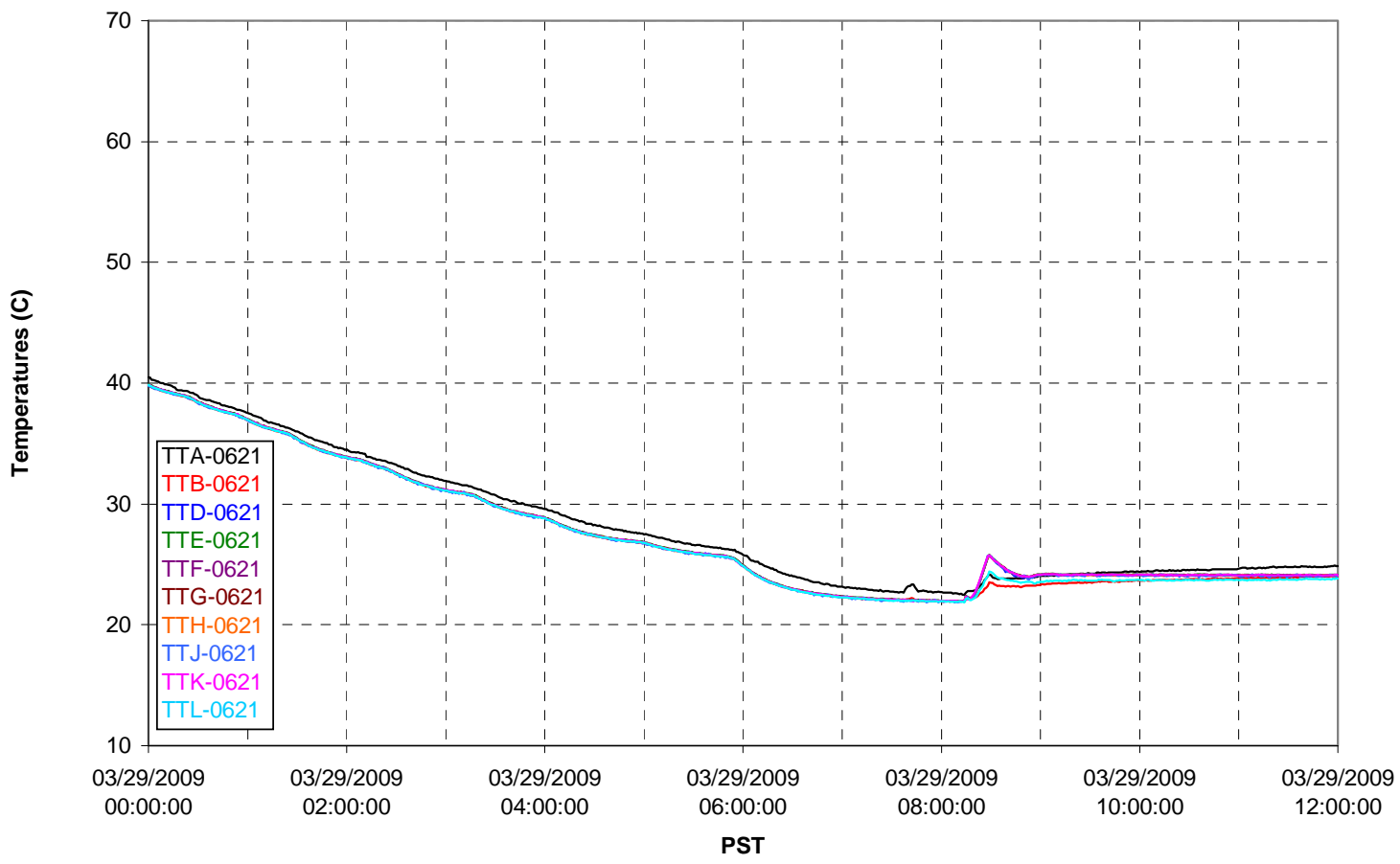


T02A temperatures

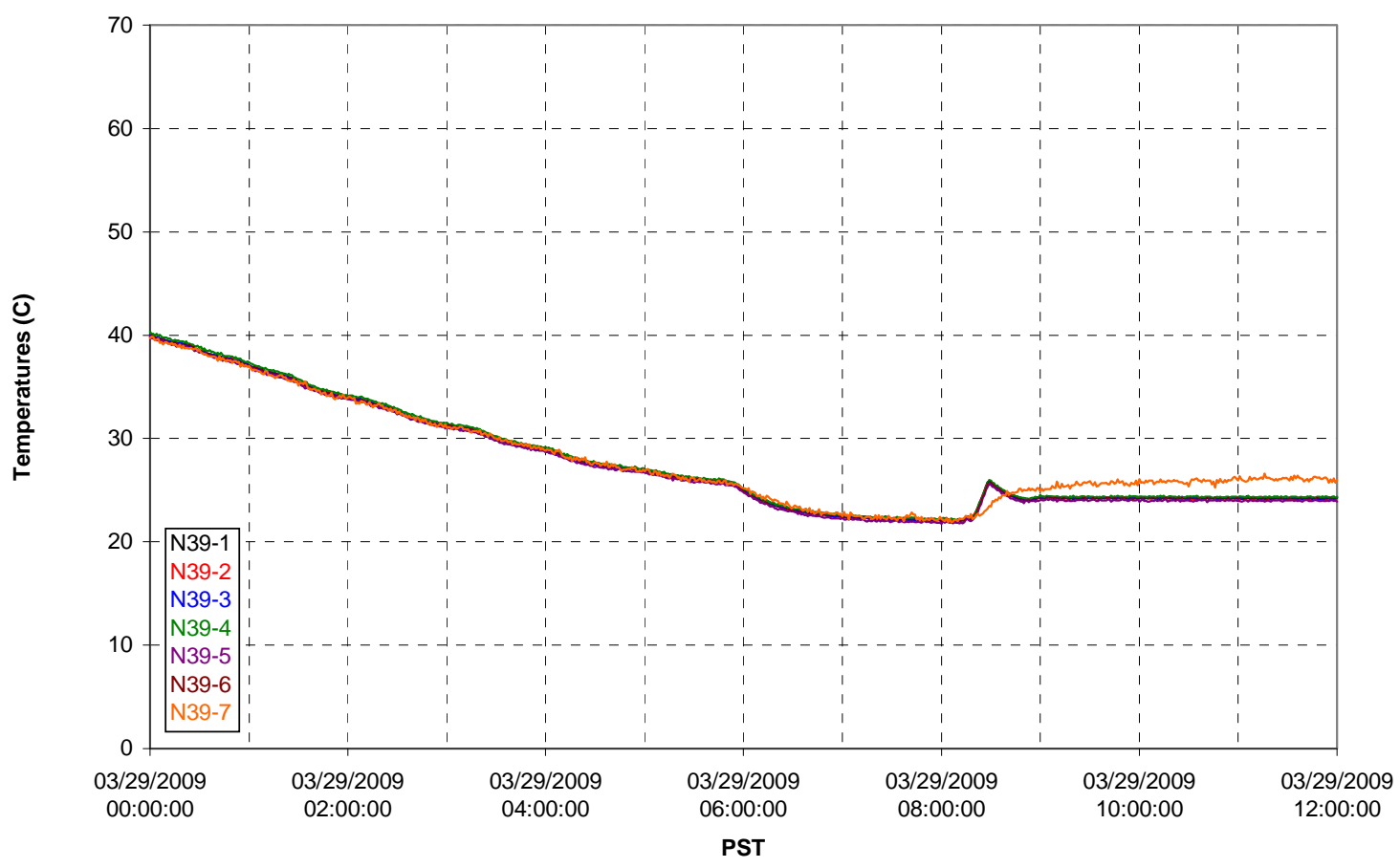

T02A temperatures

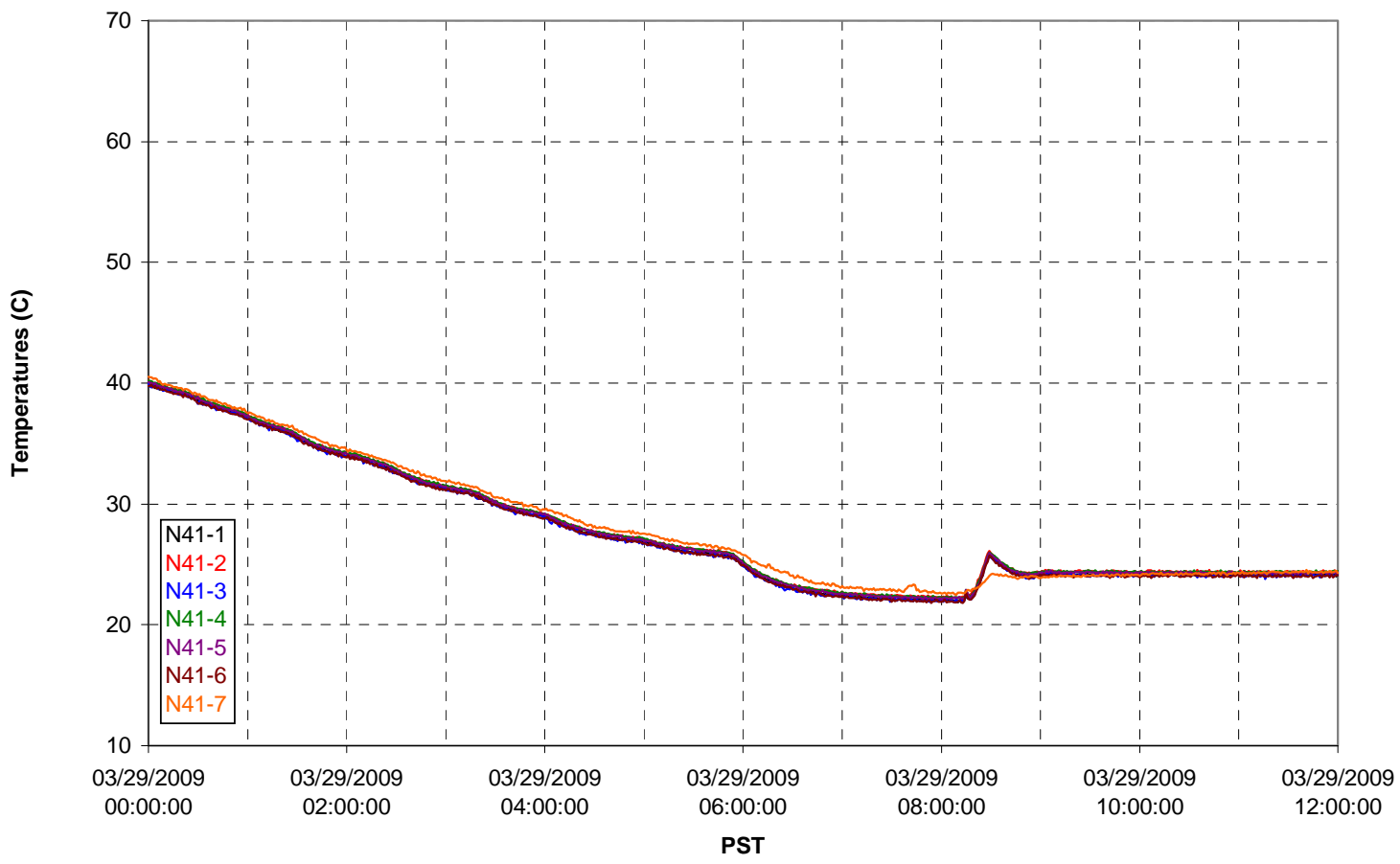


T02A temperatures

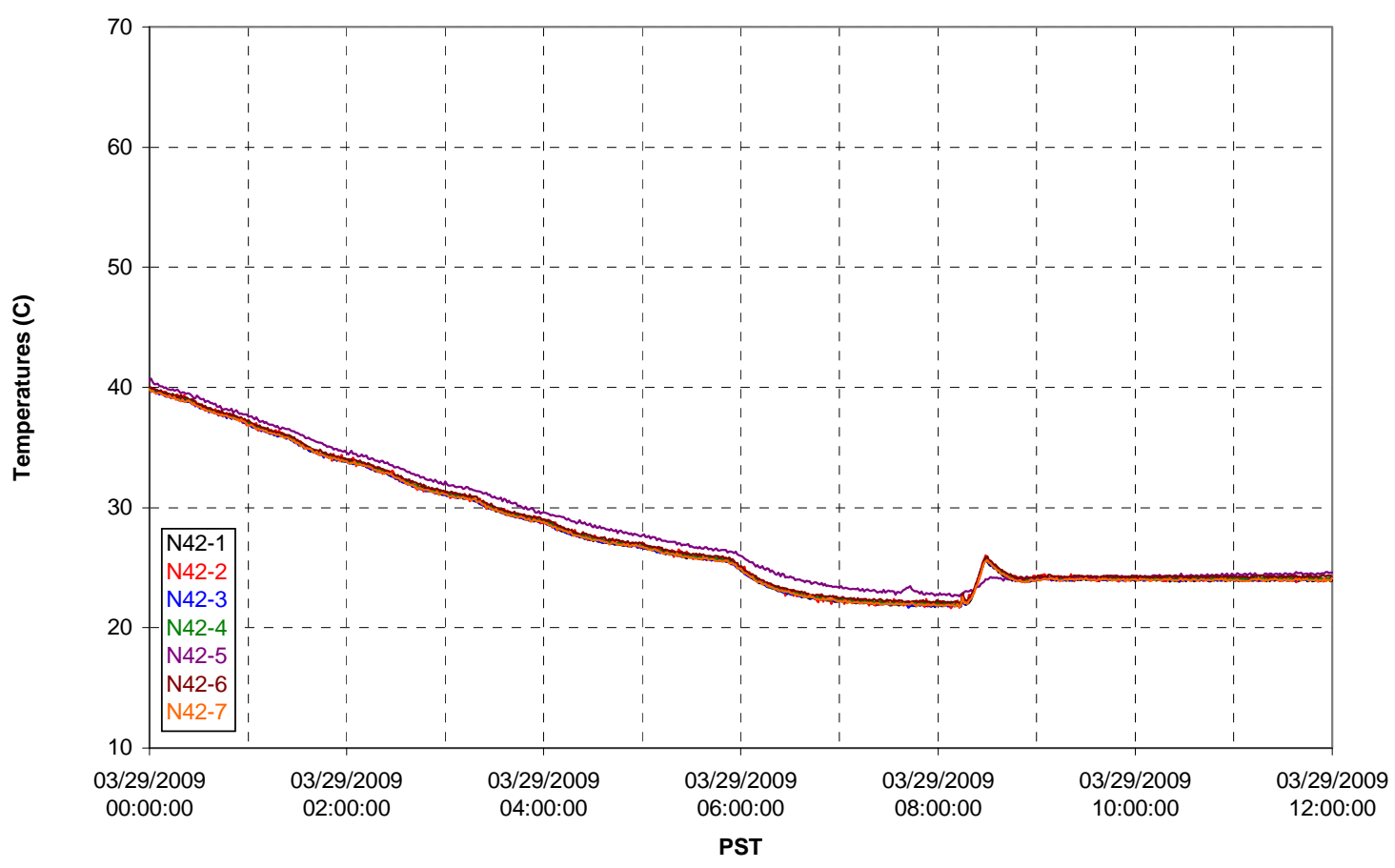

T02A temperatures

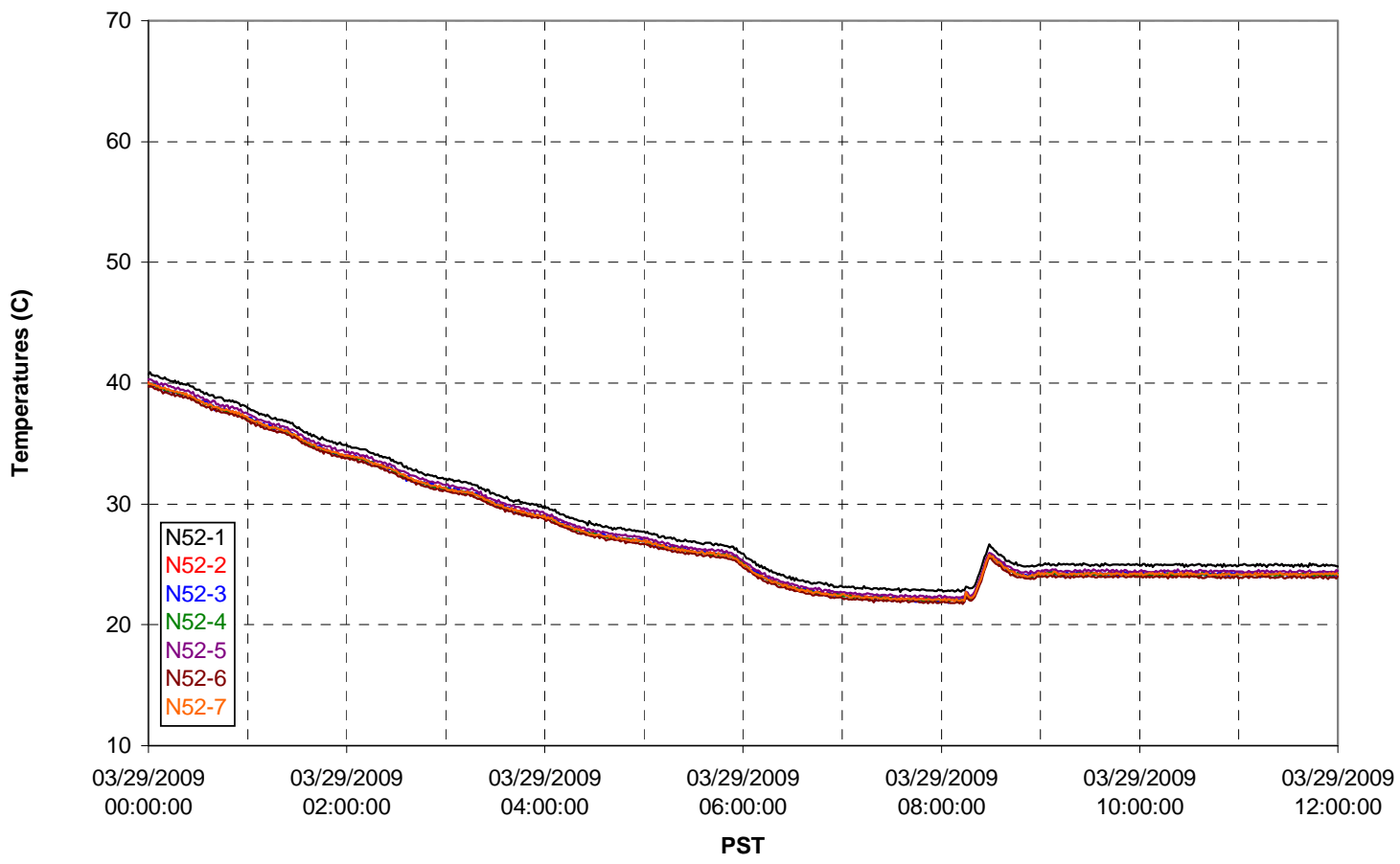


T02A Heating and Cooling

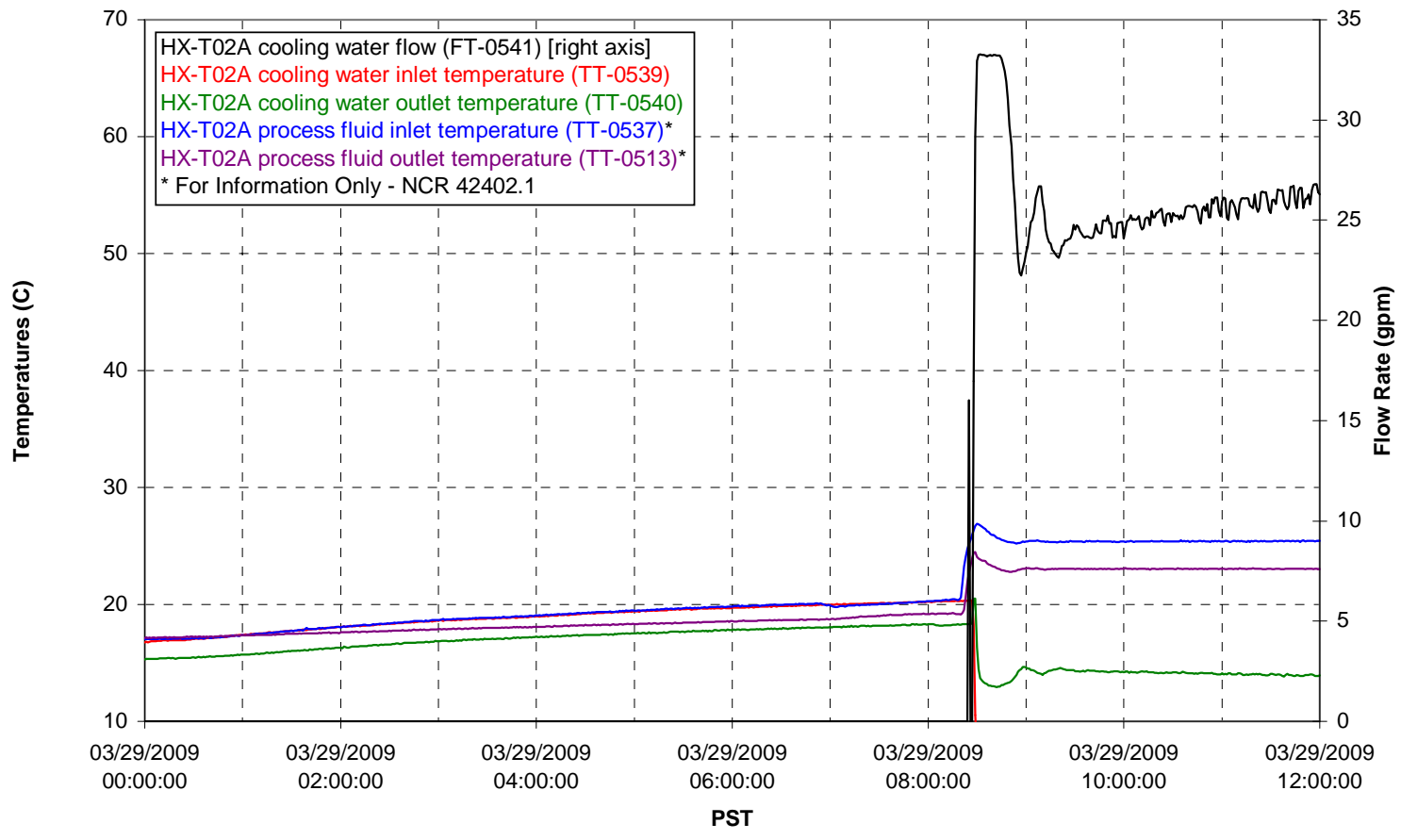

Pump Operation

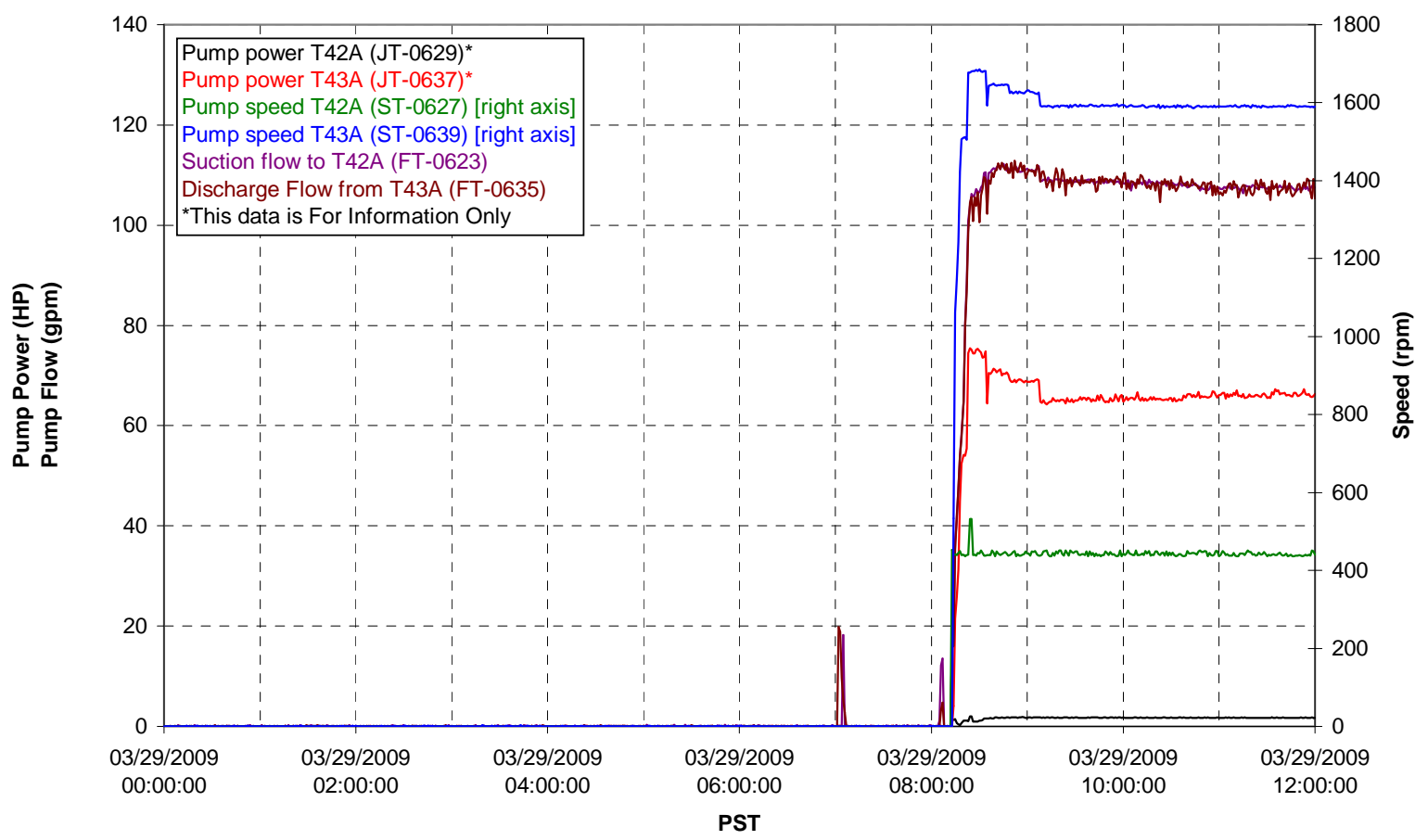


Pulsepot UFP-PP-T01A

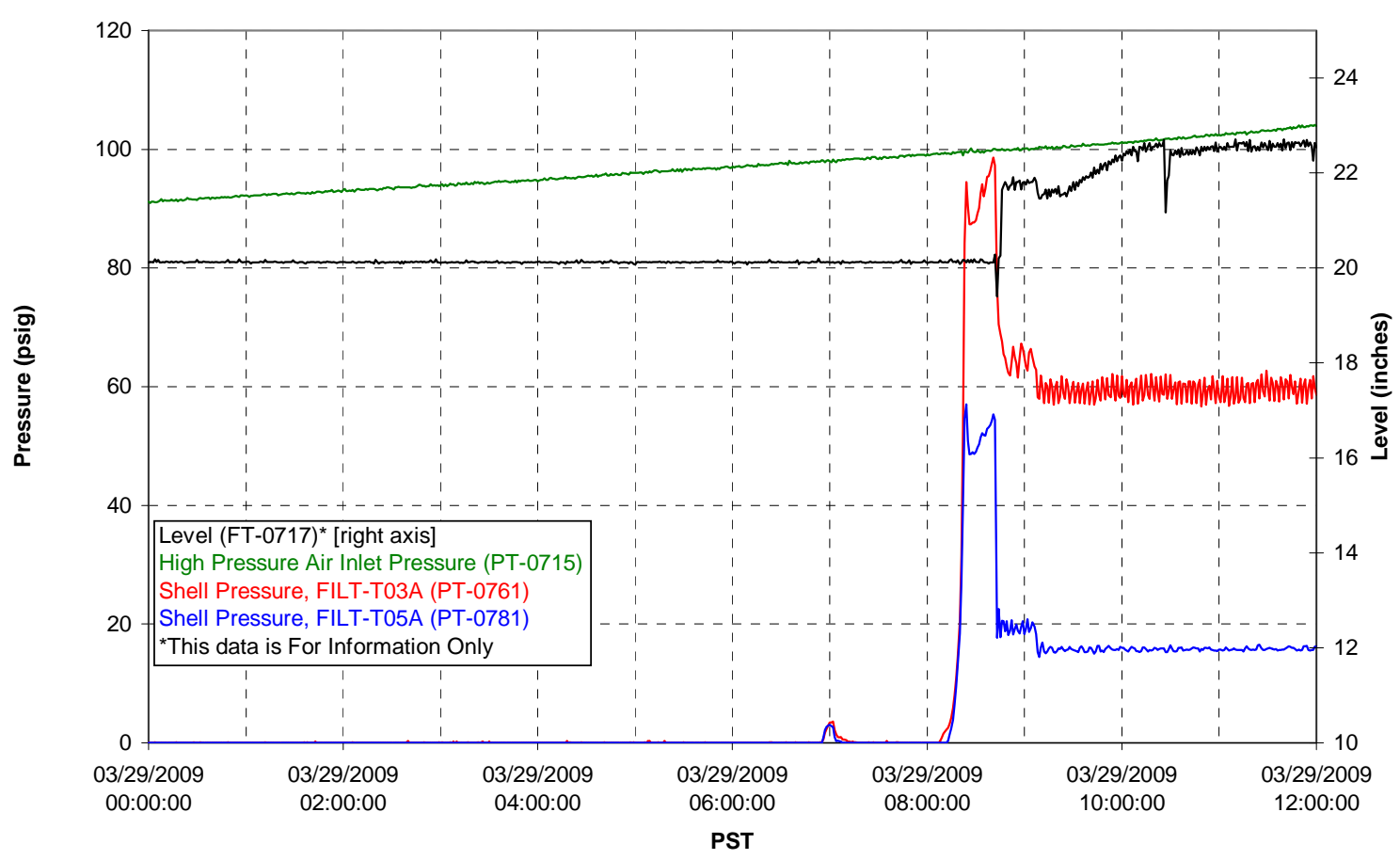

Pulsepot UFP-PP-T02A

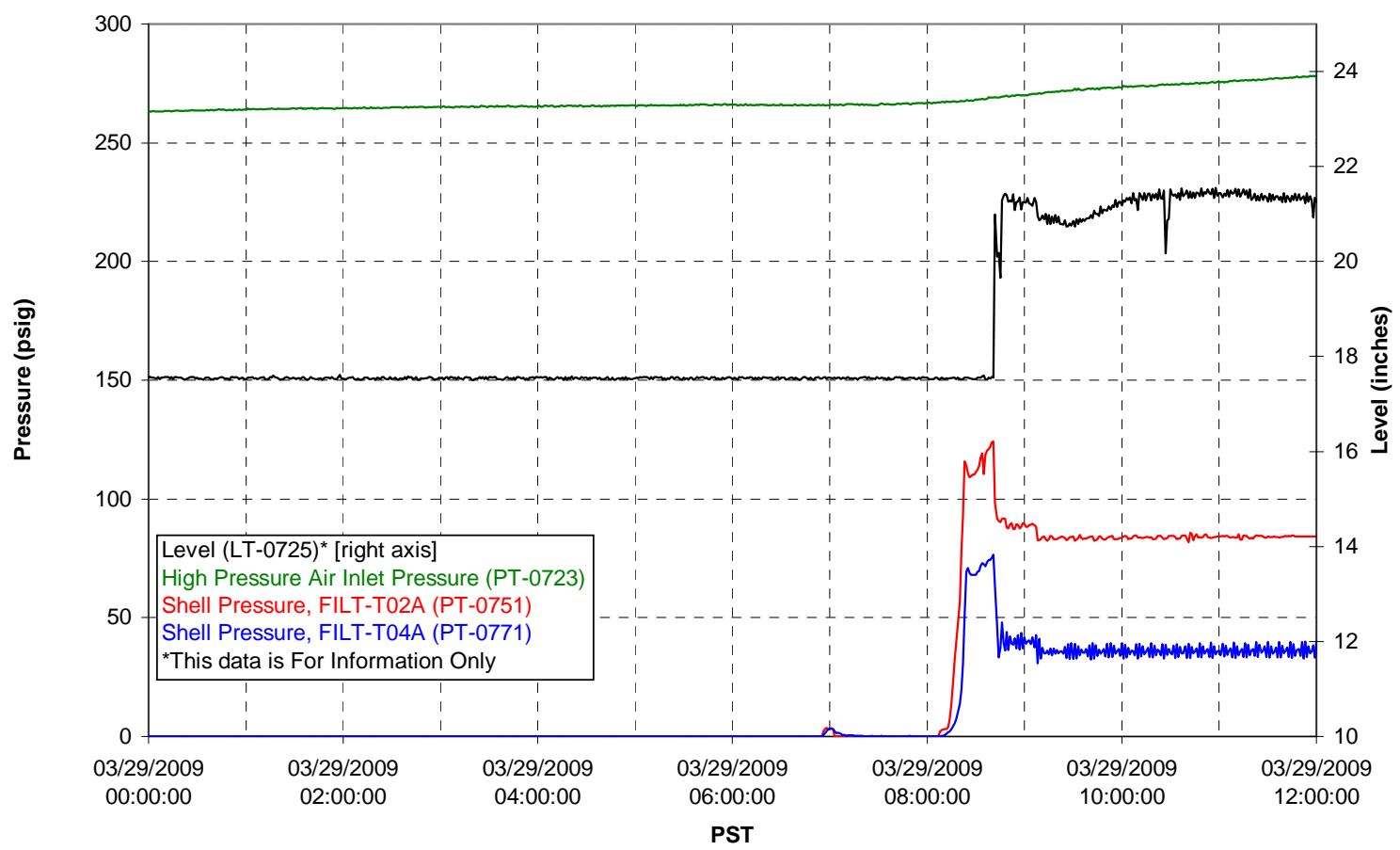


Pulsepot UFP-PP-T03A

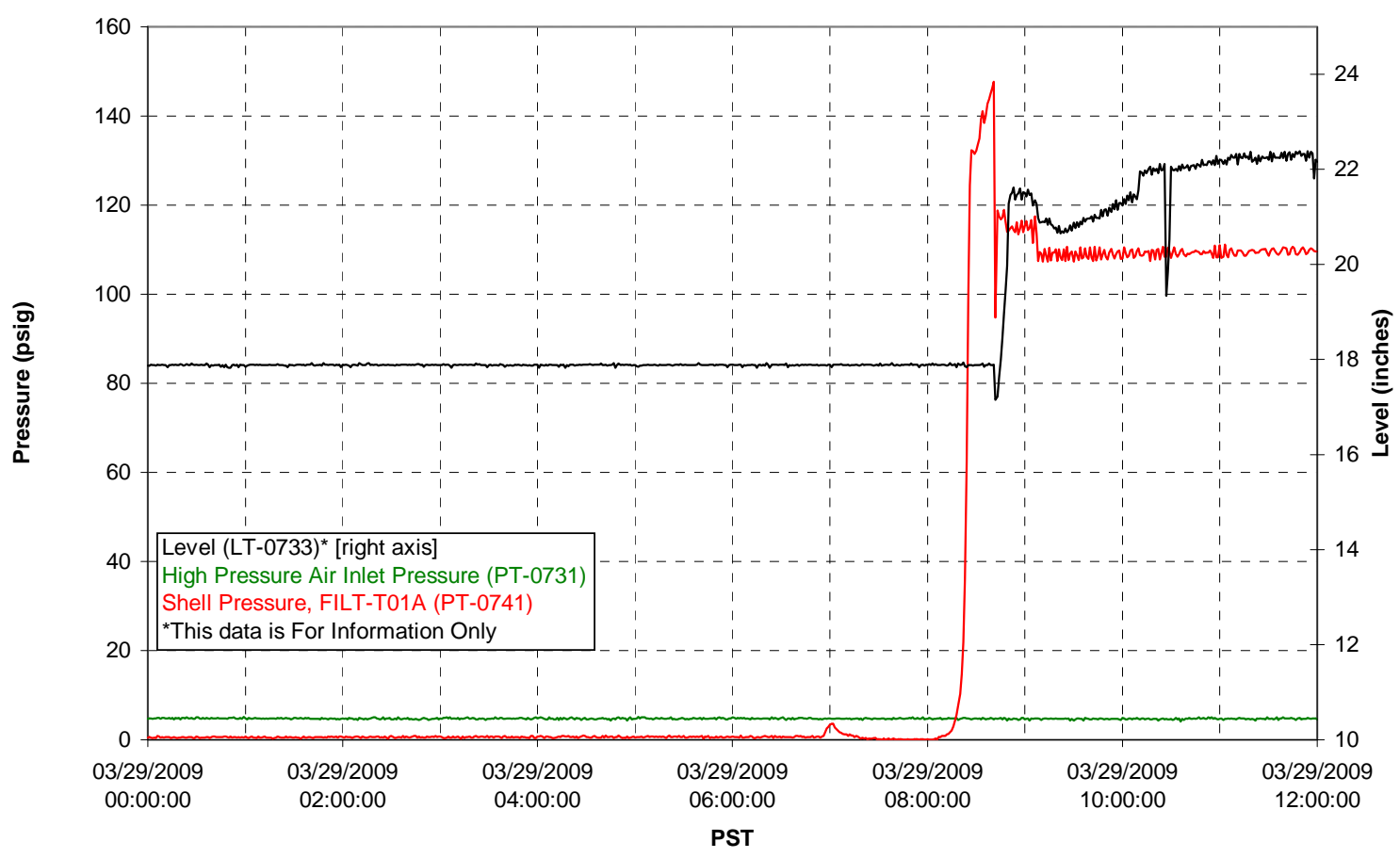

Pulsepot Levels

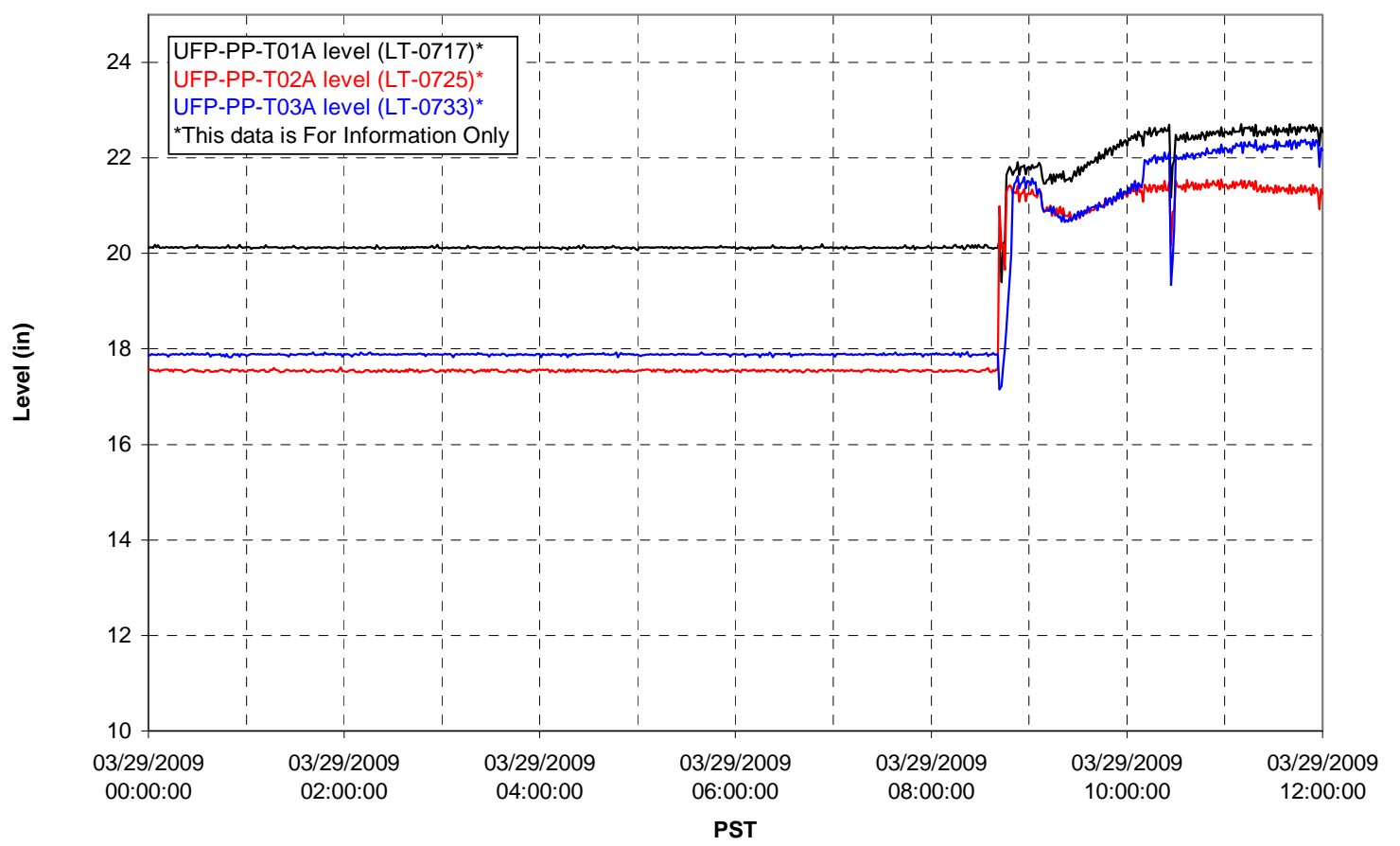


Filter UFP-FILT-T01A

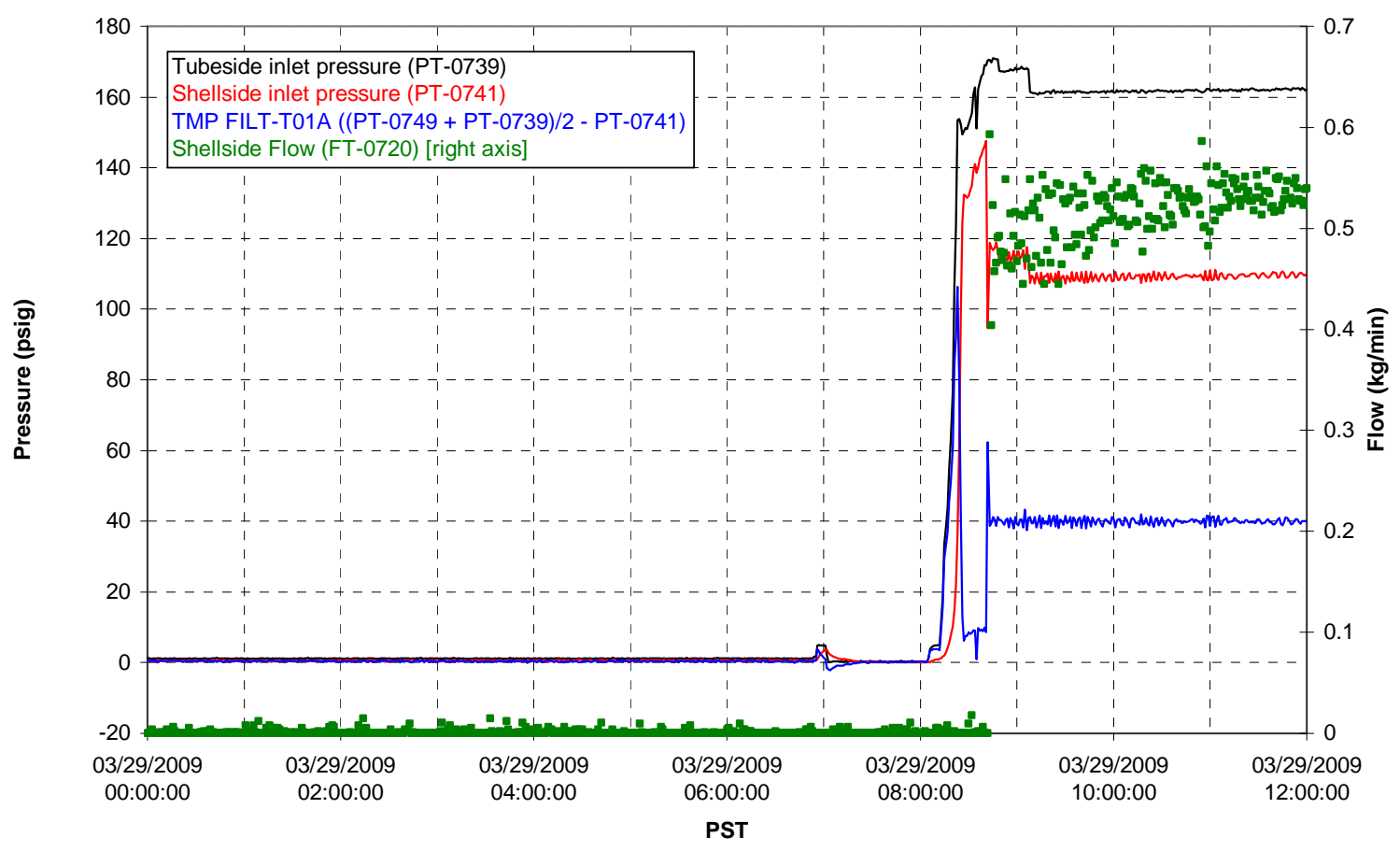

Filter UFP-FILT-T02A

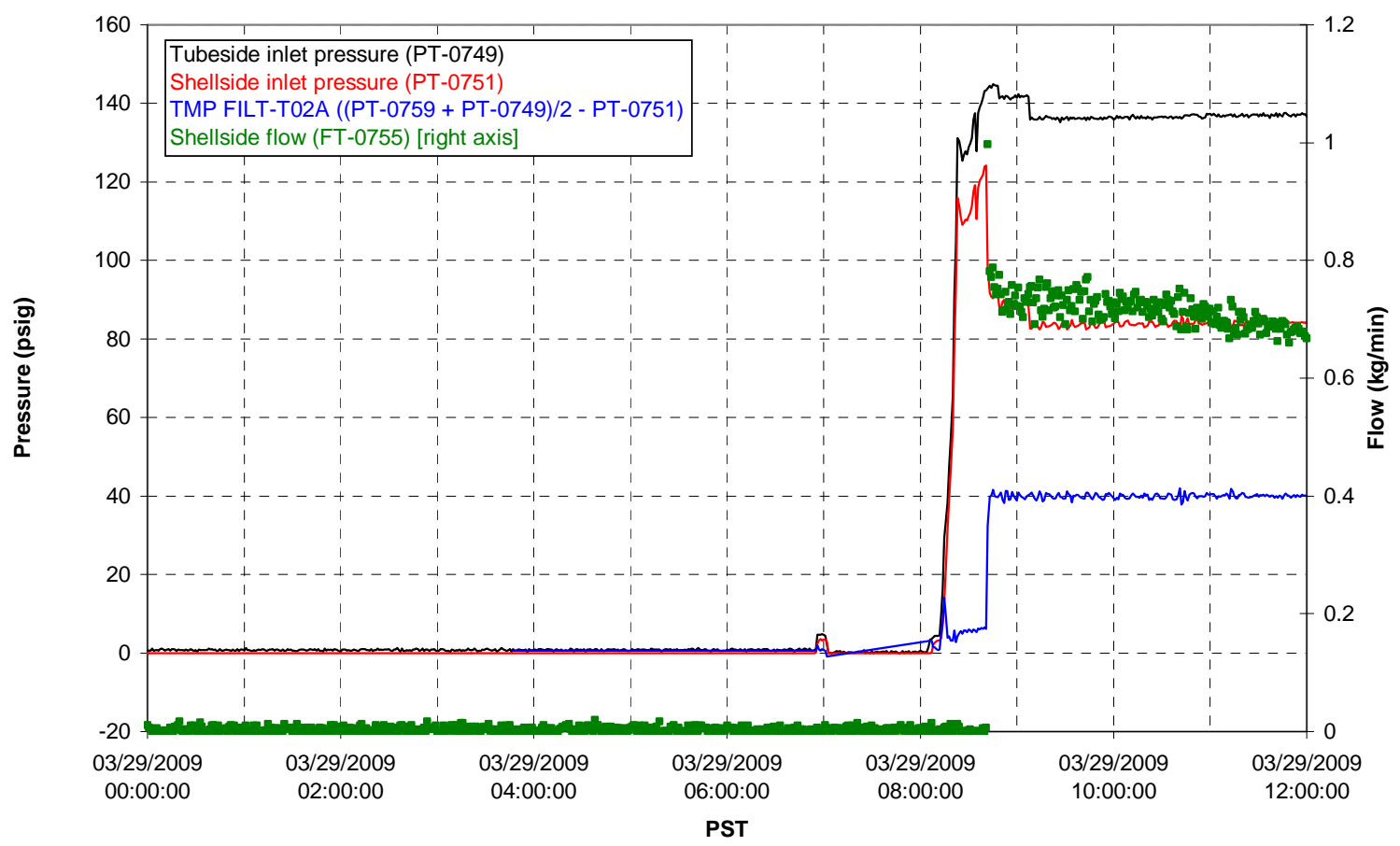


Filter UFP-FILT-T03A

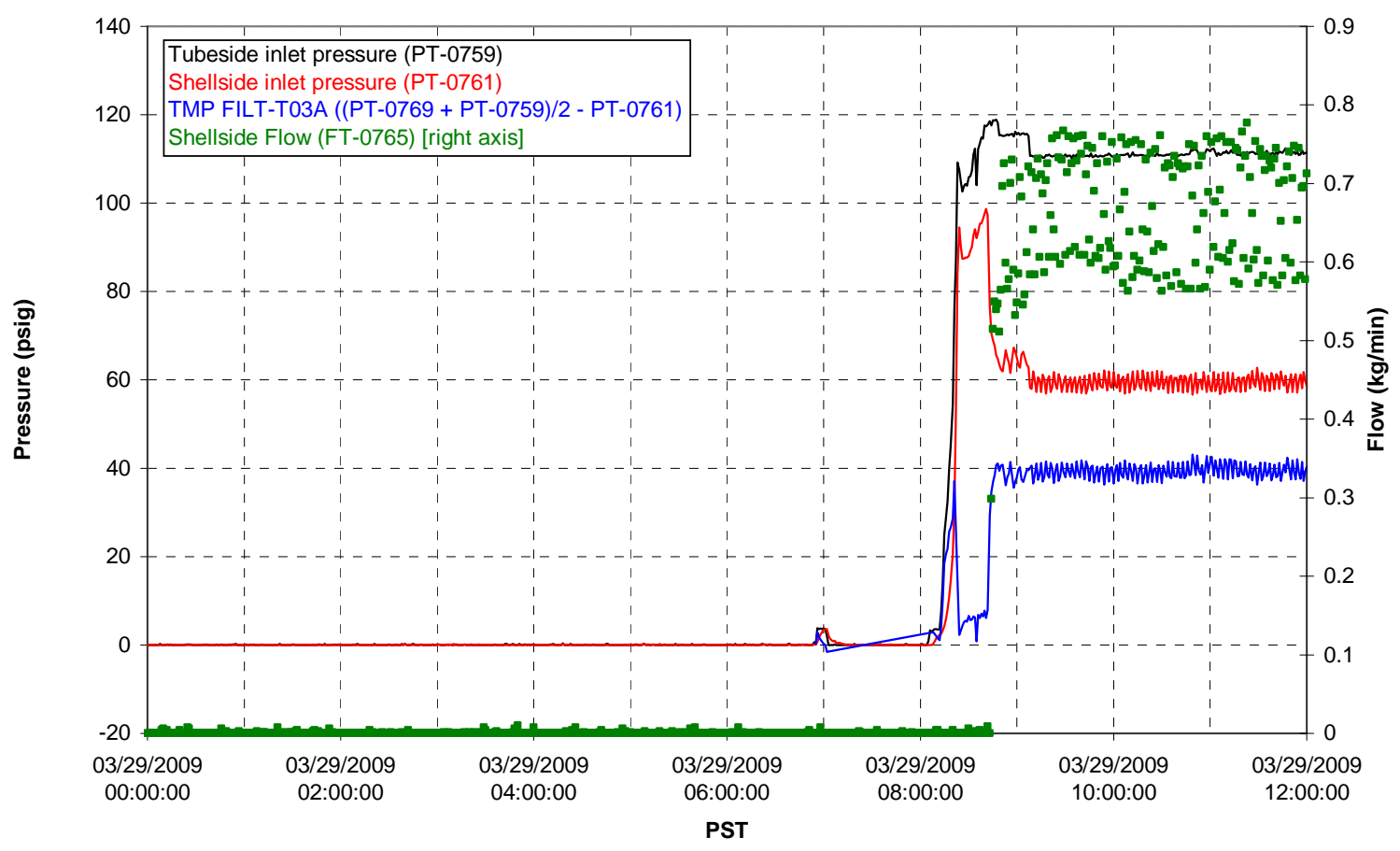

Filter UFP-FILT-T04A

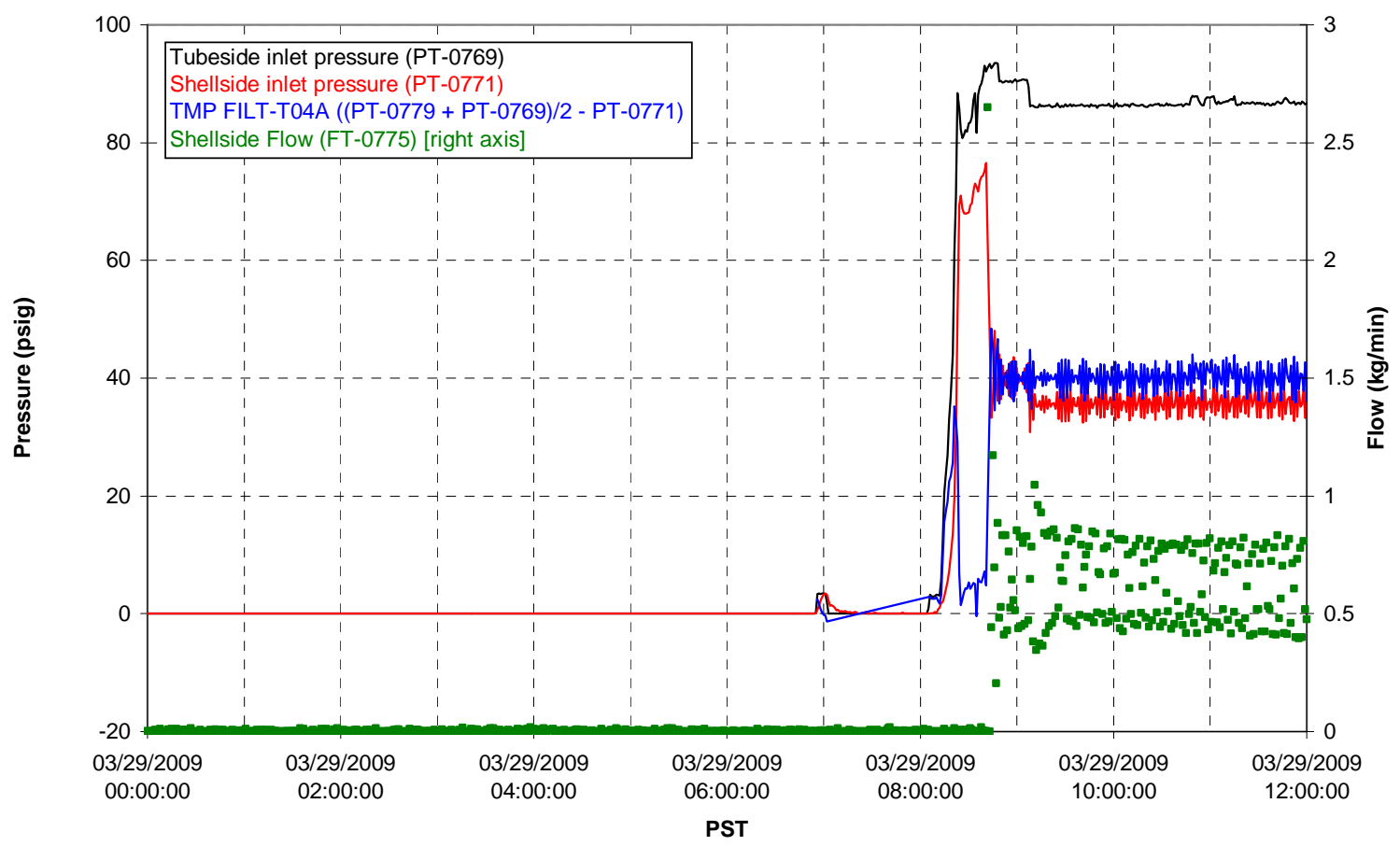


Filter UFP-FILT-T05A

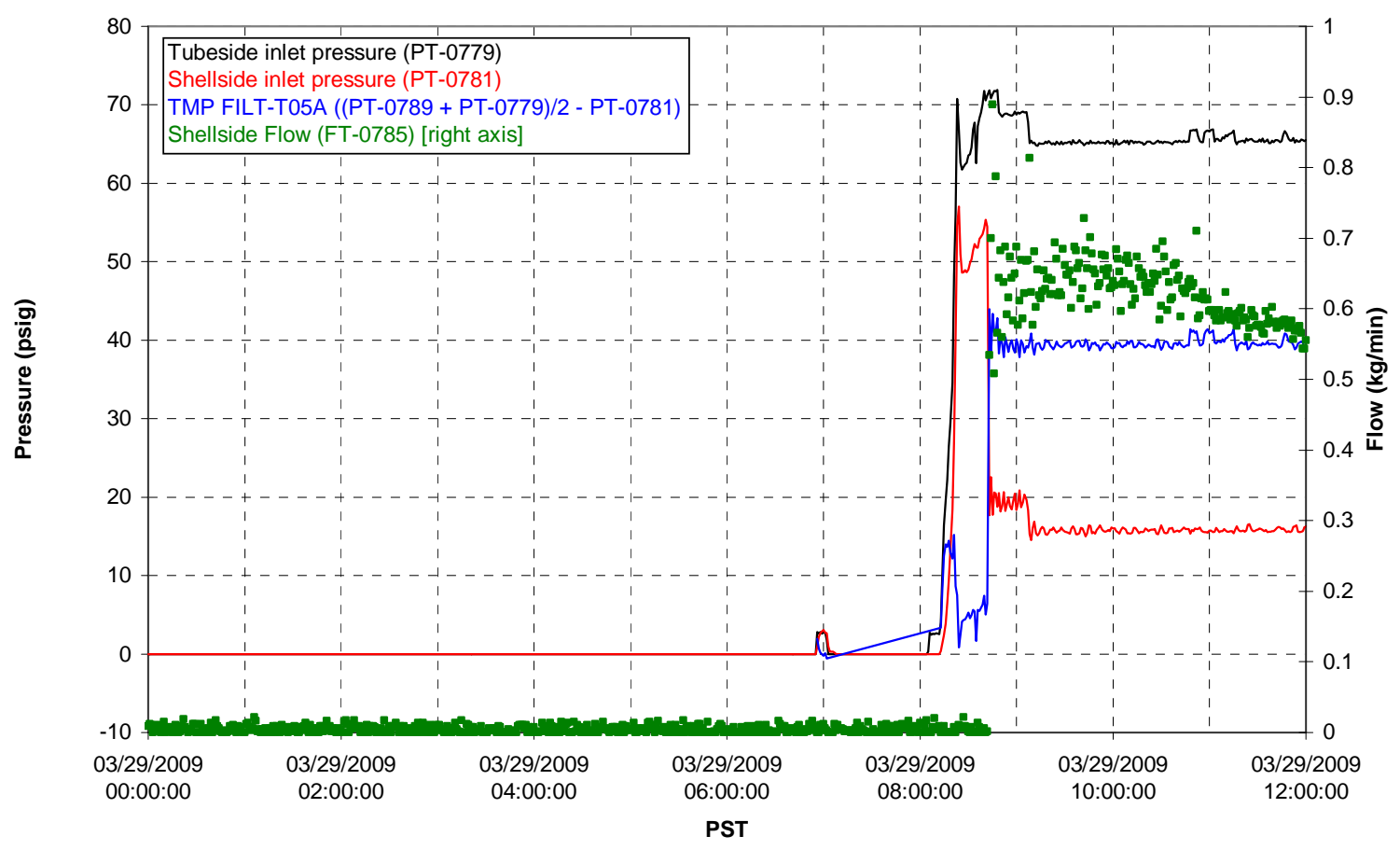

Chemical Flow

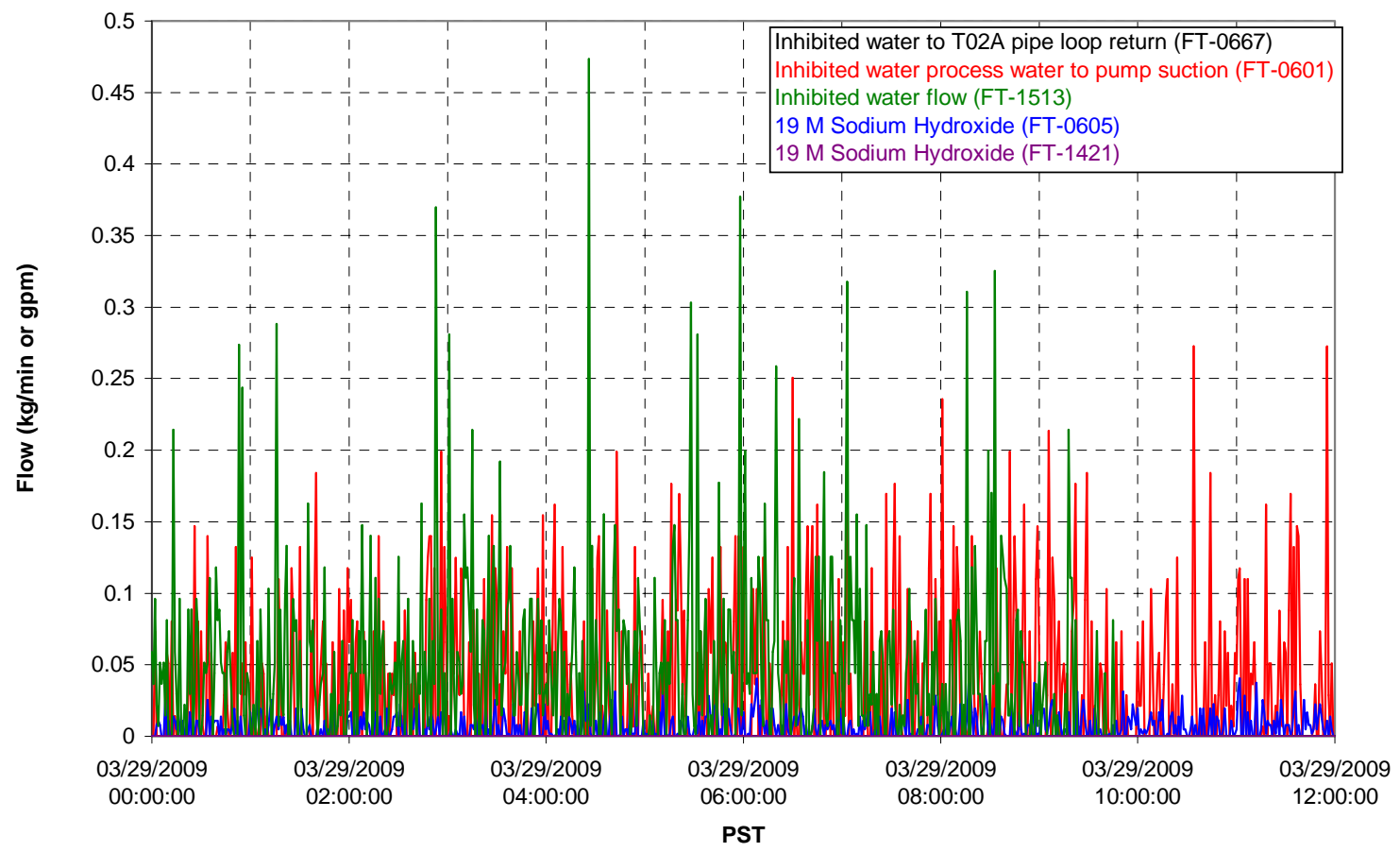




\section{Chemical Flow}

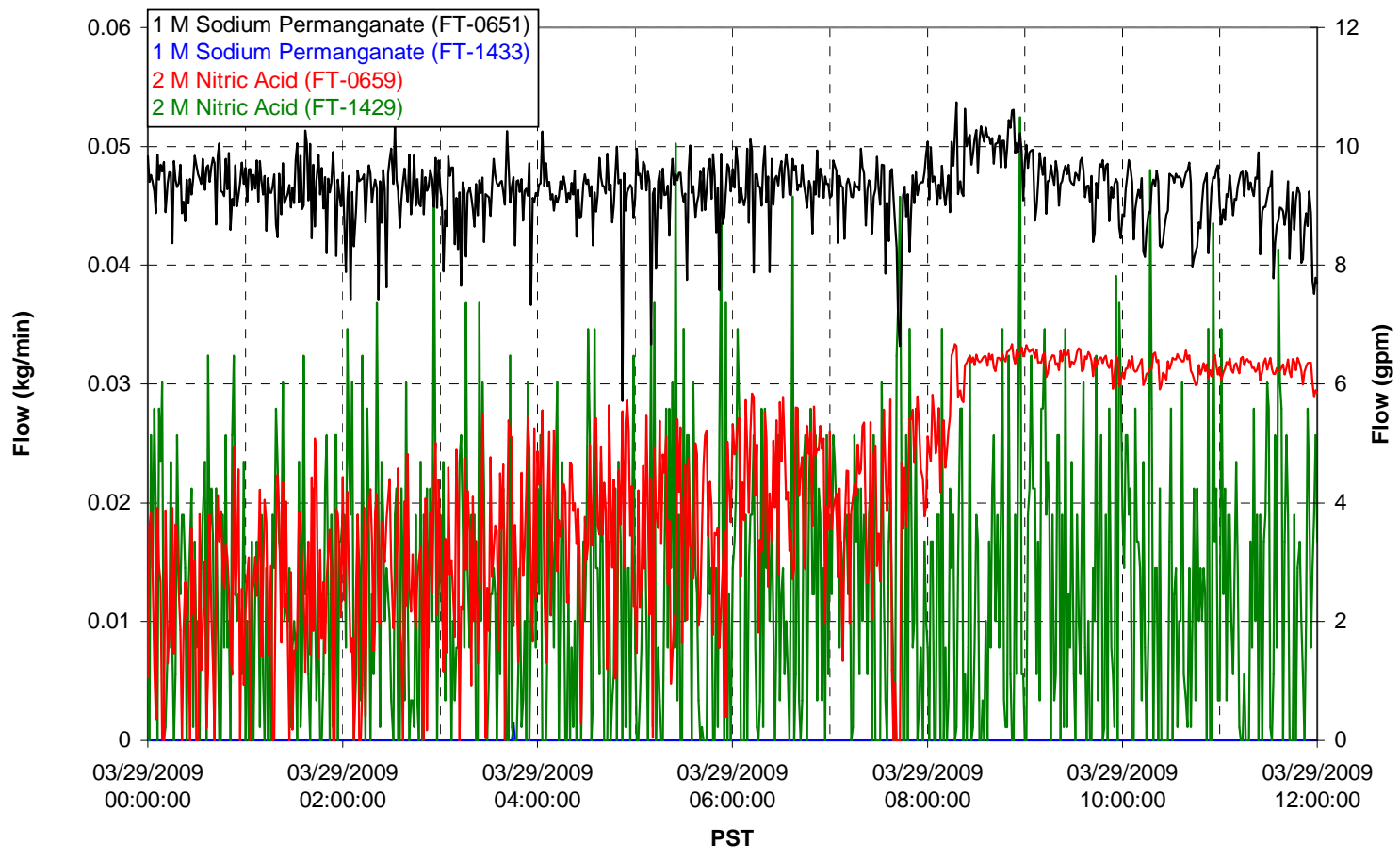

Air Flows

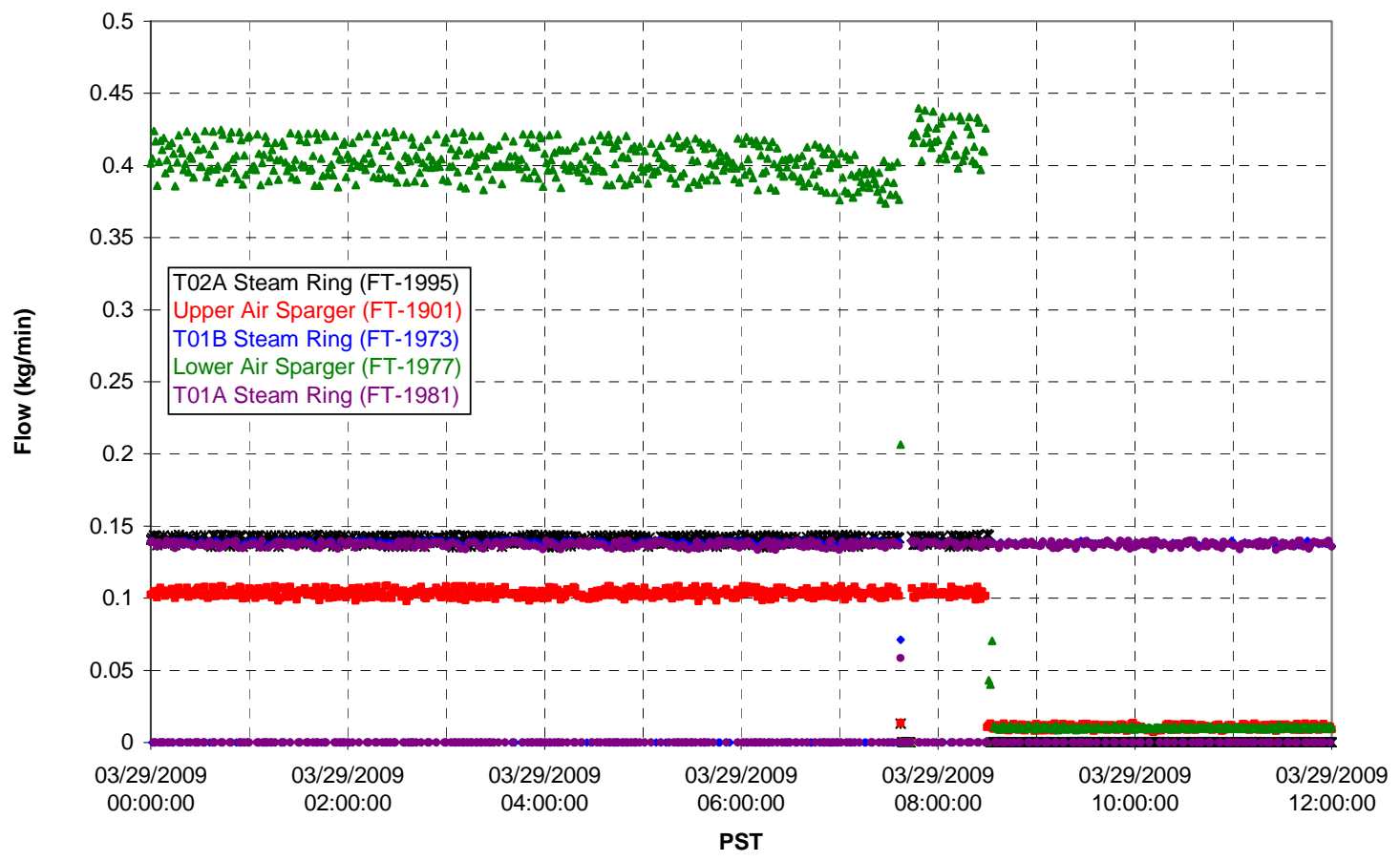


T02A Steam

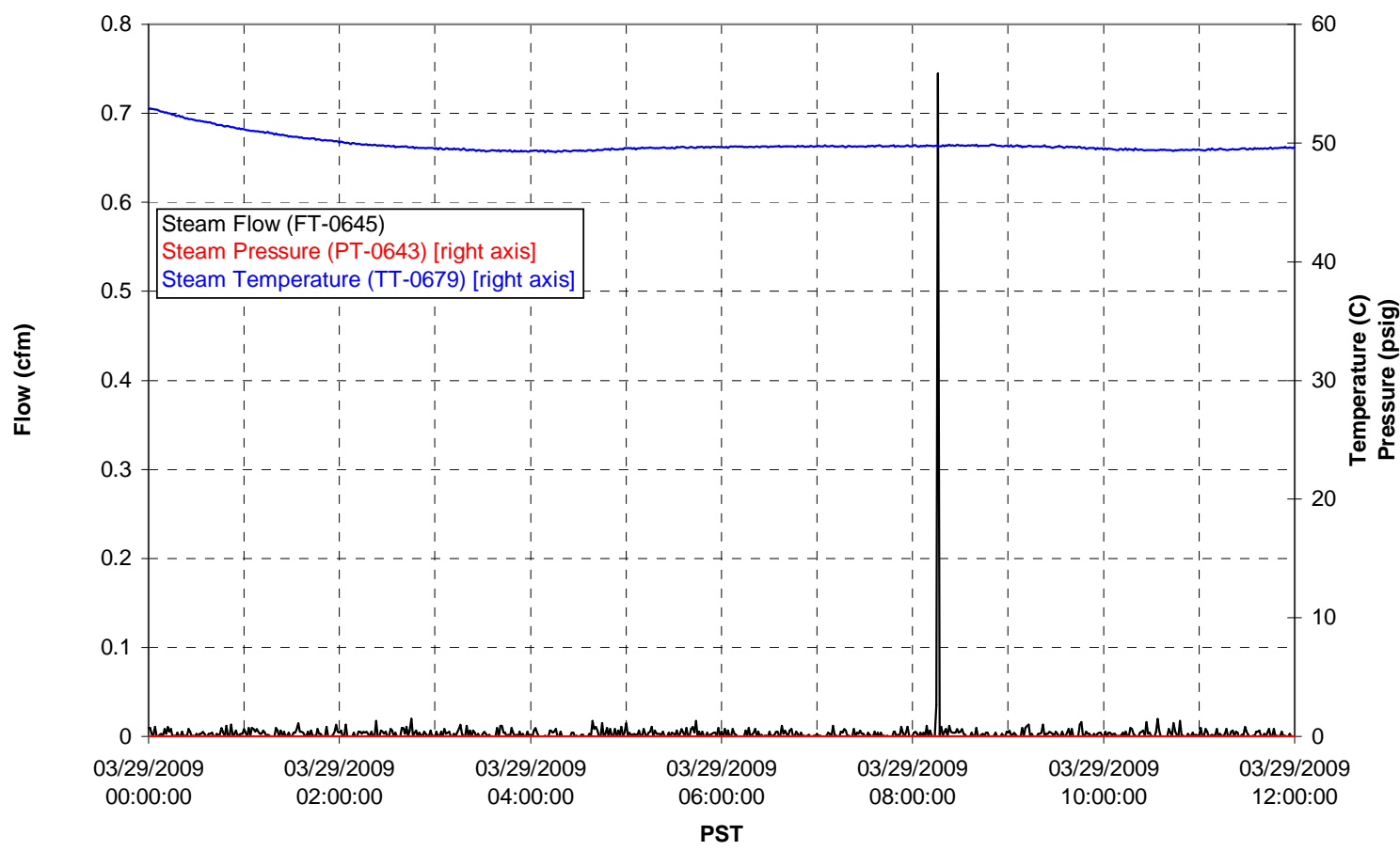

T01A Steam

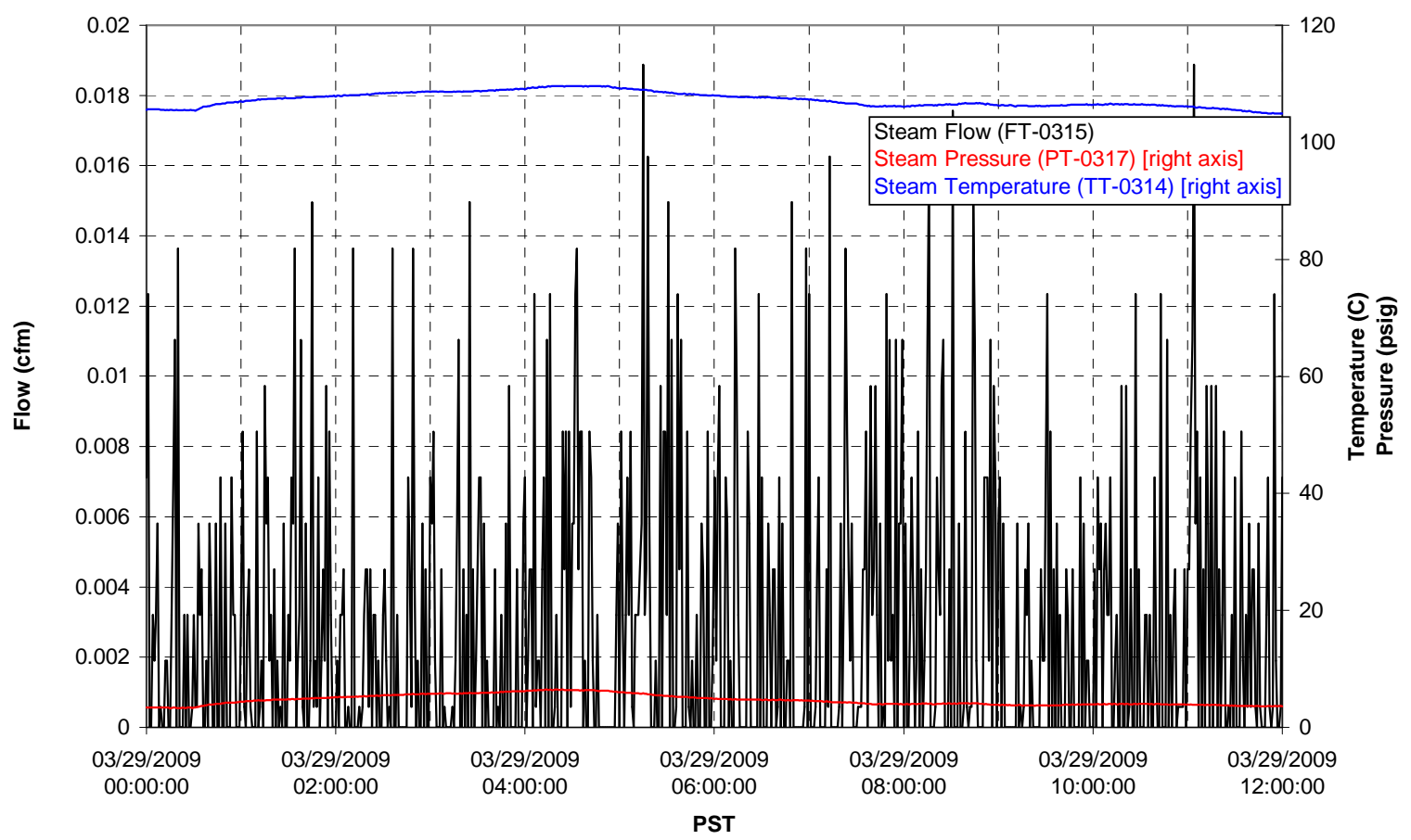


T01B Steam

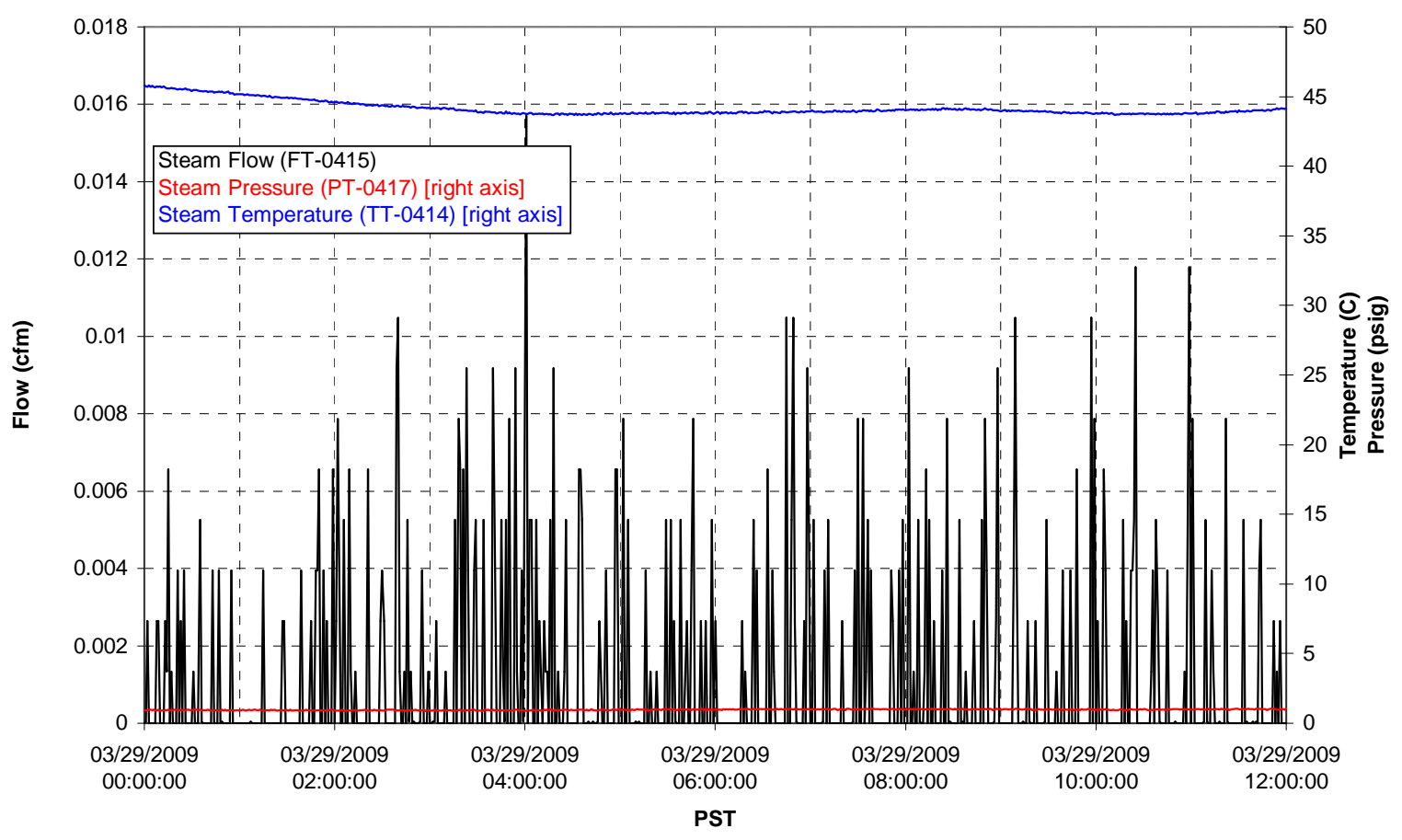




\section{Integrated Test D Data Plots 03/29/09 12:00 - 03/30/09 00:00}


T01A level

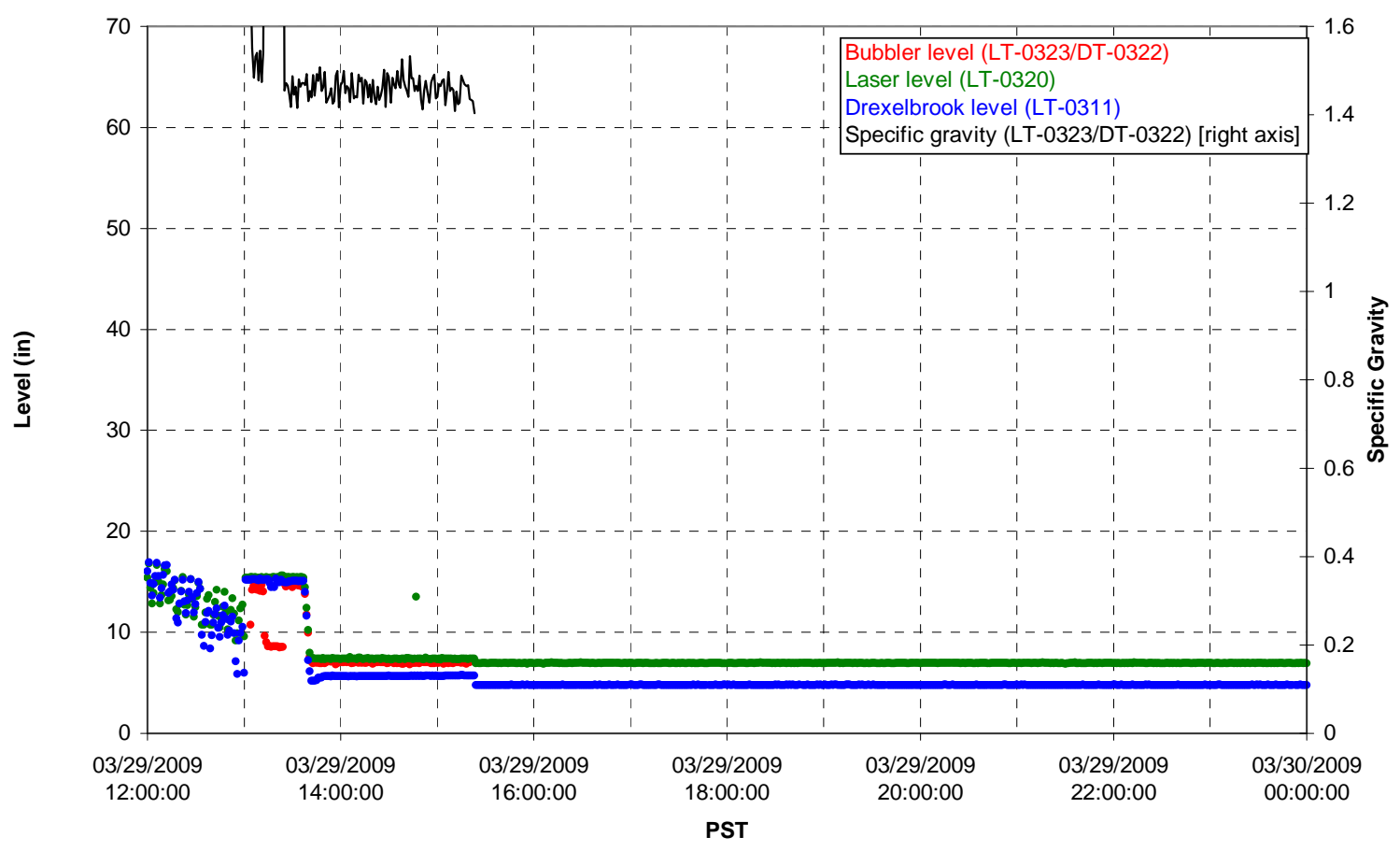

T01A temperatures

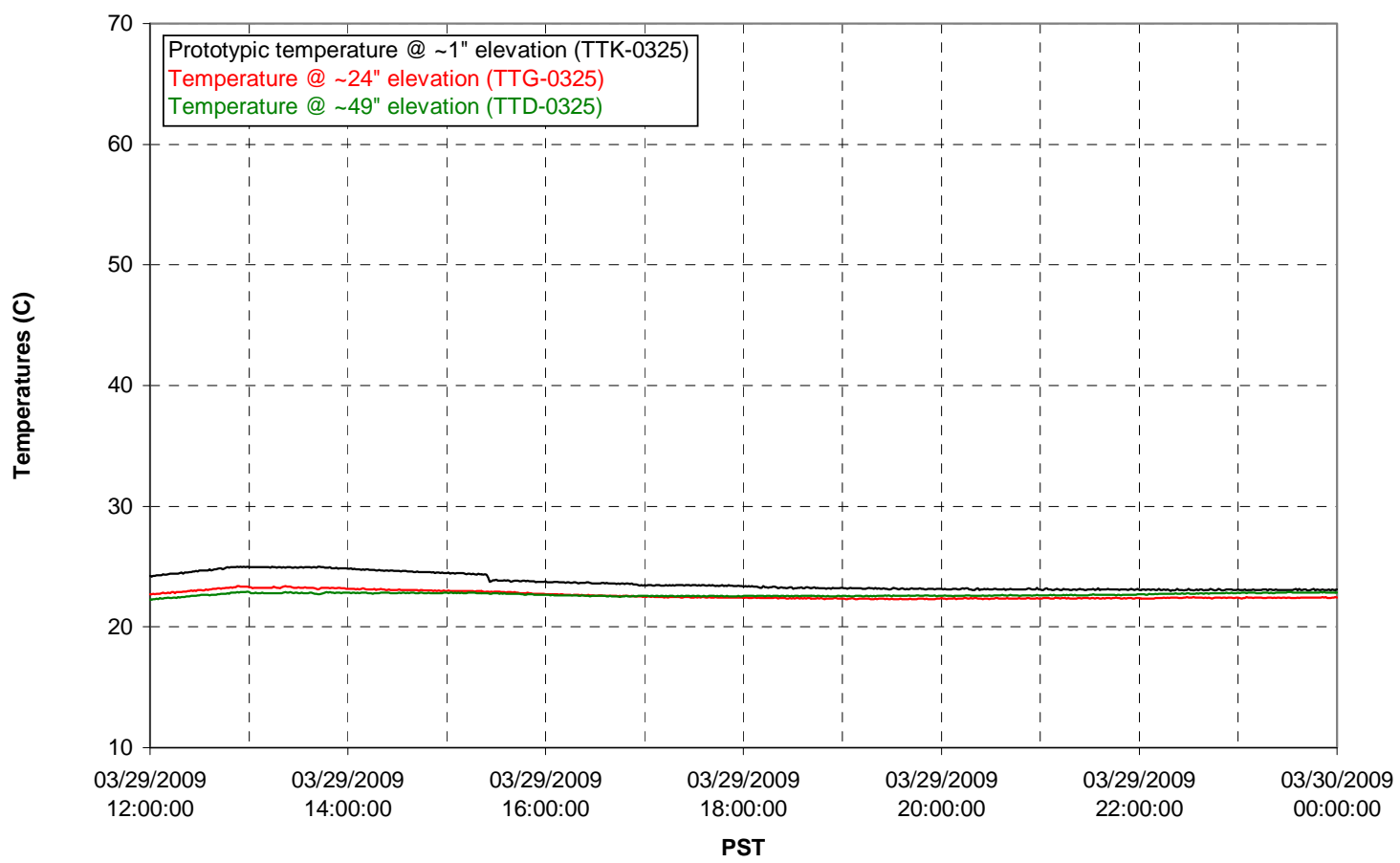


T01B level

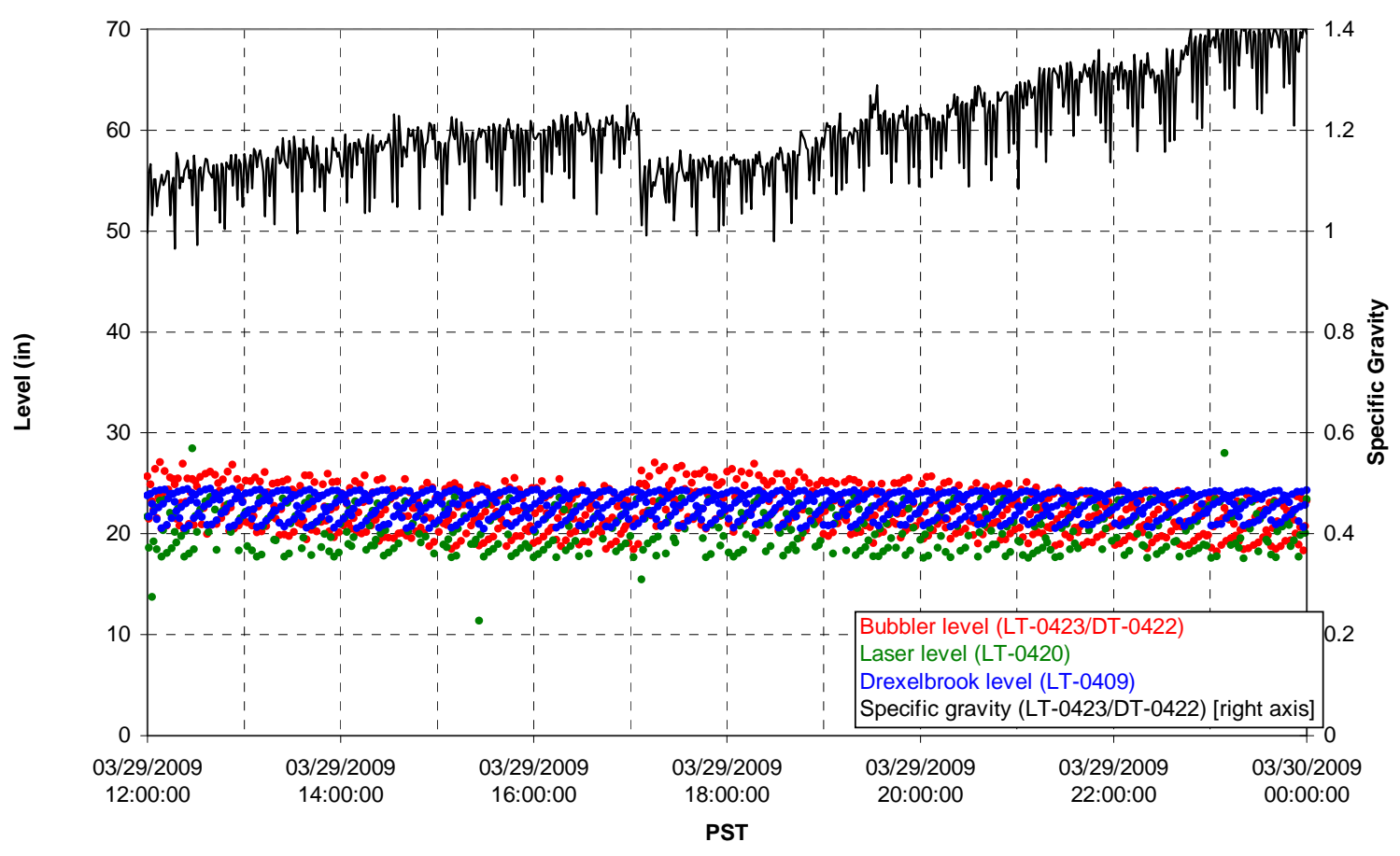

T01B temperatures

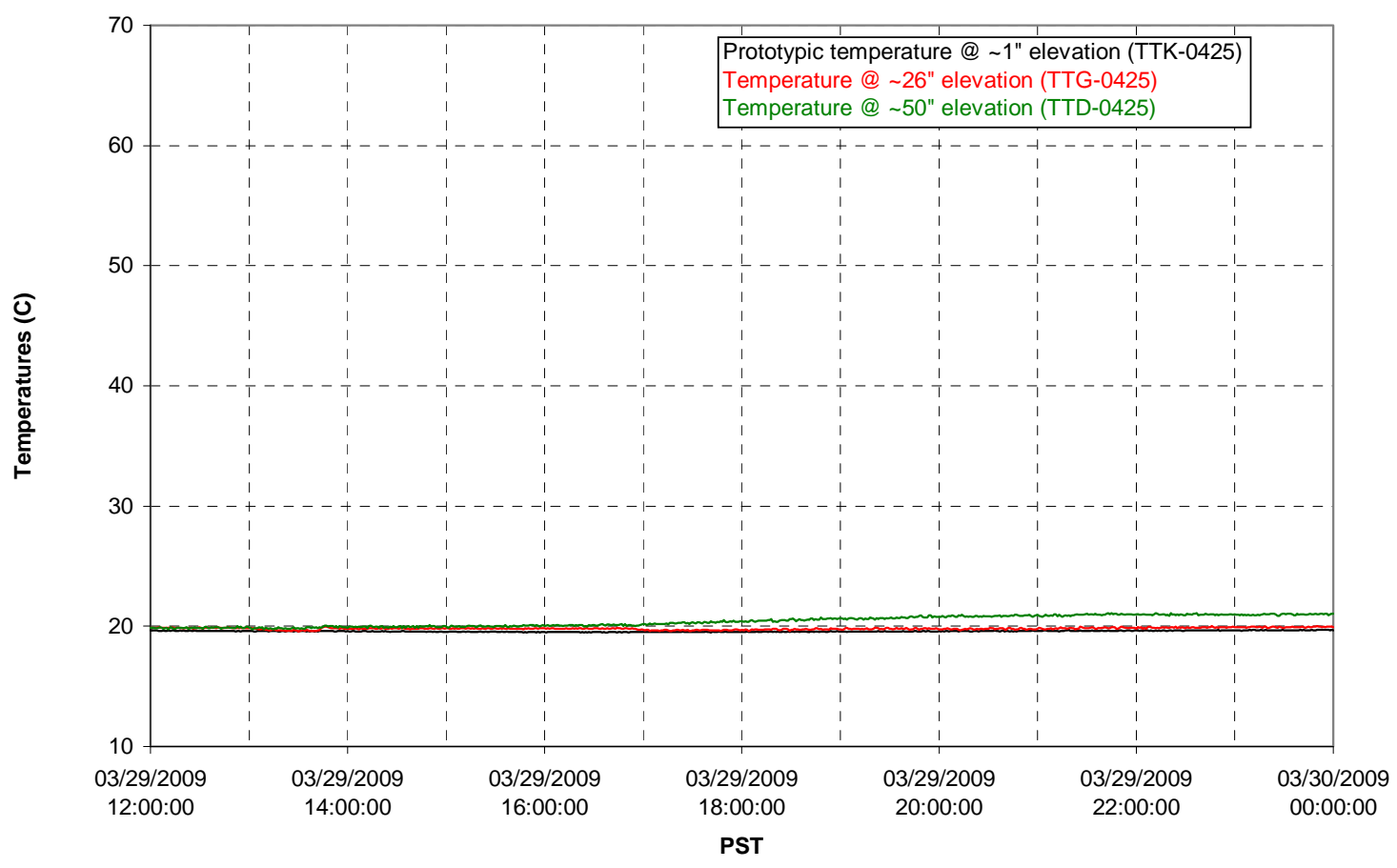


T02A level

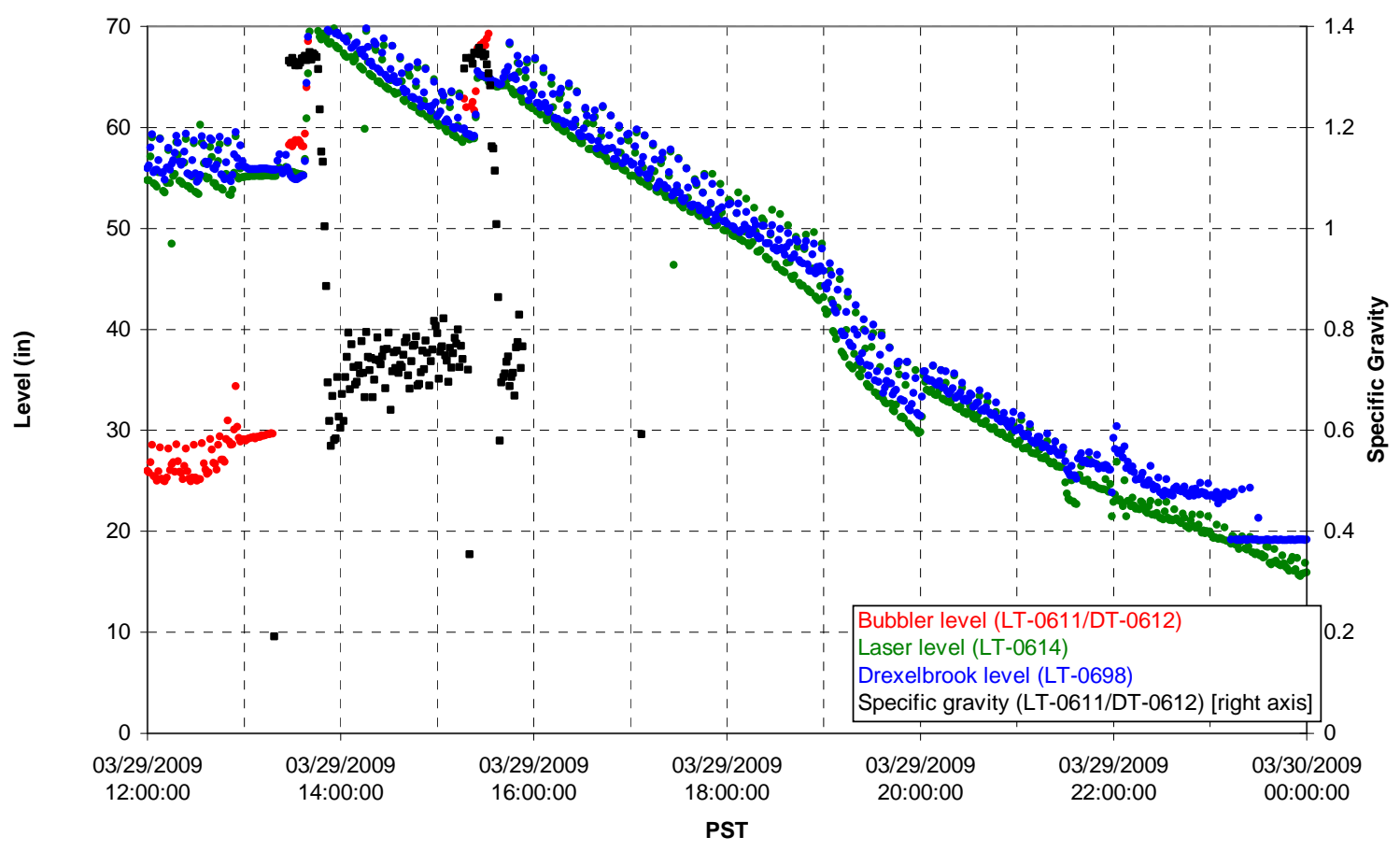

T02A temperatures

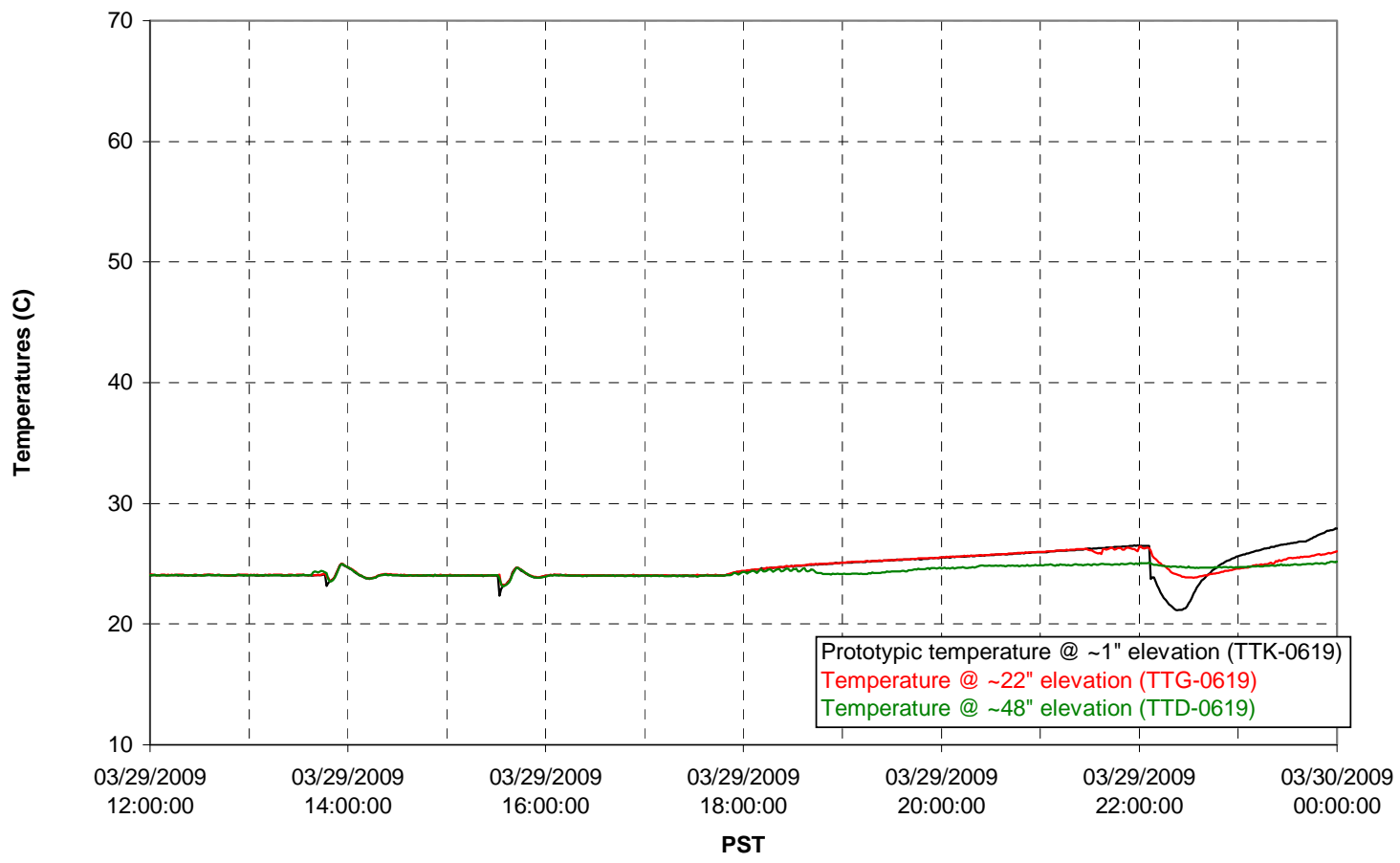


T02A and filter loop temperatures

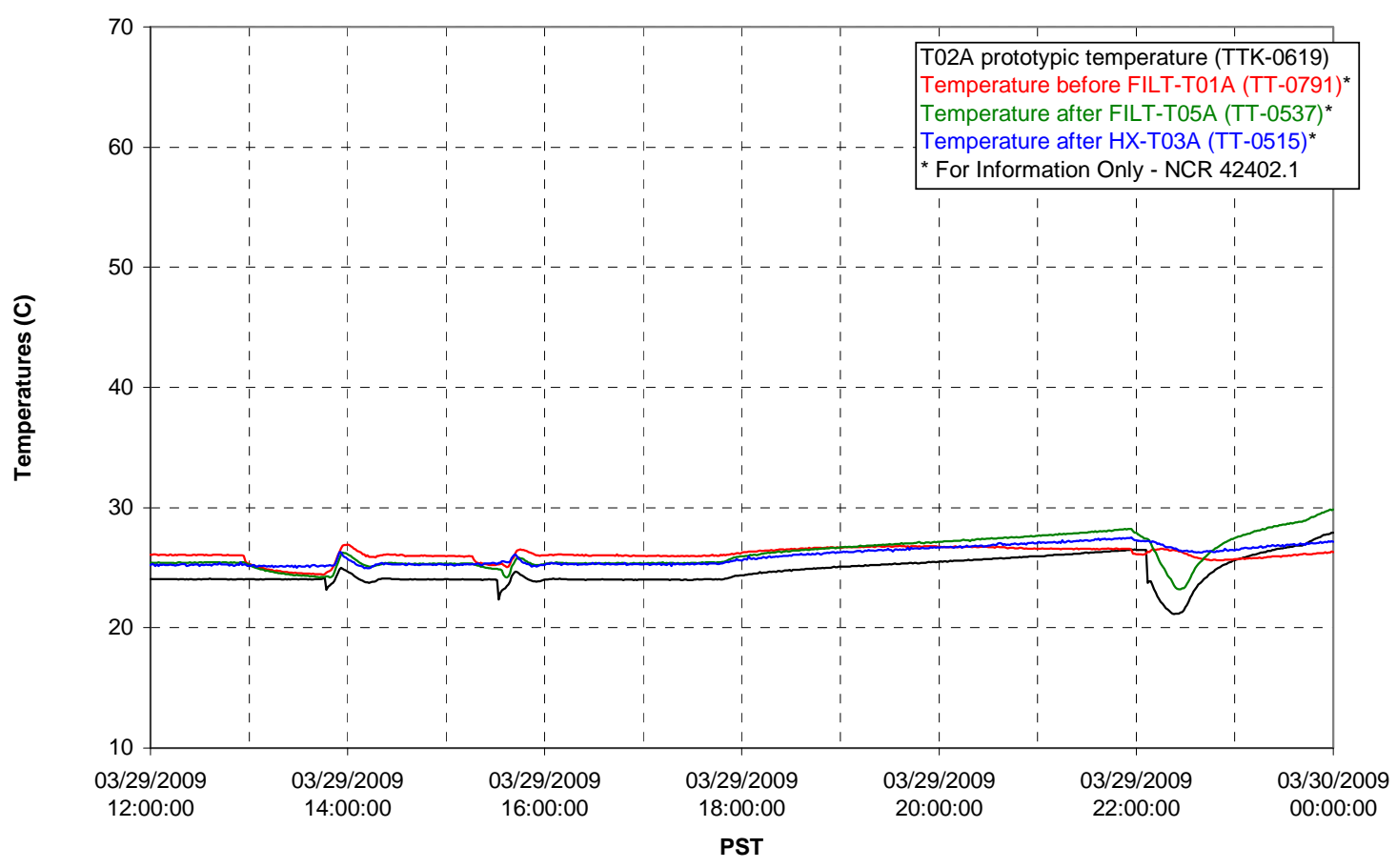

Pump Pressures and Flow

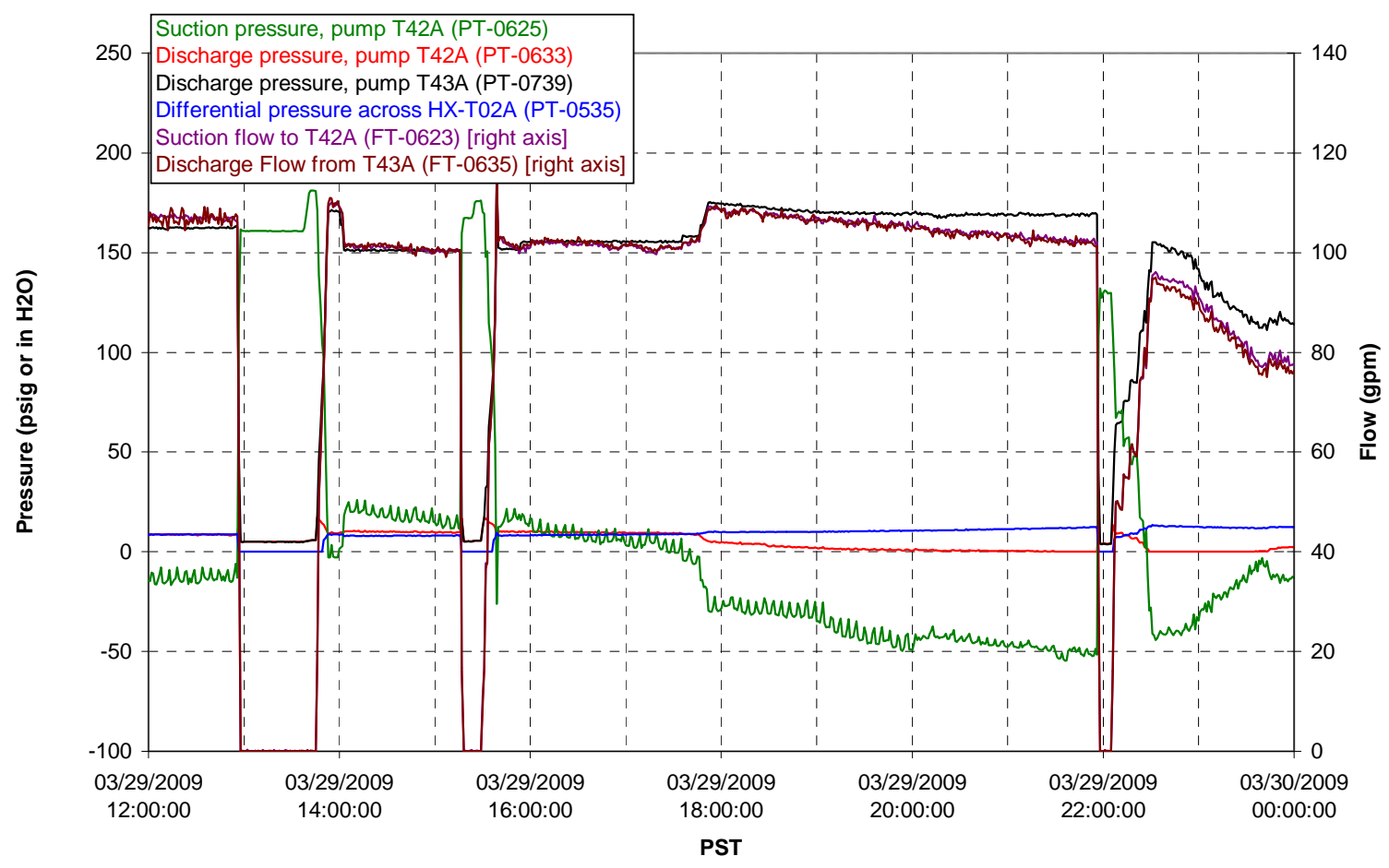


Axial pressure drop

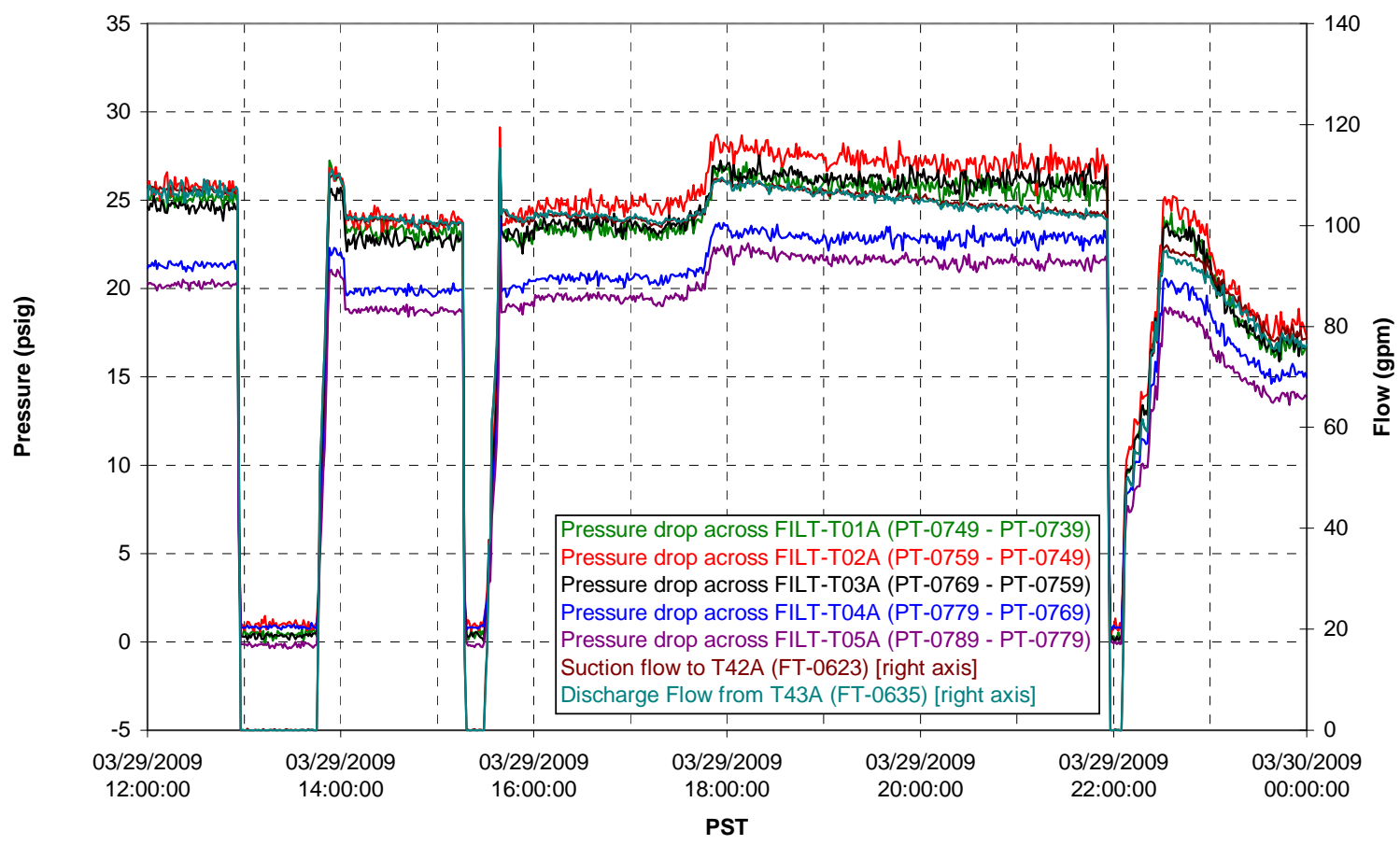

Permeate flow rates

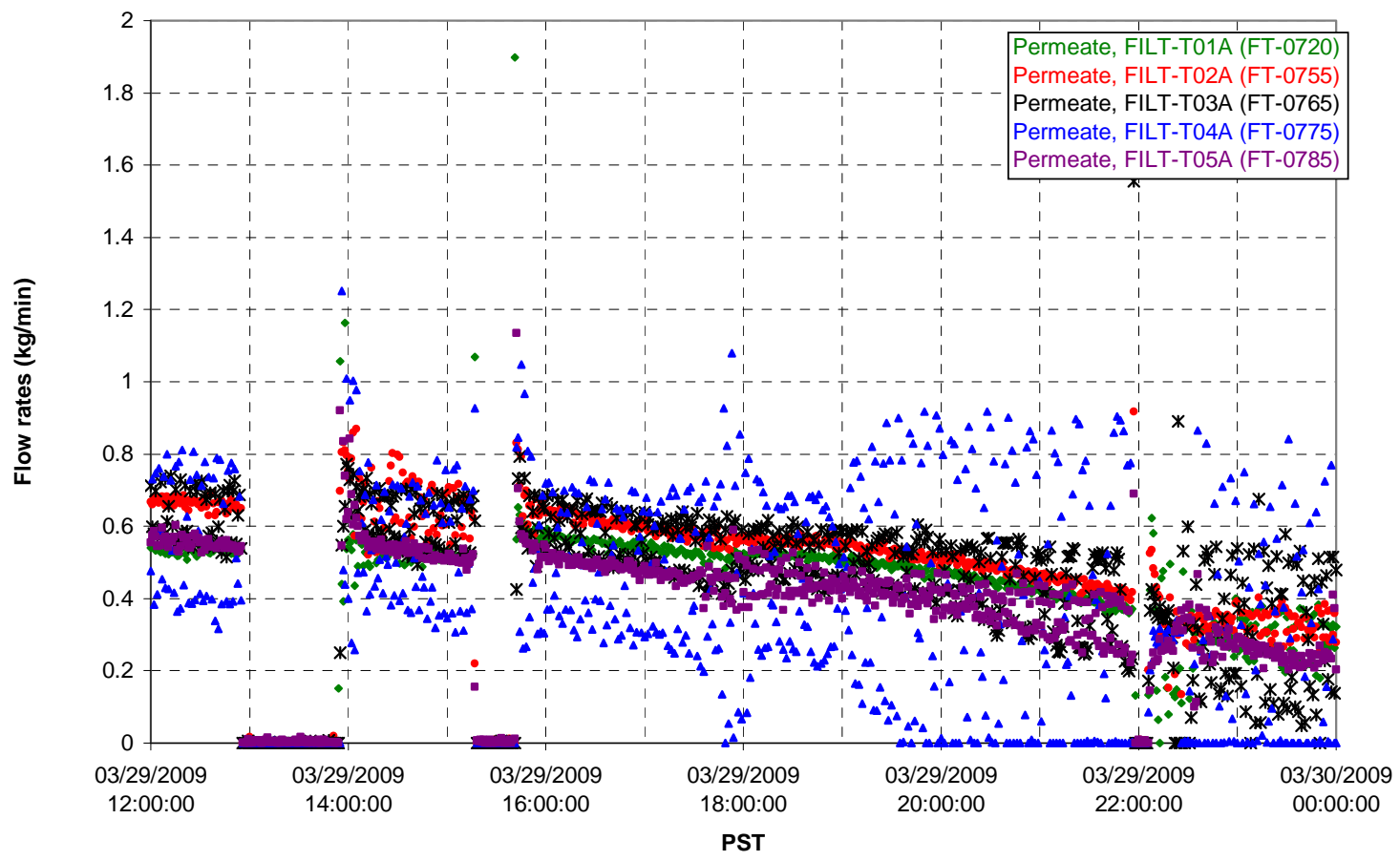


T02A Inner Temperature Tree

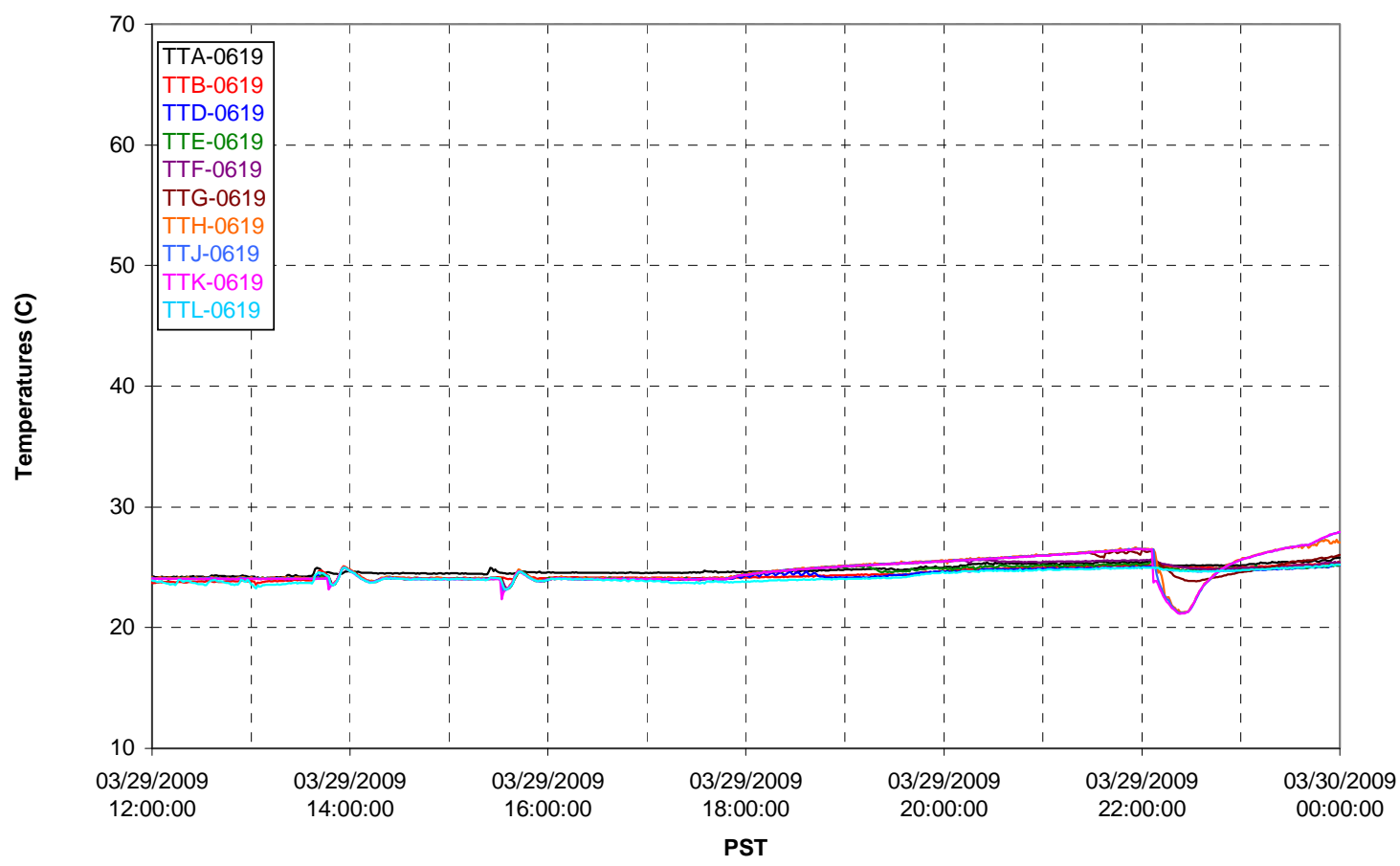

T02A Outer Temperature Tree

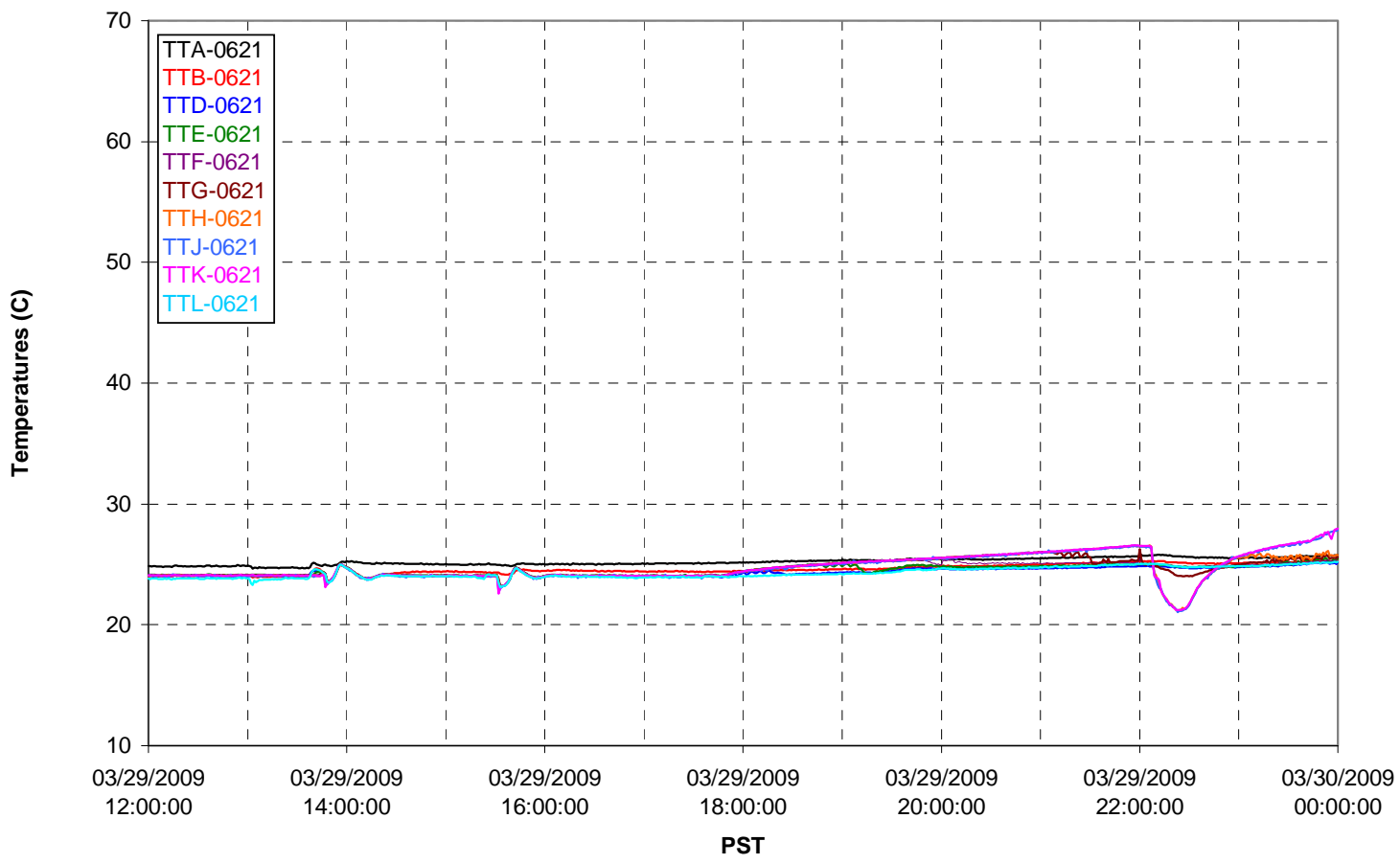


T02A temperatures

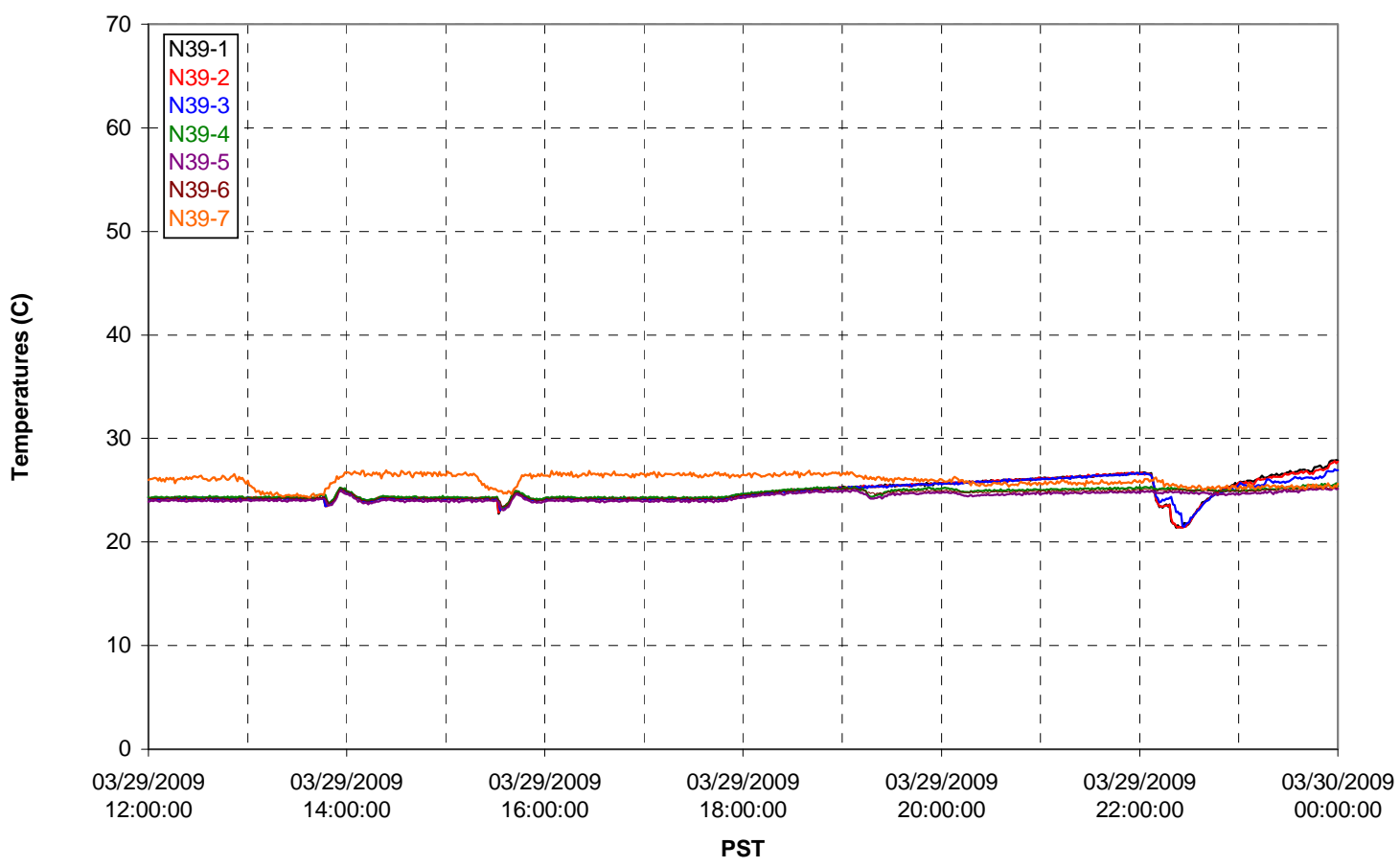

T02A temperatures

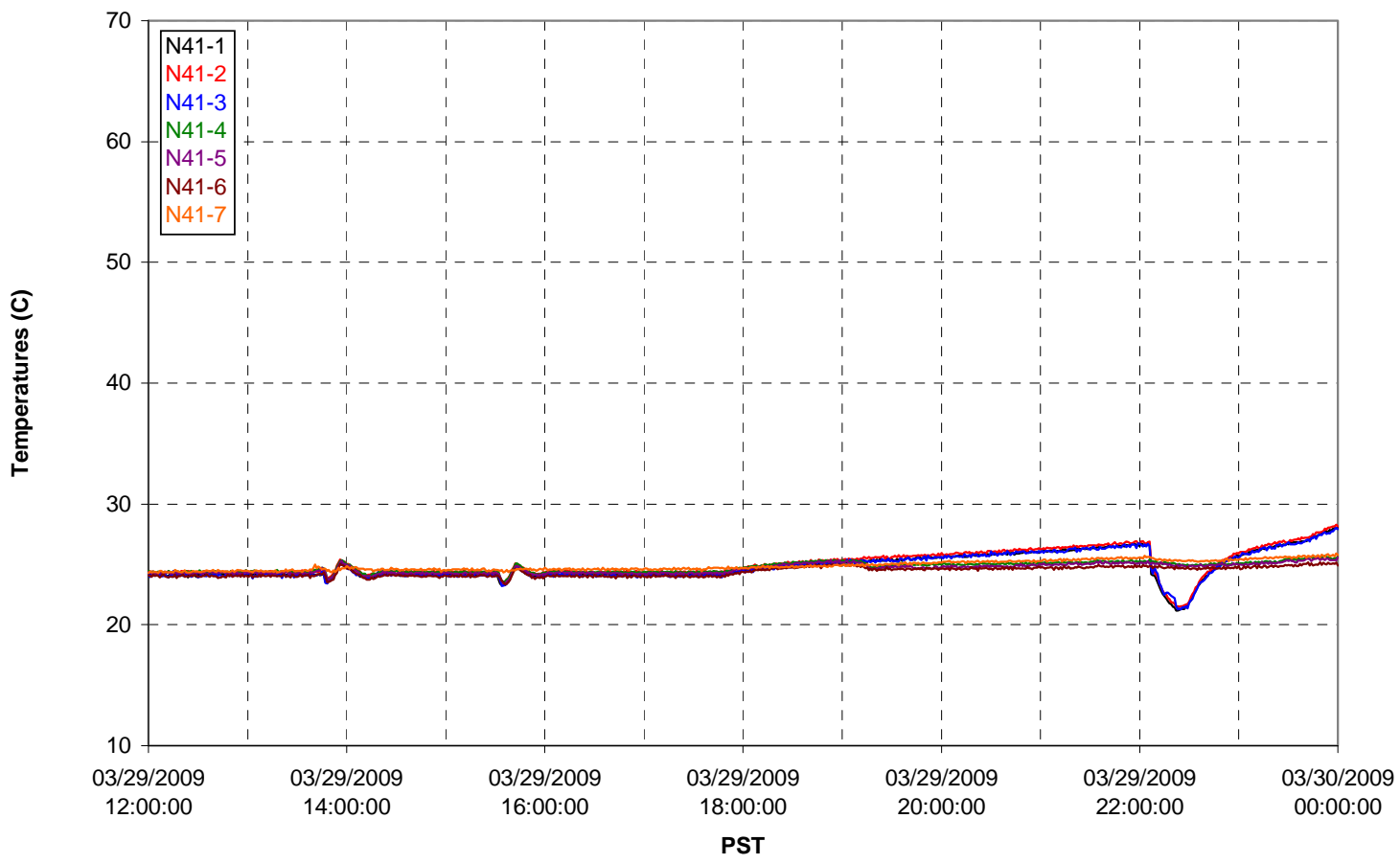


T02A temperatures

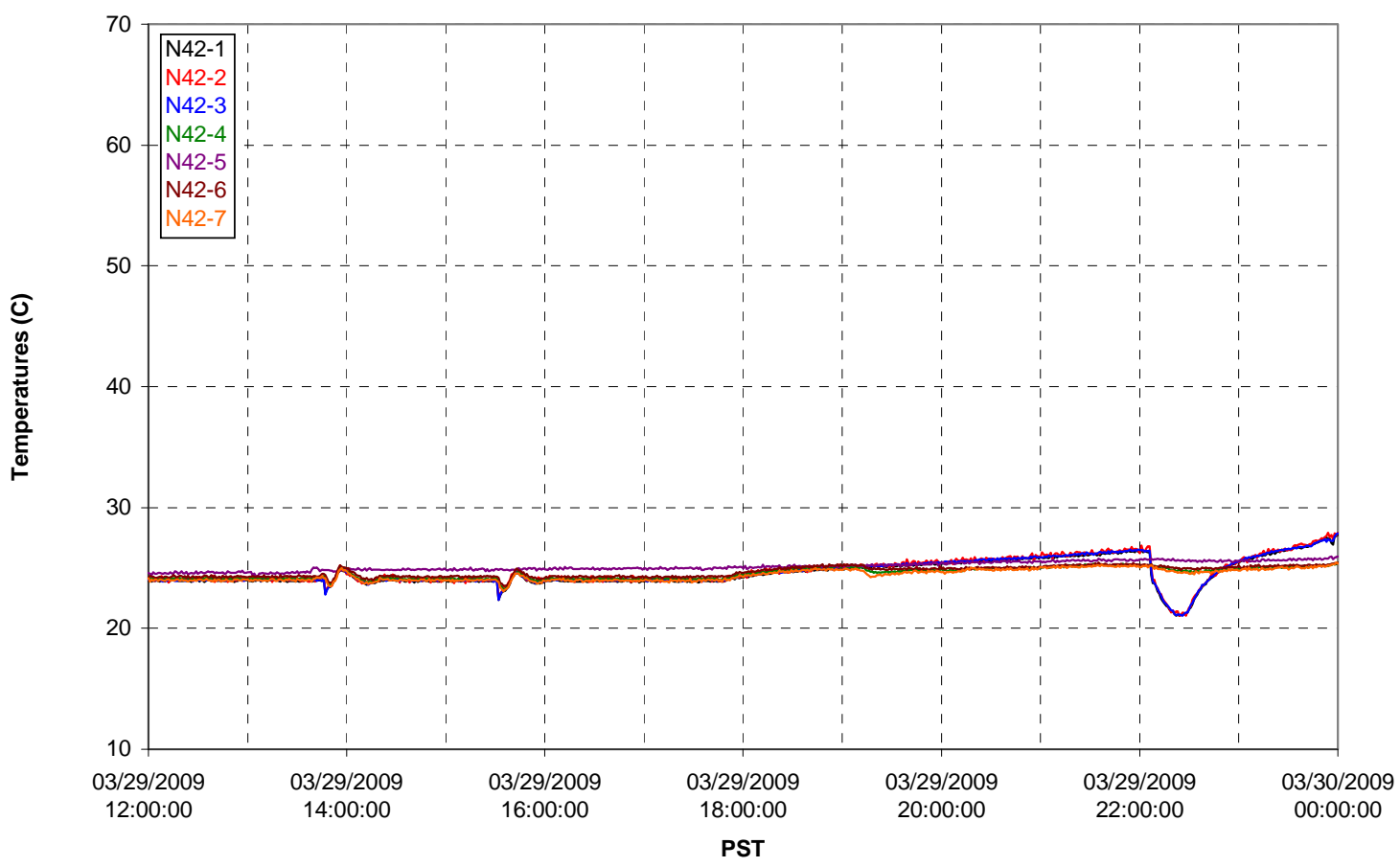

T02A temperatures

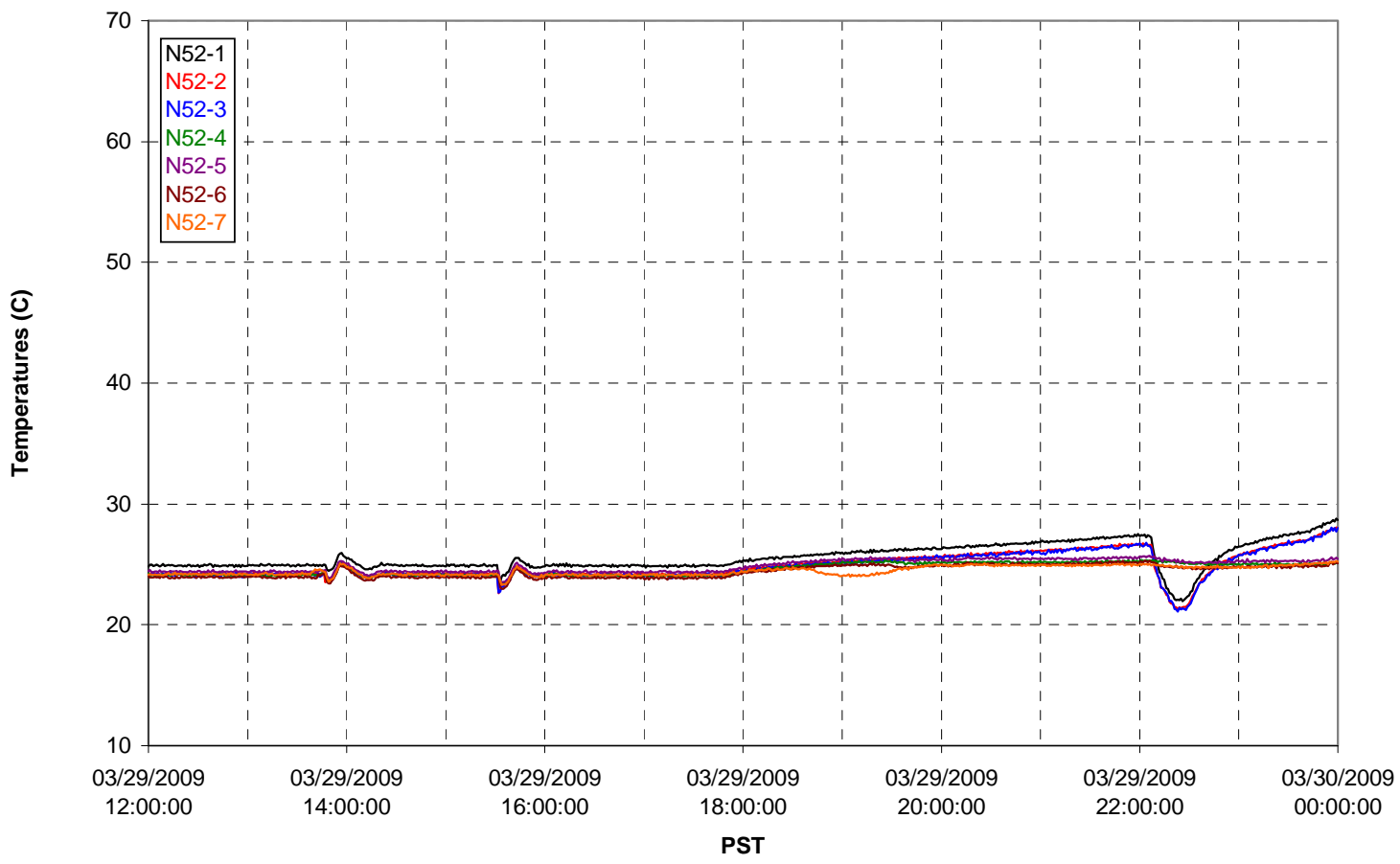


T02A Heating and Cooling
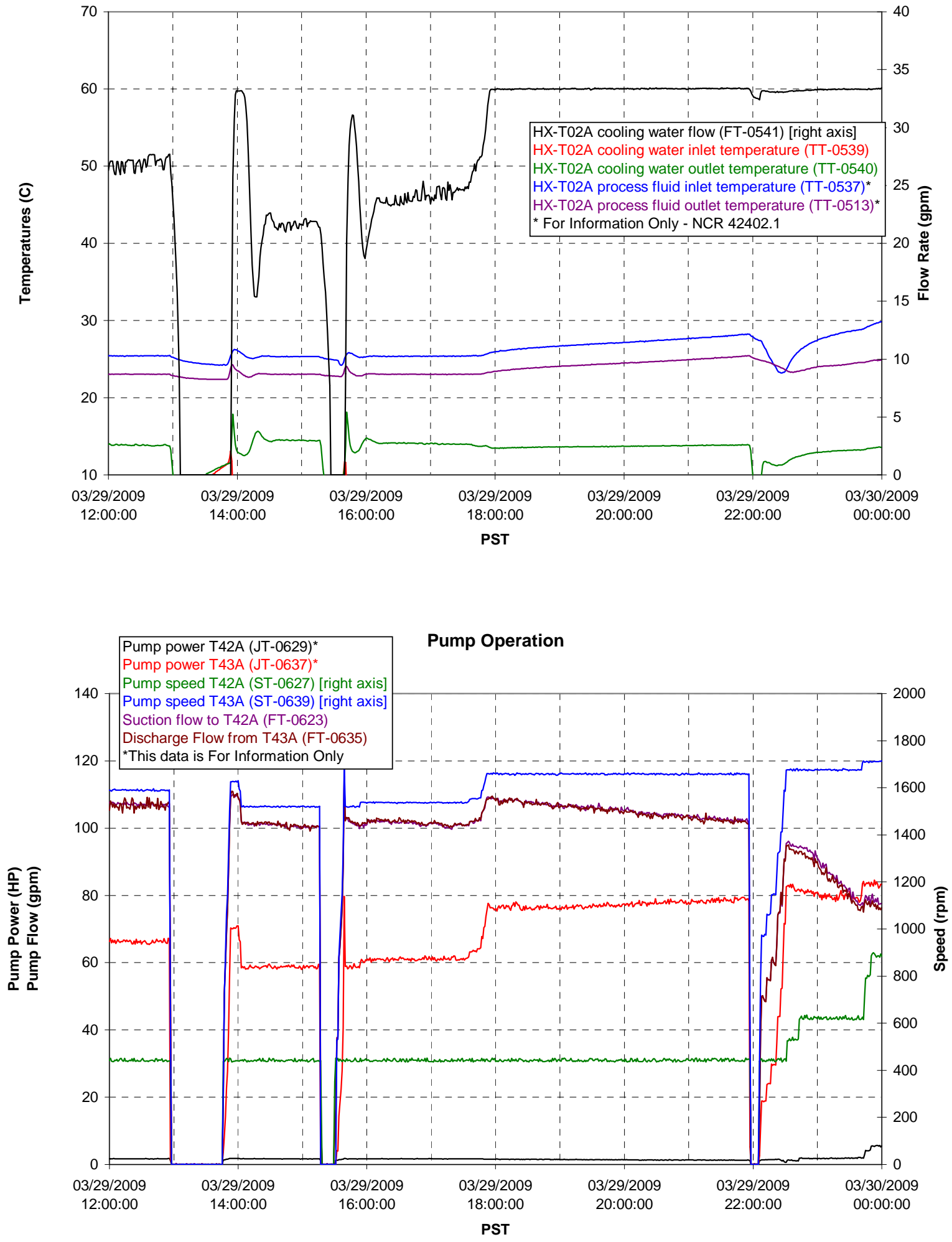


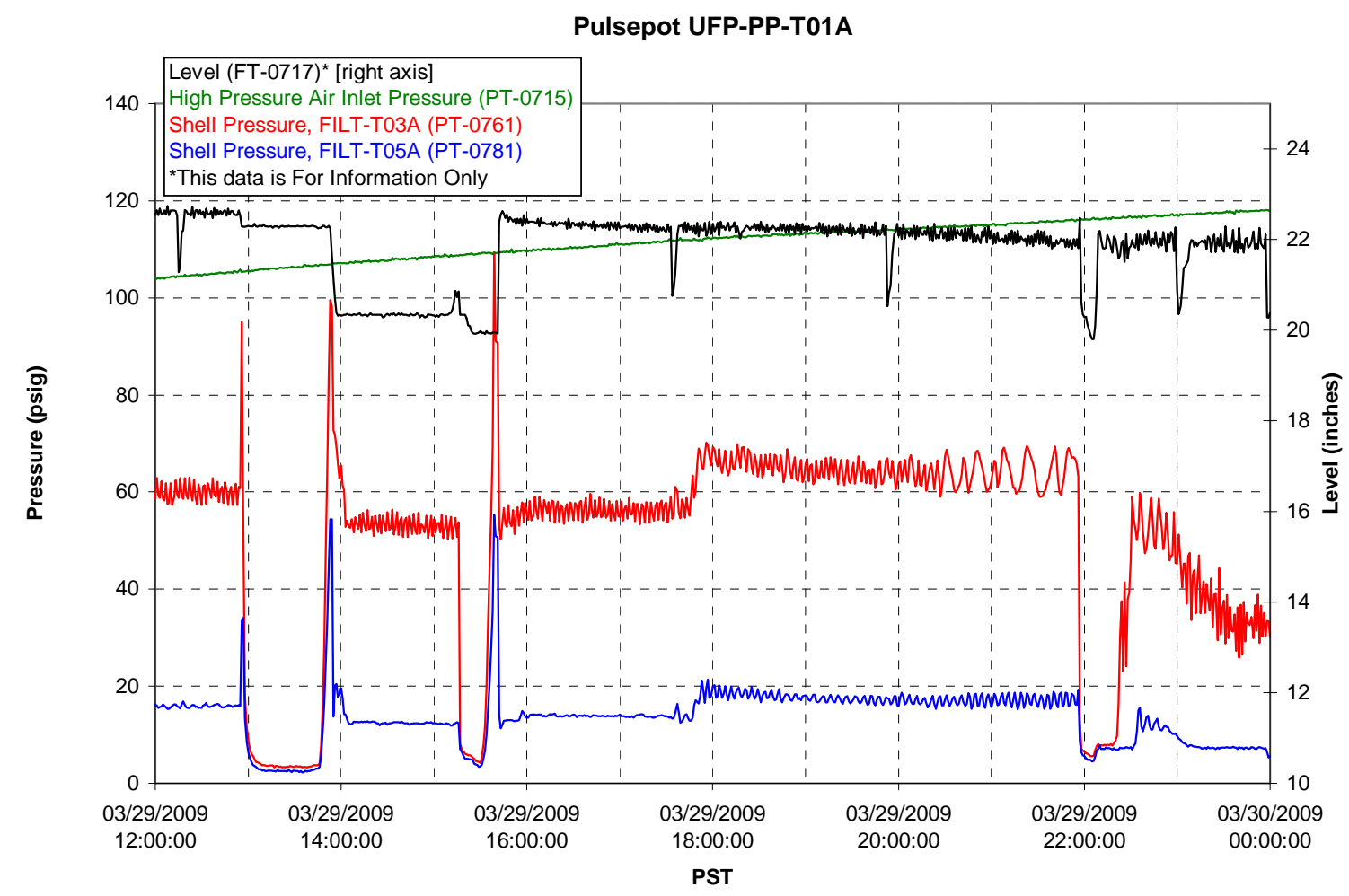

Pulsepot UFP-PP-T02A

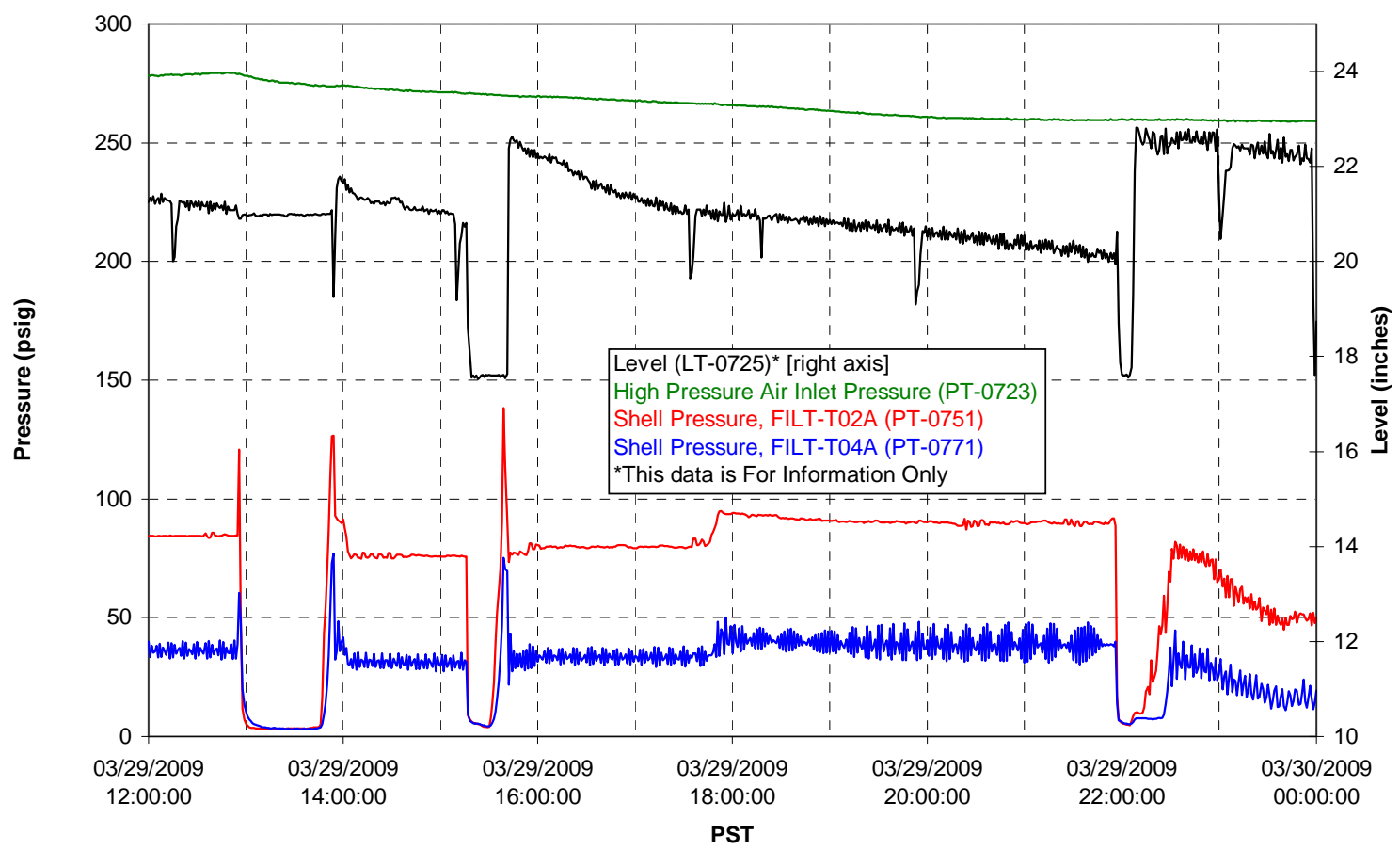


Pulsepot UFP-PP-T03A

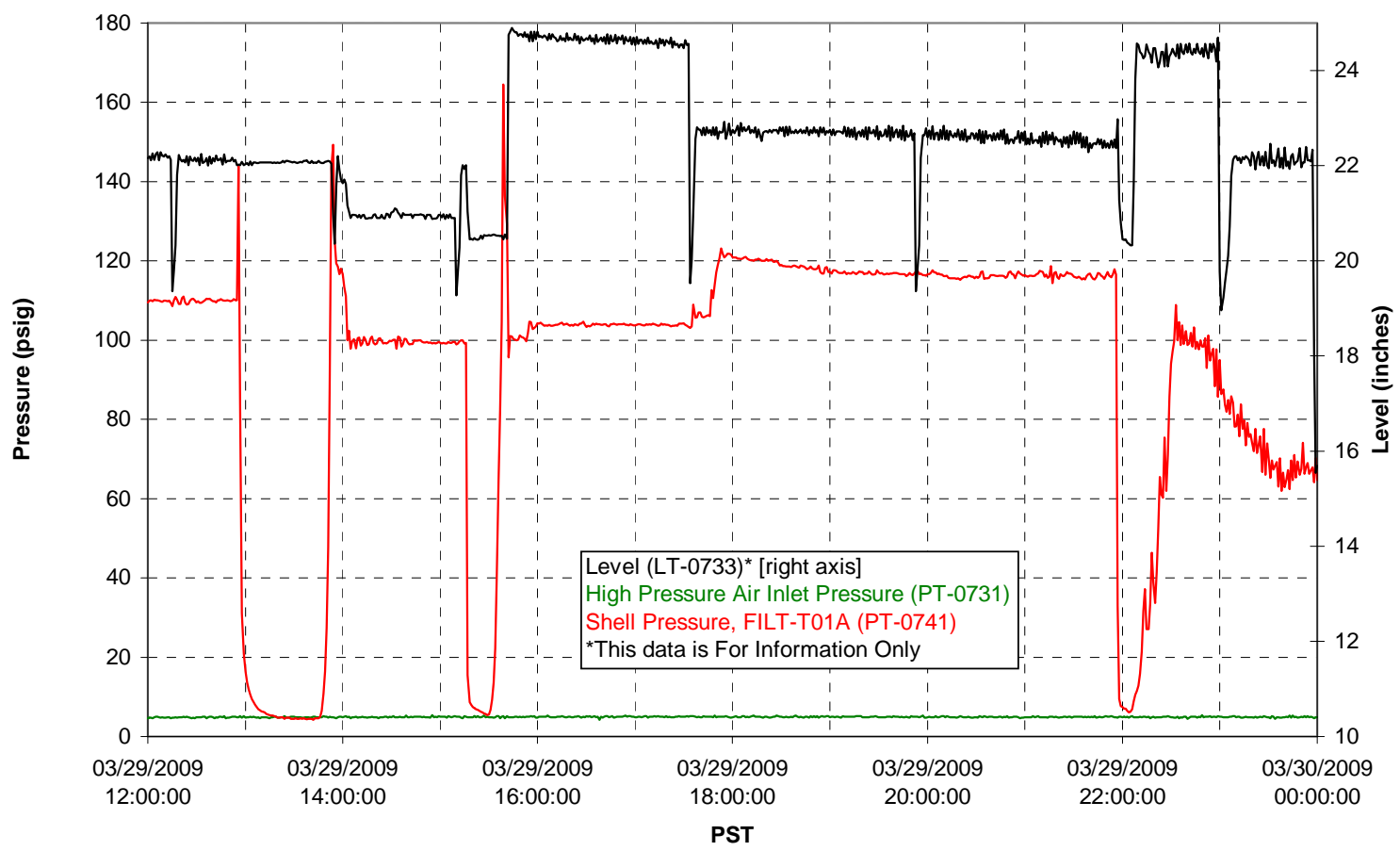

Pulsepot Levels

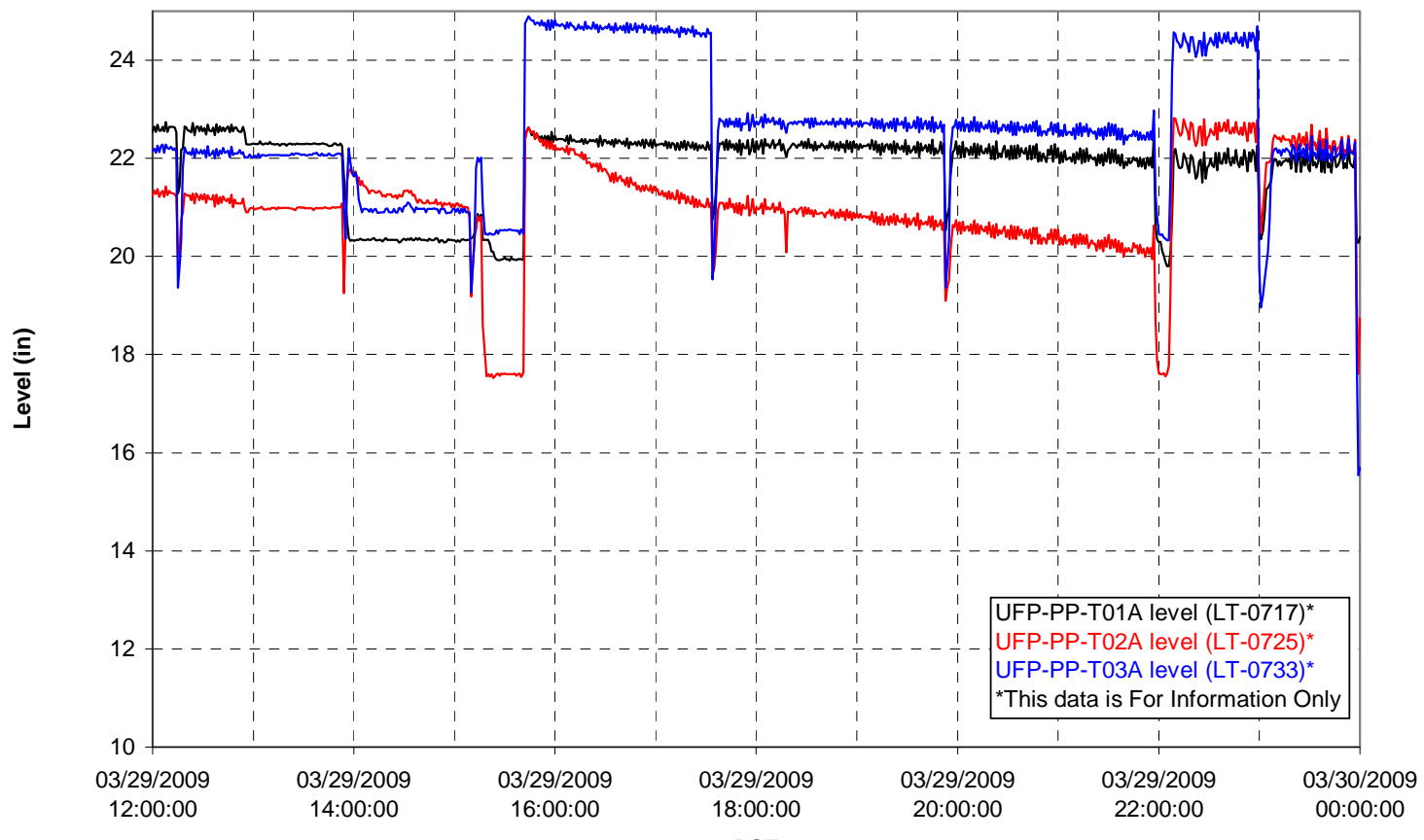


Filter UFP-FILT-T01A

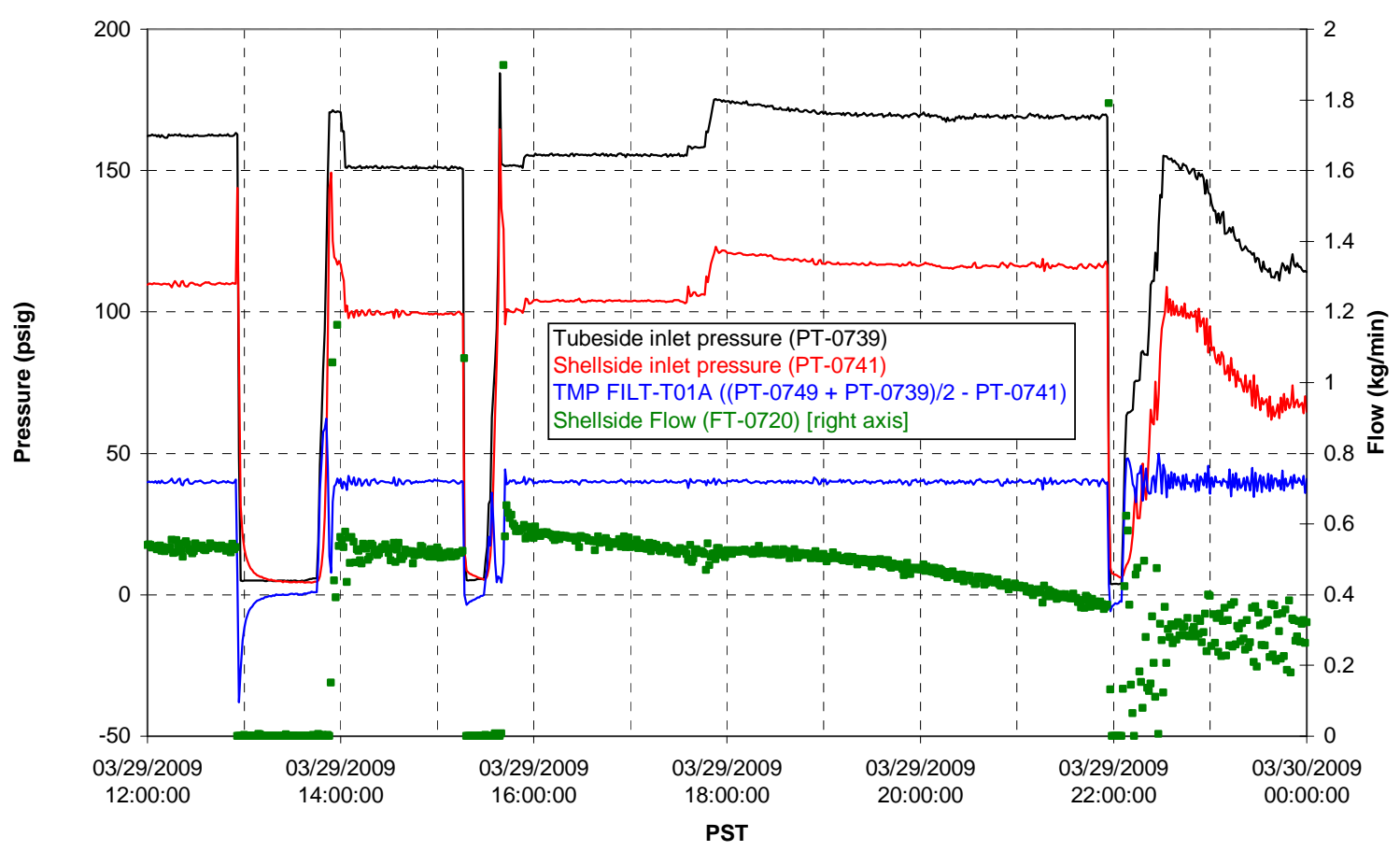

Filter UFP-FILT-T02A

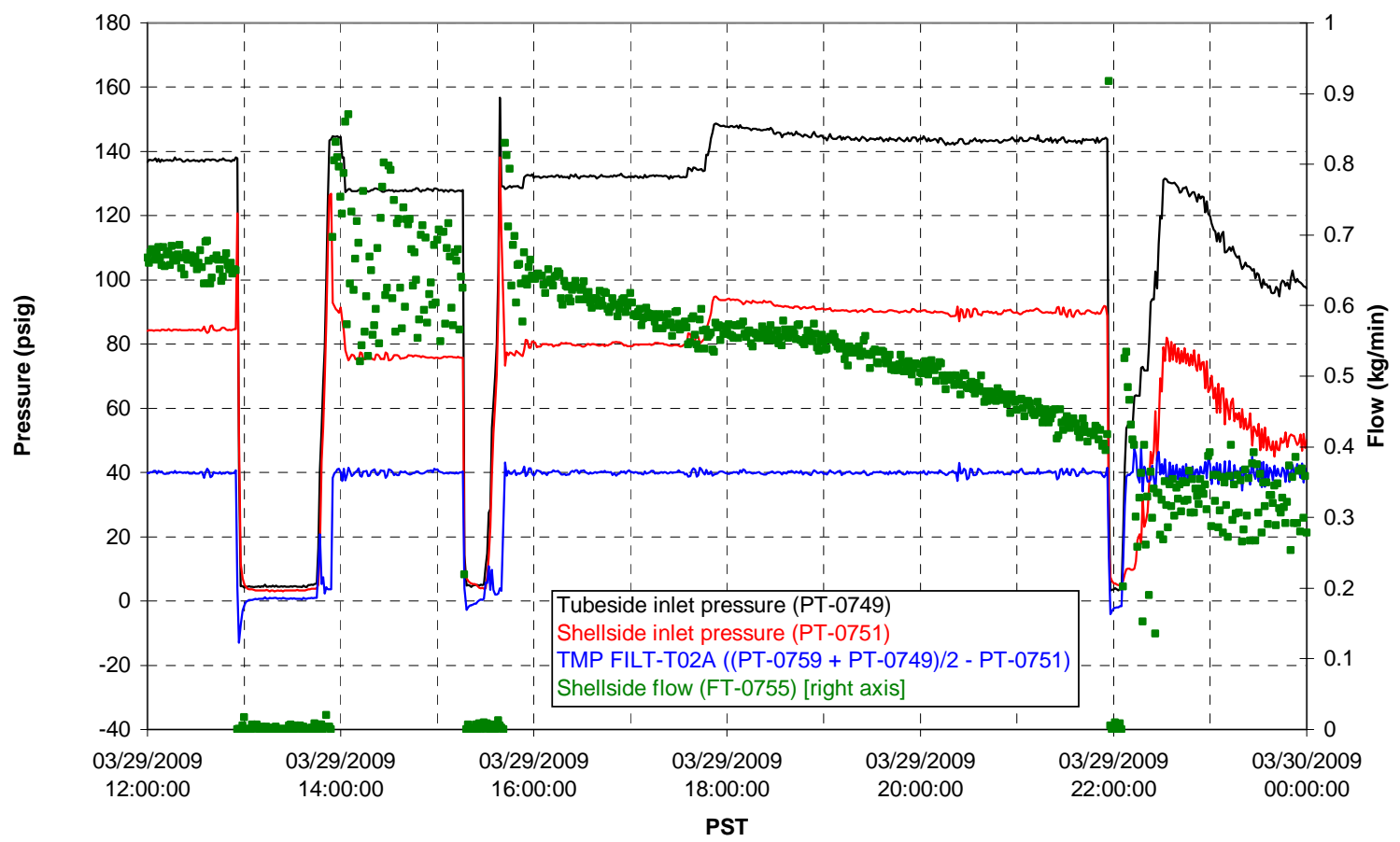


Filter UFP-FILT-T03A

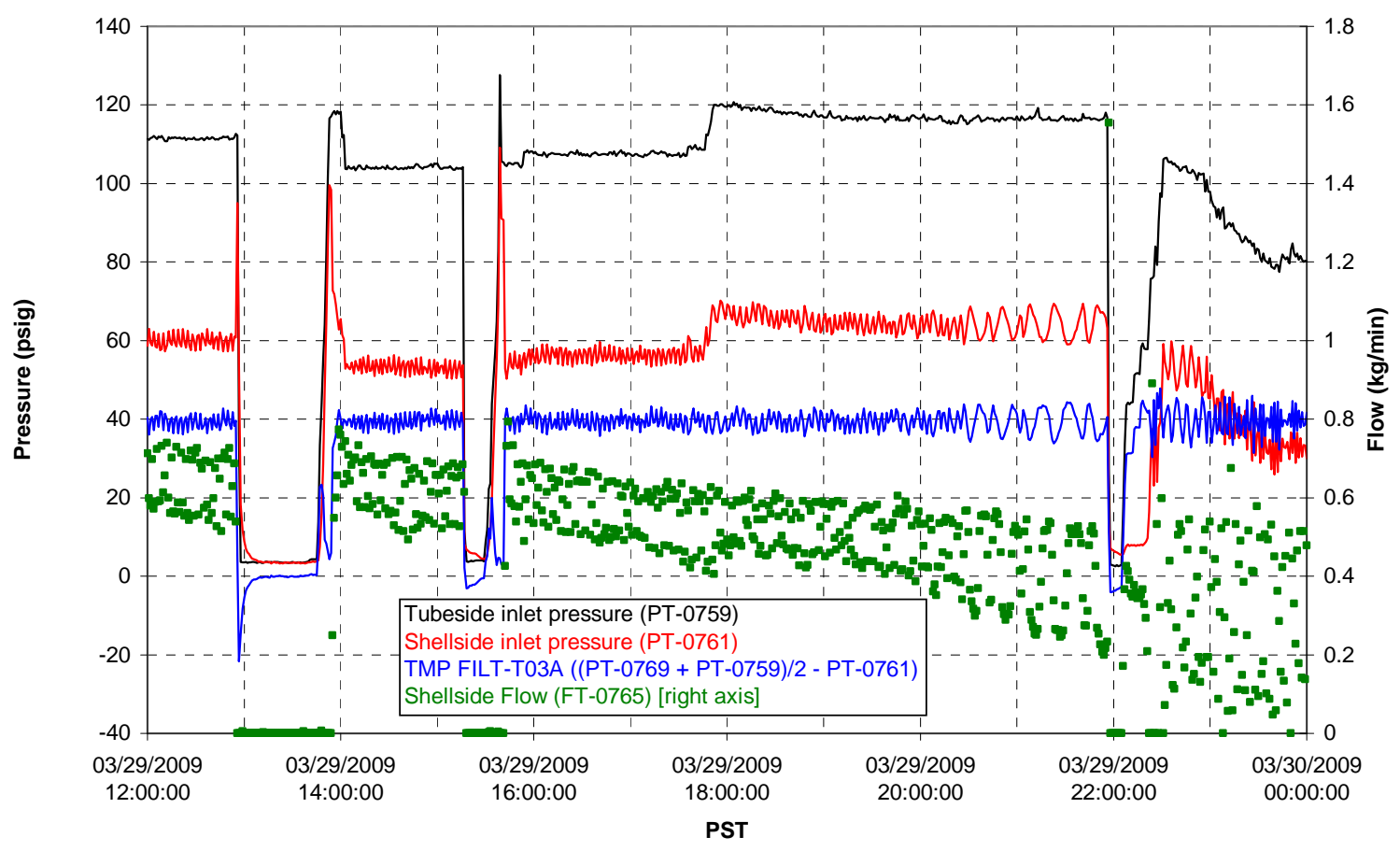

Filter UFP-FILT-T04A

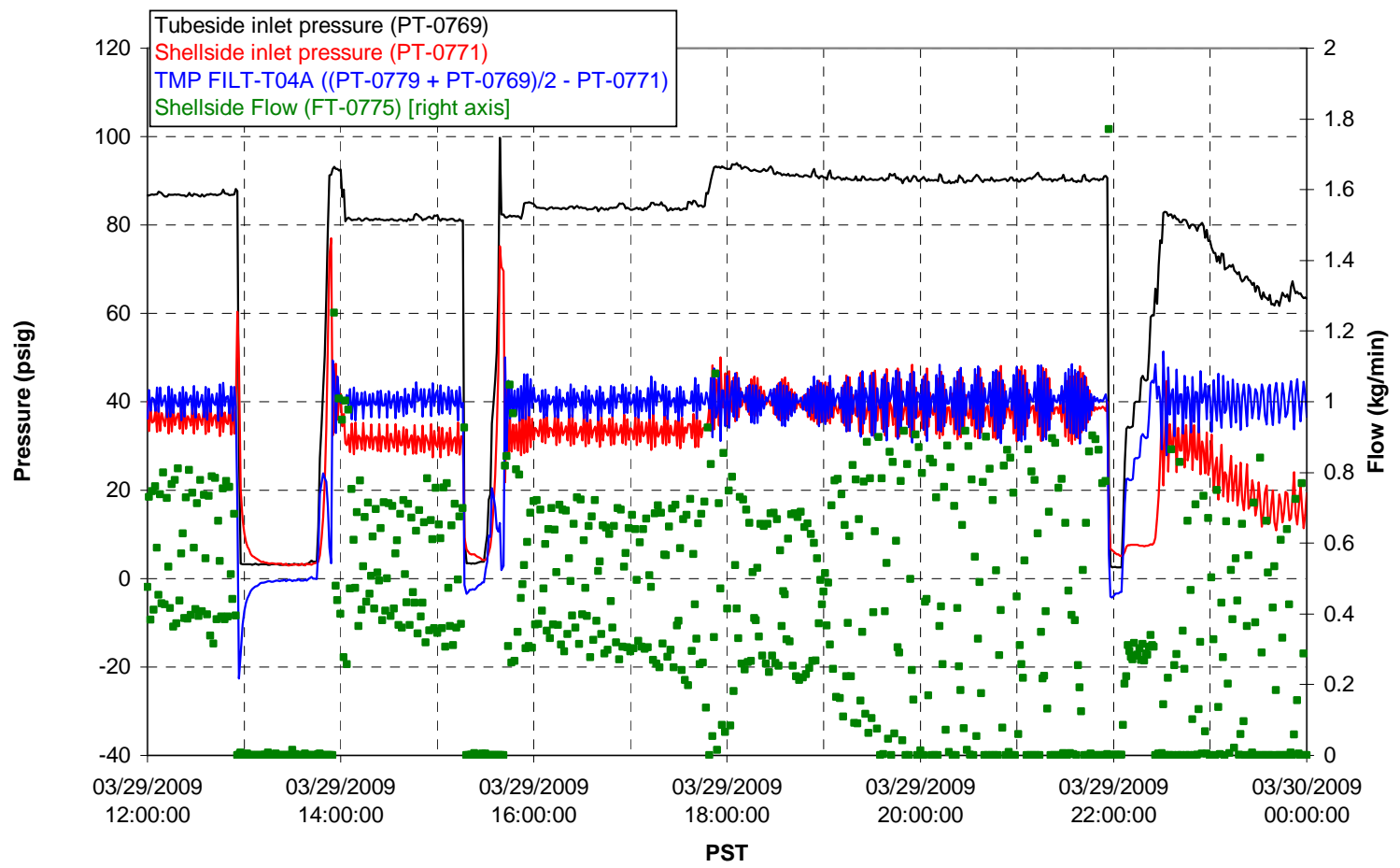


Filter UFP-FILT-T05A

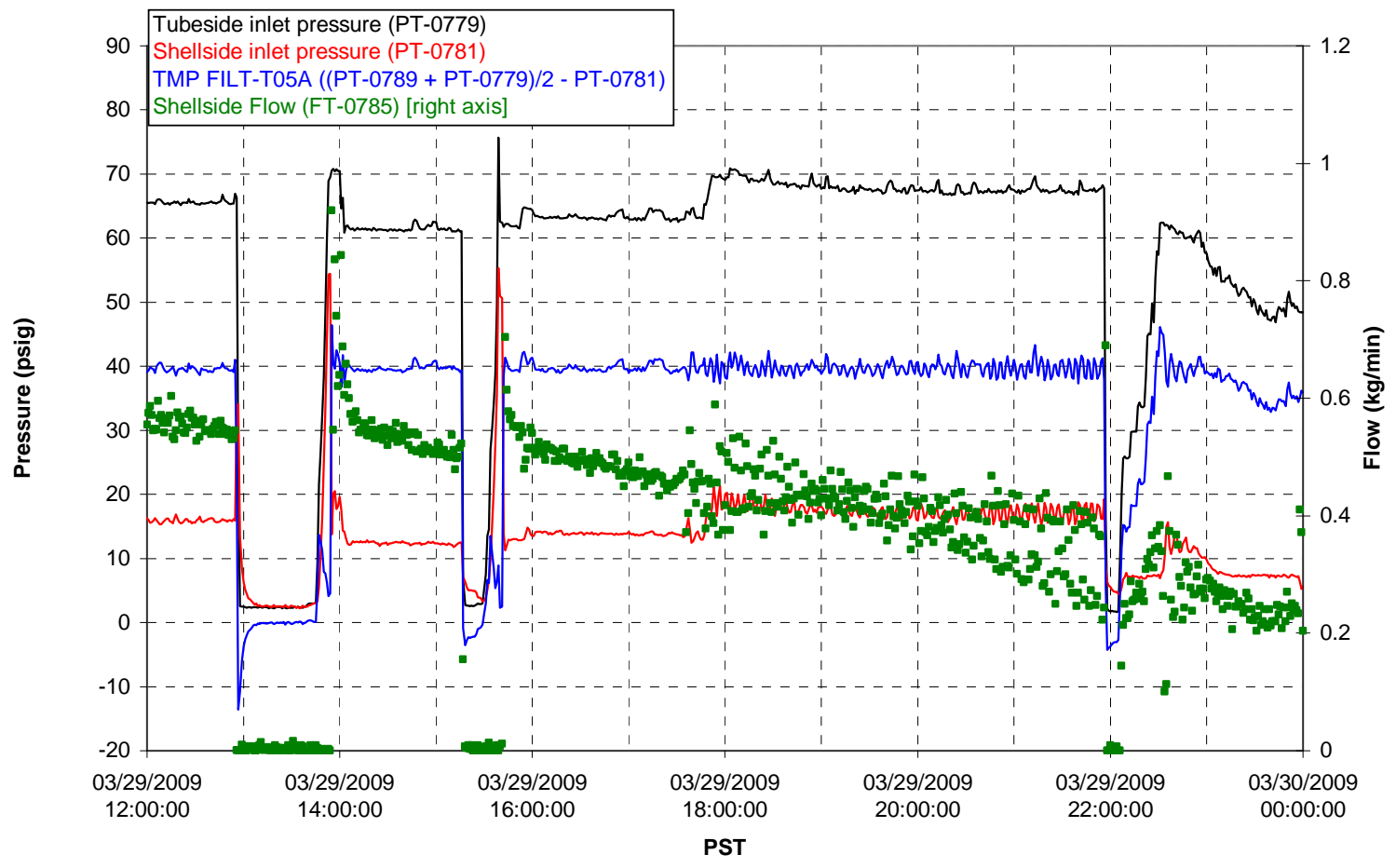

Chemical Flow

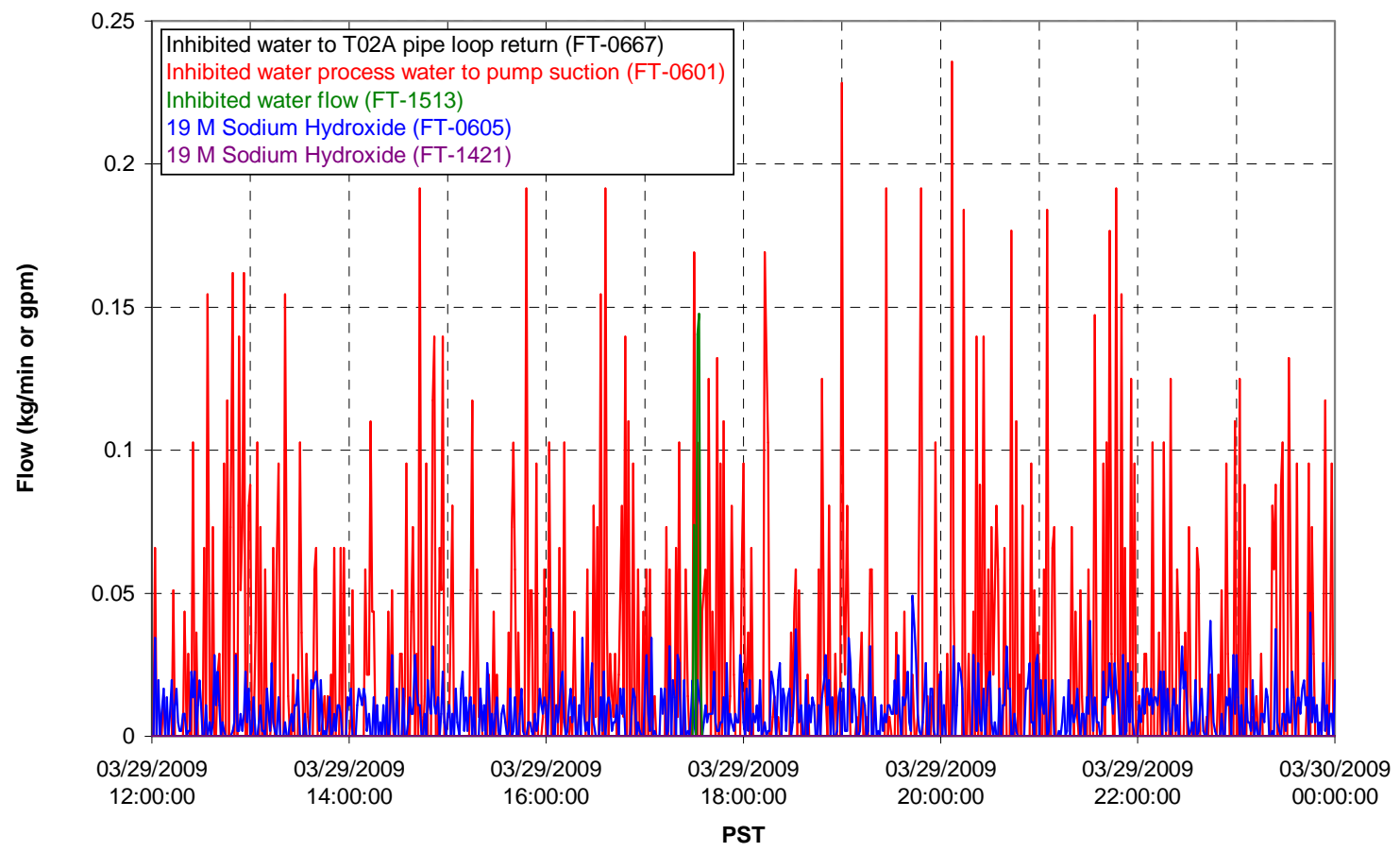




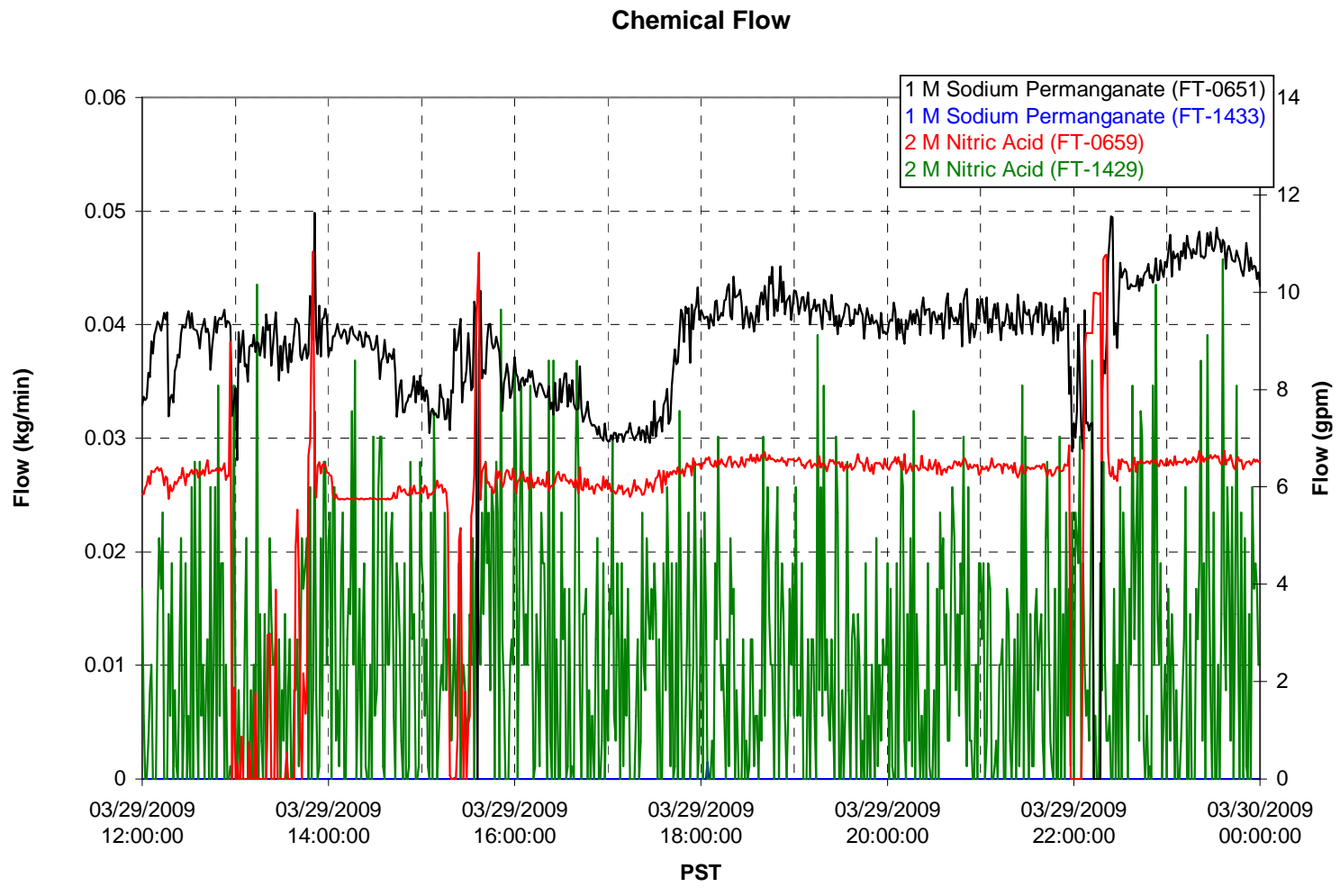

Air Flows

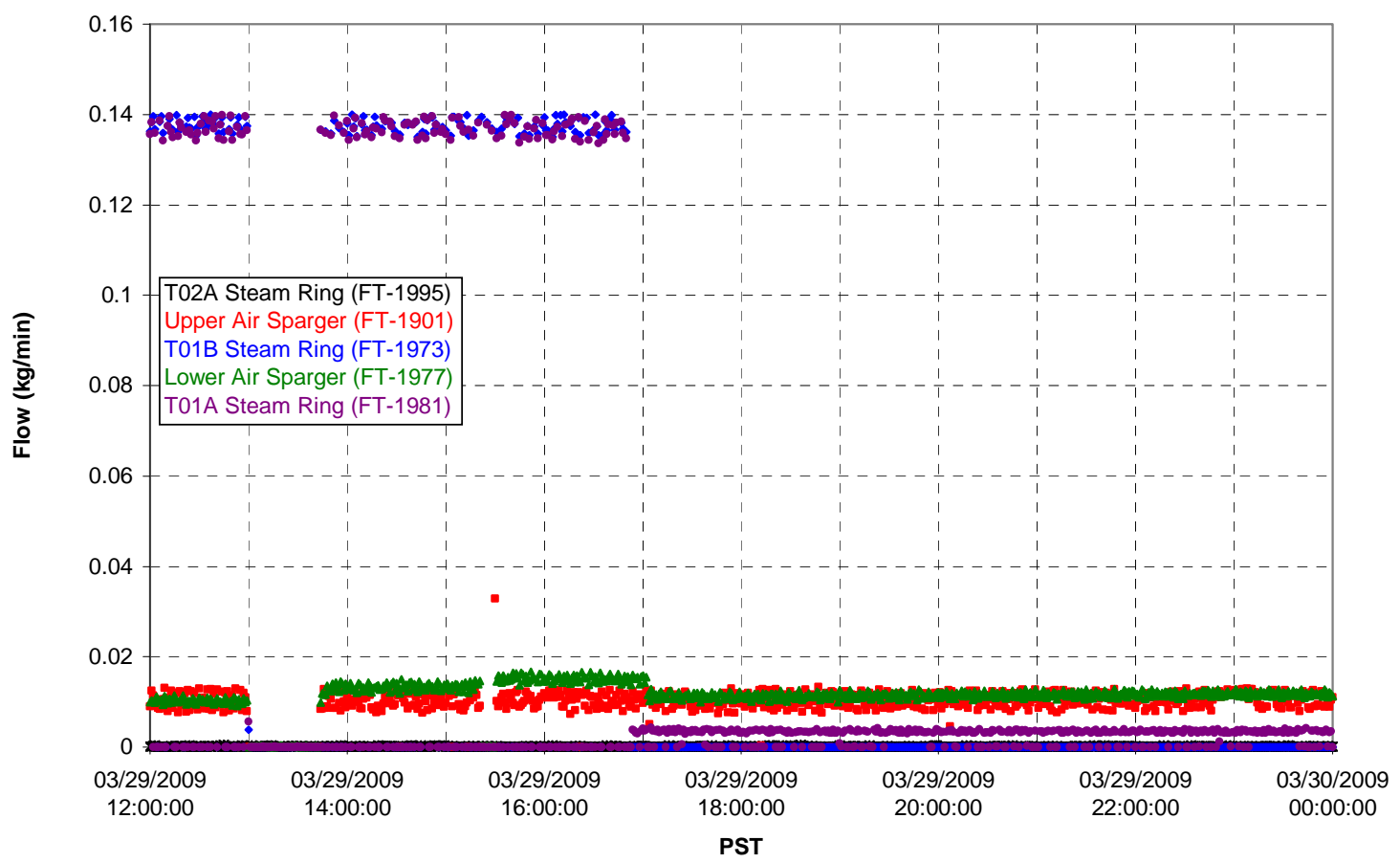


T02A Steam

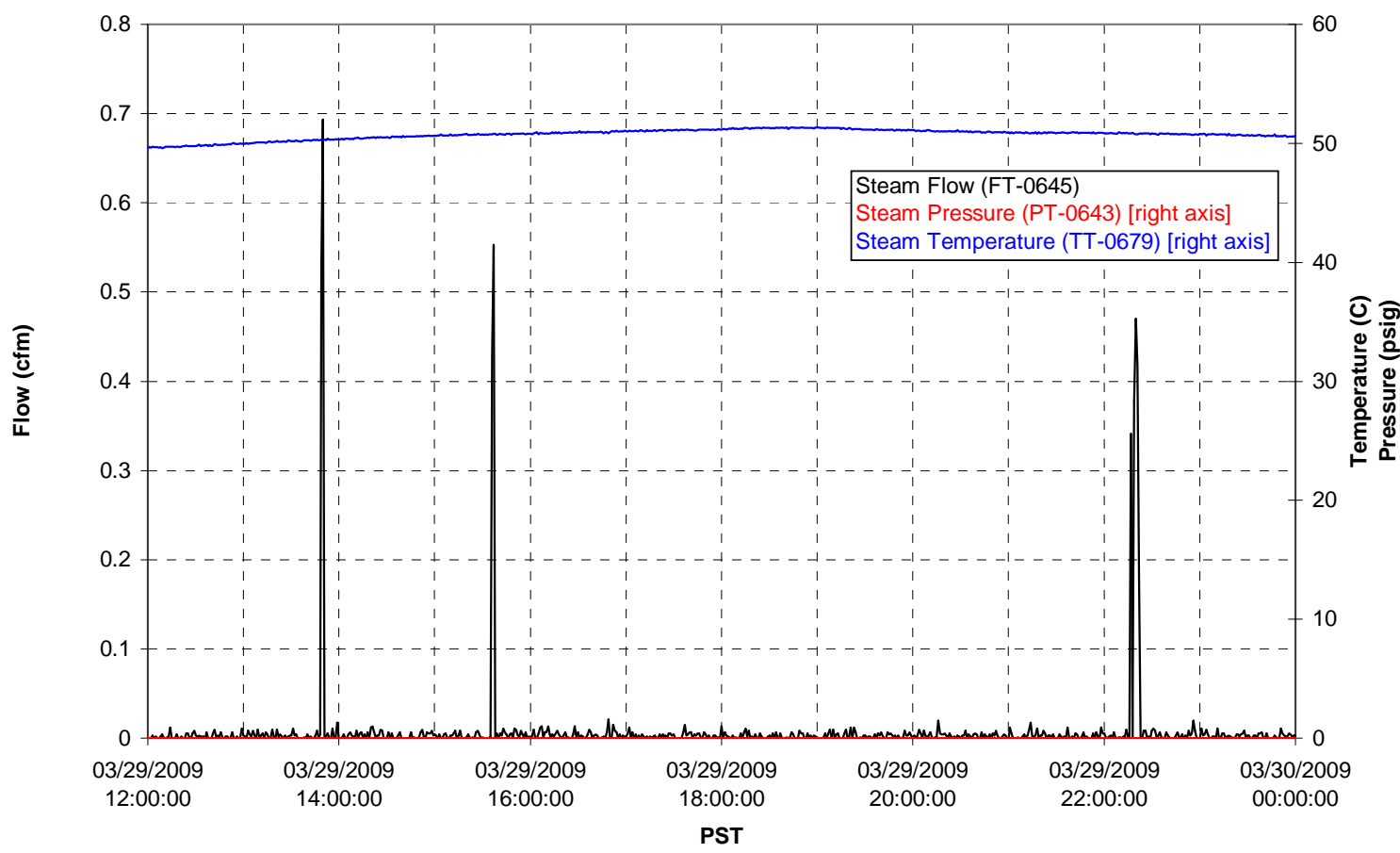

T01A Steam

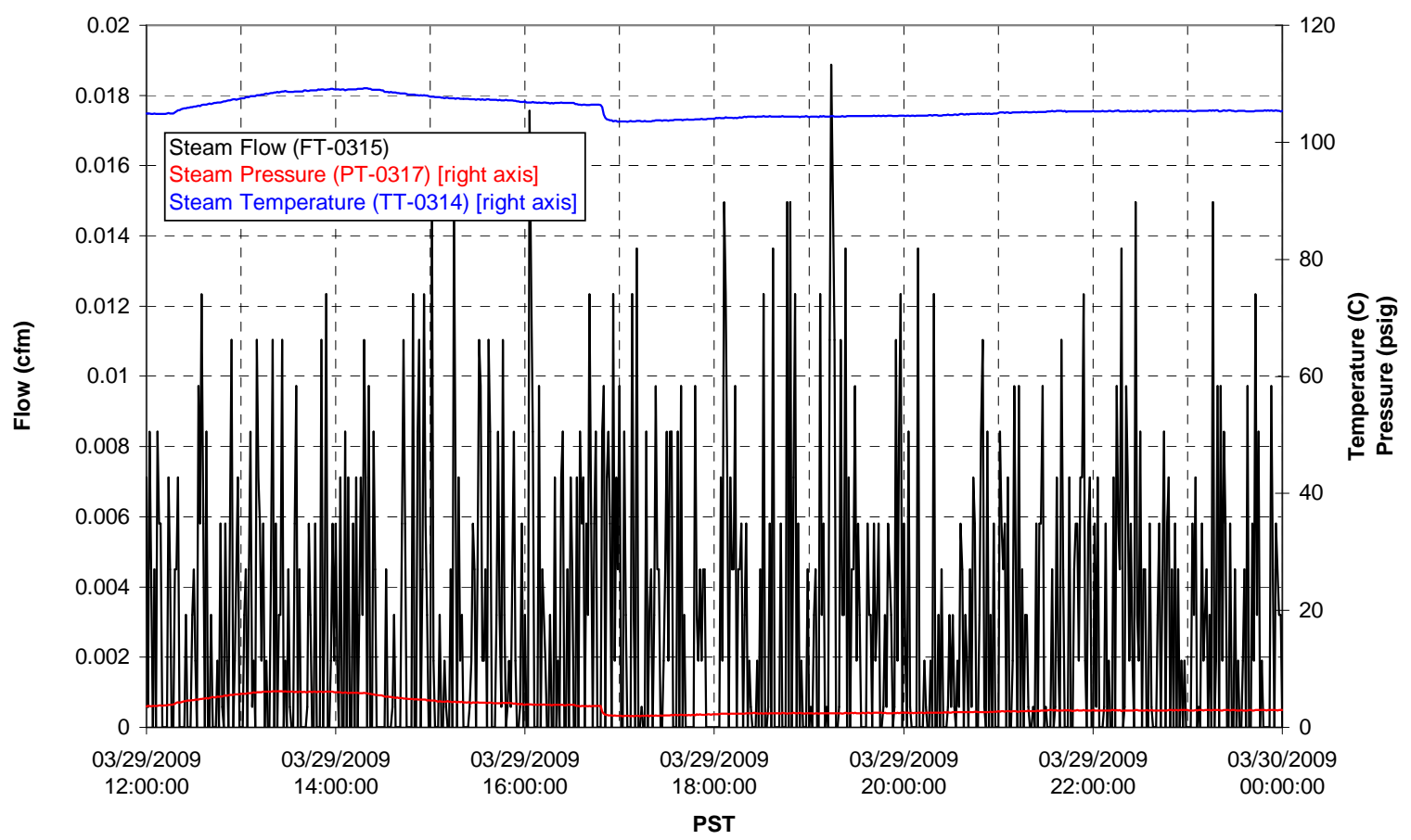


T01B Steam

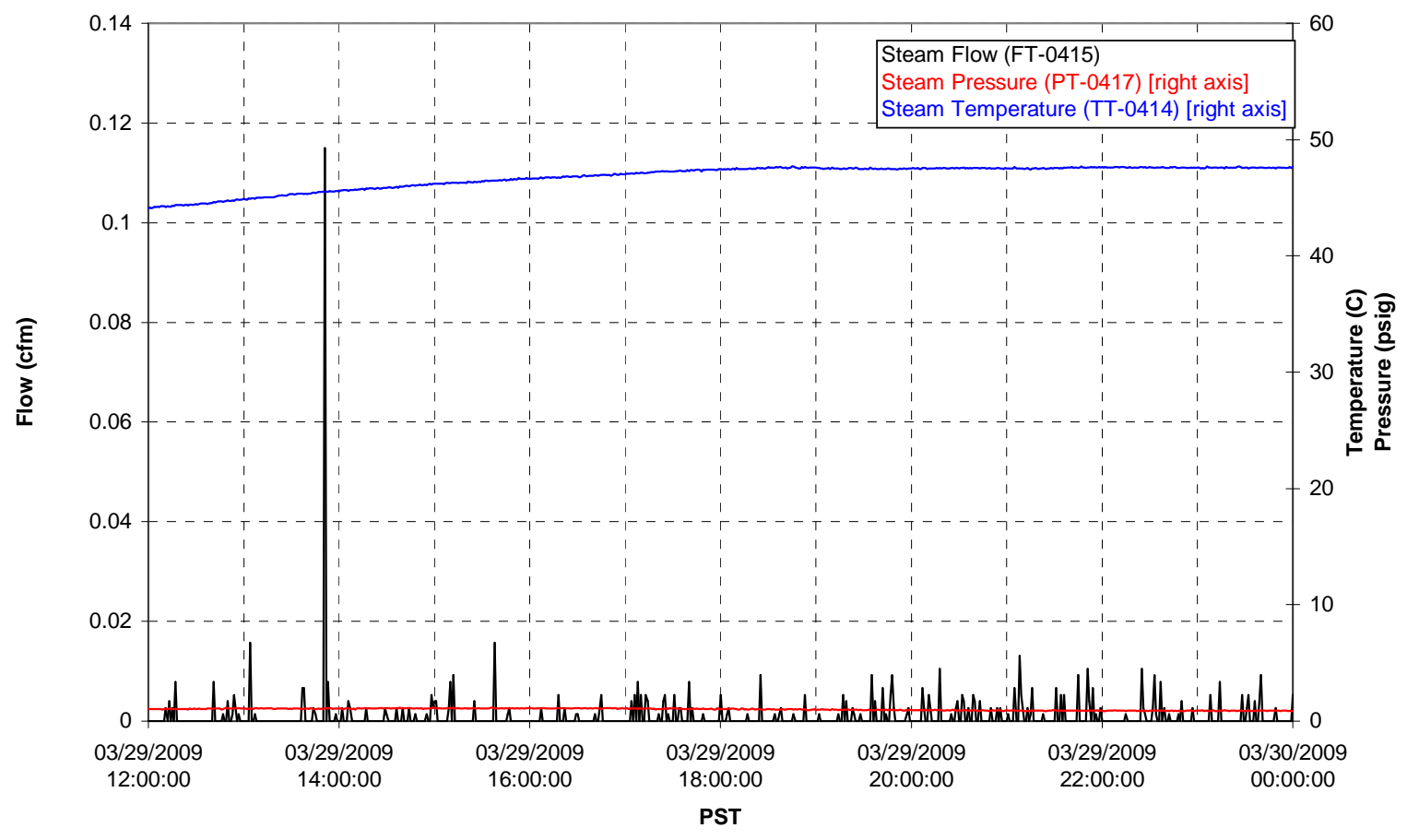




\section{Integrated Test D Data Plots 03/30/09 00:00 - 03/30/09 12:00}


T01A level

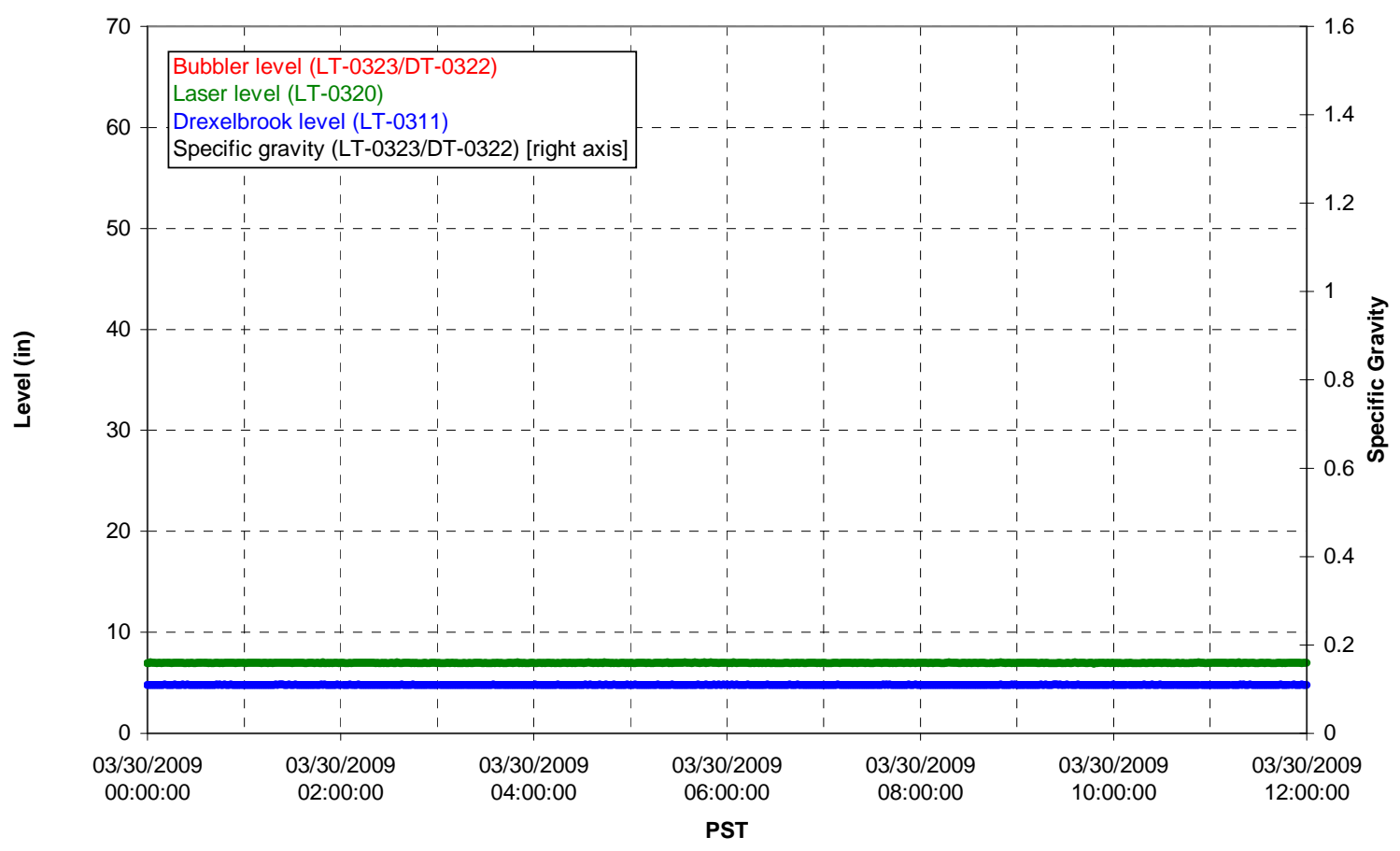

T01A temperatures

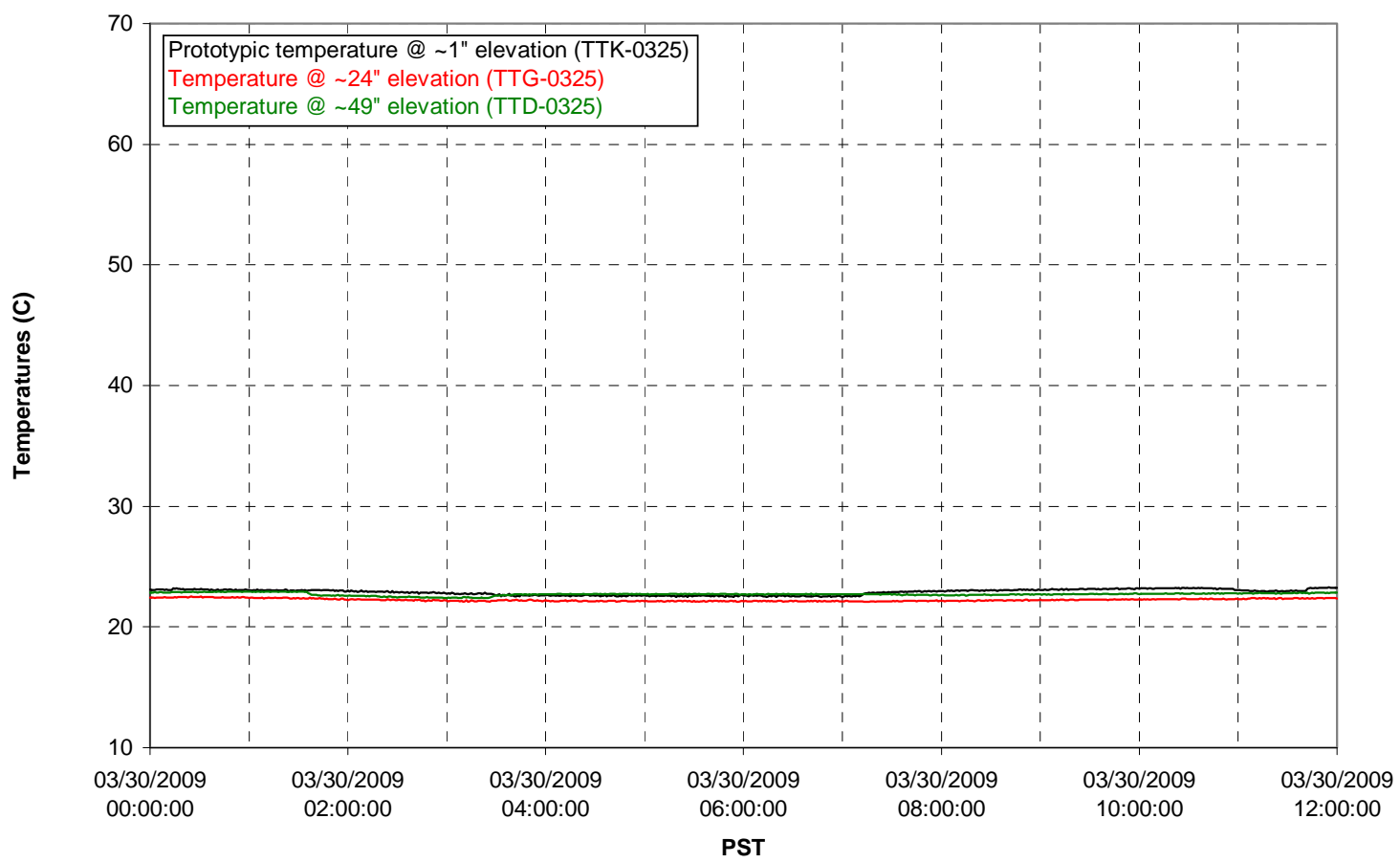


T01B level

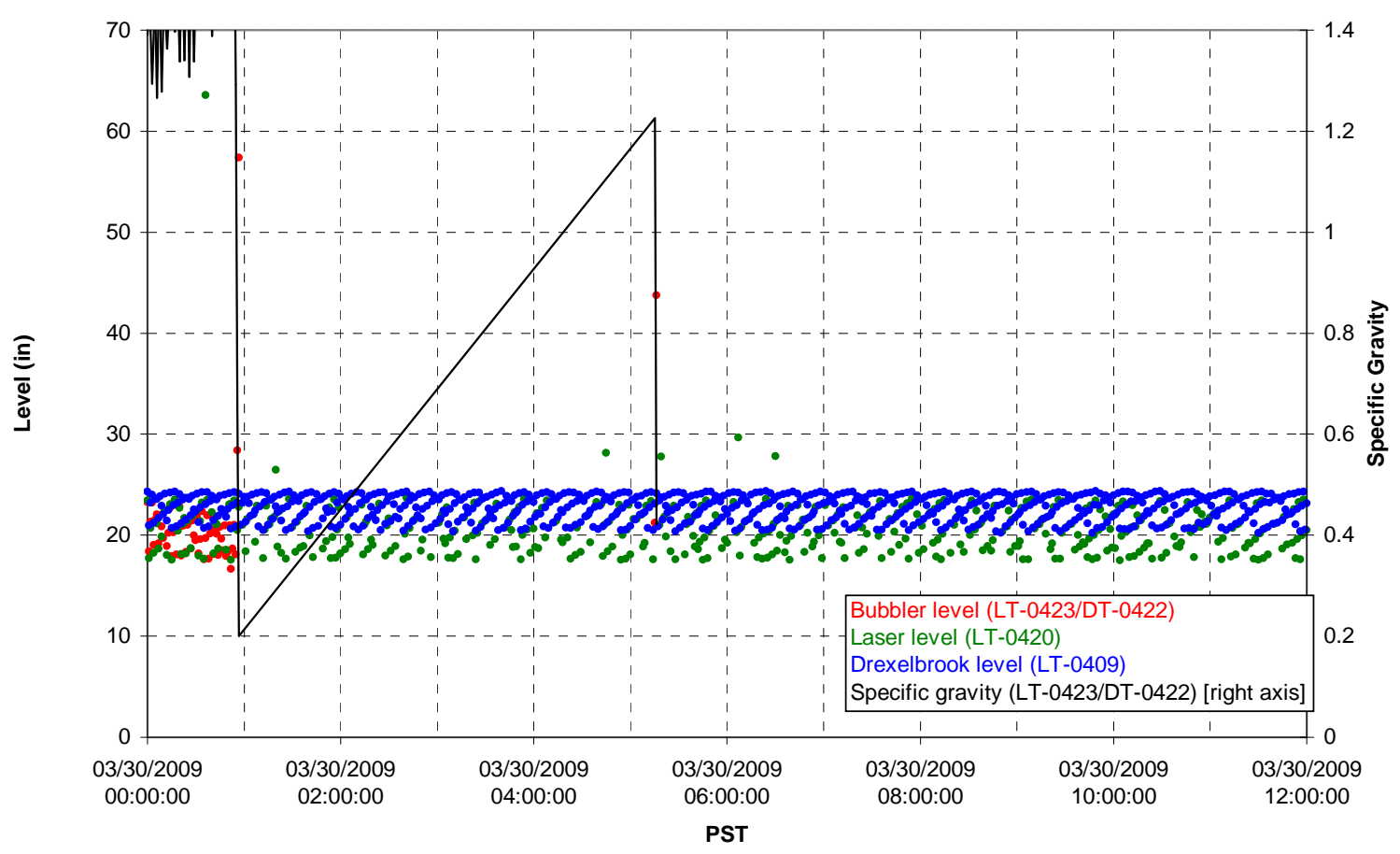

T01B temperatures

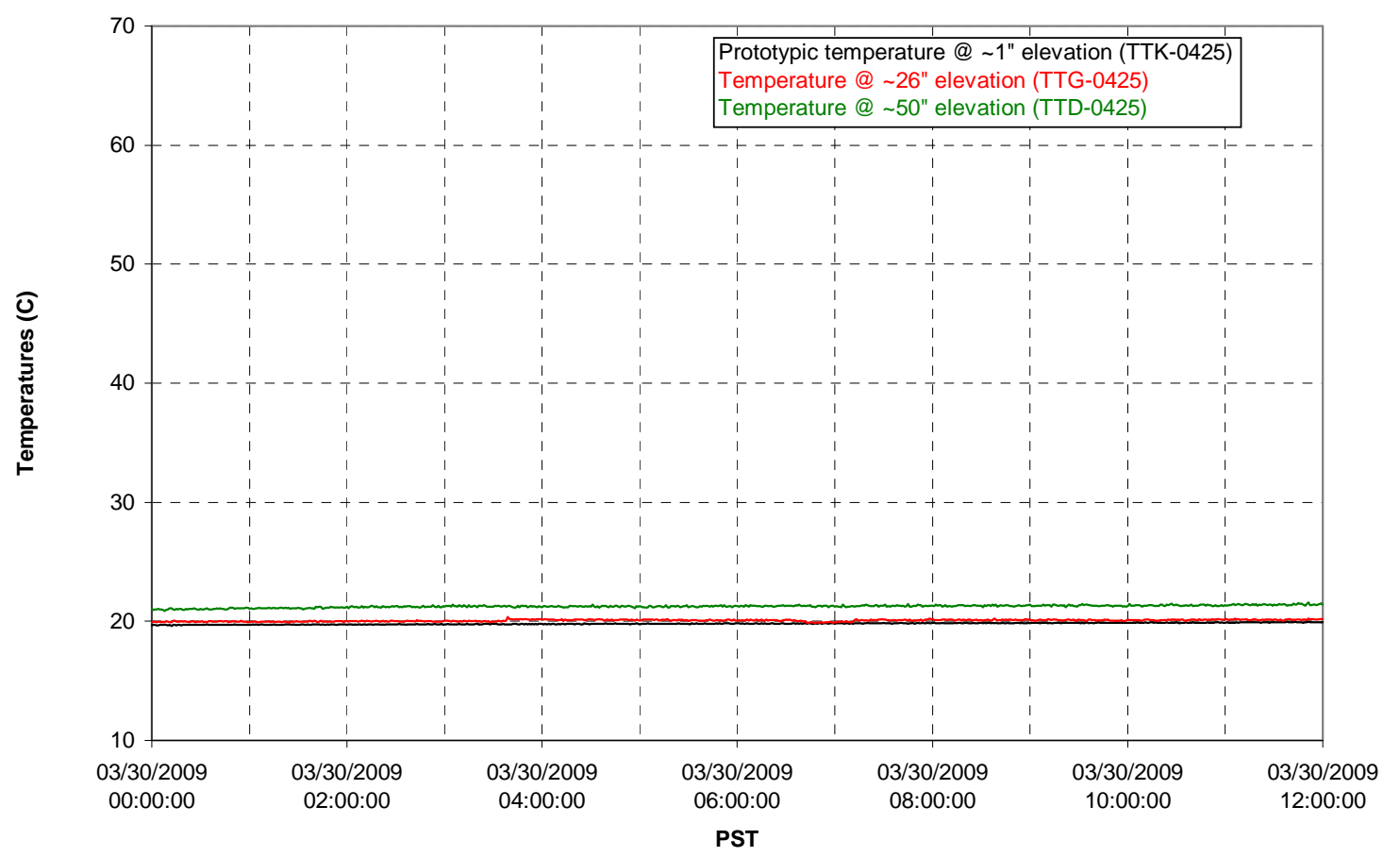


T02A level

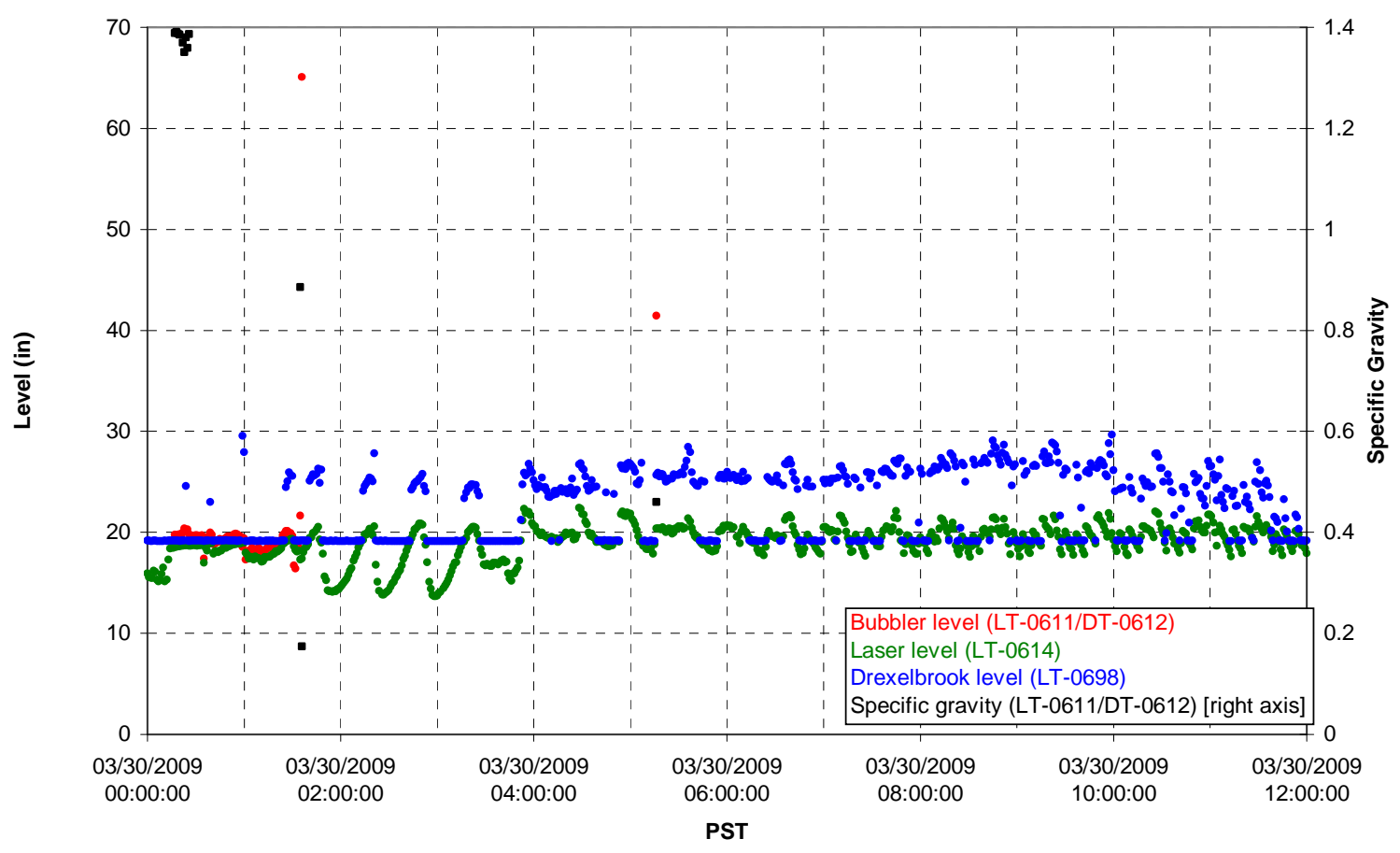

T02A temperatures

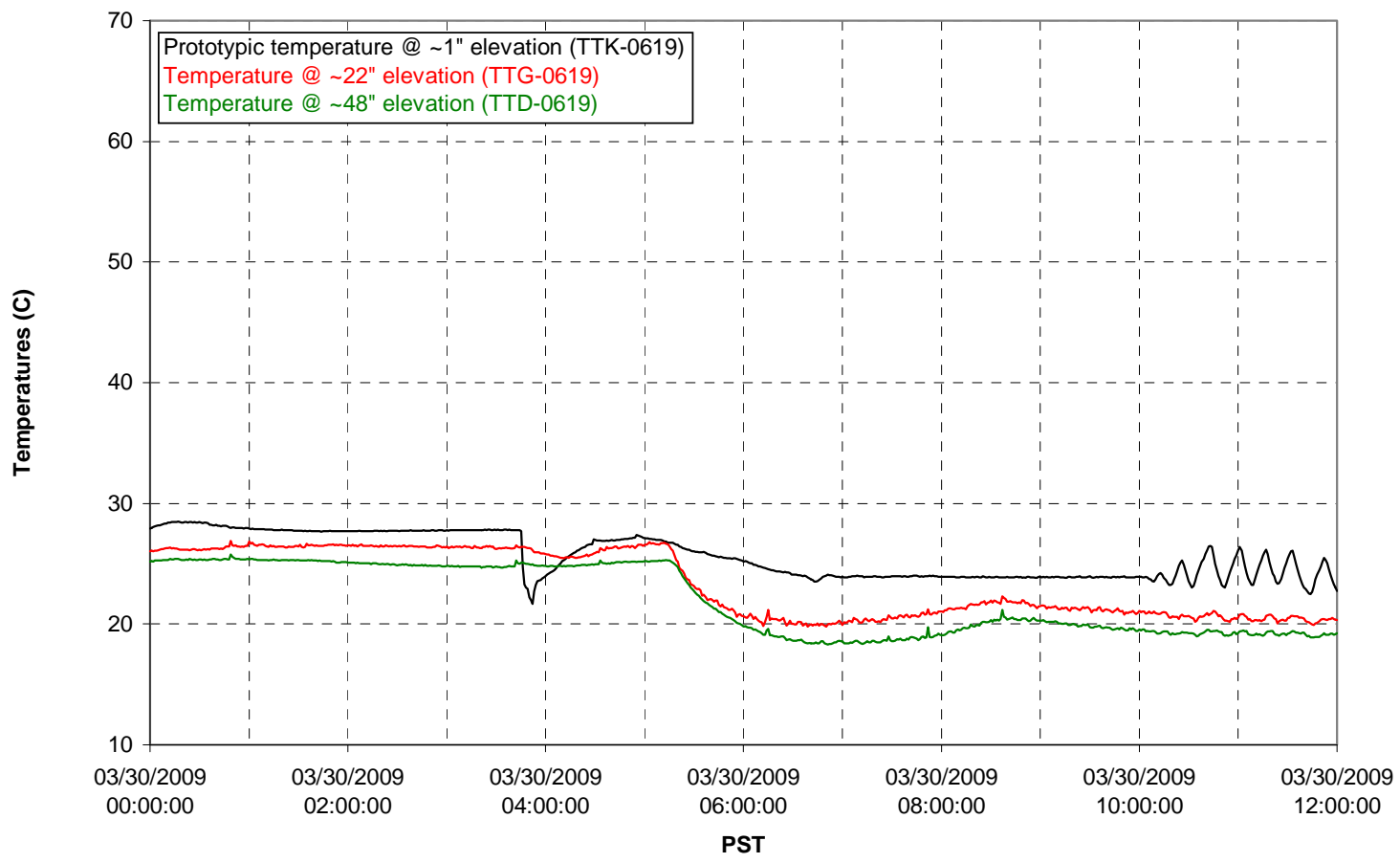


T02A and filter loop temperatures

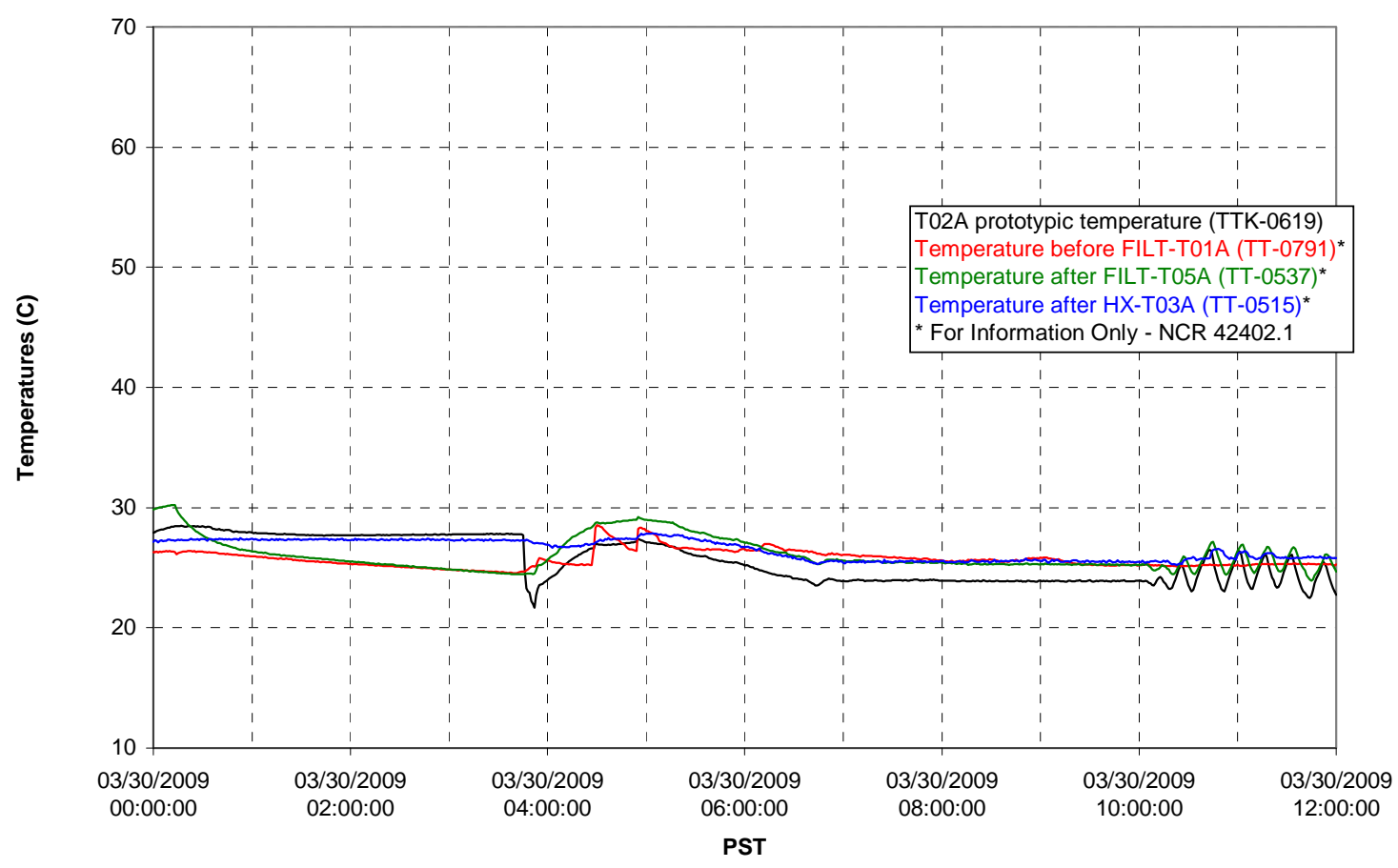

Pump Pressures and Flow

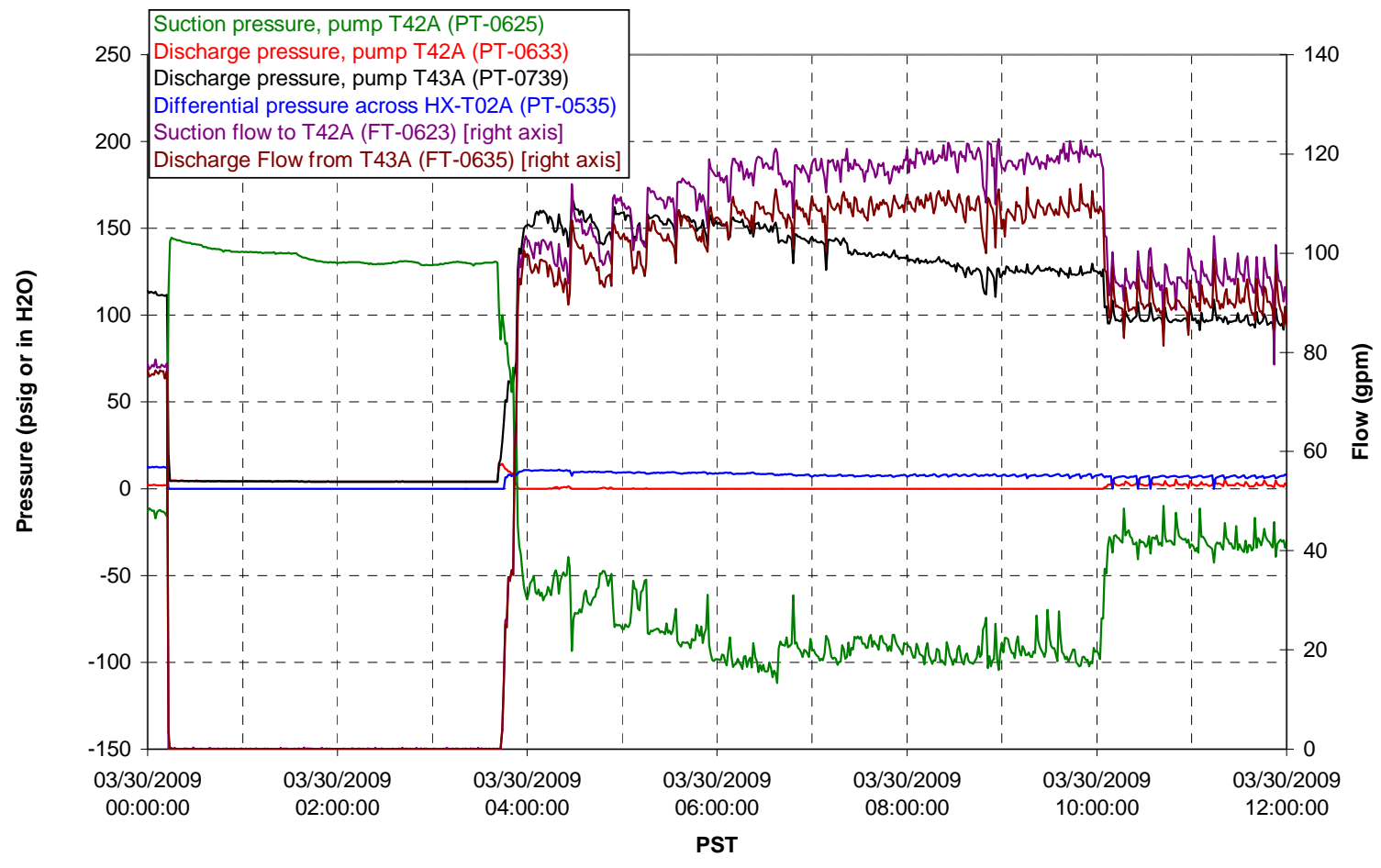




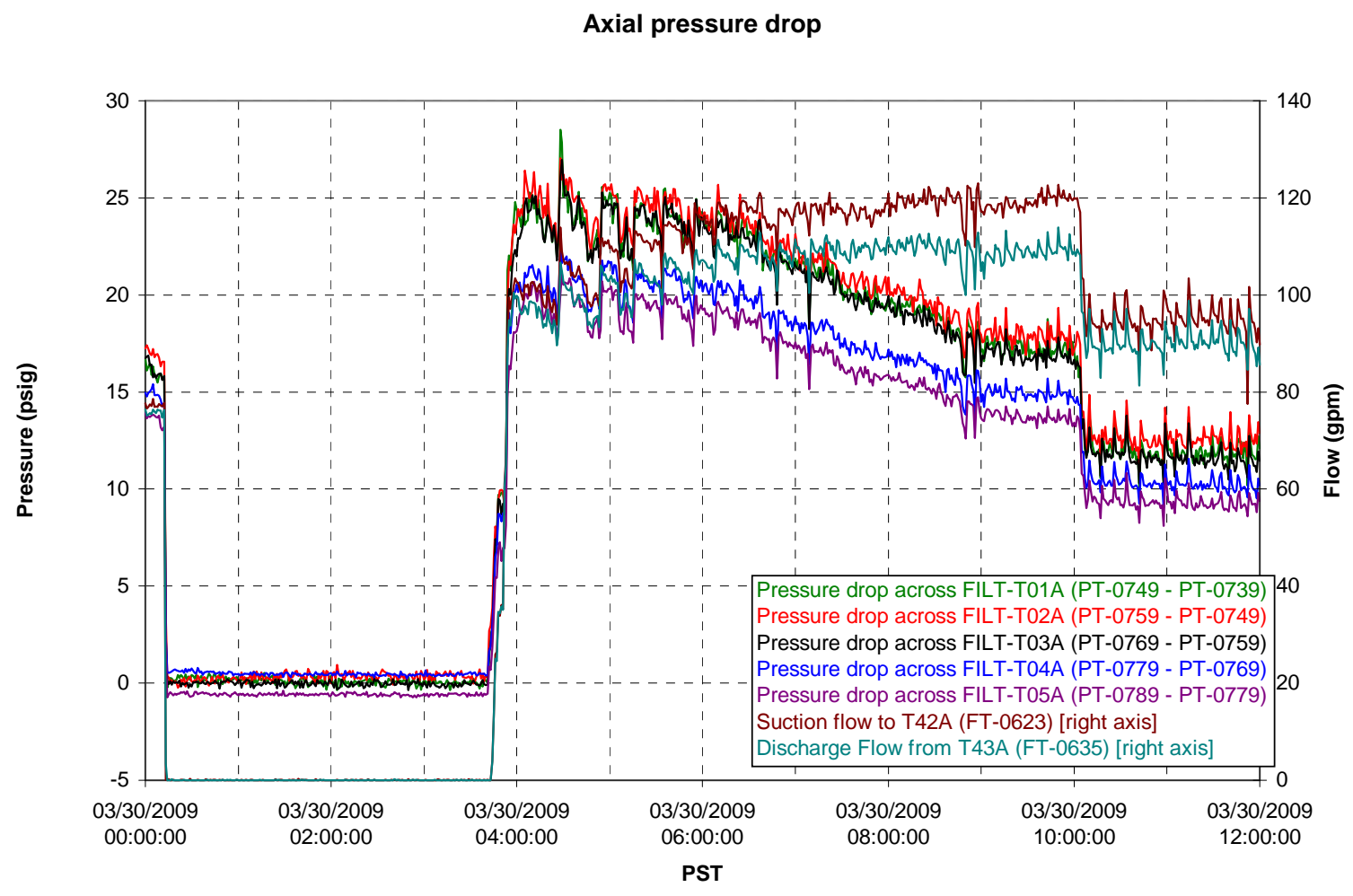

Permeate flow rates

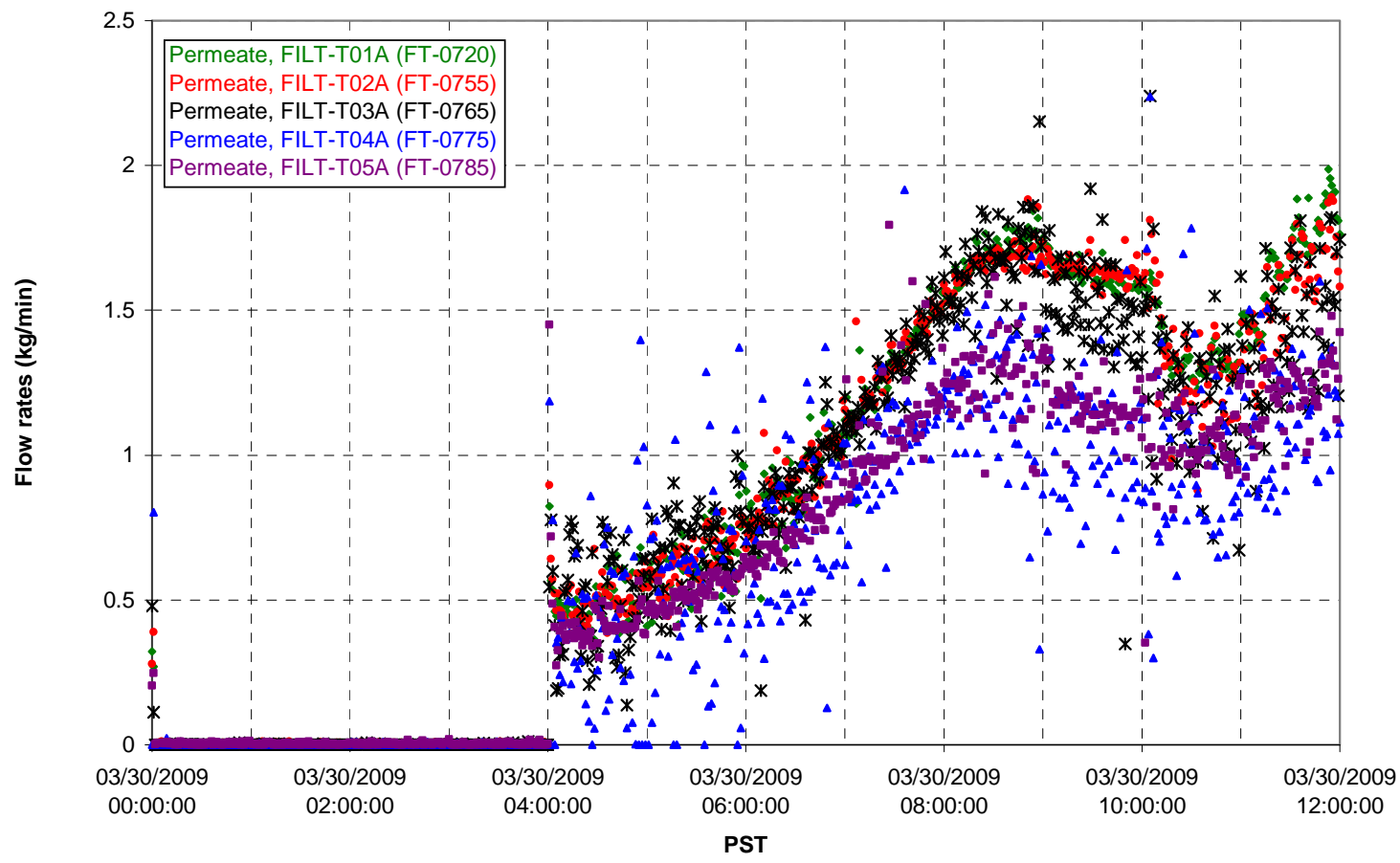


T02A Inner Temperature Tree

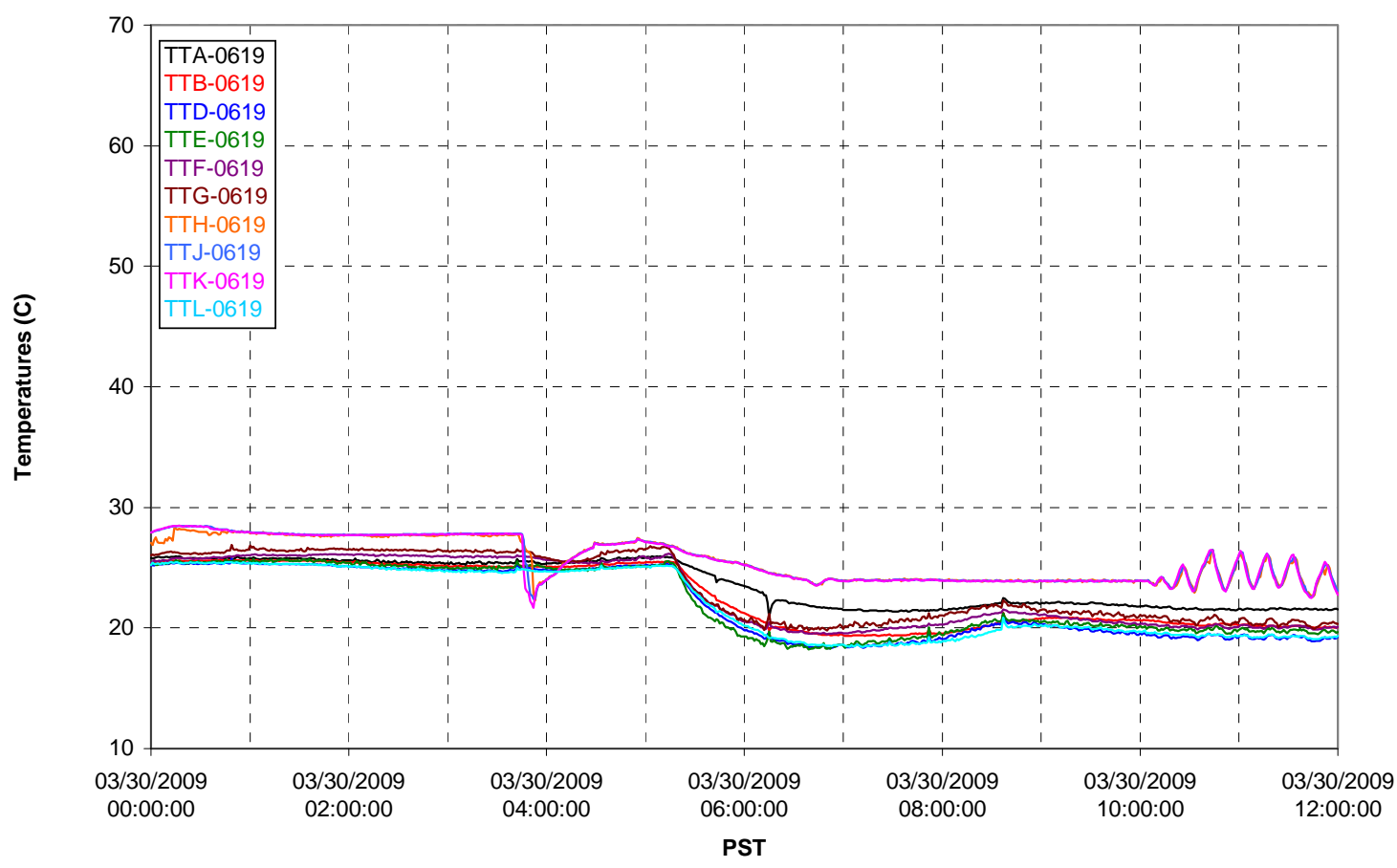

T02A Outer Temperature Tree

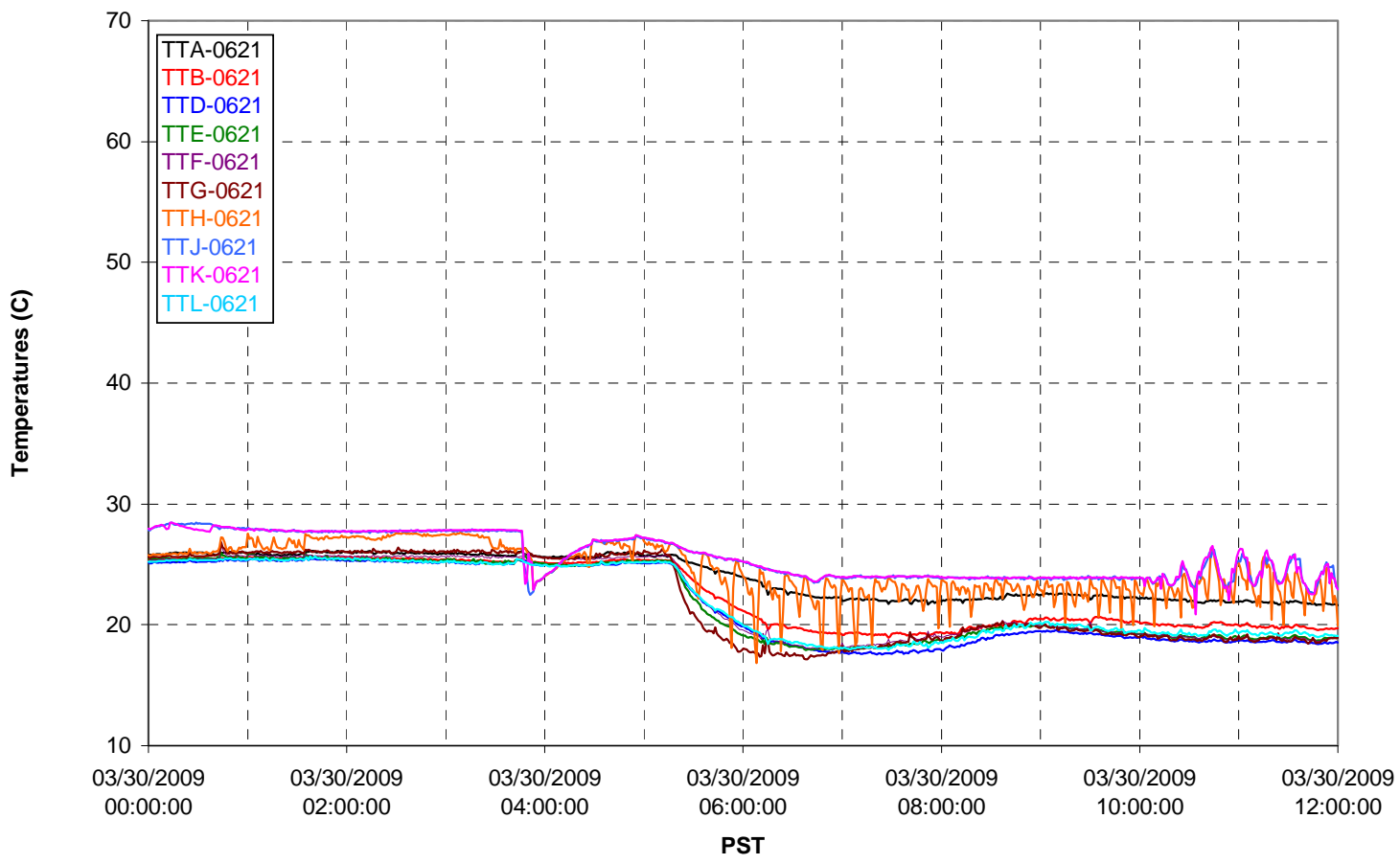


T02A temperatures

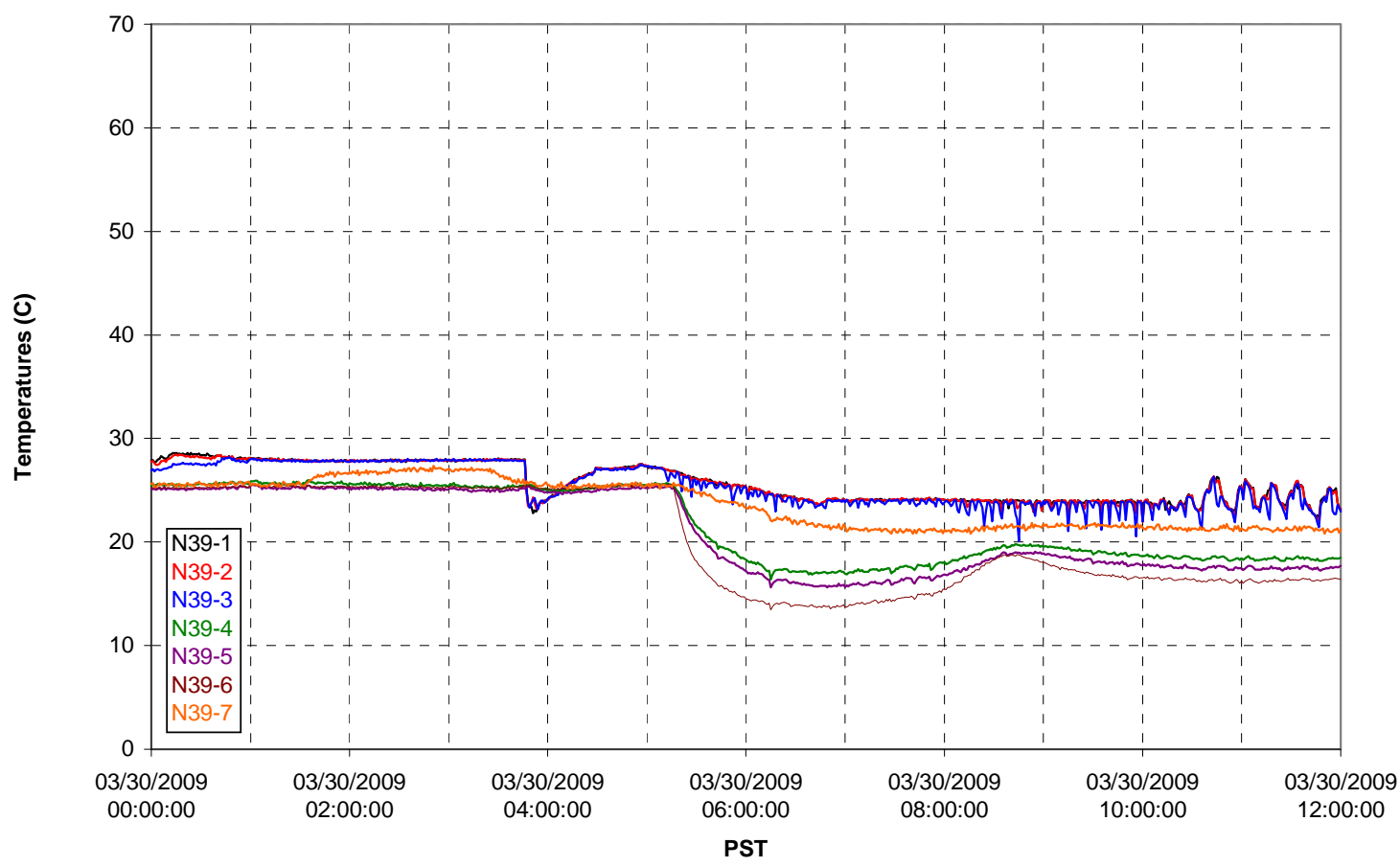

T02A temperatures

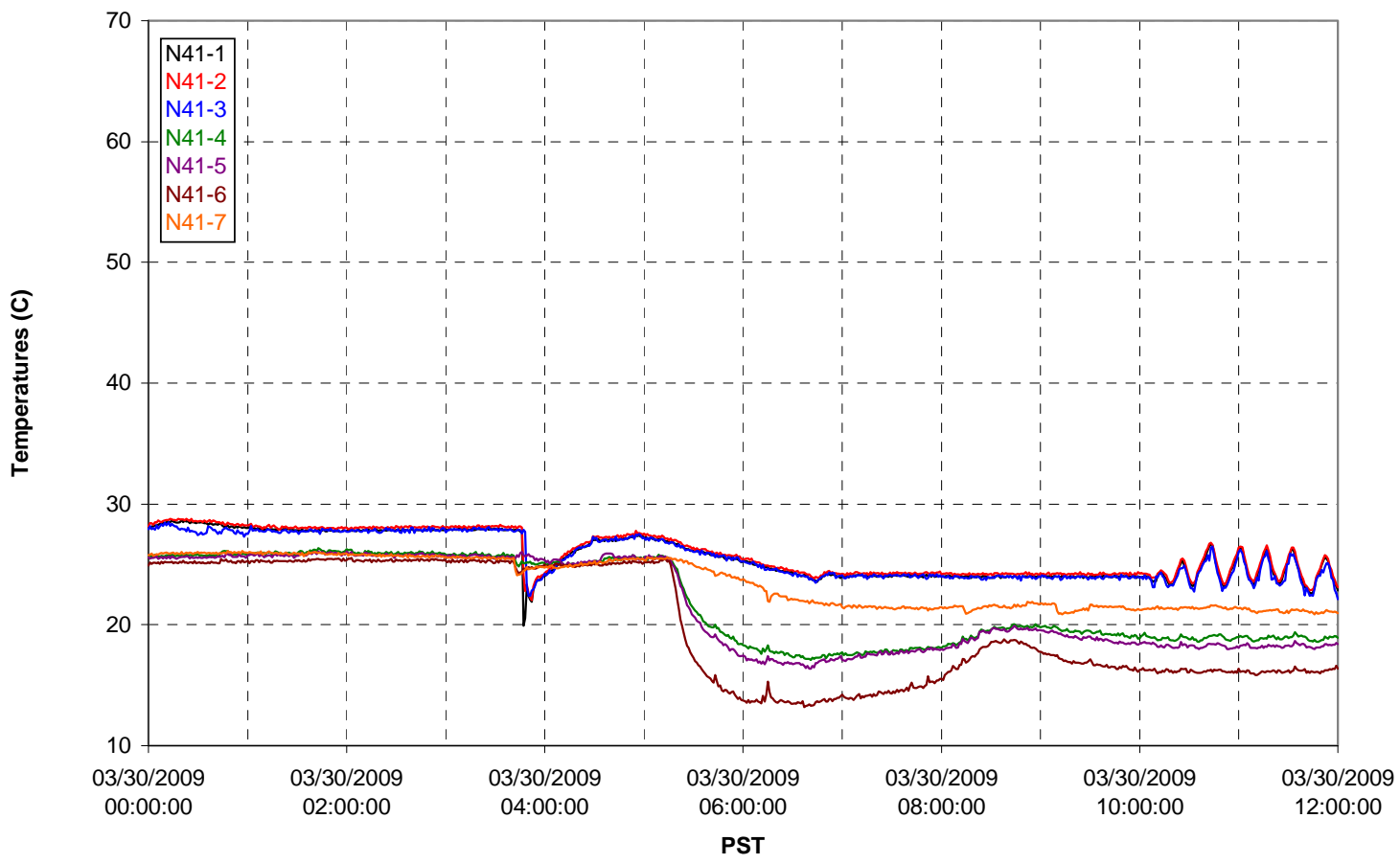


T02A temperatures

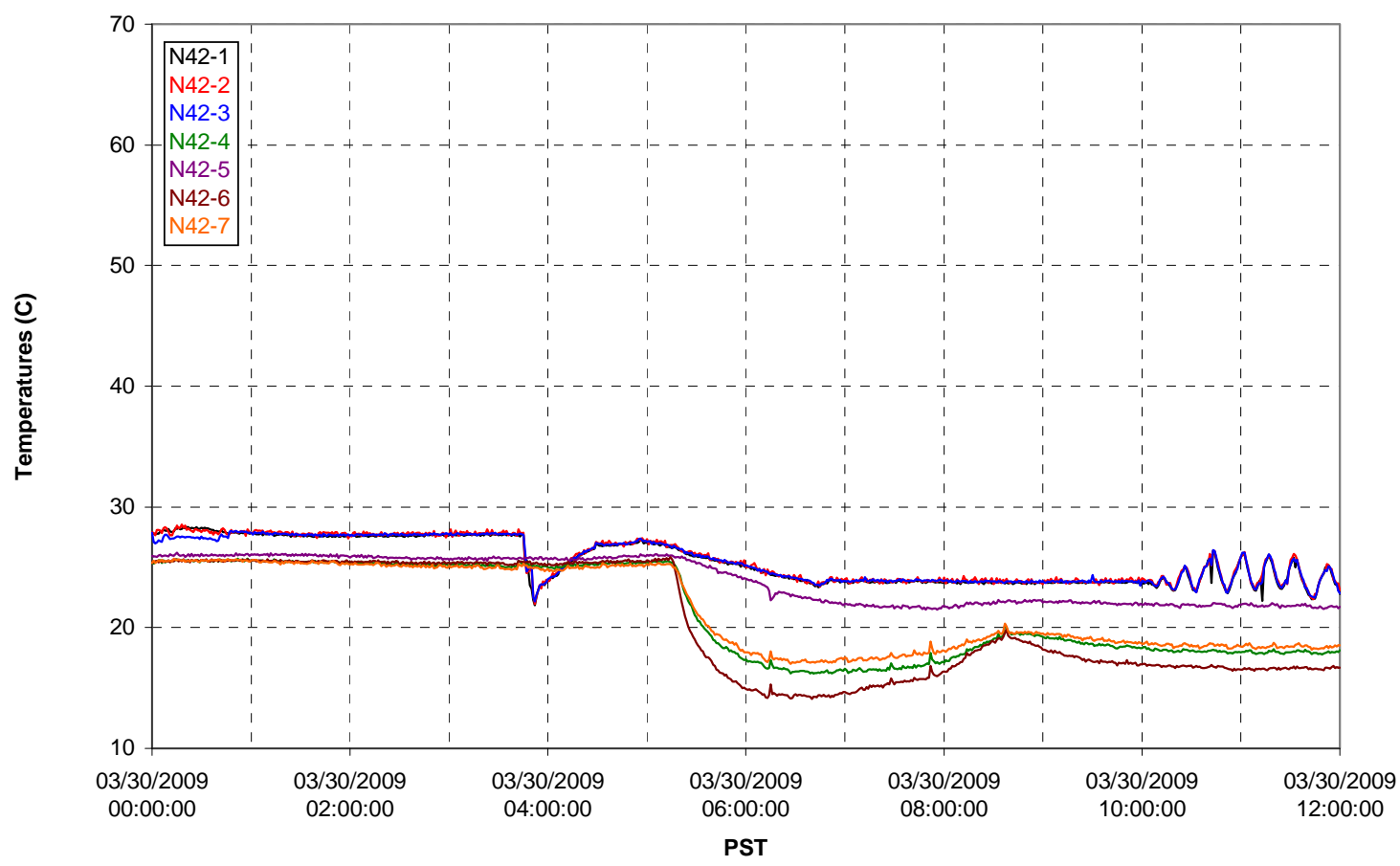

T02A temperatures

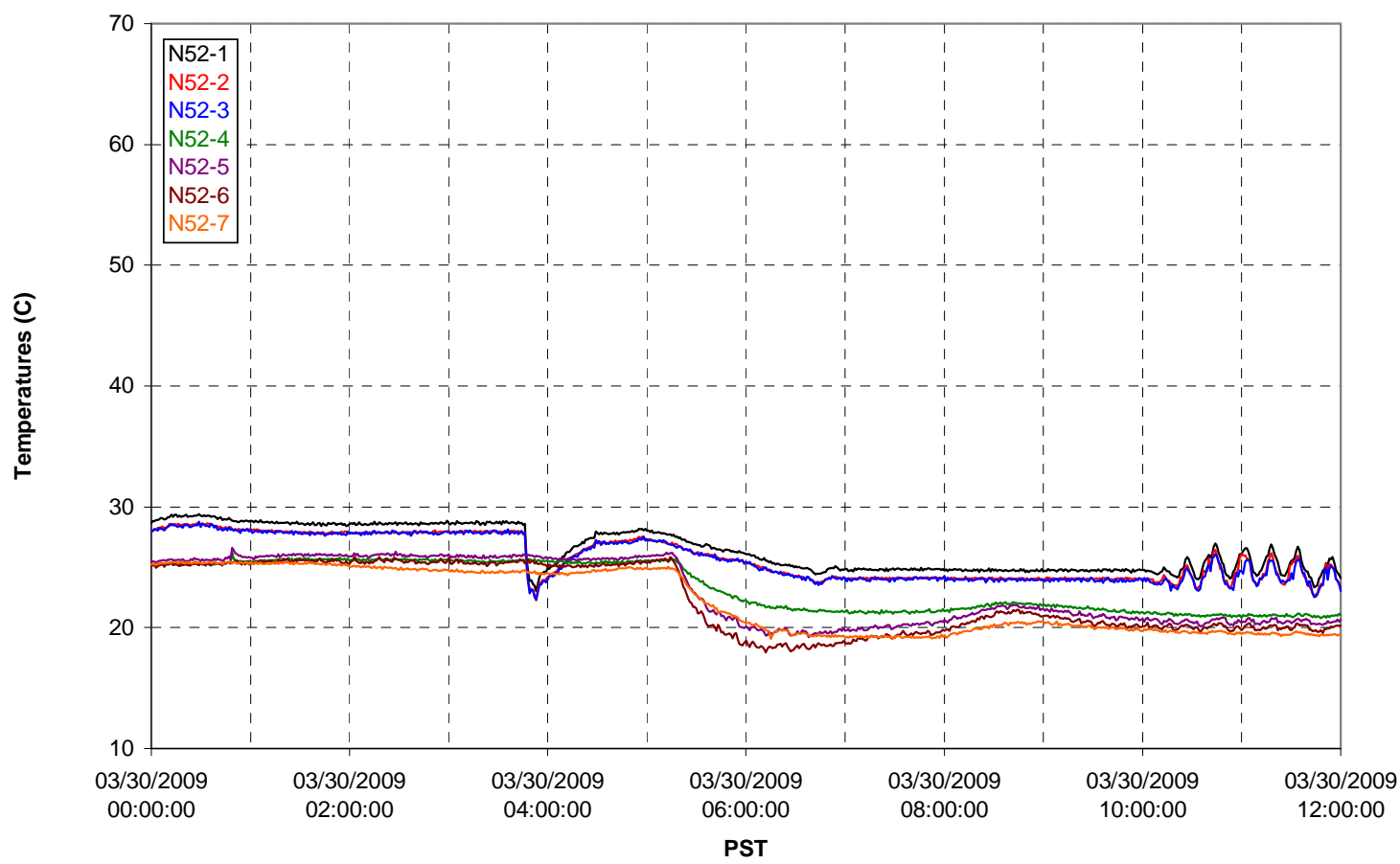


T02A Heating and Cooling

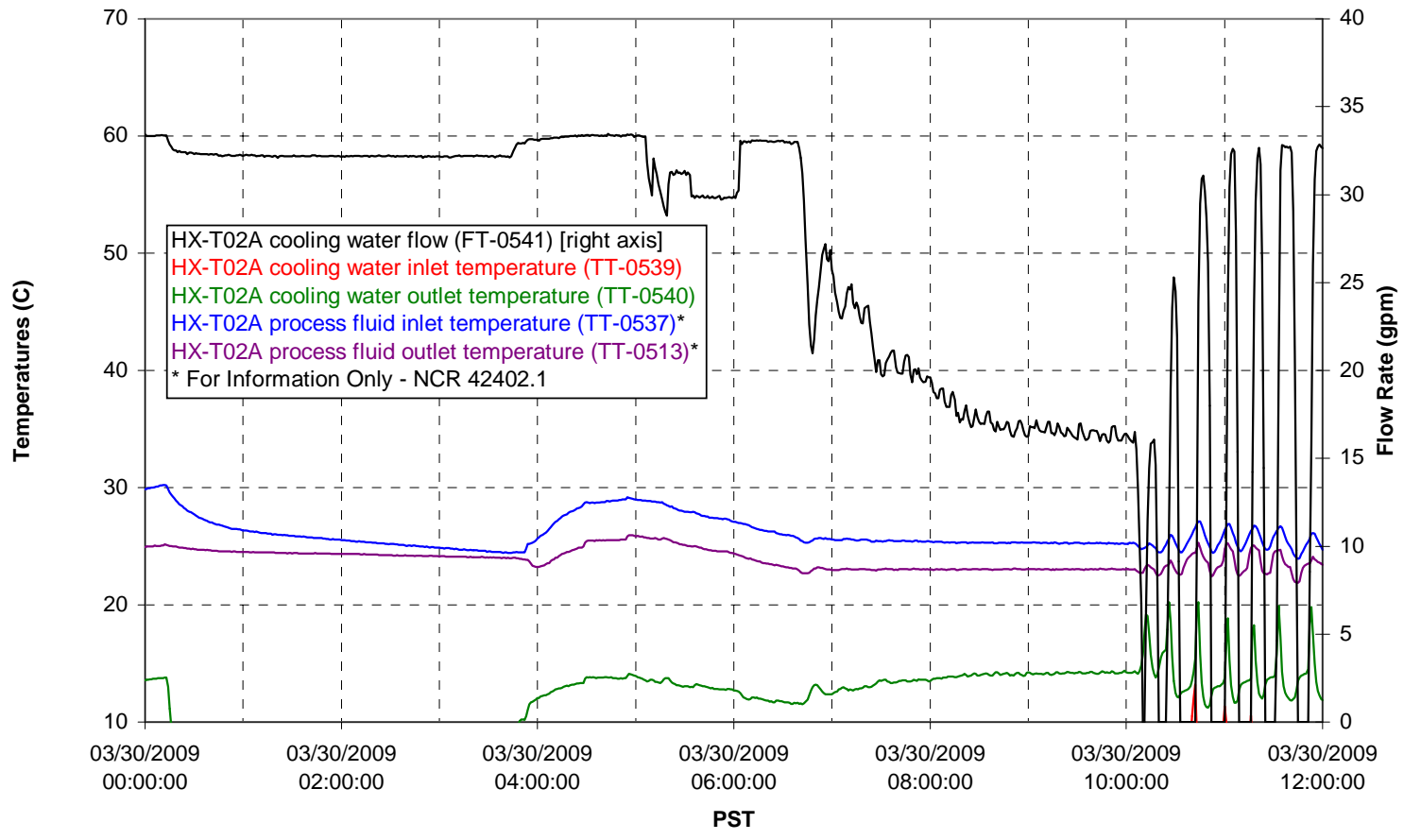

Pump Operation

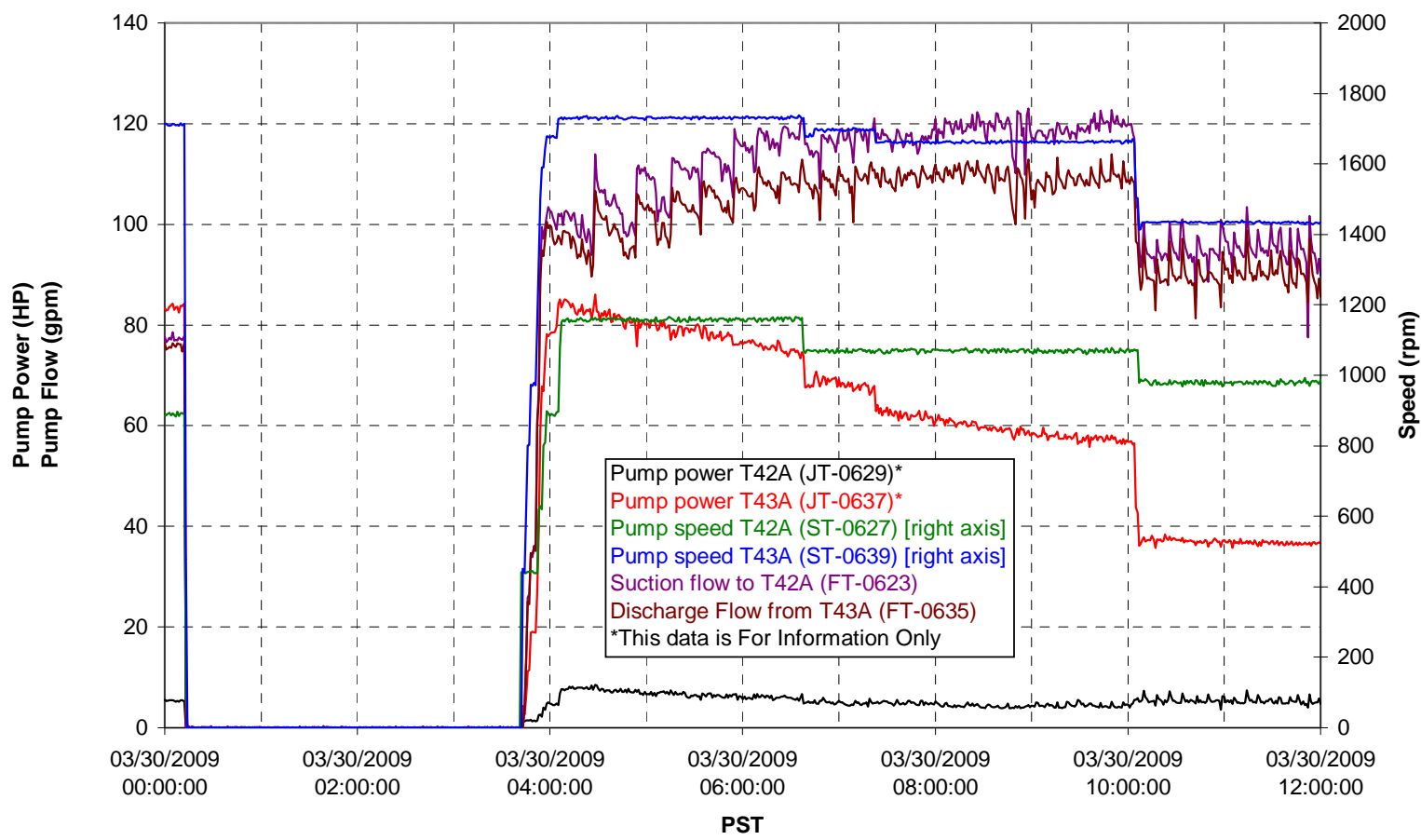


Pulsepot UFP-PP-T01A

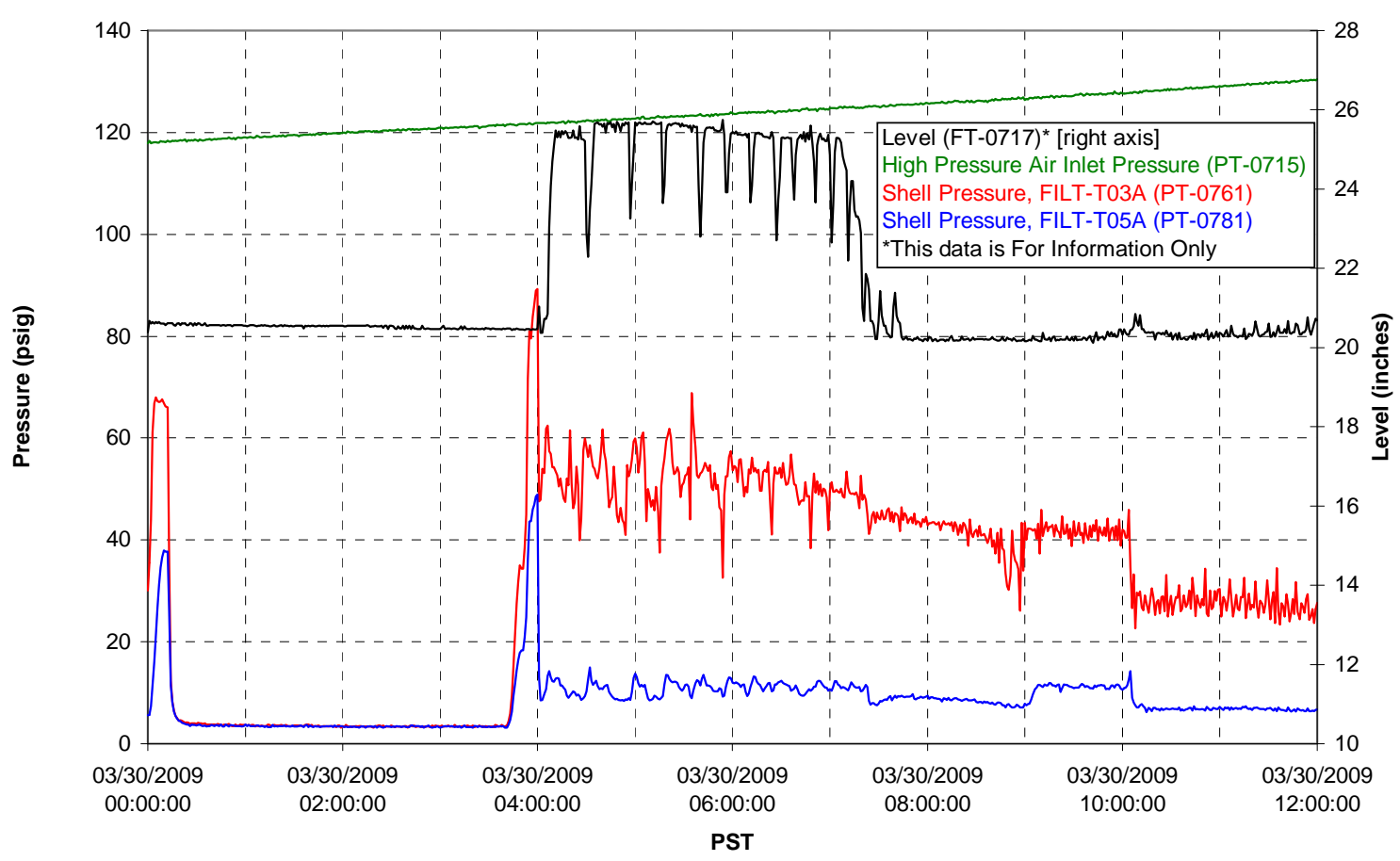

Pulsepot UFP-PP-T02A

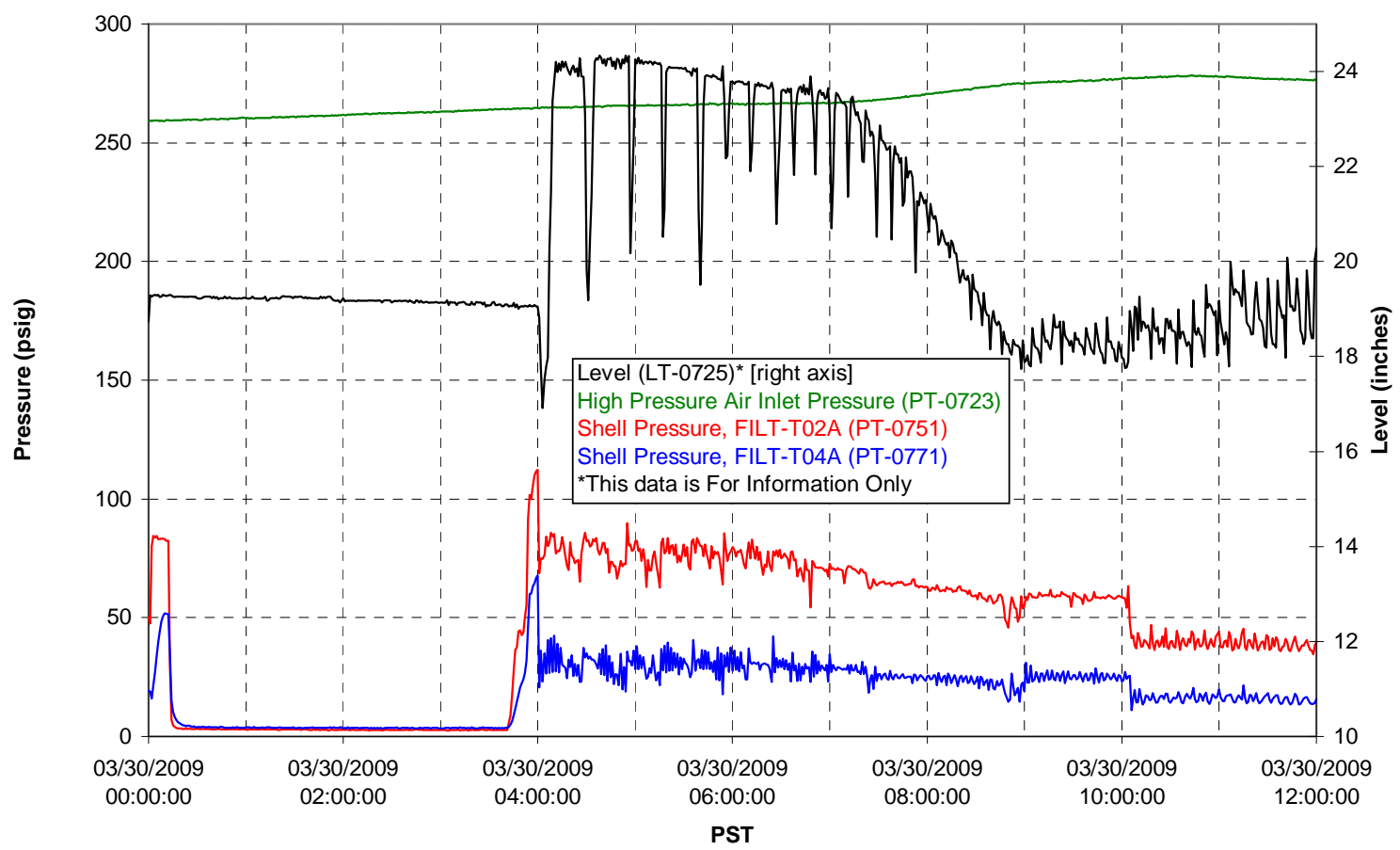


Pulsepot UFP-PP-T03A

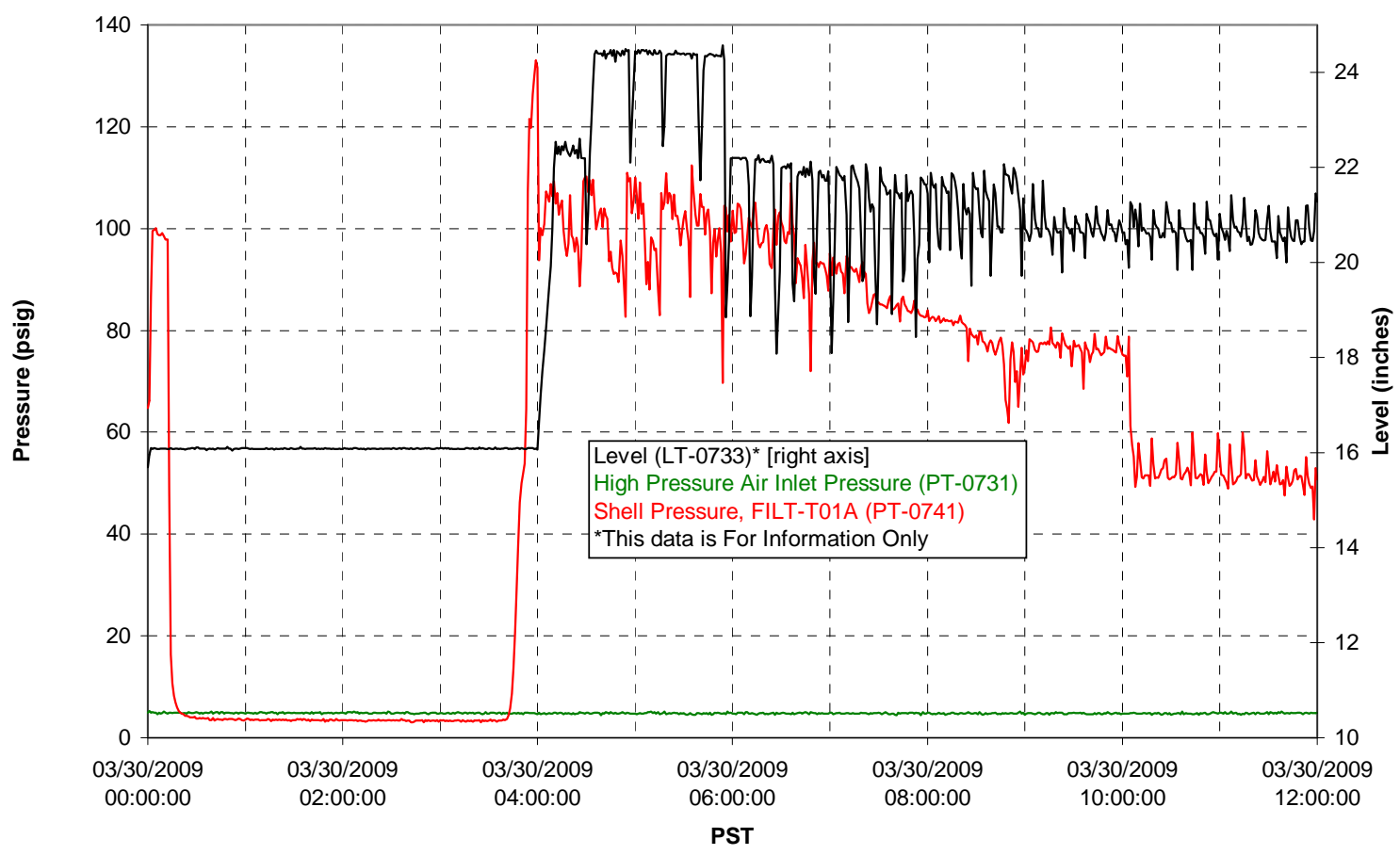

Pulsepot Levels

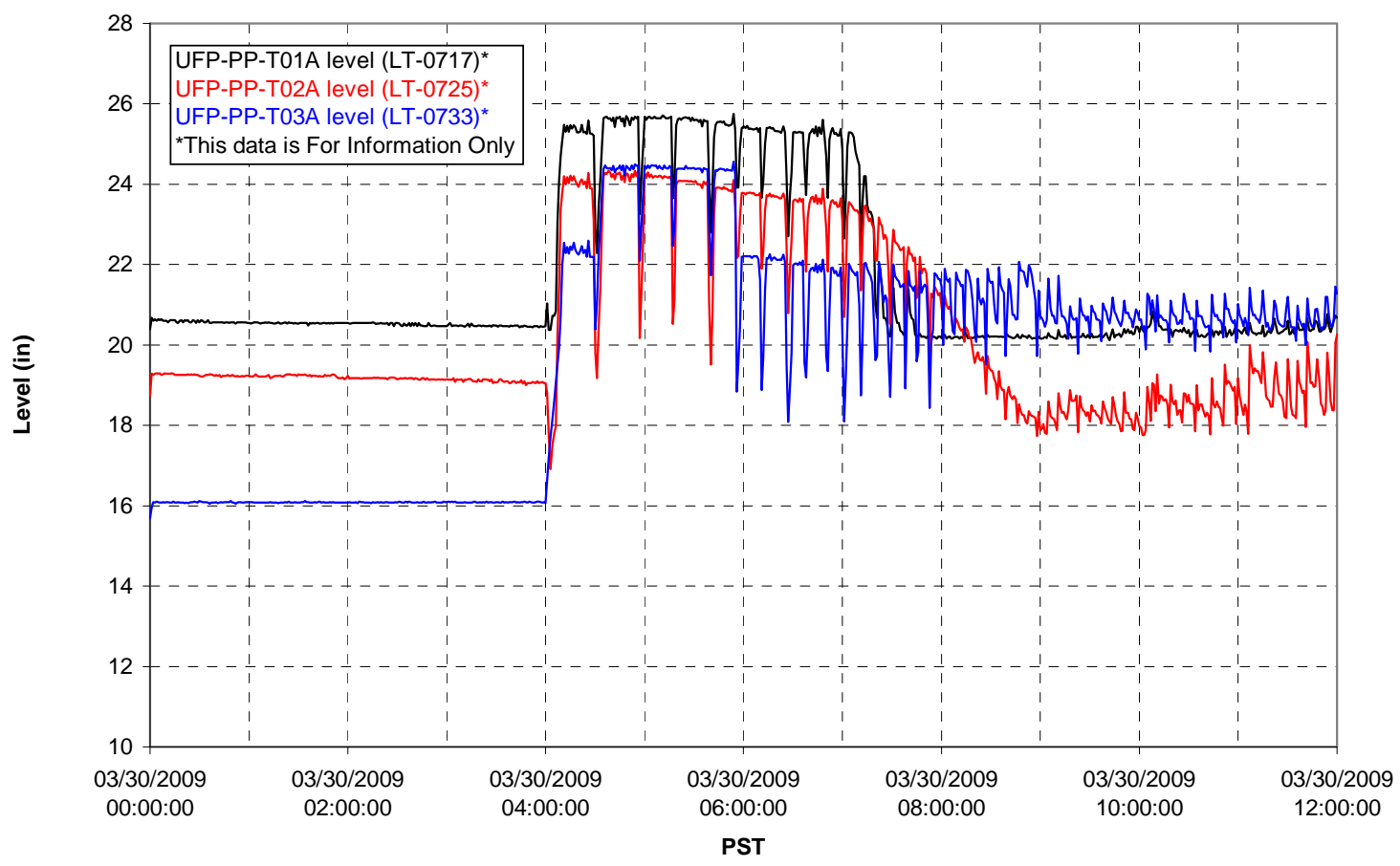


Filter UFP-FILT-T01A

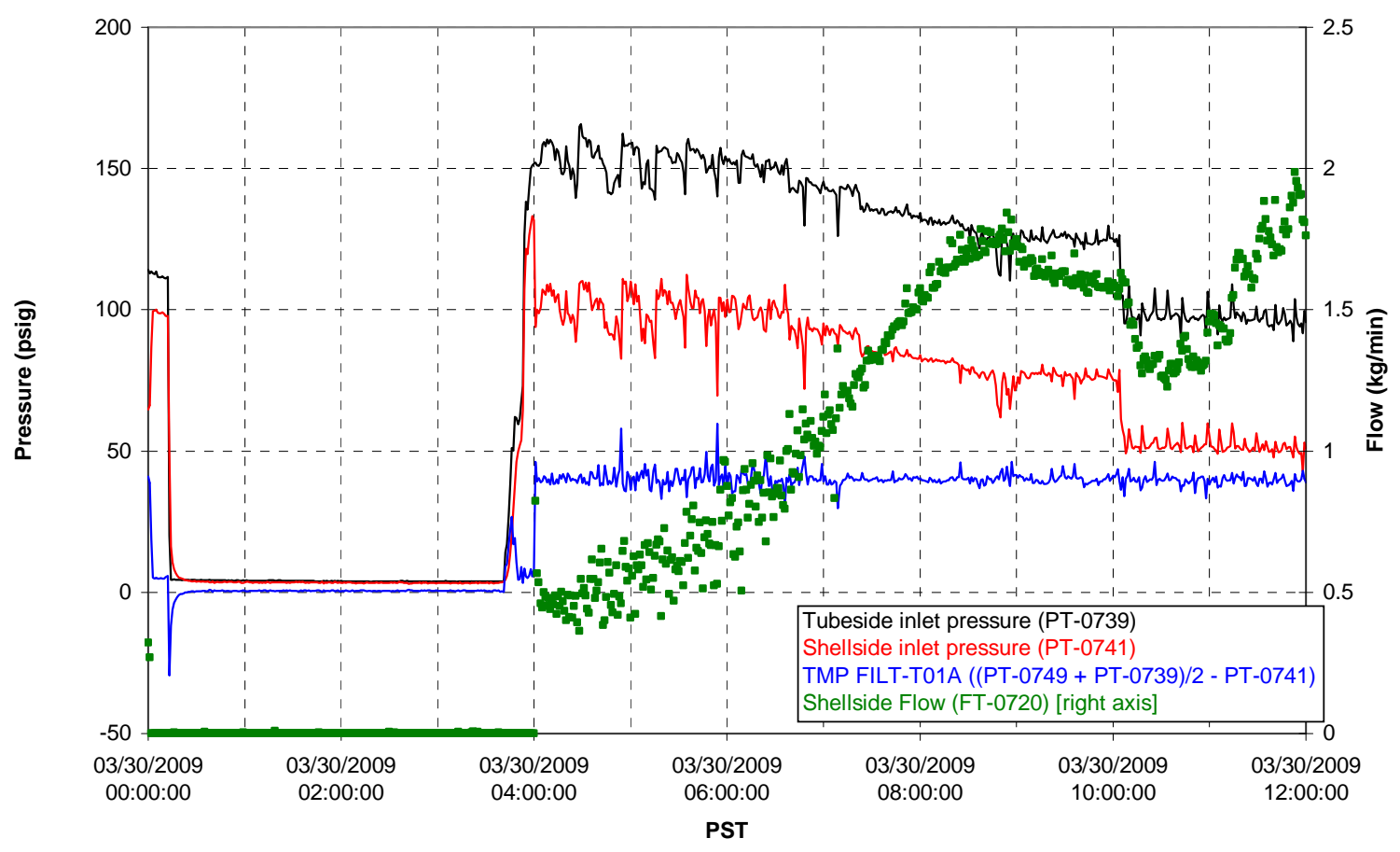

Filter UFP-FILT-T02A

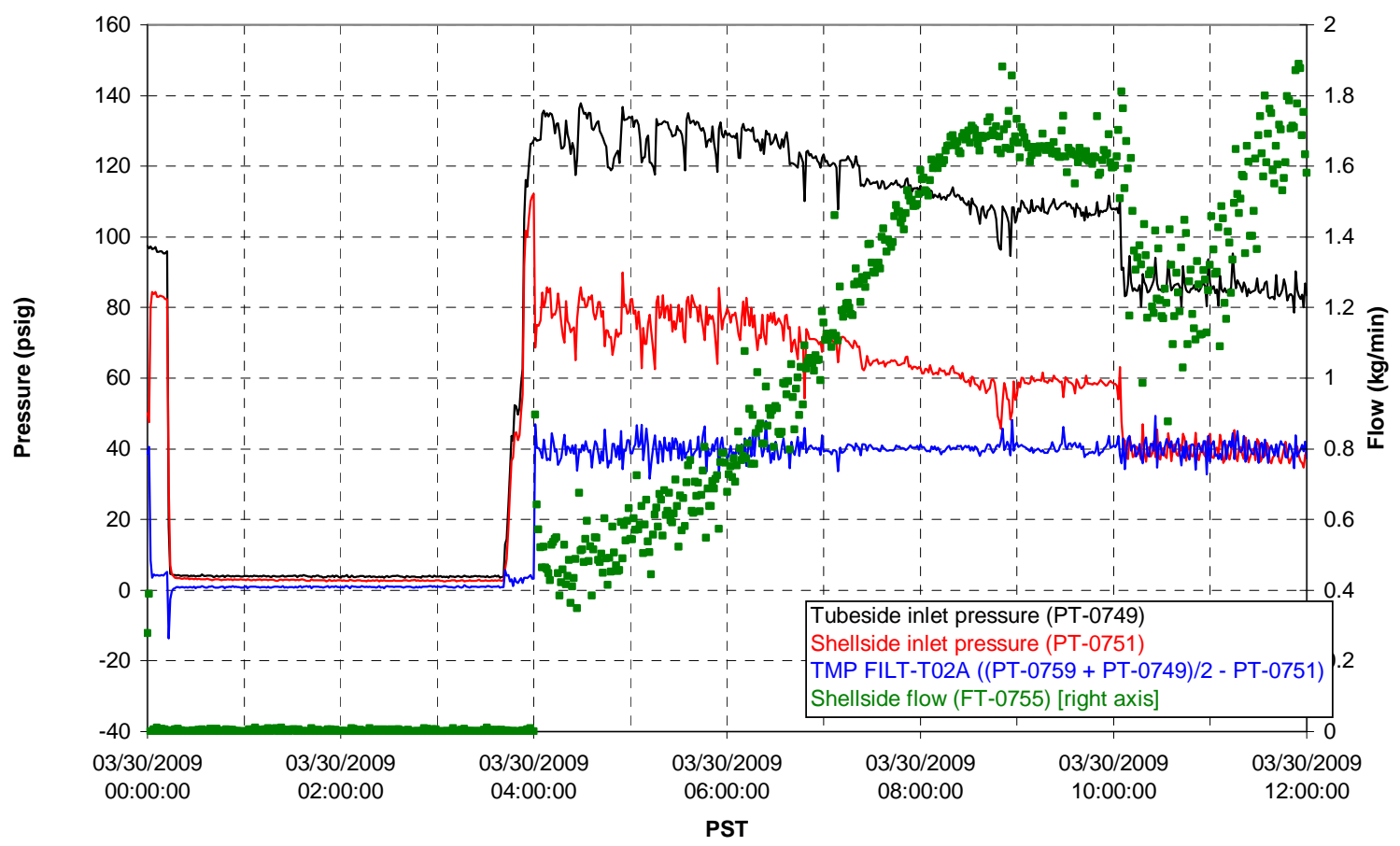


Filter UFP-FILT-T03A

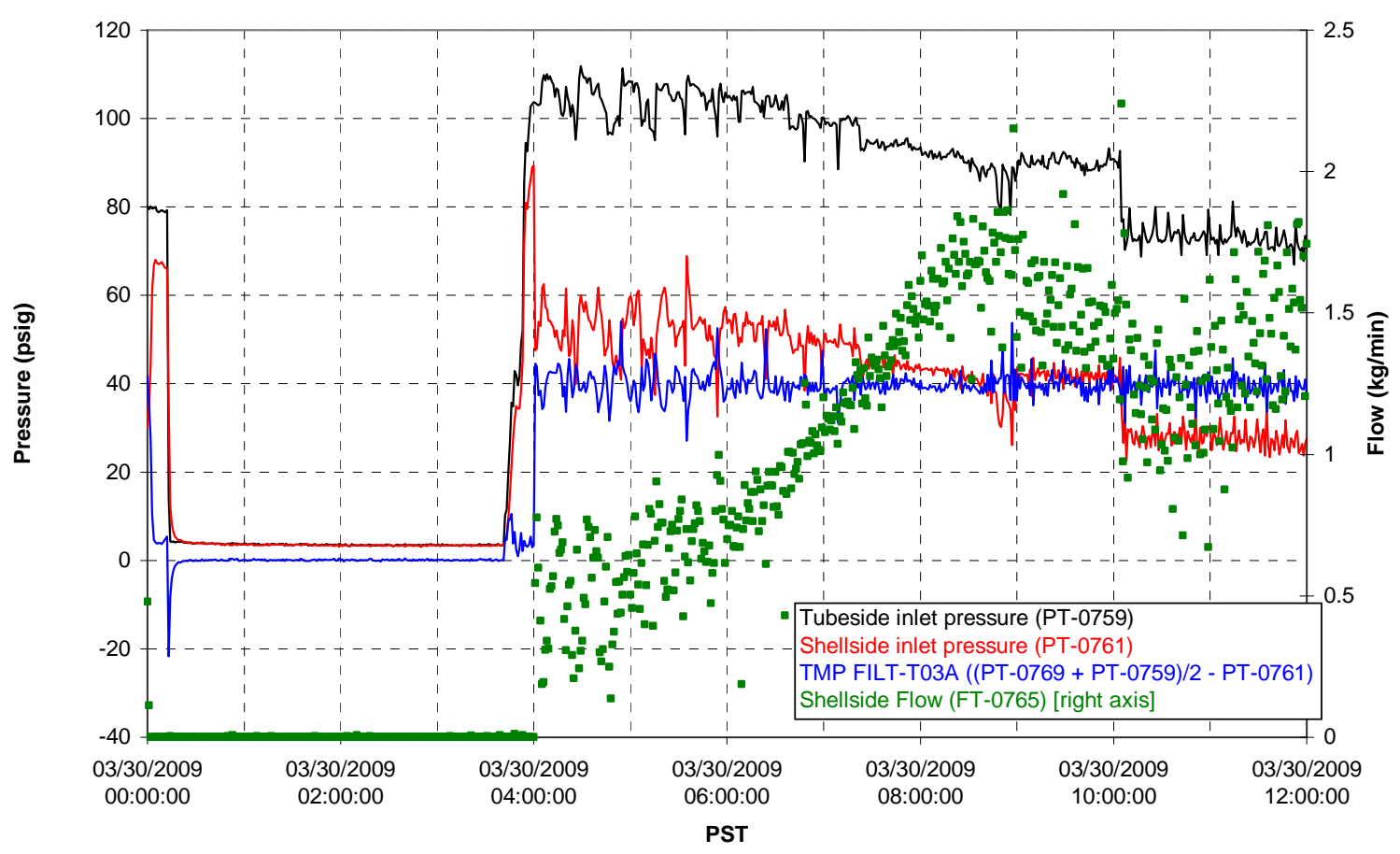

Filter UFP-FILT-T04A

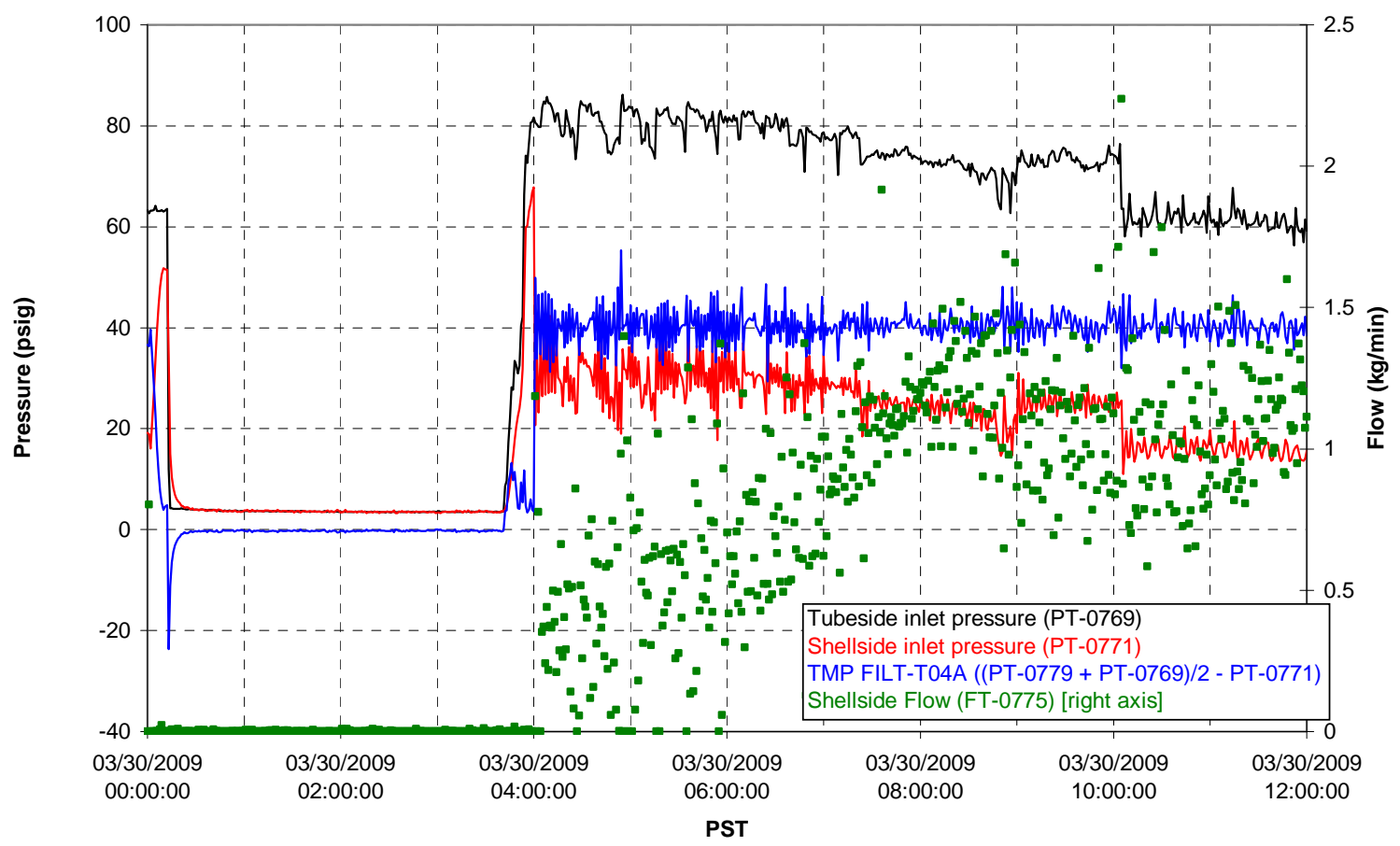


Filter UFP-FILT-T05A

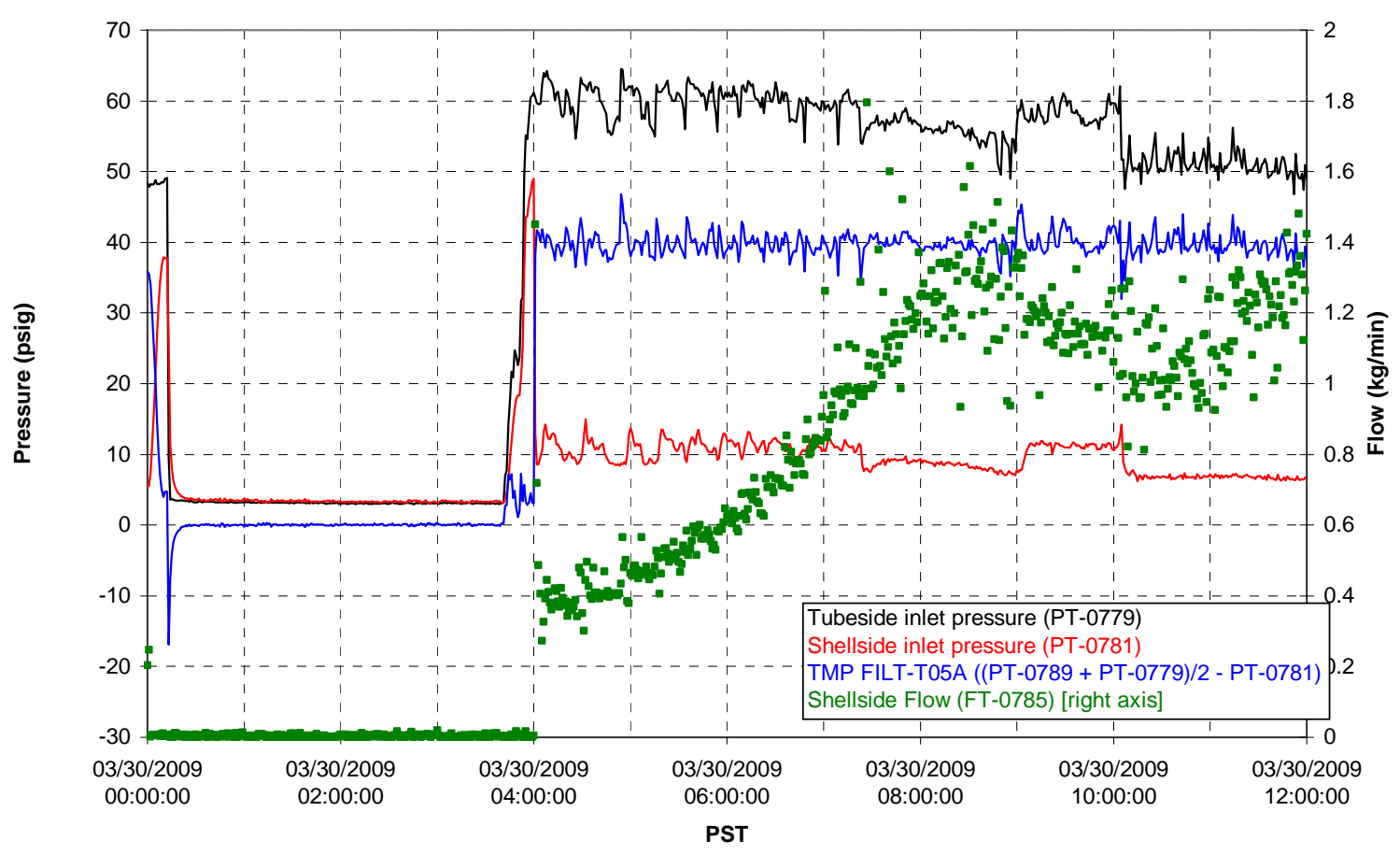

Chemical Flow

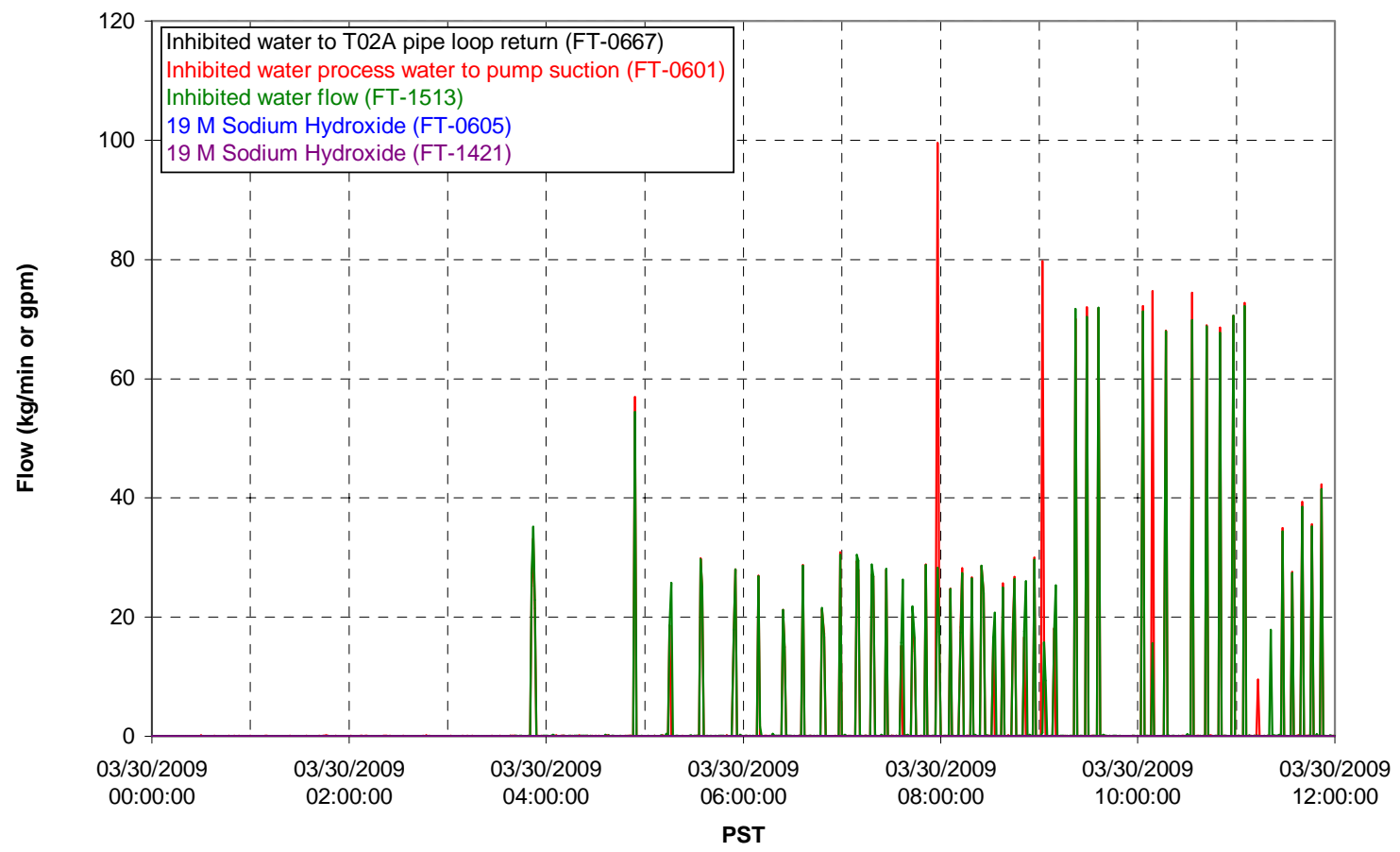




\section{Chemical Flow}

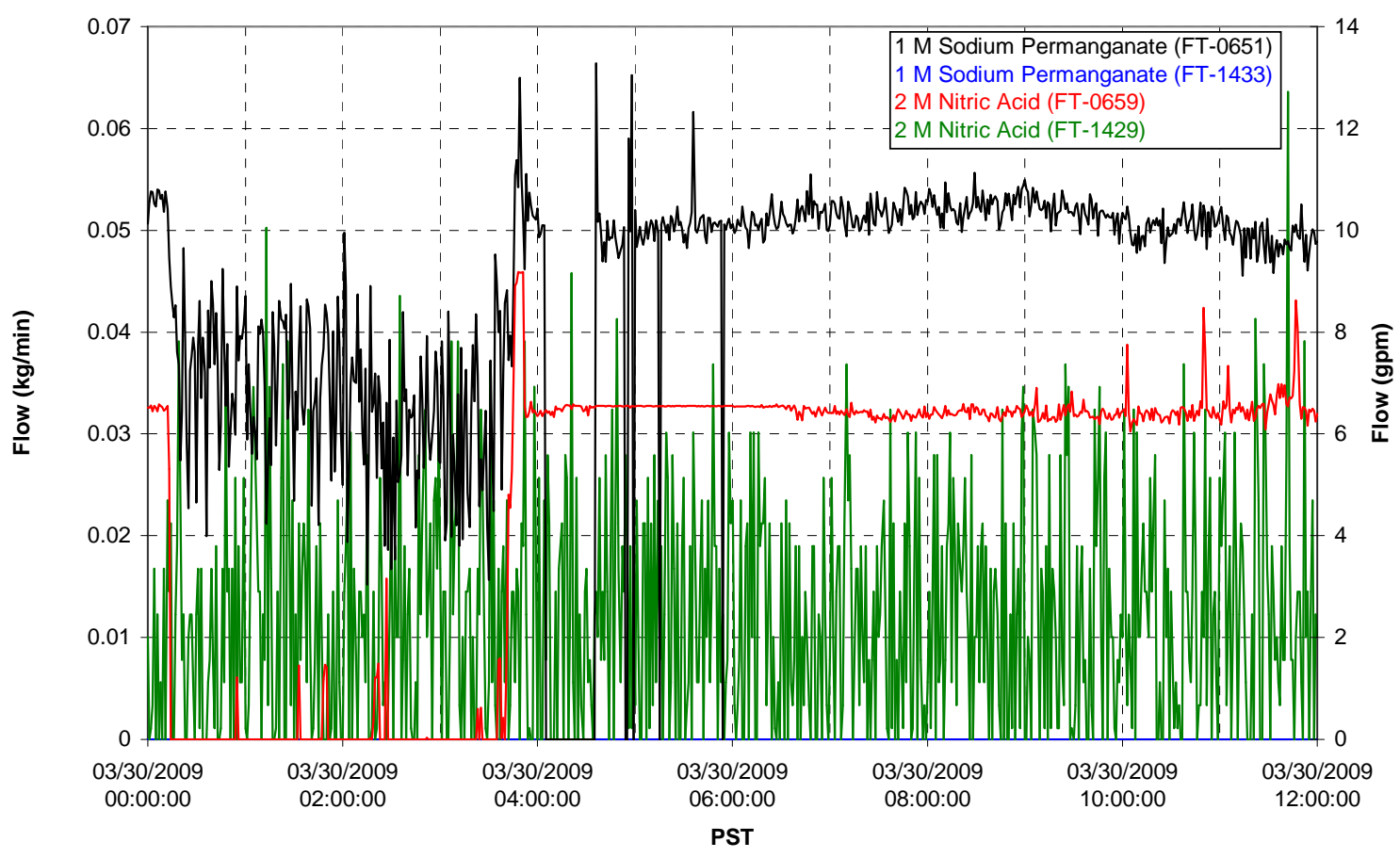

Air Flows

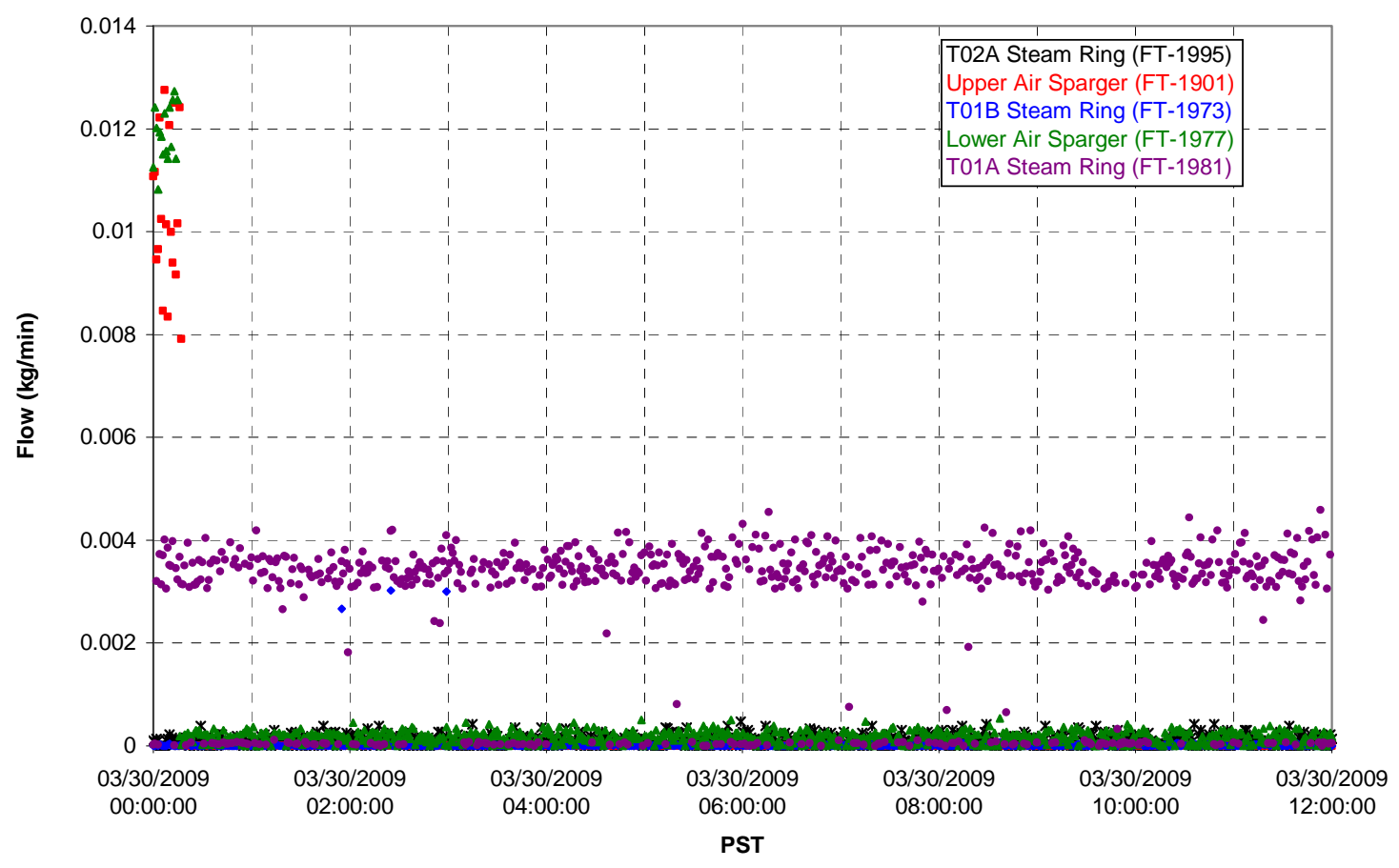


T02A Steam

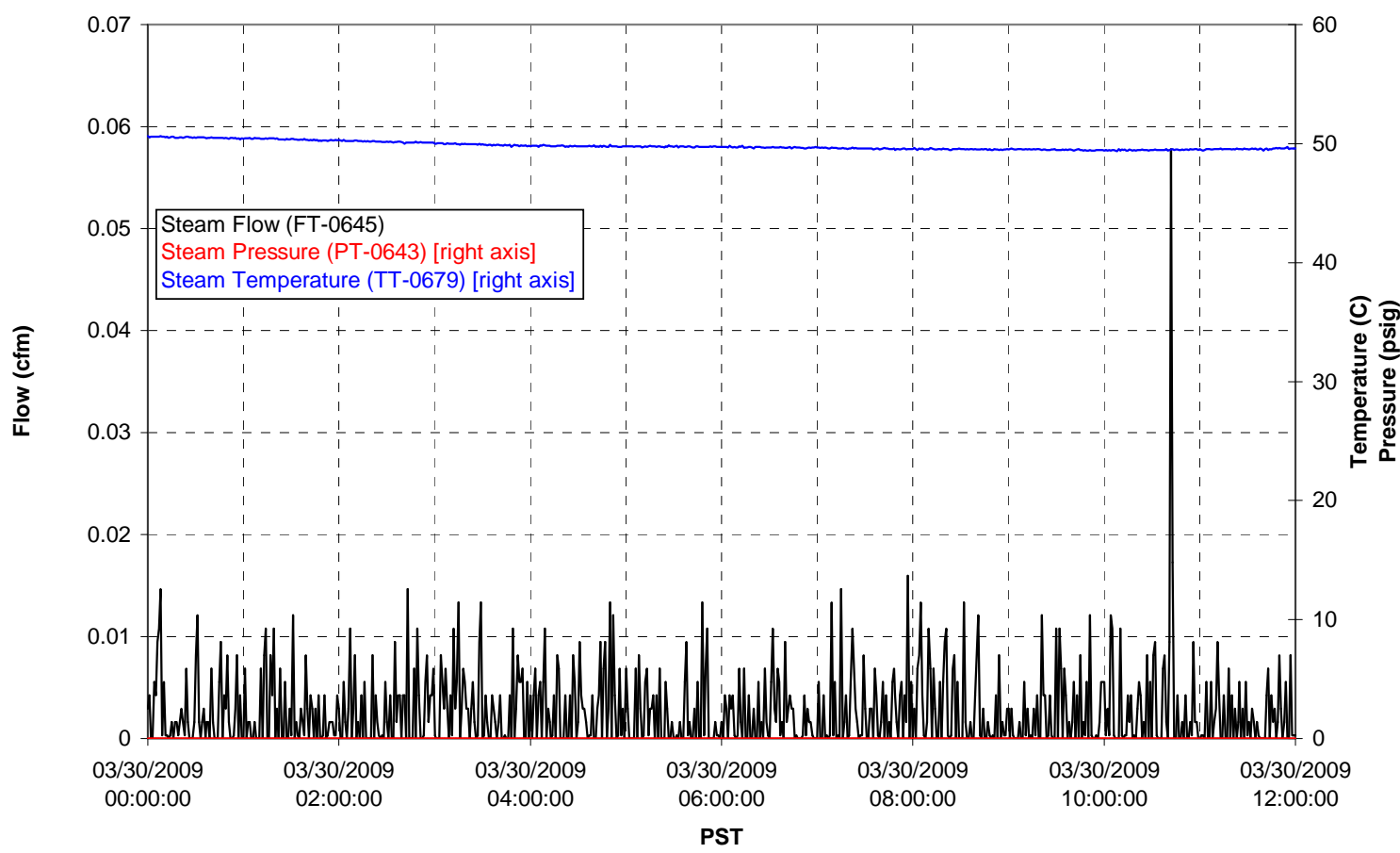

T01A Steam

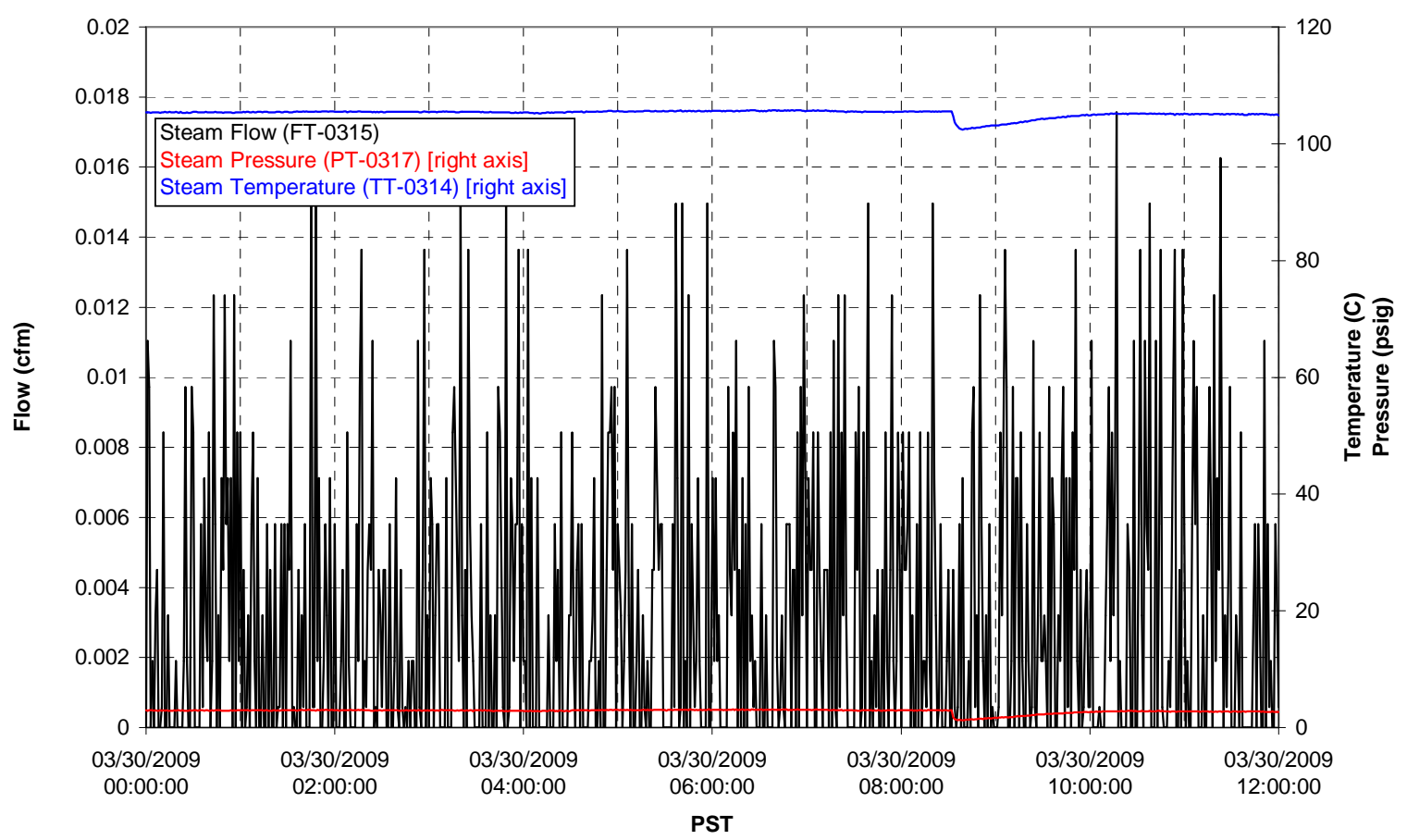




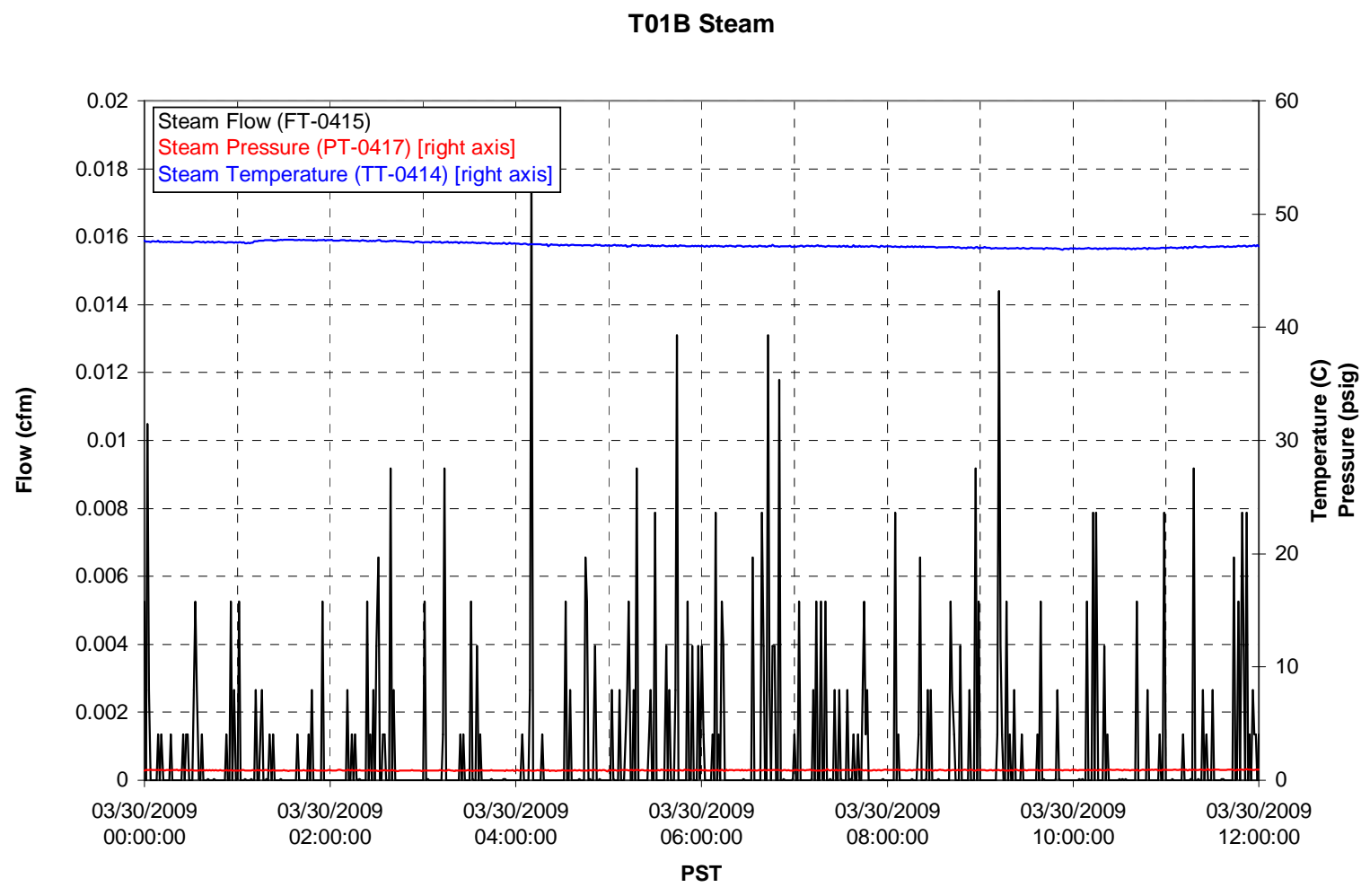




\section{Integrated Test D Data Plots 03/30/09 12:00 - 03/31/09 00:00}


T01A level

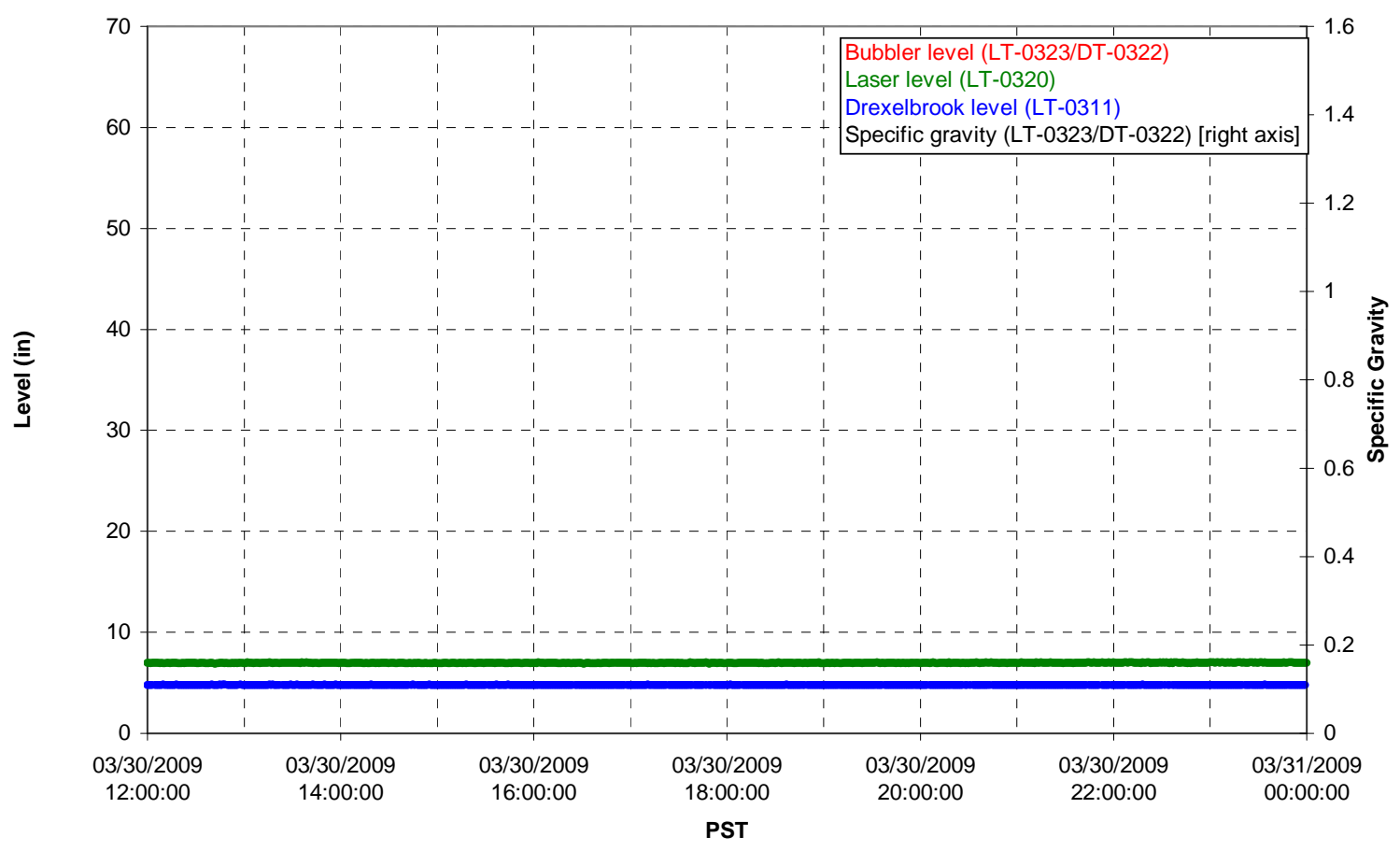

T01A temperatures

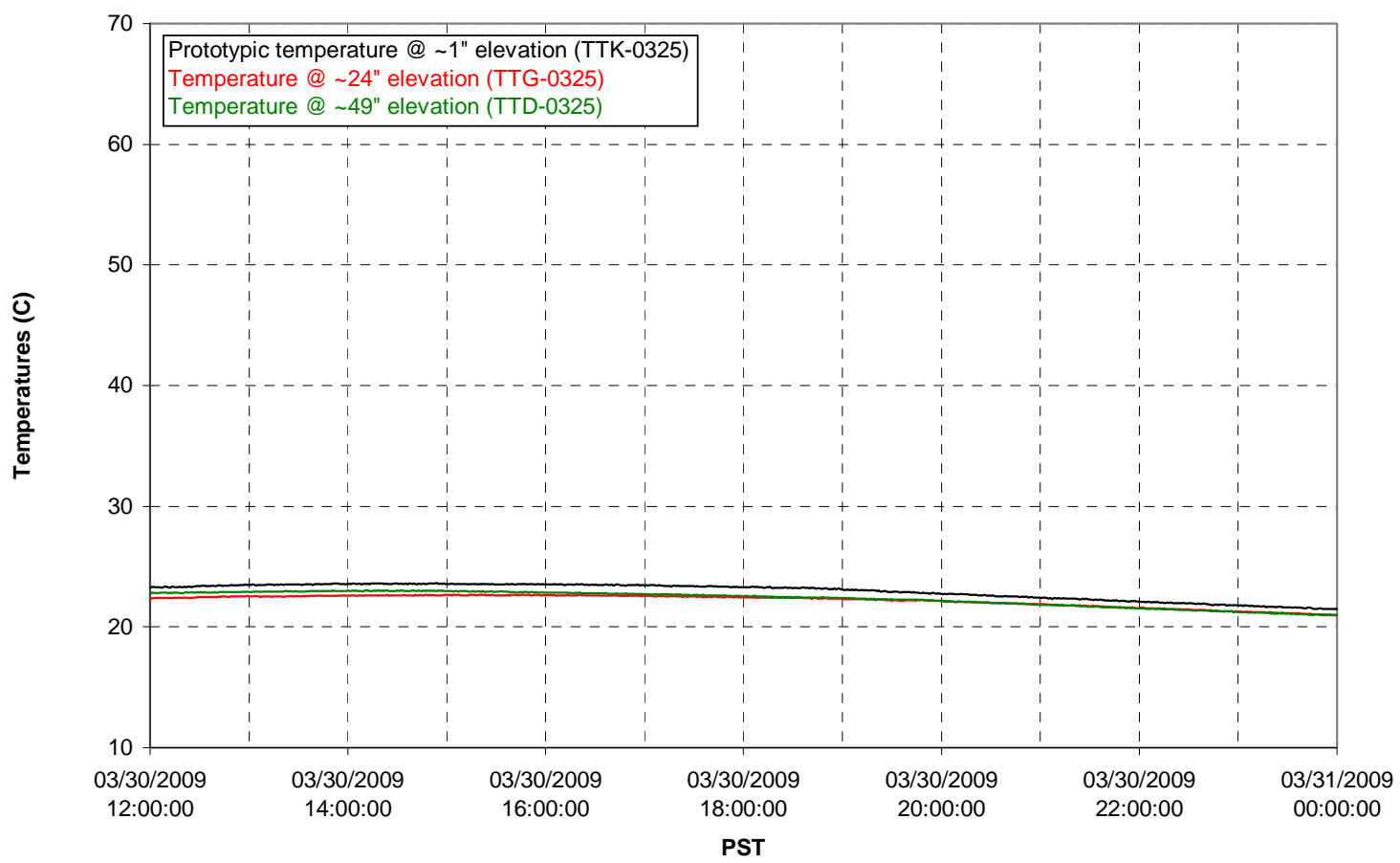


T01B level

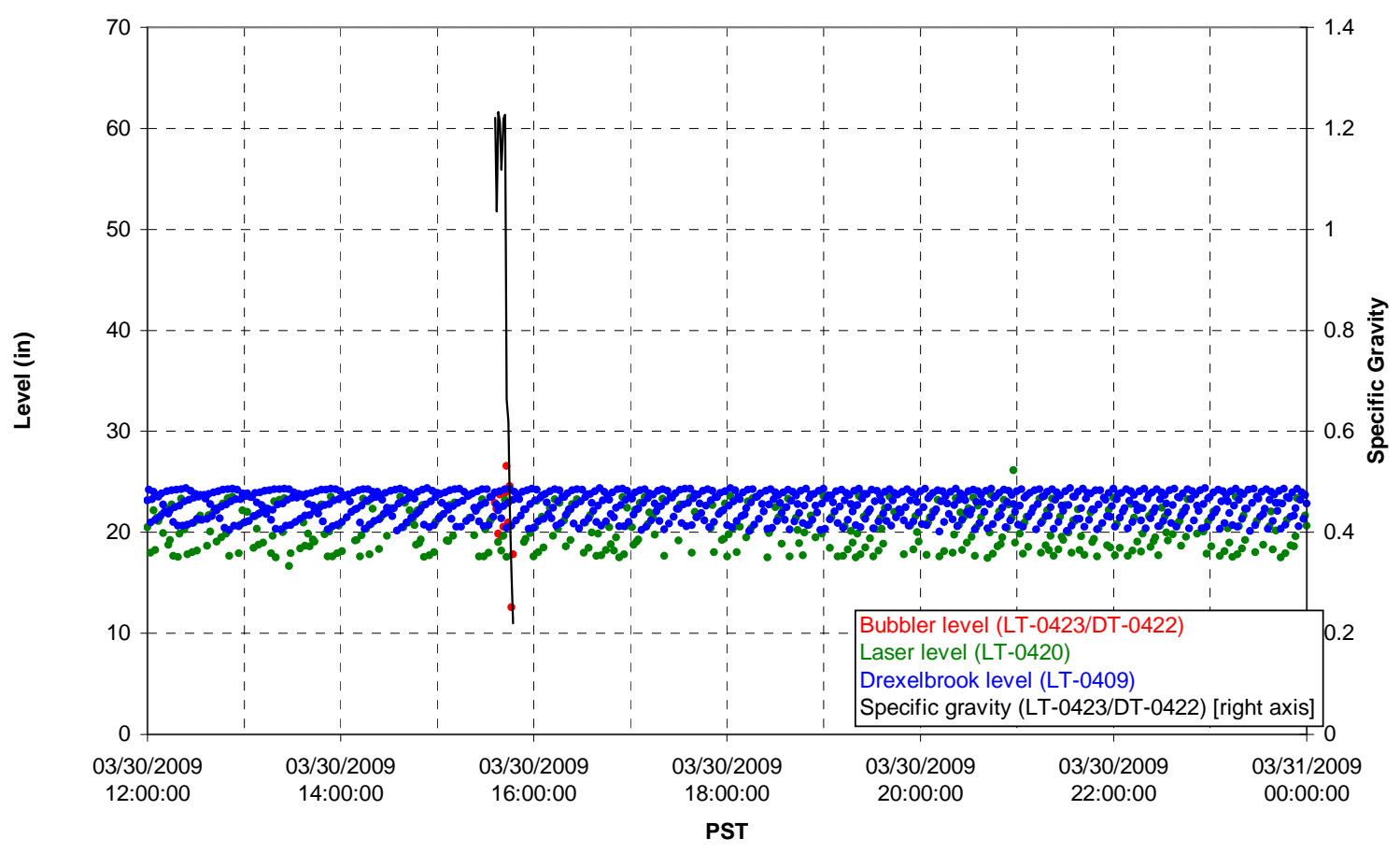

T01B temperatures

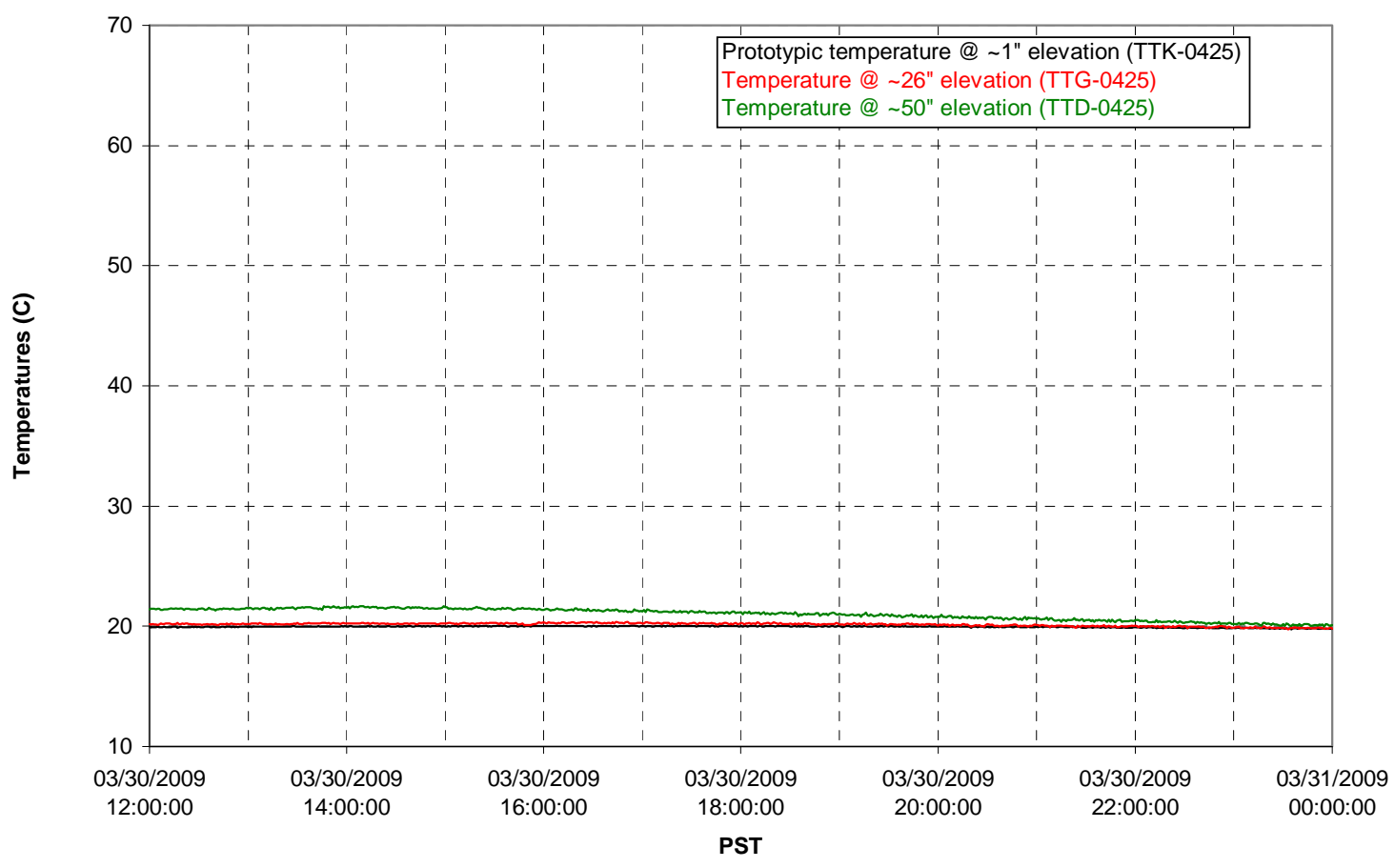


T02A level

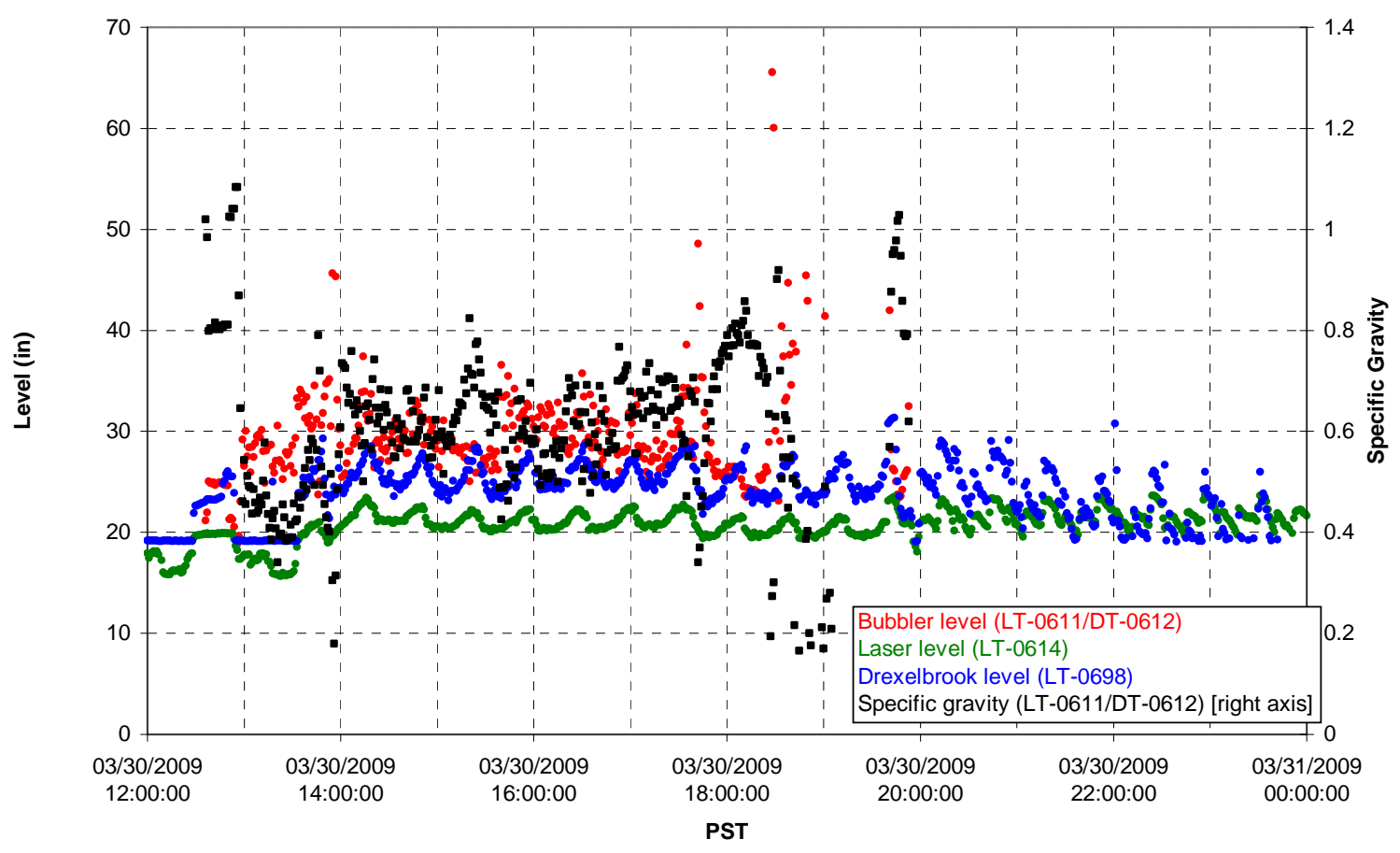

T02A temperatures

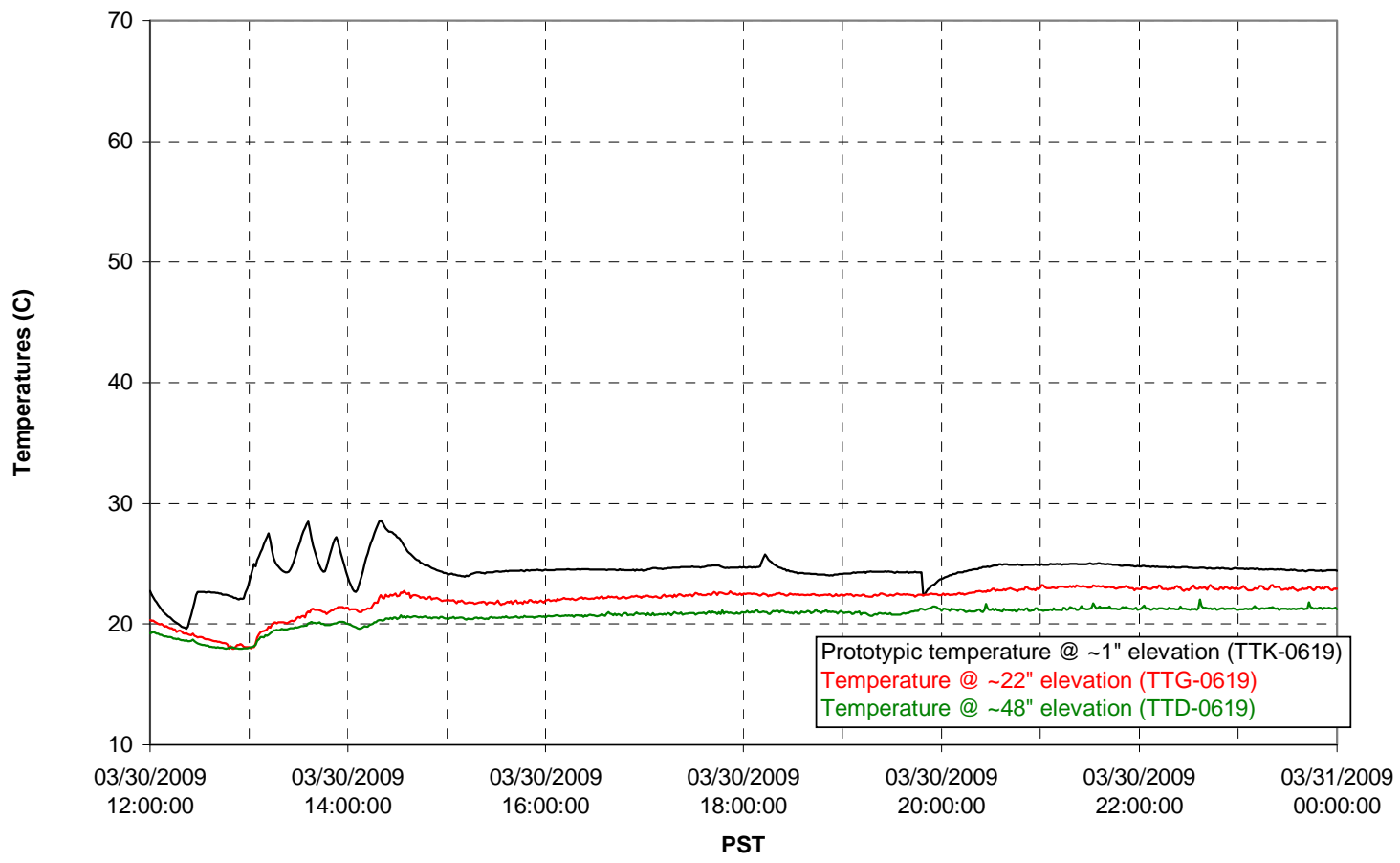


T02A and filter loop temperatures

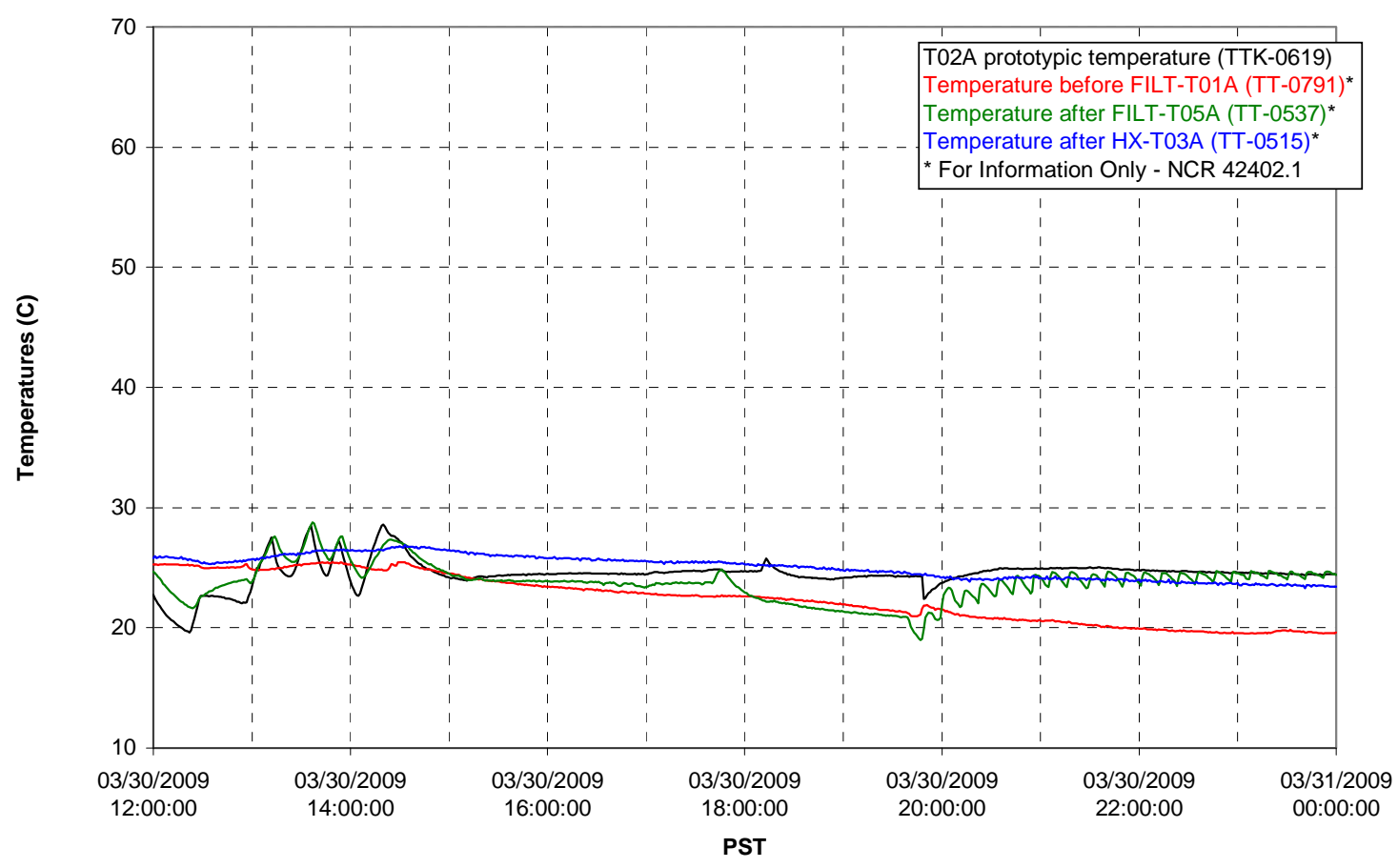

Pump Pressures and Flow

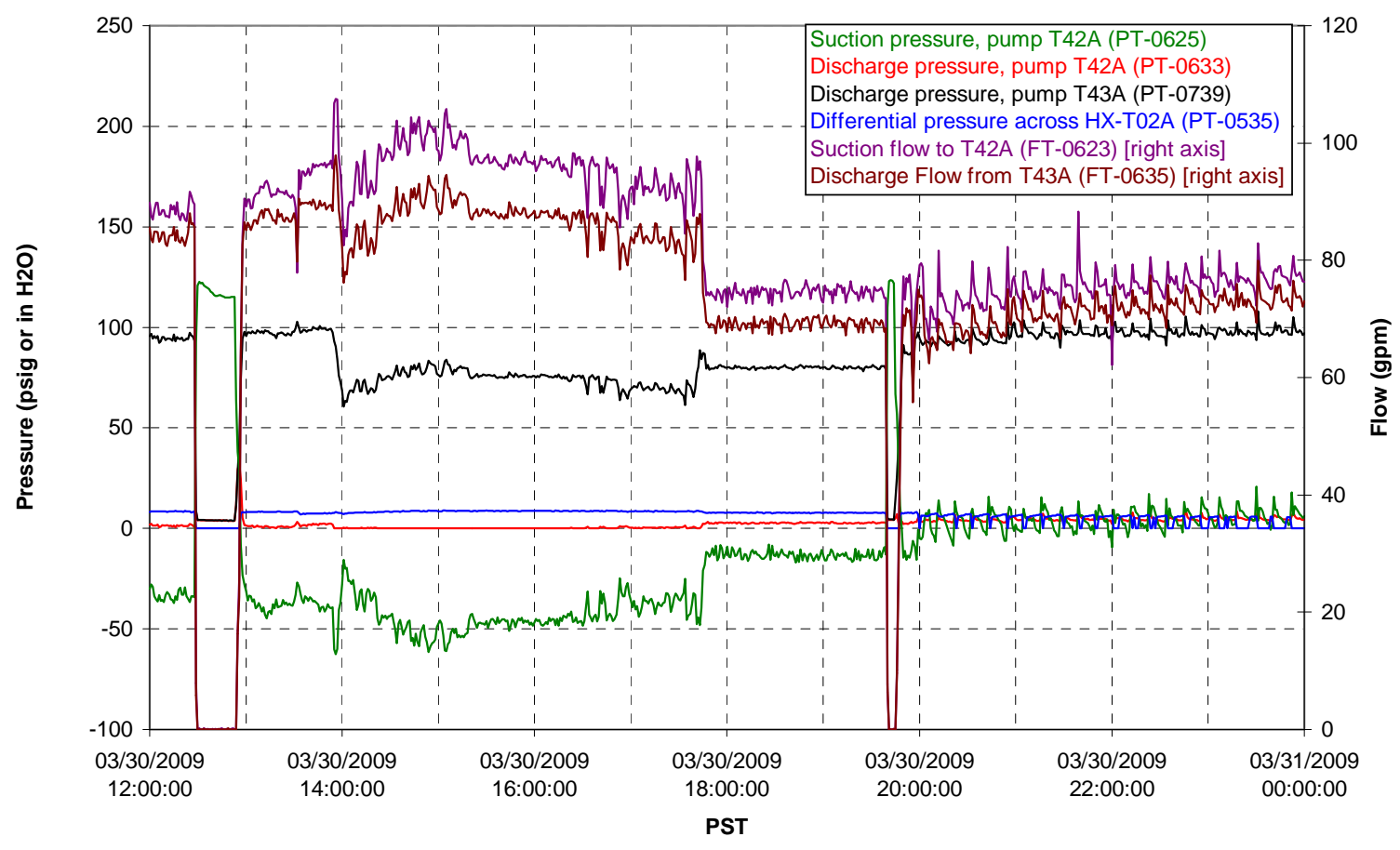




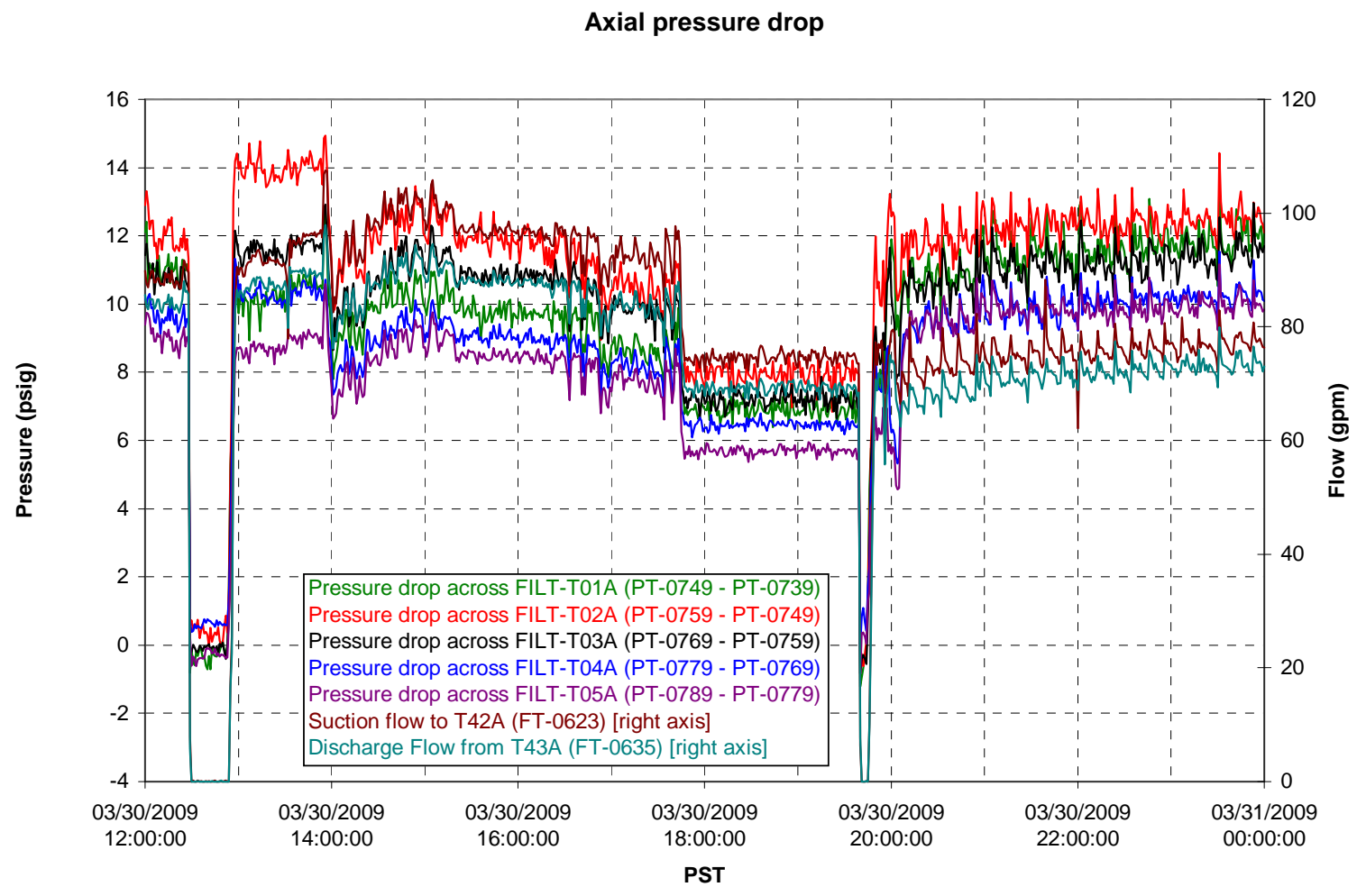

Permeate flow rates

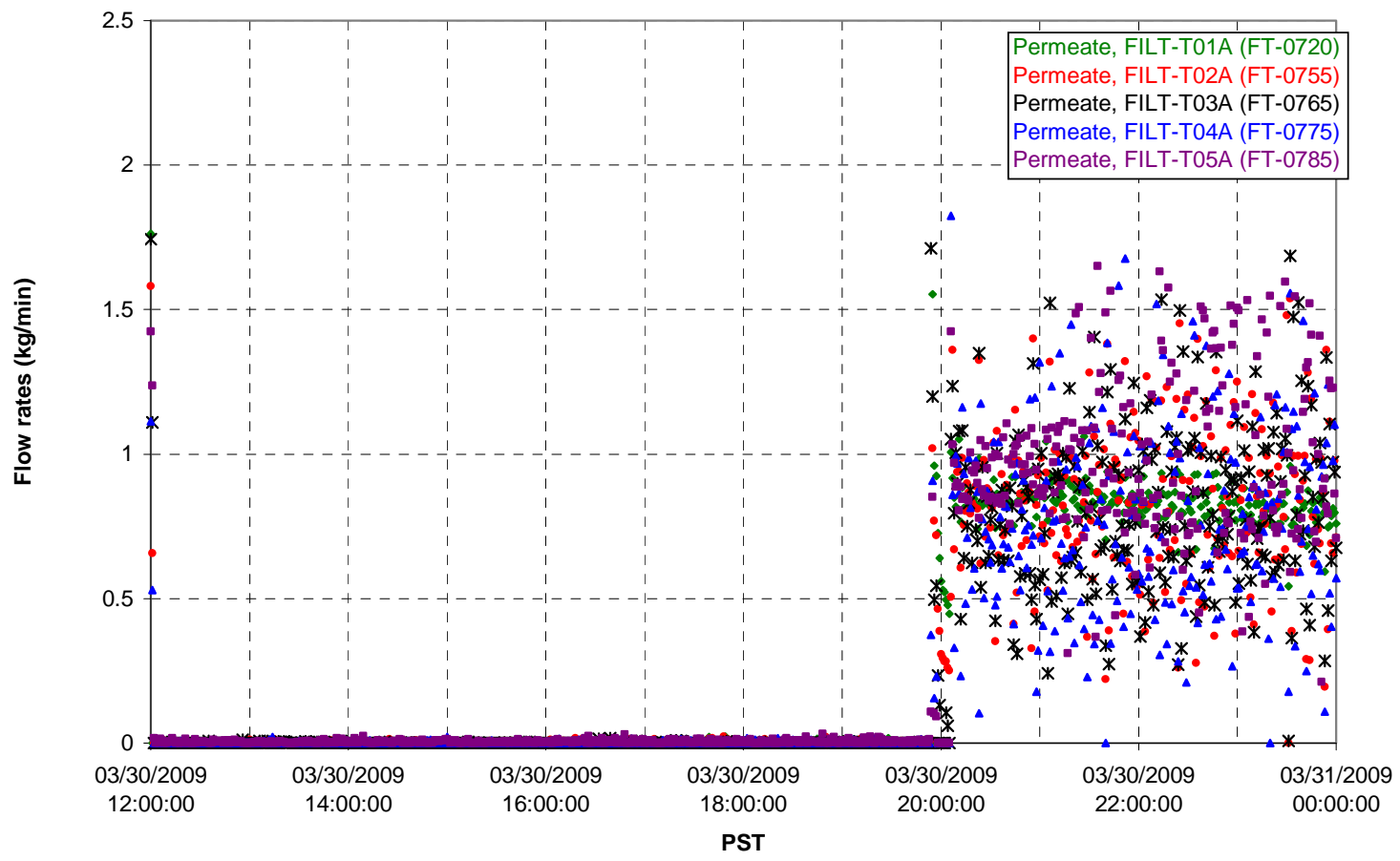


T02A Inner Temperature Tree

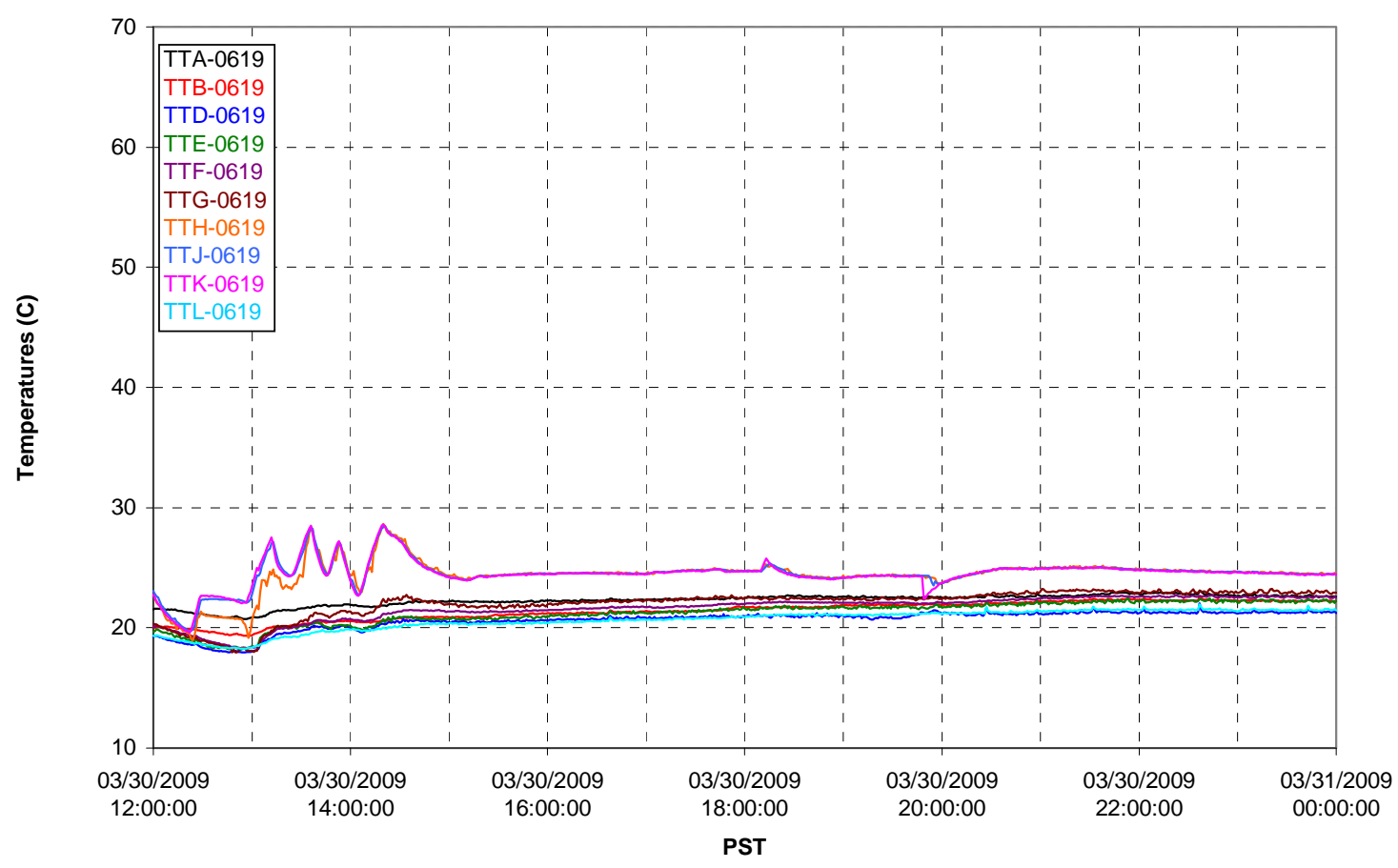

T02A Outer Temperature Tree

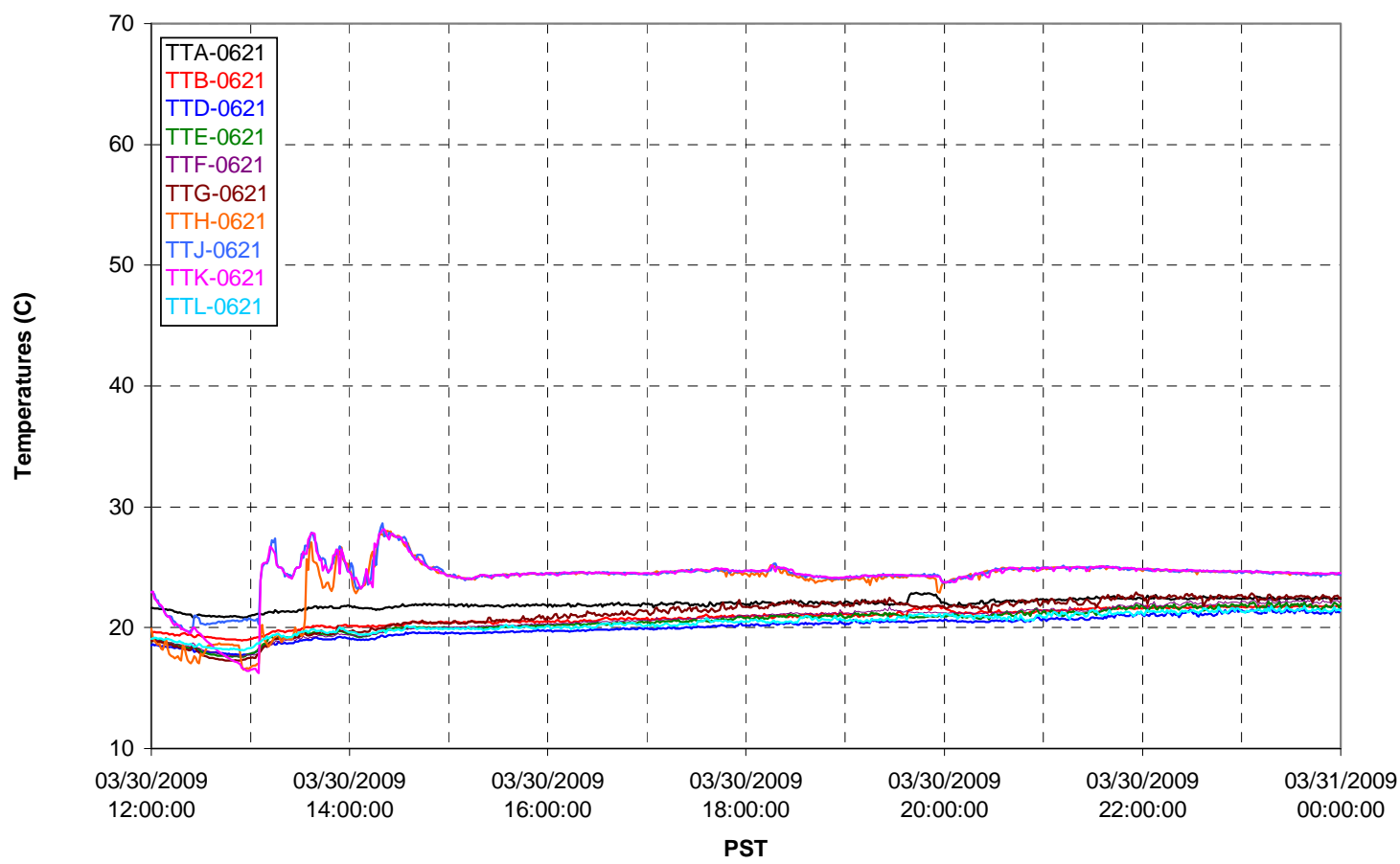


T02A temperatures

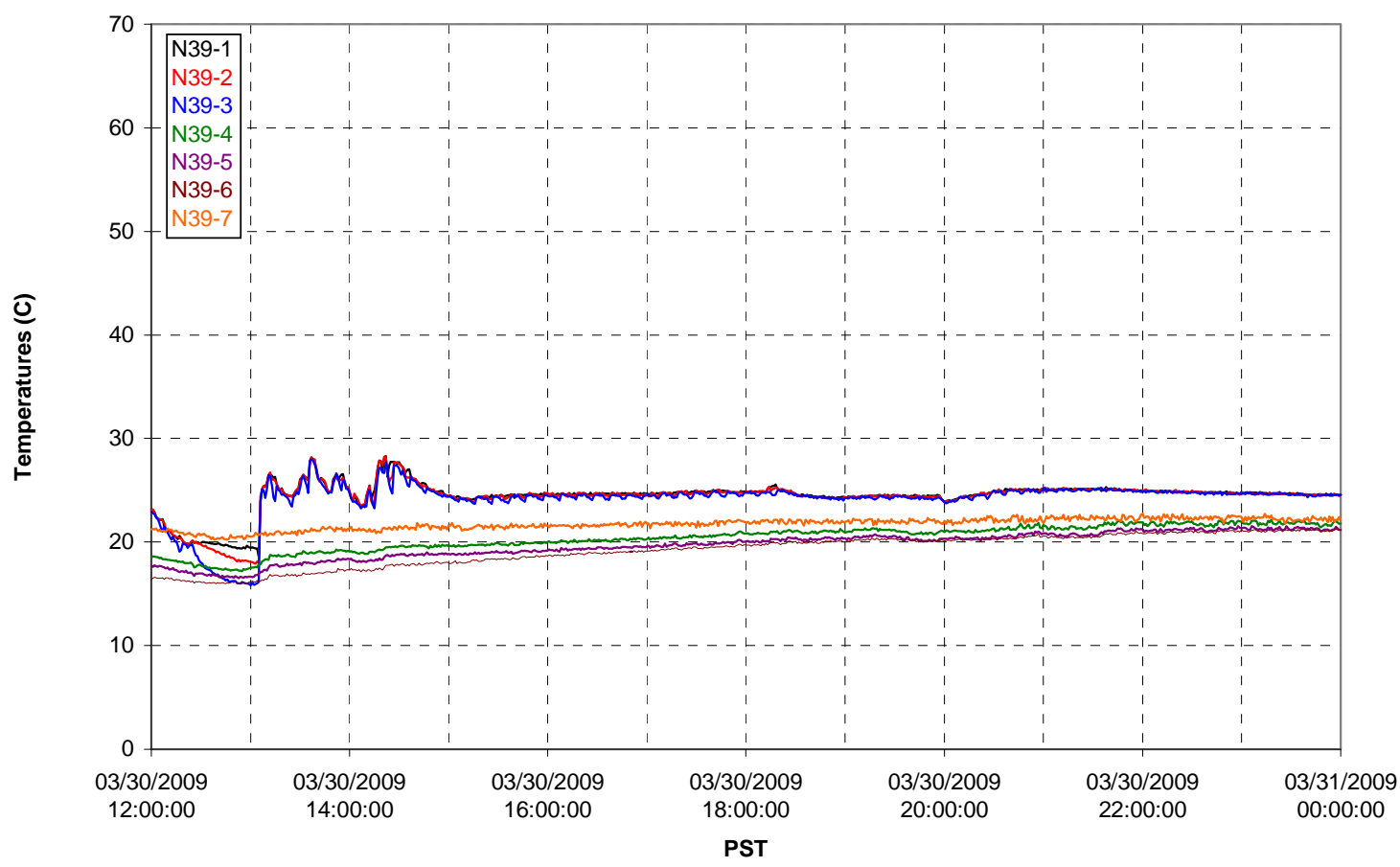

T02A temperatures

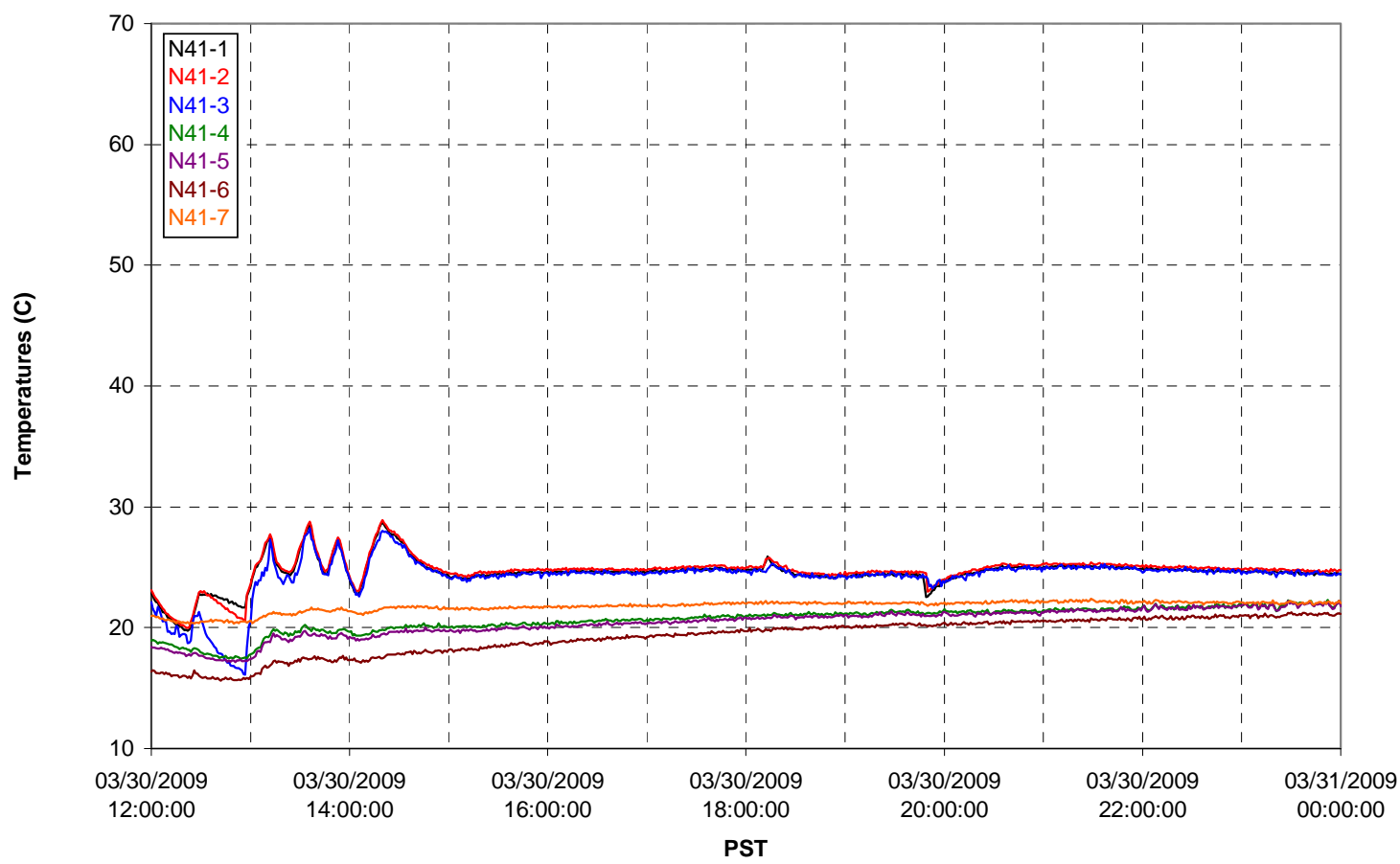


T02A temperatures

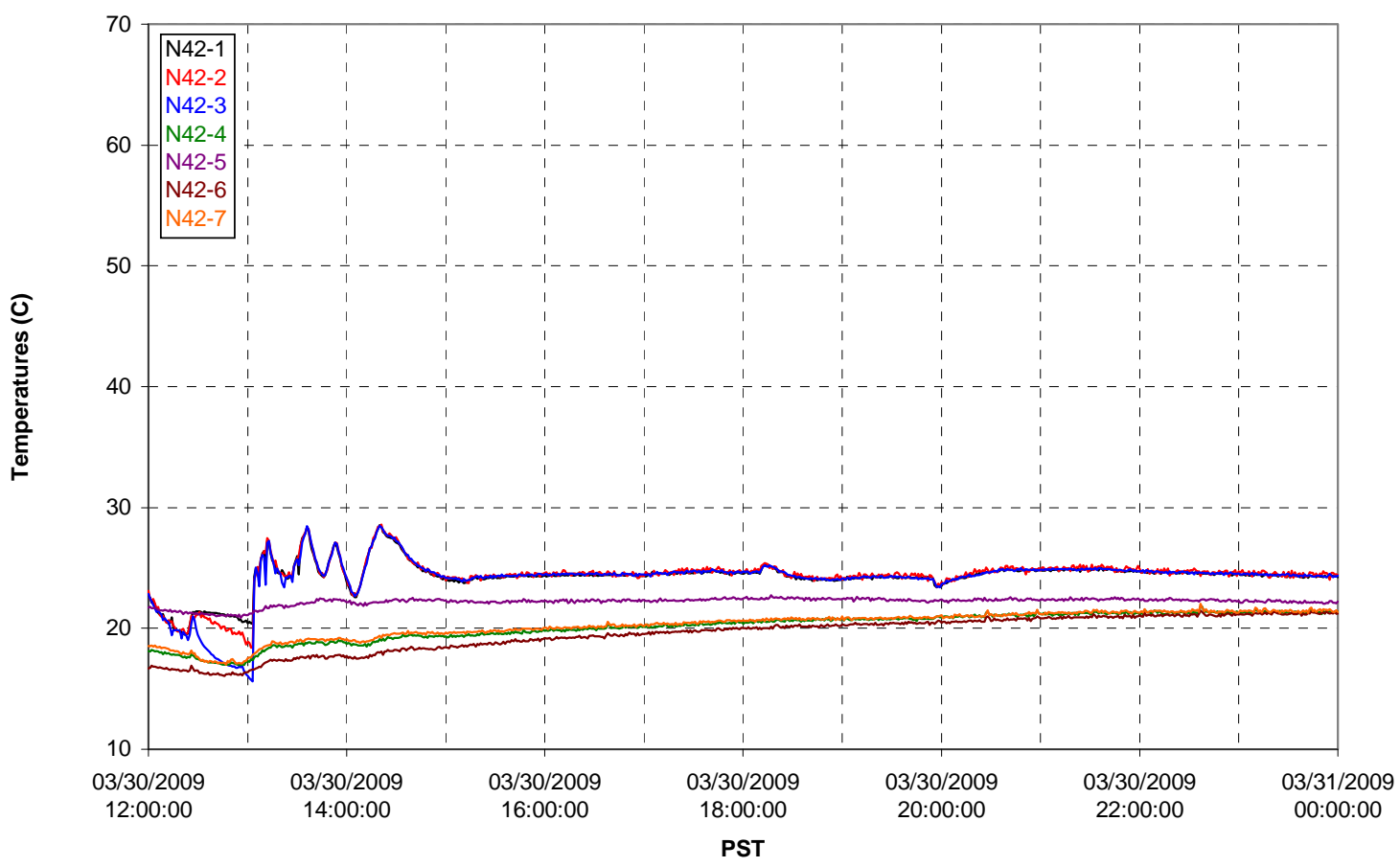

T02A temperatures

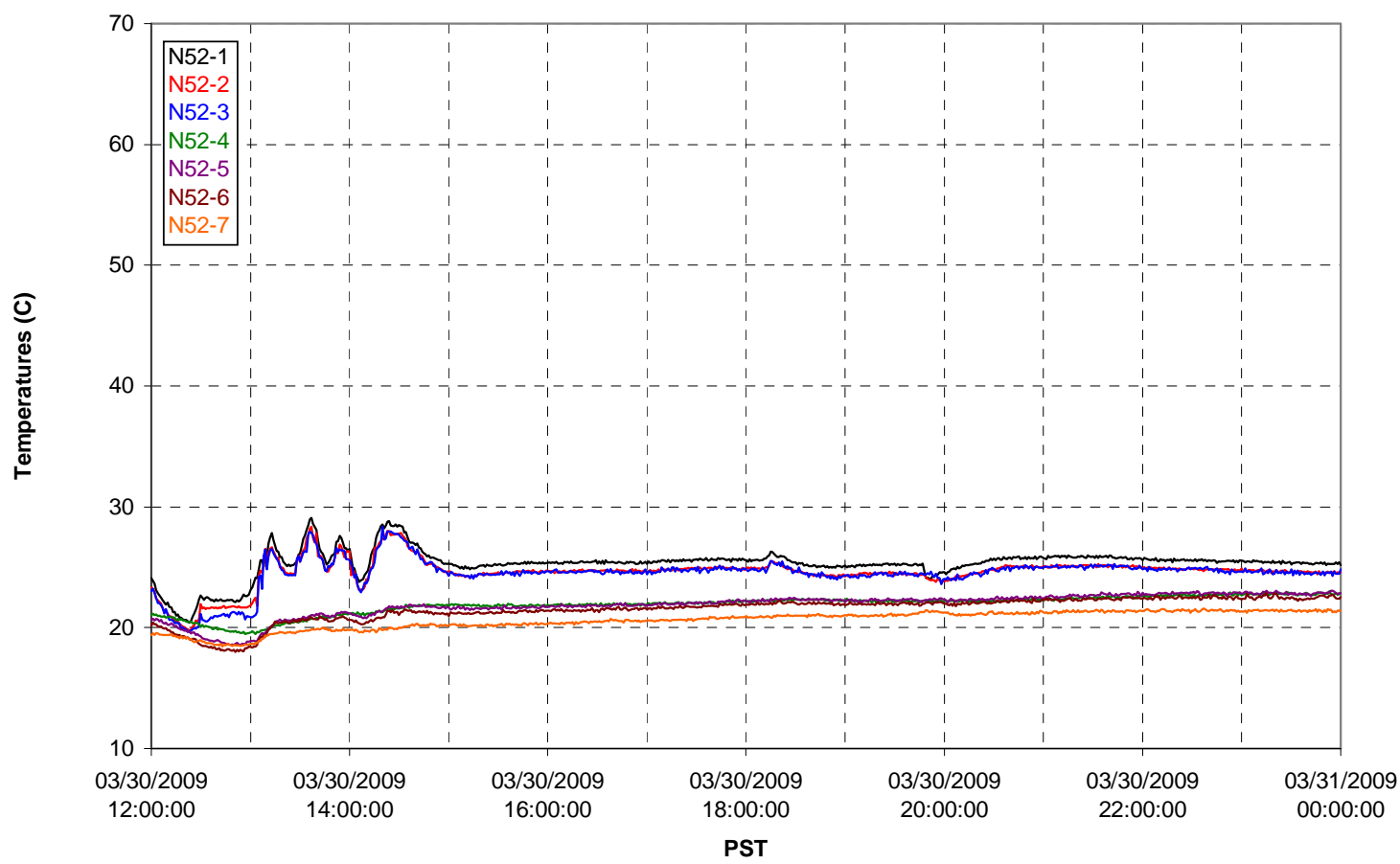


T02A Heating and Cooling
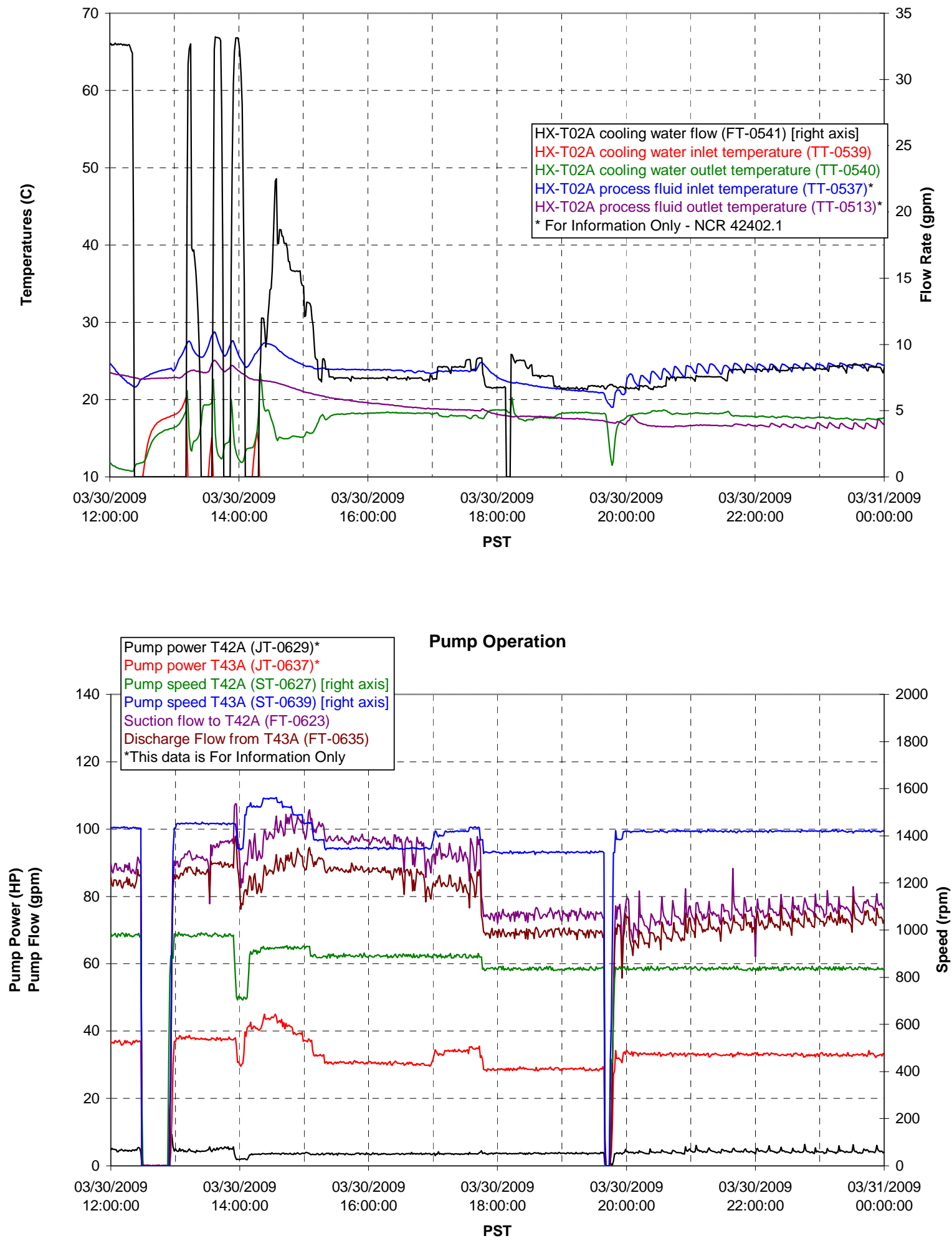
Pulsepot UFP-PP-T01A

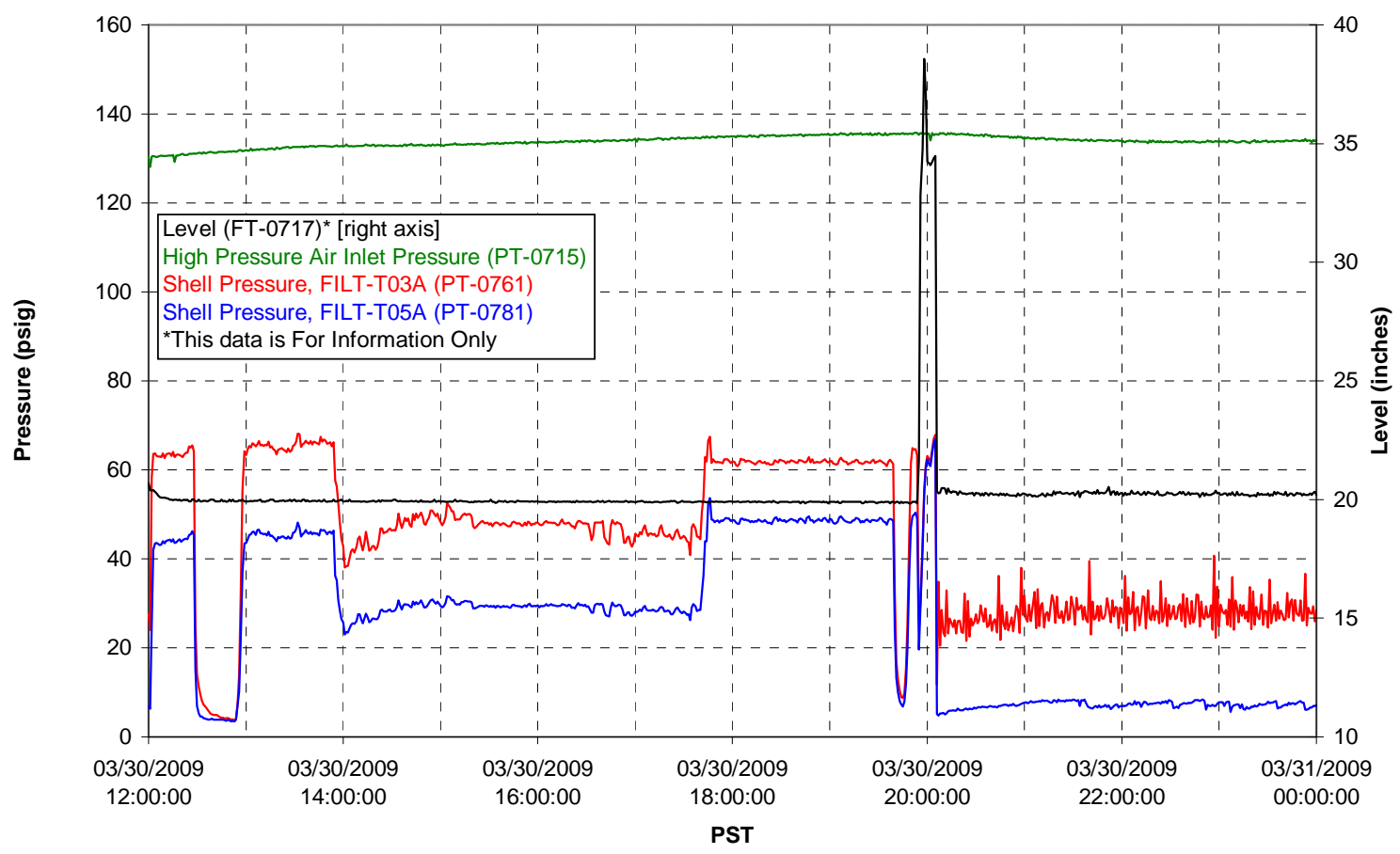

Pulsepot UFP-PP-T02A

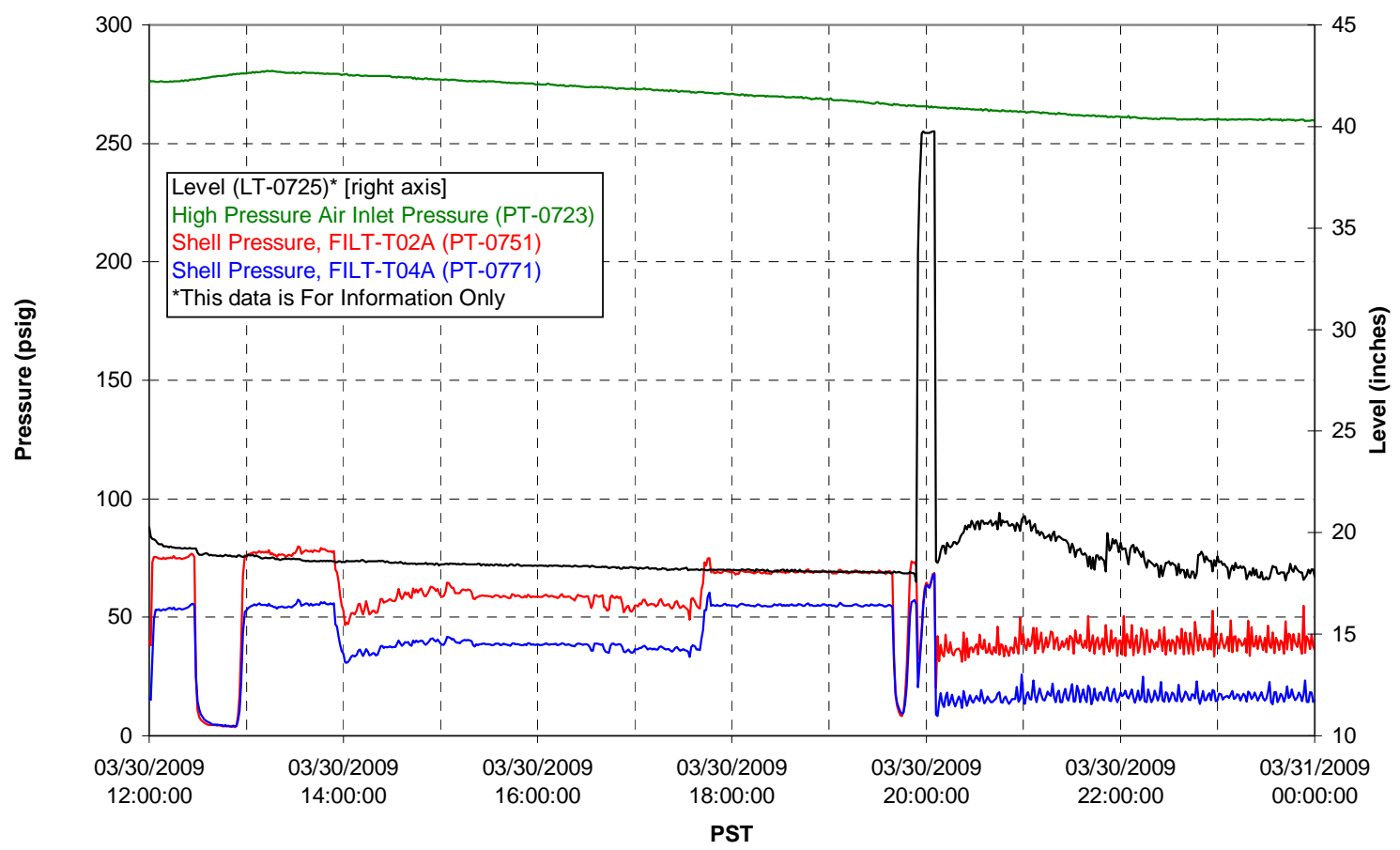


Pulsepot UFP-PP-T03A

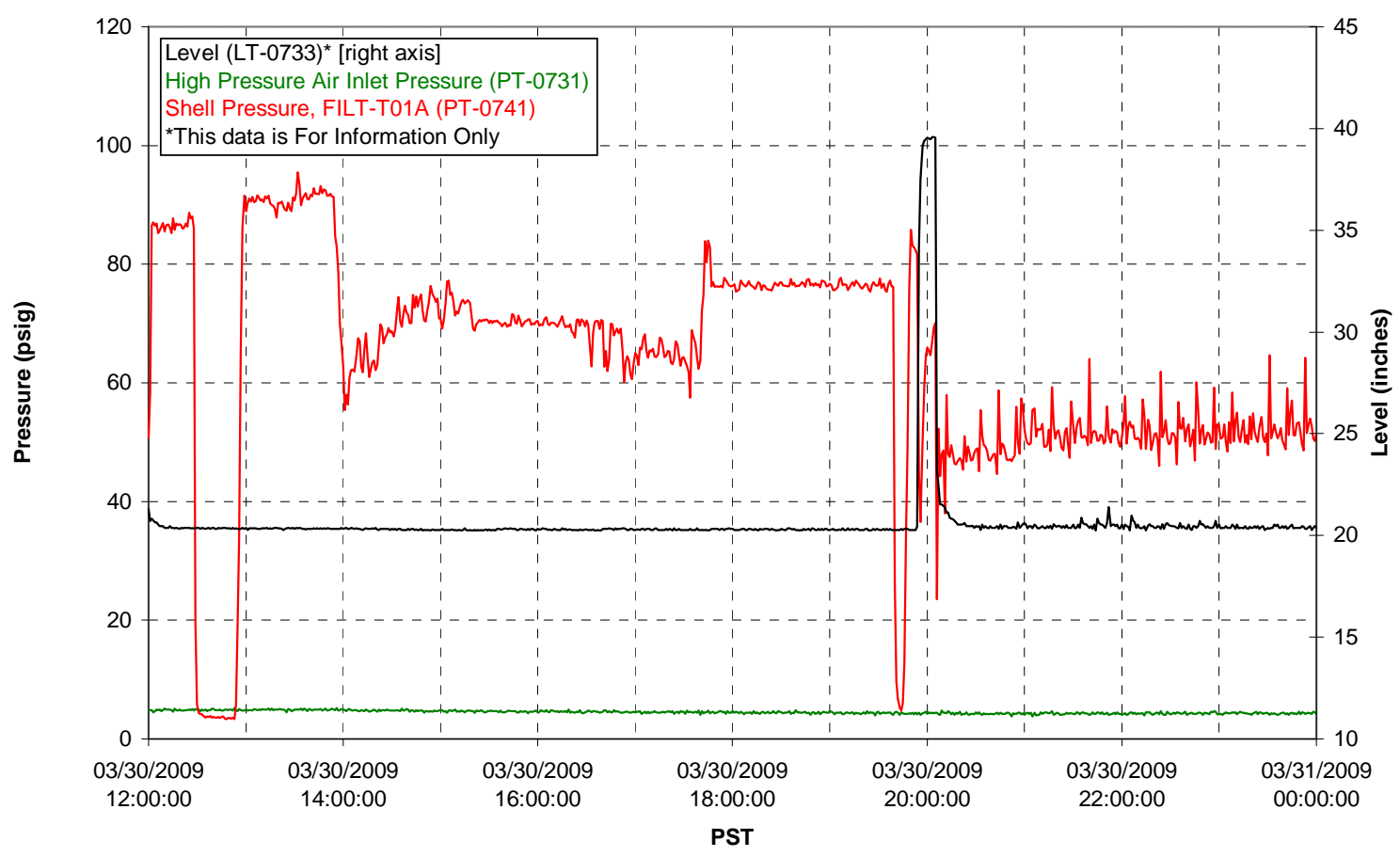

Pulsepot Levels

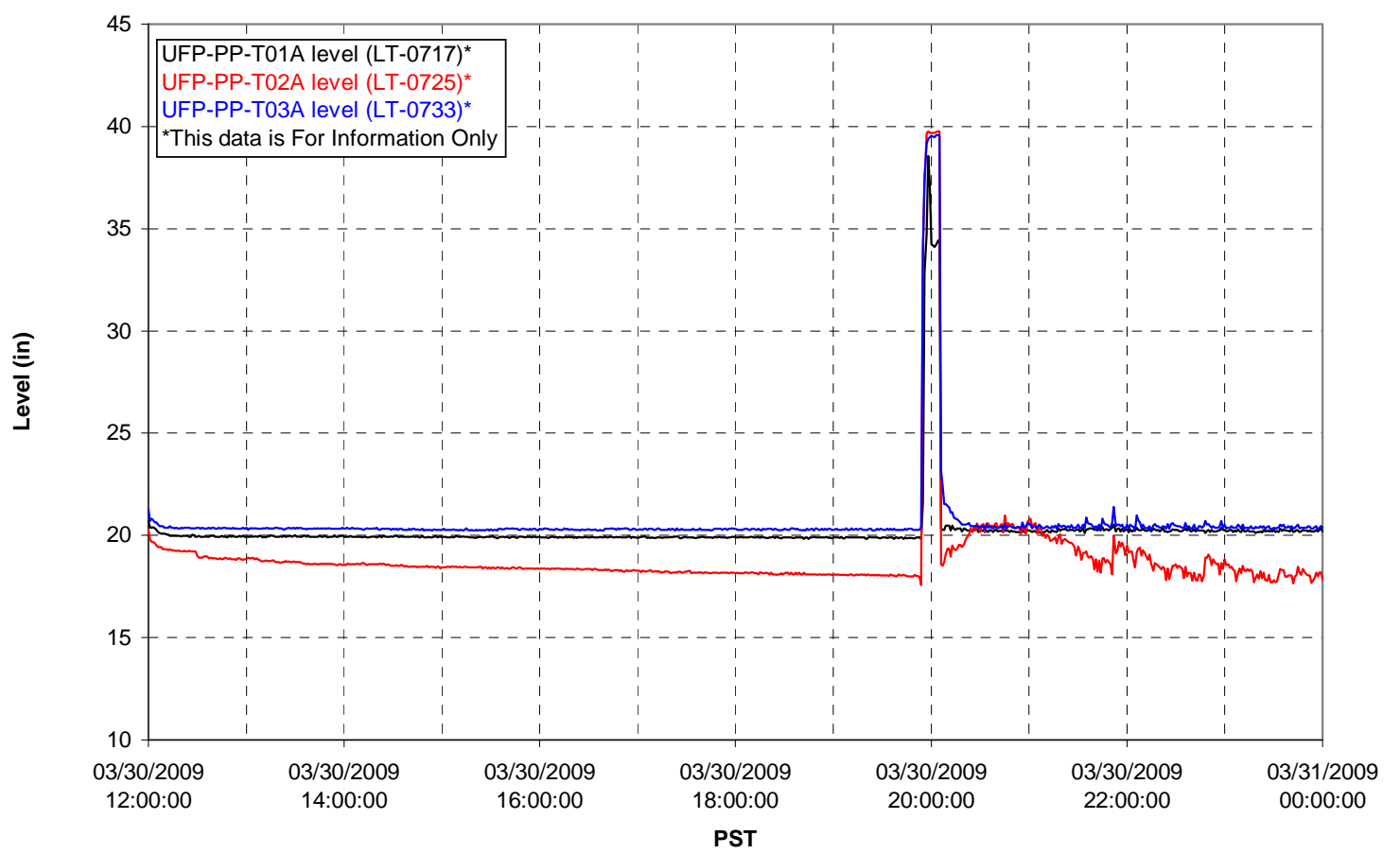


Filter UFP-FILT-T01A

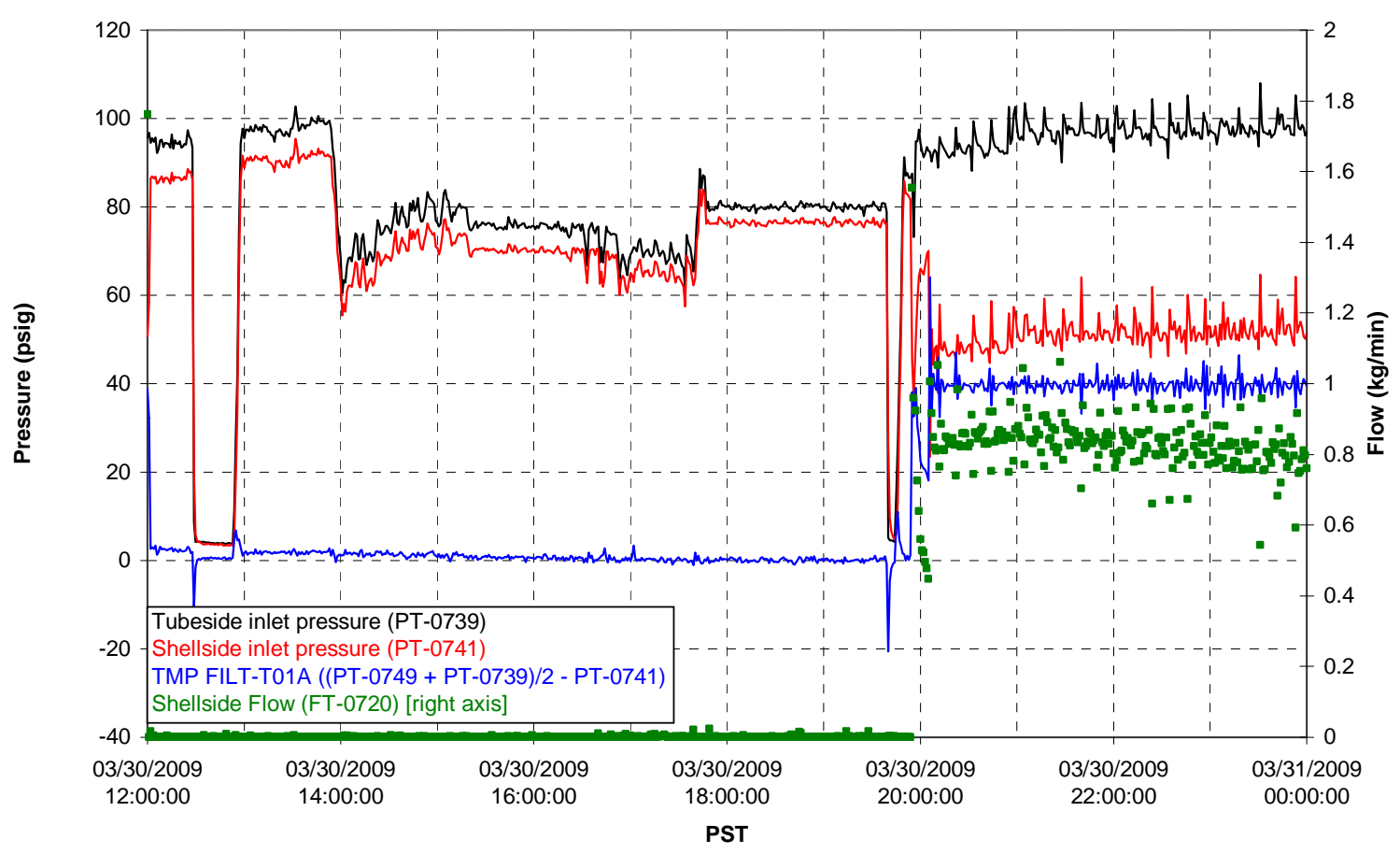

Filter UFP-FILT-T02A

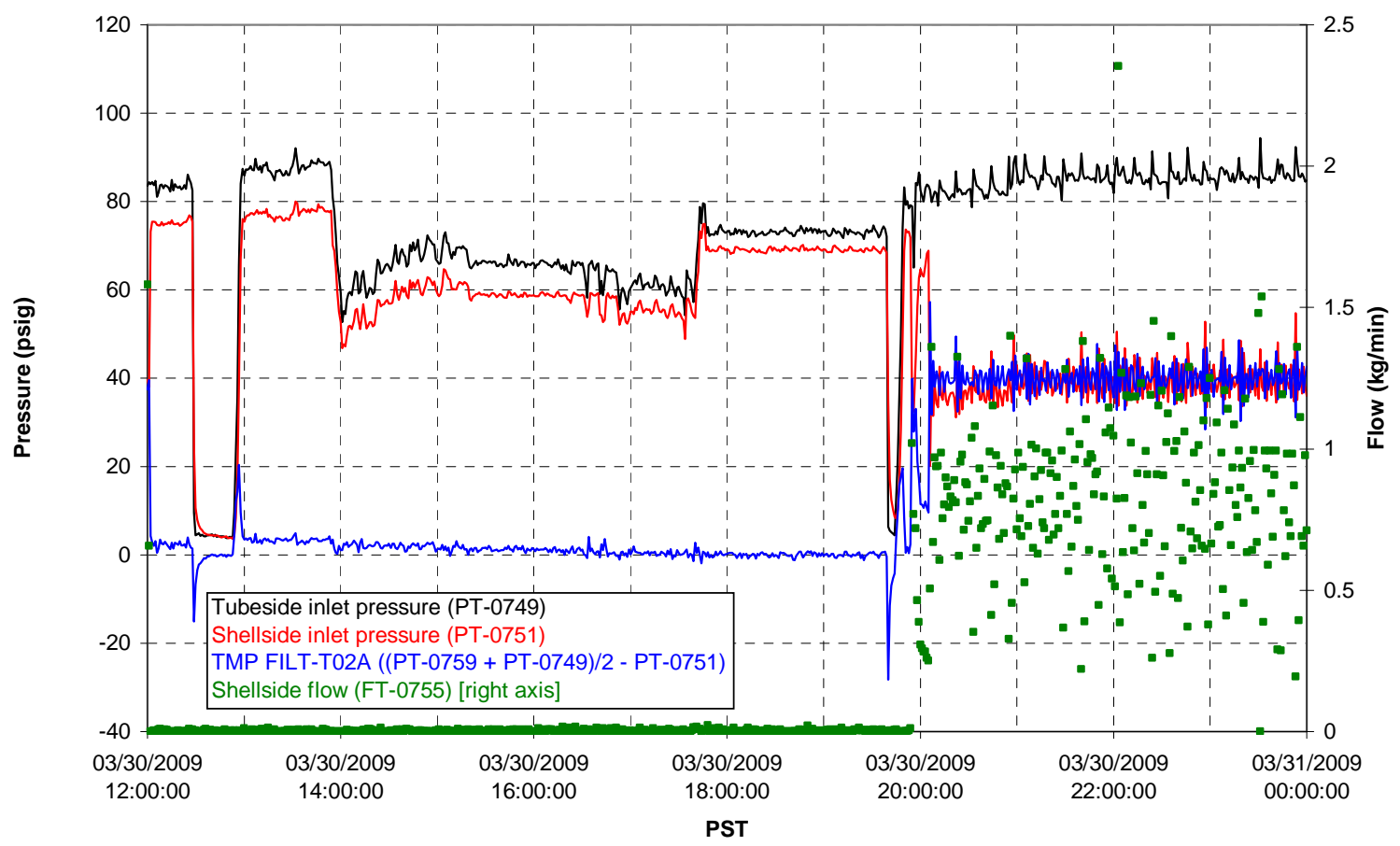


Filter UFP-FILT-T03A

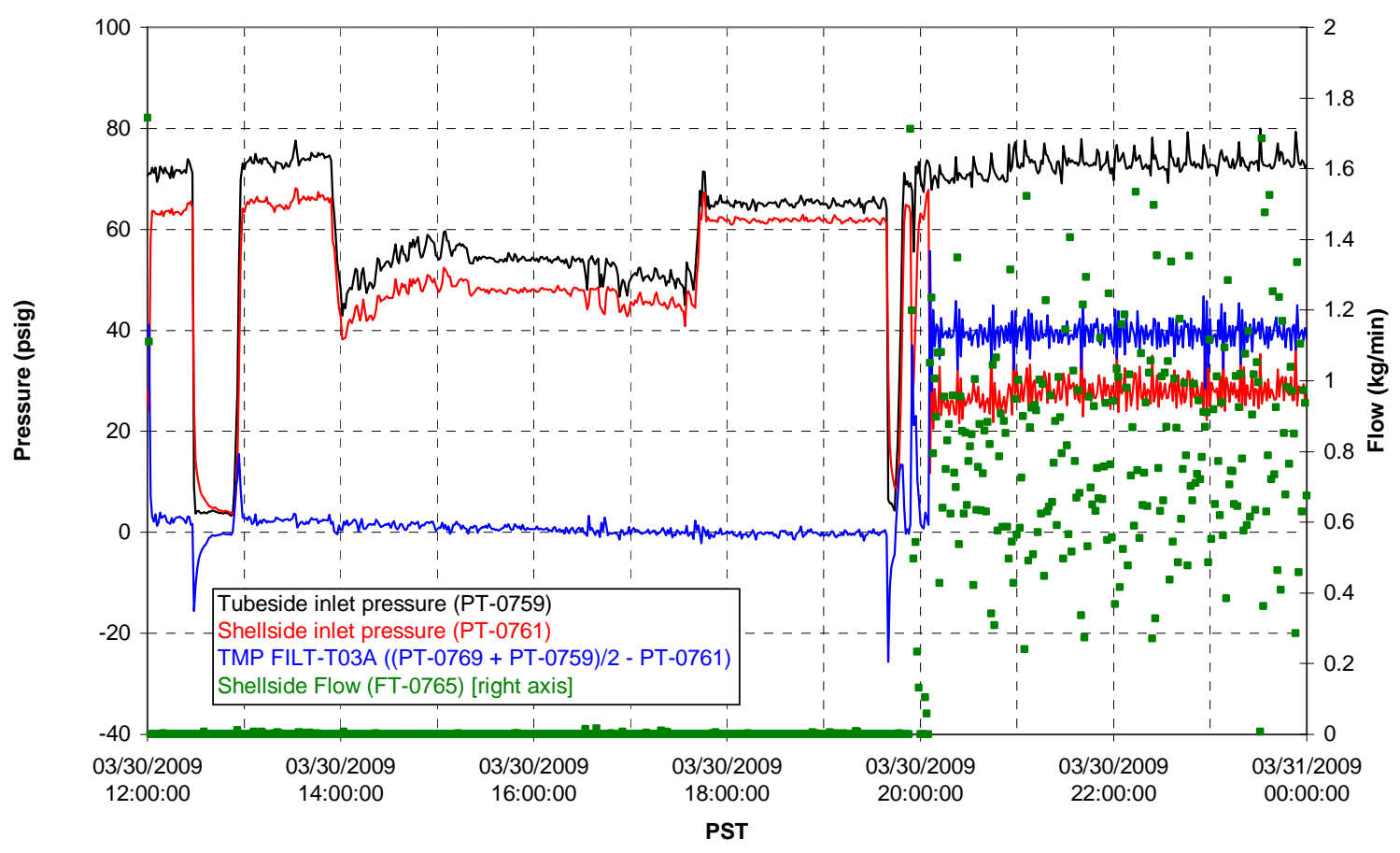

Filter UFP-FILT-T04A

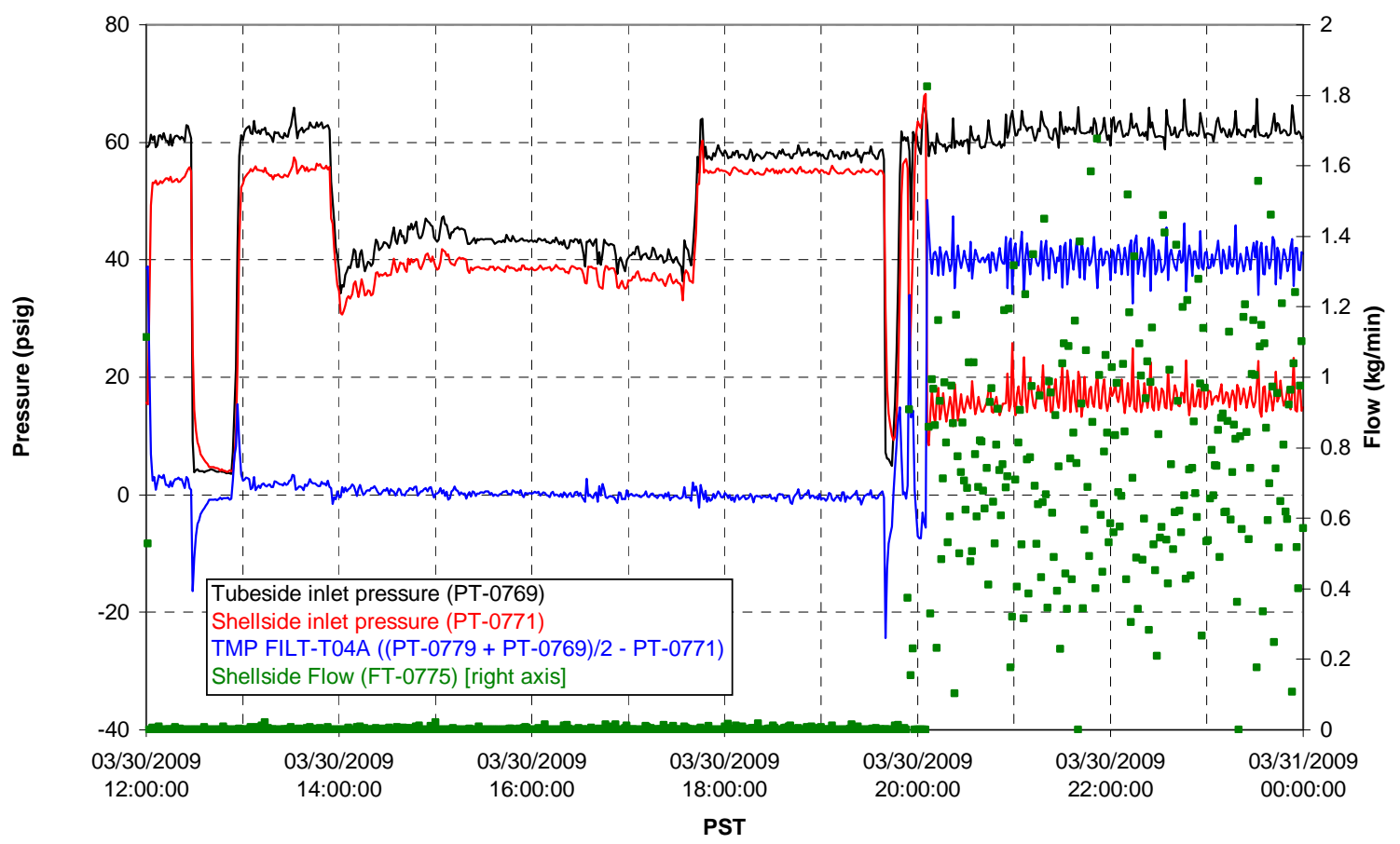


Filter UFP-FILT-T05A

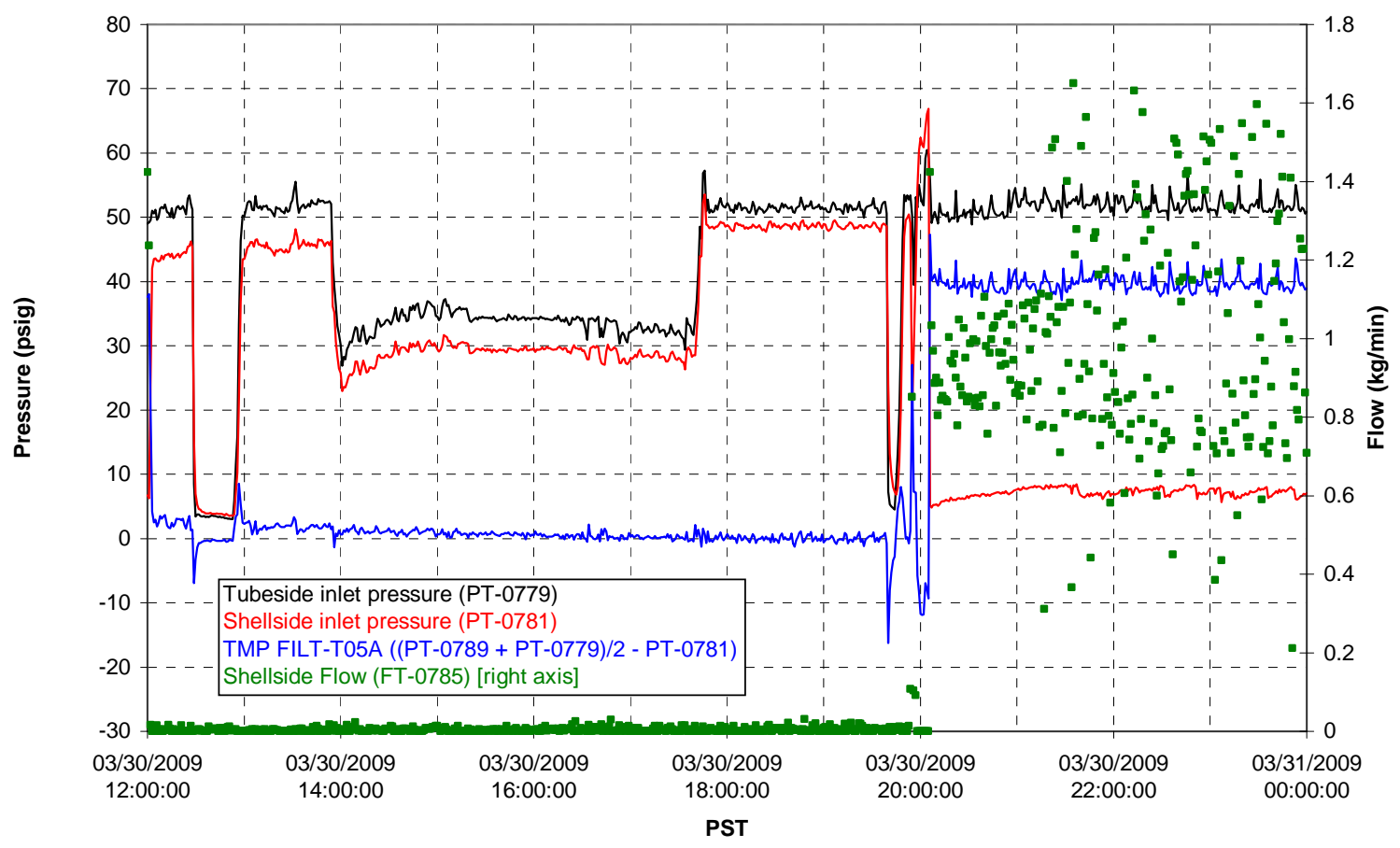

Chemical Flow

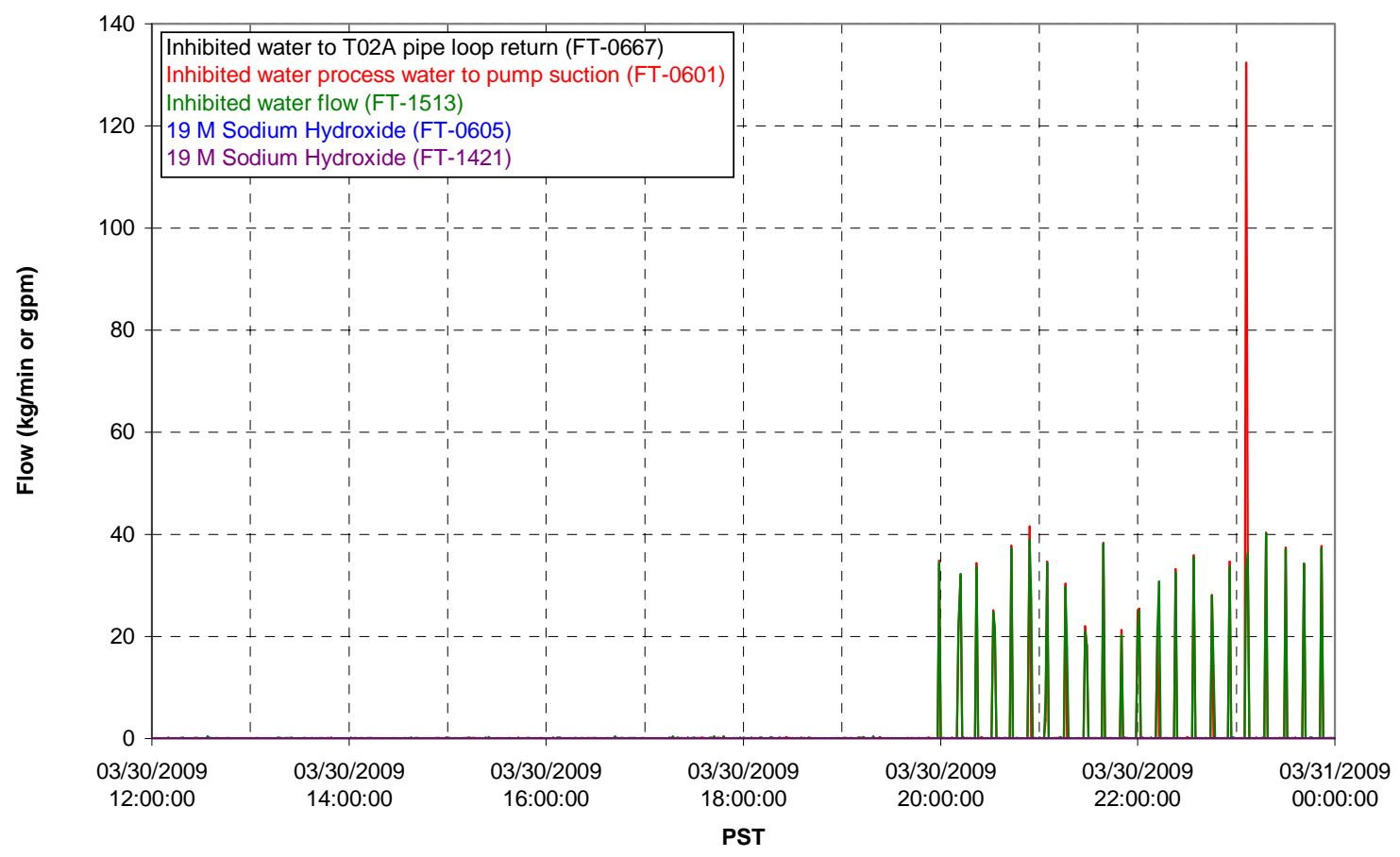




\section{Chemical Flow}

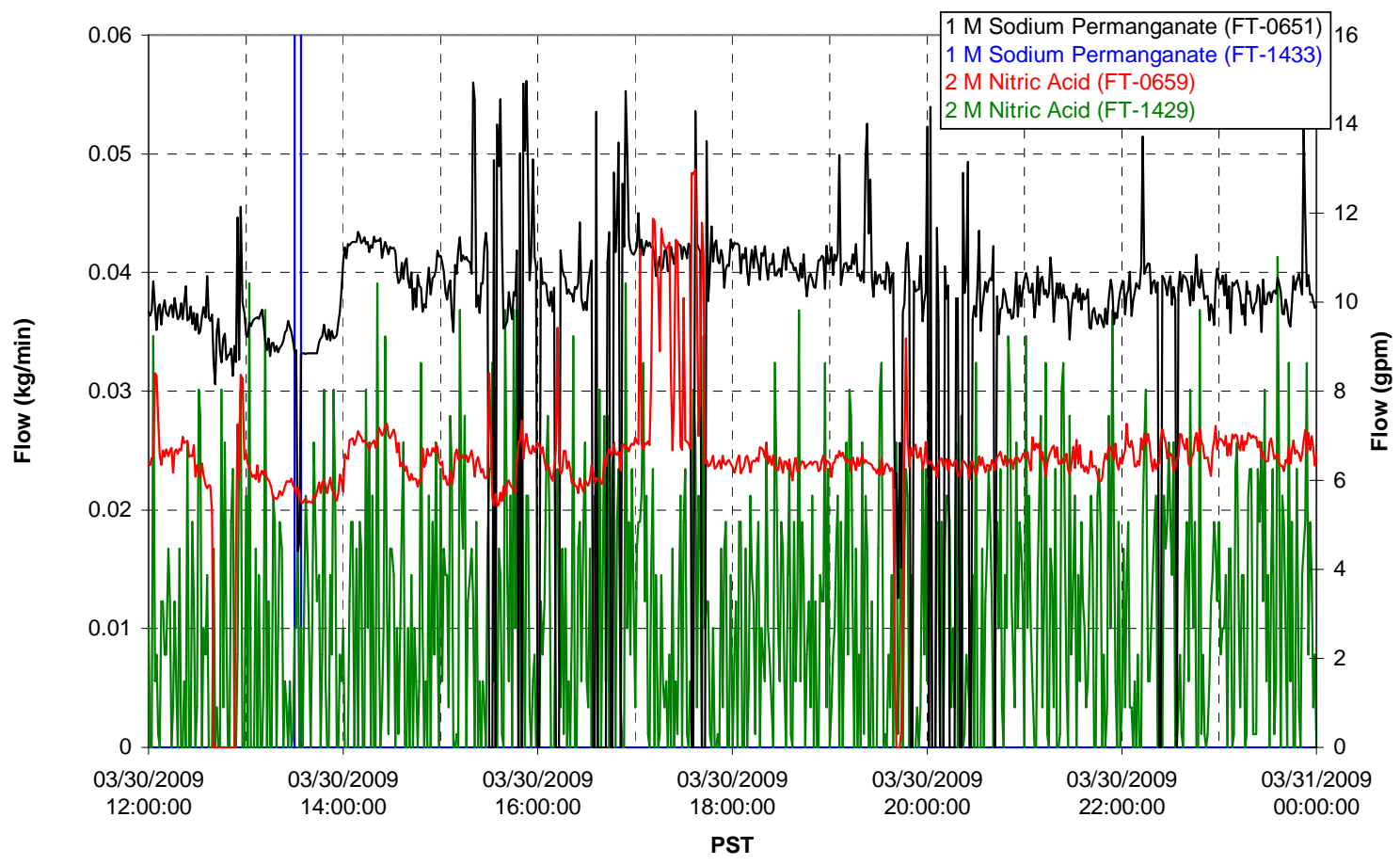

Air Flows

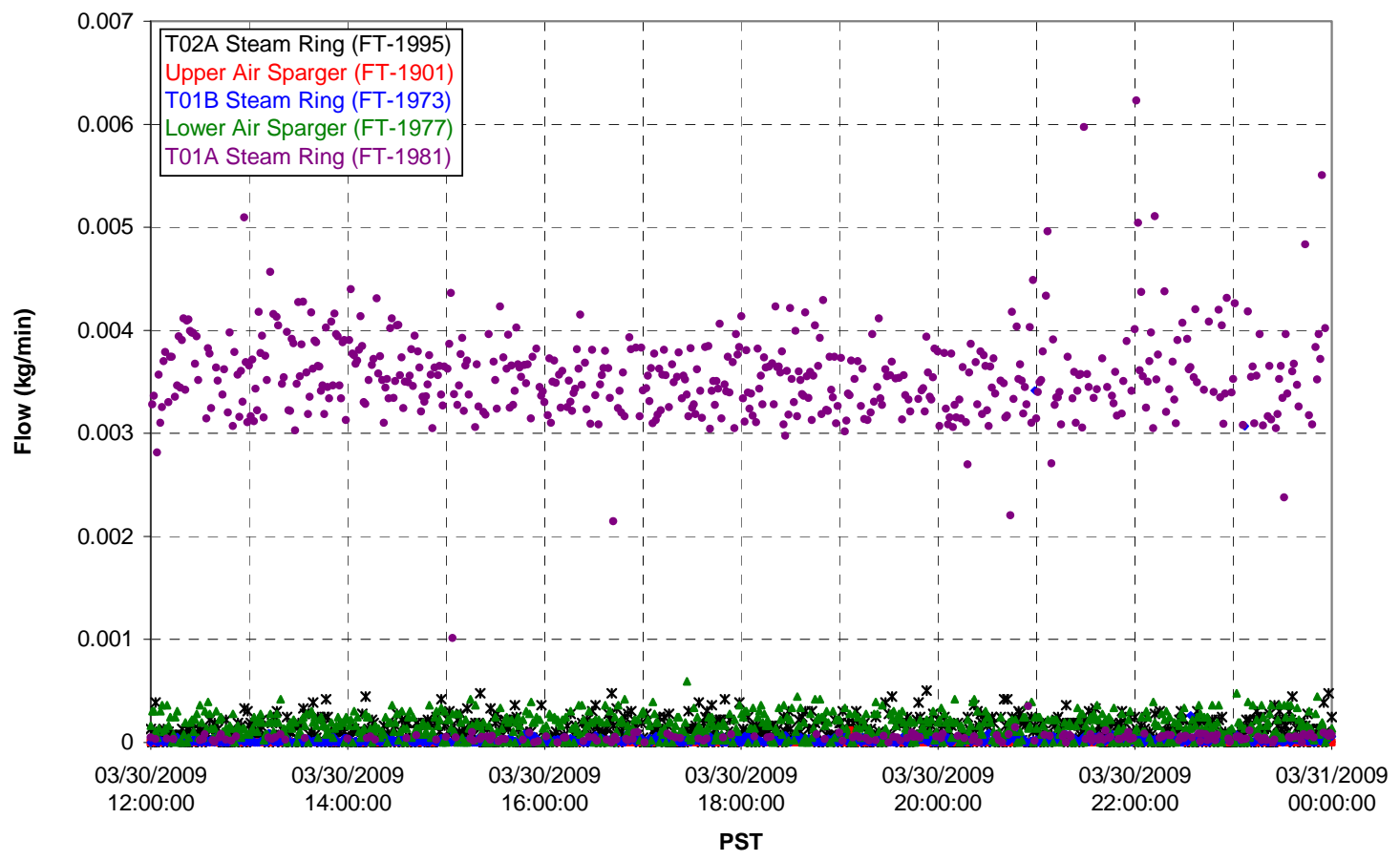


T02A Steam

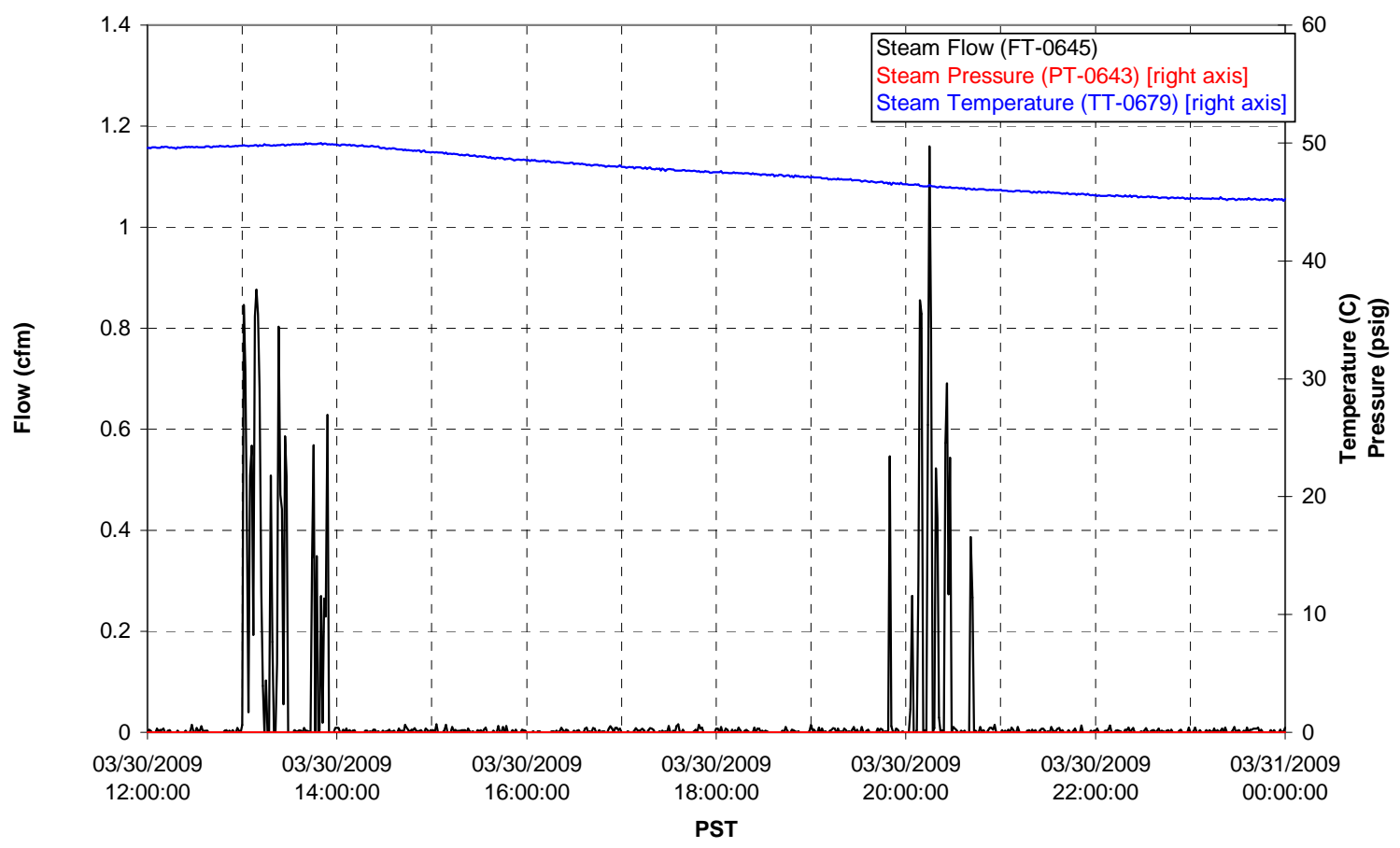

T01A Steam

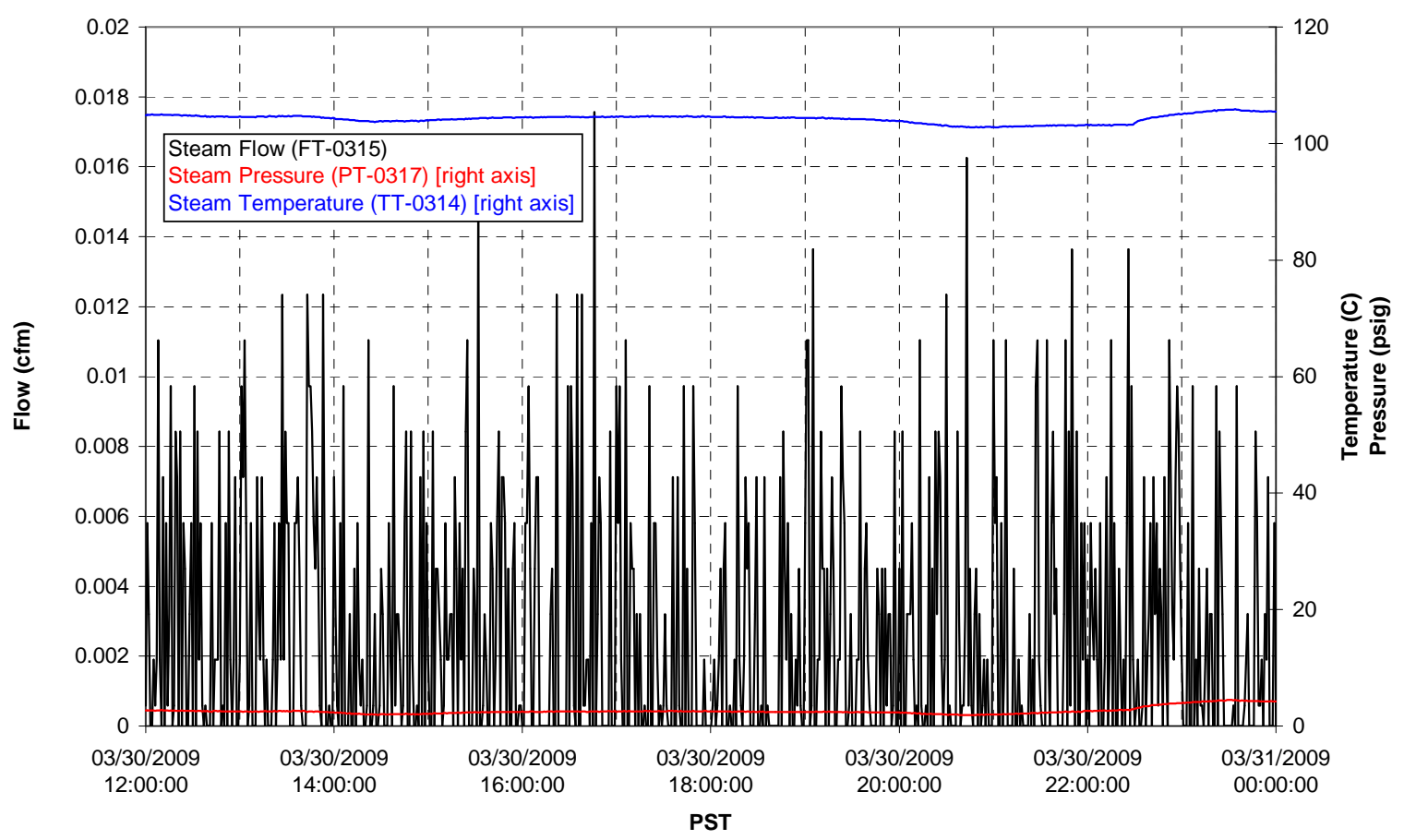


T01B Steam

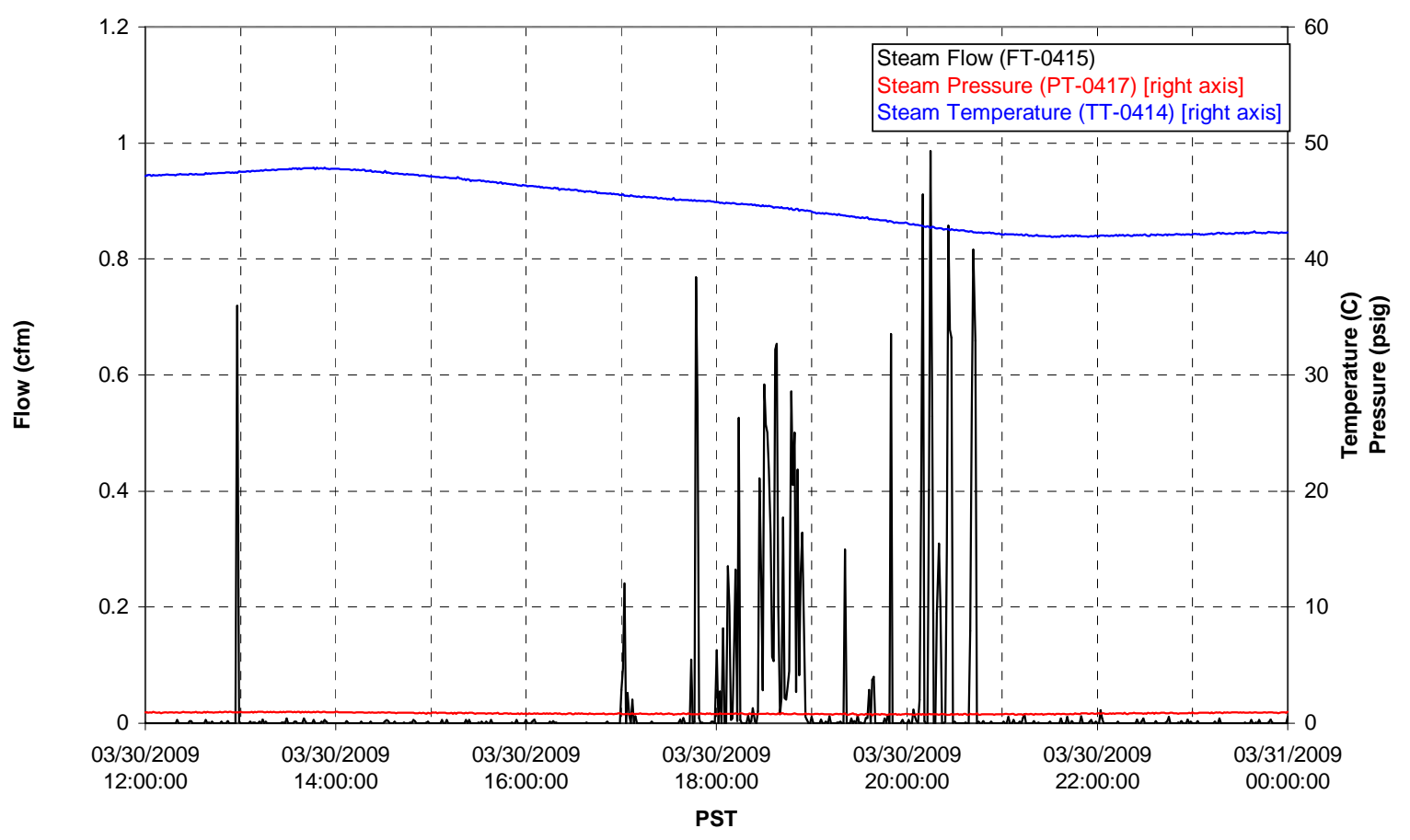




\section{Integrated Test D Data Plots 03/31/09 00:00 - 03/31/09 12:00}


T01A level

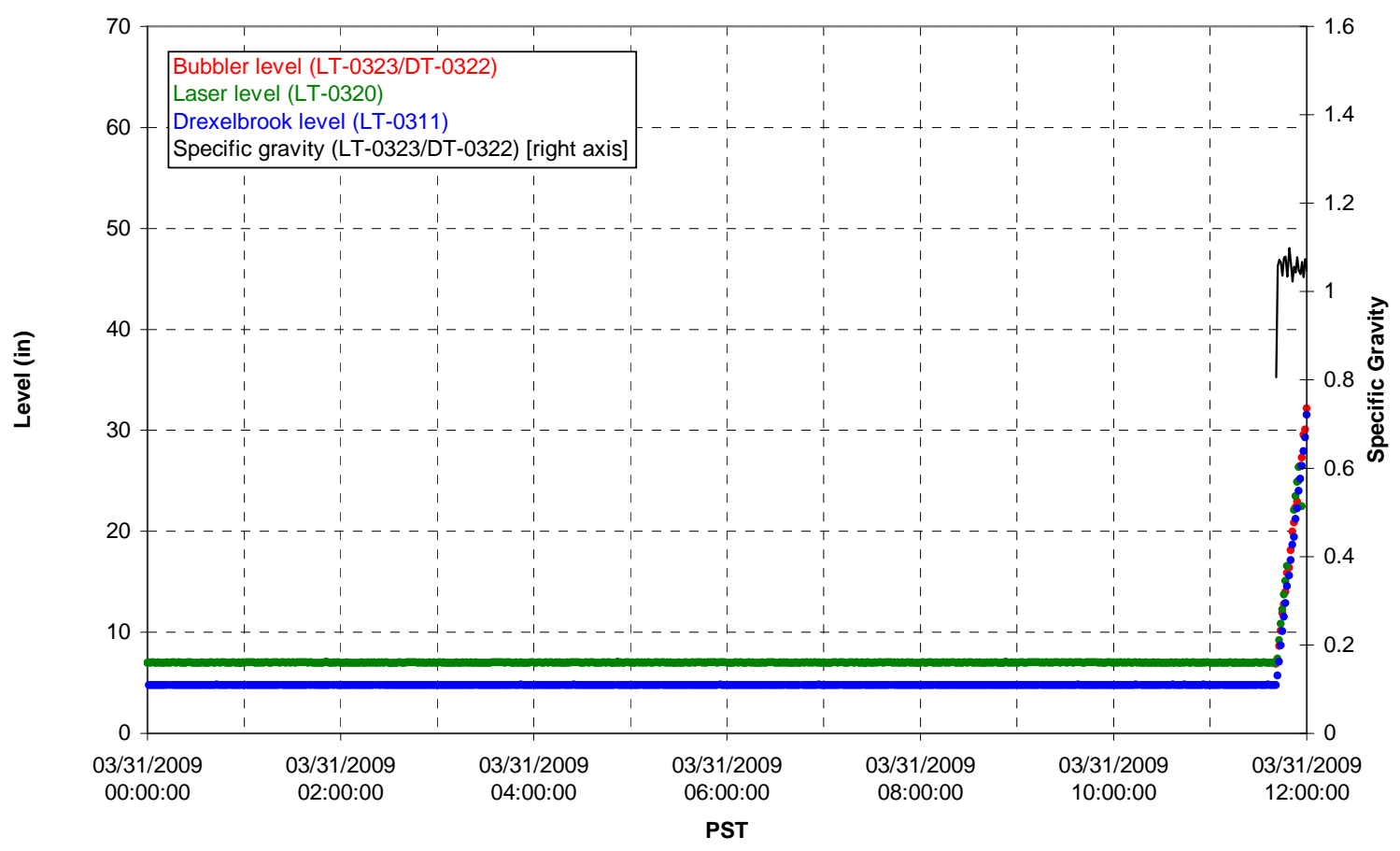

T01A temperatures

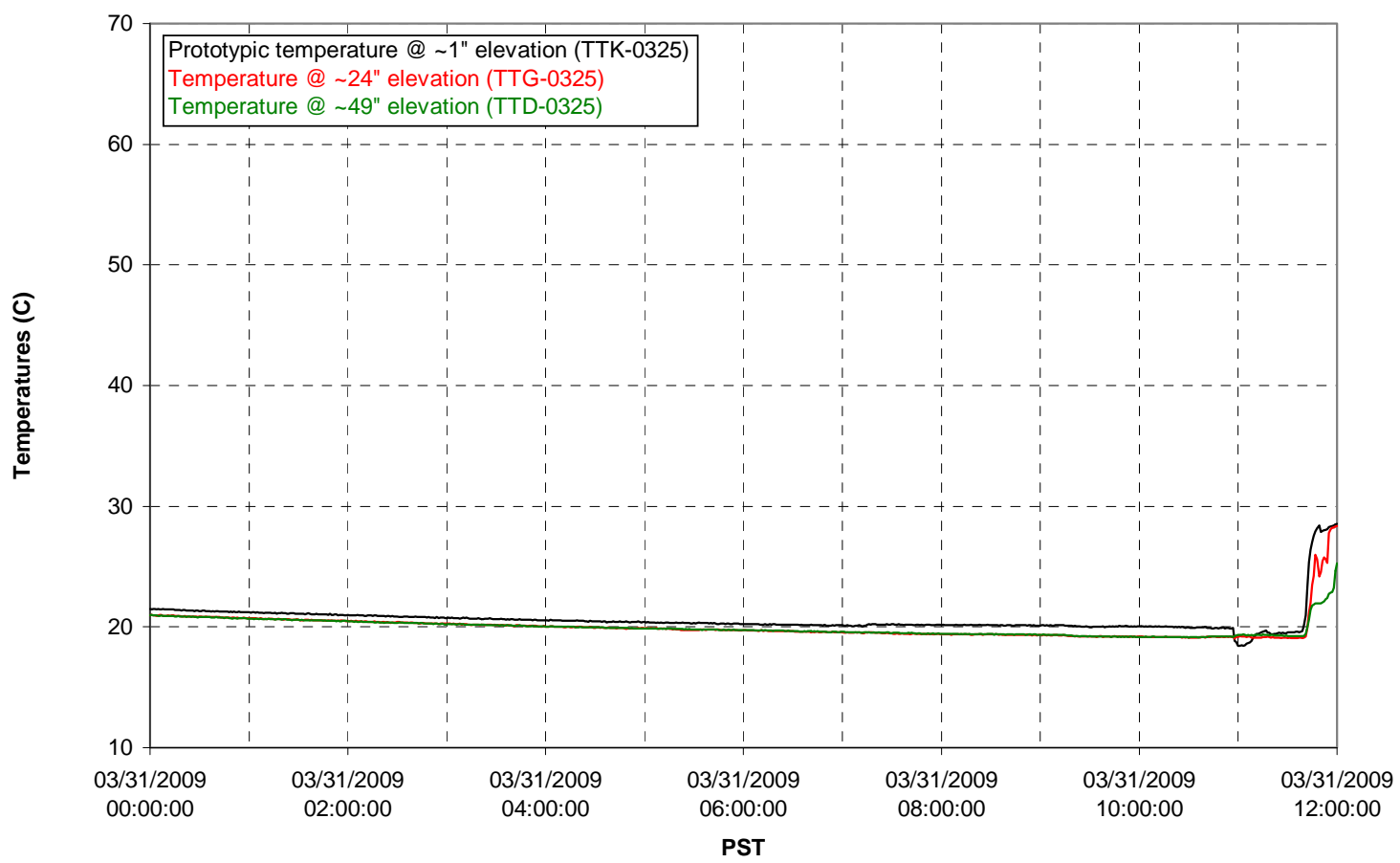


T01B level

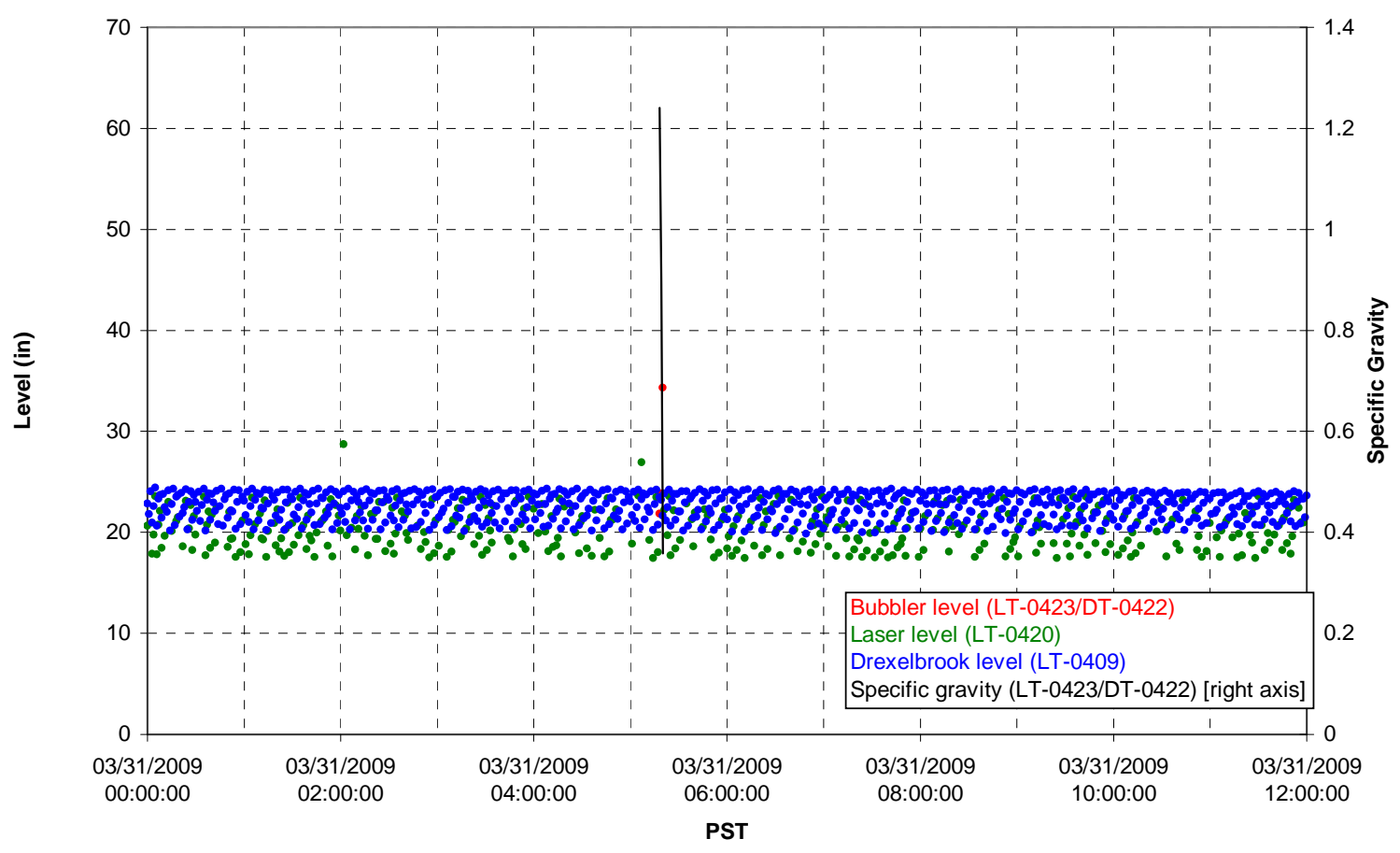

T01B temperatures

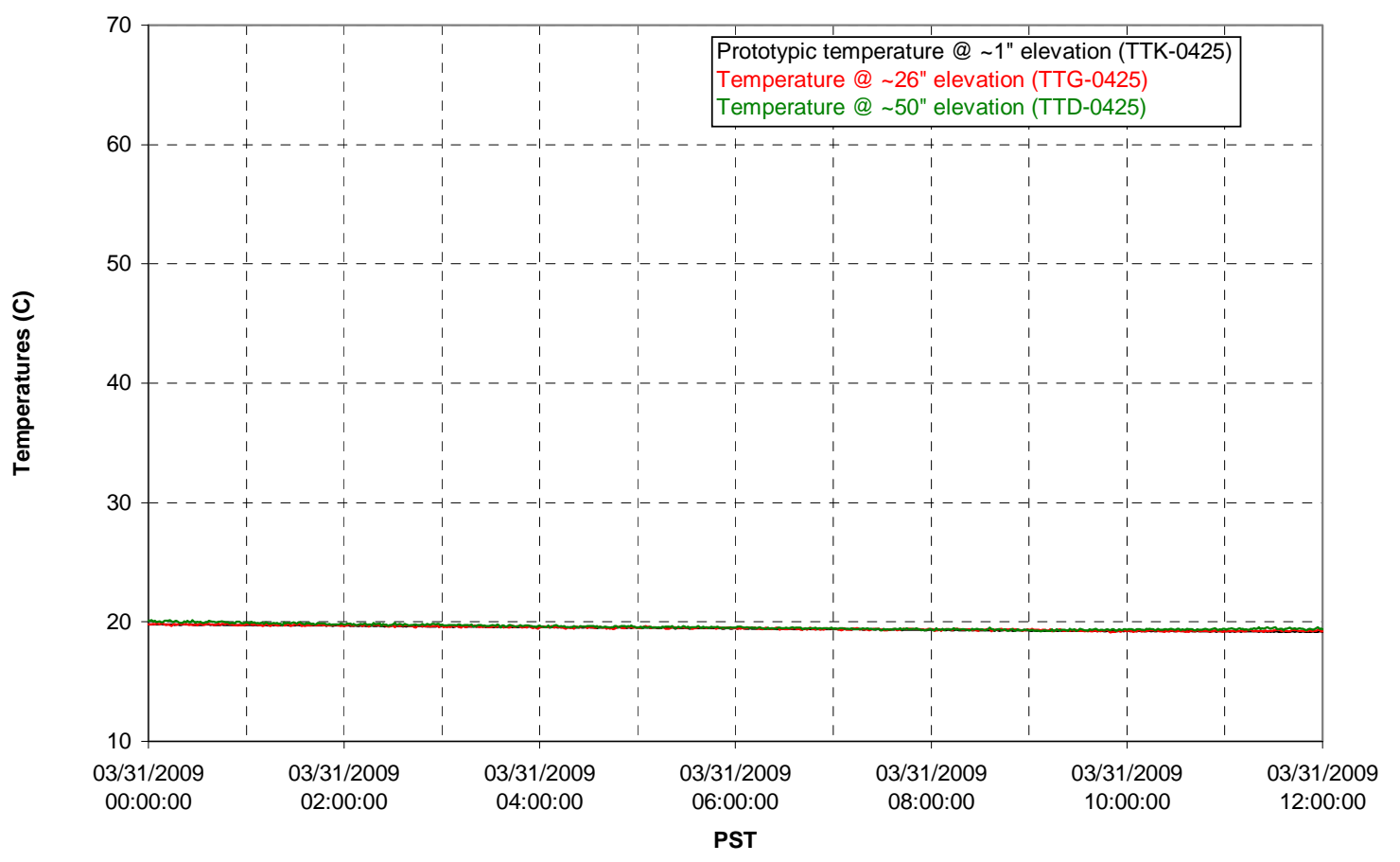


T02A level

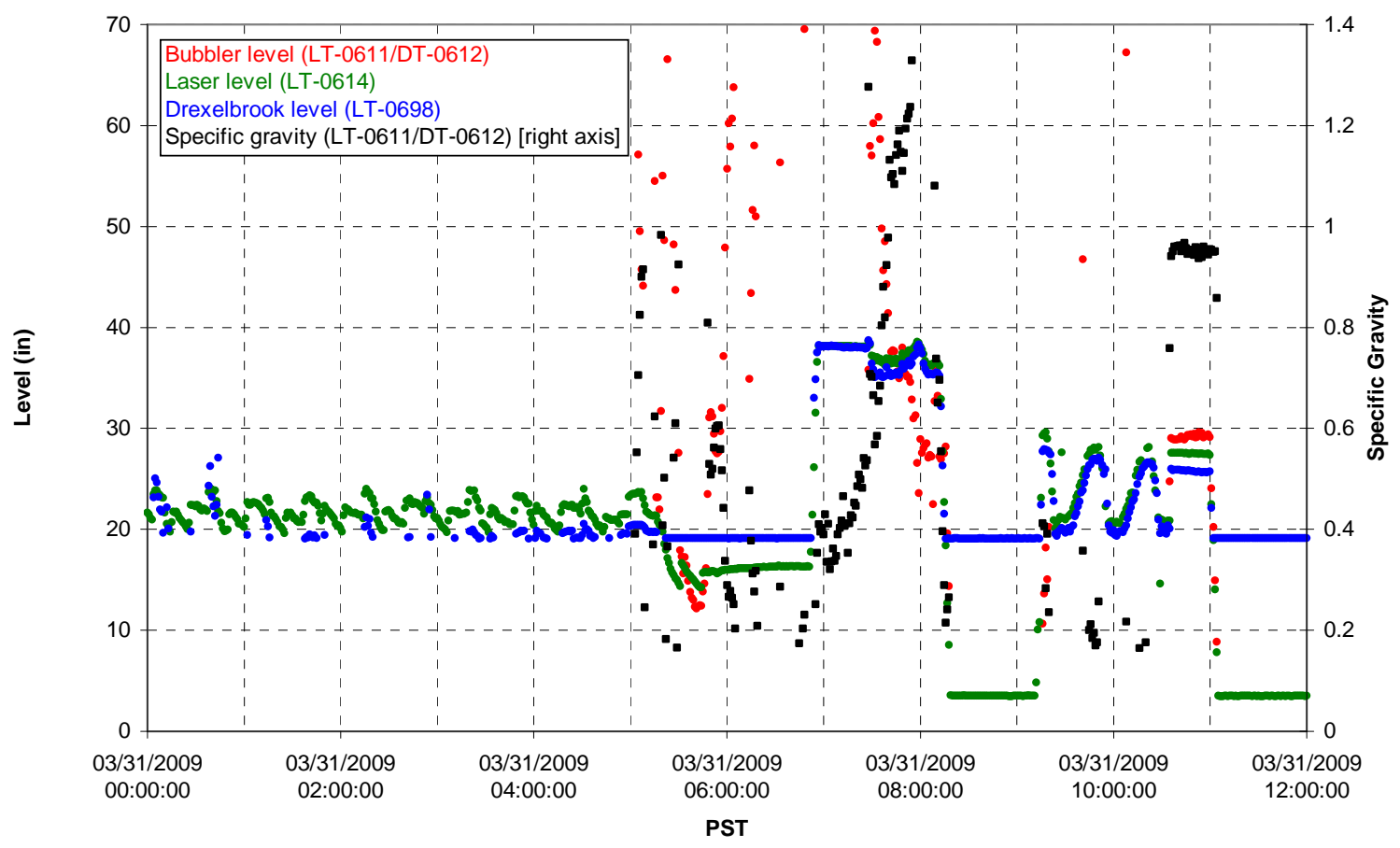

T02A temperatures

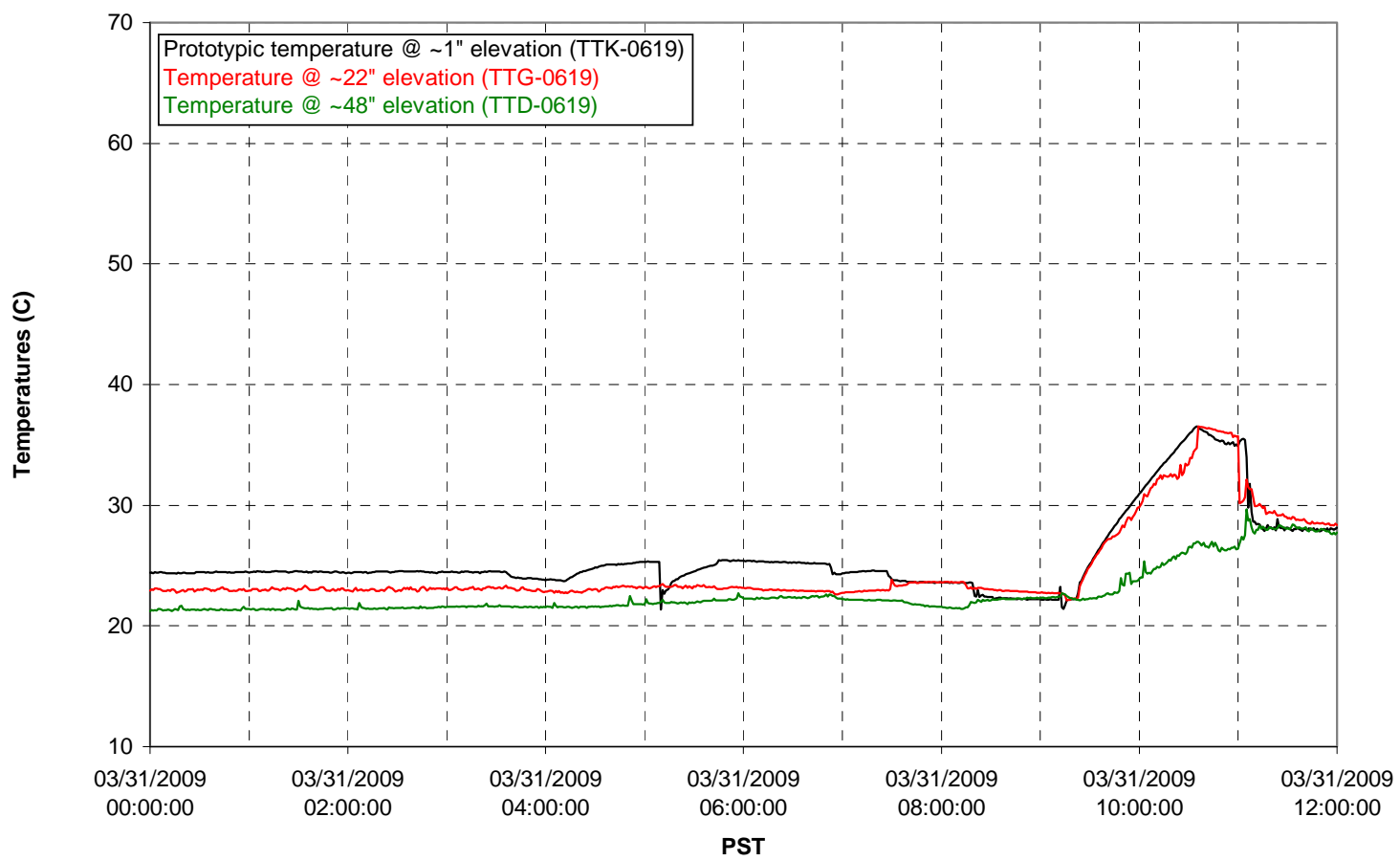


T02A and filter loop temperatures

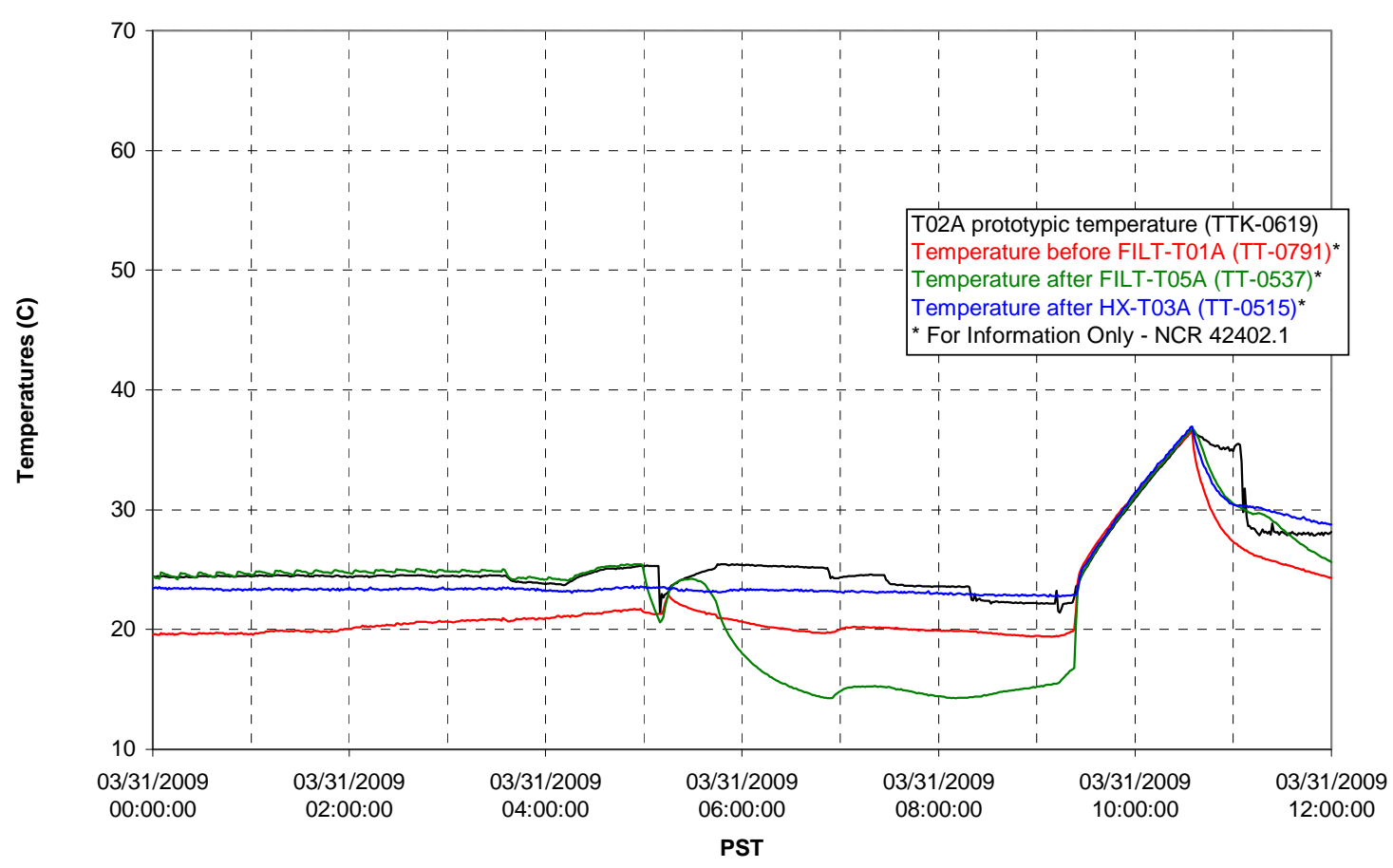

Pump Pressures and Flow

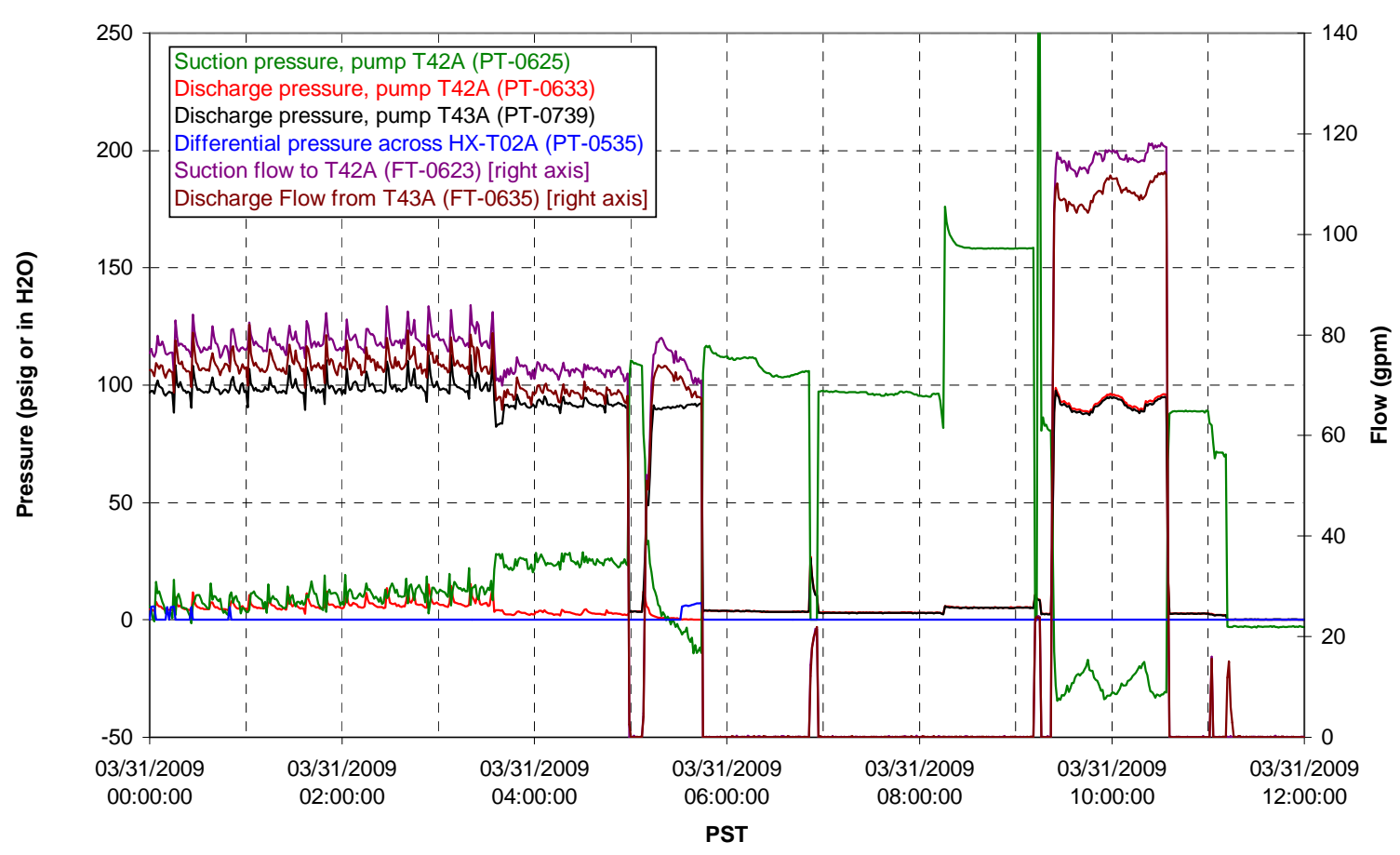


Axial pressure drop

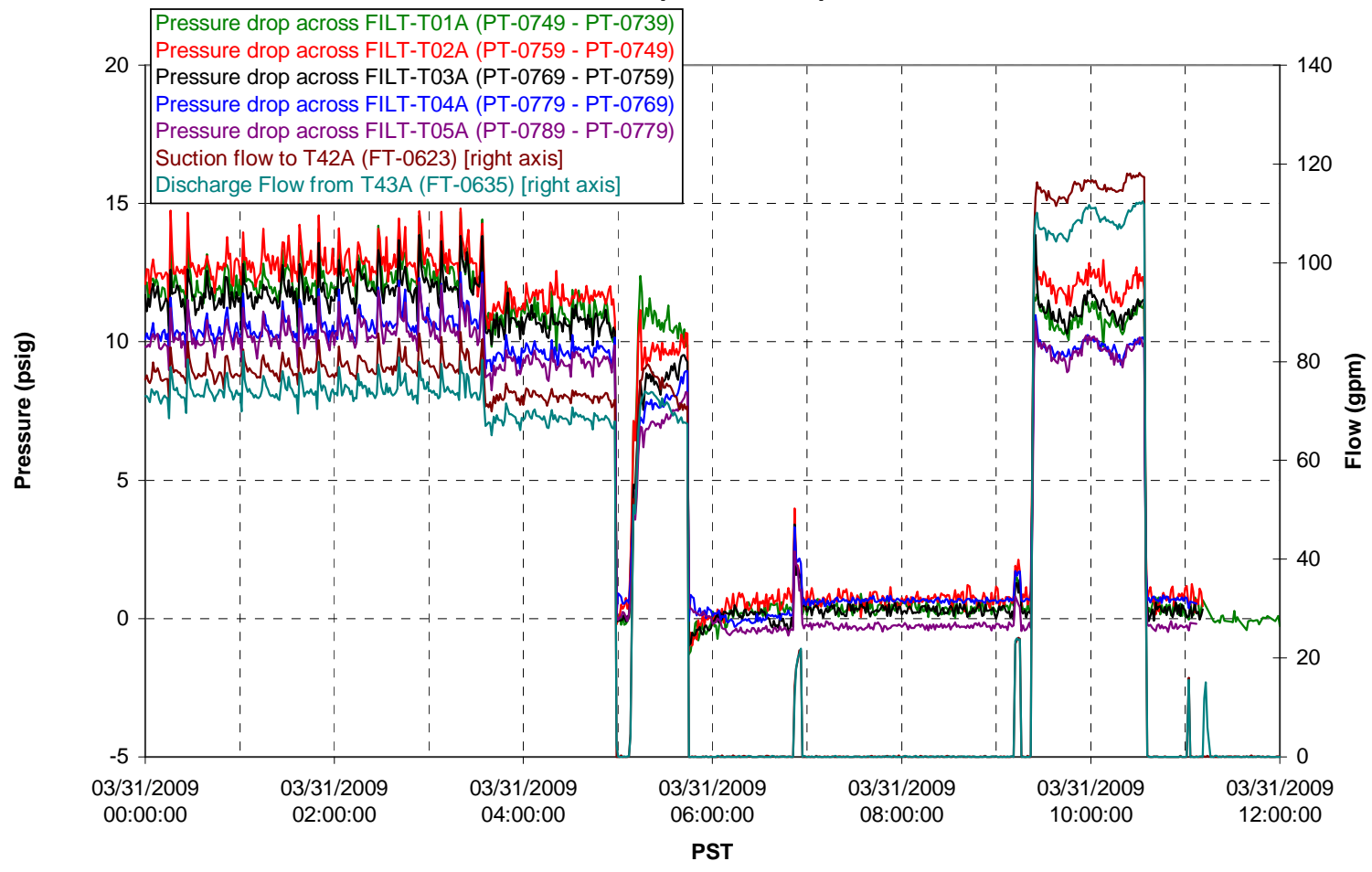

Permeate flow rates

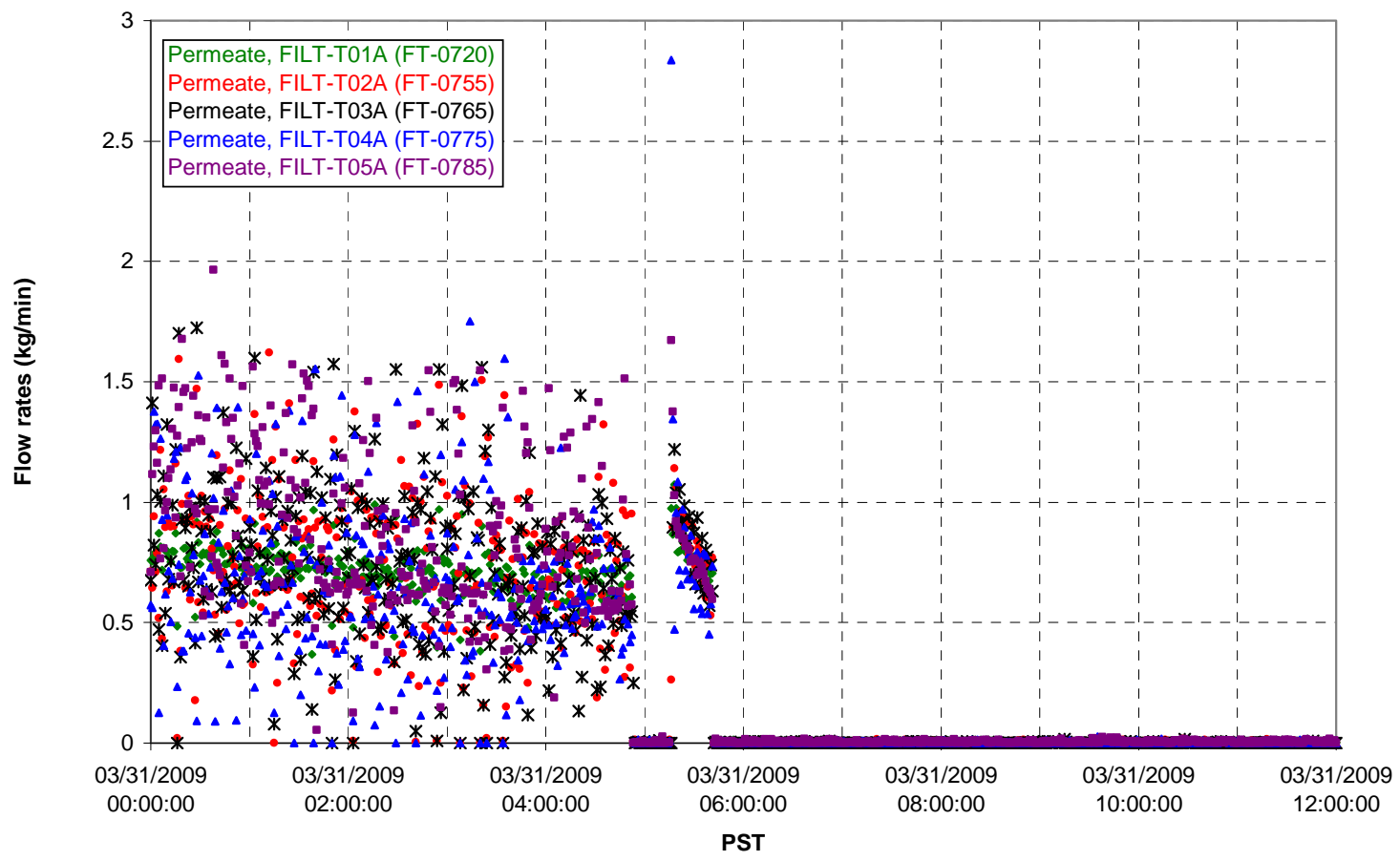


T02A Inner Temperature Tree

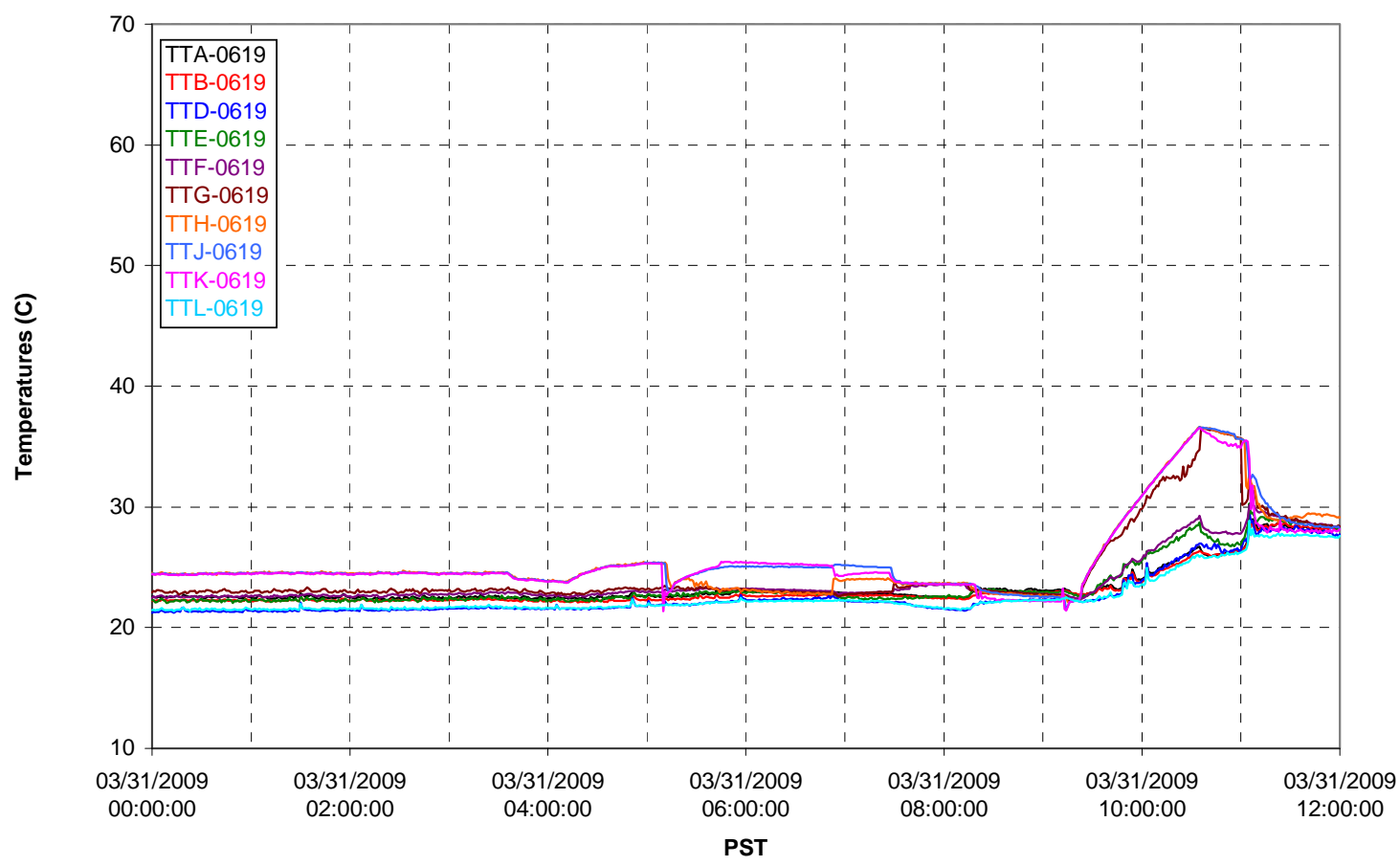

T02A Outer Temperature Tree

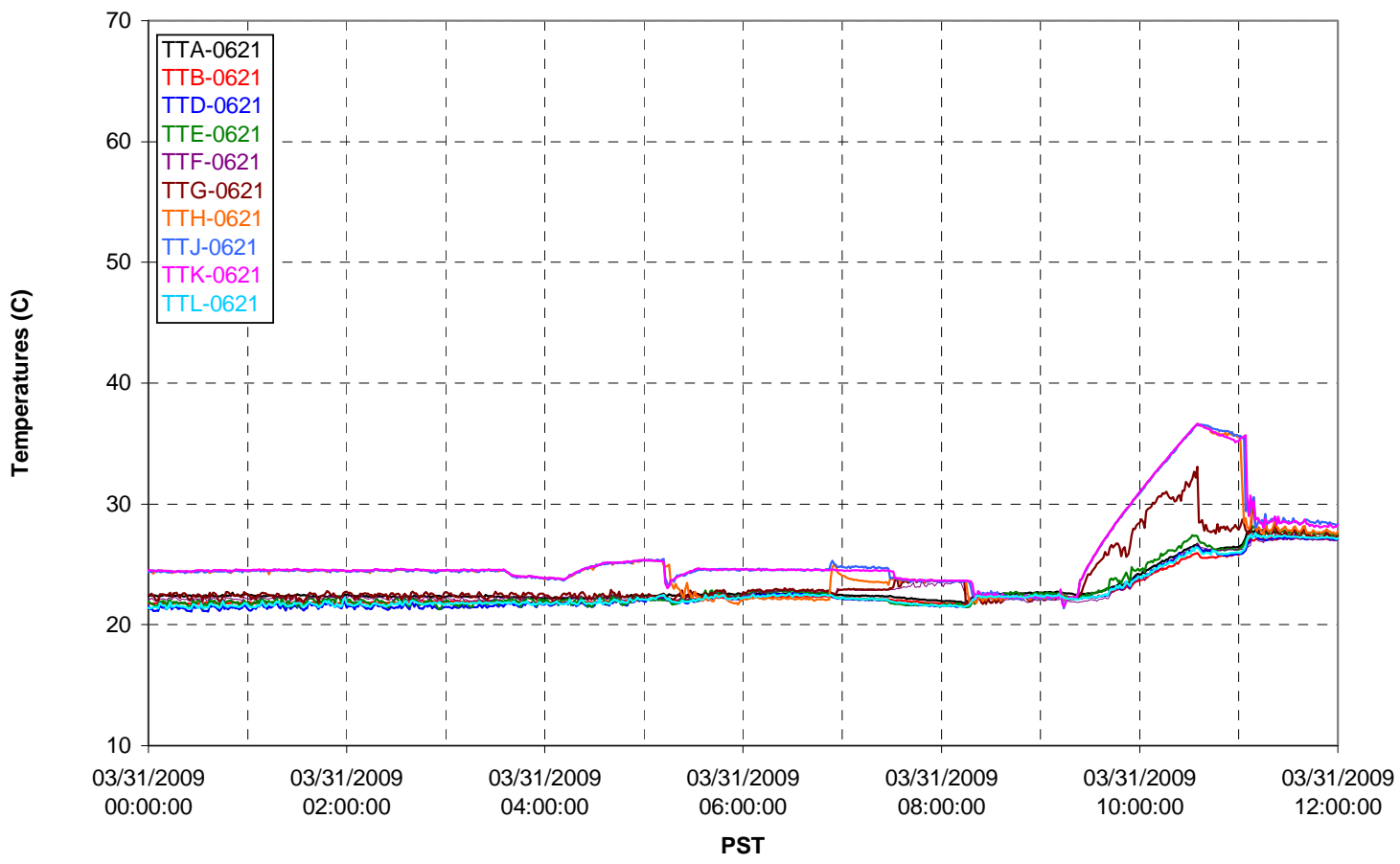


T02A temperatures

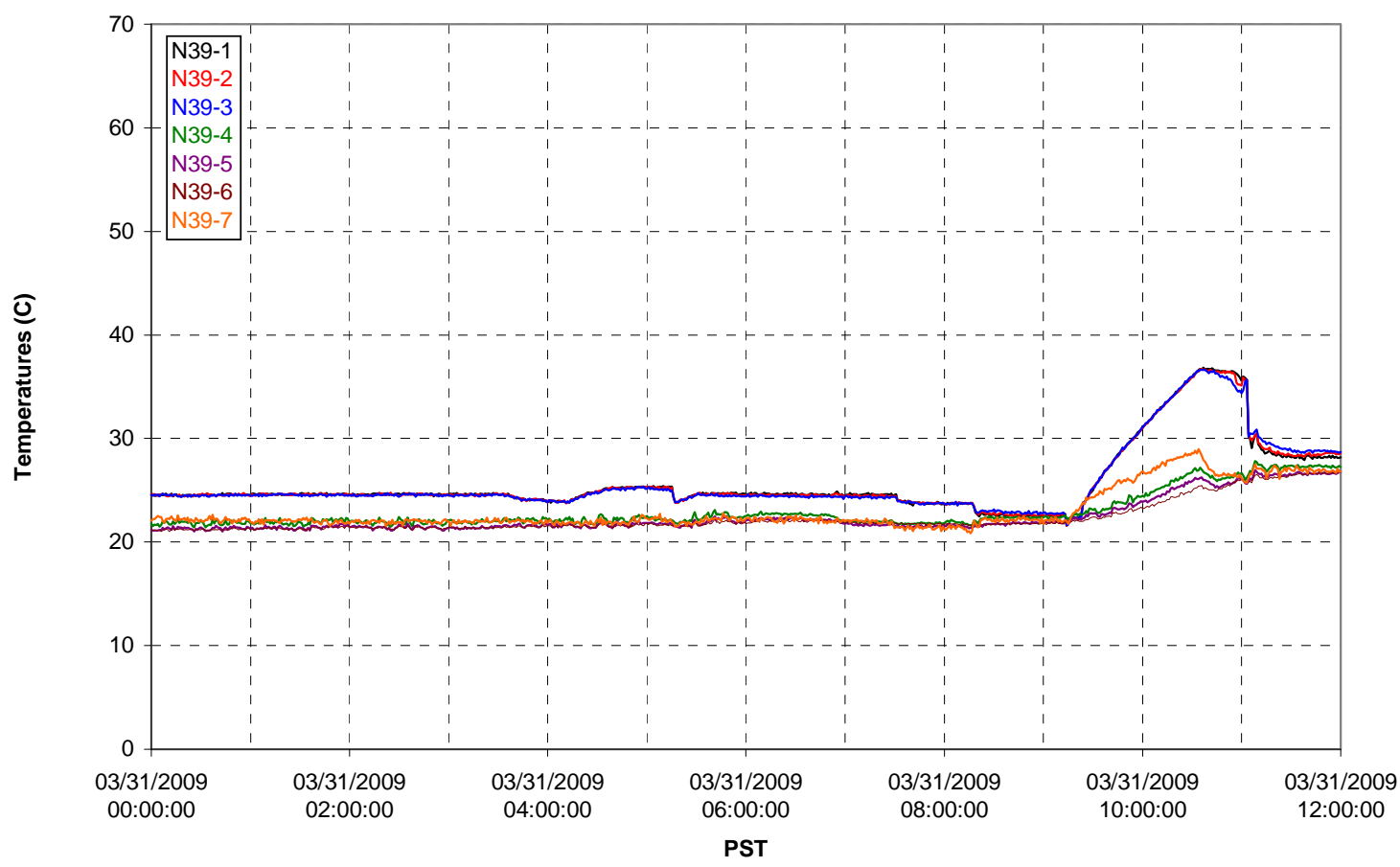

T02A temperatures

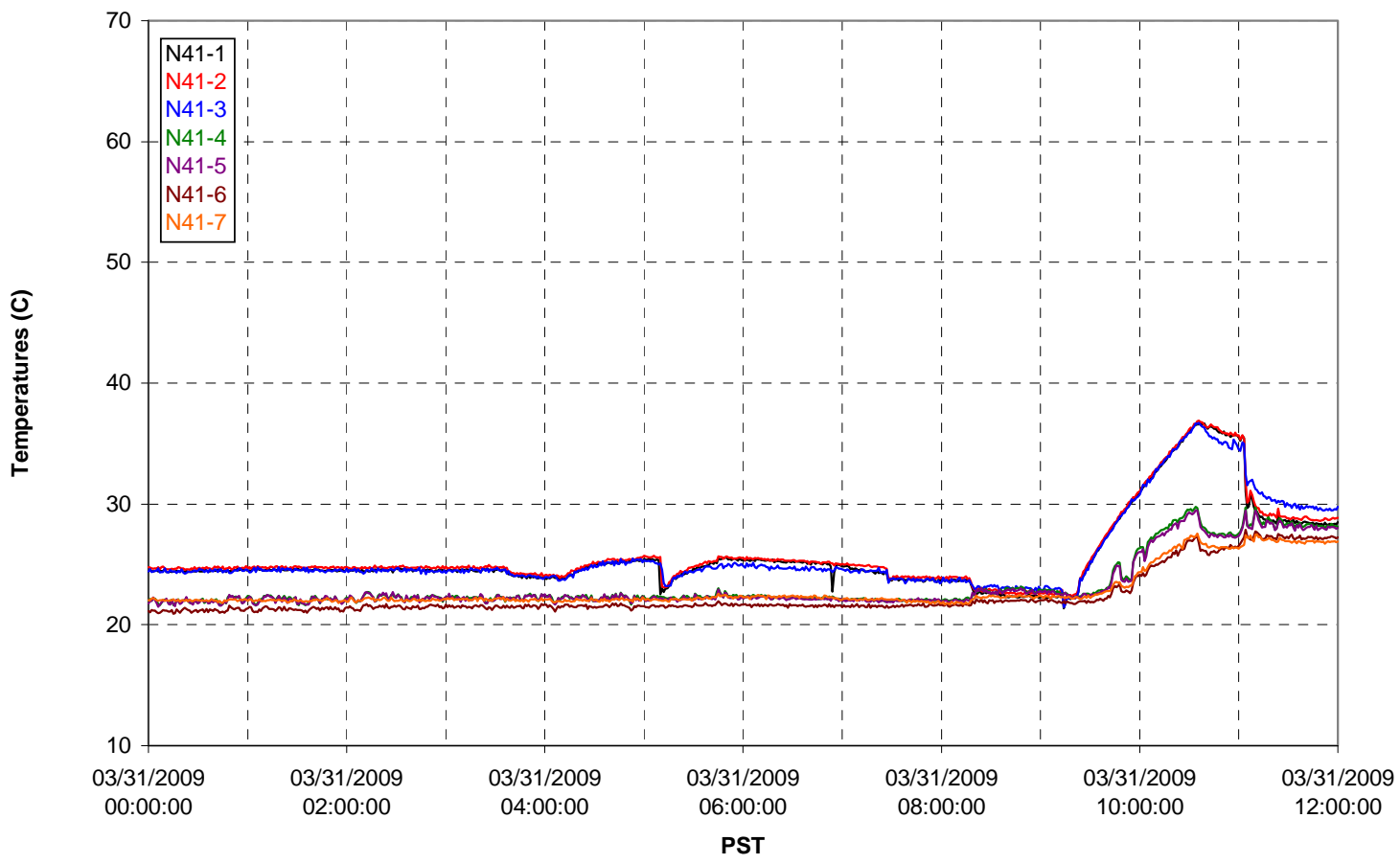


T02A temperatures

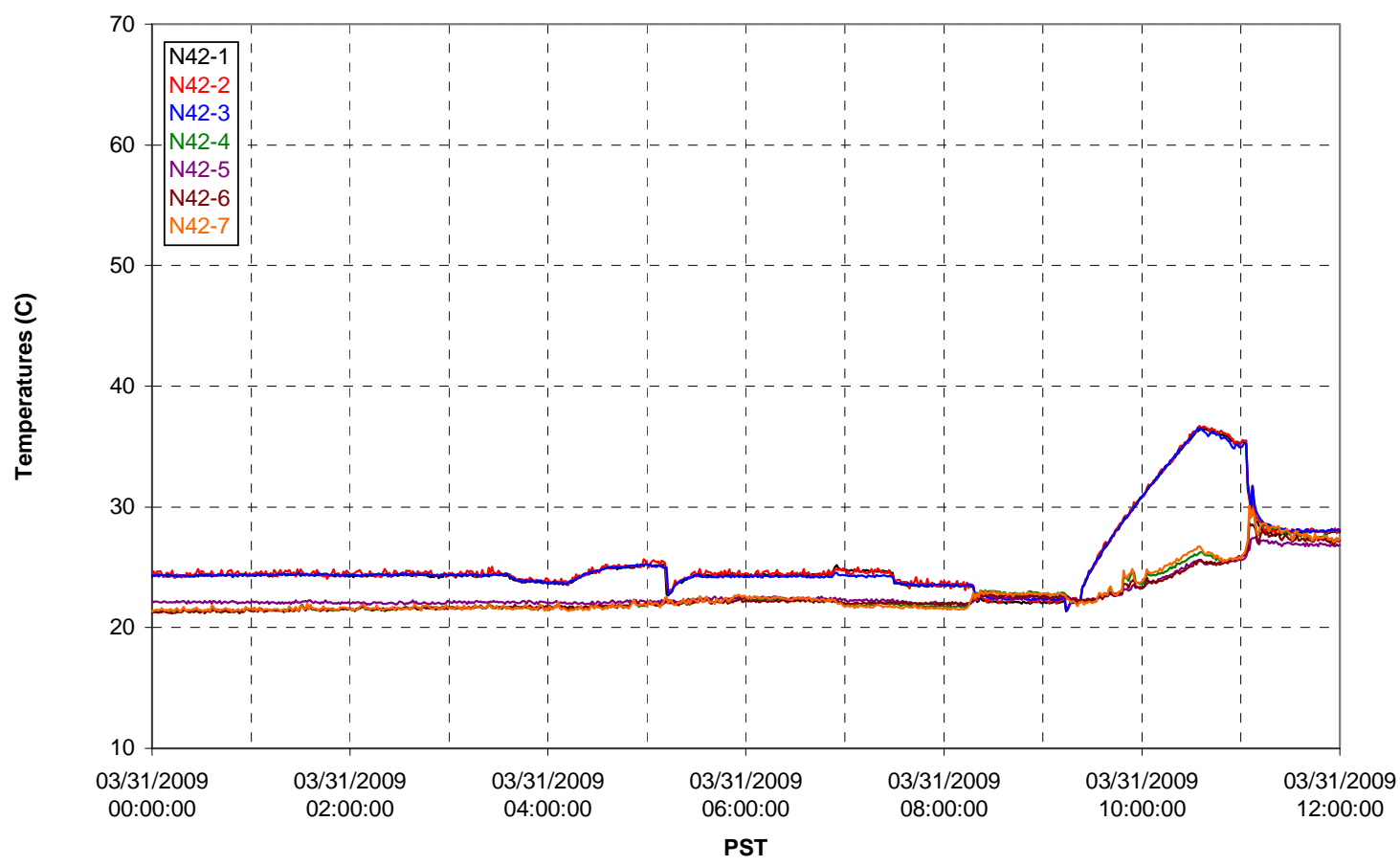

T02A temperatures

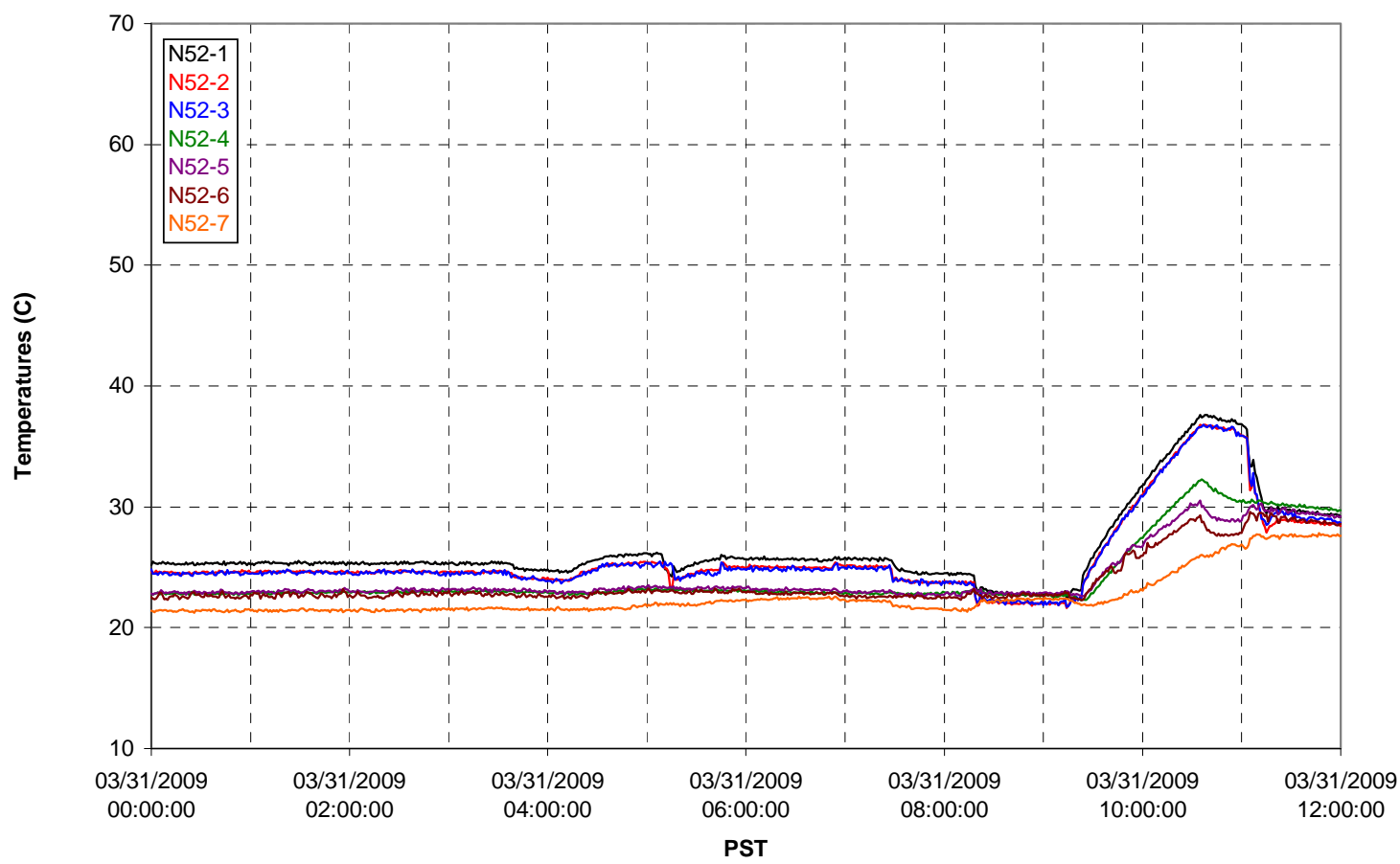


T02A Heating and Cooling
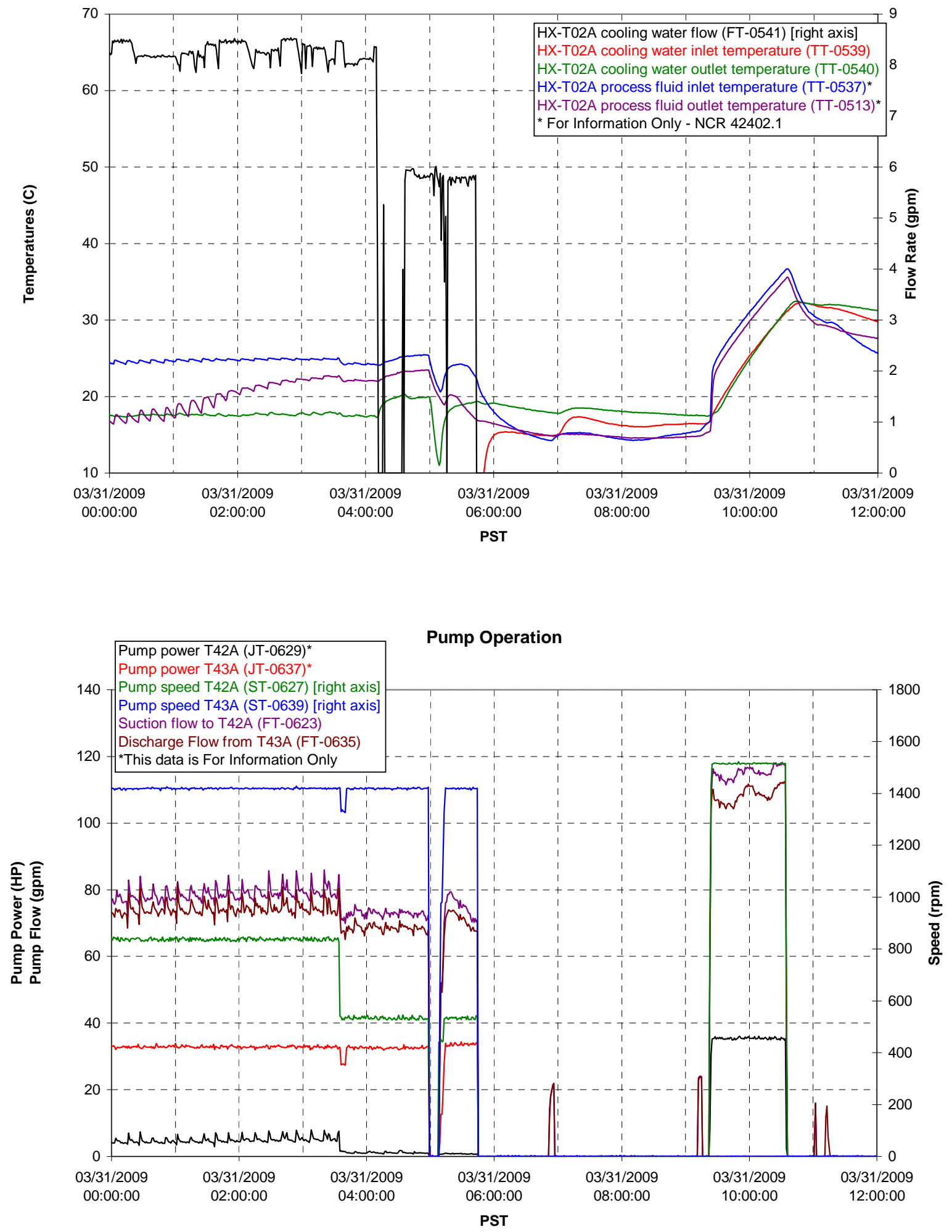
Pulsepot UFP-PP-T01A

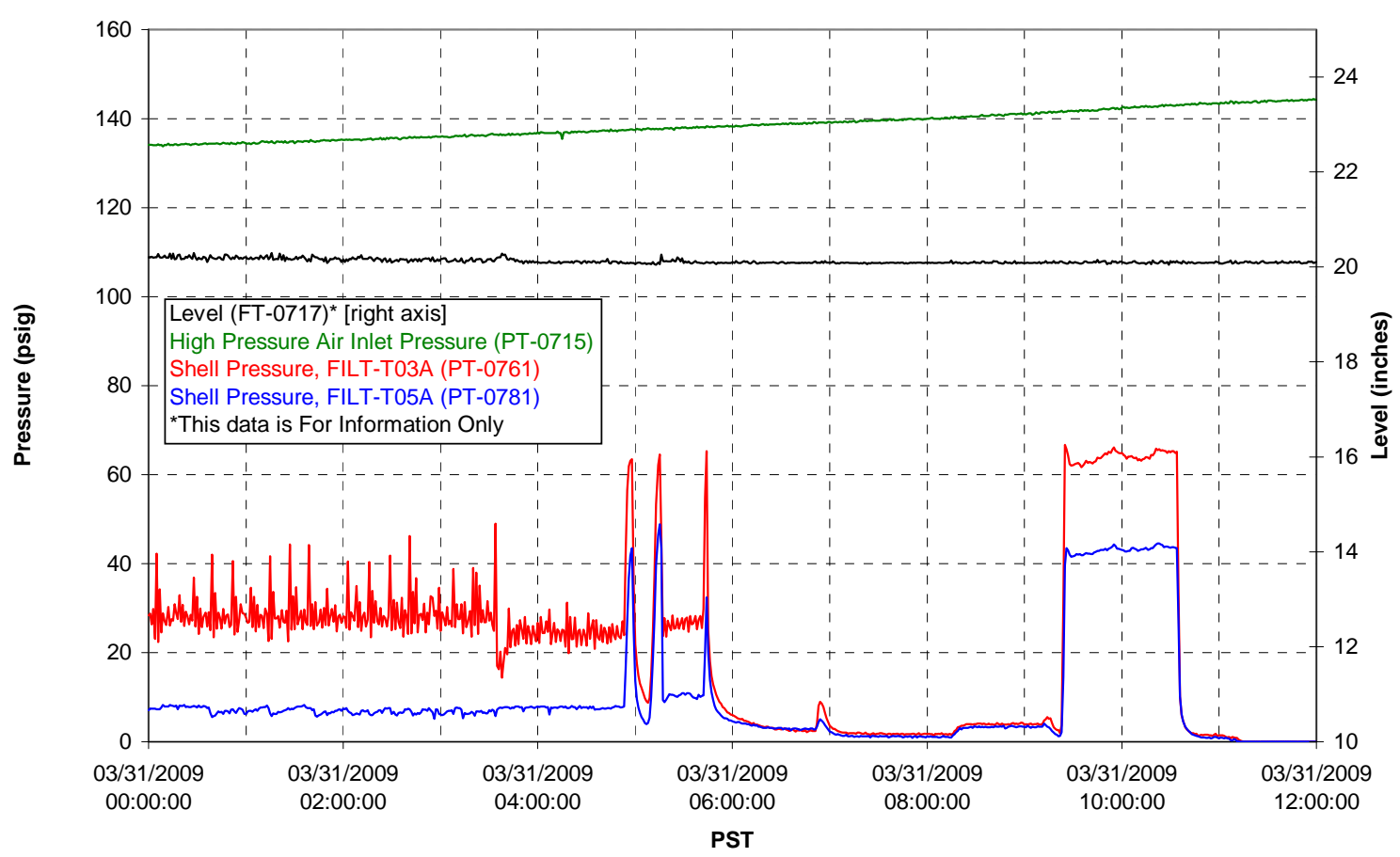

Pulsepot UFP-PP-T02A

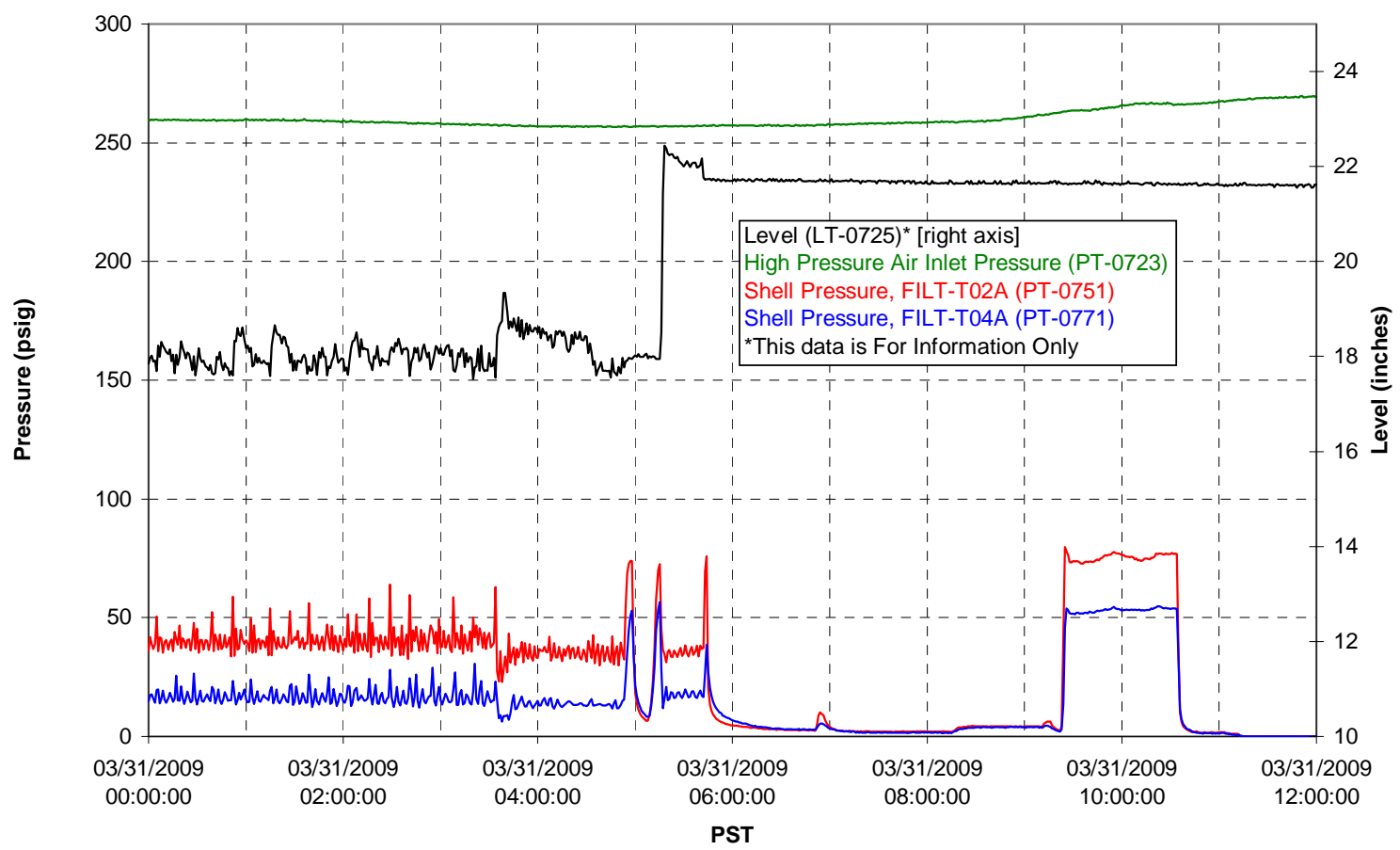


Pulsepot UFP-PP-T03A

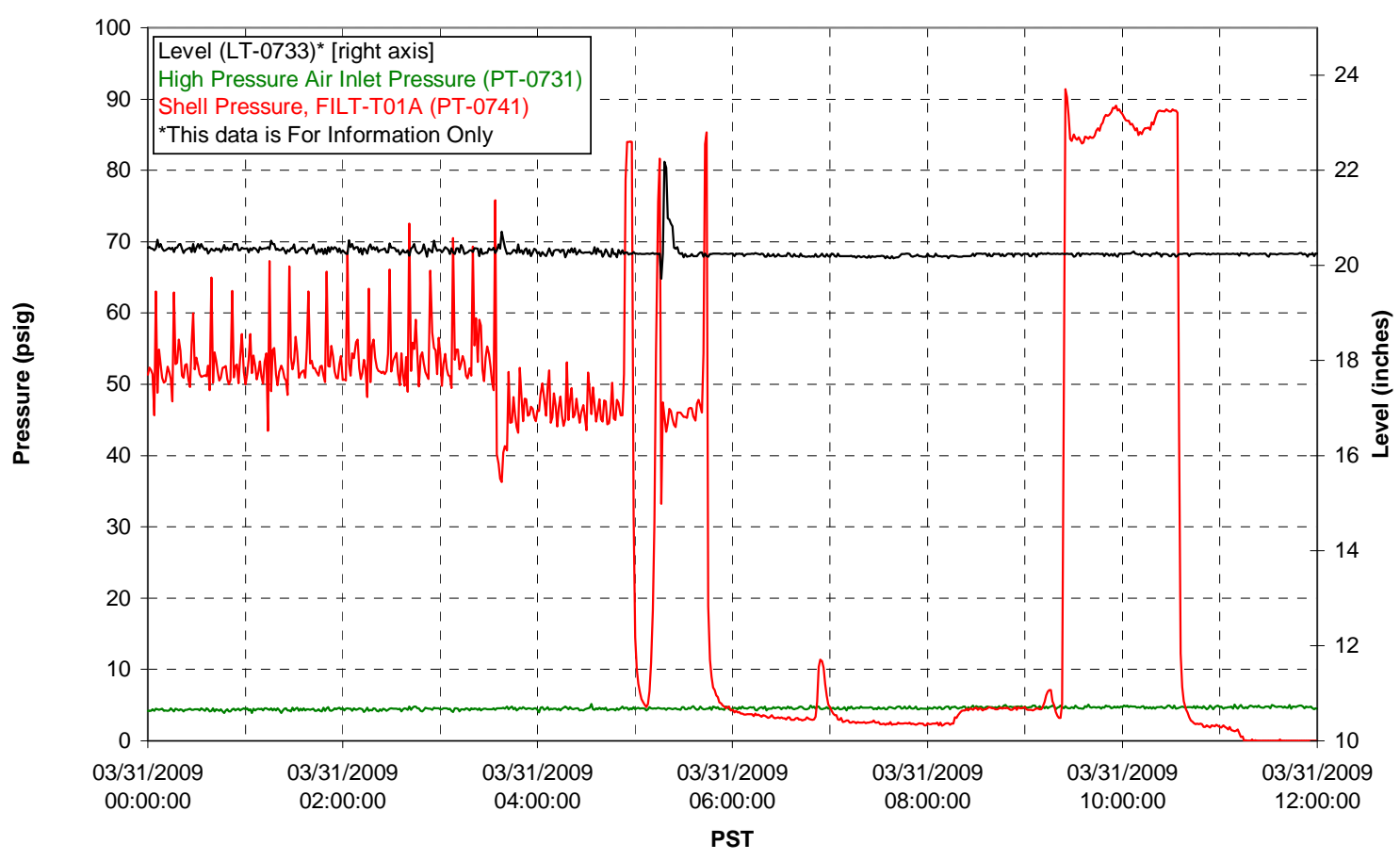

Pulsepot Levels

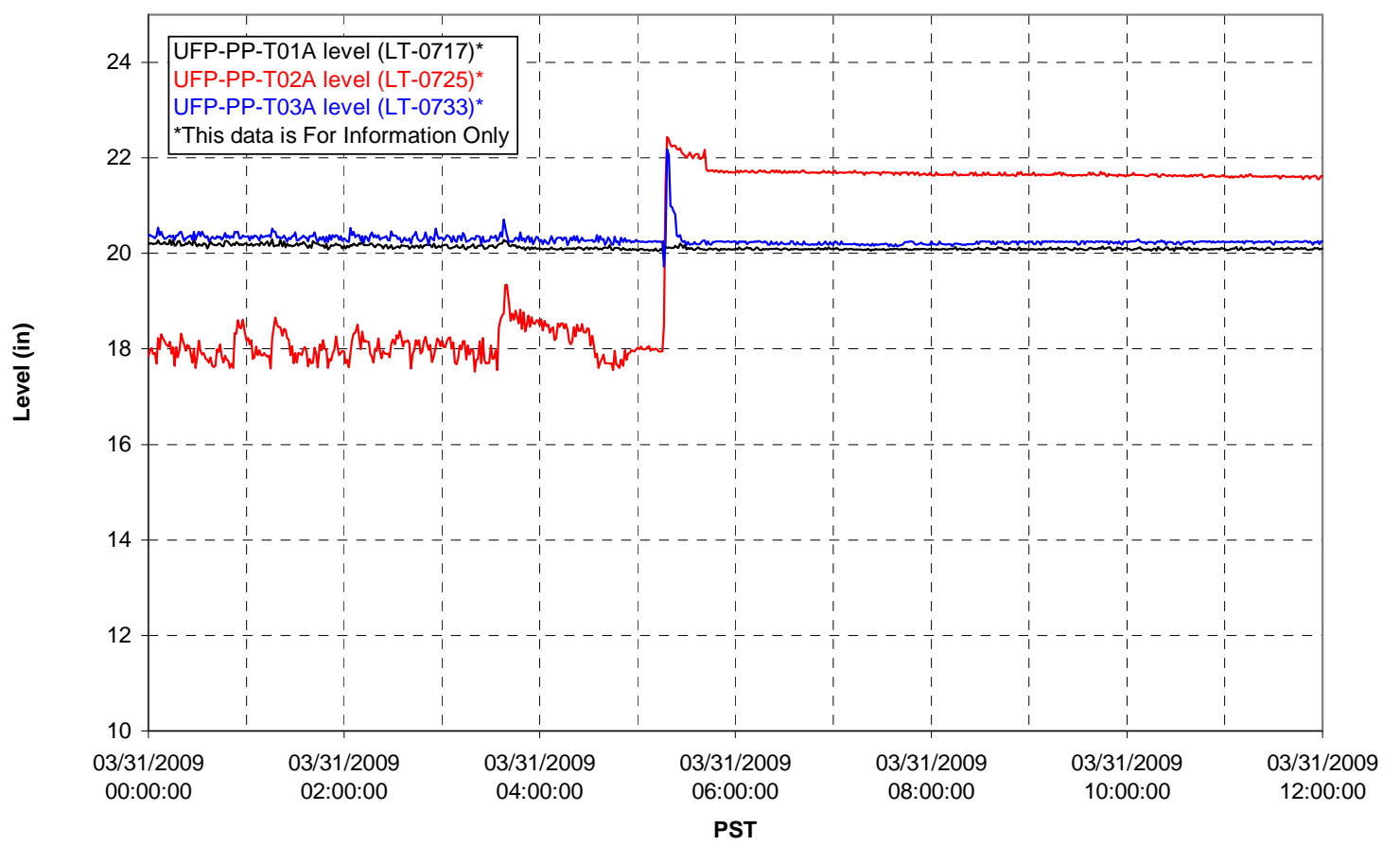


Filter UFP-FILT-T01A

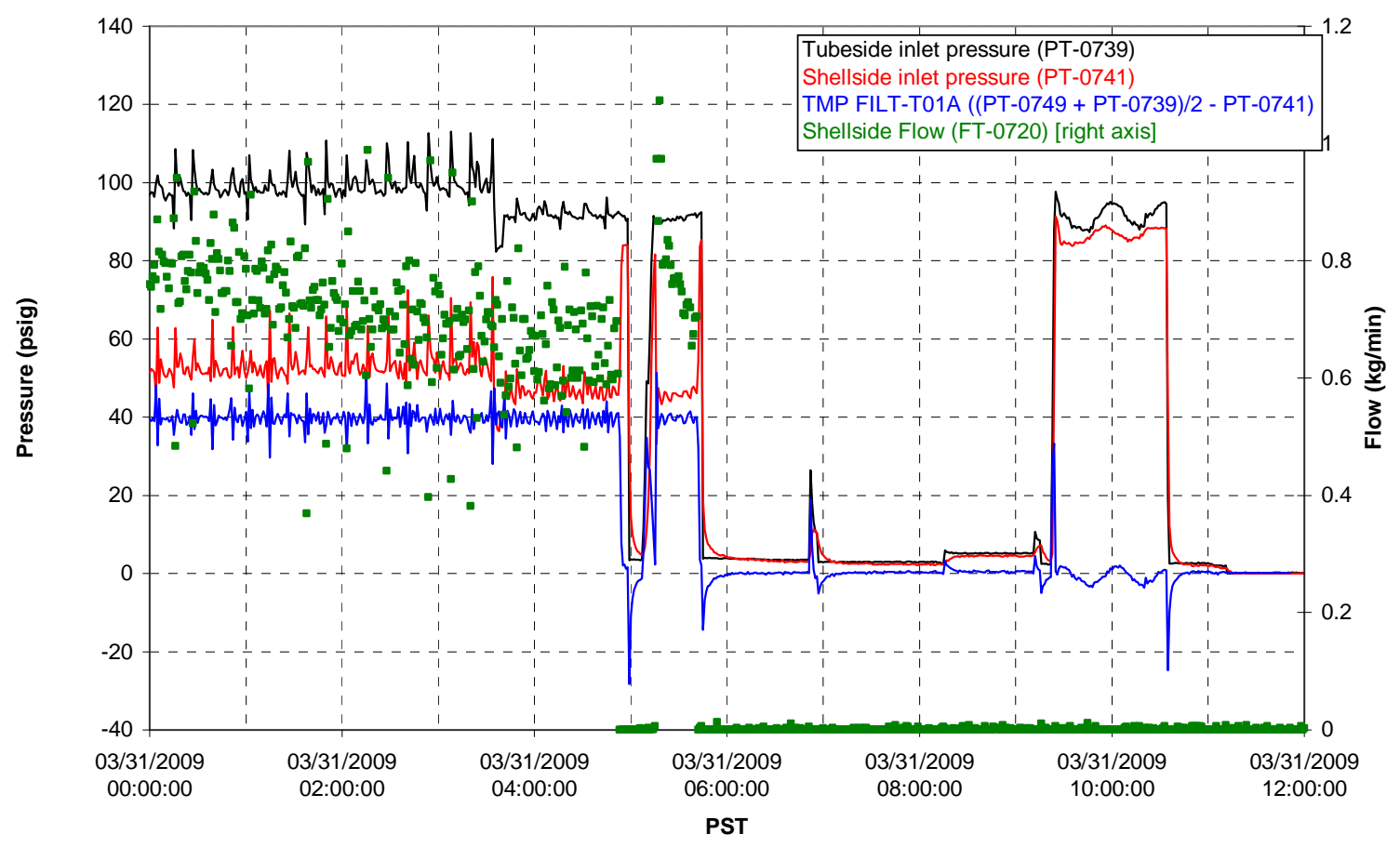

Filter UFP-FILT-T02A

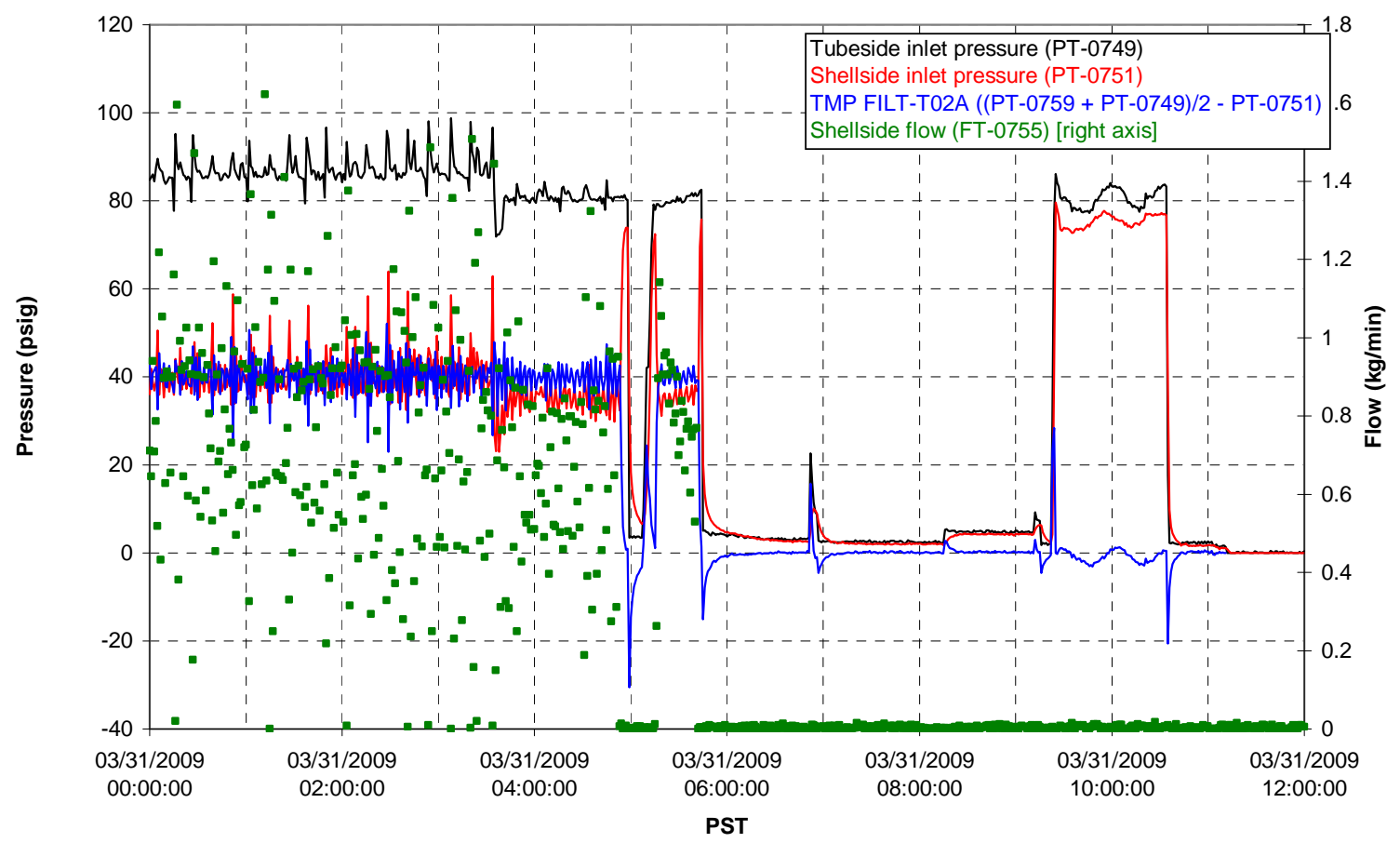


Filter UFP-FILT-T03A

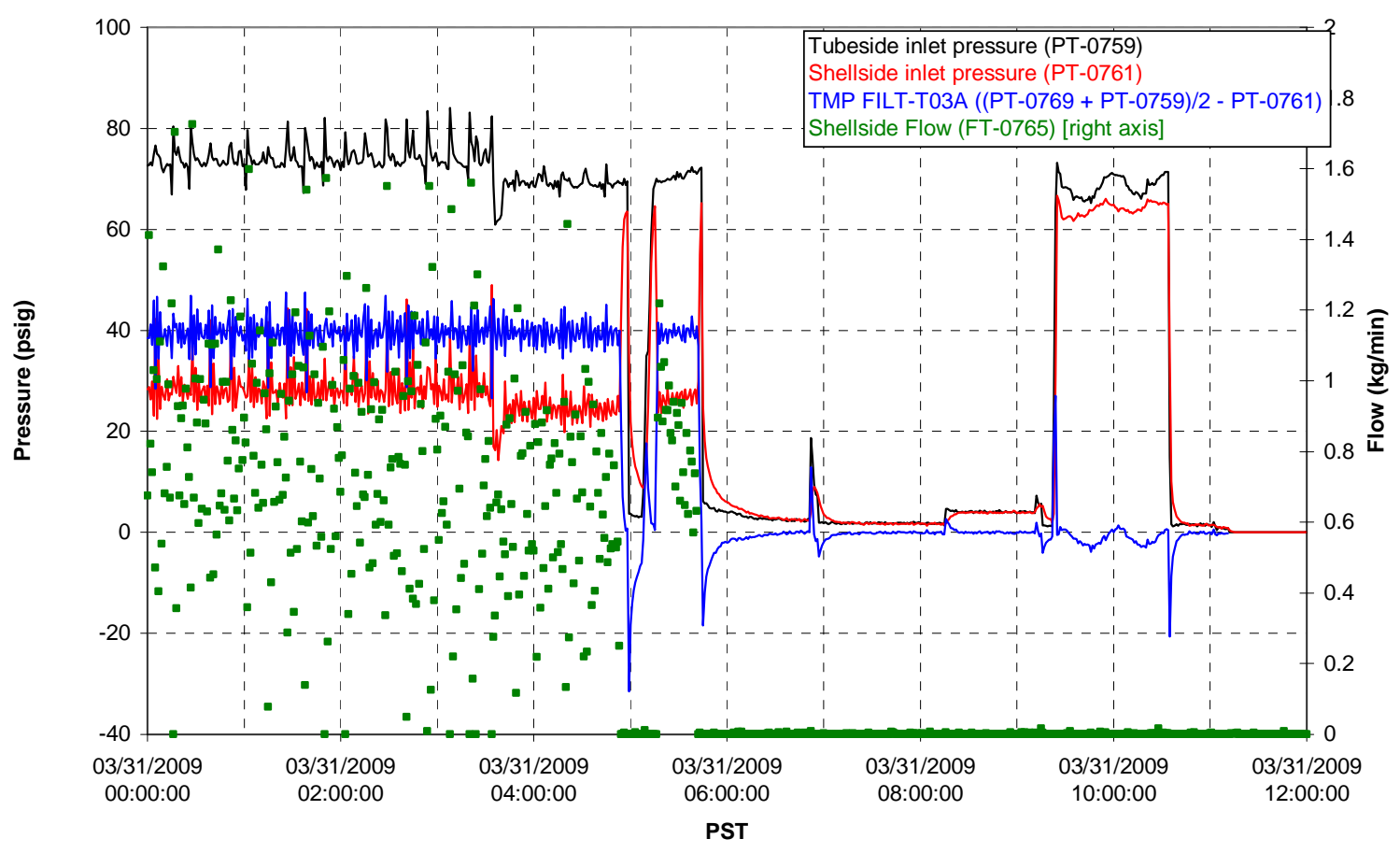

Filter UFP-FILT-T04A

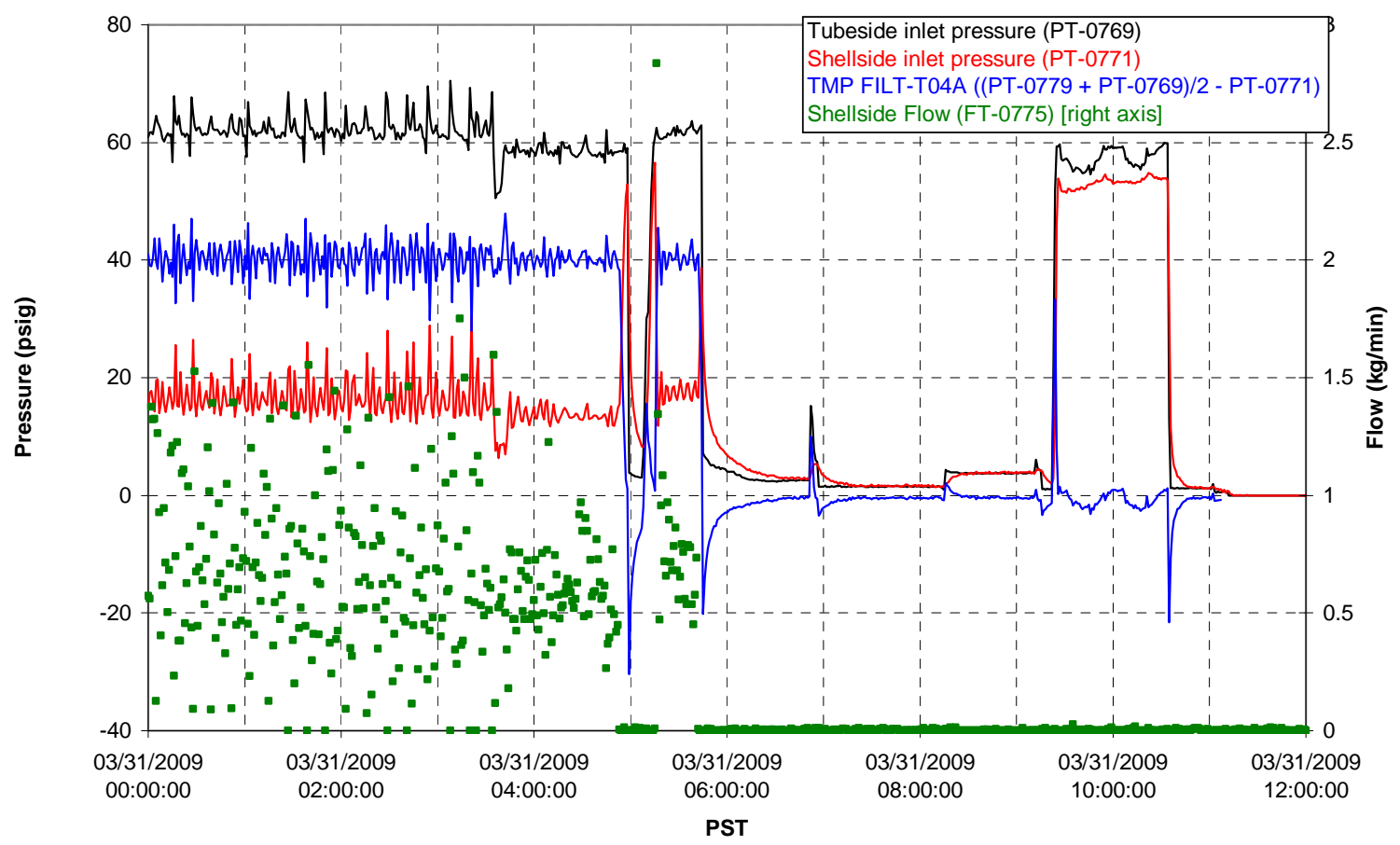


Filter UFP-FILT-T05A

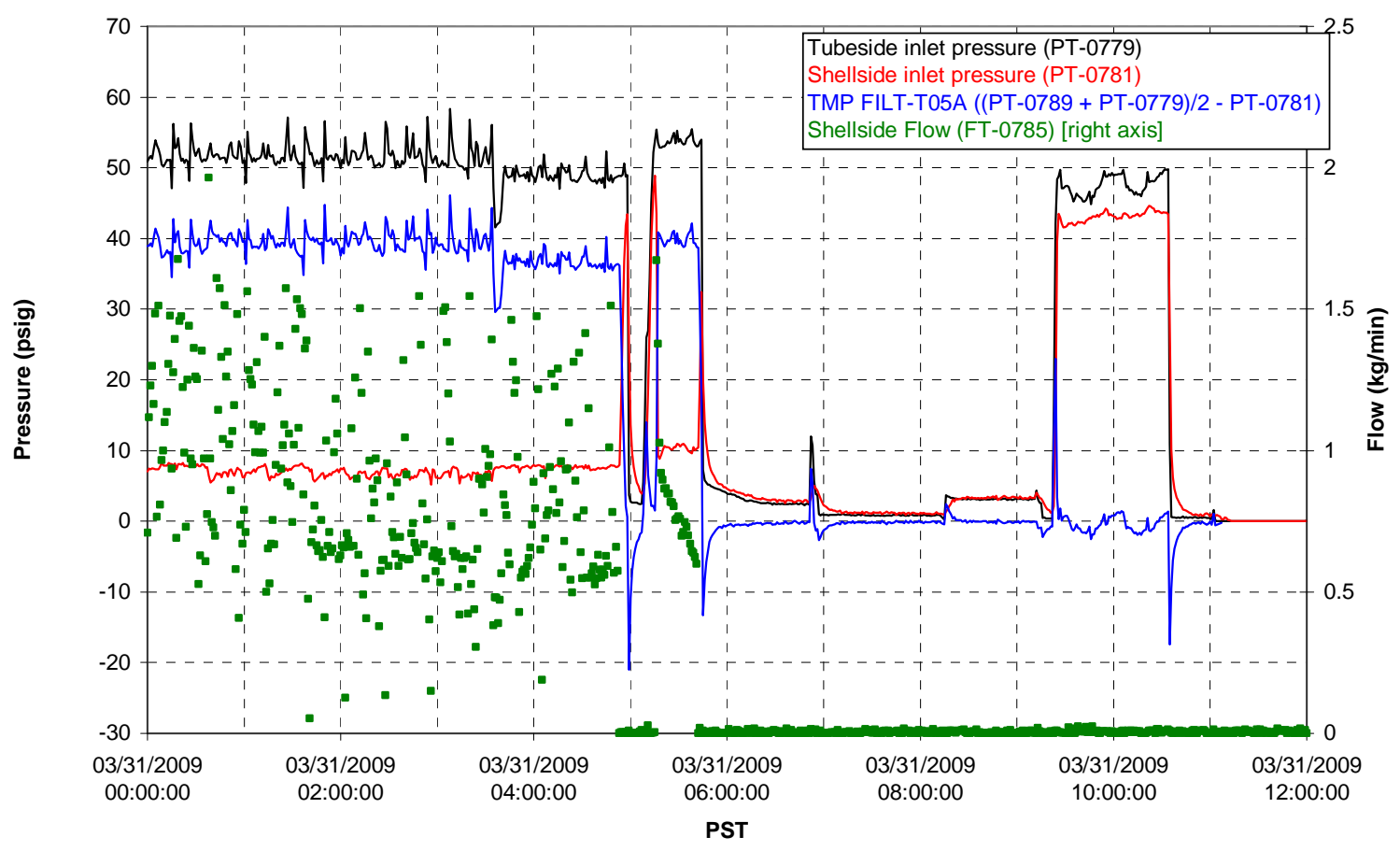

Chemical Flow

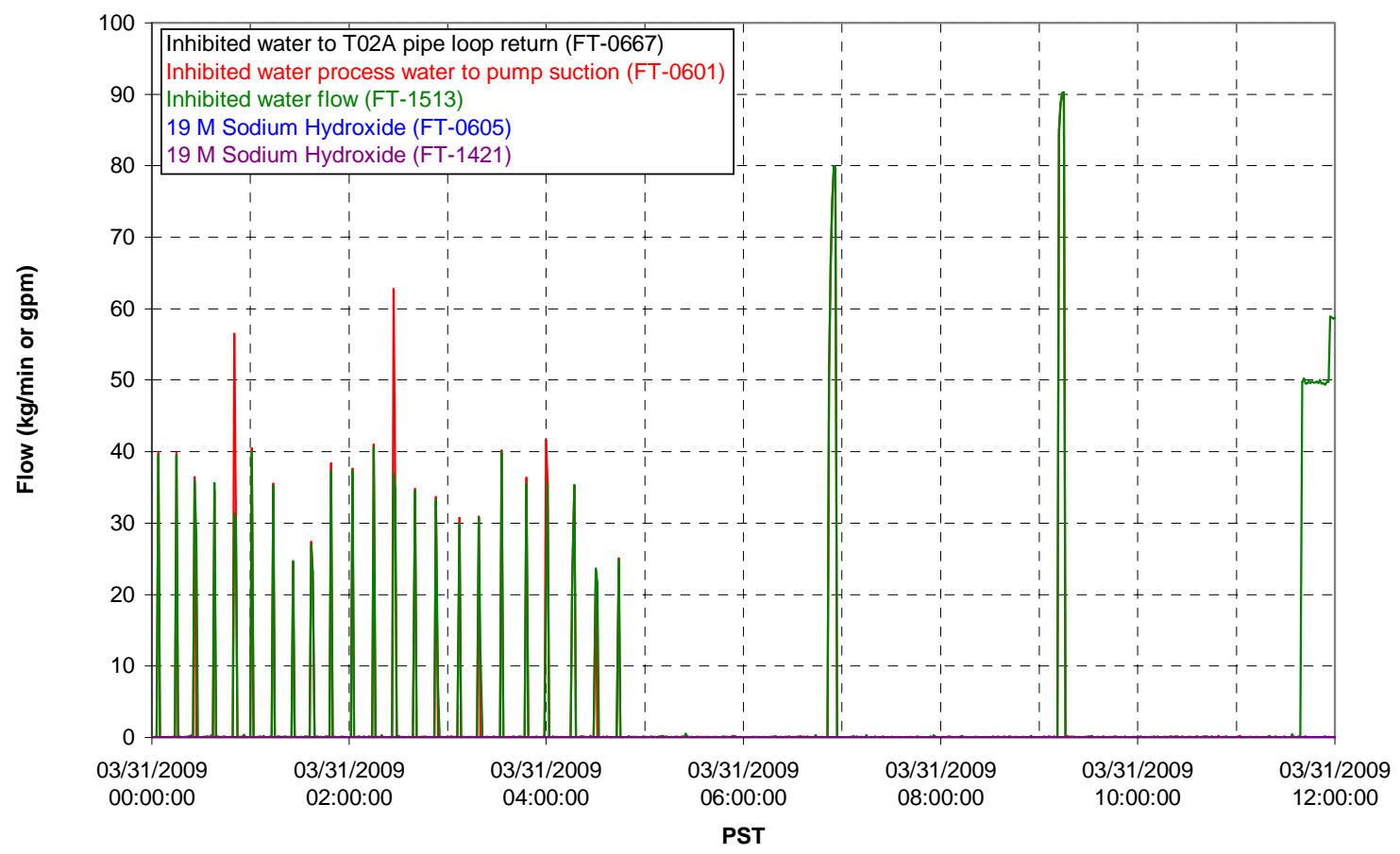




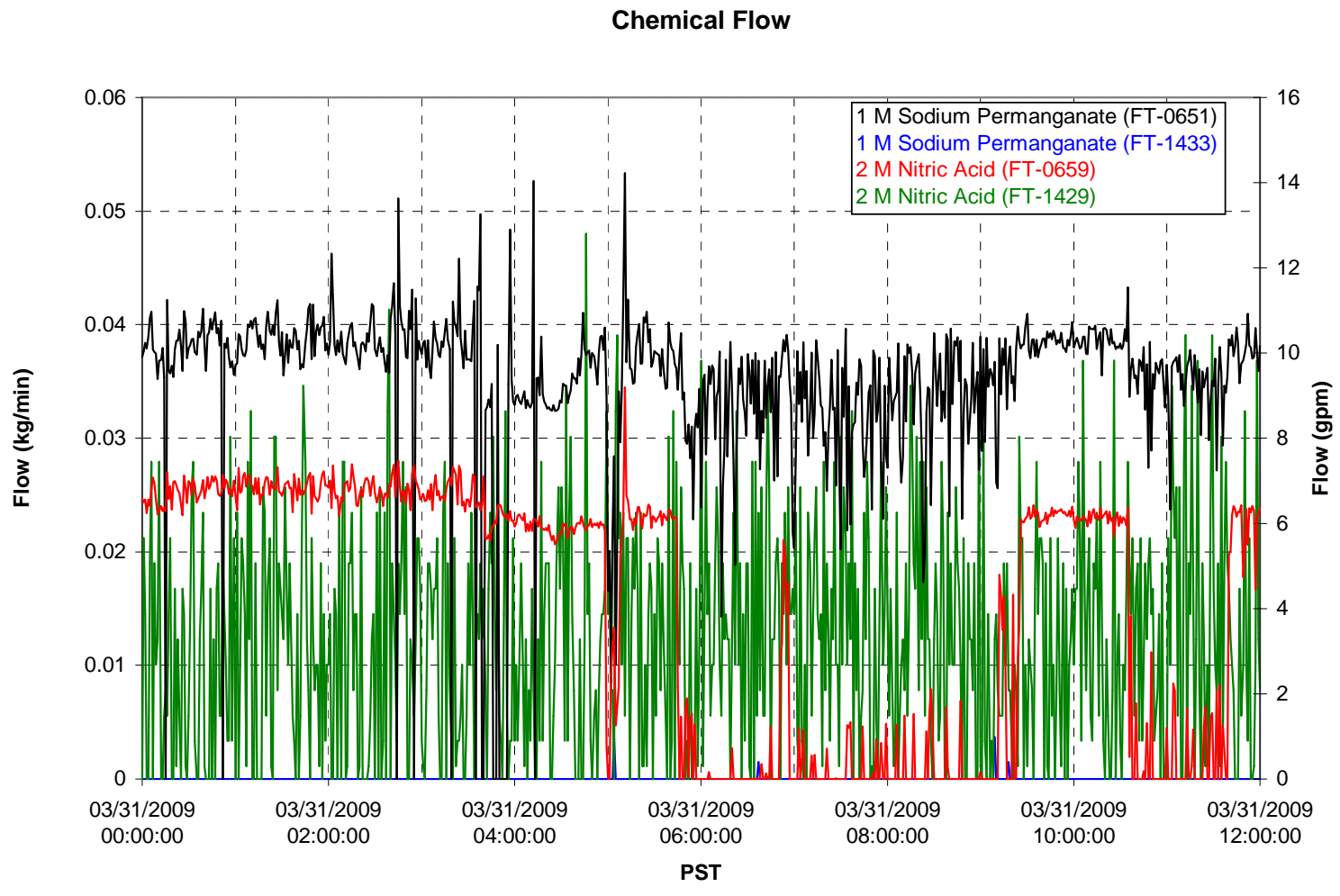

Air Flows

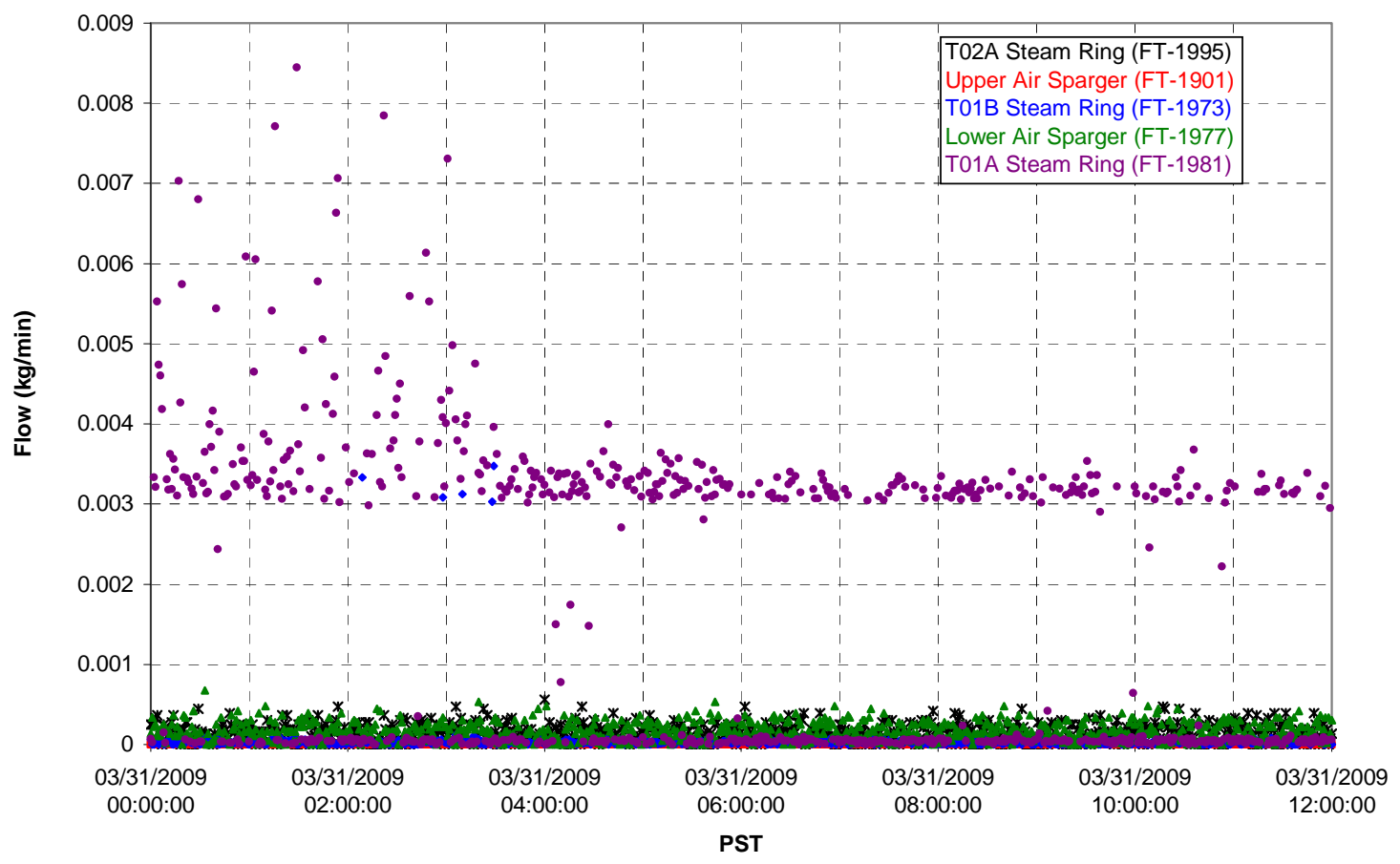


T02A Steam

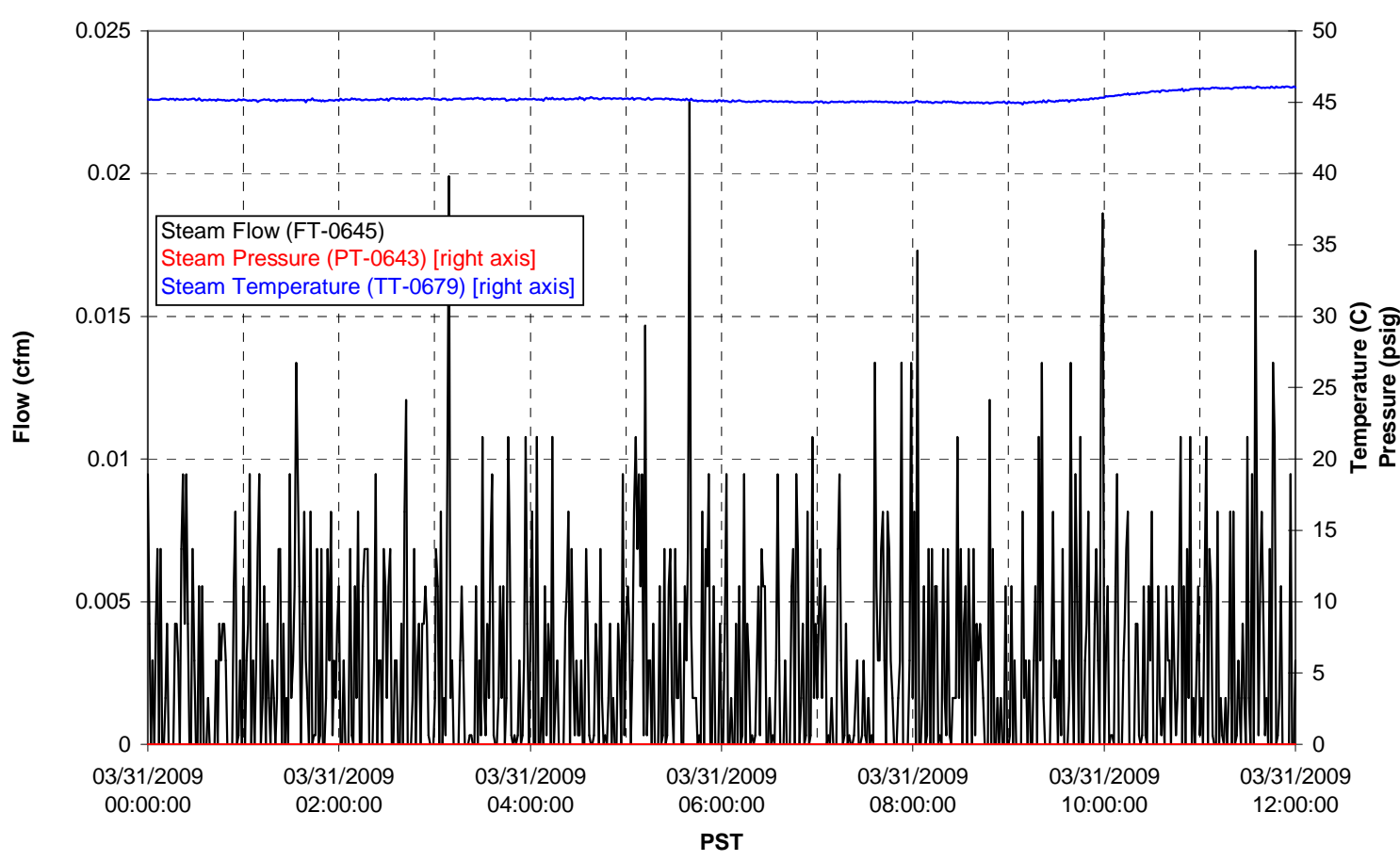

T01A Steam

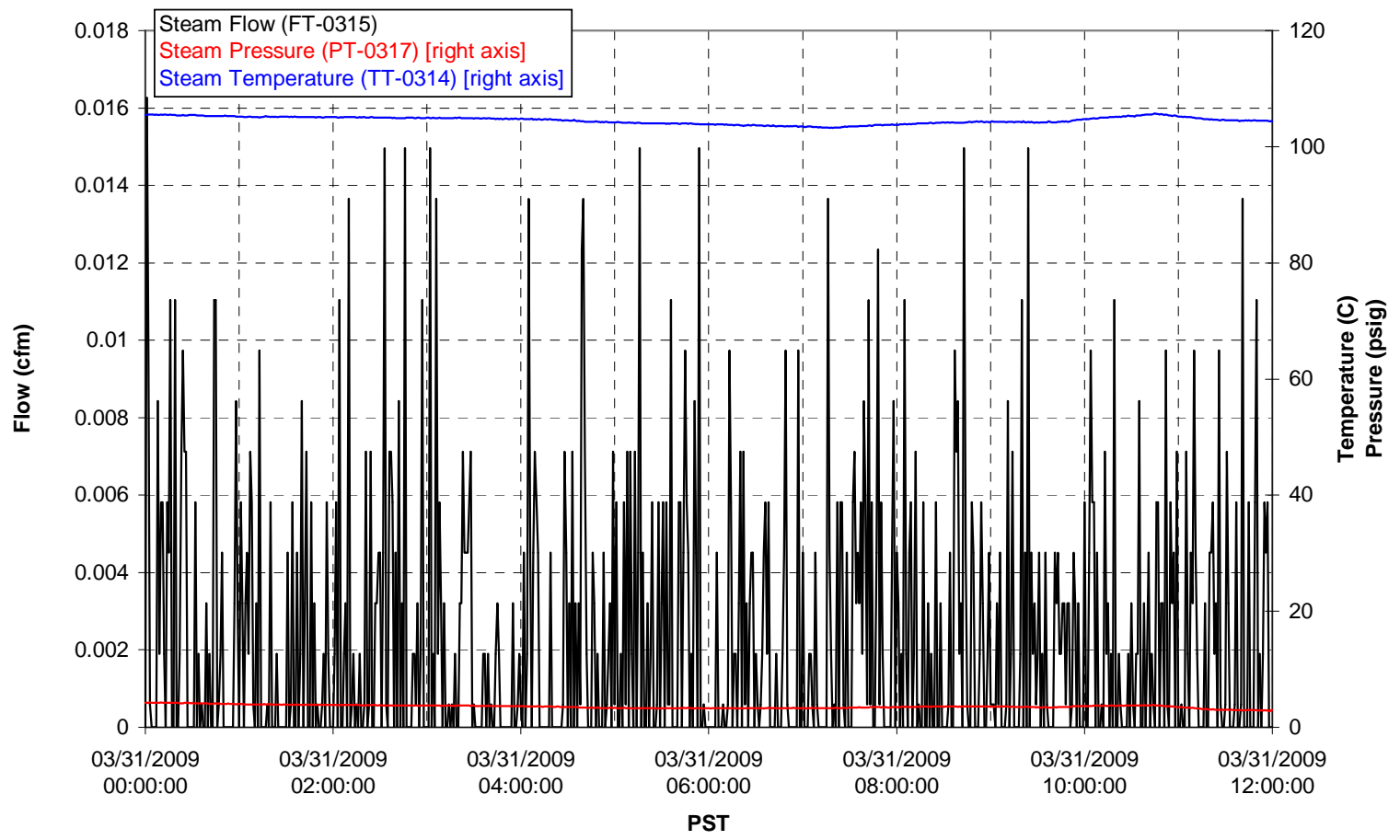




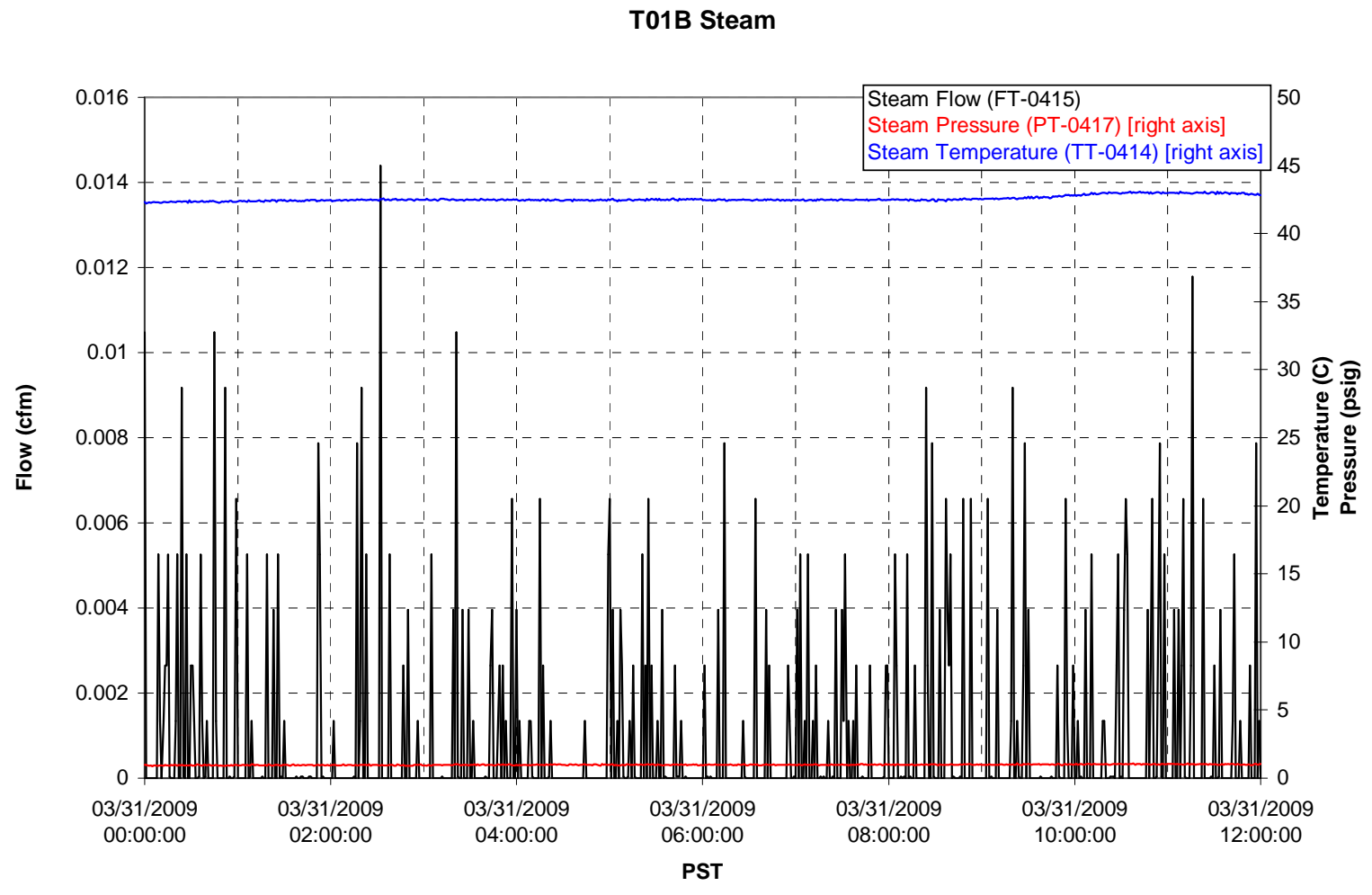




\section{Integrated Test D Data Plots 03/31/09 12:00 - 04/01/09 00:00}


T01A level

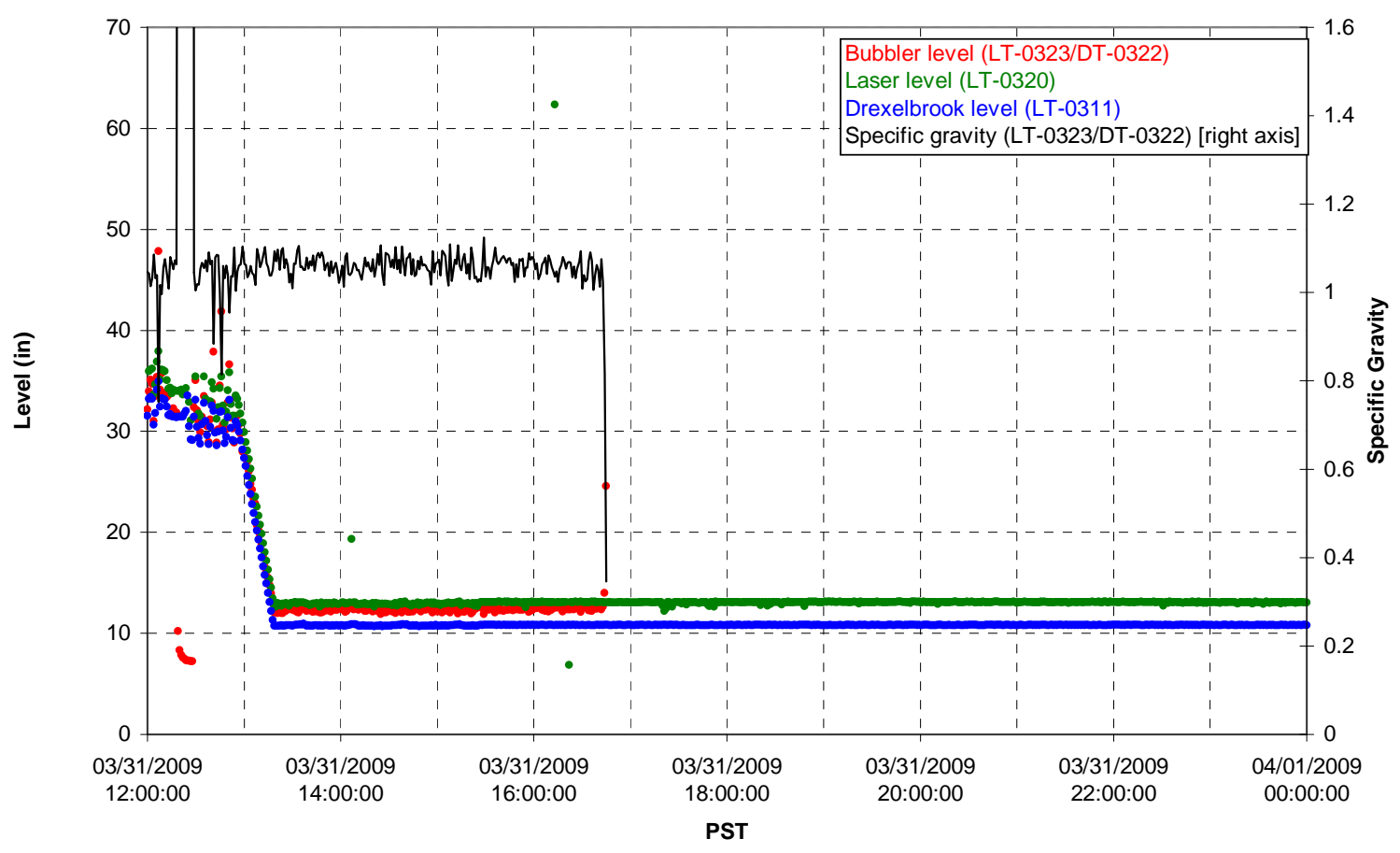

T01A temperatures

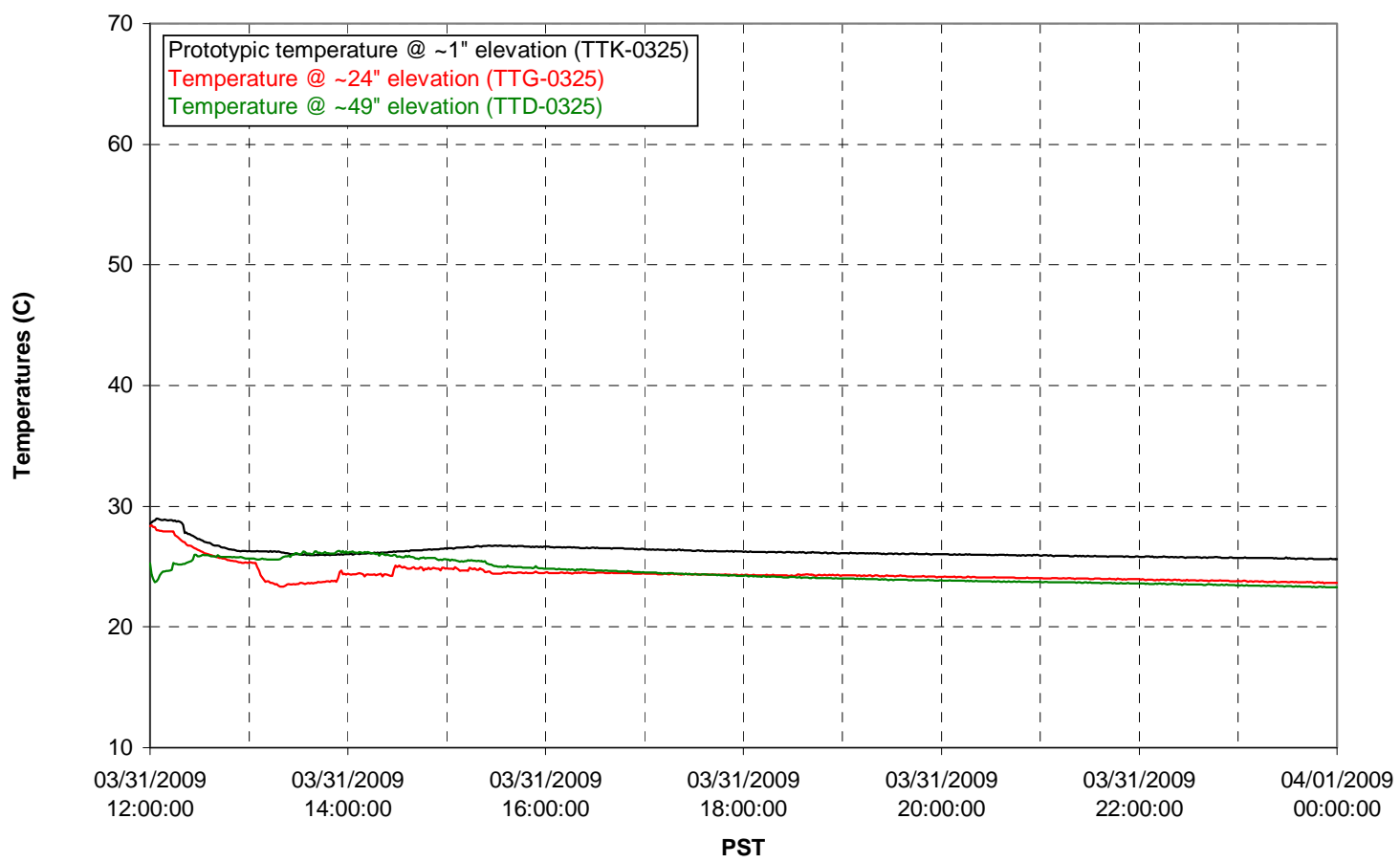


T01B level

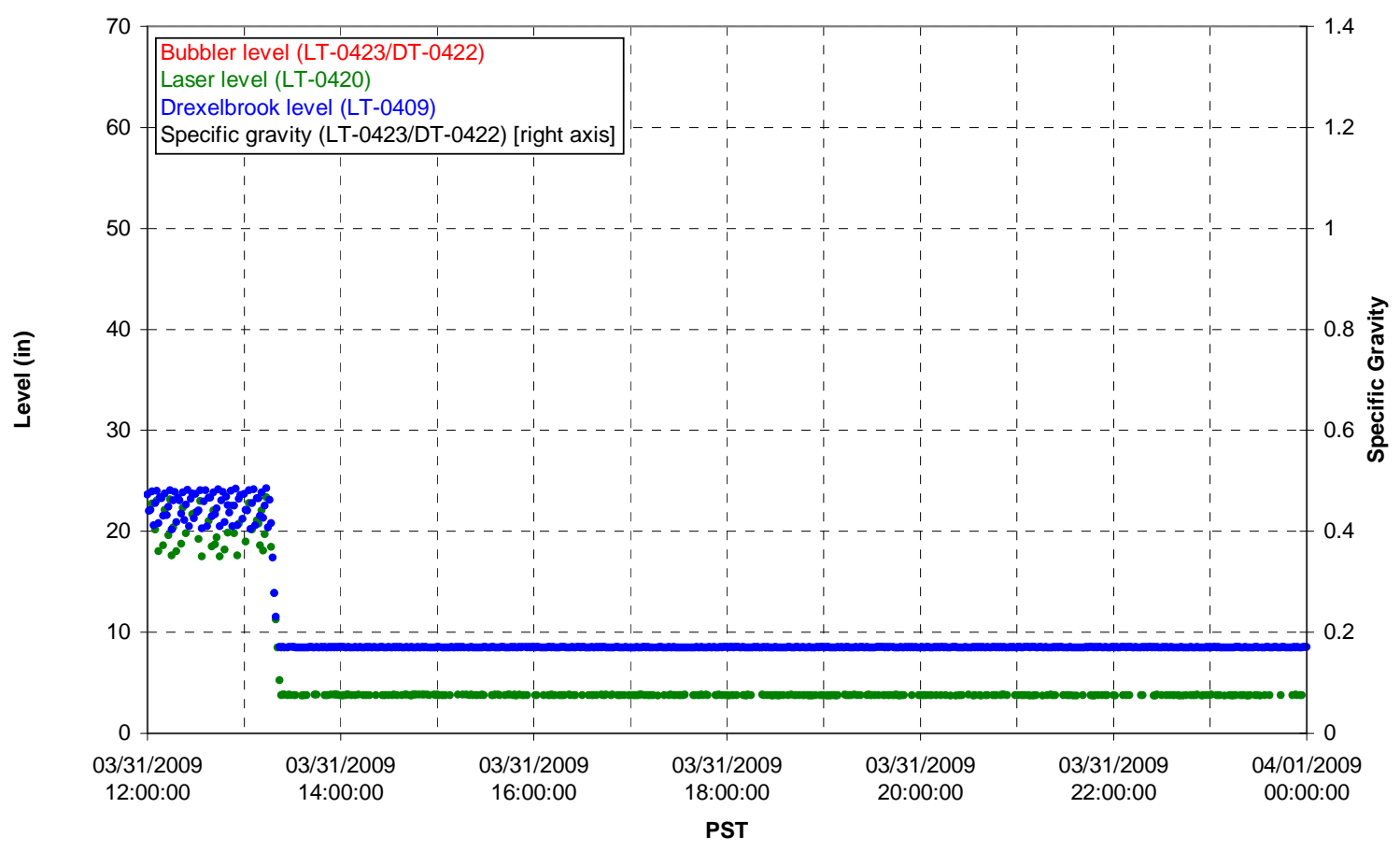

T01B temperatures

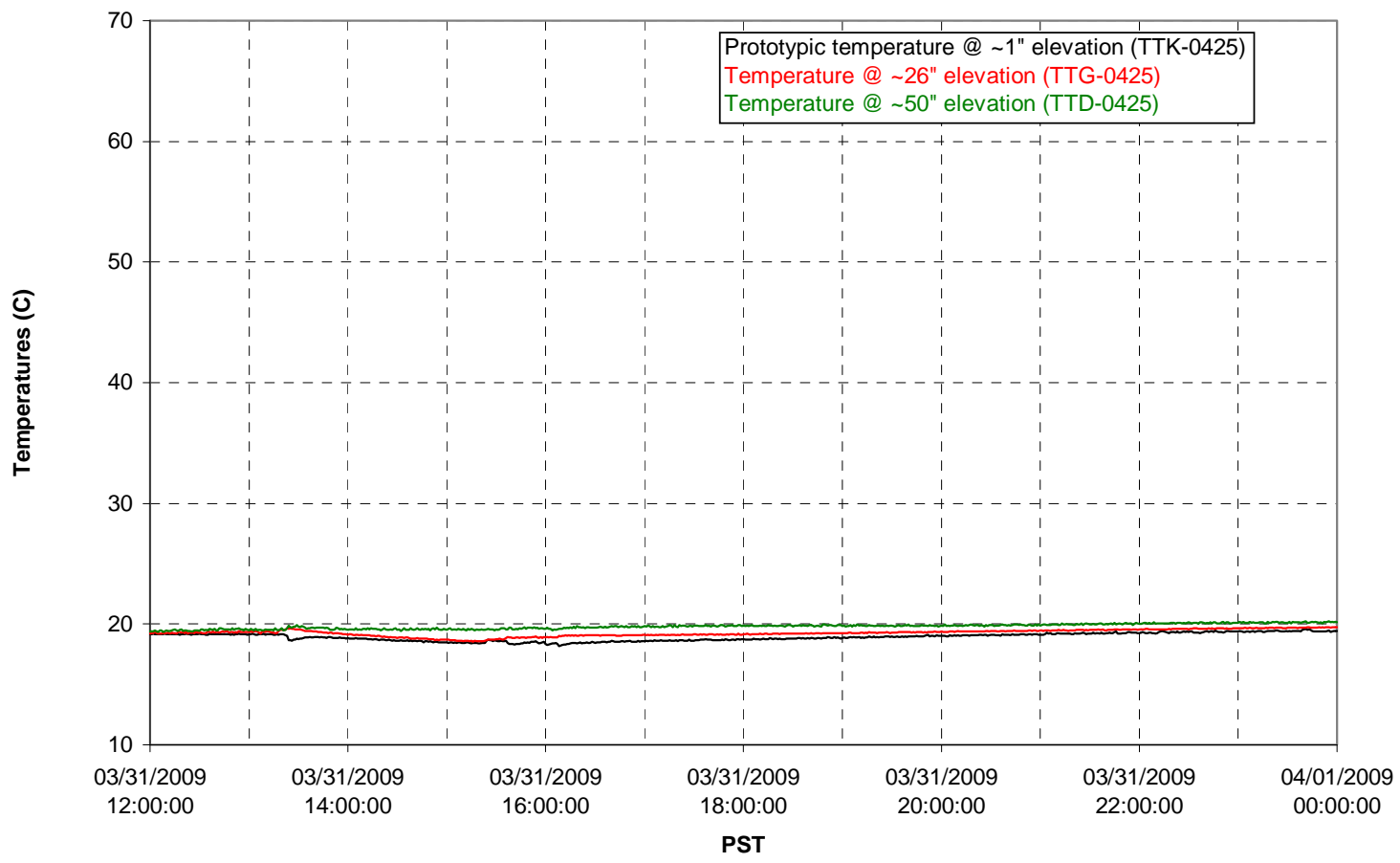


T02A level

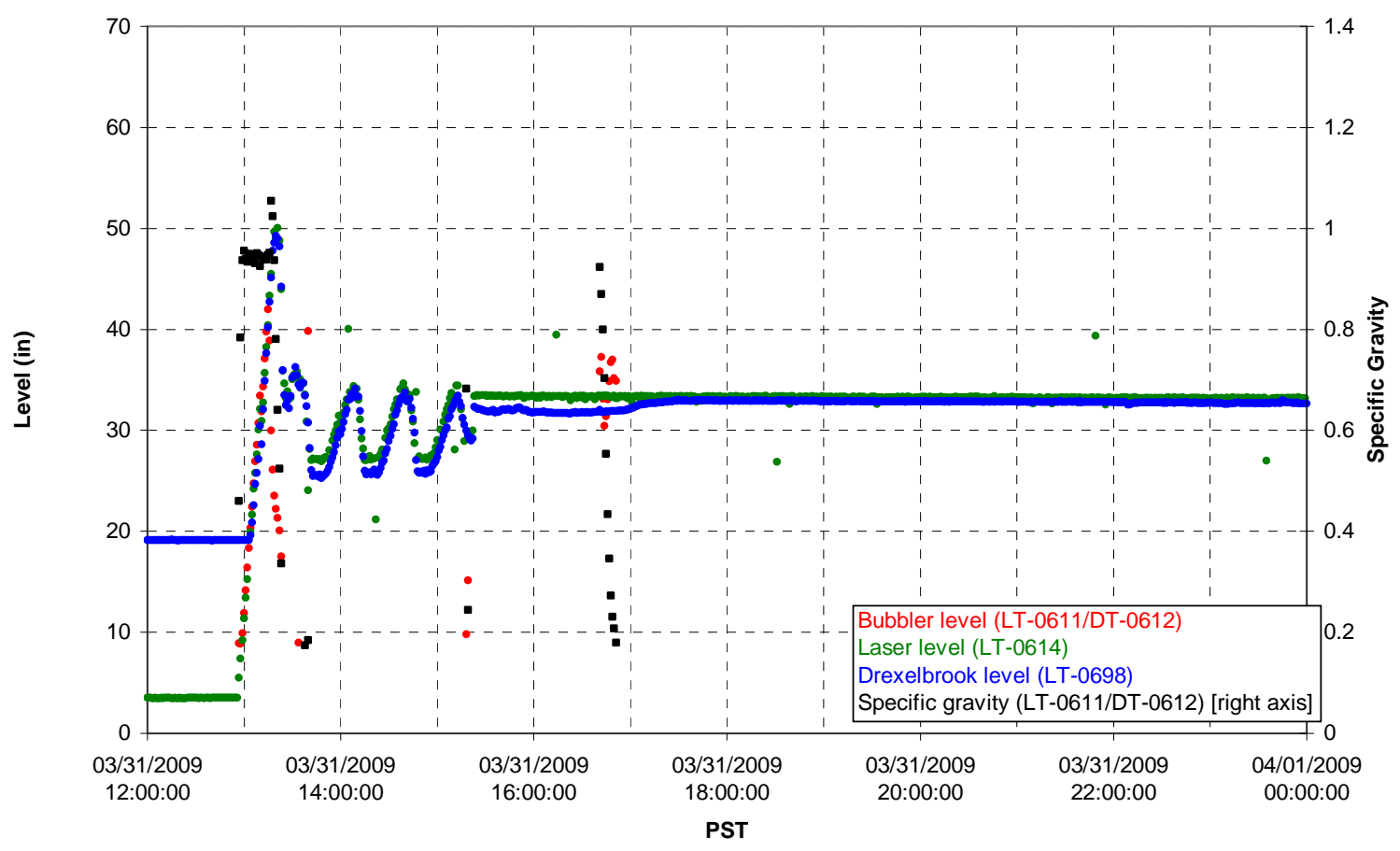

T02A temperatures

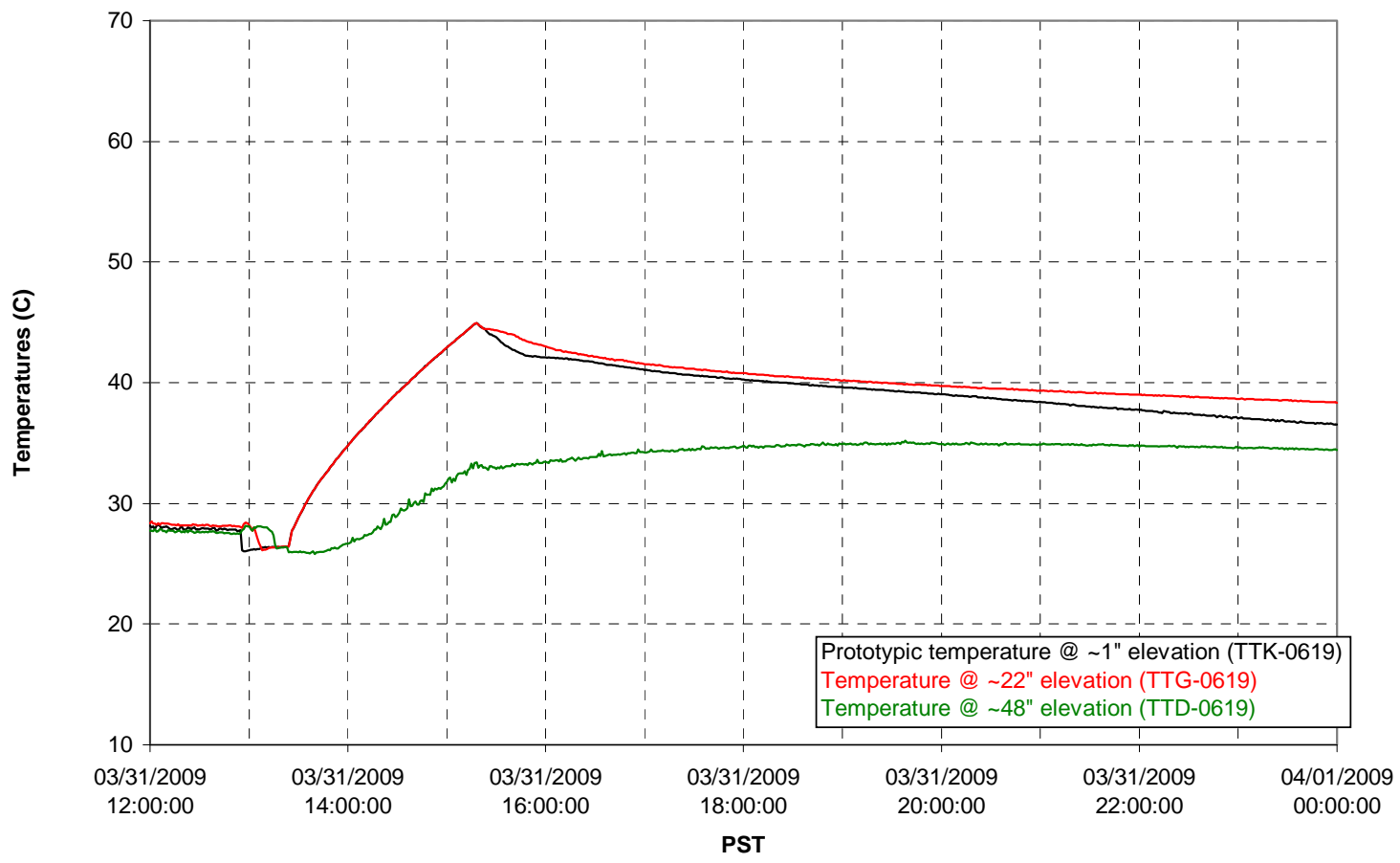


T02A and filter loop temperatures

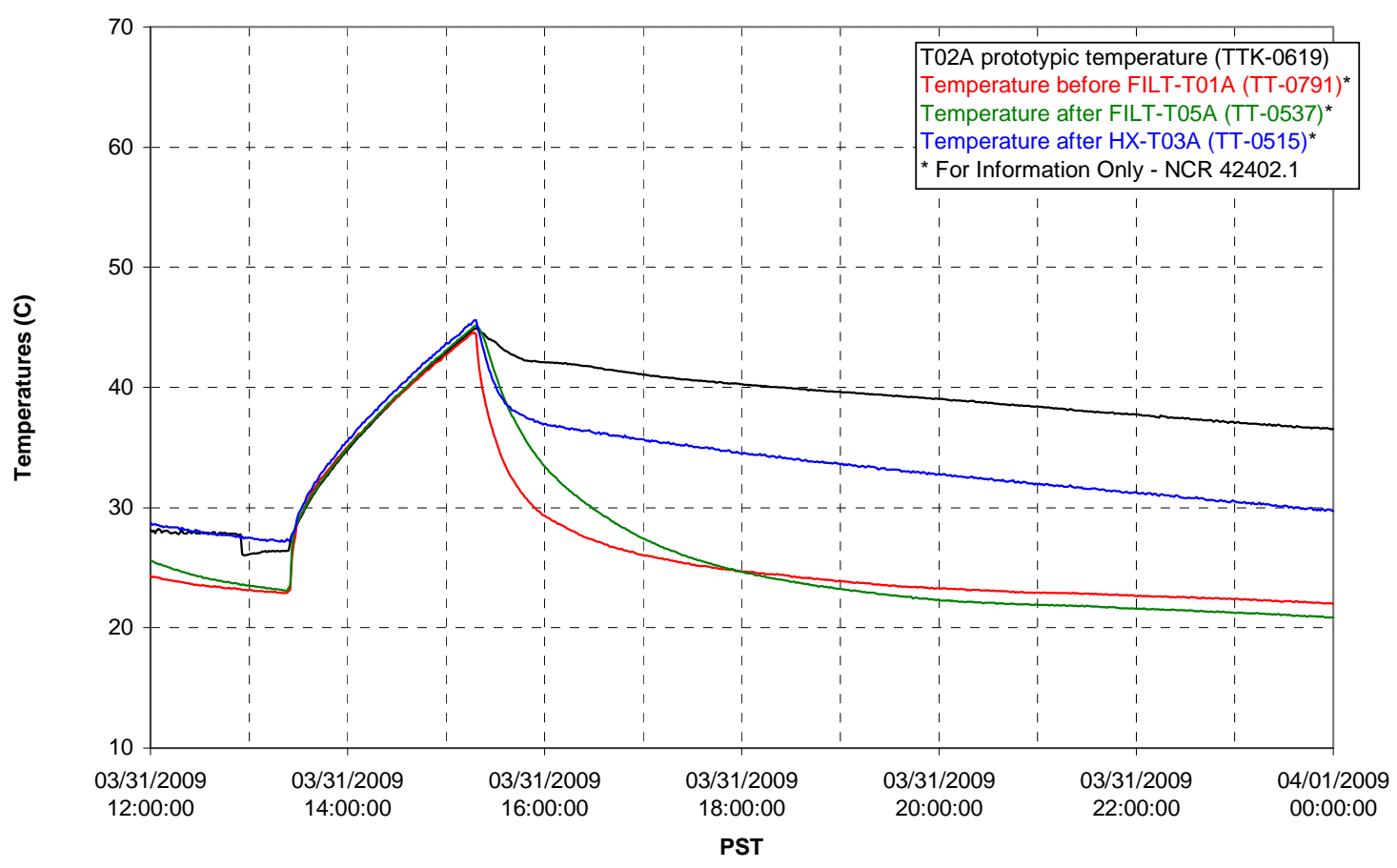

Pump Pressures and Flow

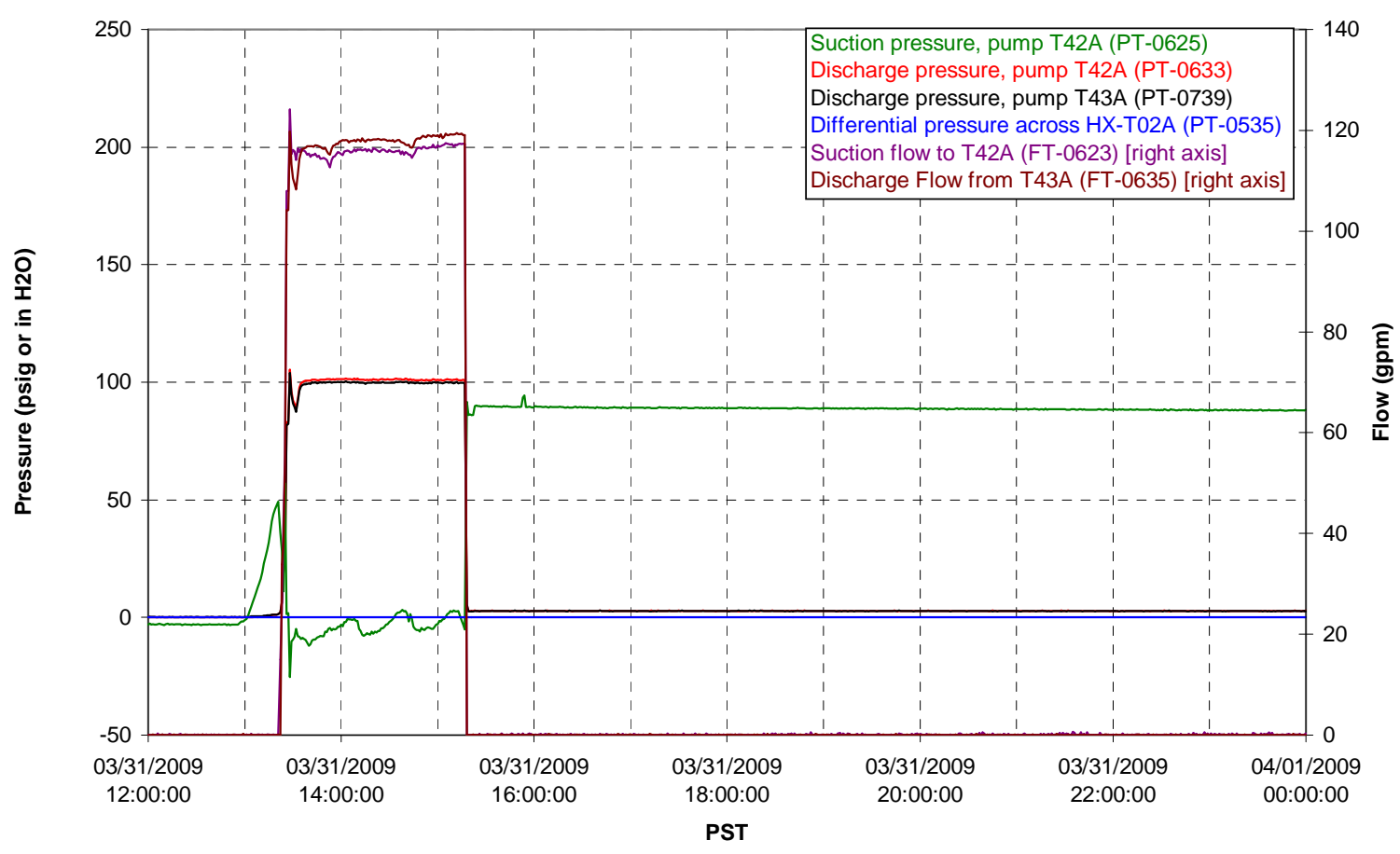




\section{Axial pressure drop}

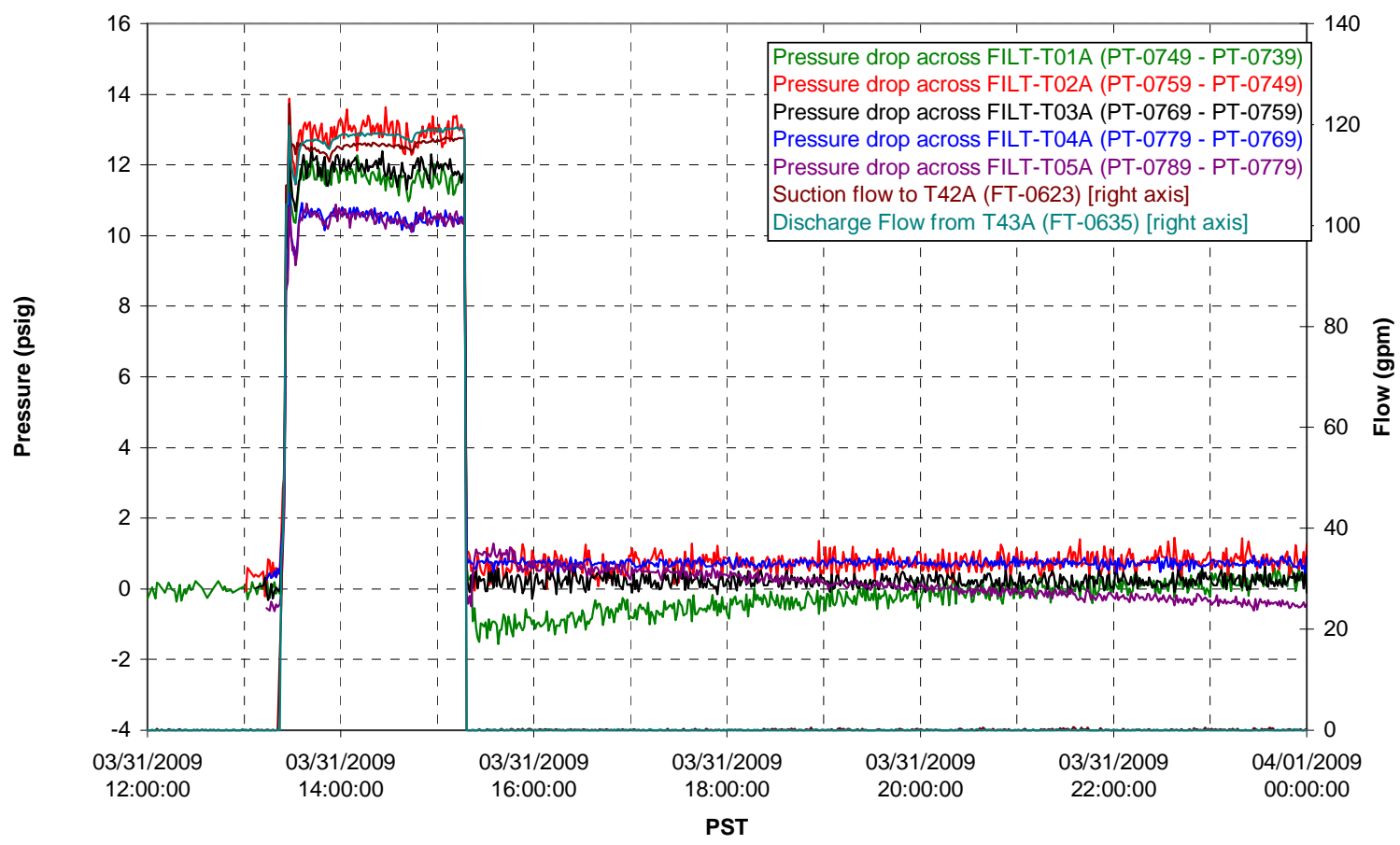

Permeate flow rates

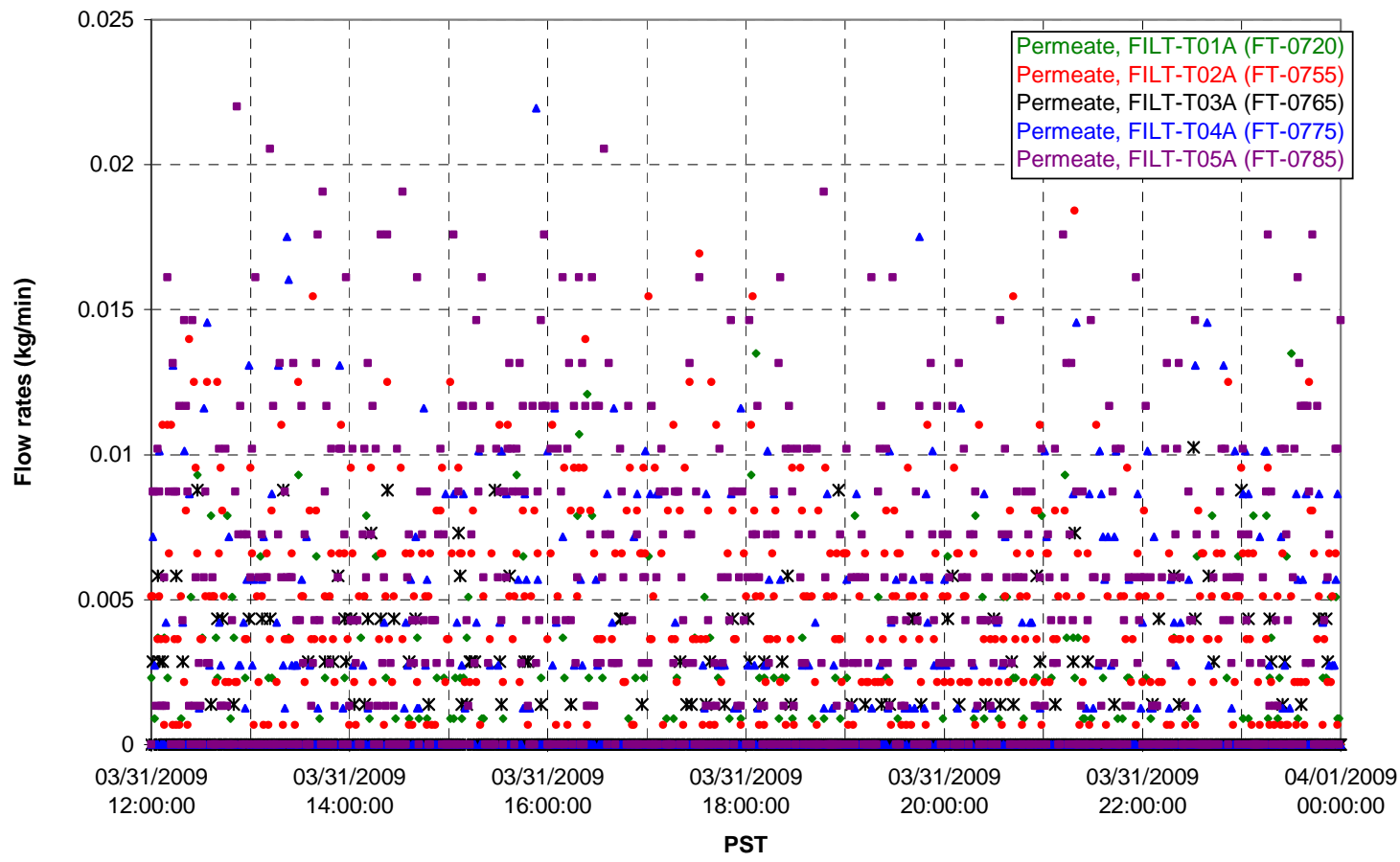


T02A Inner Temperature Tree

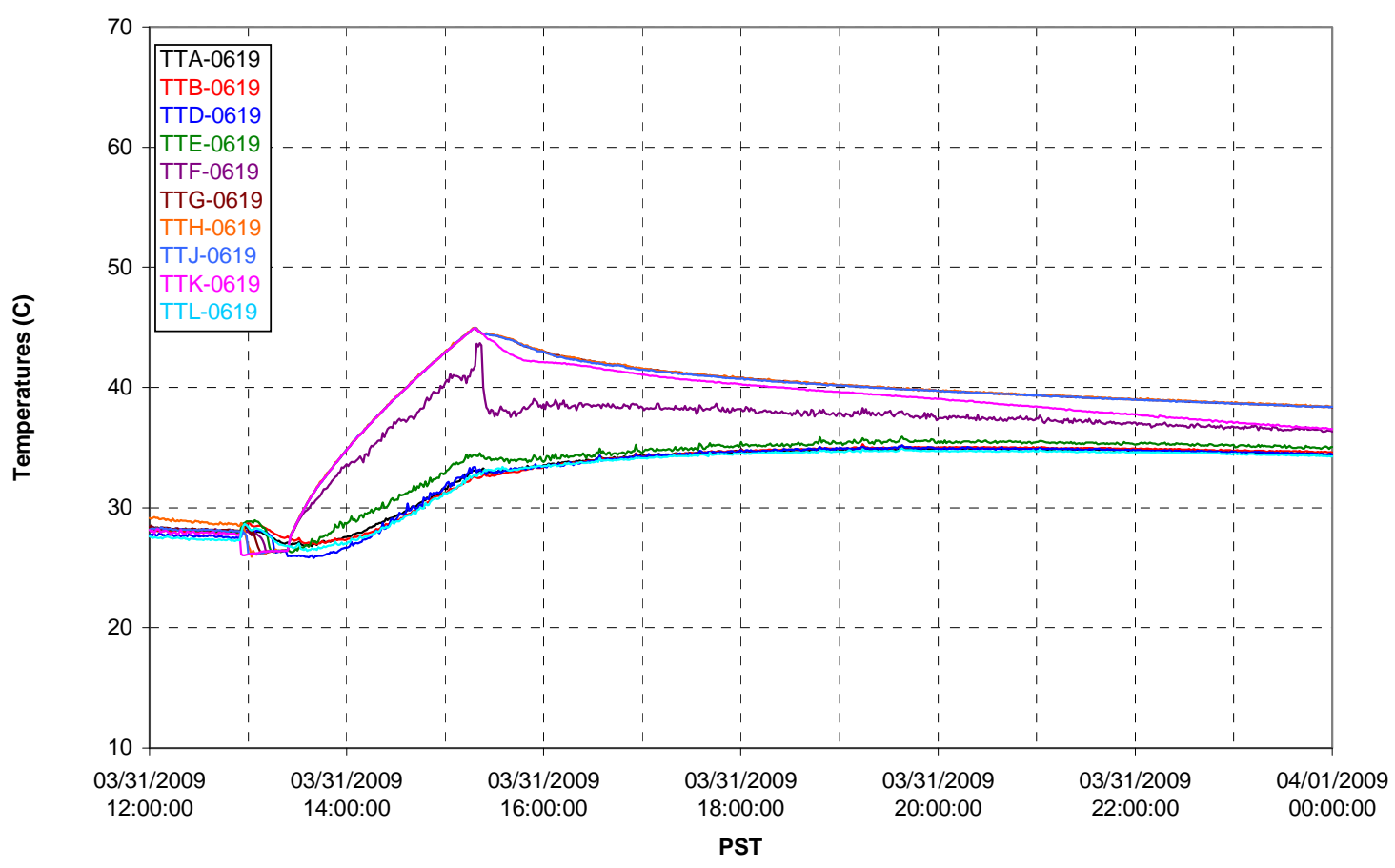

T02A Outer Temperature Tree

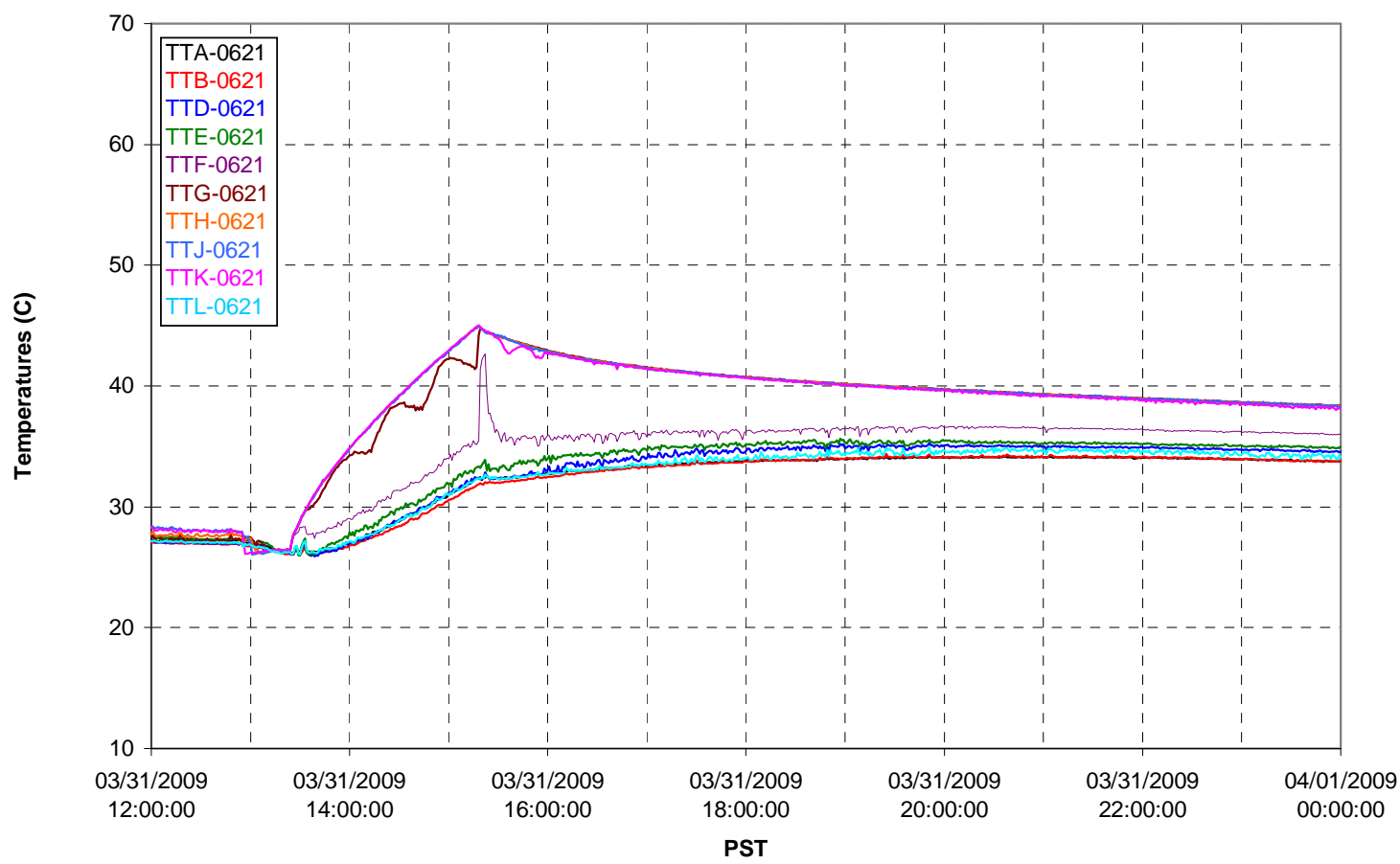


T02A temperatures

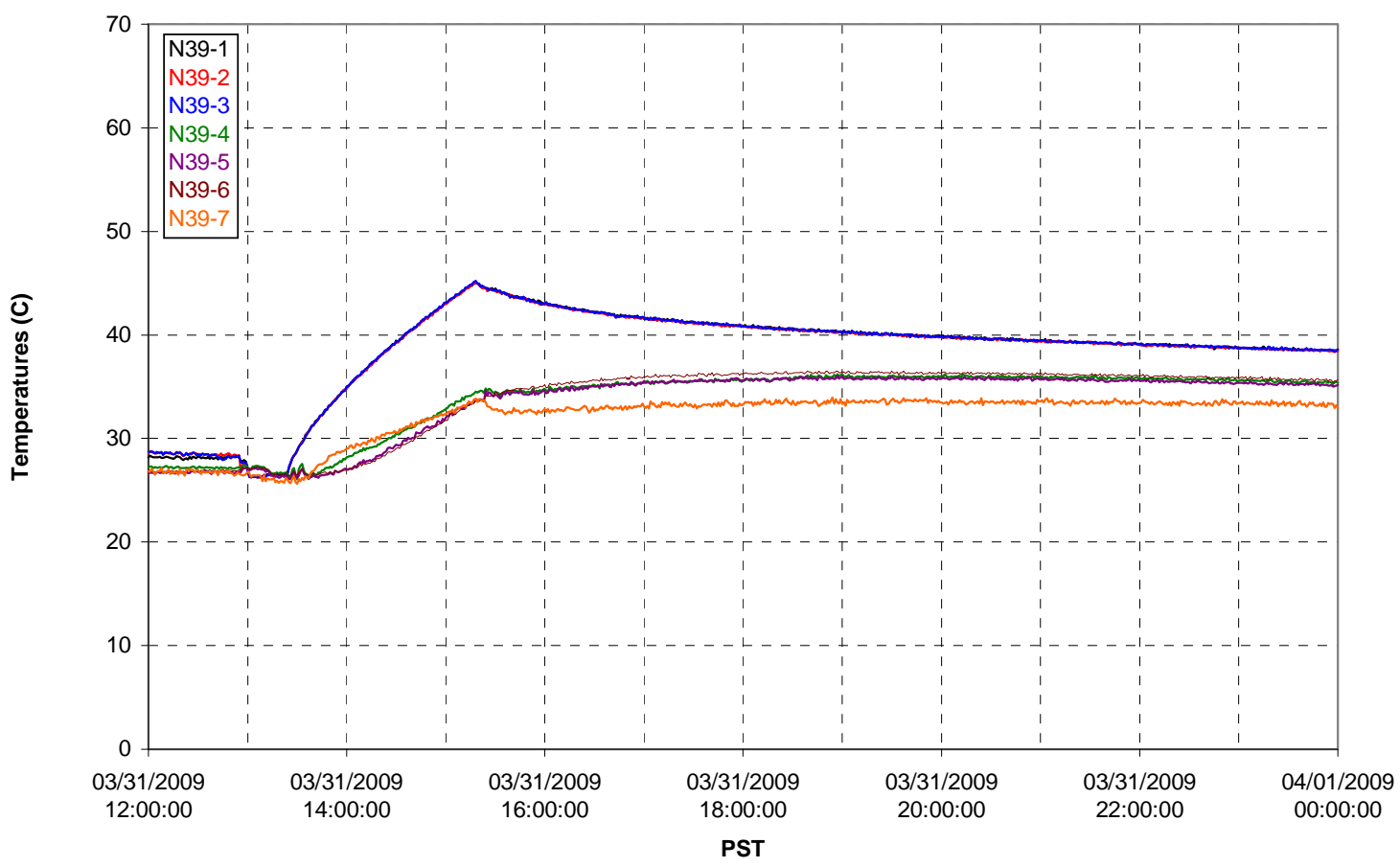

T02A temperatures

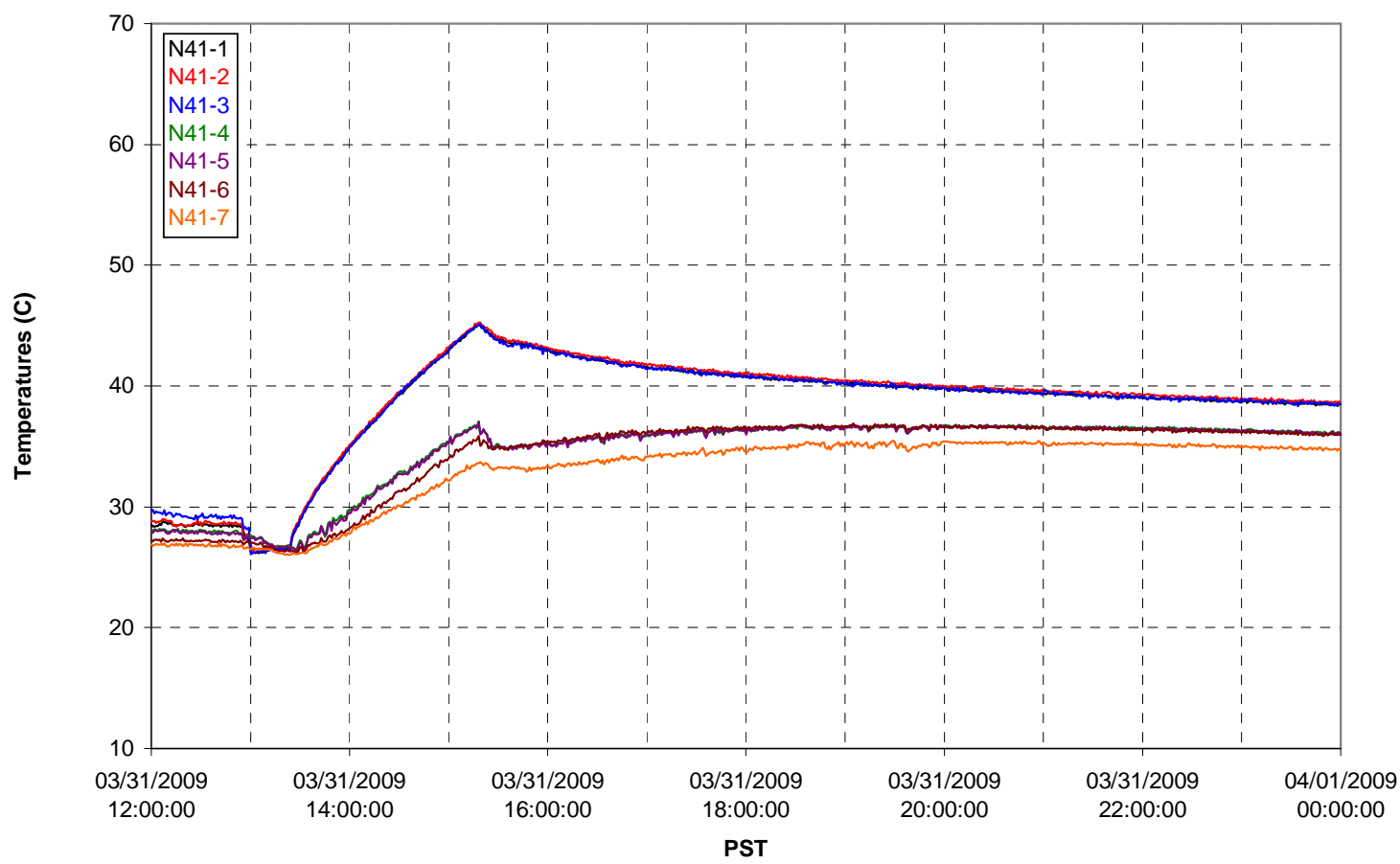


T02A temperatures

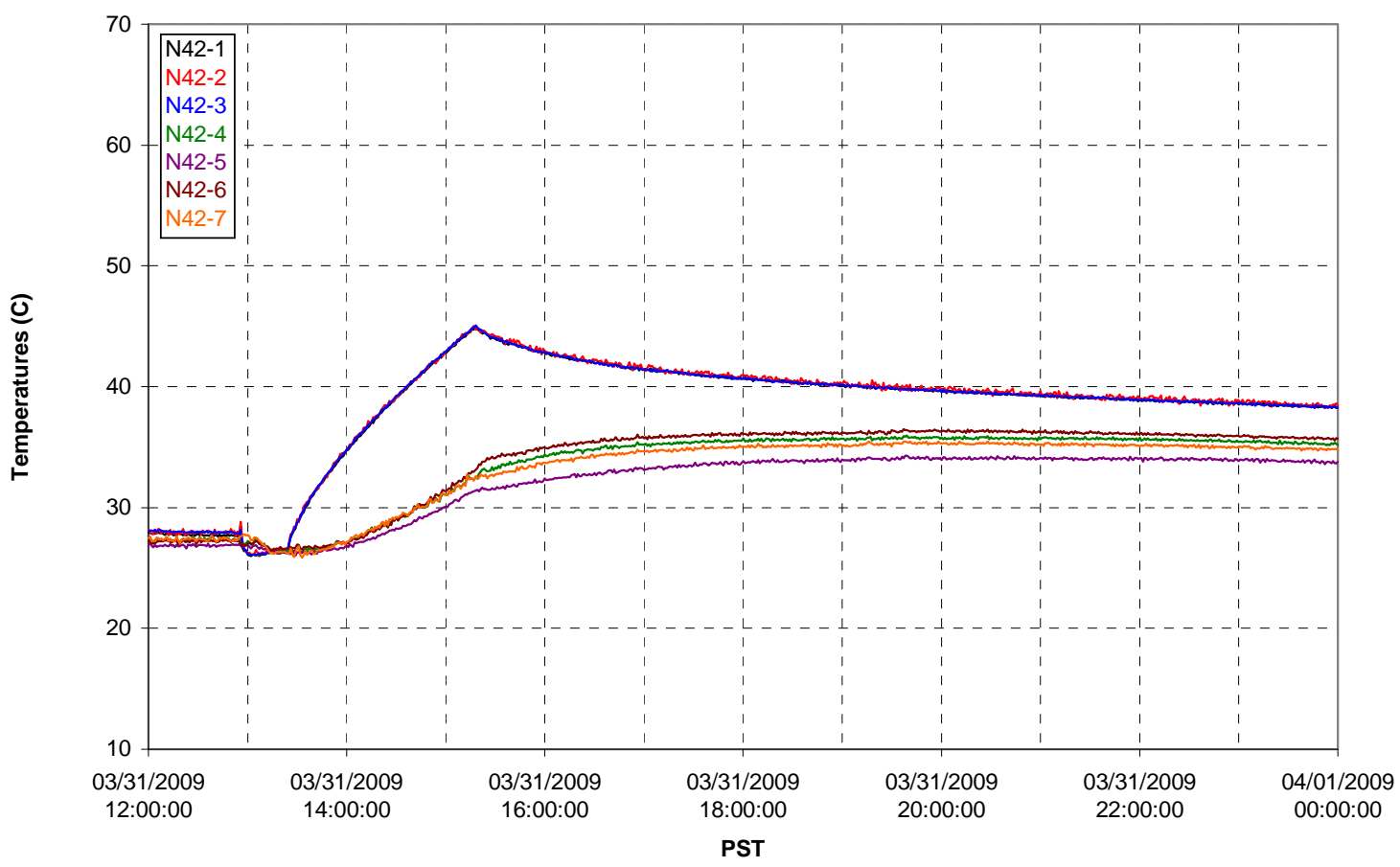

T02A temperatures

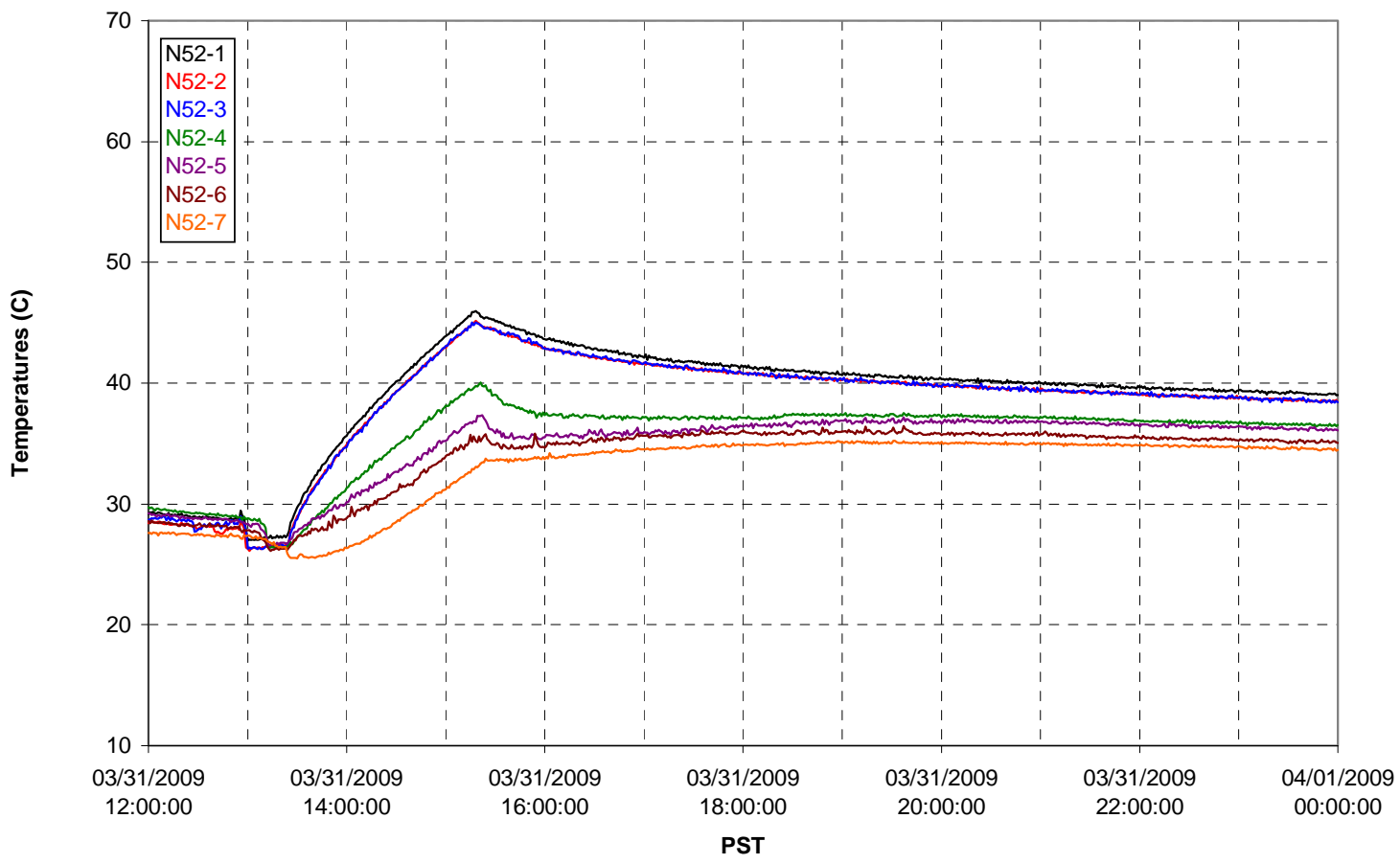


T02A Heating and Cooling

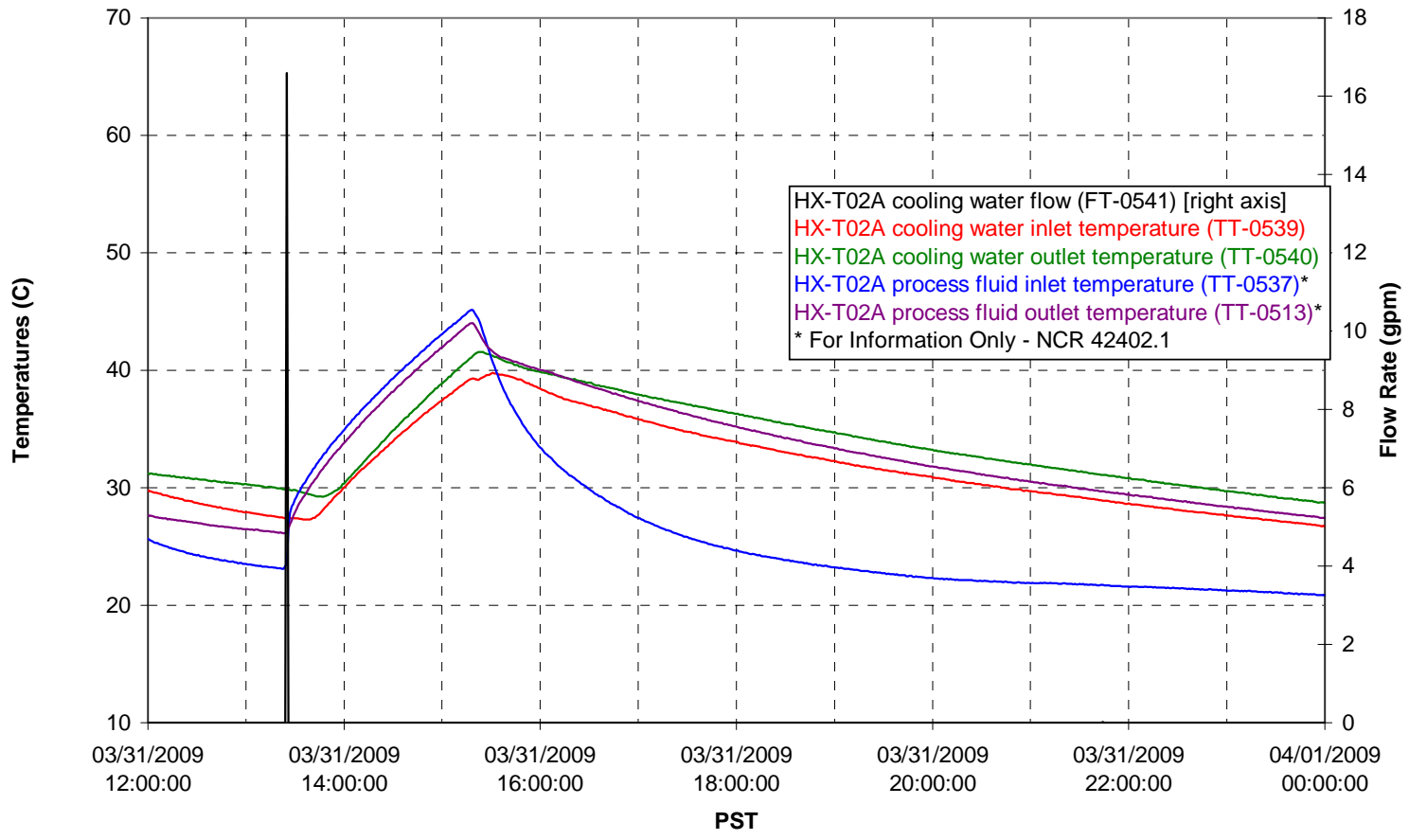

Pump Operation

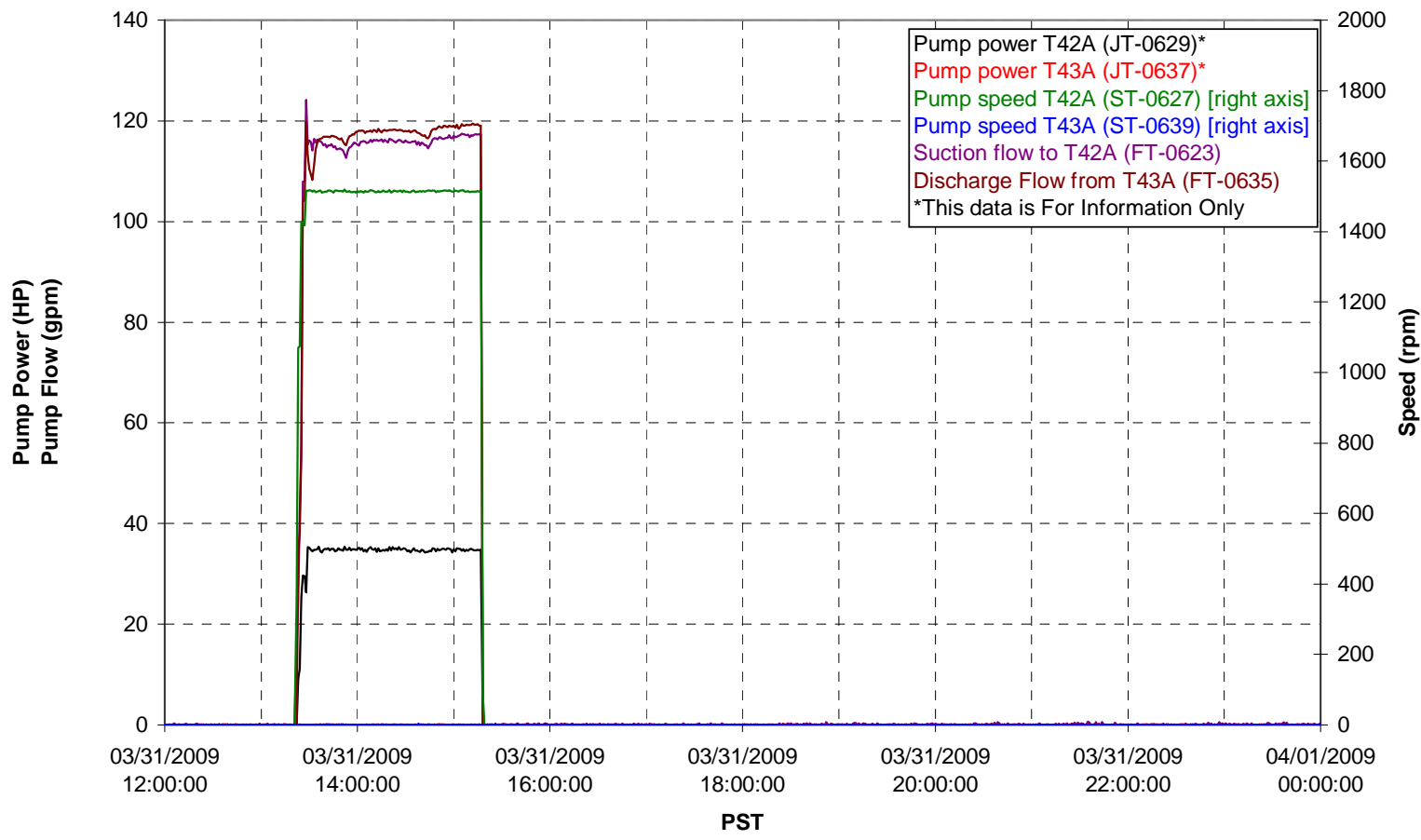


Pulsepot UFP-PP-T01A

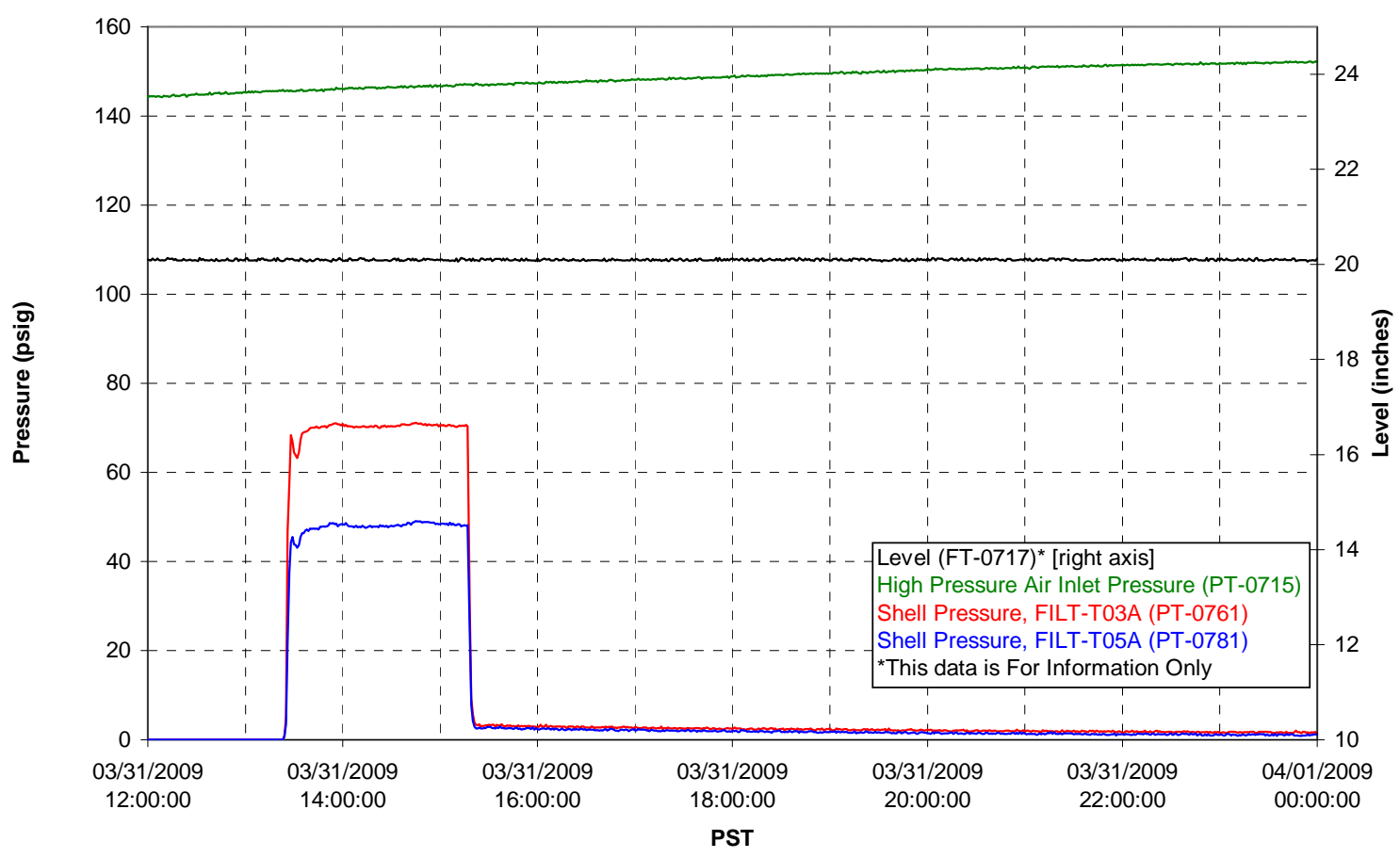

Pulsepot UFP-PP-T02A

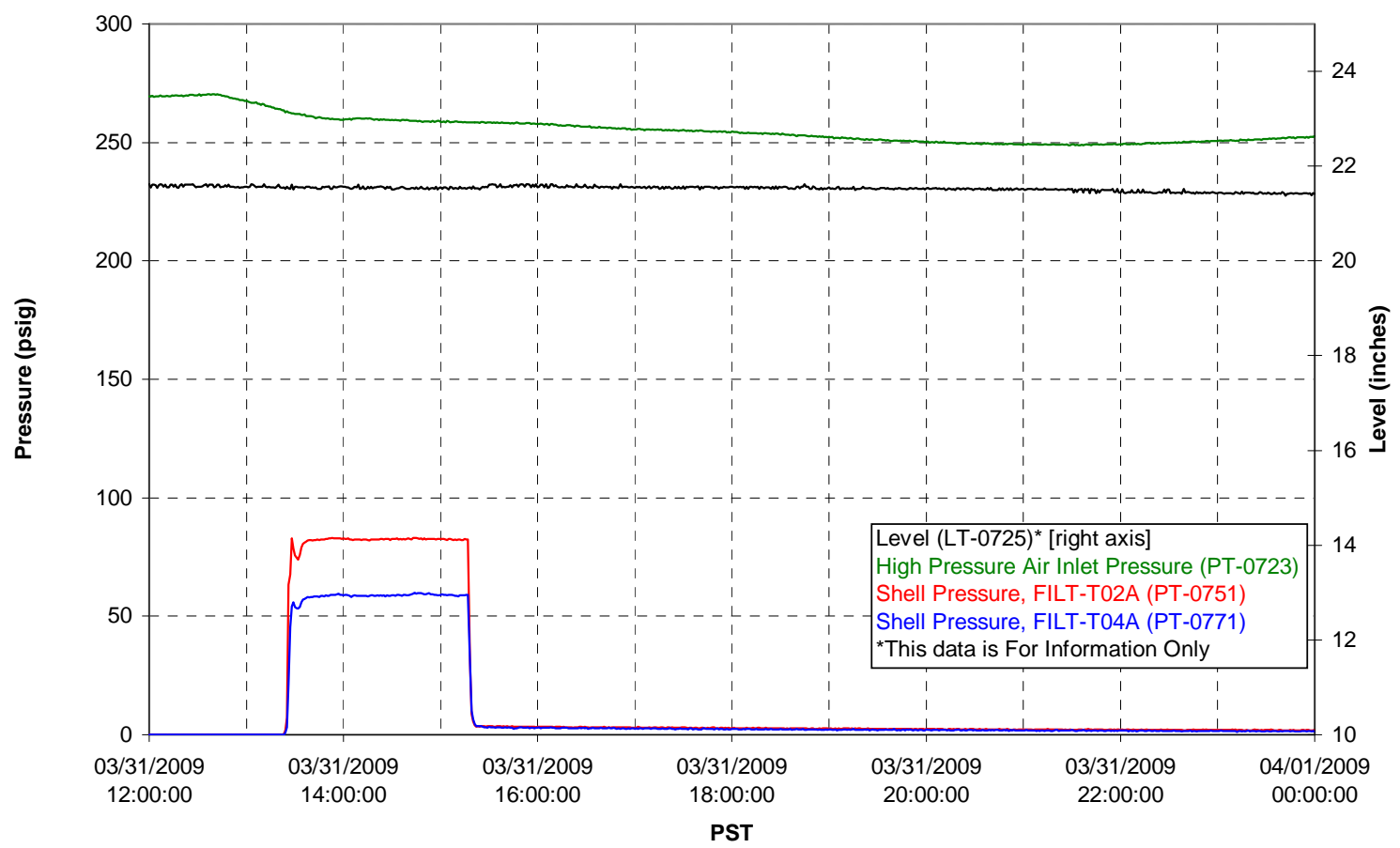


Pulsepot UFP-PP-T03A

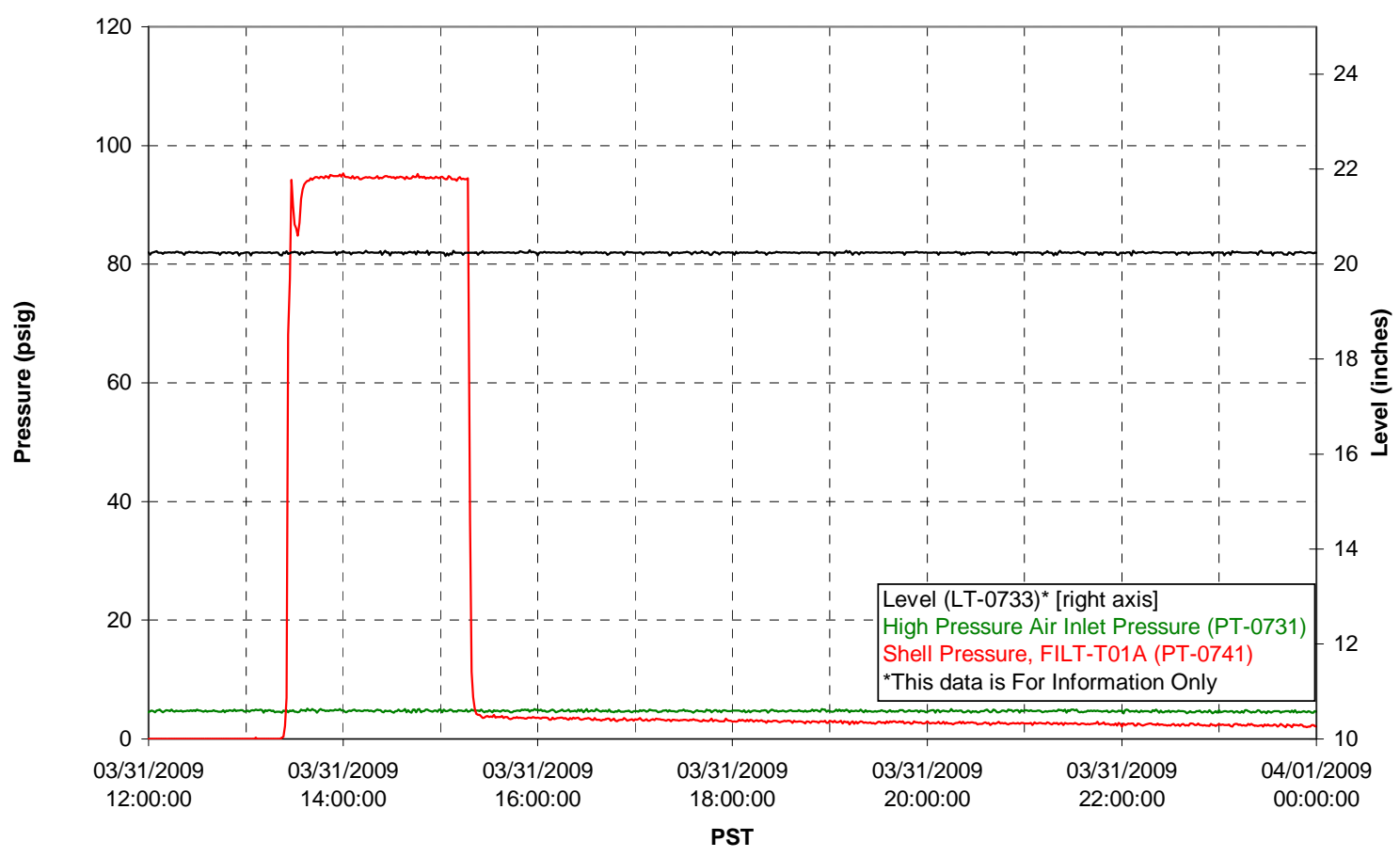

Pulsepot Levels

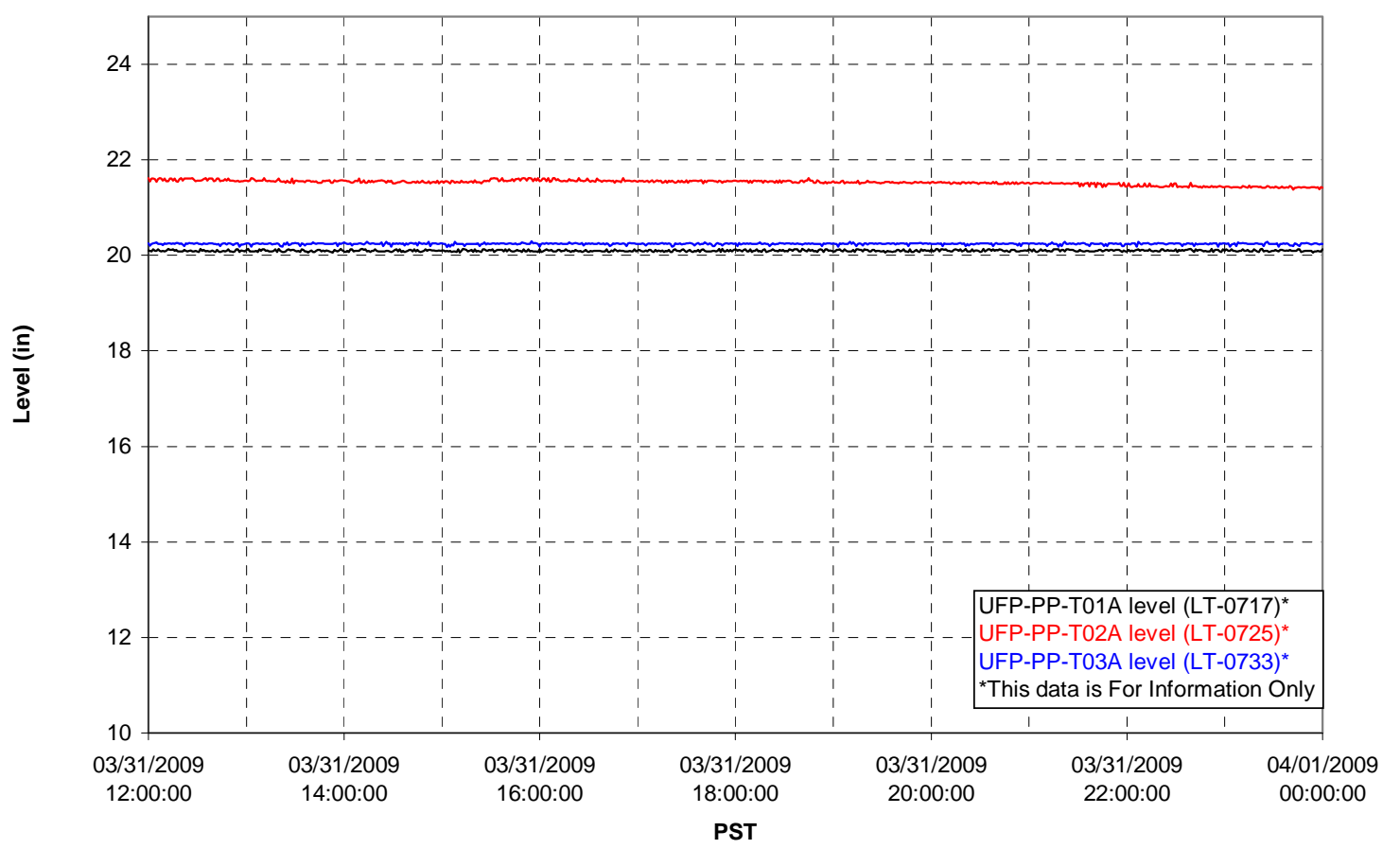


Filter UFP-FILT-T01A

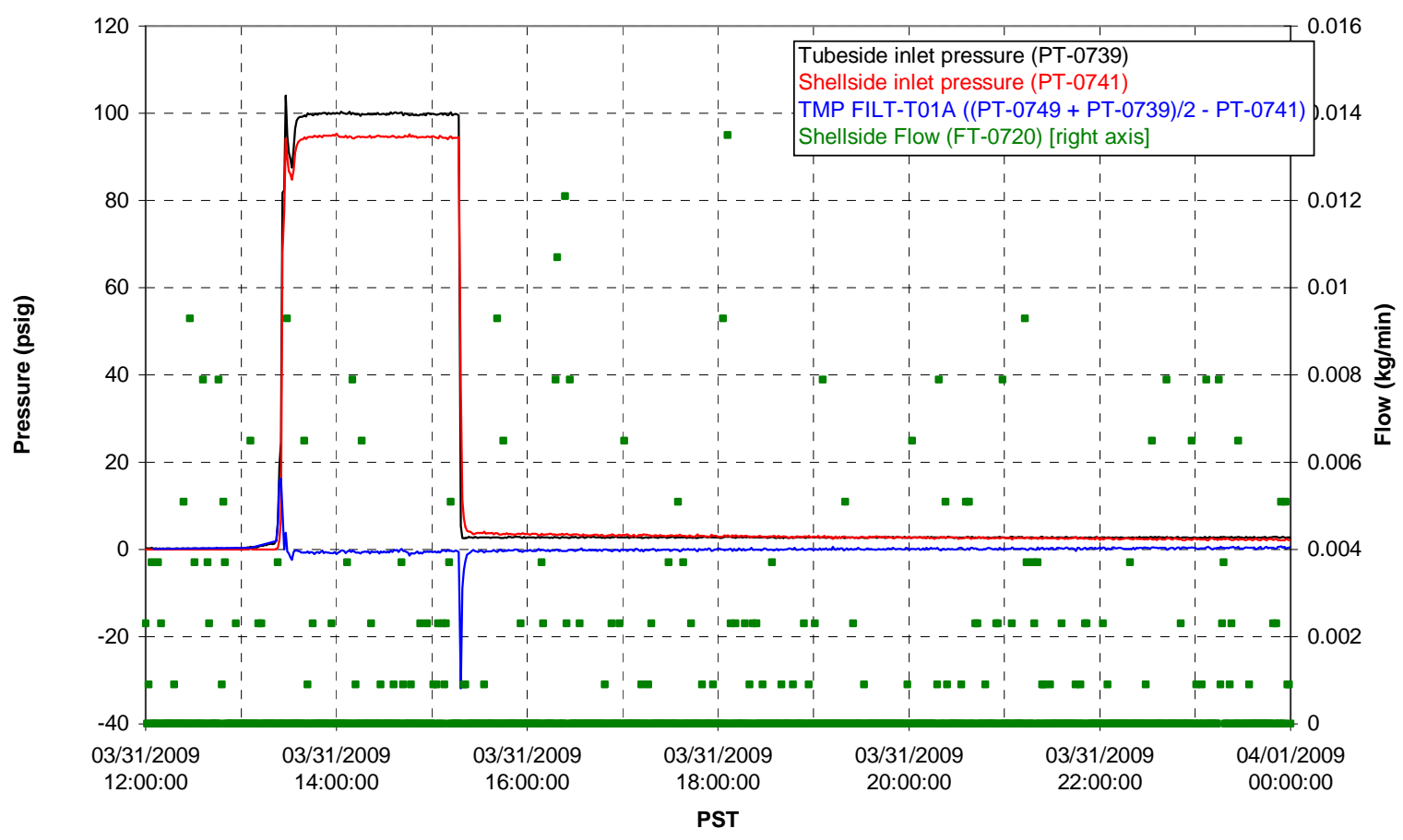

Filter UFP-FILT-T02A

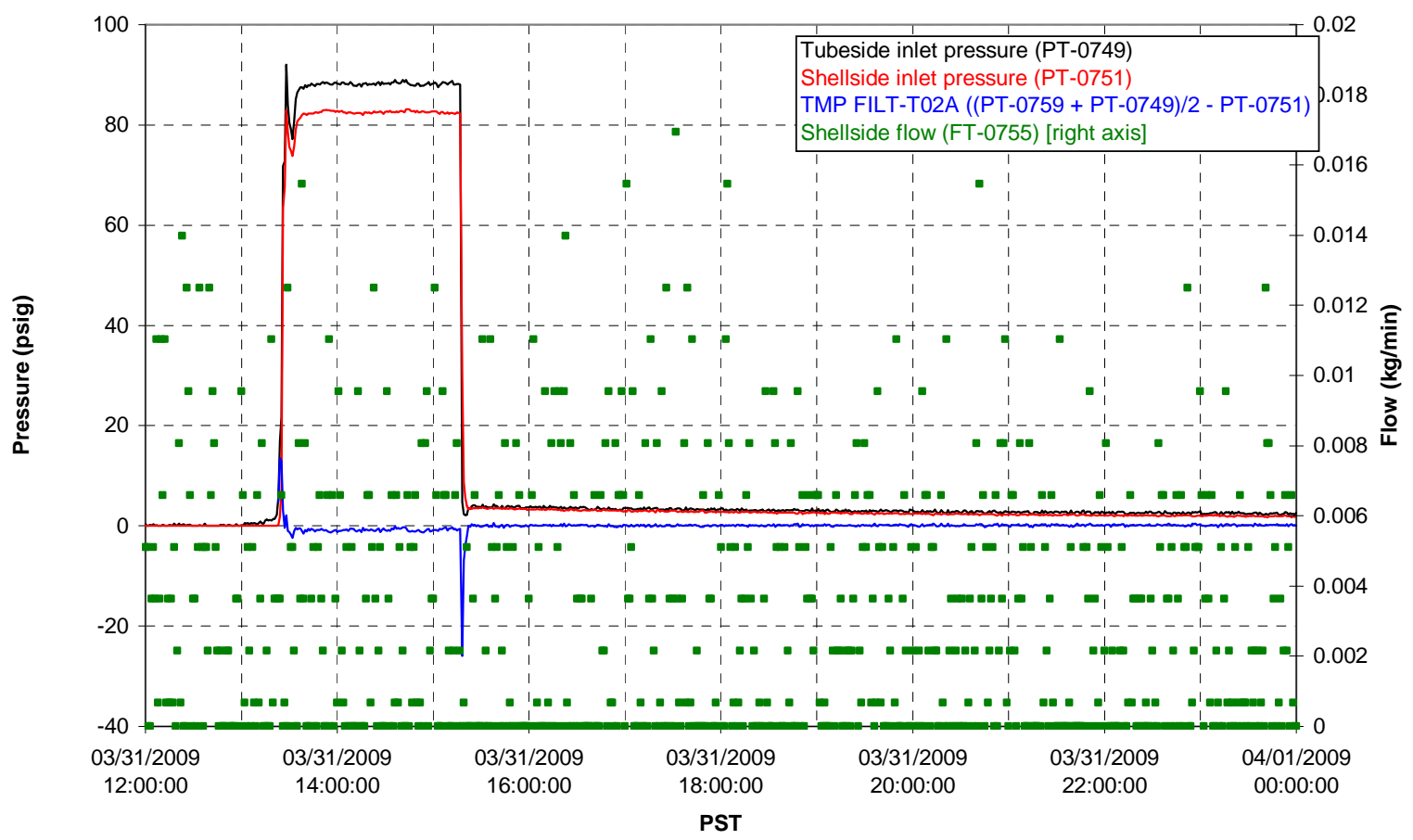


Filter UFP-FILT-T03A

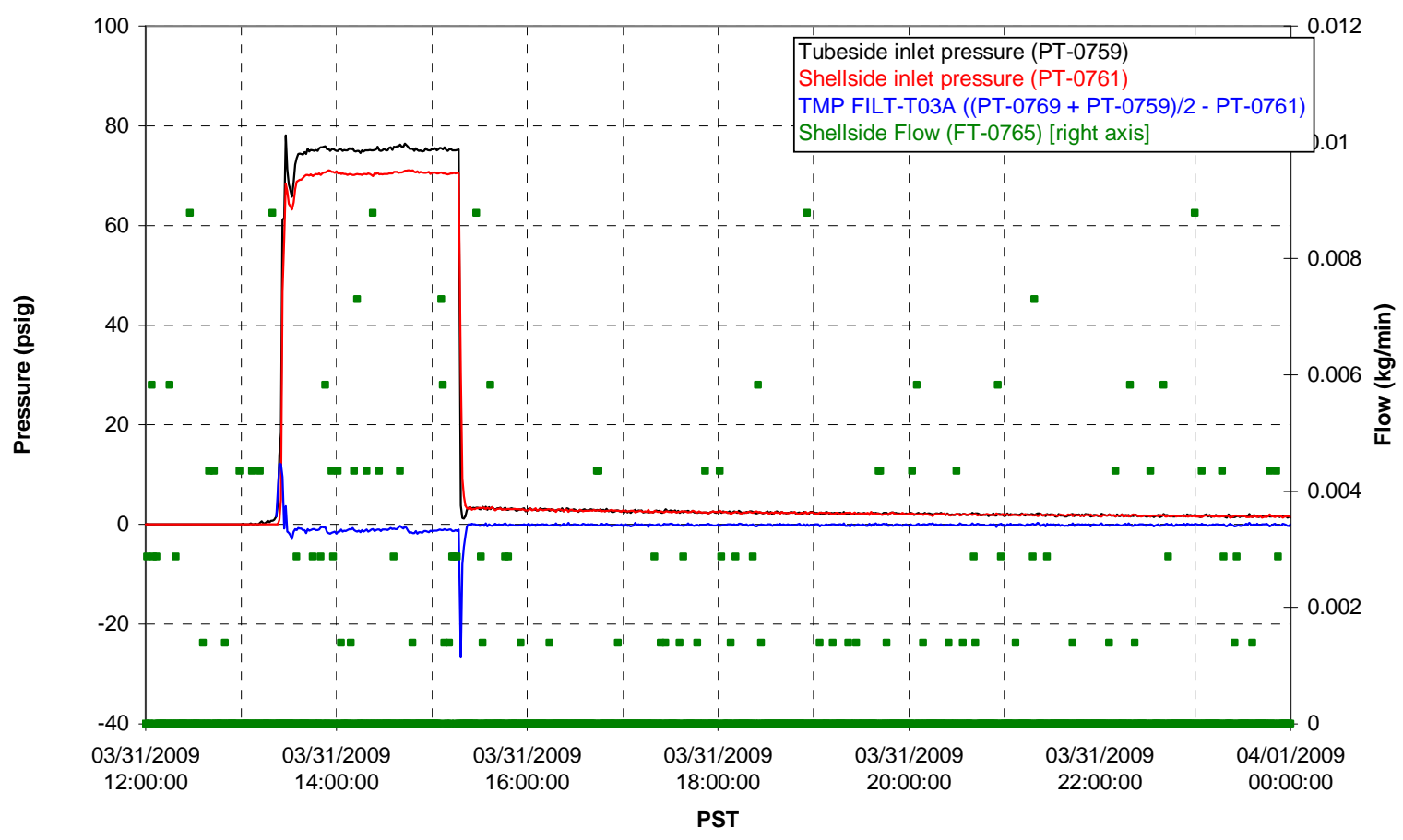

Filter UFP-FILT-T04A

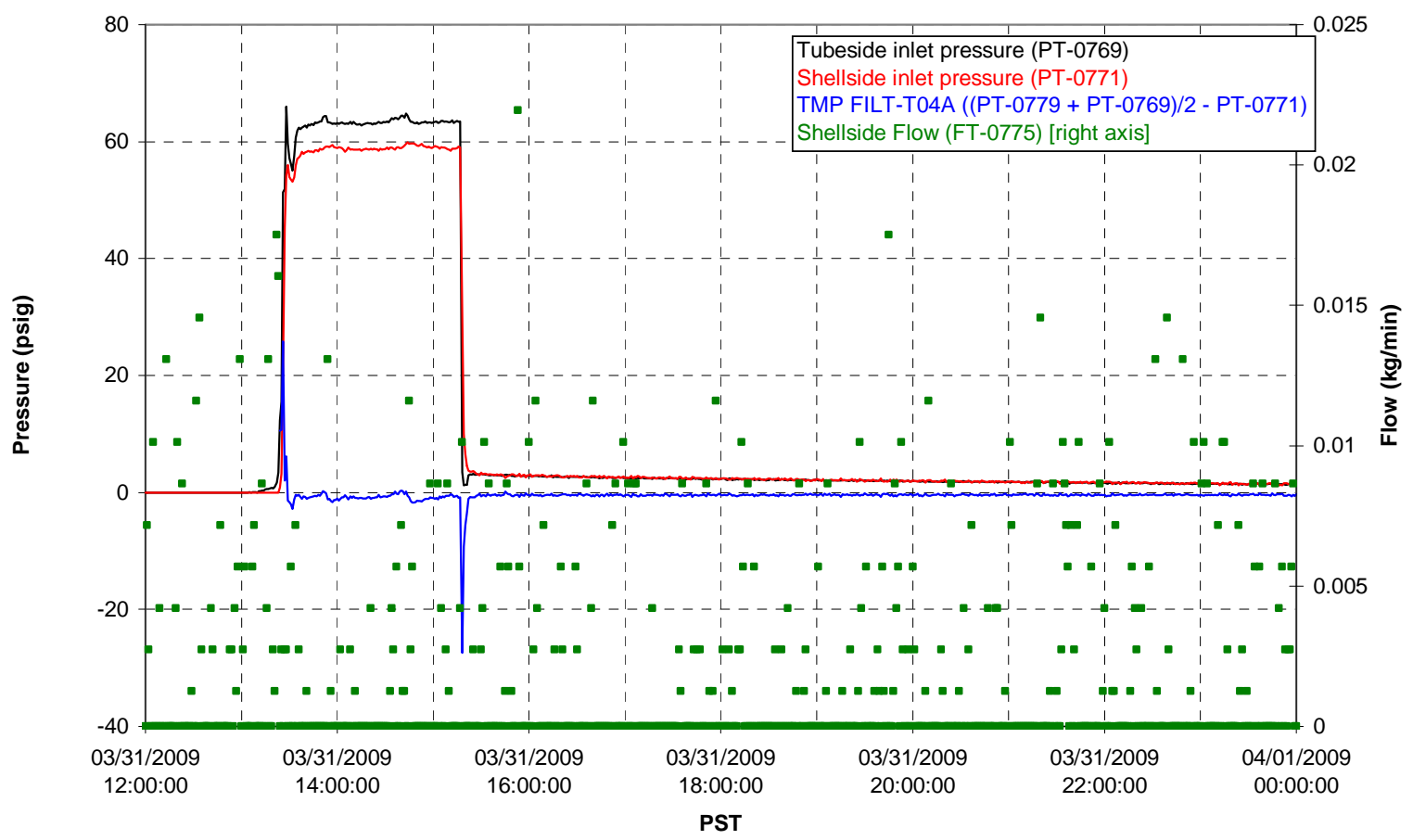


Filter UFP-FILT-T05A

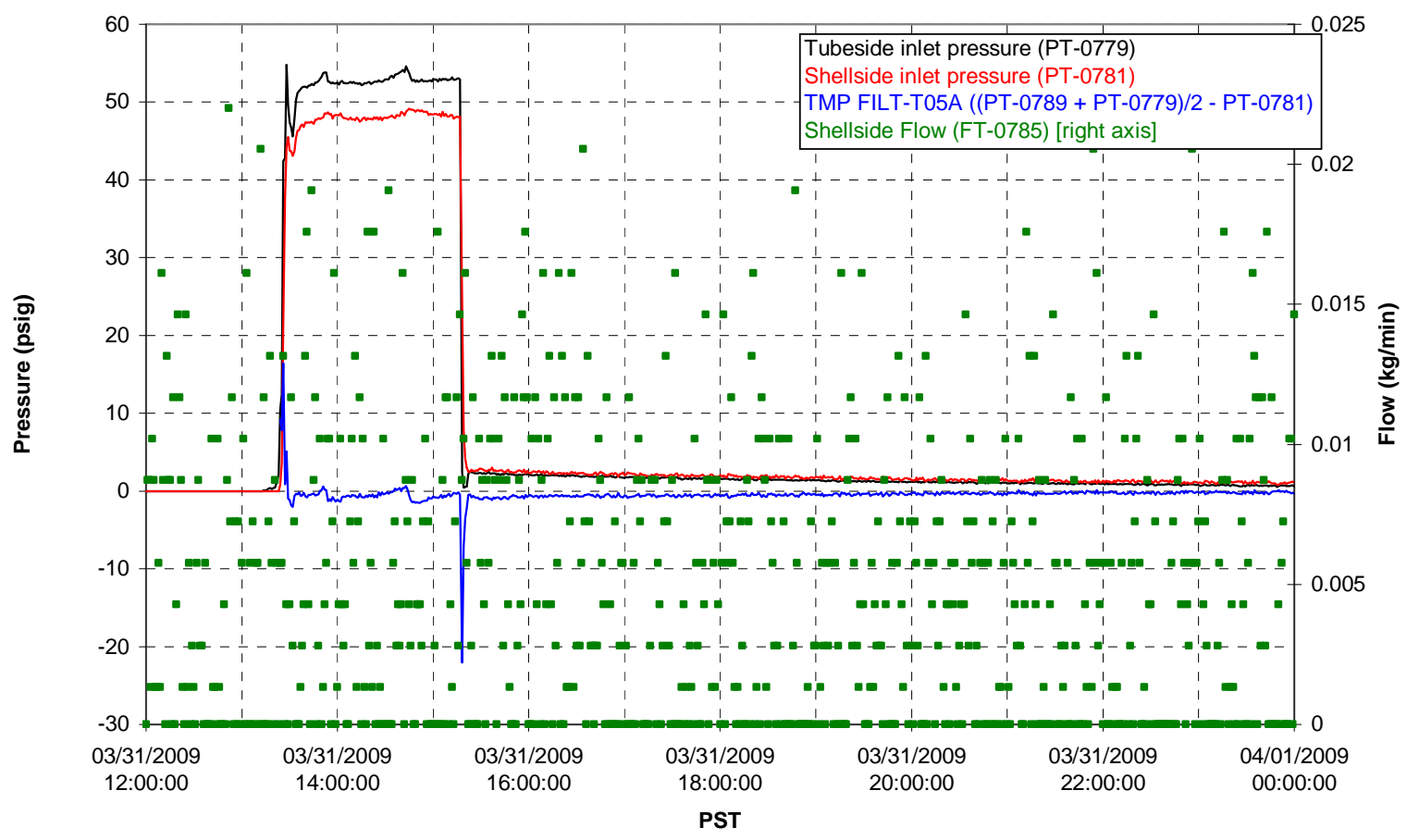

Chemical Flow

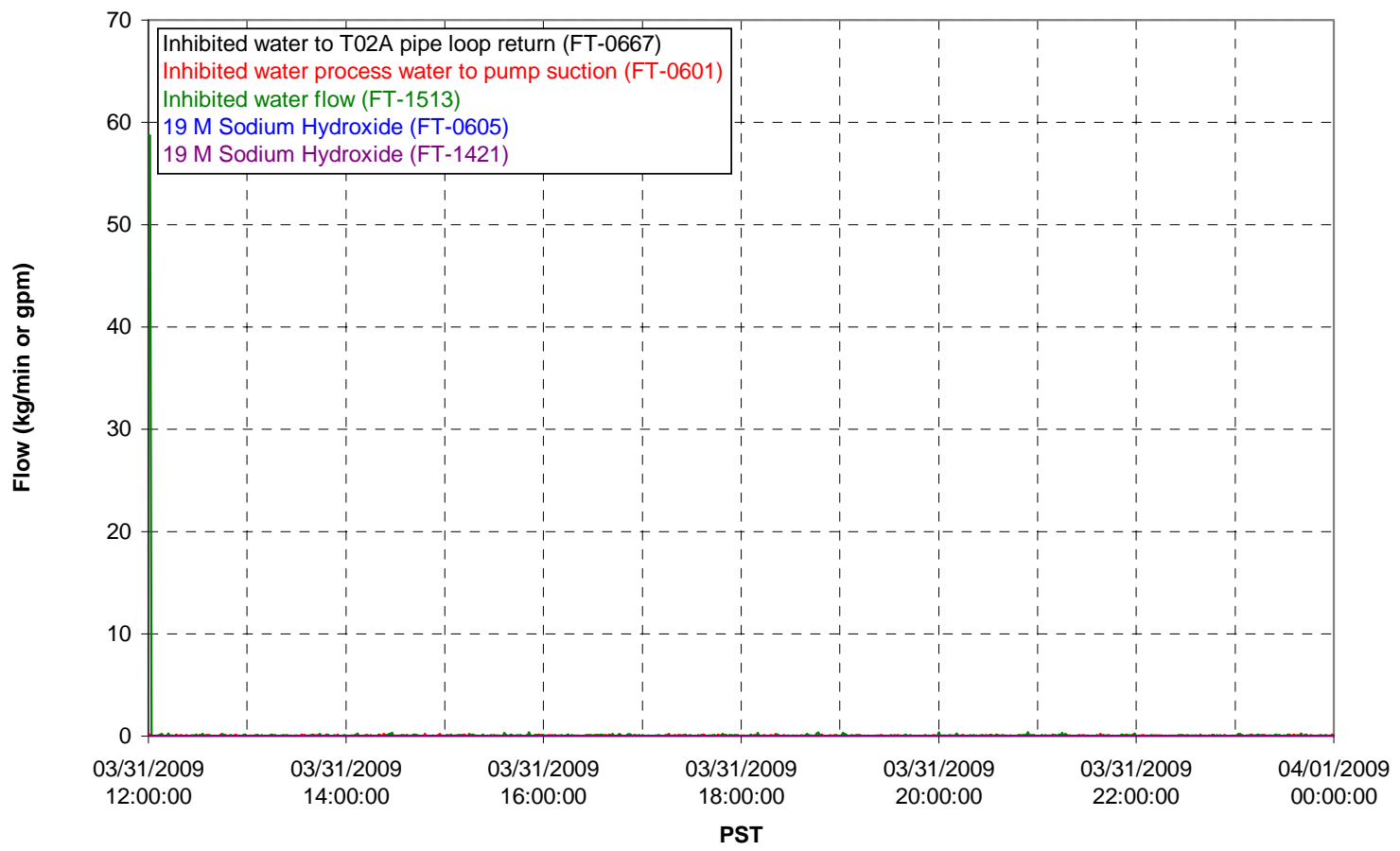




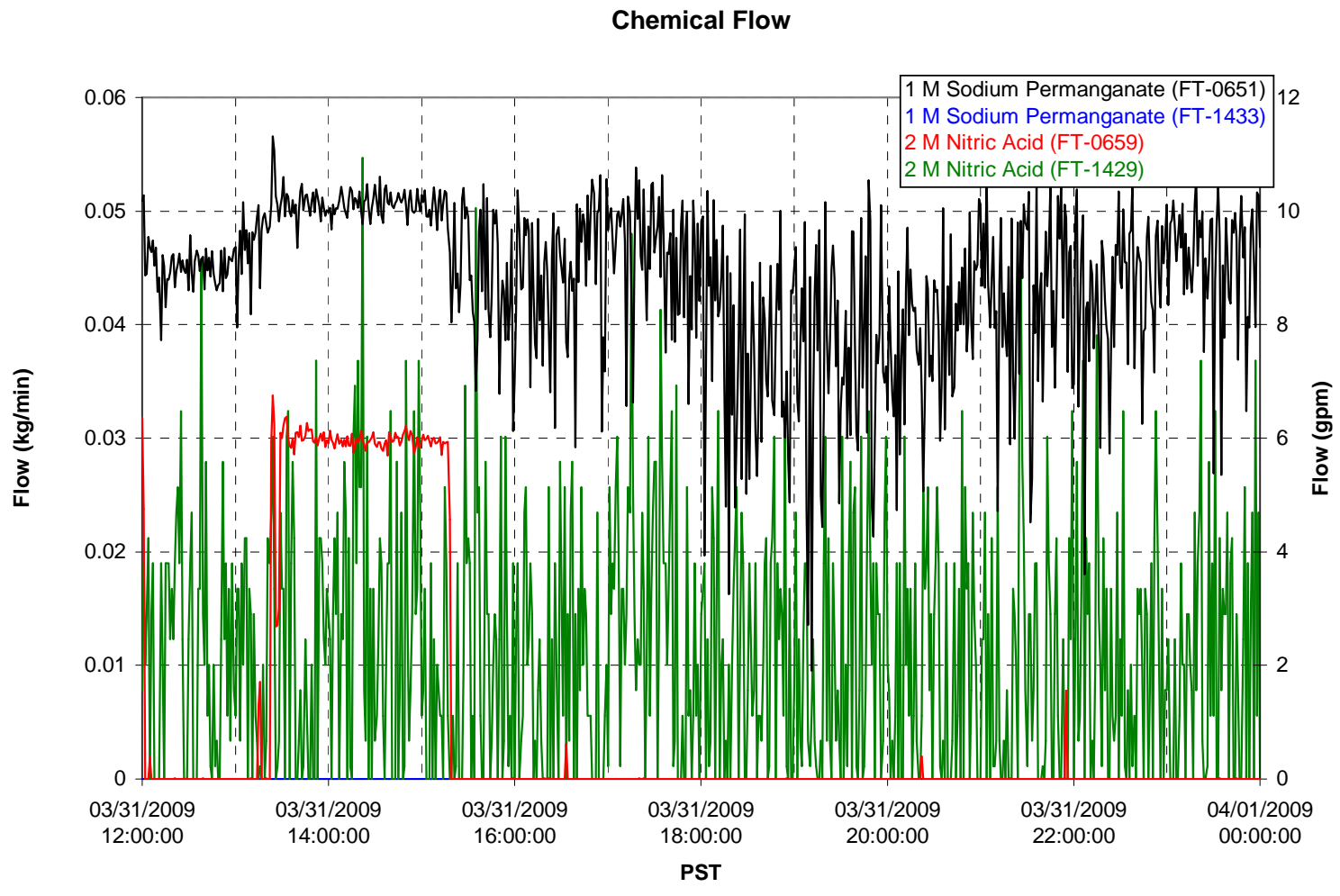

Air Flows

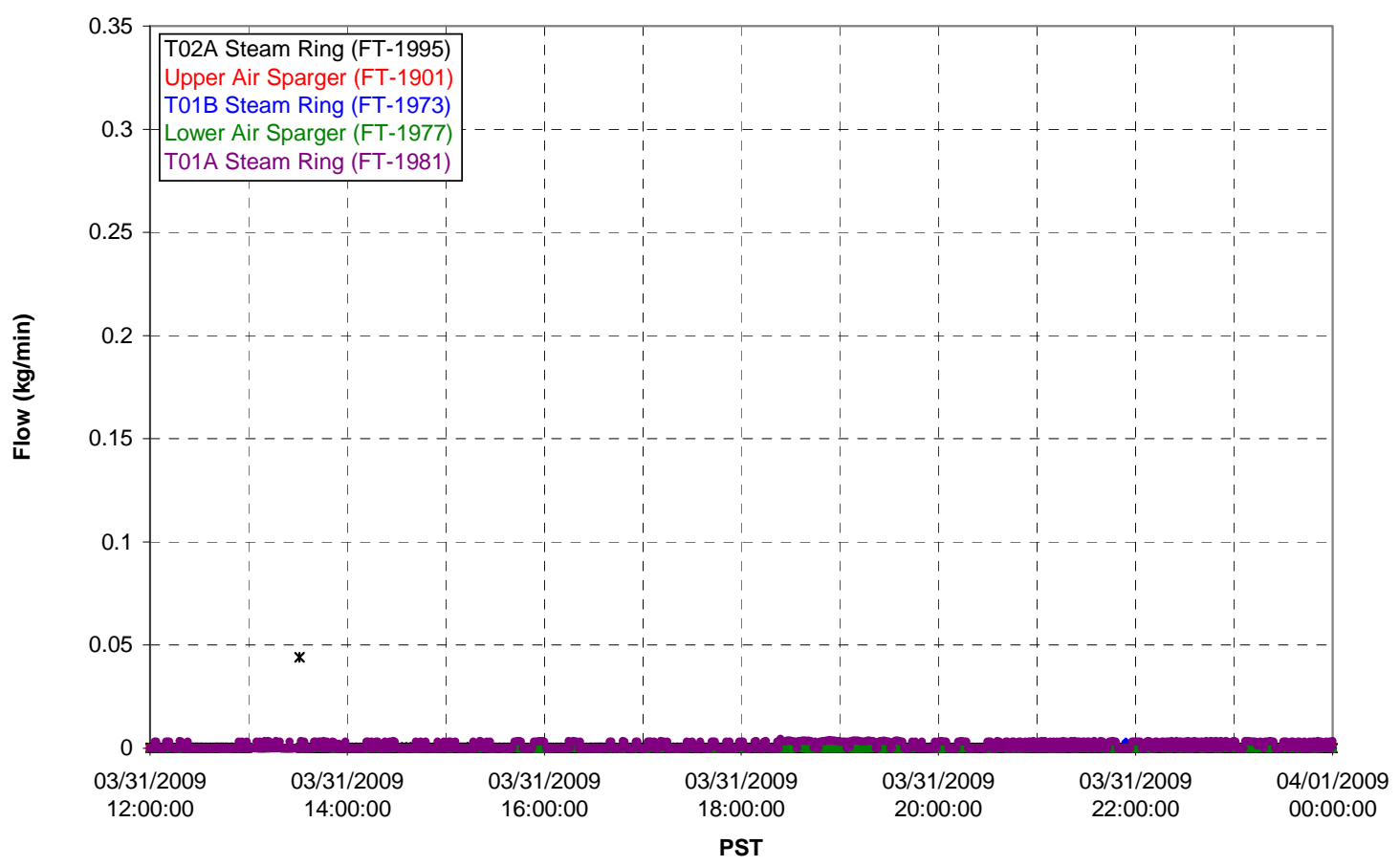


T02A Steam

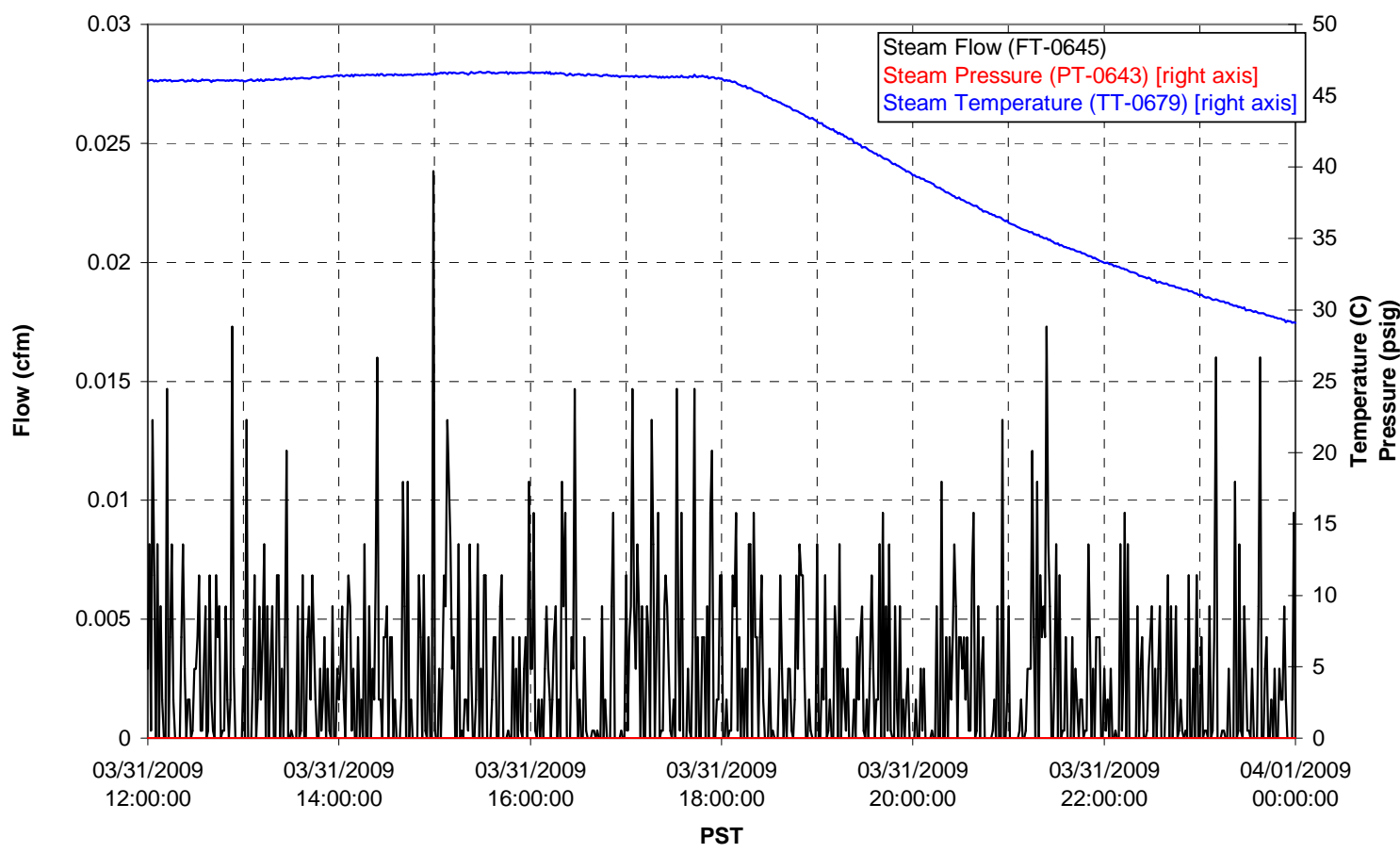

T01A Steam

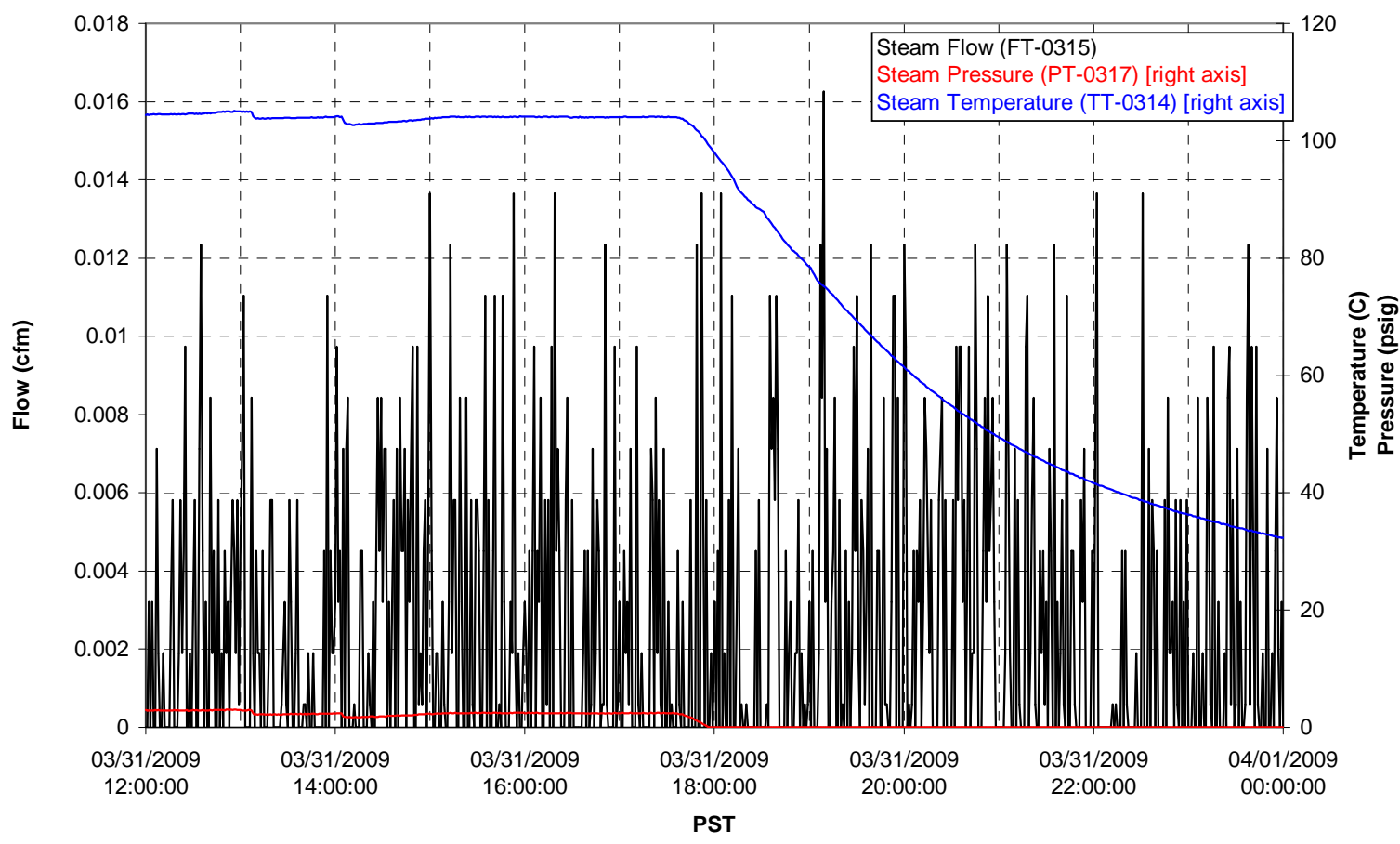




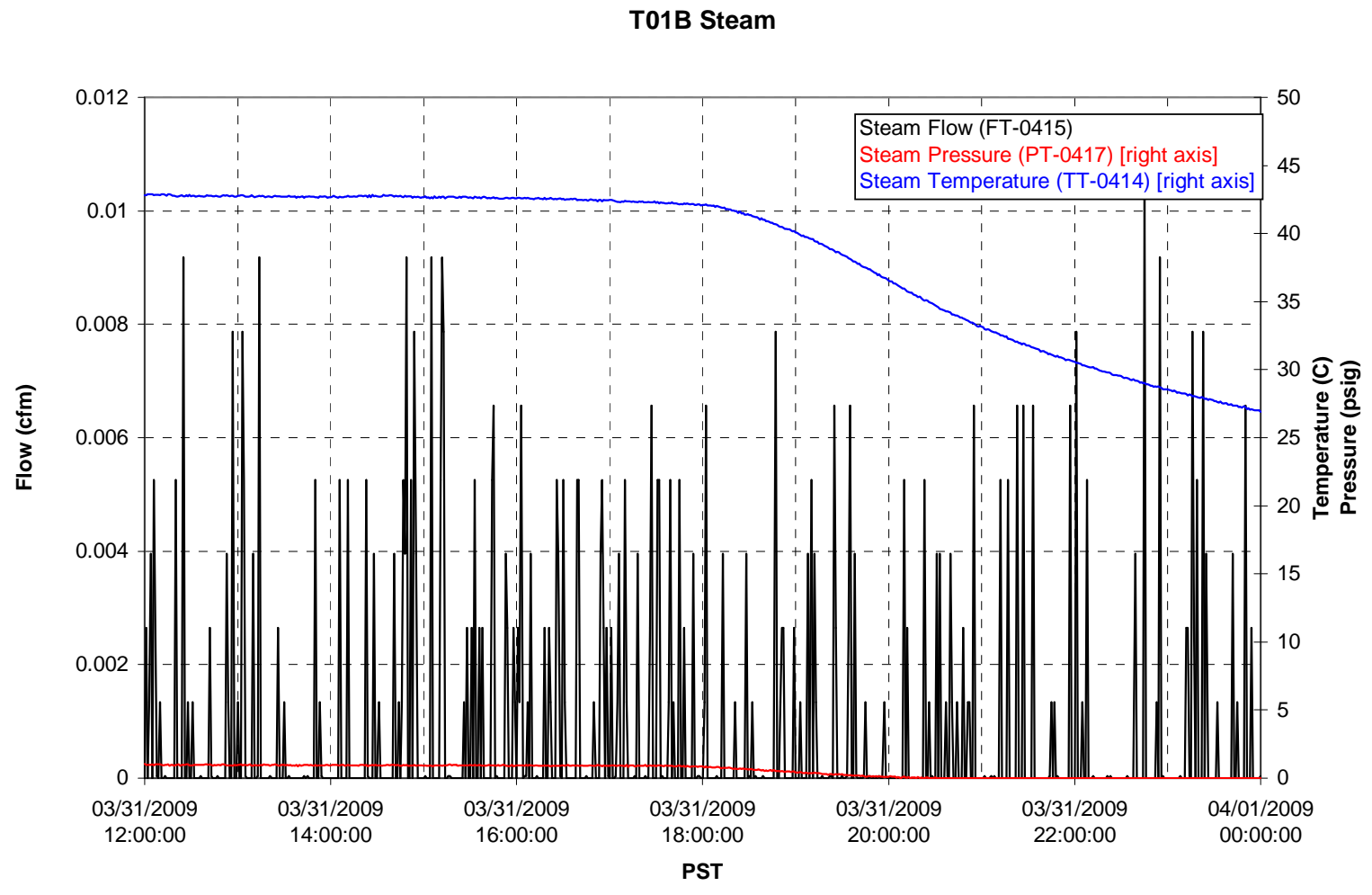





\title{
Appendix K
}

\author{
Integrated Test D Summary
}





\section{Appendix K: Integrated Test D Summary}

\begin{tabular}{|c|c|c|c|c|c|}
\hline $\begin{array}{l}\text { Test } \\
\text { Step }\end{array}$ & Test Step & Description/Purpose & Key Process Conditions & Sampling & Notes \\
\hline B.2.1 & $\begin{array}{c}\text { Prepare and } \\
\text { stage simulant } \\
\text { in } \\
\text { HLP-VSL- } \\
\text { T22 }\end{array}$ & $\begin{array}{l}\text { Prepare sufficient } \\
\text { quantity of Phase } 1 \\
\text { simulant in } \\
\text { HLP-VSL-T22 to } \\
\text { complete tests. } \\
\text { Characterize simulant } \\
\text { for specification of all } \\
\text { simulant-dependent } \\
\text { process parameters } \\
\text { (e.g., batch volumes, } \\
\text { caustic and } \\
\text { permanganate } \\
\text { additions). }\end{array}$ & $\begin{array}{l}\text { HLP-VSL-T22 agitator } \\
\text { speed set at full speed } \\
\text { ( } 68 \mathrm{rpm} \text { ) so vessel is well } \\
\text { mixed; recirculate the } \\
\text { tank with the pump. }\end{array}$ & 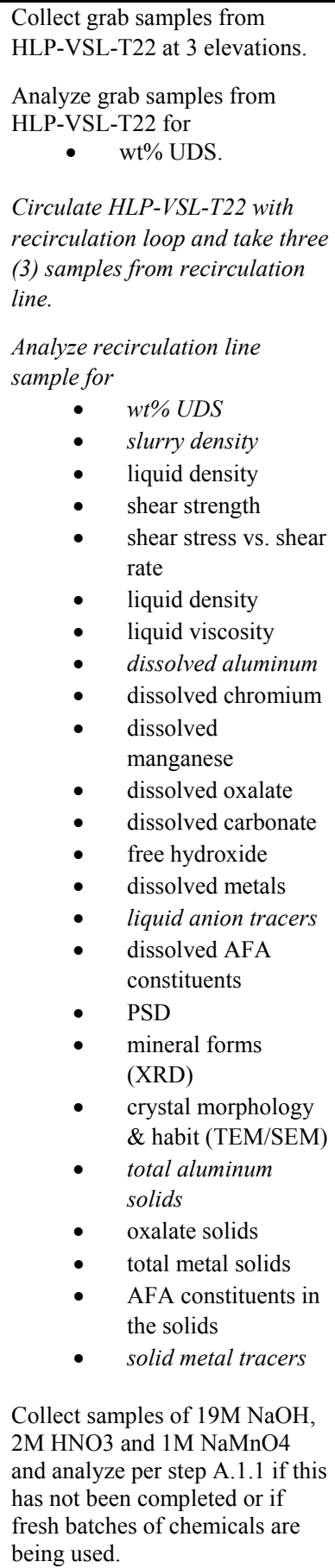 & $\begin{array}{l}\text { Started: } 22: 003 / 22 / 09 \\
\text { Completed: 04:22 3/23/09 } \\
\text { Key process conditions: Met. } \\
\text { Agitator VFD set to full speed, } 60 \\
\text { Hz. } \\
\text { Samples: Taken as indicated. }\end{array}$ \\
\hline
\end{tabular}




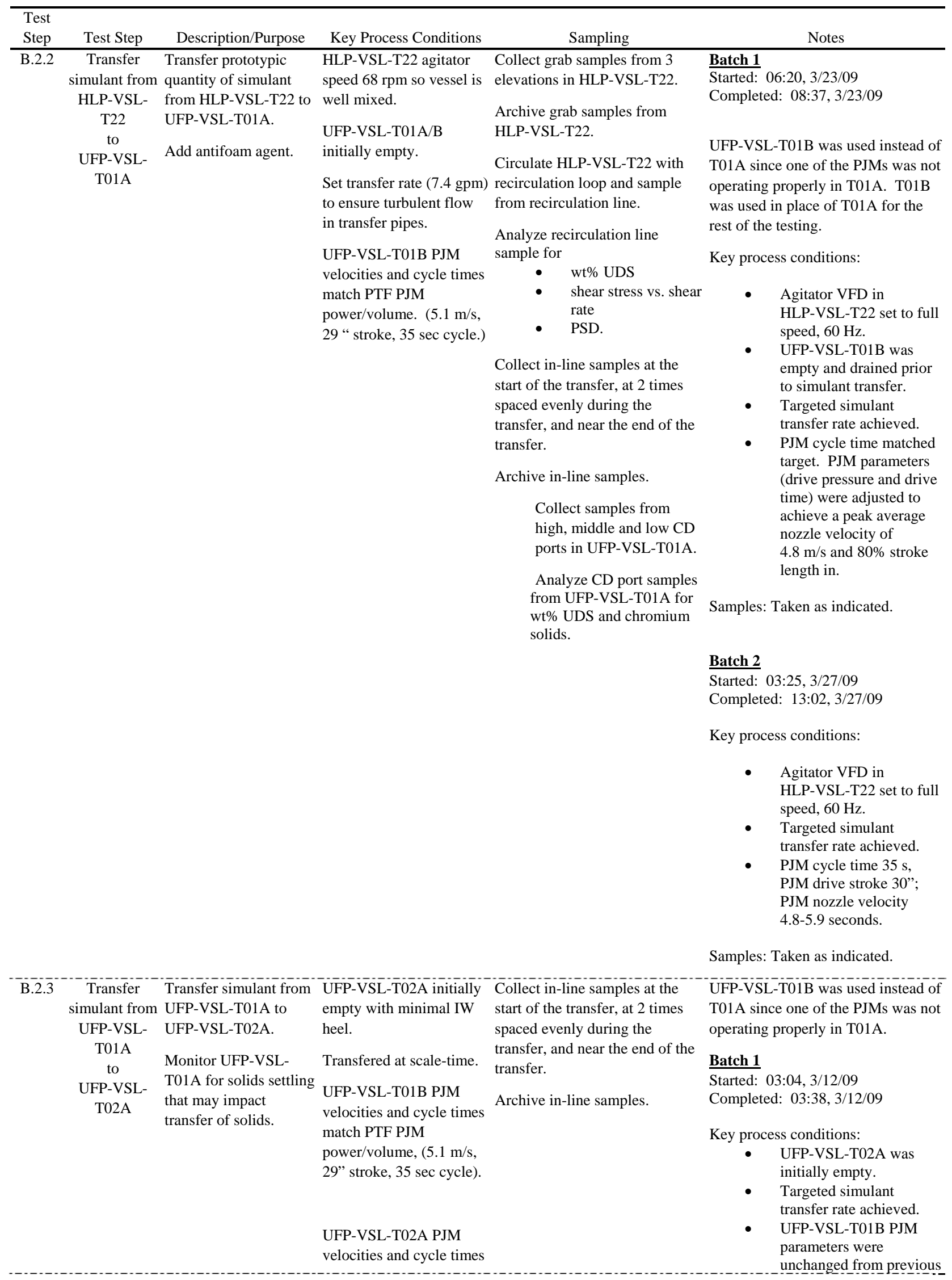




\begin{tabular}{lll}
\hline Test & & \\
Step Test Step _. Description/Purpose & Key Process Conditions & Sampling \\
& match PTF PJM & Notes \\
& power/volume. $(7.7 \mathrm{~m} / \mathrm{s}$, & disabled. \\
& 32 “ stroke, $25 \mathrm{sec}$ cycle & UFP-VSL-T02A PJM \\
& time). & tuned to $7.3 \mathrm{~m} / \mathrm{s}$ and 31.5 \\
& & second cycle time.
\end{tabular}

Samples: taken as indicated.

Batch 2

Started: 03:25, 3/27/09; 08:43, 3/27/09

Completed: 03:57, 3/27/09; 09:52, 3/27/09

Key process conditions:

- UFP-VSL-T02A had caustic leached (but NOT oxidatively leached) heel prior to simulant transfer.

- $\quad$ Targeted simulant transfer rate achieved.

- UFP-VSL-T01B PJM parameters were unchanged from previous step.

- $\quad$ UFP-VSL-T02A PJM nozzle velocity and drive stroke unchanged.

Samples: taken as indicated.

\begin{tabular}{|c|c|c|c|c|c|}
\hline B. 2.4 & $\begin{array}{l}\text { Drain } \\
\text { filter-loop }\end{array}$ & $\begin{array}{l}\text { Drain inhibited water } \\
\text { from filter-loop. }\end{array}$ & $\begin{array}{l}\text { Filter loop and permeate } \\
\text { system initially filled with } \\
\text { inhibited water. }\end{array}$ & None. & $\begin{array}{l}\text { Completed: } 07: 03,3 / 23 / 09 \\
\text { Key process conditions: } \\
\text { The shell and tube side } \\
\text { of the filter loop was } \\
\text { initially filled with dilute } \\
\text { acid prior to draining. }\end{array}$ \\
\hline B. 2.5 & $\begin{array}{l}\text { Concentrate } \\
\text { solids to } \\
20-\mathrm{wt} \% \text { UDS }\end{array}$ & $\begin{array}{l}\text { Concentrate solids, } \\
\text { adding additional slurry } \\
\text { from UFP-VSL-T01A } \\
\text { as necessary to obtain } \\
\text { prototypic level of } \\
20 \text {-wt\% UDS in } \\
\text { UFP-VSL-T02A. } \\
\text { Demonstrate control } \\
\text { strategy for make-up } \\
\text { additions from } \\
\text { UFP-VSL-T01A/B to } \\
\text { UFP-VSL-T02A during } \\
\text { concentration of solids. } \\
\text { Demonstrate } \\
\text { ultrafiltration } \\
\text { endpoints. }\end{array}$ & $\begin{array}{l}\text { Ultrafilters } \\
\text { preconditioned and } \\
\text { flushed; drained just } \\
\text { before concentration of } \\
\text { solids is started. } \\
\text { Concentrate at plant-time. } \\
\text { One 10-ft ultrafilter } \\
\text { bundle. } \\
\text { Route permeate to } \\
\text { UFP-VSL-T62A/B. }\end{array}$ & $\begin{array}{l}\text { Collect in-line sample from each } \\
\text { tenth make-up batch transfer } \\
\text { from UFP-VSL-T01A. } \\
\text { Archive in-line samples. } \\
\text { Collect permeate samples } \\
\text { between each filter bundle and } \\
\text { the pulse pots at } 3 \text { evenly spaced } \\
\text { times and inspect for particle } \\
\text { break-through. } \\
\text { Collect samples from } \\
\text { middle-low CD sample port } \\
\text { immediately after permeate } \\
\text { valves are opened, immediately } \\
\text { after every third make-up batch } \\
\text { addition. After solids } \\
\text { concentration is complete, } \\
\text { collect three (3) samples from } \\
\text { the middle-low CD port. } \\
\text { Analyze all CD sample port CD } \\
\text { port samples for: } \\
\quad \text { wt\% UDS. } \\
\text { Analyze initial and final CD port } \\
\text { samples for }\end{array}$ & $\begin{array}{ll}\text { - } & \text { Concentration was } \\
\text { conducted at plant time. } \\
\text { Concentration was } \\
\text { conducted using filter } \\
\text { one. (Note: that Batch } 2 \\
\text { was not concentrated at } \\
\text { plant time and used all } 5 \\
\text { ultrafilters.) } \\
\text { UFP-VSL-T02A PJM } \\
\text { parameters were } \\
\text { unchanged from } \\
\text { previous step. } \\
\text { Permeate was collected } \\
\text { in UFP-VSL-T62A/B. } \\
\\
\text { Samples: taken as indicated. }\end{array}$ \\
\hline
\end{tabular}




\begin{tabular}{|c|c|c|c|c|c|}
\hline $\begin{array}{l}\text { Test } \\
\text { Step }\end{array}$ & Test Step & Description/Purpose & Key Process Conditions & Sampling & Notes \\
\hline & & & & $\begin{array}{l}\text { shear stress vs shear } \\
\text { rate. } \\
\text { Analyze three (3) final CD port } \\
\text { samples for } \\
\text { - } \quad \text { wt\% UDS } \\
\text { - } \quad \text { dissolved aluminum } \\
\text { - } \quad \text { free hydroxide } \\
\text { - } \quad \text { PSD } \\
\text { - } \quad \text { total aluminum solids } \\
\text { - } \quad \text { heat mapan capital tracers } \\
\quad \text { Integrated Test B } \\
\text { only). } \\
\text { Collect permeate sample from } \\
\text { the permeate sample port } \\
\text { between the first filter bundle } \\
\text { and the pulse-pots after last } \\
\text { make-up batch has been added } \\
\text { to UFP-VSL-T02A. } \\
\text { Submit permeate sample for } \\
\text { precipitation studies. }\end{array}$ & $\begin{array}{ll}\text { - } & \text { Concentration was } \\
\text { conducted at scale time } \\
\text { using all } 5 \text { ultrafilters. } \\
\text { UFP-VSL-T01A PJM } \\
\text { parameters were } \\
\text { unchanged from } \\
\text { previous step. } \\
\text { UFP-VSL-T02A PJM } \\
\text { parameters were } \\
\text { unchanged from } \\
\text { previous step. } \\
\text { Permeate was collected } \\
\text { in UFP-VSL-T62A/B. } \\
\\
\text { Samples: taken as indicated. }\end{array}$ \\
\hline B.2.6 & $\begin{array}{c}\mathrm{NaOH} \\
\text { addition }\end{array}$ & $\begin{array}{l}\text { Add NaOH in-line to } \\
\text { suction of } \\
\text { UFP-PMP-T42A. Use } \\
\text { the pump heat to } \\
\text { continue heating to the } \\
\text { target temperature } \\
\text { specified in the run } \\
\text { sheet if necessary. } \\
\text { Use the UFP-HX-T02A } \\
\text { to cool the filter-loop } \\
\text { slurry to maintain } \\
\text { UFP-VSL-T02A } \\
\text { temperature at or below } \\
\text { the temperature } \\
\text { specified in the run } \\
\text { sheet. }\end{array}$ & $\begin{array}{l}\text { Add caustic at scale-time } \\
(10.2 \mathrm{~kg} / \mathrm{min}) \text {. } \\
\text { Temperature raised to } \\
65^{\circ} \mathrm{C} \text { using pump energy } \\
\text { only. } \\
\text { UFP-VSL-T02A PJM } \\
\text { velocities and cycle times } \\
\text { match PTF PJM } \\
\text { power/volume. See above }\end{array}$ & $\begin{array}{l}\text { Prior to adding caustic collect a } \\
\text { 1L sample from a low CD port } \\
\text { for parallel lab tests. Transport } \\
\text { this sample to AEPL for } \\
\text { leaching tests. }\end{array}$ & 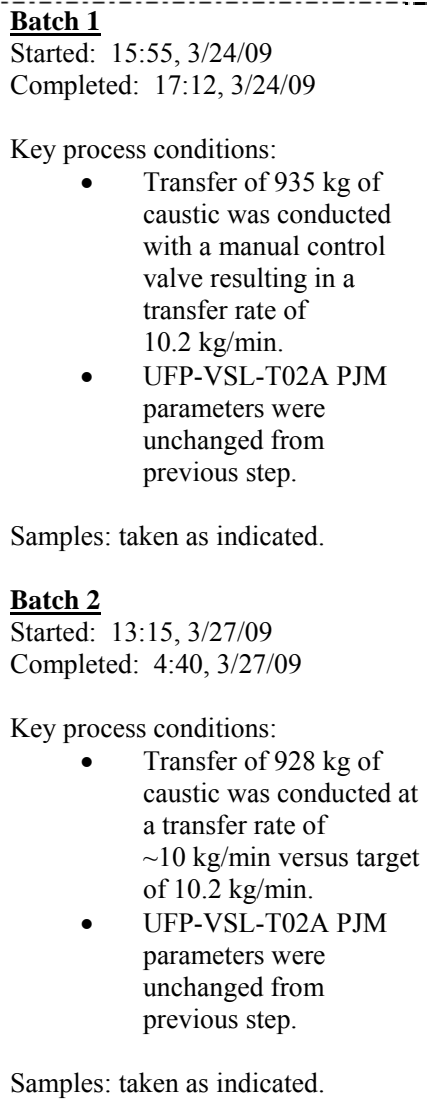 \\
\hline B. 2. & $\begin{array}{l}\text { Flush } \\
\text { filter-loop }\end{array}$ & $\begin{array}{l}\text { Flush slurry in } \\
\text { filter-loop back into } \\
\text { UFP-VSL-T02A with } \\
\text { inhibited water. }\end{array}$ & $\begin{array}{l}\text { Flush at scale-time. ( } 75 \\
\mathrm{~kg} / \mathrm{min}) \text {. } \\
\text { UFP-VSL-T02A was } \\
\text { sampled before and after }\end{array}$ & $\begin{array}{l}\text { For Integrated Test B and D, } \\
\text { collect sample from one low } \\
\text { CD port in UFP-VSL-T02A at } \\
\text { least } 10 \text { minutes after } \\
\text { UFP-VSL-T02A has been }\end{array}$ & $\begin{array}{l}\text { Started: } 12: 03,3 / 25 / 09 \\
\text { Completed: } 12: 05,3 / 25 / 09 \\
\text { Key process conditions: } \\
\qquad \quad \text { Flushed slurry in }\end{array}$ \\
\hline
\end{tabular}




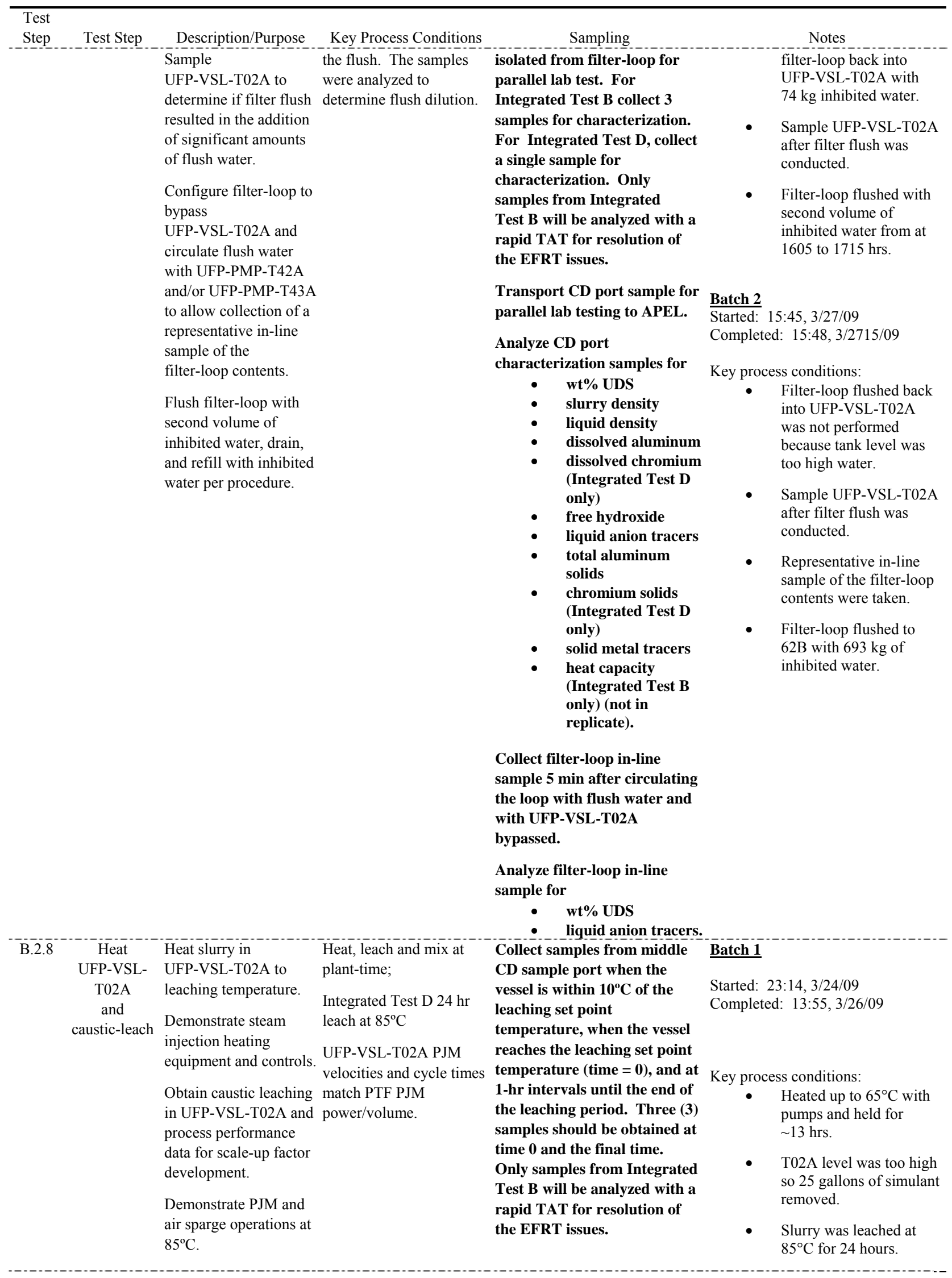




\begin{tabular}{|c|c|c|c|c|c|}
\hline $\begin{array}{l}\text { Test } \\
\text { Step }\end{array}$ & Test Step & Description/Purpose & Key Process Conditions & Sampling & Notes \\
\hline & & & & $\begin{array}{l}\text { Analyze the middle CD port } \\
\text { samples collected when the } \\
\text { vessel is within } 10^{\circ} \mathrm{C} \text { of the } \\
\text { leaching setpoint temperature, } \\
\text { at times } 0,1,2,4,8,10,12,14 \text {, } \\
\text { and } 16 \text { hr (and 18, 20, 22,and } \\
24 \text { hr in Integrated Test D) for } \\
\text { - } \quad \text { wt\% UDS } \\
\text { - } \quad \text { slurry density } \\
\text { - } \quad \text { liquid density } \\
\text { dissolved aluminum } \\
\text { dissolved chromium } \\
\text { (Integrated Test D } \\
\text { only) } \\
\text { free hydroxide } \\
\text { liquid anion tracers } \\
\text { (heat capacity } \\
\text { Integrated Test B } \\
\text { only; only for } \\
\text { samples taken when } \\
\text { the vessel is within } \\
10^{\circ} \mathrm{C} \text { of the leaching } \\
\text { temperature } \\
\text { setpoint and the } \\
\text { first sample taken } \\
\text { after the setpoint is } \\
\text { reached) (not in } \\
\text { replicate). }\end{array}$ & $\begin{array}{l}\text { PJMs was completed. } \\
\text { Samples: taken as indicated. } \\
\text { Batch 2 } \\
\text { Started: } 13: 15,3 / 27 / 09 \\
\text { Completed: } 17: 20,3 / 28 / 09 \\
\text { Key process conditions: } \\
\text { After caustic -leach line } \\
\text { flush back to T02A was } \\
\text { not completed due to } \\
\text { high level measurement } \\
\text { in T02A. } \\
\text { The formal tuning of the } \\
\text { PJMs was completed. } \\
\text { Heat up ramp time of } \\
\text { 2.6 hours. } \\
\text { Slumples: } \\
\text { Taken as indicated. } \\
85^{\circ} \mathrm{C} \text { for } 24 \text { hours. }\end{array}$ \\
\hline & & & & $\begin{array}{l}\text { For samples taken at times } 4 \text {, } \\
\text { 8, 12, and } 16 \text { hr (and } 20 \text { and } 24 \\
\text { hr in Integrated Test } D \text { ), } \\
\text { analyze for } \\
\text { • total aluminum } \\
\text { solids } \\
\text { • chromium solids } \\
\text { • } \quad \text { solid metal tracers. }\end{array}$ & \\
\hline & & & & $\begin{array}{l}\text { Archive separated liquid and } \\
\text { solid fractions of remaining } \\
\text { middle CD port samples. } \\
\text { Collect samples from each } \\
\text { submerged CD sample port } \\
\text { when vessel is within } 10^{\circ} \mathrm{C} \text { of } \\
\text { the leaching setpoint } \\
\text { temperature, when vessel } \\
\text { reaches the leaching setpoint } \\
\text { temperature, and at } 4 \text {-hr } \\
\text { intervals after vessel reaches the } \\
\text { leaching temperature until } \\
\text { leaching is finished. } \\
\text { Archive separated liquid and } \\
\text { solid fractions of CD port } \\
\text { samples. }\end{array}$ & \\
\hline B. 2.9 & $\begin{array}{l}\text { Cool } \\
\text { UFP-VSL- } \\
\text { T02A }\end{array}$ & $\begin{array}{l}\text { Cool UFP-VSL-T02A } \\
\text { contents to the filtration } \\
\text { temperature in plant } \\
\text { time using the cooling } \\
\text { jacket. }\end{array}$ & $\begin{array}{l}\text { Cool at plant-time; } \\
(12.6 \mathrm{hr}) \text {. } \\
\text { UFP-VSL-T02A PJM } \\
\text { velocities and cycle times } \\
\text { match PTF PJM }\end{array}$ & $\begin{array}{l}\text { When vessel has reached the } \\
\text { filtration temperature, collect } \\
\text { sample from each submerged } \\
\text { CD sample port. Only } \\
\text { samples from Integrated Test } \\
\text { B will be analyzed with a rapid }\end{array}$ & $\begin{array}{l}\text { Cooling } \\
\text { Batch } 1 \\
\text { Started: } 13: 55,3 / 26 / 09 \\
\text { Completed: } 02: 16,3 / 27 / 09 \\
\text { Key process conditions: }\end{array}$ \\
\hline
\end{tabular}




\begin{tabular}{|c|c|c|c|c|c|}
\hline $\begin{array}{l}\text { Test } \\
\text { Step }\end{array}$ & Test Step & Description/Purpose & Key Process Conditions & Sampling & Notes \\
\hline & & & power/volume. & 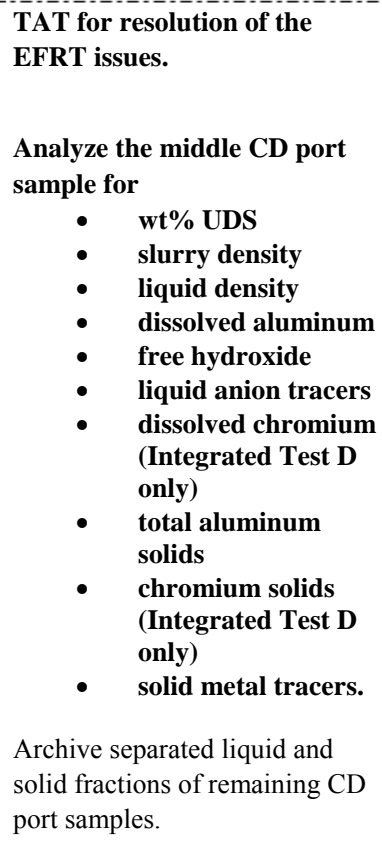 & $\begin{array}{l}\text { UFP-VSL-T02A contents } \\
\text { were cooled to } 25^{\circ} \mathrm{C} \text { in } \\
\text { 12.5. hours (plant time) } \\
\text { using the cooling jacket. } \\
\text { PJM parameters } \\
\text { unchanged from previous } \\
\text { step. } \\
\text { Samples: taken as indicated. } \\
\text { Batch 2 } \\
\text { Started: } \\
\text { 17:20, 3/28/09 } \\
\text { Completed: } 06: 00,3 / 29 / 09 \\
\text { Key process conditions: } \\
\text { - } \quad \text { UFP-VSL-T02A contents } \\
\text { were cooled to } 25^{\circ} \mathrm{C} \text { in } \\
\text { 12.7 hours (plant time) } \\
\text { using the cooling jacket. } \\
\text { PJM parameters } \\
\text { unchanged from previous } \\
\text { step. } \\
\text { Samples: taken as indicated. }\end{array}$ \\
\hline B. 2.10 & $\begin{array}{l}\text { Transfer } \\
\text { leached } \\
\text { material to } \\
\text { UFP-VSL- } \\
\text { T01B }\end{array}$ & $\begin{array}{l}\text { Transfer the leached } \\
\text { material from } \\
\text { UFP-VSL-T02A to } \\
\text { UFP-VSL-T01B for } \\
\text { temporary storage. In } \\
\text { order to provide enough } \\
\text { solids for the remaining } \\
\text { test steps and additional } \\
\text { batch of leached } \\
\text { material is required. }\end{array}$ & Nonprototypic & None. & $\begin{array}{l}\text { Completed: } 03: 35,3 / 27 / 09 \\
\text { Leached solids were transferred to } \\
\text { T01A, since T01B was used as feed } \\
\text { tank for T02A during solids } \\
\text { concentration of Batch \#2. }\end{array}$ \\
\hline B. 2.11 & $\begin{array}{c}\text { R.2.1 -B.2.9 } \\
\text { as needed }\end{array}$ & $\begin{array}{l}\text { provide a second batch } \\
\text { of leached solids so that } \\
\text { the remaining test steps } \\
\text { can be completed. }\end{array}$ & $\begin{array}{l}\text { All conditions are the } \\
\text { same except that step } \\
\text { B. } 2.5 \text { Concentrate solids } \\
\text { to } 20 \text {-wt } \% \text { will be } \\
\text { conducted using } 5 \text { filters } \\
\text { instead of } 1 \text { filter. }\end{array}$ & $\begin{array}{l}\text { The sampling protocol remains } \\
\text { the same. }\end{array}$ & $\begin{array}{l}\text { See comments above under "Batch } \\
2 \text { ". }\end{array}$ \\
\hline B. 2.12 & $\begin{array}{l}\text { Post-caustic- } \\
\text { leach } \\
\text { concentration } \\
\text { of solids }\end{array}$ & $\begin{array}{l}\text { Concentrate solids in } \\
\text { leached slurry to } \\
17 \text {-wt } \% \text { UDS. Start } \\
\text { with the material from } \\
\text { the second leach batch } \\
\text { in UFP-VSL-T02A. } \\
\text { When this batch has } \\
\text { been dewatered, begin } \\
\text { transferring the } \\
\text { material stored in } \\
\text { UFP-VSL-T01B as } \\
\text { directed by the } \\
\text { approved run sheet. } \\
\text { Demonstrate } \\
\text { post-caustic-leach } \\
\text { solids concentration } \\
\text { endpoints. }\end{array}$ & $\begin{array}{l}\text { Ultrafilters drained just } \\
\text { before concentration of } \\
\text { solids is started. } \\
\text { Concentrate at plant-time. } \\
\text { Five ultrafilter bundles. } \\
\text { UFP-VSL-T02A PJM } \\
\text { velocities and cycle times } \\
\text { match PTF PJM } \\
\text { power/volume. } \\
\text { Route permeate to } \\
\text { UFP-VSL-T62A/B. }\end{array}$ & $\begin{array}{l}\text { Collect permeate samples } \\
\text { between each filter bundle and } \\
\text { the pulse-pots at } 3 \text { evenly spaced } \\
\text { times and inspect for particle } \\
\text { break-through. } \\
\text { Collect samples from the } \\
\text { middle-low CD port before } \\
\text { permeate valves are opened, at } 8 \\
\text { times during solids } \\
\text { concentration, and after solids } \\
\text { concentration is completed. } \\
\text { Analyze all CD port samples for } \\
\text { - wt\% UDS. } \\
\text { Analyze initial and final CD } \\
\text { port samples for } \\
\text { - shear stress vs. } \\
\text { - liquid viscosity. }\end{array}$ & 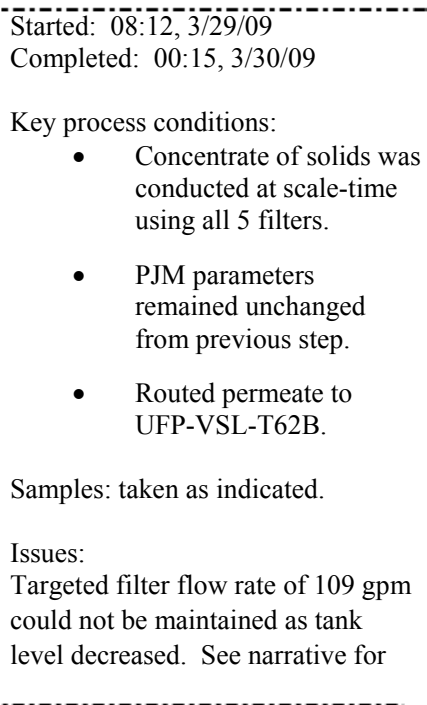 \\
\hline
\end{tabular}




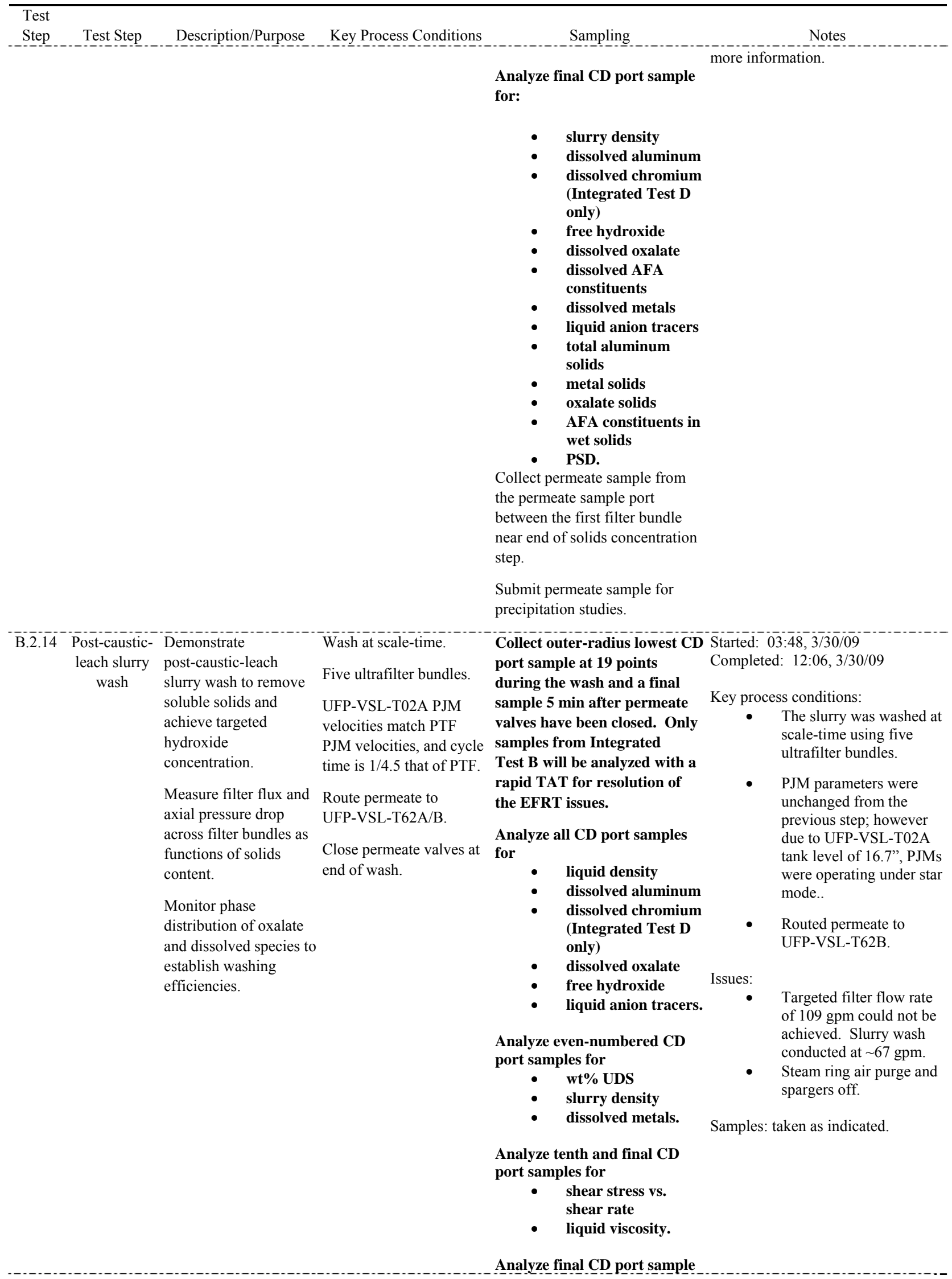




\begin{tabular}{|c|c|c|c|c|c|}
\hline $\begin{array}{l}\text { Test } \\
\text { Step }\end{array}$ & Test Step & Description/Purpose & Key Process Conditions & Sampling & Notes \\
\hline & & & & \multicolumn{2}{|l|}{$\begin{array}{l}\text { Collect permeate sample from } \\
\text { the permeate sample port } \\
\text { between the first filter bundle } \\
\text { and the pulse-pots after each } \\
\text { approximately } 40 \text { gals of wash } \\
\text { water addition. } \\
\text { Submit permeate sample for } \\
\text { precipitation studies. }\end{array}$} \\
\hline B. 2.15 & $\begin{array}{l}\text { Chromium } \\
\text { slurry } \\
\text { addition }\end{array}$ & $\begin{array}{l}\text { INTEGRATED TEST B } \\
\text { ONLY - Add chromium } \\
\text { solids (as a slurry in- } \\
\text { line at suction of } \\
\text { UFP-PMP-T42A. Add } \\
\text { AFA to maintain to } \\
\text { maintain a } \\
\text { concentration of } \\
350 \mathrm{ppm} \text {. }\end{array}$ & $\begin{array}{l}\text { Nonprototypic. } \\
\text { Permeate valves closed. } \\
\text { No change in mixing or } \\
\text { pumping parameters from } \\
\text { Step B.2.12. }\end{array}$ & None. & $\begin{array}{l}\text { As noted, this was not performed for } \\
\text { Integrated Test D as the Cr was } \\
\text { already in the slurry. }\end{array}$ \\
\hline B. 2.16 & $\begin{array}{l}\text { Wash and/or } \\
\text { reconcentrate } \\
\text { slurry solids }\end{array}$ & $\begin{array}{l}\text { INTEGRATED TEST B } \\
O N L Y \text { - Wash and/or } \\
\text { reconcentrate slurry, if } \\
\text { necessary, to remove } \\
\text { excess liquid and } \\
\text { hydroxide introduced } \\
\text { by chromium solids } \\
\text { slurry. }\end{array}$ & $\begin{array}{l}\text { Nonprototypic. } \\
\text { Concentrate and wash } \\
\text { with } 5 \text { ultrafilter bundles. }\end{array}$ & None. & $\begin{array}{l}\text { As noted, this was not performed for } \\
\text { Integrated Test D as the Cr was } \\
\text { already in the slurry. }\end{array}$ \\
\hline B. 2.17 & $\begin{array}{l}\text { Add } \\
\text { permanganate }\end{array}$ & $\begin{array}{l}\text { Demonstrate in-line } \\
\text { addition of } \\
\text { oxidative-leach } \\
\text { chemicals. }\end{array}$ & $\begin{array}{l}\text { Add chemicals at } \\
\text { scale-time. } \\
\text { UFP-VSL-T02A PJM } \\
\text { velocities match PTF } \\
\text { PJM velocities, and cycle } \\
\text { time is } 1 / 4.5 \text { that of PTF. }\end{array}$ & 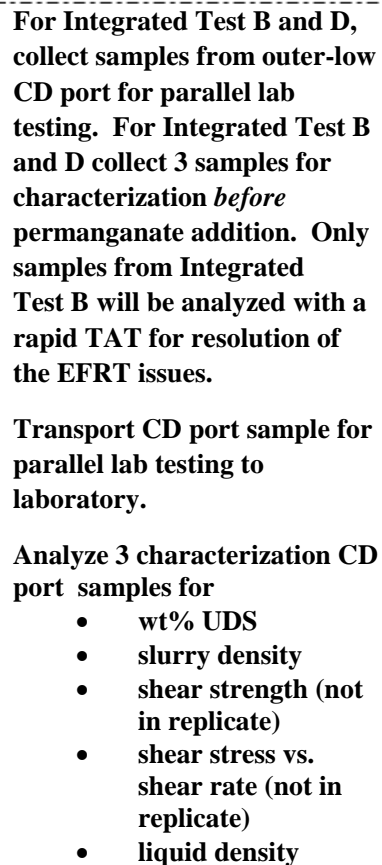 & 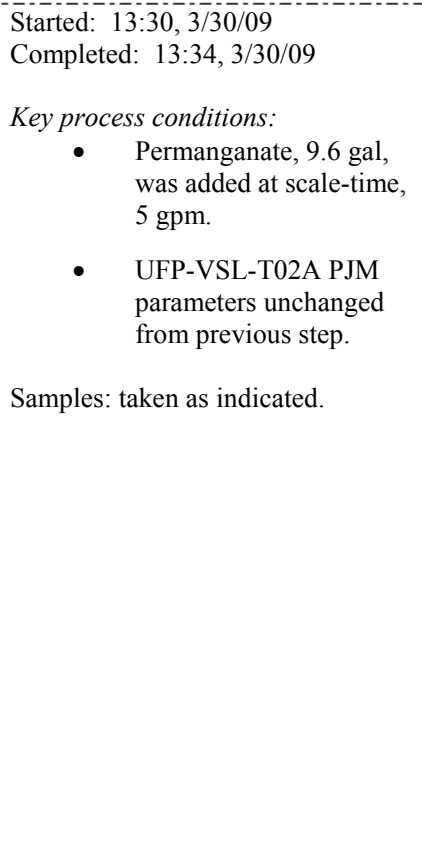 \\
\hline
\end{tabular}




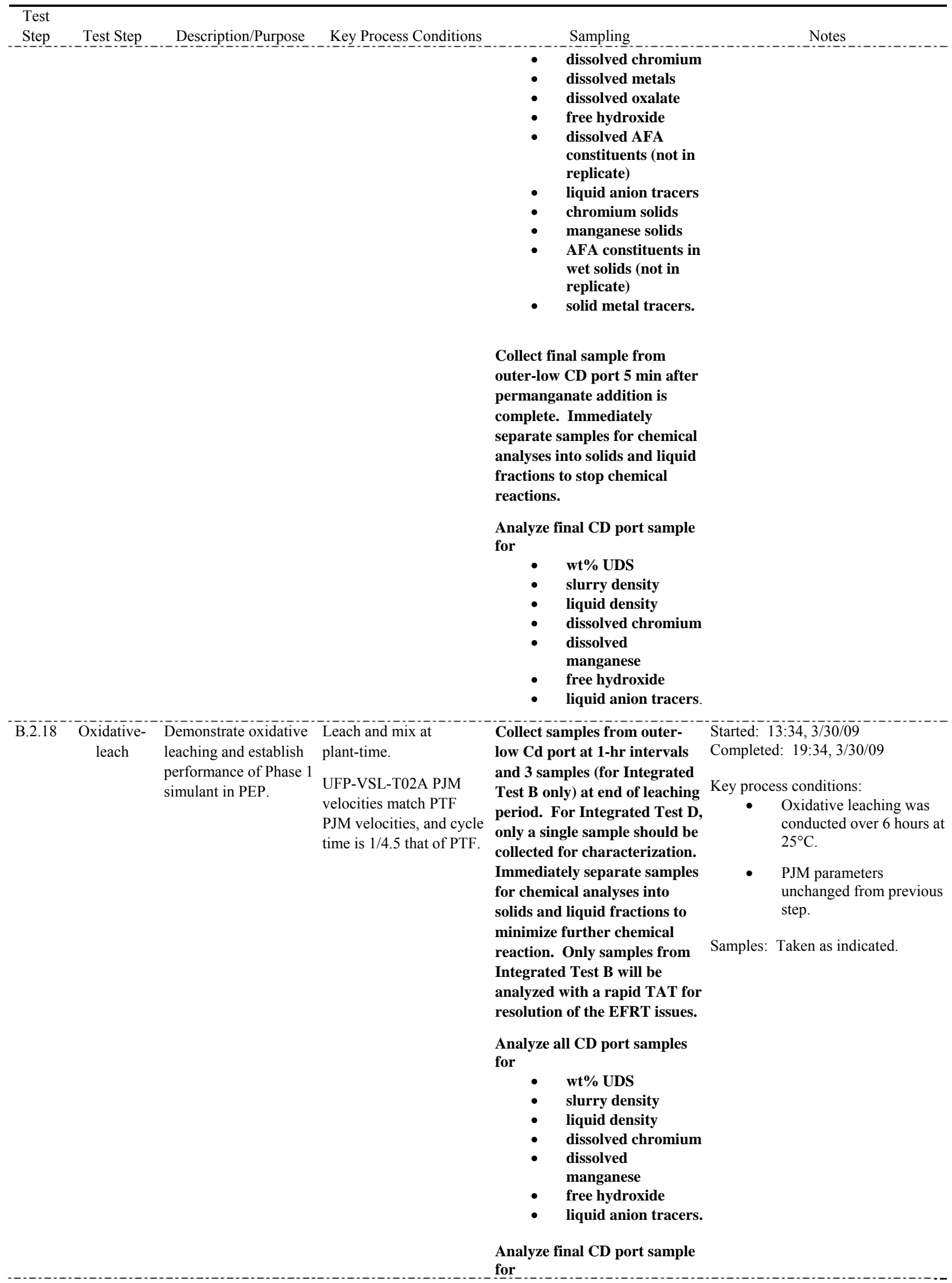




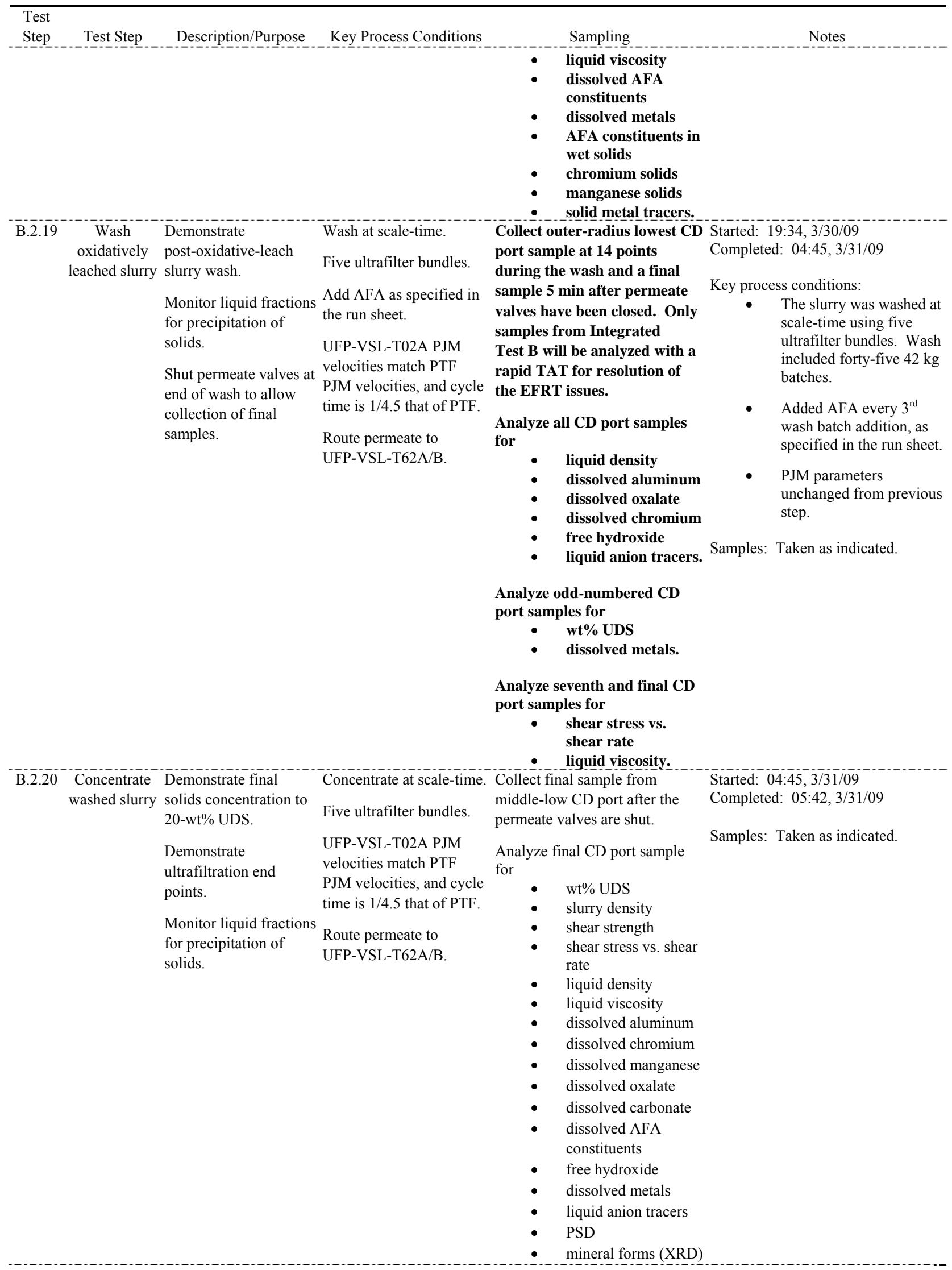




\begin{tabular}{|c|c|c|c|c|c|}
\hline $\begin{array}{l}\text { Test } \\
\text { Step }\end{array}$ & Test Step. & Description/Purpose & Key Process Conditions & $\begin{array}{ll}\text { - } & \text { Sampling } \\
& \text { \& habtal morphology } \\
\text { - TEM/SEM) } & \text { metal solids } \\
\text { - } & \text { AFA constituents in } \\
& \text { wet solids } \\
\text { - } & \text { solid metal tracers. }\end{array}$ & Notes \\
\hline B. 2.21 & $\begin{array}{l}\text { Flush } \\
\text { filter-loop }\end{array}$ & $\begin{array}{l}\text { Flush slurry in } \\
\text { filter-loop back into } \\
\text { UFP-VSL-T02A with } \\
\text { inhibited water. } \\
\text { Sample } \\
\text { UFP-VSL-T02A to } \\
\text { determine if filter flush } \\
\text { resulted in the addition } \\
\text { of significant amounts } \\
\text { of flush water. } \\
\text { Configure filter-loop to } \\
\text { bypass } \\
\text { UFP-VSL-T02A and } \\
\text { circulate flush water } \\
\text { with UFP-PMP-T42A } \\
\text { and/or UFP-PMP-T43A } \\
\text { to allow collection of a } \\
\text { representative in-line } \\
\text { sample of the } \\
\text { filter-loop contents. }\end{array}$ & $\begin{array}{l}\text { Flush at scale-time. } \\
\text { UFP-VSL-T02A PJM } \\
\text { velocities match PTF } \\
\text { PJM velocities, and cycle } \\
\text { time is } 1 / 4.5 \text { that of PTF. }\end{array}$ & $\begin{array}{l}\text { Collect filter-loop in-line sample } \\
5 \text { min after circulating the loop } \\
\text { with flush water and with } \\
\text { UFP-VSL-T02A bypassed. } \\
\text { Analyze filter-loop in-line } \\
\text { sample for } \\
\text { - wt\% UDS } \\
\text { - liquid anion tracers. }\end{array}$ & \\
\hline B. 2.22 & $\begin{array}{l}\text { Transfer } \\
\text { slurry from } \\
\text { UFP-VSL- } \\
\text { T02A } \\
\text { to } \\
\text { UFP-VSL- } \\
\text { T62 A/B or } \\
\text { totes as } \\
\text { directed by } \\
\text { the WTP PEP } \\
\text { test director }\end{array}$ & $\begin{array}{l}\text { Transfer slurry from } \\
\text { UFP-VSL-T02A to } \\
\text { UFP-VSL-62A/B or } \\
\text { totes using a portable } \\
\text { heel pump. }\end{array}$ & Nonprototypic. & $\begin{array}{l}\text { Collect sample from } \\
\text { middle-low CD port prior to } \\
\text { transfer. } \\
\text { Analyze CD port sample for } \\
\text { - } \quad \text { wt } \% \text { UDS } \\
\text { - liquid anion tracers. }\end{array}$ & \\
\hline
\end{tabular}


Appendix L

Physical Properties 



\section{Appendix L: Physical Properties}

This appendix contains abstractions from Test Data Packages. Interested readers are referred to the listed Test Data Packages listed in the title of each section for more information.

\section{L.1 Rheology (WTP-TDP-366)}

\begin{tabular}{llll}
\hline & & \\
Date: & $5 / 11 / 2009$ & Project No. & 53569 \\
To: & Brad Johnson & Internal Distribution: & \\
From: & Jaehun Chun & \\
Subject: & $\begin{array}{l}\text { Integrated Test D Rheology Data Report } \\
\text { on PEP Slurry March - April, 2009 }\end{array}$ & \\
& & \\
\hline
\end{tabular}

Specimens collected for the Integrated Test D were done under TI-WTP-PEP-082, Steps B.2.1, B.2.2, B.2.5, B.2.10, B.2.11, B.2.15, B.2.16, and B.2.17.

Multiple specimens of PEP slurry were delivered to APEL for rheological analysis on 3/31/09. Specimens were analyzed to determine either their flow curves (i.e., plots of shear stress vs. shear rate) or shear strengths. The analysis was done using an Anton Parr Rheometer MCR 301 SN80371304 (for flow curve) and Haake RS-600 (for shear strength). Rheometer calibration verifications were done 3 times for Anton Parr Rheometer MCR 301 SN80371304 and 1 time for Haake RS-600 by Maria Luna in accordance with QA procedure TPR-WTP-PEP-049. Two Newtonian standards with different viscosities were used to check the calibration of these systems: a $9.4 \mathrm{cP}$ Brookfield Standard Lot \# 062408 and a $99.0 \mathrm{cP}$ Brookfield Standard Lot \#071008. All verifications were within the $10 \%$ of the reported values.

Figures 1-4 are the calibration curves performed on the Anton Parr Rheometer MCR 301 SN80371304 with $9.4 \mathrm{cP}$ and $99.0 \mathrm{cP}$ Brookfield Standards and the Haake RS-600 with $99.0 \mathrm{cP}$ Brookfield Standard, respectively. Note that the calibration for Haake RS-600 is only a performance check of the Haake RS-600 system, since the measurements performed on this system are shear strength measurements and Newtonian standards have a shear strength of zero. 
Shear Stress vs Shear Rate

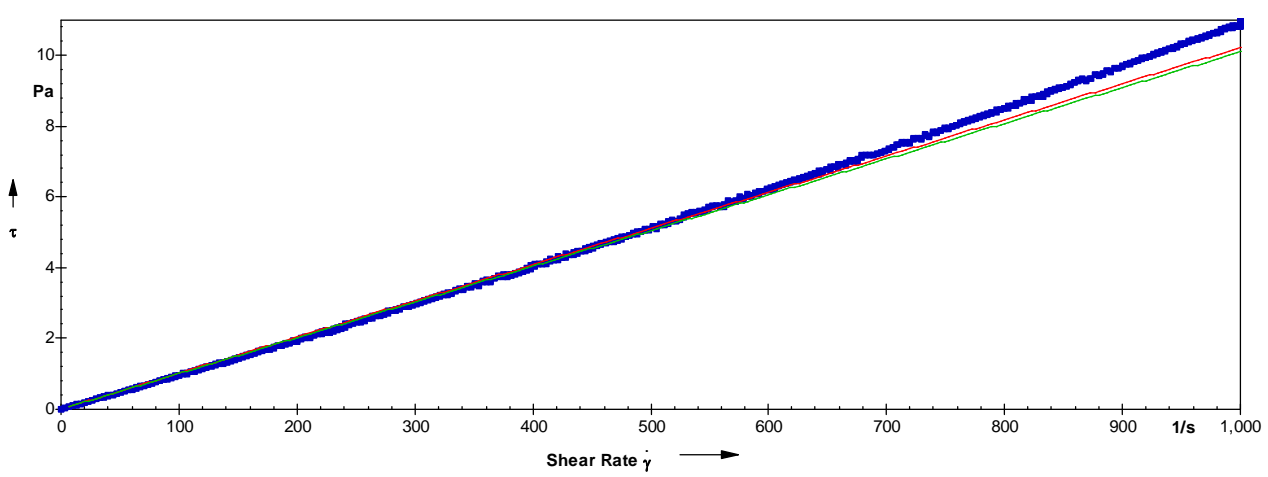

090406_9.4CP Standard 1

CC27-SN13634; $\mathrm{d}=0 \mathrm{~mm}$

- $\tau$ Shear Stress

090406_9.4CP Standard 1 Newtonian Up 1

eta $=0.010228 \mathrm{~Pa} \cdot \mathrm{s}$

$\tau$ Shear Stress

090406 9.4CP Standard 1 Newtonian Down 1

eta $=0.010106 \mathrm{~Pa} \cdot \mathrm{s}$

- $\tau$ Shear Stress

Figure 1. Flow Curve Measurement 1 of 2 of the $9.4 \mathrm{cP}$ Newtonian Standard Run on the Anton Paar Rheometer

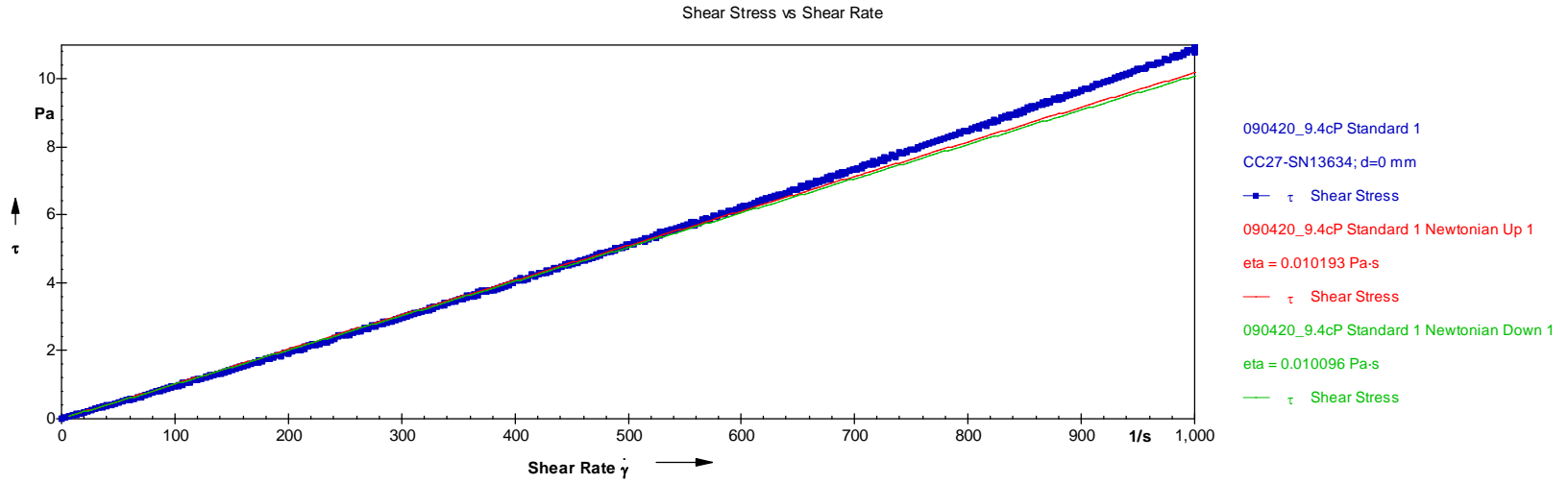

Figure 2. Flow Curve Measurement 2 of 2 of the $9.4 \mathrm{cP}$ Newtonian Standard Run on the Anton Paar Rheometer

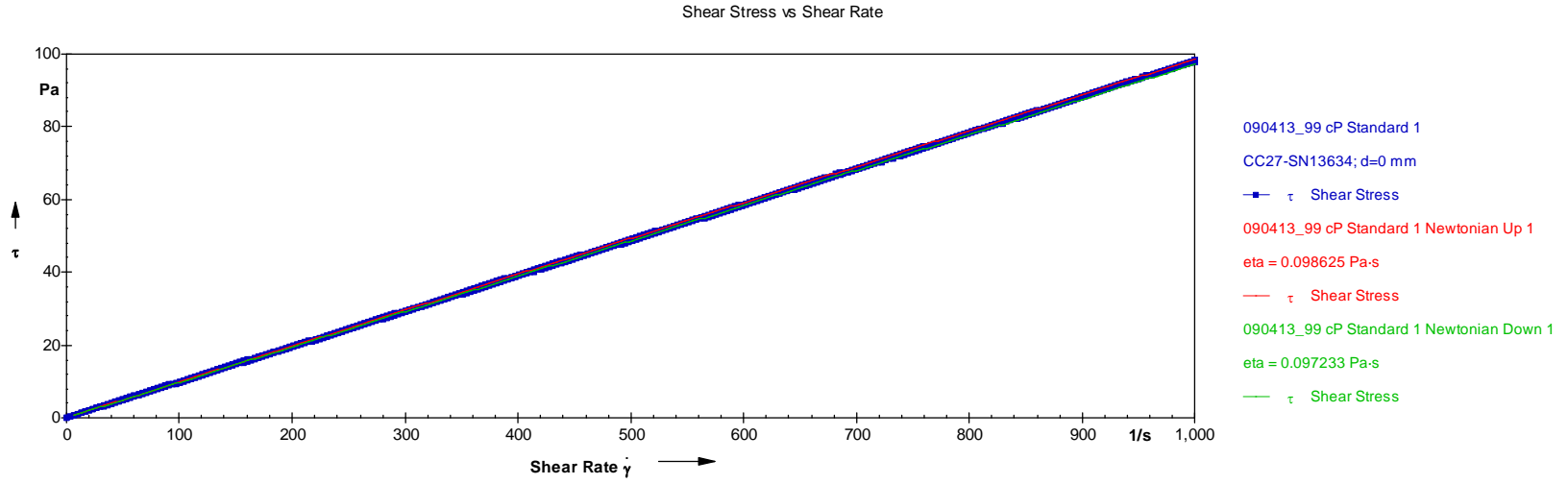

Figure 3. Flow Curve of the 99.0 cP Newtonian Standard Run on the Anton Paar Rheometer 


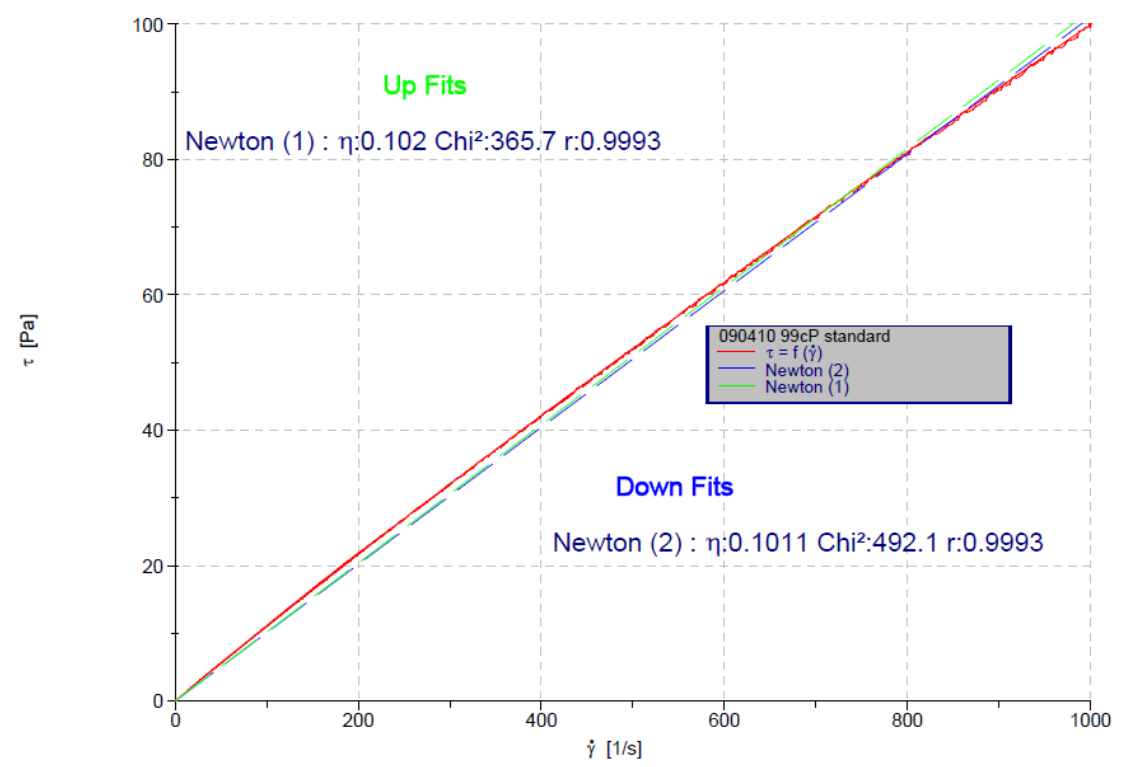

Figure 4. Flow Curve of the 99.0 cP Newtonian Standard Run on the Haake RS-600 Rheometer

The analysis was performed in accordance with procedure TPR-WTP-PEP-049 and the data were collected digitally using the RHEOPLUS/32 V3.21 21003751-33024 software (for flow curve) and RHEOWIN V2.96 software (for shear strength). The same software was used to operate the corresponding rheometers. For the flow curve measurement, the specimens were prepared for analysis by shaking the bottle before extracting the sample. In order to obtain supernatant from the slurry, the specimen was centrifuged at 1000 times $\mathrm{g}$ for 1 hour. Experimental details were recorded in laboratory record book 60127.

Flow curve tests for both slurry and supernatant were done with the cup and bob sensor system CC27-SN13634. Shear stress was measured as a function of shear rate while the shear rate was ramped from 0 to 1000 1/sec over $5 \mathrm{~min}$, followed by a 1 minute hold at $1000 \mathrm{1} / \mathrm{sec}$ and a ramp down to $01 / \mathrm{sec}$ over 5 minutes. Each specimen was generally measured three times. An initial measurement ("FRESH RUN") was made on a fresh sample taken from the specimen, that same sample was then re-run a second time ("RERUN"). The rheometer was cleaned, and a third measurement ("REPEAT FRESH RUN") was made by taking a second aliquot from the specimen. Note that the sample, D-02AML-012-XX-5359-RHE-4, was measured only two times, "FRESH RUN" and "RERUN", due to insufficient amount of the supernatant for the measurement. Samples were placed in the cup up to the designated fill line (about 8 to $10-\mathrm{mL}$ ). Settling cannot be prevented during the measurement if the particles are large and the viscosity low; however, no evidence of significant settling was seen in the data or the cup after testing. 


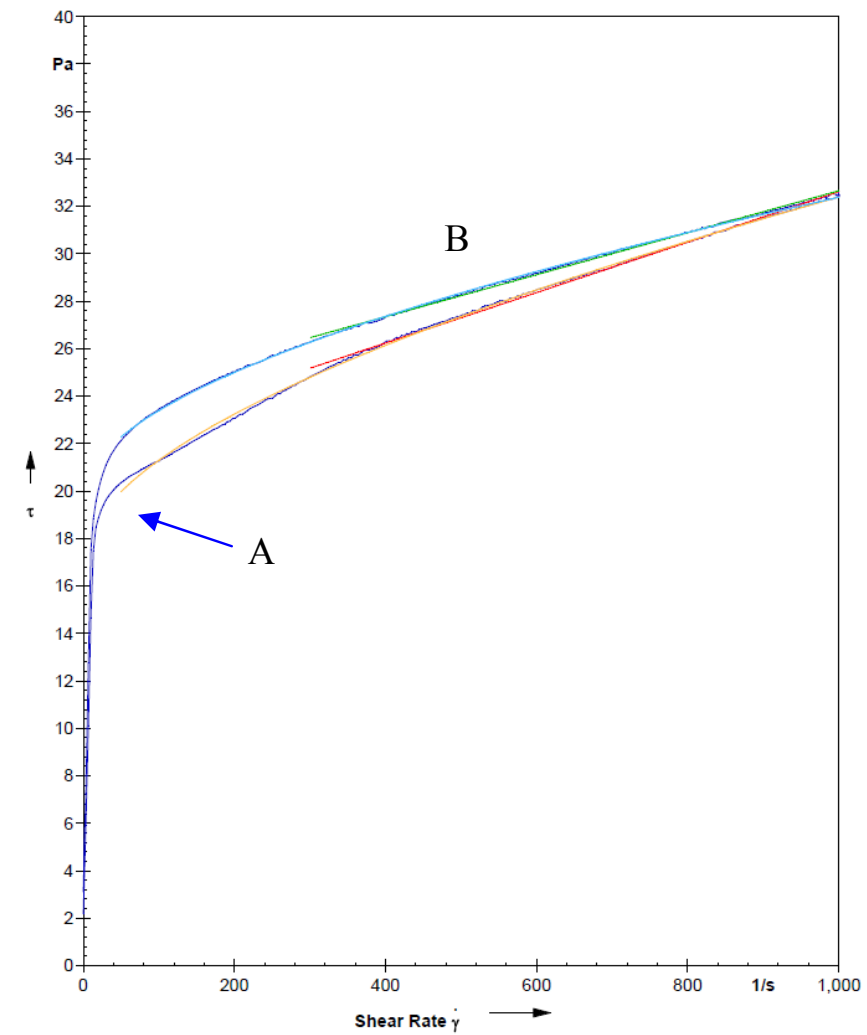

Figure 5. Typical Rheogram of a Slurry Sample with Reasonably High Yield Stress

Figure 5 is a typical rheogram of a slurry sample (sample D-02AOL-017-XX-5510-RHE-4) which can be seen in the Integrated Test D. There are two features that were typically characteristic of many slurry specimens: 1) a yield stress at the onset of flow, (indicated by the blue arrow, "A"), and 2) an approximately linear region where shear stress is linearly proportional to shear rate " $\mathrm{B}$ ". Note that the data at very low shear rates was not included in the analysis to avoid overweighting the Bingham plastic and Casson curve fit calculations performed by the RHEOPLUS/32 V3.21 21003751-33024 software. In the previous Shakedown/Functional Test, Integrated Test A, and Integrated Test B, all slurry samples showed negligible or low to intermediate yield stresses, typically less than 10 Pa (see TDP-WTP-355, TDP-WTP-359, and TDP-WTP-363 for details). Many slurry samples in the Integrated Test D showed reasonably high yield stresses, typically ranging from 12-24 Pa, and did not show slope changes and data fluctuation, mainly associated with laminar Taylor vortices (although other factors such as cavitation, minor settling, or the release of entrained gas may play a role).

However, all supernatant samples showed the slope changes and data fluctuation shown as " $\mathrm{C}$ " in Figure 6 . Figure 6 shows a typical rheogram of a supernatant sample (sample D-02AOL-019-07-5544-RHE-4), indicating that the slope change and more fluctuation (indicated by the red arrow, "C") starts around $120 \mathrm{1} / \mathrm{sec}$ below which the curve fit analysis can be performed. As described in previous analyses for the Shakedown/Functional Test and the Integrated Tests A and B, the slope changes and data fluctuation made it difficult to fit the data to a single mathematical expression because such behavior is not included in existing fitting models. The data analysis team evaluated these instabilities and decided to perform curve fit analysis using only the data prior to the discontinuity (e.g., up to about 120 1/sec as shown in Figure 6). 


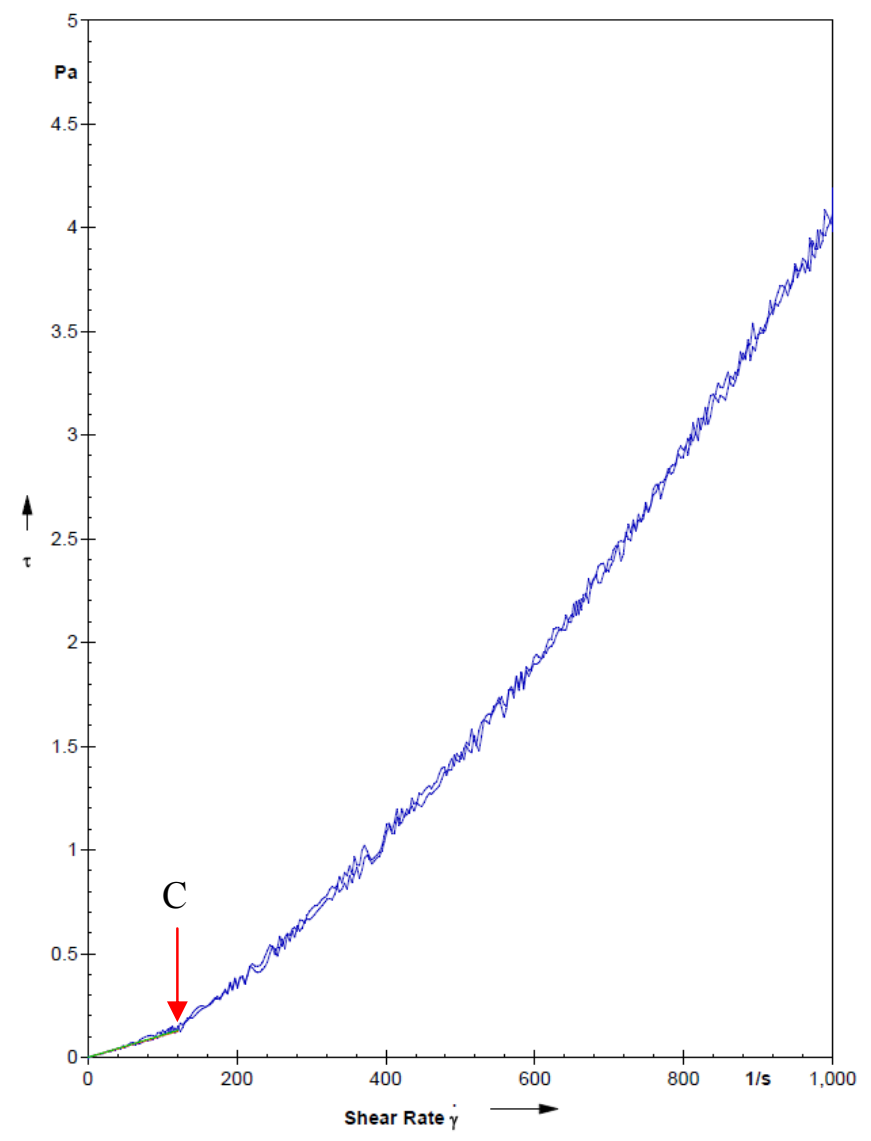

Figure 6. Typical Rheogram of a Supernatant Sample

A simple hydrodynamic theory may provide a reasonable estimate and physical insights for this instability behavior. The hydrodynamic transition from laminar Couette flow to laminar Taylor vortices occurs when the Reynolds number of the experiment exceeds a geometrically determined critical Reynolds number, $\mathrm{Re}_{c}$. Assuming the infinite length of the fluid column, the critical Reynolds number in our case may be described by ${ }^{1}$

$$
\operatorname{Re}_{c}=41.2 \sqrt{\frac{\left(R_{o}+R_{i}\right)}{2 h}}
$$

where $R_{i}$ and $R_{o}$ denote bob radius and cup radius. Here $h$ denotes a gap between the bob and cup, which is $R_{o}-R_{i}$. The Reynolds number of the experiment, Re, can be defined by $\rho h \Omega R_{i} / \mu_{\text {app }}$ where $\rho, \Omega$, and $\mu_{\text {app }}$ represent the density of the sample, the angular velocity of the bob, and the apparent viscosity of the sample respectively. Using the geometries of the cup and bob sensor system CC27-SN13634, the critical Reynolds number is expected to be about 145 . For our experimental setup, $\operatorname{Re} \approx 146$ at $1001 / \mathrm{sec}$ using reasonable sample density and apparent viscosity values of $1.2 \mathrm{~g} / \mathrm{cm}^{3}$ and $1.0 \mathrm{cP}$, respectively. Since the formula for the critical Reynolds number is based on a Newtonian fluid, one can expect that the hydrodynamic transition to laminar Taylor vortices occurs around $1001 / \mathrm{sec}$, which is very close to $1201 / \mathrm{sec}$. Consequently, the slope changes and data fluctuation as shown in "C" may be due to the onset of the laminar Taylor vortices although other disturbances are possibly coupled.

1. L. D. Landau and E. M. Lifshitz, "Course of Theoretical Physics - Volume 6: Fluid Mechanics," 2 ${ }^{\text {nd }}$ Ed., Butterworth-Heinemann, Oxford (1987), 
This simple theory can be also applied to the slurry sample shown in Figure 5 (sample D-02AOL-017-XX-5510-RHE-4). One may expect that the transition does not occur or may occur at a very high shear rate since the viscosity of the slurry is obviously expected to be much greater than that of the supernatant sample. Following the similar calculation scheme, one can calculate $\operatorname{Re} \approx 42$ even at $10001 / \mathrm{sec}$ using the sample density and apparent viscosity values of $1.2 \mathrm{~g} / \mathrm{cm}^{3}$ and $35 \mathrm{cP}$, respectively. Even though the formula for the critical Reynolds number is based on a Newtonian fluid, we can deduce that any instability due to the onset of the laminar Taylor vortices would not take place, considering a large difference between the Reynolds number based on the experiment and the critical Reynolds number (i.e., 145).

The flow curves for the most of the samples did not show significant hysteresis and the data were fit with Newtonian, Bingham Plastic, and Casson flow-curve descriptors using the RHEOPLUS curve fit software, depending on the samples' rheological behavior. The software fits the entire range of data collected. However, as explained previously, a partial range of data was used to obtain fitting parameters for most of samples in the Integrated Test D in order to avoid 1) the flow instability at a higher shear rate for supernatant samples, and 2) the overweighting the Bingham plastic and Casson curve fit calculations at a lower shear rate for slurry samples. In addition, the variation of data range for Casson curve fit is larger than that for Bingham curve fit because Casson curve fit should reflect a curvature. Appendix B contains the partial ranges of data for all samples in the Integrated Test D.

For shear strength test, a $1.6 \times 1.6 \mathrm{~cm}$ shear vane spindle was used and an enough space (at least $1.6 \mathrm{~cm}$ away from the top solid bed and the side wall and bottom of a test container) was provided for proper measurements. A and $\mathrm{M}$ factors for the tests are $116568.602 \mathrm{~Pa} / \mathrm{N} \cdot \mathrm{m}$ and $1.0(1 / \mathrm{sec})(\mathrm{rad} / \mathrm{sec})$ respectively indicated in RHEOWIN V2.96 software. A numerical value of 'A' factor $(A)$ can be calculated via the shear vane diameter $(D)$ and shear vane height $(H)$ :

$$
A=\left[\frac{\pi D^{3}}{2}\left(\frac{H}{D}+\frac{1}{3}\right)\right]^{-1}
$$

Note that $D=H=1.6 \mathrm{~cm}$ for the shear strength test. Settling times for the test with the same sample are 1,2, $4,8,16,32$, and $72 \mathrm{hrs}$. For each settling time, shear stresses were collected as a function of duration time under a constant shear rate $(0.031 / \mathrm{sec})$ during 2 minutes. Then, a maximum shear stress was obtained for each settling time.

The following table is a brief summary of samples and their specifications (chronological order). All measurements were done at $25^{\circ} \mathrm{C}$. Note that the sample ID D-02AML-05A-XX-5154-RHE-4 should be D-02IN-LINE-05A-XX-5154-RHE-4 because the location of the sample collection was changed to "Filter-Loop in-line." However, it was not changed in the COC so that D-02AML-05A-XX-5154-RHE-4 was used in this report. 


\begin{tabular}{|c|c|c|c|}
\hline Sample Name & $\begin{array}{c}\text { Date } \\
\text { Received }\end{array}$ & Date Tested & Comments \\
\hline D-T22GM-002-XX-4925-RHE-4 & $03 / 23 / 09$ & $04 / 13 / 09$ & Newtonian \\
\hline D-02AML-020-XX-5584-RHE-4 & $03 / 31 / 09$ & $04 / 13 / 09$ & Bingham \\
\hline D-02AML-05A-XX-5154-RHE-4 & $03 / 31 / 09$ & 04/13/09 & Newtonian \\
\hline D-02AML-005-XX-4950-RHE-4 & 03/31/09 & 04/13/09 & Newtonian \\
\hline D-FRPRL-001-XX-4911-RHE-4 & $03 / 31 / 09$ & $04 / 13 / 09$ & Newtonian \\
\hline $\begin{array}{l}\text { D-02AML-012-XX-5342-RHE-4 } \\
\text { (supernatant) }\end{array}$ & $03 / 31 / 09$ & 04/20/09 & Newtonian \\
\hline D-02AML-005-XX-4976-RHE-4 & $03 / 31 / 09$ & $04 / 14 / 09$ & Bingham \\
\hline D-02AML-05A-XX-5180-RHE-4 & $03 / 31 / 09$ & $04 / 14 / 09$ & Bingham \\
\hline $\begin{array}{l}\text { D-FRPRL-001-XX-4912-RHE-4 } \\
\text { (supernatant) }\end{array}$ & 03/31/09 & 04/16/09 & Newtonian \\
\hline D-02AOL-014-10-5408-RHE-4 & 03/31/09 & 04/14/09 & Bingham \\
\hline D-02AML-012-XX-5341-RHE-4 & 03/31/09 & 04/14/09 & Newtonian \\
\hline $\begin{array}{l}\text { D-02AOL-014-10-5409-RHE-4 } \\
\text { (supernatant) }\end{array}$ & $03 / 31 / 09$ & $04 / 16 / 09$ & Newtonian \\
\hline D-02AOL-014-XX-5430-RHE-4 & $03 / 31 / 09$ & $04 / 14 / 09$ & Bingham \\
\hline $\begin{array}{l}\text { D-02AML-012-XX-5359-RHE-4 } \\
\text { (supernatant) }\end{array}$ & 03/31/09 & $04 / 20 / 09$ & Newtonian \\
\hline D-02AML-012-XX-5358-RHE-4 & $03 / 31 / 09$ & $04 / 15 / 09$ & Bingham \\
\hline $\begin{array}{l}\text { D-02AOL-014-XX-5431-RHE-4 } \\
\text { (supernatant) }\end{array}$ & 03/31/09 & 04/16/09 & Newtonian \\
\hline D-02AOL-017-XX-5510-RHE-4 & 03/31/09 & $04 / 15 / 09$ & Bingham \\
\hline D-02AOL-019-XX-5577-RHE-4 & $03 / 31 / 09$ & $04 / 15 / 09$ & Bingham \\
\hline $\begin{array}{l}\text { D-02AOL-019-XX-5578-RHE-4 } \\
\text { (supernatant) }\end{array}$ & 03/31/09 & 04/16/09 & Newtonian \\
\hline $\begin{array}{l}\text { D-02AOL-019-07-5561-RHE-4 } \\
\text { (supernatant) }\end{array}$ & $03 / 31 / 09$ & 04/16/09 & Newtonian \\
\hline D-02AOL-019-07-5560-RHE-4 & 03/31/09 & 04/15/09 & Bingham \\
\hline $\begin{array}{l}\text { D-02AOL-018-06-5544-RHE-4 } \\
\text { (supernatant) }\end{array}$ & $03 / 31 / 09$ & $04 / 16 / 09$ & Newtonian \\
\hline $\begin{array}{l}\text { D-02AML-020-XX-5585-RHE-4 } \\
\text { (supernatant) }\end{array}$ & 03/31/09 & $04 / 20 / 09$ & Newtonian \\
\hline $\begin{array}{l}\text { D-02AML-020-XX-5583-RHE-4 } \\
\text { (identical to D-02AML-020-XX- } \\
\text { 5582-RHE-4) }\end{array}$ & 03/31/09 & - & $\begin{array}{l}\text { No Shear Strength test is } \\
\text { needed }\end{array}$ \\
\hline D-02AML-020-XX-5582-RHE-4 & $03 / 31 / 09$ & $04 / 17 / 09$ & Shear Strength \\
\hline
\end{tabular}




\begin{tabular}{lccl}
\hline \multicolumn{1}{c}{ Sample Name } & $\begin{array}{c}\text { Date } \\
\text { Received }\end{array}$ & Date Tested & \multicolumn{1}{c}{ Comments } \\
\hline $\begin{array}{l}\text { D-FRPRL-001-XX-4910-RHE-4 } \\
\text { (identical to D-FRPRL-001-XX- }\end{array}$ & $03 / 31 / 09$ & - & $\begin{array}{l}\text { No Shear Strength test is } \\
\text { needed }\end{array}$ \\
$\begin{array}{l}\text { 4909-RHE-4) } \\
\text { D-FRPRL-001-XX-4909-RHE-4 }\end{array}$ & $03 / 31 / 09$ & $04 / 17 / 09$ & Shear Strength \\
D-02AOL-017-XX-5508-RHE-4 & $03 / 31 / 09$ & $04 / 17 / 09$ & Shear Strength \\
$\begin{array}{l}\text { D-02AOL-017-XX-5509-RHE-4 } \\
\text { (identical to D-02AOL-017-XX- }\end{array}$ & $03 / 31 / 09$ & - & $\begin{array}{l}\text { No Shear Strength test is } \\
\text { 5508-RHE-4) }\end{array}$ \\
\hline
\end{tabular}

\section{Summary of Results}

Three samples, D-02AML-020-XX-5582-RHE-4 (identical to D-02AML-020-XX-5583-RHE-4), D-FRPRL-001-XX-4909-RHE-4 (identical to D-FRPRL-001-XX-4910-RHE-4), and D-02AOL-017-XX-5508-RHE-4 (identical to D-02AOL-017-XX-5509-RHE-4), were tested with a $1.6 \times 1.6 \mathrm{~cm}$ shear vane spindle (Haake RS-600). All samples showed continuous increases in the maximum shear strength (within the experimental uncertainty) as the settling time increases and the complete asymptotes were not observed due to insufficient settling time. Considering both the limited settling time and an asymptotic behavior as settling time approaches $72 \mathrm{hrs}$, the sample D-FRPRL-001-XX-4909-RHE-4 appears to be adequate for handling in the WTP (i.e., less than $30 \mathrm{~Pa}$ of the maximum shear strength). However, the other two samples, D-02AML-020-XX-5582-RHE-4 and D-02AOL-017-XX-5508-RHE-4, showed more than $30 \mathrm{~Pa}$ for the maximum shear strength at $72 \mathrm{hrs}$ of the settling time. Therefore, the shear strength measurements for both samples with longer settling times may be needed to ensure the adequacy for handling in the WTP.

Some samples were run only as slurries and some only as supernatants as was needed for the matrix support for that part of the Test Plan. Most slurry samples were reasonably well fitted with the Bingham plastic model. Note that Casson fitting parameters were calculated just as further references so that these parameters were not considered in the table above. Exceptions are 5 slurry samples: D-T22GM-002-XX-4925-RHE-4, D-02AML-05A-XX-5154-RHE-4, D-02AML-005-XX-4950-RHE-4, D-FRPRL-001-XX-4911-RHE-4, and D-02AML-012-XX-5341-RHE-4. All supernatants did not exhibit a yield stress and Newtonian fits appear to be the best fit of the experimental data. Note that the sample, D-02AML-020-XX-5584-RHE-4, was measured three times but the analysis for "RERUN" up-ramp cannot be performed due to abnormal behavior. 
Average Rheological Parameters for Shear Stress vs. Shear Rate Measurements

\begin{tabular}{|c|c|c|c|c|c|c|c|c|c|c|c|}
\hline & Rheology Fits & $\begin{array}{l}\text { Bingham } \\
\text { Up }\end{array}$ & $\begin{array}{l}\text { Bingham } \\
\text { Up }\end{array}$ & $\begin{array}{l}\text { Bingham } \\
\text { Down }\end{array}$ & $\begin{array}{l}\text { Bingham } \\
\text { Down }\end{array}$ & $\begin{array}{l}\text { Casson } \\
\text { Up }\end{array}$ & $\begin{array}{l}\text { Casson } \\
\text { Up }\end{array}$ & $\begin{array}{l}\text { Casson } \\
\text { Down }\end{array}$ & $\begin{array}{l}\text { Casson } \\
\text { Down }\end{array}$ & $\begin{array}{l}\text { Newtonian } \\
\text { Up }\end{array}$ & $\begin{array}{l}\text { Newtonian } \\
\text { Down }\end{array}$ \\
\hline & & Yield Stress & Consistency & Yield Stress & Consistency & Yield Stress & Consistency & Yield Stress & Consistency & & \\
\hline \# & Sample Names & $\operatorname{tau}(\mathrm{Pa})$ & eta $(\mathrm{Pa} \cdot \mathrm{sec})$ & $\operatorname{tau}(\mathrm{Pa})$ & eta $(\mathrm{Pa} \cdot \mathrm{Sec})$ & tau $(\mathrm{Pa})$ & eta $(\mathrm{Pa} \cdot \mathrm{sec})$ & tau $(\mathrm{Pa})$ & eta $(\mathrm{Pa} \cdot \mathrm{Sec})$ & eta $(\mathrm{Pa} \cdot \mathrm{sec})$ & eta $(\mathrm{Pa} \cdot \mathrm{sec})$ \\
\hline 1 & $\begin{array}{l}\text { D T22GM } 002 \text { XX } 4925 \text { RHE } 4 \\
\text { Average }\end{array}$ & N/A & N/A & N/A & N/A & N/A & N/A & N/A & N/A & $4.325 \mathrm{E}-03$ & 4.264E-03 \\
\hline 2 & $\begin{array}{l}\text { D 02AML } 020 \text { XX } 5584 \text { RHE } 4 \\
\text { Average }\end{array}$ & 22.908 & $1.190 \mathrm{E}-02$ & 26.613 & $8.987 \mathrm{E}-03$ & 16.456 & $3.426 \mathrm{E}-03$ & 22.172 & $1.552 \mathrm{E}-03$ & N/A & N/A \\
\hline 3 & $\begin{array}{l}\text { D 02AML 05A XX } 5154 \text { RHE } 4 \\
\text { Average }\end{array}$ & N/A & N/A & N/A & N/A & $\mathrm{N} / \mathrm{A}$ & N/A & N/A & N/A & $5.683 \mathrm{E}-03$ & $5.503 \mathrm{E}-03$ \\
\hline 4 & $\begin{array}{l}\text { D 02AML } 005 \text { XX } 4950 \text { RHE } 4 \\
\text { Average }\end{array}$ & N/A & N/A & N/A & N/A & $\mathrm{N} / \mathrm{A}$ & N/A & N/A & N/A & $5.130 \mathrm{E}-03$ & $5.011 \mathrm{E}-03$ \\
\hline 5 & $\begin{array}{l}\text { D FRPRL } 001 \text { XX } 4911 \text { RHE } 4 \\
\text { Average }\end{array}$ & N/A & N/A & N/A & N/A & N/A & N/A & N/A & N/A & $4.352 \mathrm{E}-03$ & 4.272E-03 \\
\hline 6 & $\begin{array}{c}\text { D 02AML } 012 \text { XX } 5342 \text { RHE } 4 \\
\text { (supernatant) }\end{array}$ & & & & & & & & & & \\
\hline & Average & N/A & N/A & N/A & N/A & N/A & N/A & N/A & N/A & $1.200 \mathrm{E}-02$ & $1.185 \mathrm{E}-02$ \\
\hline 7 & $\begin{array}{l}\text { D 02AML } 005 \text { XX } 4976 \text { RHE } 4 \\
\text { Average }\end{array}$ & 3.331 & $1.085 \mathrm{E}-02$ & 2.831 & $1.118 \mathrm{E}-02$ & 1.771 & $5.486 \mathrm{E}-03$ & 1.483 & $5.823 \mathrm{E}-03$ & $\mathrm{~N} / \mathrm{A}$ & N/A \\
\hline 8 & $\begin{array}{l}\text { D 02AML 05A XX } 5180 \text { RHE } 4 \\
\text { Average }\end{array}$ & 7.034 & $1.211 \mathrm{E}-02$ & 5.980 & $1.405 \mathrm{E}-02$ & 4.460 & $4.800 \mathrm{E}-03$ & 3.759 & $5.837 \mathrm{E}-03$ & N/A & N/A \\
\hline 9 & $\begin{array}{c}\text { D FRPRL } 001 \text { XX } 4912 \text { RHE } 4 \\
\text { (supernatant) }\end{array}$ & & & & & & & & & & \\
\hline & Average & N/A & N/A & N/A & N/A & N/A & N/A & N/A & N/A & $2.808 \mathrm{E}-03$ & $2.689 \mathrm{E}-03$ \\
\hline 10 & $\begin{array}{l}\text { D 02AOL } 014105408 \text { RHE } 4 \\
\text { Average }\end{array}$ & 16.599 & $1.006 \mathrm{E}-02$ & 16.966 & $9.702 \mathrm{E}-03$ & 12.799 & $2.396 \mathrm{E}-03$ & 13.403 & $2.135 \mathrm{E}-03$ & N/A & N/A \\
\hline 11 & $\begin{array}{l}\text { D 02AML } 012 \text { XX } 5341 \text { RHE } 4 \\
\text { Average }\end{array}$ & N/A & N/A & N/A & N/A & N/A & N/A & N/A & $\mathrm{N} / \mathrm{A}$ & $2.051 \mathrm{E}-02$ & $1.984 \mathrm{E}-02$ \\
\hline 12 & $\begin{array}{c}\text { D 02AOL } 014105409 \text { RHE } 4 \\
\text { (supernatant) }\end{array}$ & & & & & & & & & & \\
\hline & Average & $\mathrm{N} / \mathrm{A}$ & $\mathrm{N} / \mathrm{A}$ & $\mathrm{N} / \mathrm{A}$ & $\mathrm{N} / \mathrm{A}$ & $\mathrm{N} / \mathrm{A}$ & N/A & $\mathrm{N} / \mathrm{A}$ & $\mathrm{N} / \mathrm{A}$ & $1.298 \mathrm{E}-03$ & $1.245 \mathrm{E}-03$ \\
\hline 13 & $\begin{array}{l}\text { D 02AOL } 014 \text { XX } 5430 \text { RHE } 4 \\
\text { Average }\end{array}$ & 22.704 & $1.031 \mathrm{E}-02$ & 24.034 & $8.976 \mathrm{E}-03$ & 17.615 & $2.359 \mathrm{E}-03$ & 19.816 & $1.620 \mathrm{E}-03$ & N/A & N/A \\
\hline
\end{tabular}


Average Rheological Parameters for Shear Stress vs. Shear Rate Measurements

\begin{tabular}{|c|c|c|c|c|c|c|c|c|c|c|c|}
\hline \multirow[b]{3}{*}{ \# } & \multirow[t]{2}{*}{ Rheology Fits } & $\begin{array}{l}\text { Bingham } \\
\text { Up }\end{array}$ & $\begin{array}{l}\text { Bingham } \\
\text { Up }\end{array}$ & $\begin{array}{l}\text { Bingham } \\
\text { Down }\end{array}$ & $\begin{array}{l}\text { Bingham } \\
\text { Down }\end{array}$ & $\begin{array}{l}\text { Casson } \\
\text { Up }\end{array}$ & $\begin{array}{l}\text { Casson } \\
\text { Up }\end{array}$ & $\begin{array}{l}\text { Casson } \\
\text { Down }\end{array}$ & $\begin{array}{l}\text { Casson } \\
\text { Down }\end{array}$ & $\begin{array}{l}\text { Newtonian } \\
\text { Up }\end{array}$ & $\begin{array}{l}\text { Newtonian } \\
\text { Down }\end{array}$ \\
\hline & & Yield Stress & Consistency & Yield Stress & Consistency & Yield Stress & Consistency & Yield Stress & Consistency & & \\
\hline & Sample Names & tau $(\mathrm{Pa})$ & eta $(\mathrm{Pa} \cdot \mathrm{sec})$ & $\operatorname{tau}(\mathrm{Pa})$ & eta $(\mathrm{Pa} \cdot \mathrm{sec})$ & tau $(\mathrm{Pa})$ & eta $(\mathrm{Pa} \cdot \mathrm{sec})$ & tau $(\mathrm{Pa})$ & eta $(\mathrm{Pa} \cdot \mathrm{sec})$ & eta $(\mathrm{Pa} \cdot \mathrm{sec})$ & eta $(\mathrm{Pa} \cdot \mathrm{sec})$ \\
\hline 14 & $\begin{array}{c}\text { D 02AML } 012 \text { XX } 5359 \text { RHE } 4 \\
\text { (supernatant) }\end{array}$ & & & & & & & & & & \\
\hline & Average & N/A & N/A & N/A & $\mathrm{N} / \mathrm{A}$ & $\mathrm{N} / \mathrm{A}$ & N/A & N/A & N/A & $1.077 \mathrm{E}-02$ & $1.075 \mathrm{E}-02$ \\
\hline \# & Sample names & & & & & & & & & & \\
\hline 15 & D 02AML 012 XX 5358 RHE 4 & 15516 & $3056 \mathrm{~F}_{-} 02$ & 12107 & $4151 \mathrm{~F}_{-} 02$ & 6550 & $2331 \mathrm{~F}_{-} 02$ & 4016 & $2525 \mathrm{~F}_{-} 02$ & $N / A$ & $\mathrm{~N} / \mathrm{A}$ \\
\hline 16 & D 02AOL 014 XX 5431 RHE 4 & & & & & & & & & & \\
\hline & Average & N/A & $\mathrm{N} / \mathrm{A}$ & N/A & N/A & N/A & N/A & N/A & N/A & $1.029 \mathrm{E}-03$ & $1.027 \mathrm{E}-03$ \\
\hline 17 & $\begin{array}{l}\text { D 02AOL } 017 \text { XX } 5510 \text { RHE } 4 \\
\text { Average }\end{array}$ & 22.742 & $1.029 \mathrm{E}-02$ & 23.982 & $9.050 \mathrm{E}-03$ & 17.648 & $2.356 \mathrm{E}-03$ & 19.843 & $1.608 \mathrm{E}-03$ & N/A & N/A \\
\hline 18 & $\begin{array}{l}\text { D 02AOL } 019 \text { XX } 5577 \text { RHE } 4 \\
\text { Average }\end{array}$ & 12.478 & $9.765 \mathrm{E}-03$ & 15.608 & $6.737 \mathrm{E}-03$ & 8.559 & $3.145 \mathrm{E}-03$ & 12.438 & $1.403 \mathrm{E}-03$ & N/A & $\mathrm{N} / \mathrm{A}$ \\
\hline 19 & $\begin{array}{c}\text { D 02AOL 019 XX 5578 RHE } 4 \\
\text { (supernatant) }\end{array}$ & & & & & & & & & & \\
\hline & Average & N/A & $\mathrm{N} / \mathrm{A}$ & N/A & N/A & N/A & $\mathrm{N} / \mathrm{A}$ & N/A & N/A & $9.514 \mathrm{E}-04$ & $9.847 \mathrm{E}-04$ \\
\hline 20 & $\begin{array}{c}\text { D 02AOL } 019075561 \text { RHE } 4 \\
\text { (supernatant) }\end{array}$ & & & & & & & & & & \\
\hline & Average & N/A & N/A & N/A & N/A & N/A & N/A & N/A & N/A & $9.969 \mathrm{E}-04$ & $9.851 \mathrm{E}-04$ \\
\hline 21 & $\begin{array}{l}\text { D 02AOL } 019075560 \text { RHE } 4 \\
\text { Average }\end{array}$ & 12.935 & $9.203 \mathrm{E}-03$ & 15.443 & $6.939 \mathrm{E}-03$ & 9.262 & $2.689 \mathrm{E}-03$ & 12.274 & $1.462 \mathrm{E}-03$ & N/A & N/A \\
\hline 22 & $\begin{array}{c}\text { D 02AOL } 018065544 \text { RHE } 4 \\
\text { (supernatant) }\end{array}$ & & & & & & & & & & \\
\hline & Average & N/A & N/A & N/A & N/A & N/A & N/A & N/A & N/A & $1.054 \mathrm{E}-03$ & $1.064 \mathrm{E}-03$ \\
\hline 23 & $\begin{array}{c}\text { D 02AML 020 XX } 5585 \text { RHE } 4 \\
\text { (supernatant) }\end{array}$ & & & & & & & & & & \\
\hline & Average & N/A & N/A & N/A & N/A & N/A & N/A & N/A & N/A & $9.588 \mathrm{E}-04$ & $9.719 \mathrm{E}-04$ \\
\hline
\end{tabular}




\section{L.2 Scanning Electron Microscopy (WTP-TDP-360)}

$\begin{array}{llll}\text { Date: } & \text { April 16,2009 } & \text { Project No.: } & 53569 \\ \text { To: } & \text { Ofelia Bredt } & \text { Internal } & \\ \text { From: } & \text { Brian Riley } & \text { Distribution: } & \\ \text { Subject: } & \text { PEP SEM Analyses } & \end{array}$

Two specimens were received for scanning electron microscopy (SEM) examinations in support of work being performed at the Pretreatment Engineering Platform (PEP) during the course of Integrated Test D. The morphologies of these specimens were analyzed using a JEOL 5900 SEM in accordance with procedure APEL-102-SEM, Rev. 1.

\section{Sample Preparation}

Once received from PEP, the specimens were cleaned of nitrates. This cleaning process included 3 cycles of adding $\sim 30-\mathrm{mL}$ of fresh $0.01 \mathrm{M} \mathrm{NaOH}$ to the centrifuge tube, vortexing for 3 sets of 15 seconds, centrifuging at $4500 \mathrm{rpm}$ for 10 minutes, decanting and then adding $\sim 30-\mathrm{mL}$ of fresh $0.01 \mathrm{M} \mathrm{NaOH}$. These washing steps were recorded in laboratory record book BNW-60176.

After the last rinse, the $\mathrm{NaOH}$ and the pellet were vortexed, a small volume of the slurry was drawn up using a pipette, and a drop was placed on the top of an aluminum SEM sample stub. It was then placed in an oven at approximately $100^{\circ} \mathrm{C}$ to dry overnight. Once it was dry, it was coated with a thin layer of $\mathrm{Au} / \mathrm{Pd}$ using the Polaron Range plasma sputter coater in APEL/102. The Au/Pd layer was deposited using $800 \mathrm{~V}$ and $10 \mathrm{~mA}$ for $180 \mathrm{~s}$. The coated specimen was placed in an SEM sample holder and was placed in the SEM for analysis.

\section{Analysis}

Scanning electron micrographs were collected for informational purposes only using the Scan 4 option with 160 s collection times using the settings as seen below in Table 1 . See Tables $2 \& 3$ for information regarding the individual that performed the analysis as well as the date of analysis. Images at the four magnifications listed in Table 1 were compiled in a $2 \times 2$ arrangement for each sample to show a macroscopic to microscopic view of the particles. See APPENDIX A: Micrograph Collages.

\section{Results}

See figures below. 
Table 1. Parameters Used for Capturing Images

\begin{tabular}{lccccc}
\hline \multicolumn{1}{c}{ Sample ID } & $\begin{array}{c}\text { Voltage } \\
(\mathrm{KV})\end{array}$ & $\begin{array}{c}\text { Spot } \\
\text { Size }\end{array}$ & $\begin{array}{c}\text { Detector } \\
\text { Distance }(\mathrm{mm})\end{array}$ & Magnification \\
\hline D_FRPRL_001_XX_4916_XSP_4_1kx_SEI(b) & 20 & 25 & SEI & 12 & $1,000 \times$ \\
D_FRPRL_001_XX_4916_XSP_4_2500x_SEI(b) & 20 & 25 & SEI & 12 & $2,500 \times$ \\
D_FRPRL_001_XX_4916_XSP_4_5kx_SEI(b) & 20 & 25 & SEI & 12 & $5,000 \times$ \\
D_FRPRL_001_XX_4916_XSP_4_10kx_SEI(b) & 20 & 25 & SEI & 12 & $10,000 \times$ \\
D_02AML_020_XX_5587_XSP_4-BSE-1kx & 20 & 25 & BSE & 12 & $1,000 \times$ \\
D_02AML_020_XX_5587_XSP_4-BSE-2.5kx & 20 & 25 & BSE & 12 & $2,500 \times$ \\
D_02AML_020_XX_5587_XSP_4-BSE-5kx & 20 & 25 & BSE & 12 & $5,000 \times$ \\
D_02AML_020_XX_5587_XSP_4-BSE-10kx & 20 & 25 & BSE & 12 & $10,000 \times$ \\
\hline
\end{tabular}




\section{APPENDIX A: Micrograph Collages}

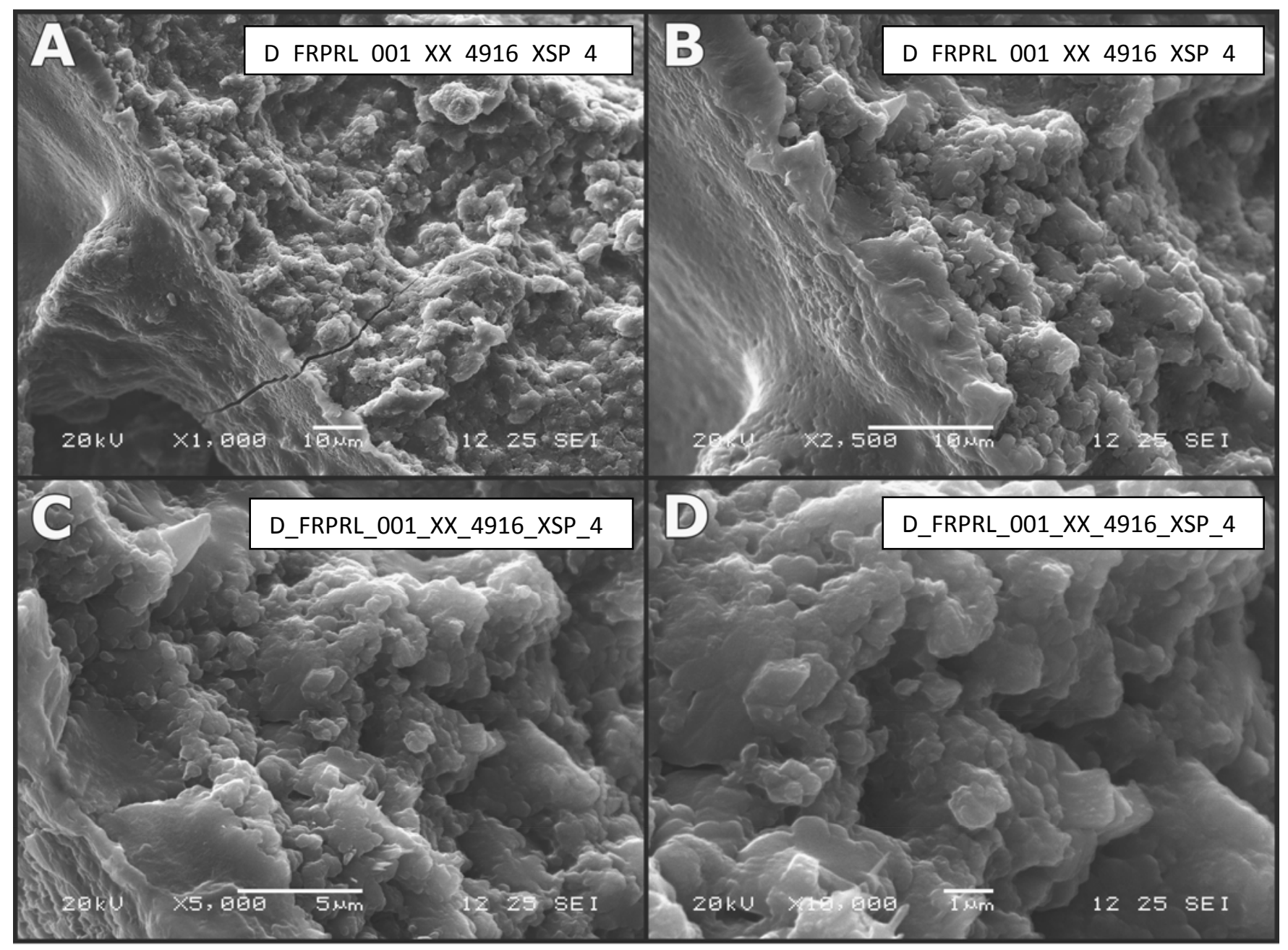

SEM micrographs from Pretreatment Engineering Platform (PEP) specimen

D_FRPRL_001_XX_4916_XSP_4. The specimen, while in the original 50-mL centrifuge tube, was rinsed with $0.01 \mathrm{M} \mathrm{NaOH}$, vortexed, centrifuged (4500 rpm for 10 minutes), and decanted $3 \times$ to clean off the nitrates. After the final rinse, the contents of the tube were vortexed in order to resuspend the pellet, and a drop of the suspended particles was placed on an Al SEM stub and placed in an oven at approximately $105^{\circ} \mathrm{C}$ to dry overnight. Once dry, the specimen was coated with $\mathrm{Au} / \mathrm{Pd}$ and analyzed using the APEL/102 SEM (JEOL 5900).

Figure 1. Scanning Electron Micrographs Collected for Informational Purposes Only on D_FRPRL_001_XX_4916_XSP_4 at Different Magnifications 
Table 2. Analysis Information

\begin{tabular}{llll}
\hline Sample ID & Date of Analysis & Analysis Performed By & Signature \\
\hline D_FRPRL_001_XX_4916_XSP_4 & 04/06/2009 & Brian Riley & \\
\hline
\end{tabular}

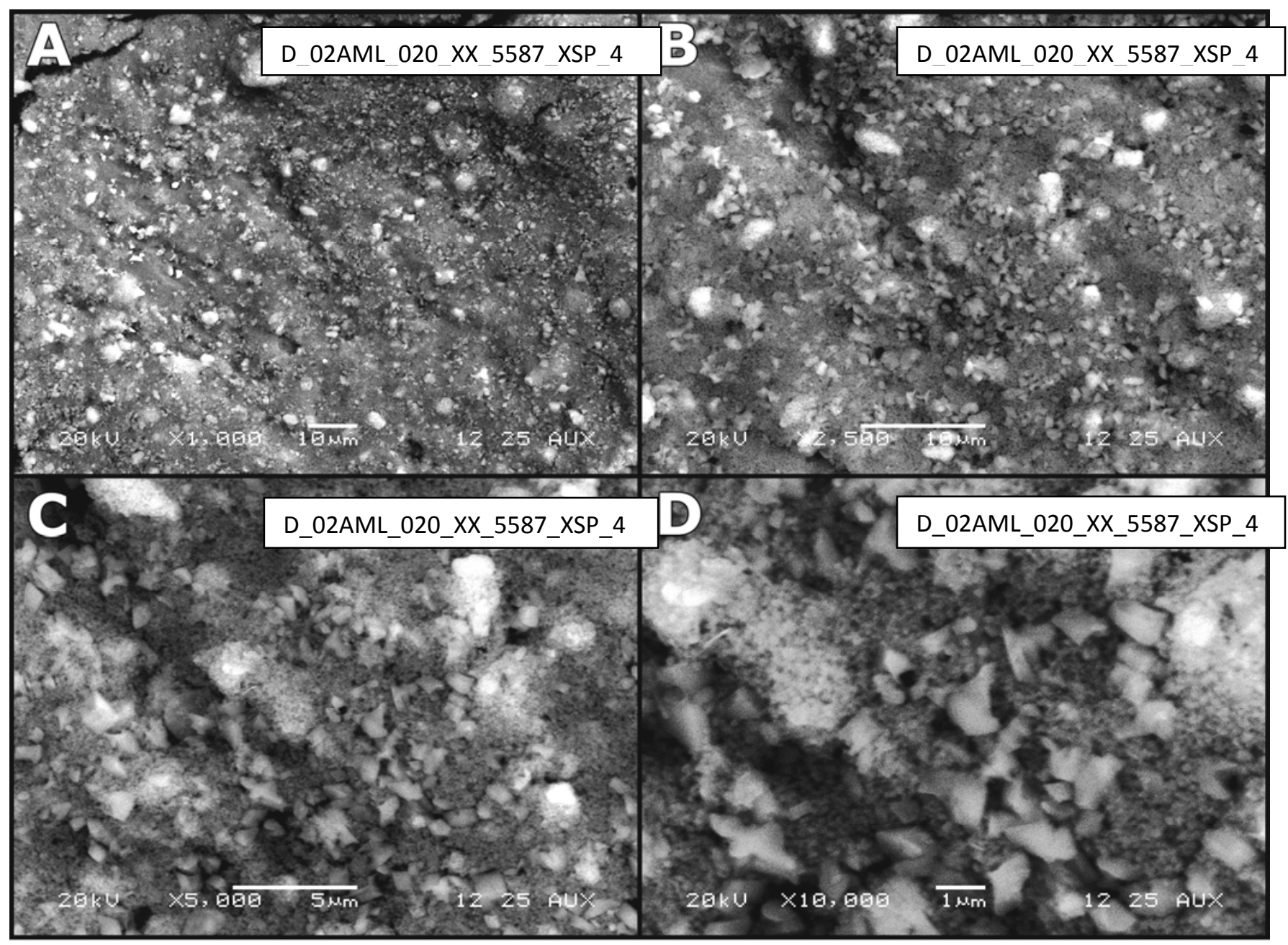

SEM micrographs from Pretreatment Engineering Platform (PEP) specimen D_02AML_020_XX_5587_XSP_4. The specimen, while in the original 50-mL centrifuge tube, was rinsed with $0.01 \mathrm{M} \mathrm{NaOH}$, vortexed, centrifuged (4500 rpm for 10 minutes), and decanted $3 \times$ to clean off the nitrates. After the final rinse, the contents of the tube were vortexed in order to resuspend the pellet, and a drop of the suspended particles was placed on an Al SEM stub and placed in an oven at approximately $105^{\circ} \mathrm{C}$ to dry overnight. Once dry, the specimen was coated with $\mathrm{Au} / \mathrm{Pd}$ and analyzed using the APEL/102 SEM (JEOL 5900).

Figure 2. Scanning Electron Micrographs Collected for Informational Purposes Only on D_02AML_020_XX_5587_XSP_4 at Different Magnifications 
Table 3. Analysis information.

\begin{tabular}{llll}
\hline Sample ID & Date of Analysis & Analysis Performed By & Signature \\
\hline D_02AML_020_XX_5587_XSP_4 & $04 / 16 / 2009$ & Brian Riley & \\
\hline
\end{tabular}




\section{L.3 X-Ray Diffraction (WTP-TDP-364)}

MEMORANDUM

$\begin{array}{llll}\text { Date: } & \text { March 13, 2009 } & \text { Project No.: } & 53569 \\ \text { To: } & \text { Ofelia Bredt } & \text { Internal } \\ \text { From: } & \text { Jarrod Crum } & \text { Distribution: } \\ \text { Subject: } & \text { PEP XRD Analyses } & \end{array}$

Sample analysis was carried out by the Pacific Northwest National Laboratory Advanced Processing and Application Group. The XRD instrument used was the Scintag PAD V X-ray Diffractometer, Property Number WD33356, located in lab 102 in the APEL building. The data range for the sample was $5^{\circ}$ to $80^{\circ}$ 2-theta, with a step size of $0.04^{\circ} 2$-theta and count time $2.0-4.0$ seconds per step. Copper K $\alpha \mathrm{X}$-rays were used. The X-ray tube operating conditions were $45 \mathrm{kV}$ and $40 \mathrm{~mA}$.

Sample Prep:

The as-received samples were rinsed 3 times with a $0.01 \mathrm{M} \mathrm{NaOH}$ solution. Rinsing consisted of four steps: adding rinsate, votexing, centrifuging, and decanting of the rinsate. The process was repeated three times. The samples were then dried at $\sim 105^{\circ} \mathrm{C}$ overnight to drive off all liquid. The dried powder was placed into a tungsten carbide milling chamber and milled for $1 \mathrm{~min}$ in the pulverizer mill made by Angstrom Inc., Belleville, MI. A portion of the powder was weighted out to the nearest hundredth of a milligram. Then SRM 674b, $\mathrm{TiO}_{2}$ internal standard, was spiked in at a known mass, given in Table 1, with the dried powder and milled again for $2 \mathrm{~min}$ to insure a homogenous mixture of the two powders. The sample was then mounted into a sample holder.

Table I: Samples Examined in this Series

\begin{tabular}{|c|c|c|c|}
\hline Identification & XRD File ID & $\begin{array}{c}\text { (a) } \\
\text { Xount Time per Step, } \\
\text { Seconds }\end{array}$ & $\begin{array}{c}\text { Internal Standard, } \\
\mathrm{wt}_{\%} \mathrm{TiO}_{2}\end{array}$ \\
\hline D FRPRL_001 XX 4916 XSP 4 & 051109A & 4 & $9.49 \mathrm{wt} \% \mathrm{TiO}_{2}$ \\
\hline D 02AML_020 XX 5587 XSP 4 & $042909 \mathrm{~A} 1$ & 4 & $10.12 \mathrm{wt} \% \mathrm{TiO}_{2}$ \\
\hline
\end{tabular}

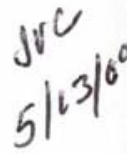

Phase identification was done by use of the JADE search match routines (version 6.0, Materials Data Inc.) with comparison to the ICDD (International Centre for Diffraction Data) data base PDF-2 release 1999, which includes the ICSD (Inorganic Crystal Structure Database maintained by Fachinformationszentrum (FIZ), Karlsruhe, Germany). Searches were restricted to the PDF and ICSD Inorganic sections.

The identified phases, ranked by relative peak intensities, are given below for each sample. Figure 1 shows the raw summed pattern of D_FRPRL_001_XX_4916_XSP_4. The background fitted patterns of D_FRPRL_001_XX_4916_XSP_4, along with the identified phases, are shown in figures 2, 3, and 4. Figure 6 shows the raw summed pattern of D_02AML_020_XX_5587_XSP_4. The background fitted patterns of D_02AML_020_XX_5587_XSP_4, along with the identified phases, are shown in figures 7,8, and 9. 
D_FRPRL_001_XX_4916_XSP_4, File: 051109A

- Rutile, $\mathrm{TiO}_{2}$, card\# 21-1276

- Bohmite, syn, $\mathrm{AlO}(\mathrm{OH})$, card\# 21-1307, Excellent overall fit. Peak locations and intensities are a good match to the pattern.

- Gibbsite, $\mathrm{Al}(\mathrm{OH})_{3}$, card\# 60-2702, Good fit.

- Amorphous material, $\sim 36^{\circ} 2 \theta$.

D_02AML_020_XX_5587_XSP_4, File: 042909A1

- Rutile, $\mathrm{TiO}_{2}$, card\# 21-1276

- Bohmite, syn, $\mathrm{AlO}(\mathrm{OH})$, card\# 21-1307, Excellent overall fit. Peak locations and intensities are a good match to the pattern.

- Amorphous material, $\sim 36^{\circ} 2 \theta$.

The patterns were also examined using RIQAS (release 4.0.0.26, 6/10/2002, Materials Data Inc.) rietveld analysis software. The phases identified above were input into the analysis along with a polynomial function for the background and an amorphous hump at $\sim 36^{\circ} 2 \theta$. To determine the weight percent of crystallinity in a sample two assumsions are made. First, the total crystallinity is assumed to add up to $100 \mathrm{wt} \%$. Second, sense the rutile $w t \%$ is known the wt $\%$ of all of the unknown phases are renormalized based on the rutile concentration. Table 2 summarizes the results of the XRD analysis to include; identified phases, mass \%, and crystallite size of each phase. Balance of material in the sample is assumed to be amorphous. Figure 5 shows the fitted pattern for sample D_FRPRL_001_XX_4916_XSP_4 and figure 10 shows sample D_02AML_020_XX_5587_XSP_4.

Table 2. Measured Concentration and Estimated Crystallite Sizes of Identified Phases

\begin{tabular}{|c|c|c|c|c|}
\hline \multirow{2}{*}{ Sample ID } & \multicolumn{2}{|c|}{ Boehmite } & \multicolumn{2}{c|}{ Gibbsite } \\
\cline { 2 - 4 } & wt \% & size, $\AA$ & wt \% & size, $\AA$ \\
\hline D FRPRL_001 XX 4916 XSP 4 & 33.5 & 404 & 58.5 & 151 \\
\hline D 02AML 020_XX 5587 XSP 4 & 42.4 & 452 & & \\
\hline
\end{tabular}

$$
\mathrm{Juc}_{\mathrm{s}} / 13109
$$




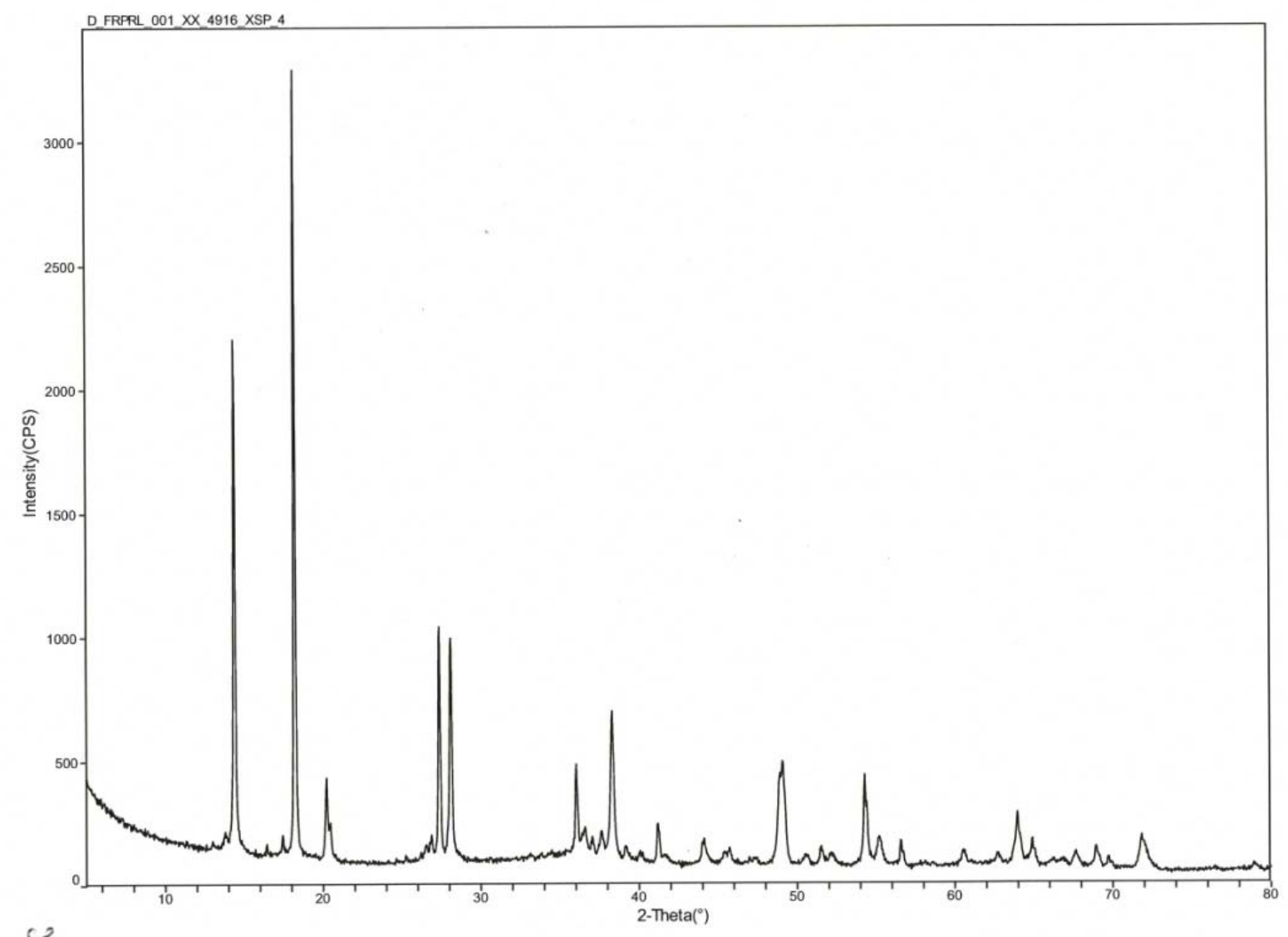

$\frac{\pi^{2}}{n^{2}}$

Figure 1. Raw pattern of sample D_FRPRL_001_XX_4916_XSP_4 


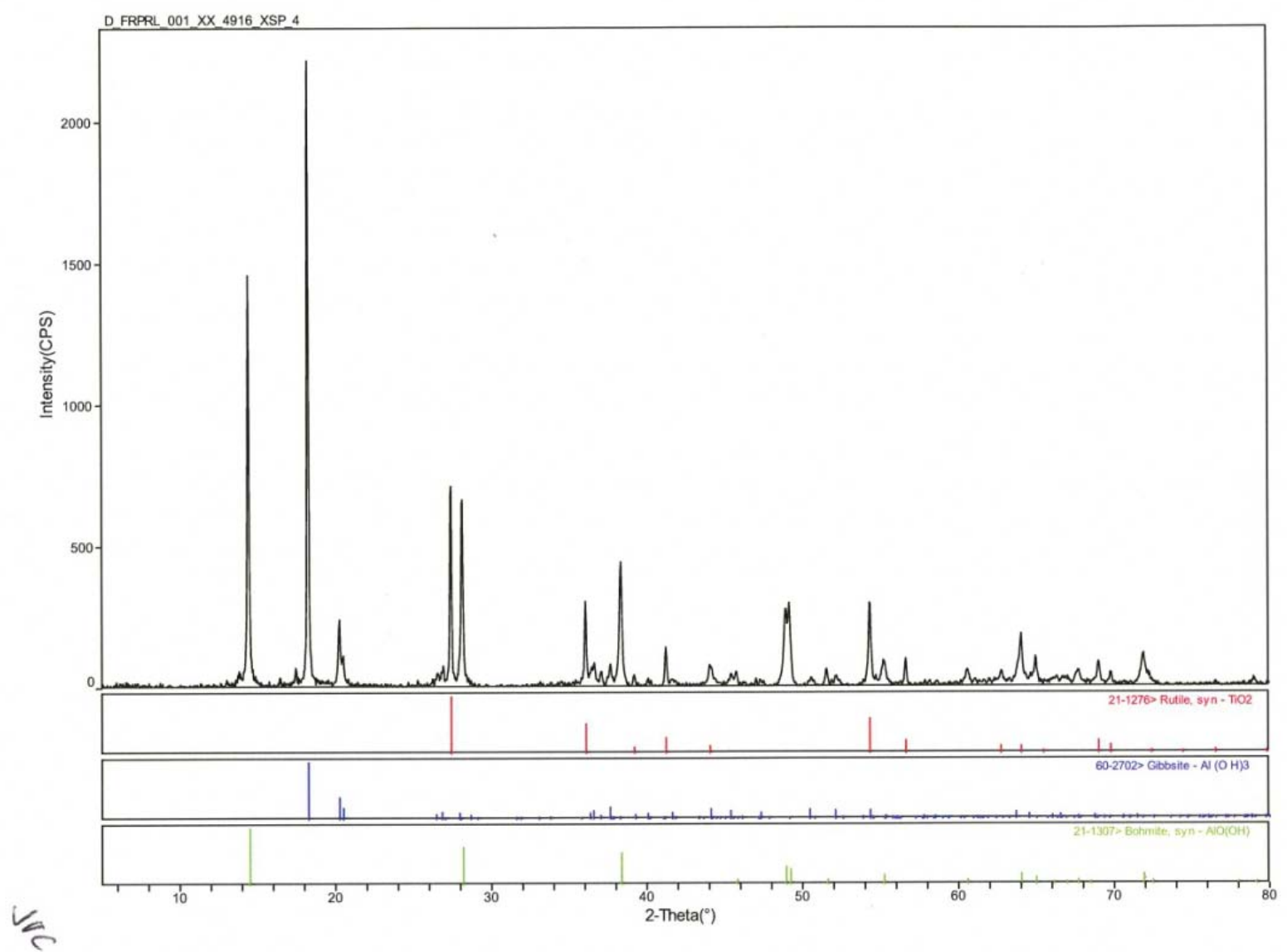

$\simeq \quad$ Figure 2. Background subtracted pattern of sample D_FRPRL_001_XX_4916_XSP_4 with identified phases 


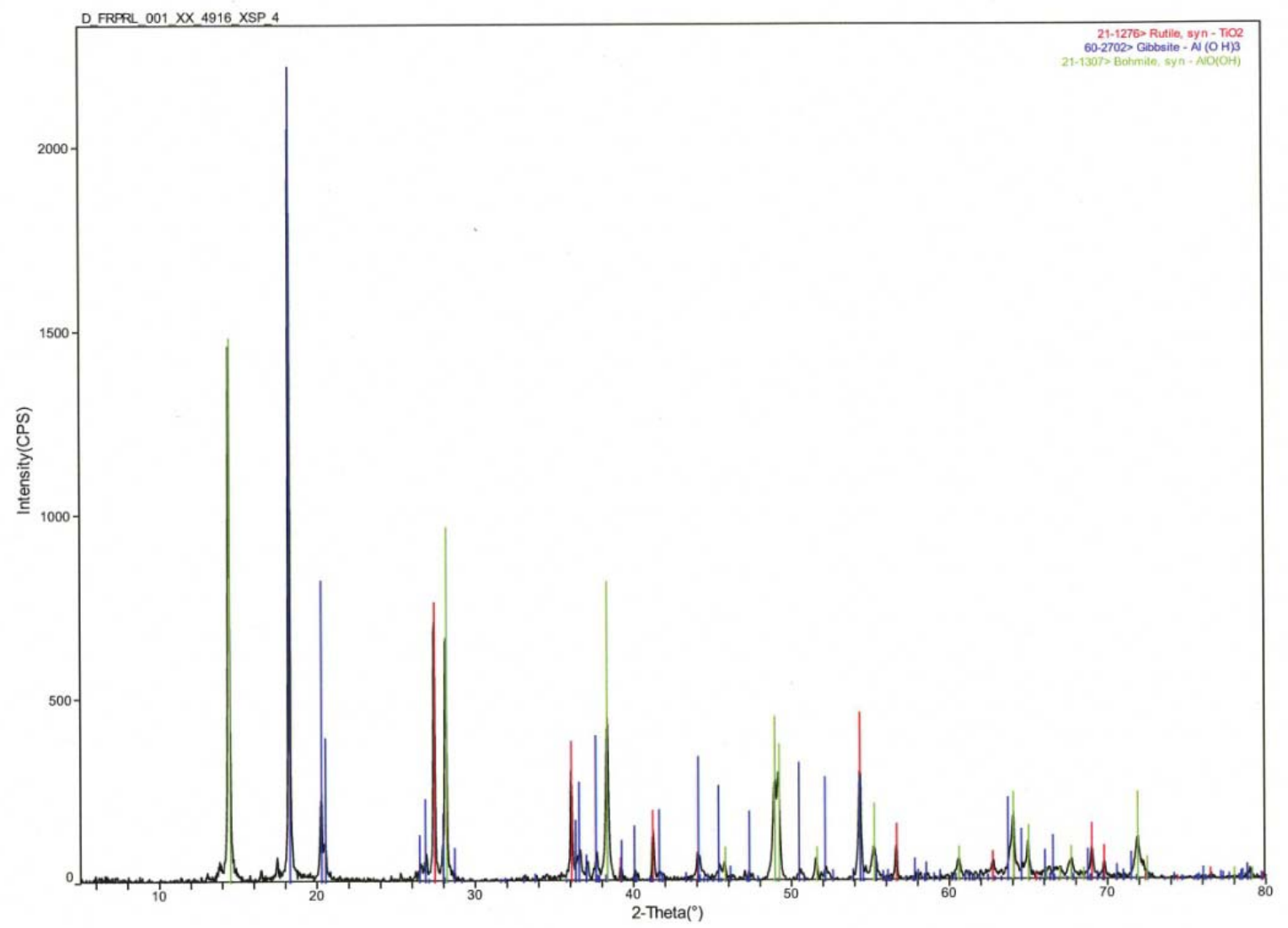

Figure 3. Background subtracted pattern of sample D_FRPRL_001_XX_4916_XSP_4 with identified phases overlaid $\frac{\pi}{a}$ 


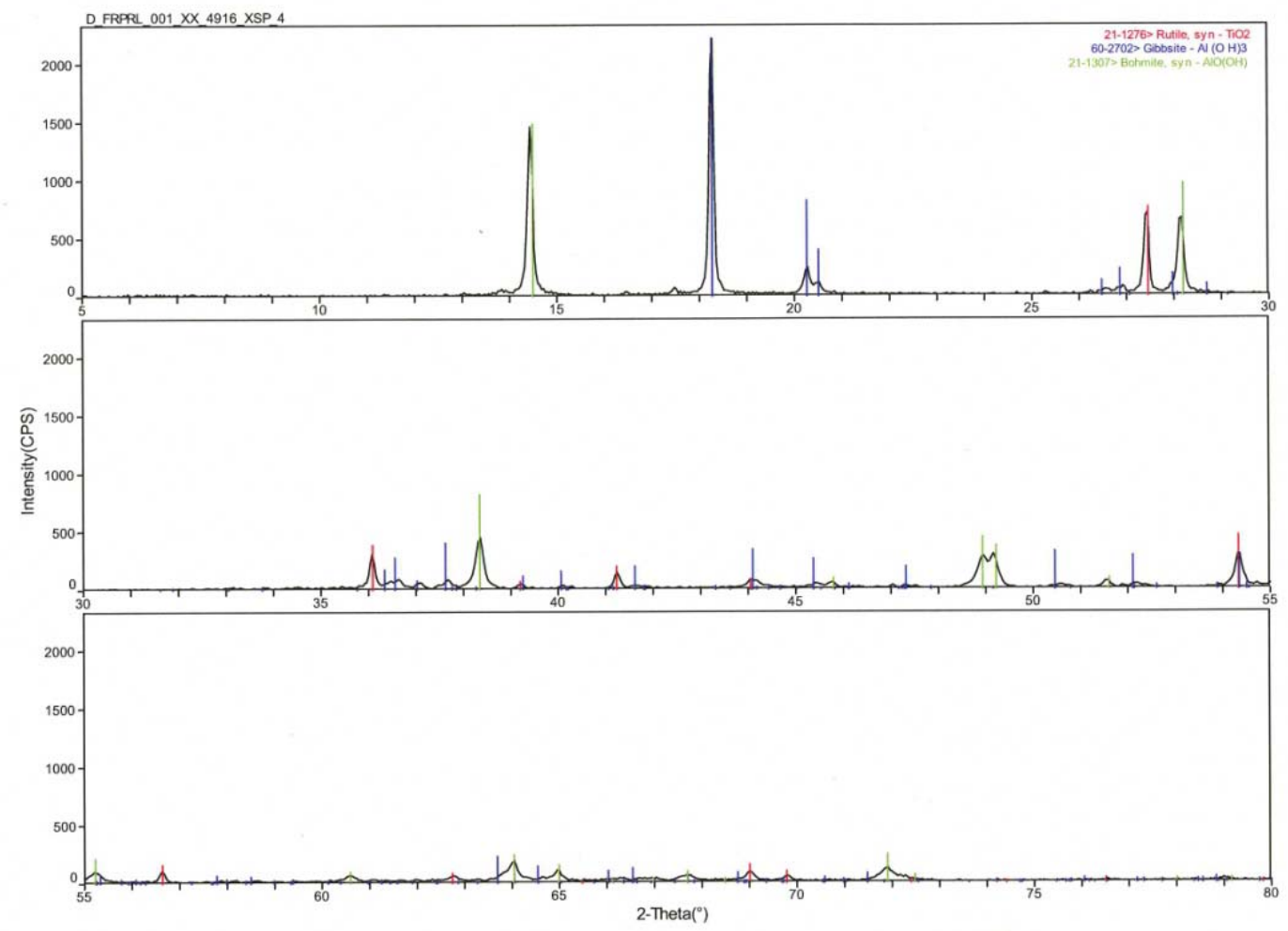

Figure 4. Background subtracted pattern of sample D FRPRL 001 XX 4916 XSP 4 with identified phases overlaid and zoomed $\frac{m}{0}$ 


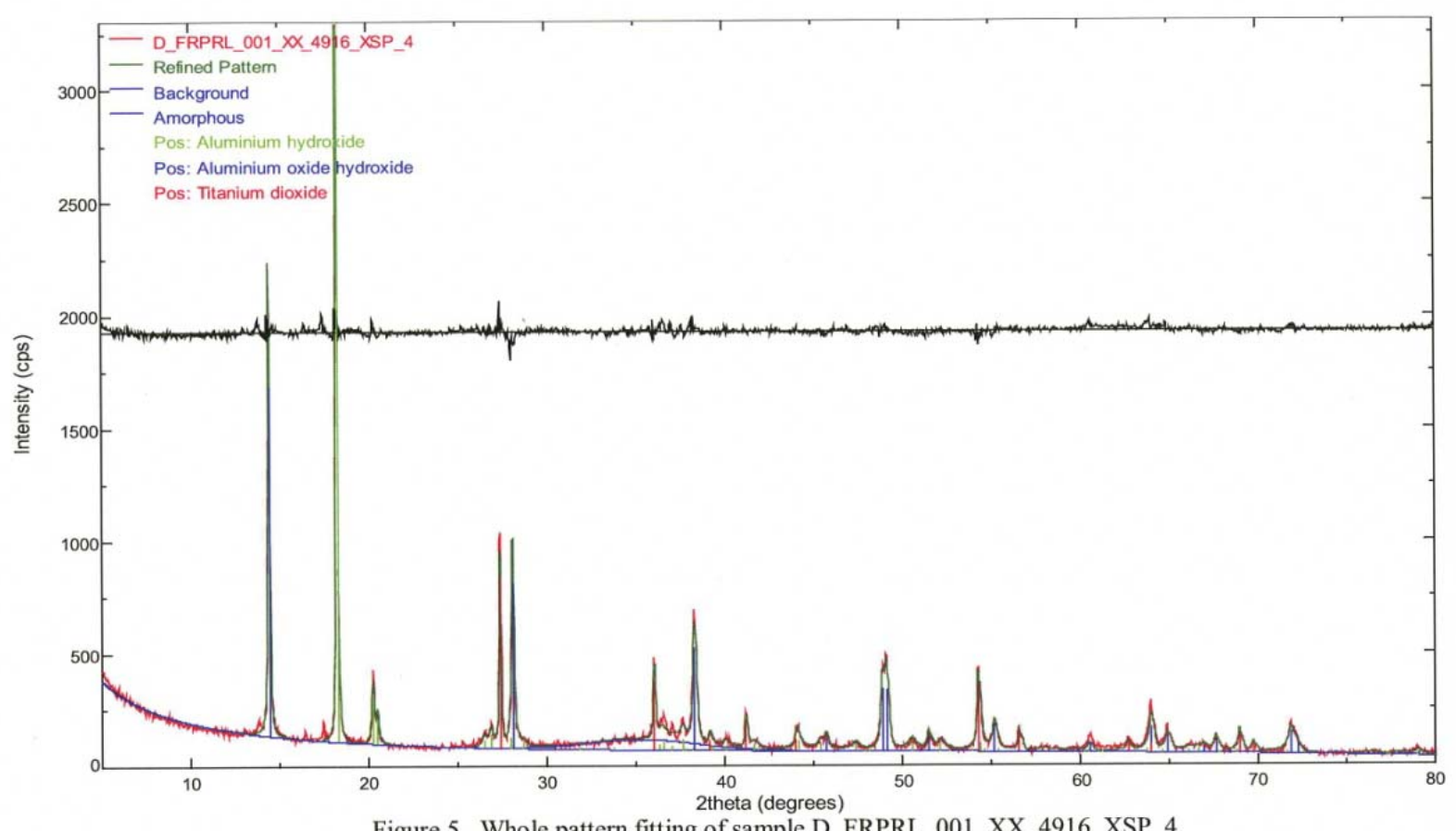

Figure 5. Whole pattern fitting of sample D_FRPRL_001_XX_4916_XSP_4

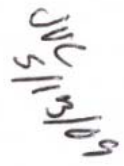




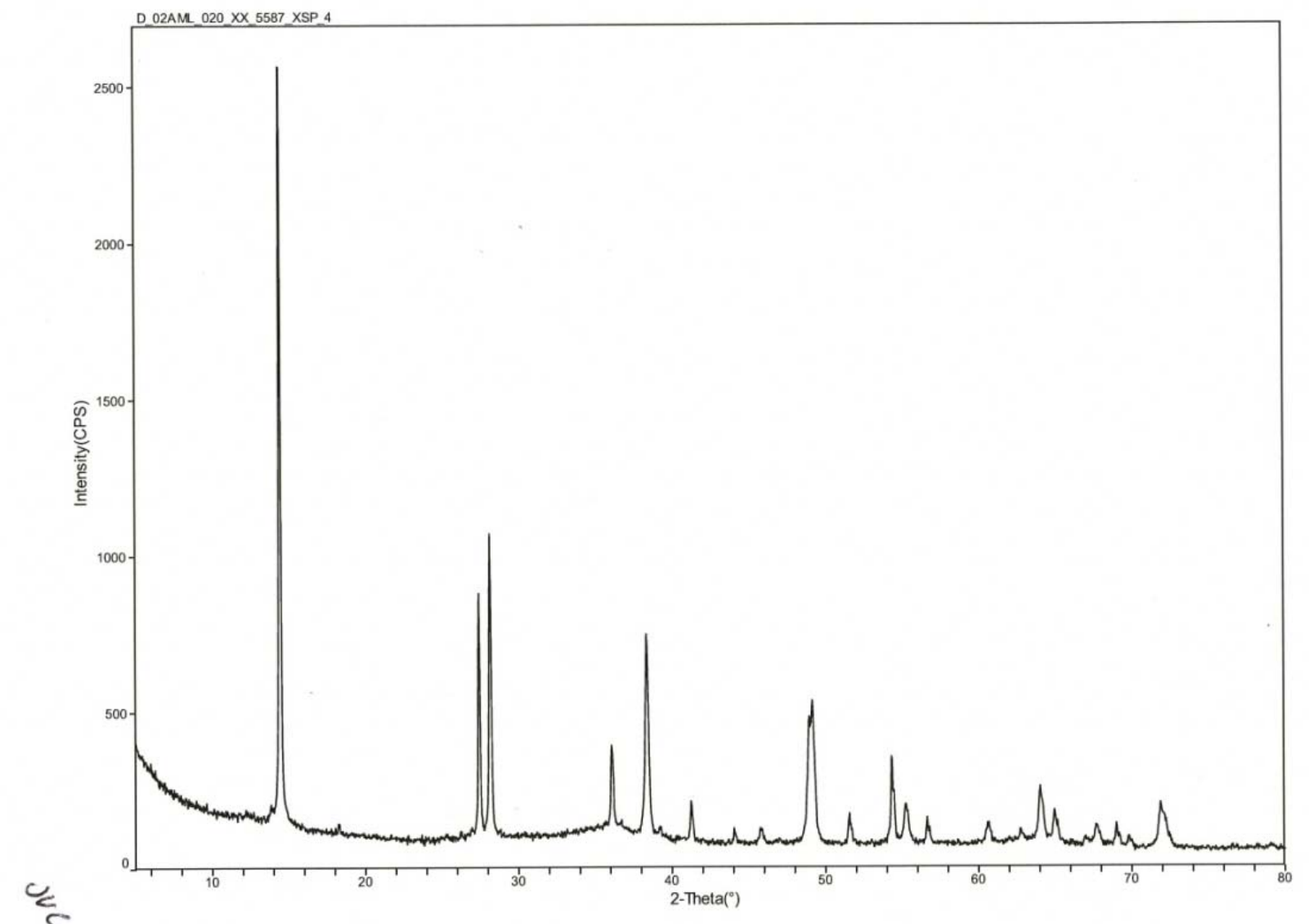

Figure 6. Raw pattern of sample D_02ALM_020_XX_5587_XSP_4 


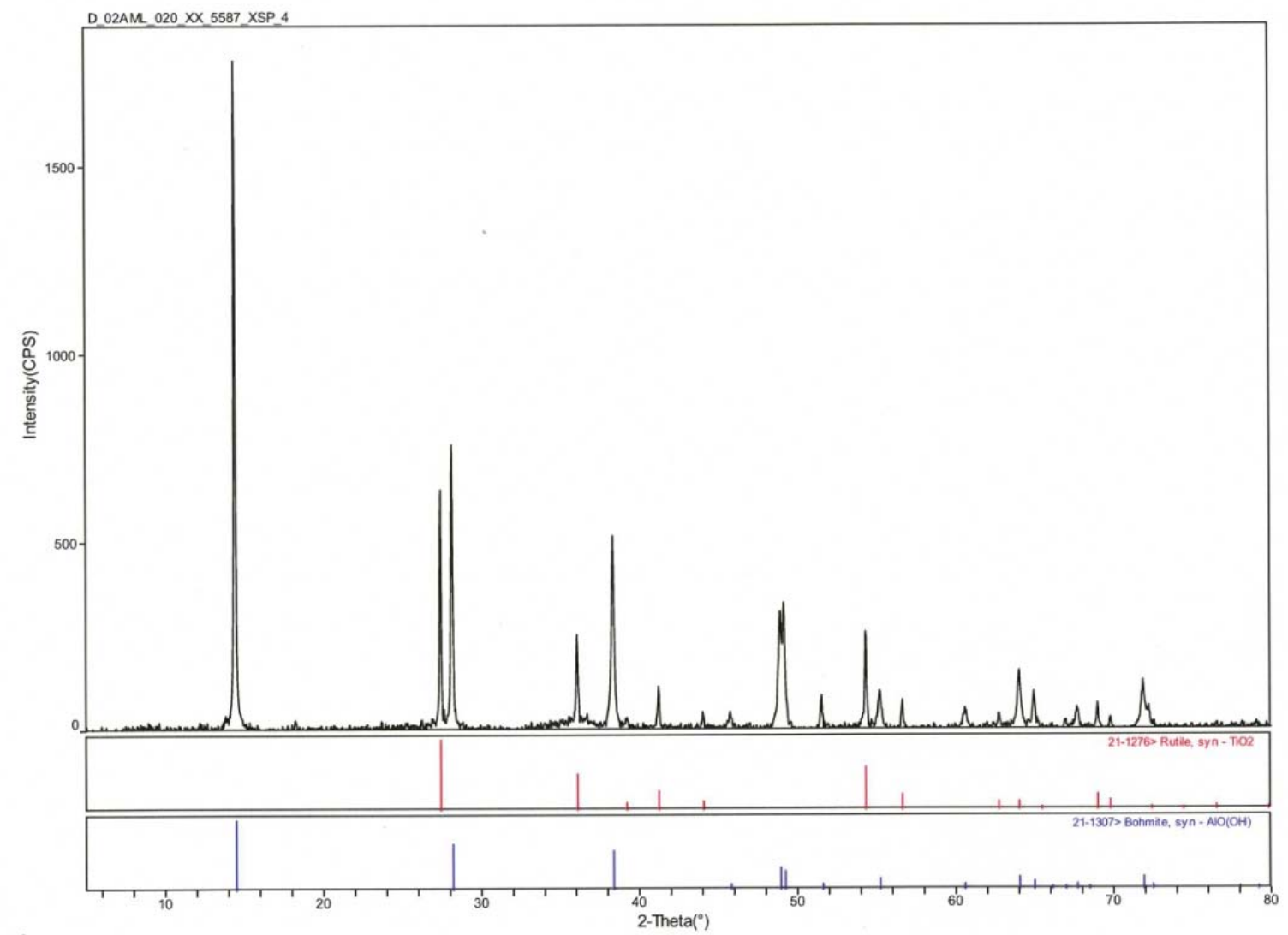

$\frac{n^{2}}{\frac{\pi}{0}}$

Figure 7. Background subtracted pattern of sample D_02ALM_020_XX_5587_XSP_4 with identified phases 


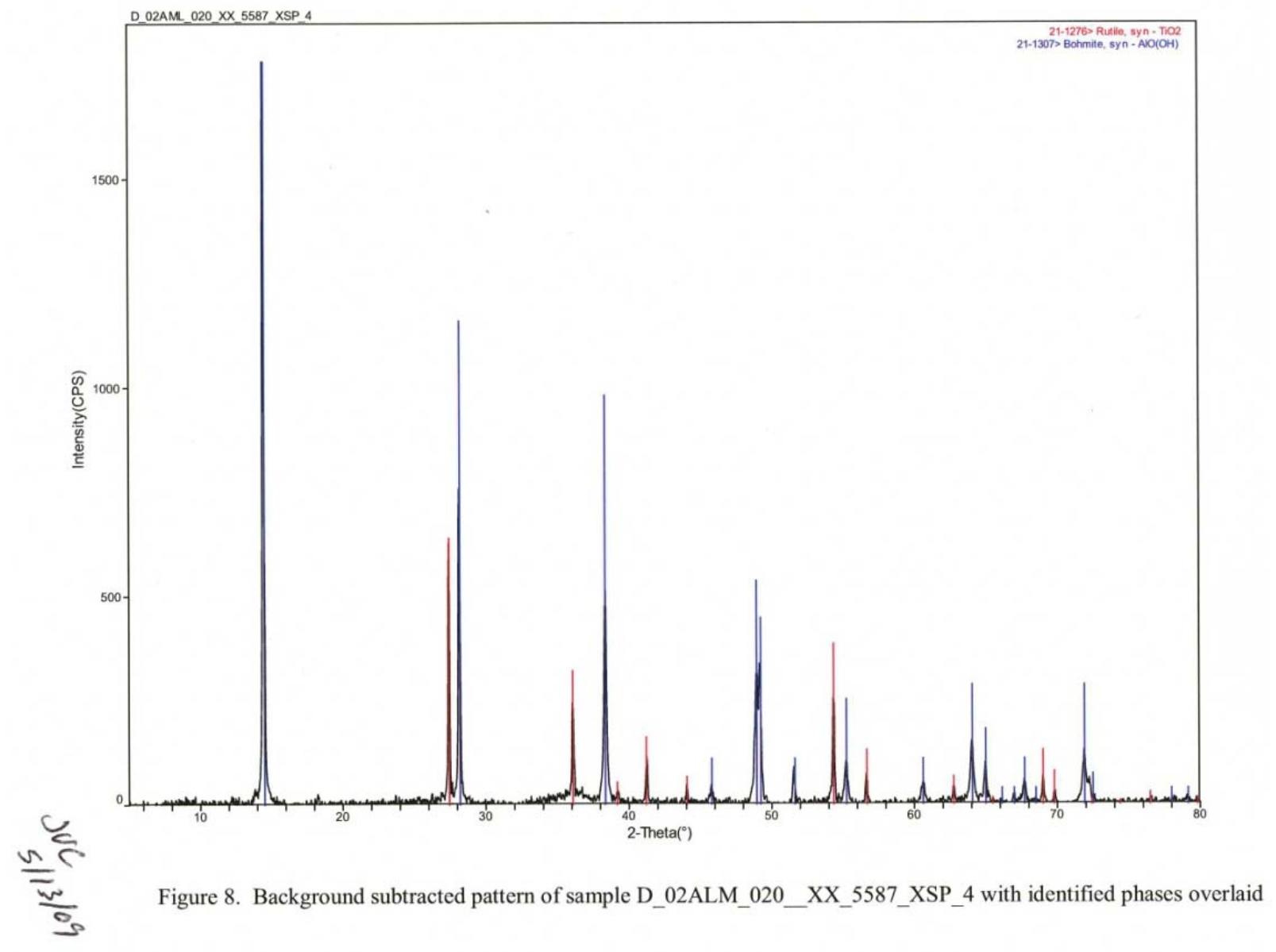




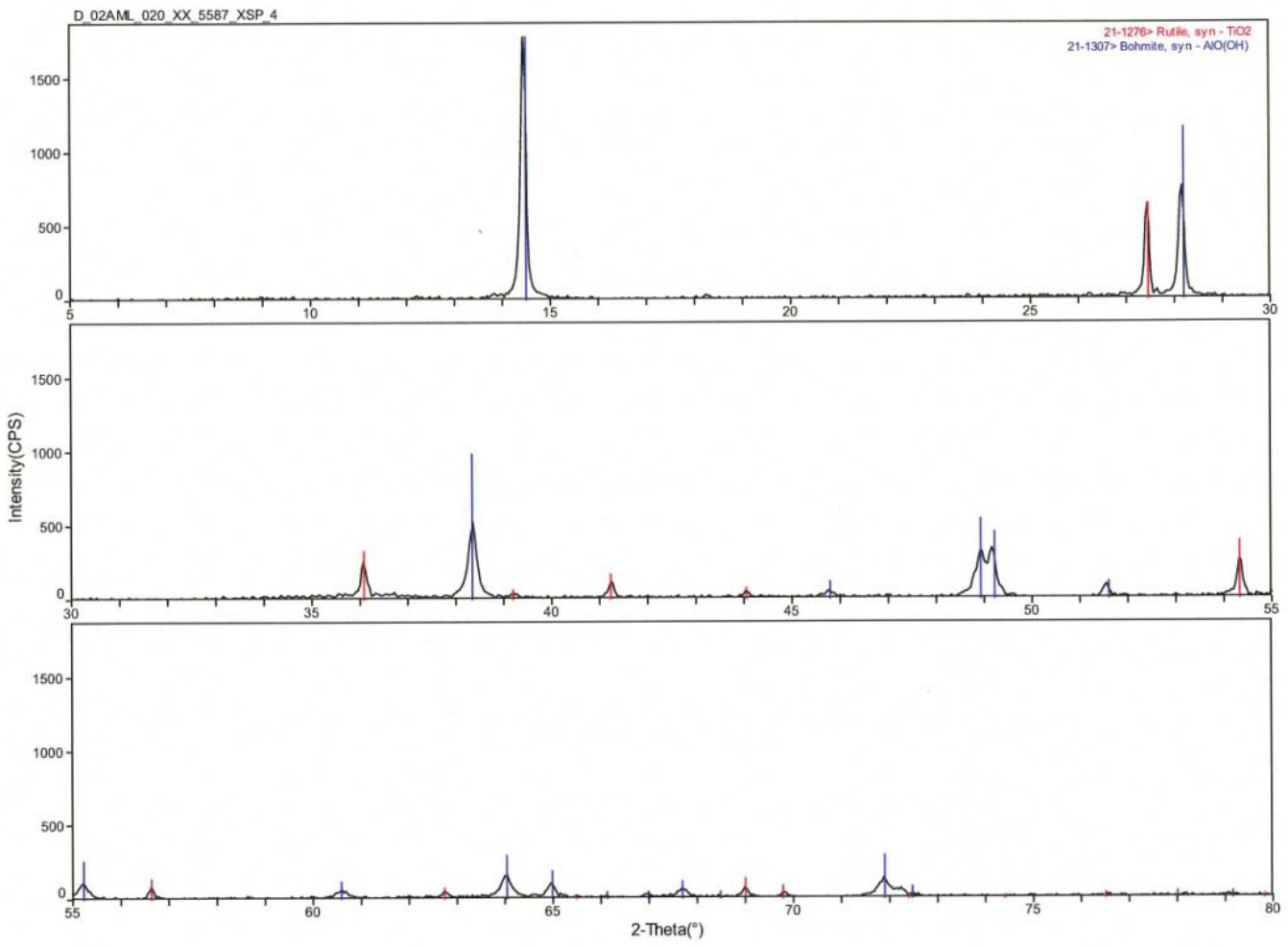

$\frac{0}{n}$

Figure 9. Background subtracted pattern of sample D_02ALM_020_XX_5587_XSP_4 with identified phases overlaid and zoomed

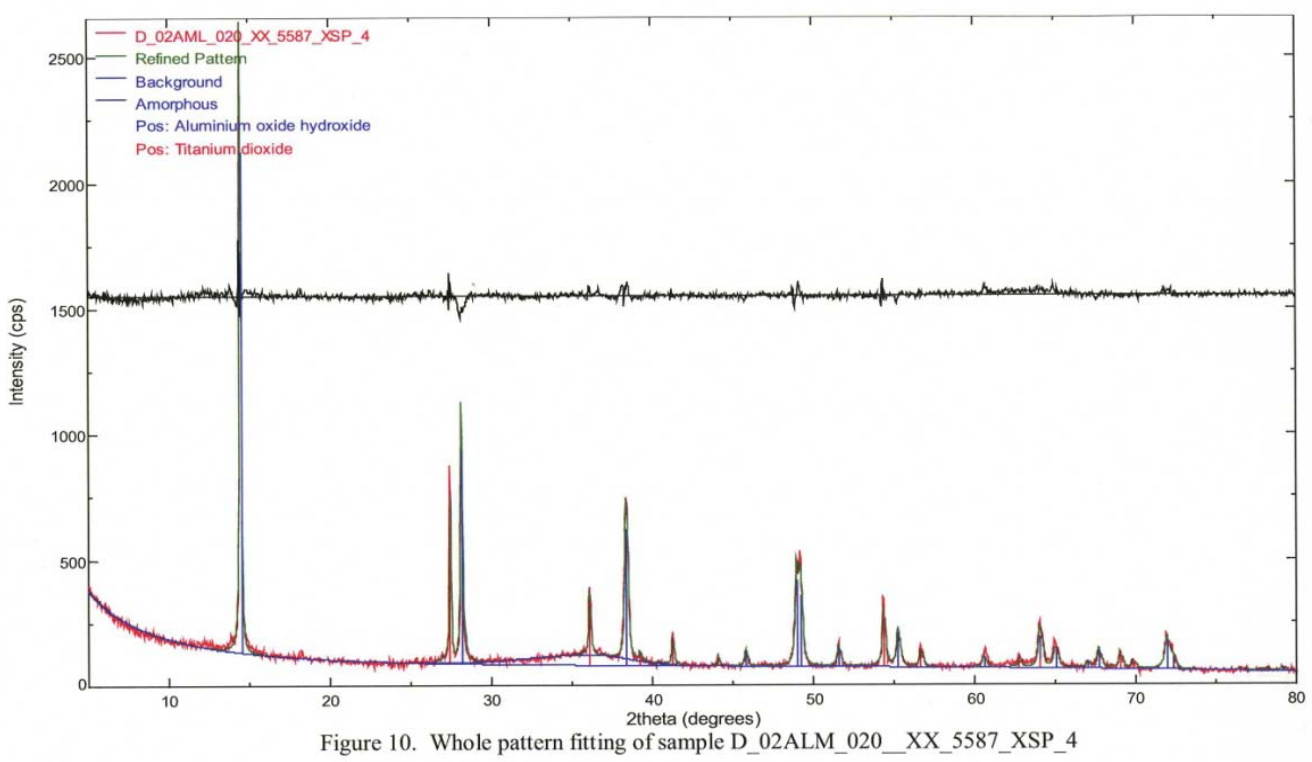

Sincerely,

Juc $5 / 13 / 09$

Jarrod Crum 
Appendix A1

ICDD cards of interest for this sample 
- PDF\#21-1276: QM=Common(+); $\mathrm{d}=$ Other/Unknown; $\mathrm{I}=($ Unknown)

Rutile, syn

$\mathrm{TiO} 2$

Radiation $=$ CuKal Lambda $=1.5406$ Filter $=$

Calibration $=\quad \mathrm{d}-\mathrm{Cutoff}=\quad \mathrm{I} / \mathrm{Ic}(\mathrm{RIR})=3.4$

Ref: Level-1 PDF

Tetragonal, $\mathrm{P} 42 / \mathrm{mnm}(136) \quad \mathrm{Z}=2 \quad \mathrm{mp}=$

CELL: $4.5933 \times 4.5933 \times 2.9592<90.0 \times 90.0 \times 90.0>\quad$ P.S $=$

$\operatorname{Density}(\mathrm{c})=4.23$ Density $(\mathrm{m})=\quad \mathrm{Mwt}=\quad \mathrm{Vol}=62.4$

Ref: Ibid.

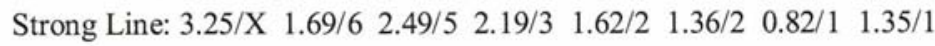

- $\quad$ PDF\#60-2702: $\mathrm{QM}=$ Calculated; $\mathrm{d}=$ Other/Unknown; $\mathrm{I}=($ Unknown)

Gibbsite

$\mathrm{Al}(\mathrm{O} \mathrm{H}) 3$

Radiation $=\mathrm{CuKa1} \quad$ Lambda $=1.5406$ Filter $=$

Calibration $=\quad \mathrm{d}-$ Cutoff $=\quad \mathrm{I} / \mathrm{Ic}(\mathrm{RIR})=1.67$

Ref: Calculated from FIZ\#6162 (ICSD@08/01/01) by Jade 6.x

Monoclinic, $\mathrm{P} 21 / \mathrm{n}(14) \quad \mathrm{Z}=8 \quad \mathrm{mp}=$

CELL: $8.684 \times 5.078 \times 9.736<90.0 \times 94.54 \times 90.0>$ P.S $=$

$\operatorname{Density}(\mathrm{c})=2.421$ Density $(\mathrm{m})=\quad \mathrm{Mwt}=\quad \mathrm{Vol}=428.0$

Ref: Ibid.

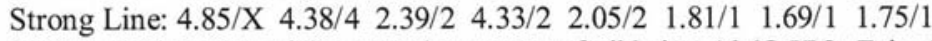

NOTE: Refinement of the crystal structure of gibbsite, $\mathrm{Al}(\mathrm{O} \mathrm{H}) 3$, Zeitschrift fuer Kristallographie,

Kristallgeometrie, Kristallphysik, Kristallchemie (-144,1977) [ZEKGA] 139 (1974) 129-135, Saalfeld H, Wedde M, $\mathrm{Dx}=2.4$.

M PDF 33-18.

$\mathrm{R}=0.032$.

Calculated density is unusual, but tolerable.

At least one temperature factor is implausible or meaningless, but agrees with the value given in the paper.

- $\quad$ PDF\#21-1307: $\mathrm{QM}=$ Common(+); $\mathrm{d}=$ Other/Unknown; $\mathrm{I}=($ Unknown)

Boehmite, syn

$\mathrm{AlO}(\mathrm{OH})$

Radiation $=\mathrm{CuKa} \quad$ Lambda $=1.5406$ Filter $=$

Calibration $=\quad \mathrm{d}$-Cutoff $=\quad \mathrm{I} / \mathrm{Ic}(\mathrm{RIR})=$

Ref: Level-1 PDF

Orthorhombic, Amam(63) $\mathrm{Z}=4 \quad \mathrm{mp}=$

CELL: $3.7 \times 12.227 \times 2.868<90.0 \times 90.0 \times 90.0>\quad P . S=$

$\operatorname{Density}(\mathrm{c})=3.07$ Density $(\mathrm{m})=\quad \mathrm{Mwt}=\quad \mathrm{Vol}=129.8$

Ref: Ibid.

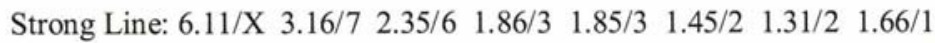




\section{L.4 Particle-Size Distribution (WTP-TDP-365)}

$\begin{array}{lll}\text { Date: } & \text { May 8, } 2009 & \text { Project No.: } \\ \text { To: } & \text { Brad Johnson } & \text { Internal Distribution: } \\ \text { From: } & \text { Bill Buchmiller } & \\ \text { Subject: } & \text { PEP PSD Analysis, Integrated Test } & \\ & \text { D, Test Instruction, TI-WTP-PEP- } & \\ & \mathbf{0 8 2}\end{array}$

Six samples were delivered for analysis under WP\# H14568. These samples were to be analyzed per instructions provided in a 02/17/2009 Letter to Analyst (LTA). Copies of the particle distribution plots for the samples are attached in addition to a copy of the LTA. The particle size distribution plots for the performance standard calibration checks are attached as well. They were collected on 03/09/2009 and 04/27/2009 using the manufacturer specified material, QAS3001B, part No. CRM00016.

\section{SAMPLE PREP}

All 6 samples were analyzed as provided using a Malvern MS2000 Analyzer with Hydro 2000S particle dispersion unit. Settled samples delivered in conical bottom centrifuge tubes, were initially agitated with a Scientific Industries, Vortex-T, Genie 2 vibrator to the discretion of the analyst. After the initial agitation, the samples were shaken by hand and the slurry transferred to the Malvern MS2000 using a poly transfer pipette. The transfer pipette was also used to keep the sample material suspended in the centrifuge tubes during transfer.

The requester of service indicated concern over potential agglomeration issues and requested that each sample, in addition to the as-received form, be analyzed after sonication. A transfer pipette was used to mix the slurry and transfer the required amount to the analyzer. Nominally 1 to 5 drops of each sample/sub-sample were placed in the Hydro 2000S particle dispersion unit using $0.01 \mathrm{M} \mathrm{NaOH}$ as the dispersion fluid. At the direction of the customer, sample D_02AML_012_XX_5343_XSP_4 was analyzed using D_PF1 permeate as the dispersion fluid. The dispersion unit has an internal sonication device with a variable speed pump/agitator. Unless noted differently, the pump/agitator was operated at a setpoint of 3000 and the sonicator operated at $0 \%$ (as-received) or $50 \%$ maximum setpoint. Sonicator setpoints of up to $100 \%$ maximum were an option at the analyst's discretion.

The amount of sub-sample required for analysis varied with the actual concentration of the sample. Neither the amount of sample nor the amount of $0.01 \mathrm{M} \mathrm{NaOH}$ dispersion solution was critical to the analytical process since the analytical software indicates graphically the amount of sample needed for analysis. The actual amounts of sample and water did not need to be, nor were they measured or 
recorded. Any additional sonication required to de-agglomerate sample(s) was noted on the respective particle size distribution data plot.

\section{ANALYSIS}

Analysis was performed per procedure TPR-RPP-WTP-626, Rev. 0, Particle Size Analysis using Malvern MS2000 (current Revision) and per the LTA provided by the responsible scientist. The ID of the Malvern MS2000 Analyzer is property\# PT20096 (serial number MAL1019545 listed on the attached data plots). The pump/stirrer speed of the Hydro 2000S particle dispersion unit (serial number MAL 1019602) integral to the analyzer was set at 3000 . Samples were allowed to circulate/sonicate in the Hydro $2000 \mathrm{~S}$ for at least 30 seconds prior to analysis.

The Malvern MS2000 Analyzer does not have the capability of calibration adjustment, and other than cleaning the lens or the sample chamber, or returning the equipment to the vendor, there are no adjustments, other than pump/stirrer speed and \% sonication, that will affect the operation of the equipment. Per the LTA, a QAS3001B, part No. CRM00016 standard was used to verify the analyzer performance on 03/09/2009 and 04/27/2009. Procedure TPR-RPP-WTP-626 requires that the performance analysis be repeated every 90 days. The following parameters were included in the standard analysis setup as per Malvern Instruction Sheet MRK704-0407-2007:

Setup name: Glass Beads (typical)

Dispersant Name: DI Water

Sensitivity: Enhanced

Analysis model: Single Mode Spherical

Particle refractive index: 1.520

Dispersant refractive index: 1.33

Successful performance of the Malvern MS2000 as defined by the customer, requires that standard $\mathrm{D}_{50}$ analysis results fall within $+/-10 \%$ of the manufacture's $\mathrm{D}_{50}$ specifications. The glass standard microspheres were analyzed on $03 / 09 / 2009$ as spherical particles and the $\mathrm{D}_{50}$ value was 62.206 microns which fell within $+/-10 \%$ of the manufacture specified volume weighted $\mathrm{D}_{50}$ value of 60.59 microns. However, it was noted that the standard was inadvertently analyzed using incorrect settings (Senstivity $=$ Normal, and Analysis model $=$ General Purpose). The raw data was re-analyzed with the Mastersizer 2000 analytical software on 04/13/2009 using the correct settings. The average $D_{50}$ results (see LRB BNW 60175, page 51) from the repeat analysis of the raw data was 63.167 microns. This $\mathrm{D}_{50}$ value still fell within the $+/-10 \%$ bracket on the vendor specified $D_{50}$ value. The re-analyzed results are included in Table 1 and the associated data plot, record 3300, is included in the Performance Evaluation section of this report. During the performance of Integrated Test D samples, on 04/27/2009, another performance evaluation was made and the results are included as well.

Each sample was sub-sampled a minimum of 2 times (noted as aliquots) to allow duplicate analysis of each sample. Per instructions on the LTA, 3 additional subsamples were to be analyzed if the initial duplicate MV (volume weighted mean diameter) values of the as-received or the sonicated sub-samples differed by more than $15 \%$. All duplicate analysis results varying by more than $100 \%$ were reviewed by the cognizant scientist. Any additional analysis requirements could be waived if the cognizant scientist agrees that agglomeration issues may cause results to be suspect. 


\title{
Table 1. Standard Analysis Results from 03/09/2009 \& 04/27/2009
}

\author{
$M V$ and $D_{50}$ results in microns
}

\begin{tabular}{|c|c|c|c|c|c|c|}
\hline $\begin{array}{c}\text { Record } \\
\text { Number }\end{array}$ & Sample Identification & $\begin{array}{c}\text { Measured } \\
\mathrm{D}_{50}\end{array}$ & $\begin{array}{c}\text { Vendor } \\
\text { specified } \\
\mathrm{D}_{50}\end{array}$ & $\begin{array}{c}\text { Measured } \\
\mathrm{D}_{50} \\
+10 \%\end{array}$ & $\begin{array}{c}\text { Measured } \\
\mathrm{D}_{50} \\
-10 \%\end{array}$ & Comments \\
\hline 3096 & QA Standard & 61.632 & 60.59 & 67.795 & 55.469 & Values pass criteria \\
\hline 3300 & $\begin{array}{c}\text { QA Standard, re- } \\
\text { analyzed raw data }\end{array}$ & 63.167 & 60.59 & 69.484 & 56.850 & Values pass criteria \\
\hline
\end{tabular}

The following parameters were included in the sample analysis setup:

\section{Setup name: Ferric Oxide Hydroxide}

Dispersant Name: $0.01 \mathrm{M} \mathrm{NaOH}$

Sensitivity: Normal

Analysis model: General purpose

Particle refractive index: 2.94

Dispersant refractive index: 1.33

For samples using D_PF1 permeate as the dispersion fluid:

\section{Setup name: Ferric Oxide Hydroxide}

Dispersant Name: D_PF1 Permeate

Sensitivity: Normal

Analysis model: General purpose

Particle refractive index: 2.94

Dispersant refractive index: 1.33

\section{COMMENTS AND OBSERVATIONS}

All samples for PEP Test D were received in a slurried state. A 1L slurry sample, D_00PF1_012_XX_5344_XSP_4 marked "Permeate" was provided (referred heretofore as Permeate D-PF1) to be used as dispersion fluid for sample D_02AML_012_XX_5343_XSP_4.

One of the samples, D_02AML_012_XX_5361_XSP_4, analyzed with the $0.01 \mathrm{M} \mathrm{NaOH}$ dispersion fluid, produced results that were outside of the $+/-15 \%$ duplicate "acceptance" requirement and therefore 3 additional aliquots sample were analyzed. It should be noted that one of the aliquots showed signs of agglomeration (e.g., record number 3160, there was a hump in the particle size distribution histogram 
between $400-500-\mu \mathrm{m}$ that was not present in the other aliquots) but the other 4 aliquots were within $+/-15 \%$.

Sample D_02AML_019_XX_5343_XSP_4, analyzed with the D_PF1 permeate dispersion fluid, also produced results that were outside the $+/-15 \%$ duplicate "acceptance" criteria; however, only enough dispersion fluid was provided to allow analysis of 3 total aliquots instead of the 5 required by the LTA. The cause for this variance was attributed to agglomeration issues as well. Agglomeration was observed in the particle size distribution histograms for records 3042 and 3048 (same aliquot). These graphs show a small tail around $200 \mu \mathrm{m}$ that was not present in any of the other analyses performed on this sample. This situation was discussed with the requestor of service. Results are shown in Table 2.

\section{Table 2. Sample Analysis Results}

\begin{tabular}{|c|c|c|c|c|c|c|}
\hline \multicolumn{7}{|c|}{ Diameter and D50 results in microns } \\
\hline $\begin{array}{l}\text { Record } \\
\text { number }\end{array}$ & Sample Name & $D_{50}$ & $\begin{array}{l}\text { Volume } \\
\text { weighted } \\
\text { mean } \\
\text { diameter }\end{array}$ & $\begin{array}{l}\text { Diameter } \\
\quad+\mathbf{1 5 \%}\end{array}$ & $\begin{array}{l}\text { Diameter } \\
-15 \%\end{array}$ & $\begin{array}{c}\text { Ultrasonic } \\
\text { level }\end{array}$ \\
\hline $2178^{*}$ & $\begin{array}{c}\text { D_FRPRL_001_XX_4916_XSP_4 - } \\
\text { Average }\end{array}$ & 7.485 & 12.741 & 14.652 & 10.830 & 0 \\
\hline $2208^{*}$ & $\begin{array}{c}\text { D_FRPRL_001_XX_4916_XSP_4 - } \\
\text { Average }\end{array}$ & 7.495 & 12.539 & 14.420 & 10.658 & 0 \\
\hline $2184^{*}$ & $\begin{array}{c}\text { D_FRPRL_001_XX_4916_XSP_4 - } \\
\text { Average }\end{array}$ & 6.704 & 9.913 & 11.400 & 8.426 & 50 \\
\hline $2226^{*}$ & $\begin{array}{c}\text { D_FRPRL_001_XX_4916_XSP_4 - } \\
\text { Average }\end{array}$ & 6.034 & 9.816 & 11.288 & 8.344 & 50 \\
\hline 2804 & $\begin{array}{c}\text { D_T22GM_002_XX_4926_XSP_4 - } \\
\text { Average }\end{array}$ & 8.585 & 15.853 & 18.231 & 13.475 & 0 \\
\hline 2828 & $\begin{array}{c}\text { D_T22GM_002_XX_4926_XSP_4 - } \\
\text { Average }\end{array}$ & 8.583 & 16.184 & 18.612 & 13.756 & 0 \\
\hline 2810 & $\begin{array}{c}\text { D_T22GM_002_XX_4926_XSP_4 - } \\
\text { Average }\end{array}$ & 7.49 & 10.179 & 11.706 & 8.652 & 50 \\
\hline 2834 & $\begin{array}{c}\text { D_T22GM_002_XX_4926_XSP_4 - } \\
\text { Average }\end{array}$ & 7.448 & 10.103 & 11.618 & 8.588 & 50 \\
\hline 2852 & $\begin{array}{c}\text { D_02AML_005_XX_4980_XSP_4 - } \\
\text { Average }\end{array}$ & 4.186 & 6.414 & 7.376 & 5.452 & 0 \\
\hline 2876 & $\begin{array}{c}\text { D_02AML_005_XX_4980_XSP_4 - } \\
\text { Average }\end{array}$ & 4.405 & 6.669 & 7.669 & 5.669 & 0 \\
\hline 2858 & $\begin{array}{c}\text { D_02AML_005_XX_4980_XSP_4 - } \\
\text { Average }\end{array}$ & 4.512 & 6.679 & 7.681 & 5.677 & 50 \\
\hline 2882 & $\begin{array}{c}\text { D_02AML_005_XX_4980_XSP_4 - } \\
\text { Average }\end{array}$ & 4.609 & 6.838 & 7.864 & 5.812 & 50 \\
\hline
\end{tabular}

*The de-ionized water (DIW) used to prepare the $0.01 \mathrm{M} \mathrm{NaOH}$ dispersion fluid for PSD analysis is typically 17.9 to $18.1 \mathrm{meg}$-ohms in purity. The DIW purity used for the dispersion fluid prep required in the analysis of these samples was 10.6 meg-ohms, due to partially depleted DIW process cartridges.

Minimal effect expected. 
Table 2. Sample Analysis Results (continued)

Diameter and D50 results in microns

\begin{tabular}{|c|c|c|c|c|c|c|}
\hline $\begin{array}{l}\text { Record } \\
\text { number }\end{array}$ & Sample Name & $D_{50}$ & $\begin{array}{c}\text { Volume } \\
\text { weighted } \\
\text { mean } \\
\text { diameter }\end{array}$ & $\begin{array}{l}\text { Diameter } \\
\quad+15 \%\end{array}$ & $\begin{array}{l}\text { Diameter } \\
-15 \%\end{array}$ & $\begin{array}{l}\text { Ultrasonic } \\
\text { level }\end{array}$ \\
\hline 2900 & $\begin{array}{c}\text { D_02AML_05A_XX_5184_XSP_4 - } \\
\text { Average }\end{array}$ & 6.549 & 9.209 & 10.590 & 7.828 & 0 \\
\hline 2924 & $\begin{array}{c}\text { D_02AML_05A_XX_5184_XSP_4 - } \\
\text { Average }\end{array}$ & 6.384 & 9.001 & 10.351 & 7.651 & 0 \\
\hline 2906 & $\begin{array}{c}\text { D_02AML_05A_XX_5184_XSP_4 - } \\
\text { Average }\end{array}$ & 6.637 & 8.931 & 10.271 & 7.591 & 50 \\
\hline 2930 & $\begin{array}{c}\text { D_02AML_05A_XX_5184_XSP_4 - } \\
\text { Average }\end{array}$ & 6.621 & 8.981 & 10.328 & 7.634 & 50 \\
\hline 3042 & $\begin{array}{c}\text { D_02AML_012_XX_5343_XSP_4 - } \\
\text { Average }\end{array}$ & 3.81 & 8.551 & 9.834 & 7.268 & 0 \\
\hline 3066 & $\begin{array}{c}\text { D_02AML_012_XX_5343_XSP_4 - } \\
\text { Average }\end{array}$ & 3.823 & 7.44 & 8.556 & 6.324 & 0 \\
\hline 3233 & $\begin{array}{c}\text { D_02AML_012_XX_5343_XSP_4 - } \\
\text { Average }\end{array}$ & 3.722 & 6.804 & 7.825 & 5.783 & 0 \\
\hline 3048 & $\begin{array}{c}\text { D_02AML_012_XX_5343_XSP_4 - } \\
\text { Average }\end{array}$ & 3.645 & 7.681 & 8.833 & 6.529 & 50 \\
\hline 3078 & $\begin{array}{c}\text { D_02AML_012_XX_5343_XSP_4 - } \\
\text { Average }\end{array}$ & 3.424 & 6.318 & 7.266 & 5.370 & 50 \\
\hline 3239 & $\begin{array}{c}\text { D_02AML_012_XX_5343_XSP_4 - } \\
\text { Average }\end{array}$ & 3.491 & 6.14 & 7.061 & 5.219 & 50 \\
\hline 3160 & $\begin{array}{c}\text { D_02AML_012_XX_5361_XSP_4 - } \\
\text { Average }\end{array}$ & 2.049 & 8.487 & 9.760 & 7.214 & 0 \\
\hline 3176 & $\begin{array}{c}\text { D_02AML_012_XX_5361_XSP_4 - } \\
\text { Average }\end{array}$ & 2.005 & 3.278 & 3.770 & 2.786 & 0 \\
\hline 3255 & $\begin{array}{c}\text { D_02AML_012_XX_5361_XSP_4 - } \\
\text { Average }\end{array}$ & 1.981 & 3.248 & 3.735 & 2.761 & 0 \\
\hline 3271 & $\begin{array}{c}\text { D_02AML_012_XX_5361_XSP_4 - } \\
\text { Average }\end{array}$ & 2.027 & 3.355 & 3.858 & 2.852 & 0 \\
\hline 3287 & $\begin{array}{c}\text { D_02AML_012_XX_5361_XSP_4 - } \\
\text { Average }\end{array}$ & 2.019 & 3.317 & 3.815 & 2.819 & 0 \\
\hline 3164 & $\begin{array}{c}\text { D_02AML_012_XX_5361_XSP_4 - } \\
\text { Average }\end{array}$ & 1.88 & 3.55 & 4.083 & 3.018 & 50 \\
\hline 3180 & $\begin{array}{c}\text { D_02AML_012_XX_5361_XSP_4 - } \\
\text { Average }\end{array}$ & 1.849 & 3.276 & 3.767 & 2.785 & 50 \\
\hline 3259 & $\begin{array}{c}\text { D_02AML_012_XX_5361_XSP_4 - } \\
\text { Average }\end{array}$ & 1.856 & 3.243 & 3.729 & 2.757 & 50 \\
\hline 3275 & $\begin{array}{c}\text { D_02AML_012_XX_5361_XSP_4 - } \\
\text { Average }\end{array}$ & 1.877 & 3.288 & 3.781 & 2.795 & 50 \\
\hline 3291 & $\begin{array}{c}\text { D_02AML_012_XX_5361_XSP_4 - } \\
\text { Average }\end{array}$ & 1.875 & 3.282 & 3.774 & 2.790 & 50 \\
\hline
\end{tabular}




\section{Table 2. Sample Analysis Results (continued)}

\begin{tabular}{|c|c|c|c|c|c|c|}
\hline \multirow{2}{*}{$\begin{array}{c}\text { Record } \\
\text { number }\end{array}$} & $\begin{array}{c}\text { Volume } \\
\text { weighted } \\
\text { mean } \\
\text { diameter }\end{array}$ & $\begin{array}{c}\text { Diameter } \\
+15 \%\end{array}$ & $\begin{array}{c}\text { Diameter } \\
\mathbf{- 1 5 \%}\end{array}$ & $\begin{array}{c}\text { Ultrasonic } \\
\text { level }\end{array}$ \\
\hline 2756 & $\begin{array}{c}\text { D_02AML_020_XX_5587_XSP_4 } \\
- \text { Average }\end{array}$ & 1.761 & 2.295 & 2.639 & 1.951 & 0 \\
\hline 2780 & $\begin{array}{c}\text { D_02AML_020_XX_5587_XSP_4 } \\
- \text { Average }\end{array}$ & 1.745 & 2.344 & 2.696 & 1.992 & 0 \\
\hline 2762 & $\begin{array}{c}\text { D_02AML_020_XX_5587_XSP_4 } \\
- \text { Average }\end{array}$ & 1.349 & 2.041 & 2.347 & 1.735 & 50 \\
\hline 2786 & $\begin{array}{c}\text { D_02AML_020_XX_5587_XSP_4 } \\
- \text { Average }\end{array}$ & 1.337 & 2.069 & 2.379 & 1.759 & 50 \\
\hline & & & & & & \\
\hline
\end{tabular}


Appendix M

\section{Integrated Test D Run Sheet}





\section{Appendix M: Integrated Test D Run Sheet}

The Run Sheet section of the Test Instruction (TI-WTP-PEP-082) provided the LTE target or setpoint values for key process operations. The LTE filled in the actual value during testing from available data. Often this data was from the HMI which is not NQA-1 qualified. Data recorded was a snapshot in time rather than an average. The following is a reproduction of the run sheet with the "actual value" column filled in from various data sources. Data provided in the "actual value" column is generally from the original Test Instruction as filled in by the LTE. In cases where certified data was available as a result of data evaluation efforts, this data was used instead. The data source is provided next to the "comments" column, with the following definitions:

HMI - the LTE obtained the value from the HMI screen, which does not provide certified calibrated readings. Reading taken as a snapshot in time with no averaging applied.

VFD - the LTE obtained this value from the VFD readout, which was not calibrated.

Local flow meter - the steam ring air purge and the air sparge values were read locally from the instrument (coriolis gas flowmeter). These local readouts were calibrated.

Test Instruction (TI) - the value or state was recorded on the Test Instruction. Timing of events, number of events (e.g., wash batches), equipment line ups, and AFA additions were documented in this manner and is the best available record.

CCP-XXX — Selected parameters were evaluated and documented in CCPs.

WTP-RPT-XXX - If a report is cited as the data source, the value was evaluated and checked via a CCP traceable through the report referenced.

The run sheet is provided for information only. 
Parameter Data Run Sheet TI-082 Rev. 0

\begin{tabular}{|c|c|c|c|c|c|c|c|c|}
\hline & $\begin{array}{l}\text { Run } \\
\text { Sheet } \\
\text { Step } \\
\end{array}$ & Operation & $\begin{array}{c}\text { Target or } \\
\text { Setpoint } \\
\text { Value } \\
\end{array}$ & $\begin{array}{c}\text { Range } \\
(-/+) \\
\end{array}$ & Units & $\begin{array}{c}\text { Actual } \\
\text { Value }\end{array}$ & Comments & $\begin{array}{c}\text { Data } \\
\text { Source } \\
\end{array}$ \\
\hline \multirow{3}{*}{$\begin{array}{c}\text { Simulant } \\
\text { storage in } \\
\text { HLP- } \\
\text { VSL-T22 } \\
\text { (Section } \\
7.1 \text { ) }\end{array}$} & \multirow[t]{3}{*}{$\bar{A}$} & HLP-VSL-T22 Operation & & & & & & \\
\hline & & Agitator speed & 60 & $-5 /+5$ & $\mathrm{~Hz}$ & 60 & & VFD \\
\hline & & $\begin{array}{l}\text { Minimum simulant volume } \\
\text { required for test }\end{array}$ & 1,600 & N/A & gal & 1660 & $\begin{array}{l}\text { Value does NOT include nominal } \\
500 \text { gal heel of HLP-VSL-T22. }\end{array}$ & TI \\
\hline \multirow{11}{*}{$\begin{array}{l}\text { Transfer } \\
\text { from } \\
\text { HLP- } \\
\text { VSL-T22 } \\
\text { to } \\
\text { UFP- } \\
\text { VSL- } \\
\text { T01B } \\
\text { (Section } \\
7.2 \text { ) }\end{array}$} & \multirow[t]{11}{*}{$\mathrm{B}$} & Total transfer volume (endpoint) & 593 & $-5 /+5$ & gal & 593 & $\begin{array}{l}\text { Assumes no previous heel in } \\
\text { UFP-VSL-T01B. Level should be } \\
\sim 67 \text { in. }\end{array}$ & HMI \\
\hline & & Transfer rate & 7.4 & $-2 /+2$ & gpm & 7.4 & & HMI \\
\hline & & UFP-VSL-T01B Operation & & & & & & \\
\hline & & $\begin{array}{l}\text { Level to initiate steam ring air } \\
\text { purge and adjust flow rate }\end{array}$ & $<15$ & N/A & in. & 0 & $\begin{array}{l}\text { Steam ring air purge should be on } \\
\text { before the rising simulant level } \\
\text { reaches the ring. }\end{array}$ & TI \\
\hline & & Steam ring air purge flow rate & 0.20 & $-0.02 /+0.02$ & $\mathrm{~kg} / \mathrm{min}$ & 0.14 & $6.1 \mathrm{scfm}$ in UFP-VSL-T01B & HMI \\
\hline & & Level to initiate PJM operation & 15 & $-2 /+10$ & in. & 16 & & HMI \\
\hline & & PJM jet velocity & 4.8 & $-0.3 /+0.3$ & $\mathrm{~m} / \mathrm{s}$ & 5.1 & & CCP- 901 \\
\hline & & PJM stroke $(80 \%)$ & 29.0 & $-3 /+3$ & in. & 29 & & CCP-901 \\
\hline & & PJM cycle time & 35 & $-1 /+1$ & $\mathrm{~s}$ & 35 & & CCP-901 \\
\hline & & $\begin{array}{l}\text { Level to add antifoam agent } \\
\text { (AFA) }\end{array}$ & 15 & $-2 /+10$ & in. & 17 & & HMI \\
\hline & & $\begin{array}{l}\text { Volume of AFA to add to } \\
\text { UFP-VSL-T01B }\end{array}$ & 1,000 & $-10 /+10$ & $\mathrm{~mL}$ & 1,000 & This volume is for undiluted AFA. & $\mathrm{TI}$ \\
\hline \multirow{6}{*}{$\begin{array}{l}\text { Initial } \\
\text { transfer } \\
\text { from } \\
\text { UFP- } \\
\text { VSL- } \\
\text { T01B to } \\
\text { UFP- } \\
\text { VSL- } \\
\text { T02A }\end{array}$} & \multirow[t]{6}{*}{$\mathrm{C}$} & Transfer volume (endpoint) & 218 & $-3 /+3$ & gal & 220 & $\begin{array}{l}\text { UFP-VSL-T02A level should be } \\
\sim 52 \text { in. }\end{array}$ & ССР-889 \\
\hline & & Transfer rate & 6.9 & $-1 /+1$ & gpm & 6.83 & Actual flow is an average & CCP-889 \\
\hline & & UFP-VSL-T02A Operation & & & & & & \\
\hline & & Level to initiate PJM operation & 12 & $-2 /+10$ & in. & 50 & $\begin{array}{l}12 \text { in. is the UFP-VSL-T02A low } \\
\text { mixing level. }\end{array}$ & HMI \\
\hline & & PJM jet velocity & 7.3 & $-0.4 /+0.4$ & $\mathrm{~m} / \mathrm{s}$ & 7.7 & & CCP- 901 \\
\hline & & PJM stroke $(80 \%)$ & 31.5 & $-3 /+3$ & in. & 32 & & CCP- 901 \\
\hline
\end{tabular}


Parameter Data Run Sheet TI-082 Rev. 0

\begin{tabular}{|c|c|c|c|c|c|c|c|c|}
\hline & $\begin{array}{l}\text { Run } \\
\text { Sheet } \\
\text { Step }\end{array}$ & Operation & $\begin{array}{l}\text { Target or } \\
\text { Setpoint } \\
\text { Value }\end{array}$ & $\begin{array}{l}\text { Range } \\
(-/+)\end{array}$ & Units & $\begin{array}{l}\text { Actual } \\
\text { Value }\end{array}$ & Comments & $\begin{array}{l}\text { Data } \\
\text { Source }\end{array}$ \\
\hline \multirow{6}{*}{$\begin{array}{l}\text { (Section } \\
7.3)\end{array}$} & & PJM cycle time & 33 & $-1 /+1$ & $\mathrm{~s}$ & 33 & & CCP- 901 \\
\hline & & $\begin{array}{l}\text { Level to adjust steam ring air } \\
\text { purge rotameter }\end{array}$ & $<15$ & $\mathrm{~N} / \mathrm{A}$ & in. & 0 & & HMI \\
\hline & & Steam ring air purge flow rate & 0.14 & $-0.02 /+0.02$ & $\mathrm{~kg} / \mathrm{min}$ & off & $4.1 \mathrm{scfm}$ in UFP-VSL-T02A & HMI \\
\hline & & $\begin{array}{l}\text { Level to initiate and adjust lower } \\
\text { air spargers to full flow }\end{array}$ & 12 & $-2 /+10$ & in. & 22 & $\begin{array}{l}\text { Full flow to lower spargers is } \\
\text { required whenever level is above } \\
\text { lower mixing level and filter-loop } \\
\text { pumps are off. }\end{array}$ & HMI \\
\hline & & $\begin{array}{l}\text { Total lower air sparger flow rate } \\
\text { (for } 5 \text { sparge tubes) }\end{array}$ & 0.40 & $-0.05 /+0.05$ & $\mathrm{~kg} / \mathrm{min}$ & 0.4 & $\begin{array}{l}\text { Total of } 12 \mathrm{scfm} \text { for the } 5 \text { sparge } \\
\text { tubes, or } \sim 2.4 \mathrm{scfm} \text { for each sparge } \\
\text { tube whenever filter-loop pumps } \\
\text { are not running. }\end{array}$ & HMI \\
\hline & & Upper air sparger flow rate & OFF & $\mathrm{N} / \mathrm{A}$ & N/A & OFF & $\begin{array}{l}\text { Upper air sparger is not turned on } \\
\text { until UFP-VSL-T02A level reaches } \\
52 \text { in. }\end{array}$ & HMI \\
\hline \multirow{8}{*}{$\begin{array}{l}\text { Concen- } \\
\text { trate } \\
\text { solids to } \\
20 \text {-wt } \% \\
\text { in UFP- } \\
\text { VSL- } \\
\text { T02A } \\
\text { (Section } \\
7.4-7.5)\end{array}$} & \multirow[t]{8}{*}{$\mathrm{D}$} & $\begin{array}{l}\text { UFP-VSL-T02A level to initiate } \\
\text { make-up batch transfers }\end{array}$ & 27 & $-1 /+3$ & in. & 27 & & HMI \\
\hline & & Make-up batch volume & 11 & $-1 /+1$ & gal & 11 & & HMI \\
\hline & & $\begin{array}{l}\text { Total number of make-up } \\
\text { batches (endpoint) }\end{array}$ & 46 & $-0 /+0$ & & 46 & $\begin{array}{l}\text { Concentrate a total of } 724 \text { gal of } \sim \\
5-w t \% \text { simulant to make } 161 \text { gal of } \\
20-w t \% \text { slurry. }\end{array}$ & HMI \\
\hline & & Make-up batch flow rate & 6.9 & $-1 /+1$ & gpm & 6.9 & & HMI \\
\hline & & $\begin{array}{l}\text { UFP-VSL-T02A final level } \\
\text { (endpoint) }\end{array}$ & 19.0 & $-1 /+3$ & in. & 18.3 & & HMI \\
\hline & & UFP-VSL-T02A Operation & & & & & & \\
\hline & & $\begin{array}{l}\text { Total lower air sparger flow rate } \\
\text { (total for } 5 \text { sparge tubes) }\end{array}$ & 0.010 & $\begin{array}{c}0.005 /+ \\
0.005\end{array}$ & $\mathrm{~kg} / \mathrm{min}$ & 0.01 & $\begin{array}{l}\sim 3.7 \text { scfh for each sparge tube } \\
\text { whenever filter-loop pumps are } \\
\text { running. }\end{array}$ & HMI \\
\hline & & Upper air sparger flow rate & OFF & N/A & N/A & Off & $\begin{array}{l}\text { Upper air sparger is not turned on } \\
\text { until UFP-VSL-T02A level reaches } \\
52 \text { in. }\end{array}$ & HMI \\
\hline
\end{tabular}


Parameter Data Run Sheet TI-082 Rev. 0

\begin{tabular}{|c|c|c|c|c|c|c|c|c|}
\hline & $\begin{array}{l}\text { Run } \\
\text { Sheet } \\
\text { Step }\end{array}$ & Operation & $\begin{array}{l}\text { Target or } \\
\text { Setpoint } \\
\text { Value }\end{array}$ & $\begin{array}{c}\text { Range } \\
(-1+)\end{array}$ & Units & $\begin{array}{l}\text { Actual } \\
\text { Value }\end{array}$ & Comments & $\begin{array}{c}\text { Data } \\
\text { Source }\end{array}$ \\
\hline & & $\begin{array}{l}\text { Number of filter bundles } \\
\text { (UFP-FILT-T02A - T05A } \\
\text { permeate valves closed) }\end{array}$ & 1 & $-0 /+0$ & & 1 & $Y$ (init.) & TI \\
\hline & & Filter-loop flow rate & 109 & $-10 /+10$ & gpm & 109 & Flow drops off near the end & HMI \\
\hline & & Transmembrane pressure & 40 & $-4 /+4$ & psi & 40 & $\begin{array}{l}\text { Lower range not applicable if back } \\
\text { pressure valve is } 100 \% \text { open. }\end{array}$ & HMI \\
\hline & & Temperature of UFP-VSL-T02A & 23 & $-2 /+2$ & ${ }^{\circ} \mathrm{C}$ & 25 & Average on $12 \mathrm{hr}$ plots & HMI \\
\hline \multirow{5}{*}{$\begin{array}{l}\text { Transfer } \\
\text { from } \\
\text { HLP- } \\
\text { VSL-T22 } \\
\text { to } \\
\text { UFP- } \\
\text { VSL- } \\
\text { T01B } \\
(1 \mathrm{st} \\
\text { refill) } \\
\text { (Section } \\
7.4)\end{array}$} & \multirow[t]{5}{*}{$\mathrm{E}$} & $\begin{array}{l}\text { Level in UFP-VSL-T01B to } \\
\text { initiate 1st refill from } \\
\text { HLP-VSL-T22 }\end{array}$ & 29 & $-10 /+1$ & in. & 29.7 & $\begin{array}{l}\text { This level should be reached after } \\
\text { the initial transfer and } \sim 14 \text { make-up } \\
\text { batch transfers. }\end{array}$ & HMI \\
\hline & & $\begin{array}{l}\text { 1st refill transfer volume } \\
\text { (endpoint) }\end{array}$ & 362 & $-10 /+10$ & gal & 362 & & HMI \\
\hline & & Refill transfer rate & 7.4 & $-1 /+1$ & gpm & 7.4 & $\begin{array}{l}\text { This is to match plant Reynolds } \\
\text { number of } 6,500\end{array}$ & HMI \\
\hline & & UFP-VSL-T01B Operation & & & & & & \\
\hline & & $\begin{array}{l}\text { Volume of AFA to add to } \\
\text { UFP-VSL-T01B }\end{array}$ & 612 & $-10 /+10$ & $\mathrm{~mL}$ & 612 & This volume is for undiluted AFA. & HMI \\
\hline \multirow{8}{*}{$\begin{array}{c}\text { Add } \\
\text { caustic to } \\
\text { UFP- } \\
\text { VSL- } \\
\text { T02A } \\
\text { (Section } \\
7.6 \text { ) }\end{array}$} & \multirow[t]{8}{*}{$\mathrm{F}$} & $19 \mathrm{M}$ caustic to add (endpoint) & 935 & $-5 /+5$ & $\mathrm{~kg}$ & 939 & & СCP-889 \\
\hline & & Caustic addition rate & 10.2 & $-2 /+2$ & $\mathrm{~kg} / \mathrm{min}$ & 11.5 & Average flow & CCP-889 \\
\hline & & Tank level after caustic addition & 55.0 & $-2 /+2$ & in. & 62 & Y (init.) & HMI \\
\hline & & $\begin{array}{l}\text { Volume of antifoam to add to } \\
\text { UFP-VSL-T02A }\end{array}$ & 400 & $-10 /+10$ & $\mathrm{~mL}$ & 400 & $\begin{array}{l}\text { Antifoam is added here to account } \\
\text { for caustic and steam additions. } \\
\text { This value is the undiluted AFA } \\
\text { volume. }\end{array}$ & HMI \\
\hline & & Ultrafiltration Loop Operation & & & & & & \\
\hline & & Filter-loop flow rate & 109 & $-10 /+10$ & gpm & 100 & & HMI \\
\hline & & Permeate valves & CLOSED & & & Closed & Y (init.) & $\mathrm{TI}$ \\
\hline & & $\begin{array}{l}\text { Maximum filter-loop } \\
\text { temperature }\end{array}$ & 71 & N/A & ${ }^{\circ} \mathrm{C}$ & 68 & & HMI \\
\hline
\end{tabular}


Parameter Data Run Sheet TI-082 Rev. 0

\begin{tabular}{|c|c|c|c|c|c|c|c|c|}
\hline & $\begin{array}{l}\text { Run } \\
\text { Sheet } \\
\text { Step }\end{array}$ & Operation & $\begin{array}{l}\text { Target or } \\
\text { Setpoint } \\
\text { Value }\end{array}$ & $\begin{array}{c}\text { Range } \\
(-1+)\end{array}$ & Units & $\begin{array}{l}\text { Actual } \\
\text { Value }\end{array}$ & Comments & $\begin{array}{c}\text { Data } \\
\text { Source }\end{array}$ \\
\hline & & UFP-VSL-T02A Operation & & & & & & \\
\hline & & Level to initiate upper air sparge & 50 & $-5 /+5$ & & $\begin{array}{l}\text { Not } \\
\text { required }\end{array}$ & & TI \\
\hline & & Upper air sparger flow rate & 0.10 & $-0.03 /+0.03$ & $\mathrm{~kg} / \mathrm{min}$ & 0.1 & $\begin{array}{l}3.0 \mathrm{scfm} \text {. This applies whenever } \\
\text { the level is above } 52 \mathrm{in} .\end{array}$ & HMI \\
\hline \multirow{5}{*}{$\begin{array}{l}\text { Initial } \\
\text { heat-up } \\
\text { of UFP- } \\
\text { VSL- } \\
\text { T02A } \\
\text { (Section } \\
7.6)\end{array}$} & \multirow[t]{5}{*}{$\mathrm{G}$} & $\begin{array}{l}\text { Initial heat-up temperature } \\
\text { (endpoint) }\end{array}$ & 65 & $-1 /+1$ & ${ }^{\circ} \mathrm{C}$ & 65 & $Y$ (init.) & HMI \\
\hline & & Initial heat-up time & $<2$ & N/A & $\mathrm{hr}$ & 14 & $\begin{array}{l}\text { Starts after } 19 \mathrm{M} \text { caustic addition is } \\
\text { complete. }\end{array}$ & HMI \\
\hline & & Ultrafiltration Loop Operation & & & & & & \\
\hline & & Filter-loop flow rate & 109 & $-10 /+10$ & gpm & 109 & & HMI \\
\hline & & Permeate valves & CLOSED & & & Closed & Y (init.) & HMI \\
\hline \multirow{9}{*}{$\begin{array}{l}\text { Back- } \\
\text { flush } \\
\text { filter- } \\
\text { loop to } \\
\text { UFP- } \\
\text { VSL- } \\
\text { T02A } \\
\text { (Section } \\
7.6)\end{array}$} & \multirow[t]{9}{*}{$\mathrm{H}$} & $\begin{array}{l}\text { Inhibited water addition for } \\
\text { filter-loop back-flush to } \\
\text { UFP-VSL-T02A (endpoint) }\end{array}$ & 74 & $-5 /+5$ & $\mathrm{~kg}$ & 78 & Average flow & CCP-889 \\
\hline & & Flush water addition rate & $\begin{array}{l}\operatorname{maximum} \\
\text { achievable } \\
\text { flow }\end{array}$ & & & $75 \mathrm{~kg} / \mathrm{m}$ & $\begin{array}{l}\text { The pump capacity is } \sim 35 \mathrm{gpm} \\
(132 \mathrm{~kg} / \mathrm{min}) \text {; observed to be } \\
\sim 22 \mathrm{gpm}(83 \mathrm{~kg} / \mathrm{min}) \text { in } \\
\text { November } 2008 .\end{array}$ & HMI \\
\hline & & Tank level after loop flush & 59.1 & $-2 /+2$ & in. & 59.6 & $\sim 254 \mathrm{gal}$ in UFP-VSL-T02A. & \multirow[t]{2}{*}{ HMI } \\
\hline & & UFP-VSL-T02A Operation & & & & & & \\
\hline & & Steam ring air purge flow rate & 0.14 & $-0.02 /+0.02$ & $\mathrm{~kg} / \mathrm{min}$ & 0.14 & $4.1 \mathrm{scfm}$ in UFP-VSL-T02A. & HMI \\
\hline & & $\begin{array}{l}\text { Total lower air sparger flow rate } \\
\text { (total for } 5 \text { sparge tubes) }\end{array}$ & 0.40 & $-0.05 /+0.05$ & $\mathrm{~kg} / \mathrm{min}$ & 0.4 & $\begin{array}{l}\text { Total of } 12 \mathrm{scfm} \text { for the } 5 \text { sparge } \\
\text { tubes, or } \sim 2.4 \mathrm{scfm} \text { for each sparge } \\
\text { tube whenever filter-loop pumps } \\
\text { are not running. }\end{array}$ & HMI \\
\hline & & Upper air sparger flow rate & 0.10 & $-0.03 /+0.03$ & $\mathrm{~kg} / \mathrm{min}$ & 0.1 & $\begin{array}{l}3 \mathrm{scfm} . \text { This applies whenever the } \\
\text { level is above } 52 \text { in. }\end{array}$ & HMI \\
\hline & & Ultrafiltration Loop Operation & & & & & & HMI \\
\hline & & $\begin{array}{l}\text { Filter-loop pumps } \\
\text { UFP-PMP-T42A and T43A }\end{array}$ & OFF & & & Off & & TI \\
\hline
\end{tabular}


Parameter Data Run Sheet TI-082 Rev. 0

\begin{tabular}{|c|c|c|c|c|c|c|c|c|}
\hline & $\begin{array}{l}\text { Run } \\
\text { Sheet } \\
\text { Step }\end{array}$ & Operation & $\begin{array}{l}\text { Target or } \\
\text { Setpoint } \\
\text { Value }\end{array}$ & $\begin{array}{l}\text { Range } \\
(-/+)\end{array}$ & Units & $\begin{array}{l}\text { Actual } \\
\text { Value }\end{array}$ & Comments & $\begin{array}{c}\text { Data } \\
\text { Source }\end{array}$ \\
\hline \multirow{8}{*}{$\begin{array}{c}\text { Final } \\
\text { heat-up } \\
\text { of } \\
\text { UFP- } \\
\text { VSL- } \\
\text { T02A } \\
\text { (Section } \\
7.6 \text { ) }\end{array}$} & \multirow[t]{8}{*}{ I } & $\begin{array}{l}\text { Target final temperature } \\
\text { (endpoint) }\end{array}$ & 85 & $-2 /+2$ & ${ }^{\circ} \mathrm{C}$ & 85 & $Y$ (init.) & HMI \\
\hline & & Heat-up time & 1.6 & $-0.5 /+0.5$ & $\mathrm{hr}$ & 1.6 & & TI \\
\hline & & UFP-VSL-T02A Operation & & & & & & \\
\hline & & PJM jet velocity & 7.3 & $-0.4 /+0.4$ & $\mathrm{~m} / \mathrm{s}$ & 7.1 & & CCP- 901 \\
\hline & & PJM stroke $(80 \%)$ & 31.5 & $-3 /+3$ & in. & 29 & & CCP- 901 \\
\hline & & PJM cycle time & 33 & $-1 /+1$ & s & 33 & & CCP- 901 \\
\hline & & Level at end of heat-up & 64 & $-2 /+3$ & in & 76 & Y (init.) & HMI \\
\hline & & & & & & & & HMI \\
\hline \multirow{4}{*}{$\begin{array}{l}\text { Flush } \\
\text { filter- } \\
\text { loop to } \\
\text { UFP- } \\
\text { VSL- } \\
\text { T62A/B } \\
\text { (Section } \\
7.6 \text { ) }\end{array}$} & \multirow[t]{4}{*}{$\mathrm{J}$} & $\begin{array}{l}\text { Inhibited water for filter-loop } \\
\text { flush to UFP-VSL-T62A/B } \\
\text { (endpoint) }\end{array}$ & 690 & $-10 /+10$ & $\mathrm{~kg}$ & 790 & & HMI \\
\hline & & Flush water addition rate & $\begin{array}{l}\operatorname{maximum} \\
\text { achievable } \\
\text { flow }\end{array}$ & & & 75 & & HMI \\
\hline & & Ultrafiltration Loop Operation & & & & & & \\
\hline & & $\begin{array}{l}\text { Filter loop pumps UFP-PMP- } \\
\text { T42A and T43A }\end{array}$ & OFF & & & Off & & HMI \\
\hline \multirow{7}{*}{$\begin{array}{c}\text { Caustic- } \\
\text { leach in } \\
\text { UFP- } \\
\text { VSL- } \\
\text { T02A } \\
\text { (Section } \\
7.6 \text { ) }\end{array}$} & \multirow[t]{7}{*}{$\mathrm{K}$} & $\begin{array}{l}\text { Caustic-leach duration } \\
\text { (endpoint) }\end{array}$ & 24 & $-0.1 /+1$ & $\mathrm{hr}$ & 24 & & HMI \\
\hline & & UFP-VSL-T02A Operation & & & & & & \\
\hline & & Temperature & 85 & $-2 /+2$ & ${ }^{\circ} \mathrm{C}$ & 85 & & HMI \\
\hline & & PJM jet velocity & 7.3 & $-0.4 /+0.4$ & $\mathrm{~m} / \mathrm{s}$ & 7.1 & & CCP- 901 \\
\hline & & PJM stroke $(80 \%)$ & 31.5 & $-3 /+3$ & in. & 29 & & CCP- 901 \\
\hline & & PJM cycle time & 33 & $-1 /+1$ & S & 33 & & CCP- 901 \\
\hline & & Level at end of caustic-leach & 71 & $-5 /+5$ & in. & 70.1 & Y (init.) & HMI \\
\hline \multirow{2}{*}{$\begin{array}{l}\text { Cool- } \\
\text { down of } \\
\text { UFP- } \\
\text { VSL- }\end{array}$} & \multirow[t]{2}{*}{$\mathrm{L}$} & Final cool-down temperature & 25 & $-2 /+2$ & ${ }^{\circ} \mathrm{C}$ & 24.8 & & $\mathrm{HMI}$ \\
\hline & & $\begin{array}{l}\text { Time to reach final cool-down } \\
\text { temperature }\end{array}$ & 12.6 & $-1 /+1$ & $\mathrm{hr}$ & 12.5 & & TI \\
\hline
\end{tabular}


Parameter Data Run Sheet TI-082 Rev. 0

\begin{tabular}{|c|c|c|c|c|c|c|c|c|}
\hline & $\begin{array}{l}\text { Run } \\
\text { Sheet } \\
\text { Step }\end{array}$ & Operation & $\begin{array}{l}\text { Target or } \\
\text { Setpoint } \\
\text { Value }\end{array}$ & $\begin{array}{l}\text { Range } \\
(-/+)\end{array}$ & Units & $\begin{array}{l}\text { Actual } \\
\text { Value }\end{array}$ & Comments & $\begin{array}{l}\text { Data } \\
\text { Source }\end{array}$ \\
\hline \multicolumn{9}{|l|}{$\begin{array}{c}\text { T02A } \\
\text { (Section } \\
7.7)\end{array}$} \\
\hline \multirow{13}{*}{$\begin{array}{l}\text { Transfer } \\
\text { from } \\
\text { UFP- } \\
\text { VSL- } \\
\text { T02A to } \\
\text { UFP- } \\
\text { VSL- } \\
\text { T01A } \\
\text { (Section } \\
7.8 \text { ) }\end{array}$} & \multirow[t]{13}{*}{$\mathrm{M}$} & Transfer volume (endpoint) & ALL & $\mathrm{N} / \mathrm{A}$ & & all & & TI \\
\hline & & Transfer rate & $\begin{array}{l}\text { No } \\
\text { targeted } \\
\text { rate }\end{array}$ & & gpm & N/A & $\begin{array}{l}\text { Transfer at maximum rate to keep } \\
\text { solids suspended. Used portable } \\
\text { diaphragm pump capability } \\
\sim 10 \text { gpm. }\end{array}$ & \\
\hline & & UFP-VSL-T02A Operation & & & & & & \\
\hline & & $\begin{array}{l}\text { Total lower air sparger flow rate } \\
\text { (total for } 5 \text { sparge tubes) }\end{array}$ & 0.40 & $-0.05 /+0.05$ & $\mathrm{~kg} / \mathrm{min}$ & 0.40 & $\begin{array}{l}\text { Total of } 12 \mathrm{scfm} \text { for the } 5 \text { sparge } \\
\text { tubes, or } \sim 2.4 \mathrm{scfm} \text { for each sparge } \\
\text { tube, whenever filter-loop pumps } \\
\text { are off. }\end{array}$ & HMI \\
\hline & & $\begin{array}{l}\text { Level to turn off upper air } \\
\text { sparger flow rate }\end{array}$ & 50 & $-10 /+0$ & in. & 50 & $\begin{array}{l}\text { Upper air spager is turned off when } \\
\text { UFP-VSL-T02A level is below } \\
52 \text { in. }\end{array}$ & HMI \\
\hline & & Level to stop PJMs & 15 & $-5 /+10$ & in. & 23 & & HMI \\
\hline & & UFP-VSL-T01A Operation & & & & & & \\
\hline & & $\begin{array}{l}\text { Level to initiate steam ring air } \\
\text { purge and adjust flow rate }\end{array}$ & $<15$ & $\mathrm{~N} / \mathrm{A}$ & in. & 25 & $\begin{array}{l}\text { Steam ring air purge should be on } \\
\text { before the rising simulant level } \\
\text { reaches the ring. }\end{array}$ & HMI \\
\hline & & Steam ring air purge flow rate & 0.20 & $-0.02 /+0.02$ & $\mathrm{~kg} / \mathrm{min}$ & 0.14 & $6.1 \mathrm{scfm}$ in UFP-VSL-T01A & HMI \\
\hline & & Level to initiate PJM operation & 15 & $-2 /+10$ & in. & 23 & & HMI \\
\hline & & PJM jet velocity & 4.8 & $-0.3 /+0.3$ & $\mathrm{~m} / \mathrm{s}$ & 4.8 & & HMI \\
\hline & & PJM stroke $(80 \%)$ & 29.0 & $-3 /+3$ & in. & 29.0 & & HMI \\
\hline & & PJM cycle time & 35 & $-1 /+1$ & $\mathrm{~s}$ & 35 & & HMI \\
\hline $\begin{array}{l}\text { Transfer } \\
\text { from } \\
\text { HLP- }\end{array}$ & \multirow[t]{3}{*}{$\mathrm{N}$} & $\begin{array}{l}\text { Level in UFP-VSL-T01B to } \\
\text { initiate } 2 \text { nd refill from } \\
\text { HLP-VSL-T22 }\end{array}$ & 29 & $-5 /+5$ & in. & 29 & $\begin{array}{l}\text { Refill is to be performed in } \\
\text { preparation for the } 2 \text { nd caustic } \\
\text { leach. }\end{array}$ & HMI \\
\hline $\begin{array}{l}\text { VSL-T22 } \\
\text { to }\end{array}$ & & $\begin{array}{l}\text { 2nd refill transfer volume } \\
\text { (endpoint) }\end{array}$ & 362 & $-10 /+10$ & gal & 362 & & HMI \\
\hline UFP- & & Refill transfer rate & 7.4 & $-1 /+1$ & gpm & 7.4 & This is to match plant Reynolds & HMI \\
\hline
\end{tabular}


Parameter Data Run Sheet TI-082 Rev. 0

\begin{tabular}{|c|c|c|c|c|c|c|c|c|}
\hline & $\begin{array}{l}\text { Run } \\
\text { Sheet } \\
\text { Step } \\
\end{array}$ & Operation & $\begin{array}{c}\text { Target or } \\
\text { Setpoint } \\
\text { Value } \\
\end{array}$ & $\begin{array}{c}\text { Range } \\
(-/+)\end{array}$ & Units & $\begin{array}{l}\text { Actual } \\
\text { Value }\end{array}$ & Comments & $\begin{array}{c}\text { Data } \\
\text { Source } \\
\end{array}$ \\
\hline \multirow{3}{*}{$\begin{array}{c}\text { VSL- } \\
\text { T01B } \\
\text { (2nd } \\
\text { refill) } \\
\text { (Section } \\
7.9 \text { ) }\end{array}$} & & & & & & & $\begin{array}{l}\text { number of } 6,500 . \text { Average } \\
\text { estimated at } 6.8\end{array}$ & \\
\hline & & UFP-VSL-T01B Operation & & & & & & \\
\hline & & $\begin{array}{l}\text { Volume of AFA to add to } \\
\text { UFP-VSL-T01B }\end{array}$ & 612 & $-10 /+10$ & $\mathrm{~mL}$ & 612 & This volume is for undiluted AFA. & HMI \\
\hline \multirow{12}{*}{$\begin{array}{l}\text { Initial } \\
\text { transfer } \\
\text { from } \\
\text { UFP- } \\
\text { VSL- } \\
\text { T01B to } \\
\text { UFP- } \\
\text { VSL- } \\
\text { T02A } \\
\text { (Section } \\
7.10)\end{array}$} & \multirow[t]{12}{*}{$\mathrm{O}$} & Transfer volume (endpoint) & 218 & $-3 /+3$ & gal & 218 & $\begin{array}{l}\text { UFP-VSL-T02A level should be } \\
\sim 52 \text { in. }\end{array}$ & HMI \\
\hline & & Transfer rate & 6.9 & $-1 /+1$ & gpm & 6.8 & & HMI \\
\hline & & UFP-VSL-T02A Operation & & & & & & \\
\hline & & Level to initiate PJM operation & 12 & $-2 /+10$ & in. & 22 & $\begin{array}{l}12 \mathrm{in.} \text { is the UFP-VSL-T02A low } \\
\text { mixing level. }\end{array}$ & HMI \\
\hline & & PJM jet velocity & 7.3 & $-0.4 /+0.4$ & $\mathrm{~m} / \mathrm{s}$ & 7.7 & & CCP- 901 \\
\hline & & PJM stroke $(80 \%)$ & 31.5 & $-3 /+3$ & in. & 31.5 & & CCP- 901 \\
\hline & & PJM cycle time & 33 & $-1 /+1$ & s & 33 & & СCР- 901 \\
\hline & & $\begin{array}{l}\text { Level to adjust steam ring air } \\
\text { purge rotameter }\end{array}$ & $<15$ & N/A & in. & 3.3 & & HMI \\
\hline & & Steam ring air purge flow rate & 0.14 & $-0.02 /+0.02$ & $\mathrm{~kg} / \mathrm{min}$ & 0.14 & $4.1 \mathrm{scfm}$ in UFP-VSL-T02A & HMI \\
\hline & & $\begin{array}{l}\text { Level to initiate and adjust lower } \\
\text { air spargers to full flow }\end{array}$ & 12 & $-2 /+10$ & in. & 23 & $\begin{array}{l}\text { Full flow to lower spargers is } \\
\text { required whenever level is above } \\
\text { lower mixing level and filter-loop } \\
\text { pumps are off. }\end{array}$ & HMI \\
\hline & & $\begin{array}{l}\text { Total lower air sparger flow rate } \\
\text { (for } 5 \text { sparge tubes) }\end{array}$ & 0.40 & $-0.05 /+0.05$ & $\mathrm{~kg} / \mathrm{min}$ & 0.40 & $\begin{array}{l}\text { Total of } 12 \mathrm{scfm} \text { for the } 5 \text { sparge } \\
\text { tubes, or } \sim 2.4 \mathrm{scfm} \text { for each sparge } \\
\text { tube whenever filter-loop pumps } \\
\text { are not running. }\end{array}$ & HMI \\
\hline & & Upper air sparger flow rate & OFF & N/A & N/A & Off & $\begin{array}{l}\text { Upper air sparger is not turned on } \\
\text { until UFP-VSL-T02A level reaches } \\
52 \text { in. }\end{array}$ & HMI \\
\hline \multirow{2}{*}{$\begin{array}{l}\text { Concen- } \\
\text { trate } \\
\text { solids to }\end{array}$} & \multirow[t]{2}{*}{$\mathrm{P}$} & $\begin{array}{l}\text { UFP-VSL-T02A level to initiate } \\
\text { make-up batch transfers }\end{array}$ & 27 & $-1 /+3$ & in. & 27 & & HMI \\
\hline & & Make-up batch volume & 11 & $-1 /+1$ & gal & 11 & & HMI \\
\hline
\end{tabular}


Parameter Data Run Sheet TI-082 Rev. 0

\begin{tabular}{|c|c|c|c|c|c|c|c|c|}
\hline & $\begin{array}{l}\text { Run } \\
\text { Sheet } \\
\text { Step }\end{array}$ & Operation & $\begin{array}{l}\text { Target or } \\
\text { Setpoint } \\
\text { Value }\end{array}$ & $\begin{array}{l}\text { Range } \\
(-/+)\end{array}$ & Units & $\begin{array}{l}\text { Actual } \\
\text { Value }\end{array}$ & Comments & $\begin{array}{l}\text { Data } \\
\text { Source }\end{array}$ \\
\hline \multirow{10}{*}{$\begin{array}{c}20-\mathrm{wt} \% \\
\text { in } \\
\text { UFP- } \\
\text { VSL- } \\
\text { T02A } \\
\text { (Section } \\
7.11 \text { and } \\
7.12 \text { ) }\end{array}$} & & $\begin{array}{l}\text { Total number of make-up } \\
\text { batches (endpoint) }\end{array}$ & 46 & $-0 /+0$ & & 46 & $\begin{array}{l}\text { Concentrate a total of } 724 \text { gal of } \\
5-w t \% \text { simulant to make } 161 \text { gal of } \\
20-w t \% \text { slurry. }\end{array}$ & HMI \\
\hline & & $\begin{array}{l}\text { UFP-VSL-T02A final level } \\
\text { (endpoint) }\end{array}$ & 19 & $-1 /+3$ & in. & 18.2 & & HMI \\
\hline & & UFP-VSL-T02A Operation & & & & & & \\
\hline & & $\begin{array}{l}\text { Total lower air sparger (idle) } \\
\text { flow rate (for } 5 \text { sparge tubes) }\end{array}$ & 0.010 & $\begin{array}{l}0.005 / \\
+0.005\end{array}$ & $\mathrm{~kg} / \mathrm{min}$ & 0.01 & $\begin{array}{l}\sim 3.7 \text { scfh for each sparge tube } \\
\text { whenever filter-loop pumps are } \\
\text { running }\end{array}$ & HMI \\
\hline & & Upper air sparger flow rate & OFF & N/A & N/A & Off & $\begin{array}{l}\text { Upper air sparger is not turned on } \\
\text { until UFP-VSL-T02A level reaches } \\
52 \text { in. }\end{array}$ & HMI \\
\hline & & Ultrafiltration Loop Operation & & & & & & \\
\hline & & Number of filter bundles & 5 & $-0 /+0$ & & 5 & Y (init.) & TI \\
\hline & & Filter-loop flow rate & 109 & $-10 /+10$ & gpm & 109 & & HMI \\
\hline & & Transmembrane pressure & 40 & $-4 /+4$ & psi & 40 & $\begin{array}{l}\text { Lower range not applicable if back } \\
\text { pressure valve is } 100 \% \text { open. }\end{array}$ & HMI \\
\hline & & Temperature of UFP-VSL-T02A & 23 & $-2 /+2$ & ${ }^{\circ} \mathrm{C}$ & 24 & & HMI \\
\hline $\begin{array}{l}\text { Transfer } \\
\text { from } \\
\text { HLP- }\end{array}$ & $\mathrm{Q}$ & $\begin{array}{l}\text { Level in UFP-VSL-T01B to } \\
\text { initiate 3rd refill from } \\
\text { HLP-VSL-T22 }\end{array}$ & 29 & $-10 /+1$ & in. & 16 & $\begin{array}{l}\text { Level should be reached after } \sim 32 \\
\text { make-up batches have been } \\
\text { transferred (since } 2 \text { nd refill). }\end{array}$ & HMI \\
\hline $\begin{array}{l}\text { VSL-T22 } \\
\text { to }\end{array}$ & & $\begin{array}{l}\text { 3rd refill transfer volume } \\
\text { (endpoint) }\end{array}$ & 362 & $-10 /+10$ & gal & 361 & & HMI \\
\hline $\begin{array}{l}\text { UFP- } \\
\text { VSL- } \\
\text { T01B }\end{array}$ & & Refill transfer rate & 7.4 & $-1 /+1$ & gpm & 10 & $\begin{array}{l}\text { This is to match plant Reynolds } \\
\text { number of } 6,500 . \text { Increased to } \\
\text { maintain prime }\end{array}$ & HMI \\
\hline (3rd & & UFP-VSL-T01B Operation & & & & & & $\mathrm{H}$ \\
\hline $\begin{array}{l}\text { refill) } \\
\text { (Section } \\
7.11)\end{array}$ & & $\begin{array}{l}\text { Volume of AFA to add to } \\
\text { UFP-VSL-T01B }\end{array}$ & 612 & $-10 /+10$ & $\mathrm{~mL}$ & 612 & This volume is for un-diluted AFA. & TI \\
\hline Add & $\mathrm{R}$ & $19 \mathrm{M}$ caustic to add (endpoint) & 935 & $-5 /+5$ & $\mathrm{~kg}$ & 932 & $Y$ (init.) & $\mathrm{CCP}-889$ \\
\hline
\end{tabular}


Parameter Data Run Sheet TI-082 Rev. 0

\begin{tabular}{|c|c|c|c|c|c|c|c|c|}
\hline & $\begin{array}{l}\text { Run } \\
\text { Sheet } \\
\text { Step } \\
\end{array}$ & Operation & $\begin{array}{l}\text { Target or } \\
\text { Setpoint } \\
\text { Value } \\
\end{array}$ & $\begin{array}{c}\text { Range } \\
(-/+)\end{array}$ & Units & $\begin{array}{c}\text { Actual } \\
\text { Value }\end{array}$ & Comments & $\begin{array}{l}\text { Data } \\
\text { Source } \\
\end{array}$ \\
\hline \multirow{10}{*}{$\begin{array}{l}\text { caustic to } \\
\text { UFP- } \\
\text { VSL- } \\
\text { T02A } \\
\text { (Section } \\
7.13 \text { ) }\end{array}$} & & Caustic-addition rate & 10.2 & $-2 /+2$ & $\mathrm{~kg} / \mathrm{min}$ & $9-12$ & $\begin{array}{l}2.0 \text { gpm. Target and range apply to } \\
\text { average transfer rate. }\end{array}$ & HMI \\
\hline & & Tank level after caustic addition & 55.0 & $-2 /+2$ & in. & 57 & Y (init.) & HMI \\
\hline & & $\begin{array}{l}\text { Volume of antifoam to add to } \\
\text { UFP-VSL-T02A }\end{array}$ & 400 & $-10 /+10$ & $\mathrm{~mL}$ & 400 & $\begin{array}{l}\text { Antifoam is added here to account } \\
\text { for caustic and steam additions. } \\
\text { This value is the undiluted AFA } \\
\text { volume. }\end{array}$ & $\mathrm{TI}$ \\
\hline & & Ultrafiltration Loop Operation & & & & & & \\
\hline & & Filter-loop flow rate & 109 & $-10 /+10$ & gpm & $90-109$ & Increase as tank level increased & HMI \\
\hline & & Permeate valves & CLOSED & & & Closed & Y (init.) & TI \\
\hline & & $\begin{array}{l}\text { Maximum filter-loop } \\
\text { temperature }\end{array}$ & 71 & N/A & ${ }^{\circ} \mathrm{C}$ & 71 & & HMI \\
\hline & & UFP-VSL-T02A Operation & & & & & & \\
\hline & & Level to initiate upper air sparge & 50 & $-5 /+5$ & & Off & & TI \\
\hline & & Upper air sparger flow rate & 0.10 & $-0.03 /+0.03$ & $\mathrm{~kg} / \mathrm{min}$ & Off & $\begin{array}{l}3.0 \mathrm{scfm} \text {. This applies whenever } \\
\text { the level is above } 52 \mathrm{in.}\end{array}$ & HMI \\
\hline \multirow{4}{*}{$\begin{array}{c}\text { Initial } \\
\text { heat-up } \\
\text { of } \\
\text { UFP- } \\
\text { VSL- } \\
\text { T02A } \\
\text { (Section } \\
7.13 \text { ) }\end{array}$} & $\bar{S}$ & $\begin{array}{l}\text { Initial heat-up temperature } \\
\text { (endpoint) }\end{array}$ & 6570 & $-1 /+1$ & ${ }^{\circ} \mathrm{C}$ & 71 & & $\mathrm{HMI}$ \\
\hline & & Ultrafiltration Loop Operation & & & & & & \\
\hline & & Filter-loop flow rate & 109 & $-10 /+10$ & gpm & 109 & & HMI \\
\hline & & Permeate valves & CLOSED & & & Closed & & $\mathrm{TI}$ \\
\hline \multirow{3}{*}{$\begin{array}{l}\text { Back- } \\
\text { flush } \\
\text { filter- } \\
\text { loop to } \\
\text { UFP- } \\
\text { VSL- } \\
\text { T02A } \\
\text { (Section }\end{array}$} & $\mathrm{T}$ & $\begin{array}{l}\text { Inhibited water addition for } \\
\text { filter-loop back-flush to } \\
\text { UFP-VSL-T02A (endpoint) }\end{array}$ & 74 & $-5 /+5$ & $\mathrm{~kg}$ & 0 & & HMI \\
\hline & & Flush water addition rate & $\begin{array}{l}\operatorname{maximum} \\
\text { achievable } \\
\text { flow }\end{array}$ & & & N/A & $\begin{array}{l}\text { The pump capacity is } \sim 35 \mathrm{gpm} \\
(132 \mathrm{~kg} / \mathrm{min}) ; \text { observed to be } \\
\sim 22 \mathrm{gpm}(83 \mathrm{~kg} / \mathrm{min}) \text { in November } \\
2008 .\end{array}$ & HMI \\
\hline & & Tank level after loop flush & 59.1 & $-3 /+3$ & in. & 65.7 & $\sim 254$ gal in UFP-VSL-T02A. & HMI \\
\hline
\end{tabular}


Parameter Data Run Sheet TI-082 Rev. 0

\begin{tabular}{|c|c|c|c|c|c|c|c|c|}
\hline & $\begin{array}{l}\text { Run } \\
\text { Sheet } \\
\text { Step }\end{array}$ & Operation & $\begin{array}{l}\text { Target or } \\
\text { Setpoint } \\
\text { Value }\end{array}$ & $\begin{array}{l}\text { Range } \\
(-/+)\end{array}$ & Units & $\begin{array}{l}\text { Actual } \\
\text { Value }\end{array}$ & Comments & $\begin{array}{l}\text { Data } \\
\text { Source }\end{array}$ \\
\hline \multirow[t]{2}{*}{$7.13)$} & & Ultrafiltration Loop Operation & & & & & & \\
\hline & & $\begin{array}{l}\text { Filter-loop pumps } \\
\text { UFP-PMP-T42A and T43A }\end{array}$ & OFF & & & $\mathrm{N} / \mathrm{A}$ & & TI \\
\hline \multirow{7}{*}{$\begin{array}{c}\text { Final } \\
\text { heat-up } \\
\text { of } \\
\text { UFP- } \\
\text { VSL- } \\
\text { T02A } \\
\text { (Section } \\
7.13 \text { ) }\end{array}$} & $\overline{\mathrm{U}}$ & $\begin{array}{l}\text { Target final temperature } \\
\text { (endpoint) }\end{array}$ & 85 & $-2 /+2$ & ${ }^{\circ} \mathrm{C}$ & 85 & & Plots \\
\hline & & Heat-up time & $1.6-1.2$ & $-0.5 /+0.5$ & $\mathrm{hr}$ & 1.2 & & $\mathrm{TI}$ \\
\hline & & UFP-VSL-T02A Operation & & & & & & \\
\hline & & PJM jet velocity & 7.3 & $-0.4 /+0.4$ & $\mathrm{~m} / \mathrm{s}$ & 7.3 & & CCP- 901 \\
\hline & & PJM stroke $(80 \%)$ & 31.5 & $-3 /+3$ & in. & 31 & & CCP- 901 \\
\hline & & PJM cycle time & 33 & $-1 /+1$ & $\mathrm{~s}$ & 33 & & CCP- 901 \\
\hline & & Level at end of heat-up & 64 & $-2 /+3$ & in & 64.9 & & HMI \\
\hline \multirow{4}{*}{$\begin{array}{l}\text { Flush } \\
\text { filter- } \\
\text { loop to } \\
\text { UFP- } \\
\text { VSL- } \\
\text { T62A/B } \\
\text { (Section } \\
7.13 \text { ) }\end{array}$} & $\mathrm{V}$ & $\begin{array}{l}\text { Inhibited water for filter-loop } \\
\text { flush to UFP-VSL-T62A/B } \\
\text { (endpoint) }\end{array}$ & 690 & $-10 /+10$ & $\mathrm{~kg}$ & 670 & & HMI \\
\hline & & Flush water addition rate & $\begin{array}{l}\text { maximum } \\
\text { achievable } \\
\text { flow }\end{array}$ & & & 74 & & HMI \\
\hline & & Ultrafiltration Loop Operation & & & & & & \\
\hline & & $\begin{array}{l}\text { Filter-loop pumps } \\
\text { UFP-PMP-T42A and T43A }\end{array}$ & OFF & & & Off & & TI \\
\hline \multirow{7}{*}{$\begin{array}{l}\text { Caustic- } \\
\text { leach in } \\
\text { UFP- } \\
\text { VSL- } \\
\text { T02A } \\
\text { (Section } \\
7.13 \text { ) }\end{array}$} & $\mathrm{W}$ & $\begin{array}{l}\text { Caustic-leach duration } \\
\text { (endpoint) }\end{array}$ & 24 & $-0.1 /+1$ & $\mathrm{hr}$ & 24 & & TI \\
\hline & & UFP-VSL-T02A Operation & & & & & & \\
\hline & & Temperature & 85 & $-2 /+2$ & ${ }^{\circ} \mathrm{C}$ & 85 & & HMI \\
\hline & & PJM jet velocity & 7.3 & $-0.4 /+0.4$ & $\mathrm{~m} / \mathrm{s}$ & 7.3 & & CCP- 901I \\
\hline & & PJM stroke $(80 \%)$ & 31.5 & $-3 /+3$ & in. & 31 & & CCP- 901 \\
\hline & & PJM cycle time & 33 & $-1 /+1$ & $\mathrm{~S}$ & 33 & & CCP- 901 \\
\hline & & Level at end of caustic-leach & 71 & $-5 /+5$ & in. & 70 & & $\mathrm{TI}$ \\
\hline Cool- & $\bar{x}$ & Final cool-down temperature & $2 \overline{5}$ & $-2 /+2$ & ${ }^{\circ} \mathrm{C}$ & 24.5 & & $\mathrm{TI}$ \\
\hline
\end{tabular}


Parameter Data Run Sheet TI-082 Rev. 0

\begin{tabular}{|c|c|c|c|c|c|c|c|c|}
\hline & $\begin{array}{l}\text { Run } \\
\text { Sheet } \\
\text { Step }\end{array}$ & Operation & $\begin{array}{l}\text { Target or } \\
\text { Setpoint } \\
\text { Value }\end{array}$ & $\begin{array}{l}\text { Range } \\
(-/+)\end{array}$ & Units & $\begin{array}{c}\text { Actual } \\
\text { Value }\end{array}$ & Comments & $\begin{array}{c}\text { Data } \\
\text { Source }\end{array}$ \\
\hline $\begin{array}{l}\text { down of } \\
\text { UFP- } \\
\text { VSL- } \\
\text { T02A } \\
\text { (Section } \\
7.14)\end{array}$ & & $\begin{array}{l}\text { Time to reach final cool-down } \\
\text { temperature }\end{array}$ & 12.6 & $-1 /+1$ & $\mathrm{hr}$ & 12.6 & & $\mathrm{TI}$ \\
\hline \multirow{11}{*}{ 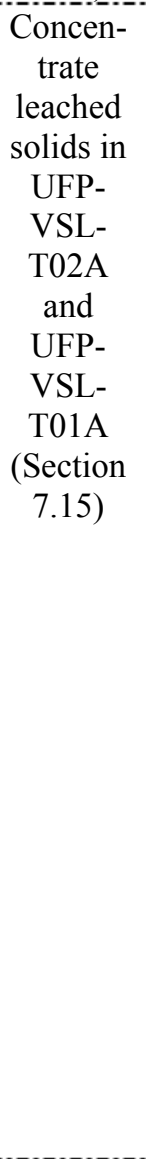 } & \multirow[t]{11}{*}{$\bar{Y}$} & $\begin{array}{l}\text { Total transfer volume from } \\
\text { UFP-VSL-T01A to } \\
\text { UFP-VSL-T02A }\end{array}$ & 264 all & $-5 /+5$ & gal & All & & $\mathrm{HMI}$ \\
\hline & & $\begin{array}{l}\text { Total transfer volume via } \\
\text { make-up batches }\end{array}$ & 220 & $-5 /+5$ & gal & $\begin{array}{l}\text { Not } \\
\text { recorded }\end{array}$ & & HMI \\
\hline & & Make-up batch volume & 11 & $-1 /+1$ & gal & 11 & & HMI \\
\hline & & $\begin{array}{l}\text { Number of make-up batches } \\
\text { (endpoint) }\end{array}$ & 20 & & & 20 & & HMI \\
\hline & & Make-up batch flow rate & 6.9 & $-1 /+1$ & gpm & 6.9 & & HMI \\
\hline & & $\begin{array}{l}\text { UFP-VSL-T02A level to initiate } \\
\text { make-up batch additions from } \\
\text { UFP-VSL-T01A }\end{array}$ & 53 & $-1 /+1$ & in. & $\begin{array}{c}55 \\
58.7\end{array}$ & $\begin{array}{l}\text { T01A transferred in } 2 \text { batches with } \\
\text { filtering in between. Laser level } \\
\text { listed. }\end{array}$ & $\mathrm{TI}$ \\
\hline & & $\begin{array}{l}\text { Target UFP-VSL-T02A level } \\
\text { after final heel-pump transfer } \\
\text { from UFP-VSL-T01A }\end{array}$ & 62 & $-2 /+2$ & in. & $\begin{array}{l}69.9 \\
64.8\end{array}$ & $\begin{array}{l}\text { After the } 20 \text { make-up batch } \\
\text { transfers, leached slurry heel from } \\
\text { UFP-VSL-T01A transferred via } \\
\text { heel-pump in two separate } \\
\text { transfers. }\end{array}$ & TI \\
\hline & & $\begin{array}{l}\text { Final UFP-VSL-T02A level } \\
\text { (endpoint) }\end{array}$ & 17 & $-1 /+1$ & in. & 18.2 & Level after drain back of loop & HMI \\
\hline & & UFP-VSL-T02A Operation & & & & & & \\
\hline & & $\begin{array}{l}\text { Total lower air sparger (idle) } \\
\text { flow rate (for } 5 \text { sparge tubes) }\end{array}$ & 0.010 & $\begin{array}{l}-0.005 / \\
+0.005\end{array}$ & $\mathrm{~kg} / \mathrm{min}$ & 0.01 & $\begin{array}{l}\sim 3.7 \text { scfh for each sparge tube } \\
\text { whenever filter loop pumps are } \\
\text { running. }\end{array}$ & HMI \\
\hline & & Upper air sparger (idle) flow rate & 0.01 & $-0.01 /+0.01$ & $\mathrm{~kg} / \mathrm{min}$ & 0.01 & $\begin{array}{l}0.26 \mathrm{scfm} \text { or } \sim 16 \mathrm{scfh} \text {. This applies } \\
\text { whenever the level is less than } 52 \\
\text { in. }\end{array}$ & HMI \\
\hline
\end{tabular}


Parameter Data Run Sheet TI-082 Rev. 0

\begin{tabular}{|c|c|c|c|c|c|c|c|c|}
\hline & $\begin{array}{l}\text { Run } \\
\text { Sheet } \\
\text { Step }\end{array}$ & Operation & $\begin{array}{l}\text { Target or } \\
\text { Setpoint } \\
\text { Value }\end{array}$ & $\begin{array}{c}\text { Range } \\
(-1+)\end{array}$ & Units & $\begin{array}{l}\text { Actual } \\
\text { Value }\end{array}$ & Comments & $\begin{array}{c}\text { Data } \\
\text { Source }\end{array}$ \\
\hline & & Ultrafiltration Loop Operation & & & & & & \\
\hline & & $\begin{array}{l}\text { Number of filter bundles } \\
\text { valved-in }\end{array}$ & 5 & $-0 /+0$ & & 5 & & TI \\
\hline & & $\begin{array}{l}\text { Number of filter bundles (use } \\
\text { UFP-FILT-T01A only) }\end{array}$ & +5 & $-0 /+0$ & & 5 & Y (init.) & TI \\
\hline & & Filter-loop flow rate & 109 & $-10 /+10$ & gpm & $80-109$ & Dependent on tank level & HMI \\
\hline & & Transmembrane pressure & 40 & $-4 /+4$ & psi & 40 & & HMI \\
\hline & & Temperature of UFP-VSL-T02A & 23 & $-2 /+2$ & ${ }^{\circ} \mathrm{C}$ & 24 & & HMI \\
\hline \multirow{14}{*}{$\begin{array}{l}\text { Post- } \\
\text { caustic- } \\
\text { leach } \\
\text { wash } \\
\text { (Section } \\
7.16)\end{array}$} & \multirow[t]{14}{*}{ B1 } & Total wash water & 2,207 & $-20 /+20$ & $\mathrm{~kg}$ & 2308 & 53 batches & ССР-994 \\
\hline & & Wash water batch flow rate & 28.0 & $-3 /+3$ & $\mathrm{~kg} / \mathrm{min}$ & 28 & $\sim 7.4 \mathrm{gpm}$ & HMI \\
\hline & & Wash water batch size & 41.6 & $-1 /+1$ & $\mathrm{~kg}$ & 41.6 & & HMI \\
\hline & & $\begin{array}{l}\text { UFP-VSL-T02A level to initiate } \\
\text { wash water batch addition }\end{array}$ & 17.4 & $-1 /+1$ & in. & 17.4 & Set points & HMI \\
\hline & & $\begin{array}{l}\text { Volume of antifoam to add } \\
\text { initially and after every 3rd wash } \\
\text { water batch to UFP-VSL-T02A }\end{array}$ & 44 & $-2 /+2$ & $\mathrm{~mL}$ & 44 & $\begin{array}{l}\text { Antifoam is added to account for } \\
\text { wash water dilution. This value is } \\
\text { concentrate. Dilute with } 3 \text { parts IW } \\
\text { to } 1 \text { part AFA concentrate. }\end{array}$ & $\mathrm{TI}$ \\
\hline & & Estimated total permeate mass & 2,500 & $-100 /+200$ & $\mathrm{~kg}$ & 2563 & 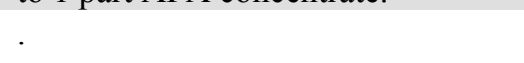 & CCP-994 \\
\hline & & Estimated total permeate volume & 583 & $-35 /+35$ & gal & 549 & & CCP-994 \\
\hline & & UFP-VSL-T02A Operation & & & & & & \\
\hline & & PJM jet velocity & 12 & $-0.4 /+0.4$ & $\mathrm{~m} / \mathrm{s}$ & 11.9 & & CCP- 901 \\
\hline & & PJM stroke ( $80 \%)$ & 31.5 & $-3 /+3$ & in. & 29.5 & & CCP- 901 \\
\hline & & PJM cycle time & 20 & $-1 /+1$ & $\mathrm{~s}$ & 20 & & CCP- 901 \\
\hline & & Steam ring air purge flow rate & $\theta .14$ & $-0.02 /+0.02$ & $\mathrm{~kg} / \mathrm{min}$ & 0 & $4.1 \mathrm{scfm}$ in UFP-VSL-T02A. & HMI \\
\hline & & $\begin{array}{l}\text { Total lower air sparger (idle) } \\
\text { flow rate (for } 5 \text { sparge tubes) }\end{array}$ & 0.010 & $\begin{array}{l}-0.005 / \\
+0.005\end{array}$ & $\mathrm{~kg} / \mathrm{min}$ & 0 & $\begin{array}{l}\sim 3.7 \text { scfh for each sparge tube } \\
\text { whenever filter loop pumps are } \\
\text { running. }\end{array}$ & HMI \\
\hline & & Upper air sparger (idle) flow rate & 0.01 & $-0.01 /+0.01$ & $\mathrm{~kg} / \mathrm{min}$ & Off & $\begin{array}{l}0.26 \mathrm{scfm} \text { or } \sim 16 \mathrm{scfh} \text {. This applies } \\
\text { whenever the level is less than } 52 \\
\text { in. }\end{array}$ & HMI \\
\hline
\end{tabular}


Parameter Data Run Sheet TI-082 Rev. 0

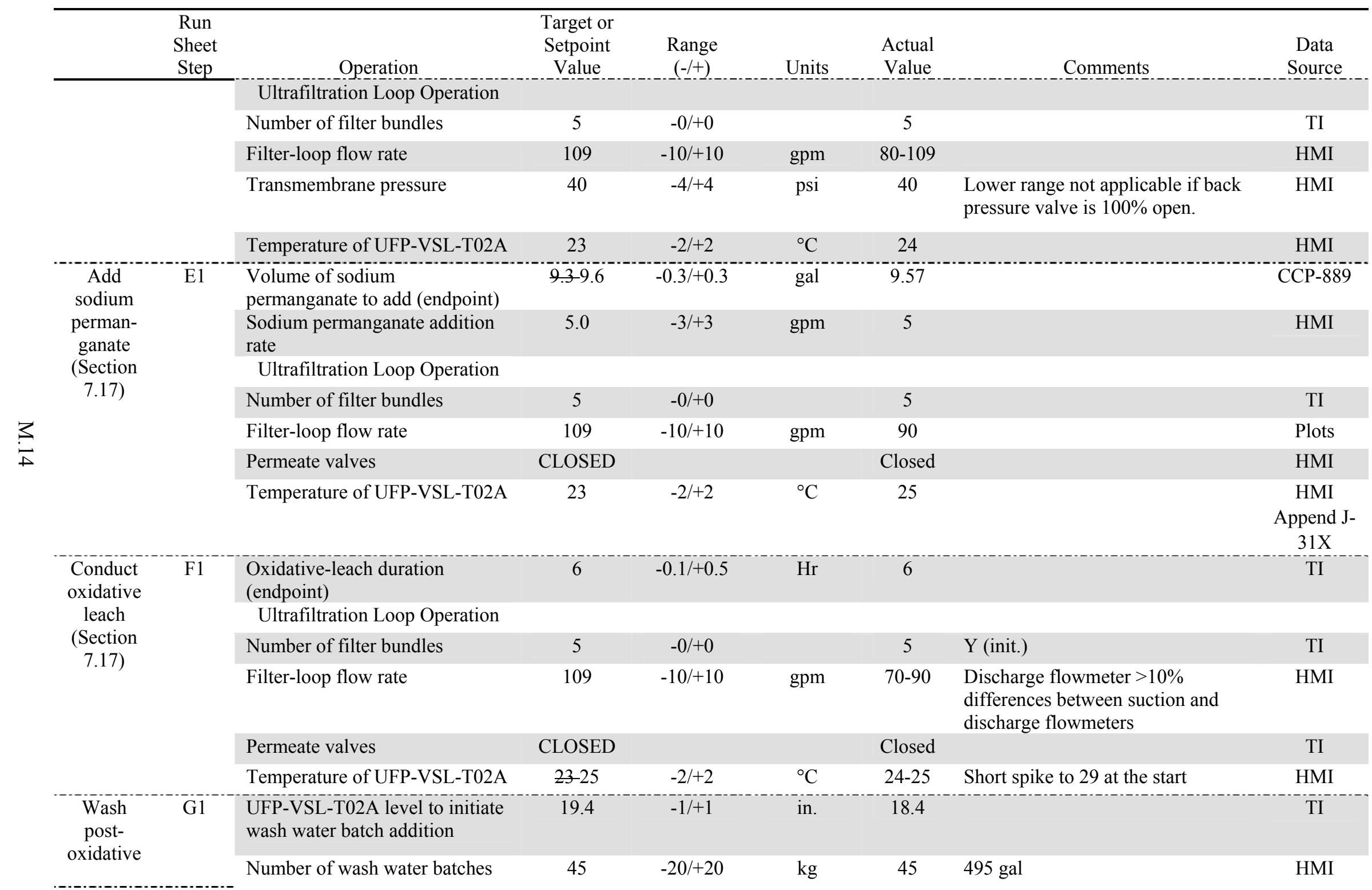


Parameter Data Run Sheet TI-082 Rev. 0

\begin{tabular}{|c|c|c|c|c|c|c|c|c|}
\hline & $\begin{array}{l}\text { Run } \\
\text { Sheet } \\
\text { Step }\end{array}$ & Operation & $\begin{array}{l}\text { Target or } \\
\text { Setpoint } \\
\text { Value } \\
\end{array}$ & $\begin{array}{l}\text { Range } \\
(-/+)\end{array}$ & Units & $\begin{array}{l}\text { Actual } \\
\text { Value }\end{array}$ & Comments & $\begin{array}{l}\text { Data } \\
\text { Source }\end{array}$ \\
\hline \multirow{10}{*}{$\begin{array}{l}\text { leach } \\
\text { slurry } \\
\text { (Section } \\
7.18)\end{array}$} & & Wash water batch flow rate & 28.0 & $-3 /+3$ & $\mathrm{~kg} / \mathrm{min}$ & 30 & $\sim 7.4 \mathrm{gpm}$ & $\mathrm{CCP}-889$ \\
\hline & & Wash water batch size & 42 & $-1 /+1$ & $\mathrm{~kg}$ & 42.9 & & CCP-889 \\
\hline & & $\begin{array}{l}\text { Volume of antifoam to add } \\
\text { initially and after every 3rd } \\
11 \text {-gal batch to UFP-VSL-T02A }\end{array}$ & 44 & $-2 /+2$ & $\mathrm{~mL}$ & 44 & $\begin{array}{l}\text { Antifoam }(\sim 14 \mathrm{ml} \text { per } 11 \text { gallon } \\
\text { wash batch) is added to account for } \\
\text { wash water dilution. This value is } \\
\text { concentrate. Dilute with } 3 \text { parts IW } \\
\text { to } 1 \text { part concentrate. }\end{array}$ & TI \\
\hline & & Estimated total permeate mass & 1,900 & $-100 /+200$ & $\mathrm{~kg}$ & 1982 & . & ССР-889 \\
\hline & & Ultrafiltration Loop Operation & & & & & & \\
\hline & & Number of filter bundles & 5 & $-0 /+0$ & & 5 & & TI \\
\hline & & & & & & & & $\mathrm{TI}$ \\
\hline & & Filter-loop flow rate & 109 & $-10 /+10$ & gpm & $69-79$ & & CCP-889 \\
\hline & & Transmembrane pressure & 40 & $-4 /+4$ & psi & 40 & $\begin{array}{l}\text { Lower range not applicable if back } \\
\text { pressure valve is } 100 \% \text { open. }\end{array}$ & HMI \\
\hline & & Temperature of UFP-VSL-T02A & 2325 & $-2 /+2$ & ${ }^{\circ} \mathrm{C}$ & $24-25$ & & CCP-889 \\
\hline \multirow{6}{*}{$\begin{array}{l}\text { Concen- } \\
\text { trate } \\
\text { post- } \\
\text { oxidative } \\
\text { leach } \\
\text { slurry } \\
\text { (Section } \\
7.18)\end{array}$} & \multirow[t]{6}{*}{$\mathrm{H} 1$} & UFP-VSL-T02A level (endpoint) & 15.5 & $-1 /+1$ & in. & 15.8 & Remove $\sim 107 \mathrm{~kg}$ of permeate. & ССР-994 \\
\hline & & Ultrafiltration Loop Operation & & & & & & \\
\hline & & Number of filter bundles & 5 & $-0 /+0$ & & 5 & & TI \\
\hline & & Filter-loop flow rate & 109 & $-10 /+10$ & gpm & 67 & & HMI \\
\hline & & Transmembrane pressure & 40 & $-4 /+4$ & psi & 40 & $\begin{array}{l}\text { Lower range not applicable if back } \\
\text { pressure valve is } 100 \% \text { open. }\end{array}$ & HMI \\
\hline & & Temperature of UFP-VSL-T02A & 23 & $-2 /+2$ & ${ }^{\circ} \mathrm{C}$ & 25 & & HMI \\
\hline \multirow{3}{*}{$\begin{array}{l}\text { Back- } \\
\text { flush } \\
\text { filter- } \\
\text { loop } \\
\text { (Section } \\
7.19)\end{array}$} & I1 & $\begin{array}{l}\text { Volume of flush water } \\
\text { (endpoint) }\end{array}$ & 341 & $-5 /+5$ & $\mathrm{~kg}$ & 341 & & TI \\
\hline & & Flush water addition rate & $\begin{array}{l}\text { maximum } \\
\text { achievable } \\
\text { flow }\end{array}$ & & $\mathrm{kg} / \mathrm{min}$ & 80 & $\begin{array}{l}\text { The pump capacity is } \sim 35 \mathrm{gpm} \text { or } \\
132 \mathrm{~kg} / \mathrm{min} \text {. In practice only } \\
\sim 22 \mathrm{gpm} \text { was achieved. }\end{array}$ & $\underset{\mathrm{J}}{\text { Appendix }}$ \\
\hline & & UFP-VSL-T02A Operation & & & & & & \\
\hline
\end{tabular}


Parameter Data Run Sheet TI-082 Rev. 0

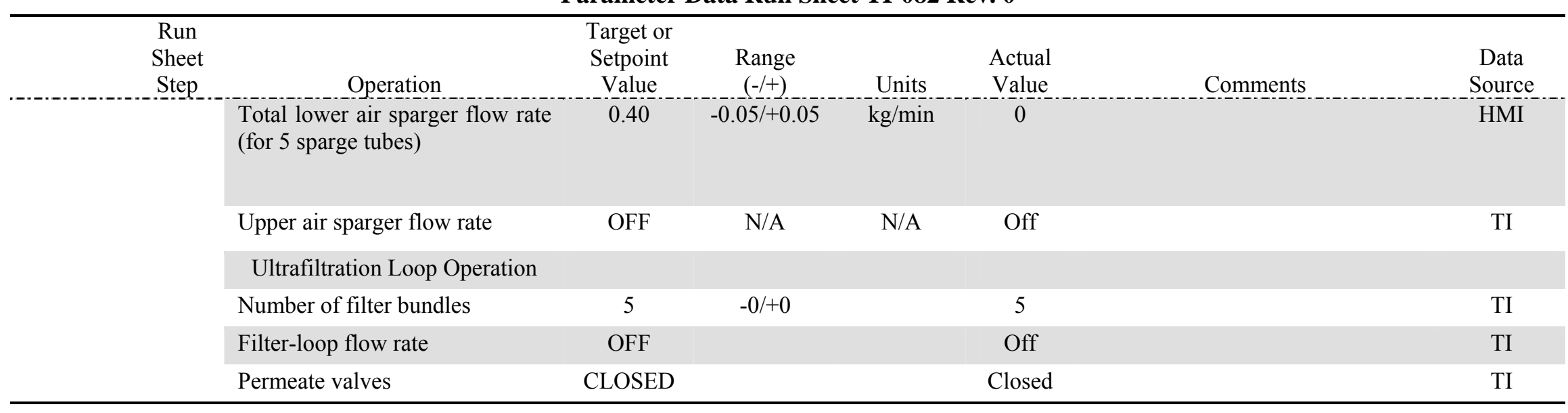


Appendix N

Reagent Analysis 



\section{Appendix N: Reagent Analysis}

The tables below provide the results of all the reagent analysis taken during Phase 1 testing. For Integrated Test $\mathrm{B}$, the following samples are most relevant:

19 M NaOH Analysis: Samples 19M NAOH 031709 1520, 19MNAOH 0317090700 (Sample taken 2 days after Integrated Test $\mathrm{B}$ batch 2 caustic addition.).

$2 \mathrm{M} \mathrm{HNO}_{3}$ Analysis: Sample: A 00C03 XXX XX 2609 ACT 2 (Sample taken as part of Integrated Test A. Acid cleaning conducted at conclusion of Integrated Test A.).

$\mathrm{NaMnO}_{4}$ Analysis: Sample: A 00C04 XXX XX 2610 OST 2 (Sample taken as part of Integrated Test A.).

CsBr Tracer Analysis: Sample: B 0CSBR 020 XX 4155 ICP 2 (Sample taken as part of Integrated Test B.). 
PEP Testing $19 \mathrm{M} \mathrm{NaOH}$ Analysis

\begin{tabular}{|c|c|c|c|c|c|c|c|c|c|c|c|c|c|c|c|c|c|c|c|c|c|}
\hline $\begin{array}{c}\text { Reagent } \\
\text { Description }\end{array}$ & $\begin{array}{c}\text { Analysis } \\
\text { Date } \\
\end{array}$ & Sample Name & Analysis & Reference File & $\begin{array}{c}\text { Free } \mathrm{OH} \\
\mathrm{M}\end{array}$ & $\begin{array}{c}\begin{array}{c}\text { Density } \\
\mathrm{g} / \mathrm{cm}^{3}\end{array} \\
\end{array}$ & $\begin{array}{l}\mathrm{C}_{2} \mathrm{O}_{4} \\
\mu \mathrm{g} / \mathrm{g} \\
\end{array}$ & $\begin{array}{l}\mathrm{NO}_{3} \\
\mu \mathrm{g} / \mathrm{g} \\
\end{array}$ & $\begin{array}{l}\mathrm{NO}_{2} \\
\mu \mathrm{g} / \mathrm{g} \\
\end{array}$ & $\begin{array}{l}\mathrm{SO}_{4} \\
\mu \mathrm{g} / \mathrm{g} \\
\end{array}$ & $\begin{array}{l}\mathrm{PO}_{4} \\
\mu \mathrm{g} / \mathrm{g} \\
\end{array}$ & $\begin{array}{c}\mathrm{Al} \\
\mu \mathrm{g} / \mathrm{g} \\
\end{array}$ & $\begin{array}{c}\mathrm{Ca} \\
\mu \mathrm{g} / \mathrm{g}\end{array}$ & $\begin{array}{c}\mathrm{Cr} \\
\mu \mathrm{g} / \mathrm{g} \\
\end{array}$ & $\begin{array}{c}\mathrm{Fe} \\
\mu \mathrm{g} / \mathrm{g}\end{array}$ & $\begin{array}{c}\mathrm{Mg} \\
\mu \mathrm{g} / \mathrm{g} \\
\end{array}$ & $\begin{array}{c}\mathrm{Mn} \\
\mu \mathrm{g} / \mathrm{g}\end{array}$ & $\begin{array}{c}\mathrm{Na} \\
\mu \mathrm{g} / \mathrm{g}\end{array}$ & $\begin{array}{c}\mathrm{Nd} \\
\mu \mathrm{g} / \mathrm{g}\end{array}$ & $\begin{array}{c}\mathrm{Sr} \\
\mu \mathrm{g} / \mathrm{g}\end{array}$ & $\begin{array}{c}\mathrm{Cl} \\
\mu \mathrm{g} / \mathrm{g} \\
\end{array}$ \\
\hline \multirow{4}{*}{$\begin{array}{c}19 \mathrm{M} \\
\mathrm{NaOH}^{(\mathrm{a})}\end{array}$} & \multirow{4}{*}{$1 / 15 / 2009$} & $\begin{array}{l}\text { S 00C01 001 XX } \\
0173 \text { DEN } 2\end{array}$ & Density & 090115-14 DEN & $18.652 \mathrm{~N}$ & 1.522 & $<19.5$ & $<86.4$ & $<64.2$ & $<19.5$ & $<59.7$ & $<9.60$ & $<4.70$ & $<0.960$ & $<9.60$ & $<4.70$ & $<0.960$ & 285000 & $<0.0188$ & $<0.960$ & $<19.5$ \\
\hline & & $\begin{array}{l}\text { S 00C01 } 001 \text { XX } \\
0172 \text { ALK } 2\end{array}$ & $\begin{array}{c}\mathrm{OH} \\
\text { Titration }\end{array}$ & $\begin{array}{c}\text { Base Titration - } \\
\text { 090115-13 - Battelle } \\
\text { PNNL (011909) }\end{array}$ & & & & & & & & & & & & & & & & & \\
\hline & & $\begin{array}{c}\text { S } 00 \mathrm{C} 01001 \mathrm{XX} \\
0171 \mathrm{TFI} 2 \mathrm{D}\end{array}$ & IC & $\begin{array}{c}\text { 090115-151C_prelim, } \\
\text { 090115-15IC, } \\
\text { Battelle_090202- } \\
12131415\end{array}$ & & & & & & & & & & & & & & & & & \\
\hline & & $\begin{array}{l}\text { S } 00 C 01001 \mathrm{XX} \\
0171 \text { ICP 2 D }\end{array}$ & ICP & $\begin{array}{l}\text { 090115- } \\
\text { 16MetalsLIQUID }\end{array}$ & $18.6 \mathrm{~N}$ & 1.519 & $<16.9$ & $<74.7$ & $<55.5$ & $<16.9$ & $<51.6$ & $<9.94$ & $<9.94$ & $<0.994$ & $<19.9$ & $<9.94$ & $<0.994$ & 293000 & $<0.199$ & $<1.99$ & 23.7 \\
\hline \multirow{4}{*}{$\begin{array}{c}19 \mathrm{M} \\
\mathrm{NaOH}^{(\mathrm{a})}\end{array}$} & \multirow{4}{*}{$1 / 31 / 2009$} & $\begin{array}{c}\text { A 00C01 XXX XX } \\
2608 \text { ALK } 2\end{array}$ & IC & $090202-12 \mathrm{IC}$ & & & & & & & & & & & & & & & & & \\
\hline & & $\begin{array}{l}\text { A 00C01 XXX XX } \\
2608 \text { ALK } 2\end{array}$ & $\underset{\text { Titration }}{\mathrm{OH}}$ & $\begin{array}{c}\text { Base Titration - } \\
12090202-13\end{array}$ & & & & & & & & & & & & & & & & & \\
\hline & & $\begin{array}{c}\text { A 00C01 XXX XX } \\
2608 \text { ALK } 2\end{array}$ & ICP & 090202-12Metals & & & & & & & & & & & & & & & & & \\
\hline & & $\begin{array}{l}\text { A } 00 \mathrm{C} 01 \mathrm{XXX} \text { XX } \\
2608 \mathrm{ALK} 2\end{array}$ & Density & 090202-12den & $18.6 \mathrm{~N}$ & 1.519 & $<16.9$ & $<74.7$ & $<55.5$ & $<16.9$ & $<51.6$ & $<9.94$ & $<9.94$ & $<0.994$ & $<19.9$ & $<9.94$ & $<0.994$ & 293000 & $<0.199$ & $<1.99$ & 23.7 \\
\hline $19 \mathrm{M} \mathrm{NaOH}$ & 2/6/2009 & $\begin{array}{c}\text { A 00C01 XXX XX } \\
2757 \text { ALK } 3\end{array}$ & $\mathrm{OH}$ & ASR $8351 \mathrm{OH}$ & 19.27 & -- & -- & -- & -- & -- & -- & -- & -- & -- & -- & -- & -- & -- & - & - & -- \\
\hline $19 \mathrm{M} \mathrm{NaOH}$ & $2 / 12 / 2009$ & $\begin{array}{c}\text { A 00CO1 XXX XX } \\
2763 \text { ALK } 3\end{array}$ & $\mathrm{OH}$ & ASR $8357 \mathrm{OH}$ & 19.22 & -- & -- & -- & -- & -- & -- & -- & -- & -- & -- & -- & -- & -- & -- & -- & -- \\
\hline $19 \mathrm{M} \mathrm{NaOH}$ & 2/18/2009 & $\begin{array}{c}\text { A 00CO1 XXX XX } \\
2807 \text { ALK } 3\end{array}$ & $\mathrm{OH}$ & ASR $8363 \mathrm{OH}$ & 18.86 & -- & -- & -- & -- & -- & -- & -- & -- & -- & -- & -- & -- & -- & -- & -- & -- \\
\hline $19 \mathrm{M} \mathrm{NaOH}$ & $2 / 18 / 2009$ & $\begin{array}{c}\text { A 00CO1 XXX XX } \\
2808 \text { ALK } 3\end{array}$ & $\mathrm{OH}$ & ASR $8363 \mathrm{OH}$ & 18.61 & -- & -- & -- & -- & -- & -- & -- & -- & -- & -- & -- & -- & -- & -- & -- & -- \\
\hline $19 \mathrm{M} \mathrm{NaOH}$ & $3 / 17 / 2009$ & $\begin{array}{l}\text { 19M NAOH } \\
0317091520\end{array}$ & $\mathrm{OH}$ & ASR $8388 \mathrm{OH}$ & 19.12 & -- & -- & -- & -- & -- & -- & -- & -- & -- & -- & -- & -- & -- & -- & -- & -- \\
\hline $19 \mathrm{M} \mathrm{NaOH}$ & $3 / 18 / 2009$ & $\begin{array}{c}\text { 19MNAOH } 0318 \\
090700\end{array}$ & $\mathrm{OH}$ & ASR $8388 \mathrm{OH}$ & 18.95 & -- & -- & -- & -- & -- & -- & -- & -- & -- & -- & -- & -- & -- & -- & -- & -- \\
\hline
\end{tabular}

PEP Testing $2 \mathrm{M} \mathrm{HNO}_{3}$ Analysis

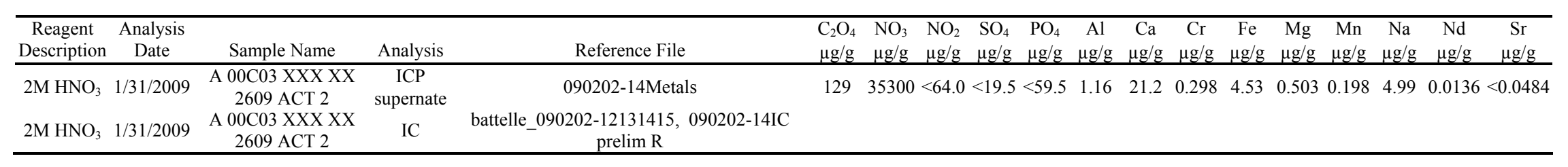


PEP Testing $\mathrm{NaMnO}_{4}$ Analysis

\begin{tabular}{|c|c|c|c|c|c|c|c|c|c|c|c|c|c|c|c|c|c|c|c|c|}
\hline $\begin{array}{l}\text { Reagent } \\
\text { Description }\end{array}$ & $\begin{array}{l}\text { Analysis } \\
\text { Date }\end{array}$ & Sample Name & Analysis & Reference File & $\begin{array}{c}\mathrm{MnO}_{4}^{-} \\
\mathrm{M}\end{array}$ & $\begin{array}{r}\text { Density } \\
\mathrm{g} / \mathrm{cm}^{3}\end{array}$ & $\begin{array}{l}\mathbf{C}_{2} \mathbf{O}_{4} \\
\mu \mathrm{g} / \mathrm{g}\end{array}$ & $\begin{array}{l}\mathbf{N O}_{3} \\
\mu \mathrm{g} / \mathrm{g}\end{array}$ & $\begin{array}{l}\mathbf{N O}_{2} \\
\mu \mathrm{g} / \mathrm{g}\end{array}$ & $\begin{array}{l}\mathrm{SO}_{4} \\
\mu \mathrm{g} / \mathrm{g}\end{array}$ & $\begin{array}{cc}\mathbf{P O}_{4} & \mathbf{A l} \\
\mu \mathrm{g} / \mathrm{g} & \mu \mathrm{g} / \mathrm{g}\end{array}$ & $\begin{array}{c}\mathbf{C a} \\
\mu \mathrm{g} / \mathrm{g}\end{array}$ & $\begin{array}{c}\mathbf{C r} \\
\mu \mathrm{g} / \mathrm{g}\end{array}$ & $\begin{array}{c}\mathbf{F e} \\
\mu \mathrm{g} / \mathrm{g}\end{array}$ & $\begin{array}{c}\mathrm{Mg} \\
\mu \mathrm{g} / \mathrm{g}\end{array}$ & $\begin{array}{c}\text { Mn } \\
\mu \mathrm{g} / \mathrm{g}\end{array}$ & $\begin{array}{c}\mathrm{Na} \\
\mu \mathrm{g} / \mathrm{g}\end{array}$ & $\begin{array}{r}\mathbf{N d} \\
\mu \mathrm{g} / \mathrm{g}\end{array}$ & $\begin{array}{c}\mathrm{Sr} \\
\mu \mathrm{g} / \mathrm{g}\end{array}$ & $\begin{array}{r}\mathbf{C l} \\
\mu \mathrm{g} / \mathrm{g}\end{array}$ \\
\hline \multirow{3}{*}{$\mathrm{NaMnO}_{4}$} & \multirow{3}{*}{$1 / 9 / 2009$} & $\begin{array}{c}\text { S 00C04 } 001 \text { XX } 0176 \\
\text { OST } 2\end{array}$ & $\begin{array}{l}\text { ICP } \\
\text { slurry; }\end{array}$ & 090112-8Metals, & 0.921 & 1.085 & $<19.4$ & $<85.8$ & $<63.7$ & 841 & $<59.3<4.60$ & $<4.60$ & 1.17 & $<4.60$ & $<4.60$ & 46800 & 19900 & $<0.0460$ & $<0.460$ & 21.2 \\
\hline & & $\begin{array}{c}\text { S 00C04 } 001 \text { XX } 0176 \\
\text { OST } 2\end{array}$ & IC & 090112-81C-prelim & & & & & & & & & & & & & & & & \\
\hline & & $\begin{array}{c}\text { S 00C04 } 001 \text { XX } 0176 \\
\text { OST } 2\end{array}$ & $\begin{array}{l}\mathrm{MnO} 4 \\
\text { Titration }\end{array}$ & 090112-8 ICP ICPMS ICP and $\mathrm{MnO}_{4}$ Tit & & & & & & & & & & & & & & & & \\
\hline \multirow{3}{*}{$\mathrm{NaMnO}_{4}$} & \multirow{3}{*}{$1 / 31 / 2009$} & $\begin{array}{l}\text { A } 00 \mathrm{C} 04 \mathrm{XXX} \text { XX } \\
2610 \text { OST } 2\end{array}$ & $\begin{array}{c}\text { ICP } \\
\text { supernate }\end{array}$ & $\begin{array}{c}\text { Permangante Normality TO\#090202-15, } \\
\text { 090202-15Metals }\end{array}$ & 1.06 & 1.106 & $<18.4$ & 96 & $<60.6$ & 934 & $<56.3<4.59$ & $<4.59$ & $<0.918$ & $<9.18$ & $<4.59$ & 51500 & 22100 & $<0.0918$ & $<0.918$ & 28.5 \\
\hline & & $\begin{array}{c}\text { A 00C } 04 \text { XXX XX } \\
2610 \text { OST } 2\end{array}$ & IC & 090202-12IC & & & & & & & & & & & & & & & & \\
\hline & & $\begin{array}{l}\text { A } 00 \mathrm{C} 04 \text { XXX XX } \\
2610 \text { OST } 2 \\
\end{array}$ & density & 090202-15DEN prelim & & & & & & & & & & & & & & & & \\
\hline
\end{tabular}

PEP Testing CsBr Tracer Analysis

\begin{tabular}{lrlllc}
\hline & & & & \\
Reagent Description & Analysis Date & Sample Name & Analysis & Reference File & $\begin{array}{c}\text { CsBr } \\
\mu \mathrm{g} / \mathrm{g}\end{array}$ \\
\hline $\mathrm{CsBr}$ & $1 / 2 / 2009$ & S CsBr 025 0990 ICP 2 & ICP solution & $090102-13 \mathrm{Cs}$ & 70300 \\
$\mathrm{CsBr}$ & $2 / 4 / 2009$ & A CsBr XXX XX 2726 ICP 2 & ICP solution & $090204-4 \mathrm{Cs}$ & 181000 \\
$\mathrm{CsBr}$ & $3 / 24 / 2009$ & $\mathrm{~B}$ 0CSBR 020 XX 4155 ICP 2 & ICP solution & $090320-15 \mathrm{MetalsLIQUID}$ & 124000 \\
$\mathrm{CsBr}$ & $3 / 24 / 2009$ & $\mathrm{~A}$ 0CSBR 014 XX 6000 ICP 2 & ICP solution & $090324-35 \mathrm{MetalsLIQUID}$ & 198000 \\
\hline
\end{tabular}



PNNL-18741

WTP-RPT-193, Rev 0

\section{Distribution}

No. of

Copies

OFFSITE
No. of

Copies

\section{ONSITE}

1 Pacific Northwest National Laboratory (authors will be notified electronically)

O.P. Bredt

K6-50

C.A. Burns

$\mathrm{P} 7-25$

J.G.H. Geeting

P7-28

E.C. Golovich

$\mathrm{K} 5-25$

C.E. Guzman-Leong

$\mathrm{K} 5-22$

B.D. Hanson

P7-27

J.L. Huckaby

H4-02

G.B. Josephson

K9-69

D.E. Kurath

K3-52

G.J. Sevigny

P7-27

Information Release (pdf)

Project File (1)

K3-52

2 Bechtel National, Inc.

WTP R\&T Docs (1)

H4-02

S. Barnes

H4-02 


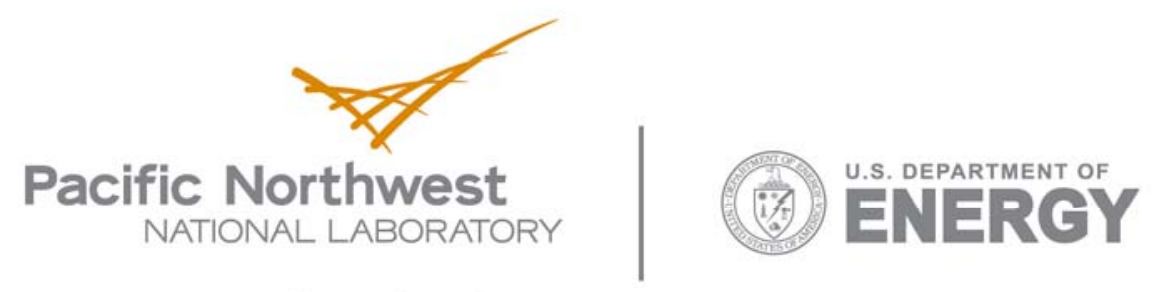

902 Battelle Boulevard

P.O. Box 999

Richland, WA 99352

1-888-375-PNNL (7665)

www.pnl.gov 